



\section{$Q L$
463 \\ B.168 \\ Bd:2 \\ Ent EXPERIMENTELLE \\ ENTOMOLOGISCHE STUDIEN}

VOM PHYSIKALISCH-CHEMISCHEN STANDPUNKT AUS.

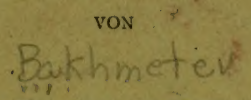

\section{P. BACHMETJEW,}

PROFESSOR DER PHYSIK $\triangle N$ DER UNIVERSITÄT ZU SOPHIA.

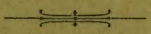

ZWEITER BAND.

EINFLUSS DER ÄUSSEREN FAKTOREN AUF INSEKTEN.

$$
\text { MIT } 25 \text { TAFELN: }
$$

SELBSTVERLAG DES VERFASSERS.

\section{SOPHIA}

STAATSDRUCKEREI 1907. 



\section{EXPERIMENTELLE}

\section{ENTOMOLOGISCHE STUDIEN}

\section{VOM PHYSIKALISCH-CHEMISCHEN STANDPUNKT AUS.}

voN

P. BACHMETIEW,

PROFESSOR DER PHYSIK AN DER UNIVERSITAT ZU SOPHIA

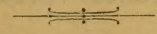

ZWEITER BAND.

EINFLUSS DER ÄUSSEREN FAKTOREN AUF INSEKTEN.

MIT 25 TAFELN.

SELBSTVERLAG DES VERFASSERS.

\section{SOPHIA}

STAATSDRU CKEREI

1907. 
Alle Rechte vorbehalten. 


\section{PROF. DR MAX StAndFuss}

IN ANERKENNUNG SEINER HERVORRAGENDEN

VERDIENSTE UM DIE EXPERIMENTELLE ENT'OMOI.OGIE

FREUNDSCHAFTLICH GEWIDMET

you!

VERFASSER. 



\section{Vorwort.}

Vor sechs Jahren erschien der erste Band meiner "Experimentellen entomologischen Studien " (Temperaturverhältnisse bei Insekten). Das Werk wurde seitens der Entom logen sehr gut aufgenommen, was man aus den Aeusserungen der fachwissenschaftlichen Presse ersehen kann (Journ. de physiol. et de pathol. génér., p. 1018-1019. 1901; Die Umschau, V. № 52, p. 1033-1034. 1901; Berliner Entom. Zeitschr., XLVI. p. 555-556. 1901; Entomol. Zeitschr., XV. № 12, p. 45-46, 수 13. p. 49-50. Guben 1901; Societ. entomol., XVI. 수 17, p. 129-132. 1901; Nature, LXV. № 1675, p. 101. London 1901; Wiener entomol. Ztg., XXI. 수 1, p. 27-28. 1902; Himmel und Erde, ㅊ: 3. p. 143-144. 1902; Russische entomol. Rundschau, . 1: p. 41-43. 1902; The Americ. Natural., 으 425, p. 401-405. 1902; Entomol. Berichte der Nederl. Entomol. Ver., 소 4, p. 24-26 1902; The Zoolog., VI. ㅇ: 734, p. 287-293. 1902; Naturwiss. Rundschau, XVII. 수 10, p. 122-124. 1902; Helios, XIX. p. 85-87. 1902; Zeitschrift für physikalische Chemie, i: 6, p. 1902; Vesmír, XXXIII. ㅊ: 4, p. 44-45. 1903; Krancher's entom llogisches Jahrb., p. 223-224. 1903; Fortschr. der Physik, 1902; Literar. Centralbl., .l: 11, p. 386-387. 1903; Berliner Tagebl., Beibl.: Der Zitgeist .l: 20, p. 3-4. 1903; Naturwiss. Wochenschr., ㅇ: 24. 1904; Wiener klinische Rundschau, i. 5. 1904; Le Temps, 10. Mai 1904. etc.). Daraufhin entschloss ich mich, auch den zweiten Band dieser "Studien" herauszugeben, unsomehr als der erste Band von der kaiserlichen russischen Akademie der Wissenschaften mit der Prämie von K. M. Bär ausgezeichnet wurde. 
Urspruinglich beabsichtigte ich ron dem vorliegenden Werke nur den „thatsächlichen Theil," welcher hereits 1901 druckfertig vorlag, herauszugeben, ohne mich in Theorien einzulassen. Die Drucklegung les zweiten Baniles im Auslinde war aber mit solchen materiellen Schwierigkeiten verbunclen, dass das Manuscript noch im Jahre 1904 ungedruckt bliel). Gegen Encle des Jahres 1904 beschloss der bulgarische Ministerrath, dieses Werk in der hiesigen Staatsdruckerei drucken zu lassen, wobei mir sehr gïnstige Bedingungen gestellt wurden. Ich bin dafür dem seligen Ministerpräsidenten Herrn D. Petkow und dem Minister des Handels und der Landwirthschaft Herm Dr N. Genadjew zu ganz besonderem Danke verpflichtet.

Anfangs des Jahres 1905 wurle mit der Drucklegung dieses Bancles begonnen. Inzwischen erschienen mehrere Untersuchungen auf dem Gebiete der experimentellen Entumologie, welche mir ermöglichten, einen festen theoretischen Standpunkt über den Einfluss ler äusseren Faktoren auf Insekten zu gewinnen, unil zwar den, !lass sich die Hauptwirkung dieser Faktoren in der Aenrlerung des liewegungszustandes des Protoplasmas in Zellen offenbart, welcher Zustand seinerseits die Entwickelung der Insekten beeinflusst. Wenn dieser Standpunkt bis jetzt von keinem Forscher vertreten wurde, so ist der Grund dazu in der ungenügenden Verallgemeinerung des äusserst reichlichen thatsächlichen Materials einerseits, und andererseits in dem noch neuen Begriff des von mir entrleckten „liritischen Punktes" zu suchen.

Auf diese Weise kam währenı der Drucklegung dieses Bandes der "theoretische Theil" desselben zu Stande.

In "thatsächlichen Theil" sinıl fast alle bis jetzt bekannt geworilenen Experimente unil Beobachtungen iiber den Einfluss der äusseren Faktoren auf Inseliten chronologisch im Auszuge angeführt, und die in Klammern stehenden Ziffern neben der Jahreszahl beziehen sich auf clie entsprechenden .l. k: im "Litteraturverzeichniss."

, Die grossen Schwierigkeiten, mit welchen die Beschaffung der nöthigen Bücher und Zeitschriften aus dem Auslande nach Sophia verbunilen ist, erlaubten mir jerloch nicht, die gesammte Litteratur zu 
berücksichtigen; deshalb ist nach jedem Kapitel noch ein Verzeichniss der ergänzenden Litteratur angebracht, welche mir leider nicht zugänglich war. Besondere Aufmerksamkeit habe ich diesmal, ebenso wie im ersten Bande meiner "Studien," der russischen Litteratur zugewendet, und ich glaube dadurch auch die der russischen Sprache nicht mächtigen Forscher zufrieden gestellt zu haben.

Das vorliegende "thatsächliche Material" ist in drei Kapitel eingetheilt: 1) Die Entwickelungsgeschwindigkeit, 2) Die Grösse und die Gestalt und 3) Die Färbung und die Zeichnung der Insekten. Der Einfluss des Klimas, der Feuchtigkeit, der Temperatur, des Lichtes und der Farbe der Umgebung, der Nahrung und chemischer Stoffe, der Elektrizität und des Magnetismus, der Reibung, der Schnürung, des Druckes, der Schwerkraft und der übrigen Faktoren auf eine jede von diesen drei Eigenschaften wird hier ausführlich behandelt. Gewisse allgemeine Sachen enthält die Einleitung zu einem jeden Kapitel.

Saison-Dimorphismus, Schutzfarbe, Nimicry und die Parthenu. genesis sind hier nur nebenbei berührt worden, da ihre ausfülırliche Behandlung in einem besonderen Werke projektiert wirci.

Im "theoretischen Theile" sind die Anschauungen verschiedener Forscher bezüglich der im "thatsächlichen Theile" beschriebenen Erscheinungen angeführt und vom Standpukte des Bewegungszustandes des Protoplasmas aus beleuchtet.

Der vorliegende Band soll in erster Linie als Handbuch für diejenigen Forscher dienen, welche sich mit der experimentellen Entomologie beschäftigen wollen; denn sie finden larin mit geringen Ausnahmen alles, was auf diesem Gebiete bis 1907 bekannt geworden ist.

Alle Zeichnungen, welche diesem Bande beigefügt sind, wurlen von mir auf Grund der Zahlenangaben der entsprechenden Forscher zusammengestellt, ausgenommen Fig. $4 a$ und Fig. 19, welche den Abbildungen von Koschewnikow resp. Sabanin entnommen sind; Fig. 21 und 22 sind nach den Abbildungen von Dr Prehn (1897. 651 ) gezeichnet. 
Die Insektennamen sind überall so angeführt, wie sie von dew betreffenclen Forschern gebraucht wurden, nur in der tabellarischen Zusammenstellung des theoretischen Theils sind die Lepilopterennamen dem Kataloge von Staudinger und Røbel entnommen.

Selbstverständlich kann ich keine Verantwortung für die eventuelle Unrichtigkeit der Angaben verschielener Forscher übernehmen. Ich war stets bemüht die Originalangaben, wie dieselben von verschiedenen Autoren erwähnt werlen, anzuführen; die Revision dersılben wäre wohl nur bei Betheiligung mehrerer Fachmänner möglich.

Die Temperatur ist, wo ausilricklich kein R. (Réaumur) oder F. (Fahrenheit) steht, nach Celsius-Thermometer angegehen.

Es erübrigt mir noch die Fachmänner höfl. zu ersuchen, die von ihnen in rliesem Buche bemerkten fehlerhaften Angaben mir gefl. mittleilen zu wollen, damit dieselben bei eventueller zweiter Autlage dieses Bandes berïcksichtigt werden können.

Der III. Band meiner "Stulien," dessen Manuscript druckfertig vorliegt, wirl die individuelle Variabilität dler Insekten behandeln.

Die Herren und die Anstalten resp. Vereine, welche es mir ('rmöglicht hiaben, diesen Banil zu Enle zu fïhlıren, und welchen ich zu besonderem Danke rerpflichtet bin, mögen hier in alphabetischer Reihenfolge angeführt werden:

L. von Aigner-Abafi in Budapest

H. Auel in Potsdam

Pio: Dr M. Hellati in Padua

Prof. A. Bezenšek in Sophia

Dr von Buttel-Reepen in Berlin

F. Dickel in Darmstadt

Prof. Dr. l.. A. Dixey in Oxford

Prof. Dr H. Ebert in München

Prof. Dr K. Eckstein in Eberswalde

Prof. Dr E. Ellers in Göttingen

Prof. Dr S. Exner in Wien

H. Federley in Ielsingfors
Dr E. Fischer in Zürich

K. Frings in Bonr

H. Gauckler in Karlsruhe

Prof. Dr Gaule in Zürich

Prof. Dr. L. von Grafí in Graz

Prof. 'Th. Kaschitschenko in T'omsk

Prof. Dr L. Kathariner in Freiburg: (Schweiz):

G. Koschewnikow in Moskau

Dr 0 . Krancher in Leipzig

Prof. N. M. Kulagin in Moskau.

Oberlehrer H. Kunze in Cassel 
+ Dr P. Leverkühn in Sophia

Gräfin Dr M. von Linden in Bomn

F. Merrifield in Brighto.1

A. Mordwilko in Warschau

Prof. Dr K. Pearson in London

Dr W. Petersen in Reral

Oberst W. Petrow in Sophia

IV. Pickel in St.-Petersburg

Dr M. C. Piepers in dem Haag

J. Portschinski in St.-Petersburg

Dr E. Quajat in Padua

Dr H. Rebel in Wien

Dr L. Reh in Hamburg

Prof. Dr H. Roedel in Frankfurt a/0.

Fräulein M. Rühl in Zürich

Prof. K. Sajó in Budapest
† Dr P. Sachse in Ballenstedt

Direktor C. Schaufuss in Meissen

A. D. Semenow in St.-Petersburg

J. Schewyrew in St.-Petersburg

Dr Chr. Schröder in Husum

Prof. Dr H. Schinz in Zürich

Prof. Dr 0. Schultze in Würzburg

Architekt A. N. Smirnow in Sophia

Prof. Dr M. Standfuss in Zürich

Prof. Dr G. Tammann in Göttingen

Prof. A. A. Tichomirow in St.-Peters-

Dr F. Urech in Tübingen [burg

Prof. Dr A. Weismann in Freiburg

(Baden)

Proi. Dr E. Verson in Padua

Prof. Dr M. Verworn in Göttingen

Academia Gioenia di Scienze Naturali in Catania

Die kais. Universität in Kasan

Das Forst-Institut in St.-Petersburg

Universitäts-Bibliothek in Wien

Die russische entomologische Gesellschaft in St.-Petersburg

Die Naturforscher-Gesellschaft in Zürich

Der naturwissenschaftliche Verein für Steiermark in Graz

Der Verein für Naturkunde in Cassel

Die Gesellschaft der Naturforscher in Saratow

Die Ural'sche Gesellschaft der Liebhaber der Naturwissenschaften in Ekaterinenburg

Die k. k. landwirthschaftliche chemische Versuchsstation in Görz.

Die Korrelitur dieses Bandes übernahm freundlichst der gewesene Direktor der wissenschaftlichen Institute und der Bibliothek S. K. H. des Fürsten von Bulgarien, Herr Dr P. Leverkühn, und nach seinem Tode Herr A. Bezenšek, Professor am hiesigen Staatsgymnasium, wofür ich beiden Herren zum grössten Danke verpflichtet bin.

Sophia, Juni 1907. 



\section{Inhalts-Uebersicht.}

\section{Thatsächlicher Theil.}

Erstes Kapitel. Die Entwickelungsgeschwindigkeit der Insekten.

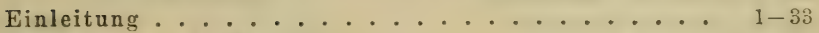

1. Einfluss des Klimas............. . . 33-38

2. Einfluss der Feuchtigkeit ......... . . $38-60$

3. Einfluss der Temperatur .......... . . 60-177

4. Einfluss des Lichtes ............. 177-184

5. Einfluss der Elektricität und des Magnetismus . . . 184-189

6. Einfluss der Nahrung und chemischer Stoffe . . . 190-228

7. Einfluss der mechanischen Reibung und der abrigen

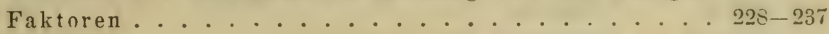

Zweites Kapitel. Die Grösse und die Gestalt der Insekten.

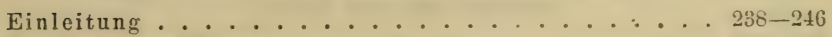

1. Einfluss des Klimas ............. 246-286

2. Einfluss der Feuchtigkeit .......... . 286-288

3. Einfluss der Temperatur . . . . . . . . . 288- 298

4. Einfluss des Lichtes .............. . . 298-299

5. Einfluss der Nahrung und chemischer Stoffe . . . 299-312

6. Einfluss des mechanischen Druckes, der Bakterien und anderer Faktoren ................... $312-313$

Drittes Kapitel. Die Farbung und Zeichnung der Insekten.

Einleitung ....................... 314-340

1. Einfluss des Klimas . . . . . . . . . . . . 340-364t

2. Einfluss der Feuchtigkeit . . . . . . . . . 364-372

3. Einfluss der Temperatur . . . . . . . . . . 372-471

4. Einfluss des Lichtes und der Farbe der Umgebung . . 471- 521

5. Einfluss der Elektricität . . . . . . . . . . . 522-524

6. Einfluss der Schwerkraft . . . . . . . . . 52t-527

7. Einfluss der Nahrung und chemischer Stoffe . . . 52

8. Einfluss der Schnürung und des mechanischen Druckes $581-566$ 


\section{Nachträge zum thatsächlichen Theil.}

Zur Entwickelungsgeschwindigkeit der Insekten.

Zur Einleitung

$567-570$

Zum Einflusse des Kilimas . . . . . . . . . . . 571-572

Zum Einflusse der Feuchtigkeit . . . . . . . . . . 572-574

Zum Einflusse der Temperatur . . . . . . . . . . 575-585

Zum Einflusse des Lichtes . . . . . . . . . . . . 585

Zum Einflusse der Elektricität und des Magnetismus . . . . . . 585

Zum Einflusse der Nahrung und chemisclier-Stoffe ..... . . . . 585-591

Zım Einflusse der mechanischen Reibung und der ubrigen Falitoren . 591-593

$\mathrm{Zu}$ der Grösse und der Gestalt der Insekten.

Zur Einleitung . . . . . . . . . . . . . 593-594

Zum Einflusse des Klinas . . . . . . . . . . . . 594-596

Zum Einflusse der Feuchtigkeit . . . . . . . . . 596

Zum Einflusse der Temperatur . . . . . . . . . . 596-597

Zum Einflusse der Nahrung und chemischer Stoffe . . . . . 597-598

Zu der Färbung und Zeichnung der Insekten.

Zum Einflusse der Feuchtigkeit

Zum Einflusse der Temperatur . . . . . . . . . . . . 598-599

Zum Einflusse des Lichtes und der Farbe der Umgebung . . . . . 599

Zum Einflusse der Elektricität : . . . . . . . . . . . 599

Zum Einflusse der Nahrung und chemischer Stoffe . . . . . . . 599-601

\section{Theoretischer Theil.}

Eistes Kapitel. Verallgemeinerungen und Theorien über den Einfluss der äusseren Faktoren auf die Entwickelungsgeschwindigkeit der Insekten.

1. Einfluss der Temperatur . . . . . . . . . 603-686

A. Einfluss konstanter hohen 'Temperaturen . . . . . . . 603-611

a) Eier. . . . . . . . . . . . . . . . 603--604

b) Raupen . . . . . . . . . . . . . 604-607

c) Puppen . . . . . . . . . . . . . . 607-609

d) Imago und alle Stadien . . . . . . . . . . . . . . 609-611

B. Einfluss konstauter niederen Temperaturen . . . . . . . 611-612

a) Eier ......................... 611

b) Raupen ......................... 611

c) Puppen . . . . . . . . . . . . . 611-612

C. Einfluss intermittierender Temperaturen ....... 6 612-633

a) Eier. . . . . . . . . . . . . . . . 612-614

b) Raupen ...................... 614-615

c) Puppen . . . . . . . . . . . . . 615-633

d) Imago und alle Stadien . . . . . . . . . . 633 
D. Temperatur-Grenzen für die Entwickelung und das Temperatur-

Optimum .................... 633-654

a) Eier. . . . . . . . . . . . . . 633-635

b) Raupen . . . . . . . . . . . . . 635-636

Einfluss hoher Temperaturen . . . . . . . . . 635

Einfluss tiefer Temperaturen . . . . . . . . . 636

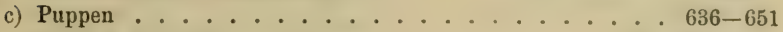

Einfluss hoher Temperaturen . . . . . . . 636-650

Einfluss tiefer Temperaturen . . . . . . . . . 650-651

d) Imago und alle Stadien . . . . . . . . . . . 651-654

E. Theorie des Einflusses der Temperatur. . . . . . . 654-686

Optimun . . . . . . . . . . . . 661-669

Vitale Temperatur-Grenzen . . . . . . . . . . . 669-684

Vitales Temperaturmaximum . . . . . . . . . 669-673

Vitales Temperaturminimum . . . . . . . . . 673-684

Anabiotischer Zustand . . . . . . . . . . 684-686

2. Einfluss der Feuchtigkeit . . . . . . 686-690

a) Eier . . . . . . . . . . . . . . . 686

b) Raupen . . . . . . . . . . . 686-687

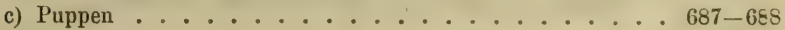

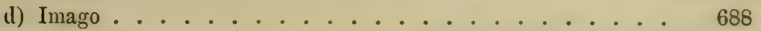

Theorien dieses Einflusses . . . . . . . . . 689-690

3. Einfluss des Lichtes .......... . 690-693

a) Eier. . . . . . . . . . . . . . 690-691

b) Raupen . . . . . . . . . . . . . . . . 691

c) Puppen . . . . . . . . . . . . . . . 691

d) Imago . . . . . . . . . . . . . . . . 691

Theorien dieses Einflusses . . . . . . . . . . . 692-693

4. Einfluss der Elektricität und des Magnetismus . . . 694-699

a) Eier . . . . . . . . . . . . . . . 694

b) Raupen . . . . . . . . . . . . . . . 694

c) Puppen . . . . . . . . . . . . . . . 694

Theorien dieses Einflusses . . . . . . . . . . 695-699

5. Einfluss der Nahrung und chemischer Stoffe . . . 699-730

A. Einfluss der natürlichen Nahrung . . . . . . . . 699-701

a) Raupen und Larven . . . . . . . . . . . 699-700

b) Imago . . . . . . . . . . . . . . . . 700-701

B. Einfluss der chemischen Stoffe . . . . . . . 701-i03

a) Eier. . . . . . . . . . . . . . . 701-702

b) Raupen und Larven . . . . . . . . . . . 702-703

c) Puppen . . . . . . . . . . . . . . 703

d) Imago . . . . . . . . . . . . . . . . . 703

C. Einfluss der Nahrung auf das Geschlecht und auf die Fortpflanzung . . . . . . . . . . . 704-705 
D. Theorien dieses Einflusses . . . . . . . . 705-730

1. Einfluss der natürlichen Nahrung . . . . . . . 705-719

2. Einfluss der chemischen Stoffe . . . . . . . . 719-723

3. Einfluss der Nahrung auf das Geschlecht und auf die Fortpflanzung . . . . . . . . 723-730

6. Einfluss des Klimas. . . . . . . . 730-748

a) Eier.................. . . . 730

b) Raupen ...................... 730

c) Puppen ........................ 731

d) Imago und alle Stadien . . . . . . . . . . 731-733

Theoric dieses Einflusses. . . . . . . . . . . . 733-748

7. Einfluss der Reibung und der übrigen Faktoren .. 748-753

a) Eier . . . . . . . . . . . . . . 748-749

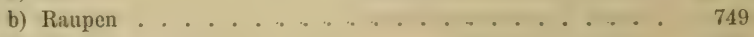

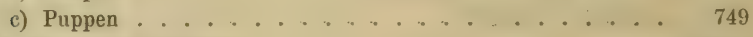

Theorien dieses Einflusses ............. . . 749-753

Zweites Kapitel. Verallgemeinerungen und Theorien über den Einfluss der äusseren Faktoren auf die Grösse und die Gestalt der Insekten.

1. Einfluss der Temperatur . . . . . . . . . . 754-762

A. Verallgemeinerungen ............ . 754-755

B. Theorien und Hypothesen dieses Einflusses . . . . . . . 755-762

2. Einfluss der Feuchtigkeit . . . . . . . . . 762-763

Theorie dieses Einflusses ............ 763

3. Einfluss des Lichtes . . . . . . . . . . : 763-765

Theorien dieses Einflusses ........... . . 763-765

4. Einfluss der Nahrung und chemischer Stoffe . . . 765-768

Theorien dieses Einflusses . . . . . . . . . . . 766-768

5. Einfluss des Klimas ............. . . 769-776

Theorien dieses Einflusses ............ 770-776

Drittes Kapitel. Verallgemeinerungen und Theorien über den Einfluss der ăusseren Faktoren auf die Fărbung und Zeichnung der Insekten.

1. Einfluss der Temperatur . . . . . . . . . ....... 777-853

A. Zusammenstellung der Thatsachen . . . . . . 777-782

a) Einfluss konstanter ho'en Temperaturen ....... . 777-779

b) Einfluss konstanter niederen Temperaturen ...... 779-781

c) Einfluss der intermittierenden Temperaturen ....... 781-782

1. 'Temperaturen höher als die mittlere.. ......... 781

2. Temperaturen tiofer als die mittlere ....... 782

B. Verallgemeinerungen des Eintlusses jeder Temperaturart . . 783-789 
pagr.

C. Theorien dieses Einflusses ............ . 789

a) Historische Uebersicht dieser Theorien . . . . . . . 789-822

1. Die Theorie von August Weismann . . . . . . . . . 789-794

2. Die Theoric von Friedrich Urech . . . . . . . . 794-801

3. Die Theorie von Max Standfuss . . . . . . . . . . 801-804

4. Die Theorie von Emil Fischer . . . . . . . . . . 8n4-809

5. Die Theorie von M. C. Piepers ....... . . 809-814

6. Die Theorie von Chr. Schroder . . . . . . . 814-816

7. Die Theorie von Gräfin M. von Linden . . . . . 816-819

8. Die Theorie von Harry Federley ....... 819-822

b) Zusammenstellung dieser Theorien und die Prüfung ihrer

Consequenzen ............. . 822-853

2. Einfluss der Feuchtigkeit . . . . . . . . . 853-858

a) Einfluss der Trockenheit ........... . . 853

b) Einfluss der Feuchtigkeit .......... 853-854

c) Der vermischte Einfluss der Feuchtigkeit und Trockenheit 854-855

d) Theorie dieses Einflusses . . . . . . . . . 855-858

3. Einfluss des Lichtes und der Farbe der Umgebung . . 858-867

A. Einfluss des Lichtes auf die künftige Färbung des Imagos . . 858-859

B. Anpassung an die Farbe der Umgebung . . . . . . . . 859-860

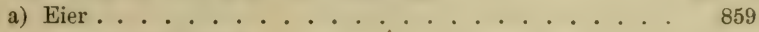

b) Raupen und Larven .................. 859

c) Puppen . . . . . . . . . . . . . . . 859-860

d) Imago . . . . . . . . . . . . . . . 860

C. Theorien dieses Einflusses . . . . . . . . . . . 860-867

4. Einfluss der Elektricität ............. . . 867-870

Die Theorie dieses Einflusses . . . . . . . . . . . 868-870

5. Einfluss der Nahrung und chemischer Stoffe . . . 870-896

A. Einfluss der natürlichen Nahrung . . . . . . . . 870-877

a) Imago .................. . . . 870-873

b) Raupen ........................ 873-877

B. Einfluss der künstlichen Nahrung ........... . 878-880

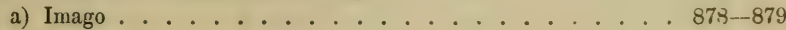

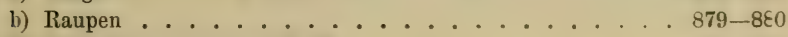

C. Einfluss der umgebenden Stoffe ............ . $880-881$

D. Theorien dieses Einflusses . . . . . . . . . . . . 881-896

1. Theorien über den Einfluss der Athemgase . . . . . . 882-883

2. Theorien über den Einfluss der Nahrung . . . . . . . 883-886

3. Die Prüfung dieser Theorien . . . . . . . . . $886-896$

6. Einfluss des Klimas. . . . . . . . . . . . . . $896-918$

Theorien dieses Einflusses . . . . . . . . . . . . 898-918

7. Einfluss der Schwerkraft und der mechanischen Erschüt terung en

Theorien dieses Einflusses 
8. Einfluss der Schnürung und des mechanischen Druckes 921-923 Theorien dieses Einflusses . . . . . . . . . 9 921-923

Viertes Kapitel. Ueber die Ursachen des Entstehens von aberrativen Formen in der Natur.

1. Der Begriff der aberrativen Formen . . . . . . . . . . . 924-929

2. Die Ansichten rerschiedener Forscher über das Entstehen von aberrativen Formen in der freien Natur . . . . . . . . 929-931

3. Consequenzen aus dem Gesammtmaterial der experimentellen Entomologie über diese Frage ............. 931-938

Nachträge zum theoretischen Theil . . . . . . . . . . 939-944

Litteratur-Verzeichniss ................. I-LXXX

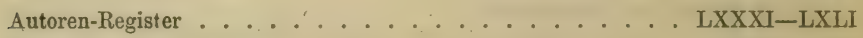
Verzeichniss der Gattungen .............. LXLII-CIII Berichtigungen ................ CIV-CVIII 


\title{
Tr. Ka.
}

\author{
ERSTES KAPITEL.
}

\section{Die Entwickelungsgesehwindigkoit dos Insekten.}

\section{Einleitung.}

1

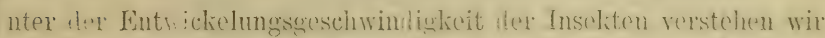

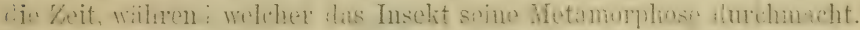

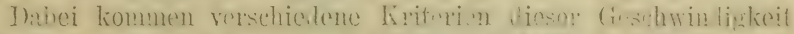

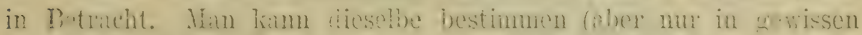

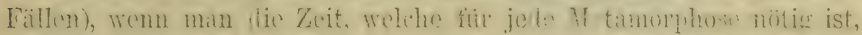

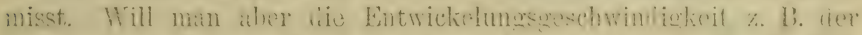

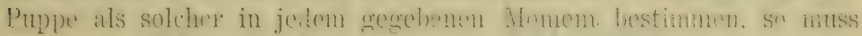

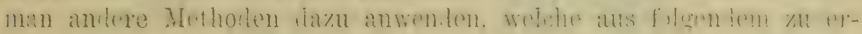
sehen sind.

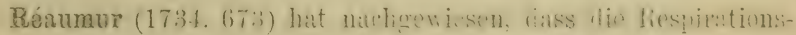

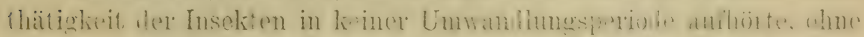

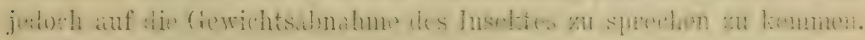

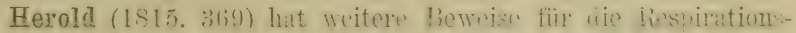

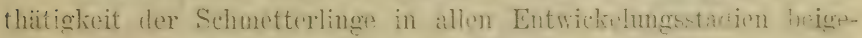

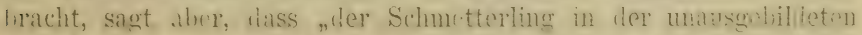
(iestalt als Puppe an Masse seinem vollkommum entwichitern Zustancle völlig gleich sei" (p. 52).

Der erste, welcher olwohl anf intirelitem Wege, tine (iewichtsabnahme der Schmetterlingspuy len knstatierte, war Rengger (1s17.

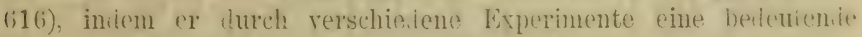
Wasserver(lunstung derselben feststellte.

Bei Rennie (1836. (ist) ist rrwathnt, ditss male Salisbury tio

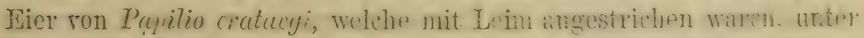

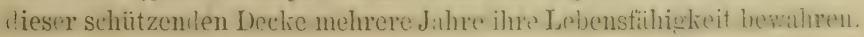

Bachmet jow, Studien. II. 
Direkte Gewichtsbestimmungen an Insekten hat zum ersten Mal Newport (1837. 621) angestellt mit folgenden Resultaten:

1. Eine Riupe von Spllinx ligustri wog, auf dem höchsten Punkte der Entwickelung angelangt,

29. August 1834. . . . 141,4 Gran,

kurz vor der Verpuppung

31. August 1834. . . . . 110,4 Gran,

und nach der Verpuppung mitsamt ier abgestreiften Haut

4. September 1834. . . . 83,2 Gran.

2. Eine zweite Raupe derselben Species wog, in der Umwancllung begriffen,
8. August 1834. . $3^{\text {h }} 30^{\prime}$ N. 92,1 Gran,
8. " $"$. . $6^{\mathrm{h}} 30^{\prime} " 91,7$ "
8. " " . $10^{\mathrm{h}} 30^{\prime}, \quad 90,0$ "
9. $"$ n . . $7^{\mathrm{h}} 30^{\prime}$ V. 88,7 , n
9. " . . $11^{\mathrm{h}} 30^{\prime}, 80,3$ "

3. Fine dritte Raupe derselben Species wog:

14. August 1835. . . . 118,2 Gran,

15.

und die Puppe

20. August 1835. . . . 71,1 Gran,

3. April 1836. . . . . 67,4

und der Schmetterling

24. Mai 1836. . . . . 36,0 Gran,

25.

4. Es wurden auch einige Versuche mit Cerula vinula und mit hungernden Raupen angestellt. Alle diese Versuche führten Newport zu dem Schlusse, dass die Gewichtsabnahme des vollkommenen Insektes intensiver als die der ausgewachsenen Raupe, und die der ausgewachsenen und sich verwandelnden Raupe intensiver als die der Puppe sei.

Indem er die Frequenz der Pulsschläge und der Respiration res Insektes bestimmte, konnte er, gestützt auf den Gewichtsverlust, welchen das Thier in dieser Zeitperiode erlitt, konstatieren, dass $z$ wischen der Intensität der Gewichtsabnahme und der Stärke der Lebensthätigkeit eine direkte Proportionalität existiert.

Ausserlem zog er aus den Beobachtungen an Sylhinx ligustri den Schluss, dass, wenn die Umwandlung in der inneren Structur der Puppe nahezu vollendet, und das vollkommene Inselit im Begriff 
sei, auszuschlüpfen, die Respirations- und ganze Lebensthätigkeit der Puppe ihr Maximum erreicht (1839. 610).

Regnault und Reiset (1849. 678) stellten Versuche mit Raupen und Puppen an und haben gefunden, dass bei diesen, wie auch bei den übrigen Thieren, mehr Sauerstoff aus der Luft aufgenommen, als vermittelst der Kohlensäure wieler ausgeschieden wird, z. B.:

dass 42,5 Gran ausgewachsener Seidenraupen in $5 \frac{1}{2}$ Stunden 0,202 gr. Sauerstoff aufnahmen und

0,220 "Kohlensäure, mithin

0,160, Sauerstoff ausschieden.

Die entsprechenden Zahlen waren bei einem anderen Experimente mit

39,0 gr. ausgewachsener Seidenraupen in $75 / 6$ Stunden

$$
\begin{aligned}
& 0,201 \text { gr. } \\
& 0,225 ~ " \\
& 0,163
\end{aligned}
$$

Dieser Umstand erklärt sich, wie wir später sehen werden, dadurch, lass ein Theil des Sauerstoffs sich mit dem Wasserstoff des Insektes $\mathrm{zu}$ Wasser verbindet.

Cornalia (1856. 153) hat Gewichtsbestimmungen an der Raupe, der Puppe und dem Schmetterling des Seidenwurms angestellt und erhielt folgende Werthe:

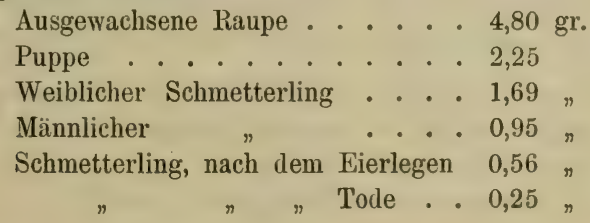

Siebold (1856. 812) beobachtete, dass die Räupchen, welche aus unbefruchteten Eiern vın Bomling mori sich entwickelten, eine längere Entwickelungsz it im Ei hatten, als die normalen: ausserdem konnten sie nicht immer die Eierschale durchbrechen.

D. Hermann und Leonard Landois (1865. 368) haben histologische Untersuchungen an Smerinthus populi u. Phitirius inguinalis angestellt und sind $\mathrm{zu}$ folgenden Resultaten gelangt:

Im centralen Nervensystem der Insekten kommen folgende Elemente vor: grosse und kleine gangliäre und multipolare Zellen. 
In den ersten Tagen des Larvenlebens vermindert sich lie Griises di.i grossen Nervenzellen, worauf sie nach 8 Thgen zuminnt und an Esits: des Larvenlehens konstant bleibt. Diese Alnahme iler Grizs: l.r. Kellen steht in Verbindung mit der Zunahme ihrer Anzahl. Wilnrom

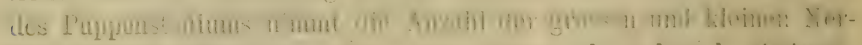
venzellen berleutenıl zu, wobei ihre Grösse sehr schwach ahiumut.

Was nun die Blutkörperehen hor Inseliten anbelangt, so aimmt ihre Anzahl bei der Larve stets zu un l prreicht ein Maximum rof

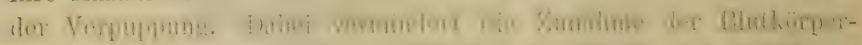
chen ihre Dimensionen unt zwar hauptsïchlich in deri ersten Tag.m des Raupenlebens, später aber nehmen diese Dimensionen zu. bir.

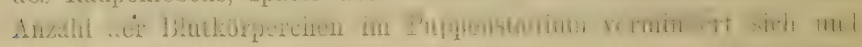
wirk noch geringer bei der Imago.

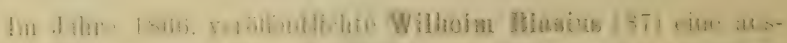

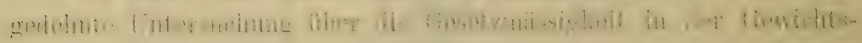
abnalme der Lepidopteren von dem Zustanio der ausgewachren th

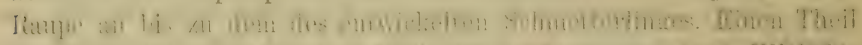

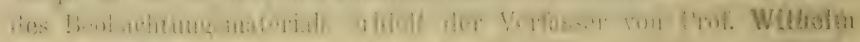

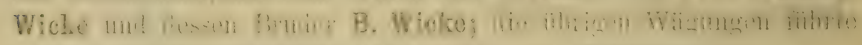

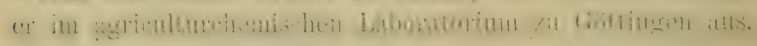

Er gelangte zu folgenden linsultaten:

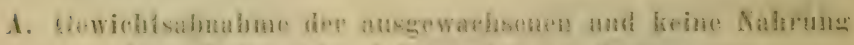

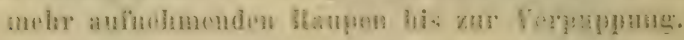

1) einzige Versuchsreihe wude mit 10 Raupen ron Tormas urticue erhalten, welche vor kurzem clas Spinngeschäft becmigt an haben schienen. Im Laufe des Tages (1. August 1865.) wurle fulgencle Reihe von Gewichtsbestimmungen angestellt:

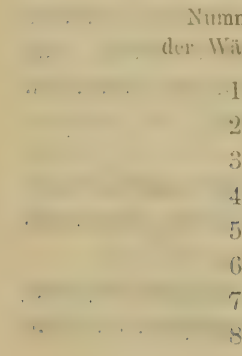

Siummer (1.). Wigung.

Zvit.

Gewicht von

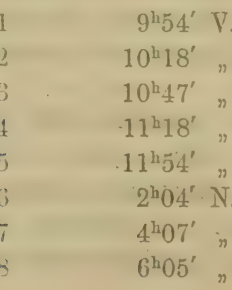

10 Raupen + Uhrglas.

10,0246 gr.

10,0220

10,0180 "

10,0141

10,0070

9,9920

9,9790 n

9,9585 
Daraus lässt sich berechnen:

\begin{tabular}{|c|c|c|c|}
\hline $\begin{array}{l}\text { Grenz n the inter- } \\
\text { valls in Nummern } \\
\text { der Beobachtmmgen }\end{array}$ & $\begin{array}{l}\text { 7. nitllume in } \\
\text { Stunden }\end{array}$ & $\begin{array}{l}\text { (inditiolu-t } \\
\text { in } \mathrm{mgr} \text {. }\end{array}$ & 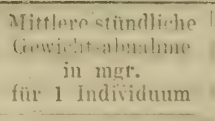 \\
\hline $1-2$ & 0,40 & 2,6 & 0,650 \\
\hline $2-3$ & 0,48 & 4,0 & 0,833 \\
\hline $3-4$ & 0,52 & 3,9 & 0,750 \\
\hline $4-5$ & 0,60 & 7,1 & 1,183 \\
\hline $5-6$ & 2,13 & 15,0 & 0,704 \\
\hline $6-7$ & 2,05 & 13,0 & 0,634 \\
\hline
\end{tabular}

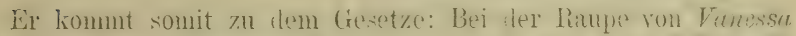
urtiene, dite zur vollstiindigen tumantlung ans dem ausqewachsenen

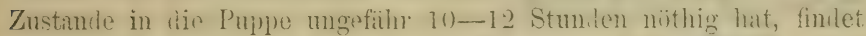
von dem Angenblicke an, wo sie das Snimngeschät heentigte, in den

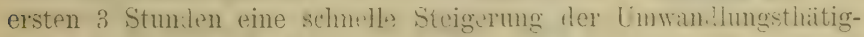
lieit statt. In dere 2. Hälite der a simmen erreicht die letatere iln

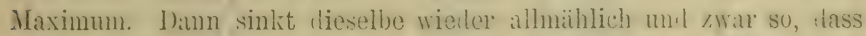
sie im Anfing der s. Stmule so stark als in der 1 . Hailfte dir 3. Stunile ist.

\section{B. Gewichtsverhust bei der Verpuppung.}

10 Raupen von Vanessa uticae, welche im Versuche $A$ gedlient haben.

Nummer. der Wägung.

Zeit.

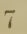

8

9

-

7

\section{August}

1. n

$2 . n$
Gewicht von 10 Raupen resp. Pappen + Uhrglas.

Daraus lässt sich berechnen:

\begin{tabular}{|c|c|c|c|}
\hline $\begin{array}{l}\text { Grenzen des Inter- } \\
\text { valls in Vimmentin } \\
\text { der Beobachtungenl }\end{array}$ & $\begin{array}{l}\text { Zeitiduer in } \\
\text { Stumden }\end{array}$ & $\begin{array}{c}\text { Gewiolitsrerlust } \\
\text { in mgr. }\end{array}$ & $\begin{array}{l}\text { Mlittlere stündliche } \\
\text { fewichtsalmalnue } \\
\text { in myr. } \\
\text { für I Individuum }\end{array}$ \\
\hline $7-8$ & 1,97 & 20,5 & 1,041 \\
\hline $8-9$ & 16,83 & 115,0 & 0,683 \\
\hline
\end{tabular}

Daraus ist ersichtlich, dass die Gewichtsabmahne der l'uppen eine riel geringere ist, als die ter Rampe. Dabei muss noch folgendes bemerkt werden: 
Zunächst finclet eine Reihe von peristaltischen Bewegungen statt, um die letzte Raupenhaut abzustreifen. Die Muskelthätigkeit des Thieres ist dabei aufs Höchste in Anspruch genommen, so dass hierdurch der Gewichtsverlust beteutenıl vergrössert wird. Nach Abstreifung der Haut, ist sowohl die feuchte Puppenhïlle als die abgestreifte Raupenhaut dem Vertrocknen ausgesetzt.

\section{Gevichtsabnahme der Puppen.}

Die hierher gehörenden Wägungen wurden mit zahlreichen Pupppen von Vanessa urticae und jo angestellt.

Hier mag nur eine Beobachtung als Beispiel angefilhrt werden. Die erste Wägung der Puppe von $V$. jo geschah am 3. Tage nach der Verpuppung und die letzte ungefihtr 18 Stunden vor dem Auskommen des Schmetterlinges.

\begin{tabular}{|c|c|c|c|c|}
\hline $\begin{array}{l}\text { Nummer } \\
\text { der Wägung. }\end{array}$ & & eit. & Gewicht der & Puppe. \\
\hline 1 & 27. Juni & $11^{\mathrm{h}} 10^{\prime} \mathrm{V}$ & 0,47810 & gr. \\
\hline 2 & 28. & $11^{\mathrm{h}} 30^{\prime}$ & 0,47540 & $n$ \\
\hline 3 & 29. & $11^{\mathrm{h}} 33^{\prime}$ & 0,47340 & $n$ \\
\hline 4 & 30. & $9^{\mathrm{h}} 35^{\prime}$ & 0,47100 & ” \\
\hline 5 & 30. & $11^{\mathrm{h}} 27^{\prime}$ & 0,47060 & $"$ \\
\hline 6 & 1. Juli & $10^{\mathrm{h}} 32^{\prime}$ & 0,46750 & $"$ \\
\hline 7 & 1. $n$ & $4^{\mathrm{h}} 45^{\prime}$ iN & 0,46670 & $n$ \\
\hline 8 & 2. & $12^{\mathrm{h}} 01^{\prime} \mathrm{V}$ & 0,46410 & $\pi$ \\
\hline 9 & 3. $n$ & $4^{\mathrm{b}} 49^{\prime} \mathrm{N}$ & 0,46060 & $"$ \\
\hline 10 & 4. " & $11^{\mathrm{h}} 24^{\prime} \mathrm{V}$ & 0,45850 & $n$ \\
\hline 11 & 5. $\pi$ & $10^{\mathrm{b}} 32^{\prime}$ & 0,45500 & $n$ \\
\hline 12 & 5. & $4^{\mathrm{h}} 31^{\prime} \mathrm{N}$ & 0,45380 & $n$ \\
\hline 13 & 6. & $4^{\mathrm{h}} 20^{\prime}$, & 0,44860 & $n$ \\
\hline 14 & 7. & $2^{\mathrm{b}} 46^{\prime}$ & 0,44060 & $n$ \\
\hline
\end{tabular}

Daraus lässt sich berechnen:

\begin{tabular}{|c|c|c|c|}
\hline $\begin{array}{c}\text { Grenzen des Inter- } \\
\text { valls in Numnern } \\
\text { der Beobachtungen }\end{array}$ & $\begin{array}{c}\text { Zeitdauer } \\
\text { in Stuuden }\end{array}$ & $\begin{array}{c}\text { Nittlere stundliche } \\
\text { Gewichtsabnahme } \\
\text { in mgr. }\end{array}$ & $\begin{array}{c}\text { Alter der Puppe } \\
\text { in Tagen }\end{array}$ \\
\hline $1-2$ & 24,33 & 0,111 & 4 \\
$2-3$ & 24,05 & 0,083 & 5 \\
$3-4$ & 22,43 & 0,107 & 6 \\
$4-5$ & 1,47 & 0,272 & 6 \\
$5-6$ & 23,09 & 0,135 & 7 \\
$6-7$ & 6,22 & 0,129 & 7 \\
\hline
\end{tabular}




\begin{tabular}{|c|c|c|c|}
\hline $\begin{array}{c}\text { Grenzen des Inter- } \\
\text { valls in Nummern } \\
\text { der Beobachtungen }\end{array}$ & $\begin{array}{c}\text { Zeitdauer } \\
\text { in Stunden }\end{array}$ & $\begin{array}{c}\text { Mittlere stundliche } \\
\text { Gewichtsibnahme } \\
\text { in mgr. }\end{array}$ & $\begin{array}{c}\text { Alter der Puppe } \\
\text { in Tiagen }\end{array}$ \\
\hline $7-8$ & 19,26 & 0,135 & 8 \\
$8-9$ & 28,80 & 0,122 & 9 \\
$9-10$ & 18,58 & 0,113 & 10 \\
$10-11$ & 23,14 & 0,151 & 11 \\
$11-12$ & 5,98 & 0,201 & 11 \\
$12-13$ & 23,82 & 0,218 & 12 \\
$13-14$ & 22,43 & 0,357 & 13 \\
\hline
\end{tabular}

Die Schlüsse, die man aus der Gewichtsabnahme während des Puppenzustandes auf die innere Entwickelung der Puppen von $V a$ nessa urticae und Vanessa jo ziehen kann, insofern dieselbe ununterbrochen und durch eine im Ganzen gleichmässig warme Witterung begïnstigt vor sich geht, lassen sich nach Blasius wie folgt aussprechen:

Die Umwandlungsthätigkeit ist während des ersten Viertels des Puppenzustandes eine verhältnissmässig bedeutende. Sie ist jetloch vom ersten Augenblick an in Sinken begriffen und sinkt schnell, aber nicht plötzlich. Sie erreicht im zweiten Viertel des Puppenzustandes ihr Minimum; von da an nimmt sie während des dritten Viertels allmählich wieler zu, wobei jedoch durch die Verhältnisse ein deutliches Schwanken leicht bewirkt werden kann. Im letzten Viertel findet eine schnelle und in den letzten Tagen eine bisweilen plötzliche Zunahme der Entwickelungsthätigkeit statt. Dieselbe gelangt in den letzten Stunilen vor dem Auskommen des Schmetterlinges allerdings auf die höchste Höhe, wobei sie jedloch für gewöhnlich keine Dimensionen annimmt, welche von denen der letzten Tagen des Puppenzustandes ïberhaupt unverhältnissmässig verschieden sincl.

Über den Einfluss der Nacht sagt ier Verfasser: „Jedenfalls wirl man von einem hindernden Einflusse eines etwaigen Schlafes in der Nacht nicht reden können, wenngleich auf der anderen Seite ein Einfluss der nächtlichen Abkiihlung der Luft sehr wahrscheinlich ist" (p. 161 und 162).

\section{Gewichtsabnahme des Schmetterlinges von dem Augenblick $\theta$ an, wo er seine Hülle durehbricht.}

Hier sei nur eine Tabelle als Beispiel angetïhrt. Vunessu jo entleerte sehr bald (innerhalb 2 Stunden) nach dem Ausschlipfen eine grosse Menge Koth und zwar vollständig. 


\begin{tabular}{|c|c|c|c|c|c|}
\hline $\begin{array}{c}\text { Nummer } \\
\text { der } \\
\text { Benbachtung }\end{array}$ & & & e i t & $\begin{array}{c}\text { Gewicht des } \\
\text { Schmetterlinges }\end{array}$ & $\begin{array}{l}\text { Mittlere } \\
\text { stumdliche Ge- } \\
\text { wichtsabnahme } \\
\text { in mgr. }\end{array}$ \\
\hline 1 & 8. & Juli & $10^{\prime \prime} 15^{\prime} \mathrm{V}$ & \multicolumn{2}{|c|}{ Ausgekrochen } \\
\hline 2 & 8. & & $2^{\mathrm{h}} 35^{-\prime} \mathrm{N}$. & $0,2281 \mathrm{gl}$. & - \\
\hline 3 & 8. & & $2^{h} 5_{5}^{\prime}$ & 0,2271 & 3,00 \\
\hline 4 & 9. & & $9^{\mathrm{h}} 00^{\prime} \mathrm{V}$ & 0,2116 & 0,86 \\
\hline i) & 10. & $"$ & $10^{\mathrm{l}} 06^{\prime}$ & 0,3834 & 1,14 \\
\hline (j) & 10. & & $4^{\ln } 20^{\prime} \mathrm{N}$. & 0,1761 & 1,12 \\
\hline 7 & 12. & & $10^{\mathrm{h}} 45^{\prime} \mathrm{V}$ & $0,1592 n$ & $(0,40$ \\
\hline
\end{tabular}

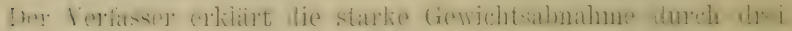

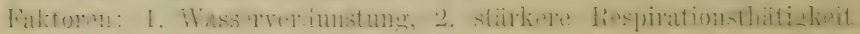
und 3. Aussonilerung der harnartigen Substanz.

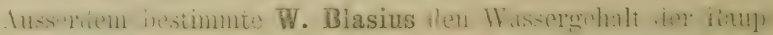

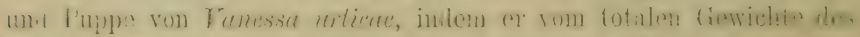

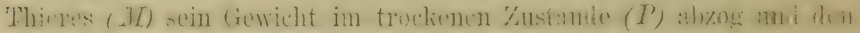

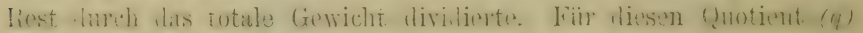
erhielt er folgende Werthe:

\begin{tabular}{|c|c|c|c|c|}
\hline Studium & $\mathrm{Z}$ e i $\mathrm{t}$ & $\begin{array}{c}.11 \\
m e 1\end{array}$ & $\begin{array}{c}I^{\prime} \\
\text { mer. }\end{array}$ & $\frac{M-I}{u}=1$ \\
\hline i Raupe & In der Umwandlung hegriffen . . . & $3(12,1$ & 81,0 & 77,63 \\
\hline 1 l'upue & Melnere Tage nach der Verpuppung & 265,5 & 59,0 & 77,779 \\
\hline 1 P'uppe & Mehrere T'age nach der Verpupumug & 252,5 & 56,5 & $77,62.4$ \\
\hline 1 Puppe & 1: Stunde nach der Verpuppung . & 2940 & 70,0 & 76,190 \\
\hline 2 Pирреn & $3^{3}$, Tage alt .......... & 520,5 & 121,3 & 76,695 \\
\hline 2 l'uppen $^{\prime}$ & $6^{1}$ Tage alt .... & 481,5 & 108,8 & $7 \pi, 404$ \\
\hline 1 P'ире & 11 'lage alt (kurz vor d. Ausschl.) & 212,5 & 46,5 & 78,118 \\
\hline
\end{tabular}

Daraus schliesst der Verfasser, obwohl reserviert, "lass clas

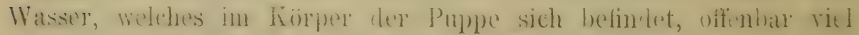
weniger intensir anmimmt als ai - fosten 'Theile, solange die Aus tins-

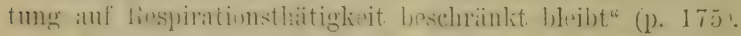

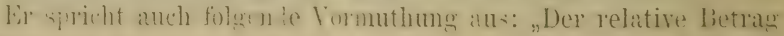

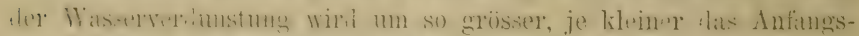

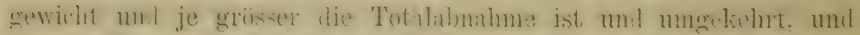
zwatr thägt eine Verkleinerung der Thatlatmalne jo mal mehr zur l'enklemerung tes relativen beitrages der Witserverilunstung bei, als rinc V'rrgrösserung des Anfangsgererichtes" (p). 176). Dies ist aber nur möglich, wenn der Wrassergehait in der That kurz nach der 


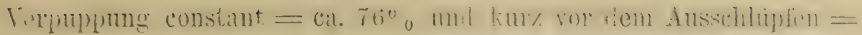
ca. $78 \%$ ist.

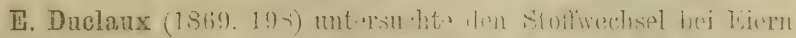

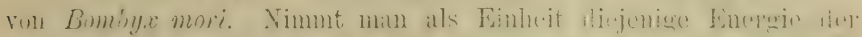

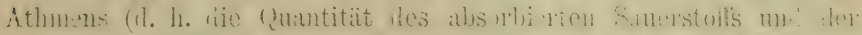

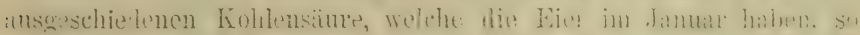

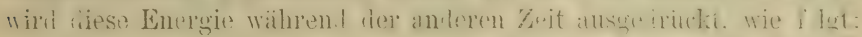

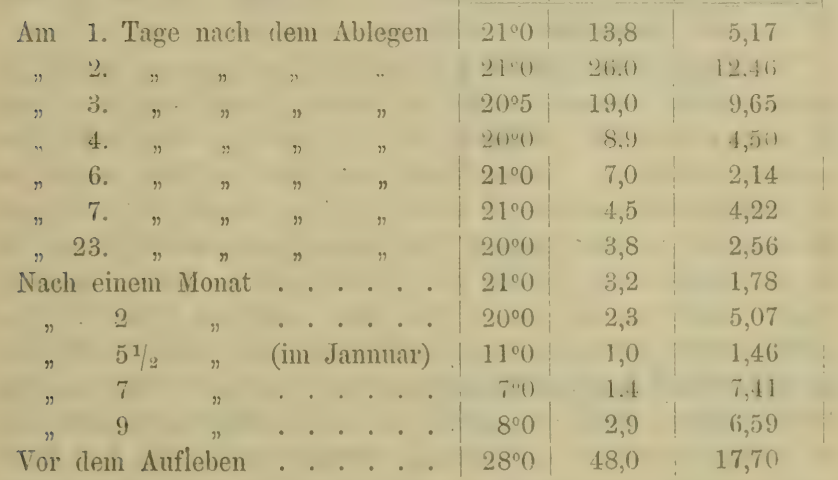

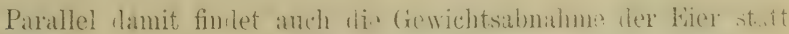
und zwar:

1 Monat nach rem Ablewen virlieren die Fier 20 ihres Gewichtes 2

Während der folgenten 6 Mon. verlieren clie Eier $1 \%$

Im Monate des Auflebens verlieren die Eier $9 \%$ " . "

Summe $13 \%$

0. von Linstow (1869. 528) bestimmte die 711- mil Almilnm.

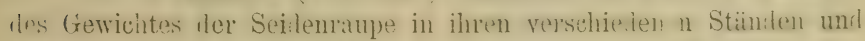

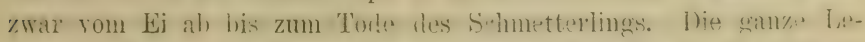
benszeit danerte 71 'lage. Ex construiorte cine Cirre, heren hori-

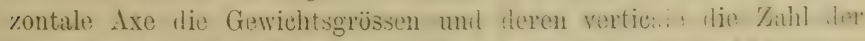

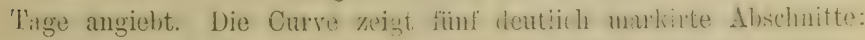

1. Die Periode, welche das Thier im Ei verluningt; eine fast horizontale Linie.

2. Die steil aufsteigenile liaupenperioile. 
3. Die steil abfallende Einspinnungsperiode.

4. Die schwach abfallende Schmetterlingsperiode.

Dabei macht er folgende Bemerkungen:

1. Über die Zeit, während welcher die Embryonalentwicklung in Ei vor sich geht, lie ich im Mittel als 22 Tage lauernd angenommen habe, liegen mir keine Beobachtungen bezuiglich einer Gewichtsverïnilerung vor; ein Stoffivechsel wirl jedenfalls statthaben, wenn er auch noch so wenig lebhaft ist; wenigstens ist bekannt, dass der Embryo im Vogelei eine relativ grosse Menge Sauerstoff durch die Schale ein- und Kohlensïure ausathmet; das Gewicht eines Ei's ist nach Haberlandt $0,00065 \mathrm{gr}$.

2. Das Gewicht einer eben ausgeschliipften Raupe ist 0,00059 gr., das iler leeren Eischale 0,00006 gr. Nach 4 Tagen hïutet die Raupe sich zum ersten Mal; sie wiegt 0,005 gr. und (ler abgestreifte Raupenbalg 0,00006 gr. Diese Zahlen sinı noch zu klein, um sie auf ler Tafel deutlich machen zu können; 4 Tage darauf tritt dit: zweite Häutung ein, wo dlass Gewicht der Raupe bereits auf $0,023 \mathrm{gr}$. und das des Balges auf 0,00018 gr. gestiegen ist. - Nach 5 weiteren Tagen häutet sie sich zum iritten Male, wobei sie schon $0,119 \mathrm{gr}$. und ihr Balg 0,00085 gr. wiegt, welches Gewicht relativ betrïchtlich bei der vierten Hüutung zugenommen hat, die am 5 . Tage nach der dritten eintritt, wo die Raupe $0,57 \mathrm{gr}$. und ler Balg $0,00352 \mathrm{gr}$. wiegt.

Einige \%eit vor den Hüutungeu nehmen die Raupen kein Futter zu sich, welche Zeit sich immer durch eine geringe Gewichtsabnahme bemerkbar macht. - Ganz ausnehmend gross ist nun die Zunahne zwischen der letzten Häutung und der Einspinnung, wo das Gewicht auf 3,22 gr. steigt. - Von nun an ist das Körpergewiclit beständig im Sinken, las in drei Perioden geschieht.

3. Die Zeit, in der die Raupe sich einspinnt, ist durch ein iuberaus steiles Abfallen die Curve gekennzeichnet, was wohl hauptsächlich auf Riechnung eines grossen Wasserverlustes $z u$ schreiben ist, da die Fäden des Gespinnstes feucht aus den Serikterien herauskontmen und an der Luft erhärten.

4. Die Puppendauer zeigt ein weit langsameres Sinken, welches durch die Respiration und Perspiration bemerkt wirl: am Ende derselben wiegt die Puppe mit Gespinnst 1,63 gr.

5. Die Schmetterlingszeit zeigt wieller ein selır jühes Abfallen; der ausgeschlipfte Schmetterling wiegt 1,3 gr., nach der Copula und dem Eierlegen nur noch $0,65 \mathrm{gr}$. und nach dem bald darauf erfolgten 'Tode $0,25 \mathrm{gr}$. 
Der Gewichtverlust der Eier von Bombyx mori während ihrer Gebriitung wurde in der Seidenbau-Versuchstation zu Görz bestimmt (1872. 968). Zu diesem Zwecke wurlen gleiche Menge Grains (je 6 gr.) einer grïn- und gelbspinnenden Seidenspinnersorte genommen. Die Bebriitung der Eier wurde künstlich im Brutapparat vorgenommen; die Wägung geschah am 5. und 10. Tage und hierauf täglich bis zum Erscheinen der ersten Räupchen. Folgende Tabelle enthält die erhaltenen Resultate:

\begin{tabular}{|c|c|c|c|}
\hline $\begin{array}{c}\text { Dauer } \\
\text { der Bebrütung }\end{array}$ & $\begin{array}{c}\text { Dargebotene } \\
\text { Wärmesumme }\end{array}$ & \multicolumn{2}{|c|}{$\begin{array}{c}\text { Gewichtsverlust in Proztnten des } \\
\text { anfänglichen Gewichtes }\end{array}$} \\
\cline { 3 - 4 } & Eier der Grünspinner & Eier der Gelbspinner \\
\hline 5 Tage & 75 & 1,4 & 1,2 \\
10 & 159 & 5,7 & 4,6 \\
11 & 177 & 6,4 & 5,4 \\
12 & 196 & 7,2 & 6,2 \\
13 & 216 & 8,3 & 7,1 \\
14 & 236 & - & 8,2 \\
\hline
\end{tabular}

Der anfänglich geringe, per Tag nur $0,2-0,3$ Perzent betragende Gewichtsverlust der Eier nimmt, wie man sieht, im Verlaufe der Bebrïtung fortwährend $\mathrm{zu}$ und steigt am Tage des Erscheinens ler ersten Räupchen bis über 1 Prozent. In Ganzen ist die Gewichtsverminderung sowohl der Eier der Grün- wie der Gelbspinner eine gleichförmige und beträgt bei beilerlei Eiern 8 Perzent. Der Verlust wird wohl grösstentheils durch die Verdunstung des wässerigen Inhaltes herbeigeführt, ist indessen gewiss auch eine Folge der Respirationsthätigkeit der Eier, welche während der Dauer ihrer Bebrütung eine lebhafte Steigerung erfuhr.

E. Verson und E. Quajat (1876. 923) fanden, dass $1 \mathrm{Ko}$. Raupen von Bombyx mori folgende Quantitiit Wasser und Kohlensäure beim Athmen abgaben:

\begin{tabular}{|c|c|c|c|}
\hline A $1 \mathrm{t}$ e $\mathrm{r}$ & $\begin{array}{l}\text { T'empe- } \\
\text { ratur }\end{array}$ & $\mathrm{CO}_{2} \mathrm{gr}$. & $\mathrm{H}_{2} \mathrm{O} \mathrm{gr}$. \\
\hline Nach der 3. Häutung & $22^{\circ}$ & 0,7381 & 7,7751 \\
\hline Bei der 4. Häutung . . . . . . & $22^{\circ}$ & 0,6058 & 6,9255 \\
\hline Im 4. Häutung . . . . . . . . & $18^{\circ}$ & 0,745 & 6,0299 \\
\hline Bèi der 4. vollendeten Häıtung . & $18^{\circ}$ & 0,8256 & 2,9933 \\
\hline
\end{tabular}




\begin{tabular}{|c|c|c|c|c|c|c|c|}
\hline$A l t e r$ & & & & & $\begin{array}{l}\text { Tempe- } \\
\text { ratur }\end{array}$ & $\mathrm{CO}_{2} \mathrm{gr}$. & $H_{3}(\mathrm{gr}$. \\
\hline Anlune lis i. Allers. & & ${ }^{\circ}$ & & & 15 & $(t, f, t): 1$, & 2,1377 \\
\hline Irilhrenil des 5. Alters & . & . & 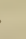 & . & $15^{\circ}$ & 0,2678 & 1,5845 \\
\hline Ende iles 5. Alter's. & & . & • & . & $15^{\circ}$ & 0,1995 & $1,58 \overline{54}$ \\
\hline Vor dem Einspinnen. & . & - & 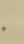 & . & $17^{\circ}$ & 0,4226 & 8,7593 \\
\hline
\end{tabular}

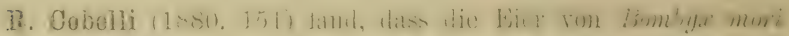

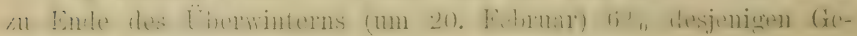
wichtes verlieren, welches sie beim Ablegen hatten.

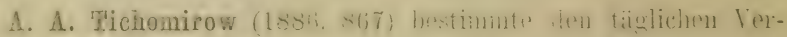

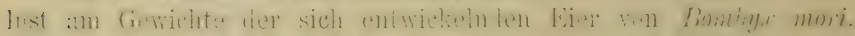

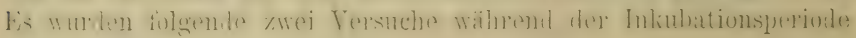
angestellt:

\begin{tabular}{|c|c|c|c|c|}
\hline T'age. & J)as absolute & Gewicht. & Der tägliche $V$ & Verlust. \\
\hline 1 & 1,0388 & $\mathrm{gl}$. & - & \\
\hline 8 & 1,0029 & $n$ & $0,0359: 7$ & gr. \\
\hline 9 & 0,9952 & $n$ & 0,0077 & $n$ \\
\hline 11 & 0,9624 & $"$ & $0,0328: 2$ & 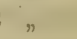 \\
\hline 12 & 0,9428 & $"$ & 0,0196 & ” \\
\hline 13 & 0,9229 & $n$ & 0,0199 & $n$ \\
\hline
\end{tabular}

\begin{tabular}{|c|c|c|}
\hline Tage. & Das absolute Gewiclit. & Der tägliche Verius \\
\hline 1 & $0,6854 \mathrm{gr}$. & - \\
\hline 3 & $0,6776 \quad$ & $0,0078: 2 \mathrm{gr}$. \\
\hline 4 & 0,6739 & 0,0038 \\
\hline 5 & $0,6687 n$ & 0,0052 \\
\hline 6 & $0,6562 \#$ & 0,0125 \\
\hline 7 & $0,6490 \quad n$ & 0,0072 \\
\hline 8 & 0,6328 , & 0,0162 \\
\hline 9 & 0,6152 & 0,0176 \\
\hline
\end{tabular}

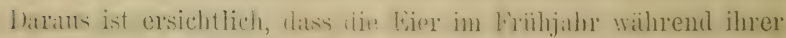
Entwickelumg am Gewidhte remplmäsig almehmen (am 6. Tage des zweitrn lersuches sind die Eier wahrscheinlich an spät abgewogen worilen).

Weitere Cntersuchungen der chemischen Zusamensetzung der Lier führten ihn zu folgenden Resultaten: 
1. Dils ("horion der Insekten enthält kein Chitin und hestroh! ans sonterbarem. Sehwefel cuthaltenden stotion (Chorionin.

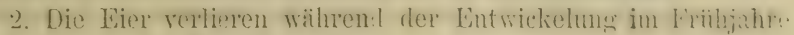
mehr als $10 \%$ von ihrem Gewichte.

3. lie Eier sin! an linte ihrer bintwickelung :irmer am liassergehalt als die ïberwinternden Eier.

1. Win Theil der trokkenen Substan\% geht ind der binwicklung verloren.

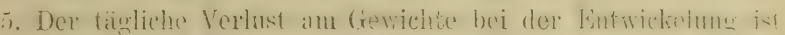

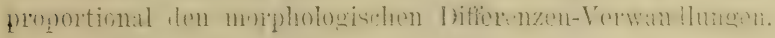

(3. Während der Eierentwickelung wird das Quantum des un-

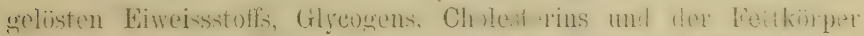

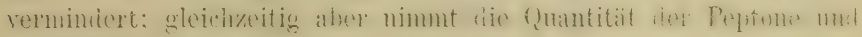
rles Lecithins zu.

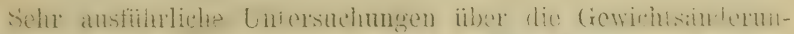

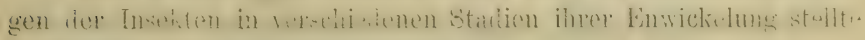
F. Urech (1890. 889) in l'uibingen an.

Bei seinei Bestimmungen unterscheidet er:

1. Athmungs- (Verbrennungs-) Wasser,

2. Saftwasser.

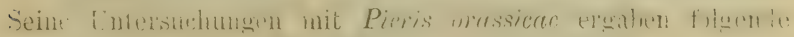
Resultate:

Schmetterling:

Gervicht der Puppe am 11. Mai Mor-

gens 7 Uhr . . . . . 0 0,3329 gr.

Das Auskriechen fand statt Mit-

tags 12 Uhr:

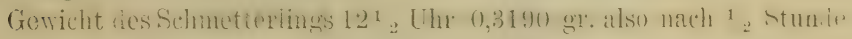
Puppenhiüle . . . . . . 0,0100"

Bis dahin entlassener Saft also . 0,0039 "

(rewicht des schmetterlines 1 Uhr . 0,257.2, "also nach 1 sim le.

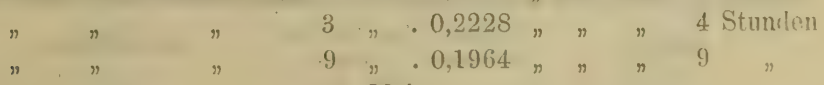

12. Mai

9 "Uhr Morgens . . . . . . 0,1806 gr. also nach 21 Stunclen Gewicnt des Sclmetterlings 13. Mai

7 Uhr Mlorgens . . . . 0,1640 gr. also nach 43 Stunden Gewicht des Schmetterlings 15. Mai

12 Uhr Mittags...... 0,1444 gr. also nach 96 Stunden. 
Er bestimmte auch die Geschwindigkeit des Flügelwachsthums dieses Schmetterlings vom Zeitpunkte rles Auskriechens an bis zur Erhärtung der Fliigel. Dabei wurde die Messung der Zunahme der längsten geraılen Linie, die sich auf dem Oberflügel, nämlich von der Flügelwurzel an bis zum entferntesten oberen Endrande des Flügels ziehen lässt, vorgenommen. Es hat sich ergeben:

Zeitdauer in Minuten. Länge der Linie in $\mathrm{mm}$.

$\begin{array}{ll}10 & 15,0 \\ 11 & 17,0 \\ 14 & 19,0 \\ 16 & 20,0 \\ 17 & 22,0 \\ 19 & 24,0 \\ 20 & 25,0 \\ 22 & 25,5 \\ 25 & 26,0 \\ \text { ngerer Zeit } & 27,0\end{array}$

Es ist interessant hier anzuführen, in welchem.Verhältnisse das Saftwasser zum Athmungswasser steht. Die Bestimmungen wurden an der Puppe von Deilephilu euphorbiae ausgeführt:

Die Gewichtsabnahme der Puppe $=0,0888$ gr.

Das abgegebene Gesammtwasser $=0,1032$ n

Die abgegebene Kohlensäure . . $=0,0570$ n

Mit Hülfe algebraischer Gleichungen und chemischer Formeln berechnet Urech:

$$
\begin{aligned}
& \text { Saftwasser . . }=0,0402 \mathrm{gr} . \\
& \text { Athmungswasser } \cdot=0,0630 \quad n \\
& \text { Gesammtwasser } \cdot=0,1032 \mathrm{gr} .
\end{aligned}
$$

Von Bestimmungen mit Phalaena pavonia minor genügt es hier Beobachtungen nur mit einer Raupe (von 4) anzuführen:

\begin{tabular}{|ccc|c|c|c|}
\hline D a t u m & & $\begin{array}{c}\text { Zeitdauer } \\
\text { in Tagen }\end{array}$ & $\begin{array}{c}\text { Das Gewicht } \\
\text { in gr. }\end{array}$ & Bemerlawngen \\
\hline 1889. Juni & 13. & 0 & 3,207 & \\
$n$ & $n$ & 16. & 3 & 4,962 & \\
$n$ & $n$ & 18. & 5 & 5,7808 & $\begin{array}{c}\text { Nach Saftabgabe Saftmenge } \\
=2,1322 \text { oder 34,41\% }\end{array}$ \\
$n$ & $n$ & 21. & 8 & 6,1964 & $\begin{array}{c}\text { des vorhergehenden Rau- } \\
\text { pengewichtes. }\end{array}$ \\
$n$ & $n$ & 23. & 10 & 4,0642 &
\end{tabular}




\begin{tabular}{|c|c|c|c|c|c|}
\hline \multicolumn{3}{|c|}{$\mathrm{D}$ a t u m } & $\begin{array}{l}\text { Zeitdauer } \\
\text { in Tagen }\end{array}$ & $\begin{array}{l}\text { Das Gewicht } \\
\text { in gr. }\end{array}$ & Bemerkungen \\
\hline 1889 & . Juni & 24. & Eins & pinnung. & \\
\hline$n$ & $n$ & 25. & 12 & 3,7000 & $=$ Puppe in Cocon. \\
\hline$n$ & $\pi$ & 27. & 14 & 2,9750 & \\
\hline$\eta$ & Juli & 7. & 24 & 2,7580 & \\
\hline$n$ & $n$ & 15. & 32 & 2,7420 & \\
\hline$n$ & August & 9. & 57 & 2,7066 & \\
\hline$\eta$ & $n$ & 23. & 71 & 2,7066 & \\
\hline n & Oktober & 25. & 134 & 2,6800 & \\
\hline n & Novem. & 7. & 147 & 2,6766 & \\
\hline$n$ & $\eta$ & 29 . & 169 & 2,6666 & \\
\hline 1890. & . Januar & 3. & 204 & 2,6526 & \\
\hline$n$ & n & 31. & 232 & 2,6466 & \\
\hline & März & 1. & 261 & 2,5082 & \\
\hline
\end{tabular}

1890. März 13. Schmetterling ausgekrochen gefunden (Weibchen).

Gewicht des Schmetterlings 1,3450 gr.

$$
\begin{aligned}
& \text { n Cocons . . } 0,3720 \text { n } \\
& \text { " } " \text { Raupenhülle .0,0278 } \text { (Die Differenz d. Gewichtes } \\
& \text { " } n \text { Puppenhülle } .0,1040 " \text { v. 1. März b trägt } 0,6594 \\
& \text { " und kommt } z \text {. Theil dem } \\
& 1,8488 \mathrm{gr} . \quad \text { von Schmetturling abge- } \\
& \text { 1890. März 17. 1,2026 Schmetterling. (gebenen Saft: zu. }
\end{aligned}
$$

18. Nach Abgang einiger unbefruchteten Eier todt.

Dass der Cocon, obschon er die Puppe nicht luftdicht abschliesst, doch raschen Lulftwechsel abhält, und so die Wasserabgabe und möglicherweise auch die Menge Athmungsprodukte vermindert, ist aus der folgenden Tabelle ersichtlich:

Gastropacha neustria.

\begin{tabular}{|c|c|c|}
\hline $\begin{array}{c}\text { Aus dem Cocon } \\
\text { herausgenommene Puppe }\end{array}$ & $\begin{array}{c}\text { Successive Zeiträume } \\
\text { in Tagen }\end{array}$ & $\begin{array}{c}\text { Im Cocon belassene } \\
\text { Puppe }\end{array}$ \\
\hline \hline $9,42 \%$ & 5 & $3,53 \%$ \\
$4,31 \%$ & 3 & $0,72 \%$ \\
$3,09 \%$ & 2 & $0,59 \%$ \\
$5,28 \%$ & 3 & $1,17 \%$ \\
\hline
\end{tabular}

Auch Wilh. Petersen (1890. 717) beschäftigte sich damit, olne jedoch seine Beobachtungen ausführlich zu veröffentlichen. Die betreffende Notiz in seiner Dissertation lautet: 
„Nach einer Reihe von genauen Wägung, lie ich an Puppen von Sphime ligustri, Smerinthus populi, ocellate, Splo. pinustri und

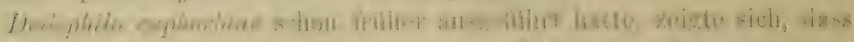

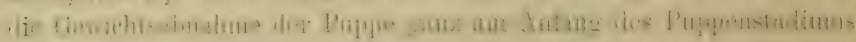
und zu Enile rlesselben ganz auffillen: stärker ist, als in der Zwisehenzeit und, da die Umbildung des Fettkürpers der Puppe zu den

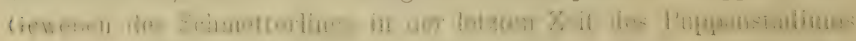
in rapiler Weise vor sich geht, so hat man bei cileser erhöhten Le-

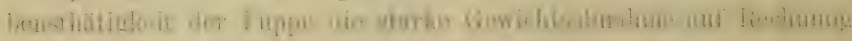
ler Alugabe ron Verbrennumgsproilucte $\left(\mathrm{CO}_{2}\right.$ und $\left.\mathrm{H}_{2} \mathrm{O}\right)$ zu setzen" (p. 262).

Er ist der Meinung, dlass zu Anfang des Puppenstadiums seln

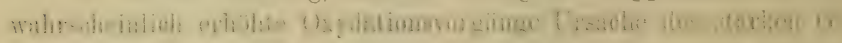
wichtsverminlerung bei der Puppe sind. Seine Versuche mit der Wirkung ozonisierter Luft auf Pupjen zeigten jedoch lieine erhöhte Oxylation.

Sehr interessante Untersuchumgen sind in dieser Richtung vou

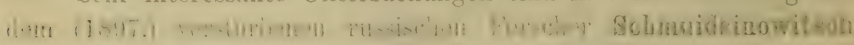
(189) 759 ) in (ler Seillenzucht-Station zu 'Tiflis ausgeführt worden. Er behandelte tahei folgenile Fragen:

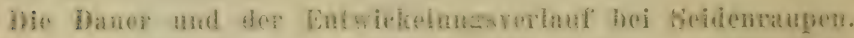

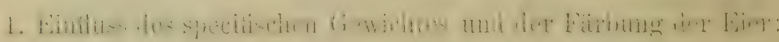

Je 0,25 bis 0,5 gr. Eier weisser japunischer unt gelber italie-

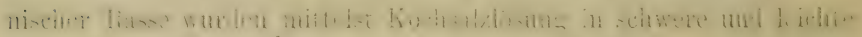
sortiert unl entwickelt. Die Räupchen der leichten und schweren

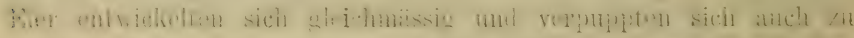

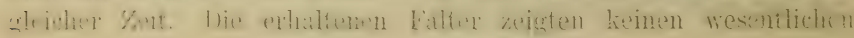
Unterschieil in der Anzahl der Weibchen und der Mïnnchen.

Daraus geht herror, dlass die hellen Eier, und folglich gleich-

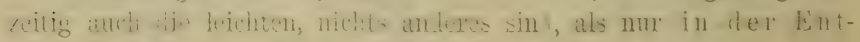
wickelung mehr fortgeschrittene Eier.

2. Einfluss der Grösse ‘ler Eier:

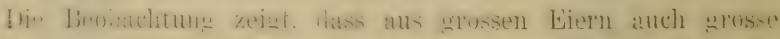

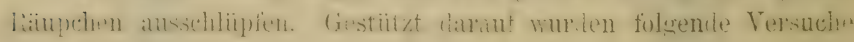
angestellt:

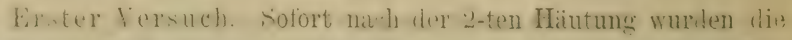

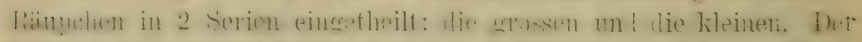

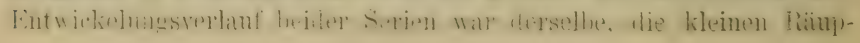


chen iberholten aber die grossen, indem die letzte IJ̈utung bec ihnen 24 Stunden früher stattfiml, als bei grossen Liaupen. Anch vio Ter-

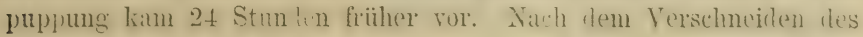
Cocons erwies es sich, class:

\section{9 grosse Raupen 24 ㅇ unil $5 \sigma^{\pi}$ ergaben, 28 kleine $n 2$ " " 26 " "}

Der zweite Versuch ergab dasselbe Resultat und zwar: 30 grosse Raupen 27 ㅇ und $3 \sigma^{\pi}$ ergaben, 28 kleine $n .2, n 26 n$ n

Diese Versuche zeigen, dass aus kloinen kätupchen ind folglich aus kleinen Eierii Irimmehen und aus grossen Weiluchen sich entrvickeln. Diese Rent ist jwioch nux dann richtig. wemn tie Räupchen gesund sind.

3. Einfluss des Geschlechtes.

Zur Vermulpung wurien nur solche Raupen zugelissen, welche am zweiten Tage dem Ki entschlipft waren. Nach iem Aufschneiden der Cocons erwies sich:

in Cocons her weissen jal anischen Lhasse aus Eiern, welche in $12 \%$ Kochsalzlösung sanken, befanden sich:

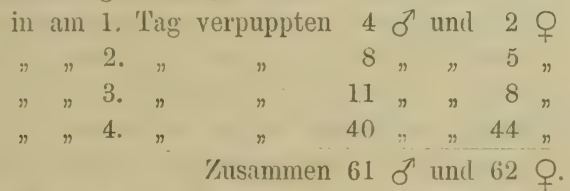

In Cocons ans Eiern, welche in h.r erwihnten Lösung schwanmen, befanden sich:

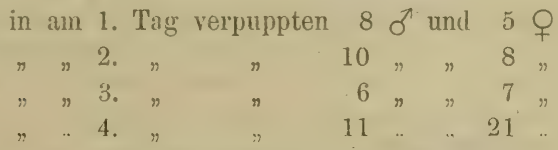

Zusammen 35 ठ und 41 ㅇ.

In Cocons der korsikanischen Rasse befanten sich: in am 1. Tag verpuppten 13 万 und 9 \&

$$
\begin{aligned}
& \text { n } 2 \text {. " } \quad 24 \text { n } 20 \text { n }
\end{aligned}
$$

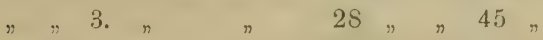

$$
\begin{aligned}
& \text { Zusammen } 65 \text { o und } 74 \text { 오. }
\end{aligned}
$$

Daraus künnen wir schliessen, dass die mïnnlichen Raupen im allgemeinen schmeller sich entwickeln und auch früher sich verpuppen als die weiblichen Raupen. 
W. J. Schmuidsinowitsch (1592. 765) bestimmte die Änlerung des Gewichtes bei P'uppen uni Schmetterlingen ron Fombyx mori in rerschielenen Eintwickelumgsstaulien. wobei er folgende Fragen zu lösen suchte:

1. In welchem Maasse siml die ron Blasius entileckten Grsetze auf den Spinner des Maulbeerbaumes anwendbar?

2. Stellen die Weibchen uni Mämmchen irgend eine Differenz in der Intensität der Lebenserscheinungen dar?

3. In welchem Maasse kommt in diesem Falle die Individualität des Thieres vor, 1 . h. welche Differenz stellen verschiedene Individuen eines orler des anderen Geschlechtes vor?

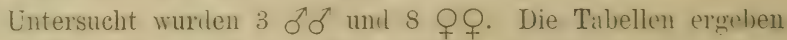
folgente liesultate, welche wir hier wörtlich iibersetzen:

"Aus der Betrachtung der Tabellen kam man sich iilserzeugen, dass die Gesetze von Blasius sich in Allgemeinen rechtfertigen. In der That sehen wir zwei Maxima des Stoffrerlustes und zwar 1. sofort nach dem Verpuppen unı 2. unmittelbar ror lem Entpuppen. Zwischen diesen Maxima muss unzweifelhaft auch ein Minimum vorhamlen sein, aber man kimn es mit Genanigkeit nicht angeben wegen der kurzen Verwanllungsperioile unil der grossen Verluste, welche der Thierorganismus erleilet $\left(0,2\right.$ bis $2^{\circ}{ }_{0}$ pro Tag). Klarer ist das Minimum zu ersehen. wenn man aus einzelnen Daten clas arithmetische Nittel zieht; es tritt dann, wie es scheint, am 3. oder 5. Tage nach iler Verpuppung ein. Der allgemeine Verlust les Gewichtes während iles Puppenstaliums schwankte bei unseren Beobachtungen fuir mämnliche Puppen ron 14,0 bis $14,6^{\circ}{ }_{0}$, uml für weibliche von 10,7 bis $14,4^{\circ}, 0$, im Durchschnitte betrug er für $\delta \delta^{\top} 14,3^{\circ}{ }_{0}$ unil für 우우 12,1) $4 \%$. Somit ist rler Stoffverlust bei $\delta \delta$, wie es scheint, etwas grösser unl ausser dem ist er in den ersten Tagen nach der Verpuppung etwas geringer als bei $\mathcal{O}_{f}$ und in den letzten Tagen grösser. Inliviluelle Verschiedeuheiten einzelner Inliviluen variirten bei $\delta \sigma^{\nearrow}$ von 0,1 bis (),5\% pro Tag unil bei of von 0,1 bis $1,3 \%$.

Ein riesiger Verlust des Stofles wurde in den meisten Fällen beim Verwamleln der Puppe in den Schmetterling beobachtet und schwanlite von $18,5 \%$ bis $45^{\circ}$; ; lurchschnittlich erreichte er $29,4^{\%} \%^{\text {" }}$ (p. 219).

Die entwickelten Schmetterlinge ergaben ihm ganz verschieilene Resultate, da die aus dem After entleerte Flüssigkeit zu bestimmen nicht immer möglich war. Folgende Tabelle enthält die Werthe nur in gewissen Momenten des Lebens (also nicht jerlen Tag): 


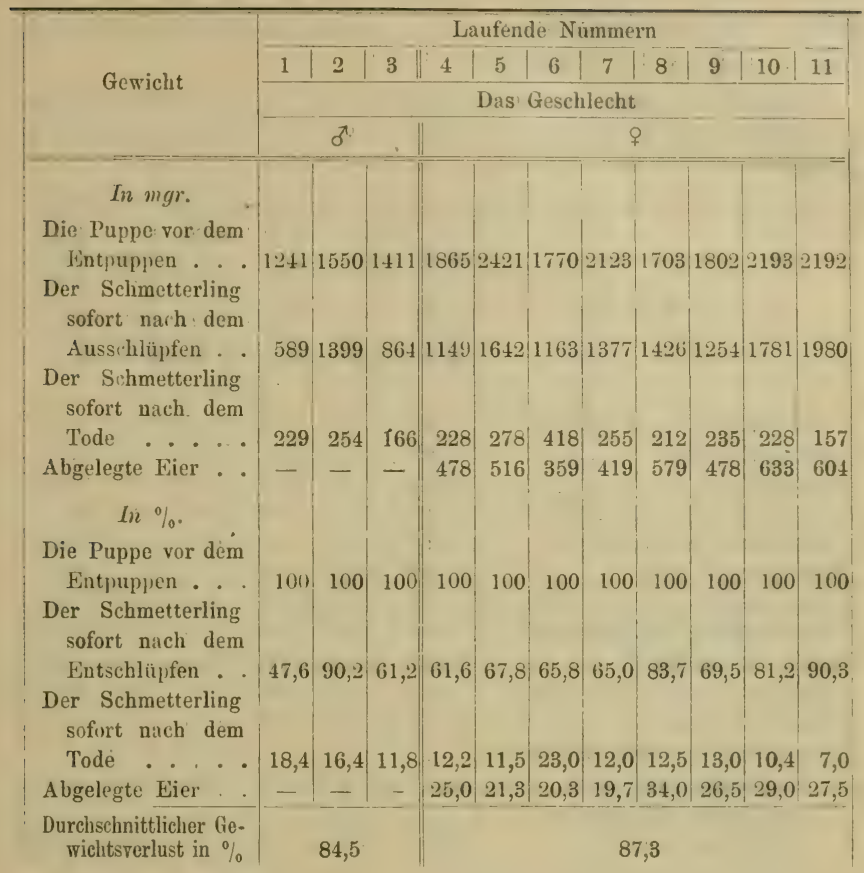

Der Gewichtsverlust bei Schmetterlingen nach ihrem Tode war jeden Tag in $\%$ folgenter (die li.li sind dieselben, wie in der vorhergehen(len Tabelle):

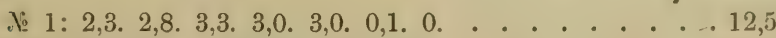

№ 2: 2,0. 2,5. 2,5. 2,6. 3,1. $0,1.0$. . . . . . . 10,8

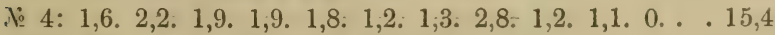

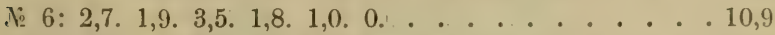

.l. $7: 1,3,1,6,4,6,4,6,1,8,2,2,3,4,7,1,3,0,0,1.0 \ldots, 28,4$

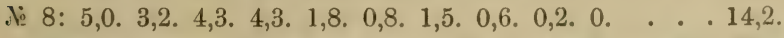

Dabei betrug die Luftemperatur $20-21^{\circ} \mathrm{R}$. und das Hygrometer zeigte $40-50^{\circ}$ an.

A. A. Golubajew (1892. 320) in Tiflis stellte Gewichtsbestimmungen an Puppen an, welche in Cocons lebend und abgestorben 
waren. Die Gewichtsabnihne wurle jeilen Tilg bestinmt und awar vom 1. Juni bis 27. August (alt. St.).

Die ahgekürzten (iewichtsergehnisse fiir die getüiteton Puppen in Cocons enthält folgende Tabelle in $\%$ des ursprünglichen Gewichtes:

\begin{tabular}{|c|c|c|c|c|c|c|}
\hline$R$ a s s e n & 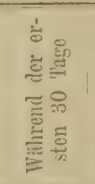 & 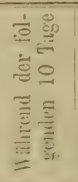 & 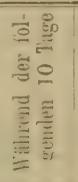 & 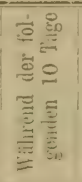 & 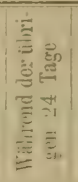 & 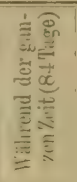 \\
\hline Turkestanische ${ }_{n}$ Ack-Pilla“ & $19,0 \%$ & $.10,93$ & 2,00 & 5,45 & 3,95 & 71,3 \\
\hline Chinesische gelbe . . . . . . & $57,6: 3$ & 10,46 & 0,74 & $-0,07$ & 0,74 & 69,5 \\
\hline Italienische gelbe . . . . . . & $5: 13$ & 9,66 & 2,59 & 0,19 & (),9 & $68,2 \pi$ \\
\hline Turkestanische "Saryck-Pilla“ . & 47,4 & 8,01 & $\tau, 29$ & 3,61 & 1,89 & 68,2 \\
\hline TVeiss-gelbe (incrociata) . . . . & 57,24 & 7,76 & 1,42 & 0,08 & 1,5 & 68,00 \\
\hline Korsikanische gelbe . . . . . & 51,09 & 10,73 & 2,36 & 0,07 & 0,5 & 67,75 \\
\hline Chorosan'sche. . . . . . . & 45,37 & 11,3 & 7,03 & 3,32 & 0,42 & 67,64 \\
\hline Turkestanische ${ }_{n}$ Pschty-Pilla & $4: 04$ & 3,26 & 12,56 & 5,27 & 3,87 & 66,00 \\
\hline Jipanische weisse . . . . . & 55,33 & 8,85 & 0,50 & 0,18 & 1,01 & 65,44 \\
\hline Chinesische weisse (von Susani). & $59,2 \quad$ &, \pm 44 & 0,36 & $|-0,12|$ & 0,92 & 64,8 \\
\hline $\begin{array}{l}\text { Japanische grüe . . . . } \\
\text { Chorosan'sche gekreuzt mit weis- }\end{array}$ & 53,33 & 8,72 & 0,78 & 0,87 & 0,55 & $6 \pm, 25$ \\
\hline $\begin{array}{l}\text { ser japanischer . . . . . } \\
\text { Weisse Bagdad'sche gekreuzt mit }\end{array}$ & 25.13 & 16,12 & 4,02 & $11,61 \mid$ & 3,82 & 61,00 \\
\hline weisser japanischer. . . . . & 34,6 & 5,23 & 11,73 & 3,24 & 0,63 & 56,43 \\
\hline
\end{tabular}

i) Gewichtshestimmungen an lebenilen Puppen simmt Cocons ergaben folgende Resultate:

\begin{tabular}{|c|c|c|c|c|c|c|}
\hline \multirow{2}{*}{\multicolumn{4}{|c|}{ Datum }} & \multicolumn{3}{|c|}{$R$ a s s e n } \\
\hline & & & & $\begin{array}{l}\text { Weisse japanische } \\
\text { gekreuzt mit gelber } \\
\text { französischer }\end{array}$ & $\begin{array}{l}\text { Gelbe } \\
\text { korsikanische }\end{array}$ & $\begin{array}{c}\text { WVeisse } \\
\text { Bagdad'sche }\end{array}$ \\
\hline Juni & i (alt. & St.) & 3. & 93,0 & 92,0 & 93,0 \\
\hline$n$ & $"$ & $"$ & 4. & 91,0 & 86,0 & 82,5 \\
\hline$n$ & $n$ & $n$ & ๖. & 91,0 & 76,0 & 67,5 \\
\hline$n$ & $n$ & $"$ & 6. & 90,0 & 57,0 & 48,0 \\
\hline$\Rightarrow$ & $n$ & $"$ & 7. & 90,0 & 38,0 & 33,5 \\
\hline
\end{tabular}




\begin{tabular}{|c|c|c|c|c|c|c|}
\hline \multirow{2}{*}{\multicolumn{4}{|c|}{$\mathrm{D} a \mathrm{tum}$}} & \multicolumn{3}{|c|}{$\mathrm{R}$ a s s e n } \\
\hline & & & & \multirow{2}{*}{$\begin{array}{l}\begin{array}{l}\text { Weisse japanische } \\
\text { gekrouzt mit gelber } \\
\text { französis her }\end{array} \\
89,0\end{array}$} & \multirow{2}{*}{$\begin{array}{c}\text { Gelbe } \\
\text { kursikanische } \\
28,0\end{array}$} & \multirow{2}{*}{$\begin{array}{l}\begin{array}{l}\text { Weisse } \\
\text { bagdad'sine }\end{array} \\
26,5\end{array}$} \\
\hline Juni & (alt. & St.) & 8. & & & \\
\hline$n$ & $n$ & $"$ & 9. & 88,0 & 25,0 & 22,5 \\
\hline$n$ & $"$ & $n$ & 10. & 83,0 & 21,0 & 20,5 \\
\hline 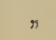 & $n$ & $"$ & 11. & 78,5 & 18,5 & 19,0 \\
\hline$n$ & $"$ & $"$ & 12. & 66,5 & 18,5 & 18,0 \\
\hline$"$ & $\pi$ & $"$ & 13. & 64,5 & 18,0 & 18,0 \\
\hline$"$ & $"$ & $n$ & 14. & 25,0 & 18,0 & 18,0 \\
\hline$"$ & $n$ & $n$ & 15. & 18,0 & 18,0 & 18,0 \\
\hline$n$ & $"$ & $n$ & 16. & 17,0 & 18,0 & 18,0 \\
\hline$n$ & $\eta$ & 川 & 24. & 17,0 & 18,0 & 18,0 \\
\hline
\end{tabular}

Der horizontale Strich in dieser Tabelle bedeutet das Ausschlüpfen des Falters. Diese Zahlen stellen wahrscheinlich die Procente ilos urspringlichen (iewichtes vor, la Golubajew lariiber nichts sagt.

N. T. Kurnali $(1994.456)$ untersuchte las Verhailtnis: zwischen dem Gewichte her Seilemraupen vor dem Einspinnen un'l rem Gewichte des Cocons am fuinten unl den folgenden Tagen uni faur für verschiedlene Rassen:

\begin{tabular}{|c|c|c|c|c|c|c|c|c|c|c|}
\hline \multirow[t]{4}{*}{ Datum } & 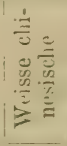 & 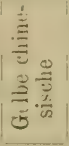 & 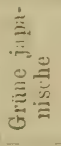 & 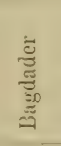 & 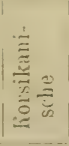 & 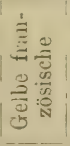 & 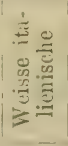 & 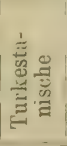 & 竎 & 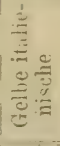 \\
\hline & \multicolumn{10}{|c|}{ Gewicht der Raupe vor dem Einspinnen in gr. } \\
\hline & 1,5 & 2,01 & 3,7 & 4,1 & $\dot{4}, 5$ & 4,0 & 2,5 & 3,4 & 1,4 & 4,5 \\
\hline & \multicolumn{10}{|c|}{ Gewirht des Cucous funf Tage nath dem linspinnen } \\
\hline 26. Mai & $\longrightarrow$ & - & 3,2 & - & - & - & - & - & - & - \\
\hline 28. $"$ & 一 & - & 2,1 & - & - & - & 1,31 & - & - & - \\
\hline 29. & - & - & 1,1 & -- & - & - & 1.30 & - & - & - \\
\hline 30. & 1,2 & - & 1,0 & 3,5 & - & - & 1,25 & - & - & 1,60 \\
\hline 31. " & 1,1 & - & 1,0 & 2,3 & - & $2,3 S$ & $1,2.3$ & 2,11 & - & 1,59 \\
\hline 1. Juni & 1,0 & - & 0,9 & 2,27 & 2,91 & 2.21 & $1,2: 2$ & 2,01 & - & 1.52 \\
\hline
\end{tabular}




\begin{tabular}{|c|c|c|c|c|c|c|c|c|c|c|}
\hline \multirow[t]{2}{*}{ Datum } & 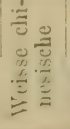 & 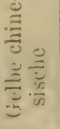 & 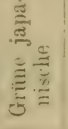 & 惫 & $\frac{3}{3}$ & 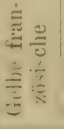 & 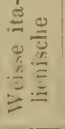 & 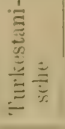 & 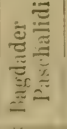 & 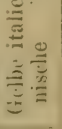 \\
\hline & \multicolumn{10}{|c|}{ Gewicht des Cocons fünf Tage nach dem Einspinnen } \\
\hline 2. Juni & 0.9 & - & 0,81 & 2,21 & 2,51 & 2.21 & 1,21 & $2,(1)$ & 2,98 & 1,52 \\
\hline 3. & 0,9 & - & 0,72 & 2,20 & 2,50 & 2,20 & 1,20 & 2,0 & $|2,71|$ & 1,51 \\
\hline 4. " & $0,8 s$ & 1,9 & 0,7 & 2,20 & 2,49 & 2,11 & 1,08 & 1.99 & 2,61 & 1,50 \\
\hline 5. & - & 1,75 & 一 & 2,19 & 2,49 & 2,10 & - & 1,99 & $|2,52|$ & 1,50 \\
\hline 6. & - & 1,70 & - & - & - & - & - & - & 2.51 & - \\
\hline 7. & - & 1,61 & - & 2,18 & - & - & - & - & - & -- \\
\hline 8. " & - & 1,55 & - & - & - & - & - & - & - & - \\
\hline 9. " & - & 1,5 & - & - & - & - & - & - & - & - \\
\hline 10. " & - & 1,5 & - & - & - & - & - & - & - & - \\
\hline
\end{tabular}

Das Ciewicht für die Raupe wurle als arithmetisches Mittel aus 10) Taupen, dasjenige des Cocons aus 20 Exemplaren bestimmt. Am folgenden Tage nach der letzten Wïgung schliipften die Schmetterlinge aus.

Daraus ist ersichtlich, dass verschiedene liassen eine verschieden starke Abnalnme des Cucons-(iewichtes mit der Zeit zeigen. Die grosse l)ifferenz zwischen dem Gewichte der spinnreifen Riande und dem fiewichte des Cocons ist offenbar damit zu erkliiren, dass die Raupe bei dem entgiiltigen Einspimnen Selirete von sich entleert.

A. Tichomirow (1895. 870) erwähnt in seinem Buche: "Gruncsütze ler pralitischen Seilenzucht" einen Versuch, welcher er vor einigen fahren ansgeiihrt hat: das Autleben der Eier von Bombyx mori, il. h. die Zeit, welche vom Momente, als die Eier aus tem kaltem Orte, wo sie iiberwinterten, ins warme Zimmer gebracht wurlen, lis zum Ausschlïpten der liaupchen verflossen war, betrug 13 Tage; wïlnenti dieser kurzen \%eit verloren die Eier $11^{\circ}$ o an ihrem (iewicht, wohei $4^{\circ},{ }^{\circ}$ auf die ersten !) Tagen und $7 \%$ auf die letzten 4 Tagen fillen. Die mikioseopische Untersuchung zeigte, dass die Entwickelung der Eier in ten ersten 9 Tagen langsamer vor sich ging als in den letzten 4 Tagen (p. 130).

포. Quajat (1895. 65.5) in Paulua bestimmte den Gewichtsverlust der Eier von Bombyx mori verschiedener lassen während der Wintermonate (December, Januar, Februar) uncl fanc: 


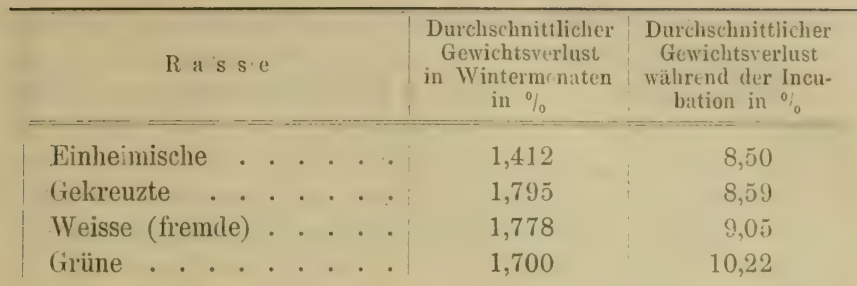

Daraus zieht er folgende Schlüsse:

1. Die einheinische Rasse verliert an Gewicht wïhrend der Wintermonate am wenigsten. Die antieren liassen hilten gleichen • Schritt.' 2. Während der Incubation verliert die rinheimische liasse an Gewicht viel weniger als die anderen Rassen; die grine japanische Rasse verliert am meisten.

Aussardem bestimmte er noch den Gewichtsverlust run Eiern währenıl der Incubation im trockenen Raume unl fand:

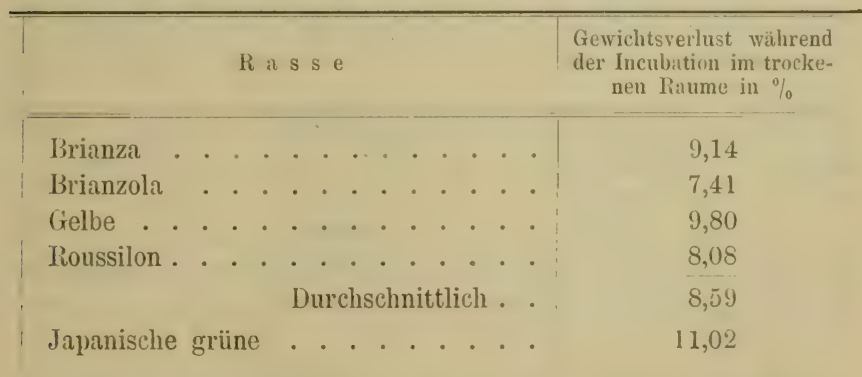

Er sagt, dass die Eier im Prïparationsstalium sehr rapil an Gewicht zu verlieren beginnen und je mehr der Gewichtsverhst vor der Incubation fortges hritten ist. lesto geringer ist der Procentsatz an weiterem Gewichtsverluste.

A. Mordwilko (1897. 391) in Warschau secierte die Pthinzenlaus Schizoneure corni Fabr. und fant im Bauch der Weihehen 1.5 his 20 zismlich entwickelte Embryonen von $0,43-0,47$ mm. Linge unl

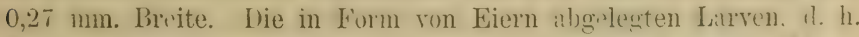
mit noch nicht ansgebreiteten Extrenitäten, halen 0,59 mm. Liange (l) unl 0,27 Broite (b), unl die kleinsten ausgrobeiteden Larven $l=0.63$ und $l=0,27 \mathrm{~mm}$. Eimen Tag darauf noch ror ther erstent Häutumg haben sie $l=0,72-0,74 \mathrm{~mm}$. und $b=0,29-0,31 \mathrm{~mm}$. 


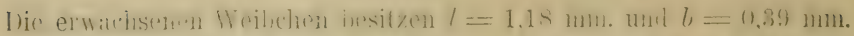

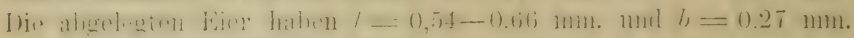

Weiter sagt er: „Ich hiclt es für nöthig, diese Daten mitzu-

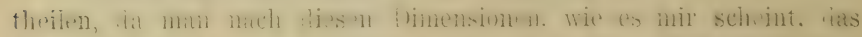

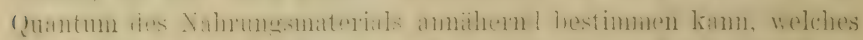

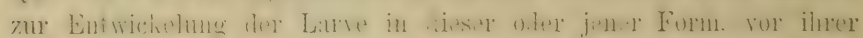

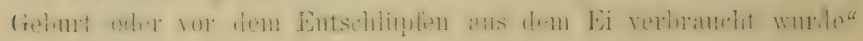
(p. 293).

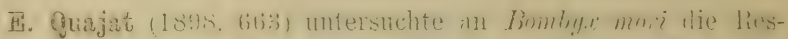

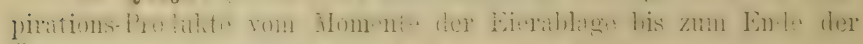

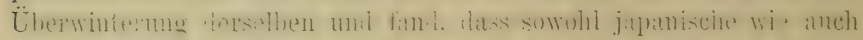

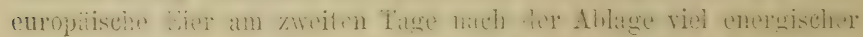

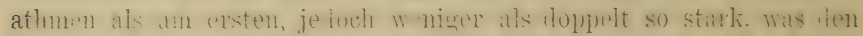

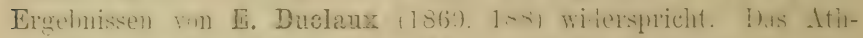

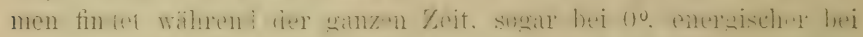

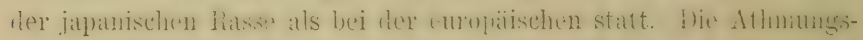

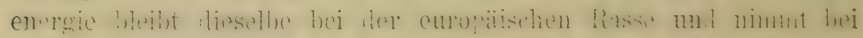

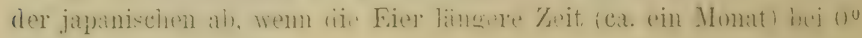
sich befinclen.

Er fand auch, dass die Athmungsenergie der Eier in keinem

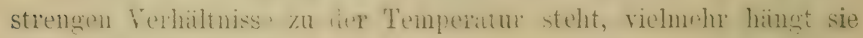
vom Alter der Eier ab.

Derselbe Forscher (1899. 664) bestimmte die Athmung der

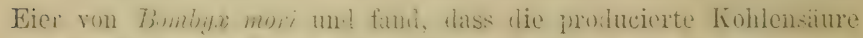

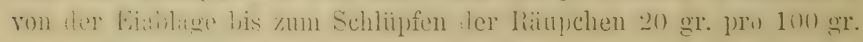
Eier betrïgt.

M. I. Porre (1900. -.5T) untersuchte die Respiration bei Lina

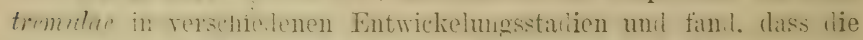
ansqescherene Kohlonsäme mit der Entwickelung cier Larve beden-

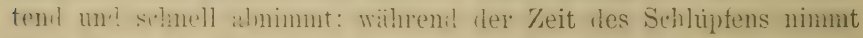

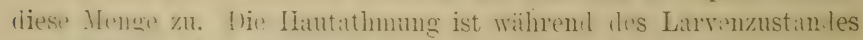
sthr thitie mol vorlangsant sich wihrend des Puppenstailiums. um im Augenblick les Schlïpfens wiecler zu steigen.

Aw th ich bestimmte den silfteloëfficient fïr verschistene

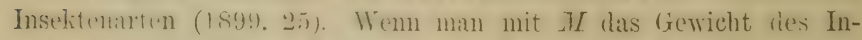
sektes in wänlirhen Zustumle, !nit $P$ sein Gewicht in trockenem Zustanle bezeichner, so beileutet $I I-P=S$ das Gewicht seines Sattes. weleher heim Trockinen (im Luftbarl bei ca. $115^{\circ}$ ) verilumptt. 
Wenn man jetzt $S$ durch $I I$ liviliert, s) erhailt man einen Guotienten. welcher angieht, wie riel Saft auf ein? (iewichtseinheit des Insektenkörpers hinzukommt, l. h.

$$
S: I I=\Re
$$

Die Grösse $K$ wollen wir Säftekoëfficient nennen.

Diese Untersuchungen wurden angestellt, wie folgt:

I)as betreffencle Inswet wurle auf einer empfin.Hichen Wage

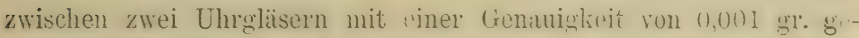
wogen, intem mam dibei beachtete, dass, wemn das Insekt "ex larva" war, es zuerst den Saft heriuslitssen musste, wolcher sich in den Verhamngsorganen befant. Darauf wurile das Inscht in ein Luftbad von $115^{\circ}$ gebraucht, wn dasselbe immerhalb weniger Seliunten starb. Das Trocknen dauerte $1-3$ Stulen, bis s in Gewicht sich nicht mehr verminlerte. Das Inselit wurde darauf noch eimmal gevogen.

In iler nachfolgenten Tabelle sinil die trhaltenen liesultate angefüht, wobei neben den Werthen, welche ich friiher veröfentlicht habe (1899. 24), noch mehrere bis jetzt nicht veriflentlichte Werthe enthalten sind:

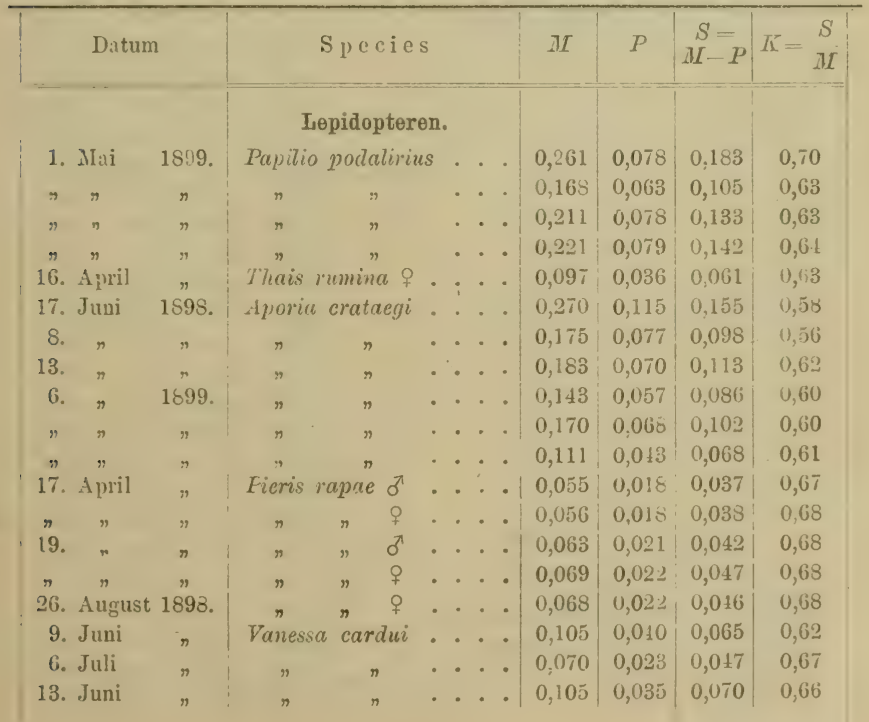




\begin{tabular}{|c|c|c|c|c|c|c|c|c|c|c|c|c|}
\hline \multicolumn{3}{|c|}{ Datum } & \multicolumn{6}{|c|}{ Species } & $I I$ & $P$ & $\begin{array}{c}S= \\
H-P\end{array}$ & $K=\begin{array}{l}S \\
M\end{array}$ \\
\hline 22. & Juni & 1898. & Vanessa & a ctalanta & & & . &. & 0,200 & 0,067 & 0,133 & 0,66 \\
\hline 1. & Mai & 1899. & $n$ & polychlo & oros & & & . & 0,225 & 0,067 & 0,158 & 0,70 \\
\hline 25. & August & 1898. & Lycaen & icarus & व & . & & . & 0,030 & 0,012 & 0,018 & 0,60 \\
\hline 9. & $n$ & $n$ & Deileph & illa euphor & $r b i$ & ae & & . & 0,595 & 0,272 & 0,323 & 0,54 \\
\hline 18. & A|ril & $\begin{array}{c}n \\
1900\end{array}$ & n' & & $n$ & & & - & 0,552 & 0,142 & 0,410 & 0,74 \\
\hline$n$ & $n$ & $n$ & $n$ & , & & & & . & 0,950 & 0,314 & 0,636 & 0,66 \\
\hline$n$ & & $n$ & n & & & & & & 0,923 & 0,273 & 0,650 & 0,70 \\
\hline 2. & Juni & 1899. & ᄁ & galii" & . & & 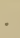 & $\cdot$ & 0,798 & $0,3 \pm 8$ & 0,450 & 0.56 \\
\hline 17. & A pril & $n$ & $n$ & $n$ & . & & - & . & 2,190 & 0,560 & 1,630 & 0,74 \\
\hline$\eta$ & $n$ & $"$ & $n$ & $n$ & . & & . & $\cdot 1$ & 1,852 & 0,424 & 1,428 & $0, \pi$ \\
\hline 20. & Juli & 1898. & Ocneria & $a$ dispar & & & & . & 0,428 & 0,124 & $0,30.1$ & $0, \bar{i} 1$ \\
\hline 21. & Juni & $\eta$ & Cossus & cossus. & . & & • & $\bullet$ & 1,333 & 0,755 & 0,578 & 0,43 \\
\hline 31. & Mai & $"$ & Phalera & a bucephal & la & & . & . & 0,275 & 0,070 & 0,205 & $0, \pi 1$ \\
\hline 24 & $n$ & $n$ & Saturni & ia pyri ठౌ & & & & • & 1,450 & 0,820 & 0,630 & 0.43 \\
\hline 17. & April & 1899. & & spini $ठ$ & & 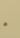 & 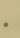 &. & 0,527 & 0,262 & 0,265 & 0,50 \\
\hline 9. & Juni & $n$ & Lasioca & ampa quer & rcif & oli & & . 1 & 2,568 & 1,792 & 1,176 & 0.69 \\
\hline 4. & $"$ & 1898. & Plusia & gamma. & . & . & 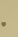 & . & $0,087 \mid$ & 0,025 & 0,062 & 0,71 \\
\hline 1. & Mai & 1899. & Abraxa & is adustato & & & & . & 0,025 & 0,011 & 0,014 & 11.56 \\
\hline & & & $D_{\text {man }}$ & Puppen. & & & & & & & & \\
\hline 7. & April & 1900. & Papilio & podaliriu & & - & & • & 1,048 & 0,262 & 0,786 & 0,75 \\
\hline$"$ & $n$ & $"$ & $\eta$ & 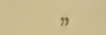 & & • & • & • & 0,730 & 0,162 & 0,568 & 0,78 \\
\hline$"$ & $"$ & $"$ & $n$ & $n$ & & & & - & 0,740 & 0,227 & 0,513 & 0,70 \\
\hline$"$ & $n$ & " & $n$ & $n$ & & - & & $\cdot 1$ & 0,895 & 0,162 & 0,733 & 0.82 \\
\hline$"$ & $n$ & $n$ & Thais c & cerisyi . & $\cdot$ & & 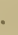 & $\cdot 1$ & 0,343 & 0,102 & 0,241 & 0,73 \\
\hline$n$ & $n$ & $n$ & $n$ & $n$ & . & $\bullet$ & - & $\cdot$ & 0,338 & 0,102 & 0,236 & 0,70 \\
\hline$n$ & $n$ & $\pi$ & $"$ & $n$ & - & 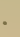 & 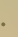 & . & 0,275 & 0,095 & 0,180 & 0,66 \\
\hline$"$ & $n$ & $n$ & $n$ & $n$ & . & • & . & . & 0,285 & 0,093 & 0,192 & 0,67 \\
\hline$n$ & $n$ & $"$ & n & $n$ & . & 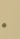 & • & * 1 & 0,357 & 0,118 & 0,239 & 0,67 \\
\hline$n$ & $\eta$ & $\pi$ & $n$ & $n$ & . & . & . &. & 0,290 & $0,08 s$ & 0,202 & 1,69 \\
\hline 23. & Februar & 1900. & $n$ & polyxena & . & & . &. & 0,306 & 0,080 & 0,2266 & 0,74 \\
\hline$n$ & $n$ & $"$ & $n$ & $n$ & • & • & - & 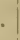 & $0,3+4$ & 0,117 & 0,227 & 0.66 \\
\hline$"$ & $n$ & $n$ & $n$ & $n$ & . & - & * & - & 0,290 & 0,087 & 0,203 & 0.70 \\
\hline$n$ & $n$ & $n$ & n & $"$ & . & • & . & . & 0,281 & 0,087 & 0,194 & $0.71)$ \\
\hline$n$ & $n$ & $"$ & $n$ & $"$ & . & & • &. & 0,307 & 0,091 & 0,216 & 0,70 \\
\hline$\pi$ & $n$ & r & $n$ & $n$ & . & " & - & . & 0,273 & 0,078 & 0,195 & 0,71 \\
\hline$n$ & $n$ & 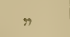 & $n$ & $n$ & . & - & • &. & 0,253 & 0,066 & 0,187 & 0,74 \\
\hline$n$ & $n$ & $n$ & $n$ & $n$ & - & & & $\cdot$ & 0,382 & 0,118 & 0,264 & 0,699 \\
\hline$n$ & n & $n$ & $n$ & ; & . & * & • & $\cdot 1$ & 0,266 & 0,082 & 0,184 & 0,70 \\
\hline$"$ & $n$ & $\pi$ & $"$ & $n$ & . & - & & . & 0,321 & 0,100 & 0,221 & 0,69 \\
\hline 2. & Juni & 1899. & Aporic & crataegi & . & & " & . & 0,378 & 0,122 & 0,256 & 0,68 \\
\hline$"$ & $n$ & $n$ & $\pi$ & $n$ & . & - & . & $\cdot$ & 0,262 & 0,100 & 0,162 & $0,6 \cdot 2$ \\
\hline$n$ & $n$ & $\pi$ & $n$ & $n$ & . & " & 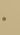 & $\cdot 1$ & 0,312 & $0,11 S$ & 0,194 & 0,62 \\
\hline$n$ & $n$ & $n$ & $n$ & $n$ & . & & - & . & 0,220 & 0,084 & 0,136 & 0,54 \\
\hline
\end{tabular}


Datum

Species

$M I \quad P\left|\begin{array}{c}S=P \\ M I-P\end{array}\right| K=\frac{S}{M I}$

2. Juni 1899. Aporia'crataegi .... $0,230 \quad 0,102 \quad 0,128 \mid 0,64$

24. Februnu 1900.

\begin{tabular}{lll|llllll|l|l|}
$n$ & $n$ & $n$ & $n$ & $n$ & $\cdots$ & $\cdots$ & 0,065 & 0,018 & 0,047 & 0,72
\end{tabular}

\begin{tabular}{llllllll|l|l|l}
$n$ & $n$ & $n$ & $n$ & $n$ & $\cdots$ & $\cdots$ & 0,065 & 0,018 & 0,017 & 0,72 \\
& $n$ & $n$ & $n$ & $n$ & $\cdots$ & 0,083 & $0,02 \mathrm{i}$ & 0,062 & 0,75
\end{tabular}

\begin{tabular}{ll|l|llll|l|l|l|l}
$n$ & $n$ & $n$ & $n$ & $n$ & $\cdots$ & 0,048 & 0,012 & 0,036 & 0,75
\end{tabular}

\begin{tabular}{llllllllllll}
$n$ & $n$ & $n$ & $n$ & $n$ & $\cdots$ & $\cdots$ & 0,063 & 0,012 & 0,051 & 0,81 \\
\hline
\end{tabular}

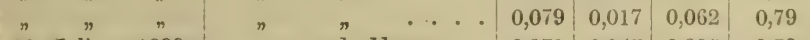

\begin{tabular}{lr|l|l|l|l|l|l|l|} 
22. Juli & 1899. & " & " polychloros.. & 0,273 & 0,047 & 0,226 & 0,79
\end{tabular}

\begin{tabular}{lll|}
$n$ & $n$ & $n$ \\
$n$ & $n$ & $n$ \\
$n$ & $n$ & $n$ \\
$"$ & $n$ & $n$ \\
$n$ & $n$ & $n$
\end{tabular}

\begin{tabular}{lll|l|l|l|l|l}
$n$ & $n$ & $\cdots$ & 0,288 & 0,055 & 0,233 & 0,81
\end{tabular}

\begin{tabular}{lllll|l|l|l}
$n$ & $n$ &. & 0,328 & 0,061 & 0,227 & 0,70
\end{tabular}

\begin{tabular}{lll|l|l|l|l}
$n$ & atalanta & $\cdots$ & 0,516 & 0,105 & 0,411 & 0,79
\end{tabular}

\begin{tabular}{lll|l|l|l|l}
$n$ & $n$ & $\cdots$ & 0,505 & 0,098 & 0,407 & 0,80
\end{tabular}

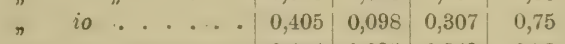

\begin{tabular}{llll|l|l|l|l|}
$n$ & $n$ & $\cdots$ & 0,444 & 0 & 095 & 0,349 & 0,79
\end{tabular}

\begin{tabular}{llllllllll|l|l|l}
$n$ & $n$ & $n$ & $n$ & $n$ & & $n$ & 0,300 & 0,068 & 0,232 & 0,77
\end{tabular}

\begin{tabular}{ll|l|l|l|l|l|} 
2. April 1900. Deilephita euphorbiae . & 1,898 & 0,446 & 1,452 & 0,76
\end{tabular}

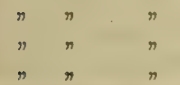

25. Februar "

26.

4. April

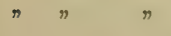

$n n$

$n " n$

23. Februar, 


\begin{tabular}{|c|c|c|c|c|c|c|c|c|c|c|c|}
\hline \multicolumn{3}{|c|}{ Datum } & \multicolumn{5}{|c|}{ Species } & \multirow{2}{*}{\begin{tabular}{|c}
$I$ \\
0,151
\end{tabular}} & \multirow{2}{*}{$\begin{array}{c}P \\
0,045\end{array}$} & \multirow{2}{*}{$\frac{\left|\begin{array}{c}S-P \\
M-P\end{array}\right|}{0,106}$} & \multirow{2}{*}{$\begin{array}{c}K=\frac{S}{I I} \\
0,70\end{array}$} \\
\hline 23. & Feber & 1900. & Thyatira & batis & . . & . . & . . & & & & \\
\hline , & $"$ & " & $n$ & $n$ & . . & . . & . . & 0,165 & 0,049 & 0,116 & 0,70 \\
\hline n & $"$ & $n$ & $n$ & $n$ & . & . & - & 0,135 & 0,042 & 0,093 & $u, 70$ \\
\hline$n$ & $"$ & $"$ & $n$ & ” & . & . . & . . & 0,168 & 0,060 & 0,108 & 0,65 \\
\hline n & 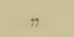 & , & $”$ & $n$ & . & . . & . . & $0,1 \& 0$ & 0,056 & 0,124 & 0,70 \\
\hline$\pi$ & 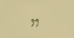 & $n$ & $n$ & n & . . & . & . . & 0,186 & 0,054 & (), 132 & 0,71 \\
\hline " & $n$ & $n$ & $n$ & $"$ & . & . & . . & 0,121 & $0,0 \pm 5$ & 0,076 & 0,63 \\
\hline r & $"$ & $"$ & , & , & . . & . . & . . & 11.281 & 11.065 .3 & 0.171 & $07 x$ \\
\hline$\pi$ & $\pi$ & $"$ & 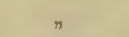 & & . & . & . . & 0,197 & 0,058 & 0,139 & 0,70 \\
\hline 16. & April & $r$ & 1) cilephila & elper & nor & . & . . & 2,218 & 0,555 & 1,663 & 0,75 \\
\hline$\pi$ & $"$ & r & $n$ & $"$ & & . & . . & 2,252 & 0,557 & 1,795 & 0,79 \\
\hline$n$ & $"$ & " & $"$ & $n$ & & . & . & 1,698 & 0,512 & 1,181 & 0,70 \\
\hline$"$ & $n$ & $"$ & $n$ & $n$ & & . & . . & 1,720 & 0,412 & $1,30 \mathrm{~s}$ & 0,76 \\
\hline r & $"$ & $"$ & Dasyschira & pud & dibur & $n d a$ & . & 0,960 & 0,286 & 0,678 & 0,70 \\
\hline$"$ & " & $n$ & " & & $"$ & & . & 1,035 & 0,310 & 0,725 & 0,70 \\
\hline$r$ & $n$ & $"$ & " & & $n$ & & . & 0,924 & 0,260 & 0,564 & 0,69 \\
\hline$"$ & $"$ & $"$ & ” & & $n$ & & . & 0,978 & 0,287 & 0,691 & 0,71 \\
\hline . & $n$ & $"$ & $n$ & & $"$ & & . & 0,900 & 0,271 & 0,629 & 0,70 \\
\hline$"$ & $"$ & $r$ & $"$ & & $"$ & & . & 0,510 & 0,158 & 0,352 & 0,70 \\
\hline$"$ & $"$ & $n$ & " & & $n$ & & . & 0,512 & 0,155 & 0,357 & 0,70 \\
\hline
\end{tabular}

\begin{tabular}{ll|l|l|l|l|l|} 
7. Juli 1898. Carabus cancellatus . - & 0,235 & 0,053 & 0,182 & 0,77
\end{tabular} 22. Nai 1899. coriaceus var.

\begin{tabular}{ll|l|l|l|l|l} 
19. A pril $\# \quad$ Carabus intricatus वे . . & 0,812 & 0,272 & 0,540 & 0,67
\end{tabular}

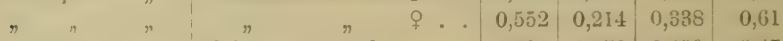

23. Juni 1898. Colosoma sycophanta . . $0,890|0,470| 0,420 \mid 0,47$

1. IIai 1899. Epicometis hirta... $|0,094| 0,029|0,065| 0,69$

"

\begin{tabular}{ll|l|l|l|l|l|} 
8. Juli 1898. Clytus spec. . . . . . & 0,075 & 0,037 & 0.038 & 0,51
\end{tabular}

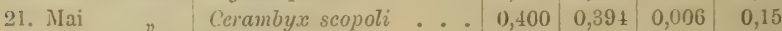

\begin{tabular}{ll|l|l|l|l|l|}
22. & 1899. & Dorcadion fulvum . . & 0,324 & 0,126 & 0,198 & 0,61
\end{tabular}

1898. Geotrupes vernalis . . . $0,485 \quad 0,187|0,298| 0,62$

\begin{tabular}{ll|lll|l|l|l|l} 
7. Juli $n$ & $n$ & $n$ & 0,445 & 0,185 & 0,260 & 0,58
\end{tabular}

22. Mrai 1899.| Melö̈ spec. . . . . . $0,302|0,104| 0,198 \mid 0,65$

21. April .. Apris mellifica . . . . 0.091 1),03t 0.0600 .61

Vespa vulgaris. . . . $|0,081| 0,028|0,054| 0,66$

Aus dieser Tabelle lassen sich folgente suhlïsse ziehen:

1. Iner siaftegehalt in ilen entwickelten Inseliten macht unter normal'm Lmstinion im allgemeinen ca. $2 / 3$ les (xesammtgewichtes des Insekts aus. 
2. Der Säftelioëfficient variirt bei verschiedenen Arten mil sogar bei rerschiedenen Exemplaten einer und derselben Art.

3. Die frösse des hö̈fficienten ist von ler Inselitengrïse un-

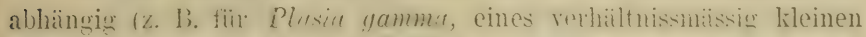

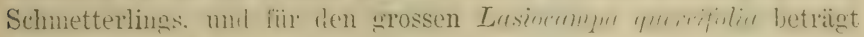
$K=(2,0,7())$.

4. Die Insekten, welche selbst oder ihre Larven im Inneren

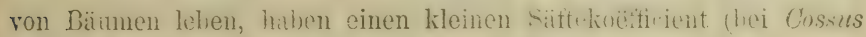
cossus $K=0,43$, bei Cerambyx scopoti $K=0,15)$.

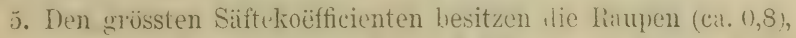
den mittluren die Puppen (von 0s, lis $0,(i)$ umb den kleinsten die entwickelten Schmetterlinge (von 0,7 bis 0,4 ).

Der letzte schluss wirl folgen lermassen erklait: Vic liaupe lïsst mit ihrer Verpuplung eine Menge Saft von sich zur IIerstel-

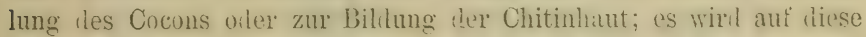

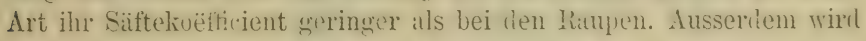

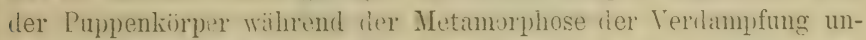

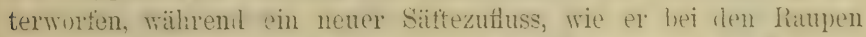
stattfiulet, nicht varhamben ist. Nach der Entpup) umg des Schmetterlinges sinıl seine Säfte viel grösserer Verilamplung unterworfen, lat derselhe scine fest: Lmbüllung verlassen hat; ausserilem laisst ller

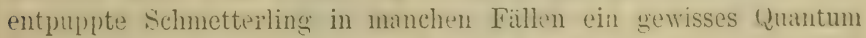

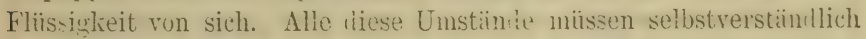
seinen Säftekoëfficient vermindernn.

Lim zu konstatieren, ob der Sättelioëflicient währent der Pupperentwickolung sich imilert, litbe ich Versuche mit P'upuesu von

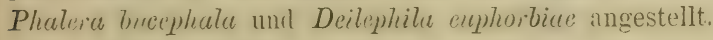

Folgende Zahlenwerthe zeigen liese Veränderung:

\section{A. Puppen von Phalera bucephala.}

23. Februar 1900. $\left\{\begin{array}{ccc}M & P & K=(M-P): M \\ 0,873 & 0,231 & 0,73 \\ 0,896 & 0,240 & 0,73 \\ 0,748 & 0,194 & 0,74 \\ 0,682 & 0,170 & 0,75 \\ 0,904 & 0,232 & 0,74 \\ 0,743 & 0,197 & 0.73 \\ & \multicolumn{3}{c}{\text { Nittel }=0,74}\end{array}\right.$


lirstes Kitpitel. Die Entwi lielungsgeschwindigkeit der Insekten.
$M$
4. April 1900. $\left\{\begin{array}{l}0,740 \\ 0,710\end{array}\right.$

\begin{tabular}{cc}
$P$ & $K=$ \\
0,225 & $(M-P): M$ \\
0,220 & 0,69 \\
Mittel $=$ & 0,70 \\
\hline & $0,69$.
\end{tabular}

D. h. während 40 Tagen (vom 28. Februar his 4. April) änlerte sich dler Sïittekoëfficient bei Puppen von Phulera brcepliala von 0,74 bis auf 0,69 , oller um $6,7^{\circ}{ }_{n}$. Daraus folgt, dass beim Stoffwechsel währenıl iler Entwickelung dieser Puppen flüssige Säfte stärkeren Antheil daran nehmen, als die festen Theile des Körpers. Ausfuhrlicher sint in dieser Beziehung die Puppen ron Ileilephila euphorbiae von mir untersucht vorden.

B. Puppen von Deilephila euphorbiae.

\begin{tabular}{|c|c|c|c|}
\hline \multirow{5}{*}{ 2. April 1900.} & MI & $P$. & $K=(M-P): M$ \\
\hline & 1,898 & 0,446 & 0,76 \\
\hline & 2,572 & 0,660 & 0,75 \\
\hline & 2,828 & 0,670 & 0,76 \\
\hline & 2,355 & 0,625 & 0,74 \\
\hline & & \multicolumn{2}{|c|}{ Mittel $=\overline{0,75}$} \\
\hline \multirow{5}{*}{ 6. April 1900.} & 2,200 & 0,434 & 0,80 \\
\hline & 2,245 & 0,537 & 0,76 \\
\hline & 2,310 & $0, \overline{5} 47$ & 0,77 \\
\hline & 1,570 & 0,362 & 0,77 \\
\hline & & \multicolumn{2}{|c|}{ Mittel $=0,78$} \\
\hline \multirow{4}{*}{ 7. April 1900.} & 2,212 & 0,490 & 0,77 \\
\hline & 2,148 & 0,388 & 0,82 \\
\hline & 2,193 & 0,530 & 0,76 \\
\hline & 1,915 & 0,380 & 0,80 \\
\hline & & \multicolumn{2}{|c|}{ Mittel $=0,79$} \\
\hline \multirow{2}{*}{ 10. April 1900.} & 2,068 & 0,485 & 0,76 \\
\hline & 1,726 & 0,345 & 0,80 \\
\hline \multirow{9}{*}{ 12. April 1900.} & & \multicolumn{2}{|c|}{ Mittel $=0,78$} \\
\hline & 2,075 & 0,348 & 0,83 \\
\hline & 2,522 & 0,358 & 0,86 \\
\hline & 1,785 & 0,485 & 0,73 \\
\hline & 2,005 & 0,620 & 0,69 \\
\hline & 1,790 & 0,558 & 0,69 \\
\hline & 2,595 & 0,541 & 0,79 \\
\hline & 2,953 & 0,787 & 0,73 \\
\hline & & \multicolumn{2}{|c|}{ Mittel $=0,76$} \\
\hline
\end{tabular}




13. April 1900. $\left\{\begin{array}{ccc}\boldsymbol{M} & P & \mathbb{I}=(\boldsymbol{M}-P): \mathbb{I} \\ 2,015 & 0,450 & 0,78 \\ 2,310 & 0,545 & 0,76 \\ 2,340 & 0,602 & 0,75 \\ 2,160 & 0,510 & 0,76 \\ 1,655 & 0,392 & 0,76 \\ 1,980 & 0,443 & 0,78\end{array}\right.$

16. April 1900.

$\left\{\begin{array}{l}2,218 \\ 2,252 \\ 1,693 \\ 1,720\end{array}\right.$

25. April 1900. $\left\{\begin{array}{l}2,545 \\ 2,687 \\ 2,135 \\ 2,084 \\ 2,022 \\ 2,598 \\ 1,628 \\ 2,152 \\ 2,800\end{array}\right.$

15. Mai 1900. $\left\{\begin{array}{l}3,140 \\ 1,970 \\ 1,930 \\ 2,780\end{array}\right.$
Mittel $=0,75$ 0,555 0,557 0,75 0,79 0,512 0,70 0,412 0,76

Mittel $=0,75$ $0,640 \quad 0,75$ $0,621 \quad 0,77$ $0,585 \quad 0,72$ $0,492 \quad 0,76$ $0,525 \quad 0,74$ $0,637 \quad 0,76$ $0,300 \quad 0,81$ $0,498 \quad 0,77$ $0,713 \quad 0,74$

$$
\text { Mittel }=0,76
$$

$0,735 \quad 0,76$

$0,575 \quad 0,71$

$0,648 \quad 0,66$

$0,796 \quad 0,72$

Mittel $=0,71$

Daraus ist ersichtlich, dass der Säftekoëfficient am 2. April 0,75 und nach 43 Tagen (am 15. Mai) nur 0,71 betrug, also geringer geworden war. Gleichzeitig scheint es, dass der Säftekoëfficient mit der Dauer der Puppenzeit anfangs zunimmt, ein Maximum (am 7. April) erreicht, um nachher zuerst längere Zeit constant zu bleiben und dann abzunehmen.

Dabei muss ich bemerken, dass diese Puppen Ende Februar von Deutschland bezogen wurden und darauf im warmen Zimmer verblieben. Wegen der starken Individualität einzelner Puppen sind diese Versuche $\mathrm{zu}$, wiederholen. 


\section{Irganzangs-Littontur an diesem Abschnit:}

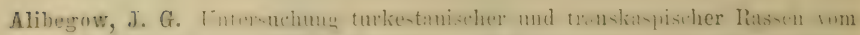
Seidenspinner des Jaulberbaumes. - Arbeiten der kaukasischen Seidenzucht-Station. Jahrg. 1890. Tiflis 1892. MII. Bd. p. 251-272. Mit einer Phototypie (russisch).

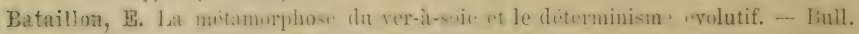
Sci. France Belgique. XXV. 1893. p. 18-55.

Roequigny-Adanson, G. de. Sur L. diminuton de poids d'un Lépiduptère livernant (Vunessa antiopa). - Rev. Scient. Bourbun. Année XV. 1901. i. 174. 1). $121-122$.

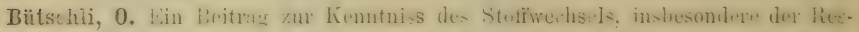
piration bei den Insekten. - Arch. für Anatom. u. Physiol. u, wissensch. Med. von Reichert und du Bois-Reymond. 1874. p. 348-361.

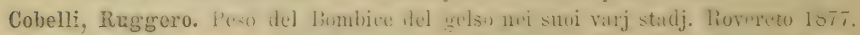

Cobelli, Ritggero. l'esu della ramat verde del fimbice del gelso. Purerete lsso.

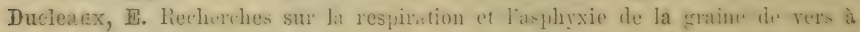
soie. - Ann. scientif. de l'école normale supér. T. 6. 1869. p. 85-109.

Ducleaux, E. Sur la respiration et l'asphyxic des graines de vers à soie. Compt. rend. 'T. 67 . 1868. p. 8:6-830.

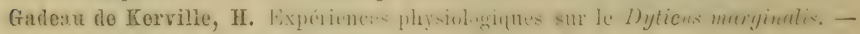
Bull. Soc. ent. France. 1597. p. 91-97.

Gal, J. Pulsations du vaisseau dorsal chez les vers-it-soie. - Bull. Soc. Nimes. XXIV. 1898. 1). $46-51$.

Grote, A. R. The changes in the structure of the wings of buttertlies. 1897.

Haberlandt, F. La perdita di peso delle uova durante l' incubazione. - La Sericolt. anstrica. Anno IV. 1872. j). 55-56. - Giornale dell' Industria serica. Anno VI. 1872. p. 122-123.

Johunson, H. Sur le développement de l'oeil composé de Vunessa. - Cungr. Zool. 1892. p. 124-126.

Kablnkow, J. und Tichomirow, A. Die chemische Kusammensetzung der Lierschale vou Anthercea pernyi. - Nachrichten des Comité für Seidenzucht. I. Liefer. 1. und 2. 1892. p. 9--11. Moskau (russisch).

Keferstein, A. lintradhtungen über die kntwickelungsgeschichte der Schmetterlinge. 1880. 116 p. Erfurt.

Lambrecht, Aug. Der Luftverbranch einer Liene und die damit zusammenhängenden Lebinsmeesse der Glieder derselben. - Bienenwirtsch. Centralbl. VII. 1871. p. $115-120$.

Luciani, L. und Lo Monaeo, D. Sui fenomeni re-peratori della crisalide del Hombice del gelso. - Boll. Soc. ent. Ital. XXV. 1893. p. 12-24.

Martin, J. Sur la reppiration des larves de Libellntes. -- Bull. Soc. P'hilom. (8). IV. 1892. 1) $122-124$.

0ttavi, 0ttavio. I/sservazioni sul variate del peso dei bozzoli. 11 bacolngo italiano. Anno III. 1880-81. p. 153-154.

Portsehinsky, J. A. Lher die Bedeutung und das Entstehen der skulptur und der Farbung auf den Flingelderken der Käfer (Carabus, Captolabrus, Pro- 
cerus und Dorcadion), - Zeitschr. für Naturwiss. 1892. Jo 3-4. (Russisch:

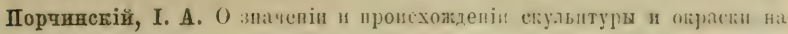
налкрндьяхъ жуковъ. - Вьеги. Еетествозн.).

Poulton, E. B. Notes in 1885 upon Lepidopterous liarvate and pupate, including an accomt of the loss of wight in the freshly formed Lepidopterous puna. - Tr. Ent. Soc. 1886. p. 137-179.

Quajat, F. Prodoti resplicatori delle uova svernate durante l' incubazione primaverile. - Anuo XXVIl. Staz. Bac. A. 1899.

Quajat, E. Prodotti respiratori delle nova del filusello durante l' incubazione normale. - Estratto d. Ann. d. R. Accad. d' Agric. d. Torino. XLII. 1899.

Quajat, E. Produits respiratoires des oenfs durant l'incubation normale. - Arch. ital. de Biolog. XXXIII. 1900. p. $425-428$.

Verson, E. Das Gewicht und der Gesundheitszustand der Grains, - Osterreich. Seiden\%-Ztg. 3. Jahr. 1871. p. $44-45$.

Verson, ๒. und Quajat, B. Intorno alla respirazione delle uova, dei bruchi, delle crisalini e d lle farfalle del filugello. . Bollett. di bachicolt. 1876. p. 3-22: auch in Ann. IV. Staz. Bac. Anno 1876.

Verson, E. Chemische analytische Untersuchnngen an lebenden Kaupen, Puppen und Schmetterlingen. - Zool. Anz. XIIY. 1890. 숭 346.

Verson, E. La composizione ehimica dei gusci nelle novit. - Boll. Mens. Bach. Ser. II. 1884.

\section{Einfluss des Klimas.}

E. Maillot (1877.541) in Montpellier beobachtete, dass die vorzeitige Entwickelung der Seilemraupen aus Eiern dann stattfindet, wenn die Eirr im trockenen und wamen Zimmer vom Weibchen abgelegt werden.

J. Jenner Weir (1879. 952) fing an 1. Juni Cucullia chamomillae, rlie gewöhnlich im April orler Anfang Mai ausschliupft. Eine so grosse Verspätung im Erscheinen dieser Species erklïrt er lurch die schlechte Witterung. Auch die Eichen hatten bis Mitte Mai keine Blätter, die Esche schlug bis zu Ende Mai noch nicht aus; und der Weissiorn blühte erst Anfang Juni.

R. Laddiman (1879. 492) beobachtete, dass die Vegetation 1879 zurückblieb, uncl die Schmetterlinge zu spät ausschliipften; nichtsdestoweniger waren einige Arten reichlicher als sonst, so dass der strenge und lange Winter ihre Anzahl nicht verminilerte. Er fing 1879 Orgia fascelina am 6. April und anno 1878 am 7. März. Auch die Schmetterlinge, deren Puppen im Zimmer gehalten wurden, zeigten einen grossen Unterschie 1 in ier Ausschlïpfungszeit, so z. B. 


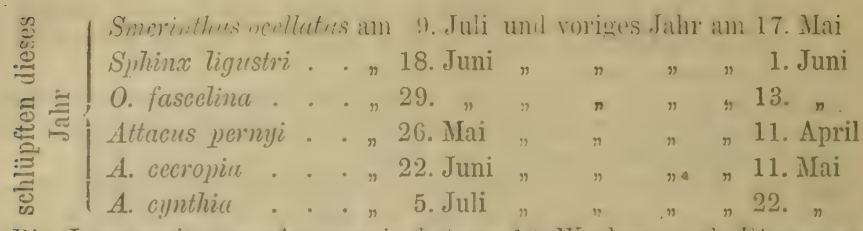

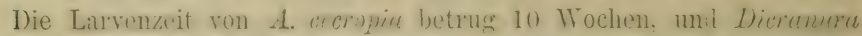

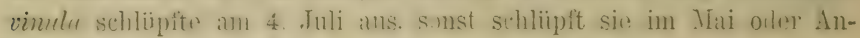
fang Juni.

C. Emery mul A. Forel (1879. 214) sagen, dass the geographische Vorhreitung der Aneisen-Arten nicht ansschlitssli.h durch die mittlere Sommerteniperatur bedingt wirl, da die Verheitumg z. B.

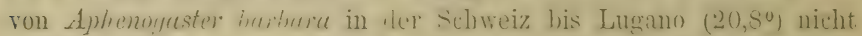

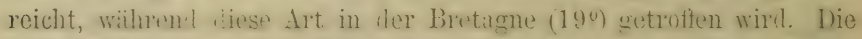
Haupt-Fakioren, welche die geographische lerheitung dieser Insekten be lingen, sint ausser der nittleren Jihrestemperatur noeh: die Kilarheit des Limmels, die Fenchtigkeit dor Erie mol der Luft, ter

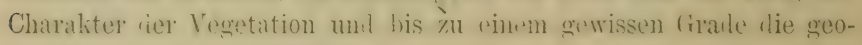
logische Natur der Gegend.

B. Leckyer $(1879.530)$ bestitigt, diss wemn die kintwickelung lor PHanz'n in Fribịihle verspaitet ist, anch bei Insekten rerspätete

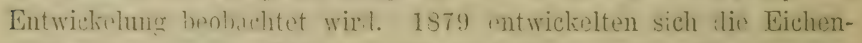
blïtter orst am 2(i. Mai nul Pieris biussicae schlïpften. erst am

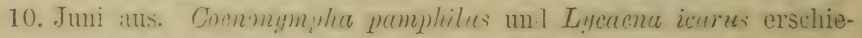

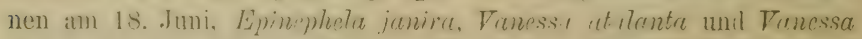
urticae am 20.-23. Juni.

Danilow (1893. 748) beolsachtete im Don-Bassin Larven von Clactius ulmi Schruk. im September uni Oktober bei regnerischem Wetter unil ainer Temperatur von 5o his $70 \mathrm{R}$. Sie haben dabei nicht gelitten.

S. Ph. Chramow (1893. 74\$) beobachtete, dass der verspiitete Mai-Lirust und dits regnerische Frühjahr die Larven ron Galerucella luteola Müll. ganz vernichtet hatten.

Iw. Schewyrew (1593. 748) sagt, dass die von Ocneria dispar abgelegten Eier len ganzen Herbst und Winter ruhig lagen, ohne durch die Schwankungen der Temperatur und der Feuchtigkeit zu verderben. 
Er stellte fest, hass die Entwickelnngserechwinigkeit der Larven von Srolytus destructor. multistriatus un-I mygmuens unter anderem anch von klimatischen Verhältnissen abhängt: die Temperaturalmahme und die Trockenheit der Luft unt der Xahrung verlangsamen und bringen sogar die Entwickelung dieser Larven zum Stillstante.

S. Solmons (1895. 806) beobachtets bei her Aufaucht von Purnassius delius-Raupen, dass sie bei trülsen Wotter san nicht f'essen, "lesto lebhafter bewegt sich die Raupe beim Somenschein. Trockinheit mul Somnenschein bei den apollo-Rampen, - Wasser, Fenchtigkeit und Somnenschein bei den delins-Riaunen" (p. 35). Die Puppe brancht bei somniger Witterung ea. S Tater, bei kiihler, trüber Witterung auch 4 uni meln Wochen zu ihrer Ausbililung.

Ludwig Biró (1997. 41), salgt, dass die Ameisenlöwen in venGuinea flinker und lehhafter als ihre europuiaschen stammerwantten sind und schreibt diesen Umstant der Wirliung des warmen tropischen Klimas zu.

J. Karsin (1897. 435) beobachtete, hass ias trockene herisse Wetter und her heisse siud-ïstliche Winl die Erhsenläuse vernichteten.

Altum (1899. 1\%) benhachtete in rier Ungebung von Eberswalite in Sommer 1898 grosse Armuth an Inseliten; zahlreich watren nur Orgyiu pudibunda unil die Blattwespen: Armatus luricis, N. salicis und Cimbee Tocomm. Diese Eischeinnung erklïrt ar durch den Eintluss des Winterwetters. Der Winter war ungewöhnlich mild, und Fehruar, März, April und Mai waren kïhl und sehr nass. Dasselle war auch im Juli ler fall. "Nasse Kiilte wirkt an cingreifendsten. Was Wunler also, wemn bei tem Mär\%, April- und Maiwetter 1898. fast die ganze Tagfalterfauna von iler Bilifliche verschwand" (p. 309). Oryyia pudibunde und die erwähnten Blatt. wespen schliipfen im Jani aus, welcher sehr warm war. Retinia buolicuna, Halias chlorana. Coleophora laricella. Hyjonomentu ceonymella uni Zenzera p!lrina. waren zahlreich, weil ihre Larten und Puppen in Trieben, Blïttern, Gespinnsten ofler im Holz leben.

Altum (1899. 11) berichtet in seiner zweiten Notiz, lass bereits Mitte November 1898 in zwei Posen'schen lievieren, Zirke und Humleshagen, zahlreiche ausgeschlïpfte Rïupchen der Nonne, sogar theilweise schon „im Spiegel" gefunilen wurlen, also reichlich 
4-5 Monate vor der Normalzeit. Als Ursachen dieser Abweichung liessen sich mit hö̈hster Wahrscheinlichkeit die vorhergegangenen abnormen IVitterungsverhältnisse erkemen, welche folgende waren:

Der IVinter $189-98$ war im allgemeinen frost- und schneefrei. Die Entwickelung ter Nomnemrïupchen in den Eiern erhielt einen ungewöhnlichen Vorsprung. Währenı der Monate: Mä̀\%, April und Mai herrschte anhaltend sehr nasskalte Witterung, wesshalb die bereits ausgeschlïpften Räupchen sich sehr langsam entwickelten. Der Juni war warm, und die Raupen erreichten ungefïhr ihre Verpuppungsreife. Mitte Juli schwärmten bereits Nomnen (14 Tage fiüher als normal). Die folgenten Sommer- und Herbstmonate waren warm und der August sehr heiss.

In einer weiteren Notiz sagt Altum (1899. 13), dass laut Oberförster v. Wurmb die Verpuppung der Nommen-Raupen in diesem Jahre (1899) selı unregelmässig stattfand und ler Flug von .Juli bis Mitte September dem Verpuppungszeitraum entsprach.

A. Semenow (1900. 807) sagt, Bezug nehmend auf das von ihm aufgestellte Genus Pseudolroscus, dass die Fauna von Turkestan ein ummittelbares liesultat ler fortschreitenden Entwickelung des kontinentalen Ḱlimas in dieser Gegend sei. Er erklärt sich mit ler von A. N. Krasnow (1888. 473) aufgestellten Formel einverstanden, und zwar

$$
F=f_{I}+f_{I I}+f_{I I I}
$$

wo $F$ die Summe aller zur Zeit vorhandenen Formen, $f_{I}$ - die palaearktische Arten, welche bis jetzt unveränlert geblieben sincl, $f_{I I}-$ das unmittelbare Resultat der Abänderung solcher Arten unter dem Einfluss iler Berlingungsänderungen für die Existenz im gegebenen Orte, unil $f_{I I I}$ - Arten, welche wïhrenıl der späteren Epoche eingewandert waren, bedeutet.

Für Turkestan erhält diese Formel den Ausılruck

$$
F=f_{I I} .
$$

'Turkestan hat sich rasch entwässert, wobei auch seine Flora am Charakter umi der Zusammensetzung einen Wechsel erlitten hat. In Folge dessen mussten sich die Organismen einer neuen Lebensberlingung anpassen: es entstanilen neue, zuweilen sehr scharfe, morphologische Eigenschaften, neue Gattungen und die Differenzierung iler Arten. 
W. Pospelow (1901. 642) beobachtete in Nord-liusslanil, diss die Puppenzeit von Botis sticticulis nur 10 Tage beträgt (von 1. bis 10. Juli alt. St.), währenil dieselbe in Süil-Russlanıl nach Keppen (448) 4 Wochen dauert. Diese Iifferenz, wirl daulurch erkliirt, dass die Raupen dieses Schmetterlinges vor iler Verpuppung ihre Cocons in der Frile anfertigen, deren Länge von der Trockenheit und der Temperatur der Oberflïche des Borlens abhïngen, mol zwar ist dieselbe diesen Falitoren direkt proportional. "Unzweifelhaft muss der Verbrauch ıles Materials zun Spinnen eines längeren Cocons die Entwickelung des Schmetterlinges ungünstig beeinflussen" (p. 7 iles Sep. Abdruckes).

R. Thiele (1901. s(61) stellte seine Beobachtungen an Schizoneura lanigera Htg. (Blutlaus) an und fand, dass dler gessimmte Generationswechsel abhängig von der Witterung ist: die \%eit zwischen den einzelnen Verwanllungsstadien ist umso kiirzer, je höher die Lufttemperatur ist.

H. Auel (1902. 17) stellte die Zucht von Pieris hrassicae in Zimmer vom $\mathrm{Ei}$ al an unl konstatierte, dass die Dauer für das Heranwachsen rler Raupen betrug: 24 Tage für dlie, welche die zweite Generation ergeben, unt 28 Tage für die, welche sich als Winterpuppe verwandeln.

\section{Ergänzungs-Litteratur zu diesem Abschnitt.}

Barret, C. G. The intluence of meteorological conditions on Insect life. - Fint. M. M. XIX. 1882, p. $1-8$.

Cazalis, Fréd. De linfluence du climat sur la production des galles à phylloxera. Bull. Soc. centr. d'agricult. et d'hortic. de l'Hérault. Année 1870. p. 328.

Cornu, Max. Intluence des chaleurs printanières sur le Phylloxera vastatrix. -. Compt. rend. LXXVIII. 1874. p. 1285-1289.

Garau, Raimondo. Influenza dei venti marini sulla riuscitı dei bachi. - Giorn. dell' Industria serica. Anno VI. 1872. p. 108-109.

Ghiliani, Vittore. Acclimazione spontanea. - Boll. Soc. Entomol. Ital. I. 1869. p. $268-270$.

Girard, Maurice. Note relative à des éclosions rapides de Lépidoptères par les chaleurs intenses du printemps. - Ann. Soc. Fnt. France. 4. Sér. T. 8. Bull. 1868. p. LXI.

Guérin-Méneville, F. E. Sur lia cause météorulogique de lil malidie des végéteaux et des vers à soie. Extrait d'une note. - Compt. rend. 1863. T. 57. p. $961-962$.

Harding, H. J. Intluence of Atmospheric Changes upon Insect Life. - Entomologist. 1864-65. Vol. 2. p. 193-194. 


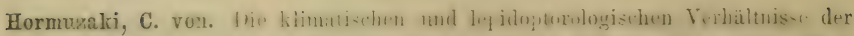
Gegend von Solka in der Bukorina, - Societ. Entom. XIII. 1898. die 2.

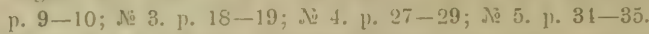

Kane, W. F. V. de. Influence of Meteorological Conditions upon Lepidoptera. The Entomologist. XiI. 1854. 1). 25-28.

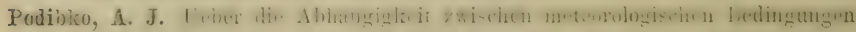
und dem Leben der Reben-Phylloxera. - Lin mündliches Referat, vorgetragen in der Sitzung der russischer Entomologischen Gesellschaft in St.Pctersburg 1894.

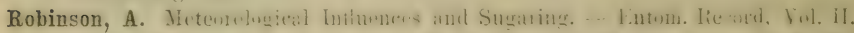
1891. א2 4. p. 88-89; Note by W. Reid. ibid. No 5. p. 113; by E. W. Brown, p. 113-114; by J. Collins, p. 119.

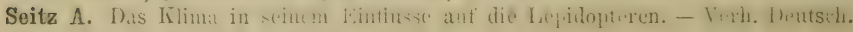
Naturf. II. 18:10. p. 142-148.

Stadd, E. F. Effect of the unusual May weather. - Entom. Record, Vol. VIII. 1896. A6 6. 3). 143 .

8.- Notes on the effects on the weather on Lepidontera, Pupae etc. - The Entomologist. 1879. p. $202-204$.

\section{Einfluss der Feuchtigkeit.}

G. Dieck (1S699. 175) erwaihnt in seinen "Beiträgen," dass "lin" südlicheren Blindkifere (Stcinkifer) die trockene Wäme nicht ans-

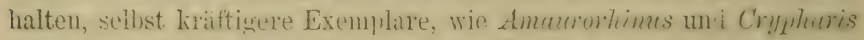
sterben. wemn sie lehen! in ter sammelfiasche heimgetragen werilen.

M. Cornu (1sis. 1.it) lnachte einige Wurzeln von Weimehen, auf welchen sich itherwinternte Phylloxern fatnit, in ein Gilus unil setzte es ier Einwirking crwirnuter trockener Luft aus. Inic mittlere

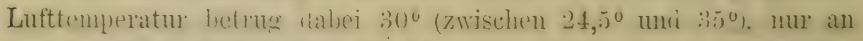

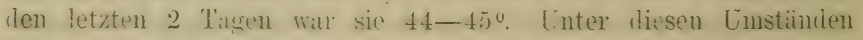
wurile die Phyllowen bereits nach 3 Tagen statt flach convex, und an darauf folgenlen Tag häutcte sich eine gewisse Anzahl von Individuen. Nach 10 Tagen wurlen 2 Eier gefunden, und nach 12 Tagen legten anch die amteren Exemplare die Eier ah. Frongloxeru. welclue nicht so hoher Tempreratur ansgesetzt war $\left(33,4^{\circ}\right)$, wurle convex erst nach 4 T'agen und lebte nach 5 T'agen auf.

W. A. Jaroschewsky (1<82. 41s) beobachtete 1880 eine starke Verminterung der Larren voun (ietreicheliter (Anisoplia) in Gouvernement Charkow. welcher Linstand durch starke und zalhlreiche liegengiisse in IIerist 187 !) und im Frühjaltr und Sommer 1880 bedingt wurde. 
P. T. Stepanow (185:2. A4ti) erbeutete in Juni $187 !$ Latrven von

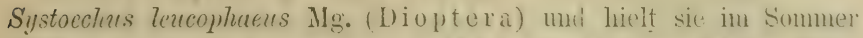
1580 in einem trockenen Zimmer whe sie anzuteuchten. Diese Larven verpuppten sich nicht ein Mal 1881 (ivis zum April). waren jetoch noch an Leben. Antere Larren dersellen Art. welche er im

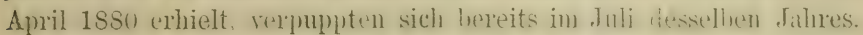

H. Gauckler (1889. 293) beobichtetr. hass lie Lianjen vem

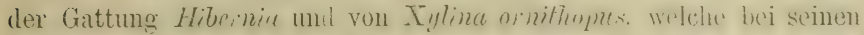
Zuchtrersuchen in Wasser fielen, starr whren, nachlem tieselhen in der liegel 6 bis s Stunilen darin verblieben warest. Als sir atus lem Wasser aber horansgenommen wurten, kampm sie wieder zu sich, "ohne anch nur den geringsten Schaten an ihrer fesmothent in Folge des langen unfreiwilligen Bates gemommen zal hatka" (p. 3.t).

In der Abhamilung: "Chemisch-analytische Lintersuchungen an lebenten Raupen. Puppen unil Schmetterlingen und an ihren secreten" vin Fr. Urech (1S90). s.t!) finden sich einige Curven, welehe

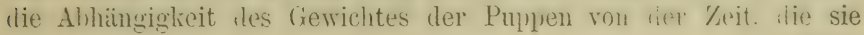
in trockener oder feuchter Luft zubrachten, angeben.

Curve IV zeigt. dass trockene Luft (in Exsicator) ifir l'uppentauer etwas abkiuzt, "wohl hesshall, weil in trockener luft die Ver.lumstumg des vor dem Auskriechen nothwen?ig zn seremiemem Saftwassers erleichtert wird" (p. 5).

Durch besondere Vexsuche br\%. Bestimmungen der Gewichts-

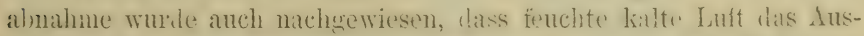
kriechen des Schmetterlings sehr verzigert. „es schien, als oh der bis auf die Fliigelausilehnumg fertige sehmetterling in rex Pupprnhülle verharren wollte, bis günstigere Witterung cintresen wimb" (1). 5).

Diese beillen Versuche wuriben nit Pieris brassime angestellt.

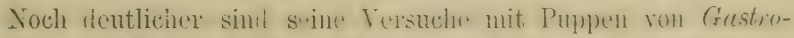

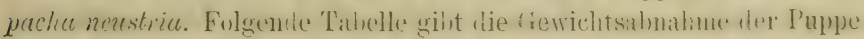
an (die Procente der (iewichtsahnahne beziehen sirh auf dias Puppengewicht an Anange ler beigesehriebenen sucessiren \%eiträumen):

\begin{tabular}{|c|c|c|c|c|c|}
\hline $\begin{array}{l}\text { an trockener } \\
\text { Luft in }\end{array}$ & $\begin{array}{l}\text { successive Zeit- } \\
\text { räume in Tayen }\end{array}$ & $\begin{array}{l}\text { an fincliter } \\
\text { Linft in }{ }^{\circ} \text { 。 }\end{array}$ & $\begin{array}{l}\text { an trockener } \\
\text { Luft in }\end{array}$ & $\begin{array}{l}\text { successive Zeit- } \\
\text { rüume in fagenl }\end{array}$ & $\begin{array}{l}\text { an fouchter } \\
\text { Luft in } \bar{c}\end{array}$ \\
\hline$\overline{5},() 7$ & 5 & $1, \pi T$ & 5,83 & $\bar{j}$ & 0.38 \\
\hline 4,83 & 3 & 2,15 & 2,96 & 3 & 0,56 \\
\hline 5,37 & 4 & 0,32 & 3,37 & 4 & 0,19 \\
\hline 5,13 & 5 & 0,56 & 7,20 & 5 & 2,86 \\
\hline
\end{tabular}


Imraus ist crsichtlich, lass eine Puppe in trockener Luft mehr an Crewicht ahnimmt, als rine antere. in fenchter Luft gehaltene.

Fritz Rühl (1892. 721) lrachte auf ten Boten eines mit.

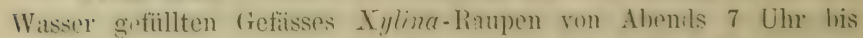
Mittags 12 [hlu. woranf sie sich im Verlaufe ron $3-4$ Stumlen so vollstandier erhalten, lass sie sofort wieler Nahrung zu sich nahmen. Empfindlicher waren die Raupen der Tagschmetterlinge. ron denen nach 4-i stimbigem Verweilen im Wasser leine mehr ein Lehenszeichen von sich gab (p. 10).

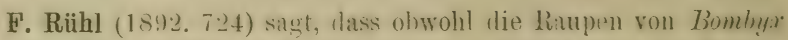
arbusculue. Frr. an Ort und Stelle (nie unter $65\left(00^{\prime}\right.$ ) sehr die Feuchtigkeit liehen, sie lloch in der Ehene äusserst trocken grehalten werken miissen; je heisser dir Augustsonne hremut, lesto schneller das Wachsthum. In regemreichen Jahren starben ihm die halherwathsenen Raupen massenhaft, dagegen war der Verlust 1892 in der bremnemien some les ungewïhnlich heissen August kamm nennenswerth.

Iw. Schewyrew (1893. 748) beobachtete, dass llie Anzahl der Raupen von Anisopterit uesculuria Schif. betentend abrahm, nach(lem es am 17.,29. Nai stark geregnet hatte $(32 \mathrm{~mm}$.). Nach dem Regen komute man tote haupen treften, welche wahrscheinlich durch eine Pilzkrankheit gestorben waren.

B. Grassi (1894. 327) fisst die Er lgallerion, welche Embiodea errichten, als Mittel auf, um dir zum Leben nöthige Fenchtigkeit aufzubewahren.

M. Standfuss (1894. 837) sagt: "Wenn grössere Massen von Saturnien-Puppen (es hanlelte sich in diesen Falle stets um 200 bis 400 Stiick) $7-10$ Wochen zwischen Juni unl Ende September sehr trocken gelegen hatten und clamn mehrere Male intensiv aufgeeuchtet wurlen. sich etwa 1\% Falter aus diesen Puppen 10-20 Tage nach dem Anfeuchten entwickehn" (p. 28).

Er ist der Meinung, diass Suturniu boisduvulii Ev., Bombyx catux L. und Bombyx rimicola $\mathrm{Hb}$., welche sämntlich als Falter im Herbst erscheinen uni im Eizustanle überwintern, sich sehr wohl durch ähnliche Veranlassungen von den verwandten Saturnillen unil Bombjciden, die noch gegenwärtig als Puppen überwintern, in vergangenen Erilepochen abgezweigt hahen kimmen. 
August Hüttner (1895. 398) erhielt von einem Simmelfreunde 5 Stuick todte Saturnic spini-Raupen, welche für ertrunken galten und vier Tage im Wasser gelegen hatten, zum Aushlasen. Er legte sie in die Fensterpalette, lie viel Somme hatte. .. Nach Verlauf von zwei Stunlen fingen die für tolt gehaltenen liaupen an, sich langsam zu bewegen und liefen Tags darauf schon recht behend umher, nahmen Futter an und spamnen sich dles nächsten Tages darauf ein."

J. Breit (1895. 112) beobachtete, dass die P'Pupen von strurropus fagi namentlich in Frühjahr viel feuchtigkeit verlangen.

Aug. Weismann (1895. 954) sagt in seinem Buche: "Nene Versuche zum Saison-Dimorphismus der Schmetterlinge:" „Das häufige Verkriippeln ist ohne '/weifel anf die sehr fenchte Luft des Brutofens zuruickzufuhren, welche die Puppenscheile nüsst und weich macth und so das Ausschlüpfen erschwert" (p. 26).

Ein Kiorrespontent (1896. 970) aus dem (iouvernement Toholsk theilt mit, dass clie FortpHanzung der Henschrecken in dieser ('xegend vom Bolen mit seiner Vegetation, vom Wetter uml hauptsächlich von periolischen Schwankungen des Wassers in den Seen abhängt, welche lie periolische Fortpflanzung belingen.

Clerici (1896. 149) giebt folgente Tabelle an, in welcher die Cocon-Ausbeute von Bombyx mori L. ahhängig von uler Luftfeuchtigkeit währenı verschiedlenen Jahren enthalten ist:

\begin{tabular}{c|c|c|c|c|c|}
\hline Jahr & $\begin{array}{c}\text { Cocon- } \\
\text { Ausbeuto }\end{array}$ & $\begin{array}{c}\text { Die relative Fench- } \\
\text { tigkeit zwischen } \\
\text { dem 1. u. 20. Juni }\end{array}$ & Juhr & $\begin{array}{c}\text { Coeon- } \\
\text { Ausbeute }\end{array}$ & $\begin{array}{c}\text { Die relativo Feuch- } \\
\text { tigkeit zwischen } \\
\text { dem 1. u. 20. Juni }\end{array}$ \\
\hline 1885 & 11,12 & 52 & 1886 & 11,75 & 66 \\
1890 & 11,37 & 54 & 1891 & 11,87 & 56 \\
1887 & 11,50 & 54 & 1884 & 12,00 & 68 \\
1892 & 11,50 & 57 & 1889 & 12,25 & 66 \\
1888 & 11,62 & 57 & 1895 & 13,00 & 69 \\
1893 & 11,75 & 60 & & & \\
\end{tabular}

Unter "Cocon-Ausbeute" muss man hier die Anzahl von Kílogrammen rler lebenden Puppen sammt Cocons verstehen, welche ein Klgr. Rohseide liefern.

A. Obuchow (1896. 613) sagt, dass die Jahre 1890 unt 1891 sehr trocken waren und das Niveau des Grundwassers in Gebirgs- 


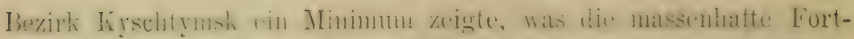

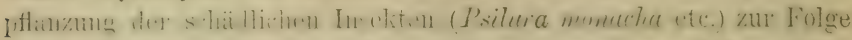

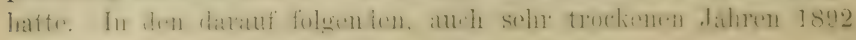
und 1893 wurde die Fortpflanzung noch grösser.

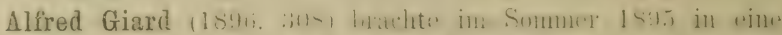

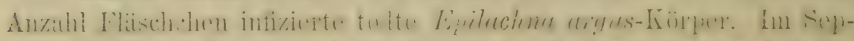

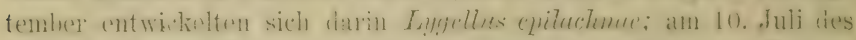

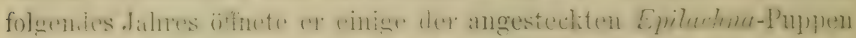

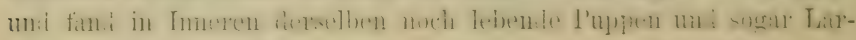

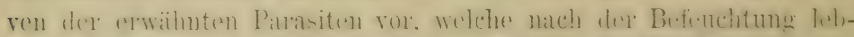

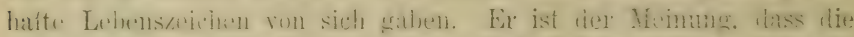

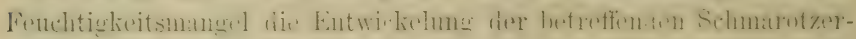
stalien um ein Jahr vorzögert hat.

C. Mokrzecki (1s!nti. 5-i) beobachtete dir Ptlinzenliuse an Wrizen rom Anfang Mai his zur Mitte duli und stellte fist. lass die

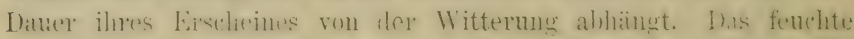

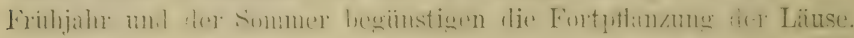

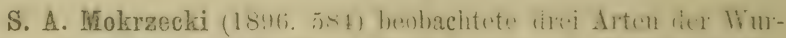

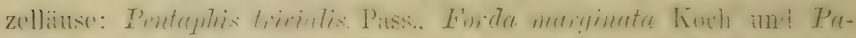

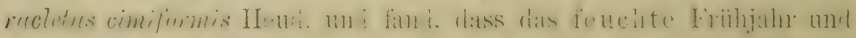

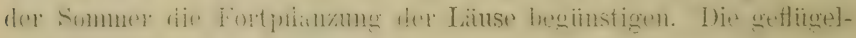
ten Indiviluen bemerkte er bereits im Anfang Juni (alt. St.).

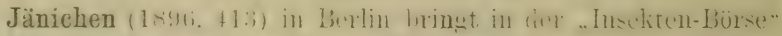

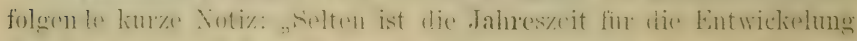

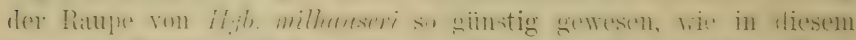

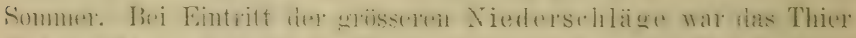

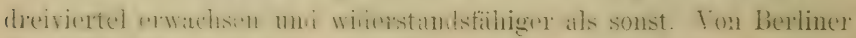

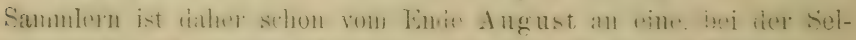

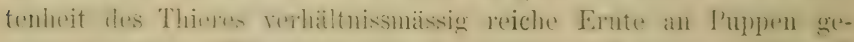

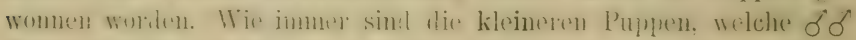
Falter ergehen, sehr sparsam."

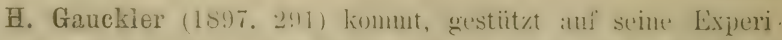

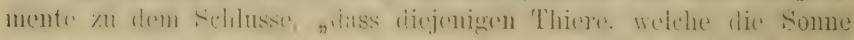

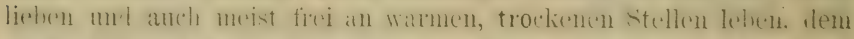

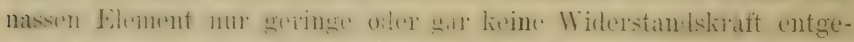

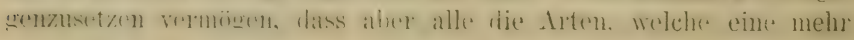




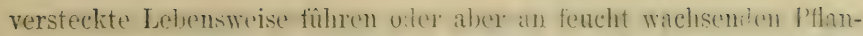
zen lehen, geleggentlich wohl auch ein tichtiges liat vertiawen lionnen" (p. 296).

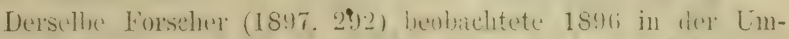

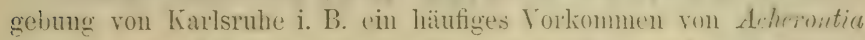

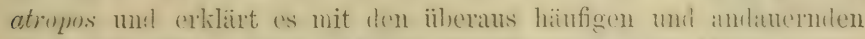

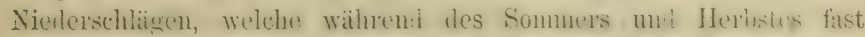

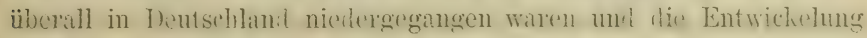
des Thieres begünstigt hatten.

Wilh. Kusdas (1897. 488) in Wien heohachtete einiw: Fille

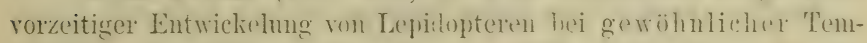
peratur unil zwar:

Dir an 11.-19. Tuli verpuppten Riupen vou Smerinthes populi

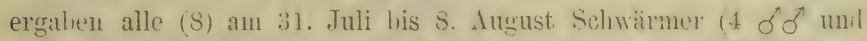

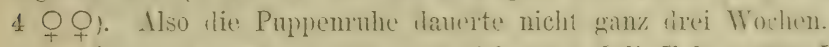

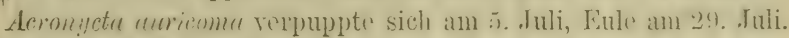

3 Stiick Aermugte linnstri verpuputen sich an 2.-.?. fuli. Eule am 20.-25. Juli.

Notodontı ziczac verpuppte sich am 30. Juli, Spinner am 13. August.

"Aus 18 stiick Fiern, welche Ente Juni von einem in Freien

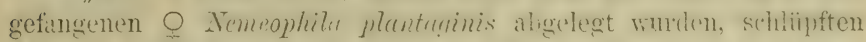

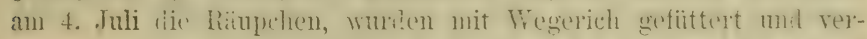

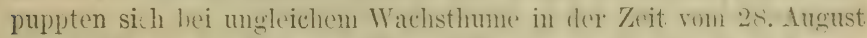
bis 21. Oktolur. Ius simmtlichen Puppen schliipften nach surch-

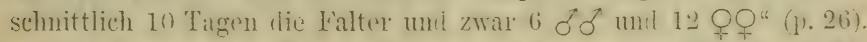

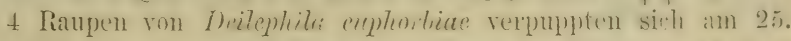

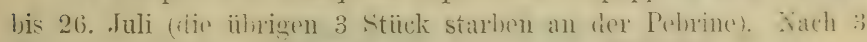
Wochen ergaben sie Schwärmer.

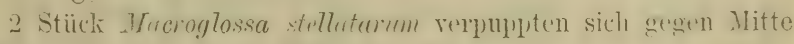
Juli und ergaben nach ca. 3 Wochen Schwärmer.

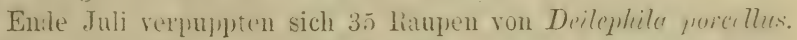
Ein Falter schlïpfte am 21. Oktober aus.

Da rler betreffende Sommer nicht zu den heissen zïlllte, so erkliirt Kusdas diese Erscheinung dureh die mehr als hänfigen viederschläge dieses Sommers, welche die Atmosphäre i. u ficucht machten.

E. Kulikowsky (1897. 48.t) Lrachte den Kïfiex A. amtivuce

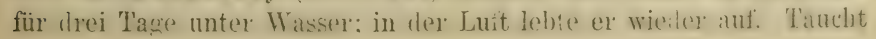


unan rlese Käfer in Karholsäure orler Spiritus fur kur\%e Zeit, so bleiben sie unbeschädigt.

W. Ganitzki (1897. 271) taụchte den Kïffer Cleonses punstirentris für zwei Tage unter Wasser; in die Luft wieder gebraucht, lebte er auf.

L. A. Stempkowska (1897. S45) erhielt Eier von Bomlyy.x mori, deren Raupen mit Blïttern von der schwarzwurzell gefuittert wurilen. Die aus diesen Eiern erhaltenen Riumphen wurlen auch mit gleichen Blättern gefiittert un I begannen nach 5 Tagen sich zu hähten, was 28 Stunden dauerte. Die zweite Häutung erfolgte nach drei Tagen und bei einigen sogar nach $4_{1 / 2}^{1}$ Tagen unl dauerte 30 Stumlen. Darauf wurilen alle schwachen uni linger als 30) Stumlen schlafenden Raupen ausgeworfen. Die dritte Häutung begann hei 13 Raupen am füntten Tage uni bei den vibrigen 97 einen Tag später: ler Schlaf dauerte bei der ersten Serie 32 unil bei der zweiten 36 Stunden; 7 Raupen, welche länger schliefen, wurilen ausgeworfen. I)ie vierte Häutung begann bei 13 Raupen am fiuften Tage unl danerte 38 Stumlen, während bei den übrigen Raupen die Häutung umregelnässig erfolgte, wobei sie alle erst nach 7 Tagen einschlicfen; das Erwachen famd bei allen erst nach 2 Tagen statt. Das Einspinnen legann am achten Tage des funften liaupenalters und dauerte bei erwähnten 13 Raupen 3 Tage; bei den ibrigen begann lie letzte kaupe am 11. Tage des 5. Alters sich einzuspinnen.

Den Grund dieser Unregelmässigkeiten sieht die Forscherin in den sehr saftigen Blättern, da es während der Aufzucht ununterbrochen regnete.

B. M. Schitkow (1997. 75\%) fütterte Raupen von Bomby $x$ : mori mit Blättern der Schwarzwurzel unl beobachtete dabei. dass die laupen Dysenterie unıl Erbrechen bekamen, als man ihnen Blätter der einjahrigen statt zweijährigen PHanze reichte. Sie starben dabei jerloch nicht unı erholten sich balı darauf. 1)ie Ursache der Störung der Verilaungsorgane lag offenbur in der grösseren Saftigkeit der Blätter.

M. C. Piepers (1898. 639) in Batavia erhielt an 17. Oktober 1890 verschielene, alle auf llerselben Pflanze gefunilenen Raupen und Puppen von Papilio antiphates Cram. Von letzteren gaben zwei bereits am 24. und noch zwei an 25. Oktober den Schmetterling. 
Die sieben Raupen verpuppten sich, und die Puppen wurden unter sonst gleichen Umstänlen aufbewahrt. Das Ausschliipfen fanil statt:

1 Raupe verpuppte sich am 23. Okt. 1890; das Ausschliupfen am 13. Jan. 1891.

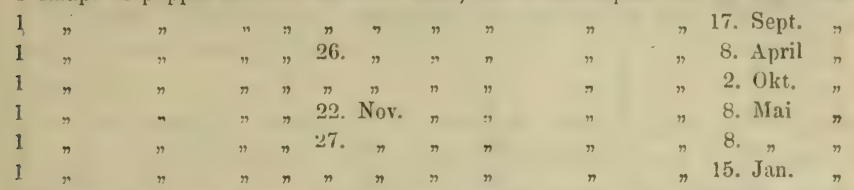

Hier waren währenıl der Puppenzeit allein die natürlichen meteorologischen Zustände: die grössere Trockenheit oıler Feuchtigkeit der Atmosphäre in den einzelnen Momenten fiir sie verschieden.

A. Caretta (1898. 136) brachte die Eier von Bombyx mori von verschiellenen Rassen ins Wasser, wo sic verschieden lange Zeit sich befanden, und kam zu folgenden Schlüssen:

1. Die vollständige Erstickung der Fier im Wasser finclet im August unl September nach 10 Tagen, im Oktober nach 16 Tagen und in December nach to 'Tagen statt, wobei die Temperatur des Wassers eine gewöhnliche ist.

2. Die Sterblichkeit der Eier bei verschiedenen Rassen ist verschierlen, z. B. betrug dieselbe bei Eiern ler japanischen grïnen Rasse nach 120-stündigem Eintauchen ins Wasser im August 3\%, und im September unter gleichen Unständen $25 \%$.

3. Bei der Coreanischen Rasse betrug die Sterblichkeit $50 \%$, gleichviel ob die Eier 550 Stunden bei $6^{0}$ oder 800 Stunden bei $0^{\circ}$ im Wasser sich befintlen; dasselbe gilt auch für die Terni-Iiasse.

Es seien hier einige Tahellen zum Klarstellen clieser schliisse angeführt.

\section{Japanische weisse Rasse.}

Eier abgelegt Ente Juni; bis Anfang December bei ca. $10^{\circ}$ aufbewahrt und nachher bei $3^{0}$ überwintert. Incubiert am 1. März und ausgeschliipft vom 21. Mürz an.

\begin{tabular}{|c|c|c|c|c|c|}
\hline \multirow{2}{*}{$\begin{array}{l}\text { Dauer des } \\
\text { Eintauchens } \\
\text { ins Wasser } \\
\text { in Stunden }\end{array}$} & \multicolumn{5}{|c|}{$\begin{array}{l}\text { Der übrig geblicbene Prozentsatz am 10. Tage des Fnt- } \\
\text { schlüpfens der Raupen }\end{array}$} \\
\hline & $\begin{array}{c}\text { August } \\
\text { bei ca, } 25,55^{\circ}\end{array}$ & $\begin{array}{c}\text { September } \\
\text { ollue ca. } 21,9^{\circ}\end{array}$ & $\left|\begin{array}{c}\text { ()ktuber } \\
\text { bei ca. } 16,6^{\circ}\end{array}\right|$ & $\left|\begin{array}{c}\text { November } \\
\text { bei ca. } 10,5^{\circ}\end{array}\right|$ & $\begin{array}{r}\text { December } \\
\text { bei ca. } 0^{\circ}\end{array}$ \\
\hline 0 & 1 & 1 & 3 & 3 & 3 \\
\hline 24 & 1 & 1 & 5 & 3 & 3 \\
\hline 48 & 1 & 1 & $\overline{5}$ & 3 & 3 \\
\hline 72 & 1 & $1, \tilde{\jmath}$ & 5 & 3 & 3 \\
\hline
\end{tabular}




\begin{tabular}{|c|c|c|c|c|c|}
\hline \multirow{2}{*}{ 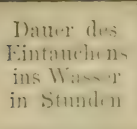 } & \multicolumn{5}{|c|}{ 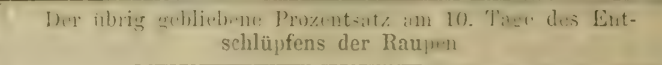 } \\
\hline & $\begin{array}{l}\text { August } \\
\text { bei ca. } 25,5^{\circ}\end{array}$ & $\begin{array}{l}\text { September } \\
1,+1 \cdots 21.9^{2}\end{array}$ & $\begin{array}{l}\text { Oktober } \\
\text { bei ca. } 16,6^{\circ}\end{array}$ & bei ca. $10,5^{\circ}$ & $\begin{array}{l}\text { 1)ecember } \\
\text { lei a. } 0^{\circ}\end{array}$ \\
\hline 316 & 2 & 2,5 & 7 & - & - \\
\hline 120 & 2 & 4 & 10 & 3 & 3 \\
\hline 144 & 25 & $20)$ & 12 & 3 & 3 \\
\hline 168 & 75 & 70 & 15 & 3 & 3 \\
\hline 192 & 97 & !) 6 & 20) & 3 & 3 \\
\hline 216 & 99,5 & 99 & 40) & 3 & 5 \\
\hline 240 & $(19,9)$ & 10() & (i) & 3 & 5 \\
\hline $26 i 4$ & - & - & $\triangle 5$ & 3 & 5 \\
\hline 292 & - & - & 90 & 5 & 5 \\
\hline 350 & - & - & 97 & 7 & 5 \\
\hline $4(1)(1)$ & - & - & (9)!.9) & 20 & 5 \\
\hline 1000 & - & - & - & - & 5 \\
\hline
\end{tabular}

\section{T'erni-Rasse und Koreanische Rasse.}

Die Fier sint Ente Juni ahgelent un l bis zum Anfang December bei $10^{\circ}$ aufbewahrt; nachher bei $3^{0}$ überwintert. Incubiert am 1. März und ausgeschlüpft vom 20. März an.

\begin{tabular}{|c|c|c|c|c|}
\hline \multirow{3}{*}{$\begin{array}{l}\text { Douver des } \\
\text { Lintaullens } \\
\text { ins Was it } \mathrm{r} \\
\text { in Stunden }\end{array}$} & \multicolumn{2}{|c|}{$\mathrm{T}$ e $\mathrm{r} \mathrm{ni}$} & \multicolumn{2}{|c|}{$\mathrm{C} \cap \mathrm{r}$ e a } \\
\hline & \multicolumn{4}{|c|}{$\begin{array}{l}\text { Der übrig gebliebene Procensatz am } 10 . \text { Tage des } \\
\text { Entschlüpfens }\end{array}$} \\
\hline & $\begin{array}{l}\text { Desember } \\
\text { bei ca. } 6,1^{\circ}\end{array}$ & $\begin{array}{l}\text { Decenber } \\
\text { bei ca. } 0^{0}\end{array}$ & $\begin{array}{l}\text { December } \\
\text { bei ea. } 6,1^{0}\end{array}$ & $\begin{array}{l}\text { Derember } \\
\text { bei ra. } 0^{\circ}\end{array}$ \\
\hline () & 3 & 5 & 2 & 1 \\
\hline 24 & 3 & - & 2 & 1 \\
\hline 200 & 3 & $\check{\jmath}$ & 2 & 3 \\
\hline 300 & ริ & - & - & 3 \\
\hline 400 & 10 & 7 & 5 & 7 \\
\hline 500 & 50 & 10 & 20 & 7 \\
\hline 600 & 90 & 15 & 50 & 10 \\
\hline 700 & 90 & 20 & - & 10 \\
\hline$\$ 00$ & - & 30 & - & 40 \\
\hline 900 & - & 50 & - & 80 \\
\hline 960 & - & 50 & - & 95 \\
\hline
\end{tabular}


Nach H. Gauckler (189!9. 29!7) geinen alle Hybue. mitheneserPuppen, welche heim Ueberwintern höheren Zimmertemperatmen (his zu $200^{\circ}$ Ri.) ausgesutat werilen, zu (irunte; sie herhirfen eines anhaltend hohen cirales ron Feuchtigkeit, der ihnen bei Zimmerzucht nicht geboten werilen kann. Dasselbe gilt auch für Stauropus fiugiPuppen.

Von etwa 16 Puppen von Pasthea coenobita, welche von An-

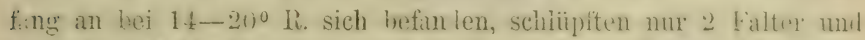
zwar 1 \& Mitte Fehruar umi 1 o Ente März. H. Gauckler zicht. daraus den Schlnss, lass licse l'uppen zu ihrer Entwickehme längere Zeii nichliger Temperaturen mit vielen Viederschlagen beviurfen. D):sselise betriffe nach ihm anch alie Puppen ron Phignlia pedaria unil Hibernia defoliaria.

Grätin M. von Linden (18999. 322) hiselt a Baupen vion Pieris irassicae in einer Flasche mit reinem sauerstolf, dabei liomnte keine einzige Puppe zu Stanle lommen, da die Liamen alle abstarben. Die Verasserin sagt: "Vielleicht war an ihrem Toul nicht nur her Samerstoff, sontern atch die feuchte Atmosphäre schul!, dem bei dem regen Stoffivechsel der Rampen und iem nothwenligen Vouhandensein grösserer PHanzenmengen komnte ich nicht verhimlern. hass die Wänl: der (tliiser fortgesetzt mit Feuchtigkeit beschiıgen waren" (p. 371).

A. S. Slrorilkow (1899. 817) kommt hei seinem Stulium russischer Collembnt ${ }^{7}$ zum sehlusse, dass die alsolute unit hesont iers relative Feuchtigkeit lex gegebenen Formation eimn wichtigere inlle spielt, als einer der Faktoren, welche die Verineitung hioser Thirre bedingen. "Kaum fehlerhaft kamn die Behauptung sein, dass fie die Oikologie dieser Insekten nicht nur Quantititen der Fenchtigkeit wichtig sini, sonlern - was rlie Hauptsache ist - die kleinen Amplituden ler Fenchtigkeit sowohl währent kiurzerer, wie anch wïhrend längerer Zeiträmme. Der Wald in unserer Gegend (Charkow) ergiebt, bei verhailtnissmässig geringerer Feuchtigkeit, ihre successive Schwankungen unl belingt durch diese seine Eigenschaften tas Leben ron Orchesella rufescens var. silvestris (var. n.) ausschliesslich immitten der Wälder" (p. 398).

W. Kolbe (1900. 463) beobachtete an Phytoctertı viminalis L., dass diese Kü̈fer Ende Juni in einen lethargischen Zustaml verf.llen 
und in Erolhöhlungen die Zeit zubringen. Wird der Boden angefeuchtot, so kriechen sie hervor; tritt die Trockenheit wienler ein, so ziehen sie sich in die Errle zuriick.

L. von Aigner-Abafi (1900. 6) sagt, indem er ïber die Verbreitung von Pentophora morio in Ungarn spricht: „Im Jahre 1884 z. B. hat clis liaupe bei Nagy-(iöcz (Comitat Bug) binnen zehn Tagen 120 Morgen Wiesen vollstämlig kahlgefressen, wobei zu bemerken ist. dass die Wiesen vorher einen Monat lang unter Wasser standen" (p. 202).

0. Schultz (1900. 78!) bewahrte die Puppen von Papilin podalirins in einem geheizten Zimmer, wobei sie "lem Einflusse grösster Trockenheit" ausgesetzt wurlen. Einige Puppen gingen ein, willırenıl die anderegn zwar Falter ergaben, dieselben gestalten sich aber nachher "zu unscheinbaren Krippeln" Diese Falter wiesen beim Verlassen der Puppenhiille dlurchaus normale Bildung auf. Die Benetzumg der ruletzt ausschliufenden Puppen kurz ror der lintwicklmo der Imago stark mit Wasser half nicht. Die Untersuchung ergah, dass die Lirallen der Vorlerfiisse entwerler völlig unentwickelt oiler zu schwach waren uml die Falter ihren Körper nicht tragen resp). sich festhalten lionnten, und somit an ver völligen Ausbildung der Fliigel gehindert wurden.

I. K. Tarnani (1900, -5.5) famil im (ivuvernement Ufa (liusslanl) dreijïhrige Larven von Maikïfer auf einer Wiese, welche jelles Jahr durch den Fhuss Belaja iberschwemmt wirl. wobei diese Larven zwei Mal unter Wasser sich befintlen: 1898 vom 1. bis 12. Mai und 1899 vom 7 . April bis 6. Mai, und dennoch am Leben blieben. „Dieser Lmstanıl zeigt, dass die Larven unter dlem Wasser ca. einen IInnat verbleiben kïmen unt dadurch nicht vernichtet werden" (p. 6).

Er beobachtete atuch, dass die Larven von Lamellicornia: Rhizotroyus. Meloluntha und Cetonia zuweilen 6 Tage in reinem Wasser (ohne Erde) liegen können, ohne dabei ilı Leben einzubüssen.

Alisch (1901. 9) ersieht als wesentlichsten Faktor der Verminlerung der Coleopteren in vermehrten Viederschlägen. Da die Zeit des hauptsäichlichsten Ei- und Larvenstadium für die meisten Coleopteren-(iattungen in die Monate Mai. Juni und Juli fällt, führt er folgenile Tabelle iler Regentage an: 


\begin{tabular}{|r|r|r|r|r|c|c|}
\hline Jahr & Mai & Juni & Juli & Summe & Ernte & Bemerkungen \\
\hline \hline 1895 & 5 & 3 & 15 & 23 & gut & \\
1896 & 5 & 12 & 10 & 27 & gut & \\
1897 & 16 & 8 & 13 & 37 & gut & \\
1898 & 15 & 14 & 17 & 46 & schlecht & Natur im Mai sehr zurïck. \\
1899 & 21 & 5 & 7 & 33 & sehr schlecht & \\
1900 & 10 & 15 & 5 & 30 & schlecht & Natur im Mai sehr zurick.
\end{tabular}

Daraus schliesst er: "das mehr oder minler häufige Auftreten von Coleopteren ist vor allem von den Nieclerschlagsmengen resp. Regentagen der Monate Mai, Juni unil Juli des vergangenen Jahres abhïngig. Eine je geringere Zahl derselben wir zu verzeichnen haben, einer desto besseren Käferernte werden wir entgregensehen" (p. 213).

E. A. Bogdanow (1901. 92) sagt, dass anhaltender liegen für die Coprophagen nicht giinstig erscheint; in dieser Zeit bleibt frischer Kuhdünger gewöhnlich fast ohne Larven unı sogar Käfer (besonters wenige sphaeridium etwas mehr Aphodii): statt dessen sincl Lumbricus und Arion oft zu beobachten. Itie Versuche mit künstlichem liegen ergaben, dass wenn der Dünger sehr nass gemacht wird, dlie Käfer meistentheils fortfliegen, während die Dipteren-Larven theilweise im Dünger beiben, theilweise unter ihn in die Erile oder fortkriechen.

H. Burstert (1901. 122) legte 40 Puppen von Sphinx pinustri auf die rechte Fliigelscheiten-Seite so, dass diese Seite stänlig stark fencht und die andere möglichst trocken gehalten wurle. Die Puppen blieben lange Zeit lebend, nachher starben sie nach und nach und zur Zeit des Schliipfens blicben nur 3 übrig, von welchen eine einen brauchbaren Falter lieferte.

J. Bruner (1902. 117) schreibt, class die Locustiden-Eier (in N. America) bei liegentiallen viel früher schliipïen als bei trockenem Wetter; sic kömnen in trockenen Jahren bis zum nächsten , Jahre überliegen, obwohl tie Temperatur eine höhere sein mag.

N. S. Bernatzky (1903. Ti) beobachtete 1901 in Gouvernement Kaluga, dass in Folge der anlanernlen trockenen Witterung ungewöhnlich viel Schmetterlinge mit nicht vollstïnlig entwickelten Flïgeln erschienen simul. Exemplare, welche in einer liste mit feuchten Blättern gezogen wurden, ergaben normale Fliigel. 
Pabst (1903. (i:2) beobachtete, dass die Raupen von Pterogon proserpinu Pall. vor der Verpuppung tagelang ruhelos umherlaufen. Man kam sie aber sehr leicht zun Vеrpuppen bringen, wenn man ihnen lockeren, trockenen Sand orler grohkimige, trockene Erile als Untergrumd bietet und sie im Brhialter dem direkten Sonnenlicht aussetzt. Er beobachtete auch, dlass wenn man den Raupen von Macroglossa fuciformis L. nasses lintter reicht, sie alle eingehen.

H. Federley (1904. 219) machte in sïl-Finland folgende Beobachtungen über die Entwickelung verschiedrner Schmetterling-Arten:

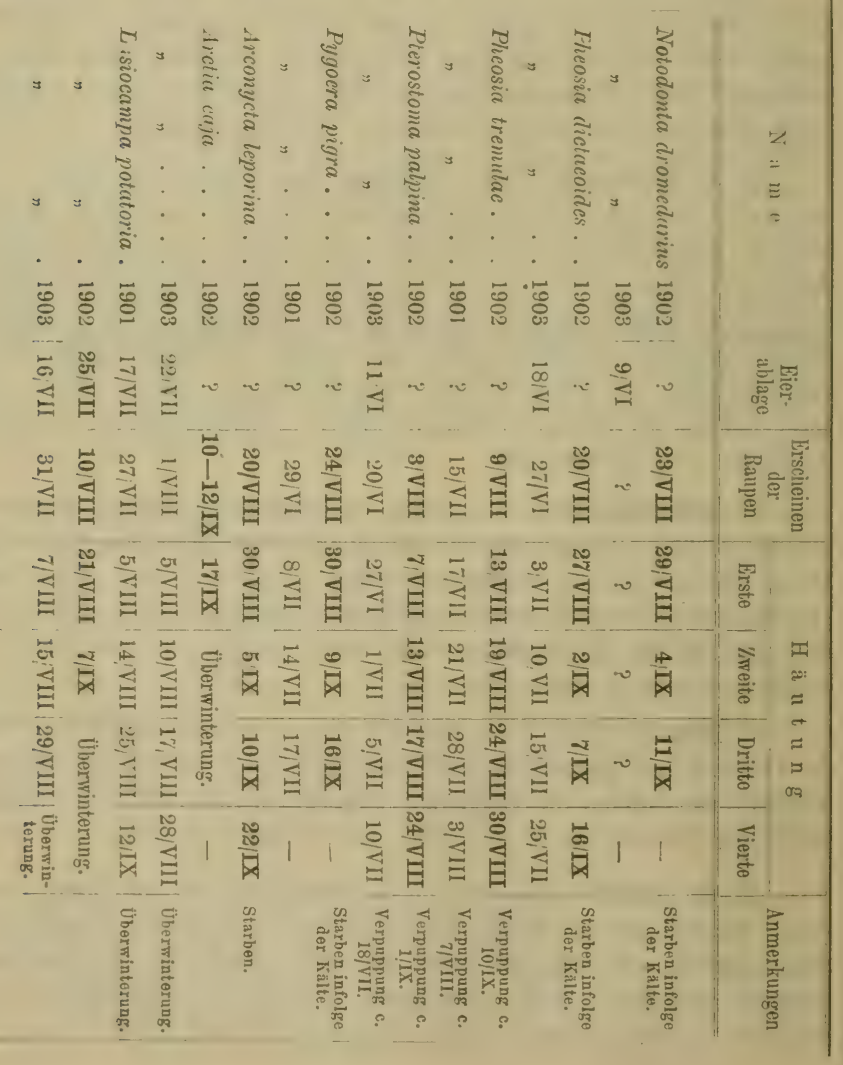


Diese zu frühe resp. zu späte Entwickelung kann daulurch erklärt werden, dass der Sommer 1901 eine ungewöhnlich hohe Mittteltemperatur mit sehr wenig Regen zeigte, während iler Sommer 1902 sehr kilt unil regnerisch war, wie es die folgende Zusammenstellung veranschaulicht:

\section{Durchschnittstemperaturen nach Celsius für Itelsingfors.}

\begin{tabular}{c|c|c|c|c|c|}
\hline J a h r & Mai & Juni & Jüli & August * & September \\
\hline \hline 1901 & 9,2 & 15,5 & 20,0 & 17,6 & 12,1 \\
$1886-1900$ & 9,4 & 14,8 & 17,1 & 15,5 & 10,6 \\
1902 & 9,6 & 12,5 & 14,2 & 13,7 & 9,4
\end{tabular}

Der totale Niederschlag in $\mathrm{mm}$ in Helsingfors.

\begin{tabular}{|c|r|r|r|r|c|}
\hline J a h r & Mai & Juni & Juli & August & September \\
\hline 1901 & 1,3 & 39,4 & 31,6 & 47,8 & 17,9 \\
\hline 1886 -1900 1) & 41,2 & 42,9 & 64,3 & 79,5 & 71,7 \\
1902 & 85,6 & 112,3 & 97,3 & 78,4 & 93,2 \\
\hline
\end{tabular}

N. Kusnezow (1904. 494$)$ ) beobachtete Embir tourica Kusuezow auf dem Süiufer des Krims auf dlunklen Steinen, welche zuweilen so stark von der Sonne erhitzt sind, dlass man dieselben mit der Haml kaum berïhren darf; "trotzlem ist die Bevöllerung auf denselben sehr thätig, wem nur eine genuigende Feuchtigkeit vorhanden ist" (p. 145).

Durch das Vorhundensein der nöthigen Fenchtigkeit erklärt "r auch den Umstand, dass Emlia in den von denselben errichteten Erigallerien sich aufhalten, nicht aber dadurch, dass diese Thiere andere Insekten in diese Gallerien einlocken wollen, um sic damn aufzufressen, da Embia thierische Nahrung nicht autinimmt.

H. Zimmermann (1904. 967) beobachtete, dass in Deutscluland die Entwickelung des Schmetterlings Lithocollelis plutuni Stumlgr. durch die Winterfeuchtigkeit un Pilze st.ırk beeinflusst wiri. "I Iass es vornehmlich die Feuchtigkeit und das mit. dieser im Zusammen-

1) Der totale Niederschlag durchschnittlich pro Jahr berechnet. 
llang stehende Auftreten von Pilzen ist, welche die Ueberwinterung zahlreicher Puppen verhinlern, zeigt sich, wem man im Herbst gesammelte Blätter trocken, wenn auch der Kälte ausgesetzt, iiberwintert. Diese ergeben reichliche Falter."

Adele Field (1904. 22.2) hielt vier Tage lang 18 Ameisen (Stenamma fulvum) unter Wasser, worauf 12 noch lehendig blieben. Als 14 andere Ameisen 6 Tage lang untergetaucht wurlen, erwachten 6 wieder: ron 12. Ameisen, welche \& Tage unter Wasser blieben, hieben am Leben 7 Exemplare.

I) ans den Versuchen von Blasius und Urech nicht zan ersohen ist, wic las Gewicht der Puppe sich änlern wiirde, wemn dieselben bei verminderter Fenchtigkeit unil miter verninderten Luftdruck sich hefinten, habe ich anch in dieser Richtung Versuche angestellt.

Es wurlen 3 Versuchsserien ausgeführt:

1. Die Puppen befanden sich unter einem Glastrichter mit. freien Luftzutritt von unten, also bei gewöhnlichem Luftelruck (Sophia lirgt ea. 500 11. viber dem Meeres-Niveau), bei gewühnlicher Feuchtigliril und bei Zimmertemperatur (von $11^{\circ}$ im Februar bis $20^{\circ}$ im Mai).

$\therefore$ Die Puppen befanden sich in einem Exsiccator mit $\mathrm{CaCl}$. auch im Zimmer.

3. Die Puppen befanlen sich in einem Exsiccator mit $\mathrm{CaCl}_{2}$ in druselben Zimmer; aber unter rermintertem Luftılruck (ca. 1/2 Atmosphäre).

Bei der letzten Versuchsserie war der Exsiccator mit einer Luftpumpe verbunlen. Ein Quecksilher-Yanometer gab den Druck an. Janit die (Qucksilber-Dämpfe keinen schällichen Eintluss auf die Puppen ausiiben kounten, hefunl sich im Manometer flissiges Paraffin. 1)a wer Druck von ${ }^{1 / 2}$ Atmosphäre im Exsiccator nur währent 1-2 stmuien herrschte (er war nicht luftlicht verschlossen), so wurde die Luftpunpe $2-3$ Mal pro Tag benützt.

lis kamen in jeiler Versuchsserie: 2 Puppen von Sphina pinastri, 2 Puppen von Thyatira butis und 2 Puppen von Thais polyxenu. Die Pupıen befanden sich in Uhrgläsern, in welchen sie auch gewogen wurikn. Die Wiigungen begamnen an 25. Januar 1900 und damerten bis Encle Mai.

Von allen ilusfïhrlichen Tabellen wirl hier nur eine angeführt; dir: an leren haben denselben Charakter. Dabei berlenten: $P$ das Ge- 
wicht der Puppe; z die Beobachtungszeit; 1,95.5 - $P$ den Gewichtsverlust zu dieser Zeit, vom Anfang an gerechnet; $p$ denselben Verlust, ausgedrückt in $\%$ nach der Formel:

$$
100 \cdot(1,955-P): 1,955=p \% ;
$$

$n$ berleutet ilie Anzahl der Stunden, welche vom Anfang dex Wägung an verflossen sind.

Sphinx pinastri L.

Unter gewöhnlichen Bedingungen.

\begin{tabular}{|c|c|c|c|c|c|c|}
\hline \multicolumn{2}{|c|}{ Datum } & $z$ & $P$ & $1,955-P$ & $p \%$ & $n$ \\
\hline 25. Januar & 1900. & $3^{\mathrm{h}} 30^{\prime}$ & 1,955 & 0,000 & 0,00 & 0,0 \\
\hline 28. & $"$ & $2^{\text {h }} 30^{\prime}$ & 1,925 & 0,030 & 1,53 & 71,0 \\
\hline 31. & $"$ & $3^{\text {h }} 30^{\prime}$ & 1,902 & 0,053 & 2,71 & 144,0 \\
\hline 4. Februar & . & $1^{\text {h }} 30^{\prime}$ & 1,880 & 0,075 & 3,84 & 238,0 \\
\hline 5. & " & $12^{\mathrm{h}}-$ & 1,872 & 0,083 & 4,24 & 261,5 \\
\hline 7. & $n$ & $12^{\mathrm{h}}-$ & 1,861 & 0,094 & 4,79 & 309,5 \\
\hline 8. & $"$ & $12^{\mathrm{h}}-$ & 1,856 & 0,099 & 5,06 & 333,5 \\
\hline 10. & $n$ & $10^{\mathrm{h}}-$ & 1,844 & 0,111 & 5,67 & 379,5 \\
\hline 14. & $n$ & $12^{\mathrm{h}}-$ & 1,824 & 0,131 & 6,69 & 477,5 \\
\hline 16. & $"$ & $11^{\mathrm{h}}-$ & 1,815 & 0,140 & 7,16 & 524,5 \\
\hline 18. & $n$ & $10^{\mathrm{h}} 30^{\prime}$ & 1,801 & 0,155 & 7,89 & 572,0 \\
\hline 21. & $"$ & $11^{\mathrm{h}}-$ & 1,783 & 0,172 & 8,80 & 644,5 \\
\hline 23. & $"$ & $11^{\text {h }} 30^{\prime}$ & 1,772 & 0,183 & 9,36 & 693,0 \\
\hline 25. & $"$ & $11^{\mathrm{b}} 30^{\prime}$ & 1,761 & 0,194 & 9,92 & 741,0 \\
\hline 28. & $n$ & $4^{\mathrm{h}} 30^{\prime}$ & 1,741 & 0,214 & 10,94 & 818,0 \\
\hline 1. März & n & $2^{\mathrm{h}}-$ & 1,731 & 0,224 & 11,46 & 863,5 \\
\hline $3 . \quad$ & $n$ & $10^{\mathrm{h}}-$ & 1,714 & 0,241 & 12,33 & 907,5 \\
\hline 8. $n$ & $"$ & $11^{\mathrm{h}} 30^{\prime}$ & 1,679 & 0,276 & 14,12 & 1029,0 \\
\hline 10. $"$ & $"$ & $2^{\mathrm{h}} 30^{\prime}$ & 1,666 & 0,289 & 14,78 & 1080,0 \\
\hline 13. " & $n$ & $11^{\mathrm{h}}-$ & 1,651 & 0,304 & 15,55 & 1148,5 \\
\hline 16. $"$ & $"$ & $3^{\mathrm{h}}-$ & 1,630 & 0,325 & 16,62 & 1224,5 \\
\hline 18. & $"$ & $9^{\mathrm{h}} 30^{\prime}$ & 1,613 & 0,342 & 17,49 & 1267,0 \\
\hline 20 . " & $"$ & $4^{\mathrm{h}} 30^{\prime}$ & 1,587 & 0,368 & 18,82 & 1322,0 \\
\hline 24. " & $"$ & $6^{\mathrm{h}}-$ & 1,555 & 0,400 & 20,46 & 1419,5 \\
\hline 28. & $"$ & $4^{\mathrm{h}} 30^{\prime}$ & 1,524 & 0,431 & 22,05 & 1514,0 \\
\hline 31. " & $"$ & $11^{\mathrm{h}}-$ & 1,502 & 0,453 & 23,17 & 1580,0 \\
\hline 3. April & $"$ & $3^{\mathrm{h}} 30^{\prime}$ & 1,473 & 0,482 & 24,65 & 1657,0 \\
\hline
\end{tabular}




\begin{tabular}{|c|c|c|c|c|c|c|}
\hline \multicolumn{2}{|c|}{ Datum } & $z$ & $P$ & $1,955-P$ & $p \%$ & n \\
\hline 5. April & 1900. & $1^{\text {h }} 30^{\prime}$ & 1,453 & 0,502 & 25,67 & 1703,0 \\
\hline 10. & $"$ & $11^{\mathrm{h}}-$ & 1,413 & 0,542 & 27,72 & 1820,5 \\
\hline 13. & 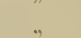 & $10^{\mathrm{h}}-$ & 1,392 & 0,563 & 28,80 & 1891,5 \\
\hline 17. & , & $11^{\mathrm{h}} 30^{\prime}$ & 1,357 & 0,598 & 30,52 & 1989,0 \\
\hline 19. & $\because$ & $2^{\mathrm{ll}}-$ & 1,334 & 0,621 & 31,7 & 2039,5 \\
\hline 22. & 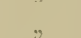 & $11^{\mathrm{l}}-$ & 1,312 & 0,643 & 32,9 & 2108,5 \\
\hline 24. & $"$ & $11^{\mathrm{h}}-$ & 1,290 & 0,665 & 34,0 & 2156,5 \\
\hline 29. & $"$ & $10^{\mathrm{h}} 30^{\prime}$ & 1,225 & 0,730 & 37,3 & 2276,0 \\
\hline 4. Mai & $"$ & $10^{\mathrm{h}}-$ & 1,167 & 0,788 & 40,3 & 2395,5 \\
\hline 6. & $"$ & $11^{\mathrm{h}}-$ & 1,140 & 0,815 & 41,7 & 2444,5 \\
\hline 12. " & \# & $7^{\mathrm{h}}-$ & 1,068 & 0,887 & 45,3 & 2596,5 \\
\hline 26. & $"$ & $4^{\mathrm{h}}-$ & 0,875 & 1,080 & 55,2 & $2929, \tilde{J}$ \\
\hline
\end{tabular}

Obwohl diese Puppe noch lebte, wurden die Wägungen wegen Zeitmangels unterlassen.

Um die erhaltenen Resultate anschaulicher zu machen, wurden diese Werthe graphisch dlargestellt (als Ordinate diente die Grüsse $p \%$ und als Abscisse die Grösse $n$ ), und von der erhaltenen Curve nur diejenigen Punkte notiert, welche $n=100,200,300$ etc. entsprachen.

Wie die oben angeführte Tabelle zeigt, wurden zwischen 12. und 26. Mai keine Wägungen gemacht, deshalb sind die Werthe für $p \%_{0}^{\circ}$ in den unten angeführten Tabellen bei solchen Puppen ausgelassen, bei welchen der Verlanf der Curve während dieser Zeit nicht als weitere regelmässige Verlängerung ller ganzen Curve zu betrachten war.

In folgenden Tabellen sind die auf cliese Weise abgekürzten Werthe fur $p \%$ angefuilnt, wobei clie Differenzen zwischen zwei benachbarten Grössen fiir $p_{0}^{0}$ in einer besondern Colonne enthalten sind:

\begin{tabular}{|c|c|c|c|c|}
\hline \multirow{2}{*}{$\begin{array}{l}\text { Nach wieviel } \\
\text { Stunden }\end{array}$} & \multicolumn{2}{|c|}{ No 1} & \multicolumn{2}{|c|}{ N. 2} \\
\hline & $p \%$ & $\begin{array}{l}\text { Verlust während } \\
100 \text { Stunden in \% }\end{array}$ & $p \%$ & $\begin{array}{l}\text { Verlust wilhrend } \\
100 \text { Stunden in \% }\end{array}$ \\
\hline 100 & 2,0 & 2,0 & 2,2 & 2,2 \\
\hline 200 & 3,3 & 1,3 & 3,6 & 1,4 \\
\hline 300 & 4,7 & 1,4 & 5,2 & 1,6 \\
\hline 400 & $5, y$ & 1,2 & 6,8 & 1,6 \\
\hline
\end{tabular}


2. Einfluss der Feuchtigkeit.

\begin{tabular}{|c|c|c|c|c|}
\hline \multirow{2}{*}{$\begin{array}{l}\text { Nach wieviel } \\
\text { Stunden }\end{array}$} & \multicolumn{2}{|r|}{ № 1} & \multicolumn{2}{|r|}{ 으 2} \\
\hline & $p \%$ & $\begin{array}{l}\text { Verlust wälırend } \\
100 \text { Stunden in } \%\end{array}$ & $p \%$ & $\begin{array}{l}\text { Verlust während } \\
100 \text { Stunden in }{ }^{\circ} \text {. }\end{array}$ \\
\hline 500 & 6,9 & 1,0 & 8,2 & $.1,4$ \\
\hline 600 & 8,3 & 1,4 & 9,8 & 1,6 \\
\hline 700 & 9,5 & 1,2 & 11,3 & 1,5 \\
\hline 800 & 10,7 & 1,2 & 12,7 & 1,4 \\
\hline 900 & 12,2 & 1,5 & 14,6 & 1,9 \\
\hline 1000 & 13,7 & 1,5 & 16,2 & 1,6 \\
\hline 1100 & 15,0 & 1,3 & 18,0 & 1,8 \\
\hline 1200 & 16,2 & 1,2 & 19,6 & 1,6 \\
\hline 1300 & 18,3 & 2,1 & 22,0 & 2,4 \\
\hline 1400 & 20,0 & 1,7 & 24,1 & 2,1 \\
\hline 1500 & 21,8 & 1,8 & 25.8 & 1,7 \\
\hline 1600 & 23,6 & 1,8 & 27,7 & 2,1 \\
\hline 1700 & 25,6 & 2,0 & 29,5 & 1,8 \\
\hline 1800 & 27,3 & 1,7 & 30,9 & 1,4 \\
\hline 1900 & 28,9 & 1,6 & 32,5 & 1,6 \\
\hline 2000 & 30,7 & 1,8 & 34,1 & 1,6 \\
\hline 2100 & 32,7 & 2,0 & 35,5 & 1,4 \\
\hline 2200 & 35,1 & 2,4 & 37,4 & 1,9 \\
\hline 2300 & 38,0 & 2,9 & 39,5 & 2,1 \\
\hline 2400 & 40.5 & 2,5 & 41,6 & 2,1 \\
\hline 2500 & 43,0 & 2,5 & 44,0 & 2,4 \\
\hline 2600 & 45,4 & 2,4 & 46,5 & 2,5 \\
\hline 2700 & 48,0 & 2,6 & 49,5 & 3,0 \\
\hline 2800 & 51,2 & 3,2 & 52,8 & 3,3 \\
\hline 2900 & 54,3 & 3,1 & 56,2 & 3,4 \\
\hline
\end{tabular}

Beide Puppen lebten am Schlusse der Beohachtungen noch.

Sphinx ligustri L.

Im Exsiccator über $\mathrm{CaCl}_{\mathrm{g}}$ und bei gewöhnlichem Luftdruck.

\begin{tabular}{|c|c|c|c|c|}
\hline \multirow{2}{*}{$\begin{array}{l}\text { Nach wieviel } \\
\text { Stunden }\end{array}$} & \multicolumn{2}{|r|}{ 상 1} & \multicolumn{2}{|c|}{ 스 2} \\
\hline & $p \%$ & $\begin{array}{l}\text { Verlust während } \\
100 \text { Stunden in \% }\end{array}$ & $p^{a}$ & $\begin{array}{l}\text { Verlust wilirend } \\
100 \text { Stumden in } \%\end{array}$ \\
\hline 100 & 3,2 & 3,2 & 2,6 & 2,6 \\
\hline 200 & 6,0 & 2,8 & 4,7 & 2,1 \\
\hline 300 & 8,3 & 2,3 & 6,2 & 1,5 \\
\hline 400 & 10,7 & 2,4 & 7,8 & 1,6 \\
\hline
\end{tabular}




\begin{tabular}{|c|c|c|c|c|}
\hline \multirow{2}{*}{$\begin{array}{l}\text { Nach wieviel } \\
\text { Stmulen }\end{array}$} & \multicolumn{2}{|r|}{ di 1} & \multicolumn{2}{|c|}{ 스 2} \\
\hline & $p \circ$ & $\begin{array}{l}\text { Verlust wälırend } \\
100 \text { Stunden in \% }\end{array}$ & $p \%$ & $\begin{array}{l}\text { Verlust während } \\
100 \text { Stunden in } \%\end{array}$ \\
\hline 500 . & 13.0 & 2,3 & 9,3 & 1,5 \\
\hline 600 & 15,4 & 2,4 & 11,0 & 1,7 \\
\hline 700 & 17,7 & 2,3 & $12, \overline{5}$ & 1,5 \\
\hline 800 & 20,0 & 2,3 & 13,8 & 1,3 \\
\hline 900 & 22,6 & 2,6 & 16,0 & 2,2 \\
\hline 1000 & 25,2 & 2,6 & 17,3 & 1,3 \\
\hline 1100 & 27,6 & 2,4 & 18,6 & 1,3 \\
\hline 1200 & 30,4 & 2,8 & 20,2 & 1,6 \\
\hline 1300 & 34,0 & 3,6 & 23,0 & 2,8 \\
\hline 1400 & 37,2 & 3,2 & 26,0 & 3,0 \\
\hline 1500 & 39,5 & 2,3 & 29,0 & 3,0 \\
\hline 1600 & 42,0 & 2,5 & 31,3 & 2,3 \\
\hline 1700 & 45,2 & 3,2 & 34,5 & 3,2 \\
\hline 1800 & 47,9 & 2,7 & 37,5 & 3,0 \\
\hline 1900 & $50, \check{5}$ & 2,6 & 40,2 & 2,7 \\
\hline 2000 & อ̃ 3,1 & 2,6 & 42,9 & 2,7 \\
\hline 2100 & 56,7 & 3,6 & 46,0 & 3,1 \\
\hline 2200 & 61,7 & 5,0 & 49,3 & 3,3 \\
\hline 2300 & 67.3 & 5,6 & 52,5 & 3,2 \\
\hline 2400 & 72,5 & 5,2 & 55,6 & 3,1 \\
\hline 2500 & 76,3 & 3,8 & 59,3 & 3,7 \\
\hline 2600 & 78,1 & 1,8 & 62,5 & 3,2 \\
\hline 2700 & 78,2 & 0,1 & (36,7 & 4,2 \\
\hline 2800 & 78,3 & 0,1 & 71,0 & 4,3 \\
\hline 2900 & 78,4 & 0,1 & 75,1 & 4,1 \\
\hline
\end{tabular}

Im Exsiccator über $\mathrm{CaC}_{3}$ beim Luftdruck von einer Halb-Atmosphäre.

\begin{tabular}{|l|l|l|l|l|}
\hline 100 & 1,6 & 1,6 & 2,3 & 2,3 \\
200 & 3,2 & 1,6 & 4,4 & 2,1 \\
300 & 4,5 & 1,3 & 6,7 & 2,3 \\
400 & 5,9 & 1,4 & 8,8 & 2,1 \\
5100 & 7,3 & 1,4 & 11,2 & 2,4 \\
600 & 8,7 & 1,4 & 13,5 & 2,3 \\
700 & 10,0 & 1,3 & 15,6 & 2,1
\end{tabular}


2. Eintluss der Jeuchtigkeit.

\begin{tabular}{|c|c|c|c|c|}
\hline \multirow{2}{*}{$\begin{array}{l}\text { Nach wieviel } \\
\text { Stunden }\end{array}$} & \multicolumn{2}{|c|}{ № 1} & \multicolumn{2}{|r|}{ № 2} \\
\hline & $p \stackrel{\%}{\%}$ & \begin{tabular}{|c|} 
Verlust wälirend \\
100 Stunden in \%
\end{tabular} & $p \%$ & $\begin{array}{l}\text { Verlust während } \\
100 \text { Stundea in \% }\end{array}$ \\
\hline 800 & 11,5 & 1,5 & 18,1 & 2,5 \\
\hline 900 & 13,0 & 1,5 & 20,6 & 2,5 \\
\hline 1000 & 14,5 & $1, \check{\partial}$ & 23,1 & 2,5 \\
\hline 1100 & 16,0 & 1,5 & 25,5 & 2,4 \\
\hline 1200 & 17,9 & 1,9 & 28,7 & 3,2 \\
\hline 1300 & 19,5 & 1,6 & 31,8 & 3,1 \\
\hline 1400 & 21,0 & 1,5 & 34,7 & 2,9 \\
\hline 1500 & 22,5 & 1,5 & 37,2 & 2,5 \\
\hline 1600 & 24,0 & 1,5 & 39,8 & 2,6 \\
\hline 1700 & 25,5 & 1,5 & 42,5 & 2,7 \\
\hline 1800 & 27,0 & 1,5 & 47,9 & 5,4 \\
\hline 1900 & 28,6 & 1,6 & 51,1 & 3,2 \\
\hline 2000 & 30,4 & 1,8 & 54,5 & 3,4 \\
\hline 2100 & 32,6 & 2,2 & 58,3 & 3,8 \\
\hline 2200 & 34,8 & 2,2 & 62,7 & 4,4 \\
\hline 2300 & 36,9 & 2,1 & 67,1 & 4,4 \\
\hline 2400 & 39,1 & 2.2 & 70,3 & 3,2 \\
\hline 2500 & 41,4 & 2,3 & - & - \\
\hline 2600 & 44,0 & 2,6 & - & - \\
\hline 2700 & 46,5 & 2,5 & - & - \\
\hline 2800 & 49,0 & 2,5 & 77,6 & - \\
\hline 2900 & 51,5 & 2,5 & - & - \\
\hline
\end{tabular}

Thais polyxena $\mathrm{L}$.

Die Wägungen wurden angefangen am 23. Februar 1900.

\begin{tabular}{|c|c|c|c|c|c|c|}
\hline \multirow{3}{*}{ 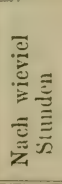 } & \multicolumn{2}{|r|}{ Ne 1} & \multicolumn{2}{|r|}{ № 2} & \multicolumn{2}{|r|}{ 스 3} \\
\hline & \multicolumn{2}{|c|}{$\begin{array}{l}\text { Unter gewöhnlichen } \\
\text { Umständen }\end{array}$} & \multicolumn{2}{|c|}{$\begin{array}{l}\text { Im Exsiccator über } \mathrm{CaCl}_{2} \\
\text { bei einer Atmospläre }\end{array}$} & \multicolumn{2}{|c|}{$\begin{array}{l}\text { Im Exsiccator über } \mathrm{Cn}_{\mathrm{Cl}} \mathrm{Cl} \\
\text { hei ciner Halb-Atmosphäre }\end{array}$} \\
\hline & $p \%$ & $\begin{array}{l}\text { Verlust wäh- } \\
\text { rend } 100 \text { Stund. } \\
\text { in \% }\end{array}$ & $1, \%$ & $\begin{array}{l}\text { Verlust wäh- } \\
\text { rend } 100 \text { Stund. } \\
\text { in } \%\end{array}$ & $p "$ & $\begin{array}{l}\text { Verlust wih- } \\
\text { rend } 160 \text { Stund } \\
\text { in } \%\end{array}$ \\
\hline 100 & 0,3 & 0,3 & 0,8 & $.0,8$ & $1, \bar{\jmath}$ & 1,5 \\
\hline 200 & 1,5 & 1,2 & 1,8 & 1,0 & 3,2 & $1, \pi$ \\
\hline 300 & 2,5 & 1,0 & 2,6 & 0,8 & 5,2 & 2,0 \\
\hline 400 & 3,0 & $0, \overline{5}$ & 3,4 & 0,8 & $6, i$ & 1,4 \\
\hline
\end{tabular}


Erstes Kapitel. Die Entwickelungsgeschwindigkeit der Insekten.

\begin{tabular}{|c|c|c|c|c|c|c|}
\hline \multirow{3}{*}{ 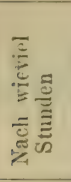 } & \multicolumn{2}{|r|}{ Ad 1} & \multicolumn{2}{|r|}{ № 2} & \multicolumn{2}{|r|}{ ㅇ 3} \\
\hline & \multicolumn{2}{|c|}{$\begin{array}{l}\text { Unter sewühnlichen } \\
\text { Uniständen }\end{array}$} & \multicolumn{2}{|c|}{$\begin{array}{l}\text { Im Exsiceator über } \mathrm{CaCl} \\
\text { bei einer } \mathrm{Atmosphäre}\end{array}$} & \multicolumn{2}{|c|}{$\begin{array}{l}\text { In Exwiccator üler } \mathrm{Ca} \text { (l. } \\
\text { bei einer Halb-Atmosphäre }\end{array}$} \\
\hline & $p \%$ & $\begin{array}{l}\text { Verlust wäh- } \\
\text { rend } 100 \text { Stund. } \\
\text { in } \%\end{array}$ & $p \%$ & $\begin{array}{l}\text { Verlust wiih- } \\
\text { rend } 100 \text { Stund. } \\
\text { in } \%\end{array}$ & $p \%$ & $\begin{array}{l}\text { Verlust with- } \\
\text { rend } 100 \text { Stund. } \\
\text { in } \%\end{array}$ \\
\hline 500 & 4,4 & 1,4 &,+ 9 & 1,5 & 8,6 & 2,0 \\
\hline 600 & 6,3 & 1,9 & 6,9 & 2,0 & 11,0 & 2,4 \\
\hline 700 & 7,5 & 1,2 & 8,0 & 1,1 & 12,8 & $1, i$ \\
\hline 800 & 8,9 & 1,4 & $10, \overline{5}$ & 2,5 & 14,3 & $1, \overline{5}$ \\
\hline 900 & $\begin{array}{l}\text { Schlüp } \\
\text { terling }\end{array}$ & $\begin{array}{l}\text { fte ein Schmet- } \\
\text { am 30. März. }\end{array}$ & 14,1 & 3,6 & 16,7 & 2,4 \\
\hline $10(1) 0$ & - & - & $\begin{array}{l}\text { Schliijfte } \\
\text { lins a }\end{array}$ & $\begin{array}{l}\text { ein schmetter- } \\
\text { m 3. April. }\end{array}$ & 20,0 & 3,3 \\
\hline 1100 & - & - & - & - & 24,0 & 4,0 \\
\hline 1200 & - & - & - & - & 29,5 & 5,5 \\
\hline 1300 & - & - & - & - & 34,7 & 5,2 \\
\hline 1400 & - & - & - & - & 39,3 & 4,6 \\
\hline 1500 & - & - & - & - & 43,6 & 4,3 \\
\hline 1600 & - & - & - & - & 47,8 & 4,2 \\
\hline$r 700$ & - & - & - & - & 43,3 & 5,5 \\
\hline 1800 & - & -- & - & - & 47,5 & 4,2 \\
\hline 1900 & - & - & - & - & 48,0 & $(?)^{0,5}$ \\
\hline
\end{tabular}

Thyatira batis.

Die Wägungen wurden angefangen am 7. Februar 1900.

\begin{tabular}{|c|c|c|c|c|c|c|c|c|c|c|c|c|}
\hline \multirow{3}{*}{ 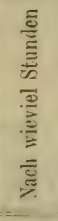 } & \multicolumn{4}{|c|}{$\begin{array}{l}\text { Unter gewühnlichen } \\
\text { Umständen }\end{array}$} & \multicolumn{4}{|c|}{$\begin{array}{l}\text { In Exsiccator uiber } \mathrm{CaCl}_{2} \\
\text { bei einer Atmosphäre }\end{array}$} & \multicolumn{4}{|c|}{$\begin{array}{l}\text { Im Exsiccator über } \mathrm{CuCl} \\
\text { bei einer Hallatmosphäre }\end{array}$} \\
\hline & \multicolumn{2}{|c|}{ te 1} & \multicolumn{2}{|c|}{ d: 2} & \multicolumn{2}{|c|}{ te 1} & \multicolumn{2}{|c|}{ Se 2} & \multicolumn{2}{|c|}{ te 1} & \multicolumn{2}{|c|}{.62} \\
\hline & $p^{2}{ }^{0}$ 。 & 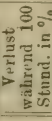 & $p \%$ & $\frac{3}{2}$ & $p^{0}: 0$ & 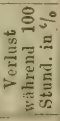 & $p \%$ & 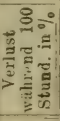 & $1 \%$ & 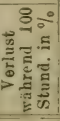 & $p^{0} \%$ & 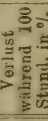 \\
\hline 100 & 5,7 & 5,7 & 11,0 & 11,0 & 7,0 & 7,0 & 12,0 & 12,0 & 3,7 & 3,7 & 3,3 & 3,3 \\
\hline 200 & 9,4 & 3,7 & 16,5 & 5,5 & 11,6 & 4,6 & 21,5 & 9,5 & 6,8 & 3,1 & 8,0 & 4,7 \\
\hline 300 & 13,4 & 4,0 & 22,3 & 5,8 & 14,7 & 3,1 & 30,0 & 8,5 & 9,7 & 2,9 & 12,7 & 4,7 \\
\hline 400 & 15,8 & 2,4 & 27,8 & 5,5 & 19,6 & 4,9 & 37,5 & 7,5 & 13,0 & 3,3 & 15,0 & 2,3 \\
\hline 500 & 19,4 & 3,6 & 31,3 & 3,5 & 23,7 & 4,1 & 42,5 & 5,0 & 14,8 & 1,8 & 18.0 & 3,0 \\
\hline 600 & 22,3 & 2,9 & 36,0 & 4,7 & 28,5 & 4,8 & 50.5 & 8,0 & 16,3 & 1,5 & 21,7 & 3,7 \\
\hline 700 & 25,3 & 3,0 & 41,0 & 5.0 & 34,3 & 5,8 & 56,6 & 6,1 & 18,6 & 2,3 & 25,0 & 4,3 \\
\hline 800 & 27,8 & 2,5 & 45,5 & 4,5 & 39,2 & 49 & 59,5 & 2,9 & 21,0 & 2,4 & 27,8 & 2,8 \\
\hline
\end{tabular}




\begin{tabular}{|c|c|c|c|c|c|c|c|c|c|c|c|c|}
\hline \multirow{3}{*}{ 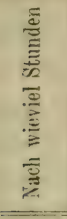 } & \multicolumn{4}{|c|}{$\begin{array}{l}\text { Unter gewöhnlicheu } \\
\text { Umständen }\end{array}$} & \multicolumn{4}{|c|}{$\begin{array}{l}\text { Im Exsiccator uber } \mathrm{Ca} l_{2} \\
\text { bei einer Atmosphäre }\end{array}$} & \multicolumn{4}{|c|}{$\begin{array}{l}\text { Im Exsiccator üher } \mathrm{CaCl}_{2} \\
\text { bei einer Halbatmosphäre }\end{array}$} \\
\hline & \multicolumn{2}{|c|}{ to 1} & \multicolumn{2}{|c|}{ to 2} & \multicolumn{2}{|c|}{ J 1} & \multicolumn{2}{|c|}{ No 2} & \multicolumn{2}{|c|}{ Se 1} & \multicolumn{2}{|c|}{ t: 2} \\
\hline & $\psi^{0}$ 。 & 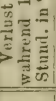 & $p{ }^{10}$ & 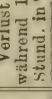 & $p \%$ & 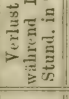 & $p \vdots_{0}^{\circ}$ & > & $p \%$ & 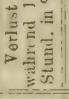 & $p *$ & > \\
\hline 900 & 30,8 & 3,0 & 52,2 & 6,7 & 44,6 & $5,4 \|$ & 62,8 & 3,3 & 23,6 & 2,6 & 31,8 & 4,0 \\
\hline 1000 & 35,2 & 4,4 & 59,7 & 7,5 & 51,4 & 6,8 & 63,1 & 0,3 & 26.2 & 2,6 & 35,3 & 3,5 \\
\hline 1100 & 37,8 & 2,6 & 62,3 & 2,6 & 58,2 & 68 & 63,2 & 0,1 & 28,9 & 2,7 & 38,1 & 3.3 \\
\hline 1200 & 39,8 & 2,0 & 63,5 & 1,2 & 64,1 & 5,9 & 63,2 & 0,0 & 31,4 & 2,5 & 41,5 & 2,9 \\
\hline 1300 & 44,4 & 4,6 & 63,5 & 0,0 & 69,8 & 5,7 & - & - & 35,8 & 4,4 & $4 \pi, 1$ & 5,6 \\
\hline 1400 & 46,9 & 2,5 & $63 ; 9$ & 0,4 & 70,5 & 0,7 & - & - & 39,2 & 3,4 & 53,0 & 5,9 \\
\hline 1500 & 49,0 & 2,1 & 64,1 & 0,2 & 70,2 & $-0,3$ & - & - & 41,8 & 2,6 & 58,2 & 5,2 \\
\hline 1600 & 52,3 & 3,3 & 64,2 & 0,1 & 70,1 & $-0,1$ & - & - & 46,2 & 4,4 & 65,0 & 6,8 \\
\hline 1700 & 56,3 & 4,1 & - & - & 70,2 & 0,1 & - & - & 50,8 & 4,6 & 71,0 & 6,0 \\
\hline 1800 & 59,0 & 2,7 & -- & - & - & - & - & -- & 55,1 & 4,3 & 73,7 & 2,7 \\
\hline 1900 & 61,8 & 2,8 & - & - & - & - & - & - & 59.8 & 4,7 & 76,0 & 2,3 \\
\hline 2000 & 65,0 & 3,2 & - & - & - & - & - & - & 64,8 & 5,0 & 76,0 & 0,0 \\
\hline 2100 & 69,5 & 4,5 & - & - & - & - & - & - & 69,7 & 4,9 & - & - \\
\hline 2200 & 71,2 & 1,7 & - & - & - & - & - & - & 73,1 & 3,4 & - & - \\
\hline 2300 & 72,8 & 1,6 & - & - & - & - & - & - & 73,3 & 0,2 & - & - \\
\hline 2400 & 73,6 & 0,8 & - & - & - & - & - & - & -- & - & - & - \\
\hline
\end{tabular}

Alle Puppen sind tot.

Fünf Parasitfliegen in Larvenzustanil, herausgefallen aus ter Puppe von Sphinx ligustri L.

Die Wägungen wurden agefangen am 17. Februar 1900.

\begin{tabular}{|c|c|c|c|c|c|}
\hline \multirow{2}{*}{$\begin{array}{l}\text { Nach } \\
\text { wieviel } \\
\text { Stunden }\end{array}$} & \multicolumn{2}{|c|}{$\begin{array}{l}\text { Im Exsiccator über } \mathrm{CaCl}_{2} \\
\text { u. bei einer Hall)-Atmosphäre }\end{array}$} & \multirow{2}{*}{$\begin{array}{l}\text { Nach } \\
\text { wieviel } \\
\text { Stunden }\end{array}$} & \multicolumn{2}{|c|}{$\begin{array}{l}\text { Im Exsiccator über } \mathrm{CaCl}_{9} \\
\text { u. bei einer Halb-Atmosphäre }\end{array}$} \\
\hline & $p \%$ & $\begin{array}{l}\text { Verlust wäll- } \\
\text { rend } 100 \text { Stund. } \\
\text { in } \%\end{array}$ & & $p \%$ & $\begin{array}{l}\text { Verlust wäh- } \\
\text { rend } 100 \text { Stund. } \\
\text { in } \%\end{array}$ \\
\hline 100 & 9,2 & 9,2 & 700 & 30,9 & 1,6 \\
\hline 200 & 9,7 & 0,5 & 800 & 32,7 & 1,8 \\
\hline 300 & $18, i$ & 9,1 & 900 & 34,3 & $1,1 i$ \\
\hline 400 & 25,0 & 6,2 & 1000 & 36,0 & 1,7 \\
\hline 500 & 27,7 & 2,7 & 1100 & 38,4 & 2,4 \\
\hline 600 & 29,3 & 1,6 & 1200 & 41,0 & 2,6 \\
\hline
\end{tabular}

Eine Fliege ist ausgeschlüft (am 3. April 19:0).

Wenn wir nur solche Puppen in Betracht ziehen, welche am Schlusse der Wägungen noch lebend waren, so lassen sich aus die. sen Tabellen folgenile Resultate ableiten: 
Die Puppen von Sphlinx ligustri kïnnen während les Zeitintervalls von Entle Januar bis Enle Mai ca. $800^{\circ}$ ihres Gewichtes verlieren, ohne dabei zu sterben. Puppen in ler trockenen Luft (im Exsiccator ïber $C a . C l_{2}$ ) verlieren im allgemeinen mehr an ihrem Gewichte als unter gewöhnlichen Unstänlen (für Spllinx ligıstri nach $2 \times 00$ Stumlen $i s \%$ gegeniuber $53 \%$ und fuir Thais polyxena nach sio Stunden $11 \%$ gegeniber $9 \%$ ); jerloch kimn diese Trockenheit auch ohne Einfluss bleiben, wie Sylhinx liynstri I: 1 im Exsiccator es aufweist (nach 2800 Stunilen ist iler Verlust $49 \%$ gegreniiber $51 \%$ bei gewöhnlicher Feuchtigkeit).

Die Trockenheit, wie es scheint (Thais polywenu). beschleunigt die Entwickelung der Puppe nicht. Der verminderte Luftliruck ist nicht für alle Puppen schädlich (unter 1/2 Atmosphäre war die Puppe von Sphinir ligustri noch nach ca. 3000 Stunden lebend, und die Parasit-Fliege nach 1200 Stunden unter diesem verminilerten Trucke hat sich sogar zum Imago entwickelt).

Im allgemeinen nimmt das Gewicht der Puppen wälıremd ilırer Entwickelung zuerst regelmässig ab, um später kurze Zeit vor lem Ausschlüpfen des Imagos rascher abzunehmen. Fs sinl jelloch gewisse Unregelmässigkeiten während der Entwickelung zu beobachten.

\section{Erganzungs-Litteratur zu diesem Abschnitt.}

Kanitz, J. G. Warum setzen die Bienen bei feucliter Witterung mehr Brut an, als bei trockener Witterung? - Preuss. Bienen-Ztg. 4. Bd. 1861. (VII.Jrg.) p. 72.

Kanitz, J. G. Hygrometrisches Verhältniss im Bienenstock. - Preuss. Bienen-Ztg. 4. Bd. 1861. (VIl. Jahrg.) p. 7.

Krause, Ernst. Die Lebenszähigkeit der Insekten. - Prometheus № 610. 1901. 12. Jahrg. 수 38. p. 603-605; 슈 611. 스 39. p. 610-612.

\section{Einfluss der Temperatur.}

Obwohl die Temperatur der Inselten keine konstante ist, sondern verïnderlich ist und in sehr grossen Grenzen variirt (hinauf bis ca. $50^{\circ}$ ), hat die äussere T'emperatur doch einen grossen Einfluss auf die Entwickelungsgesehwindigkeit dieser Thiere, wie aus dem Nachstehenden hervorgeht.

Ch. Bonnet (1779. 10:3) erzog von 16. Mai bis Anfang Juli 1842 sechs nach einander folgenile Generationen parthenogenetischer Weib- 
chen von $A_{l}$ his evonymi, indem er jecles Mal eine der erstgeborenen Larven isolierte. Der Einfluss der Temperatur anf die Entwicliclung ist aus folgenden Resultaten ersichtlich:

Das Weibchen I. Generation ist am (i. Mai $\mathrm{mm} 3^{\text {h }}$ Nachmittag geboren und warf am 21. Mai um $3^{\text {h }}$ Nachmittag das erste Junge. Die Temperatui im Zimmer war dabei 120 L. Stellt man ähnliche Angaben auch fur die andere Generationen, so erhält man:

Jas Weibchen I. Gener, gebar 15 Tage nach seiner (ieburt hei $12^{\circ} \mathrm{K}$.

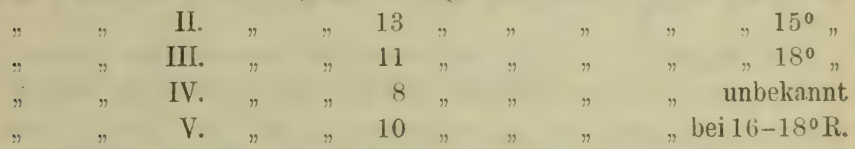

Er erzog auch von 10. Juli bis Ende September $17+3 \quad 10$ ununterbrochen nacheinander folgemler Generationen von Aphis plantaginis. Folgentle Tabelle, welche von A. Mordwilko (1900. 59:3) zusammengestellt ist, ergiebt lie von Bonnet erhaltenen Resultate:

\begin{tabular}{|c|c|c|c|c|c|}
\hline 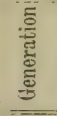 & Zeit der fichurt & $\begin{array}{l}\text { Zeit des Wurfes des } \\
\text { ersten Jungen }\end{array}$ & $\begin{array}{c}\text { Entwickelungs- } \\
\text { dauer }\end{array}$ & 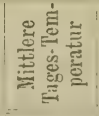 & 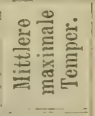 \\
\hline I. & 9. VII. $1^{\mathrm{h}}$ Nachmitt. & 18. VII. $11^{\text {th }}$ Morgens & 8 Tage 22 St. & $15,6^{\circ} \mathrm{R}$ & $16,5^{\circ} \mathrm{R}$. \\
\hline II. & 18. VII. $6 \frac{1}{2}^{\mathrm{h}}$ Abends & 28. VII. $7^{\text {h }}$ Morgens & $9,12 \%$ & $15,2^{\circ}$ & $18,8^{\circ} \pi$ \\
\hline III. & 2S. VII. 12 ${ }^{\text {h }}$ Mittags & 6. VIII $5 \frac{1}{2}^{\text {h }}$ Morgens & $8 n 17 \frac{1}{2} n$ & $17,5^{\circ} \mathrm{n}$ & $21,4^{0}$ \\
\hline IV. & 6. VIII. $8 \frac{1}{2}^{\text {b }}$ Morgens & 14. V1II. $12^{\text {h }}$ Mittags & $8 n 3 \frac{1}{2} n$ & $16,7^{\circ}$ & $20,4^{\circ} n$ \\
\hline V. & 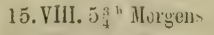 & 23. VIII. $7^{\text {h }}$ HIorgens & $8 \pi 14 \pi$ & $16,5^{\circ}$ & $19, \bar{j}^{\circ} \mathrm{n}$ \\
\hline VI. & 23.VIII. $11 \frac{1}{4}^{\text {h }}$ Morgens & 31.VIII. $11^{\mathrm{h}}$ Vachmitt. & $8, \quad 217$ & $15,6^{\circ}$ & $18,0^{\circ}$ \\
\hline VII. & 31.VIII. $2^{\mathrm{h}}$ Nachmitt. & 11. IX. $9^{\mathrm{h}}$ Abends & $\bar{T}$ & $14,9^{\circ} n$ & $17,5^{\circ} n$ \\
\hline VIII. & 11. IX. $2^{\text {h }}$ Nachmitt. & 22. 1X. $8^{\text {th }}$ Morgens & $10,18 \%$ & $\begin{array}{l}12,5^{\circ} . " n \\
\text { Vom 20. } \\
\text { Wurden } \\
\text { Kiste neben } \\
\text { rohr erzoge } \\
\text { anch v. } 25 .\end{array}$ & $\begin{array}{l}14,9^{\circ} \pi \\
\text { bis } 2.2 \mathrm{~K} \text {. } \\
\text { in einer } \\
\text { adem ofen- } \\
\text { n; dasselbe } \\
\text { bis } 27 . \mathrm{XX} \text {. }\end{array}$ \\
\hline $1 X$. & 2.2. IX. $8_{2}^{1}{ }^{\text {h }}$ Morgens & 29. IX. $\tau^{\text {" Morgens }}$ & $6 \mathrm{~T}$.ge $12 \frac{1}{2}$ st. & $\left\{\begin{array}{l}\text { Wurden in } \\
\text { neben dem } \\
\text { erzos }\end{array}\right.$ & $\begin{array}{l}\text { ner Kiste } \\
\text { fenrolir } \\
\text { n. }\end{array}$ \\
\hline
\end{tabular}

Stelit man die Entwickelungsilauer der Weibchen (von der Geburt bis zum Anfang des Wurfes der Jungen) und die entsprechende T'emperaturen zusammen, so bemerkt man zwischen ilnen ein ungekehrtes Verhältniss, d. h. je höher die Temperatur war, desto kürzer war auch die Entwickelungsdauer, wenn auch dahei der Einfluss unbekannter Faktoren bemerkbar ist.

Bonnet bemerkte auch, dass diese Art der PHanzenläuse kieine Jungen wirft, wenn die Luftemperatur $-9^{0}$ li. beträgt, his sie 


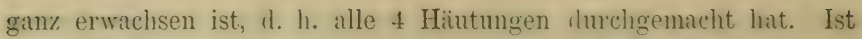
aber die Zimmertemperatur hioher, so stiort die Temperatur von 8 bis $9^{0} \mathrm{R}$., welche nur Morgens auftritt. die (ieburt nicht.

F. W. Vogel (1\$00. 42(i) fand tie nomale Temperatur zur Entwickelung der Bienenlarven von 2.;-21;0 li. Ist diese günstige Temperatur nicht vorhanden, dam finlet die Irotamorphose nicht statt, und die Zeit weiterer Entwickelung wirl versohnhen.

C. Majoli (1s13. jt:3) bescheiht cine merkwïrlige Metanm)rphose einer Seilenspimerraupe, welche nach der vierten Häutung Flïgel hekam, ohne sich za rerpuppen. Lr sieht dio Ursache dieser Erscheinumg in ler ïbermuissigen Ifitze des Znchtrammes. Die Cibersetzung dirser Beschreibung ins Ineutsche findet sich hei H. Hagen

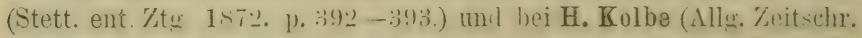
für Entomol. 1903. VIII. .1: 2-3. p. 27).

Die Entwickelung und das FortpHanzen der Ptianzenläuse wird bei nieileren Temperaturen mehr oler weniger verlangsant oler hïrt sogar vollstintlig auf, wie aus Beobachtungen von Kyber (1s1j. 491) hervorgeht. Er faml zwei Weihehen von Siphomophora rosuc gleicher (rrösse an einer liose. Eine Laus versetzte er ins geheizte Zimmer. unl die andere liess er im Freien. (April 1803, als noch kaites Wetter herrschte, unil Nachts Frost auftrit). Wihrend das erste Weibchen hereits einen Tag darauf (25. April) geboren hatte, wart die \%weite Laus die Kleinen erst spüter. als es warm wurde.

Beauvais (15:3i. j(i) versichert, dass Eiel von Bombyl: mori bei einer Temperatur von (io $^{\circ} \mathrm{R}$. (i . Iahre aufbewhirt werlen kïnmen, damn aher ist eine feuchte Wäme von $24^{\circ}$ uns dariiher nothweidlig, um sie binnen 8 Tagen zum Auskriechen zu bringen.

Schmidberger (1 $\times 399.754)$ stellte Beobachtungen an Apluis muli an und kam zu folgemlen Resultaten: Dic Dauer des Sommers, die Wärme unl schönes Wetter begünstigen die Entwickelung unl die Fortpfianzung der Pflamzenlïuse. Die Kialte verlangsant die Entwickelumg. Die getligelten Weibchen brauchen mehr Zeit zu ihrer vollstïnligen Entwickeltmg, als die flugellosen (lie ersten gebären nach 12-14 Tagen, die letzten nach $8-10$ Tagen). 
In December 1\$45. (1\$46. 972) wurle in Odessa dis Ausschlïpfen der Rïupchen von Porthesia chrysorrea beobachtet.

Verloren aus Utrecht (1\$60.910) beohichtete die Pupnen von Sphinx ligustri während ihrer Entwickelung unı konstatierte, dass der grösste Theil dieser Falter Mitte Juni ausschliiptte und zwar unabhängig ron der Temperatur der Jahreszeit. In Fïllen aber, wo die Entwickelung der Falter sich über die festgesetzte Periodes in einem .Jahre verzögerte, erschienen die Schmetterlinge im folgenden Jahre, aber auch während iler begrenzten Periode. Diesı Bיobachtungen wurden mehrere Jahre gemacht.

De Sauvageon (1860. 736) fuitterte Seilemaupen hei $: 36-37^{\circ}$ und erhielt Puppen nach 24 Tagen.

Schmid unl Kleine (1\$61. 753) meinen, dass die Bienenlarven bei rler Temperatur unter $+20^{\circ}$ R. sich gar nicht enwickehn; für die beste Temperatm zur Entwickelung halten sie ca. +22 ro $^{R}$.

Vinzenzo Barca (1\$6i3. +9) fimt, dass die Eier von Bomby mori nach dem Ablegen in die Külte gebracht, Räupchen noch in demselhen Jahre ergeben, wemn man sie aus ler Kälte ins warme Zimmer bringt.

Die erste grössere Arbeit ïber den Einthuss der iemperatur auf die Entwickelmug der Puppen wurde von G. Dorfmeister in Graz veröffentlicht.

Aus den Versuchen von G. Dorfmeister (1s(i:3. 1!)t), welche er iiber die Einwirkung verschierlener, wälnreml der Entwickelungsperiolle angewendeter. Wärmegrade auf die Fürbung ler schmetterlinge anstellte, ist der Einfluss der Temperatur auch auf die Entwickelungs-Gesehwin:ligkeit der Puppen ersichtlich. Alle diese Versuche geschalien in den Sommermonaten. Die Puppen waren von Vanessa levana var. morsa.

In den angefiihrten, von mir bearbeiteten Tabellen wirl die Zeit der Entwickelung von der Verpuppung an in Tagen gerechet.

1. 14 Puppen bei Zimmertemperatur von $17^{\circ}$ bis $20^{\circ} \mathrm{R}$.: Anzahl der Puppen: 2; 1; 4; 5; 2. Entwickelungszeit: $7 ; 8 ; 9 ; 10 ; 11$.

2. S Puppen, frisch verpuppt, wurlen 2.2 Tage der Temperatur von $+10^{\circ} \mathrm{R}$. ausgesetzt; in die Zimmertemperatur (17-180 R.) 
gebracht, enwickelten sich lie Falter nach 2 Tagen. Die Gesammtzeit der Entwickelung (von der Verpuppung an) betrug daher 24 Tage.

$\therefore$ Alle Raupen wurlen in Zimmer lis zur Verpuppung erzogen und " Tage darauf eine gewisse Zeit ( $Z$ ) hindurch einer mittleren Temperatur von $+11^{\circ} \mathrm{R}$. ausgesetzt, un! dann im Zimmer sich entwickehn gelassen. Hier entwickelten sie sich nach $Z_{1}$ Tagen; somit ist die Zeit von der Verpuppung bis zur Entwickelung $=0$ $+Z+Z_{1}$.

$$
\begin{aligned}
& \text { Anzahl der Puppen: } 1 ; 1 ; 2 ; 1 ; 2 ; 1 ; 1 ; 1 . \\
& \text { I: } \quad 1 ; \quad 1 ; \quad 2 ; \quad 2 ; \quad \because ; \quad 1 ; \quad 5 ; 7 . \\
& Z_{1} \text { : } \quad \text {; } 9 ; \quad 9 ; 10 ; \quad 7 ; \quad \& ; \quad 5 ; \quad 5 . \\
& \dot{u}+Z+Z_{1}: 9 ; 10 ; 11 ; 12 ; 10 ; 12 ; 10 ; 12 .
\end{aligned}
$$

4. Dasselbe, aber 2 Tage nach der Verpuppung in die 'Temperatur von $+11^{\circ} \mathrm{R}$. gebracht.

Anzahl der Puppen: $1 ; 1 ; 1 ; 1 ; 1 ; 1$.

$$
\begin{array}{rrrrrrr}
Z: & 2 ; & 4 ; & 6 ; & 8 ; & 10 ; & 14 . \\
Z_{1}: & 6 ; & 6 ; & 4 ; & 4 ; & 7 ; & 1 . \\
2+Z+Z_{1}: & 10 ; & 12 ; & 12 ; & 14 ; & 17 ; & 17 .
\end{array}
$$

4. Iasselbe, aber 3 Tage nath der Verpuppung in die Temperatur von $+11^{\circ} \mathrm{R}$. gebracht.

$\begin{array}{rrrrrrr}\text { Anzahl der Puppen: } & 1 ; & 1 ; & 1 ; & 1 ; & 1 ; & 2 . \\ Z: & 2 ; & 4 ; & 6 ; & 8 ; & 12 ; & 15 . \\ Z_{1}: & 1 ; & 8 ; & 4 ; & 3 ; & 1 ; & \left.0 .{ }^{1}\right) \\ 3+Z+Z_{1}: & 10 ; & 15 ; & 13 ; & 14 ; & 16 ; & -.\end{array}$

5. Die Raupen wurlen im Zimmer erzogen mol, sobald sie aufgehïngt waren, einer Temperatur von $+12,2^{\circ} \mathrm{l}$. ausgesetzt, sodann im Zimmer sich entwickeln gelassen. In rer Gesammitzeit rler Entwickelung ist auch die Zeit, die dlieselben bereits aufgehängt zur Verpuppung gebraucht haben, mit in begriffen.

Anzahl der Puppen: $1 ; 3 ; 2 ; 2 ; 1 ; 3 ; 1 ; 4$. Tage niederer $($ bis zur Verpupp.: $2 ; 2 ; 2 ; 2 ; 2 ; 2 ; 2 ; 2$. 'Temperatur (nach der ") 4; $4 ; 4 ; 4 ; 6 ; 5 ; 6 \frac{1}{2} ; 6 \frac{\mathrm{T}}{2}$. Im Zimmer entwickelt nach: $5 ; 6 ; 7 ; 8 ; 5 ; 6 ; 5 ; 6$.

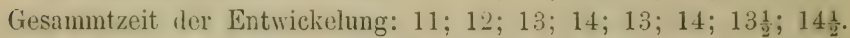
6. Dasselbe, aber statt iler Temperatur ron $+12,2^{\circ} \mathrm{R}$. nur von $+11^{0} \mathrm{R}$. ausgesetzt. funden.

') Entwickelten sich bereits bei $+11^{\circ} \mathrm{R}$. und wurden verflogen vorge- 
Anzahl der Puppen . . . . : 2; $1 ; 2 ; 1 ; 2 ; 1 ; 2 ; 1 ; 1 ; 1$. Tage nicderer ( bis zur Verpupp.: $1 ; 1 ; 1 ; 1 ; 2 ; 2 ; 2 ; 2 ; 2 ; 2$. Temperatur Inach der $\quad$ : $1 ; 2 ; 2 ; 3 ; 3 ; 4 ; 4 ; 5 ; 6 ; 7$. Im Zimmer entwickelt nach . : $9 ; 9 ; 10 ; 8 ; 8 ; 7 ; 8 ; 8 ; 8 ; 7$. Gesammtzeit der Entwickelung: 11; 12; 13; 12: 13; 13; 14;15;11; 16.

7. Dasselbe, auch der Temperatur von $+12,20 \mathrm{~K}$. ausgesetzt, aber lie Zeit, während welcher die niedere Temperatur $(+12,20$ R. eingewirkt hat, vom Momente des Aufhïngens an gerechnet.

Anzahl der Puppen . . . : 8; $5 \frac{1}{2} ; \quad 7 ; \quad 7$.

Tage niederer Temperatur .: $5 \frac{1}{2} ; \quad 5 \frac{1}{2} ; \quad 7 ; \quad 7$.

InI Zimmer entwickelt nach . : $7 ; \quad 8 ; \quad 6 ; 7$.

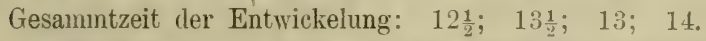

Ausserdem fand ex, dass durch Anwendung von erhöhter Temperatur während der Verpuppung von z. B. Vanessa jo, urticae etc. zugleich diese selbst beschlemigt wirl, llurch ernierlrigte aber verzögert. Er führt jedoch keine Zahlen-Werthe an.

In clerselben Abhanıllung finclet sich folgende Bemerkung: .,Ueberwinternde Puppen, die zu friih zur Entwickelung in tlas Zimmer genommen oder gar nicht rler Kälte ausgesetzt werilen, lieferm entwerler verkiimmerte, theils bleiche, theils kriippelhafte Schmetterlinge, oder sie verderben" (p. 104).

Aus diesen Versuchen von G. Dorfmeister kann man folgende Schlïsse ziehen:

1. Die Entwickelung der Puppe hört bei $+11^{\circ} \mathrm{R}$. nicht auf.

2. Je längere Zeit die Temperatur ron $17-20^{\circ} \mathrm{R}$. durch die Temperatur von $+11^{\circ} \mathrm{R}$. bei ier Entwickelung der Puppen ersetzt wird, desto grösser ist diu Dauer dieser Entwickelung. Diese Zeit kann jeloch unter diesen Umständen nicht beliebig verlängert werden (sie ist im Maximum 17 Tage).

E. Duclaux (1 6\%. 199) untersuchte den Eintluss der Kälte auf die Entwickelung der Eier von Bombyx mori. Er nahm zwei Portionen von Eiern: eine Portion wurte bei gewölnlicher Temperatur und die andere während 40 Tagen im kühlen Raume gelassen, worauf beirle Portionen in einem Brutofen allmällig auf $20^{\circ}$ erwärmt wurden. Dabei stellte sich heraus, dass clie Eier, welche im Anfang der Einwirkung der Kälte ausgesetzt wurlen, entwickelt waren, die iibrigen gar keine Embryonen ergaben.

Er bemerkt dabei, dass Eier, welche normal iiberwintert halen, Riiupchen ergeben, währenıl solche, welche ungenïgentle Üeber- 
winterung erlitten, Embryonen enthalten, ,lie jedoch nur bis zur Ausschliüfung leben. Das Ausschliipfen finilet dabei um so unregelmässiger statt, je kiızere Zeit clie Kälte eingewirkt hat.

I araus schliesst er, dass die Einwirkung der Kïilte notwendig ist, dlanit die Eier zur Entwickelıng gebracht werden kïnnen.

E. Duclaux (1871. 200) giebt folgenile \%wei Regeln an, un die Eier von Bomly mx mori zu beliebiger Zeit ausbriiten zu lassen:

1. Um die Ausbriitung ier Eier zu verhindern, muss man dieselben vom Moment iles Ablegens an bei iler Temperatur von 15 bis $20^{\circ}$ aufbewahren, darauf sie cler Einwirkung ler Kälte währenıl 15 Tagen aussetzen und zwar 3 Monate friiher, als man die Raupen zu erhalten wünseht und nachher wie gewöhnlich behandeln.

2. Un die Ausbriitung der Eier friiher zu hewirken, muss man dieselben 20 Tage nach dem Ablegen der Einwirkung der Ki:ilte währenı 2 Monaten aussetzen und sie nachher aus dieser nieleren T'emperatur herausnehmen; 6 Wochen darauf befinclen sie sich unter ılen gleichen Berlingungen. wie die normalen Eier, und lï̈nnen wie gewöhnlich behandelt werden.

E. Verson (1871. 914) stellte sehr interessante Versuche ïber den Einfluss niedriger Temperaturen auf die Lebensfïhigkeit ler Lier von Bombyy mori an. Die Eier wurden in langhalsige (ilasliolben gebracht, welche in Kältemischungen schwammen. Für die lionstante Kälte wurle durch specielle Einrichtungen Sorge getragen. Folgende Tabellen enthalten die Versuchsergebnisse.

I. Versuch: Die (trains der ungekörperten Schmetterlingen wurlen am 4. Januar in den Kälteapparat gebracht, wobei sie folgender Frostwirkungen ausgesetzt waren:

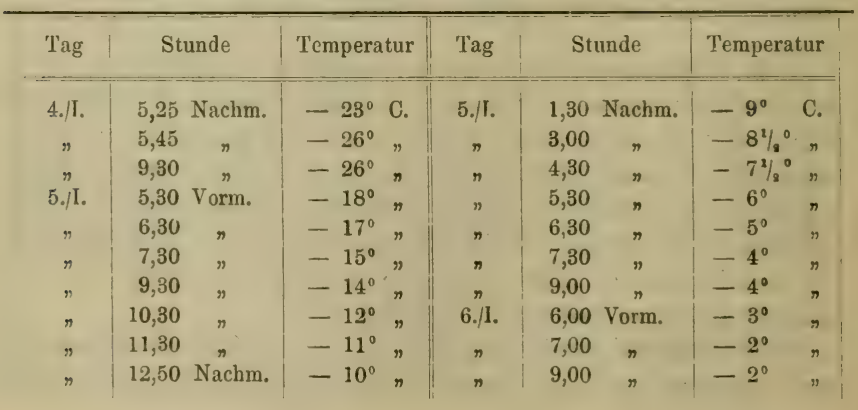


Nachilem hierauf die Grains lurch einige Zeit einer Wäme von $+4^{0}$ C. ausgesetzt blieben, wurle die kiinstliche Ausbritung vorgenommen; das Ausschlïpfen der Räupchen begann am 17. Febr. und war innerhalb 3 Tagen voliständig und regehmässig beendet. Die (irains benöthigten bis zum Ausschlüpfen eine Wärme von $360^{\circ}$ C.1)

II. Versuch: Die Eier der schwachgekörperten Schmetterlingen wurden am 6. Januar der Kältewirkung ausgesetzt, welche folgenden Verlauf zeigte:

\begin{tabular}{|c|c|c|c|c|c|}
\hline Tag & Stunde & Temperatur & Tag & Stunde & Temperatur \\
\hline 6./I. & 12,00 Vorm. & $-23^{\circ} \mathrm{C}$. & 6./I. & 6,00 Nachm. & $-6^{\circ} \mathrm{C}$. \\
\hline$n$ & 12,30 Nachm. & $-20^{\circ}$ & $n$ & 7,00 & $-5^{0} n$ \\
\hline$"$ & $1,00 \quad n$ & $-19^{\circ}$ & $n$ & 8,00 & $-4^{0} n$ \\
\hline$n$ & 2,00 & $-16^{\circ}$ & n & 9,30 & $-3^{\circ}$ \\
\hline$n$ & 3,00 & $-13^{\circ}$ & 7. 1 I. & 6,00 Vorm. & $0^{\circ}$ \\
\hline$n$ & 4,00 & $-10^{\circ}$ & $"$ & 7,00 & $+1^{\circ} n$ \\
\hline$"$ & 5,00 & $-8^{\circ} n$ & $n$ & 8,00 & $+1^{\circ} "$ \\
\hline
\end{tabular}

I) Eier wurden hierauf durch mehrere Tage einer Temperatur von $4^{\circ}$ ausgestzt und lieferten nach Einwirkung einer Wärmesumme von $350^{\circ}$ C. die Räupchen, deren Auskriechen ganz regelmässig erfolgte.

III. Versuch: Eier, welche bei der mikroskopischen Untersuchung (am 8. Januar) einen Procentsatz der Infektion von $4 \%$, einer Intensität von 0,04 zeigten. Dieselben wurden am 9. Januar einer starken Ablühlung in nachstehender Abstufung ausgesetzt:

\begin{tabular}{|c|c|c|c|c|c|}
\hline $\mathrm{Tag}$ & Stunde & Temperatur & Tag & Stunde & Temperatur \\
\hline $\begin{array}{c}9 . / \mathrm{I} . \\
" \\
" \\
" \\
" \\
" \\
n \\
" \\
"\end{array}$ & $\begin{array}{rl}10,45 & \text { Vorm. } \\
12,30 & \text { Nashm. } \\
1,00 & n \\
1,30 & " \\
2,00 & " \\
3,00 & \text { " } \\
3,30 & \text { " } \\
4,30 & \text { " } \\
5,30 \quad \text { " }\end{array}$ & 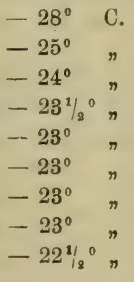 & $\begin{array}{c}9 . / \mathrm{I} . \\
n \\
10 . / \mathrm{I} . \\
n \\
" \\
n \\
n\end{array}$ & $\begin{array}{c}6,30 \text { Nachm. } \\
7,30 \quad " \\
9,00 \quad " \\
5,30 \text { Vorm. } \\
6,30 \quad \text { " } \\
7,30 \quad \text { " } \\
9,30 \quad " \\
10,30 \quad \text { " } \\
12,00 \quad \text { " }\end{array}$ & $\begin{array}{l}-21^{1} \%^{\circ} \mathrm{C} \\
-21^{\circ} \\
-20^{\circ} \\
-16^{\circ} \quad " \\
-15^{\circ} \quad " \\
-14^{\circ} \quad " \\
-13^{1} \%^{\circ} " \\
-13^{\circ} " \\
-12^{\circ} \quad "\end{array}$ \\
\hline
\end{tabular}

1) Vom physikalischen Standpunkt aus ist dies unbegreiflich, da die Wärmemenge nur mit $\mathrm{Kal}$ orien gemessen wird.

$\mathrm{Bch} \mathrm{m}$. 


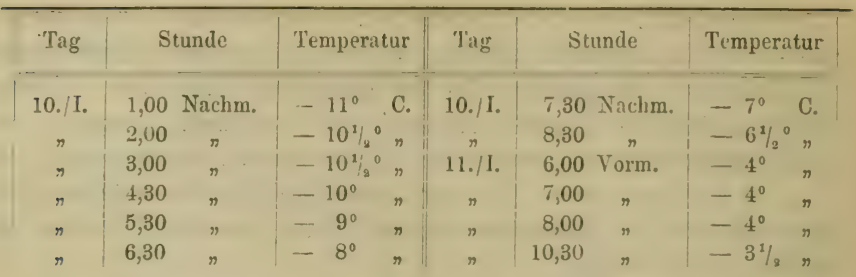

Die Ausbriitung, mit der nöthigen Vorsicht eingeleitet, lieferte aus diesen Grains nach erfolgter Linwirkung einer Wärmesumme von $375^{\circ} \mathrm{C}$. innerhalb) weniger Tage sïmmtliche Riäupchen. Diese letzteren zeigten bei der mikroskopischen Untersuchung einen sehr abweichenden lnfektionsgrad der zwischen 0 und $12 \%$ schwankte. Vergleicht man die summe aller gekörperten und nicht gekörperten Lïiupchen, so ergibt sich eine mittlere Infection derselben von $4 \%$ mit einer Intensität von 0,42 .

IV. Versuch: Grains von ungekörperten Schmetterlingen wurden in 3 Gruppen getheilt: A, B, C.

Die (iruppe A erlitt am 6. Januar eine bis auf - $23^{0}$ gehencle Abliihlung und am 9. Mai eine zweite Kïiltewirkung, welche $-23^{\circ}$ betrug.

Die Gruppe B wurle nur einmal bis auf $-28^{\circ}$ abgekiilılt.

Die Cruppe $\mathrm{C}$ verblieb bis zum 11. Januar in einem kiihlen Locale, dessen Temperatur zwischen $-1^{0}$ und $+4^{0}$ variirte.

Sämmtliche :; Proben wurden am 11. Januar wiederholt in den Kälteapparat versetzt, wo sie der nachverzeichneten Abkiihlung unterworfen wurden:

\begin{tabular}{|c|c|c|c|c|c|c|c|c|}
\hline Tag & \multicolumn{2}{|c|}{ Stunde } & Temperatur & Tag & \multicolumn{2}{|c|}{ Stunde } & \multicolumn{2}{|l|}{ Temperatur } \\
\hline $11 . / \mathrm{I}$ & 4,45 & Nachm. & $-32^{\circ} \quad \mathrm{C}$. & 12./I. & 12,00 & Vorm. & $-12^{\circ} \mathrm{C}$ & C. \\
\hline$\pi$. & 5,30 & $"$ & $-30 \%{ }^{\circ}$ & $\pi$ & 1,00 & Nachm. & $-10^{\circ} \quad n$ & \\
\hline$n$. & 6,00 & " & $-29^{\circ}$ & $n$ & 2,00 & & $-91 / 8^{0} n$ & \\
\hline ” & 6,30 & $\pi$ & $-28^{\circ} \quad$ & $n$ & 3,30 & n & $-91 / 8^{\circ} n$ & n \\
\hline$n$. & 7,00 & $n$ & $-271^{\circ}$ & $n$ & 4,30 & $"$ & $-81 \%^{\circ} n$ & $n$ \\
\hline , & 7,30 & $n$ & $-26^{\circ}$ & , & 5,30 & $n$ & $-7 \% \%^{\circ}$ & 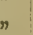 \\
\hline$n$ & 8,00 & $n$ & $-25^{\circ}$ & $n$ & 6,30 & $"$ & $-61 /{ }^{\circ} n$ & $n$ \\
\hline$n$ & 9,00 & $"$ & $-24^{0}$ & $n$ & 7,30 & $n$ & $-6^{0} \ldots$ & r. \\
\hline 12. II. & 6,00 & Vorm. & $-17^{\circ}$ & $\eta$ & 8,30 & r & $-6^{c}$ & $n$ \\
\hline$n$ & 7,00 & $n$ & $-16^{\circ}$ & 13./I. & 6,00 & Vorm. & $-3 \%^{0}{ }^{0}$, & n \\
\hline$\dot{n}$ & 8,00 & $n$ & $-15^{\circ}$ & $"$ & 7,00 & $n$ & $-3_{i}^{0} \quad$ & $”$ \\
\hline v & 9,00 & $"$ & $-144_{2}^{\circ}{ }^{\circ}$ & 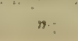 & 9,15 & $"$ & $-3^{0}$ & $n$ \\
\hline
\end{tabular}


Durch 5 Tage einer Temperatur von $+5^{\circ} \mathrm{C}$. auscesetzt, kanen hierauf diese Grains zur künstlichen Ausbriitung; die Eier der Gruppe C trockneten aber hierbei ein olne ein einziges Rüupchen zu liefern; von der Gruppe B schliıften die Rüupchen nur aus $2 \%$ der Grains aus, nachilem sie eine Wïrmesumme von $500^{\circ} \mathrm{C}$. veriraucht hatten; jene ler Gruppe $\mathrm{C}$ verfürbten sich theilweise (1/5), es erschienen nur $5,4_{0}^{\circ}$ der erwartenden Räupchen nach einer Einwirkung einer TVärmesumme von $448^{\circ} \mathrm{C}$.

VI. Versuch: Eier ungekörperter Schmetterlinge, in thri verschiedenen Abtheilungen:

a) nach einer Abkiihlung bis zu $-23^{\circ} \mathrm{C}$., liess man die Temperatur allmälig zu + 30 C. ansteigen; nach Verlauf weiterer zwei Tage, kamen die Grains sogleich in einen auf $+20^{\circ} \mathrm{C}$. erwïrmten Raum;

b) die Eier der zweiten Gruppe wurden von $-2: 3^{0}$ C. plötzlich in eine Temperatur von $+3{ }^{\circ} \mathrm{C}$. gebracht: letztere von Tag zu Tag allmälig bis auf $+20^{\circ}$ C. erhöht;

c) von $-2: 3^{\circ} \mathrm{C}$. kam die dritte Gruppe sogleich in einen auf $+20^{\circ}$ C. erwärmten Brutkasten.

Obgleich nun vorstehende Grainspartieen so plötzliche und gewaltige Temperaturveränderungen erlitten (in der Gruppe $c$ betrug die Differenz sogar $43^{\circ}$ C.!), fand doch ein vollständiges Ausschliipfen (ler Rüupchen statt; dasselbe vertheilte sich nur auf die ungewöhnliche Dauer von über zwei Wochen.

VII. Versuch: Eier von ungekörperten Schmetterlingen in vier Gruppen getheilt. Nachdem diese letzteren einer Temperatur von $13^{\circ} \mathrm{C}$. ausgesetzt worden waren, und zwar:

Gruppe a) durch 6 Stunden

$\begin{array}{rrrrr} & . . \mathrm{b}) & & 12 & \\ " & \mathrm{c}) & & 48 & \\ . & \text { d) } & & 60 & \end{array}$

wurden sie inswesammt in den frührer beschriebenen Apparat zebracht, lessen Temperatur folgenden Temperaturgang zeichmete:

\begin{tabular}{|c|c|c|c|c|c|}
\hline Tag & Stunde & 'Temperatur & 'Tag & Stunde & 'Temperatur \\
\hline $\begin{array}{c}\text { 16. II. } \\
n \\
\text { 17. / II. } \\
n \\
n\end{array}$ & $\begin{array}{l}3,42 \text { Nachm. } \\
5,45 \text {. } \\
9,00 \text { V } \\
6,00 \text { Vorm. } \\
9,30 \text { No" } \\
1,00 \text { Nachm. }\end{array}$ & 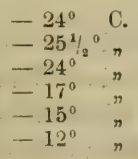 & $\begin{array}{c}\text { 17./II. } \\
\text { 18. /II. } \\
n \\
n\end{array}$ & $\begin{array}{l}3,30 \text { Nachm. } \\
9,00 \text { N" } \\
6,00 \text { Vorm. } \\
9,30 \text { Nö } \\
9,00 \text { Nächm. } \\
-\end{array}$ & 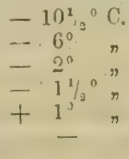 \\
\hline
\end{tabular}


An 25. Felıuar l,egann die regelmässige Belnritung sïmmtlcher (irainspartien, worauf lie Räupchen derselhen fast gleichzeitig ausschliipften. Auffallend war aber dahei. dlass die Zahl der austrocknenden Fier, die keine Rïupchen erwaben, ungewöhnlich hoch war, unl zwar un so höher, je länger die hetreffentle Partie vor ler Ahkühlung auf - $255^{\circ} \mathrm{C}$. der Temperatur von $13^{\circ}$ ausgesetzt worden war, so dass in (ler (iruppe a) die ausgetrockneten Eier $12 \%$, in b) $12,6 \%$, in c) $13 \%$ und in (l) $16 \%$ betrugen.

Ueherblicken wir die sieben Versuchsreihen. die oben als Tiepraesentanten einer grïsseren Zahl von Beoharhtungen aufweführt wurden, so ergehen sich aus ilenselhen folgende Schlusstolyerungen:

1. Die Eier des Maulheerhaumspinners hesitzen in holem (irarle die Fïhigkeit, nierleren Temperaturgralen zu widerst:hen. Ijiese Wirlerstandsfähigkeit ist jeloch nicht unhegrenzt; eine Temperatur von ungeführ $: 2^{\circ}$ C. unter Null ist im Stancle, die weitere Entwickelungsfähigkeit der Eier zu zerstören.

2. Auch einer so niederen Temperatur gegeniiber kam sich die Lehensfihhigkeit der Eier erhalten, wenn die Ahkihhlun nicht plötzlich, sondern sehr allmälig und algestuft stattfindet, $/ u$ einer solchen Auslegung scheinen wenigstens die Versuche . V. i uns zu herechtigen, hei welchen die plötzlich auf - 3:0 C. ahgekiihlten Eier sïmmtlich austrockneten, ohne ein einziges Räupchen zu lieferı, wïhrenil andere Eier, welche früher eine progressive Abkühlung erfahren hatten, sich wenigstens zum Theile aufschlossen.

3. Der (irad der während der Ueherwinterung erlittenen $\mathrm{Ab}$ kiihlung heeinflusst die Periorle ıles Ausschliipfens der Räupchen, insofern, als ‘liese letzteren um so später auskriechen, als clie erfahrene Kälte intensiver war.

I)iese Resultate bieten eine gewisse Analogie mit der Thatsache dass nach ungewöhnlich strengen Winter auch die Vegetation später in's Leben tritt.

4. Die Eier iles Maulbeerbaumspinners ertragen sehr becleutencle Temperatursprïnge, olne dass ihre Lebensfähigkeit darunter leitlet. Dic Numner $b c$ gab eine vollständige Ausbriitung, obgleich die Eier plïtzlich. von - 2:30 C. auf $+20^{\circ}$ C. erwärmt wurlen: eine Differenz von $43^{\circ} \mathrm{C}$.!

5. Gefïhrlicher kïnen plötzliche Temperaturernieslrigmgen werlen, wemn die Eier frïher schon einer Temperatur ïber $+10^{\circ} \mathrm{C}$. ausgesetzt waren. Die Nummer 7 zeigt uns, dass die Menge der in Folge der starken Abkühlung anscretrockneten Eier mit der Zeit. 
wïchst, durch welche die höhere Temperatur auf dieselben friher eingewirkt hatte.

6. Gekörperte Eier l,esitzen starken Kïltegraulen gegreniiher keine weringere Wilerstamlsfühikeit als vollkommen wesumle.

7. Die qleiche Willerstanlsfïhigkeit gegen die Kialte zeigen anch Eier, welche von schlafsiichtigen Zuchten alstammen.

Carret (1871. 133) in Chambéry briitete Riiupchen aus Eiern von Bombyx.x mori hei 250 uml ziichtete sie hei $30^{\circ}$. Nach iler 4. Häıtumg wurilen sie bei $35^{\circ}$ aufgezogen. Die Häntungen fanlen von $t$ zu 4 Tage statt und gingen sehr leicht vor sich. Das Aufsteigen in die Spimnhiitten begamn an 1!). Mai und setzte sich l,is zum 2ュ4. Mai fort. Also die Raupenzeit danerte von 28. April lis zu 1!). Mai, 1. h. 2.2 Tage: es waren aber Raupen vorhande.ı, welche schon nach 17 -18 Tagen spimmreif waren.

In einem Schreihen an den Monitenr des soies (1sí. 134) zieht er aus diesen Versuchen folgende Schliisse:

1. Mit Hilfe der kïnstlichen Heizung kann eine Aufzucht in 20 Tagen vollendet werden, während die mittlere Daner der gewöhnlichen Aufzuchten in Savoyen 50 Tage beträgt.

2. Die (irains solch heschlemigter Zuchten sind für die lieprorluction sehr geeignet.

Balbiani (1572. 45) beohachtete. dlass dic Eien von PHanzenliinsen hei nie:higen Temperaturen sich sehr langsam entwickeln. Die Entwickelung wirl aher beschlemigt, wemn die Eier der Temperatur ron 20-250 ausgesetzt werden: man darf aber dale diese (irenztemperatur nicht ïherschreiten, da die Eier bei :30 zurest die heschlemigte Entwickelmo zeigen, nachher aber zu Grumle gehen. In einem Ei von Siphonophora millefolii, welches ann 16. Novemuluer morgens alogelegt wurde, erreichte die "polare Masse" das Ficentrum bei $17^{\circ}$ nach 15 Stunden, in einem anderen Ei dersellexn Art betruy diese Zeit bei ( - $^{0}$ ca. 4 Tage; hei einem Ei von Siphonnfora jaceae erreichte die polare Masse das Eicentrum bei $17^{\circ}$ erst nach 24 Stunden.

Er fand anch, dlass die Temperatur von 6-70 die Entwickelumg des Eis nicht zum Stillstehen bringt, somblern diesellue nur verlangsant.

Nach dieser Arbeit finlgt eine spezielle Untersuchung ron E. Kalender $(18 i 2.428)$. Er besam seit 1 s6.j das Beobachtmosma- 
terial ïher heschleunigte Lintwicklung ïberwintermber schmetterlingsPuppen zu sammehn, wohei "r hauptsiichlich :3 Mothoilen anwanlte: 1. Eine allnïhlige Steigerumg der Temperatur (Methorle $X_{1}$ ). 2. Behandlung der Puppen mit einer constanten Temperatur ron 18 bis 200 R. vom Augenblicke der Verpuppung an (Methoule $\lambda I_{2}$ ). :3. I)ureh Cebersiedehn der Puppen aus der, im , Tanmar und Februar herrsehenden Temperatur in eine Wirme von $18-2.50$ li. (Mrthorle $M_{3}$ ).

Die ron ilım erhaltenen Resultate waren folgende:

A. Geometridae.

\begin{tabular}{|c|c|c|c|c|c|}
\hline Art & Verpuppung & Metlıole & Temperatur & Ausschliipfen & $\begin{array}{l}\text { Von der Verpup } \\
\text { pung bis zum } \\
\text { Ausschliipfen }\end{array}$ \\
\hline 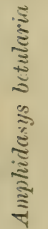 & $\begin{array}{l}\text { 17. Septemb. } \\
\text { 9. Oktober } \\
\text { 23. Septemb. } \\
\text { ? } \\
\text { 29. Septemb. } \\
\text { 3. Oktober } \\
\text { ? }\end{array}$ & $\begin{array}{l}\text { 15. Oktober } M_{1} \\
\text { 1. Novemb. } M_{2} \\
\text { 15. Januar } M_{3} \\
\text { Februar } M_{3} \\
\text { 15. Oktober } M_{1} \\
\text { 20. Oktober } M_{2} \\
\text { 9. Junuar } M_{3}\end{array}$ & $\begin{array}{c}+4^{0} \text { bis } 18^{\circ} \mathrm{K} . \\
20^{\circ} \\
19,5^{\circ} \\
? \\
?-22^{\circ} \\
20^{\circ} \\
20^{\circ}\end{array}$ & $\begin{array}{l}\text { 17. April } \\
\text { Starb } \\
\text { 11. Februar } \\
\text { März, aber tod. } \\
\text { 2. April } \\
\text { 29. März } \\
\text { 8. Februar }\end{array}$ & $\begin{array}{l}212 \text { Tage } \\
141 \text { Tage } \\
4 \text { Wochen } \\
185 \text { Tage } \\
177 \text { Tage } \\
\text { - }\end{array}$ \\
\hline
\end{tabular}

Biston hirturins unl Biston pomonarius lieferten gleiche ofler :̈hnliche Resultate. (Iner Verfasser qil, für dieselbe keine I baten an).

B. Noctuadeae.

Untersucht wurden:

1. Acronycta aceris, tridens, psi. leporina, megacephulı, und rumicis. Die im Freien gesammelten Raupen rer ersten Art ergahen in Herhst Puppen, ein Theil, welcher der Temperatur-Veränderungen im Freien ausgesetzt wurlen (Gruppe $a$ ). Ein zweiter Theil wurle nach $I_{1}$ ((iruppe $b$ ) und nach $\boldsymbol{I}_{2}$ (Gruppe $c$ ) behandelt.

$I_{1}$ lieferte keine sehr auffalenden Resultate. Das Ausschliipfen fand Encle März - Anfang April statt.

Bei $M_{2}$ war die Entpuppung im Laufe des März.

Die (iruppe a blieb bis Mitte Januar in Freien. An 15. Januar wurle nach $M_{3}\left(t=22^{\circ}\right.$ R. $)$ verfahren. Der grösste Theil entschlüpfte an 10. Februar.

Die iibrigen Arten lieferten dieselben Resultate. Nur Acronycta leporine verhielt sich, nach der Methode $\boldsymbol{I}_{\mathbf{3}}$ behandelt, anders. Die meisten Puppen starben dlabei; zwei ertrugen den plötzlichen 
Temperaturwechsel uni eine entwickelte sich im April. Die antries Puppe dagegen blieb den ganzen Sommer ïher als solche und entwickelte sich erst im September.

2. Mamestra persicariae. In Herbst 1867 wurlen 40 liaupen gesammelt, welche sich dann verpuppten. Ein Theil dersell('n (a) blieh ganz im Freien, $b$ hlieb bis .Tanuar 1868 , lort und wurde damn nach $M_{3}$ behandelt, wïhrend $c$ mol $d$ nach $M_{1}$ resp. $I_{2}$ hehanclelt wurde.

$c$ entwickelte sich im Laufe des Monates März 1 r68 in wrisseren Zeitdifferenzen.

d entwickelte sich Enle März 1868 ziemlich zu gleicher \%eit.

$b$ wurle an 7 . Januar aus einer niedrigen Temperatur in cine Stubenwärme von $20^{\circ} \mathrm{R}$. ïbersiedelt, und die Puppen zeigten hald eine grosse Lebhaftigkeit. Ausschliipfen am 29. Jamuar - 6. Fehruar.

$a$ entwickelte sich im Mai.

3. Mamestra brasicae unil oleracen zeigten dasselbe Terlialten.

4. Hadena atriplicis an 28. December nach vorher gegangenem, sehr starkem Frost in die Temperatur von $20^{\circ} \mathrm{R}$. gebracht, entwickelten sich am 21.-23. Januar.

5. Calpe libatiix schliipfte aus den überwintermlen Puppen nach wenigen Tagen bei $10-12^{\circ} \mathrm{R}$. aus.

6. Noctua gothica, Orthosia instabilis, stabilis, lota, cruila und Iylina conspicillaris. Diese Eulen entwickelten sich nach $M I_{1}$ umil $M_{2}$ in 3-4 Wochen, nach $M_{3}$ schon in 2 bis 3 Tagen.

C. B om b y cida e.

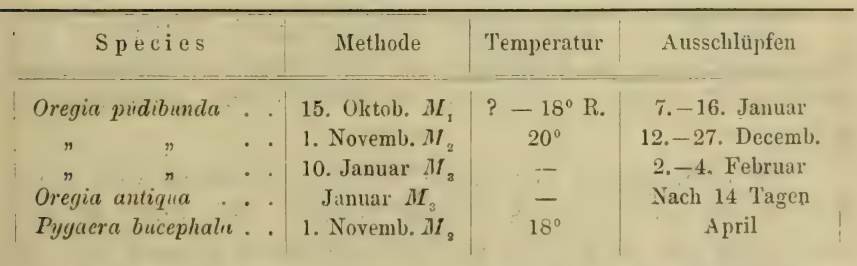

Pygaera anachoretu, reclusa unil curtulu, nach $M_{1}$ vom 1.5. Okt. behandelt, enwickelten sich Mitte Norember. $M_{2}$ bringt die Puppen gleichfalls $u m$ rliese Zeit zur Entwickelumg. $\boldsymbol{M}_{3}$ beschleunigt die Entwickelung ungemein und Puppen, welche vom 15. Januar an! nach dieser Methode behandelt wurden, kamen noch vor Fehruar zur Entwickelung. 


\begin{tabular}{|c|c|c|c|c|c|}
\hline \multicolumn{3}{|c|}{ Species } & Methode & Temperatur & Ausschlïpfen \\
\hline 3 & Notodonta & palpina & 15. Oktober $M I_{1}$ & bis $16^{\circ} \mathrm{R}$. & 30. Nov.-10. Dec. \\
\hline 2 & $n$ & $"$ & 1. November $M_{2}$ & $20^{\circ}$ & 3. -5 . Januar \\
\hline 7 & $n$ & $n$ & 15. Januar $M \Gamma_{8}$ & $20^{\circ}$ & 3. - 14. Februar \\
\hline 2 & $n$ & $n$ & 15. Uktober $M_{2}$ & $18^{\circ}$ & 17. - 22. November \\
\hline 1 & $n$ & $n$ & 20. Januar $M I_{s}$ & $22^{\circ}$ & 16. Februar \\
\hline 2 & $n$ & , & 28. Decemb. $\Psi_{8}$ & $24_{0}$ & 17. -22 . Januar \\
\hline 2 & , & camelina & 15. Oktober $M_{2}$ & $20^{\circ}$ & 3.-11. December \\
\hline $\mathrm{i}$ & $n$ & $n$ & 16. Januar $M I_{3}$ & $20^{\circ}$ & 5. Februar \\
\hline 5 & $n$ & ziczuc. & 15. Oktober $M I_{\text {, }}$ & $18^{\circ}$ & 2. - 17. December \\
\hline 2 & 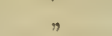 & $n$. & 13. Januar $\boldsymbol{M}_{3}$ & $20^{\circ}$ & 9.-10. Februar \\
\hline 4 & ， & $"$ & 15. Oktober $M_{2}$ & $20^{\circ}$ & 24. Nov. - 8. Der. \\
\hline 2 & $"$ & $\eta$ & 15. Oktober $M I_{\mathrm{g}}$ & $20^{\circ}$ & 21.-29. November \\
\hline 1 & $n$ & torea. & 20. (1)ktober $M_{2}$ & $20^{\circ}$ & 7. December \\
\hline 2 & $n$ & trotophus & 15. Olitober $M_{1}$ & $18^{\circ}$ & 11. - 17. December \\
\hline 7 & $\eta$ & dictaea & 15. Oktober $M_{1}$ & $18^{\circ}$ & 9.-21. December \\
\hline 5 & $"$ & $n$ & 15. (Oktober $\mathrm{MI}_{2}$ & $20^{\circ}$ & 27. Nov, -4 . Ilec. \\
\hline 8 & n & $"$ & 15. Jinuar $M_{3}$ & $20^{\circ}$ & 5.-13. Februar \\
\hline 3 & $n$ & " & 15. Oktober $M_{2}$ & $18^{\circ}$ & 3.-8. December \\
\hline 1 & $n$ & $"$ & 12. Januar $M_{3}$ & $22^{\circ}$ & 31. Januar \\
\hline 2 & $n$ & $n$ & 23. Oktober $M I_{1}$ & $16^{\circ}$ & 17. -21. December \\
\hline
\end{tabular}

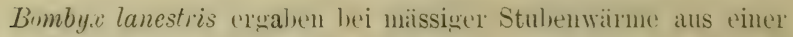
grossen Zahl Puppen in Oktoher 8-10\% Schmetterlinge: die iibrigen Puppen enthielten den vollständig entwickelten schmetterling, blieben aber bis zum April des nïchsten Jahres liegen, mul nun erst schliipfte das rollkommene Insekt aus.

Nach $M_{1}$ von Mitte Olitober's an hehandelt, entwickeln sich die Schnetterlinge im December, $M_{2}$ beschlemint die Entwickelung mul nach $M_{3}$ behandelt, erscheint der Schmetterling schon nach 2t. Stunilen.

Die Entwickelung der Puppe von Harpyia vinula wird durch $M_{1}$ und $I_{2}$ im Lanfe des Februar bewirkt. $M_{3}$ wirkt dagegen sehr lneschlemigend anf die Entwickelung dieser Puppen ein und reranlasst deren Entwickelung schon in 1s-24 Tagen. Elenso verhält sich die Puppe von Harpyia furcula.

Auf die Puppen ron Eupreria lubricipeda und Eupreria menthastri haben die drei Methorlen keinen nennenswerthen Einthss.

I hie Puppe von Euchelia iacobaeae entwickelt sich nach $M_{1}$ in Januar, nach $M_{2}$ Anfangs Januar, nach $M_{3}$ im Fehruar. 


\section{Rhopalocera.}

Die äherwintermiten Puppen von Papilio machuon entwickeln sich schon bei sehr mässiger Stuhenwärme in 4-5 Wochen. Nach $\mathrm{M}_{2}$ behandelt, kommt ier schmetterling schon nach 10-14 Tagen zur Entwickelung.

Dasselbe ist der Fall mit Pieris brassicue.

\section{E. Sesiidae.}

Die Raupe ron Sesia apiformis iiberwintert in einem Cocon und rerpuppt sich in demselhen erst Encle April. Behandelt man die Cocons vom Oktoher al nach $I_{1}$, so verpuppt sich die Raupe schon in Januar und es entwickelt sich dann der schmetterling in 4-j Wochen. Dassellee auch nach $\boldsymbol{M}_{2}$ und $\boldsymbol{M}_{3}$, nur class ein wrosser Theil der Raupen an einer Schimmelkrankheit stirbt.

\section{F. Sphingides.}

Macroglussa stellutarum entwickelt sich nach $M M_{1}$ Eule Norember unil Anfang December, nach $M_{2}$ in $4-1$; Wochen unil nach $\boldsymbol{M}_{3}$ in 14 Tagen.

Die Entwickelung von Macroglussa oenotherae aus der überwinternden Puppen erfolgte, nachitem die Puppen vom 1. Januar ah, eine Temperatur ron 220 I. erhalten hatten, am 23. Januar aher beile Schmetterlinge verkriippelten.

\begin{tabular}{|c|c|c|c|c|c|}
\hline \multicolumn{3}{|c|}{ Species } & Methode & Temperatur & Ausschlüpfen \\
\hline 3 & Smerinthus & poputi. & 15. Oktober $\boldsymbol{M}_{1}$ & $16^{\circ} \mathrm{R}$. & 4., 7. und 16. März \\
\hline 20 & r & $\eta$ & 15. Oktober $M_{2}$ & $20^{\circ}$ & 27. Jan. - 19. Feb. \\
\hline 2 & $"$ & $n$ & 17. Januar $M_{8}$ & $22^{\circ}$ & 22.-25. Februar \\
\hline 3 & $"$ & $n$ & 23. Januar $M_{3}$ & $22^{\circ}$ & 25.-27. Februar \\
\hline 7 & $n$ & ” & 19. Februar $M_{\mathrm{s}}$ & $18^{\circ}$ & 25.-29. März \\
\hline 1 & $\pi$ & $n$ & 7. Januar $\boldsymbol{M}_{3}$ & $20^{\circ}$ & 12. Februar \\
\hline 11 & $n$ & ” & 21. Februar $H_{3}$ & $20^{\circ}$ & 23. -30. März \\
\hline
\end{tabular}

Achnliche Verhältnisse wurlen auch bei Smerinthus ocellutu gefunılen, jedloch ist die Puppe nicht so empfindlich für die Eintlüsse einer erhöhten Temperatur. 


\begin{tabular}{|c|c|c|c|c|c|c|}
\hline \multicolumn{4}{|c|}{ Species } & Methode & Temperatur & Ausschlüp̣fen \\
\hline 7 & Smerintluus & ocellata. & & 15. Oktober $M_{2}$ & $18^{\circ} \mathrm{R}$. & Mlärz \\
\hline 5 & $"$ & $"$ & . & 15. Oktober $M I_{2}$ & $20^{\circ}$ & Ende Februar \\
\hline 3 & $"$ & $"$ & & 15. Oktober $M I_{2}$ & $18^{\circ}$ & 3.-9. März \\
\hline 4 & $"$ & $"$ & . & 15. Oktober $M_{1}$ & $18^{\circ}$ & 25. December \\
\hline 2 & $n$ & $n$ & & 15. Oktober $M_{1}$ & $18^{\circ}$ & 22. $-2 \pi \cdot$ Februar \\
\hline 3 & $n$ & $"$ & • & 15. Oktober $M_{1}$ & $18^{\circ}$ & 24. Februar \\
\hline 1 & $n$ & $n$ & & 12. Januar $M_{3}$ & $-2^{\circ}$ bis $22^{\circ}$ & 22. Februar \\
\hline 1 & $n$ & $\eta$ & & 19. Januar $M_{3}$ & $22^{\circ}$ & 2. Närz \\
\hline 1 & $n$ & $n$ & & 17. Februar $M_{3}$ & $22^{\circ}$ & 2. April \\
\hline
\end{tabular}

In der Natur beträgt die Puppenlauer für diese Art 276 Tage.

Versuche mit Smerinthus tiliae:

\begin{tabular}{|c|c|c|c|c|c|c|c|}
\hline & \multicolumn{3}{|c|}{ Species } & & Methode & 'T'emperatur & Ausschlüpfen \\
\hline 9 & Simerinthus & s tiliae & & & 15. Oktober $M_{1}$ & $18^{\circ} \mathrm{R}$. & 29. Jan. - 17. Feb. \\
\hline 6 & n & 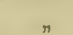 & & & 18. Uktober $M_{1}^{2}$ & $18^{\circ}$ & 8.-12. Februar \\
\hline 7 & $\pi$ & $n$ & . & & 15. Oktober $M_{2}$ & $20^{\circ}$ & 3.-9. Februar \\
\hline 2 & $n$ & " & & & 15. Oktober $M_{8}$ & $18^{\circ}$ & 17. Februar \\
\hline 2 & n & $n$ & . & & 11. Januar $M_{3}$ & $18^{\circ}$ & 18. -22 . Februar \\
\hline 5 & $”$ & $"$ & & & 23. Fubruar $M_{3}$ & $22^{\circ}$ & 27.-29. Närz \\
\hline
\end{tabular}

Die Puppe des Deilephila euphorbiae entwickelt sich, nach $M_{1}$ und $\lambda I_{2}$ behantelt, leicht in Januar, dagegen wirkt $\lambda H_{3}$ so, dass der Schmetterling erst nach $21 / 2-3$ Monaten, also im April sich entwickelt. Alle drei Methorlen wirken dann nicht, wenn die Puppe eine zweijährige Puppendlauer liat.

$M_{1}$ und $M_{2}$ veranlassen die Entwickelung von Deilepluila galii schon in December; $\lambda I_{3}$ bringt die Puppe in 4 Wochen zur Entwickelung.

Beinahe sar keine Empfänglichleit für $M \Gamma_{1}$ und $\lambda I_{2}$ zeigen I)eilephila elpenor und porcellus, dagegen werden die Puppen dieser beiden Arten sehr schnell durch $\boldsymbol{M}_{3}$ entwickelt.

Sphinx ligustri ergab folgende Resultate:

\begin{tabular}{c|c|c|c|}
\hline $\begin{array}{c}\text { Wieviel } \\
\text { Puppen }\end{array}$ & Methode & Temperatur & Ausschlüpfen \\
\hline 9 & 15. Oktober $M_{1}$ & bis $25^{\circ}-18^{\circ} \mathrm{R}$. & 27. Februar-9. März \\
5 & 15. Oktober $M_{2}$ & $20^{\circ}$ & 13. -24. A pril \\
1 & 15. Januar $M_{3}$ & $22^{\circ}$ & 28. Februar \\
3 & $-M_{2}$ & - & 28. Februar-5. März
\end{tabular}




\begin{tabular}{c|c|c|c}
\hline $\begin{array}{l}\text { Wieviu! } \\
\text { Puppen }\end{array}$ & Methode & Temperatur & Ausschlüpfen \\
\hline 3 & 15. Oktober $M_{3}$ & $20^{\circ}$ & 23.-29. April \\
4 & 15. Januar $M_{3}$ & $22^{\circ}$ & 2.-17. März \\
5 & $-M_{1}$ & $18^{\circ}$ & 3.-9. März \\
2 & $-M_{3}$ & $20^{\circ}$ & 21.-28. April \\
3 & 15. Januar $M_{3}$ & $24^{\circ}$ & 2. - 13. März
\end{tabular}

Die Entwickelung ler Puppe von Sphinix pinasti; erfolgt nach $M_{1}$ und $M_{2}$ im Verlaufe des Januars und Februars. $M I_{3}$ befördert die Entwickelung nicht.

Eine Puppe von Acherontin atropos wurde im November aus der sie umgebenden Temperatur von $4-5^{\circ} \mathrm{R}$. in eine Temperatur $12^{\circ} \mathrm{R}$. gebracht und entwickelte sich nach 23 Tagen. Ochsenheimer hat eine Puppendauer von $11 \frac{1}{2}$ Monaten beobachtet.

Aus diesen Versuchen ist ersichtlich, dass die Puppen wenigstens durch eine der drei angewaniten Methoden in ihrer Entwickelung beschleunigt werlen. Lie Methode, die Puppen aus der im Januar herschenden Temperatur ohne jellen Uebergang in eine Temperatur von $18-24^{\circ} \mathrm{R}$. zu bringen $\left(\Lambda_{3}\right)$. beschleunigt die Entwickelung der Puppen sehr; nur Pygaera bucephata und Sphine pinastri werden in ihrer Puppendauer nicht merklich durch diese Methole beeintlusst. Xicht alle Puppenarten ertragen den plötzlichen Uebergang aus einer niedrigen in eine hohe Temperatur uni sterben in Folge dessen.

Im Anschluss an eine Dissertation hat Kalender (1873. 429) sich lïngere Zeit damit beschïftigt, überwinternde Raupen-Arten durch geeignete Temperatur und passendes f'utter schon währent des. Winters zur Verwandlung zu bringen.

$\mathrm{Er}$ erhielt bei einer durchschnittlichen Stubenwïrme von $14^{\circ} \mathrm{K}$. die Schmetterlinge von Phlogophora meticulosa im Januar, von Triphaena jromuba im December und von später gesammelten Raupen nochmals zugleich mit den Schwetterlingen von Tylinu polyodon uni Agrotis triangulum im März. Die Entwickelung der Puppen von Xyllina poliodon zum Schmetterling dauerte, wie in der Natur, 6 IVochen.

Von Spinnerraupen siml im Winter durchgefüttert worden: Eupreria caju, hera, clominula, plantaginis uni Euthrix potatoriu. Hera, dominula und plantaginis ergaben im März und April Schmetterlinge. Von plantaginis wurle sogar eine zweite Generation erzielt. 
Die Raupen von caja verpuppten sich im Mirrz, auch verpuppten sich zwei Raupen von potatoria.

. Wemn auch manche Raupe die kiinstliche Durchfiitterung nicht ertragen kann, darf ich aber wohl schon jetzt meine Behauptung, dass die Ueberwinterung keine nothwendige Bedingung für die Entwicklung der iiberwinternlen Raupenarten sei. als erwiesen betrachten" (p. 367).

Er erwailhnt noch, dass Renner zu Poppelsilorf bei Bonn die befruchteten Eier von Catncala frarini im cine warme Stulse gemracht lıatte. Schon im December schliipften die Riiupchen aus, starben aber wegen Nalırungsmangel.

G. Cantoni (1872. 127) fütterte dis Raupen ron $B$ mulby mi bei $47^{\circ}$ und beobachtete dabei lieinen Nachtheil fiir diesellsen.

E. Verson und E. Quajat (1๙73. 920) erhielten Raupen ron Bumbyr mori aus Eiern am 21., 22. und 23. April uml brachten eine Serie in die Temperatur von $18^{\circ} \mathrm{r}$. und die andere in $25^{\circ} \mathrm{I}$. Die liaupen der letzten Serie verpuppten sich an 14., 15., und 1li. Mai, während die Verpuppung derjenigen der ersten Serie am 16 ., 17., 1s. und 19. Mai stattfand, also um ca. 2 Tage spoiter. Comit heschleunigt die erhöhte Temperatur die Entwickelung iler Raupen.

Diese Forscher beobachteten auch, dass die zu hohe Tempe-

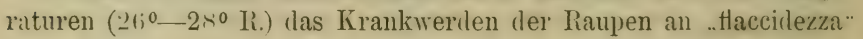
begiinstigen.

Johann Bolle (1 $873,99,100)$ stellte Versuche über den EinHluss von plötzlichen Temperaturerniedrigungen auf zur Ausbriitung ausgelegte Eier von Bombyx mori an. Die Eier wurlen am 1. December $1 \$ 72$ in die Nähe eines Ofens gebracht, nur bei Tage gelieizt, die Temperatur auf $14-1$ (i $^{\circ}$ gesteigert, während dieselbe Nachts auf ca. so herabsank. Am 1. Januar $1 \$ 73$ erschienen die Vorläufer: die sehr unregelmässige Ausschliipfung dauerte 15 Tage. Am 10. Januar solliipften etwa $10 \%$ der Eier aus, wonach sie in eine Temperatur von $5^{0}$ versetzt wurden. Am 10. April wurden die Eier zur Ausbriitung ausgelegt. 4 Tage clarauf schliipften die Räupchen bei $12^{\circ}$ aus; dies dauerte is Tagre. Die Hïutungen traten höchst unregelmässi $\not$ ein. Am Ende des 3. und 4. Lebensalters brach die Schlafsucht aus und wïthete fort bis zur Einspinnung. Daraus schliesst er, dass ,die Schlafsucht auch kïnstlich hervorgerufen 
werlen kamn und zwar durch plötzliche und starke Temperaturveränderungen zur Zeit der Ausbritung."

E. Verson (1874. 921) erwärmte frisch abgelegte Eier von Bmmbye mori von $15^{\circ} \mathrm{R}$. auf $30^{\circ} \mathrm{R}$. innerhalb s Minuten, auf $42^{\circ} \mathrm{R}$. imerhalb 10 Minuten, auf $50^{\circ} \mathrm{K}$. innerhalb 29 Minuten und auf 56;0 li. innerhalb 29 Minuten und konnte die vorzeitige Ausbriitung nicht erreichen; auch in einem Brutofen lionnten sie zur vorzeitigen Entwickelung nicht gebracht werden.

Bei Emilio Cornalia (1 556. 153) findet sich folgende stelle: "Vor einigen Jahren versicherte Herr Marelli aus Como, dass er die Eier von Bomb!yx mori noch in demselben .Jahre zum Autleben l)ringen kann, in welchem sie abgelegt wurlen. Die in ler Anwesenheit mehrer Zeugen angestellten Versuche zwingen anzunehmen, dlass diese Behaptung richtig sei."

Lübenetzky (1s74. $53 s)$ sagt in seinem "Handbuche," dlass zul Entwickelung der Bienenlarven die Temperatur nicht unter $20^{\circ} \mathrm{R}$. nothwendig ist.

Dank der grossen Exaktheit, mit welcher Aug. Weisman arbeitet, kann man den Einfluss der Temperatur auf die Entwickelungstauer der Puppen auch aus seiner "Stulien zur DescenilenzTheorie. I." (1875. 953) eliminieren.

Seine Versuche stellte er zuerst mit Puppen ron Vanessa levana bezw. prorsa an.

Aus dem 1. Versuche ergiebt sich:

Verpuppung am 7.-9. Juni. Gewöhnliche Temperatur. Entjuppung von 48 Schmetterlingen am 19.-25. Juni. Minimale Puppendauer betrïgt 10 Tage, maximale 18 und die mittlere 14 Tage.

Aus dem 4. Versuche:

Terpuppung an 25. Juni. Die Temperatur is his $10^{\circ} \mathrm{R}$. Entpuppung von 30 Schmetterlinge nam 3. August. Somit die Puppen(lauer 39 Tage.

Aus dem 5. Versuche:

Hohe Sommer-Temperatur. 70 Schmetterlinge entpuppten sich nach etwa 19-tägiger Puppenzeit.

A us dem 6. Versuche:

Hohe Sommer-Temperatur. Die Eier ergaben nach 3(1-31 Tagen Schmetterlinge. 
Aus dem 8. Versuche: ${ }^{1}$ )

Verpuppung am 13.-15. Juni. (iewoilnnliche Temperatur. Entpuppung an 29.-30. Juni. Somit heträgt die minimale Puppenzeit 14 Tage, die maximale 17 und die mittlere 15,5 Tage.

Aus dem 9. Versuche:

Verpuppung an 1s. Juni. Die Temperatur betrug bis zum 1s. . Iuli $1^{0} \mathrm{R}$., dann war sie die gewölınliche. Entpuppung an 22. Juli bis 2? 2) Die Puppenzeit beträgt somit 34 Tage.

Aus dem $10 a$. Versuche:

Verpuppung am 26. August bis 5. September. Die Temperatur $=12$ his $25^{\circ} \mathrm{R}$. Entpuppung von 3 Sclmetterlingen am 20. Oktol. Die übrigen : $:$ ïberwinterten. Die Puppenzeit somit: die maximale $=55$ Tage, die minimale $=45$ und die mittlere $=50$ Tage.

Aus dem 11. Versuche:

Verpuppung am 9. Juli. Die Temperatur vom 11. Juli bis 11. September betrug $10 \mathrm{R}$, nachher Treihhaus. Entpuppung an 19. September lis 4. Olitober. Somit ist die minimale Puppenzeit li2 Tage, die maximale 87 und die mittlere 74 Tage.

Die Versuche mit Pieriden ergaben:

Aus dem 13. Versuche: Pieris rapae. Verpuppung an 1. his : Juni. Die Temperatur hetrug vom 13. Juni bis zum 11. September $1^{0} \mathrm{R}$., nachher war sie 120 his $24^{\circ} \mathrm{R}$. Entpuppung am 3. Oktober. Die Puppendlauer 123 Tage.

A us dem 14. Versuche: Pieris napi. Verpuppung am 28. Mai - 7 . Juni. Die Temperatur his 11. September $1^{0}$ I. Am :3. Oktoher Treihhaus. (io) sichmetterlinge entpuppten sich his zum 20. Oktober. Die mittlere Puppenzeit betrïgt somit 140 Tage.

Zieht man in Betracht, dass die Puppendauer bei der Sommergeneration von Vanessa levana in ler Regel $7-12$ Tage beträgt. bei der Wintergeneration dagegen ca. 200 Tage, so erlauben diese Versuche folgende Schlïsse:

1. Die individuelle Neigung spielt in diesen Versuchen eine grosse Rolle (worauf wir in einem hesonilere Krapitel zu sprechen kommen).

2. Beile Generationen von Vunessa levana verhalten sich gegeniiher dem Einflussn der Temperatur verschieden intensiv.

3. Erhöhte Temperatur beschleunigt die Entwickelung, erniedrigte verzögert dieselbe.

$\left.{ }^{1}\right)$ Der 7. Versuch enthält nichts Einschlägiges.

2. Wahrscheinlich Ende Juli. 
E. Duclaux (1ST(i. 201) untersuche die physiologiche Einwirkung der Temperatur unter 00 auf die Eier von Bombyrs mori.

Er fand, dass Eier, welche der Einwirkung der Temperatur von $-10^{\circ}$ ausgesetzt werilen, in einem solchen Zustante verhleihen. als ob sie der Einwirkung der Kälte gar nicht ausgesetzt wären oder eine ungenügende Ueberwinterung erlitten hätten.

Die Versuche mit gelhen Eiem wurlen folgemlermassen ausgestellt: 2) Portionen von Eiern, welche ror 201) Tagen ahgelent waren, wurden während 1-2 Monaten der Einwirkmg der Temperatar 1. von $0^{0}$, 2. von -6 bis $-10^{\circ}$ ausgesetzt; darauf wurden sie bei gewölmlicher Temperatur helassen und schliesslich in den Brutofen gelıracht. Die Ausbriitung cler 1. Portion war eine vollstiuntige uni ler 2. eine unvollständige und danerte ca. 15 Tage fuir heide Portionen. Die nicht ansgehriteten Eier wurlen darauf in einen lieller gebracht. ım (lie regelmässige Frühlings-Aushritung alizuwarten; einige Rüupchen schliipften jedoch auch im Keller aus. Nachher wurden diese Fier unl noch andere, welche der hïlte nicht ansqesetzt waren. in ein nach Sülen gelegenes, ungeheiztes Zinmer webratht. Alle Eier ergaben zu gleicher Zeit Rïupchen. Die erhaltenen Resultate. sind aus folgender Tabelle ersichtlich:

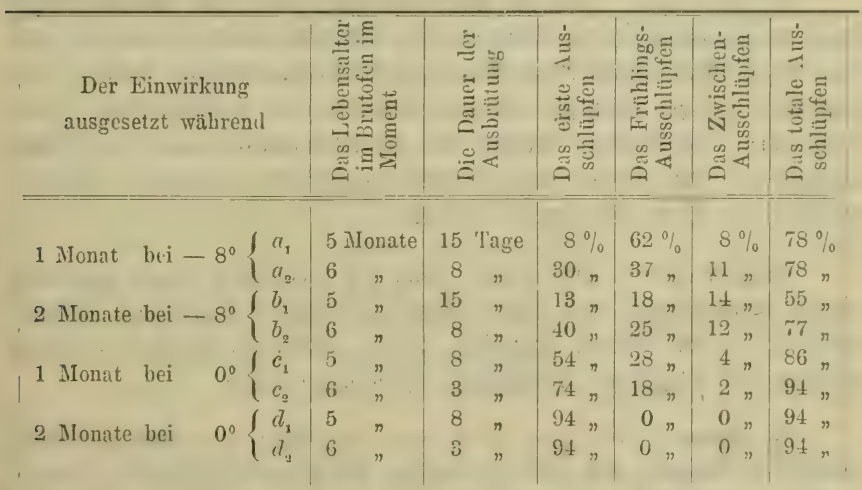

Die normalen Eier, welche wie gewöhnlich ïherwinterten, erwaben $96 \%$ Ausschliiipfungen.

Daraus ergeben sich folgende Resultate:

1. Der Einfluss der Temperatur des künstlichen Winters. Das erste Ausschliipfen ist um so vollstindiger, je geringer 
die Kïlte war. Zwei monatliches Verbleiben hei $-5^{0}$ ist demjenigen von 20 Tagen bei $0^{0}$ aequivalent.

‥ Die Einwirkung der Kältedauer. Das Ausschlüpfen finctet um so besser statt, je lïngere Zeit die Kilte eingewirkt hat.

3. Der Einfluss der Zeit, welche zwischen dem Momente des Herausnehmens der Eier aus dem heller und dem Moment des mittelst des Brutofens bewirkten Ausbrütens verfliesst. Es ist nicht vortheilhaft, diese Zeit zu rerluzieren, besonders wenn die Einwirkung der Külte ungenïgend war.

Er vermuthet, dass der "physiologische Nullpunkt" etwas höher liegt, als die Temperaturnull.

Tidemann (1ミテฺ. \テう) konstatierte, dass Friihschnee, mit kalten Herlistregen und Frost (lis - $7^{\circ} \mathrm{R}$.) wechselnil, sehr schärllich auf Raupen von Fidonia piniaria L. einwirkt.

M. Cornu (1s7s. 154) beobachtete, dass bereits die Temperatur von $10^{\circ}$ bis $8^{\circ}$ genügt, um die Phylloxera-Larven in den Winterschlaf zu versetzen; diese Temperatur ist aluer nicht tief genug, um die Weiterentwickelung einiger Indiviluen zum Stillstand zu bringen, welche bereits erwachsen sind und Eier ablegen wollen.

Er fand auch, dass die Entwickelungslauer der Wurzel-Phylloxera (angefangen vom Moment des Fixirens nicht gehäuteter Larven bis zu Ende der (Iritten Hüutung) Ende August umd Anfang September 16 Tage hetrug, während dieselbe bei 2 Individuen Ende September und Anfang Oktoher des gleichen Jahres nur 9-12 Tage ausmachte. Er erklïrt diese Erscheinung mit wïrmerem Wetter. welches am Enile der Saison eintrat.

Roulet (187s. 708) zeigte, dass Phylloxera einer und derselben Abstammung eine ganze Masse gefliigelter Individuen lieferte. wenn sie in der Wärme kultiviert wurde, während bei niederer Temperatur nur Hügellose Exemplare vorhanden waren.

G. Bolle (1878. 101) fand, dass die Eier von Bombyx mori, welche in Wasser von $500^{\circ}$ für einige Minuten eingetaucht werden, die vorzeitige Entwickelung erleiden.

18>0 erschien die letzte Arbeit von G. Dorfmeister (1879. 195). Aus derselben sind folgende Thatsachen zu ersehen (datirt von 1872):

Die Raupen von Vanessa atalanta verpupten sich bimnen 1 bis 4 Tagren bei $\left.7^{1}\right|_{2}{ }^{0}$ bis $11^{0}$ R. Die Puppen blieben dann in der 
selluen Temperatur 3 bis 7 Tage und bis zu ihrer Entwickelung im Zimmer bei einer bisweilen auch „ziemlich niedrigen" Temperatur noch 18 bis 30 Tage.

Die Raupen von Arctia villica bedürfen zu ihrer Verpuppung minclestens 9) his $10^{\circ} \mathrm{R}$. Solche Individuen, die sich bei einer von i bis $10^{\circ} \mathrm{R}$. wechselnden Temperatur verpuppten, gebrauchen nach lem vollständigen Einspinnen noch 24 bis 30 Tage zur Verpuppung und lieferten etwas verkrïppelte Schmetterlinge.

Die Häutung trat bei zu niedriger Temperatur entweller gar nicht ein, oiler verzögerte sich mintenstens sehr. Die Raupe von Bomby.r (Attacus) bernyi hedarf zur Häutumg mindestens $+160^{\circ} \mathrm{R}$.

Dzierzon (18is. 194) meint, dass die Bienenlarven bei +12 bis $15^{0}$ (C.?) sich noch entwickeln können.

Timm (1S\$2. ST6) fand, dass während der Entwickelung der Bienenlarven im Bienenstock eine Temperatur von $29^{\circ}$ bis $30^{\circ} \mathrm{C}$. und an heissen 'Tagen sogar mehr als $30^{\circ}$ herrscht.

Paul Brunbaner (1883. 116i) fïhrt in seiner sehr surgfältig ausgearbeiteten vissertation zahlreiche Tahellen an, welche auf die Beantwortung folgender Fragen sich beziehen:

1. Bei welchen mittleren Tagestemperaturen erwachen die Tagfalter, deren Raupen oder Puppen aus dem Winterschlafe?

2. Zu welcher Zeit verfallen sie in denselben, wemn dies bei derselben Temperatur geschieht, bei der sie erwachen:

3. Wie lange danert der Winterschlaf und die fur die Entwickelung günstige Zeit bei den einzelnen Arten?

t. Welches sind die ersten Frasstemperaturen iler Raupen unil die Flugtemperaturen der Imagines?

5. Welcher Unterschied besteht in der Entwickelungsilauer zwischen Sommer- und Wintergenerationen?

6. Wann und wo treten bei einer Art regelmässig zwei Generationen auf?

7. Zu welchen Zeiten kann in günstigen und ungünstigen Jahren das Verfallen in den Winterschlaf und Erwachen aus demselben vor sich gehen?

४. Welche Schliusse lassen sich aus der Beantwortung der vorhergehenden Fragen ziehen?

Unter der Annahme, dass die Temperatur keine Sprünge macht, welche durch Rïckschläge in der Witterung veranlasst werden, wurle 
die Lultemperatur (im Schatten) der Monatsviertel aus den allgemeinen Monatsmitteh für verschieslene Orte berechnet. Lntersucht wurlen 1:;:; europaiische Tagfalterarten. über die einigermassen brauchbare Angaben bei verschieclenen Autoren vorlagen.

Wir werten hier: $u$ einen Begriff iilser die sorwtiltig zusanmengestellte Tabellen zu gelen, einige Ansziige anfiilnren.

Die normalen Temperaturen, bei denen die Tagfalter aus dem Winterschlafe erwachen, ihre laupen fressen und inre Imagines fliegen.

\begin{tabular}{|c|c|c|c|c|c|c|c|c|c|c|c|c|c|c|c|}
\hline 苞 & 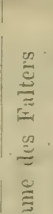 & $\begin{array}{c}\text { Ort des } \\
\text { Vorkommens }\end{array}$ & $\mid$ & 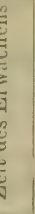 & 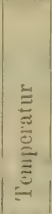 & $\approx$ & & 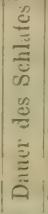 & 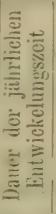 & & 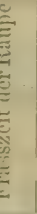 & 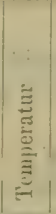 & & $\stackrel{E}{E}$ & 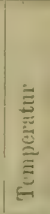 \\
\hline & $\not 4$ & & T. & II. & li. ${ }^{9}$ & T. & II. & T. & $\mathrm{T}$. & T. & II. & H. & $\mathrm{T}$ & II. & {$\left[i^{3}{ }^{3}\right.$} \\
\hline 27 & $\stackrel{\S}{\Xi}$ & $\begin{array}{l}\text { Breslau . . . } \\
\text { Görlitz . . . } \\
\text { Hirschberg . . . } \\
\text { Reichenstein . . } \\
\text { Ratibor . . . } \\
\text { Kupferberg . . } \\
\text { Kaluga . . . } \\
\text { Moskau . . . } \\
\text { Tambow : . . . } \\
\text { Arolsen . . . } \\
\text { Wetterau b.Frankf.a/I. } \\
\text { Bern . . . . } \\
\text { Riga . . . . } \\
\text { Mital . . . . }\end{array}$ & $\left|\begin{array}{r}1 \\
1 \\
1 \\
1 \\
1 \\
1 \\
1 \\
1 \\
23 \\
23 \\
23 \\
23 \\
1 \\
1 \\
23 \\
23\end{array}\right|$ & \begin{tabular}{l|}
4 \\
4 \\
4 \\
4 \\
4 \\
4 \\
4 \\
4 \\
4 \\
3 \\
4 \\
4 \\
4 \\
4
\end{tabular} & $\begin{array}{l}4,5 \\
3,7 \\
3,1 \\
3,4 \\
3,5 \\
2,2 \\
5,3 \\
5,8 \\
9,9 \\
4,3 \\
5,8 \\
4,2 \\
4,7 \\
5,5\end{array}$ & $\begin{array}{l}16 \\
25 \\
21 \\
19 \\
2 \\
10 \\
11 \\
8 \\
17 \\
13 \\
27 \\
20 \\
21 \\
13\end{array}$ & $\begin{array}{r}10 \\
10 \\
11 \\
11 \\
10 \\
11 \\
10 \\
10 \\
9 \\
11 \\
10 \\
10 \\
10 \\
10\end{array}$ & $\begin{array}{l}166 \\
157 \\
130 \\
132 \\
156 \\
141 \\
193 \\
197 \\
218 \\
130 \\
155 \\
162 \\
183 \\
192\end{array}$ & \begin{tabular}{|l|}
199 \\
208 \\
$\mid 235$ \\
$\mid 233$ \\
209 \\
209 \\
224 \\
172 \\
168 \\
147 \\
235 \\
210 \\
203 \\
182 \\
173
\end{tabular} & $\mid \begin{array}{r}1 \\
1 \\
1 \\
1 \\
1 \\
1 \\
1 \\
1 \\
23 \\
23 \\
23 \\
- \\
- \\
-1 \\
-1 \\
-\end{array}$ & $\begin{array}{c}8 \\
8 \\
8 \\
8 \\
8 \\
8 \\
8 \\
8 \\
8 \\
8 \\
- \\
- \\
- \\
- \\
-\end{array}$ & $\begin{array}{l}\mid 14,7 \\
\mid 14,0 \\
|13,4| \\
\mid 13,6 \\
14,5 \\
12,6 \\
13,5 \\
14,7 \\
14,5 \\
- \\
- \\
- \\
-\end{array}$ & $\begin{array}{r}1 \\
1 \\
1 \\
1 \\
1 \\
1 \\
1 \\
23 \\
23 \\
23 \\
23 \\
1 \\
1 \\
23 \\
23\end{array}$ & $\begin{array}{l}4 \\
4 \mid \\
4 \\
4 \\
4 \\
4 \\
4 \\
4 \\
4 \\
3 \\
4 \\
4 \\
4 \\
4\end{array}$ & $\begin{array}{l}4,5 \\
3,7 \\
3,1 \\
3,4 \\
3,5 \\
2,2 \\
5,3 \\
5,8 \\
9,9 \\
4,3 \\
5,8 \\
4,2 \\
4,7 \\
5,5\end{array}$ \\
\hline 133 & $\stackrel{\vec{\Xi}}{2}$ & $\begin{array}{l}\text { Tamb . . . . } \\
\text { Riga. . . . . } \\
\text { Mitau . . . }\end{array}$ & $\left|\begin{array}{l}23 \\
23 \\
23\end{array}\right|$ & $\begin{array}{l}6 \\
6 \\
6\end{array}$ & $\begin{array}{l}14,2 \\
13,3 \\
15,5\end{array}$ & $\begin{array}{l}26 \\
17 \\
14\end{array}$ & $\begin{array}{l}8 \\
8 \\
8\end{array}$ & $\left|\begin{array}{l}301 \\
310 \\
313\end{array}\right|$ & $\begin{array}{l}64 \\
55 \\
52\end{array}$ & $\left|\begin{array}{l}23 \\
23 \\
23\end{array}\right|$ & $\begin{array}{l}8 \\
7 \\
7\end{array}$ & $\mid \begin{array}{l}14,0 \\
13,9 \\
14,0\end{array}$ & $\mid \begin{array}{l}23 \\
23 \\
23\end{array}$ & $\begin{array}{l}7 \\
6 \\
6\end{array}$ & $\begin{array}{l}16,1 \\
13,3 \\
13,5\end{array}$ \\
\hline 89 & 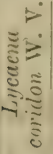 & 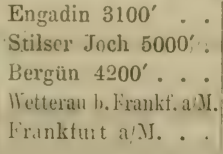 & $\left|\begin{array}{r}23 \\
1 \\
1 \\
1 \\
15\end{array}\right|$ & $\begin{array}{l}5 \\
6 \\
6 \\
6 \\
6\end{array}$ & $\begin{array}{r}10,8 \\
7,2 \\
9,2 \\
13,2 \\
13,9\end{array}$ & $\begin{array}{r}11 \\
12 \\
12 \\
9 \\
1\end{array}$ & $\begin{array}{l}9 \\
9 \\
9 \\
9 \\
9\end{array}$ & \begin{tabular}{|l|}
254 \\
254 \\
261 \\
264 \\
267 \\
287
\end{tabular} & $\begin{array}{r}111 \\
111 \\
104 \\
101 \\
78\end{array}$ & $\left|\begin{array}{r}3 \\
1 \\
1 \\
1 \\
15\end{array}\right|$ & \begin{tabular}{l|}
7 \\
8 \\
8 \\
6 \\
8
\end{tabular} & $\begin{array}{l}13,3 \\
10,1 \\
11,5 \\
13,2 \\
14,3\end{array}$ & $\begin{array}{r}23 \\
1 \\
1 \\
1 \\
1\end{array}$ & $\begin{array}{l}6 \\
7 \\
7 \\
7 \\
7\end{array}$ & $\begin{array}{l}11,5 \\
10,2 \\
10,2 \\
150 \\
14,7\end{array}$ \\
\hline
\end{tabular}


Frass- und Flugzeit sowie Temperaturen der II. Generation.

\begin{tabular}{|c|c|c|c|c|c|c|c|c|c|c|c|c|}
\hline \multirow[t]{2}{*}{ 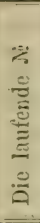 } & \multirow[t]{2}{*}{ 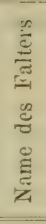 } & \multirow{2}{*}{\multicolumn{2}{|c|}{$\begin{array}{c}\text { Ort dis } \\
\text { Vorkommens }\end{array}$}} & & \multicolumn{2}{|c|}{ 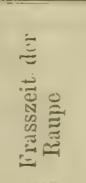 } & \multirow{2}{*}{ 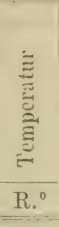 } & \multicolumn{2}{|c|}{ 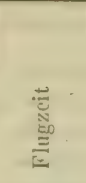 } & \multirow{2}{*}{ 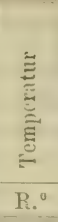 } & \multirow[t]{2}{*}{ 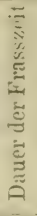 } & \multirow[t]{2}{*}{ 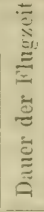 } \\
\hline & & & & & $\mathrm{T}$. & $\mathrm{Mr}$ & & $\mathrm{T}$. & M. & & & \\
\hline \multirow[t]{9}{*}{7} & \multirow{9}{*}{ 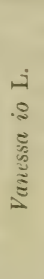 } & Breslau ... & . & . & 1 & 5 & 8,8 & 1 & 6 & 11,4 & \multirow{9}{*}{ 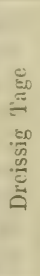 } & \multirow{9}{*}{ 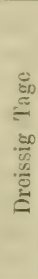 } \\
\hline & & Görlitz . . . . & . & . & 1 & 5 & 7,8 & 1 & 6 & 12,5 & & \\
\hline & & Hirschberg . . & . & . & 1 & 5 & 7,8 & 1 & 6 & 12,3 & & \\
\hline & & Reichenstein . & . & . & 1 & 5 & 8,2 & 1 & 6 & 12,1 & & \\
\hline & & Ratibor ... & . & . & 1 & 5 & 8,3 & 1 & 6 & 13,5 & & \\
\hline & & Kupferberg . . & . & - & 1 & 5 & 7,4 & 1 & 6 & 11,0 & & \\
\hline & & Kaluga . . : . & - & - & 23 & 5 & 11,3 . & 23 & 6 & 15,0 & & \\
\hline & & Moskau ... & . & . & 23 & 5 & $12, !$ & 23 & 6 & 15,0 & & \\
\hline & & Tambow . . & . & . & 23 & 5 & 12,6 & 23 & 6 & 14,2 & & \\
\hline \multirow[t]{11}{*}{23} & \multirow{11}{*}{ 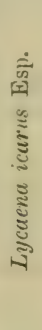 } & Beru . . . . & • & • & 1 & 7 & 12,7 & 1 & 8 & 13,6 & \multirow{11}{*}{ 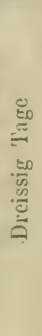 } & \multirow{11}{*}{ 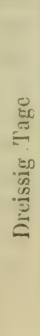 } \\
\hline & & Bergün $4200^{\prime}$. & . & . & 23 & 6 & 9,8 & 23 & 7 & 11,7 & & \\
\hline & & Apenrade .. & . & . & 23 & 6 & 12,6 & 23 & 7 & 13,7 & & \\
\hline & & Altona . . . & . & . & 23 & 6 & 14,6 & 23 & 7 & 14,8 & & \\
\hline & & Breslau ... . & . & • & 23 & 6 & 14,4 & 23 & 7 & 14,8 & & \\
\hline & & Görlitz . . . & . & . & 23 & 6 & 13,7 & 23 & 7 & 14,0 & & \\
\hline & & Hirschberg . . & . & • & 23 & 6 & 13,4 & 23 & 7 & 13,4 & & \\
\hline & & Rtichenstein . & . & * & 23 & 6 & 13,2 & 23 & 7 & 13,6 & & \\
\hline & & Ratibor ... & • & 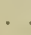 & 23 & 6 & 14,4 & 23 & 7 & 14,5 & & \\
\hline & & Kupferberg . . & . & ${ }^{\circ}$ & 23 & 6 & 12,1 & 23 & 7 & 12,5 & & \\
\hline & & 'T'imbow ... & . & . & 1 & 7 & 14,8 & 1 & 8 & 15,9 & & \\
\hline
\end{tabular}

\section{Temperatur des Erwachens der Schmetterlinge aus dem Win- terschlafe.}

1. Mittlere Erwachungstemperaturen ler über ganz Eu ropa und weiter verbreiteten Falter.

\begin{tabular}{|c|c|c|c|c|c|c|c|c|}
\hline No & $\mathrm{Name}$ & & & R. ${ }^{\circ}$ & No & $\mathrm{Name}$ & & $\mathrm{R}^{\circ}{ }^{\circ}$ \\
\hline 1 & Vanessa io ... & : & . & 4,7 & 7 & Vanessa polychloros & . & 6,5 \\
\hline 2 & Arginnis selene : & : & $\theta^{\circ}$ & 5,6 & 8 & Melitaea cinxia . . & - & 6,6 \\
\hline 3 & Pontia napi. : : & : . & . & 5,6 & 9 & Vanessa antiopa.. & . & 6,7 \\
\hline 4 & daplidice. & . . & : & 5,9 & 10 & Arginnis latonia . . & . & 6,7 \\
\hline 5 & rapae.. & . & . & 6,2 & 11 & Lycaenu alsus... & . & 6,8 \\
\hline 6 & brassicae. & . & . & 6,2 & 12 & Vanessa urticae... & . & 6,9 \\
\hline
\end{tabular}


Erstes Kapitel. Die Entwickelungsgeschwindigkeit der Insekten.

\begin{tabular}{|c|c|c|c|c|c|c|}
\hline 10 & $\mathrm{Name}$ & & R. ${ }^{0}$ & № & $\mathrm{Name}$ & R. ${ }^{\circ}$ \\
\hline 13 & Melitaea artemis. & . . & 7,0 & 37 & Lycaena acis . . . & 9,9 \\
\hline 14 & Vanessa cardui . & . . & 7,1 & 38 & " adonis .... & 10,0 \\
\hline 15 & Lycaena argiolus. & . . & 7,1 & 39 & Argynnis daplıne. . . . & 10,2 \\
\hline 16 & Vanessa c-album & . $\cdot$ & 7,2 & 40 & Thecla rubi..... & 10,4 \\
\hline 17 & $n \quad$ atalanta. & . & 7,4 & 41 & Pontia crataegi .... & 10,4 \\
\hline 18 & Pararge egeria & . $\cdot$ & 7,4 & 42 & Argynnis aglaja.... & 10,5 \\
\hline 19 & Lycaena alexis . . & . . & 7,6 & 43 & Polynmmatus phlaeas. . & 10,5 \\
\hline 20 & Argynnis pales . & - & 7,6 & 44 & virgaurea . & 10,7 \\
\hline 21 & Polyommatus circe & . . & 7,7 & 45 & Lycaena arion. . . . & 10,8 \\
\hline 22 & Argynnis euphrosyn & e. & 7,9 & 46 & Thecla betulae. . . . & 11,0 \\
\hline 23 & Lycaena agestis. . & . . & 8,1 & 47 & $r$ pinepluele janira . . . & 11,1 \\
\hline 24 & Coenonympha pamp & ohilus & 8,1 & 48 & Lycaena aegon ... • & 11,3 \\
\hline 25 & Melitaea phoebe & . . & 8,2 & 49 & Erebia liger. . . . . & 11,3 \\
\hline 26 & Pontia sinapis. . & . . & 8,2 & 50 & Lycaena argus ... & 11,5 \\
\hline 27 & Argynnis ino . . . & . . & 8,3 & 51 & cyllarus . . & 11,5 \\
\hline 28 & Porarge maera . & . . & 8,3 & 52 & Tapilio machaon.... & 11,6 \\
\hline 29 & megaera. & .. & 8,4 & 53 & Hipparchia semele... & 11,6 \\
\hline 30 & Thecla quercus . & . . & 8,9 & 5 t & Thecla pruni . . . . & 11,7 \\
\hline 31 & Colias rhammi... & . & 9,1 & 55 & Epinephele hyperanthus. & 11,7 \\
\hline 32 & Thecla W album. & - . & 9,1 & 56 & Coenonympha arcania. & 11,8 \\
\hline 33 & Colias hyale.... & - . & 9,3 & 57 & iphis . . & 12,0 \\
\hline 34 & Argynnis arsilache. & - . & 9,7 & 58 & Thecla ilicis...... & 12,2 \\
\hline 35 & $\quad$ aphirape. & . & 9,7 & 59 & Colias edusa. . . . & 12,9 \\
\hline 36 & Pontia cardamines. & . . & 9,7 & & & \\
\hline
\end{tabular}

b. Mittlere Erwachungstemperaturen ler vom höchsten Norden bis nach Italien herab verbreiteten Falter.

\begin{tabular}{|c|c|c|c|c|c|c|}
\hline № & $\mathrm{N}$ a m e & & R. ${ }^{\circ}$ & № & $\mathrm{Nam} \mathrm{e}$ & R. ${ }^{0}$ \\
\hline 1 & Argynnis dia ... & . & 6,6 & 9 & Coenonympha hero ... & 11,5 \\
\hline 2 & Melitaea maturna . & . . & 7,8 & 10 & Epinephele dejanira . . & 11,5 \\
\hline 3 & n dictynnu . & . . & 8,8 & 11 & Limenitis populi . . . . & 11,6 \\
\hline 4 & Argynnis amathusia & . . & 9,0 & 12 & Polyommatus chryseis . & 11,9 \\
\hline 5 & Melithaea athalia . & . . & 9,4 & 13 & Melitaea parthenie... & 12,0 \\
\hline 6 & Lycaenz dorylas. . & . . & 11,0 & 14 & Lycaena corydon ... & 11,3 \\
\hline 7 & Coenonympha davus & . & 11,3 & 15 & Colias palaeno..... & 13,7 \\
\hline 8 & Lycaena icarus . . & - . & 11,4 & & & \\
\hline
\end{tabular}


c. Mittlere Erwachungstemperaturen der nur in den Alpen vorkommenden Falter.

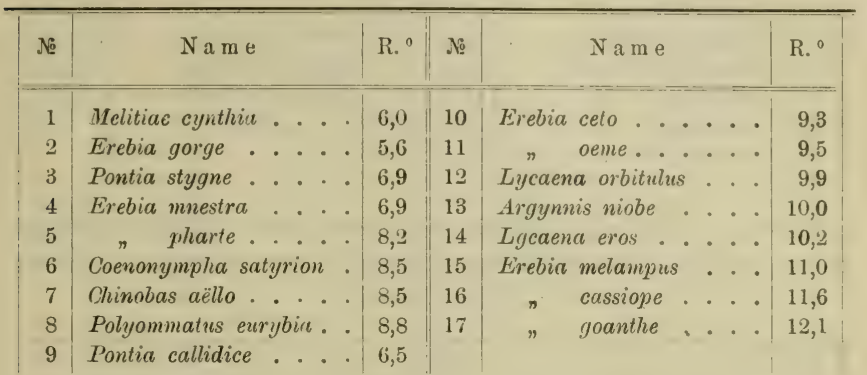

1. Mittlere Erwachungstemperaturen der vom höchsten Norden bis Norddeutschland herab vorkommenden Falter.

\begin{tabular}{|c|c|c|c|c|c|}
\hline No m e & & R. ${ }^{0}$ &. & Na m e & R. \\
\hline \hline 1 & Chinobas norra .... & 6,4 & 2 & Lyeaena optilite . . . & 10,7 \\
\hline
\end{tabular}

C. Mittlere Erwachungstemperaturen der im hohen Norden und in den Alpen zugleich vorkommenden Falter.

\begin{tabular}{|c|c|c|c|c|c|c|}
\hline No & $\mathrm{Name}$ & R. ${ }^{\circ}$ & № & $\mathrm{Name}$ & & R. ${ }^{\circ}$ \\
\hline 1 & Colias phicomone. & 7,1 & 4 & Lycaena pheretes & . . & 9,3 \\
\hline 2 & Doritis apollo . . . . & 8,0 & 5 & Pararge liera . . & . . & 9,4 \\
\hline 3 & delius . . . . & 8,7 & & & & \\
\hline
\end{tabular}

f. Erwachungstemperaturen der in Mitteleuropa oder auch in den Alpen vorkommenden Falter.

\begin{tabular}{|c|c|c|c|c|c|}
\hline$\therefore$ & $\mathrm{Name}$ & $\mathrm{R}^{\circ}{ }^{\circ}$ & No & $\mathrm{N}$ a me & R. ${ }^{\circ}$ \\
\hline 1 & Vanessa xantinomelas. . & 7,0 & 6 & Erebia pyrrha.... & 8,6 \\
\hline 2 & Erebia pronoë.... . & 7,7 & 7 & Limenitis lucilla . . . & 9,9 \\
\hline 3 & Vanessa $V$-album & 7,7 & 8 & Erebia tyndarus . . . . & 10,0 \\
\hline 4 & prorsa .... & 8,1 & 9 & $n$ euryale .... & 10,2 \\
\hline 5 & Lycaena admetus . . . & 8,7 & 10 & Lycaena enmedon ... & 10,3 \\
\hline
\end{tabular}




\begin{tabular}{|c|c|c|c|c|c|}
\hline. & $\mathrm{Name}$ & R. ${ }^{\circ}$ & $\lambda \dot{a}$ & $\mathrm{Name}$ & R. ${ }^{\circ}$ \\
\hline 11 & Argynnis paphia.... & 11,0 & 16 & Erebia medusa & 11,8 \\
\hline 12 & Hipparchia phaedra.. & 11,7 & 17 & Argynis laodice. . . & 12,1 \\
\hline 13 & Erebia meder . . . . . & 11,8 & 18 & Hipparchia statilinus . . & 12,7 \\
\hline 14 & Nemeobius lucina ... & $11, \mathrm{~S}$ & 19 & Injcaena erelus . . . . & 12,8 \\
\hline 15 & Apatura iris .... & 11,8 & & & \\
\hline
\end{tabular}

\%. Mittlere Erwachungstemperaturen der ron Mittelenropa und den $\mathrm{Al}_{\text {pen }}$ his nach Italien und Voriafrica vorkemenden Falter.

\begin{tabular}{|c|c|c|c|c|c|c|}
\hline $\mathrm{N}$ & $\mathrm{N}$ a $\mathrm{me}$ & & h. ${ }^{0}$ & is & Name & li." \\
\hline 1 & Lycaena amyntas & & 8,6 & 9 & Epincpllele tithonus & 11,6 \\
\hline$\therefore$ & Limenitis camilla & . & 8,7 & 10 & Arge galathea..... & 11,6 \\
\hline 3 & Argynnis adippe. . & . & 9,9 & 11 & Melitaea didyma. & $11, \pi$ \\
\hline 4 & Epinephele endora. & . . & 10,0 & 12 & Hipparchia proserpina. & 11,7 \\
\hline 5 & Limenitis sibylla . . & & 10,5 & 13 & I'apilio podalirius... & 11,7 \\
\hline ij & Hipparchia hermione & & 10,8 & 14 & Lyeaena battus. & 11,8 \\
\hline 7 & Lycaena hylas. . . & 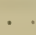 & 11,3 & 15 & Apatura ilia & $1 \div .6$ \\
\hline 8 & Hipparchia alcyone & . & 11,5 & 16 & Polyom. thersamon. . & 12,9 \\
\hline
\end{tabular}

Die Tabellen: $a, b, c, d, c, f$ und $g$ sind vollstängig (nicht ausgezogen) angeführt.

In nachfolgenler Tabelle sind für einige Orte die Zeiten zusammengestellt, in clenen die einzelnen Temperaturgrade, zwischen o ler hei denen die untersuchten Falter erwachen orler in Schlaf rertallen, eintreten. Dabei kann man zugleich ersehen, ol, die nothwentigen Wiirmegrate noch erreicht werlen. unl wie lange sie herrschen. 
3. Einfluss der Temperatur.

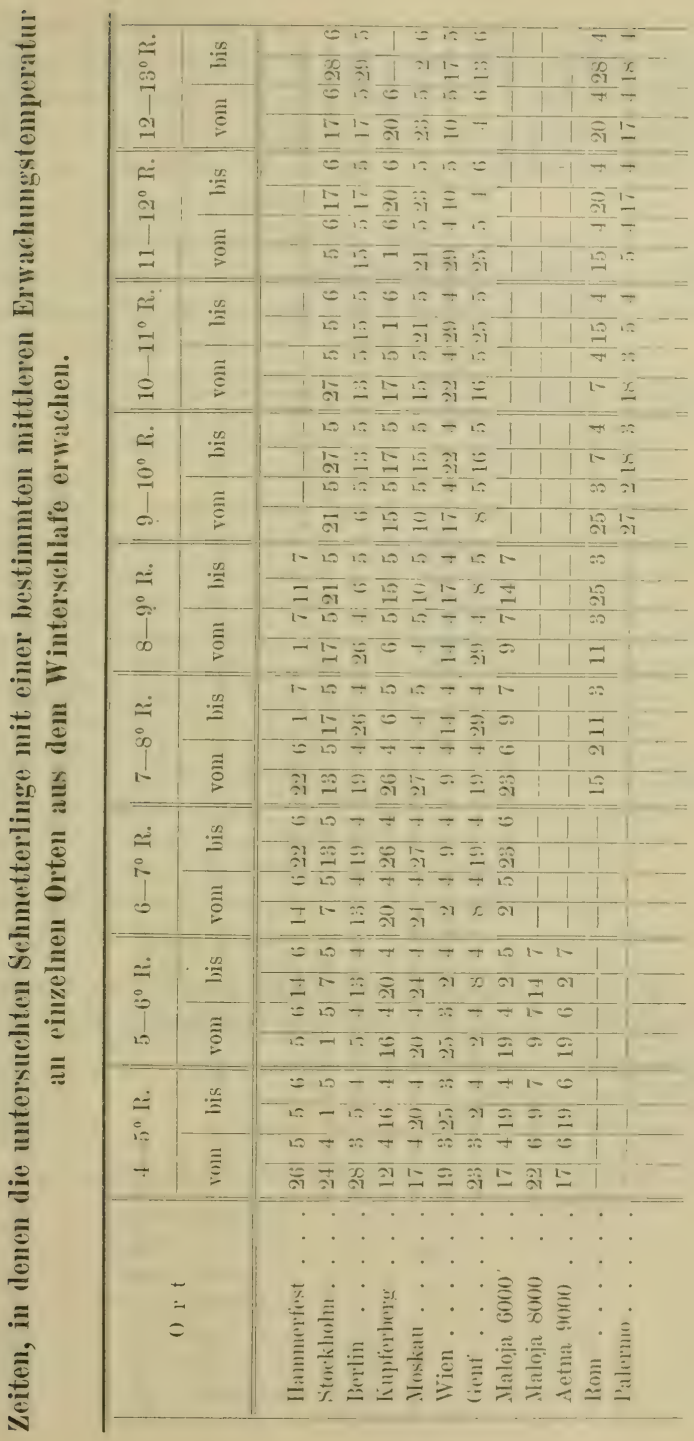




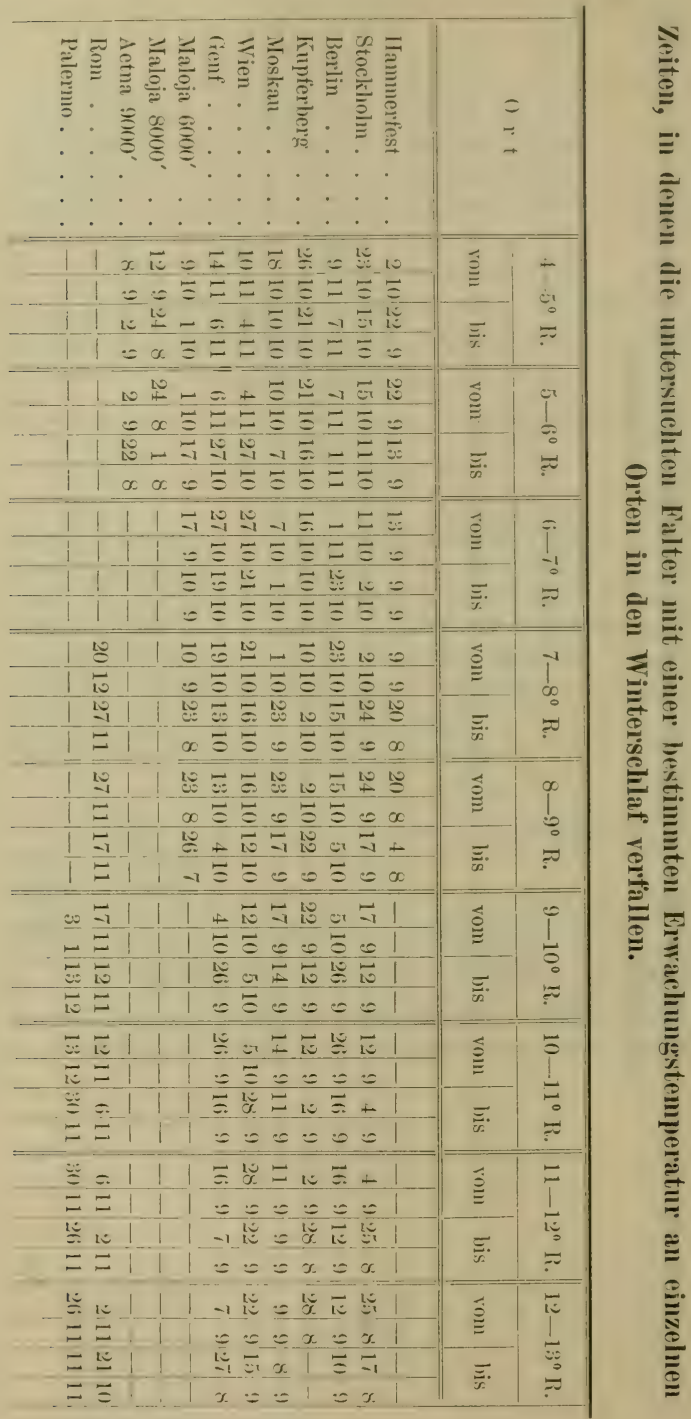


Ausser der Temperatur und Zeit bietet aber gewiss noch Interesse zu wissen, wieviel Zeit verstreicht, bis der letzte Falter sein Winterversteck verlässt, wenn der erste orler seine Raupe bereits angetroffen werden. Diese sogenannte Erwachungsdauer ist aber wieder verschierlen, je nach der Höhe oiler geographischen Breite des Ortes, fur den sie in Frage kommt.

Nachfolgende kleine Tabelle (im Auszug) enthält für die bei den Erwachungszeiten berücksichtigten Orte die Erwachungsdauer zusammengestellt, zugleich mit der Bemerkung, welcher Temperaturgrad noch erreicht wird.

\begin{tabular}{|c|c|c|c|c|}
\hline $\mathrm{Ort}$ & Breite & Länge & $\begin{array}{c}\text { Erwa- } \\
\text { cliungs- } \\
\text { dauer. } \\
\text { Tage }\end{array}$ & Bemerkungen \\
\hline Hammerfest. & 70,40 & 23,46 & 46 & Es wird nur der $9^{0}$ erreicht. \\
\hline Torneo. . . & 66,24 & 23,47 & 59 & Es wird nur der $9^{0}$ erreicht. \\
\hline Christiania . & 59,55 & 10,43 & 88 & Der $13^{\circ}$ wird nicht mehr ganz erreicht. \\
\hline Kiopenhagen & 55,41 & 12,35 & 69 & Der $13^{\circ}$ wird nicht melır ganz erreicht. \\
\hline Wien ... & 48,12 & 16,22 & 28 & Der $13^{\circ}$ wird nicht mehr ganz erreicht. \\
\hline Bergell $4000^{\prime}$ & 46,50 & 9,38 & 91 & Der $13^{\circ}$ wird nicht mehr ganz erreicht. \\
\hline$\Rightarrow \quad 6000^{\circ}$ & 46,50 & 9,38 & 89 & Der $10^{\circ}$ nicht mehr erreicht. \\
\hline$" 8000^{\prime}$ & 46,50 & 9,38 & 22 & Der $7^{\circ}$ nicht mehr erreicht. \\
\hline Triest . . . & 45,39 & 13,46 & 105 & Der $4^{0}$ mit genauer Not erreicht. \\
\hline Ankona . . & 43,38 & 13,30 & 137 & Der $4^{0}$ mit genauer Not erreicht. \\
\hline Rom. . . . & 41,54 & 12,28 & 72 & Der $6^{\circ}$ nicht erreicht. \\
\hline Palermo . . & 38,07 & 13,22 & 60 & Der $8^{\circ}$ nicht erreicht. \\
\hline Aetna $9000^{\circ}$ & 37,46 & 15.01 & 16 & Der $6^{\circ}$ nicht erreicht. \\
\hline
\end{tabular}

\section{Die Daner des Winterschlafes und der jährlichen der Entwi- ckelung der Schmetterlinge zuträglichen Entwickelungszeit.}

\begin{tabular}{|c|c|c|c|c|c|c|c|c|}
\hline Die lauf. & $\mathrm{Name}$ & & & & & & $\begin{array}{c}\text { Mittlere Dauer } \\
\text { des Schlafes. } \\
\text { Tage }\end{array}$ & $\begin{array}{c}\text { Mlittlere Dauer } \\
\text { der jührlichen } \\
\text { Entwickl. Zeit. } \\
\text { Tage }\end{array}$ \\
\hline 1 & Melitaea maturna. & & . & . . & . . & & 232 & 183 \\
\hline 10 & Argymis aplivape & & . . & . . & . . & $\bullet$ & $2+2$ & 121 \\
\hline 25 & Vanessa carlui. & 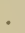 & . . & . . & . . & 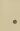 & 194 & 171 \\
\hline 26 & atalante. & & . & . . & . . & $\bullet$ & 196 & 169 \\
\hline 27 & io.... & & . . & . . & . . & & 166 & 199 \\
\hline 28 & antiopa. & 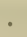 & . . & . . & . . & 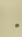 & 193 & 172 \\
\hline 29 & polychloros & . & . . & . . & . . & . & 190 & 175 \\
\hline
\end{tabular}


Erstes Tiapitel. Die Entwickelungsgeschwindigkeit der Insekten.

\begin{tabular}{|c|c|c|c|c|c|c|c|}
\hline lie limit. & Na & & & & & $\begin{array}{l}\text { Mittlere laner } \\
\text { dos Schlinius. } \\
\text { Tage }\end{array}$ & $\begin{array}{l}\text { Mittlere Dauer } \\
\text { der Jilnlichen } \\
\text { Entwickl. Zeit. } \\
\text { Tage }\end{array}$ \\
\hline 30) & Tanessa urticale . & . . & . . & . & . & 1993 & 172 \\
\hline 31 & $"$ prorst.. & . . & . . & . & . . & 217 & 148 \\
\hline 32 & $" \quad c$ allum. & . . & . & . & . & 198 & 167 \\
\hline$\$ 3$ & V allum . & . . & . & . & . . & $2 \cdot 20$ & 145 \\
\hline$\therefore 4$ & anthomelas & . & . . & . & . . & 212 & 153 \\
\hline 38 & Limenilis populi. & . . & . . & . & . & 254 & 111 \\
\hline 42 & Hipp. hermione. . & . . & . . & . & . . & 251 & 114 \\
\hline 50 & Epinepliele janima. & . . & . . & . & . & 254 & 111 \\
\hline 62 & Erebia mnestra. . & . . & . . & . & . . & 254 & 111 \\
\hline 89 & Lycaena coridon. & . . & . . & . & . . & 265 & 100 \\
\hline 113 & Thecta ilicis... & . . & . . & . & 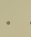 & $27 \theta$ & 95 \\
\hline 117 & Papilio poctatirins . & . . & . . & . & . & 256 & 109 \\
\hline 120 & Doritis delins .. & . . & . . & ${ }^{\circ}$ & . & 282 & 83 \\
\hline 133 & Colias palaeno ... & . . & . & . & . & 308 & $5 \bar{T}$ \\
\hline
\end{tabular}

Die trasstemperaturen der Raupen und die Flugtemperaturen der Imagines.

1. Falter mit nur einer Generation nördlich der Alpen.

\begin{tabular}{|c|c|c|c|c|c|c|c|}
\hline 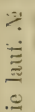 & \multirow[t]{2}{*}{ Name } & 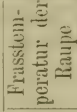 & 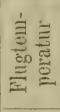 & \multirow{2}{*}{ 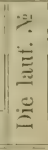 } & \multirow[t]{2}{*}{$\mathrm{Name}$} & 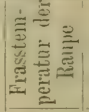 & 总 \\
\hline$\Xi$ & & Ii. ${ }^{\circ}$ & Ri. ${ }^{\circ}$ & & & i. ${ }^{\circ}$ & 1.. ${ }^{0}$ \\
\hline 1 & Melit. maturna . . & 14,0 & 11,3 & 59 & Coen. arcania & 13,6 & 13,9 \\
\hline 19 & drgyn. paphia . & 14,1 & 13,3 & 74 & Lyeaena aegon. & $13,9)$ & 13,3 \\
\hline 24 & Limenitis populi . & 14,3 & 15,7 & 79 & Polyom. virgaurea. & 13,1 & 13,0 \\
\hline 27 & Hip. hermione . . & 10,8 & 13,6 & 85 & Thecla rubi. . & 12,4 & 10,7 \\
\hline 36 & Epineph. janira. . & 14,2 & 13,5 & 86 & Papilio podatirins. & 13,3 & 12,7 \\
\hline 14 & Erebia mnestra. . & 9,6 & 7,8 & 93 & Col. palaeno ... & 14,1 & 14,3 \\
\hline
\end{tabular}

2. Winterform der Falter mit 2 Generationen.

\begin{tabular}{|c|c|c|c|c|c|c|c|}
\hline 1 & Arg. selene. . . . & 11,9 & 9,5 & 11 & Vanessa levana. & 12,5 & 8,1 \\
\hline 5 & Tanessa cardiii. & 13,2 & 7,1 & 12 & C' album & 13,6 & 7,2 \\
\hline 6 & atalanta. & 13,2 & 7,4 & 13 & $V$ allum & 15,5 & 7,7 \\
\hline 7 & io... & 13,9 & 4,7 & 14 & xanthomelas & 14,0 & 7,0 \\
\hline is & antiopu & $1: 3.2$ & 6,7 & 31 & P'upitio machuron & 13,5 & 11,6 \\
\hline 9 & polychloros & 12,7 & 6,5 & $\mid 33$ & Pont. rapae . . & 14,7 & 7,8 \\
\hline 10 & urticae. . & 13,2 & 6,9 & 39 & Col. rhamni & 14,2 & 9,1 \\
\hline
\end{tabular}


3. Sommerform der Falter mit 2 Generationen.

\begin{tabular}{|c|c|c|c|c|c|c|c|}
\hline \multirow[t]{2}{*}{ 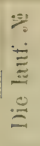 } & \multirow[t]{2}{*}{ Name } & 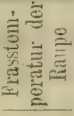 & 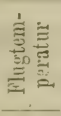 & $\begin{array}{l}\dot{\xi} \\
\Xi \\
\Xi \\
\Xi \\
\Xi\end{array}$ & \multirow[t]{2}{*}{$N$ ane } & \multirow{2}{*}{ 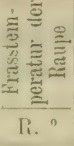 } & \multirow{2}{*}{ 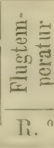 } \\
\hline & & Ri. ${ }^{n}$ & R. ${ }^{\circ}$ & 6 & & & \\
\hline 1 & Arg. selene. & 13,8 & 14,2 & $|11|$ & Tunessa prorsut. & 12,0 & 13,8 \\
\hline 5 & Vunessu cardui. & 11,7 & 13,9 & $|12|$ & e allum. & $11, \bar{T}$ & 13,9 \\
\hline 6 & atalanta. & 11,7 & 13,9 & $|13|$ & $Y$ album. & 12,8 & 15,1 \\
\hline 7 & io.... . & 9,4 & 13,0 & 14 & $"$ xanthomelas & $12, \overline{5}$ & 15,3 \\
\hline 8 & antiope & $11, \overrightarrow{7}$ & 13,9 & $|31|$ & Pepsitio machaon. & 13,4 & 14,6 \\
\hline 9 & polychloros & 11,6 & 13,5 & 33 & Pont. rapae . . . & 13,9 & 14,2 \\
\hline 10 & urticae. . & $11, \bar{T}$ & 15,9 & $|39|$ & Col. vletumini . . . & 12,6 & 14,3 \\
\hline
\end{tabular}

Interessant ist lie Berethnung, nach welcher Brunbaner die Anzahl der Generationen an einzolnen Orten ermittelt. Auch him. werilen nur einige Daten aus seinen zahlleichen 'Tahellen angefülurt.

1. Anzahl der Generationen bei Faltern, welche zwischen 4 his $5^{0} \mathrm{R}$. aus dem Winterschlafe erwachen.

(Hieher gehört Vanessa io).

\begin{tabular}{|c|c|c|c|c|c|c|c|c|}
\hline $\mathrm{Or}$ & & & & & $\begin{array}{c}\left.I^{1}\right) \\
\text { Tage }\end{array}$ & $\begin{array}{l}\text { II }{ }^{\circ} \text { ) } \\
\text { Tage }\end{array}$ & $\begin{array}{l}\text { III }^{3} \text { ) } \\
\text { Tage }\end{array}$ & IV *) \\
\hline Hammerfest & . & . & . & . . & 199 & $129-109$ & 139 & 1 \\
\hline Stockliolm . & . & . . & . & . & 199 & $182-167$ & 139 & $11 / 3$ \\
\hline Berlin . ... & . & . . & . & . & 199 & $226-216$ & 139 & 2 \\
\hline Wien . . . & . & . . & . & . . & 199 & $236-224$ & 139 & $2^{1} ! 8$ \\
\hline Botzen . . & . & . & . & $\ldots$ & 199. & $252-242$ & 139. & 3 \\
\hline Bergel $8000^{\prime}$ & . & . . & $\therefore$ & . & 199 & $82-46$ & 139 & $3 \%$ \\
\hline Botzen $8000^{\prime}$ & . & $\therefore$ & $\therefore$ & $\therefore$ & 199 & $91-62$ & 139 & $1 / 2$ \\
\hline Triest . . . & . & . . &. . & ... & 199 & $365-295$ & 139. & $3 \%$ \\
\hline Rom . . . . & . & . . & $\therefore$ & & 199 & .965 & :139 & $4-5$ \\
\hline
\end{tabular}

1) Gefundene inittlere jährliche Entwickelungszeit.

$\left.{ }^{2}\right)$ Am betreffenden Orte'mögliche jührliche Entwickelungszeit.

${ }^{3}$ ) Eirstere nach Abzug der Dauer der Sommerform.

4) Daraus abgeleitete ungefihre Anzahl der Generationen. 
2. Anzahl der Generationen bei Faltern, welche $z$ wischen $5-6^{0}$ aus rem Schlafe erwachen.

(Hieher gehörige Falter sind: Arg. selene, Pont. nupi unil daplidice, welche in ganz Europa fliegen und Melit. cynthia nebst Erebia yorge, die nur in den Alpen vorkommen. ${ }^{1}$ )

\begin{tabular}{|c|c|c|c|c|c|c|c|c|c|c|c|}
\hline Ort & $\begin{array}{c}\left.\text { E. Z. }{ }^{2}\right) \\
\text { A.s. }\end{array}$ & $\begin{array}{l}\text { E. Z. } \\
\text { P. } n .\end{array}$ & $\mid \begin{array}{l}\text { E. Z. } \\
\text { P. d. }\end{array}$ & $\begin{array}{l}\text { E. Z. } \\
\text { M.c. }\end{array}$ & $\mid \begin{array}{l}\text { E. Z. } \\
\text { E.g. }\end{array}$ & II $\left.^{4}\right)$ & $\left|\begin{array}{c}\text { Z. }\left({ }^{1} \cdot{ }^{3}\right) \\
\text { A.s. }\end{array}\right|$ & $\begin{array}{l}\text { Z.G. } \\
\text { P.n. }\end{array}$ & $\mid \begin{array}{l}\text { Z. G. } \\
\text { P. l. }\end{array}$ & $\begin{array}{l}\text { Z. G. } \\
\text { H.e. }\end{array}$ & $\mid \begin{array}{l}\text { Z.G. } \\
\text { E.g. }\end{array}$ \\
\hline Hammerfest & 183 & 162 & 176 & - & - & $109-91$ & $1 / 9-1$ & 1 & $1 / 2-1$ & - & - \\
\hline Torneo . . & 183 & 162 & 176 & - & - & $129-129$ & 1 & $1-1 \frac{1}{2}$ & 1 & - & - \\
\hline Stockholm . & 183 & 162 & 176 & - & 一 & $167-157$ & $1 \%$ & 2 & $11 / 2$ & - & - \\
\hline Bergen . . & 183 & 162 & 176 & - & - & $209-190$ & 2 & $21 / 9$ & 2 & 一 & - \\
\hline Innsbruck . & 183 & 162 & 176 & 101 & 103 & $221-211$ & $2 \%$ & $21 / 8$ & $2^{11}$ & ? & ? \\
\hline Botzen . . & 183 & 162 & 176 & 101 & 103 & $242-239$ & 3 & 3 & 3 & ? & ? \\
\hline Gratz . . & 183 & 162 & 176 & 101 & 103 & $218-201$ & $\left|2-2 \frac{1}{2}\right|$ & $2^{x}$ & $2 \%$ & 3 & 3 \\
\hline Bergell $4000^{\prime}$ & 183 & 162 & 176 & 101 & 103 & $186-180$ & 2 & $\left|2-2 \frac{1}{2}\right|$ & $\left|2-2 \frac{1}{2}\right|$ & 2 & 2 \\
\hline Botzen $4000^{\prime}$ & 183 & 162 & 176 & 101 & 103 & $131-103$ & 1 & 1 & 1 & 1 & 1 \\
\hline Rom . . . & 183 & 162 & 176 & - & - & 365 & 5 & $5-5 \frac{1}{2} \mid$ & 5 & - & - \\
\hline Aetna $9000^{\prime}$ & 183 & 162 & 176 & - & - & $75-51$ & $1 / 2$ & ${ }_{1 / 2}$ & $1 / 8$ & - & - \\
\hline
\end{tabular}

Die Tabellen, in welchen Falter angeführt sind, welche bei Temperaturen $6-7^{\circ}, 7-8^{\circ}, 8-9^{\circ}, y-10^{\circ}, 10-11^{\circ}$ und $11-12^{\circ} \mathrm{J}$. erwachen, sind hier dler Kürze wegen ausgelassen.

9. Anzahl der Generationen von Faltern, welche zwischen $12-13^{\circ}$ R. aus dem Schlafe erwachen.

Die Falter und ihre Entwickelungszeiten sind:

\begin{abstract}
Thecla ilicis $=95$
Colias edusa $=117$

Erebia goanthe $=104$

Arginnis laodice $=102$
\end{abstract}

Hipparchia statilinus $=107$

Lycaena erebus. $\quad=96$

Apatura ilia $\quad=112$

Polyommatus thersamon $=101$

1) Der Abzug der Sommerform wurde der Kürze halber weggelassen.

$\left.{ }^{2}\right)$ s) Die Buchstaben bedeuten die Namen der Falter, es sind ihre Anfangsbuchstaben. E. Z. = Entwickelungszeit, Z. G. = Zahl der Generationen.

4) Am betreffenden Orte mögliche jährliche Entwickelungszeit. 


\begin{tabular}{|c|c|c|c|c|c|c|c|c|c|}
\hline \multirow{2}{*}{ Ort } & \multirow{2}{*}{$\begin{array}{c}\text { II } \\
\text { Tage }\end{array}$} & \multicolumn{8}{|c|}{ Anzahl der Generationen } \\
\hline & & $\begin{array}{c}\text { Th. } \\
\text { ilicis }\end{array}$ & $\left|\begin{array}{c}\text { Col. } \\
\text { edusa }\end{array}\right|$ & $\begin{array}{l}\text { Erebia } \\
\text { goanthe }\end{array}$ & $\begin{array}{l}\text { Ary. } \\
\text { aodice }\end{array}$ & $\begin{array}{l}\text { Hipp. } \\
\text { statil. }\end{array}$ & $\left|\begin{array}{l}\text { Lyc. } \\
\text { ereb. }\end{array}\right|$ & $\begin{array}{l}\text { Apat. } \\
\text { ilia }\end{array}$ & $\begin{array}{c}\text { Polyom. } \\
\text { thers. }\end{array}$ \\
\hline 'Torneo . . & $36-3$ & ${ }_{3}{ }_{3}-0$ & $1 i_{3}-0$ & - & - & - & - & - & - \\
\hline Stockholm . & $69-50$ & $1 / 8$ & $1 / 8$ & - & - & - & - & - & - \\
\hline Kopenhagen & $85-64$ & $8 / 3$ & $2 / 3$ & - & - & - & - & 一 & - \\
\hline Berlin . . & $118-104$ & 1 & 1 & - & 1 & 1 & 1 & 1 & 1 \\
\hline Petersburg & $63-43$ & $1 \%$ & $1 / 8$ & - & $1 / 8$ & $\%$ & $1 \%$ & $1 / 8$ & $1 / 9$ \\
\hline Wien . . & $135-121$ & $1 \%$ & $11 / 2$ & - & $1 \%$ & $1_{2}^{11}$ & $11 / 2$ & 1 & 1 \\
\hline Genf . . . & $95-75$ & 1 & 1 & $3 \%$ & $3 \%$ & $3 \%$ & 1 & $3 / 4$ & $3 / .-1$ \\
\hline Botzen . . & $160-146$ & $1 / 9$ & $1 \%$ & $1 \%-2$ & $1 \frac{1}{2}$ & $1^{1}{ }_{2}$ & 2 & $11 / 8$ & 2 \\
\hline Mailand . . & $162-148$ & 2 & 2 & $1 / 2-2$ & 2 & 2 & 2 & 2 & 2 \\
\hline Neapel . & $186-170$ & 218 & $2 \%$ & - & - & - & - & $21 / 9$ & $2 \%$ \\
\hline Palermo. . & $212-186 \mid$ & 3 & 3 & - & - & - & - & 3 & 3 \\
\hline
\end{tabular}

Der besseren Uebersicht wegen ist noch eine Tabelle aufgestellt, welche für jeden Ort die Zahl der Falter nach den Generationen geor(net, enthält. Dabei enthält die Rubrik I die Anzahl der Falter, welche am betreffenden Orte gemäss der Erwachungstemperatur und des Vorkommens fligen. Diese Tabelle wird hier vollständig wiedergegeben.

\begin{tabular}{|c|c|c|c|c|c|c|c|c|c|c|c|c|c|}
\hline \multirow{2}{*}{\multicolumn{2}{|c|}{$\mathrm{Ort}$}} & & \multirow[b]{2}{*}{ I } & \multicolumn{10}{|c|}{ Generationen } \\
\hline & & & & $\underset{-}{-}$ & $\neg$ & $\frac{-\infty}{i}$ & $\stackrel{a}{1}$ & a & $\frac{\infty}{a 1}$ & $i_{a}^{\infty}$ & $\frac{\left.\right|_{n} ^{\pi}}{\pi}$ & ${ }_{71}^{10}$ & 20 \\
\hline Hammerfest . & . . & . & 37 & 35 & 2 & - & - & - & -- & - & - & - & - \\
\hline Torneo . . . & . . & . & 81 & 44 & 31 & 3 & - & - & - & - & - & - & - \\
\hline Drontheim . & . & & 81 & 36 & 13 & 32 & - & 1 & - & - & - & - & - \\
\hline Stockholm . & . & & 81 & 36 & 12 & 31 & - & 1 & - & - & - & - & - \\
\hline Christiania . & $\therefore$. & . & 81 & 37 & 13 & 30 & - & - & - & - & - & - & - \\
\hline Bergen . . & . . & . & 81 & 32 & 13 & 17 & - & 19 & 1 & - & - & - & - \\
\hline Kopenhagen . & . . & . & 81 & 20 & 25 & 18 & - & 17 & 1 & - & - & - & - \\
\hline Berlin . . & . . & . & 112 & 1 & 59 & 19 & - & 28 & 5 & - & - & - & 一 \\
\hline Hamburg . . & - . & . & 86 & 1 & 38 & 15 & - & 31 & 5 & - & - & - & - \\
\hline Sylt . . . & . & . & 96 & 14 & 26 & 13 & - & 41 & 2 & - & - & - & - \\
\hline Riga . . . & . . & . & 88 & 17 & 30 & 31 & - & 10 & - & - & - & - & - \\
\hline Breslau . . . & . . & . & 110 & 13 & 48 & 17 & - & 26 & 5 & - & - & - & - \\
\hline Braunschweig & . & - & 112 & - & 43 & 34 & - & 23 & 12 & - & - & - & - \\
\hline Kupferberg . & . & - & 112 & 38 & 26 & 30 & - & 17 & 1 & - & - & - & 一 \\
\hline Petersburg . & . & - & 81 & 42 & 23 & 15 & - & - & - & - & - & - & - \\
\hline
\end{tabular}




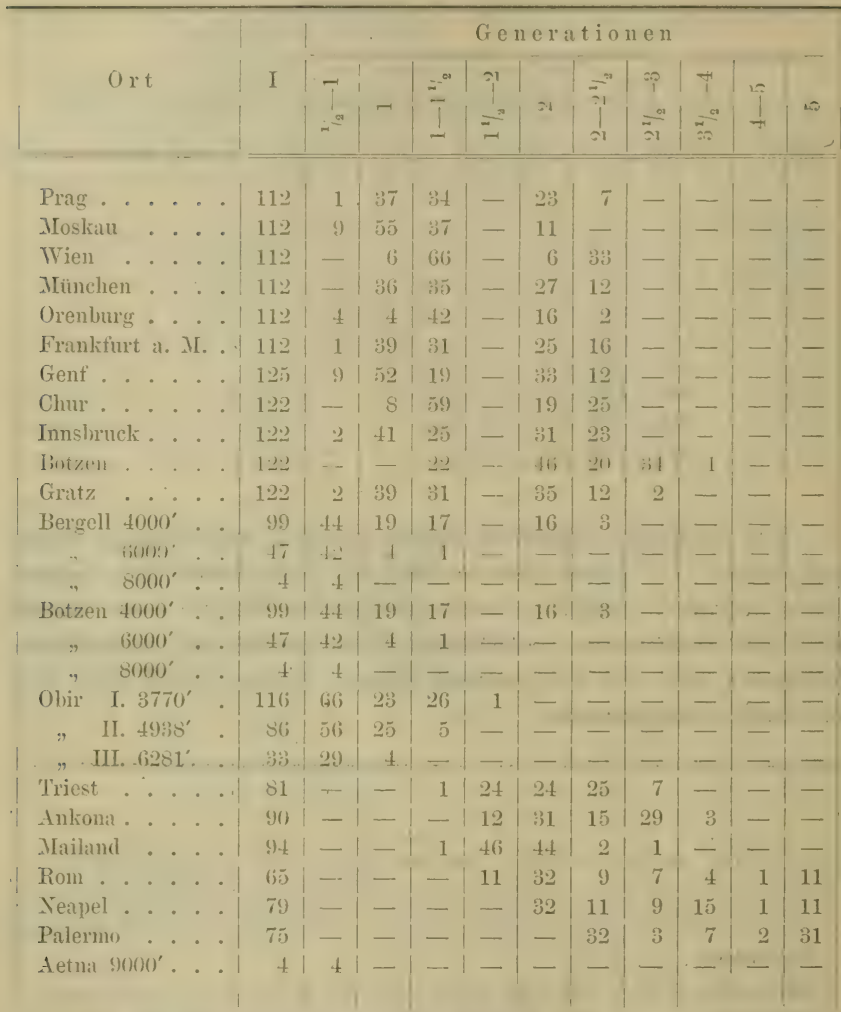

Am Encle seiner Arbeit kommt Brunbauer zu folgenden Schlüssen:

I. Die Temperaturen, welche dem Leben uni der Entwickelung der Tagfalter guinstig sind orler ihnen zum mindesten nicht scharlen, liegen, da schon die mittleren Erwachungstemperaturen um beinahe !0 R. clifferieren, zwischen ziemlich weiten (irenzen. Tiele dieser Schmetterlinge siml elen als Kosmopoliten im Stanle, sich extremen Wärmeverhältnissen anzupassen.

II. Die Daner des Winterschlafes, das Verfallen in denselben und das Erwachen daraus richten sich:

1. Nach der grösseren oder geringeren Fühigkeit der Falter. tiefere Temperaturen zu ertragen. 
2. Nach der geographischen Breite odler Höhe des Ortes, an welchem die Tagfalter gerade vorkommen.

III. Die Dauer des Verfallens ler einzelnen schmetterlinge in den Winterschlaf sowie das Erwachen aus demselben an einem bestimmten Orte hängen ab von dem rascheren orler langsameren Steigen und Sinken der Temperatur daselbst.

IV. Die Frass- und Flugtemperaturen liegen bei ihnen, da sie Tagthiere sind, uiber dem Tagesmittel.

V. Die Frass- und Flugtemperaturen der Sommerformen sinit nicht sehr von einander verschieden, doch sind erstere gewöhnlich nierlriger als letztere. Bei den Winterformen dagegen sincl jene bedeutend höher als diese.

Höhere Frass- als Flugtemperaturen haben daun auch die Fal ter mit nur einer Generation, welche also nur in der Winterform rorkommen. Der Unterschierl zwischen beilen Temperaturen ist aber geringer.

VI. Die Winterform hat gemeiniglich eine längere, oft doppelt so lange Lebensilauer als die Sommerform, den Winterschlaf algerechnet.

VII. Das Auskifiechen ıler Raupen aus den Eiern, sowie der Imagines aus den Puppen kanı un die Hälfte der gewöhnlichen Entwickelungszeit verzögert orler beschleunigt werden, je nachrlem tiefe oder hohe Temperaturen herrschen.

VIII. Der Einfluss der Tageslänge wird nur im hohen Norden merklich, von Sürlschwerlen aufwärts und richtet sich hauptsïchlich nach der Temperatur des Erwachens aus dem Winterschlafe.

Am grössten ist dieser Einfluss bei Faltern, welche bei den niedrigsten Temperaturen erwachen und an geringsten hei solchen, welche die höchste Erwachungstemperatur besitzen.

Bei Faltern mit einer solchen ron $4^{\circ} \mathrm{R}$. können am $70^{\circ} \mathrm{n}$. Br. 40 Tage günstiger Zeit gewonnen werlen, ller Tag zu 13 Stunden Entwickelungszeit genommen.

IX. Kältere orler wärmere Jahre haben in mittleren Gegendlen weniger Einfluss auf das Leben der Tagfalter als in sehr nördlichen orler sü̈llichen.

Der Winterschlaf wird in hohen Norien nur bei Schmetterlingen mit den tiefsten Erwachungstemperaturen sehr kurz, wenu die Jihre sehr warm sincl, in Italien in letzterem Falle fast bei allen Faltern. 
X. Nördlich der Alpen liommen hïchst selten unil nur in sehr wamen Jahren 3 Cenerationen ror, meist aher nur eine oler zwei.

Im hohen Norden und auf hohen Bergen reicht die Entwickelung der Falter in einem Jahre giinstiger \%eit zur Ausbilılung dersellen gewöhnlich nicht hin, weshall, liese 'Thiere oft zweimal orler Ireimal iilserwintern, bis sie fliegen. Dies hat zur Folge, dass man sie nicht alle Jahre sieht, wenigstens nicht in gleicher Menge.

Letzteres kann in mittleren (iegentien gleichfalls zutreflen, duch Hiegen sie hier mindestens alle Jahre einmal.

Das daraus abzuleitende Gesetz, hass manche Falter nur in gewissen Jahren zahlreich fliegen orler iiberhaupt sichtbar sinu, wird aber durch einfallente kiiltere oiler wärmere Jahre unterbrochen.

I)as letztere gilt auch fuir Italien und andere siilliche Länler, wem die in einem Jahre daselbst giinstige Entwickelungszeit nicht seraile din Mehrfaches von der Daner des Lehens der Schmetterlinge beträgt.

In sehr warmen Jahren liam iilnigens sogar eine ganze Generation eingeschaltet werlen.

XI. Die Anzahl der Generationen ist in sïdlichen Ländern unter den ron uns untersuchten Faltern mindestens 3; die höchste Zahl aber liirfte hei nicht iiherwinternien Faltern an Orten, wo die Sommerhitze nicht allzu gross ist und die Entwiclielung aler Tagschmetterlinge verzögert, 5 nicht übersteigen.

Goethe (1S84. 316) brachte im Winter Zweige mit Larven von Leconium vini Bché, welche bei $-18^{\circ}$ sich befanlen, ins warme Zimmer; wo dieselhen nach 2 Stunclen wieller munter wurlen.

H. Gauckler (1885. 275) untersuchte lie beschleunigte Ueberwinterung von verschierlenen Schmetterlingspuppen, inclem er lieselben vom 1 . November ab der Temperatur von $+14^{\circ}$ bis $+19^{\circ} \mathrm{R}$. anssetzte. Hier sinl die Resultate dieser Versuche gerarle so, wie sie beim Verfasser verzeichnet sincl,.angeführt:

A. Sphing i

1. Smerinthus populi: 2 Puppen; es erschien 1 Falter an 12. März 85.

2. Śmer. ocellatıs: 2 Puppen; keine Imago entwickelte sich.

3. Smer. tiliae: 1 Puppe; dieselbe vertrocknete.

4. Splinx elpenor: 2 Puppen; der 1. Falter erschien am 21. Februar, der 2. am 27. Februar 85. 
B. Bom y ces.

1. Saturnia carpini: 1 Puppe; sie ging zu Grunde.

2. Orgyia pudibunda: 1 Puppe; ठ. Falter am 11. Dec. 84.

3. Phulera bucephlati: 4 Puppen; es kamen nur 2 Imagines zur Entwicklung und zwar am 16. und am 18. März 85.

4. Sypilosomu lubriciperla: \& Puppen; es erschienen 5 Falter und zwar am: 28. März, 30. März, 6. April und 8. April 85.

5. Spil. mentica: 1 Puppe; dieselbe starb.

6. Pygaera curtula: 1 Puppe; Falter am 7. Januar 85.

7. Notodonte dictae: 6 Puppen; es schliipften nur 3 Imagines aus; am 1. Januar 85, 19. Februar und 22. Februar.

\section{Noctuae.}

1. Acronycta aceris: 4 Puppen; 2 Falter erschienen erst im Mai 85 .

2. Cymatophora or.: 10 Puppen; \& Puppen starben in Folge mbekamnter Ursachen, : Imagines erschienen ebenfalls erst im Mai des folgenden Jahres.

3. Mamestra persicariae: 5 Puppen; nur 1 Falter verliess die Puppenhülle am 19. März Sう.

4. MLam. oleracea: 5 Puppen; alle waren von Schlupfirespen berrohnt.

5. Hadena atriplicis: 3 Puppen; die 1. Imago am 13. Febr., die zweite am 19. Iebruar 85; die dritte Puppe war verschimmelt.

6. Tueniocumpa gracitis: 4 Puppen: kein Falter kan zur Entwicklung.

7. Habrostola triplasia: 2 Puppen; 1 Imago erschien am 9. Februar 85.

D. Geometrida e.

1. Ampliclasys betularia: 1 Puppe; lieferte keinen Falter.

Er heobachtete auch (1S86. 277) die Einspimmung ler Raupe von Antheraea pernyi bei Zimmertemperatur von $9^{\circ} \mathrm{R}$.

H. Kessler 1886. 449) beobachtete, dass während die parthenogenetischen Weibchen ron Siphonophora rosac in 14 und sogar 12 Tagen zur Fortpflanzung fähig sinl, ein am 21. December 1882 geborenes Weibchen im warmen Zimmer erst am 23. Januar, l. h. nach 4 Wochen gebar. Die weiteren Geburten folgten fist alle Tage, aber es traten auch mehr orler weniger grössere Pausen ein, je nachdem es kalt oder warm war. 
A. Tichomirow (1886. 866) erhielt parthenogenetische Eier von Bombyx mori unc tauchte sie in Wasser bei $3.5-40^{\circ}$ R. während 20-60 Minuten ein; lie Eier entwickelten sich darauf.

Lichtenstein 1887. 51:3) fand, dass die iberwinternile WurzelPhylloxera erwacht, sobald die Luftemperatur bis auf $10^{\circ}$ erhöht wirrl.

Fritz Rühl (1887. 716), der Grïnler der "Societas entomologica" sagt, gestiizt auf seine seit 10-1; Jahren gemachte Notizen, tlass die Beschleunigung der Entwickelung ïberwinternder Puppen durch erhöhete Temperaturen ihn nie befrieligt hat. Er erwïhnt folgende Nachtheile, die daraus erwachsen:

1. Eine häuflge Misshildung, die ılarin besteht, ılass sich öfter die Füisse nicht aus der Puppe befreien können, unıl abnorme Billlumg ler Flügel (einer wird grösser um entwickelter als der anlere).

2. Oefter eine Schwäche der Fliigelnerven, auch der Hattborsten; - manche Thiere kömmen nur schwer oder kaum gespannt werlen.

3. Sehr häufig erhält man ganz blasse rles intensiven natiirlichen Colorits entbehrende Exemplare.

Die für einzelne Arten erhaltenen Resultate sinı folgemle:

Papilio podulirius und muchuon entwickeln sich gut, ergeben aber läufig auffallend blasse Stiicke.

Pieriden erhalten öfters ganz ungleiche Flügel.

Thair: poly.rena zeigt nie dlas natiirliche (ielb; die Fliigel sinı häufig an der Wurzel verklebt.

Smerinthus ocellatu entwickelt sich gut. Die Sterblichkeit beträgt $20 \%$.

Smerinthus quercus ergibt $20 \%$ tote Puppen und auch nie tadellose Falter.

Smerinthus tiliae vertrocknet.

Smerinthus populi hat eine grössere Sterblichkeit als ocellata.

Bei Deilephila-Arten befinctet sich die Haftborste in Erschlaffung.

Hylophila masinana entwickelt sich gut, aber sieht wie verflogen aus.

Jacobaea-Puppen ergeben theils gute theils verkümmerte Falter.

Iendica, lubriciperla, menthastri, Endromis versicolora unı Agtia tau entwickeln sich normal.

Harpyiu vinula uni Stauropus fagi ergeben zu viel Krrüppel. 
F. Merrifield (1889. j(i3) liess die Puppen von Emyonia antumnaria bei erhöhten Temperaturen (ca. $30^{\circ}$ C.) sich entwickeln und beobachtete, dass die Puppenzeit für $\delta$ durchschnittlich 17

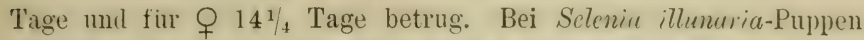
schliupften die männlichen Exemplare 4 Tage später als die weiblichen aus. Bei einigen Sommerpuppen von Selenia illustruria heträgt die Puppenzeit für ठ cal. 12,2 Tage unıl für + ca. 10, (i Tage.

Die Entwickelung der Puppen der letzten Art auf Eis geht sehr langsam vor sich: 120 Tage auf Eis sind äquivalent 2 bis 3 Tagen bei gewöhnlicher Temperatur.

Die Lebensfähigkeit der Puppen aller erwähnten Arten, welche auf Eis ca. 20 Wochen zugebracht haben, wurde nicht beeinträgtigt, obwohl das Puppenstarlium bei gewöhnlicher Temperatur nur ca. "2 Wochen dlauert; währent das entgegengesetzte Experiment, l. h. als die Puppen der Herbstgeneration der Temperatur von ca. 1 so $^{\circ} \mathrm{C}$. ausgesetzt wurlen, schlechte Folgen hatte: lie Mehrheit rler Puppen starb dabei.

F. Merrifield (18sy. 56t) stellte Versuche mit Eiern, Raupen und Puppen von rerschiedenen Geometriden an, indem er dieselben bei verschiedenen Temperaturen verschieden lange Zeit hielt, und gewann dabei folgende Resultate:

I. Eier von Selenia illunaria.

\begin{tabular}{|c|c|c|}
\hline $\begin{array}{l}\text { Wieviel Tage } \\
\text { auf Eis }\end{array}$ & $\begin{array}{l}\text { Darauf in Zim- } \\
\text { mertemperatur }\end{array}$ & $\begin{array}{l}\text { Die Anzahl der ausgekro- } \\
\text { chenen Räupchen in \% }\end{array}$ \\
\hline $\begin{array}{l}14 \text { ' Tage } \\
28 " ~ \\
42 \\
56 " 7 \\
66 " ~\end{array}$ & $\begin{array}{c}7-9 \text { Tage } \\
5-7 \quad " \\
5-7 \quad " \\
7\end{array}$ & $\begin{array}{l}100 \\
87,5 \\
75 \\
40 \\
0\end{array}$ \\
\hline
\end{tabular}

II. Eier von Selenia illustiaria.

\begin{tabular}{|c|c|c|c|c|}
\hline $\begin{array}{l}\text { Abgelegt } \\
\text { am }\end{array}$ & $\begin{array}{l}\text { Auf Eis } \\
\text { gebracht am }\end{array}$ & $\begin{array}{c}\text { Wieviel Tage } \\
\text { waren auf dem } \\
\text { Eise }\end{array}$ & $\begin{array}{c}\text { Darant } \\
\text { im Zimmer } \\
\text { verblieben }\end{array}$ & $\begin{array}{l}\text { Die Anzahl der } \\
\text { ausgekrochenen } \\
\text { Räupchen in \% }\end{array}$ \\
\hline $\begin{array}{c}\text { 5. Mai } \\
\text { 6.-7. Mai } \\
" \\
" \\
" \\
\text { 19. -22. Juli }\end{array}$ & 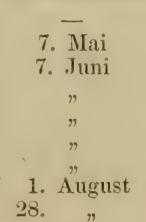 & 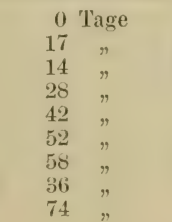 & $\begin{array}{c}18-21 \text { Tage } \\
1-13 \quad " \\
7-9 \quad " \\
7-8 \quad " \\
- \\
- \\
-\end{array}$ & $\begin{array}{l}88 \\
70 \\
95 \\
77 \\
0 \\
0 \\
11 \\
2,5 \\
0\end{array}$ \\
\hline
\end{tabular}


Aus dler I. Tabelle ist ersichtlich, dlass je längere Zeit die Eier ron $S$, illunariu anf dem Eise liegen, lesto weniger Räupchen aus den Eiern auskriechen. bic Tage bei so tülten alle Eier. währen: 14 Tagen keinen Schaden verursachen. Es scheint auch. dass whohl die Eier verschienten lamge Zeit anf dem Eise verhleihen, sie trotzlem bei gewöhnlicher Temperatur nach ca. T Tagen liäupchen ergehen. Leiler ist aus der Tabelle nicht ersichtlich, wamn die Eier nach ihrer Ablage auf's Eis gestellt wurden.

Dafür gielst uns die Auskunft die II. Tahelle fur Eier von $S$. illustruria. Die Eier wurlen an gleichen Tage ihrer Ahlage auf's Eis gestellt: je lïnger sie bei "10 sich hefanlen, desto schneller linochen sie bei gewïhnlicher Temperatur aus. Daraus scheint hervorzugehen, dass die maximale Ausbrütung der Räupchen dann eintritt, wenn clie Eier 14 Tage anf dem Eise verhliehen. Als clie Eier aber erst ea. 10 Tage nach ihrer Ablage aufs Eis gestellt wmilen, krochen daraus nur 2.5\% Riumphen aus: jefloch muss hier in Ijetracht gezogen werilen, dass sie auf dem Eise 36 Tage zuhrachten, und dass im ersten Falle bei 42-Tägigen Exposition die Eier auch zu Grunde gehen.

Folgemle zwei Tabellen zeigen die Versuche mit Raupen ron Seleniu illustraria vom Momente der Einspinnung an:

\section{Raupen von Selenia illustraria.}

\begin{tabular}{|c|c|c|c|c|c|c|c|c|c|c|c|}
\hline \multirow{3}{*}{ } & \multirow[b]{3}{*}{ 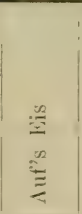 } & \multirow{3}{*}{$\begin{array}{l}\stackrel{\Xi}{\Xi} \\
. ٍ \\
\Xi \\
\Xi\end{array}$} & \multirow[b]{3}{*}{$\stackrel{\bar{\Xi}}{\stackrel{\Xi}{\bar{\Xi}}}$} & \multirow[b]{3}{*}{ 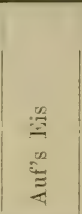 } & \multirow{3}{*}{ 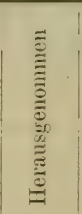 } & \multirow{3}{*}{ 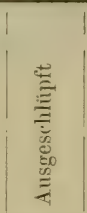 } & \multirow[b]{3}{*}{ 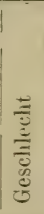 } & \multicolumn{4}{|c|}{$\mathrm{Tage}$} \\
\hline & & & & & & & & \multicolumn{2}{|c|}{$\begin{array}{l}\text { Während der } \\
\text { Verpuppung }\end{array}$} & \multicolumn{2}{|c|}{ Puppe } \\
\hline & & & & & & & & 至 & 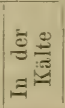 & $\frac{1}{3}$ & 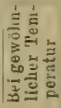 \\
\hline 23. VI. & 23. VI. & 22.VII & .28.VII. & 29.VII. & 30. VII. & - & - & | 29 & 6 & 1 & - \\
\hline : & " & $"$ & $n$ & $\Rightarrow$ & 9. IX. & 24. IX. & $\sigma$ & 29 & 6 & 42 & 1i) \\
\hline 30. VI. & 30. VI. & " & - & - & 30. VII. & - & - & 22 & - & - & - \\
\hline$\Rightarrow$ & $"$ & $"$ & - & - & " & - & - & 22 & - & - & - \\
\hline 23. VI. & 23. VI. & " & 28.VII. & 29.VII. & 9. IX. & 25. IX. & $\sigma$ & 29 & 6 & 42 & 16 \\
\hline$"$ & $\Rightarrow$ & " & $"$ & $"$ & $"$ & 23. IX. & q & 29 & 6 & 42 & 14 \\
\hline 30. VI. & 30. VI. & $"$ & - & - & 30.VII. & - & - & 22 & 8 & - & 2 \\
\hline , & $"$ & , & - & - & " & - & - & $2 \cdot 3$ & 8 & - & 2 \\
\hline
\end{tabular}


IV. Raupen von Selenia illustraria.

\begin{tabular}{|c|c|c|c|c|c|c|c|c|c|c|}
\hline \multirow{3}{*}{ 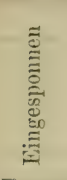 } & \multirow{3}{*}{ 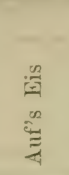 } & \multirow{3}{*}{ 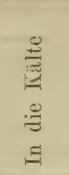 } & \multirow{3}{*}{ 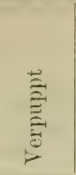 } & \multirow{3}{*}{ 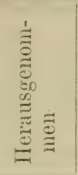 } & \multirow{3}{*}{ 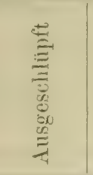 } & \multirow{3}{*}{ 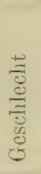 } & \multicolumn{4}{|c|}{$\mathrm{Tag} \mathrm{e}$} \\
\hline & & & & & & & \multicolumn{2}{|c|}{$\begin{array}{l}\text { Während der } \\
\text { Verpuppung }\end{array}$} & \multicolumn{2}{|c|}{ Puppe } \\
\hline & & & & & & & $\begin{array}{l}\text { Bei ge- } \\
\text { wöhnl. } \\
\text { Temper. }\end{array}$ & $\begin{array}{c}\text { Aufdem } \\
\text { Eise }\end{array}$ & $\begin{array}{c}\text { Aufdem } \\
\text { Eise }\end{array}$ & $\begin{array}{l}\text { Bei ge- } \\
\text { wöbnl. } \\
\text { Temper }\end{array}$ \\
\hline 21.VI. & 23.VI & - & 26.VI. & |25.VII. & | 6. VIII. & $\sigma$ & 2 & 3 & 29 & 12 \\
\hline & & - & 27.VI. & 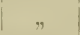 & $n$ & $\delta$ & 2 & 4 & 28 & 12 \\
\hline 29.VI. & 30.VI. & - & 6.VII. & |3.VIII. & 17. ? VIII. & q & 1 & 6 & 28 & 14 \\
\hline & 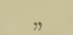 & 22.VII. & 1.VIII. & 30.VII. & - & - & - & - & - & - \\
\hline 22.VI. & 23.VI. & - & 26.VI. & 25. VII. & 8. VIII. & $\sigma$ & 1 & 3 & 29 & 14 \\
\hline & 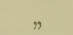 & - & $24 . \mathrm{VI}$. & $n$ & 6. VIII. & 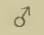 & 1 & 2 & 31 & 12 \\
\hline 29.VI. & 30.VI. & - & 4.VII. & 1.VIII. & 16. VIII. & $\delta$ & 1 & 4 & 28 & 15 \\
\hline & & - & ว.VII. & 2.VIII. & 17. ? VIII. & $\delta$ & 1 & $\check{\jmath}$ & 28 & 15 \\
\hline
\end{tabular}

Die grosse Sterblichkeit in den Versuchen rer Tabelle III. erklärt Merrifield damit. dass die Puppen aus der Käilte plötzlich in die warme trockene Luft gebracht wurlen.

\section{Vorgeschrittene Puppen von Selenia illustraria.}

\begin{tabular}{|c|c|c|c|c|c|c|c|c|c|c|}
\hline 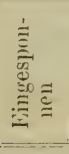 & $\begin{array}{l}\stackrel{Ð}{\Xi} \\
= \\
\triangleq \\
\Xi \\
\Xi \\
\end{array}$ & 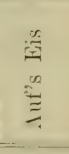 & 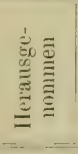 & $\begin{array}{l}\text { Ausge- } \\
\text { schlüpft }\end{array}$ & ב⿱艹 & 甚光 & 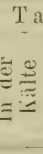 & 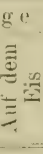 & . & \\
\hline 19.VI. & 30.VI. & 7.VII. & 5. IX. & 5. IX. & $\sigma$ & 11 & 7 & 60 & 0 & \\
\hline$"$ & $"$ & $n$ & $"$ & todt & - & 11 & 7 & 60 & 0 & Kíüppel \\
\hline , & $"$ & , & , & 3.-5. IX. & $\delta$ & 11 & 7 & 59 & 0 & \\
\hline 21.VI. & $"$ & " & $"$ & todt & - & 9 & - & - & - & \\
\hline 22.VI. & $"$ & $"$ & $"$ & todt & - & 8 & - & - & - & \\
\hline$"$ & $"$ & $"$ & $"$ & todt. & - & 8 & - & - & - & 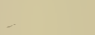 \\
\hline 24.VI. & ว.VII. & $"$ & 4.VIII. & 9. VIII. & $\sigma^{\pi}$ & 11 & 2 & 28 & $\check{5}$ & \\
\hline$"$ & $"$ & $n$ & $"$ & 14. VIII. & q & 11 & 2 & 28 & d & \\
\hline 26.VI. & $"$ & $"$ & 5. IX. & 10. IX. & $q$ & 9 & 2 & 60 & $\check{o}$ & Krüppel \\
\hline 27.VI. & $"$ & " & $n$ & 12. IX. & $\sigma$ & 8. & 2 & 60 & 7 & Krüрpel \\
\hline $28 . \mathrm{VI}$. & $"$ & $"$ & 4.VIII. & todt & - & 7 & 2 & 28 & - & \\
\hline$"$ & $"$ & $"$ & " & 14. VIII. & q & 7 & 2 & 28 & 8 & \\
\hline$"$ & $"$ & $"$ & $n$ & 13. VIII. & б & 7 & 2 & 28 & 7 & \\
\hline$"$ & $"$ & " & $n$ & $"$ & $\sigma^{\pi}$ & 7 & 2 & 28 & 7 & \\
\hline$"$ & $"$ & $"$ & 5. IX. & 12. IX. & q & 7 & 2 & 60 & 7 & \\
\hline$"$ & $"$ & $"$ & $"$ & todt & - & 7 & 2 & 60 & - & \\
\hline$"$ & $"$ & $"$ & $"$ & 12. IX. & $\sigma^{\pi}$ & 7 & 2 & 60 & 5 & Krüppel \\
\hline . & , & $"$ & $"$ & 12. IX. & 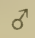 & 7 & 2 & 60 & 7 & Krüppel \\
\hline
\end{tabular}


10.t Hrstes Kapitel. Die Entwickelungsgeschwindigkeit der Insekten.

Versuche mit Eugonia antumuariu enthalten folgemle Tahellen: VI Eugonia autumaria. Forcierte Larven und Puppen.

\begin{tabular}{|c|c|c|c|c|c|c|}
\hline \multirow{2}{*}{$\begin{array}{l}\text { Einge- } \\
\text { sponnen }\end{array}$} & \multirow{2}{*}{ Vегрuриt } & \multirow{2}{*}{$\begin{array}{l}\text { Ausge- } \\
\text { schlitpft }\end{array}$} & \multirow{2}{*}{$\begin{array}{l}\text { Ge- } \\
\text { schlecht }\end{array}$} & \multicolumn{3}{|c|}{ 'T a g e } \\
\hline & & & & $\begin{array}{l}\text { Bei der } \\
\text { Verpupp. }\end{array}$ & $\begin{array}{c}\text { Als } \\
\text { Priple }\end{array}$ & 'Total \\
\hline 2. VI. & 4. VI. & - & - & 2 & - & - \\
\hline 4. VI. & 6. VI. & - & - & 2 & - & - \\
\hline 6. VI. & 7. VI. & $2 \pi . \mathrm{VI}$ & $\sigma^{\pi}$ & 1 & 20 & 21 \\
\hline$"$ & 8. VI. & - & - & 2 & - & - \\
\hline 11. VI. & 12. VI. & $27 . \mathrm{VI}$ & $\delta$ & $1^{1 / 2}$ & 15 & $1\left(6^{11}\right.$ \\
\hline .. & 14. VI. & 26. VI. & q & $2 i_{8}$ & $12^{1 / 2}$ & 15 \\
\hline 12. VI. & $"$ & $29 . \mathrm{VI}$ & $\sigma$ & $1 \%$ & 15 & $16 \%$ \\
\hline$"$ & " & 26. VI. & q & 2 & 12 & 14 \\
\hline .. & $\pi$ & $"$ & q & $1 \%$ & $12^{1 / 8}$ & 14 \\
\hline. & , & 30. VI. & $\sigma^{\pi}$ & 2 & $151 / 8$ & - $17^{2} / 2$ \\
\hline$"$ & $"$ & $29 . \mathrm{VI}$ & $\sigma^{\pi}$ & 2 & 15 & 17 \\
\hline 13. VI. & 15. VI. & $27 . \mathrm{VI}$. & q & $11 / 2$ & $12^{1} / 9$ & 14 \\
\hline .. & $"$ & $"$ & q & $1 \%$ & $12^{1} / 8$ & 14 \\
\hline. & $"$ & $30 . \mathrm{VI}$. & $\sigma^{\pi}$ & 2 & 15 & 17 \\
\hline$"$ & 16. VI. & 1. VI. & $\sigma$ & $21 / 2$ & 15 & $17^{1 /}$ \\
\hline 1s. VI. & 20. VI. & 2. 111. & 7 & $2^{11}$ & 12 & $14^{1:}$ \\
\hline 19. VI. & $"$ & 3. VII. & q & $1 \%$ & $12 \%_{2}$ & 14 \\
\hline$"$ & 21. VI. & 5. VII. & $\sigma^{\pi}$ & 2 & $14^{1} / 2$ & $16^{1} / 2$ \\
\hline$"$ & 20. VI. & 3. VII. & 우 & $1^{1}: 2$ & $12^{1 / g}$ & 14 \\
\hline$"$ & $"$ & " & q & $1 \%$ & 13 & $14 \%$ \\
\hline
\end{tabular}

VII. Eugonia autumnariı. Forcierte Larve, gekülılte Puppe.

\begin{tabular}{|c|c|c|c|c|c|c|c|c|c|c|}
\hline \multirow{2}{*}{ 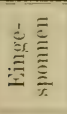 } & \multirow{2}{*}{ 言 } & \multirow[b]{2}{*}{$\begin{array}{l}\cong \\
\cong \\
\cong\end{array}$} & \multirow{2}{*}{ 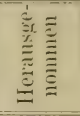 } & \multirow{2}{*}{ 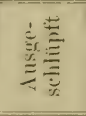 } & \multirow{2}{*}{ 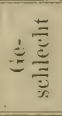 } & \multicolumn{5}{|c|}{$\mathrm{Ta} g \mathrm{e}$} \\
\hline & & & & & & 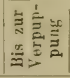 & 这 & $\stackrel{\Xi}{\Xi}$ & 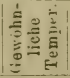 & 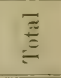 \\
\hline 5.VI. & 8.VI. & 10.VI. & 8.VII. & 16. III. & 아 & 3 & 2 & 28 & 8 & 41 \\
\hline "y & , & $"$ & 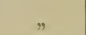 & 19. VII. & б' & 3 & 2 & 28 & 11 & 44 \\
\hline 6.VI. & 9.VI. & $"$ & $"$ & 20.VII. & व & $3 \%_{8}$ & 1 & 28 & 12 & $44^{1} \%$ \\
\hline$"$ & , & " & " & $"$ & ठ & $3 \%$ & 1 & 28 & 12 & $44^{1 / 2}$ \\
\hline$"$ & " & $"$ & " & 19.VII. & $\delta$ & $3^{1}:$ & 1 & 28 & 11 & $43 \%$ \\
\hline$"$ & 10.VI. & 12.VI. & 10.VII. & 23.VII. & $\sigma$ & 4 & 2 & 28 & 13 & 47 \\
\hline 7.VI. & $11.1 \mathrm{~T}$. & 13.VI. & 11.VII. & 20. II. & q & 4 & $1^{x / 2}$ & 29 & 9 & $42^{1 / 3}$ \\
\hline $9 . \mathrm{VI}$ & 14.VI. & 15.VI. & 13.VII. & $22 . \mathrm{VII}$. & 우 & $4 \%$ & 1 & 28 & 9 & $42^{11}=$ \\
\hline$"$ & 11.VI. & 13.VI. & 11. VII. & 19.VII. & 우 & 2 & 2 & 28 & 8 & 40 \\
\hline 10.VI. & $15 . \mathrm{VI}$. & 16.VI. & 14.VII. & $23 . \mathrm{VII}$ & 우 & $4^{1 / 2}$ & 1 & 28 & 9 & $42 \%$ \\
\hline
\end{tabular}

Hier wurde die Raupe, nachdem sie sich eingesponnen, aus tem Brutofen in die gewöhnliche Temperatur versetzt, und die Puppe 1 bis 2 Tage gekiillit. 
VIII. Éugonia autumnaria.

\begin{tabular}{|c|c|c|c|c|c|c|c|c|c|}
\hline 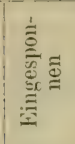 & 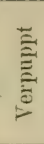 & 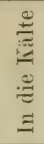 & 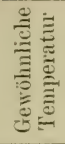 & 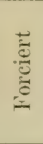 & 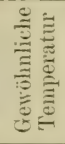 & $\begin{array}{l}\stackrel{8}{\Xi} \\
\cong \\
气 \\
\Xi \\
\Xi\end{array}$ & 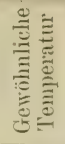 & 突芯 & 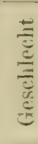 \\
\hline
\end{tabular}

21.VII. 24. ? VII. 10. VIII.12. VIII. 13. VIII. 16. VIII. $-|-|$ 16.? VIII. б

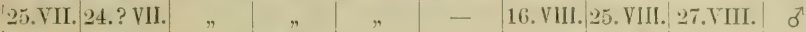

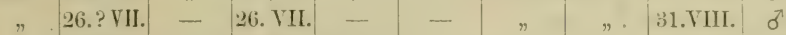
- 26.VII. 10. VIII.12.VI I. 13.VIII. - -14 - -14 III. 245.VII. 27.VII. - 15.VIII. - -1 - -16. VIII. o 30.VII. 30.VII. - 30. VII. $-\mid-16$. VIII. 25.VIII. 1. IX. $\sigma^{3}$

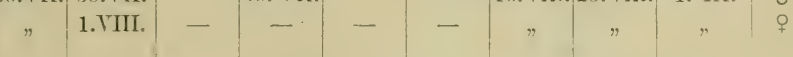

IX. Éugonia autumnaria.

\begin{tabular}{|c|c|c|c|c|c|c|c|}
\hline \multirow[b]{2}{*}{ 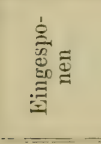 } & \multirow[b]{2}{*}{ 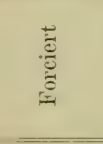 } & \multirow{2}{*}{ 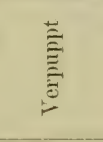 } & \multirow{2}{*}{ 光点芯 } & \multirow{2}{*}{ 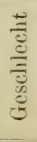 } & \multicolumn{3}{|c|}{ ' $\mathrm{T}$ a g e } \\
\hline & & & & & 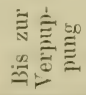 & 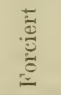 & $\stackrel{\Xi}{E}$ \\
\hline 13. VII. & 13. VII. & 14. TII. & 27. VII. & q & $1_{2}^{1}$ & $1: 3$ & $14 \%$ \\
\hline$"$ & $"$ & 15.? VII. & 29. VII. & б & $2 ?$ & 14 & $16 \%$ \\
\hline$"$ & 25. VII. & - & 6. VIII. & q & $2 \div$ & 12 & 14! \\
\hline - & 26. VII. & Puppe & 7. VIII. & $\sigma^{\pi}$ & $2 ?$ & 12 & 14! \\
\hline 26. VII. & " & 27. VII. & , & q & $1{ }^{1 /}$ & 11 & $12 \%$ \\
\hline ., & $"$ & $"$ & 9. VIII. & $\sigma$ & $1^{1}{ }_{2}$ & $1: ;$ & $14^{1 / 3}$ \\
\hline " & . & " & 10. YIII. & $\sigma$ & $1 \%$ & $13 \%$ & 15 \\
\hline$"$ & . & 2. VII. & !. Vili. & $q$ & $1 \%$ & 12 & $13^{1}$ \\
\hline
\end{tabular}

\section{Eugonia autumnaria.}

\begin{tabular}{|c|c|c|c|c|c|c|c|c|c|c|}
\hline & & & & & & & & & Tage & \\
\hline 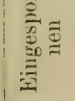 & 苞 & 言 & \begin{tabular}{l}
$\stackrel{\pi}{2}$ \\
\hdashline \\
$\Xi$
\end{tabular} & $\stackrel{\infty}{=}$ & 总 & 它 & 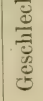 & 芯离 & 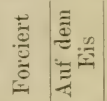 & 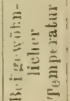 \\
\hline
\end{tabular}

\begin{tabular}{l|l|l|l|l|l|l} 
1.21.VII. 21.VII. 23.VII. 30.VII. 30.VII. 27. VIII. 7. IX. 우 & 2 & 7 & 28 & 11
\end{tabular}

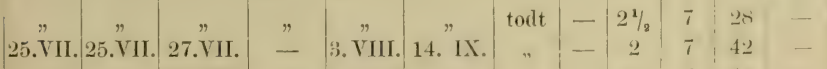

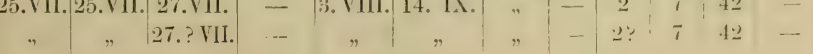




\section{Eujonia autumnaria.}

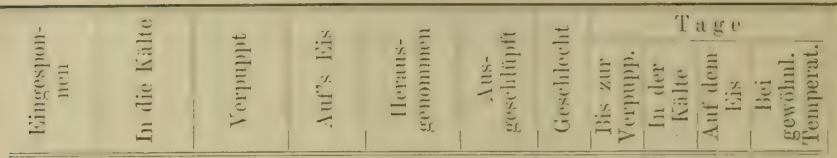

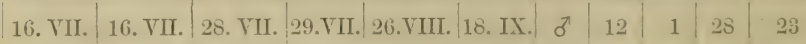

\begin{tabular}{|c|c|c|c|c|c|c|c|c|c|c|}
\hline 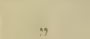 & $"$ & 26. VII. & 27.VII. & | 25. VIII. & |19. LX. & $\delta$ & 10 & 1 & 29 & 25 \\
\hline 26. VII. & 26. VII. & 9. VIII. & - & 6. IX. & 22. IX. & 우 & 14 & 42 & - & 16 \\
\hline 30. VII. & 30. VII. & 1. VIII. & 1. VIII. & 15. IX. & $19 . \mathrm{X}$. & $q$ & 2 & - & 45 & 28 \\
\hline$\Rightarrow$ & $"$ & 5. VIII. & 6. VHI. & $"$ & $"$ & $q$ & 6 & 1 & 40 & 8 \\
\hline$"$ & " & 10.VIII. & - & $"$ & |10. X. & $\sigma$ & 11 & 36 & - & 5 \\
\hline. & , & 1. VIII. & $\cdots$ & , & 4. X. & $\delta$ & $\stackrel{2}{2}$ & 4)$. & - & 19 \\
\hline .. & 2. VIII. & 2. VIII. & - & 29. IX. & $12 . \mathrm{X}$. & $\sigma$ & 3 & 58 & - & 13 \\
\hline 2.YIII: & , &. & - & 11. X. & Todt & - & - & $\pi$ & - & - \\
\hline " & 4. VIII. & t. VIII. & - & 13. X. & 21. X. & q & 2 & 70 & - & 8 \\
\hline. & , & .. & - & 21. X. & Torit & - & 2 & is & - & - \\
\hline. & ‥ VIII. & $\therefore$ VIII. & - &. &. & - & :) & $\pi$ & - & - \\
\hline 7. VIII. & 12.VIII. | & 10.? VIII. & - & ” & | 29. X. | & $q$ & 3 & 72 & - & 8 \\
\hline 8. VIII. & 13.VIII. & 13.VIII. & - & $"$ & Todt & - & б & 69 & - & \\
\hline 12.VIII. & 16.? VIII. & 16.? VIII. & - & $2 .-4$. IX. & 10. IX. & 우 & 4 ? & $48 ?$ & - & - \\
\hline 17.? VIII. & 16. IX. & 21.? VIII. & - & 21. X. & Todt & - & $4 ?$ & $45 ?$ & - & 16 ? \\
\hline
\end{tabular}

XII. Engonin alniaria (tiliaria), forciert als Raupe, gekühlt als Puppe.

\begin{tabular}{|c|c|c|c|c|c|c|c|c|}
\hline \multirow[b]{2}{*}{ 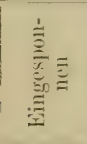 } & \multirow[b]{2}{*}{ 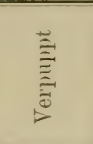 } & \multirow{2}{*}{$\begin{array}{l}\stackrel{0}{\Xi} \\
\Xi \\
\Xi \\
\Xi \\
\Xi\end{array}$} & \multirow[b]{2}{*}{ 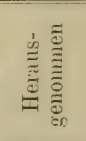 } & \multirow[b]{2}{*}{ 点 } & \multirow[b]{2}{*}{ 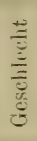 } & \multicolumn{3}{|c|}{$\mathrm{T} \mathrm{age}$} \\
\hline & & & & & & 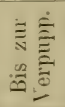 & 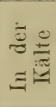 & 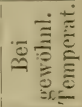 \\
\hline ๖. VI. & s. VI. & 10. VI. & 8. VII. & 21.VII. & $\sigma^{\pi}$ & 3 & 28 & 13 \\
\hline 6. VI. & 10. VI. & 11. VI. & 9. VII. & todt & - & \pm & - & - \\
\hline$"$ & $"$ & $"$ & $"$ & 24. VII. & $\sigma$ & 4 & 28 & 15 \\
\hline .* & $"$ & $\Rightarrow$ & $"$ & todt & 一 & 4 & - & - \\
\hline , & $"$ & $n$ & $"$ & 19.VII. & 우 & 4 & 28 & 10 \\
\hline 9. VI. & todt & - & - & - & - & 一 & - & - \\
\hline$"$ & 13. VI. & 14. VI. & 12.VII. & todt & - & 4 & 28 & - \\
\hline$"$ & $"$ & $"$ & $\Rightarrow$ & 22.VII. & ㅇ & 4 & 28 & 10 \\
\hline
\end{tabular}


XIII. Eugonia alniaria (tiliaria).

\begin{tabular}{|c|c|c|c|c|c|c|c|}
\hline \multirow[b]{2}{*}{$\begin{array}{l}\text { Einge- } \\
\text { sponnen }\end{array}$} & \multirow[b]{2}{*}{ Verpuppt } & \multirow[b]{2}{*}{ Forciert } & \multirow[b]{2}{*}{$\begin{array}{l}\text { Ausge- } \\
\text { schliiptt }\end{array}$} & \multirow[b]{2}{*}{ 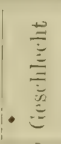 } & \multicolumn{3}{|c|}{ Tage } \\
\hline & & & & & 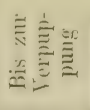 & ఏ芯芯 & 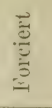 \\
\hline 3. VII. & 4.-6. VII. & 7. VII. & 17. VII. & $\sigma^{\pi}$ & $2 ?$ & $2 ?$ & $10 ?$ \\
\hline$"$ & $"$ & $”$ & 18. VII. & $q$ & $2 ?$ & $2 ?$ & $11 ?$ \\
\hline อ.. VII. & 6. VII. & $"$ & 19. VII. & $\delta$ & 1 ? & 1 ? & 12 ? \\
\hline$"$ & 7. VII. & $"$ & 20. VII. & $\sigma$ & $2 ?$ & 0 & 13 ? \\
\hline$"$ & - & 8. VII. & $"$ & $\delta$ & $3 ?$ & 1 & 12 ? \\
\hline 10. VII. & -- & 10. VII. & todt & - & - & - & - \\
\hline 13. VII. & 15. VII. & 13.. VII. & 20. VII. & $\delta$ & 2 & 0 & 13 \\
\hline- & - & 16. VII. & 31. VII. & $\sigma$ & - & - & 15 \\
\hline- & 19. VII.? & 19. VII. & 3. VIII. & $\sigma^{\pi}$ & - & - & 15 \\
\hline- & 21. VII.? & 21. VII. & ј. VIII. & q & 一 & - & 15 \\
\hline - & - & $"$ & todt & - & 一 & - & - \\
\hline
\end{tabular}

XIV. Eugonia alniuria (tiliaria).

\begin{tabular}{c|c|c|c|}
\hline $\begin{array}{c}\text { Eingespon- } \\
\text { nen }\end{array}$ & Verpuppt & $\begin{array}{c}\text { Aus- } \\
\text { geschlüpft }\end{array}$ & Geschlecht \\
\hline- & 26. VI. & 14. VII. & $\delta$ \\
- & 3. VII. & 23. VII. & \% \\
- & . & , & $\delta$ \\
3.? VII. & $4 .-6$. VII. & $23 !$ ? VII. & $\delta$ \\
13. VII. & - & 14 . VII. & $\delta$ \\
\end{tabular}


XV. Eugonia alniaria (tiliaria).

\begin{tabular}{|c|c|c|c|c|c|c|c|c|c|c|c|}
\hline \multirow{3}{*}{ 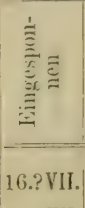 } & \multirow[b]{2}{*}{$\stackrel{\frac{ \pm}{\Xi}}{\frac{Z}{E}}$} & \multirow[b]{2}{*}{ 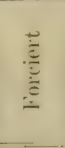 } & \multirow[b]{2}{*}{ 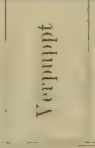 } & \multirow[b]{2}{*}{$\begin{array}{l}\frac{\infty}{3} \\
\vdots \\
\vdots\end{array}$} & \multirow[b]{2}{*}{ 兽 } & \multirow[b]{2}{*}{ 光 } & \multirow[b]{2}{*}{ 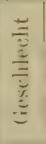 } & \multirow{2}{*}{ 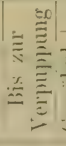 } & \multicolumn{3}{|c|}{ Puppe, Tage } \\
\hline & & & & & & & & & 竞离 & 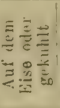 & 言 \\
\hline & - & 一 & Puppe & 21.VII. & 2. IX. & tolt & -1 & - & 5 & - & - \\
\hline 16.? VII. & 16. VII. & 一 & $"$ & $"$ & $"$ & $"$ & -1 & - & 5 & 43 & - \\
\hline 16. VII. & $"$ & - & 20. VII. & - & 10. IX. & $23 . \mathrm{IX}$. & $\sigma^{\pi}$ & 4 & 52 & 一 & - \\
\hline n & " & - & 30. VII. & 30.VII. & 28. VIII. & - & $\sigma$ & 14 & 一 & 29 & - \\
\hline - & 17. VII. & - & | P’uppe & 19.VII. & 15. IX. & 13. X. & $\sigma^{\pi}$ & - & 2 & 58 & 28 \\
\hline - & $"$ & 一 & $"$ & $"$ & $"$ & 12. X. & $\sigma^{\prime}$ & - & 2 & 58 & 27 \\
\hline - & $"$ & - & $"$ & $"$ & $"$ & todt & - & - & 2 & 58 & - \\
\hline 17. VII. & 19. VII. & - & 19. VII. & $20 . \mathrm{VII}$ & 31. VIII. & 28. IX. & $\sigma^{\pi}$ & 2 & - & 42 & 28 \\
\hline - & " & 一 & $"$ & $"$ & " & $29 . \mathrm{IX}$ & $\sigma$ & 2 & - & 42 & 27 \\
\hline - & 21. VII. & - & 21. VII. & |22.VII. & 15. IX. & 17. X. & $\sigma$ & 4 & - & 55 & 32 \\
\hline 19. VII. & 16. VIII. & - & 2:3.? VII. & -1 & 25. VIII. & 29. VIII. & $\sigma$ & $4 ?$ & $24 ?$ & 9 & 4 \\
\hline 25. VII. & $"$ & 一 & 28. III. & - & $"$ & 28. VIII. & & 3 & 19 & 9 & 3 \\
\hline 27.? VII. & - & - & Puppe & 27.VII. & 15. IX. & 16. X. & $\sigma^{\prime}$ & - & - & 50 & 31 \\
\hline 27.? VII. & - & - & $"$ & $"$ & $"$ & $"$ & वे & 一 & - & 50 & 31 \\
\hline 27. VII. & 27. VII. & - & - & - & $"$ & todt & - & - & - & - & - \\
\hline$"$ & - & 27.VII. & 28. VII. & 5. VIII. & 2. IX. & $"$ & - & 一 & - & - & - \\
\hline$"$ & - & $"$ & 29. VII. & $"$ & $"$ & $"$ & - & 一 & - & - & 一 \\
\hline 30. VII. & 30. VII. & - & 6. VIII. & - & 28. VIII. & 17. IX. & $\sigma^{\pi}$ & 7 & - & 22 & 20 \\
\hline 2. VIII. & 2. VIII. & - & $"$ & 一 & 11. X. & todt & - & 4 & - & 36 & - \\
\hline Ђ. VIII. & .9. VIII. & - & o. VIII. & $1-$ & $15 . \mathrm{IX}$. & | 21. X. & $\sigma$ & 3 & - & .37 & 36 \\
\hline
\end{tabular}

XVI. Mlustraria. Herbstpuppen, forciert.

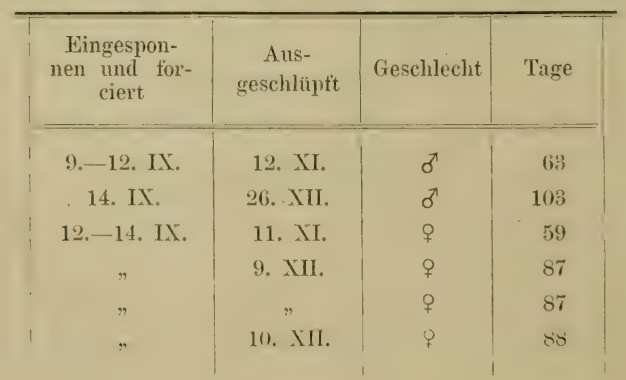


XVII. Illustiaria. Herbstpuppen.

\begin{tabular}{|c|c|c|c|c|c|c|c|c|c|c|c|}
\hline \multirow[b]{2}{*}{ 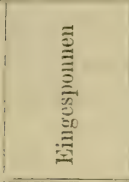 } & \multirow[b]{2}{*}{ 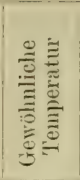 } & \multirow[b]{2}{*}{$\stackrel{5}{3}$} & \multirow[b]{2}{*}{ 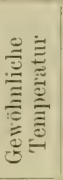 } & \multirow[b]{2}{*}{ 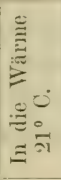 } & \multirow[b]{2}{*}{ 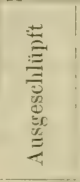 } & \multirow[b]{2}{*}{$\frac{5}{3}$} & \multicolumn{5}{|c|}{ 'T a g e } \\
\hline & & & & & & & 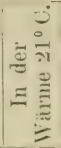 & 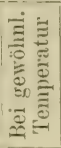 & $\stackrel{\tilde{c}}{\tilde{c}}$ & 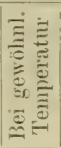 & 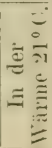 \\
\hline 12.-14.IX. & 12. XI. & 27. XI. & 1. I. & 9. I. & 13. II. & $\sigma^{\prime}$ & (6i) & 15 & 35 & 8 & 85) \\
\hline$"$ & $"$ & , & $"$ & $"$ & 28. II. & ठे & (6) & 15 & 35 & 8 & 50) \\
\hline$"$ & $"$ & $"$ & $\eta$ & $"$ & 1. I. & q & 60) & 15 & 35 & () & 1) \\
\hline$"$ & $\eta$ & " & $\eta$ & $"$ & 3.1. & f & (6) & 15 & 35 & 2 & 0 \\
\hline$"$ & $\eta$ & " & $"$ & $"$ & 22. I. & q & (6) & 15 & 35 & 8 & $1: 3$ \\
\hline 22. IX.? & $n$ & , & $"$ & " & 18. II. & 앙 & $5 \pi ?$ & 15 & 35 & 8 & 40 \\
\hline
\end{tabular}

XVIII. Illustraria. Herbstpuppen.

\begin{tabular}{|c|c|c|c|c|c|c|c|c|c|}
\hline \multirow[b]{2}{*}{ 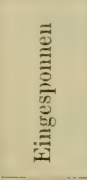 } & \multirow[b]{2}{*}{ 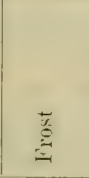 } & \multirow[b]{2}{*}{ 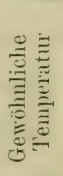 } & \multirow[b]{2}{*}{ 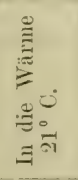 } & \multirow[b]{2}{*}{ 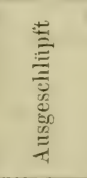 } & \multirow[b]{2}{*}{ 莣 } & \multicolumn{3}{|c|}{$\mathrm{T}$ a g e } & \multirow[b]{2}{*}{$\begin{array}{l}\stackrel{\Xi}{\Xi} \\
\Xi \\
\Xi\end{array}$} \\
\hline & & & & & & 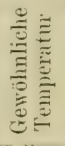 & $\stackrel{\overrightarrow{0}}{0}$ & 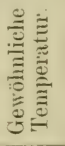 & \\
\hline 26. IX. & 27. XI. & 1. I. & 9. I. & 28.1. & $\sigma^{\pi}$ & (i2) & 35 & 8 & 19 \\
\hline$"$ & 一 & - & 29.1. & 9. II. & 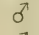 & - & - & 125 & 11 \\
\hline 17. IX. & - & - & $"$ & $"$ & $\delta$ & $\cdots$ & - & $1: 34$ & 11 \\
\hline 26. IX. & - & - & $"$ & 11. II. & $\sigma$ & 一 & - & 1.25 & $1: 3$ \\
\hline " & - & - & " & $"$ & $\sigma^{\pi}$ & - & - & 125 & $1: 3$ \\
\hline$"$ & 27. XI. & 1. I. & 9. I. & 1:3. II. & $\sigma^{7}$ & (i2) & 35 & $\therefore$ & 35 \\
\hline$"$ & $"$ & $"$ & $"$ & 14. II. & $\sigma^{\pi}$ & 62 & 涪 & 8 & 36 \\
\hline 28. IX. & $"$ & $"$ & $"$ & 15. II. & $\sigma$ & 62 & 35 & is & $: \because 7$ \\
\hline 6. X. & $"$ & $"$ & $"$ & 16. II. & $\sigma^{\pi}$ & 52. & 35 & $\therefore$ & :30 \\
\hline 2S. IX. & $"$ & $"$ & $"$ & $"$ & 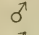 & 60 & 35 & 8 & : \\
\hline $29.1 \mathrm{X}$ & $"$ & $"$ & $"$ & 17. II. & $\sigma^{\pi}$ & 5!) & 35 & is & 39 \\
\hline 6. X. & $"$ & $"$ & $"$ & $2: 3$. II. & $\sigma^{\prime \prime}$ & 52 & 35 & 8 & 45 \\
\hline 26. IX. & $"$ & , & 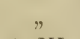 & 28. II. & $\sigma^{\pi}$ & 62 & 35 & 8 & 50 \\
\hline 2. X. & - & - & :3. III. & 11. III. & $\sigma$ & - & $\cdots$ & 152 & 8 \\
\hline 26. IX. & - & 一 & $"$ & $"$ & $\delta$ & - & - & 158 & 8 \\
\hline $28 . \mathrm{IX}$ & - & - & 29.1. & 9. II. & q & - & - & 1::; & 11 \\
\hline 14. IX. & 27. XI. & 1. I. & 9. I. & $"$ & $q$ & 74 & 35 & 8 & 31 \\
\hline 15. IX. & - & - & 3. III. & 9. III. & q & - & - & 169 & 6 \\
\hline 2. X. & - & - & $"$ & 10. III. & q & - & - & 152 & 7 \\
\hline $26 . \mathrm{IX}$ & - & - & $"$ & 11. III. & q & - & . & 158 & $\therefore$ \\
\hline
\end{tabular}


A. Jacobi (1589. 407) trug den sidne rom der Erile, in welcher Fidonia pinirria L. sich rerpuppte, wew, und fanil, dlass fast alle Puppen nachher starhen. Puppen, dp Einwirkung des Frostes ansgesetzt, wurlen anfangs lles Winters mit Reif währenı einer Yacht bedeckt umi konntrn nach dem allmähligen Auftanen in schnee und nachlier im Zimmer nicht mehr aufgelebt werden.

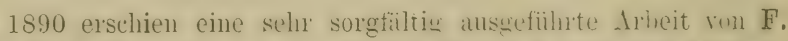
Urech (889), für welche er das nüthige Material schon seit 1881 zu sammeln begonnen hatte.

Sofort nach dem Entschliipfen des Riannehens ans tem Li. wurle das Räupchen gewogen, was anch in den folgement litgen geschah, his es sich verpuppte. Es wurlen zwei l'arallelversuche angestellt, ein Tersuch bei $150 \mathrm{mul}$ einer hei $25^{\circ}$. Folgente Tahelle enthält die erhaltenen Resultate:

Phatera bucepthala-liaupen.

\begin{tabular}{|c|c|c|c|c|}
\hline \multicolumn{2}{|c|}{ Da $t u m$} & $\begin{array}{l}\text { Zeitdauter } \\
\text { in Tagen }\end{array}$ & $\begin{array}{l}\text {.le } 1 . \\
\text { Gewicht der im } \\
\text { Kühlfass zwi- } \\
\text { schen } 10^{\circ}-15^{\circ} \\
\text { gefütter. Raupe }\end{array}$ & $\begin{array}{l}\text { Gewiclit der im } \\
\text { Thermostat bei } \\
\text { ca. } 28^{\circ} \text { gefitter- } \\
\text { ten Raupe }\end{array}$ \\
\hline \multirow[t]{13}{*}{ 1889. J } & \begin{tabular}{r|}
4. \\
16.
\end{tabular} & $\begin{array}{c}0 \\
12\end{array}$ & $\begin{array}{c}\text { aus den Eier } \\
0,0051\end{array}$ & $\begin{array}{l}\text { gekroclien. } \\
0,0768\end{array}$ \\
\hline & 19. & 15 & 0.0077 & 0,1772 \\
\hline & 20. & 16 & 0,0085 & 0,3204 \\
\hline & 22. & 18 & - & 0,3862 \\
\hline & 23. & 19 & - & $0,70>5$ \\
\hline & 24. & 20 & 0,0103 & 0,7374 \\
\hline & 25. & 21 & - & 0,9278 \\
\hline & $26:$ & 22 & 0,0154 & $0,082 t$ \\
\hline & 27. & 23 & - & 0,8682 \\
\hline & 28. & 24 & - & 0,7846 \\
\hline & 29. & 25 & - & 0,7066 \\
\hline & 30. & 26 & 0,0356 & 0,5855 \\
\hline & 31. & 27 & - & crepiert. \\
\hline \multirow[t]{6}{*}{ August } & 3. & 30 & $0,040 \bar{\tau}$ & \\
\hline & 6. & 33 & $0,10+2$ & \\
\hline & 9. & 36 & 0,1462 & \\
\hline & 12. & 39 & 0,1520 & \\
\hline & 15. & 42 & 0,2016 & \\
\hline & 16. & 43 & 0,2482 & \\
\hline
\end{tabular}




\begin{tabular}{|c|c|c|c|c|}
\hline \multicolumn{2}{|c|}{$P a t u m$} & $\begin{array}{c}\text { Zeitdauer } \\
\text { in Tagen }\end{array}$ & $\begin{array}{l}\text { Nì } 1 \text {. } \\
\text { Gewicht der im } \\
\text { Kühlfass zwi- } \\
\text { schen } 10^{\circ}-15^{\circ} \\
\text { gefütter. Raupe }\end{array}$ & $\begin{array}{l}\text { di } 2 . \\
\text { Gewicht der im } \\
\text { Thermostat bei } \\
\text { ca. } 28^{\circ} \text { gefütter- } \\
\text { ten Raupe }\end{array}$ \\
\hline \multirow[t]{14}{*}{ August } & 17. & 44 & 0,3078 & \\
\hline & 18. & 45 & $0,384.2$ & \\
\hline & 19. & 46 & 0,5272 & \\
\hline & 20. & 47 & 0,5112 & \\
\hline & 22. & $\left.48^{2}\right)$ & 0,5132 & \\
\hline & 24. & 50 & 0,8296 & \\
\hline & 25. & 51 & 1,0106 & \\
\hline & 26. & 52 & 1,2012 & \\
\hline & 27. & 53 & 1,3762 & \\
\hline & 28. & 54 & 1,5700 & \\
\hline & 29. & 55 & $1.67: 34$ & \\
\hline & 30. & 56 & 1,7982 & \\
\hline & 31. & 57 & 2.0478 & \\
\hline & 2. & 59 & $\begin{array}{c}\text { Saftabgabe } \\
\text { vorangehend. } \\
1,5550 \\
\text { Puppe. }\end{array}$ & \\
\hline October & 28. & 115 & $1 .(1500$ & \\
\hline November & 29. & 147 & 1.0082 & \\
\hline Januar & 3. & 182 & 1,0000 & \\
\hline \multirow[t]{2}{*}{ März } & 1. & 239 & $0.970-4$ & \\
\hline & $2 \pi$. & 265 & 0.9240 & \\
\hline
\end{tabular}

Die bei höhere 'Temperatur gefiitterte liaupe gieng leider vor ther Verpuppung zu Grumle, die Vergleichung mit der amleren bei niederer Temperatur gefiitterten Raupe kann also nur lis dahin, wo erstere ilı Gewichtsmaximum erreichte, das ist bis zum 25. Juli. gefïhrt werden.

I)ic Tabelle zeigt, lass die erste liaupe nach 21 'Tagen rom Auskriechen an gerechmet $0,9278 \mathrm{gr}$. wog, die antere bei nienterer Temperatur gefütterte nu 0,0125 gr., also nur etwa den 75 . Theil lavon; erst nach 33 Tagen (am 6. August), odler nach $3 \frac{3}{2}=1,6$ mal so langer Zeit war sie eben so schwer.

Um die Entwickelung der Puppe in jerlem gegebenen Momente kimnen zu lernen, hat er die successive (iewichtsalmahme der l'uppe bei verschielenen Temperaturen jerlen Tag hestimmt.

$\left.{ }^{2}\right)$ Offenbar ein Fehler beim Beobachter. 
Seme Versuche stellte er mit Puppen ron Pieris hrasicace an, leren Raupen Mitte September gresammelt wurlen Die Wägung wurde erst $1^{1}$ : Monate nach der Verpuppung vorgenommen. Die Temperatur, bei welcher die Puppen sich befanden, war:

1) variierende Wintertemperatur im Freien:

2) zwischen $8^{\circ}$ bis $12^{\circ} \mathrm{C}$. schwankende 'Temperatur,

3) " $12^{0}, 18^{0} "$ Zimmertemperatur.

Aus den beigelegten Curven sind die erhaltenen Resultate ersichtlich, wobei die Abscisse die Zeitilaner in Tagen, die Ortinate die successive procentische Gewichtsalmahme beleuten.

Daraus ist ersichtlich, dass die Geschwinligkeit der procentischen Gewichtsabnahme gegen clas Enile der Puppenzustaniles hin, sowohl bei schwankender als auch ziemlich constanter äusserer Temperatur, zunimmt; besontlers stark ist diese Zunahme bei der Wintertemperatur.

Ausserdem hemerken wir, dlass die grösste Gewichtsabnahne bei derjenigen Puppe stattfindet, welche einer höheren Temperatur ausgesetzt wurile. Dies berleutet aber, wie bereits Blasius (1866. Si) zeigte, dlass auch die Entwickelung der Puppe unter diesen Umstiiiilen rascher vor sich geht.

Das die stïrkere Gewichtsabnahme gegen Ende des Puppenzustandes hin nicht etwa nur die Wirkung des Frihlingstriebes ist, wurde rom Urech durch folgentlen Parallelversuch bewiesen:

"Im Monat April wurlen zwei Puppen, von lenen die eine schon durch das beginnente stärkere Steigen ihrer Curve die Xähe des Auskriechens des Schmetterlinges andeutete, ganz gleichen ïusseren Temperaturzuständen ausgesetzt, lennoch wurde die Differenz der procentischen Gewichtsabnahme beider Puppen fortwährenıl grösser, obschon gerade während dieser Tage die Frühlingstemperatur, ler sie ausgesetzt waren, in Winterkälte umschlug" (p. 339).

Ausserlem hat er die Puppe von Orgyia antiqua im Thermostat bei $30^{\circ}$ gehalten und eine Generation mehr bekommen, als es im Freien geschieht. Die Raupen wurden bei diesem Versuch auch bei $30^{\circ}$ gezogen. Die Raupenzeit dauerte dabei 21 Tage, die Puppenzeit nur ca. 10 Tage. Aus Eiern, welche im das Thermostat nicht gebracht waren, schliipíten bis zum März des folgenilen Jahres noch keine Räupchen.

W. Schmujdsinowitsch (1891. 756) beobachtetete, dass Seidenraupen bei $0^{0}$ bis $-4^{0} \mathrm{R}$. in den Zustani des lethargischen Schlafes 
verfallen, wobei der Stoffwechsel bei ihnen aufhört. IDieser Zustand kann mindestens $3-4$ Tage dauern. Bei iler Temperatur von 6 bis $7^{\circ} \mathrm{R}$. beginnt der Stoffwechsel vor sich zu gehen, wem auch in geringerem Maase, so dass $10 \%$ der Raupen einen $20-23$ tägigen Hunger auszuhalten vermögen (gelbe französische Rasse). Der Stoffwechsel wird bei 12 bis $14^{\circ} \mathrm{K}$. ziemlich bedeutent, so dass nach 4 tägigem Hunger ea. $13 \%$ und nach 15 tägigem Hunger ca. $93 \%$ ler Raupen zu Grunte gehen. Bei der Temperatur von $20^{\circ} \mathrm{R}$. werden die Lebensprocesse so intensiv, lass beim Hungeru $94^{\circ}$, der Raupen sterben. Je älter die Raupen sind, lesto weniger sincl sie empfindlich gegen das Hungern.

Ausserlem stellte er Versuche mit japanischer weissen liasse bei erhöhten Temperaturen an. Die Raupen, welche leei $25-30^{\circ} \mathrm{I}$. gezogen wurlen, verpuppten sich nach 15 Tagen. Bei der Temperatur, höher als $32^{\circ} \mathrm{R}$., erkrankten sie und starben.

Fr. Ball (1891. 47) experimentierte mit Iaupen und Puppen von Papilio machaon, inclem er sie eine gewisse Anzahl von Tagen in der Temperatur von $39^{\circ}$ hielt. Dabei erhielt er folgencle liesultate:

Wintergeneration.

\begin{tabular}{|c|c|c|c|}
\hline \multirow{2}{*}{$\begin{array}{c}\text { Ne des } \\
\text { Versuches }\end{array}$} & \multicolumn{2}{|c|}{ Wieviel Tage in $39^{\circ}$} & $\begin{array}{c}\text { Ruhezeit } \\
\text { der Puppen } \\
\text { in Tagen }\end{array}$ \\
\cline { 2 - 4 } & Raupe & Puppe & \\
\hline 1 & 1 & 50 & 250 \\
2 & 2.3 & 48 & $2: 35$ \\
3 & 6 & 44 & 246 \\
4 & 10 & 41 & 25.3 \\
5 & 12 & 39 & 241 \\
6 & 15 & 36 & 245
\end{tabular}

Sommergeneration.

\begin{tabular}{|c|c|c|c|c|c|c|c|}
\hline \multirow{2}{*}{ 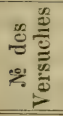 } & \multicolumn{2}{|c|}{$\begin{array}{l}\text { Wieviel Tage } \\
\text { in } 39^{\circ}\end{array}$} & \multirow{2}{*}{$\begin{array}{l}\text { Ruhezeit } \\
\text { der Puppe } \\
\text { in Tagen }\end{array}$} & \multirow{2}{*}{ 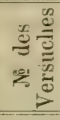 } & \multicolumn{2}{|c|}{$\begin{array}{l}\text { Wieviel Tage } \\
\text { in } 39^{\circ}\end{array}$} & \multirow{2}{*}{$\begin{array}{l}\text { Ruhezeit } \\
\text { der Puppe } \\
\text { in Tagen }\end{array}$} \\
\hline & Raupe & Puppe & & & Raupe & Puppe & \\
\hline 7 & - & 7 & 7 & 14 & 7 & 6 & 28 \\
\hline 8 & 2 & 7 & 7 & 15 & 8 & .6 & 28 \\
\hline 9 & 8 & 7 & 7 & 16 & 4 & 6 & 256 \\
\hline 10 & 7 & 7 & 7 & 17 & 8 & 2 & 256 \\
\hline 11 & 12 & 7 & 7 & 18 & 1 & 7 & 217 \\
\hline 12 & 5 & 6 & 32 & 19 & 15 & 5 & 244 \\
\hline 13 & 7 & 6 & 32 & & & & \\
\hline
\end{tabular}

Bachmetjew, Studien. II. 
Bei Versuchen di: 16, 1\%, 18 und 19 wurden die Puppen zufällig über $40^{\circ}$ erwärmt umıl dlann, wie auch ılie anderen, bei 15 bis $20^{\circ}$ liegen gelassen.

I)araus folgt, dass die Wirkung der Temperatur über $40^{\circ}$, lie Entwickelung der Puppen hemmt und ihnen solche Eigenschaften mittheilt, welche nur den Winterpuppen eigen sind.

Die Kontrolversuche ergaben, lass Puppen und Raupen, bei gewöhnlicher Temperatur (10 bis $15^{\circ}$ ) erzogen, folgende Zeit für die Puppenruhe zeigen: für die Wintergeneration 241-24.; Tage, für die Sommergeneration 14-15 Tage.

E. Wasmann (1891. 944) legte, um ،lie Ameisen zu lebhaiterer Thätigkeit anzuregen, erwärmte (ilasplatten auf die obere Gilasscheibe ler Nester, wobei die gewöhnliche Arlueiterinnen schon nach einer Woche, spätestens imerhalb 14 Tagen Eier ablegten. "Diese Versuche zeigen, dass anormale Wärmeverhältnisse wenigstens bei man. chen Ameisen eine der Ursachen sind, durch welche hei gewöhnlichen Arbeiterimnen dic Parthenogenesis hervorgerufen orler wenigstens sehn beförlert $\operatorname{wirl}^{\star}$ (p. 23).

F. Merrifield (1891. 567) setzte einen Theil der Puppen von P. falcutaria am 19. April der Temperatur von $26,7^{\circ}$ aus und beliess den anderen Theil im Freien. Die ersten Puppen ergahen Falter nach j-9 Tagen und die letzten erst am 21.-29. Mai.

Er setzte die Puppen von Vanessa urticae der Temperatur von ca. $27^{\circ}$ aus und erhielt Falter bereits nach 5-6 Tagen. 42 Puppen. bei $8,2^{\circ}$ gehalten, ergaben Falter nach $52-58$ Tagen. 9 Puppen bei $8,2^{\circ}$ ergaben Falter nach $60-67$ Tagen.

17 Puppen von Vanessa urticae, welche nur einige Stumlen alt waren, schlïpften in ler Temperatur von $8,2^{\circ}$ nach $20-42$ Tagen aus.

Puppen der gleichen Species, aber einige Tage alt, ergaben Falter bei 26,70 nach 6-7 Tagen (22. September); im Freien (ca. $5,7^{\circ}$ ) schliupten sie erst nach 3 -5 Wochen aus. Bei einer Temperatur von $8,2^{\circ}$ nach $3-7$ Wochen.

Die Puppenzeit von Bombyx quercus bei 26,70 betrug 29-40 Tage und bei $8,2^{\circ} 39-71$ Tage. Bei var. calumae betrug diese Zeit 29-42 Tage bei $26,7^{\circ}$.

Puppen von Arctia caja, in die Temperatur von $+0,5^{\circ}$ gebracht, starben alle nach einiger Zeit; bei (ler Temperatur von $8,2^{\circ}$ 
ergaben einige Puppen verkrüppelte Falter, die übrigen starben. Bei der Temperatur von $10^{0}-15^{\circ}$ starben die Puppen auch, aber nicht alle: erst bei $26,7^{\circ}$ ergaben alle Puppen Falter, aber es waren nur Männchen.

Die Puppenzeit ron Melitaen cynthia betrïgt bei 26,70 5 -6 Wochen, währenıl dieselbe in der freien Luft ca. 4 Monate dauert.

M. Bellati und E. Quajat (1S92. 61) untersuchten die Einwirkung der erhöheten Temperatur der umgebenden Luft und Wasser auf die vorzeitige Entwickelung der Eier von Bombyx mori und fan„len, da die erhöhte Temperatur stärkeren Einfluss auf die Entwickelung der Eier hat als andere Agentien, dlass dieser laktor ein nothwendiges Element und vielleicht die einzige Lrsache darstellt, welche die gesagte Erscheinung hervorruft. Sie kamen zu dem Schlusse, dass die vorzeitige Entwickelung der Eier durch eine starke Temperaturerhöhung in irgend einem Punkte des Embryos berlingt wird.

J. G. Alibegow (1892. 8) beobachtete die vorzeitige Ausbriitung am 5. Juni (alt. St.) bei (ler transkaspischen Rasse und am 20. Juni bei rler gekreuzten weissen baglarler Rasse. Die Temperatur in dem Raume, wo diese Eier (von Bombyx mori) aufbewahrt waren, erreichte zu dieser Zeit $20^{\circ} \mathrm{R}$. Er meint, lass diese hohe Temperatur die Erscheinung hervorrief. Bei Aufzucht dieser Raupen gingen viele an verschiedlenen Krankheiten zu Grunde und die iblerlebenten lieferten Falter, aus deren Eiern die Raupen zum dritten Mal im gleichen Jahre ausgebriitet waren.

Sonier (1892. 499) verjagte alle Bienen aus einem Bienenstock: wobei die Larven in Zellen noch nicht zugemacht waren; sie entwickelten sich zu Bienen während 28 Tagen (normal 19-2*1).

W. Schmujdsinowitsch (1892. 762) in Tiflis stellte folgencle Versuche an, um die Frage aufzuklären, wie der schroffe Temperaturwechsel auf die Entwickelung der Eier von Bmmbyx mori einwirkt.

Der erste Versuch wurile Mitte December (alt. St.) 1589, un I (ler zweite Anfangs Januar 1890) angestellt, wobei in beiden Fällen folgender Maassen verfahren wurde: aus der Temperatur von $+2{ }^{0} \mathrm{I}$. wurden die Eier zuerst in die Temperatur von $+10^{\circ} \mathrm{R}$. gebracht. 
Hier wurden 8 Serien für den I. und 10 Serien für den II. Versuch, je 1000 Eier enthaltend, abgezählt. Jeile Serie befand sich in einem mit Baumwolle verstopften Probierglase. Die weiteren Manipulationen hestanden in folgenlem: heim II. Versuche $\left.{ }^{1}\right)$ wurle ein Probierglas aus $+10^{\circ} \mathrm{R}$. in die Temperatur von $+20^{\circ} \mathrm{R}$. (Brutofen) grebracht. währenil das andere Probierglas zuerst i Minuten im schmelzenden Schnee sich befanı und dlann in den erwähnten Brutofen plaziert wurle. Die iibrigen Probiergläser wurten in einem Gefäss mit Wasser. von $+10^{\circ} \mathrm{R}$. liegen gelassen, wonach es imnerhalb. ; Stunlen erwärmit wurde, bis die Temperatur des Wassers 450 R. hatte. Nachilem die Temperatur $20^{\circ},: 30^{\circ}, 40^{\circ}$ und $4.5^{\circ}$ erreicht hatte, wurlen aus dem Gefässe je 2 Probiergläser herausgenommen, wobei eines derselben lirekt in den Brutofen, währeml das antlere zuerst in den schmelzenclen Schnee $\left(2^{\prime}\right)$ gebracht wurile. Beim I. Versuche wurlen die Probierglïser aus der Temperatur von $+11^{\circ} \mathrm{R}$. in den Schnes? niclit gebracht, und das Eintauchen begann vom Momente an, als clie Temperatur $+20^{\circ} \mathrm{R}$. erreichte. Die Temperatur des Brutofens hetrug die ganze Zeit $20^{\circ} \mathrm{R}$. Die Raupen begammen im ersten Versuche am 30. December (alt. St.) und im zweiten am 18. Januar auszuschliipfen, wobei die Beobachtungen 12 resp. 17 Tage danerten. und rlas Zählen der Raupen stets um y Uhr vorgenommen wurle.

Folgende Tabellen ergeben ıie Anzahl ıler ausgeschliipften Raupen jerlen Tag:

Temperatur-

schwankungen.
Der. I. Versuch. authewaht.

$\left.{ }^{2}\right)$ Die Fier des II. Versuches wurden bis zu seinem Anfange bei $2^{\circ}-3^{\circ} \mathrm{R}$.

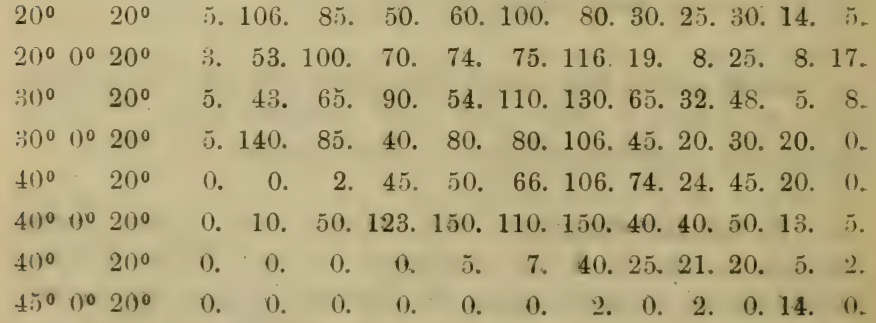


'lemperatur-

schwankungen.

Der II. Versuch.

$10^{0} \quad 20^{0} \quad 10.27 .74 .74 .70$. 90.66. 60.50.66.35.20.30.20.20.10.10. $10^{0} 0^{0} 20^{\circ} \quad 6.10 .36 .60 .30$. 74.58. 60.74.77.36.50.50.20.25.16.2. $20^{\circ} \quad 20^{\circ} \quad 6.40 .87 .36 .50 .110 .70,48.48 .(30.50 .44 .44 .17 .20,(1) .10$. $\left.20^{\circ} 0^{\circ} 20^{\circ} \quad 0.30 .70 .77 .40 .64 .66 .50 .53 .64 .30 .35 .64 .20 .35 .1\right) .5$. $30^{\circ} 20^{\circ} \quad 0.13 .65 .32 .60$. (33.65. 61.20.32.60.72.50.(i3.23. (i. 9. $30^{0} 0^{0} 20^{\circ} \quad 2.14 .74 .35 .50$. 80.35. 40.64.30.80.40.50.24.40.10.10. $400 \quad 200$ (). 3.14.25.39. 63.93. 99.69.69.58.44.52.16i.4(i.16. 5. $40^{\circ} 0^{0} 20^{\circ} \quad 0.5 .19 .34 .43$. 80.93.105.80.83.61.1i0.62.19.45. 8. : $45^{0} \cdot 20^{\circ}$ 0. 0.0 .0 .0 . 6. 0. 10.10.20.13.13. (i.10. 6. 0. 2.

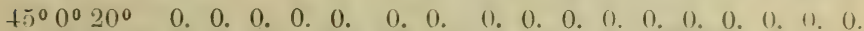

Wenn man die angefiihrten Zahlen bei dem I. Versuche je : Tage und bei dem II. je 4 Tage summiert, so erhält man folgente abgekïirzte Resultate:

\section{Der I. Versuch.}

Die Anzahl der ausgeschlüpften Raupen.

T'emperaturschwankungen. $20^{\circ} \quad 20^{\circ}$ $20^{\circ} 0^{\circ} \quad 20^{\circ}$ $30^{\circ} \quad 20^{\circ}$ $30^{\circ} \quad 0^{\circ} \quad 20^{\circ}$ $40^{\circ} \quad 20^{\circ}$ $40^{\circ}\left(0^{0} 20^{\circ}\right.$ $45^{\circ} \quad 20^{\circ}$ $45^{0} \quad 0^{0} 20^{\circ}$
1-3 Tage. 4190 . 156 119. 230.

2. 161 .
60.

$0 . \quad 12$.

0. 383

$$
210 .
$$

219.

254.

200.

0 .

135.

145 . 227.

164. 204. 238.

94.

4.
Nicht Nicht entwick. ausreselil.

\section{Der II. Versuch.}

1-5 Tage, 6 -9 Tage. 10-13 Tage. 14-17 Tage. Summe. Nicht Nieht

$10^{\circ} \quad 20^{\circ}$

$10^{\circ} 0^{0} 20^{\circ}$

$20^{\circ} \quad 20^{\circ}$

$20^{\circ} \quad 0^{\circ} \quad 20^{\circ}$

$30^{\circ} \quad 20^{\circ}$

$30^{0} \quad 0^{0} \quad 20^{\circ}$

$40^{0} \quad 20^{\circ}$

$40^{\circ} \quad 0^{\circ} 20^{\circ}$

$45^{\circ} \quad 20^{\circ}$

$45^{\circ} 0^{\circ} 20^{\circ}$ .225 .

142. 219. 217. 170. 175 .

81. 101.

0. 266. 266. 151. 213. 276. 198. 233. 193. 209.214. 219. 210. 324. 223. 358. 266. 26. 52.

0 .

0 .
60.

(i3.

47.

60.

101.

84.

83.

75 .

18.

0 .

0.

702. 200 .

98. 684. 166.150 . 740. 140. 120 . 673. 180. 147 . 694. 150. 156 . 688. 151. 161 . 711. 162. 127. 800.143 .57$. 96. 6i99. 205.

0. 1000.0 
Dieser Forscher kommt zu folgenden Schlüssen:

1). I)ie Eier dieses Spinners komnten in cliesen Versuchen sogar die T'emperatur von $45^{\circ} \mathrm{R}$. aushalten. (Im I. Versuche entwickelten sich $13,3 \%$, im II. 9,6\% aller Eier).

2). Die Erwärmung über $20^{\circ} \mathrm{R}$. unil besonilers von $30^{\circ}$ an verminlert im Allgemeinen die Anzahl der ausschlïpfenden Raupen.

3). Das Eintauchen (ler Eier, welche bis zu $+30^{\circ}$ ) crwärmt wurden, in Schnee erzeugte die gleiche Wirkung, währenıl die Ahkühlung von $30^{\circ}$ bis auf $0^{\circ}$, besonders aber von $40^{\circ}$ an, das Ausschlïpfen der Raupen beschleunigte.

A. de Caradja (1892. 129) theilt n!it, llass 1592 lie Hitze in Rumïnien in Juni sehr gross war und die Flugzeit einzelner Arten mindenstens um 14 Tage früher auftrat als sonst. Es ist auch die II. Generation beobachtet worilen und zwar:

Polyommatus var. rutilus im Juni und dann wieder im Septem.

Orgyiu antiqua Ende Juli und dann wieder am 22. September.

Sphinx linnstri fing er am 19. September, Deilephilu galii am 21. September, Macroglossa fuciformis am 26. August; Papilio podratirius zweite Generation ab. zanclaeus erschien bereits Anfang Juli unl dann wieder im September. Colias ectusa ab. helice war in diesem Jahre nicht selten und er sagt: "Helice scheint mir nur ein Pro:luct grosser Wärme zu sein; was mich in lieser Meinung bestärkt, ist der Umstand, dass ich von Toulouse, Cahors, Merens, Anch (und auch von hier) eine ganze Reihe von Exemplaren besitze, die den schönsten ununterbrochenen Uebergang von edusa bis zur typischen helice bilden" (p. 125).

Ein Gegensatz zu diesen Beobachtungen ist die Thatsache, dass von 200 Puppen (Zucht 1892) von Spilosoma mendicu var. rustica kein einziger Schmetterling in II. Generation schlüpfte, während er im September 1891 Raupen dieser Form fand.

R. Berger (1892.72) setzte die Eier von Angerona prunaria L. nach vollzogener Ablage in einem Keller mit $2^{\circ}(\mathrm{R}$ ?) Temperatur der Einwirkung derselben 8 Tage lang aus; dabei blieben $4-10^{\circ}$ 。 ler Eier ohne Entwickelung. Wartet man das Auskriechen der Räupchen nur bei dieser Temperatur in Keller ab, so versagen sogar $50-60 \%$.

$\left.{ }^{2}\right)$ Ist oftenbar ein Fehler. 
F. Rühl (1892: 722) bringt in Zusammenlang mit der hohen Temperatur, welche im Juli und August 1892 andauerte, die beschleunigte Entwickelung folgeniler Insekten: Melithaea cinxia, welche in der Schweiz nur in einer Generation fliegt, wurle am 22. August als II. Generation gefangen; lasselbe bezieht sich auf Melithaea diclyma. Mitte August wurle Melitaea dictynna und parthenie erbeutet, welche als II. Generation nicht vor 12. September auftreten. Thel. athalia II. Generation, welche sonst unbekannt ist, fing er am 27. August. Raupen von Bombyx rubi und Nem. russula. erster sonst im Oktober, letztere erst im nächsten April orler Mai erwachsen, traf man Ende August bereits ganz ausgewachsen an.

Auch in Sussari (Italien) entwickelten sich Papilio Imspiton statt im Mai 1893 im August 1892. Lygris testutu, sonst wie vor Encle September bei Zürich gefangen, wurcle bereits an 25. August gefangen.

Strohmayer (1892. 848) fand am 2. August 18926 Stiick fast erwachsene Raupen von Deilephila euphorbiae, welche sich am 6 . bis S. August verpuppten unl am 20. August den besten Schmetterling ergaben. Diese beschleunigte Entwickelung erklïrt er mit ler tropischen Hitze, welche in Sommer herrschte.

Fr. Schille (1892. 749) hielt die Puppen von Cidariı lugu lirata Stgr. (luctuatr Hb.) seit Anfang Januar im giheizten Zimmer und erhielt bereits am 17. Februar Falter.

F. Rühl (1892. 724) beobachtete, dass die Raupen von Brmbyx arbusculue Frr. in der Ebene heisse Sonne zu ihrer Entwickelung bediurfen. Kurze Zeit vor Sonnenuntergang, ja im Moment, wo eine Wolke vor dlie Sonne trat, hörte die Bewegung der Raupen sofort auf.

A. Benteli (1893. 69) fing bereits am 11. Mai 1893 Falter von Parnassins "poll" an einem Ort des Bielersees. In April und Anfangs Mai fing er in Bern Sphiner pinastri und Deilephilu porcellus, auch guttu, ludificu, coenobita, milhauseri, fucti. matromulı (17. Mai), Sphinx ligustri, Surerinthus tiliae, Dasychira pudibuntu, Agrotis exlamationis und $\quad$. nigrum. Diese frihzeitige Entrickelung: find statt wahrscheinlich in Folge der ungewöhnlich heissen Witterung.

Auch C. Frings (1893. 250) beobachtete in Bonn, dlass alle Arten in gleichem Jahre 14 Tage früher erschienen als sonst. 
J. Heissler (1893. 361) zog 1893 Antherea permyi ex oro und erhielt 3 Wochen nach dem Einspinnen Schmetterlinge. „Die Ursache dieser Erscheinung ist wohl die grosse Wärme des heurigen Sommers" (p. 97).

Zeselski (1893. 966) sagt, tlass the Temperaturerniedrigung die Fntwickelung der Bienen um drei Tage vorzïgert.

Max Fingerling (1893. 225) nahm Encle November verschiedene laupen, welche sonst überwintern, brachte sie in Februar, wenn möglich noch früher, wieder ans Futter und beschleunigte dadurch das Verpuppen um eine ganze Reihe von Wochen.

Es gelang ihm, in Herbst gesammelte und im warmen Zimmer gezogene fiaupen bald zur Terpuppung zu bringen und bereits im December entwickelte Falter zu erhalten. „Die Metamorphose wurile, vom August bis December gerechnet, in vier Monaten erreicht, während die gleichen Thiere im Ireien zu ihrer Entwickelung rom Angust bis Mai und Juni des folgenten Jahres, also ungefihr neun Monate, nöthig haben" (p. 197).

Bis jetzt gelang es ihm, solche heschleunigte Entwickelung nur bei Alyrotis triangulum. Nuenia typicu und Temeophila plantayinis zu erreichen; bei letzterer Art erhielt er sogar eine drei- bis vierfache Generation an Stelle einer einmaligen. Seine Freunde brachten Raupen aus dem Genus A!frotis. prombu und fimbria, die aus dem Ei gezogen waren, bereits vor Herbst zum Falter.

Solches Forcieren in der Entwickelung vertragen nur wenige Arten: "Plusiu chrysitis, die Leucanien, die übrigen Agrotis- und Bären-Arten werden sich nach meiner Erfahrung nie und nimmer hierzu verstehen, sagt Fingerling (p. 198).

Auch Schlupfwespen nehmen in gleichem Schritte an der kiinstlich forcierten Entwicklung ihrer Wirte teil.

S. N. Kamensky (18!)3. 434) zog Raupen voll Bomlyyx mori bei $9^{0}$ bis $11^{\circ} \mathrm{I}$. unl später bei $13-14^{\circ} \mathrm{R}$., wobei die Dauer jedes Alters fast iloppelt so lang wurde, als bei der normalen Aufzucht. Dalei wurilen die Raupen mit Blättern von Paraxacum officinale gefüttert.

F. Merrifield (1893. 568) hielt die Puppen ron Chrysophams phlaeus 10 Wochen auf Eis und tamn bei $30^{\circ}$, wobei sie in $5-6$ Tagen Falter ergaben. Die Puppen derselben Art, 10 Wochen bei $4^{0}$ 
und dann 5 Wochen bei $13^{\circ}$ gehalten, ergaben $50 \%$ verkrüppelte oder tolte Falter; in der letzten Temperatur schliipften die Falter nach $34-36$ Tagen aus.

C. von Hormuzaki (1893. 390) machte die Beobachtmmg, lass die Eulen (Tacn. stalitis, gothica, Scop. satellitu etc.) im April bei $+3^{\circ} \mathrm{R}$., heftigem Wind und etwas Regen an Ködler in Menge zuflogen. Erst bei einer Temperatur von $0^{\circ}(14$. April) fand er nichts mehr.

Iw. Schewyrew (1893. 748) sagt, dass die Raupen voll limms ulmi Schif. von einem Waldrayon bis zum anderen während des Tiges mit verschiedener Geschwindigkeit sich bewegen: dieselbe nimmt nach dem Sonnenaufgange mit steigender Temperatur zu, erreicht um 3-4 Nachmittags ein Maximum, und nimmt wieder ab. Nachts liriechen die Raupen nicht mehr.

Er beobachtete auch, dass die halberwachsenen Raupen von Bocrmia crepusculuriu IV. V. sehr stark lurch die am 1./13. Mai. 1890. herrschenden Kälte gelitten haben.

Als die durch Larven von Magdalis aberimu L. angestecliten Holzstiicke Nitte Juni (alt. St.) der Einwirkung (ler Sonne ausgesetzt wurden, starben alle darin befindlichen Larven.

G. Selmons (1894. S04) züchtete die Raupen von Parnassius apoll, und beobachtete dabei, dass die Raupe in dem kurz vor der Verpuppung gemachten lockeren Gespinst bei warmem Sonnenschein schon nach einem Tage die Puppe und nach 8 Tagen den Falter ergeben kann; bei regnerischem, kaltem Wetter aber oft erst nach 18 Tagen die Puppe und nach 7 Wochen den Falter ergielst.

F. Merrifield (1894. 570) brachte Anfangs September clie Puppen von Pieris napi in die Temperatur von $32^{\circ}$, wo sie 10 Tage verblieben. Dies hatte jerloch keinen Einfluss auf die Beschlemigung der Entwickelung.

3 levana-Puppen wurlen im Sommer der Temperatur von 26,70 ausgesetzt. Die Entpuppung trat schon nach $6-7$ Tagen ein. 4 von ihnen brachte er am 18. Juli in die Temperatur von $8,2{ }^{\circ}$ wo sie bis zum 30.-31. August lebten (73-74 Tage); vor dem Ausschliupten wurden sie ins Zimmer (ca. $19^{\circ}$ ) gebracht, wobei nach $1-2{ }^{2}$ Tagen das Ausschlüpfen stattfancl, nur 1 Exemplar entpuppte sich erst nach 32 Tagen (am 2. Oktober). 
3 levana-Puppen verbrachten bei $+0,5^{\circ} \$ 4$ Tage (bis zum 29. September), darauf blieben sie 20 Tage bei $8,5^{\circ}$ und schliesslich im Zimmer bei $59^{\circ} \mathrm{F}$. Das Ausschlïpfen im Zimmer erfolgte nach 10 , 18 und 20 Tagen.

16 io-Puppen blieben 6 Tage bei $32^{\circ}$ unil nacher bei $26,7^{\circ}$. Die Puppenzeit dauerte im Ganzen 7 Tage.

Puppen von Vanessa atalnuta (aus Berlin), welche von solchem Alter waren, lass sie bei $26,7^{\circ}$ bereits nach $4-6$ Tagen Falter ergaben, wurden 27 Tage bei der Temperatur von $8,2^{\circ}$ gehalten, olme dass sie dabei irgend einen Scharlen erlitten hätten. Puppen derselben Sendung wurien nach 20 Tagen auf Eis $\left(+0.5^{\circ}\right)$ todt aufgefunden, nur ein Exemplar ergab einen verkriippelten Schmetterling.

Der Arbeit von M. Standfuss (1894. 837) .. Ueber die Grincle der Variation und Aberration des Faltersstaliums hei len Schmetterlingen" entnehmen wir folgende Resultate:

Versuche mit erhöheter Temperatur.

\begin{tabular}{|c|c|c|c|c|c|c|c|}
\hline \multicolumn{5}{|c|}{ Species } & \multicolumn{2}{|c|}{$\begin{array}{c}\text { Bei welcher } \\
\text { Temperatur be- } \\
\text { fanden sich die } \\
\text { Puppen }\end{array}$} & $\begin{array}{l}\text { Puppenzeit } \\
\text { in Tagen }\end{array}$ \\
\hline Vanessa & \multicolumn{4}{|c|}{$C$ allumm. } & \multicolumn{2}{|l|}{$87^{\circ} \mathrm{C}$} & $7-10$ \\
\hline$"$ & polyehlo & ros & & · · & \multicolumn{2}{|l|}{$\begin{array}{ll}5 \text { Tage } & 37^{\circ} \\
\text { damn } & 25^{\circ}\end{array}$} & $14-17$ \\
\hline$"$ & urticue & . & & $\cdot \cdot$ & \multicolumn{2}{|c|}{$\begin{array}{l}21 / 2 \text { Tage } 37^{\circ} \\
\text { dann } 25^{\circ}\end{array}$} & $5_{2}^{1}-61 / 2$ \\
\hline$"$ & io . . & . & & - . & \multicolumn{2}{|l|}{$\begin{array}{l}3 \text { Tage } 37^{\circ} \\
\text { dann } 24^{\circ}\end{array}$} & $7-0$ \\
\hline$"$ & antiope & - & & . & \multicolumn{2}{|l|}{$\begin{array}{l}2 \text { Tage } 37^{\circ} \\
\text { dann } 24^{\circ}\end{array}$} & 12 \\
\hline$"$ & atalanta & & · & . & \multicolumn{2}{|l|}{$\begin{array}{l}3 \text { Tage } 37^{\circ} \\
\text { dann } 24^{\circ}\end{array}$} & $6-7$ \\
\hline$"$ & cardui & . & & . & $\begin{array}{l}6 \\
12 \\
6 \\
6 \\
\text { diann }\end{array}$ & $\begin{array}{l}40^{\circ} \\
2 \cdot 2^{\circ} \\
40^{\circ} \\
22^{\circ}\end{array}$ & $10-12$ \\
\hline$"$ & $"$ & 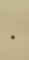 & 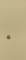 & & $\begin{array}{l}\text { 60) Stunden } \\
\text { dann }\end{array}$ & $\begin{array}{l}37^{\circ} \\
22^{\circ}\end{array}$ & $6-7$ \\
\hline Argymi & is aglaja & & - & & $\begin{array}{ll}4 \text { Tage } & 36^{\circ} \\
\text { dann } & 22^{\circ}\end{array}$ & & $5-6$ \\
\hline
\end{tabular}


Versuche mit erniedrigter Temperatur.

\begin{tabular}{|c|c|c|c|}
\hline Species & & \begin{tabular}{|} 
Wieviel Tage bei \\
$5^{0}-8^{0} \mathrm{C}$. \\
(dann bei Zim- \\
mertemperatur)
\end{tabular} & $\begin{array}{l}\text { Puppenzeit } \\
\text { in Tagen }\end{array}$ \\
\hline Vanessa $C$ album . . . . . & . . . & 28 & $35-38$ \\
\hline "polychloros ....... & . . & 14 & $21-24$ \\
\hline ..... & . . . & 28 & $37-40$ \\
\hline$" .(80 \%$ starben $)$ & . . & 42 & $55-58$ \\
\hline urticae ....... & . . . & 32 & $41-42$ \\
\hline io $(25 \%$ starben $) ..$. & . . . & 35 & $47-49$ \\
\hline$"(90 \%$ starben $) \ldots$ & .. . & 42 & $56-60$ \\
\hline 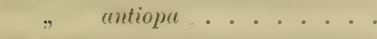 & . . & $29-34$ & $41-47$ \\
\hline$" \quad . . . .$. & . . . & 39 & $53-55$ \\
\hline ". $\quad\left(40_{0}^{\circ}\right.$ starben $)$. & . . & 44 & $59-63$ \\
\hline 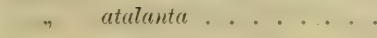 & . . . & 31 & 39 \\
\hline$" \quad . \ldots .$. & . . . & 42 & $54-56$ \\
\hline cartui........ & . . . & 23 & 35 \\
\hline$"$. . . . . . . & . . . & 28 & 38 \\
\hline Argynnis aglaja ( $85 \%$ starben) . & . . . & 28 & 40 \\
\hline$" \quad \Rightarrow \quad\left(80^{\circ}{ }_{0}\right.$ starben $)$. & . . . & 42 & 58 \\
\hline Dasychira alietis . . . . . . & . . . & 42 & $54-57$ \\
\hline
\end{tabular}

Bei dies?n Versuchen kamen ausschliesslich Puppen zur Verwendung, deren Raupen unter normalen Umständen aufgezogen wurden (Mitte Mai - Mitte August). Die Puppen waren vollkommen ausgebildet und erhärtet.

Aus diesen Tabellen ist ersichtlich, das die erhöhte Temperatur lie Entwickelung rer Puppen beschleunigt, die ernierlrigte sie verlangsamt. Diese Verlangsamung ist desto grösser, je länger die erniedrigte Temperatur einwirkt, wobei viele Exemplare zu Grunle gehen, und die Sterblichkeit wird warscheinlich auch 100\% erreichen, wenn die Einwirkungsdauer noch länger, als die in der letzten Tabelle angeführte ist.

Ausserdem zog Standfuss Falter, indem bereits vom Ei ab die hohe Temperatur zur Wirkung kam.

So brachte er die Weibchen von Arctia fasciata Esp., Dasychira abietis, Lasiocampa pruni L. und pini L. noch vor der Eierablegung in die Temperatur von $34^{\circ}$, wobei die abgelegten Eier dieser Temperatur weiter ausgesetzt wurden. Die Räupchen schliupften in $2 / 3$ der normalen Zeit aus. Darauf wurden die Raupen und die erhaltenen Puppen bei $25^{\circ}$ gehalten, und er erhielt noch in 
demsellen Jahre, also ohne Ueberwinterung der Laupen, Falter von fasciata $71 \%$, abietis $90 \%$, pruni $100 \%$, pini $80 \%$.

Bei einem zweiten Versuche befanlen sich die Eier bei $22^{\circ}$, die Raupen und Puppen dagegen wierler bei $25^{\circ}$. Ohne Überwinterung der Raupe wurle folgender Procentsatz von Faltern erhalten: fusciatu $23 \%$, abietis $12 \%$, muni $64 \%$, pini $28 \%$ : also ein wesentlich geringerer Theil als beim ersten Versuch.

In der Abhandlung: „Weitere Mittheilungenı ülser den Einflus: €xtremer Temperaturen auf Schmetterlingspuppen" von M. Standfuss (1895. 839) sind folgende Resultate zu finlen, wobei die Puppen zuerst im Eiskasten, dann im Kieller und schliesslich im Zimmer lagen:

\begin{tabular}{|c|c|c|c|c|}
\hline Species & & $\begin{array}{c}\text { Wieviel Tage } \\
\text { im } \\
\text { Eiskasten }\end{array}$ & $\left|\begin{array}{c}\text { Wieviel Tatge } \\
\text { darauf im Keller } \\
\text { (bei } 11^{\circ} \text { C.) }\end{array}\right|$ & $\begin{array}{l}\text { Puppenzeit } \\
\text { in Tagen }\end{array}$ \\
\hline Vanessa polychloros & ... & 34 & 14 & 52 \\
\hline antiopa . . & . . . & $3: 3$ & 5 & $5: 3-54$ \\
\hline atalanta. & . . . & 48 & 10 & $70-72$ \\
\hline$n \quad$ cardui.. & . . . & 33 & 5 & 47 \\
\hline Dasychira abietis. & . . . & 30 & s & $45-4 \tau$ \\
\hline Vanessa antiopa. & . . . & 10 & 0 & 16 \\
\hline
\end{tabular}

Der letzte Versuch wurile von Heppe (Rorschach) auf Anregung von M. Standfuss angestellt, wobei die Puppen in einem Holzgefässe direkt auf den Eisstücken in einem Eiskeller standen.

Wärme-Versuche sind nur mit 2 Arten angestellt.

1). Rhodocera rlumi. Puppen 48 Stunden in $39^{\circ} \mathrm{C}$., nachher im Zimmer bei $27^{\circ} \mathrm{C}$. Puppenzeit für $\delta 8$ und für 099 Tage.

2). Vanessa polychloros. Puppen 28 Stunclen in $39^{\circ} \mathrm{C}$., damn in $25^{\circ} \mathrm{C}$. Puppenzeit $10 \% / 2$ Tage.

Aus dieser Tabelle geht hervor, dass die rerzögerte Wirkung nicht dieselbe für verschierlen Vanessa-Arten ist.

F. Rudow (1894. 709) hat Xiphideia einmal im December am warmen Ofen, aus Brennholz kriechend, gefunden.

Darauf erschienen ,Nieue Versuche zum Saison-Dimorphismus (ler Schmetterlinge" von August Weismann (1895. 954). In dieser mit grosser Sorgfalt ausgeführten Arbeit befindet sich (ler VII. Abschnitt: "Wärmewirkung auf uiberwinterncle Schmetterlingspuppen." 
Verschiellene Puppen wurlen am 10. Januar 1884 in einen Brutofen mit Wasserdunstung gebracht, wobei die Temperatur 27 bis $30^{\circ}$ betrug.

Es waren folgende Arten:

1). Vanessa levanu . . . . 120 Stïck.

2). Pupilio podalivius . . . . 4 ,

3). " machainn ..... 4

4). " $\quad \operatorname{ajax} . . . . .1$. 1 ".

5). Thaix polyxena. . . . . 4

6). Doritis apollinus . . . . 4

7). Thecla rubi ...... . 1

8). Polyommatus amphidamas . 25

9). Lycaena argiolus . . . . . 4

10). $"$ iolas . . . . 4

11). Nëmeobius lucina . . . . . t

12). Pieris rapae . . . . . 12

13). "brassicue. . . . 12 ,

14). Sphinx ligustri . . . . . 2 .

15). , pinastri. . . . . 3

16). Deilephila verspertilio . . . 2

17). $\quad$, galii..... 2

18). " euphorbiae ... 20

19)., dahlii .... . 1

20). Smerinthus tiliae . . . . 4

21). $\quad$ quercus . . . 2

22).,$\quad$ populi . . . 5

Es schlïpften aus einzelne Schmetterlinge von allen Arten; notirt wurde das Datum von folgenden:

am 12. Januar 1 Doritis apollinus (verkrïppelt).

16. " 4 Polyommatus amphidamas.

17. , 3

1 Papilio podalivius.

18. " 2 " machaon.

3 Polyommatus amphidamas.

5 Pieris rapae (verkrüppelt).

5 Vanessa levana, davon 1 verkrïppelt.

19. " 1 Papilio portalivius.

6 Vanessa levana.

3 Polyommatus amphidamas.

1 Pieris rapae. 


\begin{tabular}{|c|c|c|}
\hline in 20 . & Tanuar & 1 Papilio ajax vur. telamonides. \\
\hline ." & $n$ & 5 Vanessa levana (3 verkrippelt). \\
\hline .. & " & 1 Pieris rapae. \\
\hline .. 22. & $"$ & 1 Sphinx pinastri. \\
\hline 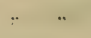 & ". & 1 Vanessa levana. \\
\hline .. & " & 2 Polyommatus amphidamas. \\
\hline . 23. & $"$ & 1 Sphinx pinastri. \\
\hline " & $"$ & 1 Polyommatus amphidamas. \\
\hline. & ,. & 1 Vanessa levana. \\
\hline 24. & .. & 1 Splinin vespertilio. \\
\hline .. & " & 1 Deilephila dahlii. \\
\hline$"$ & . & 1 Vanessa levana (verkrüppelt). \\
\hline. .28. & . & 1 Papilio podalirius. \\
\hline . & . & 1 Deilephila euphorbiae. \\
\hline .. 29. &. & 1 \\
\hline. .30. & $"$ & 2 \\
\hline$" 31$. & $"$ & 3 \\
\hline 1. & Februar & 2 \\
\hline 4. & 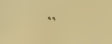 & 2 \\
\hline 6. & $\cdot$ & 1 \\
\hline.$\quad 8$. &. & 1 \\
\hline. .11. & " & 1 \\
\hline .. 12. & $\because$ & 1 Sphinx eupliorbiae. \\
\hline .15. & 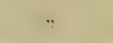 & $\because$ \\
\hline. .17. & $"$ & $" \quad$ pinastri. \\
\hline . 20. & $"$ & $" \quad$ euphorbiae. \\
\hline$" 21$. & $"$ & $1 . " \quad "$ \\
\hline " 25. & $"$ & 10 Vanessa levana (9 verkrüppelt). \\
\hline . 26. & $"$ & $" \quad$ (verkrüppelt). \\
\hline$\therefore \quad 28$. & $"$ & 1 Sphinx pinastri (verkrüppelt). \\
\hline
\end{tabular}

Daraus geht hervor, dass die Entwickelung der schon mehrere Wochen alten Puppen durch die Wärme $\left(27-31^{\circ}\right.$ C. $)$ bedeutend beschleunigt wird, „aber, wie gewöhnlich beim Treiben der Puppen, in sehr unregelmässiger Weise." Ich citiere aus diesem Buche noch folgendes:

1). Die Raupen von Chrysophanus phlaeas aus Leipzig verpuppten sich in Lindau am 15.-24. September und zwar bei Temperaturen von $27-29^{\circ}$ C. Die bei derselben Temperatur (für Feuchtigkeit der Luft war durch verdunstetes Wasser Sorge getragen) 
rerbliebenen Pupyen ergaben am 19. September - 5. Oktoher Schmetterlinge. Somit dauerte die mittlere Puppenzeit s Tage.

2). Die Raupen derselben Art, aber aus Neapler Eier'n in Freiburg i. B. aufgezogen, verpuppten sich an 25. Juli; die Puppen blieben bei der Temperatur von 70 bis $10^{\circ}$. C. und ergaben an 27 . August - 16. September Schmetterlinge. Also beträgt in cliesem Falle die Puppenzeit 33 bis 53 Tage.

3). Die Raupen von Pieris napi verpuppten sich bei $21-22,5^{\circ}$ C'. vom 30. Juni bis 2. Juli. Die Puppen blieben zuerst bei $22-25^{\circ} \mathrm{C}$. Aın 7. Juli wurlen sie in die Temperatur von $7-11^{\circ} \mathrm{C}$. gebracht, und die Entpuppung fand am 13.-22. Juli statt. Die Puppemilaner heträgt somit im Durchschnitt $1 \gamma^{\prime}$ Tage (minimum = 11 Tage, maximum $=23$ Tage). Die Puppendauer vlieser Art beträgt hei der Temperatur von $22-25^{\circ} 9$ Tage.

4). Die am 30. Juni - 2. Juli verpuppten Raupen von Pieris napi wurden sofort in clie Temperatur von $9^{\circ}$ gebracht, bei welcher sie 25 Tage verblieben. Darauf wurlen sie auf einige Stunilen ins Zimmer bei $22^{\circ}$ C., dann in den Brutofen bei $30-31^{\circ}$ C. gebracht. I)ie Entpuppung erfolgte an 26.-27. Juli. Also heträgt die Puppenzeit 25 Tage.

5). Die kurz vor 2. Juli verpuppten Raupen von Picris napi wurden hei $9^{\circ} \mathrm{C}$. liegen lassen. Am 18. August schlüpfte $1 \sigma^{\circ}$ aus: alle übrigen Puppen überwinterten in kalten Zimmer und schlüpften am 3. April - 26. Juni aus. Aus disem Versuche ist ersichtlich, dass die individuelle Neigung zur Entpuppung bei dieser Genelittion sehr bedeutend sich ändert, worauf wir in einem anderen Kapitel zu sprechen kommen.

6). Die Raupen von Pieris nupi var. bryoniae verpuppten sich a11 16.-25. Juli. „Obwohl während ries ganzen Juli unil August grosse Wärme herrschte und die Zimmertemperatur meist über $20^{\circ} \mathrm{C}$. hetrug, schliipfte in diesem Sommer doch keine der 24 Puppen aus." Darauf überwinterten die Puppen in kalten Zimmer und gaben an 26. April - 7 . Juni Schmetterlinge. Also die Puppenzeit betrug !" bis $10^{1 / 2}$ Monate.

7). 25 Raupen (lerselben Zucht wie 6) verpuppten sich im Brutofen hei $29^{\circ}$ C. $\left(26-31,6^{\circ}\right.$ C. $)$ am 17 . Juli. Nach $\tau$ Tagen schlupfte ein Schmetterling $\left(\sigma^{\top}\right)$ aus. Die übrigen Puppen überwinterten vom 30. Juli als im ungeheitzten Zimmer und schlüpften an 6. April 2. Juni "sehr unregelmässig aus." Also wierlerum nach $51 / 2-101_{12}^{1}$ Monaten: 
8). Raupen derselben Art Verpuppung an 20.-2s. Juli. Die Zimmertemperatur im August betrug noch $20^{\circ} \mathrm{C}$. Alle Puppen wurlen in warmen \%immer überwintert und ergahen an 23. März 27. Mai Schmetterlinge. Die Puppenzeit dauerte somit s-1ú Monate.

9). Die Raupen dersellyen Zucht wie im $r$ ) verpuppten sich bei der Temperatur von $30^{\circ}$ C. an 20.-28. Juli. Vom 19. August. an wurlen die Puppen in Zimmertemperatur gebracht unil nachher in's kalte Zimmer. Inas Ausschliipfen von 32 Schmetterlingen erfolgte rom 23. Mai - `. Juni. I lie Puppenzeit beträgt somit 10) bis $10^{1 / 2}$ Monatell.

10). Ueher 100 Raupen der 2. Brut von Tansssa levana verpuppten sich Anf:ung Septemlser. Die Puppen wurlen im. geheitzten Zimmer aufbewahrt und rom 10. Jannar an in Brutofen iiber Wasser hei $27-30^{\circ}$ C. gehalten. Aisschlïpfen rom 1^-29. Januar. Die Pappenzeit beträgt $41 / 2-5$ Monate.

11). Raupen von Van ssa le euna 2. Brut verpuppten sich Ende August und Anfang Septemher, und wurden im kalten Zimmer gehalten; vom 1. März his 27 . Juni hei $5^{\circ} \mathrm{C}$. und nachher bei einer Zimmertemperatur von $22-30^{\circ}$ C. Das Ausschlïpfen fanil an 8. bis 10. Juli statt. Die Puppenzeit dauerte somit üher 9 Monate.

12). Junge Räupchen der 2. Brut von Vunessa levuna wurden bei $30-32^{\circ} \mathrm{C}$. aufgezogen. Verpuppung um 8. August. Ihie Puppen bliehen bei $30-32^{\circ} \mathrm{C}$. Das Ausschliipfen erfolgte am 15.-18. August; somit die Puppenzeit $7-10$ Tage.

13). Raupen der 2. Brut von Vunessa levana verpuppten sich bei $21-22^{\circ}$ C. am 17.-22. August. Die 5 Puppen ergaben Schmetterlinge vom 2.5.-28. August also im Durchschnitte nach 7 Tagen; die ïhrigen Puppen wurden üherwintert, von welchen 86 Puppen iiber Wasser bei einer Zimmertemperatur afgehoben wurden, welche im November, Decemler und Januar nicht ïber $13-14^{\circ} \mathrm{C}$. betrug. Diese Puppen ergaben vom 16. Februar - 4. April Schmetterlinge. Die Puppenzeit dauerte somit $6-8^{1} / 2$ Monate.

14). Verpuppung von Vanessa levana (2. Brut) am 24. August. Die Puppen blieben bei $28^{\circ} \mathrm{C}$. Am 1 . bis 7 . September schlïpften Schmetterlinge aus. Die Iauer der Puppenzeit betrug 7-14 Tage.

15). Dasselbe. Die Verpuppung erfolgte an 20.-27. August; las Ausschlüpfen erfolgte vom 30. August - 4. September. Puppenzeit im Durchschnitt 10 Tage.

16). Die Räupchen won Pararge egeria wurlen bei $12,5-14^{\circ} \mathrm{C}$. aufgezogen. Die Verpuppung erfolgte am 17. bis 25. Juni und die 
Puppen rerblieben bei $14^{\circ} \mathrm{C}$. Das Ausschliipfen fand rim 12,-17. Juli statt. Die Puppenzeit dauerte somit im Durchschnitte ?f T'age.

17). Die Raupen von Pararge egeria wurden bei $25-27^{\circ} \mathrm{C}$. aufgezogen. Verpuppung um 21. Juni. Die Falter schliipften von 27. Juni - 7. Juli aus. Puppenzeit 6-16 Tage.

1S). Dasselbe, aiver bei $18^{\circ} \mathrm{C}$. aufgezogen unil ansgeschliipft. Die Verpuppung am 2. Juli. Das Ausschliipfen am 12.-15. Iuli. Somit die Puppenzeit 10-13 Tage.

19). Dic Raupen von Vanessa urticue verpuppten sich bei 27 lis $30^{\circ}$ C. am 3.-5. Juli; sie blieben bei $26-29,4^{\circ}$ C. weiter unl (iie Falter schliipften am 8.-11. Juli aus. Puppenzeit im Jurchschnitte 5 Tage.

20). Die Raupen derselben Art verpuppten sich lni $2(i-29,4$ C: rom 19.-21. Juli unil schliipften rom 23.-26. Juli aus. Pujpenzeit. ca. $41 / 2$. Tage.

21). Dasselbe, aber bei $15^{\circ} \mathrm{C}$. Die Verpuppung begam mit lem 7. August. Entpuppung am 27.-29. August. Pupnenzeit cil. 21 Tage.

22). Dasselbe, aher bei $25-32,8^{\circ}$ C. Die Verpupjung hegann ain 13. August. Das Ausschliipfen vom 18.-21. August. Puppenzeit $5-8$ Tage.

Aus diesen 22 Versuchen von August Weismann ist ersichtlich, lass, obwohl die höhere Temperatur die Entwickelung der P'uppen beschleunigt, unı die niedere Temperatur dieselbe rerzögrert, bei diłsen Versuchen die Individualität eine grosse Folle spiclt. Die Puppenzeit wirl bei der überwinternden Puppen durch die Wäme im Allgemeinen entwerler gar nicht oder sehr schwach geänlert; " kiommen hiebei auch inliviluelle Neigungen vor (13. Versuch).

Die erste Häuting der Rïupchen von Parurge egeria kisin aluch bei $10^{\circ}$ erfolgen. Die Verpuppung von Chrysopluamses phlarms. tritt bei i $-10^{\circ}$ nicht ein. Etwas ïber $10^{\circ}$ erfolgt die Verpuppung dieser Raupen, aber sie verzögert sich sehr limge und danert ibher einen Monat (vom 22. Juni bis 25. Juli).

Von einem in Genua gefangenen Pararge eyerin var: meirm: Weibchen wurlen 24 Eier gelegt, von welchen in Freiburg in lir. Siüpchen bei $17^{\circ}$ Zimmertemperatur ausschliipften. Die wejter.

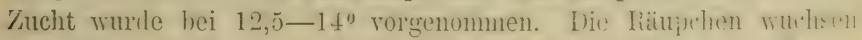
sehr langsam heran und verpuppten sich nach if his (i.) Tagin.

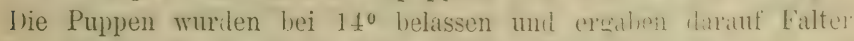
Die Puppenzeit dauerte von 17.-25. Juni bis 12.-17. Juli. 
Die Entwickelung dieses letzten Falter vom Ei zum Schmetterling dauerte bei diesen Versuchen $44-47$ Tage bei 1 s. bis 39 'Tage bei $25^{\circ}$.

M. Bellati und E. Quajat (1\$95. (i3) tauchten die Fier von Bomby $x$ mori in heisses Wasser $\left(50^{0}\right)$ währenıl $1 / 4-1 / 2$ Stunile; die Eier begannen sich sofort zu entwickeln.

Zeselski (1\$95. 966) liält die Meinung anfrecht, dlass die richtige Entwickelung der Bienenlarren nicht unter $+35^{\circ} \mathrm{C}$. stattfinden kann; wenn aber diese Temperatur etwas sinkt, wird eine Verspätung in der Entwickelung stattfinilen, und die Larven werden sich gar nicht entwickeln, wem die Temperaturabnahme noch bedeuteniler ist.

E. Fischer (1895. 225) erwähnt in seinem Buche „Tramsmmtation der Schmetterlinge infolge Temperaturänderungen," class die Puppen von Vanessa antiopa, welche vom frischen Zustance an in einer Temperatur von $35^{\circ} \mathrm{C}$. gehalten wurlen, nach s-10) Tagen Falter ergaben.

Als ex frische Puppen von Vanessa in 3 Wochen auf Eis unil nachiher in einer Wärme von $25^{\circ} \mathrm{C}$. gehalten, erhielt er nur $500^{\circ}$, Falter.

Ausserilem, sagt er noch, dlass die tiefen T'emperaturen ( $-4^{0}$ bis - $20^{\circ} \mathrm{C}$.) die Schmetterlinge schwächen, so rlass sie sich nicht aus der Puppe herauszuarbeiten vermögen.

F. Liberich (1895. 511) machte die Beobachtung, liass die Larven von Goninctena serpunctuta L. aus Eiern bei anhaltend schïnem warmem Wetter schon am 9. und 10. Tage zum Vorschein kommen. Sincl Spätfröste eingetreten; orler anhaltender Regen, so bleiben - die Eier 18-24 Tage unentwickelt.

A. Tichomirow (1895. s69) sagt, dass die erste Hüutung der Seidenraupen ca. 24 Stunden dauert; ist aber die Temperatur tiefer als die normale $\left(15-20^{\circ}\right.$ R.). so kann cliese Dauer 36 Stunden erreichen. Die Puppendauer dieser Species (Bombyx mori) beträgt 12-14 Tage bei $18-20^{\circ} \mathrm{R}$. unl nur 5-9 Tage bei $24-280 \mathrm{R}$.

Er fand, dass eine gesumle Seidenraupe beim Fressen unil gewöhnlicher Temperatur (2(1)0 R.) 50 Herzcontraktionen pro Minute hat. Bei Temperatursteigen nimmt diese Anzahl zu; so betrïgt sie 
65- ifi Schläge pro Minute bei $22^{\circ}$ R. Bei der Temperaturerniedrigung nimmt dieselbe $a b$, so z. B. beträgt sie nur $6-7$ Schläge f $\mathbf{r}$, Minute bei $8^{0}-12^{\circ} \mathrm{R}$.

M. P. Riedel (1895. (i94) fanil, dass Stenopteryx hirundinis L., welche Zweifligler-Art auf Schwalben oft anzutreffen ist, so lange auf diesem Vogel lebt, als er warm ist; von ilem Leichnam fliegen sie weg.

F. Himsl (1895. 374, 375) fing am 11. Juli 1 s92 in rler Nähe von Pausing bei Raab in Ober-Oesterreich ein $\delta$ von Autocharis cardamines und zwar in einer tiefen, von Winclen sehr geschiitzten und heissen Schlucht. Da in der Umgebung von Raah dieser Schmetterling sonst Entle April und Mai Hiegt, so zähit er das gefangene Exemplar zu der II. Generation.

Auch W. Hebhard (1s!96. 303, 304) fing diesen Schmetterling an 6. Juli 1895 in Wainoden.

K. Sajó (1896. 732) erklärt die verhültnissmässig lange Flùzeit der Weinstock-Fallkäfer (Eumolpus vitis F.) durch den Unstand, dass die Verpuppung in verschiedenen Tifen-Niveaus stattfindet, unil die von oben hinabschreitende Erwärmung nicht alle Puppen gleichzeitig erreicht.

M. Rellati und E, Quajat (1896. 122) untersuchten den Einfluss der w.üheten Temperatur auf die Entwickelung der Eier von Boml.!x mori. Die Temperatur von über $50^{\circ}$ hat auf die Eier einen verderblichen Einfluss, wenn auch nicht fuir alle Indiviluen gleichzeitig.

Als die Eier in einer verschlossenen Schachtel der 'Temperatur von $49^{\circ}$ C. innerhalb \& Minuten ausgesetzt wurden, schliipften nach 3 Tagen $3 \%$ Eier; $1 \% \%$ wurlen entwickelt, schlüpften aber nicht aus.

Bei kurzer Dauer der erhöhten Temperaturen wurlen folsendt: Resultate erhalten:

Temperatur $60^{\circ}$. Dauer 1 Minute. Ergehniss: $21 \%$ schlipften aus, $2 \%$ entwickelten sich, schlüpften aber nicht aus, $15 \%$ vertrockneten.

I)auer 15 Minuteri. Temperatur $45^{\circ}$ (: I) Ie Eier wurilen nicht beschädigt.

Dauer $6-8$ Minuten. Temperatur $48-50$ C. Dasselbe. 
Dauer, 10 Minuten. Temperatur 48-50 C. Sehädlich.

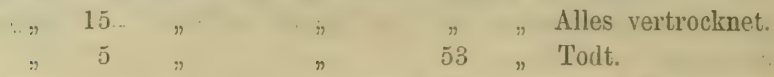

Als 4 Stunden alte Eier zwischen 2 Ührgliserm ter Linwirkung der direkten Somnenstrahlen innerhalb (i Minuten ansgesetzt wurilen, gingen sie zu Grunde. Eier, älter als 4 Stunden, blishen unbeschä̈ligt.

Die durch eine Linse ilurchgelassenen Sonnenstrahlen tülteten die Eier, welche im Brennpunkt sich befanden; dagegen entwickelten sich die Eier; welche an concentrischen Lireisen um ilicsen Punkt vertheilt waren. Dasselbe wurle beobachtet, als ias Lichthuinclel sehr rasch intermittirt wurile. Die Versuche zeigten auch, dass die beschleunigte Entwickelung der Eier nicht dem Einflusse des Lichtes, sondern ausschliesslich der Wärme zuzuschreiben ist. Resultate:

Ihre Untersuchungen mit warmem Wasser ergaben folgente

\begin{tabular}{|c|c|c|c|c|}
\hline & vährend & ausgeschl. & $\begin{array}{l}\text { entwrick. aber } \\
\text { nicht ausgesehl. }\end{array}$ & nicht ausgeschl. \\
\hline $63^{\circ}$ & $30^{\prime \prime}$ & $7,8 \%$ & $0,6 \%$ & $91,6 \%$ \\
\hline$n$ & $40^{\prime \prime}$ & $13,1 \%$ & 1,9 " & $85,0 \%$ \\
\hline , & $50^{\prime \prime}$ & 15,0 & 4,3 n & 80,7 \\
\hline $68^{\circ}$ & $15^{\prime \prime}$ & $5,6 ”$ & $0,6 ”$ & 93,8, \\
\hline $87^{\circ}$ & $12^{\prime \prime}$ & $-"$ & 1,0 " & $99,0 \%$ \\
\hline$"$ & $15^{\prime \prime}$ & 15,7 & $5,9 "$ & 78,4 \\
\hline$n$ & $25^{\prime \prime}$ & 21,3 & 17,5 & $61,2 ”$ \\
\hline$"$ & $30^{\prime \prime}$ & 19,4 & 22,4 & 58,2, \\
\hline
\end{tabular}

Keine Wirkung wurde erhalten, als die Eier im Wasser von $63^{\circ}$ während $15-20^{\prime \prime}$ sich befanden

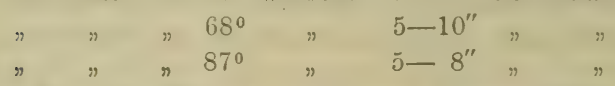

Das Alter der Eier hat dabei einen grossen Einfluss; so z B. ergab die gelbe Rasse von Istrien 5 Mimuten nach der Eierablage

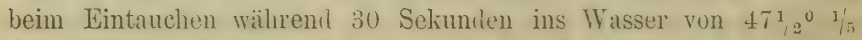
Ausschlüpfungen und 1/4 keine vollständige Entwichelung. Die Eier' ergaben ca. 1/2 Stunde nitch der Ablage unter gleichen Unstinden $30_{10}^{\prime}$ Ausschliipfungen uml $5^{\circ}{ }_{0}$ nicht vollstimlige Entwickelung; als aber die Eier 4 Stunden nach ihrer Ablage diesem Experiment ausgesetzt wurden, war der Effekt gleich Null.

Die Versuche mit intermittierenden Temperaturen fielen viel besser ats, als in der Luft und Wass:I bei gewöhnlicher Steigerung der Temperatur. Die erhaltenen liesultate waren verschieden, je 
nach der Rasse und Alter der Eier. Es miissen wenigstens 10 Uebertragungen aus einer Temperatur in die anlere vorliegen, wenn man gute Resultate erzielen will, wobei nicht die Grösse der Amplitule (Lifferenz zwischen hoher und niedriger Temperatur), sondern viel mehr die richtige Wahl der betreffenden Temperatur die Hauptiolle spielt.

Als Beispiel können die Resultate, welche mit gruner jalpanischer Rasse erhalten wurden, dienen:

Zwischen

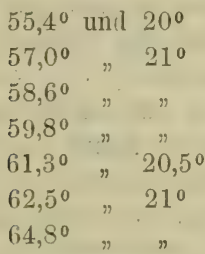

schlïpfen aus

$\begin{array}{rr}42,3 \% & \text { und } \\ 90,5 n & \text { " } \\ 100,0 \% & " \\ 48,2 " & " \\ 19,5 " & . \\ 16,9 " & " \\ 6 . & "\end{array}$

entwickeln sich, schlïpfen aber nicht aus.

$$
\begin{aligned}
& 2,9 \% \\
& 2,2 " \\
& - \\
& 13,0 \\
& 20,0 " \\
& 42,2 \ldots \\
& 94,0
\end{aligned}
$$

Es ist interessant, dass beim Steigen der hohen Tumperatur, wïhrend die niedrige fast konstant bleibt, ein Maximum von Ausschliupfungen $(100 \%)$ bei $58,6^{\circ}$ beobachtet wird.

F. Merrifield (1896. 572) fant, dass die Puppen von Genopteryx rhamni aus Nori-Italien und Deutschland die Temperatur von $0,5^{0}$ bis ca. $37^{\circ}$ wïhrent 20 Tagen gut ertrugen und nachher Falter ergaben.

M. Standfuss (1896. 840) erwähnt in seinem Hantbuche folgende Noctuiden-Raupen, welche sich durch die Temperatur von $20)^{0}$ bis $25^{n}$ treiben lassen: Agrotis molothina, polygona. signem, junthina, linogrisea, fimbria, auyur, pronuba, orbona, comes. collina, triangulum, brija, candelarum, c nigrum, ditrapezium, stigmutica, mbi, florida, dahlii, brunnea, festiva, conflua, segetum, riasina, occulta; Mamestra advena. tincta, nebulosa; Hadena basilinea, mea, hepatica, gemina mit ihren Formen, didyma, strigilis mit ihren Furmen; Mania maura; Naenia typica: Lencanir impuntens, impura, pallens, comma, conigera, loreyi, riparia, l album, congrua, albipunctu, lythargyria, turca; Mithymnu imbecilla; Caradrina quadripunctuta, respersa, alsines, taraxaci; Rusina tenebrosa; Plusiu chrysitis, bractea. putchrina, gamina, interrogationis.

Ungünstige Resultate ergab nur Agrotis molothinc. Gute Resultate ergeben diese Arten nur dann, wenn , die Raupen noch recht- 
zeitig im Herbst eingesammelt werden konnten, so dass sie noch keinen Frost oder starken Reif erhielten" (p. 138).

Von den übrigen Gruppen der Lepiloptera hat er hei folgenden Arten eine beschleunigte Entwickelung erzielt: Eimylia striata. cribrum; Nemeophilı iussulu. pluntayines und die Formen der letzteren; Callimorpha domimela und var. persona. wie deren Kreuzprodukt: var, romanovi. hera; Arctia caju. villica. purpurata. fasciatu. uulica. muculania; Spilosoma fuliginosa; Psyche v. stetinensis. viarlinu, hirsutella. standfussii; Epichnoteryx pulla; Dasychira abietis - (Boml,y.r quercus wurde von im Herbst gesammelten Rampen ohne Ueberwinterung derselben bis zur Puppe gebracht, der Falter erschien stets erst im nächsten Jahr) -- Lasincampa potatoria. pruni. quercifolia. populifolia, pini (Pleretes matromula und Aictia quenselii ergahen nach einmaliger Ueberwinterung ler Raupe len Falter).

Ohne Ueberwinterung der Raupe oder Puppe erhielt er Schmetterlinge von Laria $l$ nigrum und Bumbyr quercus. aber erst dann, als diese Arten bereits vom Ei erhöhter Temperatur ausgresetzt wurden.

Was nun die Laupen- und Puppenzeit in Einzelnheiten anbelangt, so fant M. Standfuss bei verschiedenen Temperaturen folgende Zahlen:

Lasincampa quercifoliu. Eier, liaupen und Puppen bei 31$)^{0}$. Raupenzeit betrug 70-85 Tage, die Puppenzeit 12-15 Tage.

Lasiocampa populifolia. Eier bei $25^{0}$, Raupen bei $15-200^{0}$. Raupenzeit betrug 50-70 Tage und die Puppenzeii 18 Tage.

Lasiocampa pruni. Alle Stadıen bei $30^{\circ}$. Raupenleben betrug. 28-52 Tage, Puppenruhe 10--13 Tage. Alle Stadien bei 250. Raupentauer betrug 55-68 Tage un:I die Puppenruhe 12-1s Tage.

Dasychira abietis. Alle Stadien bei $25^{0}$. Raupenzeit dauerte 45-70 Tage und die Puppenruhe 13-19 T'age.

Callimorpha domimula. Alle Stadien bei $25^{\circ}$. Raupenstadium betrug 50-68 Tage und die Puppenzeit 11-16 Tage.

Callimmpla domimula var. persona. Alle Stadien bei $25^{\circ}$. Riüpenzeit dauerte $75-87$ und die Puppenruhe 15-20 Tage.

Die Kreuzform zwischen domimula ơ und var. persona $\oint_{7}$. Alle Stadlien bei $25^{\circ}$. Die Frasszeit der Raupe währte $65-71$ und die Puppenzeit 14-19 Tage.

Arctic fusciata. Eier bei $34^{\circ}$, Raupen und Puppen bei $25^{\circ}$. laupenzeit bei 3 우 betrug $68-87$, und Puppenzeit 15-20 Tage; bei den übrigen (21 Exemplaren) $142-163$ resp. $25-31$ Tage. 
Lasiocampa pini. Eier bei $34^{\circ}$, liaupen und Puppen bei $25^{\circ}$. Die Frasszeit der Raupen dauerte $150-172$, die Pup penruhe $25-27$ Tage.

Das Treiben der überwinternden Puppen durch Erhohung der Temperatur lässt sich ohne Nachtheil fuir dieselben (aber erst von Mitte Januar ab) ansfiihren bei: Papilin hospiton. Thais pnlysena, Donitis apollimes. Anthochuris tagis. Thecla rubi. Vanessa levana, Bombyx: lanestris. Endromis versicolora. die Saturnien. Agliu tau, Diphthera ludifica und die Tuenicampa-Arten.

Beim Treiben scheinen sich nicht günstig zu entwickeln die Puppen von: Stauropus fagi. Cnethocampa pinivora. die Hyberniu-. Anisopteryx-, Pligalia-, Bistm- Amphidasis- und Eupithecien-Arten.

S. Mokrschezki (1896. 585) beobachtete ein massenhaftes Vorkommen der Blutläuse in der Ḱrym während der letzten Jahre unı crklärt es durch den warmen Winter der Jahre 1894 und 1895

E. Fischer (1896. 22!) brachte die Puppen von Vanessa urticae aus der Zimmertemperatur (ca. $25^{\circ}$ ) zuerst in clen Keller und dann nach einigen Stunden in the Temperatur von $-20^{\circ}$, wo sie $2-4$ Stunden verblieben; dabei stieg dlie Temperatur im Laufe der folgenden 5-8 Stunden wieler allmälig auf $0^{0}$. Nachdem dieser Process 14 Mal wiederholt war, konnten die entwickelten Falter aus der Puppe nicht auschlüpfen und starben.

Er fand auch, dass ,die Entwickelung des Falterorganismus hei einer constanten Temperatur von $0^{\circ} \mathrm{C}$. nicht ganz stillsteht, sondern (wenn auch sehr verlangsant) fortschreitet. Trotz dieses Vorwärtsschreitens können (loch einzelne Entwickelungsvorgänge (und zwar bei den Puppen auf ilen Flugeln) durch Kälte gehemint werden" (p. 22).

H. Gauckler (1896. 281) hat bei seinen Versuchen folgende Puppenzeiten erhalten:

1). Vanessu uiticae. Verpuppung am 3.-5. Juni (6 Puppen). Vom 15. Juni ab in der Temperatur von $8^{\circ} \mathrm{C}$. Ausschlüpfen 3.-6. Juli. Somit beträgt die Fuppenzeit in Durchschnitt 30 Tage. Sterblichkeit $=0$.

2). Vanessa uiticae. Verpuppung an 19. Juni (15 Puppen). Vom 19. Juni ab in der Temperatur von $+1,5^{\circ}$ his $+2^{\circ} \mathrm{C}$. Vom 18. Juli ab in (ler Zimmertemperatur $(22-23$ C.). Ausschliupfen am 24.-28. Juli. Sterblichkeit $=0$. Puppenzeit im Durchschnitt $=$ 38 Tage. 
3). Vunessa in. 38 Puppen haben in ler T'emperatur von $+2^{\circ}$ C. 34 Tage zugebracht. Vom 22. August ab in $22^{\circ}$ C. Ausschliipfen am 30. August -31 . September. ${ }^{1}$ ) Somit beträgt die Puppenzeit 42-72 Tage. Sterblichkeit $=0$.

4). Vanessa antiopa. Am 20. Juli wurlen 17 Puppen in die T'emp.eratur von $+2{ }^{\circ} \mathrm{C}$. geloracht; rom 22 . Angust in $23^{\circ} \mathrm{C}$. Ausshliipfen an 4.-6. September. Pupuenzeit fli-4s Tage. 2 Exempiare lirochen atus, die anderen vermodhten die Puppe nicht zu siprengen.

In einer woiterm Ahhimllung desselhen Verfassers (1 1 998. 275) fincien wir folgencle Daten:

Die liaupen von Vanessin antiopa und in verpuppten sich rom 21.-27. Juli (1897) und wirilen 10 stunden nach dem Alistreifen ler Raupenhaut in einen Eiskasten $\left(3^{\circ} \mathrm{C}\right.$.) gebracht; iort verblieh) eine Serie rom 2.2. Juli bis zum 6. August (also 16 Tage), die zweite Serie rom 25. Juli bis zum 9. August (also auch 16 Tage) uncl die dritte Serie vom 27. Juli bis zum 17. August (also 23 Tage). Das Ausschliipfen fanı statt: der ersten Serie am 14.-16. August, der zweiten Seric an 18.-21. August und der dritten Serie am 2!?. August - 1. Septemlier. Es starben von 42 Puppen nur 2 io, unt eine antirpa war verkriippelt. Somit beträgt die Puppenzeit:

Nach 16 tägiger Exposition 24-26 Tage.

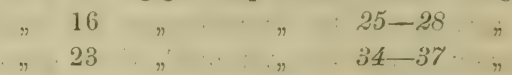

Aus diesen Versuchen geht hervor, dass die erniedrigte T'elijeratur die Entwickelung der Puppen rerlangsamt und zwar um si) mehr, je länger ،lie Puppen exponiert wurden. Die Temperatur von $+2^{\circ}$ C. scheint bei der angewendeten Dauer für die Puppen unschädlich zu sein.

Grïfin Marie von Linden und Fickert (1898. 515) hielten mehrere Tage liang die Puppen von Papilio puctalirius in der Tenperatur von ca. $30^{\circ}$ auf dem Paraffinofen und erhielten die Falter Endé Februar 'und Anfang März.

K. Sajó (1 $\$ 96.730$ ) fand im Mai in Kis-Szent-Mliklós (Ungarn) einige Entomoscelis adonidis und brachte sie in ein Glas, worin sich Erile hefand. Die Käfer frassen anfangs, dann aber verschwand einer

3) Wahrscheinlich der 30 . September gemeint. 
nach dem anderen in der Erde. Die Temperatur im dilase hetrug dic ganze Zeit 26-29 , worauf die Erile, welche kein einziges Mal bespritzt wurde, austrocknete. Die liäfer bliehen unheweglich unil waren scheintolt his Oktoher. Als die Erile herausgeschittelt wurle; machten diese Käfer binnen kurzer Zeit Bewegungen und marschierten wieder umher, als wäre gar nichts vorgefallen. "Wir halhen also hier einen wahrhaftigen Fall von Sommerschlaf vor uns" (p). $\$ 8$ ).

Er beobachtete Chrysmelu me!gerlei am :31. Lugust unl am 4. September immer morgens (zwischen $6 \frac{1}{2}$ und 7 Chr) in Parung. als es zu jener Zeit auf den freien Flugsandweilen sehr kiihl und gegen Mittag sehr warm war. "Es scheint also, dass die niedrige Temperatur die Thätigkeit dieser Art anstatt zu hemmen, vielnehr erhöht" (p. 89).

E. Verson (1897. 918) hekam von verschierlenen Orten Mitte Januar Eier von Bomingx mori, welche bei der Temperatur der umgebenden Luft von $+10^{\circ}$ fast jeilen Tag je ein Räupchen ergahen. Er erklärt diese Frscheinung mit zufälligem Bivoltismus. welcher gewöhnlich im September eintritt; dieses Jahr aher trat eine Ver-, spätung an, da von Mitte August und den ganzen September in Nord-Italien starke Kälte herrschte, worauf warmes Wetter eintrat. Einige Zuichter haben die Eier nach der Käälte wie gewöhnlich aufbewahren wollen unı unterwarfen, statt clie Temperatur allmählich sinken zu lassen, die Eier einer starken Temperaturschwankung, worauf die bereits stattgefundene Erscheinung des Bivoltismus nur beschleunigt wurde.

B. M. Schitkow (1897. 752) fütterte Räupchen von Bomby.t: mori mit Blättern der Schwarzwurzel bei 16 his $20^{\circ}$ Li.: während sir bei dieser Temperatur das für sie neue Futter gerne frassen, frassen sie es gar nicht odler nur sehr träge, als die Temperatur bis zu $2: 0^{\prime}$ R. stieg. Nachilem die Temperatur wieder lis zur friheren Gesunken war, begannen die liaupen wielter gierig zu fressen.

H. Klooss (1897. 4う5) berichtef, dass einer seiner Freunde Paupen von Ocneria dispur aus Eiern erzog, welche nie der Kälte ausgesetzt waren. Die Eier lagen jedoch fast $211 / 2$ Monate länger. bis zum Schlipfen wie die, welche er ler Kälte ausgesetzt hatte. Er selbst erhielt die zweite Generation von Ocneria dispur auf folgenie Weise: die Räupchen schliiptten schon Encle Januar aus, von welchen 
einige in den ersten Tagen des April sich rerpuppten; Ende April erschieneu die ersten Falter, hegatteten sich und legten reichlich Eier al. In diesen Eiern war Anfangs Juli der Embryo völlig entwickelt und die Eier wurden einer Kälte von :3 his $10^{\circ} \mathrm{C}$. aut die Dauer von 14 Tagen ausgesetzt. Am ㅇ․ August liegannen die liäupchen zu schliipfen; Mitte Oktoher wurilen die ersten P'uppen und am 9. November die ersten Falter erhalten.

Dammer (1897. 162) bespricht in seiner Brochure die Zuchtversuche von Harz (1886. 000) und sagt, lass der Letztere, olne es selhst zu wissen, durch Zuchtwahl nicht nur eine Schwarzwurzelblätter fressende liasse von Bombyx muri. sonlern eine gegen niedere Temperatur weniger empfindliche Rasse zu ziichten vermöchte, denn die Mortalität der Raupen wurde mit jeder weiteren Aufzucht geringer (im ersten Jahre $92,5 \%$, im zweiten $70,4 \%$, im dritten $65,62 \%$ ), trotzdem die Luftemperatur nur $15^{\circ}$ hetrug.

H. Gauckler (1897. 284) zog die Anfang Septemher geschlüpften Räupchen von Aictia caja hei $10^{\circ} \mathrm{R}$. (nachts) bis $190 \mathrm{~K}$. (am Tage). Häutungen fanden in ganzen sechs statt und zwar:

I. Häutung nach etwa 8 Tagen des Schlïpfens,

II. " gegen Mitte September,

III. " von Mitte bis Encle September,

IV. $"$ von Ende September bis Anfang Oktober,

V. " gegen Mitte Oktober,

VI. " von 20. bis 25 . Oktober.

Ein Theil der Thiere wollte nach der IV. Häutung nicht mehr fressen und wurde ins Freie gestellt. Die übrigen Raupen ergaben am 30. November die ersten Gespinnste, am 25. November waren iilier 30 Kokons vorhanden. Am 1. December schlïpfte der erste Schmetterlin $(\sigma)$, der letzte am 19. December. Die längste Zeit vom Verspinnen der Raupe his zum Schliipfen des Falters hetrug 2S Tage, die kiirzeste Zeit nur 17 Tage. Die erhaltenen Falter zeichneten sich ausserdem noch lurch grosse Lebensenergie aus.

A. Jahn $(1897,+17)$ beohachtete, dass in Folge des kalten Frühjahrs (1896) Käfer, welche gewöhnlich im April und Mai ausfliegen, drei bis vier Wochen später erschienen.

Schenkling-Prévôt (189i. T 7 ) fütterte liaupen von Acherontia atropos und Splinix convolvuli, liess sie sich einpuppen und beliess 
sie in Freien (in der (iartenlauhe). Im Fruhjahr waren sümtliche Puppen tolt, wälirend dic im Zimmer gehaltenen in Novemler ausgekommen waren.

A. Linde (1897. 513 a) schreibt, dass bei der Zucht von Acherontic atropos, Deilephila livornica und Plesogmen proserpina ihre Puppen den trockenes Moos gelegt werden mïssen, wobei das sie zuleckende Fliesspapier jeden Tag mit warmem Wasser benetzt werlen muss. IVerden dahei die Kisten mit diesen Puppen hei der Temperatur tiefer als $20^{\circ}$ gehalten, so gehen die Puppen zu Grunde.

Der letzte Umstand erklärt, warun diese Schmetterlingsarten im MLoskauer-Gouvernement nicht heimisch sinl, sondern nur von Zeit zu Zeit dort zufliegen.

H. Gauckler (1897, 28:3) sammelte die Puppen von Pieris brassicue im Herlist und hrachte dieselhen nach eingetretenem Froste in weheizte Zimmer, um eine frühere Entwickelung der Falter zu erzielen: sie kamen jetloch niemals zu einer trïheren Entwickelung als im April, also zu normaler Zeit.

0. Schultz (1897. 786 ) berichtet, dass seine Treil,versuche bei Hadena adusta nicht glücker wollten. Er hält es für unbedingt nothwendig, dass die Raupen dieser Art der Einwirkuny der kalten T'emperatur im Winter ausgesetzt werden miissen.

Ich hale in Sophia $(189-.19)$ an 15. December ein frisch ausgeschliipftes Exemplar von Polyommatus phlacas ơ gefangen. Im November und Anfangs December betrug die Temperatur bis ca. $-6^{0}$; am 15. December wurile es plötzlich warm $\left(15^{\circ}\right)$. Die grösste Kälte herrscht hier im Januar.

H. Gauckler (1897. 287) brachte die im Spätherbste oder ausganus Winter, im Februar, gesammelten Puppen von Panolis piniperila P. in ein mässig warmes Zinmer; dabei erschienen nach Heissigem Bespritzen der Puppen die Falter schon nach wenigen Tagen; sonst erscheinen die Falter in April.

W. Pickel (1898. 635) beobachtete, dlass die Temperaturerniedrigung die Entwickelung der Bettwanze (Cimer: lectularia L.) verlangsamt. Während das Auskommen der Larven aus ihren Eiern 
bei der Zimmertemperatur nach 2:2 Tagen stattfindet inach Howard [1896. :391] nach $T-10$ Tagen), hetriagt liese Periorle bei Eiem, welche innerhalh drei Stumlen dem Einthsse der Temperatur von - $4^{0} \mathrm{R}$. ausgesetzt wurlen, 24 T'age.

G. Wilh. Ruhmer (1898. 727 ) setyte die Puppen (66) ron Vanessa var. mror:a alle im sleichen Entwickelungstalimu der gleichen fialte $\left(+2^{\circ}\right.$ C.) uml gleichlange Zeit ( 24 Tage) aus, woranf die Puppen ins Zimmer $\left(17-2{ }^{0}\right.$ C.) geloracht wurden, wo sie nach. 12 Tagen Falter ergaben. Im Ganzen dauterte die Puppenzeit also :36 Tage. I)ie Puppen, welche der hälte gar nirht ausgesetzt wurden, schlüpften nach 9-11 Tagen aus. Daraus schliesst Ruhmer "lass die nierlrige Temperatur nicht nur wïhrend ihrer Einwirlung auf die Puppen deren Entwickelung hemmt, snnlern letztere derart heeinflusst, dass sogar noch später: während der Wärmezeit, ihre die Entwickelung verzögrernde Einwirkung hemerkhar ist" (p. :391). Eine Puppe, welche $2+$ Tage bei $0^{0}$ gehalten wurle, verlurachte is Tage als Puppe.

Beim zweiten Versuche wurlen die frischen Puppen auch im gleichen Entwickelungsstadium aber einer ungleichen Kältezeit ausgesetzt. Folgende Tahelle zeigt die erhaltenen Iiesultate:

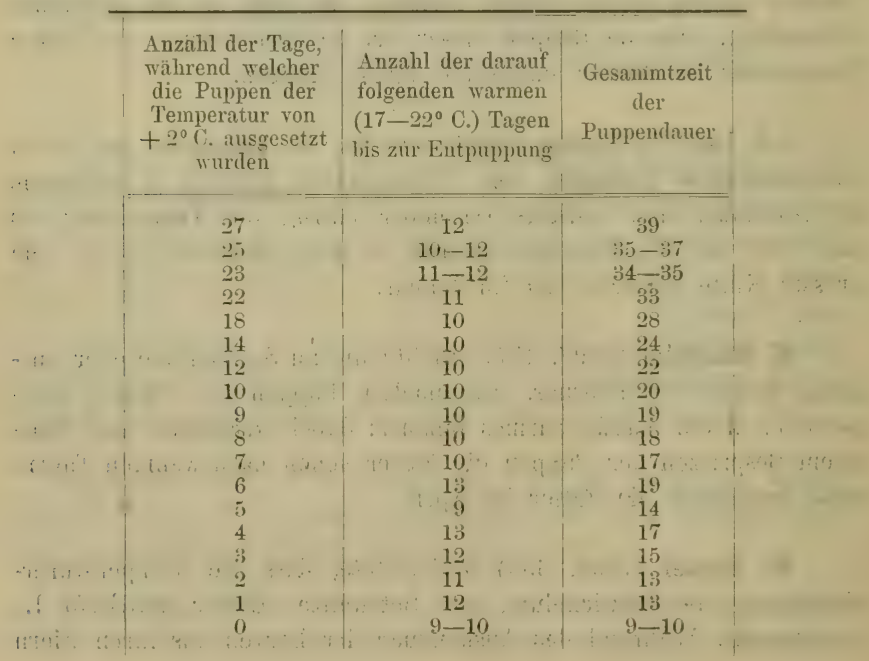


Aus der mittleren Spalte „ersieht man, dass die Zeit, welche ler Schmetterling zu seiner Entwicklung aus der Puppe nach ter Kiiltezeit, in Licht und Wärme brauchte, ziemlich gleich, also unahhängig von der Zeit ist, welche die Puppe in ler liälte blieb" (p. 41).

Ausserdem stellte dieser Forscher noch eineu dritten Versuch mit Puppen an, welche in ungleichem Entwickelungszustancle und rerschierlen lange der Kälte $\left(+2^{\circ} \mathrm{C}\right.$.) auscresetzt wurden. Folgende Tabelle enthält die erhaltenen Resultate:

\begin{tabular}{|c|c|c|c|c|c|c|c|}
\hline 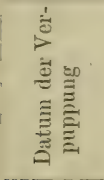 & 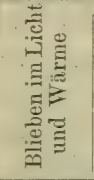 & 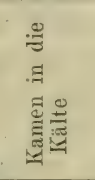 & 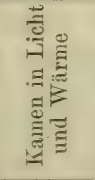 & 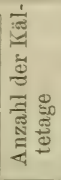 & 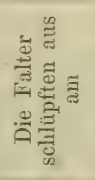 & 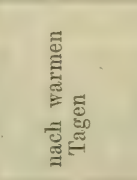 & 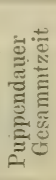 \\
\hline 13. Juli & 1 Tag & 14. Juli & 15. Juli & 1 & 25. Juli & $1+10=11$ & 12 \\
\hline 13. Juli & "2 Tage & 15. Juli & 17. Juli & 2 & 25. Juli & $2+8=10$ & 12 \\
\hline 13. Juli & 4 Tage & 17. Juli & 20. Juli & 3 & 25. Juli & $4+5=9$ & 12 \\
\hline 13. Juli & 5 Tage & 18. Juli & 23. Juli & 5 & 27. Juli & $5+4=9$ & 14 \\
\hline
\end{tabular}

Da die Falter dieser Versuchsreihe sich ausserordentlich schnelI, nämlich nach 10, die letzten beiden sogar schon nach 9 Tagen Wärme entwiclielten, so schliesst daraus Ruhmer, ndass eine gewisse (wem auch nur geringe) Entwickelung les Falters in der Puppe während der Kältezeit stattgefunden hat, was aber nur aus der grösseren Willerstandsfähigkeit alter Puppen gegen die vou aussen auf sie wirkenile Kälte erklärt werden kann" (p. 48-49).

Er beobachtete auch, als er Puppen von Vanessa var. prorsa in ler 'T'emperatur von $+2^{0}$ gehalten hatte, llass am 25. Kiiltetage aus einigm Puppen Fliegemmarlen auskrochen, die sich am Boden der Schachtel $\left(Q^{\circ}\right)$ eintonnten.

M. Standfuss (1898. 841) sagt in seiner epochemachenilen Ahlan:llum: „Experimentelle zoologische Studien mit Lepilopteren“ üher dis Wirkmng der "Frust- und Hitze-Exyerimente" folgendes:

"Wir theilen eine arissere sure gleichzeitig in den l'uppenzustan: ihhergesangener Intiviluen von einer unserer gewöhnlichen Vuncsin-Arten in zwei Theile; den einen Theil belassen wir in ter Zimmertemperatur von $23^{\circ} \mathrm{C}$, den anderen bringen wir etwa 10 Stunden nach Aistreifung der liaupenhaut in den Frostapparat, kiihlen 
ihn innerhall, einer hallen Stuncle von $+5^{\circ}$ C. auf $-12^{\circ}$ C. ah: lassen diese $-12^{\circ} \mathrm{C}$. eine Stunde hintereinamler einwirken uml dann in einer weiteren halben Stunde auf $+5^{\circ} \mathrm{C}$. wieder ansteiwen. Wir wiederholen diese Behantlung in den darauf tolgenten zwei Tagen, wälrend in der gesammten \%wischenzeit und nachler lis zum Ausschliipfen diese zweite Serie ehenfalls in einer Temperatur von $+23^{\circ}$ C. gehalten wiril. Fs zeint sich num, dass die zweite Serie keineswers nur um die 6 Stunilen spiter aussehliipft. welche sie in niederern als die normale Temperaturen verbrachte, sondern um Tage verspätet. Somit wurte nicht nur eine Unterhrechung der Entwickelung wïhrend der \%eitrlauer der Frosteinwirkmy hervorgerufen, sondern zugleich eine sehr erhel,liche Verlanosamung und Hemmung der Entwickelung ibherhaupt" (p. 18).

Ausserdem ist M. Standfuss yeneigt anzunelımen, dass hier die Zeitrlauer und 'Temperaturgrade sich gegenseitig in wewissen engen (irenzen kompensieren können, 1. h. dass hestimmte nierlere Minustemperaturen kurze Zeit einwirkend ganz denselhen Effekt rrzeugen, wie hestiumte, weniger niellrige Minustemperaturen in liutgerer Einwirkung.

Über die Wirkung der Temperatur z. B. von $+44^{n}$ C. sagt lerselhe Forscher: „So hohe Temperaturen wirken keineswegs durchweg beschleunigend, wie man anzunehmen weneigt wäre, sondern vielfach die Entwickelmo direkt unterbrechend und häufig auch noch ïher das Mass der Expositionszeit hinaus verlangsament" (p. 1S).

Dass anch eine niedrigere Temperatur als $+44^{\circ}$ C. lie Entwiclielung der Puppe hemmt, ist aus fulgenten Worten von M. Standfuss ersichtlich: „Noch hei $+t^{\circ}$ C., die trei Tage je vier Stunden lang einwirken, während dazwischen und his zum $\Lambda$ usschliupfen $+23^{\circ}$ C. angewenlet wurlen, schreitet die Entwickelung der meisten behandelten Arten hei dem gesammten verlurauchten Versuchs. material heschlemiqend vorwirts. Aler schon - 420 C. hahen hei gewissen Inıliviluen Entwickelungsstillstanıl zur Folge (p. 20).

Seine gesammten Ergelınisse mit "Frost unıl Hitze" erkliirt er, indem er sagt: "Wie wirken dieso Frost- unı Hitze-Experimente? Sie unterhrechen die Entwickelung; sie versetzen clas Inselit in einen Zustand der Lethargie" (p. 21).

Ueher die Wirkung der hohen Temperatur auf Puppen sagt er: „Wirl die Puppe zu frisch oller zu lange exponiert, so vertrocknet sie, oder ergiebt im sünstigsten Falle einen mehr oder weniger verkrippelten Falter" (p. 16). 
E. Quajat (1898. 66:3) fand, dass die Athmungseneroie der Eier von Bumbyx mori in lieinem strengen Verhältnisse zu der Temperatur steht.

H. Gauckler (1898. 294) fand, dlass ti: P'uppen von Pieris Trassicae gegen Treiben mittelst kiinstlicher Würme in Winter sich neutral verhalten, obwohl sie vorher die Einwirkung des Frostes erlitten hatten. „Die Thiere, wenngleich häufig aufcefeuchtet uml recht lehhaft, kamen doch zu keiner friiheren Entwickelung wie in der Natur; also im April".

I)ass die Zeit, während welcher die Puppen einer ernienlrigten Temperatur ausgesetzt werden, nicht olme Einfluss auf die Lehensthätigkeit der Puppen bleil,t, ist aus den Versuchen von Carl Frings (1898. 253) ersichtlich.

Er setzte die Puppen der Temperatur von $+6^{0}$ his $+8^{\circ} \mathrm{C}$. (zuweilen his $10^{\circ} \mathrm{C}$. steigend) aus. Die folgende Tahelle enthält die von ihm erhaltenen liesultate:

\begin{tabular}{|c|c|c|c|c|c|c|c|c|c|c|c|c|c|c|c|}
\hline \multicolumn{6}{|c|}{ Species } & 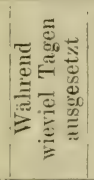 & 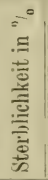 & \multicolumn{6}{|c|}{ Species } & 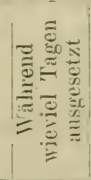 & 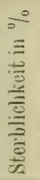 \\
\hline Apatura & iris & & . & 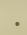 & . . & 14 & 30 & Vanessa & io & . . & . & . & . & 42 & 90 \\
\hline$"$ & $"$ & & . & - & . & 21 & 75 & Tanessa & a pols & yehlor & gros & 8 & • & 28 & 50 \\
\hline " & & & . & . & . & 28 & 100 & $"$ & & $"$ & & & . & :35 & 7.5 \\
\hline Limenitis & is sil & $y l l e$ & & . & . & 21 & 75 & Vanessa & ant & iopa & . & 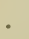 & . & 35 & 60 \\
\hline$"$ & , & & • & - & - & 28 & 90 & $"$ & & $"$ & . & . & . & $4 \check{5}$ & 90 \\
\hline Vanessu & urtic & ae & & & ren. & 35 & 60 & Vanessa & a atal & lanta & a. & . & . & 14 & 0 \\
\hline$"$ & $n$ & & II & & $"$ & 35 & 60 & $"$ & & $"$ & . & . & . & 21 & 10 \\
\hline$"$ & $"$ & & ШI & & $"$ & 14 & 20 & $"$ & & $"$ & . & : & . & 28 & 25 \\
\hline$"$ & $"$ & & $n$ & & $"$ & 21 & 20 & $"$ & & $"$ & . & - & . & 35 & 40 \\
\hline$"$ & $"$ & & ” & & $"$ & 28 & 40 & $"$ & & $"$ & . & . & . & 42 & 75 \\
\hline$"$ & $"$ & & n & & $"$ & $|35-38|$ & 60 & " & & $"$ & . & . & . & 49 & 95 \\
\hline Vanessa & io & . . & . & & . & 14 & 5 & Aretie & ca.ja & . & . & . & . & 20 & 15 \\
\hline$"$ & $"$ & . . & . & - & $\because$ & 21 & 20 & $n$ & $"$ & . & . & - & . & 35 & 25 \\
\hline$"$ & $"$ & . . & . & - & 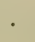 & 28 & 25 & $"$ & $n$ & . . & . & . & . & 42 & 40 \\
\hline " & ” & . . & . & & $\cdot$ & 35 & 60 & $"$ & $"$ & . . & . & . & . & 49 & 80 \\
\hline
\end{tabular}


144 Erstes hapitel. Die Entwickelungsgeschwindigkeit der Insekten.

Aus seinen Versuchen (1899. 25\%) im Jahre 1;9s lassen sich folgende Werthe zusammenstellen:

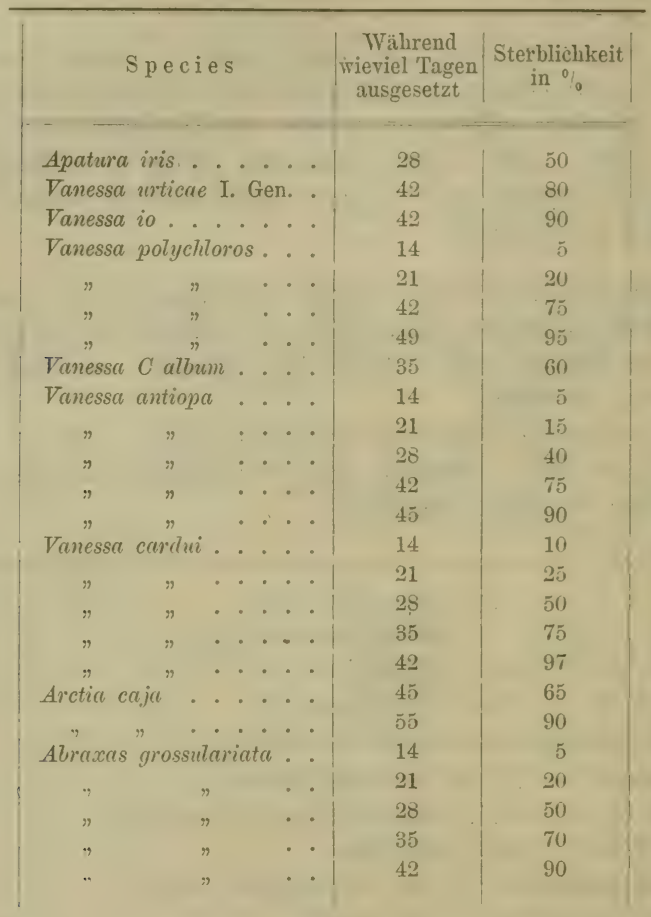

Daraus ist ersichtlich, llass je lïngere Zeit lie Puppen bei ler Temperatur von $;$ bis $8^{\circ} \mathrm{C}$. verbleilhen, lesto mehr Exemplare sterben. Es existirt eine gerrisse Dauer, so zu sigen die kritische Zeit, nach welcher alle Exemplare sterben. Diese Zuit ist für verschiedene Arten verschieıten. Aputura iis zeigte 1897 riel grüssere Sterblichkeit als im Jahre 1898.

1898-1899 veröffentlichte E. Fischer (231) seine „Beiträge zur experimentellen Lepidopterlogie"; tie clarin sich befindenden Daten lassen sich zusammenstellen, wie folgt: 


\begin{tabular}{|c|c|c|c|c|c|c|c|c|c|}
\hline 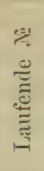 & species & & & 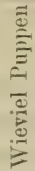 & 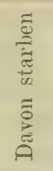 & 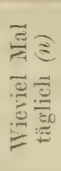 & 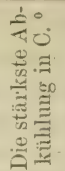 & 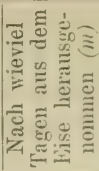 & 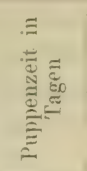 \\
\hline 1 & Vunessa wicae. & . . & . & 30 & viel & 3 & -3 & 18 & 27 \\
\hline 2 & ” & . . & . & 7 & - & 3 & -3 & 8 & $16 ;$ \\
\hline 3 & " & . . & . & 8 & 1 & 3 & -3 & 5 & 12 \\
\hline 4 & Vanessa polychlor & ros & . & 10 & - & 3 & -3 & 14 & 26 \\
\hline 5 & , & & . & 16 & - & 2 & -3 & 10 & 22 \\
\hline 6 & " & & • & 一 & - & 3 & -3 & s & 24 \\
\hline 7 & Vanessa antiopa. & . . & . & 20 & 6 & 3 & -3 & 18 & $28-30$ \\
\hline 8 & " & . . & . & 20 & 2 & 3 & -3 & 1.4 & 26 \\
\hline 9 & $"$ & . . & . & 20 & 3 & 3 & -3 & (i & $16-19$ \\
\hline 10 & Vanessa io ... & . . & . & 20 & 0 & 3 & -3 & 20 & $30-33$ \\
\hline 11 & , . . . & . . & . & 24 & $\stackrel{2}{2}$ & 3 & $-: ;$ & 1.1 & $24 i$ \\
\hline 12 & $"$. . . & . . & • & 20 & 2 & 3 & $-: 3$ & (; & 20 \\
\hline 13 & Vanessa $c$ album & . & & 11 & 2 & 3 & -3 & 8 & $18-33$ \\
\hline 14 & Vanessa cardui. & . . & • & 4 & 0 & 1 & 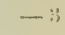 & 14 & 28 \\
\hline 15 & " & . . & - & 3 & 0 & 1 & -3 & 8 & 24 \\
\hline 16 & , & . : & • & 3 & 0 & 1 & -6 & (5) & 20 \\
\hline 17 & Vanessa atalanta & . & & 10 & 3 & 1 & -3 & 18 & 28 \\
\hline 18 & " & . & - & 6 & 1 & 1 & -3 & 8 & 24 \\
\hline 19 & " & . & & 8 & 0 & 1 & -6 & (i) & 22 \\
\hline 20 & " & . & & 8 & 2 & 1 & -12 & (6) & 20 \\
\hline
\end{tabular}

Bemerkungen. Die 8 bis 14 Stunden alte Puppen wurden zunächst in die Temperatur von $13^{\circ} \mathrm{C}$. gebracht, nach 6 Stunden bis auf $0^{\circ}$ und nach weiteren 6 Stunden unter $0^{\circ}$ bis $z u-3^{\circ} \mathrm{C}$. alsdam $n$ Mal täglich abgekühlt. Die so behandelten. Puppen wurden nach $m$ Tagen herausgenommen, noch einen $\operatorname{Tag}$ bei $15^{\circ} \mathrm{C}$. und damn bei $22^{\circ} \mathrm{C}$. gehalten. (

Die Puppen wurden für 6 Stunden in die Temperatur von $14^{\circ} \mathrm{C}$., dann in eine ron $14^{\circ} \mathrm{C}$. anf $0^{\circ}$ sinkende Temperatur gebracht und hierauf $n$ Mal täglich auf $-3^{0}$ abgekühlt. Nach $m$ Tagen wurden sie herausgenommen, 2 Tage bei $14^{\circ} \mathrm{C}$. und dann bei $22^{\circ} \mathrm{C}$. gehalten. (№ $\left.7-20\right)$.

Ausser dieser intermittirenden Abliuhlung beniitzte Ð. Fischer auch schnell sinkende Temperatur unil zwar:

21). 13 Puppen von Vunessa antiopa wurilen der Kiilte von $-6^{0}$ ausgesetzt unıl zwar lierart, llass sie im Laufe von ca. einer halben Stuncle von der Zimmertemperatur $25^{\circ} \mathrm{C}$., in ler sie sich his zur Erhärtung der Chitimhaut befanden (ci. 12 Stumien nach ryfolgter Verpuppung), auf - $1^{\circ}$ C., also in kurzer Zeit um $31^{\circ}$ C. abgekiihlt wurlen. Dies wurde, nachlem sich rie Temperatur im 
Laufe der nächsten 4 Stunlen wioler auf $0^{\circ}$ unil sorlann durch Oeffnen des Gefässes auf $18^{\circ} \mathrm{C}$. für ca. (; Stmolen erhöht hatte, am gleichen Tage noch einmal unil an jerlem der fulgenden 6 Tage je zweimal vorgenommen. 4 Puppen starben. Puppenzeit 2.:-2.5 Tage.

22). \& Puppen von Vanessa utalanta wurlen in gleicher Weise abgekühlt. 5 Puppen starben. Puppenzeit?

23). 16 Puppen von Vanessa witicue (III. (iener.) wurten in gleicher Weise abgekiihlt. 4 Puppen starben. Puppenzeit $\therefore 4$ bis $26 \mathrm{~T}$ age.

24). 10 Puppen von Vrunessu jo ebenso liehrumlelt. 3 l'uppen starben. Puppenzeit 26-28 Tage.

Webster (1899. 947) schreibt, dass Iliaspis pentu!yona Tary.Tozz. eine Temperatur ron $-22,8$ ibersteht unl hei ciner lïngere Zeit andlauernden Kälte von $-25,5$ bis $-29,5^{\circ}$ stirbt.

Scott (1899. 800) beobaclitete, class Dirspris penta!nmu Tarw.'Tozz. in Georgia (Nord Amerika) bei einer zweitägigen Kailte von -16 bis $-22,5^{\circ}$ abstarben.

Altum (1899. 12) in Eberswalde ziichtete die Raupen von Thecla betulae. Nach kurzer Puppenruhe schimmerten die falter schon durch die zarte Hülle, und bahl erschien ein Männchen. Um dem Eintrocknen der l'uppen vorzubengen, bebrauste er sie zum letzlen Mal, nund zwar etwas stärlier als frïher, wählte aber dazu leider noch nicht zimmerwarmes Brumnenwasser - und sämmtliche, wohlausgebililete, in ien. Puppenhiillen ruhenile Falter starben plötzlich $\mathrm{ab}^{\star}$ (p. 309).

In derselben Abhandlung sagt er: ... Nimentlich wirkt dbwechselung ron Schneewasser und frost verlerblich. Auch sterben die Embryonen in then Eiern und P'uppen leicht al), wenn sie ummittelbar vor ihrem Ausschlüpfen auch nur wenig iiberkältet werlen" (p. 308).

Altum (18!99. 11) berichtet in einer zweiten Notiz. class in Posen die Räupchen von der Nonne 1898 bereits gegen Mitte November ausschliuften. Nach Forstmeister Engelmann ,stand das Verhätniss der ausgefallenen Eier zu den noch geschlossenen zur Tiefe ih"er Winterverstecke in ter Rinte in geralem Verhältnisse. Je tiefer das Weibchen mit seiner Legeröhre in die \%wischenräume der grobhorkigen Rindeplatten vo!gedlungen war, lesto grösser war ler Procentsatz der bereits ausgeschliiptten jungen Raupen" (p. 16i2). 
A. M. Schtscherbakow (1899. 782) sagt in seiner Arbeit über Collembola Spitzbergens, lass Achrutes vinticus bei - 150 bis - $20^{\circ} \mathrm{R}$. vollständig durchfriert und in einem Glase mit Wasser ein Eisstïck billet. In der Wärme kehrt das Leben nach dem Aufthanen wierler zurück.

Nüsslin in Karlsruhe (1899. 612) brachte eine Anzalnl ron Tamnenpflanzen mit dem Wurzeltheil in einen Eisschrank, wobei die Temperatur in der Erile nitch unil nach auf ca. 90 heribgesetzt. wurile. Durch zu grosse Fenchtigkeit sind viele der Lïuse (Pemphigus poschingeri Holzner) zu (rrunte gegangen. An 3. September beobachtete er eine Nymphe. welche die dritte Häntung hinter sich hatte, währent in Freien keine einzige Nymphe anzutreffen war. "Es scheint darnach der Schluss einigermassen berechtigt, dass die Kälte die Umwan!lung zur Gefliigelten auslist, wenn auch nicht fïr alle Individuen, wie ja anch in der Freiheit im Oktober immer nur ein Teil derselben zu Nimphen unl (iefliigelten wirl, die iibrigen dagegen als Fundatrices ïberwintern" (p. 7).

$\mathrm{Er}$ stellte noch einen folgenlen Versuch an: im September wurlen diese Lïuse sammt den mitgebrathten PHanzen in einem Zimmer gehalten, dessen Temperatur nicht unter $12^{\circ} \mathrm{K}$. Sank. Am 10. Oktober fund sich unter diesen Lüusen keine einzige Nymphe o:ler (ieflïgelte. währenıl in der Fraiheit der grösste T'eil der Läuse zu Nymphen und Geflügelten geworden war.

Marlatt (1899. 547) beolachtete bei Washingtom. 'ass Dirtspis pentayona Targ-Tozz. bei einer 'Temperatur von -16 bis $-22^{\circ}$ grösstenteils abstarben.

Line spezielle Arbeit: „Untersuchungen ïber beschlemigte Entwickelung überwinternder Schmetterlingspuppen (Treiben der Puppen)" veröffentlichte H. Gauckler (297) im Jahre 1899.

Dabei benutze er zwei Methorlen:

A. Die Puppen wurien bereits im Herbste, kurze Zeit nach der Verpuppung, in ein geheiztes Zimmer mit Temperaturen von $14^{\circ}$ bis $20^{\circ} \mathrm{R}$. gebracht.

B. Die Puppen blieben zuerst his etwa Enrle Januar im Freien und nachher im Zimmer bei $14-200^{\circ} \mathrm{R}$.

Die erhaltenen Resultate sind aus folgenlem Ver\%eichnis ersichtlich: 
148 Erstes Kapitel. Die Entwiekelungsgesehwindigkeit der Insekten.

\section{Rhopalocera.}

1). Papilio muchaon. Xach "A" behindelt. schliipften die meisten Puppen in 20-28 Tagen.

2). Papilio poclalirius. Dito.

3). Papilio hospitm. Nach "B" behandelt, in 10-14 Tagen. Sterblichkeit ist gering.

4). Thais polyxena. Nach .A" währte lie Entwickelungsperriocle 4-5 Wochen, nach „B“ 14 Tage.

5). Thecla inbi entwickelt sich besser nach , $\mathrm{A}^{*}$ wie nach „I;" behandelt, braucht jerloch durchschnittlich etwas mehr Zeit als die Papilio-Arten.

6). Vanessu levana verhült sich gan\% ähnlich: nach "A" dlauert die Entwickelung 6 Wochen, nach „B" etwa 4 Wochen.

\section{S phingid a e.}

7). Sphinx pinustri. Nach "B" behandelt, schliipften die Falte' nicht wesentlich früher wie in der Natur.

8). Sphinx ligustri. Die Methole "A" beförlert die Entwickelung der Puppen nur wenig, indem die Falter meist erst im März und April des kommenten Jahres schlïpfen. „B“ übt einen ziemli $h_{\text {}}$ ungünstigen Einfluss auf das Leben dieser Puppen aus, der grösste Prozentsatz geht dabei zu Gruntle, die wenigen sich entwickelnten Stücke gelangen im Februar unı März zur Entwickelung.

9). Smerinthus populi. Bei diesem Schwärmer tritt die eigentiimliche Erscheinung auf, dass die Puppen desselben bei gleichen Verhältnissen und gleicher Behandlung sich stets individuell verhalten, r. h. es gebraucht jeile Puppe zu ihrer Entwickelung die gleiche Zeitlauer, so dass \%. B. solche Tiere, die sich zu gleicher Zeit verpuppten, auch sprïter zu derselben Zeit ausschliipfen. Xach ${ }_{n} A^{\text {" be- }}$ handelt, schliipft der Falter nach 8-12 Wochen, nach "B“ nach etwa 4 Wochen aus.

10). Smerinthus ocrllatus. Die Puppen dieser Species sind nicht so empfindlich für die Eintlïsse erhöhter Temperaturen: die Entwickelungstauer nach Methotle "A" beträgt etwa 3-4 Monate, nach ${ }_{n} \mathrm{~B}^{\prime} 6-8$ Wochen.

11). Smerinthus tiliac verhält sich ähnlich wie die beilen ehen genaminten Species. Nach "A" entwickeln sich die Schmetterlinge meist im Februar und Mirrz, nach "B" behandelt, in 4-6 Wochen.

12). Deiliplila galii. Aut die Puppen dieser Art wirken höhere Temperaturen sehr beschleunigent. Nach " $\Lambda^{4}$ schliupfen die 
Filter schon im December, also nach 4-5 Wochen aus; nach "B" b) hanclelt, erscheint der Schmetterling in 3-4 Wochen.

13). Deilephila enphorline kommt, nach "d" behandelt, in Januar zur Entwickelung. Die Methode „B" wirkt nicht sehr beschleunigend auf die Entwickelang der Puppen; die Falter erscheinen nich wieser Methode erst in 3-4 Monaten, also etwa im April.

14). Deilephila elpemor entwickelt sich nach "A" in ca. $4 \mathrm{MI}$ niten; nach "B" erfolgt die Entwickelung binnen weniger Wochen.

15). Deilephila porcellus. Dito.

16). Macroglussu stellatainm entwickelt sich nach Methoule "A" in $4-6$ Wochen, nach "B $\mathrm{B}^{\text {in }} 14$ Tagen.

17). Macroylossa aenotherae entwickelt sich nach Methode „B" durchschnittlich in 3 bis 4 Wochen.

III. B o m b y cid a e.

18). Earias chlorana. Entwickeln sich nach "A" nach etwa 10 Wochen.

19). Hylıph. prasinanu. Nach "A" finclet die Entwickelung" stets erst im Vorfriihling statt.

20). Euchelia jacnbaeae. Nach "A“ behandelt, schliupfen die Falter Ende April bis Mitte Mai aus.

21). Hybuc. milhuruseri. Gehen alle in höheren Zimmertempiratur zu Grunde.

22). Stauropus fagi. Dito.

23). Dasychira pulibundu. Die Puppen reagieren leicht auf höheren Temperaturen. Nach "A" schlüpften die Falter nach durchschnittlich 4 Wochen Puppenruhe.

24). Oregyic antiqu schlïpft bereits nach 14 Tagen, nach Methode "B" behandelt, aus.

25). Bomlyx lanestris. Die meisten Puppen liegen mehrere Jahre, ehe sie zur Entwickelung gelangen; dann schlüpft der grösste Prozentsatz erst im kommenden Fruhjahre aus, wenngleich tler lalter fertig entwickelt in der Puppe liegt. Bringt man die Puppen aus der im. Januar im l'reien herrschenden niedrigen Temperatur in das geheizte Zimmer, so verlassen die Schmetterlinge schon nach 24 Stumden die Puppe.

26). Enuliomis rersicolara überwintert ebenfalls in der Puppe als ausgebildeter Schmetterling und ist daher leicht durch Temperatur-Erhöhung zum Ausschliipfén zu bring:n. Nach "A" behanlelte 
Puppen liefern den Falter in 8--10 Tagen; nach "B" schliiptt der Spinner schon nach $2-3$ Tagen aus.

27). Saturnia pavonia gebraucht, nach dex einen oiler anleren Methode behandelt, etwas mehr Zeit zur Entwickelung. Nach ${ }_{n}$ " $^{*}$ schliupt ,ler Falter durchschnittlich in $4-6$ Wochen aus, nach " 13 " in etwa 14 Tagen.

28). Saturniu pyri. Nach "A" behandelte Puppen ergaben den Schmetterling niemals vor März des folgenten Jahres; nach "B“ hehandelt, kommen die Falter nicht gut aus, auch ist die Zeitlifferenz keine bedeutende.

29). Aglia tuu. Puppen entwickeln sich, nach "A" behandelt, immer erst im ersten Frïhjahr, März, auch wohl schon Enle Februar.

30). Irepana fulcuturia schlipft, nach „ $\mathrm{B}^{*}$ behandelt, schon in 14 Tagen aus, nach ${ }_{n} \mathrm{~B}^{\prime \prime}$ in $6-8$ Wochen.

31). Diepuna binaria. Nach .A" behanilelt, ergaben im oktober erhaltene Puppen den Schmetterling schon im Februar.

32). Harpyia bificla. Reagiert sehr leicht. Nach ", " hehandelte Puppen ergaben den Schmetterling im Februar und März; nach „B" behanlelt, erschienen die Schmetterlinge schon nach 14 Tagen bis 3 Wochen.

33). Harpyia vimula verhält sich analag der genannten Art.

34). Harpyia furcula. Dito.

35). Notodonta tremula. Nach Methode " $\Lambda$ " kommt ier Ialter in 4 bis 6 Wochen aus der Puppe. Methode "B" beschleunigt dieEntwickelung derart, dass der Schmetterling nach 14 Tagen bis 3 Wochen erscheint.

36). Notodonta ziczac. Methole "A" liefert den Falter in ca. 4 Wochen. Methode "B" in 14 Tagen bis 3 Wochen.

37). Notodonta trithoprlus: verhält sich ähnlich wie die beiden genannten.

38). Notodonta trepida. Puppen dieser Art wurilen nur nach Methode "B" behandelt; die Falter schlïpten im Februar und März aus. Sie gebrauchten also 4 bis 6 Wochen zu ihrer Entwickelung.

39). Notodonta tornu. Nach "A" behandelt, erschienen die Falter nach etwa 14 Tagen bis 3 Wochen.

40). Notodonta dromedarius verhält sich in seiner Entwickelung nach "A" oder "B" wie Notodonta ziczac.

41). Lophopteryx camelina. Nach "A" erfolgt die Entwickelung: der Puppen innerhalh 4-6 Wochen, nach „B $\mathrm{B}^{4}$ in etwa 14 Tagen. 
42). Pterostoma palpina. Die Schmetterlinge entwickeln sich nach Methode "A" in 4-8 Wochen; "B" lringt dieselhen in etwa 20 Tagen zur Entwickelung.

43). Phaleru bucepluch . Die P'uppe ılieser Species verhält sich gegen Temperatur-Erhöhungen höchst indifferent. Auf die Methorle „B“ reagiert dieselbe gar nicht; nach Methorle "A "behanclelte Puppen ergaben den Schmetterling erst Mitte März.

44). Pyguera anustomosis. Dies? Art ist leiclit nach der einen oler anderen Methode zum Schliipfen zu bringen, und zwar erscheinen die lalter aus nach "A" behandelten Puppen in 4 Wochen. aus denen nach Methode .IB: hehandelt alser schon in 14 Tagen.

45). Pygaera cuitula.

46). Pyyaera machoretı.

47). Pygaera pigra.

Wie bei Py!laera anastomosis.

48). Thyatira butis schliipft nach "A" in etwa 2 Monaten.

49). Cymatophora or: Nach "A" behandelt, entwickelten sich die Schmetterlinge Encle Fehruar und Anfang März.

50). Cymatophora duplaris. Dito.

IV. Noctuidae.

51). Demas coryli. Puppen dieser Art, nach Methorle „A" behandelt, schliipften erst Ende Februar.

52). Acronycta leporin . Auf diese Art wirkt die Methorle ${ } \mathrm{B}^{4}$ nicht beschleunigenıl, auch fördert "A" keine frïhere Entwickelung als im kommenden März.

53). Acromycte accris entwickelt sich nach beiden Methoden

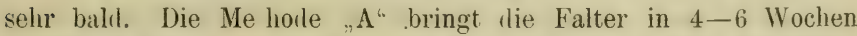
zur Entwickelung, nach "B“ schliipfen dieselben schon nach 14 'Tagen bis 3 Wochen.

54). Acronycta megacephala.

55). Acronycta psi.

56). Acronycta auricoma.

57). Acronycta rumicis.

Wie bei Acromycta aceris.

58). Panthea cocnobitı. Von etwa 16 behandelten Puppen, nach Nethode "A", schliupften nur 2 Falter, und zwar 1 б Mitte Februar und 1 ㅇ Ende März. Es geht aus diesem Versuche hervor, dass diese Puppen zu ihrer gedeihlichen Entwickelung längere Zeit niedriger Temperaturen mit viel Niederschlägen berlïrfen.

59). Mamestra pisi. Auf diese Art iibt die Methorle "A" keine grosse Beschleunigung ihrer Entwickelung aus; die Falter schliipfen 
meist erst in März. Diese Puppe, nach „ $\mathrm{B}^{4}$ hehandelt, entliisst den Schmetterling schon nach $3-5$ Wochen.

60). Mamestira brassicae.

6i1). Mamestra persicariae.

(i2). M(amestra olrivaceae.

(53). MLamestra dentina.

Wie bei Mamestra pisi.

64). Trachea atriplicis. Puppen, nach "A" behandelt, liefern ien Schmetterling im Februar, nach Mcthwle "B" meist swon nach 4 Wochen.

65). Einglerin lnciprere. Inie Schmetterlinge entwickelten sim nach . Methode „B“ bis Mitte März.

66). Caradrina taraxaci. Von dieser Art war nur eine Pupje

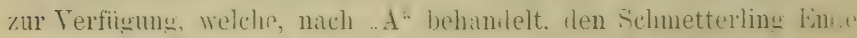
April lieferte.

67). Trenincumpa grthera. Verpuppt sich bekanntlich schon in Sommer unl Herlst: nach wenigen Wochen entriclielt sich iew

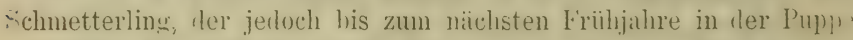
verhleibt. Dien's Thier verhält sich daher ähnlich wie Brmlyyx la, . stris und noch einige Spinnerpuppen, inlem es, nach "A" behamlet. ren Schmetterling in 3-4 Wochen entliist, nach "B" aher sch.m nach wenigen Tagen.

68). Taeniocampa st ibilis.

69). Taeniocampa gracilis.

70). Taeniocampa munda.

71). Saeniocampa incerta.

Wie bei Taeniocampa gotlica.

72). Paulis pinizerdu. Diese Eule verhält sich ebenso wie ci.t. eben genannten.

73). ('nlymnia trapezinu. Auch die Puppen dieser Art reasieren auf die Einwirkung höherer Temperaturen. Die Schmetterlinge entwickelten sich mach Methorle "A" in 3 bis 4 Monaten, also im Februar.

74). Nylomiges conspricillaris enwickelt sich nach Yethorle "A" in 4-6 Wochen, nach "B" in 8-14 Tagen.

75). Plusia triplusia. Yach Methole "A" behanilelte Puppen eræaben den Falter erst im April, also sind höhere Temperaturarade im Winter auf diese Art fast ohne Einfluss.

76). Plusia asclepialis. Wie die eben genannte. 
V. Geometridae.

77). Jodis putatu. Aus Puppen dieser Art, nach Nethode "A" belıantelt. schliipften die Schmetterlinge stets crst im Mair un I April, nach "B" schon Ende Januar.

78). Zonosoma poratu verhält sich gleich; es schliipfen die Schmetterlinge nach Methode "A" im Januar.

79). Zonosoma puncturia. Dito.

80). Cabera exanthemaria. Nach Methorle "A" im Februar und März.

81). Cabera pusaria. Dito.

82). Selenic bilunaria. Falter nach Methoile "A" im Fehrutr und März.

83). Nemoria viridaria. Nach "A" erschienen die Schmetterlinge Anfang März.

84). Selenia tetralunaria. Nur nach Methorle "A" behanilelt. Die Schmetterlinge schliipften Encle Januar unil friilı im Feln'urr. also etwa 2 Monate friiher als sonst in der Natur.

85). Rumia luteolatu. Entwickelung Anfang bis Mitte März nach Methode "A".

86). Biston hirtarius. Alle Puppen gingen zu Gruncle.

87). Bistom strutarius. Nachiem die Puppen bis zum Februar im Freien gelassen und dann ins warme Zimmer gebracht waren, entwickelten sich die Spanner sehr schnell; der erste, ein ठ bereits an 16. Februar, die übrigen folgten rasch aufeinanter, st) dass Anfang März sämtliche Stücke geschliupft waren. Sümtlich schlüpten in den Nachmittags- und Abendstumlen, und nur eine Puppe ergab einen verkrüppelten Falter.

88). Amphirlısis betularius. Auf diese Art übt die Methoule "A" nur ganz unwesentlichen Eintluss aus, auch erkranken die meisten Puppen an Schimmelbildung unil anderen Krankheiten. Nethoile „B* hat mehr Einfluss auf die Entwickelung der Puppen; die Schmetterlinge erscheinen nach dieser Behandlung nach 3-4 Monaten, also etwa in Februar. Im allgemeinen entwickeln sich die Puppen von A. betularius nur zu sehr kleinem Prozentsatze nach den Methoden des künstlichen Treibens.

89). Buarmia irepusculuru. Der Falter entwickelt sich nach „A" im Februar. Nach "B" sind keine Versuche angestellt worlen. 90). Boarmia mbrraria ebenso wie die vorige. 
91). Bupalus piniarius. Bis zum Januar des folgenilen Jahres im Freien belassene Puppen (Methorle ${ }_{n} \mathrm{~B}^{*}$ ) entlassen die Spanner bald, nach 8-14 Tagen.

92). MLacuria liturata. Verhält sich analog ver vorherigen Art.

Aus diesen zahlreichen Versuchen lassen sich folgentle allgemeine Resultate ableiten:

1). Die Mehrzahl aller im Puppenstadium iiberwinternilen Falter lässt sich "treiben."

2). Verschierlene species verhalten sich gegeniilser der Einwirkung erhöhter Temperaturen sehr verschieden.

3). Die Tagfalter-Puppen reagieren leicht auf erhöhte Temperaturen, sowohl nach Methorle "A" wie auch nach Methode "B." Nach "A" behandelte Puppen schlüpfen meist in $4-1$; Wochen aus, während nach "B" nach etwa 10 'Tagen bis 3 Wochen.

4). Sphingi d a e lassen sich auch leicht zu frühzeitiger Entwickelung bringen, loch verhalten sich einige Arten senr verschie(len gegen die angewandten Methoden "A" und "B".

5). B o m bi id a e verhalten sich recht verschierlenartig gegen die Einwirkung hoher Temperaturen.

(i). Noctuidae zeigen sehr ungleiches Verhalten gegen das Treiben, und zwar übt die Methode "A" auf viele Arten dieser Familie keinen nennenswerten Einfluss aus, während die Puppen fast aller Arten, nach „B" behaudelt, schon nach wenigen Wochen ausschliipfent.

7). Geometrid a e ertragen schwer die Berlingungen dieser Versuche und gehen meist zu Grunde.

Aus einem Briefe H. Gauckler's (14. IV. 1900) entnehme ich noch folgendes:

.. Ich operierte nach Methorle „B“, indem ich alle Puppen bis zum 16. Januar 1900 im Freien beliess, dieselben dann 2 Tage in ein ungeheiztes Zimmer brachte, und sie nunmehr erst einer Tempetatur vom durchschnittlich $+22^{\circ} \mathrm{C}$. aussetzte. Die Beobachtungszeit währte vom 18. Januar 1900 bis zum 27. Mäız 1900, nach welchem Datum ich wegen Umzuges nach einer anderen Wohnung, keine weiteren exakten Beobachtungen anzustellen vermochte.

Ich erzielte folgende Resultate:

Deileplitu elpenor 1 o entwick lte sich am 31. Januar 1900.

Taeniocampa pulverulenta 1 o entwickelte sich am 8. Februar 1900. Bumbyx lanestri: 1 올 entwickelte sich an 9. Februar 1900. 
Trenincampa gothica 1 o entwickelte sich am 10. Februar 19)0(). Pupilin muchaon 1 Q entwickelte sich am 10. Februar 1900. Jumbyx lunestris 1 ठ entwickelte sich am 15. Februar 1900. Acrmmyte rumicis 1 o entwickelte sich am 16. Februar 1900. Pirpilin muchum 1 o entwickelte sich an 17. Februar 1900. (Averration mit rothen Fiecken am Vorderrand der Unterflïgel). Acronyctu rumicis 1 Q entwickelte sich an 17. Februar 1900. Aglia tau 1 б entwickelte sich am 19. Februar 1900.

Sprilusmun fuliginosin 1 O entwickelte sich am 19. l'ebruar 1900. Pyguera pigra 1 ठ entwickelte sich am 24. Februar 1900. Zomosoma puncturia 1 o entwickelte sich am 26. Februar 1900. Emrturya atomaria 1 q entwickelte sich am 27. Februar 1900. Earices chloranc 1 o' entwickelte sich am 3. März 1900.

Pupilin muchuom 1 O entwickelte sich ain 4. März 1900. (Aberration mit grossen rothen Flecken am Vorderrande des Unterfluigel). Ifumestia oleracea 1 Q entwickelte sich am 7. März 1900. Burrmia consontaria 1 o entwickelte sich am 9. Närz 1900. Viturl. ziczac 1 ㅇ (verkrïppelt) entwickelte sich am 10. März 1900. Cabera exauthemata - entwickelte sich am 12. März 1900. Pterostomu palpinu 1 o entwickelte sich am 13. März 1900. Thyatira batis 1 б’ entwickelte sich am 23. März 1900. Cabor exauthematu 1 o entwickelte sich am 24. März 1900. Abraxas marginata 1 ठे entwickelte sich am 25. März 1900. Carudrimu caraxaci 1 q entwickelte sich an 26. März 1900. Eupithecir? (noch nicht bestimmt) 1 व enwickelte sich an 27. März 1900."

Carl Frings (1\$99. 257) erwälınt gelegentlich seiner „Expe. limente mit erniedrigter Temperatur" folgende Thatsichen:

Zu Anfang Juni 1898 kam eine Anzahl Cocons voll Saturria spiui in den Eiskasten $\left(6-8^{\circ}\right.$ C.) und rerblieb bei diesen Temperatur bis Ende Oktober, worauf sie ins Zimmer genommen wurle. Nach zweitägigem Aufenthalt in der Zinmertemperatur schlüpte ein normales $\delta$. Der Rest kam nach etwa 3 Wochen aus. Häufig hatten die Falter schwach ausgebilıte Krallen, konnten nicht anhaften unl verkrüppelten infolge dessen (p. 59).

Frische Puppen von Dasychira pudibunda wurden von ihm an acht aufeinanderfolgenden Tagen je 6 Stunden dem Froste $\left(-13^{\circ} \mathrm{C}\right.$.) ausgesetzt und dann in Zimmertemperatur gehalten. Nach 3 bis 4 Wochen schliipften normale Falter aus. „Diese kurze Frostexpositior 
hatte also die Wirkung der monatelang anhaltenlen Winterkilte im Freien ersetzt" (p. 66).

Eine Anzahl möglichst frischer Puppen von Suturmin myri. sprui uni pacmin wurlen 10 his 15 Mal je di his 10 Stmilem hei Frost $\left(-13^{\circ}\right.$ C.) exponirt. Hierauf verblieben sie his Ende Olitolner in Eiskasten ( $f_{-}-\mathrm{S}^{0}$ C.). In November schlüptte kein einziger Falter, trotzlem die Cocons im warmen Zimmer stanlen. „Seit Ihcember liegen sie im Freien in der Ueberwinterma und werlen wihrscheinlich im Friihjahre 1899 auskommen" (p. 67).

Dr. Pauls in Ballensterlt (1899. (j28) erhielt ans Eiern von Arctic hebe, welche in einem Warmzuchthasten bei 2.30 li. sich h... fan len, am 3.-5. Juni Raupen, welche Enrle Juni hartniiclig dic Nillrungsaufinahme verweigerten. Am 1. Juli wanderten die Thiere in den Feller und sehr balı von durt in then Eisschrank. Nach 4 Wnchen wurilen die Raupen wierler in die Temperatur von 2:30 It gebracht nnd ergahen am 17. August die ersten Puppen. Somit lietrïgt unter diesen Umstïnlen die Dauer der Raupenzeit 14 ' $\mathrm{T}$ age. Die Puppen wurlen bei derselben Temperatur belassen und ergaben nach zwölftägiger Puppenzeit (17.-29. August) Falter.

\%u den Betrachtungen von Dr. Pauls, dass der erhaltenu Falter zu der II. Generation angehört, ville die Kritik von J. Röber (1900. 699).

Am 22. August setzte er Nupta-Eier ins Eis bis :30. Septemher, damn in die Wärme, schliesslich in rlen Brutkasten (230 li.). Bis Anfang November hatte sie lie "tropische Wärme" nicht zur Entwickelung gereizt.

E. Quajat (1899. 627) stellte fest, dlass zur normalen Entwickelung der Raupen aus Eiern von Bombyx mori, die letzteren der Einwirkung der Kïilte während einer bestimnten Zeit ausgesetzt wrrden müssen, wobei die sinkende und die darauf steigente Tenperatur allmählig eingeleitet werden muss; sonst schliiptt ein Theil der Eier nicht. Wie lange diese nothwendige Kälte (von 0 bis $+s^{0}$ ) einwirken muss, luängt von der Vorbehandlung der Eier ab.

C. H. Vogler (1899. 928) beschrieb einen 1899 vom naturhist. Museum in Schaffhausen erhaltenen Polyports. Derselbe war stit Frühjahr 1900 unter Glas auflewahrt und liess den Sommer iiber weiter nichts wahrnehmen. Als aber Ende Närz 1901 (1901. 4.2!1) 
wietler eimmal nachgesehen wurle, war die Unterlage mit einer Lnmasse kleiner Käfer (Rhopalodontus ylabutus Bris.) herleckt. Die Mehrzahl der Thiere waren todt, andere nur scheintorlt, und diese bewammen sich halı zu regen, als sie in das geheizte Zimmer gehracht wurlen. Die Sammlungsräume sind nicht heizhar und haben ohne Zweifel von Neujahr an recht nichrige Temperatur gehabt; uml loch scheint gerade um diese Zeit das Ausschlüpfen der Thiere erfolgt $\mathrm{zu}$ sein.

L. Carpantier (1900. 132) sast, dass die Erstarrung der Insekten im Winter keinesweg dem Winterschlafe anderer Thiere entspricht, sondern es wird dieselbe wesentlich durch die Kälte verursacht, da die Insekten, welche im Winter ins warme Zimmer gebracht werlen, wieder ihre Lebensthätigkeit erhalten.

M. Bezzi (1900. 79) fand im Valtellino die fliigellose, auf d('m Schnee lebende Muicke Chionea crassipes Boh.

Nach den Beobachtungen von A. Mordwilko (1900. 593) werden die Pflanzenläuse an kalten Mai-Tagen $\left(8-10^{\circ}\right.$ R.) und speziell Weibchen von Siphonophora platanoides sehr unbeweglich. ${ }_{n}$ Sie flogen sonst bei leichter Beriihrung des Blattes weg, jetzt aher durch las unmittelbare Stossen verschoben sie sich mit grosser Miihe unl krochen sogar, als ich sie gewaltsam zwang, die Stelle zu verlassen, flogen aber jedenfalls gar nicht weg" (p. 221).

H. Gauckler (1900. 301) beohachtete 1899, dass Deilepliila urrii vom Ei ab zum Falter in nur vier Wochen sich ziichten liess. Der grösste Prozentsatz iler Falter kam leicht zur Entwickelung. $\mathrm{Er}$ vermuthet, dass der sehr heisse Sommer in erster Linie zu diesem ausserordentlich gimstigen Resultat heigetragen hahen mag.

Derselle Furscher (1900. 298) ziichtete Bom'ryx quercus vals. sicula stgr., wohei die Pupue oit mehrere Jihre ruhte, ehe der Falter entschliiphte. „Die Zimmertemperatur hat keinen wesentlichen Einfluss auf ein frïheres Schliipfen."

L. v. Aigner-Abafi (1900, 4) erwïhnt in seiner Abhamblung „Missbillungen hei Sihmetterlingen" einen eigenthimulichen Fall rom Hypertrophie, welcher in Italien heobachtet wurte, - wass sich 
nämlich die Riaupen von $B$ mbly.t mori. ohne sich zu verspinnen und zu verpuppen, sofort zu faltern verwanlelten, mul жwar zn etwas kleineren als die normalen Falter. Iliese Erscheinung wiri durch die grosse Sonnenhitze, welche die Eintwickelung der lianpen zu stark beschleunigte, erklärt.

B. Slevogt (1900. S22) hielt Puppen von Trumssu polyclilums auf einem, dem damals herrsihemlen Xordwinde ansgescotyten Fenster, uni beolsachtete, dass die P'uppenzeit statt 12-14 Tage? :3 bis 5 Wochen betrug.

G. Koschewnikow (1!)(). 467 ) mahm ans einem Bicmenstuch am 2s. Juni eine Wachsplatte mit zugemachten Kellen und liess sie auf dem Tische hei $150 \mathrm{R}$. liegen. An 22. Juli. d. h. nach 24 Tagen waren sowohl einige zur Verwanllung bereiten Larven. wie amch Puppen mit dunkelen Augen noch lehent. die meisten derselhen waren aher verfault. "Eine Verwandlung geht in diesem Fille nicht vor sich, die Larven kimnen aher zuweilen sogar währent 24 Taren am Leben heiben unı zwar in lem Stallum, in welchen sie ans dem Bienenstock herausgenommen wurden" (p. 111).

Gust. Reinberger (1900. (685) setzte die Puppen zuerst ler natiirlichen Kälte atus und lrachte sie damn im Anfang o:ler LinliJanuar ins warme Zimmer. Dabei erhielt er Falter:

$$
\text { Stpecies: }
$$

Papilio poclativius

Thais polyxena

Pieris brassicae

Splhinx ligustri

Deilephila cuphorbiae

$" \quad$ elpenor
$" \quad$ porcellus

Smerinthus populi

$\Rightarrow \quad$ occlatta

Macroglossa bombyliformis

Euchelia jacobaeae

Spilosoma urticae

Dasichira pudibuncta

Bombyx lanestris
D a t um:

Anfangs März - Anfangs April.

4-6 Wochen.

Mitte März - Mai.

Ende März - Mitte April.

Normal (Juni).

Anfangs April - Anfangs Mai.

Mitte April - Anfangs Juni.

Nitte März - Mitte Mai.

Nitte Februar - Ende April.

Mitte März - Mitte April.

Anfangs April - Ende Juni.

Mitte März - Ende Närz.

Nach 2 Monaten.

Nach 7 Wochen.

Nach 1 'lag - 2 Wochen. 
Species:

Lasiocampa trimulifotia

Endromis versicolora

Saturnia pyri

spini

Aglia tau

Harpyia vinula

Phalera buceptrala

Acromycta rumicis

Mamestra dissimilis

Harpyiu furcula
D a t $11 \mathrm{m:}$

Nach 6-7 Wochen.

Nach 14 Tigen.

Nach 2 Mumaten.

Nach 1 Mnmat bis 7 Woch. des II.

Nach 3-4 IVochen. [IVinters.

Nach 2-3 Wochen.

Nach 14-16 Wochen.

Anfangs März - Ende Mai.

Nach 6 Wochen.

Nach 10 Wochen. [berwinterung. Nach einigen Wochen, also olıne Ue.

A. Tichomirow (1900. 871) sprach die Vermutlımg aus, lass ein äusserer Reiz (z. B. die kurze Behan llung mit Wasser ron .jo0, das Geschlecht „ler aus Drohmen-Eiern sich entwickelnlen Emhryonen ändern soll.

S. Mokrzecki (1900. js(i) beobachtete an der von ilm entdeckten Oberia ocnlatu var. burysthenica. rlass diese liäfer im Zimmer am 7. Mai und im Freien erst in cler ersten Hälfte les Monat Juni zu erscheinen beginneu. Die Puppen und Larven wurlen vou ilm im Freien noch am 18. Mai gefunılen, wälırend im \%immer die ersten Puppen an 20. April erscheinen und am 7. Mai zu Kïtern werilen.

R. de Cuvolli (1900. 152) schreibt, llass Lophyrus jini L. im Zimmer frïher und während eines längeren \%eitraumes ausschliiptt, als im Freien.

C. Rengel (1901. (686) lieobachtete, dass Hycliopliilu. jiceus: bei ca. $5^{0}$ auf dem Grunde des WVassers einen geeigneten Ort zur Ueherwinterung aufsuchen und dort erstarren. Aus cliesem Zustanile bringt sie die Temperatur von $10^{\circ}$ im Winter nicht heraus, wohl aher erwachen sie bei ziemlich tiefer 'T'emperatur in Friilijahre, .rlemm ich habe wiederholt Kïfer kurze Zeit nach dem Verschwinden des Eises auf unseren Flüssen unıl Seen in Freien angetroffen" (1). 17!).

Alisch (1901. 9) kommt, gestiitzt auf seine Beolachtumen zu dem Schlusse, dass lı eiss:? und stiurmische Tage zur Zeit ller Eiablace eine Verringerung ler Kifferfrequenz zur liolge halien. 
E. Fischer (1901. 259) brachte 48 Puppen ron Aictin raja in die Temperatur von _ so; ron diesen I'uppen starlien dahei 7 ah. und die iibrigen ergaben im Laufe von $i$ Tagen Falter.

C. Frings (1901. 259) setzte frische Puppen iler Einwirkuny ler erhöhten Temperatur in einem Thermostaten aus und erhielt folgende Sterblichkeit:

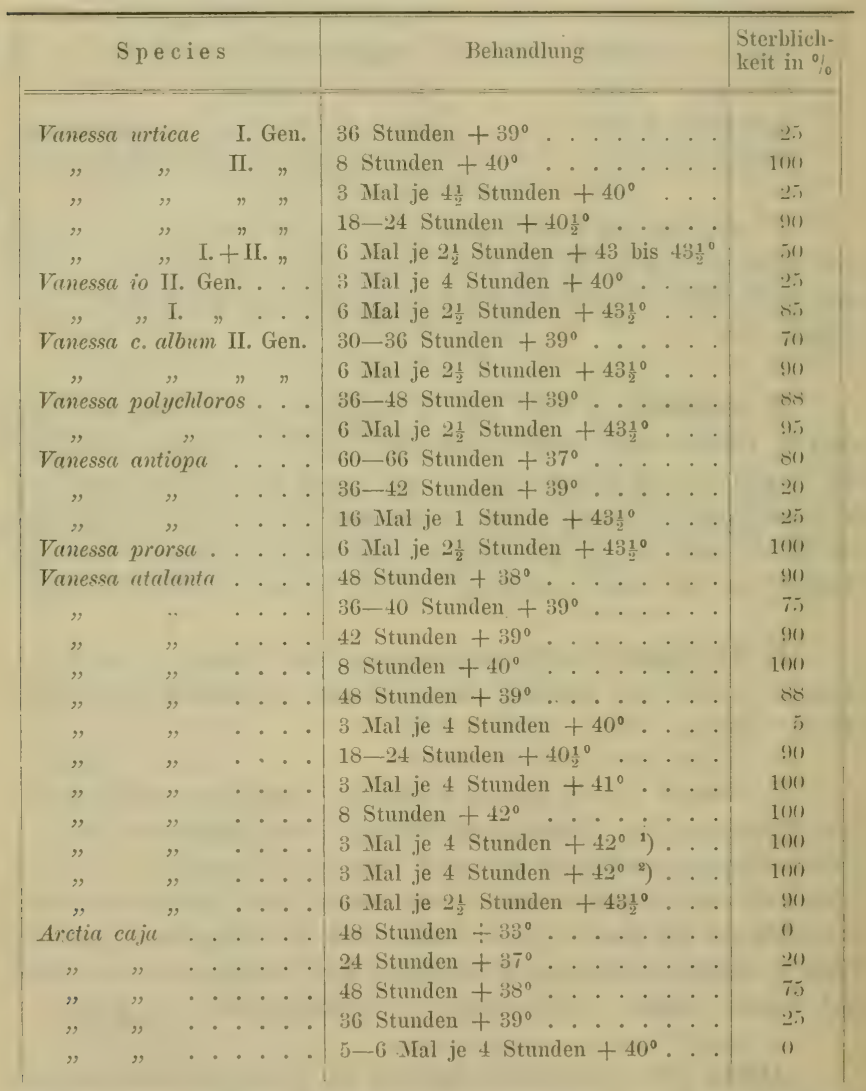

3) Puppen halbfrisch. - ${ }^{2}$ ) Puppen erhärtet. 


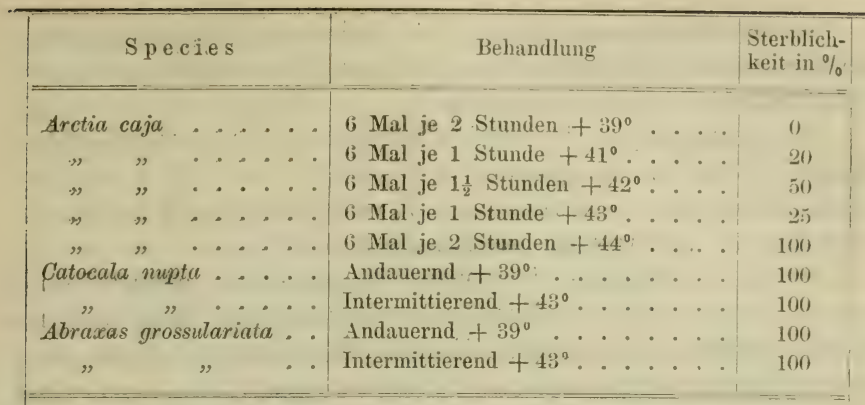

Die Versuche mit erniedrigten Temperaturen (rgaben folgende Resultate:

Papilio machaon .... 10 Mal je 8 Stunden bei $-15^{\circ} . . \quad 2(1)$

Vanessa urticae.... 6 Mal je 3-4 Stunden bei $-12^{0}: \mid 75$

Vanessa c. album .... Frostrersuch . . . . . . . 75

Catocala nupta .... $35-42$ Tage $+6^{\circ}$...... 100

Frings stellte auch Versuche mit combinierten Behanllungsmethoden an und erzielte folgende Resultate:

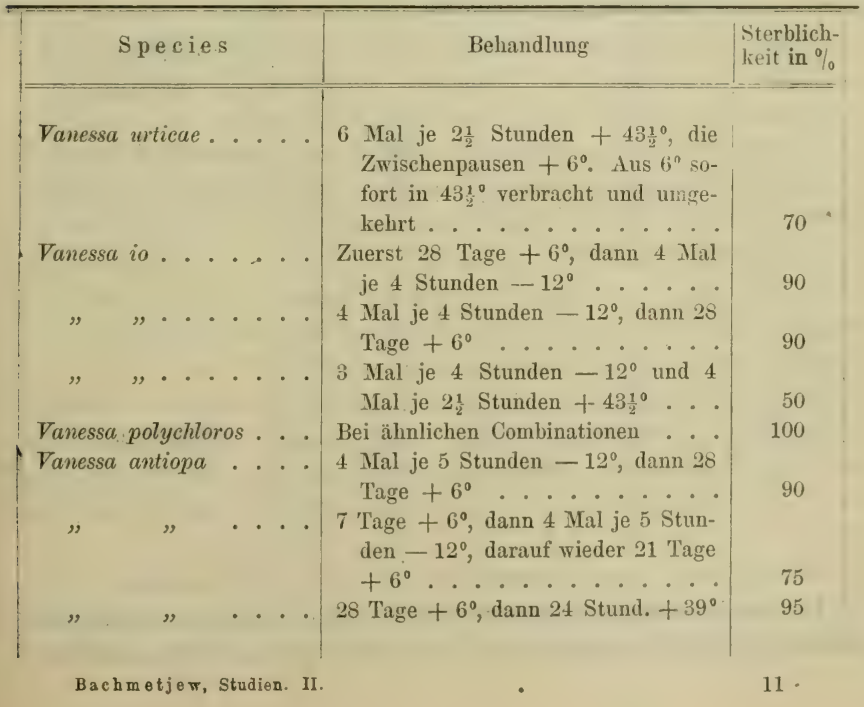


J. M. Schemigonow (1901. 744) stellte selir ansfïhrliche Versuche an ïber den Einfluss rerschierlener Temperaturen auf die Entwickelung von Ocneria monacha L.

Die gesammelten Eier wurlen wïhremul ler Versuche in einom Glasgefiisse bei ller Temperatur von $+6^{\circ} \mathrm{R}$. his $-2^{\circ} \mathrm{R}$. aufbewahrt. Die Versuche dauterten vom 27 . September lis 10 . December 1899 (alt. St.) und wurden, wie folgt, angestellt:

Je 100 Eier wurlen in einzelne Reagenzeliser geluracht, von welchen einige eine Stunde lang der Einwirkmy hoher Temperaturen in einem Lufthar von konstanter Temperatur ausgesetzt wurlen; die anderen (xläser wurden wïhrend 12 stumlen (ron 7 Uhr Abends bis 7 Uhr Morgens) vor das Fenster ins Freie gestellt, wohei der Minimal-Thermometer die tiefste Temperatur angab.

Die erhaltenen Resultate enthält folgende Tabelle:

\begin{tabular}{|c|c|c|c|c|c|c|c|c|}
\hline \multirow{2}{*}{ ํㅡㅁ } & \multirow{2}{*}{ 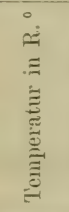 } & \multicolumn{3}{|c|}{$\begin{array}{l}\text { Wie viel Raupen schlüpf- } \\
\text { ten aus } 100 \text { Eiern in } \\
\text { jedem Glase. Wälrend } \\
\text { der Zeit: }\end{array}$} & \multirow[b]{2}{*}{ 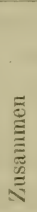 } & \multirow{2}{*}{ 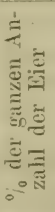 } & \multirow{2}{*}{ 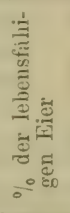 } & \multirow{2}{*}{ Bemerkungen } \\
\hline & & \begin{tabular}{|l} 
Vom \\
27. Sept. \\
1899 bis \\
1. Jan. \\
1900
\end{tabular} & \begin{tabular}{|} 
Vom \\
1. Jan. \\
bis 25. \\
Februar \\
1900
\end{tabular} & $\begin{array}{l}\text { Vom } \\
25 . \text { Febr. } \\
\text { bis } \\
10 . \text { Mai } \\
1900\end{array}$ & & & & \\
\hline 1 & $\dot{\div} \div$ & 28 & 42 & 1 & 71 & \multirow{3}{*}{71} & \multirow{3}{*}{100} & \multirow{4}{*}{$\begin{array}{l}\text { Angenommen, dass } \\
\text { alle lebensfähigen } \\
\text {. Eier schlüpften. }\end{array}$} \\
\hline 2 & 至 & 25 & 44 & 4 & 73 & & & \\
\hline 3 & 워 & 26 & 39 & 4 & 69 & & & \\
\hline 4 & +20 & $: 32$ & $: 3 ;$ & () & lis & tis & 4.5 & \\
\hline 5 & +25 & 16 & 53 & 0 & 69 & 69 & 96 & \multirow{4}{*}{$\begin{array}{l}\text { Die ausgeschliupften } \\
\text { Raupen waren sehr } \\
\text { beweglich. }\end{array}$} \\
\hline 6 & +30 & 32 & 37 & 0 & 69 & 69 & 96 & \\
\hline 7 & +35 & 28 & 31 & 0 & 59 & 59 & 83 & \\
\hline 8 & +40 & 14 & $2 T$ & 0 & 41 & 41 & 58 & \\
\hline 9 & +45 & 0 & 0 & 0 & 0 & 0 & 0 & \multirow{10}{*}{ Dasselbe. } \\
\hline 10 & $\div 50$ & 0 & 0 & 0 & 0 & 0 & 0 & \\
\hline 11 & -6 & 16 & 42 & 8 & 66 & 66 & 93 & \\
\hline 12 & -8 & 12 & 36 & 6 & 54 & 54 & 76 & \\
\hline 13 & -9 & 10 & 36 & 6 & 52 & วั2 & 73 & \\
\hline 14 & -10 & 6 & 39 & 4 & 49 & 49 & 69 & \\
\hline 15 & -11 & 4 & 35 & 3 & 42 & 42 & 60 & \\
\hline 16 & -12 & 3 & 34 & 3 & 40 & 40 & 56 & \\
\hline 17 & -13 & 0 & 31 & 3 & 34 & 34 & 48 & \\
\hline 18 & -14 & 0 & 22 & 2 & 24 & 24 & 34 & \\
\hline
\end{tabular}

I)araus ist ersichtlich, lass: 1) das Temperaturoptimum für das Ansschliipfen der Raupen hei $14^{0}-17^{\circ}$ R. liegt, und dass die Eier 
-ilieselbe Lebensfäligkeit bis $z u 30^{\circ} \mathrm{R}$. behalten, welche iiber $30^{\circ} \mathrm{I}$. abnimmt und hei $45^{\circ} \mathrm{R}$. ganz verschwinclet; 2) (lie Lebensfihihigkeit . ler Eier. angefangen von $-8^{0} \mathrm{~K}$, almimmt und hei $-14^{0} \mathrm{l}$. nur $34 \%$ betrïgt.

N. Ja. Kusnetzow (1901. 489) setzte frisch rerpuppte Iiaupen von Catocala firaxini L. der Einwirkung entweler der Temperatur von $4^{0}$ währent 2-3 Wochen oler der Temperatur von 20-390 währenı 10-12 Tagen aus. In beilen Fällen verzögerte sich die Entpuppung: bei abgekihlten I'uppen mehr als bei erwärmten. Die Füsse, Beine und Schuppen entwickelten sich nicht rollstïnlig, was auf eine starke Schwïchung les Organismus hinzeigt.

W. Petersen (1902. (5:3:3) heobachtete in Reval (Estland) in dem ahmorm warmen und truckenen Sommer 1901, dass eine Reihe von Schmetterlingen (z. B. Papilio macham L., Chilsoph. hippothae L., Acidalia immutata L.), die sonst in clieser (regend nur eine Generation haben, im Herbst nochmals frisch erschien.

H. Auel (1902. 17) beohachtete, dass die Hauer der Entwiekelung des Eies ron Pieris brassicae zum Räupchen im Frühjahre 8 Tage, während dieselhe hei sehr hoher Temperatur im Sommer nur 4 Tage beträgt. Bei $17,3^{\circ}$ betrug diese Dauer auch 8 Tage.

$\mathrm{Als}$ er die Temperatur-Versuche an Puppen dieser Species anstellte, fiml er, dass die Pupjen muter dem Einfluss direkter Bestrahlung (sehr hoher Temperatur) ahstarhen. Bei sehr hohen Temperaturen im Freien (Ende Juli) betrug die Puppenzeit 14 Tage, im gewöhnlichen Keller mit offenen Fenstern (Ende Juli) 17 Tage, uni im keller bei $15,7^{\circ}$ bis $17,5^{\circ}$ (Ende .Juli) 21 Tage. Die Zimmerzucht ergab für die Puppenzeit nur 11 Tage.

È brachte die Winterpuppen dieser Species im April auf die Suirl-, West- und Norilseite eines (rebäulles. Die zweito (iruppe brauchte :3 Tage, und die dritte Gruppe t!9 Tage lïngel zur Lintwickelung, als clie erste Gruppe. Dabei konstatierte er, llass $1: 3^{0}$ erforterlich sinı, um die Winterpuppen fïr den Beginn der Verwandlung empfindlich $\cdot \mathrm{zu}$ machen.

J. Dewitz (1902. 168) beobachtete im Herbst, lass clie Larven von Musca vomitoria sich äusserst langsam entwickelten, aluer die vollstïnlige Reife erreichten unl sich verpuppten. Marlen lieferten, 
in der kalten Jahreszeit (November, December) in Freien (Villefranche, Rhône) aufgezogen, normale Fliegen.

Normale Fliegen erhielt er auch, als die Larven im Juli zwei Mal 24 Stunden auf Eis gehalten wurden. In gleicher Weise wurden die Larven von Portrix pilleriana und sehr kleine Raupen von $\nabla a-$ nessa is behandelt. Aus ihnen gingen gefliigelte Insekten hervor.

Er hielt ein mit Nymphen und Larven von Polistes gallica besetztes Nest zweimal wïhrend 24 Stunden auf Eis und gab es dann dem zugehörigen Wespenvolk zurïck. 4 Wochen darauf erschien die erste flïgellose Wespe; ilır folgten Exemplare anch mit atrophierten Flïgeln.

W. Petersen (1902. 6:33) sagt: „Bringt man die Eier von Orgijia antiqua im Frühjahr früh senug aus der Kälte herein, so kann man den Schmetterling schon im Mai hahen, wie mir das mehrfach geglïckt ist" (p. 49).

Bei Poecilocampa populi L. machte er clie merkwürdige Beohachtung, dass die Schmetterlinge bei gewöhnlicher Zimmertemperatur nicht auskriechen wollten. "Nachilem ich bis Encle September gewartet hatte, (die Verpuppung war schon Mitte Juli erfolgt) stellte ich die Puppen, als die Witterung plötzlich kalt geworlen war, für eine Nacht in die Kälte, - am folgenden Morgen fand ich sämmtliche Falter trotz der Kühle ausgekrochen. Es scheint also hier die Kälte direct den auslösenden Reiz fiir das Auskriechen abzugeben" (p. 51).

Dieselbe Beobachtung machte er bei Eriogaster lanestris $\mathrm{I}$. „Ich habe die Puppen bei Zimmertemperatur sechs Jahre gehalten, ohme den Schmetterling zu erhalten. Beim Oeffnen erwies sich, dass bei den noch lebenden Puppen die Entwickelung nicht weiter volgeschritten war, als einige Wochen nach der Verpuppung.

Carl Frings (1902. 260). unternahm die künstliche Behandlung der Winterpuppen mit Wärme und Hitze, welche bis Ende Januar und Februar im Freien überwinterten. Nach nur eintïgigem Aufenthalte im Zimmer kamen sie für das Experiment zur Verwendung.

Papilio podalirius. 10 Tage 370 , Temperatur jeden zweiten Tag für $3-4$ Stunden bis auf $43 \frac{1}{2^{\circ}}$ steigend und wieder auf $37^{\circ}$ fallend. Schon am 9. Tage kamen im Thermostat die ersten Falter aus. Nur ein geringer Procentsatz ergab gute Falter: viele Stücke zeigten in der Puppe Kopf, Thorax und Flïgel entwickelt, den Hin- 
terleib noch ganz unfertig; oder ungekehrt, nur den Hinterleil ausgebildet.

Papilio machaon. 15 Tage $37^{\circ}$, jeden zweiten Tag für 5- 5 Stunden auf $44^{\circ}-45^{\circ}$ steigend und wieder auf $37^{\circ}$ sinkenıl. Einige Falter schlupften nach 7 Tagen, die anderen dagegen nach ca. J Wochen aus. Gut entwickelte Falter $75 \%$.

Thais polyxena. Wie poclatirius behamlelt, doch 14 Tage exponiert. $25 \%$ gut entwickelter Falter.

Polyommatus amphidamas und Vanessa levana, gleich behandelt, ergaben keine Falter.

Apatura iris. 24 und 36 Stunden 390: kein Falter. 1s Stunden 390: nur ein $\delta$.

Apatura ilia. 36 Stunden $39^{\circ}$. Ca. 60\% Falter.

Limenitis populi. 18 Stunden $39^{\circ}$. Kein Schmetterling.

Limenitis sibylla. 28-36 Stunden 390. Kein Falter. 18-24 Stunden $39^{\circ}$. Etwa $10 \%$ Falter. 3 Mal je 4 Stunden $40-41 \%$. $70 \%$ Falter.

Vanessa var. prorsa. 36-42 Stunden 380: 30\% Falter. 3 Mal je 4 Stunden $40-410: 50 \%$ Falter. 18 Stunden $40^{\circ}$ und 3 Mal je 3 . Stunden $42,5^{\circ}$ : kein Falter.

Vanessa urticae II. Gener. 30 Stunden 390: $80^{\circ}$ Falter. 18 Stunden $40^{\circ}: 75^{\circ}$ Falter. 12 Stunden $41^{\circ}: 50 \%$ gute Falter. 3 Mal je 3 Stunden $42-43^{\circ}: 70^{\circ} \%$ Falter.

Vunessa io II. Gener. 30 Stunden $39^{\circ}: 30 \%$ Falter. 3 Mal $2^{1} 1 / 2$ Stunden $42^{0}-43^{0}$ : kein Falter.

Vanessa $c$ album. 20 Stunden $40^{\circ}: 3$ Mal je 21/2-3 Stunden 42-430: kein Falter.

Vanessa polychloros. 66 Stunden $36-36,5 \%$ : $12 \%$ Falter. 36 Stunden 37,5-380: $80 \%$ Falter. 42 Stunden 37,5-380: $50 \%$ Falter. 3 Mal je $4-4 \frac{1}{2}$ Stunden $40-41^{0}: 60 \%$ Falter. $4-5$ Mal je 2 Stunden $43-43,5^{\circ}:$ kein Falter.

Vanessa antiopa. 66 Stunden $36^{\circ}: 12 \%$ Falter. 44-48 Stunden $38^{\circ}$ : 33\% Falter. 43 Stunden $39^{\circ}$ : ca. 50\% Schmetterlinge. 28 Stunden $39,5^{\circ}: 25 \%$ Falter. (i Stunden $40^{\circ}$ in 10 Stunden bis auf $36^{\circ}$ fallend, dann wieder 3 Stunden $40^{\circ}, 4$ Stunden $39^{\circ}: 20_{0}^{\circ}$ Falter. 30 Stunden $39,5^{\circ}$, während dieser Zeit möglichst oft steigend und fallend auf 41 und $38^{\circ}: 30 \%$ Falter. 20 Stunden $40^{\circ}$ : $75 \%$ Filter. 3 Mal je $41 / 2-5$ Stunden $40-410: 75 \%$ Falter. 4 Mal je 3 Stunden $42-42,5^{\circ}$ : ca. $50 \%$ Falter. 
166 Frstes Kiapitel. Die Fintwiekelungsgeschwindigkeit der Insekten.

Vanessa: cardui. 30 Stunden $39^{\circ}: 75 \%$ Talter.

Vanessa atalantr. 20 Stunden $40^{\circ}: 80 \%$ Falter. - 3 Mal je $3{ }^{1 / 2}$ Stunden 410: 60 Falter. - 12 Stunilen $41^{0}: 60 \%$ Falter. 3 Mal je $21 / 2-3$ Stunden $42-43^{0}: 60 \%$ Falter.

Melitaca rlidmma. 36 Stunien 390: 90\% Falter. - 3 Mal je 4 Stunden $40-41^{\circ}: 60 \%$ Falter: - 7 Mal je 2 Stumlen $43,50^{\circ}$ : $55 \%$ Falter.

Melitaen aurinia. 72 Stunden 370: alle Puppen todt. - 28 lis 36 Stunden 390: 80\% Falter. - 36-42 Stunilen $390^{\circ}: 50 \%{ }_{0}$ Falter. - 3 Mal je 4 Stunden 40-410: $75 \%$ Filter.

S. A. Mokrzecki (1902.587) hielt die Puppen von Das!lchira pudibundı L. und Pyyaera anachoreta W. im Zimmer, wobei die erste Art Mitte December und die zweite Mitte Januar die Schmetterlinge ergab, während dieselben im Frejen in Clarkow in Mai resp. von Mai bis September Hiegen.

V. Vermorel und Gastine (1902. 912) beschrieben eine neue Methode zur Vertilgung der dem Weinstock schädlichen Micro-Lepidopteren-Raupen, welche auf ler Einwirkung les Wasseriampfes. beruht. Dahei fanden sie, dass die Pyralis-Raupen bei 48 his $50^{0}$ schon in 3-4 Minuten sterben, bei $45^{\circ}$ in etwa 10 Minuten: bei $40^{\circ}$ verlassen die Raupen ihre Gespinnste.

A. Schugurow (1903. 782) benbachtete Ende December 1901 in Odessa im Freien Hiegenle Fliegen; an 27. December (alt. St.) fand er ausserhalb der Stault O.lessa auf Steinen Pyrhocoris aptorus L. und fing Simulia reptans L.

J. Beckmann (1903. 58) brachte die in der Xihle von St.Petersburg gesammelten Puppen vom Käfer Saperda perforata Pall. und S. scalaris L. ins Zimmer, wobei dieselben hereits am 25. Mai Imagines ergaben, währenı dliese Arten im Freien erst Ende. Juni. erscheinen.

L. R日h (1903. (i81) beobachtete die reifen Fonscolombiu fruxini Kaltb. ठૅ ठౌ bei $-2, \overline{5}$ bis $-3,7^{\circ}$ auf ter Suche nach Weibchen. Er sagt: „sie scheinen also direkt des Frostes zur Begattung zu. bedlïrfen" (p. 353). 
C. Frings (1903. 261) setzte die ïberwinterten Puppen im Februar und März der Einwirkung von erhöhten Temperaturgraden aus; dabei betrug die Sterblichkeit:

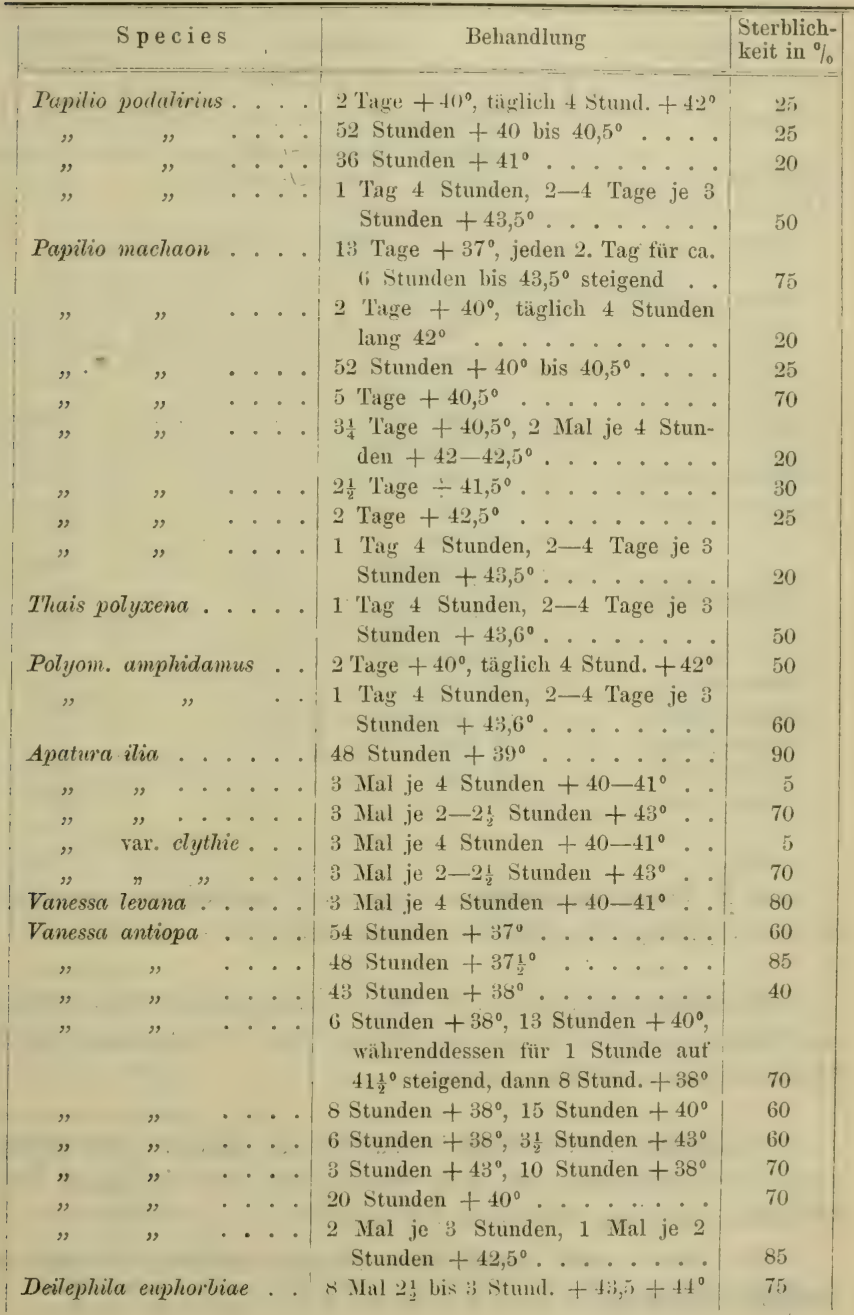


Dieselben Versuche mit ernierlrigten Temperaturgraten ergaben folgende Resultate:

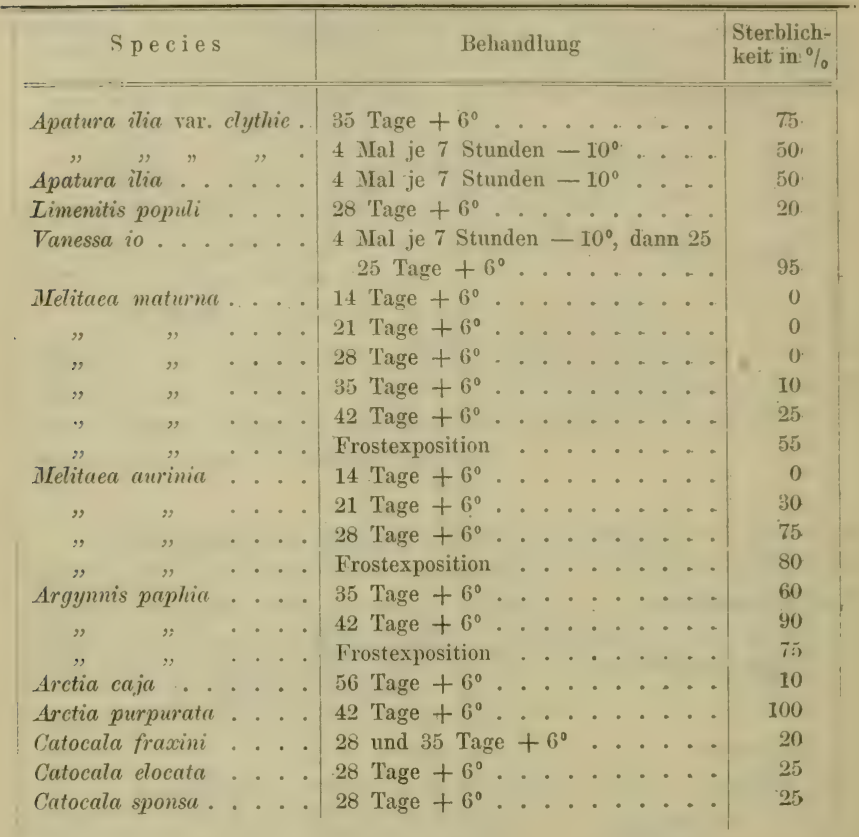

G. E. Grum-Grschimajlo (1903. 332) beobachtete auf seiner Reise nach Mongolien, llass die Mücken noch bei - $8^{0}$ leben.

N. Schugurow (1903. 783) fing in Odessa den Schmetterling Eupithecia indignata $\mathrm{Hb}$. am 9. Februar bei $+5^{0} \mathrm{R}$, und Coccinellidae am 5 . Februar bei $0,5^{\circ} \mathrm{R}$.

E. Quajat (1903. 668) untersuchte den Einfluss der verlängerten Ueberwinterung der Eier von Bombyx mori auf deren Entwickelung, wobei er diese Eier bei $0^{0}$ hielt.

Die $1890-1900$ angestellten Versuche wurden in folgende Gruppen eingetheilt: 
Gruppe A bei $0^{\circ}$ bis 30 . März, darauf bei $20^{\circ}$ bis $22^{\circ}$.

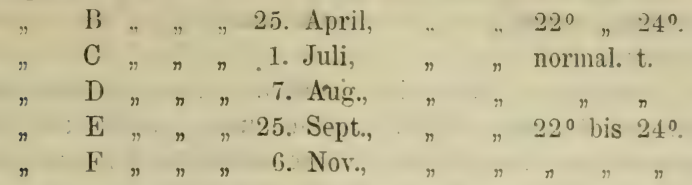

Dabei ergaben sich folgende Resultate:

\begin{tabular}{|c|c|c|c|c|c|c|}
\hline \multirow{4}{*}{ Rasse } & A & B & C & D & $\mathrm{E}$ & $\mathrm{F}$ \\
\hline & \multicolumn{6}{|c|}{ Ueberwinterungsdaner in Tagen: } \\
\hline & 135 & 160 & 225. & 262 & 309 & 351 \\
\hline & \multicolumn{6}{|c|}{ Rest der unentwickelten Eier in ${ }^{\circ}{ }_{0}$ : } \\
\hline \multirow{2}{*}{ C'hinesische runde } & 6,5 & 9,5 & 16,0 & 21.9 & $7(1), 1)$ & 89.6 \\
\hline & \begin{tabular}{l|l|l|}
$3,9,6$ \\
\end{tabular} & $\mid$\begin{tabular}{||l|l||}
4,2 & 5,3 \\
$\mid$
\end{tabular} & \begin{tabular}{l|l|l|}
8,0 & 8,0 \\
\end{tabular} & $5,0 \mid 16,9$ & $5,0 \mid 65,0\}$ & $9,0 \mid 80,0$ \\
\hline \multirow{2}{*}{ Indianische gelle } & 3.2 & 3,4 & 15,6 & 47,0 & 95,0 & 99,5 \\
\hline & $1,3 \quad 1,9$ & \begin{tabular}{|l|l||}
0,2 & 3,2 \\
\end{tabular} & $5,0 \mid 10,6$ & $5,5 \mid 41,5$ & $5,090,0$ & $14,0,85,0$ \\
\hline \multirow{2}{*}{ Koreische } & 4,6 & 16,3 & 61,5 & 73,0 & 98,0 & $(19,5$ \\
\hline & $2,8,1,8$ & $-1-$ & $2,7 \mid 58,8$ & $4,0 \mid 69,0$ & $3,095,0$ & $9,590,0$ \\
\hline \multirow{2}{*}{ Japanische weisse } & 7,9 & 14,2 & 77,0 & 86,0 & 99,0 & 100 \\
\hline & $4,43,5$ & $-1-$ & $3,4 \square 73,6$ & $1,3 \mid 84,7$ & $9,090,0$ & $5,0 \mid 95,0$ \\
\hline \multirow{2}{*}{ Japanische grüne } & 9,7 & 14,6 & 44,0 & 65,0 & 99.0 & 99,5 \\
\hline & $5,6 \mid 4,1$ & $5,8 \mid 8,8$ & $8,6|35,4|$ & $10,6 \mid 51,4$ & $14,085,0$ & $24,575,0$ \\
\hline \multirow{2}{*}{ Gelb-goldene } & 4,0 & 17,3 & 29,3 & 45,5 & 85,0 & 89,0 \\
\hline & $1,22,8$ & $\mid$\begin{tabular}{|l|l||}
4,3 & 13,0 \\
\end{tabular} & \begin{tabular}{|l|l|l}
4,7 & 24,6 \\
\end{tabular} & $6,2|39,3|$ & $5,0 \times 0,0$ & $9,0 \mid 80,0$ \\
\hline \multirow{2}{*}{$\begin{array}{c}\text { क chinesische weisse } \\
\delta \text { gelbe }\end{array}$} & 6,5 & 8,6 & 42,0 & 65,0 & 90,0 & - \\
\hline & $4,0,2,5$ & $3,9,4,7$ & $5,9: 36,1$ & $7,7157,3$ & 5,0 (1) 55,0 & $-1-$ \\
\hline \multirow{2}{*}{$\begin{array}{l}\text { ㅇ gelbe indianische } \\
\delta \text { japanische gelbe }\end{array}$} & 2,5 & 4,6 & 27,5 & 56,0 & 95,0 & 100 \\
\hline & $1,90,6$ & $1,6 \mid 3,0$ & $6.0+21.5$ & $7,7,40,3$ & $10,0,85,0$ & $20,080,0$ \\
\hline \multirow{2}{*}{$\begin{array}{c}\text { o gelbe indianische } \\
\sigma^{\top} \text { koreische }\end{array}$} & 3,4 & 5,7 & 16,1 & 37,0 & 95,0 & 99,0 \\
\hline & $2,21,2$ & $2,5,3,2$ & $4,2 \mid 11,9$ & $9,028,0$ & $5.0,90,0$ & $14,085,0$ \\
\hline \multirow{2}{*}{$\begin{array}{l}\text { q. gold-gelbe } \\
\sigma \text { gelbe indianische }\end{array}$} & 2,2 & 3,9 & 8,0 & 27,0 & 95,0 & 99,0 \\
\hline & \begin{tabular}{|l|l|}
0,7 & 1,5 \\
\end{tabular} & $0,7 \quad 3,2$ & $\begin{array}{lll}1,8,2 & 6,2\end{array}$ & $2,1,24,9$ & $5,0,90(1)$ & 9.0 .90 .0 \\
\hline \multirow{2}{*}{$\begin{array}{l}q \text { japanische weisse } \\
\delta \text { gelbe indianische }\end{array}$} & 4,2 & 11,7 & 49,1 & 68,0 & 98,0 & 100 \\
\hline & $1,4,2,8$ & \begin{tabular}{l|l|}
$2,2,3$ & 9,4 \\
\end{tabular} & $4,0,45,1$ & $4,0)(64,0$ & $3,(0) 95,0$ & $10,0,30,0$ \\
\hline \multirow{2}{*}{$\begin{array}{c}\text { O japanische weisse } \\
\text { ठै goldgelbe }\end{array}$} & 3,8 & 5,5 & 53,9 & 83,0 & 98,0 & $\therefore 100$ \\
\hline & $2,0 \quad 1,8$ & $1,8,3,7$ & $9.7+1.2$ & $3,8,79,2$ & $5,01900.0$ & $20,0 \triangle 0,0$ \\
\hline \multirow{2}{*}{$\begin{array}{l}\text { ? koreische } \\
\text { o gelbe indianische }\end{array}$} & 5,0 & 21,9 & 63,5 & 80,0 & 99.0 & 100 \\
\hline & $3,1 \mid 1,9$ & \begin{tabular}{|l|l|}
2,8 & 19,1 \\
\end{tabular} & $21,0+2,0$ & $1,8 \mid 78,2$ & $4,0195,0$ & $\left.(0.0)^{\prime} 100\right)$ \\
\hline \multirow{2}{*}{$\begin{array}{l}\text { o goldgelbe } \\
\sigma^{7} \text { koreische }\end{array}$} & 2,1 & 3,7 & 16,7 & 37,2 & 70,0 & 90,0 \\
\hline & 0.311 .8 & $1,2,2,5$ & $4.712,0$ & $3.4,33,8$ & $10.06(60.01)$ & $0,0,96,0)$ \\
\hline
\end{tabular}


In jeiler horinzontalen Colonne links und rechts von der mittleven Zahl beleuten die Ziffern die Anzahl der Fier olne bezw. nnit Embryonen.

Aus dieser Tabelle ist eisichtlich, dass die Ueberwinterungsdauer (bei ()$\left.^{0}\right)$ sehr schäıllich werden kann, sobalı diese Dauer eine gewisse Grenze iiberschreitet. Diese schälliche Wirkung ist verschieden für verschiedene Rassen.

Die Versuche, welche er an 27 verschicilenen liassen anstelite, ergaben im allgemeinen dieselben Resultate.

L. Reh (1903. (;81) sagt: „Thatsïchlich diiriten alle unsere Freiland-Schildläuse gegen Kälte ganz unempfiullich sein, sonst könnten sie eben nicht bei uns bestehen" (1) $41(i)$. Einen Anlass zu dieser Äusserung giebt ihm die Beobachtung von Goothe (Jahrb. Nassau. Ver. Nat. 1884. XXXVII. p. 120-121), welcher berichtet, dlass er im Winter Zweige mit Larven von Lecunium rini Bché., die soeben eine Külte von - $18^{\circ}$ iiberstanden hatten, ins warme Zimmer brachte, und dass letztere hier nach zwei stuniten munter umhergelaufen seien.

Wünscher (1903. 963) unternahm die Zucht einiger Schwärmer aus dem Ei, wobei sowohl die Raupen, wie auch die Puppen Tag und Nacht in einem besonders konstruirten Brutkasten bei $28^{\circ}$ bis $30^{\circ}$ sich befinden. Die Zeit für jerles Entwickelungsstadlum hetrug dabei:

\begin{tabular}{|c|c|c|c|c|}
\hline \multirow{2}{*}{$\mathrm{A} r \mathrm{t}$} & \multirow{2}{*}{ 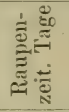 } & \multirow{2}{*}{ 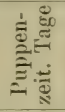 } & \multicolumn{2}{|r|}{ Zusammen } \\
\hline & & & Tage & ron bis \\
\hline Acherontia atropos $\mathrm{L}$. . . & 28 & 43 & 71 & 1. IX.-11. XI. \\
\hline 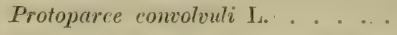 & 30 & - & - & 27. VUI. \\
\hline Deilephila lineata r. livornica Esp. & 24 & 25 & 49 & 7.VI. - 26.VII. \\
\hline Daphnis nerii L. . . . . . . . . . & 22 & 29 & 51 & 28.VI.-18.VIII. \\
\hline
\end{tabular}

Chr. Schröder (1903. 779) setzte frische Puppen von Abraxas grossulariata L. der Einwirkung der Temperatur von $38^{\circ}$ (in wasserdampfreiche Luft) fuir drei Tage je dreimal während einer Stunde aus und konstatierte folgende Sterblichlet:

Eine Versuchsreihe ergab von 47 Puppen 39 Falter, die andere Reihe ergab von 25 Puppen 21 Falter, in welchen Zahlen auch mangelhaft entfaltenile Imagines eingeschlossen sini. 
G. Lehmann (1904.507) zoy 22) Stiick pavoni-Räupchen, welche tadellose Puppen ergaben. Im folgenden Friihjahre war das Wetter nicht schön, und von 2: Puppen krochen nur 7 Falter aus; im nächsten Frühjahre kamen bei schönem Wetter weitere 13 Stück. Er erkliirt die Erscheinung, dass viele Nachtfalterpuppen die Gewohnheit hahen, mehrere Jihre liegen zu bleiben, durch die Witterungsverhältnisse, hauptsächlich durch die Feuchtigkeit und Temperatur; er sagt: „Der Eintluss ist ein giinst ger bei jeler Druckvertheilung, die mns warme Sül- oller trockene Ostwinde bringt, lagegen ungiinstig bei feuchten West- oder kalten Nordwinden" (p. 74).

E. Fischer (1904. 240) beobachtete, dass lex S'chmetterling Chruxes jasius L. unter $6^{0}$ einschlïft und völlig erstarren kann.

Adele Field (190 t. 222) stellte fest, dass dlas T'emperaturoptimum für Ameisen zwischen $24^{\circ}$ uni $27^{\circ}$ liegt. Die Temperatur von - 50, welche auf die Ameisen während 24 Stunden einwirkte, tödtete sie nicht. Die maximale Temperatur, welche sie ertragen, ist $49^{\circ}$.

H. Friese (1904. 248) theilt folgende Beobachtungen von G. Jacobson mit, welche Bezug auf das Hummelleben in arktischen Ländern (Nowaja Semlja) haben, und welche ihm brieflich mitgetheilt wurilen:

"Den ersten Bombus hyperboreus ő sah ich an 28. VII. bei schwachem Winde und $+4,1^{\circ} \mathrm{C}$. Hiegen. Sodann sah ich am 31. VII. hei $+5^{\circ} \mathrm{C}$. ein $ᄋ$ dieser Art auf einem Steine sitzen. Die giinstigsten Sammeltage waren der 2. VIII., wo ich bei hellem Himmel, aber nieulriger Temperatur $\left(+4.4-10^{\circ}\right.$ C.) $1 \delta^{\nearrow}$ und 4 o von B. hyporboreus (wovon jedoch sohr viele flogen), $2 \delta, 1$ 우 von $B$. kirlyyellus unil 2 ơ von B. laponicus erbeutete."

E. Quajat (1904. 670) brachte Eier ron Bombyx mori L. (Rasse: $\bigcirc$ goldgelb $\times \sigma^{\prime}$ aus Indien) bis zun ersten August in die Temperatur von $25-29^{\circ}$; dann theilte er diese Eier in 2 Serien a und $b$ und verfuhr mit denselben, wie folgt:

$a$ liess er bis zum 31. August bei $0^{0}$ und dann bis zum 24 . September bei $22^{\circ}$. Darauf sank lie Temperatur allmählig bis $0^{\circ}$, und am 1. März wurden die Eier in einen Brutofen gebracht. Es ergab sich, dass im Herbst die Eier sich nicht entwickelten, somlern erst im Friihjahr, wobei $2-3 \%$ ohne Entwickelung blieben. 
$b$ liess er bis zum 25. September bei $0^{0}$, worauf die Eier bis zum 18. November bei $22^{\circ}$ sich befanden; nachher sank die Temperatur nach und nach bis $1^{\circ}$. Am 14. April wurden die Eier aus $0^{0}$ - herausgenommen und in den Brutofen gebracht. Fs entwickelten sich $8-20 \%$ der Eier im Frühjahr nicht.

Aehnliche Resultate erhielt er auch mit anderen Rassen.

Thurau (1905. s63) legte im Berliner Entomologischen Verein (Sitzung vom 13. Oktober 1904) eine Deilephila euphorbiae vor. welche ganz in der Richtung auf tithymuli abweichend war. „Das Thier war aus einer in August gefundenen Raupe gezogen, und seine Puppe war 4 Stunden lang einer Kialte von $12^{\circ}$ ausgesetzt gewesen."

C. Frings (1905. 262) stellte Temperatur-Versuche in ilen Jahren 1903-1904 über verschiedene Lepidopteren-Arten an und erhielt folgende Resultate:

I. Experimente mit erhöhten Temperaturgralen.

Papilio podalirius L. Die Puppen wurden nach Durchwinterung 2 Tage der Temperatur von $40,5^{\circ}$ ausgesetzt. Es schlüpften 95\% gut ausgebildete Falter.

4-mal je $3_{12}^{1 / 2}$ Stunden $+43,5^{0}: 80 \%$ Schmetterlinge.

Papitio machaon L. 30 Stunden $+43,5^{\circ}: 75 \%$ gute Falter. Pyrameis rtalanta L. 48-54 Stunden + 370: 75\% Falter. 60 Stunden $+37^{\circ}$ : kaum $6 \%$ entwickelte Schmetterlinge. 44. Stunden $+39^{\circ}: 30 \%$ Falter.

2-mal je 3 Stunden $+43^{0}$ : sehr wenig Falter.

Pyrameis cardui L. 48-60 Stunden + 370: $75 \%$ Falter. 3 -mal je $3 \frac{1}{2}$ Stunden +40 bis $40,5^{0}: 60 \%$ Falter.

Vanessa jo L. I. Gener. 2 Tage $+35,5^{\circ}: 25 \%$ Falter. $21 / 2$ Tage $+35,5^{0}: 10 \%$ Schmetterlinge.

3 Tage $+35,50: 2 \%$ Falter.

II. Gener. $30-36$ Stunden $+390: 60 \%$ Falter.

Vanessa urticae L. III. Gener. 36 Stunden $+39^{\circ}: 75^{\circ} \%$ Falter. Vanessa polychloros L. 42 Stunden $+38^{\circ}: 70^{0_{i}^{\prime}}$ Falter.

Vanessa antiopa L. 46 Stunden + 390: 12\% Falter.

48 : Stunden $+39^{\circ}: 4 \%$ Schmetterlinge.

36 . Stunden $+39,50 \div 20 \%$ Falter.

$5^{1 / 2}$ Stunden $+38^{0}$ in 2 Stunden steigend bis $43^{\circ}$, hier $3^{1}$, Stunden verbleibend: $70 \%$ Falter. 
24 Stunden $+38^{0}, 12$ Stunden $+400: 15 \%$ Falter.

13 Stunden $+40^{\circ}, 30$ Stunden $+38^{0}: 25 \%$ Falter.

Polygonia c album L. II. Gener. 43 Stunden $+37^{0}: 50 \%$ Falter. Araschnia levana L. $3 \times$ je $\left.3{ }^{1}\right|_{2}$ Stunden $+43,50: 50 \%$ Falter. Araschnia levana var. prorsa L. 28 bis 30 Stunclen $+39^{0}$ : $35 \%$ Falter.

$2-3 \times$ je $23 / 4$ Stunden $+42,50: 20 \%$ Falter.

Parasemia plantaginis L. 24 Stunden $+370: 100 \%$ Falter Arctia caja L. 48 Stunden $+37^{0}: 12 \%$ Falter.

II. Versuche mit ernielrigten Temperaturgraden.

Pyrameis atalanta L. Frostversuch: 65\%. Falter.

Tanessa urticae L. I. Gener. 42 Tage $+6^{0}, 7$ Tage Kellertemperatur: $30 \%$ Falter.

Vanessa polychloros L. 39 : Tage $+6^{0}: 75 \%$ Falter.

Vunessa antiopa L. 42 Tage $+6^{0}: 15 \%$ Falter.

45 Tage $+60: 4 \%$ Falter.

Argynnis daphne Schiff. 35 Tage $+60: 75 \%$ Falter.

Lasiocampa populifolia Esp. 35 Tage $+6^{0}: 100 \%$ Falter. 42 Tage $+60: 50 \%$ Falter.

Dendrolimus pini L. Die Raupen wurden ohne Ueberwinterung im warmen Zimmer gezogen. Mitte December fand die Verwandlung statt. Die Puppen bei $+4^{0}$ bis $-3^{0} 42$ Tage: $70 \%$ Falter.

Catocala nupta L. 30 Tage $+6^{0}: 100 \%$ Falter.

Rhyparia purpurata L. 35 Tage $+60: 95 \%$ Falter.

42 Tage $+6^{0}: 60 \%$ Falter.

49 Tage $+60: 25 \%$ Falter.

Arctia caja L. 49 Tage $+60: 40 \%$ Falter.

Callimorpha hera $\mathrm{L} .+6^{\circ}$ : die meisten Puppen starben ab.

Vancssa antiopa L. 12 Stunden $+6{ }^{\circ} ; 28$ Stunden $+38^{0}$; 12 Stunden $+60 ; 14$ Stunden $+37,5^{0}: 10 \%$ Falter.

A. Grevillius (1905. 329) steilte die untersten und die höchsten Temperaturgrade fest, bei welchen die Goldafterraupen ( $E u$ proctis chrysorrhoea $\mathrm{Hb}$.) noch befähigt sind zu fressen. Die unterste Temperatur betrug etwa über $4^{0}$ und die höchste ca. $45^{\circ}$.

Ausserdem fand er, dass diese Ritupen unter $1^{0}$ keine Bewegungen mehr zeigen und noch am Leben bleiben bei einer vorübergehenilen Temperatur von $44^{\circ}$; eine währenıl einiger Stunden einwirkende Luftemperatur von $45^{\circ}$ tödtet sie. 
Seine Untersuchungen der Willerstanilsfähigkeit dieser liaupen gegen die Winterkälte ergaben folgende Resultate: .rie blosscrelegten Raupen können (in den Stalien des Winterschlafes) zu einem ganz. überwiegenden Prozentsatz eine währemi neun Stmon dauemile Kälte der umgebenden Luft von abwechselnd - 14 bis - $16^{\circ}$ rertragen, auch wenn sie gleich darnach einer Luftemperatur von +1 so ausgesetzt werden. Eine Kïlte von abwechselnil - 17 lis $-21^{0}$ während $21 / 2$ Stunten hält immerhin nur ein Theil von den blossgelegten Raupen aus. Nach etwa $63 / 4$-stïndigem Verweilen in einer Luft mit den zuletzt erwähnten Anfangstemperaturen unil einer etwas höheren nachtrïglichen Temperatur $\left(-15\right.$ bis $\left.-20^{\circ}\right)$ waren sümmtliche blossgelegten liaupen toitt. Die in ilen Vestern liegenten Raupen können bei einer 24-stïndigen ron etwa - 23 his - 310 wechselnilen Temperatu der umgebenden Luft unter Umstïnilen zum grössten Theil am Leben heiben. Wenn lie Temperatur an h nur für kurze Zeit - 32, hezw. - $33^{\circ}$ erreicht, sind die Sterblichkeitsprocente in den meisten faillen sehr hoch. Eine Aussentemueratur von abwechselnd etwat -26 bis $-\$ 5,5^{\circ}$ wirkt schon nach neun Stunden absolut töltlich" (p. 311).

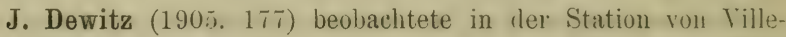
franche (Rhone), llass im Jahre 1903 die stärkeren Fänge von Trrtrix pilleriana (iibe: 1000 Stïck mit 20 Acetylenlampen) erst am 10/11. August und mehr noch am 17/18. August begannen. . Diese's späte Auftreten grosser Nenge von Schmetterlingen in ten Fängen kann durch das späte Auskommen infolge atmosphärischer Verhiiltnisse und der späten Entwickelung der Reben erkliirt werden. Min kann aber daran denken, dass ungünstige atmosphärische Eintliiss! zuerst auf die Säftezusammensetzung der Wirthptlanze und lliese auf die Konstitution des Insekts wirkt" (p. 111).

\section{Erganzungs-Litteratur zu diesem Abschnitt.}

Balbiani, G. Influence que les fortes températures pouvaient exercer sur la vitilité de ces mêmes oeufs. - Messager agricole du Midi. 10 Janv. 1877. p. T.

Bau, Alex. Die Überwinterung der Schmetterlingspuppen. - Isis (Russ.). I. Io îti. p. 4 ; p. $15-16 ;$ p. $25-26$.

Bold, Thos. Notes on the effects of the extreme ret winter of $1852-3$ on inseets. - Trans. Tyneside Nat. Field Club. II. 1854. (P. 4). p. 338-342 
Bolle, Giov. La schinsual estemporaneat del sesne del haco da seta col mezzo di agenti chimici e del coloracio. - Rivista settim. di bachicolt. X. 1878. p. 45-46; p. 53-54. Auch in II Bacologo italiano. I. 1878-9. p. 11-13. Bugnion, E. Note sur la resistance de la Teigne du fusain aux basses temperatures de l'hiver. - MIT. Schw. ent. Ges. VIII. 1891.. p. 319-321.

Butterfield, J. A. Influence of Temperature on the llatehing of Egges. - Lintomol. Record, Vol. IX. Xo 12. 1897. p. 327- ;28.

Cantoni, G. und Franceschini, E. L'alta temperaturat nell' allevamento dei bachi da seta. - Rivista settim. di bachicolt. Anno V. 1873. p. 117-11s.

Carrett. Allevamenti di bachi in una bacheria risealdata ad alta temperatura con stufa di lamiera di ferro. - La Sericoltura austriaca. Anno.IV. 1872. p. $59-61$.

Carrett. Allevamento di bachi da seta fatto in 18 giorni in una bigattierra riscaldata ad alta temperatura con una stufa di latta. - La Sericoltura Firenze. 2. ser. Anno I. 1872. p. 85-88.

Doonhoff. Beiträge zur Bienenkunde. VIII. Finthuss der Wirnte aut die Wintwickelung der Wachsschaben. - Eichstädt. Bienen-Ztg. 16. Bd. 1860. p. 212.

Dubois, Raph. Infuence de lat temperature ambiante sur les deifenses de l'organisme, chez les animaux à température rariable, pendant le sommeil hivernal. - C. R. Société Biol. P’aris. LII. (11. sér. T. II.). ỏ 34. 1900. p. $930-939$.

Ducleaux. Das Iusschhipten der Seidemanpen nach Beliehen zu beschlennigen oder zu verzögern. - Ann. d. Landwirt. Wochenbl. 11. Jahrg. 1871. p. 423.

Ducleaux, E. Dell' azione delle variazioni di temperatura sulle novit del bate da seta. - Rivista settim. di bachicolt. Anno T. 1873. p. 9-10.

Dziorzon, Joh. Verschiedenerlei: 2) Der Wänehedart der Bienen. -- Firchstält. Bienen-Ztg. 22. Bd. 1866. p. 58.

Dzierzon, Joh. Wodurch wird die Entwickelung. Ibefichtung und das Eierlegen der Königin beschleunigt? - Fichstädt. Bienen-Zeitung. 22. Bd. 1873. p. $211-213$.

Edwards, W. H. Experiments upon thr effect cold applied to chrysalids of linttertlies. - Psyche. III. 1880. p. 1-4; p. 15-19; p. 75; p. 76.

Edwards, W. H. Etiects of cold applied to the chrysalides of Buttertion. Amer. Entomologist. III. 1S80. p. 110-111.

Franceschini, Felice. L'alta temperatura. - Rivista settim. di hatchicoltura. Anno V. 1873. p. 106; anno VI. 1874. p. 94.

Girard, Maurice. Influence de la temprirature sur le déreloppenent dn Phỵlnxera. - Compt. rend. LXXIX. 1874. p. 907.

Girard, Maurice. Tote concernant l'influence du froid sur le Phylloxera hihernant. - Compt. rend. LXXX. 1875. p. 436-437.

Gumppenberg, F. v. Srstema Geonetrum zonate temperatioris septentrimnalis. Halle $1887-9: 2$.

Haberlandt, F. Teher die Möglichkeit, Eier der Maulheerhamspimmerisen 1 jähriger Generation, noch im Laufe desselben Sommers, in clem sie abgesetzt worden sind, auszubrüten. - Oesterreich. Seidenbau-Ztg. 2. Jahrg. 1870 . p. $17-18$.

Haberlandt, F. Möglichster Zeitgewinn bei der beschleunigten lint ickelmu der Schmetterlinge. - Oesterreich. Seidenbau-Ztg. 4. Jahrg. 1872. p. 99-100. 
Haberlandt, F. Seidenraupenaufzuchten dreier einander folgender Generationen im Jahre 1867. - Allg. deutsch. Ztschr. für Seidenbau. II. Bd. 1868. p. $29-31$.

Howard, L. 0. Temperature Experiments as atfecting received Ideas on the Hibernation of injourious Insects. - 28. Ann. Rep. Entom. Soc. Ontario. 1897. p. 164-165; Washington, U. S. Depart. Agricult. Div. Entomolog. Bull. 9. N. S. $18-20$.

Jourdheuille. Bull. Soc. ent. France. 1895. p. 67-70.

Eritz. Widerlesung der Behauptung des Herrn Hopffer: dass die Bienen, im Winter im Freien gelassen, leicht erfrieren. - Ver.-Bl. d. westful.-rhein. Ver. f. Bienen- und Seidenzucht. I. 1845, p. 92.

Kanitz, J. G. Brutwäme und Temperatur im Bienenklumpen. - Preuss. BienenZtg. V. Bd: (VIII. Jahrg.). 1862. p. 2.

Kanitz, J. G. Uber den Einfluss der Temperatur auf die 1Bienen. - Prenss. Bienen-Ztg. V. Bd. (VIII. Jahrg.). 1862. p. 95-96.

Kanitz, J. G. Kanu ein Bienenvolk erfrieren? - Preuss. Bienen-Ztg. I. Bu. 1855-56. p. $13-14$.

Kanitz, J. G. Erziehung rom Löniginlarren in künstlicher Wärne. - I'renss. Bienen-Ztg. 4. Bd. (VII. Jahrg.). 1861. p. 32.

Küchenmeister, Fr. Verträgt eine Bienenkönigin eine Erstarrung hei einer Temperatur von etwas über $0^{\circ}(+1-8)$ ohne Schaden für das normale Eierlegengeschäft? - Eichstädt. Bienen-Ztg. 16. Bd. 1860. p. 185.

Maurel, E. et de Ray-Pailhade. Inthence des surtaces sur les défenses de l'organisme chez les animaux à température variable pendant l'hibernation. C. R. Société Biol. Paris. LII. (11. sérié. 'T. II.). № 38. 1900. p. 1061 bis 1064 .

Meloni, Nicolò. Influenza della razza, della ibernazione e della temperatura sullo schiudimento delle nova del filugello. - Il bacalogo italiano... Anno I. 1878-79. p. 44-45.

Omboni, Cesare. Sull allevamento al alta temperatura. - Rivista settim. di bachicolt. Anno IV. 1872. p. 93-94.

Perez, J. Experience relative ì l'intluence du froid sur les spermatozoides contenus dans le réservoir seminal d'une abeille-reine fécondée. - Act. Soc. Linn. de Bordeaux. 'T. 34. (4. sér. T. 4.). 1880. p. XIV.

Perroncito, E. Azione di differenti gaz, del vuoto e della temperatura sul seme. - Rivista settim. di bachicolt. Anno XII. 1880. p. 45.

Pitra, Josef. Wämebedarf der Biene. - Preuss. Bienen-Ztg. 21. Bd. № 16. 1865. p. $188-193$.

Quajat, E. Dell' intluenza delle basse e medie temperature sulla nascita del seme bachi. - Anno X. Staz. Bac. A. 1882.

Quajat, E. Prodotti respiratori delle uova del filugello durante l'incubazione normale. - Estratto d. Ann. d. R. Accad. d'Agric. d. Torino. XLII. 1899.

Schönfeld. Kleine Beiträge zu Bienenkunde. I. Wärme. - Eichstädt. BienenZtg. 18. Bd. 1862 . p. $85-88$.

Schönfeld. Kleine Beitrüge zur Bienenkunde. IV. Noch einmal Wärme. - Eichstädter Bienen-Ztg. 19. Bd. 1863. p. 13-18.

Schönfold. Der Wärmebedarf der Biene. (Antwort an Hr. Pitra). ..- Eichstädt. Bienen-Ztg. 22. Bd.: 1866. p. p. $16-19$. 
Şhönfeld. Die Trirmeqrenzen, innerhalh deren die bienen leben. - Kächstadt. Bienen-Ztg. 22. Bd. 1866. p. 89-92.

Simaschko, J. J. Leber die Insekten, welche lebenil in Schnee antigetunden wurden. (Desoria glacialis). - Protok. der russ. Entomol. Gesellsch. in S. Petersburg. I: 1860. p. 17.

Studiati, C. Ragguaglio di un allevamento di bachi dis seta allit trmperatura poco elevata e variabile dell' aria esterna. - Rivista settim. di bachicolt. Anno XU. 1880. p. 66-67.

Swinton, A. H. Effect of sudden change of temperature upon hitr-h.r. - Ji:tomologist's Monthl. Mag. Vol, 16. 1879-80. p. 278.

Jčik J. Jakon teplotu snese viela? (Was für eine Wärme kam die liene ve:tragen?) - Věelařské Listy. II. 1878. p. 23.

Uffoln, K. Einfluss der Temperatur auf die Entwickelung zweit(1 fiencratim. Deutsche entomol. Zeitschrift. IX. 1896. p. 148-150.

Vorson, E. und Qvajat, E. Sull' allevatuento a temperatura elerat: e crexunte: di confronto a quello fatto col sistema ordinario. - Rivisfa settim. di bächicoltura. Anno V. 1873. p. 134-135.

Voyle, J. U. S. Dept. Agric., Div. Ent., Bull. 4. 1884. p. 70-73. (Finfluss der Käalte auf dic Entwickelung der Eier von Pflanzenläusen).

Wilcox, E. V. The power of resistance of Helophilus larvar to killing-lluids. Anat. Anz. XII. 1896. p. 278-280.

\section{Einfluss des Lichtes.}

J. Béclard (1s.j. 57) setzte die Larven der Flevisihtliege? (Musca rarnaria) dem Einflusse der Strahlen von versthedenen Farben aus, wobei sie ihre Entwickelung unter fïrbigen cilasglocken durchmachten. Gleichzeitig abgelegte Eier ergaben unter verschirilenen (xlisglocken auch zu gleicher Zeit Larven; nach t-5 Tagen. aher wurie in ihrer Entwickelung ein grosser Unterschiml beobacht t. Am stärksten entwickelt waren diejenigen Larven, welche unter vi,l'ster nul blauer Glasglocke sich befanclen, am schwächstem iie unter grimer Glocke. Die Spektralfarben lassen sich in Bezug auf ilyen Einfluss auf die post-embryonale Entwickelung der Fliegeni.rven in absteigemler $R$ 'ihenfolge einorilnen, wie folgt: violett, blin, rıth, weiss, grün. I)ie Larven, welche unter dem Einflusse (ler vioIetten Strahlen sich entwickelten, waren dreimal so lick und la wie die unter der grimen Glasglocke sich entwickelnden.

Marquis de Lafitole (1576. 493) fuitterte die Raupen von Arctia caja in vollstïnliger Dunkelheit; dieselben starben aber nach der dritten Häutung. 
G. Schoch (1 80 . 770) zichtete Raupen von Arctia caja in drei verschielenen Bohältern, wobei riner mit rothem, ein anderer mit violettem und ein dritter mit blauem (ilas bedeckt war.

Die unter dem Einflusse des violetten Lichtes sich hefinlenden Raupen waren viel gefrissiger als clie anrleren unı ergahen Puppen, aus welchen Schmetterlinge 14 Tage friher als ans ancleren Puppen schlüpten.

J. Loew (1sis. 533) stellte Versuche mit lebemlen P’uppen an, indem er entweler die Crewichtsverluste von Puppen im Licht uni im Inunkeln hestimmte. viler die im Hellen und im Dunkehn abgegebenen Mengen ron Luhlensiure direlit matass. Es hat sich herausgestellt, dass bei den Puppen, bei denen dass Licht keine Bewegungen zu erregen vermag, auch eine Vermelnumg der Oxylation und Kohlensiureabgabe im Lichte nicht stattfinlet: somit wiril das Gegentheil nicht durch Licht, sonlern dureh die Muskelthätigkeit erklärt.

W. J. Schmujdsinowitsch (1,31. 75S) stellte seine Versuche mit Fiern und Raupen von Bombyx: mori an, wolsei folgende farbige (iliser beniitzt wurlen: dunkel-roth, gelb, griin, dunkel-violett uml blau. Zur liontrole wurlen anch gewöhnliche Fensterscheiben und Glassscheiben, welche mit dickem. tiir das Licht umlurchlässigen Papier beklebt waren, verwendet.

1). Entwickelung der Eier. Untersucht wurden drei Rassen: die gelbe französische, die srüne japanische unl dic weisse bagrlarlische Rasse. Von jeiler Rasse wurilen je jon der farbe mul Grösse nach möglichst gleiche Eier verwenlet, welche auf Papierschnitzel mit diünem (xummi-arahicum autgelilebt, in nierlrige Papierschachtehn plaziert umb ohen mit erwilhnten Glissern beshekt wurlen. Die Schachteln hefanlen sich an den fenstern der Vorlseite ler Zuchtstation. Dic Zimmertemperatur schwankte zwischen 1ti,j und 1:0 R. Die Exposition simmtlicher Schachteln qeschah wleichzeitig. Dabei wurden folgende Resultate erhalten:

a). Die griine japanische Rassu: Riimpchen schliiptten jeden Tag in folgender Anzahl aus:

unter gewöhnlichem Glase 38. 115. 83. 15. 3. 0. 0. im Dunkeln . . . . 14. 65. 118. 52. 16. 20. 1. unter grünem Glase . . . 42. 96. 75. 47. 14. 6. 2. 
unter blauem Glase . . 34. 125. 78. 50. 39. 14. 1.

"violettem ". 29. 114. 90.48. 3. 1. 1.

" gelbem ". 30. 64. 95. 29. 22. 10. 2.

" dunkelrothem Glase 20. 85. 87. 42. 3. 1. 1.

b). Französische gelbe Rasse. Rämpchen schlipftru jecten Tag in folgender Anzahl aus:

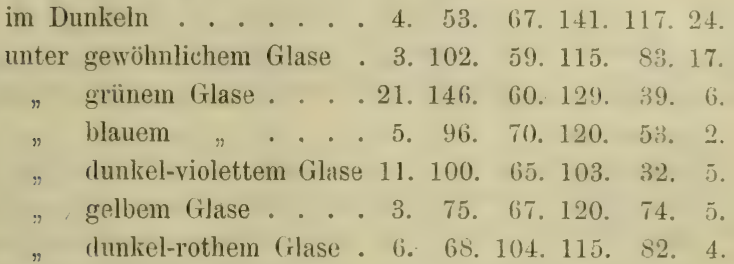

c). Die weisse Rasse von Bagdad. Rüupchen schlüpften jeden 'Tag in folgender Anzilhl aus:

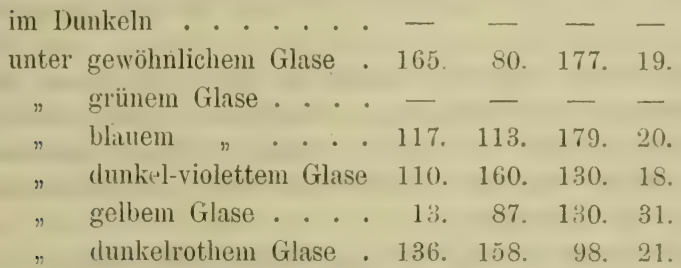

Aus diesem Tabellen ist ersichtlich, dass die Dunkelheit und ras gello Licht eine stark verzögernole Eimwirkme auf dio Eier aller drei Rassen atusiibten. Der Finfluss der anteren laririgen Lichtstrahlen ist bei verschiolenen liassen verschiehru.

2). Entwickelung der Raupen. Der Versuch wurle mit an demselben Tage (1S. IV. 1859) ausgeschliunften Raupen der golluen framzösischen Rasse angestellt. To jo Ranpen wurilen in RilrilonKisten gebracht. welche likeine Löeher an ihren Seiton zur Ventilattion trugen und in Inneren mit gewönlichem Schreibpapier, von a ussen (?) aber mit farbigem Papjer bekleht wurlen. Der crazestoff ersetzte den Bo:len. Die Kisten wurlen oben mit Gilisirn ludeckt und stanlen an (ler Nor lseite der '/uchtstation. I)ir Zimmer-

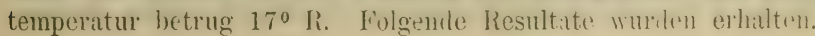




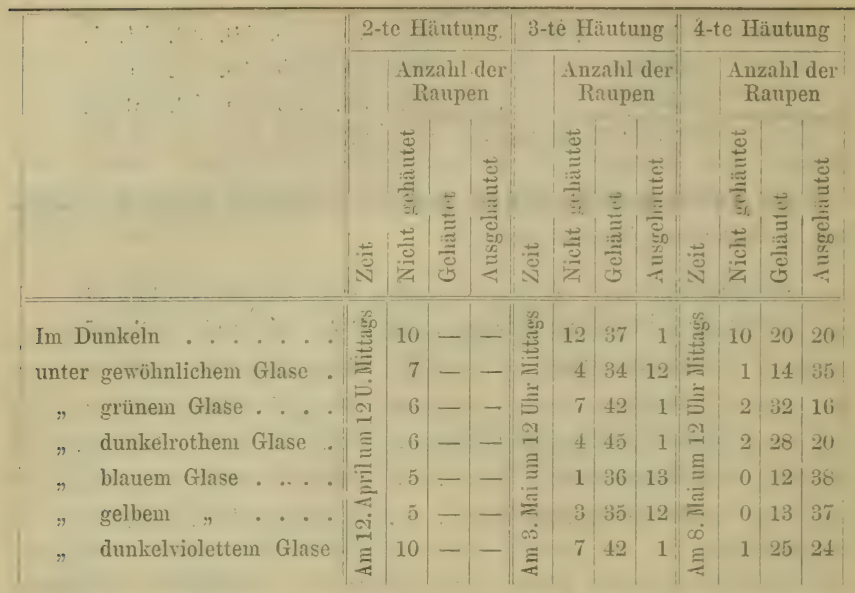

Aus dieser Taluelle geht hervor, dass ror lier 2-ten Häutung der Raupen fist liein Tinterschied in ihrer Futwickelmo unter rer-

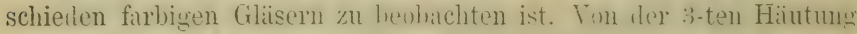
an findet dieser Unterschienl statt. mil wird noch gröisser bei der 4-ten Häutmng, und zwar rerzügert die Inulelheit die Entwirkelung der Paupen; die anderen Farhen erhalten in dieser Brziehung die folgentle Reihe: blau, gelh, gewöhnliches Licht, dunkel-riolett, roth, grün und die Dunkelheit.

I) Verpuppung fant auch nach dieser Rieihe statt, d. 1. zuerst verpuppten sich Riiuphen unter lem blanem filse und zuletzt im Dunkeln.

W. N. Rodsjanko (18!2-2. 69(i) beobaclitete, dass Gryllus domesticus L. sehr umruhig waren, als in das Glas, in rem sie sich aufhielten, das Tageslicht einfiel.

August Weismann (1895. 95.t) hrachte 5 Stïck Raupen von Vunessa cardui, welche vim Ei aus 14 Tage im Junkeln erzogen wurden, unter gelles Licht, wohei sie nach 2 Tagen abstarhem. Beim Wiederholen des Versuches, aber mit 16 Tage alten Raupen (anch im Dunkeln erz:)gen), entwickelten sich dieselhen dies Mal gut. Blaues Licht ïbte diese schiiliche. Wirkung nicht aus.

Es wurle anch beobachtet, dass die liaupchen von dieser Art, welche an 4.-6). Juni ausschliipften mul in Inukehn, unter blanem 
Lichit und unter gelbem Licht gehalten wurilen, sich am 3. resp. an 4. unıl 8. Juli verpuppten. Weismann erklärt jesloch die letztere grosse Zeitilifferenz durch schlechte, langsanere Ernïhrung. Das Aussclilípfen der Falter aus diesen Puppen fand statt:

im Dunkeln:

unter blanem Licht:

unter gelbem Licht:

am 13.-1 15. Juli.

aim 9.-10. Juli.

an 11. Juli.

A. L. $(1895.1)$ beobachtete, dass wenn die Raupen von Craterony.r dumi der Einwirkung der Sonne nicht ausqesetzt werken. sie starben, ohne nur zu gänzlichen Erwachsen gekommen zn soin.

M. Bellati unl E. Quajat (1896, 1i2, 6:3) setzten lli Fier ron l'mbyx mori dem Einflusse verschielenfarhiges Lichtes aus, wohei sie unter rothem, nrangem, grinem, blanem, violettem und schwarzem Gläsern sich befanden.

Unter gellen Glase wurle lie Entwickelung eimmal heschlennigt, das andere Mal verzögert. Die anderen Farben hatten keinen merklichen Einfluss auf die Entwickelung.

M. Standfuss (1896. 840) deckte eine Anzahl Zuchtkïsten mit verschiedlen gefärbten Glasscheiben un:l setzte die Iaupen auf diese Art der Einwirkung les farbigen Lichtes aus. Diesur Versuch ergat ihm nichts Positives. Weitere Versuche, deren Beschreibung fehlt, schienen ihm zn leweisen, dass unter violettem Lichte eine Be schleunigung des Wachstumes ler Raupe, sowie ler Entwickelung der Puppe stattfände.

W. Pickel (1598. 635) untersuchte den Eintluss rerschietlener farbiger Strahlen auf Bettwanzen (Cimex lectularic L.) und fanil, dass sie das elektrische Licht von 16 Kerzen in der Entfernung von einem Arschin nur 10 Minuten aushalten kömmen unl sich darauf in (lie Dunkelheit entfernen. Das violette Licht ertragen sie cat. 30) Minuten, das blaue, grüne, gelhe und rothe mehrere Stmolen, ziehen jedoch clie Dunkelheit vor.

Jules Gal (1898. 270) stellte Versuche über iten Eintluss iles furbigen Lichtes auf die Entwickelung der Seilenraupen an, wobei er die Glasscheiben mit Kollolium angestrichen und darauf violettes, blaues, grünes, gelbes unil rothes Pulver gestrent hatte. (; Kisten 
mit farbigen Glasscheiben enthielten je 15 Raupen von gleicher Brut unl Alter. Die Emäherung war fïr alle dieselle. Angewendet wurde kein direktes, sondern diffuses Licht.

Las Gewicht von je 15 liaupen betrug bei der dritten Haiutung (also gezogen von 19. Mai bis 7. Juni):

\begin{tabular}{|c|c|c|c|c|c|c|c|}
\hline Unter & dem & grünen & Glas & . & & & 9 \\
\hline " & $n$ & gelben & $n$ & . & . & & 0 \\
\hline : & $n$ & rothen & " & . & & & 1 \\
\hline " & $n$ & blanen & $n$ & $\cdot$ & 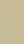 & & 1 \\
\hline$\because$ & " & weissen & $"$ & . & & & 2,5 \\
\hline$"$ & , & violetten & $n$ & • & & & 5.5 \\
\hline
\end{tabular}

Tachdem die Raupen sich verpuppt hatten, ergaben die Cocons am 19. Juni folgendes Gewicht:

Unter dem grïnen Glas: 1:3 Cocons, von welchen 2 doppelte, 2:3 gr.

\begin{tabular}{|c|c|c|c|c|c|c|c|c|c|}
\hline$"$ & gelben & $"$ & 14 & $\eta$ & $"$ & $"$ & & e & 23,3 \\
\hline$"$ & rothem & ע & 14 & $n$ & $n$ & $"$ & 1 & $n$ & 23,7 \\
\hline$n$ & weissen & $"$ & 14 & $n$ & $"$ & $n$ & 1 & $"$ & 24.1 \\
\hline$"$ & blauen & $"$ & 14 & $\pi$ & $n$ & $\eta$ & 1 & $"$ & 24,3 \\
\hline$"$ & violetten & $"$ & 14 & $"$ & " & $n$ & 1 & .. & 26,3 \\
\hline
\end{tabular}

I)ividiert man das Cocon-fiewicht durch das (iewicht der spinnreifen Raupen, so erhïlt man $46 \%$ unter dem grünen, weissen, gelben und rothen Glas mol $47 \%$ unter dem blauen und violetten Glas.

Nach dem Ausschlïpfen legten die Schmetterlinge Eier, welche gezählt wurden. Ihre Anzahl war:

Lnter dem rothen (rlase: \& Weibchen; durchschnittlich . . 307

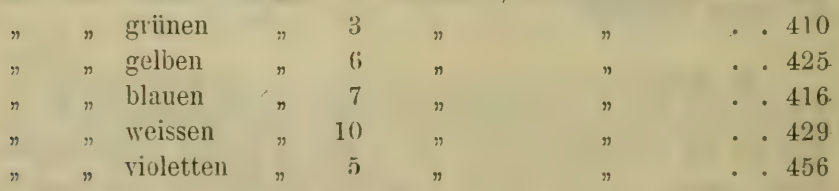

Daraus ist ersichtlich, dass das violette Licht die Enitwickelung der Seilenraupen begïnstigt, wohei das Gewicht der Cocons, die Quantitiit der Seide und die Anzahl der Eier grösser sinı als unter dem Einfluss anders gefürbten Lichtes.

L. Kathariner (1900. 440) Z.og ganz junge Riupchen von Vanessi urticue unter verschie len farbigen (illïsern auf uni erhielt. die ersten Puppen: 
im rothen Licht am 5 . Juni,

im Tageslicht hinter Chininlösung am 6. Juni,

im gelben Licht an 6. Juni,

in Dunkelheit am 7. Juni,

in blauem Licht am 7 . Juni.

Die ersten Falter schliipften:

im rothen Licht an 16 . Juni,

im Tageslicht am 16. Juni,

in anderen Lichtarten am 17. Juni,

in Dunkelheit am 19. Juni

Die Versuche mit Vanessn io ergaben in dieser lichtung nichts Positives.

Ph. C. Karl Absolon (1900, 2) fand, dlass Höhlenthiere (I)icyrtoma, Heteromurus, Tritomurus, Gamasus niveus). sowohl sehend als blind, gegen das Licht ausserordentlich empfindlich sinıl, und am Tageslicht in wenigen Minuten sterben. Lir mischte einige Höhlenthiere mit oberirdisch lehenden blinden Arten und setzte sie damn der Wirkung der Sommenstrahlen ans: „in kurzer Zeit liegen alle Troglobien tort, die ibrigen (ich hahe bei diesem Experimente Isstoma sp. und Maciotoma sp. benutzt) laufen muter herum" (p. t).

L. v. Aigner-Abafi (1901. 7 ) sagt, dass weun man den Kiasten mit Agrotis vestigialis Rott.-Raupen zur Zeit der Fütterung an die Sonne stellt, das ihr: Gerleihen sehr fördert.

C. Flammarion (1901. 241) untersuchte den Eintluss iles falbigen Lichtes auf das (ieschlecht der künftigen Schmetterlingen von Bombyx mori. indem er soeben ausgeschlïpfte liaupen (720) in 12 Behältern unterbrachte, von denen jerler mit einem bestimmten farbigen (ilas beleckt wurde. Die Versuche ergahen folgende liesultate:

Die bei freier Luft und gewöhnlichem Lichte erzogenen Raupen ergaben $500_{0}^{\circ}$ 우 uni $50 \% \sigma^{\circ}$. I asselbe Verhiiltniss wurile auch bei Hellroth und Hellgrün erhalten.

Hellblau ergab $57 \%$ ठ์

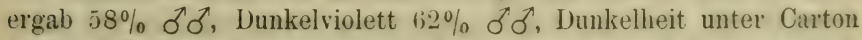
$63 \%$ ठ์ $68 \%$ ठౌరా.

Darauf wurde einer anderen Serie von liaupen die Nahrung nur in heschränkten Masse gereicht. Dabei ergaben sich unter Dun- 
kelviolett 5.5\% $\delta \delta$, unter Hellblau di30\% $\delta \delta$, unter Dunkelhlau $65 \%$ ठ

Die Kiritik diester Untersuchung vide hei Alfr. Giard (1901. 308n).

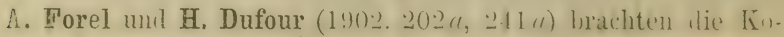

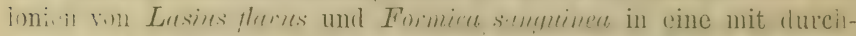
sichtiger lrelatinewant vershlisseme: Schachtel, welche sich in cinem

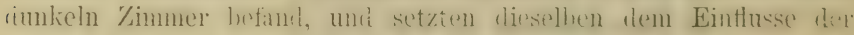

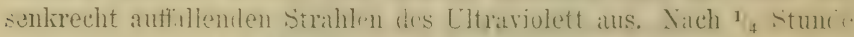
sammelten sich alle Ameisen mit. ihren Puppen in dem nicht g..-

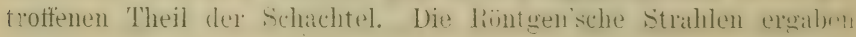
negatives Resultat.

Adele Field (190): 2.2:3) setzte Amsisenlanven der Einwirkus: rerschielener (weisser, violetter. gelher, dunkler) Lichtstrahlen ans. und stellte fest, dass diese Einwirkmo auf deren Entwickelume lieinen Einfluss ausübt.

Ergänzungs-Litteracur zu diesem Abschnitt.

Clodnew, J. W. Zur Lehre über den Lintlus des simnenlichtes aut Thiore. Kašan: 1882. (Russisch).

Lee. Attraction of light. - Canad. Ent. 1894. p. 296.

Grajat, E. Lit inthumzit della hee sullo schindimento dei seme hachi. - An. : . 1881. Staz. Bic.

\section{Einlluss der Elektricität und des Magne. tismus:}

Verson (1874. 921, 922). zeigte, dass Eier von Bomlyy mari nach 10 Tagen autleben, wem man sie der Einwirkmng der elektrischen Funken (ler Maschine von Holz) 3-4 Tage nach ihrein Ablegen aussetzt.

Nach den Versuchen von Dogiel (1877. 189) erzengt die Reizung mit dem Induktionsstrom bei Insekten eine Beschleunigung des Ierzschlages, aber nur dann, wenn dieser Strom schwach ist, sonst findet eine Verlangsamung oder gar ein Aufhören des Herzschlages statt. Wird diese starke Reizung für längere Zeit unterbrochen, so bemerkt man die Herzkontraktionen wierler, jedoch nicht von der früheren Regehnässigkeit, Stärke und Ordnung. 
W. Schmujdsinovitseh (1891. 756) in Tiflis stellte Versuclete

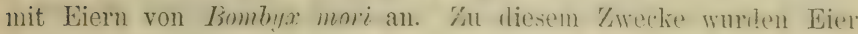
von gelher Franzisischer unt weisser Bagilater litsse benutzt. wolx.i

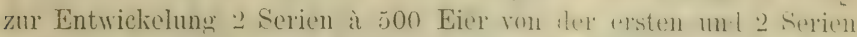
a $5(0)$ Eier von der zweiten lasse gehnancht wurlen. Je din terie

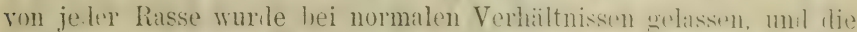

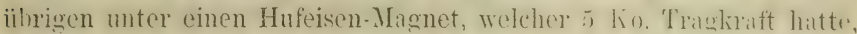

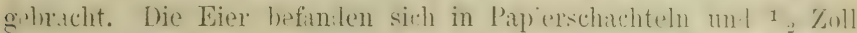
von den Polen entfernt. Die Entwickelung an! in demselluen Zimmer, auf demselhen Tishe un! unter sonst gleidhen Linstimden

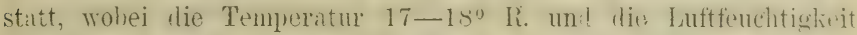
$45-55^{0}$ Schwabe-Hygrometer betrug.

Das Ausschliipfen dor Räupchen fancl gleize tig fuir beirle sirien statt und betrug jéden folgenden Tag:

1). Gelhe Französische Rasse ergab:

Bei Entwickel. unter nomal. Umstänten 11; 158; 230: 2s riäuchen Unter dem Magneten . . . . . . 20; 167; 188; 52 ,

2). Weisse Bagdader Rasse ergab:

Unter normalen Lmstïnlen . . . . 168; 185; 133; 13 lïupchen Uniter dem Magneten . . . . . . 110;184;138;67

Die Ergehnisse dieser Versuche für beile Rassen willersurrechen, nach der Meinung des Forscher's, einander, indem der Magnetismus die Fntwickelung bei der ersten Rasse währenıl der 22 ersten Tagen beschleunigt, wïhren!l bei der zweiten Rasse eine Verzïgerung beobachtet wirl.

Die Versuche von W. Schmujdsinowitsch (1 1 \$91. 75t6), welche er mit demselben Magneten, wie bei denjenigen mit Eiern. anstellte, ergaben mit Raupen folgende Resultate:

50 Räupchen der gelben Französischen Rasse wurlen unter dem Iagneten gerale so gefittert und unter sonst gleichen Lmstänlen, wie die anleren jo Räupchen nicht unter dem Magneten. Die Häutungen fimlen in beilen Fällen statt: die 1-te am 22.-2.5. April, die 2-te am 27. April, die 3-te am 3. Mai unl die 4-te am 9. Mai. Die Verpuppung begann am 19.-20. Mai. Sich zu Verpuppen fingen zuerst diejenige liaupen an, welche unter normalen Lmständen erzugen wurilen. Der Verlauf der Häutungen ist aus folgender. Tabelle zu ersehen: 


\begin{tabular}{|c|c|c|c|c|c|c|c|c|c|}
\hline \multirow[b]{2}{*}{$\begin{array}{c}\text { Die Art } \\
\text { des Ernäherns }\end{array}$} & \multicolumn{2}{|c|}{$\begin{array}{l}\text { 1-te } \\
\text { Häutung }\end{array}$} & \multicolumn{2}{|c|}{$\begin{array}{c}\text { 2-te } \\
\text { Häutung }\end{array}$} & \multicolumn{2}{|c|}{$\begin{array}{c}\text { 3-te } \\
\text { Häutung }\end{array}$} & \multicolumn{3}{|c|}{ 4-te Hïutung } \\
\hline & 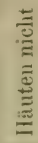 & 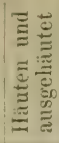 & 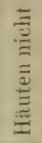 & 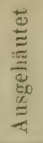 & 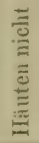 & 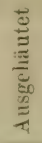 & 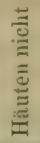 & $\underset{\Xi}{\stackrel{\Xi}{\Xi}}$ & 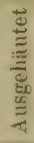 \\
\hline Normal . . . . & 1 & 49 & 10 & 40 & 15 & 35 & 16 & 32 & 2 \\
\hline Unter dem Magneten & 2 & 48 & 15 & 35 & 29 & 21 & 32 & 18 & 一 \\
\hline
\end{tabular}

Die Beolachtungen wurden in allen Fällen um 12 Uhr Mittags ausgeführt.

Diese Tabelle zeigt, dass die Entwickelung der Raupen durch den Magnetismus verlangsamt wird un l zwar desto mehr, je länger sie unter diesem Einfluss sich befanden.

W. Schmujdsinowitsch (1S91. 756) machte am 8. Mai 1890 eine Anzihl der Cocons der weissen Japanischen Rasse der Seidenspanners auf, welche ihre Verpuppung an i. Mai begannen. Je 15 бo wurlen in 2 kileine Papierschichteln gebracht, wobei eine unter ren bei friheren Versuchen beschriebenen Magneten kau. Die 2-te Schachtel diente zum Kiontrolversuch. Die Entpuppung begann an 24. Mai. wobei 2 Falter unter dem Magneten; am 25. Mai schlüpften 2 Schmetterlinge unter dem Magneten und einer aus anclerer schachtel. Die Beenligung les Lusschliipfers trat zuerst bei Puppen ein, welche unter dem Magneten waren (26. Mai).

Aut diese Art ibte der Hagnet eine merkliche Beschleunigung auf die Entwickelung der Puppen aus.

J. Testenoire unil D. Levrat (1895. 858) haben die RiöntgenStrahlen z.ur Bestimmung des Geschlechtes ler Puppe benützt und ermittelt, dass die lebenten Schmetterlinge keinen Schaden dadurch erlitten.

M. Bellati unl E. Quajat (1896. 62) brachten die Eier von Bumlyx mori zwischen den Elektromagnet von Faraday (Modell von Ruhmkorff) mit rertikalen Spulen. In einem Falle wirkte das magnetische Feld auf die Eier innerhalb 2 Stunlen, in einem anderen 3 Tage und in dem dritten mehr als einen Monat. Sogar beim Benutzen der grossen Iynamo- Maschine des phỵsikalischen Instituts 
ler Universitiat in Padua zum Magnetisieren dieses Elektromagneten hatte der Magnetismus keinen merklichen Einfluss auf die Entwickelung der Eier.

M. Bellati und E. Quajat (1896. 1i2) benutzen die stille Entlariung der Elcktrisiermaschine von Töpler, inclem sie die Konluktoren mit spitzigen Drähten versahen. Die Eier von Bomlyx mori, welche in tem elsktrischen Felde sich befanden, zeigten keine Entwickelung bei der Entfernung zwischen Spitzen von 2-3 cul. Bei grösseren Entfernungen und bei Dauer der Einwirkung von $1 / 2$ bis 1 Minute, schliipften aus Eiern Raupen. Die wierlerholte Einwirkung des clektrischen Felles ist auf die Entwickelung rer Eier schäıllich, so z. L. brachte die Einwirkumg des stillen elektrischen Lntlalung, welche währeml ${ }^{1}{ }_{2}$ Minute stattand, alle Eier von "race lieggienne" zur Entwickelung, während das Wierlerholen dieser Einwirkmng am folgenlen Tage mehr zerstreute Entwickelung zur Folge hatte, wobei 7, , $\% \%$ der Eier gar nicht zur Entwickelumg gelangten.

Die Einwirkung der Elektricität wird durch etwas erhöhte Temperatur begünstigt, wie folgendes zeigt:

'Temperatui. Anzahl der ausge-

$22^{\circ} \mathrm{C}$. $44-48^{\circ} \mathrm{C}$.
$22,8 \%$

67,8 Später schlüpf-
ten noch:

Auch andere ähnliche Versuche erwaben dasselbe Resultat.

Diese Forscher stellten noch den folgenden Versuch an: Von 23 concentrischen Glasgefässen war clas innere nit warmen Wasser gefuillt, wïhrenıl dass anılere Glas auf seiner äusserer Wanıl ein Stück Stanniol trug. I)as IVasser des inneren Gefässes und das StanniolStïck des zweiten Gefässes wurlen mit Konluktoren einer Elektrisiermaschine verbunclen. Die Eier wurden am äusseren Wande iles immeren Gefässes gegenüber dem erwähnten Stamniolstiick :ngeklebt.

Als lie Temperatur des Wassers im inneren frefässe $2: 3^{1 / 2}{ }^{0} \mathrm{C}$. betrug; und die Elektrisation 4 Minuten gelauert hatte, entschliipften aus den Eiern $1 \%$ Räupchen, $1 \%$ entwickelte sich, entschliipfte aber nicht, und $98 \%$ zeigten keine Entwickelung.

Als die Temperatur des Wassers $50,4-48,7^{\circ} \mathrm{C}$. betrug, schluipften die Räupchen aus mehr als $48^{0^{\prime}}{ }_{0}$ Eiern; entwickelt haben sich $9 \%$ Eier, ohne Räupchen zu ergeben.

Als die Eier nicht gegenüber dem erwähnten Stamiolstiickchen angeklebt wurlen, entwickelten sich keine Eier. 
188 Erstes Kapitel. Die Entwickelungsgeschwindigkeit der Insekten.

Durch besondere Tersuche wiesen diese Forscher nach, hits

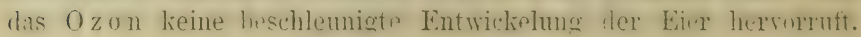
Auf feuchte Eier wirkt die elelitrische Lintlulung war nicht. Ein In luktorium ron Ruhmkorff hat ditenelles Wirkums wie die Elektrisiermaschine von Töpler, nur goh $n$ in thesem Falle mehrene Eier zu Grunde.

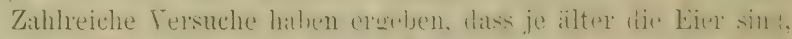
welche der Einwirkung der stillen Entlathug morrworfen werden.

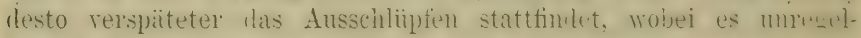
inässig. wircl.

M. Bellati $(1-9)$. (it) zeigte, dass I-Stralilen (ein glustes Inlulitorimn mit 9 Accummulatoren) keinen Einthess anf ale beschlemigte Entwickelung der Eier ron Bomlyn mori ansiilsen. I lix. Schwingungen ron Tesla ercaben liesultate. welche slenjenigen mit elektrischem liegen (fiveco elettrico) erhaltenen, ilmnlich waren. jedoch weniger entscheidend.

E. Quajat (1897. (it) stelle qualitative Bestimmmg tel Iiesyirations-Produkte rer elektrisierten Lier ron Bomlyys mori an, uni erhielt dabei folgendes:

Ihe elekrisierten Eier, mabhängig ron ter lasse. rerlang-n eine hestimmte Anzahl von Tagen zur Entwickelung vom Ifomentr. der. Elelitrisation an bis zum Ausschliipfen iler ersten Raupen. Diest Prriolle betrïgt im Juni und Juli (24-290) 9-10 Tage; bei der Temperatur unter 220 nimmt liese Periorle zu (12-13) Tage lei 16 bis 220). $100 \mathrm{gr}$. elektrisierte Eier scheilen bis zum Autleben $16,1213 \mathrm{gr}$. $\mathrm{H}_{2} \mathrm{O}$ uni 9,1102 gr. $\mathrm{CO}_{2}$ aus, währeni lasselbe Gewicht der Eier, welche aus dem Kieller bei $0^{0}$ genommen und der Einwirliung rler Temperatur von 22 -24 $4^{0}$ unterworfen werilen, ca. 10,5 g1. Wasser und ca. 8 gr. Kohlensäure ausscheiden.

Daraus ist klar, llass die Eier, welche elektrisiert und innerhall, 9 Tage inkubiert werlen, viel energischer athmen, als clie Eier. welche der Temperatur ron $0^{\circ}$ entnommen und imnerhalb $1: 5-16$ Tage inkubiert werden.

J. Testenoire und D. Levrat (1897. 858) untersuchten mittelst Rïntgen-Strahlen die Cocons von Bombyx mori, un zu erfahren, ol, aui solche Weise das Geschlecht der P'uppen festzustellen wäre. In 
her Abham llung steht je loch nicht, ob die P'uppen resp. Falter dabei beschädigt wurlen.

Arnold Pictet (1899. (i3)(i) sturlierte die Einwirluma der Elektricitiat aut die Entwirkelumg der Puppen vou Vunessu in unıl Pieris ictpae, inlem el die Puppen unl Riupen der Entlailung iler liuhmkorttischen Spirale, welche durch ein Elenent von Bunsen betriehen wurile. aussetzte. Dabei fancl er eine Hemmm an ler bistrickelmo der Flïgel: , iles arrets de dérelnppement dans la tormations res ailes" (p. 282).

Axenfeld (1899. 1Sa) brachte in eine Kiste, welche zur Hailite aus Holz. zur anleren Hälfte aus Blei bestanl, Larven von Kä̈fern. Fliegen, Bienen uml Kellerasseln, unil setzte den Behïlter der Einwirkung der Röntgenstrahlen aus. Die wiellerholten Versuche zeigten, dass die Larven dabei in die Bleiabtheilung hinïber wanılerten.

L. Weber (1900. 946 a) brachte eine Anzahl gïnzlich augenloser Larven des Nashornkï̈ers in ein offenes Cigarrenkästchen, in welchem auch ein offenes Metallkästchen sich befanl, umil setzte das yanze System der Einwirkung der Röntgenstrahlen aus. Alle Larven zogen sich dabei in das Metallkästchen zurück.

\section{Erganzüngs-Litteratur za diesem Abschnitt.}

Carlgren, 0se. Leber die Einwirkung des constanten galranischen Stromes ant niedere Organismen. - Arch. für Anat. und Physiolog. Abt.-für Phy̧s. 1900. p. 49.

Girard, Maurice. Note relative a les expériences sur liation des courants électriques sur les chrysalides des Lépidoptères. - Ann. Soc. Ent. France. 4. Sér. T. 6. 1866. p. $207-212$.

Freiwirth, 0. Verschiedenartiges Terhalten der trbeitsbienen und der Irohnen zum elektrischen Strome. - Eichstädt. Bienen-Ztg. 35. Bd. 1879. p. 191.

Slater, J. W. Intluence of Magnetism upon Insect Development. - Trams. Entomol. Soc. London. P. III. Proc. 1885. p. XV. 
Frstes Kapitel. Die Entwickelungsgeschwindigkeit der Inseliten.

\section{Einfluss der Nahrung und chemischer Stolle.}

Je:lem Ziichter ist bekannt, dass der Mangel an Nahrumg viel kleinere Exemplare, so genante .Hunger-Exemplare," ergiel)t; anderseits ist bekannt, dass das Humgern nicht immer regressiven Einfluss auf die Fntwickelung u(n Insekten ausïbt. [).r Eintlus: der Nahrung anf die Entwickelung verdient deshalh hesondere lufmerksamkeit, da einige Forscher anlere finfliisse auf diesen Einfluss re:luziert wissen wollen.

Noch Schirach ( 1761 751) benbachtete, lass die Arbeiturl,ienn eine königin kïnstlich erzeugen kömen. falls die bis dahin qewespm. Königin stirbt. Riem (177ti, (694a) zeigte, dass dir Arbeiterbirmm zuweilen Eier ablegen.

Erst Huber (1793. 393) ist es gelungen, zn benbichten. wie die Königin künstlich erzengt wird. Wem die Bienen den To:l ler Königin bemerlit hahen, fingen sie an, eine Wachsyelle, in welchel die Larve einer. Arbeiterbiene lixgt, zu erweitern, wobei trei henachbarte Zellen zerstört werden.

Kybor $(1-15,4) 1)$ beseitigte die moinstigen Bellingmenten der Ernäherung hei Siphonuphoru rosae und Rhopmlosiphum diunthi mol beobachtete wïhrent 4 Jahren nur parthenogenetische Weihchen. Die Ursachen, welche die Entwickelung der Männchen und der dierlegenten Weibihen beringen, suchte er im wathsenten Mangel der Nahrung zu finden.

Den Eintlusș der Nahrung, welcher bei der Lrzeugung der Bienenkönimimen clie Hauptrolle spielt. wies Leuckart (1458. jos) nach. Alle Iienenlarven bis zum sechsten Tage ihres Alters orhulten als Xahumg eine besontlere Milchmasse; nachher aber, wenn the tienital-Orwane sich zu entwickeln angefangen, wurlen die Larven ricr Arbeiterbienen nur mit Blumenstaub und Ifonig gefittert, währen! dic Larve der kïnftigen höniqin die urspriingliche Vahrung weiter bekam. Somit wird die Weiterentwickelung ler Larven der Arbeiterbienen, was die (ienital-Orwane anbelangt, gehemmt, anch ihre Grösse wirıl dahei, wie hekannt, geringer als diejenige der Königin.

Landois (1 N167. 498 a, 498 b) wies nach, dass mit der A teurlerung der Lehensherlingumgen zur Herbstzeit eine Aenderung in den 
Geschlechtsverhältnissen der Blattliuse eintritt, wobei erstere die Ursache der letzteren bililen.

Eugène Mouline (18(;7. 5!)(i) beobachtote, dlass Fïre ron Bimm byx mori, in Kohlensiume aufbewahrt, lïupchen ergaben.

Treat (157:3. 881) sagt, (lass Raupen, whlehe reichlich wefiittert werilen, weibliche Schmetterlinge ergeben; hei Futtrinangel schliipfen männliche Exemplare aus.

T. Gentry (1573. 306i) ist der Meinung, dass das cieschlecht der jungen Raupen nicht zu unterscheilen ist: es entsteht er'st spate' durch die Verschiedenheit im Quantum cles Futters. Als Beweis giel, er an, dass die Raupen, welche er verwass zu fiittern, sich sehr balıl verpuppten und mämnliche Schmetterlinge lieferten, wïhrend die Raupen, welche reichlich gefütert wurlen, spaiter nur weibliche lixeniplare ergaben. Er beobachtete auch, dass die liaupen, welche an krankhaften Biimmen sich aufhalten oiter in Herlst, als die Blätter. nicht mehr sattig sind, fressen, mainnliche Schmettringe eroelsen.

Duclaux (18T4. 202) brachte Eier ron bombyx mori tiir :Minute in concentrirte Schwefelsïme; nath dem Auswaschen mit reinem Wasser entwickelten sich daraus nach 10-12 Tagen fíiupchen. wenn auch nur theilweise.

W. Kurz (1874. 487) wies nach, dass die parthenogenetische Fortpflanzung bei Daphnoiden im Zusammenhange nit ller giinstigen Periorle der Existenz in ihrem Entwickelungscychns steht, wïhrun.l die geschlechtliche nur bei unginstigen Rerlingungen vorkommt, \%. B. wenn die Siimpfe unıl Teiche austrocknen.

Marquis de Lafitole (1876. 493) beobachtete, dass die liamuen von Aictic caja wegen Mangels an nierleren Pflanzen (Lüwenzalın, Schafgarbe etc.) auch junge Schösslinge von Wreimreben frassen. Er unternahm deshalb einen liutterungsversuch an $6(0)()$ Iiaupen dieser Art mit Blätteru von Wallnuss, Rosskastanien, Sumach, linchibaum, Chelidonium majus, gelhen Rüben und Lattich. Es stellte sich heraus, dass lie Raupen, welche mit Wallnuss-, liosshastanienund Sumach-Blättern gefüttert wurlen, starben mul einige wrinis ausgewachsene missgestaltet und verkriippelt waren. Luchsloumblïtter wurken einige Tage getiessen, machler aher nicht meln. 
unı die Raupen starben an Erschüptung. Chelidonium majus frassen die Raupen gierig, abee die Puppen starlen noch im (iespimnst. Nit Lattich gefüterte Rampen ergalien Puppen unil nachher auch Falter:

Dogiel (1877. 199) fant, dass folgenle stofle eime lieschlennignng des Herzschlages bei Insekten hervorrufen: Ammoniak, Arthyläther, Oxalsäure, Liarbolsäure, Silpetersiures Kali, Aconitin unr zwar in kleinen Mengen genommen.

Die Verlangsamung les Herzschlages finle: statt durch: Anmoniak, Aethyläther. Oxalsäme. Karbolsäme, Verartrin. Armpin. Ar»nitin. Salpetersaures hali unl zwar in grossen Mengen genumnen. Die gleiche verlangsammenle Wirkung hesitzen: Aethyl-1lkohol, Chl. roform, Chloralhydrat, Kohlenoxyil, Kohlensäme, Schwefelwa-serstofï. Inılifferent für die Thaitigkeit des Herzens sinl: Muscarin, ('nran, Atropin bei schwacher Wirkung, Strychnin.

Guido Susani (1878. 552) untersuchte Eier von Bumbyr mori. welche rer Einwirkung der Salz-Säure währeml is Minuten ansosetzt waren, unil fani, lass dabei 900; Röupchen erhalten weriten.

Carl Düsing (18n4. 203) sagt in seinem Buche: .Der CeberHuss ist die Bedlingung und die Crsache ler thelytolischen Parthenogenesis" (1). 190); neben Weibchen treten auch Männchen auf, aber erst gegen den Herhst, wenn wenig'r günstige Nährbedingungen cintreten. Die Zuchtversuche, welche an Blattlïusen vergenommen wurlen, ergaben, dass die Parthenogenesis mit dem Nahrungsiberfiuss entsteht und vergeht.

M. Standfuss (1884. 834) liomnte den in starkem Wachsen begriffenen Raupen von Agrotis collina B. wegen sehr früh eintrutenrem Schnee nicht sofort das nöthige Futter in genïgender Menge beschaffen. Die Folge davon war, dass er von 103 gesumlen Raupen nur 45 Falter und zwar 37 ठ์ und 8 ○ᄋ erhielt.

C. F. Morgan (1885. 594) stellte mit Pliylloxeru cust:trix Versuche an und fand, dass die mangelhafte Ernährung die Entwickelung der geflügelten Weibchen begünstigt, während die reichliche Xahrung dieselbe rerlangsamt. Am frühesten erhiclt er geflügelte Exemplare am 9. Juli. 
0. Tichomirowa (1895. 871 $a$ ) brachte finf Weibchen von Pulex serraticepes Gerv. (Flöhe) in ein Glas unı liess sie ohne Nahrung. Das erste Weibchen starb nach 9 Tagen und las letzte nach 14 Tagen.

Die Larven wurden im Frühjahre reichlich gefiittert, wobei ihre Larvenzeit um 10 Tage kürzer wurde (statt 30-31 Tage wurden die Cocons nach 19-20 Tagen erhalten), uni das Imago 17 Tage nach der Verpuppung erhalten wurde.

E. Göldi (1885. 315) stellte Versuche an Pemphigus xylostei, Pemphigus bumelice und Lachnus sp. an und fand, dass diese Blattläuse beim Mangel an Nahrung die geflügelten Formen viel früher ergaben, als es sonst vorkommt, so z. B. erhielt er dlas geflügelte Weibchen der Blutlaus (Schizoneura lanigera) schon im .Tuni.

A. A. Tichomirow (1886. 868) hat mehrere Versuche mit unbefruchteten und frisch abgelegten Eiern von Bombyx mori angestellt und zwar:

Erster Versuch. Die Eier wurden für $2 \frac{1}{2}$ Ninuten in concentrierte Schwefelsäure eingetaucht. Nach 4 Tagen fingen von 34 Eiern 12 Stiick an, sich zu verdunkeln. Nachdem diese Eier die Färbung, welche den befruchteten und überwinternden Eiern eigen ist, erhalten, wurden sie mikroscopisch untersícht. Dabei stellte sich heraus, dass der Embryo, die Zellen der primären Entoderme, das Pigment-Epithelium der serosen Membrane etc. keinen Unterschied von denen zeigten, welche auch in einem befruchteten Ei beobachtet werden.

Zweiter Versuch. Eine Portion unbefruchteter Eier, welche innerhalb 2 Wochen nach der Ablage keine Veränderung zeigten, wurle in koncentrirte Schwefelsäure $2 \frac{1}{2}$ Minuten lang eingetaucht. Von 50 Eiern erhielten 3 die Färbung der überwinternden Eier.

Dritter Versuch. Eine Portion unbefruchteter Eier wurde 3 Tage nach ihrer Ablage in 2 Theile eingetheilt. Eine Serie wurde $21 / 2$ Minuten 3 Tage nacheinander in koncentrirte Schwefelsäure eingetaucht; die andere Serie erlitt diese Operation nur ein Mal. Die Anzahl verdunkelter Eier der ersten Serie war 3 Mal grösser als die der zweiten Serie.

Harz (1886. 355 a) nahm die Fütterungsversuche nit den Blättern der Schwarzwurzel (Scorzonera hispanica L.), welche bereits 
vor 75 Jahren bekannt waren, aber dann in Vergessenheit gerathen sind, von neuem auf. Dabei wurle hemerkt, ılass während die Raupen ron Bombyx mori bei der Aufucht mit Maulbeer-Blättern nach der Raupenzeit ron 29-33 Tagen sich verpuppen, diese Periolle bei neuer Fïtterungart 54-62 Tage dauerte. Die nüchste Raupengeneration hatte etwas liürzere Raupenzeit, ilenn $7,50 \%$ Raupen, welche der vorjührigen Zucht entstammten, gelangten in 44-54 Tagen zur Verpuppung: im dritten Jahre $29,6^{\circ} 0_{0}$ in 42 bis 56 Tagen und im vierten Jahre $34.38^{\circ}$ o in 38-64 T'agen. Die geziichteten Raupen befanden sich in einer Temperatur von ca. $15^{\circ}$.

A. L. Donnadieu (1887. 192) hat beobachtet, dass die Gallen nie von Phylloxera, welche auf Wurzeln lebt, erzeugt werlen; versetzt man sie aber aus rlen Gallen an die Wurzel, so rerwanteln sie sich in geflügelte Exemplare.

J. Ritzema Bos (1887. 105) lieobachtete, lass Silpha opaca L. (Aaskäfer) wegen Mangel an organischen Substanzen sich mit Pflanzen ernähren mussten. A Aber dieses ungewöhnliche Futter batte einen nachtheiligen Einfluss auf die Fortpflanzung; wenigstes im folgenden Jahre waren ،lie Aaskäfer im Ypoliler fast alle verschwunılen" (p. 322). Dasselbe geschah mit Coprophilus striatulus F., welche, sonst von anderen Insekten oler Würmern sich ernäherni, Maiskörner frassen.

C. Keller (1 87.445$)$ stellte Beohachtungen uber len Einfluss (ler Nahrungsentziehung auf Phylloxera an. Zu diesem Zwecke trocknete er die No:lositäten der Rebwurzeln, welehe als Nahrung dienten, bei Zimmertemperatur und in Dunkeln. Als nach einigen Tagen diese Notlositäten (ler Rebwurzeln austrockneten, begaben sich viele Phylloxera-Individuen zur weiteren Metamorphose und ergaben clarauf geflïgelte Exemplare. Daraus geht hervor, lass der Mangel an Nahrung, statt clie Phylloxera zu vernichten, ihre Entwickelung zu geflügelten Inlividuen, welche dann Eier ablegten, beschleunigte.

Dass der Mangel an Nahrung das Erreichen der Endform beschleunigt, ist auch in anderen Gebieten der Zoologie bekannt. Wir nennen hier nur die Untersuchungen von Barfurth (1887. 50) über Verwandlung der Froschlarven, welcher sagt, dass das Hungern bei der Entwickelung als der progressive Faktor erscheinen kam. 
Aug. Weismann sagt, dass wir den liegress in einzelnen Theilen des entwickelten Organismus als progressive Erscheinung betrachten sollen, denn, um die Endform zu erreichen, uüssen die sich entwickelnden Thiere die unnöthig gewordenen Organe und Gewebe resorbiren.

Laraus wirl klar, warum die Insektenlarven nach iem Erreichen iles vollkommeneu Alters keine Nahrung zu sich nehmen und so einige Monate ja sogar Jahre verbleiben, um darauf im inehr entwickelter Forn zu erscheinen. (Siehe auch: Tornier (1884. 878), Seoland (1887. 802), Barfurth (1887. 51).

P. W. Iwanow (18;8. 401) sagt, dass wenn die Spalten, in denen Periplaneta orientalis sich aufhalten, mit der Pflanze Polystichum filix mas verstopft werlen, diese Insekten vertilgt werden, da sie ,len Geruch dieser Pflanze nicht ertragen können.

F. Lambert (1891. 496) fuitterte hei $20^{\circ} 100$ Seillenraupen von der chinesischen und auch so viel liaupen von der französischen (Sevenn'sche) Rasse unil kam zu folgenden Resultaten:

1). Die Zucht (ler chinesischen Rasse dauerte 4 Tage weniger als die der französischen und zwar in ersten Falle 30 Tage und im zweiten 34, wobei diese vier Tage auf das 5. Alter fallen.

2). I)as Quantum der verzehrten Blätter in verschiedenen Alter war (für die Einheit ist das Quantum angenommen, welches im 1. Alter verzehrt wird):

Chinesische Rasse: 1; 2; 5; 17 und 143.

Französische $\pi: 1 ; 3 ; 9 ; 33$ " 245.

3). Die Exkremente wogen in verschierlenem Alter:

Chinesische Rasse: $1 ; 1,1 ; 7,4 ; 29,4 ; 248,3$.

Französische $":$ : $1 ; 3 ; 18 ; 80 ; 1047$.

Daraus schliesst der Verfasser, (lass 1) iler Koëffizient der Nährkraft des Blattes mit seinein Alter abnimmt (offenbar infolge der $\mathrm{Zu}$ nahme des Gehaltes der mineralen Substanzen in (demselben); 2) die chinesische Rasse leichter das alte Blatt verilauen konnte, als die französische Rasse.

W. I. Schmujdsinowitsch (1891. 756) stellte in der Station für Seidenzucht in Tiflis Versuche mit Raupen von Bombyx mori an, um zu untersuchen, wann der Tod beim Hungern eintritt. Folgende Tabelle ergiebt die erhaltenen Resultate: 


\begin{tabular}{|c|c|c|c|c|c|c|c|c|c|}
\hline 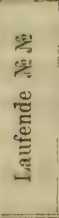 & $\begin{array}{l}0 \\
0 \\
n \\
n \\
\tilde{c} \\
\tilde{n}\end{array}$ & 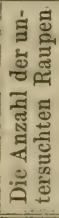 & 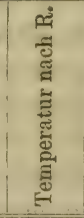 & 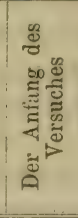 & 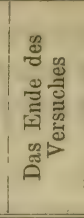 & 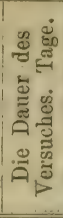 & 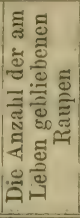 & 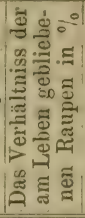 & $\begin{array}{l}\text { Dits Alter } \\
\text { der Raupen }\end{array}$ \\
\hline 1 & & 21 & $0^{\circ}$ & $17 . \mathrm{I}$. & 21. I. & 4 & 21 & 100 & \multirow{18}{*}{$\begin{array}{l}\text { Die Raupen } \\
\text { wurden zur } \\
\text { Utersuching } \\
\text { sofort nach } \\
\text { dem } \\
\text { Ausschlipfen } \\
\text { genommen. }\end{array}$} \\
\hline $\left.2^{1}\right)$ & & - & $2-7$ & $m$ & 6. II. & 20 & 7 & 33,3 & \\
\hline 3 & $\dot{0}$ & 30 & 6,5 & 7. II. & 10. " & 3 & 29 & 96,6 & \\
\hline $\left.4^{9}\right)$ & $\begin{array}{l}\infty \\
\text { in }\end{array}$ & - & - & , & 21. & 14 & 5 & 16,6 & \\
\hline $\left.5^{3}\right)$ & $\approx$ & 39 & 一 & 8. II. & 21. " & 13 & 23 & 59 & \\
\hline $\left.6^{4}\right)$ & $\omega$ & 30 & - & 7. $"$ & $25 . "$ & 18 & 2 & 7 & \\
\hline 7 & $=$ & 39 & $\bar{z}$ & 8. $"$ & $28 . "$ & 20 & 4 & 10,2 & \\
\hline 8 & $\begin{array}{l}0 \\
\infty \\
\infty\end{array}$ & 62 & 7 & 9. " & $28 . n$ & 19 & 14 & 22,6 & \\
\hline 9 & $\overline{0}$ & 19 & $"$ & 10. $"$ & 1. III. & 18 & 6. & 31 & \\
\hline $\left.10^{5}\right)$ & $: 0$ & - & " & $10 . "$ & 5. " & 23 & 2 & 10,5 & \\
\hline 11 & $\stackrel{\pi}{\pi}$ & 17 & $12-14$ & 7. & 15. II. & 8 & $1:$ & 5,9 & \\
\hline 12 & $\approx$ & 14 & 12 & 10. & 21. & 11 & 7 & i) & \\
\hline 13 & 0 & 14 & $"$ & $10 . "$ & 25. " & 15 & 1 & 7. & \\
\hline 14 & 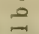 & 17 & $|12-14|$ & 7. & 8. " & 1 & 15 & 84 & \\
\hline 15 & 0 & - & " & 7. $"$ & 12. & $\bar{\sigma}$ & 14 & 82,3 & \\
\hline 16 & b & - & $"$ & 7. " & 14. " & 7 & 5) & 30) & \\
\hline 17 & & - & $"$ & 7. & 16. $"$ & 9 & 0 & 0 & \\
\hline 18 & & 30 & $10-11$ & 25. & 1. III. & 4 & 26 & 86,6 & \\
\hline 19 & & 25 & 8 & 25. IV. & $30 . \mathrm{IV}$. & 5 & 14 & 56 & \\
\hline 20 & ن. & 20 & " & 22. " & 28. & 6 & 17 & 85 & \\
\hline 21 & $\begin{array}{l}\infty \\
\infty\end{array}$ & - & $"$ & 22. " & 29. " & 7 & 7 & 35 & Nach der \\
\hline 22 & $\stackrel{\infty}{\infty}$ & - & $"$ & 22. & 3. V. & 11 & 1 & j & 2. Häutung. \\
\hline 23 & 0 & 10 & " & 22. & 29. IV. & 7 & 10 & 100 & \\
\hline 24 & $=$ & 30 & $\Rightarrow$ & 22. " & 2. V. & 10 & 30 & 100 & \\
\hline 25 & $\begin{array}{l}0 \\
\infty\end{array}$ & 12 . & $n$ & 8. V. & 15. & 7 & 7 & 58 & Nach der \\
\hline 26 & 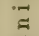 & 12 & " & ” & $16 . n$ & 8 & 3 & 25 & 4. Häutung. \\
\hline 27 & $\overbrace{2}^{\pi}$ & 12 & $"$ & " & 17. & 9 & 0 & 0 & 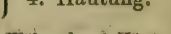 \\
\hline 28 & का & 10 . & $n$ & $"$ & 12. & 4 & 10 & 100 & Währ. der 4. Häut. \\
\hline 29 & $m$ & 36 & 20 & 6. I. & 7. I. & 1 & 33. & 91,7 & \\
\hline 30 & $\begin{array}{l}0 \\
0 \\
0 \\
0\end{array}$ & - & $\eta$ & $"$ & 8. " & 2 & 25 & 69,4 & \\
\hline 31 & $i_{0}^{\infty}$ & - & $\pi$ & " & 9. & 3 & 2. & 5,5 & Nach dem \\
\hline 32 & $z$ & - & $11-12$ & " & 9. & 3 & 33 & 91,7 & Ausschlüpfen. \\
\hline 33 & & - & $n$ & $n$ & 11. " & 5 & 21 & 58 & \\
\hline 34 & & - & -4 & $"$ & 9. " & 3 & 36 & 100 & \\
\hline
\end{tabular}

$\left.{ }^{2}\right)$ Die Raupen wurden ein Mal bis zu $15^{\circ}$ für den Versuch ${ }^{\circ} 1$ erwärmt. $-{ }^{8}$ ) Dasselbe für den Versuch №. 3. $-{ }^{8}$ ) Dasselbe $2 \mathrm{Mal}$ für die Versuche № 3 und № 4. - ") Dasselhe für den Versuch № 5. - ") Dasselbe für den Versuch te 9. 
Er zieht daraus folgende Schlüsse:

1). Bei der Erniedrigung der Temperatur bis $+10^{\circ} \mathrm{R}$. und noch tiefer, bis $-4^{\circ} \mathrm{R}$. (Versuche didi 1 und 34) hören alle Lebensfunktionen im Organismus der Raupe vorïhergehend auf, und sie verfällt in den lethargischen Zustand, welcher wenigstens 3-4 Tage ohne Schaden dauern kann.

2). Bei einer Temperatur nicht höher als $6-7^{\circ} \mathrm{R}$. findet ler Stuffivechsel, wenn auch sehr schwach, statt, wobei einige Raupen (bis zu 10\%) das Hungern 20-23 Tage (der Versuch il: 7 unil 10) aushalten können.

3). Der Stoffiwechsel ist bei $12-14^{\circ} \mathrm{h}$. ziemlich energiseh, weshalb bereits nach 4 Tagen ca. 13\% Raupen zu Grunde gehen (ller Versuch ․․ 18); nach 15 Tagen bleiben nicht mehr als $7 \%$ am Leben (der Versuch ㅊ: 13).

4). Bei $20^{\circ} \mathrm{R}$. sind die Lebensprocesse so intensiv, dass bereits nach 3 Tagen $94 \%$ Raupen. zu Grunde gehen.

5). Mit ier fortschreitenden Entwickelung werden die Raupen zum Hungern weniger empfindlich. (Versuche 느. ㄲo 22, 23, 3).

6). Die niedrige Temperatur hält die Häutung zurïck, beseitigt ,lieselbe aber nicht (der Versuch ㅊo 29).

Karl Hofmann (1891. 382) behauptet, class der Mangel am Chlorophyll des Futters den Stillstanıl im Wachsthum iler Raupen verschierlener Arten bewirkt.

F. Rühl (1892. 724) fütterte Raupen von Bombyt: arbusculae Frr. in Ermangelung von Vaccinium uliginosum mit Vacc. myrtillium. Die Raupen nahınen dieses Futter nur ungern an und gingen in Kürze alle zu Grunde. Dieselben Erfahrungen machte er mit Alnus, Corylus, Salix fragilis, Sorbus und Rhamnus. „Das einzige Futter, womit zur Noth halb- und fast erwachsene Raupen wenigstens bis zur Verfertigung eines Cocons gebracht werden können, denı eine wirkliche Verwandlung zur Puppe ist damit noch lange nicht erreicht, besteht in Salix capreae" (p. 141).

S. N. Kamensky $(1892.432,434)$ fütterte Raupen von Bomlyy mori mit Blättern von Taraxacum officinale und ziichtete sie bis zum vierten Alter, wonach sie alle starben. Dieses ungünstige Resultat wurde deshalb erhalten, weil die Blätter dieser Pflanze mehr Wasser erhalten, als die des Maulbeerbaumes und im Lrutofen (20 bis $23^{\circ} \mathrm{R}$.) schimmelich wurden. 
Derselbe Forscher (1893. 434) unternahm ein Jahr später die Aufucht dieser Raupen wierler mit Blättern von Taraxacum officinale, wobei die Temperatur des Raumes morgens $9-11^{\circ} \mathrm{R}$. betrug und später bis auf $14^{0} \mathrm{R}$. stieg. Nach dem 3. Alter wurlen die liaupen bei $18^{\circ}$ R. um später bei $20-22^{\circ} \mathrm{K}$. gezogen. Als die Raupen ilie 5. Hïutung erreichten, hörten sie auf zu fressen uml starben vor Hunger und an Krankheiten.

Die Rupen wurlen auch mit Blättern von Scor\%onera hispanica L. gefuittert, leren Eier von Prof. Harz aus München kamen. Die erhaltenen Falter und die Seide waren normal.

J. Ritzema Bos (1893. 106) sagt, lass Harpalus ruficornis F. und Harpalus weneus F., wolche sonst inselitenfressente Insekten sind, auch reife Erdbeerfriichte frässen.

G. Selmons (1894. 804) fiitterte die Lianpen von Parnassius apollo mit den in ler Sonne geröhteten Blättern des Mauerpfeffers; diese Raupen verpuppten sich viel später als diejenigen, welche mit üppig-saftigem, dunkelorïnem Manerpfeffer gefiittert waren.

0. 0. Tichomirowa und A. A. Tichomirow (1394. 474 ) in Moskan fütterten die liaupen von Bombyx mori mit Blättern von Scorzonera hispanica (Schwarzwurzel). Die Eier ron Prof. Harz in München stammten von Eltern, wolche mit Schwarzwurzelblättern aufgezogen wurilen. 11 ausgelirochene Raupen wurlen clie ganze Zeit mit Blättern der schwarzwurzel und 32 Taupen anfangs 12 Tage) mit Bliittern des Naulbeerbaumes und weiter auch mit Schwarzwurzelblättern gefuittert; diese letzteren Raupen (B) waren 5 Tage nach dem Auskriechen beileutend grösser als ilie ersteren (A).

Das Auskriechen begann àm 10. Mai.

Der Beginu iles zweiten Alters: A. 19.-21.; B. 19.-20. Mai.

$" \quad "$ dritten $\quad, \ldots 22.24 . ; n 23.24$. .

Darauf wurden beile Gruppen vereinigt und erwachten für das vierte Alter am 28. Mai, wobei einige Raupen 2 Tage schliefen. Das fünfte Erwachen fand an 1.-3. Juni statt. Die erste Raupe begann am 9. Juni sich einzuspinnen, die übrigen bis zum 16. Juni (und auch später). Zusammen wurden 21 Cocons erhalten.

E. Quajat uni D. Rossinsky (1894. 671) brachten Eier von Bombyx mori, um dieselben auszuwaschen, in eine $0,2 \%$ Sublimat- 
lösung, wo sie 2 Stunilen zubrachten. Die bivoltiner Rasse ergab kaum 5\% Rüupchen, die koreänische $-10 \%$, Terni $-15 \%$ uncl die sevenische $80 \%$. Die Entwickelung der Fier ging langsamer als sonst vor sich.

E. Quajat (1594. 657) wusch lie Eier von Bomlyye mori mit Lösungen von Sublimat (von 1 bis 2 pro mille) unil Karbolsüure (5:1000). Es hat sich herausgestellt, dass verschiedene liassen (von 12) verschierlen empfindlich gegen tlen schällichen Finfluss vlieser lösungen sind. Die empfindlichste war lie weisse chinesische liasse, und an wenigsten empfindlich die gelireuzte gelblich-weisse liasse. Es wurde jedoch kein Verhältniss zwischen dem langen Dauer des Auswaschens oder der starken Concentration der Lösung und dem schlechten Ausschliipfen der Rüupchen konstatiert. Die KarbolsïureLösung war für die Eier unschädlich.

E. Perroncito $(1894.630 a,(530) b)$ hielt die Eier von $B$ mbly $x$ mori zwei Stunden in einer Sublimat-Lösung von $1: 1000$ und fand, dass sie dabei gar nicht geschädigt wurden.

Fr. Schreiber (1894. 771) erhielt von Lophopteryx ramelinu L. aberr. giraftina Hb. 100 Eier. Am 9.-10. Mai schlïpften die Räupchen aus und wurlen zuerst mit jungen Blättern von Tilia grandifolia und parvifolia mil nach einigen Tagen mit Salix gefüttert. Nachdem $3 / 5$ aller Raupen sich verpuppt hatten, wurile der Rest mit Tilia, Populus italica, tremuli, nigra unl Betula alba gefiittert. Die Raupen entwickelten sich sehr ungleichmissig, so dass, als die erwähten $3 / 5$ sehon verpuppt waren. sich ein Theil der übrigen noch im 3. unil 4. Kileide befand, trotzlem alle zusammen in einem Kasten waren und dasselbe Futter hatten.

Die Falter fielen in der. Zeit vom 14. bis 23. Juni aus.

A. L. (1895. 1) fïtterte die Räupchen von Ciateronysx dumi L. nnit Salat und beobachtete dabei, dass sie bis nach der ersten Hüutung trefflich wuchsen; überstehen sie aber wirklich noch die zweite Häutung, so sterben sie ausnahmlos vor der dritten an Durchfall. Bei seinen Ziichtungsversuchen setzte er ihnen Löwenzahn, Mausöhrchen, Scalbiosen, Wegerich und Sauerampfer vor. ...Alle diese Pflanzen wurlen gerne angenommen, und hei allen entstanden gleich grosse Verluste" (p. 59). 
200 Firstes Kapitel. Dic Fntwickelungsgeschwindigkeit der Insekten.

E. Quajat (1895. 593) brachte die Eier von Bombyx mori auf verschieden lange Zeit in das Kohlensäure und fand:

1). Eier, in welchen die Raupen bereits entwickelt sinı, können in Kohlensäure eine gewisse Zeit ohne Scharlen aushalten; diese Zeit variirt je nach der Rasse.

2). Man kann die Eier verschie:lener Rassen 24 Stunden ohne Scharlen in Kohlensäure belassen.

3). Obwohl die Eier in Kohlensiure nach 24 Stunten noch nicht toit sind, entwickeln sie sich aher dann in der freien Luft viel langsamer als sonst. Eier, welche in Kiohlensäure 45 Stunden zugebracht lrahen, eroeben keine Raupen, da dieselben nicht im Stande sinı, die Hüle rlurchzubrechen. Nach T’2-stïndigen Aufenthalt in Kohlensäure sterben sie grösstentheils.

4). Eier leiden in liohlensäure desto weniger, je weniger ihre Entwickelung fortgeschritten ist.

5). Wenn die Eier in Kohlensäure sich befinden, wäichst die Dauer ler Inkubation stufenweise. Die Differenz beträgt 15 Tage und auch mehr.

G. Pasqualis (1895. 623) fiitterte die Raupen von Bombyx mori nach der vierten Häutung mit Maulbeerblättern, welche mit Eiweiss vermischt waren, und zwar mischte er 20 Ko. Blätter mit Eiweiss von 10 Eiern unil trocknete dieselben dann. Die Resultate, welche an zwei Rassen erzielt wurden, sind in folgender Tabelle angeführt:

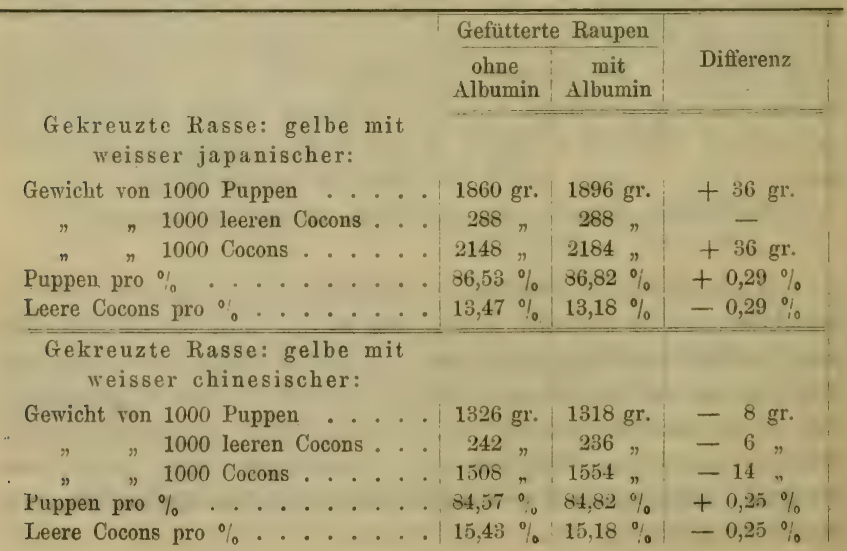


Daraus ist ersichtlich, dass bei beiden Rassen das Gespinnst mit der Puppe schwerer wirl, wenn die Raupen mit Eiweiss vermischte Blätter zur Nahrung erhalten, als sonst. Pasqualis sagt: ,il che prova che l'albumina, se ha giovato alla nutrizione dei bachi, non ha giovato punto - nei due esperimenti - ad aumentare la produzione serica" (p. 156).

Die Kritik dieser Abhandlung findet sich hei D. Vedovati (1896. 902).

0. Tichomirowa (1895. 872) futterte Seilenraupen 4 om Ei an mit Scorzonera hispanica; dabei wurle eine gewisse Beschleunigung in dem Eintreten der Häutungen beobachtet. Die Raupenzeit dauerte 27 Tage (statt 33 , wie gewöhnlich). Die erhaltene Seide besass einen viel schöneren Glanz als die gewöhnliche.

N. Passerini (1§96. 624) fiitterte Seilenraupen mit Blättern, welche mit Kalk- und Kupfersulfat-Lösung benetzt waren. und fand, dass dieses Futter auf die Raupen schällich einwirlit.

A. Silantjew (1896. 815) brachte lie Kïfer Cleonus punctiventris in Glasgefässe, wo ihnen mit Parisergrün vergiftetes Gras gereicht wurle. Da die Käfer nur einmal frassen, wurle das Futter entfernt, wolsei sie nach folgender Zeit starben:

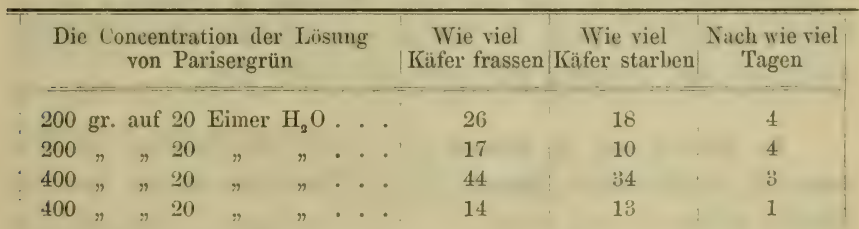

Diese verschiedlenen Resultate erklïrt er daulurch. dlass das Gras nicht gleichmässig rergiftet werien konnte.

G. Kisselow $(1896.450)$ strich Eier von Ocneria dispur mit Rohpetrolemu an und stellte fest, lass in Frühjahre daraus keine Raupen sich entwickelten.

S. Severin (1896. 809) sagt, gestiitzt auf seine zahlreiche Beobachtungen, dass die Raupen von Psilura monacha unter alleinigem Einflusse des schlechten Wetters nicht erkranken, was durch die Methorle von A. Tichomirow zu erreichen ist (Leimringe an Bäumen). 
M. Standfuss (1896. 840) erzog im warmen Zimmer lie lialljen ron Agrotis collina; weil aher bald tiefer Schnce eintrat, konnte das Futter nicht in genïgenter Menge heschaffit werten. Dabei erhielt er von 103 gesunten Paupen nur 45 Falter und zwar 37 o $\delta$ und 8 우.

Ein Mal starben ihm wegen Mangel an dahrung viele liaupen von Aglia tau; die, welche sich bereits verpuppt hatten, lieferten $34 \delta^{\prime} \delta$ un I 9 우. Der gleiche Fall kam auch bei Saturniu pu-

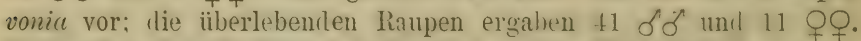

"Wir werden danach anzunehmen haben, dass tie mämnlichen Individuen Vahrungsmangel in hihherem Grate zu ertragen vermögen, als die weiblichen" (p. 195).

Die Lntersuchung des Zahlenverhäiltnisses iler heiden lieschlechter einer Art führte ihn für normale Unstinde zmm Werthe w: $m=$ 100:10j bis 107, wo $m$ und $w$ die Anzahl der mimnlichen resp. der weiblichen Individuen beslentet (untersucht wurden 40 Arten in ca. 32000 Exemplaren während 17 Jahren).

K. Sajó (1896. 391) sagt, ilass Tabaklaugenextrakt, welches 14\% Nikotin enthïlt, auf Entomuscelis-Arten gar keinen Fintluss liat. Die Larren wurden mit zweiprozentiger Lösung des lionzentrierten Tabaklaugenextraktes vollkommen iiberfutet, und einige sogar in lie Lösung hineingelegt, es war aber keine Wirkung zu bemerken. Durch Pyrethrum-Extrakt wurden die Larven zwar betiiuht, lebten aber halil wieler auf und bewegten sich noch am dritten Tag.

M. Bellati und E. Quajat (1896. (i2) untersuchten ilen Einfluss von verschiedenen Süuren auf die Entwickeimg der Eier von Bombyx mori.

Concentrierte schwefelsäure (sp. (rew. 1,832 bei $26^{\circ}$ ) leeschleunigt die Entwickelung ler Eier, wenn dieselben 30 secunlen bis $21 / 2$ Minuten darin sich befinden und nachher mit Wasser atıgewaschen werlen. $1 / 3$ am L,ben gebliebener Eier ergielst ball Räupchen.

Salzsäure törltet innerhalb 5 Minuten ca. 1/; aller Eier. Lus den diesen Process überlebenden Eiern schliipften bald $>8^{\circ}{ }_{0}$ aus unil $9 \%$ entwickelten sich, schliipften aber nicht aus. Mit der Zunahme ler Einwirkungsilauer der Säure nimmt der Procentgehalt der ausgeschlïpften Eier zuerst zu, erreicht bei cler Zeitilauer von 5 Minuten das Maximum, um nachher abzunehmen. Die Erhöhumg 
der Temperatur verstärkt die Einwirkung der Säure. Verdiunte Schwefelsäure und Salzsäure haben schwächere Wirkung.

Essigsäure unl $\Lambda$ meisensüure ergaben nach ilem Eintauchen der Eier währenı 15 Sekunilen bis 5 Minuten umregelmäissige Entwickelung; aber nie das normale Ausschlüpfen ler Raupen.

Koncentrierte Salpetersäure töltet die Eier nach 2 Minuten. Nach der Einwirkung von 50-90 Sekunden und nachherigem Auswaschen mit-Wasser fand die Entwickelung der Eier und cine partielle Ausschlïpfung der Raupen statt. Die grösste Anzahl der Ausschlüpfungen wurle für die einheimische Rasse bei der Einwirkmug ler Säure vom 1,40 specifischen Gewichte währenil 65 Sekiunden crhalten. Die Hälfte „ler Eier vertrocknete dabei unı die andere Hälfte ergab $45 \%$ entwickelte Eier. Die Einwirkung der veriliunten Säure ist dieselbe, aber langsamer.

Königswasser hat eine ähnliche Wirlung, wie Salpetersiure. Während 20-45 Sekunden waren fast alle Eier ller koreanischen Rasse todt. Die Einwirkung von 10-30 Sekunden entwickelte die Eier. Längere Zeit konnten ohne Scharlen die japanische weisse, chinesische weisse und die einheimische Rassen aushalten, und zwar wurle in denselben keine Veränderung wảırend der Einwirkung von 30, 40 und 60 Sekunilen beobachtet.

B. Witmer (1896. 961) erwähnt in seiner Alliamilung, lass das Phylloxera-Comité in der Krim die Beobachtung machte, dass Phylloxera auf wilılen Reben nie geflügelte Inlividuen hat, welche ihrerseits nie die aut einer gewissen Entferumg sich hefinıllichen kultivirten Reben anstecken kann.

K. Sajó (1896. 732) beobachtete, dlass die Larven vom Weinstock-Fallkäfer (Enmolpus vitis F.) durch Bespritzen des Borlens mit Schwefelkohlenstoft (24-28 gr: pro Quadratmeter) wïhrend der Wintersaison (November-März) zu Grunde gehen (anch Phyllowera vastativix).

M. Standfuss (1896.840) brachte sehr viel Raupen von Aylia tuu (geschwärzte Form) in die Säcke in einem Garten. I)as Frühjahn brachte inzwischen eine Reihe sehr warmer Tage, und viele liaupen starben an Mangel des Futter's. Von 151 eingesetzten liaupen erhielt er nur noch 43 sehr kïmmerliche und zwar 34 mïmliche und 9 weibliche Puppen. "Gleichwahl erwiesen sich die Männchen bei der Rückkreuzung mit Aglia tau OO$_{+}$bei einmaliger Kopulation 
als fortpflanzungsfähig, während die Weibchen nur 2-:3 Eier he:sassen" (p. 195).

Auch mit einer Brut von Saturnia pavonia ging es ähnlich: von 185 Raupen erhielt er durch Nvahrungsmangel nur 52 recht diurftige Puppen, davon 41 männlichen und 11 weiblichen (ieschlechtes.

Er negiert die Behauptung, dass Nahrungsuberfluss die Lntwickelung von einer Ueberzahl weiblicher Indivirluen zur Folge haben soll, und erklärt Resultate seiner obigen Versuche durrh die Annahme, dass die männlichen Indivituen Nahrungsmangel in höherem Grale zu ertragen vermögen als die weiblichen.

N. Ludwig (1896. 537) erklärt sich gegen die sogenamnte Futter'safttheorie, welche alle Verschielenheiten unter ilen Bienen und die Mannigfaltigkeit der Triebe, Stimmungen und Arbeitsleistungen bei den arbeitenden Bienen aus der Verschierlenheit dles largereichten Futters erklärt. Er sucht die Ursache dieser Verschiedenheiten als in den Thieren vorhanden und rorgebildet und entwickelt seine ,Veranlagungstheorie," leren Kritik bei Cl. König (189(i. li41) nachzusehen ist.

P. Marchal (1896. 546 a) fütterte Arbeiterinen von Vespa yermanica Fabr. übermässig mit Honig und rohem Fleisch, wobei sie zu ungewöhnlicher Jahreszeit parthenogenetische Eier legten.

H. Gauckler (1897. 293) berichtet iiber ein weibliches Exemplar von Attacus cynthia, welches nach ier Eierablage noch acht Tage ohne Nahrung lebte.

Derselbe Forscher (1897. 287) sagt bei tler Beschreibung von Schmetterlingen mit 5 Flïgeln (Parn. discobolus ơ, Bomb. quercus o', Pieris brassicae $\sigma^{7}$ und Brephos parthenius ठ̋): „Solehe Billungen werden also auch eher der von mir oben angerleuteten Entstehungsursache entsprechen (Überfluss an Materie)" (p. 374.)

M. Hollrung (1897. 384) beobachtete, dass der Käfer Otiorhynchus ligustici L. eine 42 tägige Hunger- und Durstperiode anstandlos zu ertragen vermochte.

J. Ingenitzky (1897. 399) brachte die Raupen vou Psyche helix in Schachteln, auf deren Boden gelöschter Kalk sich befand; sie haben dabei nicht gelitten, starben aber bali, als (ler líalk ungelöscht war. 
L. Berg (1897. (111) nahm Eier von Bombyx mori, deren Eltern mit Schwarzwurzel-Blaittern gefuittert wurden, und fütterte die am 10. Mai ausgebrïteten Rüupchen mit Blättern vom Maulbeerbaum. Der ganze Prozess der Aufucht ging glatt von sich. Die Raupenzeit dauerte 40 Tage, nur das letzte Raupenalter war etwas liinger als sonst, nämlich 11 Tage; das Einspinnen dauerte 4 'Tage.

R. Jänichen (1897. 415) ging von Versuchen von Dubois aus, welcher den Mechanismus der Wärmebildung und des Schlafes bei Murmeltrieren untersuchte und dabei zu dem Schlusse kam, dass die Ursache des Winterschafes die in Blute vorhandene Kohlensäure ist, welche auch die Temperatur des Körpers während des tiefen Winterschlafes bis zu $4,6^{\circ}$ herabdruickt.

Jänichen untersuchte die Kothballen der Raupen und kam zu. dem Schlusse, „lass die Raupen in den Winterschlaf fallen müssen, weil die im Blut derselben angesammelte und nicht gelöste bezw. nicht ausgeschiedene Kohlensäure die Thiere dazı zwingt." (p. 69).

Den Umstand, dass die liaupen bei anhaltender feuchter Aussentemperatur vorzeitig zu Puppen werien, erklärt er, indem er sagt: „Dazu trieb die Raupen, ich möchte sagen, ihr Instinkt, denn die Kohlenstoffverbindungen sollen ja noch in die überwinternile Puppe gelangen - aber die Kohlensäure im Körper ist es, muss ich sagen, die die Thiere dazu drängt oder zwingt" (p. 70).

N. W. Schwerin (1897. 752) nahm 112 am 22. Mai (alt. St.) ausgebrütete Raupen von Bombyx mori und fütterte sie bei der Temperatur von $16^{\circ}$ bis $20^{\circ} \mathrm{R}$. mit Blättern der Schwarzwurzel. Nach fünf Tagen begann die erste Häutung (bei einzelnen Raupen nach 6, 7 und 8 Tagen). Die zweite Häutung begann zur normalen. Zeit (einige verspäteten sich jedoch um einige Tage). Nach der 5-ten Häutung erhielten die Raupen 'ein ungenügendes Quantum Futter. Das Einspinnen begann an 24. Juni und dauerte bis zum 12. Juli (alt. St.) bei (ler Temperatur von 20 bis $22^{\circ}$ R. Diese Aufzucht ergab 106 Cocons von guter Qualität.

L. Luciani und D. Lo Monaco (1897. 536) fanden, dass dieSeidenraupen, welche aus einer $25 \mathrm{gr}$. Unze Eier ausschlïpfen, folgendes Quantum der Blätter von Maulbeeren fresssen: 


$$
\begin{aligned}
& \text { Im 1. Alter } 0,602 \mathrm{Ko} \text {. } \\
& \text { "2. " } 2,645 \text {. } \\
& \text { n 3. " 11,178 , } \\
& \text { n 4. n 60,831 " } \\
& \text { " 5. " } 511,539 \text { " } \\
& \text { Zusammen 586,795 Ko. }
\end{aligned}
$$

Henri Gadeau de Kerville (1897. 269) brachte den Wasser'kïfer (Dyticus marginulis) in 5 procentiges Seesalzwasser, wo er 17 Tage lang aushalten konnte, ehe er starb; (lahei ist zu berüclisichtigen, dass das Wasser des Atlantischen Oceans nur $2 \%$ Salz enthält.

E. Quajat (1897. 662) untersuchte ilie Respirations-P'rolulite (ler Eier von Bombyx mori, wobei er zwei Aufgaben zu lüsen versuchte: 1). Die Einwirkung der (Lnecksilber-I)ämpfe auf Eier und 2). Die Einwirkung der Kónhlensïure auf Eier. Er kam zu folgenlen Resultaten:

In der Periorle des Auttebens sint die Kileinsten Mengen der Quecksilber-Dämpfe schäillich: so z. B. 0,0036 gr. Dämpfe tïlten innerhalb + Tagen ca. $10 \mathrm{gr}$. Eier, d. h. 16.000 Embryonen. Iliese Wirkung ist verschierlen zu verschierlenen Zeiten: im Winter bei Dauer des Versuches ron 25 Tagen sint die (Tuecksilber lïmpfe nicht schädlich.

Die Kohlensiure tödtet im Sommer die Eier vollstïndig nach 150 Stunlen. Danert die Einwirkung der Kóohlensäure kiurzere Zeit, so leben die Eier unregelmässig und später als sonst auf. Dieselbe Empflndlichkei besitzen die Eier auch im Herbst, währent in IVinter die Eier der chinesischen und japanischen Rasse in der Kohlensäure eine Woche ohme schaden verbringen können, die europäischen Rassen sogar bis zu 15 Tagen.

E. Verson (1897. 919) priffte die Nützlichkeit des Bestreuens ler Blätter von Maulbeeren mit Reisstïrke, was schon lange in China gebraucht wird, und kan zu dem Schlusse, dass zwar solches Bestreuen die Ernäherung der Seidenraupen förlert, jedoch die Einwirkung der Stärke bedeutend schwächer ist, als der Einfluss gewöhnlicher Faktoren des umgebenden Mediums.

E. Rade (1897. 671 $a$ ) fand Anfangs November unter einem kleinem hervorstehenden Stück Rinde an einer Schwarzpappel Scharen 
ron Durytomus vorax, Coccinclla bijunctatu und Exochomus 4 - 1 stulatus und setzte dieselben 5-6 Stunden der Einwirkung des C5ankaliums unıl Abents einer Lösung von arseniksaurem Natron aus. Am folgenten Tage gegen Mittag wurlen lie hïfer wieler heriusgenommen und lebten auf.

Im Winter yefangene Rhayium inguisitor brachte er ins Cyankalimglas für längere Zeit und rlann fïr 19 Stunden in die (obenerwähnte) vergiftete Flissigkeit. Als sie dann zum Trocknen bei Seite gesetzt wurilen. verschwanden sie nach einigen Tagen uni wurlen in ten WVinlieln lebendig unil munter aufgefunilen.

Im Sommer beobachtete er solche Fälle nie.

1)iese Erscheinung erkiät sich offenbar durch sehr geringeren Stoffwechsel der Thiere im Winter.

Die weiche Beobachtung machte auch A. Grunack (1898. 333) mit Rhagium bifasciatum, inılem er sagt: "Im Erstarrungszustande ist der Käfer gegen Törltungsverstuhe derart unempfindlich, dlass ein Wierlerautlelıen nach Tagen nicht zu den Seltenheiten gehört."

Auch ein Vitarbeiter les Amsrican Naturalist (cfr. InsektenBörse. XIT. : 31. 1897. p. 183) brachte in December Larven von einer Fliege, welche im Salzsee in Vereinigten Staaten leben, auf 10 Tagen ins Salzwasser unil dann in $30_{0}^{\prime}$ Formalin. Tach 10 Tagen waren noch 3 Larven am Leben.

Rudow (1898. 711) in Perleherg brachte zwischen geöffneten Doppelfenstern ein im Freien gefundenes Hornissennest unter, llessen Waben mit ganz jungen Larven besetzt waren. Als kiunstliche Nahrung wurile einer Serie Mïnchener Bier mit etwas Fleischextrakt, der anderen rlagegen Braun- oder Weiss-IBier mit Zusatz von etwas Honig gereicht. Nach 10 Tagen waren alle Zellen gedeclielt, und nach etwa einer Woche begannen die Wespen auszuschliipteu. Alle Larven, welche mit Münchener Bier und Fleischextralit gefiittert wurden, ergaben nur Männchen, während die sïsse Kost Weibchen. und Arbeiter gezeitigt hatte.

A. Caretta (1898. 136) brachte Eier von Bombyx mori ins gewöhnliche Wasser uncl beobachtete, dass sie zu Gruncle gehen: im August und September nach 10 Tagen, im Oktober nach 16 Tagen und im December nach 40 Tagen, wenn sie sonst normal waren. 
Frisch abgelegte Eier verierben dabei sehr leicht, da sie dann viel Sauerstoff bedürfen.

M. Bellati und E. Quajat (1898. 66) haben mit Eiern von Bombyx mori Versuche angestellt, welche ausfilhrlicher an anderer Stelle von ihnen veröffentlicht werden. Hier sei nur ein Resumé dieser Versuche gegeben.

Der Sauerstoff, um nicht schädlich zu wirken, muss auf ganz. frische Eier und dauernd einwirken. Je frischer die Eier sinıl, eine desto grössere Anzahl entwickelt sich ron ihnen; wenn dagegen das Alter der Eier mehr als 24-30 Stunilen betrïgt, so schlüpfen die Räupchen unter dem Einfluss des Sauerstofts in immer geringerer Anzahl aus, um nachher gar nicht auszuschliipfen. Sauerstoff wirkt beschleunigend auf die Entwickelung der Eier nur bis zu einer gewissen maximalen Zeitdauer, worauf seine Einwirkung schwächer wirl. Da 24-30 Stunden nicht genügen, damit aus Eiern Rüupchen sich entwickeln können, während anderseits die günstige Einwirkung des Sauerstoff's mit der Zunahme des Eier-Alters schnell sich verminclert, so geniigt es nicht, lass der Sauerstoff nur einige Stunden lang einwirkt, sondern es ist nothwendig, llass diese Einwirkung noch weiter einige Stunilen llauert. Daraus folgt, dass frische Eier, welche der Wirkung des Sauerstoffs ausgesetzt sinil, die Fähigkeit erhalten, diese Einwirkung les Sauerstoffs auch weiter auszuhalten, entgegengesetzt denjenigen Eiern, welche in der Sauerstoff-Atmosphäre sich gar nicht befanden.

Verschiedene Rassen sind verschieden empfindlich gegen ilen Sauerstoff. Die Eier von chinesischen (gelben), vielleicht auch von weissen Faltern, sind weniger empfindlich als Eier von japanischen oder von unsern Rassen. Dagegen sind die Eier von chinesischen Schmetterlingen viel empfindlicher gegen anderen Faktoren als die japanischen oder unsere.

Nachdem diese Forscher den Sauerstoff durch die ozonisierte. Luft orler Stickstoffoxydul ersetzt hatten, konnten sie keine Entwickelung der Eier beobachten.

A. Mordwilko (1898. 592) beobachtete, dass die geflügelten Weibchen der Pflanzenläuse Pemphigus caerulescens und Schizoneura corni um so früher sich entwickeln, je früher die Kornpflanzen, auf welchen diese Läuse leben, welken und austrocknen. 
In einer anderen Abhandlung (1895. 591) betrachtet er "lie Circulation rer plasmatischen Stoffe in Pflanzen wälıren verschiedener Jahreszeiten und sagt: „Es wirl uns jetzt klar, warum die' Fortpflanzung der Pflanzenläuse im Sommer schwächer wirl und sogar an den meisten Holz-Pflanzen aufhört: zu dieser ' / wit wirl die Prolluktion der organischen Stoffe in Holzpthanzen geschwïcht, parallel damit wiril aurh die Circulation llieser Stoffe resthwächt und sogar zu vollstänligem Stillstanle gelıracht, infolge dessen werlen auch die Ernäherungsberlingungen für die PHanzenläuse schlerhter" (p. 9).

Was nun die Gras-Pflanzen anbelangt, so kömen die an denselben lebenten Pflanzenläuse zur Zeit sich fortpflanzen, als sie, an Holz-Ptlanzen keine genügende Nihrung für sich finilen, da, wie es Jedem bekannt ist, llas Gras im Sommer nicht so stark von ungünstigen Lebensbelingungen leilet wie die Bäume unıl mehr Säfte als die letzteren besitzen. Das Gesagte gielt nur für den Fall, wenn die Gräser nicht auf trockenen, der. Somne nicht ausgesetzen Stellen wachsen.

K. Frings (1898. 254) brachte ein Gelege von Cnethocampa processionea-Eiem samt dem linilenstiick, welchem es aufsass, in Benzin, und liess es etwa 5 Minuten lang darin, worauf das Grolege in einen, mit starkem Naphtalingeruche erfüllten Sammlungskasten kam. Im folgenden Frïhjalıre erschienen etwa aus dem vierten Theile der Eier Rüupchen. Ocneria dispar-Gelege starhen jechoch bei gleicher Behandlung ausnahmslos ab.

Bernard (1898. 76) behauptet, lass der Girmul des geringen Wachstums der Raupen von Vunessa in al). joüles O. im Futter selbst zu suchen sei. „Frassen die Raupen nur die Blïtter von urtica, so entwickelte sich aus ilmen die form joüdes, während aus den blatterfressenden Raupen normale io-Indiviluen entstanden." Pabst (1902. 691) sagt, lass anteren Ziichtern dieses Experiment nie gelungen sei.

Reichenow (1898. $682 a$ ) beobachtete, lass wem die Larven der Hirschkäfer Mangel an Nahrung lıben, sie ausschliesslich männliche Exemplare ergeben.

In den Niachrichten der kaukasischen Seidenzucht-Station (1899. 970 ) befindet sich gelegentlich der Beschreibung der Seidenzucht 
in Samarkand folgende Stelle: ,Dürftiges Futter, welches nur zwei Mal pro Tag gereicht wirl, kein geheizter liaum, in welchem ilie Temperatur unmöglich konstant gehalten werilen kam, besonters bei schlechtem Wetter, und andere unhygienische Verhältnisse verzögern die Aufzucht des Seillenspanners bis zu 50 Tagen" (p. 11).

W. Pickel (1898. 635) stellte fest, llass die Bettwanze fünf Häutungen hat, was auch mit Beobachtungen von De-Geer (1780. 166) übereinstimmt. Iie Zeit, welche zwischen einzelnen Häutungen vergeht, beträgt normal ca. 2 Wochen. Giebt man den Wanzen kein Futter, so kann diese Periode $1^{1}{ }_{2}$ Monate uml sogar mehr betragen, wobei die Häutung wiellerum ㄴ Wochen nach der Nahrungsaufnahme stattfindet. Die Wanzen können ohne Nahrung 3 und mehr Monate aushalten.

Die Bettwanzen leilen ien Geruch von schwacher Farbolsäure, Citronen- und Moschuss-Oel nicht; hahen aber ilen freruch von Aepfel- und PHaumen-Aether sehr gern.

Auch ich (1899. 25) stellte Versuche mit Oxythyrea sinctella an, um zu konstatieren, wie viel Tage clieser Käfer ohne Futter aushalten kann. Am 14. Mai wurilen in ein Glasgefäss, welches mit einem Drahtnetz ïberileckt war, 50 solche Käfer gebracht. Die letzten Exemplare starben von Hunger nach 18 Tagen. Die Kannibalen wurilen jedes Mal weggeworfen.

R. Jänichen (1s99. 416) stellte Versuche mit 32 Raupen von Lasiocampa potatoria an und kam zu dem Schlusse, dass die Kohlensäure im Körper ller Raupen allein der Grund zum Schlafe unil nicht die im Freien sinkende Temperatur ist.

J. Schtschelkanowzew (1899. 781) ermittelte, llass zur Ernäherung von Seilenraupen, welche von $4 \frac{1}{2} \mathrm{gr}$. aufgelebten Eiern ausschlüpen, bis zu ihrer Verpuppung 145-165 Ko. ScorzoneraBlätter notwendig sind.

W. Pospelow (1899. 641) verbrauchte 35,5 Ko. ScorzoneraBlätter, um Seidenraupen vun 1,55 gr. Eier bis zur Verpuppung zu ernähern. Dandolo verbrauchte zu gleichem Zwecke 43,4 Ko. Maulbeeren-Blätter. 
G. Koschewnikow- $(1899,464)$ stellte mehrere Beobachtungen am Bienenvolk an und kam zu dem Resultate, dass die reichliche Fütterung der Drohnenlarven keinen hemmenden Einfluss auf die Entwickelung ihrer Genital-Organe ausübt, entgegen der Behauptung von Vom-Rath (1849).

Gräfin Marie von Linden (1 $\$ 99.322)$ brachte Raupen von Pieris brassicae in reine Sauerstoff-Atmosphäre. Am ersten Tage frassen sie gierig, am zweiten viel weniger und am dritten und vierten Tage fingen sie an zu sterben. Keine einzige Raupe hat sich verpuppt. Dagegen vollzieht sich die Entwickelung der Puppe zum Schmetterling in reiner Sauerstoff-Atmosphäre in vollkommen ungestörter Weise; auch die Puppendauer war dabei durchaus normal (9-12 Tage). Beim Ausschliipfen beschärligten die Falter sehr leicht ihre Flïgel.

Als ein Theil der ausgefärbten Puppen der Flasche mit Sauerstoff entnommen war, starben sie alle nach sehr kurzer Zeit; „sie hatten sich demnach an ihre Sauerstofi-Atmosphäre so sehr gewöhnt, llass sie die natürlichen Bedingungen nicht melı ertragen konnten" (p. 370).

Die Blätter der Brennessel, mit Eisenalbuminat und Silberkaseïn angestrichen, welche als Futter benutzt wurlen, beschleunigten das Wachstum der Raupen von Vunessa urticae. Bei der Anwendung des Zuckers starben sie alle.

Die Verfasserin ist der Meinung, dass der das Wachstum fördernde Bestandtheil nicht das Eisen oler Silber ist, sondern nur das Albuminat selbst.

R. Thiele (1899. S60) brachte Locusta viridissimu L. unter eine gut abgeschlossene Glasglocke, unter welcher auch ein grosses, $10 \mathrm{~cm}^{3}$ fassendes Uhrgläschen mit Chloroform gefüllt, gestellt war. Das Thier fiel nach 5 Minuten in Ohmmacht, am anderen Morgen aber war es wieder ganz munter.

G. Kabis (1900, 426) fand an 13. Mai in Karlsruhe eine Puppe von Lasiocampa pini. Da in dieser Gegend pini-Puppen vor Anfang Juni nie gefunden werden, so sucht er, das auffallend friihe Puppenstadium durch grosse Fresslust iler Raupe zu erklären. Dass dies nicht auf Futtermangel zurïkgeführt werlen kann, beweist der Umstand, dass an der Fundstelle Nahrung in Fülle vorhanden war. 
A. Mordwilko (1900). 593) beobachtete, intem er P'Hanzentheile muter der Glasglocke hielt, dass die Pftamzenliuse, welche sich b. in Welken der Pflanze entwickeln, gewöhnlich goflïgelt waren.

Ausserilem kommt er in dieser Abhanllumg zu dem Schlusser. dass die Abnahme der Exemplarenanzahl ron Aphis muli im August nicht durch die Vermehrung der Feinde aleser Ptanzenlans (Comrnellu und ihre Larve, die Larres von Cecidomyin etc.) erkliart wirt. sonclern durch die Eigenschaften der als Nahrung diementen IIn]\%Pflanzen.

Al. Nazari (1900. (i)4) fütterte lie liaupen ron Bomlyy.r mori mit gewöhnlicher Nahrumg, zu welcher Bakterien-Kulturen heigemischt waren. Ile ursprïnglich gesumle liaupen komnten währemb des ganzen Larvenlebens dadurch nicht angestecki werden. Bei Füitterung mit Albuminen und Amiden wies er nach, dass die Darnschleimwanı dliese Stoffe lehhaft in Eritro- und Acrorlextrin umw:ndelt, ,lagegẹn Olivenöl unverändert blieb.

W. W. Masarakia (1900). 549) fand in einer Oel-fabrik in St.-Petersburg eine Henge von Periplaneta americann Fabr. Ind brachte sie in ein Glasgefiss, in tlem ein Stück feuchter $S$, hwammi und trockenes Brod sich befand. Das Glas stand in einem kalten Zimmer vom 20. Mai bis zum 1. September. Vom 23. Juni his 8. August wurden diese Thiere sich selbst ïberlassen, olne dass las trockene Brod und die Feuchtigkeit erneuert wurlen. Am 8. August .war im Glas alles vertrocknet, die Thiere waren alıer noch an Leben; als ihnen feuchter Schwamm hingereicht wurde, fingen sie sofort an, den Durst.zu stillen.

Es ist bekannt, lass verschielene entwickelte Insekten überwintern. Die längste Ueberwinterung hat wohl Gust. do Rossi (1900. 705) beobachtet. 1897 am 26. August bemerkte er sechs Vanessa urticue, welche, mit zusammengelegten Fligeln in die Winkel (ler Deckenbalken geılrickt, dort bis beinahe Mitte Mai ruhig sitzen blieben, dann aber an die Fenster flogen. Selbstverständlich slieben sie-iabei die ganze Zeit ohne Nahrung.

G. Koschewnikow (1900. 467) stellte Beobachtungen über den Einfluss des Hungerns aut die Entwickelung der Bienenlarven an. Am 21. Mai wurlen $\delta$-Larven, welche noch nicht zugemacht waren, aus dem Bienenstock herausgenommen und im Zimmer liegen ge- 
lassen. Die jüngeren starben frïher als die erwachsenen Larven; nach 7 Tagen waren noch viele an Lehen gehliehen: nach 12 Tagen waren nur $2 \%$ lebend.

Er brachte am 7. August Morgens zwei Wespen-Kïniginnen (Vespu silerstris Scop.) in zwei kleine Küifige. Nach 11 Tagen starb sine derselben an Hunger, und nach 12 Tagen die andere. Yon zwei $\sigma^{7}$ - Wrespen starben an Hunger: ein Exemplar nach 2, und das andere nieh 21/2 Tagen. Von zwei Wespen-Arbeiterimen starben laran: die erste nach $2^{1}$, und die amlere nach $: 3^{1 / 2}$ Tagen. Die Arbeiter von Vespa crabo starben an Hunger nach $21 /$ e Tagen.

Die Honigbiene hält nach seinen Beobachtungen verschieden lange Zeit len Hunger aus. Ebenso ausgeschliipfte junge Bienen sterben von Hunger nach $2^{1 / 2}-31 / 2$ Tagen. C̈ltere Bicnen, welche den Honig saugten, starben auch nach $:\left.{ }^{1}\right|_{2}$ Tagen, mit lem leeren Magen aher starben sie nach 10 Stunilen. Die mäunlichen Bienen starben nach 17-22 Stunden. Der schnellste Tod tritt hei männlichen Bienen dann ein, wenn sie aus dem Bienenstock firrtgejant werden; sie sterben in cliesem Falle vor Hunger nach ca. 2 Stumlen. I)ie Bienenkönigin hält ten Hunger weniger als einen 'Tag aus.

L. Reh (1900). (i79) untersuchte die Wilerstandsfilhigkeit von Jiaspinen gegen Flüssigkeiten und fänd:

1. Formol. Die Ergehnisse waren verschieilen, je nachrtem er ganze mit Obstschililiusen belegte Aepfel orler Apfelstiicke genommen hatte. S verschienlene Versuche mit ganzen, mit Asp. uncylus, forbesi onler perniciosus besetzten Arpfeln, welche anf 1 is Minuten bis 5 Stunden in $10 \%$-iges Formol untergetaucht wurlen, ergaben, dass die Lüuse noch immer lebent waren; als alver Apïelstiicke in 10\%-iges Formol gelegt wurien (Daner 25 his (i Minuten), waren die Läuse in allen Fällen tolt. Ausserden untersnchte er in Formol Zweigstiicke, welche mit $A s p$. ostreaeformis. Asp. pyri oler Diasp. ostreaeformis besetzt waren. wohei er mit 1 Stunde in ${ }_{10}^{0}{ }_{0}$-igem Formol anfing und his zu 2 Stunlen in $50 \%$-igem Formol stieg; die Läuse blieben immer leben. Daraus schliesst Reh, dass die Schildsubstanz durchaus undurchlïssig fur Formol ist. ., Seine Wirkung an den Apfelstiicken ist dlarauf zurückzuführen, dass es ‘le Apfelsubstanz in einer für die Läuse giftigen Wuise zursetzte" (p. 800).

2. Alkohol. Die mit Asp. pyri oder Diasp. ostrecceformis besetzte Zweigstiicke wurlen in 90\% Alkohol gestellt; nach 2 Stun- 
den waren die Tiere noch am Leben. Die Lïuse waren auch lebenı, als ein und rlasselbe Aststiick mit Diasp. ostreaeformis an 22. März anf 2 Stunilen in 50\%-igen Alkohol gestellt wurle, am 26. März auf $1 \frac{1 / 2}{2}$ Stunden und an 29. Mairz auf 2 Stumlen in $60 \%$-igen, an 3. April auf 1 Stunde unil am 9. April auf 2 Stunilen in 7()$\%$-igen Alkohol. Diasp. ostreaeformis, die am 8. Mai 2 Stunden in !) $\%$-igen Alkohol zugebracht hatten, lebten noch am 10. Mai; an 15. Mai dagegen waren die meisten Lüuse toilt. Unter gleichen Unstiinden blieben Asp. pyri durchaus frisch.

3. Petroleum. Das Untertauchen eines mit Diasp. rosar besetzten Rosenzweiges ergab nach 5 Tagen, dass die an der Oberfläche sitzenden Läuse tolt waren, dageren die tief unter Schichten alter Schilıle sitzenden noch am Leben zu sein schienen. Ein Zweigstiick mit Diusp. ostreneformis wurle mit Petroleum iibergossen; nach \& Tagen waren die Lüuse noch lebenr. Versuche mit Eintauchen von Aststiicken mit Asp. pyri ouler Dinsp. ostreatormis auf 50 Minuten ergaben bei einigen Aststicken toilte Läuse, anlere dagegen machten noch 5 Tage rlanach, wie Asp. pyri, sehr trïge Bewegungen der Rüsselmuskeln; nach 23 Tagen waren alle Läuse todt.

4. Halali (eine Lösung von Petroleum in plienolhaltiger Seifenlösung). Asp. ancylus, die mit 10\%-iger Lösung henetzt wurden, waren tolt, dsp. forbesi schienen dagegen nach :3 Tagen noch zu leben, Diasp. ostreaeformis lebte auch noch. Nach Ueherpinselung mit 20\%-iger Lösung erwiesen sie sich alle als toilt. I)as Eintauchen in $10 \%$-ige Lïsung ertrugen diese Läuse während 1 his $1 \%$ a Stuncien.

5. Schwefelsäure. Das Ueberstreichen von Aspiul. perniciosus mit koncentrierter Süure töıltet die Lüuse. Zweige mit Asp. pyri und Diasp. ostreaeformis wurden in $100^{\circ}$, Säure gestellt: nach $3 / 4$ Stunlen waren fast alle läuse torlt.

6. Salpetersäure. Die /weigstucke mit Diasp. ustreaeformis wuriten in 10\%-ige Lösung eingetaucht. Nach einstünligem Eintauchen waren die Lüuse noch lebend, starben aber nach zweistündigem Eintauchen.

7. Kali- bezw. Natronlauge. Asu. perniciosus, die mit koncentrierter Lauge iberstrichen waren, starben, ebenso Asp. forbesi. Tiasp. ostreacformis hielten 2 Stunden in $10^{\circ}, 0$-iger Lauge aus, ohne zu sterben und waren nach 3 Tagen noch am Leben.

S. Eau de Jarelle. Ein mit Asp. perniciosus besetzter Apfel wurde hiermit iiberpinselt; lie Lüuse lebten noch am nächsten Tag. 
9. Chloroform. 3 mit Asp. perniciosus besetzte Aepfel ergaben 3 Stunden nach dein Ueberstreichen noch lebende Läuse, welche am folgenilen Tage noch nicht toit waren.

10. Toluol. Wie bei 9). Die Läuse waren todt.

11. Glyzerin. Ein Aststiick mit 7hicisp. ostreaeformis wurde mit koncentriertem Glyzerin iiberstrichen. Nach 6-7 Tagen starben alle an der Oberfliiche sitzende Lüuse, diejenigen aher, welche unter Krusten alter Schilde sassen, waren lebend.

Seine Verouche mit gasförmigen Stoften ergaben fuigendes:

1. Blausäure. Aepfel mit $A s p$. pernicinsus wurlen unter eine Glasglocke mit. Cyankaliumstückchen, welche auf feuchtem Fliesspapier sich befanilen. gelegt uni zwar 4, 191/2 unil 24 Stunten lang. Bei den an den nächsten Tagen vorgenommenen Untersuchungen erwiesen sich die Läuse als lebend. Bei weiteren Versuchen wurden mit Läusen besetzte Apfelstücke in ein (xiftglas gesteckt, wobei die Dauer von 53 bis $1 \mathrm{H}$. Stunden betrug. Bis zu \& stimdigem Aufenthalte abwärts waren clie Läuse getötet worlen. Ausserilem wurlen Cyankaliumstiickchen in verdünnte Schwefelsäure geworfen, wobei unter iler Glasglocke Cyanwasserstoff sich lebhaft entwickelte. Aststiicke unıl Blätter mit Asp. myri, Diasp. ostreacformis unil Asp. nerii, von welchen bei einigen Exemplaren der Schild künstlich abgelöst wurle, ergaben nach 2 Stunilen noch lebenile Läuse; welche später Nachkommenschaft hinterliessen. Stuhenfliegen etc. starben unter dieser Glocke nach $1 / 2-1$ Minute.

2. Alkohol. Die mit Asp. perniciosus besetzten Aepfel unter einer Glasglocke mit warmen $\left(50-39^{\circ}\right.$ C.) Dümpfen von Alkohol ergaben nach 20 Minuten tolte Lüuse; lie Aepfel mit Asp. Porbesi in Alkohol-Dïnsten (also kalt) ergaben, dass die meisten Lüuse nach 43 Stunilen todt waren.

3. Formol. Warme Dämpfe töiten Asj. perniciosus auf Aepfeln nach 1 Stunde, nach $1 !$ Stunile aber nicht; eine männliche Larve von Asp. forbesi blieb nach $1 \frac{1}{2}$ Stunclen noch am Leben. Kalte Dämpfe töltten die Läuse während $1-3$ Stunılen nicht, wohl aber nach 48 Stunden.

4. Chloroform. Zwei Aepfel mit Asp. perniciosus araben im Chloroform-Dampf nach 24 Stunden lauter torlte Liiuse.

5. Schwefelige Säure. Ein mit $A s p$. pernicinsıs heset\%ter Apfel wurde wenig geschwefelt; an nüchsten Tage war noch eine Laus am Leben. 
L. Reh stellte Versuche mit Luftalsschluss an, inclem er die Schildliase entweder unter Wasser hielt orler dieselben mit Oel bezw. Vaseline iiberzog: cliese Thiere hielten olme Luft 2 bis 3 Tage aus.

J. Dewitz (1900. 167 a) konstatierte, dass Blausilure der Terwanillung der Raupen von Porthesia cluysorrhea hinulerlich ist.

C. Flammarion (1901. 241) fütterte die Raupen von Bombyx mori mit Blittern iles Maulheerbaumes, wetche mit Allumin, Phosphaten. Zucker uml Salz imprägnirt wurlen. Alle Raupen starben aber nach etwa 10 Tagen.

- E. A. Bogdanow (1901. 92) ziichtete die Larven der Fliege Dryomya anilis im Kuhliinger, erhielt aher aus ten Puppen keine Imago.

Alisch (1901. :1) kommt, gestiitzt auf seine Beobachtungen, zu dem Schlusse, dass eine spüte Vegetation im Frühjahre wahrscheinlich eine Verringerung vler Iräferfrequenz zu Folge hat.

F. Lambert (1901. 494) tiitterte in Montpelier die Raupen von Brmbly, mori mit Morus alla var. rosea aus Frankreich unit aus Tonkin unil famr, dass die Nahrungseigenschaft dieser Ptlanze in beilen Fällen dieselbe war.

P. Speiser (1901. 827) beobachtete, dass ciie Stechuïcken der trinerat Anopheles erst tann ihre Eier entwickeln können, wenn sie sich vorher voll Blut gesogen haben.

N. Kulagin (1901. 483) brachte lie aus den Drohnenwaben herausgenommenen Eier in Schwefelsäure-Lïsung $\left(2,3^{\circ}{ }_{0} \mathrm{SO}_{3}\right.$; spes. (rex. 1,014), wo llieselben 2 Minuten blieben. Darauf wurlen diese: Fier in Arheiterinenwalen gebracht; es wurlen dennoch nur Drohnen erhalter.

Th. Kawraisky (1901. 141) fïtterte Raupen von Bombyx mor; mit Blittern von Scorzonera hispanica bei $20^{\circ} \mathrm{K}$. I)as Aufziehen lieser Raupen ging langsamer ror sich als tlerjenigen, welche Blätter rom Maulbeerenbaum frassen, unıl zwar verspätete die zweite Häu- 
tung um 4 Tage. Vor der vierten Häutung starben die meisten Raupen an der Gelbsucht. Er erhielt nur 3-4 schlechte Cocons, wobei clie am Leben gebliebene Raupen am 17. Tage erst vor der 5. Hüutung standen. Kawraisky erklärt diese schlechte Aufzucht ciurch die Veränderung der verwendeten PHanze auf dem kankasischen Boden, da ihre Wurzeln gar nicht siiss waren.

W. Iwanow (1901. 405) kritisiert die Arbeit von Th. Kawraisky (1901. 441), indem er sagt, dass die Wurzel von Scorzonera hispanica erst dann siiss werlen, wenn sie längere Zeit dem frost ausgesetzt sind; in lliesem Jahre aber herrschte in Tiflis fast keine Temperatur unter $0^{\circ}$. Seine eigene Aufutht mit Blättern dieser PHanze ergab auch schlechte liesultate. Vor der 4. Häutung erkrankten die Raupen an der Celbsucht, und er erhielt nur 24 Cocons (ron 500 Raupen). Die von den ausgeschliipften Sclumetterlingen (rhaltenen kaupen wurlen am folgenten dahre wieler mit Scorzonera hispanica aufgezogen, ergahen aher keinen einzigen Cocon.

"Auf diese Art bin ich zu dem Schlusse gelangt, dass das Aufziehen (1s94) dem Maulheeren-Spanner nicht nur nicht half, sich an das ungeeignete Futter zu cewöhnen, sondern seinen Organismus so stark schwächte, llass er nicht mehr im Stanle war, weitere (Quälerei auszuhalten und vorzog eher zu sterben" (p. 19).

J. M. Schemigonow (1901. 744) untersuchte den Einthuss verschiedener chemischer Stoffe ant die Entwickelung rer Eier von ():neria monacha L. Je 100 Eier wurlen in einzelne Ioagenzoläser yroracht, in welche darauf die entsprechen le Flüssigkeit gegossen wurde. Die Eier blieben in dieser Fliissigkeit eine Stunde, worami die Fliissigkeit entfernt, die Eier dreimal mit Wasser ausgespuilt und anf Filtrier-Papier getrockent wurden. Reim Untersuchen ler Einwirkung des Wassers blieben die Eier im Wasser 1, 2, 3, 5, 10, 20 uncl 30 T'age, worauf die Eier auf dem Filtrier-Papier getrocknet wurien. Nach ilem Trocknen wurlen die Eier in einzelne ganz gleiche Glasgefässe gebracht und im hellen Zimmer bei $1+$ his $17^{\circ}$ stehen gelassen.

Folgende Tabelle enthält die erhaltenen liesultate: 


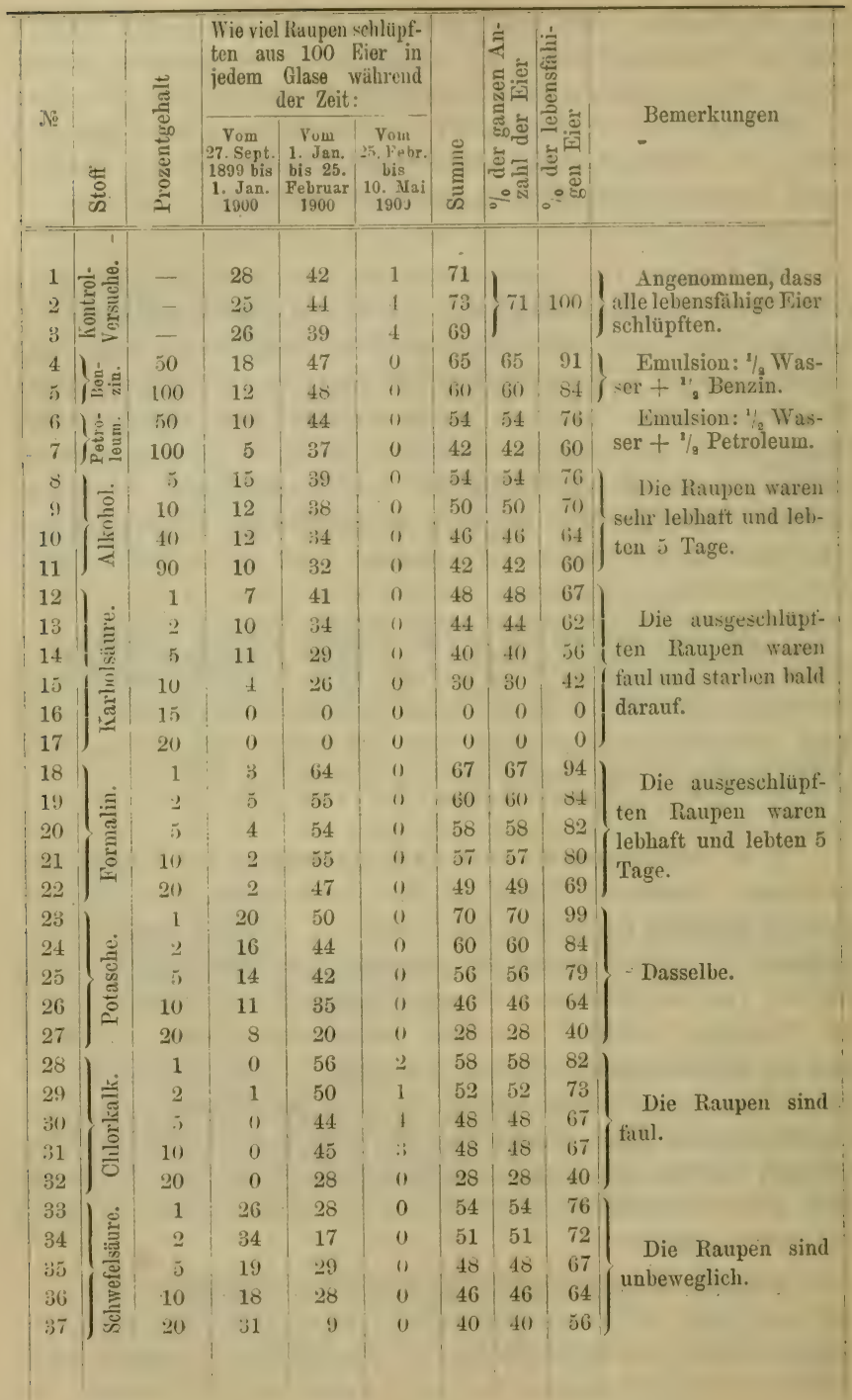




\begin{tabular}{|c|c|c|c|c|c|c|c|c|c|}
\hline \multirow{2}{*}{$\lambda_{0}^{6}$} & \multirow[b]{2}{*}{$\begin{array}{l}\text { क्ष } \\
\text { 递 }\end{array}$} & \multirow{2}{*}{ 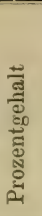 } & \multicolumn{3}{|c|}{$\begin{array}{l}\text { Wie viel Raupen schliupf- } \\
\text { ten aus } 100 \text { Eiern in } \\
\text { jedem Glase während } \\
\text { ler Zeit: }\end{array}$} & \multirow[b]{2}{*}{$\stackrel{\stackrel{\Xi}{\Xi}}{\text { ڤ }}$} & \multirow{2}{*}{ 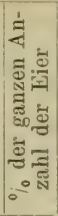 } & \multirow{2}{*}{ 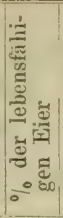 } & \multirow{2}{*}{ Bemerkungen } \\
\hline & & & $\begin{array}{l}\text { Vom } \\
\text { 27. Sept. } \\
\text { 1899 bis } \\
\text { 1. Jan. } \\
1900\end{array}$ & \begin{tabular}{|l} 
Vom \\
1. Jan. \\
bis 25. \\
Februar \\
1900
\end{tabular} & \begin{tabular}{|c|} 
Vom \\
25. Febr. \\
bis \\
$10 . \mathrm{Mai}$ \\
1900
\end{tabular} & & & & \\
\hline 38 & \multirow{5}{*}{ 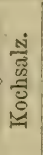 } & 1 & 14 & 35 & 0 & 49 & 49 & 69 & \multirow{5}{*}{$\begin{array}{l}\text { Die Raupeu sind } \\
\text { unbeweglich. }\end{array}$} \\
\hline 39 & & 2 & 7 & 40 & 0 & 47 & 47 & 66 & \\
\hline 40 & & 5 & 7 & 38 & 0 & 45 & 45 & 63 & \\
\hline 41 & & 10 & 4 & 36 & 0 & 40 & 40 & 56 & \\
\hline 42 & & 20 & 18 & 20 & 0 & 38 & 38 & 53 & \\
\hline 43 & \multirow{5}{*}{$\begin{array}{l}\frac{1}{0} \\
\frac{\text { a }}{\sqrt{5}} \\
=\end{array}$} & 1 & 0 & 44 & 6 & 50 & 50 & 70 & \multirow{5}{*}{ Dasselbe. } \\
\hline 44 & & 2 & 0 & 42 & 6 & 48 & 48 & 67 & \\
\hline 45 & & 5 & 0 & 40 & 8 & 48 & 48 & 67 & \\
\hline 46 & & 10 & 0 & 40 & 8 & 48 & 48 & 67 & \\
\hline 47 & & 20 & 0 & 35 & 13 & 48 & 48 & 67 & \\
\hline 48 & \multirow{5}{*}{ 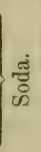 } & 1 & 23 & 36 & 0 & 59 & 59 & 83 & \multirow{5}{*}{ Dasselbe. } \\
\hline 49 & & 2 & 23 & $3: 3$ & 0 & 56 & 56 & 79 & \\
\hline 50 & & 5 & 24 & 28 & 0 & 52 & 52 & 73 & \\
\hline 51 & & 10 & 22 & 28 & 0 & 50 & 50 & 70 & \\
\hline 52 & & 20 & 27 & 15 & 0 & 42 & 42 & 60 & \\
\hline 53 & \multirow{5}{*}{ 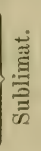 } & 1 & 23 & 33 & 0 & 56 & 56 & 79 & \multirow{5}{*}{$\begin{array}{l}\text { I)ic Raupen sind } \\
\text { leblos und gingen } \\
\text { bald zu Grunde. }\end{array}$} \\
\hline 54 & & 2 & 8 & 41 & (1) & $4 !$ & 49 & (i!) & \\
\hline 55 & & 5 & 16 & 33 & 0 & 49 & 49 & 69 & \\
\hline 56 & & 10 & 2 & 41 & 0 & 43 & 43 & 61 & \\
\hline 57 & & 20 & 3 & 25 & 0 & 28 & 28 & 40 & \\
\hline 58 & \multirow{5}{*}{ 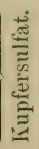 } & 1 & 18 & 37 & 0 & 55 & 55 & 77 & \multirow{5}{*}{$\begin{array}{l}\text { Die Raupen sind } \\
\text { beweglich. }\end{array}$} \\
\hline 59 & & 2 & 11 & 41 & (1) & 52 & .52 & 7:) & \\
\hline 60 & & j & 23 & $2: 3$ & 0 & 46 & 46 & bit & \\
\hline 61 & & 10 & 13 & $3: 3$ & 0 & 46 & 46 & 64 & \\
\hline 62 & & 20 & 16 & 24 & (1) & 40 & 411 & 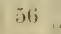 & \\
\hline 63 & \multirow{5}{*}{ 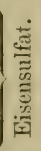 } & 1 & 9 & 44 & ) & $5: i$ & $5: 3$ & 74 & \multirow{7}{*}{$\begin{array}{l}\text { Die liaupen sind } \\
\text { faul. }\end{array}$} \\
\hline 64 & & 2 & 7 & 35 & 0 & 42 & 42 & 60 & \\
\hline 65 & & 5 & $1: 3$ & 28 & 0 & 41 & 41 & 58 & \\
\hline 66 & & 10 & 11 & 29 & () & 40 & 40 & 56 & \\
\hline 67 & & 20 & 12 & 26 & 0 & 38 & 38 & 53 & \\
\hline 68 & \multirow{5}{*}{ 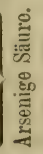 } & 1 & 20 & 35 & 0 & 55 & 55 & 77 & \\
\hline 69 & & 2 & 13 & $: 37$ & (1) & 50 & 50 & 70 & \\
\hline 70 & & 5 & 16 & 34 & 0 & 50 & 50 & 70 & \multirow[t]{4}{*}{ Dasselbe. } \\
\hline 71 & & 10) & 14 & $3: 3$ & 0 & 47 & 47 & 66 & \\
\hline 72 & & 20 & 10 & 37 & 0 & 47 & 47 & 66 & \\
\hline 73 & \multirow{2}{*}{ 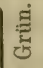 } & 1 & 6 & 58 & 0 & 64 & 64 & 90 & \\
\hline 74 & & 2 & 13 & 46 & 0 & 59 & 59 & 83 & \\
\hline 75 & $\dot{4}$ & 5 & 9 & 42 & 0 & 51 & 51 & 72 & Dasselbe. \\
\hline 76 & .0 & 10 & 9 & 32 & 0 & 41 & 41 & 58 & \\
\hline 77 & ๘ี & 20 & 9 & 21 & 0 & 30 & 30 & 42 & \\
\hline
\end{tabular}




\begin{tabular}{|c|c|c|c|c|c|c|c|c|c|}
\hline \multirow{2}{*}{.$\therefore$} & \multirow[b]{2}{*}{$\frac{F}{0}$} & \multirow{2}{*}{ 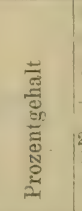 } & \multicolumn{3}{|c|}{$\begin{array}{l}\text { Thie viel Raupen schlüpf- } \\
\text { ten aus } 100 \text { Eier in } \\
\text { jedem Glase wilhrend } \\
\text { der Zeit: }\end{array}$} & \multirow[b]{2}{*}{ 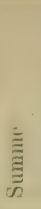 } & \multirow{2}{*}{ 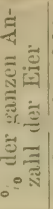 } & \multirow{2}{*}{ 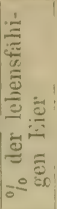 } & \multirow{2}{*}{ Bemerkungen } \\
\hline & & & $\begin{array}{l}\text { Voum } \\
\text { 27. Sopt. } \\
\text { 1899 bis } \\
\text { 1. Jan. } \\
1900\end{array}$ & $\begin{array}{l}\text { Vom } \\
1 \text { Jan. Jan. } \\
\text { his } 25 . \\
\text { Februar } \\
1900\end{array}$ & \begin{tabular}{|c|}
$\operatorname{Vom}$ \\
25. Fobr. \\
bis \\
10. Nai \\
1900
\end{tabular} \mid & & & & \\
\hline 78 & \multirow{5}{*}{ 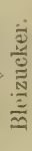 } & 1 & !) & 45 & 0 & 54 & $5-1$ & 76 & \multirow{7}{*}{$\begin{array}{l}\text { Die Raupen sind } \\
\text { fanl. }\end{array}$} \\
\hline 79 & & 2 & 9 & 39 & 0 & 48 & 48 & 67 & \\
\hline 80 & & 5 & 16 & 29 & 0 & 45 & 45 & 63 & \\
\hline 81 & & 10 & 111 & :8) & 11 & 111 & (1) & sil & \\
\hline 82 & & 20 & 11 & $24^{\prime}$ & () & 35 & 35 & 49 & \\
\hline 83 & \multirow{5}{*}{ 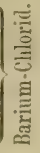 } & 1 & 0 & 41 & 20) & 61 & 61 & 86 & \\
\hline 84 & & 2 & (1) & 40 & 12 & $\therefore 2$ & $\therefore 2$ & $7: 3$ & \\
\hline 85 & & 5 & 0 . & 38 & 8 & 46 & 46 & 64 & \multirow[t]{3}{*}{ Dassellue. } \\
\hline 86 & & 10 & 0 & 20 & 18 & 38. & 38 & $5: 3$ & \\
\hline 87 & & 20 & 0 & 0 & 0 & 0 & 0 & 0 & \\
\hline 88 & \multirow{6}{*}{ 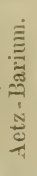 } & 1 & 0 & 38 & $2: 3$ & 61 & 61 & 86 & \multirow{6}{*}{$\begin{array}{l}\text { Sehr fuul und gin- } \\
\text { gen bald zu Grunde. }\end{array}$} \\
\hline 89 & & 2 & 0 & 28 & 28 & 56 & 56. & 79 & \\
\hline 90 & & 3 & 0 & 30 & 22 & 52 & 52 & 73 & \\
\hline 91 & & 5 & 0 & 21 & 25 & 46 & 46 & 64 & \\
\hline 92 & & 10 & 0 & 18 & 20) & 38 & 38 & 53 & \\
\hline 93 & & 20 & () & 0 & 0 & 0 & 0 & 0 & \\
\hline 94 & \multirow{8}{*}{ 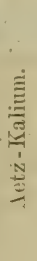 } & $1 / 4$ & () & 12 & 16 & 28 & 28 & 40 & \multirow{9}{*}{ Dasselbe. } \\
\hline 95 & & $1 / 2$ & () & 0 & 0 & 0 & 0 & 0 & \\
\hline 96 & & 1 & 0 & 0 & 0 & () & 0 & 0 & \\
\hline 97 & & 2 & 0 & 0 & () & () & 0 & 0 & \\
\hline 98 & & 3 & 0 & 0 & 0 & 0. & 0 & 0 & \\
\hline 99 & & 5 & 0 & 0 & 0 & 0) & 0 & () & \\
\hline 100 & & 10 & 11 & 0 & 0 & 11 & 11 & 0 & \\
\hline 101 & & 15 & 11 & 1) & (1) & 0 & 11 & 0 & \\
\hline 102 & & 20 & 0 & 0 & 0 & 0 & 0 & 0 & \\
\hline 103 & \multirow{7}{*}{ 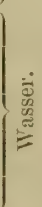 } & $1 \mathrm{Tag}$ & 30 & 35 & 0 & 65 & 65 & 91 & \multirow{7}{*}{ Beweglich. } \\
\hline 104 & & $2 "$ & 26 & 28 & () & 54 & 54 & 76 & \\
\hline 105 & & $3 n$ & 24 & 29 & () & 53 & 53 & 74 & \\
\hline 106 & & $5 \quad$ & 21. & 21 & 0 & 42 & 42 & 60 & \\
\hline 107 & & $10 \%$ & 14 & 14 & () & 28 & 28 & 40 & \\
\hline 1118 & & 20 & $\mathrm{i}$ & + & 11 & 5 & ; & 7 & \\
\hline 109 & & $30=$ & 0) & 0 & 0 & () & 0 . & () & \\
\hline
\end{tabular}

W. Iwanow (1901. 406) fïtterte Raupen von Bomby:r mori mit verschiedlenen Pflanzen und zwar: 1) gewöhnlicher kaukasischer Maulbeerenbaum Morus alba var. tatarica (hodistämmiger Baum); 2) dasselbe, aber in Form lebenden Zaunes; 3) Morus alba var. cerlrona: 4) Morus alba var. latifolia; 5) Morus rubra (Cana- 
lensis): (i) broussonetia papyrifera; 7) Broussonetia kaempferi; s) Maclura aurantiaca unl (9) Scorzonera hispanica. Zum Aufziehen wurlen je jo0 Rïupchen von der korsikinischen gelhen liasse verwendet. Dabei wurlen folgenden liesultate erhalten:

Alle Raupen, welche mit verschiedenen Sorten von Morus gefïttert wurlen, entwickelten sich normal und fingen an, sich an 28. Tage zu verspinnen.

Beim Aufziehen mit IIaclura aurantiatia fing die Verspinnung am 29. Tage an.

Die Partie der Raupen an Broussonetia papyrifera entwickelte sich sehr langsam; sie frassen dlieses Futter sehr ungern, und die Sterblichkeit war jellen Tag sehr gross. Die erste Häutung fand erst am 10. Tage, die zweite am 17. Tage, die dritte am 33. Tage statt: vor ler vierten Häutung blieben nur noch 6 Raupen am Leben und starben alle am 35. Tage.

Die Raupen am Broussonetia kaempferi entwickelten sich etwas besser, aber democh zu schwach. Die erste Häutung begann am 6. Tage, die zweite an 12. Tage, llie dritte am 19. Tage, die vierte am 27. Tinge und die Verspinnung am 40. Tage. Nach der dritten Häutung trat die Sterblichkeit an, welche stets stärker wurı. In ganzen wurden nur 24 Cocons erhalten.

I) Raupen an scorzonera hispanica entwickelten sich besser als an B. kaempferi. Die erste Häutung fimul am 6. Tage, die zweite am 13. Tage, die dritte am 19. Tage und die vierte am 25. Tage statt. Die Verspimmung begann am 39. Tage. Zuerst frassen die Raupen mittelmässig und vor der dritten Häutung erkrankten mehrere der laupen unil starben. Es wurlen nur 24 Cocons erhalten.

Da einerseits die Raupen in China die Blätter von Broussonetia papyrifera und Cudrania triloba gerne fressen und andererseits diese Raupen im nördlichen Rissland mit Scorzonera hispanica verhältnissmiassig gut erzogen werilen, so ist Iwanow der Meinung, dass die Qualität des Blattes einiger PHanzen unter dem Einflusse verschiedener klimatischer und Boden-Verhältnisse der gegebenen Gegend sich stark ändert und unter Umständen schlechtes Futter liefert.

D. Rossinsky (1901. 706) hat die Eier von Bomlyy mori währenl 2 Stunden mit wässeriger Karbolsäure-Lösung ausgewatschen und zwar mit Lösungen von folgenden Concentrationen: 1/1000, $2 / 1000,3 / 1000,4 / 1000,5 / 1000,2 / 100,3 / 100$. Die Temperatur betrug wäh- 
rend ies Auswaschens $13^{\circ} \mathrm{L}$.; nach dem Auswaschen und entsprechenilem Trocknen überwinterten diese Eier in einem kühlen Raume. Er erhielt dlabei folgente Resultate, welche bei ihm in zwei grossen Tabellen enthaltend sind:

1). Das wiolerholte Auswaschen scharlet ilen Eiern, unabhängig von der verwenleten Fliissigkeit, sogar wenn es Wasser ist.

2). Alle verwendleten Lösungen, ausser Lösungen $1 / 1000$ und $2 / 1000$, welche gïnstigere Resultate ergaben, sind den Eiern schäillich, wenn ilas Auswaschen mit ihmen auch ein Mal vorgenommen wirl.

H. Frhr. von Schilling (1901. 744) kultivierte die Lüuse Dactylopins vagabundus drei Generationen hindurch auf einer Topfpflanze, ohne Männchen zu beobachten. Die dabei immer kleiner gewordene Dimensionen der Läuse erklärt der. Verfasser lurch abnehmenile Nahrungsmenge.

L. Reh (1901. lis0) (an Schlusse seines Referats der oben angeführten Arbeit von H. von Schilling) möchte die kleiner geworflenen Dimensionen der Läuse auf den Einfluss der Parthenog̨enese zurückfiihren.

R. Thiele (1901. 861) stellte fest, rlass Blutläuse bei geringer Luftcirkulation in einer Tieie von $5 \mathrm{~cm}$. nach einem Zeitraum von lrei Wochen eingegangen und auch junge Thiere in keinem Falle vorhanclen waren. In einer Tiefe von ca. $10 \mathrm{~cm}$. trat in der liegel schon nach einigen Tagen das Absterben ein.

Ew. H. Rübsaamen (1902. 714) fand junge und alte Rebläuse 1,25 m. unter der Erdobertläche. "Würden aber an oberirdischen Pflanzentheilen gallenbiliencle Reblausformen gewaltsam an unterirdische Theile der Pflanze versetzt werlen, sie wïrlen sicher nach kurzer Zeit eingehen" (p. 230). Er beobachtete auch, dass die Anschwellungen der Wurzeln junger Apfelbäume, verursacht durch Blutläuse, noch bei $40 \mathrm{~cm}$. Tiefe sich vorfanden.

J. Dewitz (1902. 168) studierte die Erscheinungen des Apterismus bei Insekten mehrere Jahre und gelangte zu der Ansicht, dass eine Einschränkung der Oxydationsvorgänge im Organismus den Apterismus zur Folge haben kann. Er hielt Fliegenpuppen einige Zeit unter Luftabschluss uni erhielt aus solchen Puppen Fliegen, 
welche bisweilen defecte oiler öfter gar nicht aufgeblasene Flügel besassen oiler welche zwar normale Flügel hatten, aber nicht in Stande waren $z u$ fliegen.

E. A. Bogdanow (1903. 93) züchtete durch zehn Generationen Musca domestica, um zu untersuchen, ob irgend welche Veränilerungen eintreten, wenn man das gewöhnliche Futter der Larven durch ein anderes uml ihnen unbekanntes ersetzt. Die Einzelheiten der Versuche waren folgende:

\begin{tabular}{|c|c|c|c|c|c|c|}
\hline 몷 & Larven-Futter & 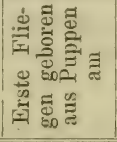 & 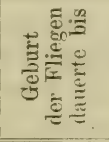 & 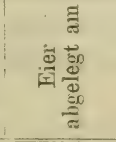 & 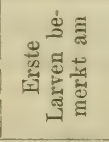 & 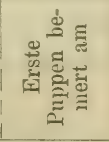 \\
\hline I: & Fleisch & - & - & $\begin{array}{l}\text { 9. Juni } \\
1896\end{array}$ & 10. Juni & 23. Juni \\
\hline II. & $\begin{array}{l}1 \text { Th. Fleisch } \\
2 \text { Th. Tanacetum } \\
\text { vulg. n. d. Ge- } \\
\text { wicht }\end{array}$ & s. Juli & 8. Aug. & 5. Ang. & 11. Aug. & 20. Aug. \\
\hline III. & $\begin{array}{l}1 \text { Th. Fleisch } \\
\text { \& Tanacet. }\end{array}$ & 31. Aug. & 20. Sept. & 4. Okt. & 6. Okt. & 13. Okt. \\
\hline IV. & $\begin{array}{l}1 \text { Th. Fleisch } \\
4 \text { Tanacet. }\end{array}$ & 30. Okt. & 11. Noy. & 13. Nov. & 16. Nor. & 2. Dez. \\
\hline V. & $\begin{array}{cc}1 & \text { Th. Fleisch } \\
5 & "\end{array}$ & 21. Dez. & 3. Jan. & 3. Jan. & 5. Jan. & 1. Febr. \\
\hline VI. & $\begin{array}{l}1 \text { Th. Fleisch } \\
6 \text { Tanacet. }\end{array}$ & 2. März. & 1. Apr. & 26. März & 27. Мах\% & 10. Apr. \\
\hline VII. & $\begin{array}{l}\text { fast nur Tana- } \\
\text { cetum }\end{array}$ & 12. Apr. & 16. Mai & 14. Mai & 15. Mai & 7. Juni \\
\hline VIII. & $\begin{array}{l}1 \\
6\end{array}$ & 14. Juni & 16. Juni & 27. Juli & 28. Juli & \\
\hline IX. & nur Tanacetum & 11. Aug. & $\ldots$ & 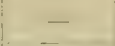 & 17. Aug. & 14. Sept. \\
\hline $\mathrm{X}$. & nur Tanacetum & 23. Sept. & 30. Sept. & 15. Nov. & - & 3. Dez. \\
\hline $\mathrm{XI}$. & nur Tanacetum & 30. Dez. & 2. Jan. & 13. Jan. & 10. Jan. & - \\
\hline
\end{tabular}

Am Resultate ergab sich, llass zehn Generationen nicht genug waren, um irgend welche Verändlerungen bei diesen Fliegen hervorzurufen.

V. Kellog: und R. Bell (1903. 447) fütterten die Raupen von Bomlyx mori statt mit Maulbeerblättern mit Lattich. Dabei betrug 
die Laumen\%eit statt if Wochen (wio gewöhnlich) : Monate. Als einer Partie von Raupen eine normale Menge des gainderten Futters, der zweiten Partie die Hailfte unil der dritten Partie nur ein Viertel dieser Menge gereicht wurle, trat die Verpuppung zuerst bei der crsten Partie, damn bei der zweiten und emillich bei der dritten ein. Die Verpuppung endigte bei der zweiten l'artir 4 Tage und hei der dritten 9 Tage später als bei der ersten.

Diese Hungerversuche wurilen bis zur dritten fieneration fortgesetzt, wobei sich herausstellte, lass hei der zweiten unl der dritten Generation die meisten liaupen fünf staft vier Häutungen durchmachten. Die mit normaler Menge grofiitterte Raupen dirser (ieneration zeigten nur $\&$ Häutungen.

E. Quajat (1903. 66i7) setzte die Eier von Bomlygx mori dex verschiedrne Zeit dauernden (z) Einwirkung des Allkohols aus, und spülte sie darauf entweder mit Wasser aus o.ler liess sie smat trocknen. Die Zeit der Einwirkung varierte zwischen 5' unl 50'. Obwohl zu den Experimenten 5 verschieilene Rassen benutzt wurlen, war trotzdem keine sehäilliche Einwirkung auf die Entwickelung der Fier zil beobachten.

Pabst (1903. 621) brachte für einige Stunlen Zyygenen in rin Cyankalimm-Glas unt beobarlitete, dass sie dabei nicht starben.

Ch. Sasaki (1904. 735) fütterte die Seilenraupen der chinesischen Si-chnen-Rasse mit Blättern von Cudrenia triloba und vom Maulheerhaum und fimd, dass wïhrend die Raupenzeit bei heiden ungefähr dieselhe war, die ersten Raupen vier und die zweiten fünf Häutungen durchnnachten.

Adele Field (1904. 222) brachte Ameisen in ein Glasgetïss, welches alle 4 Tage mit Spiritus ausgewaschen wurde, damit sich kein Schimmel ılarin bilılen könnte, unıl liess sie olme Nahrung: Wasser wurde ihnen gereicht in einem Stiickchen Schwamm.

Von 30 Cremotoyaster lineolata lebten ohne Nahrung 10 Exemplare 10 T'age und eines 18 Tage.

Von 13 Camponotus herculeunus pictus lebten ohne Nahrung 2 Exemplare 7 'Tage 
1 Exemplar 23 Tage

2

1

1

Stenamma fulvum

Camponotus pennsylvanicus

Formica lasioides

Formica fuscu subsericea

$\begin{array}{lll}n & 24 & n \\ n & 26 & n \\ n & 29 & n\end{array}$

hielten ohne Nahrung 18- 46 Tage aus.

J. Dewitz (1904. 175) fütterte die Larven von Lucilia enesar mit defibrinirtem Hammelblut (Serum) und konstatierte, disss die Larven dabei im Wachstum stark zurückblieben; die Entwickelung war eine verlangsamte und unregelmässige.

Ausserdem fütterte or diese Larven unil die Larven von $L u$ cilia erylinroceplacala mit Schnecken (Helix hortensis und aspersa), und erhielt die gleichen Resultate, wie mit Serum.

Er brachte ein Röhrchen mit Larven von Lucilia caesar in ein grösseres zugekorktes liöhrchen. In den Zwischenraum zwischen rlen beiden Tuben brachte er eine kleine Menge von gepulvertem Calciumchlorid, un den bei der Athmung iler Larven entstehenden Wasserlampf zu absorbieren. Das Resultat rieser Experimente war, dass die Verwandlung der Larven aufgehalten wurle, weil zu diesem Processe der Samerstoff der Luft nöthig ist.

Bei Versuchen mit Raupen von Porthesia chrysorrhoea wurde je eine derselben in ein grosses weithalsiges Pulverglas $(1 \mathrm{~L}$. bis (f00 cem. Inhalt) gebracht, in welchem ein Stiickhen Cyankali lag. Jabei wurde entweder die Verwandlung unterdrückt, oder man erhielt Puppen, welche gänzlicht unvollkommen waren (Halb- oder Raupenpuppen). Sie verharrten in diesem Stadium, auch wenn sie aus der Blausäureatmosphäre entfernt wurlen. Die Versuche mit Raupen von Tortrix pilleriuna zeigten auch, dass die liaupen in iler Blausïureatmosphäre genügend lange Zeit am Leben erhalten werden konnten, ohne sich zu verpuppen.

Ausserdem behandelte er Fliegenpuppen (Lucitia erythrocephala) mit verdünntem Eisessig $(1-3 \%)$ und liess sie 24 dis 48 Stunden in der Flüssigkeit. "Viele Exemplare waren vollkommen unfähig, lie Flügel zı gebrauchen, obgleich sie vollstänlig ausgebildet waren" (p. 177).

A. Grovillius (1905. 329) hat sehr ausgedehnte Fütterungsversuche mit Goldafterraupen (Euproctis chrgssorrhoea Hb.) ange- 
stellt, wobei ganze Masse von verschiedenen Pflanzen verwendet wurle, welche er in Form von Tabellen auf p. 242--255 seiner Abhandlung anfüht. Hier werlen nur die Hauptresultate dieser Versuche angeführt.

Die Goldafterraupen scheinen in len jüngsten Stalien - im Herbst - nicht in merklich höherem Grale wählerisch zu sein, als im Frühjahr, sonst fressen sie nicht gleich gern die Blätter verschiedener Pflanzenarten.

Gestuitzt auf den Gerbstoffgehalt in vershiedenen Pflanzen, kommt er zu folgendem Schlusse: „Dass die Gerbstoffe in irgend einer Weise für die Goldafterraupen von grosser Bedeutung bei der Nahrungsaufnahme sein können, scheint mir ganz plausibel zu sein. Diese Annahme wird u. a. durch dlas Verhalten von Stellaria medlia gestiitzt. Diese Art, bei welcher Deegener [der Chemilier, welcher ihm die Analyse besorgt hat] keine Spur von Gerlostoft fand, wurde in den Fütterungsversuchen nicht angeruihrt; mit Tamninlösung bepinselte Blätter wurden aber nach ein Paar Tagen (im Juni) gefressen, während die an denselben Individuen vorhanilenen nicht bepinselten Blätter unberïhrt gelassen wurden" (p. 283).

Weitere Versuche in dieser Richtung ergaben, dass der Raupenkoth noch etwas Gerbstoff enthält und folglich nur zum Theil verdaut wirl. „Es liesse sich demnach denken, dass die Gerbstofie bei den Goldafterraupen nicht oller nur zum Theil eine direkte Rolle in ernährungsphysiologischer Hinsicht speilten, dass ilınen vielmehr (ganz oder zum Theil) eine indirekte, aber deshalb nicht unwichtige Rolle, etwa als Reizmittel bei der Nahrungsaufnahme oder als ein den Unsatz und die Verdaung der Nährstoffe beförderndes Mittel zukäme" (p. 285).

G. Koschewnikow (1905. $467 a$ ) beobachtete folgende zufällige Erscheinungen:

1. Die Entwickelung der Drohnenlarven, welche mit KöniginFutter ernährt wurden.

2. Die Entwickelung der Drohnenlarven ohne Futter.

3. Die Entwickelung (ler Königinlarven bei mangelhaftem Futter und in einem engen Raume.

Die histologischen Untersuchungen ergaben in diesem Falle folgende Resultate: 
1. Die Ennälrung mit ungewöhnlichem Futter (Futter der Königinlarve) iibt keinen Einfluss auf den normalen Verlauf der Entwickelung der Geschlechtsorgane der Drohnen aus.

2. Das vollständige Hungern übt keinen verzögernden Einfluss auf die Entwickelung der Geschlechtsdriisen des Drohnenlarve aus, solange in derselben ein Vorrath des Fettkörpers sich befindet.

\section{Erganzungs-Litteratur zu diesem Abschnitt.}

Bolle, Giov. La schiusura estemporanea del seme del baco da seta col mezzo di agenti chimici e dei coloracio. - Rivista settim. di hachicolt. X. 1878. p. $45-46 ; 53 \div 54$.

Carotta, A. Allevamento di bachi ottenuti a mezzo dello schindimento estemporaneo. - Bull. Mens. Bach. Ser. II. 1894.

Dönhoff. Bilden sich die eierlegenden Arbeitsbienen durch eine reichliche Fütterung von Futterbrei? - Eichstädt. Bienen-Zeitung. 13. Bd. 1857. p. 4; Antwort darauf von Rud. Leuokart befindet sich ebd. p. 4-5.

Engel, Arth. Sur l'emploi de la Seorzonera vulgaris pour la nourriture des vers à soie. - Feuill. d. jeun. natural. 4. Année. 1873-1874. p. 146.

Forbush, Edward H. and Fernald, Charles H. The Gypsy Moth, Porthetria Dispar (Linnée). Boston 1896. 500 pp.

Gabba, Luigi. L'industria della seta. Milano 1886.

Gal, J. Études sur les vers-ì-soie. -- Bull. Soc. Nimens. XXV. 1898. p. 78--92. Garelli, Alessandro. Le patate di gran redito. Casanova-Torino.

Gatter, Karl. Wodurch unterscheidet sich das königliche Brutfutter von jenem der Arbeitsbienen? - Bienenvater (Wien). 10. Jahrg. 1878. p. 89-40.

Greatti, L. Annario Agrario. 1860; Boll. Mens. Bach. N2 5. 1892. (Raupen von Bombyx mori wurden mit Tragopagon gefüttert).

Haase, E. Ueber den Finfluss des Hungers auf die Entwickelung der Thiere, mit Berücksichtigung der Reblausfrage. - Sitzber. Gesellsch. Isis. 1888. p. $3-4$.

Harrach. Nahrungswechsel bei den Raupen in verschiedenen Zeitrüumen, Einfluss der Futterpflanze. - Entomol. Nachr. IV. 1878. p. 186.

Iwanow, W. P. Die Aufzucht wilder exotischer Seidenspinner. - Die Arbeiten der Kaukasischen Seidenzuchtstation. Vol. VII. Liefer. I. und II. 1894. p. 12-17. (Russisch).

Kanitz, J. G. Geniessen die königlichen Maden in den ersten vier Lebenstagen reichlicher Futterbrei als Bienenmaden? - Preuss. Bienen-Ztg. 4. Band. (VII. Jahrg.). 1861. p. 31.

Kanitz J. H. Nacht das weibliche Geschlechtsthier bei den Bienen mehr Nahrungsansprüche als das männliche? - Preussische Bienen-Ztg. 3. Band. $1859-60$. p. 136.

Kanitz, J. G. Wie lange kann eine Bienenmade hungern? - Preuss. Bienen-Ztg. 3. Bd. $1859-60$. p. 495 . 
Loeb, J. Liber den Einfluss von Säuren und Alkalien auf die embryonale Entwicklung und das Wachsthum. - Ausz. von R. S. Bergh. Zool. Centralbl. VI. № 11/12. 1898. p. 350.

Paspualis, G. Sul consumo della foglia in repporto alla produzione serica in diverse qualita di bachi. - Bollet. mens. di Bachicolt. Sesie III. Annata II. 으 12. 1896. p. $165-180$.

Peligot, Alex. Études chimiques et physiologiques sur les vers ì soie. - Comp. rend. Acad. sc. T. 61.1865 . p. $866-876$ !

Perroncito, E. Azione di differenti gaz, del vuoto e della temperatura sul seme. - Rivista settim. di bachicolt. Anno XII. 188ก. p. 45.

Perroncito, E. Résistance des oeufs des insectes à divers poisons, substances chimiques et agents naturels. - Comp. rend. Ass. franc. XXVI. 1898. p. $304-305$ und p. $545-547$.

Quajat, E. Bozzoli e sete ottenuti con la maclura aurantiaca. - Boll. Mens. Bach. Ser. II. 1889.

Ratzky, 0tto. Aufzucht der Seidenraupe mit Sonchus oleraceus. - mitth. d. mährisch-schles. Gesell. z. Bef. d. Ackerb., Natur- und Landeskult. 1861. p. 5. (Auch in Lotos. 17. Jahrg. 1567. p. 69).

Raulin, J. Action de diverses substances toxiques sur le Bombyx mori. - Ann. Soc. Agric. Lyon. (6): V. 1893. p. $383-397$.

Schonkling-Prévôt. Uber die Aufzucht der Raupe des Seidenspinners mit Blättern der Schwarzwurzel. - Insekten-Börse. 1897. XIV: I 48. p. 285; 궁 49, p. 291; 상 50, p. 303.

Tichomirow, A. Sullo sviluppo delle uova del bombice del gelso sotto l'influenza di eccitazioni meccaniche' e chimiche. - Boll. Mens. Bachicolt. Ser. II. 1885. p. 145.

Viguier, Cam. Fécondation chimique ou parthénogenèse? - Ann. d. Sc. Nat. Zool. (8). T. 12. 1901. № 1. p. $87-96$; № 2/3. p. $97-125,136-138$.

Winkler, Hs. Ueber die Furchung unbefruchteter Eier unter der Einwirkung von Extractionsstoffen aus dem Sperma. - Nachr. der k. Ges. Wiss. Göttingen. 2. Hft. 1900. p. $187-193$.

\section{Einfluss der mechanischen Reibung und der übrigen Faktoren.}

Alle einschlägigen Versucbe sind von verschiedenen Forschern fast ausschliesslich an Eiern von Bombyx mori angestellt worlen.

Vincenzo Barca (1871. 49) fand, dass Eier von Bombyx mori, welche an ein Stück Carton angeklebt wurden, durch Reiben während 10 Minuten mittelst einer harten Bürste theilweise auskamen.

G. Terni 1872. 856), Guido Susani (1874. 851), E. Ducleaux (1876. 202) und Andere wiederholten diesen Versuch und kamen 
7. Einfluss der mechanischen Reibung und der übrigen Faktoren.

dabei zu dem Resultate, dass der Effekt um so vollständiger gelingt, je jünger die Eier sind.

August Weismann (1875. 953) fuhr mit trischen Puppen von Pieris napi (der ersten Sommerbrut) sieben Stunilen lang auf der Eisenbahn. Diese Puppen überwinterten, statt im Juli desselben Jahres die Sommerform (var. napaeae) zu ergeben, alle im geheizten Zimmer und ergaben Schmetterlinge im Januar, Februar, März, April und Juni. Diese starke Verlangsamung in der Entwickelung erklärt er durch das erwähnte „siebenstiindige Iütteln, dem die Puppen während (ler Eisenbahnfahrt ausgesetzt waren, und zwar unmittelbar nach oler noch wälırend ihrer Verpuppung“ (p. 28).

A. A. Tichomirow (1886. 868) rieb eine Portion nicht befruchteter, frisch abgelegter Eier von Bombyx mori mit einer harten Bürste innerhalb 10 Minuten. Die erste Verlunkelung der Eier, welche den befruchteten und überwinternden Eier eigen ist, wurde nach 4 Tagen beobachtet. Der Prozentgehalt solcher Eier betrug jedoch weniger als 30 .

Ein zweiter Versuch wurde mit 100 Eiern angestellt, welche unbefruchtet und einige Stunden alt waren; dieselben wurden einige Mal zwischen zwei Stiicken Tuch gerieben. Darauf wurclen 50 Ei dunkel; wenige davon hatten jedoch die Färbung ler befruchteten und ïberwinternden Eier.

K. A. Gorbatschew (1889. 324) nntersuchte Raupen und Falter von Bombyx mori, welche aus vorzeitig entwickelten Eiern gezüchtet wurden. Da die äussere Untersuchung dieser Eier nichts besonders ergab, und das Weibchen sie mit ihrem Leib in Folge spezieller Bedingungen nicht reiben konnte, so untersuchte er mikroscopisch sowohl die gestorbenen Falter, wie auch die Raupen und die Eier; die letzteren wurden zuerst 2 Minuten in conzentrirter Salzsïure gehalten, nachher mit Wasser ausgewaschen und erst dann verrieben. Somit konnten die eventuell auf der Oberfläche des Eies sich befindenden Vibrionen in sein Inneres nicht gelangen. Es ergab sich jedoch, dass diese Eier und die daraus geschlüpften Raupen, sowie ihre Mütter Vibrionen enthielten, während bei normal sich entwickelten Eiern solche fehlten. Dieses Resultat widerspricht den Beobachtungen von Pasteur, welcher sagt, dass weder Mikrokokken noch Vibrionen auf die Nachkommenschaft vermittelst Eiern übertragen werden können. 
Gestiitzt auf cliese Ergebnisse und die "Reiz-Theorie" von A. A. Tichomirow (1886. 868) in Betracht ziehend, sagt Gorbatschew: „Alle oben erwähnten Mittel erscheinen, so zu sagen, als äussere Reize des Eies. Es frägt sich, was für eine Rolle die Vibrionen, welche so oder anders ins Innere des Eies gelangten, spielen können? - Warum gelang es mir, sie nur in solchen Eiern zu konstatieren. welche die vorzeitige Entwickelung zeigen wollten, und schliesslich. können diese Bakterien kein Stimul für den inneren Reiz des Eies sein? - Dies sind die Fragen, welche sich bei der Beurtheilung der erwähnten Thatsachen aufwerfen. Wenn man sich erinnert, lass die Bewegung der Vibrionen bei der Temperatur von $18^{\circ} \mathrm{R}$. beginnt, welche Bewegung im gegebenen Falle als die Ursache des Reizes sein kann, so erscheint es noch wahrscheinlicher, dass die Vibrinnen als eine der Ursachen gelten können, welche diesen höchst interessanten phỵsiologischen Prozess des vorzeitigen Auflebens hervorrufen $^{\text {" }}$ (p. 48 und 49).

Weiter sagt er: "Diese Mcinung, wie es mir scheint, wird auch durch die gegenwärtige Anschaung über die Befruchtung unterstuitzt, welche durch Physiologen jetzt auf den Reiz reduziert wird. "Die Natux, sagt A. P. Bogdanow (1888. 91), giebt uns ein gut bekanntes Beispiel des natürlichen Reizes des Eies. Das Spermatozoid, welches ins Innere des Eies eindringt, muss in demselben offenbar einen sehr starken Reiz hervorrufen; es kann sein, dass dieser Reiz allein bereits genügt, um das Ei zur Entwickelung zu zwingen, wenn auch das Spermatozoid bei der Befruchtung mit dem Ei nicht verschmolzen wäre. " "

Zur Berichtigung sei hier gestattet zu bemerken, dass obwohl diese Worte bei Bogdanow auf p. 177 seines Werkes sich befinden, dieselben wörtlich aus der Arbeit von A. A. Tichomirow (1886 868) entlehnt wurden und zwar von p. 16.

G. P. Taratynow (1869. 853) züchtete Seidenraupen, welche vorzeitig ausgeschlüpft waren (28. Juni a. St.). Zu diesem Versuche benützte er 300 ebenso ausgeschlïpfte Räupchen und fütterte sie bei ca. $20^{\circ}$. Die erste Häutung fand am 7. Tage (statt am 5.), die zweite am 15. und 16. Tage, die dritte am 24. und 25. Tage, die vierte am 31 . bis 35 . Tage statt. Zusammen verpuppten sich 42 Raupen am 41. bis 43. Tage, die anderen starben während der Aufzucht. Somit dauerte die Aufucht dieser Raupen 43 Tage, d. h. um 11 Tage länger als unter normalen Umständen. 
Das Ausschlüpfen der Schmetterlinge fand nach 4 Tagen nach (ler Verpuppung statt und zwar:

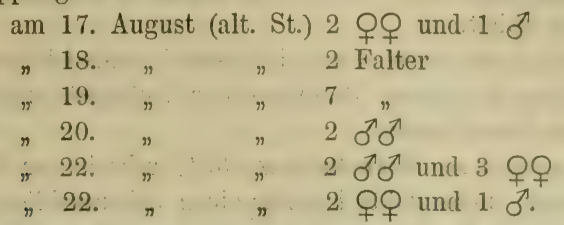

Die Schmetterlinge waren schwach, und die Männchen kleiner als sonst. Die Eierablage geschah unregelmässig (von 56 bis 290 Eiern von einem Weibchen), und sie waren meistens unbefruchtet. Es ist interessant, dass die Hälfte der Raupen in diesem Versuch Cocons unil die andere Hälfte nur ein ebenes Netz gesponnen haben. Die Gespinnste waren klein.

Er kommt somit zu dem Schlusse, dass die untersuchten Eier lirankhaft waren, und die Raupen sofort nach dem Ausschlüpfen bereits von der Pebrine angesteckt waren.

W. J. Schmujdsinowitsch (1891. 760) beschreibt in seiner Abhandlung: „Zur Frage des zufälligen Bivoltismus beim MaulbeerSpinner" seine Versuche an 100 Bruten, deren Eier ganz oder nur theilweise vorzeitig auflebten, wobei er 33 우 und ठठठ $\sigma^{\lambda}$ zusammen und 67 einzelne verriebene Falter von Bombyx mori mikroscopisch untersuchte.

Seine Resultate lauten wie folgt:

1. Die Fälle der vorzeitigen Entwickelung der Eier werden öfters an Bruten beobachtet, welche von krankhaften Weibchen abgelegt werden (von 100 Bruten waren $60 \%$ an Schlaffsucht erkrankt, und von Faltern: $62 \%$ 우우 und $\left.24 \sigma^{\top} \sigma^{\top}\right)$.

2. Die Anzahl der Fälle der vorzeitigen Entwickelung der Eier ist dem Entwickelungsgrad der Schlaffsucht unter den Raupen während ihrer Aufzucht proportional.

3. Bei weissen Rassen werden die Fälle der vorzeitigen Entwickelung öfter beobachtet, als bei farbigen.

4. In Fällen der vorzeitigen Entwickelung der Eier wird der grösste Prozentsatz der kranken Falter unter den Weibchen beobachtet.

5. Die Anzahl der Ansteckungsfälle durch Vibrionen, wenn auch ziemlich bedeutend, ist jerloch geringer als die Ansteckung durch Mikrokokken. 
Auf Grund dessen glaubt er, dass die Ansteckung der Filter durch Bakterien eine wichtige Rolle bei der vorzeitigen Entwickelung der Eier spielt.

Er beobachtete auch, dass die vorzeitig entwickelten Eier bei zwei Versuchen gelungene Resultate der Aufzucht ergaben $(\overline{7} 5 \%$ gelangten zur Verpuppung).

Im Gegensatz zu Gorbatschew (324) schreibt er dem Anstecken der Falter durch Bakterien nur einen nebensächlichen Finfluss auf die vorzeitige Entwickelung der Eier zu, nimnt aber an, dlass die Vibrionen und Mikrokokken die Eier empfinıllich gegen äusseren Reize machen, indem sie den Organismus der Schmetterlinge schwächen. Er sagt, dass die Temperatur von $18-20^{\circ} \mathrm{R}$. zuweilen die Eier von krankhaften Faltern zur Entwickelung bringt, während sie auf die gesunden Eier keinen Einfluss hat, wenn dieselben der Kïilte vorher nicht ausgesetzt waren.

J. G. Alibegow (1892. 8) in Tiflis erhielt im Juni aus vorzeitig ausgebrüteten Räupchen von Bombyx mori Falter, wobei von 17 Paaren nur ein Par gesund war. Alle Weibchen legten wiedcr Eier ab, aus welchen nach kurzer Zeit die Raupen zum dritten Mal in diesem Jahre ausschliipften, Die Temperatur des Raumes, wo die Eier aufbewahrt wurden, betrug $20^{\circ} \mathrm{R}$.

Der Unstand, dass die Eier der dritten Brut von krankhaften Weibchen abstammten, kann dabei die Ursache iler vorzeitigen Ausbrütung sein; auch die hohe Temperatur $\left(20^{\circ}\right.$ R.) blieb dabei nicht ohne Einfluss.

W. J. Schmujdsinowitsch (1892. 764) in Tiflis stellte eine ganze Reihe von Versuchen an, um die Frage der vorzeitigen Ausbrütung der Raupen von Eiern (Bomlyx mori) aufzuklären. Er hat nachgewisen, dass die Reibung der Falter an den abgelegten Eiern ihre vorzeitige Ausbrütung sehr minim beeinflusst. Auch die Erhöhung der Temperatur bis $42^{\circ} \mathrm{R}$. innerhalb 10 Ninuten oder die Ablühlung der Eier bis - $4^{0}$ übt keinen Einfluss auf die vorzeitige Ausbrütung aus. Er betrachtet das Licht auch nicht als Ursache des Bivoltismus, denn frisch abgelegte Eier kamen unter lem Einflusse des direkten Sonnenlichtes während 2 Tagen nicht aus. Er untersuchte daher den Zusamınenhang zwischen dem Bivoltismus und dem krankhaften Zustande der die Eier legenden Weibchen und kam zu folgendem Schiusse: „Auf diese Art, wenn man 
die zwei oben erwähnten Thatsachen in Betracht zieht und zwar 1) das ziemlich oft stattfindende zufällige Auskommen aus Eiern, welche von gesunden Weibchen abgelegt werden, und 2) die vollständige Unmöglichkeit, den Zusammenhang zu finden zwischen dem Grade der Ansteckung der gegebenen Partien durch verschiedene Krankheiten und der Anzahl der bei ihnen beobachteten Fälle der vorzeitigen Ausbrütung der Raupen, so kann man nur zu dem Schlusse kommen, dass die zufällige Ausbrütung vollständig unabhängig von der Ansteckung der Schmetterlinge durch diesen orler jenen Mikroorganismus geschieht, und dass die zuweilen beobachtete Uebereinstimmung der bedeutenden Anzahl von Fällen der vorzeitigen Ausbrütuug der Eier mit dem mehr oder weniger starken Krankwerden der gegebenen Partie vielleicht infolge des Umstandes vorkommt, dass die Bedingungen, welche die Entwickelung verschiedener Krankheiten begïnstigen, zu gleicher Zeit auch die zufällige Ausbrütung begünstigen" (p. 208).

1890 vom Gouvernement Kutais erhaltenen Eier vom Seidenspinner ergaben $0,2 \%$ vorzeitig ausgebrütete Raupen, während die Eier der Station für die Seidenaufzucht in Tiflis, wo Schmujdsinowitsch arbeitete, solcher nur $0,025 \%$ ergaben. Es entsteht somit die Frage, ob diese Erscheinung nicht durch den Transport bedingt sei, d. h. durch das Schïtteln, durch starkes Erwärmen der Puppen, durch das Erschweren des Athmens etc. Diese Ursachen werden auch durch den Umstand verworfen, dass bei der Aufzucht in der Station, wo sie fehlen, auch das vorzeitige Ausbrüten beobachtet wird.

Durch Versuche fand er, dass die Neigung zum Bivoltismus bei Eiern von Bombyx mori im allgemeinen erblich ist, indem er sagt: "Schmetterlinge, welche aus vorzeitig ausgebrïteten Eiern abstammen, legen Eier ab, welche keinen Bivoltismus zeigen können, aber es wiederholt sich in mehr oder weniger starkem Grade im folgenden Jahre; die Neigung zum Bivoltismus verschwindet jerloch oft; das letztere geht besonders Schmetterlinge an, welche aus den vorzeitig ausgebrüteten Eiern entstammen, die überwintert haben" (p. 215).

$\mathrm{Er}$ betrachtet daher die Erscheinung des Bivoltismus beim Seidenspinner des Maulbeerbaumes als einen speziellen Fall des Atavismus, welcher z. B. dem Vorkommen schwarzer Raupen, dunkelgefärbter Schmetterlinge, der Cocons, welche abgespitzt und an einem Ende mit einer Oefẗnung versehen sind etc., analog ist. „Bei schlechten Ernährungsbedingungen, wobei die Abweichungen von dem normalen Typus überhaupt am häufigsten beobachtet werden, 
muss man auch das Vorkommen der vorzeitigen Ausbrütung häufiger erwarten, wie es auch der Fall ist. Wahrscheinlich wurl die beobachtete Abhängigkeit der vorzeitigen Auskommens von den Ansteck'n der Schmetterlinge durch Krankheiten auch durch den letzten Umstand erklärt". (p. 217).

Victor Rollat (1894. 704) drückte 2-3 gr. Eier von Bombyx mori in einer Schachtel zusammen, welche der Kälte noch nicht ausgesetzt waren. Der Druck dauerte 12 Tage, und 15 Tage darauf entwickelten sich die Räupchen. Aus den normalen, beim Kontrolversuche benützten Eiern fand kein Entschlïpfen statt.

Um zu ermitteln, ob die comprimierte Luft dieselben Resultate ergiebt, brachte er die Eier in einen Behälter, in welchem vergrösserter Luftıruck herrschte. Die mehrere Monate alten Eier entwickelten sich dabei gut, wie folgendes Beispiel zeigt:

5 Serien von 24 Stunden alten Eiern wurlen von 9. Juni an unter Luftdruck von 3-4 Atmosphären gehalten. Die 6-te Serie diente zum Kontrolversuche. Die Zimmertemperatur betrug 25 bis $28^{\circ}$ C. Alle 24 Stunden wurde je eine Serie herausgenommen. Das Ausschlüpfen began am 18. Juni und damerte 3-4 Tage.

3 Serien und der Kontrolversuch ergaben kein positives Resultat. Die übrigen Serien lieferten:

Die Anzahl der Die Anzahl der Das Ausentschlüpften beim Versuche schlüpfen Räupclien. benützten Eier. in \%

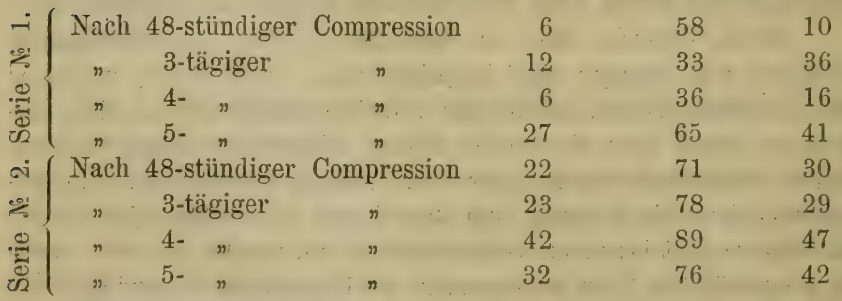

Mit Druck von 6 bis 8 Atmosphären kann man innerhalb 15 Tagen die Eier zu jeder Zeit im Jahre zur Entwickelung bringen.

M. Bellati und E. Quajat (1896. 63) frottierten mittelst einer harten Bürste Eier von Bombyx mori, welche auf Papier geklebt waren. Das schwache Frottieren hat keine Wirkung auf die Entwickelung, ein zu starkes verilrückt die Eier, bei der Anwendung 
mittleren Frottierens wird die Entwickelung der Eier beschleunigt, jedoch wenn die Eier nicht $7.1 \mathrm{alt}$ und nicht $\mathrm{zu}$ frisch sind. Es ist beobachtet worlen, wenn eine gewisse Temperatur noch nicht in Stancle ist, die Entwickelung der Eier zu beschleunigen, und dasselbe verhält sich auch mit einer gewissen Stärke des Frottierens; so wirken beide Falitoren vereinigt beschleunigend auf die Entwickelung. d. h. ein Faktor hilft dem anderen.

Im Werke "Il filugello e l' arte sericola" von E. Verson und E. Quajat (1896. 924) befinclet sich auf p. 116 und 117 die Beschreibung der Versuche von M. Bellati über den Einfluss der comprimierten Luft auf die Entwickelung der Eier von Bombyx mori, welche vermuthlich bis da noch nirgends veröffentlicht wurden. Diese Versuche wurlen mit polivoltischer Rasse vermittelst der Maschine von Cailletet angestellt. Die Eier waren nicht frisch, sondern 2 Monate alt.

Erster Versuch: Der Luftdruck betrug 8-9 Atmosphären und der Versuch dauerte vom 21. XII. bis 25. XII. 1894. Die Temperatur betrug $14-15^{\circ}$, später $23^{\circ}$. Am 25. II. 1895 wurcle keine Entwickelung von Keimen beobachtet.

Zweiter Versuch: Der Druck betrug 8-9 Atm. während 21. XII. bis 29. XII. Die Temperatur wie früher. Am 25. II. keine Keime.

Dritter Versuch: $8 \mathrm{Atm}$. von 20. XII. bis 26. XII.; die Temperatur dieselbe. Am 25. II. keine Keime.

Vierter Versuch: $8 \mathrm{Atm}$. von 20. I. bis 4. II.; die Temperatur dieselbe. Am 23. II. keine Keime.

Kontrol-Versuch: Eier unter denselben Bedingungen, aber bei normalem Druck, ergaben auch keine Keime (im Februar).

Zwei Jahre später schrieben M. Bellati und E. Quajat (1898. 66), dass ihre Versuche mit comprimierter Luft keine Entwickelung der Eier von Bombyx mori hervorrufen konnten, und versprachen diess Versuche ausfuhrlicher an anderer Stelle zu veröffentlichen.

0. Schultz (1897. 785) beobachtete oft sowohl im Freien wie auch bei gezogenen Exemplaren von Rhopaloceren und Sphingiden verschiedene Missbildungen und auch kreisrunde Löcher inmitten der Flügel. Er spricht die Vermuthung aus: „ob hier nicht Einflüsse äusserer Art, etwa Quetschungen oder Verletzungen des Individuums in seinen früheren Entwickelungsstadien, welche dann auf 
den inneren Organismus einwirkten, diese alson lerlichen Erscheinungen ins Leben rufen?" (p. 144).

B. M. Schitkow (1897. 752) erhielt Eier von Bombys mori und zwar von einer Brut, welche mit Blïttern von Schwarzwurzel gefuittert wurde; dabei fand die Aufzucht zu späterer Jahreszeit (August) und unter sonst ungünstigen Verhältnissen (grosse Sterblichkeit etc.) statt. Diese Eier wurlen in (len Brutofen gebracht und entwickelten sich sehr langsam; drei Tage nach dem Beginn der Ausbriitung wurde kaum die Halfte der Raupen erhalten. Einige von ihnen frassen die Blätter der Schwarzwurzel gern, die anderen dagegen frassen nicht und liefen herum, als ob sie anderes Futter suchten, bis sie schliesslich starben. Die erste Partie ergab Gespinnste.

J. Th. Oudemans (1898. (16) erzog vollständig kastrierte Raupen ron Ocneria dispar und stellte die Kiopulation zwischen 3 q und kastrierten Männchen her. Es wurde nachgewiesen, dass die Spermatozoiden dabei vollständig fehlten; trotzlem schliipften aus dem abgelegten Eiern (70, 42 und 160) Raupen und zwar 5, 7 und 53 aus.

A. T. Chapman (1898. 140) beobachtete, dass die kranken Raupen von Cossus ligniperda sich stets früher verpuppen als die gesunden; auch ist die Festigkeit des Gespinnstes so schwach, dass die Schlupfwespen dieselbe durchbrechen können.

Gust. Tornier (1900. 879) unternalım pathologische Untersuchungen von 76 Exemplaren missgebildeter Käfer des Berliner Museums für Naturkunde und fand: „Wirken Druck, Zug oder eine biegende Kraft, deren Energie jene Elasticitïtsgrenze des Chitins ïberschreitet, auf Käfertheile ein, so verbilden sich dieselben. Die in diesem Kampfe des lebenden Organismus mit äusseren Kräften entstandenen Verbildungscharaktere entsprechen genau denen, welche unter denselben Bedingungen an einem tniten Gebilde von gleicher Konsistenz entstehen. Eine solche Verbilıung behält der Kiäfer für Lebenszeit."

K. Manger (1901. 544) beobachtete die Dauer der Puppenruhe von Tenebrio molitor L. unil stellte fest, dass dieselbe bei 188 
Exemplaren (98 $\sigma^{\top} \sigma^{\pi}$ und 90 우) im Mittel 161/2 Tage betrug (zwischen 13 und 19 Tagen). Drei Exemplare hatten jerioch die Puppenruhe von 25 bezw. 24 und 21 Tagen) welche verkrüppelte Exemplare ergaben. Er sagt dazu: „Abnorm lange Puppenruhe bringt auch hier deformirte Imagines mit sich."

\section{Ergänzungs-Litteratur zu diesem Abschnitt.}

Bolle, Giov. Versuchszuchten, um den Einfluss der Fermente (Micrococcus) in den Puppen und Schmetterlingen auf die Samen zu erforschen. - Seidenbau Versucbsstation. Görz. 1873. p. 49-54. (A uch italienisch ebd. p. $44-49)$.

Loeb, J. Die Orientierung der Thiere gegen die schwerkraft der Erde. (Thierischer Geotropismus). - Sitzgsber. physik.-med. Gesellschaft. Würzburg 1888. 솟 1. p. $5-10$.

Rudzsky, K. A. Zur Frage über die Ursachen der so genannten kleinen Eierablagen bein Bombyx mori. - Arbeiten der kaukasischen SeidenzuchtStation. Jahrg. 1890. III. Bd. p. 223-235. Tiflis 1892. (Russisch).

Schmujdsinowitsch, W. J. Ist beim Sacksystem der Eierablage irgend eine Abhängigkeit zwischen der Form der Eierablage und den Gesundheitszustand der Schmetterlinge vorhanden? - Arbeiten der kaukasischen Seidenzucht-Station. Jahr. 1890. III Bd. p. 236-238. Tiflis 1892. (Russ.).

Sohmujdsinowitsch, W. J. Zur Frage über die Erblichkeit der Krankheiten [bei Bombyx mori]. -- Arbeiten der kaukasischen Seidenzucht-Station. Jahr. 1891. IV. Bd. p. 107-122. Tiflis 1892. (Russisch).

Schultz, 0sk. Zur Frage von der Bedeutung der Schwerkraft für die Entwickelung des thierischen Embryo. - Arch. für mikrosk. Anat. LVI. 1900. p. 309.

Schultze, 0. Neue Untersuchungen über die Nothwendigkeit der richtenden Wirkung der Schwerkraft für die Entwickelung. - Sitzsber. phys.-med. Ges. Würzburg. Jahrg. 1897. № 3. p. 41-43.

Schultze, 0. Neue Untersuchungen zur Frage von der Nothwendigkeit der Schıverkraft für die Entwickelung. - Verhandl. der Anatom. Gesellsch. auf der elften Versamml. in Gent vom 24.-27. April 1597. p. 109-116. (Separatum).

- Valery-Mayet. Éclosion des vers á soie par le frottement. - Assoc. franç. p. l'avanc. d. sc. C. R. de la 8. Sess. (1879). 1880. p. 754-756.

Verson, E. e Quajat, E. Sullo strofinamento e sulla srernatura artificiale, allo scopo di anticipare lo schiudimento delle uova del baco da seta. Ann. II. Staz. Bac. 1874. p. 3.

Verson, E. e Quajat, E. Ancora sullo strofinamente dei semi di razza anmale. - Ann. II. Staz. Bac. 1874. p. 113. 


\section{ZWEITES KAPITHL.}

\section{Die Grösse und die Gestalt der Insekten.}

\section{Einleitung.}

Unzweifelhaft ist die Grösse und die Gestalt der Inseliten als ein Produlit der Anpassung an die äusseren Verhältnisse aufzufassen, da diese beiden Qualitäten von äusseren Faktoren beeinflusst werlen. Es ist jedoch nicht zu leugnen, dass unter sonst gleichen äusseren Verhältnissen eine und dieselbe Insekten-Art Exemplare aufweist, welche sowohl der Grösse, wie auch der Gestalt nach von ein:mder mehr oler weniger sich unterscheiden. Diese sogenannte Variabilität hat ihren Grund in den individuellen Eigenschaften, welche durch die inneren Anlagen erzeugt werden.

Um die Gesetze, welchen diese Variabilität in Bezug auf die Grösse bei Inseliten folgt, festzustellen, unternahm ich die nöthigen Messungen nach analytisch-statistischer Methode bei einigen InsektenArten in einen und derselben Gegend, wobei alle Exemplare einer und derselben Art zu gleicher Zeit gesammelt wurden.

Im Nachstehenden werden die Messungen beschrieben, welche zu ihrer Aufgabe die Bestimmung der Fliigellänge haben.

Ich habe früher (1899. 22, 26) zur Messung der Flügellïnge der Schmetterlinge diejenige Linie vorgeschlagen, welche die Wurzel des Fligels mit dem entferntesten Punkte desselben verbindet, d. h. die Linie $d$ (Fig. 1).

Biegt man die Flügel eines trockenen Schmetterlings, so brechen sie bei den Wurzeln ab, wobei der Punkt $C$ nicht genau zu bestimmen ist, besonders bei weiblichen Exemplaren. Die Flügel haben dabei im allgemeinen folgendes Aussehen (Fig. 2 und 3).

Um grössere Genauigkeit bei Messungen der Flügellänge zu erreichen, ist es vortheilhafter die Linie $d_{1}$ für den Vorderflügel uncl $d_{2}$ für den Hinterflügel $\mathrm{zu}$ bestimmen, was leicht mit einem Zirkel und Maasstabe zu machen ist. 
Alle unten angeführten Messungen sind an Flügeln vorgenommen, welche von im Zimmer getrockneten Schmetterlingen abgebrochen und auf Papier aufgeklebt wurden. Dabei kamen nur die rechten Vorder- und Hinterflügel in Betracht.

\section{Messungen an Aporia crataegi $\mathrm{L}$.}

Diese Schmetterlinge wurden im botanischen Garten der Hochschule zu Sophia von 15. bis 28. VI. 1902 Abends an Pflanzen gesammelt. Im Ganzen wurden 685 weibliche und 122 männliche Exemplare erbeutet. Die Messungen wurden möglichst genau bis $0,1 \mathrm{~m} . \mathrm{m}$. angestellt und ergaben folgendes thatsächliches Material, wobei $d_{1}$ die Länge der Vorder- und $d_{2}$ die Länge der Hinterflügel und $f_{1}$ resp. $f_{2}$ die Frequenz (Häufigkeit) der Exemplare mit der gegebenen Dimension bedeuten $\left.{ }^{1}\right)$ (1903. 39):

\section{TABELLE I.}

Aporia crataegi L. 우우. $d_{1}$ von $0,1 \mathrm{zu} 0,1 \mathrm{~m} . \mathrm{m}$.

\begin{tabular}{|r|r||r|r|r|r|r|r|r|r|r|r|r|}
\hline \multicolumn{1}{|r|}{$d_{1}$} & $f_{1}$ & $d_{1}$ & $f_{1}$ & $d_{1}$ & $f_{1}$ & $d_{1}$ & $f_{1}$ & $d_{1}$ & $f_{1}$ & $d_{1}$ & $f_{1}$ \\
\hline \hline 26,1 & 1 & 28,1 & 0 & 30,1 & 3 & 32,1 & 14 & 34,1 & 6 & 35,9 & 0 \\
2 & 0 & 2 & 0 & 2 & 2 & 2 & 13 & 2 & 13 & 36,0 & 4 \\
3 & 0 & 3 & 0 & 3 & 2 & 3 & 13 & 3 & 9 & 1 & 0 \\
4 & 1 & 4 & 1 & 4 & 4 & 4 & 9 & 4 & 11 & 2 & 0 \\
5 & 0 & 5 & 1 & 5 & 2 & 5 & 16 & 5 & 17 & 3 & 3 \\
6 & 0 & 6 & 1 & 6 & 7 & 6 & 16 & 6 & 15 & 4 & 2 \\
7 & 0 & 7 & 0 & 7 & 0 & 7 & 6 & 7 & 9 & 5 & 0 \\
8 & 0 & 8 & 1 & 8 & 5 & 8 & 27 & 8 & 11 & 6 & 0 \\
9 & 1 & 9 & 0 & 9 & 3 & 9 & 15 & 9 & 13 & 7 & 0 \\
27,0 & 0 & 29,0 & 1 & 31,0 & 9 & 33,0 & 41 & 35,0 & 25 & 8 & 1 \\
1 & 0 & 1 & 1 & 1 & 3 & 1 & 13 & 1 & 3 & 9 & 0 \\
2 & 0 & 2 & 2 & 2 & 6 & 2 & 24 & 2 & 10 & 37,0 & 0 \\
3 & 1 & 3 & 0 & 3 & 4 & 3 & 14 & 3 & 3 & 1 & 0 \\
4 & 1 & 4 & 1 & 4 & 3 & 4 & 16 & 4 & 2 & 2 & 0 \\
5 & 0 & 5 & 0 & 5 & 7 & 5 & 14 & 5 & 7 & 3 & 0 \\
6 & 0 & 6 & 4 & 6 & 7 & 6 & 14 & 6 & 6 & 4 & 0 \\
7 & 0 & 7 & 0 & 7 & 2 & 7 & 15 & 7 & 3 & 5 & 0 \\
8 & 0 & 8 & 1 & 8 & 10 & 8 & 14 & 8 & 6 & 6 & 1 \\
9 & 0 & 9 & 1 & 9 & 12 & 9 & 18 & & Zusammen & 685 \\
28,0 & 2 & 30,0 & 9 & 32,0 & 28 & 31,0 & 43 & & & & \\
\hline
\end{tabular}

1) Diese Grössen sind für männliche Exemplare mit einem Strich versehen, d. h. $d_{1}^{\prime}, d_{2}^{\prime}, f_{1}^{\prime} f_{2}^{\prime}$. 
TABELLE II.

Aporia cratacgi L. 우우.

$d_{2}$ von $0,1 \mathrm{zu} 0,1 \mathrm{~m} . \mathrm{m}$.

\begin{tabular}{|c|c|c|c|c|c|c|c|c|c|c|c|}
\hline$d_{2}$ & $f_{2}$ & $d_{2}$ & $t_{2}$ & $d_{2}$ & $i_{2}$ & $d_{2}$ & $t_{: 2}$ & d. & $f_{2}$ & $d_{2}$ & $f_{2}$ \\
\hline 200 & 2 & 219 & 0 & 238 & 2 & 257 & s & 27 & 1) & 294 & 4 \\
\hline $\begin{array}{r}20,0 \\
1\end{array}$ & 0 & $\begin{array}{l}21,9 \\
22,0\end{array}$ & 1 & $\begin{array}{r}20,0 \\
9\end{array}$ & $\overline{0}$ & 8 & 9 & 7 & 12 & $\begin{array}{r}20,4 \\
5\end{array}$ & 9 \\
\hline 2 & 1 & 1 & 0 & 24,0 & 3 & 9 & З̆ & 8 & 19 & (; & 2 \\
\hline 3 & 0 & 2 & 1 & 1 & 2 & 26,0 & 23 & ? & 16 & 7 & 6 \\
\hline 4 & 0 & 3 & 0 & 2 & 0 & 1 & 11 & 25.0 & 52 & s & 4 \\
\hline 5 & 0 & 4 & 0 & 3 & 3 & 2 & 11) & 1 & 12 & 9 & 2 \\
\hline 6 & 1 & 5 & 1 & 4 & 1 & 3 & 4 & 2 & 24 & 30,0 & 7 \\
\hline 7 & 0 & 6 & 0 & 5 & 5 & 4 & 11 & $\therefore$ & 10 & 1 & 1 \\
\hline 8 & 0 & $T$ & 1 & (j & 1 & 5 & 19 & 4 & 14 & 2 & 1 \\
\hline 9 & 0 & 8 & 0 & 7 & 0 & 6 & 18 & . 5 & 15 & 3 & 1 \\
\hline 21,0 & 0 & 9 & 0 & 8 & 2 & 7 & 16 & 6 & 16 & .t & 0 \\
\hline 1 & 0 & 23,0 & 1 & 9 & 0 & 8 & 19 & 7 & 11 & $\tilde{\jmath}$ & 1 \\
\hline 2 & 0 & 1 & () & 25,0 & 15 & 9 & 12 & 8 & 9 & (j) & 0 \\
\hline 3 & 1 & . 2 & 2 & 1 & 4 & 27,0 & 45 & 9 & 9 & 7 & 0 \\
\hline 4 & 0 & 3 & 0 & 2 & 6 & 1 & 15 & 29,0 & 20 & 8 & 0 \\
\hline 5 & 0 & 4 & 1 & 3 & 5 & 2 & 24 & 1 & 6 & 9 & 0 \\
\hline 6 & 0 & j & 1 & 4 & 4 & 3 & 11 & 2 & 8 & 31,0 & 0 \\
\hline 7 & 0 & 6 & 0 & 5 & 7 & 4 & 15 & 3 & 2 & & \\
\hline 8 & 0 & 7 & 0 & 6 & 6 & 5 & 21 & & \multicolumn{2}{|c|}{ Zusammen } & 685 \\
\hline
\end{tabular}

TABELLE III.

Aporia crataegi L. ठౌ ठౌ.

$d_{1}^{\prime}$ von 0,1 zu $0,1 \mathrm{~m} . \mathrm{m}$.

\begin{tabular}{|c|c|c|c|c|c|c|c|c|c|c|c|}
\hline$d_{1}^{\prime}$ & $f_{1}^{\prime}$ & $d_{1}^{\prime}$ & $f_{1}^{\prime}$ & $d_{1}^{\prime}$ & $f_{1}^{\prime}$ & $d_{1}^{\prime}$ & $f_{1}^{\prime}$ & $l_{1}^{\prime}$ & $f_{1}^{\prime}$ & $d_{1}^{\prime}$ & $f_{1}^{\prime}$ \\
\hline 24,0 & 1 & 26,0 & 0 & 28,0 & 0 & 30,0 & 6 & 32,0 & 12 & 33,9 & 1 \\
\hline 1 & 0 & 1 & 0 & 1 & 0 & 1 & 0 & 1 & 4 & 34,0 & 2 \\
\hline 2 & 0 & 2 & 0 & 2 & 0 & 2 & 1 & 2 & 2 & 1 & 0 \\
\hline 3 & 0 & 3 & 0 & 3 & 0 & 3 & 0 & 3 & 4 & 2 & 1 \\
\hline 4 & 0 & 4 & 0 & 4 & 0 & 4 & 3 & 4 & 2 & 3 & 0 \\
\hline 5 & 0 & 5 & 0 & 5 & 0 & 5 & 0 & 5 & 5 & $\underline{4}$ & 1 \\
\hline 6 & 0 & 6 & 0 & 6 & 0 & 6 & 0 & 6 & 3 & 5 & 0 \\
\hline 7 & 0 & 7 & 0 & 7 & 0 & 7 & 0 & 7 & 2 & 6 & 1 \\
\hline 8 & 0 & 8 & 0 & 8 & 0 & 8 & 2 & 8 & 4 & 7 & 1 \\
\hline 9 & 0 & 9 & 0 & 9 & 0 & 9 & 0 & 9 & 0 & 8 & 1 \\
\hline 25,0 & 0 & $2 \pi, 0$ & 0 & 29,0 & 2 & 31,0 & 7 & 33,0 & 6 & 9 & 0 \\
\hline 1 & 0 & 1 & 0 & 1 & 0 & 1 & 1 & 1 & 3 & 35,0 & 1 \\
\hline 2 & 0 & 2 & 0 & 2 & 0 & 2 & 1 & 2 & 5 & 1 & 0 \\
\hline 3 & 1 & 3 & 0 & 3 & 0 & 3 & 0 & 3 & 2 & 2 & 0 \\
\hline 4 & 0 & 4 & 0 & 4 & 0 & 4 & 3 & 4 & 1 & 3 & 0 \\
\hline 5 & 0 & 5 & 0 & 5 & 2 & 5 & 5 & 5 & 3 & 4 & 1 \\
\hline 6 & 0 & 6 & 0 & 6 & 1 & 6 & 3 & 6 & 2 & 5 & 0 \\
\hline 7 & 0 & 7 & 0 & 7 & 0 & 7 & 1 & 7 & 3 & 6 & 0 \\
\hline 8 & 0 & 8 & 0 & 8 & 1 & 8 & 2 & 8 & 1 & 7 & 1 \\
\hline 9 & 0 & 9 & 0 & 9 & 2 & 9 & 2 & 9 & \multicolumn{2}{|c|}{ Zusammen } & 122 \\
\hline
\end{tabular}


Einleitung.

TABELLE IV.

Aporia crataegi L. ठ઼ ठ઼.

$d_{\mathrm{g}}^{\prime}$ von $0,1 \mathrm{zu} 0,1 \mathrm{~m}$. $\mathrm{m}$.

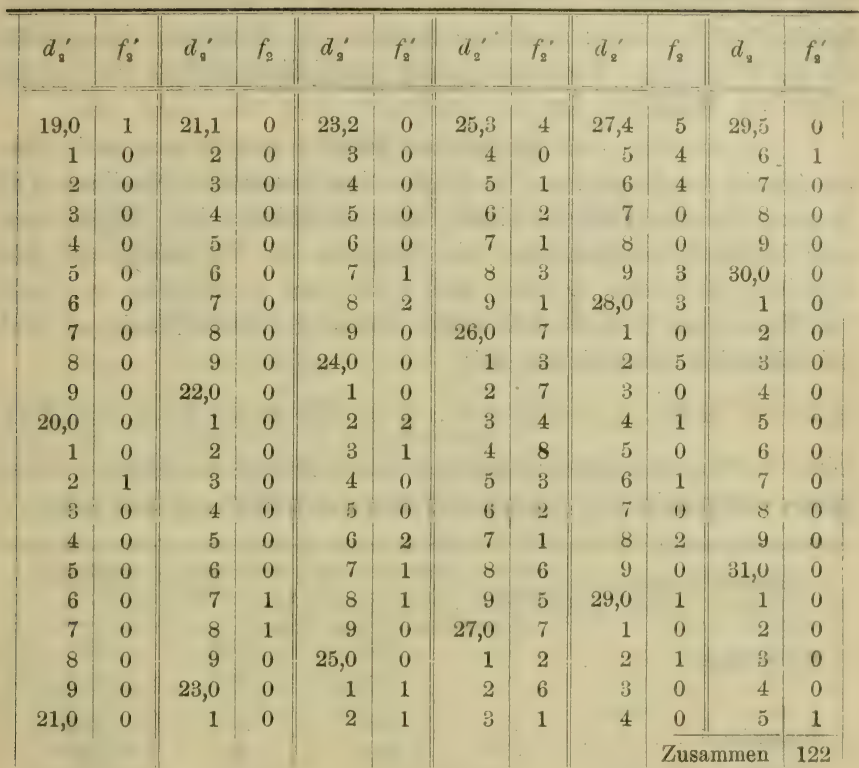

Aus diesen Tabellen ist ersichtlich, dass die Flügellänge sowohl bei weiblichen wie bei männlichen Exemplaren unter sich sehr stark variirt und zwar beträgt das Minimum resp. Maximum dieser Grösse:

\begin{tabular}{|c|c|c|c|c|c|c|}
\hline \multirow{3}{*}{ Aporia erataegi } & \multicolumn{6}{|c|}{ Die Flügellänge } \\
\hline & \multicolumn{2}{|c|}{ Weibchen } & \multicolumn{2}{|c|}{ Männchen } & \multirow{2}{*}{$\begin{array}{c}\text { Arithme- } \\
\text { tisches Mittel }\end{array}$} & \multirow{2}{*}{$\begin{array}{l}\text { Variabilitäts- } \\
\text { Amplitude } \\
\text { in } \%\end{array}$} \\
\hline & $\max$ & $\min$. & $\max$ & $\min$. & & \\
\hline Vorderflügel . . . & 37,6 & 26,1 & - & - & 31,85 & 36,1 \\
\hline Hinterflügel . . . & 30,5 & 20,0 & - & - & 25,25 & 32,9 \\
\hline Vorderflügel . . . & - & - & 35,7 & 24,0 & 29,85 & 39,0 \\
\hline \multirow[t]{2}{*}{ Hinterflügel . . . } & 一 & - & 31,5 & 19,0 & 25,25 & 48,8 \\
\hline & & & & & Mittel: & 39,2 \\
\hline
\end{tabular}


Hier bedeutet die Variabilitäts-Amplitude lie roppelte Differenz zwischen dem arithmetischen Mittel und dem Maximum (resp. dem Minimum) der Flügellänge. Bereits daraus kann man ersehen, dlass die Flïgellänge bei Aporia rataegi in rlen Grenzen variirt, welche $39,2 \%$ bilden; ausserlem variiren die Männchen viel stärker als die Weibchen. Besonrlers grosse Variabilität steller die Hinterflügel der Männchen dar.

Aus ilen vier oben angefïhrten Tabellen ersieht man auch, rlass die Anzahl iler Exemplare ( $f$ ), welche eine bestimmte Fliigellänge (d) in verschieilenen Fäilen besitzen, sehr verschieden ist. Dabei kann man jedoch beobachten, dass die Frequenz der Flügellänge mit der Zunahme der Grösse $d$, wenn auch nicht ganz regelmässig, zunimmt, ein Maximum erreicht und wierler abnimmt. Dieses Maximum tritt bei folgenden Dimensionen auf:

$d_{1}=34,0 \mathrm{~m} . \mathrm{m} ., d_{2}=28,0 \mathrm{~m} . \mathrm{m} ., d_{1}{ }^{\prime}=32,0 \mathrm{~m} . \mathrm{m} ., d_{2}{ }^{\prime}=26,4 \mathrm{~m} . \mathrm{m}$.

Diese Werthe sind etwas grösser als das arithmetische Mittel, welches in der vorhergehenilen Zusammenstellung angeführt ist, uni zwar:

\begin{tabular}{|c|c|c|c|c|}
\hline Aporia crataegi & $\begin{array}{c}\text { Ge- } \\
\text { schlecht }\end{array}$ & $\begin{array}{l}\text { Maximum der } \\
\text { Frequenz bei }\end{array}$ & $\begin{array}{c}\text { Arithmeti- } \\
\text { sches Mittel }\end{array}$ & $\begin{array}{c}\text { Differenz } \\
\text { in } \%\end{array}$ \\
\hline Vorderflügel . . . . & $\begin{array}{l}\text { क } \\
\sigma^{\pi}\end{array}$ & $\begin{array}{l}34,0 \\
32,0\end{array}$ & $\begin{array}{l}31,8 \\
29,8\end{array}$ & $\begin{array}{l}6,5 \\
6,8\end{array}$ \\
\hline Hinterflügel . . . & $\begin{array}{l}\text { q } \\
\text { d }\end{array}$ & $\begin{array}{l}28,0 \\
26,4\end{array}$ & $\begin{array}{l}25,2 \\
25,2\end{array}$ & $\begin{array}{r}10,0 \\
4,6\end{array}$ \\
\hline
\end{tabular}

Die Flügellänge, bei welcher das Maximum der Frequenz auftritt, wollen wir die frequenzielle oder normale Flïgellänge nennen, la mit dieser Länge die Schmetterlinge der gegebenen Art und des Geschlechtes am häufigsten vorkommen.

Die normale Flügellänge ergiebt verschietlene Beziehungen für weibliche und männliche Exemplare, von welchen ich hier nur eine Trleichung anführe, da die Bearbeitung dieses und ähnlichen Materials in dem III. Bande dieser "Studien" ihren Platz finden wird. Diese Gleichung ist die folgende:

$$
d_{1}: d_{1}{ }^{\prime}=d_{2}: d_{2}{ }^{\prime}
$$

und in der That, setzt man die entsprechenden frequenziellen Werthe ein, so erhält man:

$$
34,0: 32,0=28,0: 26,4
$$


ler erste Theil dieser Gleichung ergiebt, 1,062 und der zweite 1,061. Diese Werthe differieren unter sich um $0,1 \%$, was bei solchen Messungen ausser Acht gelassen werlen kann. Daraus folgt, dass das Verhailtniss zwischen den normalen Iängen ler Vorderflügel bei Weibchen und Männchen demselben Verhältnisse für die Hinterflügel gleich ist.

Van kann aber diese Gleichung auch so schreiben:

$$
d_{1}: d_{2}=d_{1}{ }^{\prime}: d_{2}{ }^{\prime}
$$

d. h. das Verhältniss der normalen Längen der Vorder-zu den Hinterflügeln bei weiblichen Exemplaren ist demselben Verhältnisse bei männlichen Exemplaren gleich.

Messungen an Epinephele janira L.

Diese Schmetterlinge wurden in einem Ort in der Nähe von Sophia während dles Monats Juli 1902 gefangen. Im ganzen wurden $155 \sigma^{\varnothing} \sigma^{\circ}$ und 139 우 gesainmelt.

Dabei ergab sich für die Flügellänge (1903. 37):

\begin{tabular}{|c|c|c|c|c|c|c|}
\hline \multirow{3}{*}{ Epinephele janira } & \multicolumn{6}{|c|}{ Die Flügellänge } \\
\hline & \multicolumn{2}{|c|}{ q } & \multicolumn{2}{|c|}{$\sigma^{7} \sigma^{7}$} & \multirow{2}{*}{$\begin{array}{l}\text { Arithmeti- } \\
\text { sches Mittel }\end{array}$} & \multirow{2}{*}{$\begin{array}{l}\text { Variabilitäts- } \\
\text { Amplitude } \\
\text { in } \%\end{array}$} \\
\hline & $\max$. & $\min$. & $\max$. & $\min$. & & \\
\hline Vorderflügel . . & 29,0 & 22,4 & - & - & 25,7 & 25,8 \\
\hline Hinterflügel . . . & 25,2 & 19,0 & - & - & 22,1 & 28,0 \\
\hline Vorderflügel . . . & - & - & 26,6 & 20,0 & 23,3 . & 33,0 \\
\hline \multirow[t]{2}{*}{ Hinterflingel . } & - & - & 22,6 & 16,5 & 19,5 & 30,8 \\
\hline & & & & & Mittel: & 29,4 \\
\hline
\end{tabular}

Hier, wie auch bei Aporia crataegi, variirt die Flügellänge bei männlichen Exemplaren stärker als bei weiblichen. Die mittlere Variabilitätsamplitude $(29,4 \%)$ ist jeloch geringer als bei Aporia crataegi $(39,2 \%)$.

Das Maximum der Frequenz ergab sich bei folgenden Flügellängen:

\begin{tabular}{|c|c|c|c|c|}
\hline \multicolumn{2}{|c|}{ Epinephele janira } & Maximum der & $\begin{array}{l}\text { Arithmeti- } \\
\text { sches Mittel }\end{array}$ & Differenz \\
\hline Vorderflügel . . . . & $\begin{array}{l}\text { 우 } \\
\sigma^{\pi} \sigma^{\pi}\end{array}$ & $\begin{array}{l}26,3 \\
23,8\end{array}$ & $\begin{array}{l}25,7 \\
23,3\end{array}$ & $\begin{array}{l}2,3 \\
2,1\end{array}$ \\
\hline Hinterflügel . . . . & $\begin{array}{l}\text { oq } \\
0^{2} \sigma^{\pi}\end{array}$ & $\begin{array}{l}21,5 \\
19,8\end{array}$ & $\begin{array}{l}22,1 \\
19,5\end{array}$ & $\begin{array}{r}-1,8 \\
1,5\end{array}$ \\
\hline
\end{tabular}


1). h. hier weicht las arithmetische Mittel, wie atuch hei Aporia crataegi, von den Dimensionen ab, hei welchen das Maximum der Frequenz auttritt.

Somit sind die normalen Werthe für diese Art:

$d_{1}=26,3 \mathrm{~m}$. m., $d_{2}=21,5 \mathrm{~m} . \mathrm{m} ., d_{1}^{\prime}=23,8 \mathrm{~m} . \mathrm{m} ., d_{2}^{\prime}=19,8 \mathrm{~m} . \mathrm{m}$.

Auch hier gielt die Gleichung:

resp.

$$
\begin{aligned}
& d_{1}: d_{1}^{\prime}=d_{2}: d_{2}^{\prime}, \\
& d_{1}: d_{2}=d_{1}^{\prime}: d_{2}^{\prime} .
\end{aligned}
$$

Was dlas Verhältniss der Vorler- resp. dler Hintertlïgel bei Weibchen und Männchen anbetrifft, so ist, da

$$
d_{1}: d_{1}{ }^{\prime}=d_{2}: d_{2}{ }^{\prime}=l_{i} \text {, }
$$

die Konstante $k_{i}$ verschieden für verschiedene Arten. F’ür Apmic crataegi ist $k=1,06$ und für Epinephele janira $k=1,10$.

$$
\text { Messungen an. Frebiu euryale Esp. }
$$

Diese Schmetterlinge wurden am Berge Vitoscha (1500) lis

\begin{tabular}{|c|c|c|c|c|}
\hline \multirow{3}{*}{ Eretia euryale } & \multicolumn{4}{|c|}{ Die Flügellänge } \\
\hline & \multicolumn{2}{|c|}{$\sigma^{2}$} & \multirow{2}{*}{$\begin{array}{l}\text { Arithmeti- } \\
\text { sches Mittel }\end{array}$} & \multirow{2}{*}{$\begin{array}{l}\text { Variabilitäts } \\
\text { amplitude } \\
\text { in } \%\end{array}$} \\
\hline & $\max$. & $\min$. & & \\
\hline Vorderflügel . . & 23,8 & 17,8 & 20,8 & 28,8 \\
\hline \multirow[t]{2}{*}{ Hinterflügel } & 19,8 & 14,8 & 17,3 & 28,8 \\
\hline & & & Mittel: & 28,8 \\
\hline
\end{tabular}
$2285 \mathrm{~m}$.), in der Nähe von Sophia am 27. VII./9. VIII. 1903 e!beutet, und zwar 132 ठ゙ ठౌ.

Dabei ergab sich für die Flügellänge (1903. 38):

\begin{tabular}{|c|c|c|c|}
\hline Eretria euryale & $\begin{array}{l}\text { Maximum der } \\
\text { Frequenz bei }\end{array}$ & $\begin{array}{c}\text { Arithmeti- } \\
\text { sches Mittel }\end{array}$ & $\begin{array}{c}\text { Differenz } \\
\text { in } \%\end{array}$ \\
\hline ügel . . & 19,8 & 20,8 & 5 \\
\hline
\end{tabular}

Das Maximun der Frequenz ergab sich bei folgenden Flügellängen:

Hier beträgt die Grösse $k=1,14$ und die frequenzielle Flügellänge für Hinterflügel unterscheidet sich von der mittleren gar nicht.

Lus ien hier beschriebenen Messungen geht somit hervor, dass. die Flügellänge bei verschiedenen Exemplaren einer und derselben Art und desselben Geschlechtes sehr stark variirt, welche Variabilitït. 
unter anderem auch von innerer Anlage abhängt. Wir sind somit gezwungen, als Maas für die normale Flügellänge diejenige ihrer Grösse zu nehmen, welche bei den meisten Exemplaren vorhanden ist, wenn wir iiberhaupt irgend eine Vergleichung zwischen Arten machen wollen, sei es für die Ermittelung des Einflusses des Klimas, orler des EinHusses jerles einzelnen äusseren Faktors auf die Grösse der Insekten.

Es muss leider bemerkt werden, dass solche ausfiilnrliche Messungen dler Flügellänge, der Fühlerlänge etc. noch fehlen, sonst würden dieselben uns eventuell zu wichtigen Resultaten führen, wie ich es für die Parthenogenese der Bienen (1903. 36) und für die Prognose Iler neu zu entileckenilen Arten in der Entomologie (1905. 42 a) zeigte.

J. NeBdham und H. Maude (1903. 605) untersuchten mittelst eines Goniometers die Schiefe des Thorax bei Odonaten. Als Basis nahmen sie die Linie an, welche durch das Gelenk von Coxa und Thorax an Mittelbein unt durch die unterhalb-seitliche Einlenkung von Thorax und Abilomen geht. Die Richtung der Naht zwischen lem ersten und zweiten Thoraxalsegmente bildet mit einer Senkrechten auf dieser Basis einen Winkel $x$, der das Maas fuir die $\mathrm{Hu}$ meralschiefe larstellt. Es wurde noch der zweite Winkel $z$ gomessen, welcher eine ilurch die Insertionsstellen von Vorder- und Hinterfliigel gehende trerale mit der Basis bildet.

Es wurden in dieser Beziehung über 100 Arten gemessen, wobei sich folgende mittlere Werthe fuir das Maximum, Minimum und das Mittel ergaben:

$\overbrace{x^{0}}^{\text {Humeralwinkel. Flügelbasiswinkel. }} \underbrace{}_{z^{0}}$

Mi. Ma. Mit. Mi. Ma. Mit.

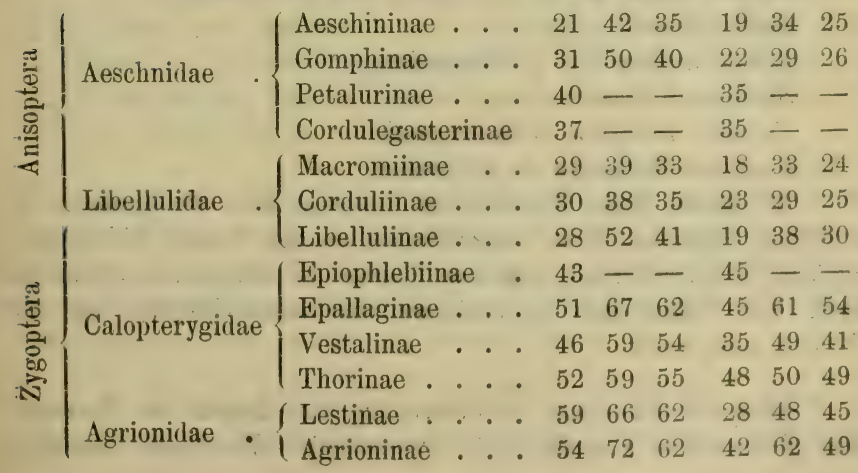


Zwischen $x$ und der Insektengrösse ist, wie es scheint, keine einfache Beziehung zu bemerken, dagegen fällt das Minimun mit der grössten und das Maximum mit der kleinsten Art zusammen.

\section{Erganzungs-Litteratur zu diesem Abschnitt.}

Büsgen. Die Entfaltung der Schmetterlingsflügel. - Inseliten-Börse. XVII. ג’̊ 32. 1900. p. 252.

Spnler, A. Phylogenie und Ontogenie des Flügelgeäders der Schmetterlinge. Zeitschr. fo wiss. Zoolog. LIII. 1892.

\section{Einfluss des Klimas.}

So lange Insekten gesammelt werden, ist schon bekannt, dass dieselben ihrer Grösse und Gestalt nach in verschiellenen Gegenden variiren. Naturgemäss war dieser Unterschied in erster Linie durch klimatische Verhältnisse zu erklären, wie auch verschierlene Untersuchungen in dieser Beziehung es zeigen.

Hagen (1846. 349) fand, dass Libellen aus verschiedenen Gegendlen Europas in der Grösse für eine und dieselbe Art unter sich sehr stark variiren. In südlichen Gegenden kommen immer Exemplare mit geringerer Grösse vor als in nördlichen Gegenden. Zwer@exemplare sind zu treffen:

Libellula depressa in Dalmatien,

Libellula conspurcata in Sicilien und Kleinasien,

Lestes virens

Lestes barbara

Synnpycna fuscal

in Kleinasien,

Cordulia metallica in Oesterreich,

Gomplus forcipatus in Kleinasien.

Er erklärt liese Erscheinung dadurch, dass die Inseliten in südlichen Gegenden früher ausschlïpfen, da das Wasser frühzeitiger erwärmt wird, während dlieselben Larven in nördlichen Gegenden mehr Zeit liaben, sich zu ernähern und auszuschlïpfen, bis das Wasser: warm wirl.

Vielleicht hat diese Untersuschung von Hagen den Vorstand der .Illustrierten Zeitschrift für Entomologie“ (Neurlamm) bewogen, 
folgende Preisaufgabe zu veröffentlichen: „Ist clie geringere Grösse von Libellula depressu und verwandter Arten in siidlicheren Gegenden wirklich eine F'olge der höheren Temperatur der Gewässer, in welchen ihre Larvenformen leben?" ${ }^{4}$ (1899. 776).

H. Meyer-Dür (1852. 580) weisst larauf hin, lass der Norden die campestren und subalpinen Arten von Lycaena verkleinert, die Vorderflügel bei Polyommatus und einigen Satyrus-Arten und (ler Gruppe von Davus verkürzt und den Aussenraml rechtwinkliger abschneidet; dass dagegen der Süden wiedler grössere Lixemplare bei Satyrus und stärkere Randzacken bei den Arten allionia und eudora erzeugt. Im Siiden sind doritis-Exemplare kleiner. Die Alpen-Natur macht Tiefland-Arten kleiner, schmiichtiger und die Vorderflügel bei Argynnis (euphrosyne) gestreckter.

Jul. Lederer (1863. 505) erhielt in Varna unl Slivio (Bulgarien) gefangene Schmetterlinge, welche grösser waren als die entsprechende Species in Wien, uncl zwar: Autoch. uusonin Hb. (gross), Hesp. sidae Esp. (sehr gross), Sesia anellata L. (ungewöhnlich gross), Calpe thalictri Bkh. (gross), Heliodes mpicola S. V. (gross). Kleiner waren: Melanargia larissa Hb. (kleiner als llie Dalmatiner), Laelia coenosa $\mathrm{Hb}$. (auffallend klein).

H. Löw (1563. 532) sagt, dlass die Fliegen Cycloguster temrirostris Lw., welche bei Slivno (Bulgarien) gefangen wurten, etwas grösser sincl als die Dalmatiner.

H. Hagen (1863. 350) fanıl, dass die syrischen Stiicke von $L$. fulva Muell. unil depressa L. von der Grösse sin!, die diese Arten in Nord- und Mittel-Europa erreichen. Die sürleuropäischen sind meist viel kleiner. Die in Grusien gefangenen Pulp. libelluloides I). sind ein Drittel kleiner als die Stammart.

J. Mann (1866. 545) fing in ler Dobrudscha (jetzige rumiinische Provinz) folgende Schmetterlinge, welche bedcutend grüsser sind, als die in der Wienergegend: Lycaena semiaryus Rott., L. cyllarus Rott., Melitaea athalia Esp., Aspilates strigillaria Hb., Lith(1)stege griseata S. V., Lithostege farinata Hufn.

C. A. Teich (1870. 855) sucht in seinem Vortrage "Klima unl Schmetterlinge" den Einfluss des Klimas auf die Grösse der Schmet- 
terlinge zunïchst dadurch zu begründen, dass die grössten Falter (Papilio priamus, Satumiu atlus etc.) Produkte der Tropen sind, währenı ,lie kleinsten Falter den gemässigten und kalten Klimaten angehören. Ja selbst an einzelnen Exemplaren derselben Species ist der Einfluss des Klimas in dieser lichtung bemerkbar, wie durch Vergleichung einzelner Schmetterlinge aus der Türkei und Dalmatien mit den .hiesigen" gezeigt wurle (z. B. Limenitis populi, Argynnis paphia etc.). Weiter sagt er: ..Die Ursache dieser Erscheinung ist aber noch wenig erforstht. Was die Grösse anbelangt, so ist es nattiirlich, lass bei grösserer Wärme sich alle Organismen ippiger entwickeln, und dass auch die Falter ler Tropen, bei dem Reichthum an Pflanzenstoffen, grösser werlen, denn jelem Ziichter ist bekannt, dass bei kümmerlicher Nahrung die Falter kleiner bleiben" (p. 2).

In ler Debatte ïber len Vortrag be:1erkte Berg, dass das Kleinwerilen iler in Europa gezüchteten Seilenspinner wohl nicht vom kälteren Klima abhänge, sondern eine Folge der Inzucht sei.

Was mu ilen klimatischen Einfluss auf die Gestalt anbelangt, so sagt C. A. Teich, lass die nordischen Falter mehr alggerundete Flïgel hałen, während die süıllichen mehr gezackt unı geschwänzt sincl. Z. B. sind die Arten aus den Gattung Vanessa und Thecla im Sürlen stärker gezackt oiler geschrwänzt als im Norien ( $C$ album verglichen mit (ter italienischen triangulum).

A. R. Wallace (1570. 940) sammelte die grössten Exemplare verschierlener Schmetterlinge auf Java, Sumatrá, Borneo in Nellfiuinea und auf den nördlichen Molukken und fand bei ihnen folgendle Flügelweite in Zoll:

Arten ron Molukken und Celebes.

Nahverwandte Arten ron Java und der indischen Region.

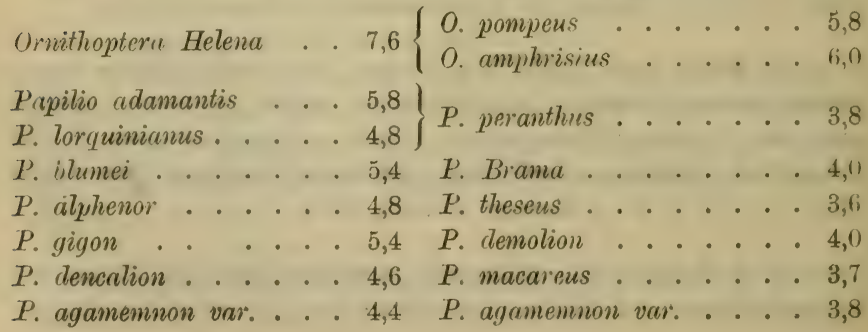


Arten von Molukken und Celebes.
Nahverwandte Arten von Java und der indischen Region.
P. eurypilus .... 4, 4,0
P. telephus
P. Jason
P. acgisthus . . . . . 4,4
P. rumu . . . . . . . 3,2
P. milon . . . . . 4,4
P. sarpedon . . . . . 3, 3
P. androcles . . . . 4,8
P. antiphates . . . . 3, 3
P. polyphontes . . . . . 4,6
P. diphilus . . . . . . . . 3,9
Leptocircus emnius
L. meges .

Arten auf Ambonia.

Verwandte Arten von Neu-Guinen und den nördl. Molukken.

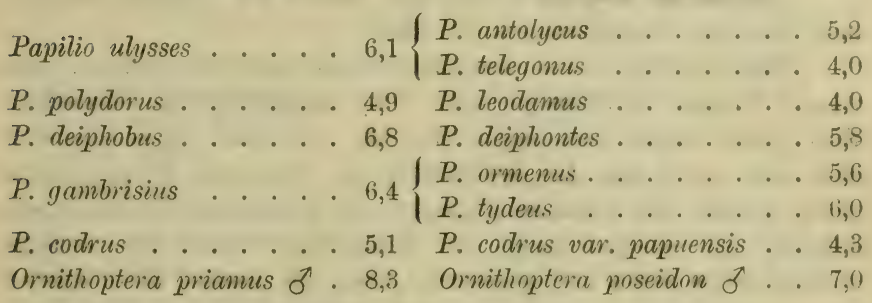

Er kommt zu folgenden Schlüssen:

1). Die Arten der indischen Region (Sumatra, Java und Borneo) sind fast unabänderlich kleiner, als die verwandten Arten, welche Celebes und die Molukken bewohnen.

2). Die Arten von Neu-Guinea unil Australien sind ebenfalls. wenn auch in geringerem Grade, kleiner als die nächsten Arten orler Varietäten der Molukken.

3). Auf den Molukken selhst sind die Arten von Ambonia die grössten.

4). Die Arten von Celebes kommen d'nen von Amlınia gleich orler übertreffen sie selbst noch an Grösse.

5). Die Arten und die Varietäten von Celebes besitzen einen auffallenden Charakter in der Form ler Vorderfluggel, welche von den verwalten Arten und Varietäten aller umgebenden Inseln verschieden ist.

6). Geschwänzte Arten von Indien oder der indischen Region werden schwanzlos, wenn sie sich nach Osten hin durch den Archipel verbreiten.

Er konstatierte auch, dass fast jede Papilio-Art, welche auf Celebes vorkommt, eigenthümlich geformte Fliigel hat, welche sie auf ilen ersten Blick von ilen verwandten Arten aller anileren Inseln 
unterscheirlen. Diese Eigenthüınlichkeit besteht erstens ilarin, ilass die Rippen odler der obere Rand viel stärker gebogen ist und in den meisten Fällen nahe der Basis eine plötzliche Biegung oder eine Ecke zeigt. Die Terias-.Irten, ein oler zwei Pieris-Arten, und die Gattung Callidryas weisen durchaus lieine bemerkbare Veränderung cler Form auf. Bei len anderen Familien giebt es nur wenige ähnliche Beispiele.

Der (irund dieser Abänlerungen ersieht or in clem Lintlusse des Ḱlimas und anderex physischen Ursachen“ (p. 203).

Bei Moritz Wagner (1875. 935) finlen wir folgende Mittheilung über die Beobachtungen von Boll:

Boll brachte von N. Amerika (Texas) nach der Schweiz eine Anzahl Puppen von Bombyx lun linge waren normal und legten Eier al. Die neue Generation wich aber sehr stark von (ler Stamuform ab) Leib und Flügel waren etwas grösser und plumper, dlagegen die gekämmten Fühler etwas schmäler und weniger üppig. Die Vordertlügel hatten eine weniger ausgeschweifte Form und gewannen etwas an Breite; noch stärlier war die Gestaltverämlerung an der schwanzartigen Verlängerung der Hinterfliigel.

E. Quajat (1878. 655) bestimmte das Gewicht ler Eier von Bombyx mori verschiedener Rassen und fand:

\begin{tabular}{|c|c|c|c|c|}
\hline \multirow[b]{2}{*}{ Ras s: } & \multicolumn{2}{|c|}{ Gewicht } & \multirow[b]{2}{*}{$\begin{array}{c}\text { Differenz } \\
\text { per } 1 \text { Unze } \\
\text { gr. }\end{array}$} & \multirow[b]{2}{*}{$\begin{array}{l}\text { Anzahl } \\
\text { gesunder Eier } \\
\text { in } 1 \text { Unze }\end{array}$} \\
\hline & $\begin{array}{l}1000 \text { freier } \\
\text { Eier gr. }\end{array}$ & $\begin{array}{l}1000 \text { gekör- } \\
\text { perter Eier } \\
\text { gr. }\end{array}$ & & \\
\hline Weiss-grüne . . . & 0,5028 & 0,4832 & 0,9745 & 49721 \\
\hline Chinesische weisse. & 0,4834 & 0,4570 & 1,3653 & 51717 \\
\hline Gelbe einheimische & 0,7038 & 0,6590 & 1,5913 & 35521 \\
\hline Gelbe französische. & 0,7075 & 0,6268 & 2,8515 & 35335 \\
\hline Gelbe friulano . . & 0,7460 & 0,7010 & 1,5084 & 33512 \\
\hline
\end{tabular}

Daraus ist ersichtlich, dass die leichtesten Eier der weissen chinesischen Rasse und die schwersten der gelben friulano Rasse sind.

W. A. Jaroschewsky (18\$3. 418) studierte Diptera, welche von ihm in der Umgebung von Charkow (Russland) gefangen wurden, und giebt für verschiedene Arten folgende Dimensionen für die Länge in $\mathrm{m} . \mathrm{m}$. an: 


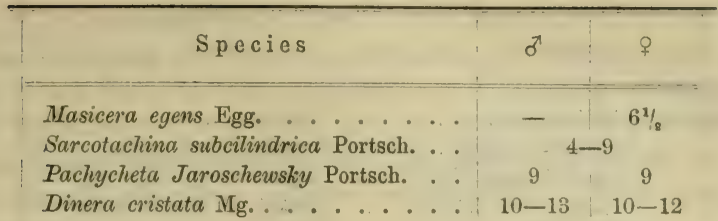

P. Iwanow (1586. 401) studierte Cicadiana im europäischen Russland und giebt folgende Dimensionen fuir verschielene Arten an:

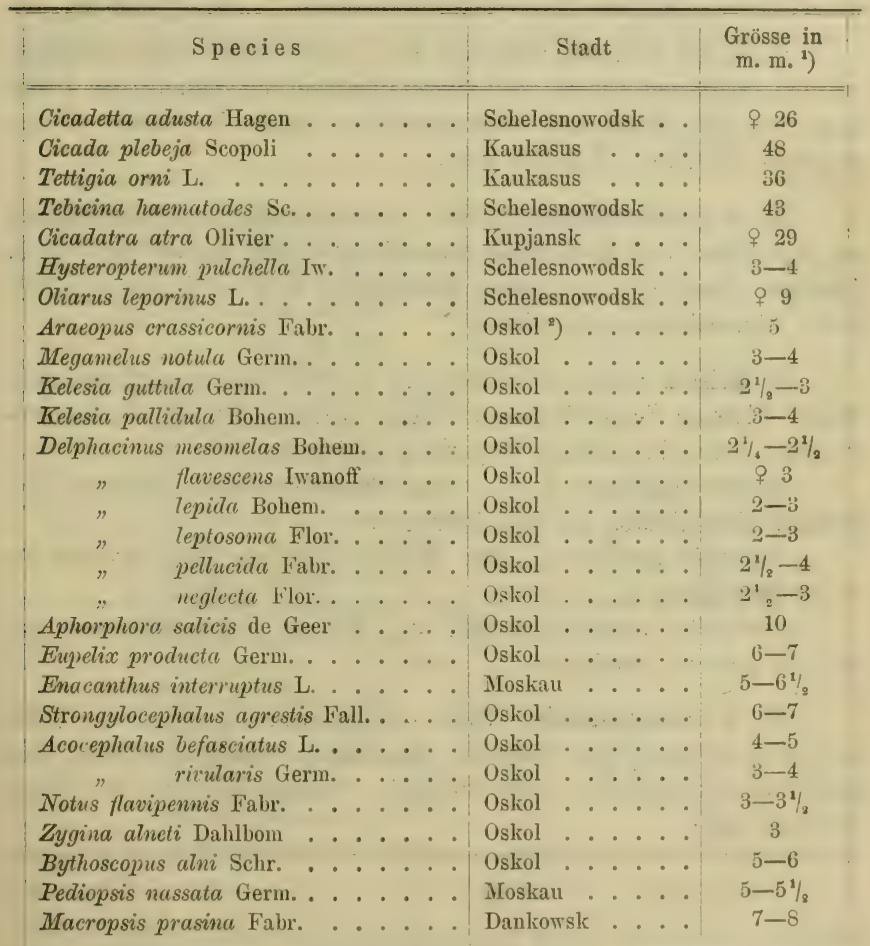

1) Unter "Grüsse" versteht der Verfasser wahrscheinlich die Länge des. Insektes.

9) Ufer des Flusses Oskol. 


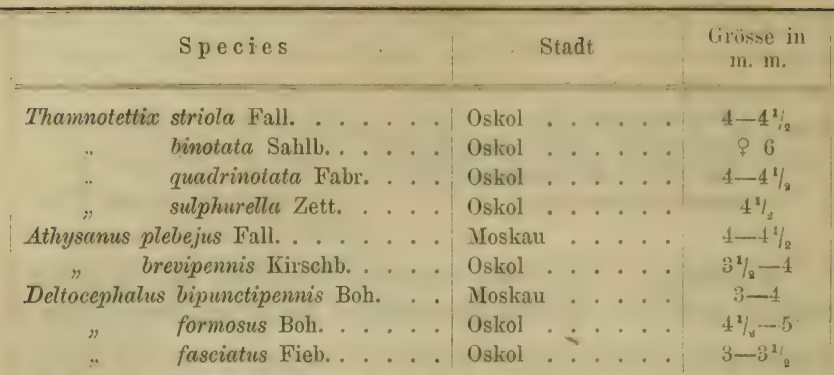

Dabei sei bemerkt, dass die Zeit, wann diese Arten gefangen wurden, nicht notiert ist, weil diese Insekten von Anfang des Friihlings bis zum Spätherbst vorkommen und sogar im Winter in erstarrtem Zustande zu finden sind.

W. A. Jaroschewsky (1886. 419) erhielt von Portschinsky ein Exemplar von Sericomyia boreulis vom Ararat, welches von in Charkow (Russland) gefangenen Exemplaren sich clurch etwas grössere Dimensionen unterscheidet.

E. Baillon (1586.44) erbeutete in Nororossiisk am Schwarzen Meere folgendle Schmetterlinge, welche grösser sincl als die entsprechenden Arten in anderen Gegenden, und zwar:

Agrotis clepuncta L. $45 \mathrm{~mm}$. Fligelspannung, währent bei Godard abgebildeten $33 \mathrm{~mm}$. betragen.

Dichonia aprilina L. unil Rusina tenebrosa Hüb. grösser als in St.-Petersburg.

Cirroedia xerampelina Hüb. 34-35 mm. Flïgelspannung, gegen $28 \mathrm{~mm}$. in Frankreich.

W. A. Jaroschewsky (1886. 419) stulierte Diptera, welche in der Umgebung von Charkow (Russland) gefarigen wurden, und giebt für verschierlene Arten folgende Dimensionen für lie Länge in $\mathrm{m} . \mathrm{m}$. an:

\begin{tabular}{|c|c|c|c|c|c|}
\hline Species & $\sigma^{7}$ & ㅇ & Species & 8 & $q$ \\
\hline Phthiria vagans Lw. & $5-$ & $4^{2} / 2-6$ & Thryptocera mariettii Rond & - & 6 \\
\hline Eumerus ornatus Mg. . & & & Homalomyiu viduata Zett. & - & 7 \\
\hline Peteina erinacea Fab. . . & 8 & - & Piopliila nigrimana Mg. . . & 2 & 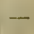 \\
\hline Phorocera nigripalpis Rond & 7 & - & Mycetaulus bipunctatus Fall. & - & 3 \\
\hline
\end{tabular}


W. A. Jaroschewsky (1887. 420) fing am 14./26. Juli 1886 in iler Ungebung von Charkow (Russland) ein Weibchen von Cynomyia alpina Zett. (Diptera), welches $14 \mathrm{~m}$. m. lang war. Zetterstedt giebt fiur liese Art $21 / 2-3 \frac{1}{2}$ lin. an. Ein Weibchen, welches in Gouvernement Ekatherinoslaw, und ein Männchen, welches in Gouvernement St.-Petersburg gefangen wurlen, hatten in der Länge 11 resp. $9 \mathrm{~m} . \mathrm{m}$.

W. A. Jaroschewsky (1887. 420) giebt folgende Dimensionen für die Länge der von ihm untersuchten Arten von Diptera an, welche in der Ungebung von Charkow (Russland) gefangen worden:

\begin{tabular}{|c|c|c|c|c|c|}
\hline Species & & & & $\begin{array}{c}\sigma^{\gamma} \\
\text { m. m. }\end{array}$ & $\begin{array}{c}q \\
\text { m. } \mathrm{m} \text {. }\end{array}$ \\
\hline Asilus cyanurus Lw. . . .. & . & . & .. & 15 & 13 \\
\hline Paragus cinctus Egg. . . . & . & . & . . & \multicolumn{2}{|c|}{$7-8$} \\
\hline " bimaculatus Mg. . . & . & . & - . & \multicolumn{2}{|c|}{$5-6$} \\
\hline Syrphus arenatus Fall. . . & & . & . . & \multicolumn{2}{|c|}{$8-12$} \\
\hline "guttatus Fall. ... & - & . & . . & $6-6^{1 / 2}$ & - \\
\hline " diaphanus Zett. . . & - & - & . . & - & 11 \\
\hline Melithreptus strigatus Staeg. & - & . & $\therefore$ & 11 & 8 \\
\hline Physocephala pusilla Mg. . & . & . & . . & 8 & $6-7$ \\
\hline Zodion pulchrum Lw. . . . & 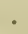 & . & - $\cdot$ & $8-9$ & - \\
\hline Clairvillia ocypterina Schin. & . & . & . . & - & $6-7$ \\
\hline Phaniosoma apennina Rond. & . & . & . . & \multicolumn{2}{|c|}{$7-8$} \\
\hline Cnephatia multisetosa Rond. . & - & . & . . & 11 & - \\
\hline Exarista falenaria Rond. . . & • & . & . $•$ & 5 & 6 \\
\hline Brachycoma metopiella Rond. & $\therefore$ & . & - $\cdot$ & $5-6$ & $4-6$ \\
\hline Erynnia nitida R.-Desv. . . & 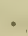 & . & . . & 4 & 一 \\
\hline Sarcophaga matertera Rond. & . & . & . . & 15 & - \\
\hline Cynomyia alpina Zett. . . . & . & . & . . & 一 & 14 \\
\hline Pyrellia serena Mg. . . . & • & - . & - & - & 9 \\
\hline Spilogaster flagripes Rond. . & • & - & - & 9 & 8 \\
\hline Lispe litorea Fall. . . . . & ${ }^{\circ}$ & - . & - . & $5-6$ & 6 \\
\hline Coenosia intermedia Fall. . . & - & - . & . & - & 5 \\
\hline Loxocera maculata Rond. . . & 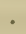 & & & 8 & - \\
\hline
\end{tabular}

Leech (1887. 504) beobachtete in Japan, dass die erste Generation von Papilio machaon, welche im März und April erscheint, die gleiche Grösse wie die europäischen Exemplare hat; aber die folgenden Generationen sinı grösser und von mehr intensiver Farbe. 
W. A. Jaroschewsky (1885. 422) giebt folgende Dimensionen für die Länge ler von ihm in Gouvernement Charkow (Russland) gefangenen Chrysidicla in $\mathrm{m}$. $\mathrm{m}$. an:

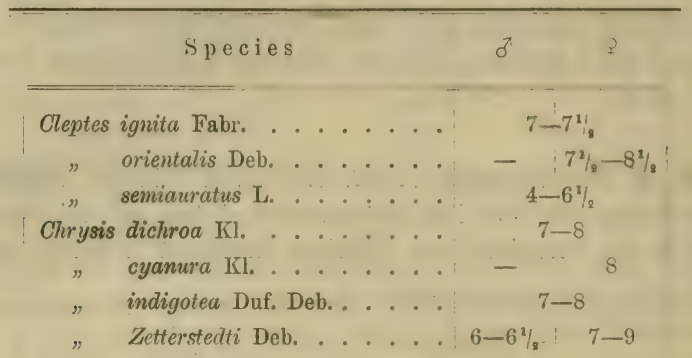

W. A. Jaroschowsky (1888. 421) untersuchte die Tenthrediniden-Fauna der Gouvernement Charkow unl führt folgende Grössen (Länge) dieser Insekten in m. m. an:

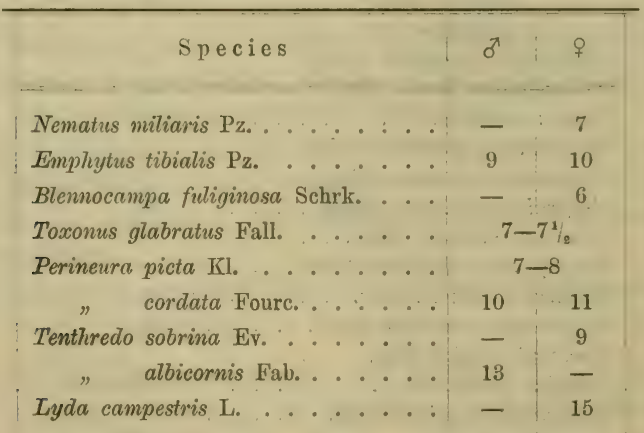

N. Schawrow (1888.741) berichtet über einen Versuch, welchen die Seidenzucht-Station in Padua mit der Brianzalla-Rasse von Bombyx mori gemacht hat. Die Eier dieses Spinners wurden an 22 verschiedene Stationen in Norl-, Mittel- und Süd-Italien versandt, wo die Aufzucht iler Raupen unter sonst gleichen Umständen und nach einer und derselben Methode stattfand. Dabei wurden folgende Resultate erhalten: 


\begin{tabular}{|c|c|c|c|}
\hline $0 \mathrm{rt}$ & $\begin{array}{c}\text { Anzahl } \\
\text { der } \\
\text { Cocons in } \\
1 \text { lílgr. }\end{array}$ & $\mathrm{Ort}$ & $\begin{array}{c}\text { Anzahl } \\
\text { der } \\
\text { Cocons in } \\
1 \text { Klgr. }\end{array}$ \\
\hline Teramo ... & 429 & Salerno & 584 \\
\hline Offida . . . & 478 & S. Buftilo . ... & 587 \\
\hline Bertinora . . & 485 & Castilgone... & 592 \\
\hline Forli . . . & 518 & Benevento.. & 593 \\
\hline Padua & 519 & Avellino ... & 600 \\
\hline Kjeti ... . & 526 & Cevit . . . . & 610 \\
\hline Ascoli-Piceno & 533 & Tolentino . . & 614 \\
\hline Lugo . . . . & 536 & Caserta : ... & 627 \\
\hline Isola di scala & 540 & Bassignano . & 657 \\
\hline Pesaro . . . & 560 & Ferrara ... & 729 \\
\hline Cali . ... . & 571 & Pedgio. Calabria & 800 \\
\hline
\end{tabular}

J. Haberfelner (1889. 340) saut, lass die von ihm erbeuteten Exemplare von Calopterus selmanni aut den Alpen (Octscher und Dürrenstein) urösser sinı, als auf den Vorbergen.

Libellulilen Japans, welche auch in Europa vorkommen, übertreften die europäischen gewöhnlich in der Grösse um ein Bedeutendes. Wie H. J. Kolbe sagt (1889. 462), beträgt Libellı albistyla in Japan $40 \mathrm{~m}$. m. für clen Hinterleib und $42 \mathrm{~m}$. m. fuir die Hinterflügel, währenı dliese Grössen in Europa nur 33 resp. $37 \mathrm{~m} . \mathrm{m}$. sincl. Dagegen sind die japanischen Libellulı quadrimaculatu, Leucorihinia mubicunda unil Symipycna fusca den europäischen in ler Grösse gleich.

Was nun die Sclmetterlinge anbetrifft, so sagt Kolbe, dass Papilio machaon L. aus Japan eine Spannweite von 100-102 m. m. haben, während diejenigen aus Europa nur $84 \mathrm{~m}$. m. erreichen. Papitio xuthus L. aus Japan misst 117 und aus Chile 96 $\mathrm{m} . \mathrm{m}$. Dieselben Grössenunterschiede zu Gunsten der japanischen Formen zeigen noch mehrere europäische Schmetterlinge z. B. Melitaea phoebe Schiff., Argynnis ino Esp., Argynnis laoclice Pall., Argymnis paphia L. und Coenomympha oedipus F. Folgende Arten sind in Japan und in Europa gleich gross: Aporia crataegi L. Pieris daplidice L., Vanessa levana L., Vanessa cardui L., Vanessa jo L., Vanessa antiopa L. etc.

Wie das Gewicht, Breite und Länge der Raupen einer und derselben Art, aber von verschiedenen Gegenden, sich ändert, zeigt folgende Untersuchung: 
G. Derewjanko (1889. 167) stellte Messungen an Seidenraupen, welche in der kaukasischen Seilenzucht-Station aufgezogen wurden, und fand:

1). Das Gewicht der liaupe schwanlite zwischen 2,505 und $5,1 \mathrm{gr}$. (für die japanische Rasse von 3,216 bis 3,54 , fuir die chinesische von $2,50-2,67$ und für die europäische von 4,005 bis 5,1 gr.).

2). Die Länge lles Körpers schwankte zwischen 4,84 uni $7,09 \mathrm{~cm}$. (für die japanische von $5,727-6,005$, für die chinesische von 4,84 bis 5,315 und für die europäische von 6,525 bis $7,09 \mathrm{~cm}$.).

3). Die Breite les Körpers schwankte für die japanische Rasse zwischen 0,83 bis 0,904 , für die chinesische 0,805 bis 0,995 und für die europäische $0,915-0,98 \mathrm{~cm}$.

4). Das Gewicht der Puppe betrug bei japanischer Rasse $1,21-1,216$, bei chinesischer $1-1,055$ und bei europäischer 1,525 bis $2,01 \mathrm{gr}$.

5). Das Gewicht des Cocons betrug bei japanischer Rasse 0,44-1,405 gr., bei chinesischer 1,09-1,465 und bei europäischer $0,23-0,25 \mathrm{gr}$.

6). Das Gewicht der Seide im Cocons schwankte bei japanischer Rasse zwischen 0,188 und 0,194 , bei chinesischer $0,18-(), 2$ und bei europäischer $0,23-0,35 \mathrm{gr}$.

7). Die Entfernung zwischen den falschen und ächten Füsschen betrug bei japanischer Rasse 3,405 bis $3,52 \mathrm{~cm}$, bei chinesischer $2,755-3,13$, bei europäischer $3,995-3,6 \mathrm{~cm}$.

Dabei wurden 15 verschiedene Rassen untersucht, und der Verfasser konstatiert die Manifaltigkeit der Ziffer-Werthe für die untersuchten Rassen, was darauf hinweist, dass der Organismus der Seidenraupe sehr veränderlich ist.

A. Jacobi (1589. 407) bestimmte die Länge von 83 Puppen von Fidonia piniaria L. unl fand: 2 Puppen bis $9,5 \mathrm{~m}$. m., 16 bis $10,0 \mathrm{~m}$. m., 20 bis $10,5 \mathrm{~m}$. m, 18 bis $11,00 \mathrm{~m}$. m., 9 . bis $11,5 \mathrm{~m}$. m., 11 bis $12,0 \mathrm{~m}$. m., 1 bis $12,5 \mathrm{~m} . \mathrm{m}$., 3 bis $13,0 \mathrm{~m}$. m. und 1 bis $13,5 \mathrm{~m} . \mathrm{m}$. Somit beträgt die Länge im Durchschnitt $10,5 \mathrm{~m} . \mathrm{m}$. Keppen fand sie (p. 203) zwischen 17,8 und 20,3 m. m., und Ratzeburg (p. 183) mehr als 13,1 m. m. Daraus folgt, dass diese Puppen in Gouvernement Kasan, wo Jacobi sein Material sammelte, viel kleiner sind als in Deutschland.

Dieser Forscher stellte auch die Gewichtsbestimmung dieser Puppen an und fand, dass 368 Puppen, welche am 7 März (alt. St.) 
gesammelt wurden, einen Durchschnittswerth für eine Puppe 82,6 mgr. ergaben. Die an der Luft getrockneten Schmetterlinge wogen im

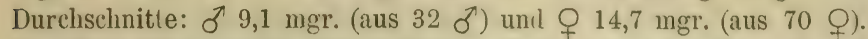
Das Gewicht einer trockenen Puppe (Mittel aus 23 Exemplaren) betrug 23,1 mgr.

W. A. Jaroschewsky (1889. 423) sagt bei der Beschreibung von Trigonalys Hahnii Spin. = T. nigra Westw., lass bei keinem von 11 Exemplaren, welche er in der Nähe von Kurjaschli-Kiloster (Gouvernement Charkow) gefangen hatte, die zweite rücklaufende Ader in die Mitte der 3. Cubitalzelle oder in den Scheitel ihres unteren Aussenwinkel mündete, folglich stellt die zweite rücklaufende Ader eine direkte unmittelbare Fortsetzung der äusseren transkersalen Cubitalader dar. Trotzlem will er diese Thiere mit einem neuen Namen nicht taufen, "da diese Unterschiede als einfache indiviluelle $\mathrm{zu}$ betrachten sind" (p. 138).

A. Hoffmann (1891. 378) fand Ende Juli Raupen von Terus hastianc L. an Salix repens und erhielt Ende August und Anfangs September 26 Falter, welche kaum 2/3 der Grösse der gewöhnlichen hastiana erreichten. Er erklärt diese kleinen Dimensionen. durch den Einfluss der Dünen Norddeutschlands, wo die Raupen. gefunden waren.

F. J. Dschejranow (1892. 197) in Tiflis bestiminte das Gewicht und die Dimensionen der Raupen, der Cocons, der Puppen und der Falter von Bombyx mori verschiedener Rassen, welche in Tiflis aufgezogen wurden. Die durchschnittlichen Werthe von 10 Exemplaren enthält folgende Tabelle: 


\begin{tabular}{|c|c|c|c|c|c|c|c|c|}
\hline \multirow[b]{2}{*}{ Rassen } & \multicolumn{5}{|c|}{ Ra upe } & \multicolumn{3}{|r|}{$\mathrm{Co}_{0}$} \\
\hline & 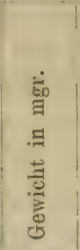 & 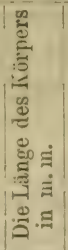 & 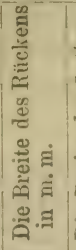 & 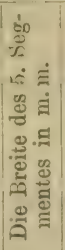 & 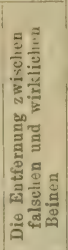 & 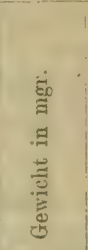 & 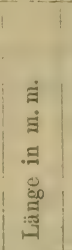 & 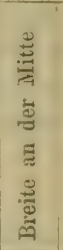 \\
\hline Italienische gelbe . : . & 4305 & 76,5 & 8,3 & 9,5 & 21,6 & 2072 & $|38,5| 1$ & 17,4 \\
\hline $\begin{array}{c}\text { Chinesische } \times \text { japanische } \\
\text { grüne }\end{array}$ & 2782 & 63,4 & 8,1 & | 8,7ว̃ & 20,3 & 1553 & 32,4 & 16,3 \\
\hline $\begin{array}{l}\text { Transkaspische } \\
\text { Gekr. weiss-gelbe } \dot{X} \text { italie- }\end{array}$ & 3380 & 70,9 & $\left.8,65^{1}\right)$ & 8,75 & 21.4 & 1729.8 & 35,351 & $1<, 85$ \\
\hline nische gelbe . . . & 3271,7 & 68 & 8,3 & 8,7 & 20,6 & 1823,6 & $|32,45|$ & 15,15 \\
\hline $\begin{array}{l}\text { Bagdader (graue) Raupen } \\
\text { Gekr. weisse japanische } X\end{array}$ & 3583 & 72.65 & 8,$3 ; 5$ & 9,15 & 21,2 & 2182,4 & $|34,2|$ & 19 \\
\hline weisse chinesische. & 2860 & 61,8 & 8,1 & $8, \infty 5$ & 19,45 & 1746,4 & 36,6 & 17,5 \\
\hline Bagdader (Tiger-Raupen) & 3379 & 69,6 & $\left.8,0^{2}\right)$ & 9,15 & 20,8 & 2144,5 & 34,75 & 16,8 \\
\hline $\begin{array}{l}\text { Korsikanische } . \text { Gekr. weisse japanische } x \\
\text { Gek }\end{array}$ & 3948 & 75 & 9 & 9,5 & 23,42 & 2194,5 & $|36,65|$ & 18,5 \\
\hline gelbe chinesische . . & 3152 & 64,6 & 8,5 & 8,85 & 20,5 & 1817 & $|32,35|$ & 17,7 \\
\hline Italienische . . . . . & 3615 & 71,0 & 8,4 & 9,3 & 23,25 & $1<23,3$ & 37,7 & 20,05 \\
\hline $\begin{array}{l}\text { Japanische grüne } \\
\text { Gekr. weisse chinesische } \times\end{array}$ & 2509 & 65,3 & 7,9 & 8,15 & 18,55 & 1379,5 & $31,2,1$ & 14,55 \\
\hline $\begin{array}{l}\text { weisse italienische } \\
\text { Gekr. weisse italienische } X\end{array}$ & 3185 & 60,55 & 8,5 & $9, \overline{0}$ & 22.2 & $\ln (x)$ & 31.75 & 18,115 \\
\hline grüne japanisehe . & 3268,0 & 69,15 & 9 & 9,45 & 22,05 & 1967,9 & 32,25 & 16,2 \\
\hline Chinesische weisse (Susani) & 8910,7 & 77.1 .1 & 9.15 & 7.7 & $2: 3,45$ & $1 \approx 69,4$ & $2 \rightarrow, 5$ & 14,7 \\
\hline Chinesische weisse (Tsche- & & & & & & & & \\
\hline Turkestanische ${ }^{\prime}$ Pschty - & 2697,2 & 60,2 & 7,0 & 8,1 & 19,25 & 1220,2 & 28,6 & 16,05 \\
\hline Pilla" weisse . . . . . & 4458,3 & 78 & 8,95 & 9,5 & 23,45 & 2000,8 & 41,6 & 17,9 \\
\hline $\begin{array}{l}\text { Brussaer weisse. } \\
\text { Japanisclte weisse. }\end{array}$ & (39) 34,3 & 75,95 & 5,75 & 9.25 & $: 2: 3,2$ & 1915,2 & 34,6 & 15,05 \\
\hline $\begin{array}{l}\text { Japanische weisse. } \\
\text { Sevenne'sehe weisse . }\end{array}$ & $4(1) 4: 3,9$ & $7: 3.43$ & 9,05 & 9,6 & 24,8 & 1839.7 & 34,4 & 15,95 \\
\hline $\begin{array}{l}\text { Sevenne sche weisse: } \\
\text { Gran Sasso. . . . }\end{array}$ & $\begin{array}{l}404,8,4 \\
4502,5\end{array}$ & 76,7 & 8,95 & $\begin{array}{l}9,5 \\
10\end{array}$ & $\begin{array}{l}23,5 \\
2: 3,5\end{array}$ & $\begin{array}{r}2250,5 \\
\left.235(1), 1^{3}\right)\end{array}$ & $\begin{array}{l}34,4 \\
: 38,05\end{array}$ & $\begin{array}{l}16,7 \\
15,5\end{array}$ \\
\hline Pyrinäische gelbe . . & $\| 4277,7$ & 75,9 & 9,1 & 9,75 & 24,7 & 2009,4 & $|33,25|$ & 16 \\
\hline Italienische gelhe . . & 3818,5 & 72,35 & 9,5 & 10,05 & $2.2,35$ & 1829,3 & 35,3 & 15,6 \\
\hline Bagdader : $\cdot \dot{P_{s}} \cdot \dot{ }$ & $41: 7,1$ & $7 s, 25$ & 8,95 & 9,4 & $24,(1)$ & 2014,9 & $: 39,9$ & 17,5 \\
\hline $\begin{array}{l}\text { Turkestanische "Pschty - } \\
\text { Pilla", samt. : } \\
\text { Gekr. weisse chinesische } X\end{array}$ & $42: 25,3$ & 73,15 & 9,5 & 9,5 & 23,85 & 2079 & 39,75 & 17 \\
\hline gelbe italienische . & 3969 & 72,35 & 9,7 & 9,7 & 23,65 & 2339,7 & 37,3 & 16,65 \\
\hline $\begin{array}{c}\text { Turkestanische "Pschty- } \\
\text { Pilla" gelbe . . . . }\end{array}$ & 3491 & 67,95 & \begin{tabular}{|l|l|}
5 & 8,9
\end{tabular} & 8,75 & 520,35 & 1926,5 & 33,6 & 19,2 \\
\hline $\begin{array}{l}\text { Carso } \\
\text { Gekr. weisse Bagdader } X\end{array}$ & 3977,4 & 70,35 & 5. 9,25 & 9,35 & 21,45 & 2184,1 & 35,85 & 16,4 \\
\hline weisse japanische. . & $42: 6,7$ & 80,55 & 10,25 & 10,6 & 24,1 & 2050,8 & 40,6 & 19,5 \\
\hline Varsk'sche gelbe . . & 3852.8 & 36,95 & $9 \quad 9,3$ & 9,45 & 521,75 & 2091 & 36,25 & 17,0 \\
\hline Carptnetti . . . . & 4117,4 & 74,85 & 9,85 & 9,11 & 121,9 & 1958,5 & 34,05 & 17,55 \\
\hline . . . . . & 4710,2 & 79,55 & $5 \quad 9,5$ & 9,95 & 523,4 & 2553 & 39,25 & 17,55 \\
\hline
\end{tabular}

Im Original steht fehlerhaft: ${ }^{1}$ ) $98,65 \ldots{ }^{2}$ ) $84,5 .-{ }^{8}$ ) $3234,1$. 


\begin{tabular}{|c|c|c|c|c|c|c|c|c|c|c|c|}
\hline \multicolumn{3}{|l|}{$\operatorname{cons}$} & \multicolumn{4}{|c|}{$\mathrm{Puppe}$} & \multicolumn{5}{|c|}{ Sehmetterling } \\
\hline 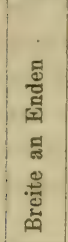 & 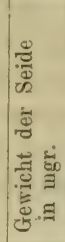 & 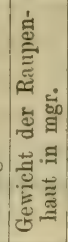 & 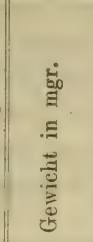 & 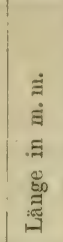 & 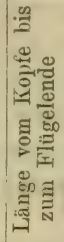 & 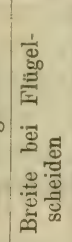 & 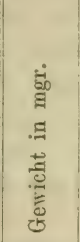 & 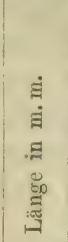 & 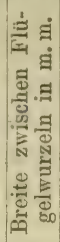 & 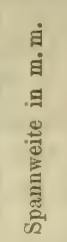 & 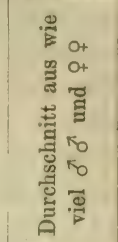 \\
\hline 18,3 & 364 & 10,5 & $176 \diamond$ & $3 ! 9$ & 3,4 & 11 & 910 & 26 & 6 & 51 & $20^{\circ}$ \\
\hline $\begin{array}{l}17,3 \\
18,1\end{array}$ & $\mid \begin{array}{l}249, \mathrm{c} \\
225\end{array}$ & $\begin{array}{l}9,5 \\
9,7\end{array}$ & $\begin{array}{r}13(03,2 \\
\left(1504,3^{1}\right)\end{array}$ & $\begin{array}{r}25,3 \\
27\end{array}$ & $\begin{array}{l}12,2 \\
12,3\end{array}$ & $\begin{array}{l}10,6 \\
11,2\end{array}$ & $\begin{array}{l}570,1 \\
879,6\end{array}$ & $\begin{array}{c}24,35 \\
27\end{array}$ & $\begin{array}{c}5,85 \\
6\end{array}$ & $\begin{array}{c}45,55 \\
48\end{array}$ & 1007 \\
\hline $\begin{array}{r}16,4 \\
19\end{array}$ & $\mid \begin{array}{c}285 \\
297,7\end{array}$ & $\begin{array}{r}8,5 \\
-\quad 6,4\end{array}$ & & $\begin{array}{l}26,1 \\
28,5\end{array}$ & $\begin{array}{l}13,5 \\
12.5\end{array}$ & $\begin{array}{l}10,5 \\
10,9\end{array}$ & & & $\left\{\begin{array}{l}5,9 \\
7,07\end{array}\right.$ & & $\begin{array}{ll}3 & 0 \\
3 & 0\end{array}$ \\
\hline $\begin{array}{l}16,2 \\
17,1 \\
19,7\end{array}$ & $\begin{array}{l}222,4 \\
289,7 \\
314,9\end{array}$ & $\begin{array}{r}8,0 \\
8,5 \\
10,4\end{array}$ & $\begin{array}{l}4 \\
4,8 \\
9,6\end{array}$ & $\begin{array}{c}26 \\
27,95 \\
29,1\end{array}$ & $\begin{array}{c}12 \\
12,55 \\
13\end{array}$ & $\begin{array}{l}10,5 \\
10,25 \\
11,1\end{array}$ & $\begin{array}{l}845,7 \\
876,6 \\
976,9\end{array}$ & $\begin{array}{c}25,7 \\
25,28 \\
27\end{array}$ & $\begin{array}{l}5,3 \\
6,5 \\
6,2\end{array}$ & $\begin{array}{l}49,5 \\
39,17 \\
51,5\end{array}$ & $\begin{array}{l}50+ \\
58+\end{array}$ \\
\hline \begin{tabular}{|l|}
17,5 \\
19,6 \\
15,8
\end{tabular} & $\begin{array}{l}246,4 \\
250,3 \\
217,8\end{array}$ & \begin{tabular}{|l|l}
7,0 \\
7,2 \\
7,6
\end{tabular} & & $\begin{array}{l}27, i \\
27,5 \\
23,4\end{array}$ & $\begin{array}{l}12,9 \\
11,8 \\
12,2\end{array}$ & $\begin{array}{r}10,0 \\
10,5 \\
9,8\end{array}$ & & $\begin{array}{c}24,9 \\
26 \\
24,5\end{array}$ & $\begin{array}{l}8,9 \\
7,2 \\
5,9\end{array}$ & & $6 \delta^{\pi}+$ \\
\hline 1 & $1: 2$ & 7,0 & 1550,47 & 26,5 & 1,72 & 11,5 & $84\left(6^{3}\right)$ & $\left.2.5,4^{3}\right)$ & $6,7^{3}$ & 年 & \\
\hline $\begin{array}{l}18,65 \\
16,4\end{array}$ & $\begin{array}{c}277 \\
214.1\end{array}$ & & & $\begin{array}{l}27,7 \\
26,9\end{array}$ & 2.05 & & $\begin{array}{l}3 \pm 0,7 \\
9 x+1,5\end{array}$ & & $\begin{array}{l}6,75 \\
6,6.5\end{array}$ & & $\begin{array}{l}4 \\
3\end{array}$ \\
\hline $1 \check{v}$ & 1 & 7.1 &,+ 0 & $2: 3$ & 11,5 & 9,55 & $47 \pi$ & 2.1 & 6,15 & & \\
\hline $\begin{array}{l}18,05 \\
16,0 \\
17,25 \\
18,2 \\
18,25 \\
16,95 \\
16,3 \\
18,15\end{array}$ & $\begin{array}{c}253,5 \\
266 \\
226,9 \\
255,4 \\
357,3 \\
275,2 \\
240 \\
317\end{array}$ & $\begin{array}{c}8,2 \\
6,9 \\
5,0 \\
10 \\
10,3 \\
8,0 \\
0 \\
10\end{array}$ & $\begin{array}{l}3 \\
2 \\
3 \\
2 \\
2 \\
5 \\
5 \\
3 \\
3 \\
9\end{array}$ & $\begin{array}{l}31,2= \\
28,3 \\
27,8 \\
28,4 \\
29,7 \\
28,25 \\
26,35 \\
30,7\end{array}$ & $\begin{array}{l}13,05 \\
13,1 \\
12,95 \\
13,2 \\
13,8 \\
13,15 \\
12,7 \\
13,7\end{array}$ & $\begin{array}{l}10,5 \\
10,8 \\
10,85 \\
11,7 \\
11,55 \\
11,4 \\
10,6 \\
11,5\end{array}$ & $\begin{array}{r}1040,8 \\
842,5 \\
878,4 \\
1225,6 \\
11142,5 \\
10.27,5 \\
795,9 \\
95 ! 9,7\end{array}$ & $\begin{array}{l}28,9 \\
25,4 \\
26,25 \\
27 \\
27,25 \\
25,6 \\
25,65 \\
28,: 3\end{array}$ & $\begin{array}{l}7,2 \\
6,95 \\
7,05 \\
7,7 \\
7,25 \\
6,05 \\
7,2 \\
7.4\end{array}$ & & $\begin{array}{l}3 c \\
30 \\
2\end{array}$ \\
\hline 17,7 & 262,9 & 8,4 & 1017,1 & 29 & $1.1,1$ & (1), & 988 & $-20,1$ & 7,05 & & $30^{2}+$ \\
\hline 18,2 & 318 & 9,6 & 1,7 & 29,5 & 13,25 & 11,45 & $10: 30,1$ & 27,75 & 7,15 & 0,95 & . \\
\hline $\begin{array}{l}19,4 \\
18,05\end{array}$ & $\begin{array}{l}227,7 \\
302,1\end{array}$ & $\begin{array}{c}10,05 \\
7,5\end{array}$ & $\begin{array}{l}1698,8 \\
1882\end{array}$ & $\begin{array}{l}29,2 \\
27,5\end{array}$ & $\begin{array}{l}12,7 \\
13,3\end{array}$ & $\begin{array}{l}10,9 \\
11,2\end{array}$ & $\begin{array}{r}900,4 \\
1082,2\end{array}$ & $\begin{array}{l}27,0 \\
26,7\end{array}$ & $\begin{array}{r}6,6 \\
7,4\end{array}$ & 54,5 & 3 \\
\hline $\begin{array}{l}21,15 \\
18,2 \\
18,55 \\
19,75\end{array}$ & $\begin{array}{l}-\overline{312}, 3 \\
355,4 \\
418,6\end{array}$ & $\begin{array}{r}9,4 \\
6,8 \\
10,4 \\
12,3\end{array}$ & $\begin{array}{c}1881 \\
1678,7 \\
1603,1 \\
2134,4\end{array}$ & $\begin{array}{l}32,55 \\
29,3 \\
28,1 \\
31,8\end{array}$ & $\begin{array}{l}13,45 \\
12,95 \\
13,45 \\
12,8\end{array}$ & $\begin{array}{ll}5 & 11,7 \\
5 & 10,8 \\
5 & 10,85 \\
11,3\end{array}$ & \begin{tabular}{|c|}
1367,9 \\
882 \\
778,8 \\
1757
\end{tabular} & $\begin{array}{l}29,7 \\
27,2 \\
26,5 \\
28,5\end{array}$ & $\begin{array}{l}7,6 \\
7,115 \\
7,1 \\
6,2\end{array}$ & $\begin{array}{l}49,1 \\
47,6 \\
50,05 \\
39,4\end{array}$ & $6 \sigma^{2}$ \\
\hline
\end{tabular}

In Original steht fehlerhaft: ${ }^{1}$ ) 2643. - ${ }^{2}$ ) 2876,8. - ${ }^{3}$ ) Ein Strich. - *) 14,25. 
W. J. Schmujdsinowitsch (1892. 766) hat zahlreiche Messungen der Eier von Bombyx mori verschieilener Rassen in der kaukasischen Seidenzucht-Station angestellt. Zu diesem Zwecke wurlen Eier von 6 Bruten benüzt, welche vorher (ler Zeit ilırer Ablage nach in einzelne Partien vertheilt waren. Jeder Partie wurden ohne Wahl 10 Eier entnommen, und ihre Dimensionen unter dem Microscop bestimmt (in relativen Einheiten; die Vergrösserung betrug 15,5 Mal).

Folgende Tabelle enthält die durchschnittlichen Werthe von. je 10 Eiern:

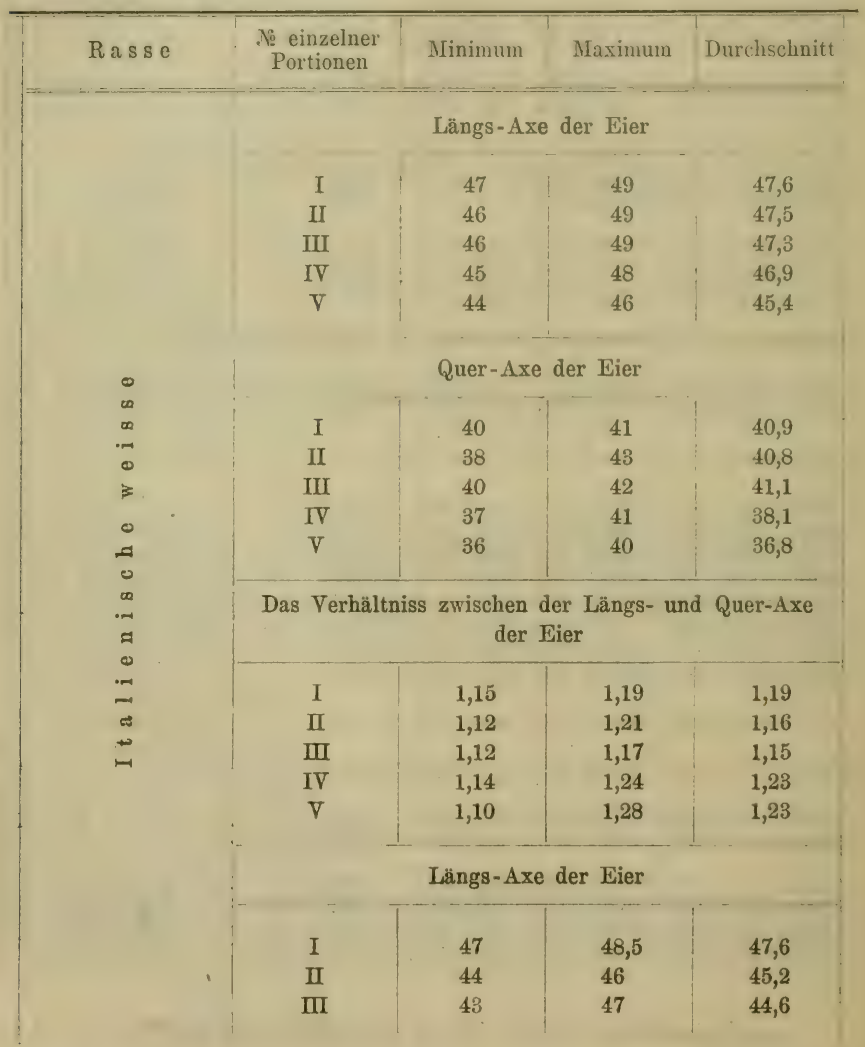


1. Einfluss des Klimas.

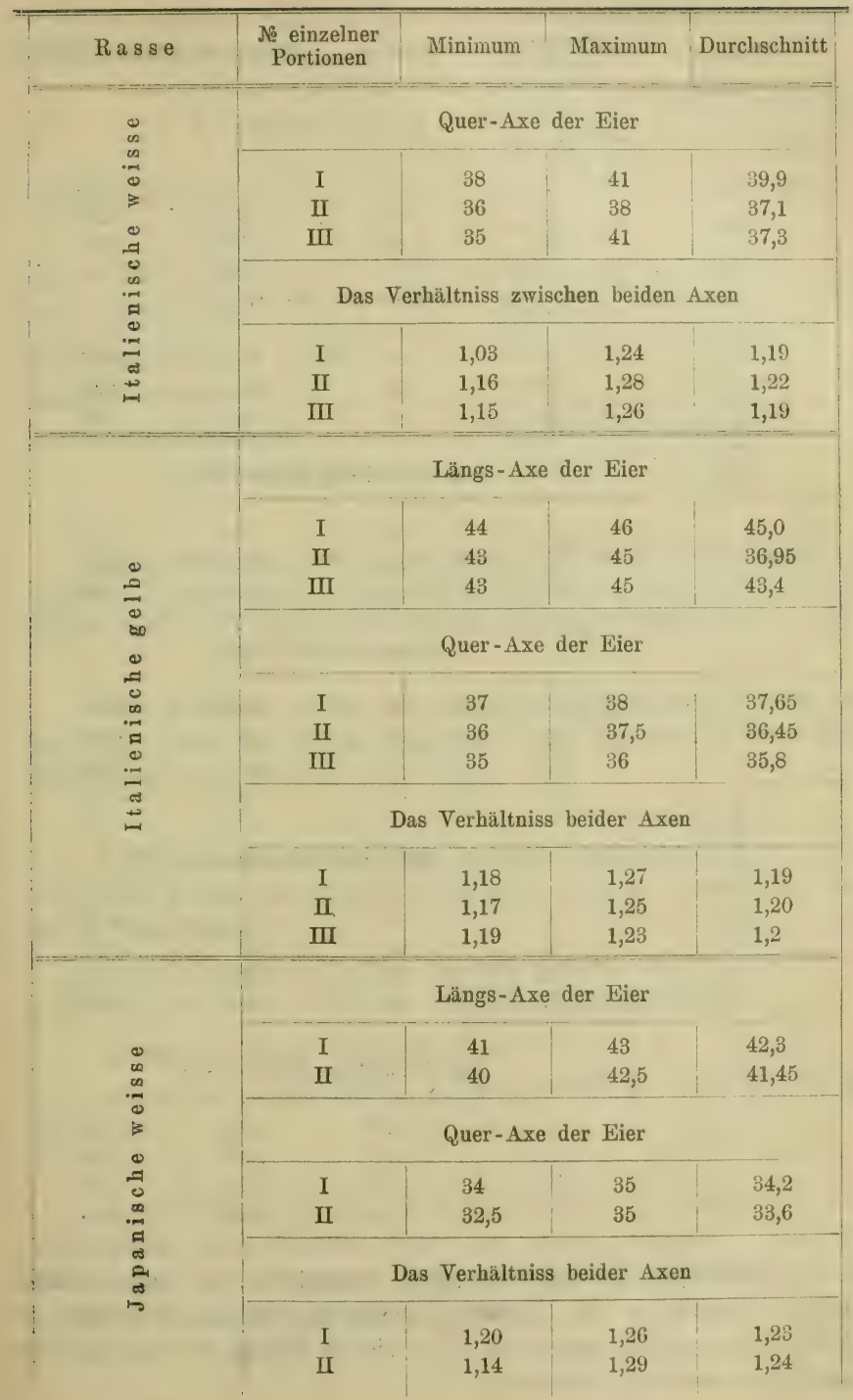




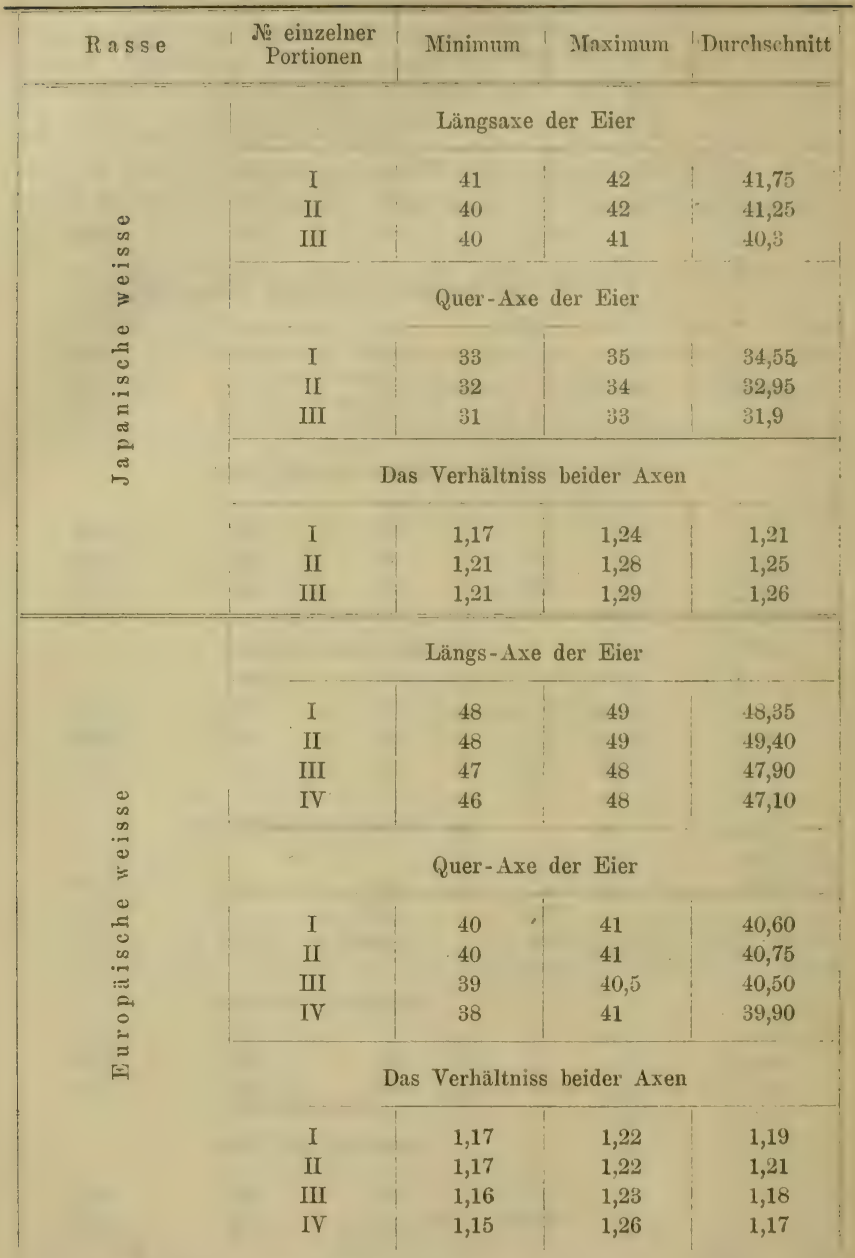

Die Grösse der Eier ist somit verschieden bei verschiedenen Rassen. Bei einer und „lerselben Rasse sind sie um so grösser, je früher sie abgelegt wurlen, l. h. ob sie im Anfang des Legens oder am Ende desselben erschienen. 
Er bestimmte auch das Gewicht von 100 Puppen und fand für verschiedene Rassen:

Ras se.

Französische gelbe weisse

Sevenne'sche gelbe

Pyrinaeische gelbe

Komurdschinskische weisse

Japanische weisse

Chinesische "Chantung"

$$
\text { "Tsche-Kiang" . }
$$

Gervicht von 100 Puppen.

160,6 gr.

156,1

173,2

160,4

$137,5 \quad$ "

122,11

109,65

89,2
Gewicht der Seide in 100 Cocons.

Hugo May sen. (1892. j50) fing in Wien Schmetterlinge von Acidalu consanguinaria Lerl., welche etwas kleiner $(10-11 \mathrm{~m} . \mathrm{m}$. Vorderflugellänge) als die Stiicke aus Dalmatien waren.

Otto Bohatsch (1892. 96) sammelte Schmetterlinge in Slavonien (Bad Lipik bei Pakrac) und fand, dass dieselben grösser sind als Exemplare gleicher Arten in Wien.

L. Krulikowsky (1892.478) sammelte Schnetterlinge im Giouvernement Kasan unil fanil folgenile Arten, welche kleiner sind als die in West-Europa:

Sesiu tabaniforme Rott., Zygaena meliloti Esp., Lithosin griseola Hb., Gnophria quadra L., Epichnopteryx pulla Esp.

Grösser als in West-Europa sind:

Limacodes testudo Schiff., Leucoma salicis L., Endiomis versicolora L.

A. Golubajew (1892. 326) in Titlis stellte Messungen der Seidenraupen verschieilener Rassen an, wobei von jerler Rasse 10 Raupen vor dem Einpuppen genommen wurien. Folgende Tabolle enthält die mittleren Resultate: 


\begin{tabular}{|c|c|c|c|c|c|c|c|c|c|c|}
\hline \multirow[b]{3}{*}{$\mathrm{Rasse}$} & \multicolumn{3}{|c|}{ Raupe } & \multirow{2}{*}{\multicolumn{3}{|c|}{$\begin{array}{c}\text { Cocons } \\
\text { Durchmesser } \\
\text { in cm. }\end{array}$}} & \multicolumn{4}{|c|}{ Gewicht in gr. } \\
\hline & & & & & & & & & & \\
\hline & 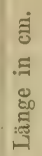 & 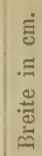 & 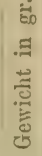 & 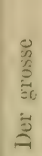 & 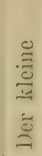 & 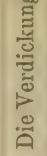 & : & 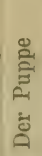 & 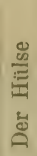 & 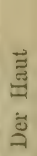 \\
\hline
\end{tabular}

Weisse Bagdad'sche gekreuzt mit weisser japanischen

Weisse chinesische gekreuzt mit weisser italionischen ....

Weisse chinesische gekreuzt mit gelher italienischen .

Weisse chinesische gelreuzt mit weisser japanischer.

Weisse italienische gekreuzt mit griiner japranischer.

Weisse japanische gekreuzt mit gelber italienischen .

Weisse japanische (q) gekreuzt mit gelber französischen ( $\left.\sigma^{-1}\right)$

Weisse Sevenne'sche(?) gekreuzt Init gelber franzüsischen $\left(\sigma^{\top}\right)$. Gekreuzte gelb-weisse gekreuzt mit geller italienischen . .

Weisse chinesische (von kaukasischer station)

Weisse chinesische (von Susani)

Turkestanische "Nay-tschi-chure"

"Turkestanische "I'sehtypilla" .

Turkestanische,. . Tily-tschi-chuve"

Turkestanische "-Ack-Pilla" .

Turkestanische "Saryk-Pilla"

Cherosan'sche (aus. dem Dorfe Lamberau)

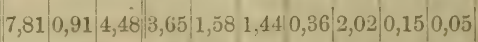
$7,030,47 \quad 3,37: 3,43 \quad 1,922,1 \quad 0,27 \quad 1,7.40,160,08$ 6.390.27:3.1 $3,1 \quad 1,0.4 \quad 1,7.40 .27 \quad 1,490,1 \quad 0,09$ 6,:38 1,03 $5.242 .051,481,5211,21 \quad 1.310,250,05$ $7,050,96: 11,3,321,671,670,261.440,260,07$ $6,170,9 \quad: 3: 323,4 \quad 1,681,640.2 \div 1,60,150,06$

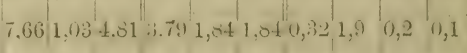
$7,2: 3,1,224,50,3,551,57 \quad 1,4+0,352,1 \quad 0,2 \quad 0,1$

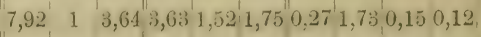

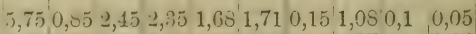

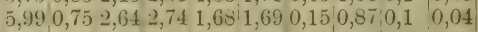

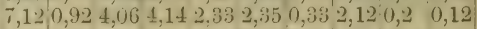
$\begin{array}{lllllllll}7,57 & 0,99 & 4 & 3,8 & 2,16,2,28 & 0,25 & 1,7 & 0,15 & 0,05\end{array}$

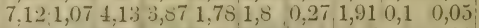
$6,991,053,553,972,452,450,352,270,020,02$ $\begin{array}{lllllll}6,98 & 1, \text { inj } 3,943,67 & 3,3622,27 & 0.26 & 2,0: 3 & 0,1 & 0,07\end{array}$

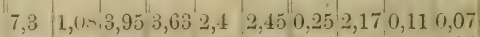

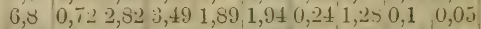
Transkaspische

Weisse hussische der Station Bagdad'sche (weisse Raupen) . Bagdad'sche (weisse Raupen mit Querringen)

Bagdad'sche (graue Raupen mit schwarzen lingen) . . . . .

Franzisische aus Hern . . . .

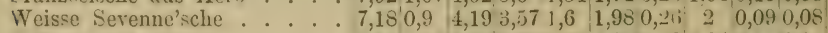

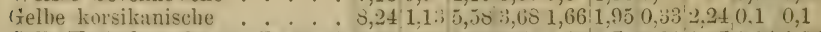

Gelbe Var'sche (schwarze Raupen) 7,91 1,01 3,03 3,71 1,65 1,7 $0.21 \quad 1,07 \quad 0.040,06$

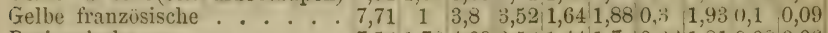

Pyrinueische . . . . . . . 7,58 1,72,4,09,3,58 $1,441,7$ 0:2 $1,810,08,0,06$

Grüne japanische; Eier der kau-

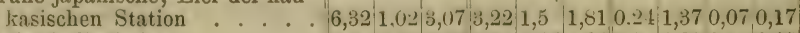

Gelbe italienische . . . . 6,9 0,95 $3,262,841,47 \quad 1,640.2$ 1,28 $0,1,0,08$

Grau Sasso . . . . . . $7,841,084,733,821,781,990,121,920,270,12$

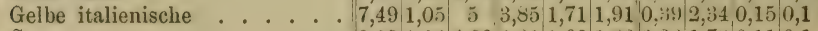

Carso . . . . . . . . $8,091,044,293,81$ 1,62 $1,830,921,730,110,1$ 
Daraus ist ersichtlich, dass die maximalen unıl minimalen Werthe bei folgenden Rassen beobachtet wurden:

a). Das Gewicht der Raupe: Minimum bei weisser chinesischer und Maximum bei korsikanischer Rasse.

b). Die Länge des Raupenkörpers: Dasselbe wie sub a).

c). Die Breite les Raupenkörpers: Minimum bei weisser chinesischen gekreuzt mit weisser italienischen und Maximum bei pyrinäischer Rasse.

1). Ler grosse Durchmesser des Cocons: Minimum bei grüner japanischen und Maximum bei turkestanischer "Naitschichuve" Rasse.

e). Der kleine Durchmesser des Cocons: Minimum bei weisser brussaer und Maximum bei turkestanischer "Saryk-Pilla."

f). Das Gewicht der Seide im Cocons: Minimum bei weisser thinesischen und Maximnm bei bagdaler mit schwarzen Raupen.

g). Das Gewicht der Pupppe: Minimum bei chinesischer Rasse und Maximum bei gelber italienischen.

h). Das Gewicht der Hülse: Minimum bei turkestanischer und Maximum bei Grau Sasso.

i). Das Gewicht der Haut: Minimum bei turkestanischer unid Maximum bei gelber italienischen Rasse.

L. Krulikowsky (1892.-1896. 479) sammelte Lepidopteren in (r)uvernement Kiasan (Russlani), wobei sich folgendes herausstellte.

Folgende Arten sinł grösser als in West-Europa (Deutschland und Oesterreich): Nerionia populuris F., Dianthoeciu nana Rott.. Lrucania conigera F., Caradrime taraxaci H')., Anphimyra pyramidea L.. Agrotis dahtii Hb., Agi. recussa Hh., Xylina ingrica IIS., Cucuellia umbrictic, L., Chariclea umbra Huin., Erastrin unculu Cl., Prothymia viriduria Hb., Catocala fraxini L., Pseuduterpna pruinata Hufn., Depressaria ocellana F., Depr. angelicella $\mathrm{Hb}$.

Folgenle Arten sinl kleiner als in West-Europa: Agrotis poly!lona F., Mamestra chrysozona Bkh., Miselir oxyanthae L., Panolis piniperda Panz., Plusia i aureum Knoch., Pl. m:neta F., Pl. Ir.ectae Schift., Chariclea delphinii L., Zanclognatha emortualis Schiff., Periculli s syringaria L., Rumia luteolata L., Eucosmia unculatı L., Aporndes floralis Hb., Botys repand.lis Schiff., Bot. rerbascalis Schift., Diasemia litterata Sc., Onectra pilleriana Schiff., Pentlina antiquuna Hb., Talaeporia pseudobombycella $\mathrm{Hb}$. 
W. J. Schmujdsinowitsch (1892. 763) bestimmte die Anzahi der Eier von Bombyx mori in einem Gramm für verschierlene liassen und fand:

Eier.

Weisse bag lader (mit schwarzen und gefleckten Raupen) 1100-1300) Weisse bagdarler . . . . . . . . . 1300-1350

Chorosan'sche . . . . . . . . . 1300-1350

Gelbe pyrinäische . . . . . . . . 1350-1400

Weisse brussaer . . . . . . . . . 1400-1450

Gelbe franziosische (kaukasischer Station) . . . . 1400-1450

Gelbe var's he . . . . . . . . . 1400-1450

Gelbe alpinische . . . . . . . . . 1400-1450

Weisse sovenne'sche. . . . . . . . . . 1400-1450

Norl-Kaukasische . . . . . . . . . . . 1450-1500

Gelbe italienische . . . . . . . . . . 1450-1500

Gelhe französische (aus Departement Hero) . . . . 1450-1501)

Transkaukasische locale . . . . . . . 1500-1700

Japanische grine........... . 1700-1900

weisse ........... . . 1700-1900

Chinesische weisse (von Susani) . . . . . . 1700-1900

gelbe (Schantung) : . . . . . 1700-1900

Herater . . . . . . . . . 1700-1900

Turbater . . . . . . . . . . 1700-1900

Japanische grüne . . . . . . . . 1900-2000

" weisse ........... 1900-2000

Chinesische weisse (T'schekian) . . . . . . 1900-2001

(von Susani)...... . 1900--2000

. 2000 u. mehr.

D. h. die schwersten Eicr sind die der weissen Bagdader und die leichtesten ler weissen Chinesischen (von Susani) Rasse.

W. P. Iwanow (1893. 402) in Tiflis bestimmte die grüsste unt die kleinste Axe der Cocons von Bombyx mori verschieslener Rassen und erhielt in m. m.:

R a s s e.

Längsaxe. Queraxc.

Chinesische weisse . . . . . 25,2 16,2

Bagdader weisse . . . . . . 43,6 21,2

Japanische grüne . . . . . . 29,6 15,7

"weisse ...... . $32,4 \quad 15,6$

Bagglarler weisse $X$ japanische weisse . $39,1 \quad 20,5$ 
Ras s e:

Längsaxe. Queraxe.

Turkestanische weisse . . . . . $33,5 \quad 16,1$

Französische gelbe . . . . . . 37,8 17,2

Italienische gelbe . . . . . . . $37,8 \quad 17,6$

Französische reisse . . . . . 36,5 17,3

Pyrinäische gelbe . . . . . . . 37,8 17,9

Turkestanische orange . . . . . 36,9 19,8

Italienische gelbe . . . . . . . $39,2 \quad 21,0$

Korsikanische gelbe . . . . . 40,6 20,4.

Die Untersuchung der mittel-asiatischen Rassen des Seidenspinners Bombyx mori wurden in rler kaukasischen SeidenzuchtStation angestellt. In den zahlreichen Tabellen befinden sich auch Dimensionen der Cocons und ihr Gewicht. Eine wesentliche Differenz zwischen ihnen und den europäischen Cocons wird nicht heobachtet, obwohl die ersteren seit 20 Jahrhunderten hekannt sind. (1893. 969).

Anton Metzger (1893. 579) fing in Friesach (Kärnthen) auf der Höhe von ca. 640 m. Exemplare von Parnassius memosyne. L., welche "heilentend kleiner" sind als solche aus der Umgebung Wien's.

Sobolew (189:3. 748) bestimmte das Gewicht der Eier von Ocneria dispar (im Gouvernement Tula, Russland) sammt der Behaarung, aler olne Rincle, und fanil, dlass 73975 Eier $100 \mathrm{gr}$. wiegen.

H. Rebel und A. Rogenhofer (1893. 674) stellten fest, llass der Falter Painassius apollo L. gegen Osten an Grösse zunimmt. Ausserlem sind in Oesterreich-Lngarn fünf Aherrationen vorhanden, welche einerseits die gigantische Form aus der Tritra (Vorrlerflügel-

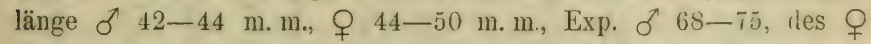
$72-85 \mathrm{~m} . \mathrm{m}$. ), andererseits eine kleine Lokalform aus Friesach in Kärnthen (Exp. heim $\sigma$ von $60-62$, beim $q$ bis $65 \mathrm{~m}$. m.) bilden.

Die Exemplare von Purnassius detius Esp. aus dem (ilockengebiete sind grösser (Exp. des бo bis $70 \mathrm{~m}$. m.) als solche aus der Schweiz (Berner Oberlanı), wo der Falter kiirzere Flïgel ( $\delta 5.3$ bis 60 m. m. Exp.) zeigt.

Wie sich die Lünge unıl die Dicke bei Seiltenraupen mit dem Alter ändert, hat N. Kurnali (1894. 486) untersucht. So z. B. letrugen diese Grössen bei Raupen der weissen italienischen Rasse in m. 111.: 
Datum: 29. IV. 30.3. V. $\quad 4 . \quad 5 . \quad$ 8. $9 . \quad$ 10. 11.12. Länge: $\quad 11,0 \quad 12 \quad 18,1 \quad 20,0 \quad 22,1 \quad 22,1 \quad 27,1 \quad 36,0 \quad 36,1 \quad 37,0$ $\begin{array}{llllllllll}\text { Dicke: } \quad 1,0 & 1,1 & 2,1 & 2,1 & 2,1 & 2,1 & 3,0 & 3,1 & 4,0 & 4,0\end{array}$ Datum: 13. V. 15. 16. 17. 18. 19. 20. 21. $22 . \quad 23$. Länge: $\quad 39,0 \quad 52,0 \quad 52,1 \quad 54,1 \quad 65,0 \quad 65,1 \quad 66,1 \quad 67,2 \quad 75,0 \quad 75,1$ $\begin{array}{llllllllll}\text { Dicke: } \quad 5,0 & 5,2 & 6,1 & 6,1 & 9,0 & 10,0 & 11,1 & 12,0 & 12,1 & 12,2\end{array}$

Über Raupen anderer Rassen sagt er:

1). Die Körperlänge nimmt von $7 \mathrm{~m}$. m. bis $81 \mathrm{~m}$. m. zu; speziell für chinesische weisse von $7,0-70 \mathrm{~m}$. $\mathrm{m}$., fiir chinesische gelbe von 2-23,1, fuir japanische grime von 15-81, fiir bagdaul'sche von $12-76$, für corsikanische von $11-79$, fiir französische gelbe von 11-75. für italienische weisse von $11-75,1$. für turkestanische von $12-69 \mathrm{~m} . \mathrm{m}$.

2). Die Dicke nimmt von 1,1 bis 14,1 m. m. zu; speziell für chinesische weisse von 1,1 bis $11 \mathrm{~m}$. $\mathrm{m}$., fuir chimesische gelbe von $1-9,1$, für japanische grïne von $1,5-11$, fïr bagilarlsche von 1,1 bis 12,2, für corsikanische ron 1-13,1, für franzüsische gelle ron $1,1-10$, fur italienische weisse von $1-12,2$, für turlestanische von $1,1-13,2 \mathrm{~m} . \mathrm{m}$.

3). Die grösste Lünge- un I Dicke-Zunahme finclet an letzten Alter und vor der Häutung statt.

D. P. Antropow (1S94. 15) ziichtete in der staatlichen Seidenzuchtstation zu Tiflis verschiedene Rassen von Bombyx mori und erhielt für die Raupen folgentle Jimensionen resp. Längen in cm.:

Russische Rasse.

\begin{tabular}{|c|c|c|c|c|c|c|c|c|c|c|}
\hline $\begin{array}{c}\text { Länge der Raupe } \\
\text { vor der }\end{array}$ & 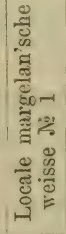 & 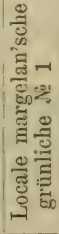 & 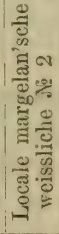 & 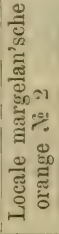 & 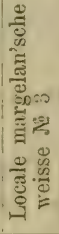 & 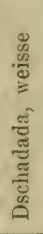 & 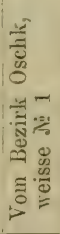 & 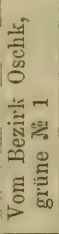 & 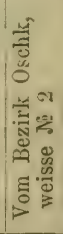 & 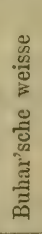 \\
\hline Errsten Häutung & 0,4 & - & $0, \overline{5}$ & 0,4 & 0,5 & 0,5 & 0,4 & 0,5 & 0,4 & 0,4 \\
\hline Zweiten & 1,3 & 1,1 & 1,3 & 1,4 & 1,4 & 1,5 & 1,4 & 1,4 & 1,3 & 1,2 \\
\hline Dritten & 1,9 & 1,7 & 2,2 & 2,0 & 2,0 & 2,0 & 2,0 & 1,9 & 2,0 & 1,9 \\
\hline Vierten & 3,8 & 3,5 & 3,9 & 3,5 & 3,7 & 4,1 & 3,5 & 3,5 & 3,7 & 3,4 \\
\hline Verpuppung . . & 5,6 & 5,5 & 5,4 & 5,2 & 5,3 & 5,3 & 5,3 & 5,2 & 5,4 & 5,2 \\
\hline
\end{tabular}


Chinesische und japanische Rasse.

\begin{tabular}{|c|c|c|c|c|c|c|c|c|c|c|c|c|}
\hline $\begin{array}{l}\text { Länge der Raupe } \\
\text { vor der }\end{array}$ & 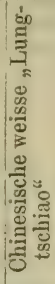 & 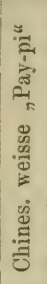 & 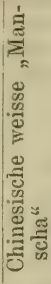 & 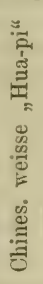 & 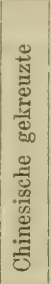 & 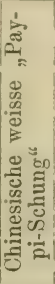 & 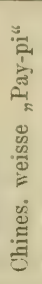 & 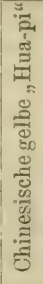 & 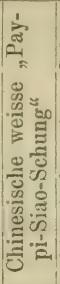 & 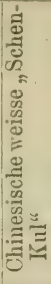 & 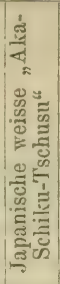 & 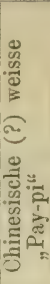 \\
\hline Ersten Häutung & 0,5 & 0,5 & 0,6 & 0,6 & 0,5 & $0, \pi$ & 0,6 & 0,6 & 0,5 & 0,5 & 0,5 & 0,6 \\
\hline Zweiten & 0,9 & 1,1 & 1,1 & 0,9 & 0,8 & 1,1 & 1,2 & 1,3 & 1,0 & 1,1 & 1,0 & 1,1 \\
\hline Dritten & 1,8 & 1,9 & 1,8 & 2,6 & 1,7 & 2,2 & 2,1 & 2,2 & 2,0 & 1,8 & 1,9 & 2,2 \\
\hline Vierten & 3,3 & 3,2 & 2,9 & 3,0 & 3,0 & 3,3 & 3,5 & 3,4 & 3,3 & 2,9 & 3,3 & 3,4 \\
\hline Verpuppung . . & 5,1 & 5,2 & 5,1 & 4,0 & 4,1 & 4,9 & 5,4 & 5,8 & 4,8 & 4,2 & 4,7 & 4,5 \\
\hline
\end{tabular}

Daraus folgt, dass verschiedene Rassen einer und derselben. Art, obwohl in einem und derselben Ort geziichtet, ihre Verschiedenheiten noch beibehalten. Diese Erscheinung wird jedoch bei verschiedenen Arten nicht in gleichem Maasse beobachiet, wie es Aug. Weismann (1895. 954) für die Färbung gewisser Schmetterlinge nachwies.

August Weismann (1895. 954) bespricht in seiner Arbeit "Neue Versuche zum Saison-Dimorphismus der Schmetterlinge: die Elemente bei Chrysophanus phlacas L., welche vom Klima unabhängig sind und betrachtet zuletzt die Schwänzchen der Hinterflügel. Er stellt drei Grade der Ausbildung des Schwänzchens auf: stark, mittel und schwach. Durch Vergleichung von Exemplaren verschiedener Gegenden unter sich kommt er zu dem Schlusse: "Aus diesen Daten erkennt man schon, dass in der That das Schwänzchen öfter bei der Sommergeneration und in heissem Klima vorkommt als bei der Frühjahrgeneration und im nördlichen Klima" (p. 17).

E. Quajat (1895. 658, 594) bestimmte das Gewicht der Eier und ihrer Schale bei Bombyx mori bei verschiedenen Rassen und fand: 


\begin{tabular}{|c|c|c|c|c|c|c|c|c|}
\hline Rass & & & & & & $\begin{array}{l}25 \text { gr. ent- } \\
\text { halten in } \\
\text { Wintermo- } \\
\text { naten Eiex } \\
\text { (Anzahl) }\end{array}$ & \begin{tabular}{|} 
Das Gewicht \\
ron 1000 \\
leeren Eier- \\
schalen \\
(gr.)
\end{tabular} & $\begin{array}{l}\text { Das Gewicht } \\
\text { der leeren } \\
\text { Eierschalen, } \\
\text { welche in } 25 \\
\text { gr. Eier ent- } \\
\text { haltend sind } \\
\text { (gr.) }\end{array}$ \\
\hline Bivoltinische weisse & e & . . & - . & . & & 58909 & $0,0 \pm 48$ & 2,639 \\
\hline Gekreuzte B. G. . & . & . . & . . & . & . & 51631 & 0,0492 & 2,540 \\
\hline Chinesische weisse & S. & . . & . & - & . & 50730 & 0,0464 & 2,353 \\
\hline$"$ & A. & . . & . . & . & . & 50505 & 0,0596 & 3,010 \\
\hline Gekreuzte B. G. : & $\therefore$ & . . & . & - & - & 49980 & 0,0528 & 2,638 \\
\hline Japanische grüne A & A. & . . & . . & . & . & 49348 & 0,0572 & 2,822 \\
\hline weisse & S. & . & • & . & - & 49000 & 0,0584 & 2,861 \\
\hline Corea'sche . . . & . & . . & . . & . & . & 48225 & 0,0568 & 2,759 \\
\hline Gekreuzte B. G. . & . & . . & . . & . & . & 48151 & 0,0588 & 2,831 \\
\hline Japanische grüne S & S. . & . . & . . & . & . & 47981 & 0,0600 & 2,879 \\
\hline weisse & M. & . . & . . & . & . & 47456 & 0,0564 & 2,676 \\
\hline$"$ & A. & . . & . . & . & . & 47276 & 0,0580 & 2,742 \\
\hline Gelireuzte G. B. . & . & . . & . . & . & . & 43986 & 0,0676 & 2,973 \\
\hline Jalova . . . . . & . & . . & . . & . & . & 42866 & 0,0636 & 2,726 \\
\hline Terni Carneo . . & . & . . & . & . & . & 41091 & 0,0696 & 2,859 \\
\hline Gelb-gestreifte . . & . . & . . & . . & . & . & 39295 & 0,0736 & $2,89: 2$ \\
\hline Gekreuzte G. B. .. & . & . . & $\therefore$ & . & . & 37425 & 0,0780 & 2,919 \\
\hline Gelbe . . . . & . . & . . & . & . & . & 36411 & 0,0820 & 2,985 \\
\hline Brianzola ... & . . & . . & . . & - . & . & 36390 & 0,0848 & 3,055 \\
\hline Cévennes M. . . & . . & . . & . . & . & . & 36221 & 0,0824 & $2,9 \Delta 4$ \\
\hline Gelbe Brianza . & . . & . . & . . & . & . & 36200 & 0,0852 & $3,0)+1$ \\
\hline Gekreuzte G. B. . & . & . . & . . & . & . & 36137 & 0,0820 & 2,963 \\
\hline Cévennes S. . . & . . & . . & . . & • & . & 36033 & $0,0 \$ 24$ & 2,969 \\
\hline Gelbe gekreuzte, & . & . . & . & • & . & 35806 & 0,0820 & 2,936 \\
\hline Istria . . . . & . & . . & . & • & . & 35221 & 0,0868 & 3,056 \\
\hline Gransasso .... & . . & . . & . . & . . & . & 33930 & 0,0922 & $3,36 \div$ \\
\hline Montana . . . & . & . . & . & - . & . & 33467 & 0,0928 & $3,10 \overline{3}$ \\
\hline Pirenei. . . . & . & . & . . & .. & $\therefore$ & 33235 & 0,0992 & 3,296 \\
\hline Weisse Indigeno & . . & . & - & - . & - & 33218 & 0,0960 & 3,188 \\
\hline Japanische weisse $\mathrm{A}$ & Mon & atec & $\cos a$ & ro & . & 52388 & 0,0504 & 2,640 \\
\hline Gekreuzte V. B. . & . . & . . & & & - & 54347 & 0,0528 & 2,869 \\
\hline Japanische weisse $C$ & Cam & aeri & no & & - & 53440 & 0,0484 & 2,338 \\
\hline Gekreuzte B. V. . & - $\cdot$ & . & - . & - . & • & 49721 & 0,0584 & 2,903 \\
\hline Chinesische IKiangst & su & . & - . & & . & 51717 & 0,0425 & 2,197 \\
\hline Gelbe ..... & . $\cdot$ & . & - & & 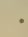 & 35521 & 0,0904 & 3,211 \\
\hline
\end{tabular}

Daraus ist ersichtlich, dass das Gewicht der Eier bei verschiedenen Rassen in grossen Grenzen variirt; dasselbe betrifft auch das Gewicht der Eierschale. 
Prohn (1897. 651) erwähnt in seiner Abhandlung, dass aus Ostindien stammende Ailanthus glandulusu in der Nähe von Strassburg von einem Züchter längere Jahre im Freien an AilanthusBäume ausgesetzt und fortgepflanzt wurite. Die Schmetterlinge sind in (ler Grösse etwas zuriick gegangen.

Martin Holtz (1897. 385) erwähnt in seinem Beitrag zur Insektenfauna Kleinasiens folgende ihrer Grösse nach abweichende Arten, welche er entwerler selbst gesammelt oller aus anleren, ihm zugänglichen Quellen bezogen hat: Papitin podatirius ab. zanclacus O ein ungewöhnlich grosses Exemplar; Papitin aleranor sehr gross; Apmria crutuegi sind grösser als hei uns; Pirris ergune siml ziemlich klein; Thecla rubi in ausserorlentlich grossen Stü(ken; Lycuena anteros meist sehr gross; Lyeaenu cyllurus of ist ganz winzig; Argynnis daphne ist grösser als in Deutschlanı: $A$. arlippe var. tauricu ist sehr gross; A. paphia var. delila und ab. anargyra simt ron hedeutenderet Grösse als die deutschen Formen: Satyrus rirce in sehr grossen Stiicken; Satyrus lriseis ab. pricutu ist sehr gross; Paraige romelanu ist sehr gross; Syrichthus malvae in grossen Exemplaren: Deilephila euphorliace ist sehr gross (rar. paralias); Callimorpha hera in sehr grossen stücken; Lasiocampa otıs riesige Exemplare; Acronycta rumicis in sehr grossen Stücken; Cutocula elocata in sehr grossen Stiicken; Catocala entychea ist gross; Gnophos ylencinaria ist gross.

In lieser Gegend beträgt im Sommer die Temperatur $40^{\circ} \mathrm{I}$. in Schatten und auf der Höhe von $1000 \mathrm{~m}$. um $i$ Uhr morgens $27^{\circ}$ R. im Schatten.

W. Pickel (1898. 635) bestimmte die Dimensionen von Bettwanzen in St.-Petersburg in verschierlenen Entwickelungsstarlien und fand:

1. Alter (vom Ausschlïpfen bis zur I. Häutung) . ca. 1,5 m. m. 2. $n(n 1$. bis zur 2. Häutung) . . . . " 2

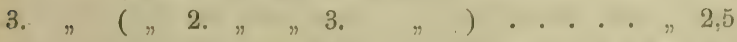

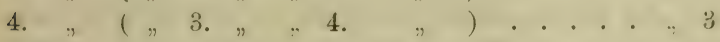

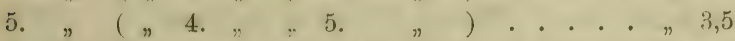

6. $n$ (Erwachsenes Insekt). . .... " 4,5-6 "

P. Iwanow (1899. 404) fand in Gouvernement Charkow mehrere Exemplare von Sphueropyx irrorator Fabricius, welche bis 
zu $10 \mathrm{~m}$. m. lang und $31 / 2 \mathrm{~m}$. m. dick waren. „Die Grösse dieser Insekten, welche in meiner Sammlung sich befinlen, übertrifft um das Doppelte diejenige, welche Marshall (1897. 546) angiebt" (p. 307).

Um len Unterschied an der Grösse der Schmetterlinge, von verschiedenen Gegenden abstammend, genauer zu untersuchen, unternahm ich die Vermessungen der Spannweite der Vorlerfliigel bei Schmetterlingen in Bulgarien und verglich die erhaltenen Resultate init denjenigen an West-Europäischen erhaltenen. Bis jetzt wurde von mir die Familie Satyridae untersucht (1898. 22; 1899. 26).

Die Messungen, welche an Melanargia gulatheu, Erchia aithiops, Erebia liyea, Satyrus hermione, Satyrus liriseis, Satyrys semele. Satyrus statilinus, Pararge maera, Puraige megaera, Epincphole janira, Epinephole tithonus und Coenonympha pamphilus vorgenommen wurden, ergaben folgende Resultate:

Die bulgarischen Arten ller Familie Satyridae sind grösser als die entsprechenden Arten in Westeuropa, wobei nur die Gattung Pararge eine Ausnahme macht und zwar die Arten Pararge maera und Pararge megaera.

Die folgende Tabelle veranschaulicht dieses Resultat, wobei $d-d_{1}$ den Unterschied an der Spannweite bulgarischer (d) und deutscher $\left(d_{1}\right)$ Schmetterlinge $\left(\sigma^{\top}\right)$ bedeutet:

\begin{tabular}{|c|c|c|}
\hline Satyrus briseis . . & . & $d-d_{1}=$ \\
\hline statilinus . & - & ” \\
\hline Coen. pamphilus . & • & $"$ \\
\hline Epinephele janira. & • & $\eta$ \\
\hline tithonus & • & $\eta$ \\
\hline Satyrus hermione . & . & 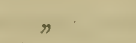 \\
\hline semele. . & . & $\eta$ \\
\hline Melanargia galathea & $a$. & $\pi$ \\
\hline Pararge maera. . & • & $n$ \\
\hline megaera. & . & $\eta$ \\
\hline
\end{tabular}

Vergleicht man die bulgarischen Arten mit den französischen, so erhält man eine noch berleutendere Differenz, so z. B. erhält man für Satyrus briseis d- $d_{1}=10,4 \%$, Satyrus statilinus $11,4 \%$ etc; ungefähr dieselbe Reihenfolge wird auch für die weiblichen Exemplare erhalten.

Folgende Tabelle zeigt, um wie viel grösser die Schmetterlingsweibchen als die Männchen bei den bulgarischen Arten sind: 


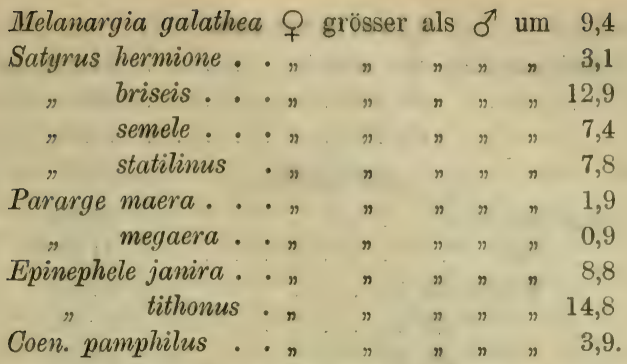

Diese Erscheinung wird natürlich damit erklärt, dass die weiblichen Exemplare in ihrem Leibe Eier haben und folglich ein grösseres Gewicht besitzen, weshalb der Schmetterling, um sich in der Luft zu erhalten, auch Flügel von grösserer Fläche haben muss, d. h. von grösserem $d$, als die männlichen Exemplare.

Über die Hauptursache der beträchtlichen Grösse der Schmetterlingen dieser Familie schrieb ich damals folgendes: „Hieraus folgt, dass, da die mittlere Temperatur des heissesten Monats in Sophia um 5 bis $6^{\circ}$ höher als die in Berlin, Wien, Hamburg, München und Zürich ist, man diesen Umstand in Zusammenhang bringen kann mit der Thatsache, dass die Puppen der Familie Satyridae der Einwirkung der Temperatur in den Monaten Juni Juli unterworfen sind, was man als eine der Hauptursachen zur Erklärung dafür betrachten kann, dass die Arten aus der Familie Satyridae in Sophia grösser sind (von $9,5 \%$ bis $2,5 \%$ ), als in den erwähnten Stälten Westeuropas. Für die Gattung Pararge, deren Arten in Sophia kleiner sind als die in Westeuropa, spielen wahrscheinlich auch andere Faktoren, welche noch weiter studirt werden müssen, mit ${ }^{u}$ (p. 51).

G. Koschewnikow (1900. 465, 467) stellte Messungen an Bienen an, wobei er die Bienen in Aetzkali kochte, sie in Glieder zertheilte und dann jeden Halbring am Rücken vom vorderem Ende bis zum hinteren mass. Folgende Tabelle enthält die erhaltenen Resultate (die Zahlen bedeuten die Summe der Längen der erwähnten Halbringe ohne die des ersten Gliedchens, also des II. + III. + IV. + V. + VI.):

Rasse oder Species.

Königin aus Tula . . . 14,5 m. m. 
274 Zweites Kapitel. Die Grösse und die Gestalt der Insekten.

Arbeiterinnen.

Apis dorsata var. zonata . . . 14,275 m. m.

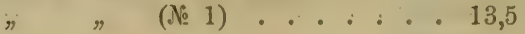

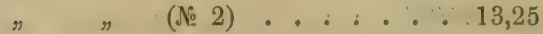

Apis mellifera.

Aus Ssaratow . . . . . . 11,33

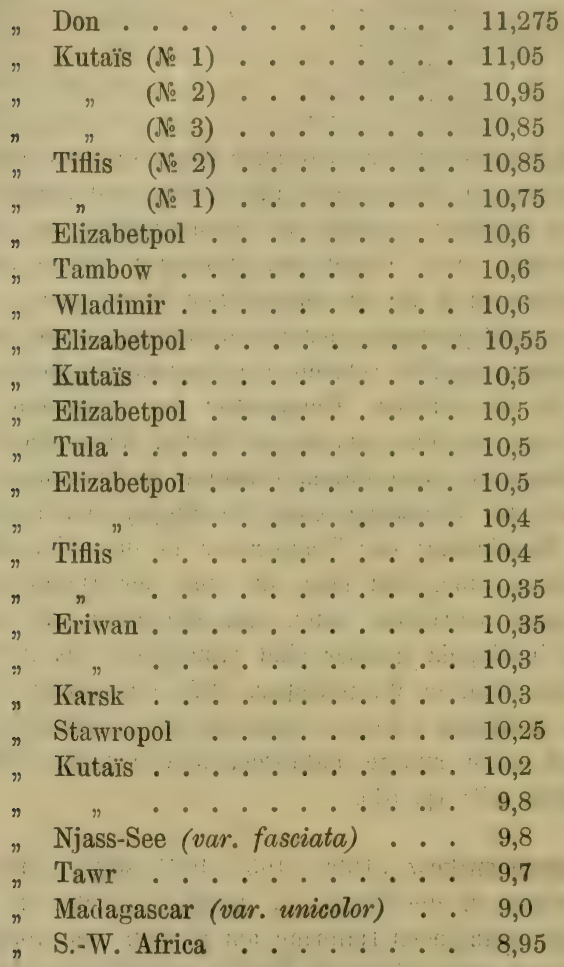

Apis indica.

Aus N. Celebes ․ . . 8,7

" Lombock . . . . . . . 8,3

" Palavan ........ 8, 8,15

Apis florea.

Aus Indien (Sangli) . . . . 6,5 
Aus dieser Tabelle zieht Koschewnikow den Schluss, dass die kaukasischen Bienen kleiner sind als die mittelrussischen, und die afrikanischen kleiner als die europäischen. Er betrachtet jedoch die Bauchlänge ıler Biene als ein zufälliges IIerkmal.

Seine Messungen der Brustlänge ergaben, dass diese Grösse bei afrikanischen Bienen 3,5-4 m. m., bei indischen (indica) 3,25 bis $3,75 \mathrm{~m}$. m. und bei russischen + kaukasischen $3,5-4,25 \mathrm{~m} . \mathrm{m}$. beträgt. Die Brustbreite beträgt: bei afrikanischen Bienen 3,5 bis $3,75 \mathrm{~m}$. m., bei indischen $3,25-3,75$, bei russischen $4-4,5 \mathrm{~m} . \mathrm{m}$. Die Bauchbreite beträgt: bei afgikanischen Bienen $3,75-4,5 \mathrm{~m} . \mathrm{m}$. und bei indischen $3,5-4,25 \mathrm{~m} . \mathrm{m}$.

Die Länge des Vorderflügels betrug bei afrikanischen Bienen $9,9,5 \mathrm{~m} . \mathrm{m}$. und bei europäischen $9-10 \mathrm{~m} . \mathrm{m}$.

Die Messungen des Saugrüssels ergaben, dass zwischen der Grösse des Bienenkörpers und der Länge des Saugrüssels keine Beziehung vorhanden ist, was der Behauptung von A. v. Berlepsch (1891. 74) widerspricht.

Folgende Tabelle enthält die Dimensionen anderer Organe:

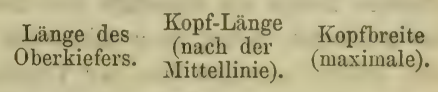

Apis dorsata. . . . . . 1,65 m.m. $4,0 \mathrm{~m} . \mathrm{m} . \quad 4,5 \mathrm{~m} . \mathrm{m}$. Apis mellifera var, fasciata (Njass-

See) . . . . . . 1,3 Apis mellifera var. fasciata (aus

Africa) . . . . . 1,2

Apis indica var. nigrociancta . . 1,2

Apis florea . . . . . 0,8
3,4

3,2

2,4
3,6

3,5

3,4

2,5

L. Krulikowski (1901. 480) fing in der Umgebung von Ssaratow (an der Wolga) Anthocharis belia Cr., welche der Sommerform A. belia var. ausonia Hb. in West-Europa entspricht. Die Exemplare in Ssaratow sind grösser als in Spanien. Dieser Schmetterling trägt den Name var. volgensis Mihi.

W. Martynow (1901. 548a) hat die Zunge der Arbeiterbienen gemessen, welche in Drohnenzellen geziichtet wurden, und find bei der Untersuchung von 100 Arbeiterinnen; dass die Zungenlänge bis zu 7,01 m. m. reicht, während die maximale Zungelänge bei normalen Arbeiterinnen in rlerselben Gegend (Moskau) 6,06 m: m. beträgt. 
W. Pospelow (1901. 642) bestimmte die Cocon-Grösse von Botys sticticalis in Russland, und fand folgende Werthe:

\begin{tabular}{|c|c|c|c|c|c|c|c|}
\hline 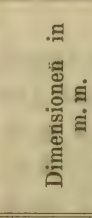 & & 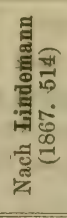 & 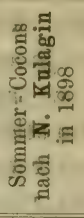 & 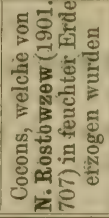 & 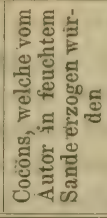 & 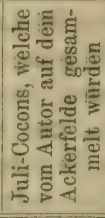 & 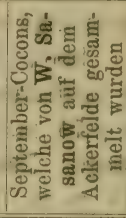 \\
\hline Länge & & 25 & $22-24$ & $21-22$ & $23-28$ & $35-38$ & $43-48$ \\
\hline Breite & $\cdot$ & 5 & 5 & 5 & $5-6$ & 5 & $5-6$ \\
\hline
\end{tabular}

Er erklärt die grosse Verschiedenheit in der Länge der Cocons. dieses Schmetterlings durch zwei Ursachen: 1). Durch die verschiedene Bodenbeschaffenheit und zwar: die normale Verpuppung findet in festem Boden statt, deshalb hat auch der Cocon nicht viel. grössere Länge als diejenige der Raupe $(20-25 \mathrm{~m} . \mathrm{m}$.). 2). Durch die trockenen Jahre, in welchen die Raupen tiefer in den Boden hinein gehen, um sich von der Trockenheit und der Hitze der Oberfläche zu schützen. Beim tieferen Hineingehen muss die Raupe eine Verbindung mit der Oberfläche des Bodens bewahren, damit der ausgeschlïpfte Schmetterling hinaus gehen kann, deshalb auch die bedeutendere Länge des Cocons in diesem Falle.

L. Sorhagen (1902. 857) schreibt, dass die bei Hamburg gezogenen Stücke von Xystophora Hornigi Stgr. durchweg grösser. (12 m. m. Flügelspannung) als die Wiener (10 m.m.) sind.

P. Born (1902. 104a) setzte eine Anzahl lebender norddeutscher und Juracaraben in Herzogenbuchsee im Freien aus, welchein diesem Flachlande sonst nicht vorkommen, um auf diese Weise den Einfluss des Klimas auf die Rassenbildung bei den Caraben zu studieren. Die ausgesetzten Thiere verschwanden aber spurlos.

Als er das bei ihm vorhandenes Material won Caraben verschiedener Gegenden untersuchte, kam er zu dem Schlusse, dass das Klima die Ursache der variirenden Formen ist. „Man bemerkt in den meisten Fällen in einem kühleren Klima eine Abnahme der Körperlänge der Caraben. Ich habe auch bei fast allen Lokalrassen 
(früheren Arten) der West- und Centralalpen öfters darauf hingewiesen, dass Hand in Hand mit dieser Grössenabnahme eine Verkïmmerung der Flügeldeckensculptur auftritt. Während in den unteren Regionen, in denen diese alpinen Käfer (Orinocaraben) auftreten, dieselben meistens egal sculptirt sint, d. h. mit sieben gleich stark ausgebildeten feinen Rippen zwischen den Grub'schen Reihen, werden in höheren Regionen die ungeraden Rippen auf Kosten der geraden immer stärker, letztere fallen schliesslich ganz weg und wir erhalten Formen mit nur fünf, drei und bei latreillei und heteromorphus hie und da sogar nur einer deutlichen Rippe."

Es sind auch umgekehrte Fälle bekannt. Hier erklärt er die Abnahme der Grösse und das Verflachen der Sculptur z. B. bei den südländischen coriaceus-Formen dadurch, dass dieses südliche Klima diesem Käfer weniger „behagt."

W. Petersen (1902. 633) stellte fest, dlass folgende Schmetterlinge grösser resp. kleiner sind als die in Deutschland resp. in der Schweiz gefangenen:

Parnassius apollo L. im sïdlichen Finnland o $45 \mathrm{~m} . \mathrm{m}$. Vorderfliigel (die Länge (ier Vorderflügel von der Wurzel bis zur Flügelspitze).

Argynnis amathusia Esp. in Estland ist auffallend klein.

Coenonympha hero L. in Estland ist merklich kleiner.

Drepana curvatula Bkh. in Estland ist grösser.

Agrotis simulans Hfn. in Estland ist kleiner.

Acidalia immorata L. hat in Estland geringere Grösse.

Acidalia incanata L. in Estland kleiner.

Acidalia violata Thbg. in Estland besitzt eine berleutendere Grösse als die bei Stettin gefangenen. Ein persisches Exemplar ist fast doppelt so gross als ein deutsches.

Larentia variata ab. stragulata $\mathrm{H}$. in Estllamel ist auffalend klein.

Ematurga atomaria L. in Estland ist berleutend kleiner (22 bis $24 \mathrm{~m} . \mathrm{m}$. Spannung).

Phragmatobia fuliginosa L. in Estland ist kleiner (Vorderflïgel $12-14 \mathrm{~m} . \mathrm{m}$.).

Zygaena scabiosae Schev. in Estland ist beträchtlich kleiner als in Deutschland.

Zygaena meliloti Esp. in Estland ist klein (VorterHiigel 11 bis $12 \mathrm{~m} . \mathrm{m}$.). 
F. Kask (1902. $435 a)$ theilt mit, dlass während dlie Grösse der Arbeiterbienen bei ausländischen Rassen im Querschnitte $5 \mathrm{~m}$. m. betrïgt, dieselbe bei Arbeiterbienen ler russischen Ostseeprovinzen $5,5 \mathrm{~m}$. m. erreicht. In erstem Falle kommen auf $1 \square$ Zoll 25 Zellen, in letztem Falle nur 23.

Alex. Reichert (1903. 684) berichtet, lass Ocneria dispar in Sibirien viel grössere Flïgelspannung hat als in Deutschland (Leipzig).

H. Gauckler (1903. 302) bestimmte die Flügellänge bei 123

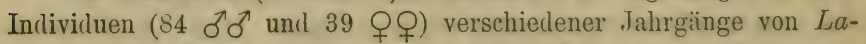
rentic picata $\mathrm{Hb}$. in Karlsruhe und erhielt folgende Resultate:

Vorderflügel bei $\sigma^{\nearrow} \sigma^{\top}$

Maximale Länge $=17,5 \mathrm{~m} . \mathrm{m}$.
Minimale $=14,5 \quad n$
Frequenzielle Länge $=16,5 \quad$ "
Mittlere Länge $=16,3 \quad$ "

Vorderflügel bei $q$ Q:

Maximale Länge $=18,5 \mathrm{~m} . \mathrm{m}$.
Minimale " $=13,5 \quad "$
Frequenzielle Länge $=15,5 \quad "$
Mittlere Länge $=16,3 \quad$ n

Die von ihm erhaltenen Werthe für Arctia caja L. $\left(20 \sigma^{\nwarrow} \sigma^{\star}\right.$ und 25 웅) waren folgende:

Vorderflügel bei $\sigma^{\top} \sigma^{\top}$ :

Maximale Länge $=28, \mathrm{~m} \cdot \mathrm{m}$.

Minimale " $=23,5$ "

Frequenzielle Länge $=26,4$ "

Mittlere Länge $=26,1$ n

Vorderflügel bei $\uparrow \uparrow:$

Maximale Länge $=36 \quad \mathrm{~m} . \mathrm{m}$.
Minimale $=29 \quad "$
Frequenzielle Länge $=32,5 \quad "$
Mittlere Länge $=33,0 \quad n$

H. Auel theilte mir seine Messungen der Flügellänge bei Pieris brassicue L. von 1900-1902 mit, welche hier zum ersten Mal veröffentlicht werden. Die Schmetterlinge wurden in Potsdam. erbeutet und ergaben folgende Resultate: 
Im August 1900 wurden 26 ठ ठ und 66 우 gefangen (II. Generation). Die meisten $\delta \sigma^{\top}$ hatten die Spannweite $68,0-68,7$, welche im Mittel $68,1 \mathrm{~m} . \mathrm{m}$. ergeben; $\nmid$ ㅇ ergeben im Mittel für die frequenzielle Spannweite $70,3 \mathrm{~m} . \mathrm{m}$.

Das Material von 1901 und 1902, welches unter verschiedenen Bedingungen gezüchtet wurde, ist nicht so zahlreich, um daraus die frequenziellen Grössen bestimmen zu können.

W. Schulz (1903. 795) fand, dass Pepsis hexamita R. Luc. von der Antillen-Insel St. Croix von derselben Art auf der Insel Newis sich durch eine geringere Grösse unterscheidet (Körperlänge 20, Vorderflügel-Länge 20, Flügelspannweite $39 \mathrm{~m}$. m.). Sceliphron fasciatum ㅇ Lep. von Haiti ist kleiner als von Cuba (17 Länge statt $18,5 \mathrm{~m} . \mathrm{m}$.).

H. Rebel (1903. 676) fand in Bulgarien folgende Unterschiede in der Grösse der Species verglichen mit anderen Ländern:

Parnussizıs apollo L. ist in allgemeinen grösser und besitzt breitere Fliigel als die Exemplare aus den Alpen.

Die im ersten Frühjahre auftretenden Stücke von Melitaea cinxia L. sind bei Sliwno grösser als die in Mai fliegende häufigere Form.

Argynnis selene Schiff. zeigt $31-33 \mathrm{~m} . \mathrm{m}$. Exp., gegen $36 \mathrm{~m} . \mathrm{m}$. zentraleuropäischer Stücke.

Argynnis hecate Esp. bei Sliwno ist grösser ( $\sigma^{\star}$ ca. 40, $q$ ca. 43 m.m. Exp.) als die zentraleuropäischen Stücke (36 resp. 40 m. m. Exp.).

Argynnis pandora Schiff. von Sliwno hat ein geringeres Ausmass als mediterrane Stücke.

Erebia medusa F. in höheren Lagen (von ca. $1600 \mathrm{~m}$. aufwärts) wird bedeutend kleiner.

Chrysophanus hippothoë L. sind grösser (Exp. bis $35 \mathrm{m.m}$.) als die zentraleuropäischen Exemplare.

Lycuenu argus L. ist auffallend klein ( $ठ$ Exp. 20 bis 23, 우 $22-25 \mathrm{~m} \cdot \mathrm{m}$.).

Hadena maillardi $\mathrm{Hg}$. ist ausnehmend gross (o Exp. $5 \mathrm{i}$ m.m.).

Chloantha radiosa Esp. Die alpinen Rilostücke sind belleutend grösser als solche aus der Ebene.

Orrhodia torrida Ld. hat bei Sliwno die bedentendere Grösse (Exp. $34-37$ m. m.) als die sizilischen Stïcke. 
Acidalia violata Thnbrg. var decorata Bkh. ist bei Sliwno sehr gross und erreicht $15 \mathrm{~m} . \mathrm{m}$. Vorderflügellänge.

Oxyptilus didactylus L. fliegt bei Sliwno in ausnehmend kleineren Stücken (Vorderflïgellänge $8-8,5$, Exp. $16-18 \mathrm{~m} . \mathrm{m}$.) als in Zentraleuropa.

Aluctia balioductyla $\mathrm{Z}$. bei Sliwno ist etwas kleiner als aus der Hercegowina.

Scythris seliniella Z. ist bei Sliwno etwas grösser als in Zentraleuropa.

Coleophor millefolii Z. hat im Rilogebiete Expansion 10 gegen $12,5 \mathrm{~m} . \mathrm{m}$. zentraleuropäischer Stuicke.

A. Moinhard (1904. 554) erwähnt bei der Beschreibung iler Schmetterlinge aus dem Jakutsk-Gebiete folgendes:

Aporia cratregi L. aus Jakutsk hat die Spannweite 52 bis $55 \mathrm{~m} . \mathrm{m}$., während die Exemplare aus Tomsk viel grösser sind (55 bis $68 \mathrm{~m} . \mathrm{m}$.).

Vanessa antiopa I. ist etwas kleirer als diejenigen aus Tomsk oder Europa.

Erebia discoidalis Kirb. (syn. lenu Christ.) ist etwas grösser als in Nord-Amerika.

Hadena lateritia Hafn. ist etwas kleiner als in Tomsk.

Fr. Klapálek (1904. 451) fand, (lass Chloroperla rivolorum Pict. von den Hohentauern viel kleiner ist als die normalen Stiicke in Prag (einige $\delta$ haben nur $16 \mathrm{~m}$. m. Fliigelspannung).

H. Auel (1904. 18) bestimmte die Flïgellänge bei Pieris brassicae L., welche rom 21.-29. August 1904 in Potsilam gefangen wurden. Er erhielt bei $77 \delta \delta^{\nearrow}$ für die frequenzielle Länge der Vorderflügel $31,2 \mathrm{~m}$. m. und für die Spannweite $65,7 \mathrm{~m} . \mathrm{m}$.

A. Meinhard (1904. 555) zog in Tomsk (Sibirien) die Raupen von Aporia cratraegi L., welche auch dort gesammelt wurden (1901), und erhielt 125 Schmetterlinge, welche $50-62 \mathrm{~m} . \mathrm{m}$. Spannweite hatten. Die Schmetterlinge, welche er aus den in Freiheit gesammelten Puppen (1900) erhielt, hatten die Spannweite 58-68 m.m. Die gezogenen Raupen von Vanessa urticae L. aus derselben Gegend ergaben sehr kleine Schmetterlinge (う0 Stück).

Lymantria dispar L. ist in West-Sajanen sehr gross $\left(\sigma^{\nearrow} 50 \mathrm{~m} . \mathrm{m}\right.$., 우 $70 \cdot \mathrm{m} . \mathrm{m}$.). 
H. Rebel (1904. 677) beobachtete bei Schmetterlingen von Bosnien und der Herzegowina folgende Abweichungen in der Grösse und Gestalt:

Limenitis populi L. in Kalinowik ist auffallend klein.

Erebia ligea L. variirt bei zunehmender Höhe der Flugplätze beträchlich und nimmt dann auch an Grösse ab.

Satyrus dryas Sc. in Doljankatal erlangt eine bedeutende Grösse (Q bis $65 \mathrm{~m} . \mathrm{m}$. Exp.).

Thecla ilicis Esp. ist grösser als mitteleuropäische Stiicke.

Lycaena amandus Schn. ठే vom Maklenpass erreicht 33 111. m. Spannweite, wogegen ein solches vom Trebević bloss $25,5 \mathrm{~m} . \mathrm{m}$. besitzt.

Coclonia quercimontaria Bastelb. Das $\delta$ aus Dervent ist sehr gross (24 m.m. Exp.). flügellänge).

Tephroclystia graphata Tr. O ist sehr gross $(11 \mathrm{~m} . \mathrm{m}$. Vorder-

Boarmia perversaria $\mathrm{B}$. $\subsetneq$ ist sehr klein.

Syntomis plegea L. in Gacko ist besonders gross ( $\sigma^{\prime}$ bis 42 m.m. Exp.).

Callimorpha quadripunctaria Poda. Sehr gross (bis 63 m.m. Exp.).

Endrosa roscida Schiff. Grösser als typische Exemplare.

Zygaena meliloti Esp. Kileiner als die Stammform.

Zygaena lonicerae Scheven. Die Stiicke aus dem Doljankatale sind sehr gross.

Ino glolulariae $\mathrm{Hb}$. Ein $\delta^{\pi}$ von Kalinovik zeigt auffallend lange Fühlerkammzähne, ein anderes $\delta$ vom Maklenpass ist sehr gross (15.5) m.m. Vorderflügellänge) mit sehr kurzen Fïhlerkammzähnen. Epichnopteryx pullu Esp. Die Stïcke von Dervent und Jablanica sind sehr gross.

Cossus terebra F. Auffallend grosses ठ von Sarajevo.

Hepialus humuli L. $q$ von Treskavica sehr gross.

Crumbus lytluargyrellus Hb. Besonders gross (Vorderfliigellänge bis 16, Exp. bis $33 \mathrm{~m} . \mathrm{m}$.). Aehnlich grosse Stricke auch von Zermatt.

Tortrix rolandriana L. Die Stücke sind breittlïgeliger als alpine.

Atemelia torquatella Z. Sehr gross mit auffallend stark gezähnelter Fühlergeissel.

Tinea roesslerella Heyd. Die Exemplare von Sarajevo sincl grïsser $(11 \mathrm{~m} . \mathrm{m}$. Exp.) als jene von Konjica (9 m.m. Exp.).

Nemotois dalmatinellus Mr. Auffallend gross: 
J. Dewitz (1905. 177) fand, dass 100 Schmetterlinge von Tortrix pilleriana $4 \mathrm{gr}$. wiegen.

W. von Reichenau schreibt mir (Mainz, 14. VI. 1905): „Den kleinen Lucanus cervus var. capreolus halte ich für eine um ein Jahr abgekïrzte Form, dadurch wird er atavistisch und kommt in der Ausbildung später erhaltener Attribute zu kurz." Versuche hat er wegen langer Dauer der Zucht nicht gemacht.

G. Koschewnikow (1905.467a) hat Messungen an 32 ठ ठ von Copris lunuris L. angestellt, welche am 21. Mai 1901 (alt. St.) im Dorfe Luschk (Gouvernement Moskau) exbeutet wurden. Die Resultate ler Messungen verschiedener Theile der Männchen sowohl aus dieser Gegend, wie auch aus einigen anderen, sind in folgender Tabelle angeführt, wobei die Bedleutung der Bezeichnungen in der Fig. 4) nachzusehen sind ( $n$ bedeutet die Anzahl der untersuchten Exemplare):

\begin{tabular}{|c|c|c|c|c|c|}
\hline \multirow[b]{2}{*}{$\begin{array}{c}\text { Gemessene Theile } \\
\text { des Körpers }\end{array}$} & \multicolumn{5}{|c|}{ G e g e n d } \\
\hline & $\begin{array}{c}\text { Luschk } \\
\text { (Gouvern. } \\
\text { Moskau) } \\
n==32\end{array}$ & $\begin{array}{c}\text { Orenburg } \\
n=1\end{array} \mid$ & $\begin{array}{c}\text { Nowaja } \\
\text { Kriuscha } \\
\text { (Bezirk } \\
\text { Bogu- } \\
\text { tscharsk) } \\
n=5\end{array}$ & $\begin{array}{c}\text { Kolomna } \\
\text { (Gouvern. } \\
\text { Moskau) } \\
n=2\end{array}$ & $\begin{array}{c}\text { Tar- } \\
\text { buschewo } \\
\text { (Gouvern. } \\
\text { Moskau) } \\
n=1\end{array}$ \\
\hline $\begin{array}{c}\text { Maximale Werthe: } \\
\text { a f }\end{array}$ & 22 & - & 23,5 & 21,5 & - \\
\hline Bauchbreite & 12 & - & 13 & 12,5 & - \\
\hline b c & 5,5 & - & 7,5 & 7,5 & - \\
\hline de & 4 & - & 5,5 & 5,5 & - \\
\hline Minimale Werthe: & & & & & \\
\hline a $f$ & 17 & - & 21 & 20,5 & - \\
\hline Bauchbreite & 9 & - & 12 & 11,5 & - \\
\hline b c & 1 & - & 4 & 5 & - \\
\hline$d e$ & 1 & - & 3 & 3,5 & - \\
\hline $\begin{array}{c}\text { Arithm. Mittel: } \\
\text { a f }\end{array}$ & 19,3 & 23,5 & 22 & 21 & 19 \\
\hline Bauchbreite & 10,7 & 13,5 & 12,2 & 12 & 11,5 \\
\hline $\mathrm{b} c$ & 2,8 & 7,5 & 5,1 & 6,2 & 3 \\
\hline$d e$ & 2,3 & 5,5 & 4,1 & 4,5 & 3,5 \\
\hline
\end{tabular}

L. v. Aigner-Abafi (1905. $7 a, 7 b)$ bestimmte die Flügellänge bei Aporia crataegi L., welche in Buda-Pest erbeutet wurden, und erhielt folgende Resultate für die Vorderflügel: 


\begin{tabular}{|c|c|c|c|c|}
\hline $\begin{array}{l}\text { Wie viel } \\
\text { Exemplare }\end{array}$ & Sammelzeit & $\begin{array}{c}\text { Maximale } \\
\text { Länge }\end{array}$ & $\begin{array}{c}\text { Minimale } \\
\text { Länge }\end{array}$ & $\begin{array}{c}\text { Frequenzielle } \\
\text { Länge }\end{array}$ \\
\hline 57 ठ ठ & 1903 & 35,5 & 28,5 & 32 \\
\hline 97 우우 & 1903 & 37 & 30 & 33 \\
\hline 171 ठூ & 1904 & 35 & 26 & 32 \\
\hline 504 우 & 1904 & 37 & 26 & 33 \\
\hline
\end{tabular}

Auch ich habe ausfïhrliche Messungen der Flügellänge bei Aporia crataegi L. von verschiedenen Gegenden angestellt, um den Einfluss des Klimas auf diese Grösse zu bestimmen.

Die Nessungen wurden so angestellt, wie es im Abschnitte "Einleitung" dieses Kapitels beschrieben ist.

In folgenden Tabellen werden Resultate angeführt, welche mit dem 1904 gesammelten Material, erhalten wurden. Dabei bedeutet:

$l_{f}$ - Die frequenzielle Flügellänge, $d . h$. solche, welche dem Hauptmaximum der Frequenz entspricht.

$M$ - Die maximale Flügellänge.

$m$ - Die minimale Flügellänge.

Die Zahlen, welche hinter jeder Stalt in Kilammern angeführt sind, bedeuten die Anzahl der Exemplare, welche diese Resultate ergaben.

Männliche Exemplare.

\begin{tabular}{|c|c|c|c|c|c|c|c|c|c|}
\hline \multirow{2}{*}{\multicolumn{3}{|c|}{$S t a d t$}} & & \multicolumn{2}{|c|}{$l_{f}$} & \multicolumn{2}{|c|}{$M$} & \multicolumn{2}{|c|}{$m$} \\
\hline & & & & 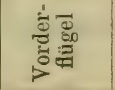 & 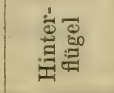 & 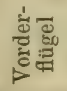 & 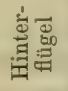 & 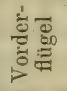 & 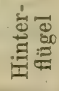 \\
\hline Sophia (200) . & . . & . & . . & 30,8 & 25,8 & 33,8 & 28,8 & 25,8 & 20,3 \\
\hline Rustschuk $(0)$ & . . & . & . . & - & - & - & 一 & - & - \\
\hline Silistra (128) & . . & . & . . & 32,3 & 26,8 & 34,8 & 29,0 & 28,8 & 23,8 \\
\hline Widin $(200)$. & . . & . & . . & 32,8 & 26,8 & 34,8 & 29,3 & 27,3 & 23,8 \\
\hline Plewna (200) & . : & . & $\because$ & 32,8 & 25,$8 ; 26,8$ & 35,0 & 29,1 & 27.0 & 21,5 \\
\hline Sadowo (200) & . . & . & . . & 32,8 & 27,8 & 35,5 & 30,0 & 27,0 & 21,5 \\
\hline Chaskowo (104) & . & . & . . & 32,$8 ; 33,8$ & 26,8 & 35,5 & 30,0 & 26,0 & 20,5 \\
\hline Samokow (200) & . & . & . . & 30,8 & 25,8 & 34,5 & 28,7 & 27,0 & 21,5 \\
\hline Küstendil (0) & . & . & . . & - & - & - & - & - & - \\
\hline T.-Pasardschik & $(20$ & & . . & 32,8 & 27,8 & 36,2 & 29,8 & 29,6 & $24,()$ \\
\hline Belgrad (129) & . . & . & : & 32,8 & 27,8 & 36,6 & 30,5 & 30,0 & 25,0 \\
\hline Buda-Pest (0) & . . & . & . . & - & - & - & - & - & - \\
\hline Kjew (200). & . & . & . & 31,8 & 26,8 & 35,1 & 29,2 & 27,9 & 22,4 \\
\hline
\end{tabular}




\begin{tabular}{|c|c|c|c|c|c|c|c|c|c|}
\hline \multirow[b]{2}{*}{$\mathrm{Stadt}$} & & & & \multicolumn{2}{|c|}{$l_{f}$} & \multicolumn{2}{|c|}{$M$} & \multicolumn{2}{|c|}{$m$} \\
\hline & & & & 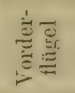 & $\stackrel{\dot{\Xi}}{\stackrel{\Xi}{\Xi}}$ & 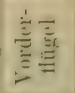 & $\stackrel{\dot{\Xi}}{\stackrel{\Xi}{\Xi}}$ & $\stackrel{\dot{\Xi}}{\vec{E}}$ & $\stackrel{\frac{1}{\Xi}}{\Xi \Xi}$ \\
\hline Uman $(200)$. & . & . . & . & 31,8 & 26,8 & 34,7 & 29,2 & 27,5 & 20,5 \\
\hline Charkow (82) . & . & . . & . . & 31,8 & 25,8 & 34,5 & 29,1 & 25,3 & 19,8 \\
\hline Ananjew (77) . & & . . & . . & 31,8 & 25,8 & 34,3 & 28,4 & 25,0 & 17,2 \\
\hline Woronesch (200) & $\therefore$ & $\because$. & .. . & 30,8 & 25,3 & 35,2 & 30,0 & 26,8 . & 21,0 \\
\hline Belgorod (200) & & . . & 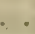 & 31,8 & 26,8 & 35,0 & 30,0 & 28,8 & 21,5 \\
\hline Pinsk (200) . . & . & . . & . . & 32,8 & 26,8 & 35,1 & 29,9 & 27,7 & 22,0 \\
\hline Eletz $(0) \ldots$ & . &. & . . & - & - & - & - & - & - \\
\hline Saratow (115) . & . & . . & . . & 32,8 & 27,8 & & & & \\
\hline Kasan (120). . & . & . & . . & 33,8 & 27,8 & 36,0 & 30,2 & $29 ; 2$ & 23,1 \\
\hline Ufa $(200) \ldots$ & . & - . & . . & 34,8 & 28,8 & 37,0 & 30,2 & 30,2 & 25,0 \\
\hline Tobolsk (205) . & . & . & . . & 32,8 & 27,8 & 36,0 & 30,0 & 29,4 & 23,6 \\
\hline
\end{tabular}

Weibliche Exemplare.

\begin{tabular}{|c|c|c|c|c|c|c|c|c|c|c|}
\hline Sophia (200) & . . & & . & • & 32,8 & 27,8 & 36,8 & 299,8 & 26,5 & 20.8 \\
\hline Rustschuk (200 & 0) . & & 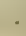 & - & 32,8 & 27,8 & 36,2 & 30,2 & 30,0 & 24,5 \\
\hline Silistra (106) & . . & . & . & . & 32,8 & 27,8 & 37,2 & $: 30,5$ & 30,8 & 24,8 \\
\hline Widin (200) & . & & - & . & 34,8 & 27,8 & 37,8 & $\because 1,3$ & 30,3 & 24.3 \\
\hline Plewna (200) & . . & & & . & 32,8 & 27,8 & 37,0 & 30,2 & 27,5 & $2 \cdot 2,7$ \\
\hline Sadowo $(0)$. & . & & - & . & - & - & - & - & - & - \\
\hline Chaskovo $(0)$ & . . & & 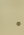 & . & - & - & - & - & - & - \\
\hline Samokow $(0)$ & . . & & . & . & - & 一 & - & - & - & - \\
\hline Küistendil (89) & . . & & . & . & 32,8 & 26,$8 ; 27,8$ & 37,1 & 30,5 & 27,0 & 22,2 \\
\hline T.-Pasardschik & $(16$ & 32) & . & - & 34,8 & 28,3 & 37,5 & $: 31,6$ & 30,8 & 24,$1 ;$ \\
\hline Belgrad (122) & . . & & • & . & 33,8 & 28,8 & 38,0 & 32,3 & 28,3 & $2: 3,1$ \\
\hline Buda-Pest $(173$ & 3) . & . . & . & , . & 33,8 & 27,8 & 36,0 & 29,5 & 27,8 & 22,0 \\
\hline Kjew (119) . & . & . . & . & . & 34.3 & 27,8 & 37,1 & $30), 0$ & 29,0 & 23,0 \\
\hline Uman (199) & . & . . & . & . & 32,8 & 27,8 & 36,0 & 29,9 & 25,1 & 20,0 \\
\hline Charkow (60) & . . & . . & . & . & 32,8 & 27,8 & 36,0 & 30,0 & 25,0 & 18,0 \\
\hline Ananjew (114) & . . & . . & & . & 33,3 & 26,8 & 35,1 & 29,9 & 27,0 & 21,6 \\
\hline Woronesch (15 & 5) . & . . & . & . & 31,8 & 26,8 & 35,8 & 30,7 & 27,5 & 22,8 \\
\hline Belgorod (154) & ... & . . & . & . & 33,$8 ; 34,8$ & 28,3 & 37,0 & 30,9 & 30,2 & 25.0 \\
\hline Pinsk $(0)$. . & . . & . . & . & . & - & - & - & 一 & - & - \\
\hline Eletz (200) . & . . & . . & . & . & 32,$8 ; 33,8$ & 27,8 & 36,6 & 31,0 & 28,5 & 23,4 \\
\hline Saratow (63). & . & . . & . & . & 34,3 & 27,$8 ; 28,8$ & - & - & - & - \\
\hline Kasan (47) . & . . & . . & & . & 34,8 & 28,8 & 37,8 & 31,0 & 30,0 & 24,6 \\
\hline Ufa $(0) \ldots$ & . & • & • & & - & - & - & - & - & - \\
\hline Tobolsk (88) & . & & & & 34,8 & 27,$8 ; 28,8$ & 38,7 & 31,2 & 31,2 & 23,6 \\
\hline
\end{tabular}


Zur Feststellung der klimatischen Einfliisse auf die angeführten Grössen dient folgende Tabelle, in welcher die meteorologischen Angaben während der Raupen- und Puppenzeit notiert sind:

\begin{tabular}{|c|c|c|c|c|c|c|c|}
\hline \multirow{2}{*}{\multicolumn{2}{|c|}{ S t a d t }} & & & \multicolumn{4}{|c|}{ Mittlere Jahreswerthe (1903 VII. - 1904 VI.) } \\
\hline & & & & Temperatur & $\begin{array}{c}\text { Die Summe } \\
\text { der Tage mit } \\
\text { der Tempe- } \\
\text { ratur }=17^{\circ}\end{array}$ & $\begin{array}{c}\text { Atmosph. } \\
\text { Niederschläge } \\
\text { in L. pro } \square \mathrm{m} \text {. }\end{array}$ & $\begin{array}{c}\text { Relative } \\
\text { Feuchtigkeit } \\
\text { in } \%\end{array}$ \\
\hline Chaskowo & . . & - . & . & 12,4 & 159 & 519 & 71 \\
\hline Sadowo & . . & . & . & 12,3 & 157 & 444 & 7.0 \\
\hline T.-Pasardsch & hik & 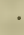 & . & 12,0 & 151 & 416 & 73 \\
\hline Belgrad . & . . & $0^{\circ}$ & & 12,0 & 148 & - & - \\
\hline Silistra . & . & • & & 11,7 & 164 & 365 & 68 \\
\hline Buda-Pest & - $\cdot$ & • & - & 11,4 & 124 & 487 & 73 \\
\hline Küstendil & . . & . & . & 11,4 & 148 & 454 & 68 \\
\hline Widin (Lom & n). & . & . & 11,3 & - & 493 & 73 \\
\hline Plewna. . & . & . & . & 11,3 & 155 & 411 & 71 \\
\hline Sophia . . & . . & • & . & 10,5 & 141 & 501 & 71 \\
\hline Rustschuk & . . & - & . & 10,4 & 157 & 424 & 73 \\
\hline Samokow . & . . & . & . & 7,9 & 111 & 466 & 73 \\
\hline Uman . . & . $\cdot$ & • & . & 7,3 & 105 & 336 & 73 \\
\hline Kjew . . & . $\cdot$ & - & . & 7,1 & 99 & 448 & - \\
\hline Pinsk . . & . & - & & 6,9 & 92 & 493 & 79 \\
\hline Charkow . & . & $\cdots$ & & 6,7 & 105 & 526 & 77 \\
\hline Belgorod . & . $\cdot$ & . & & 6,6 & 105 & 484 & 82 \\
\hline Saratow . & . $\cdot$ & - $\cdot$ & & 5,6 & 104 & 325 & 70 \\
\hline Kasan . . & . & . & & 3,3 & 86 & 410 & 71 \\
\hline Ufa ... & . $\cdot$ & - $\cdot$ & $\cdot$ & 2,8 & 89 & 461 & 73 \\
\hline Tobolsk . & . & & 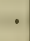 & 0,2 & 63 & 511 & 一 \\
\hline
\end{tabular}

Die Bearbeitung dieses Materials sowohl für das Jahr 1904, wie auch für das Jahr 1905 wird in den Memoiren der St.-Petersburger Akademie der Wissenschaften veröffentlicht. Hier sei nụr bemerkt, dass dabei noch das cyklische Erscheinen von Aporia crataegi in Betracht gezogen werden muss, wie es L. von Aiguer-Abafi in seinen Abhandlungen erwähnt (1905. $7 a, 7 b)$.

\section{Ergänzungs-Litteratur zu diesem Abschnitt.}

Antropow, D. P. Die Tabelle der Aufzucht der Seidenraupen in der kaukasischen Seidenzucht-Station 1892. - Arbeiten der kaukasischen SeidenzuchtStation. Jahrg. 1892. VI. Bd. 3. Liet. p. 52-58. Tiflis 1893. (Russisch). 
Raulin, J. Rélations entre les propriétés des cocons du Bombyx mori. - Laboratoire d'étude de la soie. 1893-94. Lyon 1895.

Rudow, F. Weiterer Beitrag zum Grössenverhältniss der Inselkten verschiedener Breitengrade. - Insekten-Börse. XVII. 주 9-11. 1900. p. 83.

Seitz, A. Das Klima in seinem Einflusse auf die Lepidopteren. - Verhandl. Deutsch. Naturf. II. 1890. p. 142-148.

\section{Einfluss der Feuchtigkeit.}

Bei Ad. Rössler (1881. 702) „Die Schuppenflügler" finclet sich folgende Stelle: „Fast alle Raupen bediirfen auch des Trinkens, das ihnen im Freien durch Thau und Regen ermöglicht wirl. Wenn sie auch wegen Mangels daran nicht immer sterben, so haben doch aus diesem Grunde erzogene Schmetterlinge oft kürzere Flïgel und verhältnissıässig plumperen Leib als gefangene, weil es an Saft fehlte, die Flügel vollständig auszudehnen" (p. 9).

C. Frings (1893. 250) fand in der Ungebung von Bonn im Mai 1892 auf einer sehr sumpfigen Stelle eine ILelitas, leren Unterseite mit der typischen aurinia übereinstimmte, sonst ähnlich wie didyma. Im Mai 1893 fand er an gleicher Stelle noch eine solche Aberration und eine Uebergangsform. Die Thiere sind entweder mittelgross oller sehr klein; ihre Flügel, besonders die vorderen, sinıl länger und schmäler als bei aurinia.

C. W. Barker (1895. 52) stellte in Natal seine Beobachtungen über Saison-Dimorphismus der Rhopalocera an und fand, dass die in der trockenen Jahreszeit Hliegenden Schmetterlinge sich von den Formen der Regenzeit durch geringere Grösse und Neigung zu grösserer Schärfe in den Ecken der Vorderflügel unterscheiden.

Im Herbst 1896 bettete Karl Frings (1896. 253) frische Puppen von Vanessa $C$ album und atalanta so tief in sehr feuchten Sand ein, dass die Flügelscheiden vollkommen von demselben bedeckt waren. Der Hinterleib der Puppen mit den Stigmen wurde sorgfältig vom Sande freigehalten, um eine Erstickung zu verhüten. Während der ganzen Puppenruhe waren die Flügelscheiden und überhaupt der ganze Vorderkörper der Versuchsthiere grösster Feuchtigkeit ausgesetzt. Nachher wurden dieselben herausgenommen. C album hatten schärferen Flügelschnitt. 
H. Fruhstorfer (1896. 263) fand bèi der Sommerform von $P a$ pilio aristolochiae F. lambokensis subspec. nova, welche im Lambok von Anfang Juni - mit dem Eintritt der Trockenzeit erscheint, die Flügellänge nur $35 \mathrm{~m} . \mathrm{m}$.; die normalen Exemplare messen $50 \mathrm{~m} . \mathrm{m}$.

L. v. Heyden (1897. 373) erklärt das Entstehen der kleinen Form von Lucanus cervus durch die Trockenheit, inclem er sagt: "Die typische grosse Form lebt als Larve in alten überständigen Eichbäumen im Stamme; je näher dem Boden, desto mehr Feuchtigkeit ist vorhanden, die Larve gedeiht besser und liefert grosse Ex. emplare. Die kleine Form lebt als Larve in den trockeneren stärksten Aesten" (p. 199). Seine б variiren von $70-27$ m.m.; ㅇ 39 bis 26 m.m.; nach Planet (Naturaliste, 1895. p. 230) ot von 90 bis 30 m.m. C. Frings (1897. 251) fand in der Gegend von Bonn $\sigma^{7}$ von $67-42 \mathrm{~m} . \mathrm{m}$. und ㅇ von $42-25 \mathrm{~m} . \mathrm{m}$.

E. Quajat (1903. 669) untersuchte den Einfluss der trockenen und feuchten Luft auf die Coconproduktion von Bombyx mori und fand für verschiedene Rassen folgende Werthe (die Anzahl der $\mathrm{C}_{0}$ cons in 1 Ko.):

\begin{tabular}{|c|c|c|c|c|}
\hline 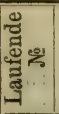 & Rasse & $\begin{array}{c}\text { Bei } \\
\text { trockener } \\
\text { Luft }\end{array}$ & $\begin{array}{c}\text { Bei } \\
\text { feuchter } \\
\text { Luft }\end{array}$ & $\begin{array}{c}\text { Unter } \\
\text { normalen } \\
\text { Um- } \\
\text { ständen }\end{array}$ \\
\hline 1 & Runde chinesische weisse. & 771 & 705 & 7.54 \\
\hline 2 & Gelbe indianische $\ldots \ldots$. & 442 & 409 & 403 \\
\hline 3 & Weisse japanische . . . . & 653 & 593 & 623 \\
\hline 4 & $q$ indianische $\delta$ massurische & 412 & 389 & 414 \\
\hline 5 & o goldgelbe $\sigma^{\top}$ gelbe indianische & 623 & 581 & 567 \\
\hline 6 & Goldgelbe . . . . . . . . & 748 & 690 & 714 \\
\hline 7 & ᄋ Sierra $\sigma^{\top}$ weisse japanische ... & 575 & 517 & 539 \\
\hline
\end{tabular}

Die Anzahl von Metern des Seidenfadens von einem Cocon (durchschnittlich) für verschiedene Rassen betrug:

\begin{tabular}{|c|c|c|c|c|}
\hline $\begin{array}{c}\text { Laufende } \\
\text { ․o }\end{array}$ & $\begin{array}{c}\text { Bei trockener } \\
\text { Luft }\end{array}$ & $\begin{array}{c}\text { Bei feuchter } \\
\text { Luft }\end{array}$ & $\begin{array}{c}\text { Unter } \\
\text { normalen Um- } \\
\text { ständen }\end{array}$ \\
\hline 1 & 575 & 465 & 584 \\
2 & 928 & 670 & 606 \\
3 & 690 & 486 & 802 \\
4 & 938 & 674 & 736 \\
5 & 710 & 563 & 683 \\
6 & 578 & 548 & 644 \\
7 & 715 & 543 & 696 \\
\hline
\end{tabular}


H. Auel (1904. 18) hat bei 77 ठ ठ von Pieris brassicae L., welche im August 1904 in Potsdam gefangen wurlen. sowohl die Fliigellänge, wie auch die Spannweite gemessen. Diese Messungen ergaben für die Spannweite den frequenziellen Werth 65,7 m.m., während der gleiche Werth der rechten Vorderflïgellängen, doppelt genommen, $62,5 \mathrm{~m} . \mathrm{m}$. beträgt.

Er fand noch, dass die $\delta \delta^{7}$ im Mittel um 2,0 m. m. kleiner sind als in den Jahren 1900 und 1903. Der Sommer 1904 war ein sehr regenarmer.

\section{Einfluss der Temperatur.}

Ueber den Einfluss der Temperatur auf die Grösse der Schmetterlinge liegen mehrere Untersuchungen vor, wenn sie auch nur einen zufälligen Charakter tragen und zwar:

1863 fand G. Dorfmeister (193), dass die in erhöhter Temperatur aus Eiern erzogenen. Hippurchia egeria L. und Colias rhamni L. kleinere, aber sonst gewöhnliche Schmetterlinge ergaben.

E. Verson und E, Quajat (1873. 920) beobachteten die Entwickelung der Raupen von Bombyx mori bei konstanter erhöhter Temperatur $\left(25^{\circ} \mathrm{R}\right.$.) und bei der Temperatur, welche von $18^{\circ} \mathrm{R}$. an jellen Tag um $1^{\circ} \mathrm{R}$. erhöht wurde, bis sie schliesslich $28^{\circ}$ erreichte.

Die bei konstanter Temperatur $\left(25^{\circ} \mathrm{R}\right.$.) geziichteten Raupen ergaben in einem Ko. 543 Cocons, während der Kontrolversuch (für dieselbe Rasse - gelbe "friuliana" - aber bei $15^{\circ} \mathrm{R}$.) 476 ergab.

Bei allmählig steigender Temperafur (von $18^{\circ} \mathrm{R}$. bis $28^{\circ} \mathrm{R}$.) ergab die bivoltinische gelbe Rasse auf ein Ko, 1143 Cocons, während der Kontrolversuch (bei $18^{\circ}$ ) solcher 1490 lieferte. Die gelbe „istriana" Rasse ergab gar keine Cocons, da die Raupen alle an "flaccidezza" starben.

Daraus folgt, dass die bei hoher konstanter Temperatur (von $25^{\circ}$ R.) gezüchteten Raupen viel leichtere Gespinnste liefern, als bei normaler Temperatur $\left(18^{\circ} \mathrm{R}.\right)$.

G. Stange (1886. 842) fing am 6. Juli 1884 am Köder ein grosses $ᄋ$ von Agrotis rubi und erhielt eine Anzahl Eier. Die daraus erhaltenen Raupen lieferten, im Zimmer gezogen, nur zum Theil 
bis Anfang Oktober die auffällig kleinen (ca. $12 \mathrm{~m}$. m. Vorderfliigellänge) Falter. Die übrigen Puppen ibberwinterten, wurlen inı Februar ins warme Zimmer genommen unl lieferten von Mitte Mai ab) die grossen (bis $16 \mathrm{~m}$. m. Vorderflïgellänge) Schmetterlinge.

H. Gauckler (1886. 278) erhielt bedeutend kleinere Falter ron Antheraca pernyi, als die unter normalen Verhältnissen erzogen werden, inclem er 10 Puppen der T'emperatur eines ungeheizten Zimmer aussetzte unil zwar den ganzen Winter über. Es schlïpften nur 3 Falter aus, wovon zwei verkrüppelt.

Frederic Merrifield (1857. 561) erhielt Falter von Selenia illunaria, indem die Puppen der Temperatur von $26^{\circ} \mathrm{C}$. ausgesetzt wurden, う̌ Generationen pro Jahr, wobei die Exemplare der zweiten Generation grösser waren als diejenigen der ersten, unil jedle folgende Generation zeigte eine sichtliche Zunahme im Verhältniss zur Grösse ihres Vorgängers.

Als C. Ed. Venus (1888. 903) Raupen von Vanessa witicue unter der Einwirkung heisser Sommerstrahlen zog, erhielt er golıglänzende Puppen mit lichtgelblicher Färbung, welche Falter ergaben, fast alle unter der gewöhnlichen Grösse, jelloch von der lebhaften rothen Färbung (var: ichnusa).

Dass dabei nicht der Mangel an Nahrung die Ursache war, beweist der Unstand, dass die Raupen die Brennesseln, welche einige Mal pro Tag frisch den Raupen gereicht wurlen, mit einer grösseren Gier und Hast frassen, „als wir sie an den Raupen iler Deilephila euphorbiae $\mathrm{zu}$ sehen gervöhnt sind.".

F. Merrifield (1891. 567) setzte die Puppen von Seleniu illu. straric, Zunaria und illunariı (Frühlings- und Sommergeneration), Drepanu falcaria, Bomlyyx quercus und B. quercus v. callune der Einwirkung der Temperatur von $26,7^{\circ}$ und $15,5^{\circ}$ aus und erhielt im ersten Falle kleinere Schmetterlinge als im zweiten Falle. Vanessa urticac ergab dabei eine geringere Differenz in (ler Grösse, bei $8,2^{\circ}$ war aber bedeutend kleiner.

Die Vorderfliigel von drei Selenia-Arten waren lünger und eckiger, wenn die Puppen bei niederen Temperaturen (bis zu $0^{\circ}$ ) sich befanden. 
S. N. Kamensky (1893. 434) futterte die Raupen von Bombyx mori mit Blättern von Taraxacum of ficinale. Bei 9 bis $14^{\circ} \mathrm{R}$. waren die Raupen, obwohl langsam entwickelt, gross; als sie später in die Temperatur von 18 bis $22^{\circ} \mathrm{R}$. gebracht wurden, wurden sie kleiner als die normalen, wobei die Sterblichkeit unter ihnen zunahm.

F. Merrifield (1894. 570, 571) setzte die Puppen von Cidaria siliceata einer Temperatur von $26,7^{\circ}$ aus und erhielt Falter, welche viel kleiner waren, als die unter normalen Umständen entwickelten. Bedeutend kleinere Dimensionen erhielt er auch bei Vanessa atalanta, indem die Puppen der Temperatur von $+0,5^{\circ}$ ausgesetzt wurden.

R. Jaenichen (1894. 410) setzte die Eier von Lasiocampa populifolia der Temperatur von $25^{\circ}$ aus; die Raupen wurden bei 15 bis $20^{\circ}$ gezogen und die erhaltenen Falter hatten nach der Angabe von M. Standfuss (1896. 840, p. 142) ठ ठ $\delta^{\pi} 37$ und $q$ ㅇ $50 \mathrm{~m} . \mathrm{m}$., wobei die Vorderflügel schmäler und am Rande tiefer gebuchtet waren.

W. Caspari II. (1895. 137) erhielt bei seiner Winterzucht sehr grosse Exemplare von Agrotis baja.

August Weismann (1895. 954) untersuchte die Schwänze der Hinterflügel bei Chrysophanus phlaeas, indem er die aus neapolitanischen Eiern dieser Species erhaltenen Puppen im Eisschrank oder in Zimmertemperatur hielt.

Von der Grösse dieses Schwänzchens sagt er: "Somit scheint die Ausprägung dieses Charakters mit der während der Puppenentwickelung einwirkenden Wärme in Zusammenhang zu stehen, indem er im geradem Verhältnis mit der Wärme zunimmt" (p. 17).

Als E. Fischer (1895. 228) die Puppen von Vanessa $C$ album der Temperatur von $+35^{\circ}$ aussetzte, erhielt er Falter mit viel weniger tief gebuchtetem Rand als diejenigen, welche Kälteversuche lieferten.

M. Standfuss (1896. 840) brachte die im Herbst gesammelten Raupen in die Temperatur von $20^{\circ}$ bis $35^{\circ}$ und erhielt unter dem 
Einfluss dieser höheren Temperatur Falter, welche hinter ihrer natürlichen Grösse zurückblieben. Diese Erscheinung beobachtete er bei: Callimorpha dominula (39 m.m. statt ca. $55 \mathrm{~m} . \mathrm{m}$.), dominula var. persona (39 m.m. statt ca. $44 \mathrm{~m} . \mathrm{m}$.), var. romanovi; Arctia fasciata (39 m. m. statt ca. 48 m.m.); Das. abietis; Lasioc. pruni, quercifolia $(35-39 \mathrm{~m} . \mathrm{m}$.) und populifolia.

Beim Treiben der Raupen, welche im Herbst im Freien gesammelt waren, wurden verkümmerte Exemplare erhalten von: Arctia liebe, Psyche villosella, Laria l nigrum, Lasiocampa lunigera, Agrotis cinerea, crassa, fatidica, Luperina matura, Hyppa rectilinea.

Die Eier und nachher auch die Raupen und die Puppen von einem Paare Lasiocampa quercifolia ( $\sigma^{\star} 58$, ㅇ $89 \mathrm{~m}$. m. Spannweite) wurden der Temperatur von $30^{\circ}$ ausgesetzt. Die erhaltenen Schmetterlinge hatten die Grösse: $\sigma^{7} \delta^{7} 35-37 \mathrm{~m} . \mathrm{m}$. und 우우 $36-39 \mathrm{~m} . \mathrm{m}$. Spannweite.

Es wurde Lasiocampa pruni vom Ei auf bei $30^{\circ}$ erzogen; die Falter hatten die Grösse: $\sigma^{7} \sigma^{7} 36-40 \mathrm{~m} . \mathrm{m}$., 우 $39-45 \mathrm{~m} . \mathrm{m}$.; bei der Temperatur von $25^{\circ}$ erwies sich: $\delta^{\top} \delta^{\top} 42-45$ und $ᄋ$ ㅇ 48 bis $56 \mathrm{~m} . \mathrm{m}$. Spannweite; während die Mutter $62 \mathrm{~m}$. m. und der Vater $50 \mathrm{~m}$. m. Spannweite hatten.

Die gleichen Versuche bei der Temperatur von $25^{\circ}$ wurden mit folgenden Arten angestellt:

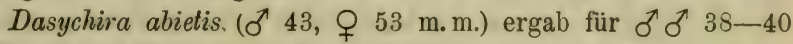
und für 우 우 $43-46 \mathrm{~m} . \mathrm{m}$. Spannweite.

Callimorpha dominula (ठ 53, ㅇ 56 m. m.) lieferte Exemplare von $37-43 \mathrm{~m}$. m. Spannweite.

Callimorpha var. persona ( $\sigma^{7} 50$, ㅇ $53 \mathrm{~m} . \mathrm{m}$.) lieferte Exemplare von ca. $40 \mathrm{~m} . \mathrm{m}$. Spannweite.

Arctia fasciata (o 46 , $q 48 \mathrm{~m} . \mathrm{m}$.) Eier bei $34^{\circ}$, Raupen und Puppen bei $25^{\circ}$. Spannweite bei drei Weibchen: 36,37 und $39 \mathrm{~m} . \mathrm{m}$., bei den übrigen Falter $55-58 \mathrm{~m} . \mathrm{m}$.

Lasiocampa pini ( $\sigma^{7} 59$, 우 75 m.m.). Alle 3 Stadien bei $34^{\circ}$. Spannweite betrug bei $\delta^{\top} \delta^{7} 65-68$, bei 우 우 $84-86 \mathrm{~m} . \mathrm{m}$.

Die bei diesen Versuchen erhaltene Grössenreduktion erklärt M. Standfuss durch die Abkürzung der Frasszeit, indem er sagt: "Je wesentlicher die Frasszeit der Raupe durch die Erhöhung der Temperatur abgekürzt wird, desto bedeutender ist die Grössenreduktion des Falters" (p. 148). In dem extremsten Falle (Las. quercifolia) wurde das Gewicht auf den siebenten Theil des normalen reduziert. 
Tritt diese Abkïrzung nicht oder doch nur sehr unbedeutenil (z. B. Arctia fasciata) ein, so erfolgt eine Vergrösserung ler Dimensionen.

Aussertem sagt er in seinem Buche, dass je heisser die Zeit, in welcher die Entwickelung zum Falter von podalirius vor sich geht, desto kürzer wird die Behaarung der Stirn und des Thorax, und desto feiner werden ilie Schwänze.

F. Merrifield (1896.572) setzte Puppen von Vanessa urticue während $12-24$ Stunilen der Einwirkung der Temperatur zwischen 35 und $40^{\circ}$ aus und heliess sie nachher bei $30^{\circ}$. Dabei wurle die äussere Tiante ler Vorlerfligel berleutend weniger winklig als bei normalen 'Fáltern.

Rudow (1897. 919) beobachtete, dass je weiter nach Norden die Wespen der Gattung Cimbex leben, desto stärlier die Puppenhiullen sind, dass aber die Bewohner günstiger gelegener Lïnder ziemlich dünne Schutzhüllen bauen.

$D^{r}$ Pauls (1898. 625) hat seine Temperatur-Experimente mit Nem. plantaginis bereits vom Ei aus angestellt. „Die Spannweite der $q$ betrug begreiflicherweise nicht viel mehr als die der Mutter $\left(34-35 \mathrm{~m} . \mathrm{m}\right.$.), mehrere $\delta^{\top} \delta^{\lambda}$ waren aber $2-3 \mathrm{~m}$. $\mathrm{m}$. breiter, als die in der Natur gefangenen. Das erste russulla-Männchen, welches ilas Licht iler Welt erblickte (15. VIII.), war in seinen Grössen-Verhältnissen erheblich zurückgeblieben" (p. 156).

$\therefore$ Bei diesen Versuchen wurde ,tropische Wärme" angewandt, leiler erwähnt der Forscher die Auzahl der Grale nicht.

.. Bei weiteren Versuschen gelang es $D^{r}$ Pauls (189S. 625) durch Versetzung in "tropische Wärme" bei Nem. plantaginis statt einer Generation deren zwei Sommergenerationen zu entwickeln. In Anbetracht der Wichtigkeit seiner Resultate, werden wir hier seine eigenen Worte citieren:

"Wie aber steht es niit der Grösse? $D^{r}$ Standfuss sagt (p. 148): Je wesentlicher die Frasszeit der Rampe durch die Erhöhung der Temperatur abgekürzt wird, lesto bedeutender ist die Grössenreduktion des Falters.

"Unsere Versuche ergeben den Beweis, dass diese These nicht absolute Gültigkeit hảt. 
"Plantaginis fressen sehr lange und wachsen sehr langsam; nehmen wir ihre Frasszeit von Juli bis Oktober (3 Monate) und April bis Mai (1 Monat) an, also in Summa 4. Monate, so ist bei meinen Versuchen - abgesehen von der Winterruhe - die Frasszeit auf 1/4 ( = 1 Monat) reduzirt. Trotzdem sind alle In lividuen ebenso gross, ja viele mehrere Millimeter in der Spannweite grösser, als die in der Freiheit geborenen.

.Nur ein Thierchen mit $33 \mathrm{~m}$. m. Flügelspannung war: schlecht geliehen, dafur aber zeigte es eine ganz ausgesprochene melatonische Färbung, ein sehr merkwürdiges Thier!

"Hingegen zeigten die 'vussula trotz der ganz gleichzeitigen Entwickelung eine entschiedene Verkleinerung, zumal die Weibchen" (p. 171).

Als Karl Frings (1898. 253) die Puppen von Vanessa urticae der Temperatur von +6 bis $+8^{0}$ aussetzte, erhielt er stark verkleinerte Falter. Puppen von Vanessa io, welche 42 Tage auf Eis verblieben, ergaben Falter von durchschnittlich $49 \mathrm{~m} . \mathrm{m}$. Breite, während normale Falter dieser Art in Bonn $60 \mathrm{~m}$. m. Spannweite haben.

Es ist hier interessant, die Untersuchungen von Robert Lauterborn (1898. 500), welche wenn nicht grade Insekten, sondern Räderthiere betreffen, anzufuihren. Er fand cie in folgeniler Tabelle angeführte Beziehung zwischen Wassertemperatur des Altrheins bei Neuhofen und Körpergrösse von Anuraea cochlearis, wobei die monatlichen Mittelwerthe der Gesammtlänge des Panzers von $600=$ $(12 \times 50)$ Exemplaren in $\mu \mu$ ausgedrückt sincl.

\begin{tabular}{|c|c|c|c|c|c|}
\hline II o nat & $\mu$ & \begin{tabular}{|} 
Wassertem- \\
peratur in C.
\end{tabular} & Monat & $\mu$ & $\begin{array}{l}\text { Wassertem- } \\
\text { peratur in C. }\end{array}$ \\
\hline Januar . . & 223 & 3 & . . & 131,5 & 26 \\
\hline Februar. & 228 & 7 & August . . & $1 \ddot{141,5}$ & 22,5 \\
\hline März . . & 216,5 & 9,5 & September. & 152,5 & 19 \\
\hline April . . & 201 & 14 & Oktober. . & 182,5 & 11 \\
\hline Mai ... & 189 & 17,5 & November . & 216 & $\therefore \therefore$ \\
\hline Juni : : : & $.132,5$ & $20:$ & December : & 222,5 & 4 \\
\hline
\end{tabular}

Graphisch dargestellt würde die Jahrescurve der Wassertemperatur - von kleinen Schwankungen abgesehen - gerade umgekehrt verlaufen als die Jahrescurve der mittleren Länge. 
"So augenfällig nun auch in dem vorliegenden Fall der Einfluss der Temperatur auf die Grösse des Panzers sich darzustellen. scheint, möchte ich doch nicht annehmen, dass die Temperatur als solche eine direkt umbildende Wirkung auf die Panzergrösse ausübt, sondern dass letztere eher abhängig ist von dem durch die Temperatur regulierten, nach den Jahreszeiten wechselnden Gehalt gewisser anorganischer und organischer Bestandtheile des Wassers" (p. 604). Zu dem Negiren der gesagten Beziehung ist er durch Untersuchungen am gleichen Thier im Teiche bei Mandach, in einer Torfgrube bei Neuhofen und in einer Lehmgrube bei Ludwigshafen geführt worden, wo Grössenschwankungen in den verschiedenen Monaten des Jahres ganz unregelmässig verliefen. Ueber die näheren Ursachen hofft er in den Verhandlungen des Naturhist.-Med. Vereins zu Heidelberg zu berichten.

Lambert (1899. 495) züchtete Bombyx mori von 20 verschiedenen Rassen, wobei eine Serie sich bei gewöhnlicher Temperatur befand und die andere, angefangen vom 4. Alter der Raupen, in die Temperatur, welche um einige Grade tiefer als die gewöhnliche $\left(21^{0}-23^{\circ}\right)$ war, gebracht wurde. Er erhielt folgende Resultate: Die Erniedrigung der Temperatur während des 5. Alters um $2^{\circ}$ bis $6^{\circ}$ ergab die Gewichtszunahme der Cocons durchschnittlich um $8,5 \%$. Die Gewichtszunahme war proportional der Zeit, während welcher der Versuch dauerte, und konnte bis zu $15 \%$ steigen.

Desto auffallender ist die Behauptung von Rudow (1900. 712), welche er nach der Untersuchung von Pauls noch aufrecht hält. In seiner Abhandlung: „Weiterer Beitrag zu den Grössenverhältnissen der

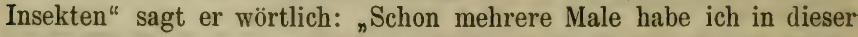
Zeitschrift Beispiele angeführt, welche bewiesen, dass die Annahme, die Temperaturverhältnisse beeinflussten die Grösse der Insekten, nicht richtig ist. An gefangenen Libellen, Heuschrecken, Hautflüglern habe ich eine Menge Messungen angestellt und bin zu dem Ergebnisse gelangt, dass verschiedene Nahrungsverhältnisse, örtliche Einflüsse und vieles andere mehr die verschiedene Grösse hervorrufen, als Breitengrade, Höhenlage und Wärmeab- oder zunahme“ (p. 188).

In seiner Abhandlung führt er weitere Thatsachen für die Behauptung an, aus welchen $\mathrm{zu}$ ersehen ist, dass „aus einem Bau dieselben Arten in solcher Grössenverschiedenheit hervorgingen, dass ein oberflächlicher Beobachter leicht verschiedene daraus machen möchte" (p. 188). 
Dass Rudow seine Schlüsse nicht nur auf Libellen, Heuschrecken und Hautflüglern anwendet, zeigt folgende Stelle: „Was ich hier von Hautflüglern erfahren habe, wird wohl auch mehr oder weniger von anderen Insektenfamilien zu berichten sein, wenn man der Sache auf den Grund geht, weshalb so auffallende Aenderungen in der Grösse vorkommen" (p. 189).

B. Slovogt (1900. 822) fand, dass die Grösse von Vanessa polychloros, deren Puppen der Einwirkung des Nordwindes ausgesetzt wurden, die Grösse der normal entwickelten $V$. urticae nur wenig übertrifft. Ausserdem fing er Ende August 1899 in Kurland auf einer sonnigen, an den Wald grenzenden Wiese 3 Vanessa polychloros (2 ठ大 $\sigma$ und 1 O), "welche man geneigt sein könnte, für natürliche Kälteerzeugnisse des Frühlings, der bei uns diesmal sehr rauh war, zu halten. Genannte Thiere erreichen kaum die Grösse von urticae, da sie nur 2,1 cm. messen" (p. 532).

L. Kathariner (1900. 439) hing die ganz frischen Puppen von Vanessa urticae, antiopa und io schräg aut, wobei sie mit ihrer rechten Flügelscheide dicht dem Glasrohre anlagen, durch welches Wasser aus der Wasserleitung $\left(14^{\circ}\right.$ bis $\left.16^{\circ}\right)$ strömte. Von der freien Seite wurden die Puppen durch die Sonne $\left(30^{\circ}\right.$ bis $\left.32^{\circ}\right)$ beschienen. Dabei wurden bei ausgeschlüpften Faltern gewisse Formveränderungen beobachtet, und zwar "sind die Schuppen an den Flügeln der rechten Seite durchgehends schmaler, ihre Rände ausserdem häufig etwas eingerollt"; da der Rand nicht selten eingezogen ist, ist der Flügel infolgedessen verbogen. Bei einer Vanessa antiopa ist der rechte Vorderflügel $\mathrm{zu}$ einem Stumpf verkümmert, der nur $2 / 3$ der normalen Länge erreicht und nur einige Millimeter breit ist. "Die Verkrümmungen der Flügel infolge ungleichmässiger Ausdehnung sind, wie die Deformationen der Schuppen, wahrscheinlich auch nur auf ein Zurückbleiben im Wachstum gegenüber denen der linken Seiten zurückzuführen"' (p. 322).

C. Frings (1901. 259) setzte Puppen von Vanessa urticae II. Generation während 36 Stunden der Einwirkung der Temperatur von $+39^{\circ}$ aus und erhielt var. ichmusa, welche aber etwas kleiner war als corsische oder sardinische Exemplare. Als er die frischen Puppen von Papilio machaon 10 Mal je 8 Stunden bei $-15^{\circ}$ exponierte und hierauf im Freien überwintern liess, erhielt er Schmet- 
terlinge, welche sich durch sehr stumpfe, breite Fliigelform und kurzgeschiänzte Hinterflügel auszeichneten.

Fr. Ball (1901. 47) erzog Raupen von Papilio machaon (Wrintergeneration) bei (ler Temperatur $39^{\circ}$ und liess bei dieser T'emperatur auch die Puppen gewisse Zeit liegen. Die Anzahl der Tage, während welchen die Raupen resp. Puppen bei $39^{\circ}$ sich befanten, war folgende:

\begin{tabular}{|c|c|c|c|}
\hline \multirow{2}{*}{$\begin{array}{l}\text { Vì des } \\
\text { Versuches }\end{array}$} & \multicolumn{2}{|c|}{ Wie viel Tage bei $39^{\circ}$} & \multirow{2}{*}{$\begin{array}{l}\text { Ruhezeit } \\
\text { der Puplen } \\
\text { in Tagen }\end{array}$} \\
\hline & Raupen & Puppen & \\
\hline 1 & 1 & 50 & 250 \\
\hline 2 & 2 & 48 & $\cdot 235$ \\
\hline 3 & 6 & 44 & 246 \\
\hline 4 & 10 & 41 & 253 \\
\hline 5 & 12 & 39 & 241 \\
\hline 6 & 15 & 36 & 245 \\
\hline
\end{tabular}

Sonst befanclen sich Raupen resp. Puppen bei $10^{\circ}-15^{\circ}$. Es ergab sich, dass obwohl die Raupen gierig frassen, trotzlem hatten die entwickelten Schmetterlinge umso geringere Dimensionen, je längere Zeit die Raupen bei $39^{\circ}$ zubrachten.

J. Dewitz (1902. 168) stellte die Versuche über den Apterismus bei Insekten an. Ein mit Larven und Nymphen von Polistes yallica besetztes Nest wurle zwei Mal 24 Stunien auf Eis gehalten uncl dann dem zugehörigen Wespenvolk zurückgegeben. Es kamen nun beständig normale Insekten aus. 4 Wochen nach der Abkühlung erschien aber die erste Wespe, welche an Stelle der Flügel Flügelstümpfe besass. Ihr folgten dann bis zum Ende der Saison andere eljenso gestaltete Thiere. Dieselben waren vollkommen lebensfähig.

Carl Frings (1902. 260) brachte die im Freien bis Februar überwinterten Puppen von Vanessa polycluloros während 42 Stunden in die Temperatur von $37,5-38^{\circ}$ und erhielt Falter, deren Hinterflügel viel zu klein im Verhältnisse zu den Vorderflügel sind. Er macht dabei die folgende Bemerkung: „Wieder ein Beweis dafür, lass stark experimentell veränderte Falter die Neigung haben, kleiner auszuwachisen als normale aus gleich grossen Puppen" (p. 18).

Sehr bemerkenswerth ist der Flügelschnitt mancher Stücke. Dieselben haben so starke und vortretende Auszackungen des Saumes, 
dass sie zuerst ganz fremdartig anınten und an Vunessa c album erinnern. Häifig ist die Spitze der Hinterflügel sogar zu einem ziemlich langen, schmalen Schwänzchen ansgezogen.

M. Standfuss schreibt mir (15. V. 1902), llass er im zeitigem Frühjahr im Freien gesammelte kleine Raupen von Melitaeu parthinie (in Neuhausen) bei einer Durchschnittstemperatur von $15^{\circ}$ erzog. Trotzlem dass die Entwickelungszeit labei lieine nennenswerthe Verlängerung erfahren hat, erhielt er auf dies: Weise eine Form, welche der alpinen var. varia sehr nahe kommt, wie es aus folgenden Dimensionen der Spannweite der Flügel zu ersehen ist:

1. Melitaea parthenie Bkh. von Neuhausen-Altenburg normal: б $33-34 \mathrm{~m} . \mathrm{m}$. ㅇ $36-40 \mathrm{~m} . \mathrm{m}$.

2. Melituea parthenie var. varia M. D. vom Albulahospitz: ठ 29-31 m.m., ㅇ $31-31 \mathrm{~m} . \mathrm{m}$.

3. Melituea parthenie von Neuhausen-Altenburg in $15^{\circ}$ von der kleinen Raupe ab erzogen: ठ大 $28-30 \mathrm{~m} . \mathrm{m}$., ㅇ 29-32 $\mathrm{m} . \mathrm{m}$.

Ausserdem wielerholte er das frühere Experiment nit Arctiı fusciata (840). Der Erfolg war der ganz gleiche, wie früher.

G. Frings (1903. 261) setzte die überwinterten Puppen in Februar und im März der Einwirkung der erhöhten Temperaturgraden aus und beobachtete dabei folgende Gestalt-Aenilerungen der Imagines:

Papitio podalirius. -52 Stunden +40 bis $40,5^{\circ}$. Die Schwänze sinl sehr ling.

Papitio machaon. $-3 \frac{1 / 4}{4}$ Tage $+40,5^{0}, 2$ Mal je 4 Stunden +42 bis $42,5^{\circ}$. Die Exemplare haben sehr kurze, stumpfe Schwänze. pelte Stücke.

Apatura ilia. -3 Mal je $2-2 \frac{1}{2}$ Stunden $+43^{\circ}$. Verkrïp-

Limenitis populi. -3 Mal je 4 Stunden +40 bis $41^{\circ}$. Krippellrafte Falter.

Vanessa urticue (II. Gener.). - 30-36 Stunden + 39º. Flügelausschnitt sehr scharf.

Van'ssa antiopa. - 48 Stunden $+37 \frac{1}{2}{ }^{\circ}$. Hinterflügel übermässig stark gczackt. Vorderflügel dagegen von normaler Grösse und Form.

Hanold (1904. 35̄3) fütterte die Raupen von Arctia caja L. im Herbst mit Löwenzahn und legte die Puppen später auf Eis. Dabei entstanden auffillend kleine Schmetterlinge. 
298. Zweites Kapitel. Die Grösse und die Gestalt der Insekten.

C. Frings (1905. 262) setzte Puppen von Papilio podalirius L. während 2 Tagen der Einwirkung der Temperatur von $40,5^{\circ}$ aus und erhielt 2 Falter mit um die Hälfte verkürzten, monströs dicken Fühlern.

Vanessa urticae-Puppen, 42 Tage der Einwirkung der Temperatur von $6^{\circ}$ ausgesetzt, ergaben glatt ausgewachsenen Falter, aber mit stark monströs ausgebuchteten Flügelrändern. Eine ähnliche Monstrosität beobachtete er 1892 bei zahlreichen, aus der Raupe erzogenen Lasiocampa otus Dr.

\section{Einfluss des Lichtes.}

Gräfin Mario von Linden (1899. 322) erzog Raupen von $\nabla a$ nessa urticae und io unter dem Einfluss vom rothen, grünen und blauen Lichte und auch im Dunkeln, wobei die erhaltenen Puppen unter diesem Einflusse bis zur Entpuppung der Falter blieben.

Die Flügellänge betrug für jeden Flügel im Durchschnitt in m.m.:

\begin{tabular}{|c|c|c|}
\hline F a r b e & Vanessa urticae & Vanessa io \\
\hline \hline Roth . . . . & 24,5 & 25 \\
Grün . . . . & 23,3 & - \\
Blau . . . . & 25,0 & 27,8 \\
Schwarz . . . & 24,6 & 28 \\
\hline
\end{tabular}

Daraus ist ersichtlich, dass die grössten Falter bei Vanessa urticae unter blauem Licht, bei Vanessa io in der Dunkelheit gezogen worden sind.

Eine Reihe normaler Falter von Vanessa io, die sich im reflektierten, an Wärmestrahlen armen Licht und nicht im direkten Sonnenlicht entwickelt haben, erreichen ebenfalls eine durchschnittliche Flügellänge von $28-\mathrm{m}$. m.

"Die Ursache dieser Erscheinung wäre also vielleicht in beiden Fällen (blau für urticae und schwarz für io) die Abwesenheit von Wärmestrahlen, eine Annahme, welche dadurch gestützt würde, dass die „Wärmeformen" beider Falter ebenfalls nur kleine Schmetterlinge ergeben ${ }^{\mu}$ (p. 262). 
Edmond Bordage (1899. 104) zog die Raupen von Atella pholanta (aus der Vanessa-Gruppe) in der Dunkelheit, wobei Futter reichlich vorhanden war, und erhielt sehr kleine Puppen, welche Falter ergaben, die nur $1 / 3$ der normalen Grösse besassen.

L. Kathariner (1900. 440) zog ganz junge Räupchen von $V a$ nessa urticae und io unter verschieden farbigen Gläsern auf und liess in gleichen Kästen auch die Puppen liegen. Die Durchschnittsgrössen der entwickelten Falter - gemessen am Vorderrand eines Vorderflügels - waren dabei folgende:

\section{Vanessa urticae Vanessa io}

I. II.

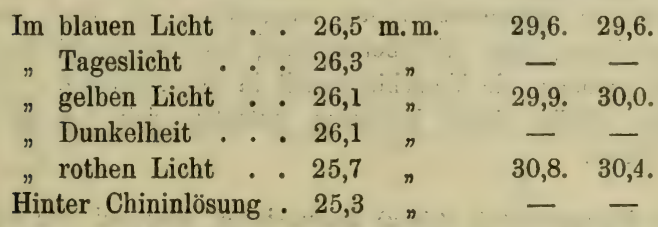

Er ist der Meinung, dass auf diese Grössen-Differenzen, die sich in "Bruchtheilen von Millimetern" bewegen, gar kein Werth $\mathrm{zu}$ legen ist.

C. Flammarion (1901. 241) setzte die Seidenraupen dem Einflusse verschiedener Lichtfarben aus, und fand, dass die Dunkelheit das Gewicht des Cocons verminderte, wogegen dasselbe unter Orange und Roth die grösste Schwere erreichte.

W.' Petersen (1902. 633) hielt die Raupen und Puppen von Vanessa urticae im Dunkeln (nicht in Kälte) und erhielt dabei sehr kleine Exemplare, die zu polaris gehören.

\section{Einfluss der Nahrung und chemischer Stoffe.}

G. Koch (1856. $457 b$ ) hat Untersuchungen an Vanessa io var. joides Dahl angestellt und kam zum Schlusse, dass diese Varietät nur auf kleinen, durch Hungern der Raupen hervorgebrachten Exemplaren beruht. 
A. Berlepsch (1860. 73) erwähnt in seinem Buche folgenden Versuch, welcher von Dönhoff gemacht wurle. Er entfernte aus der Bienenkönigin-Zelle, welchè noch nicht zugemacht war, die Königinlarve samint dem darin sich befindlichen Futter, brachte darauf in dieselbe eine andere Königinlarve im Alter von j Tirgen, welcher folglich noch 18 Stunden zu fressen blieben, unl machts die Zelle zu. Auf diese Weise wurle eine Künigin erhalten, wolche etwas grösser war als die Arbeiterin. Berlepseh meint leshalb, dass die Ursache, warum hie und da kleine Königinen entstehen, darin besteht, dass ihre Larven vor dem Ausschlüpfen sehr wenig fressen.

H. Landois (1867. $498 a, 4986)$ übertrug Bieneneier aus Arbeiterzellen in Drohnenzellen und umgekehrt, und fanl, dass nicht die Befruchtnng oder Nichtbefruchtung das Geschlecht der Bienen bedingen, sondern die Verschielenheit in der Nahrung.

Die Kritik dieser Versuche beflndet sich bi G. Kloine (1867. $452 a)$.

G. Kleine (1867. 452a) konstatierte, class bei der schlechten Limährung der Arbeiterlarven aus denselben keine Drohnen ent. stehen, sontern wiederum Arbeiterinen, aber von geringeren Dimensionen.

A. E. Brehm (1869. 111) erzog ein Exemplar Anthiax semiata oler morio L. aus einem Cocon einer Erılbiene; da die erwachsene Form dieser Diptera zwischen $2-6$ Linien variirt, so meint er, dass diese Larven deshalb verschiellene Werthe haben, weil ihnen verschiedene Quantitïten von Nahrung geliefert werden.

C. A. Teich (1870. 855) sagte in seinem Vortrage in dem Naturforscher-Verein zu Riga, dass die Falter der Tropen, bei dem Reichthum an Pflanzenstoffen, grösser werden, „denn jedem Züchter ist bekannt, dass bei kimmerlicher Nahrung die Falter kleiner werden."

Auch E. K. Robinson (1877. 695) sagt, dass, wenn die Raupen mit saftigen und üppig gewachsenen Pflanzen ernähert werden, dieselben meist grössere Schmetterlinge ergeben.

P. T. Stepanow (1882. 846) fand, dass Larven von Systocclus leucophaens Mg. (Familie Bombylidae) verschiedene Grösse haben, 
was von dem Nahrungsquantum in Cocons von Stauronotus (O:dipocta) vastor. Stev., in welchen die Larven parasitieren, abhängt. "Diese Differenz bleibt auch bei erwachsenen Exemplaren von Bumbylidae, da die Grösse der letzteren nach Loow zwischen $3 \frac{1}{2}$ bis $4 \frac{1}{2}$ Linien variiert" (p. 2).

A. v. Planta (1889. 639a) untersuchte die Zusimmmensetzung des Futtersaftes für verschiedene Bienenformen und erhielt folgende mittlere Werthe:

Königin. ' Arbeiterin. Drohne.

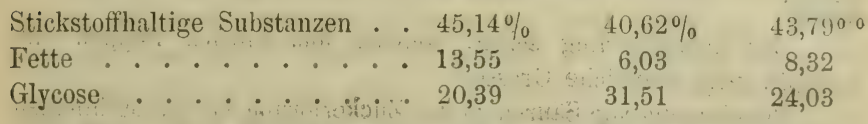

Dabei muss bemerkt werden, dass die Zusammensetzung des Futtersaftes während rler ganzen Larvenzeit nur bei der Königin dieselbe ist, sonst variieren diese Werthe je nach llem Alter der Larven, und zwar:

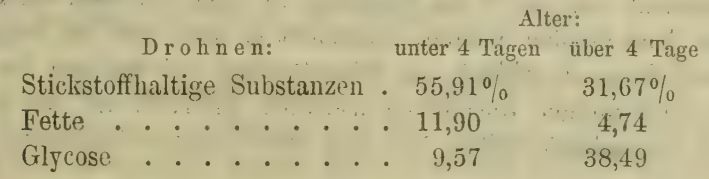

Arbeiterinen:

Stickstoffhaltige Substanzen . 53,38

27,87

Fette . . . . 8,38

Glycose . . . . . 18,09

44,93

Die Krritik dieser Untersuchungen befindet sich bei G. Koschewnikow (1905. 467 a, p. $133-135)$.

Ganz eigenartige experimentelle Untersuchungen stellte in lieser Beziehung A. Troska (1890. 884) an. Er mischte eine licke Lösung von gewöhnlichem Zucker mit Gummi arabicum, bis das Ganze die Consistenz einer lockeren Salbe gewann, und bestrich damit die Fliigelhülsen der Puppen in Form eines $1 \mathrm{~m}$. m. breiten Gurtes.

Dabei beobachtete er folgende Erscheinungen:

1). Die meisten Puppen fallen bald in eine Art ron Hypnotismus oder Schlaf.

2). Es findet bei den meisten Arten eine leutliche Endosmose der Zuckerlösung statt und zwar am stärksten gleich nach der Ver- 
puppung und in der letzten Zeit vor der Bildung des Schmetterlings, oder wenn die Puppe in einem wärmeren Raum sich befindet.

3). Diese Imprägnirung kann man bei sehr lange liegenden Puppen höchstens $3-4$ Mal wiederholen, widrigenfalls sie schädlich wirken kann.

4). Der ausgeschlüpfte Schmetterling besitzt stattliche Grösse.

5). Die Puppen nehmen wenige Tage nach dem Beginn der Imprägnirung an Gewicht zu, wobei auch ihr Volumen sich vermehrt.

6). Die in der Puppe lebenden Parasiten gedleihen dabei sehr schnell.

Der Schmetterling selbst, welcher aus solchen Puppen entschlüpft, zeigt stattliche Grösse.

Beimischung von Säuren zu der Zuckerlösung ist auszuschliessen. Der Zusatz von Kochsalz ergiebt zwar sehr kräftige Schmetterlinge, aber mit gänglich unentwickelten Flügeln. Eine Beimischung von Silbernitrat zu der Nährflüssigkeit tödtet die Puppen, wenn man dies Experiment eher als 8 bis höchstens 14 Tage vor dem voraussichtlichen Ausschlüpfen anstellt. Geschieht es aber erst bei Beginn der Entwickelung, so schlüpft ein Schmetterling, bei welchem die Flügel trotz vollständiger Ausbildung merklich kleiner als bei gewöhnlichen Exemplaren bleiben und auch eine feinere Zeichnung haben.

Jos. Haberfelner (1891. 445) zog Saperda scalaris mit Laubholz und erhielt grössere Fxemplare als bei der Zucht mit Lärchen und Fichten. Auch Clytus lama und Callidium aeneum kommen grösser aus Lärchen, als aus Fichten.

Rössler (1892. 703) erfuhr brieflich von $D^{r}$ Krancher, dass er die Raupen von Atlas einmal mit Götterbaum, einmal mit Berberitze gefuittert habe, wobei die erstere Futterpflanze günstiger sei, da er damit grössere Falter erhalten habe.

S. N. Kamensky (1892. 431) fütterte Raupen von Bombyx mori mit Blättern des Maulberbaumes, welche mit wässeriger Lösung von Pikrinsäure imprägnirt wurden, und erhielt Cocons und Schmetterlinge von sehr geringen Dimensionen.

Derselbe Forscher (1893. 434) fuitterte dieselben Raupen mit Scorzonera hispanica und konnte keinen Unterschied in der Grösse der erhaltenen und normal gefütterten Scmetterlinge beobachten. 
Carl Frings (1893. 249) zog die Raupen von Arctia caja mit in Salzwasser gestellten Pflanzen und erhielt Schmetterlinge, welche etwas kleiner als gewöhnliche caja waren.

A. Weismann (1894. 953a) züchtete Musca vomitoria bei mangelhafter Ernäherung und erhielt Fliegen von sehr kleinen Dimensionen.

Lud. Heissler (1894. 362) erhielt von E. Hein einige Exemplare von Vanessa urticae und io, welche durch Fütterung der Raupen mit Brennesseln, welche mit grünem und rothen Tintenwasser oder mit Mineralwasser eingefrischt wurden, und hat festgestellt, dass diese Thiere auffallend klein waren. „Dies erscheint deshalb begreiflich, weil die Beimischungen des Wassers in dem Saftstrome des eingefrischten Futters bis in die Blätter emporsteigen. Die Raupen sind gezwungen, ein mehr oder weniger giftiges Futter zu fressen, und verkimmern oder gehen zu Grunde" (p. 107).

0. 0. Tichomirowa und A. A. Tichomirow (1894. 871) fütterten die Raupen von Bombyx mori mit Blättern der Schwarzwurzel (die Eltern dieser Eier wurden auch an diesen Blättern aufgezogen) und erhielten Raupen, welche unmittelbar vor dem Einspinnen 8 bis $9 \mathrm{~cm}$. Länge hatten.

A. L. (1895. 1) fütterte die Räupchen von Crateronyx dumi L. mit Salat, Löwenzahn, Mäusöhrchen, Scabiosen, Wegerich und Sauerampfer und erhielt Schmetterlinge, „die jedoch an Grösse gegen die aus freilebenden Raupen gezogenen Exemplaren zurückbleiben" (p. 59).

August Hüttner (1895. 398) fütterte Raupen von Parnassius apollo mit Sedum telephium, welche Pflanze in eine mit präparirtem Wasser (Wasser + Fisenvitriol + Gallussïure) gefüllte Flasche gestellt war. Er erhielt Falter von normaler Grösse und Form.

G. Selmons (1895. 805) fand in Graubünden (Schweiz) auf $1800 \mathrm{~m}$. über dem Meere ein männliches Exemplar von Lucanus cervus (zur Zeit im Schulmuseum von Bergün), welches von mittlerer Grösse war. Dort findet sich keine einzige Eiche.

Später (1895. 728) korrigiert er die erwähnte Höhe auf 1300 m. 
A. จ. Caradja (1895. 131) bemerkt zur Beobachtung von G. Selmons, dass die Larve von Licanus cervus ausser in Eichen auch in Birnbäumen lebt. Schaufuss (1895. 739) bemerkt in Bezug auf die Notiz Selmons, 'dass neben der Eiche auch die Buche als WWohnung der Hirschkäferlarve dient.

M. Standfuss (1896. 810) lionnte ilen Raupen von Aglin tuı (geschwärzte Form) kein geniigeniles Futter reichen und erhielt von 151 Raupen nur 43 sehr lïmmerliche Puppen. Die später aus diesen Puppen erhaltenen $\delta \delta$ hatten 46 - $\delta$ m m. m., die $q$ 의 62 bis

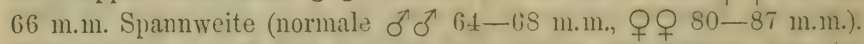
Weil dabei nur 9 Weil)chen waren, so zieht er den Schluss, dass die Männchen zı einer sehr erheblichen Grössemredulition ohne sichtliche Beeinträchtigung ihrer Fertilität fühig sind, unl dass sic Nahrungsmangel in höherem Grale zu ertragen vermögen als die weiblichen Individuen.

L. H. (1896. 337) fütterte die liaupen von I)eilephila mrii mit Blättern des "bekannten gewöhnlichen blanen Flieilers". Die spuiter erhaltenen Schmetterlinge waren kleiner als sonst.

A. Mordwilko (1896. 589) beobachtete bei Dryobins roboris L. anormale Formen mit schwachen Flïgelanfängen. Diese Erscheinung wirl durch den Einfluss äusserer Falktoren exklärt, hiuptsïchlich aber durch die Nahrung, da, wie Göldi (1885. 315) feststellte, bei Nahrungsmangel ungefliigelte Pflanzenläuse dis gefligelte Generation erzeugen. Mordwilko sagt: "Wenn der Nahrungsmagel die Entwickelung der geflïgelten parthenogenetischen Weibchen (bei Siph/r)nopliora) hervoruft, so kann man vermuthen, dass die reichere Nahrung die Entwickelung der ungeflïgelten parthenogenetischen Weibchen begünstigt".

Gleich nach der Publikation von Troska stellte E. Fischer (1896. 229) die gleichen Versuche mit Puppen von Sutumia pyri, Papitio machaon und Dcilcnhila euphorliae an, konnte aber keine Einwirkung feststellen, da, wie er sagt, die Chitinhaut für alle wässerigen, nicht sehr ätzenclen Flüssigkeiten undurchlässig ist. Er hat auch Puppen von Pioris biassicae, Papìitio machaon, Deilephila euphorbiae an den Flïgeldecken täglich mit Fuchsin orler Methylenblau, sowie anderen intensiven Furbstoffen bestrichen, aber nie auch nur 
die gerinste endosmotische Durchdringung der Puppenhaut nachweisen können. Die ausgeschlüpften Falter waren ebenso ganz normal.

P. Marchal (1897. 546) glaubt die Unterschiede zwischen nahe verwandten Arten Cecidomyia destructor (Hessenfliege) und Cecidomyia avenae in der Verschiedenheit der Nahrung zu suchen; die erste Art entwickelt sich nur auf Weizen, die zweite nur auf Hafer. Er beobachtete auch, dass gut gefiitterte männliche Larven von Cecidomyia destructor grosse $\sigma^{\top} \sigma^{\top}$ ergaben, während schlecht gefuitterte weibliche Larven stets kleine $q \nmid$ erzeugten. Auf diese Weise negiert er den Einfluss der Fütterung auf die Geschlechtsbildung, giebt jedoch zu, dass solcher Einfluss bei späteren Generationen nicht ohne Bedeutung sein kann.

H. Gauckler (1897. 287) sagt gelegentlich seiner Beschreibung über Missbildungen einiger Falter, dass die Ursache solcher Missbildungen auf eine kümmerliche Ausbildung der Puppe an den betreffentlen Stellen, wo die Flügel liegen, zurückzuführen ist. "Die Puppe konnte infolge Mangels an Materie, Blut, Fett u. s. w. an einzelnen Stellen sich nicht an allen ihren einzelnen Teilen gleichmässig entwickeln. Also eine Schwächnng des Organismus an einer bestimmten Stelle kann die Ursache zur Entstehung solcher anormalen Flügelformen sein" (p. 86-87).

H. Gauckler (1897. 285) erhielt von H. Locke in Wien ausgeblasene Raupen von Saturnia pyri $135 \mathrm{~m} . \mathrm{m}$. lang bei ca. $20 \mathrm{~m}$. m. Dicke; eine Raupe von Lasiocampa quercifolia hatte eine Länge von $155 \mathrm{~m} . \mathrm{m}$. Diese ansehnliche Grösse erreichten die Raupen infolge vermehrter Fresslust, da die Thiere am 24. Juni 1896 gefunden wurden, also zu einer Zeit, wo sonst in jener Gegend (Baden bei Wien) quercifolia längst verpuppt ist. H. Locke erzog in den Jahren 1889 und 1891 aus solch grossen Raupen Falter und erhielt quercifolia $\nmid \nmid$ von 100 bis $120 \mathrm{~m} . \mathrm{m}$., von Flügelspitze zu Flügelspitze gemessen, während die erzogenen pyri-Falter $\sigma^{\top} \sigma^{\top}$ und 우 우 eine Flügelspannung von 190, 200 und $220 \mathrm{~m}$. m. zeigten.

L. Berg (1897. 70) in Bessarabien nahm Eier von Bombyx mori, deren Eltern mit Schwarzwurzel-Blättern ernährt wurden, und fütterte die am 10. Mai ausgebrüteten Räupchen mit Blättern 
vom Maulbeerbaum. Es hat sich ergeben, dass die Cocons von dieser Zucht viel grösser und schwerer waren als diejenigen, welche von der Brut erhalten wurden, die nie mit Schwarzwurzel-Blättern gefiittert waren. Auch die Seide war weicher und glïnzender, und ihr Quantum betrug 20-25\% mehr als das der gewöhnlichen Rasse.

Er schliesst daraus, dass die erwähnte Nahrungs-Aenderung die Rasse verbessern kann.

Am 23. August 1898 hielt Edmond Bordage (1S99. 104) auf dem IV. internationalen Congress der Zoologen in Cambridge einen Yortrag, in welchem er unter Anclerem folgende Beobachtung mittheilte:

Er zog die Raupen von Atella pholanta (Familie der Vanessidlae) bei vollem Lichte, aber bei starkem Nahrungsmangel und erhielt sehr kleine Puppen, von welchen Schmetterlinge ausschliipften, die nur 1/3 der normalen Grösse hatten. $2 / 3$ aller Raupen konnten dieses Hungern nicht aushalten und starben.

Rudow (189S. 711) fitterte ganz junge Larven in einem Hornissennest mit Bier und Fleischextrakt resp. Bier und Honig und erhielt Wespen von doppelter Grösse der bekannten Formen.

Gräfin Marie von Linden (1899. 322) trug auf die Blätter der normalen Nährpflanzen verschieclene Stoffe in Form von Lösungen auf und fuitterte damit die Raupen von Vanessa urticue. Die erzielten Resultate waren die folgenden:

\begin{tabular}{|c|c|}
\hline$S t \circ f f$ & $\begin{array}{l}\text { Flügellänge } \\
\text { der Schmet- } \\
\text { terlinge im } \\
\text { Durchschnitt }\end{array}$ \\
\hline Defibriniertes Blut & $21 \mathrm{~m} . \mathrm{m}$. \\
\hline Eisenalbuminat (4 Theile metall. Eisen auf 1000 Wasser). : & 26 \\
\hline Argonin-Silber-Kaseïnverbindnng (5\% Lösung) . . . . . . & $26,4 \eta$ \\
\hline Zucker: gesättigte, wässerige Lösung . . . . . . . . & 25 \\
\hline Lupulin: alkoholischer $5 \%$ Auszug aus der Frucht . . . . . & 25 \\
\hline Capsicum: alkoholischer ätherischer $10 \%$ Auszug aus der Frucht & $22,2 "$ \\
\hline Morphium: $1 \%$ wässerige Lösung . . . . . . . . . & $20,8 \pi$ \\
\hline Atropin: $1 \%$ wässerige Lösung . . . . . . . . . & alle starben \\
\hline
\end{tabular}

Daraus ist ersichtlich, dass die Grösse der Falter in hohem Grade abhängig ist von den Stoffen, die der Raupe mit dem Futter zugeführt werden. Ausserlem wurle beobachtet, dass je jünger die 
Raupen waren, bei denen die Fütterung begonnen wurde, desto stärker die Grösse des Schmetterlinges beeinflusst wurde.

Die Verfasserin meint, dass der Einfluss dieser Stoffe, als Nahrungsmittel, auf die Flïgellänge des Schmetterlinges vielleicht dahin zu deuten ist, dass "das Puppenstadium dabei abgekürzt wird, wie ja auch die Schmetterlinge von überwinternden Generationen, die vorzeitig noch im selben Herbst zur Entwickelung gelangen, meist grösser sind als ihre im Frühjahre ausschlüpfenden Brüder und Schwestern" (p. 369).

Die Puppen wurden auch in reiner Sauerstoff-Atmosphäre bis zum Ausschlïpfen der Falter gehalten, wie die entstehende Kohlensäure mittelst Ätzkali entfernt wurde. Die Flügellänge betrug dabei im Durchschnitt $23 \mathrm{~m} . \mathrm{m}$.

Rudow (1900. 713) beobachtete oft, dass die Wespen, wie z. B. Mauerwespen, Odynerus, Trypoxylon, Splhex, Ammoplita, Xylocopa, ILyarhyle und Osmia unter einander ihrer Grosse nach um das Doppelte variieren. Die Ursache dieser Erscheinung „liegt sicher in grösserer oller geringerer Menge des Larvenfutters, welches die Mutterwespe ungleichmässig fuir die Brut vertheilt hat" (p. 10).

Andererseits werden auffallende Grössenunterschiede einiger Arten, z. B. Ichn. luctatorius und Pimpla examinator beobachtet, bei welchen man die Grössenverschiellenheiten kaum begreifen kann, da diese Insekten keine Mühe wegen der Futterbeschaffung haben. Auch beobachtet man bei Libellula quadrimaculatı und depressa, welche in ungezählten Schaaren plötzlich wantern, um nach kurzer Zeit zu verschwinden, Grössenunterschiede von 1 c.m. „und zwar nicht nur zwischen Männchen und Weibchen" (p. 11).

In der letzten Zeit veröffentlichte Rudow (1900. 712) seine weiteren Beobachtungen, auf Grund deren er die Behauptung ausspricht, dass die Nahrung der Hauptfaktor sei, weshalb die Insekten einer und derselben Art belleutende Grössenverschielenheiten zeigen.

Seine Beobachtungen erstrecken sich hauptsïchlich auf Hautflügler. Die Töpferwespen, Trypoxylon, zeigen Unterschiede zwischen 9 und $15 \mathrm{~m} . \mathrm{m}$. innerhalb jedes Geschlechtes. Cemonus unicolor lieferte Stücke von $8-14 \mathrm{~m} . \mathrm{m}$, besonlers im weiblichen Geschlechte recht auffallend verschiedlen, während die Männchen im Ganzen bestän ligere Grösse aufweisen. Bei rlen Gattungen Stigmus, Pussaleucus, Pemphredon und ähnlichen waren schwankende Grössen seltener.. 
zu beobachten, wohl aber bei Solenius und Ectemius. (Solenius cephalotes und Sol. cexcinctus haben aus einem Stück Balken Wespen von $23 \mathrm{~m} . \mathrm{m}$. bis herunter zu $13 \mathrm{~m} . \mathrm{m}$. ausschlüpfen lassen. Ectemius zeigt Unterschiede von $11-17 \mathrm{~m} . \mathrm{m}$. innerhalb derselben Wolnnung).

Weitere Grössenunterschiede wurden beobachtet bei:

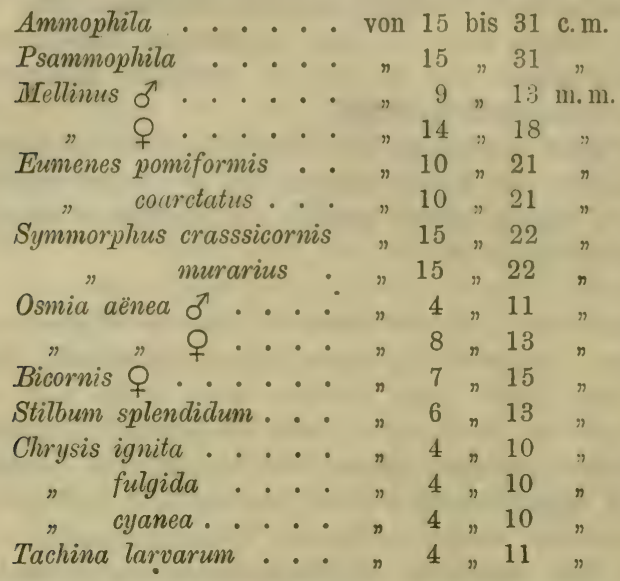

Die Honig und Blüthestaub sammelnden Bienen, Anthophiliden sind im Allgemeinen beständiger in der Grösse. Die kleinen Pteromaliden, welche gewöhnlich in grosser Anzahl zusammen eine Bienenzelle schmarozend bewohnen, zeigen stets eine gleiche Grösse, während echte Ichneumonen sich gewöhnlich nach der Körpergrösse ihrer Wirthe richten.

Ueber die Ursache dieser Grössenverschiedenheit sagt Rudow: "Der Grund solcher Grössenverschiedenheiten ist allein in der ungleichen Menge von Larvenfutter zu suchen. Die Ursache der verschiedenen Versorgung der Larven liegt wiederum im Wetter, während bei Sonnenschein die Insekten fleissig bei der Arbeit sind, werden sie durch Regen daran gehindert. Dann scheint bei den Thierchen die verflossene Zeit am meisten massgebend $\mathrm{zu}$ sein, welche sie, ohne genaue Prüfung, dazu bringt, nach einer gewissen Anzahl Stunden oder Tage die Zelle zu schliessen" (p. 189).

A. Mordwilko (1900. こ93) stellte fest, dass Pflanzenläuse, welche zur Zeit des Welkens der Pflanzen, welche er unter einer 
Glasglocke hielt, sich entwickeln, viel geringere Grösse haben, als diejenigen, welche an gesunden Pflanzen sich aufhalten. Durch denselben Umstand erklärt er auch die verhältnissmässig geringere Grösse der Sommer-Generationen von Chaitophorus lyropictus an Blättern von Acer platanoides und campestre, Rhopalosiphum berbericlis an Blättern von Berberis vulgaris, Plıylluphis fagi an Blättern von Fagus silvatica etc. im Vergleich mit Generationen, welche im Frühjahr vorkommen.

G. Koschownikow (1900. 467) bestimmte die Länge der Halbringe an Rücken der Bienenmännchen, welche aus "Puckel-Larven" 1) ausschlüpften, und fand:

Gliederlänge: II. III. IV. V. VI. VII. Glied.

Gewöhnliches $\sigma^{7}: \quad 2,9 \quad 2,7 \quad 2,8 \quad 2,8 \quad 2,4 \quad 1,4 \quad m . m$.

Kleines $\sigma^{\nearrow}: \quad 2,4 \quad 2,5 \quad 2,4 \quad 2,4 \quad 2,0 \quad 1,0$

Die letzten Exemplare ergaben ausserdem: die Körperlänge $12,5 \mathrm{~m} . \mathrm{m}$. (normal 14-15), die Körperbreite 4,5-5 m. m. (normal 5,5 bis 6 ).

Die vergleichenden Messungen an Puppen ergaben: die Puppenlängre (ler "Puckeligen" 14-14,5 m. m." (normal 18,5-19,5), die maximale Dicke 5,5-6 m.m. (normal 6,5).

Daraus zieht er den Schluss, dass sowohl die Dimensionen wie auch die Form der Wachszellen die Entwickelung der Bienen beeinflussen, sagt aber nicht, ob dieser Umstand durch die Nahrungsmenge bedingt wird.

E. A. Bogdanow (1901. 92) züchtete die Larven rler Fliege Dryomyza anilis im Kuhlïnger; dieselben blieben sehr klein.

W. Iwanow (1901. 406) fütterte die Raupen von Bombyx mori mit verschiedenen Pflanzen und erhielt unmittelbar vor und nach der Einspinnung folgende Resultate (als Mittel von 25 Raupen):

') Unter „Puckel-Larven" versteht man Larven und Puppen der Bienenmännchen, welche in für Arbeiterbienen bestimmten Wachszellen sich entwickeln, wobei die Bienen über solche Zellen einen stark convexen Deckel („Puckel“) aufbauen. 


\begin{tabular}{|c|c|c|c|c|c|c|c|}
\hline \multirow[t]{2}{*}{ Pflanze } & \multicolumn{2}{|c|}{$\begin{array}{l}\text { Dimensionen } \\
\text { der Raupen } \\
\text { in } \mathrm{m} . \mathrm{m} \text {. }\end{array}$} & \multirow{2}{*}{ 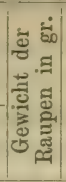 } & \multirow{2}{*}{ 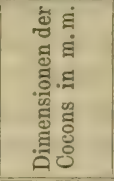 } & \multirow{2}{*}{ 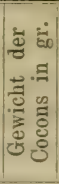 } & \multirow{2}{*}{ 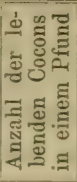 } & \multirow{2}{*}{ 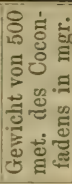 } \\
\hline & Länge & Dicke & & & & & \\
\hline $\begin{array}{l}\text { Morus alba v. tatarica } \\
\text { (hochstammiger Baum) }\end{array}$ & 71,6 & 10,4 & $|3,70|$ & $39 \times 19$ & 1,99 & 188 & 156,5 \\
\hline $\begin{array}{l}\text { Morus alba v. tatarica } \\
\text { (Zaum). . . . . }\end{array}$ & 71,8 & 10,5 & $|3,96|$ & $38 \times 18$ & 2,11 & 180 & 165,2 \\
\hline Morus alba $\nabla$. latifolia. & 71,7 & 10,9 & 4,07 & $39 \times 18,8$ & 2,34 & 198 & 155,8 \\
\hline Morus alba v. cedrona. & 77 & 11,8 & 4,64 & $39,7 \times 18,8$ & 2,56 & 186 & 169,5 \\
\hline Morus rubra canadensis. & 68,9 & 10 & 3,41 & $36,2 \times 18,2$ & 1,69 & 240 & 126,8 \\
\hline Maclura aurantiaca... & 71 & 10,6 & 3,85 & $37,5 \times 18,2$ & 2,07 & 227 & 164,4 \\
\hline Broussonetia kaempferi . & - & - & 一 & - & - & 255 & - \\
\hline Scerzonera hispanica . . & - & 一 & - & - & - & 248 & 一 \\
\hline
\end{tabular}

V. Kellog und R. Bell (1903. 447) fütterten die Raupen von Bombyx mori statt mit Maulbeerblättern mit Lattich uuil beobachteten dabei, dass die Raupen in allen Starlien schwerer und die Puppen grösser werden. Der Kokon war nur halb so schwer unil die Seide weniger stark und elastisch, als bei gewöhnlichem Futter.

Bei vermindertern Futtermenge wurde eine Zwergrasse erhalten.

Ch. Sasaki (1904. 735) fütterte die Seicien-Raupen, welche aus Eiern einer zu Si-chuen in China gezüchteten Rasse schlïpften, mit $\mathrm{Cudrenia}$ triloba- und mit Maulbeerblättern. $20 \mathrm{Cudrenia-Rau-}$ pen ergaben Kokons, welche 0,2135 gr. wogen, während tlas KokonGewicht von 20 mit normalem Futter gezogenen Raupen 0,2065 gr. betrug. Er züchtete noch die Raupen der Matamukashi-Rasse mit Blättern des wilden und des kultivierten Maulbeerbaumes (1904.735) und fand, dass die Raupen, welche mit wilden Blättern gefüttert wurlen, grösser und schwerer waren (und zwar in allen Stadien) als die anileren. Die mittlere Fadenlänge der ersten Raupen betrug $583 \mathrm{~m}$. und die Farlendicke 0,0192 m.m., während diese Grössen bei anderen Raupen $577 \mathrm{~m}$. resp. 0,0264 m.m. betrugen. Die Qualität der Seide von ersteren Raupen war beleutend besser als von anderen.

L. Reh (1904. 681) konstatierte, lass Chionaspis saticis L. in der Grösse selır verschieden ist; am grössten sind die Formen von der Erle, am kleinsten die von der Pappel. Er fand andere Unter- 
schiede in der Anzahl der Plattenhaare und der Drüsengruppen der Weibchen, und zwar:

Seitliche Platten Platten am am letzten Segment: vorletzten Segment:
Drüsengruppen

med. ant. lat. post lat.

$14,5 \quad 25,25 \quad 22$

$12 \quad 25 \quad 17$

$\begin{array}{lll}18,2 & 30 \quad 25\end{array}$

$\begin{array}{lcclll}\text { Erle . } & 6 & 6,75 & 14,5 & 25,25 & 22 \\ \text { Esche . } & - & - & 12 & 25 & 17 \\ \text { Pappel . } & 5,5 & 4 & 18,2 & 30 & 25\end{array}$

J. Dewitz (1904. 175) fütterte die Larven von Luciliu cuesur und erythrocephala mit defibrinirtem Hammelblut oder mit Schnecken und erhielt normale Fliegen, die aber ihrer Grösse nach sehr stark variierten.

Ausserdem brachte er Raupen von Porthesia chrysorrthoca in Blausäureatmosphäre und erhielt gänzlich unvollkommene Puppen. Ihre Form war zylindrisch. Die Segmente waren deutlich abgesetzt, gerundet und nicht ineinander geschoben. Die Flïgelscheiden waren kürzer als bei normalen Puppen.

G. Koschewnikow (1905. $467 a$ ) züchtete in Aquarien Anopheles maculipennis Meig. und fand, dass sie die Flïgellïnge = 145-135 haben, während die im Freien gefangenen diesen Werth bis zu 184 haben. Er erklärt die Verminderung der Flügellïnge in diesem Falle durch die mangelhafte Ernäherung.

A. Pictet (1905. 637 a) fütterte die Raupen von Ocneria dispar L. mit Nussblättern. Die darauf entstandene II. Generation wurde in derselben Weise aufgezogen; sie ergab kleinere Schmetterlinge für beide Geschlechter. In III. Generation waren die Schmetterlinge zwei Mal kleiner als die normalen. Taraxacum-Fütterung erzeugte bedeutend grössere Exemplare.

Er beobachtete, dass wenn man einer Raupe (Vanessa witicae) die Nahrung zu bestimmter Zeit güinzlich entzieht, wenige Tage nach der letzten Häutung, sie sich verpuppt unl einen Zwergfalter ergiebt. Zieht man Raupen mit tagtäglich ungenügender Nahrung auf, so verpuppen sie sich, manchmal vor der letzten Hïutung, ergeben Zwerge, welche aber zudem meist erheblich variieren. 


\section{Ergänzungs-Litteratur zu diesem Abschnitt.}

Došek, Jos. Fr. Proč jsou některé krílorny velké a jine opět malé? (WTarum sind einige Föniginnen gross, und andere klein?) - Véelar. IY. 1870. p. $50-51$.

Heller, Adolf. Co jest pričina rozličné relikosti liráloren? - Včelař. IV. 1870. p. $91-93$.

Himmelstoss, W. Haben grosse Tïnigimuen ror den kleinen einen Vorzug? und wenn das der Fall ist, was hat der Bienenzüchter bei Erziehung solcher zul beobachten, um kräftige und grosse Königinnen zu bekommen? Ver.-Bl. d. westfal, rhein. Ver. für Bienenzucht und Seidenbau. 4. Jahrg. 1868. p. $151-154$.

Malies. Wie erklärt sich das Torkommen auftillend kleiner Königinnen? Preuss. Bienen-Ztg. 1878. p. 137-139.

\section{Einfluss des mechanischen Druckes, der Bak- terien und anderer Faktoren.}

J. Vogel (1865. 926 a) beobachtete, dlass, wenn die Bienenkönigin der ïgyptischen Rasse, welche viel kleiner ist als die europäische, ihre Eier in die Zellen der gewöhnlichen Biene ablegte, lie ausgebildeten Bienen immer grösser waren als die ägyptischen.

Alexander Reichert (1892. 683) in Leipzig erhielt von einer grösseren Aporia-crataegi-Zucht einen Falter, bei welchem je die beilen Vorder- und die beiden Hinterfliggel gleichmässige symmetrische Einbuchungen zeigten; das Geäler der Flügel war leicht gewellt. Die Puppe, aus welcher dieser Schmetterling schlüpte, hatte den Brustgürtel ungleich scharf angezogen. Der Referent dieser Mittheilung, $\mathbf{D}^{\mathrm{r}} \mathbf{K r}$. - bringt die Abbildung sowohl dieses Schmetterlings, wie auch der Puppe, und sagt: „Der ungleich grössere Druck wirl eben auch eine ungleiche oller besser unvollkommene Ausbildung der Flïgel zur Folge gehabt liaben" (p. VIII).

Zarudski (1893. 966) fand, dass die Arbeiterbienen, welche in Drohnenzellen gezüchtet werden, etwas grösser sind als die gewöhnlichen. 
A. Voelschow (1893. 930) beobachtete im Herbst 1891, lass an allen Baumstämmen die Leichmame von Raupen von Dasychira pudibunda ab. concolor Strgr. hingen. Es gelang ihm jedloch, eine grosse Zahl scheinbar lebensfähigen einzutragen und daraus 7 Puppen zu erhalten. Die entwickelten Schmetterlinge waren wesentlich kleiner als normal. Dabei sei bemerkt, dass die Puppenruhe statt 8 Monate nur \& Wochen dauerte, und die Schmetterlinge im December ausschlüpften.

L. H. (1896. 337) beobachtete eine gedriickte Raupe von Deileplite nerii, welcher grosse Tropfen von durchsichtigem, hellem, grünem Safte am Maule und After hingen. Trotzdem ergab sie einen Falter, welcher als Verkriipplung ein Paar merkwïrlige, aber ganz symmetrische Ausschnitte an beiden Unterflügeln hat.

E. A. Bogdanow (1903. 93) ziichtete durch zehn Generationen Irusca domestica, um zu untersuchen, ob es möglich sei, in einigen Generationen die Flïgelverkümmerung kïnstlich hervorzurufen, wenn man den Fliegen sofort nach der Geburt aus den Puppen die Flügel abschneidet. Als Nahrung dienten Zucker, Dünger und Milch. „Die genaue Untersuchung der Fliegen hat aber keine, auch nur kleine Abweichung von der Norm entdecken lassen; wenn einigen Fliegen Flïgel versuchsweise nicht abgeschnitten waren, konnten sie so gut wie normale fliegen" (p. 267). 


\section{DRITTES KAPITEL. \\ Die Färbung und Zeichnung der Insekten.}

\section{Einleitung.}

In dem vorliegenderı Abschnitt werden Untersuchungen beschrieben, welche auf die Insektenfarben Bezug haben, wenn das Insekt sich unter normalen Umständen befindet.

J. Swammerdamm (1752. 798) war der Erste, welcher die Entwickelung der Zeichnung an den Schmetterlingsflügeln untersuchte, wenn auch nur bei Vanessa urticae. Er sagt: „Wollte man diese Thiere Tag vor Tage zergliedern, man würde die wunderbarsten Veränderungen der Farben gewahr werlen, die man sich immer einbilden kann, und wie diese allgemach von einem blassen, weissen und grauen Grunde dunkel, hochbraun, hellroth, blau, schneeweiss und anders färbig werlen. Es geht damit so wunderbar zu, rlass man es schwerlich beschreiben kann" (p. 234). Weiter: „Aher nicht allein die Flügel nehmen an Grösse zu, sondern auch alle ihre Farben und Zeichnungen wachsen an und breiten sich aus. Was vorhin kleine Fleckgen, unsichtbare Pünctgen waren, ist nun zu einer erkenntlichen angenehmen Auszierung geworden" (p. 236). Bevor er die Flügel aus der Puppe herausnahm, brachte er die Puppe in heisses Wasser; nach dieser Behandlung wurden die Flügel undurchsichtig und härter und konnten leichter vom Leibe entfernt werden.

Bereits Schelver (1802. 743) fand, dass die himmelblaue Farbe und gelben Seitenflecken am Hinterleibe der Libellula depressa der Haut nur aufgelegte Farben und daher abstreifbar sincl.

Gadeau de Kerville (1875. 269) fand bei seinen mikroscopischen Untersuchungen, dass die Schuppen der albinistischen Schmetterlinge viel weniger Pigmentkörnchen besitzen, als die Schuppen der normal gefärbten Schmetterlinge. 
Von Leidig (1876. 510) untersuchte den Puder vom Leibe der Libelle und fand, dass es ein blauer und gelber Stoff von krümeliger Beschaffenheit ist, dazwischen mit einzelnen grösseren Formen von Fettglanz. Er betrachtet diesen Stoff als eine wachsartige Substanz.

Silberflecken oder Perlmutterfarben erkliirt er durch Interferenz des Lichtes, welches auf die zart geschichtete Cuticula einfaillt, wobei die Schüppchen mit Luft gefüllt sind. Werden die Schuppen mit Wasser befeuchtet, so verschwindet der Silberglanz, weil dadurch die Luft vertrieben wird, und es bleibt nur die darin befindliche wirkliche Farbe (Argynnis-Arten).

Hermann Hemmerling (1878. 365) unternahm nach dem Vorschlag von Leydig die Untersuchung der Hautfarbe der Insekten für seine Inaugural-Dissertation. Es wurden mehrere Arten der Rüsselkäfer (Circulionidae) auf den Bau der Haut und die Beschaffenheit der Farben untersucht. Die Hautflïche der Rüssler ist, namentlich im frischen Zustande von einem eigenthümlichen Pu:ler oder Reif bedeckt, der sich leicht abwischen lässt. Bei Lixus puraplecticus wird die gelbliche Farbe durch eine körnige Masse erzengt, welche in Kalilauge nicht schwindet, sondern nur lichter wird. ChIorophanes viridis besitzt den gleichen Puder. In ganz besonderer Menge ist das Hautsecret bei Otiorhynchus ligustici vorhanden, wo es die Hauptursache der grauen Färbung dieses Käfers bildet. Es handelt sich in diesen Fällen um Durchschwitzung eines Stoffes, der, mit der Luft in Berührung gekommen, zu Körnchen, tafelförmigen Klümpchen oder in anclerer Form erhärtet.

Hagen (1882. 351) wies nach, dass die Libellen deshalb irisieren, weil die beiden Hautschichten der Flügel einen Zwischenraum haben.

K. S. Mereschkowsky (1884. 560) untersuchte das thierische Pigment - das rothe Lipichrom - welches zuerst von A. P. Bogdanow (1856. 89; 1857. 90) entdeckt und später noch ein Mal von Wurm (1871. 964) unter dem Namen Tetronerythrin beschrieben wurde. Er kam bei diesen Untersuchungen zum Schlusse, dass dieses Pigment die Rolle spielt, die Hautathnung der niederen Thiere zu verstärken. Da die Inselkten dieses Pigment nicht besitzen, so erklärt er diese Erscheinung wie folgt: „Es ist bekannt, dass Insekten, dank des Tracheen-Systhems, welches durch ihre feinsten Verzweigungen 
in allen Organen vertreten ist, so stark mit Sauerstoff virsorgt sin.l, wie keine andere Thiergruppe. Man kann leshalb erwarten, wenn das Lipochrom wirklich nur zum Athmen dient, dass bei solchen Thieren die Hautathmung ganz ïberfliissig wiril, und das Lipochrom fehlen wirl. Dies sehen wir auch in der That: kein Inselit hesitzt las rothe Lipochrom, und wemn es mit iler Zeit gefunlen wiril, so wir.l es nur in seltenen Ausnahmsfillen stattfinclen" (1). 84 umi 85).

Krukenberg (1884. 477) komnte den blauen Farbstoff aus blauen Schuppen durch kein Lösungsmittel gewinnen; er schliesst daraus, dass die blaue Farbe rler Schmetterlinge nur eine optische Täuschung sei, indem über dem dunklen Grunıle trübe Schichten sich befinden. Diese Suhlussfolgerung hat er übrigens auch an einigen blauen Vogelfedern nachgewiesen.

E. Schatz (1 885.738$)$ kommt zu dem Schlusse, dass die rothe Farbe der Schuppen eine Mischung einer (gelben) Farbe mit einer optischen Farbe sei. Er extrahierte nämlich den Farbstoff vermittelst Alkohol aus orangegefürbten Schuppen von Eurcma motcrpia und aus blutrothen Schuppen von Eurema coccinata und erhielt in beiden Fällen den gelben Farbstoff. Durch die Interferenzerscheimungen erklärt er auch die violette Färbung der Cullosune zone, bei welcher die Schuppen in der Wirklichkeit karminroth gefärbt sind.

E. Haase (1586. 33s) behauptet, dass clie weisse Farbe vieler Männchen der Gattung Pieris dadurch entstanclen ist, dass die grosse Anzahl Duftschuppen mit Luft gefüllt und pigmentlos sincl.

N. Schæwrow (1888. 741) sagt, dass die Fürbung des Cocons vom Pigment abhïngt, welches in der äusseren Schicht des Seidenfallens sich befindet. Dieses Pigment wird an den Fäden abgelagert, indem die Wände der die Seide producierenden Drüse dasselbe aus dem Blute ausscheiden. Dieses Pigment ist dem Chlorophyll sehr ähnlich und ist wahrscheinlich nichts anderes als Chlorophyll, welches eine grwisse Unänderung beim Verdauen erleilet.

J. Blanc (1888. 82) vermuthet, gestützt auf seine Untersuchungen, dass der Farbstoff der Seide durch das Blut der Ranpe von Bombyx mori produziert wird und durch die Wände der Seidendrüse in das Reservoir durchdringt. 
A. Jacobi (1889. 408) untersuchte die Entwickelung der Zeichnung an den Schmetterlingsfligeln bei 200 Puppen von Fidtoniu piniaria L. und kam zu folgenden Resultaten:

1). Der gelbe o.ler gelbliche Flïgel ohne Zeichnung ist das Ausgangsmaterial der Zeichnungsentwickelung; es werden hier leren drei Hauptmerkmale in Betracht gezogen:

a) Die Querstreifung der oberen Seite des Vorlerflügels ist den $\delta$ und $q$ gemein; sie ist das Vorbild der für die Abtheilung der Giom. fasciata Gppbg. characteristischen Typuszeichnung.

b) Die dunkelbraune, in ler Mitte ausgebuchtete Querbinde des Hinterflügels ist das Resultat der Verschmelzung der zu den frühesten Zuständen der Zeichnung gehörenden, gesonderten halbmond - oder laurenförmigen Flecken; diese Flecken und die sich daraus entwickelnde Querbinde sind den beiden Geschlechtern gem(in.

c) Der dunkelbraune $V$-förmige Streifen in der Mitte des Innenrandes an Vorderflügel beim $\delta$ bildet sich auch zeitig; in schiefer Richtung dem heruntersteigenclen Querstreifen gegenïber anwachsend, theilt er den grossen in Zellen $1_{6}$ und 2 liegenden Fleck in zwei eiförmige Flecken; in den Fällen, wo diese nicht

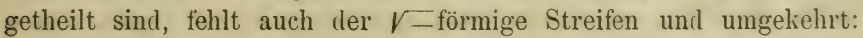
wenn beim , besonders bei dessen dunklerer andromorphen Form, die zwei eiförmnigen Flecken ausgeprägt sind, ist auch dieser Streifen vorhanden.

2). Die Entwickelung der Flügelzeichnung kann als Hülfsmerkmal in der rationellen Systematik der Schmetterlinge dienen.

Der Abhandlung sind 6 Figuren beigegeben.

J. F. von Bemmelen (1889. 68) fand, dass die Puppenfluigel von Pieris brassicae in den ersten Tagen ungefärbt und durchsichtig sind; nach einigen Tagen werden die Vorderflügel weiss, später auch die Hinterfliigel, und dieser Zustand bleibt unverändert bis zum zweiten Tage vor dem Ausschlüpfen. Dann treten die schwarzen Flecken und der gelbe Ton der Unterseite auf.

Bei Vanessa cardui und urticae erscheint auch zuerst das Weissliche und zuletzt Dunkelbraun und Schwarz.

F. G. Hopkins (1889-94. 387-389) untersuchte die weisse Farbe der Pieriden und fand, dass sie nicht eiener Diffraction zuzuschreben ist, sondern ein wirkliches Pigment bildet, welches ein Derivat der Harnsäure darstellt; auch das Roth und Gelb sind Derivate dieses Stoffes. 
C. Schäffer (1890. 737) war ler Erste, welcher untersuchte, ob die verschiedenen Farben des Schmetterlingsfliigels unmittelbar vor dem Ausschliupfen des Imago auftreten, oler ob sie allmählig sich entwickeln. Er fand an Puppen von Vunessa urticae, dass zuerst die blauen Flecke in weisslicher Farbe auftreten und sich nachher mit scharf begrenzten dunkeln Rändern umgeben, welche sich später zur Randbinde verschmolzen. Die Zeichnung der Hinterflügel entwickelte sich langsamer als die der Vorderflügel.

A. Spuler (1890. 832) sagt, dass Grïn bei Schmetterlingen kein Pigment, sondern nur optische Farbe sei.

E. Verson (1890. 916) fand, dass die Fliigel des Schmetterlings bereits in der Raupe angelegt sind, inclem er in seiner $\mathrm{Ab}$ hamllung: "La Formazione delle ali nella Larva del Bombyx mori" sagt: „E cio spiega ampiamente come possa avvenire che, a malgrado di uno sviluppo relativamente cosi avanzato, l' ala rulimentale possa rimanere perfettamente celata alla superficie, sotto la cuticola che verrà spogliata appena al tempo della transformazione in crisalicle" (p. 14).

M. Standfuss (1891. 835) erwähnt in seinem Handbuche, dass die rothen und h llbraunen Farbentöne in der Puppe viel früher als die grauen, grauschwarzen und schwarzbraunen erscheinen. Diese Beobachtung ist an Puppen von Vanessen gemacht worlen.

F. Urech (1891. 890) stellte Untersuchungen an, um zu elmitteln, wie die Färbung der Puppenfliigelchen während der Puppenzeit sich entwickelt. Zu diesem Zwecke benützte er die Puppen von Vanessa urticae uni Vanessa io. Zuerst erscheinen alle Flïgelschuppen weisslich gefärbt, dann der Reihe nach: gelb, röthlich, braun, schwäzlich.

E. Haase (1891. 339) fand, dass die Zeichnung in frühen Puppenstadien keineswegs scharf begrenzt ist und beständig bleibt, sonilern dass sich dieselbe in der Puppe nach ganz bestimmten Richtungen umbildet.

A. B. Griftiths $(1892.330,330$ a) untersuchte das grüne Pigment von einigen .Papilio-Arten, von Parthenos gambrisius, von Hesperia-Arten, von Limenitis pocris, von Halias prasinana, von 
Larentia-Arten, von Cidaria miata und von Inn statices, bei welchen dieses Pigment das gleiche ist.

Warmer Alkohol und Aether lösen dieses Pigment nicht auf. Es wird durch das kochende angesäurte Wasser ausgezogen und bleibt nach dessen Verlampfung als amorpher grüner Körper zurïck. Die Analyse ergab für ihn die Formel $\mathrm{C}_{11} \mathrm{H}_{12} \mathrm{Az}_{8} \mathrm{O}_{10}$. Dieses Pigment ist eine zweibasische Säure, löslich in Alkalien und wird durch SilberNitrat niederschlagen. Das Silbersalz hat die Formel $\mathrm{C}_{11} \mathrm{H}_{10} \quad \mathrm{Ag}_{2}$ $\mathrm{Az}_{8} \quad \mathrm{O}_{10}$ und ist in Alkohol leicht löslich, in Aether unlöslich. Die alkoholische Lösung hat Drehungsvermögen $(\alpha)_{\mathrm{D}}=+29^{\circ}$. Dieses sauere Pigment zerfällt durch Kochen im Wasser in Harnsäure, Oxalsäure und Kohlensäure. Durch die Bearbeitung mit Salzsäure zerfällt es in Harnsäure. Es ist sehr wahrscheinlich eines der Derivate der Harnsäure und wird in Flügeln durch die wandernden Zellen abgelagert. Griffiths giebt ihm den Namen "LepidopterenSäure" (acide lépidoptérique).

F. Urech (1892. 892), untersuchte den grünen Farbstoff in den Fluggelchen der Puppe von Pieris brassicae, zu welchem Zwecke er die Flügel des Schmetterlings bezw. der Puppe mit einem wollenen Knäuel entschuppte. Die durchsichtigen Flügel zeigen beim Schmetterling eine sehr schwache grünlichblaue Trübung, bei der Puppe ist dieselbe smaragdgrun (mit Ausnahne des Geällers); diesen Intensität-Unterschied erklärt er durch grössere Flächenaus lehnung bei Schnetterlingsflügeln. Das zerschnittene grüne Puppenflügelchen färbt gewöhnliches Wasser schnell grün; nach dem Verdampfen des Wassers bleibt eine tiefgrüne häutige Masse zurück, welche bei wiederholtem Eintrocknen unlöslich wird. Beim starken Erwärmen der Lösung verschwindet die Farbe, ebenso auch in der Kälte bei Zusatz von Alkali, während sich der Farbstoff sogar in concentrierter Schwefel- oder Salzsäure lange erhält. Concentrierte Salpetersäure verwandelt das Grün des Flügelchens beim Eindringen ins Flügelgewebe in Violett, das sich zuletzt durch Roth in Gelb verändert. Alkalilösung veränilert die Farbe momentan in Schwach-Gelb.

Die Untersuchung ergab, dass dieser Stoff kein Chlorophyll ist; er dringt auch nicht in lie Schuppen und ist wahrscheinlich die Muttersubstanz des Schuppenpigments. Dieser grüne Stoff fehlt bei Papilio machaon und bei untersuchten Spinner-Eulen-SphingilenSpecies. Bei Vanessa urticae-Puppen ist er von schwach röthlichem Tone. 
In seiner weiteren Abhanllung: „Beobachtungen über die zeitliche Succession des Auftretens der Farbenfelder auf den Puppenflugelchen von Pieris brassica" beschreibt F. Urech (1892. 891) seine Untersuchungen an Puppen, welche während der Monate März, April und Mai vorgenommen wurden, wobei die Flügelchen schon beschuppt waren.

Zuerst erscheinen alle Flügelschuppen weisslich gefärbt; sehr bald darauf tritt eine gelbe, fast hellorangene Färbung auf der Unterseite der Hinterflügel und dem Vorderrande der Unterseite der Vorderflügel auf. Wo später die schwarzen Flecken und schwarzen Bänder vorhanden sind, erscheint jetzt eine Färbung, welche an die Oelflecken auf weissem Papier erinnert; erst später tritt dann allmählig schwärzliches Pigment auf, welches einige Zeit später ganz schwarz wird.

F. Urech (1892. $892 a$ ) untersuchte die Eigenschaften der Schuppenpigmente bei fo!genden Lepidopteren:

A. Pieriden: Rhodocera rhumni, Colias, Anthocharis, Pieris brassicae.

B. Papilioniden: Papilio machaon.

C. Lycaeniden.

D. Nymphaliden: Vanessa io, V. urticae, V. c-album, $V$. atalanta, $V$. antiopa.

E. Zyga enen: Zygaena philipendula.

F. Bombyciden: Arctia caja.

G. Sphingiden: Deilephila euphorbiae.

Er erhielt von diesen Species verschiedene Pigmente, welche im Wasser oder Sodalösung löslich und in Äther und Alkohol unlöslich waren. Sie sind deshalb nicht identisch mit denjenigen, welche Krukenberg aus Vogelfedern ausgezogen hat. „Dies ist wohl im Zusammenhange mit der Verschiedenheit der Bildung des Blutes und seiner chemischen Zusammensetzung und etwa auch mit der histologischen Beschaffenheit der Häute bei diesen beiden Thierstämmen " (p. 306). Bei einigen Farbstoffen trat die Murexidprobe deutlich ein. In Betreff der Natur der Lepidopterenfarben führt er folgende allgemeine Eintheilung an:

1. Schuppen, die nur chemischen Farbstoff enthalten und keine Interferenzfarbe zeigen können.

2. Schuppen, die chemischen Farbstoff enthalten, aber auch Interferenzfarben zeigen kônnen, z. B. Schuppen an Vanessa-Arten. 
3. Schuppen, die nur Interferenzfarben zeigen auf dem Flügel, aber auch chemischen, in Wasser löslichen Farbstoff enthalten, z. B. an Lycaena-Arten.

An Schuppen, die Interferenzfarben zeigen, kann man zwei Unterscheidungen machen:

a. Die Interferenzfarben sind nur sichtbar, wenn man die Schuppen vom Flügel wegnimmt und in bestimmte Lagen zu rlen Lichtstrahlen bringt (z. B. Schuppen (ler Vanessa-Arten).

b. Die Interferenzfarben sind im reflektierten Licht auch an den im Flügel steckenden Schuppen sichtbar, meist nur in zwei Farben variierend, je nach der Stellung zum reflektierten Licht (z. B. Apatura iris, Lycaena-Arten).

4. Schuppen, deren Farbenerscheinungen auch noch durch die Unterlage bedingt sind, z. B. die blau und violett erscheinenden Schuppen der Vanessa-Arten; nur über dunklem Grunde erscheinen sie so.

5. Verschieden gefärbte, sich überdeckendle Schuppen zeigen oft die Mischfarbe, z. B. bei Papilio machaon blaue und rothe Schuppen des Oberauges auf dem Hinterflügel, man sieht einen lilarothen sichelförmigen Streifen.

F. Urech (1893. 893) untersuchte die Farbe der Lepidopterenund Käferschuppen bei ca. 100 Species, wobei er bei chemischer Versuchsmethode Wasser, 10\%-ige und 28,5\%-ige Salzsäure, 48\%-ige Salpetersäure und 20\% Ammoniaklösung gebrauchte; für die physikalische Versuchsmethode diente ihm ein Mikroscop mit ca. 800facher Vergrösserung.

Die Ergebnisse dieser Untersuchung sind in zahlreichen Tabellen verzeichnet. Die Zusammenfassung mag hier wörtlich wiedergegeben werden, wobei sich die Farbenbezeichnung auf die Farbe bezieht, wie sie die Schuppen am Schmetterlingsflügel zeigen:

„1). Das schwarz erscheinencle Schuppenpigment ist fast ausnahmlos bei allen Species in Wasser, auch stark erhitztem unlöslich, hingegen geht mit Salpetersäure immer Pigment in Lösung, doch nie mit ganz schwarzer Farbe, meist umbrabraun, auch olivenbraun. Bei vielen Species geht das Pigment auch mit Salzsäure, besonders koncentrirter, in Lösung.

2). Auch die braunen Pigmente sind meistens bei allen Gattungen in Wasser unlöslich, hingegen fast immer löslich in Salzsäure, besser noch in Salpetersäure. Im Wasser sind einige braune Pigmente von Nymphalidenspecies ziemlich leicht löslich. 
3). Rothe und orangene Pigmente sind unter den Pierilen-, Lycaeniden-, Nymphaliden- und Zygaeniden-Species in Wasser löslich, zum Theil auch unter den Papilioniden; nicht habe ich Wasserlöslichkeit erhalten unter den Sphingiden, Arctilen, Bombyciden, Saturniden und Geometriden. Unter den Noctuen sind rothe und orangene Pigmente weniger häufig und nicht in gesättigten Farbentönen, zu den Ausnahmen hiervon gehört z. B. Catocala, bei dieser Gattung ist das Pigment in Wasser kaum löslich und bei den übrigen von mir untersuchten Noctuengattungen nie, sondern erst in Salzsäure.

Durch Säure wird das orangene und rothe Pigment bei vielen Species gelb und dureh Ammoniak wieder orange bezw. roth.

4). Für gelbes Pigment ist die Löslickeit ähnlich wie bei Orangegelb; überall, wo das Orange einer Species löslich ist in Wasser, ist es auch das Gelb, wenigstens das (er Oberseitenschuppen, während dem Gelb nur genäherte Farbetöne, wie Ledlerfarbe, Isabellfarbe, hellbraune Farbe und ähnliche mehr, oft unlöslich in Wasser sind. An Orangeroth schliesst sich das Gell daher meist auch im Falle von Unlöslichkeit in Wasser an, es ist also unlöslich bei Sphingiden, Arctiden, Lipariden, bei Noctuen und Geometrilen; löslich bei Pierilen (bei Papilioniden schwieriger), bei Lycienilen, Nymphaliden, Satyriden und Bombyciden.

In Salzsäure ist gelbes Pigment fast immer löslich, ebenso in Ammoniak, durch welches es in einigen Fällen etwas intensiver gelb wird, aber kaum orangeruth, in wenigen Fällen grünlichgelb nach vorangehender Extraktion mit Salzsäure.

5). Weiss unter den Pierilen stark als Pigment vertreten, ist meistens auch in Wasser löslich, unlöslich oder doch sehr schwer löslich fand ich es bei Nymphaliden, Apaturiden, Arctiden, Lipariden, Hadeniden und unter den Geometriden und Tineiden; es war nicht immer entscheilbar, ob es bei diesen Gattungen nicht nur Reflexfarbe in Folge von Luftschichten ist, z. B. bei Leucoma salicis, in welchem Falle sich selbstverstänulich kein Pigment lösen kann.

6). Grünes Pigment liommt unter den Pierilen, Lycaenilen und Geometriden wasserlöslich vor, unlöslich ist es bei Atychia (Ino) pruni und Pupilio eurymedes; an Salzsäure gaben die grünen Schuppen meistens gelbliches Pigment ab. Als Interferenz- und dichroitische Farbe kommt Grün oft vor.

7). Violett und Blau sind besonders unter den Rhopaloceren vielfach vorkommende Farben, so bei Lycaenilen und Nymphaliden, unter den Heteroceren bei Zygaeniden. Meistens sind sie Interfe- 
renzfarben, die unter dem Mikroscop mit stärkeren Objectivsystemen und daher geringem Abstande vom Präparate nicht mehr sichtbar sind; die Schuppen erscheinen farblos oder weisslich. Nur in wenigen Fällen geht mit Wasser orler Säure ein bläuliches Pigment in Lösung; ich beobachtete es an Smerinthus occllata. Wo Blau eine dichroitische Erscheinung ist, ist auch ein Pigment daran betheiligt, dlas mit gelbiicher Farbe extrahiert werden kann" (p. 325 und 326).

J. Gonin (1894. 321) kam durch seine Untersuchungen zu dem Schlusse, dass die Imaginalscheiben der Flügel der Schunetterlinge bereits bei der Raupe angelegt werden.

F. G. Hopkins (1894. 389) untersuchte die Flügel-Farben der Pieriden und kam zu folgenden Resultaten:

1). Die Flügel-Schuppen der weissen Pieriden enthalten Harnsäure, und zwar hat diese Substanz dieselbe Beziehung zur Schuppe, wie die Pigmente bei den farbigen Pieriden, sie functioniert somit factisch als weisses Pigment.

2). Das gelbe Pigment, das bei den Pieriden so weit verbreitet ist, ist ein Derivat der Harnsäure.

3). Die Eigenschaften dieses gelben Farbstoffes und die Ergebnisse seiner Analyse führen zu der Erkenntniss, dass die Pigmente der verschiedenen, gelb gefürbten Gattungen illentisch sincl.

4). Dieses gelbe Pigment kann liünstlich dargestellt werden durch Erhitzen auf hohe Temperatur von Harnsäure mit Wasser in zugeschmolzenen Röhren. Das so entstandene Prodult ist ursprünglich von Hlasiwetz als Mycomelinsäure beschrieben worilen.

5). Die Ilentität des natiiriichen mit (lem kïnstlichen Prorlukt wirl durch die Thatsache erwiesen, dass beide bei gleicher Behandlung ein purpurfarbiges Derivat geben, welches ein gut charakterisiertes und leicht ilentificiertes Absorptionsspelitrum besitzt.

6). Das künstliche, gelbe Prorlukt ist noch nicht in reinem Zustande gewonnen worlen, aber es kann soweit gereinigt werden, dass es deutlich alle allgemeinen Eigenschaften des natürlichen Pigmentes zeigt.

7). Das natürliche Pigment, wie es für die Analyse dargestellt wird, ist fast sicher ein chemisches Individuum.

8). Es zeigte sich, dass diese gelbe Substanz im Verein mit einem nahe verwandten, rothen Stoff, alle chemischen Pigmentierungen der Flügelschuppen der gefärbten Pieriden crklären liann, wenn 
auch Modifieationen entstehen können durch das Hinzutreten optischer Wirkungen:

W. Bateson (1894. 55) setzte die rothen, orangenen und gelben Pigmente der Schmetterlinge auf chemischem Wege in einander um.

Hugo May (1895. 551) separierte ein Dutzend mit markanter Rückenzeichnung ausgestatteter Raupen von Colias chrysotheme Esp., um $\mathrm{zu}$ beobachten, ob die Verschiedenheit der Zeichnungsanlage bei der Raupe auf den Geschlechtsunterschied der Falter zurückzuführen sei. Sie ergaben später jedoch sowohl $\delta^{\top} \delta^{\prime}$ wie auch $ㅇ$ ㅇ․

B. Walter (1895. 942) betrachtet die optischen Farben als Oberflächenfarben.

Alfred G. Mayer (1896. 553) untersuchte die Farbenentstehung auf den Schmetterlingsflügeln während des Puppen-Zustandes bei Danais plexippus L. und Callosoma promethea und fand, dass die Flügel in der Puppe zuerst glasartig sind, später werden sie undurchsichtig und weiss, was aber keinesweg ein Pigment darstellt, sondern die Folge einer Diffraktion ist. Darauf tritt an die Stelle dieser Farbe schmutzig Ockergelb und Mattbraun (einige Stellen bleiben inmer weiss); endlich beginnen die bleibenden Farben zu erscheinen und zwar zuerst auf dem Mittelfelde der Flügel zwischen den Adern, dann auf den Adern selbst und schliesslich an den Flügelspitzen. Nach ilen erwähnten Farben tritt Schwarz, zuerst als Graubraun auf.

Er fand, dass in der Falterschuppen bisweilen auch blaues Pigment vorkommt.

M. Standfuss (1896. 840) beobachtete die Reihentolge des Farbenauftrittes in der grünen Puppe von Pararge megaera und aegeria. Zuerst bemerkt man eine eigentümliche rothbraune Marmorierung, bevor die Totalfärbung des Flügels durch die Schale durchscheint; der ausgeschälte Falter zeigt dann das lichte Rothbraun ausgebildet, die dunkel gefärbten Stellen des Flügels aber noch in albinistischer Färbung. Auch Anthocharis cardamines, Zegris eupheme, Tecla betulae $ᄋ$ und ilicis $ᄋ$ eignen sich für diese Beobachtungen. 
Simroth (1896. 816) sagt in seiner Abhandlung: "Ueber die einfachen Farben im Thierreich," dass die Farben in ler Natur nach der gleichen Reihenfolge aufgetreten sind, wie sie im Spektrum vertheilt sind, und zwar war das Roth die ursprüngliche Farbe in den Organismen, dann kam das Gelb und Grün, und es geht allmählig in Schwarz iiber. Bei den Pflanzen und niederen Organismen herrscht daher: Roth, Gelb und Grün; bei den psychisch und mechanigch höher stehenden Thieren kommen die zusammengesetzten Farben:' Schwarz und Braun. Er erklärt es damit, lass in alten geologischen Zeiten eine dicht wasserreiche Atmosphäre allein die rothen Strahlen des Sonnenlichtes durchliess, welchen auch die Farbe der Organismen entsprach; oder das Protoplasma ist wohl erst allmählig geeignet geworden, nicht allein auf die längsten Lichtwellen, sondern auch auf die kürzeren zu reagieren.

Hemmerling (1896. 366) untersuchte Lixus paraplecticus und fand, dass die gelbliche Farbe des Thieres durch ein körnige Masse, deren grössere Element eine Art krystallinische Zuschärfung haben, erzeugt wird. In Kalilauge löst sich diese Masse nicht, sondlern sie wird nur lichter.

A. Spuler (1897. 833) hält das grüne Pigment bei Schmetterlingen für eine wirklich vorhandene chemische Verbindung.

Vogler (1897. 927) untersuchte die Schuppen der Anthrenen und fand, dass die weissen Schuppen aus farblosem Stoff bestehen, und dass das glänzende Weiss durch Lufteinschluss zu Stande kommt.

P. Iwanow (1897.403) beobachtete, dass die Fürbungs-Nuancen beim Imago der Ichneumoniden sich ändlert, was von der Zeit abhängt, welche seit der Entpuppung verflossen ist.

M. C. Piepors (1897. 638) tritt in seiner Abhandlung: „Ueber die Farbe und den Polynorphismus der Sphingiden-Raupen" als entschiedener Gegner des Mimetismus auf. Während eines Zeitraumes von etwa 28 Jahren, die er in Niederländisch Ost-Indien verlebte, sammelte er eine ganze Masse von Beobachtungen unı beschreibt in den gegenwärtigen Abhandlungen 130 Sphingiden-Raupen.

Die Grundfarben, welche unter diesen liaupen am meisten vorkommen, lassen sich in zwei Gruppen vertheilen, als: 1) gelb und 
grün in allerlei Nüancen, von gelblich weiss an bis zu hellgelb, roth, gelb, ockergelb, und orangeroth oder als grasgrün, weisslich grün, graugrün orler blaugrün, olivengrün, (lunkelgrïn; 2) braun, gleichfalls in allerlei Nüancen, hellbraun, bräunlichgrau, rothbraun, ilunkelbraun bis zu schwarz. Zwischen den beiden Gruppen bestehen jedoch zahlreiche Uebergänge. In den frühesten Stadien ihrer Ontogenese besteht bei keiner Raupe der Di-oler Polrmorphismus; immer sind die Raupen dann allein grün oder gelb. In den weiteren Starlien erst ändert ein Theil der Raupen ihre Farbe und geht in die zweite Kategorie über, während ein anderer Theil sich nicht verändert und auch im erwachsenen Zustancle gelb oder grün bleibt, obwohl die Schattierung dieser Farben sehr verschieden wird. Dies geschieht so bei Individuen ein und derselben Brut.

Die Farbenwechsel kommt auf zweierlei Weise zu Stancle:

1). Das Gelb oder gelblich Grün wird dunkler unil röthlicher, woraus Orange, bisweilen auch Lehmgelb entsteht; das Roth nimmt dann manchmal zu, sorlass die Farbe dunkel rosenroth wirl; es wird solann mehr gesättigt und dunkler, als in Braunroth übergehend, woraus es dann wieder verschwindet, indem es ein Dunkelbraun zurücklässt, das sich zuweilen bis zu schwarz abschattet.

2). Das Grün wird dunkler und bräunlich und geht dann erst in Braun über, welches sich noch mitunter als grünlichbraun zeigt, später dunkelbraun wird und zuweilen sich bis zu Schwarz abschattet.

Bei dieser Aenderung der Grundfarbe erlangen manchmal die secundären Farben eine grosse Ausdehnung. Bei dliesen Raupen offenbart sich eine Evolution: „Eine Evolution nämlich in der Farbe, von hellgelb nach schwarz hin, die vollkommen auf diese Weise langsam fortschreitet und bei jeder Art von ihrem eigenthïmlichen Entwickelungsgang abhängig ist" (p. 55). "Weiter wird ausschliesslich oder wenigstens dominierend Gelb bei ausgewachsenen Raupen nicht mehr angetroffen; die vorhin genannten Fälle sind mithin offenbar nur noch einige wenige, aus sehr verzögerter Evolution entstandene Ueberreste eines Zustandes, der früher allgemein gewesen sein muss" (p. 56).

"Kurz; von solchen Arten, wo die Evolution am weitesten vorgerückt ist, trifft man in ausgewachsenen Zustande nur schwarze Raupen an, von solchen, wo sie etwas weniger fortgeschritten ist, neben ilen schwarzen auch noch andere, welche die Uebergangsfarben Braun, Roth, Isabellafarbe oder sogar noch das ältere Grün oder Gelb zeigen; bei denen, wo sie noch etwas verzögert ist, be- 
steht noch kein Schwarz, sondern in ausgewachsenem Zustande trägt ein Theil der Raupen die eine oder andere von diesen Uebergangsfarben, während die übrigen noch griin oder gelb sind; die am weitesten zurückgebliebenen Raupen endlich sind noch allein $\mathrm{gr}$ ü oder gelb" (p. 59).

Piepers ist daher der Meinung, dass wenn der Zeitpunkt heranbrechen wird, wo die Evolution ganz geendigt sein wirl, Schwarz allein nur noch die Grundfarbe aller Sphingiden-Raupen sein wird und zwar in allen Stadien ihrer Entwickelung.

Von dem "angeblichen" Schutz in dem Farbenwechsel kurz vor der Verpuppung sagt er, dass in den Tropen, wo die Mehrzahl dieser Raupen lebt, der Boden fast immer mit einer dunklen Masse von Pflanzen-Ueberresten berleckt ist. „Eine darunter und dazwischen kriechende Raupe wird gewiss nicht von kleinen Säugethieren, Vögeln oler eilechsenartigen Thieren, welche obentrein alle in solchen Gegenden meistens auf Bäumen leben, bemerkt werden" (p. 72). Zieht man in Betracht, dass die Raupen eine sehr kurze Zeit (im Maximum 3 Stunden) sich auf dem Borlen aufhalten muissen, um einen für ihre Verwandlung geeigneten Ort zu finden, so erscheint es unwahrscheinlich, dass „für einen so kurzen Zeitraum ihres Lebens sie dann einen so besonderen Schutz bekommen haben sollten, und das noch wohl unter Umstänlen, in welchen dieser ihnen kaum nöthig war!" (p. 73). Ausserlem sieht in erster Stelle das durch Verfärbung entstandene Grau oder Braun ihrer Hautfarbe keineswegs immer der Farbe des Bodens ähnlich; auch befinden sich die Raupen zu dieser Zeit in der Bewegung, zu ihrem Schutze sollten sie aber unbeweglich "wie die Umgebung" bleiben. Noch einen Umstand erwähnt er: diese Verfärbung besteht nicht bloss bei den grünen Sphingiden-Raupen, sondern in gleichem Masse, wenn auch weniger auffallend, bei denen, welche doch schon braun oder grau sind, und bei welchen sie also zum Schutze ganz überflüssig sein würde.

Auf Grund dieser Erörtungen betrachtet Piepers die von verschiedenen Forschern ausgesprochene Ansicht, dass die von der Puppenzeit stattfindende Verfärbung den Raupen als Schutzmittel dienen soll, „als Phantasie."

Den Umstand, dass die erwachsenen Raupen sich an der Unterseite der Blätter aufhalten, erklärt er durch ihren Körperbau. Ihre Füsse sind nicht dazu geeignet, an den glatten Flïchen zu haften; deshalb sind sie auf die untere Seite der Blätter angewiesen, 
wo die Adern hervorragen, welche sie mit ihren Füssen fest greifen können. Sehr junge Raupen z. B. von Chaerocampa actous Gram. sind leicht und halten sich auf der oberen Seite der grossen Blätter der wilden Caladium-Pflanzen. Einige junge Raupen, die auf nicht so grossen Blättern leben, scheinen dann durch das Spinnen einzelner Fäden sich dort anzuklammern.

Die Thatsache, dass Raupen, welche bei Tage schlafen, dazu etwas dunkle Orte aufsuchen, erklärt er nicht durch den Schutz oder die Sicherheit, sondern durch die Gewohnheit der Nachtthiere, das starke Tageslicht zu meiden.

Ueber den Einfluss der Farbe der Lichtstrahlen, welche aus ihrer unmittelbaren Ungebung auf die Raupen einwirken, sagt er, dass dieser Farbenwechsel unabhängig von aller Anpassung sich vollziehe, wenigstens bei Sphingiden-Raupen, und dass diese Erscheinung ,anderen Ursachen ihr Entstehen verdanken muss" (p. 85).

Die Ursache der Evolution der Raupenfurbe glaubt er einer Correlation zuzuschreiben, doch sagt er weiter: „Es verdient mehr den Vorzug, einstweilen unsere Unwissenheit zu bekennen, als eine nicht motivierte Erklärung (lafür zu ersinnen" (p. 86).

Ein Jahr darauf erschien die weitere sehr umfangreiche Abhandlung "Die Farbenevolution (Phylogenie der Farben) bei den Pieriden" des gleichen Forschers (1898. 639), in welcher er ca. 1000 Arten untersuchte. Auch unter den Pieriden trifft man einen mehr oder weniger stark ausgeprägten Polymorphisıns. Diese Untersuchung ergiebt, lass die rothe Farbe ursprünglich weiter verbreitet war als heute. Die rothe Farbe wird in erster Linie durch Gelb und dann durch Weiss verdrängt; bei einigen Arten verblasste die schwarze Farbe zu Weiss.

Wegen allgemeinen Resultaten, siehe man seine Theorie im "Theoretischen Theil" des gegenwärtigen Buches.

M. C. Piepers (1898. 639) erwähnt in seinem Buche, dlass J. Th. Oudemans zu Amsterilam nach eingehenden Untersuchungen fand, die grüne Färbung an der Unterseite der Hinterflügel von Cyllo leda L. werde einzig durch eine Lichtrückstrahlung auf einen Theil der Deckschuppen hervorgerufen. Piepers bemerkt seinerseits, dass „diese grüne Farbe auf diesem Exemplar je länger je mehr verschwindet" (p. 244). 
Friedr. Urech (1898. 898) wieclerholte seine frühere Untersuchung (1892. 891) über das frühzeitige Auftreten der SchuppenPigmentstoffe von Pieris brassicae und machte die genauere Benbachtung, „dass die, wie oben bemerkt, anfangs wie Ölflecken aussehenden, später schwarzen Flecken da, wo sie auf beiden Seiten der Flügel an gleicher Stelle auftreten, mikroscopisch betrachtet, schön grün erscheinen, und zwar infolge des Durchschimmerns des smaragdgrünen Farbstoffes, der sich zwischen den Fliigellamellen befindet" (p. 1). Dies beweist, dass das schwarze Pigment nach ilem weissen und gelben Pigment in den Schuppen auftritt: „ob erst hier entstehend aus vorher eingeführten Blutbestandteilen, oder als fertiges Pigment aus dem interlamellaren Raume eingeführt, ist noch zu untersuchen" (p. 2).

Aus dem Resultate: „Es ist also die Farbe oder auch der Mangel an Farbe (farblose durchsichtige Schuppen), welche zeichnet" (p. 2) ausgehend, macht er folgende, in Klammern stehende Zusätze zur Erweiterung der Weismann'schen Definition (1895. 954) der Farbenzeichnung: "Nun ist aber die "Zeichnung" nur in unserer Idee etwas von der "Grundfarbe" Gesondertes, in Wirklichkeit verhält es sich hier nicht wie bei einem Bild, bei dem zuerst die Zeichnung und dann die Farben aufgesetzt werden, sondern das, was wir "Zeichnung" nennen, ist nur ein anderer Farbenstreif der einen Schicht von farbigen [einfarbigen] Schuppen, welche die Flügelfärbung ausmachen [oder eine streifenförmige Abwesenheit farbiger Schuppen ersetzt durch farblos bleibenile oder erst später sich ausfärbende]. Es ist also "Zeichnung" genetisch dasselbe wie "Färbung" und biologisch auch, insofern sie zu sympathischer oder auffallender Färbung zusammenwirken" (bei Weismann p. 73).

F. Urech (1898. 896) untersuchte Schuppen-Pigmente von Vanessa io L. und von ab. iokaste Urech und erhielt folgende Resultate, welche hier wörtlich angeführt werden:

Vanessa io L. (Normalform).

Die gelben Schuppen zwischen den schwarzen Costalflecken der Vorderflügel-Oberseite
Vanessa io ab. ioliaste (Urech).

Die schwärzlich braunen Schuppen, welche die gelben Schuppen der Normalform zwischen den schwarzen Costalflecken der Vorderflügel:Oberseite vertreten, 
verhalten sich folgenderweise im durchgehenlen Lichte:

sie erscheinen ockergelb, sie erscheinen theils honiggelb, theils ockergelb,

im zurückgeworfenen Lichte

ockergelb schimmernd uni et- aschgrau glänzend, stellenweise mit was interferenzfarbig. -

Interferenz-Farben. -

\section{Heisses Wasser}

extrahiert weisslichen Stoff.

extrahiert schwierig krümelige, honiggelb gefärbte Substanz, also nicht schwärzlich braunes Pigment.

Konzentrierte Salzsäure

extrahiert sehr leicht das Pig- extrahiert das Pigment ziemlich ment:

leicht.

Salpetersäure (wässerige)

extrahiert leichter wie Salzsäure. | extrahiert leicht.

Wässeriges Ammoniak

extrahiert weisslichen Stoff, die extrahiert clas schwärzlich braune Schuppen bleiben gelblich. Probe $\mid$ Pigment nicht. auf Harnsäure ohne Ergebniss.

Daraus ist ersichtlich, dass die Pigmente bei ab. ioliaste andere chemische Reaktionen besitzen als bei Vanessa io (Normalform).

Gräfin Mario von Linden (1898. 515) beniitzte bei ihren "Untersuchungen ïber die Entwickelung der Zeichnung des Schmetterlingsflügels in der Puppe" Puppen von verschielensten Entwickelungsstadien. Dieselben waren theils in künstlich erhöhter, theils in gewöhnlicher Zimmertemperatur gehalten worlen. Die zu untersuchenden Flügel wurden in absoluten Alkohol gebracht und nachher in venetianisches Terpentin eingebettet.

Untersucht wurden: Papilio podalirius, Papilio machaon, Thais polyxena, Vanessa levana und Vinessa urticae, wobei folgende allgemeine Resultate erzielt wurden: „Die Schmetterlingszeichnung setzt sich ganz allgemein aus einer Reihe von Elementen zusammen, welche im Laufe ler Puppenentwickelung nach einander entstehen und sich erst kurze Zeit vor dem Ausschlüpfen des Falters zur Imaginalzeichnung vereinigen. Diese allmählige Entwickelung rler Zeichnung prägt sich am deutlichsten bei denjenigen Formen aus 
die phylogenetisch als weniger fortgeschritten zu betrachten sind. Alle Falter, welche schon auf einer höheren Entwickelungsstufe stehen, zeigen frühzeitig eine Musterung der Flügeltläche, welche grosse Aehnlickeit mit der fertigen Zeichnung hat und zum Theil wenigstens durch die verschiedenartige physikalische Beschaffenheit der Schuppen hervorgerufen wird. Diese erste Flügelmusterung bringt nur die Gattungsmerkmale, nicht aber Artkennzeichen der Falter zum Ausdruck. Sämmtliche Ergebnisse weisen darauf hin, llass die Flügelzeichnung in der Schmetterlingspuppe im Laufe der Zeit Umwandiungen erleidet, welche die Zeichnungsgesetze Eimer's und die von ihm darauf gegrïndeten verwandtschaftlichen Beziehungen der Papilioniden auf das schönste bestätigen. Die Untersuchungsergebnisse beweisen ferner, dass die Forilerungen des biogenetischen Grundgesetzes auch durch das Puppenstarlium (ler Schmetterlinge bestätigt werden" (p. 46).

Im Einzelnen fand sie:

1). Dass zwischen Grundfarbe und Zeichnung ein durch ihr zeitlich getrenntes Auftreten bedingter Unterschierl zu machen ist. 2). Längszeichnung stellt in der Ontogenie wie in der Phylogenie die niederste Entwickelungsstufe dar.

3). Die Imaginalzeichnung des Pupilio podalirius durchläuft in ihrer Entwickelung die alebion- unı glycerion-Stufe, ein Beweis für die Entstehung der Arten durch Genepistase.

4). Die Ausfärbung des Flügels und das Verschnelzen von Binden vollzieht sich auf der Flügelfläche in den meisten Fällen von hinten nach vorn und von innen nach aussen. Flïgelrand und Flügelrippen erhalten in allen Fällen ihre definitive Färbung zu allerletzt.

5). Wir beobachten in der Mehrzahl der Fälle, dass der Hinterflügel dem Vorderflügel in der Entwickelung der Zeichnung voraus eilt; dasselbe gilt für die Oberseite beider Flügel gegenüber ihrer Unterseite.

6). Die Lage und der Verlauf der Binden ist von der Gestalt der Flügel abhängig.

7). Die Farbenfolge auf dem Puppenflügel vollzieht sich wie folgt: Hellgelb, Orange, Karmin, Zinnober, Braunroth unil zuletzt Schwarz. Die optischen Farben kommen später.

M. Baer (1898. 43) unterscheilet bei Insekten zweierlei Pigmente: diffus und körnig. Im ersten Falle ist das Chitin als 
solches gefärbt, im letzten Falle sind Pigmentkörner in dasselbe eingelagert.

Diffuse Pigmiente sind:

1) Lehmgelb bei Junonia orithya, Catonephele numilia. Dieser Farbstoff ist als solcher ausziehbar; 2) Mattgelb bei Delias belisuma; 3) Graubraun bei Junonia laomedia; 4) Mattbraun und Ockerbraun bei Danais chrysippus; 5) Rostbraun bei Vanessa urticae ist durch heisses Wasser oder Salpetersäure ausziehbar, Salzsäure zieht orangrothen Farbstoff aus, Ammoniak - scharlachrothes Pigment; 6) Glänzendes Rothbraun bei Catonephenele mumilin; 7) Schwarzbraun bei Delias belisama; 8) Dunkelschwarzbraun bei Hebomoin glaucippe; 9) Grau bei Delias belisama und Delias egialea; 10) Orange im Afterfleck von Pupilio machaon; 11) Orangeroth bei Rhodocera rhamni; 12) Karminroth in der Prachtbinde von Papilio antheus ist leicht durch Ammoniak ausziehbar, in Salzsäure wird es gelb; 13) Leuchtendes Roth bei Catagrammı pithcas; 14) Glänzendroth bei Callicore marchalii; 15) Glänzendes Rothgold bei Polyommatus virgaurea ist durch heisses Wasser, Salzsäure und Aimmoniak ausziehbar; 16) Braunroth bei Junoniu orithya; 17) Weiss höherer Stufe bei Pieriden; dieser Farbstoff ist stets eine Mischung von weiss und gelb.

Körnige Pigmente sind (ausschliesslich bei Pieriden):

1) Citronengelb bei Rhodocera rhamni, löslich im Wasser; 2) Schwefelgelb bei Delias egialea; 3) Chromgelb bei Delias belisana; 4) Rothgelb bei Anthocharis cardamines, löslich in heissem Wasser, Salzsäure und Ammoniak; 5).Gelbroth bei Callosune achine.

Ausserdem fand er bei seinen Untersuchungen nie grünes Pigment in Schmetterlingsschuppen, dagegen beobachtete er eine Grünfärbung der Flügelmembran bei Papilio antheus, Pupilio phorcas, Papilio agamemnon, Colaenis dido und Danais cleona. Das Grün auf ler Hinterflügelunterseite von Anthocharis cardamines ist eine reine Mischfarbe, erzeugt durch gleichmässige Vermischung satt kanariengelber Schuppen mit schwarzen oder graubraunen Schuppen.

Unter optischen Farben unterscheilet er solche, welche durch eine Schuppe und solche, welche dlurch zwei verschiedene Schuppen hervorgebracht werden.

$\mathrm{Zu}$ den ersten werden gerechnet: 1) Glänzend blau bei Lycaeniden (Bithys sichaeus); 2) Schiller-Azurblau bei Apatura iris; 3) Weiss niederer Stufe bei Limenitis sibylla; 4) Schwarz. 
$\mathrm{Zu}$ den zweiten werden gerechnet: 1) Silberblau bei Papilio asterias; 2) Violett bei Callima rumiu; 3) Blauviolett bei $\mathrm{Hy}$ polimnas salmacis; 4) Glänzendes Blau bei Morpho anaxibia.

Die durch Kombination von Pigmont und uptischen Farben enstandenen Farben sind: 1) Seidenblau bei Papilio ulysses; 2) Röthlich-Violett bei Callosune jalone; 3) Smaragdgrün bei priamus.

L. Reh (1900. 679) stellte fest, dass die durch das Petroleum getödteten Diasp. ostreaeformis eine diffuse, hell karminrothe Färbung zeigten. "Es scheint also der fleichrothe geformte Farbstoff dieser Art durch das Petroleum gelöst und etwas verändert zu werden" (p. 802). Dieselben Pflanzenläuse werden bei der Anwendung von $10 \%$-iger Schwefelsäure entweder entfärbt oder diffus roth-violett. Die 10\%-ige Lösung von Salpetersäure entfärbt diese Läuse oler macht sie bräunlich oder gelbbräunlich, einige auch diffus röthlichviolett. Als er die gelben Läuse in Kali- bezw. Natronlauge brachte, wurden dieselben braun; die rothen Läuse dagegen wurden schwarz.

G. Jacobson (1900. 409) beohachtete den Ausfärbungsvorgang nach dem Verlassen der Puppe bei verschiedenen Coccinellidenund Chrysomeliden-Arten nnd konstatierte folgendes:

1). Die konstanten Makeln sind die bei der Ausfärbung zuerst auftretenden.

2). Ontogenetisch ist die helle Färbung bei den bunten Käfern die primäre.

3). Die dunkelste Varietät einer Art durchläuft bei der Ausfärbung nacheinander die Stadien der helleren Varietäten und zwar das Stadium der hellsten (forma livida), der gefleckten (forma maculata) und der quergestreiften (forma tigris), um zuletzt in das Stadium der einfarbig dunkelen Form zu treten (forma concolor).

A. S. Skorikow (1900. 818) kam, bei seiner Bearbeitung les auf Spitzbergen von A. A. Birula gesammelten Materials, zu dem Resultate, dass eine Reihe von Arten des Isotoma durch die Fürbung und Anzahl der Äuglein sich von einander unterscheilen und zwar: 1. sexoculata, mit 6 Äuglein, ist dunkelgrau; I. quadrioculata. mit 4 Äuglein, ist grau; I. binoculata, mit 2 Äuglein, ist weiss; I. fimetaria, ohne Äuglein, ist auch weiss. Daraus schliesst er, dass die sucsesive Abnahme der Äuglein parallel mit der Entfärbung der 
Körperoberfläche vor sich geht, wobei die Entfärbung früher eintritt, als der vollständige Verlust der Äuglein.

Pabst (1900. 619) fand, dass die verschiedene Färbung, welche bei Raupen von Arctia purpuratı vorkommt, auf ılen zukünftigen Schmetterling keinen Einfluss ausübt, auch nicht in Bezug auf das Geschlecht.

Grigory Koschewnikow (1900. 467) sagt, dass die Färbung der Bienen für diese Insekten keine Bedeutung im Sinne der Nuitzlichkeit, lẹ Anjassung zum umgebenden Medium etc. hat. "Dis Bienenleben ist gut genug studiert worden, und die heisseste Phantasie kann sich keine einzige Kombination vorstellen, bei welcher die bei der Gattung Apis vorhandenen Farben irgend eine praktische Belleutung für das Thier haben könnten" (p. 27). Er ist ler Meinung. dass nicht ein Mal dann die fragliche biologische Bedeutung gefunden würle, wenn unsere Kenntnisse der Biologie der gegebenen Form sich: weiter entwickeln werden, also nie!

Bezüglich dieser Behauptung vergleiche man meine Abhandlung: „Warum tliegen die Tagsschmetterlinge nur am Tage und die meisten Nachtschmetterlinge in der Nacht?" (1901. 30), in welcher die binlogische Bedeutung der Färbung beim Fliegen ler Insekten, wenn auch kurz, erörtert wird.

Gräfin M. von Linden (1902. 523) sagt wegen der Beziehung zwischen Zeichnung unıl Blutgefässnetz bei Inseliten fölgendes: „Im Insektentliigel werlen die Blutbahnen durch die gleichzeitig Luftkanäle führenten Adern dargestellt, und zwar sind es nicht nur die Längsadern des Flïgels, welche gleichzeitig als Cirkulations- und Atmungsorgane dienen, auch die meisten Queradern führen Blut und Tracheen, so rlass bei den Neuropteren und Orthopteren der ganze Flügel mit seinem Adernetz dem Blatt einer dicotylem Pflanze nicht unähnlich ist. Wenn nun beim Uebergang von der Puppe zu der Imago der grösste Theil der Flügelflïche der Chitinisierung anheimfällt, vollzieht sich noch in den die Adern begrenzenden Zellen der Stoffiwechsel, und wie bei der Pflanze so sind auch hier die Stellen regster Assimilation durch farbige Spuren gekennzeichnet. Ich habe eine Zusammenstellung gezeichneter Fligel von den Vertretern der verschieilensten Inselitenorlnungen gemacht und überall gefunden, dass die dunkeln Punkte und Striche auf Adern oder 
an deren Begrenzungen lagen und sich von hier aus in die Flïgelzellen hinein ausclehnen". (p. 832).

Ferner hielt sie es nicht für ausgeschlossen, dass mancher farbige Fleck im Flïgel iurch Diffusion der Farbstoffe darunter liegender pigmentierter Organe hervorgerufen werden kann.

Inbetreff der Natur des Flügelstoffes in Flügeln betrachtet sie als Bildungsstätte der Pigmente den Raupenilirm und als Bililungsstoff den von den Raupen aufgenommenen Pflanzenstotf, und schliesst daraus, dass wir es in dem gelben wie in rlem rothen Farbstoff mit einem Umwanllungsprodukt des Chlorophylls zu thun haben, mit einer Farbenmetamorphose, wie wir sie beim Ausreifen der Früchte verschiedener Pflanzen beabachiten können.

"Aber bald nach der Verpuppung lösen sich die das liaupendarmepithel bildenden Zellen aus ilurem Zusammenhang los, unil man beobachtet gleichzeitig grosse amöboile Zellen, die sich mit len Epithelzellen belaten. Diese Phacyten so wie das Blut, das den rothen Farbstoff in Lösung enthält, sorgen für die Verbreitung des Pigmentes, und wir können auf Scanittpräparaten sehen, wie sich kleine Farbstofftropfen und die mit Firbstoff belatenen Zellen am Rande der Blutbahnen und unter der Epidermis, beson'lers in ler Umgebung der Stigmen, ansammeln. Von hier aus dringt das Pigment in die Epithelzellen ein und schlägt sich auf vorher gelbgrün gefärbten Kö̈mchen nięler. In den Flügeln orinen sich die amöboilen pigmentführenten Zellen in den Querarlern unter ilen Schuppenreihen an. Wie die übrigen Epithelien, so nehmen anch die Schuppenzellen den Farbstoff auf. Er schlägt sich anfings nur in den Schuppenmutterzellen lörnig nieder, dringt aber später in Lösung in die Schuppen selbst ein und diffun:liert nicht selten bis in die Puppenhülle, so dass hi r ein Abiruck der rothen Theile des Flügelmusters entsteht. Es wirl indessen nie der ganze Vorrat von rothem Farbstoff zur Färbung der Eliilermis verwendet, ein grosser Theil bleibt im Darm und färbt den Urin des auskriechenilen Schmetterlings". (p. 835 und 836$)$.

Ueber die physiologische Rolle der Farbstoffe hat M. v. Linden zwei Ansichten: entweler sinil sie Abscheidungsprnilukte les Stoffwechels, als: lieservestoffe, o.ler aber als wichtige Vermittler der Sauerstoffaufnahme zu betrachten.

Die Kritik der Untersuchungen von M. v. Linden befintet sich in der Abhandlung von Chr. Schröder (1903. 779) auf p. 188-194. 
Pabst (1903. 621) erwähnt als besondere Eigentümlichkeit, dass die Puppe von Smerinthus tiliae L. grünes Blut hat, welche Färbung durch sogenanntes Metachlorophyll erzeugt wird.

J. Villard (1903. 925a) hat in der Haut der pflanzenfressenden Oedipola parapleura spektralanalytisch das Vorhantensein von Chlorophyll nachgewiesen; bei der fleischfressenden Locusta viridissima war es nicht vorhanden.

M. Gräfin von Linden (1903. 527) kommt beim Studium des rothen Pigments der Vanessen zu folgenden Schlüssen: „Die Schuppenpigmente entstehen im Darm der Raupe vor ihrer Verpuppung. Sie erscheinen hier als ein Umwandlungsprodukt der den Darminhalt der Raupe bildenden Chlorophylllösung. Sie erfiillen so, wie vorher das gelöste Chlorophyll, die Darmepithelien, werlen vom Blute aufgenommen und im Körper verbreitet, und zwar entweder in körnigem Znstand (Kinschlïsse der Blutzellen) orler in Lösıng. Auf diese Weise gelangen sie in das Körperepithel, wo sie sich an bestimmten, für die Athmung des Insekts besonders wichtigen Stellen als rothe Farben niederschlagen. $\mathrm{Ob}$ das rothe Pigment inclessen irgendwelche physiologische Bedeutung für den Gasaustausch hat, konnte ich nicht feststellen."

P. Speiser (1903. 828) sagt, dass die Larven (ler Gattung Chironomus Mg. dadurch merkwürdig sind, dass sie rothes Blut besitzen, wobei der rothe Farbstoff mit dem des Menschenblutes identisch und echtes Hämoglobin ist. Dieser Farbstoff ist nicht an die Blutkörperchen, sondern an das Blutwasser, die Hämolymphe, gebunden. Die Innagines dagegen haben kein rothes, aber häufig grünes Blut, mit Ausnahme von ganz jungen Exemplaren, bei welchen der rothe Farbstoff bei der Wurzel sitzt, hier die ganze Gegend des Flügelgelenks einnimmt und sich zwischen der oberen und der unteren Flügellamelle befindet.

W. Tower (1903. $880 a$ ) studierte das Entstehen der Färbung und Zeichnung bei Coleopteren, Lepidopteren, Orthopteren und Hymenopteren. Die Färbung wird hauptsächlich durch die Pigmente (gelb, braun, schwarz), welche im Chitin sich befinden, verursacht; zu diesen Pigmenten kommen noch die irisierenden (optischen) Farben hinzu. Die Färbung der Epidermis ist hauptsächlich nur bei Larven $\mathrm{zu}$ beobachten. $\mathrm{Er}$ betrachtet die Zeichnungen in Chitin und 
Epidermis als phylogenetisch ältere und die durch Schuppnn erzeugten als jungere.

W. Biedermann (1904. 79a) untersuchte die Schillerfarben bei Insekten. Der Schiller wird durch die Interferenz des Lichtes in sehr dünnen Chitinlamellen erzeugt, wobei das diffuse gelbe bis braune Pigment, welches unter diesen Lamellen sich befinclet, die Farbe des Schillers unter Umständen modifizieren kamn. So z. B. bei Cetonia entsteht das Grïn durch die Ueberlagerung les optischen Blau über Pigmentgelb. In dieser Beziehung untersuchte er folgende Coleopteren-Gattungen: Smaragdisthes, Potosia, Cetonia, Sternocera etc.

Die Untersuchung der Lepidopteren: Argynnis, Lycaena, Amblypodia, Diorhina, Hypochrysops, Morpho, Papilio, Enploea, Apatura etc ergab, dass ihre optische Farbe durch die zwischen den beiden Lamellen der Schuppen liegende Luft entsteht. Die verschiedene Dicke dieser Luftschicht bedingt verschierlene Farbentöne.

\section{Ergänzungs-Litteratur zu diesem Abschnitt.}

Anderson, Joseph. On the Colours of Lepidoptera. - Science-Gossip. 1872 (1873). p. 175.

Batelli, Andrea. Sopra le colorazioni di alcuni larve di Lepilotteri. - Bull. Soc. Ent. Ital. XI. 1879. p. 139-141.

Bergé, c. Notes pour servir à l'étude de la coloration des tégunents chez les Insectes. - Compt. rendu de la Soc. Entomolog. Belge, XXXIII. 1889. p. 177--178.

Bogdanow, A. Les pigments des insectes sont-ils isolables? - Bull. soc. imp. des natur. Moscou: XXXVII. № 1. 1864. p. $346-348$.

Bohn, A. L'évolution du pigment. Paris 1901. 96 pag.

Brücke. Physiologie der Farben. Leipzig 1887.

Buckell, F. J. On the Development of Pigment in Nemenbius lucina. - Entomol. Record. Vol. VI. № 11. 1895. p. $257-258$.

Chapman, T. A. On the Wing-Scales and their Pigment in Lepidoptera. (Note's on Mr. Mayer's Paper.). - Entom. Record. Vol. IX. № 4. 1897. p. 78-79.

Chapman, Th. Ostracoda from the Chara-marl at Hitchin. - Trans. Ifertfordhire: Soc. XI. 1902.'p. 60-62.

Cockerell, T. D. A. The evolution of metallic Colours in Insert. - Ent. Nows. I. 1890. p. $3-6$.

Cockerell, T. D. A. What are the uses of bright Colours in II ymenoptera? Ent. News. I. 1890. p. 65-68. 
Croft, W. B. Colours of Butterflies not due to Diffraction. - Nature, LXT. 1902. p. 198.

Croft, W. B. The Colours of Wings in Butterflies. - Nature, LXV. 1902. p. $391-392$.

Edward, W. H. and Wilson, Joseph Martin. Chemical change of coloration in Butterflies wings. - Psyche, III. № 75. 1880. p. 87-88.

Eimer. Orthogenesis der Schmetterlinge. Leipzig 1897.

Friedmann, F. Ueber die Pigmentbildung in den Schmetterlingsflügeln. - Zeitschrift f. wissensch. Zoolog. - LXVI. 1899. p. 88-95.

Gamble, T. W. Colour-change in Animals. - Trans. Manchester Micr. Soc. 1899. p. 92.

Hellins. On the colouring matter and on cocoons of some of the silk-spinning Lepidoptera. - Entomol. M. M. XVIII. 1882, p. 260-261.

Hopkings, F. G. Chemistry of pigment in yellow Butterflies. - Nature, ILT. 1891. p. 197; auch in: Proceed. of the Chemical Society of London, 1889. p. 117 .

Kratz, L. Ueber die Farben der Lepidopteren, - 29;30. Ber. d. Ver. für Naturkunde. Kassel, 1883. p. 63-65.

Krüger, Edg. Entwickelungsgeschichte des Insektenflügels. - Verhandl. Naturw. Ver. Hamburg. N. F. VIII. 1900. p. XXXVII-XXXVIII.

Kunckel, J. d'Herculais. Sur les changements de coloration et sur le rôle des pigments dans les phénomènes d'histolyse et d'histogenèse qui accompagnent les mues et la metamorphose du Criquet pélerin. -- Bull. Soc. Ent. Fr. LXI. 1892. p. 25-2\%.

Linden, M. v. Die Firben der Schmetterlinge und ihre Ursachen. - Leopoldina, XXXVIII, 소 11. 1902. p. 124--133.

Mayer, A. G. On the color and color-patterns of moths and butterflies. - P'roc. Boston Soc. XXVII. 1897. p. 243-330.

Mayer, A. G. On the color and color-patterns of moths and butterflies. - Bull. Mus. Harvard. XXX. № 4. 1897. p. 169-256.

Mayer, A. G. Effects of natural selection and race - tendency upon the color patterns of Lepidoptera. - Bull. Mus. Brooklyn Inst. I. 1902. p. 31-86.

McAldowie, A. M. On the coulors of animals, and the arrangement of pigment in Lepidoptera. - Science Gossip. XV. London 1879. p. 36-38.

Mérejkkowsky, c. de. Sur la tétronérythrine dans le règne animal et sur son rôle physiologique. - Compt. rendu Acad. Sc. Paris. XCIII. 1881. p. $1029-1032$.

Méréjkowsky, C. de. Nouvelles recherches sur la zoonérythrine et autres pigments animaux. -- Bull. Soc. zool. de France. 1883. p. 81.

Méréjkowsky, C. de. Matériaux pour la connaissance des pigments animaux. St.-Pétersbourg 1883. (Russisch).

Moberly, J. C. Change of Colour in Pupa of Apatura iris just before Emergence. - Eetomol. Record. XII. 추 12. 1900. p. 350-351.

Merrifield, F. Experiments on the Colour - susceptibility of the pupating larva of Aporia crataegi, and on the edibility of its pupa by Birds. Entomol. Monthly Mag. (2) XI. (36) 1900. p. 186-187. 
Newbegin, Marion J. The pigments of animals. - Nat. Scien. VIII. 1896. p. $94-100 ;$ p. $173-178$.

Newbegin, M. J. The Colours and Pigments of Butterflies. - Natural Science. XIV. 1899. p. 138-142.

Oppenheim, Mor. Ueber einen von Pediculus pubis gebildeten Farbstoff. Arch. Derm. Syph. LVII. 1904. p. 235-244.

Piepers, M. C. The evolution of colour in Lepidoptera. - Notes from the Leyden Museum. Vol. XXII. 1900. 즈 I/II. o I. p. 1-24.

Piepers, M. C. On the evolution of colour in Lepidoptera. - Proceedings of the Fourt International Congress of Zoology Cambridge, 22.-27. August, 1898. London 1899. p. 232-235.

Portschinski, J. A. Ueber die Veränderungen der Färbung einiger Raupen (Harpyia vinula, Aglia tau). - Protok. der russ. Entomol. Gesellsch. St.-Petersburg. XXVII. 1892. p. 18. (Russisch).

Poulton, E. B. On the artificial production of a gilded appearance in certain Lepidopterous pupae. - Rep. Brit. Ass. 1886. p. 692-693.

Poulton, E. B. Uses of colours to insects in the struggle for existence. - Proc. Entom. Soc. Washington. 1895. p. 139-141.

Puhlmann, E. Zum Kapitel: Farbenveränderung bei Schmetterlingen auf chemischen Wege. - Gubener Entomol. Zeitschr. № 24. VIII. 1894. p. 199.

Riding, W. S. Parallel Colour Variation in Larvae and Pupae (of Zonosoma annulata and $Z$. porata). - Entomol. Record. 12. No 3. 1900. p. 80.

Russel, A. Change of colour in pupa of Apatura iris just before emergence. The Entomolog. Record. and Journ, of Variat. XII. № 11. 1900. p. 294.

Semper, C. Beobachtungen über die Bildung der Flügel, Schuppen und Haare bei Lepidopteren. - Zeitschrift für wissenschaftliche Zoologie. VIII. 1857. p. 326 .

Soule, Caroline G. Color-variation in larvae of Papilio polycenes and other notes. - Psyche, VIII. 1899 p. 435-436.

Standfuss, M. Die Beziehungen zwischen Färbung und Lebensgewohnheit bei den palaearctischen Grossschmetterlinger. - Vierteljahrsschr. Naturforsch. Gesell: Zürich. XXXIX. 1894. p. 85-119.

Tower, W. L. The development of the colors and color patterns of Coleoptera, with observations upon the development of color in other orders of Insects. - The décennial publications, X. Chicago 1903. p. 33-70.

Tutt, J. W. Pupal development and colour of imago. - Ent. Rec. IV. A2 12. 1893. p. $311-315$.

Tutt, J. W. On the development of pigment in Nemeolius lucina. - Ent. Rec. V. 1895. p. 257 .

Tutt, J. W. The development of the Wing, Wing-Scales and their Pigments in Butterflies and Moths. - Ent. Rec. IX. 1897. № 6. 1) 131-136; 소 7. p. $159-162$; № 8. p. 198-200.

Uroch, Friedr. Kennzeichnung und kritische Bemerkungen über Terminolngisches, Wärmeenergetisches und Farbenevolution meiner erzielten Iherrationen von Vanessa io und urticae. - Zool. Anz. XXII. ㅊo 582. 1899. p. $121-133$.

Verhoeff, c. Weitere Lntersuchungen über den Ausfärhungsurocess. - Entonol. Nachr. XVIII. 1892. p. 54-5s. 
Verhoeff, C. Zur Fintwickelung von Hemerobius subnelulosus und über Verfairbung der Neuropteren. - Ent. Nachr. XVIII: 1892. p. 279 und p. 298. Walker, F. A. On Colours in Nature. - Journ. Vict. Inst. XXIII. 1890. p. 81-10s. Westhoff, F. Ueber Melanismus verschiedener Coleopteren. -- 5. Jahresber. d.

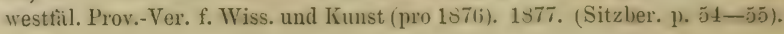

\section{Einfluss des Klimas.}

Die Litteratur iiber den Einfluss des Kilimas auf die Färbung und Zeichnung der Insekten ist so zahlreich und so zerstreut in verschiedenen Zeitschriften, dass man enorme Mühe anwenden muss, um alle einzelnen Thatsachen zu sammeln. Deshalb werden hier nur einige davon angefürt, wobei Saison-Formen und Aberrationen resp. Variationen, welche bereits Namen erhielten, ganz ausgelassen werlen.

Der Einfluss des Klimas ist ein complizierter Faktor und setzt sich zusammen aus den Einflüssen der Temperatur, der Feuchtigkeit, der atmosphärischen Druckes, der Solation etc. Die Winkel zwischen diesen Componenten zu bestimmen und auf diese Art die Resultierente, also den Einfluss des Klimas, zu ermitteln, ist bei jetzigem Stande der Entomologie noch nicht möglich. Immerhin sind die in diesem Abschnitt mitgetheilten Thatsachen von Bedeutung für künttige Spekulationen in der erwähnten Richtıng.

In der 33. Versammlung der schweizerischen Naturforscher zu Solothurn in der Section für Botanik und Zoologie gelangte eine Arbeit von A. de la Harpe (1848. 343) zur Vorlage, aus welcher Secretair Meyer-Dür im Sitzungsprotokol vom 25. Juli 1848 einige Fakta hervorhob. A. de la Harpe fand, lass Lithosiu aurita und ramosa eine und dieselbe Art sind. Aurita erscheint zuerst auf niedrigeren Alpen von ca. 4000' Höhe; verfolgt man sie höher, so finden sich die schwarzen Punkte immer grösser, bis sie auf Alpen von $6000^{\prime}$ sich zu Streifen verlängern und die Lithosia ramosa bilden. Auf noch bedeutenderen Höhen werden diese Streifen so stark, dass sie die Grundfarbe bilden, und das Gelbe zuletzt nur noch in streifenartigen Spuren erscheint. Dieser Fall ist analog bei Pontia napi, die schon auf dem Jura auf $3400^{\prime}$ rauchgrau vorkommt und noch höher die ganz dunkle var. bryoniae hervorbringt. Bei den Militheen- und Argynnis-Arten nimmt diese Einwirkung einen anderẹn 
Charakter an. Das brennende Rothgell, wird in höheren Regionen düsterer, matter, die hellen Stellen melır fahlgelb. A. de la Harpo meint, dass Artemis des Flachlandes und die hochalpinische Nerope eine und dieselbe Art sei.

Die ganze Arbeit wurde in „Bull. des séances ile la Soc. Tandoise des sciences natur. 1849" abgedruckt.

De la Harpe (1848. 355) sagt darin, lass dlas kalte Kilima auf die Schmetterlinge umgekehrten Einfluss ausübt als auf warmblütige Thiere. Die Schmetterlinge, welche sich auf Alpen aufhalten, sincl schwärzer als diejenigen, welche in wärmeren Gegenılen zu treffen sind. So z. B. kommt Pieris napi var. brioniae, welcher schwärzer ist als napi, nur in Alpen vor; dasselbe bezieht sich auch auf den dunkleren Colias phycomone, welchen der Vortragende fuir eine Varietät des helleren Colias hyale hält. Auch Lycaenen, Argynnis und Melitaea sind auf Alpen dunkler als sonst. Besonders auffallend ist in dieser Beziehung Argymis pales var. pa lemelas, von Bugnion auf Alpen entleckt. Die schwarzen Satyren (satyres nègres) der Alpen sind sngar ron Boisduval in eine besondere Gattung Erebia eingetheilt worden.

4 Jahre später hielt uiber das gleiche Thema H. Mejer-Dür einen Vortrag (1852. 580) in Sion, welchem wir folgende Stellen entnehmen:

Betrachtet man vorerst den klimatischen Einfluss nach horizontaler Verbreitung, so finden wir, dass:

$1^{\circ}$ Der Norden:

a) die rothgelben Farben der Oberseite triibt und matt macht bei den Gattungen Satyrus und Argynnis;

b) die hellgraue oder weissliche, marmorirte Unterseite der Hinterflügel bräunt und verdïstert wie bei der Gruppe von Satyrus maera und megaera.

Dass dlagegen:

$2^{\circ}$ Der Süden:

a) alle rothgelben und rothen Farben erhöht und die schwarzen Flecken verkümmern macht, bei Melithaea; ryction);

b) die weissblauen Lycaenen noch stärker abbleicht (bei co-

c) das Grau der Unterseite der reinblauen Lycaenen in's angenehm Braungelbe umwandelt (adonis, alexis); 
1) Ilas Metallgrïn an der Flügelbasis auf der Unterseite vermindert und vergelbt (Lycaena);

e) so auch auf der Oberseite der braunen Weibchen die blaue Ueberstäubung;

f) den rothgelben Satyrus-Arten oben eine goldblonde Behaarung erhält (adrasta, aristaeus);

g) gelblicheres, intensiveres Weiss bei den weiblichen Pontien erzeugt;

h) blasses Gelb bei Papilio podalirius, aber erhöhtes, mehr chromgelbes, bei machaon.

Auch die Alpen-Natur zeigt ihre Wirkung; sie macht:

a) die Unterseite blasser (bei selene);

b) verdiustert und verblasst die rothgelben Farben bei 1 Lel. artemis (var. merope) unı bräunt die hellgraue Unterseite bei $L_{i j}$ caence argus und aegon;

c) erhöht das feurige Roth bei Vanessa urticae;

(l) verdunkelt die Oberseite der weiblichen Pontien (napi);

e) verleiht einen herrlichen Schiller tem Weibchen von $A r$. gynnis pales;

f) verkleinert die weissen Flecken (ler Oberseite unl verwischt und trübt die Unterseite bei Hesperia (cacclice, serratulae und caecus).

G. Koch (1856, 457 b) fand, lass die Färbung von Chelonic plantaginis I. je südlicher desto feuriger, und je nördlicher desto blasser ist.

Jul. Lederer (1863. 505) erhielt die in Slivno (Bulgarien) gefangene Exemplare von Heliothis peltiger S. V., welche sehr dunkel, olivgrün nnd sehr scharfgezeichnet waren, „die fast zur Annahme einer anderen Art verführen könnten. Die mir ausgeblasen vorliegencle Raupe differirt aber nicht von peltiger." (p. 27). Im Hochgebirge (in Bulgarien) gefangene Exemplare von Satyrus cordula Fab. halten dass Mittel zwischen cordula und var. bryce. Die bei Varna (Bulgarien) gefangenen Exemplare von Acictalia immoraria L. stellten Uerbergänge zur tesselaria vor. Bei Slivno gefangene Exemplare ron Hypochalcia dignella $\mathrm{Hb}$. waren sehr dunkel. Pteroph. metzneri Z., bei Varna gefangen, war dunkler und langfliigliger als das von Zeller beschriebene Exemplar. 
H. Löw (1863. 532) erhielt von Slivno (Bulgarien) Dipteren, welche folgende Unterschiede an ihrer Fürbung besassen:

Tabanus albipes Fbr. Die Exemplare gleichen in der Färbung (ler Behaarung ganz und gar den kleinasiatischen Exemplaren dieser Art; von den sïditalienischen Exemplaren unterscheiden sie sich durch die weissere Farbe der hellen und durch das reinere und lebhaftere Colorit der rothen Behaarung.

Cyclogaster tenuirostris Lw. Die Behaarung ist etwas weisslicher als bei den dalmatinischen Exemplaren.

Hypoderma lineata Vill. gleicht in der Farbe der Behaarung: ganz den daurischen Exemplaren, während bei den westeuropaischen, besonders bei den spanischen, der Kopf, das Schildchen und der vorlere Theil iles Hinterleibes viel gelblichere Behaarung haben.

J. Mann (1866. 545) fand, dass die Schmetterlinge, wulche er in der Dobrudscha (jetzige rumänische Provinz) fing, durch die Färbung von denen, welche in der Wienergegend vorkommen, sich unterscheiden. Dieser Unterschied wurde jedoch bei folgenden Arten konstatiert: Melitaea athalia Esp. ist grell gezeichnet; Thalpochares rosina $\mathrm{Hb}$. ist in der Färbung ganz matt, und es fehlt ihr das schöne Rosenroth; Aspilates strigillaria $\mathrm{Hb}$. nähert sich in ler Färbung der var. creturia Ev.

Goosens (1870. 322) unterscheidet drei Hauptvarietiiten von Raupen:

1). Varietäten nach den verschiedlenen Häutungen bei den meisten Raupen,

2). Varietäten nach den verschiedenen Oertlichkeiten, wo sich die Raupe findet,

3). Zufällige Varietäten.

Die zweite Varietät betrachtet A. Käferstein (1880.443) als identisch mit der klimatischen Raupen-Varietiit.

C. A. Teich (1870. 855) sagt in seinem Vortrage über "Klima und Schmetterlinge," dass die tropischen Falter "nicht selten in seidenartigem Himmelblau, im schönsten Smaragigrün und in feuerigem Rubinroth prangen," während die nordischen Falter meist in braune und graue Farben sich kleilen. Das Blasswerilen nach Norden wurde insbesondere an den Gattungen Lycaena, Polyommatus und Colias gezeigt. „Die lebhaftere Farbe scheint zum Theil durch 
Wärme leelingt zu sein, wie die Zucht ron Vanessa prorsa und ihre Varietät levana zeigt" (p. 2).

A. R. Wallace (1870. 940) sagt, dass die Weibchen mehrerer Papilio-Arten auf Amboina und Ceram dunkel gefirbt sind, wihhend sie auf den anliegenden Inseln brillanter sincl.

A. Fuchs (1873. 266) machte Beobachtungen im Freien über las Entstehen von Paraige adrasta $\mathrm{Hb}$. var. maja unıl kam zu ilem Schlusse, dass "die mangelhafte Nahrung, dlie starlie Hitze des Sommers, die gewöhnliche Trockenheit des Juli diese Varietait hervor bringen" (1. 106). Es sei hier bemerkt, llass die Puppe von maju nach seinen Beobachtungen nur 14 Tage liegt. wälırend die Puppenzeit bei adrasta 3 Wochen dauert.

Moritz Wagner (1875. 935) theilt folgenle Beolsachtungen ron Boll mit:

Boll besuchte 1870 seine Heimath in der Schweiz unl brachte aus ller Stadt Dallas (N. Amerika) eine Anzahl Puppen von Bombyy Tunu mit, welche in Amerika sich auf Juglans nigra ernähern Im Mai 1871 entwickelten sich die Schmetterlinge und ergaben die texanische luna. Aus den abgelegten Eiern entwickelten sich liaupen, welche gelblicher als in Texas waren, und mit Blättern von Juglaus regia gefuittert wurden; sie verpuppten sich und lieferten im August Schmetterlinge, welche von den texanischen in der Farbe und Zeschnung sehr stark abwichen. Diese Abweichungen waren so bedeutend, dass die ausgeschlïpten Schmetterlinge alle Kennzeichen einer hesonderen Art an sich trugen, und alle 35 Exemplare ganz gleich waren. Bei der Stammart ist die Farbe ein in das Gelbliche spielentes Grün, während die Farbe der neuen Art als ein schönes Citronengelb auftritt; der carmoisin-rothe, nach innen weisslich eingefasste Randstreifen, welchen die Vorderflügel der luna tragen, ist bei der "neuen Art" fast ganz verschwunden und nur durch eine sehr schmale, dunkelgelbliche Färbung des äussersten Randes angedeutet. Am merkwürdigsten aber ist bei der "neuen Art" die Entstehung einer neuen Zeichnung auf den Vorilerflügeln, welche in einem dunkeln, aussen etwas ausgezackten Querstreifen auftritt, während solcher auf den Vorderfliugeln der Stammart ganz fehlt. In den nördlichen Staaten Amerikas kommt eine dieser "neuen Species" sehr ähnliche Art vor, welche in Texas fehlt. Ene weitere Generation konnte nicht erhalten werden, da alle Raupen starben. 
W. A. Jaroschewsky (1883. 418) fand folgende Abänderungen an der Färbung bei Dipteren, welche in der Ungebung ron Charkow (Russland) gesammelt wurden:

Chrysomyia pallipes Mg. An den Schenkeln der mittleren Beine befindet sich ein brauner Ring, worlurch dieses Inselit an Chrysomyiu cyaneiventris Zett. sich nähert.

Brachypalpus angustus Egg. besitzen belleutendere Verbreitung: der schwarzen Färbung an den Beinen, als es aus der beschreibung von Schiner folgt.

Conopidae vitellinus Lw. hat grössere Verbreitung der schwarzen Färbung an den Schenkeln, als Loew beschrieb.

Phasia sola Rond. unterscheidet sich von der Beschreibung von Rondani durch einen verschwommenen röthlichen Fleck seitlich am ersten Bauchsegment.

Tysta semicana Egg. ठ̋ besitzt einen deutlichen röthlichen Fleck seitlich am ersten und zweiten Bauchsegment, welchen weder Schiner noch Egger erwähnen.

Exorista capillata Rond. unterscheidet sich von der Grundform durch je einen röthlichen Fleck nur seitlich am zweiten Bauchsegment; am dritten Segment fehlen diese Flecken.

Phorocera polleniella Rond. besitzen die glänzenden schwarzen Querstreifen (Q) nur an den Bauchseiten und nicht am Rïcken.

Apodacra seriemaculata Macq. haben die Endglieder der Fühler braun gefärbt.

Dinera cristata Mg. haben hell röthliche Fühler.

Syntomocera brevicornis Egg. besitzt seitlich am Leib röthliche Flecken.

Aricia carbo Schim. hat auf der Oberseite des Leibes bei der Betrachtung in gewisser Lage graue Färbung mit einem dunkelen länglichen Streifen.

Piophila casei L. hat gelbe Oberschenkel der Vorlerbeine.

L. Knatz (1883. 455a) untersuchte die Schmetterlingsarten ron Kiassel und führt folgende vorkommende Farbenveränderungen an:

1. Grüne Färbung wechselnd mit ruther bei ein und derselben Art, zuweilen mit Uebergängen von der einen Farbe in clie andere (Smerinthus tiliae), zuweilen ohne solche (Ellopia prosupiaria). Gleiches findet sich bei manchen Raupen, deren Schmetterlinge aber ebensowenig in der Farbe rerschieden sincl, wie die Raupen der grünen und der rothen Schmetterlinge. 
2. Flavescenz. Es kommt bei vielen Arten, die fast kein oder wenig Gelb unter ihren Farben haben, vor, dass das Gelb sich auf sonst weisse, graue oder braune Stellen verbreitet oder überhaupt die ganze Oberfläche der Flügel färbt. wöhnliches.

3. Hellere und dunklere Färbung. Dies ist etwas sehr ge-

4. Erhebliche und partielle odler allgemeine Verdunkelung bei einzelnen Exemplaren oder bei Varietäten, indem entweller schwarz gefärbte Schuppen Stellen, die sonst hell sind, überdecken, oder die hellen Schuppen überall eine dunklere Färbung annehmen.

๖. Erhebliche und partielle oder allgemeine Verbleichung, indem entweder weissgefärbte Schuppen Stellen, die sonst dunkel sind, überdecken, odler die sonst dunkeln Schuppen überall eine bleiche Farbe annehmen.

K. Bartels (1883. 52 a) fand in Kassel ganz hellgelbe Exemplare von Phytodecta quinquepunctata Fabr., die gewöhnlich ziegelroth mit schwarz sind.

W. A. Jaroschewsky (1886. 419) beobachtete bei seinen Studien der Diptera in Gouvernement Charkow (Russland) folgende Färbungsabweichungen von der Beschreibung, welche andere Autoren machten:

Oxycera IEigenii Staeg. haben am Rücken gelbe Langsstreifen ununterbrochen.

Argyra leucocephala Mg. var. c. Zetterst. hat die Schenkel der mittleren Beinen an der Basis braun.

Campsicnemus scambus Fill. besitzt keine schwarzen Streifen auf der Oberseite der Vorder- und Mittelschenkel.

Callomyia elegans Mg. besitzen auf der Spitze der hinteren Schenkel einen dunkelbraunen Fleck, welchen weder Schiner noch Meigen erwähnen.

Gaedic connexa Mg. hat seitlich auf dem 1. und 3. Leibsegment keine gelb-rötliche Färbung.

Phorocer a nigripalpis Rond. hat am Thorax eine dicke gelblichgraue Bestäubung.

Thryptocera mariettii Roncl. haben die ganzen Fühler gelbröthlich.

Phortisia foeda Wied. Die Fühler sind schwarz.

C'ampogaster relicata Mg. Die Schenkel der Vorder-Beine sind theilweise gelb-röthlich. 
Stromoxys iritans L. haben schwarze Palpen, und der Leib ist fleckenlos.

Limnopliora carbonaria Mg. haben gelbliche Schuppen, statt: weisse (nach Meigen).

Anthomyic pullula Zett. hat auch die mittleren Füsse röthlichbraun.

Mycetıulus bipunctatus Fall. besitzt selır entwickelte gelb-röthliche Färbung am Grundtheil des Leibes, dasselbe an den Füissen.

Loxocera nigrifrons Macq. hat eine grosse Terbreitung der gelb-röthlichen Färbung an der unteren Seite des Leibes.

Meromyza variegata $\mathrm{Mg}$. hat längliche schwarze Flecken am Leibe.

Empheria striata Mg. Der dunkele Längsstreifen am Leibe ist. kaum zu merken.

Idioptera fasciata L. Der dunkele Spitzstreifen ler Flügel zerfällt nicht in einzelne Flecken.

Limnobic xantoptera Mg. hat am Leibe die dunkele Linie schwach entwickelt.

E. Baillon (1886. 44) erbeutete mehrere Exemplare von $\mathrm{Ne}$ meoptila russula L. in Noworossiisk am Schwarzen Meere, welche viel lichter gefärbt sind, als die vom Inneren Russlands; Calymnia pyralina View. ist bedeutend dunkler unl Talpochares purpurina Hüb. matter als nach der Beschreibung von Duponchel.

W. A. Jaroschewsky (1887. 420) beobachtete bei Dipteren, welche er in der Umgebung von Charkow sammelte, folgenile Färbungsabweichungen von der Stammform:

Asilus cyanurus Lw. haben ganz schwarze Füsse.

Puragus cinctus Schin. und Egg. Die Weibchen besitzen längs dem Augenrantle einen graul-weissen Streifen (statt gelblichen). Die Fühler sind schwarz, die Beine röthlich.

Paragus bimaculatus Mg. $\$$ ㅇ haben röthliche Beine und gelbe Schildspitze (statt rothgelb). ठ̋ hat am Leibe keine sehwarze Fürbung.

Platycheirus clypeatus Mg. besitzen auf ller oberen Seite des Leibes vier Paar rothgelbe Flecken.

Syrphus arcuatus Fall. $q$ q haben die Hinterschenkel bis zur Hälfte schwarz, und ठౌర braun.

Syrphus guttatus Fall. haben die weissen Flecken auf dem. Rücken schwach ausgelrückt. 
Syrplus umbellatarum Fab. haben den Leib auf der Oberseite stark glänzend.

Syrphus diaphanus Zett. Das Grum!glied der Fühler ist theilweise röthlich.

Melittreptus strigatus Staeg. haben gelhe Beine mit braumen Füssen.

Melithreptus taeniatus $\mathrm{Mg}$. Das Schilichen ist sehwarz (statt gelb) behaart.

Pliysoceplicala pusilla Mg. hat röthliche Färlımg ohne eine Spur dunkler Querstreifen.

Clarvillia ocypterina Schin. Der Leil, ist zweifarbig, "lie Grenze zwischen heiılen Färbungen ist schärfer als nach dler Beschreibung von Schiner.

Phaniosoma apennina Ronul. hat schwach braune Färbung der Flügel.

Gymnochaeta viridis Fill. hesitzt zuweilen auf llem grimen Körper hellblaue Irisfarbe.

Cnephatia multisetosa Ronı. Die ersten zwei Fühlerglierler sind röthlich, unıl das letzte ist schwarz; fast das ganze Schilıchen dunkel-röthlich.

Erynnia nitidı R.-Desv. Thorax mit schwacher grauen Bestäubung.

Gastrolepta gentilis Romi. $ठ ð$ haben schwach braune Fligel; der Rücken ist glänzend-schrvarz.

Homalomyia pretiosa Schin. haben ein ganz schwarzes (statt schwarz unıl am Ranıle licht bräunliches) Schildchen.

Coenosia intermedia Fall. hat gelbe Schenkel.

Loxocera maculata Ront. ist nach der Färbung eine Uebergangsform zu $L$. elongata Mg.

Bibio clavipes $\mathrm{Mg}$. ist der Färbung nach dem Bibio dorsalis $\mathrm{Mg}$. ähnlich.

Chironomus pedtellus Deg. Die obere Hälfte ller Füsse ist schwarz.

L. Krulikowsky (1887. 478 a) konstatierte, dass Setina mesomella L. in der Ungebung der Stait Sarapul (Gouvern. Wjatka) auf den Vorderflügehn keine schwarzen Punkte besitzt. Von 5 Exemplaren, welche in der Ungebung der Start Urschum (desselben Gouvernements) erbentet wurlen, wurden nur bei einem diese Punkte konstatiert. 
W. A. Jaroschowsky (1888. 422) heschreibt Chrysidirlae, welche er in Gouvernement Charkow sammelte, un:l welche sich iler Färbung nach von Dahlbom's (1854. 160) Excmplaren durch Folgeniles unterscheiden:

Cleptes orientalis Dlb. sinil oben dlunkel bläulich-grïn.

Bei Hedychrum ardens Latr. ist nur iler vorilere und mittlere Thorax gold-röthlich.

Hedychrum coriaceum Dlb. hat grüen Hintertheil des Schildchens; das Hinterschildchen und der hintere Theil des Thorax sind blau; das Leib ist dunkel kupfer-1roth, aber nicht glänzenıl.

Hedychrum roseum Rossi. haben am Leibe keine "Spur von Gelb-Roth.

Chrysis dichroa Kl. hat das Schildehen unt ilen vorileren und mittleren Thorax golı-röthlich; ler hintere Rücken blau, ıler Leib oben gìld-röthlich mit Irisgrün.

W. A. Jaroschewsky (1888. 421) fand bei seinem Studium der Fauna Tenthredinidae in Gouvernement Charkow folgende Färbungsabweichungen von der Beschreibung, welche von anderen Autoren gemacht wurle:

Nematus miliuris $\mathrm{Pz}$. hat am Kopfe zwischen den Fühlem keinen schwarzen Fleck. Die braunen Flecken befinden sich auf der Oberseite des Leibes auf allen Segmenten.

Phyllotoma vagans Fall. hat schwarzen Kopf, ler Leib ist gelbrỏthlich, Hinterfüsse sind schwärzlich.

Emphytus tibialis K1. Pz. $\bigcirc$ ㅇ haben die obere Hälfte del Hinterfüsse weiss (statt "ein Drittel").

Athalia rufoscutellata Moscary haben keine schwarze Färbung an der Spitze der Hinterfüsse.

Athalia maculata Moscary haben ilie ersten zwei Leilsegmente schwarz.

Blennocumpa fuliginosa Schrk. sinıl glänzenıl schwarz, die Flügel sind schwärzlich.

Perineura picta Kl, haben gelbe Beine.

Perineura ornata Lepel haben am Schilılchen einen gelben Fleck.

Perineura nassata L. haben röthlich-gelben Leib.

Perincura cordata Fourc. haben schwarze Schenkel der Hinterbeine.

Tenthredo sobrina Ev. haben am schwarzem Leib das 4. und 6. Segment röthlich-gelb. 
Tenthredo albicornis Fab. hat das 7., 8. und 9. Fülllerglied gelblich-weiss.

Tenthredo atra L. hat alle Schenkel gelbröthlich.

Lyda campestris L. hat schwarzen Rücken und gelhes Schilıchen.

L. Krulikowsky (1889. 478b) beobachtete bei Lepislopteren, welche 1887 in Gouvernement Wjatka gesammelt wurien, folgenule Abweichungen von normalen Formen:

Papilio machaon L haben im Frühjahr clie gelbe Färbung auf Hinterflügeln (oben) in der 3. und 4. Zelle begrenzt von schwarzblanem Bånde durch einen fla hen Bogen (vgl. Borge's Schmetterlingsbuch. VI. Autl. Taf. I. Fig. $3 c$ ), währenı bei Herbstexemplaren diese gelle Färbung in dem genannten Band spitzförmig hineingeht (vgl. E. Hoffmann, Die Schmetterlinge Europas. Taf. I. Fig. 3).

Leucophusia sinapis L. haben im Juni nur sehr schwache Spuren von Grau an dem vorileren Eck iler Vorilerfligiel (oben).

Polyommatus virgaureac L. haben am Vorilerflügel entwerler .zwei orler nur einen Wurzelpunkt.

Fumea pulla Esp. $ठ る$ haben durchsichtigere Flügel als in St. - Petersburg.

Acidulia emaryinata L. sind bleicher als in Kasan.

Cidaria truncata Hufn. haben auf den Vorderfliigeln mehr Weiss.

J. Haberfelner (1889. 340) sagt dass die von ihm erbeuteten Exemplare von Calopterus selmanni auf den Alpen (Oetscher und Dürrenstein) schön metallglänzend und auf Vorbergen ganz schwarz sinı, Pterostirhus jurinei dagegen unveränilert bleibt.

S. H. Scudder (1889. 801) fant, class clie Weibchen von $\mathrm{Pa}$ pitio turnus L. unı glaucıs L. desto dunkler sinı, je süllicher sie in Norl-Amerika vorkommen; lie Farbe der Männchen von Lycuena jseudoargiolus Bsıl. sinı im Süllen clunkler umd nähern sich der Farbe des Weiluchens aus den nördlichen Gegenden.

L. Krulikowsky (1890.478) beobachtete, dass die Schmetterlinge im Gouvernement Wjatka folgende Abweichungen von ter normalen Form haben:

Papilio machaon L. Die II. Generation besitzt mehr dunkelscelbe Färbung und nähert sich auf diese Art der var. aurantica Speyer.

Senta maritima Tauscher. Nähert sich der ab. nigricostata Stgr. 
Hypochalcia ahcnellı Schiff. Die Exemplare haben fast keine Zeichnung auf den Flïgeln.

Ausserdem konstatierte er, lass bei den meisten Species, welche auf dem weissen odler gelben Gruncle schwarze Punkte besitzen, diese letzteren 1889 entwerler reduziert wurlen (sowohl in (ler Anzahl, wie auch in (ler Ausbreitung) otler ganz verschwunten waren. Diese Arten sind folgende: Pieris rapae, var. similis, Carterocephalus silvius, Setina irrorella, S. mesomella, Calligenia rosea. Nemeopllila plantaginis, Spilosoma lubricipectu, S. menthastri, Ocneria dispar, Acronycta leporina, Zonosoma pentularia, Z. punctariu, Zerene grossulariata, Z. sylvatu, Z. maryinatu, Angerona prunaria, Hypoplectis adspersaria, Venilia macularia, Amphidusis betularia. Cidaria corylata.

James J. Walker (1890. 801) erwähnt in seinen "Notes," (lass beide Arten: Rhodocera cleopatra und rhamni an beiden Seiten der Strasse von Gibraltar vorkommen, also unter vollkommen gleichen Tempcraturverhältnissen.

Fritz Rühl (1890. 719) fing Melithaca parthenie Bork. var. varia Bischof. und fand, dass ihre Färbung von der Höhe ïber das Meersniveau abhängt und zwar: „auf dem Abstieg rom Albula nach Ponte wird der Falter lichter und grösser uml bleibt sich gleich auch auf dem Beverser Kamm, aber schon auf dem IVege zu ilen Bernina-Häusern gewinnt er wieder das Ansehen der Simplon-Exenplare und erreicht am Fusse des Cambrena-Gletschers die dunkele Färbung der Stücke aus den höchsten Regionen des Stilfser Joch" (p. 36).

A. Hoffmann (1891. 378) sammelte in Hannover und auf den Dünen der Nordsee Raupen von Teras hastiana L. und erhielt aus ersterem Ort $66 \%$ einfarbig schwarzbraune und aus den letzteren $12 \%$ einfarbig braune Schmetterlinge. Die verilunkelncle Tendenz zeigt sich auch bei Acronycta menyanthictis View., Acronycta v. bradyporina Tr., Teras hippophaëana Heiden. Er erklärt diese Verdunkelung der Färbung durch den Einfluss des Nordseeklimas.

L. Krulikowsky (1892. 47Se) führt folgende Abweichungen bei Schmetterlingen an, welche in der Ungebung der Stadt Wjatka erbeutet wurden: 
Polyommatus virgauereac L. sind Ü̉)ergänge zu var. oramula Frr.; $\delta$ ठ haben ein Fleckchen auf der Querlinie der Vorderfluigel und nähern sich somit der var. esthonica Huene.

Polyommatus phlueas var. eleus I. sind blasser als in Suil-Europa.

L. Krulikowsky (1892. 478) erbeutete im Gouvernement Kiasan Exemplare von Gnophria quartra L., welche blasser sind als in Deutschland.

Hugo May sen. (1892. 550) fing in Wien Schmetterlinge von Acidalic consanguinaria Led., welche gelber (strohfarben) gefïrbt waren als die Stiicke aus Dalmatien.

Otto Bohatsch (1892. 96) sammelte Schmetterlinge in Slavonien (Bad Lipik bei Pakrac) und stellte fest, lass dieselben lebhafter gefärbt sind als Exemplare gleicher Arten in Wien.

H. Rebel und A. Rogenhofer (1893. 674) sagen, lass der Falter Parnassius upollo L. in der Oesterreich-Ungarischen Monarchie in funf Aberrationen vorkommt und zwar von der rein kreileweissen Form aus dem Velebit bis zu tiefschwarz bestäubten Stïcken aus den österreichischen Voralpen. „Bei zunehmender Höhe in den Voralpen werden die Exemplare namentlich im weiblichen Geschlechte allmählig (lichter grau bestäubt (dïsterer), die Staubbinde des $\delta$ vor dem Saum der Vorderflügel ilunkler und schärfer, die Analflecke auf den Hinterflügeln sehr häufig roth gekernt" (p. 58).

Der Falter Parnassius delius Esp. kommt in drei Aberrationen vor. Die $q$ Exemplare aus dem Glocknergebiete haben einen breiteren glasigen Saum, schärfere Staubbinde und grössere Augenflecke als solche aus der Schweiz (namentlich lem Berner-Oberlande).

Der $\sigma$ Falter Parnassius mnemosyne L. aus bedeutender Erhebung zeigt zuweilen die schwarzen Flecken ober dem $\Lambda$ nalwinkel der Hinterflügel ebenso deutlich, wie sie gewöhnlich nur beim auftreten.

Klemensiewicz (1893. 551) fing in Galizien oft Lygris populata ab. musunaria Frr. und beobachtete, dass cliese Art in Gebirge eine grosse Neigung zum Melanismus zeigt.

L. Krulikowsky (1893-96. 479) sammelte Lepillopteren in Gouvernement Kasan (Russland) und fand folgendes:

Agrotis aceris L. ist blasser als in West-Europa.

" polygona F. ist dunkler als in West-Europa. 
Agrotis cla7ılii $\mathrm{Hb}$. ist intensiver gefürbt als in West-Europa. Mamestra genistae Blkh. ist matter als in Regensburg.

Dianthoeciu nana Rott. ist dunkler als in West-Europa.

Miselia oxyacanthae W. ist blasser als in Regensburg.

Leucania conigera F. ist intensiver gefärbt als in West-Europa. Caradina taraxaci Hb. ist dunkler als in West-Europa.

Anphipyra pyramidea $\mathrm{L}$. ist intensiver gefürbt als in WestEuropa.

Xylina ingrica HS. ist blasser als in Lifland und St.-Petersburg.

Cucullia umbratica L. ist dunkler als in West-Europa.

Plusia $c$ aureum Knoch. ist weniger intensiv. gefärbt als in West-Europa.

Plusia moneta F. ist blasser als in West-Europa. bractea Schiff. ist blasser als in West-Europa.

Chariclea umbra Hufn. ist intensiver gefärbt als in West-Europa.

Erastria uncula Cl. ist dukler als in Deutschland.

Prothymia viridaria $\mathrm{Hb}$. ist dunkler als in West-Europa.

Catocala fraxini L. ist mehr hell-grau als in West-Europa.

Zanclognatha emortualis Schiff. ist dunkler als in West-Europa.

Pseudoteryna pruinata Hufn. ist intensiver gefärbt als in WestEuropa.

Pericallia syringaria L. ist blasser als in Dresden.

Cidaria vittata Bkh. ist dunkler als in West-Europa. Aporodes floralis $\mathrm{Hb}$. ist dunkler als in West-Europa.

Botys repandalis Schiff. ist blasser als in West-Europa. $"$ verbascalis Schiff. ist blasser als in West-Europa. Ancylosis neglectella Hein. ist dunkler als in Gouvernement Saratow.

Oenectra pilleriana Schiff. ist dunkler als in West-Europa. Penthina antiquana $\mathrm{Hb}$. ist blasser als in West-Europa. Talaeporia pseudobombycella $\mathrm{Hb}$. ist dunkler als in West-Europa. Depressaria ocellana F. ist dunkler als in West-Europa. angelicella $\mathrm{Hb}$. ist dunkler als in West-Europa.

Otto Bohatsch (1894. 97) sammelte im Gebiete des Schneeberges in Niederösterreich und konstatierte, dass die Schneebergform von Hadena maillardi H.-G. und Hadena lateritia Hufn. viel dunkler als jene der Ebene ist.

A. von Caradja (1894. 130) sagt gelegentlich der Erklärung des Vorkommens von Amph. betularius ab. doubledayaria in Deutsch- 
land, dass den endlichen Sieg der dunklen Form über die helle Stammart sehr complicirte Verhältnisse bedingen, welche wohl hauptsächlich in dem säcularen Wechsel der Krlimate zu suchen sincl. „Es ist auch wohl zu beachten, dass die dunklen Aberrationen unil Varietäten in feuchten und kalten Klimaten entstehen" (p. 34). Ferner sagt er, dass die milchweisse. Form des $\delta$ ron Spilosomu mendica var. rustica $\mathrm{Hb}$. dem jetzigen continentalen unil trockenen Klima der Molilau, Bukowina und Kaukasuslänıler "loch noch hesser angejasst ist, als die jeilenfalls in oceanischem fílima ursprünglich enstanlene unil diesem entsprechend organisirte mendica" (p. 34).

E. Hofmann (1894. 381) sagt in seinem Buche üler die Gattung Setina: „Die Farbe gelb, je höher ilı Flugort im Gulbirg ist. desto mehr breitet sich die schwarze Farbe aus, namentlich werden lie Rippen durch das Zusammenfliessen der Punkte schwarz un! bilden so alpine Varietäten" (p. 43 und 44).

1895 erschienen "Neue Versuche zum Saison-Dimorphisimus iler Schmetterlinge" ron August Weismann (954). Dieser Schrift entnehmen wir folgendes, was auf den Einfluss des Krlimas Bezug hat:

"Es ist längst bekannt, dass manche Stücke von Chrysophanus phlaeas kleine hellblaue Flecke auf der Oberseite der Hinterfliigel an Saum tragen und zwar sowohl beim Weibchen als beim Männchen. „Vergleicht man die Stücke aus dem Süden mit denen aus dem Torden, so ergiebt sich, dass wohlausgebildete Flecke ïberall vereinzelt vorkommen, Andeutungen überall häufig sind, class aber keilı Zusammenhang $z$ wischen Klima und dem Ausbildungsgrad der blauen Flecke besteht" (p. 14).

Zum Beleg führt er eine ganze Reihe dieses Schmetterlings aus verschiedenen Gegenden an, und sagt weiter: „Die blauen Flecke sind also individuelle Variationen, welche überall und unter den rerschiedensten Temperaturen gebildet werden" (p. 15).

Derselben Meinung ist er auch in Betreff der rothen Bincle auf der Unterseite der Hinterflügel bei phlaeas.

H. Lhotte (1896. 260) zïchtete zu Rouen (Frankreich) den amerikanischen Seilenspinner Actias luna, wobei es sich ergab, dass 〈liese, auf dem ganzen Gebiete der nordamerikanischen Staaten in zwei Generationen erscheinende Art in Frankreich eine einfache 
Generation angenommen hat. Als die Zucht in einer solchen Jahreszeit vorgenommen wurde, dass die Puppe zu ïberwintern genöthigt war, so veränclerte sich in diesem Falle die Färbung uncl Zeichnung der Flügelsäume und sogar die Form der Hinterflügel auf eine eigenthümliche Weise.

Martin Holtz (1897. 385) sammelte in KKleinasien (Cilicien), wo die Temperatur an der Küuste bisweilen $40^{\circ} \mathrm{R}$. im Schatten unıl in Lagen über $1000 \mathrm{~m}$. Höhe in der siebenten morgenstunde schon $27^{\circ} \mathrm{R}$. im Schatten beträgt. Er erwänht folgendle abweichende Arten: Doritis apollinus besitz vorwiegend hellle Grundfürbung; bei Parnassius mnemosine tritt die weisse Fleckenbinde auf dem durchsichtigen Aussenrand der Vorderflügel stärker hervor als bei den europäischen Stiicken, die schwarzen Zeichnungen auf den Hinterflügel sind bindenartig erweitert; Rhodocera var. taurica zeichnet sich vor den typischen Stücken durch matteres Orange der Vorderfligel aus; Thestor nogelii $\sigma^{\top}$ ist auf der Oberseite ganz zeichnungslos; Polyommatus phlacas in sehr dunklen Stiicken; Lycaena semiargus zeichnet sich durch rothe Randmonde auf der Unterseite der Hinterflügel aus und kommt diese ab. bellis nur in Taurus vor; Limenitis camilla ist von mitteleuropäischen Stïcken durch geringere Ausilehnung der weissen Zeichnungen verschieilen; Vanessa c-allum besitzt den Innenrandfleck der Wurzelreihe in ungewöhnlicher Auslehnung, ähnlich wie bei. V. polychloros; $V$. witicue ist lebhaft gefärbt mit zurückgedrängter, schwarzer Zeichnung (var. turcica); V. curclui mit matt rosenrother Grundfïrbung; bei Melitaec phoebe sind die schwarzen Zeichnungen des Mittelfeldes auf der Unterseite der Hinterflügel zu einer Reihe rautenförmiger Flecke zusammengeflossen; Argyrnis daphne ist lebhafter gefürbt als in Deutschlanı; $A$. niobe besitzt lebhaftere Grundfärbung und schärfere Zeichnung der Unterseite (var. taur( ); A. puphic var. delil ohne Silberzeichnung auf der Unterseite der Hinterflügel (ab. ancirgyra); Satyrus briseis mit ausserordentlich breiten Binclen (var. magna); Pararge maera hat feuerig rostrothe Färbung der Vordertliigel (var. orientalis); $P$. megaera besitzt stärkere braungraue Zeichnung auf der Oberseite der Hinterfligel; Deilephila euphorliae hat die weisse Behaarung in der Mitte und an den Seiten des Schopfes (var. paralias); Bombyx neustria ist sehr matt gefürbt und gezeichnet; Hurpyia interrupta zeigt eine vollständige Trennung des oberen und unteren Theiles der Mittelbinile, wie si s sich mu heim ơ finilet; 
Acontia lucicla mit fast ganz schwarzen Hinterflügeln; Catoculu mupta etwas heller und eintönig; Boarmia gemmaria ist bunt unil kräftig gezeichnet; Gnophos glaucinaria stark gebänlerte Stücke.

A. Martin (1897. 548) fand Encle Juli im Bodenthal (Hirschgrund) 3 Exemplare von Chrysomelu fastuosa L., welche "weit farbenprächtiger" waren, als zwei bei Strassl)erg (Unterharz) gefangenen Exemplare derselben Art.

Aus dem Vortrage von Dönitz in der Sitzung des Berliner Entomologischen Vereins (1899. 188) "Uelser die Echtheit der Farbentöne der brauen und grünen Form ron Ornithoptera (Icarus) zalmoxis," geht hervor, dass durch die sogennante Tropenfüule das Blau der zulmoxis in Braum (und Grïn) ïbergehen kann. Es ist aber nicht erwiesen, dass das Braun nicht auch die natürliche Farbe sein kann. Dönitz hat beobachtet, dass einzelne Stücke der zalmoxis so viele weisse Schuppen zwischen den blauen eingestreut besitzen, tlass er die Vermuthung ausspricht, es würten gelegentlich ganz weisse Thiere gefangen werden.

Die entgegengesetze Erscheinung - Melanismus - wird in den letzten Jahren häufiger beobachtet und wurde Gegenstand der Besprechung in Sitzungen (les Berliner Entomologischen Vereins. So z. B. wies Rey (1900. 689) auf clie zunehmende Verbreitung von Amphidasys betularius ab. doubledayarius Mill. und Psilura monachu ab. eremitı Ochs. in süiöstlicher Richtung in Deutschland. Ebenso verhält es sich mit Boarmiu crepusculariu ab. biunctuluria Bkh. ( $85 \%$ der Stanmform).

Hensel (1900. 367) bemerkte in der gleichen Sitzung, dass das Auftreten der angeführten melanistischen Aberration periodischen Schwankungen unterliegt. Bei monacha sei bereits vor einigen Jahren eine Ueberzahl dunkler Falter beobachtet worlen. Später habe wieder rlie helle Form das Uebergewicht erhalten. Diese Schwankungen erklärt er mit ilem Fehlen gewisser Vorbedingungen, welche das Vererben der vom Charakter der Stammart abweichenden Eigenschaften auf die Nachkommenschaft erst ermöglichen.

Thurau (1900. 864) sagt dazu, (lass der Melanismus sich nicht immer rererbt und erwähnt seine Aufucht von Angerona prunaria L. 
Eier, nachweislich von der ab. sordiatı stammend, ergaben kein einziges Strick dieser Abart. Er sagt, llass Argynnis ab. valesina Esp. in einigen Gegenden Deutschlands die Stammart paphia an Zahl übertreffe oder ganz verdrängt habe, was von mehreren Anwesenden bestätigt wird (für Tirol, Schweiz, Stettin, Eberswalde).

Der Aufforderung der "Inseliten-Börse," iiber dlas Vorkommen schwärzlicher Aberrationen in letzter Zeit Nachricht zu geben, haben verschiedene Entomologen folge geleistet:

Baron Raoul de Vrière (1900. 934), Christian Storch (1900. 847), Th. Voss (1900. 931), H. Gauckler (1900. 299) erstatteten ausführliche Berichte darüber, aus welchen zu ersehen ist, (lass in gewissen Fällen die Abarten die Stammform bereits verdrängt laben, wenn vorläufig auch noch nicht ganz.

J. Breit (1900. 113) fing in der Ungebung von Duisseldort wïhrend einer Reihe von Jahren verdunkelte Formen von Melitaea aurinia, Amphiclasys betularius, Boarmia roboraria. Boarmia consortaria, Boarmia crepuscularia, Drynobia melagona. Er beobachtete, dass diese schwarzen Abarten von Jahr zu Jahr hier häufiger auftreten. Die Ursache dieser Erscheinung erblickt er in den eigenthümlichen Witterungsverhältnissen der letzten Jahre.

W. L. Tower (1900. 880) untersuchte den Käfer Leptinotarsa decemlineata Say, welcher östlich von den Felsengebirgen zwischen $32^{\circ}$ und $55^{\circ}$ nördliche Breite verbreitet ist, und fand, dass linter dem Einfluss der klimatischen Verhältnissen auf diesem grossen Gebiete eine merkliche Rassenbildung beginnt und zwar erst nachlem dort die Kartoffelkultur eingeführt wurde. Bis jetzt fand er schon 6 Typen, welche von einander durch ihre Färbung sich unterscheiden.

J. Krasilschtschik (1900. 472b) fand, dass während die untere Seite der Flügel von Heliothis dipsaceus in Nord-Kaukasus helle grau-gelbe Färbung hat, diese Färbung in einigen Gegenden dieses Rayons (z. B. in der Nähe des Dorfes Blagodarnoje auf Bujowol, Gouvernement Stawropol) grell gold-röthlich ist.

L. Sorhagen (1901. 823) führt die Verlunkelung des dem norddeutschen Kü̈stengebiet angehörigen Kleinschmetterlings Tortrix podana Sc. auf das Küistenklima zurück. Da dieser Schmetterling polyphag und nicht nur auf Oleaceen angewiesen ist, wie Major 
Hering ammehmen möchte, so ist dessen Meinung, die auffalencle Verdunkelung sei dieser Nahrung zuzuschreiben, nicht zutreffenil.

J. Dahlström (1901. 161) schreilut das Vorkommen von zahlreichen und verschiedenartigen Apatura-Aberrationen dem Einflusse nasskalten Wetters auf die zum Schlüpfen reife Puppe zu. 1901 herrschte bis 18. Juni grosse Dürre, dlann trat Regen ein, welcher im Geleit von Nordwind vier Tage währte, an 21. Juni aber war ein Gewitter und dann bis 27-ten täglich Regen und kalter Norilwind; am 28-ten kam wieller warmes Wetter unı nun fanclen sich auch zahlreiche Variationen ein.

K. Kraepelin (1901. 473a) sagt, ilass die Eischeinung iles Melanismus im Niederelbgebiet auffallend verbreitet ist und bei einer ganzen Reihe von Arten beobachtet wurle. Es sind dies: Dasychiru pudibunda var. concolor Strlgr., Psilura monacha var. eremita Ochish., Hadena monoglypha var. olscura Stdgr., H. scolopncina var. hammoniensis Sauber, H. opliogramma vai. surtur Stugr., Amplicdasis betularius var. doubledayaria Mill., Tortrix podana var. sauberiuna Sorh. und Lithocolletis schreberella var. obumbrata Sorh.

S. und M. Tschugunow (1902. 885) beobachteten, dass Stücke von Papilio machaon in West-Sibirien keine intensiv gelbe Färbung haben, wie es z. B. bei Exemplaren an der Wolga der Fall ist, sondern bleicher sind. In dieser Gegent sind viele Sümpfe vorhanden.

W. Petersen (1902. 633) beobachtete in Estlan!l folgende Abänderungen in der Färbung der Schmetterlinge: lichter.

Argynnis amathusia Esp. ist auf der Oberseite bedeutend

Hyloicus pinastri L. hat ein sehr düsteres Braungrau.

Drepana curvatulı Bkh. ist heller und lebhafter gefarbt als in Deutschland.

Acronicta rumicis L. ist bedeutend lichter.

Agrotis simulans Hfn. ist bedeutend dunkler als im Süden. Agrotis occulta L. ist viel dunkler als in Deutschland. Acidalia immorata L. besitzt weissliche Färbung. Larentic caesiatı Lang. ist dunkler als in Mittel-Europa. Selenia bilunaria Esp. ist blasser, mit wenig scharfer Zeichnung. Phrugmatobia futiginosa L. Die Flügel sind dünnbeschuppt. Endrosu irrorella Cl. ist sehr bleich und sehr diunbeschuppt. 
A. Trost (1902. Ss4 $九$ ) fiml in Steiermak auf ler Büreralpe bei Mariazell Exemplare ron MLlituea dictynn Esp. mit ganz schwarzen Hinterflügeln.

Alex. Reichert (1903. 684) ermittelte, lass Ocneria dispar $\delta \delta$ in Sibirien sehr dunklel gefiribt sind unıl einen blauen Glanz haben, der den deutschen Schmetterlingen ganz fehlt. Die IVeibchen sind heller, ihre Querlinien auf den Oberflïgeln sind zu schwarzen Flecken aufgelöst. Die Weibchen werden immer heller, je mehr ihre Heimat östlich liegt; die Stücke von Askold sinıl fast rein weiss. Die Raupen unterscheiden sich auch durch ihre Zeichnung von den europäischen, mit denen sie kaum eine Aehnlichkeit besitzen.

Pabst (1903. 621) sagt, dass in Chemnitz Smerinthus populi L. in günstigen Sommer zweimal erscheint, und zwar im Mai, dam wiedler vom August bis September. Die Schmetterlinge der zweiten Generation sind sehr hell, gelblich, in der Färbung fast wie Sm. quercus Schiff.

H. Fruhstorfer (1903. 264) traf auf seiner Dampffahrt längs der annamitischen Küste auf jeder Station wiedler eine neue Färbungs-Metamorphose von Appias lilythea F. Die Reise führte ihn von Norden nach Süiden und allmälig aus einer regenreichen Gegend in eine trockenere Zone. Die Intensität der schwarzen Flïgelumrahınung und Zeichnung (ler Hinterflügel-Unterseite nahm immer mehr ab und liess langsam ein fast reines Weiss Platz greifen. „Das Verhalten dieser Art bietet eines der anschaulichsten Beispiele für die Veränderlichleit der Pieriden, welche durch klimatische Einflüsse hervorgerufen wird" (p. 41).

Überdies sagt er: "Ausserlem fing ich in Siam eine ganze Reihe von Uebergangstïcken (Ixias pyrene L.). Auffalend ist nur, dass in N. Indien, China, Tonkin beide Zeitformen ihre gelbe Farbe behalten, während in S.-Annam, Siam und Birma die Trockenzeitform weiss wird" (p. 41).

H. Rebel (1903. 676) konstatierte folgende Unterschiede in der Färbung der bulgarischen Schmetterlinge:

Die Rilostücke von Parnassius apollo L. sind meist etwas dichter grau bestäubt als Exemplare von dem Balkan.

Die bulgarischen orangegelben Stiicke von Colias myrmidone. Esp. var. balcanica Pbl. sinı noch clunkler als die bosnischen. 
Die bulgarischen Stücke von Argynnis pulrs Schiff. stimmen . mit solchen aus den Hochgebirgen Bosniens überein und unterscheiden sich auf der Unterseite von typischen alpinen Stïcken durch die deutliche schwarze Zeichnung der Vorderflügel und die deutliche Ocellenbildung der Hinterflügel.

Erebiu medlusa F. wird in höheren Lagen (von ca. $1600 \mathrm{~m}$. aufwärts) berlentend dlunkler, die Augenflecke und die Binle mehr reduziert.

Chrysophanus hippothö̈ L. $ठ \sigma^{\nearrow}$ haben in Rilo die rotgelbe Randbinde der Hinterflügelunterseite rlentlicher als zentraleuropäischen Exemplare. Die weiblichen Exemplare nähern sich ler var. candens HS.

Smerinthus quercus Schiff. ist etwas grünlicher gelb als ungarische Stiicke.

Chloantha radiosa Esp. auf dem Rilo ist berlentend dunkler als in der Ebene.

Orrhodia torrida Ld. hat in Slimno etwas hellere Hinterfligel als in Sizilien.

Ancylolomia palpella Schiff. hat bei Sliwno etwas dunklere Bestäubung der Vorderflügel als die ungarischen Stiicke.

Oxyptilus didactylus L. bei Slirno ist weniger rötlich gefärbt als in Zentraleuropa.

Coleophora onopordiella Z. bei Slivno ist dunkler als ungarische Exemplare.

H. Rebel (1904. 677) beobachtete bei Schmetterlingen von Bosnien und Herzegowina folgende Abweichungen in der Färbung:

Melitaea cinxia L. Einige $\bigcirc$ vom Maklenpass sind oberseits schwärzlich verdunkelt.

Mel. didlyma O. von Jablanica ( $\left.\sigma^{\nearrow}\right)$ iibertrifft durch ihr auffallend dunkeles, tiefrotbraunes Kolorit der Oberseite alle sonstigen Lokalformen.

Argynnis amathusia Esp. $\sigma^{\top} \sigma^{\top}$ sind oberseits oft stark verdunkelt.

Erebia ligea L. variirt bei zunehmender Höhe der Flugplätze beträchlich. So müssen Stücke aus hohen Lagen des Prenjgebietes (K1. Prenj 1650 m.) zufolge der zusammenhängenden Saumbinde der Hinterflïgeloberseite noch zu ligea gestellt werden, zeigen aber andererseits die Mittelbinde der Hinterflügelunterseite beim $\$$ zuweilen auch wurzelwärts scharf weiss begrenzt, was sonst nur bei euryale sich findet. 
Satyrus semele L. ist auffallend verdunkelt.

Satyrus dryas Sc. hat sehr grosse Augenflecke (ier Vorderflügel. Coenonympha iphis Schiff. aus dem Gebirge (Trebević, Lakat) hat sehr grosse Augenflecke der Hinterfliigelunterseite.

Heliothis armigera $\mathrm{Hb}$. ist stark verdunkelt.

Codonia suppunctaria $\mathrm{Z}$. hat weniger helle Unterseite als die Stücke aus Dalmatien.

Scotosiu rhumnata Schiff. von Stolac ist sehr dunkel und viel schwächer gezeichnet.

Tephroclystic semigraplata Brd. 을 ist sehr dunkel, fast zeichnungslos.

Biston graccarius Stgr. $\delta$ ist dunkler als in Istrien und heller als in Dalmatien.

Boarmia perversaria $B$. $q$ ist auffalend schwärzlich verdunkelt.

Ematurga atomaria L. $\delta$ von Sarajevo ist auffalend dunkel.

Selidosema ericetaria Vill. ist in Konjica dunkler und dichter bestäubt.

Scoctiona conspersaria Schiff. in Gacko ist auffalend gleichmässig, dicht grau bestäubt.

Zyguena achilleae Esp. Stücke von Ubli haben die Flecken (ler Vorilerflügel grösser, die rothe Färbung mehr mennigroth.

Zygacna stocchudis Bkh. var. dubia Stgr. Die Stücke ron Vucija bara zeigen auf den Vorlerflügeln nur fünf Flecken.

Psorosa dahliella Tr. Schwach gezeichnet.

Titanio phrygialis $\mathrm{Hb}$. Entbehrt des blauen Schimmers alpiner Exemplare.

W. Petersen (1904. 633a) beobachtete am Ural, dass die SüdFormen ler Lepidopteren auf Bergspitzen sich aufhalten, welche von der Sonne erwärmt werden, während die Nordformen an sümpfigen, mehr kälteren Orten, am Fusse derselben Berge fliegen.

A. Trost (1904. 884a) lionstatierte, dass die steierischen Exemplare von Satyrus dryas Sc. an lebhafter Farbe und Zeichnung gegen diejenigen aus Süiltirol weit zurück stehen.

E. Hoffer (1904. 376a) studierte in Steiermark las Farbenvariiren der Hummeln. Folgender Versuch klärte ihm die Ursachen des Farbenvariirens auf: "Am 10. August 1890 bekam er ein grosses Nest des Bombus agrorum mit etwa 150 Individuen. Das Nest war auf der Schattenseite eines Hauses auf sandigem Boden gefunden 
worlen. Er tat es in einen grossen Blumentopf auf ein gegen Sürlen gelegenen Fensterbrett. Anfungs hatten alle die Normalfarlbung, also viel schwarz auf Thorax und Abdomen. Da die Somne ungemein heiss auf dieses Fenster brannte, so goss er fast tiiglich Wasser in den Blummentopf, dessen unterer Teil gewöhnliche Gartenerile enthielt, währenıl sich auf derselben rlie mit ilırem leststoffe (Moos) berleckten Waben befanden. Die anfangs ausschlïpfenden jungen Hummeln hatten noch die Färbung ihrer älteren Geschwister, die rom 19. August an sich entwickelnden waren dlurchgehends wunlerschöne gelbe florclis, sollass, nachlem sich die früher ausgelirochenen $q$ in clie Winterquartiere begeben und die $\sigma^{\star}$ ins Freie rerflogen hatten, während die älteren $\bigcirc$ zugrunile gegangen waren, im ganzen Veste nur floralis lebten. Dass in diesem Falle hohe Tageswärme, Licht und Feuchtigkeit der Grunıl der gelben Färbung waren, ist wohl zweifellos." Solche Versuche stellte Hoffor auch in clen späteren Jahren an, und wandelte auch lichte floralis durch Entziehumg ron Sonnenlicht und Wärıne in die gemeine Form und sogar in minorum und tricuspis um.

H. Galvagni (1905. 270a) sammelte Coenomympha pamphitus L. im Küstenlanle (Oesterreich-Ungarn) und fand, dlass „diese Art dlort unter dem Einflusse der halophytischen Vegetation (Salzwiesen) eire wohl in den Formenkreis iler var. marginata Riuhl zu ziehende Lolialrasse ausgebildet hat. Sie ist feurig rotgelb gefürbt. Die Exemplare (ler II. oder III. Generation waren noch immer lebhatter gefärbt als die lebhaftesten Stücke aus Niederösterreich.

L. v. Aigner-Abafi (1905. 7c) fanil im Hochgebirge Ungarns von Pieris napi ab. bryoniae besonders dlunkle Stïcke und zwar in der. Tátra und im südlichen Siebenbürgen.

H. Rebel (1905. $677 a$ ) demonstrierte in der Sektion für Lepidopterologie iler Wiener zool.-bot. Gesellschaft ein $ᄋ$ ron Lupernia zollitioferi Frr., welches am 23. September 1903 in Chodau bei Karlsbad erbeutet wurde. Beim Vergleichen mit Herrich-Schäffers Bild 104 (q) erwies sich das Karlsbader Exemplar bedeutend heller, der ïussere gezackte Querstreifen der Vorderflügel weniger deutlich und die rlunkle Saumbinde der Hinterflügel weniger scharf begrenzt.

E. Ulbrich (1905. $886 a$ ) fancl in Ungarn sehr dunkel gefärbte Euclictia triquetru, Acidalia ornata mit breitem Band auf clem Oberflïgel uni Caustolomu flavicrivia mit reslucirten braunen Flecken. 
Wilhelmine Enteman (1905. 214a) untersuchte die amerikanische Wespengattung Polistes. Die Arten der Wüstengegenden Arizonas und des Südwestens Norilamerikas sind viel bleicher gefïrbt und entbehren der dunklen und warmen Töne des Braun und Schwarz, welche die nordischen Formen aufweisen. Die kälteren un feuchten Gegenden, so die Kiüsten Nordamerikas unıl Furasiens bringen melanistische Formen hervor. Daraus zieht sie den Schluss, dass die Entwickelung des Pigmentes wesentlich von der Temperatur und Feuchtigkeit abhängt.

H. Federley (1905. 219a) ziichtete in Helsingfors Lymantria cispur L. aus Eiern, welche aus dem südlichen Schweden stammten, und erhielt etwas dunklere Falter als der gewöhnliche deutsche Typus, was besonders bei dem $q$ auffallen:l war. In einer deutschen Brut, die er gleichzeitig mit den schwe:lischen unter ganz älnlichen Verhältnissen züchtete, waren alle $ㅇ$ 일 heller.

Aglia tuu L., welche er am Ladogasee (Finnland) gefangen hat, hatten die schwarze Bestäubung dichter und die Ocellen ein wenig grösser als bei der gewöhnlichen europäischen Form.

Riesen (1906. 694b) fand, dass Parasemia plantaginis ठ ठ ohne schwarzen Mittelpunlit auf den Hinterflügeln vorzugsweise im Osten (Ostpreussen, Polen, Schlesien), und mit diesem Mittelfleck mehr im Westen (Harz) vorkommen. Die $q$ q mit rothen Hinterflügeln kommen überall vor, die mit gelben nur in höher gelegenen Gegenden.

H. Fruhstorfer (1906. 264a) besichtigte die Sammlung ron B. Hagen und fiund, dass die Falter, welche auf der Insel Banka, ini Mai 1905 gesammelt wurden, in einem äusserst potenzierten albinotischen Kleide erscheinen, „ja die memnon-Rasse der Insel X. B. ist wohl die hellste Form, die wir bisher kennen, und dasselbe gilt auch für eine IIycalesis und mehrere Euthaliden." Er meint, dass diese Schmetterlinge den Trockenzeitformen angehören.

\section{Ergänzungs-Litteratur zu diesem Abschnitt.}

Abafi, A. Lepkek színváltozása. - Rovart. Lanok, VI. ł 1. 1899. p. 12-16. [Farbenänderungen der Lepidopteren. (Ungarisch)].

Adams, C. C. Geographical Distribution of Variations in Io. - Science, N. S. Vol. 13. . 316. 1901. p. 113. 
Birchall, Edwin. On Melanism. - Entomologist's Monthl. Mat. XilI. 15i6-7. p. $130-133$.

Bruner, L. Notes on the wing-color of N. American Locusts lielonging to the subfamily Edipodinae and its seeming relation to climatic conclitions. Science. XXI. 1893. p. 133.

Distant, W. L. On a supposed climatic rariation in the wing-colour of some Orthoptera. - Science. XXI. 1893. p. 245-246.

Elwes, Henry John. On the Butterflies of Bulgaria. - Trans. Entom. Soc. London. 1900. P. II. p. 183-206.

Hormuzaki, C. v. Einige bemerkenswerthe Lepidopterenformen aus der Bukowina. - Societas entomol. VIII. ㄱo 8. 1893. p. 58-59.

Jordan, K. An Examination of the Classification and some other results of Eimer's researches on Eastern Papilios: A Review and Reply. - Toritates Zoologicae. V. 1898.

Kennel, J. Sexueller Dimorphismus bei den Schmetterlingen. Dorpat 1896.

Kleine, G. Findet bei den Bienen in den verschiedenen Theilen Deutschlands ein Unterschied statt? - Eichstädt. Bienen-Ztg. 18. Bd. 1862. p. 206-207.

Mathew, G. F. Effect of change of climate upon the emergence of certain species of Lepidoptera. - Tr. E. Soc. 1891. p. 503-507.

Seitz, A. Allgemeine Biologie der Sehmetterlinge.-- Zool. Jahrb. Alth. f. Syst. V. 1890 . p. $281-343$.

Seitz, A. Das Klima in seinem Einflusse auf die Lepidopteren. - Verlı. Deutsch. Naturf. II. 1890. p. 142-148.

Trimen, Roland. Proceed. Entomol. Soc. London. 1898.

\section{Einfluss der Feuchtigkeit.}

H. Meyer-Dür (1852. 580) sagt, dass Arge galathea auf Wiesen und an heissen trockenen Berglehnen in grüngelben Stücken zu treffen ist, während diese Art auf Torfmooren und Sumpfgegentlen weissliche Grundfarbe besitzt. Weiter dass die Bodenart hauptsächlich nur auf die Farben ler Unterseite wirkt. Weisser, trockener Kalkfels verwandelt das Braungelb in Weissgelb (coridon), während schwarzer Kalkschieferfels die hellgrauen Farben verdunkelt.

J. Jenner Weir (1876. 950) meint, lass die Feuchtigkeit der Atmosphäre während des Gewitters gewisse Farben bei soeben ausgeschlïpften Faltern ändern kann. Er machte folgenden Versuch: Procris globulariae, welcher im Moment des Ausschlüpfens grün war, wurle in einen Dampfkasten gebracht, wobei seine grüne Färbung sich in dunkelbronzene umwandelte; nach dem Trocknen wurle er wieder grün. 
E. K. Robinson (1S77. 695) heobachtete, llass Raupen, welchen saftige Ptlanzen gereicht werlen, meist blass gefïrbte Schmetterlinge ergeben.

W. Prest (1877. 649) ernührte die Raupen von Amphidasis letularia mit trockenen PHanzen und erhielt im Verlaufe weniger Generationen vollständig schwarze Schmetterlinge. Bei Abraxas grossulariata wurde das Braun durch weiss und bei Arctia caja das Braun durch weiss und Roth ersetzt.

Nach Butler (1879. 124) fand Swinhoe, dass Cyllo leda L. zu Bombai das ganze Jahr hindurch sowohl in der leda- als auch in der ismene-Form vorkoinmt, was den Angaben von de Nicéville (1885. 611) widerspricht, welcher behauptet, dass die erste Form während der Regen- und die letzte während der Trockenzeit zu treffen ist.

Lionel de Nicéville (1885. 611) berichtet, dass die Indischen Falter Cyllo (Melanitis) leda L. und Cyllo (Melanitis) ismene Cram. eine und dieselbe Art sind. Der erste Schnetterling kommt wälırend der Regen- und der zweite während der regenlosen Zeit vor.

C. Ribbe (18s9. 690) fand im indo-australischen Archipel, dass die Raupen der grünen Varietäten von Ornithoptera priamus nur auf solchen Aristolochia-Arten sich aufhalten, welche auf trockenem Boden wachsen, während die Raupen der goldgelben Varietäten croesus auf Batschian nur auf solchen Pflanzen leben, welche auf sumpfigen Boden wachsen.

F. Rühl (1889. 718) beobachtete, dass Argynnis euphrosyne L. in nassen Jahrgängen mit zahlreicheren und breiteren schwarzen Zeichnungen versehen ist, namentlich ist oft das Wurzelfeld ganz schwarz.

Otto Habich (1891. 347) in Hernals bei Wien beobachtete öfters, dass die Trockenleit des Futters einen Einfluss auf die Färbung der Schmetterlinge ausübt. So z. B. fand er Eupithecia sobrinata im Freien gewöhnlich hellgrün mit dunkelgrïner Dorsale und weisser Laterallinie. Diese Färbung ändert mit zunehmender Trockenheit des als Futter dienenden Juniperus communis von 
gelb bis roth ab unl die Raupen nehmen Zeichnungen an, welche man bei denselben in Freien vergebens suchen wïrle.

R, Berger (1892. 72) sagt, dass die schwarze Form von Aglia tau in der Freiheit nur als Raupe auf ganz feuchten Walistellen abgeklopft werle. „Die Fenchtigkeit iles Staniortes ier Futterplanze, der grössere Consum von Feuchtigkeit durch lie liaupe ist gewiss mit Recht zu den Momenten zu zählen, welche das Erscheinen schwarzer Formen in der Freiheit befördern" (p. 60).

Fritz Rühl (1892. 721) beschreibt in seinem Buche (len Pup)jenkasten System Davis (p. 51), wobei die Puppen ïber heissem Wasser sich befinclen und Schmetterlinge ergeben, bei welchen die schwarze Färbung begünstigt wird.

C. Frings (1893. 250) fing in der Umgebung Bonn's am 26. Mai 1892 auf einer sehr sumpfigen Stelle eine Mclitaea, lleren Unterseite mit ierjenigen typischer aurinia übereinstimmte, sonst ähnlich wie didyma und olne Spur der für aurinia so charakteristischen hellgelben Fleckenzeichnungen. Im Mai 1893 fing er an gleicher Stelle eine deutliche Uebergangsform ron der aurinia-GruntForm zu der eben beschriebenen Aberration und noch ein Exemplar dieser Aberration.

F. Rühl (1893. 726) beobachtete, dass die grïne Farbe der Flïgel von Ellopia prosapiaria var. prasinaria $\mathrm{Hb}$. beim Flug in regnerischem Wetter leidet, wobei diese Exemplare der Stammform nahe kommen.

M. Standfuss (1894. 837) feuchtete mehrere Male intensiv die Saturnia-Puppen an, welche 7-10 Wochen zwischen Juni und Enile September sehr trocken gelegen hatten, und erhielt aus diesen Puppen 10-20 Tage nach dem Anfeuchten etwa $10 \%$ Falter, welche sämtlich mehr odler weniger verschwommene und verwaschene Zeichnungen besassen.

Als August Weismann (1895. 954) die Puppen von Chrysophlanus phlaeas L. im Eisschrank bei $7-10^{\circ}$ hielt, bemerkte er bei ausgeschlüpten Faltern, "dass die Feuchtigkeit des Eisschrankes nicht selten das Roth ganz blassgelblich machte" (p. 7). An einer 
anderen Stelle sagt er: „Die Zeichnung wird bei vielen Schmetterlingen im Eisschrank verwaschen, nicht blos bei phlacas, sondern auch bei Vanessa urticae und levana und anileren Puppen, welche lange in Eisschrank gewesen waren; alle geben öfters Schmetterlinge mit verwaschener Zeichnung" (p. 16).

C. W. Barker (1895. 52) beobachtete in Natal, class die Schmetterlinge einer und derselben Spezies, welche in der trockenen Jahreszeit fliegen, sich von den Formen der Regenzeit durch geringeren Unfang oder gänzliches Verschwinden dunklerer Zeichnungen der Flügeloberseite, durch Zusammenfliessen der Zeichnungen der Flügelunterseite zu einer dunkleren Grundfarbe, sowie durch Schrumpfen oder:Schwinden etwa vorhandener Augenflecke unterscheiden.

M. Standfuss (1896. 840) spricht die Vermuthung aus, llass der Albinismus der Eintrocknung der Puppe zu zuschreiben sei, da er an sehr heissen Lehmen Puppen von Epinepleele janira und Coenonympha pamphilus fand, welche ihm albinistische Falter ergaben, "loch reichte das Material nicht hin, un für die Unbestreitbarkeit des Schlusses genügende Sicherheit zu bieten" (p. 200).

Er brachte auch etwa 30 Puppen von Deilephila nerii in ein kiihles Zimmer auf eine stark durchnässte Sandunterlage. Die auf dem Sand aufruhende Seite der Puppe wurde bei lem Falter albinistisch; diejenigen Puppen, welche am Bauche gelegen hatten, ergaben allinistische Billung symmetrisch ausgeprägt.

Otto Habich (1896. 348) in Wien crwähnt gelegentlich der Beschreibung von Coenonympha pamplitus L. ab. cburnea sibi, welche elfenbeingelbe Färbung besitzt, die Feuchtigkeit als die Ursache des Albinismus, indem er sagt: "Theilweiser Albinismus tritt häufiger auf, besonders bei dem Genus Erebia, Pararge, Coenympha etc., liurz, bei Arten, wo die Puppen ohne weiteren Schutz frei auf (ler Erdoberfläche liegen und rührt wohl meist von zu starker Feuchtigkeit her, welche die Ausbildung des Pigmentes hinclert."

R. Jänichen (1897. 414) brachte die Raupen von Lasiocampa potatoria in ein Glas, auf dessen Boden Wasser sich befand, wobei sie den ganzen Winter, ohne zu schlafen, gefüttert wurlen. "Unter der Einwirkung des verdunsteten Wassers behielt die Raupenhaut die erste helle Färbung bis Mitte November. Erst dlann zeigte sich 
nach einer Häutung das ilunkle Kleil, als die Thiere \$-10 Tage olıne feuchten Untergrum gestanden hatten" (p). 183).

Wilh. Kusdas (1897. 488) in Wien erhielt von einem im Freien gefangenen $q$ Nemeopluita plantuginis 18 Eier, welche am 4. Juli Räupchen ergaben, die ihrereseits bereits an 28. August bis 21. Olitober sich rerpuppten. Aus sïmmtlichen Puppen schlïpften

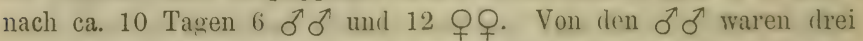
normal gezeichnet, während die drei anderen eine Abweichung zeigten: die schwarze Zeichnung auf den Hinterflïgeln beschränkte sich auf zwei ganz feine und kurze Streifen aus rler Wurzel und einige Flecken am Saume. Die IIinterflïgel waren fast einfarbig orangegelb. Die Puppe ron Deilephila euphorticie ergab ihm am 6 . August (nach 3-wöchentlicher Puppenruhe) einen Falter, welcher auffillend starke rosenrothe Fürbung rer Vorderfliigel unıl Schultern aufwies.

Da die Zucht bei gewöhnlicher Temperatur stattfand und der Sommer sehr feucht war, erklärt Kusdas die vorzeitige Entwiclielung durch die feuchte Luft. Ob die Färbungsabweichung durch diese allzugrosse Feuchtigkeit und lurch die Redultion rler Puppenruhe entstanden ist, muss noch dahin gestellt bleiben.

Karl Frings (1898. 252) bettete im Herbst 1896 frische Puppen von Vunessa $C$ album und atalanta so tief in sehr feuchten Sand ein, dass die Flügelscheiden vollkommen ron demselben bedeckt waren. Der Hinterleil) der Puppen mit den Stigmen wurde sorgfältig vom Sanile freigehalten, um eine Erstickung zu verhüten. Während der ganzen Puppenruhe waren die Fliigelscheiden und überhaupt der ganze Vorlerkörper der Versuchsthiere grösster Feuchtigkeit ausgesetzt. Nachher wurden dieselben herausgenommen. $C$ album hatten die Zunahme der dunklen Zeichnungen auf Ober- und Unterseite. Sämmtliche atalantı zeigten etwas verschmälerte Vorlerfliigelbinde nebst blassen Flecken in derselben.

Bei M. C. Piepers (1895. 639) finclet sich folgende Stelle: ,Wie der Rotterlammer Entomolog Schuyt mir mittheilte, sah er in einer Sammlung in Kö̈n ein Exemplar von Papilio machaon, welches Schiller zeigte und aus einer Puppe ausgekommen sein soll, welche geraume Zeit im Wasser gelegen hatte" (p. 174).

In demselben Buche erwähnt ex, (lass Jenner Weir Versuche mit indischen Schmetterlingen angestellt hat, indem er die Raupen 
in einer künstlich feucht gehaltenen Atmosphäre zïchtete. Die erhaltenen Falter sahen denjenigen ähnlich, welche in Indien während der Regenzeit vorkommen (p. 188).

Auch Dohertỳ (1897. 190) berichtet dässelbe.

E. Schumann (1899. 796) fand bei feuchter unil kalter Witterung, welche im Mai und Juni herrschte, bei liawitsch einen ganz schwarzen Maikäfer und bei Posen zwei Anisoplia segetum $q$, bei denen das am Schildchen befindliche Schwarz so überhand genommen hatte, dass nur an der Schulter ein wenig Braun zu sehen war.

Oskar Schultz (1899. 788) besass 1897 eine Raupe ron $P(\iota$ pilio machcoon L., welche die letzten vier Leibesringe tief'schwarz gefärbt zeigte; dazu sagt er: „Der Ansicht, dass die dunkle Färbung (ler Raupe von feuchter Witterung abhängig ist - wie wohl hier und da verlautet - kann ich mich nicht anschliessen. Die ganz schwarze Varietät der Raupe wurle nach anhaltend trockenem Wetter gefunden ${ }^{\prime}$ (p. 331).

Derselbe Forscher (1900. 789) lielt die Puppen ron Papilio podalirius I. Generation im warmen Zimmer, wobei sie dem Einflusse grösster Trockenheit ausgesetzt wurlen. Von mehreren ausgeschlïpften Exemplaren zeigte eins eine aberrative Zeichnung und zwar: „Die zweite (rom Saum aus gerechnet) der schwarzen Querbinden auf den Vorderflügeln, welche am Vorderrand breit angelegt ist und nach dem Innenrand zu spitzer verläuft, zeigte gelblichweisse Bestäubung, llie stärker hervortrat als bei allen mir zu Gesicht gekommenen typischen Stücken. In dem oberen Verlauf des Querstreifens war diese weisse Pigmentation durch die schwarze Grundfärbung rippenartig breit lurchbrochen" (p. 57). Das Stück verkrüppelte nachlier.

H. Burstert (1901, 122) hielt die Puppen von Splinir pinastri in einer Lage, in der sie auf der einen Flügelscheiden-Seite ständig stark feucht, auf der anderen möglichst trocken gehalten wurlen. Von 40 Puppen schlüpte nur. ein Falter, die anderen gingen zı Grunde. Dieser Falter hat auf der Flügelpartie der rechten Seite, welche der Feuchtigkeit ausgesetzt war, hellere Farbe und ist zeichnungsloser, als dies links und überhaupt bei normalen Stiicken der Fall ist. „Man gewinnt den Eindruck, als sei hier durch die wi- 
drigen äusseren Verhältnisse letliglich die Aushlildung der feineren Zeichnung gehemmt, und das zur Verfiigung stehende dunkle Pigment an einzelnen, günstig gelegenen Stellen abgelagert worden. Das dunkle Pigment ist also nicht vermehrt, sondern nur ungenügend vertheilt" (p. 165). Dieser Versuch zeigt somit, lass eine lokale Reizwirkung auf die Puppe einseitige, aberrative Zeichnungsverschiebung des Falterflügels berwirken kann.

F. Fuchs (1904. 268) brachte die Raupen von Acidaliı similata Thnbg. in einen feuchten Kieller, wo sie oft tagelang verblieben. Es schlüpfte var. griseata Fuchs (Q). „Demnach scheint sich die Varietät unter feuchten klimatischen Verhältnissen zu entwickeln." Diagnose: Alle Flügel gleichmässig grau, mit starker Zeichnung.

H. Federley (1904. 219) fing in Süd-Finnland 1901 Vanessa antiopa ab. lintneri Fitsch. und 1902 wurle an Finnischen Meerbusen von J. A. Palmén Parnassius apollo ab. brittingeri Rbl. und Rghfr. gefangen.

"Die beiden Sommer 1901 und 1902 waren in Süil-Finnland besonders bemerkenswert durch ihre extremen Temperatur- und Niederschlagsverhältnisse unı zwar dergestalt, ılass der erste eine ungewöhnlich hohe Mitteltemperatur mit sehr wenig Regen zeigte, während der spätere sehr kalt und regnerisch war."

Da ab. lintneri Fitsch. als Synonym mit der von Fischer durch erhöhte Temperatur erzielte var. epione Fschr. betrachtet werlen muss (und wohl auch ab. daubii Strlfs.), so erklärt der Verfasser das Vorhandensein dieser ab. in Finnland durch die oben erwähnten meteorologischen Verhältnisse im Jahre 1901.

Das Entstehen der ab. brittingeri Rbl. erklärt der Verfasser slurch die ausserordentlich kalte und feuchte Witterung, unter welcher die Raupe und Puppe 1902 gelebt haben.

B. Slevogt (1905. 822 $\iota$ ) beobachtete, llass Argynnis aglaja L. Weibchen in feuchten Jahren stark an ab. emilia Quens. errinnerten.

A. Ulbricht (1905. 887) sammelte in der Umgegend von Duisseldorf Emphytus serotinus Müll. „Die ganz schwarzen Exemplare (serotinus Müll.) fand ich nur in dem sumpfigen Eller Wald (bei den hiesigen Schmetterlingssammlern bekannt durch seine Melanismen) und die am hellsten gefärbten (var. cereus Kl.) nur in dem trockneren Calcum." 
H. Federley (1905. 219a) hielt während rles ganzen Winters im Freien 14 Puppen von Leucoclonta bicoloria ab. unicolora Motsch und erhielt zwischen 28. V. und 29. VI. 6 typische bicoloriu, 3 unicolora, 3 albidce und 2 bicoloria trans. ad albiclam. Er vermuthet, dass hier nicht die Temperatur-, sondern die Feuchtigkeits- und Lichtverhältnisse die Hauptrolle spielen, indem dieselben ihren Einfluss auf Raupen und Puppen ausgeiibt haben.

A. Pictet (1905. 637a) fand, ${ }^{1}$ ) dass eine Fütterung der Raupen von Vanessa urticae und polychloros und von Ocneric dispar mit nassen Blättern (also mit einem Futter, wie es draussen in Freien eine 6-8 tägige Regenperiode auch hervorruft) Falter mit normaler schwarzer Zeichnung ergeben, lagegen Puppen, die 8 Tage in feuchter Atmosphäre gehalten werden odler 8 Tage lang künstlichem Regen ausgesetzt werden, viel dunklere Falter schlüpfen lassen. Vanessa urticae z. B. fiel unter solchen Umständen mit scharf schwarz markiertem Geïder und mit so stark ausgesprochenem Rand aller 4 Flügel aus, dass die blauen Flecken fast erstickt waren. Es bestätigt das die allgemeine Kenntnis von der melanotischen Wirkung der Feuchtigkeit. Wichtiger ist es, was über die Temperaturgrade gesagt warl. Warme Feuchtigkeit $\left(30-35^{\circ} \mathrm{C}\right)$ scheint auf die Puppen keine Einwirkung zu haben, und zwar deshalb nicht, weil diejenigen Puppen, die sich keinen Kokon fertigen, mit einer fettigen Substanz umgeben sind, welche sie gegen Regen schutzt, sodass es etwa 8 Tage dauert, ehe die Feuchtigkeit diese Substanz durchdringt. Nun weiss man, dass Wärme die Entwicklung der Falter beschleunigt und so kommt es. dlass z. B. Vanessa io und urticae unter der Einwirkung warmer Feuchitigkeit statt 15-18 nur 8 Tage Puppenstadium durchmachen, und diese Zeit ist dann zu kurz, um der Feuchtigkeit genügende Wirkung zu verschaffen. Trotzdem glaubt Pictet, dass einzelne Vanessa urticae neben den Spuren der Wärme auch Spuren von Verdunkelung durch Feuchtigkeit aufwiesen. - Kälte dagegen verlangsamt rlie Entwicklung der Puppen; in einer feuchten Atmosphäre von $8-15^{\circ} \mathrm{C}$ brauchen $V$. urticae und io 3 Wochen, von $5-10^{\circ} \mathrm{C}$ 4 Wochen Puppenruhe. Die Feuchtigkeit kann also einwirken und Pictet erhielt bei solchen Versuchen 90\% Falter mit schwarzem Geäder und verschwindenden blauen Randtlecken. Die Puppen von Vanessa io scheinen weniger von der Feuchtigkeit beeinflusst zu

1) Nach der „Insekten-Börse" (XXII. ’o 37. 1905) referiert. 
werden, als clie von urticac. - Auch hier gilt aber die Erfahrung, dass sich die Tiere an den Wechsel der Verhältnisse gewöhnen. Raupen von Ocneria dispar, die fast einen Monat lang - mit Unterbrechung - nasses Futter bekommen hatten, ergaben in erster Generation Falter, deren Weibchen auf clen Unterflügeln eine graue Zeichnung hatten. In zweiter ebenso behanilelter Generation aber erschien diese Zeichnung nicht wieder.

A. Ducke (1906. 197 «) beobachtete, dass verschiedene Hymenoptera am oberen Amazonas Neigung zur Verdunklung iler Färbung zeigen. ${ }_{n} \mathrm{Ob}$ dies wohl mit dem Waldreichtum und ilem regenreichen Klima zusammenhüngen mag? Guyana hat ja aher ganz ähnliche klimatische Verhältnisse und doch weichen z. B. die von nir am äusserst regnerischen Oyapoc gesammelten Stiucke in der Färbung nicht von denen cler trockenen Gegend von Obiclos ab."

\section{Ergänzungs-Litteratur zu diesem Abschnitt.}

Küchonmeister, Fr. Wie entstehen Albinos in Stocke? - Eichstädt. BienenZeitung. 14. Bd. 1858. p. 169-170.

\section{Einfluss der Temperatur.}

Die ältesten Angaben über diesen Einfluss latieren von 1852. M. Standfuss (1896. 840) sagt: ${ }_{n}$ Aus der Sammlung meines Vaters besitze ich ein Pärchen Vanessa ab. porima O., also die Zwischenform zwischen Vanessa levana L. und var. prorsa L. mit der Bezeichnung Iagleburg 1852 „Puppen im Keller gehalten“" (p. 236).

Darauf erzielte G. Koch (1856. 4576) Vanessa levana subvar. porima. W. V. durch Zucht im Keller.

Dorfmeister hielt am 27. Juni 1863 in der Versammlung des naturwissenschaftlichen Vereins fuir Steiermark in Graz einen Vortrag über Arten und Varietäten der Schmetterlinge, in welchem er zum Schlusse sagt: „Indess bin ich nach mehrjährigen Versuchen so glücklich gewesen, die Erziehung aller Uebergänge (von Vunessa 
prorsa zu $V$. levuna) aus Raupen zu bewirken, und will mir daher vorbehalten, meine Notizen hierüber nächstens dem löbl. Vereine vorzulegen; erlaube mir aber zugleich, die vorgezeigte Reihe der Varietiiten der Vanessa levana zur Verfügung zu stellen" (p. 98) (1864, 193).

Diesem Versprechen kam er in der Vesammlung von 27. Februar 1864 nach. Sein Thema lautete: „Ueber die Einwirkung verschierlener, während der Entwicklungsperioden angewendeter Wärmegrale auf die Fürbung und Zeichnung der Schmetterlinge" (1864. 194).

Die ersten Versuche datieren von 1845, als er die Raupen iler Vanessa antiopa und später der Puppen der Vanessa levana in Eiskübel setzte, ohne jedloch eine Verïnderung an den Schnetterlingen $\mathrm{zu}$ erzielen. Die eigentlichen Versuche wurlen 1859 und 1860 angestellt. Es wurle konstatiert, dass die Temperatur auf die Fïrbung und die Zeichnung des künftigen Schmetterlings einen Einfluss ausïbe und zwar den grössten während der Verpuppung, zunächst aber kurz nach derselben.

Bei vielen wird durch eine erhöhte Temperatur eine hellere, lebhaftere, durch eine erniedrigte eine weniger lebhafte Grundfarbe berwirkt, so z. B. bei Vanessa jo, urticae etc. Bei Euprepia caja wird die rothgelbe Grundfarbe der Hinterflïgel durch erhöhte Temperatur in Mennigroth, lurch erniedrigte in Ockergelb verwandelt.

Die von der Jugend an bis zur Verpuppung in einer höheren Temperatur erzogenen Raupen ier Xantlia cerago W. T. lieferten die var. flavescens Esp.

Die Versuche mit Raupen der Vanessa levana wurden in den Sommermonaten angestellt. Die Zimmer-Temperatur variirte zwischen $17^{\circ}$ und $20^{\circ} \mathrm{R}$.

Die erhaltenen Resultate stellt Dorfmeister in folgenden Tabellen zusammen: 
TABELLE I.

Verschiedene Versuche mit Raupen und Puppen iler Van. levana L. (var. prorsa).

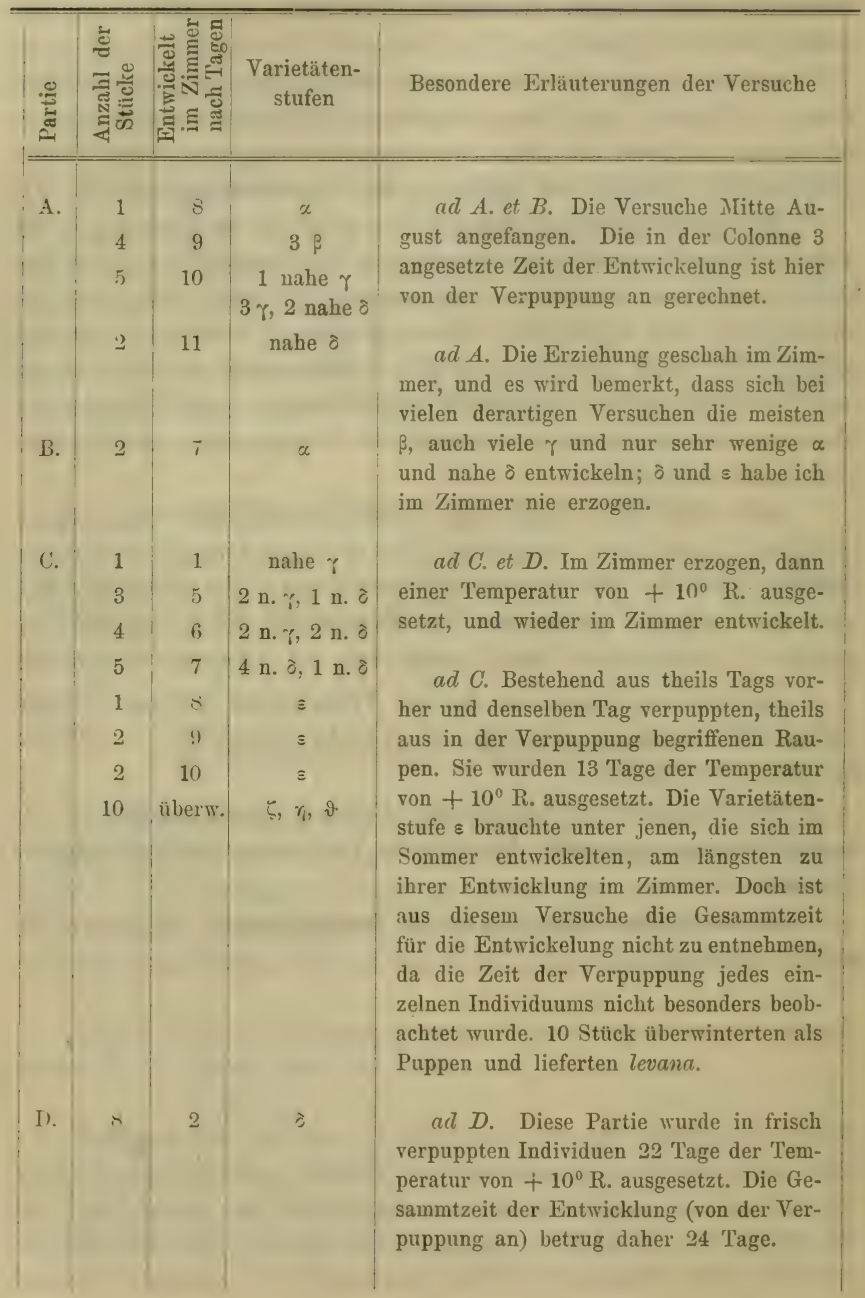


TABELLE II.

Ueber Versuche mit im Zinnmer erzogenen und daselbst verpuppten dergleichen Raupen.

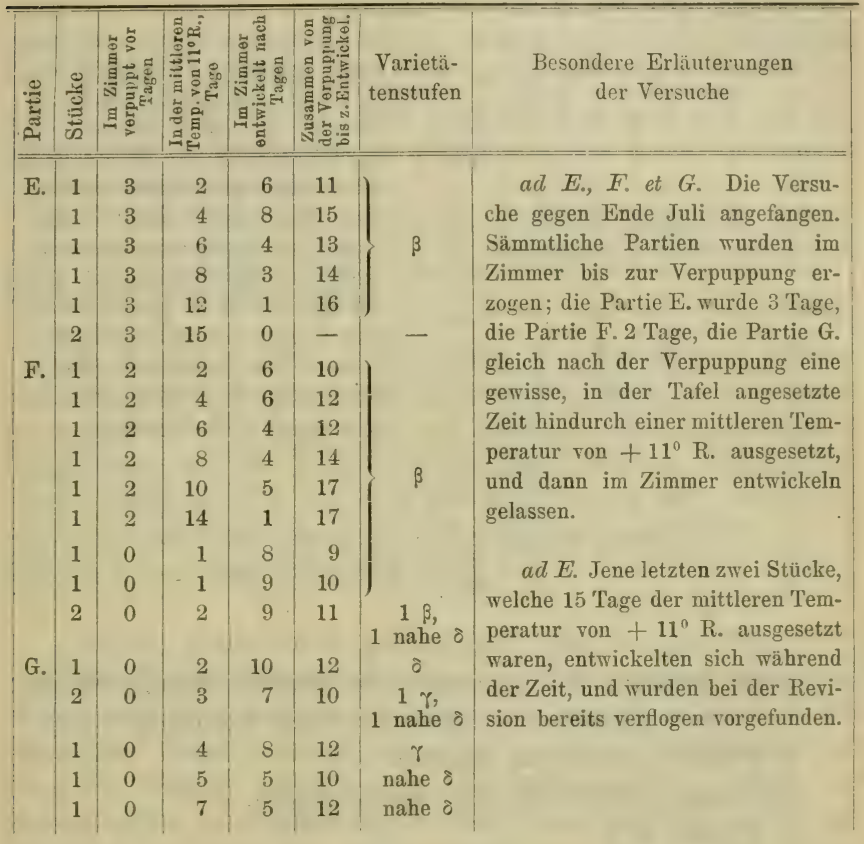

TABELLE III.

Ueber Versuche mit im Zimmer erzogenen unil in der Verpuppung begriffenen derlei Raupen.

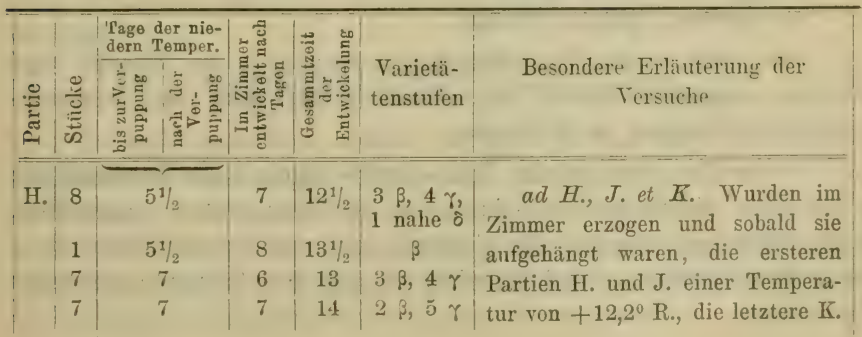




\begin{tabular}{|c|c|c|c|c|c|c|c|}
\hline \multirow[b]{2}{*}{ 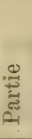 } & \multirow[b]{2}{*}{ 苞 } & \multicolumn{2}{|c|}{$\begin{array}{l}\text { Tage der nie- } \\
\text { dern Temper. }\end{array}$} & \multirow{2}{*}{ 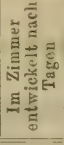 } & \multirow{2}{*}{ 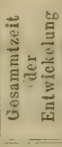 } & \multirow{2}{*}{$\begin{array}{l}\text { Varictä- } \\
\text { tenstufen }\end{array}$} & \multirow{2}{*}{$\begin{array}{l}\text { Besondere Erlauterung der } \\
\text { Versuche }\end{array}$} \\
\hline & & 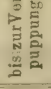 & 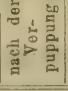 & & & & \\
\hline \multirow[t]{8}{*}{ J. } & 1 & 2 & 4 & 5 & 11 & $\beta$ & \multirow{18}{*}{$\begin{array}{l}\text { einer mittleren Temperatur von } \\
+11^{0} \text { R. ausgesetzt, sodann im } \\
\text { Zimmer entwickeln gelassen. In } \\
\text { der Gesammtzeit der Entwicklung } \\
\text { ist bei allen drei Partien auch die } \\
\text { Zeit, die dieselbe bereits aufge- } \\
\text { hängt zur Verpuppung gebraucht } \\
\text { haben, mitbegriffen, welche Zeit } \\
\text { bei der Partie H. nicht, bei J. } \\
\text { und K. aber besonders beobachtet } \\
\text { wurde. Die Versuche H. und J. } \\
\text { wurden am 18. August, jener K. } \\
\text { aber am } 17 \text {. Juli begonnen. }\end{array}$} \\
\hline & 3 & 2 & 4 & 6 & 12 & $\beta$ & \\
\hline & 2 & 2 & 4 & 7 & 13 & $\beta, \gamma$ & \\
\hline & 2 & 2 & 4 & 8 & 14 & nahe $\gamma$ & \\
\hline & 1 & 2 & 6 & 5 & 13 & $\beta$ & \\
\hline & 3 & 2 & 6 & 6 & 14 & $\gamma$ & \\
\hline & 1 & 2 & $61 / 2$ & 5 & $13^{1} / 2$ & $\beta$ & \\
\hline & 4 & 2 & $6^{1} / 2$ & 6 & $14^{1} / 2$ & $2 \beta, 2 \gamma$ & \\
\hline \multirow[t]{10}{*}{ K. } & 2 & 1 & 1 & 9 & 11 & $\beta$ und $\gamma$ & \\
\hline & 1 & 1 & 2 & 9 & 12 & $\gamma$ & \\
\hline & 2 & 1 & 2 & 10 & 13 & $\gamma$ & \\
\hline & 1 & 1 & 3 & 8 & 12 & $\gamma$ & \\
\hline & 2 & 2 & 3. & 8 & 13 & $\gamma$ & \\
\hline & 1 & 2 & 4 & 7 & 13 & $\gamma$ & \\
\hline & 2 & 2 & 4 & 8 & 14 & $\gamma$, nahe $\delta$ & \\
\hline & 1 & 2 & 5 & 8 & 15 & $\varepsilon$ & \\
\hline & 1 & 2 & 6 & 8 & 16 & nahe $\varepsilon$ & \\
\hline & 1 & 2 & 7 & 7 & 16 & nahe $\varepsilon$ & \\
\hline
\end{tabular}

Dabei bedeuten die grichischen Buchstaben folgende Formen: ๙. Prorsa, seltenere Var. mit sehr wenig Zeichnung.

ß. Prorsa, gewöhnliche Varietät.

భ. Prorsa, gewöhnliche Var. als Uebergang.

o. Porima 시 1.

๕. Porima 수 2 .

ఢ. Levana, dunkel, als Uebergang.

$\eta$. Levana, gewöhnliche.

ๆ. Levana, hellste Varietät.

Die vier ersten Varietätenstufen erscheinen im Sommer und Herbste desselben Jahres, die letzten 3 nur nach der Ueberwinterung der Puppen im Frühjahre.

Über die Ursache der Temperaturwirkung sagt Dorfmeister: „ich wage nicht zu entscheiden, ob die Temperatur unmittelbar, oder mittelbar vermöge der dadurch hervorgerufenen Verzögerung oder Beschleunigung der Entwicklung auf die Färbung einwirke" (p. 108). 
1870 hielt C. A. Teich (1870). 855) seinen Vortrag ïlser: "Klima und Schmetterlinge." Nach den Sitzungs-Protokollen iles Naturforscher-Vereins zu Riga fühte Herr Teich aus, "lass wenn man die Raupen von der Herbstgeneration dieser Art [gemeint $V_{11-}$ nessa levuna] in einem Zimmer mit milier T'emperatur aufbewahrt, man noch in demselben Jahr die tiefbraunen Filter von Prorsa erhält. Hält man dagegen einen Theil dieser Raupen in einem lälteren Raum, so überwintern sie als Puppen und geben im Frühjahr die bleichbraune Levana."

Ob dieser Forscher diese Versuche selbst angestellt, oder die Resultate der Untersuchung von G. Dorfmeister entnommen hat, kann man nicht sicher sagen.

E. Kalonder (1872, 42S) erwähnt in seiner Inaugural-Dissertation, dass er fand, als die iberwinternden Puppen von ILamestra persicariae am 7. Januar 1868 aus einer niedrigen Temperatur in Stubenwärme von $20^{\circ} \mathrm{R}$. gebracht wurlen, zeigten die entwickelten Falter (zwischen 29. I. uni 6. II. 1868) schönere und lebhaftere Färbung und Zeichnung als die normal überwinternlen; er beschreibt jedoch diese Zeichnung nicht.

Die Ergebnisse von G. Dorfmeister haben die gebührente Aufmerksamkeit der Gelehrten erst dann auf sich gezogen, als August Weismann (1875. 953) seine "Studien zur Descendenz-Theorie" veröffentlichte. Dieser Gelehrte bekam die Arbeit von Dorfmeister erst dann zur Einsicht, als seine eignen Untersuchungen in dieser Beziehung schon fast beenilet waren. Man kann also wohl sagen, dass der erste Grundstein für künstliche Reprorluktion von Schmetterlings-Aberrationen von Dorfmeister-Weismann gelegt worden ist.

Die Ergebnisse der Versuche von Aug. Weismann sind seiner oben erwähnten Schrift in abgekürzter Form entnommen und lauten wie folgt:

A. Versuche mit Vanessa levana.

1. Zucht aus Eiern, welche an 12-15. Mai 1868 im Zwinger von einem Weibchen. der Winterform gelegt waren. Ausschliupten ler Raupen am 20-22. Mai, Verpuppung terselben am 7-9. Juni.

Die Puppen wurden bei gewöhnlicher Temperatur aufbewahrt und ergaben am 19-25. Juni 48 Schmetterlinge, welche alle Prorsaform besassen, drei Weibchen mit ziemlich viel Gelb. 
2. Am 12. August 1868 gefundene Raupen (der dritten Generation) verpuppten sich anfangs September, wurlen in ungeheizten Zimmer aufbewahrt. Im September schlüpften noch 3 Schmetterlinge aus und zwar in Prorsa-Form, die anderen überwinterten und ergaben, als sie Ende Februar in das geheizte Zimmer versetzt wurden, rom 1-17. März 1869 mehrere Schmetterlinge, alle von Levana-Form.

3. Am 17. Juni 1869 gefunclene Raupen wurlen nach ihrer Farbe sortirt; die gelben mit hellbraunen Dornen ergaben bei gewöhnlicher Temperatur am 8-12. Juli 13 Schmetterlinge, von welchen 12 gewöhnliche Prorsa-Form zeigten, ein orgab Porima-Form.

4. Von gleichzeitig wie unter 3) gefundenen Raupen der Generation II. wurlen am 25. Juni 30 Puppen in den Eisschrank gesetzt $\left(8-10^{\circ}\right.$ R.). Am 3. August waren fast alle ausgeschlïptt. Alle wiesen die Zwischenform (Porima) auf, welche der Prorsa-Form näher stand.

5. Eine grosse Anzahl gleichzeitig gefundener Raupen iler Generation II. verpuppten sich und wurle bei holher Sommer-Temperatur aufbewahrt. Nach etwa 19-tägiger Puppenzeit schliuptten von 28. Juni-5. Juli etwa 70 Schmetterlinge aus, alle von Pinrsa-Form, mit Ausnahme von 5 Porima.

6. Ein $q$ des vorigen Versuches legte am 4. Juli Eicr ab. Bei der damals herrschenden, hohen Sommerwärme ergaben diese Eier schon nach 30-31 Tagen die Schmetterlinge (III. Generation). Alle (18) waren Prorsa, keine vollständige Porima.

7. Am 8. August gefundene junge Raupen ler IV. Generation wurilen bei 17 bis $20^{\circ} \mathrm{R}$. erzogen. Verpuppung: 21-2:3. August. Davon wurlen:

a) 56 Puppen fünf Wochen lang auf (las Eis gesetzt $\left(0-1^{\circ}\right.$ R.), dlann im ungeheizten Zimmer überwintert. Sie ergaben alle im April 1870 die Levana-Form und eine Porima.

b) Eine, etwa gleiche Anzahl der Puppen wurle bei $12-24^{\circ} \mathrm{R}$. gehalten, aber kein einziger Schmetterling schlüptte im Olitober und November mehr aus. Die Puppen wurden dann im ungeheizten Zimmer ïherwintert uml ergaben im April - Mai lauter Levana.

8. Anfangs Juni 1870 gefundene Raupen der II. Generation verpuppten sich vom 13-15. Juni und lieferten bei gewöhnlicher Temperatur am 28-30. Juni 7 Prorsa. .

9. Puppen derselben Generation wurden unmittelbar nach der Terpuppung an 18. Juni 1870 bei $0-1^{0}$ R. gehalten: blicben so 
bis zum 18. Juli und gaben damn bei gewöhnlicher Temperatur am 22. Juli 7 Levana, 5 Prorsa und 8 Porima.

10. Ausgervachsene Raupen ler IV. Generation, am 20. August 1870 gefunden, verpuppten sich am 26. August bis 5. September. Die Puppen wurden in 3 Gruppen getheilt:

a) wurde unmittelbar nach der Verpuppung in rie Temperatur $12-25^{\circ} \mathrm{R}$. gebracht und blieb so bis zum 20. October. Von etwa 40 Puppen schliipften nur 4 aus und zwar 3 als Prorsa und 1 als Porima. Die übrigen Puppen überwinterten und lieferten alle Levana.

b) wurde im Zimmer aufbewahrt, vom November an in geheizten bei $6-15^{\circ} \mathrm{K}$. Kein Schmetterling schlüpte in diesem Jahre aus. Vom November ab wurde diese Partie Puppen mit $c$ vereinigt.

c) wurde unmittelbar nach (ler Verpuppung einen Monat auf das Eis gesetzt, lann aber von 28. September bis 19. October in das Treibhaus. Auch hier schlüpfte kein Schmetterling aus. Die Puppen überwinterten nun mit denen von Partie $b$ im geheizten Zimmer (uiber Wasser) bei $6-15^{\circ} \mathrm{R}$. und lieferten am 6. Februar bis 2. Mai nur Levana (1S Stück).

11. Zucht der II. Generation ans Eiern der I. Generation. Ausschliipfen aus dem Fi an 6. Juni 1872, Verpuppung um den 9. Juli. Voun 11. Juli bis 11. September wurden die Pnppen auf Eis gestellt $\left(0-1^{0}\right.$ R.), clann in das Treibhaus gebracht, woselbst alle am 19. September - 4. Oktober ausschlüpiten unil zwar: 3 Prorsu, 32 Porima und 22 Levana (liese letzteren sincl alle grösser als die im Freien vorkommenden).

12. Am 22. September 1872 gefundene Raupen ler IV. Generation wurden in zwei Gruppen getheilt:

a) wurde bei $11-25^{\circ}$ R. zur Verpuppung gebracht und bliel, dann im Treibhaus bis in den December; von Mitte December an wurden dann die Puppen im ungeheizten Zimmer aufbewahrt und schlïpften am 6-19. Juni 1873 aus, alle als Levana (21 Stïck).

b) wurde im ungeheizten Zimmer erzogen unil lort de'n Winter über gelassen. Vom 28. Mai an schlüpften die Schmetterlinge aus, alle als Levana.

B. Versuche mit Pierillen.

13. Im April eingefangene Weibchen von Pieris rapae legten Eier. Diese lieferten Raupen, welche sich vom 1-3. Juni verpuppten. Die Puppen wurden rom 3. Juni bis 11. September auf Eis gestellt 
$\left(0-1^{0}\right.$ R. $)$, vom 11. September lis 3. Octolser in das Treibhaus $\left(12-24^{\circ}\right.$ R.). Dort schliipften 8 Schmetterlinge aus. Alle Winterform. Eine Puppe schlüpte nicht mehr im Treibhaus aus, son lern iiberwinterte und gab im geheizten Zimmer an 20. Jannar 1873 ein 옹 ebenfalls von der Winterform.

14. Am 27. und 28. April 1872 eingefangene Weibchen ron Pieris nupi legten Eier. Die aus ihnen erzogenen Raupen verpuppten sich am 28. Mai - 7. Juni. Die Puppen wurden kurz nach der Verpuppung auf Eis gestellt, wo sie bis zum 11. September blieben Am 3. Oktober ins Treibhaus versetzt, lieferten sie lort bis zum 20. Oktober 60 Schmetterlinge, alle mit scharf ausgeprägten Characteren der Winterform. Die übrigen Puppen überwinterten im Zimmer und lieferten am 2S. April - 2. Juli 34 Schmetterlinge.

15. Mehrere der in Mai 1873 ausgeschlüpften Schmetterlinge (les Versuches 14) legten Eier. Die Raupen verpuppten sich und wurden in 2 Gruppen getheilt:

a) Mehrere Puppen bei gewöhnlicher Sommertemperatur aufbewahrt gaben am 2. Juli Schmetterlinge der Sommerform.

b) Die anderen Puppen wurden unmittelbar nach der Verpuppung auf Eis gestellt und blieben über 3 Monate im Eiskeller (vom 1. Juli bis 10 . Oktober). 3 schliipften am 20. Oktober aus als Winterform, die anderen überwinterten im ungeheizten Zimmer uni schliipften erst Anfangs Juni 1874 ans. Alle (5) zeigten die Charactere der Winter form.

16. Auf einer Alpe in ler Gegend von Oberstorf wurden an 12. Juni 1871 Pieris napi var. bryoniae eingefangen. Aus den abgelegten Eiern kamen Raupen. Aus Puppen schliipfte in demselben Sommer nur ein einziger Schmetterling var. bryoniae aus. Die übrigen Puppen überwinterten im geheizten Zimmer, und ergaben am 22. Januar - 3. Juni 15 var. bryoniae.

Diese Versuche stellte August Weismann an, indem er ron folgendem Standpunkt ausging: "Wenn der Saison-Dimorphismus seinen Grumd nicht in der indirecten Einwirkung verschielener Jahreszeiten hat, so kann derselbe in einer directen Einwirkung der wechselnden äusseren Lebensbedingungen liegen, die ja ohne Zweifel bei der Wintergeneration andere sind, als bei der Sommergeneration. Zwei Faktoren sind es vor Allem, von denen ein solcher Einfluss vermuthet werden kümnte: Temperatur und Entwickelungsdauer, d. h. Dauer der Puppenzeit" (p.6). 
M. Cornu (187s. 154) setzte Phylloxera vastatrix, welche beim Ueberwintern an Wurzeln von Weinreben sich befanten, der Einwirkung erhiohter Temperatur bis zu $45^{\circ}$ aus unit erhielt Exemplare von goldgelber Färbung, wie solche sonst nur im Sommer vorkommen,

Darauf erschien die zweite Arbeit von G. Dorfmeister: "Ueber len Einfluss iler Temperatur bei der Erzengung ler SchmetterlingsVarietäten" (1880. 195), welche als Ergänzung und Erläuterung seiner ersten Arbeit anzusehen ist.

Hier folgt der Auszug aus diesen Versuchen.

18\%1. Die Verpuppung von $V$. atalanta fand bei verschiedenen nicht sehr niedrigen Wärmegrarlen statt; hieraut wurden die Puppen 1 bis 4 , ja sogar 7 bis 8 Wochen einer Temperatur von $+71 / 2 \mathrm{R}$. bis $-2^{\circ}$ R. ausgesetzt, sorlann zur Entwickelung in das Wohnzimmer übertragen.

Die Puppen, welche bei einer Temperatur bis zu $5^{1} / 2^{0} \mathrm{l}$. sich befanden, ergaben nachher bei $10^{\circ}-11^{\circ} \mathrm{R}$. Varietaten, während solche, deren Puppen die Temperatur von $+1^{0}$ oder gar -1 bis $2^{\circ} \mathrm{P}$. auszuhalten hatten, theils zu Grunle gingen, theils nur verkrüppelte Schmetterlinge lieferten.

Die Verpuppung bei einer höheren oder niedrigeren Temperatur scheint keinen bemerkbaren Einfluss gehaht zu haben.

1872. Die Raupen von $V$. atalanta verpuppten sich bimen 1 bis 4 Tagen bei $+71 / 2^{0}$ bis $11^{0} \mathrm{R}$. Die Puppen blieben clann in lerselben Temperatur 3 bis 7 Tage und benöthigten bis zu ihrer Entwickelung im Zimmer bei einer bisweilen auch „ziemlich nietrigen" Temperatur noch 18 bis sogar 30 Tage. Es wurden auch Varietäten erhalten.

Mit Anwendung von „etwas verringerten Wärme“ auf Puppen von Vanessa urticae erhielt er Übergänge zu der in Lapplanı erscheinenden Form.

1864 war er der Meinung (levana, caja), dass die Temperatur auf die Färbung und Zeichnung des Schmetterlings den meisten Einfluss während der Verpuppung ausübe, zunächst aber kurz nach derselben. Seine Experimente mit ilen atalanta 1871 und 1872 haben diese Meinung zum Wanken gebracht; er ist jetzt (ler Ansicht, dass die Farbengebung nach der Terpuppung eintrete. 
W. H. Edwards (1880. 210), ein Nordamerikanischer Entomologe, stellte Kälte-Versuche mit Puppen von Pupilio a jax an. Dieser Schmetterling kommt als hellere Wintergeneration (Papilio telamonides und Pilp. val.shii) unil als dunklere Sommergeneration ( $P$ cup. marcellus) vor. Durch Einwirkung der Kälte auf die Puppe entstanil die hellere Wintergeneration, obgleich unter normalen Bellingungen aus den Versuchspuppen die Form der Sommergeneration hïtte entschliupfen müssen. Die Charaktere iler Wintergeneration wurlen desto ausgeprägter, je längere Zeit die Kälte einwirkte. Dabei wurde beobachtet, dass die Puppen spätestens 3 Tage nach ihrer Verwandlung in die Eiskammer gebracht werden müssen, damit die Kälte diese aberrative Form hervorrufen kamn.

Rössler (1881. 702) erwïhnt in seimem Buche, dass lie Farbe der Schmetterlinge verdunkelt wird, wenn man die schon begommene Entwickelung der Puppe durch Kälte kiinstlich hemmt.

W. von Reichenau (1882. 682) ziichtete die Raupen unl Puppen ron Vanessa urticae unter dem Einfluss direliter Sonnenstrahlung, und erhielt Falter, deren Verhältnisse denen von var. turcica sich näherten.

Die Zucht derselben im Herbst bei $5-12^{\circ}$ C. ergab ${ }_{n}$ sehr diistere, ins Braun-Gelbe sich ziehende Falter mit sehr grossen, schwarzen Flecken."

H. Gauckler (1886. 279) vergass ein Kästchen aus dlünnem Holz mit Puppen von Deilephila euphorbiae auf dem eisernen Ofen, wobei die Temperatur des Kästchens nach 10 Minuten bis zu $70^{\circ} \mathrm{R}$. stieg. Von 12 Puppen blieb eine am Leben und ergab nach ca. 7 Monaten einen wohlgebildeten, intensiv gefärbten, männlichen Falter. Leider beschreibt er die eventuelle Zeichnungs-Aenderung der Flügel nicht.

G. Stange (1886. 842) setzte einige noch im Oktober durch Zucht erhaltene Puppen von. Agrotis promuba etwa 3-4 Wochen der Winterkälte aus, als die Entwickelung der Schmetterlinge schon begonnen hatte uni erhielt dadurch einen auflällig getärbten Schmetterling, während die übrigen Puppen starben. „Derselbe hat ganz dunkel braungraue, ziemlich stark seidenglänzende Vorlerflügel, mit noch dlunklerem Aussemrand und hellerem Imnenranı. Von der Zeich- 
nung ist nur der schwarze Fleck nahe der Spitze, die Nierenmakel und der Kamm zwischen Nieren- und Ringmakel als brauner Fleck sichtbar, während die letztere selbst mit dem helleren Vorderrande zusammenfliesst. Das Gelb der Unterflügel ist viel trüber und schwach mit Grau gemischt, die schwarze Aussenbinde dagegen matter, so dass der ganze Unterflügel weniger grell gezeichnet erscheint" (p. 279).

Eine Anzahl Cidaria tristata ergaben bei gleicher Behandlung keine Veränderungen.

$\mathrm{Er}$ zog anch vom Ei ab im warmen Zimmer die Raupen von Agrotis rubi, ein Theil der Puppen ergab (Anfangs Oktober) aufiällig kleine Falter, welche matt gezeichnet waren. Die übrigen Puppen überwinterten, wurden in Februar wieder ins warme Zimmer gebracht, wo sie Mitte Mai grosse, lebhaft gezeichnete Schmetterlinge ergaben.

Fritz Rühl (1887. 716) sagt, dass die Beschleunigung dler Entwickelung überwinternder Puppen durch erhöhte Temperaturen sehr häufig ganz blasse, des intensiven Colorits entbehrende Exemplare ergiebt. So z. B. wird Papilio podalirius und machcon blass, Thais polyxena nicht so intensiv gelb, Hyloplita prosinana ganz verblichen. Die normale Farbe bleibt erhalten bei Smerinthus ocellata, Deilephila-Arten, Euchelia jacobaeae, Spilosoma mendica, lubricipedu, menthastri, Endromis versicolora und Aglia tau.

Aberrationen und Variationen konnte er dabei nie erhalten, hält es aber für möglich, wenn "naturwidrige" Temperaturen auf die Puppen einwirken, "obschon dieser Einfluss bis zur Stumle nicht nachgewiesen ist."

C. Ed. Venus (1888. 903) züchtete Raupen von Vanessa urticae in einem Holzkasten, welcher oben mit einer Glasscheibe zugedeckt war und der Einwirkung heisser Sonnenstrahlen zwisehen 8 und 11 Uhr ausgesetzt wurde. Ungefähr der dritte Theil der Raupen erlag der Hitze, die anderen hängten sich zur Verpuppung unter dem oberen Theile iles schmalen Holzramens auf. Venus sagt: „Gross war mein Erstaunen, als ich, statt der gewöhnlichen braungrauen, mit einigen Goldpunkten besetzten urticae-Puppen, solche von lichtgelblicher Färbung und am ganzen Körper mit dem schönsten Goldglanze überzogen, erblickte." Die Puppen vertrockneten jedoch nachher. 
Ein Jahr spïter stellte er dieselhen Versuche noch ein Mal an und erhielt auch die schönen goldglïnzenten P'uppen, welche Falter mit lebhaft rother Farhe der var. ishunsı ergahen. „Die heilen schwarzen Mittelflecke der Vorilerfliigel waren hei allen nur rulinänter vorhanten, bei einigen versehwintent klein und bei zwei Exemplaren fehlten sie ganz" (p. 210).

Lord Walsingham (563) heohachtete, llass die der Kïlte exponierten Puppen Falter mit dunkler Färumn ergeben, und dass das Forcieren entgegengesetzte Resultate liefert.

Frederic Merrifield (1889. 563) in Brishton stellte Temperaturversuche an einigen Geometriden an.

Eugonia autumuaria Raupen von einem und demselben Paar wurlen in Serien eingetheilt und folgenten Temperaturen ausgesetzt: 1) Sowohl Raupen als Puppen hei $26,7^{\circ}, 2$ ) Raupen bei $26,7^{\circ}$, llie Puppen hei $8,2^{\circ}, 3$ ) Raupen lei $18,3^{\circ}$, die Puppen hei $26,7^{\circ}, 18,3^{\circ}$ mil $0,5^{\circ}$. Alle Puppen, welche sich hei $0,5^{\circ}, 8,3^{\circ}$ unil $18,3^{\circ}$ hefanden, erwahen dunkle und sturk gefleckte Falter. Alle forcierten $\left(26,7^{\circ}\right)$ Puppen prorluzierten hlasse Schmetterlinge und meistens ohne Flecken.

Daraus zieht er den Schluss, dass die lorittischen autumnarin keine dunkele Rasse darstellten, sondern aus Exemplaren bestanden, welche jetzt aus Puppen bei $18,3^{\circ}$ und nieilriger ausschlïpfen.

Eugonia alniaria Puppen ertraceen die Kälte hesser als autumnaria. Als die Puppen 15 Tage der Temperatur von $0,5^{\circ}$ ausuesetzt wurden, ergahen die ausgeschlïpten Falter eine helle Färbung, welche aber in Begriffe war, dunkel zu sein.

Selenia illustraria Puppen wurden der Temperatur ron 0,50 auscresetzt unil zwar während der Zeit von 2 bis 20 Wochen. Die Kontrollpuppen derselben Brut betanden sich bei gewöhnlicher Temperatur. Die Kälte erzeugte einen deutlichen Unterschied in der Zeichnung (hauptsächlich in der Wellenlinie). Die Färbung war gewöhnliches Bräunlich zum Dunkel neigend, nahm aber unregelmässig init der Expositionsilauer $z u$.

Das entregengesetzte Experiment (das Forcieren der Herlustpuppe oder die Temperatur von $15,5^{\circ}$ ) ergab, dass die Falter, welche sich zuerst entwickelten, in ihrer Färbung der Sommerform nähler stariten als der Frühlingsform; sie wurden um so dunkler (alıer nicht regehnässign), je länger die Puppenzeit dauerte. Einige 
dieser Puppen, welche einige Wochen nach ılieser Behandlung dem kalten Winterwetter für 6 Wochen auscesetzt wurden, ergalien sehr dunkel gefärbte Exemplare.

F. Merrifield (565) hielt 1891 einen Vortrag „Ueher den Einfluss kïnstlicher Temperaturen auf die Färbung von Vanessc urticae und gewissen anderen Arten von Lepidopteren." Lr konstatierte, dlass die Färbung von Selenia illustraria sowohl der Friilhlings- wie auch der Sommer-Generation und die Färbung der Eunomos automnaria wesentlich durch die Temperatur beeinflusst wird, welcher die Puppen im vorletzten Starlium ausgesetzt wurden, d. h. in demjenigen Stadium, in welchem die Ausfärbung noch nicht stattfand.

Um zu erfahren, ob ein ähnlicher Einfluss bei beilen Generationen von Selenia illunaria unı S. lunaria erhalten wird, setzte er mehrere hunderte Puppen dieser Arten der Einwirkung der Temperaturen von $26,7^{\circ}, 15,5^{\circ}, 10,5^{\circ}$ und noch weniger Gralen aus, und erhielt dieselben Resultate, wie mit oben erwälnnten Arten. Die Puppen, welche nierleren Temperaturen ausgesetzt waren, ergaben fast ausnahmlos dunklere Falter, als ıliejenigen, welche bei höheren Temperaturen sich befanden. Platypteryx falcataria (Frühlingsgeneration) ergah) (lieselbe Resultate. Es hat sich herausgestellt, lass die untere Seite von Se enia stärker beeinflusst wurde als lie obere und bei Männchen mehr als bei Weibchen. Je gesunter die Puppen waren, ılesto stärker war der Einfluss der Temperatur.

Vanessa urticae ergab dieselben Hauptresultate, wenngleich der Einfluss nicht so beträchtlich war. Die Temperatur von $8,2^{\circ}$ verursachte bei langer Dauer eine starke Zunahme der Verdunkelung. Die Temperatur von 10 bis $15^{\circ}$ beeinflusst auch die blauen Hall)monle. Einige Exemplare bei $8,2^{\circ}$ ergaben var. polaris.

Puppen von Bombyx quercus und var. callunae reagierten schwächer.

Chelonia caja reagierte schwach und ergab keine stark abweichende Varietät. Die höheren Temperaturen erhellten die Grundfarbe der Vorlerflügel, und die Hinterflügel wurden gelber. Die nielteren Temperaturen riefen die Ausbreitung der dunkeln Flecken und das Zusammenfliessen der Querbinden hervor.

H. Huber (1891. 395) schreibt: „Diese Geheimisskrümerei, namentlich geülst auch bei der Aufucht der Raupen in der Erwar- 
fun-, mitfelst Futter-, Licht- unil Temperaturwethel Aherrationen zul erzielen, hätte bereits fallen sollèn" (p. 21).

R. Berger (1892. 72) (rhielt dunkle Alerratiomen von Schuetterlingrn, inden or 8 Tage im keller $\left(2^{\circ}\right)$ belassene bier einen Tag dem Sommenlicht und damn währomd des nächsten Tages dem Schatten anssetzle und so fort in gleichmässiger Alwechselme bis zur Entwickelung der Räupchen. Die geschlüpften Räupchen liess er während der ersten 6 Lehonstage unter den günstigsten Bedingmoen heranwachsen, aher die crste Häutung vollzogen sie in ziemlich dunklem Keller. Damit erreichte or die Verlïngorum des Raupenlebens 1 m 10-18 Tage. „In dieser verlüngerten Itebusilaner einer-, in tem plötəlichen Wechsel vom warmen Sonnenlichte zn einer kihlen Kellertemperatur in Innkeln anderseits, liegt das ganze Geheimniss der geheimnisskramemilen Lepidopterologen, welche dir dunklen Aberrationen'erziehen" (p. 60).

Froderic Morrifield (1892. 567) experimentierte mit mâssig erhöhten und mässig erniedrigten Temperaturen und erhiet folgende Resultate:

Selenia illumaria. P'uppen von Frïhlings- (44 Stück) mul SommerGeneration (mehr als 100 ) wurlen den Temperaturen von $26,7^{\circ}$ (., 15,5 C., 10,5 C. 'md in Freien (ca. 5,40 C.) ausgesetzt.

bie nienteren 'lemperaturen ergaben dunklere Falter mit Ausnahme von einigen $q \bigcirc ;$ von unten sind sie anch dunkler als die normalen.

Bei mässig ernienlrigten Temperaturen wirl die Färbung dunkler und zwar proportional der Expositionszeit. Diese Erscheinung schreilut er den physiologischen Veränlerungen zu, wolche bei niederen T'imjeraturen sehr lamgsam vor sich gehen, so dass man mehrere Wochen lraucht, un das hervorzurufen, was beim Treiben nach einigen Tagen stattfinclet.

lin Exemplar, welches bei der 'Temperatur von $26,7^{\circ}$ ausschliiplte, war heller als diejenigen, welche nicht forciert wurlen.

Selenia lunaria. Von beilen Generationen. Die den niederen Temperaturen ausgesetzte Puppen ergaben dunklere Falter, als iliejenigen, welche höheren Temperaturen ansgesetzt wurlen.

Selenia illustraria. I. Generatiou (100 Puppen). Temperaturen: 1) $\left.\left.26,7^{\circ}, 2\right) 15,5^{\circ}, 3\right)$ im Freien (ca. $\left.5,4^{\circ}\right)$. 1)ie zweite Temperatur (erab) dunklere Falter als die erste und die dritte noch dunklere. 
II. Generation (80 Puppen). Temperaturen: 1) 26,70, 2) $8^{\circ}$. Die letzten Falter waren dumkler als die hei der ersten Temperatur.

P. falcataria. 3 Puppen wurilen iler Temperatur von 26,70. anseresetzt und 4 im Freien (Ende Mai) belassen. Die letateren ergaben ilunklere F'alter mit verstirkter Zeichnumg.

Allgemeine Resultate, welche mit Selenia erhalten wurilen, sind:

1. Bei allen Selenia (und auch bei automnarin) wird the untere Seite der Flügel stärker verünlert als die obere.

2. Die Männchen werlen stärer heeinflusst als die Wribchen (Ausnahme bei illustraria).

3. Je gesunder resp. stärker die Puppe ist, desto ausgeprïgter ist der Effekt.

Vunessa urticac. Mehr als 100 ganz frische l'uppen wurden in einen kühlen laum gehracht. Der Effekt war schwach, nur die längere Exposition ergab gute Resultate.

12 Puppen wurden forciert und ergaben gleichmässige Falter. 51 Puppen wurilen bei Temperatur von $8,2^{\circ}$ exponiert. 42 Falter schlüpften nach 2-58 Tagen aus und waren in allgemeinen dunkler als die forcierten. 9 Stuck schlüpten nach 60-67 Tagen ans uni waren noch dunkler.

Exposition einige Stunden nach der Verpuppung. 8 Puppen wurden forciert und 17 einer Temperatur von \$,20 ausgesetzt; nach 20-42 Tagen schlüpften die letzteren aus und waren dunkler als die ersten.

Exposition einige Tage nach ter Verpuppung (am 22. September). 5 Puppen hei 26,70, schlïplten nach 6-7 Tagen aus. 13 Puppen im Freien (ca. 90), schlüpften nach $3-7$ Wochen aus. Die letateren Falter waren dunkler als die ersten.

Im allgemeinen lassen sich die Versuche mit Vanessa urticue wie folgt zusammenfassen: Die kurze Exposition erwielst eine leichte Verdunkelung der Farbe; es findet eine Farben-Rerluktion beim (relb statt und der Unterschied zwischen hellen und dunklen Stellen wird stärker; die dunkeln Stellen werien verloreitert, hauptsächlich aber die blauen Hallmuonde. Die lange Exposition (8-9) Wochen) bewirkt die Verstärkung der dunklen Färbung, wobei die extremen Exenplare sich der var. polaris nähern.

Bombyx quercus und var. callunue. I)ie liaupen wurlen leei $26,7^{\circ}$ belassen und spimnten sich nach einer Woche ein. 7 schlipften nach 39-40 Tagen aus und ergalien hell gefärlte Falter. 15 Raupen wurden in die Temperatur von $8,2^{\circ}$ geluracht; $15 \delta \delta$ schliipften 
nach 39-71 Tagen aus. Das zuerst ausgeschliipfte Exemplar war dunkel und das letzte noch dunkler. Die Zwischen-Exemplare hatten. eine leichte Verdunkelung des hellen Bandes.

2 Puppen iler rar. cullunae, welche in der Temperatur von $26,7^{\circ} 27-46$ Tage verbracht haben, ergaben viel hellere Falter als die gewöhnlichen, wobei ein $\subsetneq$ eine grosse Aehnlichkeit mit der südlichen Form hatte.

Die zweite Serie ergab unter gleichen Umständen 3 ठ und 2 o, welche etwas dunkler als die vorhergehenden waren, aber doch noch zu hell für diese Species.

9 ㅇ und 6 J, welche in Freien (im Juni - Juli) ausschlüpften, waren dunkler als die durchschnittlichen.

Im allgemeinen kann man für diese Species sagen, dlass die höhere Temperatur die Falter mehr erhellt, als die niedrige; dies ist besonders bei Männchen zu beobachten, die Weibchen ändern sich weniger. Das Treiben ergiebt einen röthlichen Hauch sowohl bei $ᄋ$ wie auch bei $\delta^{\nearrow}$. Man kann die forcierten var. callunce bezüglich der Färbung als quercus betrachten.

Arctic caja. Die*meisten Puppen, welche der Wirkung cler Temperatur von $+0,5^{\circ}, 8,2^{\circ}$ und $10-15^{\circ}$ ausgesetzt wurden, starben ab, während solche, welche bei der Temperatur von $26,7^{\circ}$ sich befanden, alle Falter ergeben. Die Grundfarbe der Vorderflügel bei diesen Faltern war blasser; die Färbung der Hintertlügel war gelblichorange; die dunkeln Flecken hatten die Tendenz sich zu vereinigen und waren kleiner als sonst. Die meisten Abweichungen in der Zeichnung stellten die schwarzen Querbinden der abdominalen Segmente dar: sie waren viel länger und breiter bei denjenigen Faltern, deren Puppen den niederen Temperaturen ausgesetzt wurden, als bei solchen, welche in hohen Temperaturen sich befanilen. Ausserdem wurde bei $26,7-32^{\circ}$ die Zunahme des "pallor" des Brauns der Vorlerflügel, besonders gegen den äusseren Rand hin, wo die Färbung verschwommen und fein gefleckt schien, erzielt.

Merrifield giebt folgeniles Verzeichniss der Falter an, deren Puppen auf die erwähnten Temperaturen nicht reagierten: Frühlings-Generation von Papilio machaon, podalirius (aus dem südlichen Spanien), Thais polyxena, Argynnis paphia, Dicranura vinula, Agrotis orbona (comes), Melitaea cynthia. Schwache Wirkung wurde bei Pieris brassicae, Pieris rapae und Vanessa levana (Frühlingsgeneration) beobachtet. 
Fritz Rühl (1892. 721) beschreibt in seinem Buche den Puppenkasten System Davis (p. 51), wobei die Puppen über dem heissen Sand sich befinden und Schmetterlinge ergeben, bei welchen die weisse Färbung begünstigt wird.

E. Heyer (1893. 372) brachte die Puppen von Antheren pernyi in eimen hellen luftigen und kühlen Keller und erhielt Stiicke, die lebhaft rothbraun in der Grundfarbe sind, sämmtliche Zeichnungen sind bedeutend klarer und lebhafter. Die Augen der Hinterflïgel sind nach der Seite der Flugelwurzel hin mit einer Anhangzelle von der Grösse eines halben Auges in weinrother Farbe und nach vorn mit einer schwarzgerandeten rothgelben Zelle versehen. Frühjahrs-Stiicke und die aus warm gestellten Puppen erzielten Herbstfalter sincl säınmtlich blass zimmt arbig und mit einfachen Augen auf allen Flügeln und matten, nicht besonders hervortretenden Zeichnungen ausgefallen.

L. Heissler (1893. 361) erhielt Antherea pernyi 3 Wochen nach dem Einspinnen der Raupen in Folge der grossen Wärme des Sommers. Die Thiere „zeigen nichts von dem schönen bräunlichgelben Anflug, sondern erscheinen mit einem deutlichen Stich in's Grüngraue, ähnlich wie man mitunter Yamamai-Falter beobachtet" (p. 97). Die Falter aus den überwinterten Puppen zeigen diesen Farbenunterschied nicht.

F. Rühl (1893. 723) sagt gelegentlich der Beschreibung von Karl Jordis am ४. August 1892 in der Nähe von Frankfurt a. M. gefangenen Melitaea parthenie Borkh. ab. und var. Jordisi Rühl: "Die hier in Rede stehenden Formen sind zugleich ein Beweis für die von Herrn von Caradja und mir ausgesprochenen Ansichten und Beobachtungen, dass 1892 zweite Generationen frühzeitig auftraten, aber auch, dass in gleicher Localität der Einfluss der hohen Temperatur sich nicht nur auf Erzeugung lichterer, sonilern auch gleichzeitig sehr dunkler Formen äussern kann" (p. 165).

F. Rühl '(1893. 726) beobachtete, lass die grüne Farbe dler Flugel von Ellopia prosapiaria var. prasinaria $\mathrm{Hb}$. beim Fluge in der Sonnenhitze leidet, wobei diese Exemplare der Stammform nahe kommen. 
F. Merrifield (1893. 568) erhielt von englischen Chryssphanus phlaeas 70 Puppen und stellte mit ihnen folgende Versuche an:

1. Ein Theil wurde in eine Temperatur von $27-30^{\circ}$ gebracht. Die erhaltenen Schmetterlinge hatten grosse schwarze Flecken, wolsei die Vorderflugel eine schwache schwarze Bestäubung besassen.

2. Die Puppen wurden 10 Wochen bei $4^{0}$ unil dlamn 5 Wochen bei $13^{\circ}$ gehalten. Die ausgeschlüpften Falter besassen kleine schwarze Flecken, ein breites rothes Banil auf den Hinterfliigeln und waren hell gollfarbig.

3. Die Puppen wurden 10 Wochen auf dem Eis und dann bei $30^{\circ}$ gehalten; sie ergaben Falter mit schwarzer Bestäubung und schmalem Kupferband auf dem Hinterfliigel. Da diese Falter die Sommerform aufwiesen, so geht daraus hervor, llass die letzten Tage der Puppenzeit für die Färbung entscheilenıl waren.

R. Jaenichen (1894. 410) liess die Räupchen von Lasiocampa populifolia bei $25^{\circ}$ aus dem Ei schlüfen; die Raupen wurden bei $15-20^{\circ}$ gezogen. Die dabei erhaltenen Schmetterlinge (rar. autumnulis Jaen.) haben dunklere violletbraune Grundfarbe, wobei die schwarze Bestäubung sich vermehrte, zumal auf der Oberseite des Hinterleibes.

Frederic Merrifield (1894. 570) veröffentlichte im März 1893 seine "Temperature Experiments in 1893 on several species of $\mathrm{Va}$ ness $a$ and other Lepiloptera," welchen wir folgendes entnehmen:

Die Raupen von Sommerbrut von Pieris napi verpuppten sich Anfangs September, und 10 Puppen wurden der Einwirkung der Temperatur von $32^{\circ}\left(90^{\circ} \mathrm{F}\right.$.) wälırend 10 Tagen ausgesetzt, die iibrigen wurden in Freien gelassen. Obwohl diese Zeit bei der Frühlingsbrut zun Ausschlüpfen vollständig genügt, entpuppten sich bei dieser Temperatur doch keine Falter.

Einige dieser Puppen wurden der Wärme Anfangs Feloruar, die anderen im März ausgesetzt. Der Unterschied zwischen den erwähnten 10 Faltern und den übrigen, welche am 20. IV. - 9. V. ausschlïpften, war derselbe, wie auch zwischen forcierter Sonnenlurut und den Puppen. welche abgekühlt waren.

Pararge egeria. Die Puppen wurden entweder der Temperatur von $26,7-32^{\circ}$ ausgesetzt oder auf Eis gelegt $\left(+0,5^{\circ}\right)$; bei diesen Temperaturen lirachten sie einige Wochen $\mathrm{zu}$, wobei sie auch von einer Temperatur in die andere versetzt wurden. Beim Forcieren 
ergaben die Falter kleinere helle Flecken, welche jerloch nicht scharf markiert waren. Die Grundfarbe war bedentend heller und zuweilen mit kleinen dunkeln Fleckchen bestreut.

Die Puppen, welche der Temperatur von 18,30 ausgesetzt wurden, ergaben nicht so stark dunkle Falter, wie die forcierten.

Einige Puppen, welche zuerst auf Eis sich befandlen und nachher forciert wurden, ergaben intensiver dunkel gefärbte Falter, die Anzahl der hellen Flecken war aber dieselbe, wie bei einfach forcierten und von derselben Grösse, wie bei Faltern, deren Puppen nierleren Temperaturen ausgesetzt wurden.

Einige Exemplare, welche von im August abgelegten Eiern gezogen wurden, ergaben dieselben Resultate, wie die April-Generation.

Cidaria silaceata. Von April-Eiern erhaltene Puppen wurlen der Temperatur-Einwirkung auf gleiche Weise ausgesetzt, wie diejenigen von Pararge egeria.

Die Puppen, welche bei 26,70 sich befanden, ergaben Falter mit leicht gebrochener Querlinie und von mehr Ocker-Farbe; die Temperatur von mehr als 26,70 ergab düstere und homogenere Farbe. Die Unterschiede in der Färbung und Zeichnung waren jerloch geringer, als Merrifield es: erwartete.

Araschnia levana. Die Puppen stammten aus Deutschland. Die Ende April erhaltene 13 Paar Schmetterlinge wurden mit Orangen gefüttert und auf Brennesseln gesetzt; es wurien jedoch nur 3: Eier erhalten, aus welchen von 11. V. an 11 Räupchen auskrochen, die sich nachher alle verpuppten.

3 Puppen wurden der Temperatur von $26,7^{\circ}$ ausgesetzt und ergaben nach $6-7$ Tagen die charakteristische schwarze Form von prorsa.

4 Puppen im Alter von 1-8 Stunden wurden am 18. Juni in eine Temperatur ron $8,2^{\circ}$ gebracht, wo dieselben bis zum $30 .-31$. August verblieben (also 73-74 Tage); vor dem Ausschliipfen befanden sie sich im Zimmer bei ca. $19^{\circ}$, wobei nach $1-2$ Tagen 3 Puppen levana-Falter ergaben, das vierte Stiick war auch levanu, entschlüpfte aber erst nach 32 Tagen (am 2. Oktober).

Die übrigen 4 Puppen wurden bis 29. September (84 Tage) auf Eis $\left(+0,5^{\circ}\right)$ belassen, darauf in die Temperatur von $8,5^{\circ}$ und schliesslich nach 20 Tagen ins Zimmer bei $59^{\circ} \mathrm{F}$. gebracht. 3 Falter entschlüpften nach 10, 18 und 20 Tagen, wobei das erste Stiick verkrüppelt und das vierte grestorben war. Die Falter waren charakteristische levana. 
Vanessa polychloros. 138 Puppen wurden verschiedenen Temperaturen (von $38,2^{\circ}$ bis $+0,5^{\circ}$ ) verschierlen lange Zeit ausgesetzt und von einer Temperatur in die andere versetzt.

Es wurde konstatiert, dass nieilere T'emperaturen die Grunifarbe verdunkeln und die dunkle Zeichnung verbreiten, wälırenıl die hohen Temperaturen hellere Grundfarbe erzeugen und die wellse Zeichnung verbreiten. Die blaue Färhung ist bei mässig ernieslrigten Temperaturen stark ausgeprägt, wobei auch deutliches Entstehen von Halbmonden auf den Vordertliigeln beobachtet wird, während die niedrigst angewanite Temperatur sie durch Schwarz zu ersetzen beginnt.

Vanessa atalanta. Die ier Temperatur von $26,7^{\circ}-32^{\circ}$ ausgesetzten Puppen ergaben Falter mit düsterorangen Bändern. Bei noch höherer Temperatur wurde starkes Entwickeln der orangenen Farbe sowohl nach der Intensität wie auch nach der Verbreituug erhalten.

Niedere Temperaturen bewirken ein starkes Ersetzen der schwarzen Theile durch Weiss, "Lavendel" oder metallisches Blau-Grün. Der grosse weisse Fleck wird stark verbreitet.

Vanessa (Grapta) c-album. Wegen Mangel an Beobachtungsmaterial konnten keine Einzelheiten beobachtet werden.

Vanessa io. 60 Puppen wurden verschiedenen Temperaturen ausgesetzt (von $38,2^{\circ}$ bis $\left.+0,5^{\circ}\right)$.

Die der Temperatur von $38,2^{\circ}$ ausgesetzten Puppen starben alle ab.

16 Stück wurden 6 Tage bei $32^{\circ}$ und nachher bei $26,7^{\circ}$ gehalten; nach einem Tage schlüpften alle aus. Bei der Verminderung der Temperatur wurle die Tendenz zum Verschwimmen ("disintegration") der Augen auf den Vorderflügeln beobachtet und zwar so stark, dass eine Puppe, welche 22 Tage bei $0,5^{\circ}$, dann 20 Tage bei $8^{\circ}$ und schliesslich 18 Tage im Keller verbrachte, einen Falter ergab, bei welchem das Auge in eine Reihe von kleinen weissen Fleckchen, umringelt von bläulicher Farbe, zerfallen war.

Das Eisen macht die blaue Färbung lebhatter und das enge dunkle Marginalband noch etwas dunkler. Auf der unteren Seite der Flïgel wurden sehr unberleutende Aenderungen beobachtet.

Vanessa antiopa. 70 frische Puppen, aus Berlin an 18. Juli erhalten, wurden sofort den Temperaturen von $38,2^{\circ}$ und tiefer ausgesetzt. Das Ausschlüpfen bei $38,2^{\circ}$ fand nach $3-5$ und bei $26,7^{\circ}$ nach 4-7 Tagen statt. Alle Falter waren normal.

Merrifield gibt am Schlusse seiner Abhandlung folgendes Resumé: 
1. Der Temperatureinfluss ist verschieden, je nachdem bei welcher Periode des Puppenstadiums derselbe angewendet wirl.

2. Eine mittlere Temperatur übt keinen Einfluss aus, während eine höhere odler tiefere Farben- und Zeichnungs-Aenderungen hervorruft.

3. Zwei Bruten in verschiedenen Jahreszeiten reagieren verschieden stark auf die Temperatur.

4. Dies wird auch dann beobachtet, wenn beide Generationen einer und derselben Temperatur ausgesetzt sind.

5. Wenn auch gewisse Effekte der direkten Einwirkung der Temperatur zuzuschreiben seien, bewirkt die Temperatur bei den anderen Schmetterlingen, wie es scheint, einen Rückschlag (throw back) zu der Form der Ahnen. Dadurch wird auch erklärt, warum bei einigen Species die Farbe sich verdunkelt und bei anderen heller wird.

Unmittelbar nach dieser Abhandlung folgt die genaue Beschreibung der erwähnten aberrativen Formen von Merrifield, welche Frederick A. Dixey (1894. 185) übernahm.

Ernest Hein (1894. 358) setzte die Puppen von Vunessa uticae und $i o$, deren Raupen mit den mit Tintenwasser impregnierten Brennesseln gefüttert wurlen, neinem gewissen Kältegrade aus. Bei kalt behandelten Sommer-Puppen wird sich durch vorangegangenen Einfluss der farbigen mineralischen Substanzen, sowie des farbigen Lichtes die Farbenveränderungen der ausgeschlüpften Falter bedeutend bemerkenswerther erweisen" (p. 66). Diese Veränderungen beschreibt er jedoch nicht.

F. Rudow (1894. 709) fand, dass Chrysopa vulgaris Schul. im Sommer grïn gefürbt, im Winter aber blassroth ist.

Der berühmte Experimentator auf dem Gebiete der Lepidopterologie, M. Standfuss, veröffentlichte 1894 seine Abhandlung: "Ueber die Gründe der Variation und Aberration des Falterstadiums bei den Schmetterlingen" (1894. 837), in welcher auch die Versuche über den Einfluss der "Wärme" und "Kälte" auf die Färbung und Zeichnung der ausschlüpfenden Falter beschrieben wurden.

Die Versuche mit Puppen, welche, nachdem sie sich vollkommen ausgebildet und erhärtet zeigten, den erhöhten Temperaturen ausgesetzt wurden, ergaben folgende Resultate: 
1. Papitio machaon. 17 Puppen von Zürich ergaben bei $37^{\circ} \mathrm{C}$. in 7-10 Tagen 15 gut entwickelte Falter. Einige dieser Stücke gleichen durchaus Exemplaren, wie sie im August etwa bei Antiochia und Jerusalem fliegen:

2. Vanessa c-album. Puppen bei $37^{\circ} \mathrm{C}$. Es entstand die lichte, namentlich unterseits sehr helle, gelbbraune Form iles Falters, mit weniger scharf markierter Zeichnung und weniger tief gebuchtetem Flügelsaum.

3. Vanessa polychloros. 5 Tage bei $37^{\circ} \mathrm{C}$., dann $25^{\circ} \mathrm{C}$. Es erfolgte: Reiluction iler blauen Randflecke der Hinterflügel und les dunklen Aussenrandes der Vorlerfligel. Aufhellung der Flïgel durch Lichtwerden der braunen Grundfarbe und Zunahme gelber Schuppen zwischen den schwarzen Flecken am Costalrande der Vorlerfliigel unil an iler ïusseren Begrenzung iles schwarzen Wurzeltleckes iles Hinterflügels.

Die Unterseite aller Flügel wird eintöniger in cler Färbung dadurch, dass der Aussentheil derselben dunkler und den basalen Theilen fast gleich gefärbt wird:

4. Vanessa urticae. 60 Stunden bei $37^{\circ} \mathrm{C}$., nachher bei Zimmertemperatur. Alle stattgefundenen Abänderungen bedeuten eine gewisse Annäherung des gewöhnlichen Typus von Vanessa urticae an Vanessa io.

5. Vanessa io. Puppen 72 Stunclen bei $37^{\circ} \mathrm{C}$. Der Falter zeigt der gewölnnlichen Form gegenüher nur geringe Veründerungen.

6. Vanessa antiopa. 48 Stunclen bei $37^{\circ} \mathrm{C}$. Die erhaltenen Falter zeigen die Reduktion des Blau des Aussenrandes. Auf den Hinterflügeln zeigt sich dabei iler gelbe Aussenrand, zumal von der ausgezogenen Spitze bis zur Dorsalecke hin, breiter als normal, wodurch das Blau, wie die Grundfarbe des Flügels zurückgedrängt wird. Auf den Vorderflïgeln dehnt sich das Gelbe wellen- oder bogenförmig nach der blauen Fleckenreihe hin aus und verdrängt dieselben dabei in sehr verschiedenem Masse. Auch die Unterseite zeigt, abgesehen von dem unerheblich mehr geschwärzten Flügelrande, keine Differenzen der Grundform gegenüber.

Als die Puppen dieser Art 60 Stunden einer Temperatur von $37^{\circ}$ C. ausgesetzt und dann in $24^{\circ} \mathrm{C}$. gehalten wurden, ergaben dieselben Vanessa antiopa var. daubi Stlfs., welcher Falter an die mexikanische Vanessa cyanomelas Doubl. Hew. sehr lebhaft erinert.

7. Vanessa atalanta. 7.2 Stunden bei $37^{\circ} \mathrm{C}$., dann 3-4 Tage bei $24^{\circ}$ C. Die ausgreschlüptten Falter zeigen die Charactere der 
Annäherung an Vanessa callirrhoë F. und deren Localformen: var. vulcanica Gorlt. von den Canaren etc.

8. Vanessa cardui. 6 Stunden bei $40^{\circ}$ C., dann 12 Stunden bei $22^{\circ} \mathrm{C}$, , dann abermals 6 Stunden $40^{\circ} \mathrm{C}$, von da ab $22^{\circ} \mathrm{C}$. Die meisten Falter ergaben die reguläre Form, die wenigen - ab. elymi Rbr.

Als die Puppen 60 Stunden bei $36-37^{\circ}$ C. und nachher bei normaler Temperatur verblieben waren, ergaben sie eine ausserordentlich lichte Form, welche der tropischen und den in den deutschen Colonien in Ost- und Westafrika vorkommenden Formen sehr ähnlich ist.

9. Argynnis aglaja. 4 Tage $36^{\circ} \mathrm{C}$, , dann $22^{\circ} \mathrm{C}$. Der Falter zeigt oberseits ein sehr leuchtendes Braunroth; die schwarze Zeichnung. bleibt unverändert.

Bei Kälte-Versuchen wurden die nicht ganz frischen Puppen in einem Eisschrank gehalten, wobei die Temperatur in demselben zwischen 5 und $8^{\circ} \mathrm{C}$. schwankte. Die erhaltenen Resultate sind die folgenden:

1. Papilio machaon. Exposition 28 Tage. Falter gleichen der schweizerischen und deutschen Form aus überwinterten Puppen.

2. Vanessa c-album. Exposition 28 Tage. Die Falter sind viel schärfer gezeichnet mit wesentlich dunklerer, vielfach mit moosgrünen Farbentönen gemischter Unterseite und schärfer gebuchtetem Flügelsaum. Diese Abänderung entsteht durch Zurückhleiben des Wachsthums gewisser Flügeltheile, namentlich intercostaler.

3. Vanessa polychloros. Exposition 14 Tage. Ergebniss: die braune Grundfarbe wirl dunkler, die blauen Randflecken der Hinterflügel grösser und lebhafter, der dunkle Aussenrand der Verderflïgel breiter, es treten drei verloschene blaue Flecken in den mittleren Theilen: des Aussenrandes auf.

Auf der Unterseite wird der Gegensatz zwischen den basalen und äusseren Flügeltheilen grösser durch Aufhellung (ler Färbung der letzteren.

Als die Puppen 28 Tage exponiert wurden, zeigten die ausgeschlüpften Falter die oben angegebenen abweichenden Charactere in gesteigertem Masse.

Nach 42-tägiger Exposition zeigten sich die Falter nach dem Entschlüpfen in den Vorderflügeln überwiegend normal. Auf der Unterseite stellt sich ein rothbrauner Farbenton ein.

4. Vanessa urticae. Exposition 32 Tage. Die Falter errinern durch ihre Charactere sehr an die nordamerikanische Vanessa milberti Godt. 
Nach 42-tägiger Exposition ergaben die P’uppen m?isi var. polaris Stgr.

5. Vanessu io. Exposition 3.j Tage. Ercrebniss: ab. fischeri.

Nach 42-tägiger Exposition wurilen die ausgeschiüpften Falter auf der Unterseite aller Flïgel ähnlich iler Vanessı urticae orler Vanessa polychloros. Die Grundfarbe auf ier Oberseite rler Vorilerfliigel gewann stark gelbliche Beimischung. Der Augenfleck iler Hinterflügel wurde mehrfach stark, theilweise bis zu fast vollkommenem Verlöschen reduziert. Die Stelle, welche die Mitte der Augenzeichnung an cler Spitze der Vorlerflügel bildet, erhielt reichliche schwarze Schuppen, dem an dieser Stelle bei urticae liegentlen schwalzen Fleck entsprechend.

6. Vanessa antiopa. Exposition 29-34 Tage. Es traten Merkmale auf, wie sie Vanessa urticae, polychloros etc. auf ihren Hinterfligeln oberseits ganz klar noch gegenwärtig zeigen.

Exposition 39 Tage. Die augenfälligsten Merkmile dieser Form sind: "Die Vermehrung" des Blau und das "Schmälerwerilen" des gelben Ausserrandes auf beiden Flïgelpaaren.

Exposition 44 Tage. Ergebniss: ab. roederi Stdf.

7. Vanessa atalanta. Exposition 31 Tage. Die erhaltenen Formen schwanken individuell ziemlich stark.

Oberseite: Der weisse Costalfleck vergrössert sich, die rothe Binde der Verderflügel wird in der Mitte von zwei schwarzen Querschatten durchshnitten, die etwa $1 / 1 / 2 \mathrm{~mm}$ Abstand ron einander haben, der Zwischenraum zwischen diesen Querschatten ist bisweilen fast vollkommen mit schwarzen Schuppen ausgefullt. Ebenso wird der unterste Theil der rothen Querbinde an der Dorsalecke meist durch eine schwarze Linie, welche längs der hier befindlichen Rippe verläuft, abgeschnürt.

Bei den extremsten Stücken wirl der abgeschnïrte rothe Fleck in der Dorsalecke durch schwarze Bestäubung fast verleckt. Weiter treten blaue Schuppen zwischen dem weissen Costalfleck und der rothen Binde auf, und in selten ${ }^{\circ}$ Fällen auch innerhalb der rothen Binde an der Dorsalecke.

Auf den Hinterflügeln nehmen die schwarzen Punkte in dem rothen Bande am Aussenrande meist an Grösse ab und erhalten ebenso wie die Rippenenden, welche innerhalb dieses Bandes liegen, blaue orler gelbliche Bestäubung. Der blaue Fleck im Analwinkel nimmt grössere Dimensionen an. 
Unterseite: Das Blau zwischen dem weissen Costalfleck und der rothen Binde der Vorderflïgel nimmt sichtlich zu.

Die schwarzen Querschatten, welche die rothe Binde, die einen Stich ins Violette erhält, durchschneiden, sind auch hier gut ausgeprägt. Die Hinterflügel erhalten eine verwaschene, verschwommene Zeichnung und durchweg, am meisten aber am Aussen- und Vorderrande, eine starke Aufhellung durch sich reichlich einstellende gelbe und blane Farbentöne.

Exposition 42 Tage. 11 Puppen entschliipften 10 fast normale Falter; der 11. Falter gehörte ler eben geschilderten, sehr abweichenden Form an, nur war der weisse Costalfleck der Vorderflïgel nicht vergrössert, sonilern schmäler als bei normalen Stiicken.

8. Vanessa cardui. Exposition 23 Tage. Es wurden Formen erhalten, welche denjenigen aus Lappland entsprechen.

Exposition 28 Tage. Fast dasselbe wie vorher; einige Exemplare waren aber noch dunkler.

9. Argynnis aglaja. Exposition 28 Tage. Die braunrothe Grunclfarbe ändert sich nicht. Die schwarzen Flecken an der Basis der Vorlerflügel nehmen an Umfang zu, nicht aber die weiter nach aussen liegende Punktreihe und die Zeichnumg des Aussenrandes der Fluigel, ebenso auch nicht die Zeichnung der Hinterfliigel.

Exposition 42 Tage. Die Falter sind beile aberrativ. Ober. seite: Die braunrothe Grundfarbe wird diisterer, die basalen Zeichnungsmomente der Vorlerflügel vergrössern sich. Die Fliigelbasis unterhalb der Mittelzelle wird geschwärzt. Die weiter nach aussen liegenden Punktreihen beginnen auf beiden Flügelpaaren zu schwinden. Die Bogenzeichnungen vor dem Aussenrande der Vorder- wie (ler Hinterflügel verlängern sich liegelig nach innen. Unterseite: Die Zeichnungsmomente der Vorilerflügel vergrössern und verkleinern sich den Veränderungen der Oberseite ganz entsprechend. Auf den Hinterflügeln verdunkelt sich das Graugrün zwischen den drei Silberflecken am Costalrande zu schwarzbrauner Färbung, auch an einigen anderen Stellen tritt am Rande der Silberflecken diese Verdiisterung auf.

10. Dasychira abietis. Exposition 42 Tage. Die in den lichten Grund eingestreuten schwarzbraunen Schuppen nehmen zu. Auch auf den Hinterflügeln werden die wenigen Schattirungen nach dem Analwinkel hin dunkler und schärfer abgegrenzt. 
Ein Jahr später erschienen "Weitere Mittheilungen über den Einfluss extremer Temperaturen auf Sclmetterlingspuppen" von M. Standfuss (1895. 839).

Seinen Wärme-Tersuchen entnehmen wir folgendes:

1. Rhodocera rhammi. Puppen 48 Stunten in $39^{\circ}$ C.. dann noch: männliche 6 Tage, weibliche 7 Tage in $27^{\circ} \mathrm{C}$. Die Fligel des $\delta$ sind ähnlich wie bei var. farinosa 7 . von Kleinasien. Die Färbung der Oberseite ist unveränlert, clie Unterseite ist dunkler. Bei weiblichen Exemplaren findet die Verschiebung der Fligelform fast gar nicht statt, hingegen tritt hier oberseits gelbe, der männlichen ganz gleichgeartete Färlung auf. Unterseits gleichen die Weibchen den normalen männlichen Exemplaren.

2. Tanessa polychloros. Exposition 3!90 C., dam noch 9 Tige $25^{\circ}$ C. Ergebniss: var. erythromelas Stgr. von Algier.

Die Kälte-Versuche führten zu folgenden Resultaten:

1. Vanessa polychloros. Exposition 34 Tage Eiskasten, dam 14 Tage im Keller $\left(+14^{\circ}\right.$ C.) und schliesslich Zimmertemperatur. Ergebniss: ab. dixeyi Stdf.

2. Vanessa antiopa. Exposition 33 Tage im Eiskasten, darauf 5 Tage $11^{\circ} \mathrm{C}$, , dann Zimmertemperatur. Ergebniss:

Oberseite: Ier gelbe Rand beiler Flügelpare wird schmäler und bleicher als bei normalen Stïcken, zudem sehr stark schwarz bestäubt, namentlich auf den Vorderflügeln. Die braune Grundfarbe wird verdunkelt, die blauen Flecken am Aussenrande vergrössert, aber mit vielen schwarzen Schuppen durchsetzt und dadurch getrül)t und weniger leuchtend. Bei einem Exemplar geht diese Trübung so weit, dass die blauen Flecken der Vorlerfluigel am Costal- und Dorsalwinkel fast verschwinden.

Unterseite: Hier erscheint diese Form ausserordentlich stark gezeichnet. In der basalen Flügelhälfte finden sich längs der Rippen viele gelbe Schuppen ein. Der darauf folgende Flügeltheil erhält reichliche Beimischung brauner Farbentöne, und die nach den lichten Aussenrändern hin die Grenze bildenden, in normaler Gestalt flach dreieckigen oder bogrenförmigen, dunkelbleifarbenen Flecken werden bei dieser Form ausserordentlich gross, lichtblaugrau und spiessförmig nach der Flügelbasis hin verlängert. Der helle Saum der Aussenränder ist auch hier deutlich verschmälert und durch dunkle Schuppen verdüstert. 
3. Vanessa atalanta. 48 Tage im Eiskasten, dann 10 Tage im Keller, schliesslich in der Zimmertemperatur. Ergebniss: ab. merrifieldi Stclf.

4. Vanessa cardui. 33 Tage im Eiskasten, dann 5 Tage im Keller, nachher Zimmertemperatur. Errelmiss: clie zuletzt ausgeschlüpften Falter waren ab. wishotti Stdf.

5. Dasychira abietis. Exposition 30 Tage, darauf 8 Tage im Keller, dann Zimmertemperatur. Die zuletzt erscheinenden Individuen gehörten der 1894 charakterisierten Form an.

Heppe (1894. 837), Zahnarzt in Rorschach, brachte die Puppen von Vunessa untiopa vom 8. bis 18. Juli 1895 in einem Holzgefïss direct auf die Eisstuicke; dann wurlen die Puppen in Zimmertemperatur gebracht und ergaben Falter, welche oberseits und unterseits einen starken Schiller zeigten. Standfuss (837), welcher diese neue Form zur Einsicht erhielt, nannte dieselbe Vanessa antiopu ab. heppei.

Standfuss (837) erwähnt die Versuche von Weskamp, Eisenbahnsekretär in Nayen (Rheinprov.), wobei der letztere die Puppen von Vanessa polychloros bei $+2^{\circ} \mathrm{C}$. gehalten hat und eine Form mit mehr oder weniger Schiller auf Ober- wie Unterseite erhielt.

F. Morrifield (1894. 571) hielt einen Vortrag in der Entomologischen Gesellschaft zu London über Temperaturexperimente in Jahre 1893 bei verschiedenen Arten von Vanessa und anderen Lepidopteren, welchem folgendes entnommen ist:

Pieris napi der Sommer- sowie der Wintergeneration (summer-, winter-pupating brood) hängt zum Theil von der charakteristischen Saison-Färbung, aber nicht vollständig von der Temperatur ab, welcher die Versuchsobjecte ausgesetzt werden.

Pararge egeria ergab viel lebhaftere Zeichnung und Färluung bei niederen Temperaturen, aber es war keine Amnäherung an die helle, südeuropäische Form.

Cidaria silcceata. Tiefe Temperaturen verursachten bei der Sommergeneration eine Aehnlichkeit mit der Wintergeneration. Hohe Temperaturen riefen einen schwachen und einförmigen Effekt hervor.

Vanessa polychloros wird beim Forcieren der Puppen gelber, gleichgultig ob die Puppen vorher in hoher oder tiefer Temperatur verblieben. Das Aussetzen der Puppen in niedern Temperaturen brachte zunehmende Breite des dunklen Randes hervor, gleichviel ob später forciert wurde oder nicht. Die intermittirende 
Temperatur änderte die Zeichnung insofern, als eine schwache, rantähnliche liette von gelblich-wolkigen Flecken mit kleinen schwarzen Mittelpunkten auf allen Flügeln hervorwerufen wurle. Einige Puppen, welche strenger liälte ausgesetzt waren, ergaben eine sehr dunkle Form, der Vanessa :xanthomelas ähnlich.

Vanessa atalanta-Puppen reagierten sehr stark auf hohe Tenperaturen, inclem die goldbraunen Theile in der Austehnung und Helligkeit zunahmen; es exschienen auch neue Scharlachflecken an den Vorderflügeln. Extreme Temperaturen verursachen eine grosse Ausdehnung der blaugrünen und weissen Zeichnungen und machen die Färbung intensiver.

Tanessa c-album-Puppen iler I. Generation (Schmetterlinge schlïpfen im Juli aus) reagieren auf mässig erniedrigte Temperaturen viel stärker als diejenigen ler II. Generation (im September ausschlüpfende Schmetterlinge). Dies stimmt mit den Beobachtungen von W. H. Edward an Nord-Amerikanischen Faltern: Grapta interrogationis und Grapta comma überein.

Vanessa untiopa ergab keine günstigen Resultate, da die Puppen zu alt waren.

Darauf fand eine Discussion statt, an ler F. A. Dixey, Swinhoo und Hampson theilnahmen.

Chronologisch foìgt ein junger Zürcher, E. Fischer, welcher derartige Versuche bereits 1892 anstellte. M. Standfuss hatte von ihm damals zur Einsicht eine durch Kïlte erhaltene aberrative Form von Vanessı io bekommen, welche er als ab. fischeri Stilf. beschrieb (1892. 836).

Die erste Arbeit veröffentlichte E. Fischer im Jahre 1895 unter dem Titel: „Transmutation der Schmetterlingen infolge Temperaturänderungen. Experimentelle Untersuchungen über die Phylogenese der Vanessen" (1895. 228). Er führt aus: Am 25. September 189.2 wurden 500 frische Puppen von Vanessa jo in den Eiskeller direkt auf's Eis gestellt. Nach 3 Wochen in die Zimmerwärme gebracht, begannen die Falter vom 8 . November an, auszuschlüpfen, und ergaben 15 aberrative Formen, unter welchen auch Vanessa jo, aberratio fischeri Stdf. (\$36) sich befand. Die anderen Puppen gingen zugruncle, weil sie entweder zu weich oder zu hart auf's Eis gestellt wurlen, oder die ausgebildeten Aberrationen die Puppenhülse bloss am Nacken zu sprengen vermochten, alsdann stecken blieben und abstarben. 
Im Frühjahr 1893 brachte Fischer Puppen von Vanessa urticao in einen eigens für diese Experimente konstruierten Eiskasten und suchte besonders die kürzeste Zeit zu bestimmen, innerhalb welcher die Kälte eine neue Form hervorzurufen vermag.

Die Beobachtungen zeigten, dass bei einer Temperatur von $+1^{0}$ bis $0^{0}$ C. 8 Tage genügen, um eine aberrative Form zu erzeugen.

Im Juni 1893 wurilen ea. 600 Puppen von Vanessce io $\mathrm{L}$. in den erwähnten Eiskasten gel)racht und nach 3 Wochen herausgenommen. Es ergaben sich nur 50 Uebergangsformen von normalen Faltern zur ab. fischeri, die anderen Puppen gingen entweder zugrunde oder ergaben normale Falter.

Ausserdem experimentierte er im gleichen Sommer mit einer grossen Zahl Puppen von Vunessa antiopa L. Dic Abweichungen bei clen meisten Stïcken war ziemlich stark und so erschien Vanessı antiopa L. aberratio artemis Fschr. „Die Grunltarbe ist derjenigen der normalen antiopa gleich orler ein dunkleres Sammethraun, das darlurch in seiner Auslehnung reduziert erscheint, dass der schwarze Vorsaum, der den blauen Flecken zur Basis dient, auf den Vorler- und Hintertlügel sich verbreiterte und zwar bei letzteren oft derart, dass die braune Grundfarbe fast ganz verlrängt ist. Diese Auslehnung des schwarzen Vorsaumes hat auch peripher stattgefunden, so dass dadurch der schwefelgelbe Saum durchschnittlich mehr o.ler weniger, bei is Exemplaren bis auf die Hälfte verschmälert ist, während er im übrigen keine abweichendle Färbung zeigt." Die blauen Flecken auf der verbreiterten schwarzen Binde sind sehr vergrössert.

Ganz analoge Versuche wurden auch mit Vanessa polychloros, c-album und Papilio machaon L. angestellt und ergahen mehr oder weniger abweichende: Formen.

Im Herhst 1893 sammelte E. Fischer ca. 3000 Raupen von Vunessa io II. Generation, von denen 1000 Puppen in den Eiskeller gestellt und nach 3 Wochen herausgenommen wurden. Sie ergaben aher nur 20 Falter ab. fischeri, die underen sind moistentheils zugruncle gegangen.

Die ïbrigen 2000 Puppen wurlen in Blechschachteln gebracht, in (lenen stark angefeuchtetes Moos lag. Die vielen Puppen starben aber im Eiskeller ab.

Die Versuchsergebnisse im Sommer 1894 waren:

1. Frische Puppen von Vanessa antiopa L. wurlen: 
a) 3 Wochen auf Eis gehalten (400 Puppen) nnd nachher in einer Temperatur von $35^{\circ}-38^{\circ}$ bis zum Ausschlüpfen der Falter gehalten. Alle ergaben eine zwischen der normalen und der ab. artemis stehende Form.

b) 4 Wochen auf Eis umrl nachher in $35^{\circ}$ gehalten. Es entstand ebenfalls eine Zwischenform, jecloch mit grösseren blauen Flecken.

c) 3 Wochen auf Lis und nachher in $35^{\circ}$ gehalten. Alle lieferten eine Form, als ob sie von Anfang an einer Temperatur von $35^{\circ}$ ausgesetzt gewesen wären, also die ab. epione.

(l) 3 Wochen auf Eis uiıl damn in $35^{\circ}$ gehalten. Der Falter zeigte ziemlich vergrösserte blaue Flecken, die schwarze Binıle war auf den Vorderflügeln in ovale Flecken zertheilt, deren Kerne eben durch die blauen gebillet wurden.

e) 2 Wochen in verschlossenen Blechschachteln unter Eis aufhewahrt und lieferten die exquisitesten Exemplare der ab. artemis.

Unter den bei (l) und e) genannten Faltern trat auch zerstreut ab. hygiaea Hdrch. auf.

2. Frische Puppen von Vanessa polychloros L. wurien 3 Wochen auf Eis und nachher in $35^{\circ}$ gehalten. Die schwarzen Flecken waren ganz erheblich vergrössert, und es trat dem Innerande der Vorlerflügel entlang ein schwarzer Streifen auf, während die blaten Keilflecken sich durchschnittlich merkbar vergrössert hatten. Die Unterseite bot besonders auf den Hintertlügeln durch lehmgellse Beschuppung ein ziemlich helles Mittelfeld dar.

3. Frische Puppen von Vanessa io L. wurlen 3 Wochen alif Eis und nachher in 250 gehalten. $50 \%$ starben ab. Die Zeichnung mannigfacher und markanter als dies bei in $\mathrm{L}$. der Fall ist.

4. Frische Puppen von Vanessa prorsa L. wurden 2-3 Wochen auf Eis und nachher in $25^{\circ}$ gehalten. Es erwiesen sich die mannigfachsten Abstufungen von der typischen schwarzen Sommerform bis zu solchen, die der rothen Winterform sehr nahe standen.

5. Puppen von Vanessa cardui L., ebenso behandelt, entwi(kelten sich zu einem Falter, der etwas diusterex war.

6. Puppen von Vanessa atalanta L., ebenso behandelt, ergaben Falter, bei welchen die rothe Bincle der Vordertlügel schmäler war und von 2 schwarzen Querstreifen in der Mitte durchschnitten wurde, während in hinteren Theile derselben ein siebenter weisser Punlit auftrat. Die Unterseite war stellenweise etwas heller. 


\section{Wärme-Versuche:}

Eine Anzahl frischer Puppen von Tunessa urticae wurde im Mai Temperaturen von $34^{\circ}-38^{\circ} \mathrm{C}$. ausgesetzt. Die Falter erschienen nach wenigen Tagen und zeigten eine Annäherung an die im Süılen vorkommende var. ichnusa Bon. Ein kleiner Theil der Puppen ergab die bunte var. turcica Stilgr. in ganz typischen Exemplaren.

Vanessa io veränderte sich auffallend wenig, während Vanessa antiopa eine Form ergab, welche gerade das Gegentheil der ilurch Kälte erzeugten war. Diese Form ist unter dem Namen Vanessa antiopa L. aberratio epione Fschr. in der Gubener entomologischen Zeitschrift beschrieben worden (227).

Vanessı polychloros reagierte ähnlich auf hohe Wärme, wie urticae, während Vınessa c-album dabei wesentlich lichter auf iler Ober- und Unterseite ausfiel.

Die 1894 angestellten Wärme-Versuche ergaben folgende Resultate:

1. Puppen von Vancssa antiopa L. wurden ron frischem $\mathrm{Zu}-$ stande an gehalten:

a) in einer Temperatur von $35^{\circ}$. Nach $8-10$ Tagen wurle ab. epione Fschr. erhalten.

b) etwa 3 Stunden lang und dann täglich wieder 2-3 Stunden in einer Temperatur von $40^{\circ}-42^{\circ}$, dazwischen bei $35^{\circ}-38^{\circ}$. Alle Puppen ergaben ab. artemis Fschr., als ob dieselben von Anfang an auf Eis gehalten worden wären.

c) in einer Temperatur von $35^{\circ}-38^{\circ}$. Es wurden erhalten: ab. epione Fschr., zwei Uebergangsformen zu ab. hygicuea Hdrch. und eine typische ab. hygiaea und endlich eine neue Form.

2. Puppen von Vanessa cardui L. in einer Temperatur ron $36^{\circ}$ ergaben etwas lichtere Exemplare.

3. Puppen von Vanessa atalanta L. bei $36^{\circ}$ ergaben eine Form, welche rler südlichen Vanessa callirrhoü nahe steht.

Zum Schlusse dieses Theils bemerkt E. Fischer, dass zwischen den normalen Formen (io unil antiopa) und den als Aberrationen (fischeri, artemis, epione) beschriebenen natürlich Uebergänge in allen Abstufungen vorkommen.

Eine zu scharfe Kritik dieser Untersuchungen von E. Fischer enthält die Abhandlung' von T. Garbowski (1995. 272). 
Darauf erschien die zweite Arbeit von August Weismann: :) Vene Versuche zum Saison-Dimorphismus der Schmetterlinge" (189:5. 954)

Seine Versuche lassen sich kurz wiellergeben wie folgt:

I. Versuche und Beobachtungen an Chrysophunus phlueus L.

Neapler Eier, in Neapel aufgezogen, ergaben Falter, welche den Namen var. elpus verdienen.

Neapler Eier, in Freiburg a ufgezogen:

1. Puppen hei gewöhnlicher Zimmertemperatur. Von 3is Schmetterlingen waren 8 entschielen var. cleus, die iibrigen zeigten keine schwarze Bestäubung des Rothgolı, wohl aber alle breitere unil tiefer schwarze Rändler und grössere schwarze Flecken als die deutschen phlaeas.

2. Puppen bei $7-10^{\circ} \mathrm{C}$. Von 51 ausgeschlïpften Schmetterlingen sind 2 etwas schwärzlich bestäubt, die übrigen repräsentiren ein Mischmasch von Merkmalen der südlichen und solchen der nörıllichen Form. Solche Exemplare kommen in der freien Natur nicht vor.

Deutsche Eier, in Deutschland aufgezogen:

Eier unter erhöhter Temperatur (2.j-350 C.); die ausgeschlüpften Räupchen auf lebentlen Rumex acetosella-PHanzen bei 27-290. Die 35 Räupchen ergaben 25 Puppen und diese bei $27-38^{\circ}$ ergaben 24 Schmetterlinge, von welchen minlestens 8 Stück grenau dem gewölınlichen deutschen phlaeas gleichen. Zwei Stücke können als var. eleus bezeichtnet werden. Die ïbrigen sind etwas dunkler als die gewöhnliche rleutsche Form.

Somit beeinflusst die Temperatur, welche auf die Puppe einwirkt, die Färbung des Schmetterlings.

Vom Klima unabhängige Zeichnungselemente bei phlaeas sincl: 1) Die blauen Flecke, 2) Die rothe Bincle auf der Unterseite der HinterHliigel, 3) Die Schwänzchen der Hinterflügel.

\section{Versuche mit Pieris napi.}

Am 8. Juni 1887 legten die Freiburger-IVeibchen Eier. Das Ausschlïpfen iler Rä̈upchen erfolgुte bei $21-22^{\circ}$ am 14. Juni. Die Verjuppming fand rom 30. Juni bis 2. Juli im Zimmer bei $21-22$, , 0 statt.

Erster Versuch. Die Puppen zuerst bei $22-25^{\circ} \mathrm{im}$ Zimmer. Das Ausschliipfen wïr:le sonst nach 9 Tagen stattfinden. 45 Puppen wurden am 7. Juli nach erfolgter Verpuppung in den Eisschrank gebracht $\left(7-11^{\circ}\right)$. Zwischen 13, uni 22. Juli schliipften 35 Schmet- 
terlinge aus, von welchen 26 von ausgeprägter Sommerform waren, die übrigen zeigten unten stärkere grüne Arlerbestäubung. Am 24. Juli wurden die noch nicht ausgeschliipften Puppen in den Brutofen $\left(29,2^{\circ}\right)$ gebracht. Nur 3 Schmetterlinge schlüpften am 25 . Juli aus und zwar von der Sommerform, die übrigen liessen sich erst im folgenden Jahr zum Ausschlüpfen herbei. Sie überwinterten im Keller und wurden im April ins Zimmer gesetzt. Dort schlüpften vom 29. April bis 2. Juni 1888 noch 12 Schmetterlinge aus, alle von exquisiter Winterform; alle kleiner als die im Jahre 1887 ausgeschlüpften Stücke derselben Brut.

$\mathrm{Z}$ weiter Versuch. Die Puppen wurden unmittelbar nach erfolgter Verpuppung in den Eisschrank gesetzt $\left(9^{\circ}\right)$.

1. 4 derselben blieben darin vom 28. Juni bis zum 23. Juli, und es schlüptte keine aus. Darauf wurden sie einige Stunden bei $22^{\circ}$, dann im Brutofen bei $30-31^{\circ}$ gehalten, und es ergaben alle 4 am 26. und 27. Juli nicht sehr scharf ausgeprägte Winterformen.

2. 12 kürzlich verpuppte und zwei bereits zur Verpuppung angesponnene Raupen wurten am 2. Juli in den Eisschrank gesetzt $\left(9^{\circ}\right)$. Am 18. August schlüpfte $1 \delta^{\circ}$ als entschiedene Winterform aus; alle übrigen Puppen überwinterten im kalten Zimmer und schlïpften zwischen 3. April und 26. Tuni 1888 aus, alle als ausgeprägte Winterform.

Versuche mit Pieris napi var. bryoniae.

Erster Versuch. Die Eier von Davoser-Weibchen. Die Verpuppung erfolgte vom 16. bis 25. Juli 1837. Bei Zimmertemperatur (iiber $20^{\circ}$ ) schlüpften sie im Juli und August nicht aus. Darauf iiberwinterten sie im kalten Zimmer und ergaben vom 26. April bis 7. Juni 24 völlig normale bryoniae.

$\mathrm{Z}$ weiter Versuch. 25 Individuen derselben Brut wurden theils kurz vor, theils kurz nach ihrer Verpuppung in den Brutofen gebracht (ca. 290). Am 23. Juli schlüpfte ein $\delta^{\top}$ ans, als Sommerform von napi. Die übrigen Puppen überwinterten (bis zum 30. Juli im Brutofen, dann im kalten Zimmer) und schliipften (2.2 Stiick) vom 6. April bis 2. Juni als völlig normale bryoniae aus. (Eine Ausnahme: die gewöhnliche Färbung durch Weiss unterbrochen).

Dritter Versnch. Die Eier von Davoser-Weibchen. Die Räupchen schlüpften vom 26. Juni his 1 . Juli aus und wurilen bei 17-230 aufgezogen und am 25. Juli in zwei Serien getrennt: 
Serie I in Raupenzwinger bei Zimmertemperatur. Verpuppung vom 20.-28. Juli. Alle Puppen überwinterten im warmen Ziminer und gaben zwischen 23. März und 27. Mai 1889 völlig normale Schmetterlinge.

Serie II wurde am 25. Juli 1888 aus $23,8^{\circ}$ Zimmertemperatur in den Brutofen bei $30^{\circ}$ gebracht und dort belassen bis zum 19. August. Die Verpuppung zwischen 20. und 28. Juli. Die Puppen vom 19. August an bei Zimmertemperatur und im Winter im kalten Zimmer. Zwischen 23. Mai und 7. Juni 1889 schlüpften 32 Schmetterlinge aus; zwischen den Stücken von Serie I und II ist liein Unterschied. Nur $1 \delta^{\nearrow}$ weicht von allen übrigen ab und gleicht der Sommerform von napi.

Vierter Versuch. Eier von Davoser-IVeibchen. Am 23. Juni schliupften die Räupchen aus. Wurden bei $26-31^{\circ}$ plaziert. Die meisten starben am 5. Juli an Pilzkrankheit. Am 7. Juli schliipfte ein einziger Schmetterling aus, welcher beinahe vollständig einem gewöhnlichen Sommerweibchen von $P$. napi var. napacae ähnelte.

\section{Versuche mit Vanessa levana-prorsa.}

Erster Versuch mit levana. Ueber 100 Eier und Räupchen der 2. Brut wurden ain 8. August gesammelt und bei gewöhnlicher Temperatur aufgezogen. Verpuppung: Anfang September. Die Puppen wurlen im geheizten Zimmer aufbewahrt und dort schliipfte: 1 prorsa aus.

Vom 10. Januar 1884 wurden die Puppen im Brutofen äber Wasser bei $27-30^{\circ}$ gehalten. Die Schmetterlinge schlüpften zwischen 18. und 29. Januar aus und ergaben 1 porima.

Am 1. März wurden die Puppen aus dem Brutofen lierausgenommen fund ins warme, später ins ungeheizte Zimmer gesetzt. Ergebniss: am 24. Mai 1 levana.

Zweiter Versuch mit levana. Puppen der 2. Brut von 1884, die sich Endle August und Anfang September verpuppt hatten, wurden im kalten Zimmer überwintert und dann am 1. März in den Eisschrank bei $5^{0}$ gebracht und dort bis zum 27. Juni gelassen, von da ab aber ins Zimmer gestellt $\left(22-30^{\circ}\right)$. Zwischen 8. und 10. Juli schlüpften 9 levana aus. 2 davon zeigten schwache Annäherung an porima.

Dritter Versuch mit levana. Eier und junge Räupchen ler zweiten Jahresbrut, im Freien am 29. Juli gesammelt, wurden in Brutzwinger bei $30-32^{\circ}$ aufgezogen. Die meisten verpuppten 
sich am 8. August und blieben im Brutofen bei $30-32^{\circ}$. Zwischen 15. und 26. August schlïpften 15 prorsa aus, die anderen starben ab. Vierter Versuch mit levana. Eier und junge Räupchen der 2. Brut, am 29. Juli im Freien gefunilen, wurlen bei gewöhnlicher Zimmertemperatur aufgezogen und verpuppten sich bei $21-22^{\circ}$ am 17.-22. August. Von 241 Puppen schlüpften 5 jrorsu vom 25. bis 28. August aus.

Die übrigen 236 Puppen wurlen im Oktober in zwei Serien gesondert:

1. 150 Puppen im Brutofen bei $27^{\circ}$. Sic bewegten sich ziemlich lebhaft bis zum 14. Januar, am 2. März waren aber alle torlt und faulig.

2. 86 Puppen bei Zimmertemperatur über Wasser (November, December und Januar 13-140). Zwischen 16. Februar und 4. April schlüpften 36 levanc aus.

Fünfter Versuch mit levana. Am 16. August im Freien gesammelte junge Räupchen der 2. Brut wurden bei $30-31^{0}$ aufgezogen, vom 29. August ab wurde die Temperatur auf 27-280 gehalten. Vom 24. August an Verpuppung. Zwischen 1. und 7. September schlüpften im Brutofen 56 prorsa aus. Die anderen, bei 13-140 aufbewahrt, ergaben am 9. Februar - 1. März levana.

Sechster Versuch mit levana. Gesammelt (halbwüchsige Räupchen) am 16. August. Zuerst bei $30-31^{\circ}$, später bei $27-28^{\circ}$. Die Verpuppung vom 20.-27. August. Ergebniss: 14 prorsu. Die anderen bei $13-14^{\circ}$ autbewahrt, ergaben am 9 . Februar -1 . März levana.

Siebenter Versuch mit levana. Am 16. August gefundene ältere Räupchen bei $27-31^{\circ}$. Verpuppung 21.-23. Ergelmiss: 3 piorsa am 6.-10. September, die anderen todt.

IV. Versuche mit Pararga egeria und var. meione.

Erster Versuch mit egeria. Ein in Genua gefangenes meione-Weibchen legte 24 Eier ab, welche am 21. April 1884 in Freiburg i. Br. bei $17^{\circ}$ Räupchen ergaben. Nach der ersten Häutumg: (5. Mai) wurden sie bei $10^{\circ}$ gehalten und nachher bei $12,5-14^{\circ}$. Die Verpuppung (15 Puppen) erst am 17.-25. Juni. Die Puppen bei $14^{0}$ gelassen. Zwischen 12. und 18. Juli schliipften 15 Schmetterlinge aus, alle kleiner und weniger stark gelb als solche, die im März und April in Genua gefangen worden waren, aber bräunlicher als in Deutschland gefangene Exemplire. 
Zweiter Versuch mit egcria. Von 20 Eiern einer egeria aus Zürich, die am 20. Mai 1886 gelegt waren, schlüpften bei 190 am 30. Mai 20 Räupchen aus unil wurilen in Temperaturen von $25-27^{\circ}$ plaziert. Verpuppung am 18.-25. Juni. 9 Falter schlïpften am 27. Juni - 7. Juli aus, alle normal.

"Die sülliche Form meione lässt sich zwar durch Einwirkung von nierlriger Temperatur $\left(10-14^{\circ}\right)$ in ihrer Färbung beeinflussen und minder lehhaft gefïrbt machen, allein sie bleibt doch immer noch lebhafter in der Farbe, als die nördliche Form egeria. Umgekehrt wird die Brut der nördlichen Form durch Einwirliung höherer Temperatur (250) nicht sichtloar veränclert" (p. 37).

\section{Versuche mit Vanessa urticae.}

Erster Versuch (18S6). Die vor der 2. Häutung stchenden Räupchen zuerst bei $27^{\circ}$, vom 2. Juli ab bei $30^{\circ}$. Verpuppung am 3.-5. Juli. Die Puppen bei $26-29,4^{\circ}$. Am S.-11. Juli 46 Schmetterlinge, alle lebhaft roth, ohne die dunkeln Schatten auf der Grundfarbe.

$\mathrm{Z}$ weiter Versuch (1886). Eier uni eben ausgeschlüpfte Räupchen am 6. Juli vom Canton Bern (3000' iiber dem Meer). In Freiburg i. Br. wuchsen sie bei $26-29,4^{\circ}$, verpuppten sich am 19 . bis 21. Juli und schlüpften am 23.-26. Juli aus. Die 36 Schmetterlinge zeigten nichts besonderes.

Dritter Versuch (1886). Ein Theil der Raupen vom II. Versuch bei $15^{\circ} \mathrm{im}$ Kieller. Die Verpuppung begann am 7. Aurust Am 27.-29. August schlüpften die Schmetterlinge aus. 10 Exemplare sind ein wenig dunkler als die von Versuch II, die Flecken grösser. Von var. polaris, weit entfernt.

Vierter Versuch. Freiburger-Räupchen, frisch ausgeschlüpft, aufgezogen bei $17-23^{\circ}$, vom 16 . September an bei $17-20^{\circ}$. Die Verpuppung am 25.-2S. September. Die 22 erhaltenen Schmetterlinge sind im Ganzen eher hell, die Flecken klein.

Fünfter Versuch (18s6). Freiburger-Räupchen, frisch ausgeschlïpft. Aufgezogen bei $30^{\circ}$. Verpuppung vom 13. August an. Am 18.-21. August schlüpften 35 Schmetterlinge aus, alle lebhaft roth und mit relativ wenig Schwarz, die Flecken klein bis zum völligen Verschwinden. Stehen der corsischen Varietät ichnusı ganz nahe.

Aug. Werner (1895. 956) brachte eine Anzahl Puppen von Papitio machaon durch künstliche Wärme ( ${ }^{\circ}$ ?) zur Entwickelung. 
"Zunächst erschienen einige Falter mit liräftig geller Bestäubung, auch hier und da ein Stiick mit rothen Flecken am Vorderrande und weiter herunter in der gelben Fleckenreihe der Hinterfliigel. Ferner zwei Thiere mit ganz rothbraunen Augenflecken, ohne blaue resp. bläulichweisse Bestäubung derselben." Zwei Falter waren richtige Uebergänge zu hospiton. „Diese Thiere haben Form und Grundfarbe des machaon, während sie im Kolorit des Auges und der Anlage des schwarzen Binde entschieden zu hospiton neigen" (p. 15s).

W. Caspari II (1895. 137) erhielt bei seiner Winterzucht (welche näher nicht beschrieben ist) Agrotis janthina mit weisser Bindle auf den Vorderflïgeln, die parallel dem Rande läuft; ferner ergab Agrotis fimbria sehr gesättigte Farben, wie die des Süilens; Agrotis stiymatica wird ölters schwarz; Agrotis baja liefert öfters einfarbige Stiicke, während andere derselben Art sehr bunt werden.

M. Standfuss (1896. 840) sagt in seinem Buche, dass je heisser die Zeit, in welcher die Entwickelung der Falter von podulirius vor sich geht, desto lichter und durchschimmernder wird das Weiss der Flügel, desto ausgedlehnter die helle Färbung an der Spitze der Schwänze und desto weisser Thorax und Leib.

In seinem "Handbuche" beschreilbt M. Standfuss (1896. 840) seine Versuche über das Treiben der Raupen durch Erhöhung der Temperatur, welchen wir folgendes entnehmen:

Lasiocampa quercifolia. Eier, Raupen und Puppen wurden der Temperatur von $30^{\circ}$ ausgesetzt. Dabei wurde eine geringe Zunahme der schwärzlichen Bestäubung erzielt.

Lasiocampa pruni. Dieselbe Behandlung, wie oben. Die zweite Serie bei $25^{\circ}$. Bei beiden Reihen wird die Gesantfärbung von dem feurigen Rothbraun nach Gelbroth hin algestumpft.

Dasychira abictis. Bei $25^{\circ}$ vom Ei auf. Die schwarzbraune Zeichmung der Schmetterlinge geht zuriick, woslurch sie heller werden.

Callimorplu dominula. Alle drei Stadien bei 250. Das lioth der Hinterflügel wird düsterer und die Flecken der Vorderfliigel erhalten durchweg ein gelbes Kolorit noch dunkler, ähnlich wie die Lokalform von Brussa.

Arctia fasciata. Eier bei $34^{\circ}$, Raupen und Puppen bei $25^{\circ}$. Dabei wurde eine weitgehende Variabilität in den Färbungsverhält- 
nissen erhalten. Theils erfolgte eine sehr wesentliche Reduktion ler schwarzen Zeichnungselemente in dem basalen Drittel der Vorderfliigel, aber nur bei männlichen Indiviluen, theils eine starke Ueberlıandnahme dieser schwarzen Flecken und Binden bei mehreren weiblichen Individuen.

Urapteryx sambucaria. C. Jordis in Franlfurt a./MI. ziichtete bei ca. $23^{0}$ die II. Generation. Es wurde var. olivucen Strlfs. erhalten.

Die in diesem "Handbuche" beschriebenen Experimente (p. 236 bis 283) sind theils frïher, theils werden sie weiter unten angeführt.

1896 erschien die zweite Arbeit von E. Fischer (229): „Neue experimentelle Untersuchumgen und Beobachtungen iiber das Wesen und die Ursachen der Aberrationen," in welcher zum ersten Mal die Versuche mit Temperuturen unter $0^{\circ}$ und zwar bis zu $-20^{\circ}$ beschrieben werden.

Diese Untersuchungen ergaben folgende Resultate:

Kälteexperimente $\left(0^{\circ}\right)$.

\section{Vanessa urticae $\mathrm{L}$.}

a) ca. 24 Stunden alte Puppen wurden 2 Wochen auf Eis $\left(0^{0}\right.$ bis $\left.+1^{0}\right)$ und hierauf in $+20^{\circ}$ gehalten und ergaben eine Annäherung an var. polaris Stdgr.

b) $4-8$ Tage alte Puppen $3-4$ Wochen auf Eis und nachher bei $20^{\circ}$. Nur 6 Exemplare waren typische var. polaris.

c) 2-5 Tage alte Puppen 5-6 Wochen auf Eis und nachher l.ei $20^{\circ}$. Ergebniss (15 von 100 Puppen, die übrigen gingen zugrunde): 4 var. polaris, 5 der var. polaris sich nähernde Exemplare, 2 ab. ichnusoides, 1 der ab. ichnusoirles ähnliches Stiick, 3 Individuen, die eine Annäherung an ichmusoides verriethen.

d) 2-4 Tage alte Puppen (280 Stiick) 6 Wochen auf Eis, (lann bei $25^{\circ}$, ergaben zu $2 / 3$ der var. polaris genäherte Individuen, zu $1 / 3$ dunkle Formen von urticae.

e) 2 Tage alte Puppen (500 Exemplare) $4-5$ Wochen auf Eis, (lamn bei $25^{\circ}$, ergaben das nämliche Resultat wie sub a).

f) 4 Tage alte Puppen (100 Stiick) $4-5$ Wochen auf Eis; wieder das gleiche Resultat wie sub d).

g) Ganz frische Puppen $\left.{ }^{1}\right|_{2}$ bis 1 Tag alt (120 Stiick) 5-6 Wochen auf Eis, ergaben zu $1 / 3$ die ab. polaris, zu ca. $1 / 3$ etwas dlistere, trübgefärlte Formen und bis $1 / 3$ gingen zugrunde. 


\section{Vanessa io $\mathrm{L}$.}

a) Frische Puppen (300 Stück) bei $0^{0} 2$ Wochen lang, dann bei $25^{\circ}$. Die Falter waren zu $2 / 3$ normal, zu $1 / 3$ der ab. fischeri Stdls. genähert.

b) 4-6 Tage alte Puppen (180 Stiick) 4 Wochen bei $0^{0}$ ergaben das gleiche Resultat, wie sub a); es waren aber 2 Exemplare a b. fischeri dabei.

c) 4-8 Tage alte Puppen 5 Wochen bei $0^{\circ}$. 13 Stücke ab. fischeri.

\section{Vanessa antiopa $\mathrm{L}$.}

a) 2 Tage alte Puppen $2-3$ Wochen auf Eis ergaben der ab. artemis Fschr. sich nähernde Formen.

b) 4-6 Tage alte Puppen 4 Wochen auf Eis ergaben ein ganz ähnliches Resultat, wie sub a).

c) 2-4 Tage alte Puppen (250) 5 Wochen auf Eis. Fast alle Puppen starben ca. 10 Tage, nachlem sie vom Eise genommen, an Infektion $\mathrm{ab}$, die anderen ergaben $\mathrm{ab}$. artemis Fschr.

\section{Vanessa prorsa L.}

a) Frische Puppen (200 Stiick) 2 Wochen auf Eis, dann bei $25^{\circ}$, ergaben mehrere Uebergangsformen zu ab. porima $\mathrm{O}$.

b) $2-5$ Tage alte Puppen 3 Wochen auf Eis (400 Stück); die Hälfte ergab ab. porima, die anderen waren nahezu normal. Bei 2 Exemplaren entsprachen die Vorderflügel der a b. porima, die Hinterflügel der prorsa.

c) Frische Fuppen 4-5 Wochen auf Eis; $4 / 5$ ergab Uebergänge zu ab. porima, 1/5 ganz typische porima-Falter, 6 Exemplare levana, 4 Stücke - Vorderflügel levana, Hinterflügel prorsa, 1 Stück prorsu mit braungelben Flecken.

\section{Wärmeexperimente (1895) ( 36,5 bis $\left.38^{\circ}\right)$.}

\section{Vanessa antiopa L.}

a) $1 \mathrm{Tag}$ alte Puppen bei $37^{\circ} 60$ Stunden lang, dann bei $25^{\circ}$. $2 / 3$ ging zugrunde, $1 / 3$ ergab Falter, die zwischen antiopa und der Wärmeform ab. epione Fschr. standen.

b) 80 Stück bei $38^{\circ} 3$ Tage lang, dann bei $25^{\circ}$. Die Schuppen waren zum grössten Theil gar nicht gebildet worden. 
c) Frische Puppen bei $37^{0} 60$ Stunden lang, dann bei $25^{\circ}$. Grundfarbe braun, stark mit schwarzen Schuppen besprengt, die gelbe Farbe fast verdrängt. Blaue Flecken verwrössert.

d) Bei 36,50 70 Stunlen lang 60) Puppen. Dasselbe wie sub a).

\section{Vanessa levana L.}

50 Puppen der Wintergeneration, schon mehrere Wochen alt, wurlen vor ier Ueberwinterung bei $35^{0} 7$ Tage lang aufluewahnt, dann bei $30^{\circ}$. Diese Falter schliipften erst 3 bis $4 \frac{1}{2}$. Wochen nach Beginn des Experimentes aus. Die Falter waren levana-Individuen, jedock etwas düster, oft stark schwarz bestäubt.

\section{Papilio machaon L.}

60 Puppen vor der Ueberwinterung 10 Tage lang bei $36^{\circ}$, dann 3 Wochen bei $30^{\circ}$. Es ergal) sich eine helle Form, den suictlichen Varianten nahe stehend.

Kälteexperimente mit Temperaturen von $-4^{\circ}$ bis $-20^{\circ}$ (1895).

Die zu untersuchenden Puppen wurden in Blechschachteln ge. bracht und diese dann in eine Kältemischung von Eis und Kochsalz gestellt. Die Puppen wurlen aus der Zimmertemperatur (250) zuerst in den Keller und nach einigen Stunden in die Kältemischung gestellt; die Temperatur sank ca. 1 Stunde hierauf unter $0^{\circ}$, blieb dann 2-4 Stunden auf einer bestimmten Tiefe, bis sie sich im Laufe der folgenden 5-8 Stunden wieller allmählich auf $0^{0}$ erhöhte.

\section{Vanessa io L.}

Es wurle 8 Puppen (ca. 3 Tage alt) allmählich bis $\mathrm{zu}-20^{\circ}$ abgekiuhlt und zwar 8 mal nacheinander, d. h. 8 aufeinanderfolgende Tage, dann noch 4 Tage bei $0^{\circ}$ gehalten und nachher bei $25^{\circ}$, worauf sie nach weiteren 12 Tagen ausschliipften. Ergebnisse: '2 ab. antiyone Fschr., 1 Uebergangsform zu ab. antigone, 2 normale io mit etwas diusterer Färbung.

\section{Tanessa antiopa L.}

12 Puppen in gleicher Weise behandelt, ergaben: 1 Uebergansform zu ab. hygiaea Hdrch., 1 antiopa.

Das Experiment wurde wielerholt mit 12 Puppen in gleicher Weise; es ergab: 1 antiopa mit sehr diisterem Kolorit, 2 antiopa 
mit theilweise ausgelöschten hiauen Flecken unil verkleinertem gelben Fleck am Costalrande, 1 antiopa, zur Kälteform ab. artemis etwas hinneigend, 1 Uebergangsform zu hygiaea.

\section{Vanessa urticae $\mathrm{L}$.}

200 Puppen ebenso behandelt ergahen, nachdem sie 14 Mal. abgekühlt waren: 1 ab. polaris, 1 urticae mit albinotischer Färbung, 4 normale urticae, $2 \mathrm{ab}$. ichnusoides.

\section{Vanessa prorsa. L.}

50 Puppen. 12 Mal -14 bis $\cdots 16^{\circ}$ ausgesetzt. 23 Falter entsprachen der ab. porima.

\section{Vanessa polychloros L.}

20 Puppen. 12 Mal auf $-14^{\circ}$ bis $-16^{\circ}$ abgekiihlt. Ergebniss: 1 der ab. testudo nahestehende Form, 5 ilunkle polychloros, 4 schmutzigbraungelbe Individuen.

12 Puppen. 18 Mal anf $-12^{\circ}$ bis $-13^{\circ}$ aingekiihlt. Egebniss: 2 der ab. testudo genäherte Stiicke, 3 dunkelbraune polychloros, 1 ab. testudo. Esp.

\section{Vanessa cardui: L.}

14 Puppen. 18 Mal bis auf $-10^{\circ}$ bis $-12^{\circ}$ abgelitihlt. Ergebniss: 3 diistere curdui, 1 Uebergangsform zu al), elymi Rbr., 1 cardui normal.

25 Puppen. 15 Mal bis auf -80 bis $-12^{\circ}$ abgekiihltt. Lirgebniss: 8 cardui normal, 1 ah. elymi hlur., 4 Uehergänge zu ah. elymi.

\section{Vanessa atalanta L.}

13 Puppen. 18 Mal der Temperatur von $-6^{\circ}$ bis $-10^{\circ}$ ausgesetzt. Ergelsnisse: 1 ab. merrifielıli, 3 ab. lilymene, 1 Uebergangsform zu ab. Tilymene Fschr., 3 Uehergünge zu ab. merrifieldi.

\section{Vanessa urticae $\mathrm{L}$.}

12 Puppen. 20 Mal bis $\mathrm{zu}-5^{\circ}$ abgelïhlt, ılann 2 Tage bei 00 , darauf in Zimmertemperatur ca. 180. Die Ergebnisse: 1 ab. ichnusoicles, 1 Uehergangsform zu al). ichmusoides, 1 ab. poluris.

Prehn (1896. 649a) sagt, dlass das Intensivwerilen iler Farben bei $ठ \delta$ in Allgemeinen durch mehr erhöhte Bluttemperatur als bei $q Q$ erzeugt wiril, da die letzteren infolge des Eiervorrats im 
ganzen umbeholfen sind, während die Männchen melnr Anstrengung machen müssen, um zur Begattung zu kommen.

F. Merrifield (1896. 572) setzte lie Puppen von Gonopteryx rhammi aus Noril-Italien und Deutschland der Einwirkung von verschierlenen Temperaturen aus (von $0,5^{\circ}$ bis zu ca. $37^{\circ}$ ). Die Exposition dauerte 20 Tage.

Die hohen Temperaturen verursachten die Zunahme ler gelben Schuppen hei $q_{\rightarrow}$. Niedere Temperaturen vermintern die Ausilehnung des orangenen Flecks an der Oberseite der Vorderflïgel beiler Geschlechter, so dass er bei einigen Exemplaren kaum zu erkennen war. Im Allgemeinen wurle eine grosse Aehnlichkeit mit rar. furinosa von Osteuropa, Armenien und Syrien und mit rar. nepalinsis von Nord-West-Indien erreicht.

Er stellte auch Versuche mit Vanessa-Puppen an. Die besten Resultate mit höheren Temperaturen wurden mit Gralen zwischen $35^{\circ}$ und $40^{\circ}$ erzielt, wobei die Puppen bei dieser Temperatur $12-24$ Stunden und nachher bis zum Ausschliipfen bei $30^{\circ}$ verblieben. Diese Versuche ergaben für Vanessa atulanta die Verbreitung uni Erhellung der Scharlachbänler und das Erscheinen eines langen Anstrichs von graublauen Schuppen in der Nähe rles inneren Randes der Vorderflïgel und der inneren Seite des Scharlachbandes. Bei Vunessu urticae waren die drei wohl bekannten isolierten Flecke an den Vorlertliigeln fast ganz verschwunden, der blaue war beileutend verkleinert und der ïussere Rand der Vorderfliigel sehr schmal geworden.

Die Versuche mit niedrigen Temperaturen (wahrscheinlich bis zu $0,5^{\circ}$ ) ergaben der var. polaris sehr ähnliche Exemplare. Auch $V$. antiopa erhielt bei Kälte-Versuchen eine bedeutencle Verbreitung: der blauen Flecke und die Verdunklung der Ründler.

Diese Versuche ergaben auch, dass hauptsächlich die Sommerpuppen rlurch variable Temperaturen beeinflusst werden; es wurle jedoch beobachtet, dass die Puppen der Nachtsschmetterlinge durch die Temperatur im Frülijahr stark beeinflusst werden. Raupen, welche bei verschiedenen Temperaturen erzogen wurden, hatten keinen Einfluss auf die künftige Färbung der Falter.

H. Gauckler (1896. 281, 28:) experimentierte mit Puppen von Vanessu urticue, in unil untiopu. Seine Resultate waren folgenile: 
1. Vanessa urticuc. Fast erwachsene Raupen wurden am 31. Mai gesammelt. 6 erhaltene Puppen brachte er in einen Eisschrank $\left(8^{\circ} \mathrm{C}\right.$.), nach 30 Tagen in die Zimmertemperatur. Alle Falter zeichnen sich durch ganz intensive Färbung aus; besonders ist das Gellnoth aller Flïgel von leuchtender Farbe, etwa wie es bei der südlichen var. ichnusa. Die schwarzen Flecken am Costalrand der Oberflügel, wie auch die 2 in der Flügelmitte stehenden, sind gross und tiefschwarz.

Gleichzeitig gefundene, noch nicht lange dem Ei entschlüpfte Räupchen ergaben von 16. bis 18. Juni Puppen, welche in die Temperatur v̀on $+1 \frac{1}{2}$ bis $+2^{0} \mathrm{C}$. und nach 30 Tagen in dre Temperatur von $22-23^{\circ} \mathrm{C}$. gebracht wurden. Ergebniss: das Gelbroth aller Flïgel ist sehr matt unl die Beschuppung eine sehr dlünne; die Flïgel sind schwärzlich bestïubt. Das Blau der äusseren Fleckenreihe aller Flügel ist erheblich natter geworden, und die Flecke selbst kleiner.

2. Vanessa io. Ain 15. Juli wurden nahezu erwachsene Raupen gesammelt. Die Puppen zuerst $3+$ Tage bei $+2{ }^{\circ} \mathrm{C}$, damn bei $+22^{\circ} \mathrm{C}$. Ergebniss: von 38 Puppen schlïpften nur 3 Falter: eine ab. fischeri Stdf., die anderen zwei hatten die charakteristische Zunahme gelber Schuppen, besonders auf den Adern.

3. Vanessa antiopa. Verpuppung am 16. Juli. Die Puppen wurden zuerst der Temperatur von $+2{ }^{\circ} \mathrm{C}$. und nach 32 Tage ler Zimmertemperatur von $23^{\circ} \mathrm{C}$. ausgesetzt. Von 17 Puppen entwiclielten sich nur 2 Falter, wobei einer Charactere der ab. duubii stilf. trug, und der andere dem Stücke sehr ähnlich ist, welches bei M. Standfuss in seinem Handbuche auf Seite 250-51 beschrieben und auf Taf. VII, Fig. 3 abgebillet ist. Das characteristische bei diesen beiden Antiopa ist die Zunahme der gelben Schuppen.

Dieser Forscher sagt zum Schlusse: „Es scheint nun, nach diesen wenigen Resultaten zu schliessen, dass bei Temperaturen in unmittelbarer Nähe von $0^{0}$ C. bei einigen Species der Gattung $V_{\text {c }}$ nessa entschieden Neigung zur Biidung von gelben Schuppen vorhanden ist."

E. Fischer (1897. 230) beschrieb eine neue Methorle zur Erzeugung der Kälte-Aberrationen, wobei die Kälte-Experimente aut einen sehr kurzen Zeitraum reduziert wurden. Er umwickelte einen kleinen Blechcylinder, in welchem sich die Puppen befanden, mit Baumwolle, hïngte ihn an einem Farlen schräg anf und liess aus 
einem mit einem Tropthahn verschenen (iefiiss Schwefelither auf die Bammolle fallen, wobei die Temperatur his auf $-8^{\circ} \mathrm{C}$. sinken lionnte.

Ein auf cliese Weise angestelter Versuch mit einen Tag alten Puppen von Tanesse urticne ergah fingenle Resultate: 24 Puppen wurten irei Nal ziemlich rasch, d. h. innerhall, 50 Minuten, von $+20^{\circ} \mathrm{C}$. auf $-2^{\circ} \mathrm{C}$. algelïhlt, wobei die Temperatur von $-2^{\circ} \mathrm{C}$. nur 5 Minuten anhielt, dann verlulieben sie in der Zimmertemperratur bis zum Ausschlipfen. Ergebniss: 15 aberrative Formen um zwär lauter. Uebergänge zu der ab. ichnusoides de Selys.

Ein zweiter Versuch ergah von 14 Falter auch 8 lnochgralige Uebergänge zu ab. ichnusoides.

F. Merrifield (1897. 573) stellte seine durch livilte erhaltenen Aherrationen von verschiedenen Schnetterlingen in der InselitenGallerie des britischen historischen Museums aus.

Diese aberrativen Formen wurden hauptsichlich hei drei Temperaturen erhalten: $26,7^{\circ}$ bis $38.5^{0}, 5,4^{0}$ bis $10,5^{0}$ un: $0,5^{0}$, wobei lie Sommer-Puppen im Algemeinen stärker beeinflusst wurden als die Winterpuppen. Puppen von Aporia cratargi unı Argynnis paphia, ler Einwirkung der Kälte ausgesetzt, ergahen dunklere Schmetterlinge.

Die durch die Einwirkung der erwähnten Temperaturen erhaltenen Abänderungen können in drei Hauptkatengorien getheilt weriten:

1. Eine allgemeine Färbungs-Aenderung, ohne dass the Form der Zeichnung dabei geänlert wiri, wemn auch ihre Abnahme oler Zunahme in Betref der Intensität zu beobachten ist.

Diese Erscheinung wird, wie es scheint, durch den direkten Einfluss der Temperatur hervorgerufen, welcher die starke Entwickelung jedoch nicht hemmt.

2. Eine Aenterung in Folge der Verschiebung von verschieden gefïbten Stellen, welche entweder verschwimmen oder so gruppiert werden, dass die Zeichnung geändert wirl.

3. Eine Aculderung im allgemeinen äusseren Aussehen unil zwar in Folge der unvollstïndigen Entwickelung verschiedener Stellen oder ihrer Pigmente.

Alle untersuchten Puppen ergahen nur 5\% aberrative Formen.

1 s98 veruffentlichte M. Standfuss seine „Experimentellen zoologischu'n Sturlien mit Lepiclopteren" (841). In dieser Arbeit giebt 're unter anlerem dinen Ueherlilick iiber die Hauptergebnisse der ron ihm ansegefilırten Temperatur-Fxperinente an ralterpuppen. 
I. Experimente an Lepidopteren-Puppen mit konstanten, mässig erhöhten, orler mässig erniedrigten Temperaturen in den Jahren 1895 bis Ende 1897; Wärmeund Kälte-Experimente.

Es gelangten folgende Arten zur Untersuchung:

Papilionidae: Pap. podalirius L. I. und II. Generation, Pap. machaon L. I. und II. Generation, Pap). hospiton Géné, Thais cerisyi var. deyrollei Obthr., Dorit. "upollinus Hust., Parn. apollo L., Parn. delius Esp.

Pieridae: Apor. crataegi L., Pier. Urassicae L. I. und II. Gener., Pier. napi L. I. und II. Gener., Pier. daplidite L. I. und II. Gener., Col. myrmidtme Esp. II. Gener., Rhorl. rhumni L., Rhorl. cleopatia L. I. Gener.

Lycaenidae: Thccla betulue J., Polyomm. dispar val. rutilus Wernb., Polyomm, anphidamas Esp. I. und II. Gener.

Nymphalidae: Apat. iris L., Apat. ilia S. V., Limen. populi L., Limen. camilla S. V., Limen. sibilla Hb., Ven. levena L. und var. prorsa L., Van. c. album L. I. und II. Gener., Tan. urticue L. I. u. II. Gener., Van. jo L. I. und II. Gener., Van. polychloros L., Van. antiopa L., Van. atalanta I. und II. Gener., Fan. cardui L. I. und II. Gener., MLelit. aurinia Rott., ILelit. didiyma O. I. Grener., Argymn. lathonia L. I. Gener., Argymn. agluja L., Argymn. paplia L.

Satyridae: Satyr. semele L.

Sphingirla e: Deileph. euphorbiac L., Deilcph. porcellus L.

Arctidae: Callim. dominula L., Arct. caja. L., Arct. villica L., Arct. purpuratx L., Arct. hebe L., Arct. casta Esp., Spil. fulirinosa L. I. Gener.

Bom b ycidae: Dasych. abietis S. V., Bom?. quercus L., Lasioc. pruni L., Lasioc. quercifotic L., Lasioc. populifolia S. V., Lasioc. pini var. montana Stgr., Saturn. caecigena Cupido.

$\mathrm{Noctuidae:} \mathrm{Agrot.} \mathrm{ripae} \mathrm{Hb}$.

Geometridae: Geom. vernaric Hb., Boarm. rep:ndata L.

Die dabei benutzten Temperaturen waren: mässig erhöhte $+37^{\circ}$ bis $+39^{\circ} \mathrm{C}$, ausnahmsweise sogar bis $+40^{\circ} \mathrm{C}$; mïssig ernieilrigte zwischen $+4^{0}$ und $+6^{0} \mathrm{C}$., ausnahmsweise sogar bis $+5^{0} \mathrm{C}$. Die Einzelheiten bei diesen Experimenten sind in seinem "Handbuche* beschrieben worden.

"Von besonter's klar ausgeprägten Formen, die sich hier ergaben, seien folgende erwähnt: 
1. Durch Kialte wurle die Sommergeneration von P. p. podulirius L. (Wallis), Pier. daplidice L. (Berlin) und ron Polyomm. amphidamas Esp. (Leipzig) in vielen Intliviluen volliommen in die Form aus überwinterter Puppe umgeprägt.

2. Die zweite (ieneration von P(1). podulirius L., ebenfalls aus dem Wallis, konnte durch Wärme in die viel charakteriestischere Sommergeneration sïdlicher Gegenden, als in die typische var. zunclacus Z., wie sie sich z. B. bei Neapel und auf Sicilien findet, umgestaltet werden. Sat. semele L. (Berlin) erfuhr durch das gleiche Experiment eine sehr greifbare Anmäherung an var. aristuens Bon. von Corsica und Sardinien. Lasiosmpa quercifolia L. (Zürich) erhielt auf demselben Wege das Fileid von Dalmatiner Exemplaren und Spilos. finliginosa L. in ihrer Sommerform von Zürich das cler süillichen var. fervida Stgr. Bei Parn. apollo L. (Wallis) entstancl durch

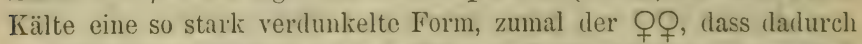
die oberösterreichische var. brittingeri Rghf. häufig genug noch überboten wurile. Auch Parn. delius Esp. (Graubünten) wurile bei gleicher Behandlung in gleichem Sinne verändert.

3. Durch Wärme liess sich von Parn. apolio L. (Wallis) clas Weibchen hinsichtlich seiner Fälbung vollkommen in den mïnnlichen Typus ïberführen, und bei dem Männchen wurlen entsprechend die dunklen Schuppen des Aussenrandes der Vordertliigel von innen her durch weisse ersetzt.

Eine ganz analnge Umgestalltung ihrer Fliigelbekleidung, das heisst einen Ersatz der dunkien Schuppen an den Aussenrändern durch weisse, erfuhr Ap. ratuegi $\mathrm{L}$. ebenfalls durch Wärme.

Kälte gestaltets Colius myrmicione Esp). in einem rrheblichen Pruchtheile der weiblichen Individuen zu ab. collu Stgr. um, währent das Orange der Männchen nach Gelh hin ahgestumpft wurle.

4. I3ei ehen gemanter Art traten durch Kälte bei dem weiblichen fieschlecht ofter Lmgestaltungen in dem Zeichnungscharaliter ein, die einen antfallenden Ankling an das Farbenmuster anderer

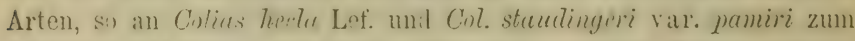
Ausebuck brachten. Polymme, dispor var. rutilus Wernb. gewamn durch lialte ein liepritge, dis eine merkwiirtige Anniberung an das Kileil von Polyomm. hippothoë L. darstellte.

5. Schliesslich stellten sich in sehr einzelnen Stiicken wiederum eigentliche Aberrationen ein.

Durh Warme gestaltete sich Ton. antiupu in wenigen Intividuen zu einem Uebergang nach ab. luggiaca Hdrch. um. 
Durch Kälte ging aus Walliser Sommerpuppen die auf Taf. I. Fig. 7 dargestellte Aberratio von Pap. poctalirius L. hervor, und Col. myrmidone lieferte in ihrer zweiten Generation (von Regensburg und Wien) Individnen wie das anf Taf. I, Fig. S reproducierte, bei welchem die lichton Flecken in der Aussenramdbinde der Volderflïgel verloren gehen un I die gelbrothe Grundfarbe mit vielen dunkeln Schuppen durchsetzt ist. Ferner entstanden, ebenfalis durch Kïilte bei langandauernder Einwirkung, Stücke von Vunessa urticue L. und Van. polychloros L. mit zusammentliessendem zweiten unil driten Costalfleck - diese von der Basis gezählt - der Vortlerflügel" (p. 6, 7, 8).

II. Experimente mit Graden unter $0^{\circ} \mathrm{C}$. in den Jahren 1896 und 1897; Frostexperimente.

Wegen methodischer Ausführung dieser Versuche, sei hier die Beschreibung wörtlich gegeben:

"Zuerst gelangten ov C. zur Anwendung, die mit Hilfe des Frostapparates (Ammoniakver(lunstung), von $+5^{\circ}$ C. an allmählich herbeigeführt, eine Stunde festgehalten und dann allmählich wieder bis auf $+5^{\circ} \mathrm{C}$. rückgängig gemacht wurden. Verbracht wurlen von Sommerpuppen nur Individuen, die 12 bis 16 , höchstens 20 Stunden alt waren, weil sich Puppen dieses Alters nach den bisherigen Versuchen als am meisten für Beeinflussung empfänglich gezeigt hatten. Das Einsetzen der Puppen aus der jeweiligen Tagestemperatur in diese Temperatur von $+5^{\circ} \mathrm{C}$, wie das Entfernen aus dem Frostapparat, nachiem diese Temperatur wieler erreicht war, crfolgte direkt, also ohne jele Anwenlung von Uebergangstemperaturen. Ferner verblieben alle Puppen nach Beendigung der experimentellen Behantlumg bei dliesen wie bei allen folwenden Frostexperimenten bis zum Ausschliipfen in der Tagestemperatur.

Zunächst wurle eine Puppenserie nur einen Tag eimmal, lam eine zweite an len zwei ersten Tagen je einmal, dam rine britte entsprechent an dhei aufeinanter folgeniten Tagen dieser Behandlun. ausuesetz. - Ganz in derselben Weise wulle mit -20 unl - jo operiert" (p. 8, 9).

Diese Versuche ergaben talellosa Falter, welche aber alle normal waren.

Tanessa-Arten wurlen so behandelt, lass eine sirir eimmal, ein zwite zweimal, eine dritte dreimal und rine vierte viermal an 
ersten Tage je eine Stunıle lang der Minimaltemperatur von $-20 \mathrm{C}$ unterworfen wurde.

Auch bei diesen Versuchen zeigten die ausgeschliipften Falten keine Veränderung ihres Gewandes.

Es wurle ein ganz wleiches Experiment mit 12 verschiedenen Serien, aber mit ciner Minimal-Temperatur ron - 50 ausereführt. Hier entlich ergab die vierte Serie. aber nur diese, zwei Tanessu antiopa mit verbreitertem Gelb) (les Aussenrantes. Die vierte bis zwölfte Serie ergaben ferner Uebergänge zu $V_{\text {un }}$. in ab. belisarim Obthr. und zwei typische Individuen dieser Form (in Serie 11 unl 12 je ein Stïck) im ganzen nur 12 Exemplare aus etva 500 Puppen.

Vollstïnlig resultatlos blieb wieder eine einmalige sechsstiundige Exposition einer Serie bei $0^{0}$, einer zweiten bei $-2{ }^{0}$ uml einer dritten bei $-5^{0}$, endlich ebenso eine neunstiinuige Exposition dieser Serien bei je dengleichen drei verschiedenen Graden.

Es folgten Versuche mit -8 , dann mit -10 , dann mit -12 , $-15,-18$ (einzeln auch $-20^{\circ}$ ), die täglich je zweimal ebentills von $+5^{0} \mathrm{C}$. ab allmählig herbeigeführt und allmählig auf $+5^{0}$ rückgängig gemacht wurden.

Bei diesen letzten Versuchen schwankte die Expositionszeit zwischen 2 bis 4 Stunden, wobei die Minimaltemperatur bei jerlem Versuche 2 Stunden lang innegehalten wurde.

Als den Ergebnissen nach günstigstes experimentelles Vorgehen ergab sich (labei eine 5-6 Tage lang fortgesetzte, täglich je zweimal zwei Stunden lang wiederholte Einwirkung von $-10^{\circ}$ bis $-120^{\circ} \mathrm{C}$.

Nun ergab es sich, dass stets nur ein kleiner Bruchtheil $(2 \%-15 \%)$ des Versuchsmaterials aus den normalen Typus heraustritt. Dieses Abweichen von der normalen Form erfolgt dann, wenn grosse Individuenmassen untersucht werden, wobei diese Abänderung selbst bei dem gleichen Experiment nicht nur in höchst verschiedenem Grale, sondern auch in recht mannigfaltiger Richtung stattfindet.

Die wichtigsten abweichenden Formen sind:

Papilio machaon ab. atromarginata Rot., Vunessa urticae ab. atrebatensis Boisu., Vanessu urticae ab. ichnusoides Sel. Long., Vunessa io ab. belisaria Obthr.

Vanessa polychloros L., antiopa L., atalanta L. und cardui L. ergaben zahlreiche Aberrationen, welche bei Standfuss nicht beschrieben, sondern nur abgebildet worden sind.

Es ist interessant zn bemerken, dass Standfuss die Ausfürbung bei Puppen, welche der Einwirkung der extremen Temperil- 
turen ausgesetzt wurlen, in amlerer Reihefolge beobichtet hat, als es unter normalen Umständen der Fall ist. "Zunächst begann diese Ausfärbung relativ spät und kürzere Zeit vor dem Ausschlüpfen des Falters als bei normalen Indiviluen; ferner wurlen speziell die schwarzen Zeichnungselemente früher sichtbar, als dies bei regulär sich entwickelnden Sticken der Fall ist und theilweise sogar noch virr dem Auftreten der rothen und rothbramnen Farbentöne, als sei hier eine vollkommene Umkehrung in der Reihenfolge des Erscheinens dieser beiđen Farbentöne eingetreten" (p. 27). Diese Beobachtung ist von ihm gemacht worken an den stark geschwärzten Aberrationen von Vanessa polychloros und Vanessn urticae. Normal tritt bei diesf $\mathrm{n}$ Arten zuerst das Roth, dam das Rothbraun und schliesslich das Schwarzbraun ein.

III. Experimente mit Graden iiber +40 C. in den Jahren 1895 bis 1897; Hitzeexperimente.

Die Puppen wurden der Temperatur von $+42^{\circ}$ bis $+450 \mathrm{C}$. $1 \frac{1}{2}$ bis $2 \frac{1}{2}$ Stunden ausgesetzt. Zwischen den Expositionen und nach denselben bis zum Ausschlïpfen verblieben die Puppen in normaler Temperatur. Die Exposition fand erst nur einmal, dam zweimal statt und höchstens 6 Tage nacheinander.

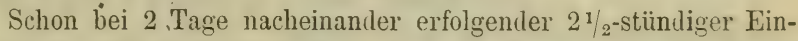
wirkung von $42^{\circ} \mathrm{C}$. ergab sich die typische Vunessa polychloros ab. testudo Esp., aber ein Exemplar unter $37 \pm$ ausgeschlüpften Exemplaren. Es schlüpfte auch eine Aberration von Van. polychloros aus, welche von der mit Frost erhaltenen Aberration durch nichts zu unterscheiden ist.

Bei dreimal täglich zweistünliger Einwirkung von $+45^{\circ} \mathrm{C}$. resultierte Van. antiopa ab. hygiacu IIlrch. Durch $+45^{\circ}$ C., die fünf Tage lang täglich $1 \frac{1}{2}$ Stunden angewendet wurden, entstand Ianessa atalanta ab. Kilemensiewiczi Schille. Ausserdem wurden noch einige Uebergänge zwischen der Stammform und diesen Aberrationen erhalten.

Tunessa cardui ab. elymi Rbr. enstand bei 3 Tage nacheinander $1 \frac{1}{2}$ Stunden lang vorgenommener Exposition von $+44^{\circ} \mathrm{C}$.

Vanessa c-album ab. $f$-album Esp. wurde auch bei dieser Experimentreihe erhalten.

Diese Versuche ergaben noch einige typische Aberrationen ron Melit, aurinia Rott. un I didyma $\mathrm{O}$. 
In demselben Jihle erschien die zweite Lntersuchung von H. Gauckler (1895. 295). Er stellte seine Experimente nit nie lriegen Temperaturen an Vanessa-Pupuen, wohei die Ex;ositionszeit möglichst abgekïrzt wurde.

Alle Raupen verpupten sich am 21.-27. Juli 1897. Die Pup)pen kamen 10 Stunlen wach dem Abstreifen ler Raupenhitut in len Fiskasten $\left(+3^{\circ}\right.$ C.). Alle Puppen wurken zuerst in 3 Serien eingetheilt:

I. Serie: 12 Puppen von Vanessa io 16 Tage exponiert; II. Serie: -20 Puppen (13 io und T Tan. antiona) 16 Tage exponiert: III. Sorie: 3 io und 7 antiope 23 Tage exponiert. Nachher Zimmertemperatur.

Es wurilen dabei folgende Resultate erhalten:

1. Vanessa io. Aus Serie I. 2 schliupften nicht aus, 2 zeigten schwach, fahl rothlraune Beschuppung der Obertlizgel mit blassEraucm Rancle. Das Blau des Prachtanges spieit in's Grau. I) Lne Lnterfitigel sinı schwärzlichorau mit wenig brauen Schuppen. 4 Falter zeichnen sich durch ein schönes, sattes liorthbratun der Oberfliigrel ans. Das Prachtauge vergüssert und ruthbram. Diese 4 Falter lililen rinen Leberwang zu der ab. fischeri St:lfs. 1 Stück mit fehlemten Schuppen.

Aus Serie II entwickelten sich 3 ab. fischneri Stulfs. Einige weitere Stücke ergaben normale Falter.

Die III. Serie ergab keine Vanessı io.

2. Vunessa antiopa. II. Serie ergab normale Filter. III. Serie ergal, 4 Stück ab. roederi Stclfs., pleich tem bei Standifuss im Hanlbuche (p. 250) heschriebenen und auf Taf. VII, Fig. 3 aligelilleten Exemplar, uml ferner cin unsymmetrisches Stiick.

Weil von 42 Puppen 21 aberrative Falter exhalten wurlen, schreist Gauckler dieses Ergebniss in erster Linie der kiirzeren i)aur. der Eisexposition, wie auch den nicht allzu tiefen Temperaturgraden zu.

Als Gräfin Marie von Linden un! Fickert (1898. 515) ,lie P'uppen von Papilio podulirius in der Temperatur von 300 mehrere Tace hielten, wurlen daraus Schmetterlinge erhalten, welche sich sehr stark in Bezug auf lie Entwickelungsstufe ihrer Flïgelzeichnumg von der Wintergeneration unterschielen. Die Verschmelzung der Bin len II, III unl V, VI anf der Oberseite dex. Vorderfliigel ist nilhezu eine volliommene zu nemen und die allgemeine Zun hhme 
der schwarzen Beschuppung spricht sich auch in der grösseren Breite der Binden aus. "In diesem Falle unterliegt es somit keinem Zweifel, dlass die Zeichnung des Falters durch die künstliche Wärmewirkung in lerselben Richtung fortgeschritten ist, in welcher die Zeichung seiner südlichen Verwandten unter dem Einfluss les Klimas sich entwickelt hat" (p. 15).

Friderich Urech veröffentlichte 1898 seine "Ergebnisse von Temperatur-Experimenten an Tanessa io L." (1898. 896). Er erhielt ron Íunessa io-Puppen durch höchstens viermalige. je drei bis vier Standen dauernde Ablühliüng, wobei die Trmperatur auf etwa -10 bis $-14^{\circ}$ C. sank und sogleich wieder allmählich auf (1) nach etwa zwei Stunilen gestiegen war, ab. iokuste Urech, welche an lie ab. nutigone Fischer sich als löhergradige Stufe anschliesst. Bei der neu erhaltenen Aberration ist alles gelbe, weissliche, rosa farbige und b]ïuliche Schuppen-Pigment der Volerfligel-Oberseite verschwun:len, bezw. durch rothbraunes orler schwärzliches ersetzt. Er erhielt bei diesen Versuchen auch ab. fischeri Stlfs. mit verschie lenen Subaberrationen und ab. antigone Fschr. mit ihren Subaberrationen. Merkwürdigerweise erhielt er aber auch solche, bei denen die Vorlerflügel-Oberseite hochgradige ab. antigone Fschr. ist, die Hinterflügel-Oberseite hingegen normale Vanessa io.

Als er die Puppen ron Vanessa in der Einwirkung ron Wäime jn trockenem Luftraume aussetzte, von so hoher Wärme, wie sie ïberhaupt noch ohne Verdorren der Puppe andauernd längere Zeit hinilurch zulässig war, erhielt er ab. culore nigrum maculutı Lrech.

$\mathrm{Er}$ erhielt auch mittelst Kïltewirkung von +20 bis $-10^{\circ} \mathrm{C}$. Exemplare, die sich in die Aberrationsstufen fischeri, antigme und inliaste einreihen lassen, jerloch nie mit drei bis vier zchwarzen Flecken, welche calorc nigrum maculatu charaliterisieren.

Dem Vortrage ron F. Urech: „Mittheilungen über die diesjührigen aberrativen und chromatotarachüischen Versuchsergebnisse an einigen Species der Vanessa-Falter" (1898. 897), welchen er in (ler "Société zoologique suisse" gehalten hat, entneimmen wir folgendes:

„Durch ahwechselnde Einwirkung ron Eiskastontemperatur und gewöhnlicher Temperatur auf die noch junge Pupper von I'ancssa urticae wurden folgenle Aberrationen erhalten: 1. Tanessa urticae ab. polaris artifice. 2. Trancssus urticue ab. donur. Urech (bisher irhmu- 
soides u cifice genamnt, ichnusa ist aber Wärmeform) durch abwechselnde Linwirkung von Kältemischung etwa $-1^{0}$ bis $-5^{c}$ abwechselnd mit gewöhnlicher Temperatur erhalten, nïmlich a) inferior, b) meilia, c) superior, entsprechent zunehmenter Ersetzung von gelbem und rotbraunem Pigmente durch schwärzliches."

Im gleichen Jahre veröffentlichte Carl Frings in Bom seine "Experimente mit erniedrigter Temperatur im Jahre 1897" (253). Er setzte die Puppen Temperaturen ron $+6^{0}$ bis $+S^{0}$ C., steigend bis $+10^{\circ}$ C. ans; dabei reagierten einige Arten trotzt langer Expositionszeit gall nicht, es sind dies: Callimorpla dominulu, Bombyx: quercus und Lasiocampu potatoria. Die Puppen wurten möglichst balı nach ilırer Erhärtung in die Kialte gebracht. Die dabei erhaltenen Resultate sind in Kürze folgende:

\section{Apatura iris.}

a) 14 Tage Exposition. Ca. $70 \%$ der Puppen lieferten talellose Falter. Aberrative Formen.

b) 21 Tage exponiert. Keine $25 \%$ gute Falter. Die Formen sind aberrative.

c) 28 Tage exponiert. Alle Puppen starben ab!

2. Limenitis sibylla.

a) 21 Tage exponiert. Ca. $25 \%$ gut ausgeschlïpft. Aberrative Formen.

b) 28 Tage exponiert. Weisse Zeichnung vermehrt. Nur $10 \%$ ausgeschlüpft.

\section{Vanessa urticae.}

I. Generation.

a) 35 Tage exponiert. $40 \%$ der Puppen lieferten gute Falter. Alle Zeichnungen der erhaltenen Aberrationen sind verschwommen. Diese Form steht zwischen Vanessa urticue var. japonica und Vumessa milberti God. (aus Califurnien).

II. Generation.

a) 35 Tage exponiert. $40 \%$ gut geschlüpft. Aberrative Form.

III. Generation.

a) 14 Tage exponiert. $80 \%$ gut entwickelt. Diese Serie trägt nur die Kennzeichen der Herbstgeneration in rerstïrktem Massstabe zur Schau. 
b) 21 Tage exponiert. $80_{0}^{\circ}$ gut ausgeschlïpt. Fast wie oben.

c) 28 Tage exponiert. $60 \%$ gut entwickelt. Falter erinnern sehr an var. ichnusa Bon.

d) 35-38 Tage exponiert. Ca. 40\% gute Falter. Die Schwärzung erreicht einen hohen Grad. Müssen als Uebergänge zu var. polaris Stdgr. aufgefasst werden.

Trotz der Verwendung eines grossen Materials sind clie bei der I. Generation resultirenden prachtvollen Aberrationen bei der II. und III. Generation nicht mehr aufgetreten.

\section{Vanessa io.}

a) 14 Tage Eisexposition. $95 \%$ gut ausgeschliipft. Die erhaltenen Falter stellen einen Uebergang zu ab. fischeri Stulfs. dar und sind entschieden ähnlich den Faitern II. Generation.

b) 21 Tage exponiert. $80 \%$ gut ausgewachsen. Aberrative Formen. Blau reduziert, schwarz vergrössert.

c) 28 Tage exponiert. $75 \%$ Falter. Rippen bei fast allen Stücken gelb.

d) 35 Tage exponiert. $40 \%$ gut geschliipft. Die Falter dieser Serie stellen die ab. fischeri in etwas abgeänderter Weise dar; bei einigen derselben tritt die bekannte Annäherung an den witicae. Charakter deutlich hervor.

e) 42 Tage exponiert. Keine $10^{0},{ }_{0}^{\prime}$ gute Falter. Einige typische ab. fischeri.

\section{Vanessa polychloros.}

a) 28 Tage exponiert. Ca. $50 \%$ gute Falter. Ein Stück normal, alle andern ganz typische Exemplare der ab. dixeyi Stdfs.

b) 35 Tage exponiert. Ca. $25 \%$ gut ausgewachsen. Die Falter sind sehr verschieden von einander, trozdem sie alle der ab. dixeyi angehören. Unterseits sind alle Stücke noch mehr wie diejenigen der Serie a) aufgehellt.

\section{Vanessa antiopa.}

a) 35 Tage exponiert. Ca. $40 \%$ gut geschlüpft. Aufgehellte Exemplare, wollurch eine Annäherung an die polychloros-Zeichnung herbeigeführt wiril.

b) 45 Tage exponiert. 10\% Falter. Grosse Achnlichkeit mit dem bei Standfuss (840) Taf. VII, io 3 abgebildeten Stück. 


\section{Vanessa atalanta.}

a) 14 Tage exponiert. $100 \%$ Falter. Die Hälfte der Falter normal; die andere Hälfte zeigt auf den Vorderfligeln verschmälerte Prachtbinde, welche in der Mitte lreit schwarz durchschnitten ist.

b) 21 Tage exponiert. $90 \%$ Falter. Diese Thiere sincl als Uehergänge zu ab. merrifieldi Stulfs. zu betrachten. Die Hinterflïgel dieser Form erinnern stark an Tunessa cullirhö Gorlt. (Cinaren).

c) 28 Tage exponiert. $75 \%$ gute Falter. Binclen noch mehr verschmälert, auf den Vorderfliigehn 3 Mal breit schwarz durchgeschnitten.

(i) 35 Tage exponiert. 60\% Falter. Prachtbinte der Vorlerflügel in vier Flecke aufgelöst. Die meisten Falter sinil als typische ab. merrificldi Stdfs. aufzufassen.

e) 42 Tage exponiert. $25 \%$ Falter. Denkbar typischste ab. merrificldi.

f) 49 Tage exponicrt 5\% Falter. Der Costalfteck so stark verorössert, dass beinahe der wanze Ramm zwischen ihm uni der Binde weiss ausgefüllt ist.

\section{Arctia caja.}

Die Raupen stammen aus den verschiedensten Gegenden, die Puppen wurden bald nach ihrer Ausfärbung exponiert.

a) und b) 14 und 21 Tage exponiert. $950_{i}^{\prime}$ Falter. Keine gemeinschaftlichen Abweichungen.

c) 28 Tage exponiert. 850, Falter. Eine Alnahme der weissen Zeichnumg im Mittelfelite der Vorderfliigel bei dex Hälfte der Falter.

d) 35 Tage Exposition. $750_{0}^{\circ}$ Falter. Buinahe alle Exemplare zeigen lie ebengenannte Abweichung. Lin Stück weist am linken Unterfliigel die denkbar typischsten Charaktere der ab. confluens auf, der rechte hat aber nur Andeutungen dieser Charaktere.

e) 42 Tage exponiert. Ca. 60\% Falter. Die besprochenen Abweichungen treten noch stïker auf. Mittelfeld meist zeichnungslos.

f) 49 Tage exponiert. $20 \%$ Falter. Aussenrandfeld durch enorme Verbreitumg der äusseren Aeste der $\mathrm{x}$-Zeichnum vollkommen weiss.

Unter denselben Belingungen experimentierte Carl Frings auch im Jahre 1898 und erbielt folgendes (1899. 257): 
1. Apatura iris.

1897 starben sämtliche Puppen, die 28 Tage exponiert worlen waren, ab. 1898 bei 28 Tage Exposition wurlen $50 \%$ tallellose Falter, darunter ein $\sigma$, erhalten. Die Falter entsprechen ilen 1897 gezogenen Stücken mit 21-tägiger Exposition.

\section{Vanessa urticae.}

I. Generation.

42 Tage exponiert. $20^{\circ}$ o gut ausgeschlïpft. Entsprechen ginz den 1597 durch 35 Tage Expositionszeit erzielten Exemplaren (I. Generation).

\section{Vanessu io.}

42 Tage exponiert. Ca. $10 \%$ gute Falter. Einige typische Exemplare der ab. fischeri.

\section{Vanesse polychloros.}

a) 14 Tage exponiert. $100 \%$ Falter. Uebergänge zu ab. dixeyi Stdfs.

b) 21 Tage Exposition. Ca. S0\% Falter. Wie eben, Saum noch stärker verbreitet.

c) 28 und 3.; Tage Exposition. Dasselbe wie bei a) $u$ m b) 1597 .

(l) 42 Tage exponiert. 25\% Falter. Ueberaus stark veriunkelt. Der blatuen Halbmonde der Hinterfliigel verlüschen fast vollkommen. Variationen der sehr veränderlichen ab. dixcyi.

e) 49 Tage exponiert. 5\% Falter. Typische, doch dunkel gehaltens ab. dixeyi.

\section{Vanessa c album.}

II. Generation.

a) 35 Tage exponiert. $40 \%$ gute Falter. Flïgel stark ausgezackt. Yor dern Saume vielfach gelbe Töne. Uniterseite ciunkel.

\section{Tanessa antiopa.}

a) 14 Tage exponiert. $95 \%$ Falter. Uebergänge zu ab. roederi Strlfs.

b) 21 Tage exponiert. 8.,\% Falter. Die meisten Exemplare sinl typische ab. roecleri.

c) 28 Tage exponiert. $60 \%$ Falter. Ausserorilentlich variabel.

(i) 35 Tage exponiert. Dasselbe wie sub a) 1897 . 
e) 42 Tage exponiert. 250\% Falter. Die Anlibillermong an den polychloros-Typus ist recht augenfällig.

f) 45 Tage expmniert. 10\% Falter. Zwei Gruppen: die eine hat eine trappante Annäherung zum polychloros-Typus, während die andere allgemeine Schwärzung des ganzen Thieres zeigt.

\section{Vanessa atalanta.}

42 und 49 Tage exponiert. Ab. merrieficldi Stilfs. 35 Tage exponiert. Form und Anorinung der Bindflecke dieselben wie bei Vanessa dejeanii Godt (Java).

\section{Tanessa cardui.}

a) 14 Tage exponiert. 90\% Falter. Alle dunkele Zeichnungen stark ausgesprochen.

b) 21 Tage exponiert. $75 \%$ Falter. Uebergänge zu ab. viskotti Stclfs.

c) 28 Tage exponiert. 50\% Falter. Einige typische ab. visliotti.

(i) 35 Tage exponiert. 25\% Falter. Wie sub c), jedoch Vorderflïgel mehr geschwärzt. Ein Stück hat normale Vorder- ein anderes normale Hinterflügel.

e) 42 Tage exponiert. $3 \%$ Falter. Nicht so vercluistert. Schwarze Färbung zwischen dem Costalfleck und dem Schlusse der Mittelzelle wird grösstentheils durch eine helle, strahlenartige Zeichnung aufgehellt.

\section{Arctia caja.}

a) 45 Tage exponiert. $35^{0}$. Falter. Nittelfeld oft volliommen zeichnungslos.

b) 55 Tage exponiert. $10 \%$ Falter. Meist das ganze Aussenrandsfeld durch die enorm verbreitete und ausgeflossene $\mathrm{x}$-Zeichnung weiss.

Da bei den meisten Exemplaren dieselben Abweichungen auftraten (25 Tage exponiert), welche fortschreitend sich verstärkten (bis 55 Tage Exposition), wodurch die Falter hochgradig aberrativ erschienen, schlägt C. Frings vor, diese Form als ab. schultzii Frgs. $\mathrm{zu}$ bezeichnen. Sie wird charakterisiert wie folgt: „weisse Zeichnung im Mittelfelde der Vorderflügel verlöschend, im Wurzelfelde häufig verbreitet, $x$-Zeichnung und besonders deren äussere Aeste so stark nach dem Saume hin ausgeflossen, dass das Aussenr.undsfeld vollkommen o ier fast vollkominen wei is erscheint. HinterHigel normal." 


\section{Saturnia pavonia.}

Schon im Jahre 1897 entwickelten sich die Falter infolge Einwirkung nielerer Temperatur während der Herlstmonate zu ganz abnormer Zeit, im November. Die anderen Exemplare hatten zwei Winter im Freien unl den zwischen diesen liegenten Sommer im Eiskasten zugebracht. Im Frühahr unı Herbste, jeclesmal $4-6$ Wochen Zimmertemperatur. In Frühjahre 1898 entwickelten sich aus diesen Exemplaren nur \& Falter: vier normal, die anleren vier, 3 ठ $\sigma^{7}$ und 1 o aberrativ mit verwaschenen Zeichnungen.

Zu Anfang Juni 1898 kamen die Cocons, unter denen sich auch eine Anzahl Suturnia spini befanden, wieder in den Eiskasten und rerblieben in demselben bis Ende Olitober, worauf sie ins Zimmer genommen wurden. Nach 2 Tagen schlüpfte ein normales $\delta$ aus; nach 3 Wuchen kam der grösste Theil der Puppen ans. Sümtliche Saturnir spini waren normal. Bei einigen war die Zeichnung verwaschen, sonst normal; die andern waren aberrativ, sehr verdiistert.

Jedenfals ist die überaus ungleiche Entwickelung der Falter bei gleicher Behandlung sehr bemerkenswert.

\section{Abraxas grossulariata.}

a) 14 Tage Exposition. $95 \%$ Falter. Die schwarzen Flecken nehmen ab.

b) 21 Tage exponiert. $80 \%$ Falter. Wie eben, am Saume der Hinterflügel oft nur zwei Flecken.

c) 28 Tage exponiert. 50\% Falter. Die schwarzen Flecken nehmen bedeutend $a b$, an den Säumen sind sie jedoch wiedler normal vertreten. der Flecken.

d) 35 Tage exponiert. 30\% Falter. Fortschreitende Alnalume

e) 42 Tage exponiert. $10 \%$ Falter. Falter hell; die Fleckenzeichnung verschwindet melır und mehr.

Weiter stellte er auch Versuche mit intensivem Frost an.

Bei der Anwendung stark erniedrigter und intermittirender Temperatur (durchschnittlich $-13^{\circ}$ ) wurden liickenlose Uebergangsreihen ron den feisten Anfüngen bis zu den extremsten Exemplaren erzogen und zwar bei: Vunessa urticae ab. ichuncsoicles de Selys, Vanessa io ab. belisaria Obthr. (antigone Fschr.), Vanessa antiopa ab. hygiaea Hilrch., Vanessu ataluntre ab. Kilemensiencic:ei Schille (litymene Fschr.). Die letztgenannte Art lieferte bei den Frostexperimenten auch Exemplare der ab. merrifieldi Stclfss. 
Ausser diesen Vanessen wurlen frische Puppen von Dusychirc puclibunda an acht aufeinanderfolgenten Tagen je sechs Stunden dem Froste ausgesetzt und dann in Zimmertemperatur gehalten. Nach 3-4 Wochen schlïpften normale Falter aus. Diese liurze Frostexposition hatte also die Wirliung der monatelang anhaltenden Winterkälte im Freien ersetzt.

Frische Puppen von Saturnia pyri, spini und paroniu wurlen 10 bis 15 Mal je 6 -10 Stunlen bei Frost exponiert. Irirauf verblieben sie lis Ende Oktober im Eiskasten hei einer Temperatur von 6-8 . Im November sthlïpfte kein einziger Falter. Seit December. liegen sie im Freien in der Ueberwinterung.

G. Wilh. Ruhmer (189S. 727) veroffentlichte eine Abhandlung: „Die Uehergänge von Aruschnia levana L. zu var. prorsa L. und die bei der Zucht anzuwenlende Kältemenge," in welcher er dic Prüfung der Versuche von Weismann beschreibt.

I. Versuch: Ain 26. Juni 1896 brachte er 100) fast erwachsene Raupen von var. morsa in den Raupenkäfig und fütterte sie, wonach am 30. Juni die ersten 20 Puppen entstanclen. An demselben Tage wurden sie in einer Blechschachtel am Deckel mittelst starlier Schellacklösung hefestigt und auf Eis gestellt (die Temperatur am Deckel war $+2^{\circ}$ C.). Dasselbe geschah die fulgenden Tage mit je einer Schachtel, welthe die an diesem Tage erhaltenen Puppen enthielt. Im ganzen waren es 4 Schachteln mit zusammen 70 P'uppen. Sach 24-tägiger Exposition (für jele. Schachtel) wurden die Puppen lem diffusem Lichte unt der Stubenwïme (18-220 C.) auswesetz.t. Ergelmiss: $66^{\circ}$ promu und 1 lecumu. Die Puppe, aus welcher levanu ausschlüpfte, lay zufällig auf dem Boden einer der Schachtel während der ganzen Exposition, somit bei $0^{\circ}$.

Dieser Versuch ergibt somit die Thatsache, dass „aus den I uppen, welche im gleichen Entwickelungsstadium, während gleicher zeit dromselleen Wärmegrale ausqesetzt sind, sich auch Falter der gleichen Form entwickeln."

II. Versuch: Die Puppen von Arasclenia prorsa wurden im

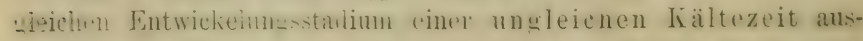
gesetzt. Die Temperatur war, wie vorher, +20 C. Nach einer

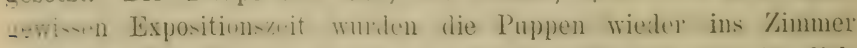

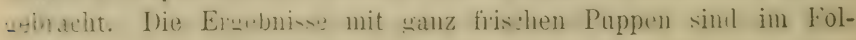
uemien zusammengestellt: 
Die Expositionszeit 27 Tage. Ergehniss: 5 reine levana, 1 fast levana.

Exposition $2 \overline{5}$ Tàge. Ergebniss: 15 Uebergänge von porima zu levana.

Exposition 23 Tage. Ergebniss: Alle 12 porima.

$\begin{array}{rrrll}n & 22 & & & \text { fist porima. } \\ " & 18 & n & n & n \\ " & 14 & n & n & \text { Aehnelt schon porima. } \\ " & 12 & n & n & \text { Nur wenig weiss im Oberflügel. } \\ " & 10 & n & n & \text { Näher an porima. } \\ " & 9 & n & n & \text { Mitte zwischen prorsa und }\end{array}$

porima.

Exposition 8 Tage. Ergebniss: Mitte zwischen prorsa und porima.

Exposition 7 Tage. Ergebniss: Uebergang von prorsa zu porima, näher an prorsu.

Exposition 6 Tage. Ergebniss: Fast porima!

gelblich:

$\begin{array}{lllll}n & 5 & n & n & \text { Unreine prorsa. } \\ n & 4 & n & n & \text { Fast porima! } \\ n & 3 & n & n & \text { Das Weiss der Oberflügel wird }\end{array}$

Exposition 2 Tage. Ergebniss: Die Oberflügel wie prorsu; die rothen Linien der Unterfliugel breiter; in der weissen Binte am Saum gelblich.

Exposition 1 Tag. Ergelnniss: Oberflügel wie morsa. Die weisse Binde wird am Saum gelblich.

Exposition 0 Tage. Ergebniss: Gewöhnliche morsa.

Daraus folgt, dass je länger die Puppen der Temperatur ron $+2^{\circ} \mathrm{C}$. ausgesetzt werilen, lesto stärlier werden die ausgeschliinften Falter geänlert, wobei sie die Uebergänge von morsa zu prima. von porima zu levanu und schliesslich hei 27 -tägiger Exposition reine levuna ergehen. Einige Unregehmässigkeiten arklät Ruhmer mit eventuchlen Fehlern, inclem vielleicht nicht ganz trische Puplen der Kälte ausgesetzt wurden.

III. Versuch: Die Puppen wurden in ungleichem Entwickelungszustande und verschieden lange der gleichn hillie $\left(+2^{\circ}\right.$ C. $)$ ausgesetzt.

Die folgente Tabelle ergiebt die erhaltenen Resultate: 


\begin{tabular}{|c|c|c|}
\hline $\begin{array}{l}\text { Blieben } \\
\text { in Licht } \\
\text { und } \\
\text { Wärme }\end{array}$ & $\begin{array}{l}\text { Anzahl } \\
\text { der } \\
\text { Kältetage }\end{array}$ & $R e: u l$ a $t$ \\
\hline $1 \mathrm{Tag}$ & 1 Tag & $\begin{array}{l}\text { Prorsa. Auf den Unterflügeln ist die rothe Dop- } \\
\text { pellinie schwach angedeutet. }\end{array}$ \\
\hline 2 Tage & 2 Tage & $\begin{array}{l}\text { Prorsa. Die rothe Doppellinie der Unterflügel } \\
\text { schon recht teutlich. }\end{array}$ \\
\hline 4 Tage & 3 'Tage & $\begin{array}{l}\text { Uebergang von prorsa zu porima. Rothe Linie } \\
\text { deutlich, schwarzes Band zusammenhängend. Ober- } \\
\text { flügel Stich ins gelbliche. }\end{array}$ \\
\hline 5 Tage & 5 Tage & $\begin{array}{l}\text { Wie so eben. Das Weiss der Oberflügel schon } \\
\text { bräunlich. }\end{array}$ \\
\hline
\end{tabular}

Grätin Marie von Linden (1898. 515) hielt die Puppen von Tanessa levana zuerst mehrere Wochen hinlurch im kalten Gang, dann in der letzten Zeit den Puppenruhe im Paraffinofen bei $30^{\circ}$. Die entschlüpften Falter ergaben ihrer Zeichnung nach ein Gemisch von Faltern des levana-, prorsa- und porima-Typus.

E. Fischer veröffentlichte 1898-1899 seine "Beiträge zur experimentellen Lepidopterologie" (231), in welchen Puppen ausschliesslich ron Vanessa-Gruppe zur Anwendung liamen unil die Expositionszeit bei rlen Kälte-Experimenten abgekürzt wurle. Die Erfahrung hat ihm gezeigt, dass die Puppen olme Schaden täglich 2 bis 3 Mal unter ov C. abgekïhlt werden kömnen, wenn dabei die Feuchtigkeit nicht zu gross ist. Die Puppen wurlen in einem Alter von 8 bis 12 Stunden verwendet.

Kälteexperimente:

1. Vanessa urticae: Erster Versuch. 30 Puppen wurden zuerst in den Keller in eine Temperatur von $+13^{\circ} \mathrm{C}$. gebracht, nach 6 Stunden bis auf $0^{0} \mathrm{C}$, unr nach weiteren 6 Stunden unter $0^{\circ}$ C. bis $\mathrm{zu}-3^{\circ}$ C., alsılanm 3 Mal täglich abgekïhlt. Nach 18 Tagen wurden die Puppen herausgenommen, noch einen Tag in liellertemperatur von $+15^{\circ} \mathrm{C}$. gehalten unl dam in die Temperatur ron $+22^{\circ} \mathrm{C}$. gebracht. s Tagen darauf wurden erhalten: 13 der urticae ähnliche Stiiclie und 10 der al. ichmusoides des Selys angehörende Falter, wovon 3 Uebergänge und 7 typische.

Zweiter Versuch. Dieselbe Behanllung. Alter der Puppen ca. 12 Stunden. Exposition acht 'Tage. Ergebniss: 7 der ab. ichnusoides angehörente Stiichi, woron 5 stark ansgeprägte Ciebergänge 
mit zur Hälfte geschwïrzten Hinterfliigeh und 2 tyjuische nit schwarzen Hinterflügeln.

Dritter Versuch. IDieselhe Behanllung. Alter der P'upen ca. 8 Stunden. Exposition 5 Tage. Ergehniss: + mormale urticue, 1 Stïck mit grossen blauen Flecken, 1 Stiick ohne blane Flecke der Hinterflügel unl 1 der ab. ichnusoicles zugehïremiles Stiick.

2. Vanessa polychloros: Erster Versuch. 7 Puppen ca. 14 Stunten alt, dreinal täglich auf $-3^{\circ} \mathrm{C}$. abgekiihlt. Nath $1 \pm$ Tagen wurten sie ans dem Eishehailter entfernt, zwei Tage im Kieller bei $+15^{\circ} \mathrm{C}$. gehalten, hierauf in $+22^{\circ} \mathrm{C}$. gelmacht. Lirgemiss: 3 normale Falter, 2 mbestimmte (nicht ganz auswershliipft), 1 Uehergans zu ab. testudo und 1 dunkle prolychloros (zu testudto neigeni).

Zweiter Versuch. 16 Puppen 8 bis 12 Stunden alt, 6 Stunden bei $+14^{\circ} \mathrm{C}$, damn 6 Stunden auf Eis (allmilliche Abkiihlung bis auf $0^{\circ}$ C.) und hierant Emiedrigung ant $-3^{\circ} \mathrm{C}$. Thiglith nur $\therefore$ Mal anf $-3^{\circ} \mathrm{C}$, im gam\%n 10 Mal algekihhlt. Dic Pujpen wurden hierant noch 2 Tage im lieller gelassin und damn ins Zimmer gebracht. Ergeiniss: 1 normaler Falter, 1 polychloros mit vergrösserten, blamen Flecken der Hinterflïgel (a), 2 Ucherainge zu testucto (b) unil 6 Exemplare, die zwischen (denen von a) mul h) stehen.

Dritter Versuch. 6 Puppen 10 bis 12 Studen alt, genau wie die im ersten Versuch behantelt, aber schon nach 8 Tagen aus dem Eise entfernt. Ergeluniss: 3 normale Falter, 1 polychlores mit vergrösserten, blanen Flecken, 1 Lebergang zn als, testudo und 1 typische ab. testudo.

3. Tanessa antiona: Erster Versuch. 14 Puppen im Durchschnitt 12 Stunilen alt, wurden für 6 Stmrien in Fellertemperatu $\left(14^{\circ} \mathrm{C}.\right)$, dann ca. 4 Stunden in eine von $14^{\circ} \mathrm{C}$. anf $0^{\circ} \mathrm{C}$. sinliente Temperatur gebracht unl hierauf 3 Mal täglich auf $-3^{\circ} \mathrm{C}$ alogekühlt. Nach 18 Tagen wurlen sie herausgenonmen, 2 Tage im Keller $\left(14^{\circ}\right.$ C.), dann in Zimmer (220 C.) gehalten. Ergebniss: 3 ganz typische Falter der ab. Ingiuce Hilrch., 3 (ler typischen ab). hygiaea äusserst nahe stehenle Falter; 7 Unbergünge zu ab. Tuypiceec und 1 Falter entspricht der gewöhnlichen antiopa.

Zweiter Versuch. Dieselhe Behamllung, aher nur 1.1 Tage lang. Ergelniss: 5 normale, nur in geringem Masse an hyginur erinnernile Falter, 6 der ab. artemis Fschr. angehöremie Stiickr. \& Uebergänge $\mathrm{zu}$ ab. hygiaea und $3 \mathrm{ab}$. hygiaca.

Dritter Versuch. Dieselbe Behandlung, aber nur 6 Tage

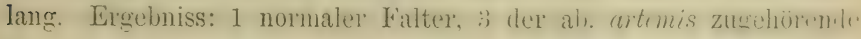


Falter, 9 Uehergänge zu ab. hyggiaen (3 geringgralige unı 6 hochgradige) und 4 typische ab. hygiaca.

4. Vanessa in. Die 12 Stunlen alten Puppen wurlen in gleicher Weise wie die von antiopa :3 Nal taglich ahgekühlt. Nach 20 Tagen wurden die Puppen in gleicher. Weise wie die von antiopa in Zimmer-Temperatur gebracht. Ergelnniss: 3 normale Falter, 5 ganz gexing veränlerte, 11 Uebergänge zu untiyone (5 geringgralige und 6 hochgradige) und 1 typische ab. antigone Fschr.

Zweiter Versuch. Die gleiche Behandlung, aber nur 14 Tage. Alter (ler Puppen 12 Stunlen. Ergebniss: 1 ganz normaler Falter, 6 fast normale, 13 Uebergänge (8 geringgradige und 5 hochgratlige) und 2 typische ab. antigone.

Dritter Versuch. Die gleiche Behanllung, aber nur 6 Tage lang. Alter der Puppen 12 Stunden. Ergebniss: 3 ganz und 2 fast normale Falter, 6 stark ausgeprägte Uebergänge und 7 typische Stiicke von ab. antigone.

5. Fanessa c-album. Die Behandlung wie im Versuch I bei io. Expositionszeit \& Tage. Puppenalter 12 Stunden. Ergebniss: 2 fist normale Falter, 3 Falter mit erheblich verkleinerten schwarzen Mittelfeldflecken der Vorlerflïgel und verschwommener Zeichnung der Hinterfliigel, 2 ähnliche Falter mit verbreitetem zweiten schwarzen Costalfleck und 1 ab. f-album.

6. Tanessa cardui: Erster Versuch. Behandlung wie die ron antiopa (I. Versuch), aber täglich nur emmal auf $-3^{\circ} \mathrm{C}$. abgekühlt, nur 74 Tage lang. Puppen 12 Stunden alt. Ergebniss: 1 fast normaler Falter und 3 Uebergänge zu ab. elymi Kbr.

Zweiter Versuch. Ebenso behandelt, aber nur 8 Tage lang. Alter: 12 Stunden. Ergebniss: 2 Uebergänge zu ab. elymi unı 1 typisches Stück von ab. clymi Kbr.

I)ritter Versuch. Exposition of Tage lang, täglich eimmal auf $-6 \circ$ C. abgekühlt. Alter: 12 Stunden. Ergebniss: 1 fast normaler Falter und 2 gut ausgeprägte Uebergänge zu elymi.

Vierter Versuch. Exposition 6 Tage lang, täglich auf $-12^{\circ} \mathrm{C}$. abgekühlt. Alter: 12 Stunden. Ergebniss: 1 fast norınaler Falter und 3 stark ausgesprochene Uebergänge zu elymi.

7. Vanessa atalanta: Erster Versuch. Puppen in allen 4 Versuchen 12 Stunden alt, täglich einmal auf $-3^{0}$ C. abgekühlt, 18 Tage lang. Ergebniss: 5 geringgradige Uebergänge zu ab. litymene Fschr., 1 hochgradig ausgebildeter Uebergang zu lilymene und 1 typische ab. klymene. 
Zweiter Versuch. Ebenso behandelt, aber nur \& Tage lang. Ergebniss: 1 fast typisches Stück von ab. klymene.

Dritter Versuch. Täglich ein Mal auf $-6^{\circ}$ C. abgekiihlt, 6 Tage lang. Ergebniss: 2 fast normale Falter, 1 geringgradiger Uebergang, 2 stark ausgesprochene Uebergänge und 2 typische ab. kilymene.

Vierter Versuch. Einmal täglich auf $-12^{\circ}$ C. abgekühlt, 6 Tage lang. Ergebniss: 2 fast normale Falter, 2 stark ausgesprochene Uebergänge, 1 geringgradiger Uebergang und 1 typische ab. Tilymene.

In derselben Abhandlung beschreibt E. Fischer: Kïlte-Experimente mit schnell sinkender Temperatur.

1. Tanessa antiopa. 12 Stunden alte Puppen wurlen von $+25^{\circ}$ C. im Laufe von ca. einer halben Stuncle auf $-6^{\circ}$ C. abgekühlt (also um $31^{\circ}$ C.). Dies wurle, nachlem sich die Temperatur in Laufe der nächsten 4 Stunlen wietler auf $0^{\circ} \mathrm{C}$. und sodann durch Oeffnen des Gefässes auf $+18^{\circ}$ C. für 6 Stunden erhöht hatte, am gleichen Tage noch eimmal und an jedem der folgenden 6 Tage je zweimal vorgenommen. Ergebniss: 2 aberrative Falter, die der Fig. 16 (bei Fischør) ähnlich aussahen, 3 mit vergrösserten blauen Flecken, 2 ziemlich stark veränflerte Stücke (bei Fischer in Fig. 51 abgebildet) und 2 einander ähnliche Aberrationen (bei Fischer in Fig. 50 abgebildet).

2. Vanessa atalanta. Die gleiche Behandlung, Ergebniss: 1 fast tṛpische ab. lilymene Fschr. und 2 Uebergänge zu derselben.

3. Tunessa urticae. Die gleiche Behandlung. Alter: 25-30 Stunden. Ergebniss: 6 ausserordentlich dunkle, zum Theil an ab. ichnusoides de Selys erinnernile Falter, 2 ebenso veränclerte Falter, aber mit einer starken Schwärzung der Hinterflügel und sehr verkleinerten blauen Flecken, 1 in der Fig. 7 (bei Fischer) abgebildet, 1 der ab. ichnusoides verwandte Aberration, 2 Falter ohne irgend welche Reste der blauen Randflecken auf allen Flïgeln.

4. Vanessa io (II. Generation). Puppenalter 30 Stunden. Ebenso behandelt. Ergebniss: 2 ab. antigone Fschr., 1 an ab. testudo erinnernder Falter, 3 Aberrationen (bei Fischer in Fig. 26 dargestellt) und 1 ungemein hochgrallig ausgeprägte Aberration; diesellee ist auf ıler Ober- und Unterseite vollständig geschwärzt und zeichnungslos. E. Fischer nennt sie ab. extrema Fschr.

In derselben Abhandlung löst E. Fischer die Frage, ob wirklich bei hoher Wärme die gleichen Aberrationen entständen, wie 
bei $0^{\circ}$ bis $-20^{\circ}$ C. Zu diesem Zwecke brachte er die Pupren in einen Brutapparat und setzte sie hier eins zwischen +4()$^{0}$ m.l $+43 \frac{1}{2^{0}}$ C. schwankenten Temperatur hei hoher Feuchtigkeit, tiaglich drei bis fünfmal je $1 \frac{1}{2}$ lis 3 Stmilen lang aus, unt zwar nur in den ersten zwei Tagen. Während der Pausen bei gewöhrilicher Temperatur.

Die dabei erhaltenen liesultate waren in kmzem folgenle:

1. Vanessa urticae. I. Serie. 12 Puppen, sechsmal innerhalb 2 Tagen bei 40 bis $43^{1}{ }^{\circ}$ C. je trei stumlen lang gehalten, erwben: 3 tote Puppen, : norutale Falter, 2 der var. ichunce Bon. zugehörente Formen, 2 schwach, 2 stark ausgespro hene Uelherginge zu ichnusoides de Selys.

II. Serie. 10 Puppen, achtmal innerhalh 2 Tagen ehense br. hantelt, ergaben: it tote Puppen, :3 normale Falter, 2 geringeralig. Uebergünge zu ichnusoides uni 1 typische ab. ichnusoilus.

2. Vanessa polychloros. I. Serie. 12 Puppen, sechsmal inner-

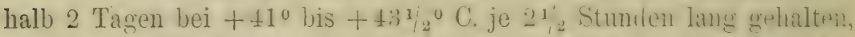
ergaben: 4 tote Puppen, 1 normaler Falter, 4 Lalter bei henen der zweite und dritte Costalfleck, die beilen Nittelfehler uni Lunesrandflecken sehr stark reluziert waren: ferner :- Usherwinge zu al. testudo Esp. und 1 typische testudo.

Ir. Serie. 14 Puppen, achtmal ilerselben Temijeratur ansqesetzt, liefurten: 5 tote Puppen, 4 fist nomale Falter, 2 missig ansgeprägte Uelsergïnge zu testudo, 2 typische testudn, 1 testudo nit sehr breitem, schwarzem Ramile der Vorlerthiggel; alle drei schwalzen Costalflecken mul beile Lunemrandtlecken ganz zusammengetlossen.

3. Vanessa antiopa. I. Serie. 10 Puppen, wie die I. Serie von polyclbloros exponiert, ergalsen: 1 tote Puppe, 3 der ab. artemis Fschr. angehïremte Falter, 6 Falter, bei ilenen auf ilen Vorilerfliigeln die blauen Flecken zum Theil geschwunten, der gelbe Saum verbreitet, aul' den Hintertlïgeln die blauen Flecken ilagegen stark vergrössert waren.

II. Serie. 14 Puppen, wie die II. Serie run polychloros exponiert, lieferten: '2 tote Puppen, 2 (ler ab. artemis angehörenile Falter, 4 normale Falter, 3 auf den Vorderflügeln iler ab. lyygiaca entsprechentle Falter, 3 Falter, deren Vorilerfliigel der typischen hygiaict. deren Hintertliigel aber der normalen Form otler eler der ab. wrtemis entsprechen.

4. Tanessa io. I. Serie. 18 Puppen, wie I. Serie von polychitoros behandelt, ergahen: 5 tote Pupuen, (j rast normale Falter, 
3. Stiicke mit geringen Anklïngen an autigune, 4 fisst typische Exemplare von antigone.

II. Serie. 12 P'uppen, wie II. Serie ron polychloros behandelt, lieferten: 3 tote Puppen, 5 normale Falter, 2 fast typische antigone, 2 antigone-Falter mit schwarzem Fleck in ersten Intercostalraum.

5. Vanessu cardui. I. Serie. 8 Puppen, wie I. Serie von polychloros exponiert, ergahen: 2 tote Puppen, 2 sehr hell gefärbte, fast normale Falter, 3 Stiicke mit Simptomen von ab). clymi, 1 fast typische elymi.

II. Serie. 10 Puppen, wie II. Serie von polychloros behanlelt, lisferten: 1 tote Pupje, 1 Falter, dessen Lnterseite der typischen elijmi entsprach, währeni ilie Olserseite wenig verändert war, 3 normale Falter, 2 Exemplare mit reilucierten Mittelflecken, ') schwach ausgesprochene Uebergänge zll clymi, 1 ab. clymi mit normaler Unterseite.

6. Tanessa atalanta. I. Serie. 12 Puppen, wie I. Serie von polychlorns behandelt, ergaben: 3 tote Puppen, 4 normale Falter, 3 stark ausgeprïgte Uebergänge zu lilymene, 2 typische ah. litymene.

II. Serie. 10 Puppen, entsprechend der II. Serie von polychioros exponiert, ergaben: 2 tote Puppen, 3 normale Falter, 3 scinwach ausgeprägte Uebergänge zu lilymene, 2 typische lilymene, aber Unterseite fast ganz normal.

"Alus diesen Experimenten geht hervor, dass bei $+40^{\circ}$ bis $+431 / 2^{\circ} \mathrm{C}$. gleiche Formen entstehen, wie bei antiopu bei $+35^{\circ} \mathrm{C}$. mul bei allen untersuchten Vanessa-Arten bei $0^{\circ}$ bis $-20^{\circ} \mathrm{C}$., aber mit lem charakteristischen Unterschiede, dass regulïrerweise zuerst die Oberseite und erst dann die Unterseite, auch in erster Linie der Vorderflïgel unı erst in zweiter cler Hinterflïgel verämlert wirc.."

Ausserdem stellte E. Fischer Versuche an, wohei die Puppen den direkten Sonnenstrahlen ausgesetzt wurlen (InsolationsExperimente).

Die Puppen wurlen frei in ler Luft aufgehängt unıl der Einwirkung ver Sonne je ca. 5 Stunden lang an 2 aufeinander folgenden Tagen ausgesetzt; labei betrug die Temperatur in ler Mitte les Puppenkïrpers, wie es Parallelversuche mit chloroformierten Puppen ergaben, von $36^{\circ}$ bis $41^{\circ}$ C. Exponiert wurlen 30 Puppen ron Tinessa urticae, 20 von polychloros, 25 von antiopa, 30 ron io, 25 von cardui, 24 von atalanta und ergaben:

1. Criticae: 2 kirippelige, normale Falter, 17 sehr feurige, zu ichnusa B.m. neigen!le Falter, 9 Falter mit sehr verkleinerten Mittelfeldtlecken, 2 mässige Ucbergänge $\mathrm{zu}$ ichnusoides. 
2. polychloros: 14 normale Falter, 2 der var. fervida angehörenle, 2 Falter mit sehr breitem, schwarzem Sium, verkleinerten Mittelfeldflecken, 1 der testudo angehörende Form.

3. antiopa: 3 tote Puppen, 7 normale, etwas zu ab. eprone Fschr, neigende Falter, 3 artemis, 8 epione, 2 Uebergünge zu hygiara, 3 auf den Vorderflïgeln der typischen hygiaea, auf den Hinterflïgeln der artemis entsprechende Falter.

4. io: 8 tote Puppen, 6 normale Falter, 8 fast normale Falter mit schwarzem Innenrandfleck, 5 Stiicke mit Symptomen der antigone, 2 auf den Vorderflügeln typische antigone.

5. cardui: 6 tote Puppen, 2 ganz normale Falter, 15 sehr hell gefärbte, 2 Uebergänge zu elymi.

6. atalanta: 7 normale Falter, 12 der Van. callirhoc genüherte Stücke, 3 Uebergänge zu lilymene, 2 typische klimene.

Daraus ist ersichtlich, dass diese Experimente mit direkter Sonnenbestrahlung der Puppen fast ganz dieselben Resultate ergaben: wie die mit dem Brutapparat ausgeführten.

$D^{r}$ Pauls (1899. 62S) brachte die Eier ron Arctia hole in einen Warmzuchtkasten $\left(23^{\circ} \mathrm{l}\right.$. $)$, welche am 3 . resp. 5. Juni auskrochen. Ende Juni verweigerten die Raupen hartnäclig die Nahrungsaufnahme. Am 1. Juli wanderten die Thiere in den Kieller und sehr bald ron dort in den Eisschrank. Nach 4 Wochen wurden die Raupen wieller in die Temperatur von $+23^{\circ} \mathrm{R}$. gebracht und ergaben am 17. August die erste Puppe. Die ausgeschliiptten Falter zeichnen sich durch das glänzende prachtvolle Karminroth ler Unterflügel unil die auffallend reiche helle Zeichnung der Oberflügel aus.

L. Kathariner (1899. 436) fing Encle Juli in wenigen Tagen vier aberrativ gefärbte Tagfalter und zwar: Erebia lappona Esp., Erebia stygne O., Limenitis sibillla L. und Epinephela janiru L., welche an gewissen Stellen ler Flügel fahlgelbe Färbung haben. Er erklärt diese Aberrationen mit störendem Einflusse der killten, feuchten Steine, an welchen die Puppen mit der betreffenden Partie vermuthlich lagen, wobei die Umsetzung des ursprünglichen ocliergelben Pigments in die definitive Farbe nicht stattfinden konnte.

E. Schumann (1899. 796) schreibt: „Der Einfluss der feuchten und kalten Witterung macht sich nicht nur auf die Schmetterlinge 
sondern auch auf die Käfer geltencl. In diesem Jahre mit seinem nasskaltem Mai und Juni wurden bei Posen zwei Anisoplia segetum ㅇ gefangen, bei denen das am Schildchen befindliche Schwarz so überhand genommen hatte, dass nur an der Schulter ein wenig Braun zu sehen war."

Lambert (1S99. 495) züchtete Bomlyx mori von 20 verschiedenen Rassen, wobei eine Serie bei gewöhnlicher $\left(21^{\circ}-23^{\circ}\right)$ Temperatur sich befand und die Raupen der anderen, angefangen vom 4. Alter, in die Temperatur, um $2-6^{0}$ tiefer als die normale, gebracht wurden. Die Färbung der Cocons wurde dabei eine gleichmässigere und hatte eine weniger scharfe Nuance.

L. Kathariner (1900.440) stellte Frost-Experimente an V'anessa io, wobei die meisten erhaltenen Falter dünnbeschuppte Vorłerflügel mit verschwommener Zeichnung erhielten, dic gelben Flecken fielen fast ganz oder völlig.

G. Jacobson (1900. 409) spricht die Vermuthung aus, dass die Temperaturversuche mit Coccinelliden- und Chrysomelidenpuppen viel anschaulichere Resultate als dieselben Versuche mit Schmetterlingspuppen ergeben werden, da die Fürbung der letzteren im Puppenstadium sich noch entwickelt, während die ersteren nach dem Ausschlüpfen, nach seinen eigenen Beobachtunger, zuerst entwerler weiss, hellrosa oder gelblich sind, und erst später sich allmählig ausfärben.

Emil Irmscher (1900. 400) setzte die Puppen von Psilura monacha L. den Sonnenstrahlen aus und erhielt aus sümmtlichen Puppen Uebergänge zu ab. eremita.

Carl Frings (1900. 258) setzte seine Versuche auch im Jahre 1899 fort: „Ausser Versuchen mit mässig erniedrigter Temperatur, wie in den Vorjahren bei +6 bis $+8^{0}$ angestellt, wurden besonders die im Jahre 1898 begonnenen Experimente mit intermittirendem Frostgrade in grossem Masstabe fortgesetzt; hierbei gelangte meist $-15^{\circ}$, öfters aber auch $-20^{\circ}$ zur Anwendung".

Seine Resultate lauten:

Papilio podalivius. Frostversuch. Puppen der II. Teneration. Es schlïpften charakteristische Exemplare I. Generation aus. Die in 
Normaltemperatur verbliebenen Puppen lieferten Uebergänge zu ab. zanclaeus Zell.

Apatura iris. 35 Tage $+6^{\circ} .20$ Puppen ergaben 5 Falter. Die Grundfurbe.graulsaun. Der Schiller ist sehr stark rehuziert.

Vanessa urticae. I. Gener. 40 Tage $+6{ }^{\circ} .35 \%$ gute Falter. Zum grössten Theil var. polaris Stclgr. - II. (iener. 49 Tage +60 . $2 \%$ gute Falter. Uebergänge zu var. poluris. - I. und III. Gener. mit Frost behamielt, ergab ab. ichnusoides de Selys und einige Exemplare mit hocheratig asymetrischer Zeichnung.

Vanessa polychloros. Frostexperiment. liebergänge zu ab. I)ixeyj Stdfss. und zu ab. testudo Esp.

Vanessa C. album. Frostexperiment. F. album Esp.

Vancssa antiopa. Frost. Bei den meisten die Vorderflingel wie bei ab. Mygiuca Hihch. Anstatt blaner Flecken waren weissgraue. "Genau dieselbe Unwandlumg der irisirenden Schuppen komnte ich bei Vun. io a b. belisaria Obtr. benbachten."

Vanessa atalanta. 42 Tage $+6^{\circ}$. Uebergänge zu ab. merrifieldi Stlfss. - Frostexperiment. Uebergänge und typische ab. litemensiewiczi Schille.

Arctia caja. Die Puppen knmnten clie Temperatur ron $-15^{\circ}$ bis $-8^{0}$ nicht aushalten und starben ab.

1. Serie. 22 Tage +1 bis $+3^{0}$. Die Flecken der Hintertligel mehrfach vergrössert; die Vorlerflügelzeichnung ist in Verbreitung begriffen.

II. Serıe. 4 Mal bei $0^{0}$ bis $-1^{0}$ je $1 \frac{1 / 2}{2}$ Stunden exponiert. Die meisten Falter sint normal. Sonst nahm die weisse Zeichnung zu.

III. Serie. 6 Mal bei -1 bis $-2^{0}$ je 3 Stunden exponiert. Wie bei II. Serie. Die Hinterflügel sind zart rosenroth.

IV. Serie. 6 Mal bei -3 bis $-4^{0}$ je 2 Stunden exponiert. 2 entgegengesetzte Aberrationsrichtungen. 1. Weisse Zeichnung ist im Schwinlen begriffen; ler Hinterleib ist fast schwarz. 2. ab. schultzii Frings mit verbreiteter weissen Zeichnung.

V. Serie. 5 Mal bei -5 bis $-6^{0}$ je 2 Stunden exponiert. $50 \%$ gute Filter. I)ie Abweichungen zerfallen in die a b. confluens und ab. schultzii, ein Falter war a b. futura Fickert.

Saturniu pavonia. Puppen aus dem Jalıre 1596, welche die Winter im Freien, die Sommer im Eiskasten und also, die kïnstlichen eingerechnet, fünf Ueberwinterungen durchgemacht hatten, schliupften im Frühjahre 1899 aus. Sie waren stark verwaschen gezeichnet, schr dium beschuppt und glichen in Lebergängen den- 
jenigen Aberrationen, welche als Seltenheit in den Hochalpen vorkommen.

Saturnia pyri. Aelnnliche Abweichungen wie bei paronia.

Abraxus grossulariatu. 250 Puppen mit Frost behanilelt. Nur 2 Falter schlïpften aus: eine ab. dohrni König und eine Aberration, welche bei Ch. Oberthür (1S96.6136) auf Taf. 19 unter . 321 und Taf. 21 ㅊo 382 abgebildet sind.

A. Schülke schreibt mir (11. I. 1900): „Ich faml dann spüter noch, dass Rhodocerc rhamni ơ durch Kälte blass wirl, auch Liparis dispar durch Iiälte charakteristisch veränlert wirl, wie in den experimentellen zoologischen Stulien von Standfuss erwähnt ist. Dass von Tanessu urticue die var. ichnusoides sprungweise auftritt, glaube ich nicht, da ich im vergangenen Sommer alle Uebergangsformen, von unmerlilich vergrösserten schwarzen Flecken bis zı ganz extrem ausgebildeten ichmusoides erhalten habe."

A. Mordwilko (1900.593) spricht in seiner sehr unfangreichen Arbeit „Zur Biologie und Morphologie der Pflanzenläuse (Fam. A phididae Pass.) ${ }^{4}$, deren Fortsetzung noch folgt, die Neinung aus, dass die Färbung und die Beschaffenheit der Oberflïche des Körpers (ier Pflanzenläuse eine Anpassung gegen die starke Wirkung der strahlenden Sonnenwärme darstellt. Pflanzenläuse, welche ler direkten Einwirkung der Sonnenwärme ausgesetzt sind (Aufenthaltsort: obere Seite der Blätter, Halm, junge Aeste), sinil bei sonst dunliler Färbung ihres Körpers am Küicken glänzent, zuweilen mit Metallglauz, während diejenigen Pflanzenliuse, welche die von der Sonne geschützen Pflanzentheile zu ihrern Aufenthaltsort gewïhlt haben, gewölnlich eine matte Obertläche besitzen, oft mit einer grauen Bestïubung:

Als Beispiel dunkler Pflanzenläuse mit der glänzenden Rüickenoberfläche (speziell ungeflügelte Exemplare) führt er folgende Arten an:

Siphonophora serratılae ist braun, metallglänzend; lebt an Halmen von Cirsium arvense, oleraceum.

Siphonophora campanulae ist rohtbraun, glänzend; lebt an Halmen und Aesten von Campanula rotundifolia.

Siphonophora jaceae ist dunkelbraun, kupferglänzent; lebt an Halmen und Kelchen von Centaurea, Scabiosa, Carduus.

Siphonophora picridis ist braun, metallglänzend; lebt an Halmen und an Kelchen von Picris, Crepis, Hieracium, Cichorium etc. Myzus coritsi ist schwarzglänzend lebt an Sprossspitzen und unter den Blättern von Prunus cerasus etc. 
Aphis lychnidis ist schwarzglänzend; lebt zwischen Bliithen und Knospen und auch an Halmen von Lychnis diurna.

Aphis persicae ist braunglänzend; lebt an Sprossenspitzen und unter den Blättern von Amygdalus persica etc.

Chaitophorus populi ist braun- und schwarzglïnzend; lebt an Sprossenspitzen und unter den Blïttern von Populus alba und tremula etc.

Dryobis roboris ist schwarz, metallglïnzend; lebt an Eichenästen.

Lachnus fasciatus ist schwarzglänzend mit der Wachs-Bestäubung; lebt an der unteren Seite der Tannensprossen.

Lachmus mudus ist harzgelb oder rostgelb bis rostilunliel, metallglänzend; lebt an hellgelber oder hellbrauner Rinde der Tamnenstïmme und Tannenäste.

Lachnus pineus ist rostgelb, hell und dunkel, metallglïnzend; lebt an Tannensprossen.

Stomachis quercus ist braun-glïnzend; lebt in Rindenrissen ron Eiche und Birke.

„Einige Arten der PHanzenläuse, welche an den ron der Sonne belichteten Theilen sich aufhalten, stellen jeiloch, wie es scheint, eine Ausnahme vor, indem sie keine glänzente Ruickenoberfläche

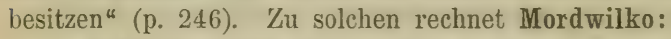

Aphis papaveris und rumicis (mattgrau), Aphis sombuci (von dunkelgrün bis bram), Aptis craccae, galii, hederae, euphorbiae ete. Einige dieser Arten sind eigentlich nicht braun, sonlern scheinen unter dem Nikroscop dunkelgrün. Ausserdem sind geflügelte Exemplare glänzend und die jungen meistens graugrün und sogar hellgrün.

Oft trifft man unter nicht braunen orler schwarzen Ptlanzenläusen, welche z. B. griin, roth und hellbraun sind, auch glänzende Rückenobertläche, wobei sic auch an den der Sonne ausgesetzten Pflanzentheilen leben; z. B. Siphonophora rosae (grüglïnzend), S. cerealis (grün-, gelb- bis rothbraunglänzend), S. tanaceticola (roth, sehr glänzend), Rhopalosiphum lactucce (hellgrün, glänzend), $R h$. clianthi (gelbgrün, glänzend), $R h$. mympherce (olivgrün, mit fettigem Glanz), Aphis cardui (einfarbig grün oder oben dunkel, stark glänzend); auch einige Lychnis, welche hellbraun oder harzbraun sind, besitzen den metallischen Glanz, z. B. L. nudus, pineus etc.

Die meisten Pflanzenläuse, welche keine dunkle Färbung besitzen und dennoch die der Sonne ausgesetzten Pflanzentheile bewohnen, haben auch keinen Glanz; sie sind gewöhnlich weiss oder grauweiss bestäubt und einige sind sogar behaart. „Die weisse oder 
weissgraue Pflaun oder Staub schützt, wie es scheint, die Pflanzenläuse vor der schädlichen Einwirkung der Sonnen- (Wärme-) Strahlen; behaart sind auch die Pflanzenläuse, welche dunkel oder braun gefärbt sind" (p. 248).

„Einige Pflanzenläuse, welche die der Sonne ausgesetzten Pflanzentheile bewohnen, sind zuweilen mehr oder weniger ähnlich der Fürbung der Farbe jener Pflanzen, auf welchen sie sich aufhalten" (p. 249). Zu solchen Arten werden gerechnet: Symydlobius oblongus (Birke), Luchnus tacriatus (Tannë), Lachnus agilis (Tanne), Vacuna betulae (Birke). „Ob dieser Uinstand irgend eine Rolle zum Schutze vor der schällichen Wirkung der Sonnenstrahlen spielt oder nicht, kann man vorlänfig nicht sagen" (p. 249).

Es giebt Pflanzenläuse, welche die der Sonne nicht ausgesetzten Pflanzentheile bewohnen, obwohl sie meistens nicht glänzend sinl, welche eine mehr oder weniger glänzende Oberfläche haben, z. B. DIyzus ribis, Rhopalosiphum ligustri, Aphis prunicola, Paracletus cimiciformis.

Den Umstand, dass die geflügelten Individuen derjenigen Arten, welche als ungeflügelte keinen Glanz haben, dennoch glänzend sincl, erklärt Mordwilko dadurch, dass die geflügelten Weibchen von einer Pflanze auf die andere überfliegen und somit der Wirkung der Sommen- resp. Wärme-Strahlen ausgesetzt sind, während die ungeflïgelten Weibchen durch ihren Aufenthaltsort davor geschiitzt werden können.

Zum Schlusse sagt Mordwilko: „Wenn diese oder jene Beschaffenheit der Haut und die Wachsabsontlerungen die Pflanzenliuse in gewissem Maasse vor der schädlichen Einwirkung der warmen Sonnenstrahlen schiitzt, so schützt dieselbe Beschaffenheit die Läuse auch vor rapiden Temperaturschrvankungen ihres Körpers, indem sie die Körperwärme verhindert, sich auszustrahlen, was für das Wohlhaben der Pflanzenläuse eine grosse Beleutung haben muss, besonders aber für diejenigen Arten, welche die ler Sonne ausgesetzten Pflanzentheile bewohnen" (p. 251).

Richard Zang (1900. 965) in Darmstadt fand am 21. Mai zwei Exemplare von Carabus auratus L. mit auffallend dunklen, fast schwarzen Beinen. Einige Tage später fanıl er noch ein Thier mit vollständig schwarzen Extremitäten und ebensolchen Numitheilen. Diese Schwarzfärbung war jedoch weniger ausgebillet bei Exemplaren, welche er Ende Mai erbeutete. Wegen der Ursache sagt er: "Es ist 
wohl nicht daran zu zweifeln, dass dies Melanismen von auruta sind, zumal der Sommer des vorhergegangenen Jahres sehr heiss war" (p. 122).

B. Slovogt (1900. 82:2) stellte die (ilïser mit Puppen von Vanessa polychloros auf ein lem damils herrschenten Nordwinde ausgesetztes Fenster. Yon ilen ausgeschilipften Faltern war nur ein kleiner Theil normal gefirlst, ${ }_{n}$ lie meistcn Falter dagegen zeichneten sich durch einen äusserst breiten schwar\%en saum aus, welcher dem letzten Vorderran'sflecken icr Vorderfliigel so sehr sich nïhert, dass der hellgelbe Grum fast ganz verschwindet umi nur einen ähnlichen Fleck an iler Spitze, wie xanthomelas ihn hit, nachlïsst. Das Bram iler Oberseite ist ein sehr dunkles. Die blanen Ram!monile der Hinterflügel nimmt man kaum waln" (p. 532). Ein Licmplar hatte das Bestreben, sich der Abart testudo Esch. zu nülıern.

L. Kathariner (1900. 439) stellte folgende Versuche an, um die Ursachen des „partiellen Albinismus" bei Schmetterlingen zu erklären: Ein horizontal gestelltes Glisroln wurle in Terbinlung mit der Wasserleitung gebracht, so class es stïnlig von fliossentem Wasser durchströnt wurile. Zuerst wurle ı!er Versuch mit ganz frischen Puppen von Tanessa witicae angestellt, welche, schrïg hïngent, mit ihrer rechten Flïgelscheide dicht dem Giasrohre anlagen. I)ie Puppen waren vom 15. bis 28. Juni len Vormittag über auf (ler linken Seite intensiver Somnenstrahlung (30 bis $\left.32^{\circ}\right)$ ausgesetzt, währen! ihre rechte Seite lem kalten $\left(1 t^{0}\right.$ bis $\left.16^{\circ}\right)$ Glasrohr zugekehrt war.

Vom 28. Juni an schlüpften die Falter aus. „Ein sonst ganz normaler Falter zeigt an rechten Vorderfligel einen fahlgelben Streifen, der von der Basis des dritten Vorderrandfleckes aus durch den eckigen Vorsplung (les Seitenran'les zielit. Die Verfärbung betrifft in gleicher Weise die rothgelbe Grundfarbe uni die schwarzen unil gelben Ranıstreifen; die blauen Samnflecken erscheinen mehr grau. Auch auf der Unterseite ist jenem Streifen entsprechend eine Verfärbung angerleutet. Ausserlem ist die rothgelbe Gruniffurbe des ganzen rechten Vorlerflügels viel mehr gelb und weniger feurig als die des linken" (1) 321). Diesulben Veränterungen erlitt atuch das zweite Exemplar, bei welchem noch eine etwa ${ }^{2}$; der Fläche ausmithenle Partic ganz unbeschuppt ist. "Auf ler Unterseite sind an der entsprechenden Stelle die Schuppen hell'r, grau statt schwarz, graugell) statt braungelb." Bei einem dritten Falter fimlet sich die 
Verfäroung an ller Ecke rles rechten Unterflïgelseitenramiles. Auch die anleren Exemplare zeigten ähnliche Veränlerungen.

Bei diesen Versuchen war das abgekiihlte Glasrohr fast stänlig mit Wasser aus der Luft beschlagen.

Darauf wurilen Versuche mit Puppen von Vanessa untiopa und io angestellt, wubei die Sonne während der beirlen ersten Tage nicht sehien unl das Rohr ron aussen mit Fenchtigkeit nicht beschlagen war. „Obsehon damit die eine rermuthete Lrsache, almorme Fenchtigkeit, ausgeschaltet war, ergab sich iloch dasselle Resultat". Vanessa antiopa erhielt fahlgrau verfärbte Flügelpartien, wobei viele Schuppen gar keinen Farbstoff enthielten; die schwarzen Schuppen sind grau, der ganze rechte Fliigel hat eine hellere Grumlfarbe als der linke.

Dieser Forscher ersieht somit die Ursache dieser Erscheinung nicht in der Feuchtigkeit-, soniern in der Temperatur-Differenz zwischen einer und der anderen Seite der Puppe, wobei "lie chemischen Umsetzungen der Schuppenfarbstoffic (bei $+160^{\circ}$ ) langsamer sich vollziehen als bei $+32^{\circ} \mathrm{C}$. Die linken Flügel in unserem Falle werlen ilaher, wenn iler Schmetterling ausschlïpft, ihre definitive Färbung erreicht haben, während div rechten noch nicht ausgefürbt $\sin l^{u}$ (p. 322).

E. Fischer (1901. 23(i) stellte in tlen Jahren 1898-1900 weitere Wäme-Experimente mit Vanessa-Puppen an, wobei er einen Thermostat mit Gasleitung benuitzte. Die erhaltenen Fesultate waren. folgende:

Vanessu io L. Temperatur $38^{\circ}$. Die erhaltenen Schmetterlinge waren typische Formen der Kälte-Varietüt fischmi Strlfss., sowohl deren Uebergänge.

Tanessu witicue L. (II. Gener.). Temperatur $38^{\circ}, 39^{\circ}$ unil $41^{\circ}$. Resultat: var. polaris Stgr. "Es stimmen viele dieser durch Wärme $\left(40^{\circ}\right.$ bis $\left.41^{\circ}\right)$ gewomnenen mit den in ler freien Natur in Norwegen etc. vorkommenden Stïcken der var. polaris Stgr. sogar weit besser überein, als die durch kïnstliche Kïilte erzengten!" (1). 307).

Vanessu levana var. prorsu L. Terinperatur $38^{\circ}$ bis $4.1^{\circ}$. Resultat: var. porimu 0 . unl einige der Winterform levanu nahe liommente Stiicke.

Vancssin polycluloros L. Temperatur $39^{\circ}$ his $41^{\circ}$. Die erwartete Iialte-Variation dixp!i Strlfs. wurle nicht erhultem. Temperatm $36^{\circ}$

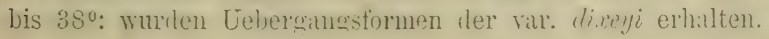


Vanessa antiona L. Temperatur 380-410. Einige Puppenserien ergaben nur Uebergänge zur var. artemis Fschr.; „antere Puppenserien ergaben die var. artemis Fschr. in einer ganzen Reihe von Stücken in einer so hochgradigen Ausgestaltung, wie sie selbst durch sechs Wochen dauernde Kälte-Einwirkung kaum erreicht werlen können" (p. 325).

Vunessa atalanta L. Frische (noch weiche) Puppen waren zwei Tage lang bei $39^{\circ}$ gehalten worden. Es schliiplte die Kïlteform var. merrifieldi Stdfs.

Vanessa cardui L. Temperatur 38-410.' Schlüpften äusserst charakteristische Stücke von var. visliotti Stlfs.

N. Ja. Kusnetzow (1901. 489) sammelte in ler Umgebung von St.-Petersburg Raupen von Catocala fraxini L., welche ummittelbar vor der Verpuppung orler frisch verpuppt waren, und setzte dieselben der Einwirkung entweder der Temperatur von $4^{0}$ währenı $2-3$ Wochen oder der Temperatur von $20-39^{\circ}$ während $10-12$ Tagen aus. Dabei wurden folgende Resultate erhalten:

1. Der blaue Band der Hinterflïgel in beiden Fällen wurde breiter und intensiver als bei normalen Schmetterlingen.

2. Bei einigen Exemplaren (bis zu 20\%) wurden bei Wurzeln der Hinterflügel Stellen erhalten, welche mit blauen Schuppen berleckt waren (im Original fig. A).

Die Fürbung der Vorierflügel wurde bei diesen Versuchen unregelmässig geändlert. Es wurden Exemplare erhalten, bei welchen die Vorderflügel stark geschwärzt sind, wie bei $C$. elocata Esp., und Exemplare mit sehr hellen Flügeln.

Gestuitzt auf diese Resultate, kommt der Verfasser zum Schlusse, dass der himmelblaue Fleck bei Flügelwurzeln infolge der ungenïgenden Entwickelung des schwarzen Pigments entstanden ist; somit erscheint die Entwickelung der schwarzen Pigmentirung als secundär und neu bei dieser Schmetterlingsgattung.

Da im zoologischen Museum der Petersburger Akademie der Wissenschaften 2 Exemplare ( $\sigma^{\top}$ und $\not$ ) von Cat. fraxini sich befinden, welche in Central-Asien 1879 gefangen wurden und der oben beschriebenen Aberration sehr ähnlich sind, so giebt der Verfasser ihnen den Namen var. muculata n. (im Original fig. B.).

Carl Frings (1901. 259) setzte Puppen von verschiedenen Schmetterlingsspecies in ganz frischem Zustande möglichst bald nach 
dem Abstreifen der Raupenhaut der Einwirkung der erhöhten Temperaturgrade aus. Zu diesem Zwecke wurde ein regulierbares Thermostat verwendet. Dabei wurden folgende Resultate erhalten:

Vanessa urticue I. Gener. - 36 Stunden +39. Uebergänge zu var. ichnusa Bon., var. polaris Stdgr.

Vanessa urticae II. Generation. -- Dieselbe Exposition. Var. ichnusa Bon.

3 Mal je $4^{1 / 2}$ Stunden $+40^{0}$. Täglich eine Exposition. Stark reduzierter Innenrandfleck, Grundfarbe oft mit viel gelber Mischung, blaue Flecken verkleinert. Falter.

18-24 Stunden $+40^{1} / 2^{0}$. Puppen 12 Stunden alt. Normale

I. und II. Generation. - 6 Mal je $2 \frac{1}{2}$ Stunden +43 bis $431 / 2^{0}$. Ab. ichnusoides de Selys, Uebergänge zu dieser ab, var. polaris Stdgr.

Vanessa io I. Generation. - $36^{\circ}$ Stunden $+39^{\circ}$. Aehnlich der var. fischeri Stdfss.

II. Generation. $-3 \mathrm{Mal}$ je 4 Stunden $+40^{\circ}$. Aehnlich ler Vanessa urticae var. polaris, Uebergänge zu ab. belisavia Obthr. Obthr.

I. Generation. $-12,18$ und 24 Stunden $+40^{1} 2^{0}$. Ab. Zelisaria

I. Generation. -6 Mal je $2 \frac{1}{2}$ Stunden $+43^{1 / 2} 2^{0}$. Ab. Zelisuria, einige Exemplare mit stark reduziertem Hinterflügelauge und fast ganz normalen Vorderflügeln.

Vanessa c. album II. Generation. - 30-36 Stunden +390.

Eine neue Form: Costalflecken der Vorderflügel stark verkleinert und verwischt, Innenrandfleck im Schwinden begriffen, der dunkle Saum der Vorderflügel ganz schınal. Hinterflügel-Zeichnung gänzlich verloschen. Vor dem Saume aller Flügel tritt meist eine Reihe grosser, ovaler, hellbrauner Flecken auf.

3 Mal je 4 Stunden $+40^{\circ}$. Normalfalter.

6 Mal je $21 / 2$ Stunden $+43 \frac{1}{2}{ }^{0}$. Ein verdüsterter Falter mit stark ausgeprägter, schwarzer Zeichnung.

Vanessa polychloros. $-36-48$ Stunden $+39^{\circ}$. Ab. testudo Esp. und Combinationen.

6 Mal je $2 \frac{1}{2}$. Stunde $+431 / 2^{0}$. Ab. testudo.

Vanessa antiopa. $-60-66$ Stunden $+37{ }^{\circ}$. Var. claubii Stdfss. Uebergänge zu ab. hygiaea Hilrch. (Vorderflügel) und zu var. roederi Stafss. (Hinterflügel).

$36-42$ Stunden $+39^{\circ}$. Var. roederi.

16 Mal je 1 Stunde $+43 \frac{1}{2^{0}}$. Var. epione Fschr., ab. hygiaea. 
Tanessa prorsa. -6 Mal je $2 \frac{1}{2}$ Stunden $+43 \frac{1}{2} 2^{0}$. Ab. porima und levana.

Vanes:a atalanta. - 48 Stumelen $+39^{\circ}$. Wie bei Standfuss im "Handbuche" (1896. S46), auch eine (imbination diese'r Form mit ab. klemensiewiczi Schille.

36-40 Stunden $+39^{\circ}$. Standfuss'sche Wärmeform.

42 Stunden $+39^{\circ}$. Dieselbe Hauptform.

48 Stunilen $+39^{\circ}$. Standfuss'sche Wärmeform.

3 Mal je 4 Stunden $+40^{\circ}$. Ab. Tilemensievoiczi.

18-24 Stunden $+421 / 2^{0}$. Normalfalter.

3 Mal je 4 Stunden $+41^{\circ}$. Ab. Tolemensiewiczi, der var. merrifieldi Stufss. ähnliche Formen.

3 Mal je 4 Stunden $+42^{\circ}$. Ab. Tilemensierviczi.

6 Mal je $21 / 2$ Stunden $431 / 2^{0}$. Fast normale Falter.

Rhodocera rhamni. - 36-42 Stunden +390. Die Standfuss'sche Form („Handbuch“ p. 240-241).

Arctia caja. - 48 Stunden $+33^{\circ}$. Die Fransen des Vordergflüel-Aussenrandes sind ganz oiler fast gamz weiss; Grun!larbe der Hinterflügel mit starkem Stich in's Gelbe.

36 Stunden $+35^{\circ}$. Ab. confluens.

24 Stunden $+37^{\circ}$. Ab. futura Fickert.

48 Stunden $+38^{\circ}$. Uebergänge zu ab. schultzii Frgs.

36 Stunien $+39^{\circ}$. Hinneigung 7.1 ab. confluens, Uebergänge zu ab. futura.

$5-6$ Mal je 4 Stunden $+40^{\circ}$. Normalfalter.

6 Mal je 1 Stuncle $+41^{\circ}$. Teine Neigung zu ab. confluens.

6 Mal je $11 / 2$ Stunden $+42^{\circ}$. Neigung zu ab. confluens, ab. futura.

6 Mal je 1 Stunde $+43^{\circ}$. Neigung zu ab. confluens.

6 Mal je 2 Stunclen $+44^{\circ}$. Uebergänge $\mathrm{zu}$ ab. futura (nur die Vorderflügel waren aberrativ).

Bombyx neustria. -6 Nal je $2 \frac{1}{2}$ Stunden $+43 \frac{1}{2}{ }^{0}$. Normale Falter.

Die Versuche, welche Frings mit ernielligten Temperaturgrarlen angestellt liat, fülırten ihn zu folgenilen Resultaten:

Papilio machaon. - Die möglichst frischen, oft noch weichen Puppen wurden im Herbste 10 Nal je 8 Stunden bei $-15^{0}$ exponiert. Hierauf überwinterten sie im Freien und licferten im Friihjahre zum grüssten 'Theile normale Falter, eine ah), nigrofasciatn Pothlie, anch Formen, liei welchen die Charalitere der ans iiherwin- 
terten Puppen stammenden I. Generation extrem entwickelt sind, daher könnte man die experimentell erzielten Falter als eine jotenzierte Winterform bezeichnen.

Vanessa urticae. -6 Mal je $3-4$ Stunden bei $-12^{\circ}$. Kleine Uebergänge zu ab. ichnusoides de Selys.

Vanessa c. album. - Frostversuch. Ab. f. album Lisp. Uebergänge.

Vunessa ataianta. - Im Oktober entstandene Puppen wurden im ungeheizten Zimmer aufbewahrt. Mitte December wurclen sie in's warme Zimmer genommen. Erhalten wurden Uebergänge zu var. merrifieldi.

Catocala nupta. $-35-42$ Tage $+6^{\circ}$. Aehnlichkeit mit C. fir xini ab. obscura.

Beim Frostexperiment ergab nupta nur Normalfalter.

Schliesslich stellte Frings Versuche mit comlinirten Behandlugsinethoden an, um festzustellen, ob durch Einwirkung verschiedener Behandlungsinethoden vielleicht Combinationen zweier Formen herzustellen seien. Dabei wurden folgende Resultate erzielt:

Vanessu urticae. -6 Mal je $2 \frac{1}{2}$ Stunden $+43^{1} / 2^{0}$, die Zwischenpausen $+6^{0}$. Aus $+6^{0}$ sofort in $+43^{1 / 2^{0}}$ verbracht und umgekehrt. Weichen nicht stark von der Hitze-Hauptform ab, welche die Zwischenpausen in Normaltemperatur verbrachte.

Vanessa io. - Zuerst 28 Tage $+6^{\circ}$, dann 4 Mal je 4 Stunden $-12^{\circ}$. Var. fischeri Stlfss., ohne einen Anklang an ab. belisaria Obthr.

4 Mal je 4 Stunden $-12^{\circ}$, dann 28 Tage $+6^{\circ}$. Var. fiischeri, keine ab. belisaria.

3 Mal je 4 Stunden $-12^{0}$ und 4 Mal je $2 \frac{1}{2}$ Stunden $+43^{1} / 2^{0}$. Frost und Hitze wurden abwechselnd angewandt; die Zwischenpausen betrugen nur 5-10 Minuten. Ziemlich stark veränderte Stufe von ab. belisaria. Immer ist die Grundfarbe tief braunroth, wie bei Wärme-io.

Vanessa antiopa. -28 Tage $+6^{0}$, dann 4 Mal je 5 Stunden $-12^{\circ}$. Eine Neigung zu ab. hygicea besteht nicht.

4 Mal je 5 Stunden $-12^{\circ}$, dann 28 Tage $+6^{\circ}$. Alles Blau ist $\mathrm{zu}$ Grau verblasst.

7 Tage $+6^{\circ}$, dann 4 Mal je 5 Stunden $-12^{\circ}$. darauf wieder 21 Tage $+6^{\circ}$. Ein geringer Anklang an ab. hygiaea, Aehnlichkeit mit var. epione Fschr.

28 Tage $+6^{0}$, dann 24 Stunden $+39^{\circ}$. Beide Flügelpaare schillern in ihrer ganzen Fläche; der Saum ist überall graugelb; im Uebrigen wie 35 Tage bei $+6^{\circ}$. 
E. Fischer (1901. 235) untersuchte die Frage, bis zu welchem Grade bei entsprechender Verlingerung der Expositionszeit die Temperatur vermindert werden diurfe, um ïberhiupt noch typische Aberrationen $\mathrm{zu}$ ergeben.

Gestiitzt auf seine frïheren Versuche kommt er zum Schlusse, dass verschiedene Vanessa-Arten sich in dieser Beziehung verschiolen verhalten, und zwar: die geringste Temperaturerhöhung bratuhen, um eine Aberration, orler einen Uebergang zu ergeben, die Van 's:su antiopa L. und sodann polychloros L. weiter folgen etwa der lisihe nach io L., curclei L., urticae L., atalanta L. und c. album L., d. H. io L. und curdui L. können auch bei $+39^{\circ}$ bis $+41^{0}$ schon typische Aberrationen bilden, während urticae L., atulanta L. unil besonders c. album L. schon $+42^{\circ}$ bis $44^{\circ}$ (letztere Grale wenigstens 1 bis 2 Mal je 2 Stunden) benöthigen, um aus der normalen Entwickelung heraustreten zu können.

Zum Schlusse sagt er:

Bei Frost- und Hitze-Einwirlung kann die Expositionszeit noch mehr, als man bisher glaubte, verkürzt werden, inclem schon eine blos zweimalige, kaum 1 Stunde dauermile Ablïhlung auf - su typische Aberrationen ergab.

Bei Verlängerung (ler Expositionszeit traten Aberrationen auch bei geringerer liälte $\left(0^{\circ}\right.$ bis ca. $\left.+4^{0}\right)$ und, was noch bemerkenswerter und wichtiger ist, auch ohne Anwendung der Hitzegrade $\left(+43^{\circ}\right.$ bis $+45^{0}$ ) bei Wärme von $+41^{0}$ bis hinunter $\mathrm{zu}+36^{\circ}$ und mit einer 2 bis 3 maligen Einwirkungsdauer von 6 bis 10 Stunden auf.

Aus diesem letzten Befunde ergiebt sich nun der wichtige Schluss, dass die Vanessa-Aberrationen in der freien Natur nicht blos durch öftere Temperaturen von $+44^{\circ}$, sondern offenbar schon durch eine an 2 bis 3 aufeinander folgenden Tagen stattfindende mässige Erwärmung auf $+36^{\circ},+38^{\circ},+40^{\circ},+41^{0}$ von je 6 bis 10 Stunden Dauer, oder endlich blos 1 bis 2 maliges Steigen auf $+44^{\circ}$ und nachheriges längeres Verharren zwischen $+41^{\circ}$ uml $+36^{\circ}$ auftreten liönnen, und dass dieser Fall in der Natur als relativ oft vorkommend angenommen werden darf.

Chr. Schröder (1901. 778) sammelte einige Hunderte Larven von Adulia bipunctuta L. und brachte die Puppen 24 Stunden nach ihrer Ausbildung in den Hitze-Apparat, welcher mit oben angebrachter Durchlüftungs- und unterer. Wasserverdunstungsvorrichtung versehen war. Die Temperatur im Apparate betrug während einer 
Stunde $39^{\circ}-40^{\circ}$; dann wurle die Lampe ausgelöscht und die Ventilation voll zur Wirkung gebracht, so llass weitere 10 Minuten eine Abkühlung auf die Zimmertemperatur (140-2.2") erzengten Diese Einwirkung wieterholte er dreimal täglich um $\tau$ h. m., 1 h. n. und 7 h. n. an je drei aufeinander folgenden Tagen.

Die erste Serie von 53 Puppen ging dabei zu Grunde. Unier sonst gleichen Voraussetzungen erhöhte er deshall) die Temperatur fernerhin nur auf $37^{\circ}$, und erhielt von 266 Puppen 164 normale bipunctata, dio übrigen 102 waren fast alle die Uebergangstormen zu der var. lumubris. Ws., nämlich die Varietiiten: 3 herbsti Ws., 4 unifusciate Fabr., 3 perforata March., 0 udelue Schr, 11 olivicri W's. 34 puntherina L., 25 semirubra Ws., 18 i-mestulutu L., +4 -maculata Scop., 0 sublunata Ws., o lumubris Ws. Ton den gleichzeitig eingetragenen 424 Puppen gehörten in ihren Imagines der bipunctatu L. 287, den Varietäten: herbsti Ws. 10, unifisriat i Fabr. t, prerforata March. 0, adclae Schr. 2, olivieri Ws. 0, pantherina L. 1, semirubra Ws. 3, 6-pustulata L. 91, 4-maculata Scop. 21, sublunatu 3 Individuen an.

liechnet man diese Daten auf $100 \mathrm{um}$, so ergiebt sich folgender Resultat:

\begin{tabular}{|c|c|c|c|c|c|c|c|c|c|c|}
\hline $\mathrm{N}$ & & $\mathrm{a}$. & $\mathrm{m}$ & e & & & & & $\begin{array}{c}\text { A } \\
\text { 266. "Temperatur- } \\
\text { Formen“ }\end{array}$ & $\begin{array}{c}\text { B } \\
424, \text { Normal- } \\
\text { Formen" }\end{array}$ \\
\hline 1. bipunctute & 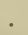 & . & . & & . & & . & . . & $61,65 \%$ & $67,69 \%_{0}$ \\
\hline 2. herbsti. . & . & . & . & . & . & & . & . . & 1,13 & 2,36 \\
\hline 3. unifasciata & . & . & . & & . & & . & . . & 1,05 & 1,41 \\
\hline 4. perforata & . & . & . & & . & & . & . . & 1,13 & 0,0 \\
\hline 5. adelae. . & . & . & . & & . & & . & . & 0,00 & 0,47 \\
\hline 6. olivieri . & . & . & . & & . & & . & . & 4,14 & 0,0 \\
\hline 7. pantherina & . & . & . & & . . & & . & . & 12,78 & 0,24 \\
\hline 8. semirubra & . & . & . & & . & & . & . & 9,04 & 0,71 \\
\hline 9. 6-pustulata & . & . & . & & . . & & ${ }^{\circ}$ & . & 6,77 & 21,46 \\
\hline 10. 4-maculata & . & - & . & & . & & 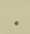 & . . & 1,05 & 4,95 \\
\hline 11. sublunata & . & . & . & & & & 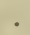 & . & 0,00 & 0,71 \\
\hline 12. lugubris :- & $\theta^{\circ}$ & $\therefore$ & ... & & & & • & . . & 0,00 & 0,00 \\
\hline
\end{tabular}

Die hier gewählte Reihenfolge der Formen erklärt sich nach Schröder aus seiner späteren Charakterisierung der Zeichnungsphylogenie.

Indem er die erhaltene Tabelle graphisch darstellt (Or.linate $=$ Prozentsatz, Abscisse = die . 
"lass die durch extreme (hohe) Temperaturen erzielten Tariationen unberlingt Hemmungstormen, nicht aleer progressive sin l" (p. 357).

Fr. Ball (1901. 47) brachte die Raupen ron Papilio machaon der Winter- und Sommergeneration während verschierlen langer Zeit (von 1 bis 15 Tagen) in die Temperatur von $39^{\circ}$ und liess darauf die Puppen bei derselben Temperatur liegen: Winterpupen von 36 bis 50 Tagen und Sommerpupuen ron 2 bis 7 Tagen. Die Entwickelungszeit resp), die Puppenruhe wurde dabei bei der Sommergeneration entweler um die Hälfte (statt 15 Tagen nur 7 ) reluziert, oder verlängert (statt 15 Tagen 32 Tage). Bei ler Wintergeneration blieb sie fast unverïnlerlich. Die erhaltenen Schmetterlinge ergaben folgende Formen:

Die Wintergeneration ergal) normales Ḱleid; sie reagiert auf die Wärme also nicht.

Die Sommergeneration ergal) abweichende Färbung (im Simne ron Standfuss) und zwar desto stärker, je kïrzer die Puppenruhe war.

Bei Versuchen mit der Sommergeneration stieg die Temperatur zufällig iiher $40^{\circ}$ uml die Puppen, obwohl nachher bei $10^{\circ}-150$ liegen gelassen, hatten die Puppenruhe wie die Wintergeneration (ca. 245 Tage). Die Fürbung war wie bei der Wintergeneration.

D.raus zieht Ball den Schluss, dass die Iiaupen resp. Puppen, welche immer höheren und höheren Temperaturen ausgesetzt werilen, weniger und weniger auf die Wärme reagieren.

E. Fischer (1901. 237) hielt 41 Puppen ron Aictia caja bei der Temperatur von $-S^{0}$ und erhielt aberrativ veränderte Falter. Diese aberrative Bildung bestand in einer Verbreitung der dunkeln, also auf den Vorlerflügeln der braunen, auf den Hinterfliigeln der schwarzen Flecken, so lass diese theilweise, bei einigen (männlichen) Exemplaren sogar vollständig miteinander zusammenflossen.

C. Frings (1902. 260) stellte Experimente mit erhöhten Temperaturgraden an verschiedenen Puppen-Arten an und erhielt folgende Resultate:

Papilio podalirius. 10 Tage $+37^{\circ}$, Temperatur jeden zweiten Tag für $3-4$ Stunden bis auf $431 / 2{ }^{0}$ steigend und wieder auf $37^{0}$ failend. Es liess sich dadurch die deutsche Winterform von podalirius direkt in die siideropäische Sommergeneration (var. zanclaeus Zell) umprägen. 
Papilio machaon. 15 Tage $37^{\circ}$, jeden zweiten Tag für 5-6 Stunden auf $44-45^{\circ}$ steigend und wieder auf $37^{\circ}$ sinkenil. Aus mitteleuropäischen machaon-Puppen der Wintergeneration konnte dadurch die var. centralis Stlgr. und, allerdings seltener, die südeuropäische unil syrische ab. spluyrus $\mathrm{Hb}$. erhalten werden.

Thais polyxena. Wie podalirius behandelt, doch 14 Tage exponiert. Es schlüpften meist Normalfalter aus, einige Uebergänge von ab. ochracea St:lgr. und eine neue Aberration, welche eine gewisse Aehnlichkeit mit mach:on ab. nigrofasciatus hat.

Polyommatus amphidamus und Vanessa levana, gleich behandelt, ergaben keinen Falter.

Apatura iris. 24 und 36 Stunden $39^{\circ}$. Keine Puppe schlüpite. 18 Stunden $39^{\circ}$. Eine Hinneigung zu ab. jole Schiff.

Apatura ilia. 36 Stunden $39^{\circ}$. Weisse Zeichnung verschnälert, Schiller intensiv, anstatt des Analauges der Hinterfiligel meist nur ein gelbes Fleckchen auf Ober- und Unterseite.

Var. clythie. Dieselbe Exposition. Resultat: var. dilutior Stugr.

Limenitis populi. 18 Stunden $39^{\circ}$. Keine Abänderungen.

Limenitis sibyll $x$. 18-24 Stunden 390. Rostroth der Unterseite verdüstert, in Vorderflügel-Mittelfelde in der Auslehnung zurïckgegangen und durch Schwarzgrau ersetzt. 3 Mal je 4 Stunden $40^{\circ}$ bis $41^{\circ}$. Normal.

Vunessa var. prorsa. $36-42$ Stunden $38^{\circ}$. Var. porima O.; mangelhafte Beschuppung. 3 Mal je 4 Stunden $40^{\circ}$ bis $41^{\circ}$. Vorderflügel prorsa, Hinterflügel mehr levana.

Vanessa urticae II. Generation 30 Stunden $39^{\circ}$. Combination von var. ichnusa Bon. mit ab. ichnusoides de Sel.

Vanessa io II. Generation 3u Stunden 390. Der var. fischeri Stcl's ähnlich, hat aber weder die aufgehellte Grundfarbe noch die charakteristisch veränderte Unterseite. Eine kleine Hinneigung zu ab. belisaria Obthr. ist bei manchen Exemplaren nicht zu verkennen. 3 Mal je $21 / 2$ Stunden $42^{\circ}$ bis $43^{\circ}$. Uebergang zu ab. belisaria.

Vanessa polychloros. 66 Stunden $36^{\circ}$. Saum der Vorderflügel verschmälert, Hinterflügel am Rande verduistert, die blauen Flecken noch eben zu erkennen. Unterseite sehr dunkel. 3 Nal je $4-4^{1 / 2} 2$ Stunden $40^{\circ}-41^{\circ}$. Ab. testudo. 2 Mal je 4 Stunden $43^{\circ}$. Ein Exemplar links ganz typische testudo.

Vanessa antiopa. 66 Stunden $36^{\circ}$. Uebergänge zu var. daubii Strlfs. $44-48$ Stunden $38^{\circ}$. Grundfarbe fast ganz schwarz. 30 Stunden $39,5^{\circ}$. Wälırend dieser Zeit möglichst oft steigend und fallend 
auf 41 . mil $38^{\circ}$. Ziemlich tspische hygiaea. 20 Stunden $40^{\circ}$. Nahe kommende var. roerleri Stilfs. (Kälteform), auch einige typische ab. Tyygiaer. 3 Mal je $4 \frac{1}{2}-5$ Stunden $40^{0}-41^{\circ}$. Typische ab. hygiaea. 4 Mal je 3 Stunden $42^{\circ}-42,5^{\circ}$. Ab. luygiaca. 5 Mal je $2-2 \frac{1}{2}$ Stumlen $43^{0}-43,50$. Ab. Tyggiaea. 2 Hal je 4 Stumlen $43,5^{\circ}$. Hinterflügel typische higgiaca.

Zu ciiesen Versuchen mit $V$. antiopa knippt Frings folgende Bemerkung: „Ueberhaupt hat die weitaus iberwiegrenle Merzahl meiner mit Wärme erzogenen Varietäten eine den Kïlteformen durchaus diametral entgegengesetzte Entwickelungsrichtung und nur als seltene Ausnahmen erschienen bei Wärme Falter mit einigen Charakteren der Kälteserien" (p. 26).

Vanessa cardui. 30 Stunden $39^{\circ}$. Formen stimmen mit denjenigen überein, welche bci Standfuss (840) Taf. VII. .li j abgebildet sind.

Vanessa atalanta. 20 Stunden $40^{\circ}$ : ein Uebergang zu ab. Klemensieviczi Schille. - 3 Mal je $3 \frac{1}{2}$, Stunden $41^{0}$ : infolge der bedeutend reduzierten Pracht-Binde erinnert der Falter an eine rax. merrifieldi Stılfs; der Costalfleck ist aber nicht vergrössert. 12 Stunden $41^{0}$ : normale Falter. -3 Mal je $2 \frac{1}{2}$ Stunden $42-43^{n}$ : recht verschiedene ab. lilcmensiewiczi und ihre Cebergänge.

Melitrea didymu. 36 Stunden 390: die erwartete var. meridionalis resultierte nicht, sondern im Gegentheil eine Form mit vermehrten schwarzen Zeichnungen. - 3 Mal je 4 Stunden 40-410: meistens normale Schmetterlinge. - 7 Mal je 2 Stunden 43,50: Die Form wie bei Standfuss (841) auf Taf. IV. ㅊo 10.

Der Verfasser sagt: "In der Gattung Argynnis existirt also offenbar ebensowohl eine Reihe analoger Aberrationsformen, wie bei den Vanessen" (p. 35).

Melituea aurinia. 28-36 Stunden 390: bedeutend schwärzer als sonst Sülformen, wie var. provincialis Boisd. und var. ilserica Obthr. wurden nicht erzielt. - 36-42 Stunden $39^{\circ}$ : alle schwarze $\mathrm{Z}$ chnungen sehr stark ausgeprägt. -3 Mal je 4 Stunden $40-41^{\circ}$ : die schrarze Zeichnung ist so verbreitet, lass grosse Theile der Flügel geschwärzt erscheinen.

Callimorpha dominula. 24 Stunden $39^{\circ}$ : weisse Flecken sind gelb überstäubt.

Sıturnia pyri. Behanilung wie podalivius: mangelhafte Beschuppung. 


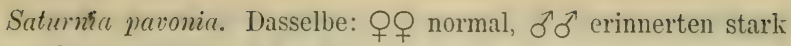
an Exemplare aus Rom, Neapel.

Cato ala mupta. 36 Stunden 390: vollkommen normal.

Pabst (1903. 621.) beobachtete, dass wenn Ino statices L. in feuchter, kiihler Abendluft an den Stengeln sitzen, zeigt sich oft, dass sich Grün in Roth verwanilelt, welches sich aber schon in der warmen Hand wierler umfärbt.

Chr. Schröder (1903. 779.) setzte die Puppen ron Abruxas grossulariata $\mathrm{L}$. vom nächsten Tage nach ihrer Bildung an für die weiteren drei Tage je dreimal während einer Stunde einer Temperatur ron $3 \delta^{\circ}$ aus (in wasserlampfreicher Luft), und erhielt aberrative Formen, welche aus den von ihm angeführten Figuren näher zu ersehen sind.

C. Frings (1903. 261.) stellte die Versuche mit erhöhten Temperaturgraden im Februar und März 1902 mit folgenden iiberwinterten Puppen an:

Papilio podalirius. -2 Tage $+40^{\circ}$, täglich 4 Stunden $+42^{\circ}$. Trat öfters ab. undecimlineatıs Eim. auf, auch ab. rechuctus Schultz.

52 Stunden $+40^{\circ}$ bis $40,5^{\circ}$. Ab. undecimlineatus Eim. mit Neigung zu ab. schultzii Bathke; eine dünnbeschuppte ab. reductus.

36 Stunden $+41^{\circ}$. Ein stark geschwärzter Uebergang zu ab. scliultzii Bathke.

1 Tag 4 Stunden, 2-4 Tage je 3 Stun'en $+43,5^{\circ}$. Ab. schultzii, Utbergänge $\mathrm{zu}$ ab. reductus.

Papilio machaon. - 13 Tage $+37^{\circ}$, jeden 2. Tag für ca. 6 Stunden bis $+43,5^{\circ}$ steigend. Meist normal, eine var. centralis Stdgr.

6 Tage $+39,5^{\circ}$. Var. centralis, welche aber eher als ab. aurantiacus Speyer zu betrachten ist.

2 Tage $+40^{\circ}$, täglich 4 Stunden lang $42^{\circ}$. Var. centralis, ab. tenuivittatus Spengel.

52 Stunden $+40^{\circ}$ bis $40,5^{\circ}$. Ab. temuivittatus Sp., ab. nigrofasciatus Rothke, auch eine Anzahl Falter, welche in auffallenilester Weise mit einer Reihe machaon ubereinstimmen, die Frings 1900 bei Frosteinwirkung erzog (259). „Die betreffentlen beilen Reihen sind kaum von einander zu unterscheiden!"

5 Tage $+40,5^{\circ}$. Var. centralis, ab. immaculatus Schultz.

$3^{1} / 4$ Tage $+40,5^{0}, 2$ Mal je 4 Stunden $+42^{0}$ bis $42,5^{\circ}$. Ab. bimaculatus Eim., var. centralis, ab. temivittatus, ab. immaculatus, 
Uebergänge zu ab. cviltatıs, eine gewisse Neigung zur Bilıng von ab. nigrofasciatıs. $21 / 2$ Tage $+41,5^{\circ}$. Wie vorstehen $\%$.

2 Tage $+42,5^{\circ}, \mathrm{Ab}$. nigrofusciatus - Uebergang.

1 Tag 4 Stunden, 2-4 Tage je 3 Stunilen $43,5^{\circ}$. Ab. bimaculatus, Hinneigung zu ab. nigrofusciatus.

Thais polyxena. - 1 Tag 4 Stunden, 2-4 Tage je 3 Stumlen $+43,6^{\circ}$. Ziemlich bedeutende Reduction aller schwarzen Zeichnungen.

Polyomnatus amphidumas (Wintergeneration). - 2 Tige $+40^{\circ}$, täglich 4 Stunlen $42^{\circ}$. $\sigma^{\top} \delta^{\star}$ iberaus stark verlüistert, mit der Sommergeneration var. obscura Strgr. übereinstimment. $q$ o $\mathrm{im}$ Wurzel-und Mittelfelı der Vorderflügel ebenfalls geschwärzt.

1 Tag 4 Stunden, 2-4 Tage je 3 Stunilen $+43,5^{\circ}$. Wie ohen; Säum der Vorder- und Hinterflügel bei beilen Serien geschwärzt. Apatura itia. -48 Stunlen $+39^{\circ}$. Nur ein $\sigma^{7}$ mit weissen Binden und vollkommener, gelber clythic-Ranizeichnung.

Apatura itia und var. clythie. - 3 Mal je 4 Stunden $+40^{\circ}$ bis $41^{\circ}$. Alle normal.

3 Mal je $2-2 \frac{1}{2}$ Stunden $+43^{0}$. Ilia ergab ab. itiudes trans; var. clytlie ergab ab. astasioides Stdgr. trans.

Limenitis populi. -3 Mal je 4 Stunden $+40^{\circ}$ bis $41^{\circ}$. Yormale Zeichnung.

Vanessa levana. - 3 Mal je 4 Stunden $+40^{\circ}$ bis $41^{\circ}$. Bei einigen sehr stark verbreitete schwarze Zeichnung, bei anderen alles Schwarz bedeutend reduziert.

Vanessa urticae (II. Generation). - 30-36 Stunden +390. Wie die früher erzielten Wärme-urticae.

Vanessa antiopa. -54 Stunden $+37^{\circ}$. Var. daubii Stdfss

48 Stunden $+37^{1} / 2^{0}$. Wie eben, Hinterflügel in Grundfarbe und Saum meist völlig geschwärzt.

43 Stunden $+38^{\circ}$. Wie 1901 bei +38 , ab. dorfmeisteri Fschr., ab; hygiaea Hdrch. trans.

6 Stunden $+38^{\circ}, 13$ Stunden $+40^{\circ}$, während dessen für 1 Stunde auf $41^{1} / 2^{0}$ steigend, dann 8 Stunden $+38^{\circ}$. Vergrösserte blauen Flecken, ab. hygiaea.

8 Stunden $+38^{\circ}, 15$ Stunden $+40^{\circ}$. Ab. Tygiaea.

6 Stunden $+38^{0}, 31 / 2$ Stunden $+43^{\circ}$. Ab. hygiaea.

30 Stunden $+39,5^{\circ}$, möglichst schwankend von $38-41^{\circ}$. Ab. hygiaea mit verdüsterten Säumen.

3 Stunden $+43^{\circ}, 10$. Stunden $+38^{\circ}$. Ab. hygiaea.

20 Stunden $+40^{\circ}$. Ab. hygiaea. 
2 Mal je 3 Stunden, 1 Mal je 2 Stunden $+42,5^{\circ}$. Ab. hygiaea trans. Argynnis paphice. - 3 Mal je 4 Stunden +40 bis $41^{\circ}$. Normal.

Deilephila euphorbicae. - Im November vor und im März nach der Ueberwinterung je 8 Mal $21 / 2$ bis 3 Stunden $+43,5^{0}-44^{\circ}$. Sehr hell, Roth theilweise von einem schmutzigen Grau ersetzt.

Seine Versuche mit erniedrigten Temperaturgralen ergaben folgende Resultate:

Apatura ilia var. chythie. Schiff. - 35 Tage +60. Wie 1901.

Apatura ilia und var. clythie. - 4 Mal je 7 Stunden $-10^{\circ}$. Uebergänge zu ab. astasioides Stdgr.

Limenitis populi. -28 Tage $+6^{\circ}$. Weisse Flecken der Vorderflügel dlunkel bestäubt, Hinterflügel-Binde auf $1 / 3$ reduziert.

Limenitis sibylla. -4 Mal je 6 Stunden $-10^{\circ}$. Ab. nigrina Weym.

Vunessa c. album. Frostexposition. - Uebergïnge zu ab. $f$. allum Esp. Ein Exemplar kommt an Schwärzung auf Ober- und Unterseite den extremen, durch Hitzegrade entstandenen polychloros ab. testudo Esp. gleich.

Vanessa io. Kombinationsversuch. -4 Mal je 7 Stunden $-10^{\circ}$, dann 25 Tage $+6^{\circ}$. Var. fischeri Stdfss. (1898 erhielt er beim Frostversuch einen Falter mit den Voriderflügeln der var. fischeri und den HinterHiugeln der ab, belisaria Obthr.)

Melitaea maturna. - 14 Tage $+6^{\circ}$ - Normal.

21 Tage $+6^{0}$. Schwarze Zeichnung verdunkelt.

28 T'age $+6^{0}$. Wie oben.

35 Tage $+6^{0}$. Mittelband sehr stark geschwärzt, sonst wie oben.

42 Tage $+6^{\circ}$. Schwarze Zeichnung meist verwaschen. Vorlerflügel-Querbinde fehlt, die Linie vor dem Saume auf den Vorderflügeln verdoppelt, 2 Reihen Randmonde:

Frostexposition. - Normal.

Melitaea aurinia. - 14 Tage $+6^{\circ}$. Vorderflügel verdüstert. Hinterflügel-Randmonde geschwärzt.

21 Tage $+6^{\circ}$. Wie oben.

28 Tage $+6^{0}$. Schwärzung weit bedeutender.

Frostexposition. Querbinden beiler Flügel fehlen.

Argynnis paphia. - 35 Tage $+6^{\circ}$. Im Mittelfelde der Vorderflügel sind die schwarzen Flecke stark seitlich aus- und zusammengeflossen. Auf den Hinterflügeln ist die innere Fleckenreihe reduziert, die äussere vergrössert.

42 Tage $+6^{0}$. Ebenso, die Hinterflügel stärker abweichend. 
Frostexposition. - Ab. ocellata Frgs.

Arctia caja. - 56 Tage $+7^{\circ}$. Ab. schultzii Frgs., ab. futura. Eine Reihe Arctidlen, z. B. Cullimorplua dominula, Aictia hebe, villica, aulica, flaviu, scheinen eine analoge, d"r extremen ab. futur F. von caja entsprechende Abe:rationsform 7.1 bilden mit einfarligen Vorderflügeln und geschwärzten Hinterflügeln.

Arctia purpurata. - 42 Tage $+6^{\circ}$. Grosse schwarze Hinterfliigel-Flecken und die Flecken iler Vorlerttugel zu Querbinten angiordnet.

Catocala fraxini. -28 und 35 Tage $+6^{\circ}$. Normal.

Catocala elocata und sponsa. -28 Tage $+6^{0}$. Normal.

T. Chapman (1904. 139a) konstatierte, dass die Fürbung von Heodes phlaeas durch die Temperatur beeinthusst wird, bes mnlers am Encle ler Puppenzeit. Die Temperatursteigerung geht mit iler Verdunkelung parallel.

Hanold (1904. 353) demonstrierte in der Sitzung vom 19. November 1903 des Berliner Entomologischen Vereins einige Aberrationen von Arctia caja L. Es waren Schmetterlinge der II. Generation, deren Raupen im Herbst mit Löwenzahn gefüttert unı die Puppen auf Eis gelegt waren. Auf den Vordertlügeln versulıwindet las Weiss, bei einem Schmetterling ist sogar Schwarz an Stelle des Weiss gretreten. Die Hinterfliigel sind gelblich.

C. Lorez (1904. 535) erhielt durch stärkere Erwärmung der Puppen von Arctia flavia Fuessli eine neue ab. obscura Lorez. Diagnose: Alis posterioribus obscurior coloris brumneis. Durch Einwirkung geringer Kälte auf die Puppen erhielt er Arctiı flavia ab flavoctbdaminalis Lorez. Diagnose: Abrlomine pedibusque coloris flavis.

Thiele (1904.862) legte eine grössere Anzahl Van essen-Puppen auf Eis und erhielt $V$. antiopa $L$. mit stark verbreiterter heller Randbinde und ohne die blauen Flecken am Saum. $V$. io L. ergab Formen mit halb oder ganz verschwundenen Augen. $V$. utalanta L. zeigte die rothe Binde der Vordertlügel in dej Diagonillichtung verschoben; die grossen weissen Vorderrandtlecken sind verbreitet.

E. Krodel (1904. 475) stellte Versuche mit niederen Temperaturen an Puppen von Lycaena-Arten (corydon Porla und damon 
Schiff.) Er stellte fest, dass bei diesen Arten die Flïgelzeichnung dann deformiert werden kann, wenn die Puppen 5-6 Stunden alt sind. Er brachte die Puppen in eine Eis-Kochsalzmischung, die bei einer Aussentemperatur von ca. $+20^{\circ}$ R. eine Unterlitillung bis zu $-14^{\circ} \mathrm{R}$. ermöglichte. Dem Kältemaximum waren die Puppen ungefähr eine halbe Stunde ausgesetzt, wonach die Temperatur in Kïhlapparat nach 6 Stunden nach und nach der Aussentemperatur gleichkam. Die Puppen wurden alsdamn auf 2 Stunden an die Luft gebracht und getrocknet. Die Abkühlung erfolgte täglich 2 Mal $\left(10^{\mathrm{h}}\right.$ morgens und $6^{\mathrm{h}}$ abends) und dauerte 6 Tage.

Von 142 damon- und ca. 100 coridon-Puppen erhielt er 12 corydon- und 22 damon-Aberrationeu (einschliesslich aller Uebergangsformen), bei welchen die typischen Ocellen entwerler theilweise orler gärzlich fehlen, orler stark über das normale Mass hinaus radial verlängert, oder endlich beide Aberrations-Extreme an einem und demselben Thiere gleichzeitig auftreten. Die Oberseite ist stets neutral geblieben.

Die erhaltenen Formen sind:

Lycrena corydton ab. cinnus H. "Ein Zweifel darïber, dass die Hüloner'sche Fig. 830/831 cinnus zu corydon P. und nicht, wie lange Zeit geschehen, zu bellargus R. zu ziehen soi, besteht fuir mich nun nïcht mehr" (p. 107).

Lycuenu dumon ab. gillmeri Krrodel. Diagnose: "Alis anticis, posticisque subtus non ocellatis".

Lycacna damon ab. extensa Kirodel. Diagnose: "Ocellis ad lineas extensis".

Eine Form, welche der asiatischen Art L. phyllis Chr. ähnlich ist.

Eine Form, welche L. dolus II. (bei Hübner Fig. 828/829) sehr nahe kommt.

Lycaena argus L. ab., welche mit (ler von Herrich-Schäff̈er unter Fig. 247 abgebildeten argus var. übereinstimmt.

Krodel kommt zu folgenilen allgemeinen Schlüssen:

Die Discoidalftecken bei hier untersuchten Arten sind kmstinte Faktoren, dagegen sind die Augenflecken äusserst variable Zeichnungselemente.

Die orangegelben Pigmente der Flügelunterseiten von Lycaena coridon P. haben sich selbst im extremsten Falle als recht konstante Faktoren gezeigt.

Von eiriem kompensatorischen Verhältnisse der Beschuppung beider Flügelm 'nbranen, wie man solches bei anderen kïnstlich 
erzielten Aberrationen glaubte annehınen zu müssen, kann im vorliegenden Falle keine Rede sein.

Die im Freien vorkommentlen $L$ y ca en a-Aberrationen, b i welchen die Ocellenzeichnung entweder eine Reduktion oder eine Vergrösserung ihrer einzelnen Elemente aufweist, sind als vermutlich durch Einfluss intensiver, in kurzem Zeitraume periodisch auftretenter Temperaturschwankungen entstanden, zu betrachten.

Er nimmt an, dass das schwarze Pigment an den bezüglichen Stellen der Fliigelfläche infolge der indirekten Alternierung der Zeichnungsentwickelung durch Kï̈lteeinfluss nicht zur Entwickelung gekommen ist, von einem "Verschwinden" also nicht gesprochen werden kann.

E. Fischer (1904. 240) unternalın 1903 die Zucht von Chrraxes jasius-Raupen unit beeintlusste die erhaltenen Pupjen durch abnorme Temperaturen. "Wie sich diese Art darauthin verändern würde, liess sich im Voraus schon sagen un.l zwar gestützt auf die bei den nahe verwandten Apatura-Arten, namentlich bei v. clytic Schiff. beobachteten Veränderungen: clytic wird bei mässiger Kälte aufgehellt, die braungelbe Farbe nimmt überhand, bei tiefer Kälte tritt das Gegenteil ein (ab. astasioides Stgr.), und diese beiden Erscheinungen zeigen sich auch bei entsprechenden Wärme- resp. Hitzegraden. Die mit jasius angestellten Versuche bestätigten diese Erwägung als vollkommen richtig."

Er erhielt dabei zwei neuen Formen: Charaxes jasius L. var. bachmetjevi Fschr. und ab. hageni Fschr.

Die erste Form zeigt die Veränderungen nur auf der Oberseite aller Flügel, wobei die Hinterflügel einen direkten Uebergang zu dem abyssinischen Charaxes epijasius Reiche zeigen, während die Vorderflügel sehr lebhaft an die Weibchen der sexuelldimorphen Ch. achaemenes Feld. und gurleriana Dewitz (beide aus Angola, Manica etc.) erinnern.

Die zweite Form weist die Zeichnung auf der Unterseite aller. Flügel sehr vereinfacht auf. Die Oberseite der Vorderflügel ist mit derjenigen von epijasius vollkommen identisch. Auch die Hinterflügel ausser dem Saum sind uberall total geschwärzt.

Er erhielt auch eine dritte Form, welche die Combination beiler ersten Formen darstellt (lie Vorderfliigel $=a$ b. hageni, während die Hinterflügel $=$ var. bachmetjevi); mithin stimmt dieses Stück auf Vorder- und Hinterflügeln ganz auffallend mit Ch. epijasius überein. 
C. Frings (1905. 262) setzte Puppen von verschiedenen Schmetterlingsarten der Einwirkung sowohl der Wärme wie auch ler Kälte aus, und erhielt folgende Resultate:

I. Experimente mit erhöhten Temperaturen.

Papilio poctalivins L. 2 Tage $+40,5^{\circ}$. Es wurle erhalten ab. schult «ii Batke, einige Uebergänge zu dieser Aberration, ab. un tt-: cimlineatus.

4-mal je $3^{1 / 2}$ Stundèn $+43,5^{0}$ : Neigung zu ab. schultzii.

Pupilio machaon L. 30 Stunclen $+43,5^{\circ}$ : ab. nigrofusciatus Rothke, Uebergänge zu ab. tenuivittutus Spengel. „Wir sehen, dass zwei entgegengesetzt laufende, aberrative Entwickelungsrichtungen bei derselben Behandlungsmethode auftreten" (p. 138).

Pyrameis ritulanta L. $48-54$ Stunclen $+37^{\circ}$. Derselbe Resultat, wie derjenige von M. Standfuss (1898. 841).

60 Stunden $+37^{\circ}$ : Dasselbe, wie oben.

44 Stunden $+39^{\circ}$ : Verschiedene Charaktere der Wärmeform.

2-mal je 3 Stunden $+43^{\circ}$ : Neigung zur Bildung der ab. lileménsiewiczi.

Pyrameis cartui L. 4S-60 Stunden $+37^{\circ}$ : Tropenform von M. Standfuss (1898. 841).

3 -mal je $3 \frac{1}{2}$ Stunden $+40^{0}$ bis $40,0^{0}$ : normale Falter.

Vancssa io L. I. Generation 2 Tage $+35,5^{\circ}$ : Alle gelbe Färbung der Vorderflïgel röthlich überhaucht, die blauen Interferenzschuppen reduziert.

$2^{1} / 2$ Tage $+35,5^{0}$ : wie 1900 bei $+39^{0}(259)$.

3 Tage $+35,5^{0}$ : Augenfleckzeichnungen auf beiden Fliigelparen bedeutend vergrössert, sonst wie vorsteheni.

II. Generation 30-36 Stunden +390: Der var. sardoa Stcler. sehr ähnlich. „Eine Andeutung des schwarzen Flecks inmitten des Vorderflügel-Feldes ist meist mit einen dunklen Querschatten verbunden, der ganz in derselben Weise verlïuft, wie bei $V$. urticae var. polaris Stdgr." (p. 147).

Vanessa uiticae L. III. Gener. 36 Stunden +390: Dieselben Veränderungen, wie bei Exemplaren der I. und II. Gener. auch bie $39^{\circ}$.

Vanessa polychloros L. 42 Stunden $+38^{\circ}$ : ab. testudo Esp. „Eine Reihe meiner Stücke besitzt ein breites, schwarzes Band zwischen dem mittleren Costal und dem Innenrandsflecken, ganz entsprechend den Zeichnung-Veränderungen bei Van. urticae var. polaris Stdgr." (p. 148). 
Vanessa antiopa L. 45 Stunden +390: Die weissen Vorderrandsflecken sind reiluziert, die inneren oft bis zum Verschwinden, (irunulfarbe verdunkelt, die der Hinterilügel ganz schwarz. Ein Stiick besitzt nahezu unbeschuppte Hinterflügel.

48. Stumlen $+49^{\circ}$ : Eine Hinneigung zu al). Tyygiuce Hilrch.

36 Stunden $+39,5^{0}$ : Uebergänge zu ab. Tygiata Hdrch.

$5^{1 / 2}$ Stunden $+38^{0}$ in 2 Stunden steigend bis $43^{\circ}$, hier $3 \frac{1}{2}$ Stunden verbleibend: ab. hygiaea Hdrch.

24 stunlen $38^{\circ}, 12$ Stunden $+40^{0}$ : Blaue Flecken stark vergrössert, Saum verschmälert und geschwärzt.

13 Stunden $+40^{\circ}, 30$ Stunden $+38^{\circ}$ : var. daubii Stlfss.

Polygonia c. album L. II. Gener. 43 Stunden $+37^{\circ}$ : Herbstgeneration.

Araschnia levana L. 3-mal je 31/2 Stunden +43,50: Meist normal. Die erzielten, aberritiven Erscheinungen sondern sich merkwïrdigerweise nach len Geschlechtern: $\delta^{\top} \sigma^{\pi}$ verdunkelt, $q q$ anfgehellt. „Sehr auffallend ist es, dass bei den experimentell erzielten, verdiusterten $ठ る$, die erhalten gebliebenen Reste der rotgelben Grundfarbe genau mit den weissen Vorderflïgel-Zeichnungen von var. prorsu L. liorrespondieren. Die Vorlerflügel-Zeichnung meiner Aberrationen stimmt in geralezu überraschender Weise mit var. prorsa ïberein" (p. 154).

Araschnia levana var. prorsa L. 28-30 Stunden +390: ab. porima $\mathrm{O}$. und levanu in allen Übergangsstufen, Übergänge zu ab. veismanni Fchr.

$2-5 \times$ je $2^{3 / 4}$ Stunden $+42,5^{0}$ : var. prorsa, ab. porima, Übergänge zu ab. weismanni.

Purasemia plantaginis L. 24 Stunden $+37^{0}$ : Theilweise ab. hospita. Schiff.

Arctiı caja L. 48 Stunclen $+37^{\circ}$ : ab. futura F., clie meisten, wie früher.

\section{Versuche mit erniedrigten Temperaturgraden.}

Pyrameis atulanta L. Frostversuch: ab. lilemensiewiczi Schille.

Vanessa urticae L. I. Gener. 42 Tage $+6^{\circ}, 7$ Tage Kellertemperatur: Uebergänge zu var. polaris Stdgr.

Vanessa xanthomelas Esp. 35 Tage $+6^{0}$ : var. grïtzneri Fschr.

Vanessa polychloros L. 39 Tage $+6^{0}$ : var. dixeyi Stlfss. und die geschwärzte Form ohne Blau.

42 Tage $+6^{0}$ : verdusterte Falter. 
Vunessic antiopa L. 42 Tage $+6^{\circ}$ : Starke Verdiusterung der Grundfarbe.

45 Tage $+60^{0}$ : Der Saum dicht geschwärzt; Grundfarbe sehr verdüstert; alle Raniflecken weissblau, enorm vergrössert. Unterseits läuft durch die Mitte aller Flügel ein deutliches, helles Banil.

Polygonia c. ulbum L. II. Gener. Frostexperiment: ab. f. album Esp). Argynuis daplune Schiff 35 Tag. $+6^{0}$ : Das Flügelfeld ist schwarz. 42 Tage $+6^{0}$ : Grundfarbe ziemlich verdunkelt.

Argynnis paphic L. Frostexperiment: ab. ocellata Frgs., ein normales und ein vollkommen schwarzes Exemplar.

$L$ (csiocrmma populifolia Esp. 35 Tage $+6^{0}$ : Grundfarbe hellgelb, Zeichnung auf den Hinteritügeh fehlend. Vorderflügel-Adern verlauten oft in Wellenlinien.

42 Tage + (;0: der var. aestiva Stlgr. nahe kommende Exemplare.

Denctrolimus pini L. 42 Tage $6^{0}$ bis $-3^{0}$ : alle Zeichnungen erscheinen undeutlich, die Färbung matt.

Rhyparia purpurata L. 35 Tage $6^{\circ}$ : ab. atromaculata; die purpuratı-Form des Amurgebietes mit sehr verkleinerten VorderflïgelFlecken.

42 Tage $+6^{0}$ : Resultat wie oben.

49 Tage $+6^{0}$ : Wieder dieselben Variationen.

Arctic caja L. 49 Tage 60: Uebergänge zu ab. schultzii Frgs. und zu ab. futura F., Arctia interscalaris var. suttactra Moore (cajula Stdgr.).

Callimorpha hera L. 60: normale Falter.

Vanessa antiopa L. 12 Stunden $6^{\circ}, 28$ Stunden $38^{\circ}$, 12 Stunden $6^{\circ}, 14$ Stunden $37,5^{0}$ : var. daubii Stdfss.

E. Galvagni (1905. 270a) sagt, dass Ennomos fuscunturia ab. effuscaria Rbl., welche or in Hietzing (Oesterreich) erbentete unil welche bisher nur aus Siebenbürgen bekannt war, sich in Folge der Wirkung der diesjährigen (190t) abnormen Sommertemperatur gebildet hat.

W. Neuburger (1905. 606) beschreibt Vanessa urticae L. ab. dannenbergi Neubgr., welche von $\mathrm{D}^{\mathrm{r}}$ med. Dannenberg gelegentlich einer bei $-3^{\circ}$ ausgeführten Vanessa urticac-Zucht erhalten wurle und welche neben ab. ichnusoides Selys zu stellen ist. Bei dieser neuen Form zeigen Vorder- und Hinterfliigel anstatt der blauen Flecken des Aussenrandes Flecken von ausgesprochen strohgelber 
Farbe und zwar sind die gelben Fleclien der Hinterfliigel lieilfurmig. längs der Adern finclet sich auf den Hintertliigeln zwischen den gelben keilförmigen Flecken stärkere schwarze Bestäubung, welck bis auf die Fransen reicht. Unterseite einfirbig schwarz.

0. Schultz (1905. 791) erhielt durch die Kailte-Exposition der Puppen von Cullimorrilua domimula L. eine neue Form ab). marita Schultz (Vordertlügel einfarbig, olıne Flecken).

Call. dominula ab. paucimacula Schult\% ,resultiert auch bei Temperatur-Experimenten (Krodel)". (I)iagnose: Al. ant. mac. minutis et evanescentibus).

0. Seifert (1905. 803a) brachte rlie Puppen von Aretic morima Guérin für $2-3$ Stunden in die Temperatur von $-12^{\circ}$, dam in die Temperatur von $4^{\circ}$, damn wieler in $-12^{\circ}$ etc., und wiederholte dieses Verfahren 30 Tage. Im Resultat wurden Schmetterlinge erhalten, welche hellere Fürbung hatten; die schwarzen Flecken auf iler Dorsalseite des Abclomens wurden durch rothe ersetzt.

H. Federley (1905. 219a) hielt Puppen ron rerschiedenen Lepilopteren-Arten verschieden lange Zeit in verschielenen Templeraturen und erhielt folgende Resultate:

Lymantria dispar L.:

1. $12-36$ Stunilen alte Puppen 41 Stunden in $37-38^{\circ}$ olme Feuchtigkeit. - Resultat: vier verschiedene Abstufungen: a) Grumlfarbe etwas heller. Zeichnung ziemlich normal. Der Mittelschatten ist dem Mittelfleck mehr oller weniger genähert. Die beilen Schuppentypen sind sehr veränlert: der schmale Typus ist so gut wie verschwunlen, der breite Typus ist noch breiter geworlen. b) Grundfarbe braun. Der Mittelschatten läuft durch den Mittelfleck. Die Hinterfliigel ohne Zeichnung. Die Beschuppung wie bei a). c) Zeichnung undeutlich. Grundfarbe grau. Die Schuppen haarähnlich. d) Grundfarbe schmutzig hellgraubraun. Zeichnung verschwunden. Der erste Schuppentypus wird durch breite und kurze, ziemlich kleine Schuppen ohne Processus (Zähne) repräsentiert; ler zweite Typus weist eine schmale, fast haarähnliche Form auf.

2. 67 Stunden in $38-39^{\circ}$ ohne Feuchtigkeit. - Resultat: Die Beschuppung sehr mangelhaft. Vorderflügel schmutzig weiss, Hinterflïgel hellgrau. Zeichnung auf beiden Flügeln verschwunden. Weibchen in zwei Typen: a) Alle Flügel vollkommen durchsichtig. 
Zeichnumg verschwunilen. b) Grunlfarbe schmutzig gelbweiss. Zeichnung verwischt. Schuppen bei allen Exemplaren stark verändert.

3. 2-20 Stunden alte Puppen zuerst 48 Stumlen in $38-39^{\circ}$, sodann 24 Stunlen in $39-40^{\circ}$ ohme Fuchtigkeit. -- Liesultat: Die äussere Querlinie ist mit dem Mittelschatten vollstiin.lig verschmolzen (ein $Q$ ); alle übrigen Exemplare turchsichtig unr zeichnungslos.

4. 2-18 Stunden alte Puppen 24 Stunden in $39-40^{\circ}$ olme Feuchtigkeit. - Resultat: Falter weichen nicht allzusehr von der normalen Form ab.

5. Ueber 24 Stumlen alte Puppen 45 Stunlen in $39,5^{0}$ in sehr feuchter Luft. - Resultat: zwei Individuen ziemlich normal; ein Stück glasklar. Alle Schuppen gehören dem breiten Typus an.

6. Unter 20 Stunilen alte Puppen 52 Stumlen in 39,5-40. Resultat: alle starben.

7. Unter 24 Stunden alte Puppen 27 'Trige in 00 , solann noch 1s Tage in 10-150 bei starker Fenchtigkeit. - Resultat: stark verdunkelt (die (Uuerlinien verbreitet, auch der Mittelschatten). Die Beschuppung ist nicht sehr dicht und enthält die Schuppen nur von breiten Typus.

8. Ueber 24 Stunilen alte Schuppen 40 Tage in $6^{\circ}$ bei sehr grosser Feuchtigkeit, nur $\nmid$ ㅇ. - - Resultat: Grundfarbe schmutzig braungelb. Zeichnung sehr verwischt. Mittelschntten ziemlich breit. Die Schuppen sinl schmal; die Beschuppung undicht.

9. 3-24 Stunden alte Puppen 27 Tage in $0^{\circ}$. Falter nach 23-29 Tagen. - Resultat: stark verlunkelt. Die Beschuppung sehr dicht, die Schuppen gross unil ohne Processus.

Diese Versuche zeigen, llass „sowohl mässige Wärme als Kïllte für die Bildung des schwarzen Pigments giinstig ist, wogegen eine sehr starke Steigerung der Temperatur dieselbe theilweise oder vollkommen hemmen kann. Auch eine zu starke orler lang anhaltende Kälte bei gleichzeitiger, grosser Feuchtigkeit, der Luft scheint ähnliche Veräntlerungen wie Hitze hervorzurufen. Diejenigen Partien der Flügel, welche vor allem zum Melanismus neigen, sind das Saumteld und das Feld zwischen dem Mittelschatten und der äusseren Querlinie. Die Veränderungen in der Zeichnung sind recht launenhaft und zeigen sehr wenig gemeinsame Zuige" (p. 25).

Was nun die Schuppen anbelangt, so sincl hier folgende allgemeine Resultate festzustellen: sowohl die Kälte als auch schwache Wärme übt auf die Schuppen einen ähnlichen Einfluss aus. „Dieser 
Eintluss wird in der Schuppenform deutlich wahrgenommen, intem dieselbe liurz und breit wird, während gleichzeitig die Processus an Zahl und Grösse abnehmen o:ler total verschwinlen. Ist die Wirliung eine nicht allzu starke gewesen, so bleibt die Beschupunng dicht, war sie aber stärker, so bemerken wir, lass die Schuppen weniger dicht stehen. Wird die Wäme aher noch gesteigert, erhalten wir recht dünnschuppige Flïgel, deren Schuppen kleiner sinı, denen fast immer die Processus mangeln, mil die sogar in einzelnen Füllen eine deformierte Gestalt zeigen. Es scheint also, als ob auch Hitze unter gewissen Unstänlen ähnlich wie starke oder lange anhaltenle Kälte wirken könne" (p. 26).

Melacosoma neustria L.:

1. 2-18 Stunden alte Puppen 24 Stunden in $39-40^{\circ}$ olne Feuchtigkeit. - Resultat: ungewöhnlich dunkel. Querlinien sinł sehr nahe an eimander gerückt und fast parallel. Schuppen fist unverändert. Der var. parallela Staud. sehr ähnlich.

2. 2-20 Stumlen alte Puppen 72 Stunden olne Feuchtigkeit in 38-390 und in 39-40\%. - Resultat: ơ ungewölnnlich hellgells ohne clunklere Suhattirungen. Die beilen Querlinien liegen weit von einanler enternt. $q$ zeigt ähnliche Veränderungen. Schuppen stark veränclert.

3. Unter 20 Stunden alte Puppen 52 Stunilen in $39,5-40,5^{\circ}$. Resultat: hellbraun. Mittelbinle etwas breiter. Schuppen zeigen keine starke Veränderungen.

4. 27 Tage in $0^{\circ}$, wonach noch 18 Tage bei sehr grosser Feuchtigkeit in 10-15\% - Resultat: hell; Schuppen fast normal.

Aus diesen Versuchen geht hervor, dass abgesehen von var. parallela Staul. "die übrigen abweichenden Formen unter einander sehr wenig Uebereinstimmung zeigen." Was die Schuppen anbelangt, so "scheint lie mässige Hitze ein Breitwerden des Corpus (squamae) und allmähliges Verschwinden der Processus zu veranlassen, wogegen stärkere Hitze die Schuppen rerkleinert. Bei dem Kälteversuche konnte eine Tendenz der haarähnlichen Schuppen, breiter zu werden, und ein Abnehmen derselben an Zahl konstatiert werden" (p. 30)

Saturnia pavonia $\mathbf{L}$.:

1. Die Puppen wurden aus dem Freien bei $-5^{0}$ in ein geheiztes Zimmer gebracht und nach 24 Stunden in $39,5-40,5^{\circ}$ (rährend 47 Stunden). - Resultat: Zeichnung unverändert, nur stark abgeblasst. Schuppen stark verkümmert. 
2. Wie sub 1, aber 71 Stunden in $40,0-40,5^{\circ}$. - Resultat: Verblassen ler Farben. Zeichnung unveränlert. Schuppen besser entwickelt als im 1. Versuch.

3. Sofort nach der Verpuppung 71 Stunden in $34^{\circ}$. Teberwintern draussen, von wo sie bei $-20^{\circ}$ in +120 gebracht wurden. Nach 20 Stumlen 5 Tage in $30^{\circ}$. Drei Tage nach einanter bis $42-43^{\circ}$ gesteigert und dlamm wieler in $30^{\circ}$. - Resultat: Fïrbung unl Zeichnung unveräinlert. Schuppen veränlert: Corpus grösser, Processus an Länge und an Zahl abgenommen.

4. Ueberwinterte Puppen wurien am 11. II. in ein geheiztes Zimmer gebracht und voin 11. II. bis 17. II. während je 1 Stunde der Temperatur von $42-45^{\circ}$ ausgesetzt, dann in $30^{\circ}$. - Resultat: Färbung und Zeichnung unverändert. Schuppen haben grosses Corpus mit feinen und recht kurzen Processus.

5. Puppen wurden am 13. III. in $17-18^{\circ}$ gebracht; zwei Tage larauf wurden sie während 30 Tage der Temperatur von -20 bis $+11^{\circ}$ ausgesetzt, wonach die Entwickelung in Wohnzimmer stattfanı. - Resultat: Färbung und Zeichnung unverändert. Zunahme des Corpus auf Kosten der Processus.

6. Puppen wurlen im Spätherost der Frostwirkung ( ${ }^{0}$ ?) ausgesetzt. Dann wie im Versuche 5. - Resultat: Färbung und Zeichnung normal. Die Schuppen nähern sich in ihrer Form dem Kältetypus.

7. Kurz nach der Verpuppung 48 Tage in $6^{\circ}$. Ueberwinterung im Freien. Am 15. I. in $22^{\circ}$ und dann von 16. I. bis 21. I. während je $1 \frac{1}{2}$ Stunden in $-17^{\circ}$. - Resultat: alle Falter aberrativ: das dunkle Pigment hat sich auf Kosten des hellen vermehrt. Die Flügel haben einen rothen Schimmer; ein orangenfarbenes Pigment bei $\sigma^{\top} \sigma^{\top}$ in dem Felde ausserhalb der äusseren Querlinie. Die doppelte Querlinie wurle viel breiter. Der Augenfleck ziemlich gross. Schuppen bei $ठ$ : das Corpus ist gross und recht breit, während die Processus

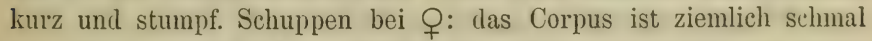
und trägt höchstens drei gewöhnliche Processus oder nur zwei recht lange solche.

8. Kurz nach der Verpuppung in $0^{\circ}$; überwinterten sodann im Freien; am 5. III. in $18^{\circ}$ und von 6. III. bis 11. III. während je 2 Stunden in $-19^{\circ}$. - Resultat: keine aberrative Falter. Schuppen wenig verändert.

Aus diesen Versuchen ist ersichtlich, dass die Wärme- und Hitzeexperimente keine bemerkenswerthen Veränderungen in der Zeichnung hervorrufen. Bei den Frostexpositionen dagegen waren 
die durch Versuch 7. erhaltenen Falter sowohl an Fürbung als au h an Zeichnung recht stark aberrativ. Die Veränlerungen in ler Schuppenform sind zum Theil den unter ïhnlichen Verhältnissen erzielten Verwandlungen bei Lymandric dispar L. ganz analog.

\section{Aglia tau L.:}

1. Die überwinterten Puppen wurden Nitte Februar in 170 gebracht. - Resultat: Färbung und Zeichnung unverändert. Schuplen abgerundeter, die Processus sind kleiner.

2. Die ibberwinterten Puppen wurden Ende Mïrz, nachdem sie einen Tag in $17^{\circ}$ gehalten worden waren, während 44 Stunden der Temperatur von $38,5-40,5^{\circ}$ ausgesetzt, wonach sie noch 28 Stunden in $25-26^{\circ}$ und dann bis zum Auschliipten in $18-20^{\circ}$. - Resultat: Fïrbung und Zeichnung unverändert, nur die blane Interferenzfurbe in den Ocellen ist sehr schwach ausgebilitet. Schuppen lanzettförmig ohne Processus.

Aus diesen Versuchen geht hervor, dlass die Schuppen sehr stark veründert werden: „durch mässige Wärme wird dlas Corjuts vergrössert und die Processus verkleinert, wihrend sturke Wirme schmale und lange Schuppen hervorruft, die entweder ganz processuslos oder an der Spitze tief gespalten sein kömnen" (1). 47).

Demas coryli L.:

1. Die im Freien überwinterten Puppen wurten, nachlem sie einen Tag in $17^{\circ}$ gehalten worlen waren, wïhrend 44 Stunden einex: Temperatur von $38-40,5^{\circ}$ ausgesetzt, wonach sie noch 28 Stumilen in $25-26^{\circ}$ blieben; bis zum Ausschliipfen in 180. - Resultat: „Di" grauen Partien der Flügel zeigen nicht die reingraue Farbe der normalen Falter, sondern sind mehr schmutzig grau mit bräunlichem Aufluge. Auch das Braun im Mittelfelde ist blasser und weniger rein in der Farbe, und die schwarzen Zeichnungen shliesslich, die bei den normalen Stücken recht scharf sind, erscheinen hier undeutlich und oft ganz verwischt" (p. 48). Schuppen verändert und zwar stark verschmälert, die Processus nehmen an Zahl ab.

Arctia caja L.:

1. $12-36$ Stunden alte Puppen 41 Stunden in $37-38^{\circ} .-R$ sultat: Farben verwischt, die Zeichnung der Vorderfliigel ganz zusammengeflossen. Den Hinterflïgeln mangeln die schwarzen Flecken. Das Corpus der Schuppen schmäler, die Prucessus sind weniger zahlreich.

2. $12-36$ Stunden alte Puppen 34 Tage in $0^{\circ}$. - Resultat: die meisten Falter normal. Die Form der Schuppen schmäler, die Processus an Zahl geringer. 
Leucodonta bicoloria Schiff., ab. albida B. und ab. unicolora (Mén.) Motsch.

Dis Material stammt von zwei unicolora-Weibchen. 1. Am 14. X. wurlen die Puppen aus dem Freien bei $0^{\circ}$ in $18-22^{\circ}$ gebracht. Resultat: vom 11. XII. bis 17. III. schlïpften aus: 2 allicla, 1 bicoloria, 1 unicolora, 3 bicoloria trans. ad albidam, 3 albida trans. ad unicoloram.

2. Bis zum 4. IV. im Freien. Vom 4.-12. IV. in $17^{\circ}$. Vom 12.-15. IV. 72 Stunden in $38-39,5^{\circ}$, dann bis zum Ausschlüpfen in $17^{\circ}$. - Resultat: 1 licoloria, 2 unicolora, 1 albida trans. all unicoloram.

3. Am 14. X. 3 Stunden in $-17^{\circ}$ und am folgenden Tag wieder 2 Stunden in $-10^{\circ}$ und dann bis zum 3. IV. im Freien. Bis zum Ausschlïpfen in 170. - Resultat: 1 albida, 1 bicoloria, 2 unicolora.

4. Während des ganzen Winters im Freien aufbewahrt. Resultat: 6 bicoloria, 3 albida, 3 unicolora, 2 bicotoria trans. ad albidam.

„Diese Versuche geben uns also keine Erklärung über die Entstehung der Aberrationen albida und unicolora" (p. 8).

Dannenberg (1906. 163b) stellte zwei Reihen von Experimenten über die Einwirkung verschiedener Temperaturen auf die frische Puppe aus der Gruppe der Vanessa-, Apatura- und LimenitisArten an: mit mässig erhöhter oder erniedrigter Temperatur und solche mit extrem hoher bezw. niedriger Temperatur. Bei der ersten Reihe $\left(35^{\circ}\right.$ bis $37^{\circ}$ und $1^{\circ}$ bis $\left.10^{\circ}\right)$ entstehen die Varietäten, bei der zweiten Reihe $\left(42^{\circ}\right.$ b:s $45^{\circ}$ und unter $\left.0^{\circ}\right)$ entstehen die Aberrationen.

Für die erste Reihe kann als Beispiel Vanessa urticae dienen. Die veränderten Falter sind unverkennbar identisch einerseits mit v. turcica und v. ichmusu, mit v. polaris anderseits und neigen sngar zu Vanessa io v. milberti. Hier gelingt auch annïhernd die Unwandlung von Vanessa levana in v. prorsa und vollkommen die Unwanıllung von v. prorsa in Vanessa levana. Die infolge Kälteeinwirkung bei Vanessa antiopa und Pyr. atalanta u. a. vorkommenden Abweichungen sind als vorzeitliche Varietäten aufzufassen (z. B. al. fischeri). Anilere meist infolge von Wïmeeinwirkung auftretende Formen sind als fortschrituliche aufzufassen. 
Bei der ersten Versuchsreihe rufen Wïme und Tïilte entgegengesetzte Wirkungen hervor, bei der zweiten Reihe entstehen dagegen durch Frosteinwirkung genau die gleichen Abweichungen, wie bei Hitzeeinwirkung.

"Als was siml nun diese Aberrationen aufzufassen? Bei ohelflächlicher Betrachtung könnte man leicht bei antiopa z. B. eine fortlaufende Reihe konstruieren, die anfïngt bei der durch liälte entstehenden v. roederi mit sehr vergrösserten blauen Flecken und schmalem gelben Ranile (Reihe 1), die damn ïbergeht zur normalen antiopa und schliesslich unter Verkleinerung der blauen Flecken endigt bei der durch Fehlen der blauen Flecken unl sehr breitem gelben Rande ausgezeichneten hygiaea (Reihe 2). Und da wir die v. roederi als vorzeitliche (phylogenetisch ïltere) form auffissen, so müssen wir in der ab. hygiaen und den analngen antleren (verdunkelten) Aberrationen die am meisten vorgeschobenen, fortschrittlichen Formen sehen. Diese Auffissung hat man ja auch von den nicht experimentell entstandenen dunklen Formen. Gegen eine solche Auffassung spricht hauptsïchlich die Entstehung der gewonnenen Aberration. Wir sahen oben, dass Hitze unil Forst hemmen:l wirken, wie aber pin hemmender Einfluss fortschrittliche Formen erzeugen soll, vermag ich mir nicht zu erklären. Eher müsste man an einen Rückschlag (Atavismus) lenken, wofür ausser der Entstehungsweise die Einfachheit der Zeichnung und das Einanderäihnlichwerilen verschiedener Arten sprechen könnte".

Durch diese Versuche wurden erzielt: $P$. ab. lilemensiewizci, v. merrifieldi; V. ab. belisaria, ab. atrebatensis, v. polaris, ab. testudo, ab. Inygiaea, v. roederi, ab. $f$ album; ferner $A$. ab. iole, ab. idiales. ab. astasioides, ab.eos, L. ab. nigrina unil noch unbekannte Formen und Monstra von $V$. urticae.

\section{Ergänzungs-Litteratur zu diesem Abschnitt.}

Aaron. Mr. E. M. Aaron, recondet some experiments made on the effects of temperature upon larvae. -- Tr. Amer. Ent. Soc. XI. 1884. p. XXXII.

Butler, Arth. G. Concerning so-called Temperature-Forms of Butterflies. Papilio, III. № 3. 1883. p. 62-65.

Chapman, T. A. Melanism and Temperature. - Entomol. Record. Vol. II. ㅊ: 3. 1831. p. $55-56$.

Edwards, W. H. The Butterflies of North America with coloured drawings and descriptions. 1891. 
Fenn, C. Temperature versus Heredity in Producing Variation. - Entomol. Record, Vol. II. № 3. 1891. p. 55.

Fischer, E. Natürliche und künstliche Umformung der Lebewesen. - Ber. St. Gall. nat. Ges. 1900-1901. 1902. p. 316-327.

Frohawk. Entomologist. 1893. p. 294.

Merrifield, F. Temperature and Variation. - Entom. Record, Vol. I. Vi 10. 1891. p. $272-273$.

Merrifield, F. Effects of Temperature on the Colouring of Lepidopteri. - Entom. Record, Vol. III. № 3. 1892. p. 49.

Merrifield, Frederic. An Addres read before the Entomological Sncicty of London at the annual Meeting on the 17 th. January, 1906. 29 pp. London 1906.

Raband, Etienne. D'ou proviennent les variétés et les aberrations? - Le Naturaliste. VII. Ann. № 19. 1885. p. 151.

Seifert. Journ. N. York ent. Soc. 1897. p. 98.

Shelodon, W. G. Moisture Theory of Melanism. - Entom. Record, Vol. I. di 5. 1891. p. 126.

Smith, W. W. Humidity the Cause of Melanochroism in New-Zealand. - Entom. Record, Vol. I. № 5. 1890. p. $125-126$.

Waters. Influence of Mild Winter on Lepidoptera. - Entomol. XYI. 1S8t. p. 164.

Woir, J. Jenner. Effect of Temperature on Lepidoptera. - Entomolosist. XV. 1882. p. $115-116$.

\section{Einfluss des Lichtes und der Farbe der Umgebung.}

G. Koch (1856. 4576) beobachtete, lass Raupen von Eupithrcir absynthiaria H. im Herbst aut den Blüthen verschiedener Ptlanzen sich finden, von denen sie die Farbe annehmen. Auf Wasserhauf (Eupatorium cannabinum) sind sie rosenroth, auf Jakobsblume, Goldruthe u. a. gelb, auf Beifuss (Artemisia vulgaris) grün.

Nach der Beobachtung von A. Gartner (1861. 273) ist die Raupe von Colias myrmidone Esp. bräunlich bis grünlich, nach der ersten Häutung ist sie trübgrün, nach der zweiten grün, nach der Iritten purpur-braun, wie das Cytisus-Laub im Herbst, auf welchem sie sich aufhält. Dann überwintert die Raupe. Im Friihjahre ist clie purpurbraune Färbung der Raupe verschwunden, indem sie wieder grün geworden ist, gerade so wie das frische grün der Pflanze.

A. Rössler (1863. 700) sagt, dass der Schmetterling Pluciune petraria Esp. bei Tage auf Erde ruht, meist auf verwelktem Laube, wo er seiner gleichen Farbe wegen schwer zu bemerken ist. Die Raupen von Eupithecia ienotata H., welche er auf Campanula 
trachelium fand, hatten licht gelbbraune Farhe, wie das verwellite Blatt der Nahrungspflanze.

v. Prittwitz (1S67, 654) sagt hei Beschreilung der liaupe von Eriopus pteridis, dass folgende Farben-Aenderungen dieser Raupe ziemlich constant vorkommen:

1. Raupe citronengelb, Sättel und deren $A$ bsrenzungen fast gleichtarbig.

2. Wie ad 1, Sättel weiss umzogen;

3. Körper ockergelb, Sättel gleichfarbig, weiss odler gelblich umzogen.

4. Körper Heischfarlig, Sättel dunkler, weiss oder gelblich umzogen.

5. Raupe braun oiler ziegelfarbig, Siittel gelb umzogen.

6. Wie ad 5. aber purpurroth.

7. Raupe grün in allen Nüancen, vom hellsten Gelbgrün lis zum dunkeln Blaugriin.

8. Wie ad 7, Sättel braun, roth fleischfarbig.

9. Raupe grün mit unterwärts roth begrenzter Stigmatallinie.

Zwischen allen finden sich zahlreiche Uebergïnge, so dass man nicht zweifeln kann, immer nur eine Art vor sich zu haben. Die braunen und rothen finden sich auf dürren Pteriden.

Die ersten Experimente ïber den Einfluss des Lichtes auf die Farbe der Puppen stellte T, W. Wood (1567. 962) an. Lr untersuchte Pieris brasicae, Pieris rapae, Vanessa jolychloros und Papilio machaon. Die Raupen verpuppten sich in Behiiltern, welche innen mit verschiedenen Farben ausgelegt waren, und waren entsprechend lem Grunde, auf welchem sie sich befanden, gefïrbt. In Schachteln, welche innen schwarz waren, wurden die Puppen dunkel, auf weissem Papier fast weiss.

Als Ursache dieser Erscheinung wurle von ihm eine photographische Empfindlichkeit der Haut angenommen, obwohl diese Annahme durchaus nicht selbstverständlich war. Denn es sind Fïlle rascher Farbenanpassung bekannt, die auf anderen Umstïnden beruhen, z. B. bei Fröschen und Fischen. Nach Beobachtungen von Ernst Brücke (1851. 115) beruht die merkwürdige Fühigkeit des Farbenwechsels bei dem Chamäleon auf verschiedener Lagerung eines und desselben Farbstoffes vermöge der Zusammenziehbarkeit der ihn tragenden Zellen, der sog. Chromatophoren. 
L. Möller (1867. 582) sagt über den Einfluss des Lichtes aut die Farbe der Insekten folgendes: „Je stïrker das Licht ist, desto intensiver wird die Fürbung. Der Farbenton, wie auch das meist auf Interferenz des Lichtes beruhende Farhenspiel des Körpers der Insekten nimmt graduell zu mit der grösseren Intensitiit des Lichtes. Bleich und farblos bleiben die Larven, welche in der Erde oder an dunkeln, schattigen Orten leben, zu welchen kein Tageslicht dringen kann" (p. 17).

Er fand, dass Elap)lorus riparius L. in dem hellen Quarzsande an dem Ufer der Werra (Thüringen) eine hellbrüunliche Farbe hat, bei Mühlhausen aber an den Rünilern der Wassertiimpel auf wiesigem Grunde und an der Unstrüt eine grüne.

Was nun die Färbung der Wasserinsekten betrifft, so sagt er: „Das Licht nimmt mit der Tiefe des Wassers, wie bekannt, nicht nur an Intensitït ab, sondern es wird auch gehrochen und in Farben zerlegt. Zunächst werden die blauen Strahlen zurücligeworfen, und in Uebereinstimmung damit herrschen in der obersten Schicht die blauen Thiere vor, wie dies die Gyrinus-Arten bestätigen. Etwas tiefer werden die grünen Strahlen reflectirt, und hier finden wir die Dyticus- und Cybister-Arten. In noch grösserer Tiefe enıllich werden die gelben Strahlen zurückgeworfen, wodurh dic gelbliche oder bräunliche Färbung der Gattungen Haliplus, Hydroporus, Noterus, Laccophilus, Philhydrus, Berosus etc. bedingt werden mag" (p. 20).

A. R. Wallace (1870. 940) fand auf malayischen Inseln Cicindela gloriosa mit ihrer sehr tiefen sammtartigen grünen Farbe lediglich auf nassen moosigen Steinen, wo sie nur mit der grössten Schwierigkeit zu entdecken war. Eine grosse braune Art (Cicindela heros) wurde hauptsächlich auf abgestorbenen Blättern an Waldwegen gefunden; und eine, welche er nur auf dem nassen Schlamm salziger Marschen gesehen hat, hatte ein glänzendes Olivengrün, welches so genau der Farbe des Schlammes glich, dass man sie nur bei Sonnenschein an ihrem Schatten unterscheiden konnte. Wo das sandige Ufer korallinisch oder fast weiss war, fand er eine sehr blasse Cicindela; wo es vulkanisch oler schwarz war, konnte man mit Sicherheit auf eine dunkele Art derselben Gattung rechnen.

Bates theilte ihm mit, dass der am srikanische Käfer (Jnychoceros scopio, welcher nuf einem rauh berindeten Bamme mit Namen Tapiribá gefunden wird, so genau der Rinde in Farbe und lisuhigkeit 
gleicht, dass er, solange er sich nicht bewegt, absolut unsichtbar ist. Dasselbe gielt auch für Onychoceros concentricus.

Er erwähnt auch, dass Joseph Greene eine auffallencle Harmonie zwischen den Farben jener britischen Schmetterlinge konstatiert, welche im Herbst und Winter fliegen, unt den vorherrschenten Farben der Natur in diesen Jahreszeiten. Im Herbst herrschen verschiedenartige Schattirungen von Gelb und Braun vor und er zeigt, dass von 72 Arten, welche um cliese Zeit fliegen, nicht weniger als 42 entsprechencle Färbungen haben. Oryyia antiqua, O. gonostigma, die Gattungen Xanthie, Glaea und Ennomos sind Beispiele davon. Im Winter herrschen graue und silberatige Fürbungen vor, unil die Gattung Chematobia und viele Arten von Hybernia welche während dieser Zeit fliegen, besitzen entsprechende Farben.

Andrew Murray hat bemerkt, wie genau die Raupe von Satumin javonia in ihrer Grunlfarbe der jungen Kinospen des Haidenkrautes, von welchen sie sich ernährt, gleicht, und dass die rothen Flecken, mit. welchen sie geschmückt ist, mit den Blättern und Blumen-Kinospen derselben Pflanze correspondiren.

In der Debatte über den Vortrag "Kilima uni Schmetterlinge" von C. A. Teich (1870. 855) schreibt Nauck lie lebhaftere Fürbung ler tropischen Thierwelt dem dort intensiveren Sonnenlichte zu unl erinnert daran, dass die Bauchseite der meisten Thiere wenig gefärbt ist.

E. Kalender (1872. 428) theilt folgende seine Beobachtungen mit:

Die Raupen von IIacroylossa stellatarum sind zuweilen vollständig schwarz gefärbt mit weissen Chagrin-Punkten. Sie liefern jeloch stets den gewöhnlichen Schmetterling.

Er hat im Sommer 1868 eine O Notoclonta dictaea auf der Maschwiese bei Göttingen gefangen, welche in der Gefangenschaft Eier absetzte, aus denen weissgrïne und braune Räupchen schlüpften. Er hält deshalb Not. dictaea und Not. dictaeoïdes für eine und dieselbe Art.

Smcrinthus populi hat zweierlei Raupen: eine einfach grüne un l eine grüne, längs der Seite rothgefleckte. Dieser Forscher fand, dass sämmtliche gefleckte Raupen helle und mehr rothbraun gefärbte schmetterlinge lieferten, während die einfach grauen Raupen graue, weiss bestäubte Schmetterlinge ergaben. 
Auch bei Sm. ocellatus findet man gefleckte Raupen und diese liefern Schmetterlinge, welche stïrker weissgrau auf den Oberflïgeln bestäubt sind.

R. Meldola (1873. 556) bestätigte die Angaben Wood's an Puppen von Pievis rapae und brassicae.

Ch. Darwin (1874. 164) legte der Entomologischen Gesellschaft in London die Betrachtungen der Mrs. Barber vor, welche in Cap an Papilio nireus gemacht waren. Die Raupe der Papilio nireus lebt auf Orangenbäumen und auch auf einem Baume (Vepris lancenlata). Die Farbe der Raupe stimmt nun mit der ihrer Nahrung. Mrs. Barber fand, llass diese Puppe die Farbe jedes beliebigen Gegenstandes, an dem sie sass, mehr oder weniger vollstänlig annahm.

M. E. Barber (1874. 48) machte mit den Puppen von Papilio niveus die Beobachtung, lass sie die verschierlensten Farben von Naturgegenständen, wo sie sich anhaften, annahmen; eine Raupe konnte jedoch nach der Verpuppung nicht roth werden, indem sie in ein Stück Scharlachtuch eingehüllt wurde, sondern die erhalteno Puppe war grün.

Meldola (1874. 557) bemerkt zu diesen Beobachtungen der Mrs. Barber: "The action of light upon the sensitive skin of a pupil had no analogy with its action on any known photographic chemical. No known substance retained permanently the colour reflecterl on it by adjecent objects", indem er den photographisch-chemischen Process dabei negiert.

Carl Dietze (1874.181) fand die Raupen von Eupithecic naunta Hb. an den "Kempen" bei Tegernse in Baiern und berichtet dariil)er,

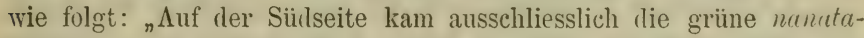
Form vor, in der Farbe genau den grünen, noch geschlossenen Blüthenähren der Erica carnea angepasst; auf dem Nordabhange traf ich bloss die roth, weiss und grün gezeichnete Raupenform, die genau den Blüthenstand der Calluna vulgaris, ihrer Futterpflanze, wiedergiebt" (p. 214). Weiter sagt er, dass viele Raupen trotz Anpassung mit Parasiten behaftet waren.

Die Raupen von Eupithecia scabiosatı Bkh. (piperata Steph.) werten auf dem Gipfel und Süilabhange des „Rempen" an vielen PHanzen, vorziiglich aber an Scabiosa columbaria angetroffen. 
Ausser den grünen und rothen Varietäten kam an stellen, wo die Scabiosen ausgeblüht hatten, eine ockergelbe Spielart ler Raupe vor; ein Exemplar war sogar fast ganz schwarz.

V. Graber (1877. 326) sagt, dass wenn die Raupen ron Vinesia polychloros unter dem gelben Glas erzogen werlen, die entschlüpften Falter schiefergraue Randtlecken statt der blauen haben.

Sidebotham (1877. 810) experimentierte mit ganzjungen Raupen des Permutterfalters, indem ei einen Theil derselben in ein grelbes, einen anderen in ein blaues Glassgefäss, den dritten in ten gewöhnlichen Züchtapparat brachte. In die beilen ersten Gefässe konnte das Licht auch durch die Luftlöcher nur als gelb oder blau einfallen. Es stellte sich heraus, dass die blaubeleuchteten Raupen in grosser Zahl starben, auch von den Puppen kamen viele um; von len gelbbeleuchteten nur eine. Die Schmetterlinge aus rlem blauen Gefässe waren im Allgemeinen viel kleiner als die gewöhnliche Art: das Braungelb der Fliigel zeigte sich heller, Gelb und Orange lief zusammen. Die aus dem gelben waren gleichfalls kleiner, das Braungelb war lachsfarben, die Marmorirung schärfer, die blauen Zeichnungen am Flügelende schieferfarbig.

Nach Beobachtungen von P. Cameron (1878. 125) halen diejenigen Blattwespenlarven, welche für die Thiere ungenitssbar sincl, meistens bunte Färbung; die aber von Vïgeln, Laufkäfern etc. verfolgt werilen, besitzen fast dieselbe Farive wie die Blätter, auf welchen diese Larven leben. Somit wäre die grelle Fürbung der Larven eine Schutzfärbung.

G. Schoch (1880. 770) ziichtete Raupen von Arctia caj\& in drei verschiedenen Behältern, wobei der eine mit rothem, der andere mit violettem und der dritte mit blanem Glase beleckt war. Die unter dem Einflusse des violetten Lichtes befindlichen Raupen waren gefrässiger als die anderen und ergaben Puppen, aus welchen Schmetterlinge ausschliipften, die keine merklichen Abweichungen von den unter rothem und blauem Lichte gezogenen zeigten.

Adolf Rössler (1881. 702) sagt in seinem Buche von der Raupe von Eupithecic assimilatu Gn.: "Die Raupen, so lange sie grün sind, schmiegen sich an die Unterseite der Blïtter, roth geworden verstecken sie sich in welkes Laub." (p. 191). 
W. A. Jaroschewsky (1S83. 4ls) sagt, dass Aportacra seriemaculata Nacı. (Diptera) seiner Fürbung nach in sehr grossem Grade dem umgebenden Medium (Sand) ähnlich ist.

Nich Beobachtungen von A. Speyer (1883. 830) wechselt die Raupe der gemeinen, polyphagen Eupithecia absinthiata ihre Farbe mit der ihrer Nahrung. Auf Artemisia vulgaris erscheint sie, dem Aussehen der jüngeren oder älteren Blïthen entsprechend, in scheckiger, bald mehr grauer, bald mehr röthlicher Fürbung, mit weisslichen und dunklen Zeichnungen, auf den Bliithen des Haidekrantes wird sie tribroth, auf denen der Goldrute (Solidago virgaureae) gelb, etc. Die Schmetterlinge, welche aus diesen verschieden gefärbten Raupen auschliiplen, zeigen jedloch keinen Unterschied in der Fürbung.

Lohmann (18S4. 506) fand die griinen Raupen von Eriopus purpureofusciata auf grünen Weleln des Adlerfarn (Pteris aquilina), während die gelben und röthlichen auf welkenden Theilen sich vorfanden.

Bei H. Gauckler in seiner Abhandlung: „Biologisches über Cymatophora or" (18S4. 276) steht die folgenile Stelle: "Wie sich das Leben iler Raupe ihrem Aufenthaltsorte angepasst hat, so hat dies auch die Farbe und Gestalt derselben gethan. Die Farbe variert von blassgrün bis weissgelb bei der mehr erwachsenen Raupe, während die jungen Räupchen etwas dunkler gefärbt sind unıl in den Seiten schwärzliche Punkte, in Reihen stehend, haben" (p. 2).

Nach E. B. Poulton (1886. 644) ist die Raupe von Sphin: ligustri, welche auf Liguster sich findet, grïn; wird aber die aut Liguster gefangene Rimpe mit Syringa gefuittert, so wird sie allmählig matt gefïrbt. Er fand, dass die Färbung der Raupen von Smerinthus ocellatus durch erblichen Einfluss, durch die Farbe der Blätter, nicht aber durch die Substanz der verzehrten Blïtter; bedingt wird. Individuelle Variationen spielen hier anch eine Rolle.

A. Wilkins (1886. 960) beobachtete in Turkestan die wilden Raupen von Bombyx mori und fand folgendes: "Eine detaillirte Vergleichung der Fürbung der grauen Raupen mit der Farbe der Maulbeeräste ergab mir eine so bemerkenswerthe Aehnlichkeit von Nuancen, dass man sie uniibertrieben als ilentisch nennen muss" (p. 88). 
G. Stange (1886. 842) sagt bei (ler Beschreibung der laupe? von Eupitheria trisignariu: "Merkwirrdig ist, dass die sonst rein grïne Raupe fast regelmässig auf dem Rücken dunkler, manchmal fast schwarz gefärbt wird, wenn sie auf Dolilen lebt, deren Stiele stark mit Blattlïusen besetzt, alss dunkler gewor.len sind" (p. 281-282).

1857 veröffentlichte Edw. Ponlton (1S87. 646) seine "ColourRelation," worin er eine Masse sorgfilitig anges ellter Lntersuchumgen vorführt.

Poulton experimentierte hauptsiichlich mit Vanessce urticue, io, Papilio machuon, Pioris brassicue, rapue und einigen Arten der Gattung Zonosoma.

Die Versuchs-Anordnung bei Poulton und die erhaltenen Iiesultate sind folgende (nach dem fasslichen Fieferate von W. Petersen):

I. Sechs erwachsene Raupen von Vanessa io wurden in ein Glas gesetzt, das mit gelbgriinem Papier beklebt war, sie lieferten alle die seltenere gelbgrüne Varietät der Puppe, obwohl eine lerselben als ganz frische Puppe gleich nach (lem Abstreifen der Raupenhaut auf schwarzer Unterlage in Dunkelheit gebracht wurle.

II. Das Hauptversuchsmaterial bildeten über 700 Exemplare von Vanessa urticae. Zuerst stellt Poulton folgende Stufen für die Färbung fest:

1. Sehr dunkel, mit dem ausgeilehntesten Cuticular-Pigment, keine goldenen Flecke oder nur eine leise Spur.

2. Dunkel, normale Form, nicht so dunkel wie (1), zuweilen mehr golden, aber noch wenig.

3. Licht, normale Form; hier drei Unterstufen: dunkel (5), Mittelstufe (3) und licht (3).

4. Sehr licht; oft mit viel Gold, zuweilen leicht röthlich.

5. Die hellste Varietiit oft vollständig goldglänzend.

Als Hintergrund zur Verpuppung wurde gewählt: Griin, Schwarz, Weiss und Gold. Es ergab sich folgendes:

\begin{tabular}{|c|c|c|c|c|c|c|c|c|c|}
\hline Hintergrund & (1) & (2) & $\begin{array}{c}\text { (3) } \\
\text { dunkel }\end{array}$ & (3) & $\begin{array}{l}(3) \\
\text { licht }\end{array}$ & (4) & (5) & & \\
\hline Grün . . . & 2 & 8 & - & 25 & - & 1 & 3 & $=39$ & Exemplare \\
\hline Schwarz ... & 11 & 29 & 27 & 22 & 14 & 2 & - & $=105$ & $n$ \\
\hline Weiss . . . . & - & 7 & 21 & 37 & 44 & 25 & 11 & $=145$ & $n$ \\
\hline Gold . . . . & -- & 1 & 2 & 7 & 16 & 27 & 14 & $=\frac{67}{365}$ & Exemplare \\
\hline
\end{tabular}


Orange hatte keinen Einfluss, bei Grün neigte die Fürbung der Puppen mehr zu "dunkel", was Poulton auf Rechnung der schwächeren Beleuchtung in den Gläsern setzte. Im Übrigen ist der Effect eclatant. Ferner ergab sich, dass Puppen, welche dicht bei einander verpuppt waren, unter sonst gleichen Verhältnissen der einzeln hängenden, zum Dunkelwerden neigten.

Nun suchte Poulton den Moment resp. die Zeitlauer festzustellen, wo sich die Empfindlichkeit für die Farbe rler Umgebung zeigt. Er unterscheidet in der letzten Perinde des Raupenlebens drei Stadien. Stadium I: die Raupe verliisst die Futterpflanze und sucht sich einen Ort zur Verpuppung. Stadium II: die Raupe sitzt bewegungslos, gewöhnlich in gelirümmter Haltung auf der zur Verpuppung auserkornen Stelle. Stadlium III: sie hängt mit dem Kopf abwärts, nachdem sie sich mit den Haken des Hinterendes in die zu Ende des vorigen Stadiums gesponnenen Seidenfïlen eingehaclit hat. Dieses Stadium III erreicht sein Enle mit dem Abstreifen der Raupenhaut. Die Zeitdauer des Stadiums I hïngt natürlich von der Lokalität ab und ist in der Regel kurz. Stadium II dauert durchschnittlich 15 Stunden, Stadium III durchschnittlich 17-18 Stunden (14-20). In den meisten Fïllen, meint Poulton, ist eine Raupe (sc. Vanessa urticcue) wahrscheinlich sensitiv für die Farbe der Umgebung ca. 20 Stunden, welche den letzten 12 Stunden des Stadiums III vorhergehen, auch habe es den Anschein, dass Dunkelheit die Zeitdauer der beiden letzten Stadien verlängere.

Zur Ermittelung der Sensibilitït im Stadium II und III wurden nun folgende Experimente gemacht:

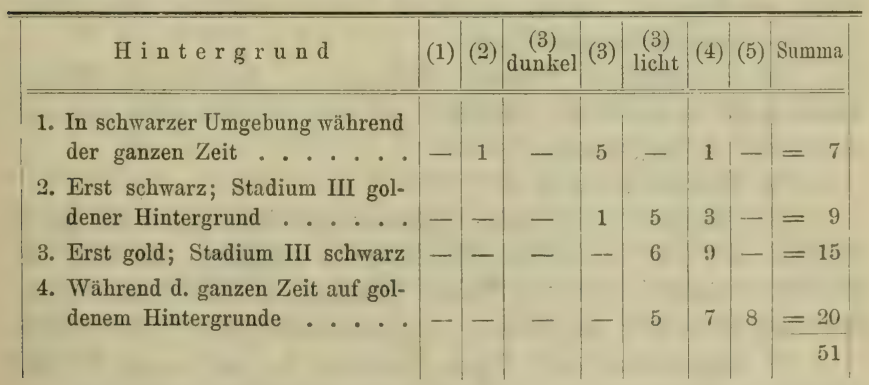

Daraus ergiebt sich nun, dass die Raupen in beiden Stadien II und III sensitiv sind, in letzterem aber weniger, besonders wenn 
man berïclisichtigt, dlass eine Neigung zu helleren Formen entschieden vorherrscht. Vor allem aber ist dalurch das Vorurtheil, als sei die Puppe und nicht die Raupe sensitiv, beseitigt.

Da es sich nun, wie Poulton meint, um einen Einfluss der Ungebung auf das Nervensystem der Raupe, also einen pliysiologischen Vorgang handelt, wurde eine licihe von Experimenten vorgenommen, welche den Sitz der Sensibilitiit feststellen sollten. Am niichsten likg es, an die Augen zu denken. Bei tiner Anzahl von Raupen wurden die Ocellen mit unlurchsichtigem schwarzem Lack iiberstrichen, und die so prïparirten liaupen in verschiedenfarbigen Behïltern zur Verpuppung gebracht; die Resultate waren dieselhen, wie bei ungeblendeten Raupen. Da die Raupen bei der Blendume angenscheinlich iritirt wurden, und dieser Umstaml vielleicht als Reiz zur Bildung hellerer Puppen dienen linnte, anderseits viclleicht die Blenlung bei schwarzem Hintergrumle die Dunkelhilitung der Puppe begünstigen konnte, so wurden zwei Partien, goblentete und ungeblendete, schwarzem Hintergrumle und Dunkelleit ausgesetzt. Das Resultat aber war nahezu das Gleiche, und somit die Blendung als bedeutungslos erwiesen.

Ferner erwog Poulton die Möglichlieit, dass die Dornen der Raupe nervöse Lundorgane beherbergten, welche für die Farbe der Umgebung empfindlich wären. Die Dornen wurlen vorsichtig abgeschnitten, aber auch dann lieferten die Raupen entsprechent der Umgebung helle und dunkle Puppen.

Durch sehr simnreich eingerichtete Versuche mit Contrastfarlien. welche auf dieselbe Raupe zu gleicher Zeit wirken, zeigt Poulton nun, dass nicht ein Simnesorgan am Kopf oder etwa in der vorteren Hälfte des Körpers, sonclern die ganze Kürperoberfliiche gleichmäissig die Farbenempfindlichkeit bezitzt.

III. Versuche mit Tanessa atalantr L. Nur wenige Raupen wurden hier benutzt und ergaben auf schwarz unil gold dieselhen Resultate wie bei Vanessa urticae.

IV. Papilio machaon L.

Acht Raupen auf braunem Hintergrunde lieferten lebhaft grüne Puppen, eine auf der grünen Futterpflanze verpuppt, gab eine entschieden braune Varietät - ler Puppe. Poulton hält es fiir wahrscheinlich, dass diese Art ihre frühere Anpassungsfähigkeit verloren habe.

V. Experimente mit Picris brassicae L. und rapae L. Auf schwarzem Hintergrunde ergab sich als interessantes Resultat bei $P$. rupae, dass die Pigmentbildung durch stärkere Beleuchtung 
gesteigert wurde. Bei weissem Hintergrunde trat der Effekt (nämlich hellere Puppen) deutlicher hervor, wenn die Beleuchtung stärker war.

Von den Farben des Spectrums erwies sich bei Pieris brassicac sowohl wie bei rapac Dunkelorange als am meisten wirksam bei tler Verhinderung von Pigmentbildung. Poulton gewamn bei den Experimenten den Eindruck, als ob weisses Licht, das nicht reflektiert war, sondern direkt die Raupenhaut traf, gar keinen Effekt habe und bemerkt, dass weitere Versuche entscheilen müssten, wie farbiges Licht, das direlit auffällt, wirkè.

Geblenilete Thiere gaben dieselben Resultate, wie normale.

Auch bei rapae zeigte sich bei Wechsel les Hintergrundes, dass Stadium II und die erste Hälfte von Stadium III die kritischen seien.

VI. Die Versuche mit Zonosoma-Arten gaben wegen unzureichenden Materials unsichere Resultate.

VII. Vier Cocons von Saturnia pavonia, die auf schwarzem Calico angesponnen waren, zrigten dunkelbraune Färbung, während Raupen, welche frei beleuchtet, nachlem sie angefangen hatten sich einzuspinnen, auf hellem Hintergrunde helle Gespinnste lieferten.

Die Untersuchungen von Fritz Müller (1887. 597) an dimorphen Puppen von Papilio polydlamas ergaben, dass diselben die Fähigkeit der sogenannten Farbenphotographie nicht besassen.

Die von Barber (1874. 48) beobachteten Erscheinungen an Papilio nireus wurden von Roland Trimen (1857. 882) geprüft und bestätigt.

C. Ed. Venus (1888. 903) brachte Raupen von Vanessce urticae in einen Holzkasten, welcher oben mit einer Glasscheibe zugeileckt war, und setzte dieselben der Einwirkung heisser Sonnenstrahlen aus. ${ }^{2 / 3}$ der Raupen blieb am Leben und verpuppte sich unter dem olseren Theile des schmalen Holzrahmens. Die Puppen hatten lichtgelbliche Färbung und waren am ganzen Körper mit dem schönsten Goldglanze überzogen. Leider vertrockneten sie bei diesem Versuche.

Er wiederholte diesen Versuch im nächsten Jahre und erhielt wieder die schönen goldglänzenden Puppen, welche var. ichmusa ergaben.

Von William White (1888. 539) bewogen, hatte G. Griffiths unabhängig von Poulton Versuche angestellt, welche ihn zu denselluen 
Resultaten geführt haben. Die Abstufungen in iler Färlung deN Puppen wurden auf die Poulton'schen Stufen reduziert. Es wurien 76 Puppen von Pieris rapae L. untersucht. Die gliisernen Behïlter wurden mit schwarzem, rothem, gelbem, grünem und blauem Papier ausgelegt.

Diese Versuche ergaben folgende Resultate:

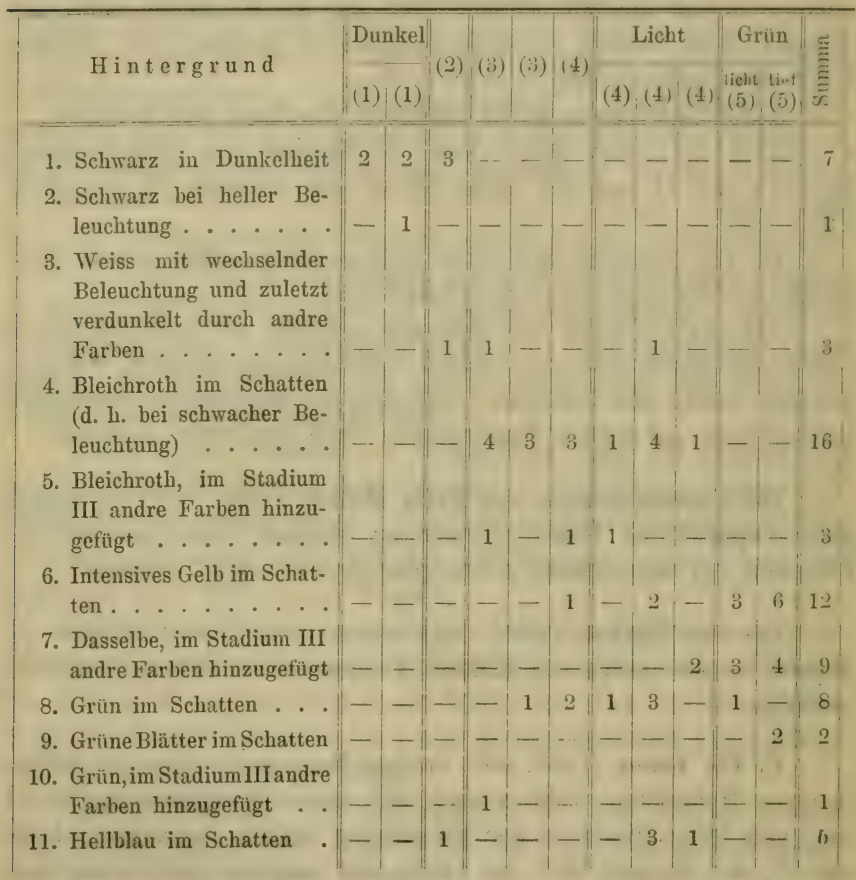

White fasst die Ergebnisse der Griffiths'schen Untersuchungen. folgendermassen zusammen:

a) Griffiths bestätigt Poulton's Beobachtungen, dass dlunkle. Umgebung einen verzögernden Einfluss auf die Periode vor iler Verpuppung ausübt.

b) In dem Misslingen der Versuche mit entgegengesetzt wirlienclen Farben (wobei diese in Stadium III angewendet keinen Effect hervorbrachten) ist eine genaue Bestätigung der Resultate Poulton's zu sehen, welcher bei Pieris und Vanessa die frische Puppe nicht 
farbenempfindlich fand und Stailium II als die Hauptzeit der Farbenempfindlickkeit festellte.

c) Die allgemeinen Resultate iiler Wirkungen der Farben bestätigen die Versuche Poulton's, besonders ist dies mit Schwarz und Gelb, weiter auch mit Grün und Weiss der Fall.

(l) Der Effect von. gelbem Hintergrunite, welcher die Biliung von oberflächlichem Pigment hindert und grüne Puppen entstehen lässt, ist besonders auffallend und bestätigt Poulton's Vermuthung, dass grüne Puppen im Freien durch die im Grun der Blätter enthaltenen gelben Strahlen zu Stande kommen.

N. Schawrow (1888. 741) schreibt, dass die Cocons der wilden Seidenspinner, welche auf der Baumrinde befestigt sinıl, gewöhnlich braun, blass oller grünlich gefärbt sind und ähneln der Färbung nach dieser Rinde; sind aber die Cocons auf den Bliittern befestigt, so haben sie eine ähnliche Firbung, wie die trockenen Blitter. Dies wirl besonilers bei Attacus atlas, An. cynthic etc. beobachtet.

Darauf erschien die Magister-Dissertation von Wilhelm Petersen (1890. 632) „Zur Frage der Chromophotographie bei Schmetterlingspuppen". Leiler konnte er erst liurz vor Schluss seiner Untersuchung Einsicht in die Arbeiten von Poulton und Griffiths nehmen.

Petersen versuchte zuerst festzustellen, welches Stadium der Entwickelung die Anpassungsfähigkeit in Bezug auf die Färbung besitzt. Die Versuche mit Raupen von Pieris brassicae uni Pieris rapae erwiesen, „dass es gleichgiiltig ist, ob die Raupen bis zur Zeit ler Verpuppung in blauem, rothem, grïnem, weissem Licht orler in Dunkelheit gehalten wurlen; auf die Farbe der Puppe hat dies keinen. Einfluss, wenn die Raupen später, d. h. sobald sie zu fressen aufhörten und sich zur Verpuppung anschickten, unter ganz gleiche Verhältnisse gebracht wurden" (p. 233).

Somit lag es am nïchsten. die Reactionsfähigkeit in den Anfang des Puppenstadiums zu verlegen. Es stellte sich haraus, dass dliese Annahme "ein entschierlener Irrthum ist": mit ganz frischen Puppen konnte die entsprechendle Färbung nicht erzielt werlen. Auf diese Weise konnte man nicht mehr bezweifeln, dass die Empfindlichlieit für die Farbe der nächsten Umgebung noch in die Raupenzeit fiel, „und zwar in die Periole vom Aufhören der Nahrungsaufnahme bis zum Abstreifen der Raupenhaut" (p. 235). Dieses Stadium nennt. Petersen "das kritische Stadium". 
Er benutzte zu seinen Versuchen Glashehiliter, die von innen mit dem hrtreffenlen farbigen Papier ausgelegt wurlen. Ausserilem kamen Behïlter mit Fenstern aus farbigem (ilase unil farbige GlasKuppeln in Verwentung, welche üher Glasschalen aus demselluen farbigen Glase restellt wurlen. Fin Theil iler liaupen wurle im Dunkeln zur Verpuppung gebracht:

Gebraucht wurden: 100 Puppen von Pieris rupac, 200 von Pieris brassicre, 140 von Fancssa uticae, 39 ron Platysamia cecropia (N. Am.) und Antherea permyi (Indien).

100 Vanessa urticae wurlen im Dunkeln zur Verpuppung gebracht. Die Puppen waren im Al]gemeinen sehr dunkel, vor allem aber konnte man an keiner einzigen goldene Flecken bemerken.

40 Vanessa urticae waren als Raupen nicht so dunkel gehalten worlen, wie die früheren, demgemiiss die Puppen auch etwas lichter, einige mit einer Spur von goldenen Flecken versehen.

39 Raupen von Platysamia cecropiu, an iler weissen Gaze angesponn n, lieferten ganz weisse Crespimnste. Bei den sich am gelblichen Holz des Kïfigs verpuppenden sind die Gespinnste hellbräunlich tingirt und an Boden des Behälters tiefbraun.

Ein ähnliches Verhalten zeigt sich bei den (respinnsten von Antherea permyi.

Die Resultate mit Picris liassicae und rapae enthalten folgende Tabellen:

(Siehe dic Tabelle I auf Seite 485 und die Tabelle II auf. Seite .486).

In Allgemeinen stimmen diese Resultate also mit denjenigen von Poulton und Griffiths überein. Auf Einzelnheiten eingehend, muss man bemerken, dlass Petersen, als er grünes Papier als Hintergrunil benützte, lieine einzige grïne Puppe erhielt, während die im Freien auf grünen Blïttern gefundenen Puppen, sowohl von rapae, als brassicae, ein leuchtendes Grün zeigten. Die spelitroscopische Untersuchung des beniitzten Papiers ergab, dass dasselbe keine gelben Strahlen durchliess, während das Grün der Blätter reich an gelben Strahlen ist , und diese miissen im vorliegenden Fall die virksamen sein ${ }^{\mu}$ (p. 244).

Wie bei anderen Bombyciden, so beobachtete Petersen auch bei Raupen von Platysaria cecropia, dass die ganze weisse GazeWand mit einem feinen weissen Seidengewebe besponnen wurde, während das Gespinnst zwischen den Zweigen der Futterpflanze braun war. Diese Erscheinung erklärt er, wie folgt: 
4. Einfluss des Lichtes und der Farbe der Ungebung.

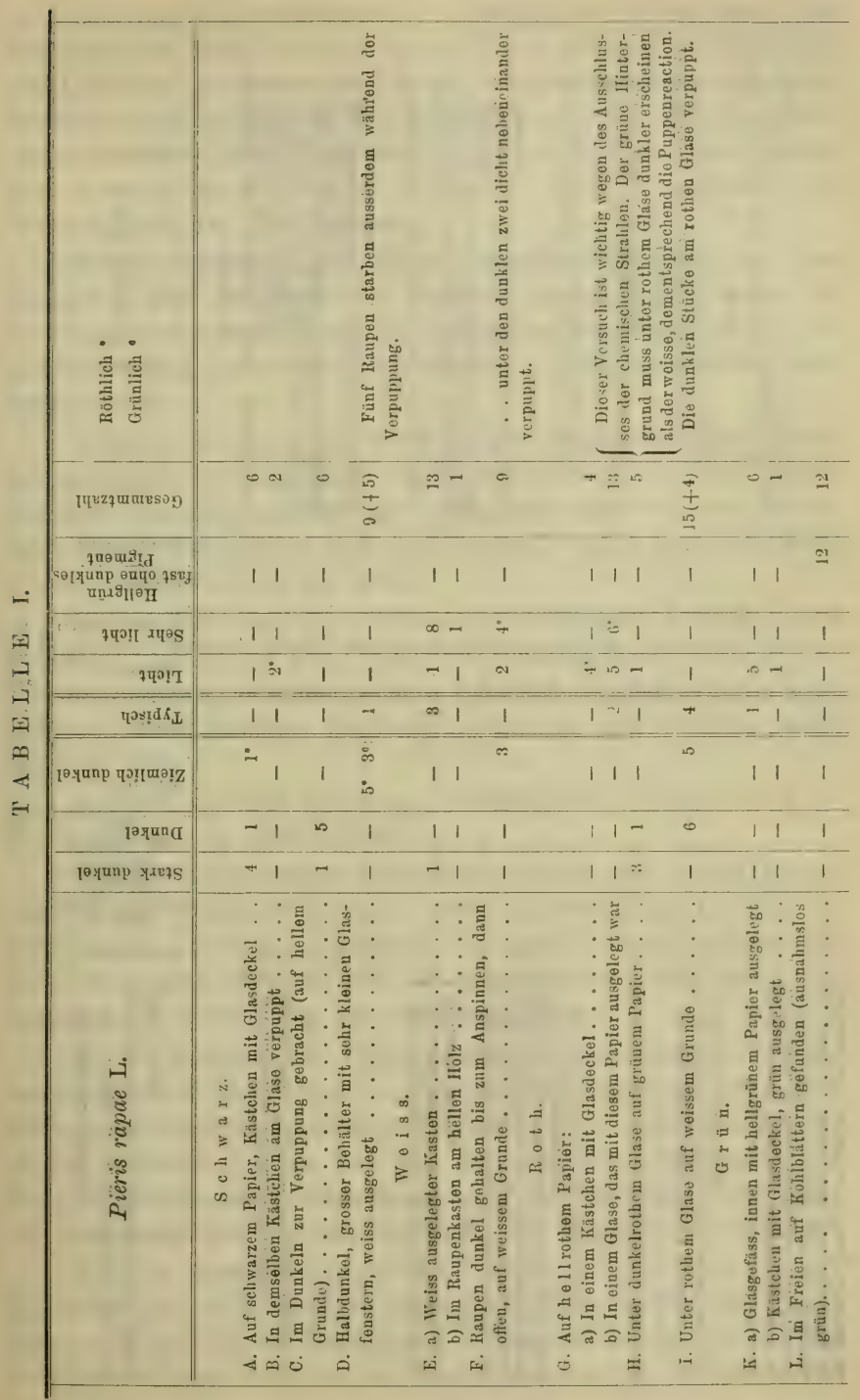




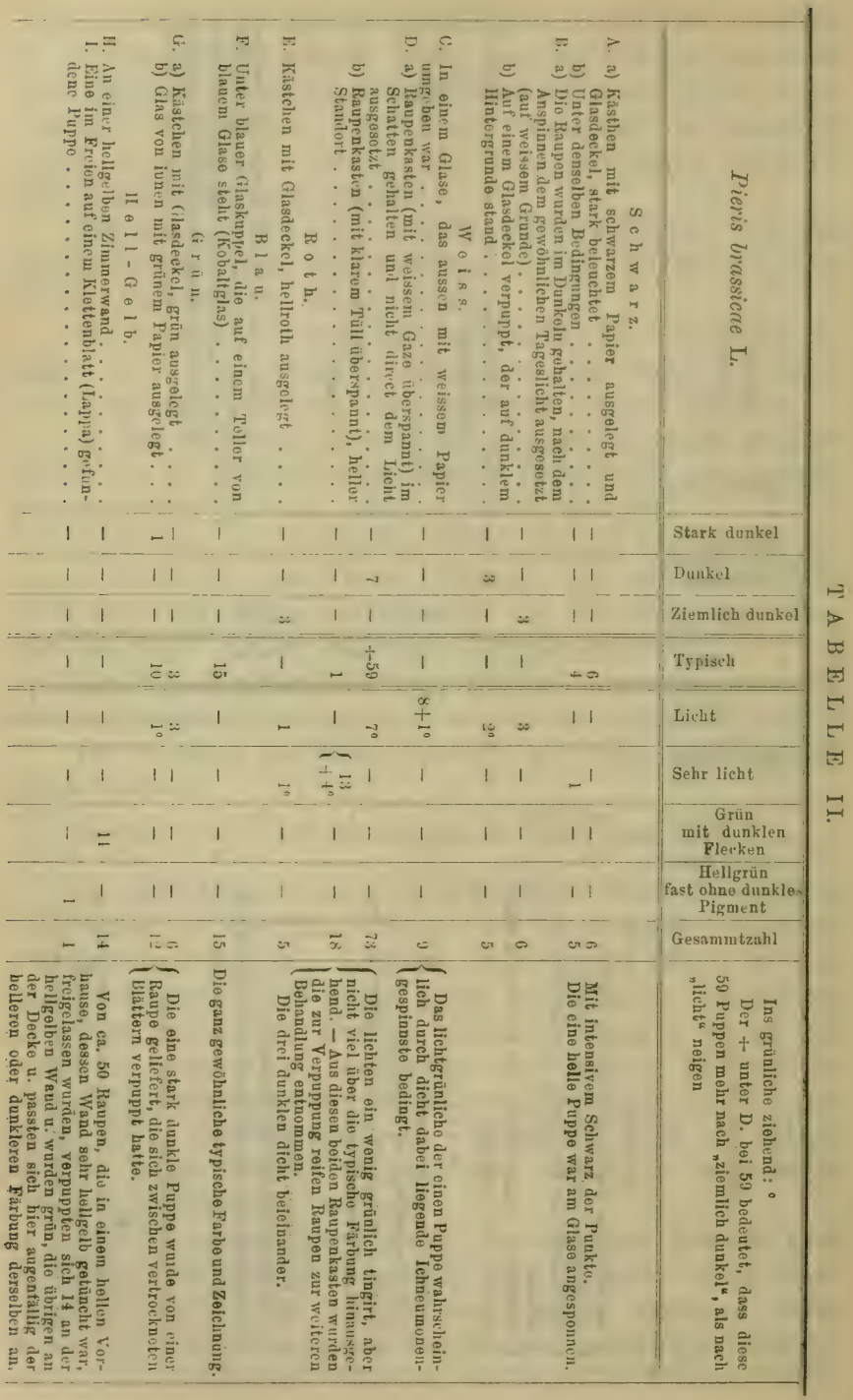


„Für das Zustandekommen der brïunlichen Färbung sind zwei Annahmen möglich. Entweler ist das Secret der Sericterien fähig auf Lichtreize $\mathrm{zu}$ reagiren, d. h. im vorligenden Falle auf heller (irundlage hell zu bleiben, bei dunkler Ungebung oder überhaupt sehr schwacher Beleuchtung aber braun zu werden, oder es sind hier accessorische Drüsen im Spiel, die unter dem Einfluss des Nervensystems der Raupe stehen.

Die Lnzulässigkeit der ersten Annahme folgt schon aus dem Unistande, dass die Faten des inneren Cocons, welches unter der bisweilen tiefbramenen Hülie des Aussengespinnstes vollkomnen vor Lichteinwirkung geschiitzt ist, dennoch in beiden Gespinnsten hellbraun bleiben.

Dagegen liisst sich zu Gunsten der zweiten Annahme durch mikroscopische Untersuchung leicht constatiren, dass der braune Farbstoff wie der Leimstoff nur mechanisch am weissen Seidenfarlen haftet, wesshalb er sich auch so leicht diurch Auswaschen mit Wasser entfernen lässt" (p. 241).

Welche Ursachen die Umfärbung der Raupen bedingen, sagt Petersen, gestiitzt aut seine näher nicht beschriebenen Versuche mit Cossus-Raupen, „dass auch andere Ursachen als chemisch durch die Nahrung hervorgerufene bei der Umfärbung der Raupen thätig :sind ${ }^{\prime \prime}$ (p. 245).

Derselbe Forscher führt am Schlusse seiner Untersuchung folgendes Resumé an (hier abgekürzt):

I. Die Puppen einiger Schmetterlingsarten oder deren Cocons besitzen die Fähigkeit, je nach ihrer Umgebung und den auf sie einwirkenden Umständen, bestimmte Färbungen dauernd anzunehmen. Diese Färbungen erweisen sich im Allgemeinen, jeiloch nicht ausnahmslos, als nützlich für die Erhaltung der Art.

II. Die Reaktion der Puppenoberfläche auf die von der Umgebung reflectirten Lichtstrahlen macht den Eindruck eines rein mechanischen, chromophotographischen Prozesses. Eine Analogie mit einem photographischen Prozess, bei dem die chemischen Strahlen thätig sind, ist deshalb nicht anzunehmen, weil die Reaktion unabhängig von dem Ausschluss oder der Mitwirkung der chemischen Strahlen ist.

III. Die Reactionsfähigkeit auf Lichtreize fällt nicht in das Puppenstadium selbst, sondern beginnt von dem Moment an, wo die Raupe sich den Ort zur Verpuppung ausgesucht hat und die künftige Cuticula rer Puppe noch von der Raupenhant bedeckt ist; sie erreicht 
einige Stun len (vielleicht 10 bis 12 Stunlen) vor dem Act der Verpuppung ihr Ente. Nachlem in diesem kratischen Stadium der Reiz für die Pigmentablagerung ausgelöst ist, dauert diese in der bestimmten lichtung, nun unabhängig von äusseren Umständen, fort und ist erst einige Stunden nach dem Abstreifen der Raupenhaut beendet.

IV. Die Färbung (ler Puppe beruht auf Pigmentablagerung in der Cuticula und Hypodermis. Das Pigment in den Hypodermiszellen ist bei der Raupe grün und bleibt bisweilen auch bei der Puppe grün. Bei den dunkel gefärbten Puppen wird die dunkle Färlung durch Pigmenteinlagerung in die Cuticula hervorgerufen. Die chukle Pigmentirung findet sich besonders um die Wurzel der Haare herum, welche die ganze Puppenobertliiche bedecken unil verbreitet sich von den dunklen Haarwurzeln unter (lem Mikroscop sehr schwach gelblich tingirt oder ganz licht, bei dunklen Stiicken schwiirzlich.

V. Der Anreiz zur Ablagerung dunkler Cuticular-Pigmente ist abhängig von der Einwirkung verschiedener Farben und Helligkeitsgrade im kritischen Stadium.

Gelbes Licht (oder Orange) verhindert am meisten die Ablagerung dunkler Pigmente in der Cuticula, und lässt letztere durchsichtig bleiben, so dass die Puppe durch die grunen Hypodermalpigmente grün erscheint. Lichtarten nach beiden Seiten des Spectrums von Gelb aus bewirken eine stärkere Ablagerung dunkler Pigmente als Gelb. Stellt man dieses Verhalten graphisch durch eine Curve dar, welche bei Gelb ihren Höhepunlit hat, so fiillt dieselbe nach der Seite von Roth schneller ab, als nach Violett. Diese Curve zeigt eine auffallende Uebereinstimmung mit der Curve der Kohlenstoffassimilation bei Pflanzen, welche farbigem Lichte ausgesetzt werden." ${ }^{\text {"1) }}$

Es ist zu gleicher Zeit die Helligkeitscurve des Spectrums, und damit im Einklange steht die Thatsache, dass auch bei Einwirkung von weissem Licht in stärkeren Helligkeitsgraden die Bildung dunkler Pigmentflecke in der Cuticula eingeschrïnkt wird, während Dunkelheit dieselbe befördert.

IX. Sehr merkwürlig ist die Thatsache, dass griine Fürbung der Puppe nicht etwa durch Einwirkung von rein grünem Lichte

1) Nach dem Vorgange Draper's hat man für die Zahl der in gleichen Zeiträumen ceteris paribus abgeschiedenen Gasblasen bei der Assimilation unter farbigem Licht folgende Verhältnisse festgestellt: Roth 25,4, Orange 63, Gelb 100 , Grün 37, Blau 22,1, Indigo 13,5, Violett 7,1 . 
erzeugt wird, sondern durch gelbes Licht, oder grïnes, in welchem gelbe Strahlen reichlich vertreten sind. Und es ist auffallend, dass schon ein sehr helles, weissliches Gelb ausreicht, um eine intensiv grüne Färbung der Puppe hervorzurufen.

Hier wird uns die Annahme eines rein photochemischen Vorganges sehr nahe gelegt.

"Nach meiner Ansicht haben wir es also hier mit Vorgïngen zu thun, die sich in den Zellen der Hypodermis unter (lem Einfluss äusserer Lichtreize unabhängig vom Nervensystem des Thieres abspielen " (p. 267).

In der gleichen Abhandlung steht auf p. 237 folgende Bemerkung:

"Mein damaliger Versuch war insofern nicht resultatslos, als aus der Zucht eine Anzahl Exemplare der nordischen var. polaris stgr. hervorgingen, während die Mehrzahl mehr orler weniger zu dlieser Form neigte, und dieses Ergebniss ist insofern merkwürdig, als es darauf hinzudeuten scheint, dass während des Raupenlehens clie künftige Fürbung des Schmetterlings durch Lichtwirkung beeinHusst "werden kann."

L. Krulikowsky (1890. 478c) beobachtete in Wjatka (Russlani) Decticus verrucivorus L.; welche meistens grün waren, es kamen aber auch graue Exemplare vor. Diese Art lebt auf Weiden.

Morris (1890. 595) erhielt bei seinen Versuchen weisse, rothe, orangene, schwarze und blaue Puppen von Danais cliysippus, obwohl dieselben in der Natur nur als grune uni aschgrane zu treffen sincl.

M. Standfuss (1891. 835) setzte, verschiedene Raupen von klein auf dem Einflusse des farbigen Lichtes aus, konnte aber bei erhaltenen Faltern keine Abänderung der Färbung orler Zeichnung beobachten.

F. Merrifield (1891. 565) stellte, veranlasst durch Mitglieder der "Entomologischen Gesellschaft in London", Versuche mit Puppen von Selenia illustraria an, welche dem Einflusse des Lichtes von verschiedenen Farben ausgesetzt wurden; erhielt aber negative Resultate. Kein Einfluss wurde auch bei Puppen beolsachtet, welche in vollstïndiger Dunkelheit sich befanden. 
C. G. Barrett (1891. 565) hielt einen Vortrag in der Entomologischen Gesellschaft zu London über den Einfluss les Lichtes auf die Färbung der Schmetterlinge. Dic laupen wurden unter farbigen Gläsern erzogen, ergaben jerloch kieine positiven liesultate.

Jenner Weir äussert sich, gestützt auf die Sammlungen von F. Merrifield, gegen diesen Schluss. F. Merrifield selbst unterstiitzt die Schlussfolgerung von Barrett.

E. B. Poulton erwähnt in der stattfindenden Diskusion, dass seine Versuche mit Gnophos obscurata positive liesultate fiir Imago ergaben. Puppen, welche auf Kreide lagen, ergaben helle, und solche, welche auf Braunkohle waren, dunkele Falter. Sind die Puppen aber alt, mit welchen dieser Versuch gemacht wirl, so ergiebt sich keine Aenderung in der Färbung des Imago.

A. Hoffmann (1891.378) beobachtete an ller Küste der Norlsee helle Boden-Varietäten von verschiedenen Schmetterlingen und erklürt diese Verhellung durch den Einfluss des weissen Dünensindes; ferner sagt er: „Der weisse Sand bringt nicht etwa die hellen Farben bei Schmetterlingen hervor, er zwingt aber viele ständige Bewolner solcher Gegenden, die helle Schutzfirbung nach und nach anzunehmen und weiter zu vererben" (p. 129).

F. Merrifield (1892. 567) stellte Yersuche an, un zu entscheiden, ob das Licht irgend eine Einwirkung auf die ausschliipfenden Falter ausiibe.

Frühlings-Generation von Selenia illustraria-Puppen (32 Stïck) wurlen in Partien zu je 2 Paaren eingetheilt und am 1. Februar im Schlafzimmer (die Temperatur schwankte zwischen $46-57^{\circ} \mathrm{F}$. und stieg zuweilen bis zu $63^{\circ} \mathrm{F}$.) in Töpfen gebracht, welche mit purpurrothen, blauen, grïnen, gelben, orangen, rothen und farblosen Glasscheiben zugedeckt waren. Eine Partie befand sich in vollständiger Dunkelheit und eine andere unter dem Eintlusse des Lichtes, welches durch die Lösung von Kalium-Bichromat durchging. Alle Serien wurden der Einwirkung direliter Sonnenstrahlen ausgesetzt.

Die Ausschlüpfung fand zwischen 8. M̈̈r\% und 6. April statt. Die erhaltenen Falter zeigten aber in ihrer Färbung keinen merklichen Unterschied.

Er stellte auch Versuche mit 7 Puppen von ILlitaca cyntliu an, welche aus ihren Cocons herausgenommen und auf den Borlen aines Blumentopfes gebracht wurilen. Durch die zurleckenden Glas- 
scheiben wirkte das direkte Sonnenlicht ein. Ausserdem wurlen an.lere 7 Puppen in einen anderen Topf, aber in den Cocons gelassen, gebracht, wobei sie in Staniol eingewickelt waren. Alle 14 Puppen schlïpften zwischen 3 . und 27. Inli aus. Unter beiden Partien war jedoch keinen Unterschied in der Färbung zu bemerken.

Fritz Rühl (1892. 721) untersuchte ca. 1500 Puppen von Vunessa urticae und fand, dass diese, in einer Höhe von 6-8000' gefundenen Puppen, oft an sehr feuchten Felswänden aufgehängt, sozusagen einfarbig oder zeichnungslos sind; sie trugen die Mauerfarbe des Felsens, höchstens ist die dem Lichte zugekehrte Seite um eine Nuance heller, von goldglïnzenden Punkten aber keine Spur zu finclen. Steigt man 1000-1500' herunter, wo Sennhiutten sich befinden, so findet man die Melırzahl der Puppen zwischen den Latten (ler Unzäunung aufgehängt, wobei alle Segmente der Puppe, auf welche das Sonnenl cht einwirken konnte, heller als der übrige Theil des Puppenkörpers gefärbt sind, und bei einzelnen Puppen machen sich schon schwache Spuren glänzender Schüppchen bemerkbar.

Auch auf die ïussere Umhïllung, den Cocon oder das Gespinnst, ist die Einwirkung der Sonne massgebend. Rühl traf in rissiger Kieferrinde Dutzende Male aui der Sonnenseite die Gespinnste lich ter und heller gefärbt als im Schatten.

L. Krulikowsky (1892. 479) sagt, lass Eccrita lucticra Hb.Schmetterling selır schwer von der Farbe der Umgebung zu unterscheiden ist.

N. Cholodkowsky (1892. 140a) hat bei der Untersuchung der Coniferen-Lüuse beobachtet, dass die Färbung von Lachnus pini L. der Farbe der Rincle, auf welcher diese Läuse sich aufhielten, so sehr ähnelte, dass die Läuse nicht ohne grosse Mühe auffindbar wïren, wenn die neben ihnen stets laufenden Ameisen dieselben nicht verrieten.

1892 veröffentlichte Edward B. Poulton (1892. (647) seine umfassende Abhandlung: "Further experiments upon the colourrelation between certain lepidopterous larvae, pupae, cocoonr, and imagines and their solroundings," welcher wir folgende Resultate entnehınen:

Nachdem er bereits friiher (1887. 645) nachgewiesen, dass die Fähigkeit der Farbenanpassung bei der Raupe weder durch die 
Augen noch durch die behaarten Dornen belingt wird, wandte er sich der Untersuchung der physikilischen Beschaffenheit der HautFärbung zu.

$\mathrm{Zu}$ diesem Zwecke untersurhte er Ampliclasis betuluriu, welche Art eine sehr grosse Farbenempfänglichkeit besitzt. Dieser Schmetterling verdankt die grüne Farbe einem in Oelkügelchen eingelagerten Farbstoff in der Fettschicht, die sich zwischen der Epilermis und ien oberflächlichen Muskeln befindet. Die Epilermis selbst kann aussertem einen dunkeln Farbstoft beherbergen, der dimn das grüne Pigment rerdeckt und die Haut lraun erscheinen lïsst.

Die verschiedenen Fürbungen entstehen hier also nicht durch verschiarlene Lagerung der unverïnierlichen Farbstofte, sontrin dadurch, dlass der Farbstofl neu gebildet und unter dem Einfluss dies Lichtes verïnlert wirl. Die wirksamsten Aenlerungen erfolgen mit dem dunkeh Farbstoff in den Epilermis-Zellen, aber auch der diunter liegenile griite wirl beeinflusst. Der Bereich der dadurch erzengbaren Färbungen erstreckt sich vom Braun, Grün und Grau einerseits nach Schwarz, andererseits nach Weiss.

Er versetzte auch Raupen aus dunkler in helle Uimgebung und umgekehrt und fand, dass eine Veriinderung der ersten Fürbung im Sinne der Einwirkung der zweiten Umgebung bemerklich war, so lange sie innerhalb der Stadien sttattfindet, in denen dis Raupe die Empfindlichkeit besitzt.

Um die Beobachtung von Barber (1874.48) zu prufen, brachte Poulton den vorderen und hinteren Theil der Raupe in verschielene Cingebungen. Es wurde jedoch keine örtliche Wirkung beobachtet, sondern eine auf dem ganzen Körper gleichförmige, mittlere Fürbung, die von dem Terhältnisse der Oberflächen beider Theile abhing, auch ohne vorwiegenden Einfluss des vorderen Theiles.

Zur noch näheren Feststellung der grössten Empfindlichkeit stellte er folgenden Versuch an: Er übertrug die Raupen von einer Ungebung in die andere und fand, dass die erste Umgebung meist von grösserem Einfluss als die zweite auf die Färbung, welche die Raupe o.ler Puppe nach der Häutung oıler Verpuppung annahn, war. Diese zweite Häutung ist natürlich unter der frïheren vorgebildet, besitzt ober noch keinen Farbstoff. Die zukünftige Farbe dieser Haut wril aiso beeinflusst, olne dass sie noch einen Farbstoff enthält. Er hült die Annahme für möglich, dass die oberflächlich gefürbte Schicht in einen Zustanil von „complete physiological unity “ (p. 392) sich befinlet, und dass das Nervensystem die Lichtwirkung fortleitet. 
Kunckel d'Herculais (1892. 485) stellte Beobachtungen ïber die Veränderung c!er Fürbung bei Schistocerca peregrina Oliv. in Süd-Algier 1891 an. Diese Art der Orthopteren war bis jetzt in zwei Varietäten bekannt: rosa-rothe und gelbe. Es hat sich aber herausgestellt, dass diese Farbenïnderungen einer und derselben Art eigen sind, und nur vom Entwickelungs-Starlium abhïngen. Nach dem Ausschlïpfen sind diese Thiere grünlich-weiss, damn werden sie unter dem Einfluss des Lichtes braïnlich und nachher schwarz mit gelben und weissen Punkten; bei weiterer Entwickelung werden die Kö̈rperseiten rosa-roth, dann ganz roth, úm schliesslich nach und nach gelb zu werten. Bei jeiler Metamorphose sind die Excremente rosa-roth gefärbt.

Die Exemplare, welche im Schatten geziichtet werlen, erhalt'n keine scharfe Färbung und werden in Alliohol rosa-roth, ob es jungुe oder alte: Exemplare sincl.

L. Heissler (1894. 363) ziichtete junge Raupen von Vanessa urticue, io, Pieris brassicae etc. unter farbigen Gläsern, konute aber bei daraus erhaltenen Faltern keine Farbenänderung beobachten.

1894 erschien die Inauguraldissertation von Christoph Schröder: "Entwickelung der Raupenzeichnung und Abhängigkeit der letzteren von der Farbe iler Cingebung" (772), welche reiches Beobachtungsmaterial enthält. Untersucht wurden ausschliesslich die Raupen der Gattung Eupithecia, wobei sie bereits vom Ei an den reflektierten Lichtstrahlen verschietlener Farben ausgesetzt wurlen.

Bei dieser Untersuchung wurden die Raupen in drei verschiedene Behälter gebracht und zwar:

a) Einfache Trinkgläser ( $\mathrm{h}=12 \mathrm{~cm}, 2 \mathrm{r}=7 \mathrm{~cm}$.).

b) Schachteln ( $\mathrm{h}=2 \frac{1}{2}, \mathrm{~cm}, 2 \mathrm{r}=7 \mathrm{~cm}$.).

c) Reagiergläschen ( $\mathrm{h}=7 \mathrm{~cm}, 2 \mathrm{r}=1 \frac{1}{2} \mathrm{~cm}$.).

Dahei wurden die einfachen Trinkglïser mit entsprechendem farbigem Papier, welches einen Schnitt trug, umgewickelt. Die Schachteln wurlen mit farbigem Papier ausgelegt und durch eine Glasplatte rerschlossen, auf welche ein Streifen von gleicher, nach untell gerichteten Farbe unter Winkel geklebt war. Schliesslich wurlen lie Reagiergläschen in Papierröhren, welche schief geschnitten und mit Glas versehen waren, geschoben.

Das benutzte farbige Glanzpapier war in folgenclen Tönen: Schwarz, Braun, Hochroth, Gelb, Griin, Hellblan, Violett, Weiss, Gold, und Silber gewählt: 
Die erhaltenen Resultate sind in folgendlem zusammengestellt: wobei die Arten in aufsteigender Reihe der Vollkommenheit ihrer Zeiclinnng nach geordnet:

\section{Abraxas grossulariata (L.).}

In a) 130 Individuen. Eine Variation der Zeichnung wurle nicht beobachtet.

\section{Abraxas maryinata (L.).}

In c), a) 128 Individuen. Negatives Resultat. Jedoch dunkelgriiner Ton bei 11 unter Schwarz gezogenen Individuen.

\section{Eupithecia abietaria (Goeze).}

21 Individuen. Negatives Resultat; nur fand sich bei den unter. Gelb gezogenen eine unerheblich hellere Grund- und Zeichnungsfarbe, als bei den unter Schwarz gehaltenen.

\section{Cabera pusaria (L.).}

In c), a) 112 Individuen. Es wurde eine nicht unerhebliche Variation in Bezug auf die Stärke der Zeichnung erzielt; eine verschiedene Lage ihrer Elemente war dagegen nicht zu bemerken (4 Formen).

\section{Cabera exanthemata (Scop).}

In c), a) 88 Indivieuen. Eine nicht sehr wesentliche Variation in Bezug auf die Stärke der Zeichnung wurde erhalten (2 Formen).

\section{Ematurga atomoria (L.).}

In c), a) 38 Individuen. Die Variation in der Stïrke (ler Zeichnung war sehr erheblich; einige Raupen besassen am Vorderrande der Seitenlinie eine starke Schattierung (2 Formen).

\section{Cidaria ferrugata (Clerck).}

In c) 45 Individuen. Es zeigte sich eine erhebliche Variation in der Stärke der Zeichnungselemente (2 Formen).

\section{Acidalia trigeminata (Haw.).}

In b) 176 Individuen. Auch hier wurde nur eine Variation in der Stärke der Zeichnung beobachtet. (2 Formen). 


\section{Acidalia uversata (L.).}

In b) 274 Individuen. Die erzielte Variation der Zeichnung erstreckte sich auch hier nur auf stärkeres orler schwïcheres Hervortreten derselben (3 Formen).

\section{Eupithecia absinthiata (Clerck).}

In a) 41 Individuen. Es wurde eine sehr erhebliche Variation in der Stärke der Zeichnung und das Fehlen grösserer Theile derselben beobachtet. Eine Verschiebung in der Lage der Zeichmung:elemente fand sich jedoch nicht (2 Formen).

\section{Eupithecia castigata (Hb.).}

In c), a) 26 Individnen. Wie die vorige Art nur in Bezug auf Stirlie der Zeichnung variierend, jedoch nicht in ganz so hohem Grade (2 Formen).

\section{Timandra amata (L.).}

In c), a) 45 Individuen. Es wurde nur eine ziemlich unwesentliche Variation in der Zeichnungsstärke erreicht (2 Formen).

\section{Eupithecia pusillata (F.).}

In a) 18 Individuen. Die Variabilitït der Zeichnung beschrünkt sich nicht nur auf eine Verschiedenheit in der Stärke, sondern es wurlen auch solche liaupen gezogen, welche eine ontogenetisch jüngere und damit phyletisch ältere Zeichnung, nïmlich diejenigen des ersten Stadiums der normal sich entwickelnden Inılividuen besassen (2 Formen).

\section{Eupithecia euphrasiata (H.-Sch.).}

In a) 37 Individuen. Auch hier liess sich, abgesehen von einer Variabilität in der Stärke der Zeichnung, eine solche in Bezug auf die phyletiche Stufe derselben feststellen (2 Formen).

\section{Eupithecia succenturiata (L.):}

In c) 39 Individuen. Es gelang bei dieser Art ebenfalls, sowohl eine erhebliche Variation der Stärke, wie auch eine phyletisch ältere Stufe der Zeichnung zu erzielen (3 Formen).

\section{Erstens:}

\section{Eupithecia satyrata (Hb.).}

In a) mit den Blïten der Schlehe (Prunus spinosa) gefïttert. 56 Individuen. Ausser einer sehr erheblichen Variation in der 
Stiirke konnten auch zweifellos phyletisch :iltere Zeichnungen beobachtet werlen (3 Formen).

\section{Zweitens:}

In c), a) mit cien Bliiten des Heilekraut (C'alluna vulgaris) gefuittert. 17 Indiviluen. Es waren ähnliche Erfolge zu bemerken, wie oben, doch wurde die phyletisch ältere Zeichnumgstorm nicht erhalten.

\section{Enpithecia allipunctuta (Haw.).}

In a) $2: 3$ Intivilnen. Anch liese Art zeigte, abgesehen von einer sehr merklichen Variabilitiat in ter Stärke der Zeichnmg, auf das dentlichste cine solche in lex phyletichen Stufe derselben (3 Formen).

\section{Eupithecia oblongata (Thunb.).}

Erstens:

In a) nacheinander mit ten Blïten der Osterblume (Anemone nemorosa), (ler Weile (Salix sp.) und der schlehe (l'runus spinosa) gefuitteit. 42 Individuen. Neben einer sehr erhehlichen Verschiedenheit in der Stärlie der Zeichnung konnte auch nicht mincler grosse Variation in Betreff der phyletischen Entwickelunwsstufe derselben festgestellt werden (4 Formen).

Zweitens:

In c), a) 26 Inılivituen mit den Bliiten des schafgarle (Artemisia rulgaris) gefuittert. Das Ergebnis schliesst sich durchaus an das vorige an.

19 und 20. Eupithe ia imnotata (Hufn.) und var. frexinata (Crew).

Erstens:

In a) mit den Bliiten der Schlehe (Prunus spinosa) gefüttert. 68 Indiviluen. Diese Art zeigte sowohl in der Stiirlie der Zeichnung wie auch in Beziehung auf die phyletische Stufe derselben lie erheblichste Variation, welche beobachtet wurde (5 Formen).

Zweitens:

In a) mit den Blïttern der Schlehe gefüttert. 11 Individuen. Es wurden ausschliesslich Zeichnungsformen, welche zu der 1. Form zil rechnen sind, erzielt. Aus den aus Raupen erhaltenen Puppen schlüpfen Schmetterlinge, welche zweifellos zur var. fruxinata Crew. gehören; es gelang eine Paarung herbeizuführen, welche ein Gelege ron 28 Eiern "ergab. 
Weiters wird dann die Frage beantwortet werden müssen, ob und inwiefern jede Farbe einen bestimmten Einfluss auf die Variation der Zeichnung ausübe:

1. Schwarz, 17. d. h. auf 17 Arten angewandt. Bei der Einwirkung dieser Farbe enstanden stets die phylitisch juingsten ler iberhaupt gefundenen Zeichnungsformen mit stärkst erhaltenen, dunklen Zeichnungselementen.

2. Braun, 9. Die Zeichnung lässt dieselbe Variationsrichtung wie unter schwar, jeiloch in geringerer Intensitüt erkenmen.

3. Hochrot, 9. Zeichnung im allgemeinen unbeeinflusst, durchaus normal, in einzelnen Fällen jedloch zweifellos nicht unerheblich erhellt und verschmälert.

4. Gelb, 23. Im Gegensatz zu Schwarz ruft diese Farbe stets die phyletisch älteren Zeichnungsformen hervor und eine theils ausserorlentlich starlie Erhellung, sowie Verschmälerung ihrer Elemente.

5. Griin, 15. Es ist eine gleiche Variationsrichtung wie unter Gelb zu verzeichnen, loch in etwas verminderter Intensitit, so dass zwar phyletisch ïltere Zeichnungsformen auftreten, aber weniger hïufig und dann auf einer so nierleren Entwickelungsstufe, wie unter vorgenannter Farbe.

6. Helblau, 15. Zeichnung durchaus normal.

7. Violett, 2. Diese Farbe scheint ebenfalls kaum einen nennenswerthen Einfluss ausüben zu können.

8. Weiss, 10. Es zeigt sich meist eine sehr starke Erhellung und Verschmälerung der Zeichnung bis zum Verschwinden grösserer Theile derselben; selten entstehen auch phyletisch ïltere Formen.

9. Goll, 7. Die Zeichnung variirt in gleicher Richtung mit noch erheblicherer Intensität wie unter Gelb.

10. Silber, 7. Die Variation wie unter Weiss, vielleicht etwas stärker.

Daraus geht hervor, dass Gold, Gelb, Grün, Silber, Weiss helle, meist grünliche Grundfarben erzielten, Schwarz und Braun dagegen dunkle, oft bräunliche Farben, während Roth, Blau, Violett mehr oder weniger einflusslos blieben.

Schröder stellt folgende Normen für die Stïrke der Zeichnungsvariabilitït in Bezug auf die Lebensweise der Raupen auf:

1. Von Laubblättern lebende Raupen. Zeichnung lïngsstreifig, aus wenigen Linien bestehend (Geometriden!); fast nicht variabel. 
2. Von Nadelhölzern lebende Raupen. Zeichnung meist unterbrochene Längsstreifung; in rem einzigen beobachteten Falle sehr variabel.

3. Ton den Blätern niedriger Pflanzen lebente liatipen. Zeichnung hoch entwickelt; phyletisch nicht variabel.

4. Von Blüten lebenle Raupen. Zeichnumg sehr entwickelt. ausserordentlich variabel.

5. Von Blättern oiler Bliiten lebenle liaunen. Zsichmug je nach der angenommenen Lebonsweise einfach orler hoch entwickelt, von der stärksten Variabilitiit.

(i. In Inneren von Pflanzenteilen (Cherms-(xallen) lelun it Raupen. Zeichnung in (lem beahachtet.n lalle noch vorhanlen. jedoch durchaus nicht variabel.

7. Hierzu die ungeniessbaren nicht variabel.

Es ist somit müglich, len experimentalen viuhweis zu lieferm. dlass die Zeichnung, ein liologischer Schutz für ihren Triterer, in ihrer Variahilitit von der Farbe ter L'mgebung quleitet wiril.

Die Kritik dieser Untersuchung rim Schröder lefindet sich in der Abhandlung von M. C. Piepers (189)7. 638) aluf p. $\$ 1 \mathrm{~mm} / \mathrm{th}$.

Ernest Hein (1894. 357) sclureilut in seiner Notiz "litwats üher Kunstziichtung" unter Ander'm folgentes: „Der Forscher wielt aher nicht wie sonst die Futterpflanze in gewöhnliches lirbloses Witsser. sondern lïsst seinen lieben Thierchen ein wohl noch schöner als die Farbe ler Blätter, welche ihnen zur Nahrung dienen, entgegen leuchten, " und ferner: „Ein vergleichenter Blick des Forschers besagt ihm zwar, dass seine schmetterlinge nicht dlieselbe Farbe, jil sogil nicht einmal eine spur ron simiragdgriin zeigen, wohl aber eine Farbenïnilerung angenommen haben, die ihn sehr erfreut und seine Lieblinge immerhin schün erscheinen lässt." Leiler schreibt er nicht, welche Arten untersucht und welche Abänderungen erhalten wurden.

Émile Blanchard (1895. 86) brachte frisch ausgelirochene Riiupchen von Vanessa io in Schachteln, welche mit blauem, violettem, grünem und rothem Glase zugedecht waren. Die Futterpflanze stanil in Wasser und wurde nur im dunkelen Zimmer gewechselt. Eine Serie von Raupen wurle im vollständig dunkelen Raume gezüchtet. Simmtliche Raupen ergahen Falter, deren Fürbung von der normalen eh durch nichts unterschieil. 
August Weismann (1895. 954) erhielt am 27. Mai 1854 von einem Weibchen von runessa cardui zahlreiche Eier, welche er in drei Gruppen eintheilte: die 1. Gruppe bliel, im Junkeln, die 2. unter blauem Licht und die 3. unter gelhem Licht, in welchem die ausgeschliipften Rïupchen aufgezogen wurilen. Die gegen Mitte .Juli erhaltenen Schmetterlinge unterschieilen sich gar nicht von anleren carlui dieser Gegend, werler in Zeichnung noch in Firrhung, nur latten sie alle relativ viel Blau in den Augenflecken auf dur I'nterseite der Hinterflügel.

In dersellen Abhandlung befindet sich folginle stelle:

"Als die Raupen (von Chrysophamus phlue.s) nahezn ausgewachsen waren, bliehen viele ganz grïn, anderen zeigten die lebhaft weinrothen Lüngsstreifen auf grunem Grunde, eine Farbenanpassung an die roth schimmernilen Stengel vieler Apfelptlanzen, deren Roth genau von derselhen Schattirung ist wie das ler liaupe. Beide Raupenfïrbungen sind also rorzïgliche schutzfirbungen" (p. 6).

C. Keller (1896. 446) berichtet iiber eine folgenle Farhenanpassung: „Der Gebirgspass von Dscherato besteht durchweg aus Urgebirgsformation, bald aus feinkörnigem Gomygranit, von fleischrother Fïrbung, bahl aus röthlichem Granitporphyr mit grossen rothen Felispathstiicken, die an der verwitterten Oberfliiche zuweilen isolirbar sint. Die dort wohnenden Heuschrecken haben auf ihren grauen Flïgeln Flecken, welche eine Nachahmung des eingesprengten Feldspats sind."

Schenkling-Prévôt (1896. 745) sagt, ılass Pecliculus cupuitis Deg. schmutzigweiss oder weissgrau bis schwarz ist, je nach der betreffenden Menschenrasse.

M. Standfuss (1896 840) schliesst aus seinen Versuchen, dass die Färbung variabler Puppen von der Farbe des Untegrundes abhänge, aber nur bei einer gewissen Temperatur. Er hat nämlich Raupen von Tanessa cardui in die Temperatur von $+40^{\circ} \mathrm{C}$. und von Vanesset urticae in die Temperatur von $+37^{\circ}$ C. gebracht, wobei clie Verpuppung bei diesen Temperaturen in einem, beilerseits mit weissen Leinen bespannten, dem vollen Tageslichte ausgesetzt $m$ Holzrahmen stattfand. Die Puppen ergaben annïhernd weisse Totalfïrlung. Dagesen inderte die Tenperatur von $+18^{\circ}$ bis $23^{\circ} \mathrm{C}$. den naturlichen, graubraunen Colorit nicht. 
M. C. Piepers (1897.638) beobaclitete in Batavia junge grïne Iiaupen von der javanischen Chacrocumpa acteus Gram. (auf Vitis (liscolor), welche später rothbraun werden uni der Farbe der unteren Seite der Bliitter dieser Pflanze gleichliommen. Es besteht jedoch zwischen beilen kein Zusammenlıang, da dieselben Raupen auf den stets ilunkelgrinen Blittern von Colocasia antiquorum lıäufig braun werden, wïlırend lingegen einige immer gr ï bleilıen.

Schenkling-Prévôt (1897. 746) sagt, rlass die meisten (irottenkäfer die braun- bis graugelbe Schutzfärbung tragen.

Ludwig Biro (1S97. S1) beolachtete in Neu-Guinea springenile Ameisen (genus Strumigenys) und stellte fest, dass die Anpassung der Ameise zur Farbe ilırer Ungebung (einer staubherleckten Stelle) vollkommen ist, "denn sie brauchte nur noch die glïnzenden Fiefer $\mathrm{zu}$ verbergen, damit ihr glanzloser brauner Körper zwischen den Staubkörnchen gänzlich unbemerkbar werde" (p: 137).

Prehn (1597. 650) erwïhnt in seiner Abhandlung, dass Lithimus nigrocristatus, ein Riüsselkïfer von Marlagascar, tïuschend seiner Nahrungsptlanze, der Flechte Parmelia crinita, gleicht.

Es seien hier noch wenig bekannte "Anpassungen" der Raupen an die Umgebung erwälnt: "Die Farbe des Felsens tragen z. B. fast alle Polia, damn im hohen Norden Anomog. lactabilis. In der Jugend ist ferner $S p h$. pinastir seiner Färbung nach den Nadeln seiner Nahrungsptlanze angepasst, im Alter mehr den Zweigen" (p. 26-27). Er hetrachtet die bei Smer. populi öfter auftretenclen rothen Flecke als eine Anähnlichung an die im Herbst Flecke bekommenden Weilen- unıl Pappelblïtter. "Die Larve von Xylom. conspicillaris ist, wenn sie jung Ginsterblïtter frisst, grün, später aber zieht sie sich ein gelbes, sie verbergendes Ḱleid an, da danu die hochgelben Schnetterlingsbliiten dieses Strauches ihre Nahrung bilden; wenn Cuc. praecana auf Reinfarn (Tanacetum) lebt, findet man sie gelb, auf Artemisium aber grün gefürbt. Die Raupe von Amph. betularius ist, je nach ler Farbe ler Zweige, an denen sie lebt, bald grau, bald griin, bald braun, auch gelblichgriin. Smer. ocellata tritt auf der helleren Korbrveide gelblichgrïn, auf gewissen Weidenarten aber dunkelgrün“ (p. 27). Er beobachtete auch, dass Notocl. zic:zac an Wollweiden mit heller Unterseite viel heller gefïrbt ist als an Pappeln. 
Werneburg (1897. 955) sagt, dass die Raupe von Brioph. ulgue auf grauen Flechten grau, auf gelben aber gelblich ist; Eriop. purpurcofasciata hat auf frischem Farnkraut eine griine, auf dür gewordenem aber eine rothbraune Farbe: Hactena basilinea lebt im Jugendzustande in Getreideähren und zeigt sich grün wie diese, wenn sie später aber sich am Boden von niederen Ptlanzen nährt, wird sie, der Farbe der Erilbodens entsprecheni, braungrau.

H. T. Peters (1897. 631) beobachtete in Brasilien, dlass dler Filter Metamorpha (Colaenis) dido seine Eier nicht auf die Blïtter von Passiflora, sondern auf die gelben Spitzen der Ranken legt. Die Eier halten genau deren Farbe. Die ausgeschliipften Rüupchen haben schmutzig gelbgrüne Farbe und halten sich auf Bliittern. Nach der ersten Haiitung ist die Raupe röthlich rund sitzt an der Unterseite des Blattes, an rler gleichfalls röthlichen Mittelrippe desselben.

Der Falter Ectima livia ist aschgrau mit schwarzloraunen Querwellen und hat eine breite, weisse Binde auf ilen Vordertligeln; er sitzt auf flechtenbewachsenen Stämmen, deren Fürbung ihm täuschend ähnelt.

H. Gauckler (1897. 284) zog Rüupchen von Aictiı caja vom Ei ab und hielt die Zuchtkïsten von Anfang der Zucht an vollkomman dunkel, auch die Puppen im Dunkeln. Trotzlem, dass die cajaRaupen sehr das direkte Sonnenlicht in der Natur lieben, erhielt er bei seinen Versuchen keine Abweichungen an der Farbe und Zeichnung ler Falter.

Max Müller (1897. 599) schreibt: „Auf den Blïttern meiner Georginen hatten sich massenhaft die Raupen der Knötericheule (Mamestra persicariae L.) eingefunden. Ihr allgemeiner Farbenton entsprach nicht nur dem Blattgrün, sondern die dunklen Riuickenflecke erinnerten auch auffallend an das Blattgeader. Ebenso ruhten an den vertrockneten Blütenkörpern öfters die Larven des Geissblattspanners (Crocallis elinguaria L.); aber selbst ein geiibtes Auge hatte einige Mühe, beide Arten aufzufinden" (p. 120-121). Die Raupen von Amphidasis betularius sind auf Birken rinclerfarbig, auf Eichen aschgrau, auf Ulmen melır gelblich, auf Pappeln und Weiden gelblich grün und oben rostfarben angehaucht. Die liaupen von Ocneria clispar sind auf Tannen und Lärchen dunkler als auf Kiefern. 
0. Hamann (1597. 352) sagt in seinem Buche "Europiilische Iöhlenfauma", dass die Tausenlfüsser in den Höhlen ndurchğingig“" eine Farbenïnlerung zcigen. (Die Kritili llariber vicle bei C. Verhoeff [908]).

Paul Grosser (1897. 331) heobachtete bei Gelegenlıeit seiner lieisen auf St. Helena folgende Anpassung der Orthopteren an die Farbe der Ungebung: „An zwei entgegengesetzten Orten konnten wir zwei sehr augenfällige Farbenanpassungen von Heuschrecken beohachten. Das eine Mal lebten diese Insekten auf dem mit grauen Flechten beilecliten heligrauen Basalten des östlich an den Mont Vesey sich anschliessenden Hïgels und hatten genau denselben grauen Farbton; las anlere Mal waren sie in clen rosafarbenen Kriech1)tlanzen, welche in beschränlitem Maasse auf der Prosperous-Bay-Ebene wachsen, zu Hause und zeigten dieselbe zarte rosa Färbung. Die angepassten Farben sinl von auffallend kurzem Bestanl, so dass sie leider schon wenige Tage, nachrlem die Thiere gesammelt waren, sellsst in der Dunkelheit, dem gewöhnlichen Braun wichen."

Rudow (1S98. 711) setzte die Larven in Zellen eines Hornissennestes der Einwirkung verschieden gefärbten Lichtes aus. Die aus Arbeiterzellen bestehenten Waben wurden in mehrere Theile eingetheilt. Zur Erzengung des Lichtes diente ein Ruhmkorff'scher Induktor von 8 Volt Spannung und eine Hittorff'sche und eine Geissler'sche Röhre.

Das Hittotff'sche (griine) Licht wurle, durch rothe Glasscheiben abgediumpft, auf eine Partie der Zellen geleitet; das Geissler'sche (violette) Licht wurile den Larven entweder ungehin lert oler durch Kobaltglas zugeführt. Als mit dem galvanischein Strom pausiert wurde, wurden die Larven dem Einflusse des Tageslichtes durch gefärbte Gläser ausgesetzt.

Diese Versuche ergaben anstatt gelb und braunroth gefärbter Wespen solche bei Bestrahlung durch blaues Licht ganz dunkel gefärbte Exemplare, welche bei einer satten braunrothen Grundfarbe kaum einige abweichende Zeichnungen sehen lassen. Die rothen Lichtstrahlen lieferten hellgelb gefärbte Individuen, deren Zeichnungen roth auf gelbem Grunde sich abheben; „manche Arten aber sind wirkliche Kakerlaken geblieben, mit röthlich schimmernden Augen."

Die Resultate mit violet tem Lichte werilen in dieser Abhandlung nicht erwähnt. 
Carl Verhoeff (189s. y08) sagt, dass ïrmere Pigmentierung kein Bereis dafür ist, dass das Thier der Höhlenfauna angehört und umgekehrt, reichliche Pigmentierung wir.l auch bei Thieren getroffen, welche in Höhlen sich aufhalten. So z. B. kommen in Deutschland völlig blinde I)iplopodlen vor: Blanimlus guttulatus Gerv., Brachydrsmus superus. Latz. und Polydesmus germanicus Verh., welche so pigmentarm sincl, dass sie in dieser Hinsicht den Höhlentiplopoden um nichts nachstehen; die von ihm in einer Banathöhle gefundenen Polydesmus spelaeorum Verh. und Julus strictus Latz. hesitzen: der erstere ganz das Aussehen einer oberirilischen Art (reichliche Pigmentierung), wählırend der letztere, der auch olerirlisch vorkommt, schneeweiss, blind und pigmentlos ist.

Jaroslav R. von Lomnicki (1898. 534) sagt bei seiner Betrachtung des Rufinismus: „Pigmente entstehen und erhalten sich nur in den die strahlende Energie des Lichtes aufnehmenlen Organismen" (1). 357). Dieser Schluss widerspricht jedoch den Beobachtungen verschiedener Forscher, welche bunt gefürbte Schmetterlinge beim Ziehen vom Ei ab in vollstiindiger Dunkelheit erhalten haben.

Pabst (1898. 618) sagt in seiner Abhandlung, dass dlie überwinternden Puppen von Papilio podalivius, welche gewöhnlich wenig iiber der Erde hängen, von licht-weissgell) durch braungelb bis braunschwarz variiren. „Diese Farben dienen ihnen zwischen dem fahlen, toten Grase und den braunen, diirren Blïttern als Schutz vor Verfolgung". Weiter sagt er: „Die Raupen der zweiten Generation verpuppen sich an den Zweigen und auf den Blättern ihrer Nahrungspflanzen, ihre Puppen sind schön grïn, und diese Farbe schiitzt sie am besten zwischen dem Laubwerk" (p, 145).

Am 23. August 1898 hielt Edmond Bordage (1899. 104), Directeur du Muséum d'histoire naturelle de l'lle de la Réunion (Bourbon), einen Vortrag in dem IV. internationalen Congress der Zoologen in Cambrilge iiber: „Expériences sur la rélation qui existe entre la couleur du Milieu et la couleur des Chrysalides de certains Lépideptères," welchem wir folgendes entnehmen:

Er fand an 5 verschiedenen Spezies, dass die Farbe des umgebenden Mediums auf die Raupe einwirkt und nicht auf die Puppe. Diese Empfindlichkeit gegenüber dem umgebenden Merlium war am stärksten während der letzten 20 Stunden der Raupenzeit, und zwar 
als die Raupe nicht mehr frass, unbereglich wurle und sich mit dem Kopf nach unten aufhing.

Seine Versuche stellte er an mit:

I. Atella pholauta (Familie ler Vanessilae). Die Raupen leben auf Flacourtia cataphracta unil F. ramontchi. Puppen sind meist griin mit rothem Ende. Bei einigen Puppen ist die Grundfarbe durchsichtig weiss.

Puppen, an Baumbliittern befestigt, sini griin, wenn nur die Stelle nicht stark beleuchtet ist, wïhrend die an den stark beleuchteten Stellen befestigten Puppen eine Fïrbung mit Silberglanz haben.

Die Versuche ergaben folgende Resultate:

1. Die Flïchen, auf welchen die Verpuppung stattfinclet und welche einen Metallglanz haben, erzeugen bei Puppen ein glïnzentes Aussehen.

2. Weisse Flächen oder hell angestrichene ergeben Puppen meist mit einem Glanz.

3. Dunkel angestrichene Flächen, wobei die Farbe ganz verschielen sein kann, ergeben nur grime Puppen olne glïnzenile Punkte.

4. Sehr schwach beleuchtete in vollständiger Dunkelheit sich lefintende Flächen ergaben schwarze Puppen, welche in der Natur sonst nicht vorkommen. Iie Punkte verlieren dabei fast ilıren Glanz.

Daraus folgt, dass die Lichtintensitït auf die Fïrbung der Puppen einen grossen Einfluss hat. Die gefürbten Flïchen wirken insofern, dlass sie mehr oder weniger Licht durchlassen oiler reflektieren.

II. Euploea goudotii (Familie der Danaidae). Die Raupe lebt auf Nerium oleander. Die Puppen sind entweder silberweiss o:ler goldgelb mit einem Stich ins Grüne; beide Formen kommen gleich häufig vor.

Die Farbe der Flächen hat fast keinen Einfluss auf die Färlung der Puppen; die Wirkung wird nur bei metallglänzenlen Flächen beobachtet und zwar:

Silberglïnzende Flïchen ergeben meist golıglïnzende Puppen. In cler vollständigen Dunkelheit werden Puppen erhalten, lleren Farben im Freien gar nicht vorkommen, so z. B. entwickeln sich auf ılem gewölınlichen Grunde mit Metallglanz Streifen und symetrische Flecken von schwarzbrauner Farbe auf allen hervortretenden Stellen der Puppe (2 Puppen waren am Bauch silberglänzend, wälırend (ler Rïcken vollstündig schwarz war, die dritte Puppe wurle nicht schwarz, hatte aber auch keinen metallischen Glanz). Die iibrigen. Puppen, welche unter gewöhnlichen Umstänılen sich befanten, 
erhiclten diese so eigenthiimlich entwickelten Flecken und Streifen selbst bis zur Entpuppung gar nicht.

Bordage betrachtet diesen Glanz als Erschreckungsmittel.

III. Danais chiysippus (Familie ler Danaidae). Die Puppen kommen in drei Farben vor: 1) blassrosa, 2) hellgriin und seltener 3) gelblich.

Die Versuche mit dieser Art ergaben folgendle Resultate: Auf hell gefärbten orler metallglïnzenden Flächen werden meist grüne P'uppen erhalten, wïhrend auf dunkel angestrichenen Flächen die meisten Puppen weiss oder rosaroth sind. Der Glanz der goldenen Punkte blieb in allen diesen Versuchen fast derselbe. Auf schwarzen Flichen bei schwacher Beleuchtung nalım die Anzahl iler rosarothen In l weissen Puppen stark zu. Bei vollständiger Dunkelheit wurde (ii s: Differenz noch auffallender. Es wurden, wenn auch sehr selten, auch rothe Puppen erhalten, aber nur dann, wenn die Raupen schlecht ernährt wurlen, wobei diese Farbs wahrscheinlich durch ParasitenLarven erzeugt wirl; wenigstens ergaben solche Puppen stets verkriippeite Falter.

IV. Papilio demolers. Die Raupe lebt auf Citronen- und OrangenBäumen oder auf Triphasia trifoliata. Die Farbe der Puppen ist grau oder grünlichgelb; am Bauch ist sie grünlichgelb und an Rücken zuweilen braun-röthlich. Bordage erhielt graue Puppen, welche sich auf der grauen Baumrinde befestigt hatten, und grime Puppen, welche an Blïttern des Baumes waren; auch das Entgregengesetzte (50\%) war zu beobachten,

Er brachte die Raupen in Holzkisten, deren Wände zur Hälfte griin un l zur Hälfte braun-röthlich angestrichen waren. An den Ecken der Kisten wurilen vollständig graue oder grünlichgelbe Puppen und auch ein gewisser. Procentsatz Puppen mit braun-rothem Rücken erhalten. Bei diesen Versuchen bekamen die Puppen zuweilen ihre lraune Fïrbung gegen die gelbe Wand, während andere den gelhen Bauch gegen die braun-rothe Wand. Puppen auf schwarzen Fliichen oder in vollstïnliger Dunkelheit wiesen keinen Unterschied von denen auf, weiche bei vollem Lichte sich verpuppten.

Bordage ist der Meinung, dass dabei der Zufall eine grosse Rolle spielt. Von 5 Raupen verpuppten sich 2 auf einer griinen und 3 auf einer grauen Flïche und ergaben die entsprechende Fïrbung. Ein anderer Versuch mit einer grösseren Anzahl von Rıupen ergal), dass diese Erscheinung ganz zufälig stattfand. 
V. Papilio disparilis. Die Raupen lehen auf denselben Pflanzen, wie dlie vorige Art und die Puppen hahen dlieselbe Färlung. Der Vortragende glaubt, gestiitzt auf die Versuche von Fritg Müller, dass die Puppen dlieser Art gegen den Einfluss des Lichtes unempfinilich sind, stellte aher lieine solche Versuche an. Es scheint ihm wahrscheinlich zu sein, dass dlie Gattung Pajpilio die gesagte Eigrnschaft hereits verloren hahe, imlem er sigt: „Si, comme cela parait jrobahle, il a existé autrefois une alaptalilité, générale pour less chrysalirles des représentants lu gemre Papilin, cette faculté, pum les raisons qui nous échappent, semhle av.jir complètement disjaru à l'époque actuelle; ou, si elle existe encore - soit lins tinute son intégrité, soit déjà diminnée et en voie le disparition - ce n'est pent-être que chez quelques rares espèces sur lesquelles on n'a pais encore expérimentés (p. 242).

In einem spuiteren Zusatze zu diesem Vortrage theilt Bordage noch folgende Beobachtungen mit:

1. Eıploca goudotii. Die Puppen dieser Art, welche an imneren İsten des Baumes und folglich in Schatten waren, hatten den liicken hraun-schwärzlich und den Bauch silberglïnzend gefärbt, wälırend diejenigen Puppen, welche sich an äusseren Aesten befestigten, diese Färbung nicht besassen und nur einen Metallglanz hatten (diese Resultate sind denjenigen in ganz dunkelem Raume erhaltenon ähnlich).

Daraus schliesst Bordage, dass "warning coloration" später entstand, während in der vorhergehenden Epoche nprotective coloration" (homochromie) vorhmden gewesen war und verteiligt in dieser Beziehung die Meinung von Poulton.

2. Dunais chrysippus. Die Puppen sind griin und etwas dunkel. Bordage heobachtete, dass die Puppen, welche auf der goldglänzenlen, Tilgs und Nachts beleuchteten Flïche sich bəfanden, grïn oder rosaroth und weiss geworden sind, wobei die Anzahl der ersteren doppelt so gross war wie die der letzteren.

An der darauf stattfindenden Diskussion nahınen Theil:

1. Roland Trimen (1899. 104), welcher sagte, dass die Versuche mit Papilio lyaens eine grosse Empflindlichkeit der Puppen dieser Art gegren die Anpasung an die Farben des umgebenden Mediums ergaben. Griine Puppen reproduzieren das Grün der Blätter, die braunen - das Braun der Baumrinde, die gelben - das Gelb der einwirkenden Flächen, die rothen - das Roth rler Ziegelsteine. Es sin! jeloch in clieser Richtung noch wenig Versuche angestellt worlen. 
2. H. Caracciolo (1899. 104) sprach von Dumuis chrysippus. Die Raupe frisst "Wild Ipecacuanha," wesshall, weler clie Raupe, noch die Puppe oiler der Schmetterling für dlie Vögel geniesshar ist. Hunderte von Puppen sind griin und ein Anpassung an die Farbe des umgehenden Mediums wirl nicht bemerkt. Die in der Gefangenschaft verpuppten Raupen ergehen blassgraue his röthliche Puppen. welche nicht immer Falter ergeben.

Frederic Míorrifield (1899. 575) untersuchte die successive Bildung des Pigments in der Puppe von Papilio machaon, indem er die Verwandlung der reifen Raupe in die Puppe an einem dunkelen Stengel von Stunte zu Stunde beobachtete. Anfangs war die Puppe ganz grïn, ausgenommen das After-Segment, welches ganz diunkel war. Eine Stunle darauf war die Fïrbung dunkler, die Grundfarbe aber gelh. Nach weiteren 4 Stunlen waren die dunkelen Stellen noch dunkeler. 12 Stunden nach der Verpuppung war die grime Färbung ganz verschwunden, und die Puppe wurde ganz dunkel. Eine zweite Puppe zeigte diesalhe Erscheinung. Die Temperatur der Luft hetrug dabei $60-64^{\circ} \mathrm{F}$. Bei niederen Temperaturen wiirle dieser Process bis zu 4 Wochen dauern.

Die Pigmentation der Puppe, welche sich an einem griinen Stengel verpuppte, wurde nicht so stark verïndert und wurle nicht dunkel.

Diese Versuche wurden Ende September angestellt.

Theodor List (1899. 529) stellte bei der Lntersuchung von Mytilaceen des Golfes von Neapel fest, dass die in Grotten lebenden Formen sich durch einen deutlichen Pigmentmangel auszeichnen. Seine Beobachtungen fasst er zusammen, wie folgt: "Das Licht hat einen wesentlichen Einfluss auf die Pigmentablagerung der Lamellibranchiaten, eine verstärkte Belichtung ruft eine stärkere Pigmentah)lagerung hervor, ebenso ein Lichtmangel eine Alnahme des Pigments". (p. 631-632).

Gräfin Marie von Linden (1899. 322) crzog die Raupen von Vanessa urticae (erste Generation) und Vunessa io, welche annähernd gleichen Alters waren und die zweite bezw. dritte Häutung überstanden hatten, in Glaskästen, deren Boden ein feines Sieb bildete, und deren Scheiben mit Gelatinplatten (nach dem Vorgange von Kirsçmann) von rather bezw. griiner oder blauer Farbe beklebt wurien. Eine Raupenserie wurle auch in vollkommener Dunkelheit erzogen. 
Die Resultate dieser Versuche waren im allgemeinen die folgenden:

Die Veränderungen in der Grundfarbe der Imagines von Vanessa urticae, deren Raupen unil Puppen rothem Lichte ausgesetzt waren, wurden am intensivsten und glïnzendsten. Durch die Einwirliung des grïnen Lichtes trat Verdüsterung ein, im blauen Licht und in cler Dunkelheit erhielt die Grunlfarbe einen helleren Ton. Bei Vanessa io blieb die Grunlfarbe ziemlich unverïndert, und die gelben Ränderflecke ergaben dieselben Veränderungen, wie die bei Vanessa urticae beobachteten.

Die Verschiebungen in ler Flügelzeichnung waren bei $V a$ nessu uticae keine sehr grossen. Die läufigsten Variationen sind: 1. Schwinden des vorileren dunklen Seitenrantzellfleckes unl 2. Verdüsterung der Flügelspitze durch rlunkle Bestäubung der Adern. Die Variation 1 wurde unter rothem Licht gar nicht beobachtet, bei den unter grüner Beleuchtung anfgewachsenen Faltern an einem Zwölftel der Gesammtzahl, bei den unter blauen Strahlen und im Dunkeln entwickelten Faltern an einem Drittel des Versuchsmaterials. Die Variation 2 ist aligemeiner: sie wurde bei einem Drittel cler ersten, einem Viertel der zweiten, nahezu der Hälfte der dritten un:l einem Fünftel der vierten Versuchsreihe beobachtet.

"Abgeändert sind im übrigen ausserlem der schwarze Seitenrimcl, der bei den Imagines, die sich unter blaner Beleuchtung entwickelt hatten, besonders breit geworden ist, die gelben Streifen am Seitenrand, die bei der rothen Serie am breitesten sind, die Gestalt der dunklen Bin ten am Fliigelvorilerrand, die bei den in der Dunkelheit aufgewachsenen Schmetterlingen in eigenthümlicher Weise eingeschnürt erscheinen, und endlich die blauen Flecke am Seitenranil, welche bei den unter blauem Licht gezogenen Faltern in auffallender Weise riickgebildet wurden" (p. 321).

Bei Vanessa io war'n diese Verschiebungen die folgenden: 1) das Auge im Vordertlïgel, dessen Aussenrand bei Serie 1 durch Schuppen der Grundfarbe voin eigentlichen Augfleck abgetrennt ist; 2) das blaue Auge im Hinter- und Vordertliigel, das bei den im blauen Licht aufgewachsenen Schmetterlingen ain grössten, bei denen, (lie rothem Licht ausgesetzt waren, am kleinsten ist; 3) die Länge und Breite der gelben Binden, die bei den unter blauer Beleuchtung entstandenen Imagines am grössten, bei der rothen Serie am kleinsten ist. 
Zum Schlusse sagt Marie von Linden: „Jeclenfalls genügen die erzielten Ergebnisse, um zu zeigen, dass die beschriebenen Abänderungen in vollkommen gleichen Richtungen verlaufen, wie sie durch den Einfluss der Temperatur erzielt werilen können; sie sprechen für eine Abänderung der Falter nach wenig bestimmten Richtungen für Orthogenesis - " (p. 321).

L. Kathariner (1899. 437) brachte im Juli mehrere Hunderte von Raupen von Vanessa io in drei verschiene Kästen.

In folgendem sind die Puppen der Stammform als "dunkele", bezw. "ganz dunkele“, die zur Varietät gehörigen als "helle", bezw. "ganz helle" bezeichnet.

1. Etwa 100 Raupen wurden in einem hellen Holzkasten untergebracht, der, vorn und an den Seiten mit grossen Drahtgazefenstern versehen, dem Tagelicht voll ausgesetzt wurcle. Von 69 erhaltenen Puppen waren:

$$
\begin{aligned}
& \text { Dunkel. . . } .21=30 \%(\text { ganz dunkel } 11) \\
& \text { Hell . . } 48=70 \%(" \text { hell } 40) .
\end{aligned}
$$

2. Ein Kasten wurde innen halb schwarz, halb weiss angestrichen, jederzeit also die Hälfte der Decke, des Bodens, der Vorder- und Riickwand und die ganze Seitenwand. Beide Hälften wurden mittelst eines grossen Drahtfensters in der Vorderwand gleich stark belichtet.

Von 150 Raupen verpuppten sich 103 und zwar zuerst auf der weissen Hälfte des Kastens und zuletzt auf der schwarzen. Es waren:

$$
\begin{aligned}
& \text { Auf Schwarz . . . } 44=42,7 \% \text {. } \\
& \text { Auf Weiss . . } 59=57,3 \% \text {. }
\end{aligned}
$$

Davon waren folgende Puppen:

$$
\begin{aligned}
& \text { Dunkel. . . . . . . . . . 50 } 50=51,5 \% \text { }=48,5 \% \text {, } \\
& \text { Heli . . }
\end{aligned}
$$

Auf der schwarzen Hälfte waren:

Dunkel . . . 43 $=98 \%$ (ganz dunkel 38).

$$
\text { Hell . . . . 1 }=2 \% \text { (ganz hell } 0 \text { ). }
$$

Auf cler weissen Hälfte waren:

$$
\begin{aligned}
& \text { Dunkel . . . } 10=17 \%(\text { ganz dunkel } 0) \text {. } \\
& \text { Hell . . . 49 }=83{ }^{\prime}{ }_{0}(\text { ganz hell } 34) .
\end{aligned}
$$

3. 23 Raupen wurden in einem absolut dunkeln Kellerraum bei $+18^{\circ} \mathrm{C}$. bis zur Verpuppung erzogen. Von 23 Puppen waren: Dunkel . . . $17=74 \%$ (ganz dunkel 16).

$$
\text { Hell . . . } 6=26 \% \text { (ganz hell 5). }
$$


Aus diesen Versuchen ist ersichtlich, class die sonst seltene helle Spielart in überwiegender Mehrheit gegenüber der ilunkeln typischen Form auftrat, d. h. lass das normale Verhältniss der Stammform zur Varietat sich unkehrte. Die Schuld daran trïgt, nach Kathariner, ler Lichteinfluss, wobei es sich bei diesem Vorgang un einen chemisch-physikalischen Prozess, ähnlich der Erscheinung, welche 0. Wioner (1895. 959) als „mechanische Farbenampassung" bezeichnet, handelt; "sie entsteht iurch Auslese der Farhstoffe, welche der zerstörenilen Einwirkung der Belenchtungsfarlxe am besten wilcrstehen; das sincl die gleichfirbigen". Fulglich ist liese Farbenempfindlichlieit der Raupen- bzw. Puppenhaut nicht durch Zuchtwahl erworben unl schliesst auch keine Zielstreligheit ein.

In September erhielt dieser Forscher wieler eine grüssere Anzahl von Raupen der II. Generation ron Vunesse io unil wieilerholte ren Versuch 2). Es wurle bestätigt, dass ganz helle Puppen nur in der weissen Hälfte des Kastens auftraten.

Der Unterschied in Resultaten dieses Versuches gewenuiber den früheren bestand in folgendem:

1. Die Raupen bevorzugten jetzt nicht die helle Hälfte des Kastens, sondern die dunkele.

2. Jetzt standen 7 hellen Puppen gegenïber 61 dunkelgefiirbte, und nicht die Hälfte, wie früher.

Kathariner erklärt diesen Unterschieil durch die Temperaturverhältnisse, da im Juli die Temperatur 20-300 C. war unl im Anfang September $22-23^{\circ}$ C. betrug, wobei die wenigen hellen Puppen zur Entwickelung kamen. Gegen den 10. September sank die Temperatur auf $15^{\circ}$ C. und blieb anch weiter dieselbe; die währenı dieser Zeit verpuppten Raupen ergaben die dunkele Form.

Somit wäre der Antheil einer gewisser Wärme, wie es Standfuss (1896. 840) fand, bestätigt.

Kathariner erwähnt kuxz seinen Versuch mit urticue-Raupen, die bei ihm auf ganz weissem Grunde sich verpuppten und die typische, dunkelbraungrau gefürbte Form ergaben.

Eine völlige Analogie mit der Farbenphotographie lehnt er deshalb ab.

Welchen Einfluss die dabei entstandenen verschiedenfarbigen Puppen auf die Färbung des liüftigen Schmetterlings haben, sagt er ein Jahr später (1900. 438): „Auch bei den Faltern, deren Puppen normalerweise dem Lichte ausgesetzt sind, z. B. Vanessaarten, hat die Entziehung jeglicien Lichtes sellsst bei der Zucht von der jungen 
Raupe ab, wie ich aus eigenen Versuchen weiss, keinen nemnenswerthen Einfluss auf die Farbe unl Zeichnung des Schmetterlings" (p. 165). Er ist der Meinung, dass, wenn in einem orler dem anderen speziellen Falle das Licht einen gewissen Einfluss doch ausüben konnte, dies höchstens the Farbe als solche, nie aber die Vertheilung der verschiedenen Farben, d. h. die Zeichnung zu beeinflussen vermochte: „ler Grun I dafür muss in der Structur der betreffentlen Flügelpartie selbst gesucht werden."

L. v. Aigner-Abafi (1900. 5) beschreibt die Lebensweise der Raupe von Lycrena jolıs O., welche in der Fruchtschote ron Coluteia arborescens bis zur Verpuppung lebt. Er sagt: "Die Farbe ler Raupe richtet sich zumeist nach der Färbung der Schote, worin sie lebt; in grünen Schoten ist sie blassgrün, in rothen rüthlich unil in reiferen weissen Schoten braunweisslich, oft lichtbram, auch ins Rosa spielend ${ }^{*}$ (p. 225).

K. Berg (1900. 69) schreil,t, lass manche ler auf Termitarien leobachteten Insekten (hauptsïchlich Cicindeliden) sich in ihrer Färbung dem Lehmroth ihrer Umgebung nähern.

E. Danilow (19)0. 163a) konnte deu Schmetterling tropus ulmi Schieff. sehr schwer von der jungen Baumrinde unterscheiden, auf welcher derselbe sass. Ceber die Färbung der Raupe von Demıs coryli L. sagt er: "Ende des Sommers, als es hier warme somige Tage noch sehr viel giebt, verbiergt sich die Raupe zwischen den Blïttern, entgeht dem Licht und besitzt die weisse Färbung, welche den Ueberschuss an Sonnenstrahlen von der Oherflïche der Raupe reflektiert. Bei einer ungenügenden Beleuchtung unıl Wärme, wie es im Herbst oder im Zimmer der Fall ist, nehmen die Raupen dunklere Färbung an, welche die Wärme absorbiert" (p. 131).

Alexander Mordwilko (1900. 593) fand, dass melirere Arten von Pflanzenliusen, welche die der Sonne ausgesetzten Pflanzentheile bewohnen, zuweilen eine Färbung haben, die derjenigen der Pflanze. mehr o.ler weniger ähnlich ist. Diese Arten sinıl z. B. Symydı tiıș oblongus (Birkenrinde), Lachnus taeniatus (Tannenrinde), Lachuus agilis (Tannenföhre) Vacuna betulae (unter den Birkenbliittern) etc. Da er die Färloung als das Schutzmittel gegen die warmen Sonnenstrahlen betrachtet, sagt er: „Ob ılieser Uinstinıl irgend eine Bedeutung 
gegen schädliche Wirkung der Sonenstrahlen hat, kamn man vorlïufit: nicht sagen" (p. 249).

Oskar Schultz (1900. 785) sagt in einer kurzen Notiz: „Was die Färbung der machaon-Puppen betrift, so kimn von einer Anpassung derselben an ihre Umgebung wohl nur in bedingter Weise die Redr sein. Zwar findet man häufig Puppen dieser Art, dlie in ilırer Fïrbung vom hellsten Grün bis zum tiefsten Schwarzbraun wechsehn, der Umgebung nicht ïbel angepasst; rloch giebt es, wie man in Freien unı bei der Zucht grösserer Mengen dieser Raupen mit Leichtigkeit feststellen kann, nicht wenige Fälle, die von diesel Anpassung eine Ausnahme bilden" (p. 56).

E. Fischer (1900, 234) fand, dass das Farbemmuster der Vor(lerflügel-Oberseite in der Chitinschale der Flügelscheile der Puppe kopiert wirl. Diese Erscheinung wird durch hohe Temperatur l,egünstigt. Eine grössere Anzahl Puppen von Vanesso urticue, polychloros, antiopa und io wurden der Temperatur von $38^{\circ}$ bis $41^{\circ}$ vier bis acht Stunden lang in noch ziemlich weichem Zustanlle ausgesetzt. Nach dem Ausschlïijfen der Falter zeigten die leeren l'uppenhülsen von $V$. io die rothe, von $V$. urticue sogar die rothe unt schwarze? Farbe der Vorlerflïgel-Oberfläche copiert. Bei den meisten Puppenhuilsen von io verschwand der oft ïusserst intensiv rothe Farbstoff nach einigen Wochen gänzlich, obwohl dieselben in völliger Dunkelheit gehalten worden waren.

I. M. Bastelberger (1900. 54) züchtete die liaupen von Eupithecia criceata Rbr. und Eupithecia millieraia Stgr. und erhielt Falter, welche keinen durchgreifenden Unterschied constatieren liessen; er hielt deshalb die zweite Art für $E$. criceata Rbr. und bemerkt dabei: „Wenn man aber die grosse Veränderlichkeit und (las Anpassungsvermögen der Eupithecien-Raupen kennt, so kann es nicht Wunder nehmen, auf dem Wachholder eine Form zu finden, bei der die Schutzfürbung den Charakter der abgestorbenen, braun gewordenen Nadeln angenommen hat" (p. 147).

Andrea Giardina (1900. 310) in Palermo beobachtete dlas Ausschlüpfen der Larven von Ameles spallangania Rossi. Nachlem die Larve das Ei verlassen, streckt sie die Antennen und Beine, wobei die Färbung des Körpers sich verdunkelt. Dieser plötzliche 
Farbenwechsel „kann nicht die einfache und alleinige Folge des Einflusses der athmosphärischen Luft sein, da diese Zutritt auch zum Eineste hatte, sondern wird eher eine Wirkung des Lichtes sein". Dieselbe Fürbungsän(lerung beobachtete er auch bei ILantis religiosa L. (1899. 309).

Ph. C. Karl Absolon (1900. 2) sagt bei der Betrachtung verschiedener Entwickelung des Pigmentes der Höhlenthiere: „Manche Exemplare von Heteromurus ofler Dicyrtoma sinıl so stark pigmentiert, dass die blassgelbe Grunlfarbe völlig schwindet; „lie Thiere scheinen dann purpurroth zu sein (v. purpurcue mihi); wieder bei manchen Exemplaren fehlt diese Pigmentierung fast gänzlich. Verschiedene Entwickelung der Pigmentierung hängt wahrscheinlich mit ler Localität zusammen, wo die erwähnten Formen leben. Ich habe nïmlich beobachtet, dass die stark pigmentierten Arten aus der NicováScála-Höhle stammen, die schwach oller gar nicht pigmentierten aus der Šošìtier-Höhle und Katharinenhöhle" (p. 4).

L. Kathariner (1900, 440) verwenclete bei seinen Versuchen iiber den Eintluss der verschiedenen Strahlen des Spelitrums auf Puppe und Falter von Vanessa uticae und io ganz junge Raupen leicher Abstammung und brachte sie in ganz gleich gebauten innen weiss angestrichenen Zuchtkasten, welche auf demselben Tisch sich befanilen. Un den Einfluss der ultravioletten unil iler ultrarothen Strahlen zu beseitigen, stellte er vor die Einfallsutfinung eine Cuvette mit einer Lösung ron schwefelsaurem Chinin bezw. Alaun.

\section{Versuche mit Vunessa urticae.}

Die Räupchen eines Nestes wurlen in 6 Gruppen getheilt uni unter verschielenen Beleuchtungsarten aufgezogen. Die erhaltenen Puppen hatten folgende Färbungsunterschiede:

1. Im vollen Tageslicht: Puppenzahl 24. Alle hell weisslichbraun mit mehr ocler weniger Metallglanz.

2. In vülligrer Dunkelheit: 24 Stiick. Davon 15 dunkel röthlichgrau mit dichter brauner Rieselung auf Fligeldecken und Rïcken und ebensnlchen Flecken auf slen Hinterleibsringen, ohne Metallglanz. 9 Stück heller, mit blasssilbernen Flecken am Rücken.

3. Im rothen Licht (hinter Rubinglas): 21 Stiick. 15 ziemlich hell mit gelber Grumlfarbe unil mit Metallglanz. Dunkel und ohne Metallglanz 6. 
4. Im gelben Licht: 10 Stiick. 8 bronzegelb und goliglïnzend, 2 ähnlich denen aus Tageslicht.

5. Im blauen Licht (hinter Kiobaltylas): 14 Stiick. Alle röthlichgrau, die meisten stark dunkel, mit wenig Metallglanz.

6. Hinter Chininlösung: 10 Stiick. 6 wie aus Tageshicht, davon 3 goldglänzend; dunkel 1 .

\section{Versuche mit Vanessa io.}

Die ganz jungen Räupchen eines Nestes beim Aufziehen ergaben folgende Puppen:

1. Im Tageslicht: a) auf weissem Grund eines zur Hälfte schwarz, zur Hälfte weiss angestrichenen Kastens: 10 Stiick. 5 gelblichweiss mit sehr spärlicher und feinliniger bräunlicher Rieselung, 5 weissgrau. Alle hellfarbig. b) auf schwarzem Grund: 18 Stiick. Alle dunkel röthlichgrau mit dichter und breitliniger brauner Rieselung.

2. Im rothen Licht: 22 Stück. Alle sincl lebhaft grünlichgelb. Die Makeln an Hinterrandle und clie Körperspitzen sincl lellhaft karminroth.

3. Im gelben Licht: 17 Stück. Alle von derselben Farbe, wie die der vorigen Gruppe mit lebhaftem Metallglanz.

4. Im blauen Licht: 22 Stück. 18 dunkel, wie die der Gruppe 1 b); 4 hell, wie die von 1 a).

Ausserdem zog er die Räupchen von Vanessa io bis unmittelbar vor der Verpuppung in Tageslicht auf und erst dann die Raupen den verschiedenen Beleuchtungsarten ausgesetzt. Das Resultat war folgendes:

1. Im Tageslichte (hinter weissem Mull): 14 Stück. 12 davon hell gefärbt, wie dlie Puppen aus 1 a) des vorigen Versuches. 2 ziemlich dunkel, wie bei $1 \mathrm{~b}$ ).

2. In der Dunkelheit (hinter weissem Mull): 18 Stuick. Alle ganz dunkel, in der Färbung übereinstimmend mit den im Tageslicht auf schwarzem Grund hängenden Puppen der Serie 1 b) des vorigen Versuches.

3. Im rothen Licht (hinter Alaunlösung): 12 Stïck. 11 davon hell grünlichgelb, wie im vorigen Versuch.

4. Im gelben Licht: 13. Alle ausnahmslos hell grünlichgelb.

5. Im blauen Licht: 13. Dunkel 9, hell 4 .

Da aus diesen Versuchen hervorgeht, dass Dunkelheit, Tageslicht bei schwarzem Hintergrund und blaue Strahlen die Bildung der 
dunkelbraunen Zeichnungsfarbe begünstigen, so kommt dieser Forscher zum Schlusse, „dass der rothgelbe Theil des Spektrums die Entstehung der braunen Farbe verhindert" (p. 376). Ferner sagt er: „Aus dieser Annahme eines activ verhindernden Verhaltens der rothgelben Strahlen gegeniiber dem braunen Pigment erklärt sich dann auch verhältnissmässig einfach die dem Untergrunde angepasste "Sehutzfärbung" (p. 377). Er ist der Meinung, dass von "chemisch aktiven" bezw. "inaktiven Strahlen" im allgemeinen in der Biologie nicht die Rede sein darf, da die beiden Hälften des Spektrums einen gegensïzlichen Einfluss auf die Farbe der Puppenhaut haben, und zwar verhält sich der „chemisch aktive" Theil analog dem völligen Lichtmangel, der "chemisch inactive" dagegen ähnlich dem weissen Tageslicht eine Hellfärbung bedingt.

Am Schlusse seiner Arbeit sagt er: „Unter dem Einfluss solcher Erwägungen werden wir es deshalb auch nicht weiter verwunderlich finclen, wenn trotz der ausgesprochenen Abhängigkeit (ler Puppenfarbe von der Art der Belichtung das Farbenkleid des Falters nichts derartiges erkennen lässt" (p. 380). Er hat nämlich die Reduktion der schwarzen Flecken bei Falter von Vanessa urticae im rothen Licht bei $1 / 5$, im gelben bei $1 / 5$, im blauen bei $1 / 14$, im Tageslicht bei $1 / 12$, in der Dunkelheit bei $1 / 1_{2}$ erhalten; auch andere Verschiedenheiten in der Zeichnung und Färbung wurden dabei beobachtet; diese Merkmale können jedoch nach ihm, innerhalb einer einzigen normalen Zucht vorkommen und nur auf individueller Variabilität beruhen.

Aus diesen Versuchen geht auch hervor, dass die Behauptung von R. Meldola (1873. 556), dass nicht die Puppenhaut als solche lichtempfindlich sei, sondern eine farbige Umgebung, in welcher die Raupen gehalten werden, theilweise verändernd auf die Färbung der Puppen einwirke, unrichtig ist.

I. Lebedinski (1900. 503) fand in der Höhle Suuk-Hoba (in Krym), in welcher vollständige Dunkelheit herrschte, einige Vertreter (ler Familie Poduridae (die Arten konnte er nicht bestimmen), welche entweler himmelblan oder isumrud-grün gefärbt waren, wobei diese Färbung am Bauch heller war.

R. Tümpel (1901. 886) beobachtete die Lebensweise einiger Heuschrecken-Arten und fand, dass Meconema varium F. während des ganzen Tages regungslos unter einem Eichenblatt sass. "Zu 
liesem Aufenthaltsorte passt seine zartgrüne Farbe vorzïglich, da es sich nicht von der hellgrünen Blattunterseite abheht" (p. 7).

Karl Dietze (1901. 182) fancl in Trrol aut Hippophae rhamnoides Raupen von Eupithecic frosinulu $C_{r}$, , deren Fürbung dem silbrigen Blatte dieser Pflanze angepasst war.

Chr. Schröder (1901. 777) erhielt aus einer Copula von Faltern rler Tephroclystia (Enpithecia) vulyatu Hw. etwa 8.5 Eier, von denen 78 schliipften. Die Räupchen wurlen auf vier Zuchtgliaser vertheilt, deren drei mit weissem (a), schwarzem (c) bz. citronengelbem (b), stark reflektierenlem Papier um cylinclrische Theile umklebt waren: das vierte Glas (1) blieb frei. Ins erstere wurlen je 20, ins letztere 1s Riiupchen sofort nach dem Verlassen des Eies gegeben. Dir? Räupchen wuchsen unter normalen äusseren Bedingungen auf un wurilen mit jungem Laub von Prunus spinosa L. gefiittert, dis tïglich frisch aber in geringer Menge gereicht wurle. Zwischen (las Futter (der a)- und b)-Raupen brachte Schröder Strcifen vom weissen, bz. citronengelben Papier.

Diese Versuche ergaben folgendes: Von clen 9 erwachsenen a)-Paupen zeigten 6 eine haselfarbige Grundfürbung, die 3 anteren waren dunkler. Unter den 12 erwachsenen b)-Raupen besassen 7 eine bernsteinähnliche Grundfarbe; 4 gehörten mehr den normalen (1)-Raupen, die letzte den a)-Raupen an. Die $S$ erwachsenen c)-Raupen wiesen bis auf 3 einen ausgeprägt kastanienfarbenen Gruml auf; die 3 anderen Individuen neigten zu (ler Type d). Diese, also die Normalform, hatte bei 8 ier 10 Intlivirluen eine gelbbraune Grunifarbe; die beiden anderen Individuen näherten sich der Type h).

Chr. Schröder (1901.775) hielt Puppen von Adalia bijunctatu L. völlig im Dunkeln, und erhielt normal gefürbte. Kü̈fer mit vielleicht etwas abweichender Farbentönung. Daraus schliesst er, dass die Belichtung nicht das bestimmende Agenz für die Ausfürbung bilılet. Er liat jeiloch den Eindruck erhalten, dass sich die Zeitlauer der Ausfirbung als eine Funktion der Licht- oder Wïrme-Intensitiit (selbstredend innerlalb bestimmter (irenzen) darstellt.

E. Fischer (1902. 209) bespricht bei seinen Untersuchungen über die Vererbung erworbener Eigenschaften die Färbung der Schmetterlinge und frägt, weshalb erscheinen auf der Oberseite 
die Farben etwas stiirker, satter und saftiger, als unterseits? und antwortet: „weil die Oberseite bei diesen an Tage Hiegenden Faltern dem Sonnenlichte mehr zugewendet ist, und daher stärker bestrahlt wirl, als die mehr abwïrts gerichtete Unterseite" (p. 132).

I. Vosseler (1902. 932) beobachtete in Nordafrilka, dass einige Orthopteren (Truxalis) nach ihrer Haütung in grüner Umgebung griin werden; diejenigen, welche auf Holz oder Steinen sitzen, werden gran oder braun.

D. Pomeranzew (1902.640 b) beobachtete, dass Nemutus suxesenii, als junge Larve von blassgrüner Farbe, junge Nadeln vou Picea excelsa frisst; vor der letzten Häutung aber, nachılem dieselbe die Färbung der vorjïhrigen Nadeln der Fichten angenommen hat, frisst sie nur die alten Nadeln.

I. Devitz (1903. 174) untersuchte die Einspinung der Raupen von Bombyx lauestri und Saturnia pyri. Da in Zuchtlkasten keine Erde vorhanden war, wollten die Raupen von B. lanestri sich nicht verwandeln. Bei genauerem Nachsuchen fand er jedloch theils in Spalten, theils ain Boden des Zuchtkastens, theils besonders im Inneren les grossen gemeinschaftlichen Nestes eine Anzahl von Kiokons: dieselben waren weiss (graulich odler gelblich) und nur zwei, welche auf den Futterptlanzen angefestigt waren, waren braun. Die Raupen von S. pyri, welche in eine weisse mit einem Stuick weissen Pilpiers zugedeckte Kartonschachtel gebracht waren, fertigten Kokons von weisslich grauer Farbe; später wurde die Farbe hellbraun. Er zieht daraus den Schluss, dass die Raupen bei der Bildung ihrer Kokons den Inhalt der Malpighischen Gefïsse entleeren unil class sie aus diesem Stoffe die äussere Schicht, die Kruste des Kokons bilden.

Æ. Verson (1904. 919a) kritisiert die oben angeführte Untersuchung von I. Devitz, indem er die spätere Färbung der Kokons (z. B. in der Gattung Saturnia) den Auswurfstoffen der Raupen zuschreibt; „so dass das noch feuchte Gewebe von ilnen durchtränlit und häufig sogar mit beigemischtem fremden Material zu einer festen Masse gleichsam verleimt wird" (p. 398). „Ob jedoch die Kokonschale heller oder dunkler ausfällt; ob die dunkle Farbe nur stellenweise oder mehr gleichmässig auf der ganzen Oberfläche derselben sich ausbreitet - daran dürfte die grössere oder geringere Helligkeit des 
Stantortes wahrlich keinen Einfluss ausüben; die oben geschiltlerten Modalitiiten, unter welchen die Bildung und die Ausfulır des zeitweise gefürbten Darmsaftes in den spimnreifen Raupen vor sich gehen, reichen jedenfalls hin, um ähnliche Verschierlenheiten in einfachster Weise zu rechtfertigen, - insoweit sie natiirlich von der Gegenwart eigener in der Spinndrüse selbst erzeugter Farbstoffe nicht abhängig sind" (p. 399).

I. Dewitz (1904.177b) verwirft lie oben erwähnte Kritik von E. Verson, indem er sagt, gestiitzt auf die Beobachtungen verschie(lener Forscher: „Die Entleerungsprodukte geben den Kiokons Farbe und die Farbe des Kokons richtet sich nach der Beleuchtung. Man muss also folgern, dass die Beleuchtung auf die Entleerungsproilukte wirkt, falls man nicht hier sowohl wie bei lanestris zu dem entfernteren Schlusse greifen will, dass die Beleuchtung erst in irgend einer Weise auf (len Organismus der Raupe wirkt" (p. 619).

H. Ruhe (1904. $726 a)$ erwähnt folgende Fälle, wo die Raupen ihrer Färbung nach der Umgebung genau angepasst sind:

Vor der Ueberwinterung ist die Raupe von Pamphila silvius grïn (im Sommer ist das Gras grïn), nach der Ueberwinterung gelb (im Frühjahr ist das Gras durchweg gelb gefärbt).

Eine ähnliche Anpassung ihrer Färbung derjenigen der Umgelumg haben die Raupen von: Odonestis pruni, Epicnaptera tremulifolia, Gastpopacha quercifolia, Gattugen: Agrotis, Leucanie, Catocala.

I. Vosseler (1902. 932) beobachtete Orthopteren in Algerien unil Tunesien und fand bei ihnen zahlreiche Beispiele weitgehender Anpassung an ilrre Umgebung, welche in Farben- und Skulpturverhältnissen besteht und auf alle exponierten liörpertheile sich erstreckt, wohingegen die beim ruhenden Thier nicht sichtbaren Theile oft mit auffallenden Prunkfarben ausgestattet sind.

Diese Thiere haben die Fähigkeit, ihre Färbung bei jeller Häutung zu verändern. Unmittelbar nach der Hüutung sind diese Thiere farblos oder leicht gelblich gefürbt. Die Häutungen erfolgen stets in den Vormittagsstunden, zur Zeit der wirksamsten Belichtung.

L. Melichar (1904. 558) beobachtete, dass clie Zikade Athysanus stactogalus der Färbung ihres Körpers nach sich den klima- 
tischen Verhültnissen aupasst: „lie in süllichen Gegenden vorkommende Art ist gleich den Blättern der Tamarix dunkelgrïn gefïrbt, während die bei uns (Wien) auf in Ziergürten kultivierten Tamarix vorkommenden Zikaden viel heller gefärbt sind."

A. Trost (1904. 884a) fand auf der Strasse ein Puppenkokon ron Cerura bificla Hb. "Das Puppengespinst war lart wie Holz und befand sich seitlich an einem Strassenpflocke. Es hatte genau die Farbe und Form wie ein an den Holzpflock angeschleutertes und angetrocknetes, ovales, flach gewölbtes Stïck Strassenkotes (p. 111).

M. Holtz (1904. 386) erbeutete in Griechenland einen neuen Schmetterling Lygris peloponnesiacu Rbl., ılessen Raupe meist grün, selten braun vorkommt, und in ersterer Färbung den Blattstielen :̈hnlich sieht, in letzterer den Zweigen gleicht.

G. Warnecke (1904. 943) beobachtete, dlass die Raupen von Apatura iris L. beim Ueberwintern sich in eine Ritze oder Vertiefung ain Fuss des Stammes einschmeigen, wo sie sich nach der Farbe ihrer Umgebung dunkelbraun oder grau färben.

I. Oudemans (1904. 617) untersuchte die Lage der Schmetterlingsflügel in Ruhe bei verschiedenen Arten und kam zum Schlusse, dlass eine Einwirkung des Lichtes auf die Entwickelung des Ruhekleiles im Laufe der Phylogenesis stattger̂nden hat.

H. Müllenberger (1904. $596 a$ ) brachte junge Raupen von Vanessa urticae in eine Flasche von dunkelrothem Glase. Die einzelne lebend gebliebene Puppe ergab einen wesentlich dunkler gefärbten Schmetterling; Hinterflügel und das Blau an den Flügelrändern waren tiefschwarz.

N. Cholodkowsky (1905. 144) erzog Raupen von Vanessı uticue L. in Glaskïsten mit doppelten Wänden, indem zwischen den Glasplatten eine wässerige Alaunlösung eingegossen war (die Dicke der Lösung $=1,5 \mathrm{~cm}$.). Die äusseren Wände des Kastens waren blau, roth odler gelb gefürbt. Die Farbe wurde spektroscopisch für rein gefunilen. Auf diese Weise erhielt er 87 Schmetterlinge (29 aus dem blauen, 28 aus dem gelben und 30 aus dem rothen Kasten). Die Schmetterlinge hatten im allgemeinen die normale Farbenverthei- 
lung, „nur fast ausnahmslos mit starlier Neigung zum Vorherrschen der schwarzen Schuppen. Der grosse schwarze Wur\%elfleck und ier Randsaum der Vorder- und Hinterflïgel waren merlilich erweitert, die beiden schwarzen Mittelfleclie des Vorderfliigels aber besonders gross." I)iese Variationen waren ler var. poluris Stgr. sehı ïhnlich.

Nach diesen Versuchen glaubt er schliessen zu dürfin, dass die monochromatische Beleuchtung der Wirkung der erniedrigten Temperatur im gamzen aequivalent ist, besonclers da die fontrolVersuche bei n:mrmaler („weisser") Farbe licine solche Variationen ergaben.

N. Kusnezow $(1906.490$ a) kritisiert die Versuche von N. Cholodkowsky (1905. 144) iiber die Erzeugung kïnstlicher Formen von Vanessa urticae durch monochromatische Beleuchtung der Raupen und Puppen, indem er zavei Fehlerquellen anfiilırt:

1. I)ie Unmöglichleit, die Intensitit verschiedenfarl,iger Beleuchtungen direkt zu vergleichen unı somit die Energie-Quantititen bei verschiedener Wellenlïnge zu bestimmen. Die Intensitiit der LichtEnergie ist aber, wie bekannt, ein Faktor von grüsster Wichtigkeit für den Organismus.

2. Der Untorschied in der Zuyammensetyung des Futters, welcher unter dem Einfluss verschiedener Lichtwellen entsteht.

Er lïsst deshalb keine Möglichkeit zu, irgenıl welche Folgerungen aus diesen Versuchen zu ziehen; "auch ist Anstellung ron Versuchen nach der bisher gebrïuchlichen Methodik ganz unnütz."

\section{Ergänzungs-Litteratur zu diesem Abschnitt.}

Batenson, W. On Variation in the Colour of 'Cocoms of Eriogaster lanestris and Saturnia carpini. - Tr. Ent. Soc. 1892. p. 45-52.

Batenson, W. On Variation in the Colour of Cocons, Pupae and Larrae: further expiriments. - Tr. Ent. Soc. 1892. p. 205-214.

Bates, H. W. Mimetic Forms among Insects. - Amer. Naturalist. Vol. 1. 186r. p. $155-156$.

Blanchard, E. On the coloration of certain Insects of the order Lepidoptera. Ann. Nat. Hist. (6). XVII. 1896. p. 328.

Blutenmüller. Variation in colour of sphingid larva. - Bull. Am. Mus. IT. 1892. p. 65.

Bonhote. Green and lrown pupae of Papitio podalirius. - Entomologist. XIT. 1892. p. 44.

Brauner. Ueber den Farhenwechsel von Chrysopa vulgaris Schn. - Zool.-bot. Verein in Wien. II. p. 12. 
Ciaccio, G. V. Della natura c cagione unde muove il color cangiante negli ucchi delle Tabanidae, e dei mezzi refrattivi che in loro si trovano. - Mem. Ac. Bologna. (5). 1894. p. 247-254.

Flammarion, c. The Action of different rays of the sular spectrum on the development of Silkworms. - Exper. Stat. Res. XU. 스 10. 1900. p. 969. Auch in: Bull. miner. agr. XIX. № 5. p. 865-868.

Gould, L. Expriments in 1890, 1891, on the Colour-relation between certain Lepidopterous larvae and their sorroundings, together with some other observations on Le pidopterous larvae. - Tr. Ent. Soc. 1892. p. 215-245.

List, Theod. Ueber den Einfluss des Lichtes auf die Ablaterung ron Pigment. - Arch. für Entwickelungsmech. VIII. 1899. p. 618.

Merrifield, F. Colour of pupae and surrounding. - Proc. Ent. Soc. 1592. p. 3 ).

Merrifield, F. and Edw. B. Poulton. The Colour-relatim between the pupite of Papitio machaon, Pieris napi, and mony other species and the surroundings of the larrae preparing to pupate. - Trans. Entomol. Soc. London. IV. 1900, p. 369-433.

Poulton, E. B. Notes upon, or sugrested ly, the Colurirs, Markings, and Protective Attitudes of certain Lepidopterous Larvac and pupae, and of a phytophagous hymenopterous larva. - Trans. Entomol. Soc. 1884. p. 27-60.

Poulton, E. B. Further Notes upon the Markings and Attitudes of Lepidopterous Larvae together with a complete account of the life-history of Sphinx ligustri and Selenia illunaria (larvae). - Trans. Ent. Soc. 1885. p. $281-329$.

Poulton, E. B. Notes in 1886 upon Lepidopterous Larvac. - 'Trans. Ent. Suc. 1887. p. $281-321$.

Poulton, E. B. Notes in $18 s 7$ upon Lepidopterous Larvae etc., including a complete account of the life-history of the larvae of Splinin convolvuli and Aglia tau. 'Trans. Ent. Soc. 1888. p. 515-606.

Poulton, E. B. Experiments in 1893, 1894 and 1896 upon the Colour-Relation between Lepidopterous Larvae and their Surroundings. amil Especially the Effect of Iichen-covered Bark upon Odonoptera lidenata, Gastropacha quercifolia etc. - Trans. Entom. Soc. London. 1903. p. 311-374.

Poulton E. B. The Colours of Animals: their Meaning and I'se especially considered in the case of Insects. London. 1590. (International scientific. series. Vol. LXVIII).

Roelofs. Sur les rapports qui existent entre la coloration des curculionides et les contrées qu'ils habitent. - Com. Rend. Entomol. Belg. Ann. XXI. 1878. p. CCLXVI-CCLXXU.

Russel, S. G. C. Colour Variation in the Pupae of Lu-iommuta megaera and L. aegeria. - Entomol. Record. Vol. 4. № 9. 1893. p. 243.

Rye E. C. Influence of Colour on Insects. - Entomol. Monthly Mag. XX. 1883. p. $15-16$.

Weir. Colour of chrysalids and enviromment of Pieris napi. - Entom. Sos. London. 1888-89. p. 156-157.

Willem, Vict. L'influence de la lumière sur la pigmentation de Isotoma tenebricola. - Ann. Soc. Entom. Belg. XLV. (VI). 1901. p. 193-196. 


\section{Einfiuss der Elektricität.}

E. Bellier de Chavignerie (1858. 67) glaubt, dass bei der Erzengung der Varietäten die elektrische Entladung nicht olne Einfluss bleibt, da er 5 Lycuenu adonis F. während eines Gewitters fing., welche alle lila statt blau gefirbt und ror einigen Stunilen ausgeschlïpft waren.

Den ersten experimentellen Versuch in dieser Beziehung stellte Nic. Wagnèr (1865. 936) an. Er benutzte intermittirende Inilulittionsströme, welche er auf Puppen von Tanessa urticae einwirken liess. Als die Ströme zu stark waren, wurile das Pigment und die Flügelmembran zerstört; schwache Ströme verwandelten das Roth in Orange, das Schwarz in Roth. Als er gleichgerichtete constante Ströme bei seinen Versuchen anwanite, erhielt er die Verbreitung ler schwarzen Flecken.

Der Marquis de Lafitole (1S76. 493) sagt, dass er nur dann durch Zucht Varietäten von Arctia caju erhalten hat, wenn am Tage des Ausschlüpfens ein Gewitter niederging.

I. Fallon (1S83. 218) erhielt Arctia caja, bei welchem die Oberfliigel ganz braun waren; die Unterflügel waren auch braun, aber etwas heller als die Oberflügel. Die Umrisse der gewöhnlichen Flecken waren noch zu beobachten. Die Entpuppung diests Falters fand in der sehr stïrmischen Nacht vom 27. zum 28. Mai 1882. während eines Gewitters statt.

$\mathrm{Er}$ erwähnt folgende Fïlle des Vorkommens des albinistischen Falters: Ain 3. Juli 1873 fand er in dem Walde von Sénart während eines heftigen Gewitters eine Melanargia galathea $q$, bei welcher die schwarze Farbe durch eine weissliche ersetzt war. Am 16. August 1577. fing er auf dem Simplon, während eines Gewitters, ein Polyommatus xarthie , bei welchem das Braun der Vorderflügel durch Strohgelb unıl das Braun der Hinterflügel durch Schwarz ersetzt war. Am 26. Juli 1882. fing er wïhrend eines Gewitters inr Walde von Sénart eine Epinephele janira , bei welcher die Vorder- und Hinterflügel auf der rechten Seite albinistisch waren.

E. Fischer (1896. 229) stellte :̈hnliche Versuche, wie Wagner, im Friihjahr 1894. an, aber ohne positive Resultate. Auch wurden 
lie Puppen in Eisenfeilspäne eingebetet und der konstante resp. faralarsche Strom in ziemlicher Stiirke tagelang olıne Unterbrechung hinılurchgeleitet. Die aus solchen Puppen geschliipften Falter waren aljer ganz normal. Beniitzt wurlen dabei Vunessa io, autiopa, urticae, atalanta und Papilio machaon. Die Richtung des Stromes war ebenfalls ohne Eintluss. Nur als die Elektroden, welche aus Nadeln bestanilen, direkt auf die Puppen gesetzt wurilen, erhielt er eine Zerstörung der Schuppen durch den faralayschen Strom an jenen Stellen, auf welche die Elektroden angesetzt worden waren.

Marie von Linden (1899. 519) stellte ihre Versuche mit ziemlich frischen, aber trockenen Puppen von Vanessa urticue an. ${ }_{n}$ Ein Theil derselben wurde in eine eiserne Schachtel gelegt, die durch eine Glasplatte isoliert war, und an welche die Elektroden angesetzt wurilen. Ein Induktionsstroin kam von einer Ruhmkorff-Spirale, welche von einem Daniel-Element gespeist wurde. Um den Wielerstand zu verringern, wurle der Boden, auf welchem sich die Puppen befanclen, stark angefeuchtet. Die Puppen reagierten am Anfang und am Ende des Puppenstadiums am deutlichsten auf die elektrische Reizung.

Der zweite Versuch ist insofern modificiert worlen, dass die Elektrorlen direkt an der Flügelachsel und an der Flügelspitze aufgesetzt wurlen, wobei die beiden Kontaktstellen zuvor befeuchtet wurlen. Die Stromstärke blieb wie früher. „Die Puppen reagierten kurz nach dem Verpuppen unıl kurz vor ihrem Ausschlüpfen. Tetanus trat inclessen nie ein."

Bei diesen Versuchen erhielten die ausgeschlïpften Falter "sehr satte und lebhafte Färbung. Der schwarze Seitenrand der Flügel war meistens sehr breit geworden. Die blauen und gelben Schuppen am Seitenrand der Flügel hatten sich wenig entwickelt, und die dunklen Binten waren eingeschnürt. Bei einem einzigen Exemplar aus der zweiten Versuchsreihe war die Spitze des elektrisierten Flügels verwaschen gelbgrau geworden, eine Verïnderung, wie sie auch bei unter hohen Kältergraden gezogenen Imagines beobachtet wird."

Arnold Pictet (1899. 636) setzte die Puppen von Vanessa io und Pieris rapae der Einwirkung der elektrischen Entladungen des Ruhmkorff's Induktoriums (gespeist von 1 Element von Bunsen) aus. Dabei fand er, dass diese Einwirkung die Fliigel-Nembrane der Puppe, in welcher die Flïgel bereits entwickelt waren, an vielen Stellen 
anbrennt. Diese "Brennwunden" erscheinen nach drei Tagen in Form von schwarzen Punliten. Die ausgeschliupten Falter hatten in diesen Stellen keine Schuppen, da sie sich entweder nicht entwicliehn konnten oder verbramit waren. Diese Flecken sin l beim schmetterling 81/2 Nal grösser, als sie bei der Puppe waren uml entsprechen der Lage nach genau den "Brennwunden“ der Puppe.

Die Puppen, welche noch keine entwickelten Fliigel hatten, ergaben Krüppel, deren Aussehen bezüglich der erwiihnten Flecken den oben besprochenen Schmetterlingen sehr ähnlich waren ( 010 obtient des avortons, ressemblant énormément à ceux obtenus précédemment" [p. 283]).

\section{Einfluss der Schwerkraft.}

Obwohl es schon lange bekannt war, dass einige Puppen, aus ihrer Ruhelage verschoben, verkriippelte Schmetterlinge erweben, wurle der Eintluss der Schwerkraft auf die Firrlung erst in cler n’usten Zeit studiert.

E. Fischer (1896. 229) brachte die Puppen in eine mit Baumwolle gefiillte Schachtel so hinein, dass dieselben mit dem Kopfende nach der gleichen Wand der Schachtel linschauten. Darauf wurde die Schachtel an ein Band befestigt und manuell in Rotation gesetzt; der Drehpunlit war also in der schwingenden Hand gelegen.

Es wurden zwei Versuchsserien angestellt: a) und b).

a) Kopfende dem Drehpunkte der Centrifugiervorrichtung zugekehrt:

Die Puppen wurden täglich 5 Minuten lang centrifugiert und nachher die Schachtel jeweilen so in Ruhe gestellt, dass die darin befindlichen Puppen mit dem Hinterende, in dem die Körpertlüssigkeit sich durch das Centrifugieren besonders angesammelt hatte, nach unten gerichtet waren, wodurch der Effekt das Centrifugierens unterstiitzt werden sollte.

\section{Vanessa urticae L.}

Von 50 Puppen schliipften nach $12-15$ Tagen 25 Schmetterlinge aus, die anderen gingen an Infektion zugrunde.

„Die blanen Randtfeclie der Vorderflügel waren fast bei allen Inclividuen total verschwunclen, die cier Hinterthïgel reduciert; der 
dumklere Aussenranıl war in seiner Breite ziemlich reluciert, stellenweise von braungelben Schuppen durchsetzt. Die Unterseite etwas verdunkelt" (p. 34).

\section{Vanessa polychloros L.}

Erster Virsuch: 60 Puppen ergaben 14 Falter. 11 Stiicke erwiesen eine Reduktion der schwarzen Flecken des Mittelfeliles der Vorlertlügel unl ziemlichstarke Vermehrung der gelben Schuppen an Apex. Auf len Hinterflügeln waren die blanen Flecken kleiner. Die iibrigen 4 Puppen ergaben: Ein fast typisches Stuick von ah. testudo Esp.; eine Uebergangsform zu ab. testudo.

Zwreiter Versuch: 50 Puppen ergaben 38 Falter. 1/3 normal, die ïbrigen zeigten geringe Abweichumgen ler elf ersten Versuche.

Dritter Versuch: 30 Purpen ergaben 17 Schmetterlinge, worunter 15 normal und 2 Exemplare, bei welchen der dem Imenwinkel ıler Vorlerflïgel zunächst gelegene schwarze Fleck total rerschwun(len war.

\section{Vanessa io $\mathrm{L}$.}

120 Puppen ergaben 114 gut entwickelte Falter, bei denen meist cler 3. weisse Fleck im blanen Fleck sehr in clie Lünge gezogen war, wïhrend das (ielb durchschnittlich sich mehr ausgerlehnt latte. Bei einem Exemplar hatte sich am Vorilerrand iler VorderHligel ein metallgrüner Schiller eingestellt, unt es waren die Flïgel mit schwach golılen glänzenden Schuppen spärlich ïlıersät.

\section{Vanessa antiopa L.}

80 Puppen ergaben 27 Falter, bei welchen meistens der gelbe Rami sehr verschwommen gegen die schwarze Binle hin abgegrenzt. war; bei 4 Exemplaren erschien überties der I. gellue Costalfleck rerkleinert und etwas diisterer.

b) Kopfende dem Drehpunkte ab-, das Hinterende dem Drehpunkte zugekehrt, somit der Einfluss der Schwerkraft, wie er in der freien Satur auf die Stiurzpuppen sich geltend macht, verstärkt.

Von 2.; polychloros-Puppen gingen 12 zugrunde; die anderen erwiesen eine Vermehrung des schwarzen Pigments, aber niemals im Anschluss an schon vorhandene schwarze Flecken, sondern an ganz anilere Stellen; fermer verlief oft ein schwarzer Streifen vom Ende der Mittelzelle zun III. schwarzen Costalfleck (7 Exemplare). 
E. Fischer giebt folgentes Résume seiner Versuche:

1. Eine Verschiebung trat bei den durch die Centrifugalkraft beeinflussten Faltern ein, wenn auch in Durchschnitt keine bedeutende.

2. Die aufgetretene Verschiebung deutete weder auf die bei $0^{0}$ C., noch die bei $30-35^{\circ}$ C. erzogenen Aberrationen hin, sie nïherten sich also werler den nördlichen noch tlen siirllichen Varianten der betreffenden Species.

3. Es zeigte sich in einigen Stïcken eine Amnïl:erung an die durch Temperaturen unter $0^{\circ} \mathrm{C}$. erhaltenen seltenen Formen; bei polychlorns traten diese Formen als typische Stiiclie (2 an iler Zahll) auf.

H. Robel (1896. 675) sagt in seiner Rezension cler Arbeit ron E. Fischer über diesen Punkt folgendes:

„Wenn die (unbedeutenden) Verïnderungen cler Falter, die cler Verfasser bei diesen Versuchen erzielte, thatsïchlich im Zusammenhange mit der Gravitation stehen, so ist hieran allein die veriinderte Ruhelage der Stiirzpuppen schuld, nicht aber ein tiiglich durch fïnf Minuten manuell in Anwenlung gebrachtes Centrifugieren, bei welchem die für so kurze Zeit einwirkende Fliehkraft nach der organischen Beschaffenheit der Puppe kaum den durch sie abyeschwïchten Einfluss der Schwerkraft compensirt haben diirfte" (1). 89).

Es ist interessant anzufuihren, dass 0. Schultze (1894. 793) bei seinen Centrifugalversuchen mit Froscheiern eine sehr unbedeutende Rotationsgeschwinligkeit beniitzte und doch zu positiven Resultaten kam. Er sagt: "Ich konnte zeigen, dass die normale Struktur iles aus dem Eierstock entleerten Eies beherrschende richtende Wirkung der Schwere erst bei einer ausserordentlich langsamen Rotation durch abnorme Schwerwirkung aufgehoben werden kann. So sterben Eier, welche nach der Befruchtung einmal im Verlaufe von 4 Stunden um eine horisontale Axe in Zwangslage gedreht werden, ab und entwickeln sich niemals" (p. 2).

Trotzden, dass 0. Schultze eine ausserordentlich langsame Rotation für solche Versuche empfiehlt, stellte Gräfin M. von Linden (1899. 519) ihre Schleuderversuche mit einer lileinen Centrifuge mit noch grösserer Geschwindigkeit an, so lass zu frische Puppen schon beim ersten Centrifugieren in einen formlosen Brei verwandelt wurcen. 
Die Anorlnung der Versuche war wie bei E. Fischer. Die Puppen wurden jeclen Taw während zehn Minuten centrifugiert. „Die Verïnderungen, die an den Imagines der Vanessa urticae, welche ïberhaupt zum Ausschliipfen gelangten, erzielt worlen sind, stimmen im grossen und ganzen mit dem iiberein, was wir an elektrisierten Faltern beobachtet haben. Besonders ist zu erwähnen, dlass bei mehreren Schmetterlingen, auch solchen, die nicht zum Ausschlüpfen kamen und kïnstlich der Puppenhülle entnomnen wurlen, die eigenthümliche gelbgraue Verfärbung der Flügelspitzen eingetreten war" (p. 323).

\section{Einfluss der Nahrung und chemischer Stoffe.}

Diese verwikelte Frage hat manche Forscher beschiiftigt, und es sind so viele Beabachtungen in dieser Richtung vorhanden, dass es mir nicht möglich war, sie alle zusammenzustellen. Ich führe deshalb nur die wichtigsten an.

Es ist schon lange bekannt, dass gewisse Falter eine FarbenAenderung erleiden, sobald die Raupen mit anderen Pflanzen gefuittert werden. So z. B. verwandelt sich Aglia tau L. in eine dunkle ab. lugens, ${ }^{1}$ ) wenn Buchen, Linden und Eichelı gegen Nussbaum gewechselt wird. Arctia caja zeigt die Verminderung der weissen Binden der Vorderfliigel, wenn die Raupe mit Waldnussblïttern gefuittert wird. Entgegengezetzte Beobachtungen wurlen z. B. an Sphinx ligustri Ligustrum vulgare, Syringa vulgaris, Persica, Fraxinus excelsior, Sambucus nigra, Ilex aquifolia, Viburnum lantana, Spiraea chamaedrifolia gemacht, und doch sind uns keine Raupen- resp. Schmetterling-Varietäten bekannt.

Keferstein (1845-1850. 442) beobachtete, dass Raupen von Dasychira selenetica Esp., welche alle mögliche Pflanzen fressen, immer gleich gefärbte Schmetterlinge liefern.

1) Im Privatgesprech sagte mir Prof. M. Standfuss, dass er fest überzeugt sei, dass durch Waldnussblattfütterung Aglia tau ab. lugens Stndf, niemals erzielt werden wird; dagegen ist er geneigt anzunehmen, dass Spliinx ligustri ab. spiraeae Esp. wohl eine durch abweichende, nicht recht zusagende Nahrung entstandene kleine, verkümmerte, bleichgefärbte Form des Ligusterschwärmers ist. 
G. Koch (1856. 457 l) fanl, dass die Färhung von Chelonic plantaginis L. rom Futter sehr abhängig ist, llaher die Menge der Variationen. Die Raupen von Chesias spartiuria Hüb. werlen gelllich, wenn sie die Blïthen des Besenstrauchs (Sarothamnus scoparius Wim.) verzehren, während die amleren, die von dessen Blüttern leben, griin bleiben.

Schmidt (1858. 755) fand die Raupe von Toctuch scroplutariae auf Scroplularia und Verbasem nigrum, erstere war weiss odler bläulich, letztere inehr oder weniger grünlich gelb.

L. Glaser (1863. 314a) bei der Besprechung von Smerinthus populi var. tremulae Blih. sagt folgendes: „An Espen finclen sich iilırigens auch die Raupen des gewöhnlichen Pappelschwärmers sehr oft, uml nur durch lingere Anfeinanderfolwe der Generation ant Espe allein wircl eine merliliche Varietiit erzengt" (p. 83).

Er ziichtete die Raupen ron Chelonia caja L. mit Salat un। beabachtete, dass der schmetterling, im Fall anhaltender Fiitterung damit, selır bleich wird.

Rössler (1864. 701) beobachtete, lass die Raupen ron Eupitheciu innotuta Knoch. welche sich auf Schlehen (Prunus spinosa) aufhalten, grïn sinl, wïhreml die auf Artemisia campestris lebenden Raupen roth gezeichnet sind).

Weymer (1865. 957) fanul die Raupe von Papilio galuthea hellröthlich, gelb und griin.

Gabriel Koch (1865. 458) sieht als Ursache les Entstehens der Farbe in der Puppe den Farbstoff der Pflanze selbst an.

H. Christoph (1867. 145) beobachtete hochröthliche, gelbe und wriine Raupen von Noctua puniceago; lie von Noctua serena grïn, -relh o:ler rothbraun; Toctua glancu lebt auf Heidelbeeren und ist theils griun, theils roth. Bei Beschreibung der Raupe von Mycteroplus pumicengo sagt er: "Eine nicht seltene Varietiit hat statt gelber griine Fürhung. Die aus solchen grinen Raupen gezogenen Schmetterlinge hatten die gewöhnliche Färbung" (p. 242-243).

L. Möller (1867. 582) sagt, dass die polyphagischen Spannerraupen, je nach ihrer Futterptlanze, rie sie sich von Jugend an gewählt 
haben, eine verschiedene Färbung erhalten. So ist z. B. die Raupe von Amphiclasis betnlaria Hiib. rindenfarbig und gellorin, wenn sie auf Birken lebt; aschgrau auf Eichen; gelbram an Rïstern; gelbgrün und auf dem Riiicken rostfarbig beschattet auf Weiden und Pappeln. Unter den Spimnern sind z. B. die Raupen der Liparis monacha aut Kiefern weissgrau, auf Fichten dunkelgrau und auf Lïrchen fast scliwarz.

Er hat gefunlen, dass die nackte Raupe von Cncullia tonucet; ilıre weisse Grumlfarbe verliert und gelb wird, sobalıl wir sie nicht mit ilen grïnen Blättern des Bainfarn (Tanacetum vulgare L., oder mit solchen von Reifuss (Artemisia vulgaris L. oder Art. abrolanum L.), sondern mit der gelben Bliithe der zuerst genannten PHanze fuittern. Die Raupen von Smerinthns tilice L., welche mit Lindenblättern, gefüttert werlen, geben grïnlich gefirlote Falter, wälırend von jenen auf Ulmen die röthliche Varietiit entsteht.

Ausserlem führt er noch folgende Thatsachen an: die Schmetterlinge von Chelonia caja L., Ch. villica L., Ch. aulica L. etc., deren Raupen von Jugend auf mit Garten-Salatbliittern (Lactuca sativa L.) gefiittert werden, heller gefürot und einfacher gefleckt, als an Nesseln (Urtica) oder an der Tollkirsche (Atropa bella(lonna L.) aufgezogene. Die Raupe von Liparis monacha L. viebt auf Apfelbïumen einen bei weitem blasser gefirliten Falter als auf Kiefernarleln.

Mac Lachlan (186\%. 539) sammelte Raupen von Eıpithecia absinthicatc, wohei die auf Senecio jacobaea lebenten gelblich, die auf Centaurea nigra röthlich und die auf Matricaria weisslich waren. Die erwachsenen Raupen lirachte er alle auf Senecio jacobaea; es erwies sich aber, dass die röthlichen unı weisslichen Raupen nicht mehr gelb wurden.

v. Prittwitz (1867. 654) beobachtete folgenile Varietiiten ler Raupe von Noctua pterides: 1) citrongelb, 2) ockergelb, 3) Heischfarbig, 4) braun, 5) purpurroth, 6) grïn in allen Niiancen.

Richter (1869. 691) erhielt die braungelbe Varietiit von Smerinthus tilice, indem er clie Raupe mit Birke ernilhrte. Ein anderes Mal (1869. 692) zog er aus Eiern der Noctua promulu bei gleichem Futter braune und grïne Raupen. 
A. G. Butler (1869. 123) sagt, lass die Raupe von Protopurce (Sphinx) eurylochus, welche einfach griin unil nur mit gelben Schrägstreifen versehen ist, sich von ler giftigen Litrea venenosa ernährt.

Goosens (1870. 322) fanil auf Ginster zwei Raupen, die eine griin, die andere gelb. Beide Raupen verpuppten sich und gaben Weiber van Gcometra spartiata. Beile Schmetterlinge legten Eier, und zwar legte der von der grïnen Raupe grüne, und iler aus iler gelblichen gelbe.

Als C. A. Teich (1870, 855) in seinem Vortrage über clen Einfluss der Nahrung auf die Färbung ler Schmetterlinge zu sprechen kam, sagte er: „Auf die Farbe scheint auch die Nahrung von Einfluss zu sein. denn füttert man die Raupen der braunen dretia cajı mit Schöllkraut, so werden die sonst ziegelrothen Hinterfliigel gelb, giebt man ihnen aber Bilsenliraut, so werien clie Falter fast einfarbig kaffeebraun." Enclich wurde clarauf hingewiesen, dlass viele Raupen die Farbe der sie nährenden Pflanzen besitzen.

In der Debatte ïber (len Vortrag "protestirten" Dr Felsko und Prof. Nauck gegen die Ansicht, dass die Farbe der Nahrung die Farbe der Thiere bedingen könne, da sich die aufgenommenen Stoffe im thierischen Körper zu ganz neuen Verbindungen vereinigen; nur wo der aufgenommene Farbstoff unverdaulich ist, kann die Nahrung einen färbenden Einfluss haben, wie z. B. Fïtterungen mit Alkannawurzeln zeigen.

Frey (1871. 242) beobachtete, dass die auf Blïttern von Stachys sylvatica lebenden Raupen von Pterophorus cosmoctuctydus $\mathrm{Hb}$. Schmetterlinge von gleicher olivenbrauner Fürbung liefern, ılagegen Raupen, welche auf Samenkapseln von Aquilegia sich aufhalten, nur wenige Schmetterlinge mit der erwïhnten Fïrbung ergeben.

Bei der Spannergattung Eupithecia fand A. Speyer (1872. 829), dass manche Arten als Raupe viel auffallenderen Abïnderungen unterworfen sind, als man bei dem entwickelten Schmetterling wahrnimmt, währenı bei anderen das umgekehrte Verhältniss stattfindet. 
G. Capiomont (1874. 128) beobachtete, dass die Raupen von Geometra pomonaria, welche auf Eichen leben, grünlich sind, wäl-rend die auf Linden bräunlich.

Dietze (1874. 181) beobachtete, dass die Raupe von Geometra venosata, welche auf Silene lebt, schmutzig griin ist, die aber, welche auf Lychnis vespertina vorkommt, schmutzig roth gezeichnet ist.

J. Jenner Weir (1876. 950) beniitzte verschieclene Pflanzen als Futter für Raupen, konnte dadurch aber keine aberrative Formen von Schmetterlingen erzielen. In der Abhandlung sind wetler Pflanzen noch Schmetterlinge benannt.

Der Marquis de Lafitole (1876. 493) fütterte die Raupen von Arctia caja mit Blättern von Chelidonium majus; obwohl die Raupen dieses Futter gierig frassen, starben sie alle als Puppen: das einzige Exemplar ergab einen Falter, welcher keine Varietät darstellte. Durch Fütterung mit Lattich wurden blassere Schmetterlinge erhalten.

Fuchs (1876. 267) beobachtete, dass diejenigen Raupen von Eupithecia pusillata, welche sich von Lärche (Larix) ernähren, eine russige Färbung haben.

J. W. Slater (1877. 819) sagt, dass die bei den Vögeln nicht beliebten Raupen auï Giftpflanzen leben, und dass ilhre bunten Farben sehr wahrscheinlich durch diese Giftstoffe erzeugt werden, denn einfach gefärbte Raupen leben auf ungiftigen Pflanzen und werlen daher von Vögeln verfolgt.

W. Prest (1877. 649) ernährte die Raupen von Ampluidusis betularia mit halbverwelkten oder trockenen Pflanzen und erhielt im Verlaufe weniger Generationen vollständig schwarze Schmetterlinge. Durch das gleiche Futter wird das Verhältniss von Braun und Schwarz zu Weiss bei Abraxas grossulariata, dasjenige von Braun und Schwarz zu Weiss und Roth bei Arctia caja geändert.

Esper (1880. 216) fuitterte Raupen von Spliinx ligustri mit Tabakpflanze (Nicotiana) und Bilsenkraut (Hyoscyamus niger) und erhielt Falter mit viel dunklerer Färbung als gewölnlich. 
Adolf Rössler (1881. T02) fiitterte Arctiı çja rom Ei mit Schmeeleere (Symploricarpus racemosus), wolnei jerle Generation tunkler werlenrle Exemplare lieferte, hei denen das Weiss auf der Obertliche mehr und mehr verschwand und die schwaren Flecken ler Unterfliigel sich verwrösserten uni zusammenflossen. Fïtterung mit Salat erzeugt gewentheilige Aböntermo mit viel Weiss unl wenig Schwarz, mehr gelbe als rothe Unterfliigel.

H. Gauckler (1882. 274) fütterte lie Liaupen ron Aictia caju mit Aconitum napellus (Eisenlut), wobei sie dies: Pflanze mit grosser Gier frassen und lieferten nachher schmetterlinge mit ausserorlentlich breiten weissen Binden auf den Vortertliigeln; iler grosse braune Fleck auf $A$ st 2 und der Dorsalrippe in Zelle $I^{\text {b }}$ am Innenrancle cler Vorterflüwel wirl durch eine weisse Bincle setheilt.

Durch Aufzucht rler Aictia coja-Raupe mit Weilen erhielt er schmetterlinge, welche sich durch vorherrschendes Braun auf den Vorderfligeln und wrosse, beinahe zusammentliessende schwarz blaue Flecke der Hinterfliigel auszeichneten. Bei einem Stiicke sind die weissen keilförmiqen Flecke des Vorderraniles zu Punkten herabgesunken, währenı bei einem anıleren Exemplar nur noch ein einziger kleiner Fleck vorhanden ist, und die weisse schrïge Binte, vom Aste 6 bis 7 zum Samme nach innen gehenul, viinzlich fehlt.

Er fütterte auch Hadena pisi mit rer dunklen amerikanischen Nessel, welche ihm ausseror(lentlich dunkle schmetterlinge lieferte, bei welchen die weissgelbe Wellenlinie sehr schwach ausgeprägt ist unıl kurz vor ihrer Erweiterung zu dem gelben Flecke wänzlich aufhört. Der gelbe Fleck selbst iiher dem Innenwinkel ist selır lilein.

Bieger (1882. s0) erhielt Aictia caja mit viel breiter'n weissen Querhinlen, nachlem er die Raupe mit Schneebeere ernährt hat.

L. Knatz (1883. 455a) erzog aus (ler Puppe je ein Exemplar von Chareclea umlira unil Thyatira batis, beirle auffallend bleich. Bei dem ersteren suchte er die Erkliirung darin, dass auf die Puppe ein Tropfen von lem Sekret eines anileren vorher ausgekrochenen Schmetterlings gefallen war: bi dem anderen darin, dass das Thier zu einer wanz ungewöhnlichen Zeit, nümlich nach nur 14-tïwiger Puppenruhe im August auskroch, wïhrend die Art sonst und nur in einer Generation, nachlem die Puppe den wanzen Winter ïler geruht, im Mai und Juni erscheine. 
K. Bartels (1883. $455 a$ ) füite in der Sitzung des Vereins fuir Naturliunile zu Cassel (am 12. Miirz 1883) bei, dass bei Kïifern elıenfills Pigmentmangel vorkomme und suchte diesen dadurch zu erklïren, class es den betreffenden Thieren an den zum Geileilien erforlerlichen Lebenshedingungen, Nahrung, Temperatur etc. gemangelt habe.

v. Vultée (1883. 455a) sprach am 12. März 18\$3 im Anschluss an den in gleicher Sitzung des Vereines fuir Naturkunde zu Cassel wehaltenen Vortraw von Knatz iiber verschiedene Varietïten des - rumetterlings Euprepia caja, die er dadurch erzielt hatte, dass er den Raupen verschiedene Pflanzen als Futterstoff gegeben hatte. Jie betreffenden Indiviluen wurden vorgezeigt. Nïheres dariiber steht in der Notiz nicht.

Als die Raupen von Arctia caja mit Salat ernïhrt wurlen, erhielt W. Pollack (1886. 640) dunkel gefürbte Spinner.

G. Stange (1886. 842) fütterte die aus dem Ei erhaltenen liaupen von Eupithecia nanata mit Vaccinium oxycoceus. Die erhaltenen Schmetterlinge unterschieden sich von denen, deren Raujen Calluna frassen, durch weniger vorspringende Ecke des Mittelfeldes und eintönigere Fürbung, indem die das Mittelfeld aussen hegrenzende helle Binde dunkler geworden ist und gegen den Innenrand fast ganz verlischt.

L. Krulikowsky (1887. 478a) konnte keinen Zusammenlang zwischen der Nahrung der Raupe von Smerintlı:!s tilice L. und der Färbung dieses Schmetterlings feststellen.

A. 0. Kowalewski (1887. 468) fütterte Fliegenlarven mit einer Mischung von verschierlenen Farlsstoffen und Salzen und fand, dass die das Herz ungebenden Zellen und die Zellen, welche den girlandenförmigen Zellenstrang bilden, sehr stark gefiirbt wurlen. Besonders gut gelangen die Versuche mit Karmin und silbersalzen; durch die letzteren werden die erwähnten Zellen braun, durch Methyl-Blau blau gefürbt. Die Zellen des Verdaungskanals und das Blutplasma blieben ungefïrbt. Er kommt somit zum Schlusse, dass alle diese Farbstoffe ins Blut der untersuchten Insekten :relangen.

Fr. Rühl (1888. 717) machte Ernährungs-Versuche mit Raupen von Eupithecia pusillata F. Mit Juniperus communis wefuit- 
tert blieben sie bis zur Verwandlung grin; mit Larix europaea gefüttert wurden sie braun (allerdings nur nach der zweiten Hïutung bis zur Verpuppung). Raupen von Eupitheria scabiosatu, mit Scabiosa gefüttert, wurden schiferllau; während mit Hypericum gefuitterte Raupen gelb oder griin wurlen, je nachdem ob nur die Blätter oder die Bliiten zur Nahrung dienten.

Dieser Entomologe beobachtete auch, lass die wolıgelbe Raupe von Dasychira putibunda, welche sich sonst von Buchen nährt, schwarz wird, wenn man sie mit Eichenlaul, füttert. Die Raupe von Orgyia antiqua erhiilt eine viel dunklere Fïrbung, wemn sie mit Betula alba gefüttert wird.

Laut Eimer (1888. 212) fütterte Zeller Raupen von Papilio podalirius mit Garten- und Kiulturpflanzen und erhielt dadurch fast durchsichtige und schuppenlose Schmetterlinge.

R. Schneider (1888. 768) fand, dass Wasserkïifer, welche sich in eisenhaltigen Sümpfen aufhalten, eine grosse Resorption des Eisens nicht nur im Darmkanal, sondern auch in Muskeln und dem Fettkörper zeigen.

A. 0. Kowalewsky (1889. 469) führte in den Körper von verschiedenen Insekten mittelst einer feinen Spritze 1\% Lösung von Eisenchlorid $\left(\mathrm{FeCl}_{3}\right)$ ein und untersuchte einige Stunden darauf die Gewebe des Insektenkörpers, wobei sie mit der Lösung von Ferrocyankalium bearbeitet wurden. Alle Netze der Pericardial-Zellen wurden dabei blau gefïrbt, auch die Muskeln und theilweise dio Speichen- und Web-Driisen wurden blat. Die Pericardial-Zellen wurden durch Karmin (beim Einspritzen in den Insektenkörper des Ammonium-Karmins) roth gefürbt. Daraus folgt, dass die genannten Theile des Insektenkörpers das Eisen und Karmin absorbieren.

Louis Blanc (1889. 83) negiert die Möglichkeit, (lass die Farbstoffe, welche den Raupen als Nahrung dienten, die Seide färben kömnen. Er stellte seine Versuche mit Raupen von Bombyx mori an, welche mit thierischen, Anilin- und Pflanzen-Farbstoffen gefuittert wurlen, wobei diese Stoffe entweder als wässerige Lösungen oder als Pulver ilen Blättern des Maulberbaumes beigemischt wurden. Nur die pulverförmigen Stoffe ergaben scheinbar positive Resultate. Die Raupen, welche mit Indigo gefiittert wurden, ergaben keine 
Cocons, erhielten aber die himmelblaue (irundfarbe, welche jedoch zufïllig nicht untersucht werden konnte. Karmin iibte keinen schädlichen Einfluss auf die Raupen aus, und sie spannen orangene $\mathrm{Co}_{0}$ cons. Die mikroscopische Untersuchung ergab, dass die Seide deshalb rüthlich wurde, weil an ihrer Obertliiche der Farbstoff haftete, so ،lass die seide gar nicht durchgefïrbt war. Fuchsin fürbt alle Gewehe des Epstheliums beim Veriaungskanul, Speicheldrïsen, Malpighi-Gefïsse und den Fettkörper durch; es stellte sich jeiloch heraus, dass nur das Protoplasma der Zellen gefärbt war, nicht aber der Kern.

A. Troska (1890. 884) mischte eine licke Lösung von gewöhnlichem Zucker mit Gummi arabicum zusammen, bis das Ganze die Consisten\% einer lockeren Salbe gewann, und bestrich damit die Fliigelhiilsen ler Puppen in Form eines $1 \mathrm{~mm}$. breiten Gurtes. Diese Imprägnirung kann man bei sehr lange liegenden Puppen höchstens 3-4 Mal wiederholen, widrigenfalls sie schällich wirken kann. Dabei fallen die meisten Puppen bald in "eine Art von Hypnose oder Schlaf."

Die auf cliese Weise prïparirten Puppen werilen dunkler. Die grauen überwinternden Puppen von Papilio machaon werden ¿labei grïn. Der Schmetterling selbst, welcher aus solchen Puppen entschliipft, zeigt folgendes:

1. Er besitzt eine gesättigtere, dunklere Farbe.

2. Es zeigen sich an zahlraichen Exemplaren kleine Aberrationen. Das Roth wird erheblich schärfer, manche zeigen sogar rothe Flecken an den Stellen, wo andere Exemplare derselben Art sie nicht haben. So bei Sphinx ligustri, Smerintlus ocellata, Papilio machaon, Thais polyxena und cassandra. Ein Papilio machaon zeigt einen leicht ausgeschweiften Vorderfliigel; zwei Weibchen von Sat. pyri haben auf den Oberfliigeln neben der bekannten Wellenlinie (ausserhalb der Augen) einen innerhalb der letztern Linie durch die Augen laufenden und bis an den Vorderrand reichenden schwarzen Streifen u. s. w.

Alle diese Versuche sind mit ungefïhr 40 Arten angestellt worden.

Der Zusatz von einem Tropfen Anilinroth berwirkt bei Schmetterlingen beim Ausschliipfen an den haarigen Stellen der Fliigel rothe Knötchen.

Am 26. Januar 1890 theilte Kallenbach (1890. 430) in ler Versammlung der Ned. Entom. Vereenigung mit, class er in seiner 
Kiollektion sehr dunkle Exemplare ron Spilosoma lubricipeda besitze, welche durch Füttern der laupen mit im Salzwasser getränkten Blättern geziichtet wurlen. Solche Varietiiten liommen anch im Freien vor und zwar auf Helgoland in der Nähe der See.

Villon (1890. 925) fütterte die Raupen von Bombyx mori mit Blättern des Maulbeerbaumes, zu welchen Inıligo, Marena uml Cixhenille beigemischt waren, und erhielt Seide, welchr entsprechemi gefärbt wurde.

A. Seiler (1890. S03) sammelte junge liäunchen von slictiu caja unıl fütterte dieselhen mit den verschiedensten Pflanzen, welche in Salzwasser gestellt wurlen. Es kamen nur ganz normal gefürbte Thiere zum Vorschein. Keinen Einfluss übten auch Wallnusshliitter aus.

Émile Blanchard (1890. 85) kam durch längere Beobachtung zum Schlusse, dass der Stoff, welcher die Seide zusammensetzt, bereits in Blättern des Maulbeerbaumes sich vorfindet. Die Verdaungsprodulite gelangen ins Blut und von dort zu den Wïnden der Seide bildenden Drüsen, welche die Rolle einer Membran spielen; hier werden the Stoffe, welche zur Bildung der Seide und für die Nihrung bestimmt sind, von einander durch die Dialyse getrennt. Er konnte diese Erscheinung oft beobachten, indem er die Blätter mit pulverförmigem Incligo oder Karmin bestreute. Die Abhandlung ist kurz unil undeutlich.

Otto Habich (1891. 347) in Hernals bei Wien machte die Beobachtung, dlass die Fürbung der Raunen bei vielen Arten des Genus Eupithecia von der Nahrungspflanze abhängig ist. So finclet sich \%. B. Eupithecia oblongata auf Buphthalmum salicifolium lebhaft gelb, auf Scabiosen bläulich, auf Peucedanum alsaticum grünlichgelb und auf Cirsium blassroth.

Eupithecia absinthiata auf Calluna rosemroth, auf Solidago gelblich und auf Artemisia grünlichbram, wïhrend man wierler auf Eupatorium cannabinum in ter Zeichnung ganz abreichencle Stücke findet.

Auch die Trockenheit des Futter's spielt dabei eine grosse Rolle. So z. B. findet man Eupithecia sobrinata im Freien gewölnnlich hellgrün mit dunkelgrüner dorsaler und weisser Laterallinie. Diese Färbung indert mit zunehmender Trockenheit des als Futter die- 
nemlen Juniperus communis von gelb bis roth ah, uni die Raupen nehmen Zeichnungen an, welche man bei tenselben im Freien rergebens suchen wiirde.

E. cligituliata hat die Färlung der Staubgefïsse ron Digitalis lutea und sonst keine Zeichnung; ist aber diese Raupe genöthigt. sich von den Simmenkapseln zu ernïhrn, so färbt sie sich von grïn bis rosa uni nimmt gleichfalls die Querzackenzeichnung tler $\mathrm{F}$.: linariata an.

Auch E. assimilata gehört zu diesen variirenden Arten.

W. I. Schmuidsinowitsch (1891. 761) fütterte Raupen von. Bomby mori mit Bliittern des Maulbeerbaumes, welche mit pulverför'migem Indigo, Karmin oder Methyl-Violett angerieljen waren. Methyl-Violett erwies sich als giftig. Die Raupen, welche mit Indigo o ler Karmin gefüttert wurten, waren schon nach 2 Tagen bliiulich o.ler röthlich; ihre inneren Organe waren jedoch nicht gefirbt, auch die Seide erlitt keine Aenderung in der Farbe. Er ist der Meinung. dass, obwohl diese Stoffe die Gewebe der liaupe nicht färben, diesılben in ihrem Blute jedoch vorhanden sind.

Fritz Rühl (1891. 720) fütterte die auf buchen gesammelten goldgelben Rïupchen von Dasychira pudibundu L. mit Eichenlliittern, w.bei sie schwarze Fïrbung angenommen haben, jeiloch ohne Eintluss auf das spätere Imago.

Jos. Haberfelner (1891. 341) machte bei Superda scolaris in Nieder-Oesterreich die Beobachtung, dass die in Lumbholz lebenden Exemplare bei dem Erscheinen mit einem schöneren Gelb ausgestattet sind, als jene, welche er aus Lïrchen und Fichten zog. Auch Clytus lama unı Cullidium aencum kommen schöner aus Lüirchen, als aus Fichten.

S. N. Kamensky (1892. 432) fütterte die Ilaupen von Bomby., mori mit Bliittern von Toraxacum officinale und beobachtete, dass sie sich am Ende des eisten Alters von normalen Raupen dadurch unterschieden, dass ihre Färbung etwas dunkler und "der Färbung des gewelkten Blattes von Taraxacum officinale ähnlich war". In anderen Altern hatten diese Raupen mehr intensive Fïrlumg als die normalen, die Zeichnung war schärfer, die Verbindungsstellen zwischen den Ringen und dem Horn waren gelb gefärbt.

Derselbe Furscher (1893. 434) stellte die gleichen Versuche auch im folgenten Jahre an unil erhielt auch schärfere Zeichmmg 
ler Raupen (wie z. B. bei japanischer Rasse), wobei am Riicken die yelbe und röthliche Färbung zu bemerken war. Besonders klar war diese Färbung im 4. und 5. Alter und verschwand bei todten Raupen sogar im Spiritus.

0. Krancher schrieb an Rössler (1892. 703), dlass wenn man Atlas-Raupen mit Götterbaum fïttert, die Falter "prächtigere" Farben besitzen, als bei der Fiitterung mit Berberitze.

S. N. Kamensky (1892. 431) fütterte Raupen von Bombyx mori mit verschiedenen färbenden Stoffen, um zu untersuchen, ob sie ins Blut der Raupe iibergehen und dann die Seiıle färben. Zum Versuche wurden je $1 \mathrm{gr}$. Eier von gesunder und kranker weisser japanischer Rasse genommen. Die tärbenten Stoffe wurden zum Futter auf dreierlei Weise beigemengt:

1. Die Blïtter des Maulbeerbaumes wurden von beiden Seiten mit farbigen Pulvern eingerieben (Indigo, Karmin, Kampesch-Holz).

2. Die Aeste des Maulbeerbaumes wurilen in die gesättigte wässerige Lösung von Ammoniak-Karmin (von Hoyer), Indigo-Natrium Sulfil, Fuchsin, Eosin, Nigrosin und Pikrinsäure eingetancht und nach einiger Zeit herausgenommen und getrocknet.

3. Die Farbstoffe wurden mit Eiweiss vermengt uncl auf die obere Seite ler Blätter aufgetragen. Parallel damit wurclen die Blätter nur mit Eiweiss und Eigelb allein angepinselt.

Nach der vierten Häutung wurde den Raupen auch Eiweiss mit Anilingelb und Anilingrün, oder mit Eisenchlorid und nachher mit Ferrocyan-Kalium vermengt als Futter gegeben.

Die Raupen frassen sehr gern Eiweiss mit Karmin, Indigo, Ammoniak-Karmin, Eosin und Nigrosin, auch in Lösung die Pikrinsäure und Kampesch-Holz und erkrankten dabei nicht; starben aber vom Eiweiss mit Extractum ligni campechiani (wahrscheinlich wegen Harz), vom Fuchsin (wahrscheinlich wegen Arsenik), vom Indigo-Natrium Sulfid (wahrscheinlich wegen der Schwefeligen-Säure) und von Anilinfarben: Gelb, Grün, Dunkel und Hell-Grün.

Dieser Vorversuch ergab folgende Resultate:

1. Cocons waren weiss, ungefärbt, obwohl verschiedene Organe der Raupen, verschiedene Farben annahmen. Die Raupen wurden mit folgenden Stoffen gefiittert: Kampeschholz, Fuchsin und Extractum ligni campechiani mit Eiweiss, Anilinfarben. Durch das Kampeschholz wurde der Verdaungskanal orange-rosa, die Malpighi-Gefässe orange, 
clas Hierz rosaroth und die Reservoirs der Driisen, welche die Seide ausscheiden, gelblich gefarbt.

2. Cocons waren gefärbt, obwohl sich die Raupen die Farbstoffe nicht angeeignet hatten, da sie nicht durchgefärbt waren. Die Färbung der Cocons wurde daclurch erhalten, dass die den Blättern beigemischten Pulver von Indigo und Karmin der Oberfläche der Seide anhafteten.

3. Cocons waren gefärbt uncl die Raupen im Inneren auch mehr oder weniger durchgefärbt und zwar so stark, dass sogar die embryonalen Genitalorgane durch Pikrinsaüre orange gefärbt waren. Die Fïrbung der Cocons, obwohl schwach, war jedoch überall, d. h. bei allen Schichten, gleichmässig vertheilt, wobei diese Seicle von der normalen orangenen sich durch nichts unterscheiden konnte. Die dabei verabreichten Farbstoffe waren: Pikrinsäure, Eosin und Ammoniak-Karmin von Hoyer.

Er kommt somit zu folgenden Schlïssen: a) Nicht alle Farbstoffe, sondern nur die im Wasser löslichen, eignet sich der Organismus der Raupen an; b) Dic Raupe, welche sich mit der Farbe angeschmiert hat, wird nach der Häutung wieder rein, während die Raupen, welche sich den Farbstoff angeeignet haben, auch nach der Häutung gefärbt erschcinen.

Ein Jahr später veröffentlichte lerselbe Forscher (1893. 433) weitere Untersuchungen über die gleiche Frage, wobei er die Raupen mit Blättern fütterte, welche mit Pikrokarmin und Pikronigrosin impregniert wurlen. Er wies nach, dass die Raupen sich die Pikrinsäure wirklich aneignen und dieselbe auch dlurch die Driisen, welche die Seide entwickeln, ausscheiden.

Gebrüder Daniel (1892. 163) sagen in ihrer Anleitung zur Tödtung von Insekten mittelst Schwefeldioxyd, dass die bleichenden Eigenschaften dieses Gases sich bei manchen besonders empflndlich gefärbten Arten (grüne Cassiden, manche Conthariden, Coccinellen) bemerkbar machen; lingegen bleiben die hellen Farben bei fast allen übrigen Familien viel besser conservirt, welche bei Benützung von Cyankalium, Aether, Chloroform, Benzin, Schwefelkohlenstoff und Alkohol fast stets mehr oder weniger d unkel gefärbt werden.

H. Domenitzki (1892. 191) fand, dass der Käfer Oxythyrea haemorhoidalis $\mathrm{F}$ vor der afrikanischen Ostliüste, welcher auf der 
Stirn einen röthlichen Fleck besitzt, denselben vollstïn lig verliert. wenn man den Kïfer in Weingeist wirit; bei mit Natrimm arsenst getödten Thieren bleibt er deutlich.

A. Kowalewsky (1 S92.470) fand, dass Inrligo-Karmin, welcher in den Insektenkörper eingespritzt wirl, durch Malpigni-Gefiisse ausgeschieden wird. Auch die in den Inselitenkörjer eingefiilurte Lösung von Ammonium-Karmin wird durch Pericardial-\%ellen ausgeschierlen. Der Fettkörper reagiert auf heide Lösungen niclit, solange er gesund ist.

F. Sikora (1592. S13) erhielt hei der Zucht exotis.her hiter Varietiiten un I sagt: „Die Lintwicklung eines Kitters wirl in einem ihn bisher gänzlich fremten Holze nicht olıne Eintluss, namentlich auf die Färbung sein" (p. 140).

A. Voelschow (1893. 930) trug eine grosse Zahl von scheinlsar lehensfähigen und erwachsenen Raupen von Dasychiru juclibundu ab. concolor Stilgr. ein (der Herbst 1591 war für diese Raupen sehr ungiinstig - an allen Baumstïmmen lingen die Leichname) unl er erhielt nur 7 Puppen, welche merkwïrdigerweise die Falter statt nach $\&$ monatlicher, nach $\&$ wöchentlicher Puppenruhe im December iieferten. Diese Schmetterlinge waren alle hell und wesentlich kleiner als normal" (p. 51).

F. Rühl (1893. 725) Sagt, dass Zonosoma annulata Scliulze bei Fütterung mit Acer campestre stark gezeichnete dunkle Exemplare und bei Fiitterung mit Betula alba blasse Stücke mit uncleutlichen Zeichnungen sich ergeben. Ausserdem erzog er mit Salix caprea schöne Varietiiten von Abraxas grossulariata L.

E. Poulton (1893.647 $九$ ) stellte Nahrungsversuche mit Raupen von Agrotis pronulu an und lionstatierte, dass ilhre grïnen und gelben Hautfarben nur dann entstanden, wenn sie chlorophyll- orler etiolinhaltige Nahrung zu sich nahmen.

Carl Frings (1893. 249) zog die Raupen von Arctia caja mit in Salzwasser gestellten Pflanzen und erhielt normal gefürbte Schmetterlinge, nur ein $ठ$ wies sehr verkleinerte weisse Querstreifen und sehr grosse und theilweise verschmolzene schwarze Unterfligelflecke auf. 
Fr. Schreiber (1894. 771) fing in copula Lophopteryx camelina L. aberr. giraffina Hh. und erhielt über 100 Stiick Eier. Die Raupen wurien mit Salix gefuittert unl verpuppten sich darauf ${ }^{3 / 5}$ aller Raupen; der Rest wurde gefuttert mit: Tilia, Populus italica, tremula, nigra und Betula alba. Die zuerst verpuppten Raupen ergaben dunkele Falter, die ibbrigen waren lichtel und lileiner. „Ich glaube nun anmehmen zu liömnen, dlass meine wirklichen giruffiua alle von der Zucht mit Salix herrihiren und dass dieselben dann infolge des geänderten Futters lichter wurlen" (p. 22.2).

Er liess eine Anzahl giraffina in copula gehen unc fuitterte die erhaltenen laupen mit Salix. Diese Zucht ergab lurchwegs auffallend grosse und dunkle Falter.

E. Hein (1894. 425) fütterte die Raupen ron Tunessu urtica: durch 8 Tage mit Brennesseln, welche in blaugefïrbtem Sprulelwasser in einem mit einer rothen Gelatimpapierhiille iberzogenen Zuchtglase steckten, und erhielt daraus Falter, deren Grunifarbe ockergelb ist und an leren Vordertlügeln sich zwischen den 3 schwarzen Vorderrantflecken blassgelbe Flecke befinden. Ferner erscheinen die oberen der beiden schwarzen Punlite jeiles VorderHliigels bedeutend kleiner als die unteren Punlite, sowie anch sämmtliche blaue Randflecke der Flügel sich kleiner und mit iler schwarzen Umrandung verschwommen zeigen.

Vanessa urticae-Raupen, welche er durch 14 Tage mit Brennesseln in kaltem Sprulel fuitterte, lieferten Falter von prachtvoll lunkelockergelber Grunilfarbe. Dieselben Raupen, welche ebenfalls so lange mit griinem Tintenwasser gefuittert wurden, lieferten Falter von ockergelber Grundfarbe. Die Hinterfligel dieser Falter zeigten schmutzigockergelbe Binden und neben den unweit les Innenrandes ler Vorderflïgel sich befindenden grossen schwarzen Flecken fehlten die gelblichen Flecke. Die Farbenzeichnung wurle dabei nicht geändert.

Tanessa io-Raupen, durch ca. 14 Tage mit Brennesseln in kaltem Sprudel gefüttert, lieferten Falter, die nur wenig Farbenänderungen zeigten; dasselbe wurde auch bei Fütterung mit Brennesseln in rothem Tintenwasser erhalten.

Vanessa io-Puppen, welche 11 Tage in Schwefelpulver gelegen waren, lieferten Falter mit einer intensiveren schwarzen Farhe.

Derselbe Forscher (1894. 359) schreibt später, dass bei diesen Versuchen die Beigabe löslicher Substanzen zum Wasser, in welchem 
die Pflanze steckt, eine mässige (etwa $30^{\circ}{ }^{\prime}$ ) sein soll, während eine reichliche Beimischung solcher Substanzen entschieden sowohl den Pflanzen als den Thieren schadlet. Die stärlisten Farbenänderungen zeigen bei diesen Versuchen Arctien und Saturnien.

Lud. Heissler (1894. 362) erhielt von E. Hein zur Einsicht je 4 Exemplare von Vanessa niticae und io, welche durch prïparirtes Futter erhalten wurlen, betrachtet aber die olsen erwïhnten Firbenänderungen als einen Zufall, welcher auch im Freien rorkommt.

Ernst Hein (1894. 358) fütterte die ganz jungen Rüupchen von Vanessa uricae und io mit Brennesseln, welche entweller in das Tintenwasser, welches ans $1 / 3$ griiner Netalltinte uml $\frac{2 ! 3}{3}$ Wasser bestand; in das rothe Tintenwasser, oder in kaltes Mineralwasser (?) gesteckt wurlen. Die Farbenänderungen der dabei erhaltenen Falter verspricht er später zu beschreiben.

L. Heissler (1894. 363) wiederholte die Versuche ron E. Hein (358), indem er das Futter für die Raupen von Trunessa urticue. io, Pieris brassicae u. s. $\mathrm{w}$. in verschiedenen Anilinfarb-Lösungen, in Salzlösungen eingefrischt hat. Bei dliesen Versuchen gingen die Raupen entweder zu Grunle oder ergahen normale Falter.

Edward B. Poulton (1894. 648) theilte die aus Eiern eines Weibchens von Tryphaena promba, ausgeschlüptten Raupen in drei Gruppen, die im Dunkeln verschieden ernährt wurden. Eine Gruppe erhielt als Futter die gelben, etiolirten (vergeilten) Blätter aus dem centralen Theile des Herzes vom Kohl; die zweite erhielt weisse Mittelrippe solcher Blïtter, von denen clie gelbe Spreite entfernt war und die dritte bekam die tiefgrünen, äusseren Blätter derselben Pflanze. Somit enthielt die Nahrung im ersten Falle kein Chlorophyll sondern Etiolin, im zweiten auch kein Chlorophyll und nur wenig Etiolin, von welchem die Raupen übrigens nichts erlielten, und im dritten Falle reichlich Chlorophyll. Die Versuche ergaben, dass die Raupen der ersten und dritten Gruppe theils griine, theils braune Grundfürbung bekamen, während die der dritten Gruppe eine weisse Grundfarbe behielten.

Josef Philipps (1894. 634) benützte ein Verfahren, die Farben der Schmetterlinge auf chemischem Wege zu rerändern, welches 
im folgenden besteht: Man bringt die Schmetterlinge auf nassen Sand unter die Glasglocke, wo auch ein Glaskolbchen mit übermangansaurem Kiali, Salzsäure und Eisessig sich befindet. Alsbald tritt eine Entwickelung von "farblosem Gase mit Chlorgeruch" ein unil eine Verfärbung der Schmetterlinge findet statt. „Viele Farben werilen nicht angegriffen, andere werden intensiver, wieder andere verschwinden, einige nur vorübergehend oler verïndern die Nüance". Der Verfärbungsprocess ist oft schon in einer halben Minute fertig. Pieris-Arten, phicumone, hyale, rhammi etc. werlen gelblich, machaon dunkelgelbbraun, zermattensis goldgelb. Pieris-Arten werden nach einigen Tagen an ler Luft blass rosa schillernd, später dunkelrosa. Er schreibt diese Farbeänderungen der Einwirkung des Ammoniakgehaltes der Luft $\mathrm{zu}$, wenigstens entstehen gewisse Verfärbungen sofort, wenn ein Schmetterling in eine Schachtel mit "kohlensaurem Ammoniak“ zusammengebracht wird.

August Hüttner (1895. 398) erhielt mehrere Raupen von Parnassius apollo und fütterte sie mit Selum telephium, welche in eine mit präparirtem Wasser (Wasser, Eisenvitriol und Gallussäure) gefüllte Flasche gestellt war. Futter und Wasser wurden alle zwei Tage erneuert. Von 20 Raupen erhielt er 8 Puppen resp. Falter. Unter diesen Thieren war besonilers ein Exemplar stark abgeänilert: Grösse, Form, Zeichnung und Beschuppung ganz normal, die Bestäubung iler Unterflügel am Innerranile gegen den ovalen Fleck zu etwas verloschener. In Zelle 1 des Vorderflügels ist iler schwarze Fleck schwach roth gekernt, ebenso ist iler schwarze Fleck in Zelle 5 hinter der Mittelzelle schwach roth gekernt. Der schwarze ovale Fleck am Innerrande der Hinterfliigel ist ebenfalls roth geliernt und befindet sich zwischen diesem unil dem unteren Augentlecke ein schwarzer Fleck. Die Grundfarbe auf der Unterseite der Fliigel ist lebhafter gelb, als bei normalen Stücken.

Eine kurze Besprechung les obigen Versuches finclet sich bei $\mathrm{D}^{\mathrm{r}}$ Heissler (1895. 364), wobei er (las Entstehen solcher Aberration nicht in dem Einflusse des Futters sieht, sondern betrachtet sie als "Spiel der Natur," inclem er sagt: "Ich habe cliese beillen Aberritionen unter dem obigen Titel veröffentlicht, damit doch endlich einnal derartige zwecklose Spielereien aufhören. Aberrationen sinıl ein seltenes Spiel rler Natur, Uebergänge zu anleren, Rüickschläge auf friihere Formen, ileren Ursache ilunkel ist. Sie lassen sich nicht 
erzwingen. Also wer mit solchen Spielereien und die Zeit und Miihe auf Besseres verwendet!"

W. Caspari II. (1895. 137) fütterte Raupen mit präparirten Futter (־) unl erhielt „von, grossartigen Farbenänlerungen keine Spur, wenigstens keine nennenswerthen" (1) 186). Die Raupen gingen hei seinen Versuchen massenhaft zu Grumle, weil die Beimischungen (?) dles Wassers in die Blitter gelangten und die PHanz'n und auch die Raupen vergifteten.

Inilem er Smerinthus ocellata zweimal auf , ilerselben" PHanze in Freien an einem heissen Orte $z 0 g$ (llas zweite Mal Inzucht), erhielt er fast lanter ocellatı ab. rosea. "Dis siml die einzigen Fälle, wo ich sagen kann, dass vielleicht las Futter auf die Abämlerung dieser Falter sehr oder theilweise einwirkte" (p. 188).

M. Standfuss (1896. 840) fïtterte die Raupen von Callimorplu domiunla von klein auf mit Pfianzen, die in Kochsalzlauge eingefrischt stanclen. Dabei erhielt das Roth der Hintertliigel kenntlich einen Stich ins Gelbliche. Er macht auch darauf aufmerlisam, dass die Formen von Callimorpha dominulı unil hera „mit gelben Hinterfliigeln sich konstant orler loch noch am zahlreichsten in nicht gar zu grosser Entfernung von der Meereskiiste finılen" (p. 208).

Er fuitterte auch eimmal 100 Arctia rillicu-Paupen mit rohem Rinulteisch und erhielt keine abweichenten Falter. Er reichte den Raupen (hauptsächlich von Arctiiclen) von klein auf als Futter Pflanzen, welche in Lösungen von Sïuren, Alkalien, Farbstoffen, liochsalz etc. eingefirischt wurlen. "Es liess sich wohl oft genug eine Verkïmmerung in Fïrbung und Grösse nachweisen, aber eine wr. sentliche Verschicbung in Farbe orler Zeichnung niemals" (p. 213).

Inrlem er noch Smerinthus tiliae, welche sich regulär in einer griinen und einer brauen Form finclet, Ellopia prostpiuria, welche in Wïliern von Pinus silvestris (Kiefer) rothbraune Fürlung hat, uncl in grimer Form als rar. prasinaria in Wällern ron Picea rulgaris (Fichte) vorkommt und Smerinthus tiliae (der von Lindenalleen ïberwiegend die grïne Form liefert und aus Wällern von Eiche oiler Birke meist lie braune Form) als Beleg anfiihrt, welcher scheinbar dafür spricht, dass die Nahrung die Fürbung beeinflusst, weist er darauf hin, dass die hier beobachtete Farbenïnderung durch leuchtigkeit- unı Lichtverhältnisse, welche in verschierlenen Wällern rerschierlen sinıl, orler durch anılere Dinge vielleicht zu erklären seien. 
E. Fischer (1896. 229) priifte ,lie Untersuchungen von Troska (1590. 884), konnte aber keine Einwirkung feststellen. Er wies sogar nach, ılass von der genannten Zuckerlösung gar nichts in den Puppenkörper hingelange, da die Chitinhaut für alle wïsserigen, nicht sehr ätzenılen Fliissigkeiten unlurchlïssig ist. Alle ausgeschliipften Falter waren nach solcher Behandlung ganz normal.

Er untersuchte auch die Einwirkung von Chloroform, Ïther und Alkohol auf die Puppen. „Die Puppen wurden in eine, die genannten Narcotica in Gasform enthaltende Schachtel gelegt, so lange, bis sie auf Reize nicht mehr reagierten, worauf sie noch einige Stunden in einem mit dem betreffenden Narcoticum ganz schwach durchsetzten liaume verblieben. Dies wurle an 6 aufeinanderfolgenden Tagen wiederholt; alle P'uppen ergaben tarlellose, aber auch ganz normale Falter" (p. 23).

Nach seiner Vermuthung sollen, wenn im Raupenkörper durch liuinstliche Ernährung ein Silberalbuminat gebildet oder metallisches Silber deponiert würde, hell gefürbte Falterspezies (Pieriden, Papilioniden, Vanessen etc.) die Dunkelfürbung erhalten.

E. Topsent (1896. 877) betrachtet Eumolpus vitis und obscurus als eine und llieselbe Art, wohei nach seiner Meinung ausschliesslich die Nahrungspflanze für die Färbung massgebend ist. Wenn die Larve sich auf (lem Weinstocke entwickelt, so entsteht ılie Form mit braunen Flïgeldecken, wenn sie sich aber auf Epilobium entwickelt, so ist die Form schwarz.

Die Kritik lieser Untersuchung finclet sich bei Karl Sajó (1897. 733).

S. I. Metalnikow (1896. 578) spritzte in den Körper der Aeschna-Larven die Lösung von Ammonium-Karmin ein und fand, dass gewisse grosse Zellen les Fettliörpers (fettfrei) in illrem Inneren den Karmin ablagern.

L, Krulikowski (1896. 479) fütterte Raupen von Acidalia dimidiata Hufn. mit Salat, erhielt jedloch keine rosarothe Fürbung der Schmetterlinge, wie es bei E. Hofmann (380) p. 133 mitgetheilt ist.

L. H. (1S!)6. 337) fütterte die Raupen von Deiliphila nerii mit Blättern des gewöhnlichen blauen Flieders, welche ausserorlent. 
lich rlunkel gefirbte Schmetterlinge mit gar keinem Rosa in clen Oberflügeln ergaben. Auch die Zeichnung wich wesentlich ab: dis Unterflügel waren einfach aschgrau und hatten nur eine schlangenförmig durchlaufende hellere Binde.

H. Krauss (1897. 474) sagt, dlass Benzinclampf ılie Farben ıler Insekten änclert, besonclers schönes Gelb leilet später, es bräunt sehr; Essigäther- wie Aetherilampf verïnilern die Farben auch.

Karl Sajó (1897. 734) äussert sich, wie folgt: „Was Herr Krauss über Aether und Benzin sagt, ist nur in dem Falle richtig, wenn die Entoma von diesen Flüssigkeiten ganz durchnässt werden uncl in diesem Zustande längere Zeit hindurch liegen bleiben" (p. 439). Er sagt auch, dass wenn die zu erweichenden Insekten lange Zeit auf dem nassem Sande, zu welchem einige Tropfen Karbolsïure hinzugegeben wurden, liegen, lieselben die zarten Nüancen verlieren.

H. Gauckler (1897. 284) erhieit aus Eiern Räupchen von Arctia caja und fütterte eine Serie mit Salat und die andere mit Symphoricarpus racemosus (Schneebeere). Die ausgeschliipften Schmetterlinge aus beiden Serien hatten keinen Unterschiell roneinander, weder in der Fïrbung noch in der Zeichnung.

0. Hamann (1897. 352) sagt, lass der Nahrungserwerb für die Thiere der Höhlen im Allgemeinen sich nicht schwieriger gestalten wird, als der der oberirdischen Verwanılten. (Die Kritik dariiber vide bei C. Verhoeff [1898. 908]).

M. C. Piepers (1897. 638) ernährte auf Java eine urspriinglich grüne Raupe von Chaerocampa alecto L. mit röthlichen BigoniaBlättern und beobachtete dabei, dass sie immer mehr rothbraun wurde; "bestimmt schien der Farbstoff der Nahrung die Ursache davon zu sein, denn auch die noch feuchten Excremente der Raupe waren dermassen ılamit getränkt, dass sie auf weissem $\mathrm{Holz}$ unı Fliesspapier röthliche Flecke zurïckliessen" (p. 80). Der darauf folgende Zusatz zeigt aber, lass Piepers diese Erscheinung nicht als eine allgemeine Regel betrachtet: "Auch auf anderen, nicht rothen Blättern lebende Raupen dieser Art werlen loch rothbraun. Und die grosse Menge der Sphingiden-Raupen lebt allein auf griinen Blïttern und wirl trotzlem zum Theile braun“ (1). S0). 
P. Marchal (1897. 546) hält es für möglich, dass der Unterschied zwischen Cecidomyia destructor und Cecidomyia avenae dadurch $\mathrm{zu}$ erklären ist, llass $C$. avenae nur auf Haber und $C$. destructor nur auf Weizen sich entwickelt, sonst sind beile Fliegen einer und wlerselben Art.

Jaroslav R. von Lomnicki (1898. 534) kommt bei seiner Betrachtung des Erythropodismus (die Erscheinung des Auftretens (ler rothbeinigen Formen) zum Schluss, dass diese Erscheinung durch „Sparsamkeit in ller Energieschaffung" zu erklïren ist. „Die Bildung und Erhaltung der Pigmente setzt einen gewissen Energieverbrauch voraus. Wenn eine gut pigmentierte Art auf schwierige Daseinsbedlingungen trifft ( $\mathrm{z}$. B. rauheres Klima und damit verbundene Armuth der Nahrungsmittel), so entwickelt dieselbe aus der Verdauung, also Zerstörung der complicierten Eiweissstoffe viel weniger der kinetischen Energie, als die Artgenossen, welche sich zufälliger Weise in besseren Daseinsbedingungen befinden, mehr Nahrungsstoffe flnden, mehr der kinetischen Energie aus der Zerstörung der complicierten Eiweissstoffe, in welchen potentielle Energie aufgespeichert ist, entwickeln. Das kleinere Quantum der entwickelten Energie vermag nur kleinere Arbeit zu leisten, oder anders kann: nicht so viele Arbeiten vollziehen, kann nicht so viele Funktionen gleichı̈̈ssig in Bewegung setzen, wie in dem Falle eines grösseren Quantums dieser Energie. Nun ist der Organismus gezwungen, seine Energieausgabe zu verkleinern, an der Energie zu sparen, und es ist selbstverständlich, dass die Strebung in dieser Richtung sich offenbart (lass minder nützliche Arbeiten, die wenig wichtigen Funktionen für den Organismus eingestellt werlen. Die Carabus-Arten sparen in schweren Lebensbedingungen an der Bildung und Erhaltung der Pigmente in den Extremitäten, es erscheinen demnach erythropocle Formen" (p. 356).

Er sagt weiter, dass in Galizien der Erythroporlismus der Laufkäferarten eine gewöhnliche Erscheinung ist, so z. B. kommt dort Carabus cancellatus var. tuberculatus Dej., Carabus granulatus ab. rubripes etc. vor.

Eine ähnliche Erscheinung ist auch der Rufinismus; es giebt Käferarten, unter welchen man manchmal auf unpigmentierte, röthliche Individuen trifft. Rufinismus hat denselben Ursprung wie Erythroporlismus, wobei die Pigmentlosigkeit der Höhlenthiere ihre 
Ursache nicht nur in der Ersparniss der Energie, sondern auch im Fehlen einer gewissen Art iler strahlenilen Energie hat.

Was nun' den Einfluss ıles Lichtes auf die Färl)ung betrifft, so hat Carl Verhoeff (1898. 908) wirlersprechenile Thatsachen konstatiert (vide Kapitel III. 4.).

Carl Verhoeff (1898. 908) schreibt wegen der Nahrung in unterirlischen Höhlen: „In mehr als einer Höhle habe ich mich erstaunt gefragt, wie es iiberhaupt möglich ist, ılass ılie gefuntlenen Kerlhthiere ihr Leben fristeten, da von Nahrung ungemein wenig, oft gar nichts als nackte Flächen zu erspähen war" (p. 137 u. 138). $\mathrm{Er}$ meint, dass die meisten Höhlenthiere ihr Fortleben nur durch die verhältnissmässig gleichmässige unı niedlrige "Würme" erhalten können, welche eine „geringere Lebensenergie" erzeugt, spricht aber gleichzeitig die Vermuthung aus, dass diese Thiere vielleicht lingere Zeit in Schlaf verfallen.

Gräfin Marie von Linden (1899. 322) stellte folgencle Versuche an der Universität, zu Bonn an:

Die Raupen von Vanessu urticae wurlen mit Brennessel, ileren Blätter mit verschielenen Stoffen angestrichen waren, gefüttert. Diese Stoffe waren: defibriniertes Blut, Eisenalbuminat (vier Theile metallisches Eisen auf 1000 Wasser), Argonin-Silber-Kaseïnverbin lung (5\% Lösung), Zucker (gesättigte, wässerige Lösung), Lupulin (allioholischer $5 \%$ Auszug aus (ler Frucht), Capsicum (alkoholisch-ätherischer $10 \%$ Auszug aus (ler Frucht), Morphium ( $1 \%$ wässerige Lösung), Atropin (1\% wässerige Lösung).

Bei den entwickelten Schmetterlingen wurile folgenie Verïnderung der Grundfarbe konstatiert:

"Kräftigere, glänzendere Farben erzeugt die Fütterung mit Eisenalbuminat, Zucker, Lupulin. Heller gefärbt erscheinen die mit Blut gefütterten Schmetterlinge, die Zeichnung wirl bei manchen von ihnen sogar unileutlich, verwaschen. Eine auffallende Verilunkelung der Grundfarbe trat bei Fütterung von Argonin und Morphium ein. Die mit Morphiumlösung gefütterten Falter sincl ausserlem vor den anileren durch eine grössere Beimischung von Roth ausgezeichnet. Auch die mit Capsicum gefuitterten Raupen ergaben ziemlich dunkel gefürbte Schmetterlinge."

Die Veränlerungen der Zeichnung der Falter bei diesen Versuchen waren ilenjenigen, welche durch Wärme- resp. Kälte- 
wirkung erzielt wer(len, "vollkommen analog." Die hauptsächlichsten Veränderungen sind:

1. Verschwinden orler bedleutenile Redulition iler schwarzen Flecke in den Seitenrandzellen.

2. Rerluktion der blauen Randflecke.

3. Reduktion der gelben Schuppen im Seitenrand dex Vorilerflügel und Verbreitung des schwarzen Randes.

4. Verlüsterung der Flügelspitze.

Ansserlem wurden Versuche mit Puppen von Tanessu uiticae unıl Pieris brassicae angestellt, indem dieselben in eine Atmosphäre von reinem Sauerstoff gebracht waren. Die entpuppten Schmetterlinge ergaben wenig glänzencle abgeschossene Farben, welche einen bräunlichgelben statt rothgelben Grundton hatten. Bєi einigen Schmetterlingen waren die dunklen Flecke in den Zellen des Seitenraniles geschwunden. Die Zeichnung war bei allen Faltern verwaschen. Die dlunkle Binde längs des Seitenrandes war mit vielen gelben Schuppen untermischt. Der dunkel gezeichnete Seitenrant in den Hinterflügeln durch zackigen Verlauf ausgezeichnet.

Pauls (1899. 627) in Ballenstedt brachte unter die Glasglocke einen Tag vorher gefangene und mit Chloroform getöltete Falter; unter derselben Glocke befand sich der mit Salmiakgeist stark getrïnkte Sand. Vanessa io wurle dabei schwarz braun, "namentlich wenn die Flügel sich mit der Flüssigkeit imbibiren."

Carl Verhoeff (1899. 909) fand ein Bruchyclesmıs subtervanens, welches sich ilurch grasgrüne Fürbung auszeichnete. Die miliroskopische Untersuchung ergab, dass die Trümmer frisch gefressener Blätter den Darm anfüllten und das Chlorophyll den ganzen Kïrper grïn durchfärbt hatte.

N. Cholodkowsky (1899. 141) beobachtete, dlass dlie jungen Läuse Lachnus maculosıs n. sp, welche sonst ilunkelbraun oiler srünlichgrau sinı, im Alkohol hellbriun mit zienlich viel schwarzen Punkten werilen. Das geflügelte Weibchen dieser Art wirl im Alkohol bräunlich und oben mit zwei schwarzen unterbrochenen Längsstreifen geziert, sonst ist es am Kopf und Thorax schwarz, ঐas Abılomen röthlichbraun, oben lïngs ıler Nittellinie unı quer über die Ringe weiss bestäubt. 
Luchnus abieticola n. sp. ist im Leben ilunkelgrau mit weisslichen Querstreifen; im Alkohol ist es bräunlich mit 6 Längsreihen kleiner schwarzer Punkte am Rücken.

B. Slevogt (1900. 822) erwähnt in seiner Abhanllung, lass er in der Sammlung eines libauschen Entomologen Vanessa xanthomelas mit abgeänilerter Zeichnung sah. Dieser Entomologe erzog die gefunilenen Raupen mit Birkenlaub. Von 50 Raupen verpuppten sich nur 4. Die Falter haben eine weit llunklere Fïrbung, wobei die sunst getheilten, schwarzen Punlite am Vorderranile iler VorilerHiigel sich zusammen geflossen ilarstellen. Die Unterseite glich völlig der von polychloros.

I. Krasilschtschik (1900. 472 ) beobachtete, dass die Färbung der jungen Raupen von Heliothis dipsaceus und $H$. scutosus vor der Nahrung abhängt: diejenigen, welche die inneren Blumenorgane fressen, werden geblich-braun, welche aber sich von grünen Blättern ernähren, nehmen die grine Färbung ron diesem oder jenem Nuance an.

Ausserilem machte er fulgende Fütterungsversuche an Raupen von Heliothis dipsaceus:

Gewöhnliche grau-grüne Raupen, welche ausschliesslich mit Leinekïptchen gefüttert wurden, nahmen bald gebliche Färbung an. Raupen, welche hungern, werlen hell-grün mit glänzenllem Chitin. Die Futterpflanzen Thymus serpyllum gemischt mit Medicago ertheilten den Raupen dunkele sammtartige Färbung.

Ph. C. Karl Absolon (1900. 2) untersuchte die Frage über den Nahrungserwerb der Höhlenthiere und fand, dass überall genug faulende Stoffe und die mächtigen Schichten des Fledermausguanos sich finclen. Dieser Guano besteht aus den unverdauten Thierresten. In ilen von ihm untersuchten Höhlen wachsen auch ïpig verschiedene Schimmel, Pilze und Moose. Nur eine Höhle (von 180 des mährischen Karstes), Šošivker-Höhle, besitzt von allen diesen Dingen nichts, als nur nackte Stalaktiten. Hier verfolgen sich die einzelnen Indlividuen gegenseitig; so z. B. Acariden verfolgen eifrig die Collembolen und saugen sie aus, „lie Collembolen selbst ernähren sich. einerseits mit diesen faulenden Resten, welche von dem Festmahle der Gamasiden zurück geblieben sind, oder mit ihren Excrementen, lauptsächlich aber mit organischen Säften, welche in dem von len Stalaktiten herabstrimenlen Wasser enthalten sinil" (p. 195). 
G. Koschewnikow (1900. 466, 467) fütterte hungrige Bienen m.t Hüssigem Honig (orler Zuckersyrup), zu welchem eine geringe Ienge von ferrum sesquichloratum beigemischt wurde. Nach $1 / 4$ Stunde secierte er sorgfältig die Biene und senkte ihren Fettlïrper zuerst in die Lösung von ferrokalium-cyanatum ein und nachher in Spiritus oder in mit $\mathrm{HCl}$ angesäuertes Wasser. Dabei benbachtete er, dass im Inneren der ächten Fettzellen ein blauer Nielerschlag von Berlinerblau sich billete. Daraus ist ersichtlich, dlass dlie Fettzellen dlas Eisen aus den Blute absorbieren, in welches es mit der Nahrung gelangt.

Als er ılie Biene zuerst nit zuckeriger Eisenlösung unıl nachher mit zuckeriger Ferrocyankalium-Lösung fütterte, fand $\mathrm{rl}$ einen Tag: darauf nach dem Secieren in ihrem Körper keine Spur vom Berlinerblau. Die blaue Färbung wurle nur dann erhalten. wenn rlie präparierte Biene in dlen angesäuerten Alkohol eingetaucht wurle, unil zwar nur im Darmkanal, nicht aber in den Fettzellen.

Die Oenocyten besitzen nicht die Fähigkeit das Eisen aus dem Blute zu absorbieren.

N. Cholodkovsky (1900. 142) stulierte den Lebenscyklus der Chermes-Arten und kam zu folgenilem Schlusse: "Wenn der Chermes viridanus wirklich die bei Ch. viridis Batz. fehlenilen Exsules ersetzt, so liegt der Gerlanke sehr nahe, dass der Ch. viridanus von len auf die Lärche emigrierten Viridis-Generationen abstammt, wobei die letztercn zu einer gesonderten, speziell an die Lärche angepassten und rein parthenogenetischen Species geworlen sind unil gewisse morphologische Besonilerheiten erworben haben..... Wenn wir annehmen, dass die Exsules sich bis ins Unbegrenzte parthenogenetis"h fortzuptlanzen im Stande sind, so können dieselben bei der Unmöglichkeit einer Zuriickwandlerung auf die Fichte zu beständigen Bewohnern der Zwischenpflanze werden, auf welcher dieselben alsilann eine besondere Species bilden. Da num die von ihnen dabei erworbenen morphologischen Merkmale.infolge des Saugens aut́ dler Zwischenpflanze entstanden, so können wir den Schluss ziehen, dass die betreffen rlen Merkmale durch die Veränderung der Nahrung hervorgerufen sincl. Wenn also aus den Exsules selbstïndige Arten (wie vielleicht der Ch. viridanus) entstehen, so ist ller Ursprung dieser Arten dem veränderten Einfluss der äusseren Faktoren uni zwar namentlich dem Einflusse der Ernährung zuzu-

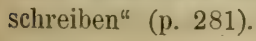


Ferner sagt el: "Die hier mitgetheilten Thatsachen unıl Analogien machen, glaube ich, wenigstens sehr wahrscheinlich, lass die äusseren Faktoren, inshesondere die Berlingungen der Ernährung, auf die Organismen einen stark abïnlerten Einfluss ausiiben kïmmen und ilass als Resultate clieses Einflusses nicht nur leichte, schnell vergehendle Umgestaltungen (Ernährungsmorlificationen nach Nägeli), sonilern auch stabile Formen sich entwickeln künnen, welcht an ihrer Konstanz den sogenannten ,guten" Tarietätien und Arten nicht nachstehen" (p. 283).

Besonders leicht entstehen solche Abänilerungen bei llen parasitären ołler halbparasitären Organisınen, wobei die stabile Abünılerung nur dann erscheint, wo der äussere Einfluss in irgend welcher Weise das Idioplasma trifft.

B. Slevogt (1900. 821) fütterte Raupen von Arctic cuju mit Brennesseln und erhielt die Stammform; sämmtliche Thiere dagegen, die eine in seinem Garten wachsende, verwilderte Lupinenart frassen, entwickelten sich zur ab. flavescens.

Die ausserordentliche Mamnigfaltigkeit der Farben un!l Zeichnungen bei Orrhodic vuccinii unil ligula erkliirt er sich aus dem Polyphagismus der Raupen beider Arten. „Die rerschieclene chemische Zusammensetzung der PHanzensïfte muss ja auf clas zukiinftige Kileil (les Falters eine nicht zu unterschätzende Wirkung ausiiben." (p. 181).

H. Gauckler schreibt mir (1900). 30. XII.): "Ich selbst habe eine Reihe derartiger Versuche angestellt, jedoch bis heute nicht publicirt. Bei Fütterung der caja-Raupen mit $\Lambda$ conitum napellus erhielt ich sehr grosse Exemplare mit breiten weissen Binden auf den Oberflügeln und prächtigem Zinnoberroth der Unterfluigel mit sehr kleinen blauen Flecken. Die Raupen von Orghia antiquu L. erzog ich vor einigen Jahren mit Eichenblïttern, deren Aeste ich in ziemlich concentrirte Salzwasserlösung stellte. Die Thierchen frassen jedoch mit Unlust an diesen salzigen Blïttern und gingen meist nach der zweiten Häutung ein. Einige wenige ïberstanten die letzten Häutungen, (loch brachte ich nur ein einziges Exemplar zur Verpuppung und dieses eine Exemplar lieferte leiler ein normales an dem keinerlei Veränderung zu bemerken war:"

Karl Dietze (1901. 182) fütterte dlie jungen Raupen ron Eupithecia fraxinata mit Artemisia campestris und erhielt bei 
ihnen eine im Freien nicht beobachtete Färbung, welche der ler tamarisciata-Raupe ähnlich war, nümlich: grün, weiss, schwärzlich, immer ohne roth. Bei der dritten Generation schon waren die Falter innotata, tamarisciata, fraxinat gïnzlich entstellt: kurzflügelig, aher nicht verkrüppelt. Die von der Sommer-Generation abstammenten HerbstRaupen nalmen, mit den verschiedenen Blättern gefüttert, trotzlem das grün-weiss-rothe Artemisia-Kleid an.

A. Serebrjanikow (1901. $808 a$ ) züchtete die liaupen ron Gastropacha pini Ochsh. an verschiedenen Bäumen und erhielt folgende Resultate:

1. Raupen gezüchtet an Larix europaea. Verwenlet wurden 10 Raupen. Die neun Schmetterlinge haben die gelbe resp. gelbliche Färbung. Die weissen Flecken sind fast verschwunden.

2. Paupen gezüchtet an Pinus pinea. Wegen Mangel an clieser Nahrung wurilen ilie Raupen nur 1s Tage gefüttert. Die Färbung ist fast typisch, nur der Grundton ist bedeutend zarter.

3. Raupen gezüchtet an Pinus montana. Gezogen wurden 5 Raupen. Die erhaltenen Schmetterlinge weichen von den typischen nicht $a b$.

4. Raupen gezüchtet an Pinus cembra. Die dazn verwendeten 10 Raupen ergaben Schmetterlinge mit aschgrauer Färbung an Vorderflügeln; die braune Fïrbung fehlt ganz. Weisse Flecken sind kaum bemerkbar.

5. Raupen gezüchtet an Picea excelsa. Alle Farben und Zeichnungen sind mehr odler weniger verschwommen. Randbänder der Oberflügel sind grau. Bei der Wurzel erscheint eine zigzagförmige dunkle Bincle, hinter welcher eine schmutzigbraune breite Binde auftritt. Weisse Flecken sinı schwach entwickelt.

F. Tomala (1901. $876 a$ ) liess Raupen von Sesia empiformis auf Stengeln von Euphorbia luciula und erhielt später S. empiformis var. Inunyurica. Weitere Versuche (1904. S7(;乙) stellte er mit Sesia annelata Z. an, indem er die typische Art aus den Wurzeln von Ballota nigra gezogen hat. Die erhaltenen Schmetterlinge ergaben Aberrationen. Daraus schliesst er, llass die FutterpHanzen auf die Bilılung von Farbenvarietiiten ausschlaggebend seien.

I. Dewitz (1902. 168) stellte fest, dass die Verfürbung irischer, weisser Fliegenpuppen durch eine Oxỵlase bewirkt wird und dass 
die Verfärbung verhindert wird durch die Wirkung der Enzyme. aufhebenden Mittel.

Pabst (1902. 620) fütterte liaupen von Vunessu urticue vom ersten Tage ihres Lebens in ganz dunkel gehaltenem Käfig mit Brennessel, die in konzentrierter Chlornatriumlösung stand. Dabei wurden ganz dunkle Falter erhalten. Die schwarzen Flecken auf dem 3. und 4. Felde iler Oberflügel waren bei ihnen sehr gruss, und der Oberflügelrand war breitschwarz ohne blame Flecken.

D. Levrat und A. Conte (19(1)2. 50!) a) stellten Fütterungsversuche mit Raupen von Attacus orizaba und Bomliyx mori an, indem denselben Neutralroth mit der Nahrung gereicht wurde. Die Seirle färbte sich dabei roth. Methylblau ergab mittelmässige Resultate und Pikrinsäure gar keine. Es wurde noch festgestellt, dass das Cirü der Seile von Antherea yamamai Chlorophyll enthält unil das Gelb cler Seile von Bombyx mori vom Gelb der. Nahrung abhängt. I)araus schliessen die Autoren, dass die Farben der Seide nicht von Raupen selbst produciert werilen.

Carl Frings schreibt mir (24. VI. 1903), dass er Anfang der neunziger Jahre Arctia caja-Raupen von klein auf mit in Salzwasser gestellten Pflanzen erzog. Die Falter wichen sehr entschielen und constant in der Richtung der ab. futura F. ab. Das Weiss ler Vorderflügel war reduciert und die dlunklen Flecken der HinterHiigel sehr stark - bis zum Zusammentlissen - vergrössert."

I. Dewitz (1904. 175) brachte Raupen von Porthesic chrysorkoed in die Blausïureatmosphäre un!l erhielt unvollkommene Puppen von schmutzigheller Farbe. Die Flügelscheiden waren ganz farblos. Solange die Puppen in der Blausäureatmosphäre verweilten, ïnlerte sich nichts an ihrer Fïrbung; wurlen sio aus llieser Atmosphäre entfernt, so färbten sie sich im Laufe mehrer Tage dunkelbraun.

I. Devitz (1904. 176) fanil, dass durch mehrtigige Einwirkung iles denaturierten Alkohols, dem ein wenig Wasser beigemischt wird, hei gewöhnlicher Temperatur otler bei erhöhter Wärme auf dem Abdomen von noch weissen oder in den ersten Anfängen der Verfiirbung stehenden Nymphen eines Hymenopters (Orthopelma 
Tuteolator Grav.) die spätere natürliche Zeichnung künstlich hervorgerufen wird.

M. Gillmer (1905. $310 a)$ zog die Abart Mimas tiliae ab. trunnea Bart. aus ganz normal gezeichneten tiliae-Raupen mit Birke.

I. Flögel (1905. 241 a) beobachtete am 20. Juni 1903 in Hamburg Aphis ribis L. an einem Strauche von Ribis nigrum und fand, dlass dieselben durchaus nicht gelb odler grüngelb wie dieselben Blattliuse an Ribis rubrum waren, sondern ganz blass weissgriin. In Bezug auf die Ursache frägt er selbst: „Ob Einfluss ler veränderten Nahrung?"

L. Sitowski (1905. $816 a, 816 b)$ fütterte Raupen von Tineola biselliella mit Wollwatta, die mit in Alkohol gelöstem rothen Farb-• stoff (Sulan III) gefärbt und dann getrocknet war. Die Raupen wurden deswegen rosaroth und zwar am meisten gefärbt war der Fettkörper, dlie Zellen des Verdaungskanals war schwach rosa gefärbt, dagegen blieben die Muskeln und das Chitin, das den Körper umgibt, farblos. Schmetterlinge, welche lliese Raupen ergaben, zeigten eine deutliche Rosafärbung; am meisten tritt die rothe Färbung zwischen den Segmenten hervor, wo das den Hinterleib bedeckende Chitin am diinnsten ist. Eine lleutliche Rosafärbung zeigt sich auch auf lem Kopfe unter den Schuppen und auch an den Femora. Ueberhaupt tritt die Färbung überall clort zutage, wo sich Fett befinilet. Die Untersuchung des Inneres des Schmetterlings zeigte, dass der Farbstoff hauptsächlich in zwei Organen zuriickgehalten wird, nämlich in dem Fettkörper und in dem Eierstosk, ferner im Darminhalt unil in den Zellen des Darmes. Die von solchen Weibchen abgelegten Eier sind auch rosaroth gefärbt und sind vollständlig entwickelungsfähig. Anilere Farbstoffe, wie Methylenblau, Gentianaviolett, Krap1extrakt und Neutralroth ergaben negative Resultate.

H. Sikora (1905. $813 a$ ) untersuchte die Gespenstheuschrecki? (Raphiclerus scabrosıs) und fanı, dass die Färbung des ơ mit der der Aeste, und die des ㅇ mit der der Blätter übereinstimmt. Den Zusammenhang zwischen dieser Färbung uncl der Beschaffenheit des Futters konnte er entgegengesetzt der Behauptung von Creolen nicht finilen. 
H. Federley (1905. 219a) hielt Puppen von Lymantria dispar L. dreimal wïhrend 24 Stunden $30-45$. Minuten in sehr starkem detherlimpfe. Vollkommen erhïrtete Puppen ergaben nach 21-22 Tagen Schmetterlinge mit ein wenig vermehrtem schwarzen Pigment.

A. Pictet (1905. 6:3 7 a) stellte ausgeclehnte Fiitterungsversuche an verschielenen Raupen an unil kam zn folgenden Resultaten: ${ }^{1}$ )

liaupen von Onerin risprar (Normalnahrung Eiche), welche mit Nussblättern aufgezogen wurlen, ergaben in erster Generation Mämchen, der'n Graubraun einen gelblichen Ton anginommen hatte, die Zeichnungen waren verwischt; lie Wribchen zeigten keinen merklichen Unterschiel. In zweiter Generation (bei fortgesetzter Nuss blattfütterung) war die (irundfarbe ier Männchen weiss geworlen, und die Zeichnung bei beiden Geschlechtern war noch heller geworilen. In dritter Generätion war die Flugelzeichnung kaum mehr erkennbar, die Männchen waren fast völlig weiss ausgefallen. Ziemlich denselben Einfluss iibte die Fütterung mit Mispel (Mespilus germanicus), Rosskastanie, Eberesche (Pirus aucuparia). Raupen von Ocneria dispar, die mit Esparsette (Onobrychis satira), mit Pimpernelle (Poterium) und mit Löwenzahn (Taraxacum) aufgezogen wurden, gaben in erster Generation Falter mit verdunkeltem Grunle und intensiverer Zeichnung, in zweiter Generation verstärkten sich diese Variationen noch.

Eine zweite Versuchsreihe zeigte, dass die durch solche anormale Fütterung während einer feneration erworbenen Eigenschaften sich nicht verlieren, wenn in zweiter und dritter Generation normales Futter gereicht wird, selbst noch in vierter Generation verharren einige Stücke in aberrativen Äusseren. Bei Biston hirtarius uni Himera pennaria bringen Nussblätter und Pimpernelle denselben Erfolg herror. Bei Lasiocampa quercus erzielte man mit Nussblättern in einer Generation eine Aufhellung der fahlen Binde, mit Esparsette gefüttert, wurlen die Schmetterlinge sehr dunkel, so dass sie an var. clpina erinnerten, mit Blättern von Laurocerasus vulgaris ger̈üttert, wur.len namentlich die Männchen dunkler. Reichte man Abraxas grossuluriata Evonymus japonicus statt Ev. europaeus. so gab es in den ersten '2 Generationen nur eine schwache Variation, erst in der dritten verstärkte sie sich zu einer Verminderung der schwarzen Flecken und einer Authellung der gelben

1) Entnommen, Dank der Liebenswürdigkeit des Dir. C. Schanfuss, dem fasslichen Referate in der "Insekten-Börse," XXII. o 35. 1905. 
Binde, die bisweilen selbst zum Verschwinten neigte. Analoge Variationen lieferte Fütterung von Pännien und Nussblättern an $S a$ turnia pavonia und von Laurocerasus an Bomlyy lanestris. Porthesia chrysorhoea, mit grossen Blättern von Laurocerasus aufgezogen (statt Eichen- und Fruchtbaumliub), gab keine Variationen, wenn man sie aber mit jungen Schossen ron Laurocerasus aufzog erhielt man in grossen Prozentsatze die ab. punctata.

Bei Bomby.x neustria erhielt man schon in erster Generation bei den Männchen die braune Weibchentärbung, wenn man sie mit jugem Laurocerasuslaube fütterte. Psilura monacha, die man mit Nussblättern (statt Eiche und Coniferen) aufzog, waren $25 \%$ der Falter ab. eremita, 35\% ab. nigra, nur 40\% normal gefärbt. Bei Vanessa urticae konnte man durch Fütterung mit den Blïten von Nesseln (statt der Blätter) die ab. urticoides erzielen.

Diese überraschenden Erfolge ordnet Pictet in fılgende Kategorien: 1. Variationen, die durch Fütterung der Raupen mit verschiedenen Baumlaub entstanden (Nuss, Mispel, Epheu, Laurocerasus vulgaris, Pirus aucuparia, Evonymus japonicus. Humulus lupulus. 2. Variationen, die durch Fütterung von Raupen mit dem Laube von Kräutern entstanden (Taraxacum, Lattich, Onobrychis sativa, Poterium, Paeonia) (selbstverstïndlich ist in beillen Kategorien eine von der natürlichen abweichende Nahrung gemeint). 3. Alle Ausnahmen.

Bei eingehender Betrachtung der vorliegenlen Resultate sieht man, sagt Pictet, dass die mit Baumlaub gefuittert'n Raupen albinotische Falter ergaben, die mit Kraut gefütterten melanotische. Damit kommen wir zu dem Schlusse, dass es weniger die chemische Beschaffenheit der verzehrten Blätter ist, als ileren Strulitur, welche auf die Variationsbildung Einfluss hat und dass das schwerverdauliche und schwerbekömmliche Baumlaub einen schlechten Einfluss auf die Entwicklung der Raupe und die Pigmentation des Falters ausübt, während die Krautptlanzen mit ihrem grösseren Reichtum an Nährstoffen die Entwicklung der Raupen und damit die intensivere Entfaltung dier Pigmente begünstigen. Das, was wir von der Albinose und Melanose wissen, willerspricht dieser Anschaung nicht. IVenn Ocneria dispar bei 2 Generationen mit Nussblattfütterung und einer eingeschobenen mit normaler Futterung leutlich albinotische Falter unil dann bei einer 4. Generation, die wierler mit Nussblättern autgezogen warl, Falter ergab, die den albinotischen Charakter aufgegeben hatten und zur typischen Färbung zurïckgekehrt waren, kann 
man daraus entnehmen, dass die Thiere sich inzwischen an die ungewöhnliche Nahrung so gewöhnt haben, lass lliese sie nicht mehr stört und infolgedessen nicht mehr ihre Färbung beeinflusst. Denselben Fall bietet Abraxas grossulariata, die durch 3 Generationen mit Evonymus japonicus aufgezogen, eine albinotische Variationsneigung verrät, insofern sich die schwarzen Flecke stark verkleinern und die gelbe Binde dem Verschwinden nahekommt, in 4. Generation aber jede Variabilität aufgibt, ja in einzelnen Stücken sogar eine über das normale hinausgehende Färbung annimmt. Diese Gewöhnung an den Nahrungswechsel nach einigen Generationen zeigt, dass die durch die Nahrung hervorgerufenen Abweichungen lieine feststehenden sein können, sondern nur veriibergehende sincl. Das wirl noch weiter llurch einen Versuch an Abraxas grossulariatı erhärtet. Die vorerwähnten Raupen 3. Generation wurlen in 2 Lose gespalten, deren eines weiter mit Evonymus japonicus gefütert (und lieine Variation mehr zeigte), (leren anderes mit jungen Laurocerasusfutter genährt ward. Die Falter des letzteren Loses wiesen ziemlich dieselben albinotischen Abweichungen auf, wie die durch 3 Generationen mit dem japanischen Pfaffenhütchen gefütterten. Man kann daraus schliessen, dass es nicht der Einfluss der Nahrung selbst, sondern vielmehr der Einfluss der Nahrungswechsels ist, welcher die Variationen hervorruft. Übrigens hat Pictet seit 2 Jahren Raupen ler genannten Art in Freiheit von Eiche abgelesen und gefunden, diss die daraus entstandenen Falter ganz analoge Albinose zeigten, wie die Zuchtergebnisse, dass also Eichenfutter denselben Einfluss ausiibt, als Evonymus japonicus.

Est ist leicht, den Raupen ungenügende Nahrung zu bieten, schwieriger ist es, ihnen eine Überernährung zutheił werden zu lassen; man kann das eben nur dadurch thun, dass man ihnen Blätter darreicht, die besonderen Reichtum an Nährstoffen enthalten; das sind, nach Pictet, die Blätter von Kräutern. Mit ihnen erzielt man darum Farben, Melanose. Aber man erzielt noch etwas weiteres mit der Überernährung: dass bei allen den Arten, welche einen Larven-Geschlechtsmerkmal der Weibchen annehmen, ebenso wie Unterernährung, diesselben Raupen die sekundären Geschlechtskennzeichen der Männchen annehmen und diese noch nach einer weiteren Generation mit normaler Nahrung beibehalten wird. Das hat Pictet namentlich bei Ocneria dispar feststellen können.

Wenn man einer Raupe die Nahrung zu bestimmter Zeit gänzlich entzieht, wenige Tage nach der letzten Häutung, so verpuppt 
sie sich unil ergibt einen Zwergfalter, aber ohne jedwerle Farbenabweichung. Zieht man aber Raupen mit tagtäglich ungenïgender Nahrung auf, so verpuppen sie sich, manchmal vor der letzten Häutung, ergeben Zwerge, welche aber zudem meist erheblich rariieren; und zwar erhielt Pictet von zweien solcher Zuchten von Vanessa urticae melanotische Exemplare. „Diese würlen also eine Ausnahme zur voraufgestellten Regel bilden." Weitere Ausnahmen beobachtete Pictet an Psilura monacha, die, lurch zwei Generationen mit Nussblättern aufgezogen, zum grossen Theile die melanotischen ab. eremita und ab. nigra ergab und an Arctia caja, deren bekannte Melanose man mit Nussblattfütterung durch zwei Generationen hindurch erhält. Im allgemeinen aber ist es Thatsache, dass ungenügende Nahrung einen Mangel an Ausfärbung der Pigmente hervorruft; Raupen von Aporia crataegi, die im crivachsenen Zustande zweimaliger Fastenperiode unterworfen wurden, gaben Falter mit ganz glasigen Flügeln, also der extremsten Albinose.

Oft verzehren Raupen Blüten ihrer Nährpflanzen, ohne dass dies den geringsten Einfluss auf die Färbung hat; es scheint aber, dass Blütennahrung auf solche Raupen, die an Blütter gewöhnt sincl, lenselben albinotischen Ausschlag gibt, wie anderer Nahrungswechsel nach der ersten Kategorie. Ocneria dispar mit Rosenbliitenblïttern ernährt, gab dieselben ganz weissen Falter, wie mit Nussblättern ernährt. Eine Ausnahme bietet hier wieder Vancssa urticue, die, wie erwähnt, bei Bliitenfutter in die ab. urticoides schlägt.

Auch auf die Färbung der Raupen hat die Ernïhrung Einfluss: es ist bekannt, dass namentlich glatte Raupen je nach dem eingenommenen Futter verschieden gefärbt erscheinen; man kennt eine Noctuenraupe, die grïn ist, wenn sie Esparsette und Klee orler Rosenlaub frass, und roth, wenn man sie mit Blüten iler beilen letztgenannten Pflanzen füttert. Dagegen gibt es eine grüne Raupe aut Eichenlaub und ihre nächste Verwandte, die dasselbe Laub frisst. ist roth. "Die verschiedenen Arten verdauen verschieden und setzen das Chlorophyll bald in einen grünen, bald in einen rothen oder braunen Farbstoff um." Merkwürdig ist aber eine Beobachtung Pictet's an Raupen von Lasiocampa quercus, deren Fürbung, je nach (ler Ernährung wechselte. Mit Laucocerasuslaub gefüttert, nahmen sie nach 8 Tagen auf jedem dorsalen Ringe einen weissen viereckigen Fleck an, mit Epheu gefüttert, bekamen sie graue Rückenlinie, mit Esparsette gefüttert, wurden sie gelblich, mit Weile gefüttert, backsteinfarben braun. Die Raupen von Ocneriu dispar werten bei Es- 
parsette- und Taraxacumfutter sehr dunkel uni bekommen sehr ausgesprochene Tuberlieln (seliundïre $q$ Abzeichen), bei Pimpernellefutter werden sie grau, bei Rosskastanienfutter grünlich, bei Nusৎblattfutter sehr hell mit gelber Vorderpartie ( $\sigma^{7}$-Äusseres). Die Raupen von Arctia caju werden bei liosskastanienfutter grünlich und verlieren bei Päionienfütterung etwas ihr Haar. Päonienfutter macht weiter Satumia pavoniu-Raupen bram, Nussblattfutter grau, Laurocerasus sehr hellgrïn, Eiche sehr lebhaft grïn. Die Raupen von Vanessa urticue sind und bleiber bei normalem Futter bis zur Verpuppung entwerler gelblich oder schwarz. Die gellen werdem bei Fütterung mit Hopfenblättern schwarz, ebenso wenn man sie mit Nesselblüten aufzieht. Aber zwischen der laupenfärbung und ler ihrer Falter besteht im allgemeinen kein Zusammpnhang, wenn auch die dunkeln (Esparsette- und Löwenzahn-) Raupen von Ocneria dispar unil (Hopfen- und Yesselblütenraupen) von Vunessa urtica: Melanosen und die hellen (Nussblattraupe) von Ocneria dispar Albinosen ergaben.

Aus diesen Futterungsversuchen zieht Pictot folgenile Schlïsse: 1. Die Ernährung der Raupen spielt recht wohl eine gewisse Rolle bei der Färbung der Schmetterlinge. 2. Eine schwerverdauliche Nahrung ruft im allgemeinen ungenïgende Pigmentation hervor und erzeugt so albinotische Variationen. 3. Hingegen bringt ein nährstoffreiches und reichliches Futter meist eine Vermehrung der Fürbung des Pigmentes hervor und erzeugt melanotische Variationen. 4. Gewisse Arten (V. urticae, polychloros, io, Psilura monacha, Arctiı caja), bilden eine Ausnahme von der Regel und bei ihnen ergibt ungenügenıle und Blüten-Ernährung Melanosen. う. Die Männchen werden durch ilen Nahrungswechsel mehr in ihrem schliesslichen Kleide beeinflusst, als die Weibchen. 6. Die Raupenfärbung änlert nach dem gereichten Futter ab und steht manchmal in Beziehung. zur Falterfärbung. 7. Schwerbelïmmliche Pflanzen führen bei gewissen Raupen zur Ausbildung männlicher sekundïrer Merkmale, umgekehrt, nährstoffreiche zur Ausbildung von weiblichen sekundären Merkmalen.

\section{Ergänzungs-Litteratur zu diesem Abschnitt.}

Backer. Iction of Cyanide of Potassium on coleur. - Entomol. M. M. XXI. 1884. p. 66 . 
Bertelli. Nouvelles expériences sur la coloration fournies par les vers à soie soumis au regime de la garance et de l'indigo (Extr. du journ. d'Agricult. prat. pour le midi de la France. 1853).

Cockerell, T. D. A. Chemistry of insects-colours. - The Entomol. XXIII. 1890. p. 200.

Coste, F. H. P. Contributions to the Chemistry of insect coluurs. - The Entomologist. XVIII. 1890. p. $128-132$.

Coste. On Insect Colours. - Nature. XLV. 1892. p. 513-517.

Coste, F. H. P. The Cyanide reaction with yellow Lepidoptora. - Entomologist. XXVI. 1893. p. 1-5.

Covordale. The action of ammonia upon some Lepidorterous Pigments. - Entomologist. XVII. 1884. p. 204-206.

Leverat, $\mathbf{G}$. aud Conte, A. On the origin of the natural coloration of silks of lepidoptera. - U. S. dep. agric. div. ent. Bull. № 44. 1904. p. 75-77.

Mo Lachlan, Rob. Remarks on the Supposed Influence of the food of the Larvae in causing Variation in Lepidoptera. - Trans. Ent. Soc. London. 3. Ser. I. 1862. - Proc. p. 15-16. - Zoologist. XIX, 1861. p. 7687-7688.

Poulton, E. B. The experimental proof that the colours of certain Lepidopterous Larvite are largely due to modified Plant Pigments derived from Food. Proc. Roy. Soc. London. LIV. 1893. p. 41-42, p. 417-430.

Stoin, Siegfried. Ueber Fütterung der Seidemraupen und über den Einfluss der chemischen Bestandtheile der Seide auf das Färben derselben. - Ver.-Bl. d. westfäl.-rhein. Ver. f. Bienen- und Seidenzucht. 16. Jahrg. 1865. p. 93-94.

Thiele, I. Varietäten von Arctia caja und ihr Futter. - Berl. Ent. Zeit. XXVI. 1891. p. 7.

Vorhoeff, C. Physiologische Notizen. - Berl. Ent. Zeit. XXXVI. 1891. p. 125-128.

\section{Einfluss der Schnürung und des mechanischen Druckes.}

August Weismann (1875. 953), machte die sonderbare Beobachtung, dass mechanische andauernde Bewegung auf die Entwickelung der Puppen ähnlich einwirkt, wie Kälte, d. h. dass sie dieselbe verzögert und zugleich Rüichschlag veranlasst. Er reiste sieben Stunden lang auf der Eisenbahn mit Raupen von Pieris napi (der ersten Sommerbrut), von welchen viele in der Verpuppung begriffen waren. Die Falter schliipften erst im folgenden Jahre und "erwiesen sich als exquisite Winterform", obwohl diese Puppen im geheizten Zimmer gehalten wurden.

Chr. Schröder (1896. 774) erhielt Ende April ein etwas „verkrüppeltes" Exemplar von Papilio machaon, bei welchem der linke Oberfluggel wurzelwärts vom Innenrande zum Vorderrante eingeknickt 
war, was durch den allzu starken Druck des Bindfarlens auf die Puppe zu erklären ist; dabei wurile die ganze Flïgelflïche saumwärts von ler Missbililung auffillenı blasser gefärbt als iler rechte Fliigel. Das gleiche gewährt auch die Unterseite les Flügels. Diese blasse Fürbung nerweckt den Anschein, als ob lie weitere Ausfärbung des Flïgels an jenem scharfen Einilrucke, welcher sich naturgemäss auch in dem Zusammenpressen der Alern, Tracheen und Fliigelmembranen verfolgen lassen wird, gescheitert ist, als ob die weitere Stoffzufuhr jenen Wirlerstanil nicht hat ïberwinilen können" (p. 342).

Emil Fischer (1897. 230) lielt die Puppe von Vunessa antiopa zwei Wochen bei $0^{0}$ unl erhielt einen Falter, dessen Zeichmung ler Hinterfligel ler Kälteform ab. artemis Fschr. entsprach, wiihrent auf den Vorlerthiggeln keine Zeichen der Kïltewirkung sich zeigen, „denn alle ibbrigen blaten Flecke sind nicht grüsser geworlen, sondern im Gegentheil gan\% verschwunten. Die schwarze Binle, auf ler die blauen Flecke normaliter stehen, hat sich aufgelüst uni ist von schwefelgelhen schupr'n stark thurchsetzt: es sieht gerale aus, als ob die schwarzen, braunen un'l gelben Schupyen zum Theil "ihren Platz gewechselt" hïtten. Es fïllt besonders auf, thass das schwarze Pigment sich hauptsiichlich um die Ailern herum, zumal um den gellen Saum, angelegt lat." Auf der Unterseite ist der Falter normal, nur eine kleine wellige Verschiehung ler Flügrelrippen ist zu bemerken.

Fischer erklïrt diese Aenilerung an den Voriertliggeln durch den starken Drucli iler an jener stelle zu selır einges nnkten Fligelscheilen bei der Puppe. „Ein solcher Druck kann nun bedingt sein durch abnorme Verwachsungen, o:ler wie clies nicht selten rorkommt, lurch missige Impression oler Verschiebung." Er heobachtete wiederholt eine abnorm starke Einsenkung der Flïgelscheilen bei Puppen von Tanessu io, wolsei an iler entsprechenden Stelle des ausgeschliipften Falters eine beleuten!l diinnere, aber durchaus gleichmässige Beschuppung mit etwas vers ohwommener Zeichnung beohachtet wurle.

Carl Frings (1897. 252) schniurte einige anz frische Tunessa atulantu-Puppen mittelst eines feinen Seilentalens einige Millimeter hinter der Wurzel iler Vorlerfliigelscheiden. Der Fulen wurk kuxz vor dem Ausschlïpfen entfernt unil ein Theil der Falter representierte hiüppel: lie anderen Schmetterlinge waren gut entwickelt, 
wobei der Oberflïgel an der Stelle, wo ler Faulen aufgesessen hatte, eine Knickung oller einen unbeschuppten Streifen zeigte, von hier ab war das Schwarz der Grundfarbe matter, das feurige Rotl der Bincle zu einein blassen Rosa, bei einem Stiicke sogar bis zu weisslichem Rosa alggetönt und das Blau zu Graublau erblasst." Die HinterHliigel blieben von dieser Verfärbung unberiihrt: sie waren vollkommen normal.

Frd. Urech (1897. 895) bespricht die von ihm erzielten Ergebnisse der Schnürung von noch weichen Puppen der Fanessa urticae quer ïber clie Flügelchen, wobei die ausgeschliipften Falter normal glatt entfaltete Flügel hatten, an welchen sich aber folgenile schnürwirkungen zeigten:

1. Es sind die Stellen an den Vorderflïgeloberseiten, welche von dem Drucke des Fadens unmittelbar getroffen wurden, frei von Schuppen oder doch sehr schuppenarm, nicht ganz glatt, bisweilen sogar wenig verzerrt, auch (las Flügelgeäiler (sog. Rippen) zeigt an getroffener Stelle Deformationen.

2. Von der Schnürungslinje an nach auswärts, ı. h. gegen den Seitenrand dles Flïgels hin, ist der Schuppenfarbstoff mehr orler weniger verändert worden (sog. Verfärbnng), hingegen nicht nach iler Fliigelwurzel hin. Die typische Farbenzeichnung ist aber nicht etwa eine ganz anilere geworden, die Species lässt sich noch auf den ersten Blick erkennen. Es sind nicht alle Farbstoffarten gleich starken Verïnlerungen unterworfen, so z. B. haben sich clie schwarzen Flecken am Costalrande und im Mittelfelde meist unveränılert erhalten, während dlas gelbe und gelbrothe Pigment isabellfarbig bis umbrabraun geworilen ist, und die interferenzfarbigen blauen Flecken theilweise verschivunten sind. Das neue Pigment verhält sich auch chemisch anders, es ist unlöslich in Wasser und weniger leicht löslich in ller Chlorwasserstoffsiiure als der platzentsprechenile Farbstoff des Schmetterlings der ungeschnürten Puppe. Er nähert sich in seinen Eigenschalten mehr denen des Pigmentes der Unterseite der Vorderflïgel.

3. Die Thatsache, dass innerhalb der Schnürungsgrenze. il. l. nach der Fliigelwurzel hin, das Pigment unveränclert bleibt, hingegen die ausserhalb liegenilen vom Drucke nicht umittelbar getroffenen Schuppen verfürbt sinı, ist besonders beachtenswerth, da sie Anteutung giebt ïber llie Beziehung der Schuppen zu den Farbstoffen betreff's iler Entstehungsorte der Farbstoffmuttersubstanzen, sie müssen 
also nach der Richtung der Flïgelwurzel hin liegen, von woher iler Blutstrom kommt, und von woher auch die neuen normalen Farbenzeichnungen im Zeitlaufe der Phylogenese auftreten (Fimer's posteroanteriore Gesetze). Es hat Alfred Geldsborougt Mayer nachgewiesen. dass die Schuppenfarbstoffe nicht erst in len Schupjen entstehen, sondern schon im Blute ler Flügellamellen enthalten sinl. Die typischen Pigmentstoffe müssten demnach von den bezüglichen Schuppen oder ihren Scheilen ausgelesen werlen. was in Folge eines Zusammenpassens einer besonleren an ihnen noch nicht erkannten feinen Structur mit der stereochemischen Constitution ler Pigmentstoffmolecule für möglich gehalten warden kann. Wenn dann aber ilurch Druckatrophie mittelbare Störungen dieses Zussamenstimmens bewirkt werlen, so findet Verfürbung orler nicht Ausfärbung der Schuppen statt.

4. Unbeantwortet bleibt noch die Frage, wieso ler sichnürumgsdruck bezw. die Druckatrophie den Farbenchemismus zu ändern vermöge. Auf welche Weise unl durch welche Mittel der verïnlerte Farbstoff entstehe, ob er nur eine weitere Verwandlung des normalen Farbstoffes ist, also ein Derivat (Abkümmling) daron, orler ein ganz anderer nener, oder einer der übricen, die in den Flügelschuppen etwa der Unterseite normal geblieben sind; fur Letzteres spräche fast das nalıe übereinstimmente chemisch? Verhalten. Es ist aber auch denkbar, dass das Blut, wenn es die Zone iler Schniirdrucligewebsatrophie passiert, etwas entmischt wird und keinen gelben und gelbrothen Farbs̉toff mehr fertig an die Schuppen, welche jenseits der Schnïrungslinie gegen den peripherischen Seitemranil des Flugels hin liegen, abgeben kann, oder anderenfills das normal gello unil gelbrothe Schuppenpigment nur verumreinigt uni darum verfärbt viler auch wirklich chemisch veründert. Von Vunessa iuticae sind die Schuppenpigmente leider noch zu wenig ihrer chemischen Natur unl Zusammensetzung nach untersucht und bekannt, um jetzt schon diese Frage beantworten zu künnen, eher wirl es mögli:h werilen, bei ilen Pieriden, deren Pigmente die genau erkannte Harnsïure uni Abkömmlinge davon sinıl, vorausgesetzt, lass auch hier durch Schnürung (bezw. Druckatrophie) Pigmentänderungen stattfinden, was noch nicht experimentiert ist.

5. Die durch Schnüruug entstanilenen ganz ähnlichen Verfärbungen, aber melnr in abgerundeten Formen (kreisförmig, hofartig), wurden an einigen $r$. urticuc-Schmetterlingen erhalten, deren Puppen nicht gesehniirt worlen waren, aber theils zufällige, theils absichtiche Miss- 
himillungen erfahren hatten, die auf eine Druckwirkung bezw. Druckatrophie hinauskommen dürften.

6. Zur Unterscheilung vom natürlichen typischen scharf gegensätzlichen Albinismus und Melanismus schlage ich vor, die durch Schniirung bezw. durch Druckatrophie willkürlich erhaltbaren, meist unsymmetrischen, vermischt albinismus- und melanismusïhnlichen Erscheinungen als Farbenstörungen oder mit dem griechischen Ausilruck Chromotaraxis lurch Druckatrophie zu bezeichnen.

Schwach geschniirte Pieris brassicae-Sommer-Puppen ergaben ihm nur normal gefärbte Schmetterlinge.

In einer weiteren Abhandlung (1898. 897) iiber chromatotarachäische Falter theilt Urech die gleichen Versuche mit. Je nach der Stïrke des Schnurdruckes wirl bei Vanessa urticac entweder

1. Nur die Farbe des Schuppenpigments in peripherischer Richtung eine andere und die Schuppen und Fliigelhaut bleiben glatt, oder

2. Es wird auch die Flïgelhaut an der Schniirungslinie etwas geknickt oder gerissen.

3. Es werden auch die Schuppen etwas schrumpfig und treten in geringerer Anzahl auf.

4. Die Schuppen sind von der Schnïrungsstelle an in peripherischer Richtung nicht mehr entstanden.

Auch bei Vanessa io wurde durch Schnürung eine Verïnderung des Pigmtntstoffes erhalten, wobei meist starke Verschrumpfung iles ganzen Flügels eintritt.

Fried. Urech (1898. 899) sagt weiter iiber den gleichen Gegenstand folgendes: „Die Thatsache, dass nicht zu beilen Seiten der Schnürungslinie bezw. der Druckzone eine Farbstoffänderung stattfindet, sondern nur peripherisch nach auswärts, weist darauf hin, dass der Druck eine Fortsetzung von physiologischèn Vorgängen, die sich von der Fliigelwurzel her fortsetzen, hemmt. Da bei mässigem Schnurdruck das Flügelwachstum und die Beschuppung nicht gehemmt wird, denn die Flïgel entfalten sich vollstïndig der Form und Grösse nach (die Schuppen werden nicht deformirt und sind normal gelagert, nur (ler Farbstoff ist ein anderer geworden), so muss das den Farbstoff liefernde Mittel durch den Schnürungsilruck, sei es direkt oder inclirekt, in seiner Verrichtung gestört worlen sein" (p. 33). 
Auch ich stellte Versuche mit mechanischem Druck an. Mittelst Hebelvorrichtungen wurle verschieilener Druck auf ien Thorax iler Puppen von Sphinx ligustri während 3 Monaten ausgeïlst. Die Puppen kamen leider nicht zur Entwickelung.

Chr. Schröder (1901. 778) faml, dass die Scliniirung als Hemmung (ler Ausfärbung sich erweist, wenn sie an llem völlig ausgebildeten Flügel des eben ausgeschlïpften Käafers (Adaliı bipunctata L.) vorgenommen wird. 


\section{Nachträge zum thatsächlichen Theil.}

Zur Entwickelungsgesehwindigkeit der Insekten.

\section{Zux Cinleitung.}

F. Urech in Tübingen machte sehr ausführliche Gerwichtsuntersuchungen an verschiedenen Lepidopteren von der Raupe bis zum Imago. Seine Resultate von 1890-1891 konnte er jedoch nicht veröffentlichen und stellte mir das gesammelte Material zur Verfügung, welches hier in der von mir bearbeiteten Form zum ersten Mal zum Abilruck kommt.

Zuerst werde ich lie Wägungs-Resultate anführen, welche an ganz frischen Puppen von Vanesssen bis zum Auskriechen des Schmetterlings erhalten wurden. Alle Puppen datieren von Mitte Juli 1890.

\begin{tabular}{|c|c|c|c|c|c|c|c|c|c|c|}
\hline \multirow{4}{*}{ 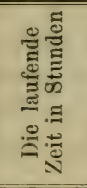 } & \multicolumn{10}{|c|}{ Ganz frische Puppen von: } \\
\hline & \multicolumn{9}{|c|}{ Vanessa antiopa } & V. io \\
\hline & No 1. & № 2 & № 3 & No 4 & № 5 & № 6 & 스 7 & № 8. & 수 9 & No 1 \\
\hline & \multicolumn{10}{|c|}{$\begin{array}{l}\text { Gewichtverlust der Puppe während des Zeitintervalls von } \\
25 \text { Stunden in } \% \text { des ursprünglichen Puppengewichtes }\end{array}$} \\
\hline 0 & & & - & - & - & - & - & - & - & - \\
\hline 25 & 1,6 & 2,0 & 2,3 & 0,5 & 2,4 & 0,6 & 0,6 & - & 1,5 & - \\
\hline 50 & 1,2 & 1,5 & 1,4 & 0,5 & 1,6 & 0,5 & 0,5 & 0,2 & 0,9 & 1,6 \\
\hline 75 & 1,5 & 2,4 & 0,6 & 0,6 & 1,9 & 0,8 & 0,8 & 1,0 & 0,4 & 0,5 \\
\hline 100 & 2,3 & 2,9 & 1,4 & 1,1 & 1,4 & 0, & 0,8 & 1,1 & 3 & 5 \\
\hline 125 & 2,6 & 2,2 & 1,6 & 1,2 & 1,7 & 1,0 & 1,1 & 1,0 & 3 & , \\
\hline 150 & 3,6 & 4,4 & 1,2 & 1,4 & 1,7 & 1 , & 1,1 & 0,8 & & 5 \\
\hline 175 & 3,7 & 4,8 & 1,2 & 1,8 & 2,0 & 1, & 1,2 & 0,6 & & 0,8 \\
\hline 200 & - & - & - & 1,9 & 2,2 & 1,9 & 2,0 & 0,5 & 0,4 & 1,0 \\
\hline 225 & - & - & - & - & - & 3,2 & 3,0 & 0,6 & 0,8 & 0,7 \\
\hline 250 & - & - & - & - & - & - & - & 0,6 & & 0,5 \\
\hline 275 & - & - & - & - & -. & - & - & 0,6 & 0,2 & 0,4 \\
\hline 300 & - & - & - & - & - & - & - & 1,0 & 0,2 & \\
\hline 325 & - & - & - & - & - & - & - & 1,0 & 0,1 & - \\
\hline 350 & - & - & - & - & - & - & - & 1,3 & 0,3 & - \\
\hline 375 & $\div$ & - & - & - & - & - & - & 1,7 & 0,2 & - \\
\hline 400 & - & - & - & - & - & - & - & - & 0,7 & - \\
\hline 425 & - & - & - & - & - & - & - & - & 1,7 & - \\
\hline Summ & $14,9^{\circ}$ & $20,2 \%$ & $9,7^{0}{ }_{0}$ & $9,0 \%$ & $14,9 \%$ & $11,2^{\circ}$ & $11,1 \%$ & $12,0^{\prime \prime}$ & $9,7{ }^{\prime \prime}$ & $7,0^{\circ}$ \\
\hline
\end{tabular}

Alle diese Puppen befanden sich bei Zimmertemperatur. 
Wie rliese Tabelle zeigt, spielt bei solchen Versuchen die Indivilualität der Puppen eine sehr grosse Rolle. So z. B. beträgt die Puppenzeit von Vanessa antiopa in diesen Versuchen von 175 bis 425 Stunden; auch der Gesammtverlust an Puppengewicht vom Anfung bis zum Ende der Puppenzeit ist verschieden bei verschiellenen Exemplaren, unil zwar beträgt derselbe von $20,2 \%$ bis $9,0 \%$.

Diese individuellen Eigenschaften können durch verschierlenez urspriingliches Gewicht der Puppen nicht erkliirt werlen, wie wie Reihe für den Gesammtverlust an Puppengewicht (s), verglichen mit dem ursprïnglichen Gerwicht der Puppen ( $p$ ), es veranschaulicht:

$\begin{array}{llllllllll}\text { s: } 20,2 \% & 14,9 \% & 14,9 \% & 12,0 \% & 11,2 \% & 11,1 \% & 9,7 \% & 9,7 \% & 9,0 \% & 0\end{array}$ p: $\quad \begin{array}{lllllllll}0,654 & 0,794 & 0,625 & 0,672 & 0,844 & 0,844 & 0,550 & 0,683 & 0,632 .\end{array}$

Die allgemeine Regel, welche wir aus oben angeführter Tabelle ableiten können, besteht darin, dass der Gewichtverlust (in \%) der Puppe während gleichen und nacheinander folgenden Zeitintervallen zuerst langsam zunimmt, erreicht bei 100 bis 125 Stunden ein schwaches Maximum, nimmt dann etwas ab, um zu Enile der Puppendauer wieder bedeutenil zuzunehmen.

Betrachten wir jetzt die Resultate, welche mit Puppen von Papilio machaon erhalten worden sind. Aus einer dieser Puppen (№ 1), schlüpfte ein Schmetterling (25. II. 91), während die zweite (d: 2) vertrocknete. Beide Puppen waren ursprünglich ca. $1 \frac{1}{2} \mathrm{Wo-}$ chen alt (am 13. IX. 90) und wurden in Wärme gehalten (ca. 14 ${ }^{\circ}$ ).

\begin{tabular}{|c|c|c|c|c|c|c|c|c|c|}
\hline \multirow{3}{*}{ 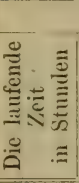 } & \multicolumn{9}{|c|}{ ca. $11 / 2$ Wochen alte Puppen von Papilio machaon } \\
\hline & \multicolumn{2}{|c|}{ № 1} & \multicolumn{2}{|c|}{ ㅅ․ 2} & \multirow{2}{*}{ 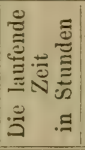 } & \multicolumn{2}{|c|}{ № 1} & \multicolumn{2}{|c|}{ do 2} \\
\hline & 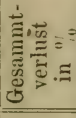 & 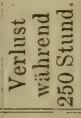 & 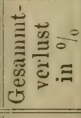 & 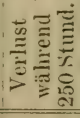 & & 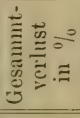 & 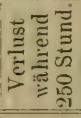 & 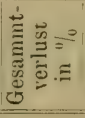 & 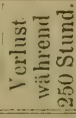 \\
\hline 0 & - & - & - & - & 3000 & 17,3 & 2,8 & 19,0 & 2,9 \\
\hline 250 & 1,4 & 1,4 & 1,1 & 1,1 & 3250 & 18,2 & 0,9 & 20,7 & 1,7 \\
\hline 500 & 2,4 & 1,0 & 2,1 & 1,0 & 3500 & 19,2 & 1, & 22,3 & $\overrightarrow{1}$ \\
\hline 750 & 3,5 & 1,1 & 3,2 & 1,1 & 3750 & 20,7 & 1,5 & 24,5 & 2 \\
\hline 1000 & 4,7 & 1,2 & 4,3 & 1,1 & 4000 & 24,0 & 3,3 & 28,0 & 3,5 \\
\hline 1250 & 5,8 & 1,1 & 5,5 & 1,2 & 4250 & - & - & 30,7 & 2,7 \\
\hline 1500 & 7,0 & 1,2 & 6,8 & 1,3 & 4500 & - & - & 33,2 & 2,5 \\
\hline 17 & 8,3 & 1,3 & 8,4 & 1,6 & 4750 & - & - & 35,5 & 2 , \\
\hline 2000 & 9,6 & 1,3 & 10,1 & 1,7 & 5000 & - & - & 38,1 & 2 \\
\hline 2250 & 10,8 & 1,2 & 12,0 & 1,9 & 5250 & - & - & 39,8 & 1,7 \\
\hline 2500 & 11,9 & 1,1 & 13,9 & 1,9 & 5500 & - & - & 45,5 & 5,7 \\
\hline 2750 & 14,5 & 2,6 & 16,1 & 2,2 & 5750 & - & - & 53,0 & 7,5 \\
\hline
\end{tabular}


Hier ist dieselbe Regel zu beobachten wie bei Vanessen, nur tritt das erste (schwache) Maximum bei 3000 Stunden auf.

Interessant ist der Verlauf des Gewichtverlustes $(\mathrm{g})$ während gleichen und nach einander folgenden Zeitintervallen bei der Puppe .2 , welche in Folge der Vertrocknung keinen Schmetterling ergab. Bis zu 4000 Stunden, als aus der Puppe ㅊ: 1 ein Schmetterling schlïipte, ist dieser Verlauf bei beiden Puppen sehr ähnlich gewesen, nachher nahm aber die Grösse $(\mathrm{g}) \mathrm{ab}$, erreichte bei 5250 Stumlen. ihr Minimum, um auf einmal stark zuzunehmen; man kann daher mit grosser Wahrscheinlichkeit behaupten, dlass diese Puppe zwischen 5250 und 5500 Stunden starb.

Um zu sehen, wie sich das Gewicht der Raupe unmittelbar vor und während der Verpuppung ändert, sind hier einige der betreffenden Wägungen von F. Urech angeführt.

Vanessa antiopa 쓰 8 .

\begin{tabular}{|c|c|c|c|c|c|}
\hline \multicolumn{2}{|c|}{ Raupe vor der Verpuppung } & \multicolumn{2}{c|}{ Raupe während der Verpuppung } \\
(aufgehängt)
\end{tabular}

Die Aenterung des Gewichtes des Schmetterlings ist aus unten. angeführter Tabelle ersichtlich. Am 31. Juli war die Puppe von Vanessa antiopa L. (in ler oben angeführten Tabelle für Puppen, 
nicht erwähnt) um $12^{\text {h }}$ Mittags noch vorhanden und wog 0,4816 gr.: um $12^{\mathrm{h}} 15^{\mathrm{\prime}}$ fing sie an auszuliriechen; um $12^{\mathrm{h}} 20^{\mathrm{\prime}}$ war der Schmetterling bereits fertig. 스 4 von Vanessa antiopa war am 20. Juli um $8^{\mathrm{h}}$ noch als Puppe und wog 0,5740 gr.; die Wiigungen dieses Schmetterlings wurden von $12^{\mathrm{h}}$ Mittags an begonnen.

Vanessa antiopa Imago.

\begin{tabular}{|c|c|c|c|c|c|}
\hline \multicolumn{3}{|c|}{ Nicht nummeriert } & \multicolumn{3}{|c|}{ 스 4} \\
\hline $\begin{array}{c}\text { Datum } \\
1890\end{array}$ & Tages-Stunde & $\begin{array}{c}\text { Gewicht } \\
\text { des } \\
\text { Thieres }\end{array}$ & $\begin{array}{c}\text { Datum } \\
1890\end{array}$ & Tages-Stunde & $\begin{array}{c}\text { Gewicht } \\
\text { des } \\
\text { Thieres }\end{array}$ \\
\hline 31. Juli & $12^{\mathrm{h}} 15^{\prime}$ Nachmitt. & 0,4728 & 20. Juli & $12^{\text {h }} 00^{\prime}$ Mittags & 0,5070 \\
\hline$r$ & $12^{\mathrm{h}} 20^{\prime}$ & 0,4720 & 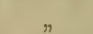 & $12^{\mathrm{b}} 40^{\prime}$ Nachmitt. & 0,4766 \\
\hline 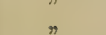 & $12^{\mathrm{h}} 25^{\prime}$ & 0,4612 & 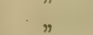 & $1^{\mathrm{h}} 15^{\prime}$ & 0,4380 \\
\hline$n$ & $12^{\mathrm{h}} 30^{\prime}$ & 0,4600 & $n$ & $2^{\mathrm{h}} 30^{\prime}$ & 0,3700 \\
\hline 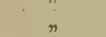 & $12^{\mathrm{h}} 40^{\prime}$ & 0,4380 & $"$ & $3^{\text {h }} 30^{\prime}$ & 0,3338 \\
\hline$n$ & $12^{\mathrm{h}} 45^{\prime}$ & 0,4290 & $n$ & $5^{\text {h }} 00^{\prime}$ & 0,2910 \\
\hline$"$ & $12^{\mathrm{h}} 50^{\prime}$ & 0,4266 & 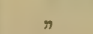 & $6^{\mathrm{h}} 00^{\prime}$ & 0,2700 \\
\hline$n$ & $12^{\mathrm{b}} 55^{\prime}$ & 0,4200 & $n$ & $10^{\mathrm{h}} 00^{\prime}$ & 0,2570 \\
\hline 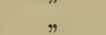 & $1^{\text {h }} 05^{\prime}$ & 0,4190 & 21. Juli & $7^{\text {h }} 30^{\prime}$ Vormitt. & 0,2442 \\
\hline , & $1^{\mathrm{h}} 15^{\prime}$ & 0,4170 & $\eta$ & $12^{\mathrm{h}} 00^{\prime}$ Mittags & 0,2396 \\
\hline n & $1^{\mathrm{b}} 25^{\prime}$ & 0,4158 & $n$ & $2^{\mathrm{b}} 00^{\prime}$ Nachmitt & 0,2230 \\
\hline , & $1^{\text {h }} 35^{\prime}$ & 0,4130 & $n$ & $5^{\mathrm{h}} 00^{\prime}$ & 0,2216 \\
\hline$n$ & $1^{\mathrm{h}} 55^{\prime}$ & 0,4124 & n & $9^{\mathrm{h}} 30^{\prime}$ & 0,2178 \\
\hline$\eta$ & $2^{\mathrm{h}} 10^{\prime}$ & 0,4097 & 22. Juli & $7^{\mathrm{h}} 00^{\prime}$ Vormitt. & 0,2108 \\
\hline${ }^{n}$ & $2^{\text {b }} 30^{\prime}$ & 0,4078 & $\pi$ & $12^{\mathrm{h}} 30^{\prime}$ Nachmitt. & 0,1970 \\
\hline$\pi$ & $3^{\mathrm{h}} 00^{\prime}$ & 0,4048 & " & $5^{b} 00^{\prime}: n$ & 0,1946 \\
\hline$"$ & $4^{b} 00^{\prime}$ & 0,4000 & 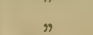 & $10^{\mathrm{h}} 00^{\prime}$ & 0,1920 \\
\hline n & $5^{\mathrm{h}} 00^{\prime}$ & 0,3970 & 23. Juli & $7^{\mathrm{b}} 00^{\prime}$ Vormitt. & 0,1880 \\
\hline$n$ & $6^{\text {b }} 00^{\prime}$ & 0,3908 & 24. & $1^{\text {b }} 30^{\prime}$ Nachmitt. & 0,1614 \\
\hline$\pi$ & $7^{\text {b }} 00^{\prime}$ & 0,3887 & 26. $"$ & $7^{\text {h }} 00^{\prime}$ Vormitt. & 0,1373 \\
\hline$"$ & $11^{\text {h }} 00^{\prime}$ & 03228 & & & \\
\hline 1. August & $3^{\mathrm{h}} 00^{\prime}$ Vormitt. & 0,3782 & & & \\
\hline$"$ & $\delta^{\text {h }} 00^{\prime}$ & 0,3750 & & & \\
\hline$"$ & $1^{\mathrm{h}} 00^{\prime}$ & 0,3632 & & & \\
\hline
\end{tabular}

I. Regen (1906. 677aa) bestimnte die Athmungsverhältnisse von Gryllus campestris L. im wachen und schlafendem Zustande. Im ersten Falle (bei $1^{0}$ ) athmet das Thier (im vorletzten Larvenstadium) durchschnittlich $0,2694 \mathrm{mgr} . \mathrm{CO}_{2}$ in einer Stunde aus, währenıl im zweiten Falle (bei $0^{\circ}$ ) diese Menge $0,02452 \mathrm{mgr}$. beträgt. 


\section{Zum Einfiusse des KIimas.}

L. Möller (1867. 582 ) beobachtete in Thïringen, dass bei günstiger Witterung die Rampen von Simira venosa Borkh. und Drymoniu dodonea Wien. Ver. schon im Mai, bei ungünstiger Witterung aber erst in Juli erscheinen.

Baron Nolcken (1868. 611b) erklärt das Nichtvorhandensein von Acherontia atropos in baltischen Gouvernements durch kaltes und feuchtes Wetter in dieser Gegend, wobei plötzliche Temperaturänderung und häufige nächtliche Sommer-Fröste die Puppen zu Grunde richten.

Th. Reisen (1892. 685a) sagt, dass ein wärmeres Kilima und eine heissere Jahreszeit ein reichlicheres Eierlegen der Maulwurfsgrille bewirken.

P. Marchal (1897. 546) hielt Cecidomyia destructor Say von April 1895 bis April 1896 bei den günstigsten Bedingungen (IV̈rme und Feuchtigkeit) und erhielt sechs Generationen, während diese Fliege im Freien 2-3 Generationen ergiebt. Die Generationen flogen in seinen Versuchen:

\section{I. im April.}

II. in der ersten Hälfte Juni.

III. im Juli.

IV. im August.

V. von der Hälfte September bis zur Hälfte Oktober.

VI. von der zweiten Hälfte Oktober an.

Schüffner $(782 a)$ beobachtete auf der Insel Sumatra, dass Malaria-Muicken, welche am Strande sich aufhalten, berleutend grösser sind, als die Exemplare, welche im Inneren der Insel sich entwickeln. Die ersteren leben 15 Tage, die letzteren nur 2.

K. Rossikow (1905. $705 c$ ) beobachtete, lass die Raupe von Agrotis segctum Schiff. nach 2 Wochen die fïnfte Häutung durchmacht, sobald die Bedingungen dazu günstig sind (reichere Nahrung, genügende Wärme etc.); bei dem Mangel an Nahrung, bei dauernder Kälte und Ueberschuss an Feuchtigkeit findet diese Hüutung erst nach vier Wochen statt. 
0. Nüsslin (1905. 612 a) heobachtete, llass kïhles und trübes Tetter die Entwickelung von Tomicus typoyraphus L. (I. Generat.) so stark aufhält, dass diese Kïfer nicht einmal Enle September schwarmf:̈hig sind. Andauernde trockene Hitze bewirlit das Erscheinen sogar einer dritten Generation.

\section{Zum Einfusse der Feuchtigkeit.}

G. Koch (1856. 457 b) beobachtete, dlass Colicus erlusa L. in warmen, trockenen Jahren (wie 1834, 1848, 1857-59) oft zahlreich, in nassen iusserst selten oder fast nirgenils zu selıen sind.

A. Strubell (1888. 848a) trocknete die Larven von Heterodera schachtii Schmilt während mehreren Monaten unıl nachılem er sich ïberzeugte, dass dieselben scheinbar todt waren, brachte er sie in lie feuchte Luft, wobei sie wieder auflebten. Larven lieser Species können im Wasser ca. 5 Wochen leben.

F. Enock (1891. 214 $\alpha$ ) beobachtete, dass frisch ausgeschlüpfte Larven von Cecidomyia destructor Say einen gewissen Grail der Feuchtigkeit zu ihrer Wanderung bediirfen, sonst gehen sie zu Gruncle.

Joseph (1892. 423 $\beta$ ) stellte fest, dass diejenigen Höhlen am reichsten von Käfern bewohnt sind, in welchen es feucht ist und kein scharfer Luftzug weht.

E. Bataillon (1893. 54a, 54b) beobachtete, dass die mit Wasserdampf gesättigte Luft die Verwandlung der Raupen von Bombyx mori hindert.

S. Mokrzecki (1894. 583a) beobachtete, dass die Regenlosigkeit, die starke Trockenheit, i:ie stetig hohe Temperatur des Frïljahres und des Sommers die Lntwickelung und die Verbreitung von verschierlenen Insekten sehr fördert, z. B. von Ocneria dispar und monacha, Isophia taurica Eversm., Capnodis tenebrionis L., Perotis lugubris F., Eurygaster naurus Fabr.

Vanha und Stoklasa (1896. 901 a) fanden, dass unentwickelte Eier von Heterodera schachtii Schmidt im Wasser sehr bald zu Grunde gehen, währenı Larven, welche noch in Eiern sich befinilen, 
in Wasser nich 18 Stumlen sterben. Die erwachsenen Raupen gehen im Wasser nach 4-う Tagen zu Grunde.

A. Giard (1896. 308) brachte einige tote Puppen von Epilachna argus Fourcr., welche von Lygellus cpilachnue Giarl angesteckt. wurlen, in ein (ilastliischchen. Ein Jahr darauf öffinete er das Flïschchen, befeuchtete die toten Puppen unı beobachtete dabei, dass die Larven der Parasiten lebhafte Lebenszeichen von sich gaben. Er ist der Meinung, dass ler Feuchtigkieitsmangel die Entwickelung der Parasiten um ein Jahr verlängert hat.

P. Marchal (1897. 546) brachte einen Theil iler falschen Cocons von Cecicumyia destructor. Say im Juli in feuchte Gefüsse und den anderen Theil in trockene, und erhielt Imagines in den ersteren bereits im August und in len letzteren erst nach 2 Monaten, nachiem dieselben befeuchtet wurden.

A. Serebrjanikow (1901. $808 a$ ) lionnte keinen Einfluss iler Feuchtigkeit auf ،lie beschleunigte oder verzögerte Entwickelung der Eier von Gastropachu pini Ochsh. konstatieren. Das Eintauchen iler Eier ins Wass:x, wemn auch nur fuir kurze Zeit, verzögert ihre Entwickelung.

A. Giard (1902. 308/) fand, dlass die Larve von Sciaria mochllaris ganz austrocknen kann und wieder lebent wirl, sobald sie sich wieler in normalen Verhältnissen befindet. Diese Austrocknung liamn mehrere Male wiellerholt werden ohme Schiulen für die Larve.

B. Galli-Valerio und J. Rochaz de Jongh (19)3-1905. 270 , $270 \gamma$ ) lionstatierten, dass die Larven von Culex uni Anopheles auf feuchter: Erde tagelang an Leben bleiben; auf trockener Erle nur bis 12 Stunilen. Die Nymphen sind gegeniiber die Trockenheit sehr widerstandsfähig und können, wenn der Boden auch nur ein wenig Feuchtigkeit aufweist, sich vollkommen entwickeln.

F. Tomala (1904. 87ib) hat festgestellt, dass die Raupe von Sesia anuclate Z. in der Wurzel ihrer Nährptlanze überwintert und sich dort auch verpuppt. Ist der Standort der Pflanze feucht genug und der Sonne ausgesetzt, so ist die Entwickelungsgeschwindigkeit schneller, sonst erhält man kleinere Schmetterlinge. 
I. Dowitz (1905. 177 a) konstatiert, dass sich die Zahl der Raupen der Traubenmotte (Conchylis amliguella Hülon.) in den feuchten unl kühlen Sommern vermehrt, währen:l sie sich verminilert, wenn das Wetter trocken und warm ist.

Die Raupe von T. pillerianı verhailt sich in dieser Beziehung ganz anderes.

Un festzustellen, wie lange Doicution sturmii ohne Jahrung am Leben erhalten werlen kann, habe ich die zu diesem Zwecke am 2. V. 1900 erbeuteten Käfer in vier Serien, zu je 100 Exemplare, getheilt, und dieselben am 3. V. un 3 Uhr Xichmittag in vier Draht-Kästen im Zimmer gelassen. Einer von diesen Kästen befand sich über einem grossen Gefäss mit Wasser, lamit sich die Käfer stets in sehr feuchter Lutt befinden: die übrigen Kïisten stanlen im Schatten unter gewöhnlichen Umstïnden. Die toten Käfer wurden jellen Tag sorgfältig entfernt, um den Kíannibalismus zu beseitigen.

Dirjenigen Kïfer, welche sich in gewöhnlicher Luft befanten, lebten noch am 5. V., während von denen in feuchter Luft sich befindenden nur $25 \%$ am Leben geblieben waren.

Dabei änlerte sich der Säftelioëfficient (vd. p. 25), wie folgt (das Mittel aus 25-30 Exemplaren):

\begin{tabular}{|c|c|c|c|c|}
\hline \multirow{2}{*}{$\begin{array}{c}\text { Datum um } \\
3^{\text {h } 30^{\prime}}\end{array}$} & $\begin{array}{c}\text { In } \\
\text { feuchter } \\
\text { Luft }\end{array}$ & \multicolumn{2}{|c|}{ In gewöhnlicher Luft } \\
\cline { 3 - 5 } & Serie I & Serie II & Serie III \\
\hline \hline 15. V. & - & - & - & - \\
16. V. & - & - & - & - \\
17. V: & 0,60 & 0,58 & - & 0,59 \\
18. V. & 0,61 & - & 0,56 & 0,57
\end{tabular}

Gräfin von Linden (1905. 527e) hielt die frischen Puppen von Vanessa urticae in trockener Luft (in einem Gefässe iiber die Schwefelsïure) und konnte keinen Unterschied in der Puppenzeit konstatieren.

I. Regen (1906. 677 $\mathrm{c} a$ ) brachte 150 Gryllus campestris L. in eine mit Wasserdampf gesättigte Atmosphüre bei $0^{0}$, wo sie durch 2 Monate hinlurch den Wintersehlaf hielten. Wenige Exemplare gingen dabei zugrunde, und viele von ihnen entwickelten sich im Frühjahre wieder. 


\section{Zum Cinfusse der Temperatur.}

Ratzoburg (1839.673a) sagt, llass die ganze Lebensdauter von Gastropacha pini Ochsh. bei verschieltenen Temperaturen fulgende. Zeiten beträgt:

$\begin{array}{crrrrrr}\text { bei }+12^{0} & \text { bis }+14^{0} & \text { R. } & 204 & \text { Tage } \\ " & 14 & & 17 & & 149 & \\ " & 16 & n & 19 & & 116,5 & " \\ " & 19 & n & 22 & & 97,5 & \end{array}$

Die jungen Räupchen schlïpfen aus den Eiern bei guinstigen Verhältnissen nach $20-25$ Tagen und bei ungünstigen nach 36 Tagen.

Herpin (1842. 370a) fand, dass Apion apricans Herbst bei $60^{\circ}$ stirbt.

G. Koch (1856. 457 b) beobachtete im Olitober des warmen Jahres 1846 noch eine dritte Generation von Acherontia utropos Raupen.

L. Glaser (1863. 314a) erwïlint in seinem Buche, dass Stein aus den wohlgerathenen Puppen von Macriglossu oenotherae Esp. mittelst der Wolnstuben-Wärme die Falter alle um Weihnachten herum erhielt.

Regener (1865. 677b) beobachtete, dass die Raupen von $G a-$ stropacha pini Ochst. für die Herstellung des Cocons 12 Stunten bei $18^{\circ}-28^{\circ} \mathrm{R}$. und 3 Tage bei $13^{\circ} \mathrm{R}$. gebrauchen. Zur Verpuppung brauchen diese Raupen 2 Tage bei $16^{\circ}-22^{\circ}$ R. und 15 Tage bei $8^{\circ}-11^{\circ} \mathrm{R}$

Er bestimnte auch die Futtermenge für diese Raupe, abhängig von der Temperatur. Angenommen, dass diese Menge bei $3-4^{\circ} \mathrm{R}$. einer Einheit gleich ist, dann steigt dieselbe nit der Temperatur, wie folgt:

$$
\begin{array}{ccccccc}
5^{0} & 7-9^{0} & 9-11^{0} & 12-15^{0} & 14-17^{0} & 16-19^{0} & 19-22^{0} \\
1,5 & 4 & 5 & 6 & 7 & 8 & 14
\end{array}
$$

Lange (1866. 498c) brachte lie liaupen von Gustropacha. pini Ochsh. zum Gefrieren. Nach dem Auftauen und Verpuppen ergaben dieselben Schmetterlinge. 
L. Möller (1sti7. 58\%) beobachtete in Thïringen, class bei günstiger Temperatur Apumea didyma Borkh., Aputura iris L. und Limenitis sibylla Fabr. sich im Juni entfalten, bei ungïnstiger Temperatur erst im Juli bis August, ja sogar im September. In den warmen Jahren 1846 und 1865 kamen die Falter Acherontia atropos L. sämmtlich im Herbste zur Entwickelung, wähırend dieses in anleren Jahren erst im Frühjahre erfolgt.

Kalender (1573. 429) fanıl, dass die Leberwinterung der Raupen ron klimatischen Verhältnissen abhängig und keineswegs ein nothwendige Lebensbedingung sein dürfte.

Taschonberg (1874. $852 a$ ) beobachtete die Entwicliclung iler liiupchen ron Dendrolimus pini L. bereits 13 Tagen nach ter Eierablage, wenn der Sommer warm und trocken ist; hei lialter Witterung dauert diese Entwickelung ca. 5 Wochen.

Altum (1S82. 11a) beobachtete die Raupen von Gustropuchu pini L. und konstatierte folgendes:

Das Aufsteigen der Raupen auf die Bäume begamn bei der Boilentemperatur von $2,5^{\circ} \mathrm{R}$. und fand am lebhaftesten bei $4,5^{\circ}$ bis $5,5^{\circ}$ I. statt. Für die kleinen Raupen betrug diese Temperatur $4,4^{\circ} \mathrm{K}$. und fiir die grossen $6,4^{\circ} \mathrm{R}$.

Es wurde folgende Anzahl von Raupen an Leimringen gefangen: B. i der Bodentemper. $=7^{\circ}$ h. und der Lufttemper. $=120 \mathrm{l}$. 775

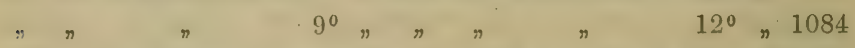

Bei der Bollentemperatur $=8-10^{\circ} \mathrm{R}$. befanten sich alle Raupen in voller Thätigkeit.

A. Strubell (1888. 848a) lionstatierte, lass die Larven von Heterodera schachtii Schmidt die Temperatur von $15^{\circ}$ bis $20^{\circ}$ und die Eier dieser Species $25^{\circ}$ aushalten künnen. Beidle Formen sterben jedoch in der Temperatur von $35^{\circ}$.

A. Silantjew (188s. $815 a$ ) beobachtete den Flug von Melolontha Tippocastani Ente Juli; dasselbe von Plylloperta Torticola. Agelastica alni erschien Anfangs September, Myelophitus piniperda an 10. Auwnst. Der Flug von Tomicus typograplus und T. chulcomraphus begamn (nach den Beobachtungen von N. A. Cholodkowsky) am 
22. Juni. Scolytus ratzeburgii befand sich im Puppenstadium ca. einen Monat (statt 2 Wochen, wie gewöhnlich).

Die Ursache dieser verspäteten Entwickelung ersieht er in meteorologischen Verhältnissen. Das Frïhjahr 1888 war sehr warm; am 22. April sank die Temperatur plötzlich sehr stark, es beg.um zu schneien und die Kälte dauerte ca. eine Woche.

Keinen Einfluss hat diese Witterung auf die Entwickelung von Lophyrus pini gehabt.

S. Mokrzecki (1894. 583a) theilt folgendes aus dem Taschenbuche von E. A. Junge mit: Am 18. April 1893 wurile in Kioktebel (Schwarzes Meer, Russland, in der Nähe von Theodosien) am Meeresufer eine Masse von der Wanze Eurygaster maurus Fabr. beobachtet, welche vom Sülwind aus lem Meere ausgeworfen wurden. Sie waren bei $5^{0} \mathrm{R}$. starr; bei $7^{\circ} \mathrm{R}$. fingen sie sich $\mathrm{zu}$ bewegen und erst bei $13^{\circ}$ R. zu fliegen.

M. Hollrung (1894. $383 a$ ) stellte fest, dass die Eier von Heterodera schachtii Schmilt in heissem Wasser $\left(35^{\circ}\right.$ bis $\left.52^{\circ}\right)$ noch am Leben bleiben.

Judeich und Nitsche (1895. 423a) beobachteten im kalten Sommer, dass die Entwickelung der Eier von Dendrotimus pini L. ca. 5 Wochen dauert. Sie stellten auch fest, dass die jungen Räupchen dieser Art aus den Eiern bei normalen Umständen nach 3 Wochen schlïpfen; bei ungünstiger Witterung schlïpfen dieselben nach 5 und mehr Wochen aus.

J. Krulikovski (1895. 478e) beobachtete in ler Stalt Wjatka die II. Generation des Schmetterlings Lycaena argiolus L. Diese Erscheinung schreibt er der ausserordentlichen Hitze zu, welche 1891 herrschte.

Die II. Generation verschiellener Schmetterlinge erschien in Wjatka 1891 infolge grosser Hitze viel früher als sonst.

Bellvoye und Laurent (1897. 66a) fanden, dass die Entwickelung der Eier von Dendrolimus pini L. im warmen unil trockenen Sommer nur 12 Tage dauert.

G. B. Schulz (1899. $795 a)$ erhielt aus Eiern von Bombyx quercus v. sicula Stgr. Encle September (1897) die Raupen, welche 
im Winter mit Epheu gefüttert wurden. Der erste Schmetterling schlüpfte im Februar 1898. Im März dessellen Jahres war eine grössere Anzahl ausgekrochen, dann trat eine Pause bis Juli ein, worauf wielerum einige Falter erschienen, unil der Rest der Cocons, etwa 30, und zwar alle lebend, ergab im September 1899 noch keinen Schmetterling. Er erklärt dieses „Ueberliegen" darlurch, dass die überwinterten Puppen plötzlich in Zimmerwärme gebracht wurlen.

G. Stichel (1899. $846 a$ ) theilte in ler Sitzung les Berliner Entomologischen Vereins folgende Beobachtung von Jul. Kricheldorf mit. Die Puppen von einem Endromis versicolora $q$ wurten zur Ueberwinterung ins Freie gebracht. Im März wurlen diese Puppen ins Zimmer gebracht und bald darauf verliessen die Falter ihre Hïllen bis auf ca 12 Stück. Hirauf wurilen die übrig gebliebenen Puppen bis etwa 12. September unbeachtet gelassen, um welche Zeit abermals einige Falter auskamen.

K. Rossikow (1899. 705a) beobachtete in Süd-Russlanul, dass die Larven von Pachytylus migratorius L. nach der 1. und 2. Häıtung bei der Ernierlrigung der Luft-Temperatur bis zu $9^{\circ}$ infolge 1-2 regnerischer Tage alle zu Grunde gingen. Die optimale Temperatur zum Ausschliipfen dieser Larven nach dem Regen ist $14^{\circ}$ während 3-4 Tage vor dem Ausschlüpfen.

J. Laborde (1900. 491 ( ) brachte die Puppen von Eutemis botrana Schiff. auf $1 / 2$ Minute ins Wasser von $55^{\circ}$, wobei sie starben. Die Puppen von Conchylis ambiguella Hübn. sterben dabei bei $50^{\circ}$.

E. Danilow (1900. 163a) sah Anisopteryx aescularia W. V. bei $3^{\circ} \mathrm{R}$. fliegen. Er beobachtete auch, dass die Larven von Cladius uncinatus Klug. bei einer Luftemperatur von $7^{\circ}$ bis $5^{\circ} \mathrm{R}$. frassen, wobei es schneite und regnete.

Grassi (1901. $327 a$ ) fand, dass die ganze Entwickelung von Anopheles claviger $\mathrm{F}$. bei $20-25^{\circ}$ ca. 30 Tage dawert.

Kerschbaumer (1901. 448a) fand, dass Culex pipiens seine ganze Entwickelung durchmacht:

innerhalb $3-4$ Wochen bei $15-20^{\circ}$,

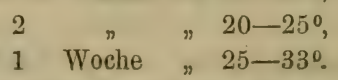

Im Wasser unter $12^{\circ}$ findet die Entwickelung von Culex nicht statt. 
Ja. Schroiner (1901. $771 a$ ) beobachtete 1899 im Gouvernement Ekaterinoslaw (Bezirk Werchnedneprowsk), dass die Puppenruhe von Aporia crataegi L. nur 8 Tage dauerte, während dieselbe sonst 10-12 Tage beträgt.

A. Serebrjanikow (1901. 808 a) bestimmte die Zeit, welche zur Entwikelung der Eier von Gastropacha pini Ochsh. bei verschiedenen Temperaturen nöthig ist. Dieselbe betrug:

bei $10,5^{\circ} \mathrm{R}$. entwickeln sich die Eier nach $17-18$ Tagen.

\begin{tabular}{|c|c|c|c|c|c|c|c|}
\hline$\Rightarrow 14,6^{\circ}$ & " & $"$ & $n$ & $n$ & n & $n$ & $15-16$ \\
\hline $19,7^{\circ}$ & $n$ & $n$ & $\eta$ & $n$ & $"$ & $\eta$ & 14 \\
\hline$\Rightarrow 25^{\circ}$ & n & verderben & die & Eier & nach & & 13 \\
\hline $30^{\circ}$ & "n & $"$ & $n$ & $n$ & $n$ & & 9 \\
\hline$" 35^{\circ}$ & , & $n$ & $n$ & " & ” & & 5 \\
\hline $38^{\circ}$ & $n$ & $n$ & $\eta$ & n & $n$ & & $2-3$ \\
\hline $40^{\circ}$ & $n$ & $n$ & $n$ & n & $\eta$ & & 2 \\
\hline
\end{tabular}

$\mathrm{Er}$ beobachtete auch das Ausschlüpfen' der Räupchen aus Eiern, welche unter dem Einflusse der schwankenden Temperaturen sich befanden und ermittelte, dass bei der Tagestemperatur $=20^{\circ} \mathrm{R}$. und der Nachttemperatur $=9^{\circ} \mathrm{R}$., (die mittlere $\mathrm{t}=14,7^{\circ} \mathrm{R}$.) (las Ausschlüpfen nach 16-17 Tagen stattfand, und dieses Ausschlüpen 15-16 Tage bei der mittleren Temperatur von 24,70 R. dauerte (die Tagestemperatur betrug $31^{\circ} \mathrm{R}$. und die der Nacht $10^{\circ} \mathrm{R}$.).

Dieser Beobachter kommt, gestützt auf seine Versuche, zum Schlusse, dass die Winterkälte eine nothwendige Bedingug für die weitere Entwickelung der Raupen von $G$. pini ist. Die TemperaturErhöhung während der Winterruhe wirkt auf diese Raupen verderblich.

Er fand, dass die Raupen dieser Species zu ihrer Verpuppung 2 Tage bei $16^{\circ}-19^{\circ} \mathrm{R}$. gebrauchen.

S. Mokrzecki (1901. $586 a$ ) theilt nach dem Briefe des Agronomes Arutünow folgendes mit: das Wasser, erwärmt bis $50-53^{\circ} \mathrm{R}$., nit welchem die Raupen von Eurycreon sticticalis L. auf dem Kraut begossen wurden, bewirkte, dass sie im Anfang leblos schienen; nach 10-15 Minuten fingen sie jedoch an sich zu bewegen. Die Raupen von Pieris brassicae L. starben dabei. Das Wasser von $60^{\circ} \mathrm{R}$. ist auch im ersten Falle tötlich.

V. Vermorel und G. Gastine (1902. 912) experimentierten mit Raupen von Tortrix pilleriana, inclem sie dieselben mit einer 
Glocke aus Zinkblech zudeckten und unter dieselbe Wasserdampt leiteten. Es ergab sich dabei, dass diese Raupen bei $48-50^{\circ}$ (Daner 3-6 Minuten) und bei $45^{\circ}$ (Dauer 10 Minuten) starben.

A. Trost (1903. $884 a$ ) hielt Puppen ron Acherontia atropos L. im geheizten Zimmer und erhielt die Schmetterlinge oft schon Ende November oder anfangs December; sonst fliegt diese Species in Steiermark im Juni-November.

K. Rossikow (1903. 705 ל) beobachtete in den Gouvernements Ufa und Tschernigow und im Kaukasus, dass die Entwickeluungs(lauer von Phlyctaenodes (Eurycreon) sticticalis L. unter dem Einfluss der Temperatur weder verkürzt noch verlängert wird und 3 Wochen diauert. Der Einfluss der Temperatur besteht hauptsächlich darin, dass bei niederer Temperatur die Raupen, besonders die jungen, keine Nahrung zu sich nehmen und aus Erschöpfung sterben.

B. Galli-Valerio und J. Rochaz de Jongh (1903-1905. 270 $\beta$ ) $270 \gamma$ ) stellten fest, (lass Eier von Culex und Anopheles die Kälte gut ertragen. Im Wasser bei $43^{\circ}$ halten sie 3 Minuten aus. Larven auf Eis gelegt, vertragen die Temperatur bis $z u-4^{0}$, aber trocken gelegt, gehen sie bei niedrigen Temperaturen schnell zu Grunde; die hohe Temperatur im Wasser halten sie bis zu $40^{\circ}$ ans. Die Nymphen vertragen die Kälte ebenso wie die Larven, hohe Temperaturen richten sie aber schnell zu Grunde.

W. Petersen (1904. 633 a) konstatierte, dass Arctia caja in Ekaterinenburg (Ural) seine Entwickelung während eines Jahres lurchmacht, hingegen diese Entwickelung in der Schweiz zwei Jahre. dauert.

I. Schewelew (1904. $747 a$ ) fand, dass nur dann, wenn die Lufttemperatur in einem Bienenstock $34-35^{\circ}$ beträgt, eine Entwickelung der Bienenfamilie stattfindet.

J. Portschinski (1904. $640 a$ ) sagt, dass die Ueberwinterung von Anopleeles claviger F. im Gouvern. Woronesch bereits vom Ende Juni an bei mittlerer Temperatur $17-16^{\circ}$ beginnt. Ihre Flugzeit beginnt z. B. bei Moskau Mitte April bei einer Abendtemperatur $7-17^{\circ}$. 
E. Knoche (1904. 457 a) machte seine Beobachtungen am Borlienkäfer Hilesinus piniperda und fraxini. Er fand, dass das Minimum der Schwärmtemperatur und das der stetigen Eiablage 9,5 resp. $9,1^{\circ}$ beträgt.

S. Mokrzөcki (1905. 587 a) beobachtete, dass der Küifer Zabrus tenebroides G. unter lem Einfluss der Sommerhitze und bei Mangel an Nahrung sich in die Erde auf die Tiefe von 1 Fuss eingräbt und dort in einen tiefen Schlaf verfällt, welcher bis zum October dauert, bis die Herbstkälte denselben wieder erweckt. Dasselbe beobachtete er bei Entomoscelis adonidis Pall und bei Eurygaster maurus Fabr.

I. Dewitz (1905. 177a) beliess die Raupen von Conchylis ambiguella Hübn. während $10-15$ Minuten bei $45^{\circ}$ und konstatierte, dlass sie entweder tot waren, oder schwer erkrankten und nach einigen Tagen starben.

R. Fink (1905. 226a) fand, lass die Zeitdauer einer Generation Ephestia huehniella Zell. in Nord-Amerika ca. 9 Wochen beträgt. Auf die Anzahl der Generationen hat die Temperatur einen grossen Einfluss: bei warmer Witterung und in warmen Lokalen löst eine Generation die andere $a b$; unter normalen Verhältnissen entwickelt sich nur 1 Frühlings- und 1 Herbstgeneration.

Er ermittelte auch, dass das Puppenstadium von Galerucella luleola im Juli 7 Tage, im September 12 und im Oktober 24 Tage dauert.

H. Federley (1905. 219a) erhielt in Helsingfors, von zwei Leucodonta bicoloria ab. unicolora Motch. $q$ 우 am 10.-11. VI. 1903 eine ziemlich grosse Anzahl Eier, welche er bis zur Verpuppung züchtete. Die Verpuppung fand vom 19. VII. bis Ende Juli statt.

Vier verschiedene Versuche ergaben folgende Resultate:

I. Am 14. X. wurden 15 Puppen aus dem Freien bei ca. $0^{0}$ in ein geheiztes Zimmer gebracht und auf den Ofen gestellt, wo die Temperatur zwischen $18^{\circ}$ und $22^{\circ}$ schwankte. Von December an wurden die Puppen bis zum Frühjahr in ca. $18^{\circ}$ gehalten. Das Ausschlïpfen fand zwischen 11. XII. 1903 und 17. III. 1904 statt. (Nur 10 Falter).

II. Bis zum 4. IV. 1904 in Freien. Vom 4.--12. IV. in ca. 170. Vom 12.-15. IV. 72 Stunden in $38^{\circ}$ bis $39,5^{\circ}$, dann bis zum Ausschlüpfen in ca. $17^{\circ}$. Es schliipften nur 4 Falter aus, und zwar vom 19. V. bis $26 . \mathrm{V}$. 
III. 10 Puppen wurden am 14. X. 19033 Stunden in $-17^{0}$ und am folgenden Tag wieler 2 Stunden in $-10^{\circ}$ gehalten. Bis zum Ausschlïpfen in ca. $17^{\circ}$. Es schlïpften nur 4 Falter aus und zwar vom 22. V. bis 10 . VI.

IV. Während des ganzen Winters im Freien aufbewahrt. Es schlüpften 14 Falter aus und zwar von 28. V. bis 29. VI.

Versuche mit Lymantria dispar L. ergaben folgende Resultate:

I. 15 Puppen, 12-36 Sturilen alt, wurden 41 Stunclen in $37^{\circ}-38^{\circ}$ im Thermostat, ohne Feuchtiglieit, mit guter Ventilation gehalten. 14 Falter entwickelten sich innerhalb 14-18 Tage nach der Exposition.

II. 10 Puppen bei $38-39^{\circ}$ während 67 Stunden in demselben Thermostat. Schmetterlinge, die meisten verkriippelt, nach 14-18 Tagen.

III. Puppen, 2-20 Stunden alt, zverst 48 Stunden in $38^{\circ}$ bis $39^{\circ}$, sodann 24 Stunden in $39^{\circ}$ bis $40^{\circ}$ im Thermostat (trocken). Falter entwickelten sich nach 16-19 Tagen (sümmtlich verkrüppelt).

IV. 25 Puppen 2-18 Stunden alt, 24 Stunden in 39-40 (trocken). 11 Falter nach 19-20 Tagen.

V. 24 Puppen, 24 Stunden alt, 45 Stunden in $39,5^{\circ}$. Die Luft sehr feucht. Nur drei $ᄋ$ $Q$ entwickelten sich.

VI. 12 Puppen, 20 Stunden alt, 52 Stunden bei $39,5^{\circ}$ bis $40^{\circ}$. Alle starben gleich nach der Exposition.

VII. 42 Puppen, alle über 24 Stunden alt, 40 Tage in $6^{\circ}$ bei sehr grosser Feuchtigkeit. 40 Falter mehr oder weniger stark verkrüppelt. Das erste Stück schlïpfte nach 13 Tagen aus.

VIII. 35 Puppen, 3-24 Stunden alt, 27 Tage in $0^{\circ}$. 32 Falter nach 23-29 Tagen.

Die Versuche mit Malacosoma neustria L. ergaben folgende Resultate:

I. 15 Puppen, 2-18 Stunden alt, 24 Stunden in $39^{\circ}$ bis $40^{\circ}$ in trockener Luft. Alle Falter entwickelten sich gut.

II. 5 Puppen, 2-22 Stunden alt, 72 Stunden $38-39^{\circ}$ und $39-40^{\circ}$ (2 Tage).

III. 8 Puppen, alle unter 20 Stunden alt, 52 Stunden in 39,5 . bis $40,5^{\circ}$. Nur 4 Falter.

IV. 5 Puppen 27 Tage in $0^{\circ}$ und noch 18 Tagen bei sehr srosser Feuchtigkeit in $10^{\circ}$ bis $15^{\circ}$. Falter nach 23 Tagen.

Die Versuche mit Saturnia pavonia L. ergaben folgende Resultate: 
I. 20 Puppen wurden aus dem Freien bei $-5^{\circ}$ in ein geheiztes Zimmer gebracht unil nach 24 Stunden in den Termostat eingesetzt, wo sie 47 Stunden bei 39,5 bis $40,5^{\circ}$ blieben. 10 Falter nach 8-10 Tagen; die ïbrigen überwinterten zum zweiten Mal.

II. 20 Puppen wie bei Versuch I behandelt, aber 71 Stunden in $40,0-40,5^{\circ}$. 13 Falter nach $8-10$, alle verkriippelt; die ïberigen überwinterten.

III. Ganz frische Puppen wurden 71 Stunden in $34^{\circ}$ gehalten. Ueberwinterten draussen, von wo sie bei $-20^{\circ}$ in $12^{\circ}$ gebracht wurlen; nach 20 Stunden 5 Tage in $30^{\circ}$ gehalten. Drei Tage nach einander wurde die Temperatur allmählich bis $42-43^{\circ}$ gesteigert, was 1 Stunde in Anspruch nahm. Die Temperatur sank dann wieder langsam, so dass sie nach $7-8$ Stunden wieder $30^{\circ}$ war. Entwickelungsilauer nach der Exposition $0-5$ Tage. Alle Falter waren fehlerfrei.

IV. 15 im Freien überwinterte Puppen wurden an 11. Februar in $18^{\circ}$ gebracht und jeden Tag (6 Tage) während $1-1 \frac{1}{2}$ Stunden der Temperatur von 42 bis $46^{\circ}$ ausgesetzt; dann 2 Tage in $30^{\circ}$ gehalten. Falter, alle gut, am 22.-25. Februar.

V. 25 Puppen wurden am 13. März in $17-1 \mathrm{~S}^{\circ}$ gebracht; nach 2 Tagen wurden sie während 30 Tage wechselnder Temperatur von $-2^{\circ}$ bis $11^{\circ}$ ausgesetzt, dann in Wohnzimmer gebracht. Entwickelungsdauer von 16 Puppen 9-11 Tage. Die uibrigen iiberwinterten.

VI. 10 Puppen wurden im Spätherbst Frostexposition ausgesetzt. Später wie im Versuche V. Entwickelungslauer von 6 Puppen nach den Experimenten 6-8 Tage; die übrigen überwinterten.

VII. 20 ganz frische Puppen 48 Tage in $5^{\circ}$. Sie überwinterten sodann im Freien bis zum 15. I. wo sie, in $22^{\circ}$ gebracht, 5 Tage während $11 / 2$ Stunden der Temperatur von $-18^{\circ}$ ausgesetzt wurden. Zwischen den Expositionen wurden die Puppen einer Temperatur von $25^{\circ}$ bis $29^{\circ}$ ausgesetzt. Das Ausschlüpfen am 25. I. - 7. II. (8 Falter, 4 Puppen überwinterten und 8 starben).

VIII. 20 ganz frische Puppen 12 Tage in $0^{\circ}$; überwinterten sodann im Freien; am 5. III. in $18^{\circ}$ und 6 Tage während 2 Stunden in $-15^{\circ}$ bis $-21,5^{\circ}$. Nur 6 Falter am 14.-15. III.

Aglia tau L. ergab folgende Resultate:

I. 5 im Freien aufbewahrte Puppen wurden Mitte Februar in $17^{\circ}$ gebracht. Alle schlüpften nach $15-20$ Tagen aus.

II. 10 im Freien autbewahrte Puppen wurden Ende März, nachdem sie einen $\mathrm{Tag}$ in $17^{\circ}$ gehalten worlen waren, während 
44 Stunden rler Temperatur von 38,5 bis $40,5^{\circ}$ ausgesetzt, wonach sie noch 28 Stunden in $25^{\circ}$ bis $26^{\circ}$ und dann bis zum Ausschliipfen (10-18 Tage) in 18 bis $20^{\circ}$ blieben.

Demas coryli L. ergab folgende Resultate:

8 im Freien überwinterten Puppen 1 Tag in $17^{\circ}$, dann 44 Stunden in 38 bis $40,5^{\circ}$ und 28 Stunden in $25-26^{\circ}$; ljis zum Ausschlüpfen (9-11 Tage) in $18^{\circ}$.

Arctia caja L. ergab folgende Resultate:

1. 6 Puppen, 12-13 Stunden alt, 41 Stunden in $37-38^{\circ}$. Nur ein verkriippelter Falter nach 17 Tagen.

II. Puppen, 13-36 Stunden alt, 34 Tage in $0^{\circ}$. Entwiclielungsdauer nach der Exposition 18-25 Tage.

I. W. Wasiljew (1905. $943 a$ ) erwälınt in seiner Abhandlung, dass die Ruupen von Dendrolimus yini L. bei der maximalen Lufttemperatur von 7 bis $8^{0} \mathrm{R}$. und rler minimalen von $-1^{0}$ bis $-2^{0} \mathrm{R}$. von ihrem Winterschlaf erwachen. Die Entwickelung ller Eier dieser Art dauert während eines trockenen und warmen Sommers nur 12 Tage.

Gräfin von Linden (1905. 527e) erzog Raupen von Vanessa urticue bei $30-35^{\circ}$. Die Puppenruhe betrug bei dieser Temperatur in Durchschnitt 5-6 Tage (die normale Zeit beträgt 12-13 Tage). Bei der Temperatur von $40-43^{\circ}$ und genügender Feuchtigkeit in Thermostaten wurde bei diesen Raupen keine Lethargie, Lähmung oder Starre beobachtet; fressen konnten sie bei dieser Temperatur nicht. „Bei einer Raupe, lie kurz vor ihrer Verwandlung in den Thermostaten eingelegt worlen war $\left(40-43^{\circ}\right)$, dauerte die Metamorphose kaum eine Minute" (p. 421).

A. Silfvenius (1906. 815 ) beobachtete im Sommer 1899, dass lie erhöhte Temperatur des Vassers die Zeit des Puppenstadiums von Agraylea multipunctata Curt. verkürzt.

I. Regen (1906. 677aa) beobachtete, dass Gryllus campestris L. in Winterschlaf verfällt, sobald das arithmetische Mittel vom Maximum und Minimum der Tagestemperatur an sonnigen Herbsttagen nicht mehr viel von Null Grad verschieden ist; vorausgesetzt, dass solche Temperaturen anhalten. Der Winterschlaf wird abgebrochen bei einem mehrtägigen Maximum von etwa $7^{\circ}$ und einem Minimum von etwa $2^{\circ}$. Seine Versuche ergaben, dass die Thiere (meist im vorletzten Larven- 
stadium) auch einige Grade unter Null durch längere Zeit, ohne zu gefrieren und ohne Nachtheil ertragen können. Gefrieren sie bei tieferer Temperatur vorübergehenıl ganz, so erwachen sie zwar wieder, erholen sich aber nicht mehr.

\section{Zum Ginfirsse ales Michtes.}

A. Serebrjanikow (1901. $808(\iota)$ sagt, dass die Lichtstärke. keinen Einfluss auf die Entwickelungs-Geschwindigkeit der Eier von Gastropacha pini Oschsh. ausübt, la bei seinen Versuchen bei sehr starkem Licht und in der Dankelheit die Entwickelungszeit 19-20 Tage betrug.

H. Müllenberger (1905. 596a) hielt junge Raupen von Tanessa urticae in einer Flasche von dunkelrothem Glase. „Die Räupchen gediehen gut, aber bis zur vollständigen Entwickelung, also bis zum Schmetterling, brachte ich nur ein Stück."

S. Holmes (1905. 384a) fand, lass Ranatra stark positiv phototactisch sind; diese Empfindlichkeit verliert sich durch die Erniedrigung der Temperatur.

F. Carpanter (1905. 132a) stellte fest, dass Diosophila ampelophila positiv heliotropisch ist.

\section{Zum Cinfusse der Elektricitint und des vagnetismus.}

Gräfin von Linden (1905. 527e) untersuchte den Einfluss radioaktiver Strahlen (Radiumbromid 5 mgr.) auf die Entwickelung ler Raupen und Puppen von Vanessa urticae in verschiedenen Altersstadien und erhielt negative Resultate: die Puppenruhe war eine vollkommen normale.

\section{Zum Einfusse der Vahrung und chemischer Stoffe.}

S. Mokrzecki (1894. 583a) brachte die Wanzen Euryyuster snaurus Fabr. in eine Flasche und reichte ihnen keine Nahrung. Bald darauf wurden sie unbeweglich und verfielen in eine Art Lethargie. Sobald aber ihnen frisches Futter gereicht wurile, kamen sie wieller zu sich. Nach den Beobachtungen dieses Autors kömmen 
die Wanzen dieser Art in diesem Zustande bis zu 8 Monaten verbleiben:

Er brachte ein Weizenblatt mit 13 Eiern von der Wanze Eurygaster mourus Fabr. für eine Minute in Spiritus. Das Blatt wurde dabei gebleicht und in die Herbarium-Sammlung plaziert. Nach 12 Tagen schlïpten aus diesen Eiern die Wanzen.

A. Serebrjanikow (1901. $808 a$ ) behandelte die unbefruchteten Eier von Gastropacha pini Ochsh. wie folgt:

10 Eier wurden ins Wasser von $35^{\circ}$ R. aul 25 Minuten gebracht. 4 Eier wurlen 1 Minute in schwacher Salzsïure gehalten und nachher mit Wasser ausgewaschen.

16 Eier wurden folgendermassen behandelt: 9 Eier wurilen während 25 Minuten in Wasser bei $35^{\circ} \mathrm{R}$. und 7 Eier während 1 Minute in Salzsäure gehalten und nachlıer mit Wasser ausgewaschen.

15 Eier wurden während 25 Minuten in Wasser von $30^{\circ} \mathrm{R}$. gehalten.

20 Eier wurden während 5 Minuten mit einer Bürste gerieben. 25 Eier blieben im Wasser von $25^{\circ} \mathrm{R}$. während 45 Minuten.

10 Eier wurden während 5 Minuten in Salzsiure gelıalten unil nachher mit Wasser abgespült.

20 Eier wurden während 4 Stunclen unı 10 Eier währenıl 9 Stunden im Luftbad bei $30^{\circ} \mathrm{R}$. gehalten.

Alle diese Eier ergaben keine Räupchen. Negative Resultate wurden auch dann erhalten, als den frisch geschlüpften Weibchen der Bauch so geklemmt wurde, dass dieselben keine Eier legen konnten. Diese Klemme wurde nach 7 Tagen entfernt und die Weibchen legten einige Eier, aus welchen sich jerloch keine Rüupchen entwickelten, obwohl grale in diesem Falle Goosens (Ann. Soc. entom. France. Sér. 6. T. VI. 1876. p. 429) parthenogenetisch entwickelte Räupchen erhalten hat.

W. Pospelow (1901. 642) schreibt die unvollständige Entwickelung der Eierstöcke bei Phlyctaenodes sticticalis L. den meteorologischen Bedingungen, der Nahrung und dem Boden zu. Er sagt, dass die Schmetterlinge II. Generation sich aus Puppen entwickelten, welche sich in weicher Ercle befanden, und zwar frühzeitig, weil der Sommer $1901 \mathrm{zu}$ heiss und $\mathrm{zu}$ trocken war; dabei fanten sie in dieser Gegend ungenügende Nahrung und hatten infolge dessen unvollständig entwickelte Eier. 
Kerschbaumer (1901. 448a) konstatierte, dass die Larven von Anopheles claviger F. auch in gesalzenem Wasser leben können, wenn der Salzgehalt 1,1\% nicht überschreitet.

Grassi (1901. 327a) fütterte Anopheles claviger F. nur mit Zuckerwasser und fand, dass diese Mücken dabei einen ganzen Monat lebten (bei der Temperatur $15-26^{\circ}$ ). Ein $\sigma^{\nearrow}$ ernährte sich nur vom Fruchtsaft und lebte 25 Tage; diese Mücke lebt im Freien gewöhnlich 40-70 Tage.

K. Rossikow (1903. 705b) kritiesirt diese Anschauung, indem er sagt, (lass hier ein Parasit Microclossia primu die Ursache war, welcher von I. Krasilschtschik (1902. 472c) entileckt wurde.

I. Krasilschtschik (1903. $472 a$ ) untersuchte die Wirkung verschiedener Gifte auf die Entwickelung der Inseliten. Die zu untersuchenden Raupen wurden in grossen Glasgefässen bei der Temperatur $18-20^{\circ} \mathrm{R}$. gehalten, wobei ilhnen diejenigen Futterpflanzen gereicht wurden (alle 2-3 Tage), welche sie im Freien beniitzen. Die Pflanzen wurden mit gelösten Giften bespritzt und erst dann in die Gefässe gebracht, als das Lösungsmittel verdampft war.

Folgenile Tabelle enthält die erhaltenen Resultate: 


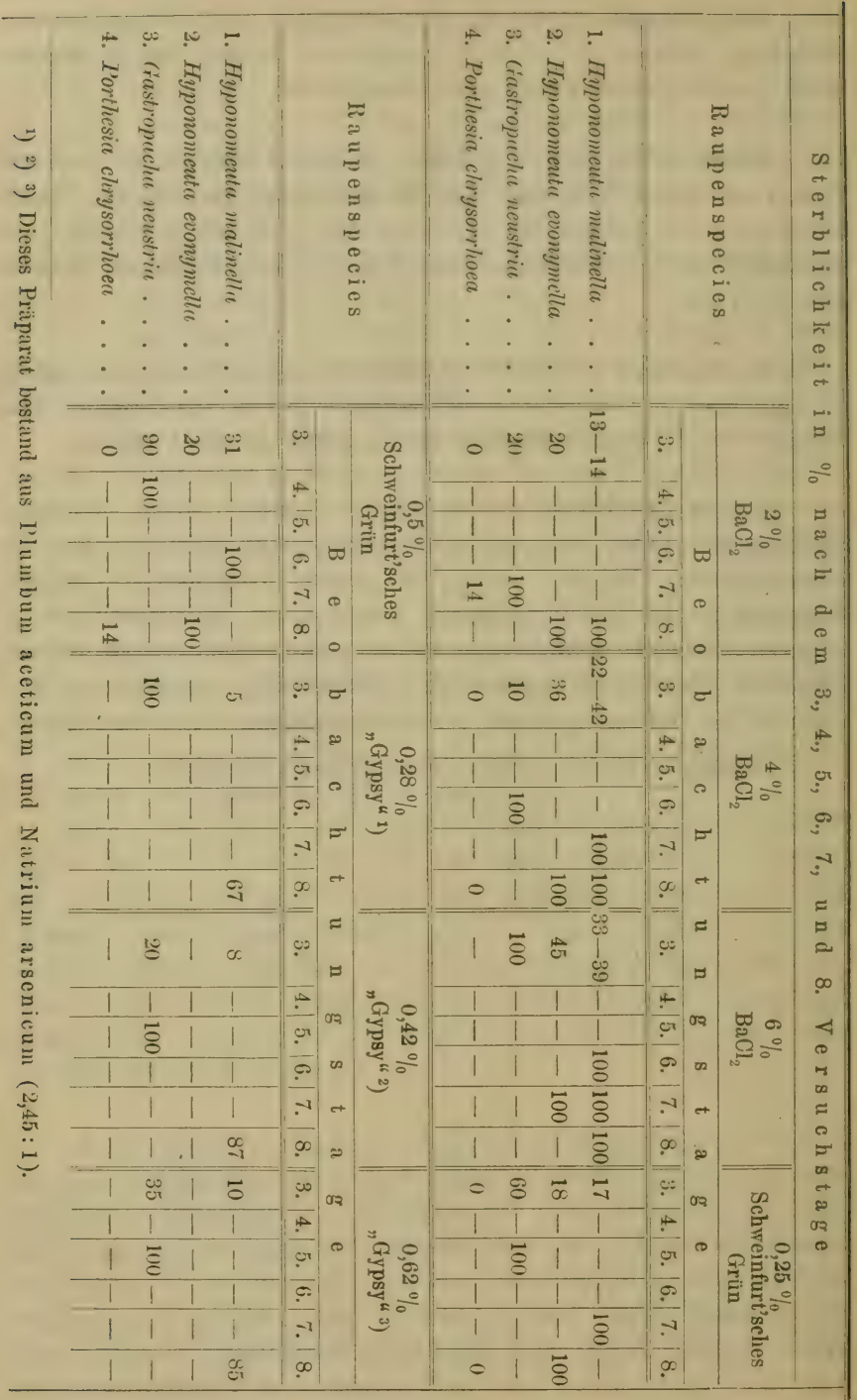


Johnson (1903. 423 $\alpha$ ) beobachtete, dass bei guter Ernährung von Anopheles claviger F. grosse Puppen entstehen und bei schwacher Ernährung kleine Puppen. Aus len ersteren entwickelten sich $71,43 \%$ 우 und $28,57 \%$ ठ $\sigma^{\top} \sigma^{\top}$ und aus den letzteren $20 \%$ 우 und $80 \%$ o $\sigma^{7}$. Die Larven von Culex pungens, welche bei ungenügender Ernährung erzogen wurden, ergaben $66,7 \%$ ठ $ठ \sigma^{\circ}$ und $33,3 \%$ 우 우.

H. Heath (1903. 355b) hat Versuche angestellt, rlurch Aenclerung des Futters bei Termiten Soldaten resp. Arbeiter aufzuziehen, jerlorh mit negativem Erfolge.

N. Sieber und S. Metalnikow (1904. 811a) fütterten die Raupen von Galleria mellonella (Bienenmotte) mit reinem, sticlistofffreiem Wachs, und konstatierten, dass sie dabei nicht wachsen, wohl aber bei der Fütterung mit rohem Bienenwachs, welches über $20 \%$ Stickstoff enthält.

Gräfin von Linden (1904. $527 b$ ) konstatierte, dlass Raupen, Puppen und Imago von Vanessa urticce einen 12-36 stündigen Aufenthalt in Kohlensäureatmosphäre ohne Scharlen aushalten können.

A. Field (1905. 223a) ermittelte, dass Formica subsericea bis 9 Monate lang hungern kann.

Gräfin von Linden (1905. 527d) experimentierte mit Puppen von Papilio podalirius und fand, dass die gelbrothen Lichtstrahlen die Aufname der Kohlensäure von der Pupı,e begünstigen. Eine Puppe nahm infolge dessen während 3 Monate etwa $35 \%$ an Gewicht zu.

Gräfin von Linden (1905. 527e) fütterte die Raupen von Vanessa urticae mit Brennesselblättern, die zuerst mit Hydrochinonkristallen bestreut worlen waren und fand, dass sie viel längere Raupenzeit hatten, als die mit dem normalen Futter erzogenen. 24-36 stündiger Aufenthalt der Puppen in Kohlensäureatmosphäre übt keinen Einfluss auf die normale Puppenzeit aus; lagegen erhärtet die Puppenhülle in diesem Gase nicht. In Stickstoffatmosphäre sterluen diese Raupen erst nach 48 Stunden; Puppen halten 48 Stunden aus, gehen aber später in der Luft meistens zu Grunde. In Luftveriluinn- 
tem Raume vormögen die Raupen beim Drucke von 0,02 Atmosphären nicht zu leben. während die Puppen, welche 24 Stunilen lang unter diesen Umständen sich befunden hatten, noch eintwickelungsfähig blieben.

E. Goeldi (1905. 315a) untersuchte Steyomyia fasciata und Culex fatigans und fand, dass Honig und Zuckersäfte die Lebenstauer dieser Müicken verlängern, dagegen verzögert diese Nalnung die Eierablage sogar um 100 Tage. Das Blutsaugen ist also bei diesen Species eine unentbehrliche Bedingung für die Eierablage geworlen.

H. Federley (1905. 219a) hielt die Puppen von Limantria dispar L. dreimal wïhrend 24 Stunden je 30-45 Minuten in sehr starkem Aetherdampfe. Waren die Puppen noch nicht eine Stunde alt, so starben sie nach der ersten oder zweiten Narkuse, wogegen alle vollkommen erhärteten Puppen gut ausschliipften.' Die Entwickelung wurde hierdurch stark verzögert (21-22 Tage nach der letzten Narkose).

I. W. Wasiljow (1905. 943a) lronstatierte, dass frisch ausgeschliipfte Räupchen ron Dendrocimus pini L. 10 Tage ohne Futter aushalten können.

K. Lampert (1906. $497 a$ ) liess sein Zimmer mit Formalindämpfen desinfektieren, in welchem in Gläsern, die mit durchlässigem Netzstoff zugebunden waren, eine Anzahl Blatta orientalis und germanica, mehrere Larven vom Speckkäfer, 3 Blattwespenlarven und Mehlwürmer sich befanden. Das Zimmer ist ca. $70 \mathrm{~m}^{3}$ gross und wurde demgemäss der Formaldehyd-Apparat mit $1100 \mathrm{~cm}^{3}$ Formaldehyd von $40 \%, 1650 \mathrm{~cm}^{3}$ Wasser, $650 \mathrm{~cm}^{3}$ Brenn. Spiritus von $86 \%$ beschickt. Die Entwickelung der Formalindämpfe dauerte 4 Stunden, worauf zum Verzehren desselben eine weitere Stunde lang Ammoniak von $25 \%$ verflüchtigt wurde. Sämtliche Arthropoden ïberstanden die Einwirkung der Dämpfe ohne jeden Nachtheil.

F. Döflein (1906. 185a) fand in Ceylon die pilzzüchtenden Termiten. "Das schwammige Holzgerüste ist der Pilzgarten der Termiten, es sind "Pilzkuchen" (nom. nov. Döflein), auf dem sie eine Kulturform eines Pilzes aus (ler Gattung Rhozites züchten, dessen zu eigenthümlichen Verdickungen („Mycelköpfchen ${ }^{*}$ ) ausgewachsene 
Hyphen den Termiten zur Nahrung dienen". Er wies nach, dass sämtliche Larven und Nymphen nur mit Mycelköpfchen gefüttert werden. „Der König und die Könnigin nahmen das Mycelköpfchen an und frassen es in ter nämlichen Weise wie die anderen Individuen. Dagegen ist es nie gelungen, einen ausgewachsenen Soldaten oder Arbeiter zur Annahne der Mycelköpfichen zu bringen". Er spricht die Verumthung aus, dass bei dieser Art die Larven ein konzentriertes und leicht ausnutzbares Futter in Form der Mycelköpfchen erhalten, dass dieselben die dauernde Nahrung der Geschlechtsthiere ilarstellen, während sie den Larven der Arbeiter und Soldaten von einem bestiminten Alter an vorenthalten werden und diesen an ihrer Stelle ein anderes Futter gereicht wird. „Dadurch wird die weitere Vermuthung angeregt, dass dies Futter bei der Differenzierung der Kasten im Staat von Termiten obscuriceps eine wichtige Rolle spielt."

I. Regen (1906. 677aa) brachte Gryllus campestris L. in Kohlentioxyil. Nach 15 Sekunden wurden die Thiere bewusstlos. Nach 1 Stunde wurden sie herausgenommen und erholten sich vollständig. Ähnlich verhalten sich Thiere, die höchstens eine Stunde in reinem Stickstoff zugebracht haben, doch mit dem Unterschied, dass sie zwar wieder erwachen, sich aber nicht mehr erholen.

\section{Zum Einfusse der mechanischen Rebung und der übrigen Taktoren.}

Dziorzon (1849. 205a; 1853. 205b) stellte die Vermuthung auf, dass aus unbefruchteten Bieneneiern sich ausschliesslich Drohnen und aus befruchteten Eiern nur Arbeiterbienen entwickeln.

F. Plateau (1868. 639b) stellte die Lehre von dem Befruchtetsein aller Bieneneier und der Geschlechtsbestimmung $\mathrm{n}$ a $\mathrm{ch}$ der Ablage durch äussere Einflüsse seitens der Arbeitsbinen auf.

J. Perez (1S78. 630c) konstatierte, dass eine italienische Bienenkönigin, welche von einer französischen Drohne befruchtet wurcle, nur 161 Drohnen reiner italienischen Rasse ergab; von den übrigen 139 waren 83 französischer Rasse und 66 Bastarden. $\mathrm{Er}$ benützt diese Thatsache, um die Theorie von Dziorzon zu verwerfen, indem er sagt, dass die Drohnen auch aus befruchteten Eiern sich entwickeln können. 
Die Kritik dieser Versuche befindet sich bei M. Sancon (1878. $735($ ), bei M. Girard (1878. 313a) und bei G. Koschewnikow (1905. $467 a)$.

L. Knatz (1883. 455b) fancl eine durch einen tief eingedrungenen Distel-Stachel verwunclete Puppe von Vanessa cardui, welche einen vollständig ausgebildeten, nicht verkriippelten Schmetterling gal).

A. Weismann (1894. 953a) sagt, um die Parthenogenese bei Bienen zu erklären, dlass die Befruchtung die Thätigkeit der weillichen "Iden" reizt, währenıl die männlichen "Ilen" für ilıre Thätigkeit dieses Reizes nicht bedürfen. Daher entwickeln sich aus befruchteten Eiern weibliche Bienen und aus unbefruchteten die mïnnlichen.

F. Dickel (1897. 178a; 1903. 179) sagt, dass alle Eier, welche von einer befruchteten Bienenlïnigin abgelegt werlen, befruchtet sind. Das künftige Geschlecht der Bienen wird dabei durch die äusseren Faktoren bedingt, hauptsächlich durch die Arbeiteribienen (durch ilır Belecken der Eier).

Eine scharfe Kritik der Untersuchungen von Dickel befindet sich hauptsïchlich in den Ablandlungen von H. von Buttel-Reөpen (1902. 124a; 1904. 124b) unil von G. Koschewnikow (1905. 467a).

H. Reichenbach (1902. 682a) stellte fest, class rie Weibchen von Lasius niger Fabr. sich aus unbefruchteten Eiern entwickeln.

J. Danysz (1903. 163c) setzte die Raupen von Ephestia liuehniella der Wirkung der Radium-Strahlen aus. Für diese Versuche wurde eine Radium-Röhre vom Activitätswerthe von 500.000 benutzt. Eine Anzahl der so behandelten Raupen, wobei die Wirkung 24 Stunden dauerte, starb innerhalb 2-3 Tagen, eine weitere Anzahl nach 8 Tagen. Ein Theil der Raupen blieb dabei lebend und zwar von Februar bis August, während die Controllpuppen zweimal sümmtliche Metamorphosen während dieser Zeit durchmachten.

Der Bienenzüchter S. Lawlinzew in Wolsk, Gouvernement Saratow, schreibt mir (am 24. VI. 1904.): "Ich sencle Ihnen je 100 Arbeiterbienen und Drohnen, welche von der Königin italienischer Rasse (Apis ligustrica), geboren 1902, abstammen; dieselbe wurde von einem $\delta$ lokaler Nordrasse befruchtet. Die auffallendle Eigen- 
schaft dieser Arbeiterbienen besteht darin, dass sie sich in zwei ungefähr gleiche Serien eintheilen lassen: eine stellt, der Färbung der ersten drei Bauchringe nach, die reine italienische Rasse vor, die zweite dagegen von demselben Bienenstock unıl derselben Kïnigin hat die Merkmale Iokaler Nordrasse. Dasselbe bezieht sich atuch auf die Drohnen. In anleren Bienenstöcken, welche gleiche Königinnen haben, wird dies nicht beobachtet."

\section{Zu der Grösse und der Gestalt der Insekten.}

\section{Zur Einleitumg.}

Horner (1820. 390a) führt in seiner vom 1. Januar 1820 datirenden Notiz folgende Messungen der farbigen Ziegel der Schmetterlingsflügel an: „Die Flügel der Schmetterlinge sind Häute, mit farbigen Ziegeln bedeckt, leren Länge von 0,7 bis 0,10 und deren Breite von 0,03 bis 0,06 Pariser-Linien variirt; sie sind unten ausgezackt, meistens in 4, oft auch in 3 oder 5 Zacken, - machen den Flügelstaub aus, und hängen mit einem Stiele an kleinen Hülsen, die sich auf der Haut befinden, und in regelmässigen Reihen fortlaufen. Die Distanz der Punkte in der horizontalen Reihe beträgt 0,017,in der verticalen oder nach der Länge der Ziegel 0.021 PirriserLinien, so dass in einem Längenzoll sich $70 s$ in horizontaler, und 572 in verticaler Richtung befinden, also ein Quarlratzoll mindenstens 400,000 solcher Punkte fasst. - Nach einer Messung enthalten die 4 Flügel eines gewissen Schmetterlings 3,86 Quadratzolle, so dass also zur Bekleidung eines einzigen Schmetterlings iiber $11 / 2$ Millionen solcher Ziegel erfordert werden."

L. Krulikowski (1889. 4786) sammelte 80 Exemplare ron Pieris napi L. in Wjatka (Russland) und fand bei ihnen folgendle Flügellängen:

\begin{tabular}{|c|c|c|c|c|c|c|c|}
\hline \multicolumn{4}{|c|}{ Maximale Länge } & \multicolumn{4}{|c|}{ Minimale Länge } \\
\hline \multicolumn{2}{|c|}{ I. Generation } & \multicolumn{2}{|c|}{ II. Generation } & \multicolumn{2}{|c|}{ I. Generation } & \multicolumn{2}{|c|}{ II. Generation } \\
\hline б' & $q$ & ठे & $q$ & $\sigma^{\pi}$ & q & $\sigma^{\pi}$ & q \\
\hline 23,5 & 24 & 26,5 & 27,1 & 20 & 21 & 23,2 & 22,5 \\
\hline
\end{tabular}


A. Serabrjanikow (1901. 808 i) unternahm die Lïngenanessungen ler Raupen von Gast,muactu pini Ochsh. währenil ihrer Celserwinterung in St.-Petersburg uni erhielt folgenile Riesultate:

\begin{tabular}{|c|c|c|c|c|}
\hline \multirow{2}{*}{$\begin{array}{l}\text { Die Länge } \\
\text { in } m m \text {. }\end{array}$} & \multicolumn{2}{|c|}{1898} & \multicolumn{2}{|c|}{ - 1599} \\
\hline & $\begin{array}{l}\text { Anzahl der } \\
\text { Exemplare }\end{array}$ & $\therefore 0$ & $\begin{array}{l}\text { Anzahl der } \\
\text { Exemplare }\end{array}$ & $=0$ \\
\hline $50-55$ & 19 & 13,7 & 11 & 12,8 \\
\hline $45-50$ & 37 & $26 i, 5$ & 22 & 25,5 \\
\hline $40-45$ & 15 & 13,0 & 4 & $4, \pi$ \\
\hline $35-40$ & 14 & 10,1 & 14 & 16,4 \\
\hline $30-35$ & 26 & 18,5 & $2: 2$ & 25,5 \\
\hline $25-30$ & 19 & 13,7 & 6 & 7 \\
\hline $20-25$ & 5 & 3.6 & 6 & T \\
\hline Summe. & 138 & 100 & 85 & 100 \\
\hline
\end{tabular}

J. Schreiner (1905. 771b) hat den Schmettering C(trpocapis jomonella L. gemessen und fand:

Die Körperlänge $=10 \mathrm{~mm}$., Exp. der Vorierfl. $=20 \mathrm{~mm}$.

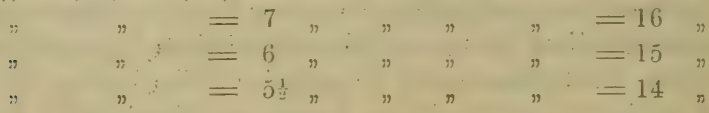

\section{Zuna Einallusge des Honnas.}

L. Möller (1867. 582) Sagt, dass der geringere Luftilucli in ien höheren Bergregionen einen gerwissen Einfluss auf die Form der Insekten ausiibt. So haben in den Alpen z. B. eine Anzihl Küter wft eine mehr abgeplattete Gestalt. Er and, ilass Strropus aethiops l'anz. uni Caralus irregularis Fabr. in der Gegend des Ihlefeldes aur dem Hainich (in Thiuringen) „lebhaft an jene Formeigenthümlichlieit erinnern" $\left(700^{\prime}\right.$ bis $900^{\prime}$ Höhe).

L. Krulikowski (1889, 4786 ) fand bei einem Weibchen von Lim!nuirs pantic ah. valesinu Esp., welches aus dem Gouvernement :imbirsk stamute, die Fliigellänge nur $21 \mathrm{~mm}$., wïhrend die Wreibchen aus cien Gourernement Wjatlia $28-35 \mathrm{~mm}$. haben. Er konstatierte aluch, dass uis Männchen von Fumen pulla Esp). in Kasan etwas lileiner sin' als in St.-l'tersisur. Die Flügellänge bei IIrmestra nebulosu Hufn. in Wjatka beträgt 19,4-30 mm. 
P. G. Strobl (1900. 84ia) fanl, dass Phyycidenon fumutor. vitr. iroglodytes Gr. in Steiermark ron momalne Form (I. I. G. Gravenhorst. Ichneumonologia emplnter. 182!) sich durch geringer"

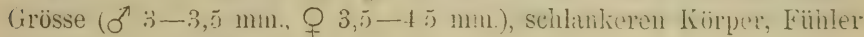
und Beine unterscheilet.

A. Trost (1904. $584(\ell)$ siminlte in Striermark schmetterling. iml konstatierte, diss die steicrischen Exemplare von Sotymes dryges $\therefore$ der Grösse nach weit zurich gegen diejenigen aus Süittirol stehen

F. Federley (1905. 219a) sagt, dass Agliu tuu L. von Ladog: see (Fimnland) grösser ist als die mitteleuropäische Art.

E. Galvagni (1905. 270a) fand für Extmplare von Linnsmos fuscunturie al). effuscuric lihl, welche $\mathrm{er}$ in Hietzing (Oesterreich) erbentete, folgende Diemensionen (Expansion):

Frühjarsgeneration: die $\sigma^{\nwarrow}$ von $32-35 \mathrm{~mm}$., die ㅇ $35-38 \mathrm{~mm}$. Herbstgeneration: " " $30-32, \quad$ " $32-34$ "

H. Auel (1905. Privatbrief vom 30. IX.) hat bei Pirris bicussicuc L. sowch? dì Flügellänge als auch die Spannweite gemess’n unl erhielt für Potsdam folgende Resultate für ठ઼

"Die ausgeglichenen Differenzen zwischen dier iloppelten rechten Fliggellänge und der Spannweite bei $\delta$ fur beite Jahre sind folgente:

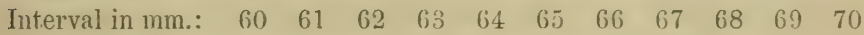
Differenz 1904: $2,8-3,0 \quad 3,1 \quad 3,2 \quad 3,3 \quad 3,3 \quad 3,4 \quad 3,4 \quad 3,5 \quad 3,6$

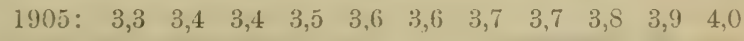

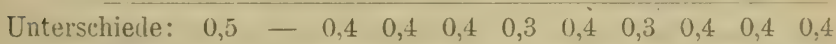

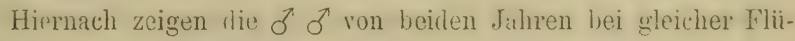
grolspunumg eine mgleich grosse Distanz rer Flügelwurzeln, was einer stiukeren Toruxbilhung für 1905 (mehr Regen) gleichbeleutenil ist."

B. Slovogt (1905. 822 b) erhielt aus der Lingegent Mukilens (An:mischurei) Schmetterlinge unt fami bei ihnen folgenle cirössenunterschiede im Vergleich mit den europuiischen drten:

Lepticlia sinapis L. Fast im ein Drittel' grösser.

Gonopteryx ilumni L. „Ein Riese gegeniber don enrop:iischen Briìlern. ${ }^{6}$

Satyrus dryas Sc. Viel grösser: 
N. Adelung (1906. 2a) bestimnte Celes variubilis var. subcocruleipennis Charp. von Tobolsli und fand, dass diese Orthoptera viel grösser ist, als H. de Saussure in seinem "Prodromus Oedipodiorum" angiebt, und zwar:

\begin{tabular}{|c|c|c|c|c|}
\hline & & $\delta$ & & 우 \\
\hline ang. & corp. & 20,6 & $\mathrm{~mm}$. & $26,5 \mathrm{~mm}$. \\
\hline & pron. & 4,3 & $"$ & 5,6 \\
\hline & elytr. & 18,0 & $"$ & $22,0 \quad \#$ \\
\hline
\end{tabular}

B. Wanach (1906. 942a) sammelte 1905 bei Potsilam 5355 IIaikäfer, davon 5364 Melolontha hippocastani F. und 21 ilecl. vulgaris. Als Gewicht wari durchschnittlich für 1 万 0,58 gr., für 1 ㅇ 0,87 gr. ausgerechnet; indessen wiegen die grössten Männchen wesentlich mehr als die kleinsten Weibchen, das leichteste und schwerste der einzelnen gewogenen Männchen wog nämlich 0,44 bez. $0,77 \mathrm{gr}$., das leichteste und schwerste Weibchen 0,60 bez. $1,13 \mathrm{gr}$

\section{Rum Einfusse der Feachtigkeit.}

Schima (1905. 750a) sammelte in ler Umgebung von Triest Pieris rapae var. rossii Stef. und fand, dass die Exemplare von 1904 meist etwas kleiner waren als die 1903 gesammelten. Er schreibt diesen Umstand der grossen Hitze und Trockenheit zu, welche 1904 herrschte.

\section{Zum Linfusse der Temperatur.}

T. Chapman (1904. 139)a) untersuchte Heodes jhlaens und fand, dass die Grösse der Exemplare von der Entwickelungsdauer abhängt: wo sich die Larve langsamer entwickelt (z. B. in Lappland), dort ist das Imago grösser. Daraus würde folgen, dass in kälteren Gegenden $H$. phlaeas grösser wird als in den wärmeren, welcher Schluss auch durch meine Messungen der Flügellänge bei Aporia crataegi von verschiedenen Gegenden Nord- und Süı-Europas bestätigt wird (1905. 42b).

Gräfin von Linden (1905. 527e) setzte Raupen von Vunessa urticae in die Temperatur $30-25^{\circ}$, wo sie sich auch verpuppt haben. Die ausgeschlïpften Falter hatten $36-46 \mathrm{~mm}$. Spannweite, während dieselbe bei den Knntrollfaltern im Minimum $44 \mathrm{~mm}$. betrug. 
I. Regen (1906. $677 \mathrm{aa}$ ) beobachtete, nachiem sich die Larven von Gryllus campestris L. im Fruihjahre das letzte Mal gehäutet hatten, dass jene Thiere, welche die längste Zeit bei $0^{0}$ zugebracht hatten, kleiner waren als die, welche gar keinen Winterschlaf gehalten hatten oder nur eine kürzere Zeit der Kälte $\left(0^{\circ}\right)$ ausgesetzt worden waren.

\section{Zum Elufusse der Vahrung und ehenniseher Stoffe.}

L. Sitowski (1905. 816a, 816b) untersuchte die Motte Tineola biselliella, indem er die Raupen dieser śpecies auf einem rohen Wollstoff züchtete. Die Raupen haben grössere Dimensionen gehabt als diejenigen, welche auf Wollwatta gezuichtet wurden.

I. W. Wasiljew (1905. 943a) bestimmte die Länge der in Sibirien verkommenden Raupen von Dendrolimus scyregatus Butl. während verschiedener Monaten (1898) und fand:

$\begin{array}{lccccc}\text { Zeit: } & \text { Mai } & \text { Juni } & \text { Juli } & \text { August } & \text { September. } \\ \text { Länge in cm.: } & 2,38 & 3,83 & 4,79 & 5,30 & 5,64 \\ \text { Energie des Wachsthums: } & 1,45 & 0,96 & 0,51 & 0,34\end{array}$

Ich bestimmite das Gewicht lebender Exemplare von Dorcalion sturmii, welche in Sophia an 15. V. 1900 erbeutet wurlen. Vier Serien zu je 100 Exemplaren wurlen vom 15. V. $3^{\text {h }}$ Nachmittags ohne Nahrung gelassen. Die I. Serie wurde in sehr feuchter Luft gehalten, die übrigen in gewöhnlicher Luft. Die Wägungen von je 30 Exemplaren jeder Serie ergaben folgende Resultate, wobei belleutet:

$\mathrm{P}$ das Gewicht von 30 Exemplaren in gr.

p $\#$ n 1 n

L lebenge Exemplare

'T bei $115^{\circ}$ getrocknete Exemplare.

\begin{tabular}{|c|c|c|c|c|c|c|c|c|c|}
\hline \multirow{3}{*}{$\begin{array}{l}\text { In welchem } \\
\text { Zustande }\end{array}$} & \multirow{3}{*}{$\begin{array}{c}\text { Datum } \\
\text { um } \\
3^{\text {h }} 30^{\prime}\end{array}$} & \multicolumn{8}{|c|}{$\mathrm{S} \quad \mathrm{e} \quad \mathrm{r} \quad \mathrm{i} \quad \mathrm{e}$} \\
\hline & & \multicolumn{2}{|c|}{ I. } & \multicolumn{2}{|c|}{ II. } & \multicolumn{2}{|c|}{ III. } & \multicolumn{2}{|c|}{ IV. } \\
\hline & & $\mathrm{P}$ & $\mathrm{p}$ & $\mathrm{P}$ & $\mathrm{p}$ & $\mathrm{P}$ & $p$ & $\mathrm{P}$ & $\mathrm{r}$ \\
\hline L & \multirow{2}{*}{ 16. V. } & 3,000 & 0,100 & 3,813 & 0,127 & 3,390 & 0,113 & 3,348 & 0,112 \\
\hline $\mathrm{T}$ & & - & - & - & - & 一 & - & - & - \\
\hline L & \multirow{2}{*}{ 17. V. } & 3,065 & 0,102 & 3,265 & 0,109 & 一 & - & 3,340 & 0,111 \\
\hline $\mathrm{T}$ & & 1,225 & 0,041 & 1,343 & 0,045 & - & - & 1,373 & 0,046 \\
\hline $\mathrm{L}$ & \multirow{2}{*}{$18 . \mathrm{V}}$. & 2,844 & 0,095 & - & - & 3,160 & 0,105 & 3,150 & 0,105 \\
\hline $\mathrm{T}$ & & 1,104 & 0,037 & - & - & 1,375 & 0,046 & 1,345 & 0,045 \\
\hline
\end{tabular}




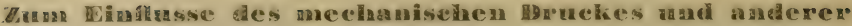 Falitoren.}

L. Krulikowski (1859).4787) beobathtete, dass, wemn man die Liaupen ron Gortynu flocayo Schiff., welche an Ente Juli uni Anfangrs

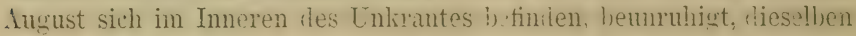
darauf sebr kleine Schmetterlinge ergeben (10-15 mm.).

A. Morse (1905. .55 a) sumnelte in Torit-Amerika Henscherchen unil Heupferile (ca. (j000 Exemplare in an Arten) unl kam zum Schlusse, dass die Fellthiere lange Flïgel hahen, wähend itie

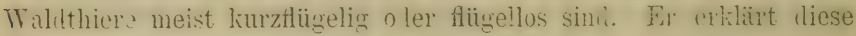
Erstheinung dalurch, dass dis ersten Thiere mehr $\%$ Hiegen un! die zweiten mehr zu springen haben.

\section{Zu der Färbung und Zeichnung der Insekten.}

\section{Zun Esnfusse der Feuchtigheit.}

(xrä̈in von Linden (1905. 527e) liess lie Raupen von Tanessu urticae in trockener Luft sich verpuppen, wohei die Puppen lort weiter blieben. „Die aus diesem Versuch hervorgegangenen Sclmetterlinge zeigten in Bezug auf Fürbung, Zeichmung un? Beschaticnheit (ler Schuppen keinen wesentlichen Ënterschierl im Vorgleich zu den normalen Thieren" (p. 424).

\section{Lum Cinfusse den Tenpenatur.}

Gräfin von Linden (1905. 527e) hielt die Puppen ron Tenessa urticue bu 32-350 unt erhielt Vanessa urticae var. ichnusu. „Die Ierkmale der sibllichen Verwaniten waren un so charakteristisch r. entfaltet, je linger lie Raupen unter erhöhter Temperatur g:leht hatten" (p. 41s). Raupen, velche bei $45^{\circ}$ sich verpupten mul als Pupuen noch 2 Stunden in dieser Temperatur verhorachten, ergaben Falter, bei welchen die blanen Seitemranlteche im Vorler- unt Hintertligel stark vergrössert waren, ganz ähnlich, wie es bi Kältevarietäten angetroffen wird (jedoch kein Uebergang zu polaris). Dabei wurle beobachtet, dass "die hohe Temperatur (uber $40^{\circ}$ ) keineswegs ein frühur anftretendes Zcichmungstarlium auf lem Puppenflügel fixiert hatte, sondern im Gegentheil die Entwiclielung der Zeichnumg ausserorilentlich beschlemigt, inlem ältere Zeichnungsstit- 
dien übersprungen wuilen und die neueren zu einer weiteren Aus. breitung gelangten, als es normalerweise der Fall ist" (p. 224).

I. Regen (1906. 67т (uu) fand, dass die Larven von Giyjlus. compestiv L, mahlem sie sich im Frühjahr das letzte Mal gehäutet hatten, rerschieilen gefärbte Thiere ergaben, je nachiem ob sie lïngere oller liüzere Zeit bei $0^{9}$ zligel)racht hatten. Die Fliigelrecken iler ersteren waren ganz schwarz, bei manchen Exemplare: blau schimmernd. Die Elytren ler letzteren Thiere hingegen wiesen grössere oller kleinere gelbe Fulder auf oiler waren mit Ausnahn: des schwarzen Geälers ganz gelb. „Eine länger anlauerncle Einwirkung der Kälte währen! des Winterschlafes auf die Larren ron Gryllus compestris L. hat also in den Elytren her Geschlechtsthier" eine vermehite Billung des schwarzen Pigments zur Folge. Da das Geäder stets s'hwarz ist, lie zwischen den einzelnen dilern liegenten Theile der Fligellecken hingegen schwarz ole: gelb pigmentiert sein kïnnen, folgt, dass bei Giy!luts campestiv L. llas schwarze Pigment ursprünglich in ien Alern gebillet wurile" (p. 134).

Durch rerschielene Versuche hat er festgestellt, "flass das obengenannte Pigment bei Gryllus campestris L. nur in Gegenwart von Satierstoff schwarz wirl" (p. 135).

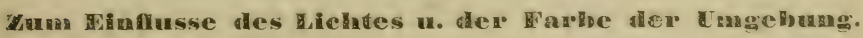

B. Slevogt (1906. $822 c$ ) erbeutete am 4 . VII. 1906 in Bathen (baltische Prorinzen) 3 Exemplare ron Polygonin f-rlbum Es;), welche in baltischen Provinzen bis jetzt noch nicht beobachtet wurie. "Es liegt die Verumtung nahe, dass die Raupen an jener, ier Somme sehr ansqesetzten Steinwand sich verpuppten mel lurch ine bestinclige Erhitzung die hibschen Furhen- un: Zeichungstrïnierungen hervorgerufen worden sind."

\section{Zurn Einfusse der Elektricitä.}

Gräfin ron Linden (1905. 527c) setzte die liaupen und Pupluen von Tancssa urticue ler Einwirkung ratioaktirer Strahlen (Iiatium. bromil) aus un:l konstatierte in der Zuchomung ler ausareschliuften Falter lieine Abweichungen; "lie einzige Veränderung, the bei einzelnen Stiicken zu beohachten war, betraf die Nuancierung der roten (irumlfurbe, die ifteres einen fleischfarionen statt rotgellon Ton angenommen hatte ${ }^{-}$(p. 428). 


\section{Zum rinfusse der Nalarung und eheanischer Stoffe.}

Gräfin von Linden (1905. 527e) bestreute die Brennesselblätter mit Hydrochinon und erzog die Raupen von Vanessu urticac mit diesem Futter. Nach einem Tag zeigten sie viel rothen Farbstoff auf der äusseren Haut, und zwar llort, wo die Raupe sonst grünlich oder gelblicht gefürbt ist. Die erhaltenen Puppen zeigten einen Mettalglanz, ergaben aber ganz normal gefïrbte Falter. Versuche, bei welchen normale Puppen 24 Stunten in Kohlensäureatmosphäre gehalten wurden, ergaben ab. ichnusoides und einige Formen, welche uns an var. polaris erinnern. "Vanessu ichnusoirles ist wenigstens in Bezug auf einzelne Merkmale als eine höher entwickelte Vanessa polaris zu betrachten" (p. 432). Dabei gebrauchen die aberrativen und normalen Falter eine und dieselbe Keit zu ihrer Entwickelung. Vanessa urticae ab. ichmusoides wurle auch damn erhalten, als die Puppen 48 Stumlen in Sticlistoffatmosphïre gehalten wurlen; Vunessa io ergab dabei ab. Delisaria. Uebergïnge zu ab. ichnosoides entstehen auch dann, wenn die Puppen 24 Stunden in der Luft bej 0,02 Atmosphärendruck verbleiben.

\section{Zum Litteratur-Verzeichniss.}

Corinaldi, A. Influenze che fauno variare, il peso delle uova. - Boll. Mens. Bachicolt. Ser. II. 1884.

Crampton, H. E. An experimental study upon Lepidoptera. - Axch. Entwickelungsmech. IX. 1899. p. 293-317.

Dewitz, I. Die Bekämpfung der ampelophagen Microlepidopteren in Frankreich. Centralbl. Bakteriol., Parasitenk. und Infektionskr. II. Abth., XV. 1905. № 15-16. p. 449-467: [Diese Raupen sterben bei $45^{\circ}$ ].

Flammarion, C. Influence 'des couleurs sur la production des sexes. - C. R. Ac. Sc. Paris. T. 133. 1901. 수 8. p. $377-400$.

Friedmann, F. Ueber die Pigmentbildung in den Schmetterlinsflügeln. - Zeitschr. f. wiss. Zool. LXVI. 1899. p. 88-95.

Girard, Maurice. Note sur la chaleur considérable de larves de la Galleric cerella. Ann. Soc. Entomol. Fr. 4-e sér. tome IV. 1865. p. 676-677.

Holle. Schmetterlinge Deutschlands. 1565. [Beziehung zwischen der Nahrung und der Färbung].

Janet, Ch. Observations sur les Guêpes. 85 pag. Paris. 1903. [Die Beziehung zwischen der Temperatur und der Eieranzahl].

Kellog, V. I. and Bell, R. G. Notes on Insect Bionomics. - Journ. Exp. Zool. I. p. 357-367. Baltimore 1904. [Beziehungen zwischen dem Gewichte und. der Zeit, zwischen der Nahrung und dem Geschlechte]. 
Knaggs. Decoying butterflies. - Entomologist. XXVI. 1s93. p. 154-156.

Laboulbène. Bull. Soc. Entomol. Fr. p. XLVII. 1565. [Ueber den Einfluss der Elektricität auf die Färbung der Schmetterlinge].

Levrat, D. et Conte, A. Sur l'origine de la coloration naturelle des soies de Lépidoptères. - C. R. Acad. Sc. Paris. CXXXV. № 17. 1902. p. 700-702.

Mayer, A. G. Some Experiments with a Chrysalis. - Entomolog. News. IIV. 1903. p. $286-287$.

Merrifield, F. Experiments on the colour-susceptibility of the pupating larva of Aporia crataegi, and on the edibility of its pupa by birds. - The Entomologist's Monthly Magazine. 1900. p. 186.

Pictet, A. L'influence des changements de nourriture sur les chenilles et sur la formation du sexe de leurs papillons. - Compt. rend. Soc. de phys. et d'hist. Nat. Genève. XX. 1902. p. 66-69.

Pistot, A. L'influence des changements de nourriture des chenilles sur le d'éveloppement de leurs papillons. -- Compt. rend. 85. Sess. Soc. Hebvet. sc. Nat. p. 164-166. 1902. Auch in: Genève. Arch. d. sc. phys. et nat. 1902. p. $146-147$.

Pictet, A. Variations des papillons provenant des changements d'alimentation de leurs chenilles et de l'humidité. - Arch. sc. phys. et nat. Genève. Ann. 107, Période 4. Tome XVI. 1903. p. 585-588.

Pictet, A. Notes complémentaires sur les rariations des papillons provenant de l'humidité. - Soc. de Phys. et d'Hist. Nat. Bull. des séances. 1903. p. 2.

Piorret. L'identité d'Anthocharis Belia avec Ausomia et de Belemia avec Glauce a encore besoin de nouvelles observations pour être admise. - Ann. Entomolog. de France. II. sér. t. II. 1844. p. 68-70.

Poulton, E. B. The experimental proof of the value of colour and markings in Insects in reference to their Vertebrate enemies. - Proc. Zool. Soc. 1887. p. $191-274$.

Poulton, E. B. and Mac Munn, C. A. Colours of Animals. I. Bionomics by E. B. P. II. Chemistry by C. A. Mac Munn. - Enc. Brit. XXVII. 1902. p. 146-151.

Schollenberg, G. Abnorme Lebensweise der Raupe von B. quercus und deren Einfluss auf die Fntwickelung des Falters. - Entomol. Zeitschr. XIV. № 10, 1900, p. 69 .

Smith, G. The Temperature of Insects. - The Zool. (4). VI. 1902. p. 287-293. Standfuss, M. Zur Frage der Gestaltung und Vererbung auf Grund achtundzwanzigjähriger Experimente. - Vortrag in der Züricher Naturforsch. Gesellsch. am 13. Januar 1902. 15 pag. Zürich 1905. (Neudr. nach d. gleichnamigen Veröffentl. in der "Insekt.-Börse“" 1902).

Standfuss, M. Der Einfluss der Umgebung auf die äussere Erscheinung der Insekten. - Insekt.-Börse. XXI. №ํ № 39, 40, 41. 1904.

Tomala, Nándor. A radium hatása a lepkék bábjaira. - Rovart. Lapok, XI. 1904. 수 3. 45-47. (Ungarisch: Radioactivität und ihre Wirkung auf Schmetterlingspuppen). [Referat der Arbeit von Danysz].

Xąmbeu. Mélanges entomologiques. - Soc. Pyrenees-or. XLIII. 1902. p. 110-124. [Insekten und Frost]. 



\title{
Thecenetischer 'Theil.
}

\author{
ERSTES KAPITEL.
}

Verallgemeinerungen und Theorien über den Einfluss der äusseren Faktoren auf die Entwickelungsgesehwindigkeit der Insekten.

\section{Einfluss der Temperatur.}

1) ie Thatsachen, welche auf diesen Eintiuss Bezug haben unl welch": im "thatsïchlichen Theile" (erstes Kapitel) beschrieben wurlen, erlauben uns folgende Verallgemeinerungen zu machen:

\section{A. Einfuss konstanter hohen Temperaturen.}

Unter liesem Einfluss werien wir solche konstante Temperituren rerstehen, welche iiber $15^{\circ}$ siml und welche auf dlas betreffende Stalium iles Insektes währenıl seiner gimzen Entwickelungszeit in diesem Stadium eingewirkt haben.

\section{a) Eier.}

Eier verschieflener Species erleiden im Allwemeinen bei erhölten Temperaturen beschleunigte Entwiclielung. Bei Dentrolimus piri betrïgt die Lierruhe bei normaler Temperatur 3 Wochen (Judeich unci Nitsche [423a], Ratzeburg [673a]), bei $34^{0} \mathrm{nu} \% / 3$ der normalen Zeit (Standfuss [837]), in warmen Zimmer 12 Tage (WasiIjew [9Ł3a], Taschenberg [852a], Bellvoye unl Laurent [66ı]). hei anieren Temperaturen beträgt die Entwickelungszeit der Eicr Alieser Species (Serebrjanikow $[808 a]$ ):

$$
\begin{aligned}
& \text { bei } 10,5^{0} \text { R. . . . 17-18 Tage, } \\
& " 14,6^{\circ} " . . .515-16 \text {. } 16 \\
& " 19,7^{\circ} " \text {. . . . } 14
\end{aligned}
$$


Die Eier von Arctia fasciata, Dasychira alictis und Lasiocampa pruni, welche von ihrer Ablage ab in $34^{\circ}$ gehalten werden, ergeben Räupchen nach $2 / 3$ (ler normalen Zeit (Standfuss [837]). Die Eier von Pieris brassicae ergeben Räupchen in Frühjahre nach 8 Tagen, bei $17,3^{\circ}$ auch nach 8 Tagen und bei sehr hoher Temperatur im Sommer nach 4 Tagen (Auel [17]). Die Eier von Orgyjic antiqua erleiden bei $30^{\circ}$ frihzeitige Entwickelung (Uroch [859]).

Die Eier der Pflanzenläuse entwickeln sich bei $20^{\circ}$ bis $25^{\circ}$ beschleunigend und bei $30^{\circ}$ zuerst beschleunigend, dann aher verderben sie (Balbiani [45]).

Die Athmungsenergie der Eier von Bumbyx mori steht in keinem strengen Verhältnisse zu rer Temperatur (Quajat [663]).

b) Raupen.

Die Raupenzeit von Bombyx mori wiril durch die Erhöhung der Temperatur abgekürzt unıl zwar beträgt dieselhe:
25 Tage bei $22,5^{\circ}$
(Verson und Quajat [920])
23
n $\quad 31,2^{0}$
24
$30-37^{\circ}$
(de Sauvageon "[736])
$17-22$
$" \quad \Rightarrow 30-$
(Carret [133])
15
$31-37,5^{0}$
(Schmujdsinowitsch [756])
sterben, $40^{\circ}$

Es wurle ein Mal beobachtet, (lass bei der grossen Sommerhitze die Entwickelung der Raupe von Bombyx mori so rasch vor sich ging, dass dieselbe nach der 4. Häutung, ohne sich zu verspinnen und zu verpuppen, sofort zum Falter sich verwandelte (Majoli [543]).

Die Raupenzeit anderer Lepislopteren wirl lurch die Erhöhung ler Temperatur abgekürzt bei:

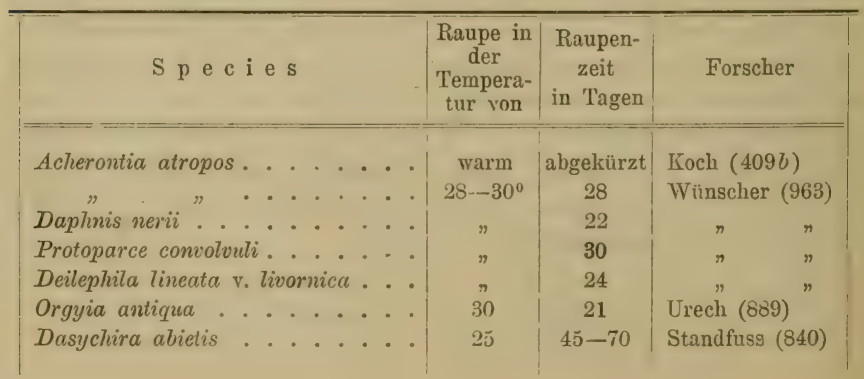




\begin{tabular}{|c|c|c|c|c|c|c|c|c|c|c|c|}
\hline $\mathrm{S} p \mathrm{pe}$ & $\mathrm{i}$ & e $\mathrm{s}$ & & & & & & $\begin{array}{l}\text { Raupe in } \\
\text { der } \\
\text { Tempera- } \\
\text { tur von }\end{array}$ & $\begin{array}{c}\text { Raupen- } \\
\text { zeit } \\
\text { in Tagen }\end{array}$ & \multicolumn{2}{|c|}{ F'orscher } \\
\hline Laria l nigrum . & & - . & - & - $\cdot$ & • $\cdot$ & - & - & $20-25^{0}$ & abgekürzt & Standfuss & $(840)$ \\
\hline Lasiocampa quercus & & : & • & . . & . & . & • & $"$ & & $n$ & $n$ \\
\hline Gastropacha quercif & fol & & - & . $\cdot$ & · & · & & 30 & $70-85$ & & \\
\hline$" \quad$ populif & fol & & - & . . & . & . & - & $15-20$ & $50-70$ & Jaenichen & $(411)$ \\
\hline Odonostis pruni . & - & . . & - & . . & . & - & - & 30 & $28-52$ & Standfuss & $(840)$ \\
\hline$m \quad n \quad$ & - & · & . & $\cdots$ & . & . & - & 25 & $55-68$ & $"$ & " \\
\hline Dendrolimus pini & - & - & $\therefore$ & . . & - & - & - & & $150-172$ & $"$ & $n$ \\
\hline Agrotis polygona. & - & - & . & .. & - & $\cdot$ & . & $20-25$ & abgekürzt & ” & $"$ \\
\hline signum . . & - & $\cdot$ & . & . . & $\cdot$ & . & . & $n$ & $"$ & $n$ & $"$ \\
\hline janthina . & - & . & · & . . & - & - & $\cdot$ & $"$ & $"$ & $"$ & $n$ \\
\hline$" \quad$ linoyrisea & · & · & · & · $\cdot$ & · & · & - & $"$ & $"$ & $"$ & $n$ \\
\hline fimbria .. & - & . & - & . & · & - & - & $"$ & $"$ & $n$ & " \\
\hline$" \quad$ augur. . & - & - . & - & . $\cdot$ & • & · & - & $"$ & $n$ & $n$ & $\pi$ \\
\hline$" \quad$ pronuba. & - & - & - & $\cdot \cdot$ &. & - & - & $\pi$ & $n$ & $"$ & $n$ \\
\hline$"$ orbona . & - & . & - & .. & - & . & . & $"$ & $"$ & $n$ & $n$ \\
\hline comes . . & · & $\cdot$ & $\cdot$ & $\cdot \cdot$ & $\cdot$ & . & . & $"$ & $n$ & $n$ & $"$ \\
\hline collina. . & - & - & - & - · & - & - & - & " & $n$ & $"$ & $"$ \\
\hline triangulum & - & - & . & - . & $\cdot$ & · & - & ” & $n$ & $"$ & $n$ \\
\hline baja... & . & . & . & . . & . & . & . & $"$ & $"$ & $n$ & $n$ \\
\hline candelarum & . & . & · & . $\cdot$ & . $\cdot$ & - & . & $"$ & $"$ & ", & $n$ \\
\hline c nigrum. & - & - & - & . . & - . & - & - & $n$ & n & $n$ & $"$ \\
\hline ditrapezium & & - & - & . . & . & . & . & $n$ & $"$ & $n$ & $"$ \\
\hline stigmatica & - & . & . & . . & . & . & . & $"$ & $n$ & " & $n$ \\
\hline rubi... & - & . & · & . . & . & . & . & $\eta$ & $"$ & $n$ & $n$ \\
\hline " fiorida. . & - & . . & - & - . & - $\cdot$ & . & . & 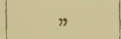 & $n$ & $n$ & ” \\
\hline dałllii . . & . & . & - & . . & . $\cdot$ & . & . & $n$ & $"$ & $"$ & - \\
\hline brunnea . & - & - & - & - . & - & • & . & $"$ & $n$ & . $"$ & " \\
\hline primulae. & - & . & - & . . & - $\cdot$ & - & - & " & $n$ & $n$ & $n$ \\
\hline cenflua. . & - & . & . & . & - & - & . & $n$ & $n$ & n & $"$ \\
\hline$" \quad$ segetum . & - & $\cdot$ & · & - $\cdot$ & - . & - & - & $n$ & $n$ & $"$ & $n$ \\
\hline$" \quad$ prasina & - & . & . & . . & . . & . & - & $n$ & " & $"$ & $n$ \\
\hline " occulta.. & . & . & . & . & . . & . & . & $"$ & $n$ & $"$ & $n$ \\
\hline Mamestra advena & - & . & - & . . & . . & . & - & " & 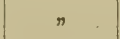 & $"$ & $n$ \\
\hline tincta & - & $\cdot$ & - & . . & . & - $\cdot$ & - & $r$ & $n$ & $n$ & $n$ \\
\hline "nebulosa & . & : & - & . . & . . & - $\cdot$ & - & $"$ & » & $n$ & $"$ \\
\hline Miana strigilis. . & - & $\dot{0}$ & - & . . & . . & - & - & " & 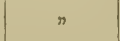 & $n$ & $n$ \\
\hline Hadena rurea ... & - & $\cdot$ & - & . $\cdot$ & - & - & - & $n$ & $n$ & $"$ & $”$ \\
\hline hepatica. & - & . & . & . . & - . & - $\cdot$ & - & n & $"$ & $"$ & $"$ \\
\hline basilinea & - & $\cdot$ & $\cdot$ & . $\cdot$ & $\cdot \cdot$ & - & - & $n$ & $n$ & $n$ & $n$ \\
\hline gemina . & & & $\cdot$ & $\therefore$ & & . & · & $n$ & $n$ & $n$ & $n$ \\
\hline " secalis ab. & $l e$ & & & tigm & & - & - & $"$ & $n$ & " & $n$ \\
\hline Mania maura . & - & - & - & - $\cdot$ & - $\cdot$ & • $\cdot$ & - & $n$ & $n$ & $n$ & ” \\
\hline
\end{tabular}




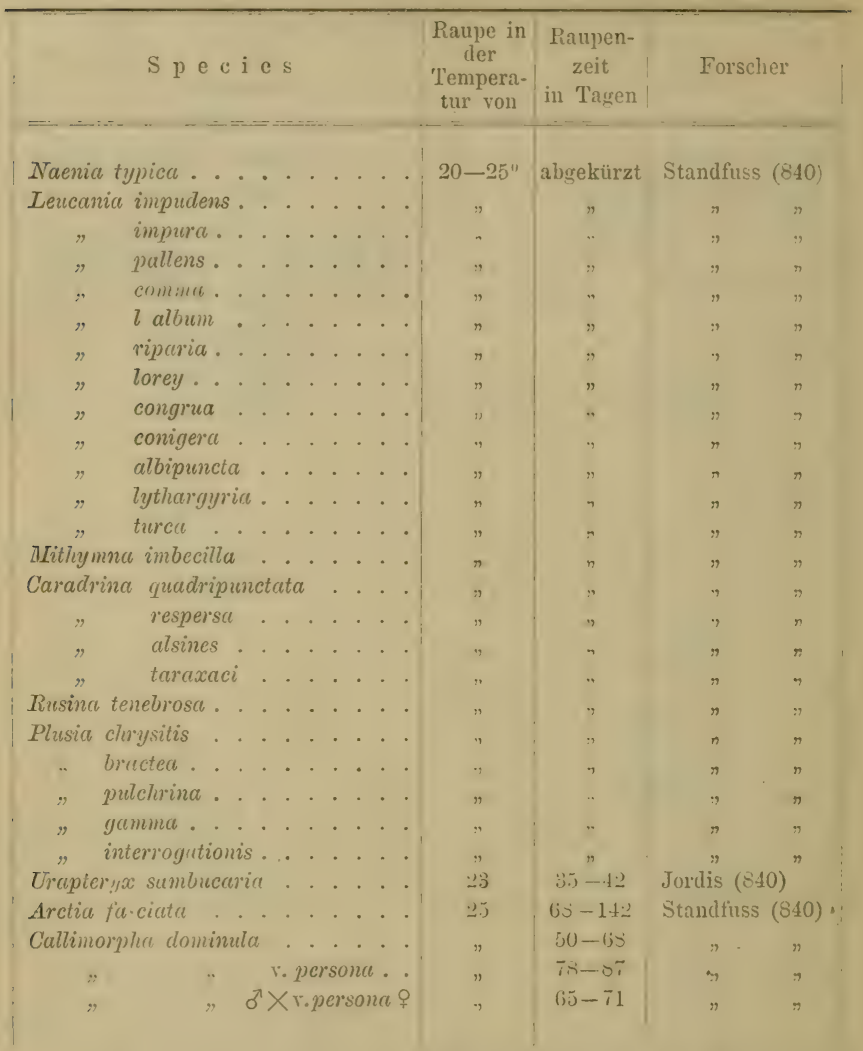

Ohne genaner Angabe lier Temperatur und der liampenzeif wird die letztere abgekïrzt noch bei: Agrotis trianyulum, Vicenu: iypice, Nemeopleita plantaginis, Alyrotis pronulia, Agrotis jimbriu (Fingerling [225]); Vunessa io, Vunessu urticue (Dorfmoistor [194]]). Dieselise wird nicht abgekiirzt bei Aqrotis molothina (Standfuss |840]), Plusin chrisitis. Leucanien, cinigen Agrutis- unil BärenArten (Pingerling [225]), wenn die laupen auch noch rechtzeitiv im Herlust ringesammelt weritm. so tass sie noch lieinen Frost oiler starken lieif trhielten, was nach Standfuss (Sh(1)) eine nothwenlig. Bedingung zum Forcieren ist. 
Auch bei einigen näfer-Larven beschleunigt die erhöhte Temperatur die Entwickelung (Beckmann [58]: Saperila perforata, Saperdu scalaris; Mokrzecki [586]: Oberia oculatu var. borysthenica).

Zur Herstellung des Cocons brauchen die Raupen, je nith der Temperatui, verschielen lange Zeit. Dendrolimus pini brancht dazu 12 Stunden bei $18-28^{\circ} \mathrm{R}$. und 3 Tage bei $13^{\circ} \mathrm{R}$. (Regener $[67 \tau \iota]$ ). Zur Verpuppung braucht diese Art 2 Tage bei $16-22^{\circ} \mathrm{R}$. unil 15 Tage bei $8-11^{\circ}$ R. (Regener $[677 a]$ ).

Die Nahrungsiufnahme der Raupen wächst mit der Temperatur (Regener [677b]: Denctiolimus pini. Siehe Fig. 5), aber nur bis zu ciner gewissen Grenze (Schitkow [752]).

Lässt man die Raupen bei verschiedenen Temperaturen ohne Nahrung, so ist die Sterblichkeit derselben umsu grösser, je höhrr lie Temperatur ist (Schmujdsinowitsch [756]: Bomby.r mori).

Diə Herzcontraktionen nehmen mit der Zunahme der Temp'ratur zu (Tichomirow [869]: Bomlyyx mor. Siehe Fig. 6).

$$
\text { c) Puppen. }
$$

Die Entwickelung der nicht ïberwinternien Puppen wirl durch (iie erhöhten Temperaturen beschleunigt. Dasselbe wird auch ly:i einigen Species von überwinternden Puppen beobachtet, wils aus folgender Tabelle zu ersehen ist:

\begin{tabular}{|c|c|c|c|c|c|c|c|c|c|c|}
\hline & $\mathrm{S} \mathrm{p} \mathrm{e} \mathrm{c}$ & i $e$ & & & & & & $\begin{array}{l}\text { Bei welcher } \\
\text { Temperatur }\end{array}$ & $\begin{array}{l}\text { Puppen- } \\
\text { zeit } \\
\text { in Tagen }\end{array}$ & Forscher \\
\hline Papitio & machron & . & $\ldots$ & . . & . & & . & $37-38^{0}$ & $7-10$ & Standfuss (840) \\
\hline 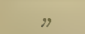 & $\eta$ & . & . . & - . & . . & . & • & 39 & 7 & Ball $(47)$ \\
\hline Pieris 7 & brassicae. & . & .. . & . . & . . & . & • & $16-17,5$ & 21 & Auel (17) \\
\hline$"$ & " & . & . & - & •. & . & . & im Keller (Juli) & 17 & $"$ \\
\hline$"$ & 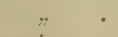 & . & . . & - . & - . & . & . & im Freien(Juli) & 14 & $"$ \\
\hline$"$ & napi. . . & - & . $\cdot$ & - & - : & . & 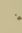 & $22-25$ & 9 & TVeismann (954) \\
\hline$"$ & $" \quad$ v. bry & $y 0 n$ & iace & 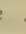 & . & s. & 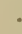 & $36-31,5$ & 7 & $"$ \\
\hline Gonopte & ery $x$ rham & & . . & - & . & . & . & $39-27$ & $8-9$ & Standfuss (859) \\
\hline Pyrame & eis atalanto & & 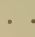 & - & - : & . & 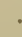 & 26,7 & $4-6$ & Merrifield (570) \\
\hline$"$ & & & . . & • & •. & . & . & $37-25$ & $6-7$ & Standfuss (837) \\
\hline$"$ & cardui & - & . & . & . & r. & 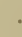 & $40-22$ & $10-12$ & $n$. \\
\hline$"$ & $"$ & $\cdot$ & " & . & • & . & . & $37-22$ & $6-7$ & $n$ \\
\hline Vanesse & u io... & . & . & • & •. & . & 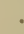 & $27-32$ & 7 & Merrifield $(570)$ \\
\hline$"$ & $" \therefore$. & . & . & • & - : & 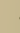 & 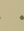 & $37-25$ & $9-12$ & Standfuss (837) \\
\hline$"$ & wricae. & . & . & . & . & & & 8,2 & $60-67$ & Merrifield (567) \\
\hline$"$ & $n$ & . & 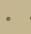 & $\bullet$ & - & 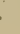 & 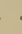 & 27 & $5-6$ & $\eta$ \\
\hline
\end{tabular}


I. Fapitel. Theoretisches über die Entwickelungsgeschwindigkeit.

\begin{tabular}{|c|c|c|c|c|c|c|c|c|}
\hline $\mathrm{S} p$ e $\mathrm{c} \mathrm{i}$ & $\mathrm{e}$ & & & & & $\begin{array}{l}\text { Bei welcher } \\
\text { Temperatur }\end{array}$ & $\begin{array}{l}\text { Puppen- } \\
\text { zeit } \\
\text { in Tagen }\end{array}$ & Forscher \\
\hline Vanessa urticae. . & - & - & - & . . & - . & $26-29,4^{0}$ & 5 & Weismann (954) \\
\hline . & . & · & $\cdot$ & - & - & $25-32,8$ & $5-8$ & $n$ \\
\hline$\cdot \cdot$ & . & · & $\cdot$ & - & - & i5 & 21 & $"$ \\
\hline . & . & - & - & - & - & $37-25$ & $5-6$ & Standfuss (837) \\
\hline polychloros & $s$. & - & - & . & - & $37-25$ & $9-12$ & $n$ \\
\hline$"$ & - & . & - & $\cdot$ & - & $39-25$ & 10 & (839) \\
\hline antiopa . & - & - & . & - & - & $37-25$ & 12 & (837) \\
\hline$\eta$ & - & . & . & - & . & 35 & $8-10$ & Fischer (22১) \\
\hline Polygonia c album & - & - & - & - & - & 37 & $7-10$ & Standfuss (837) \\
\hline$"$ & . & - & - & $\cdot$ & . & 37 & $6-8$ & $(840)$ \\
\hline$" \quad n$ & . & . & $\cdot$ & - & - & 36 & 7 & $n n$ \\
\hline Araschnia levana. & - & $\cdot$ & - & $\cdot$ & - & 26,7 & $6-7$ & Merrifield (570) \\
\hline - & - & $\cdot$ & - & - & - & - Hochsommer & 19 & Weismann (953) \\
\hline 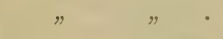 & - & $\cdot$ & - & - & - & $15-31$ & $45-55$ & " \\
\hline$"$ & $\cdot$ & . & - & - & - & $10-13$ & 39 & $n$ \\
\hline II & I. 1 & Bru & & - & - & $30-32$ & $7-10$ & $n$ \\
\hline$"$ & $"$ & & & - & - & 28 & $7-14$ & in \\
\hline 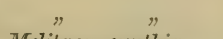 & $"$ & & & - & - & $21-22$ & 7 & $n$ \\
\hline Melitaea cyntlia : & - & . & - & - & • & 26,7 & $35-42$ & Merrifield (567) \\
\hline$"$ " & - & - & • & - & - & im Freien & 120 & $" n$ \\
\hline Argynnis aglaja . & . & . & 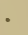 & . & 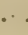 & $36-22$ & $5-6$ & Standfuss (837) \\
\hline Pararge egeria . & - & - & - & - & . . & 14 & 24 & Weismann (954) \\
\hline$\cdot$. & • & $\cdot$ & - & - & - & 18 & $10-13$ & $n \quad n$ \\
\hline$" \quad \cdot$ & $\therefore$ & - & - & - & . & $25-27$ & $6-16$ & $"$ \\
\hline$" \quad \Rightarrow \quad$ v. $m e$ & reio & & - & - & - & 14 & 24 & $n$ \\
\hline Chrysophanus phlaea & & - & - & - & . . & $27-30$ & 8 & $n$ \\
\hline$n n$ & & $\cdot$ & - & - & - & $7-10$ & $33-53$ & $n$ \\
\hline Acherontia atropos & & $\cdot$ & - & - & . & $28-30$ & 43 & Wünscher (963) \\
\hline Daphnis nerii . . . & $\dot{ }$ & & - & 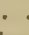 & & $\pi$ & 29 & $n$ \\
\hline Deileptita lineata v. & $l$ & ivor & $r n i$ & & & $"$ & 25 & Weismann (954) \\
\hline Orgyia antiqua . . & - & - & - & $\cdot$ & • & 30 & 10 & Urech (889) \\
\hline Dasychira abietis . & - & - & - & • & - & 25 & $13-19$ & Standfuss (840) \\
\hline Bombyx mori... & $\cdot$ & . & - & - . & - & $22,5-25$ & $12-14$ & Tichomirow (869) \\
\hline$" \quad \Rightarrow \quad \cdot$ & . & $\cdot$ & - & - . & - & $30-35$ & $5--9$ & $n$ \\
\hline Lasiocampa quercus & . & - & - & - & - & 8,2 & $39-71$ & Merrifield (567) \\
\hline Gastropacha quercifo & $\dot{o} \dot{i}$ & $i a$ & • & 0 & • & $\begin{array}{c}26,7 \\
30\end{array}$ & $\begin{array}{l}29-40 \\
12-15\end{array}$ & Standfuss $(840)$ \\
\hline$" \quad$ populifo & fot & $i a$ & . & . & .. & $15-20$ & 18 & Jaenichen (411) \\
\hline Odonostis pruni. . & - & - & - & & - & 30 & $10-13$ & Standfuss (840) \\
\hline$" \quad \cdot$ & 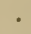 & - & . & - & - & 25 & $12-18$ & $n$ \\
\hline Dendrolimus pini. & . & - & - & : & & 25 & $25-27$ & $n$ \\
\hline Drepana falcataria & - & . & & & & 26,7 & $5 \mathrm{x}$ & Merrifield (567) \\
\hline$"$ & $\cdot$ & $\cdot$ & & & & gew.t. (April) & $39 \mathrm{x}$ & $n$ \\
\hline
\end{tabular}




\begin{tabular}{|c|c|c|c|c|c|}
\hline $\mathrm{S} p$ e c i e & & & $\begin{array}{l}\text { Bei welcher } \\
\text { Temperatur }\end{array}$ & $\begin{array}{c}\text { Puppen- } \\
\text { zeit } \\
\text { in Tagen }\end{array}$ & Forscher \\
\hline Catocala fraxini .. & & . & $20-39^{\circ}$ & $10--12$ & Kusnetzow (4S9) \\
\hline .. & 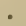 & . . . . & 4 & $14-21$ & \\
\hline Ennomos autumnaria & 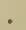 & . . . . & 30 & $14-17$ & Merrifield (563) \\
\hline Selenia tetralunaria . & & . . & 30 & $12-10$ & $\eta$ \\
\hline . & - & . . . & 21 & $59-103$ & $(56 \pm)$ \\
\hline Urapterix sambucaria & . & . . . & 23 & $10-15$ & Jordis $(840)$ \\
\hline Arctia fasciata . . & - & . . . & 25 & $15-31$ & Standfuss $(840)$ \\
\hline " liebe..... & . & . . . & 29 & 12 & Pauls (628) \\
\hline Callimorpha dominula & • & . . . & 25 & $11-16$ & Standfuss (840) \\
\hline$n$ & & persona & 25 & $15-20$ & $\eta$ \\
\hline$\Rightarrow \sigma^{\pi}>$ & $x v$ & -pers. 우 & 25 & $14-19$ & ” \\
\hline
\end{tabular}

Diese beschleunigte Entwickelung in Folge erhöhter Temperaturen hängt von dem Zustand $a b$, in welchem die Puppe im Anfang: sich befand. „Wirl die Puppe zu frisch exponiert, so vertrocknet sie, oder ergiebt im günstigsten Falle einen mehr oder weniger verkrüppelten Falter" (Standfuss [841]).

Die beschleunigte Entwickelung ohne genauer Angabe der T'emperatur und der Puppenzeit wird durch die Wärme noch bei folgenden Species verursacht: II. Generation von Papilio podalirius bei $30^{\circ}$ (v. Linden und Fickert [515]), Aporia crataegi, Puppenruhe 8 Tage (Schroiner [771a]), Pieris brussicae (Urech [889], Blasius [87]), Acherontia atropos ergiebt Falter in November (Trost [884a], Möller [582]), Deilephila nerii (Gauckler [301]), Macroglossa oenotherae ergiebt Falter um Weinachten (Glaser [314a]), Lophyrus pini (de Cobolli [152]), Bombyx quercus, Laria l nigrum (Standfuss [840]), Dusychiva puclibunila, Pygacra anachoreta (Mokrzocki [587]), Cidaria lugubrata (Schille [749]), Galerucella luteolı (Fink [226 $九]$ ). Die erhöhte Temperatur ıles Wassers verkürzt die Puppenzeit von Agraylea multipunctata (Silfvenius [815b]).

\section{d) Imago und alle Stadien.}

Die erhöhten Temperaturen beschleunigen die ganze Entwickelung der meisten Insekten-Arten.

Culex pipieus macht seine ganze Entwickelung:

in $3-4$ Wochen bei $15-20^{\circ}$ (Kerschbaumer [448a])

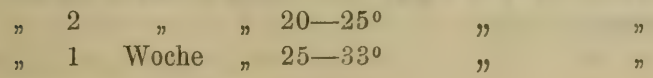


Bei Anopheles claviger dauert die ganze Lintwickelung bei 20 bis $25^{\circ} 30$ Tage (Grassi [327a]).

Pararge cyeria var. meione macht ihre ganze Entwickelung in 44-47 Tagen bei $18^{\circ}$ und in 29-39 Tagen bei $25^{\circ}$ (Weismann [954]).

Durch die grosse Hitze können sich die Raupen (Bomlıxx mori), olne sich zu verspinnen und zu rerpuppen, sufort zu Faltern rerwandeln (Majoli [543]).

Folgende Tabelle zeigt die Summe von Raupen- un: Puppenzeit unter dem Einfluss erhöhter Temperatıren für verschielene Lepidopteren-Species:

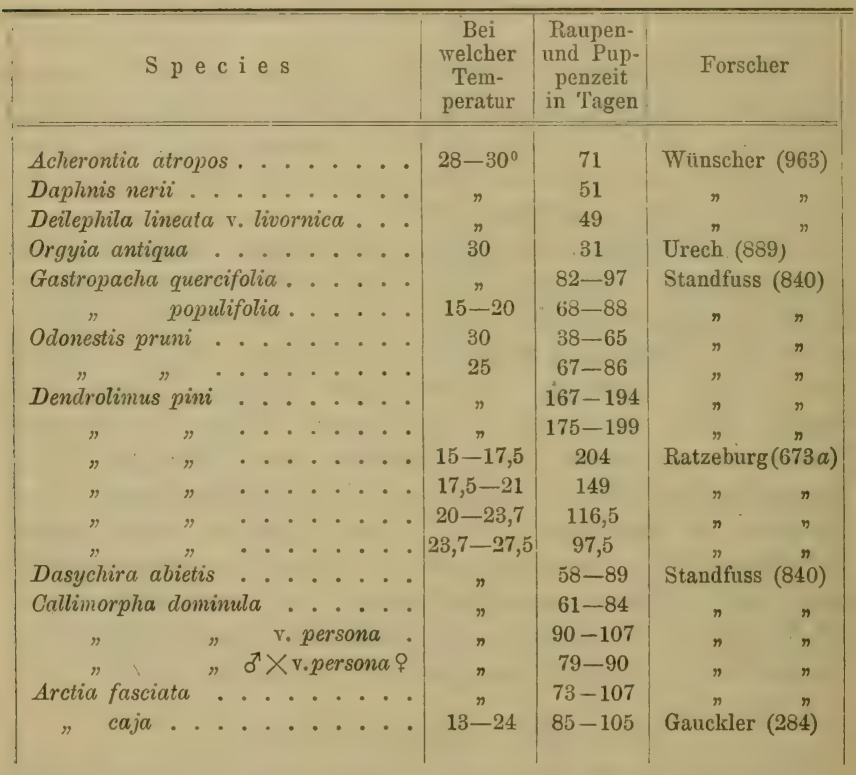

Werden die Eier von weiter unten angeführten Species in der Temperatur $34^{\circ}$ resp. $22^{\circ}$ gehalten und die Raupen und Puppen in beiden Fällen bei $25^{\circ}$, so exhält man folgenden Prozentsatz der Imagines (Standfuss [840]): 


\begin{tabular}{|c|c|c|c|c|c|}
\hline \multirow{2}{*}{\multicolumn{2}{|c|}{ S p e c i es }} & & & \multicolumn{2}{|c|}{ Eier bei } \\
\hline & & & & $34^{\circ}$ & $22^{\circ}$ \\
\hline Arctia fasciata . & & . . & & $71 \%$ & $23 \%$ \\
\hline Dasychira abietis & & & & $90 \%$ & $12 \%$ \\
\hline Odonostis pruni. & & & •. & $100 \%$ & $64 \%$ \\
\hline Dendrotimus pini & * & - & . & $80 \%$ & $28 \%$ \\
\hline
\end{tabular}

\section{B. Einfluss konstanter niederen Temperaturen.}

Unter diesem Einfluss werden wir solche konstante Temperaturen verstehen, welche unter $15^{\circ}$ sind und welche auf das betreffende Stadiuın des Insektes während seiner ganzen Entwickelungszeit in diesem Siadium eingewirkt haben.

\section{a) Eier.}

Die Entwickelung der Eier wird durch die Abnahme der Temperatur in allgemeinen verlangsamt (Gastropacha pini: Razteburg [673a], Judeich und Nitsche [423a], Taschenberg [852a]; Gonioctena sexpunctata: Liberich [511]; A phis-Species: Balbiani [45]; Angerona prunaria: Berger [72]).

\section{b) Raupen.}

Die Entwickelung der Raupen wird durch niedere Temperataren verlangsamt (Parnussius apollo: Selmons [804]; Pararge egeria var. meione: Weismann [954]; Chrysophanus phlaeas: Weismann [954]; Phalera bucephala: Urech [889]; Bowbyx mori: Kamensky [434], Tichomirow [869], Schmujdsinowitsch [756]; Uropus ulmi: Schewyrew [748]).

\section{c) Puppen.'}

Die Entwickelung der Puppen wird durch die niederen Temperaturen verlangsamt (Parnassius apollo: Selmons [804]; VanessaArten: Weismann [954], Dorfmeister [194], Merrifield [567], Standfuss [837], Weismann [953], Slevogt [822], Merrifield [570]; Pieri.s brassicae: Auel [17], Urech [889]; Pararge egeria: Weismann [954]; Chrysophanus phlaeas: Weismann [954]; Argynnis-Arten: Standfuss [837]; Dasychira-Arten: Standfuss [837]; Bombyx quercus: Merrifield [567]; Arctia caja: Merrifield [567]; Arctia villica: Dorf- 
meister [195]; Catocala fraxini: Kusnetzow [489]; Ennomos ulniaria: Merrifield [564]; Ennomos autımnaria: Merrifield [564]: Selenia telralunaria: Merrifield [564]; Musca vomitaia: Dewitz [168]; Käfer-Arten: Jahn [417]).

\section{Einfluss intermittierender Temperaturen.}

Unter diesen Temperaturen verstehen wir solche, welche währenıl längerer odler kürzerer Zeitperioden mehr oder weniger schnell sich ändern. Diese Temperaturen können sowohl ab- wie auch aufsteigen oder unter einander gemischt werlen.

\section{a) Eier.}

Eier einiger Species bediurfen zu ihrer Entwickelnng ilie vorherige Einwirkung der Kälte, und zwar:

Eier von Bombyx mori:

Werden diese Eier bei $7,5^{\circ}$ aufbewahrt, so liönnen sie ohne Verderben 6 Jàhe lang liegen (Beauvais [56]).

Zu ihrer normalen Entwickelung müssen sie zuerst der Einwirkung der Kälte, welche gewölnnlich $0^{\circ}$ beträgt, ausgesetzt werlen, und dann derjenigen der Wärme (gewöhnlich 20) (Borca [49], Quajat [627], Ducleaux [199]).

Je längere Zeit diese Kälte auf die Eier eingewirkt hat, um so besser findet das Ausschlüpfen der Rüupchen bei der Zimmertemperatur statt (Ducleaux [201]). Diese Zeit darf gewisse Grenzen nicht ïberschreiten (135 Tage, welche jedoch von der Vorbehandlung der Eier und (leren Rasse abhängen), sonst schlüpft ein Theil der Eier nicht (Quajat [664, 668]).

Die Zeit, welche zwischen dem Momente des Herausnehmens der Eier aus der Kälte und dem Momente des mittelst des Brutofens hewirkten Ausschlüpfens verfliesst, ist nicht vortheilhaft zu reduzieren, besonders wenn die Einwirkung der Kälte ungenügend war (Dusleaux [201]).

Zweimaliges Verbleiben (ler Eier bei $-8^{0}$ ist demjenigen von 20 Tagen bei $0^{0}$ xquivalent (Ducleaux [201]).

Eier, welche der Einwirkung der Temperatur von $-10^{\circ}$ ausgesetzt werilen, verbleiben in einem solchen Zustande, als ob sie der Einwirkung der Kälte gar nicht ausgesetzt wären (Ducleaux [201]).

Je stïrker die Abkïhlung ler Eier während ihres Ueberwinterns. war, desto später schliipfen sie (Vorson [914]). 
Die Abkühlung der Eier von $30^{\circ}$ bis auf $0^{\circ}$ (besonders aber von $40^{\circ}$ an) beschleunigt das Ausschliupfen der Paupen in der Wärme (Schmujdsinowitsch [762]).

Eier anderer Species:

Eier von Ocneriu dispar, welche während 14 Tagen in die Temperatur von $3^{0}$ bis $10^{\circ}$ gebracht werden, ergaben nach 1 Monat Raupen. Diese Eier ergaben Raupen auch ohne Ueberwintern, aber $2^{1} / 2$ Monate später (Kloos [454]).

Eier von Ocneria monacha, welche 1 Monat lang ler Einwirkung der Kïlte $\left(7\right.$ bis $\left.-2^{0}\right)$ ausgesetzt werden, ergaben zwischen 17,5 und 22,50 100\% Rïupchen; bei etwas höheren Temperaturen nimmt dieser Prozentsatz zuerst langsam und von $30^{\circ}$ an rascher ab, bis er bei $45^{\circ}$ gleich Null wirl (Schemigonow [744]).

Frisch gelegte Eier von Angerona primaria, gehalten 8 Tage lang bei $2^{\circ}$, ergaben bei Zimmertemperatur Räupchen (nur $4-8 \%$ bleiben unentwicke̊lt) (Berger [72]).

Die maximale Ausbriitung der Räupchen von Selenia illustraria findet statt, wenn die Eier zuerst 14 Tage auf Eis verbleiben und je frischer sie waren (Merrifield [564]).

Bringt man Eier von Orgyia antiqua im Frïhjahre aus der Kälte ins Zimmer, so erhält man im Mai Schmetterlinge (Petersen [633]).

Eier von Catocula nupta, welche 1 Monat bei $0^{0}$ gehalten werden, dann allmïhlig auf $29^{\circ}$ erwärmt, ergeben keine Räupchen nicht einmal nach 1 Monat (Pauls [628]).

Die vorzeitige Entwickelung:

Dieselbe kann bei Eiern von Bombyx mori auch ohne vorherige Einwirkung der Kälte hervorgeruten werden und zwar:

Die vorzeitige Entwickelung der Eier wird durch (vielleicht ausschiliesslich) die erhöhte Temperatur bedingt (Bellati und Quajat [61]).

Dafür braucht man die Temperatur von $25^{\circ}$ (Alibegow [8]). oder wenn man die Eier für 15-30 Minuten ins Wasser von 500 bringt (Bolle [101], Tichomirow [866], Bellati und Quajat [ii3]). Die Erwärmung in der Luft iiber $25^{\circ}$ (besonders von $37,5^{\circ}$ an) vermindert die Anzahl ausschlïpfender liaupen.

Bringt man die Eier von $21^{\circ}$ in eine höhere Temperatur (T) und umgekehrt (wenigstens $10 \mathrm{Mal}$ ), so wird bei $\mathrm{T}=58,6^{\circ}$ das Maximum $(100 \%)$ der Ausschliipfungen erreicht (Bellati und Quajat [62]). 
Bringt man die Eier in die Temperatur von $20^{\circ}$, so erleiden sie keine vorzeitige Entwickelung (Ducleaux [199]). Keine Entwickelung wird auch dann erhalten, wenn die Eier von $18,7^{\circ}$ auf $37,5^{\circ}$ resp. auf $52,5^{\circ}$ und $62,5^{\circ}$ erwäimt werden (Verson [921]).

Das sonstige Verhalten der Eier:

Die allmählige Abliihlung der Eier von Bombyx mori bis $-32^{\circ}$ zerstört ihre weitere Entwickelungsfähigkeit nicht. Plötzliche Erwärmung von $-23^{\circ}$ auf $+20^{\circ}$ schadet ihnen. Geführlich ist es auch, wenn die Eier, welche schon frïher ïber $10^{\circ}$ erwärmt wurilen, plötzlich in die Kälte gebracht werilen (Verson [914]).

Eier von Bombyx mori, welche in Luft ron $50^{\circ}$ einige Minuten (bis 10') gehalten werden, werden nicht beschälligt (Bellati und Quajat [62]). Sie können sogar $56,2^{\circ}$ aushalten (Schmujdsinowitsch [762]).

Eier der Bettwanze, welche bei Zimmertemperatur nach 22 Tagen Larven ergeben, ergaben dieselben erst nach 24 Tagen, wenn sie auf 3 Stunden in die Temperatur von $-4^{0} \mathrm{R}$. gebracht wurden (Pickel [571]).

Die Athmungsenergie der Eier. von Bomlyyx mori steht in keinem strengen Verhältnisse zu der Temperatur (Quajat [663]).

\section{b) Raupen.}

Einige Raupen-Arten miissen zuerst der Einwirkung der Kälte im Winter ausgesetzt werden, sonst lassen sie sich nicht treiben. (Schultz [786]: Hadena adustata; Pauls [628]: Arctia hebe; Serobrjanikow [808a]: Gastropacha pini; Standfuss [840]: Pleretes matronula, Arctia quenselii).

Bei den meisten Arten kann das Treiben (bei 20--250) leicht angestellt werden, wenn die Raupen noch recht zeitig im Herbst eingesammelt werden, so dass sie noch lieinen Frost oder starken Reif erhielten (Standfuss [840]: zahlreiche Arten vic. p. 133). Daraus folgt, dass für die Entwickelung der meisten Raupenarten die Ueberwinterung keine nothwendige Bedingung ist (Kalonder [429]).

In gewissen Fällen müssen die Arten zum Treiben bereits vom Ei der Wirkung erhöhter Temperatur ausgesetzt werden (Standfuss [840]: Laria l nigrum, Bombyx quercus).

Die Raupenzeit wird durch die Erniedrigung der Temperatur verlängert (Kamensky [434]: Bombyx mori; Selmons [304]: Parnassius apollo). 
Die Verpuppung wird durch die Wärme beschleunigt und durch die Kälte verzögert (Dorfmeister [194]: Vunessa io, Vanessa uiticae).

Der Stoffwechsel der Raupen von Bombyx mori beginnt bei $7,5-9^{\circ}$ und verdoppelt sich bei $15-17^{\circ}$ (Schmujdsinowitsch [756]. Die Futtermenge nimmt für Dendrolimus pini mit der Temperatur zu (Regener [6776]. Vill. fig. 5). Ohne Nahrung können die Raupen von Bombyx mori desto lünger aushalten, je nierlriger die Temperatur ist (Schmujdsinowitsch [756]).

Herzcontractionen der Raupen von Bombyx mori betragen bei $27,5^{\circ} 65$ Schläge, bei $25^{\circ} 50$ Schläge und bei $10^{\circ}$ bis $15^{\circ} \mathrm{nur} 6$ bis 7 Schläge (Tichomirow [869]. Vid. fig. 6).

\section{c) Puppen.}

Die Entwickelung der ïbewinternden Puppen liann durch die Erhöhung der Temperatur beschleunigt werden, wobei gewöhnlich zwei Methoden in Anwendung kommen (Gauckler [297] Kalender [428]): $A$. Die Puppen werden bereits im Herbst, kurze Zeit nach der Verpuppung in die Temperatur von $18^{\circ}$ bis $25^{\circ}$ gebracht. $B$. Die Puppen bleiben zuerst bis Ende Januar im Freien und nachher bis $18^{\circ}$ bis $25^{\circ}$.

Die Entwickelung verschiedener Species verhält sich gregenüber erhöhten Temperaturen sehr verschieden.

Die Tagfalter reagieren leicht auf erhöhte Temperaturen, sowohl nach der Methorle $A$, wie auch nach der Methode $B$. Tach $A$ behandelte Puppen schliipfen meist in $4-6$ Wochen aus, wïhrend die nach $B$ nach etwa in 10 Tagen bis 3 Wochen. Ausnahme bilden Pieris brossicae und Pieris napi, welche nach der Methorle $A$ keine beschleunigte Entwickelung zeigen (Gauckler [283]; Mørrifield [570]; diesellue wird aber beobachtet, wenn man die Methorle $A$ sofort nach der Verpuppung von Pieris brassicae anwendet (Kalender [428]; Urech [889]; Blasius [87]).

$\mathrm{Sph}$ ing i $\mathrm{a} \mathrm{e}^{\mathrm{1}}$ ) lassen sich auch leicht zu frühzeitiger Entwickelung bringen, doch verhalten sich einige Arten sehr verschieden gegen die angewandten Nethoden $A$ und $B$. Ausnahme bildet Deilephila euphorbiae für die Methode $B$ (Gauckler [297], Rheinberger [685]) und auch für die Methode $A$, wenn die Puppe zwei-jährige Puppendauer hat (Kalonder [428]), und Sphinx pinastri für die

1) Diese Eintheilung ist hier nach der alten Systematik, wie es bei Kalender und Gauckler steht, angeführt. 
Methorle $B$ (Kalender [428], Gauckler [297]). Smerinthus titiae trocknet bei der Methoile $A$ meistens ein (Rühl [716], Gauckler [275]).

B o m b y cid a e verhalten sich recht verschiedenartig gegen die Entwickelung hei hohen Temperaturen. Gar keinen Einfluss iilt die Methorle $B$ auf Phalera bucephala (Kalender [428], Gauckler [297]) und die Methode $A$ auf Bombyx quercus var. sicula aus (Gauckler [301], Schulz [716l]), auch keine ron beirlen Methorlen wirkt auf Eupreria lubricipedı unt menthastri (Kalender [428]).

Joctuirlae zeigen sehr ungleiches Verhalten gegen das Treiljen, uni zwar übt die Methole $A$ auf viele Arten llieser Familie keinen nemmenswerthen Einfluss aus, wïhrend die Puppen fast aller Arten, nach $B$ behanilelt, schon nach wenigen Wochen ausschlïpfen. Diese letzte Methole iilit keinen Einfluss auf Acronycta leporina aus (Gauckler [297])

Ge ometrid a e ertragen schwer die Bellingungen dieser Versuche und gehen meist zu Grundle.

Die Wirkung der Methorien $A$ un:l $B$ auf die Entwickelung rler Puppen rerschielener Schmetterlings-Arten ist aus folgender Tabelle ersichtlich:

Treiben ler uberwinternden Schmetterlingspuplen.

(Die Arten sind nach dem Cataloge ron Staudinger und Rebel geordnet).

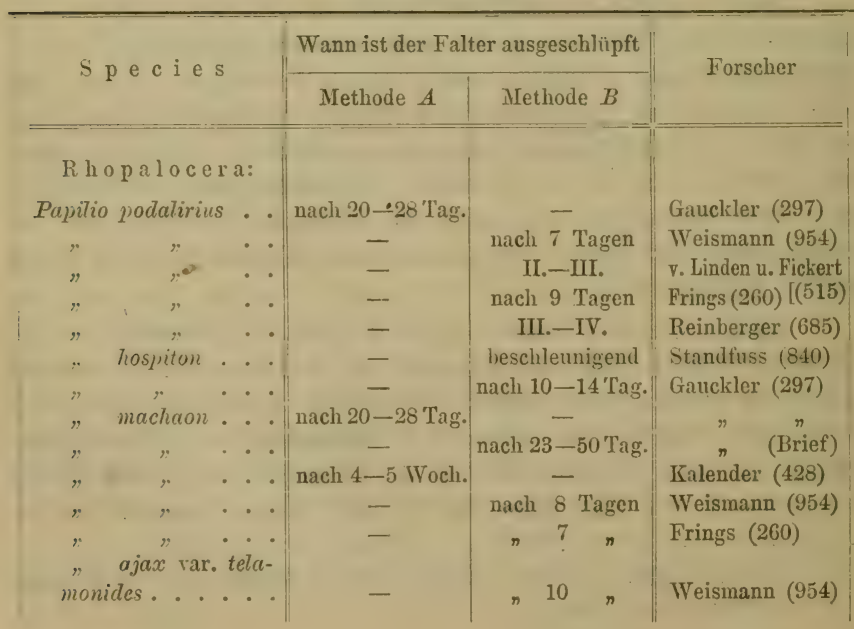


1. Einfluss der Temperatur.

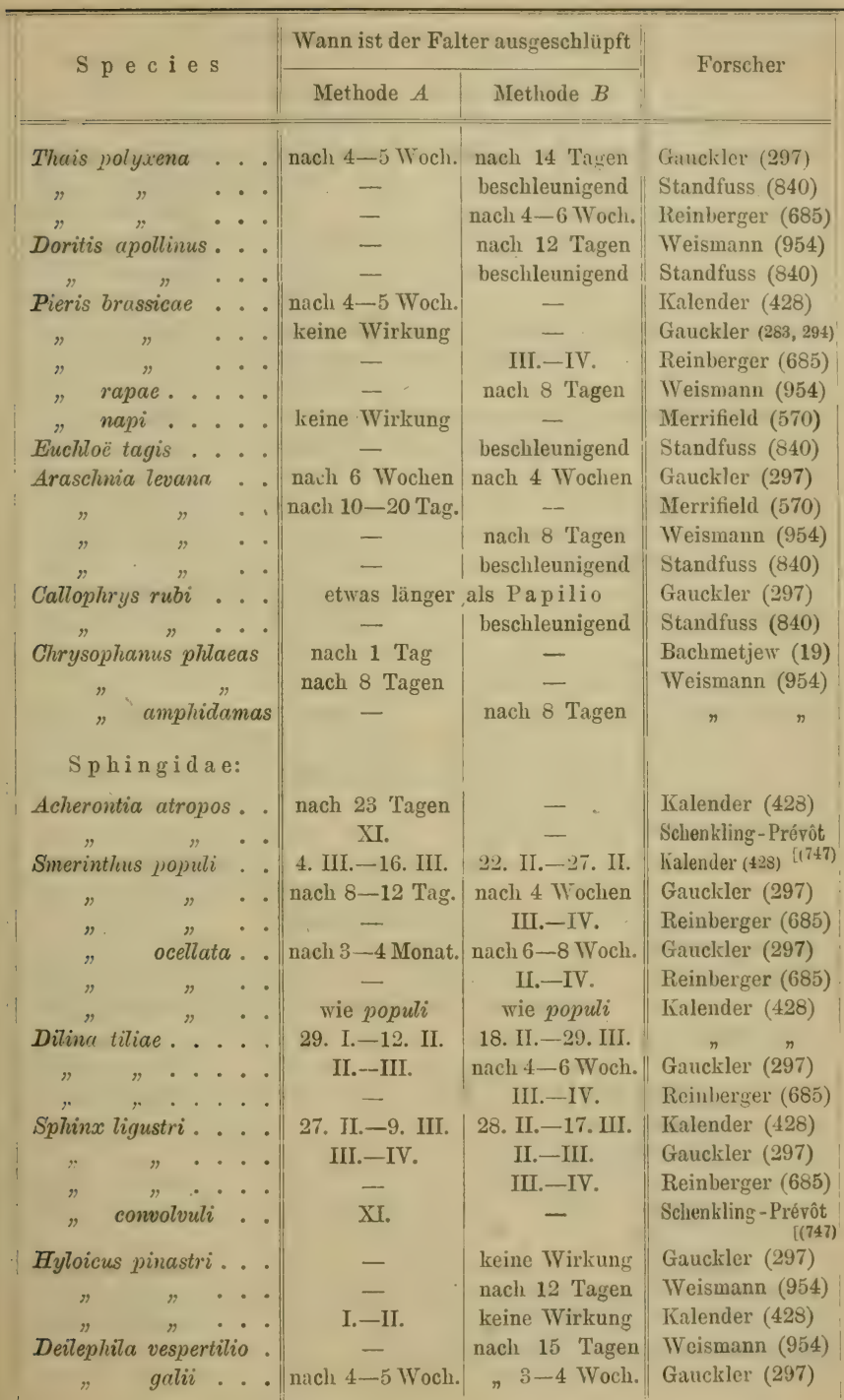


I. Kapitel. Theoretisches über die Entwickelungsgeschwindigkeit.

\begin{tabular}{|c|c|c|c|}
\hline \multirow{2}{*}{ S p e c i e s } & \multicolumn{2}{|c|}{ Wann ist der Falter ausgeschlüpft } & \multirow{2}{*}{ Forscher } \\
\hline & Methode $A$ - & Meth & \\
\hline \multirow{3}{*}{$\begin{array}{cl}\text { Deilephila } & \text { galii } . . . \\
" & \text { dahlii. . . } \\
" & \text { euphorbiae. }\end{array}$} & XII. & nach 3 Wocl & $(428)$ \\
\hline & - & $" \quad 15$ Tagen & Weismann (954) \\
\hline & I. & IV. & Kíalender (428) \\
\hline \multirow{4}{*}{$\begin{array}{cc}" & " \\
" & " \\
\text { Chaerocampa } & " \\
\text { elpenor . }\end{array}$} & - & nach 14-32 Tag. & Weismann (954) \\
\hline & I. & IV. & Gauckler (297) \\
\hline & - & VI. & Reinberger (685) \\
\hline & nach 4 Monaten & nach wenig. Woch. & Gauckler (297) \\
\hline \multirow{6}{*}{$\begin{array}{ccc}" & " & . \\
\text { Metopsilus } & \text { porcellus } & . \\
" & " & . \\
\text { Macroglossa } & \text { stellatarum }\end{array}$} & keine Wirkung & sehr schnell & Kalender (428) \\
\hline & - & IV. $-\mathrm{V}$ & Reinberger (685) \\
\hline & nach 4 Monaten & nach wenig. Woch. & Gauckler (297) \\
\hline & keine WVirkung & sehr sclinell & Kálender (428) \\
\hline & - & IV.-VI. & Reinberger (685) \\
\hline & XI. - I. & nach 2 Wochen & Kalender (428) \\
\hline \multirow{4}{*}{$\begin{array}{cc}" & " \\
" & \text { aenotherae } \\
\text { Hemaris fuciformis. } & \\
\text { Notodontidae: }\end{array}$} & nach 4-6 Woch. & $" n " n$ & Gauckler (297) \\
\hline & - & $\begin{array}{l}n-4 \text { " } \\
n \quad 23 \text { Tagen }\end{array}$ & Kalender $\stackrel{n}{n}(428)$ \\
\hline & - & IV.-VI. & Reinberger (685) \\
\hline & & & \\
\hline Cerura furcula . . . & II. & nach 1 Tag & Kalender (428) \\
\hline \multirow{4}{*}{ 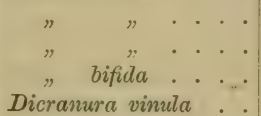 } & II.--UI. & nach $2-3$ Woch. & Gauckler (297) \\
\hline & - & $n$ einig. & Reinberger (685) \\
\hline & II.-III. & $n 2-3 \quad n$ & Gauckler (297) \\
\hline & IT & $n n$ & \\
\hline \multirow{5}{*}{ 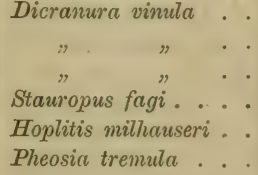 } & II. & 1 Tag & Kalender (428) \\
\hline & - & "14-16 Woch. & Reinberger (685) \\
\hline & gehen alle & zu Grunde & Gaucklex (297) \\
\hline & " & $" \quad "$ & " " \\
\hline & $\begin{array}{c}9 .-21 . \text { XII. } \\
\text { nach } 4-6 \text { Woch. }\end{array}$ & $\begin{array}{c}5 .-13 . \text { II. } \\
\text { nach } 2-3 \text { IVoch. }\end{array}$ & $\begin{array}{l}\text { Kalender (428) } \\
\text { Gauckler (297) }\end{array}$ \\
\hline Notodonta ziczac... & $"$ & & $n n$ \\
\hline$" \quad " \quad \cdot \cdot$ & 2.-17. XII. & 9.-10. II. & Kalender (428) \\
\hline \multirow{3}{*}{$\begin{array}{ll} & \text { dromedarius } \\
" & \text { phoebe torva } \\
" & \text { tritophus. }\end{array}$} & nach 4 Wochen & nach $2-3$ Woch. & Gauckler (297) \\
\hline & $n 2-3$ & - & $n$ \\
\hline & $n 4$ & nach $2-3$ Woch. & \\
\hline \multirow{3}{*}{$\begin{array}{l}\text { " trepida .. } \\
\text { Leucodonta bicoloria } \\
\text { ab. unicolora .... }\end{array}$} & 11.-17. XII. & & Kalender (428) \\
\hline & - & nach 4-6 TVoch. & Gauckler (297) \\
\hline & 11. XII.-17. III. & & Federley $(219 a)$ \\
\hline \multirow{2}{*}{$\begin{array}{c}\text { Lophopteryx camelina } \\
"\end{array}$} & nach 4-6 Woch. & nach 2 Wochen & Gauckler (297) \\
\hline & & 5. II. & Kalender (428) \\
\hline Pterostoma palpina.. & 30. XI.-10. XII. & 17. I. -16. II. & \\
\hline
\end{tabular}


1. Einfluss der Temperatur.

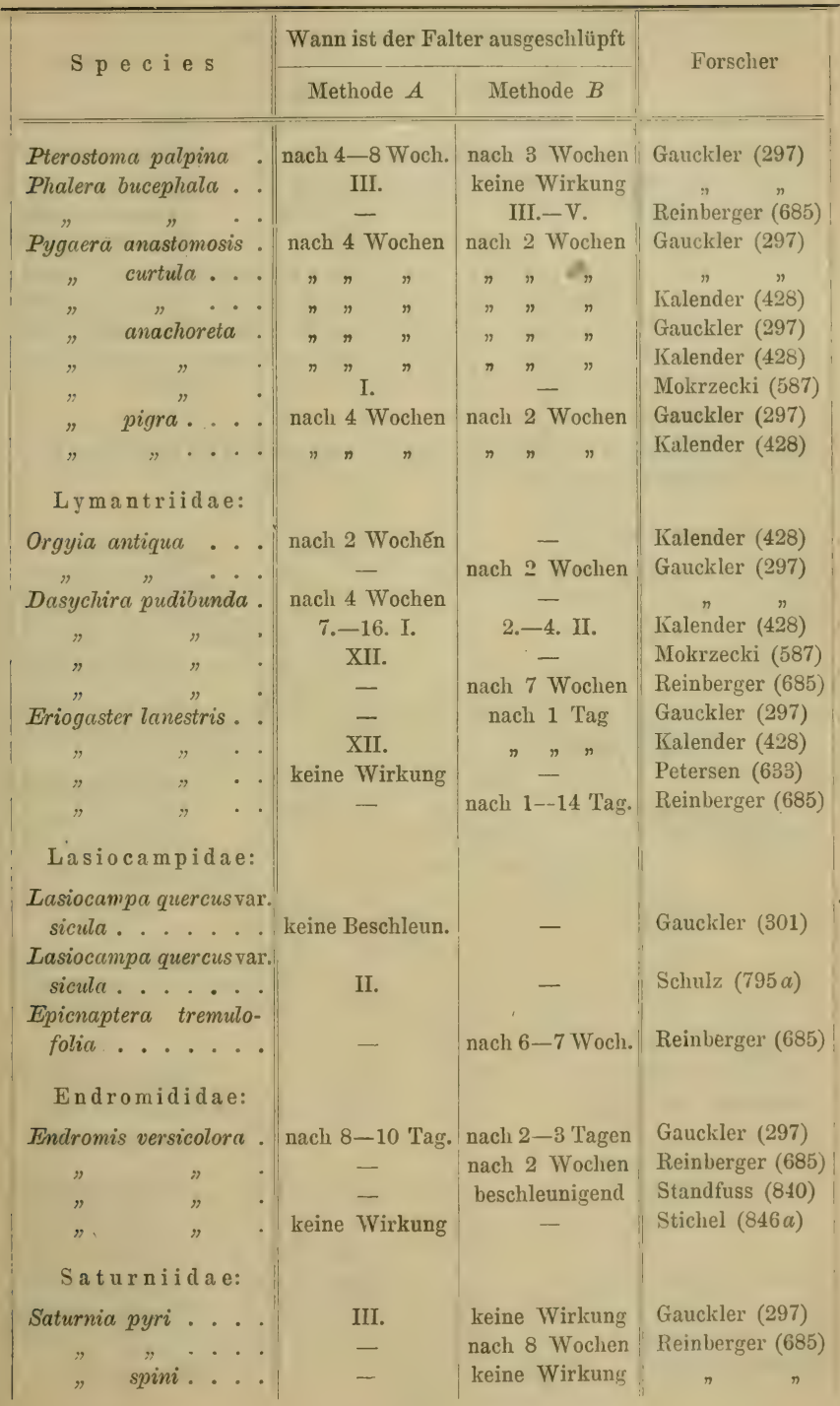




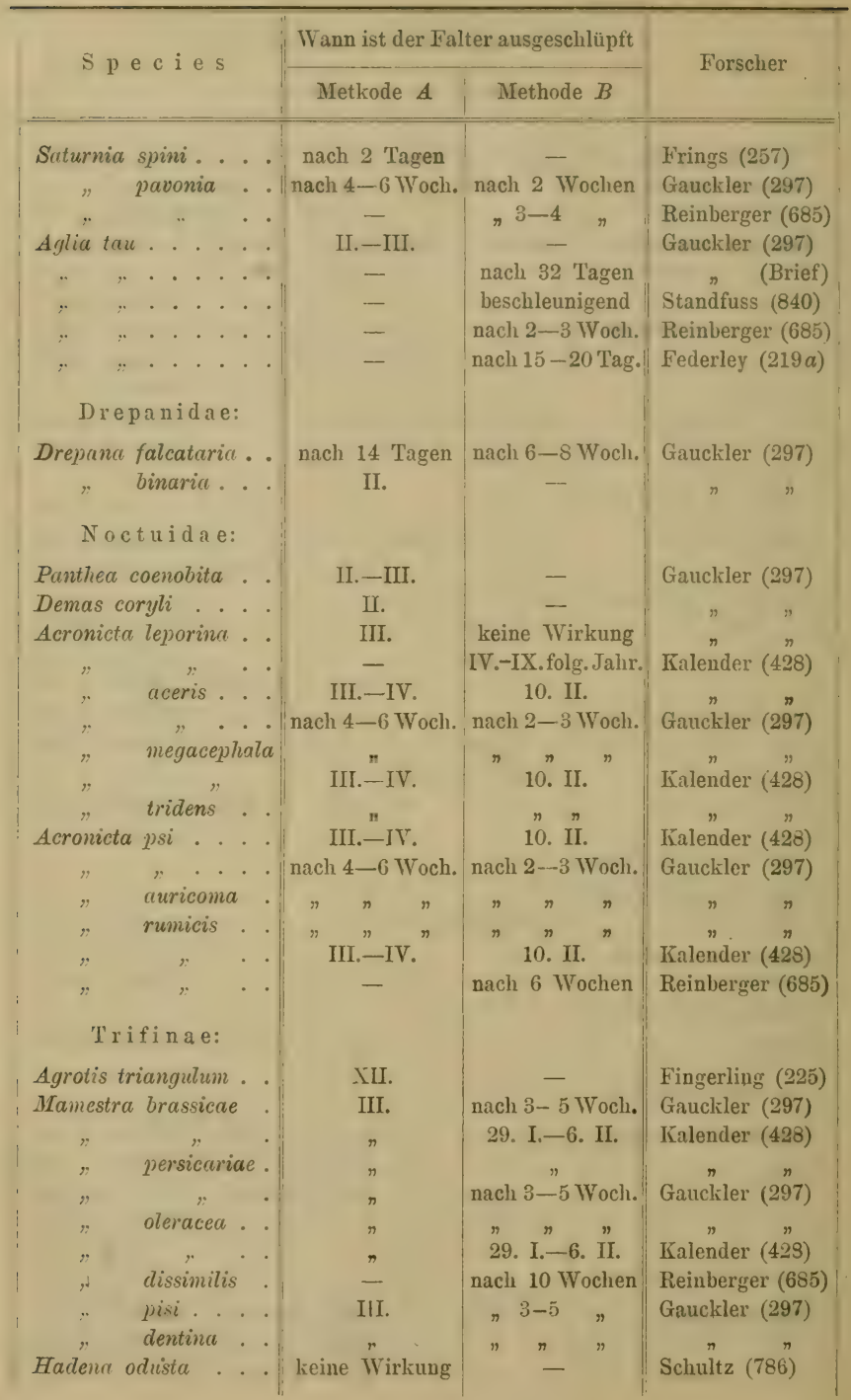


1. Einfluss der Temperatur.

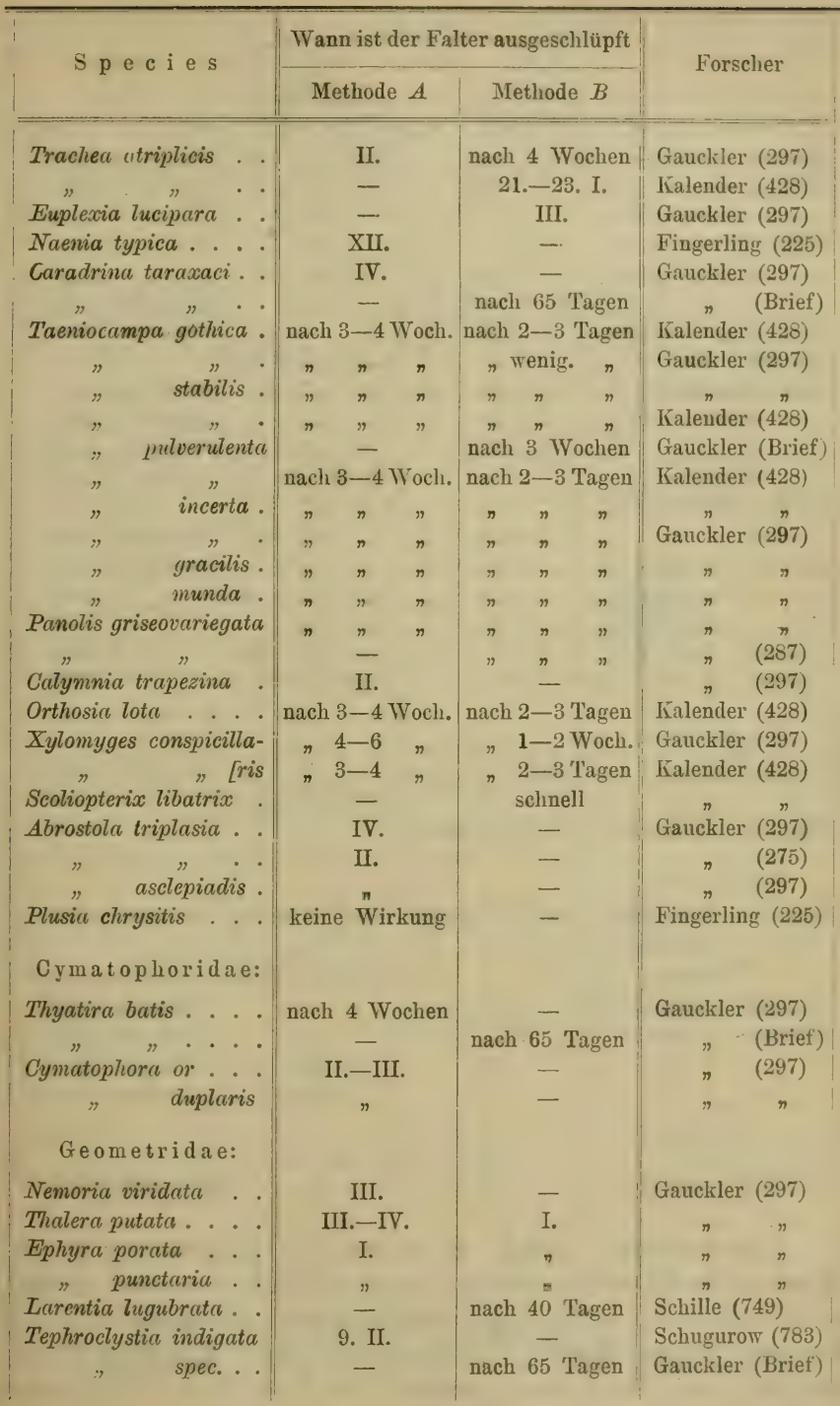




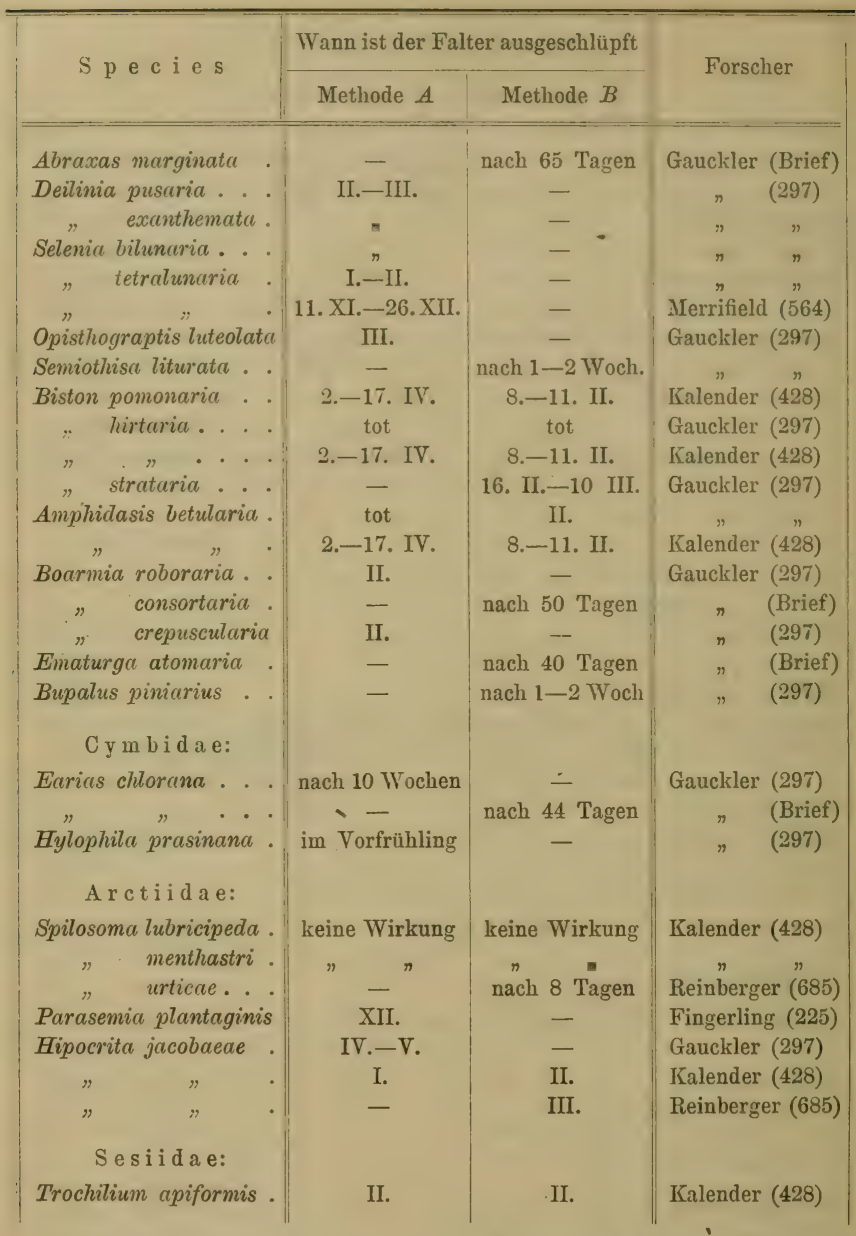

Ueberwinternde Puppen, die zu friih zur Entwickelung in das Zimmer gebracht werden, oder gar nicht der Kälte ausgesetzt, liefern verkümmerte orler lirïppelhafte Schmetterlinge (Dorfmeister [194]: Araschnia levana; Rühl [716]: Smerinthus tiliae; Standfuss [840]: Stauropus fagi, Cnethocampa pinivora, die Hybernia-, Anisopte- 
ryx-, Phigalia-, Biston-, Amphidasis- und Eupithecien-Arten; Gauckler [297]: Stuniopus fuyi, Hyloc. milhauseri, Biston hirtarius).

Werilen die überwinternden Puppen gewisser Arten der Einwirkung ler Kï̈lte nicht ausgesetzt, so können dieselhen bei Zimmertemperatur Jahre lang unentwickelt bleiben (Petersen [j69]: Poecilocampa populi, Eriogaster lanestris).

Ersetzt man die monatelang anhaltenile Winter-Kiälte im Freien durch kurze Frostexposition der Puppen (-130 \& Tage nacheinandler je 6 Stunden), so schliipfen einige Arten bei Zimmertemperatur nach drei Wochen aus (Frings [257]: Dasychira pudibundu).

Bei einigen Arten (Satumia spini) braucht diese kïnstliche Abkïhlung nicht mehr als $6-8^{0}$ während 5 Monate stark sein. Wirl aber die Puppe dieser Art dem Frost von $-13^{\circ}$ ausgesetzt, so finclet bei Zimmertemperatur keine beschleunigte Entwickelung statt (Frings [257]).

Werden frische Puppen (Vanessa levana II. Gener.) während verschiedener Dauer der Temperatur von $2^{\circ}$ ausgesetzt, und dann bei Zimmertemperatur liegen gelassen, so entwickeln sich darauf die Puppen unabhängig von der Zeit, während welcher sie in der Kälte blieben (Ruhmer [727]).

Die spezielle Wirkung ler intermittierenden Temperaturen auf die Entwickelungszeit einzelner Puppenarten ist aus folgender Tabelle ersichtlich, in welcher die Species nach dem Cataloge von Staudinger und Rebel ( $843 a)$ angeführt sind:

\begin{tabular}{|c|c|c|}
\hline Species und Behandlungsweise & $\begin{array}{c}\text { Falter } \\
\text { wieviel Tage } \\
\text { nach der } \\
\text { Exposition }\end{array}$ & Forscher \\
\hline $\begin{array}{l}\text { Papilio podalirius } \\
\text { (Ende Januar): } \\
10 \text { Tage } 37^{\circ} \text {, Temperatur jeden zweiten Tag } \\
\text { für } 3-4 \text { Stunden bis auf } 43,5^{\circ} \text { steigend } \\
\text { und wieder auf } 37^{\circ} \text { fallend . . . . } \\
\text { Papilio machaon } \\
\text { (Ende Januar): } \\
15 \text { Tage } 37^{\circ} \text {, jeden zweiten Tag für } 5-6 \text { Stun- } \\
\text { den auf } 44-45^{\circ} \text { steigend und wieder auf } \\
37^{\circ} \text { sinkend . . . . . . . . . . }\end{array}$ & 7 & Frings (260) \\
\hline
\end{tabular}




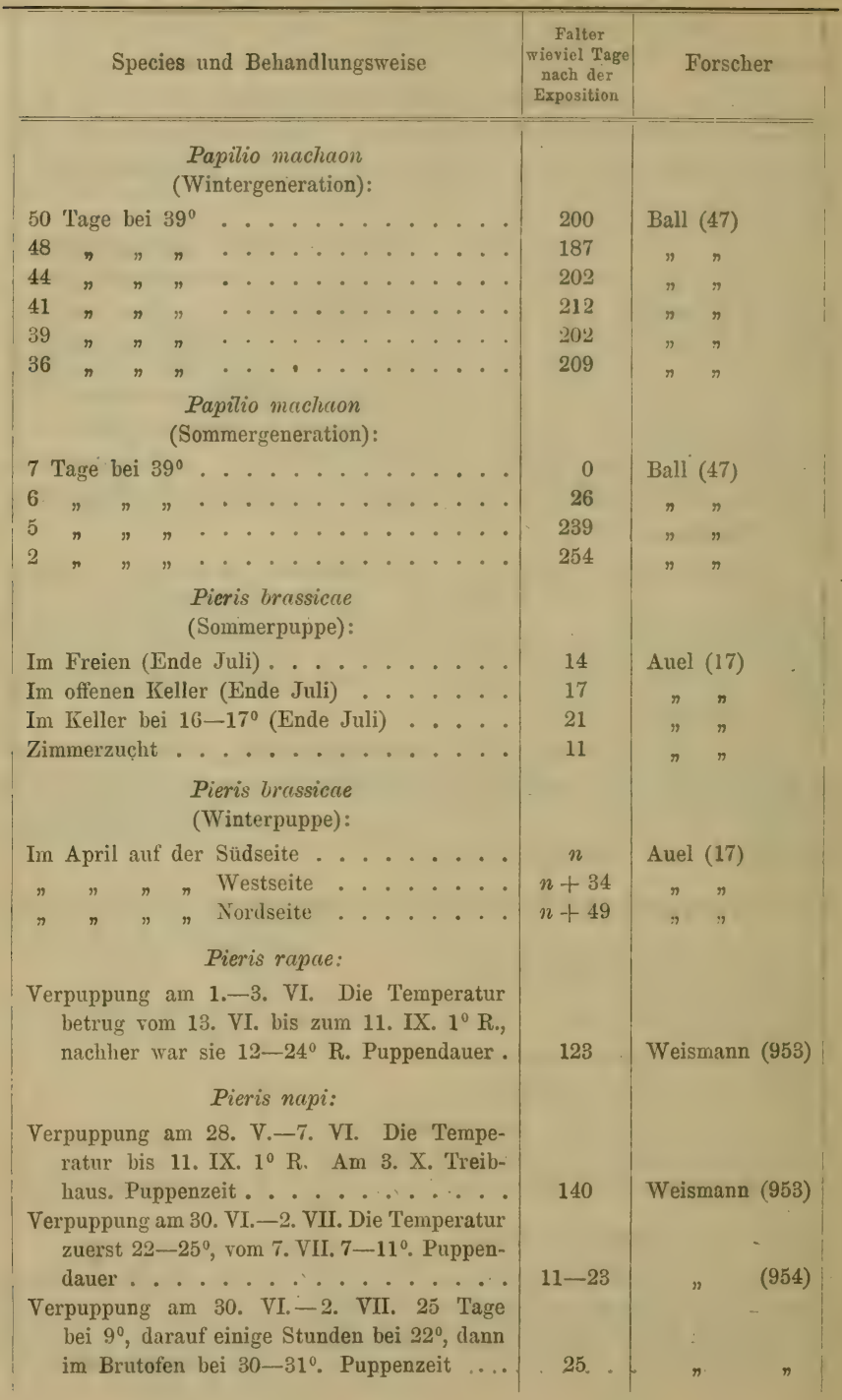




Species und Behandlungsweise

Pieris napi v. bryoniae:

Verpuppung am 16.-25. VU. Im Juli und August bei $20^{\circ}$, dann im kalten Zimmer. Entpuppung 26. IV.-7. VI. Puppenzeit . . Verpuppung am 17. VII. Die Temperatur $26-31,6^{0}$. Puppenzeit . . . . . . . Die übrigen Puppen überwinterten rom 30. VII. ab. Puppenzeit ..........

\section{Gonopteryx rhamni:}

48 Stunden bei $39^{\circ}$, nachher bei $27^{\circ}$. Puppen-

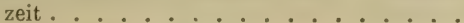

\section{Pyrameis atalanta:}

3 Tage bei $37^{\circ}$, dann bei $24^{\circ}$. Puppenzeit ... 31 Tage bei $5-8^{0}$, dann bei Zimmertemperatur. Puppenzeit ........... . .

42 Tage bei $5-8^{\circ}$, dann bei Zimmertemperatur. Puppenzeit. . . . . . . . . .

48 Tage bei $0^{\circ}$, darauf 10 Tage bei $11^{\circ}$. Puppenzcit . . . . . . . . . .

6 Stunden bei $14^{\circ}$, dann in eine von $14^{\circ}$ auf $0^{0}$ sinkende Temperatur gebracht und hierauf $\operatorname{cin}(n)$ Mal täglich auf $-3^{0}$ abgekühlt. Nach $m=18$ Tagen herausgenommen, 2 Tage bei $14^{\circ}$ und dann bei $22^{\circ}$ gehalten. Puppenzeit ........... . . Dasselbe bei $m=8$. Puppenzeit .....

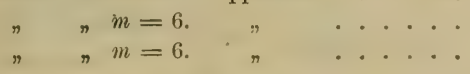

\section{Pyrameis cardui:}

6 Stunden $40^{\circ}, 12$ Stunden $22^{\circ}, 6$ Stunden $40^{\circ}$, dann $22^{\circ}$. Puppenzeit . . . . . . .

60 Stunden $37^{\circ}$, dann $22^{\circ}$. Puppenzeit . . .

23 Tage bei $5-8^{\circ}$, dann bei Zimmertemperatur. Puppenzeit ............

28 Tage bei $5-8^{\circ}$, dann bei Zimmertemperatur. Puppenzeit ........... . .

33 Tage bei $0^{\circ}$, darauf 5 Tage bei $11^{\circ}$. Puppenzeit ..............

Wie seine Versuche mit atalanta, aber: $m=14$. Puppenzeit

\section{Falter \\ wieviel Tage \\ nach der}

Exposition

Forscher

$270-315$

Weismann (954)

7

$255-320$

8-9

Standfuss (839)

$6-7$

Standfuss (837)

39

$54-56$

$70-72$

Standfuss (839)

28

Fischer (231)

24

22

20

10-12

Standfuss (837)

$6-7$

35

38

47 


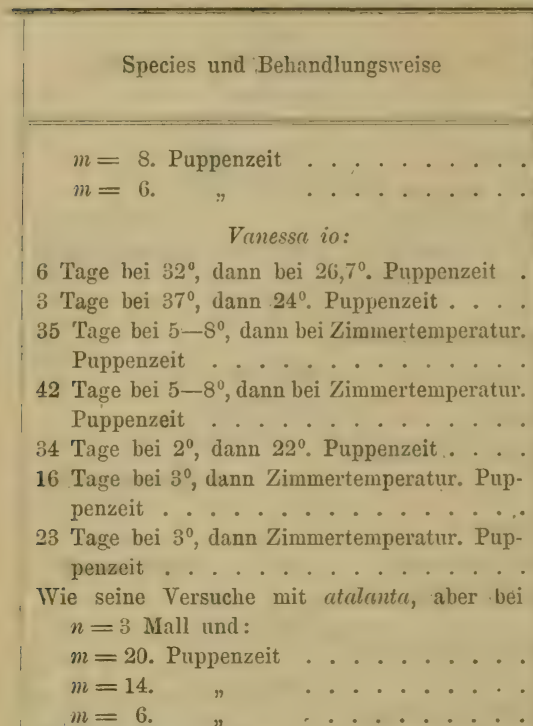

Wie seine zweiten Versuche mit urticae. Puppenzeit ............

\section{Vanessa urticae:}

$2 \frac{1}{2}$ Tage $37^{\circ}$, dann $35^{\circ}$. Puppenzeit .... 32 Tage bei $5-8^{0}$ Tage, dann bei Zimmertemperatur. Puppenzeit . . . . . .

Verpuppung am 3.-5. VI. Vom 15. VI. bei $\diamond^{\circ}$. Puppenzeit $\ldots \ldots \ldots \ldots$...............

Ein Monat bei $2^{0}$, dann bei $22-23^{\circ}$. Puppen-

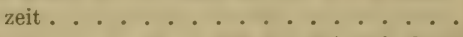

Verpuppung am 3.-5. VII. bei $27-30^{\circ}$, dann $26-29,4^{\circ}$. Puppenzeit . . . . . .

Verpuppung am 19.-21. VII. bei $26-29,4^{\circ}$. Puppenzeit

Dasselbe aber bei $15^{\circ}$. Puppenzeit ....

Bei $13^{0}$; nach 6 Stunden bei $0^{0}$; nach 6 Stunden bei $-3^{0}$, dann ein Mal täglich abgekiültt. Nach $m=18$ Tagen herausgenommen, 1 Tag bei $15^{\circ}$, dann bei $22^{\circ}$. Puppenzeit .

Falter

wieviel Tage

nach der

Exposition

\section{(}

\begin{tabular}{|c|c|}
\hline 24 & Fischer (231) \\
\hline 20 & $n$ \\
\hline 7 & Merrifield (570) \\
\hline $7-8$ & Standfuss (837) \\
\hline $47-49$ & $n$ \\
\hline $56-60$ & \\
\hline $42-72$ & Gauckler (281) \\
\hline $24-28$ & $(275)$ \\
\hline $34--37$ & " \\
\hline $30-33$ & Fischer (231) \\
\hline 26 & $n$ \\
\hline 20 & n \\
\hline $26-28$ & , \\
\hline $5^{1} / 2-6^{1} / 2$ & Standfuss (837) \\
\hline $41-42$ & $"$ \\
\hline 30 & Gauckler (281) \\
\hline 38 & $"$ \\
\hline 5 & Weismann (954) \\
\hline $4^{1 / 2}$ & $n$ \\
\hline 21 & $n$ \\
\hline 27 & Fischer (231) \\
\hline 16 & $n$ \\
\hline 12 & $n$ \\
\hline
\end{tabular}


Falter

Species und Behandlungsweise wieviel 'Tage

nach der

Exposition
Im Laufe einer $1 / 2$ Stunde von $25^{\circ}$ auf $-6^{0}$ abgekühlt. Im Laufe der nächsten 4 Stımden auf $0^{\circ}$, dann für 6 Stunden auf $18^{\circ}$. Am gleichen 'Tage noch einmal und an jedem der folgenden 6 'lage je zweimal vorgenommen. Puppenzeit . . . . .

\section{Vanessa polychloros:}

5 Tage $37^{\circ}$, dann $25^{\circ}$. Puppenzeit ....

14 Tage bei $5-8^{\circ}$, dann bei Zimmertemperatur. Puppenzeit

28 Tage bei $5-8^{0}$, dann bei Zimmertemperatur. Puppenzeit

34 Tage bei $0^{\circ}$, dann 14 Tage bei $11^{\circ}$. Puppenzeit . . . . . . . . . . .

28 Stunden in $39^{\circ}$, dann bei $25^{\circ}$. Puppenzeit . Wie seine Versuche mit urticae, aber: $m=14$ Tage. Puppenzeit .

$m=10$, $m=8$,

\section{n}

Puppen auf einem dem Nordwinde ausgesetzten Fenster. Puppenzeit

\section{Vanessa antiopa:}

2 Tage $37^{\circ}$, dann $24^{\circ}$. Puppenzeit .... 29-34 Tage bei $5-8^{\circ}$, dann bei Zimmertemperatur. Puppenzeit ... . . . . .

39 Tage bei $5-8^{\circ}$, dann bei Zimmertemperatur. Puppenzeit

44 Tage bei $5-8^{0}$, dann bei Zimmertemperatur. Puppenzeit

33 Tage bei $0^{\circ}$, dann 5 Tage bei $11^{\circ}$. Puppenzeit . . . . . . . . . . .

10 Tage bei $0^{\circ}$, dann bei Zimmertemperatur. Puppenzeit

32 Tage bei $2^{\circ}$, dann bei $23^{\circ}$. Puppenzeit .

16 Tage bei $3^{0}$, dann Zimmertemperatur. Puppenzeit ...........................

23 Tage bei $3^{\circ}$, dann Zimmertemperatur. Puppenzeit

Wie seine Versuche mit atalanta, aber:

$m=18$ Tage. Puppenzeit .

$m=14 \quad n$

$m=6 n$
$24-26$

Fischer (231)

$14-17$

Standfuss (837)

$21-21$

$37-40$

52

$10^{1} 2$

26

22

24

$20-35$

12

Standfuss (837)

$41-47$

$53-50$

$59-133$

$53-54$

16

$46-48$

Gauckler (281)

$24-28$

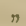

$34-37$

$2 \pi-30$

Fischer (231)

26

$16-19$

Fischer (231)

Slevogt (822)

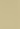

1 
I. Kapitel. Theoretisches über die Entwickclungsgeschwindigkeit.

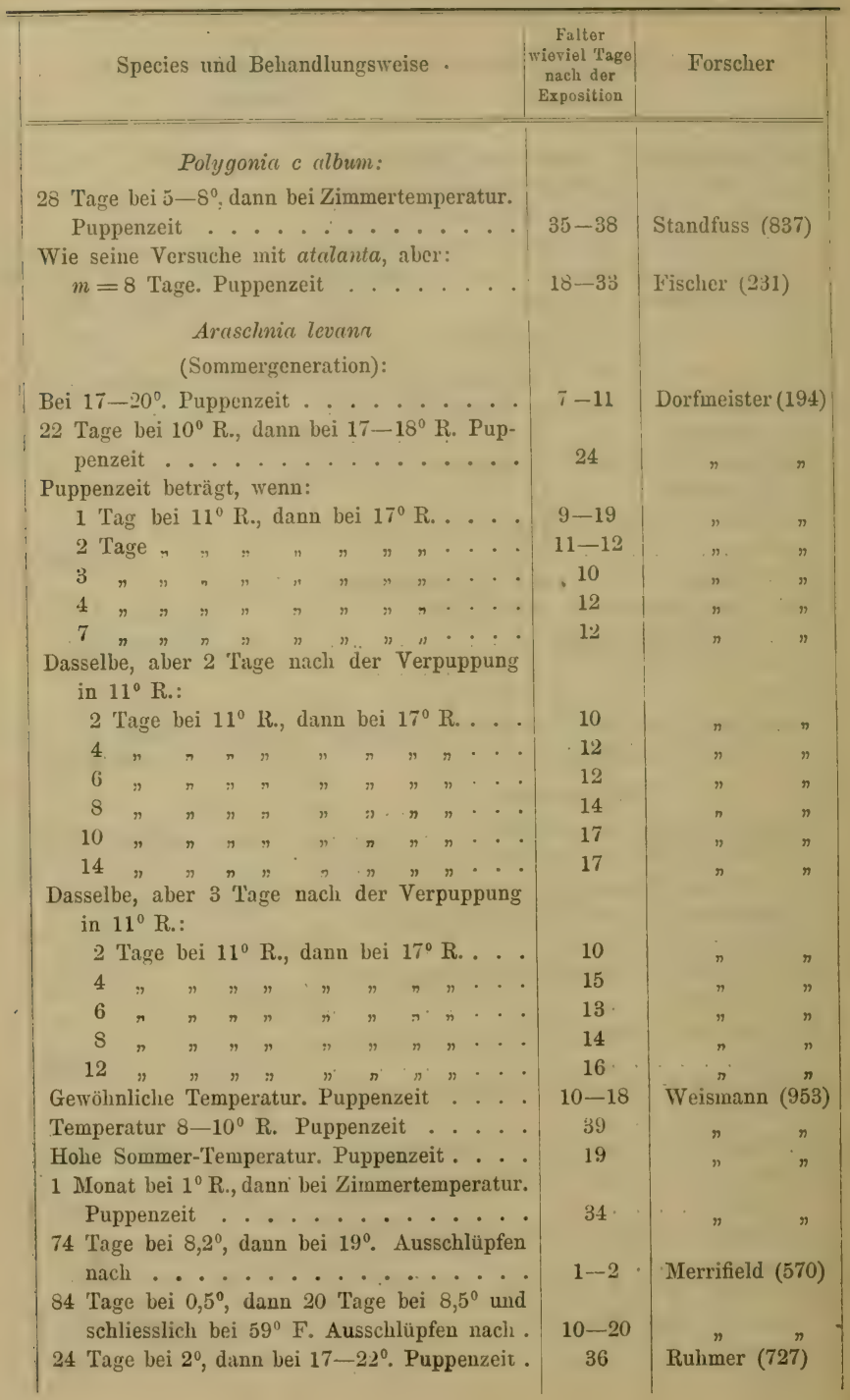




\begin{tabular}{|l|l|}
\hline \hline Species und Behandlungsweise & $\begin{array}{c}\text { Falter } \\
\text { wieviel Tage } \\
\text { nach der } \\
\text { Exposition }\end{array}$
\end{tabular}$\quad$ Forscher

$n$ Tage bei $2^{\circ}$, dann bei $17-22^{\circ}$. Die Puppenzeit betrug:

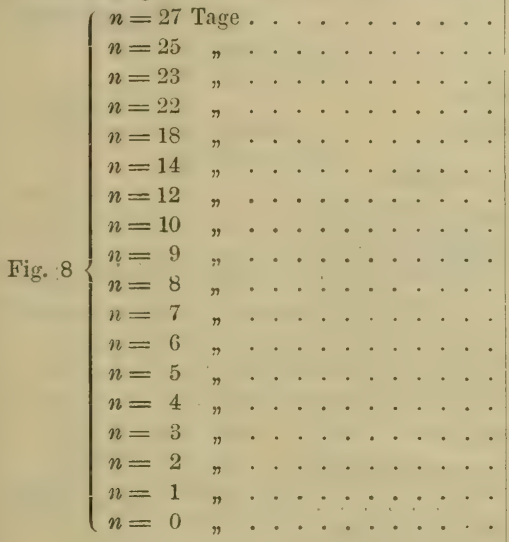

Araschnia levana

(TVintergeneration):

Verpuppung am 26. VIII.-5. IX. Temperatur $12-25^{\circ}$ R. Puppenzeit . . . . . . . .

2 Monate bei $1^{0} \mathrm{R}$., nachher Treibhaus. Puppenzeit

Verpuppung Ende August. Puppon im kalten Zimmer. Vom 1. Marz bis 27. Juni bei $5^{\circ}$, dann bei $22-30^{\circ}$. Puppenzeit . . . . .

Verpuppung um 8. VIII. Die Temperatur 30 bis $32^{\circ}$. Puppenzeit . . . . . . . .

\section{Argynnis aglaja:}

4 Tage $36^{\circ}$, dann $22^{\circ}$. Puppenzeit .... . 28 Tage bei $5-8^{\circ}$, dann bei Zimmertemperatur. Puppenzeit. . . . . . . . . .

42 Tage bei $5-8^{\circ}$, dann bei Zimmertemperatur. Puppenzeit

\section{Chrysophanus phlaeas:}

10 Wochen bei $0^{\circ}$, dann bei $30^{\circ}$. Entpuppung nach
39

$55-37$

$34-35$

33

28

24

22

20

19

18

17

19

14

17

15

13

13

$9-10$

Ruhmer (727)

$$
\begin{array}{ll}
" & " \\
n & " \\
" & " \\
" & " \\
& "
\end{array}
$$

45-55 Weismann (953)

$62--5 T$

\section{0}

$5-6$

Standfituss (837)

40 50 $5-6$ 


Species und Beliandlungsweise $\quad \begin{gathered}\text { Falter } \\ \text { wioviel Tage } \\ \text { nach der } \\ \text { Exposition }\end{gathered} \mid$ Forsclier

10 Wochen bei $4^{0}$, dann bei $13^{\circ}$. Entpuppung nach ................. 34-36

Bei $27-29^{\circ}$. Puppenzeit . . . . . . . 8

Bei $7-10^{\circ}$. Puppenzeit . . . . . . 33-53

\section{Deilephila euphorbiae:}

4 Stunden bei $12^{\circ}$. Ausschlüpfen . . . . . Oktober

Thurau (863)

Leucodonta biculoria ab. unicolora:

Bis zum 4. IV. im Freien. Vom 4.-12. IV. in $17^{\circ}$; vom 12.-15. IV. 72 Stunden in 38 bis $39,5^{\circ}$; dann bis zum Ausschlüpfen in $17^{\circ}$. Am 14. X. 3 Stunden bei $-17^{0}$; am 15. X. 2 Stunden bei $-10^{\circ}$; dann bis zum 3. IV. im Freien. Bis zum Ausschlüpfen in $17^{\circ}$. 22.V.-10.vI

Den ganzen Winter in Freien. Auschlïpfen . . 28.V.-29.VI

\section{Dasychira abietis:}

42 Tage bei $j-8^{0}$, dann bei Zimmertemperatur. Puppenzeit ...................

30 Tage bei $0^{\circ}$, dann 8 Tage bei $11^{\circ}$. Puppenzeit

\section{Dasychira pudibunda :}

8 Tage je 6 Stunden bei $-13^{n}$, dann Zimmertemperatur. Entpuppung nach .....

\section{Lymantria dispar:}

41 Stunden in $37-38^{\circ}$. Ausschlüpfen nach . . $54-57$

Standfuss (837) $45-47$

Federley (219a) 9.V.-26.V. $n$

67 Stunden in $38-39^{\circ}$. Ausschlüpfen nach . . 48 Stunden in $38-39^{\circ}$, dann 24 Stunden in $39-40^{\circ}$. Ausschlüpfen nach . . . . . .

\begin{tabular}{|c|}
$20-28$ \\
$14-18$ \\
$14-18$ \\
$16-19$ \\
\\
$16-17$ \\
$15-16$ \\
$19-20$ \\
alle todt \\
13 \\
$23-29$
\end{tabular}

Frings (257)

Federley $(219 a)$

\section{Dendrotimus pini:}

Beim Tage $25^{\circ}$, Nachts $11^{\circ}$. Puppenzeit . . Beim Tage $30^{\circ}$, Nachts $12,5^{\circ}$. Puppenzeit . . 24 Stunden in $39-40^{\circ}$. Ausschliupfen nach . . 52 Stunden in $39,5-40^{\circ}$ Ausschlüpfen nach 40 Tage in $6^{\circ}$. Ausschlüpfen nach ..... 27 Tage in $0^{\circ}$. Ausschlüpfen nach .... Saturnïa pyri:

Frische Puppen wurden 10 bis 15 mal je 6 bis 10 Stunden bei $-13^{\circ}$ exponiert. Bis 


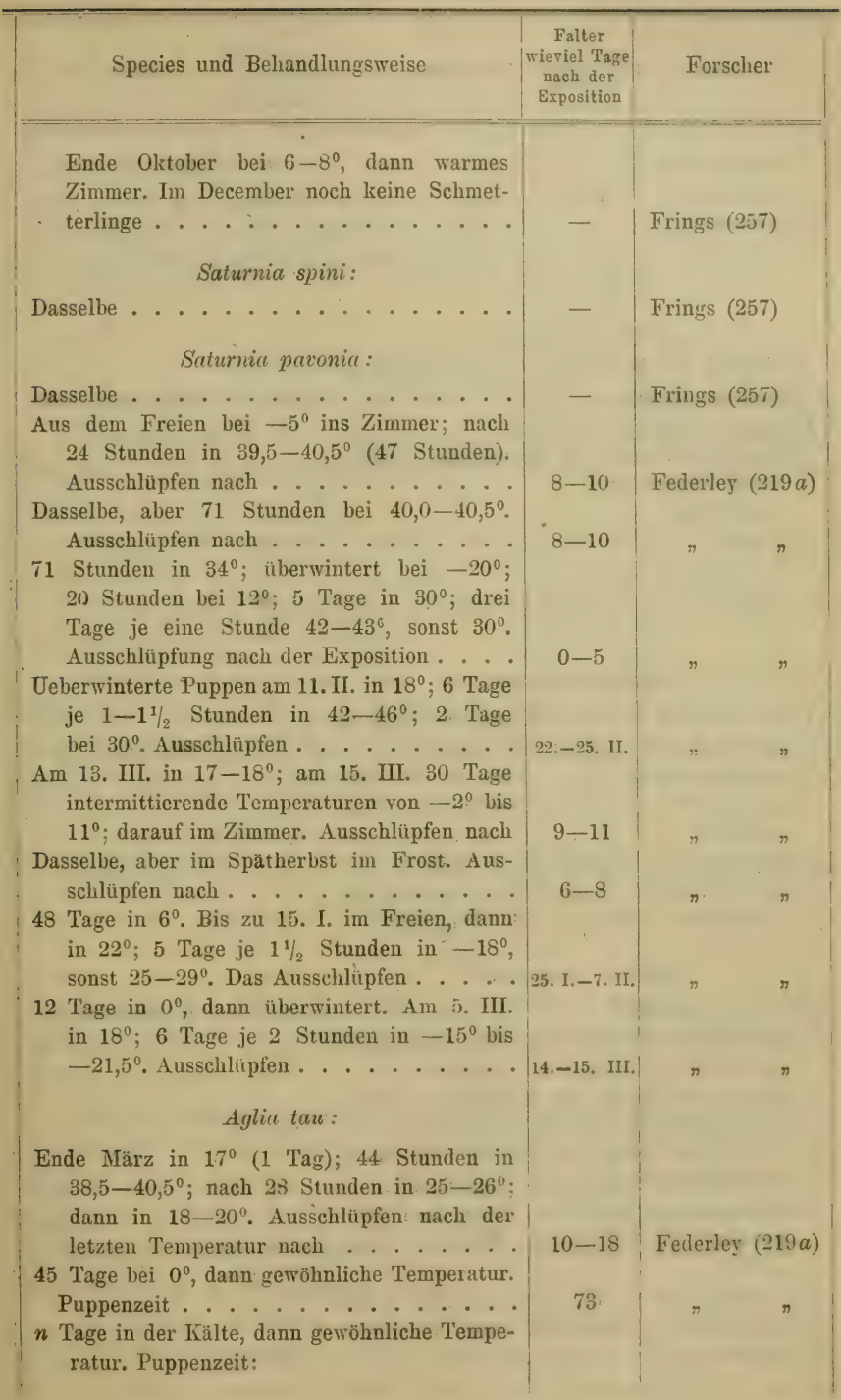




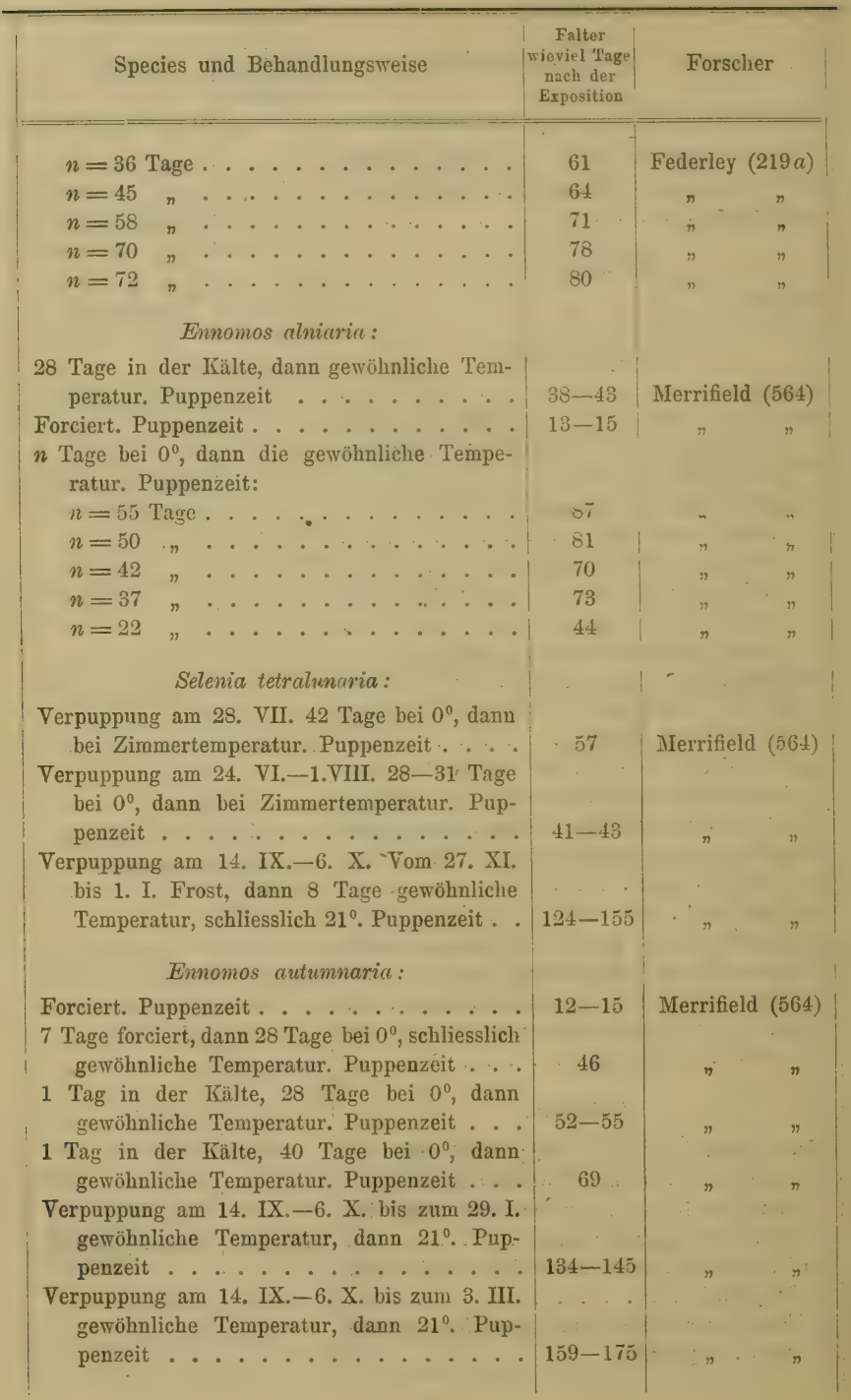




\begin{tabular}{|c|c|c|}
\hline Species und Behandlungsweise & $\begin{array}{c}\text { Falter } \\
\text { wieviel Tage } \\
\text { nach der } \\
\text { Exposition }\end{array}$ & $\because$ Forscher \\
\hline Arctia caja: & & \\
\hline $\begin{array}{l}\text { Bei } 10-19^{\circ} \text { R. Puppenzeit. . . . . } \\
41 \text { Stunden in } 37-38^{\circ} \text {. Ausschlüpfen nach . } \\
34 \text { Tage in } 0^{\circ} \text {. Ausschlüpfen nach der Expo- } \\
\text { sition nach }\end{array}$ & $\begin{array}{l}17-28 \\
17 \\
18-25\end{array}$ & $\begin{array}{l}\text { Gauckler }(284) \\
\text { Federley }(219 a)\end{array}$ \\
\hline
\end{tabular}

\section{d) Imago und alle Stadien.}

Linige Arten bediurfen zu ihrer Begattung eine gewisse Külte: Fonscolombia fraxini suchen das Weibchen bei $-2,5$ bis $-3,7^{0}$ (Reh [681], und Aphis brassicue begatten sich bei $-7^{\circ}$ (Lichtonstein [513]). [730]).

Chrysomela megerlei paren sich bei kühler Witterung (Sajó

Einige Arten legen umso schneller die Eier ab, je höher đie Temperatur ist:

Ameisen-Arbeiterinnen legen im sehr warmen Nest spiitestens innerhalb 14 Tagen Eier ab (Wasmann [944]).

Aphis plantaginis kann während 2 Monaten 10 Generationen ergeben (Bonnet [103]).

\section{Temperatur-Grenzen fïr die Entwickelung und das Tempe- ratur-0ptimum.}

a) Eier.

Die meisten Untersuchumgen in dieser Bezi hung sind mit Eiern von Bombyx mori angestellt worlen, welche zu folgenlen Iiesultaten geführt haben:

Zur normalen Entwickelung der Raupen aus Eiern von Bombyx mori müssen die letzteren der Einwirkung der Kïilte (ron (10 bis $+\$^{0}$ ) während einer von der Vorbehanllumg der Eier ablingigen Zeit ausgesetzt werden, wobei lie sinkende und che daranf steigente Temperatur allmählig eingeleitet wérden muss: sonst schlïpft cin Theil der Eier nicht (Quajat [666]).

Kühlt man die Eier langsam ab, so verlieren sie ihre Lebensfähigkeit nicht eimmal bei $-32^{\circ}$ (Vorson [914]). Beim Lirwirmen über $25-37^{\circ}$ verlieren einige Fier ihre Lehensfähigkeit, welche 
aher hei j60 noch nicht vollstïnlig verschwinlet (Schmujdsinowitsch [762]).

Eier können im Wasser die Temperatur $50^{\circ}$ wenigstens während $1 / 2$ Stunle aushalten, wobei sie sich sofort zu entwickeln beginnen (Bellati und Quajat [63]).

Kühlt man die bis zu einer nohen Temperatur (von 55 bis $65^{\circ}$ ) erwärmten Eier bis zu einer tieferen Temperatur $\left(20^{\circ}\right)$, so erreicht dabei das Ausschliipfen der Raupen bei einer gewissen Temperatur $\left(58,6^{\circ}\right)$ ein Maximum $(100 \%)$. Dabei spielt nicht die (irösse der Differenz zwischen hoher und niedriger Temperatur die Hauptrolle, sondern viel mehr die richtige Wahl der betreffenten Temperatur (Bellati und Quajat [62]).

Bringt man lic Lier aus der Temperatur ron $30^{\circ}, 40^{\circ}, 45^{\circ} \mathrm{in}$ die Temperatur von $0^{\circ}$ unil darauf in die Temperatur von 20$)^{\circ}$, so erhält man (las Maximum $(75-80 \%)$ der ausgeschlïpften Riiupchen bei der Amplitule $40^{\circ}, 0^{\circ}, 20^{\circ}$ (Schmujdsinowitsch [762]).

Werilen die Eier plötzlich in die Temperatur von $32^{\circ}$ gebracht. so trocknen sie alle aus (Verson [914]).

Plotzliche Erwärmung der Eier von $-23^{\circ}$ auf $+20^{\circ}$ scharlet ihnen nicht. Gefülırlich ist es, wenn die Eier, welche schon friiher über $10^{\circ}$ erwärmt wurlen, in die Kälte plötzlich gebracht werlen (Verson [914]).

Werden die Eier in die Luft von $48^{\circ}$ gebracht, so werien sie nach 6-8 Jinuten noch nicht beschïligt: (ler Scharlen tritt erst bei der Dauer von $10^{\circ}$ Minuten ein, bei 15 Minuten trocknen sie alle aus. Im Wasser verlerben die Eier bei dieser Temperatur erst nach 240 Minuten (Bellati und Quajat [63]).

Eier anderer Species ergaben folgende Resultate:

Eier von Heterocter schachtii behalten ihre Lehensfähigkeit im Wasser sogar bei $35-52^{\circ}$ (Hollrung [383a]); in (ler Luft rerderben dieselben bei $35^{\circ}$ (Strubell [848a]).

Eier von Dendrolimus pini verderben bei verschiedenen Temperaturen nach folgender Dauer:

bei $25^{\circ} \mathrm{R}$. verderben sie nach 13 Tagen

(Serebrjanikow [808a]).

$\begin{array}{llllllll} & 30 & n & n & n & n & 9 & n \\ & 35 & n & n & n & n & 5 & n \\ & 38 & n & n & n & n & 2-3 & n \\ & 40 & n & n & n & n & 2 & n\end{array}$


Die optimale Temperatur zum Ausschliipfen iler Larren ron Pachytylus migratorins betrïgt $14^{\circ}$. Bei $9^{\circ}$ gehen slie Embryonen zu Grunde (Rossikow [705a]).

Bleiben die Eier von Selenia illunaria 14 Tage bei 0u, so erleilen sie dadurch keinen Scharlen, verterlen aber, wenn diese Daver 66 Tage beträgt! (Merrifield [564]),

Eier von Ocnerin dispar verlieren ihre Lebensfilhingeit erst bei $56^{\circ}$ (Schemigonow [744]).

Eier von Angerona prunaria ergeben Räupchen noch bei $2^{v}$ (Berger [72]).

b) Raupen.

\section{Einfluss hoher Temperaturen.}

Die Raupen sterben:

\begin{tabular}{|c|c|c|c|}
\hline S p e c i e s & $\begin{array}{c}\text { Bei wie } \\
\text { viel }\end{array}$ & $\begin{array}{l}\text { WVährend } \\
\text { welcher Zeit }\end{array}$ & Forscher \\
\hline Pieris brassicae . . . . & $62-66$ & nach einig. Sekund. & Mokrzecki (586a) \\
\hline Bombyx mori . . . . & 40 & - & Schmuidsinowitsch (756) \\
\hline$" \quad " \quad$ (erkranken) & $32,5-35$ & 一 & Verson u. Quajat (920) \\
\hline Euproctis chrysorrhoea. & 45 & nach einig. Stund. & Grevillius (329) \\
\hline Eurycreon sticticalis . . & 75 & $\eta \quad$ Sekund. & Mokrzecki $(586 \epsilon)$ \\
\hline Cochylis ambiguella. . . & 45 & $\Rightarrow 10-15 \quad "$ & Dewitz (177a) \\
\hline Tortrix pilleriana . . . & $48-50$ & $3-4$ Minut. & Vermorell und \\
\hline . . & 45 & 10 & Gastine (912) \\
\hline Heterodera schachtii.. & 35 & - & Strubell ( $848 a)$ \\
\hline
\end{tabular}

Die Raupen fressen noch:

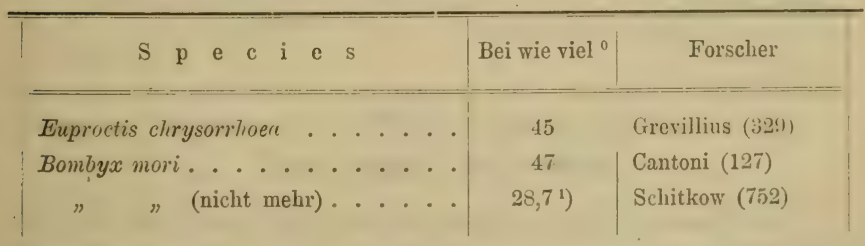

1) Gefüttert mit Blättern der Schwarzwurzel. 


\section{Einfluss tiefer Temperaturen.}

Die Raupen sterben:

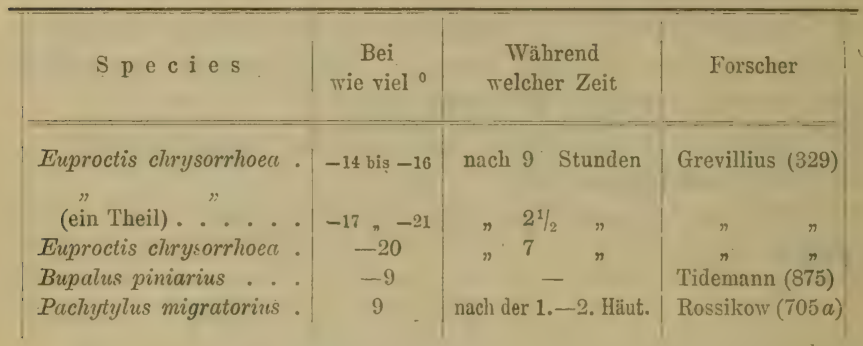

Die Raupen fressen:

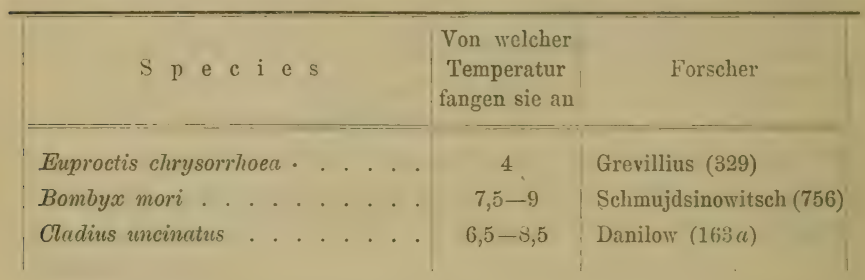

Die Raupen verpuppen sich:

\begin{tabular}{|c|c|c|}
\hline$\therefore$ p e c i e s & $\begin{array}{l}\text { Von welcher } \\
\text { Temperatur } \\
\text { fangen sie an }\end{array}$ & Forscher \\
\hline $\begin{array}{l}\text { Chrysophanus phlaeas. . . } \\
\text { Dendrolimus pini (braucht } 2 \text { Tage bei) } \\
\text { Antheraea pernyi . . . . . . . . . . . . . } \\
\text { Arctia villica . . . . } \\
\text { Fliegen (in Vanessu levana-Puppen). }\end{array}$ & $\begin{array}{c}10 \\
20-24 \\
11 \\
11,2-12,5 \\
0\end{array}$ & $\begin{array}{l}\text { Weismann (954) } \\
\text { Serebrjanikow (808a) } \\
\text { Gauckler (275) } \\
\text { Dorfmeister (195) } \\
\text { Ruhmer (727) }\end{array}$ \\
\hline
\end{tabular}

c) Puppen.

\section{Einfluss hoher Temperaturen.}

Verschierlene Lepillopteren-Arten leilen unter dem Einfluss intermittierender Temperaturen verschieden stark. Folgende Tabelle giebt die Sterblichkeit infolge dieses Einflusses in ${ }^{0}{ }_{0}$ an: 


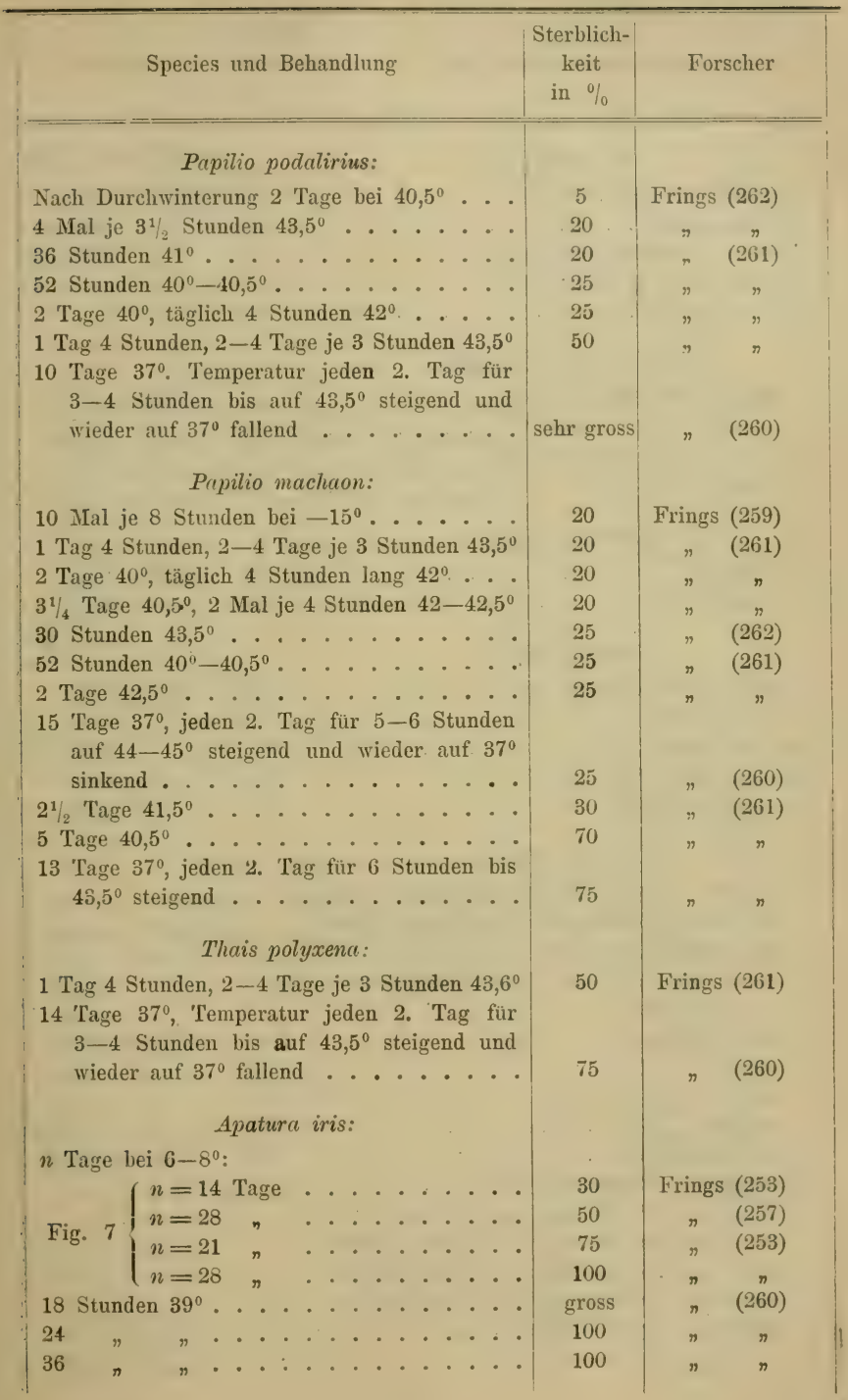




Species und Behandlung $\quad \begin{gathered}\text { Sterblich- } \\ \text { keit } \\ \text { in } \%\end{gathered} \mid$ Forscher

\section{Apatura iliu:}

3 Mal je 4 Stunden $40-41^{\circ} \ldots \ldots$

36 Stunden $39^{\circ} \ldots \ldots . . . . . . . . .40$

4 Mal je 7 Stunden $-10^{\circ} \ldots . . . .50$

$3 \mathrm{Mal}$ je $2-2^{1 / 2}$ Stunden $43^{0} \ldots \ldots$

48 Stunden $39^{\circ} \ldots \ldots . . . . . . .99$

Apatura itic var. clythie:

3 Mal je 4 Stunden $40-4 !^{\prime \prime} \ldots \ldots$

$4 \%, 7,-10^{\prime \prime} \ldots . . . .50$

$3 "$ " $3-2{ }^{1 / 2}$ Stunden $43^{\circ} \ldots . . . .70$

35 Tage $6^{0}$. .

Limenitis populi:

28 Tage $6^{\circ} \ldots . . . . . . .$.

18 Stunden $39^{\circ} \ldots \ldots \ldots$

Frings (261)

Limenitis sibylla:

3 Mal je 4 Stunden $40-41^{0} \ldots$

21 Tage bei $6-8^{\circ} \ldots . . . . . .45$

18-24 Stunden $39^{\circ}$

28 Tage bei $6-8^{0}$

\section{Pyrameis atalanta:}

6 Stunden bei $14^{\circ}$, dann in eine ron $14^{\circ}$ anf $0^{0}$ sinkende Temperatur gebracht und hierauf 1 Mal täglich auf -3 bis $-12^{\circ}$ abgekühlt. Nach $m$ Tagen 2 Tage bei $14^{\circ}$ und dann bei $22^{\circ}$ :

$m=6$ Tage

$m=8$,

$m=6$

$m=18$ auf $0^{\circ}$ und. 6 Stunden bei $18^{\circ}$, am gleichen Tage noch einmal und an jedem der folgenden 6 . Tage je 2 Mal ...... 


\begin{tabular}{l|c}
\hline Species und Behandlung & $\begin{array}{c}\text { Sterblich- } \\
\text { keit } \\
\text { in } \%\end{array} \mid$ Forscher \\
\hline
\end{tabular}

Bei. $6-S^{n} n$ Tage:

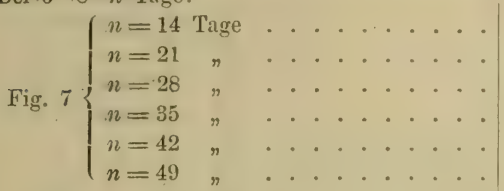

Pyrumeis cardui:

6 Stunden bei $14^{\circ}$, dann in eine von $14^{\circ}$ auf $0^{\circ}$ sinkende Temperatur gebracht und hierauf 1 Mal täglich auf -3 bis $-12^{\circ}$ abgekiilrlt. Nach $m$ Tagen 2 Tage bei $14^{0}$ und dann bei $22^{\circ}$ :

$$
\begin{aligned}
& m=14 \text { Tage } \\
& m=8 \\
& m=6
\end{aligned}
$$

$n$ Tage bei $6-8^{0}$ :

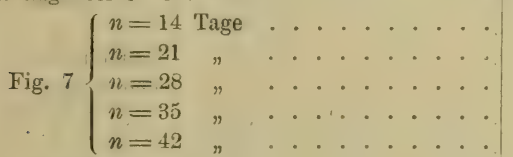

Fischer (231)

30 Stunden $39^{\circ}$

\section{Vanessa io:}

6 Stunden bei $14^{\circ}$, dann in eine ron $14^{\circ}$ auf $0^{\circ}$ sinkende Temperatur gebracht und hierauf 3 Mal täglich auf $-3^{0}$ bis $-12^{\circ}$ abgekühlt. Nach $m$ Tagen 2 Tage bei $14^{\circ}$ und dann bei $22^{\circ}$ :

$$
\begin{aligned}
& m=20 \text { Tage } \\
& m=14 \quad " \\
& m=6 "
\end{aligned}
$$

$$
\text { " } n
$$

Frings (257)

$3 \mathrm{Mal}$ je 4 Stunden $40^{\circ}$..........

Fischer (231) 


\begin{tabular}{|c|c|c|c|c|c|c|}
\hline Species und Behandlur & & & 1 & & $\begin{array}{c}\text { Sterblich- } \\
\text { keit } \\
\text { in } \%\end{array}$ & Forscher \\
\hline 23 Tage $3^{0} \ldots \ldots \ldots$ & & & . . & . . & 5 & Gauckler (281) \\
\hline 3 Mal je 4 Stunden $40^{\circ}$. . . . & . & & . . & . . & 5 & Frings (259) \\
\hline 20 Stunden $40^{\circ}$....... & & & . . & . . & 20 & $" \quad(260)$ \\
\hline 35 Tage bei $5-8^{\circ} \ldots \ldots$ & & & . . & . & 25 & Standfuss (837) \\
\hline $48-54$ Stunden $37^{\circ} \ldots .$. & & & . . & . . & 25 & Frings (262) \\
\hline Frostversuch . . . . . . . . & & & . . & . . & 35 & " \\
\hline $30-36$ Stunden $39^{\circ} . \ldots$ & & & . . & . . & 40 & " \\
\hline $3 \mathrm{Mal}$ je $31_{2}$ Stunden $41^{\circ} \ldots$ & & & . . & . . & 40 & $(260)$ \\
\hline 12 Stunden $41^{\circ} \ldots \ldots$ & . & $\cdot$ & . . & . . & 40 & $"$ \\
\hline $3 \mathrm{Mal}$ je $2^{1} / 2-3$ Stunden $42-43$ & . & . & . & . & 40 & $"$ \\
\hline 3 Wochen bei $0^{\circ}$, darauf $25^{\circ}$. & - & $\dot{0}$ & $\therefore$ & . & 50 & Fischer (228) \\
\hline 3 Mal je 4 Stunden $-12^{\circ}$ und & 4 & $\mathrm{Ma}$ & al je & 2,5 & & \\
\hline Stunden $43,5^{\circ} \ldots \ldots$ & - & - & $\cdot$ & . . & 50 & Frings (259) \\
\hline 44 Stunden $39^{\circ}$. . . . . . & & - & . & . . & 70 & $(262)$ \\
\hline 30 Stunden $39^{\circ} \ldots \ldots$ & . & - & . & . . & 70 & $n$ \\
\hline $36-40$ Stunden $39^{\circ} \ldots . .$. & . & $\cdot$ & . $\cdot$ & . . & 75 & $(259)$ \\
\hline 2 Tage $35,5^{\circ} \ldots \ldots \ldots$ & . & . & . & . . & 75 & $(262)$ \\
\hline 6 Mal je $2^{1} / 2$ Stunden $43,5^{0}$. & & - & . $\cdot$ & . . & 85 & (259) \\
\hline 48 Stunden $39^{\circ} \ldots \ldots$ & & $\cdot$ & . . & . . & 88 & $\eta$ \\
\hline 42 Tage bei $5-8^{0} \ldots . .$. & & & . & . $\cdot$ & 90 & Standfuss (837) \\
\hline $18-24$ Stunden $40,5^{\circ} \ldots \ldots$ & & . & . & . & 90 & Frings (259) \\
\hline 42 Stunden $39^{\circ} \ldots \ldots$ & & - & . & . . & 90 & \\
\hline 48 Stunden $38^{\circ} \ldots . . .$. & & - & $\cdot \cdot$ & . $\cdot$ & 90 & $n$ \\
\hline $2^{1 / 2}$ Tage $35,5^{0} \ldots \ldots$ & . & . & . : . & . . & 90 & $(262)$ \\
\hline $6 \mathrm{Mal}$ je $2 \frac{1}{2}$ Stunden $431_{2}{ }^{0}$.. & & . & . . & . . & 90 & $(259)$ \\
\hline 28 Tage $6^{\circ}$, dann 4 Mal je 4 Stu & in & den & -12 & & 90 & $n$ \\
\hline $4 \mathrm{Mal}$ je 4 Stunden $-12^{\circ}$, dann & & $8 \mathrm{~T}$ & Tage 6 & $6^{0}$. & 90 & $n$ \\
\hline 60 Stunden $37^{\circ}$. . . . . & . & . & . & . & 94 & $(262)$ \\
\hline 4 Mal je 7 Stunden $-10^{\circ}$, dann & 2 & $5 \mathrm{~T}$ & Tage 6 & $6^{0}$. & 95 & $(261)$ \\
\hline 3 Tage $35,5^{0} \ldots \ldots \ldots$ & & . & . . & . & 98 & $(262)$ \\
\hline 2 Mal je 3 Stunden $43^{\circ} \ldots$. & & - & . . & . . & - sehr gross & $n$ \\
\hline 8 Stunden $40^{\circ}$. . . . . . & & . & . . & . & 100 & $(259)$ \\
\hline $3 \mathrm{Mal} 2^{1} / 2$ Stunden $42-43^{\circ}$. . & & $\because$ & . $\cdot$ & . . & 100 & $(260)$ \\
\hline 3 Mal je 4 Stunden $41^{\circ} \ldots$ & & . & . . & . . & 100 & $(259)$ \\
\hline 8 Stunden $42^{\circ} \ldots \ldots .$. & & . & . & . . & 100 & $\pi$ \\
\hline 3 Mal je 4 Stunden $42^{\circ} \ldots$. & & & . & - · & 100 & $\pi$ \\
\hline Vanessa urticae: & & & & & & \\
\hline 10 Tage gewöhnliche Temperatur & & dan & $\mathrm{nn} \cdot 8^{\circ}$ & $\therefore$ & 0 & Gauckler. (281) \\
\hline Ein Monat bei $1,5-2^{\circ}$, dann 22 & & $23^{0}$ & o. & . . & 0 & $n$ \\
\hline 30 Stunden $39^{\circ}$ (II. Generation) . & & . . & $\cdot \cdot$ & . . & 20 & Frings (260) \\
\hline 18 Stunden $40^{\circ} \ldots \ldots \ldots$ & & & $\cdot$ & $\therefore$ & 25 & $n$ \\
\hline
\end{tabular}


Species und Behandlung

Sterblich-

keit

in $\%$

Forscher

36 Stunden $39^{\circ}$ (III. Generation) . . . . . 25

36 Stunden $39^{\circ}$ (I. Generation) . . . . . . 25

3 Mal je $4^{11}{ }_{12}$ Stunden $40^{\circ} \ldots . . . . . .25$

3. Mal je 3 Stunden $42-43^{\circ}$. . . . . . 30

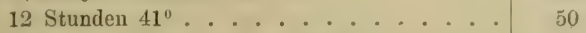

6 Mal je $2 \frac{1}{2}$ Stunden $43-43,5^{0}$. . . . . 50

42 Tage $6^{\prime \prime}, 7$ Tage hellertemperatur (I. Gener.)

$6 \mathrm{Mal} \mathrm{je} 2^{1} / 2$ Stunden $43,5^{0}$, die Z wischenpausen

$6^{0}$. Aus $6^{0}$ sofort in $43,5^{\circ}$ gebracht und

6 Mal je $3-4$ Stunden bei $-12^{\circ}$. . . . . . 18-24 Stunden 40,5" . . . . . . . . . . . 8 Stunden $40^{\circ}$ (II. Generation)........ $n$ Tage bei $6-8^{\circ}$ :

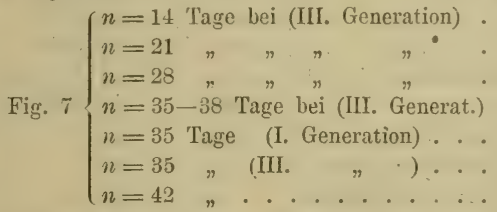

Im Laufe von $1 / 2$ Stunde von $25^{\circ}$ auf $-6^{0}$.

Im Laufe der nächsten 4 Stunden wieder auf $0^{\circ}$ und 6 . Stunden bei $18^{\circ}$, am gleichen Tag noch einmal und an jedem der folgenden 6 Tage je 2 Mal . . . . . . .

Zuerst $13^{\circ}$, nach 6 Stunden bei $0^{\circ}$, nach weiteren 6 Stunden bei $-3^{0}$, täglich $3 \mathrm{Mal}$. Nach $m$ Tagen bei $15^{\circ}$ und dann bei $22^{\circ}$ :

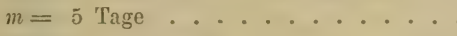
$m=18$,

\section{Vanessa polychloros:}

36 Stunden $37,5-38^{\circ}$. . . . . . .

42 Stunden $38^{\circ} \ldots \ldots . . . .$.

3 Mal je $4-1^{1 / 2}$, Stunden $40-41^{0}$.....

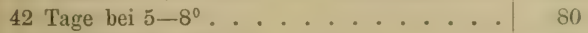

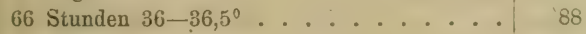

34-48 Stunden $39^{\circ}$. . . . . . . . . . 88

$6 \mathrm{Mal} \mathrm{je} 2^{1} / 2$ Stunden $43,5^{0}$. . . . . . . . . 95

$4-5 \mathrm{Mal}$ je 2 Stunden $43-43,5^{\circ} \ldots . . . .100$

Fischer (231)

\section{(253)}

75

100

20

20

40

60

60

60

80

25

$$
\text { " (262) }
$$$$
n
$$ 


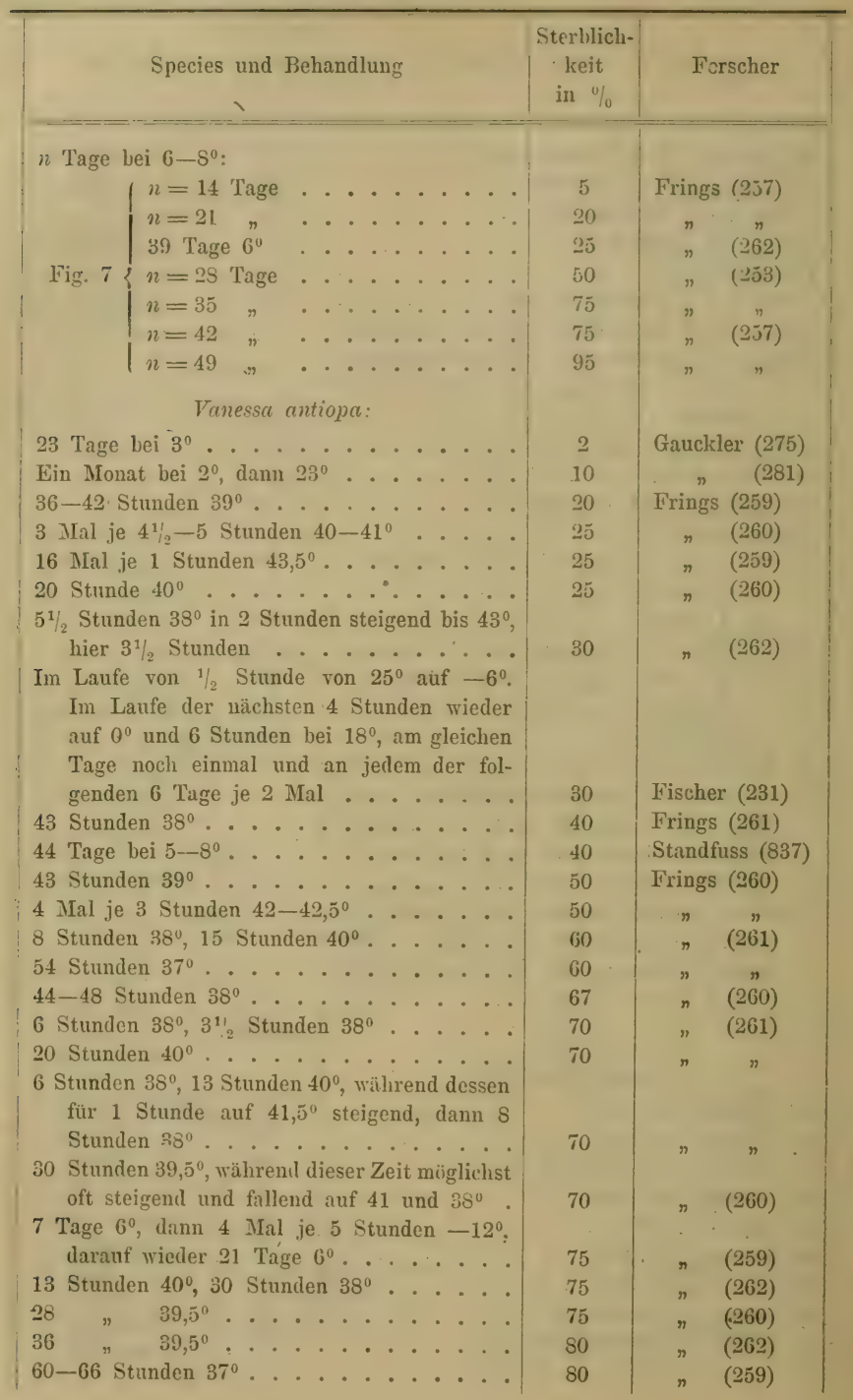




Species und Behandlung $\left|\begin{array}{c}\text { Sterblich- } \\ \text { keit } \\ \text { in } \%\end{array}\right|$ Forscher

2 Mal je 3 Stunden, 1 Mal je 2 Stunden $42,5^{\circ}$ 24 Stunden $38^{\circ}, 12$ Stunden $40^{\circ}$..... 48 r $37,5^{\circ} \ldots \ldots . . . .$.

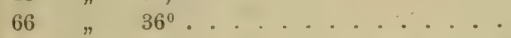
46 . $39^{\circ}$.

$12,6^{0}, 28$ Stunden $38^{\circ}, 12$ Stunden $6^{\circ}$,

14 Stunden $37,5^{\circ} \ldots . . . . . . .990$

4 Mal je 5 Stunden $-12^{\circ}$, dann 28 Tage $6^{0}$. 28 Tage $6^{\circ}$, dann 24 Stunden $39^{\circ} \ldots$... 48 Stunden $39^{\circ}$........... 6 Stunden $40^{\circ}$ in 10 Stunden bis auf $36^{\circ}$ fallend, dann wieder 3 Stunden $40^{\circ}, 4$ Stunden $39^{\circ}$.

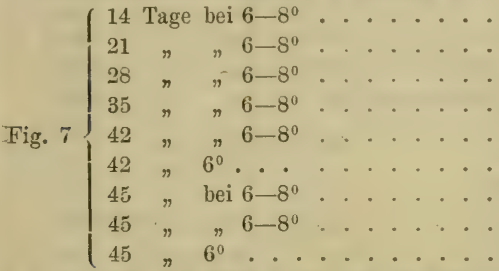

6 Stunden bei $14^{\circ}$, dann in eine von $14^{\circ}$ auf $0^{\circ}$ sinkende Temperatur gebracht und hierauf $3 \mathrm{Mal}$ täglich auf $-3^{0}$ bis $-12^{0}$ abgekühlt. Nach $m$ Tagen 2 Tage bei $14^{\circ}$ und dann bei $22^{\circ}$ :

$m=14$ Tage ...........

$m=6$, . . . . . . . .

$m=18$

\section{Polygonia $c$ album:}

6 Stunden bei $14^{\circ}$, dann in eine von $14^{\circ}$ auf $0^{\circ}$ sinkende Temperatur gebracht und hierauf 3 Mal täglich auf $3^{0}$ bis $-12^{\circ}$ abgekühlt. Nach 8 Tagen 2 Tage bei $14^{\circ}$ und dann bei $22^{0} 0$

43 Stunden $37^{\circ}$ (II. Generation) . . . . .
35 Tage bei $6-8^{\circ}$. . . . 30-36 Stunden $39^{\circ}$ (II. Generation) .... Frostrersuch ............ 6 Mal je $22^{1} / 2$ Stunden $43,5^{0}$....... 20 Stunden $40^{\circ}, 3$ Mal je $2^{1} / 2-3$ Stunden $42-43^{\circ}$
85 85

85

88

88

90

95

96

98

Frings (261)

3

(2)

" $\quad$ (259)

(262)

(260)

15

40

60

75

85

90

90

96

$$
\text { r }
$$

Fischer (23.1)

15

Fischer (231)

20

60

Frings (262)

70

75

90

(259)

$n$ 


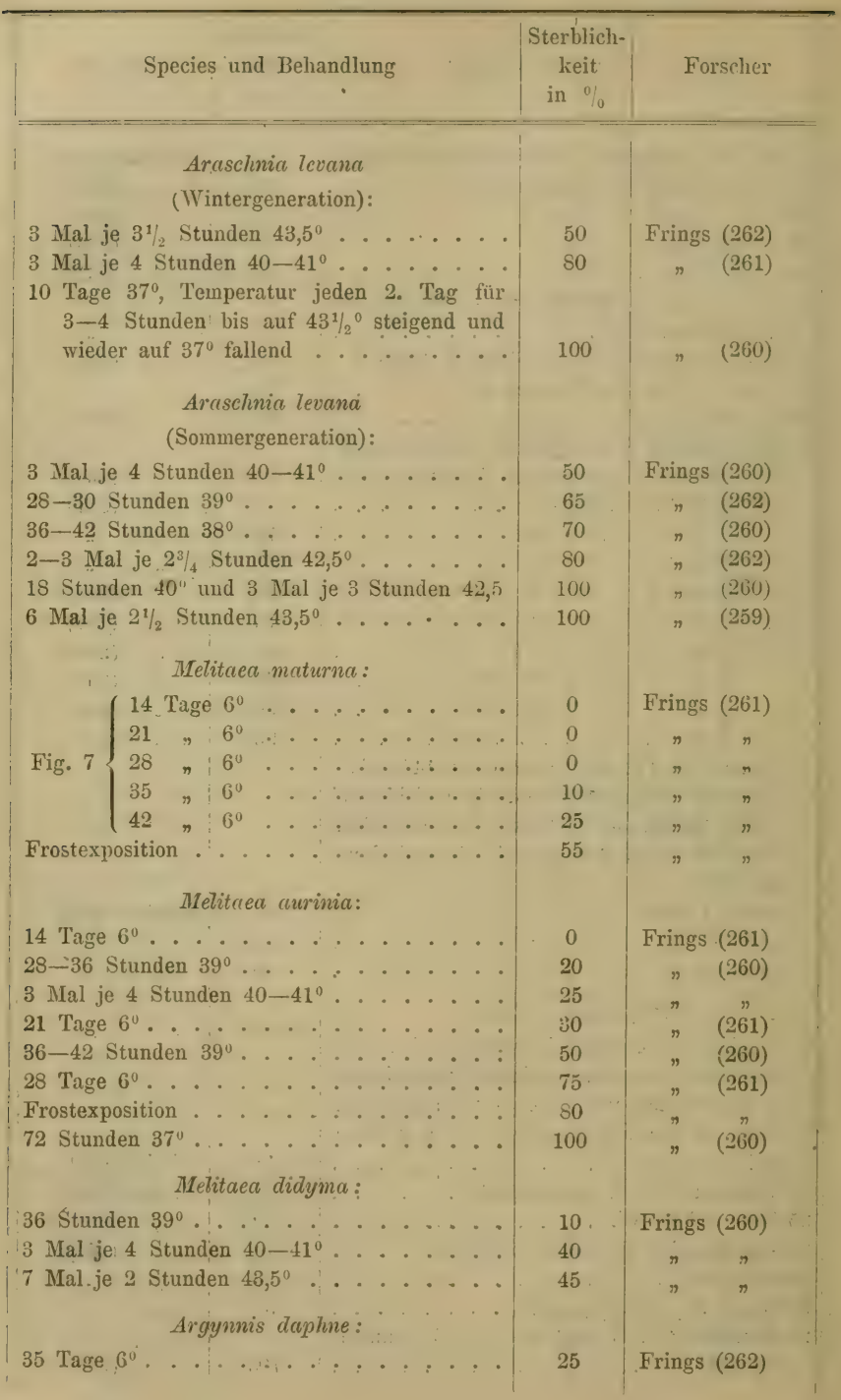




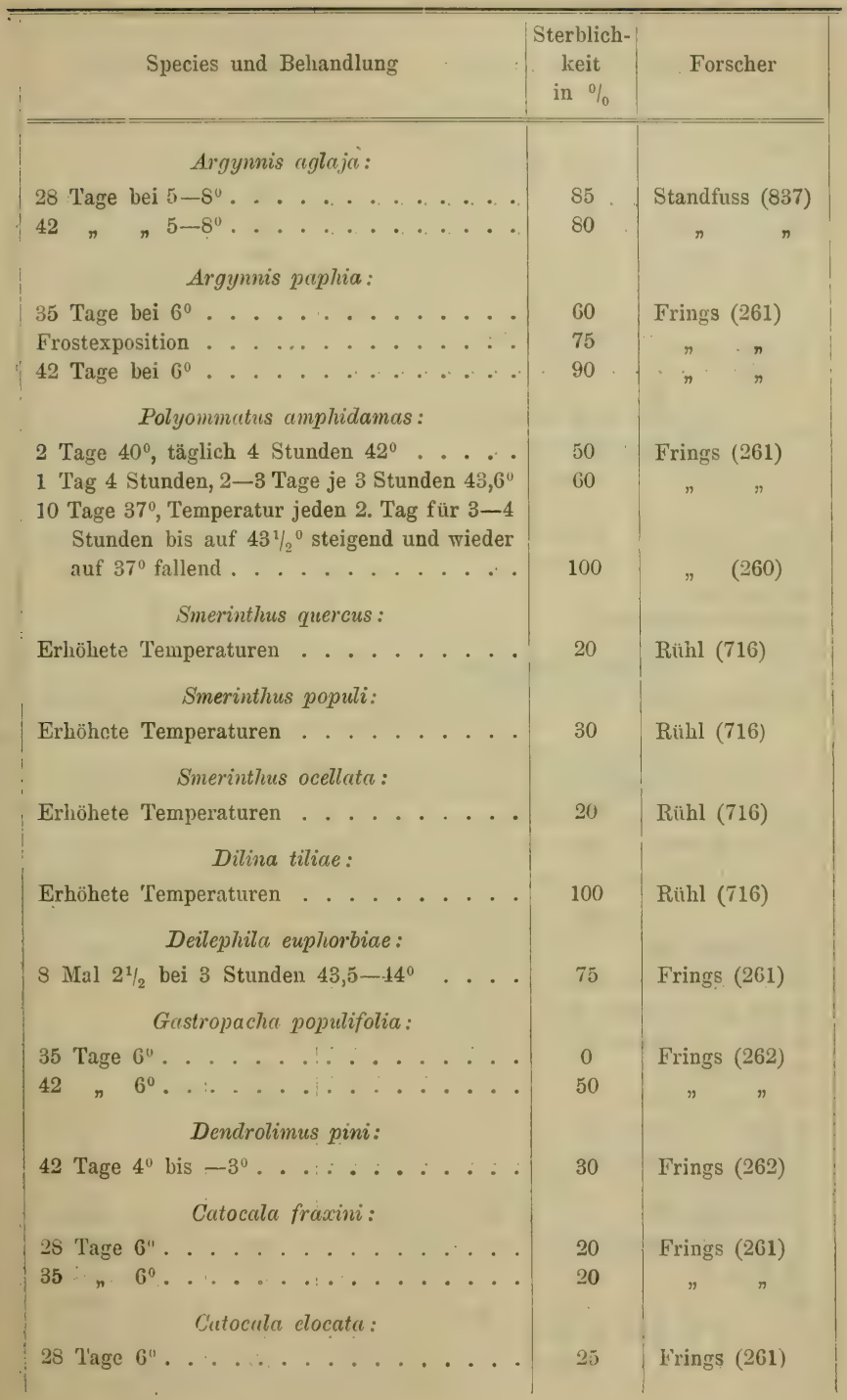


I. Kapitel. Theoretisches über die Entwickelungsgeschwindigkeit.

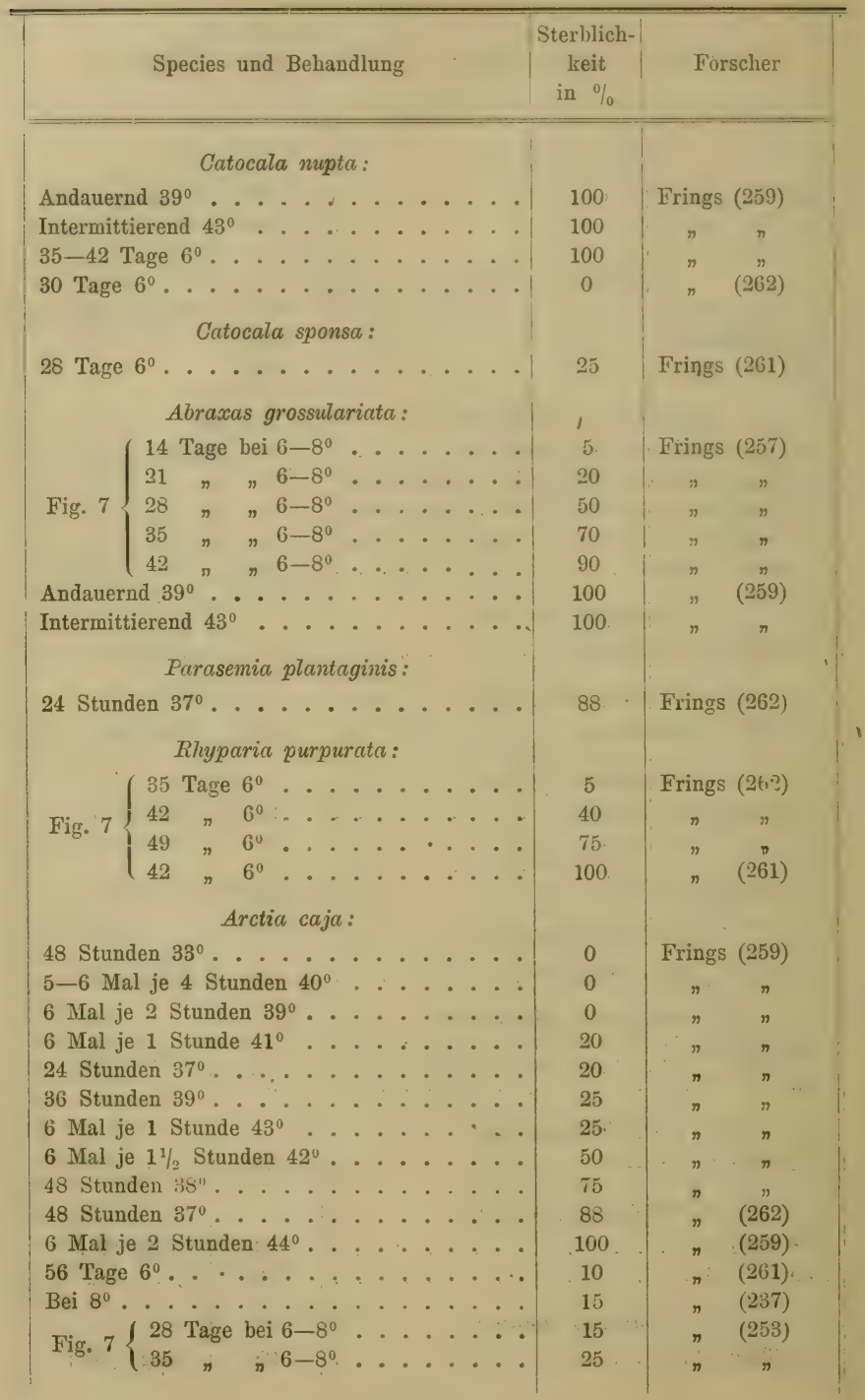




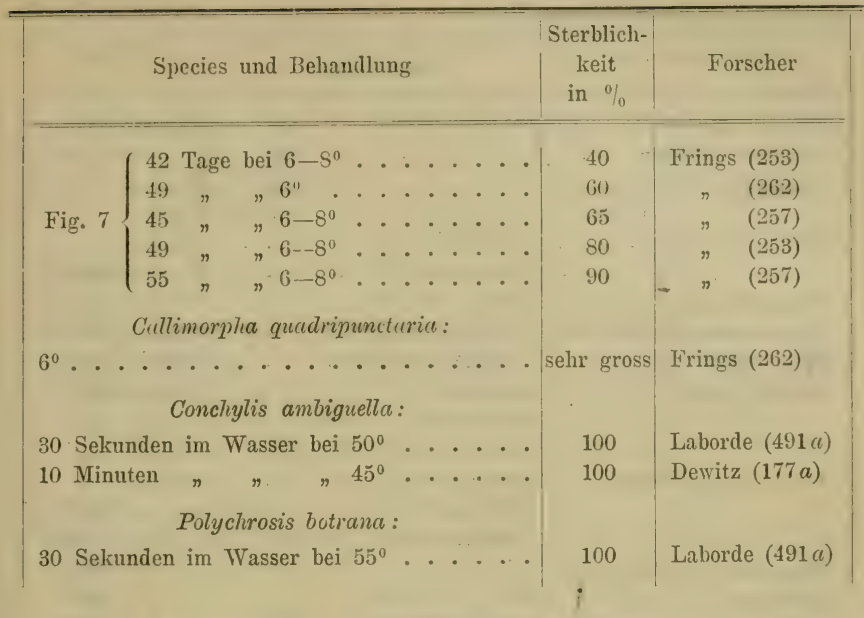

Aus dieser Tabelle und auf Grund der Thatsachen, welche im 3. Abschnitt: "Einfluss der Temperatur" (p. 60-174) angeführt wurden, kann man folgende Resultate ïber die Temperaturgrenzen für die Entwickelung der Puppen ableiten:

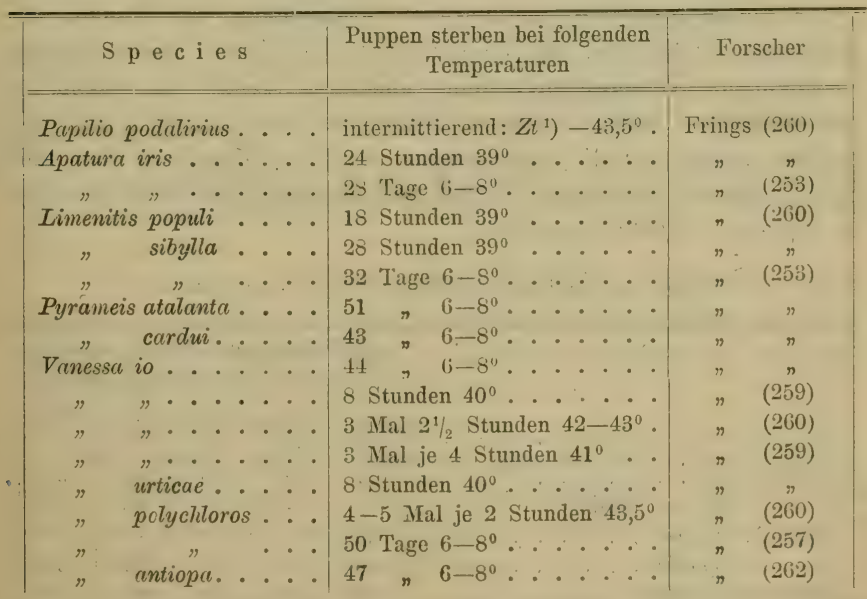

1) Zt bedeutet Zimmertemperatur. 


\begin{tabular}{|c|c|c|c|}
\hline S p e c i e s & & $\begin{array}{c}\text { Puppen sterben bei folgenden } \\
\text { T'emperaturen }\end{array}$ & Forscher \\
\hline Vanessa antiopa & . . & intermittierend: $Z t-40^{\circ}$. . & Frings (260) \\
\hline Folygonia $c$ album . & . . & $, \quad, \quad-43^{\circ}$. & $n \quad n$ \\
\hline Araschnia levana (I) & . & .. - $43,5^{\prime \prime}$. & . \\
\hline$" \quad(\mathrm{II})$ & . . & $"-42,5^{0}$ & \\
\hline Melitaea auriniı . & & 72 Stunden $37^{\circ}$. . . . & \\
\hline . . & & 31 T'age $6-8^{0} . . . .$. & (261) \\
\hline Argynnis paphï . . & . . & $44 \quad n \quad 6-8^{n} \ldots \ldots$. & " \\
\hline Polyommatus ampliidan & mas & intermittierend: $Z t-43,5^{\prime \prime}$. & $(260)$ \\
\hline Dilina tiline . . . . & . . & erhöhte Temperatur . . . . & Rühl (716) \\
\hline Catocala mupta . . & . & andauernd $39^{\circ} \ldots \ldots$ & Frings (259) \\
\hline $\begin{array}{llll}. & . .\end{array}$ & . . & 35 Tage $6^{\prime \prime}$. . . . . & , \\
\hline$n \quad n \quad \cdots$ & . . & intermittierend: $Z t-43^{\circ}$. . & " \\
\hline Abraxas grossulariata & . . & andauernd $39^{\circ} \ldots \ldots$. . . & , \\
\hline .. & . & 42 Tage $6-8 " . . . .$. & (253) \\
\hline , & & intermittierend: $2 t-43^{\circ}$. & $(258)$ \\
\hline Rhyparia purpurata. & . . & 54 Tage $6^{\circ}$. . . . . . & (261) \\
\hline Arctia caja. . . . & $\therefore$ & $58 \quad, \quad 6-8^{\circ} \ldots . .$. & $(257)$ \\
\hline$" \quad, \quad \ldots .$. & . & intermittierend: $Z t-44^{\circ}$. & (259) \\
\hline Conchylis ambiguella & . . & $1 / 2$ Minute im Wasser bei $50^{\circ}$ & Laborde (491a) \\
\hline "l & & 10 Minuten im Wasser bei $45^{\circ}$ & Dewitz $(177 a)$ \\
\hline Polychrosis botrana. & & $1 / 2$ Minute im Wasser bei $55^{0}$ & Laborde $(491 a)$ \\
\hline
\end{tabular}

Zur besseren Vergleichung der Sterblichkeit der Puppen verschierlener Arten unter sich können wir die in dieser Tabelle häufigst vorkommende Temperatur nehmen und zwar $6-8^{0}$; da jedoch die Sterblichkeit $=100 \%$ bei dieser Temperatur nicht immer verzeichnet ist, so stellen wir die vorhandenen Angaben graphisch dar (vide fig 7). Die aus erhaltenen Curven entnommenen Sterblichkeiten sind in fnlgender Tabelle angeführt:

Nach der graphischen Methode (Fig. 7) berechnet.

\begin{tabular}{|c|c|c|c|c|c|c|c|c|c|c|c|c|c|c|}
\hline & \multirow{2}{*}{\multicolumn{4}{|c|}{$S$ p e c i e }} & \multirow{2}{*}{\multicolumn{2}{|c|}{$\mathrm{s}$}} & & & & \multicolumn{5}{|c|}{$\begin{array}{l}\text { Sterblichkeit der Puppen in } \% \\
\text { bei } 6-8^{0} \text { nach wie viel Tagen }\end{array}$} \\
\hline & & & & & & & & & & $20 \%$ & $40 \%$ & $60 \%$ & $80 \%$ & $100 \%$ \\
\hline Apatura & iris . . . & & & & • & & & . & . & 11 & 16 & 20 & 24 & 28 \\
\hline$"$ & ilia var. $c$ & clyt & thie & & . & & . & . & . & - & - & - & 36 & - \\
\hline Limenitis & s populi. & . & . & & . & . & . & . & . & 28. & - & - & - & - \\
\hline " & sybilla. . & . & . & & . & & 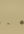 & . & . & - & - & - & 24 & 32 \\
\hline Pyramei & s citalanta & . & . & . & . & 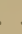 & . . & 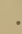 & . & 26 & 34 & 40 & 45 & 51 \\
\hline .. & cardui. . & . & . & . & . & . & . & . & . & 19 & 25 & 31 & 37 & 43 \\
\hline
\end{tabular}




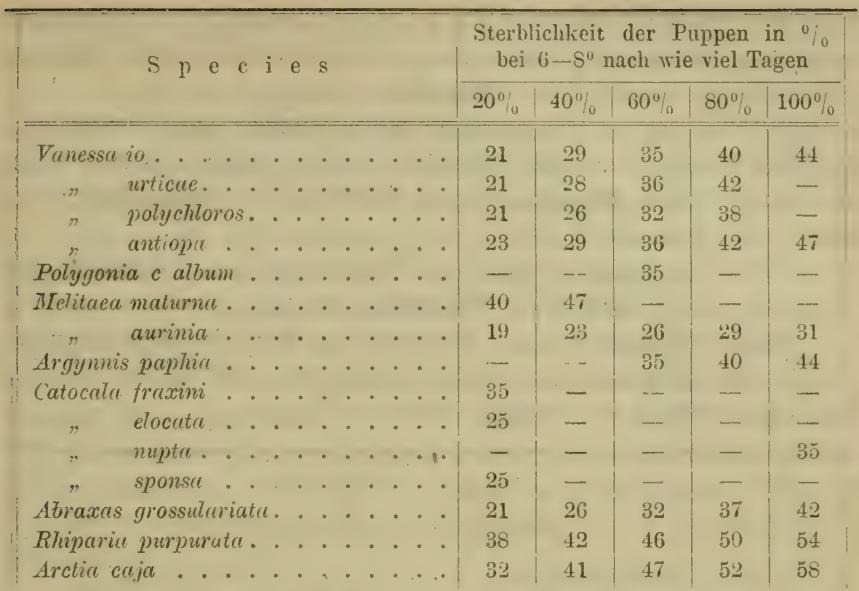

Aus dieser Tabelle ist ersichtlich:

1. Die empfindlichste von allen hier verzeichneten Arten ist Apatura iris, da die Sterblichkeit derselben $=100 \%$ bereits nach 28 Tagen erreicht wird, während am wenigsten empfindlich Arctia coja ist, da ihre Sterblichkeit $=100 \%$ erst nach 58 'Tagen auttritt.

2. Die Sterblichkeit unter sonst gleichen Unstänlen ist lieine konstante Grösse, sondern änuert sich in verschiedenen Jahren fiir gewisse Species (z. B. bel Alraxas grossulariata, Arctiu cuja, Vanessa atalantu $\mathrm{etc}$.).

3. Die Sterblichkeit ist im Allgemeinen keine lineare Funktion der Expositionstage, sonilern dieselbe nimmt zuerst langsam unl :später' rascher zu.

4. Fïr einige Arten (z. B. Mclitaca maturna, Pyrameis utalntu, Melitaea anrinia etc.) ist eine gewisse Expositionslauer (z. B. für Tilyparia purpurata 34 Tage, für Melitatu aurinia 14 Tage etc.) ohne Bedeutung für ihre Sterblichkeit.

Weitere Resultate sind folgende:

Die meisten Arten sterben bei der intermittierenilen Temperatur: Zimmertemperatur, $43^{\circ}$, Zimmertemperatur. Der Tol tritt bei nicht so hohen Temperaturen bei verschielenen Graden ein, je nach der Dauer der Exposition.

Die Temperatur uiber $40^{\circ}$ h e $\mathrm{mm}$ t ile Entwickelung der Puppen .uni theilt ihnen solche Eigenschaften mit, welche nur den Winter- 
puppen eigen sinl (Ball [47]). Die Entwickelung kimn diabei sogar roribergehend unterbrochen sein, wobei die Puppe in einen Zustand (ler Lethargie versetzt vird (Standfuss [8+1]).

Winter-Puppen von gewissen Arten können ohne Scharlen in (lie hohe Temperatur nicht gehracht werlen, bevor dieselhen nicht üherwintert haben (Standfuss [8t)], Merrifield [56:3], Gauckler [297], Rühl [716] Kalender [428]).

Wird die Puppe zu frisch der Einwirkung hoh Temperaturen exponiert, so vertrocknet sie (Standfuss [841]).

Welche Temperatur zur Entwickeluug iler Bienenlarven notlıwenlig ist, ist genau noch nicht entschierlen, wie es die filgenle Zusammenstellung der Angaben zeigt:

\begin{tabular}{|c|c|c|}
\hline B i e nen laren & $\begin{array}{c}\text { Tempera- } \\
\text { tur }\end{array}$ & Forscher \\
\hline 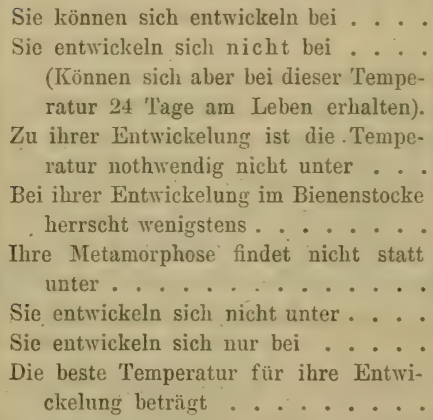 & $\begin{array}{c}25^{\circ} \\
29-30^{\circ} \\
32^{\circ} \\
35^{\circ} \\
34-35^{\circ} \\
35^{\circ}\end{array}$ & $\begin{array}{l}\text { Lulienetzki (538) } \\
\text { Timm (876) } \\
\text { Vogel (926) } \\
\text { Zeselski (966) } \\
\text { Schewclew (747a) } \\
\text { Schmidt u. Kleine (753) }\end{array}$ \\
\hline
\end{tabular}

\section{Einfluss tiefer Temperaturen.}

Viele Puppenarten ertragen den plötzlichen Uebergang aus einer niedrigen in eine lohe Temperatur nicht und sterben in Folge ilessen (Kalender [428], Merrifield [564]).

Einige Puppenarten sterben, wenn sie im Winter im Freien gelassen werden (Acherontic atropos: Linde [513a], SchenklingPrévôt [747]; Deilephila lineata var. livornica: Linde [513a]; Pro. topure convolvuli: Schenkling-Prévôt [747]; Pterugon proserpina: Linde [513a]; Bupulus piniarius: Jacobi [407], Tidemann [875])

Einige Arten sterben, wenn sie einige Tage bui $0^{0}$ gelassen werden (Merrifield $[567,570]$ ), während die anderen ohne Nachtheil 
20 Wochen bei dieser Temperatur aushalten liönnen (Merrifield [563], Berger [72]), obwohl ihre normale Puppenzeit nur einige Tage beträgt.

Die Entwickelung der Lepidopteren-Puppen steht bei $0^{0}$ nicht ganz still, sondern schreitet fort, wenn auch sehr langsam. (Fischer [229]); diese Verlangsamung ist (lesto grösser, je älter die Puppe vor ller Einwirknng lieser Temperatur war (Ruhmer [7.27]).

Die tiefen, intermittierend angewaniten Temperaturen verursachen nicht nur eine Unterbrechung der Entwickelıng wïhrent der Zeitlauer der Frosteinwirkung, sondern zugleich eine sehr erhebliche Verlangsamung unı Hemmung der Entwickelnng ïberhiupt, und zwar über das Mass der Expositionszeit hinaus (Standfuss [841], Fischer [231], Merrifield [563]).

Diese tiefen Temperaturen $\left(-4\right.$ bis $\left.-20^{\circ}\right)$ schwächen in Allgemeinen die entwickelten Falter so stark, lass dieselben selten aus der Puppe ausschliipfen kïnnen (Standfuss [841], Fischer [228], Frings [257]).

$\mathrm{Zu}$ trische Puppen, der Einwirkung niellerer 'Temperaturen ausgesetzt, sterben ab. Es existiert ein bestimmter Härtegrad iler Pupuenschale, vor dessen Erreichen die Puppe in der Kiilte stirbt (Fischer [232]).

\section{d) Imago und alle Stadien.}

Die Temperaturen, welche dem Leben und der Entwickelung der Tagfalter günstig sin 1 oder ihnen zum mindesten nicht schaden, liegen, da schon dis mittleren Erwachungstemperaturen um beinahe $9^{\circ}$ R. differieren, zwischen ziemlich weiten Grenzen.

Die Dauer des Winterschlates, das Terfall: $n$ in denselben und das Erwachen daraus richtet sich:

1. Nach der grösseren orler geringeren Filhigkeit der Falter, tiefere Temperaturen zu ertragen.

2. Nach der geographischen Breite odler Höhe des Ortes, an welchem die Tagfalter gerade vorkommen

Die Dauer des Verfallens der einzelnen Schmetterlinge in den Winterschlaf, sowie das Erwachen aus delinselben an einem bestimmten Orte hängen ab von dem rascheren oder langsameren Steigen und Sinken der Temperatur daselbst.

Die Frass- und Flugtemperaturen liegen bei ihnen, da sie Tagthiere sind, über dem Tagesmittel.

Die Frass- und Flugtemperaturen der Sommer Hormen sind nicht sehr von einander verschieilen, doch sims erstere gewöhnlich 
nie hriw als letatere. Bei den Winterfurmen dagren sind jene bedeutend höher als diese.

Höhere Frass- als Flugtemperaturen haben clann auch die Falter mit nur einer Generation, welche also nur in der Winterform rorkommen. Der Unterschicd zwischen beiden Temperaturen ist aber geringer.

Die Winterform hat gemeiniglich eine liugere, oft rloppelt so lange Lebens!lauer als die Sommerform, ilen Winters hlat alggerechnet.

Dis Auskifechen der haupen aus den Eiern, sowie tler Imagines aus den Puppen kamn um die Hïlite der wewöhnlichen Entwichelungszeit vorzügert o:ler beschleunigt werilen, je nichrlem tiefe oder hohe Temperaturen herrschen.

Der Einfluss der Tageslänge wirl nur in holen viorlen merlikch, von Sülschweden aufwïrts und richtet sich haupsïchlich nach der Temperatur des Erwachens aus dem Winters:hlafe,

Am urössten ist dieser Einfluss bei Faltern, welche bei den nieulrigsten Temperaturen erwachen, unl an geringsten bei solchen, welche die höchste Erwachungstemperatur besitzen.

Bei Faltern mit einer solchen von $4^{0}$ R. können am $70^{\circ} \mathrm{n}$. Br. 40 Tage gïnstiger Zeit gewonnen werden, der Tag zu 13 Stunden Entwickelungszeit genommen.

Kïltere oler wärmere Jalne haben in mittleren Gragenten weniger Einfluss auf das Leben dex Tagfalter als in sehr nördlichen oder siidlichen.

Der Wintersehlaf wirl im hohen Norden nur bei Schmetterlingen mit den tiefsten Erwachungstemperaturen sehr kurz, wenn die Jahre sehr warm sind, in Italien im letzteren Falle fast bei allen Faltern.

Nördlich der Alpen knmmen höchst selten und nur in selır warmen Jahren 3 Generationen vor, meist aber nur eine oder zwei.

In hohen Norlen und auf hohen Bergen reicht die für die Entwickelung der Falter in einem Jahre günstige Zeit zur Ausbildung derselben gewöhnlich nicht hin, weshalb diese Thiere oft zweimal oder dreimal überwintern, bis sie fliegen. Dies hat zur Folge, dass man sie nicht alle Jahre sieht, wenigstens nicht in gleicher Menge.

Lutzteres kann in mittleren Gegenilen gleichfalls zutreffen, rloch fliegen sie hier'minclestens alle Jahre einmal.

Das daraus alızuleitende Gesetz, dass manche Falter nur in gewissen Jahren zahlreich Hiegen oler iiberhaupt sichtbar sincl, wird aber durch einfallenie kältere orler, wärmere Jahre unterbruchen. 
Das Letztere gilt auch für Italien und andere sïdliche Lündler, wenn die in einem Jahre daselbst günstige Entwickelungszeit nicht gerade ein Mehrfaches von der Dauer des Lebens der Schmetterlinge beträgt.

In schr warmen Jahren kann übrigens sogar eine ganze Generation eingeschaltet werden.

Die Anzahl der Generationen ist in sïllichen Lïnlern unter len von uns untersuchten Faltern mindestens 3; die höchste Zahl aber diurfte bei nicht iiberwinternden Faltern an Orten, wo clie Sommerhitze nicht allzu gross ist und die Entwickelung der Tagschmetterlinge verzögert, 5 nicht übersteigen.

Diese von P. Brunbauor (116) abgeleitete Regel dürfen auch für andere Insekten angewendet werlen, wenn gleich das betreffende thatsïchliche Material zur Zeit noch zu gering ist (Jacobson [409], Knoche [457a], Bonnet [103], Mordwilko [59:3, Danilow [163a], Schugurow [783], Kerschbaumer [448a], Mokrzecki [583a], Rengel [686i], Grum-Grschimajlo [332], Cornu [15.t]).

Ausser dem Winterschlaf giebt es für einige Species noch den Sommerschlaf (gewöhnlich bei $26-29^{9}$ ), aus welchem die Inseliten bei Herbstkälte wieder erwachen (Sajó [730]: Entomosceli aclonidis; Mokrzecki [587a]: Zabrus tenebroides, Entomosceli actoniclis, Eurypuster muurus; Kolbe [463]: Phytodecta viminalis; Strubell [848a]: Heterodera schachtii).

Fïr jede Insektenart existiert ein Temperaturmaximum, bei welchem das Insekt stirbt, was ans folgender Tabelle zu eisehen ist:

\begin{tabular}{|c|c|c|c|c|c|}
\hline S pec i e s & & & & $\begin{array}{c}\text { Das lnsekt } \\
\text { stirbt bei folgender } \\
\text { Temperatur } \\
\text { der Umgebung }\end{array}$ & Forscher \\
\hline Saturnia pyri... & . & . & & $46^{\circ}$ (eigene Temper.) & Bachmetjew (29) \\
\hline Ameisen .... & . . & . & & 49 & Field (222) \\
\hline Bienen . . . . . & . . & . & . & 41 & Dönhoff (186) \\
\hline,$\quad . . .$. & . . & . & . & 48. & Schönfeld $(769 a)$ \\
\hline (Arbeiterin). & . . & . & . & $43,7-55$ & Koschewniliow (462 \\
\hline$\Rightarrow$ (Drohne) . . & . . & . & . & $37,5-55$ & $n$ \\
\hline$" \quad$ (ganz junge). & . . & $\bullet$ & & $65-66$ & $"$ \\
\hline Carabus granulatus. & . : & 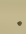 & & 42,5 & $\eta$ \\
\hline Phyllopertha horticole & a. & ${ }^{\circ}$ & . & $42,5-43,7$ & $"$ \\
\hline Gewöhnliche Wespe. & . & & & $46-47,5$ & $n$ \\
\hline Dyticus marginatis . & . & . & & 40 & Gadeau de Ǩerville (269) \\
\hline Podura semilote. & $\therefore$ & . & . & 35 & Nicolet $(611 a)$ \\
\hline
\end{tabular}




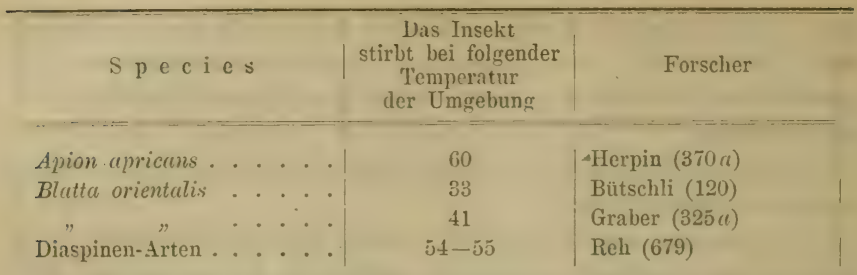

Ein bestimmtes Temperaturminimum. bei welchem die Insekten sterben, existiert nicht (Bachmotjew [29]), wenn einige Fnrscher ein solches auch angeben.

Ein Temperaturoptimum ist nur fiir wenige Species beliannt und ist gen.u auch nicht $\mathrm{zu}$ bestimmen (Ameisen 24-270: Field [222]).

\section{E. Theorie des Rinflusses der Temperatur.}

Die eigene Temperatur eines Insektes im beliebigen Entwickelungsstalium ist, wie ich gezeigt habe (21), lerjenigen des ungebenlen Iediums fist gleich, wenn das Insekt im Ruhezustamle sich befindet, sonst steigt sie bei ler Bewegung oft sehr beträglich lariber. Die vigene Temperatur eines Inselites wird nur dann tiefer als die des ungebenten Mediums beobacht't, wenn das Inselit in liaupen- oiler P'uppenstalium über die gewöhnliche Temperatur hinaus erwärmt wirl, was durch die Verlampfung seiner Säfte zu erklären ist.

Wirl ein Insekt, z. B. ein Schmetterling, über die gewöhnliche Temperatur hinaus erwärmt, so beobachtet man, dass er bis zu ciner gewissen eigenen Temperatur (ron ca. $33^{\circ}$ an) sehr beumruhigt wirl und bald darauf nicht mehr flattern kann. Es tritt bei ihm labei, wie ich gezeigt habe (2S), eine vorübergehende Wärmestarre seiner Flïgelmuskeln ein, da er, darauf in die gewöhnliche Temperatur gebracht, sich wieder erholt. Erreicht aber seine eigene Temperatur ca. $48^{\circ}$, so erholt er sich nicht mehr: seine Flügelmuskeln erlitten die permanente Wärmestarre. Bei ungetühr $50-5: 3^{\circ}$ (je nach der Feuchtigkeit (ler Luft) stirbt der Schmetterling.

Wird der Schmetterling num abgekühlt, so verlangsamen sich seine Bewegungen, welche bei ca. $0^{0}$ eigener Temperatur kaum zu bemerken sinl. Bei weiterer Abliuhlung seines Kö̈rpers bleiluen s ine Säfte noch flussig, bis schliesslich der sogenannte kritische Punkt (21) eintritt. In diesem Moment fangen seine Süfte zu erstarren an, wobei die Temperatur des schmetterlings plützlich bis 
zuin normalen Erstarrungspunkt der Säfte (ca. - $1^{0}$ ) steigt. Vor diesem kritischen Punkt unl nach $-1^{0}$ waren die Inselitensäfte unterkïhlt. Wird der Schmetterling nach dieser Temperatursteigung wieiler abgekühlt, so gefrieren alle seine Säfte bei ca. - 4,50 vollstïnlig $(32 a)$. In die gewönliche Temperatur darauf gebracht, Hiegt der Schmetterling wieder nach dem Auttauen. Erst dam, wemn er nach dem Erstarren aller seiner Säfte bis zu einer gewissen Temperatur, welche noch tiefer liegt (ler todte Punkt), abgeliuhlt wird, kann er nicht mehr aufgelebt werden: es tritt bei ihm dabei die allgemeine permanente Kältestarre ein (gewöhnlich der Tol genannt).

Aehnliche Resultate erhielt für die Einwirkung der Kälte Müller-Turgau $(600 a)$, inclem er ausschliesslich mit Pflanzen resp. deren Früchten experimentiert hat. ${ }^{1}$ )

Um auf die Ursache der Wärme- und Kältestarre näher zu kommen, wollen wir die einschlägigen physiologisehen Untersuchungen von Julius v. Sachs (729) an Pflanzen betrachten.

Dieser Gelehrte veröffentlichte 1863 in der Zeitschrift "Flora“ (Regensburg) eine Abhandlung über die vorübergehenilen Starrezustïnde periodisch beweglicher und reizbarer Pflanzenorgane. Er fand, dass der bewegliche Zustand, d. h. die Fähigkeit auf Reize zu antworten (bei Mimosa) und periodisch die Stellung zu verändern (bei Mimosa und Hedysarum gyrans) in bestimmte, der Spezies eigenthümliche Temprraturgrenzen eingeschlossen ist; überschreitet die Temperatur der umgebenilen Luft diese Grenzen nach unten oder nach oben, so werden die Bewegungsorgane starr, kehrt die Temperatur wieder in jene Grenzen zurück, so kommt auch die Fühigkeit, auf bestimmte Reize zu antworten und sich periodisch zu bewegen, wieder.

Den unbeweglichen Zustand, welcher durch die niedere Temperatur bewirkt wird, nennt er "lie vorübergehende Kältestarre" (wobei keineswegs an Gefrieren oder Erfrieren zu denken ist); (len unbeweglichen Zustand, welcher durch zu hohe Temperatur herbeigeführt wird, nennt er "vorübergehende Wärmestarre" (p. 85).

$\left.{ }^{1}\right)$ Leider waren mir diese Untersuchungen frühex nicht bekannt, weshalh ich dieselben im I. Bande meiner "Studien" (29) nicht angeführt habe. Auch Kodis (1898. 460 a) beobachtete die Unterkühlung der thierischen und pflanzlichen Gewebe (Muskeln bis $\mathrm{zu}-18^{\circ}$, Frösche bis $-10^{\circ}$; andere Werthe werden nicht angefüht). 
Ueber die genaue Bestimmung der Temperaturen, bei welchen Liilte- resp. Wärmestarre auftritt, sagt er: „Da der Starrezustand erst nach längerer Einwirking ler niesleren Luftemperatur eintritt unl umgekehrt aucli eine höhere, günstige Temperatur längere Zeit einwirken muss, um den beweglichen Zustaml herheizuführen, so ist es nicht leicht, über den höchsten Temperaturgraul, welcher die Kültestarre bewirlit, genau in's Reine zu kommen, da man die Temperaturverhältnisse nicht gut nach Willkïr rewuliren kamn" (p. 86). Weiter sagt er: „Fünfzehn Giral (Cels.) kimn also ungefähr als der Wendepunkt betrachtet werden, oberhall, ilessen die Temperatur im Stanle ist, den loeweglichen Zustan'l zu erlialten, wemn sie lange genug danert: unterhalb dieser Grenze dagegren lann jede T'emperatur, wemn sie limreichent lange dauert, den Starrezustand erzeugen " (p. 86).

Über die Wümestarre, die hei verschierlen hohen Temperaturen eintritt, je nachdem dieselben längere oder kürzere Zeit eingewirkt haben, sagt er: "Sümmtliche hier mitgetheilten Versuche führen zu dlem Resultate, dass schon bei $40^{\circ} \mathrm{C}$, wenn liese Temperatur eine Stuncle lang gewirkt hat, cin rasch voriihergeheniler starrezustand erzeugt wird; dass $45^{0}$ C. wïhrent ${ }^{1}$ ' Stunle eineu ähnlirhen Etfekt hervorlringen, lass ferner $49^{\circ}$ bis $50^{\circ} \mathrm{C}$. die vorïbergehente Wärmestarre in sehr kurzer Zeit hervorufen; bei $52^{\circ} \mathrm{C}$. aber tritt wenigstens an den jüngeren Blittern permanente Starre unt nach einigen Tagen der Tod ein. Nach ten vorliegenten Versuchen dlarf man also ammehmen, dass der bewtglich Zustanıl der Mimosa pulica zwischen den Temperaturgrenzén $15^{\circ} \mathrm{C}$. un ca. $40^{\circ} \mathrm{C}$. einges raturen, welche um einige Grade unter 40 liegen, bei längerer. Dauer eine vorïbergehentle Wärmestarre erzeugen können" (p. 90).

Ein Jahr später (1864) veröfẗ̇ntlichte J. v. Sachs [729] eine Abhandlung "Ueber iie olsere Temperaturgrenze ler Vegetation", in welcher das Wesen der oben beschriebenen Erscheinungen, wemn auch nicht vollständig (siehe die Anmerkungen auf p. 132 seines Inches [729]), erklïrt wirl. Er entleckite nämlich vorïbergehenrle Märme- resp. Kältestarre des Protoplasmas und beschreibt sie, wie folgt: „Bei Temperaturen, welche wenig unterhalb der törltendeu (irarle liegen, erleilet las Protoplasma eine merkwiirlige, bisher mulekannte Veränlerung, die ich als „vorïbergehenile Wärmestarre les Protoplasma's" bezeichne. In diesem Falle? mimlich erstart das Protoplasma scheinbar so, ais ob es fïr immer 
getödtet wäre, dabei bleibt zuweilen das Fadennetz in seiner Form erhalten, öfters aber zieht es sich auf eine oder mehrere Klumpen zusammen; in dieser Unbeweglichkeit verbleibt es nun entwerler einige Minuten lang odler dieselbe dauert selbst mehrere Stunden; dann aber beginnen, nach erfolgter Ablïhlung, die erstarrten Fäden wieder zu strömen oder wenn sich dass Protoplasma auf Klumpen zusammengezogen katte, so treten nun nach und nach wieder Fäden hervor, die sich endlich in der früheren Form ausbilden und die Körnchenströmung deutlich zeigen" (p. 128).

Es muss hier noch einmal hervorgehoben werden, dass, "die verübergehende und die bleibende Wärmestarre des Protoplasma's bei Temperaturen auftritt, welche tief unter der Gerinnungswärme des Eiweisses liegen; und umgekehrt zeigen folgende Beobachtungen, dass die Kältestarre auch bei Temperaturen stattfindet, welche lioch über dem Gefrierpunkt des Zellsaftes liegen" (p. 132).

Er fand, dass die Kältestarre des Protoplasma's bei verschiedenen Pflanzen bei $10^{\circ}$ bis $16^{\circ}$ auftritt, je nachdem, wie lange diese Temperatur eingewirkt hatte. Zweige $z$. B. von Solanum lycopersicum waren ïber Nacht im Zimmer bei $17^{\circ} \mathrm{C}$. aufbewahrt worden; in den Haaren war deutliche doch sehr langsame Bewegung des Protoplasma's zu sehen. Ein im Garten neben die Kürbispflanzen gestelltes Thermomter zeigte um $6 \mathrm{Uhr}$ Morgens (17. September) $11^{\circ}$ C., um 8 Uhr $12,5^{\circ}$. In den Haaren junger Fruchtknoten und Blattstiele war die Bewegung erloschen, das Protoplasma besass aber seine typische Anorinung. Die im Freien kältestarr gewordenen Zweige von Solanum lycopersicum wurden in dem Hitzeapparat 20 Minuten lang bei $30-40^{\circ}$ erwärmt: die Haare dieser Pflanze zeigten alsdann deutliche und ziemlich rasche Bewegung des Protoplasma's.

Diese und ähnliche Versuche von J. $\nabla$. Sachs zeigen, dass bei Temperaturen unter $15^{\circ}$ die Kältestarre und über $40^{\circ}$ Wärmestarre des Protoplasma's auftritt. Diese Starre ist nur vor übergehend und hört auf, wenn die betreffende Pflanze wieder erwärmt resp. abgekühlt wird. Sie kann aber permanent werden, wenn beide Temperaturen bedeutend unter $15^{\circ}$ resp. über $40^{\circ}$ fallen resp. steigen, um schliesslich den Tod zu verursachen, welcher nach Sachs (729. p. 136) „ebenso gut durch chemische Veränderung der Molekïle wie durch Verrückung derselben aus ihrer Lage wird eintreten können:" 
Auch folgende seiner Worte sind wichtig: „Die überraschende Aehnlichkeit der durch hohe Temperatur getölteten Zellen dïrfte darauf hinweisen, dass der Vorgang der Töltung in beiden Fällen ein ähnlicher ist und sich auf dasselbe Princip zurückführen lässt" (p. 136).

Man würde vielleicht sagen, dass die hier beschriebenen und von Sachs entcleckten ${ }^{1}$ ) Erscheinungen lieinen Bezug auf Inseliten haben können. Jedoch, wie ich gezeigt habe (24), besitzen sowohl die Pflanzen, wie auch Inseliten eine veränderte Temperatur, welche derjenigen der umgebenden Luft fast gleich kommt (Pflanzen untersuchte ich damals in Form kurzer Stengel).

Ausserdem zeigen die Inseliten- und auch PHanzensäfte Unterkältungserscheinungen und sterben auch bei einer und derselben hohen Temperatur.

Wir wollen deshalb eine Parallele zwischen den von J. Sachs an Pflanzen und von anderen Forschern an Insekten beobachteten Erscheinungen ziehen.

Die Insekten (in unserem spezielien Falle Lepi(lopteren) ergeben analoge aberrative Formen, ob auf Puppen der Frost oder die Hitze einwirkte, wie es verschiedene Forscher nachwiesen. Eine „überraschendle" Aelnnlichkeit der Starre des Protoplasma's, welche durch nieilere oder hohe Temperatur bei Pflanzen verursacht wird, beobachtete auch Sachs.

Die Wärmestarre des Protoplasma's tritt bei Pflanzen über $40^{\circ}$ ein; diese Temperatur kann auch etwas niedriger sein, wenn sie „lange Zeit" andauert. Wie ich zeigte (28), tritt die voribergehende Lähmung gewisser Flügelmnskeln bei Schmetterlingen bei der Temperatur über $35^{\circ}$ und die permanente bei ca. $53^{\circ}$ ein, ohne dass der Falter dabei stirbt. Sachs beobachtéte die permanente Wärmestarre von Mimosa pudica bei $52^{\circ}$ und der Tod erst nach einigen Tagen. Bei mir starb der Falter, welcher die permanente Lähmung seiner Flügel bei ca. $53^{\circ}$ erlitt, auch erst nach 24 Stunden.

Das Gefrieren der Pflanzenzäfte betrachtet Sachs (729. p. 35) als unschädlich. Die Versuche der anderen Forscher mit Insekten ergaben auch dasselbe Resultat, wobei ich zeigte, dass dieses Gefrieren nur dann unschädlich ist, wenn die Temperatur des Insekts nach der Erstarrung seiner Säfte diejenige des „kritischen Punktes“ noch nicht überschritten hat (24).

$\left.{ }^{1}\right)$ Einzelne Thatsachen wurden allerdings noch vor ihm entdeckt und zwar von Nägeli (1860), Max Schulze (1863), Kabsch (1862), P. de Candolle (1806) u. A. 
Interessant ist auch die Erscheinung, dass ein Schmetterling, welcher eine gewisse Zeit in einem kalten Luftbarle zubrachte und vollständig bewegungslos wurde, sich, wie ich fand (24), wieder zu bewegen anfängt, sobald seine eigene Temperatur beim Liegen im Zimmer ca. $14^{\circ}$ beträgt. Sachs beobachtete auch, dass die Kältestarre bei Mimosa pudica bei $16^{0}$ nicht mehr eintritt.

Somit kommen wir zum Schlusse, dass es höchst wahrscheinlich erscheint anzunehmen, dass auch bei Insekten die Wärmeresp. Kältestarre des Protoplasmas in Zellen ihres Körpers stattfindet.

Auf diese Weise wären die „Hemmung" (Fischer), der "lethargische Zustand" (Standfuss) und die "Lähmung" (Bachmetjow) bei Insekten durch die "Starre" (Sachs) des Protoplasmas in Zellen zu erklären.

Um den ganzen Vorgang über den Bewegungszustand des Protoplasmas in einer Zelle klarer vorzustellen, stellen wir die besprochenen Erscheinungen schematisch dar.

In der Fig. 9 bedeuten die Ordinaten die Temperaturgrade und die Abscissen die Zeit, während welcher die Abkühlung resp. Erwärmung stattfindet.

Betrachten wir als Beispiel eine frische Puppe von Vanessa urticue, welche zur Zeit bei Zimmertemperatur (ca. $25^{\circ}$ ) sich befindet. Dabei können wir auf zweierlei Arten verfahren: entweder erwärmen wir die Puppe oder wir kühlen sie $a b$; demgemäss erhalten wir:

1. Die Puppe wird erwärmt. Ihre Lage auf der Curve war im Anfang im Punkte $Z$. Je näher sie sich zum Punkte $W$ schiebt, desto lebhafter ist die Protoplasmabewegung in Zellen, desto stärker. ist der Stoffivechsel und folglich geht auch die Entwickelung schneller vor sich. Nun kommt die Puppe in den Punkt $W$. Das Protoplasma wird beginnen, die Wärmestarre $\mathrm{zu}$ zeigen, ${ }^{1}$ ) welche permanent wird, wenn die Puppe in den Punkt $A$ gelangt. Erwärmt man die Puppe noch weiter, so tritt im Punkte $B$ der Tod ein.

2. Die Puppe wird abgekühlt. Ihre Lage vom Punkte $Z$ nähert sich zum Punkte $K$. Das Protoplasma der Zellen bewegt sich immer langsamer und langsamer; der Stoffwechsel ist geringer und die Entwickelung langsamer. Jetzt kommt die Puppe in den Punkt $K$, und das Protoplasma der Zellen beginnt, die Kältestarre

1) Bevor dieses aber stattfindet, erreicht das Protoplasma ein Maximum der Bewegungsintensität ( 0 ptimum). 
zu erleiden, welche allerdings nur vorübergehend ist. Vom Punkte $N_{1}$ nach unten an werden die Säfte unterkühlt und in Punkte $T_{1}$ (kritischer Punkt) entsteht das erste feste Embryo der Sätte (ein Eiskryställchen); im Punkte $N_{2}$ beginnt die Anzahl solcher Embryonen sich zu vermehren, und das Gefrieren der Säfte schreitet fort. Enıllich gelangt die Puppe in den Punkt $T_{2}$, in welchem alle ihre Säfte erstarren, und verfällt in den anabiotischen Zustand $(29 a, 31 a)$. Im Punkte $T_{3}$ tritt die permanente Kältestarre les Protoplasmas ein und schliesslich findet der Tod statt (totale permanente Kältestarre).

Aus dieser graphischen Darstellung ist ersichtlich, dass die vorübergehende Wärmestarre viel einfacher ist, als die Kültestarre, indem die letztere in ihrem Temperaturgebiet (von $K$ bis $T_{2}$ ) einige komplizierte Erscheinungen enthïlt, und zwar: von $N_{1}$ bis $T_{1}$ werden die Säfte unterkühlt, in $T_{1}$ beginnt das Gefrieren dieser Säfte und von $N_{2}$ bis $T_{2}$ wird die gefrorene Menge der Säfte immer grösser und grösser. Im Zusammenhange mit diesem Unterschied zwischen beiden Arten der Starre steht folgende Schlussfolgerung von E. Fischer (229): „Diese Zustände der Hemmung werden an leichtesten durch Kälte erzeugt" (p. 49), weil, sagen wir, dabei nicht nur die Starre "allein, sondern noch die oben erwähnten Faktoren die Rolle mitspielen, während die Hemmung bei hohen Temperaturen nur durch die Wärmestarre allein hervorgerufen wird.

Es wird hier nicht überflüssig sein zu erwähnen, dass die graphisch dargestellte Kurve (Fig. 9.) den Bewegungszustand des Protoplasmas nur derjenigen Zellen darstellt, welche von den entsprechenden Temperaturen beeinflusst werden, und nicht des ganzen Organismus; denn, wenn die auf (ler Oberfläche des Körpers sich befindenden Zellen beim Abkühlen z. B. die Temperatur $15^{\circ}$ erreichten und somit die Kältestarre zu erfahren begannen, haben die inneren Zellen noch etwas löhere Temperatur und folglich noch keine Starre; erst später verfallen auch sie in diesen Zustand und zwar in diesem Falle nicht durch längere Einwirkung der Temperatur von $15^{\circ}$, sondern durch weitere Erniederung der Temperatur, weil die durch den Stoffwechsel entwickelte Verbreunungswärme (vide das 3. Kapitel des theoretischen Theils, Abschnitt 1) (len Liörper im Inneren von der Annahme der Temperatur von $15^{\circ}$ schïtzt. Somit ist es möglich, dlass, während z. B. die Flügel der Puppe bereits nim Punkte $N_{1}$ " sich befinden, das Innere des Thoraxes noch "in einem Punkte“ bleibt, welcher etwas höher als $K$ liegt: 
Das soeben Gesagte wird durch Versuche von M. Girard (313) bestätigt; er fand, dass bei entwickelten Inseliten mit starker Luftcirkulation eine bedeutende Temperaturdifferenz in Thorax und im Bauch beobachtet wird. Der Thorax stellt eine wirkliche Wärmequelle dar. Bei Erdbienen und Sphingiden erreicht diese Differenz $4-6^{\circ}$ und zuweilen $8-10^{\circ}$; bei Bombyciden erreicht liese Differenz $3-4^{0}$; bei Insekten, welche gar nicht fliegen, wird keine Differenz beobachtet. Bei Larven wird eine grössere Temperaturdifferenz des Körpers in seinem Inneren und auf seiner Oberfläshe beobachtet. Diese Differenz ist zehn Mal grösser als bei entwickelten Insekten. Die Ursache dieser Erscheinung sieht er in der Verdunstung an der Oberfläche der Haut. Dass so grosse Differenzen nur dann beobachtet werden, wenn die umgebende Luft keine niedere Temperatur beträgt und folglich ein starker Stoffwechsel noch stattfinden kann, ist aus Untersuchungen desselben Forschers ersichtlich, welcher sagt, dass im Winter die nackten, starr gewordenen Raupen und Puppen entweder die Temperatur der umgebenden Luft haben oder eine etwas höhere.

Aus allem bis jetzt Gesagten geht somit hervor, dass der Finfluss der Temperatur auf die Entwickelungsgeschwindigkeit der Insekten darin besteht, dass durch die Temperaturänderung auch die Aenderung des Bewegungszustandes des Protoplasmas bedingt wird, d. h. die Beschleunigung resp. Verzögerung dieser Bewegung und ihr temporärer resp. permanenter Stillstand (Wärme- resp. Kältestarre). Als direkte Folge dieser Aenderung ist die Aenderung des Stoffwechsels zu betrachten (vide das 3. Kapitel des theoretischen Theils, 'Abschnitt 1).

Wir wollen einige Punkte resp. Rayone auf der Curve für den Bewegungszustand des Protoplasmas (Fig. 9) etwas näher betrachten.

\section{0 p timum.}

Der Begriff und die Bedeutung des Optimums hat zum ersten Mal J. v. Sachs (729) für die Pflanzen formuliert. Nach ihm „überall, wo sich physiologische Wirkungen durch eine zur Abscissenaxe zurückkehrendle Kurve darstellen lassen, bedeutet das Optimum denjenigen Punkt der Abscisse, an welchem die maximale (die höchste) Ordinate steht" (p. 82). Später entwickelte L. Errera (214b) dieses Gesetz weiter, und es lautet jetzt, dass zur günstigen Entwickelung eines gegebenen Organismus eine gewisse Quantität oder Intensität 
eines aiisserlichen Agens nothwendig ist. Ich habe dieses Gesetz bei Anorganismen geprift und fand es auch dort bestätigt (38a).

Wenn wir vom Temperatur-Optimum bei Insekten sprechen wollen, so müssen wir zunächst die graphische Darstellung der physiologischen Wirkung der Temperatur auf ihren Organismus und deren Funktionen betrachten.

Nehmen wir z. B. die Flïgellänge beim männlichen Schmetterling irgend einer Art. Ist $t$ die Temperatur und $l$ die Flügellänge, so ist $l_{M}$ die Flügellänge beim Temperaturoptimum $t_{n}$. In diesem Falle zeigt die Curve (schematisch dargestellt auf Fig. 10) bei der optimalen Temperatur ein Maximum $M$.

Nun kann die Curve bei der optimalen Temperatur auch ein Minimum ( $m$ ) zeigen (Fig. 11). Als Beispiel kann die Puppendauer ( $n$ ) dienen; d. h. dass bei einer gewissen günstigen Temperatur $\left(t_{0}\right)$ die Puppendauer $\left(n_{m}\right)$ ein Minimum erreicht.

Somit werden die Eigenschaften resp. Funktionen des Insektenorganismus bei dem Temperaturoptimum entweder durch ein Maximum oder Minimum ausgedrüickt.

Auf unserer Curve (Fig. 9) befindet sich der Optimum-Rayon zwischen den Punkten $W$ und $K$, d. h. zwischen ca. $15^{\circ}$ und ca. $38^{\circ}$. Diese Temperaturen sind natïrlich die mittleren und variiren von Species zu Species, hauptsächlich aber sind sie verschieden für verschiedene Entwickelungsstadien, da dabei die Lufttemperatur sich sehr stark von der eigenen Temperatur des Insektes unterscheiden kann. Die eigene Temperatur z. B. einer Raupe wird sich bei höheren Temperaturen unbedingt bedeutender von der Luftemperatur unterscheiden als diejenige eines Schmetterlings, und zwar infolge der starken Verdampfung der Raupensäfte.

Die Temperaturen in Punkten $W=38^{\circ}$ und $K=15^{\circ}$ bedeuten, wie es aus der Curve ersichtlich ist, dass von diesen Temperaturen hinauf resp. hinunter vorïbergehende Wärme- resp. Kältestarre stattfindet. Wäre die optimale Temperatur das mittlere von oben angeführten Grenzen, dann würde das Optimum bei $(38+15): 2=26,5^{\circ}$ liegen, resp. bei $Z$. Die Versuche verschiedener Forscher bestätigen dies in der. That.

Grevillius (329) beobachtete, dass Raupen von Euproctis chrysorrhoea bei $4^{\circ} \mathrm{zu}$ fressen anfangen und bei $45^{\circ}$ aufhören. Das arithmetische Mittel beträgt somit $(45+4): 2=24,5^{\circ}$. Schmujdsinowitsch (756) fand, dass Seidenraupen bei $0^{\circ}$ in den Zustand des lethargischen Schlafes verfallen; folglich bei $1^{0}$ konnten sie noch 
fressen. Cantoni (127) fütterte diese Raupen bei $47^{\circ}$. Das Mittel davon ist $(47+1): 2=24^{\circ}$.

Ausserdem sind Angaben vorhanden, welche direkt zeigen, dass der Punkt $Z=26^{\circ}$ wirklich dem Optimum entspricht, und zwar:

Field (222) fand für Ameisen, dass ihre optimale Temperatur bei $24-270$ liegt. Die Raupenzeit von Bombyx mori beträgt:

bei normaler Temperatur 50 Tage (Carret, 133)

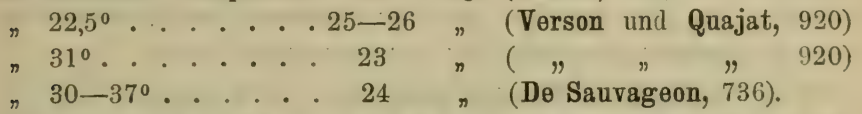

Hier liegt das Minimum der Raupenzeit zwischen $22,5^{\circ}$ und $31^{\circ}$, also die optimale Temperatur liegt tiefer als bei $31^{\circ}$.

Es scheint aus diesen Angaben hervozugehen, dass die optimale Temperatur sowohl für die Bewegung des Protoplasmas wie auch für die vitalen Funktionen der Insekten bei ca. $26^{\circ}$ liegt.

Wir wollen jetzt versuchen, die Curvenform für vitale Funktionen der Insekten $\mathrm{zu}$ bestimmen.

1. Die Untersuchungen von Tichomirow (869) an Raupen von Bombyx mori ergaben, dass die Anzahl ihrer Herzcontractionen von der Temperatur, in welcher sie sich befinden, ablängt. Fig. 6 veranschaulicht diese Abhängigkeit.

Aus dieser Figure ist ersichtlich, dass die Anzahl der Herzcontractionen für die Temperaturen, welche Tichomirow bei seinen Versuchen angewendet hat, direkt proportional diesen Temperaturen ist.

Nun hat Schmujdsinowitsch (756) festgestellt, dass bei diesen Raupen der Stuffwechsel bei $7,5-8,7^{0}$ ror sich zu gehen beginnt. Wir können somit annehmen, dass die Curve von Tichomirow ihren Anfang bei ca. $8^{0}$ nimmt, was aber schon eine, wenn auch unbedeutende Krümmung in der Curve verursacht.

Ueber den weiteren Verlauf dieser Curve (nach oben) kann man sagen, nbwohl keine Angaben vorliegen, dass sie nicht so schnell steigen wird, und wird bei einer gewissen Temperatur ein Mlaximun zeigen, um nachher zur Temperaturaxe sich zu nähern.

2. Regener (677b) bestimmte die Futtermenge für Raupen von Dendrolimus pini bei verschiedenen Temperaturen und fand die Abhängigkeit, welche auf Fig. 5 graphisch dargestellt ist. Da die Curve wahrscheinlich in Folge anderer Nebenfaktoren gewisse geringe Unregelmässigkeiten zeigt, ist noch eine theoretische Curve gezogen. 
664 I. Kapitel. Theoretisches über die Entwtckelungsgeschwindigkeit.

Diese Curve zeigt keine Proportionalität, sondern sie steigt etwas rascher mit der Temperaturzunahme, und hat ihren Anfang bei ca: $0^{0}$.

Ueber den weiteren Verlauf dieser Curve (nach oben) kann man mit grosser Wahrscheinlichkeit dasselbe behaupten, was für die Curve Fig. 6 gesagt worden ist, besonders wenn man die Beobachtungen von Schitkow (752) in Betracht zieht, welcher sagt, dass die Raupen von Bombyx mori (mit der Schwarzwurzel gefüttert) bei $23^{\circ} \mathrm{R}$. entweler gar nicht oder nur sehr träge fressen.

3. Verschiedene Forscher bestimmten lie Puppenzeit von $V a$ nessa urticae bei verschiedenen konstanten Temperaturen. Ihre Resultate sind auf Fig. 12 graphisch dargestellt. Diese Curve ist gestützt auf die mittleren Werthe gezogen. Sie zeigt ein Minimum bei $28^{\circ}$, und ihr Verlauf iiber $30^{\circ}$ ist noch unbekannt.

4. A. Weismann (954) bestimmte die Puppenzeit von Pararge egeria bei drei verschiedenen Temperaturen, welche uns, wenn auch annähernd, eine Curve zu konstruiren erlauben, welche auf Fig. 12 dargestellt ist.

Es sind eigentlich drei Curven: zwei sind construirt, gestützt auf lie maximalen resp. minimalen Grössen für die Zeit, und die dritte stellt die mittleren Werthe dar.

Die I. Curve muss entschierlen ein Minimum zeigen, da bei $18^{\circ}$ die Zeit 13 Tage und bei $26^{\circ}$ schon 16 Tage beträgt. Was nun die Curve II und III anbetrifft, so ist ihr Minimum analog der I. Curve gezeichnet. Dabei muss bemerkt werden, dass die Curve für Vanessa urticae-Puppen (Fig. 12) nach der Temperatur $28^{\circ}$ unmöglich so langsam aufsteigen kann, wie sie vor $28^{\circ}$ abgestiegen ist, da vom Minimum (bei $28^{\circ}$ ) bis zum notierten Anfang der Curve (bei $6^{\circ}$ ) auf der Abscissen-Axe $28-6=22^{\circ}$ sind, und folglich, damit die Curve symmetrisch verlaufen kann, soll der entsprechende Endpunkt der Curve auch gleich weit vom Minimum entfernt sein, $d$. h. bei $28+22=50^{\circ}$ liegen. Dies wäre aber eine Unmöglichkeit, da erstens, wie die Versuche von Standfuss (841) und Anderen ergeben, die V anessa-Puppen die Temperaturen von $44^{\circ}$ nicht einmal während einiger Stunden ertragen können, und zweitens kann der Anfang der Curve nicht bei $6^{\circ}$ sein, sondern bei noch niederer Temperatur; der andere Ast der Curve sollte, der Symmetrie wegen, bei noch höherer Temperatur als $50^{\circ}$ endigen, d. h. im Gebiete der permanenten Wärmestarre oder des Todes. 
Wir kommen somit zum Schlusse, dass, da der aufsteigende Ast der Curve nach $28^{\circ}$ nicht symmetrisch mit dem absteigenden Aste sein kann, die Axe dieser parallel-ähnlichen Curve auch nicht vertikal zur Abscissen-Axe stehen kann.

Der Analogie wegen ist auch die Axe der I. Curve (für Pararge egeria) nicht senkrecht zur Abscissen-Axe gezeichnet, sondern vorläufig parallel mit der Axe für urticae-Curve. Auf diese Weise entstanden die drei erwähnten Curven.

Leider sind die Angaben für die Puppenzeit anderer Species, abhängig von der konstanten Temperatur, nicht so ausgedeht, dass man Curven mit dem Minimum erhalten kann; deshalb kann man jetzt keine weitgehenden Schlüsse über den Verlauf der Curve machen. Sonst wäre von grosser Wichtigkeit zu ermitteln: 1) Unter welchem Winkel die Curven-Axe zur Alsscissen-Axe steht und ob dieselbe immer parallel mit der Curven-Axe für andere Species ist? 2) Befinden sich die Minima der Curven, welche mittelst der minimalen resp. maximalen Werthe für eine und dieselbe Species konstruirt sind, auf einer und derselben Axe (wie für Pararge egeria angenommen) oder nicht? 3) Welche allgemeine Gesetze lassen sich aus solchen Curven für verschiedene Species von überwinternden und nicht überwinternden Puppen ableiten? etc.

Man kann jedoch schon jetzt sagen, dass, wie die Curven I und II zeigen, die Trennung der Curven für minimale und maximale Werthe einer und derselben Species so gross für eine gewisse Species sein kann, dass die untere Curve (II) mit ihrem Minimum die Abscissen-Axe, berïhren wird. Die Folge davon wäre, dass die Puppenzeit in diesem Falle gieich Null wird, d. h. das Puppenstadium würde gar nicht existieren, oder mit anderen Worten, die Raupe hätte „ohne sich $\mathrm{zu}$ verspinnen und $\mathrm{zu}$ verpuppen " direkt einen Schmetterling ergeben. Solcher Fall wurde von Majoli (543) an einer Raupe von Bombyx mori beobachtet.

Wir sind somit zum Schlusse gekommen, dass die Curve für vitale Funktionen, abhängig von konstanter Temperatur, ein Minimum resp. ein Maximum aufweist, und dass sie an eine Parabel erinnert, deren Axe zur Abscissen-Axe jedoch nicht senkrecht steht.

Wir wenden uns jetzt zur Betrachtung der in termittierenden Temperaturen.

1. Bellati und Quajat (62) untersuchten den Einfluss der intermittierenden Temperaturen auf die Entwickelung der nicht überwinternden Eier von Bombyx mori, indem sie dieselben von einer 
hohen Temperatur in $21^{\circ}$ und umgekehrt 10 Mal iibertragen haben. Die Abhängigkeit der Anzahl der (labei entwickelten Rüupchen (in \%) von diesen hohen Temperaturen ist aus Fig. 13 ersichtlich. Diese Curve hat ein Maximum bei $58,6^{\circ}$. Die geringe Abweichung von lem regelmässigen Verlauf der Curve bei $61,3^{\circ}$ ist wohl dadurch verursacht, dass in diesem Falle die niedere Temperatur nicht $21^{\circ}$, sondern nur $20,5^{\circ}$ betrug.

2. Schemigonow (744) brachte die bei $6^{\circ} \mathrm{R}$. bis $-2^{\circ} \mathrm{R}$. aufbewahrten Eier von Ocneria monacha für eine Stuncle in eine höhere Temperarur und erhielt je nach der letzteren verschiedene $\%$ von lebensfähigen Eiern. Die auf Fig. 1.t graphisch dargestellte Abhängigkeit (nur rechts von der Ordinaten-Axe) ergiebt ein Maximum der Curve resp. das Temperaturoptimum für das Ausschlïpfen der Raupen.

3. Bellati und Quajat (62) brachten die nicht iiberwinternden Eier von Bombyx mori in eine hohe Temperatur ( $87^{\circ}$ resp. 630) für einige Sekunden und erhielten bei gewöhnlicher Temperatur ein gewisses \% Räupchen. Die Anzahl (ler entwickelten Räujchen (in \%) abhängig von der Dauer dieser hohen Temperatur ist graphisch auf Fig. 15 dargestellt.

Die Curve für $87^{\circ}$ wird bei ca. 32 Sekunden der Entwickelungsdauer wahrscheinlich das Maximum zeigen; was die Curve für $63^{\circ}$ anbetrifft, so zeigt sie kein Maximum und wird es wahrscheinlich nicht haben, wie es weiter unten erörtert wird.

Leider sind diese interessanten Versuche von den genannten Forschern nicht weiter ausgedehnt worden, um gewisse feste Angaben für weitere Schlüsse zu haben; trotzdem werdem wir versuchen, weitere Consequenzen aus diesen Curven $\mathrm{zu}$ ziehen.

Die Curve für $87^{\circ}$ zeigt, lass je längere Zeit die Temperatur $87^{\circ}$ auf die nicht überwinternden Eier eingewirkt hat, desto mehr Eier zur Entwickelung angeregt werden. Es muss jedoch ein Maximum der entwickelten Räupchen eintreten und zwar aus folgenden Gründen:

Das Eiweiss gerinnt bei einer gewissen Temperatur, welche vom Wassergehalt abhängt (Lewith, 509 $\alpha$ ); so z. B. gerinnt es mit $25 \%$ Wasser bei $74-80^{\circ}$, dasselbe mit $18 \%$ Wasser bei $80-90^{\circ}$ und Eiweiss mit $6 \%$ Wasser bei $145^{\circ}$. Wir wollen annehmen, dass diese Gerinnung bei Eiern von Bomlyyx mori bei $65^{\circ}$ stattfindet. Es ist klar, dass Eiweiss in den Eiern dann ganz gerinnt, wenn das ganze Ei die Temperatur von $65^{\circ}$ annimmt, wofür eine gewisse Zeit. 
nothwendig ist. Ist diese Zeit vorhanden, dann (oder vielleicht schon früher) wird aus diesen Eiern kein einziges Räupchen ausschlüpfen, und folglich wird die Curve die Abscisse $=0 \%$ berühren (in der Fig. 15 ist dies bei $52^{\circ}$ angenommen, wenn die Curve symmetrisch verläuft). Daraus folgt, dass, da die Curve bei ihrem weiteren Verlauf absteigen muss, sie irgendwo ein Maximum erreichen wird.

Gestiitzt darauf, kann man voraussagen, dass die Curve z. B. für $100^{\circ} \mathrm{ihr}$ Maximum viel früher erreichen wird als die Curve für $87^{\circ}$, denn $100^{\circ}$ werden dlas ganze Eiweiss im Ei in einer kürzeren Zeit zum Gerinnen bringen als $87^{\circ}$, und folglich wird der rechte Ast dieser vorausgesagten Curve die Abscissen-Axe nicht wie friiher bei $52^{\prime \prime}$, sondern z. B. bei $26^{\prime \prime}$ berühren. Demgemäss wird auch die Curve für $68^{\circ}$ ihr Maximum viel später erreichen als die Curve für 870. Nun kommt die Curve für $63^{\circ}$, welche kein Maximum haben sollte, da rlas Eiweiss in Eiern von Bombyx mori, wie wir angenommen haben, erst bei $65^{\circ}$ gerinnt und folglich ist die Existenz fuir das Maximum beseitigt.

Ein Maximum für diese Curve und für die Curven für niedrigere Temperaturen als $63^{\circ}$ wirl aber dennoch eintreten, wenn auch viel später, da die Eier in Folge des Stoffwechsels doch nach einer gewissen Zeit verderben müssen.

$\mathrm{Ob}$ alle Maxima verschiedener Curven eine gleich grosse Ordinate haben, kann man ohne weiteres nicht entscheiden.

Wie wir gesehen haben, bringt eine höhere Temperatur die Eier früher zur Entwickelung ( $87^{\circ}$ nach $12^{\prime \prime} 10^{0}$ ) als eine nicht so hohe $\left(63^{\circ}\right.$ nach $20^{\prime \prime} 1 \%$ ), was durch den "Reiz" von Tichomirow (868) zu erklären ist, welcher um so schneller durch die hohe Temperatur zu Stande kommt, je höher diese Temperatur ist. Nun mïssen Temperaturen existieren, bei welchen dieser "Reiz" nicht vorhanden ist, da sie dazu zu schwach sind, wie z. B. die Temperatur $7,4^{\circ}$, bei welcher Beauvais (56) die Eier 6 Jahre ohne Schaden aufbewahrt hat. Daraus folgt, dass die Curve für $7,5^{0}$ eine Gerade sein wird, welche mit der Abscissen-Axe zusammenfällt, da bei dieser Temperatur die Anzahl der entwickelten Eier $=0 \%$ ist.

Es giebt Angaben, dass gewisse Temperaturen auch über $7,5^{c}$ die nicht ïberwinternden Eier von Bombyx mori zur Entwickelung nicht anregen können. So z. B. sagt Ducleaux (199), dass die Eier, welche bei $30^{\circ}$ gelassen wurden, sich nicht entwickelten. Die Ent- 
wickelung, wie es scheint, beginnt erst dann, wenn die Temperatur $24^{\circ}$ (Beaurais, 56) bis $25^{\circ}$ (Alibegow, 8) erreicht ist. ${ }^{1}$ )

Somit befinden sich auf der Abscissen-Axe $=0 \%$ nicht nur die Curve (resp. die Gerade) für $7,5^{\circ}$, sondern auch die Curven von dieser Temperatur an bis zu $25^{\circ}$.

Nun kann man die Frage aufwerfen, was geschieht mit den Eiern, wenn man sie der Temperatur tiefer als $7,5^{\circ}$ während einer gewissen Zeit aussetzt und dann bei gewöhnlicher Temperatur liegen lässt?

Diese Frage ist von mehreren Forschern beantwortet worden, jedoch, wie auch für die höheren Temperaturen, leider ungenügend. So z. B. sagt Quajat (664), dass die Eier; welche der Einwirkung der Temperatur von $0^{0}$ bis $+8^{0}$ ausgesetzt wurden, sich entwickeln, in die gewöhnliche Temperatur gebracht, je nach (ler Vorbehandlung (ler Eier. Numerische Angaben fehlen. Duclaux (201) fand, dass die Eier, welche der Einwirkung der Temperatnr von $-10^{\circ}$ ausgesetzt werden, in einem solchen Zustande verbleiben, als ob sie der Einwirkung der Kälte gar nicht ausgesetzt wären. Verson (914) stellte fest, dass die Eier, von $-23^{\circ}$ sofort in die Temperatur von $20^{\circ}$ gebracht, 100\% Räupchen ergaben. Ausserdem sagt er, dass die plötzliche Abkühlung der Eier auf $-32^{\circ}$ dieselben zerstört.

Mehr oder weniger brauchbare Resultate liefern die Untersuchungen von Quajat (668) über den Einfluss der Temperatur von $0^{0}$ auf die Eier von Bomlyx mori während verschierlener Zeitlauer, worauf sie in die Temperatur von $20^{\circ}$ bis $24^{\circ}$ gebracht wurden. Diese Resultate sind auf Fig. 16 graphisch dargestellt.

Aus dieser Darstellung ist ersichtlich, dass verschiedene Rassen verschiedene Resultate ergeben, aber für alle Rassen gielt die Regel, dass 19 Wochen bei $0^{\circ}$ vollständig genug sind, um den maximalen Prozentsatz der entwickelten Eier $(98-92 \%)$ zu erhalten. Weiteres Verbleiben der Eier in $0^{\circ}$ vermindert diesen Prozentsatz und lrann die Eier bei ca. 50-wöchentlicher Zeitdauer alle verderben. Obwohl

1) Diese Temperaturen sind wohl zu niedrig, da die Eier dabei nicht im Wasser, sondern in der Luft sich befanden (vide Lewith [509 $\alpha$ ] und Tichomirow [868]). Es giebt Angaben von Verson (921), dass die Entwickelung der Eier noch nicht hervorgerufen worden ist, als $37,5^{\circ}$ während 480 Sekunden auf dieselben im Wasser eingewirkt haben; dasselbe für $50,5^{\circ}$ während 600 Sekunden und für $62,5^{\circ}$ während 1750 Sekunden. Man kann aber nicht mit Bestimmtheit behaupten, dass die Entwickelung unter diesen Umstanden nach noch längerer Zeit nicht zu Stande kommen würde. 
diese Curven kein Maximum resp. Minimum zeigen, so muss ein solches wohl auftreten und zwar zwischen Null-wöchentlicher und 19-wöchentlicher Zeitdauer, sagen wir bei $n$ Wochen.

Wenn $0^{0}$ bei $n$-wöchentlicher Wirkungsdauer (und nachherigem Verbleiben bei gewöhnlicher Temperatur) ein Maximum $(100 \%)$ der entwickelten Eier verursacht, so werden noch tiefere Temperaturen dieses Maximum bei der anderen Zeitdauer hervorrufen.

Nimmt man mit Maillot (5.2) an, dass die zeitweise kiinstliche Erniedrigung der Temperatur deshalb die Ruhepause der Eier von Bombyx mori abkïirzen kann, weil die Kälte die Eisubstanz in der Weise verändert, dass diese eine grössere Fähigkeit sich zu oxyllieren erhält, so kann man vermuthen, dass die Maxima der entwickelten Eier desto früher eintreten werden, je tiefer die einwirkende Temperatur ist. Diese Vermuthungen sind auf Fig. 17 graphisch dargestellt.

\section{Vitale Temperatur-Grenzen.}

Wie die Curve für den Bewegungszustand des Protoplasmas in Zellen (Fig. 9) zeigt, tritt rechts und lings vom Temperaturoptimum verzögerte Bewegung des Protoplasinas ein. Nach gewissen Temperaturen tritt bei weiterer Verzögerung dieser Bewegung vorübergehende Wärme- resp. Kälte-Starre ein, bis sie sich schliesslich in die permanente Starre umwandelt, wobei der Tod der Insekten stattfindet.

\section{Vitales Temperaturmaximum.}

Die vorübergehende Wärmestarre findet zwischen 38 und $40^{\circ}$ statt. Ueber diesen Punkt sagt z. B. Schultze (792): „Die Bewegung verlangsamt sich in allen Fällen von $38-40^{\circ}$ an (beim Protoplasma in Härchen der Staubfälen von Tradexantia virginica, in brennenden Härchen der Urtica urens und in Zellen der Blätter von Vallisneria spiralis), kehrt aber, wenn die Temperatur nicht über $48^{\circ}$ stieg, bei der Ablühlung meist bald zu der ursprünglichen Schnelligkeit zurück."

Meine Untersuchungen an Schmetterlingen ergaben, dass sie in Folge des Summens ihre eigene Körpertemperatur erhöhen und bei einer gewissen Temperatur zu summen aufhören (28). Ich führe hier als Beispiel eine Tabelle aus diesen Cntersuchungen an. 
Deilephila elpenor vor einigen Stunden ausgeschlüpft. Zimmertemperatur $=19,0^{\circ}$.

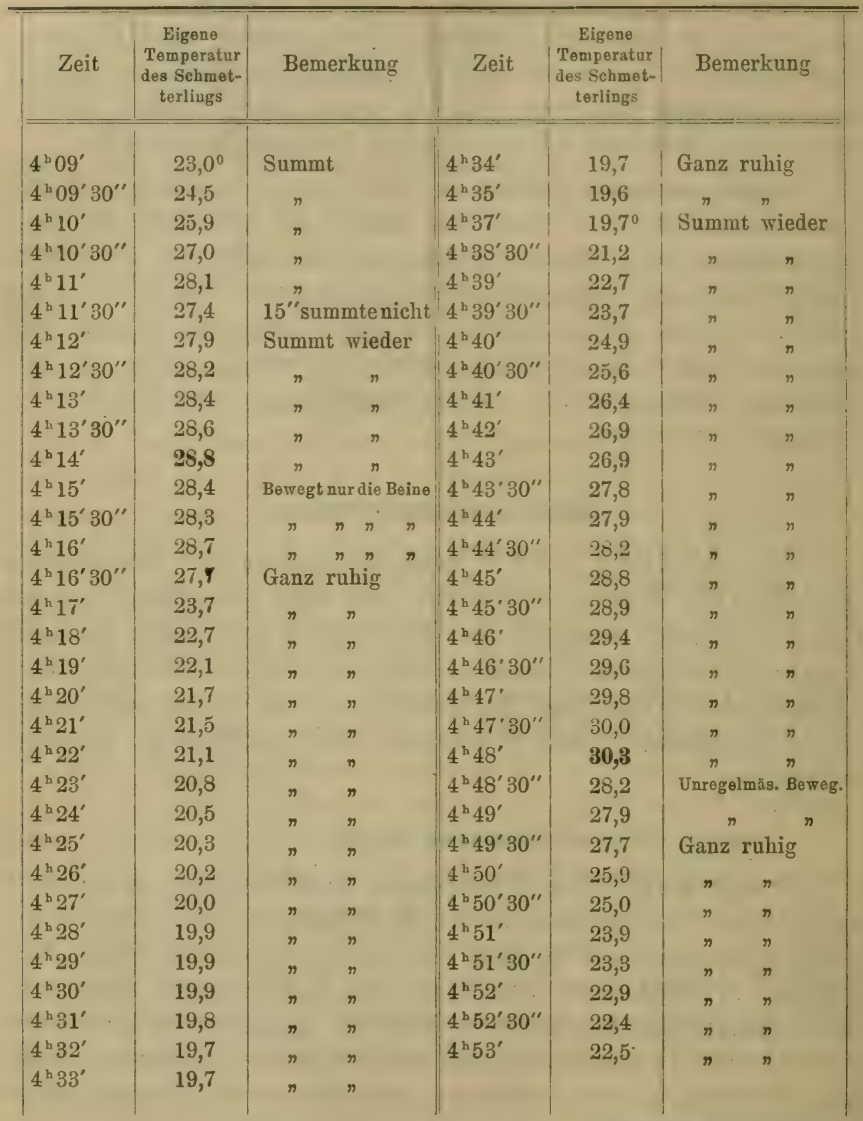

Aus dieser Tabelle ist ersichtlich, dass die Temperatur des Schmetterlings bei Zimmertemperatur $\left(19,0^{\circ}\right)$ beim Summen rasch stieg, sie erreichte un $4^{\mathrm{h}} 14^{\prime}$ ein Maximum $\left(28,8^{\circ}\right)$ und fiel dann allmälig bis zu 12,60. Als der Schmetterling zum zweiten Mal zu summen begann, stieg seine Temperatur um $4^{\mathrm{h}} 48^{\prime}$ im Maximum 
bis $30,3^{\circ}$. Als der Schmetterling im ersten Falle die Temperatur $28,8^{\circ}$ und im zweiten Falle $30,3^{\circ}$ erreichte, hörten seine Flügelbewegungen auf und er bewegte darauf $1^{\prime} 30^{\prime \prime}$ lang nur seine Beine, um nachher ganz ruhig zu werden.

Dieser Versuch und andere ähnliche, auch an anderen Lepidopteren-Species angestellten, beweisen, dass bei einer gewissen hohen Temperatur dles Schmetterlingskörpers die Flügelmuskeln eine Wärmestarre erleiden, welche vorïbergehend ist, da der Schmetterling beim Abkühlen wieder zu summen anfängt.

Weitere Versuche in dieser Beziehung ergaben (28), dass die Temperatur der vorïbergehenden Wärmestarre um so höher liegt, je höher die Lufttemperatur ist, und zwar betrug sie für verschiedene Exemplare von Deilephila elpenor:

Die Lufttemperatur: $\quad \begin{array}{llll}19,0^{\circ} & 19,2^{\circ} & 28,5^{\circ} & 29-34^{\circ}\end{array}$ Vorübergehende Wärmestarre: $28,8^{\circ} \quad 34,8^{\circ} \quad 37,0^{\circ} \quad 42,1^{\circ}$

Sie ist jecloch davon abhängig, ob der Schmetterling zum ersten Mal die vorübergehende Wärmestarre erleidet oder bereits zu wiederholten Malen. Folgende Tabelle zeigt diese Abhängigkeit:

Deilephila elpenor.

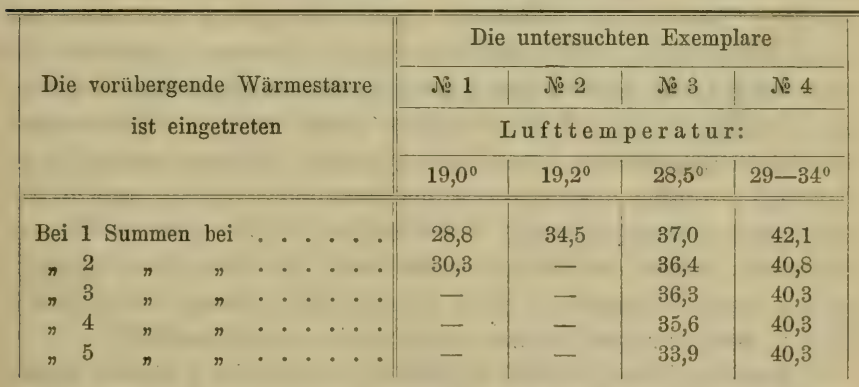

d. h. bei mittleren Lufttemperaturen tritt die vorübergehende Wärmestarre nach jedem Summen bei immer höheren und höheren Temperaturen auf, während bei höheren Lufttemperaturen das Umgekehrte beobachtete wird. Dieses sogenannte Anpassungsvermögen ist ausführlicher im Kapitel III des theoretischen Theils (Abschnitt 1) besprochen worden.

Somit können gewisse Organe bei Insekten, wie z. B. in unserem Fall die Flügel, ihre vorïbergehende Wärmestarre bereits bei $28,8^{\circ}$ erleiden, was durch die Anpassung aber bis zu $42,1^{\circ}$ gesteigert werden 
kann. (Ueber die lokale Wärmestarre vile Kapitel III les theoretischen Theils, Abschnitt 1). Die Versuche von Standfuss (841) und anderen an Schmetterlings-Puppen zeigten, dass die voriilsergehende Wärmestarre sogar bis zu $44^{\circ}$ ausgedehnt werlen kann Er sagt: „So hohe Temperaturen $\left(+44^{\circ}\right)$ wirken keineswegs ilurchwegs beschleunigend, wie man anzunehmen geneigt wïre, sonilern vielfach die Entwickelung direkt unterbrechend und häufig auch noch ïber das Mass der Expositionszeit hinaus verlangsamenil."

Erwärmt man das Protoplasma in Zellen iiber $48^{\circ}$, so erleilet dasselbe permanente Wärmestarre (Fig. 9), welche dem Tode gleich kommt. Bei Inseliten, wie es scheint, tritt diese Starre etwas früher ein. So z. B. sagt Fischer (228): ${ }_{n}$ Solche von ca. $45^{\circ}$ dürfen (für Puppen) nicht angewendet werden, weil bald der Tod, wahrscheinlich durch Gerinnung ler Eiweisskörper eintritt." Immerhin hielten die Raupen von Vanessa urticae, der Einwirkung der Sonnenstrahlen ausgesetzt, in Versuchen von Reichenau (682) die Temperatur von $45^{\circ}$ aus. Die Puppen von Vanessa antiopa hielten in Versuchen von Standfuss (841) dreimal täglich zweistiindlige Einwirkung von $45^{\circ}$ innerhalb fünf Tagen aus. Ich fand (29), dass der Schmetterling Saturnia pyri dann stirbt, wenn die Temperatur seines Körpers $46^{\circ}$ erreicht. Reh (679) stellte fest, llass Schieldliuuse bei $4 S-50,2^{\circ}$ während 2 Stunden noch nicht todt waren. Er sagt: "Schon bei $52^{\circ}$ sind einige Läuse nach $3 / 4$ stündiger Wirkung abgestorben, die höhere Temperaturen, z. Th. von noch lïngerer Dauer ertrugen. Hier müssen entschieden individuelle Umstände mitwirken. Im Allgemeinen wird man sagen dürfen, dass $54-55^{\circ}$ das Maximum darstellt, welches die Schildläuse ertragen können. Während sie bei $54^{\circ}$ nach 10 Minuten abstarben, gingen sie bei $55^{\circ}$ schon nach 22 Ninuten zu Grunde. $\mathrm{Ob}$ sie erstere Temperatur noch längere Zeit, letztere vielleicht für kürzere Zeit ertragen können, bleibt noch zu untersuchen."

Diese und viele andere Thatsachen, welche im I. Bandle meiner "Studien" (29) angefiilnt sind, machen klar, dass das vitale Temperaturmaximum für eine und dieselbe Species von der Zeit ablängt, während welcher das bətreffende Insekt diese Temperatur auszuhalten hat. Dabei spielen folgendle Faktoren eine Rolle:

a) Der Stoffwechsel. Ist die Temperatur der Luft erhöht, so steigt die Pulsation und die Athmung des Insekts; folglich verbraucht es von seinem Körper mehr Material, welches in Form von Kohlensäure und Wasser entweicht, als bei gewöhnlicher Temperatur. Das Insekt stirbt in diesem Falle nicht in Folge der erhöheten T'em- 
peratur, sondern an Erschöpfung, besonders wenn es keine Nahrung einnimmt.

b) Die Feuchtigkeit. Ist lie Lufteuchtigkeit gering, oder die Luft gar trocken, so verlampft das Wasser der Insektensïfte viel stïrker als sonst, und das Insekt stirbt wiederum nicht direkt wegen der erhöhten Temperatur, sondern in Folge iler Austrocknung.

c) Die Wärmeleitungsfähigkeit des Insektenkörpers. Kleine Differenzen an der Behaarung, an der Beschaffenheit der Obertläche etc. des Inselites einer und derselben Species liönnen offenbar auf die Grösse des vitalen Temperaturmaximums einen gewissen Einfluss haben. Die Folge davon wird sein, rlass unter sonst gleichen Umstänlen ein Exemplar derselben Species stirbt und ein ancleres noch am Leben bleibt.

d) Die Grösse. Dieselbe Rolle wie unter c).

e) Der Säftekoëfficient. Unter sonst gleichen Umstïnden wirl dasjenige Exemplar einer Species früher sterben, welches mehr Wasser in seinen Säften enthält, (l. h. bei welchem die Säfte wässeriger sincl. Dies wird durch Untersuchungen von Lewith $(509 \alpha)$ bestätigt. Er fand, dass Eiweiss, wenn es erwärmt wird, bei verschiedenen Temperaturen gerinnt; so z. B. gerinnt Eiweiss mit $25 \%$ Wasser bei $64-80^{\circ}$, dasselbe mit $18 \%$ Wasser bei $80-90^{\circ}$ und Eiweiss mit $6 \%$ Wasser bei $145^{\circ}$; das ganz wasserfreie Eiweiss gerinnt nach Haas erst bei $160-170^{\circ}$. Somit ist die Gerinnungsfähigkeit der Insektensäfte, welche Eiweiss enthalten, von ihrem Wassergehalte abhängig.

Zieht man alle diese Umstände in Betracht, so stellt sich heraus, dass, wenn bei erhöhten Temperaturen das Inselit 1) nicht erschöpft wäre, (d. h. kiinstlich gefüttert wäre, 2) nicht austrocknete, (l. h. in entspreheni feuchter Luft sich befinlen wïrile, 3) gleiche Wärmeleitungsfühigkeit und gleiche Grösse seines Kïrpers für eine gegebene Species liätte, so wiirde dann sein Leben nur davon abhängen, ob seine Säfte resp). Eiweiss des Körpers bei der gegebenen Temperatur gerinnen wïrlen oller nicht. Dann würde das vitale Temperaturmaximum nichts anderes ausclrïcken, als dass bei dieser Temperatur seine Säfte gerinnen. Keunt man aber den Wassergehalt in den Eiweisskürpern des Inselites, zumal solchen, welcher fï̈ die Lebensfähigkeit unbelingt nothwendig ist, dann würle sich die Frage über das vitale Temperaturmaximum nur auf die Bestimmung dieses Wassergehaltes reduzieren lassen.

B « c h metjew, Studien. II. 
Vitales Temperaturminimum.

Wird das Optimum-Rayon auf der Curve Fig. 9 nach links ïberschritten, so tritt die Kältestarre des Protoplasmas in den Zellen ein, welche zuerst aber vorübergehend ist. Für das Protoplasma ler Pflanzen beträgt diese Temperatur ca. $15^{\circ}$, variert aber von Species zu Species.

Für Insekten scheint diese voribergehende Kältestarre etwas tiefer als bei $15^{\circ} \mathrm{zu}$ liegen, wie es einige der beobachteten Thatsachen aufweisen.

Werden die Puppen irgend einer Lepidopteren-Species von Anfang an bei einer konstanten niederen Temperatur während einer gewissen Zeit $(Z)$ liegen gelassen und darauf in die gewöhnliche Temperatur gebracht, so wird die Gesamtzeit der Puppendlauer dadurch verlängert. Diese Abhängigkeit ist aus folgenılen Beispielen ersichtlich:

1. Ruhmer (727) liess die Puppen von Araschnia levana (Sommergeneration) alle im gleichen Entwickelungsstadium $Z$ Tage bei $2^{\circ}$ liegen, worauf die Puppen ins Zimmer $\left(17-22^{\circ}\right)$ gebracht wurden. Fig. 8 veranschaulicht die ermittelte Abhängiglieit. Die erhaltene Gerade zeigt, dass die Gesamtzeit der Puppendauer direkt proportional der Grösse $Z$ ist.

2. Morrifield (564) stellte die gleichen Versuche mit den Puppen von Eugonia alniaria und automnaria an. Fig. 18 veranschaulicht die erhaltenen Resultate.

Zieht man die Werthe für $Z$ von $Z_{g}$ ab, so erhält man folgende Tabelle:

\begin{tabular}{|c|c|c|c|}
\hline$Z$ & Araschnia levana & Eugonia alniaria & Eugonia antomnaria \\
\cline { 2 - 3 } Tage & $Z_{g}-Z$ & $Z_{g}-Z$ & $Z_{g}-Z$ \\
\hline \hline 0 & $9,5-0=9,5$ & $(15-0=15)$ & $(42-0=42)$ \\
5 & $14,5-5=9,5$ & $(22-5=17)$ & $(45-5=40)$ \\
10 & $20-10=10$ &,$(28-10=18)$ & $(47-10=37)$ \\
15 & $25,5-15=10,5$ & $(35-15=20)$ & $(50-15=35)$ \\
20 & $31-20=11$ & $(41-20=21)$ & $(52-20=32)$ \\
25 & $36,5-25=11,5$ & $48-25=23$ & $(55-25=30)$ \\
30 & - & $55-30=25$ & $(57-30=27)$ \\
35 & - & $61-35=26$ & $60-35=25$ \\
40 & - & $68-40=28$ & $62-40=22$ \\
45 & - & $74-45=29$ & $65-45=20$ \\
50 & - & $81-50=31$ & $67-50=17$ \\
55 & - & $87-55=32$ & $70-55=15$ \\
60 & - & - & $73-60=13$ \\
65 & - & - & $75-65=10$ \\
70 & - & & $78-70=8$ \\
& & &
\end{tabular}


Aus dieser Tabelle ist ersichtlich, dass $Z_{g}-Z$ für Araschnia levana und Eugonia alniaria lesto grösser ist, je längere Zeit $(Z)$ die Puppen bei $0^{0}$ liegen. Diese Abhängigkeit leutet darauf hin, dass die Puppen bei $0^{0}$ sich gar nicht entwickelt haben und dass dieser Umstand sogar später (bei gewöhnlicher Temperatur) eine geringe für Araschnia levana und eine viel bedeutendere Verlängerung der Puppenzeit von Eugonia alniaria zu Folge hatte.

Da die Werthe $Z_{g}-Z$ für Eıgonia automnaria mit der Zunahme von $Z$ abnehmen, zeigt dieser Umstand, dass die Entwickelung dieser Puppen bei $2^{0}$ nicht still stand, sondern, wenn auch langsam, fortschritt. Zu dem gleichen Schluss kam auch z. B. Fischer (229), indem er sagt: „Die Entwickelung des Falterorganismus bei einer constanten Temperatur von $0^{0}$ steht nicht ganz still, sondern (wenn auch sehr verlangsamt) schreitet fort. Trotz dieses Vorwärtsschreitens können doch einzelne Entwickelungsvorgänge (und zwar bei den Puppen auf den Flügeln) durch Kälte gehemmt werden."

M. Standfuss (841) nahm zwei Serien von Vanessa-Puppen und brachte eine Serie in die Temperatur von $+23^{\circ}$, während die zweite Serie folgendermassen behandelt wurde: 10 Stunden nach der Abstreifung der Raupenhaut wurden die Puppen in einen Frostapparat gebracht, wo sie sich innerhalb einer halben Stunde von $+5^{0}$ auf $-12^{\circ}$ abkïhlten und bei der letzten Temperatur eine Stunde verblieben, darauf wurden sie in einer weiteren halben Stunde auf $+5^{0}$ wieder erwärmt. Diese Behandlung wurde in den darauf folgenden zwei Tagen wielerholt, während in der gesamten Zwischenzeit und nachher bis zum Ausschlüpfen diese Puppen ebenfalls in einer Temperatur von $23^{\circ}$ gehalten wurden. Es ergab sich, dass die zweite Serie keineswegs nur um 6 Stunden später ausschlüpft, welche sie in niederem als die normalen Temperaturen verbrachte, sondern um Tage verspätet. "Somit wurde nicht nur eine Unterbrechung der Entwickelung während der Zeitdauer der Frosteinwirkung hervorgerufen, sondern zugleich eine sehr erhebliche Verlangsamung und Hemmung der Entwickelung überhaupt" (p. 18). Aehnliche Erscheinungen beobachteten auch andere Forscher.

Diese erhebliche Verlangsamung in der Entwickelung lässt sich durch die vorübergehende Kältestarre des Protoplasmas leicht erklären. Die Puppe, welche eine halbe Stuncle in der Temperatur von $-12^{\circ}$ zubrachte, erlitt offenbar die Kältestarre des Protoplasmas in ihren Zellen, welche auch dann nicht verschwand, als die Puppe bei $+5^{0}$ sich befand. Erst als die Temperatur der Puppe selbst 
im Zimmer (bei $+23^{\circ}$ ) auf ca. $14^{\circ}$ stieg, begann die Kuältestarre langsam abzunehmen (wie es meine Versuche mit Schmetterlingen ergaben), denn, wie Sachs sagt, „muss die giinstige Temperatur längere Zeit einwirken, um den beweglichen Zıstand herbeizuführen" (729, p. 86). Die Puppe verblieb bei anormalen Temperaturen, wie Standfuss sagt, während 2 Tagen 6 Stunden; damit aber die Protoplasma-Bewegung wieller die frïhere Energie, welche ihr bei $23^{\circ}$ eigen ist, erreichen kann, braucht man nach jerlem Versuch noch eine "längere Zeit" (Sachs), so dlass zu diesen fo Stunden nach dem ersten Versuch noch einige Stunden, unil nach dem zweiten Versuche vielleicht noch mehr zugerechnet werlen muss. Im Resultate erhalten wir eine bedeutenrlere Verlangsamung in der Entwickelung als um 6 Stunden.

Zur besseren Vorstellung dieses Vorganges ist es nothwendig; die Erscheinungen der "Nachwirkung" zu Hülfe zu nehmen. Ich erlaube mir deshalb hier in Kürze diese Erscheinung an einigen Beispielen zu erklären.

Wir belasten einen vertikal aufgehängten dünnen Eisenilraht mit einem Gewicht von z. B. $1 \mathrm{~kg}$. Der Dralit wird sofort eine gewisse Verlängerung angeben, welche aber jerlen Tag zunehmen wird, obwohl nicht proportional der Zeit. Erst nach ca. 2 Jahren erreicht der Draht seine maximale Verlängerung, die dem belastenden Gewichte entspricht, wonach seine Länge konstant bleiben wird. Entfernen wir jetzt das erwähnte Gewicht, so erhält der Draht seine ursprüngliche Länge nicht sofort, sondern wieder nach Jahren, obwohl er im ersten Moment des Entlastens eine bedeutende Verkürzung zeigen wird. Dies ist elastische (positive und negative) Nachwirkung.

Wir haben vor uns eine geladene Leiden'sche Flasche ohne Verbindung mit einer Elektrisier-Maschine. Wir entladen sie und erhalten einen Funken. Nach einer Minute nehmen wir den Entlader und erhalten wieder einen wenn auch kleineren Funken. Nach einer weiteren Minute wird noch ein Funken erhalten u. s. f., bis der Funke so klein wird, dass wir sagen können, er existiert fur uns nicht mehr. Dies ist elektrische Nachwirkung.

Wir beleuchten einen phosphorescierenden Schirm mit Sonnenstrahlen eine Minute lang und bringen ihn nacher in die Dunkelheit. Er phosphoresciert zuerst stark, dann schwächer und schwächer und erlischt vollständig viel später als nach einer Minute. Dies ist optische Nachwirkung. 
Wir leiten durch eine Gliihlampe einen schwachen elektrischen Strom. Nachdem der Strom die Stärke von z. B. 5 Ampère erreicht hat, bemerken wir das erste Licht. Wir vorstärken den Strom und sehen schönes weisses Licht. Jetzt vermindern wir die Stromstärke; das Licht wird immer schwächer und schwïcher und schliesslich verschwinciet es für unser Auge. Die Beobachtung ergiebt, dass der Lichtreiz für unser Auge nicht bei früheren 5 Ampère, sondern erst bei z. B. 4 Ampère aufhört, mit anderen Worten: wir können die abnehmende Lichtintensität bis $\mathrm{zu}$ viel kleinerem Werte verfolgen als beim Zunehmen dieser Intensität. Dies ist physiologische $\mathrm{Nachwirkung.}$

Es giebt "Nachwirkungen" auf jedem Gebiete der Naturwissenschaften und sogar im sozialen Leben (siehe meine Abhandlungen: "Die Nachwirkung in der physikalischen Welt." Zeitschr. für Phys. und Math. Kíjew 1894; "Wie dressiert man die Molekuile." Bulgar. Rundschau. II. № 1. Sophia 1894; „Die Nachwirkung. Physiko-psychologische Studie“. Bulgar. Rundschau. II. ㅊ. 2. Sophia 1894; "Ueber den Einfluss des umgebenden Mediums auf die elastische Nachwirkung (ler Metall-Drähte." Journ. russisch. Phys.-Chem. Gesellsch. XXVIII. St.-Petersburg 1896).

$\mathrm{Zu}$ dieser Kategorie der Erscheinungen gehört unzweifelhaft auch das langsame Verschwinden der Starre des Protoplasmas, obwohl die Zellen sich längere Zeit bei günstiger Temperatur befinden. Die Moleküle, welche aus ihrer Lage verschoben sind, kommen eben nicht sofort in die friihere Lage, wenngleich die Ursache dieser Verrückung schon längst verschwunden ist.

Durch das oben erwähnte Vorwärtsschreiten der Entwickelung auch bei $0^{0}$ kann man unter anderem auch die folgenden Resultate von Quajat (668) erklären:

Dieser Forscher brachte Eier von Bombyx mori in die Temperatur von $0^{\circ}$, wo sie verschieden lange Zeit lagen. Nachher, in die gewöhnliche Temperatur $\left(20-24^{\circ}\right)$ gebracht, ergaben sie verschiedene Anzahl der Räupchen (Fig. 16). Dass die Eier von Bombyx mori zuerst überwintern resp. eine gewisse Zeit bei ca. $0^{\circ}$ gehalten werden müssen, damit sie sich bei gewöhnlicher Temperatur zu Räupchen entwickeln können, war schon lange bekannt. Fig. 16 zeigt, dass für verschiedene Rassen 19 Wochen genügen, um die Entwickelung der Eier durch $0^{\circ}$ anzuregen; liegen sie bei $0^{\circ}$ noch länger, so vermindert sich die Anzahl der später auszuschlüpfenden Räupchen. Dies zeigt, dass . die sich entwickelnden Embryonen in ihrer Entwickelung bei $0^{0}$ weiter 
schreiten, nach 19 Wochen aber wahrscheinlich an Erschöpfung zu sterben anfangen.

Ungefähr dieselbe Resultate erhielt Merrifield (564) mit Eiern von Selenia illustraria und S. illunaria. (Fig. 20). Hier ergiebt sich das Maximum der nach der Wirkung von $0^{\circ}$ ausgeschlïpiten Rüupchen bei rler 10-tägigen Exposition.

An Erschöpfung sterben auch die Puppen verschieılener Species, sobald sie sich zu entwickeln begannen und in dieser Entwickelung durch niedere Temperaturen verlangsamt werden. Z. B. Frings $(253,257,261)$ exponierte bei 6-80 während verschieden langer Zeit verschiedene Puppen-Species und brachte sie nachher in die gewöhnliche Temperatur. Fig. 7 zeigt die Sterblichkeit in \% für verschiedene Species bei verschieden langer Exposition. Im allgemeinen schadet dabei die 10-15-tägige Exposition nicht, erst nach 20-30 Tagen beträgt die Sterblichkeit ca. 20\%, nach 40 bis 50 Tagen erreicht sie $100 \%$.

Die Temperatur der vorïbergehenden Kältestarre, obwohl sie für gewisse Arten bei $15^{\circ}$ beginnt, wie ich es bei Erklärung der Frage, warum die Tagesschmetterlinge nur an Tage flieger (30), erörtet habe, liegt doch bei manchen Arten auch weit unter $0^{\circ}$. So z. B. beobachtete $R \theta$ h (681) die reifen Fonscolombin fraxini Kialtb. bei $-2,5$ bis $-3,7^{\circ}$ auf der Suche nach Weibchen. Bezzi (79) fand auf dem Schnee lebende Mücke Chianea crassipes Boh. und Grum-Grschimajlo (332) behauptet, dass die Mücken in der Mongolei noch bei $-8^{\circ}$ leben. Lichtenstein (513) beobachtete bei $-7^{0}$. das Copulieren der Aphis brassicae und Mordwilko (593) fand die erwachten Wurzelläuse Pemphigus caerulescens bei $-3^{\circ}$.

Bei Raupen und Puppen tritt die vorübergehende Kältestarre im allgemeinen also schon über $0^{0}$ ein, wenn auch nicht für alle Theile des Organismus.

Die allgemeine vorübergehende Kältestarre kann nur dann eintreten, wenn sämtliche Insektensäfte, folglich auch das Protoplasma gefrieren, weil unter diesen Umständen die Bewegung in Zellen unmöglich ist. Dies findet erst im Punkte $T_{2}$ (Fig. 9) statt. Diese allgemeine Starre oder anabiotischer Zustand dauert bis zum Punkte $T_{3}$, nach welchem die permanente Kältestarre eintritt. Der Tod im eigentlichen Sinne des Wortes findet hier nicht statt, da die Säfte dabei nicht gerinnen, wie es z. B. bei hohen Temperaturen der Fall ist, sondern das Thier kann deshalb nicht 
mehr zum Leben kommen, da das Protoplasma die permanente Kältestarre erfahren hat.

Worin besteht diese permanente Kältestarre? Sachs (729) sagt in Bezug auf den Tod, welcher nach der Wärme- resp. Kältestarre eintritt: „dass er ebenso gut durch chemische Veränderung der Moleküle wie durch Verrückung derselben aus ihrer Lage eintreten können wird." „Die überraschende Aehnlichkeit der durch Erfrieren und der durch hohe Temperatur getöteten Zellen dürfte darauf hinweisen, dass der Vorgang der Tötung in beiden Fällen ein ähnlicher ist und sich auf dasselbe Prinzip zurïckführen lässt."

Man kann sich einverstanden erklären, dass der Tod durch chemische Veränderung der Moleküle bedingt wird, wie z. B. durch das Gerinnen des Eiweisses der Säfte resp. des Protoplasmas, aber der Process der permanenten Starre, welche dem Tode vorangeht, ist durch Verrückung der Molekiile aus ihrer Lage zu erklären, was wir jetzt versuchen werden.

Wir nehmen einen konkreten Fall aus dem Gebiete der Physik. Ein metallischer Draht, welcher vertikal aufgehängt ist, wird mit einem Gewichte belastet. Diese Belastung dauert eine gewisse Zeit, z. B. 2 Wochen. Nach der Entfernung der Belastung wird die vorher bewirkte Verlängerung des Drahtes nach und nach verschwinden und der Draht wird wieder die ursprüngliche Länge erhalten. Diese Erscheinung ist analog der vorübergehenden Starre. Je grösser die Belastung war (je tiefer die Temperatur für die Kältestarre resp. je höher dieselbe für die Wärmestarre war), desto längere Zeit braucht der Draht, um in die ursprüngliche Lage zurück $\mathrm{zu}$ kommen (in unserem Fall das Protoplasma in den normalen $\mathrm{Zu}-$ stand). Schliesslich wird der Draht (Protoplasma) mit einem so grossen Gewicht ( \pm Temperatur) belastet, dass seine Elastizitätsgrenze (vorïbergehende Starre) überschritten wird. Der Draht (Protoplasma) bleibt auch olıne Belastung (Temperatur) verlängert (permanent erstarrt) und wird nie seine ursprüngliche Länge (Zustand) wieder erreichen. Dies wird in der Physik durch zu starke Verrückung der Moleküle im Drahte erklärt.

Somit ist die permanente Starre auf die Verrückung der Moleküle im Protoplasma zurückzufuihren. Das Zerreissen des Drahtes wäre dem Tode analog.

Leider ist das entomologische Material weder quantitativ noch qualitativ genügend, um die Anwendung der Gleichungen aus der Elastizitätslehre entsprechend zu prüfen. 
Betreffs der Temperatur, bei welcher die permanente Ki:iltestarre eintritt, so ist dieselbe für verschielene Species verschieden, wie auch die Elastizitätsgrenze für verschierlene Materinlien verschieden ist, was aus folgender Zusammenstellung ersichtlich ist, wobei rlie Temperatur während einiger Stunlen bis zu einigen Tagen einwirkte:

\begin{tabular}{|c|c|c|c|c|c|c|c|}
\hline S pecie & & & & & & $\begin{array}{c}\text { Permanente } \\
\text { Kältestarre tritt } \\
\text { ein bei }\end{array}$ & Forscher \\
\hline Eier. & & & & & & & \\
\hline Ocneria monacha.. & . . & & 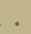 & . & . & tiefer als $-18^{\circ}$ & Schemigonow (744) \\
\hline Bombyx mori. . . & . . & . & . & . & . & $n-20$ & Quajat (656) \\
\hline$" . .$. & . . & - & . & . & . & $n \quad-30$ & Verson (914) \\
\hline$" . .$. & . . & . & . & . & . & $n-40$ & Pictet $(954 a)$ \\
\hline Ocncria dispar . . . & . . & . & . & . & . & $n \quad n$ & Kulagin $(480 a)$ \\
\hline Bombyx rubi.... & . & . & - & . & - & $n \quad n-50$ & Spallanzani $(825 u)$ \\
\hline \multicolumn{8}{|c|}{ Raupen resp. Larven. } \\
\hline Culex pipiens. . . . & . . & . & • & . & . & -4 & Roedel (698) \\
\hline Culex-Species.. & . . & . & . & . & . & -4 & Galli-Valerio und J. Rochaz \\
\hline Anopheles-Species & & . & . & . & . & -4 & de Jonglı. (270ß, 270\%) \\
\hline Bombyx mori. . & . & . & . & . & . & tiefer als -5 & Schmujdsinowitsch (756) \\
\hline Oniscus sp.... & . . & . & . & . & . & -6 & Roedel (698) \\
\hline Tinea besiliella ... & . . & . & . & . & . & tiefer als -8 & Howard $(391 a)$ \\
\hline Smerinthus populi. . & . . & . & . & . & . & -10 & Roedel (698) \\
\hline Melolontha vulgaris. & . . & & . & . & . & tiefer als -14 & Ponchet (642a) \\
\hline Lecanium vini ... & . . & . & . & . & • & $\pi \quad n-18$ & Goethe (317) \\
\hline Systoechus leucophacn & & . & . & . & . & $r \quad-19$ & Stepanow (846) \\
\hline Vanessa io..... & . . & . & $\because$ & . & & $" n$ & Pouchet $(642 a)$ \\
\hline Euproctis chrysorrhoe & & . & . & . & . & -20 & Grevillius (329) \\
\hline Erebia-Species.. & . . & . & • & - & . & tiefer als -35 & Holland $(383 \alpha)$ \\
\hline Oeneis-Species.. & & & - & - & - & $n \quad n \quad r$ & $n \quad=$ \\
\hline Lamia sp. . . . & . . & & . & . & & $"-42$ & $\operatorname{Ross}(704 a)$ \\
\hline \multicolumn{8}{|c|}{ Puppen resp. Nymphen. } \\
\hline Culex-Species . . & . . & & - & • & . & -4 & Galli-Valerio und J. Rochaz \\
\hline Anopheles-Species & is . & . & • & . & & -4 & de Jongh. $(271) \xi, 270 \gamma)$ \\
\hline Vanessa-Species. & . . & & . & . & - & tiefer als -14 & Urech (896) \\
\hline Pieris brasicae . . . & . . & ${ }^{\circ}$ & . & . & . & $n-16$ & Réaumur (673) \\
\hline Vanessa-Species. & . . & & - & - & - & $n \quad-20$ & Standfuss (841) \\
\hline$"$ & - . & & • & - & • & $n$ & Fischer (229) \\
\hline$n, n$, & . & - & - & - & - & $n$ & Frings (258) \\
\hline Pieris brassicae. . . & . . & & . & . & & $n-25$ & Roedel, (698) \\
\hline
\end{tabular}




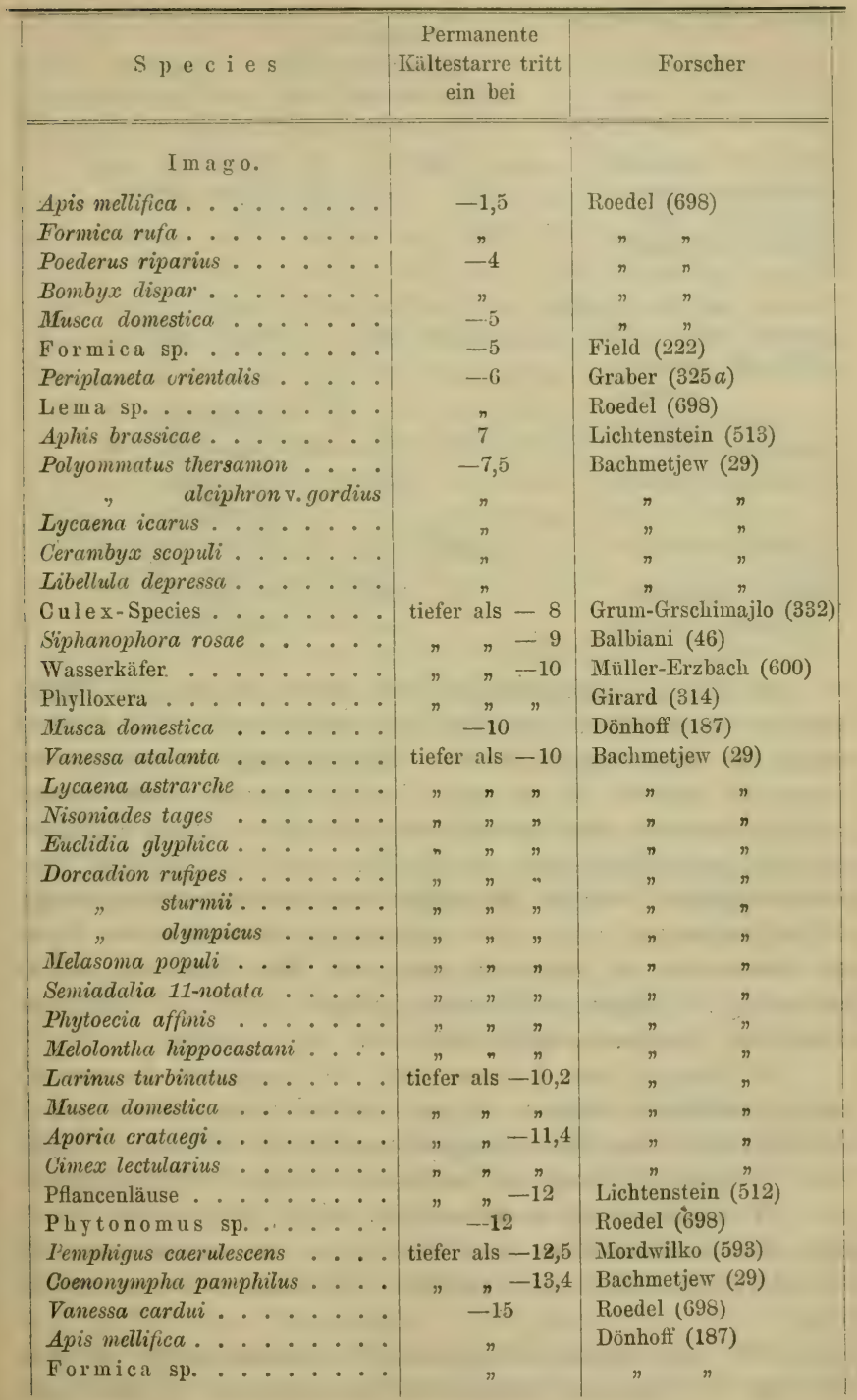




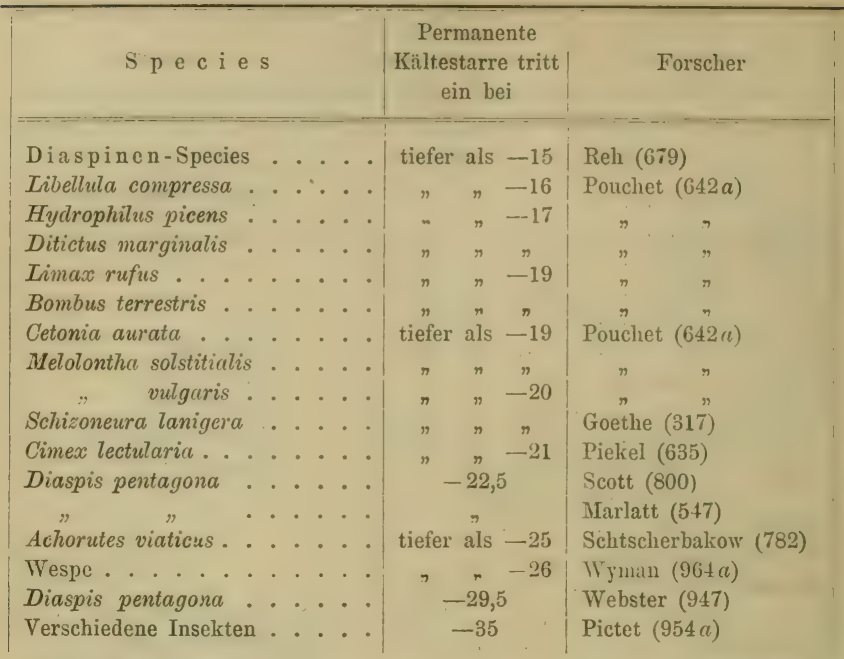

Aus dieser Zusammenstellung ist ersichtlich, dass die Temperatur, bei welcher Eier verderben, noch von keinem Forscher erreicht. worden ist, obwohl dabei sehr tiefe Temperaturen, wie z. B. $-50^{\circ}$, angewendet wurden. Es ist wahr, dass die Eier von Bombyx mori z. B. in Versuchen von Verson (914) bei -30 zu Grunde gingen, aber dies geschah erst dann, als die Eier plötzlich auf diese Temperatur abgekiihlt wurden; sie blieben aber noch entwickelungsfähig, als die Temperatur bis zu $-30^{\circ}$ allmählig erniedrigt wurde. Es ist hier interessant zu bemerken, dass, wie Mac Kendrick (447a) ermittelte, die Sporen von Microben im faulen Blute und in anderen organischen Substanzen nicht einmal bei $-182^{\circ}$ sterben.

Bei Raupen resp. Larven liegt die Temperatur der permanenten Kältestarre zwischen $-4^{\circ}$ und $-42^{\circ}$ oder tiefer. Für Pu ppen resp. Nymphen liegt diese Temperatur zwischen $-4^{\circ}$ und $-25^{\circ}$ oder tiefer, während für Imago sie zwischen $-1,5^{\circ}$ und $-35^{\circ}$ variert.

Wir können somit im allgemeinen sagen, dass je höher das Entwickelungsstadium des Insekts ist, um so weniger tief die Temperatur ler permanenten Kältestarre für dasselbe liegt.

Worin mag nun der Grund dieser Erscheinung liegen? Es kann sein, dlass von allgemein biologischem Standpunkt aus die Kältestarre 
bei höheren Entwickelungsstadien deshalb früher als bei niedrigen entritt, weil die Differenzierung der Organe schuld daran ist, vom physikalischen Standpunkt aus aber lässt sich dieser Vorgang durch verschiedene Unterkältungsgrade der Säfte erklären.

Wie ich bereits im I. Bande meiner "Studien" (29), zuerst aber in "Naturwissenschaftlichen Rundschau" (v. p. 1602-1611. St.-Petersburg 1898) nachgewiesen habe, erleiden die Insektensäfte bei der Abkiihlung unter $0^{0}$ eine Unterkältung, welche in erster Linie von der Ablkühlungsgeschwindigkeit abhängt. Sind aber alle Umstände, bei welchen diese Unterkältung stattfindet, für alle Insekten gleich, dann hängt ler Unterkältungsgrad von den Dimensionen der Blutgefässe resp. der Zellen ab.

Diesbezügliche Untersuchungen stellte ich mit para-Nitrotoluol in Form von Kï̈gelchen an, welche in einer wässerigen Lösung von $\mathrm{CaCl}_{2}$ schwammen (28a). Die Unterkältung dieser Kügelchen war umso tiefer, je kleiner ihr Durchmesser war. Dass eine Flüssigkeit eine desto stärkerc Unterkältung zeigt, je enger das Kapillarröhrchen ist, war schon lange bekannt.

Somit vird eine umso tiefere Unterkältung in Gefässen (resp. Zellen) der Insekten stattfinden, je geringere Dimensionen ihre kleinste Axe besitzt. Daraus folgt, dass die erwähnte kleinste Axe bei Inagines grösser sein dürfte als bei Puppen, und bei Puppen grösser als bei Raupen.

Der Unterkältungsgrad der Säfte im Insektenorganismus spielt eine wichtige Rolle im Insektenleben schon deshalb, weil Insekten durch direkten Einfluss der Temperatur nie zu Grunde gehen, solange ihre Säfte noch flüssig bleiben; erst beim Gerinnen (ler Säfte (bei hoher Temperatur) ist das Inselkt sicher tot, oder kann nach dem Erstarren der Säfte bei gewissen Belingungen die permanente Kältestarre erhalten; also in beiden Fällen müssen die Säite zuerst fest sein.

Nun hängt der Unterkältungsgrad von der Abkühlungsgeschwindigkeit der Säfte ab und kann unter Umständen eine sehr erhebliche Grösse erreichen (siehe den I. Band meiner "Studien"). Während dieser Zeit und in diesem Zustande hat das Insekt keine permanente Kältestarre, wie es z. B. Wyman (964a) beobachtete: „Eine Wespe bei $-26^{\circ}$ war nicht gefroren und machte beim Anrühren noch reflektorische Bewegungen." Wir haben somit das Mittel in Händen, die Insektensäfte bis zu einer beliebig tiefen Temperatur im fluissigen Zustande zu erhalten: es muss nur eine passende 
Abkühlungsgeschwindigkeit gewählt werden. Diese Möglichlieit erscheint umso wahrscheinlicher, da auch Tammann ${ }^{1}$ ) in (ler letzten Zeit sehr stark unterkühlte Flüssigkeiten kurch passende Abkïhlungsgeschwindigkeiten erhielt, welche bei noch stärkerer Unterkiiltung nicht mehr erstarren können und sich in "amorphe" liörper (harte Flüssigkeiten) umwandeln.

Schon daraus wird es kilar, dass die permanente fïultestarre nicht bei einer bestimmten tiefen Temperatur eintritt, sonclern auch bei den tiefsten Temperaturen vermielen werlen kann (virgleiche Mac Kendrick [447a]). Und doch tritt diese Starre dlurch die Einwirkung der tiefen Temperatur ein. Meine Untersuchungen zeigen, dass sie erst nach dem kritischen Punkt $T_{1}$ (Fig. 9) eintreten kann.

Bei cliesem Punkt erscheint in Inselitensäften ein Embryo des Eis-Krystalls, welches das weitere Erstarren der Sä'te bedingt, wobei die Temperatur des Insektes bis zum Punkte $N_{2}$ anf ein Mal steigt (bis zum normalen Erstarrungspunlit in Folge des Freiwerdens der Erstarrungswärme). Die Erstarrung der Insektensäfte wirl bei ca. $-5^{0}$ vollendlet $(32 a)$ und bei $T_{3}$ beginnt die permanente Kältestarre.

Dieser Punkt $\left(T_{3}\right)$ liegt nicht bei einer bestimmten Temperatur, sondern, wie ich es früher (24) vermuthet habe, bei derselben Temperatur, bei welcher der Punkt $T_{1}$ liegt. Anlass zu dieser Vermuthung gab mir ein sehr zahlreiches Material eigener Untersuchungen. Später fand ich von 153 Fällen 24 Fälle, welche mit dieser Regel nicht überreinstimmten (29); deshalb betrachte ich diese Regel nicht für allgemein gültig, sondern nur als einen speziellen Fall und zwar gilt sie nur für eine gewisse mittlere Abkühlungsgeschwinligkeit des Insektes.

\section{Anabiotischer Zustand.}

Auf der Curve (Fig. 9) befindet sich ein Rayon zwischen den Punkten $T_{2}$ und $T_{3}$, in welchem die Insekten sich in der Anabiose befinden. Wir wollen dieses Rayon nïher betrachten.

Durch kalorimetrische Messungen ter Schmetterlingspuppen habe ich festgestellt, dass die Insektensäfte vollstänclig erst bei $-4,5^{\circ}$ erstarren $(32 a)$, und zwar:

bei $-1,05^{\circ}$ erstarren $31 \%$ der Säfte in der Puppe

$\begin{array}{llllllll}n-2,0 & n & 73 & n & n & n & n & n \\ n-3,0 & n & 88 & n & n & n & n & n\end{array}$

1) G. Tammann. Zeitschr. für phys. Chemie. XXV. dỉ 3. p. 441. 1898. 
bei $-4,0^{\circ}$ erstarren $97 \%$ der Säfte in ler Puppe " $-4,5 \quad 100 \quad$ " n" "

Somit liegt der Punkt $T_{2}$ auf der Curve bei ca. $-5^{\circ}$. Wie ich gezeigt habe (29), sterben die von mir untersuchten Insekten beim Gefrieren der Süfte nicht, sonclern viel später (beim Punkte $T_{3}$ ).

Auf diese Art erhalten wir einen Zustand des Insektes, in welchem es keinen Stoffwechsel haben kamn, denn seine Säfte sind erstarrt, wodurch die Blutzirculation unmöglich wird. Ein Insekt ohne Stoffiwechsel kann nicht als lebend betrachtet; es ist aber auch nicht gestorben, da es den Punkt $T_{3}$ noch nicht erreichte. Es befinclet sich folglich zwischen $T_{2}$ und $T_{3}$ in leblosem (anabiotischem) Zustande.

Dieser Zustand ist nicht ein lethargischer, denn bei der Lethargie geht der Stoffirechsel, wenn auch selır langsam, dennoch vor sich, bis das Insekt schliesslich an Erschöpfung stirbt. Dieser Zustand kann vielmehr mit eincr Penleluhr verglichen werlen, bei welcher das Pendel absichtlich zum Stillstehen gebracht wurde. Die Uhr ist dabei nicht verdorben, geht aber nicht. Ein Stoss auf das Pendel und die Uhr ist wieder intakt. Wie die Uhr mit stillstehendem Pendel umbegrenzt lange Zeit unverdorben bleiben kann, so kann vermuthlich auch dias Inselit im anabiotischen Zustande beliebig lange Zeit verbleiben, ohne dabei zu sterben.

Die Thatsachen, welche in Kapitel I (Einfluss der Temperatur auf (lie Entwickelungsgeschwindigkeit), angeführt sind, wobei Insekten, nachdem sie sogar bis $-35^{\circ}$ abgekühlt wurden und dabei ganz gefroren waren, nach dem Authauen wieder auflebten, beweisen das Vorhandensein des anabiotischen Zustandes.

Ich werde hier nur eine dieser vielen Thatsachen anführen. In dem Anhange zur zweiten Reise des Capitän Ross (704u) zur Auffinclung der nordwestlichen Durchfahrt finclet sich fulgendes Faktum angeführt: Ungefähr 30 Raupen wurlen Mitte September in eine Büchse gethan und während der nächsten drei Nonaten der strengen Wintertemperatur ausgesetzt. Man brachte sie dann in eine warme Kajüte, wo sie alle binnen weniger als 2 Stunden wieder lebendig wurden. Sie wurien abermals einer Temperatur von $-33,5^{\circ} \mathrm{R}$. ausgesetzt und froren augenblicklich zu Eis. In diesem Zustande blieben sie eine Woche, und als man sie wieder in die Wärme brachte, kamen nur 23 wieder zum Leben. Diese liess man nach 4 Stunden noch einmal hart gefrieren und nach 8 Tigen wieder aufthauen. Diesmal kamen nur 11 Stiick mit dem Leben davon. Bei 
einem vierten Versuche gleicher Art erwachten nur noch 2 zum Leben, die den ganzen Winter übertauerten und sich zu einem Gespimnst verpuppten. Eine gab einen vollkommenen Falter, Lamia, aus der anderen schliipften 6 Fliegen aus.

Die ausfiihrliche Litteratur, welche sich speciell auf die Anibiose bezieht, finclet sich in meiner Abhandlung: "Biologische Analogien bei schwimmenden p-Nitrotoluol-Küigelchen" (38a); andere meiner Abhandlungen über die Anabiose sind an anderem Orte zu lesen $(27 a, 29 a, 31 a, 32 b)$.

\section{Einfluss der Feuchtigkeit.}

\section{a) Eier.}

Lepid op teren-Eier liönnen mehrere Tage (bis zu 40) olme Scha(len im Wasser verbleiben (Bombyx mori: Caretta [136]; Pentophora morio: Aigner-Abafi [6]); einige Arten dagegen gehen dabei balıl zu Grunde (Heterodera schachtii: Vanha und Stoklasa [901a]).

Je frischer die Eier sind, desto schneller ersticken sie im Wasser (Caretta [136]).

Die Sterblichlieit der Eier einer und derselben Species im Wasser ist für verschiedene Rassen verschieden (Carotta [136]).

Die Feuchtigkeit beschleunigt noch verzögert die Entwickelung einiger Arten (Dendrolimus pini: Serebrjanikow [808a]), während bei anderen Arten dabei eine Beschleunigung beobachtet wird (Locustiden-Eier: Bruner [117]). Das Eintauchen der Eier ins Wasser verzögert die Entwickelung der Eier einiger Arten (Dendrolimus pini: Serebrjanikow [808a]).

Die periodische Fortpflanzung der Heuschrecken wird durch periodische Schwankungen les Wasssers in den Seen bedingt (970); Psilura monacha pflanzt sich riesig fort bei minimalem Niveau des Grundwassers (Obuchow [613]).

\section{b) Raupen.}

Raupen verschiedener Species können im Wasser einige Stunden bis zu einigen Tagen ohne Schaden verbleiben (Saturnia spini 4 Tage: Hüttner [398]); Xylina-Arten 17 Stunden: Rühl [721]; Hibernia-Arten 8 Stunden: Gauckler [280]; RhopaloceraArten 4 Stunden: Rühl [721]; Heterodera schachtii 5 Tage: Vanha 
und Stoklasa [901 a]). Auch die Larven vom Maikäfer könne- unter Wasser 1 Monat ohne Schaden verbleiben. Die Larven von Lamellicornia, Rhizotrogus, Melolontha und Cetonia halten unter diesen Umstänilen 6 Tage aus (Tarnani 854]).

Die Entwickelung gewisser Raupen-Arten wirl durch Feuchtigkeit begünstigt (Acherontia atropos: Gauckler [292]: Sesia unuelata: Tomala [876b]; Conchylis ambiguella: Dowitz [177a]; während dieselbe der anderen Arten dabei schwächer vor sich geht (Oenophthira pilleriana: Dowitz [177a]; Bombyx mori: Bataillon [54a, 54b]; Cecidomyia destructor-Larven: Enock [214 $\propto]$ ).

Raupen, die an trockienen Stellen leben, ertragen die Feuchtigkeit nicht (Gauckler [291], Pabst [621]).

Zur Verpuppung gewisser Larven-Arten ist rlie Feuchtigkeit nothwendig, sonst verbleiben sie Jahre lang, ohne sich zu verpuppen (Systocchus leucophueus: Stepanow [846]; Lygellus epilachnae: Giard [308]; Sciaria medullaris: Giard [308b]), während Regengüsse oder starke Feuchtigkeit für andere Arten schädlich sind (Larven von An isoplia-Käfer: Jaroschowsky [418]; Raupen von Anisopterix aesularia: Schowyrew [748]; Bombyx mori: Bataillon [54a, 54b]: Notodonta dromedarius, Plieosia dictaeoides, Ph. tremulae, Pterostama palpina, Pygaera pigra, Acronycta leporina, Arctia caja, Lasiocampa potatoria: Federley [219]).

Gewisse Raupen-Arten lieben die Feuchtigkeit nur in hohen Regionen, in (ler Ebene aber nicht (Bombyx abrusculae: Rühl [724]).

Die Entwickelung einiger Raupen-Species wird durch sehr saftige Blätter der Futterpflanze gestört (Bombyx mori: Stempkowska [\$4う], Schitkow [752]; Macroglossa fuciformis: Pabst [621]).

\section{c) Puppen.}

Die Puppenzeit wird unter dem Einfluss der feuchten Luft abgekürzt bei folgenden Arten: Smerinthns populi, Acronycta auricoma, Acronycta ligustri, Notonda ziczac, Nemeophila plantaginis, Deilephila cuphorbiae, Macroglossa stellatarum, Deilephila porcellus (Kusdas [488]), Saturnia spini, pavonia, pyri (Standfuss [837]), Cecidomyia destructor (Marchal [546]).

Die Entwickelung der Puppen wird durch die Feuchtigkeit bei folgenden Arten begünstigt: Acherontia atropos (Gauckler [292]), Stauropus fagi (Breit [112]), Hiboc. milhauseri (Gauckler [297] Colias edusa (Koch [457a]). 
Der Feuchtigkeitsmangel verzügert die Entwickelung bei Lygellus epilachnae (Giard [308]), verkürzt sie bei Puplen von Pieris brassicae (Urech [889]), begünstigt lieselbe bei einigen Wurzelläusen (Mokrzecki [584]) und bleibt olne Einfluss leei Fanessa urticae und in (v. Linden [527e]).

Anhaltender Regen ist ungünstig für die Entwickelung von Coprophagen (Bogdanow [92]) uml ron len meisten KäterLarven (Alisch [9]).

Bei noch grösserer Feuchtigkeit finılet ،lie Verkriippelumg der auszuschlüpfenden Schmetterlinge der meisten Arten statt, inclem die Krallen der Vorderfïsse sich selnr schwach entwickeln, wobei die Ausbililung tler Fliigel gehindert wiril, da die Falter ilıren hörper nicht melr tragen künnen (Weismann [954], Schulz [789]).

Starke Feuchtigkeit fördert sehr die Entwickelung der Inseliten: Ocneria dispar, monachu, Isophia taurica, Capnoctis tenelmionis, Perotis luyul,ris, Eurygaster maurus (Mokrzecki [583a]).

Beim Niveau-Ninimum des Grunilwassers pflanzen sich gewisse Species massenhaft fort (Psiluru monacha etc.: Obuchow [613]).

\section{d) Imago.}

Einige Arten leiden Feuchtigkeitsschwankungen nicht (Orchesellu rufescens var. silvestris: Skorikow [817]).

Starke Feuchtigkeit wirkt schïllich auf einige Insekten-Species (Dorcadion sturmii: Bachmetjew (p. $57+$ des II. Bancles der "Stuctien ${ }^{4}$ ), währeni clie anteren Species sich labei sehr günstig entwickeln (PHanzenläuse: Mokrzecki [584, 585]).

Einige Käfer-Species halten die trockene Wärme nicht aus un! sterben dabei (Anaurorhinus und Chrypharis: Dieck [178]: Höhlen-Käfer: Joseph [423ß]).

Einige Species verfallen bei trockener uni warmer Luft in lethargischen Zustant (Phytodecta viminalis: Kolbe [463]; Heteroderu schachtii: Strubell [848a]; Entomosceli adonidis: Sajó [730]; Zubrus tenebroides, Entomosceli acloniclis, Eurypaster maurus: Mokrzocki $[587 a])$.

Die verschiedenen Arten der Imagines halten verschielen lange Zeit unter lem Wasser aus ohne zu sterben (Cleonus punctiventris 2 Tage: Ganitzki [271]; A. austrica 3 Tage: Kulikowski [484]; Stenamma fulvum 8 Tage: Field [222], Ameisen 41/2 Tage: De$\operatorname{vaux}[167 \alpha])$. 


\section{Theorien dieses Einflusses.}

Wie die Temperatur so auch die Feuchtigkeit sollte ihr Optimum für die günstigste Entwickelung der Insekten haben. Leider sind solche Untersuchungen bis jetzt noch nicht systematisch angestellt worden, um allgemeine Schlïsse ziehen zu können. Man weiss nur, dlass, während die starke Feuchtigkeit für gewisse Species sehr schädlich ist, dieselbe die Entwickelung anderer Species sehr günstig. förilert. Daraus können wir schliessen, dass das Feuchtigkeit-Optimum für verschierlene Species nicht dasselbe bleibt.

Die Feuchtigkeit kann direkt und indirekt auf die Insekten wirken.

Direkte W irkung der Feuchtigkeit besteht darin, dass bei dem Mangel derselben gerwisse Raupen- und Puppen-Species in Folge Verdunstung des Sattwassers aus ihrem Körper sich besser entwickeln können, wie es z. B. Jrech (889) für die Puppen von Pieris brassicae fand. Seine Versuche zeigen nänlich, dass die Entwickelung dieser Puppen in trockener Luft etwas kiirzer ist als in der feuchten. Diesen Unstand erklärt er dadurch, dass in trockener Luft die Verdunstung des vor dem Auskriechen nothwendig zu secernierenden Saftwassers erleichtert wird. Findet diese Verdunstung des Saftwassers nicht statt, so erleiden die Imagines der meisten Arten eine Verkrïppelung, indem die Krallen der Vorderflügel sich sehr schwach entwickeln, wobei die Ausbildung (bei Lepidopteren) der Flügel gehindert wird, da die Falter ihren Körper nicht mehr tragen können (Weismann [954], Schultz [789]).

Indirekte Wirkung der Feuchtigkeit besteht darin, dass die Raupen und Puppen bei sehr starker Feuchtigkeit durch verschiedene Pilz-Iŕrankheiten geschwächt werden resp. daran sterben. Auch das zu feuchte Futter verursacht bei Raupen eine Störung der Verdaungsorgane (Standfuss [835]).

Von Krankheiten der Raupen sind bekannt: 1) der Darmkatarrh, 2) die Muscardine oder Kalksucht, 3) die Schwindsucht, 4) die Gelboder Fettsucht (Grasserie), 5) die Pebrine odler Gattina, 6) die Flacherie oder Schlaffsucht (nicht Schlafsucht). Einige dieser Krankheiten sind sicher den Feuchtigkeitsverhältnissen zuzuschreiben.

Dass die indirekte Wirkung der Feuchtigkeit auf die Raupen ziemlich kompliziert ist, ist aus folgender Stelle der Abhandlung von E. Fischer (240a) ersichtlich: „Die genannten Fülle sind vielmehr darauf zurückzuführen, dass bestimmte Pflanzen in nassen 
Sommern durch fortwährenıl zu starke Benetzung der Blätter mit Regen und die darlurch behinderte Transpiration, sowie infolge zu starker Durchtränliung des Bodens mit Wasser uni die dadurch bedingte Schäligung der Wurzeln unıl auch durch anhaltend starke Wasseraufnahme eine Stoffwechselabnormitait, zum minlesten eine chemische Veränderung der Blätter erfahren, wie wir sie beim Kontrollversuche mit eingefrischten Pflanzenstengeln in kurzer Zeit enttehen sahen. Anclererseits werden in heissen Jahrgängen iturch starke Austrocknung die Blïtter erfahrungsgemäss ebenfalls geschïdigt; nur kommt es dabei vor, dass die mehr trockene Nahrung die Entwickelung der Raupe zur Puppe wesentlich beschleunigt; was man bei antiopa, polichloros, xanthomelas, curdui u. a. wierlerholt beobachten konnte. Auch aus der Pflanzenwelt ist es bekannt, dass Trockenheit, venn nicht zu extrem, die Reifung beschleunigt, aber dabei das Wachstum, d. h. die Massenzunahme des Individuums beeinträchtigt. Durch die schnellere Entwickelung entgehen aber viele Raupen der Infektion, denn je länger jene dauert, desto grösser ist für eine bestimmte Art das Risiko, was gleichfalls bei den Raupenzuchtē̄ zu konstatieren ist.". (p. 536):

Andererseits ist bekannt, dass das Befenchten der Cocons von Saturnia-Arten (Standfuss [837]) die Puppenzeit bedeutend verkürzt. Diesen Umstand kïnnte man dadurch erklären, dass die Feuchtigkeit die im Cocons sich befindliche Kohlensäure (Jạnichen [415]) absorbiert und auf diese Weise den neuen Stoffwechsel der Puppe hervorruft. Es ist hier interessant, das von Standfuss (840) aufgestellte Gesetz anzuführen: "dass Arten mit langer Puppenruhe die Falter im Frühling oder im späteren Herbste, also nach Zeiten umfangreicher Niederschläge, liefern, während sich die Sommerfauna fast durchweg aus schnell sich von der Puppe zum Falter entwickelnden Arten zusammensetzt ${ }^{*}$. (p. 185).

\section{Einfluss des Lichtes.}

\section{a) Eier.}

Die Dunkelheit und das gelbe Licht verzögern die Entwickelung der Eier einiger Species; die anderen Lichtstrahlen wirken verschieden bei verschiedenen Rassen (Bombyx mori: Schmujdsinowitsch [758]). Keinen Einfluss der Lichtstrahlen erhielten Béclard (57) mit Musca: 
carnaria, Bellati und Quajat (62) mit Bombyx mori, Serebrjanikow (808a) mit Dendrolimus pini.

\section{b) Raupen.}

Die Dunkelheit verzögert die Entwickelung der Raupen (Vanessa carclui: Weismann [954]; Bombyx mori: Schmujdsinowitsch [758]; Crateronyx dumi: A. L. [1]; Arctia cuja: de Lafitole [493]).

Das dunkelrothe Licht wirkt schädlich auf Raupen von Vanessa urticae (Möllonborger [596a]).

Verschiellene Lichtstrahlen wirken verschierlen stark auf die Entwickelung; nach abnehmender Reihenfolge orlnen sich die Strahlen wie folgt:

Blau, Gelb, Dunkel-Violett, Roth, Grün (Schmujdsinowitsch [7581) Violett, Blau, Roth, Weiss, Grün . . (Béclard [57])

Violett, Blau, Roth . . . . . . (Schoch [770])

Violett, Weiss, Roth .......(Gal [270]).

Daraus folgt, dass die Entwickelung am stärksten von violettem Lichte und am schwächsten von grïnem Lichte begïnstigt wirl.

\section{c) Puppen.}

Farbiges Licht, je nach iler Farbe, wirkt verschieden stark auf die Entwickelung. Violettes Licht beschleunigt die Entwickelung (ler Puppen stärker als Tageslicht (Arctia caja: Schoch [770], Standfuss [840]).

Die Dunkelheit verlängert die Puppenzeit (Vanessa urticae: Kathariner [440]).

Gelbrothe Lichtstrahlen förilern die Aufnahme der Kohlensäure durch die Puppe (v. Linden [527 d]).

\section{d) Imago.}

Einige Insekten werden durch das Tageslicht sehr beunruhigt (Gryllus domestica: Rodsjanko [696]; Drosoplhilu ampeloplita: Carpanter [132a]; Ranatra: Holmes [384a]; Lasins flavus und Formica sanguinea: Forel und Dufour [202a, 241a] etc.) unil sterben sogar in wenigen Minuten (Dicyrtoma, Heteromurus, Tritomurus, Gamasus nevius: Absolon [2]).

Die Bettwanze hält verschierlene Lichtstrahlen verschieden lange Zeit aus; am stärksten wirkt das weisse Licht, dann violettes und schliesslich blaues, grünes und rothes (Pickel [635]). 


\section{Theorien dieses Einflusses.}

Es ist vielfach gesagt worlen, dass die stärlier brechbaren Lichtstrahlen die Lebensprozesse fördern, während die schwächer brechbaren Strahlen dieselben hemmen. Dies soll sowohl für Pflanzen wie für Thiere ihre Geltung haben (Hertwing [370b]). Sachs (729) zeigte aber, dass das Chlorophyll sein Maximum der zersetzenden Wirkung in Bezug auf die liohlensäure bei schwächer brechbaren Lichtstrahlen hat; dagegen steht die Bliitenbillung mit der Anwesenheit der stärker brechbaren Strahlen in nahem Zusammenhange.

Wenn wir in Betracht ziehen, dass z. B. für die Höhlenthiere das Vorhandensein des Lichtes selı schällich ist (Absolon [2]) unıl dass gewisse Larven resp. Raupen nur dann gut gedeihen, wenn sie z. B. im Inneren des Baumstammes, in der Erle orler schliesslich einfach im Schatten sich befinden, so müssen wir mit Kathariner [440] sagen: "Je nach dem Organismus und dem organischen Prozess ist bald der eine, bald der andere Theil des Spektrums von fördernder oder hemmender Einwirkung."

Ausserdem muss man dabei die Entwickelung von dem Wachsthum streng unterscheiden, denn, wie Kathariner sagt, die erstere (organische Differenzierung) von letzterem (Massenzunahnne) ganz unabhängig sein kann.

Wie die Versuche von Weismann (954), Schmujdsinowitsch (758) A. L. (1), de Lafitole (493) und Möllenberger (596a) ergeben, wir il die Entwickelung der Raupen im Dunkeln verlangsamt, und zwar zuweilen so stark, dass sie dabei sterben. Die Verlangsamung in der Entwickelung im Dunkeln findet auch bei Puppen statt (Weismann [954], Kathariner [440]). Hier muss bemerkt werden, dass diese Versuche mit Arten angestellt wurden, welche unter normalen Umständen sich beim Tageslichte entwickeln. Daraus könnte man den Schluss ziehen, lass diejenigen Arten, welche sich normalerweise im Dunkeln entwickeln, in ihrer Entwickelung durch Licht gehemmt werden. Es fehlt jerloch an Versuchen, welche diese Schlussfolgerung bestättigen sollten.

Was nun den Einfluss verschiedener Strahlen des Spelitrums auf die Entwickelung der Raupen resp. Larven anbelangt, so haben wir die Versuche von Schoch (770) und Standfuss (840), welche ergeben, dass das violette Licht die Entwickelung beschleunigt. Auch hier wurde mit Arten experimentiert, welche sich normaler- 
weise beim Lichte entwickeln. Die anderen Strahlen wirken schwächer; so wirkt das rothe Licht schwächer als rlas violette.

Wollte man den Einfluss verschiedener Lichtstrahlen auf die Entwickelung durch chemische Aktivität erklären, dann müssten sie die folgende absteigende Reihe bilden: Violett, Blau, Grün, Gelb, Orang, Roth. Die Versuche von Schoch (770) geben: Violett, Blau, Roth, was der nöthigen Reihenfolge entspricht; dagegen ergeben die Versuche von Schmujdsinowitsch (758) die Reihe: Blau, Gelb, Dunkel-Violett, Roth, Grün, was (ler chemischen Aktivität widerspricht. Wir können somit mit Kathariner (440) sagen: "Von chemisch aktiven bezw. inaktiven Strahlen im allgemeinen darf in der Biologie nicht die Rede sein, wie dies schon Sachs vor Jahren mit berechtigter Schärfe betont hat."

Sollten die chemischen Prozesse, welche in der Puppe während ihrer Entwickelung vor sich gehen, der Lichtwirkung zugeschrieben werden, dann müsste eine Vermehrung der Oxydation bezw. der Kohlensäureabgabe unter dem Einflusse des Lichtes stattfinden. Loeb (533) hat aber gefunden, dass dies nicht der Fall ist, und dass das Licht bei Schmetterlingspuppen hemmend aut die Oxydation wirkt.

Wir haben hier offenbar mit sehr komplizierten Erscheinungen $\mathrm{zu}$ thun. Einerseits können hier Faktoren elektrischer Natur die Rolle spielen, wie z. B. die Photoelektrizität, welche mit der Elektrizität der Zellen in Wechselwirkung steht (Bernstein [77a]) und welche die Entwickelıngsreize im Organismus hervorrufen und sie auch modifizieren kann. Andererseits kann das Wachsthum des Organismus nicht parallel mit der Entwickelung verlaufen, wobei der Stoffwechsel eine komplizierte Funktion der Wirkung von verschieden gefärbten Lichtstrahlen sein kann. Auch können hier Lebensvorgänge bestehen, welche denjenigen der Pflanzen analog sind, wie v. Linden (527c) dies bei Schmetterlingspuppen konstatierte. Sie fand auch $(527 d)$, dass gelbrothe Lichtstrahlen die Aufnahme der Kohlensäure durch Puppen fördern. Hinzu können noch phototropische Erscheinungen kommen, welche Rádl (671c) durch den Lichtıruck zu erklären versucht. Allerdings ist dieser Lichtdruck sehr gering (1 mgr. auf $1 \mathrm{~m}^{2}$ ), aber er kann nur die Rolle des schwachen Linienstromes im Telegraphenapparat von Hughes spielen, um den starken Lokalstrom (die inneren Kräfte des Organismus) zur Wirkung zu bringen (Rádl [671b]). 


\section{Einfluss der Elektricität und des Magnetismus.}

\section{a) Eier.}

Werden die Eier von Bombyx mori für eine kurze Zeit ins elektrische Feld (stille Entladung) gebracht, so wird ihre Entwickelung dadurch begünstigt (Bellati und Quajat [62], Verson [921, 922]). Die wiederholte Wirkung der Elektricität ist schärllich (Bellati unı Quajat [62]).

Die Nachtheile für diese Wirkung der Elektricität sind: Feuchtigkeit, Temperaturerniedrigung und das Alter (Bellati unil Quajat [62]).

Röntgen-Strahlen halen keinen Einfluss auf die beschleunigte Entwickelung [Bellati [64]).

Während Bellati und Quajat (6:2) keinen merklichen Einfluss des magnetischen Feldes auf die Entwickelung konstatieren konnten, fand Schmujdsinowitsch [7.56], dass dieses Feld bei gelber franzüsischer Rasse von Bombyx mori die Entwickelung beschleunigt und bei der weissen Bagdader Rasse dieselbe verzögert.

Die elektrisierten Eier von Bombyx mori athmen viel enfrgischer als die gewöhnlichen (Quajat [662]).

\section{b) Raupen.}

Die Entwickelung der liaupen von Bombyx mori wird in magnetischen Felde verlangsamt und zwar desto mehr, je lïnger die Raupen unter diesem Einflusse sich befinden (Schmujdsinowitsch $[7.56]$ ).

Die Larven von Küfern, Fliegen und Bienen werden durch Röntgen-Strahlen beunruhigt (Axenfeld [18a], Weber [946a]); dagegen üben die radioaktiven Strahlen keinen schäıllichen Einfluss :uf die Raupen aus (v. Linden [52T门]). Raupen von Ephestia Tinehniclla sterben unter dem Einfluss der Radiumstrahlen (Danysz [163c]).

\section{c) Puppen.}

Elektrische Entlandungen hemmen die Entwickelung der Flügel (Pictet [636]).

Das magnetische Feld übt eine merkliche Beschleunigung auf die Entwickelung der Puppen aus (Schmujdsinowitsch [756]).

Röntgen-Strahlen wirken auf die Puppen unschädlich (Testenoire und Levrat [858]), auch wirl die Puppenruhe durch rallioaktive Strahlen nicht veränilert (v. Linden $[527 e]$ ). 


\section{Theorien dieses Einflusses.}

Warum die Eier von Bombyx mori durch verschiedene Mittel, wie Elektricität, Reibung, Säuren, heisses Wasser etc. aufgelebt werden, d. h. statt zu überwintern, einige Tage nach der Einwirkung dieser Faktoren Räupchen ergeben, sagte Duclaux im Congress der Seidenzïchter in Mailand (1876. 202) unter anderen folgendles: „Die Elektricität, die Reibung etc. sind höchst wahrscheinlich nur verschiedene Mittel, um irgend einem physiologischen Mechanismus einen Stoss zu geben, welches ein Mal in Bewegung gesetzt, immer gleiche Wirkung erzeugt."

10 Jahre später schrieb A. Tichomirow [1886. 868]: „Uns sei es erlaubt, in dieser Beziehung etwas weiter zu gehen, als es Duclaux gethan hat. Jener unbekannte "physiologische Mechanismus," welchen er erwähnte, ist nicht melir und nicht weniger als eine der hauptsächlichen Eigenschatten, welche dem Ei sowoll, wie auch allem Lebenden eigen sind. Diese Eigenschaft ist der Reiz." Weiter sagt er: „Es ist kein Wunder, dass, während die Muskelfasern durch den Reiz contragieren, die Nervenzelle - den Impuls übermittelt etc., auch das Ei auf den Reiz mit seiner Entwickelung antwortet. Also in dieser Empfindlichkeit des Eies liegt nach meiner Meinung jene Grundursache, welche Duclaux aufsucht, um die Thatsache zu erklären, dass so verschiedene Mittel, wie die Reibung, die Elektricität, das Eintauchen in Säure etc. auf die Eier gleichartig einwirken. Die gleiche Wirkung aller dieser scheinbar so verschiedenen Mittel ist von meinem Standpunkt aus sehr bergreiflich: sie alle reizen die Eier."

Dieser Reiz darf seiner Grösse nach für die günstige Entwickelung eine gewisse Grenze (Optimum) nicht überschreiten, wie es auch die Versuche von Bellati und Quajat (62) zeigen. Sie konstatierten, dass die stille Entladung bei der Entfernung zwischen Spitzen von $2-3 \mathrm{~cm}$. keine Entwickelung der Eier hervorruft; erst bei grösserer Entfernung findet dieselbe statt. Auch clürfen die Eier nach der begonnenen Entwickelung durch Elektricität nicht mehr gereizt werden, da die Embryonen dabei gelehmt werden, gerade so, wie wenn die überwinterten Eier nach der Entwickelung im Brutofen wieder dem Einflusse der Iiälte ansgesetzt sein würden. Dass zu starke Einwirkung der Elektricität der Entwickelung schädlich ist, ergeben die Versuche von Pictet (636). 
Mit diesen Thatsachen stehen im Einklange auch die Versuche von Dogiel (189), nach welchen schwache Intunktionsströme eine Beschleunigung des Herzschlages bei Inseliten bewirken, während starke Ströme dasselbe verlangsamen und zum Stillstehen bringen.

Somit gielt auch hier das biologische Gesetz von Rudolf Arndt: "Kleine Reize fachen die Lebensthütigkeit an, mittelstarke förlern sie, starke heben sie auf."

Da es Insekten giebt, welche ihre Entwickelung im Wasser durchmachen, so kann man vermuthen, dass die elektrischen Entladungen in unserer Atmosphäre auf die Entwickelung dieser Insekten einen gewissen Einfluss ausüben werlen, indem der Sauerstoffgehalt im Wasser dabei geändert wird.

0. Berg und K. Knauthe (71) untersuchten in dieser Beziehung den Einfluss der elektrisierten Luft auf den Sauerstoffgehalt des Wassers und kamen zum Schlusse, dass unter dem Einfluss elektrischer Spannungen, wie sie sich mit einer Elelitrisiermaschiene erzeugen lassen, in organisch verunreinigtem und in reinem Wasser eine starke Zehrung des aufgelösten Sauerstoffs stattfinclet. Diese Zehrung erklärt sich durch Annahme von elektrolytischen Prozessen, sowie von Bindung des Stickstoffs der atmosphärischen Luft. Durch den letzteren Prozess werden leicht oxydable Verbindungen geschaffen.

Die Versuche von Hans Euler (217) ergaben jedoch, dass „unter dem Einfluss der Luftelektricität der Gasgehalt von reinem oder von salz- und bakterienhaltigem, aber noch klarem Wasser nicht wesentlich geändert wird “ (p. 5). Er negiert aber den Éinfluss des in der Luft unter dem Einfluss der Elektricität gebilleten Ozons nicht, und glaubt, dass der Ozon die biologisch-chemischen Prozesse katalytisch beeinflusst.

Während die Röntgenstrahlen bei dauernder Einwirkung z. B. auf den menschlichen Organismus in demselben gewisse Störungen verursachen, ist ihre schädliche Wirkung auf Insekteneier und Puppen bis jetzt nicht konstatiert worden: sowohl Eier (Bellati [64]), wie auch Puppen (Testenoire und Levrat [858]) reagieren auf die Röntgenstrahlen nicht merklich; wohl aber ist der Einfluss dieser Strahlen auf Imagina und Raupen resp. Larven ein sehr bedeutender.

Axenfeld (18a) beobachitete, dass verschielene Insekten aus den Orinungen der Kïifer, Zweifliigler und Hauttlïgler unter dem. 
Einfluss der Röntgenstrahlen beunruhigt werden und davon laufen. Er erklärt diese Erscheinung durch den Gesichtssinn, da liünstlich geblendete Thiere den Röntgenstrahlen nicht aus dem Wege gingen.

Weber (946a) ist gegen die Erklärung von Axenfeld, da seine eigenen Versuche mit den der Ocellen entbehrenden Larven von Oryctes nasicornis ergaben, dass diese Thiere schon nach kurzer Zeit durch Röntgen-Strahlen beunruhigt werden und sich nach dem vor diesen Strahlen geschützten Platz begehen. „Es beweist eben wohl nur, lass eine Einwirkung auf Nervenendigungen der Haut stattgefunden hat, wie ja auch beim Menschen eine beachtenswerte Reihe von Fällen, wo nach langer Expositionszeit Hautenzïndung: mit Haarausfall eintrit, bekannt ist. Die vielleicht Schmerz erzeugende Einwirkung der chemisch wirksamen Strahlen hat die Flucht der Tiere vor denselben erzeugt."

Es sincl uns unzweifelhaft positive Resultate aus dem Gebiete der Botanik über die Wirkung der Röntgen-Strahlen bekannt.

So fand Koernicke $(461 \mathrm{c})$ an keimenden und auch an trockenen Pflanzensamen, dass die Röntgen-Strahlen das Wachsthum derselben hemmen, aber erst eine gewisse Zeit nach der Bestrahlung, wobei verschiedene Samenarten verschiedene Willerstandsfähigkeit gegen diese Wirkung besitzen (z. B. reagieren die Samen von Brassica napus viel schwächer als die von Vicia faba).

Widersprechende Resultate ergaben auch die Untersuchungen des Einflusses der Radiumemanation.

Gräfin v. Linden $(527 e)$ konnte keinen Einfluss der radioaktiven Strahlen auf die Entwickelung von Vanessa-Raupen uncl Puppen konstatieren, während Danysz (163c) einen sehr schädlichen Einfluss derselben auf die Raupen von Ephestia kuchniella beobachtete.

Die negativen Resultate von Gräfin v. Linden sind wohl durch die geringe Aktivität des zu ihrer Verfïgung gestellten Radiumbromids zur erklären, obwohl sie sagt, dass es ein als sehr aktiv erprobtes Radiumpräparat war und die Exposition bis zu 12 Stunden dauerte. Der Aktivitätswerth des Präparates von Danysz betrug 500.000.

Viel besser ist dieser Einfluss auf Bakterien und niedere Pilze studiert worden, was wir in Ermangelung anderer entornologischen Angaben hier in Kürze anfiihren.

Groen (327b) benützte bei seinen Versuchen 0,010 gr. Radiumbromid, wobei zur Wirkung hauptsïchlich $\beta$-Strahlen liamen. Untersucht wurden Mikroben: Staphylococcus pyogenes aureus, S. p. albus, S. cereus flavus, S. c. albus und etwa 20 pathogene Spaltpilze. Alle 
gingen nach 15 stündiger Exposition zu Grunde, nur die Sporen wurlen erst nach 72 Stunden getödtet. Auf die Entfernung von $10 \mathrm{~cm}$. wurile keine lieimtötencle Wirkung beobachtet.

Dixon $(185 \alpha)$ gebrauchte zu seinen Versuchen $0,005 \mathrm{gr}$. Ra:lium. bromid und auch nur $\beta$-Strahlen. Er untersuchte Bacillus pyocyaneus, B. typhosus, B. prodigiosus und B. anthracis. Die Exposition lauerte 4 Tage von der 4,5 mm. Entfernung. Die Bacillen starben dabei nicht, aber ihr Wachsthum wurde aufgehoben.

Dauphin (164a) untersuchte clie Entwickelung von Chlamyilosporen und fant, dass dieselbe um die Radiumröhre herum, wenigstens auf die Entfernung von $2 \mathrm{~cm}$. vom Centrum der Röhre, nicht stattfinclet. Die Pilze, welche noch weiter entfernt waren, entwickelten sich 4 Mal langsamer als sonst.

Koernicke (461c) untersuchte Schimmelpilze und Baliterien und erhielt im wesentlichen dieselben Resultate wie Dauphin. Zuerst finclet unter dem Einfluss (ler Radiumstrahlen eine Beschleunigung des Wachsthums statt und dann die Hemmung; diese Hemmung war voribbergehend und verschwand allmählig nach der Beseitigung der Bestrahlung. Dieselben Resultate erhielt er auch mit Samen von Brassica napus und Vicia faba.

Dorn, Baumann uni Valentiner (195a) benutzten Ruliumbromid mit dem Alitivitätswerth $=3000$ zur Untersuchung von pathogenen Bacterien, wobei $\beta$-Theilchen und $\gamma$-Strahlen zur Anwendung kamen. Typhusbazillen, Mäusetyphusbazillen, Choleravibrionen und Diphteriebazillen entwickelten sich unter dem Einfluss der Emanationsluft nicht und starben nach 5 Tagen.

Auch an anderen Thieren resp. Pflanzen sind Versuche mit Radiumemanation angestellt. worden:

Bohn (98a) ermittelte an Vorticellen, Planarien, Asseln, Daphnien und Anneliden, dass diese Thiere unter dem Einflusse der Radiumstrahlen in einen lethargischen Zustand verfallen.

Dixon (185 $\beta$ ) untersuchte die Wirkung der Radiumstrahlen $(0,005$ gr. Radiumbromid) auf die Keimung von Kressensamen. Es findet eine Verlangsamung der Entwickelung innerhalb eines Radius von $2 \mathrm{~cm}$. von dem Radiumbromid statt; auch gewisse morphologische Abänderungen dieser Keimlinge wurden beobachtet. Später war kein schïllicher Einfluss zu bemerken, obwohl der Versuch 13 Tage dauerte.

Willcock $(960 \alpha)$ wählte als Objekt für seine Untersuchungen Protisten und Süsswasserpolypen aus. Die Menge von Radium- 
bromid betrug $0,005,0,010$ und $0,050 \mathrm{gr}$. Einige Thiere bewegten sich sofort unter ,lem Einfluss der Radiumstrahlen, die anderen dagegen waren nach 2 Stunden todt, ohne vorher auf die Bestrahlung zu reagierẹn.

Tour $(879 a)$ untersuchte den Einfluss der Radiumstrahlen (Chlorradium) auf die Entwickelung des. Hühnchens im Ei und fand, dass dabei specifische Missbildungen in der Entwickelung stattfinden: stärker werden die centralen Theile des Keimes beeinflusst als die peripheren.

Bauchard, Curie und Balthazard (106a) liessen Mäuse Radiumemanation einathmen. Die Thiere starben dabei.

Alle diese Versuche zeigen somit, dass der Einfluss der Radiumstrahlen auf die Entwickelung der Organismen im allgemeinen hemmend ist; dies wird bei langdauernden Einwirkung resp. stärkerer Emanation beobachtet, wïhrenıl die kurzdauernde Emanation die Entwickelung beschleunigt. Der Umstand, lass eine Anzahl von Raupen in den Versuchen von Danysz (163c) nach 24-stündiger Einwirliung der Radiumstrahlen starb, der Rest aber während 6 Monaten am Leben blieb, während welcher Zeit die Controlraupen zweimal sämmtliche Metamorphosen der Entwickelung durchmachten, kann zur Erklärung mancher rïtselhaften Erschienungen benutzt werden. So z. B. überwintern einige Exemplare gewisser Puppenarten einige Jahre hindurch (z. B. Satımia spini, Deilephila cuphorbiae etc.). Die Ursache dieser Erscheinung kann ausser in den klimatischen Verhältnissen auch in der Radioactivität der das Puppenlager umgebenden Stoffe liegen, welche die Entwickelung der Puppen verlangsamen. Diese Vermuthung ist umso wahrscheinlicher, dass die Radioactivität, wie bekannt, vielen Stoffen eigen ist und wurde auch für den Erdboden nachigewiesen.

\section{Einfluss der Nahrung und ehemischer Stoffe.}

\section{A. Einfluss der natürlichen Nahrung.}

\section{a) Raupen und Larven.}

Die Ranpeuzeit hängt von der Futterpflanze ab. So beträgt dieselbe bei Bombyx, mori, gefuittert mit: Maulbeerblättern . . . . . . . . 29-33 Tage Cudrenia triloba (Sasaki [735]) … . 29-33 " 
Broussonetia kaempferi (Iwanow [406]). . . 40 Tage

Morus-Sorten (Iwanow [406])

Lattich (Kellog und Bell [447])

Scorzonera hispanica (Schitkow [752])

Die Anzahl der Häutungen bei der Futteränclerung änclert sich bei gerwissen Species (Bombyx mori: bei Lattich [Kellog und Bell, 447] und bei Cudrenia triloba [Sasaki, 735] nur 4 statt 5 Hüutungen, wie sonst); wird aber wieder normal nach der 2.-3. Generation (Kellog und Bell [447]).

Trockenes Futter verzögert die Entwickelung bei einigen species (Parnassius apollo: Selmons [804]; Bombyx mori: [969a]), bei anderen , dagegen wird dieselbe beschleunigt und vollstïndiger (Pemphigus caerulescens, Schizonenia corni: Mordwilko [59:2, 593]; Phylloxera: Donnadieu [192]).

Der Mangel an Chlorophyll des Futters bewirkt den Stillstand im Wachsthum der Raupen verschiedener Species (Hofmann [382]).

Reichliche Nahrung verkürzt die Larvenzeit (Pulex scrraticepès: um 10 Tage [Tichomirowa, 871a]) und die ungenügende verlüngert dieselbe (Bombyx mori: beim Lattich-Futter beträgt die Raupenzeit 90 Tage, bei $1 / 2$ Quantum 94 Tage, bei $1 / 4$ Quantum 99 Tage [Kellog und Bell, 447]); Bettwanzen: einzelne Häutungen statt nach 2 Wochen nach $1 \frac{1}{2}$ Monaten ohne Nahrung [Pickel, 635]).

Verschiedene Species können verschieden lange Zeit olıne Nahrung bleiben (Denclrolimus pini: 10 Tage, Wasiljow [943a]; Bombyx mori: 23 Tage bei $7^{\circ}, 15$ Tage bei $14^{\circ}, 3$ Tage bei $20^{\circ}$, Schmujdsinowitsch [756]; Bienenlarven: 12 Tage, Koschownikow [467]). Je älter die Raupen sind, desto weniger leiden sie beim Hungern (Schmujdsinowitsch [756]).

\section{b) Imago.}

Mangelhafte Ernährung begünstigt die Entwickelung der geflügelten Individuen von Phylloxera (Keller [445], Morgan [594], Donnadieu [192]) und Pflanzenläusen (Mordwilko [592], Göldi [315]). Entgegensetzte Resultate liegen von Singerland $(816 \alpha)$ vor. 
Verschierlene Species können verschieden lange Zeit olne Nahrung bleiben (Periplaneta americana: 45 Tage, Masarakia [549]; Vanessen: bis zu 9 Monaten, de Rossi [705]; Oxythyrea cinctella: 18 Tage, Bachmotjew [25]; Pulex serraticepes: 14 Tage, Tichomirowa [871a]; Bettwanzen: über 3 Monate, Pickel [635]; Vespa silvestris: Königin 12 Tage, Arbeiterin $3 \frac{1}{2}$ Tage, $\sigma^{7} 2^{1 / 2}$ Tage; Vespa crabro: Arbeiterin 21/2 Tage; Apis mellifera: Königin 1 Tag, Arbeiterin $3^{1 / 2}$ Tage, o 22 Stunden, Koschewnikow [467]; Formica subsericea: 9 Monate, Field [223a]; Anopheles claviger: 40-70 Tage, Grassi [327a]; Otiorhynchus ligustri: 42 Tage, Hollrung [384]; Attacus cynthia: 8 Tage nach der Eierablage, Gauckler [293]; Eurygaster maurus: über 8 Monate, Mokrzecki [583a]; Crematoyaster lineolata: 18 Tage; Camponotus herculeanus pictus: 29 Tage; C. pennsylvanicus: 47 Tage; Stenama fulvum: 46 Tage; Formica lasioides: 39 Tage; Formica subsericea: 9 Monate; Formica fusca subsericea: 110 Tage, Field [222, 223a]; Dorcadion sturmii: über 4 Tage, Bachmetjew [p. 574 dieses Bandes]).

\section{B. Einfluss der chemischen Stoffe.}

\section{a) Eier.}

Werlen rlie Eier von Bombyx mori mit gewissen Säuren behandelt, so erleiden sie die frühzeitige Entwickelung $(1 / 2$ Minute in $\mathrm{H}_{2} \mathrm{SO}_{4}$ : Bellati und Quajat [62], Tichomirow [868], Ducleáux [202]; in $\mathrm{HCl} 5$ Minuten: Bellati und Quajat [62], Susani [852]).

Werlen unbefruchtete Eier von Bombyx mori vier Tage nacheinander je $2 \frac{1}{2}$ Minuten mit $\mathrm{H}_{2} \mathrm{SO}_{4}$ behandelt, so zeigen sie alle Eigenschaften, welche einem befruchteten Ei eigen sind (Tichomirow [868]). Eier, welche aus den Drohnenzellen herausgenommen und dieser Behandlung unterzogen werden, ergeben wieder nur Drohnen (Kulagin [483]).

Das Abwaschen der Eier von Bombyx mori mit verschielenen Lösungen schadet stets beim wiederholten Mal, wenn es sogar reines Wasser ist (Rossinsky [706]), sonst leiden sie dlabei nicht, wenn die Lösung 0,2\% Sublimat (Quajat und Rossinsky [671], Perroncito $[630 a, 630 b]$ ) oder 0,4\% Carbolsäure enthält (Quajat·[657], Rossinsky [671]).

Werden die Eier von Ocneria monacha in verschiedene Flüssigkeiten gebracht, so beeinflussen dieselben die Lebensthätigkeit der Eier verschieden stark. Je stärker die Concentration ist, desto 
stärker ist der Einfluss. Getöltet werlen clie Eier, unter gleichen Umstänilen, von Lösungen: $15 \%$ Carbolsäure, $1.5 \% \quad \mathrm{BaCl}_{2}, 20 \%$ $\mathrm{Ba}(\mathrm{OH})_{2}, 0,5 \% \mathrm{KOH}$. Ist die Flüssigkeit reines Wasser, so sterben die Eier nach 3i) Tagen (Schemigonow [744]). Beim Anstreichen dieser Eier mit Petroleum sterben sie (Kisselow [4:0]).

Werden die Eier anderer Species mit verschiellenen ngiftigen" Flüssigkeiten angestrichen resp. bespritzt, so sterben sie llabei nicht immer. Hier genügt es nur auf Krasilschtschik [424a], Mokrzecki [583a], Frings [254], Quajat [667] himzuweisen).

Bringt man Eier von Bomby $e$ mori in clie Kiohlensïure, so verderben sie nach einer gewissen Zeit (nach ca. 72 Stunden), welche umso kürzer ist, je frischer die Eier sincl, oder wenn sie aufgelebt sind (Quajat [657, 662], Mouline [596]). Dasselbe bezieht sich auch auf Quecksilberdämpfe (Quajat [662]).

Eier von Bombyx mori, in Sauerstoff gebracht, werden nicht beschädigt, wenn sie frisch sincl. Ihre Entwickelung wirl dabei nur bis zu einer gewissen maximalen Dauer beschleunigt, sonst wird sie wieder geschwächt. Die Eier entwickeln sich nicht, wenn sie sich in ozonierter Luft oder Stickstoffoxydul hefinden. (Bellati und Quajat [66]).

b) Raupen und Larven.

Gewisse Verbindungen, welche mit der Futterpflanze von Raupen gefressen werden, beschleunigen die Entwickelung der letzteren (Brennessel + Eisenalbuminat für Vunessa urticae, v. Linden [517]; Maulbeerblätter + Reisstärke für Bombyx mori, Verson [919]), resp. machen sie die Gespinnste schwerer. (Maulbeerblätter + Eiweiss für Bombyx mori, Pasqualis [623]). Anilere Verbinilungen dagegen verzögern die Entwickelung (Bremnessel + Hydrochinon für Vanessu urticae, v. Linden [527e]) oder schaden den Raupen (Brennessel + Zucker für Vanessa urticae, v. Linden [517]; Maulbeerblätter + Kalk- und Kupfersulfat-Lösung für Bombyx mori, Passerini [624]; Maulbeerblätter, imprägnirt mit Albumin, Phosphaten, Zucker, Kochsalz für Bombyx mori, Flammarion [241]).

Die Raupen resp. Larven, welche "vergiftetes" Futter fressen oder sich in einer "giftigen" Fliissighkeit eine gewisse Zeit lang befinden, gehen dabei nicht immer zu Grunde (es genügt hier auf Sajó [731, 732], Dewitz [167a], Lampert [497a], Kerschbaumer [448a] hinzuweisen). Im Sauerstoff können die Raupen nur einige Tage aushalten (Pieris brassicae: v. Linden [517]), im Stickstoff 
und Kohlensäure halten sie ohne Schaden 36 Stunden (Tanessa urticae: v. Linden $[527 b, 527 e])$.

Werden die Raupen resp. Larven mit einer Nahrung gefüttert, welcher gewisse Bestanltheile entzogen sind, so gedeihen sie dabei entweder gar nicht oder sehr verlangsamt (Wachs ohne Stickstoff fïr Galleria mellonella, Sieber und Metalnikow [811a]; defibrirtes Hammelbluth für Lucilia caesur, Schnecken für Lucilia erytlirocephala, Dewitz [175]; der Mangel am Chlorophyll für verschierlene Raupen-Species, Hofmann [382]).

Gewisse chemische Stoffe beschleunigen die Herzschläge, andere dagegen verzögern dieselben (Dogiel [189]).

\section{c) Puppen.}

Fliegenpuppen, welche einige Zeit unter Luftabschluss gelassen werden, ergeben Imagines mit defekten Flïgeln (Dowitz [168]). Der 0,02 starken Atmosphären-Druck schadet während 24 Stunden nicht (Vanessa urticae, v. Linden [527e]).

Zur Verwandlung von gewissen Larven ist Sauerstoff nöthig (Lucilia caesar: Dewitz [175]).

Gewisse Puppen-Species können (unter dem Einfluss der gelbrothen Lichtstrahlen) so viel Kohlensïure aus der $\mathrm{CO}_{2}$-Atmosphäre aufnehmen, dass ihr Gewicht dabei un $25 \%$ zunimmt (Pupilio porlalivius: v. Linden $[527 d]$ ).

Die Entwickelung der Puppen, welche eine kurze Zeit im Alther-Dampf gelegen sind, wird sehr verzögert (Limantria dispar: Federley [219a]). Die Stickstoff- und Kohlensäureatmosphäre üben keinen Einfluss aus (Vanessa urticae: v. Linden [527e]), nur die Puppenhülle wird dabei nicht erhärtet.

\section{d) Imago.}

Musca domestica, mit anderem ihr unbekannten Futter durch zelın Generationen hinclurch gefüttert, zeigt keine sichtbaren Veränderungen (Bogdanow [93]); dagegen Anopheles claviger, nur mit Zuckerwasser gefüttert, lebt statt 40-70 Tage nur 30 Tage (Grassi [327a]).

Verschiedene Species können verschieden lange Zeit in verschiedenen "giftigen" Lösungen und Gasen ohne Schaden aushalten (Reh [679], Rade [671a], Grunack [333], Gadeau de Kerville [269], Thiele [S60], Pabst [621], Silantjow [815], v. Linden [527b]). 


\section{Einfluss der Nahrung auf das Geschlecht und auf die Fortpflanzung.}

Die Parthenogenesis entsteht beim Mangel an Nahrumg (Pflanzenläuse: Kyber [491]) und vergeht mit dem Nahrungsiiberfluss (Blattlïuse: Düsing [203]). Aenderung der Lebensbedingungen zur Herbstzeit ruft auch die Aenderungen des Geschlechtsverhältnisses der Blattläuse hervor (Landois [498a, 498b]).

Werden Arbeiterinnen von Vespa germanica mit Honig und Fleisch gefüttert, so legen sie zu ungewölnnlicher Jahreszeit parthenogenetische Eier ab. (Marchal [546a]).

Anopheles- und Culex-Weibchen haben das Blutsaugen als eine unentberliche Bellingung für die Eierablage (Göldi [315a], Speiser [827]).

Reichliche Nahrung der Bienenlarven übt keinen hemmenten Eintluss auf die Entwickeiung der Genitalorgane bei Drohnen aus (Koschewnikow [467a]).

Das vollstänlige Hungern übt keinen verzögernden Einfluss auf die Entwickelıng der Geschlechtsdrüsen der Drohnenlarven aus, solange in derselben ein Vorrath des Fettkörpers sich befindet (Koschewnikow [467a]). Dagegen fand Pospelow (642), dass die ungenügende Ernährung eine unvollständige Entwickelung des Eierstockes bei Phlyctacnodes sticticalis zur Folge hat. Obwohl Rossikow (7057) diese Erscheinung (ler Wirkung des Parasits Microclossia yrima zuschreibt, hat Standfuss (840) nachgewiesen, dass bei vollständigem Hungern der Raupen von Aglia tau, bis ihre Anzahl nur 30\% (ler ursprünglichen betrug, die daraus sich entwickelten Weibchen nur 2-3 Eier ablegten, wälırend die Männchen fortpflanzungsfähig waren. Auch Bos (105) beobachtete, dass der Wechsel des thierischen Futters gegen das pflanzliche einen nachtheiligen Einfluss auf die Fortpflanzung von Silpha opaca und Corpophilus striatulus hat.

Raupen und Larven, welche mangelhafte Nahrung haben, ergeben später Männchen (Lepidopteren: Gentry [306], Treat [881]; Hirschkäfer: Reichenow [682a]; Aglia tau, Suturnia pavonia: Standfuss [835, 840]; Wespen: Rudow [711]: Anopheles claviger, Culex pungens: Johnson [423a]). Reichere Nahrung erzeugt Weibchen (Wespen: Rudow [711]; Anopheles claviger, Culex pungens: Johnson [423a]; Bienen: Huber [393], Schirach [751], Leuckart [508]; Lepidopteren: Genry [306], Treat [881]). Es giebt auch widersprechende Resultate: z. B. bei Termiten (Heath [3556] und Bienen 
(Ludwig [537]) verursacht die Aenderung des Futters keine Aenderung dieser Formen.

\section{Theorien dieses Einflusses.}

\section{Einfluss der natürlichen Nahrung.}

Es giebt "polyphage" und "monophage" Raupen- resp. Larven-Species. Die ersten fressen die meisten der Pflanzenarten, die letzten dagegen pflegen nur auf einer Pflanzenart zu leben.

Es liegen Versuche vor, welche zeigen, dass ein Futter bei einigen monophagen Species sich durch ein anderes 'ersetzen lässt.

So fütterte 'W. Iwanow (406) die Raupen von Bombyx mori (Korsikanische gelbe Rasse) mit folgenden Pflanzenarten: Morus alba var. cedrona, Morus alba v. latifolia, Morus rubra v. canadensis, Morus alba v. tatarica, Broussonetia papyrifera, Broussonetia kaempferi, Maclura aurantiaca, Scorzonera hispanica und erhielt gute Resultate mit Ausnahne von B. papyrifera (In China fressen sie auch diese Pflanze und noch Cudrania triloba).

Kamensky $(432,434)$ fütterte die Raupen von Bombyx mori mit Taraxacum officinale und erhielt sie bis zu 5. Alter.

Köppen (448) beschreibt einen Fall, wo Vanessa cardui wegen Mangels an gewöhnlichem Futter die Obstgartenpflanzen überfielen.

Pictet $(637 a)$ berichtet, dass Abraxus grossulariata, die man lange für monophag hielt, jetzt nicht selten als Raupe auf Eiche, Schwarzdorn, Weissdoın, Pfaffenhütchen gefangen worden ist.

Harz (434) gewohnte Bombyx mori nach und nach zu Scorzonera hispanica. Das erste Jalı fütterte er die Raupen mit dieser Pflanze abwechselnd mit Maulbeerblättern und erhielt nur 1\% Puppen; das zweite Jahr erhielt er bei auschliesslicher Fütterung mit S. hispanica $7,5 \%$ und im vierten Jahre betrugen die Puppen $34 ; 3 \%$.

Wenn die Zucht der monophagen Species mit andern Pflanzenarten nicht inmer gelingt, so spielen dabei verschiedene Ursachen mit.

So z. B. starben in Versuchen von Harz (432. Briefliche Mittheilung) Bombyx mori-Raupen bei der Fütterung mit Taraxacum officinale nach 14 Tagen, während Kamensky (434) sie bis zum 5 . Alter brachte. Der letzte Forscher beobachtete (432), als er bei erstem seiner Versuche die Raupen nur bis zum 4. Alter brachte, 
dass die Blätter viel Säfte in sich enthielten und bei ungenügender Ventilation und in Folge erhöhter Temperatur im Incubator zu gähren begannen, was eine grosse Sterblichkeit zwischen den Raupen verursachte. Beim zweiten Versuche (434) benützte er zum Fiittern verschnittene und mit Löschpapier getrocknete Blätter und brachte die Raupen bis zum 5. Alter.

Während Harz (434) bei der ersten Zucht der Raupen von Bombyx mori mit Scorzonera hispanica nur $1 \%$ Puppen erhielt, erhielt Tichomirowa (872) bei ilerselben Zucht von 135 Rüupchen 126 Puppen, indem sie den jungen Räupchen Blätter zum Fressen gab, welchen auf der Unterseite den Blattadern entlang das Häutchen abgescheelt wurde. Günstige Resultate wurden bei derselben Zucht später auch von anderen Seidenziichtern erhalten (Schitkow in Simbirsk [752], Schwerin in Nischni-Nowgorod [799], Stempkowska in Woronesch [845], Berg in Bessarabien [70] etc.)

Ausser diesen mehr technischen Zucht-Schwierigkeiten spielt eine gewisse Rolle auch die individuelle Beschaffenheit der Raupen einer und derselben Species. So sagt Grevillius (329), welcher verschiedene Pflanzen als Futter für Eıиroctis chrysorrhoea untersuchte: ${ }_{n}$ Auch scheint die von den Goldafterraupen unter den Pflanzen getroffene Auswahl — wie es ja auch bei anderen Insekten der Fall ist - je nach den äusseren Unständen und wohl auch nach der individuellen Beschaffenheiten (ler Raupen etwas wechseln zu können, es scheint mit anderen Worten, dass die Raupen je nach den vershiedenen Oertlichkeit usw. manche Pflanzenarten anderen Arten in grösserem oder geringerem Grade vorziehen, resp. sich an bestimmte Arten in ungleichem Grade gewölınen können" (p. 279).

Auch kann die chemische Aenderung der Zusammensetzung der betreffenden Pflanzenart in verschiedenen Orten die Ursache des Nichtgelingens der Zucht sein.

So ziichtete Kawraiski (441) in Tiflis (Kaukasus) die Raupen von Bombyx mori mit Scorzonera hispanica, wobei er alle, auch die kleinsten Vorschriften in Betracht zog, welche von Tichomirowa (872) bei ihrer sehr gelungenen Zucht in Moskau angegeben wurlen. Trotzdem erhielt er aus einem gr. Eier nur 4 schlechte Cocons. Er ist der Meinung, dass Scorzonera in Tiflis eine gewisse Abänderung in seiner Beschaffenheit erlitten hat, was die Gelbsucht bei Raupen verursachte. Dieselben schlechten Resultate wurden in Tiflis auch von Iwanow. (405) erzielt. 
Lambert (496) ziichtete in Montpellier Raupen von Bombyx mori mit Maclura aurantiaca und erhielt von 200 Räupchen nur 5 Cocons. Dieselbe Zucht und nach denselben Vorschriften in Tiflis (Iwanow [406]) ergab Resultate sogar besser als mit Maulbeerblättern.

Die Zucht der Raupen von Bombyx mori mit Broussonetia papyrifera in Tillis (Iwanow [406]) gelang nicht, während sie in China (N. Rondeau) sehr gut ausfiel.

Dass die Zusammensetzung gewisser Pflanzenarten in verschiedenen Orten sich ändert, wird durch Analysen verschiedener Chemiker bewiesen.

Die angefuihrte Tabelle giebt die Resultate dieser Analysen für Maulbeerblätter (Morus alba) an.

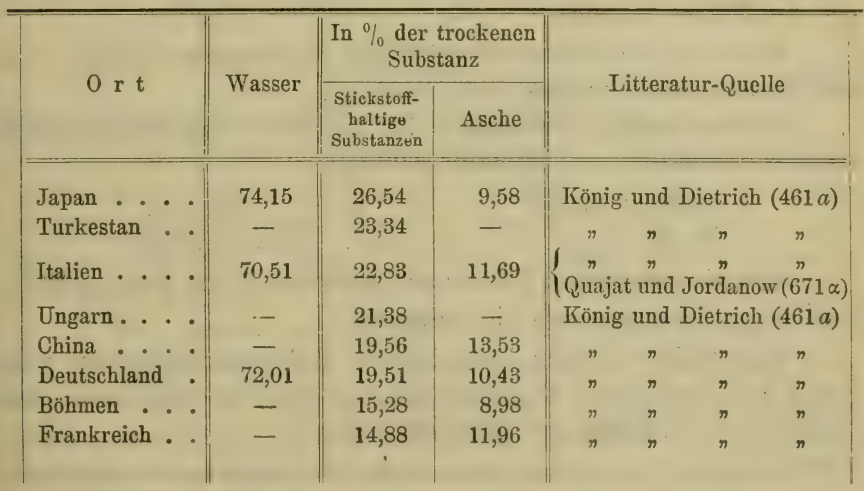

Aus dieser Tabelle ist ersichtlich, dass der Gehalt z. B. der stickstoffhaltigen Substanzen in Morus alba-Blättern in Japan fast doppelt so gross ist als in Frankreich.

Diese Schwankungen in der Zusammensetzung können durch die Ursachen, welche in der Pflanze selbst liegen (das Blattalter, die Lage des Blattes und der gesunde oder krankhafte Zustand der Pflanze), und durch physiko-geographische Bedingungen für das Wachsthum der Pflanze erklärt werden (Klima, Relief des Ortes, seine Höhe über dem Meeresniveau, Erdboden, seine Abhänge etc.), Es ist interessant, hier einige diesbeziigliche Analysen von Morus alba-Blätter anzufuihren. 
I. Kapitel. Theoretisches über die Entwickelungsgeschwindigkeit.

Die chemische Zusammensetzung, abhängig vom Alter der Blätter:

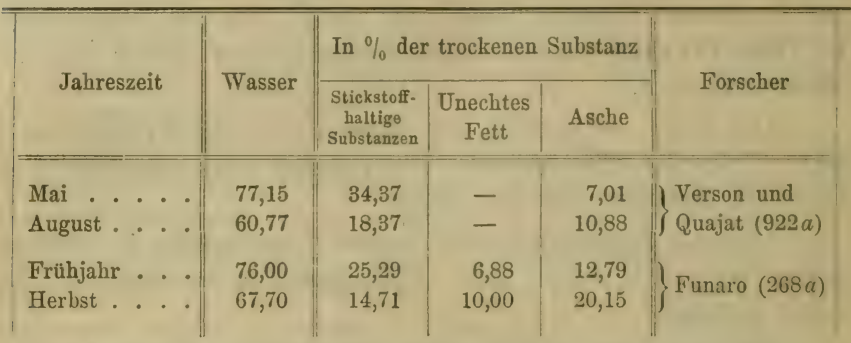

Daraus ist ersichtlich, dass der Gehalt der sticlistoffhaltigen Substanzen und des Wassers mit dem Blattalter ab- und der Asche und des Fettes zunimmt.

Abhängigkeit der chemischen Zusammensetzung von dem Gesundheitszustand der Blätter:

Stickstoffhaltige Substanzen in $\%$ der trockenen Substanz ergaben (Neumayr und Ullmann $[607 a]$ ):

$$
\begin{aligned}
& \text { gesunde Blätter . . . . . 22,30\% } \\
& \text { kranke " . . . . . } 17,70 \% \text {. }
\end{aligned}
$$

Also die erkrankten Blätter enthalten bedeutend weniger stickstoffhaltige Substanzen als die gesunden.

Abhängigkeit der chemischen Zusammensetzung von der Lage und der Beschaffenheit des Grundbodens am gleichen Ort (König und Diotrich [461a]):

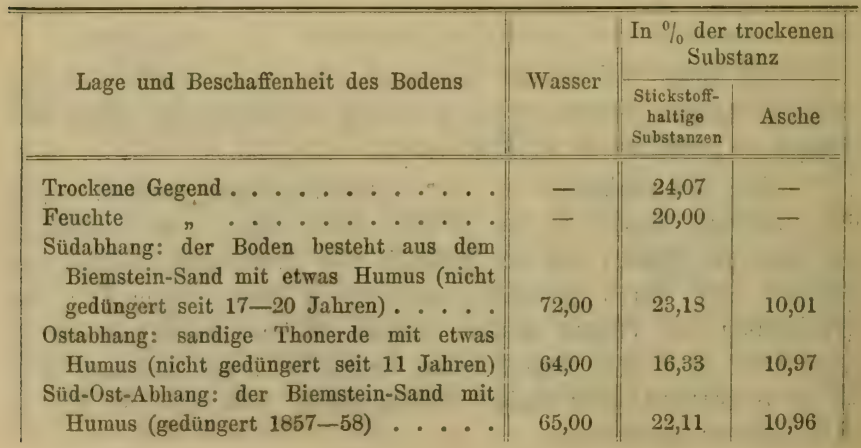


Somit ist der Gehalt an stickstoffhaltigen Substanzen und Wasser reichlicher, wenn die Maulbeerbäume an Südabhängen oder in feuchter Gegend wachsen.

Wenn im allgemeinen die chemische Zusammensetzung des Futters für monophage Raupen massgebend sein soll, weshalb sie nur die oder jene Pflanze als Futter haben, so müssen in diesem Falle andere Surrogate, welche diese Pflanze ersetzen, mehr oder meniger dieselbe Zusammensetzung haben. Dies wird in der That beobachtet.

Sabanin $(729 a)$ bearbeitete die in der Litteratur vorhandenen Analysen verschiedener Futterpflanzen, indem er alle diese Pflanzen in 8 Gruppen eintheilte und für jede Gruppe das arithmetische Mittel berechnete.

Diese Gruppen enthalten folgende Species:

I. Die Blätter von Morus alba und ihre Varietäten.

II. $n " n$ Scorzonera hispanica.

III. " $"$ "Wurzelfruchtpflanzen (Zucker- und Gelbrüben): Daucus carota, Beta vulgaris, Zuckerrübe.

IV. Die Blätter der Baumspecies: Acer campestri, Alnus, Betula alba, Castanea, Fagus sylvatica, Populus tremula, Quercus pedunculatus, Robinia pseudoacacia, Salix alba, Sorbus aucuparia, Ulmus, Viscum album, Vitis vinifera, Acer dasycarpum.

V. Die Blätter verschiedener Gräser: Bromus schraderi, Dactylis caespitosa, Sorghum saccharatum, Sorghum vulgare, Zea mais, Flint mais, Dent mais, Cirsium lanceolatum, Galeopsis tetrahit, Humulus lupulus, Leontodon taraxacum, Plantago lanceolata, Plantago major, Rumex crispus, Urtica dioica, Helianthus annuns, Iris germanica, Baumwollpflanze, Arundo donax.

VI. Die Blätter von Papilionaceen: Medicao sativa, Trifolium pratense, Vicia faba, Vicia sativa.

VII. Verschiedene Gräser (Gartenpflanzen): Agrostis canina Agrostis vulgaris, Agrostis major, Aira caespitosa, Alopecurus geniculatus, Alopecurus pratensis, Anthoxanthum odoratum, Avena elatior, Aveua flavescens, Avena pubescens, Bromus mollis, Baldingera arundinacea, Calamagrostis canadensis, Dactylis glomerata, Festuca ovina, Festuca pratensis, Geyceria fluitans, Holcus lanatus, Lolium italicum, Lolium perenne, Phleum pratense, Poa annuna, 
Poa pratensis, Poa trivialis, Setaria germanica, Zea mais, Andropogon provincialis, Panicum crus-gali, Setaria italica.

VIII. Gräser von Papilionaceen: Anthyllis vulneraria, Hedysarum coronarium, Lupinus luteus, Medicago falcata, Medicago sativa, Melilotus alba, Onobrychis sativa, Ornithopus sativa, Pisum sativum, Trifolium incarnatum, Trifolium hybriclum, Trifolium pratense, Vicia sativa, Vicia sepium, Arachis hypogaea, Lathyrus sylvestris.

Folgende Tabelle enthält die maximalen, minimalen und die mittleren Werthe für jede Gruppe, wobei $Z$ die Anzahl der Analysen bedeutet, aus welchen diese Werthe berechnet wurden:

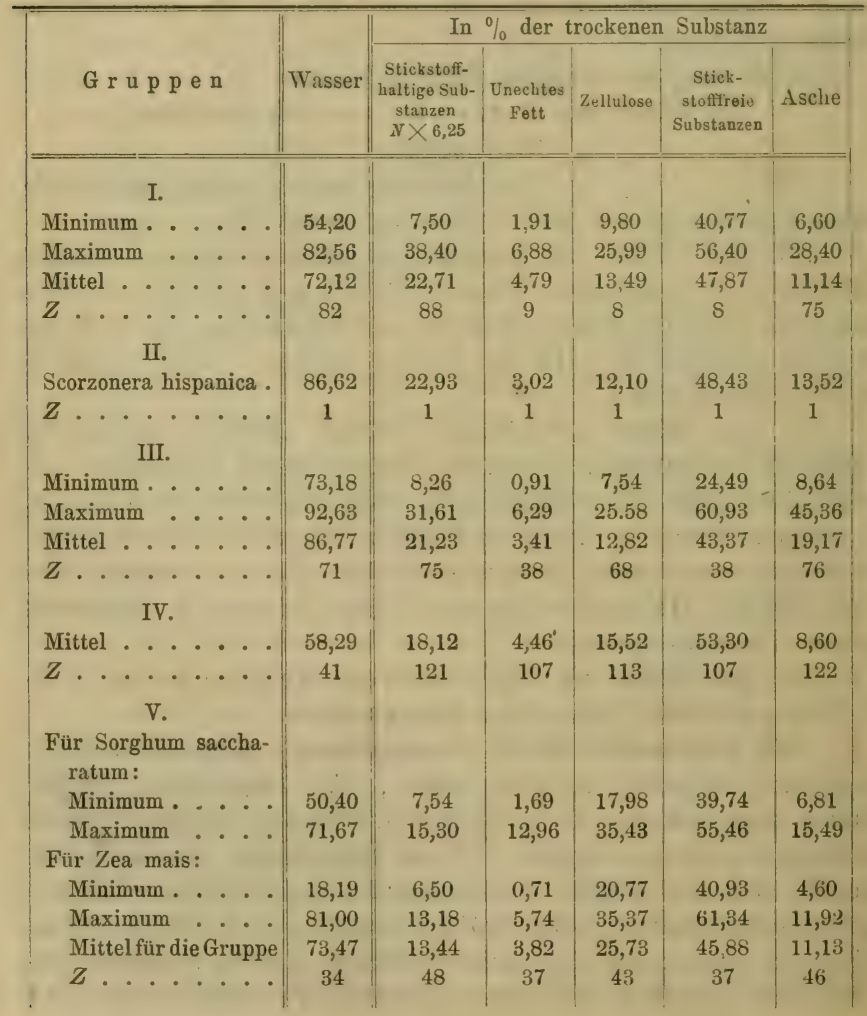




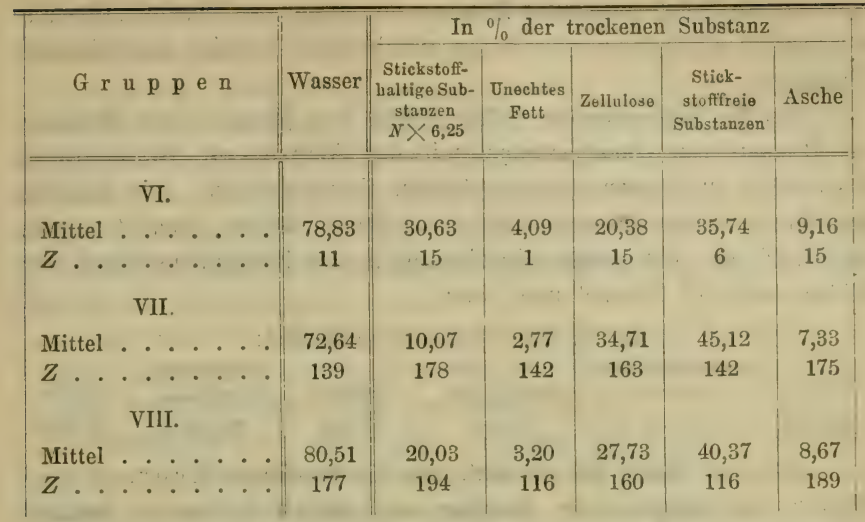

$\mathrm{Zu}$ besserer Veranschaulichung sind diese Werthe graphisch dargestellt (Fig. 19).

Aus dieser Tabelle ist ersichtlich, dass der Zusammensetzung von Morus alba (I) am nächsten Scorzonera hispanica steht mit Ausnahme vom Wassergehalt, welcher für Scorzonera grösser ist als für Morus.

Da die Analyse von Scorzonera hispanica vom I. Scholzinski (in agronomischem Laboratorium der Universität zu Moskau) gemacht wurde, so hat Sabanin $(729 a)$ die mittleren Werthe für Morus alba nur aus solchen Analysen berechnet, welche gleichfalls im Juni und Juli gemacht wurden. Er erhielt dabei folgende Resultate:

Wasser. $\begin{gathered}\text { Stickstoff- } \\ \text { haltige Subst. Asche. }\end{gathered}$ Blätter von Morus alba . . . . 27,04 23,01 12,80 " $\quad$ Scorzonera hispanica . $86,62 \quad 22,93 \quad 13,52$

Also der Gehalt der stickstoffhaltigen Substanzen in beiden Species ist noch näher geworden. Sabanin sagt: "Somit stehen die gelungenen Resultate der Zucht von Bomlyxx mori mit den Blättern von Scorzonera hispanica, welche 0. 0. Tichomirowa erreicht hat, und welche auf die Gedanken über die Aehnlichkeit der chemischen Zusammensetzung der Blätter von Morus alba und Scorzonera hispanica führten, in der Harmonie mit den Angaben der chemischen Analyse" (p. 10).

Dass in diesem Falle nicht etwa Scorzonera hispanica als Species das gewohnte Futter (Morus alba) ersetzte, sonclern nur 
đie sehr ähnliche chemische Zusammensetzung der Blätter zwischen den beiden Pflanzenspecies daran schuld war, beweist die folgende Thatsache:

Als 0. Tichomirowa (872) wegen des Mangels von Blättern die Raupen von Bombyx mori mit der Wurzel von Scorzonera hispanica zu füttern begann, starben sie massenhaft. Die Analyse der Wurzel dieser Pflanze, welche von Dolin (461b) gemacht wurde, zeigt wirklich eine grosse Abweichung in der Zusammensetzung der Blätter und der Wurzel und zwar

in $\%$ der trockenen Substanz:

$\begin{array}{cccccc}\text { Wasser. } & \begin{array}{c}\text { Stickstoffhaltige } \\ \text { Substanzen. }\end{array} & \text { Unechtes Fett. } & \text { Celulosa } & \begin{array}{c}\text { Stickstofffreie } \\ \text { Substanzen. }\end{array} & \text { Asche. } \\ 80,39 \% & 5,31 & 2,55 & 11,58 & 79,81 & 0,848\end{array}$

Aus der Praxis ist bekannt, dass die trockenen ScorzoneraBlätter den Raupen von Bombyx mori schällich werden liönnen. Die Analyse der Blätter dieser Pflanze in frischem und trockenem (auf der Sonne "wie Heu“) Zustan(le, welche Salow (734a) gemacht hat, ergab, dass ein Theil der eiweisshaltigen Substanzen bei langem Liegen der Blätter in Amide übergeht.

Alles dies in Betracht ziehend, kommen wir zum wahrscheinlichen Schlusse, dass monophage Raupen auch andere Pflanzen zu ihrem Futter gebrauchen können, wenn ihre chemische Zusammensetzung derjenigen der "Normal-Pflanze" nahe steht. Man könnte sogar den theoretischen Schluss ziehen, dass die Raupen, statt mit den Pflanzen, mit künstlich bereiteten Substanzen gefüttert werden könnten, wenn nur die letzteren die gleiche Zusammensetzung mit den "Normal-Pflanzen" haben.

Es muss hier noch eine Erscheinung hervorgehoben werden. Werden den Raupen von Bombyx mori statt Morus alba-Blätter die Blätter verschiedener Varietäten dieser Species oder von Morus rubra, Broussonetia kaempferi, Maclura aurantiaca (Iwanow [406]), Scorzonera hispanica (Tichomirowa [872]) als Futter gereicht, so machen sie stets 5 Häutungen, wie gewöhnlich, durch Werden sie dagegen mit Cudrenia triloba (Sasaki [735]) orler mit Lattich (Kellog und Bell [447]) gefüttert, so häuten sie sich nur $4 \mathrm{Mal}$, wobei ihre Raupenzeit viel länger wird (statt ca. 30 Tage 90 Tage).

Dieser Umstand zeigt, dass diese zwei Species für die Raupen von Bombyx mori entfernter liegen als die anderen erwähnten Pflanzenarten, da die Raupen längere Zeit brauchen, damit ihr 
Organismus an dieses neue Futter sich gewöhnen kann. Nach $2-3$ Generationen haben sie jedoch die normale Anzahl der Häutungen.

Also hier haben wir einen interessanten Fall der Anpassung: der monophagen Raupen an anderes Futter. Somit entsteht die Frage, ob die Polyphagenie nicht als ein Anpassungsvermögen der Raupen $z u$ betrachten ist, welches bei ihnen während einer langen Zeit-Periodle ausgearbeitet worden ist? (Mit dieser Frage ist dann eine andere verknüpft: ob monophage Raupen philogenetisch jünger zu betrachten sind als die polyphagen?)

Was nun die Polyphagenie anbetrifft, so müssen wir zuerst die Frage beantworten, welche Umstände bei der Eierablage in Bezug auf die Wahl der. Pflanzenart bestimmend sind.

Grovillius (329) sagt: „Die Annahme liegt wohl am nächsten, dass die betreffenden Pflanzen irgend welche Stoffe enthalten, die auf den Geruchsinn (ler Falter anziehend wirken" (p. 227).

Dass der Geruchsinn bei Insekten sehr entwickelt ist, ist schon lange bekannt. Schon Roesel (699a) war davon unterrichtet. Die Caraben werden gefangen, indem man in einen eingegrabenen Topf zerdrückte Schnecken bringt, welche nicht ein Mal von Hunden nach dem Geruche entdeckt werden können. Favre (218b) beobachtete, dass Saturnia spini $\delta^{\top} \sigma^{\top}$ mittels Geruchsinn die Weibchen auf die Entfernung von $3 \mathrm{~K}$ Klm. entdecken können. O. Schultz (784a) sagt: „Die Kärfe werden durch starke Blumendüfte von weither angelockt; stark riechender Käse übt beim Fang auf gewisse Falterarten (Limenitis populi, Apatura-Arten) unwilerstehlichen Reiz aus; die meisten Noctuen-Arten können anderen Ködermitteln (Honigmischung, Apfelschnitte) nicht widerstehen; die aasfressenden Insekten wittern ihre Nahrung und Beute schon aus weiter Entfernung. Männchen gewisser Schmetterlingsarten (Bombyx, Lasiocampa, Saturnia, Endromis, Aglia u. a.) werden durch (len Duftapparat ihrer Weibchen aus weiter Ferne angelockt" (p. 425).

Allein der Geruchsempfindung bei der Wahl der betreffenden Pflanze ging die Geschmacksempfindung geschichtlich voran, denn um $\mathrm{zu}$ wissen, wo er seine Eier ablegen soll, musste der Falter zuerst mit dem Geschmack der betreffenden Pflanze bekannt gewessen sein, resp. dies von der Raupe geerbt haben.

In der letzten Zeit sprach Lagerheim (493a) die Vermuthung aus, dass gewisse polyphagen Raupen deshalb nur eine bestimmte Anzahl von Pflanzenspesies bevorzugen, weil die letzteren Gerbstoff in sich enthalten. 
Lin diese Theorie zu prïfen, unternahm Grovillius (329) sehr umfangreiche Untersuchungen mit verschiedenen Pflanzenarten, welche dem Goldafter (Euproctis chrisorrhoea) als Futter dienen. Im ganzen wurlen 93 Pflanzenspecies auf ihren Gerbstoff- und Wassergehalt untersucht. Er sagt: „Ein Vэrgleich zwischen dem von Lagerheim mitgeteilten Verzeichnis der in ihrem Verhalten zu den Raupen der Cheimatobia brumuta von ihm beobachteten Pflanzen und den in der obigen Tabelle aufgeführten, von den Crolilafterraupen melir oder weniger gern gefressenen, bezw. vermielenen Arten zeigt, wenn auch, wie $\mathrm{zu}$ erwarten war, die einzelnen Pflanzen manchmal in beiden Fällen sich verschieden verhalten, doch im grossen mehrere unverkennbare Aehnlichkeiten. Hier wie dlort sind die besonilers gern gefressenen Arten am zahlreichsten unter ilen Rosifloren, ferner auch unter den Cupuliferen und Salicaceen vertreten. Von den Pflanzen der Feldschichten nehmen die Poligonaceen unter den Futterspecies des Goldfalters einen berleutenden Platz ein; von dem Frostspanner wird Lagerheim viviparum stark angegriffen, die übrigen von Lagerheim beobachteten Arten - Rumex domesticus, Acetoas, Acetosella (und Rheum undulatum) werilen gefressen, aber in nicht besonders hohem Grade. Sehen wir jetzt nach, wie sich der Gerbstoffgehalt (in den trischen Blättern) verhält, so gehören. die Cupuliferen, Rosifloren (speziell die Rosaceen) und Salicaceen zu den gerbstoffreichsten Futterpflanzen des Goldafters. Von den untersuchten Copuliferen und Betulaceen enthalten Carpinus, Quercus, Castanea und Alnus glutinosa den meisten Gerbstoff; Fagus, Corylus und Betula weniger, aber doch verhältnissmässig viel. Die Arten der drei ersten Gattungen werden an meisten bevorzugt, die übrigen ziemlich gern gefressen. Diese Pflanzen verhalten sich also, wie es die Theorie von Lagerheim verlangt. Nur Alnus glutinosa macht insofern eine Ausnahme, als sie zwar gelegentlich kahl gefressen wird, jedoch nicht zu den bevorzugtesten Arten gehört. (Auch Alnus pubescens verhält sich nach Lagerheim der Cheimatobia gegenüber ausnehmencl: sie wird von derselben nur in der Not gefressen)" (p. 282).

Wir sehen somit, dass die Theorie von Lagerheim nur im allgemeinen bestätigt wird und dass es wahrscheinlich ausser dem Gerbstoff noch andere Stoffe (z. B. bei den Rosifloren usw.) giebt, welche den Goldafterraupen besonders gut munden und dazu beitragen, die betreffende Pflanze zur Eierablage seitens dieser Falter zu wählen. So z. B. enthält Polygonum amphibium f. terrestris nur 
$0,02 \%$ Gerbstoff, wird aber von Raupen dieser Species verhältnissmässig gern gefressen.

Die weiteren Untersuchungen von Grovillius ergaben, "lass die Gerbstoffe bei den Goldafterraupen nicht orler nur zum Teil eine direkte Rolle in ernährungsphysiologischer Hinsicht spielten, dass ihnen vielmehr eine indirekte, aber deshalb nicht unwichtige Rolle, etwa als Reizmittel bei der Nahrungsaufnahme orler als ein den Unsatz und die Verdauung der Nährstoffe beförderndes Mittel zukäme" (p. 285). Diese Schlussfolgerung wird durch chemische Analysen des Raupenkots bestätigt, welche ergaben, dass die mit der Nahrung aufgenommenen Gerbstoffe, wenn überhaupt, dann nur zum Theil verdaut werden.

Auf diese Art kommen wir zum Schlusse, dass die Wahl der Pflanzenspecies bei polyphagen Raupen durch besondere Stoffe bestimmt wird, unter welchen den ersten Platz, wenigstens für gewisse Raupenspecies, Gerbstoffe behaupten. Diese Stoffe spielen die Rolle des Reizes bei der Aufnahme der Nahrung und haben, wie es scheint, ihr Optimum (Obstbäume in Versuchen von Grovillius).

Man könnte vermuthen, dass diejenigen Pflanzen, welche von polyphagen Raupen unberührt gelassen werden, durch künstliche Reizmittel dennoch als Futter für die Raupen dienen können. Dies wird in der That durch den Versuch von Grevillius bestätigt. Die Blättter von Stellaria media welche keine Spur von Gerbstoff enthalten, wurden von Raupen gar nicht berührt; als diese Blätter aber mit Tanninlösung bepinselt wurden, begannen die Raupen dieselben zu fressen.

Es kann auch sein, dass der reizende Stoff, welcher in der Pflanze enthalten ist, durch einen anderen, welcher den Raupen widerwärtig ist, überwogen wird. Diese Vermuthung scheint unter anderem durch folgende Thatsache bestätigt zu werden. Im Gouvernement Ufa (Bezirk Belebeewsk) fressen die Raupen von Aporia cra-tacgi die Blätter von Amygdalus nana. Kaltenbach [430a] giebt diese Pflanze als Futter für Aporia crataegi nicht an, sondern nur Crataegus, Cydonia, Mespilas, Pronus padus, P. cerasus, P. domestica, P. spinosa, Pyrus malus, P. communis, Sorbus und Quercus). Wasiljew (943b) beobachtete, dass Prunus hamaecerasus, welche neben Amygdalus nana in Ufa wächst und welche zu derselben Gattung mit der letzteren gehört, von Raupen unberührt galassen wurde. 
Um den Geschmack der fremden Pflanze kennen zu lernen, haben die Raupen verschiedene Wege und Mittel, abgesehen von künstlicher Zucht.

In der Mehrzahl der Fälle legen die Falter ihre Eier an solchen Pflanzen $a b$, welche von ihren Raupen gerne gefressen werlen. Ist aber die Menge der vorhandenen Falter eine sehr beleutende, so legen sie ihre Eier auch an den wenig bevorzugten Pflanzen ab.

Grovillius (329) beobachtete bei Euproctis chrysorrloca, lass sie ihre Eier sogar an Frangula alnuis abgelegt haben, deren Blätter von den Raupen nur in der äussersten Noth gefressen werden; auch an Sarothamnus scoparius und Juncus effusus, welche nicht zu Futterpflanzen dieser Species gerechnet werden.

Fernald und Kirkland (219b) baobachteten für diese Species die Ablage der Eier, wenn sie in sehr grosser Menge fliegen, an Baumstrünken und sogar Laternenpfählen!

Auf diese Art haben die Raupen der "polyphagen" Species die Gelegenheit, den Geschmack auch der "fremden Pflanzenarten zu versuchen, und wenn diese Pflanze ihnen nicht schädlich wird, lassen sie aiene Nachkommenschaft, welche an diese Pflanze gewöhnt ist."

Auch bei den "monophagen" Raupen kann dasselbe stattfinden. Wir sehen somit, dass z. B. Dendrolimus pini-Raupen, welche sonst in Frankreich ausschliesslich Pinus silvestris (Judeich und Nitsche [423a]) fressen und nie Pinus laricio und Pinus montana überfallen, fressen in Russland sehr gern Pinus pinea, Larix sibirica und L. europaea (Serebrjanikow [808a]). Diejenigen Raupen, welche bei solchen Wanderungen die ihnen schädlichen Pflanzen treffen, werden natürlich sterben. So z. B. beobachtete Bechstein (10a), dass die Raupen von Dendrolimus pini durch den Mangel an ihren Futterpflanzen bewogen, die Blätter von Hanf frassen, aber bald dabei starben.

Auf diese Weise hat sich z. B. Acherontia atropos an Kartoffel gewöhnt. Aigner-Abafi (6a) sagt: "Seitdem es evident erwiesen erscheint, dass Acherontia atropos an zahereichen Pflanzen lebte, bevor er sich an acclimatisierte Pflanzen, wie Lycium und besonders die Kartoffel (in deren Urheimat die Art, nicht ein Mal das Genus vorkommt) derart gewöhnte, dass dieselben in Ungarn seine Hauptnahrung bilden, seitdem halte ich es für gewiss, dass auch der Oleanderschwärmer in Gegenden, wo der Oleander spärlich vorkommt, sich auch von anderen Pflanzen nährt" (p. 227). Deilephila nerii traf man nämlich in Deutschland an Vinca minor. 
"Monophage" Raupen giebt es somit nicht, alle sind polyphag; wenn auch mit beschränkter Wahl der Pflanzenarten.

Eine noch nicht vollständlig gelöste Frage ist auch die über das Erscheinen der geflügelten Weibchen der Pflanzenläuse.

Mordwilko (593) sagt darïber: "Schon der Umstand, dass die Larven der parthenogenetischen Weibchen, welche gleichfalls von parthenogrenetischen Weibchen abstammen, bis zu einer gewissen Zeit einander ähnlich sinil, - der Unterschied aber zwischen geflügelten und ungefliigelten Individuen erst vor der dritten Haütung auftrittist dem Schlusse günstig, das aus irgend einer gegebenen Larve des parthenogenetischen Weibchens nach Belieben sowohl ein gefllïgeltes wie auch ungefluigeltes Individuum entstehen kann, und dass diese Entwickelung durch äussere Faktoren und nicht durch innere Ursachen bedingt wird" (p. 953).

Als einen dieser äusseren Faktoren ersieht Macchiati (539a) im Futtermangel, indem er die geflïgelten Weibchen (emigrante von Lichtenstein) immer (lann erhielt, als die Futterpflanze absichtlich zum Welken gebracht wurde.

Mordwilko (593) erhielt dieselben Resultate mit Aphis papaveris. Er übertrug diese Läuse vom Rheum auf Zweige von Evonymus europaea, welche in ein Glas mit Wasser gesteckt wurden, und erhielt nach $11 / 2-2$ Wochen ausschliesslich geflïgelte Weibchen und Nymphen.

Aenliche Beobachrungen machten auch viele andere Forscher (S. B. Kyber [491], Göldi [315] etc.). Auch bei Phylloxera wird dasselbe konstatiert (Donnadieu [192], Keller [546] etc.).

Umso auffallender sind die Resultate, welche Singerland (816) mit Mijzus achyranthis erhalten hat. Bei konstanter Temperatur (im Gewächshause) und unter strenger Kontrolle erhielt er in der Zeit vom 2. IV. 1890 bis zum 17. I. 189360 Generationen parthenogenetischer Abstammung. Die Entwickelungszeit jeder Generation dauerte 15-20 Tage, und er schreibt diese verlingsamte Entwickelung der ungenügenden Beschaffenheit der Futterpflanze zu. Trotzdem dass er diesen Läusen auch schlechte Futterpflanzen reichte, wobei sie nur $1 / 3$ der normalen Grösse hatten, erhielt er stets flügellose Weibchen.

Wenn einerseits auch bekannt ist, dass grade durch das Hungern gewisse Organe zur Entwickelung kommen, z. B. die Flügel bei der Puppe, die Beine bei hungernden Froschlarven etc., indem 
das im Körper vorräthige Material zur Ausbillung dieser Organe hergerichtet wurde, kann man mit Bestimmtheit doch nicht sagen, dass dasselbe auch bei Pflanzenlüusen durch Hungern stattfinclet, wenn man die Versuche von Singerland in Betracht ziehen will.

Die Erklärung dieser Erscheinung scheint in anderen Umständen zu liegen und zwar:

J. Dewitz (168) erklärt das Nichtyorhandensein der Augen und Flügel bei einigen Höhleninsekten durch das Einwirken des Höhlenmediums, welches in bestimmtem Sinne auf gewisse Processe im Organismus wirkt. Er sagt: „Ich glaube, dass die innere Secretion des Organismus durch das Medium beeinflusst wird und dass diese Veränderung der Sekretion auf die Ausbildung der Organe in diesem Falle auf die Ausbildung der Flügel und Augen zurückwirkt." Weiter sagt er: "In ähnlicher Lage wie die Höhlenthiere befinden sich die parasitischen Insekten, welche grösstenteils ohne Flügel sind. Nach meinem Dafürhalten stehen die Insekten dieser Gruppe theils unter dem vergiftenden Einfluss der von der Haut ausgeathmeten Gase oder des Schweisses, theils unter dem Einfluss der reducirenden Bestandtheile des Blutes oder der Gewebesäfte, welche beide von den Thieren eingesogen werden" (p. 65).

Somit wäre es möglich, dass die Pflanzenläuse, welche an üppigen Pflanzen sich entwickeln, nicht deshalb keine Flügel besitzen, weil sie sich gut ernähren, sondern weil in ihrem Körper beim Aufhalten auf solchen Pflanzen vielleicht Enzyme sich bilden. Die Bildung dieser Stoffe findet aber nicht statt, wenn die Pflanzen gewellkt sind. Uebrigens können diese Sekrete auch indirekt den Apterismus hervorrufen, indem dieselben im Organismus der Thiere durch die umgebenden Gase „in ihrer Thätigkeit oder in ihrer Beschatfenheit oder in ihrer Menge" beeinflusst werden. Diese umgebenden Gase können z. B. Kohlensäure resp. reiner Sauerstoff sein, welche Nachts resp. beim Tage von der Pflanze ausgeschieden werden. Ist die Pflanze gewelkt, dann ist auch ihr Athmen gestört und das umgebende Gas wird nun die Luft sein, was das Wachsthum der Flügel zur Folge haben wird. In diesem Falle ist also nicht der Nahrungsmangel die Ursache der Reproduktion von geflügelten Individuen, sondern die Zusammensetzung der diese Individuen umgebenden Atmosphäre.

Diese Vermuthung wird nicht nur durch die erwähnten Versuche von Dewitz, sondern auch durch die Versuche von v. Linden $(527 e)$ bestätigt. v. Linden fand nämlich, dass die Flügelmembran 
der Schmetterlinge, deren Puppen in reinem Sauerstoffe lagen, und ebenso die Flügelrippen viel dünner und zarter waren, als es normalerweise der Fall ist.

\section{Einfluss der chemischen Stoffe.}

Die frühzeitige Entwickelung der Eier von Bombyx mori wird beobachtet, wenn man sie einige Sekunden in Schwefelsäure oder einige Minuten in Salzsäure hält und nachher auswäscht. Diese Thatsache wurde von mehreren Forschern konstatiert (Ducleaux [202], Susani [852], Tichomirow [868], Bellati und Quajat [62] etc.) und findet ihre Erklärung in der "Reiz-Theorie" von Tichomiraw (868), nach welcher nicht nur die niedrige Temperatur, sondern die elektrischen Funken, das Frottieren, die Hitze und in unserem Falle auch die stark angreifenden Flüssigkeiten resp. Gase im Stande sind den auslösenden Reiz auf die ruhenden Eier auszuüben, nach welchem sie sich sofort $\mathrm{zu}$ entwickeln beginnen. Ausführlicher ist diese Theorie in diesem Kapitel, 4. und 7. Abschnitt beschrieben worden.

Auch unbefruchtete Eier von Bombyx mori werden zur Entwickelung z. B. durch Schwefelsäure gereizt (Tichomirow [868]). Wie bekannt, hat man in (ler letzten Zeit parthenogenetische Eier auch von anderen Thierklassen durch Chemikalien zur Entwickelung gebracht (Delage in ,C. R. Acar. Scienc. Paris, 1901," "Arch. Zool. exp., 1901;" Wilson in „Arch. f. Entw. mech., 1901," „Biol Bull., 1901," "Tagbl, Int. Zool. Congr., 1901;" Loeb in "Amer. Journ. of Physiol., 1901," "Arch. f. Entw. mech., 1902;" Viguier in "C. R. Acarl. Scienc. Paris., 1901;" Rawitz in "Arch. Entw. mech., 1901;" Bullot in "Arch. Entw. mech., 1904;" Giard in "C. R. Soc. Biol., 1901;" Hunter in "Amer. Journ. of Physiol., 1901;" Bataillon in "Arch. Entw. mech., 1901-1904;" Mathows in "Amer. Journ. of Physiol,, 1901;" Loeb, Fischer und Neilson in "Arch. für Physiol. Pflüger, 1901, “ etc.). So z. B. setzte Loeb $(531 a, 531 b)$ zum Meerwasser, in welchem unbefruchtete Eier von Meerigeln sich befanden, eine gewisse Menge von Magnesiumchlorid hinzu. Als nach 2-stündigem Verbleiben in demselben die Eier wieder in gewöhnliches Meerwasser gebracht wurden, begannen sie sich zu entwickeln und ergaben Larven (Pluteus). Die Entwickelung wich dabei von der normalen in ihrer Form ab (Delage [166a]).

Loeb ersieht die Ursache der weiteren Entwickelung der unbefruchteten Eier von Meerigeln in den Ionen, indem er sagt: „Das Meerwasser besitzt entweder keine genügende Menge von Ionen, 
welche für die Mechanik der Zelltheilung nothwendig sind (wie $M I g$, $K, H O$ etc.), oder es enthält Ionen, welche diesem Processe hinderlich sind ( $\mathrm{Ca}, \mathrm{Na}$ etc.), orler es findet sowohl das eine wie auch das andere statt. Die Innen und nicht Nuclënen sinil hauptsïchlich für den Process der Entwickelung nothwendig."

Delage $(166 i)$ wies jerloch nach, liss ein Spermatozoid des Meerigels ein Ei unter keinen Umständen an Magniumgehalt bereichern kann, da er weniger Magnium in sich entlält als das Ei selbst. In Folge dessen ersetzte Loob seine "Ionen-Theorie ${ }^{\text {(lurch die }}$ "Theorie des osmotischen Druckes," welche auch von Delage angenommen wird. Hier sei bemerkt, dass die Versuche ron Herbst (367a) mit befruchteten Eiern von Sphaerechinus granularis, Echinus microtuberculatus und Strongylocentrotus lividus etwas abweichende Resultate ergaben. Er hielt diese Eier statt in Meerwasser in Lösungen $(3,7 \%)$ verschielener Salze und beobachtete verschienlene Abweichungen in der Entwickelung. Das Gesetz der umgekehrten Proportionalität des osmotischen Druckes und des Molekulargewichtes gilt z. B. nur für die Salze einbasischer Säuren, während die Sulfate ihm nicht folgen.

Bataillon (54c, 54d) vermuthet, dass die Salzlösungen deshall) die parthenogenetische Entwickelung bei unbefruchtetem Ei hervorrufen, weil sie beim Zusatze zum Meerwasser, in welchem das Ei sich befindet, dem Ei das Wasser entziehen.

Obwohl Delage (166c) auch diese letzte "Dehydrations-Theorie" vertheiligt, nimmt er in cler letzten Zeit neben dem osmotischen Druck auch andere Faktoren an, welche unbetruchtete Eier zur parthenogenetischen .Entwickelung anregen. Er sagt: „Das Ei reagiert auf die entsprechenden Reize, gleichviel welcher Natur sie seien, dadurch, was ihm eigen ist - durch die Zellvertheilung, wie die Netzhaut, indem sie auf die empfindende Reizung: mechanische, physikalische oder chemische reagiert, das erzeugt, was ihr eigen ist, nämlich die Lichtempfindung."

Daraus ist ersichtlich, dass auch die Dehydration nicht als die unmittelbare Ursache des besprochenen Prozesses von Delange betrachtet wird, sondern als eine der Reizformen, womit auch Petrunkewitsch $(633 d)$ einverstanden ist. Somit liegt keine Nothwendigkeit vor, die Reiz-Theorie von Tichomirow zu verlassen, umso mehr, da in der letzten Zeit Jickeli $\left(423 \alpha^{\prime}\right)$, gestiitzt auf ein sehr reichhaltiges Material, zum Schlusse kam, dass allerlei Schädigungen und Verletzungen der Zellen ihre Theilung und Vermehrung 
zur Folge haben, zu welchen wohl auch die die künstliche Parthenogenesis erzeugenden Faktoren gehören.

Jeder Raupe ist zur normalen Entwickelung ein bestimntes Quantum des gewohnten Futters nothwendig. Es ist allerlings nicht ausgeschlossen, dass auch anderes, ungewohntes Futter von Raupen eingenommen wird, wobei ihre Entwickelung entwerler verzögert, beschleunigt, oder normal bleibt. Alles kommt darauf an, ob das betreffende, kïnstlich geänderte Futter von Raupen gut oder schwer assimiliert wirl. So z. B. wird die Entwickelung der Raupen von Vanessu urticae beim Fiittern mit Brennessel + Eisenalbuminat beschleunigt, beim Füttern mit Brennessel + Hydrochinon verzögert und bleibt normal, wenn man ihnen nur Brennessel reicht (v. Linden $[517,527 e])$.

Die Giftigkeit des Futters ist ein relativer Begriff bei Inseliten. So z. B. leben die Raupen Deilephila euphorbiae, galii und nicec auf Euphorbia-Species, Raupen von Thais polyxenc auf AristolochiaArten, Raupen von Heliothis armiger auf der Tabakspflanze, 'Plusia moneta auf Aconitum, Gonopteryx rthamni auf Rhamnus catharticus etc., welche alle $\mathrm{zu}$ sogenannten giftigen Pflanzen gerechnet werden. Auch bei Larven resp. Imagines anderer Insektenordnungen wird dasselbe beobachtet. So z. B. zeigte Goetschmann im Vereine für schlesische Insektenkunde Paprikapulver mit Larven von Anobium paniceum L. vor; Lasioderma serricorne Fabr. greiit Tabak in jeder Form an.

Auch Insekten, welche nie in anderer Atmosphäre als nur in (ler Luft gelebt haben, können längere Zeit "giftige" Gase resp. Flüssigkeiten ohne Schaden ertragen. So z. B. begoss Sajó (731) (lie Larven von Entomoscelis-Arten mit 10\% Nikotin-Lösung und beobachtete dabei keinen schädlichen Einfluss. Reh (679) hielt Asp. perniciosus 24 Stunden lang unter einer Glocke mit Cyankaliumstïcken; die Läuse erwiesen sich als lebenıl. Asp. pyri, nerii und Diasy. osteraeformis starben in Cyanwasserstoffatmosphäre nicht einmal nach 2 Stunden.

Bei der Beurtheilung solcher Thatsachen muss mann jelloch sehr vorsichtig sein, da dabei verschiedene Nebenumstände in Spiel kommen können. Es kann sein, dass beim Begiessen (ler Raupen resp. Larven mit den für diese Arten sonst giftigen Flüssigkeiten die letzteren wegen der Beschaffenheit der Haut (z. B. Haare, Warzen etc.) nicht überall mit dem Körper unmittelbar in Berührung 
kommen und auf diese Art dem Inselit die Möglichkeit bieten, den dazwischen sich befindenden Luftvorrath einzuathmen. Auch ist es möglich, dass die Insekten in giftigen Gasen eine Zeit lang ihr Athmen auf ein Minimum reduzieren, oder mit der an ihrem Körper noch haftenden Luft athmen.

Ausserdem können die sunst giftigen Substanzen für die Entwickelung der Insekten sogar förlern:l sein, wenn clieselben in bestimmten minimalen Quantitäten gereicht werilen. Dogiel (159) stellte fest, dass Ammoniak, Oxalsäure, Karbolsäure, Aconitin etc. in kleinen Mengen den Herzschlag beschleunigen, wïhrend dieselben Substamzen in grossen Mengen verlangsamend wirken.

Wir sehen also, dass auch "Gifte" ihr Optimum bei der Entwickelung der Insekten haben, wie es bei anderen Agentien beobachtet wird.

Gewisse Thatsachen deuten darauf hin, dass die chemischen Substanzen, welche im Stoffwechsel der Insekten Theil nehmen, nicht immer aut den ganzen Organismus ihre Wirkung ausiben. So z. B. konstatierte M. v. Linden (527e), dass obwohl die Schmetterlingspuppen längere Zeit in (ler Kohlensäureatmosphäre ohne Schalen verbleiben können, bei ihnen der Chitin jedoch nicht gebillet wird. Sie sagt: „Das Erhärten (ler Puppenhiulle kann somit nicht als ein Austrocknungsprocess eines von den chitinbildenden Zellen abgesonderten Seliretes betrachtet werden. Wir missen diesen Vorgang als einen Lebensprocess ansehen, der sich nur in Gegenwart von Siuterstoff abspielen kann und in einer Metamorphose des Plasmas der Epithelzellen besteht" (p. 442).

Auch wirken gewisse Substanzen schäılich auf die Entwickelung nur gewisser Organe. Dewitz (168) fand, dass eine Einschränkung der Oxylationsvorgänge im Organismms den Apterismus zur Folge haben kann. Dasselbe ist auch von M. v. Linden (527e) konstatiert. Dowitz (175) behandelte Fliegenpuppen mit verdünnter Essigsïure und fand, dass, obwohl die Fliegen dann vollständig ausgebililet waren, sie ihre Fliigel doch nicht gebrauchen konnten. Man kann somit die Vermuthung aussprechen, dass z. B. die Thierlïuse deshalb keine Flügel haben, weil das Medium, wo sie sich aufhalien und sich fortpflanzen, verschiedene Gase (z. B. Schwefelwasserstoff, Kohlensïure etc.) ausscheidet und dalurch die Entwickelung der Flügel hemmt.

Die Verwandlung von einem Stadium in das andere kann durch gewisse chemische Stoffe verhindert werilen. Dewitz $(175,167 a)$ 
Lielt Raupen von Tortrix pilleriana und Porthesia chrysorrhoca in der Blausäreatmosphäre. Sie lebten geniigend lange Zeit darin, konnten sich aber nitht verpuppen. Die Kohlensïure-Atmosphäre hat dieselbe Wirkung auf die Larven von Lucilia caesar. Quajat (657) beobachtete, dlass Eier von Bombyx mori, welche sich in Kohlensäure 77 Stunden lang befanden, keine Räupchen ergaben.

Warum der Sauerstoffmangel die Entwickelung der Eier hindert, ist aus den Versuche von Loeb (531c) an Fisch- und Seeigeleiern ersich!lich, welche ergaben, dass zuerst moleculare und dann morphologische Aenderung'n in den Zellen hervorgerufen werden, die ihrereseits die Lebenserscheinungen hemmen. Bemerkenswerth sind die Untersuchungen von Tangl $(\$ 52 \alpha)$ uber lie Entwickelungsarbeit im Vogelei. Er sigt: "In den Anfangsstadien der Embryogenese ist zur Entwickelung der lebenden, embryonalen Substanz die Umwandlung einer grösseren Menge chemischer Energie erforilerlich, also grössere Arbeit als zur Entwickelung derselben Substanzmenge in den reiferen Stadien." Nun zeigen die Versuche von Quajat (657), dass die Eier von Bombyx mori umso weniger in der Kohlensäure leilen, je weniger ihre Entwickelung fortgeschritten ist. Sind die an Vegeleiern gewonnenen Resultate auch für die mori-Eier anwenubar, so muss man zulassen, dass die Entwickelungsarbeit in den jüngeren Stadien keinen Sauerstoff erforilert, und folglich findet die Umwandlung der chemischen Energie ohne Sauerstoffverbrauch statt.

\section{Einfluss der Nahrung auf das Geschlecht und auf die Fortpflanzung.}

Der Einfluss iler Nahrung auf die Geschlechtsbildung ist noch gegenwärtig eine Streitfrage.

Einerseits liegen Beobachtungen vor, aus welchen zu ersehen ist, dass bei mangelhafter Ernährung mehr $\sigma^{\top} \sigma^{\nearrow}$ als $ㅇ ㅜ$ sich entwickeln, welche aber ihren Grund in der grösseren Wilerstandsfähigheit der $\sigma^{\top} \sigma^{\star}$ als der 우 gegen das Hungern haben. Andererseits sind That-

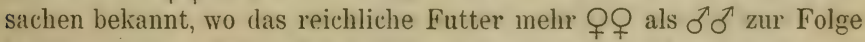
hatte, und beim Mangel der Nahrung umgekehrt. Ausserdem steht es fest, dass das Futter nicht nur sekundäre männliche resp. weibliche Merkmale hervorruft, sondern auch die Entwickelnng der Genitalorgane hemmen resp. beschleunigen kann.

Wir wollen zuerst diese Beobachtungen näher betrachten.

Standfuss (840) liess 151 Raupen von Aglia tau bei ungenïgender Nahrung sich weiter entwickeln; die am Leben gebliebenen. 
Raupen ergaben $34 \delta \sigma$ und 9 웅. Unter gleichen Umstänilen erhielt er von 185 Raupen von Saturnir pavonia 41 ठ $\delta$ und 11 우 von 103 Agrotis collina-Raupen $37 \sigma^{\top}$ und 8 우 (835). Er erklärt den erhaltenen Ueberschuss der $\sigma^{\top} \sigma^{\wedge}$ über die $ㅇ$ 우 durch die Annahme, dass die männlichen Individuen Nahrungsmangel in höherem Grade zu ertragen vermögen als die weiblichen.

Die gleiche Erklärung kann man wohl (len Beobachtungen von Gentry (306) und Treat (881) an Lepidopteren und von Reichenow $(682 a)$ an Coleopteren geben.

Ausser der Kritik liegen jedoch die Versuche von Rudow (711) vor. Dieser Forscher fuitterte eine Serie von Wespenlarven mit Mïncher Bier gemischt mit Fleischextrakt und die andere Serie mit Braun- oder Weiss-Bier mit Zusatz von etwas Honig. Die erste

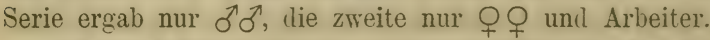

Auch Johnson $(423 \alpha)$ experimentierte mit Anopheles claviger: bei guter Ernährung erhielt er $71,4 \%$ 우 $q$ und $28,6 \%$ ठ $\delta^{\top}$, bei mangelhafter dagegen $20 \%$ 우 und $80 \% \sigma^{\top} \delta^{\top}$. Die Versuche mit Culex pungens ergaben bei mangelhafter Ernährung $66,7 \% \sigma^{\top} \sigma^{\top}$ und $33,3 \%$ 우우.

Von älteren Untersuchungen seien hier erwähnt diejenigen von Landois (498b) mit Raupen von Vanessa urticae. Er fütterte mehrere Tausende Räupchen, einige reichlich, die anderen mangelhaft, und erhielt aus den ersteren $q$ 을 und aus den letzteren $\sigma^{\top} \sigma^{\top}$. Als er die Räupchen zuerst reichlich gefüttert hat und nach einiger Zeit mangelhaft, erhielt er lauter $q$ 우 mit kümmerlich entrvickeltem Eierstock.

Einige Forscher negieren den hemmenilen resp. progressiven Einfluss des Nahrungmangels resp. seiner Verschiedenheiten auf die Entwickelung der Genitalorgane. Es sind aber Thatsachen vorhan(len, welche diesen Einfluss zu bestätigen scheinen.

Pospelow (642) fand, dass der Eierstock von Plilyctaenodes sticticalis bei ungenügenter Ernährung eine unvollständige Entwickelung zeigt. Rossikow (705乙) erklärt diese Erscheinung durch die Wirkung des Parasits Microclossia prima.

Koschewnikow (467a) fand, dass die Ernährung dler Drohnenlarve mit dem Futter, welches gewöhnlich von der Königinlarve eingenommen wird, keinen Einfluss auf den normalen Entwickelungsgang ler Genitalorgane hat. Weiter sagt er: "Vollständiges Hungern übt keinen hemmenden Einfluss auf die Eutwickelung der Geschlechtsdrisen und einiger anderen Organen der Drohnenlarve aus, bis die Vorräthe des Fettkörpers vorhandes sind“ (p. 139). 
Vom-Raht $(930 a)$ beobachtete, dass die überreichliche Ernährung der Drohnenlarven die Entwickelung der Geschlechtsllüisen schädigt.

Grassi und Sandias (327) fanden bei Termiten auf Sicilien 15 verschiedene Formen (Kasten) in einem Nest. I)ie Untersuchung von Calotermes flavicollis Fabr. und Termes lucifugus Rossi ergaben, dass die Nahrung, welche den jungen Larven gereicht wird, uiber diese oder jene Form entscheilet. Dabei ändert sich sowohl die Menge wie auch die Beschaffenheit der Nahrung; auch kommt eine specifische Wirkung des Speichels hinzu, welcher dem Futter beigemischt wird.

Silvestri $(815 d)$ untersuchte südamerilianische Termiten und sagt: „Aus den Eiern können sich je nach dem Willen der Arbeiter infolge besonderer Nahrung gechlechtsreife Individuen oder Arbeiter orler Soldaten entwickeln, also das Idlioplasma eines jeden Eies ist im Stande, auf die durch verschiedene Nahrung gegebenen Reize verschieden zu reagieren und gewisse körperliche Eigenschaften hervorzubringen, andere zu unterdrïcken" (p. 290). Zum Schlusse sagt er: „Ich schreibe also die Entstehung der verschiedenen Kasten bei den Termiten den folgenden Faktoren zu: Variation als Wirkung des Futters und der Thätigkeit, Vererbung, Auslese, Atavismus" (p. 328).

v. Buttel-Reepen sagt in seinem Vortrag (124c): "Bei den Hummeln werden viele der sogenannten Arbeiterinnen bei reichlicher Ernährung an Grösse dem Mutterweibchen vollkommen gleich und sind in keiner Weise von diesem zu unterscheiden; es sind dann eben nur unbefruchtete vollkommene Weibchen mit allen Instinkten der Königin" (p. 37).

Reichenbach (682a) fütterte Arbeiter von Lasius niger L. mit Invertzucker und zerschnittenen Mehlwürmern, wonach sie parthenogenitische Eier ablegten. aus welchen typische Arbeiter (statt ठठす) sich entwickelten.

Dickel (179) stellte sehr ausgedehnte Untersuchungen an Apis mellifica und ham zum Resultate, dass die Entwickelung einer oder der anderen Bienenform aus dem Ei der Thätigkeit der Arbeiterinnen zuzuschreiben ist, welche durch die Bespeichelung der Eier und durch die- Ernährung der Larven mit geeignetem Futter das kunftige Geschlecht der Biene bestimmen.

Gerade dieser Forscher war die Ursache, dass die bekannte Theorie von Dzierzon (205a) von neuem revidiert wurde. Nach 
Dziorzon ergeben alle unbefruchtete Bieneneier ausschliesslich Drohnen, während aus befruchteten Eiern stets Arbeiterinnen resp Königinnen sich entwickeln; also der das Geschlecht bestimmenile Falitor ist die Befruchtung: Diese Theorie wurle seiner Zeit ron v. Siebcld (\$12) gepruft und als richtig befunden.

Nun wurlen nach der Aufstellung der "Bespeichelungstheoric" ron Dickel (178a) neue Untersuchungen rein theoretischer Natur von Weismann (9.53b), Paulcke unil Petrunkewitssh (6337), 633c) an Bienenpiern angestellt, welche theils neue, theils den früheren widersprechende Resultate lieferten. Experimentelle Beweise pro oder contra bei beiden Theorien wurlen nicht geliefert, weshalh auf dem Zoologen-Kongress in Tübingen (1904) zwischen den Vortragenden $\nabla$. Buttel-Reepen (124ל) und den an der Discussion Theil genommenen starke Meinungs-Verschictenheiten stattfinilen, bis der Vortragende selbst zum Schlusse sagte: „Dass die Müglichlieit (bei grosser Unwahrscheinlichlieit) vorliegi, dass auch unter besouleren uns noch unbekannten Bedingungen aus unbefruchteten Eiern vielleicht Arbeiterinnen bzw. weibliche Wesen (und vice versa) hervorgehen können, wird nicht bestritten (vgl. die Cameron-Weismannsche Theorie), aber unter (len normalen Verhältnissen sehen wir im Bienenstaat diese Möglichleit nach dem heutigen Stanle der Wissenschaft allem Anschein nach nicht verwiklicht" (p. 77).

Ich beschränlie mich jetzt nur auf das Gesagte bezüglich ier Theorien ron Dzierzon und Dickel, da meine eigenen Untersuchugen, welche ihrem Charakter nach nicht hierher passen, bald an anderem Orte veröffentlicht werden.

Sehr auffallend ist es, class man bis jetzt noch keine Analysen (ler Nahrumg solcher Inseliten besitzt, bei welchen die Kasten ver-, muthlich durch quantitative und qualitative Nahrungsverschielenheiten gebildet werilen. Nur eine solche Untersuchung speziell für die Bienennahrung ist ron v. Planta $(639 a)$ angestellt worlen.

Die mittleren Werthe der Zusammensetzung der Nahrung für die ganze Larvenperiode betragen:

Königin. Arbeiterin. Drohnc.

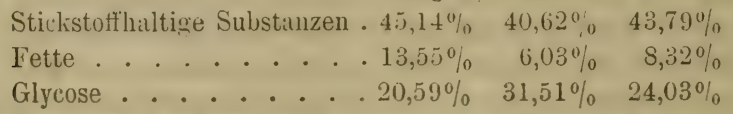

Koschewnikow $(467 a)$, kritisiert diese Untersuchung, welche gewisse Ungenaugkeiten enthält (z. B. entgegen der Behruptung von v. Planta sind die Gedärme der reifen Arbeiterinlarve mit unver- 
dautem Pollen überfüllt. Auch die Ernälirungszeit der Königinlarve gielst v. Planta um einen Tag länger an: 7 Tage statt 6), und berechnet aus seinen Angiben die Zusammensetzung der Nahrung für die zweite Periode der Larven (vom vierten Tage an) bei der Annahme, dass die Nahrung der Königin- und Arbeiterinlarve währenı der ersten drei Tage idendisch sei. Er erhält:

Königin. Arbeiterin.

\begin{tabular}{l} 
Stickstoffhaltige Sulstanzen . $36,90 \% \%$ \\
Fette . . . . . . . . . . . $18,72 \%$ \\
Glycose . . . . . . . . . $22,69 \%$ \\
\hline
\end{tabular}

Es liegen auch Thatsachen vor, welche zeigen, dass die ungenügente Fütterung die Eierentwickelung bedeutend reduziert und umgekehrt.

Als Marchal (546a) die Arbeiterimmen von Vespa yermanica mit Honig und Fleisch fütterte, erhielt er von ihnen parthenogenetische Eier zu ungewöhnlicher Jahreszeit.

Perez $(630$ d) sagt, dass mangelhafte Ernährung der Arbeiterinnen-Larven bei Bienen die Atrophie der Eier bedingt.

Standfuss (840) ziichtete 151 Raupen von Aglia tuu, wobei 67 an Hunger starben; die ïbrigen ergaben 9 우, welche aber je 2-3 Eier ablegten. Die 34 ठ ठ waren dagegen fortpflanzungsfähig.

Ritzema Bos (105) beobachtete, dass die Fortpflanzungsfähigkeit von Silpha opaca unl Coprophilus striatulus fast Null wurde, als diese Käfer gænöthigt waren statt thierisches Futter Pflanzen zu gebrauchen.

Morảwilko ( 593 ) beobachtete, dass die geflügelten $q$ 우 der Aphis-Arten viel schmäleren Leib und weniger Embryonen unil Eier haben als die ungeflïgelten. Da die geflïgelten $q q$ bei ungünstigen Nahrungsverhältnissen entstehen, bringt er die erwähnte Armuth mit dem Nahrungsmangel in Zusammenhang.

Singerland $(\$ 16 \alpha)$ konstatierte, dass $q$ o von Myzus achyvanthis bei schlechtem Futter nur 1/3 der Nachkommen hervorbringen als sonst.

Göldi (315a), Speiser (827), Galli-Valerio und Bochaz (270ß, $270 \gamma$ ) etc. fanden, dass das Blutsaugen bei Anopheles und Culex eine unentberliche Berlingung für die Eierablage ist, wobei diese Ablage 48-72 Stunden nach dem Saugen stattfinlet (Koschewnikow $[467 a]$ ). Hier ist nicht ohne Beleutung zu bemerken, lass, wie Koschownikow (467a) fand, der Eintluss der Nahrung auf den 
Eierstock von Anopheles maculipennis Meig. nicht immer beobachtet wirl, und zwar von Anfang August (Woronesch in Russland) ruft bei ihnen das Blutsaugen nicht die Entwickelung des Eierstockes, sonilern die Vermehrung des Fettlörpers hervor. Er sagt: „Die Zeit der zweiten Eierablage bestimmt ilen Anfang der Verfettung. Nach 2-maliger Ablage beginnt die eingenommene Nahrung, welche früher die Entwickelung der Eier bewirlite, anf die Entwickelung des Fettkörpers zu wirken. Es findet eine wunderbare Aenderung in der Selbstregulierung des Organismus statt: diejenigen Nährsiifte, welche früher von einem Systhem der Organe intensiv verbraucht wurlen, werden einige Tage später ron anderem Systhen der Organe benützt" (p. 110).

Dass die qualitative resp. quantitative Aenderung des Futters die secundären Geschlechtskemnzeichen erzeugen kamn, ist aus folgenden Thatsachen ersichtlich:

Pictet $(637 a)$ züchtete Raupen von Ucneria dispar, wobei er ihnen entwerier eine ungenügende Menge Futters (Unterernährung) gereicht hat, oder sie mit Blättern fütterte, die besonderen Reichthum an Nährstoffen enthielten (Ueberernährung). Dabei hat es sich herausgestellt, dass die Unterernährung zur Ausbildung männlicher sekundären Merkmale führt, während die Ueberemährung die Ausbildung von weiblichen sekundären Merkmalen hervorruft, und diese noch nach einer weiteren Generation mit normaler Nahrung beibehalten wirl.

Dickel (179a) entfernte die Königin aus einem Bienenstock, und da die Waben noch nicht unbesetzt waren, begannen einige Arbeiterinnen bei der reichlichen Ernäherung parthenogenetische Eier zu legen, aus welchen sogenannte falsche Drobnen sich entwickelten. Diese Drohnen hatten sekundäre weibliche Merkmale, von welchen Dickel sagt, wie folgt: „Die Schienen des dritten Fusspaares normaler Drohnen und Mutterbienen sind an gleicher Stelle gewölbtrund und bei den Drohnen fast unbehaart, wo sie bei Arbeitern hohl-rund und am Rande der Rundung auffallend behaart sind (sog. Körbchen). Unter den falschen Drohnen habe ich stets nur einen geringeren Prozentsatz solcher gefunden, die hierin normalen Drohnen genau glichen. Bei einem Theil war die Stelle flach, bei anderen etwas und wieder anderen bemerkenswert vertieft; bei verschiedenen Exemplaren nahezu wie bei Arbeitsbienen. Auch bez. der umgebenden Behaarung an dieser Stelle habe ich mehr oder weniger Abweichuungen nach dem Typus der Arbeiter hin vorgefunden " (p. 134, 135). 
Dass die Drohnen, welche aus den Eiern der Arbeiterbiene sich entwickeln, einen Unterschied auch bei ihrer embryonalen Entwickelung von den Drohmen, welche aus Kiönigineiern entstehen, aufweisen, hat bereits Petrunkewitsch (633c) gefunden. Ich bin auch zum Schlusse gekommen (39a), dass sowohl die Untersuchungen von Petrunkewitsch und Dickel, wie auch die Resultate rler analytischstatistischen Methode das Vorhandensein der "fulschen" Drohnen sicher feststellen.

Aus allen hier angeführten Thatsachen ist ersichtlich, dass in gewissen Fällen die Fortpflanzungsfähigkeit der Inseliten durch die mangelhafte Nahrung gehemmt wird. Dabei können die Nachkommenschaften gewisser Insekten-Species sekundäre Geschlechtsmerkmale erhalten, welche auch dann bei weiteren Generationen bleiben, wenn die Nahrung wieder normal wird. Dadurch liann auch die Hemmung in der Entwickelung der Genitalorgane entstehen, wenn auch in gewissen Fällen zuerst der Fettliörper zu verbrauchen begonnen wird.

Was nun direkte Geschlechtsbildung durch die Nahrung der Larve resp. durch die äusseren Einflüsse, welchen die Eier ausgesetzt werlen, z. B. durch die Bespeichelung, anbelangt, so befinciet sich diese Frage, wegen ihrer grossen Verwickelung, noch im Stadium der Hypothesen, obwohl man im Prinzipe nichts dagegen haben kann, wenn man der Nahrung resp. den Speichelsekreten (oder ähnlichen Stoffen) den auslösenden Reiz zuschreiben will.

Die Thatsache, dass ein unbefruchtetes Bienenei stets Drohnen ergiebt, leutet darauf hin, dass aus demselben unter Umständen auch Arbeiterinnen sich entwickeln können. Einige, z. B. Dzierzon, ersehen dafür. als nothwendige Bedingung das Eindringen eines Spermatozoides ins Ei; die anderen dagegen betrachten diese Bedingung als einen speziellen Fall.

So z. B. schlug Tichomirow (871) vor, gestiitzt auf seine "Reiz-Theorie", das unbefruchtete Bienenei kïnstlich zu reizen, um daraus die Arbeiterin zu erhalten. Wenn Kulagin (483) dabei, indem er Schwefelsäure als Reizmittel benützte, keine positiven Resultate erhielt, so beweist er noch inmer kein Gegentheil. Es müssen systematische Versuche in dieser Richtung mit verschiedenen reizenden Faktoren angestellt werden, zu welchen auch die Produkte der Speicheldrüsen der Arbeiterinnen zu zählen sinıl.

Andererseits ist bekannt, dass aus parthenogenetischen Eiern, z. B. der Ameisen, auch weibliche Wesen entstehen kïnnen. Schon 
diese Thatsache zeigt, dass die Befruchtung lieine nothwentige Bedingung der Geschlechtsbildung sein kann.

Dass nicht etwa die äusseren Faktoren an der Geschlechtshildung betheiligt sinı, sondern dass die Bestimmung des Geschlechtes ausschliesslich dem Organismus der Mutter überlasson ist, wirl auch von einigen Forschern vertheidigt, unter welchen v. Lenhossék $(507($ ) und 0. Schultze $(794 \imath)$ zu nemen sinul. Allein anch diese Präformations-Theorie berlarf einer gewissen Aenderung, wie ich es im III. Bande meiner "Studien" zeigen werle.

\section{Einfluss des Klimas.}

\section{a) Eier.}

Legt Bombyx mori die Eier im trockenen un: warmen Zimmer ab, so findet die vorzeitige Entwickelung derselben statt (Maillot [541]). Eier einiger anderen Species reatgieren daraut nicht (Ocneria dispar: Schowyrew [748]; entgegengesetzte Resultate: Altum [11, 13]).

Wärmeres Iilima bewirkt reichliches Eierlegen einiger Species (Maulwurfsgrille: Reisen [685a]).

Eier vieler Species entwickeln sich bei giimstigen klimatischen Verhältnissen rascher als sonst (Ratzəburg [673u]).

\section{b) Raupen.}

Günstige klimatische Verhïltnisse beschleunigen die Entwickelung der Raupen (Agrotis segetum: Rossikow [705c]; Simyru venosa, Drymonia dodonea: Höller [582]; Parnassius delius: Selmons [806]).

Die Temperaturabnahme und die Trockenheit der Luft verlangsamen und bringen die Entwickelung eniger Larren-Species sogar zum Stillstanile (Scolytus destrictor, mulistriatus, pygmaens: Schewyrew [748]). Regnerischer Herbst schaclet einigen Arten nicht (Ciadius ulmi: Danilow [748]), während das regnerische Friijahr die Larven einiger Species vernichtet (Gulerucell « luteola: Chramow [748]).

Verbraucht eine Raupe für ein Gespinnst in cler Erde in Folge spezieller klimatischen Verhältnisse mehr Material, so wird ihre Puppenzeit länger als sonst (Botys sticticalis: Pospelow [642]).

Raupen, welche die II. Generation der Schmctterlinge ergaben, gebrauchen mehr Zeit zu ihrem Heranwachsen, als die, welche sich als Winterpuppen verwandeln (Pieris brassicae, Auel [17]). 


\section{c) Puppen.}

Nasse und kalte Witterung im Friihjahr verlangsamt das Ausschlüpfen der Falter (Cucullia chamomillae: Woir [952]; unbestimmte Arten: Laddiman [492]; Parnussius iblius: Solmons [806]; unbestimmte Arten: Altum [12]) nicht nur im Freien, sonilern auch im Zimmer (Smerinthus ocellatus, Spluinx ligustri, Orgia fascelina, Attucus pernyi, A. cecropia, A. cynthia, Dicranura vinula: Laddiman [492]). Eine Ausnahme machen solche Insekten, welche in Trieben, Blättern unil Gespinnsten leben (Retinia buoliana, Halias chlviana, Coleophora laricella, Hyponomenta evonymella, Zeuzer myrina: Altum [12]).

Verspätet sich die Entwickelung der Pflanzen im Frülijahre, so verspätet sich auch die Entwickelung der Insekten (Oryic fascetina, Smerinthus ocellatus, Splinx ligustri, Attacus periayi, A. cecropia, A. cynthia, Dicramura vinula: Laddiman [492]; Pieris Urassicae, Cocnonympla pamplilus, Lycaena icurus, Epinephela janira, V(1nessa atalanta, V. urticae: Lockyer [530]).

\section{d) Imago und alle Stadien.}

Heisse Witterung verursacht die 2-te Generation von Lepilopteren, wo sonst nur eine fliegt (Papilio podalivius III. Gener.: do Caradja [129]; Antocharis cardumines: Himsl [374, 375], Hebhard [303, 304]; Melithaea cinxia, MI. dictynna, M. parthenie, M. athatia: Rühl [722]; Polyommatus var. rutilus: de Caradja [129]; Lycaena argiolus: Krulikowski [428f]; Sرlhinx iigustri, Deilephitu galii, Macroylossa ficiformis: de Caradja [129]; Orgyia antiqua: de Caradja [129], Urech [889]; Arctia hebe: Pauls [628]; Ephestice linchniella: Fink [197a]).

Kältere oder wärmere Jahre haben in mittleren Gegenden weniger Einfluss auf das Leben der Tagfalter als in sehr nördlichen oder südlichen (Brunbauer [116]).

Nörllich der Alpen liommen höchst selten und nur in sehr warmen Jahren 3 Generationen vor, meist aber nur eine oder zwei (Brunbauer [116]).

In hohen Norilen uni auf hohen Bergen reicht für die Entwickelung der Falter in einem Jahre die gïnstige Zeit zur Ausbildung derselben gewöhnlich nicht hin, weshalb liese Thiere oft zweimal oder dreimal überwintern, bis sie fliegen. Dies hat zur Folge, dass man sie nicht alle Jahre sieht, wenigstens nicht in gleicher Menge. 
Letzteres kann in mittleren Gegenden gleichfalls zutreffen, doch fliegen sie hier mindestens alle Jahre einmal (Brunbauer [116])

Die Anzahl der Generationen ist in südlichen Ländern unter. den meisten Lepidopteren-Species minlestens 3; die höchste Zahl aber dürfte bei nicht überwinternden Faltern an Orten, wo die Sommerhitze nicht allzu gross ist und die Entwickelung der Tagschmetterlinge verzögert, 5 nicht ïbersteigen (Brunbaurr [116]).

Keinen Einfluss auf die Entwickelungsgeschwindigkeit hat die heisse Witterung auf Sphinx ligustri (?) (Vorloren [910]), Spilosoma mendica var. rustica (de Caradja [129]), Phlyctaenodes sticticalis (Rossikow [634f]), Dendrolimus pini. (Silantjew [815a]).

Frühzeitige Entwickelung infolge heisser Witterung erleilen folgende Species: Parnassius apollo (Benteli [69]), Pararge egeria var. meione (Weissmann [954]), Apamea ditlyma, Apatura iris, Limenitis sibylla (Möller [522]), Acherontia atropos (Trost [\$84a]), Möller [822]), Sphinx pinastri, Splinxx ligustri (Bonteli [69]), Deilephila euphorbiae (Strohmayor [848], D. porcellus, Smerinthus tiliae (Benteli [69]), Antherea permyi (Heissler [361]), Stauropus fagi, Hoplitis milluaseri, Dasychira pudibunda, Panthea coenrbita, Trichosea ludifica, Agrotis exclamutionis, Agrotis c nigrum, Pericallia matronula (Benteli [69]); Cecidomyia destructor (Marchal [546]), Tomicus typographus (Nüsslin [612a]), verschiedene Species von Pflanzenläusen (Bonnet [103], Schmidberger [754], Kessler [449], Balbiani [45], Thiele [861]).

L. Möller (522), gestüzt auf seine 25-jährige Sammelthätigkeit ler Insekten, sagt folgeniles über den Einfluss des Krimas auf Insekten: "Auf das Geleihen eines Insekts ist meist weniger lie Witterung (les ganzen Jahres, als die kürzerer Zeiträume, ja oft selbst die von nur wenigen Wochen und Tagen von entscheilender Einwirkung, da die Witterung selten während der ganzen Lebensdauer ler Insekten einen gleichmässig günstigen oder nachtheiligen Einfluss ausübt, sondern das Insekt gewöhnlich nur in Einem seiner Verwandlungszustände davon am empfindlichsten berührt wird" (p. 10?

Er sagt, dass bei ungünstigem Wetter die Eier weniger leiden, als deren Puppen und noch mehr die Larven. Am empfindlichsten gegen nasse Kälte, namentlich bei wiederholtem Aufthauen und Gefrieren, sind die Larven während der Häutung.

Phylloxera liefert geflügelte Exemplare, wenn sie in der Wärme kultiviert wird, sonst ungeflïgelte Excmplare (Roulet [708]). 
Zu entgegensetzten liesultate kam auf experimentellem Wege Nüsslin (612).

Bei einigen Insekten wird die Entwickelungsgeschwindigkeit durch die Temperatur-Abnahme, durch die Trockenheit der Luft und durch Nabrung verlangsamt (Schewyrew [748]); bei anderen Species dagegen verursacht die Trockenheit eine beschleunigte Entwickelung (Selmons [806]). Trockenes und heisses Wetter vernichtet die Erbsenläuse (Karsin [435]).

Schreitet die Entwickelung des Klimas in einer Gegend in anderer Richtung fort, so ändert sich auch die Insektenfauna in dieser Gegend (Semenow [807], Krasnow [473]).

Die geographische Verbreitung der Ameisen wird nicht ausschliesslich durch die mittlere Sommer- resp. Jahres-Temperatur belingt, sondern auch noch durch Kilarheit des Himmels, die Feuchtigkeit der Lrde und der Luft, durch den Charakter der Vegetation, und bis zu einem gewissen Grade durch die geologische Natur der Gegend (Emery und Forel [214]).

\section{Theorie dieses Einflusses.}

Das Klima wird als eine Zusammensetzung der meteorologischen Elemente betrachtet. Folglich lässt sich der Einfluss des Klimas auf die Entwickelung (ler Insekten auf diese Elemente reduzieren.

Wir haben gesehen, wie die Temperatur, die Feuchtigkeit etc. auf die Entwickelungsgeschwindigkeit der Insekten wirken. Daraus würde folgen, dass zur Bestimmung des Einflusses des Klimas auf die Insekten nur die Bestimmung der Summe der Komponenten genügend wäre. Es ist jedoch nicht so. Erstens können wir aus diesen Klimakomponenten keine Resultierende bestimmen, da eine Komponente in den einen Einheiten, die andere dagegen in den anderen ausgedrückt wird (z. B. die Temperatur in Graden und der Luftdruck in mm.). Zweitens sind (lie Einflüsse einzelner meteorologischen Komponenten keine linearen Funktionen, d. h. ihre Wirkungen sind nicht proportional (direkt oder umgekehrt) ihrer Intensität, da in erster Linie z. B. schon das Optimum vertreten ist. Es kann in einer Gegend z. B. das Optimum der Temperatur vorhanden sein, während die Feuchtigkeit über oder unter diesem Optimum liegt, oder umgekehrt. Die Sache verkompliziert sich noch mehr, wenn wir noch die dritte Komponente (z. B. das Licht) oder gar die vierte hinzuziehen. 
734 I. Trapitel. Theoretisches über die Entwickehnusgeschwindigkeit.

Daraus folgt, dass der Einfluss des Tilimas ein sehr komplizierter Faktor für die Entwickelung der Inseliten ist, und seine Bestim mung im mathematischen Sinne erst dann erleichtert sein wirl, wenn die Koëffiziente einzelner meteorologischen Elemente zuerst bestimmt werden (vide (las II. Kapitel des theoretischen Theils, 5. Auschnitt).

Wir können jecloch den Einfluss des Klimas schon jetzt in allgemeinen Zügen skizzieren.

Der Einfluss des Klimas auf die Entwickelung der Insekten kann direkt und indirekt ausgeibt werden.

Direkter Einfluss besteht darin. dass gewisse Arten und in gewissen Entwickelungsstadien z. B. in Folge herrschenter holten Temperatur und ungenügender Feuchtigkeit in der betreffenden Gegend nicht existieren können, oder umgeliehrt -- geraule sich günstig fortpflanzen können.

In d irekter Einfluss ä̈ssert sich hauptsächlich durch die Qualität und Quantität des für Inseliten unentberlichen Futters.

Wir betrachten zuerst den indirekten Einfluss des Krlimas, da die Bedingungen, welche das Gedeihen dieser oder jener Ptlanzen, begünstigen, im Grossen und Ganzen mit denjenigen für Insekten zusammenfallen.

In erster Linie ist für jede Pflanze ein gewisses Quantum von Wärme, Feuchtigkeit, Licht etc. erforderlich. Beim Optimum dieser Agentien gedeihen sie am besten. In zweiter Linie spielt eine wichtige Rolle auch der Umstand, ob die betreffende Pflanze eine solche Organisation besitzt, dass sie mehr odler weniger bedeutende Abweichungen von diesem Optimum zu ertragen vermag. Falls sie diese Organisation nicht besitzt, geht sie zu Grunde und mit ihr auch die Insekten, welche sie zu ihrem Futter hatten.

Als ein Beispiel solcher Organisation will ich hier auf die Unterkältungsfähigkeit der PHanzensäfte aufmerksaın machen.

Wie meine Untersuchungen über die Unterkältung (ler Inseltensäfte $(21,24)$ und überhaupt der Flüssigkeiten $(2 \triangleleft a, 29,38 a)$ ergeben, hängt diese Unterkältung von verschiedenen Umständen $a b$, hauptsächlich aber von der kleinsten Axe des Raumes, welchen die betreffencle Flüssigkeit einnimmt. Je kleiner diese Axe ist, desto stärker ist die Unterkältung. Daraus folgt, dass je feiner die Kapillare und je kleiner die minimale Axe der Pflanzenzelle sind, desto stärker können in ihnen die Fflanzensäfte unterkühlt werden. Dieser Umstand hat zur Folge, dass bei PHanzen, welche diese Bedingungen erfüllen, die Säfte bei viel tieferer Temperatur erstarren werden, 
als im umgekehrten Falle. Da aber nach der Erstarrung der Säfte und nach einmaligem Sinken der Temperatur bis zu ungeführ demselben Grade, bis zu welchem die Unterkältung stattfand, die Pflanze permanente Kältestarre erleilet (vile fig. 9), so folgt daraus, dass in kälteren Gegenilen nur solche Pflanzen wachsen kömnen, welche feinere Gefässe besitzen.

Selustverstänllich ist das nur eine von mehreren Kónsequenzen der Unterkältungserscheinungen. Hätten wir z. B. noch die Abkühlungsgeschwindigkeit hinzugezogen, dann müssten die Pflanzen, um dieser neuen Berlingung zu entsprechen, z. B. eine gervisse Bekleidung mit bestimmter Wärmeleitungsfähigkeit besitzen etc. (Harze, mit welchen $z$ B. Fichten durchtrankt sind, und welche schlechte Wärmeleiter sind, spielen die soeben erwähnte Rolle für Nordyflanzen).

In tropischen Gegenden müssen die Pflanzen andere Fühigkeit besitzen, um der grossen Hitze zu widerstehen.

Ausser der Temperatur haben auch, wie gesagt, die Fenchtigkeitsverhältnisse einen grossen Einfluss auf die Vegetation. Dem Lichte kommt auch eine grosse Rolle zu.

Hier seien noch die Versuche von Bonnier (103a) über die Anpassung der Pflanzen an das Alpenklima erwähnt. Er fand an Pflanzen, welche aus der Ebene in verschiedene Höhen versetzt wurilen, dass die Hauptursachen der erhaltenen Abänderungen der Gestalt, des Baues und der physiologischen Funktionen im Alpenklima sincl: 1) die stärkere Beleuchtung; 2) die grössere Trockenheit der Luft; 3) die niedrigere Temperatur. (Diese Ptlanzen wurden auf tlemselben Boden, wie in der Ebene, kultiviert). Die Abänderungen im Bau unıl Gestalt dlieser Pflanzen in Folge des Alpenklimas waren h:uptsächlich folgende: stärkere Entwickelung der unterirdischen Theile, die Verengerung der Gefässe (wie erwähnt, ist dieser letzte Umstanı deshalb vom Vortheil für die Pflanze, damit ihre Säfte stärkere Unterkältungsfähigkeit erleilen können), kïrzere Luftsprosse, dickere Rindengewebe, kleinere Blätter, grössere Blüthen. Was nun die Aenderung der physiologischen Funktionen anbelangt, so besteht dieselbe in intensiverer Chlorophyll-Assimilation und Chlorovaporisation.

Auch in Zellen selbst können gewisse Aenderungen stattfinden, welche ihnen erlauben, sich an höhere Temperaturen anzupassen. So hielten Davenport und Castle (165) Metazoen vom Ei an 28 Tage in Wasser von $25^{\circ}$; die Wärmestarre trat dabei bei $43,5^{\circ}$ ein. 
Als aber diese Thiere bei $15^{\circ}$ erzogen wurden, geriethen sie in Starre schon bei $40,3^{\circ}$. Wenn man in Betracht zieht, rlass der Torl bei hohen Temperaturen durch Gerinnung des Protoplasmas bedingt wird, die Gerinnungstemperatur ist aber umso höher, je geringer

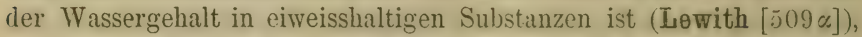
so liegt der Schluss nahe, dass eine vermehrte Wilerstandsfähigkeit solcher Thiere bei langsamer Temperatursteigerung durch eine Verminderung des Wassergehaltes des Protoplasmas bedingt wirl.

Verschiedene meteorologischen Verhiiltnisse bedlingen somit verschiedene Vertheilung der Pflanzenwelt. Die wirkliche Vertheilung der Pflanzenarten hängt jeiloch noch von einer Summe interer Faktoren ab, von welchen der hauptsächlichste die Bolenbeschaffenheit ist; dann kommen hinzu die Winilverhältnisse, die Configuration der Gegend, der Kampf um's Dasein zwischen rerschiecienen PHanzenarten, der Kampf zwischen den PHanzen und len schällichen Insekten etc.

Ihrerseits hat auch die Vegetation einen gewissen Einfluss auf das Klima der Gegend, und folglich besteht zwischen den beilen bis zu einem gewissen Grade eine Wechselwirkung. Ziehen wir noch in Betracht die Einmischung des Mens:hen, so erhalten wir ziemlich komplizierte Verhältnisse für die Vertheilung der Pflanzen auf dem Erdball und folglich auch der Insekten.

Wallace $(940 a)$ sagt: „Hunderte von Arten von Lepidopteren z. B. lïnnen im Larvenzustande nur auf einer einziger Pflanzenart existiren; so dass selbst wenn das vollkommene Insekt in ein neues Land getragen werden würde, der Bestand der Rasse von dem geniigenden Vorhandensein derselben oder nahe verwandten Pflanze abhängig wäre. Andere Insekten haben das ganze Jahr hindurch saftige vegetabilische Nahrung nöthig und sind deshaib auf die tropischen Gegenden beschränkt; einige können nur in Wiisten leben, andere nur in Wäldern; einige sind abhängig von Wasserpflanzen, andere von einer Bergvegetation. Viele stehen während irgend eines Theiles ihrer Lebenszeit auf eine so intime Weise mit anderen Insekten im Verbinduug, das sie ohne dieselben nicht existiren können; so z. B. die parasitischen Hymenopteren und Dipteren. Ferner haben Inselkten in jedem Stadium ilırer Existenz Feinde - las Ei, die Larve, die Puppe und das ausgebildete Thier; und das massenhafte Vorhandensein irgend einer dieser Feincle liann ihr Ueberleben in einem Lande, welches sonst sehr gut für sie passen würde, unmöglich machen" (I. p. 41-42). 
Dass ein fist übereinstimmender Parallelismus zwischen den Entwickelungen der Pflanzen und Insekten vorhanden ist, beweisen folgende Thatsachen:

Weir (952) beobachtete, dass, als sich die Entwickelung gewisser Pflanzen, welche als Futter für Cucullia chamomillae dienen, wegen des schlechten Wetters verspätete; verspätete sich auch das Ausschlïpfen dieses Schmetterlings.

Lockyer (530) bestätigt, dass, wenn die Entwickelung der Pflanzen im Frühjahre verspätet ist, auch bei Insekten verspätete Entwickelung beobachtet wird.

Laddiman (492) beobachtete, dass die Vegetation 1879 zurickblieben ist, auch die Schmetterlinge zu spät ausschlïpften. Auch die Schmetterlinge, deren Puppen im Zimmer gehalten wurden, zeigten eine grosse Verspätung in der Ausschlüpfungszeit.

Aendert sich das Klima in einer gewissen Gegend in einer bestimmten Richtung, so ändert sich auch ihre Flora. Krasnow (473) giebt für die Zasammensetzung der Flora in einer jeder Gegend die Formel an:

$$
F=f_{I}+f_{I I}+f_{I I I},
$$

wo $F$ die Summe aller zur Zeit vorhandenen Formen, $f_{I}$ - die palaearktische Arten, welche bis jetzt unverändert geblieben sind, $f_{I I}-$ das unmittelbare Resultat der Abänderung solcher Arten unter dem Einfluss der Bedingungsänderungen für die Existenz im gegebenen Orte, und $f_{I I I}$ - Arten, welche während der späteren Epoche eingewandert waren, bedeutet. $\mathrm{Er}$ findet, dass die Flora im mittleren Asien zu dem Typus sich nähert, welches durch die Formel $F=f_{I I}$ ausgedrückt wird, was nach der Meinung von Semenow (807) auch für die mittlere asiatische, besonders aber für die turanische Fauna anwendbar ist.

Er sagt: „Diese Fauna, als unmittebares Resultat der stätig sich entwickelten Kontinentalität des Klimas und der rasch stattfindenclen Austrocknung der Gegend, begleitet durch die entsprechende Aenderung des Charakters und der Zusammensetzung der Vegetation, stellt ein lehrreiches Bild der Anpassung der Organismen zu den neuen Bedingungen vor, was durch die Ausarbeitung neuer, zuweilen sehr scharfer morphologischen Eigenthïmlichkeiten, durch die Ausscheilung neuer Arten, durch die Verbreitung und Differenzierung der Arteu begleitet wird" (p. 50). Es ist hier interessant zu bemerken, dass, wie Wolkins $(959 u)$ constatierte, Parhydissus sartus Solsky deshalb aus der turanischen Fauna nicht verschwunden sind, 
weil sie auf tie Konlturptlanzen übergegangen sind, welche jetzt in Turkestan die in Folge ber Klimaänderung verschwunlene Waldregetation theilweise ersetzen.

Insektenfauma k:nn sich in der gegebenen Gegrent auch durch die Akklimatisation der Arten ändern, wie es verschicdene Beispiele zeigen.

Antherea cynthiu ist aus iler äthiopischen Region (Ostinulien) in die paläarktische unl auch in die antarktische Region eingefüht worlen und pflanzt sich hier sehr gut fort (z. B. in Franlireich, Italien, Schweiz, New-York, Philalelphia). Suturnia pyri akklimatisierte sich in der Umgebung ron Stuttgart (Hofmann [381]), Purnassius apollo im Riesengebirge, der japanische Schmetterling Antherea yamamuy in Elsass (Proln [651]). Pieris irassiren, uni rayae wurden nach Nortanerika eingesehleppt und verbreiteten sich lort so rasch und in solcher Menge, dass die einheimischen $\mathrm{Obracea}$ und Protodice durch sie verdrïingt werien und verschwinden. 1860 wurde Pieris rupue zum ersten Mal bei Queheck gefingen, 1868 in New-Yorli, 1873 hei Charleston uni 1874 in Florita. 1892 erreichte dieser Schmetterling das Felsengebirge unt ist auch im Südosten von Camala gefangen worden (Sendder [801]). Auch Sesia tipuliformis, Trochilium upiforme, Liparis dispar haben sich in Toriamerika éingebürgert. Acheroniu utropos ist vor ca. 2)0 Jahren aus Africa oder Ostiniien nach Europa eingewandert und hat sich über ganz Südeuropa verbreitet (Pabst [617a]).

Der Käfer Doryphora decemlineuta ist ron Nordamerica nach Frankreich und Deutschland eingeschleppt, wo er slen Kartoffeln grossen Scharlen verursachte; Viptus hololeucus ist von Kileinasien zuerst nach Russland eingewandert, von dort verbieitete er sich ïber England, Deutschland, Frankreich, und Norwegen. Der Furopäer Scolytus rugulosus akklimatisierte sich in Norilamerica. As Beispiel einer Akklimatisierung eines Insektes ler newotropischen Region in der äthiopischen kann Rhynchoprion penetruns dienen. Die amerikanische Art Periplunetc americana ist oft in St.-Petersburg getroffen worlen (Masarakia [549]). Phylloxera iastutrix ist von Norlamerica eingeschleppt und hat sich in ganz Europa verbreitet. Die ägyptische Biene Apis fusciata lebt sehr gut in Deutschland, und die europäische Honigbiene in Brasilien und in Nordamerica. BLonomorium pharconis bildete grosse Kulonien in Berlin (Prehn [651]).

Passen die klimatischen Verhältnisse und die Vegetation ler gegebenen Gegend für die Entwickelung der neu eingewanderten 
Insektenarten, so bïrgern sie sich rort ein uni pflauzen sich fort. Ist es aber nicht der Fall, so gehen sie entwerler zu Grunde oder passen sich selbst an die neuen Bedingungen an, indem gewisse Gewohn heiten unl gar der Entwickelungsverlanf eine bestimmte Aenderung erleiden.

So z. B. wurden die Hummel von Europa nach Neu-Seeland eingeführt, un dort cien Klee zu befruchten. Die Thiere haben sich völlig an das dortige Ǩlima gewöhnt, ja sogar neue Gewohnheiten angenommen, z. B. sie legen mit Vorliebe ihre Nester unter den Wurzeln einer Fichtenart an.

Bombyx mori, dessen Raupen in seiner Heimat (China) MorusArten fressen, gewöhnt sich auch an andere Pflinzen. So z. B. ist seine Zucht mit Scorzonera hispanica in Nord-Gouvernements Iiusslands vollstänlig gelungen (vile p. 706); auch fressen seine Raupen Lattich, wobei sie, weil dieses Futter ungewohnt ist, zuerst statt 5 nur 4 Häutungen durchmachen, nachher gewöhnen sie sich aber an Lattich so, dass die Anzahl der Häutungen nach der 2. oller 3. Generation wieder normal (5) wirl (Kellog unil Bell [44i]). (Ueber die Futteränierung ville dieses Kapitel, 5. Abschnitt).

Die Aenderung in Entwickelungsverlauf ist am besten bei europäichen Lepidopteren studiert worlen. In Nordgegenden haben gewisse Lepiciopterenarten nur 1 Generation, weil das rauhe Kilima die Entwickelung weiterer Gencrationen nicht begunstigt. Nördlich der Alpen liommen eine oier zwei Generationen vor und nur in sehr warmen Jalnen drei. In Südeuropa haben diese Spezies 3 und melhrere Generationen. Im hohen Norken und auf hohen Bergen reicht die günstige Zeit zur Entwickelung der Falter nicht hin, weshalb sie oft zweimal oler ireimal überwintern, bis sie fliegen. Dies hat zur Folge, dass man sie nicht alle Jahre sieht, wenigstens nicht in gleicher Menge (Brunbauer [116]).

Auch bei Saison-Formen ist die Aenderung der Entwiclielungszeit sehr klar ausgeprägt. So z. B. beträgt die Puppentaner bei ler Sommergenerution von Vanessa levana in der Regel 7-12 Tage, bei ler Wintergeneration dagegen ungefäh 200 Tage. Diese verschieden lange Puppendauer erklärt Woismann (953), wie folgt: „Die Entstehung der morsa-Form aus der levana ilenke ich mir ungefähr folgendermassen: Dass eine sogenannte Eiszeit während der Diluvialperiode in Europa bestanden hat, ist sicher. Mag dieselbe nun ein wirkliches Polarklima über unsere gemässigte Zone ausgebreitet haben, oder mag nur eine geringere Kiälte mit vermehrten atmo- 
sphärischen Niederschlägen geherrscht haben, jedenfalls war der Sommer damals kurz und relativ kühl, und die vorhandenen Tagfalter konnten alle nur eine Generation im Jahre hervobringen, sie waren alle Monogoneuonten. $\quad$. levana wird also damals nur in der Levanaform vorhanden gewesen sein. Als nun das Klima allmählig. wieder wärmer wurde, musste ein Zeitpunkt eintreten, in welchem der Sommer so lange dafuerte, dass eine zweite Generation sich einschieben konnte. Die Puppen der Levanabrut, welche bisher len langen Winter über im Schlaf zubrachten, um erst im nächshten Sommer als Schmetterling zu erwachen, konnten jetzt doch während desselben Sommers, in dem sie als Räupchen das Ei verlassen hatten, als Schmetterlinge umherfliegen und erst die von diesen abgesetzte Brut überwinterte als Puppe. Somit war jetzt ein Zustand hergestellt, in welchem die eine Generation unter bedeutend andern klimatischen Verhältnissen heranwuchs, als die zweite" (p. 14).

Wie oben erwähnt, wenn eine Insektenspecies sich den klimatischen Verhältnissen und der Vegetation angepasst hat, pflanzt sie sich in dieser Gegend fort, sonst stirbt sie aus. In dieser letzten Beziehung haben wir ein interessantes Beispiel in Versuchen von Acherontia atropos, sich in Europa zu akklimatisieren.

Dieser Schmetterling ist vor ca. 200 Jahren aus Africa orler Indien nach Europa eingewandert. Er ist jetzt in Süleuropa heimisch geworden, von wo er durch rasches Fliegen auch nach Deutschland kommt und hier Eier ablegt. Die Raupen fressen hier ausser der Kartuffelpflanze noch Lycium barbarum, Fraxinus excelsior, Evonymus europaeus, Datura stramonium, Syringa vulgaris, Daucus carota, Rubia tinctorum, Philarlelphus coronarius, Pyrus malus und sogar Brassica oleracea (Pabst [617a]). Ende September verwandeln sich die Raupen zu Puppen, aus welchen in demselben Herbst Schmetterlinge erscheinen. Pabst (617a) wies nach, dass die Weibchen dieser Generation stets unfruchtbar sind, "da bei ihnen allen die Eierstöcke bis auf ein Minimum verkiummert sind oder gänzlich fehlen" (p. 141). Sogar Weibchen, welche ihm am 11. April des folgenden Jahres schlüpften, erwiesen sich ebenfalls unfruchtbar. Daraus würle folgen, lass diese Species in Deutschland sich nicht fortpflanzen kann.

Nun sind die Weibchen der Herbstgeneration, welche im südlichen Europa aus den nicht uiberwinterten Puppen auschlïpfen, auch unfruchtbar. Normalen Eierstock haben nur Weibchen, welche aus den überwinterten Puppen sich entwickel (Ende Mai) und von der 
zweiten Generation (Ende Juli). Somit müssen die Weibchen der 1. Generation, um fruchtbar zu sein, aus normal überwinterten Puppen sich entwickeln; in Deutschland aber gehen die im Freien überwinterten Puppen zu Grunle (in Chemnitz), wie es auch in den baltischen Provinzen der Fall ist (Baron Nolcken [611b]).

Es bleibt somit dieser Species speziel für Deutschland nur ein Ausweg zur Fortpflanzung: die Fähigkeit zum Ueberwintern zu erwerben, wie es in Niellerösterreich und in der Umgebung von Wien bereits stattfand. Solche Fähigkeit scheint in gewissen Orten Deutschlands bereits erreicht zu sein. So z. B. theilt Gaukler aus Karlsruhe (292) mit: „Eine irrige Ansicht scheint mir auch zu sein, dass die atropos-Puppen unseren deutschen Winter nicht ertrügen, da bekanntlich erstens viele Puppen lebend und wohl gebildet im Fruihjahre gefunden werden, zweitens aber die oft zahlreich erscheinenden Schmetterlinge sicher nicht von im Sommer vielleicht zutällig nach Deutschland geflugenen wenigen Weibchen abstammen. Auch ist der Falter selbst gar nicht so sehr empfindlich gegen niedrige Temperaturen, da man denselben schon mitten im Winter (bei milder Temperatur natürlich) lebend angetroffen hat" (p. 303).

Im Zusammenhange mit den Zügen von Acherontia atropos steht die Frage über die Wanderzüge der anderen Insekten überhaupt.

Seit langer Zeit sind die Wanderungen von Stauronotus maraccanus Thunb. bekannt. Diese Heuschreke fliegt von Zeit zu Zeit in grosser Menge von Afrika nach Europa und verursacht einen kolossalen Schaden. Auch machte früher grosse Wanderungen $\mathrm{Pa}$ chytylus migratorius. Man könnte meinen, dass solche Massenwanderungen der Insekten deshalb vorkommen, weil die Thiere durch den Nahrungsmangel dazu getrieben werden. Dem ist jedoch nicht so, denn auch bei Schmetterlingen sind solche Wanderzüge beobachtet worlen.

So sah Reiber (681a) 1879 vom 3. bis 8. Juni nacheinander ungeheuere Mengen von Vanessa cardui über Strassburg in der Richtung von Sïden nach Norden vorïberziehen. Am 5. Juni ruhten sich Tausende von diesen Schmetterlingen beim Hospitz am St.-Gotthardsberge aus. Am 7. Juni flogen diese Schmetterlinge bei Bischheim und bei Rheinweiler; am 8. Juni in der Schweiz bei Wezikon (1 Klm. breiter Schwarm von Südwesten nach Nordosten); am 10. Juni bei Angers in Frankreich. Man sah diese Schwärme bis zum 25. Juni noch in Gaisberg, in der Gegend des Bodensees, in St. Galen, Glosau, Karlsruhe, Buihl, Paris, Rennes etc. Ormerod (616a) sagt, dass diese 
Sclmetterlinge in grossen Massen ans siilwestlichen Theilen Afrikas herstammen, wo sie rom 15. bis 20. April in Algier beobachtet wurden; am 3. Nai kamen sie uach Spani'n, am 27. Mai ̈̈berschritten sie die Pyrenäen, am 5. Juni die Alpen u. s. w. his nach Deutschlanı und Oesterreich.

Was speziell iliese interessante Wanilerung anbetrifft, so vermuthet Sajó $(733 a)$. nlass aus einem sulchen Schwarme eine Anzahl immer ermattet zurïcklbleibt oder anch stirbt, wïhrend hingegen aus den Gegenden, durch die rel Zug geht, dort geborene frische Exemplare zum Mitfliegen verleitet werclen" (p. 260).

Solche ungehenere Schmetterlingsziige sind in Eurnot his j. tht beobachtet worlen bei: Pieris Irassicac, Pieris nu.i, Pievis rapue, Vanessa cardui, Vanessa uiticae, Plusire yummu, Psilneru inomuchu, Nemeoplitus plantaginis, Hihermin defoliarin un! H. unrantiaria, Cucullia imbratica.

Die Ursache lieser Erscheinung ersehen rerschietene Forscher in verschiedenen Umständen.

So ersieht Piepers (6376) die wahrscheinliche Ursache dieser Erscheinung im Reproductionstrieb ler Schmetterlinge. Diesen Schluss zieht er, gestiitzt auf 30 Angaben, welche er fiir Catopsitia crocale $\mathrm{Cr}$. von 1872 bis 1889 in Niederländisch-Ost-Intien ges:unmelt hat. Als analoge Erscheinung fiihrt er ren Copulationsalst bei Bienen; Mücken, Ameisen und Termiten an.

v. Aigner-Abafi ( $i \zeta)$ sagt: „Nach allem diurfte e's wohl lieinem Zweifel unterliegen, dass die Ursache des Wamlerns rler Inseliten, namentlich der Raup: $n$ und Schmetterlinge, einzig riurch das Aufsuchen reichlicherer Nahrung bedingt wirl ${ }^{\text {" }}$ ( 1. 103). Er meint nämlich, dass lie Falter, welche auf dem Durchzuge sich befinclen, aus Gegenden kommen, in welchen ihre Raupen eine grosse Verheerung angerichtet hatten, so lass clie für ihre Nachkommen höchst besorgten Falter für dlie Ernïhrung der ausgeschlïpften Raupen nicht genïgend PHanzen vorfanden, es daher vorzogen, einen hierzu geeigneteren Ort aufzusuchen.

Sajó (733a) sucht diese Ursache in nervöser Erregung der Inseliten, welche vor Regen und Gewitter bei ihnen beobachtet wirl. Er sagt: „Sobald ein Regen, ein Gewitter, oder auch nur berleutende Bewölkung im Anzuge ist und der Luftuluck eine mit diesen atınosphärischen Erscheinungen verbundene Veränilerung erleidet, scheint durch clie ganze tierische Bevöllierung des betreffenden, in Mitleilenschaft gezogenen Gehietes eine Alteration im Nerrenleben vorugehen" 
(p. 230). "Ihre Aufreguug wirl aber auch noch auf eine andere Weise herbeigeführt oler mintestens gesteigert. Man kimn vielfach beobachiten, dass sobalı viele Individuen einer Irt licht bei einander leben, das ganze Volk gar bald unruhig wird" (p. 257).

Eine sehr interessante Ansicht spricht Prohn (firla) aus. Nachlem er die Insektenfauna in Europa zur 'T'ertiirzeit und dann zur Fiszeit betrachtet hat (ilas Verhiiltniss des Lanles zum Meer resp. zum Eis vile auf fig. 21 unıl fig. 22), kommt er zum Schlusse, dass die silbirische Einwanderung von Insekten nach der Eiszeit von Norlost nach Suilwest hin ror sich ging. Damm sagt er: "Vielleicht hängen mit dieser im grossen ganzen, also ron Osten nach Wresten gehenter Richtung auch die Ziige der Falter zusimmen. Diese sinıl vielleicht eine Eigentümlichkeit, die sich aus der der Eiszeit folgenden Epoche vererbt hat (man lenke nur an len Wanderinstinkt unserer Tögel). Aus Sibirien ron Osten her fand die Wanlerung statt, da aber dieses Land sicher längere Sommer hatte als der schmale, vegetationsberleckte Gürtel zwischen dem allmählich zuriickweichemien Gletschereis des Noriens und dem der Alpen, so werilen bei plützlich einbrechender Kälte die ersten Einwanderer wohl oft wieder nach Osten hin geflïchtet sein. Als dann die Temperatur stieg und der Pflanzenwuchs lïnger anhielt, mögen sich die an ihm abgelegten Eier zu Faltern entwickelt hahen; liese aber iberraschten die Vorboten des nahenden W'inter's, uni da sie noch nicht alilimatisiert waren, zogen sie sich wieder nach derselben Richtung hin zurück, um dort ihre Eier abzulegen, aus denen sich dann die Falter entwickelten, die im nächsten Jahre wiederum nich Wresten zogen. Was nun die von Südlen nach Norden gerichteten Ziige betrifft, so könnte man annehmen, dass sie zuerst von solchen ausging, die inmitten der Vegetationzone lebten, noch an nirdere Temperatur gewohnt waren und n!n in heissen Sommern entweiter nach Torden oder nach Süden hin das ilınen zusagendere Klima aufsuchten" (p. 333).

Wenn wir uns mit Sajós Ansichten cinverstam!en erkliiren, dass die Luftdepression und die Anhäufung grosser Massen von Insekten den Impuls zum gemeinschaftlichen Ziehen geben kimn, so bleibt doch die Frage offen, warum diese Inseliten so eine lange Reise unternehmen. Der Erklärung von Piepers, das diese langen Flïge auf das engste mit ilem Reprodulitionstriel) verbumlen sind, wie solche Hochzeitsfliige auch z. B. bei Bienen beobachtet werden, widersprechen die Thatsathen, welche an emropiischen Schmetterlingen beobachtet wurden. 
1877 wurde in Siebenbürgen eine Massenwanderung von $T^{\top} a$ nessa cardui beobachtet, wobei lauter $\sigma^{\circ} \sigma^{7}$ gefangen worden sincl. 1882 beobachtete Gaetke (269a) zu Helyoland einen grossen Zug von Hibernia defoliaria und $H$. aurantiaria. Dieser Schwarm konnte keine $\mathcal{O}_{+}$haben, la sie keine Flügel haben.

1881 beobachtete Weindiger (946b) Libellula 4-maculata, welche über Dresden und Umgebung in ungeheurer Menge flogen. Dieser Schwarm bestand nur aus $ठ す$.

Also in diesen Fällen ist der Reprodulitionstrieb vollständig ausgeschlossen. Wenn v. Aigner-Abafi (6b) auch sagt, dass die Weibchen beim Zuge von 1877 hinterherfliegen konnten, weil sie etwas schwerfälliger sind, so ist dasselbe z. B. beim Zuge von Hibernia (1882) absolut ausgeschlossen. Ausseriem fliegen in der Regel die $\sigma^{\top} \sigma^{\prime}$ den $q$ q nach und nicht umgekehrt (schon wegen der Geruchempfindung).

Was nun die Ansicht von v. Aigner-Abafi anbetrifft, dass die Schmetterlinge deshalb auswandern, weil sie reichlichere Nahrung fïr ihre Nachkommen aufsuchen, so steht sie auch nicht im Einklang mit Thatsachen. $\mathrm{Zu}$ was brauchen dann die in Algier sich befindenilen Insekten eine für sie ungeheuere Meeresstrecke zurückzulegen, um nach Europa zu kommen, und warum sind Vanessa carclui, welche 1879 vom 15. bis 20. April von Algier weggeflogen und am 3. Mai in Spanien angelang sind, nicht dort geblieben, sondern übersetzten die Pỵrenäen, Alpen erreichten und am 7.-16. Juni Deutschland und Oesterreich? Wären die Raupen der in grosser Menge ausgewanderten Schmetterlingsspecies auschliesslich „monophag“, daun könnte man noch von der Verheerung der Futterpflanze reden; die Raupen z. B. von Plusia gamma sind aber "polyphag“ uni gerathen bezüglich der Nahrung wohl niemals in Verlegenheit. Auch der Umstand, dass Hibernia-Zug (1882) nur aus $\sigma^{\nearrow} \sigma^{\lambda}$ bestand und bestehen konnte, spricht entschieden gegen das Aufsuchen des „geeigneten Ortes" für die Eierablage.

Es bleibt somit nur die Theorie von Prehn, welche noch vor ihm von Speyer $(830 a)$ als "eine sehr kühne Phantasie" bezeichnet wurde.

Als Prehn diese Ansicht aussprach, waren ihm 20 Zïge von Schmetterlingen bekannt, von welchen „ihren Flug von Sülen nach Norden oder umgekehrt 7 richteten, dagegen von Osten nach Westen oder umgekehrt 13, also fast das Doppelte." Seit dann sind noch folgende Richtungen in Europa bekannt geworlen: 
1876. Pieris brassicue von Norden nach Süden (in Salzburg. Fritsch $[262 a])$.

1879. Vanessa cardui von Süden nach Norden (von Algier bis nach Deutschland. Ormerod [616a]).

1884. Pieris nari von Norden nach Süden (in Ober Engadin. Ficke $[219 c])$.

1888. Vanessa cardui von Süden nach Norden (in Fogaras, Siebenbürgen. v. Aigner-Abafi $[\mathrm{b} b]$ ).

1892. Vanessa cardui in südwestlicher Richtung (in Vurfu Mare. Csiki $[7 \alpha])$.

1892. Vanessa cardui von Osten nach Westen (in Zibiusgebirge Kimakowicz [449a]).

1900. Pieris brassicae von Norden nach Süd-Süd-Osten (in Stralsund bei Borgwallsee. Krüger $[476 a])$.

1900. Pieris brassicae von Norden nach Süden (in Bodenbach. Grund [334]).

1903. Vunessa cardui von Osten nach Westen (in Veröcze bei Budapest. $\quad$ v. Aigner-Abafi $[7 \alpha])$.

1903. Vanessa cardui von Osten nach Westen (in der Hohen Tátra. Meissner $[7 \alpha])$.

1903. Vanessa cardui von Nordosten nach Südwesten (in der Hohen Tátra. Kovács $[7 \propto])$.

1903. Vanessa cardui von Norden nach Süden (in Szolnok. Vágó $[7 \propto])$.

19u3. Vanessa cardui von Osten nach Westen (im nördlichen Theile von Siebenbürgen. Csiki $[7 \alpha]$ ).

Wir haben somit noch 7 Richtungen von Norden nach Süien, 4 von Osten nach Westen und 2 von Nord-Osten nach Siid-Westen.

Obwohl das Hauptprinzip der Theorie von Prehn sich auf der Einwanderung der Insekten nach postglazialer Epoche von Sibirien nach Europa her, also von Osten nach Westen, stützt, immerhin giebt er die Erklärung auch für die Züge von Norden nach Süden und umgekehrt. Um diese Theorie besser zu begründen resp. zu verwerfen, muss man noch mehr thatsächlichen Materials besitzen.

Wie bereits im Anfange dieses Abschnittes gesagt wurde, ist (ler Einfluss der meteorologischen Elemente auf die Inseliten ein ziemlich verwickelter. In der letzten Zeit erschien ein Beitrag auf diesem Gebiete von G. Lehmann (507), welchem wir folgendes entnehmen: 
In ganz Zentraleuropa sind es hauptsiichlich zwei Winctrichtungen, eine westliche und eine östliche, welche abwechselnol vorherrschen und darlurch die Veränderlichlieit des Wetters bedingen. Die Winirichtung hängt vom Luftiluck ah: sie geht vom höheren Druck (Maximum) zum tieferen (Minimum oter Depression, Cyclon) hin. Diese barometrischen Depressionen hewegen sich fast immer von Westen nach Osten. Nach Deutschlanl z. B. Kommen sie vom Atlantischen Ocean unil bringen den stänligen Wechsel des Wetters: ist aber anf dem Lande das Maximum vorhanlen, so hat man in der Regel schönes Wetter.

„Wenn auf unserer Wetterkarte hei ausgesprochen anticyelonaler, also günstiger Wetterlage, die Isobaren, 1. h. die Linion, welche die Orte mit gleichem Barometerstanle verbin:len unil gewöhnlich annähern:t parallel verlaufen, wenn diese Isobaren plötzlich anfingen, einen unregelmässigen Verlauf zu zeigen und rom Ifeere hry verschiedene Ansbuchtungen nach dem Festlande zu sentlen, um der Herrschaft des niederen Druckes auch kontinentales Terrain abzugervinnen, so entstehen Theil-Depressionen, und es folght ilamn in den lavon betroffenen Gebieten auf meist kiurzere Zuit eine Aenlerung lies Wetters. Eine gewisse Staumg ler Luftmassen scheint einzutreten bei ganz unbestimmten Winden, unl driicken!le Schwiile ist das Charakteristikum dieser Wetterlage; allmählig beileckt sich der Himmel, die elelitristhe Spannung innerhalb der Atmosphäre scheint rapid zu wachsen und das Endergebniss ist ein mehr oder weniger heitiger Gewitterregen." I)ies ist das Bild der sogenannter lokalen Gewittererscheinungen.

In derartigen schwiilen Nächten werlen die seltenste Thiere, hauptsächlich Noctuen gefangen. „Zieht man in Betracht, dass der Hauptzweck des Sthwärmens die Fortpflanzung ist, so liegt der Schluss nahe, dass manche $q$ o umbefruchtet bleiben, wenn der den Geschlechtstrieb erfihrungsgemäss anregende Luftzustand währenil der Flugzeit der fraglichen Spezies einmal ausbleibt." Im allgemeinen kann man sagen: der Einfluss ist ein günstiger bei jouler Druckvertheilung, die uns warme Siit- oiler trockene Ostwinde bringt, dagegen ungïnstig bei feuchten West- oder kalten Nordwinden.

Hier sei noch folgendes bemerlt: Sajó (733a) sagt, dass die Insekten zu gewissen Zeitpunkten, „die ganz entschieden mit den barometrischen Depressionen zusammenfallen, in eine abnorme nervöse Gereizheit geraten. Der Geschlechtstrieb erreicht zu solchen Zeiten seinen Höhepunkt." Er fand, dass in dieser Hinsicht beson- 
ders Harpalus-Arten und die Wasserwanzengattung Coriza als meteorologisch sehr empfiniliche Inseliten zu bezeichnen sind.

Es wäre interessant zu untersuchen, ob dabei die Luftılepression die Hauptrolle spielt, odler vielleicht der elektrische Zustand ler Luft, welcher bei der Luftclepression entsteht. Von der Entscheidung: dieser Frage wiirile möglicherweise auch die Lösung der Msssmwanderungen der Insekten nach gewisser Richtung in Riamme ahhiüngen.

Wie oben erwilhnt, erscheinen einige Insektenarten in gewissen Zonen periodisch. Dieser Umstand ist dem Einflusse der parasitischen Insekten zuzuschreiben, hauptsächlich aber ler unzureichenılen giinstigen Zeit für die Entwickelung.

So sagt. Brunbauer (116): "Im lohen Norilen unl auf hohen Bergen reicht die Entwickelung der Falter in einem Jahre giinstiger Zeit zur Ausbiliumg derselben gewölnnlich nicht hin. weshalb diese Thiere oft zweimal orler dremal überwintern, bis sie fliegen. Dies hat zur Folge. dass man sic nicht alle Jahre sieht, wenigstens nicht in gleicher Menge. Das tharaus abzuleitende Gesetz, dass manche Falter nur in gewissen Jahren zahilreich fliegen orler überhaupt sichtbar sind, wirl aber lumch einfallemle kältere orler wärmere Jahre unterbrochen."

Die günstige Zeit zur Ausbillung der Inseliten in verschiedenen Zonen hängt, wie Merriam $(560 a)$ zeirte, von ler gesammten Wärmemenge ab, welche eine bestimmte Spesies braucht, um ihren Entwickelungs- und Reproductions-Cyclus zu vollenlen. Diese Wïrme lässt sich bestimmen, wenn man die Summe dier tïglichen mittleren T'emperaturen ïber $0^{0}$ während der Jahreszeit les Wachsens uni der Fortpflanzung nimmt. Diese physiologische Kion stante („lie Summe der Temperaturen") hat zun ersten Mal in die Wissenschaft Baussingault (55a) für die PHanzen eingeführt.

Diese Hethode, die gesammte Wärmemenge zu bestimmen, kann man natïlich nur als einen empirischen Versuch solcher Messungen betrachten. Woejkow (962a) sagt: „In fler That wirken hier unvergleichbar kompliziertere Falitoren und muss, ausser ller Luittemperatur, besonders noch die direkte Wirkung. des Sonnenlichtes und der Wärme auf die Pflanzen hinzugezogen werlen. Niemand zweifelt daran, dass unsere Kornpflanzen keine vollstänlig reife Samen ohne direkte Lichtwirkung ergeben werlen, dass eine solche vollstänlige Reifung im Schatten nicht möglich ist, wenn die Summe der Temperaturen auch höher wäre" (p. 295). 
Wenn das periodische Erscheinen der Inselitenarten im gr.ıssen und ganzen durch die unzureichende Wärmemenge in betreff niler Zone zu erklären ist, ist die Erklärung des periodischen Erscheinens nur eines Geschlechtes gewisser Insekten viel schwieriger. Diese Thatsache ist bei den Pflanzenläusen beobachtet worlen.

Lüstner (538a) konstatierte für Chionuspis sulicis, welche auf Weiden leben, dass ein Jahr nur $q$ q dieser Species rorkommen und im nächsten Jahre die Aeste nur mit $\sigma^{\nearrow}$ berleckt sinı. Dasselbe bezieht sich auch auf Diaspis fallax.

Göthe (318a) sagt, dass er 1898 fist nur $ठ \delta$ von Aspidiotus ostreaeformis var. oblongus gefunden hat.

Rəh (689a) erhielt von Lüstner briefliche Mittheilung iiber die Periolicität im Auftreten von $\delta$ und $q$ bei Schildläusen, welche lautet:

\begin{tabular}{|c|c|c|c|}
\hline Aspidiotus & ostreacform & is $1897-99$ & übe \\
\hline 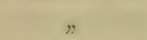 & $n$ & 1900 & $n$ \\
\hline Diaspis fal & $\operatorname{llax}$ & 1897 & nur \\
\hline 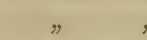 & & $1898-99$ & überwiegend \\
\hline Mytilaspis & pomorum & $1897,98,99$ & nur \\
\hline Chionaspis & sulicis & $1897-98$ & nur \\
\hline$"$ & $n$ & 1899 & überwiegend \\
\hline
\end{tabular}

Dabei bemerkt Reh, dass $\delta \sigma^{\pi}$ von IIytilaspis pomorum in Deutschland überhaupt noch nicht beobachtet sinl. Er selbst beobachtete im Winter 1898/99 unter 262 Aspidiotus ancylus und unter 100 Aspidiotus fortbesi kein einziges $\delta$. Im Winter 1899/1900 waren dagegen $\sigma^{\top} \delta$ sehr häufig. Wegen der Ursache dieser Erscheinung sagt er: "Es dürfen wohl zweifellos alle die erwähnten Befunde zurückzuführen sein auf meteorologische Einflüsse" (p. 162).

\section{Einfluss der Reibung u. der übrigen Faktoren.}

\section{a) Eier.}

Das Frottieren mittelst einer harten Bürste beschleunigt die Entwickelung der Eier (Barca [49], Terni [856], Susani [851], Ducleaux [202], Bellati und Quajat [62]) und zwar desto stärker, je jünger die Eier sind.

Wird das Frottieren an unbefruchteten Eiern vorgenommen, so erhalten sie die Färbung (ler befruchteten Eier (Tichomirow [868]). 
Weibchen, welche mit aus kastrierten Raupen sich entwickelten Männchen von Ocneria dispar in Copula eingehen, legen Eier, von welchen später Raupen sich entwickeln (Oudemans [616]).

Der mehrere Tage dauernde Druck ruft bei Eiern von Bombyx mori, welche der Kälte noch nicht ausgesetzt waren, die frühzeitige Entwickelung hervor. Auch der Luftlruck von 8 Atmosphären bewirkt dasselbe (Rollat [704]). Bellati und Quajat [66] konnten dies an 2 Monate alten Eiern nicht constatieren.

Die Erscheinung des Bivoltismus von Bombyx mori-Eiern wird in den meisten Fällen dann beobachtet, wenn die Falter durch Bakterien angesteckt waren (Gorbatschew [324], Alibegow [8], Schmujdsinowitsch [760, 764], Taratinow [853]).

\section{b) Raupen.}

Raupenzeit von Bombyx mori dauert bedeutend länger, wenn die Raupen sofort nach dem Ausschlüpfen durch Pebrine angesteckt sind (Taratynow [853]). Chapman (140) beobachtete aber, dass die kranken Raupen von Cossus ligniperda stets früher sich verpuppen als die gesunden.

\section{c) Puppen.}

Das Rütteln während oder nach der Verpuppung verlangsamt bedeutend die Entwickelung (Pieris napi, Weismann [953]).

Abnorm lange Puppenruhe bringt deformirte Imagines mit sich (Tenebrio molitor: Manger [544]).

\section{Theorien dieses Einflusses.}

Die vorzeitige Entwickelung der Eier (Bivoltismus bei Bombyx mori) erklärten verschierlene Forscher durch verschillene Ursachen, und zwar:

E. Maillot (541) hält als eine (ler Ursachen des Bivoltismus die Reibung und die Stösse beim Transport der Eier. Er spricht die Vermuthung aus, class die alleinige Reibung des Weibchenleibes an die im trockenen Zimmer abgelegten Eier dieselben so stark elektrisieren können, dass sie zur Entwickelung kommen.

Gorbatschew (324) schloss, durch eine besondere Vorrichtung, die Möglichkeit aus, dass das Weibchen die abgelegten Eier mit ihrem Leib reiben kann, und erhielt dennoch die vorzeitige Entwickelung dieser Eier. Da die mikroscopische Untersuchung die Anwesenheit der Vibrionen in Eiern erwies, so schliesst er daraus 
dlass diese Vibrionen als eine der Ursachen sein kömnen, welche ien Bivoltismus hervorrufen.

Derselben Meinumg ist auch Taratynow (\$53), welcher ile Eier durch Pebrine angesteckt gefunden hat.

Alibegow (8) hält die Meinung aufrecht, hass die Ursache iler vorzeitigen Ausbrütung die krankhatten Weibchen sind.

Die ausfiihrlichen Untersuchungen von Schmujdsinowitsch (1891. 760; 1892. 764) gel)en andere Deutung dieser Erschcinumg.

Er konstatierte, dass die Fäle der vormitigen Entwickelung der Eier öfters an Bruten beobachtet werien, welche von kiankhaften Teibchen abgelegt sind, un'l glaubt, dass lie Ansterkung der Falter durch Bakterien eine wichtige Rolle bei ler rorzeitigen lintwickelung rer Eier spielt, welche jedoch einen nebensïchlichen Einfluss auf den Biroltismus hat. Er nimmt an, dass die Tibrionen und Milirohokken die Eier empfin!lich gegen äusseren lieize machen, indem sie den Organismus der Schmetterlinge schwächen.

Ein Jahr später stellte er fest, lass lie frïhzeitige Entwicliclung der Eier werler durch Licht, Temperatur, Reibung ler Falter an den abgelegten Eiern, noch durch las Schiitteln erklïrt merden kann; vielmehr zeigten seine V'ersuche, hass ler Bivoltismus bei Eiern von Bomlyyx mori in allgemeinen erblich ist. Ilie schlechten Ernäherungsbeilingung? erleichtern das Auftreten dieser Erscheinung.

1893 untersuchte er (767) noch eimmal !liese Firge mol liam $\mathrm{zu}$ folgenden Resultaten:

1. Die Neigung zum zufälligen Bivoltismus ist crblich und liann bei jeder zweiten Generation beobachtet werden.

2. Irgend einen Zusammenhang zwischen dieser Neigung und der Ansteckung der Schmetterlinge durch verschieilene Mikroorginismen zu finden, ist unmöglich.

3. Weisse Rassen haben diese Neigung stärker als die gelben; dieselbe wirl auch häufig bei Rassen beobachtet, welche dunkel gefärbte Raupen haben.

4. Die Aufzucht der bivoltinischen laupen gelingt auch so gut, wie die 'der gewöhnlichen.

Dieser Forscher spricht auch jetzt die Vermuthung aus, dass der zufällige Bivoltismus die erbliche Prädisposition zu seiner Ursache hat, indem derselbe eine der Atavismus-Erscheinungen vorstellt.

Was num die Entwickelung der Eier sowohl durch das Frottieren und durch den Druck, wie auch die Entwickelung der unbefruchteten Eier anbelangt, so ist die betreffencle Theorie von Ticho- 
mirow (868) gigeben worlen, welche in allgemeinen Zügen im 4: Abschnitt dieses Kapitels angeführt ist. Hier wird sie weiter entwickelt.

Inlem Tichomirow seine "Reiz-Theorie" bespricht, sagt er „Die Natur giebt uns ein gut bekanntes Beispiel des matürlichen Reizes des Eies. Das Spermatozoil, welches ins Innere des Eies eindringt, muss in lemselben ofienbar einen sehr starken Reiz hervorrufen; es kann sien, dass dieser Reiz allein bereits genügt, um das Ei zur Entwickelung zu zwingen, wenn auch das Spermatozoill bei der Befruchtung mit rlem Ei nicht verschmolzen wäre."

Nach dieser Theorie kömnen die Versuche von Oudemans (616) leicht erklärt werden. Er kastrierte die Raupen von Ocncrin dispar mud liess die von ihnen erhaltenen Schmetterlinge mit Weibchen in Copula eingehen. Die abgelegten Eier waren selbstverstïndich unbefruchtet; trotzlem entwickelten sich daraus Raupen und nachher Schmetterlinge. Der Reiz, welcher den Eiern durch die Reibung: les Penis im Geschlechtsorgane les Weibchens mitgetheilt wurde, zwang die Eier zur weiteren Entwickelung.

Dass die blosse Reibung labei diit Rolle des auslösenden Reizes spielte, beweisen die Versuche von Barca (49), Terni (S56), Sasani (851), Ducleaux (202), Bellati und Quajat (62), Tichomirow (868).

Ein anilerer Fall, welcher auch leicht nach der Reiz-Theorie zu erklären ist, ist von Goossens ( $323 a$ ) be bbachtet worlen. Diesem Forscher entschliupte im Zuchtkasten aus einer Dendrolimus piniPuppe ein sehr grosses Weibchen. Er tödete es, und da der Schmetterling dennoch begann, Eier abzulegen, klemmte er das Ende des Eierruhres mittelst einer besonderer Vorrichtung fest zusammen. Nach S Tagen blieben die im Anfang abgelegten Eier unveränlert, was noch ein Mal beweist, dass sie unbefruchtet waren. Das Weibchen bewegte noch die Fühler und ihre letzten Leibsegmente zeigten Contractionen. Nachlem die iilemm-Vorrichtung entfernt wurde, legte das Weibchen noch 4 Eier, welche am folgenten Tag lila gefärbt erschienen und nach 5 Tagen Räupchen ergaben, welche jedoch bei der zweiten Häutung starben.

Hier waren die Contractionen der Leibsegmente während \& Tage die Ursache dieser parthenogenetischen Entwickelung der Eier. Durch diese Contractionen wurden die Eier an einander gerieben und wurden dadurch zur Entwickelung gereizt. 23 Jahre später wiederholte diese Versuche Serebrjanikow (808a), kam aber zu negativen Resultaten. Obwohl er dieselbe Ǩllemm-Vorrichtung, wie Goossens 
gebrauchte, sind seine Versuche trotzdem nicht ganz ilentisch. Er töltete die Weibchen vor dem Versuche nicht und in Folge dessen konnten die Reflexe an Leibsegmenten nicht dieselben sein, wie in Versuchen von Goossens; ausserlem sagt er nicht, ob seine Weibchen Riesen-Exemplare waren, was möglicherweisse auch eine wichtige Bedingung sei. Der Hauptunterschied aber bestand darin, dass in seinen Versuchen die Weibchen vorher keine Eier abgelegt haben und folglich war der Eierstock ganz voll, wodurch die Reibung nicht in vollem Masse zu Stanle kommen konnte, sondern wurle nur der zur Entwickelung der Eier ungenügende Druck auf dieselben ausgeübt.

In der letzten Zeit wurde die Vermuthung von Tichomirow (868), dass der beim Eindringen des Spermatozoides in das Ei hervorgerufene Reiz allein bereits genügen wïrde (also ohne Zusammenschmelzung des Spermatozoiles mit (lem Ei) die Eier zur weiteren Entwickelung zu zwingen, in glänzender Weise von Winkler $(960 a)$ bestätigt. Dieser Forscher bearbeitete unbetruchtete Eier mit Extractionsstoffen aus lem Sperma und erhielt deren Furchung.

Der Einfluss des Rüttelns, welchen Weismann (953) an frischen Pieris nnji-Puppen beobachtete, wobei sie in ihrer Entwiclielung bedeutend verlangsamt wurden, findet seine Erklärung in folgenden Thatsachen, wenn auch aus anlerem Thierbereiche.

Horvath fand beim Sthütteln von Bacterien, dass zu ihrer Entwickelung eine gewisse Ruhe nöthig ist. Auch die Beobachtungen von Tumas, Hansen und Russel weisen darauf hin, dass ein Schïtteln von gewisser Stärke und Dauer auf manche kleine Lebewesen fördernd wirken kann.

S. Meltzer fand, dass das Schütteln verschiedene Wirkungen auf verschielene kleine Organismen ausiibt. Die rothen Blutkörperchen wurden trotz der starken und lange dauernden Bewegung nicht zerstört; beim Hinzusetz ${ }^{\circ}$ von feinkörnigen, unlöslichen Substanzen trat beim Schütteln immer ein Zeitpunkt ein, wo weler in der Blutfluissigkeit noch in den sich absetzenden Substanzen irgend etwas von den Blutkörperchen zu entdecken war. Die Versuche mit verschiedenen Bacillen ergaben, dass schwaches und kurz dauerndes Schütteln für ihre Vermehrung förderlich, dagegen starkes und langdauerndes Schütteln zerstörend wirkt. Dieser Forscher fand auch, dass die Erschütterung als Lebensfaktor ein Minimum, ein Optimum und ein Maximnm hat. 
W. Ramsden (672) schüttelte Eieralbumin, Eierglobulin, Kartoffeleiweiss etc. und fand, dass jeder dieser Stoffe sowohl in saueren Lösungen wie auch in vielen neutralen und alkalischen Lösungen in den festen Aggregatzustand iibergehen, d. h. sich in der geronnenen Modification ausscheiden kann. Dass dabei nicht die Hitze die Rolle spielt, wurde an anderen Substanzen konstatiert.

Aus diesen Versuchen kann man den Schluss ziehen, dass die Puppen während 7-stündiger Eisenbahn-Reise ein solches Schütteln erfahren haben, welches den optimalen Werth überschritt und die Entwickelung der Puppen dadurch verlangsamt wurde.

Noch tiefere Deutung der Ursache dieser Erscheinung ist in Versuchen von D. Mottier $(595 b)$ zu suchen. Er fand bei der Untersuchung der Wirkung der Centrifugalkraft auf Algen, dass zur normalen Vertheilung des Zellinhaltes 3 Wochen oder noch mehr nöthig waren, nachdem die Wirkung der Centrifugalkraft beseitigt wurde. Somit kann die Bewegung des Protoplasmas in Puppenzellen durch Schütteln so stark beeinflusst werden, dass es seine normale Bewegung nach Wochen und Monaten wieder erreichen wird, was selbstverständlich (vide fig. 9) die Entwickelungsgeschwindigkeit stört.

Als Folge abnorm langer Puppenruhe können unter diesen und ähnlichen Umständen deformierte Imagines entstehen, was Manger (544) an Tenebrio molitor wirklich konstatierte. 


\section{ZWEITES KAPITEL.}

\section{Verallgemeinerungen und Theorien über den Einfluss der äusseren Faktoren auf die Grösse und die Gestalt der Insekten.}

\section{Einfluss der Temperatur.}

\section{A. Verallgemeinerungen.}

$\mathrm{R}$ gewöhnliche, gefüttert werden, ergeben Schmetterlinge von kleineren Dimensionen (Standfuss [840]: Callimorpla dominula, v. persona, v. romanovi, Dasychira abietis, Lasiocampa pruni, lunigera, quercifolia, populifolia, Arctia hebe, Psyche villosella, Laria l-nigrum, Agrotis cinerea, crussa, futidica, Luperina matura, Hyppa rectilinea; Dorfmeister [193]: Pararge egeria, Rhodocera rhamni; Kamensky [434]: Bombyx mori; Pauls [625]: Nemeophila russulu; Ball [47]: Papilio machaon; Venus [903]: Vanessa urticae).

Raupen einiger Species, welche bei Temperaturen, höher als die gewöhnliche, gefüttert werlen, ergeben Schmetterlinge von grösseren Dimensionen (Standfuss [840]: Arctia fasciata, Lasiocampa pini; Pauls [625]: Nemeophila plıntaginis).

Werden Puppen der Einwirkung der Temperaturen über die normalen ausgesetzt, so ergeben dabei gewisse Species grössere Schmetterlinge (Merrifield [561]: Selenia illunaria). Andere Species verhalten sich dabei entgegengesetzt (Merrifield [567]: Selenia illustraria, lunaria, Drepana falcaria, Bombyx quercus, v. callune, Cidaria siliceata [570]; Frings [259]: Vanessa urticae, Vanessa polychloros [260]; Ball [47]: Papilio machaon).

Werlen die Puppen der Einwirkung der Temperaturen unter der normalen ausgesetzt, so ergeben dabei gewisse Species grössere Dimensionen (Slevogt [822]: Vanessa polychloros). Gewisse Species 
verhalten sich aber entgegengesetzt (Merrifield [567]: Vanessa urticae, Vanessa atalanta [571]; Gauckler [278]: Antheraea pernyi; Frings [253]: Vunessu uiticae, Vunessa io; Haneld [353]: Arctia caja).

Puppen einiger Species, welche an der Ueberwinterung verhindert werden, ergeben Schmetterlinge mit kleineren Dimensionen (Stange [842]: Agrotis rubi). Die anderen Species verhalten sich entgegengesetzt: sie ergeben grössere Dimensionen, wenn die Anzahl der Generationen in demselben Jahre durch Forcieren vermehrt wird (Merrifield [561]: Sclania illunaria; Pauls [625]: Nemeophila plantaginis).

Die bei k.oher Temperatur $\left(31^{\circ}\right)$ gezüchteten Raupen von Bombix mori liefern viel leichtere Gespinnste als bei gewöhnlicher Temperatur $\left(22^{\circ}\right.$ ) (Vorson und Quajat [920]); gagegen ergiebt die Erniedrigung der Temperatur während des 5. Alters um $2-6^{\circ}$ die Gervichtszunahme des Cocons (Lambert [495]).

Werden Puppen gewisser Species der Einwirkung höherer Temperaturen als die gewöhnliche ausgesetzt, so erhalten die Schmetterlinge viel weniger gebuchtete Flïgerränder (Fischer [228]: $V a$ nessu c album; Standfuss [837]: Vanessa c album; Merrifield [572]: Vunessa urticae); andere Species ergeben das Gegentheil (Jänichen [410]: Lasiocampa populifolia; Frings [260]: Vanessa polychloros; Vanessa urticae, Lasiocampa otus [262]; Vanessa antiopa [261]).

Werden Puppen gewisser Species dem Einflusse der niederen oder höheren Temperaturen ausgesetzt, so erhalten die Schmetterlinge schmälere resp. ungenügend entwickelte Schuppen auf den Flügeln (Kathariner [439]: Vanessa urticae, io, antiopa; Federley [219a]: Lymantria dispar, Melacosomu neustria, Saturnia pavonia, Aglia tau, Demus coryli, Artia caja; Frings [260]: Vanessa levana v. prorsa, Saturnia pyri; Frings [261]: Papilio podalirius; Frings [262]: Vanessa antiopa; Gauckler [295]: Vunessa io, Vanessa urticae: [281, 282]; Standfuss [840]; Fischer [231]).

\section{B. Theorien und Hypothesen dieses Einflusses.}

Standfuss [840] ersieht die Ursache der Dimensionen-Recluktion der Schmetterlinge in der Abkürzung der Frasszeit der Raupen, indem er sagt: „Je wesentlicher die Frasszeit der Raupen durch die Erhöhung der Temperatur abgeküirzt wird, desto bedeutender ist die Grössenreduktion des Falters. Wird anderers its die Zeit der Ernährung, also das Raupenleben, trotz der Erhöhung der Temperatur 
nicht oder doch nur sehr wenig abgekürzt, ^lann erfolgt eine Vergrösserung “ (p. 148).

Man könnte glauben, dass, wenn die Frasszeit der Raupen durch die Erhöhung der Temperatur abgekïirzt wird, dabei die Raupen weniger Nahrung zu sich nehmen und auf diese Weise sogenannte Hungersexemplare liefern, welche durch kleinere Dimensionen charakterisiert werden. Die Versuche von Venus (903) verwerfin jedoch diese Vermuthung: Raupen von Vanessa urticae, welche unter der Einwirkung heisser Sonnenstrahlen sich befanden, frassen die Brennesseln, welche einige Mal pro Tag frisch gereicht wurlen, mit einer grösseren Gier und Hast, als wir sie an len Raupen von Deilephila euphorbiae zu sehen gewohnt sind.

Trotzdem, dass Standfuss seine Gesetzmässigkeit aus zahlreichen Versuchen abgeleitet hat, sind Fälle bekannt, welche beweisen, dass diese These nicht die absolute Guiltiglieit hat. Pauls (732) rerluzierte durch die erhöhte Temperatur die Frasszeit der Raupen von Nemeophila pluntayinis auf $1 / 4$ der normalen Zeit und erhielt Schmetterlinge, welche grösser sincl, als clie in der Freiheit geborenen.

Auch Rudow (712) erblikt die Ursache der Dimensionenänderungen bei Insekten in verschierlenen Nahrungsverhältnissen.

Obwohl die Untersuchungen von Lauterborn (500) an Räilerthieren in verschiedenen Monaten ihn zum Schlusse fuihrten, dass die Körpergrösse von Anurcea cochlearis in ungekehrtem Verhältnisse $\mathrm{zu}$ der Wassertemperatur steht, ist er lurch spätere Untersuchungen dieser Frage zum Resultate angelangt, dass eine Beziehung zwischen der Temperatur und der Grösse der Thiere in keinem einfachen Verhältnisse steht; Ursache dieser Erscheinung liegt in dem wechselnden Gehalte gewisser anorganischer und organischer Bestandtheile des Wassers, welcher je nach der Jahreszeit durch die Temperatur reguliert wird.

Somit kommen wir zum Schlusse, dass die Dimensions-Aenderungen der Insekten in erster Linie von der Ernährung resp. von der Nahrungsassimilation abhängt, was ihrerseits durch die Lufttemperatur beeinflusst werden kann. Es ist natürlich noch nicht genug, dass eine Raupe mit einer grösseren "Gier und Hast" fressen soll, um später einen grösseren Schmetterling zu ergeben; dazu kommt noch die Frage, ob diese unnatülich grosse Nahrungsaufnahme assimiliert werden kann und ob die Verdaungsorgane der Raupe dabei nicht gestört werden. 
Die Wirkung fler Temperatur auf den Stoffivechsel eines Thieres ist nach Rubner (708a) als ein äusserer Reiz aufzufassen, welcher, von der Haut des Thieres empfangen, durch reich entwickeltes Nervensystem ins Innere des Organismus übertragen wird und auf diese Art die Steigerung oder Herabsetzung des Stoffwechsels des Protoplasmas beeinflusst.

Um verschiedene Fälle, welche in dieser Beziehung von verschiedenen Forschern an Raupen resp. Schmetterlingen beobachtet wurden, zu erklären, wollen wir die Abhängigkeit der Spannweite der Schmetterlingsfliigel von der Temperatur, bei welcher die betreffende Raupe gefüttert wurde, graphisch darstellen, wobei die Ordinatenaxe die Spannweit $(d)$ und die Abscissenaxe die Temperatur $(t)$ bedeutet (vide fig. 23 und 24).

Fig. 23 zeigt uns die schematische Darstellung der Abhängigkeit der Grösse $d$ von $t$ für den Schmetterling Dendrolimus pini und Fig. 24 dasselbe für Callimorphtha dominula. Bei Dendrolimus pini nimmt $d$ mit der Zunahme der Temperatur $\mathrm{zu}$, während bei Callimorpha dominula das Gegentheil beobachtet wird (Standfuss [840]). Der Punkt $A$ resp. $A^{\prime}$ auf der Curve entspricht der gewöhnlichen Temperatur, bei welcher die normale Spannweite erhalten wird.

Da beide Curven eine und dieselbe Erscheinung, wenn auch für verschiedlene Species, charaliterisieren, so können sie in eine gemeinschaftliche Curve combiniert werden, welche Fig. 25 darstellt.

Warum hier zuerst die Curve der Fig. 23 und dann die der Fig. 24 gezeichnet ist und nicht umgekehrt, wird weiter unten erörtert.

Aus dieser Curve geht hervor, dass die früheren beiden Curven die Verlängerung zu einander bilden, indem sie den Punkt $O$ gemeinschaftlich haben. Der Punkt $O$ bedeutet das 'Temperaturoptimum $\left(t_{0}\right)$ für die Spannweite der Flïgel einer und derselben Schmetterlingsspecies, d. li. diejenige Temperatur $\left(t_{0}\right)$, bei welcher die betreffende Raupe erzogen werden muss, damit die künftigen Schmetterlingsfliigel ihre maximale Spannweite erreichen.

Diese Curve zeigt auch, dass die Verminderung der Spannweite der Flügel einer und derselben Species nicht nur bei niedrigeren, sondern auch bei höheren Temperaturen als die optimale $\left(t_{0}\right)$ stattfindet Die Bestätigung dieses ergeben uns die Versuche mit Venessa urlicae. Morrifield (567) und Frings (221) fanden, dass die Raupen dieser Species, welche dem Einflusse der Temperatur von $8^{\circ}$ ausgesetzt wurden, kleinere Schmetterlinge ergaben. Kleinere Schmetterlinge erhielt auch Venus (903) bei direkter Einwirkung der Son- 
nenstrahlung (also ca. $40^{\circ}$ ). Somit haben Frings und Merrifield den Punkt $A$ und Vonus den Punkt $A^{\prime}$ ermittelt, während der Punkt $O$ bei gewöhnlicher Temperatur beobachtet wird.

Hätten wir bei dieser Combination zuerst die Curve der Fig. 24 und dann die der Fig. 23 gezeichnet, dann hätten wir statt Maximum 0 ein Minimum erhalten, was den soeben angefiihrten Experimenten mit $V$. urticae widersprechen würde.

Die Curve (Fig. 25) nimmt ihren Anfung leshalb nicht bei $O^{0}$, sonilern bei $t_{n}$, weil die Raupen bei $O^{0}$ keinen Stoffwechsel haben und erst bei $4-7^{\circ} \mathrm{zu}$ fressen anfangen (Eurroctis chrysorrhoea, Grovillius [329], Bombyx mori, Schmujdsinowitsch [756]). Auch bei zu hoher Temperatur $\left(t_{h}\right)$ fressen die Raupen nicht, indem sie zu Grunde gehen (Euproctis chrysorrhoea bei ca. $45^{\circ}$, Grevillius [329]); die Curve hat deshalb hier ihr Ende.

Die Thatsache, dass einige Species bei Temperaturen (bis zu $t_{0}$ ), höher als die gewöhnliche $\left(t_{1}\right)$, grössere Exemplare ergeben, wïrrle mit dem Curvenstïck $A B O$ im Einklange stehen; dagegen würde der umgekehrte Fali, l. h. Species, welche bei Temperaturen (bis zu $t_{0}$ ), höher als die gewöhnliche $\left(t_{1}\right)$, kleinere Exemplare ergeben, im Widerspruche $\mathrm{zu}$ dem Curvenstïck $A B O$ stehen. Dieser Umstand zwingt uns als gewöhnliche Temperatur für die ersteren Species $t_{1}$ und für die letzteren Spesies $t^{\prime}$ anzunehmen, damit dann für den zweiten Fall das Curvenstiik $O A^{\prime} B^{\prime}$ in Betracht komme. Da aber die gewöhnliche Temperatur eine bestimmte Grösse vorstellt (z. B. 18 ${ }^{\circ}$ ), und $t_{1}$ und $t_{1}{ }^{\prime}$ unter sich verschieden sind, so ergiebt sich daraus, dass $t_{1}$ und $t_{1}^{\prime}$ die gewöhnliche Temperatur zur gleichen Zeit nie ausdriicken können. Wir verfallen somit in ein Labyrinth, aus welchem es nur einen Ausgang giebt, und zwar den, anzunehmen, dass die Grösse $t$ nicht die absolute Temperatur, sondern etwas anderes, mit derselben zusammenhängendes ausdrückt.

Um dieses "Etwas" zu ermitteln, wenden wir uns zu einigen physikalischen Erscheinungen, bei welchen ähnliche Schwierigkeiten $\mathrm{zu}$ uiberwinden waren.

Nehmen wir für einen Moment an, $d$ sei der durch eine bestimmte und konstant wirkende magnetisirende Kraft erzeugte Magnetismus, $t$ die mechanische Deformation (Zug- resp. Druckkraft); Dendrolimus pini sei ein Eisendraht und Callimorpha dominula ein Nickeldraht, auf welche die erwähnte Kräft der Läuge nach wirkt unı welche unter sonst gleichen Umständen sich befinden. Wie die Versuche ergeben, erhalten wir für Eisen die graphische Darstellung der 
Fig. 23, wobei der Punkt $A$ die Grösse des Magnetismus eines gewöhhnlichen (nicht deformirten) Eisendrahtes, der Punkt $B$ eines solchen im gedehnten Zustande und der Punkt $C$ in comprimierten Zustande angiebt. Auf diese Weise bedeutet $t$ rechts von $t_{1}$ die Zugund links die Druckkraft. Für Nickel wurde das Schema der Fig 24 erhalten, wobei $t$ rechts von $t_{1}{ }^{\prime}$ wiederum die Zug- und links die Druckkraft bedeutet; der Punkt $A^{\prime}$ entspricht der Grösse des Magnetismus des gervöhnlichen Nickeldrahtes.

Combiniert man die Curve für Eisen mit der Curve für Nickel, so wird die Curve der Fig. 25 erhalten.

Wenn diese Combination zulässig ist, dann sollen folgende neue Erscheinungen beobachtet werden:

1. Der Magnetismus eines der Länge nach gespannten Eisendrahtes soll bei grösserer Zugkraft als $t_{0}$ sich vermindern und die Erscheinungen eines Nickeldrahtes zeigen.

2. Der Magnetismus eines der Länge nach comprimirten Nickeldrahtes soll bei grösserer Druckkraft als $t_{0}$ sich vermindern und die Erscheinungen eines Eisendrathes zeigen.

Es ist mir gelungen, alle diese Erscheinungen wirklich zu constatieren ${ }^{1}$ ).

Daraus zog ich den Schluss, dass Eisen ( $A$ in der Fig. 25) und Nickel $\left(A^{\prime}\right)$ in elektro-magnetischer Beziehung ein und dasselbe hypothetische Metall $(O)$ sind, mit dem Unterschied, dass Eisen $(A)$ stark comprimirtes hypothetische Metall $O$ (und zwar mit der Kraft $\left.t_{n}-t_{1}\right)$ und Nickel $A^{\prime}$ dasselbe Metall $O$, aber in stark gespanntem Zustande (und zwar mit der Kraft $t_{1}^{\prime}-t_{0}$ ), vorstellen. Mit anderen Worten: Nickel ist sehr stark gedehntes Eisen (mit der Kraft $t_{1}{ }^{\circ}-t_{1}$ ) und Eisen ist stark comprimirtes Nickel (mit derselben Kraft $t_{1}{ }^{\prime}-t_{1}$ ).

Nun war die Schwierigkeit zu überwinden, warum Nickel $\left(A^{\prime}\right)$, wenn es sehr stark gedehntes Eisen ist, in den dem Eisen angehörigen Punkt $A$ zuriickkehrt, d. h. warum tritt beim Nickel, welches sich selbst überlassn wirl, kein Gleichgewicht ein? Es wurde dann

1) Journ. russ. phys.-chem. Gesellsch. zu St.-Petersburg: XVl. p. 427451. 1884; XVII. p. 65-76. 1885; XXI. p. 39-43. 1889; XXI. p. 264-287. 1889; XXIII. p. 220. 1891; XXIII. p. 301-324. 1891; XXIII. p. 430-435. 1891; XXIV. p. 1-8. 1892; Exner's Repert. der Physik: XXVI. p. 13 $\vec{\imath}-1+5.1890$; XXVI. p. 557-564. 1890; XXVI. p. 705-732. 1890; XXVH. p. 442-447. 1891; XXVII. p. 625-630. 1891; XXVII. p. 607-624. 1891; Wied. Ann. XLUI. p. $723-737.1891$. 
angenommen, dass die deformirende Kraft $\left(t_{1}{ }^{\prime}-t_{1}\right)$, welche aus Eisen Nickel erzeugte, fortlauert, auf Eisen zu wirken, um auf liese Art die Existenz des Nickels aufzubewahren.

Ein glücklicher Zufall eröffnete die dunkele Seite dieser Erscheinung. Als statt der deformirenden Kraft aut der Abscissenaxe die Atomgewichte in aufsteigender Peihe aufgetragen wurlen, ergab sich, dass Crom auf dieser Curve den Punkt $C$ unil Kobalt den Punkt $C^{\prime}$ einnimmt. Das magneto-elektrische Verhalten des Kobaltes unter dem Einfluss der Spannung und der Compression stimmt mit dem Verlaufe des Curvenstückes $O C^{\prime} A^{\prime}$ überein. Crom wurile bis jetzt noch nicht untersucht:

Somit wurde es mehr als wahrscheinlich, dass in ler erwähnten Beziehung Crom comprimirtes Eisen, Kobalt indess comprimirtes Nickel resp. gedehntes Eisen vorstellt. Auch die anderench emischen Elemente fanden den entsprechenden Platz auf dieser Curve, nur in anderen Quadranten des Coordinatensysthems.

Die magneto-elektrischen Erscheinungen auf der Ordinatenaxe der bereits untersuchten Elemente erwiesen sich als Function des Atomgewichtes auf der Abscissenaxe, dargestellt durch eine wellenförmige Linie ${ }^{1}$ ). Gleichzeitig waren diese Erscheinungen als Function der spannenden Kraft erkannt. Daraus folgt, dass die Atomgewichte als verschieden starke Spannungen (Energie) zu betrachten seien.

Der letzte, obwohl auf anderem Wege abgeleitete Satz, wurde auch von W. Ostwald ${ }^{2}$ ) ausgesprochen, welcher die Materie als eine besondere Form der Energie betrachtet.

Kehren wir zu unserem Schema fur die Schmetterlinge (Fig. 25) zurüch, so müssen wir, gestützt auf das oben Erwähnte, jetzt sagen, dass die Temperatur $t$ auf der Abscissenaxe die Wärmespannung darstellt, und zwar im analogen Sinne, wie vorher die Atomgewichte als verschiedene Kraftspannungen betrachtet. wurden.

Somit ist $t$ als absolute Temperatur nur für eine und dieselbe Species, welche im Punkte $A$, orler $A^{\prime}$ sich befindet, gültig; mit anderen Worten: wenn wir die Species $A$ betrachten, so ist $t_{1}$ seine gewöhnliche Temperatur, rechts von $t_{1}$ ist die Zunahme, links die Abnahme der Temperatur; für die Species $A^{\prime}$ ist die gewöhnliche Temperatur $t_{1}{ }^{\prime}$.

1) Berl. Chem. Berichte. XXIV. p. 88. 1901; Exner's Repert. XXVI. p. 557-564. 1900.

$\left.{ }^{2}\right)$ Zeitschr. f. phys. Chem. XVIU. p. 305-321. 1895. 
Aus der oben angefuihrten Analngie geht auch hervor, dass die Species $A^{\prime}$ durch die vergrösserte Energiespannung aus der Species $A$ entstanden haben soll, oder, was dasselbe ist, dass die Art $A^{\prime}$ und $A$ phylogenetisch von verschiedenem Alter sind ${ }^{1}$ ).

Diese Prinzipien habe ich ausführlicher in meiner Abhandlung: „Ein Versuch, das periodische System der palaearktischen Lepidopteren aufzustellen (Zur Prognose der neu zu entcleckenden Arten in der Entomologie)" (42 $\iota)$ niedergelegt. Hier wollen wir nur einige Consequenzen dieser Hypothese betrachten, zu welchem Zwecke die Familien Lasiocampidae und Arctiidae benutzt werden, da in diesen Familien Arten vorhanden sind, welche beziiglich des Einflusses der Temperatur auf die Flügeldimensionen näher untersucht worlen sind und ausserdem im Catologe der Lepidopteren von Staudinger und Rebel (843a) nicht weit von einander entfernt sind.

Nehmen wir die Gattung Arctia. Standfuss (840) untersuchte 2 Species dieser Guttung und zwar Arctia fusciata und Arctia hebe. Die erste Art gehört zu der I. Gruppe (vide Fig. 25), d. h. dass die Spannweite der Flügel mit der Zunahme der Temperatur zunimmt; die zweite Art gehört zu der II. Gruppe, da die Spannweite dieser Species mit der Zunahme der Temperatur abnimmt.

Stellen wir diese Resultate schematisch dar, so erhalten wir Fig. 26, welche zeigt, dass sowohl die Temperatur wie auch die Grösse der $N N^{0}$ dieser Species im Cataloge von Staudinger und Rebel die gleiche Reihenfolge haben.

Die alte Gattung Nemeophila ergiebt auch dasselbe und zwar: Pauls (625) fand, dass Nemeophila (Parasemia) plantaginis der I. Gruppe und Nemeophila (Diacrisia) russula (sanio) der II. Gruppe angehören. Wie die schematische Darstellung auf Fig. 27 ergiebt, haben die Temperutur und die Grösse der $N N^{0}$ eine und dieselbe Reihenfolge.

Die alte Gattung Lasiocampa hat, wie Standfuss (840) fand, Lasiocampa (Selenepheru) lunigera, Lasiocampa (Gastropacha) quercifolia und Lasiocampa (Odonestis) pruni, welche zu der I. Gruppe gehören, während zu der II. Gruppe Lasiocampa (Dendrolimus) pini gehört. Fig. 27 zeigt die schematische Darstellung für diese Arten. Damit auch hier die oben beobachtete Regelmässigkeit im Verlaufe der $N N^{0}$ und der Temperatur constatiert werden kann, müssen wir

$\left.{ }^{1}\right)$ Ob die Art $A^{\prime}$ oder $A$ alter ist, kann man mit Bestimmtheit jetzt nicht sagen, da auf der Erde zu verschiedenen geologischen Zeiten nicht immer die regressive, sondern auch die progressive Wärmespaunung stattfind. 
zwei Curven mit einander combinieren. Bei wellenförmigem Charakter dieser Curven wird von links nach rechts nach der II. Gruppe wieder die I. folgen müssen, und hier können wir Dendiolimu: pini plazieren. Auf diese Weise erhalten wir auch hier die oben erwähnte Regelmässigkeit.

Wir können diese Regelmässigkeit vorläufig nicht als eine allgemeine Regel betrachten, da zur Zeit nur mangelhaft thatsïchliches Material zu Verfügung steht; es wäre aber interessant, die daraus folgenilen Schlüsse experimentell zu prïfen, und zwar:

1. Da einige Exemplare von Arctia fasciata ( $\$$ : 4204) durch die Erhöhung der Temperatur grösser und einige kleiner als sonst werlen, so befinclet sich diese Art an der Curve (Fig. 25) beim Punkte 0 . Folglich werden durch die Erhöhung der Temperatur die kleineren, mit fasciata benachbarten 느으. (z. B. Arctia villica, flavia, caja) grössere Dimensionen erreichen, während die grösseren 니 (z. B. Arctia aulica, festiva, maculosa, crusta) diabei kleinere Spannweite haben werden.

2. Da einerseits Selenephera lunigera (․․ 993) und andererseits Odonestis pruni (. 1000) der II. Gruppe angehören, so werden die 스시오 994, 995, 996, 997, 998, 999 (Epicnaptera ilicifolia, trenmlifolia, glasunowi, suberifolia, Gastropacha quercifoliu, populifolia) unter dem Einfluss der erhöhten Temperaturen ihre Spannweite auch vermindern, wie es für quercifolia bereits der Fall ist.

Ich begünge mich hier mit den angeführten Auseinandersetzungen und verweise auf die oben citierte Abhandlung (42a), welche Rhopalocera bis zu dํ 449 enthält.

\section{Einfluss der Feuchtigkeit.}

Der Mangel an Feuchtigkeit reduziert oft sehr bedeutend die Grösse der Insekten (Rössler [702]: Raupen verschiedener Species; Barker [52]: einige Rhapalocera in Natal; Fruhstorfor [263]: Papilio bristolochie F. lamboliensis; $\nabla$. Heyden [373]: Lucanus cervus ${ }^{\circ}$ Auel [18]: Pieris arassicae; Schima [750a]: Pieris rapae var. rossii). Der Ueberschuss an Feuchtigkeit verursacht bei einigen Schmetterlingen den schärferen Flügelschnitt (Frings [253]: Vanessa $c$ album); bei anderen Species findet dies statt bei trockener Jahreszeit (Barker [52]: einige Rhopalocera in Natal). 


\section{Theorie dieses Einflusses.}

Rössler (702) erklärt die Reduktion der Flügellänge bei Schmetterlingen, deren Raupen resp. Puppen in der ungeniigend feuchten Luft sich befanden, durch das Fehlen der nöthigen Quantität der Säfte in ihrem Körper, wobei die Schmetterlinge ihre Flügel nicht vollständlig auszudehnen vermögen.

v. Heyden (373) ersieht die Ursache der Grössenreduktion der Insekten durch die trockene Luft in dem Stuffivechsel, welcher in der feuchten Luft stärker vor sich geht.

Es muss unzweiwelhaft ein Feuchtigkeitsgrad geben, bei welchem die Insekten am besten sich entwickeln können und folglich die maximale Grösse erreichen. Leider ist dieses Optimum noch nicht bestimmt. Näheres darüber vide dieses Kapitel, Abschnitt 5.

\section{Einfluss des Lichtes.}

Werden die Raupen von Vanessen im Dunkelen erzogen, so ergeben sie kleinere Puppen und Schmetterlinge als sonst (v. Linden [517]. Bordage [104], Petersen [633]).

Grünes Licht vermindert viel stärker die Fliigellänge der Vanessen als die Dunkelheit (v. Linden [517]).

\section{Theorien dieses Einflusses.}

L. Kathariner (440), welcher unter dem Einflusse verschieden farbigen Lichtes nur sehr geringe Aenderungen der Flugellänge der Vanessen erhalten hat, meint, dass das Licht keinen Einfluss auf die Dimensionen der Schmetterlinge ausübt.

M. von Linden (517), welche belleutendere Grössen-Differenzen erhalten hat, ersieht die Ursache des Lichteinflusses in der Abwesenheit der Wärmestrahlen und stützt diese Vermuthung auf die Thatsache, dass die „Wärmeformen" (ler beilen von ihr untersuchten Species (Vanessa urticae und io) ebenfalls kleine Schunetterlinge ergaben.

Diese letztere Vermuthung ist jedoch nicht genügend begründet und zwar schon deshalb, weil nach den Versuchsergebnissen dieser Forscherin die "Wärmeformen" von Vanessa urticae und io kleiner also die normalen sind, was den Resultaten der anderen Forschern widerspricht (Merrifield, Frings). 
Auch die Meinung von Kathariner, dass das Licht keinen Eintluss auf die Dimensionen der Schmetterlinge ausïbe, widerspricht den Thatsachen, welche Petersen (633) und Bordage (104) mit Vanessen in der Dunkelheit erhalten haben.

Um aus diesen Widersprüchen herauszukommen, müssen wir annehmen, dass die individuellen Verschiedenheiten zwischen den Exemplaren einer und derselben Vanessa-Species viel zu gross sind, um den Einfluss des Lichtes auf die Flügellänge zu bemerken.

Bei solchen Versuchen sollte man fïr jelles farbige Licht wenigstens 200 Raupen von jeder Species, wie ich es gezeigt habe (39), nehmen und dann die Vergleichung zwischen denjenigen Dimensionen der Flügellänge machen, welche die grösste Frequenz haben. Bei Kathariner figurierten aber im Maximum 60 Raupen resp. Puppen, wobei er einfach die Durschnittsgrösse der Flügel genommen hat; die Aenderung der maximalen Frequenz und des arithmetischen Mittels kann aber unter Umständen mit einander nicht parallel verlaufen. Die Anzahl der Raupen in Versuchen von $\nabla$. Linden ist näher nicht angegeben.

Was nun die Resultate von Bordage (104) und Petersen (633) anbelangt, so ist es ihnen zufällig gelungen, die günstigsten Verhältnisse $\mathrm{zu}$ treffen, welche weiter nicht präzisiert werden können, und bei welchen die Dunkelheit die Flügellänge stark rerluzierte.

Die wahrscheinlichsten Hypothesen dieser Reduction sind:

1. Die Abwesenheit der Wärmestrahlen und infolge dessen die niedrigere Temperatur, bei welcher die Raupen aufgezogen werden. Die Erniedrigung der Temperatur wird aber bei den hier in Betracht kommenden Arten durch die Verminderung der Flügeldimensionen begleitet, wie es die Versuche anderer Forscher beweisen.

2. Die Aenderung der Gewohnheit der Raupen. Die Raupen der erwähnten Arten fressen beim Lichte; in der Dunkelheit werden sie nur dann fressen, wenn sie sehr hungrig sind und wahrscheinlich fressen sie auch weniger als sonst. Die nicht genügende Aufnahme der Nahrung muss aber, wie es bereits erwähnt wurle, die Dimensionen des künftigen Schmetterlings reduzieren.

Um die erste Hypothese zu prüfen, sollte man zu den Versuhen auch solche Species heranziehen, welche durch die Erniedrigung der Temperatur grösser wurlen, z. B. Bombyx quercus (Merrifield), Callimorpha dominula (Standfuss) etc. Zur Prüfung ler zweiten Hypothese sollten solche Raupen genommen werden, welche Nachts fressen, wie z. B. Acherontia atropos etc. 
Erst nach der Anstellung dieser Versuche könnte man die berechtigte Vermuthung prifen, ob die Färbung der Raupe und das auf ihr fallendes farbige Licht nicht in einem nahen Zusammenhange stehen zu der bei solchen Versuchen erhaltenen Aenderung der Fliigellänge der Schmetterlinge und überhaupt der Dimensionen der Inseliten.

\section{Einfluss der Nahrung und chemischer Stoffe.}

Ist die Futterpflanze reichlich vorhanden und ist dieselbe saftig und üppig, so ergeben die Raupen Schmetterlinge von grösseren Dimensionen als in jenem Falle, wenn die Futterpflanze gewelkt oder ein Futtermangel vorhanden ist (Robinson [695], Standfuss [840], Bordage [104], Koch [457b], Weismann [953a], Gauckler [285], Pictet [637a], Kellog und Bell [447]).

Dasselbe gilt auch fïr andere Insektenordnungen (Rudow [712], Mordwilko [593], Berlepsch [73], Kleine [45ะa], Koschewnikow $[467 a])$.

Werden die .Raupen von Bombyx mori, leren Eltern mit Schwarzwurzel-Blättern gufüttert warden, mit Blättern von Maulbeerbaum gefïttert, so ergeben sie $25 \%$ mehr Seide als die der gewöhnlichen Rasse (Berg [611]).

Wirl die Futterpflanze geändert, so kann dieser Umstand entweder grössere (Rössler [703], Haberfelner [341], Sitowski [816a]), oder kleinere (Haberfelner [341], Bogdanow [92], A. L. [1], L. H. [337], Iwanow [406]), oder gleichgrosse Schmetterlinge ergeben (Kamensky [431]).

Dasselbe gilt auch für andere Insektenordnungen (Selmons [805], Rudow [711]).

Futterpflanze, vermengt mit gewissen chemischen Stoffen, ergiebt im allgemeinen Schmetterlinge von kleineren Dimensionen als die normalen (Kamensky [431], Frings [249], Heissler [362], v. Linden [519]). Allein es sind Fälle bekannt, wo die Schmetterlinge dlabei grösser (v. Linden [519]) oder wenigstens gleich gross sind (Hüttner [398], Kamensky [434]).

Werden die Puppen mit einer Zuckerlösung angepinselt, so ergeben sie grössere Schmetterlinge (Troska [884]). Die Versuche von Fischer (229) bestätigen dieses Resultat nicht. 


\section{Theorien dieses Einflusses.}

Gräfin v. Linden sieht die Ursache der grösseren Dimensionen der Schnetterlinge in der Abkürzung der Puppenzeit, „wie ja auch die Schmetterlinge von überwinternilen Generationen, die vorzeitig noch im selben Herbst zur Entwickelung gelangen, meist grösser sind als ihre im Frühjahre ausgeschlüpften Brüller und Schwestern."

Die Hauptursache der Abkürzung der Puppenzeit liegt in der Temperatur, welcher die Puppe ausgesetzt wird. Nun haben wir gesehen, dass einige Lepidopterenspecies in Versuchen von Standfuss (840), welche bei höheren 'Temperaturen $\left(20-35^{\circ}\right)$ erzogen wurden, hinteri hrer natürlichen Grösse zurïckgeblieben sind, wenngleich die anderen Species grössere Dimensionen ergaben. Schon dieser Uinstand zeigt, dass der Abkürzung der Puppenzeit nicht die allegemeine Rolle zukommt, von welcher v. Lindon spricht, vielmehr halen wir es hier mit denjenigen komplizierten Erscheinungen zu thun, von welchen in diesem Kiapitel (Abschnitt 1) die Rede war.

Was nun die Aenderung des Futters anbelangt, welches die Dimensionen cler Insekten beeintlusst, so liegt die Ursache offenbar in der chemischen Zus:tmmensetzung desselben. Da fïr jede Raupe resp. Larve voraussichtlich eine g`wisse optimale qualitative Zusammensetzung (bei gleicher Quantität) nothwendig ist, damit dieselbe am besten wachsen kinn, so kommen hier drei Fälle in Betracht: 1) Futter mit unteroptimaler, 2) Futter mit optimaler und 3) Futter mit überoptimaler Zusammensetzung.

Annähernde Beispiele für diese drei Fälle sind aus folgender Tabelle ersichtlich:

\begin{tabular}{|c|c|c|c|}
\hline \multirow{2}{*}{ Insektenspecies } & $\mathrm{F} \quad \mathrm{u} \quad \mathrm{t}$ & $\mathrm{t}$ e $\mathrm{r}$ & \multirow{2}{*}{ Forscher } \\
\hline & $\begin{array}{l}\text { über- resp. unter- } \\
\text { optimales }\end{array}$ & optimales & \\
\hline Vanessa urticae & $\begin{array}{c}\text { Brennesseln }+ \text { rothe } \\
\text { Tinte }\end{array}$ & 一 & Heissler (362) \\
\hline Panessa urticae & $\begin{array}{c}\text { Brennesseln }+ \text { defi- } \\
\text { briniertes Blut }\end{array}$ & $\begin{array}{l}\text { Brennesseln + Argo- } \\
\text { nin + Silber-Kaseïn- } \\
\text { verbindungen }\end{array}$ & v. Iinden (519) \\
\hline Vanessa urticae & $\begin{array}{c}\text { Brennesseln }+ \text { Mor- } \\
\text { phium } 1 \%\end{array}$ & Eisenalbuminat & $n n$ \\
\hline Vanessa io. & $\begin{array}{l}\text { Brennesseln }+ \text { rothe } \\
\text { Tinte }\end{array}$ & - & Heissler (362) \\
\hline
\end{tabular}




\begin{tabular}{|c|c|c|c|}
\hline \multirow{2}{*}{ Insektenspecies } & $\begin{array}{lll}F^{\prime} & \mathrm{u} & \mathrm{t}\end{array}$ & $t \quad e r$ & \multirow{2}{*}{ Forscher } \\
\hline & $\begin{array}{c}\text { iiber- resp. unter- } \\
\text { optimales }\end{array}$ & optimales & \\
\hline Daplnis nerii . & Blaner Flieder & - & L. H. (337) \\
\hline Bombyx atlas. & Berberitze & Götterbaum & Rössler (703) \\
\hline Limanat. dispar & Nussbaumblätter & Taraxacum & Pietet $(637 a)$ \\
\hline Bombyx mori. & $\begin{array}{l}\text { Maulbecrblät. + Pic- } \\
\text { rinsäure }\end{array}$ & $\begin{array}{c}\text { Scorzonera his- } \\
\text { panica }\end{array}$ & Kiamensky (431) \\
\hline Bombyx mori . & $\begin{array}{c}\text { Morus rubra } \\
\text { canadensis }\end{array}$ & $\begin{array}{l}\text { Morus alba v.ced- } \\
\text { rona }\end{array}$ & Iwanow (406) \\
\hline Bombyx mori : & $\begin{array}{c}\text { Morus albav.ta- } \\
\text { tarica }\end{array}$ & \begin{tabular}{|} 
Morus alla v. la- \\
tifolia
\end{tabular} & $n$ \\
\hline Arctia caja . . & Ges:lzene Pflanzen & - & Frings (249) \\
\hline Saperda scalaris & Fichte & Laubholz & Haberfelner (341) \\
\hline Tineola biselliella & Wollwatta & Wollstoff' & Sitowski $(816 a)$ \\
\hline Clytus lama.. & Fichte & laubholz & Haberfelner (341) \\
\hline Callidium aeneum & $n$ & $"$ & $\eta$ \\
\hline Driomyza anilis & Kuhdünger & - & Bogdanow (92) \\
\hline Wespen .... & - & Honig + Bier & Rudow (711) \\
\hline Chionaspis salicis & Pappel & Erle & Reh (681) \\
\hline
\end{tabular}

Es ist vorläufig schwer zu bestimmen, ob das betreffencle Futter über-oder unteroptimales ist, leshulb sind beide Kategorien in einer Colonne angeführt worden.

Die Fresslust ist dabei nicht massgebend, da gewisse Pffanzen, welche sonst optimales Futter vorstellen, unter Umstänlen nicht gern gefressen werden, woran die Beschaff nheit der Obertläche z. B. der .Blätter schuld ist. So z. B. fand Tichomirowa (872), dass die jungen Räupchen von Bomlyyx mori die Blätter von Scorzonera hispanica nicht fressen; wirl aber die Haut der unteren Blattseite entfernt, so fressen sie dieses Futter so gern, dass die von ihnen producierte Seide sogar besser ist als bei der Maulbeer-Fütterung.

Auch giebt es Pflanzen, welche von Raupen nur dann gefressen werden, wenn man sie mit gewissen Substanzen bepinselt und welche vom Raupenorganismus nicht assimiliert werden. So z. B. werden die Blätter von Stellaria media, welche keine Spur von Gerbstoff enthaltẹn, von Euproctis chrysorrhoea-Raupen gar nicht beriihrt; als diese Blätter aber mit Tanninlösung bepinselt wurden, begamnen die Rupen dieselben zu fressen, trotzlem dass der Gerbstoff von Ritupen nicht assimiliert wird (Grevillius [329]).

Ist die Qualität des Futters dieselbe und wird nur die Quarntität geändert, so giebt es dabei auch drei Fälle: 1) Futter mit 
der unteroptimalen, 2) Futter mit (ler optimalen und 3) Futter mit der überoptimalen Menge.

Bei rler optimalen Menge des Futters erhalten die Inseliten die ihnen eigenen maximalen Dimensionen, vorausgesetzt, dass dabei auch die übrigen zum Wachstum nothwendigen Faktoren ilr Optimum aufweisen.

Bei ungenügender Futtermenge entwickeln sich verschiedene Theile des Insektenorganismus so zu sagen auf eigene Kosten, wobei sie offenbar kleiner werlen als sonst. Die Entwickelung les Organismus, ein Mal in einer bestimmten Richtung begonnen, bleibt eben nicht still stehen, sondern sie schreitet fort. Können sich verschiedene Organe bei betreffender mangelhaften Futtermenge noch entwickeln, so verwandelt sich die gegebene Stadienform zum Imago, widrigenfalls stirbt sie. Diese minimale Futtermenge, bei welcher sich das Insekt noch entwickeln kann, ergiebt die mögliche minimale Dimension, sogenannte "Hungersexemplare." (Standfuss $[841 \alpha]$ ).

Der dritte Fall (Futter mit (ler ïberoptimalen Menge) hat vorläufig nur thecretische Bedeutung, dia es zur Zeit schwicrig ist, z. B. den Raupen eine "Uebernährung" zutheil werden zu lassen. Höchst wahrscheinlich würden dabei die Verdaungsorgane gestört werden und die Entwickelung würde nicht normal vor sich gehen wobei die Dimensionen des Insektes unter denjenigen stehen würden, welche bei optimaler Futtermenge erreicht werien.

Dabei können noch spezielle Fälle vorkomnen. Erstens kann man den Raupen resp. Larven von Ei an die mangelhafte Nahrung bieten, und zweitens kann man die Nahrung zu bestimmter. Zeit gänzlich entziehen. Solché ''rersuche hat z. B. Pictet (637a) angestellt, wobei er in beiden Fällen Zwerge erhielt, welche aber in anderer Richtung nicht vergleichbar waren. Er erhielt nämmlich im ersten Falle Exemplare ohne jetwede Farbenabweichung. Aehnliche Versuche stellte auch Koch $(4576)$ an, wobei er ans Vanessa io eine andere Form ( Vanessa iodes) erhielt.

Systematisch angestellte Versuche, wie sie z. B. Pictot (637, $637 a$ ) begann, würden $\mathrm{zu}$ wichtigen Resultaten in dieser Richtung , führen. 


\section{Einfluss des Klimas.}

Die meisten Insekten einer und derselben Art sind in sïllichen Gegenden grösser als in nördlichen (Lycaena- und Satyrus-Arten, Meyer-Dür [580]; Ant. ausonia. Hesp. sidae, Sesia anellata, Calpe thalictri, Heliodes rupicola, Lederer [505]; Cyclogaster tenuirostris, Löw [532]; Lycaena semiargus, cyllurus, Melitaea uthalia, Aspilates strigillaria, Lythostege greseatu, forinata, Mann [545]; Teich [855]; Sericomyia borealis, Jaroschewsky [419]; Cynomyia alpina, Jaroschewsky [420]; Papilio podalirius ab. zanclaeus, Pap. ulexunor, Aporia crataegi, Thecla rubi, Lycaena anteros, Argynnis daphne, adlippe var. taurica, paphia var. delila, paphia ab. anargyra, Satyrus circe, briseis ab. pircuta, Pararge roxelana, Syrichtus malvae, Deilephila euphorbiae, Callimorpha hera, Lasiocampa otus, Acronycta rumicis, Catocala enthyshea, Gnophos glancinaria. Holtz [385]; Satyridae, Bachmetjew [26]; Acidalia consanguinaria, May [550]; Argynnis amathusia, Coenomympha hero, Agrotis simulans, Acidalia immorata, Acid. incanata, Larentia variata ab. stragulata, Ematurga atomaria, Plorugmatolia fuliginosa, Zygaena scabiosae, Zygaena meTiloti, Petersen [633]; Fidonia piniaria, Jacobi [412]). Sesia tabaniforme, Zygaena meliloti, Lithosin griseola, Guophria quadra, Epichnopteryx pulla, Krulikowski [478]; Agrotis potygona, Mlamestra chrysozona, Miselia oxyanthae, Panolis piniperda, Plusia c aureum, Pl. moneta, Pl. Iractue, Chariclea delphinii, Zunclognatu emortualis, Pericallia syringaria, Rumia luteolatu, Eucosmia unclulatu, Aporodes floralis, Botys repandalis, Bot. verbascalis, Diasemia litterata, Onectra pilleriana, Penthina antiquana, Talaeporia pscudobomlyycella, Krulikowski [479]; Dichonia aprilinu, Rusina tenebrosa, Baillon [44]).

Es giebt einige Insekten, welche in siidlichen Gegenden kleiner sind, als in nördlichen (Lỳbellen, Hagen [349]; Parnassius doritis, Meyer-Dür [580]; Melanargia larissa, Luelia coenosa, Lederer [505]; Pieris ergune, Lycuena cyllarus, Holtz [385]; Pararge maera, meyaera, Bachmetjew [26]; Apis mellifera, Koschewnikow [664, 467]; Parnassius delins, Rebel und Rogenhofer [67+]; Drepana curvatula, Acidalia violata, Petersen [633]; Yystophora hornigi, Sorhagen [824]; Aglia tuu, Federley [219a]; Limacodes testudo, Leucoma salicis, Endromis versicolora, Krulikowski [478]; Neuronic populuris, Dianthoecia nuna, Leucania conigera, Curadrina taraxici, Anphipyra pyramidea, Agrotis dalulii, Agr. rcoussa, Xylina ingrica, Cucullia umbratica, Chariclea umbra, Erastria uncula, Prothymia viridaria, 
Catocala fraxini, Pseudoterpna pruinata, Depress ria ocellanu, Depr. angelicetla Krulikowski [479]; Anthocharis beliı var. ausoniı, Krulikowski [480)]; Ocneria dispar, Reichert [684]).

Einige Species sind in südlichen und nördlichen Gegenden gleich gross (Libell. fulva, depressa, Hagen [350]).

Gezacktere und geschwänzte Flügel haben die Schmetterlinge mehr im Sülen (Teich [855], Weismann [954]).

Die unter gleichen Breitengrallen liegenden Gegenden besitzen umso grössere Insekten, je mehr sie nach Osten (Ausgangspunkt Deutschland) liegen (Papilio machuon, Leech [504], Kolbe [462]; Libellen, Melitata phoebe, Argynnis ino, laodice, paphia, Coenonympha oedipus, Kolbe [462]; Ailanthus glandulosa, Prehn [651]; Parnassius apollo, Rebel und Rogenhofer [67t]; Ocneria dispar, Roichert [684]; Leptidia sinapis, Gonopteryx rhamni, Satyrus dryas, Slevogt [822l]; Celes variabilis var. subcocruleipennis, Adelung [2u]; Parn ıssius apollo, Argymnis hecate, Chrysophanus hippothoë, Hudena maillardi, Orrhodia torrida, Acidalia violuta var. decorata, Srylhris scliniella, Rebel [676]; Ausnahmen bilden: Aporia crataegi, Pieris daplidice, Vanessa levana, carclui, io, antiopa, Kolbe [462]; Argynnis selene, Argynnis pandora, Erebia medusa, Lycriena argus, Oxyptilus didactylus, Aluctia batiodaclyta, Coleophora millefolii, Robel [676]).

Werden die Eier von Bombyx luna odler mori von N.-America resp. China orler Japan nach Europa gebracht, so haben die Schmetterlinge grössere Spannweite und breitere Flügel, resp. werden die Raupen grösser (Wagner [935], Derewjanko [167], Schmujdsinowitsch [766], Golubajew [319], Antropow [15].

\section{Theorien dieses Einflusses.}

Hagen (349) erklärt die Erscheinung, dass die in süllichৎn Gegen len vorkommenclen Libellen eine geringere Grösse haben als die in nördlichen Gegenden, dadurch, dass die Insekten in südlichen Gegenden früher ausschlüpfen, da das Wasser frühzeitig erwärmt wirl, während dieselben Larven in nördlichen Gegenden melır Zeit haben, sich zu ernähren und auszuschlüpfen, bis das Wasser warm wird.

Teich (855) erklärt die bedeutendere Grösse der in Tropen vorkommenilen Insekten durch den Reichthum an Pflanzenstoffen und die Ueppigkeit der Vegetation, "denn jedem Züchter ist bekannt, dass bei kümmerlicher Nahrung die Falter kleiner bleiben."

Berg (855) vermuthet die Ursache des Kleinwerdens der in Europa gezuichteten Seidenspinner in der Inzucht. 
Wallace (940) ersieht die Ursache der Gestaltabänderungen bei Schmetterlingen in indischen Regionen in dem Einfluss des Kilimas und nanderer physischen" Bedingungen; während Weismann (954) auf expirimentellem Wege fand, dass die Schwänzchen der Hinterflügel bei Polyommatus phlaeas vom Klima unabhängig sind, obwohl die geschwänzten Schmetterlinge mehr in südlichen Gegenden vorkommen.

Will man den Einfluss des Klimas auf die Grösse und Gestalt der Insekten erklären, so muss man die einzelnen Cumponenten, welche die Resultierencle (das Klima) ergeben, betrachten Diese Componenten sind: die Temperatur, die Feuchtigkeit, der atmosphärische Druck, das Licht, der elektrische Zustand der Atmosphäre, von welchen Faktoren jeder für sich einen Einfluss auf Insekten ausüben kann.

Dass alle diese Faktoren nicht in gleicher Richtung die Insekten beeinfluss $\mathrm{n}$, ist aus den vorhergehenden Abschnitten dieses Kapitels ersichtlich, und zwar:

Die Temperatur. Die bei erhöhter Temperatur erzogenen Raupen ergeben für einige Spezies grössere für die anderen kleinere Schmetterlinge als sonst. Auch bei Puppen wird dasselbe beobachtet, wenn dieselben durch verschiedene Temperaturen beeinflusst werden. Dabei kann vorkommen, dass die Raupe und die Puppe einer und derselben Species in verschiedenen Richtungen durch die Temperatur beeintlusst werden.

Wir erhalten somit folgende mögliche Fälle:

1. Die Raupe bei erhöhter Temperatur erzogen. Resultat: grössere Dimensionen des Schmetterlings.

2. Die Raupe bei erliöhter Temperatur erzogen. Resultat: kleinere Dimensionen des Schmetterlings.

3. Die Puppe bei erhöhter Temperatur. Resultat: grössere Dimensionen des Schmetterlings.

4. Die Puppe bei erhöhter Temperatur. Resultat: kleinere Dimensionen des Sihmetterlings.

Kombiniert man den 1 . mit dem 3. Fall, so erhält man grössere Dimensionen des Schmetterlings. Die Kombination des 2. und des 4. Falls ergiebt Schmetterlinge von kleineren Dimensionen. Beim Kombinieren der Fälle 1 mit 4 oder 2 mit 3 können die Schınetterlinge entweder grösser, gleichgross, oder kleiner erhalten werden, je nach der Species und der Grösse des Einflusses.

Die Feuchtigkeit. Dieser Faktor wirkt auch verschielenartig auf die Grösse verschiedener Insekten. Die meisten Schmet- 
terlings-Species werlen unter dem Finfluss dieses Falitors kleiner. Auch ihr Flügelaussehnitt (z. B. bei Vanessa c-allum) wird dalsei schärfer.

Somit sinı die möglichen Fälle ıler Abänılerungen dieselben, wie unter dem Einflusse der Temperatur.

Das Licht. Raupen gewisser Species, in Dunlelheit gezüchtet, ergeben entweder grössere (z. B. Tunessa io) oiler kleinere (z. B. Atella pholanta) Schmetterlinge als beim Tageslichte. Für die meisten Species ist dieser Einfluss gleich Null. Der Einfluss des Lichtes in dieser Beziehung auf die Puppen ist unwahrscheinlich.

Der Luftdruck. Pujpen, welche sich unter stark vermindertem Drucke eine gewisse Zeit befinden, ergeben Imagines mit schwach entwickelten Fligeln. Der Einfluss auf Raupen ist anch sehr wahrscheinlich.

Der Einfluss der anderen Faktoren auf die Grösse und Gestalt der Insekten ist unbekannt.

Bevor wir zur Kombination (ler hier besprochenen Falitoren, welche alle zusammen das "Kilima“ billen, iibergehen, miissen wir zuerst feststellen, was wir unter normalem Kilima uni normalen Dimensionen der Insekten verstehen werden.

Wenn die Forscher auf dem Gebiete der experimentellen Entomologie sagen, dass sie unter lem Einfluss eines gegebenen ïusseren Faktors einen Schmetterling, z. B. Sutyrus briseis, von grösseren Dimensionen, als unter gewöhnlichen Umständen, erhalten haben, so wird als Norm ein Exemplar der betreffenden Gegend genommen. Auf diese Weise, wirl man z. B. in Deutschland sagen, dass Puppen von Satırus biriseis, welche dem Einfluss der höheren Temperatur, als die in Deutschland während ihrer Puppenzeit herrschende, ausgesetzt wurden, grössere Schmetterlinge als sonst ergaben. Stellen wir einen ähnlichen Versuch in Bulgarien an, so werden die erhaltenen Schmetterlinge kleiner, als die in Bulgarien im Freien gefangenen, da hier diese Species olmedlies um 9,5\% grösser ist als in Deutschland (Bachmetjew [26]). Daraus würde folgen, dass die erhöhte Temperatur die Dimensionen von Satyrus briseis in Bulgarien vermindert und in Deutschland vergrössert.

In Anbetracht eines solchen Paradoxon miissen wir zum Vergleich nicht die relative, sondern eine absolute Norm wählen.

Für die günstigste Entwickelung eines Organismus ist ein bestimmtes Quantum des äusseren Agents nothwendig, wobei clieser Organismus seine vollständige Grösse, welche er im Maximum haben 
kann, erreicht. Dieser Begriff ist in dem Gesetze des Optimums eingeschlossen. In unserem Falle muss es also für die Entwickelung irgend eines Inselites ein Optimum der Temperatur, der Feuchtigkeit, des Lichtes, des Luftdruckes etc. geben, dann erreicht er seine maximal mögliche Dimensionen.

Die optimalen Grössen dieser Agentien sind bis jetzt noch nicht bestimmt worden, und es ist schwierig, sie sogar annäliernd $\mathrm{zu}$ bestimmen, da dieses Optimum nicht nur für verschiedene Species, sondern für verschiedene Organe einer und derselben Species voraussichtlich verschieden sein wirl. Folgende Beispiele erläutern diese Vermuthung:

Raupen von Lasiocampa pini, gezüchtet bei erhöhter Temperatur $(T)$, ergeben grössere Schmetterlinge als unter gewöhnlichen Umständen; während die Raupen von Las. quercifolia das entegengesetzte Resultat ergeben (Standfuss [840]). Daraus folgt, dass das Temperatur-Optimum für Las. pini höher als $T$ und für Las. quercifolia tiefer als $T$ liegt, sollen wir das Optimum im Sinne von I. Sachs (729) verstehen.

Werclen die Wespenlarven eine gewisse Zeit auf Eis gehalten, so ergeben sie vollkommen lebenstähige Wespen, aber nur mit Flügelstiimpfen (Dewitz [168]). Diese Thatsache weist darauf hin, dass die Temperatur nur die Entwickelung der Fliigel beinflusst hat.

Da das Optimum verschiedener Agentien für verschiedene Species und sogar für ihre einzelnen Organe verschiellen ist, so werden wir in folgendem nur die Spannweite der Schmetterlingsfluigel in Betracht ziehen. Unter normalen Flügeln verstehen wir folglich solche, welche unter dem Einflusse der günstigsten (optimalen) Bedingungen ihr Maximum erreicht haben; alle anderen sind anormal. Unter dem normalen Klima muss man somit ein solches verstehen, welches aus optimalen Komponenten (Temperatur, Fenchtigkeit etc.) zusammengesetzt ist. Die Normalität des Keimes variiert ron Species zu Species.

Stellen wir nun die Einwirkung der Temperatur auf die Spannweite der Schmetterlingsflügel vom Raupenstadium an schematisch dar (Fig. 26).

Die Abscisse dieses Coordinatensystems bedeutet die verschiedenen der Reihe nach folgenden Entwiskelungsstarlien. Die Ordinate bedeutet die Spannweite, wobei oben die mögliche maximale und unten die mögliche minimale Dimension verzeichnet ist. 
Befinden sich die Raupe und die Puppe in der optimalen Temperatur, so verläuft die Entwickelung der Abscissenaxe nach und ergiebt schliesslich das Imago $R$ mit der maximulen Spannweite der Flügel.

Befindet sich die Raupe nicht in der optimalen Temperatur, sondern in einer höheren oder tieferen $(t)$, so würde diese Rizupe, wenn es möglich wäre ${ }^{1}$ ), das Puppenstadium nicht zu passieren, im Punkte $A$ einen Schmettering ergeben, bei welchem die normale Spannweite um die Grösse $e c$ vermindert wäre. Da aber die Puple derselben Temperature $(t)$ weiter ausgesetzt wirl, so können hier vier Hauptfälle vorkommen, und zwar:

1. Die Temperatur $t$ wirkt auf die Puppe nachtheiliger als auf die Raupe. Resultat: Schmetterling $R_{1}$, bei welchem die maximale Spannweite um die Grösse $e a$ vermindert ist.

2. Die Temperatur $t$ wirlit auf die Puppe gerale so nachtheilig als auf die Raupe. Resultat: Schmetterling $R_{2}$, bei welchem die muximale Spannweite um die Grösse $e b$ vermindert ist.

3. Die Temperatur $t$ wirkt auf die Puppe indifferent. Resultat: Schmetterling $R_{3}$, bei welchem die maximale Spannweite un die Grösse $e c$ vermindert ist.

4. Die Temperatur $t$ wirkt auf die Puppe günstig. Resultat: Schmetterling $R_{4}$, bei welchem die maximale Spannweite um die Grösse $e d$ vermindert ist.

Hätten wir ein solches Schema auch für die Einwirkung der Feuchtigkeit auf die Spannweite der Schmetterlingflïgel vom Raupenstadium an dargestellt, so würden wir qualitativ ähnliche Fälle erhalten.

Versuchen wir jetzt den Einfluss der Temperatur und der Feuchtigkeit mit einander zu kombinieren.

Dabei sind drei Fälle möglich: 1) Der gegeben Grad der Feuchtigkeit verhält sich gegenüber der Entwickelung indlifferent;2) Derselbe wirkt in gleicher Richtung mit der Temperatur und 3) Er wirkt in entgegengesetzter Richtung als die Temperatur.

Für den ersten Fall erhalten wir dasselbe Schema, wie für die Einwirkung der Temperatur allein (Fig. 26). Zur Erläuterung des 2. und 3. Falles dienen Fig. 27 und Fig. 28.

1) Einen solchen Fall beschreibt Majoli (543), wobei die Raupe bei sehr hoher Temperatur, ohne sich zu verspinnen, sofort einen Falter ergab. Dabei muss man die Untersuchungen von Vorson (916) in Betracht ziehen, nach welchen die Imaginalscheiben der Flügel schon sehr früh in der Raupe angelegt werden. 
Die in der Fig. 27 und 28 mit Strichen bezeichneten Linien bedenten den Einfluss der Temperatur allein, wie es in der Fig. 26 dargestellt ist.

Da im 2. Falle die Wirkungen der Temperatur $(t)$ und der Feulhtigkeit $(f)$ summiert werden, so verläuft die Resultierende $t+f$ unter grösserem Winkel zu der Abscissenaxe als die Temperaturcurve $(t)$. Am Encle der Raupenzeit $\left(A^{\prime}\right)$ angelangt, würde die Curve $t+f$ parallel den entspechenden Verzweigungen für die Temperaturcurve verlaufen, d. h. die Linien $A^{\prime} r_{4}{ }^{\prime}\left\|A R_{4}, A^{\prime} r_{2}^{\prime}\right\| A R_{2}$, $A^{\prime} r_{1}^{\prime} / \mid A R_{1}$ ergeben, wenn die Puppe nur unter dem Einfluss der Temperatur allein sich befinden würde; da aber die Feuchtigkeit auf die Puppe einwirkt, so erleilen die entsprechenden Verzweigungen der Resultierenden $t+f$ auch hier die dargestellten Abweichungen, wobei die Schmetterlinge $R_{4}{ }^{\prime}, R_{3}{ }^{\prime}, R_{2}{ }^{\prime}$ und $R_{1}{ }^{\prime}$ erhalten werden.

In der Fig. 28 ist der dritte Fall dargestellt, d. h. die Einwirkung der Diff renz zwischen $t$ und $t$. Die Verzweigungen cler Curve $t-f$ ergeben die Schmetterlinge $R_{4}{ }^{\prime \prime}, R_{3}{ }^{\prime \prime}, R_{2}{ }^{\prime \prime}$ und $R_{1}{ }^{\prime \prime}$.

Dabei können verschiedene spezielle Fälle entstehen. Ist z. B. für das Raupenstadium die den Temperatureinfluss aufhebende Wirkung der Feuchtigkeit gerade so gross wie die Temperaturwirkung selbst, dann ist die durch $t-f$ bewirkte Veränderung offenbar gleich Null. Nit anderen Worten: bei schlechten Temperaturverhältnissen, aber bei sehr günstigen Feuchtigkeitsverhältnissen kann die maximale Spannweite des betreffenden Schmetterlings unverändert bleiben. Auch kann das Zusammenwirkẹn der Temperatur und Feuchtigkeit (der 2. und 3. Fall) gleich starke Abänderungen an (ler Spannweite verursachen, wie die 'J'emperatur allein, allerdings nur unter gewissen Umständen. So z. B. kann $R_{3}{ }^{\prime \prime}=R_{4}, R_{1}{ }^{\prime \prime}=R_{2}, R_{3}{ }^{\prime}=R_{2}, R_{2}{ }^{\prime}=$ $R_{1}$ sein und folglich auch $R_{3}{ }^{\prime}=R_{1}{ }^{\prime \prime}$, da sie einzeln $=R_{2}$ sincl.

Wenn die Kombination der Temperatur- und FeuchtigkeitsEinwirkung bereits komplizierte Resultate ergiebt, so wird die Sache noch komplizierter, wenn hinzu noch der Einfluss der übrigen das "Klima" zusammensetzenden Faktoren kommt.

Fig. 26, 27 und 28 stellen nur den konstanten Einfluss der bestimmten Temperatur, resp. der Temperatur uud Feuchtigkeit zu gleicher Zeit dar. Nun bleiben diese Faktoren nie konstant, sondern erleiden bereits während 24 Stunden bedeutende Schwankungen: so z. B. ist die Lufttemperatur beim Tage grösser und die Feuchtigkeit kleiner als des Nachts. Diese Schwankungen sind während verschiedener Jahreszeiten verschieden. Würden wir in diese Details ein- 
gehen, so hätten wir für die Einwirkung der Temperatur und der Feuchtigkeit statt Grade verschierlen gekrümmte Linien erhalten, welche einander in verschierlenen Punkten schneiden würlen.

So viel uiber die Spannweite der Schmetterlingsflügel. Nun kommen die Krallen, Fühler etc. in Betracht, welche entweder in anderer Richtung odler mit anderer Intensitït als die Fliigel beeinflusst werden. Als Resultat erhalten wir verschiedene Varietäten, Arten etc., welche durch die Vererbung, Zuchtwal etc. immer stabiler werden.

Diese allgemeinen graphisch dargestellten Betrachtnngen ergeben, dass für die Ermittelung des Klima-Einflusses auf die Gestalt und Dimensionen der Insekten zuerst eine ganze Reihe von Bestimmungen der meteorologisch-physiologischen Natur angestellt werlen muss. Erst dann kann man sagen, was dem Einflusse der klimatischen Faktoren zuzuschreiben sei und was aus inneren Ursachen entstanden sei (z. B. die Inzucht, bellingt durch die Isolierung der gegebenen Gegend von den benachbarten, die Kreuzung etc.).

Die Theorie des Klima-Einflusses auf die Grösse und Gestalt der Insekten führt uns zu folgenden allgemeinen Schlüssen:

Das Klima kann die Insekten in mannifaltigster Richtung verändern, inclem es verschieden stark auf verschierlene Organe einer und derselben Species einwirkt.

Wirken die klimatischen Komponenten alle in einer Richtung, wenn auch verschieden stark, so können verschiedene Klimata eine und dieselbe Verändlerung des betreffenden Insekts nicht hervorrufen.

Wirken diese Komponenten, wenn auch nicht alle, nach verschiedenen Richtungen, so kann unter ihrem Einflusse in verschiedenen Klimas eine und dieselbe Abänderung gewisser Insekten entstehen.

Das Vorhandensein derselben Abänilerungen bei Insekten in verschiedenen Gegenden ist somit noch kein Kriterium für die Gleichheit des Klimas in diesen Gegenden.

Die konkreten Fälle, welehe aus der hier kurz entwickelten Theorie hervorgehen, werden im IIr. Bande meiner "Studien" näher besprochen und zwar speziell für Aporia crataegi, gestiitzt auf Messungen von über 50.000 Flügeln aus ca. 60 verschieilenen Gegenden Europas und Asiens. 


\section{DRITTES KAPITEL.}

Verallgemeinerungen und Theorien über den Einfluss der äusseren Faktoren auf die Färbung und Zeichnung der Insekten.

\section{Einfluss der Temperatur.}

\section{A. Susammenstellung der Thatsachen.}

a) Einfluss konstanter hohen Temperaturen.

W erden frische Puppen ilem Einflusse hoher Temperaturen (bis 390) während einiger Tage ununterbrochen ausgesetzt, so wird bei den meisten Schmetterlingsarten sowohl die Färbung wie auch die Zeichnung mehr oder weniger geändert (Dorfmeister [194], Weismann [953, 954], Merrifield [563, 565, 570, 572], Standfuss [837, 840, 841], Fischer [228, 229, 235, 236], v. Linden und Fickert [515], Kalender [476], v. Reichenau [682], Gauckler [279], Stange [842], Rühl [718, 721], Venus [903], Walsingham [563], Heyer [372], Jänicher [410], Werner [956], Urech [896], Pauls [628], Kusnetzow [489], Heissler [361], Irmscher [409], Frings [259, 260, 261, 262], Ball [47], Lorez [535]. Federley (219a]. Dannenberg [163b], v. Linden [527e]).

Unter diesen Umständen werden Sommer-Puppen stärker beeinflusst, als die überwinternden Puppen (Merrifield [573], Standfuss [841]), welche schrwache oder gar keine Abänderungen der Schmetterlingsfärbung ergeben (Rühl [716]). Winterpuppen werden nur dann stark beeinflusst, wenn sie in Frühjahre dem Einflusse hoher Temperaturen ausgesetzt werden (Merrifield [573]).

Puppen, welche dem Einflusse hoher Temperaturen ausgesetzt werden, ergeben in den meisten Fällen hellere Färbung der Schmetterlinge und zwar bei: 'Papilio podalirius (Standfuss), Papilio machaon (Fischer), parnassins appollo (Standfuss), Pieris napi (Merrifield), Aporia cratacgi (Standfuss), Vanessa c alloum (Fischer, Standfuss), V. polychloros (Morrifield, Standfuss), V. io (Dorfmeister). V. atalanta (Merrifield), V. urticae (Merrifield, Dorfmeister), V. cardui 
(Standfuss, Fischer), Antherea pernyi (Hөyer), Lasiocampa pruni, Dasychira abietis (Standfuss), Pararge egeria, Engonia antumnuria, Arctia caja'(Merrifield). Diese Färbung kann auch intensiver werden und zwar bei: Rhodocera rhamni (Merrifield, Standfuss), Vanessa urticae (Weismann, Venus), Catocala fraxini (Kusnetzow), Argynnis aglaja (Standfuss), Arctia cuja (Dorfmeister), ALumestra persicariae (Kalender). Deilephila euphorbiae (Gauckler), Agrotis rubi (Stange), oder dunkler als sonst und zwar bei: Polyommutus phlaces (Merrifield, Weismann), Vanessa io (Urech), P(tpilio podulivius (v. Linden und Fickert), Lasiocampa quercifolia (Jänichen, Standfuss), Selonia illustraria (Merrifield):

Werilen frische Puppen von Vanessa-Arten einige Tage dem Einflusse der hohen Temperaturen (bis $39^{\circ}$ ) ausgesetzt, so ergeben dieselben folgende Abarten resp. Varietäten: $T$. levana var. prorsa (Merrifield), var. porima (Weismann); c-album helle Form (Standfuss, Fischor); polychloros var. erythromelas Stgr. (Standfuss), ab. dixeyi Stulfs. (Uebergänge, Fischer), ab. testudo Esp. (Frings); urticae var. ichnusa Bon. (Weismann, Venus, Frings, Fischer, v. Linden) ab. ishnnusoides de Selys (Frings), var. turcica (v. Reichenau, Fischer), ab. epione Fschr. (Uebergänge, Fischer), var. polaris (Fischer, Frings), Annäherung an $V$. io (Standfuss); io ab. fischeri Stdfs. (Ficher, Frings), ab. belisaria (Frings), ab. colore nigrum muculata Urech (Urech); antiopa v. claubi St:lfs. (Standfuss, Frings), ab. epione Fschr., ab. hygiaea Hdrch. (Fischer, Standfuss [Uebergänge]), var. röderi Stdfss. (Frings), v. artemis Fschr. (Fischer); atalanta v. vulcanica Godt. (Standfuss, Fischer, Frings), v. merrifleldi Stdfs. (Fischer); cardui helle Form (Standfuss, Fischer), var. vislutti Stdfs. (Fischer).

Puppen anderer Species ergeben unter diesen Umständen folgende Abarten und Varietäten: Papilio poclalirius var. zuncleus Z. (Standfuss, Frings), ab. undecimlineatus Eim., ab. reductus Schultz, ab. schultzii Rothke (Frings); Papilio machaon Uebergang zu hospiton (Werner), ähnlich wie von Antivchia (Standfuss), var. centralis, ab. sphyrus, ab. aurantiacus Spejer, ab, tenuivittutus Spengel, ab. nigrofasciatus Rothke, ab. immaculatus Schultz (Frings); Thais polyxena ab. ochracea Stdgr. (Frings); Rhod sera rhamni var. farinosa Z., var. nepalensis (Merrifield, Standfuss, Frings); Pieris napi var. napaeae (Woismann); P. amphidamas var. obscura Stdgr. (Frings); Apatura ilia var. clythie = var. dilutior (Frings); Satyrus semele var. aristaeus Bon., Spilosoma fuliginosa var. fervida Stdgr. (Standfuss); 
Lasiocampre populifutia var. autumnalis (Jänichen); Lasiocampa quercifolic dalmatinische Form (Standfuss); Melacosoma neustria var. parallela Stilgr. (Federley); Xanthia cerago var. fluvescens Esp. (Durfmeister); Callinorpha dominula Lokalform von Brussa (Standfuss); Purasemia plantaginis ab. hospita Schiff, Arctia caja ab. futura, ab. schultzii (Frings); Arctia fluvic ab. obscura Lorez (Lorez); Catocala fraxini var. muculata nov. (Kusnetzow); Uraiteryx sambucuria var. olivacea Stdgr. (Standfuss).

Raupen, welche bei hohen Temperaturen erzngen werilen, haben keinen Einfluss auf die künftige Färbung der Schmetterlinge (Merrifield [573]).

Werden die Puppen einige Tage ununterbrochen bei hoher Temperatur $\left(39^{\circ}\right)$ gehalten, so ergeben einige Species Schmetterlinge mit kaum gebiluteten Schuppen (Fischer [229], Frings [260], Federley $[216 a])$.

\section{b) Einfluss koustanter niederen Temperaturen.}

Werden frische Puppen dem Einflsse niederer Temperaturen (bis $0^{\circ}$ ) während einigen Wochen ununterbrochen ausgesetzt und nachher bei Zimmertemperatur liegen gelassen, so wird bei den meisten Schmetterlingsarten sowohl die Färbung, wie auch die Zeichnung mehr oder weniger geänilert (Dorfmeister [194, 195], Weismann [953, 954], Edwards [210], Merrifield [563, 567, 568, 570, 571, 572, 573], Standfuss (837, 841], Fisch $\bullet \mathrm{r}$ [228, 229]. Rössler [702], v. Reichenau [682], Stange [842], Walsingham [563], Heyer [372], Heppe [837], Gauckler [281, 282, 295], Frings [253, 257, 258], Ruhmer [727], Slevogt [822], Schülke, Kathariner [439], Kusnetzow [489]).

Puppen, welche dem Einflusse niedriger Temperaturen ausgesetzt werden, ergeben in den mristen Fällen dunklere Färbung der Schmetterlinge und zwar bei: Pamassio apollo, P. delius (Standfuss), Aporia crataugi (Merrifield), Polyommatus phlacas (Weismann, Merrifield), $P$. dispur var. ruthilus (Standfuss), Vanessa c-album (Standfuss), V. urticae (Merrifield, Weismann, Standfuss, Frings, Fischer), V. polychloros (Frings, Merrifield, Standfuss, Slevogt), V. io (Frings), $V$. antiopa (Standfuss), $V$. carclui (Standfuss, Frings), Argynnis aglaja (Standfuss), Arg. paphia (Merrifield), Bombyx quercus (Merrifield), Dusychira abietis (Standfuss), Agrotis pronuba (Stange), Arctia caja, Selenia lunaria, Sel. illunariu, Sel. illustraria, Eugonia antomnaria (Merrifield). Die hellere Färbung ergeben dabei: 
Papitio ajax (Edwards), Colyas, mermydone (Standfuss), Vanessa atalanta (Merrifield, Fischer, Frings), Lymenitis sybilla (Frings), Pararge egeria, Eugonia alniaria (Merrifield), Abraxas grossulariata (Frings).

Werden frische Vanessa-Puppen dem Einflusse niedlerer T'emperaturen ausgesetzt, so ergeben sie folgende Abarten und Varietäten: Vanessa levana, prorsa, porima (Fischer, Weismann, Ruhmer); polychloros ab. dixeyi Stdfs. (Standfuss, Frings), Annäherung an xanthomelas (Merrifield), an var. tesúudo Esp. (Slevogt), xanthomelas var. grütaneri Fschr. (Frings); urticue var. polaris Stdgr. (Merrifield, Frings, Standfuss, Fischer), var. ichmusı Bon. (Frings, Gauckler), ab. ichnusoides (Fischer), V. milberti Godt. (Standfuss); io ab. fischeri Stdfs. (Fischer, Standfuss, Gauckler, Frings); utulanta ab. merrifieldi Stclfs. (Standfuss, Frings); untiopa ab. rocderi Stlfs. (Standfuss, Frings, Gauckler), ab. heppei Stclfs. (Hөppe), ab. urtemis Fschr., ab. epione Fschr., ab. lyygiaea Hdrch. (Fischer), ab. daubei Stdfs. (Gauckler); cardui ab. wislotti Stılfs. (Standfuss, Frings).

Puppen anderer Species ergeben unter diesen Umständen folgende Abarten resp. Varietäten: Parnassius apollo var. brittingeri, Colias mermydone ab. alba, Papilio podalivius $=$ Winterform, $P$. machaon $=$ Winterform, Pieris daplidice $=$ Winterform, Polyommatus amphidamas $=$ Winterform, Colias mermydone $=$ Colias hecla und Col. staudingeri var. pamiri, Polyoumctus dispar var. rutilus $=P o l$. hippothoë (Standfuss), Arctia caja ab. confluens, ab. schultzii Frgs., ab. futura (Frings), Pieris rapae $=$ Winterform, Pieris napi $=$ Winterform (Weismann), Cidaria siliceata $=$ Wintergeneration (Merrifield), Cutocalaf raxini var. maculata nov. (Kusnetzow), Lasiocampa populifolia var. autumnalis Jaen. (Jaenichen), Arctia flavia ab. flavoabdaminalis Lorez (Lorez), Charaxes jusius var. bachmetjevi Fschr., ab. hageni Fschr, epijasius (Frings), Lasiocampa populifolia var. aestiva, Rhyparia purpurata ab. atromaculutu, Arcta caja = Arctia interscalaris var. suttadra Moore (Frings), Callimorpha dominula ab. maritu Schultz (Schultz).

Bei einigen Arten wird sowohl die Zeichnung verwaschen wie auch die Beschuppung dünn, wenn die Puppen längere Zeit dlem Einflusse der Temperatur von ca. $+2^{0}$ ausgesetzt werden (Vanessa urticae, Gauckler, Frings; Saturnia pyri, spini und pavonia, Frings).

Die Abänderung an der Färbung und Zeichnung der Schmetterlinge wir:l ‘lesto stärker, je lïngere Zeit die Puppen dem Einflusse 
einer und derselben niedrigen Temperatur ausgesetzt sind (Rhumer, Frings, Standfuss, Fischer, Merrifield).

Die Zeit, welche nöthig ist, um die künftige Färbung unı Zeichnung des Schnetterlings bis zu einem gewissen Grade abzuändern, hängt von cler Temperatur ab, welche auf die Puppe einwirkt, und zwar ist diese Zeit umso kïrzer, je niedriger die Temperatur ist (Standfuss, Fischer, Frings, Gauckler, Merrifield).

Wirkt eine und lieselbe Temperatur auf gleich entwickelte Puppen eine und dieselbe Zeit hindurch, so werlen alle Exemplare der zu untersuchenilen Species gleich geändert (Ruhmer. Nachgewiesen vorläufig nur für Vanessa levana verschiedener Generationen).

\section{c) Einfluss der intermittierenden Temperaturen.}

\section{Temperaturen höher als die mittlere.}

Werden Puppen kurz nach der Verpuppung diesem Einflusse kurze Zeit (bis zu 3 Stundlen) ausgesetzt unil wird dieser Prozess einige aufeinanderfolgende Tage wiellerholt, so wirl im allgemeinen nicht nur die Färbung, sondern auch die Zeichnung von Imago geänlert (Standfuss [841], Fischer [231], Schröder [778], Irmscher [400], Frings [259, 260, 261, 262]).

Wird die Temperatur auf diese Weise von der Zimmertemperatur bis $40-45^{\circ}$ gestiegen, so entstehen bei Vanessa folgende Abarten resp. Varietäten: Vanessa c albırm ab. $f$ albınn Esp). (Standfuss); polychloros ab. testudo Esp. (Standfuss, Fischer, Frings), ab. dyxcyi Stdfs. (Standfuss), var. fervida Stlgr. (Fischer); urticae var. ichnusa Bon., var. ichmusoides de Selys (Fischer, Frings), var. polaris (Frings); antiopa ab. higiaec Helrch. (Standfuss, Fischer, Frings), ab. artemis Fschr. (Fischer), ab epione (Fischer, Frings), ab. roederi Stlfs., ab. dautii Stlfs. (Frings); ctalanta ab. lilemensiewizi Schill. (Standfuss, Fischer, Frings), Van. callimhoë F. (Fischer, Uebergänge); cardui ab. elymi Rbr. (Standfuss, Fischer, Frings); io var. antigone (Fischer) ab. Zelisaria Obthr., var. polaris Stılgr., var. surcon Stdgr. (Frings); var. prorsa ergab levana und ab. porima (Frings).

Dabei kommt oft vor, dass die Vorterfliigel der einer Abart und die Hinterflugel der anderen Abart angehören ( $V$ unessa antiopa: Fischer, Frings; Vanessa levana v. prorsa: Frings; Churaxes jusius: Fischer). Auch nicht alle Exemplare einer und derselben Art werlen gleichmässig geändert, so dass zwei und mehrere Abarten mit ihren Uebergängen aus den exponierten Puppen ausschlüpfen. 


\section{Temperaturen tiefer als die mittlere.}

Werden Puppen kurz nach der Verpuppung (Härtegrail narh Fischer [232]) diesem Einflusse kurze Zeit (bis zu 6 Stun len) ausgesetzt, wobei die Temperatur allmählig sinkt unı wieder steigt, und wird dieser Prozess einige aufeinanderfulgenle Tage wielerhult, so können dabei Abarten und Varietäten entstehen (Standfuss [ $\left.{ }^{4} 41\right]$, Fischer [230, 231] Frings [257, 258]. Urech [896, 897], Merrifield $[568,570]$, Seifert [803a], Krodel [475]).

Das günstigste Verfahren für die meisten Species besteht nach Standfuss darin, dass man die Puppen von $+5^{0}$ in die Temperatur von $-10^{\circ}$ bis $-12^{\circ}$ für 2 Stunilen und dann wieder in die Temperatur von $+5^{\circ}$ bringt; dieser Proz'ss wirıl wälrend einiger Tage je 2 Mal wiederholt un.l die Puppen bei Zimmertemperatur bis zum Ausschlüpfen liegen gelassen. Fischer hielt bei meisten seiner Versuche die Puppen 6 Stunden bei $-3^{0}$ bis $-13^{\circ}$, dann 6 Stunden bei $0^{0}$ und 6 Stunden bei $-3^{\circ}$ bis $-12^{\circ}$. Diesen Prozess wiederhulte er 3 Mal pro Tag während 5 bis 18 Tage und liess darauf die Puppen bei Zimmertemperatur. Auch das rapile Temperatursinken schallet den Puppen nicht (von $25^{\circ}$ bis $-6^{\circ}$ während 30 Minuten, Fischer [231]), obwohl es 2 Mal täglich wiedlerholt wird.

Unter diesen Umstänilen behanclelte Vanessa-Puppen ergaben folgende Abarten und Varietäten: Vanessa c-ulbum ab. f-album Esp. (Fischer, Frings); polychluros ab. testud, Esp. (Fischer, Frings); urticae ab. atrebatensis B.is.l. (Standfuss), ab. dixey (Frings) und ab. ichnusoides de Selys (Standfuss, Fisch $\mathrm{Hr}$, Frings); io ab. belisaria Obthr. (Standfuss, Fischer), antigone Fschr., (Urech, Frings), ab. extrema Fschr. (Fischer), ab. iokaste Urech und ab. fischeri Stdfs. (Urech); antiopa ab hygiaca Hilrch. (Fischer, Frings) und artemis Fschr. (Fisch $\ni$ ); atulanta ab. Klemensiewiczi Schille [lilymme Fschr.] (Fischer, Frings) und ab. merrifieldi Stufs. (Frings), cardui ab. elymi Rbr. (Fischer).

Andere Species, glei h behandelt, ergaben: Papitio machaon ab. atromarginata Rot. (Standfuss), ab. nigrofasciuta Rothke (Fischer); Limenitis sibylla ab. nigrina Weym., Argynnis paphia ab. ocellata (Frings); Lyoaena coridon ab. cinnus Krodel, damon ab. gillmeri Krodel, damon ab. extensa Írodel (Krodel); Arctia caju ab. schultaii Fschr., ab. confluens und ab. futuru Fickert (Frings); Abraxas grossuluriata ab. dolırnii König (Frings). 


\section{B. Yerallgemeinerungen des Einflusses jeder Temperaturart.}

Werlen nicht zu frische und nicht zu alte Puppen („Härtegrad der Puppenschale" von Fischer [232]) dem Einflusse der Temperatur ausgesetzt, so beeinflusst dieselbe das künftige Kleid verschieden stark, und zwar:

1. Der Temperatureinfluss ist verschieden, je nachlem, bei welcher Periode des Puppenstadiums derselbe angewendet wird.

2. Eine mittlere Temperatur übt keinen Einfluss aus, während eine höhere oder tiefere Farben- und Zeichnungs-Aenderungen hervorruft.

3. Zwei Bruten in verschiedenen Jahreszeiten reagieren verschieden stark auf die Temperatur.

4. Dies wird auch dann beobachtet, wenn alle Generationen einer und derselben Temperatur ausgesetzt werden.

5. H he resp. niedrige Temperaturen rufen bei einigen Species die Verhelıung, bei den anderen die Verdunklung der Färbung hervor.

6. Dieser Umstand lässt vermuthen, dass bei gewissen Species unter dem Einfluss der Temperaturen ein Rückschlag zu der Form der Ahnen stattfindet.

7. Die Abänderung des Schmetterlingskleides wird desto stärker, je längere Zeit die Puppen einer und derselben Temperatur ausgesetzt sind.

8. Diese Abänderung ist desto stärker, je weiter die betreffencle Temperatur von der mittleren Temperatur entfernt ist.

Die durch die Einwirkung der Temperaturen erhaltenen Abänderungen können in drei Hauptkategorien eingetheilt werden:

1. Eine allgemeine Färbung:änderung, ohne dass die Form der Zei.hnung dabei geändert wird, wenn auch ihre Abnahme oder $\mathrm{Zu}$ nahme in Betreff der Intensität zu beobachten ist.

2. Eine Aenderung in Folge der Verschiebung von verschieden gefärbten Stellen, welche entweder verschwimmen oder so gruppiert werden, dass die Zeichnung geändert wird.

3. Eine Aenderung im allgemeinen äusseren Aussehen, und zwar in Folge der unvollständigen Entwickelung verschiedener Stellen oder ihrer Pigmente.

Eine sehr wichtige Thatsache für die Theorie dieses Einflusses besteht darin, dass gewisse hohe Temperaturgrade die gleichen Schmetterlingsformen erzeugen, wie bestimmte niedere Temperaturgrade. Diese Thatsache ist aus der beigelegten Tabelle ersichtlich. 


\begin{tabular}{|c|c|c|c|c|c|c|c|c|}
\hline 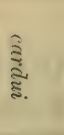 & 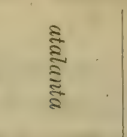 & 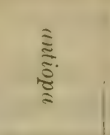 & $\tilde{o} \cdot$ & 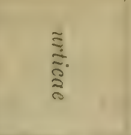 & 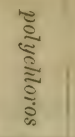 & 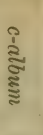 & 政 & \\
\hline 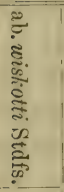 & 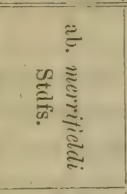 & 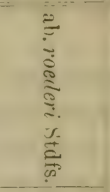 & 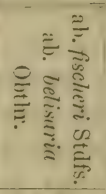 & 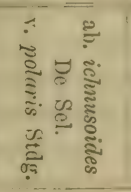 & 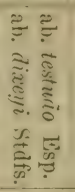 & 1 & 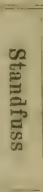 & $\begin{array}{l}\text { Z } \\
0.1 \\
0\end{array}$ \\
\hline 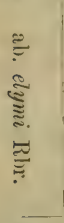 & 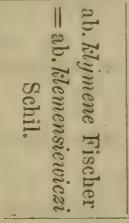 & 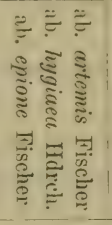 & 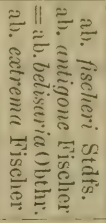 & 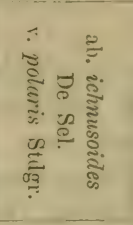 & 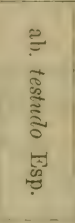 & 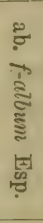 & 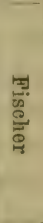 & 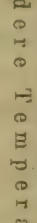 \\
\hline 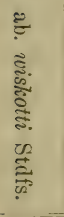 & 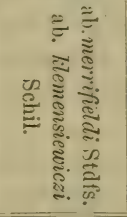 & 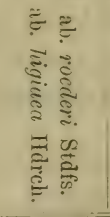 & 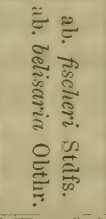 & 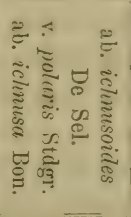 & 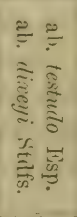 & 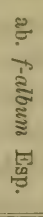 & 島. & $\begin{array}{l}\vec{a} \\
\vec{z} \\
0 \\
0\end{array}$ \\
\hline 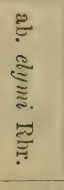 & 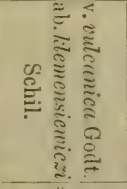 & 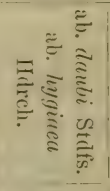 & $i$ & 1 & 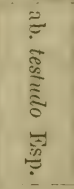 & 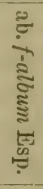 & 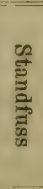 & $\overrightarrow{7}$ \\
\hline 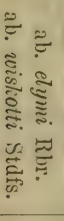 & 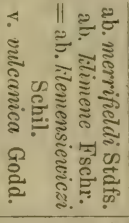 & 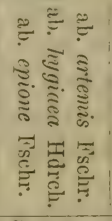 & 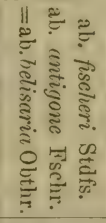 & 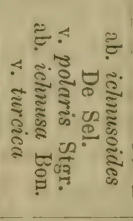 & 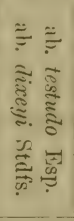 & 1 & 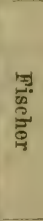 & $\begin{array}{l}= \\
0 \\
-1 \\
0 \\
\Xi \\
0 \\
0 \\
0 \\
0 \\
+\infty\end{array}$ \\
\hline 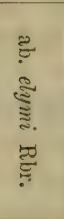 & 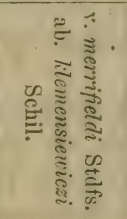 & 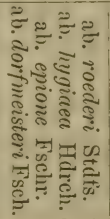 & 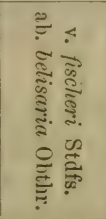 & 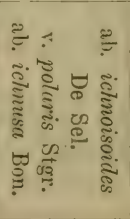 & 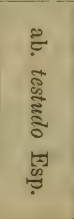 & 1 & 国 & $\begin{array}{l}\approx \\
H \\
0 \\
F\end{array}$ \\
\hline
\end{tabular}


Die Behandlungsweise, mittelst welcher die Abarten der $\mathrm{Va}$ nessa-Gruppe erhalten wurden, ist aus folgender Zusammenstellung ersichtlich:

Varietäten resp. Aberrationen von Pyrameis, Vanessa und Polygonia, welche auf experimentellem W'ege erhalten wurden.

\begin{tabular}{|c|c|c|}
\hline $\begin{array}{l}\text { Varietäten resp. } \\
\text { Aberrationen }\end{array}$ & Forscher & Die Behandlung der Puppen \\
\hline $\begin{array}{l}\text { Pyrameis atalanta ab. } \\
\text { klemensiewiczi Schile } \\
\text { (klymene Fschr.) }\end{array}$ & $\begin{array}{cc}\text { Stanidfuss (841) } \\
\text { Fischer } & (229) \\
\pi & (231) \\
\pi & n \\
\pi & n \\
" & n \\
\pi & n \\
\text { Frings } & (258) \\
n & (259) \\
n & (260) \\
& \\
n & (262)\end{array}$ & 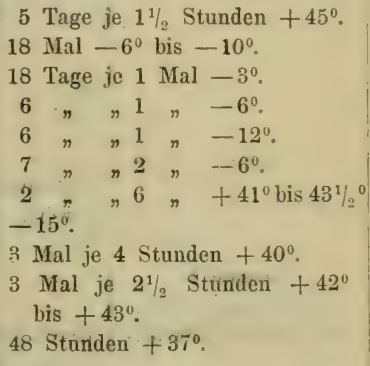 \\
\hline $\begin{array}{l}\text { Pyrameis atalanta } \\
\text { ab. merrifieldi Stdfs. }\end{array}$ & $\begin{array}{l}\text { Standfuss (839) } \\
\text { Fiseher }(229) \\
n \quad(236) \\
\text { Frings }(257) \\
n \quad n\end{array}$ & $\begin{array}{l}48 \text { Tage } 0^{\circ} \text {. } \\
18 \text { Mal }-6^{\circ} \text { bis }-10^{\circ} \text {. } \\
2 \text { Tage } 39^{\circ} \text {. } \\
42 \text { Tage }+8^{\circ} \text {. } \\
\text { Intermittierend }-13^{\circ} \text {. }\end{array}$ \\
\hline $\begin{array}{l}\text { Pyrameis atalanta } \\
\text { จ. viulcanica Godt. }\end{array}$ & $\begin{array}{l}\text { Standfuss (\$37) } \\
\text { Fischer (228) }\end{array}$ & $\begin{array}{l}72 \text { Stunden }+37^{\circ} \\
\text { Einige Táge }+36^{\circ}\end{array}$ \\
\hline $\begin{array}{l}\text { Pyrameis cardui } \\
\text { ab. elymi Rbr. }\end{array}$ & $\begin{array}{l}\text { Standfuss (837) } \\
\bar{n}(841) \\
\text { Fischér }(229) \\
" \quad(231) \\
\text { Frings }(262)\end{array}$ & $\begin{array}{l}2 \text { Mal je } 6 \text { Stunden }+40^{\circ} \text {. } \\
3 \text { Tage je } 1 \frac{1}{2} \text { Stunden }+44^{\circ} \text {. } \\
18 \text { Mal }-6^{\circ} \text { bis }-10^{\circ} \text {. } \\
8 \text { Tage je } 1 \mathrm{Mal}-3^{\circ} \text {. } \\
2 \text { Tage je } 6 \mathrm{Mal}+41^{\circ} \text { bis } 43^{1} 1^{\circ} \text {. } \\
48 \text { Stunden }+37^{6} \text {. }\end{array}$ \\
\hline $\begin{array}{l}\text { Pyrameis cardui } \\
\text { ab. wiskotti Stdfs. }\end{array}$ & $\begin{array}{l}\text { Standfus\$ (839) } \\
\text { Fischer (236) } \\
\text { Frings (257) }\end{array}$ & $\begin{array}{l}33 \text { Tage } 0^{\circ} \\
+38 \text { bls }+41^{\circ} \\
28 \text { Tage }+8^{\circ}\end{array}$ \\
\hline
\end{tabular}




\begin{tabular}{|c|c|c|}
\hline $\begin{array}{c}\text { Tarietäten resp. } \\
\text { Aberrationen }\end{array}$ & Forscher & Die Behandlung, der Puppen \\
\hline $\begin{array}{l}\text { Vanessa io } \\
\text { ab. fischeri } \text { Stdfs. }\end{array}$ & $\begin{array}{l}\text { Standfuss (837) } \\
\text { Fischer }(828) \\
n \quad(229) \\
\text { Gauckler (281) } \\
\text { Urech }(903) \\
\text { Fischer }(236) \\
\text { Frings }(253) \\
n \quad(259) \\
n . \\
n\end{array}$ & $\begin{array}{l}35 \text { Tage }+6^{\circ} \text {. } \\
21 \text { n } 0^{\circ} . \\
28 n 0^{\circ} . \\
34 "+2^{\circ} \text {. } \\
16 \text { }+3^{\circ} \text {. } \\
4 \text { Mal je } 3 \text { Stunden }-10^{\circ} \text { bis }-14^{\circ} \text {. } \\
38^{\circ} \text {. } \\
42 \text { Tage }+8^{\circ} \text {. } \\
36 \text { Stunden } 39^{\circ} \text {. } \\
28 \text { Tage }+6^{\circ} \text {, dann } 4 \text { Mal je } 4 \\
\text { Stunden }-12^{\circ} \text {. } \\
4 \text { Mal je } 4 \text { Stunden }-12^{\circ} \text {, dann } \\
28 \text { Tage }+6^{\circ} \text {. }\end{array}$ \\
\hline $\begin{array}{c}\text { Vanessa io } \\
\text { ab. betisaria Obth. } \\
\text { (ab. antigone Fschr.) }\end{array}$ & $\begin{array}{c}\text { Standfuss (841) } \\
\text { Fischer }(229) \\
n \quad(231) \\
n \quad n \\
n \quad n \\
\text { Urech }(903) \\
\text { Frings } \\
\quad(257) \\
n \quad(259) \\
n \quad n\end{array}$ & 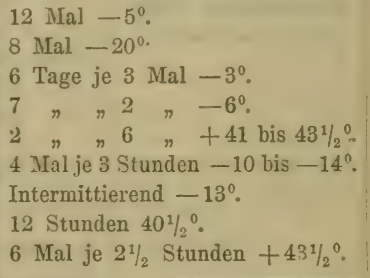 \\
\hline $\begin{array}{l}\text { Vanessa io } \\
\text { ab. ioliaste Urech. }\end{array}$ & Urech (903) & 4 MIal je 3 Stunden $-10^{\circ}$ bis $-14^{n}$ \\
\hline $\begin{array}{l}\text { Vanessa io ab. colore } \\
\text { nigrum maculata Urech. }\end{array}$ & Urech (903) & Trockene zulässigste Wärme. \\
\hline $\begin{array}{l}\text { Panessa io } \\
\text { v. extrema Fschr. }\end{array}$ & Fischer (231) & 6 Tage je 3 IIal ${ }^{2} / 2$ Stunde $-6^{0}$. \\
\hline $\begin{array}{l}\text { Vanessa io } \\
\text { v. sardoa Stdgr. }\end{array}$ & Frings (262) & 30 Stunden $+39^{\circ}$ \\
\hline $\begin{array}{l}\text { Vanessa urticae } \\
\nabla . \text { polaris Stgr. }\end{array}$ & 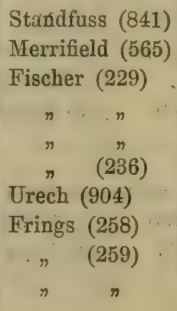 & $\begin{array}{l}42 \text { Tage }+6^{\circ} \\
+8,2^{\circ} \text {. } \\
35 \text { Tage } 0^{\circ} \\
14 \text { Mal }-20^{\circ} \\
20 \mathrm{Mal}-5^{\circ} \\
+40^{\circ} \text {. } \\
\text { Intermittierend } 0^{\circ} \\
40 \text { Tage }+6^{\circ} \\
36 \text { Stunden }+39^{\circ} \\
2^{1}{ }_{2} \quad\end{array}$ \\
\hline
\end{tabular}


1. Einfluss der Temperatur.

\begin{tabular}{|c|c|c|}
\hline $\begin{array}{c}\text { Varietäten resp. } \\
\text { Aberrationen }\end{array}$ & Forscher & Die Behandlung der Puppen \\
\hline $\begin{array}{l}\text { Vanessa urticae } \\
\text { v. turcica Stgr. }\end{array}$ & $\begin{array}{l}\text { Reichenau (682) } \\
\text { Fischer. (228) }\end{array}$ & $\begin{array}{l}\text { Direkte Sonnenstrahlung. } \\
\text { Einige lage }+34^{\circ} \text { bis }+38^{\circ} \text {. }\end{array}$ \\
\hline $\begin{array}{l}\text { Vanessa urticae } \\
\text { v. iclenusa Bon. }\end{array}$ & $\begin{array}{l}\text { Venus (903) } \\
\text { Weismann (954) } \\
\text { Gauckler (281) } \\
\text { Frings (253) } \\
\qquad \quad \text { (259) }\end{array}$ & $\begin{array}{l}\text { Heisse Sonnenstrahlen. } \\
30^{\circ} \text {. } \\
30 \text { Tage }+8^{\circ} \\
28 \stackrel{ }{ } \text {. }+8^{\circ} \\
36 \text { Stunden }+39^{\circ}\end{array}$ \\
\hline $\begin{array}{l}\text { Vanessa urticae } \\
\text { ab. ichnosoides Selys. }\end{array}$ & $\begin{array}{c}\text { Standfuss }(841) \\
\text { Fischer }(229) \\
" n \\
" n \\
" \quad(231) \\
\text { Urech }(804) \\
\text { Frings } \\
" 257) \\
" \quad(258) \\
" \quad(259)\end{array}$ & $\begin{array}{l}35 \text { Tage } 0^{\circ} \text {. } \\
14 \text { Mal }-20^{\circ} \text {. } \\
20 \text { " }-5^{\circ} \text {. } \\
8 \text { Tage je } 3 \text { Mal }-3^{\circ} \text {. } \\
2{ }^{\circ} " 8 \text { " } 8 \text { bis } 43^{1} 2_{2}^{\circ} \text {. } \\
\text { Intermittierend }-5^{\circ} \text {. } \\
-15^{\circ} \text { " }-13^{\circ} \text {. } \\
2^{1} /_{2} \text { Stunden }+43^{\circ} \text { bis } 43^{1} 2_{2}^{\circ} \text {. }\end{array}$ \\
\hline $\begin{array}{l}\text { Vanessa polychloros } \\
\text { ab. testudo Esp. }\end{array}$ & $\begin{array}{l}\text { Standfuss }(841) \\
\text { Fischer }(229) \\
. " \quad(231) \\
\text { Frings }(259) \\
\Rightarrow \quad " \quad " \\
" \quad(260) \\
n \quad(262)\end{array}$ & 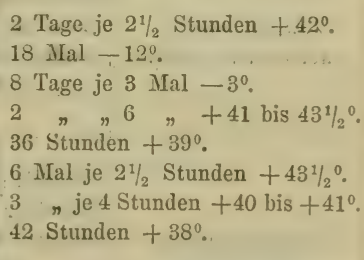 \\
\hline $\begin{array}{l}\text { Vanessa polychloros } \\
\text { ab. dixeyi Stdfs. }\end{array}$ & $\begin{array}{l}\text { Standfuss (839) } \\
\text { Frings }(254) \\
\qquad \quad \quad(262)\end{array}$ & $\begin{array}{l}34 \text { Tage } 0^{\circ} . \\
28 \quad "+8^{\circ} \\
39 \quad "+6^{\circ} .\end{array}$ \\
\hline $\begin{array}{l}\text { Vanessa polychloros } \\
\text { v. erythromelas Stgr. }\end{array}$ & Standfuss (839) & 48 Stunden $+39^{\circ}$ \\
\hline $\begin{array}{l}\text { Vanessa xanthomelas } \\
\text { v. grützneri Fschr. }\end{array}$ & Frings (262) & 35 Tage $+6^{0}$ \\
\hline $\begin{array}{l}\text { Vanessa antiopa } \\
\text { ab. hygiaea Hdrch. }\end{array}$ & $\begin{array}{l}\text { Standfuss (839) } \\
\text { Fischer }(228) \\
\qquad \begin{array}{c}n \\
n\end{array}\end{array}$ & $\begin{array}{l}3 \text { Tage je } 2 \text { Stunden }+45^{\circ} \\
21 \text {. } \\
\text { Einige Tage }+35^{\circ} \text { bis }+38^{\circ} \text {. } \\
35 \text { Fage } 0^{\circ} \text {. }\end{array}$ \\
\hline
\end{tabular}




\begin{tabular}{|c|c|c|}
\hline $\begin{array}{l}\text { Varietäten resp. } \\
\text { Aberrationen }\end{array}$ & Forscher & Die Behandlung der Puppen \\
\hline $\begin{array}{l}\text { Vanessa antiopa } \\
\text { ab. hygiaea Hdrch. }\end{array}$ & $\begin{array}{cc}\text { Fischer } & (231) \\
\text { Frings } & (257) \\
n & (259) \\
n & (260) \\
n & n \\
n & n \\
n & n \\
n & n \\
n & (261) \\
n & n \\
n & n \\
n & n \\
n & n \\
n & n \\
n & (262)\end{array}$ & 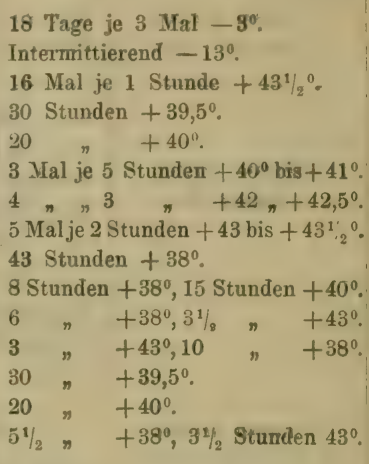 \\
\hline $\begin{array}{c}\text { Vanessa antiopa } \\
\text { ab. dorfmeisteri Fschr. }\end{array}$ & Frings (261) & 43 Stunden $+38^{\circ}$ \\
\hline $\begin{array}{l}\text { Vanessa antiopa } \\
\text { ab. roederi Stdfs. }\end{array}$ & $\begin{array}{l}\text { Standfuss (837) } \\
\text { Gawekler (295) } \\
\text { Frings (257) } \\
\qquad \quad(259)\end{array}$ & $\begin{array}{l}44 \text { Tage }+6^{\circ} \\
23 \pi+3^{\circ} \\
21 \pi+8^{\circ} \\
36 \text { Stunden }+39^{\circ} .\end{array}$ \\
\hline $\begin{array}{l}\text { Vanessa antiopa } \\
\text { v. daubi Stdfs. }\end{array}$ & $\begin{array}{l}\text { Standfuss (837) } \\
\text { Gauckler (281) } \\
\text { Frings }(259) \\
\begin{array}{cc}\eta \quad(261) \\
n \quad(262)\end{array}\end{array}$ & $\begin{array}{l}60 \text { Stunden }+37^{\circ} \text {. } \\
32 \text { Tage }+2^{\circ} \text {. } \\
60 \text { Stunden }+37^{\circ} \text {. } \\
54 \text {. }+37^{\circ} \text {. } \\
12 \text { Stunden } 6^{\circ}, 28 \text { Stunden } 38^{\circ} \text {, } \\
12 \text { Stund. } 6^{\circ}, 14 \text { Stund. } 37,5^{\circ} \text {. }\end{array}$ \\
\hline $\begin{array}{l}\text { Vanessa antiopa } \\
\text { v. heppei Stdfs. }\end{array}$ & Standfuss (837) & 10 Tage $0^{\circ}$. \\
\hline $\begin{array}{l}\text { Vanessa antiopa } \\
\text { ab. artemis Fschr. }\end{array}$ & 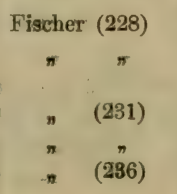 & $\begin{array}{l}14 \text { Tage } 0^{\circ} \text {. } \\
\text { Einige Tage je } 3 \text { Stunden }+40 \\
\text { bís }+42^{\circ} \text {. } \\
6 \text { Tage je } 3 \mathrm{Mal}-3^{\circ} \text {. } \\
2 \% " 8{ }^{\circ}+41 \text { bis } 43^{1 / 2^{\circ}} \text {. } \\
+38^{\circ} \text { bis }+41^{\circ} \text {. }\end{array}$ \\
\hline
\end{tabular}




\begin{tabular}{|c|c|c|}
\hline $\begin{array}{l}\text { Varietāten resp. } \\
\text { Aberrationen }\end{array}$ & Forscher & Die Behandlung der Puppen \\
\hline $\begin{array}{l}\text { Vanessa antiopa } \\
\text { ab. epione Fschr. }\end{array}$ & $\begin{array}{l}\text { Fischer (228) } \\
\text { Frings }(259)\end{array}$ & $\begin{array}{l}21 \text { Tage } 0^{0} \text {. } \\
\text { Einige Tage }+34^{0} \text { bis }+38^{\circ} \text {. } \\
16 \text { Mal je } 1 \text { Stunde }+431_{2}^{\circ} \text {. }\end{array}$ \\
\hline $\begin{array}{l}\text { Vanessa c album } \\
\text { ab, } f \text { album Esp. }\end{array}$ & $\begin{array}{l}\text { Standfuss (841) } \\
\text { Fischer (231) } \\
\text { Frings (262) }\end{array}$ & $\begin{array}{l}3 \text { Tage je } 1^{1 / 1} / 2 \text { Stunden }+44^{0} \text {. } \\
6 \text { Stunden } 14^{\circ} \text {, } 4 \text { Stunden } 0^{\circ} \text {, dann } \\
8 \text { Tage je } 3 \text { Mal täglich }-3^{\circ} \text {. } \\
\text { Frostexperiment. }\end{array}$ \\
\hline
\end{tabular}

\section{Theorien dieses Einflusses.}

\section{a) Historische Uebersicht dieser Theorien.}

\section{Die Theorie von August Weismann.}

1875 veröffentlichte A. Weismann (953) seine "Studien zur Descendenz-Theorie. I. Ueber den Saison-Dimorphismus der Schmetterlinge, ${ }^{\prime}$ in welchen er seine Temperatur-Versuche mit Schmetterlingspuppen beschreibt.

Um den Saison-Dimorphismus zu erklären, vermuthete er zuerst, dass „die Verschiedenheiten der Schmetterlinge sekundärer Natur seien" und zwar: 1) Verschiedenheiten der Raupen und 2) Anpassung durch Naturzuchtung. Diese Vermuthung stellte sich im Verlaufe der Untersuchung aber als unrichtig heraus.

Weiter suchte er den Grund des Saison-Dimorphismus, in einer direkten Einwirkung der wechselnden äusseren Lebensbedingungen, und zwar: 1) in der Temperatur und 2) in der Entwickelungsdauer (Dauer der Puppenzeit).

Es ist ihm gelungen, durch entsprechende Temperaturen alle Individuen der Sommergeneration von Pieris napi in die Winterform umzuwandeln, und zwar alle vollständig; es war aber nicht möglich, die Wintergeneration von Vanessa levana durch Anwendung von Wärme zur Annahme der Sommerform zu zwingen, trotzdem die Puppenzeit dabei von sechs auf drei Monate herabgesetzt wurde.

Aus den von ihm mitgetheilten Versuchen geht hervor, "dass die Kälte und Wärme nicht die unmittelbare Ursache sein können, warum eine Puppe die prorsa-oler die levana-Form aus sich entwickelt; liefert doch die letzte Generation überhaupt immer die levana- 
Form, mag sie nun lialt oller warm behandelt werden, nur die erste und zweite können zum Theil und melır orler weniger vollkommen zur Annahme der levana-Form bestimmt werden, und zwar durch Anwendung von Kiälte. Die Kälte ist also bej ihnen die mittelbare Ursache der Umwandlung in tie levana-Form. Desshalb sagt er weiter: "Die Ursache dieser vischillenen Reaction auf gleichen Reiz hann nur in der Constitution, der physischen Natur der betreffenden Generation liegen, nicht aber ausserhalb lerselben." (p. 13).

Er betrachtet desshalb die levana-Form als primäre, ursprüngliche Gestalt der Art, die prorsu-Form als secunläre, welche llurch allmählige Einwirkung des Sommerklimas entstanilen ist, wobei die Verwandlung der Sommergenerationen durch fiälte in die Winterform „auf Rückschlag zur Stammform, auf Atavismus“ beruht.

Zur Vorstellung der Einwirkungsart des Kilimas macht er den folgenden Vergleich: "Die Wirkung des Kimas ist offenbar am besten vergleichbar mit der sogenannten cumulativen Wirliung, welche gewisse Arzneistoffe auf den menschlichen Kürper ausiben; die erste kleine Dosis bringt kaum bemerkbare 'Veränderungen herror; wird sie aber vielmal wielerholt, so summirt sich die Wirkung; es tritt Vergiftung ein" (p. 16).

Da man aber geneigt sein könnte, nicht die Temperatur direkt varantwortlich $\mathrm{zu}$ machen, sondern vielmehr die durch die Temperatur bewirkte Verlangsamung oder Beschleunigung der Entwickelung, so sagt er: "Ich gestehe, dlass ich lange Zeit hindurch in diesem Moment den wahren Grund des Saison-Dimorphismus gefunden zu haben glaubte." Aus seinen Béobachtungen geht jelloch hervor, "lass nicht die Entwickelungsdauer in einzelnen Falle die Gestalt des Schmetterlings bestimmt, also den Ausschlag giebt, ob Winter- oder Sommerform entstehen soll, sondern dass umgekehrt die Puppendaucr abhängig ist von der Entwickelungsrichtung, welche der werdende Schmetterling in der Puppe eingeschlagen hat" (p. 26).

In dem III. Kapitel derselben Untersuchungen wirft er schliesslich die Frage auf: "Wodurch bewirkt Klima-Wechsel eine Aenderung in Zeichnung und Färbung eines Schmetterlings, und in wie weit bestimmt die klimatische Einwirkung die Qualität der Abänderung?" und antwortet, gestützt auf Beobachtungen an Vanessa levana und Polyommatus phlacas: "Ich bin der Ansicht, dass nicht die Entwickelungsdauer das umwandelnde Princip ist bei sler Bildung klimatischer Varietäten der Schmetterlinge, 
sondern lediglich die Temperatur, welcher die Art während ihrer Verpuppung ausgesetzt ist". (p. 39).

Um die Wirkung der Wärme auf Zeichnung und Fïrbung einer Schmetterlingsart darzustellen, stellt er zuerst fest, "lass die Qualität der Abänderung wesentlich nicht von der einwirkenden Wärme, sondern vom Organismus selbst abhängt“. (p. 40).

Indem er die italienische Sommerform von Polyommatus phlaeas mit ihrer Winterform vergleicht, sagt er: "Man könnte nun daraus den Schluss ziehen, dass durch grosse Wärme der Chemisums des Stoffwechsels bei phlueas in der Weise verändert werde, lass weniger rothes und mehr schwarzes Pigment erzengt werde. Aber so einfach ist die Sache nicht." "Nicht die Quantität des erzeugten schwarzen Pigmentes unterscheidet beide Formen, sonilern der Modus seiner Vertheilung auf' den Flügeln“ (p. 40). Die Umwandlung iler Zeichnung erklärt er "nicht aus der Natur der Wärme, sondern nur aus der Natur der betreffenden Art." In dieser Beziehung drückt er sich allgemeiner aus, wie folgt: „Die Entwicklungsrichtung der Art wird eine andere. Die complicirten chemisch-physikalischen Vorgänge im Stoffwechsel des Puppenschlafs verschieben sich allmählig lerart, dass daraus als End-Resultante eine neue Zeichnung und Färbung des Schmetterlings horvorgeht" (43).

"Dass wirklich bei diesen Vorgängen die Constitution der Art die Hauptrolle spielt, nicht aber das äussere Agens, die Wärme, dass diese vielmehr nur die Rolle des Funkens übernimmt, der, wie Darwin sich einmal treffend ausdrückt, die brennbare Substanz entzündet, während die Art und Weise des cingeleiteten Verbrennungsprocesses 'von der Qualität des explodirenden Stoffes abhängt, dafür sprechen noch weitere Thatsachen" (p. 43).

In der zweiten Abhandlung: "Neue Versuche zum Saison-Dimorphismus der Schmetterlinge“ ergänzte A. Woismann (954) seine angeführte Theorie durch die Annahme der Neigung zum Alternieren. Indem er die früher veröfientlichte Theorie kurz bespricht, sagt er: "Obgleich ich auch heute noch diese Ansicht für richtig und eine direkt abändernde Wirkung der Wärme für erwiesen ansehe, so bin ich doch allmählig zu der Ueberzeugung gekommen, dass dies nicht die einzige Art der Entstehung saisondimorpher Verschiedenheiten ist, sondern dass es auch einen adaptiven SaisonDimorpismus giebt". (p. 47). 
Er bespricht die sais:n-dimorphen Arten bei Satiriden der Gattungen Yphthima, Mycalesis und Melanitis und sagt: „Dass aber das Auftreten complicirter Zeichnungs- und Färbungelemente, wie es Augenflecken sind, nicht einfach die direkte Wirkung von Wärme oder Kälte, Trockenheit oder Feuchtigkeit sein kann, liegt auf der Hand. Diese Einflüsse sind nicht die wirlkliche Ursache solcher Bildungen, sondern nur der Reiz, welcher ihre Anlage auslöst, d. h. zur Entwickelung veranlasst" (p. 48). Weiter sagt er: „Es giebt also zwei verschierlene Wurzeln iler Erscheinung des Saison-Dimorphismus, inlem einmal direkte Wirkung wechselnder äusserer Einfliisse, nämlich ler Temperatur, diesen Wechsel in der äusseren Erscheinung bedingen kann, andererseit aber Selectionsprocesse" (p, 49)).

Speziell auf die Erklärung des Saison-Dimorphismus bei Vanessa Tevana kommend, sagt er unter anderem: "Viele dieser Umwandlungen können also unmöglich einfach chemische Processe sein, veranlasst durch Einwirkung höherer Wärme auf die Pigmentbildner des Puppenflügels und vergleichbar etwa der Röthung des blauen Lakmuspapiers in Säure. Alles, was ich darüber vor zwanzig Jahren geschrieben habe, halte ich heute noch für vollkommen richtig: "ausgehend von der vorhandenen Zeichnung" hat sich "eine neue entwickelt." Aber während ich damals noch glaubte, diese Neubildung doch immerhin als eine Reaction des specifischen levana-Organismus auf höhere Wärme betrachten zu müssen, erkenne ich jetzt, dass Wärme hierbei ïberhaupt nicht als eigentliche Ursache mitspielt, sondern dass es sich um einen Züchtungsprocess handelt, der unabhängig von der Temperatur vor sich ging und der einen Theil der Ide zu prorsaIlen allmählig umstempelte. Diese prorsa-Ide wurden aber zugleich so eingerichtet, dass sie bei Einwirkung höherer Temperatur, wenn dieselbe im Beginn der Puppenperiode einwirkte, activ werlen, während bei niederer Temperatur die levana-Ide activ werden. Wïrme ist also nur der Auslösungsreiz für die prorsa-Anlage, Kälte der für die levana-Anlage .... Diese Thatsachen zwingen zur Annahme, dass abgesehen von Wärmeeinflüssen, ein Alternieren der beiden Formen von der Natur vorgesehen ist, dass in der ersten Brut die prorsa-Ide, in der zweiten, d. h. der ersten Generation von Schmetterlingen des folgenden Jahres, die Tevana-Ide im Voraus schon zur Activität disponirt sind, und dass sie vom wirklichen Activwerden nur durch besondere äussere Einflïsse abgehalten werden liönnen. Der wichtigste dieser Einfliisse ist die Temperatur zur Yerpup- 
pungszeit und zwar in dem Sinne, dass viele Individuen der ersten Jahresbrut durch Kälte zur levana- oder doch porima-Form bestimmt werlen können, und nahezu die meisten Individuen der zweiten Brut durch Hitze zur prorsa-Form. Offenbar ist Alles darauf eingerichtet, dass im Sommer ausgeschliipfte Falter die prorsa-Form besitzen. und zwar auch dann, wenn der Sommer nicht heiss ist, und dass alle im Frühjahr ausschlüpfenden Falter die levana-Form besitzen, auch wenn das Frühjahre recht warm ist, wie es ja oft bei uns v rkommt" (p. 60).

Zuletzt sagt ex: „ich möchte heute bei gereifterer Einsicht in die Vererbungsvorgänge den Begriff des Rückschlages überhaupt nicht mehr beim Saison-Dimorphismus anwenden" (p. 65). "Ein Theil dieser Farbenveränderungen wird wohl als direkte Beeinflussung des Farbenchemismus des Flügels durch die Temperatur angesehen werden dïrfen ${ }^{\mu}$ (p. 72).

P. Kramer (472) behandelte die Theorie ıles Saison-Dimıphismus bei den Schmetterlingen, wie dieselbe von Aug. Weismann ausgesprochen wirl, mathomatisch, indem er folgende Hauptmomente dieser Theorie der Schrift Weismann's entnahm: "Vanessa levana hat zur Eiszeit nur eine einzige Generation im Laufe eines Jahres gehabt. Als das Klima allmählich wärmer wurde, musste ein Zeitpunkt eintreten, in welchem der Sommer so lange dauerte, dass eine zweite Generation sich einschieben konnte. Die Puppen der levanubrut, welche bisher den langen Winter über im Schlafe zubrachten, um erst im nächsten Sommer als Schmetterlinge zu erwachen, konnten jetzt noch während desselben Sommers, in dem sie als Räupchen das Ei verlassen hatten, als Schmetterlinge umherfliegen und erst die von diesen abgesetzte Brut überwinterte als Puppe. Somit war ein Zustand hergestellt, in welchem die eine Generation unter bedeutenl andern klimatischen Verhältnissen heranwuchs als die zweite." "Die Wirkung des Klima's wird zu vergleichen sein der sogenannten cumulativen Wirkung, welche gewisse Arzneistofie auf den menschlichen Körper ausüben." — "Die Wirkungen summiren sich, und so kann eine allmähliche Veränderung in Farbe und Zeichnung hervorgebracht werden." - "Die Individuen sind in verschiedenem Gralle geneigt, auf solche Einwirkungen (wie Wärme) zn reagiren; dass die Disposition, die gewöhnliche Entwickelungsrichtung aufzugeben, verschieden gross ist bei verschiedenen Individuen." 
Die mathematische Entwickelung der Formeln führte ihn zu folgenden Schliissen:

1. Durch cumulative Vererbung entsteht unter ilen hier hesprochenen Verhïltnissen eine ungehenere Menge von Thiergrupyen lerselben Art, die unter sich verschiedene Abänlerungsmaase habe.

2. Diejenigen Gruppen, welche das geringste und höchste vorhatndene Abänderungsmass besitzen, sinl an wenigsten zahlleich, dagegen sind die Gruppen, welche ein mittleres Mass von Abinderungen erfahren haben, am zahlreichsten.

3. Eine ununterbrochene Reihe von Abänderungen existirt jederzeit.

4. Auch eine beliebig grosse Zeitdauer änlert hierin nichts.

„Somit wäre das Ergebniss unserer genauen Betrachtung der Entwicklung nicht zu dem gewünschten und von Prof. Weismann geforderten Ziele gerliehen, eine einzige von der Wrintertorm wesentlich verschiedene Sommerform verständlich zu machen." „Es ist völlig unbegreiflich, wie durch solche cumulative Vererbung unl Beeinflussung durch Temperaturdifferenzen eine bestimmte Zeichnung in eine andere bestimmte Zeichnung iibergehen kann" (p. 417, 418).

Ueber diese Anschaung von Kramer sagt Ph. Bertkau (59) folgendes: „Obwohl die Reflexionen scheinbar mit Nothwendigkeit zu dem Resultate führen, dass die ron Weismann angezogene Erlilärungsweise nicht zutrifft (was ïbrigens auch meine Ansicht ist), inlem sie die Ausführungen rein mathematischer Formeln sind, so ist jenes Resultat doch illusorisch, da die Formeln, aus denen es abgeleitet wurde, nicht unanfechtbar sind, gerade wie es mit Naegeli's "Terilrängungsgleichungen" der Fall ist. Die Mathematik beweist sehr viel, aber nur da, wo die Verhältnisse, ihren gegenwïrtigen Fähigkeiten entsprechend, einfache sind" (p. 393).

\section{Die Theorie von Friedrich Urech.}

1890 erschien die Arbeit von F. Urech (889): "Chemisch analatysche Untersuchungen an lebenden Raupen, Puppen und Schmetterlingen und an ihren Secreten," in welcher er sich gegen die Auffissungsweise der Wärmewirkung von Darwin auspricht, dass nämlich die Wärme nur wie ein Funken wirkt, wodurch die chemisch-physsiologischen Processe aufgelöst werclen. „Olne Wärme ist kein Lebe- 
wesen möglich. .... Wärmeenergie wirl rom lebenden Organismus sowohl aufgenoinmen als auch abgegeben, und dies geschieht nach Gesetzen, welche beim Studimu der Wärme gefunden wurlen, und bieten bei mechanischer Vorstellungs- und Darstellungsweise der Wärme auch die Briicke um die chemisch-physiologische Vorgängen des Wachsthums also auch Ontogenie und Phylogenie auf mechanische Gesetze zu reduzieren" (p. 23, 24). Weiter sagt er: „Zufuhr von Wärme von etwas höherer Temperatur lüst nicht nur physiologischchemische Umsetzungen aus, sondern kann auch den Energieinhalt des betreffenden Körpers vermehren, oler setzt sich beim Uebergange auf denselben in andere Energieformen um, oder leistet wenigstens äquivalente Arbeit, deren Grenzwerth durch das Gesetz der positiven und negativen Entropie bestimmt ist" (p. 24).

Indem er die Wärme- und Tiälte-Formen von Vanessa levana betrachtet, sagt er: „Der durch Wärmeaufnahme, also Temperaturerhöhung bewirkte Zustand eines Systems geht leicht in einen anderen niedriger Temperatur entsprechenden Zustand linunter, weil mechanische Energie sich völlig in Wärme verwandeln kann und diese ohne Zwang auf umgebende Körpersysteme von niedriger Temperatur übergeht. Der umgekehrte Vorgang ist hingegen mit Schwierigkeiten verbunden, es müssen andere Energieformen vermittelnd eintreten, in der freien Nafur findet er aber statt; die ursprüngliche Winterform (Vanessa levana) geht unter (lem Einflusse der steigenden Soinmerwärme in die Sommerform (Vunessa prorsa) iiber (p. 24).

In einer anderen Ahhandlung beschreibt er (890) seine Beobachtungen über die verschiedenen Schuppenfarben und die zeitliche Succession ihres Auftretens (Farbenfelderung) auf den Puppentlügelchen von Vanessa urticae und io, und er kommt zum Schlusse, dass zuerst die weisse Farbe auftritt, dann gelb, roth, braun und schliesslich schwarz, also eine Reihenfolge nach zunehmender Wellenlänge und abnehmender Schwingungszahl bildend. Als Ursache dieser Erscheinung erachtet er hauptsächlich die Wärme, bezw. das successiv wärmere Klima, da "nach den tropischen Ländern hin die Schmetterlingsfarben wärmer (im Sinne der Maler) werden, in arktischen Zonen heller sind" (p.' 8).

Auch später hat er (891) dieselbe lieihenfolge bei Pieris brassicae beobachtet, nämlich: weiss, gelb und schliesslich schwarz. Diese successive Farbenentstehung "ist das Ergebniss sehr vieler äusserer und innerer Wirkungen auf phyletisch langdauerndem

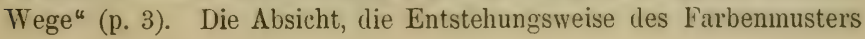


während der Entwickelung des Indiviluums, also in der Ontogenie, mechanisch erklïren, $\mathrm{l}$. h. die chemisch-physiologischen Vorgänge des Wachsthums auf mechanische Gesetze relucieren zu wollen, ist ohne Verwendung und Verflechtung mit dem Vererbungsvorgang verfehlt und erfolglos" (p. 4). Weiter sagt er, dass Wärme das Dunkelwerden von Pigmentfärbung begünstigt.

1896 erschien eine wichtige Untersuchung von Urech (894): „Beobachtungen von Compensationswrrgängen in der Farbenzeichnung etc." Ausgehend von Prinzipien, welche in Betreff des Ausgleiches, der Compensation oder des Gleichgewichtes in dem Organismus mit gegebenem Stoffe von Geoffroy St. Hilaire, Goothe, Eimer, Weismann u. A. ausgesprochen wurlen, unternahm er Schuppenfarbstoffe der Schmetterlinge, und die zeitliche Reihenfolge ihres Auftretens in der Puppe im Zusammenhange mit der Einwirkung höherer oder nielerer kiunstlichen Temperatur als die der natürlichen Umgebung während der Puppenruhe zu untersuchen, um die Guiltigkeit der Correlations- und Compensationsgesetze auch in dieser Richtung zu prüfen. „Nur dies : Crrelations- und Compensationsgesetze ermöglichen es, Wilerspriiche zwischen der Variation der Farben und den auf hier in Betracht kommenden histologischem Gebiete anerkannten Regeln, dlass Wärme Pigment ansammle, vermehre und hellere Farbentöne in dunklere (bei Vanessa z. B. Gelb in Orange, dies in Roth, Roth in Rothbraun bis Schwärzlichbraun) uberführe, als nur scheinbare zu beseitigen" (p. 4).

Gestuitzt auf die Experimente von Dorfmeister $(196,195)$ und E. Fischer (228) kommt er zu folgenden zwei Sätzen:

I. Ontogenetisch wirkt die Wärme correlativ betreffend heller und dunkler Farbstoff- und Interferenzfarbenänderungen.

II. In phylogenetischen Zeitläufen kann die Wärıne merkbar, Farbstoff vermehrend und verdunkelnd, die Kälte farbstoffvermindernd und aufhellend wirken.

Diese Sätze erstrecken sich nicht auf die Wirkung von Wärme und Kälte, die den direkten und arlaptiven Saisondimorphisums im Farbenmuster vieler Schmetterlingsspecies auslöst.

Folgende tabellarische Zus:ammenstellung enthält die Versuchsergehnisse von E. Fischer, welche Urech ihm (im August 1895) zur Prüfung, Beurtheilung und Ergänzung anf Grundlage seiner Sammlung vorlegte: 


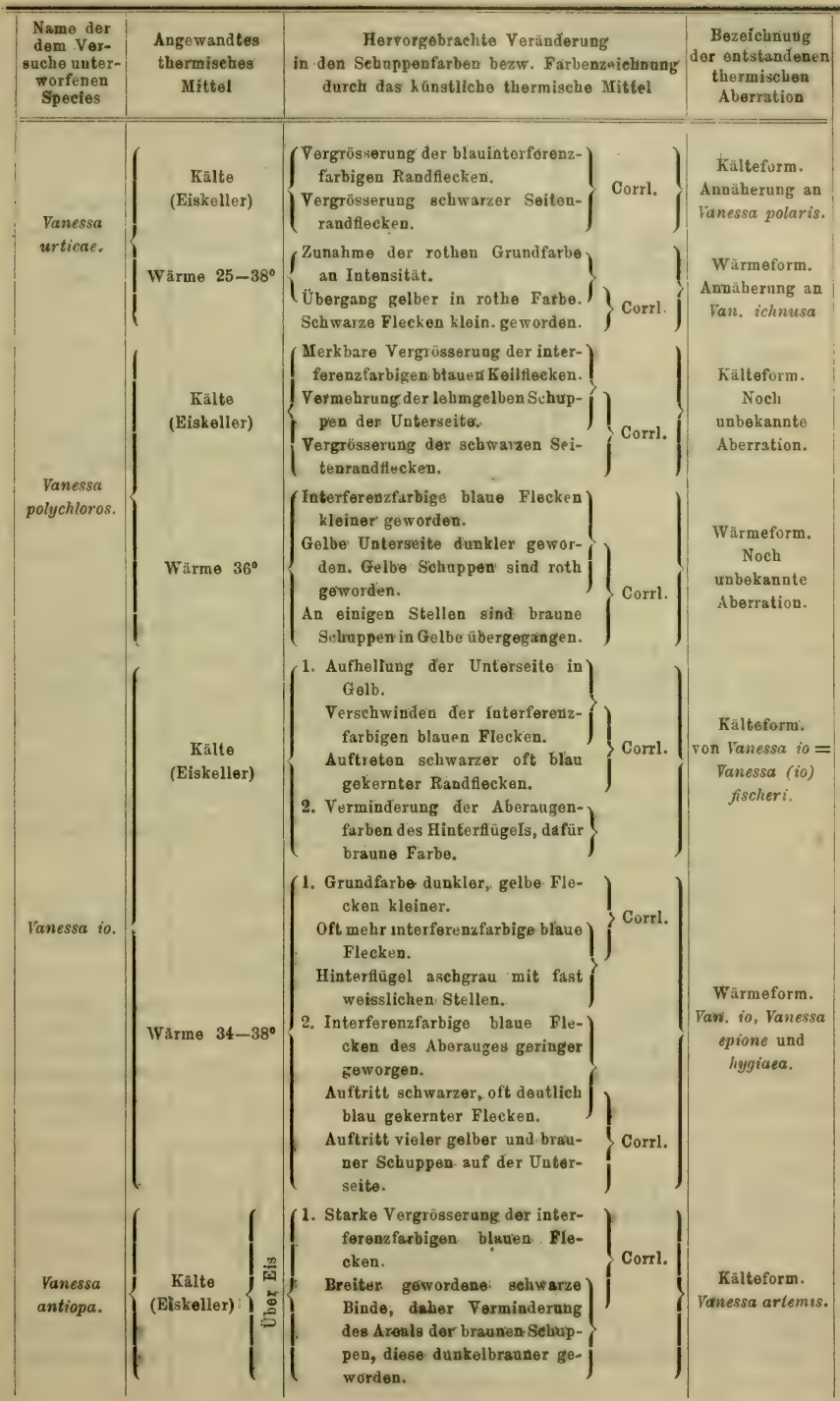




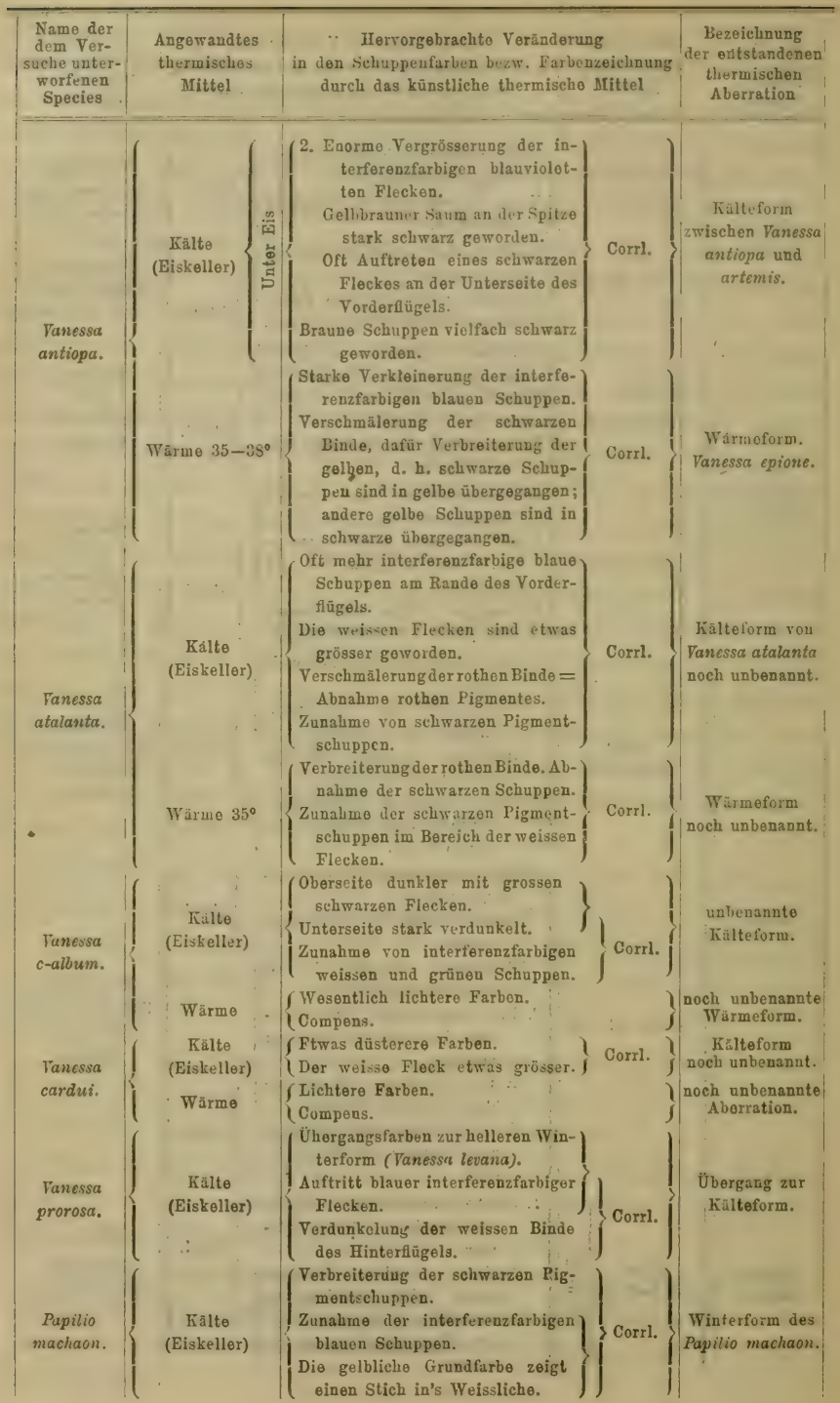


Lm die Gesetzmïssigkeit sowohl in Betreff der Correlation als auch der Wärmewirkung auf die Farben zu erkennen, muss dabei der Unterschier zwischen Pigment und Interferenzfarben (z. B. Blauviolett) strenge gewahrt werden.

Aus den Angaben dieser Tabelle geht hervor, dass Kälte eine Vergrösserung der Flecken aus interferenzfarbigen blauen Schuppen. ja manchmal auch ganz neue blaue Flecken hervorbringt, d. l. Kïilte erzeugt nicht nur hellere Pigmentfarben, soniern auch Pigmentverminderung. Wenige Widersprüche mit Correlation "werlen sich wohl auch noch als nur scheinbare heraustellen."

Um zu beurtheilen, wo Wärme bzw. Kälte nur auslösend, unc wo sie energetisch verändernd wirke, wo sie also correlativ, regressiv oder progressiv wirke, weist er auf die Nothwendigkeit hin, die Farbenmuster der verïnderten Kälte- und Wärmeformen genauer uml grïnllicher $\mathrm{zu}$ stulieren und $\mathrm{zu}$ beschreiben. "Es ist nicht unwahrscheinlich, dass die Correlation unter den Farbstoffen verschiedener chemischer Zusammensetzung, sowie verschiedener Abstammung (also nicht nur verschiedener Abtönung der Farbe infolge von Concentrationsunterschielen, verschiedener Stellung, Anreihung umi Neigung (der Schuppen) nicht immer in (lem Gegensatze von einerseits dunkler, andererseits heller sich äussern wird, sondern dass, wenn dem Correlationsvorgang chemische Eingriffe (Umsetzungen, Synthesen, Spaltungen, Polı̣merisationen, Umlagerungen) folgen, beiderseits dunklere oder hellere Farbstoffe entstehen" (p. 12).

Er warnt, voreilige Schlüsse über die Färbungsänderung der Flïgel bei Einwirkung ler Kälte orler Wärme auf Puppen zu ziehen, denn der Synchronismus der Entwickelung des Farbenmusters uni der übrigen Körperorgane könne durch verschiedene Unstände qestört werien; man denke nur an die verschiedene Wirkung der feuchten und trockenen Wärme bzw. Kailte; dazu kommen noch als solche Falitoren: elektrisch-atmosphärische Zustïnde unil anilere Nahurung.

Um die von Krukenberg gefundene Thatsache der Vertheilung eines bestimmten Farbstoffes bei verschielenen Vogelarten in verschiedenen Körpertheilen zu erklären, giebt er folgendes interessante Beispiel: „Einem Individuum, z. B. der Puppe, steht nur ein beschränktes bestimmtes Quantum Pigmentstoff oder Muttersul]stanz dazu zu Verfügung, das Quantum ist möglicherweise schwanken! und abhängig von der Menge der Reservenahrung, welche die Raupe noch vor der Verpuppung aufnehmen kann. Mit einer solchen bestimmten Menge der Muttersubstanz für die verschiedenen Farbstoffstufen 
muss das Flügelorgan bei den Wechselwirkungen mit Licht unil Wärms auskommen. Wenn nun die dunkleren Farben von Gelb nach Orange, Roth, Rothbraun und Schwärzlichbraun lin zunehmende Substitutionsproilukte eines chemischen Farbstoffkörpers durch mehrere Radikale sind, so zeigt schon eine verallgemeinerte chemische Gleichung diesen Farbenmechanismus; z. B.

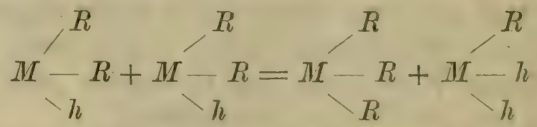

( $I$ bezeichnet die die Färbung verursachente Atomgruppe im Farbstoffmoleciil), dass dunkleres Pigment nur dann entstehen kann, wenn gleichzeitig ein Antheil helleren Pigmentes entsteht, so dass sich also z. B. Orange in Gelb und Roth differenziert. Concentriert sich ein Quantum Farbstoff an einer Stelle, so ist dafür an einer anderen weniger vorhanden, die weniger materiellen impoderablen Interferenzfarben (Scheinfarben) helfen dann oft aus" (p. 15, 16).

In einer weiteren Abhandlung desselben Forschers (896) finclet sich die Erklärung, warum bei Kälte-Experimenten das schwarze und bei Wärme-Experimenten das helle Pigment bei Vanessu in auftritt. Er sagt: "Wenn die Puppe in einen Kälteherd (Kältemischung) gebracht wird, so tritt Wärmeenergie aus ihr aus (Uebergang von höher temperierter Wärme auf materielle Systeme von niederer Temperatur). Damit das Leben der Puppe sich erhalte, muss der Puppen-Organismus diesen Wärmeverlust in ihr zu ersetzen streben, d. h. neue Wärme produzieren; es geschieht dies durch Verbrauch von chemischer Energie bezw. durch Verbrennungsvorgänge an Stoffvorräten, z. B. Fett, als durch Oxydations- und auch dabei erfolgende chemische Kondensations-Vorgänge, wobei Wärme erzeugt wird. Da die Puppe keine Nahrung aufnimmt, sonclern nur Sauerstoff von aussen, so muss sie das Brennmaterial sich selbst entnehmen, d. h. es wird zuerst, weil am leichtesten, Wasserstoff von den chemischen Bestandteilen im Blute, darunter auch Pigınentstoffe, zum Teil zu Wasser verbrannt: es entstehen kohlenstoffreichere chemische Körper, sogenannte Kondensations - und Reduktions-Produkte, die meistens dunkłer gefärbt sind, daher tritt dunkleres Pigment auf. Auch Kondensationen bezw. Reduktionen anderer Art können unter Wasserausscheidung stattfinden, ähnlich $z$. B. wie die dunklen Hưmusverbindungen aus farblosen, stickstofflbaltigen Kohlenstoffiverbindungeñ." 
Es kann auch andererseits Wärmezufuhr die Geschwindigkeit der metamorphosischen Lebensvorgänge in der Puppe, der Athmung und der partiellen Oxylation vermehren und so kohlenstoffreichere, dunklere Pighentstoffe durch chemische liondensations- und Reduktionsvirgänge hervorbringen; darum entstehen auch in der Regel durch erhöhte Kilimawärme und durch kïnstliche Einwirkung erhöhter Wärme dunklere Schmetterlings-Subspecies (bzw. Aberrationen) aus liälterem Klima angehörenden Species mit helleren Farbentönen" (p. 5, 6).

Ein Jahr darauf veriffentlicht F. Urech (900) kritische Bemerkungen ïber Wärmeenergetisches ron Vunessa in und wicue. In dieser Abhandlung erklürt er, warum auch die Külte das l'jgment verlunkelt uni zwar bei ein und derselbon Species, und kommt bei dieser Erklärung zun Schlusse, dass die Temperaturifferenz (zwisthen (ler gewiohnlichen und Versuchstemperatur) oller, wie er sagt, der Wärmesturz diabei das Entscheilente ist, denn ,gleiche oder doch sehr ähnliche Aberration kommt zu Stande, einerlei ob die T'empe ratur von sehr tiefen ciralen zu höheren ansteigt, orler von weniger tiefen zu sehr hohen, also z. B. von $-10^{\circ} \mathrm{zu}+15^{\circ}$ oller von $+25^{\circ} \mathrm{zu}+410^{0}$. Beides Mal ist die Differenz gleich gross, nämlich $\left(-10^{\circ}\right)+15^{\circ}=25^{0}$ und $40^{\circ}-15^{\circ}=25^{0 *}$ (p. 130).

Weiter spricht er sich dafür aus, lass bei dleser firscheinung sowohl (lirekte (unmittelbare), als auch indirekte (mittelbare) T'mperitur inwirkung vorliege, „demn wemn mässige Wärme und Kailte schon direkt einwirkt (auf den Firbstoffichemismus u. a. m.), warum sollten es Hitze und Frost nicht auch, und sogar noch in erhöhtem Grade thun?" (p. 131).

Er hat auch festgestellt, dass bei Vanessa-Speries durch Einwirkung abnormer Temperaturen auf die noch junge Puppe eine gesetzmässige Reihenfolge in den Schuppenfarben des Fliigelmusters stittfinlet, und zwar werden gelbe Schuppenpigmente durch orangene, diese tlurch röthlich-braune, diese durch umbrabraune bis schwiirzliche ersetzt.

\section{Die Theorie von Max Standfuss.}

Intem M. Standfuss bereits 1891 seine Ansichten über die Wirkung der Temperatur auf die Färbung der Lepidopteren ausprach (835) und dann weiter entwickelte $(836,837,840)$, legt er seine Theorie über diese Frage in seinen „Experimentellen zoologischen Studien mit Lepidopteren" (841) klar dar. 
Zuerst stellt er fest, lass die Kïlte eine Hemmung in der Entwickelung der Puppen herrorruft, intem er sagt: "Somit wurile nicht nur eine Unterbrechung der Entwickelung wilhrend der Zeitdauer der Frosteinwirkung hervorgerufen, sonflern zuwleich eine sehr erhebliche Verlangsamung und Hemmung der Entwickelung ïberhaupt." Weiter: "Die Hemmung der Entwickelung unl das aberrative Kileid fallen bis zu einem hohen Grate zustummen. Auch ist es Regel, dass die zuletzt erscheinenden Stïcke in höherem Grarle von dem normalen Typus abweichen als die fruiher ausschliipfenten" (p. 18). Die Temperatur von $+44^{\circ}$ erzengt analoge Erscheinungen: die zuletzt ausschlïpfenden Falter sind die aberrativsten. „ro hohe Temperaturen wirken keineswegs durchweg beschleunigend, wie man anzunehmen geneigt wäre, sondern vielfach die Entwickelung direlit unterbrechend und häufig auch noch ïber das Mass her Expositionszeit hinaus verlangsamend" (p. 18).

Er meint, dass ein uud derselbe Effelit erzengt wirl, ob grössere Kälte liurze Zeit oller geringere Kälte längere Zeit aul die Puppen einwirkt, d. b. dass die Temperatur und die Zeit der Einwirkung in ungekehrtem Verhältnisse zu einander stehen.

Kïlte- und Wïrme-Versuche einerseits uml Frost- und HitzeVersuche andererseits haben unter sich einen prinzipiellen Unterschied, wie es aus folgender Stelle von Standfuss zu ersehen ist: „Bei Kälte- und Wärme-Versuchen erfolgte Umgestaltung des gesamten Materials und zwar bei verschielenem Vorgehen in verschiedenem Sinne und Masse, indess bei gleichartiger Richtung und olne beson. der's grosse Schwankungen von Individuum zu Individuum. Niemals trat eine durch das Külteexperiment hervorgerufene specifische Entwickelungsrichtung bei Wärmeeinwirkung auf die gleiche Species ebenfalls auf, niemals auch erfolgte das Ungekehrte. Es handelt sich ganz offenbar un eine direkte Einwirkung. Das jeweilige Kälteexperiment und das daraus resultierende Falterkleid, ebenso wie das Wärmeexperiment und der sich darauf ergebende Imaginaltypus verhalten sich wie Ursache und Wirkung. - Ganz anders bei dem Frost- und Hitze-Experiment: Hier erfolgt niemals eine Umprägung sïmtlicher Versuchsobjelite in gleichem, von der Normalform abweichendem Sinne. Zunächst ist zu betonen, dass sich durchaus als Regel der bei weitem grösste Theil derselben in keiner Weise ändert. Ferner lassen sich in dem verschobenen Rest zwar für gewisse Individuengruppen eine Anzahl von Gesetzmïssigkeiten in der Umgestaltung deutlich erkennen, aber lie eine Individuengruppe läuft dabei 
oft genug, verglichen mit einer anderen, in volkommen 'divergenter' Richtung, selfbst bei ein und lemselben Experiment. Weiter resultieren bei den Minusgralen, wenn eine gewisse Grenze überschritten ist, selbst bei sehr wesentlichn Unterschieden (z. B. bei - so bis -1So C.) qualitativ die gleichen Abweichungen, nur nicht in glejchem Prozentsatze, und ähnlich liegt es bei der extremen Plusreihe. Bei den Kälte- unl Wärme-Experimenten dagegen genügten sellsst geringe Gradunterschiede, wenn nur konstant angewendet, un unter sich verschiedene Varietätemreihen su erzeugen" (p. 21).

Somit kommt er zum Schlusse, dass Hitze unil Frost die Entwickelung der Puppen unterbricht, wobei das Inselit in einen Zustamil der Lethargie versetat wiril. Diese extremen Temperaturen nwirken nicht direkt, sonlern indirekt, indem wahrscheinlich auf der Basis dieses lethargischen Zustandes sich Vorgänge abspielen können, die eine Veränlerung des Schmetterlings in eigenthïmlicher Richtung bedingen; und zwar ist es für die Gestaltung dieser Entwickelungsrichtung annïhernd gleichgiiltig; ob das lethargische Stadium durch Frost, durch Hitze, vielleicht auch noch durch andere störende Einflüsse provociert wurde" (p. 22).

Warum die Einwirkung der Wärme oder der Kälfe auf die Puppen nicht dieselbe bei verschiedenen Arten von Lepidopteren ist, sagte Standfuss bereits 1894 (837) folgencles: „Fragen wir nach den Gründen, wesshalb bei den dargelegten Versuchen sich die eine Art lediglich in ilırẹm gegenwärtig zu beobachtenilen Rahmen verschiebt, die antere Art aber über diesen Ruhmen hinaustritt, so dïrfte die Sache so liegen, dass diejenigen Arten, welche in ihrem gegenwärtigen, oler doch einem diesem sehr ähnlichen Gewande schon sehr lange Zeiträume hindurch auf der Erile vorhanden waren, - das heisst, kurz ausgedriickt, phylogenetisch iiltere Arten “ - unter die erste Krategorie fillen; hingegen diejenigen Species, welche ihr gegenwärtiges Kleid erst wesentlich kiirzere Zeit besitzen - also phylogenetisch jüngere Arten - der zweiten Liategorie angehören" (p. 25).

In seinem "Handbuche" (840) sagt ex: „Je grösser die Zahl der Generation ist, welche schon ein gewisses Ixleid getragen haben, desto mehr ist dieses Kleid gegenüber äusseren (Temperatur-) und inneren (Hybrations-) Eiflïssen geschiitzt und befestigt" (p. 290). Die Unterschiede in der Reaktionsfähigkeit ruhen in letzter Linie also in den häufigeren oder weniger häufigen Einwirkung der dieses Gewand bedingenden äusseren Faktoren. 
Lir beobachtete (837), dass die Puppen bei Hitze-Versuchen (4t) fast hei allen Arten balı alstarben, während crniedrigte T'mperaturen von ihmen gut ertrigen wurien. „I)iese Thatsachen legen die Annahme nahe, dass die gepriffen Arten in den vergangenen Eriepochen gezwungen waren, sich sehr viel mehr an niedrigere Temperaturen zu accomorliren als an höhere" (p. 27).

Die Verenfachnung der Farbenzeichnung unter dem Eintusse der höheren Temperatmen ersieht Standfuss $(\$ 41 \%)$ in (ler Abliirzung ler P'uppenzeit, indem er sagt: "Nittiulich wird die Entwiclielung aus der l'uppe zum Falter lurch das Kälteexperiment verlangsant, durch das Waimeexperiment aber beschlemigt. Man wircl daher amnehmen diurfen, eine schnelle Entwickelung verhimere die Herausugestaltung eines bis in feine Einzelhtiten hin in iusgelilleten Zeichnungs-IIusters. Thatïchlich sind unter den tropischen Insekten nur schablonenhaft angelegte Zeichnungsmotive iiberaus häufig" (p. 11).

Die Kritik dieser Theorie befinlet sich bei Fischer (23ii)

\section{Die Theorie von Emil Fischer.}

189.5 erschien die erste Arbeit von E. Fischer (22S): "Tramsmutation der Schmetterlinge infolge Temperaturänlcrungen", aus welcher folgendes zu ersehen ist:

Er glaubt, dlass das biogenetische Grunlgesetz von Häckel auch auf die Schmeterlingspuppen anzuwenden sei und sagt, , tass jeter einzelne sich entwickehnte Falter in cler Puppe suecessive alle jene Zeichnungsstadien abgekürzt wielerhole, welche die betreffenle Art im Laufe ihrer phyletischen Entwickelung durchlau.en hat, oder: dass die Ontogenie (jedes Falters) eine kurze liekapitulation der l'hylogenie (ler betreffenten Species) sei." Weiter sigt er: „Dabei brauchen ja die Farben als solche nivht augenfällig zum Vorschein zu kommen, sondern bloss die ilnnen (später) zu cirmule liegenden Elemente, die spätern "Farbenträger" in ihren ersten $\Lambda$ nlagen aufzutreten, um balı von denen des nächstfolgenden phỵletischen Starliums in allmïhligem Uebergang verdrängt zu verilen" (p. 27).

Demgemäss wird das angelegte phyletische Stadium in dem entsprechenden Momente von der Kälte fixiert. Wirkt die Kälte noch längere Zeit ein, dann kommen die phyletisch späteren Stadien nicht mehr zur Entwickelung; "ler Falter wird durch die andauernde Kï:ilte auf seinem fixierten Stadium erhalten, er bleibt auf demselben stehen bis zu seiner augenfialligen Ausfärbung'“ (p. 2S). 
Er nimmt auch an, dlass die Entwickelung (ler Puppen, welche dem Eiflusse der Temperatur von $0^{0}$ andauernil ausgesetzt werilen, eine Hemmung erleidet uni zwar , llurch den Mangel der zur Entwickelung des Organismus nöthigen Wärme" (p. 30).

In einem weiteren Abschnitt ( Wirkung stark gesteigerter Wärme $\left[40^{0}-42^{\circ}\right]^{\prime \prime}$ ) erklïrt er die durch die hohe Wärme „verminderte oller aufgehobene Reaktion" auf den Puppenkörper dadurch, dass diese Atherschwngungen relativ sehr viele sind, um einen lieiz auf ciie Puppen auszuïben, und „die Puppen reagieren nicht mehr auf so hohe Wärme, weil sie sich im Laufe ihrer phylogenetischen Entwickelung nie an solche anzupassen Gelegenheit hatten" (p. 31). Als Resultat erhält man Falter, als ob die Puppen die ganze Zeit einer Temperatur von $0^{0}$ ausgesetzt gewesen wären.

Somit nimmt er einen Stillstand in der Entwickelung der Puppe an, welche entweder zu hohen oder zu nielligen Temperaturen ausgesetzt ist, wobeil eine Rückschlagsform sich ergiebt.

bei der Wirkung der mässig erhöhten Wärme (ca. 350) entsteht eine neue "noch nie dagewesene" Form und ist "eine direlite Folge der Realition der Puppe auf eine über die gewöhnliche gesteigerte Temperatur" (p. 33). Solche Temperaturen durchliefen die Falter in der phyletischen Entwickelung nie.

Die Thatsache, dass die Aberration hygicuca Freyer von Puppen, die sowohl bei 10 wie auch bei $35^{\circ}$ gehalten werden, entstehen, erklärt er durch besondere Anlagen, welche vermuthlich schon in der Raupe vorhanden seien.

Ein Jahr darauf veröffentlichte er die zweite Untersuchung (229), in welcher er sich wegen des Stillstandes in. der Entwickelung der Puppen unter dem Einfluss extremer. Temperaturen deutlicher ausspricht, und zwar will er die Entwickeluugshemmung "nur auf (lie Zeichnungsstadien bezogen wissen, nicht auf den Organismus als Ganzes" (p. 20).

Um die Annahine einer partiellen Hemmung zu prüfen, untersuchte er den Färbungsprozess des Falters Vanessa antiopa am Ende des Puppenstadiums und erhielt folgende Resultate:

1. Die Entwickelung des Faltersorganismus bei einer constanten Temperatur von $0^{0}$ steht nicht ganz still, sondern schreitet (wenn auch sehr verlangsamt) fort.

2. Trotz dieses Vorwärtsschreitens können doch einzelne Entwickelungsvorgänge (und zwar bei den Puppen auf rlen Flïgeln) durch Kälte gehemmt werden. 
Er erhält seine frühere Ansicht auch jetzt aufrecht: „dass die Rückschlagsformen nur durch Hemung der während der I)ifferenzierung der Schuppen wielerholten phyletischen Zeichnungsstadien entstehen und dass diese Hemmung durch rerschierlene Falktoren wie Kälte, hole Wärme etc. gesetzt werlen liönne" (p. 49).

Indem er die Vertheilung des schwarzen Pigments bei śberrativen Formen ron Vanessen betrachtet, kommt er zum Schlusse, dass der Grund, warum das schwarze Pigment zuweilen in den Adern sich ablagert und in die Intercostalräume nirht gelangen kam, in mechanischen Widerstïnden liegt, , denn die hohlen Fliigelatern setzen dem die Farbpignente zuführenclen Blutstrome einen weit geringeren Willerstant entgegen, als die eng aneinanterliegenten beiden Membranen der Intercostalräume" (p. 54). Um gewisse Ausmahmen zu erklären, nimmt er an, dass verschiedene schwarze Pirmentflecke als in ihrer feineren chemischen Zusammensetzung verschiedene Körper aufzufassen sini, zu welchem Schlusse auch Urech gelangte.

Weiter sagt er: „Ob ausser den erwähnten chemischen und mechanischen Widerstänlen noch andere Unstänle die Kompensation bedingen helfen, ob das Arlersystem der Fligel, resp. die 2 Hauptadergiebite mit ihren besonderen Verzweigungen, orler ob, was Oberunıl Unterseite betrifft, die Beschiffenheit der beiden Flïgelmembranen, oler gar eine besondere Struktur der Schuppen der liompensation zugrunde liegt, kann heute noch nicht bestimmt gesagt werten" (p. 55).

Zum Schlusse stellt er alle Rückschlagsformen der Vanessen zusammen und erhält folgende Tabelle:

\begin{tabular}{|c|c|c|c|}
\hline$A_{1}$. & $A_{2}$ & $A_{3}$ & $A_{4}$ \\
\hline $\begin{array}{l}\text { Miocen formen. } \\
\text { Küinstliche Kälte- } \\
\text { formen } \\
\left(-4^{0} \text { bis }-20^{\circ}\right)\end{array}$ & $\begin{array}{l}\text { Eiszeit formen. } \\
\text { Küunstliche Kälte- } \\
\text { formen }\left(0^{\circ}\right)\end{array}$ & $\begin{array}{c}\text { Mitteleurop. } \\
\text { Formen }\end{array}$ & $\begin{array}{c}\text { Südliche Va- } \\
\text { rietäten. } \\
\text { Kunstliche Wärme- } \\
\text { formen }\left(35-38^{\circ}\right)\end{array}$ \\
\hline $\begin{array}{l}\text { ab. ichmusoides } \\
\text { (de Solys) }\end{array}$ & $\begin{array}{l}\text { var. polaris } \\
\text { (Stdgr.) }\end{array}$ & urticae $\left(\mathrm{I}_{\text {.. }}\right)$ & $\begin{array}{l}\text { var. ichnusa } \\
\text { (Bon.) }\end{array}$ \\
\hline ab. testudo (Esp.) & ab. dircyi (Stdfs.) & polychloros (L.) & $\begin{array}{l}\text { var. erythromelas } \\
\text { (Stdgr.) }\end{array}$ \\
\hline $\begin{array}{l}\text { al. antigone } \\
\text { (Fischer) }\end{array}$ & $\begin{array}{l}\text { ab. fischeri } \\
\text { (Stdfs.) }\end{array}$ & io (L.) & io (L.) \\
\hline $\begin{array}{l}\text { ab. hygiaea } \\
\text { (Hdrch.) }\end{array}$ & $\begin{array}{l}\text { ab. artemis } \\
\text { (Fischer) }\end{array}$ & antiopa ( $\left.\mathrm{I}_{2}\right)$ & ab.epione(Fschr.) \\
\hline ab: elymi (Rbr.) & $\begin{array}{l}\text { ab. vislotti } \\
\text { (Stdfs.) }\end{array}$ & cardui (I.) & cardui. (L.) \\
\hline $\begin{array}{l}\text { ab. klymene } \\
\text { (Fischer) }\end{array}$ & $\begin{array}{l}\text { ab. merrifieldi } \\
\text { (Stdfs.) }\end{array}$ & atalanta (L.) & $\begin{array}{l}\text { rar. vulcanica } \\
\text { (Godt.) }\end{array}$ \\
\hline
\end{tabular}


In weiterer Arbeit (231) weist Fischer nach, dass bei gewissen hohen Temperaturgraden die gleichen Formen entstehen wie bei bestimmten niederen Temperaturgraden, eine Thatsache, welche er bereits 1894 an $V$. antiopa beobachtet hat. Die jetzt beschriebenen und in der Abhandlung "Lepidopterologische Experimental-Forschungen" weiter ergünzten Experimente von Fischer führten ihn zum Sehlusse, lass T. polychloros ab. testudo Esp., T. urttcac ab. ichumsnides De Sel. und var. polaris Stgr., T. in ab. antigone Fschr., $T$. (nntiopa ab. artemis Fschr., ab. hygiaea Hdrch. und ab. eprone Fschr., $T$. atalanta ab. lilymene Fschr. und $V$. cardici ab. elymi Rbr. sowohl bei hohen, wie bei tiefen Temperaturen entstehen können.

In der Abhandlung "Lepidopterologische Experimental-Forschungen" (236) führt er folgende Zusammenstellung der bei Frost-, Kälte-, Wärme- und Hitzeexperimenten erhaltenen Aberrationen resp. Varietäten der Vanessa-Gruppe an:

\begin{tabular}{|c|c|c|c|c|}
\hline$D_{1}$ & $B$ & $A$ & $\bar{C}$ & $\overline{D_{2}}$ \\
\hline $\begin{array}{l}\text { Frost-Aberra- } \\
\quad \text { tion } \\
\left(0^{\circ} \text { bis }-20^{\circ}\right)\end{array}$ & $\begin{array}{l}\text { Kälte-Varia- } \\
\text { tion } \\
\left(0^{0} \text { bis } 10^{\circ}\right)\end{array}$ & Normal Form & $\begin{array}{c}\text { Wärme-Varia- } \\
\text { tion } \\
\left(+35^{\circ} \text { bis }+42^{\circ}\right)\end{array}$ & $\begin{array}{c}\text { Hitze-A berra- } \\
\text { tion } \\
\left(+42^{\circ} \text { bis }+46^{\circ}\right)\end{array}$ \\
\hline $\begin{array}{l}\text { al. ichnusoides } \\
\text { Selys. } \\
\text { ab. antigone }\end{array}$ & $\begin{array}{l}\text { var. polaris } \\
\text { Stdgr. } \\
\text { var. fischeri. }\end{array}$ & $\begin{array}{c}\text { T. urticae } \\
\text { L. } \\
\text { Vanessa io }\end{array}$ & $\begin{array}{l}\text { var. ichnusa } \\
\text { Bon. } \\
\text { var. . . . }\end{array}$ & $\begin{array}{c}\text { ab. ichnusoides } \\
\text { Selys. } \\
\text { ab. antigone.. }\end{array}$ \\
\hline $\begin{array}{l}\text { Fischer. } \\
\text { ab. testudo } \\
\text { Esp. }\end{array}$ & $\begin{array}{l}\text { Stats. } \\
\text { var. dixeyi } \\
\text { Stdfs. }\end{array}$ & $\begin{array}{c}\text { L. } \\
\text { V.polychloros } \\
\text { L. }\end{array}$ & $\begin{array}{l}\text { var. fervida } \\
\text { Stdgr. }\end{array}$ & $\begin{array}{l}\text { Fiselier. } \\
\text { ab. testudo } \\
\text { ․ Esp. }\end{array}$ \\
\hline $\begin{array}{l}\text { ab. hygiaea } \\
\text { Hdrch. } \\
\text { ab. elymi Rbr. }\end{array}$ & $\begin{array}{l}\text { var. artemis } \\
\text { Fischer. } \\
\text { var. wiskotti } \\
\text { Stdfs. }\end{array}$ & $\begin{array}{l}\text { V. antiopa } \\
\text { L. } \\
\text { Pyr. cardui } \\
\text { L. }\end{array}$ & $\begin{array}{l}\text { var. epione } \\
\text { Fischer. } \\
\text { var. . . . . }\end{array}$ & $\begin{array}{l}\text { ab. hygiaea } \\
\text { Hdrch. } \\
\text { ab. elymi } \\
\text { Rbr. }\end{array}$ \\
\hline $\begin{array}{c}\text { ab: Klymene } \\
\text { Fischer. }\end{array}$ & $\begin{array}{l}\text { var. merrifieldi } \\
\text { Stdfs. }\end{array}$ & $\begin{array}{c}\text { Pyr. atalanta } \\
\text { L. }\end{array}$ & vax... . . & $\begin{array}{l}\text { ab. Klymene } \\
\text { Fischer }\end{array}$ \\
\hline
\end{tabular}

Wie hieraus $z u$ ersehen ist, entstehen bei $D_{1}$ : und $D_{2}$ die gleichen Formen, bei $B$ unl $C$ dagegen einanter vollkommen entgegengesetzte (vrgl. die oben in diesem Abschnitte angefuihrte Tabelle).

Gestiitzt auf diese Thatsache, leitet er den Schluss ab, dass "diese Aberrationen nicht das Produkt einer specifischen Wirkung rer genamnten tiefen Kïlte und überhaupt nicht das Produkt einer specifischen Wirkung irgend welcher Temperaturen sein kömnten, sonilern dass diese Temperaturen nur als Hemmungs-Falitoren 
wirkn un $l$ dass somit diese Hemmung suwohl durch tiefe Kialte, als auch clurch hohe Wärme gesetzt werilen könne" (p). 6).

In derselben Abhantlung giebt er noch die folgrente Tabelle:

\begin{tabular}{|c|c|c|c|c|c|c|}
\hline $\bar{c}$ & $D_{1}$ & $B_{1}$ & $A$ & $C^{\prime}$ & $B$ & $D_{2}$ \\
\hline 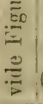 & $\begin{array}{c}\text { Frost- } \\
\text { A berration } \\
\left(0^{0} \text { bis }-20^{\circ}\right)\end{array}$ & $\begin{array}{c}\text { Kälte- } \\
\text { Variation } \\
\left(0^{\circ} \text { bis }+10^{\circ}\right)\end{array}$ & $\begin{array}{l}\text { Normale } \\
\text { Form }\end{array}$ & $\begin{array}{l}\text { Wirme- } \\
\text { Variation } \\
\left(+i 5^{\circ} b i s+3 i^{c}\right)\end{array}$ & $\begin{array}{c}\text { Wärme- } \\
\text { Variation } \\
\left(+36^{\circ} \text { bis }+41^{\circ}\right)\end{array}$ & $\begin{array}{c}\text { Ilitze- } \\
\text { Aberration } \\
\left(+42^{\circ} \text { bis }+46^{\circ}\right)\end{array}$ \\
\hline I & ichinusoides & polaris & urticae & iclunusa & polaris & iclmusoides \\
\hline II & antigone & fischeri & io & - & fischeri & antigone \\
\hline III & testudo & dixeyi & polychloros & $\begin{array}{l}\text { erytlurome- } \\
\text { las }\end{array}$ & dixeyi & testudo \\
\hline IV & hygiaca & artemis & antiopa & epione & artemis & lyygiaea \\
\hline $\mathrm{V}$ & elymi & wiskotti & cardui & - & viskotli & elymi \\
\hline VI & lilymene & merrifieldi & atulanta & - & merrifieldi & litymene \\
\hline VII & weismanni & porima & prorsa & - & porima & weismanni \\
\hline
\end{tabular}

Dabei sei bemerkt, dass nilentisch ihrem Wesen nach unl nur graduell verschieden sind:"

1. ab. ichnusoides Selys und ab. atrcbatcnsis B., sowie die sehr dunkle ab. nigrita Fickert.

2. ab. antigone Fschr., ab. betiscria Obth., ab. ioriaste Trech und die ganz schwarze ab. extrema Fschr.

3. ab. kilymene Fschr. und ab Flemensiewiczi Schille.

4. var. artemis Fschr. und var. rödcri Stdfs.

Es ist ihm gelungen, diese Gesetzemässigkeit nicht hloss für die Gruppe der Vanessen nachzuweisen, sondern auch für Aretia caja (v. schultzii Frings bei $+39^{\circ}$ ), P(1pitio machaon, Apaturu ilia, v. clytie und Charaxes jasius Kälte-Varietäten durch hohe Wirme zu crzielen.

Die der $C$-Reihe analogen Formen fehlen in diescr Tabelle, ta sie „sehr wohl als blosse Uebergänge $\mathrm{zu}$ den Frostal,errationcn $D_{1}$ aufgefasst werden können."

Aus dieser Tabelle zieht er den Schluss: "Auch die mässige Kälte wirkt tatsächlich nicht als solche, nicht spezifisch und nicht direkt; sonst könnten diese Kälte-Variationen $B_{1}$ doch gimz unmöglich durch gewisse, zeimlich hohe Wärmegrade $\left(B_{2}\right)$ auch erzielt werden" (p. 272).

Aus seiner Hemmungs-Theorie ausgehend, stellte er Ycrsuche mit narkotischen Mitteln, hauptsächlich mit Schwefeläther an, um 
aberrative Formen. wie sie durch die Temperaturexperimente erzielt werien, zu erhalten. Bei diesen Versuchen unter einer zwei-bis dreimaligen, je ca. 3 Stunden dauernden tiefen Narkose, gelang es ihm in der That, ausgesprochene Aberrationen (D-Formen) zu erhalten, und zwar zu $100^{\circ}$ ab. ichmesoirles, ab. nigivita, ab. antigone, ab. ioliaste, ab. Tyygiaen und ab. Tilymene. Dabei wurde auch die? Verlangsamung der Entwickelung (ler Puppen heobachtet, welch'r Umstand zu Gunsten seiner Theorie spricht, lenn dass eine tiefo Narkose die Lebensfunktionen der Puppe in einen beinahe latenden Zustand versetzt, lässt sich an der völligen Reaktionslosigkeit d’r Puppe bri äusserer Reizung und aus ler verzögerten Entwickelung erkennen. Die Ilemmung ist mithin der primäre Zustand, d. h. die Ursache, die aberrative Veränderung aber ist die Folge!" (p. 317). Bei leichterer Narkose erkiclt er $B$-Formen.

Die Kritik dieser Theorie befindet sich bei Garbowski (272) und Schröder (780).

\section{Die Theorie von 11. C. Piepers.}

M. C. Piepers sprach in verschielenen seimen Arbeiten sthr originelle Ansichten über die Farbenänlerungen bei Lepidopteren aus. Da er sich „auf cine bein:the 50-jährige Uebung in (ler Beobwhtung, auf eine 28-jührige Gelegenhit dazu in den Tropen" beruft, so ist es nöthig seine Ansichten etwas ausführlicher zu besprechen.

In seiner Arbeit: „Ueber die Farbe und den Polymorphismus der Sphingiden-Raupen" (638) beschreibt Piopers die Farbenänderung bei 130 Raupen während des Verlanfes ihrer Entwickelung unter gewöhnlichen Umstänilen. Die Grundfarben, welche unter diesen Raupen am meisten vorkommen, hassen sich in zwei Gruppen vertheilen: 1) gelb und griun in allerlei Nuancen, 2) braun gleichfalls in allerlei Nuancen. Der Farbenwechsel kommt auf zweierlei Weise zu Stande:

1. "Das Gelb oder gelblich Grün wird dınkler und röthlicher, woraus Orange, bisweilen auch Lehngelb entsteht; das Roth nimnit dann manchmal noch zu, sodass die Farbe dunkel rosenroth wird; es wird soilann mehr gesättigt und dunkler, also in Braunroth übergehend, woraus es dann wieder verschwindet, das sich zuweilen noch bis zu Schwarz abschattet.

2. Das Grün wird dunkler und bräunlich unıl geht dann erst in Braun über, welches sich noch mitunter als griinlichbraun zeigt, später dunkelbraun wir.l un.I zuweilen sich bis zu Schwarz abschattet, 
1. h. ausser wenn die gelblichgrüne Farbe neben der röthlichbraunen o.ler braunen, jede auf einigen Theilen des Körpers bestehen bleibt, und so die bereits erwähnten Fälle von Marmorirung entstehen" (j. 52, 53).

Dies gilt für die Grundfarbe. Eine Evolution der Farbe findet somit bei diesen Raupen von hellgelb nach schwarz hin statt. Weiter sagt er: „Kurz, von solchen Arten, bei denen die Evolution am weitesten vorgerückt ist, triftt man im ausgewachsenen Zustande nur schwarze Raupen an; von solchen, bei welchen sie etwas weniger fortgeschritten ist, neben den schwarzen auch noch andere, welche die Uebergangsfarben Braun, Loth, Isabellafarbe oiler sogar noch das ältere Grün oder Gelb zeigen; bei denen, wobei sie noch etwas verzögert ist, bestehen noch lieine schwarzen, sonlern ein Theil der Raupen trägt in ausgewachsenem Zustante cine oder die andere ron diesen Uebergangsfarben, während die ïlrigen noch grün oder gelb sincl; die am weitesten zurichgebliebenen liaupen endlich, sind noch allein grün oder gelb" (p. 59).

Daraus geht hervor, dass die Grundfarbe aller SphingillenRaupen am Ende der Evolution nur Schwarz sein wird. „Diess Evolution wirkt bei allen, aber bei jerler Speries ander's, schneller oder langsamer je nach deren Eigenthümlichlieit in ihrer besonderen Entwickelung“ (p. 63).

Gestiitzt auf diese Schlüsse, verwirft Piepers die Farbenanpassung der Raupen an die Umgebung (die Schutzfarbe) und spricht sich gegen den Darvinisums aus.

Ein Jihr später erschien seine zweite Arbeit: „Die Farbenevolution (Phylogenie der Farben) bei den Pieriden" (639), in welcher er seine Evolutions-Lehre weiter entwickelt und gewisse Umänderungen einführt, weil die friihere Meinung „auf weniger vollständigen Wahrnehmungen aufgebaut war" (p. 72).

Die Untersuchung von ca. 1000 Falter-Arten der P i e r i d enFamilie führte ihn zum Schlusse, dass "nicht Schwarz, sondern Weiss das Eniziel" der Farbenentwickelung ist (p. 116). Weiter sagt er: "Der Verlauf dieser Evolution kann damit natirlich noch nicht abgeschlossen sein, sondern es darf wohl bestimint angenommen werien, dilss auch die weisse Farbe ihrerseits wieder verdrängt werden wird. l)ürfte ich darüber eine Vermuthung zu äussern wagen, dann w wirle es die sein, dass der erstfolgende Zustand der sein würde, dass die Flügelschuppung verloren geht, sodass die Flügel ten glasartigen Charakter erhalten wurden, welcher Macroglossa fuciformis L., M. 
bombyliformis Ochs, Potidea hylas L., und den Sesiden eigenthiimlich ist" (p. 238).

Der Verfasser kommt zu folgenten allgemeinen Schluissen:

„Dass diese Erscheinung (die Farbenevolution) vollkommen den Charakter einer langsamen Umwandlung trägt, welche in Folge eines uralten, bereits bei der Stammart der ganzen Familie bestehenden erblichen Dranges, stets in einer bestimmten Richtung fortschreitet, und so allmählich zur Entfürbung des in den Fliigel. schuppen enthaltenen Pigmentes führt, um vielleicht später ein gänzliches Verschwinden dieses Farbstoffes uud endlich der Schuppen selbst zu verursachen;

dass jedloch der Verlauf diesser Evolution der Einwirkung iüsserer Einflüsse unterworfen zu sein scheint, welche dieselbe verzögern oder beschleunigen kömnen, und sogar wahrscheinlich gewissermaassen direkt davon abhängig ist; da er doch nicht immer ungestört fortschreitet, sondern mehrfach durch Zeitrïume von Stillstand unterbrochen wird, und dann derartige, als Reize wirkende Einfliisse, nöthig zu haben scheint, un wieder zu einem weitsren Fortschritt angeregt zu werden;

dass jedoch die Farbenzeichnung der Pieriden nicht allein die Folge der genannten Erscheinung ist, sondern zum Theil auch durch Farben von anderem Ursprung gebildet wird, und zwar offenbar von einem jüngeren, da dliese letzteren nämiich bisweilen die ersteren, welche durch die Evolution beherrscht werden, vertreiben oder varändern;

und dass diese neueren, die sogenannten Interferenzfarben gleichffalls, jetzt wenigstens, häufig erblich sind; dass sie aber nichts destoweniger, höchstwahrscheinlich ursprünglich durch die Wirkung äusserer Einflüsse entstanden sein müssen;

dass dies günzlich dem analog zu sein scheint, was sich bei dem Albinismus von Säugethieren und Vögeln zeigt, welcher ebenfals in Folge von äusseren Einflissen $\mathrm{zu}$ entstehen scheint, und doch da, wo dieselben Einflüsse fortdiuernd bestehen und demnach kumulativ wirken können, erblich wird;

dass aber dieser Albinismus, wo er bei den Lepidoptera auftritt, sowohl iu seiner Entfärbungsweise des bereits erwähnten Pigmentes, als auch in dem Wesen seines Verlaufes, wiederum eine unverkennbare Verwandschaft mit der Farbenevolution in der genannten Schmetterlingsfamilie aufweist. 
Aus Alledem wird es nun, meiner Meinung nach, sehr wahrscheinlich, dass auch diese Farbenevolution, deren Verlauf doch immer noch für äussere Einflüsse so emptinllich ist, als ein Process angesehen werden muss. bei welchem eine ursprüngliche bei der Stammform der genannten Familie vielleicht ebenfills durch äussere Eintliisse entstandene allgemeine rothe Färbung, welche im Iaufe der Zeit erblich geworden ist, stets fortfüht sich umzuwandeln, und zwar in einer bestimmten Richtung, liorrelativ jedoch immer durch die fortlaufende Entwickelung des ganzen Organismus, die si h doch bei jerier Art und sogar bei jedem Indivilumm verschieden itussert, beherscht, und dabei immer noch der Wirkung von äusseren EinHliissen unterworfen ist. Wiewohl roch die Lrtzteren nur zeitweise Effecte, eine zeitliche Störung orler eine Amregung, bewerlistelligen können, es sei demn, dass dieselben Interferenzfurben erzengen, und diese im Laufe der Zeit durch kumulative Einwirkung konstant, und damit zu einem integrierenten Theil des Organismus werden, was dann wiederum die Erblichkeit mit sich bringt; in welchem Falle sie eventuell auch die ïlteren Farben und damit den Verlau. ihrer Evolution zerstören können" (p. 253, 254, 255).

Auf Grund seiner Theorie der Farbenevolution erklät er die Farbenänderung infolge äussereer Einfliisse, Saisondimurphisums, Melanismus und Albinismus im II. Abschnitte seiner umfangreicher Abhandlung in ganz entgegengesetzter Weise als andere Forscher.

Ueber den Einfluss der Temperatur auf die Färbung der Schmetterlinge im Puppenstalium sagt er: „Nicht in Temperatureintliissen, sondern in einem ungleichmässigen Verlauf der Farbenevolution scheint der Grund für jene Farbenunterschiede zu liegen". "Gleichwohl geht daraus allein dies hervor, dass abnormale Temperaturen solche Veränderungen hcrvorrufen können; keineswegs aber, dlass einerseits der Wärme, andererseits der Kïlte, in dieser Hinsicht feste und desshalb direct daraus folgernde Resultate zugeschrieben werden diirfen" (p. 152).

Indem er bei seiner, Kritik der Schlussfolgerungen, welche verschielene Forscher bei ihren Experimenten gewannen, eine grosse Anzahl von Thatsachen anführt, sagt er: „Es ist desshalb wohl keineswegs angängig mit Dorfmeister es für bewiesen zu halten, dass erstens, erhöhte Temperatur lebhafte und intensive Färbung, zweitens, ernielrigte Temperatur matte Färbung hervorruft" (p. 154).

Die Erklärung der Farbenänderung bei T'mperaturexperimenten durch die Annahme des bekannten biogenetischen Grunigesetzes von 
Ernst Haeckel betrachtet er als sehr wahrscheinlich, "lenn einzig und allein das Abnormale bringt die $\mathrm{Hemmung}$ hervor, jeiloch ist es gleichgültig, ob dies als aussergewöhnliche Würme oler als anssergewölnnliche Kälte auftritt" (p. 157); dabei nimmt er an, dass die Richtang der Farbenevolution bei Vanesser ebenfills von lioth nach Schwarz verläuft; ggerade umgekehrt also von dem, was Fischer und Standfuss, alle beide mit dieser Evolution unbekannt, angenommen haben" (p. 158).

Dass Standfuss durch Kialte rerschiedene Formen ron Trunessa io erhielt, welche eine so leutliche Annüherung an Funessu urticue zeigten, erklärt Piopiers dulurch, "dass ein älteres Startium der Entwickelung des erstgenannte Falters eintrat, in welchem er sich noch nicht soweit, wie jetzt von der ursprünglichen, ihm mit $V$. urticue guneinsannen Grundform seiner Familie entferut hatte" (p. 15i). Die prorsa-Form betrachtet er als eine in fler Farbenevolution weiter als die levana-Form geförderte Rasse.

Ueber den Saison-Dimorphismus sagt Piopers: In den Fällen des Saism-Dimorphismus ist es nicht dieser Unterschied in der Empfindlichlieit (gegen die äusseren Einfliisse) - obgleich derselbe auch rlort besteht und z. B. die Variabilitït der prorsa-Form verursacht welcher die Scheidung zwischen den Formen beherrscht, sundern diese entsteht hauptsächlich dadurch, dass die verschierienen lilimitischen Einflüsse, denen die Puppen der einzelnen Generation unterworfen sind, zuweilen die weitere Farbenevolution bei dem Schmetterling hemmen, zuweilen aber als Reiz auftreten, welcher den

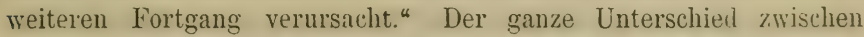
den Saison-Rassen besteht allein in dem Auftreten oder Nichtaultreten dieses Reizes" (p. 207).

Die Erscheinung des Melanismus hält er nicht für den dirckten Einfluss von Wärme oder Kälte als solche, sonilern als die durch dieselben hervorgerufene $\mathrm{Hemmung}$ (ler Farbenevolution resp. als das Weitertreiben dieser Evolution, bei welcher die Wärme odler Kälte die Rolle eines Reizes spiel. „In beiden Fällen nun, kann je nach der Richtung, in welcher sich die Farbenevolution bei einem solchen Falter bewegt, offenbar eine merkliche Ausbreitung des Schwarz in seiner Farbenzeichnung die Folge dovon sein, was dann vielfach als eine melanistische Erscheinung angesehen wird" (p. 219).

Den Albinismus betrachter er auch als eine Erscheinung derselben Art, jedoch in viel stärkerem Maasse, da die Einwirkung nux auf einen bestimmten Theil des Organismus beschränkt bleibt, 
„in weichen Fällen sie (ïussere Einflüsse) den Farbstoff ganz vder theilweise verschwinden lassen oder wohl avch durch chemische Einwirkung ausbleichen. Dies ist aber gleichwohl ein Vorgang von durchaus anderer Art als die Farbenevolution: und dieser ist dann auch wohl als eigentlicher Albinismus allein berechtigt diesen Xamen zu führen" (p. 227). "Das starke Auftreten les Weiss in ler Familie der Pieriden ist also keine Erscheinung von eigentlichem Albinismus, sonlern von Farbenevolution" (p. 232), da clieses Weiss nicht als die ursprüngliche, sondern als eine während dieser Evolulution aufkommende Farbe, in llieser Familie zeigt" (p. 231).

Eine kurze Kritik der Ansichten von Piepers finilet sich bei Gräfin M. von Linden (518 u. 520).

\section{Die Theorie von Chr. Schröder.}

Nachdem Chr. Schröder die Temperatur-Versuche an Adaliu bipunctata L. (778) und Abraxas grossulariutı L. (779) anstellte, entwickelte er die Theorie des T'emperatureinthusses auf die Färbung und Zeichnung der Inseliten in seiner Arbeit: „Die ZeichnungsVariabilität von Abraxas grossulariata L." (779).

$\mathrm{Er}$ betrachtet die durch extreme Temperaturen erhaltenen Formen als Riickschlagsformen, indem er von der Amnahme ausgeht, dass die ursprüngliche Zeichnung nicht nur bei Küifern, sonlern auch bei den Lepidopteren entsprechend der Richtung der Längsarlern angelegt gewesen ist. „Diese Zeichnungselemente aber sincl es auch, welche die Temperaturformen bei $-1 b r$ giossulariutu L. unil Arctic caju L. kemnzeichnen. Die Mehrbildung an Pigment tritt auf den querbindenartigen, weissen Grundfarbenresten als Flecken, öfters als (unregelmässige) Längslinien auf, zwischen denen durch weitere Ausdehnung der Zeichnung die Grundfarbe mehr oder minder verschwinden kann. Es ist nur ein sehr annehmbarer Gellanke, dass jener Theil der Flïgelfläche, welche phylogenetisch ältere Zeichnungen getragen haben, bei einer Zunahme der Pigmentbildung in erster Linie betroffen werden". (p. 181).

Den eigentlichen Grund des Temperatureinflusses ersieht Schröder in der Aenderung les Temperatur-Optimums, wie ihm auch eingehende Beobachtungen an Aphiden und den Larven der $A d$. bipunctata L. gezeigt haben. Er sagt: "Eine Verminderung oder Erhöhung der Temperatur hat eine Herabsetzung der Energie zur Folge. Für Temperaturunterschiede aber sind auch die Insekten und ihre Entwickelungsstadien sehr empfindlich und jene, denen die 
lionstitutionelle Fähigkeit hierfür zukommt, begegnen der durch Temperatureniedrigung hervorgerufenen Verlangsamung (bezw. Hemmung) ihres Entwickelungsganges durch Mehrbilıung des die Lichtund Wärmestrahlen am stärksten absorbierenilen schwarzen Pigments, zumal ihnen die Möglichkeit der Billung von Körperwïrme durch erhöhte Nahrungsaufnahme fehlt. In den Bezichnugen iler extremen pasitiven und negativen Temperaturen auf las Optimum liegt auch jeilentalls eine Möglicheit des Verstänınisses dlafuir, dlass beile dieselben aberrativen Formen zu erzeugen vermögen" (p. 1S2).

Indem er annimmt, dass das Pigment der Wärmebindung dient, sagt er: "Hiernach erklärt sich die Zeichnungs-Variabilität der Imilgines bei experimenteller Temperatureinwirkung auf die Puppen in recht einfacher Weise, wie ich schon andeutete, als Reaktion des Organismus gegen die gehemmte Entwickelung, normal die Folge eines geringeren Plus orler Minus an Wärme in Bezug auf rlas Optimum dem durch ein entsprecheniles Minus oder Plus an Pigment, (l. h. geringere orler grössere Wärmebinulung innerhalb gewisser Grenzen, begegnet werden kann" (p. 184).

Nachdem er sich in einer weiteren Abhandlung (780) gegen die Theorie von Fischer erklärt, sagt er: "Ich stelle der Hemmungs(u. a.) Theorie die folgende von mir bereits (779) ausgesprochene gegenüber, die eine ganz ungezwungene Erklärung liefern diirfte. Es liegen mir die Ergebnisse einer Anzahl von Beobachtungsreihen namentlich an Tephroclystia-Spezies, der Dasychira pudibunda L., Abraxas grossulariata L, Amplidasys betularia L. u. a., vor, die mit völliger Sicherheit dartun, dass diese Raupen durch eine vermehrte Pigmentbildung die Entwickelungshemmung zu paralysieren suchen, ler sie bei unternormaler Temperatur ausgesetzt sinı. Die zugehörigen Inagines scheinen gleichfalls einer erhöhten Pigmentbilıung zuzuneigen; eine Notwendigkeit liegt hierfür aber bestimnt nicht vor. In weiteren habe ich gerade jetzt eine eingehendere physikalische Untersuchung der Wärmeabsorptionsfähigkeit, z. B. von lietulariø L. und ihrer ab. doubledayaria Mill, Lymantria monacha L. und ab. cremita O., mudibunda L. und ab. concolor Stgr., Boarmia consortaria F. und ab. humperti Hump., vorläufig abgeschlossen, die es ausser Frage stellt, dass die überwiegend mit Schwarz pigmentierten Schuppen der abs. ein ganz erheblich höheres Absorptionsvermögen für Wärme besitzen als die Stammformen von überwiegend weisslicher, rein optischer Färbung. Dieser Unterschied vermag durchaus jene physiologische Erklärung für diese Erscheinung zu begrïnden. 
D.as Material für eine vermehrte Pigmenthililung der Imago stuht der Raupe, wie dem ersten Puppenstadium zur Verfügung. . . Mögen die Pigmente nun Umwandlungsprodukte des Chlnopinglls o:ler, wie andere Autoren meinen, Zersetzunesprolukte des Stofficechsels ans der Verwandtschaft der harnsamen Verbindungen sein o:ler aus anleren Bestandteilen der Blutfliussigkeit hervorgehen, jeilt ntalls erübrigt der ausdrückliche finweis, dass tem Orwanismus dhe Banstoffe für eine Mehrbilitung an Pigment zur Verfügung strhen. Will man ausserilem die Möglichkeit ciner direkten Beinflussung diceses Lmwanllungsfrozesses durch die Temperatur amelnmen, wie sie die Temperatur-Experimente nicht unwahrscheinlich machen, s) wirl man einer wesentlichen Schwierigkeit in der Amname meiner Autfassung nicht mehr begegnen können" (p. 441, 442).

\section{Die Treorie von Gräfin M. von Linden.}

M. v. Linden ist lie Anhängerin der Theorie von Einer !ur die ontogenetische Entwickelung der Zeichnung, nach weleher bei den aherrativen Formen aus längsgestreiften Faltu'n gefleclite, aus getlechten querwestrilte, ans diesen einfurbjge Formen hervorgehen, orler aber es können sich die Binden der längsgestreiften Formen olme liebergang zur Fleckung stark verbreiten und direlit zur Kinfarbigkeit iiberführen.

Sie giebt zu, dass die aberrativen Formen sich als Hemmungsbildungen betrachten lassen, ,aber als einseitige Hemmungsbihlungen, progressiver Latur, demn wären sie regressiver Art, so müssten Vorderfliigelrant und Flïgelwurzel überhapt zeichnungslos b'eiben. Geh 'mut in ihrer' Ausbildung wiri nur die Grundfarbe der liligel. Wir erzielen durch die Einwirkung der Hitze und les Frostes eine abgekiurzte Entwickelung des Zeichnungsmusters, die sich bei den extremen Formen in sprungsweisen Veränderungen kiundgiebt, die entsprechend der Theorie Rimer's, deren Forderungen bei allen meinen Untersuchungen ïher die ontogenetische Entwickelung der Flügelzeichnung bestïtigt wurlen, fortschrittlichen Charaliter tragen" (524. p. 595, 596).

Bei der Besprechung der Experimente von Fischer, aus welchen hervorgeht, dass liälteformen auch durch bestimmte hohe Wïrmegrale erzogen werden können, sagt sie: „Das Experiment wirft also meiner Ansicht nach keineswegs die bisherige Annahme der spezifischen Kälte- und Wärmewirliung in Sinne Standfuss'es, es zeigt nur aufs neue, dass sehr hohe Wärmegrade, die mehr als anregent atuf die 
Schmetterlingspuppen einwirken, einen ähnlichen Finfluss haben wie die niedere Temperaturen, die den Stoffwechsel zeitweilig jedenfalls lähmend beeintlussen" (p. 597).

Zwei Jahre später (1904. 527 a) spricht v. Linden ihre Ansichten über die Ursache der Farbenänderung deutlicher aus.

Indem sie konstatiert, dass die durch Wärme entstandenen Vanessenformen allgemein eine Zunahme rother Schuppen und eine Beimischung braunrother Töne und die feurigere (irundfarbe anfiveist. während die Kälte neben einer Aufhellung der Grundfarbe die Vermehrung schwarzer Zeichnungselemente bewirkt, trägt sie: „ob die Temperatur vielleicht einen direkt veränilernilen Einfluss auf die Schmetterlingspigmente : auszuüben vermag?"

Sie vermuthet, dass dem Auftreten des schwarzen Farbstoffes ein Zerfall des rothen vorauszugehen hat. "Der rote Farbstoff stellt (527 $t$ ) einen eiweissartigen Körper dar, er enthält eine aromatische Gruppe, die unter gewissen Bedingungen abgespalten und durch die Oxydation in einen schwarzbraun gefärbten Kïörper verwamlelt werlen kann, der mit schwarzbraunen Schuppenpigment identisch zu sein scheint. Alle Vorgänge nun, welche sich im Puppenorganismus abspielen und eine Herabsetzung der Lebenstätigkeit bedingen, führen zur Bildung des melainartigen'Pigments. Damit wird die Stoffwechseltätigkeit der Puppe massgebend für die Pigmentbildung, es ist aber deshalb durchaus nicht gesagt, dass die entstehenden Färbungsvarietäten phylogenetisch bedeutungslos wären" (p. 628).

Weiter sagt sie, dass bei den Temperaturexperimenten der Stoffwechsel der Puppe erheblich beeinflusst wirl, und zwar steigen die Oxydationsprozesse bei mässig erhöhten Temperaturen, und der Falter entwickelt sich schneller, während bei der Kälte die Puppendaner länger wird und die Stoffwechselvorgänge im Organismus herabgesetzt werden.

"Ganz verschieden von der Wirkungsweise mässig erhöhter und ernieulrigter Temperaturen ist der Einfluss extremer Kälte und extremer Hitze. ... Diese Erfahrung zeigt, dlass Aberrationen am leichtesten unter Bedingungen entstehen, die fuir den Puppenorganismus am meisten schwächend und schädigend wirken, denn es ist bekannt, dass das Auftauen gefrorener Organe zu einem um so grösseren Eiweisszerfall führt, je rascher ilasselbe stattfindet. Auch ungewöhnlich hohe Temperaturen wirken auf die Körpergewebe in ähnlicher Weise zerstörend wie ein grosser Frost. Diese Veränle- 
rungen, die sich, wenn sie den gesamten Organismus treffen, in der Erscheinung des Hitzschlages kundgeben, sind zum grossen Teil in einer ungeniigenden Oxydation in einer Ueberlarlung iles Blutes durch Kohlensäure zu suchen. Auch hier ist Eiweisszerfall die nothwentige Folge der Schäıligung, die sich bei der Schmetterlingspuppe durch vollkommene Realitionslosigkeit, durch ausgelelnte Lähmungserscheinungen zu erkemmen giebt. Dies? Auffissung ler Hitz- un l Frostaberrationen, als las Resultat ausserorilentlicher Stoffirechselstiirungen während des Puppenlebens, findet cine Bestätigung darin, dass auch antere Eingriffe, die physiologisch ähnlich schïiligenl wirken, zur Biliung analoger Aberrationen führen" (1). 629).

Spïtere Cntersuchungen von M. v. Linden hatten ren Zweck zu ermitteln, welche Einflüse die Pigmente der Puppe hzw. des werdenden Falters direkt verïnlern, und welche derselben einen incl irekten Einfluss ausüben, inılem sie den Stoffivechsel der Iampe, der Puppe ouler des Falters in der einen orler anderen IVeise verändern. Als Versuchsobject wählte sie Vanessa urticue.

Bei Temperaturen unter $40^{\circ}$ konstatierte sie, dass "lie Ernälrungszeit abgekiirzt, das Wachstum der Raupe darlurh beinträchtigt und die Entstehung kleiner unpigmentierter lebhaft schillernder Puppen beslingt wirl. Auch auf die Entwiclielung rler Puppen wirkt die Wärme beschleunigent. Die Puppenruhe wiril schon bei $32-35^{\circ}$ Ungebungstemperatur un die Hiilfte der Zeit verkürzt. Die Falter zeichneten sich durch eine Vermehrung der roten Schuppen der Grundfarbe gegenuiber dem Gelb und Schwarz der Zeichnung aus."

Bei Temperaturen über $40^{\circ}$ beobachtete sie "Eintritt von Lethargie, Lühmung oder Starre, namentlich wenn in dem Thermostaten für genïgende Feuchtigkeit gesorgt war, nie." Die Verpuppung wird durch hohe Wärmegrade bedeutend abgeliurzt. Dabei (bei $45^{\circ}$ ) wurle beobachtet, dass "die hohe Temperatur keineswegs ein früher auftretendes Zeichnungsstadium auf dem Puppenflügel fixiert hatte, sondern in Gegentheil die Entwickelung der Zeichnung ausserordentlich beschleunigt, indem ältere Zeichnungsstadien übersprungen wurden und die neueren zu einer weiteren Ausbreitung gelangten, als es normalerweise der Fall ist." "Der ganze Vorgang der Verfärbung trägt hier, wo wir ihn von Anfang an beobachten können, ein entschieden fortschrittliches Gepräge, denn Färbungsstufen, die der normale Falter innerhalb von Tagen rlurchläuft, folgen sich hier innerhalb von Stunden. Wir beobachten hier eine abgekiirzte Entwickelung, keine Entwickelungshemmung der Zeichnung.“ 
Als die Puppen bei gewöhnlicher Temperatur in liohlensïureresp. Stickstoffatmosphäre gehalten wurten, ergaben sie bei normaler Puppenzeit ab. ichnusoicles. In luftverliinntem liaume wurlen Uebergänge zu ab. ichnusoides erhalten.

M. v. Linden kommt zum Schlusse, lass mässige lemperaturerhöhnugen einen direkten Eintuss auf die Farbonloiliung in der Schmetterlingspuppe ausiiben. „Wenn wir die Verdunklung der roten Grundfarbe des Schnetterlingstlügels auf eine dirchte Wiirmewirkung zurickzufiihnen berechtigt sinil, so muss die Bihlume des schwarzbraunen Pigments der indirekten Wirkung der thermischen Reize zugeschrieben werlen. Temperaturerhöhungen bis unter $40^{\circ}$ verhindert das Entstehen melanotischer Pigmente sowohl in der Puypenhülle wie auch in der Zeichnung cles Falter's. 'Temperaturerniedrigung bewirkt im Gegentheil eine Zunahme der dunkeln Farbstoffe. Erhöhter Stoffirechsel, beschleunigte Entwickelung ist ler Entstehung dunkler Pigmente somit unginstig, während diese in einer Verlangsamung der Lebensprozesse eine günstige Bedingung für ihre Bildung finden. ... Der Hauptfiktor bei der Aberrationsbilliung ist die zeitweilige Hemmung der Oxyclationsvorgünge im Puppenorganismus. Es ist gleichgiiltig, ob wir diesen Zustand durch Sauerstoffentziehumg erreichen, odler dadurch, dass wir durch äussere Reize die Realitionsfähigkeit des Plasmas verringern oder aufheben, und auf́ diese Ircise die Oxydationsvorgänge unterbrechen. Hitze und Frost wirken direkt auf das Plasma, sie heben die Irritabilitiit resselben auf, wie es auch durch narkotische Nittel geschehen kann. ... Wir kömen also verallgemeinernd sagen, dass jeder Einfluss, der bei der jungen Puppe die Verbrennungpsrozesse herabsetzt, dass jeder Einfluss, der die Atmungstätigkeit hemmt, aberrative Bildungen zur Folge hat, Bildungen, die sich durch eine Uoberhandnahme schwarz pigmentierter Schuppen und durch die Realition des roten Farbstoffs auszeichnen."

\section{Die Theorie von Harry Federley.}

Diese Theorie ist aus der Abhandlung von Harry Federley: "Lepidopterologische Temperatur-Experimente mit besonderer Berücksichtigung der Flïgelschuppen" (1905. 219a) ersichtlich.

Als er Puppen der Wirkung einer mässig erhöhten Temperatur ausgesetzt hat, „d. h. einer Temperatur, die noch nicht auf die Lebensfunktionen einen herabsetzenden Einfluss ausiibt," erhielt er gut entwickelte Schuppen, welche dicht neben einander stehen und 
vor allem ein grosses, mit wenigen sehr lileinen und stumpfen Processus versehenes Corpus besitzen; als er aber die Puppen dem "schädlichen Einflusse der gesteigerten Temperatur" aussetzte, erhielt er die stellenweise undichten un l oft an Grösse reluzierten Schuppen, was darauf hindeutet, "lass die Temperatur wirklich Stoffwechselstörungen hervorgerufen hat. Es hat ren Anschein. als ob die Schuppenmutterzellen stellenweise ron der Wärme cretiitet worden wären."

Die Wirkung der mässig erhöhten Temperaturen auf Schuplen stellt er sich theils als eine inlirekte, theils als eine direkte ror. „Erstere bestelit in einer lirüftigen Anregung des Stoffirechsels, speziell iler Circulation der Hämolymphe, velche lebhafter und griun llicher wiril und darlurch wahrscheinlich zur Zeit der Entwickelung der Schuppen eine reichlichere Chitinabsonderung ermöglicht, was wiederum die bedeutende Grösse dier Schuppen erklären wirrle. Die d irekte Einwirkung zeigt sich als ein? Vergrösserung des Volumens (ler Tiörpersïfte, wo:lurch dieselben einen grösseren Druck ausïben."

Hitzeexperimente ergaben, "lass die Temperatur ausschliesslich eine störencle Einwirkung auf len Stoftumsatz ausgeiibt hat, was cie Schuppen auch sofort verraten. Die Chitinbildung ist cine ganz defekte gewesen, und die Merzahl der Schuppenmutterzellen sogar von der Hitze getötet worden, was sich in den oft fast schuppenlosen Flügeln kund gibt.“ Bei diesen Experimenten befanden sich die Puppen während der Exposition in einem lethargischen Zustanil und auch noch mehrere Tage nach dem Versuche. Dass daljei Stoffivechselstörungen auch eingetroffen waren, bestiitigen der grosse Prozentsatz der verkrüppelten Falter und die vielen getöteten Puppen. In gewissen Fällen komnte auch eine Verzögerung in der Entwickelung beobachtet werden.

Kälteversuche ergaben Schuppenformen, welche mit ilen Schuppentypen der Kälteversuche eine sehr grosse Ahnlichkeit zeigen. "Als Ursache der Veränderungen bei der Wärmeexposition betrachtete ich die durch die Wärme gesteigerte Intensität der Stoffirechseltïtigkeit unil den vergrösserten Druck. Man könnte sich denken, dass die Kälte auch eine anregende Wirkung auf die Lebenstätigkeit der Puppe ausübt, wie sie es ja tatsächlich unter Umständen bei anderen Organismen tut, aber diese Erklärung würde höchstens fïr die Versuche mit intermittierender Kälte gelten, lagegen nicht fur diejenigen mit anhaltender, unternormaler Temperatur." Er vermuthet diese Ursache in dem gesteigerten Druck der Säfte, welcher wirklich 
stattfinlen kann, da der Hauptbestandtheil der Säfte, nämlich Wasser, bei Ablïhlung sich zuerst zusammenzieht, dann aber bei weiterer Abkühlung sich wieder ausdehnt.

„Die Reizbarkeit der Puppen während dieser Exposition wird sehr wenig herabgesetzt, was wiederum beweist, dass eine Temperatur von $0^{0}$ bis $+6^{0}$ in der Entwickelung keine Störungen, sondern nur eine Verlangsamung hervorruft." "Frostexperimente verhalten sich zu den Kälteexperimenten wie die Hitzeversuche zu den Wärmeexpositionen. Denn währenı weder bei mässig erhöhter noch bei mässig erniedrigter Temperatur Stoffwechselstörungen eintreffen, treten sie sowohl bei den Hitze- als auch bei clen Frostexpositionen in den Vordergrund, wenn sie auch in den beiden Fällen ziemlich verschieden zum Vorschein kommen. Gemeinsam für beide ist die undichte Beschuppung, welche übrigens bei den Hitzeformen immer am undichtesten ist. Dieselbe muss als eine Folge der schädlichen Einwirkung der extremen Temperaturen betrachtet werden. Letztere ubbt zweifelsohne einen direliten Einfluss auf das Plasma der Schuppenmutterzellen aus."

Wenn bei diesen Versuchen die Schuppen lange nicht so stark deformiert sind, wie bei den Hitzeformen, so „muss man doch annehmen, dass kräftiger wirkender Frost, weit hochgradiger veründerte Schuppenformen hervorrufen würde, und dass die Differenz zwischen den Frost- und Hitzeformen somit bedeutend ausgeglichen werden kömnte."

Nachlem er alle von ihm erhaltenen Schuppenaberrationen uiberblickt, kommt er zum Schlusse, "dass die Veränlerungen nie fleckenweise auftreten, sondern immer eine streng bilaterale Symmetrie zeigen. Diese Tatsache beweist völlig, dass die Veränclerungen der Schuppen das sichtbare Resultat tiefgreifender Stoffwechselveränderungen oller -störungen sind unil denselbe'n also in erster Linie ihre Entstehung zu ver(anken haben."

$\mathrm{Er}$ ist der Ansicht, dass die Schuppenveründerungen durch die extremen Temperaturen der direkten Einwirkung dieser Temperaturen zuzuschreiben sind, wenn dabei auch ihre indirekte Wirkung auf dem Wege des Stof'ivechsels vorhanten ist.

Was nun das Verhalten der Pigmentaberrationen zu den Schuppenaberrationen anbelangt, so sagt er, dass die Veränderungen nicht immer von einander abhängig sein müssen. "In den meisten Fällen gehen die Veränderungen jedoch Hand in Hand."

Nach der Meinung von Federloy zeigun die extremsten Aberrationen einen unzweideutig pathologischen Charakter uml können 
nicht als phylogenetische Itemmungswebilde angesehen werilen, uni glault nicht, shass wir durch Einwirliung extremer Temperaturen o) ler anderer iusserer Reize auf die Puppe Ii iickschlagsformen (ausgestorbene Formeni), weder in Bezug auf lis Zeichnung noch auf die Schuppenform, hervorufen liönen." Er giebt aber zu, lass sowohl regressive als progressive Formen im Sime Standfuss soln gut erzielt werden können.

In wesentlichen schliesst or sich der Theorie v. Linden's an.

\section{b) Zusammenstellung dieser 'Theorien und die Prüfung ihrer Consequenzen.}

Wir werlen die soeben hetrachteten Theorien zum leichteren Vergleichen noch ein Mal liurz präzisieren Dahei sind die Tcrmina nach ler genauen Furmulierung Fischer's (236) zu rerstehen, und zwar:

$A$ - Formen $=$ normale Formen (bei gewöhnlicher Temperatur),

$B_{1}$-Formen $=$ Kälte-Variationen $\left(\right.$ bei $0^{\circ}$ bis $\left.+10^{\circ}\right)$,

$C$ - Formen $=$ Wärme-Variationen $\left(\right.$ bei $+35^{\circ}$ bis $\left.+37^{\circ}\right)$,

$B_{2}$-Formen $=$ Wärme-Variationen $\left(\right.$ bei $+36^{\circ}$ bis $\left.+41^{\circ}\right)$,

$D_{1}$-Formen $=$ Frost-Aberrationen $\left(0^{\circ}\right.$ bis $\left.-20^{\circ}\right)$,

$D_{2}$-Formen $=$ Hitze-Aberrationen $\left(+42^{\circ}\right.$ bis $\left.+46^{\circ}\right)$.

1. Die Theorie von A. Weismann (Reiz-Theorie):

Die Temperatur ist im allgemeinen keine direkte Ursache der Formenbildung, sondern nur der Re iz.

Ein Theil der Färbung kam auch als direkte Folge der Temperaturwirkung betrachtet werden.

Der Atavismus tritt dabei nicht auf.

2. Die Theorie von F. Uroc'a (Oxylations-Theorie).

Beim Uebergang der Puppe von höher temperierter Wärme auf materielle Systeme von nierlerer Temperatur strebt ler Puppen-Organismus diesen Wärmeverlust in ihr $\mathrm{zu}$ ersetzen; es geschieht dies rlurch Verbrennungsvorgänge an Stoffvorräten, also durch Oxylations- und dabei erfolgenle chemische KondensationsVorgänge. Die Pigmentstoffe werilen rabei zum Theil zu Wasser verbrannt: es entstehen kohlenstoffreichere chemische Kö̈rper (Kondensations- mol Redultions-Produlte), die meistens dunkler gefärbt sind, daher tritt dunkleres Pigment auf.

Anlererseits kimn Wärmezufuhr die Geschwindigkeit ier Puppe, der Athmung und der partiellen Oxydation vermehren 
und so kohlenstoffreichere, dunklere Pigmentstoffe durch chemische Konlensations- mol Relultions-Vorgänge hervorbringen; darum entstehen bei erhöhter Wärme dunklere Subspecies aus kälterem Kilima angehörenden Species mit helle ren Farbentönen.

Die durch die Temperaturexperimente hervorgernfenen Farbenäderungen sind Kompensationserscheinungen.

3. Die Theorie von M. Standfuss (Theorie der indiviluellen Anomalien).

Die Frost- und Hitze-Experimente unterbrechen die Entwickelung, sie versetzen das Insekt in einen Zustanıl der Lethargie; sie wirken auf die Färbung indirekt.

Mässig hohe und niedere Temperaturen haben specifische und entgegengesetzte Wirkung des Reizes, inclem sie Rückschlagsformen erzeugen können (aus nördlichen Formen entstehen durch Kälte regressive und durch Wärme progressive Formen; aus süllichen Formen entstehen durch Kialte progressive und durch Wärme regressive Formen).

Aberrationen sind individuelle Fïrbungsanomalien ohne atavistische Bedeutung.

4. Die Theorie von E. Fischer (Hemmungs-Theorie).

Alle Formen (nit Ausnahme von $C$-Formen) werden nicht durch die speciflsche Wirkung der Temperaturen, sondern nur durch die Entwickelungs-Hemmung erzeugt.

Specifiche Wirkung der Temperatur finclet nur bei $C$-Formen statt.

Alle Formen sind atavistiche Formen (mit Alsnahme von $C$-Formen).

\section{Die Theorie von M. C. Piepers (Correlations-Theorie).}

Wärme und Kälte verhindern die Entwickelung, den normalen Standpunkt in der Farbenevolution zu erreichen. Sie treten auch als Reize auf, (lie Evolution weiter zu treiben.

Die Farbenevolution kann clurch klimatische Eintlisse beschleunigt oder verzögert werden.

6. Die Theorie von Chr. Schröder (Wärmebingungs-Theorie). $B_{1}-, B_{2^{-}}, D_{1}$ - und $D_{2}$-Formen stellen Reaktionen des Organismus dar, um die durch unternormale Temperaturen hervorgerufene Entwickelungsverlangsamnung zu paralysiren. 
$C$-Formen sincl einer erhöhten Temperatur eigen.

Die Temperaturformen sim durch riickschlägige Zeichnungsanlagen charakterisiert, ohne dass sie deswegen strats die primïre Zeichnung überhaupt widergeben müssten.

7. Die Theorie von M. v. Linden (StoffwechselstörungsTheorie).

Die Temperaturwirkungen rufen clie zeitweilige Hemmung der Oxydationsvorgänge hervor.

Direkte Temperaturwirkungen gelten für lie rothe Grumlfarbe, die indirekten für die schwarzbraunen Pigmente.

Nur eine direkte Temperaturwirkung haben lie mïsig erhöhten Temperaturen.

\section{Die Theorie von H. Federley (Druck-Theorie).}

Mässig erhöhte Temperaturen wirken direkt (Vergrösserung des Volumens der Körpersäfte und ilıres Druckes) unil indirekt (Anregung des Stoffwechsels).

Mässig erniedrigte Temperaturen rufen ähnliche Formen wie die nässig erhöhten Temperaturen, wobei als Crsache ler gesteigerte Druck der Säfte zu betrachten ist.

Die Hitze bewirkt den lethargischen Zustand un I lie St offwechselstörung und töltet schliesslich dlas Plasma.

Der Frost bewirkt die Stoffwechselstörung und übt einen direkten Einfluss auf das Plasma der Schuppenzellen aus.

Die bei extremen Temperaturen erlialtenen Aberrationen sind pathologische, keine atavistische Formen und sind einander ähnlich.

Regressive und progressive Formen können nur im Sinne von Standfuss entstehen.

Fassen wir alle diese Theorien zusammen, so kommen wir zu folgenden Fragen, welche die Lösung dieser Theorien zur Aufgabe gehabt haben:

1. Wirken die Temperaturen auf das werlende Kleiı des künftigen Schmetterlinges direkt oder indirekt, und worin besteht diese Wirkung?

2. Was stellen die dabei erhaltenen aberrativen Formen vor?

Folgende Tabelle enthält die Ansichten verschiedener Forscher ïber die direkte o:ler indirekte Wirkung der Temperatur auf 
das werdende Falterkleid (speziell von Vanessen), wobei das Zeichen $(+)$ die entsprechende Behauptung des betreffenten Forschers berleutet.

\begin{tabular}{|c|c|c|c|c|c|c|c|}
\hline $\begin{array}{c}\text { Aberrative } \\
\text { Formen resp. } \\
\text { Temperatur- } \\
\text { Intervale }\end{array}$ & $\begin{array}{c}\text { Die } \\
\text { Tempera- } \\
\text { turwir- } \\
\text { kung }\end{array}$ & 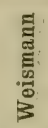 & 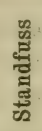 & 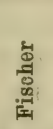 & 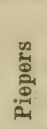 & 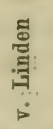 & 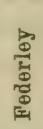 \\
\hline $\begin{array}{l}D_{2} \\
B_{2} \\
C \\
B_{1} \\
D_{1}\end{array}$ & $\begin{array}{l}\stackrel{\Xi}{0} \\
\vdots \\
\vdots\end{array}$ & + & $\begin{array}{l}+ \\
+ \\
+\end{array}$ & + & + & $\begin{array}{l}+ \\
+ \\
+ \\
+ \\
+\end{array}$ & $\begin{array}{l}+ \\
+ \\
+ \\
+\end{array}$ \\
\hline $\begin{array}{l}D_{2} \\
B_{2} \\
C \\
B_{1} \\
D_{1}\end{array}$ & 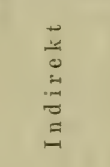 & & + & $\begin{array}{l}+ \\
+ \\
+ \\
+ \\
+\end{array}$ & & $\begin{array}{l}+ \\
+ \\
+ \\
+\end{array}$ & $\begin{array}{l}+ \\
+ \\
+ \\
+ \\
+\end{array}$ \\
\hline
\end{tabular}

Aus dieser Tabelle ist ersichtlich, dass tast alle Forscher für $C$-Formen eine direkte Wirkung der Temperatur und für $\nu_{2}$ und $D_{1}$-Formen eine indirekte annehmen. Auffalend ist die Stellung von Fischer: währenı seine Ansichten über die indirekte Wirkung der Temperatur mit denjenigen von Federley und v. Linden zusammenfallen, weichen sie sehr stark von clenselben für die direkte Wirkung ab. Der Grund liegt darin, dass Fischer unter der indirekten Wirkung der Temperatur den Rückschlag zur Stammform (Atavismus) versteht und somit die direkte Wirkung selbstverständlich nicht zulassen kann, während v. Linden und Federley die Stoffwechselstörung resp. Stoffwechselanregung in der indireliten Wirliung der Temperatur ersehen, also kieinen $R$ ii ckschlag dieser Wirkung zuschreiben. Standfuss steht mit seinen Ansichten in der Mitte zwischen Fischer einerseits und Foderley und v. Linden andererseits, indem er nur einen beschränkten Rückschlag der Temperaturwirkung zuerkennt und die Aberrationen bei extremen Temperaturen als pathologische Formen betrachtet.

Um alle hier angeführten Theorien auf ihre Consequenzen zu prüfen, wollen wir den Bewegungszustand des Protoplasmas in Zellen unter dem Einfluss verschiedener Temperaturen in Betracht ziehen und sich zu diesem Zwecke der Fig. 9 bedienen. 
Im I. Kapitel des theoretischen Theils (1. Alschnitt) wurle ler Bewegungszustand des Protoplasmas in Zellen eingehend hehanlelt, hier möge nur erwähnt werilen, dass, wie Sachs (729) fimul, die Bewegung des Protoplasmas verschimlene Geschwindigkeiten lesitzt, unil zwar wirl sie verlangsant bei 'T'emperaturen. welche über oder unter der normalen liegen. I)iese Bewegung hirrt auf, wem die Temperatur iles Protoplasmas ca. $15^{\circ}$ resp. $4^{\circ}$ beträgt, wobei die vorübergehende Külte- resp. Wärmestarre anftritt. Unter oder iiber diese Temperaturen limaus tritt lie permanente Starre auf, was seinerseits den Tod verursacht.

Diese verschiedenen Bewegungszustänte rles Protoplasmas, wel :he Sachs in Pflanzenzellen entileckt hat, beziehen sich auch auf Inseliten, wie ich es in verschielenen meinen Abhandlungen nachwies, hauptsächlich aber bei der Untersuchung der „Lïhmung bei Lepilopteren infolge erhöhter Temperatur ihres hörpers" (28). Ich brachte damals verschieilene lebend angenagelte (an die thermoelektrische Xarlel) Schmetterlinge in einen Thermostat bei verschierlenen Temperaturen und beobachtete, bei welcher eigerien Temperatur der Schmetterling zu summen resp. Hattern aufliört. Ein Beispiel wirl diesen Vorgangklarer darstellen.

Zum Versuche wurde Splinx pinastri benïtzt, wobei die Temperatur im Thermostate $18,5^{\circ}$ betrug. In Folge des Summens stieg die eigene Temperatur des Scmmetterlings bis zu $33^{\circ}$, wobei er zu summen plötzlich aufhörte, nicht aber der Müiligkeit wegen, sonderı, wie es nachgewiesen wurle, wegen der partiellen Lähmung der Fliigelmuskeln, welche Lähmung bei der darauf statgettundenen Abkühlung wieler verschwunden war. Diese vorïbergehende Wärmestarre des Protoplasmas in Zellen der Fliigelmuskeln tritt nicht immer bei $33^{\circ}$ auf, vielmehr hängt diese Starretemperatur von cler Lufttemperatur ab, bei welcher der betreffende Schmetterling vor iem Versuche sich befand, und von der Wiederholung des Summens, wie es folgende Zusammenstellung meiner Versuche mit Sulinx pinastri veranschaulicht:

\begin{tabular}{|c|c|c|}
\hline \multirow{2}{*}{$\begin{array}{l}\text { Die partielle Lahmung } \\
\text { eingetreten resp. die Kör- } \\
\text { pertemperatur stieg bis }\end{array}$} & \multicolumn{2}{|c|}{ Lufttemperatur } \\
\hline & $18,5^{0}$ & $32,5^{0}$ \\
\hline bei 1. Summen & 33,6 & 43,9 \\
\hline$" 2$. & 33,3 & 43,2 \\
\hline$n 3$. & 33,0 & 42,6 \\
\hline$n 4 . \quad n$ & 29,8 & - \\
\hline
\end{tabular}


d. h. je höher die Lufttemperatur ist, bei umso höherer Temperatur seines Körpers erleilet ler Schmetterling die vorïbergehende Wärmestare. Das Wiederholen des Summens erniedrigt die Starretemperatur.

Ausserdem fand ich damals, dass die permanente Wärmestarre (ler Flïgelmuskeln in trockener Luft bei ca. $48^{\circ}$ unil in feuchter Luft bei ca. $54^{0}$ auftritt.

Es scheint, dass die Untersuchungen von Sachs, Max Schultze (792) und Anderen iiber den Bewegungszustmol des Plasmas den Entomologen unbekannt geblieben seien; wenigstens gebrauchte Niemand von ihnen den Austruck "Starre" in diesem Sinne, und der Lebenszustand der Puppe bei extremen Temperaturen (Hitze und Frost) wurle stets durch die "Hemmung", "Lethargie" etc. bezeichnet, ohne auf die Details und das Wesen der Ursache diesen Zustandes näher einzugehen. Hier genïgt, nur die Worte von E. Fischer (229) auzufïhren, welcher "die letzte Ursache" der Hemmung in einer durch die Kälte erzeugten Veränderung und Verlangsamung des Strffwechsels, speziell in einer Afficierung des Nerven- und Circulationssystems sucht und sagt: "Möglicherweise liegen die Grïnle noch viel tiefer und verborgener, unil es wird erst noch zahlreicher experimenteller Beobachtungen bedürfen, bevor man sicherzustellen imstante ist, welche Deutung fiir alle liese Erscheinungen die allein richtige ist."

Dass durch den Bewegungszustand des Protoplasmas viele erst jetzt an Insekten entileckten Erscheinungen vorausgesagt werlen konnten, geht z. B. aus den Untersuchmungen von M. Standfuss hervor. Er sagt in seinen "Studien" (841), dass die Temperaturen ron $+4^{0}$ und $+6^{0}$, welche mehrere Wochen lang anhaltend auf Puppen einwirken, wemn auch ausnahmweise Aberrationen im Gefolge haben. Er meint, dass auch bei $+3^{0},+2^{\circ},+1^{0}, 0^{0},-1^{0},-2^{\circ}$, $-3^{0},-4^{0}$ Aberrationen in gewisser Anzahl sich bilden sollen, "lann nämlich, wann diese Grade längere Zeit einwirlien" und setzt weiter fort: "Es ist nicht nur denkbar, sondern wahrscheinlich, dass hier Zeitlauer und Temperaturgrale sich gegenseitig in gewissen engen Grenzen kompensieren liönnen; ich meine so; das bestimute niedere Minustemperaturen kurze Zeit einwirkent ginz lenselben Effekt erzeugen, wie bestimmte, weniger nielrige Minustemperaturen in längerer Einwirkung" (1). 20).

Abgesehen von den angewanilten Temperaturgraden, bestïtigt sich cliese Vermuthung durch die Untersuchungen von Sachs, welcher 
fand, das bei Mimosa pudica ein vorübergehender Starrezustand bei $40^{\circ}$ erzeugt wird, wenn diese Temperatur eine Stunde lang gewirkt hat; die Temperatur von $45^{\circ}$ ruft einen ähnlichen Effelit hervor, wenn sie $1 / 2$ Stunde thätig war; bei $49^{\circ}$ trirtt die Starre in noch kïrzerer Zeit auf. Dies widerspricht auch den mechanischen Gesetzen der Deformation nicht, unl ist vielmehr eine direlite Folgerung aus denselben.

Obwohl die hier kurz erwïhnten unl im I. Kapitel (les theoretischen Theils, Abschnitt 1) ausfuihrlicher besprochenen Erscheinungen der Pflanzen- und Inseiten Physiologie eine grosse Analogie unter sich haben und somit anf die gleiche Ursache, nämlich auf die Wärme- risp. Kältestarre des Protoplasmas reluziert werilen sollen, So zwingen uns doch die anderen Thatsachen, gewisse Begrenzungen und Zusätze dabei zu machen, umsomehr als die Puppen sowohl eine andere chemische Zussammensetzung, wie auch eine andere anatomische Konstrultion ihres Körper's haben, als die Pflanzen.

In erster Linie mïssen wir annehmen, dass bei der Einwirkung ler Kïlte resp. Wärme nicht alle Zellen gleichzeitig die Starre des Protoplasmas erleiden werden, sondern zuerst solche, welche sich auf der Oberfläche des Puppenkörpers befinden und erst später die inneren, was ohne weiters klar ist.

Diese Aunahme drängt sich auf, weil dadurch die partielle Entwickelungshemmung bei Puppen zu erklären wäre. Belianntlich kam E. Fischer zu dem Schlusse, dass bei niederen Tempereturen nur die den Farben zu Grunde liegenden "Elemente" in ihrer Weiterentwickelung gehemmt werlen, im übrigen aber schreitet der Organismus der Puppe in der Entwickelung weiter, wenn auch bedeutend verlangsamt.

Von grosser Wichtigkeit ist es auch, festzustellen, ob das Protoplasma die Wärme- resp. Kältestarre in allen Zellen bei einer und derselben eigenen Temperatur erleidet. Die vorhandenen Thatsachen sprechen, wie es scheint, dagegen.

Nach Nägeli (603) hört bei Nitella syncarpa die Strömung in der Zelle erst dann auf, wenn die Temperatur auf $0^{0}$ sinkt. Sachs fand in den Haaren von Cucurbita pepo bei $16,5^{\circ}$ eine so langsame Bewegung des Protoplasmas, dass sie nur schwierig zu erkennen war, und sie war ganz erloschen, als die Temperatur 12,50 betrug, während bei Solanum lỵcopersicum unter gleichen Umständen (lie Haare wenigstens in einzelnen Fällen strömende Bewegung zeigten. Was dagegen die Beweglichkeit der Seitenblättchen anbetrifft, so fand 
Kabsch (427), dass sie bei Hedysarum gyrans in beständiger Ruhe sind, wenn die Temperatur $22^{\circ}$ beträgt; selbst bei $23-24^{\circ}$ sei die Bewegung noch fast unmerklich. Sachs fand für den unbeweglichen Zustand bei Mimosa pudica die Temperatur von $15^{\circ}$.

In der neusten Zeit hat Jas. Clark (147) in dieser Beziehung viele Versuche angestellt. Pflanzenarten, welche auf dem Monte Rosa und auf dem Gletschhorn (10.000 Fuss hoch) gesammelt waren, zeigten alle Strömungsbewegungen im Parenchym der Stengel bei $0^{0}$. Die Protaplasmabewegung bei $0^{0}$ beobachtete er auch bei Solil anella alpina, S. pusilla, Crocus verna, Primula integrifolia etc., welche auf den niedrigeren Schweizer-Alpen bliihen. Aehliche Resultate wurden erhalten von Winterpflanzen der Stellaria media, Cerastium triviale und Seneciovulgaris in Englanl. Das Stengelparenchym der meisten unserer Getreidearten giebt ein Minimum der Protoplasmabewegung bei ca. $5^{\circ}$. Für Onobrychis sativa, Lupinen, indische Roggen liegt das Minimum zwischen $S^{0}$ und $11^{\circ}$; für Tomaten bei $14^{\circ}$ und für die meisten Treibhausptlanzen bei $18^{\circ}$ und dartiber.

Diese Minima sinil jedloch nicht lionstant, so z. B. giebt Cochlearia officinalis von der englischen Meereskiiste ein Minimum von $5^{\circ}$ bis $7^{\circ}$ und von der Horneckalp etwa $1^{\circ}$; Asphorlelus albus vom Riederhorn (Schweiz) $2^{\circ}$ und in seiner Heimath (Nittelmeer) $7^{\circ}$ bis $10^{\circ}$. Exemplare des Potamogeton marinus vom FullySee (7000 Fuss) zeigten Strömungsberegungen im Blatt bei (00, als sie jedoch 6 Monate im botanischen Garten zu Tuibingen verweilt haben, zeigten sie ein Minimum von $7^{\circ}$.

Das Minimum für die Zellen der Wurzel ist in der Regel niedriger, als für die des Stengels und der Blätter, der Unterschied betrug in einigen untersuchten Sumpfpflanzen $8^{\circ}$.

Aus diesen Angaben ist ersichtlich, dass die Kältestarre für verschiedene Pflanzenspecies bei verschiedenen Temperaturen eintritt.

Dasselbe gielt auch für die Wärmestarre, wie es folgende Versuche ergeben: 1) Zweige von Cucurbita pepo und Solanum lycopersicum wurden sulange erwärmt, bis die Luft neben den Blättern $49^{\circ}$ erreichte und dann 10 Minuten lang bei $49^{\circ}-50,5^{\circ}$ erhalten. In den Haaren beider Pflanzen war das Protaplasma in rascher Strömung, besonders bei Cucurbita war dieselbe äusserst lebbaft. 2) Ein Blüthenzweig von Tradescantia wurde auf $49^{\circ}$ erwärmt (neben den Blüthen) und diese Temperatur 3 Minuten angehalten. Das Protoplasina der Haare eines Staubfadens war in Ruhe; 
aber schon mach 3-4 Minuten begamn dir Bewegung wieler. Nach abermals 10 Vinuten, während welcher tas 'Thermometer neben den Blïthen 46-480 zeigte, wurile wieiler ein Statuffarlen untersucht: las Protoplasma der Haare zeigte eine sehr langsame Bewegung. 3) Die Bliithe, welche die letzten Staulfiulen goliefert hatte, war nun seit einiger Zeit etwa halbe Stumle wieler in Luft ron $20^{\circ}$. Ein jetzt herausgenommener St:ubfailen z: igte das Protoplisma der meisten Haare in Strömung, in manclinn Haarzellen aber fimrl es sich in Ruhe. (Sachs).

Wie oben erwähnt, hat Clare lie Veränderungen der T'rmperaturstarre des, Protoplasmas durch das Akklimatisieren filir die Kälte nachgewiesen. Dasselhe ergiel,t sich aus Versuchen von C. B. Davonport unı W. R. Castle (165) auch für die Wärne. Sie untersuchten Metazoen (Kaulquappen), wobei diese Orgunismen von Ei an 28 Tage in Wasser von $25^{\circ}$ gehalten wurlen. I)ie Wärmestarle tratt bei $43,5^{\circ}$ auf. Als diese (Uuppen aber bei $15^{\circ}$ gezogen wurlen, zeigten sie die Sturre schon hei 40,30. I)iese Alkomociation wiril von Thieren beibehalten; so z. B. als sie 17 Tage bei $15^{\mathrm{C}}$ verblieben, wiesen sie die Starre erst bei 41,50 auf. Diese Forscher vermuthen die Frkilirung dieser Erscheinung in ter Verminderung des Wassergehaltes im Protoplasma.

Dי diraus zu ziehenle Schluss; dass lie Wärme- resp. Kïltestarre des Protoplasmas bei verschiedenen Spezies und bei verschiedenen Temperaturen eintritt, ist insofern wichtig, als man dalurch das Entstehen der aberrativen Schmetterlinge für jele Spezies bei verschiedenen Temperaturen erklären kann.

Die Temperaturen, bei welchen die Kältestarre des Gesammt-Organisums eines Inselites eintritt, sind auch je nach der Spezies verschieden.

So z. B. erhielt Dönhofi (18T) mit Fliegen (Nluscu domestica) folgende Resultate: 1) 5 Stunden bei $-1,5^{\circ}$. Die Thiere bewegen sich. 2) 8 Stunden, anfangs bei $-3^{\circ}$, zuletzt bei $-2^{\circ}$. Die Thiere bewegen die Beine. 3) 12 Stunden, anfangs bei $-3,7^{\circ}$, zuletzt bei $-6,3^{\circ}$. Scheintot. Bei Erwärmen leben sie wieder aut. 4) 3 Stunden, anfangs bei $-10^{\circ}$, zuletzt bei $-6^{\circ}$. Gestorben.

Mussehl (6008) hat ermittelt, dass eine einzelne Biene (Apis mellifica) bei $+5^{\circ}, \mathrm{R}$. erstarrt.

V. Graber $(325 a)$ sagt bezïglich des sogenannten „lokomotorischen Minimums" bei der Küchenschabe (Periplaneta orientalis): „Der schlaftrunkene Zustand stellt sich olne Ansnahme binnen 2 bis. 
3 stmilen boi allen Inlividuen ein, wenn man die Temperatur bis anf 20 über Null sinken lïsst" (p. 243). Dieses Nininum war bei liesen Inseliten in Mittel $+4^{0}$. Als die Temperatur $-4^{0}$ war, hatten lie 'Thiere the Fühigkeit der freiwilligen Ortsbewegungen für immer verluren, 4 . h. bei dieser Temperatur trat bei ihnen die permanente Starre ein. Der Tot trat bei $-6^{0}$ ein.

Auch ich stellte solche Versuche an (29), wobei die Insekten bei $0^{0}$ eine Stumle verblieben; es ergab sich, dass in diesem kalten Luftbarle Dorcudion rufires noch starke, Larinus turbinatus mittelsturke, Dorcadion sturmii schwache, MLusca domesticn lieine Bewegungen hatte. Das letztere Inselit lebte bei Zimmertemperatur wieder auf.

Weitere genauere Untersuchungen in clieser Beziehung stellte ich mit rem Falter Deilephila enphorticae an. Derselbe wurde mit seinem Thorax an eine thermoelelitrische Nalel angespiesst, welche eigene Temperatur des Insekts angab, und in ein kaltes Luftloul gebracht. Hier sei der Auszug aus dem Beobachtungsprotoliol (3./16. VI. 1900) gegeben, wobei $t_{i}$ die Temperatur des Schmetterlings mil $t_{l}$ diejenige des Luftbades bedeutet.

\begin{tabular}{|c|c|c|c|}
\hline Zeit & $t_{l}$ & $t_{i}$ & $\mathrm{~B}$ e $\mathrm{merk} \mathrm{r} \mathrm{g}$ e $\mathrm{n}$ \\
\hline $3^{\mathrm{h}} 04 \frac{1^{\prime}}{2}$ & $17,0^{\circ}$ & $26,5^{0}$ & Bervegt die Flügel nicht, nur die Beine. \\
\hline $08 \frac{1}{2}$ & 12,0 & 16,8 & $\begin{array}{l}\text { Wurde mit einem Stäbchen gereizt. Bewegt lansgam } \\
\text { seine Flügel. }\end{array}$ \\
\hline 13 & 10,4 & 14,0 & Noch làngsamer. \\
\hline 17 & 10,3 & $: 12,2$ & Ganz schwache Flügelbewegungen. \\
\hline 19 & 10,3 & 12,1 & $\begin{array}{l}\text { Nur schwache Bewegungen mit Flügeln, mit Beinen } \\
\text { gar keine. }\end{array}$ \\
\hline $21 \frac{1}{2}$ & 10,2 & 11,8 & Wurde wieder angestossen. Bewegungen etwas stärker. \\
\hline 25 & 10,2 & 11,4 & Fast bewegungslos. \\
\hline $26 \frac{1}{2}$ & 8,2 & 9,5 & Dasselbe. Das Luftbad im Eiswasser. \\
\hline 36 & 3,2 & 5,0 & Ganz schwache Bewegungen. \\
\hline 50 & 1,5 & 3,0 & 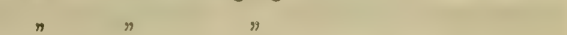 \\
\hline 58 & 0,1 & 2,0 & $n$ \\
\hline $4^{\text {h }} 04^{\prime}$ & $-2,4$ & $-0,5$ & Kaum merkliche Bewegungen. \\
\hline 06 & $-2,9$ & $-0,9$ & Bewegungslos. \\
\hline 08 & 20,4 & 1,4 & Aus dem Bade herausgenomen. \\
\hline 09 & $n$ & 4,8 & Bewegungslos. \\
\hline $10 \frac{1}{2}$ & $n$ & 7,9 & Schwache Bewegungen mit Flügeln und Beinen. \\
\hline 11 & $n$ & 8,5 & Auch mit Fühlern. \\
\hline 14 & $n$ & 1,2 & Will flattern, aber schwach. \\
\hline 22 & , & 16,7 & Ruhig und wieder schwaches Flattern. \\
\hline
\end{tabular}




\begin{tabular}{|c|c|c|c|}
\hline Zeit & $t_{l}$ & $t_{i}$ & $\mathrm{~B}$ e $\mathrm{m}$ e $\mathrm{rk}$ u $\mathrm{g}$ e $\mathrm{n}$ \\
\hline $4^{\text {h }} 32^{\prime}$ & $20,4^{\circ}$ & $19,0^{\circ}$ & Rulig, auch wèn gereizt wird. \\
\hline 35 & $\eta$ & 19,3 & Etwas stärkeres aber unregelmässiges Flatterń. \\
\hline 45 & $n$ & 20,0 & Unregelmässig. \\
\hline 46 & $n$ & 20,9 & Starkes S ummen! \\
\hline 48 & $n$ & 27,0 & Ruhig. \\
\hline 51 & $n$ & 22,2 & Schwaches Flattern. \\
\hline 56 & $n$ & 20,7 & Ruhig. \\
\hline 59 & $\eta$ & $21 ; 6$ & Schwaches unregelmässiges Flattern. \\
\hline
\end{tabular}

Aus dieser Tabelle ist ersichtich, dass der Schmetterling schon bei der Lufttemperatur von $17^{\circ}$ die Fähigkeit zum Summen verlor, trotzdem dass seine eigene Temperatur im Anfange noch $26,5^{\circ}$ betrug. Das Reizen mit cinem Stäbchen nützte auch nicht. (Es muss benerlit werden, dass dieser Schmetterling bei der Lufttemperitur von 21,50 sehr stark summt [28]). Dieser Umstand ist wohl dadurch zu erlilïren, dass einige näher zur Oberfläche (les Körpers liegenilen Flügelmuskeln voribergehende Starre erlitten. Es ist interessant, diss die Kialtestarre des Protoplasmas bei Mimosa pullica auch bei ca. 150 eintritt. (Sachs).

Die vollständige Bewegungslosigkeit des Schmetterlings trat bei eigener Temperatur von $-0,5^{0}$ ein. Nachdem der Schmetterling wiecter in clie Zimmertemperatur gebracht war, begann er fast sofort schwache Bewegungen mit Flügeln, dann mit Beinen und cullich mit Fühlern zu machen. Den Versuch, zu flattern, machte er jeloch erst bei einer eigenen Temperatur von $12^{\circ}$, und zu summen erst bei $t_{i}=20,9^{\circ}$.

Der Umstand, dass die Säfte dieses Schmetterlings gar nicht zu gefrieren begannen, wie ich dies auch früher zeigte (24), ileitet darauf hin, dass die Bewegungslosigkeit nur in Folge der von Sachs entıleckten Kältestarre des Protoplasmas stattfand.

Dass in diesem Versuche der Schmetterling sich hei Zimmertemperatur sehr rasch erholte und schon bei $1,4^{\circ}$ eigener Temperatur gewisse Bewegungen zeigte, während meine früheren (24) Versuche ergaben, dass ein gefrorener Schmetterling erst bei $14^{\circ}$ eigener Temperatur die ersten Bewegungen zeigt, wird dadurch erklärt, dass bei dem gegenwärtigen Versuche der Schmetterling sich nur bis $-0,5^{\circ}$ abliuhlte, hingegen bei früheren Versuchen diese Abkühlung viel tie"er stattfand, wobei ein Theil der Säfte sogar zum Gefrieren gelangte. 
Gestiitzt larauf, gewinnen wir folgenle wahrscheinliche Vorstellung iiber die Vorgänge im Insektenlörper bei seiner Ablïhlung: Zuerst werlen die an iler Oberfläche des Körpers sich hefintenden Zellen abgekiihlt und demgemäss erlciden sie lie Kïltestarre bei einer gewissen Temperatur friiher als Zellen, welche im Inneren des Körpers liegen. Datlurch werılen selbstverstïnıllich in erster Linie die Fliigel, die Beine unıl Fühler betroffen; erst, wemn die Abkïhlung weiter fortschreitet, erhalten auch die tiefer liegenden Schichten die Kültestarre uml endlich, nachlem die unterkiihlten Säfte zu gefrieren beginnen, wird das Inselit den Punkt $T_{2}$ (Fig. 9) erreichen, in welchem alle seine Süfte gefrieren; dann gelangt es in das Gebiet des anabiotischen Zustancles, um schliesslich beim Punlite $\mathrm{T}_{3}$ die permanente Küiltestarre zu erleirlen. Niar das Insekt in der Nähe von diesem "kritischen Punkte" $\left(T_{1}\right)$ und wiril es aus rem kalten Luftbarle wieler in Zimmertemperatur gebracht, so verlieren zuerst die äusseren Organe die Kïältestarre: die Flügel, Deine und Fïhler, welche das Insekt aber erst dlam zu bewegen im Stanile sein wiril, wenn gewisse innere Theile seines Körpers die Kältestarre verloren haben. War dagegen das Insekt weit von diesem Punkte entfernt, also nur schwach abgekiihlt, so wird es bei Zimmertemperatur sofort die :̈usseren Organe bewegen, nachlem dieselben die Kältestarre verloren haben werden, da die inneren Organe durch Kültestarre gar nicht betroffen wurden.

Daraus ist ersichtlich, dass parallel damit auch die Entwickelung gewisser Organe gestört oiler gar aufgehoben wirl, je nachriem, welche nietlere Temperaturen beim Versuche angetvenctet wurlen. In einem Falle kann nur die Fürbung orler Zeichnung, in anterem die Fligel selbst, in drittem die Beine orler Fühler uni en llich ein Theil imerer Organe ungenïgende Entwickelung erhalten.

Aehnliche Erklïrung (ler Vorgänge kann man beim Zuhilfenehmen der "Wiirmiestarre" auch bei hohen Temperaturen geben, ${ }^{1}$ ) nur sind hier die Terhältnisse einfacher als beim Abkïhlen, wie die Curve ler Fig. 9 es veranschaulicht (Vrgl. auch 1. Abschnitt des I. Kapitels im theoretischen Theile).

Wenden wird uns zur Betrachtung der Einwirkung zuerst extremer Temperaturen (Hitze und Frost) auf die Färhmg und

1) Dabei kommt noch der wahrscheinliche Umstand in Betracht, dass die Temperaturen, bei welchen diese oder jene Zellen im Organismus die Viärmestarre erleiden, verschieden sind.

Bachmotjew, Studien. II. 
\%(ichnumg der Insekten, wobei wir dic oben erwihhnten Auseinandersetzungen beim Aufsuchen der Ursache dieser Wirkung benitzen werden.

Verschietene Forscher sprathen tie Meinung aus und einige ron ilmen haben sie anch bewiesen, dass der kinftige Farbstiff $z$. B. eines Schmetterlings bereits in Blute der Puppe rorhanlen ist und nur aus dem Blute an entsprechenden Stellt-n ther Fligel alogelagr it wird. Dies bezieht sich selbstrerstänilich auf die optischen Farhen nicht, welche keinen Pigmenten entstammen. (Vrol. die "Einleitung" zum III. Kapitel des thatsächlichen Theils).

Wenn dem so ist, dann sind folgende Fälle moglich:

I. Die der Einwirlimg extrimer 'Temperaturen ause:etzic Puppe erleilet die Cirkulationsinderung resp. Cirkulationshemmung rles Blutes.

II. Bei hohen Temperaturen, bei welchen die roribergelente und partielle Starre eintritt, crleiden alie Furbstofle eine Vuränderung durch den gesteigrarten Stoffwechsel, also im Sinne von F. Urech (896).

III. Die Zellen verlieren infolge der Wärme- resp. Külltestarxe die Fähigkeit, die pigmentbillenden Stoffe aus dem Blute, anzulocken."

IV. Die im Blute enthaltenen Farbstoffe erleilen lurch die Einwirkmg extremer Temperaturen cine Vexünlerung in ihrer Zusammensetzung und in der Farbe, oder sie kommen gar nicht oler nur ungenügend zur Ausbildung.

Wir wollen alle diese Möglichkeiten der Reihe nach anf ihre Wahrscheinlichkeit prüfen.

I. Bereits Dogiel (189) hat nachgewiesen, class the Kïite das Herzschlagen bei Insekten verlangsamt und Tichomirow (S69) fami, lass die Anzahl der IIerzcontraktionen bei lianen mit der Abrahme (ler Temperatur abnimmt (vile Fig. 6). Wird das betreffende Insekt bis zu noch nielligeren Temperaturen aljgekïhlt, so unterkihlen sich, wie ich gezeigt habe (29), seine Sïfte, um schliesslich zu gefrieren zu beginnen, was unzweifelhaft eine Circulationsstörung hervorrufen muss.

Wir wissen noch nicht, in welchen speziellen Theilen des Inseliteukörper's dabei zuerst die Blutcirkulation gestört wird, die Versuche z. B. von K. Knauthe (457) aber zeigen es uns bei Fröschen. Er setzte Frösche während der Nacht in Freien der Einwirliung liünstlich erzeugter niederer Temperatur (Schnee + Kíochsalz) aus, wo- 
bei sie sich Morgens steifgefruren uni brüchig zagten, die Eingeweice waren gefroren und dias Herz war von Lisrinde mugeben. Als die Thiere ins warme Zimmer gebracht wurikn, weicliten sie nach ca. 6-5 Stmulen wieuler auf. Zuerst begamn eine schwache Bewegung der linken, dam der rechten Vorkammer, eindlich auch der Herzkammer. Die ersten Contraktionen erfolgten selı unregelmässig. Auch Miüler-Erzbach (6it)0) beobachtete bei eingeirorenen Fröschen sogar mittelst des Mikroskopes keinerlei Blutströmung. (b)wohl liese Thiere im mässig warmen Zimmer nath ca. $31_{1}^{\prime}$ Stun ien wievier zu athmen anfingen, und die Blutströmung kehrte allmailig, anfimes mit Unterbrechung, wieder.

Das Erstarren des Blutes ist aber nicht die einzige Ursache (ier Cirkulationstörung, dieselbe kam auch ror dem Einfrieren des Blutes stattfinden. Erstens werlen die Sïte dirch die Abliihlung dichter, was bis zu einem gewissen Minus-Grad fortschreiten wird (Wasser hat sein Dichtemmaximum bei $4^{0}$, weil aber in Saiften verschielene Salze aufgelöst sincl, muss für sie clieses Maximum tiefer liegen), uni infolgetessen wird auch der Reibungsköffici-nt zunehmen. Jun aber werilen sich auch die Blutgefïsse infolge ler Abliihlung zusammenziehen und die Blutbewegung wird noch mehr erschwert. Es kimn unter Lmständen der Fall eintreten, lass gewisse Kapillare nicht mehr alle Bestandtheile des Blutes turch sich passieren lassen werlen, und das Blut nicht im Stanie sein wiri, die vielleicht gerate dort nöthigen pigmentlililenten Stolie mitzubringen.

In dieser Beziehung ist (iie Bemerkung von E. Fischer (229) interessant: „Man gewinnt den Einiruck, als ob dias (schwarze) Pigment hauptsächlich an den Adern sich abzulagern gezwungen gewesen sei unl rass es ni:ht in die Interustalräume gelangen konnte, es liegt äusserst nahe, ren Grund dafür in mechanischen Willerstiinden zu suchen, denn die hohlen Fliig, ladern setzen dem die Farbpigmente zuführenden Blutstrome einen weit geringern Wilcrstand entgegen, als die eng aneinanterliegenten beiden Membranen der Intercostalräıme."

Zieht man noch die Thatsache in Betracht, dass je enger eine Kapillarröhre ist, desto stäker sie im Stanle ist, die Koncentration einer Lösung zu änclern, so wiril es uns noch mehr einleuchten, dass die sich unter dem Einfluss der Kälte zus:mmenzielıenlen Kapillaren z. B. in einer Puppe nicht nur die Blutcirkulation mehr und mehr erschweren, sontern auch die Zusammensetzung des Blutes verämlern werden. 
F. Urech (895) und E. Fischer (229) waren ciie ersten, welche durch das Schnüren die Blutcirculation bei Puppen gestört haben und auf diese. Weise wirklich abgeänlerte Zeichnung und Färbung der Schmetterlingsflïgel erhielten. Auch waren Fälle vorgeliommen, wo man aberrative Falter erhielt, deren Puppen au den betreffencien Stellen nachweisbar starken Druck erlitten hatten.

Aus dem Gesagten können wir den Schluss ziehen, dass die Möglichleit, durch dlie Blutcirkulationsinnlerungen die Aenlerungen an Farben und Zeichnung bei Inseliten zu verursachen, seln wahrscheinlich erscheint.

II. Die zweite Möglichkeit, ılass nämli’h bei hohen Temperaturen, bei welchen die voriibergehenle und particlle Starre eintritt, die Farbstuffe eine Veränilerung durch den gesteigerten Stoffwechsel erleiden, erscheint auch als sehr wahrscheinlich.

Wir werden hier sie Luftemperaturen betrachten, welche üher $38^{\circ}$ liegen. In diesem Falle tritt, wie ich gezeigt liale (28), zuerst die partielle, vorïbergehende Lähnung gewisser Muskehn dies Insekts ein.

Dass die Athmung des Insekts mit der Zunalume der Luttemperatur steigt, ermittelten verschienlene Forscher. So z. B. fiml Blasius (87) unrl später F. Urech (S89), dass die grösste Gewichtsabnahme bei dcrjenigen Puppe stattfinclet, we]che einer höheren Temperatur ausgesetzt wurle. Dies deutet auf die Zunuhme des Stoffirechsels bei Puppen mit steigender Temperatur hin. Leider wurden cliese Versuche nicht höher als bis zu ca. $20^{\circ}$ verfolgt.

H. M. Vernon (913) stellte Versuche mit Fröschen an uni fanı, dass "die Kohlensïureentwickelung der Frösche bei allmähliger Erwärnumg derselben nur innerhalb enger Grenzen zwischen tlen Temperaturen $2^{\circ}$ und etwa $17,5^{\circ}$ sich ïnlert; aber ïber diesem Punlte nimmt die $\mathrm{CO}_{2}$-Entwickelung mit der Temperatur schnell zu." Auch diese Versuche wurden nur bis zu $30^{\circ}$ angestellt.

Um festzustellen, ob der Stoffwechsel auch bei noch höheren Temperaturen und speziell bei der Starre mit der Temperatur steigt, habe ich folgenten Versuch mit Deilephila elpenor-Falter angestellt (28): Dieser Schmetterling, an eine thermoelektrische Naclel angespiesst, wurcle in ein Thermostat, in welchem sehr feuchte Luft war, gebracht. Folgende Tabelle ergiebt die erhaltenen Resultate, wobei $Z$ die Zeit, $t_{i}$ die Temperatur des Schmetterlings und $t$ die Temperatur der umgebenden Luft bedeutet: 
2. VI 1900. Deiteptita elpenor, ror 24 Stunlen geschliipft.

\begin{tabular}{|c|c|c|c|c|c|c|c|}
\hline$Z$ & $t_{i}$ & tl & Bemerkung & $Z$ & $t_{i}$ & $t_{l}$ & Bemerkung \\
\hline $5^{\text {h }} 19^{\prime}$ & $34,5^{n}$ & $29,2^{\circ}$ & Ruhig. & $6^{\text {h }} 40^{\prime}$ & $45,9^{\circ}$ & $41,4^{\circ}$ & Ruhig. \\
\hline 24 & 32,4 & 29,9 & $n$ & 43 & 46,5 & 41,8 & Unregelmässige \\
\hline 29 & 33,6 & 30,4 & $"$ & & & & Bewegungen. \\
\hline 33 & 34,1 & 30,7 & $n$ & 47 & 46,8 & 42,4 & Unregelmässige \\
\hline $40^{\circ}$ & 34,9 & 31,6 & $n$ & & & & Bewegungen. \\
\hline 45 & 36,0 & 32,6 & $n$ & 54 & 47,7 & 43,2 & $\begin{array}{l}\text { Unregelmässige } \\
\text { Bewegungen. }\end{array}$ \\
\hline 50 & 37,1 & 33,4 & $"$ & $7^{\text {b }} 04^{\prime}$ & 48,5 & 44,6 & Ruhig. \\
\hline 55 & 37,9 & 31,4 & $n$ & 14 & 49,6 & 45,6 & $n$ \\
\hline $6^{\text {h }} 00^{\prime}$ & 38,7 & 35,3 & $"$ & 18 & 50,4 & 46,2 & Schwache Flü- \\
\hline 05 & 39,5 & 35,9 & $n$ & & $50, \pm$ & 70,2 & gelbewegungen. \\
\hline 10 & 40,4 & 36,5 & Flattert $2^{\prime \prime}$. & 23 & 51,6 & 47,2 & Schwache Flü- \\
\hline 16 & $41, \overline{7}$ & 37,4 & Ruhig. & & & & gelbewegungen. \\
\hline 21 & 42,2 & 38,4 & $"$ & 29 & 52,6 & 48,0 & Ruhig. \\
\hline 25 & 43,2 & 39,4 & Elattert $2^{\prime \prime}$. & 37 & 53,8 & 48,8 & Flügel gesenkt. \\
\hline $6^{\text {h }} 30^{\prime}$ & 43,8 & 40,0 & Ruhig. & 44 & 54,3 & 49,2 & Bewegt nur mit \\
\hline 35 & 44,8 & $40,-4$ & Flattert $2^{\prime \prime}$. & & & & \\
\hline
\end{tabular}

Bei diesem Versuche hat der Schmetterling gar nicht gesummt, sonilern nur hie und da sehr kurze Zeit geflattert. Da das Flattern, wie ich früher fanıl, die Temperatur des Körpers nur unbedeutend zu steigern vermag, so muss die Differenz $t_{i}-t_{l}$ als Folge des starken Athmens betrachtet werden. Ausserdem gerieth der Schmetterling um $6^{\text {h }} 37^{\prime}$ in permanente Starre bezüglich der Fliigelmuskeln (Flügel gesenkt) und hatte dabei auch um $5^{0}$ höhere Temperatur als die der Luft; dieser Umstand deutet auch darauf hin, dass sogar in diesem Falle der Stoffwechsel rasch vor sich geht. Als der Schmetterling aus dem Thermostaten entfernt wurde, behielt er die gesenkte Form der Flügel noch am folgenden Tage bei und starb erst nach 24 Stunden.

Aus diesen Untersuchungen geht somit herror, dass die Zunahıne des Stoffwechsels mit dem Steigen der Temperatur ununterbrochen zunimmt, wenn auch die Flïgelmuskeln eine permanente Starre dabei erfahren.

Wie der gesteigerte Stoffwechsel die Veränderung der Pigmentelemente erzeugen kann, sagt F. Urech (896): „Es kann nun aber auch andererseits Wärmezufuhr die Geschwindigkeit der metamorphosischen Lebensvorgänge in der Puppe, der Athmung und der partiellen Oxylation vermehren und so kohlenstoffreichere, ilunklere 
Pigmentstofie durch chemische lionimsations- unil lieilulitionsrolgänge hervorbringen."

H. v. Linden (527e) äussert sich, wie folgt: „Wir können also verallgemeinernd sagen, dass jeder Eintuss, der bei der jungen Pupue die Verlorennungsprozesse lierabsetzt, class juler Einfluss, der die Atmungstätigkeit hemmt, aberrative Isildungen zur Folge hat, Billungen, die sich durch eine Ueberhandnahme schwarz pigmentierter Schuppen unil durch dic Redulition les roten Farbstoffs auszeichnen." "Die Schmetterlingspuppe he larf zur Pildung melanotischer Pigmente des Sauerstorfs" "Am Anfang der Puppenruhe sind weniger Chronogene im blut enthalten, wie in spüteren Tagen, wïhrend die oxjolierenten Enzsme anch der jungen Puppen nicht fehlen." "Erhühter St of fwechsel, beschleunigte Entwickelung ist der Entstehung dunkler Pigmente unginstig, wilhrend diese in einer Verlangsamung der Lebenprozesse eine guinstige Bedingung finlen." Weiter sagt sie $(527 u)$ : „Diese Verändermeen, die sich, wenn sie den gesamten Organismus treften, in ier Erscheinung des Hitzeschlages kundgeben, sind zum grossen Theil in einer ungenügender Oxydation, in einer Uebrrladung lles Blutes turch Kohlensäure zu suchen Auch hier ist Eiweisszerfall die notwendige Folge der Schädigung."

H. Federley (219a) sagt: „Dass gerale schwarz diejenige Farbe ist, welche am allgemeinsten durch kräftige Eingrifie in die Entwickelung der Schmetterlinge erzielt wirl, scheint mir durch die Untersuchnugen von Mayer (553a) ïber die Zusammensetzung ter Pigmentfariven eine Erklärung zu erhalten. Mayer hat nämlich gefumlen, dlass alle Farben der Schmetterlinge sehr unrein sind und dass alle ein beleutendes Prozent schwarz entlaalten. So gibt z. B. eine Untersuchung der weissen Farbe aui der Oberseite von P'ieris rapae L. folgendes Resultat: $17 \%$ schwarz, $13 \%$ smaragilgrïn, $100_{0}^{\prime}$ citronengelb und $60 \%$ weiss. Alle dunkleren Farben wie braun und grau haben dagegen einen viel grösseren Gehalt an schwarz Unter solchen Unstïnden scheint es mir weniger erstaunlich, dass die meisten Farben eine Neigung zum Schwarzwerden zeigen, denn die extremen Temperaturen üben gewiss auf die Zusammensetzung der kiinftigen Pigmentstoffe, seien sie nun Reserverstoffe, Harnprodukte oder Chlorophyllderivite, grossen Einfluss aus. Geschieht dies nun zu Gunsten des in allen Farben befindlichen schwarzen Bestancltciles, so ist das Resultat natürlich eine Schwarzung der imaginalen Farben. Dass diese Veränderung in der Zusammensetzung der Far- 
ben keine grosse zu sein braucht, geht aus den von Mayer angegehenen Zahlen hervor." "Bei sehr hohen mi niedricen Temperaturen wird wohl der gesammte Organismus ron der Tumperatur getroffen, und dieselbe ruft mehr odler weniger liräftice Störungen in dem Stoffwechsel hervor, was sich wohl auch meistens in gleichstarken aberrativen Verïntermngen beiler Fligglpatare liund gibt."

Da bei hohen Temperaturen Wämestarr der Flügehmolieln eintritt, so ist es nicht ausgeschlossen, lass dabei auch verschielene Theile ter in der Puppe sich entwickeltenden Fligel diese sturre erleilien, welcher Umstanl die Athumng noch mehr erschweren wirl, wie es aus folgenten Worten von I. Dewitg (168) zu ersehen ist: "Bekanntlich reihen auch die MLorphologen die Fliigel der Inseliten nicht selten den Athmungsorganen an. Sie werlen auch als homolog: mit den Trachenkiemen der wasserbewohmenden Insektenlarven angesehen. Im Stalium der Puppe und heim frisch ausgekommenen Insekt ist rler Flïgel von Blutlïufen und Tracheen durchzogen."

Wenn es anch sehr wahrschinlich erscheint, dass die Pigmentstofie durch erhöhten Stoffwechsel geänilert werden dïmnen. so liommt in diesen Falle noch die Wirkung der veränderten Athemmechanik auf las Nervensystem hinzu, wie es Schumburg und N. Zuna (\$61) am menschlichen Organismus in Hochgebirgen konstatirten. Iliese Forscher fanlen nämlich, dass die Athemgrösse mit der zumehmemien Höhe wuchs, das specifische Gewicht des Blutes in der IJöhe aber nicht grösser war als in ler Ebene, obwohl an gewissen Stellen ties Körpers eine Vermehrung der Blutkörperchen beolachtet wurle; sie schreiben die heobachtete grössere Zahl der Bluthörperchen der Wirkung einer veränderten Blutvertheilung zu.

III. Die Möglichkeit, dass die Zellen infolge der Wärme- resp. Kältestarre die Fühigkeit verlieren, die pigmentlilienten stofle aus dem Blute „anzulocken", ist schwer zu urüfen, da in dieser Bezichung gar keine Experimente an Inseliten gemacht wurlen.

Immerhin wollen wir dit einschlägigen Lntersuchungen an Pflanzen betrachten.

Zuerst muss bemerkt werlen, alass lie PHanzenzellen die ilnen nicht "passenden" Farbstoffe im allgemeinen nur tham aufnehmen, wenn die Zellen getöltet sincl. So schnitt J. Sachs (729) aus dem. Gervebe von weissen Riibenwurzeln (Beta vulgaris) unl aus festem Fruchtparenchym von Cucurbita pepo Würfel ron cal. 1 cm. Seite. Vorher hatte er durch Auskochen ilunkelrother liibenwmrzeln eine sehr ciunkelrothe Flissigkeit hergestellt. Yon jenen Wiirfeln wurlen 


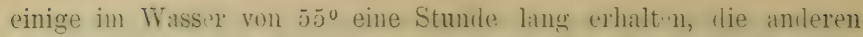
aber nicht erwïmt; darauf wurlen siimmtliche Wiufel in die rothe Lösung gelegt; nach 24 Stunden fand sich num, dass die frischen Würfel von dem rothen Farbstolf nichts aufgenommen hatten; diagegen waren die durch $55^{\circ}$ getölteten Würfel von weisser Iiunlielrübe durch und durch tief blutroth gefïrlht, bei denen von Cucurbita war die Färbung an allen Seiten 2-3 mm. tief einge:hungen. "Auch dieser Versuch zeigt, lass die Zellen für Farbstoff permeabel werten, soball sie sturch $55^{\circ} \mathrm{C}$. getüiltet worlen sinl, wis erfirorene Gewebstiicke schon dargethan haben."

Leiler füht dieser Forscher lieine Versuche an, wolche ergeben würden, wie sich die Zellen bei Temperaturen über 40", als' bei der Wärmestarre, verhalten.

Gewisse fuir uns nöthige Anhaltspunlite enthält die Abhandlung von J. Sachs: "Ueber den Einfluss der Temperatur auf das Errgriinen der Blätter." In dieser Ablandlung kommt er zum folgenden Schlusse: "Sïmmtliche ron mir beobachtete, ten verschiedensten Fumilien angehörenden MLono- mil bikntylen berlüfen zu ihrem Ergrünen des Lichtes, aber auch gleichzeitig einer hinrei hend hohen Temporatur, deren Minimum von dem spezifischen Charakter ier Pflanze abhingt; bei diesen Pflanzen ist sowohl Licht ohne himreichente Temperatur als auch diese ohne Licht nicht im Stanile, den grünen Firbstıff auszubilıen. Dagegen könuen alle von mir darauf beobachteten Cymnospermen (Pinus pinea, canadensis, sylvestris, Strobus und Thuja orientalis) auch in tiefster Finsterniss in ihren Kotylerlonen grïnen Farbstoff bilden, dazu bedürfen sie aber gleich den ersteren einer hinreichend hohen Temperatur" (p. 139).

Wir wollen einige Beobachtungen zuerst bei Cymnospermen auseinanderlegen, weil sie am nächsten diejenige Erscheinung zeigen, welche auch bei Insekten beobachtet wird.

J. Sachs säete zahlreiche Samen von Pinus pinea, strobus unil canaclensis in Töpre. welche in der Dunkelheit aulbewahrt wurten. Bei hinreichend hoher Temperatur $\left(12^{0}-15^{\circ}\right)$ zeigten sich die Kotylerlonen der Pinuskeime schon innerhalb des Endosperms grün, sobald die Wurzel aus dem Samen austrat. Bei einem im Norember und December angestellten Versuch, wo in dem Kelleraum die Temperatur binen 4 Wochen von $11^{\circ}$ auf $8^{\circ}$ und $7^{\circ}$ sank, blieben bei Pinus pinea in einem Falle die liotyleilonen sehr hell gelbgrün, an anileren Exemplaren wurde nur die Basis der Kotyledonen grün- 
lich, alles Uebrige blieb gelb. Dasselbe ergab auch P. canadensis. P. strobus hat bei dieser niederen Temprratur nicht gekeimt.

Fiir Mono- und Dikotylen genigen folgende Beispiele:

Phaseolus multiflorus. In drei Blimentöpfen hatten je drei Keimptlanzen im Finstern sich entwickelt, sie waren vollstänlig vergeilt, die halb entfalteten Primorlialblïtter hellgelb. Alle drei Töpfe wurden nachher folgendermassen behandelt:

1. Die Pflanze ist icm Lichte ausgesetzt. Die Temperatur dicht neben der Pflanze beträgt $30-33^{\circ}$. Nach 7 Stunden waren clie Bliitter rein und satt griin. Bei derselben Temperatur aber in Dunkelheit sich befinlliche Blitter derselben Pthanze behielten ihr ursprïngliches reines Hellgelb.

2. Die Pflanze ist dem Licht ausgesetzt. Die Temperatur beträgt $17-20^{\circ}$. Die erste Spur einer hellgrünen Färbung trat erst nach 5 Stunden ein, die Färbung war selbst nach 7 Stunden noch unbedeutenı; die verfinsterte Pflanze dieses Topfes blieb völlig unverändert gelb.

3. Die Temperatul schwankte zwischen $8^{\circ}$ unil $10^{\circ}$. Nach 7 Stunlen waren sowohl die beleuchteten als die verfinsterten Blätter noch unverändert gelb.

Weil Zea Mais, Alleum cepa, Cucurbita pepo u. A. bei 13-140 beim Lichte selbst nach 7 Stunclen noch kcine Spur grüner Färbung zeigten, unil bei Phaseolus multiflorus lieselbe bei $17-20^{\circ}$ nach 5 Stunlen eintrat, so kamn man sagen, dass die grüne Farbe unter dem Einfluss des Lichtes erst dann in Pflanzen entsteht, wenn die Temperatur ca. $16^{0}$ beträgt. Die Pflanzen, welche ohne Licht grïn werden kümnen (Cymnospermen), haben (lazu, wie C. Böhm zeigte (98) cine höhere Temperatur als $6-7^{0}$ R., und nach J. Sachs über $11^{\circ}$ C. nöthig.

Da die Kältestarre der Zellen bei Pflanzen bei ca. $16^{\circ}$ eintritt, so können wir aus den Untersuchungen von J. Sachs den Schluss ziehen, dass das Ergrinen bei nieleren Temperaturen als $16^{\circ}$ deshalb nicht stattfindet, weil bei dieser Temperatur die Kältestarre des Protoplasmas eintritt, oder mit anderen Worten, die in der lialtestare sich befindenden Zellen haben keine Fähigkeit, die Pigmente zu erzeugen resp. hervorzurufen.

Leiler sind keine Angaben für die Wärmestarre bekannt.

Damit kommen wir zum Schlusse, rlass auch diese ciritte Möglichkeit sehr wahrscheinlich ist. 
IY. Dis letzte Möglichlieit zerfällt in zwei Theile: 1) die Pjomente kommen bei der Einwirkung extremer Temperaturen gar nicht orler nur ungenügend zur Ausbilılung; 2) dir im Blute erhaltenen Farbstofte erleiden dabei eine Veränlermg in ihrer Zusammensetzung: und in rler Farbe.

Der erste Theil dieser Vorausetzumg hat eine grosse Wahrscheinlichkeit für sich.

186.5 veröffentlichten D. Hermann unl Ieonard Landois cine: Abhandlung: "Ueber die numerische Entwickelung ler histologisehn Elemente des Insektenkörpers" (3(;8), in welcher sio zu folgenlm Resultate kamen: im Puppenstadium nimmt die Anzahl der gross"in und kleinen Nervenzellen beicutend zu, während , lie Anzahl dex. Blutkörperchen sehr stark abnimint. Somit geht im P’upenstalium nicht nur eine starke Neubililung der Muskehn uni ihrer Flemente vor sich, sontern es ändert sich auch di, Zusammensetzung iles Blutes.

In der neusten Zeit fanden verschichene Forscher, dass diic Pigmente in ren Fliggeln bei Puppen nicht aul eimmal, sonirin succesiv auftreten, unil zwar nacl: F. Uresh (890) nach folgenter. lieihenfolge: weisslich, gelb, röthlich, bram, schwäizlich. Diese Faristoffe siml Derivate ler Harnsäuregruppe uml, ihre lieihenfolge ist analog derjenigen im Farbenspektrum, unl es entspricht ihr aurh diejenige von chemisch-homologen fieihen ron Farbstoflen, d. h. the Atomameihung im Molekul unter zunehmeniler Verdichtung" (891).

Untersuchungen anterer Forscher ïber das succesive Auftreten der Pigmente der Fliggel bei der Pupnenentwickelung sini in „thatsächlichen Theile" (III. Kapitel, Einleitung) nachzusehen.

Die Pigmentstoffis, sincl somit in einer Puppe nicht ron rornherein fertig rorhanlen, sonlern, machen auch ihre Evolution durch, wie auch antere Theile les Organismus is thun. Denensprechent muss das Entstchen der Pignentstoffe im Insektenorganismus in näherem Zusammenhange mit der Temperatur stehen, il. h. es muss ein Maximum, ein Minimum uml ein Optimum der Temperatur geven; dabei ist es gleichgültig, ob die Pigmente als Auscheilungsfrodukte gewisser Organismuselemente oiler, wic Uroch (S91) rermuthet, Derivate der farblosen Xanthinstoffe, die in lirimeliger Form in vielen Schmetierlingsschuppen enthalten sinu, betrachtet werlen.

Die Wärmereize kïmnen in der Puppe auf die Zellen mittelst hesonderer Organe iibertragen werilen, wie es $\mathbf{M}$. v. Linden (; 22 ) fanc. Sie untersuchte die Simneshare auf der Pulpenhülle der 
Schmetterlinge und gelangte 7.11 dem Lrcehnisse, "lass ron dem Augenblick :m, wo der Chitinisirungsprocess der Puppenhülle beenligt ist, eine periphere Nervenausbreitung ausserhalb des Silnmetterlingskörpers zwischen Puppenhülle und Epilermis bestelit, deren Endigungen mit dem Simnesorgane auf der Pupuenhiulle in Verbindung stehen uni die Beziehumgen des werlenicn Schmetterlings zur Aussenwelt durch die Puppenhiille hindurch vermitteh" ( p. 128). Die Verfasserin zweitelt daran, dass diese Organe Tastorgane sind, und vermuthet, dass wir es hier mit einem Organ zir thun haben, das für 'T'emperaturreize empfänglich ist.

Es ist überthissig, hier näher llarauf einzugehen, wie die Temperatur die Evolution der Farbstofie ändern kam, denn wir haben bei der Besprechung dier Entwickelung des Insektenorganismus bereits gesehen, dass die extremen Temperaturen dieselbe hemmen (ville I. Kapitel, 1. Abschmitt les theoretischen Theils). Dasselbe muss wohl auch im behandelten Falle stattfinden.

Hicr seien nur die Ansichten von Oskar Schultz (757) ïber den Albinisnus der Lepidopteren angefüht. Iniem er len Albinismus als die Folge einer Hemmungsbildung betrachtet, sagt er: „Auf einer früheren Billungsstufe des Lepirlopterons, im Puppenstalium, entwickeln sich allmählig, bei der einen Art schneller, bei der anderen langsamer, die Farbenpigmente auf din Flügeh und an den sonstigen Körpertheilen des Thieres unil finden ihre volle Auspräigung nicht lange vor dlem Zeitpunkt, wo das Ynsekt die schiitzende Chitindecke durchbricht. Fiallt num in dieser Zeit irgend eine Störung vor, welche krättig genug ist, sich der Formation jenes Stoffes zu willersetzen un!l dieselbe ganz zu unterirücken, so wiri das zur Inago entwickelte Insekt sich unserem Auge in vollkommensten Zustanle des Albinisums prïsentieren. Lreignet sich indessen die Störung, welche eine solche Hemmungsbildung zu veranlassen in Stande ist, spaiter, zu einer Zeit, wo bereits die Bilumng des Pigments seinen Anfing genommen hat, so tritt die Erscheinumg des Albinismus bei dem Individum, sobalil es seine Metamur|phose? vollendet hat, weniger vollkommen auf."

Was nun den zweiten Theil der ausgesprochenen Voraussetzung anbetrifft, d. h. ob die im Blute enthaltenen Farbstoifie bei der Linwirkung der extremen Temperaturen eine Veränlerung in jhrer Zusammensetzung und Firbe erleilen, so liegt auch hier cine gewisse Wahrscheinlichlieit llieser Prozesse vor, wie es' ans folgendem $\mathrm{zu}$ ersehen ist. 
Fodorloy (219a) fanl hei seinen Temperaturersuchen an Schmetterlingen das Verschwinden des schwarzen l'iement;, „und es ist dies sowohl bei den nierlrigen als auch bei den hïchsten Temperaturen iler Fall gewesen." An besten wirl dies bei Lymuntria dispar beobachtet; aber auch bei Saturnia, Aretia und Demus coryli wurlen bei erhöhter Temperatur blasse Falter erhalten. Dass fast alle Farben durch Einfluss extremer Temperaturen in Schwarz verwandelt werien können, beobachtete pr bei folgenien Spezies: Weiss bei Lymantria dispur o, Sutumia pavonia o; (irau bei $L$. disipur ơ, S. pavonia O; Roth bei Aictiu caja, S. puvonia ó, Q; Braun unl Rothbraun bei $S$. puronia of. Weiter sagt er: "Die extremen Temperaturen iiben gewiss auf lie Zusammensetzung der künftigen Pigmentstoffe grossen Einfluss aus."

M. $\nabla$ on Linden $(527 c)$ fanl, class währem! die erhühte Temperatur clas Entstchen ankler Pigmente suwohl in cler l'uppenhiille wie auch in der Fïbung des Falters verhindert (bei $V a$ nessa urticae), was auch tü die Melanose des flutes hei Insektpnlarven ilurch Temperiturerhöhung beobachtet wird (v. Fürth [268a]), bewirken die Hitzegrate eine Zunahme dunkler Zeichnmg. Sie sagt weiter: „Die noch höheren 'Temperaturen wie $40^{\circ}$ inhibieren die Melanose im Blut vollkommen, inlem sie die Tyrosinase zerstören."

Urech (900) brachte die zur Veryuppung hängende Raupe in die Temperatur ron $-6^{0}$ und beobachtete labei folgendes: „ES tritt sehr leicht Blutlymphe aus iem Flügelgervebe, die Puppe ist unbeweglich, nach mehrstünliger wierierholter Linwirkung zersetzt sich späiter das Blut, und gerade an den Flügelstellen tritt zuerst Schwärzung und rapide Fäulniss auf." Er betrachtet (891) the in len V.anessa-Fliigeln entstehenden Farbstoffe "nicht etwa zu Pigmentzellen gewordene Leucocyten, die an Epithelzellen ihr Pigment abgaben," sonlern als Derivate von der Harnsüuregruppe angehörenten Stoffen, wie z. B. las Purpurin, die grüne Mykomelinsïure. „Diese Farbstoffe sind nicht mit den farblosen Xanthinstoffen zu verwechsehn, die in krumeliger Form in vielen Schmetterlingsschuppen enthaltend sind, somlern wahrscheinlich Derivate von ihnen, die durch lïngere Zeit einwirkende Wärme entstanden sinll." Ausserdem fancl er (892), dass die wässerige Lösung von grïnem Farbstoff, welcher sich in ten Flïgeln der Puppe von Pieris brassicue befindet, bei starkem Erwärmen farblos wird.

Obwohl die lier angefiih:ten Meinungen, welche seit der Veriftentlichung der ersten Abhandlung Weismann's (953) in dieser 
Tichtung dlatieren, die Veränlerung gewisser Pigmente durch rite direkte Wirkung der extremen Temperaturen wahrscheinlich machen, kann man doch gewisse Bedenken dagegen erhelsen. Man kann sich fragen, dass wenn dem so ist, warum verünlert sich damn das Farbenkleid bei überwinternilen Imagina nicht (also beim Frost)? Warum wird dlasselbe auch dann nicht geändert, wenn der Schmetterling sich bei lir Temperatur des Hochsommers befinlet?

Wenn man einerseits darauf die Antwort geben kamn, dass bei Imagina die Farbenevolution bereits beenlet worlen ist und die Pigmente sich sozusagen im Gleichgewichte befindlen, so liam mam anlererseits fragen, warum wirl dann der zuerst bei der Puppenentwickelung an Flügeln entstanlene Pigment (nach M. v. Linden [521] Gelb der Vanessen) durch den Hochsommer resp. Winter nicht geändert?

Die grosse Wahrscheinlihkeit zu Gunsten der direkten Wirkung der extremen Temperaturen auf die Firbenïnderung wirid nur dann erhalten, wenn wir die Zusammensetzung der Pignente bei Insekten besser kenen lernen werden. Erst damn kamn man sirh überzeugen, ob cliese Stoffe wirklich ilne Farbe bei Hitze uml Frost ändern. Ueber die Zusammensetzung der fraglichen Pigmente sind die Forscher zur Zeit verschiedener Meinung.

So z. B. betrachtet Hopkins $(387,388,389)$ liese Pigmente als Derivate der Harnsäure oiler ihr nahe verwandte Stofic. Derselben Meinung ist anch A. G. Mayer $(552,553)$, Urech (\$9:3), Griffiths $(330,330 a)$ u. A., während M. V. Linden $(521,523)$ und Schawrow (7t1) diese Pigmente für Abkömmlinge von Chlurophyll halten.

Nur eins steht fest, dass die chemische Zusammensetzung dier Pigmente bei verschiedenen Insekten-Spezies nicht immer dieselhe ist. Vielleicht durch diesen Umstami lassen sich lie nexativen Resultate von Foderloy (219a) bei seinen Temperaturexperimenten erklären.

Wir kommen somit zu dem Schlusse, dass alle vier hier angeführten Ursachen der Fürbungsänilerungen bei Inselkten in Folge der extremen Temperaturen sehr wahrscheinlich sind, obwohl es clurhlatus nicht nothwendig ist, dass sie alle auf eimmal dabei in Betracht kommen müssen.

Wenden wir uns nun zur Betrachtung der Einwirkung $11 \mathrm{itt}$ lerer Temperaturen auf die Fürbung uml Zeichnung der Inseliten. 
Wie Max Schultze (792) sagt, verlangsunt sich lic Bewegung Ins Protoplasmas in PHanzenzellen in allen Fillien von $39-40^{\circ}$ an, kehrt aber, wenn die Temperatur nicht iiler tse stieg, bei der Abliuhlung meist balı zu ier lirsprimgliclıen schnelligkeit zurück.

Darails geht hervor, dass die Wämestarre les Protoplasmas bei einer höheren Temperatur als $3 S^{\circ}$ stattimlet. Dat anlererseits J. Sachs fand dass die Fialtestarre unter 150 beginnt, so ist ler Temperaturintervall ron $15^{\circ}$ bis $35^{\circ}$ ron jeglicher stare frei. Diese Grenzen fallen mit denen bei Inselsten bobachteten ungefalir zusammen.

Lis ist bekannt, dass in gerissen (monzen lie Erliobung der Temperatur aten Stofiwechsel bei Insedten beschlennigt uml ac Emiedrigung derselhen diresen Wechsel rerlangsant: dasselbe bezieht sich auch auf die Entwickelungsgeschwinligkeit. Heil nur ler Temperaturintervall zwischen $15^{\circ}$ und $38^{\circ}$ rom der Starre hei ist, so kann die besagte Erscheinung unabhängig von ler starre nur imerhalb dieser Grenzen stattfinlen. In diestm Falle wirl lie Temperaturwirkung frei von den Starreerscineinungen dies Protoplasmas sein, unl folglich ist lie $\mathrm{H}$ mmung in der Entwiclielung cies Puppenkörpers dabei vollständig ausgeschlossen.

Es kömen somit nur zwei mögliche imachen in Betracht grezngen werlen, welche ats folgen der mässigen Temperaturen sein diurfen: 1) die Veränderung des Stofiwechsels, und 2) die direkte Einwirkung dieser Temperaturen aui i- Entwickelung der Farbstoffe.

Wir wollen diest beiten möglichen Ursachen der Aentertung des werlenden Falterkleides getrennt betrachten.

Was die direkte Einwirkung der miissigen (ron $15^{\circ}$ bis $35^{\circ}$ ) Temperaturen auf die liunftige Färbung des Falters anbelangt, so sagen darïber verschiedene Forscher folgendes:

Weismann (954) sagt: „Ein Theil dieser Furbenverünterungen wirt als direkte Beeinthussung des Farbenchemismus des Flügels durch die Temperatur angesehen werlen diurfen." Piepers (639) äussert sich, wie folgt: "Vermuthlich hat camals wohl auch eine chemische Veränderung des Farbstoffe's in den Fliigelschuppen in Folge der trockenen Wärme stattgehaht." Standfuss (841) sagt von seinen Kiälte- (bis $+4^{0}$ ) und Wärmeversuchen (bis $\left.+35^{0}\right)$ : „Es handelt sich ganz offenbar um eine direkte Einwirkung." M. v. Linden (52Te) sagt: "Verfirbung ler Schmetterlinge ist dem direkten Einflusse der mässigen Temperaturerhölung zuzuschreiben." Sogar 
Fischer (236), welcher die T'eniperaturfurnen , hurch Atavismus erklïrt, sagt: "Die $C$-Formen $(+35$ bis +370$)$ sind direkte, specifische Produkte der mässig gesteigerten Würnı, sie sind überhaupt die einzigen spezifischen Prolukte eines bestimmten Temperatur-Gebietes, die wir bis jetzt kennen gelernt haben." Nur die mïssige Kiäle wirkt nach ilm „nicht specifisch unı nicht cirekt, suntern sie ist ('ine durch mässige Entwickelungshemmung vermittelte."

Obwohl auf diese Art die meisten Forscher die direkte Temjeraturwirkung aü die Färbung des werdenten Imagos anriennen, muss jedoch folgendes bemerkt werden:

Unter direkter. Wirkung der Temperatur versteht man gewöhnlich ihre Wirkung, ohne dass dibei andere Faktoren Theil nehmen. Wenn z. B. nachgewiesen wäre, dass die Temperatur, wollen wir sagen von $30^{\circ}$, ilen hetreflenden Pigment zersetzen und dadurch eine amlere Farbe hervorrufen würile, oder die unter normalen Umstänlen stattfindende chemische Reaktion so beeinflüssen würrle, llass labei statt eines Farbstoftes ein anlerer zum Lintstehen käme, dann könnte man von direkter Temperaturwirkng sprechen. Da aber s) eine Wirkung iter mässigen Temperaturen auf die Insektenpigmente nuch von kieiner Seite sicher nachgewiesen wurle, kann man sagen, (lass, wemn eine solche Wirkmg der extremen Temperaturen (iiber $40^{\circ}$ und unter $0^{\circ}$ ) wahrscheinlich ist, ist dieselbe fur die missigen T'emperaturen un wh $\mathrm{r}$ scheinlich, sonst wirden rerschieleue Entwickolungsformen (Rumpe, Puppe, Imago) ilure Faribe stantig antern, je nach der lufttempiratur, bei welcher sie sich befinlen, was in der Wirklichkeit aber nicht beobachtet wird.

In kam theshalb vermuthen, dass verschieilene Forscher unter direkter Wirkung der mässigen Temperituren auf dip Fïrbming der Insekten cine Wirkung betrachteten, welche, wenn sie auch physiologische Prozesse ungestaltet hat. jerloch die Färlung mit Hiilfe andercr chemischen Substanzen zur Ábänlerung brachte.

Noch Franeis Bacon vermuthete, lass ile Furben der Thiere aus Abfallprodukten ies Körpers entstehen möchten. Später wurle diese Vermuthung von verschielenen Forschern bestïingt, welche fanden, rlass die Farbstoffe ler Insekten Abkömmlinge ron Harnsïure sind (nur M. v. Linden betrachtet sie als Chlorophyll-Derivate). Diese Abfallprodulite sind selbstrerstänllich beim Stoffirechsel des Inselites entstanlen, wobei der Temperatur dic beschlemnigenle resp. verzögernde Rolle zukım. 
Leber die Rolle des Stoffwechsels für die Aenterung des furbigen Irleiles des werilentlen Falters sagen verschiel'ne Forscher, wie folgt:

A. Weismann (953) sagt: „Die chemisch-physikalischen Vorgainge im Stofiwechsel des Puppenschlafes verschiehen sich allmählig derart, dass eine neue Zeichnung und Fïil)ung les Schmetterlings hervorgeht." (p. 43).

M. v. Linden (527c) fand, dass die mässige Wärme die Ruhezeit der Pupue abkiirzt, wobei die Lelwnsthïtigkeit hüher angespamt ist unil die Oxilationsprozesse somit sehnoller verlatem werden. Die mässige Kïlte verlängert di: P’upenzeit; die Stoftwechselvorgänge im Orgmismus sind de:mach herabgesetzt.

H. Federley (219a) betrachtet lie durh mirssige Temperaturen entstehenien aberrativen Formen ,hauptsiichlich als dis lusultat iler, durch gesteigerte oler erniellrigte Temperatur rerïnderten Stoffwechseltätigkeit in (ler Puppe" (p. 108).

Besteht sımit die Wirkming mässiger 'l'emperatur auf alie Färbung ker Insekten in erhöhtem oler verziggertem Stuffwechsel des Organismus, so muss es labei ein Optimm der Temperatur gehen, bui welchem die Firben als normal betrachtet werilen müssen.

Fischer (236) fant, dass die Temperaturen ron $u^{0}$ bis $10^{0}$ ( $B_{1}$-Formen) dieselben aberrativen Formen erzengen, wie die Temperaturen von $36^{\circ}$ bis $41^{\circ}$, inlem er sagt: "Auch clie mässige Kälte wirkt tatsüchlich nicht als solche, nicht specifisch und nicht direlt; sonst liönten diese Kilte-Variationen $B_{1}$ loch ganz unmöglich rurch g: wisse, ziemlich ho Wärmegrate $\left(B_{2}\right)$ auch erzielt werlen." Aus diesen Untersuchungen ist ersirhtlich, dass die optimale Temperatur für das Farbenlileil zwischen Temperatmen für $B_{1}$ - und $B_{2}$-Formen liegt. Nun hat Fiseher zwischen diesen Temperaturintervallen ansser den normalen Formen noch die C-Form, welche bei $35^{\circ}$ bis $37^{\circ}$ entsteht. Er s!gt: "Die C $C$-Furmen von Pyr. ainlinta umi carlui sinl vielleicht schon einmąl dagewesen, wenn die Standfussisihe Amnlime, dass ctalunta unil cardui im Gegensatz zu allen anderen Vanessiden nicht von nürilicher, sontern süilicher Herliunft seien, richtig ist. Alle übrigen $C$-Formen sind dagegen sicher solche, die sich \%. T. jetzt schon als erdgeschichtlich neue, jünste Varietiiten im siillichen Theil des Verbreitungsgebietes der betref- fenten Normalart gebililet haben (wie var. ichnusa Bon., var. erythromelus Anst., rar. epione Fschr.) oder doch in nicht gar ferner Zukunft sich offenbar dort einstellen werden." 
Wir können sımit sagen, dass das Temperaturoptimum, bei welchem normal gefärbte Falter entstehen, nicht konstant, sondern lokaler Natur ist. In Deutschland z. B. beträgt es ca. $26^{\circ}$ und in Süd-Italien über $30^{\circ}$, was auf die Accomodationsfahigkeit (vrgl. das I. Kapitel, 1. Abschnitt des theoretischen Theils), verbunden mit Vererbung erworbener Eigenschaften (Standfuss [841], Fischer [237], Frings) zurückzuführen ist. Streng genommen, ist das Temperaturoptimum nicht an eine bestimmte Temperatur gebunden, sondern umfasst eine ganze Reihe von Graden, was durch die individuellen Eigenschaften verschiedener Exemplare einer und derselben Spezies zu erklären ist. (Vrgl. die Untersuchung von P. Jensen $\left[423 \alpha_{1}\right]$ ïber individuelle physiologische Unterschiede zwischen Zellen bei Polythalamien. Er fand eine chemische Differenz des Protoplasmas in Zellen (ler einzelnen Individuen).

Als Mass des Stoffwechsels wird gewöhnlich die Athmungsintensität angenommen, d. h. die Quantität des verbrauchten Sauerstoffs resp. der ausgeschiedenen Kohlensäure und Wasser. Befindet sich z. B. eine Puppe in der Luft, so gehen in ihr die Verbrennungsprozesse bei erhöhter Temperatur rascher vor sich, und sie werden verlangsamt, wenn die Puppe in eine niedrigere Temperatur gebracht wird (vrgl. die Einleitung zum I. Kapitel im thatsächlichen Theil). Da dabei das Farbenkleid des künftigen Schmetterlings geändert wird, so war daraus der Schluss zu ziehen, dass die vermehrten, resp. die herabgesetzten Oxydationsvorgänge die Pigmentstoffe zu ändern im Stande sind, und zwar werden diese Pigmente dabei so geiindert resp. ihr Entstehen wird verhindert, dass der erhöhte Stoffivechsel die Farben heller macht, während seine Herabsetzung dieselben verdunkelt.

Einen schlagenden Beweis dafür findet $M$ : v. Linden $(527 e)$ in ihren Versuchen mir Vanessa urticae-Puppen in reinem Sauerstofi olme Erhöhung der Temperatur, wobei die Falter wirklich blasser geworden sind, wenn auch die schwarzen Flecken noch fast dieselben geblieben sind. Als sie die Oxydationsvorgänge daclurch herabgesetzt hat, dass die Puppe, statt in die Luft bei erniedrigten Temperaturen, in die Kohlensäure bei gewöhnlicher Temperatur gebracht wurde, erhielt sie ab. ichnusoides. Unter gleichen Umstïnden wurde in der Stickstoffatmosphäre Vanessa io ab. belisaria erhalten.

Auch P. Solowiow (822e) erhielt bei gewöhnlicher Temperatur Vanessa urticae var. ichnusa Bon., indem die Puppe von der Verpuppung an in der Sauerstoffatmosphäre gehalten wurde. 
Wir wollen zuerst die Versuche in reinem Sauerstoff betrachten, welches Gas, zum Athmen der Puppe benützt, die ichnusa-Form erzeugte.

Diese Form entsteht bei der Einwirkung der Temperaturen zwischen $30^{\circ}$ (Weismann [954]) und $39^{\circ}$ (Frings [259]) ( erhielt sie bei $32-35^{0}[527 \mathrm{e}]$ ) und man könnte somit denken, dass die Ursache des Entstehens dieser Form in erhöhtern Stoffwechsel liegt. Nun erhielten Frings (253) und Gauckler (281) diese Varietät auch bei der Einwirkung der Temperatur von $8^{\circ}$, also auch bei herabgesetztem Stoffwechsel der Puppe. Somit kann man nicht behaupten, dass der Stoffwechsel die Hauptursache des Entstehens von var. ichnusa $\mathrm{zu}$ betrachten ist.

Die Versuche mit anderen Gasen, bei welchen der Stoffwechsel herabgesetzt wird, ergaben im Schwefelätherdampf: Vunessa urticae ab. ichnusoides Selys und ab. nigrita Fickert, Vanessa io ab. antigone Fischr (= belisaria Obthr.) und ab. ioliaste Urech, Fanessa antinpa ab. hygiaea Holrch., Pirameis atalcnta ab. lilymone Fschr. (=lilemensiewicai Schille) (Fischer [236]). In Kohlensäure: Vanessı urticae ab. ichnusoides Selys. In Stickstoft: Vanessa io ab. antigone Fschr. (= betisaria Obthr.) (v. Linden [527e]). Will man das Entstehen dieser Formen durch den verminderten Stoffwechsel in der Puppe erklären, dann sollten sie denselben gleich aussehen, welche bei erniedrigten Temperaturen erhalten werden. In der That wurden ichmusoides bei $0^{0}$ bis $-20^{\circ}$ (Standfuss [841], Fischer [229, 231], Urech [804], Frings [257, 258]), antigone bei $-3^{0}$ bis $-20^{\circ}$ (Standfuss [841], Fischer [229, 231], Urech [903], Frings [257]) ioliaste bei $-10^{\circ}$ bis $-14^{\circ}$ (Urech [903]), hygiaea bei $0^{\circ}$ bis $-13^{\circ}$ (Fischer [228, 229, 231], Frings [257]) lilymene bei $-3^{\circ}$ bis $-15^{\circ}$ (Fischer [229, 231], Frings [258]) erhalten.

Nun sind aber Versuche bekannt, bei welchen diese Formen auch durch erhöhte Temperaturen erhalten wurden. So entsteht ichnusoides auch bei $40^{\circ}$ bis $43^{\circ}$ (Fischer [231], Frings [259]), antigone bei $38^{\circ}$ bei ${ }^{\circ} 39^{\circ}$ (Fischer [236], Frings [259]), hygiaea bei $35^{\circ}$ bis $45^{\circ}$ (Standfuss [839], Fischer [228], Frings [259, 260, 261, 262]), klymene bei $37^{\circ}$ bis $45^{\circ}$ (Standfuss [841], Fischer [231], Frings [259, 260, 262]).

Mann könnte dagegen erwidern, dass bei solchen hohen Temperaturen die Puppen gelähmt werden, wobei auch der Stoffwechsel gestört wird und als Resultat werden dieselben Formen erhalten, welche auch bei gewöhnlicher Temperatur bei herabgesetztem Stoff- 
wechsel. also in Stickstoff. Kohlensäure ocler Aetherlampf, entstehen. Dieser Erwiderung wilersprechen jedoch die Thatsachen.

Wie ich gezeigt habe, findet der Stoffwechsel bei Insekten auch bei diesen hohen Temperaturen statt; wenigstens zeigen die Versuche z. B. mit Deilephila elpenor (vide die Tabelle auf p. 837), dass zwischen der Körpertemperatur des Insektes und derjenigen der umgebenden Luft eine bedeutende Differenz vorhanden ist, d. h. der Körper ist stets um ca. $5^{0}$ wärmer als die Luft, welche Differenz sogar bei $49,2^{\circ}$ der Luft- resp. bei $54,3^{\circ}$ der Kööpertemperatur beobachtet wird, was nur durch das gesteigerte Athmen zu erklären ist.

Wir kommen somit zum Schlusse, dass die Ursache des Entstehens von aberrativen Formen nicht in Stoffwechselinderung zu suchen ist. Sie liegt viel tiefer und muss in einer Frscheinung gesucht werden, welche durch die Einwirkung aller möglichen Faktoren, einzeln genommen, verursacht wird. Diese Erscheinung ist die Bewegung des Protoplasmas in Zellen.

Auf die Bewung des Protoplasmas üben ihren Einfluss verschiedene Faktoren aus: die Temperatur, die umgebenden Gase, das Schütteln, die Centrifugalkraft etc., welche in weiterfolgenden Abschnitten ausführlich besprochen werden. Hier sei nur bemerlit, dass jeller dieser Faktoren sein Optimum für die Bewegung des Protoplasmas in Zellen besitzt. Ist dieses Optimum nicht vorhanden, so verlangsamt sich die erwähnte Beweguug oder Strömung, gleichviel ob dabei der betreffende Faktor von optimaler Grösse resp. Intensität nach links oder nach rechts abweicht, $\mathrm{d}$. h. ob dersclbe ab oder zunimmt. Diese Verlangsamung hat ihren Ausdruck unter anderem auch in der Aenilerung des Farbenkleides der Inseliten. Ein Faktor, welcher anf die Bewegung des Protoplasmas seinen Einfluss auszüuben im Stande ist, wird auch aberrative Formen erzeugen können. Wie wir gesehen haben und wie die Fir. 9 es veranschaulicht, ist die Temperatur einer dieser Faktoren.

Von diesem allgemeinen Standpunkt aus betrachtet, können wir von der Temperatur, als einem der Falitoren, welcher seinen Einfluss auf den Bewegungszustand des Protoplasmas in Zellen ausïben kann, folgendes in Bezug auf die Entstehung aberrativer Formen sagen:

Der Organismus (die Puppe) befindet sich bei optimaler Temperatur $Z$ (vide Fig. 9). Es entstehen normale Formen. Dabei muss 
der Begriff des Optimums als relativ aufgefasst werden, denn das Optimum variiert nicht nur von Species zu Spezies, sondern ist auch verschieden für verschiedene Indiiviluen einer und derselben Spezies, was durch die Akkomadation des Protoplasmas und ihre verschie. lene chemische Zusammensetzung in verschiedenen Intividuen zu erklären ist.

Beim Steigen der Temperatur bewegt sich das Protoplasma rascher und es entstehen zuerst $C$-Formen, dann $B_{2}$-Formen, wobei beim Entstehen der letzteren Formen das Protoplasma in gewissen Zellen bereits die vorübergehende Wärmestarre zu erleilen beginnt. Beim weiteren Steigen der Temperatur erhalten alle Zellen iles Organismus die voriijergehende Wärmestarre und es entstehen dabei $D_{2}$-Formen Höchst wahrscheinlich tritt dabei die Flïssigkeit aus den Zellen heraus, da dieselben in Folge der Ausdehnung des Protoplasmas sie nicht mehr beibehalten können werden. Die Farbstoffe werden in diesem Temperaturrayon von der Temperatur direkt beeinflusst. Diese Formen sind pathologische Erscheinungen, welche bei weiterem Erwärmen die permanente Wärmestarre erhalten und schliesslich in Folge der Gerinnung der Eiweissstoffe sterben.

Beim Ablühlen bewegt sich das Protoplasma langsimer, wobei zuerst die $B_{1}$-Formen entstehen werlen. An der unteren Temperaturgrenze für das Entstehen dieser Formen erleiden alle Zellen des Organismus die vorübergehende Kältestarre, wobei bei weiterem Abkühlen die Säfte aus den Zellen heraustreten werden, wie es Sachs bei Pflanzenzellen beobachtete, cla die Säfte bei ca. $0^{0} \mathrm{ihr}$ Dichtemaximum haben werien, und folglich bei noch tieferer Temperatur sich wieder auslehnen werden. Besonders erleiden einen grossen Verlust an Wassergehalt die Zellen im Punkte $N_{2}$, wo die Temperatur einen "Sprung" erleidet, und wo die Säfte $\mathrm{zu}$ gefrieren beginnen. Hier und auch etwas friiher entstehen die $D_{1}$-Formen, welche demgemäss auch als pathologische Erscheinungen zu betrachten $\sin l$. Sie unterscheiden sich in biologischem Sinne von den $D_{2}$-Formen dadurch, dass während $D_{2}$-Formen bei noch höheren Temperaturen in Folge des Gerinnens des Protoplasmas sterben, die $D_{1}$-Formen bei noch tieferen Temperaturen zuerst in anabiotischen Zustand gerathen, und schliesslich die permanente Kältestarre erleiden, in Folge deren sie aber nicht sterben, sondern, wenn man sie nicht wieder erwärmen würde, in diesem Zustande beliebig lange Zeit verbleiben können. Nicht das Gefrieren tödtet die Phlanzenzellen, sagt Sachs, sondern die Art unil Weise, wie sie aufgetaut werlen. 
Wie die Pigmente in Folge der Bewegungsänderung des Protoplasmas erzeugt werlen, kann man bei gegenwärtigem Stande der Wissenschaft noch nicht sagen. (Vrgl. R. E. Fuchs $\left[268 \alpha^{\prime}\right\rceil$ ).

\section{Einfluss der Feuchtigkeit.}

\section{a) Einfluss der Trockenheit.}

Nach anhaltend trockenem Wetter treten ganz schwarze Varietäten der Raupe von Papilio machaon auf (0. Schultz [788]).

Werden die Puppen von Papilio pordulirius dem Einflusse der grössten Trockenheit ausgesetzt, so zeigt bei Schmetterlingen die schwarze: Querbinde auf den Vorderflügeln gelblich-weisse Bestäubung (0. Schultz [788]). Auch Puppen von Epinephele janira und Coenonimpla pamplitus, welche an heissen Lehnen hängen, ergeben albinistische Formen (Standfuss [840]), während Schmetterlinge von Melanargia galathea, welche heisse trockene Berglehnen bewohnen, grüngelbe Stücke ergeben (Meyer-Dür [580]), Ulbricht (887) fand die hell gefärbte var. cereus K1. nur an trockenen Orten.

Keinen Einfluss erhielt M. v. Linden $(527 \epsilon$ ) bei Vanessa urticae.

Die trockene Nahrung beeinflusst die Farbe der Raupen: die Färbung von Eupithecia sobrinata auf Juniperus communis ändert sich von gelb bis roth (Habich [347]), von Oinithoptera prianus auf Aristolochia-Arten ist die Färbung grün (Ribbe [690]). Raupen von Amphidasis betularia, gefüttert mit trockenen Pflanzen, ergeben im Verlaufe weniger Generationen vollständig schwarze Schmetterlinge; bei Schmetterlingen, von Abraxas grossulariata wird das Braun durch Weiss, und bei Arctia caja durch Roth und Weiss ersetzt (Prest [649]).

\section{b) Einfluss der Feuchtigkeit.}

Werden die Raupen von Lasiocampa potatoria in der Feuchtigkeit gehalten, so behalten sie die erste helle Färbung lange Zeit, sonst sind sie dunkel (Jänichen [414]). Raupen von goldgelber var. croesus werden auf Pflanzen getroffen, welche auf sumpfigem Boilen wachsen (Ribbe [690]); dasselbe gilt auch für Emphytus serotinus Mill. (Ulbricht [887]). Raupen, welchen saftige Pflanzen gereicht werden, ergeben meist blass gefärbte Schmetterlinge (Robinson [695]). 
Dagegen beobachtete Pictet (637a), dass Vanessa urticae, $V$. polychloros und Ocneria dispar dabei gar nicht geändert werden.

Raupen, welche in feuchter Luft erzogen werlen, ergeben Varietäten (Fuchs [268]: Acidalia similata var. griseatu Fuchs [gleichmässig grau]).

Werlen Puppen von verschielenen Schmetterlingsarten in der Fenchtigkeit gehalten, so schlïpten daraus anderes gefürlte Exemıllare aus: Melanagaria galathea ist weisslich (Moyer-Dür [580]), Nemeophila plantaginis hat beschränlite weisse Zeichnung, Deilcphila euphorbicu mit starker rosenrothen Färbung der Vorderflügel (Kusdas [488]), Melitaea didyma hat die Unterseite von aurinia (Frings [250]), Aglia tau ist schwarz (Berger [72]), Argynnis euphrusyne bezitzt verbreitete schwarze Zeichnung (Rühl [71s]), die Ausbreitung des Pigments wird bei Erebia, Pararge, Coenonympha etc. verhinclert (Habich [348]), Chrysophanus phlacas ist blassgelblich, bei Vanessa levana, urticae und Chr. phlaeas ist die Zeichnung verwaschen (Woismann [954]). Verwaschene Zeichnung ergiebt auch Satumia pyri und spini (Standfuss [837]), Papilio machaon hat Schiller (Piepers [639]), Vanessa c album zeigt die Zunahme der dunkelen Zeichnung auf der Ober- uncl Unterseite, während bei Vanessa atalanta eine Abnahme der Binde und weisser Flecken beobachtet wirl (Frings [253]), Aporia crataegi ergiebt var. angusta Turati (Drenowsky [195l]), Vanessa urticae, V. polychloros, V. io, Ocneria dispar werden dunkler (Pictot [637 a]); ilunkler werden auch andere Species (Rühl [721]).

Einige Inseliten, in einen sehr feuchten Raum gebracht, änlem voribergehend ihre Färbung (Weir [950]: Procris ylounluriac wird statt grïn dunkelbronzen; Rühl [726]: Ellopia prosapiaria var. prasinaria $\mathrm{Hb}$. nähert sich der Stammform).

Feuchte Witterung ergiebt schwarze Maikäïer uncl Anisoplic segetum mit schwarzem Schild (Schumann [796]).

\section{c) Der vermischte Einfluss der Feuchtigkeit und Trockenheit.}

Wird ein Theil einer Schmetterlingspuppe dem Einflusse der Feuchtigkeit, der andere Theil dem Einflusse der Trockenheit ausgesetzt, so erlält der erste Theil beim Sclmetterling hellere Farben (D)ilephila nerii, Standfuss [840], Splinx pinastri, Burstert [122]).

In Gegenden, wo die Regen- und Trockenzeit abwechselnd auftreten, erscheinen zu dieser Zeit auch abwechselnd zwei Former 
einer und derselben Species (Lionel de Nicéville [611]: Cyllo leda L. und Cyllo ismene Gram; Barker [52]).

Wenn in einer Gegend die Feuchtigkeitsverhältnisse plötzlich geändert werden, so entstehen dabei Varietäten (Federloy [219]: Parnassius apollo ab. brittingeri Rb?, bei feuchter Witterung, $V a$ nessu untiopa ab. lintneri Fitsch. $=$ ab. daubii Stelfs. $=$ var. epione Fschr. bei Trockenzeit; Slovogt [822a]: Argymis aglaja ab. cmilia Quens. bei Regenzeit).

\section{d) Theorie dieses Einflusses.}

R. Jänichen (415) äussert sich iiber die Ursachen der Variabilität ıler Inselitenfärbung wie folgt: „Bedingen die Kohlenstuffver binlungen im Blut der Raupen die auftretende Veränderlichkeit im Falterkleide, so ist als sicher anzunehmen, dass bei der winterlichen Temperatur, die auf das einzelne Thier in Freien änsserlich mehr oder weniger wirkende Feuchtigkeit das Auftreten der Variabilität beim Faltergewand zur Folge hat; denn es ist doch wohl ausser Frage, dass diese Feuchtigkeitsgrade bei allen Raupen ein und derselben Art, in Folge des ungleichen Aufenthaltes oder der Unterschiede des Wintersitzes, nicht ganz gleich werden oder es werlen können" (p. 87).

Nach ihm soll nicht nur die mehr oiler weniger gleich starke Ausscheidung der relucirten Kohlensäure nach Winterschlaf einen Eintluss auf die Veränderlichkeit des Farbenkleides beim späteren Falter ausüben, sondern auch die bis zum Verpuppen aus der Nahrung noch hervorgehenden Ansammlungen von Kohlenstoffverbiniungen.

W. Kusdas (488) zïchtete bei gewölnnlicher Temperatur Deilephila euphorbiae und erhielt nach 3-wöchentlicher Puppenruhe Falter mit auffalend starker rosenrothen Fürbung der Vorderfliigel. Er schreibt diese vorzeitige Entwickelung (er allzugrossen Feuchtigkeit des Sommers zu.

Zieht man in Betracht, dass nach Jänichen (415) verschieden starke Ausscheidung der reduzierten Kohlensäure (nach Winterschlaf) einen Einfluss auf die künftige Färbung des Falters ausübt, so lassen sich die Beobachtungen von Kusdas dadurch erkliiren, dass die grosse Luftfeuchtigkeit die Ausscheidung der Kohlensïure aus dem Puppenkörper beschleunigte, wodurch auch die vorzeitige Entwickelung stattfand.

Die vorzeitige Entwickelung der Puppen durch ihr Befeuchten beobachtete auch Standfuss [837] bei Saturnia-Arten, wobei die 
Falter eine mehr oder weniger verschwommene und verwaschene Zeichnung besassen. Diese Farben- resp. Zeichnungs-Aendernugen könnte man dadurch erklären, dass die Feuchtigkeit des Cocons die in seinem Inneren befindliche Kohlensäure absorbierte, wodurch die Kohlensäure-Starre (ähnlich der Wärmestarre) des Protoplasmas in Zellen beseitigt wurde, und die Puppe begann ihre Entwickelung von neuem an. Da diese Entwickelung keineswegs als normal angesehen werlen darf, so werden selbstrerständlich auch die Farben nicht in normaler Weise entwickelt, wie es beim Einfluss auch anderer Faktoren beobachtet wird.

Wie es aus den in diesem Abschnitt angefiihrten Thatsachen ersichtlich ist, wirkt die Feuchtigkeit ein Mal in albinistischer und das andere Mal in melanistischer Richtung auf das werlende Kleid der Insekten.

Die melanistische Richtung wird beobachtet bei: Vanessc urticae, polychloros, io, c ulbum, atalanta, Argynnis euphrosyne, Ocneria dispar, Aglia tau, Nemeopliila plantaginis, Naikäfer, Anisoplia segetum.

Die albinistische Richtung wird beoba htet bei: Melannryia galathea, Chrysophanus phlaeus, Erebia-, Pararge-, Coenon y m pha - Arten.

Ueber die Erscheinungen des Albinismus und Melanismus sagt Standfuss (840): „Beruht der Albinismus in typischer Ausbildung auf einer individuellen, inneren, unerklärten Hemmung der normalen Entwickelung - als unechter, als Schein-Albinismus aber auf einermeist in ihrer äusseren Veranlassung sehr wohl nachweisbaren theilweisen Verkümmerung - so ist im Gegensatz dazu das Wesen des Melanismus wohl dahin auszusprechen, dass er ein Hinausschiessen über das normale Ziel, eine Ueberproduktion, ein Uebermass an. Kraft und Lebensenergie darstellt. Vielleicht hat die Erscheinung also das mit dem typischen Albinismus gemein, dass sie die FoIge einer indiviluellen, inneren Beanlagung ist" (p. 203).

Unsere Fälle sind kein totales weder Albinismus noch Melanismus, sontern sie sind nur partielle Erscheinungen, „Farbenstörungen" (Urech, Kathariner).

Die Ursache des partiellen Albinismus ersieht Standfuss (840) in der übermässigen Feuchtigkeit, während die Versuche von Kathsriner (439) ergaben, dass "die Feuchtigkeit als solche keine Rolle spielt." Er ist geneigt, die Ursache der Temperatur zuzuschreiben. 
Die oben angeführten Thatsachen sind Resultate der Einwirkung mehrer Faktoren zur gleichen Zeit. Die Farbenschwärzung, welche Rühl (721) erhielt, intem er die Puppen über heissem Wasser hielt, könnte im Sinne Kathariner's erklärt werden. Blass gefärbte Schmetterlinge, welche in Fütterungsversuchen mit saftigen Pflanzen bei Robinson (695) entstanden, haben ihre Ursache möglicherweise in der Nahrung resp. in der Verdaungsstörung. Die von Standfuss (837) erhaltene verwaschene Zeichnung liönnte, wie wir gesehen haben, durch anormale Entwickelung erklärt werden etc.

Würde man alle diese Nebenfaktoren entfernen und unter sonst gleichen Umständen nur den Einfluss der Feuchtigkeit untersuchen, so könnte man fragen, iibt die Feuchtigkeit ihre Wirkung auf das werdencle Kleid der Insekten aus?

Wie wir gesehen haben, erhielt Kathariner (439) bei der Untersuchung der Puppen von Vanessa urticae, io und antiopa ohne abnormer Feuchtigkeit die Farbenstörungen. Auch M. v. Linden (527e) erhielt keine nenneswerthen Abweichungen in der Färbung von Vanessa urticue, indem sie die Puppen in einem trockenen Raum hielt. Es liegen aber Versuche vor, welche die Wirkung der Feuchtigkeit als solcher sehr plausibel machen.

So erhielt Standfuss (840) albinistische Bildung bei Deilephilu nerii, indem er die Puppen in ein kïhles Zimmer auf eine stark durchnässte Sandunterlage brachte. Hier konnte die "Temperaturdifferenz," von welcher Kathariner (439) spricht, nicht stattfinden, da das Zimmer ohne dies kühl war; ausserlem albinistisch wurde nur die Seite, welche auf dem Sande lag. Aehnliche Resultate erhielten Burstert (122) mit Sphinx pinastri und Frings (252) mit Vanessa $c$ album und atalanta. Positive Resultate erhielt auch Pictet $(637 a)$ mit Vanessa urticae, polychloros und Ocneria dispar, deren Puppen 8 Tage in feuchter Atmosphäre gehalten wurden.

Somit kommen wir zum Schlusse, dass die Feuchtigkeit das künftige Kleid der Insekten zu ändern im Stande ist, wobei die Ursache ihrer Wirkung eine directe und indirekte sein kann.

Die directe Wirkung kann darin bestehen, dass die Feuchtigkeit, besonders die Nässe die Puppenhülle durchdringt und auf diese Weise die Insektensäfte verdünnt. Dafür sprechen die Versuche von Troska (884), wenngleich Fischer (229) sie nicht kunstatieren konnte.

Die indirekte Wirkung kann sich verschieden äusseren. Erstens, kann die Feuchtigkeit, speziell die Flïssigkeitsschicht an der Oberfläche der Puppe den Zutritt lles Sauerstoffs zum Puppen- 
organismus verhindern und dadurch die Ausbildung der normalen Pigmente hemmen. Zweitens kann die Feuchtigkeit die Starre dis Protoplasmas verursachen, ähnlich wie sic die anderen Faktoren erzeugen.

In diesem letzteren Falle muss es ein Optimum der Feuchtigkeit fïr die normale Entwickelung des Insektenorganismus geben (vide p. 689), welches für verschiedene Species voraussichtlich verschieden gross ist. Wird dieses Optimum nach links oder rechts überschritten, so entstehen Störungen in der Entwickelung les Organismus und folglich auch in der Ausarbeitung und Vertheilung der Pigmente.

\section{Einfluss des Lichtes und der Farbe der Umgebung.}

A. Einfluss des Lichtes auf die künftige Färbung des Imagos.

Werden die Raupen verschiedener Schmetterlingsspecies unter farbigem Licht erzogen und auch die Puppen darin liegen gelassen, so erleidet dadurch die Fürbung des Imagos keine Abänderung (Schoch [770], Standfuss [835], Kathariner [438], Barrett [565], Blanchard [86], Merrifield [567]).

Widersprechende Resultate erhielten Sidebotham [810] mit Argynnis-Art, Graber [326] mit Vanessa polychloros, Kunckel d'Herculais [485] mit Schistorca peregrinu Oliv., v. Linden [517] mit Vanessa urticae und io, Müllenberger [596a] und Cholodkowski [144] mit Vanessa urticae).

Auch die Dunkelheit hat keinen Einfluss auf die künftige Färbung des Imagos (Kathariner [438], Gauckler [284], Løbedinsky [503], Schröder [778], Merrifield [567]).

Verschieden gefärlbte Raupen einer und derselben Species ergeben normal gefärbte Imagina (Speyer [830], Christoph [145], v. Prittwitz [654], Krulikowski [478c], Bastelberger [54]).

Widersprechenle Resultate erhielt Kalender [428] mit Smerinthus populi und ocellatus.

Verschieden gefärbte Puppen einer und lerselben Species ergeben normal gefärbte Schınetterlinge (Kathariner [438]), wenn ihre Farbe nicht durch die Hitze geänlert wurde (Vonus [903]).

Keinen Einflus hat das farbige Licht auf die künftige Färbung der Schmetterlinge auch dann, wenn die Zucht vom Ei ab unter der 
Wirkung dieses Lichtes angestellt wird (Weismann [954]). Trotzdem halten viele Forscher die Meinung aufrecht, dass intensiveres Licht auch lebhaftere Färbung der Imagina hervorruft (v. Lomnicki [534], Möller [582], Nauck [855], Fischer [238]).

\section{B. Anpassung an die Farbe der Umgebung.}

Es wird hier nicht beabsichtigt, das ungeheme Gesimtmaterial in Bezug auf die "Schutzfärbung", "Schreclfärbung“" etc. vorzuführen, da die Frage über Polymorphismus und Mimicry an und für sich schon eine besondere Studie ausmachen würde, sondern es werden hier Thatsachen betrachtet, welche zur Lösung der Frage über rlen Einfluss der Farbe der Ungebung auf Insekten mehr auf experimentellem Wege gewonnen wurden.

\section{a) Eier.}

Es wird tagtäglich beobachtet, dass die Eier meister Species die Färbung der Futterptlanze besitzen.

\section{b) Raupen und Larven.}

Raupen resp. Larven meister Species haben ähnliche Färbung, wie die Stellen der Futterpflanze, wo sie sich aufhalten (Prehn [650], Lehmann [506], Rössler [700, 702], Stange [842], Peters [631], Werneburg [955], Müller [599], Piepers [638], Aigner-Abafi [5], Dietze [181, 182], Darwin [164], Barber [48], Trimen [882], Gartner [273], Gauckler [276], Poulton [644, 647], Wilkins [960], Warnecke [943], Pomeranzew [640b], Koch [457b], Ruhe [7:6b], Holtz [386]).

Einige Species besitzen diese Fähigkeit nicht (Caraciollo [104], Piepers [638]).

Farbiges Licht verändert die Färbung der Raupen, und zwar: Gold, Gelb, Grün, Silber und Weiss erzielen bei Raupen (20 Eupithecia-Arten) helle, meist griinliche Grundfarben, Schwarz und Braun dagegen dunkle, oft bräunliche Farben, während Roth, Blau, Violett mehr oder weniger einflusslos bleiben (Schröder [772, 777]). Keinen Einfluss konstatierte Heissler (363), (Vancssa urticae, Pieris brassicae etc.).

\section{c) Puppen.}

Die Puppen meister Species nehmen die Fürbung der Umgebung an (Rühl [721], Merriffield [575] Trimen [104], Pabst [618]) 
Auffallende Ausnahmen von dieser Regel sind: dimorphe Puppen von Pripilio polydamas (Müller [597]), Papilio machaon (0. Schultz [788]).

Die Färbung der Puppen wird durch las farbige Licht beeinflusst (Poulton [646], Meldola [556], Wood [962], Morris [595], Griffiths [539], Petersen [632], v. Linden [517], Kathariner [437, 440], Bordage [104]). Negatives Resultat erhielt Merrifield (565) mit Selenia illustraria.

Auch die Färbung der Wespen-Larven wird durch das farbige Licht geändert (Rudow [711]).

Die Färbung der variablen Puppen hängt von der Farbe der Umgebung nur bei einer gewissen Temperatur ab $\left(37^{0}-40^{\circ}\right)$; bei $18^{\circ}$ bis $23^{\circ}$ findet keine Aenderung statt (Standfuss [840], Kathariner [437]), resp. der Prozess dauert mehrere Wochen (Merrifiold [575]).

Die Empfindlichkeit der Raupe resp. Puppe gegenüber dem umgebenden Medium ist am stärksten während der letzten Stunden der Raupen- resp. der ersten Stunden der Puppen-Zeit (Poulton [646], Merrifield [575], Bordage [104], Griffiths [330], Petersen [632]).

Diese Fähigkeit der Farbenanpassung bei der Raupe wird weder durch Augen noch durch behaarte Dornen bedingt (Poulton [646]).

$\Lambda$ uch das Puppengespinnst nimmt die Färbung des umgebenden Mediums an (Trost [884a]: Cerura bifida; Schawrow [741]: wilde Rasse von Bombyx mori, Attucus atlas, An. cyntie etc.; Dewitz [174]: Bombyx lanestri, Saturnia pyri).

\section{d) Imago.}

Imagines meister Species haben die Färbung der Umgebung (Schmetterlinge: Hoffmann [378], Rössler [700], Meyer-Dür [580], Danilow [163a], Krulikowski [479], Wallace [940], Möller [582]; Käfer: Bərg [69], Schenkling-Prévôt [746], Prehn [650]; Fliegen: Jaroschewsky [418]; Ameisen: Biró [81]; Heuschrecken: Keller [446], Grosser [331], Tümpel [886]; Pflanzenläuse: Mordwilko [593], Cholodkowsky [140a]; Läuse: Schenkling-Prévôt [745]).

\section{Theorien dieses Einflusses.}

Nachdem Wood (1867. 962) zum ersten Mal konstatierte, dass das Licht die Färbung der Puppen beeinflusst, nahm er an, dass die 
Ursache dieser Erscheinung in der photographischen Empfindlichkeit der Haut liegt.

Meldola (1874. 557) negierte den photographisch-chemischen Prozess, da bei Versuchen von Barber (48) die Puppe grün blieb, trotzdem dieselbe in ein Stück Scharlachtuch eingehüllt wurde.

Poulton (1886. 644) wies nach, dass die Fürbung der Raupen durch erblichen Einfluss, durch die Farbe der Blätter, nicht aber durch die Substanz der verzehrten Blätter bedingt wird. Die Puppe passt sich der Farbe der Umgebung nur dann an, wenn die Raupe unmittelbar vor der Verpuppung von diesem farbigen Lichte beeinffusst wurde, was später auch von anderen Forschern bestätigt wurde (Griffiths [539], Petersen [632], Merrifield [575], Bordage [104]).

Poulton vermuthete zuerst, dass die Ursache dieser Erscheinung in dem Einflusse der Umgebung auf das Nervensystem der Raupe, also in einem physiologischen Vorgang, liegt. Seine Versuche sowohl mit augenlosen Raupen und mit solchen, bei welchen die Dornen abgeschnitten werden, wie auch mit Contrastfarben crgaben, dass die ganze Körperobertläche der Raupe gleichmässig die Farbenempfindlichkeit besitzt.

Die Untersuchungen von J. Loeb (531) ergaben, dass das Licht bei Schmetterlingspuppen hemmend auf die Oxyclation wirkt, und da nun die Billung dunkler Cuticularpigmente durch gelbes Licht und grössere Helligkeit gehemmt, durch Dunkelheit aber sichtlich gefördert wird, so könnte man geneigt sein, die dunklen Pigmente als das Produkt von Oxydationsvorgängen anzusehen.

Petersen (1890. 717) wiederholte die Versuche von Poulton und Griffiths und lam zum Schlusse, dass wir es hier mit Vörgängen $\mathrm{zu}$ thun haben, die sich in den Zellen der Hypodermis unter dem Einflusse äusserer Lichtreize unabhängig vom Nervensystem les Thieres abspielen.

Bei weiteren Untersuchungen stellte Poulton (647) fest, lass verschiedene Färbungen der Puppe unter dem Einflusse des farbigen Lichtes nicht durch verschiedene Lagerung der unveränderlichen Farbstoffe entstehen, sondern dadurch, dass der Farbstoff neu gebillet und unter Einfluss des Lichtes verändert wirl. Er hielt die Annihme für möglich, (lass die oberflächlich gefärbte Schicht in einem Zustand von "complete physiological unity" sich befindet, und dass das Nervensystem die Lichtwirkung fortleitet. Derselben Ansicht ist auch v. Linden (522). 
Nachdem die hier angeführten Thatsachen bekannt geworden sind, gab Otto Wiener (1895. 959) die Theorie der mechanischen Farbenanpassung in der Natur.

Er unterscheidlet zunächst Scheinfarben, welche durch Interferenz, unı Körperfarben, welche durch Absorption entstanden sincl.

Weiter stellt er fest, dass es Stoffe giebt, in denen farbige Beleuchtung ïbereinstimmende Körperfarben erzeugt, die ihre Farbe also nicht der Interferenz, sonlern einer ihnen eigenthümlichen, lurch die chemische Beschaffenheit bedingten Absorption verdanken.

Diesen Vorgang erklärt er dlamit, dass solche Stoffe iurch Belichtung entstehen und sagt weiter: „Warum aber entstehen die mit der Beleuchtungsfarbe gleichfarbigen Verbinilungen? Was hat z. B. bei rother Beleuchtung ein rothes Photochlorid I) fur einen Vorzug gegenüber einem andersfarbigen?

${ }_{n}$ Es hat den physikalischen Vorzug, diese Farbe besser zu reflectiren, als die andersfarbigen Verbindungen. Farbiges Licht aber, das reflectirt wird, wird nicht absorbirt und kann daher auch keine Zersetzung hervorbringen, für welche die Absorption des Lichtes Vorbedingung ist. Vun allen möglichen Verbindungen, welche aus dem durch die Belichtung gestörten chemischen Gleichgewicht hervorgehen können, besitzt also die rothe Verbinulung den Vorzug der Unzerstörbarkeit bei fortgesetzter Beleuchtung. Nach den Vorstellungen der kinetischen und neueren chemischen Theorien müssen wir aber annehmen, dass bei dem gestörten Gleichgewicht alle möglichen Verbindungen zeitweilig thatsächlich von einigen Molecilgruppen gebilden werden. Von diesen bleiben aber nur die rothen dauernd ungestört, während die andersfarbigen das rothe Licht absorbiren und also darlurch auch wieler zerstört werden können" (p. 232).

Einen Stoff, welcher die von dieser Erklärung behufs vollkommener Farbenwiedergabe geforderten Eigenschaften besitzt, nennt er farbenempfänglich.

"Was noch das Zustandekommen der Farbenwiedergabe betrifft, so nennt man die Erwerbung der Widerstandsfähigkeit gegen äussere Einwirkungen eine Anpassung. Daher könnte man die so entstandenen Farben Anpassungsfarben nennen, wobei man sich be-

1) Unter Photochloriden versteht man nach Carey Lea (502) verschiedenfarbige Verbindungen von Chlor und Silber, welche obwohl aus Silberchlorid und- chlorür bestehend, doch nicht durch bestimmte Verhältnisszahlen ausdruckbar sind. 
wusst bleibt, dass es sich um einen physikalisch-chemischeu, im letzten Grunde mechanischen Vorgang landelt. Eine derartige Anpassung kann man als eine mechanische Anpassung bezeichnen" (p. 233).

Nach einer grossen lieihe von rein physikalischen Versuchen kommt Wiener schliesslich zum letzten Kapitel: „Mechanische Farbenanpassung in der Natur," in welchem er hauptsächlich die Versuche von Poulton bespricht und zu erklären versucht.

Er weist zunächst nach, dass die biologische Erklärung der Schutzfärbung nicht genügen kann; "es tolgt aber keineswegs, llass natiirliche Auslese nicht im Spiele war zur Hervorbringung des farbenerıpfänglichen Pigments der Raupen“ (p. 271).

"Sollte nun die Farbenanpassung der Raupen mit der Farbenwiedergabe ler Körperfarbenphotographie zusammenhängen, so müsste der dunkle Farbstuff von selbst im Dunkeln gebildet werden und die hellen Färbungen durch die Einwirkung des Lichtes auf ihn zu Stande kommen" (p. 270).

Die Versuche von Poulton zeigen wirklich, dass im Dunkeln vorzugsweise dunkle Raupen und Puppen, im Lichte dagegen zwischen hellen Gegenständen helle gebildet werden.

${ }_{\text {}} \mathrm{Da}$ die Raupenhaut in hohem Grade sich (ler Farbe des Laubgrïns anpassen kann, so muss das von ihm ausgehende Licht auch besonilers im Stande sein, das dunkle Pigment zu zerstören, das sich beim Fehlen des Lichtes in der Haut bildet und ansammelt" (p. 271).

Poulton hat gezeigt, dass besonders der gelbe Bestandtheil des von grïnen Blättern ausgesandten Lichtes in hohem Masse den dunkeln Farbstoff der Epidermis von Pieris brassicae unil rapae zu vernichten vermag.

Wiener erklärt noch andere von Poulton und Morris beobachteten Erscheinungen uni kommt zu folgendem Schluss: „Nach allem wird man wenigstens bei den Raupen einen Zusammenhang mit der Körperphotographie anerkennen, insofern sie einen Farbstoff beherbergen, der in gewissem Maasse die Eigenschaften eines farbenempfänglichen Stoffes besitzt" (p. 278).

Dem letzten Kapitel: "Zusammenfassung uni Schluss" seien noch folgende Stellen zu entnehmen:

"Es ist grundsätzlich möglich, dass farbige Beleuchtung in geeigneten Stoffen gleichfarbige Körperfarben erzeugt. Diese Möglichkeit und die Erkenntniss ihrer Ursache bilden die neue Grundlage einer Art Farbenphotographie, die man als Körperfarbenphotographie bezeichnen kann" (p. 280). 
„Die Farbenwiedergabe kann als Farbenanpassung bezeichnet werden; denn sie entsteht durch Auslese der Farbstoffe, welche der zerstörenden Einwirkung der Beleuchtungsfarbe am besten wilerstehen; das sind die gleichfarbigen" (p. 280--281).

Obwohl die hier kurz besprochene Theorie der Farbenanpassung von $\mathbf{0}$. Wiener viele beobachteten Thatsachen sehr gut erklärt, ergiebt sie doch, dass wir beim Einfluss des Lichtes auf Inseliten noch mit verschiedenen verwickelten physiologischen Vorgängen zu thun haben; deshalb schliesst Wiener seine Abhandlung mit folgenden Worten: "Ich glaube, dass mit Vorstehenilem die Arbeit des Physikers betreffs der mechanischen Farbenanpassung im Wesentlichen gethan ist, und es hat jetzt die des Chemikers- unil Photographen einerseits, des Biologen andererseits zu beginnen, bezichungsweise das physikalische Ergebniss nutzbar zu machen" (p. 281).

Es seien hier die Versuche von E. Steinach (844) angefiihrt, welche er an Fröschen angestellt hat. Er zerstörte durch Verschneiden die Nerven-Verbindung der Haut des Froschbeines. Diese Haut mit verchschnittenen Nerven erwies sich gleichwohl gegen Licht ebenso empfindlich, wie die intacte. Er belilebte auch einzelne Stellen der im Dunkeln gehaltenen Laubfrösche mit schwarzen $\mathrm{Pa}$ pierstreifen und stellte die Thiere der Lichteinwirkung aus. Die Haut wurde dann hell, an geschützten Stellen aber dunkel. Daruus folgt, dass das Licht die Pigmentzellen der Haut direkt errege und in den Contractionszustand versetze.

1896 entreckte Standfuss (840) die 'Thatsuche, dass die Färbung variabler Puppen, abhängig vom Lichte der Umgebung, nur bei gewissen hohen Temperaturen stattfindet, welche höher als $23^{\circ}$ liegen (für Vanessa-Arten), was später auch von Merrifield (575) und Kathariner (440) bestätigt wurde. Somit konnte man das Mislingen der Versuche einiger Forscher in dieser Beziehung erkliren.

Die Theorie der Farbenphotographie von Zenker (965a), welche von $\mathbf{0}$. Wiener entrickelt wurde, wurle in der neusten Zeit von R. Neuhauss (598) gepruft. Er benützte bei seinen Versuchen Filtrierpapierstreifen, welche in verschiedenen Mischungen geballet wurden. Als sehr geignet erwies sich die Mischung: Erythrosin (oder Eosin) + Uranin (oder Thiazogelb) + Methylenblau + Chlorophyll. Zu dieser Mischung wurde Gelatine mit Wasserstoffsuperoxyd zugesetzt. Nach 5 Minuten langein Belichten im direkten Sonnenlichte unter einem farbigen Transparent erhält man ausexponierte Farben. Zur vollständigen Fixierung wird das fertige Bild 
kurze Zeit in einer Kupfersalzlösung gebarlet und darauf ausgewaschen. Somit wird die obige Theorie bestätigt, dass nämlich die gleich gefärbten Stoffe das auffalende Licht reflektieren und folglich nicht verändert werlen, während die ungleich gefärbten Stoffe dieses Licht absorbieren und folglich zersetzt (ausgebleicht) werlen. Im Resultate bleibt also nur der mit dem Licht gleich gefärbte Stoff. R. Neuhauss verspricht, seine Versuche mit anleren Körperfarben anzustellen, wodurch die "Anpassung" der Insekten an die farbige Umgebung auf chemich-physikalische Prozesse sich reduzieren lassen wird.

Wenn die Theorie der Farbenphotographie in der Form, wie sie hier entwickelt wurde, für Raupen- resp). Puppenstadium angewendet werden kann, bleibt noch vieles für Im a go zu untersuchen übrig.

Wie oben erwähnt, beobachteten verschiedene Forscher, dass das Licht das werdende Falterkleid abändert. Diese Versuche sind aber nicht einwandfrei. Die dunkleren Schmetterlinge von Vanessa urticae, welche Müllenberger (596a) erhalten hat, indem er die Raupen und die Puppen unter dem Einflusse des rothen Lichtes crzog, sind höchst wahrscheinlich in Folge der erhöhten Temperatur entstanden. Cholodkowsky (144), welcher die thermische Wirkung des Lichtes durch die Alaunlösung beseitigte, erhielt unter dem Einfluss des blauen, gelben und rothen Lichtes aus den Puppen von Vanessa urticae die der var. polaris sehr ähnliche Form. Abgesehen von dem ersten Punkt der Einwenlung von Kusnetzow (490a) gegen diese Versuche von Cholodkowsky, kann die Zusammensetzung der Futterpflanze bei diesem monochromatischen Lichte wirklich eine Aenderung erleiden und dadurch das kïnttige Farbenkleid des Schmetterlings änilern. (Vrgl. Abschnitt 5 dieses Kapitels). Auch gegen ähnliche Versuche anderer Forscher kamm man dieselben Einwände machen und zwar unso mehr, da negative Resultate von anderer Seite in dieser Richtung vorliegen, besonters aber schwerwiegend sind die Resultate von Morrifield (565), welcher sogar durch die Dunkelheit keine Abänderung in der Färbung erhalten konnte.

Sind dic bisherigen Experimente in dieser Beziehung nicht einwandfrei oler sie führten zu negativen Resultaten, so kamn man im Prinzip doch zulassen, dass die Lichtwirkung nicht olıne Einfluss auf das Farbenkleid des künftigen Imagos bleibt.

Wie Loob (531) nachwies, wirkt das Licht hemmend auf die Oxydation bei Schmetterlingspuppen. Es kann also wohl möglich sein, dass die Entstehung von Pigmenten dabei nicht normal vor sich gehen wird und wir erhalten eine aborrative Form des Imagos. Es 
kann sein, dass die dabei erhaltenen Aenderungen sehr unbeleutend ausfallen, welche aber konstatiert werden können, wenn man rlie analytisch-statistische Methode dabei anwenden würde (vide p. 238).

Die Lichtwirkung bleibt nicht ohne Einfluss auch auf die Färbung des bereits fertig formierten Imagos, wie es aus der Arbeit von Standfuss zu ersehen ist. „Es zeigt sich da bei Beobachtung der lebenden Tiere, dass die im Zustande der vollkommenen Ruhe dem Lichte ausgesetzten Teile des Körpers und der Flügel gle ichartige Färbung besitzen. Hingegen weisen die in der Ruhe gecleckten Teile überwiegend eine von jener Färbung abweichendle auf, und zwar sind die infolge der Lebensgewohnheit der Art lem Lichte immer entzogene Teile des Körpers und der Flügel verschwommen und $\mathrm{m}$ a t t gefärbt, während dem Lichte ausgesetzte Teile weniger indifferente, s c h är fer charakterisierte Färbung und Zeichnung anfweisen." $\mathrm{Da}$ verschiedene Insekten die Flïgel in der Ruhe verschieden tragen, so ist auch das Ruhekleid in seinen Färbungsverhältnissen ein recht verschiedenes. Eine Fülle von Beispielen, welche Standfuss anführt, beweisen in eclatanter Weise die Wirkung des Lichtes auf die Färbung und Zeichnung des fertigen Imagos. Daraus ist ersichtlich, ndass der frisch entwickelte Flïgel durchaus kein starrer und völlig aus dem Kreislaufe der Stoffe ausgeschalteter Teil des Hautskelettes ist, sondern Leben und Reaktionsfähigkeit besitzt" (841a).

Diese Lichtwirkung auf das Imago unterscheidet sich von derjenigen auf die Raupe oder Puppe durch die Kraft, mit welcher sie ausgeuibt wird, was offenbar auf verschieden intensive Realitionsfähigkeit dlieser Stadien zuruckzuführen ist. Auf die Raupe resp. Puppe wird der Einfluss der Lichtwirkung bereits während der Entwickelungsdauer dieser Indiviluen ausgeübt, hingegen bei Imagina ist das Ruhekleid in Folge der Finwirkung des Lichtes im Laufe der Phylogenie entstanden (Oudemans [617]).

Durch diese phyletische Wirkung des Lichtes könnte man die Färbung der Höhlenthiere erlklären. So z. B. beobachtete Absolon (2) stark pigmentierte Arten aus Nicová Scála-Höhle und schwach oder gar nicht pigmentiert aus der Sošůvker-Höhle. Es ist zu erwarten, dass der Nachweis geliefert wird, dass die erste Höhle später von Insekten als Aufenthaltsort bezogen war als die letzte. Dass dabei nicht etwa die Augenlosigkeit die Ursache des Albinismus sein kann, beweisen die Beobachtungen von Verhoeff (908). Dieser Forscher konstatierte, dass völlig blinde Diplopoden: Blaniulus guttalatus Gerv., Brachydesums superus Latz. und Polydesmus germanicus, welche 
in Deutschland vorkommen, so pigmentarm sind, dass sie in dieser Hinsicht den Höhlendiplopoden um nichts nachstehen, trotzdem sie oberirdisch sich aufhalten. Ausserdem wies Grabor (326) nach, dass einige Insekten, auch nachdem sie geblendet waren, einen ausgesprochenen Farbensinn und ein Unterscheidungsvermögen für Helligkeitsstufen zeigen (bei diesen Versuchen wurden die Wärmestrahlen ausgeschlossen).

Die Einwirkung des Lichtes auf Imago im Laufe der Phylogenese kann eventuell durch die klimatischen Verhältnisse beschleunigt resp. verzögert werlen. Melichar (558) beobachtete, dass die Zikade Athysanus stactogalus der Färbung ihres Körpers nach sich den klimatischen Verhältnissen anpasst: "die in siidlichen Gegenden vorkommende Art ist gleich den Blättern der T a marix dunkelgrün gefärbt, wälırend die bei uns (Wien) auf der in Ziergärten kultivierten Tamarix vorkommenden Zikaden viel heller gefärbt sind."

\section{Einfiuss der Elektricität.}

Es ist oft beobachtet worden, dass die Schmetterlinge, welche kurz vor dem Gewitter ausschliipfen, Farbenänclerung erleiden (Bellier de Chavignerie [67], de Lafitole [493], Fallon [218]).

Diese Farbenänderung besteht meistens darin, dass die normale Färbung heller wird (Lila statt Blau bei Lycaena odonis; weissliche Farbe statt Schwarz bei Melanargia galathea; Strohgelb statt Braun bei Polyommatus xunthe; albinistische Flügel bei Epinephele janira), wern auch ein umgekehrter Fall beobachtet wurle (Oberflügel bei Arctia caja ganz braun ohne weisse Figuren).

Die auf experimentellem Wege gewonnenen Resultate bestätigen diese Beobachtungen, aber nur für schwache Wechselströme (statt Roth Orange, Wagner [936]; statt Blau resp. Schwarz Gelbgrau, v. Linden [517]).

Gleichstrom verursacht die Verdunkelung (die Verbreitung der schwarzen Flecken bei Vanessa urticae, Wagner [936]).

Starke Induktionsströme, welche auf Puppen einwirken, zerstören. das Pigment und das Flügelmembran resp. die Schuppen (Wagner [936], Fischer [229], Pictet [636]).

Wirken die Wechselströme auf die noch nicht entwickelten Puppen, so ergeben dieselben verkrüppelte Schmetterlinge (Pictot [636]). 


\section{Die Theorie dieses Einflusses.}

Direkt hat bis jetzt noch Niemand etwas theoretisches über diesen Einfluss veröffentlicht.

Indirekte Beobachtungen bestehen in folgendem:

Man hat oft beobachtet, dass Fische in einem See oiler Meere nach riem heftigen Gewitter massenhaft zu Grundle gehen, obwohl das Gewitter zuweilen mehrere Meilen entfernt von dem betreffenden Orte niederging.

Die erste Vermuthung über die nähere Ursache dieser Erscheinung würde darin bestehen, das die im Wasser enthaltene Luft eine solche Veränderung unter dem Einfluss der elektrischen Entladungen erleidet, dass dieselbe für das Leben der Fische schällich ist.

Wir besitzen in dieser Richtung die Versuche ron 0 . Berg und K. Knauthe (71). Sie untersuchten den Einfluss ler elektrisierten Luft auf den Samerstoffgehalt des Wassers und fanilen eine starke Zehrung des aufgelösten Sanerstoffs. Diese Zehrung crkliiren sie durch die Annahme von elektrolytischen Prozessen, sowie von Bindung des Stickstoffs der atmosphärischen Luft. Durch den letzteren Prozess werden leicht oxydable Verbindungen geschaffen.

Die Versuche von H. Euler (217) ergaben jeiloch, dass iler Gasgehalt im Wasser dabei nicht wesentlich geïndert wirl. Dagegen nimmt er an, dass der bei der Elektrisierung der Luft sich billende Ozon die biologisch-chemischen Prozesse katalytisch beeinflusst.

Somit könnte man daraus den Schluss ziehen, dass der bei Ge. wittern entstehende Ozon auf katalytischem Wege odler auch vielleicht direkt die Färbung der zu schliipfenden Schmetterlinge beeinflusst. Diese Schlussfolgerung gewinnt noch mehr an der Wahrscheinlichleit, wenn man berïcksichtigt, dass der Ozon sehr stark oxydirende Eigenschaften besitzt und folglich im Stande ist zu bleichen, d. h. die Färbung heller zu machen.

Die Thatsachen stimmen damit überein, da nach dem Gewitter Blau in Lila, Schwarz in Weiss, Braun in S'rohgelb bei den verschiedenen Schmetterlingen umgewandelt wird.

Setzt man die Puppen dem direkten Einflusse der Elektrizität aus, indem man iluren Körper mit den Elektroden verbindet, so können dabei sehr komplizierte Érscheinungen zu Tage treten.

Bei der Verwendung des mässigen Gleichstromes muss nothwendigerweise die Elektrolyse der Säfte stattfinden. Es ist sehr wahrscheinlich, dass dabei auf dem negativen Elektrode Wasserstoff, 
ein reduzicrendes Mittel, und auf dem positiven Elektrode Sauerst.off, ein oxydierendes Mittel, sich ausscheiden werden. Diese Gase in status nascendi werilen unberlingt ihre Wirkungen auf das Pigment der Fliigel ausüben. Dabei sind zwei Fälle möglich: 1) sind die Elektroden nicht angefeuchtet und die Puppenhïlle trocken, so werlen sich dic erwähnten Gase im Inneren der Puppe sammeln und dort ihre Wirkung ausüben; 2) sind dagegen die Elelitroden angefeuchtet, so werden die Gase nur an der Oberfläche dir Puppenhülle sich ausscheiden und in die Luft entweichen; also kommen sie gar nicht zu der Wirkung.

Ausser dieser rein chemischen Wirkung kann der Gleichstrom (len Puppenkörper erwärmen und auf diese Art die Entwickelung beschleunigen, wobei unter Umständen die „Wärmeformen" entstehen können.

Sind mässige Wechselströme bei Experimenten verwendet worden, so könen sie nur die Erwärmung des Puppenkörpers und die damit verbundene erwähnte Consequenz hervorrufen. Die Elektrolyse ller Säfte fällt in diesem Falle weg.

Bei starken Gleich- oder Wechsel-Strömen werden die Brandwunden und sogar der Tod eintreten, was durch die Beobachtungen verschiedener Forscher auch bestätigt wird.

Nun kann auch bei mässigen Strömen, besonders bei Wechselströmen eine Starre des Protplasmas in Zellen stattfinden und die Puppen werden uns in diesem Falle Exemplare resultieren, welche mit denjenigen durch die Hitze- oder Frost-Versuche erhaltenen grosse Aehnlichkeit haben werden. Einen ähnlichen Fall beobachtete M. v. Linden (517).

Somit kann der Einfluss der Elektricität auf die Färbung der Insekten als aus drei Componenten zusaminengesetzt betrachtet werden und zwar:

Die I. Componente: die chemische Einwirkung (die oxydierende Wirkung des Ozons resp. Sauerstoffs oder die reduzierende Wirkung des Wasserstoffs).

Die 1I. Componente: die physikalische Einwirkung (die Joule'sche Wärme).

Die III. Componente: die physiologische Einwirkung (die Starre). $\left.{ }^{1}\right)$

') Obwohl die physiologische Wirkung nur auf chemische resp. physikalische Faktoren sich reduzieren lassen wird, trotzdem wird hier dieselbe als selbständig betrachtet, da die Starre bis jetzt noch nicht vom physikalisch-chemischen Punkt aus geklärt ist. 
Damit ist noch nicht gesagt, lass der betreffencle Einfluss nur durch diese drei Ursachen zu erklären ist und zwar durch die Oxydation resp. Reduktion, durch die Joule'sche Wärme und durch die Starre. Es ist sogar sehr wahrscheinlich, dass der Reiz hier nicht olne Antheil bleibt, wenn man bedenkt, welche Wirkungen die elektrischen Wellen im Körper hervorrufen; sie werden aber gerade durch die intermittirenden Ströme erzeugt und entstehen auch beim Gewitter.

\section{Einfluss der Nahrung und chemischer Stoffe.}

\section{A. Einfluss der natürlichen Nahrung.}

Unter natürlicher Nahrung verstehen wir eine solche, welche von künstlichen Beimischungen frei ist. Weil wir zwischen den "monophagen" und "polyphagen" Raupen keine strenge Grenze ziehen (vide Kapitel I, Abschnitt 5 des theoretischen Theils), so kann diese Nahrung auch für "monophage" Raupen in breiten Grenzen variieren.

Folgende tabellarische Zusammenstellung ergibt die von verschiedenen Forschern bei Fütterungsversuchen erhaltenen Resultate:

\section{a) Imago.}

Arctia caja.

\begin{tabular}{|c|c|c|c|c|}
\hline Nahrung der & Raupe & & $\begin{array}{l}\text { Färbung und Zeichnung } \\
\text { des Imagos }\end{array}$ & for \\
\hline $\begin{array}{l}\text { Schneebeere. } \\
\text { Salat . . . } \\
\text { Eisenhut... } \\
\text { Weiden . . . } \\
\text { Schöllkraut . } \\
\text { Bilsenkraut. } \\
\text { Lattich... } \\
\text { Chelidonium } \\
\text { Wallnussblätte } \\
\text { Symphorica } \\
\text { cemosus. }\end{array}$ & $\begin{array}{c}\cdots \\
\cdots \\
\cdots \\
\text { er maju } \\
\text { rpus r } \\
\text { r. }\end{array}$ & 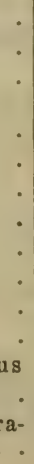 & 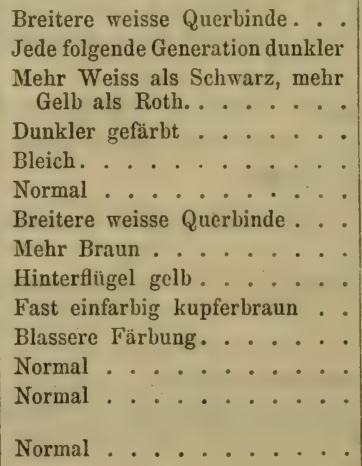 & $\begin{array}{l}\text { Bieger (80). } \\
\text { Rössler (702). } \\
\text { Rössler (702). } \\
\text { Pollak (640). } \\
\text { Glaser (314a). } \\
\text { Gauckler (284). } \\
\text { Gauckler (274). } \\
\text { Gauckler (274). } \\
\text { Teich (855). } \\
\text { Teich (855). } \\
\text { De Lafitole (493). } \\
\text { De Lafitole (493). } \\
\text { Seiler (803). } \\
\text { Gauckler (284). }\end{array}$ \\
\hline
\end{tabular}




\begin{tabular}{|c|c|c|}
\hline Nahrung der Raupe & $\begin{array}{l}\text { Färbung und Zeichnung } \\
\text { des Imagos }\end{array}$ & Forscher \\
\hline $\begin{array}{l}\text { Brennessel . . . . } \\
\text { Lupinenart . . . } \\
\text { Acontium napellus } \\
\text { Lactuca sativa. . } \\
\text { Trockene Pflanze... } \\
\text { Nussblätter .... }\end{array}$ & $\begin{array}{l}\text { Normal } \\
\text { ab. flavescens. } \\
\text { Breitere weisse Querbinde } \\
\text { Heller, einfacher gefleckt } \\
\text { Weiss und Roht statt Braun und } \\
\text { Schwarz } \\
\text { Melanistisch }\end{array}$ & $\begin{array}{l}\text { Slevogt (821). } \\
\text { Slevogt (821). } \\
\text { Gauckler (274). } \\
\text { Moller (582). } \\
\text { Prest (649). } \\
\text { Pictet }(637 a) .\end{array}$ \\
\hline
\end{tabular}

Andere Species.

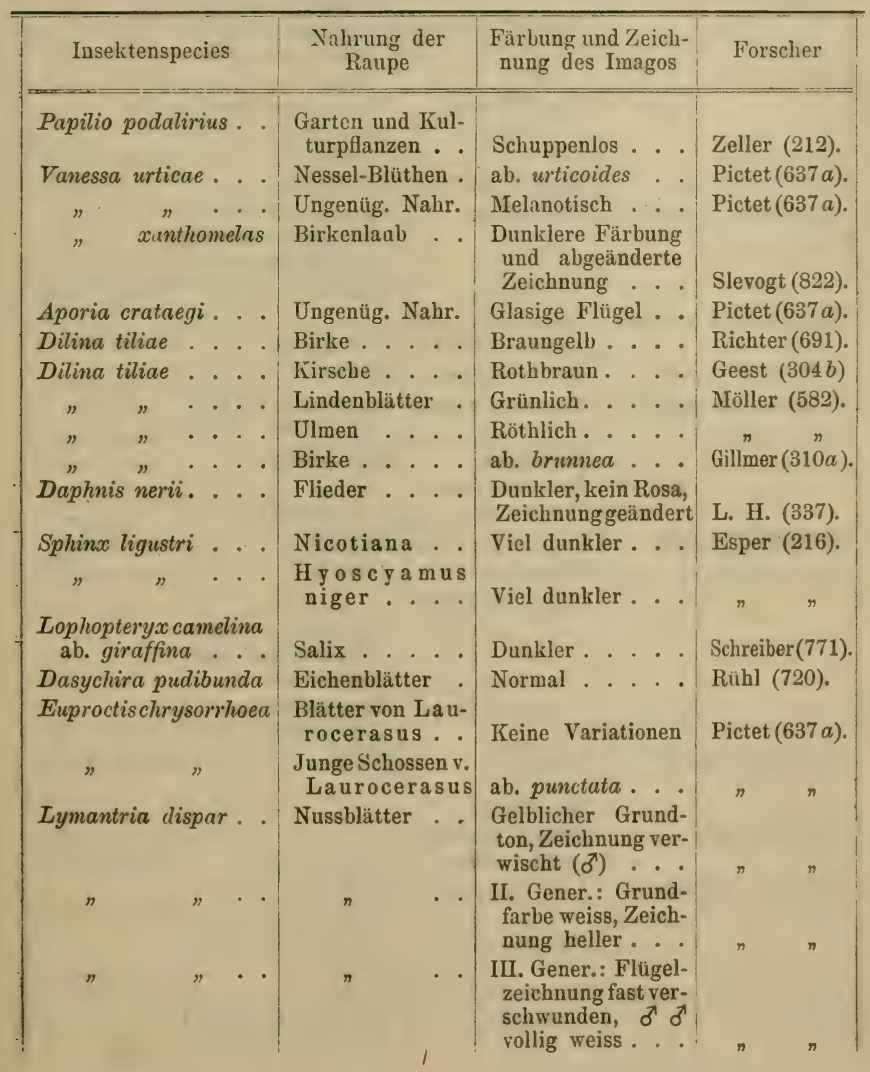




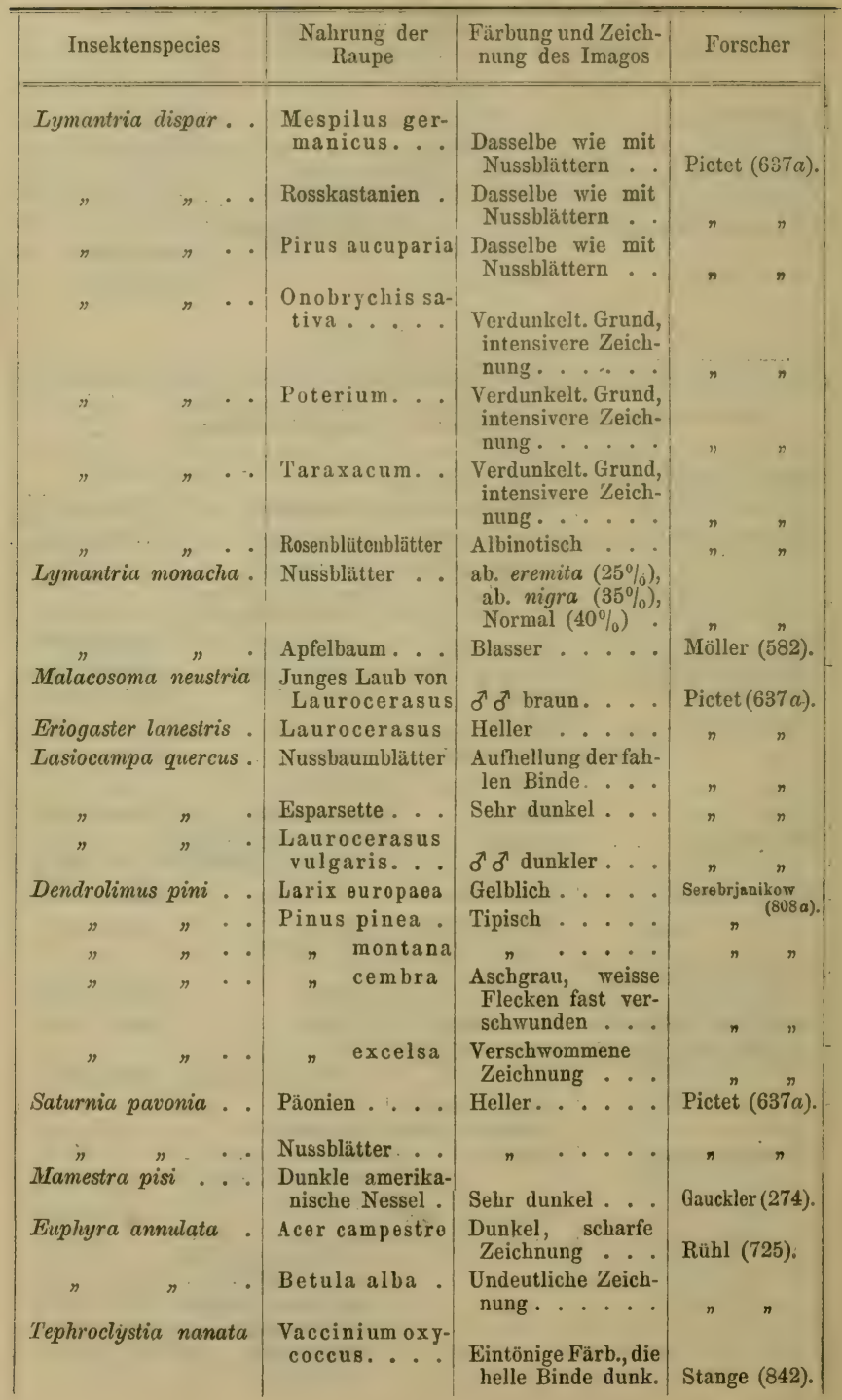


5. Einfluss der Nahrung und chemischer Stoffe.

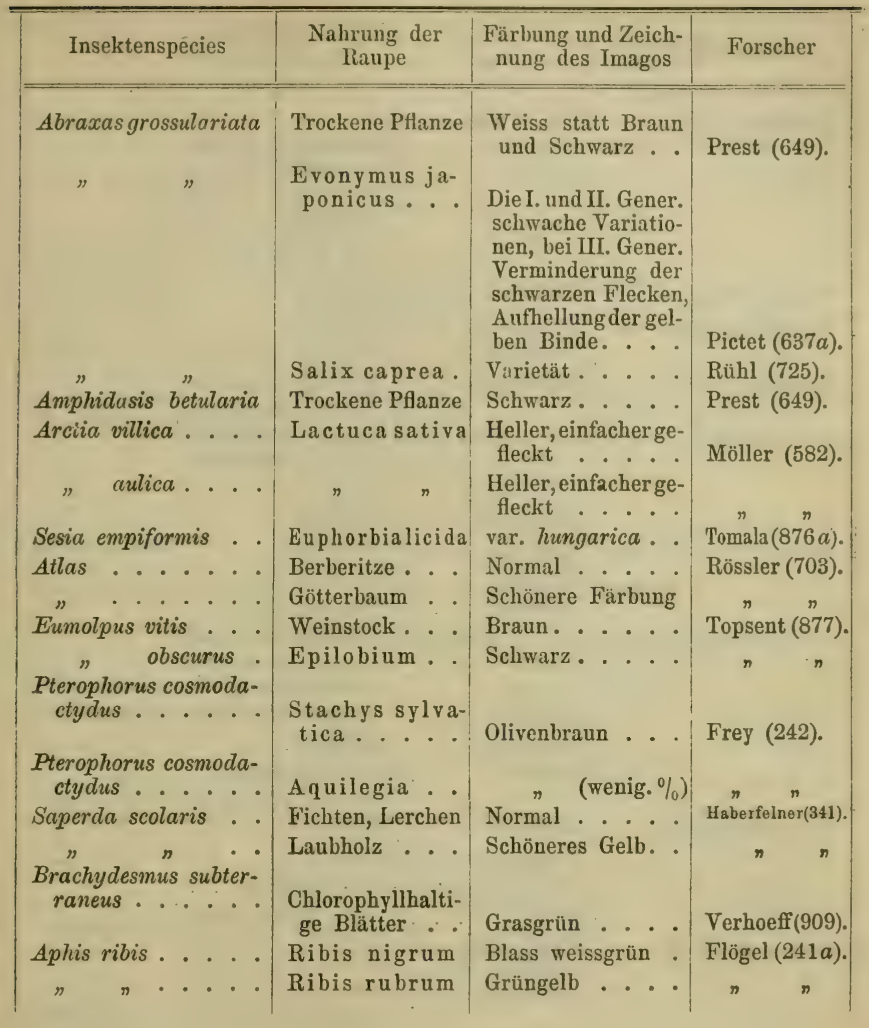

b) Raupen.

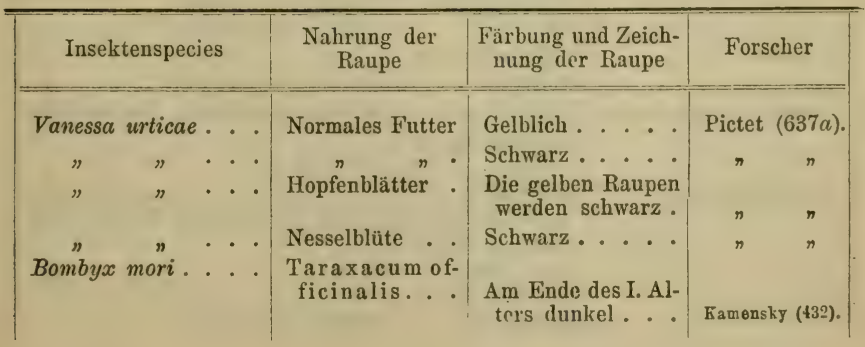




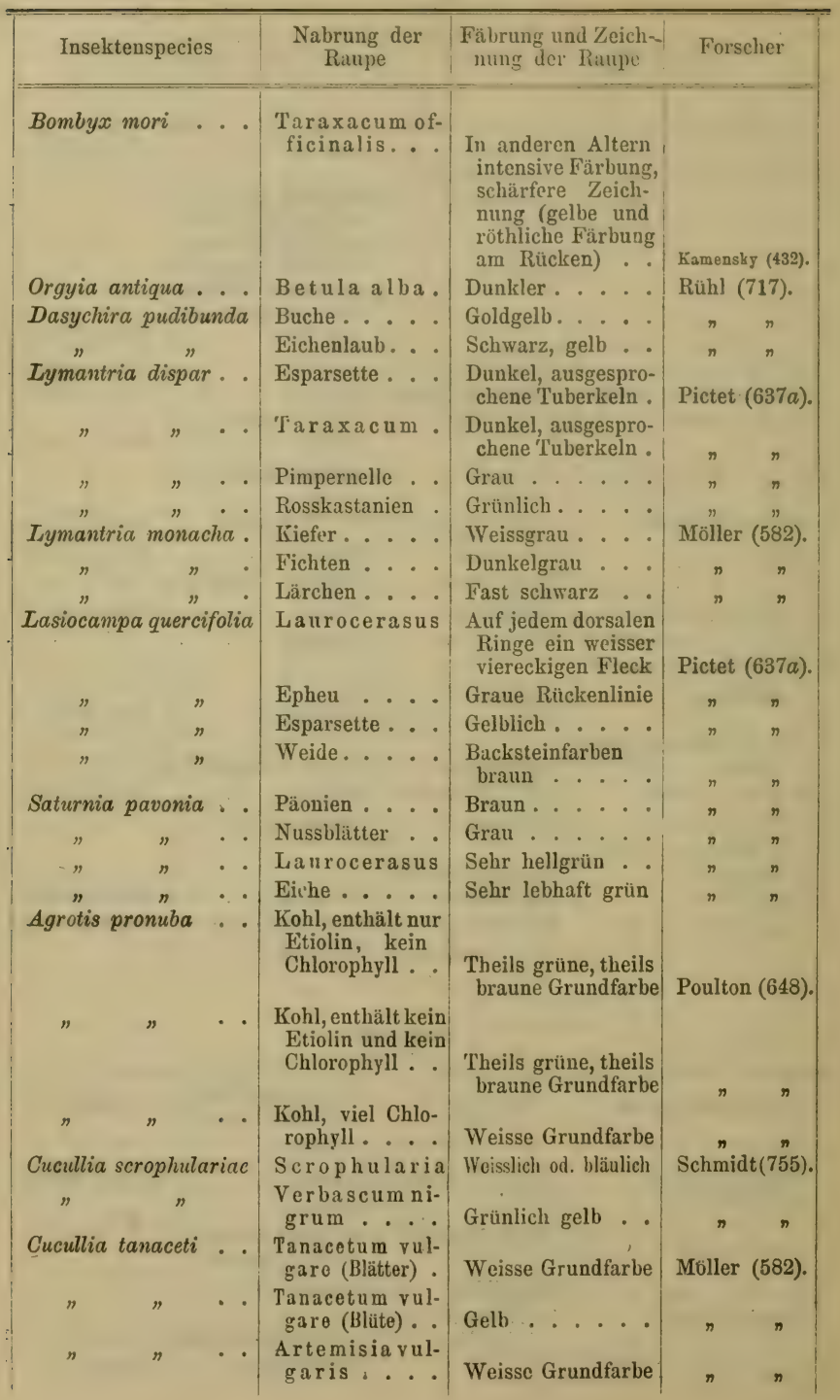




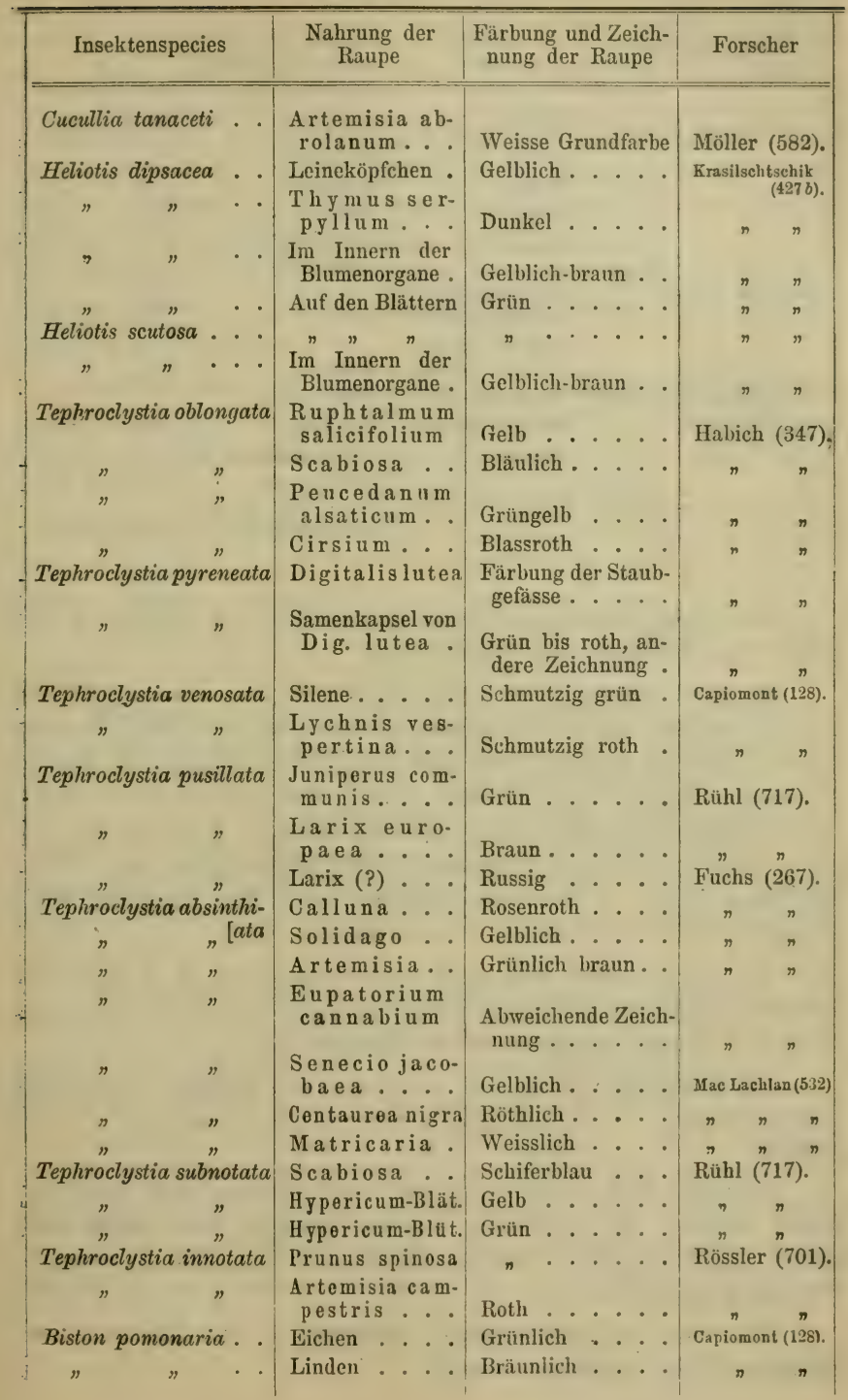




\begin{tabular}{|c|c|c|c|}
\hline Inselitenspecies & $\begin{array}{l}\text { Nahrung der } \\
\text { Raupe }\end{array}$ & $\begin{array}{l}\text { Färbung und Zeich- } \\
\text { nuug der Raupe }\end{array}$ & Forscher \\
\hline 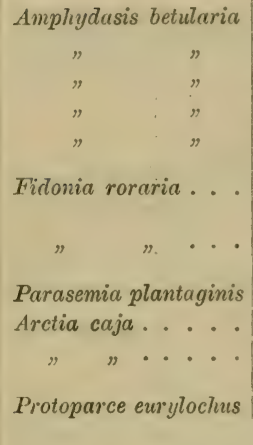 & $\begin{array}{l}\text { Birken . . . . } \\
\text { Eichen . . . } \\
\text { Rüstern. . . . } \\
\text { Wciden . . . } \\
\text { Pappeln. . . . } \\
\text { S a rot h a m n u s } \\
\text { scoparius (Blät.) } \\
\text { S a rot h a m n u s } \\
\text { scoparius (Bliit.) } \\
\text { Verschiedene Pflanz. } \\
\text { Rosskastanienbl. } \\
\text { Päonien. . . . } \\
\text { Litrea venenosa }\end{array}$ & $\begin{array}{l}\text { Gelbgrün . . } \\
\text { Aschgrau . . . } \\
\text { Gelbgrau . . . } \\
\text { Gelbgrün . . . } \\
\text { Auf dem Rücken } \\
\text { rostfarbig. . . . } \\
\text { Grün . . . . } \\
\text { Gelblich . . . } \\
\text { Sehr variabel . } \\
\text { Grünlich ... } \\
\text { Verlieren etwas ihr } \\
\text { Haar . . . } \\
\text { Grün mit gelben } \\
\text { Schrägstreifen . . }\end{array}$ & $\begin{array}{cc}\text { Möller }(582) . \\
n & n \\
n & n \\
n & n \\
\text { Koch } & (457 b) . \\
n & n \\
& n \\
\text { Pictet }(637 a) . \\
n \quad " \\
\text { Butler }(123) .\end{array}$ \\
\hline
\end{tabular}

Aus dieser Zusammenstellung und aus dem III. Kapitel, 7. Abschnitt (des thatsächlichen Theils) folgt:

Es giebt Raupen-Species, welche, obwohl mit verschiedenem Futter gezogen werden, trotzdem gleich gefärbt sind (Vanessa urticae: Nesseln, Hopfenblätter [Pictet, 637a]; Lymantria dispar: Esparsette, Taraxacum [Pictet, 637a]; Saturnia pavonia: Eiche, Laurocerasus [Pictet, $637 a$ ]; Cucullia tanaceti: Tanacetum vulgare, Artemisia vulgare [Möller, 582]; Tephroclystia absinthiata: Solidago, Senecio jacobaea [Fuchs, 267; Mac Lachlan, 539]; Amphidasis betularia: Birke, Weide [Möller, 582]).

Ein umgekehrter Fall wird auch beobachtet, d. h. eine und dieselbe Species, mit gleichem Futter gezogen, ergiebt verschieden. gefärbte Raupe (Agrotis pronuba [Richter, 691]).

Der häufigste Fall ist der, dass eine und dieselbe Species bei verschiedenen Futterpflanzen verschieden gefärbte Raupen ergiebt.

Normaler Fall ist natürlich der, dass Raupen einer und derselben Species, mit gleichem Futter gezogen, auch unter sich gleich gefärbt sind (Einfluss des Lichtes etc. vide in entsprechenden Abschnitten).

Was nun die Imago-Färbung anbetrifft, so sind hier auch verschiedene Fälle beobachtet worden. 
Raupen einer unil derselben Species ergeben, mit verschiedenen Pflanzen gefüttert, gleich gefärbte Imagines (Arctia caja: Salat [Gauckler, 284], Chelidonium majus [de Lafitole, 493], Wallnussblätter [Seiler, 803], Symphoricarpus racemosus [Gauckler, 284], Brennessel [Slovogt, 821]; Sphinx ligustri: Nicotiana, Hyoscyamus niger [Esper, 216]; Lymantria dispar: Nussblätter, Rosskastanien, Pirus aucuparia, Mespilus germanicus [Pictot, 637a]; Dendrolimus pini: Pinus pinea, Pinus montana [Serebrjanikow, 808a]; Saturnia pavonia: Päonien, Nussblätter [Pictot, 637a]; Dasychira selenetica: [Keferstein, 442]; und alle "polyphagen" Species).

Raupen einer und derselben Species ergeben verschieden gefärbte Imagines, wenn die Futterptlanz auch dieselbe ist (Arctia caja: Schneebeere [Bieger, 80; Rössler, 702]; Salat [Rössler, 702; Pollak, 640; Glaser, $314 a$; Gauckler, 284]).

Am häufigsten wird der Fall beobachtet, dass eine und dieselbe Species bei vorschielenen Futterpflanzen verschieden gefärbte Imagines ergiebt.

Normalerweise sind alle Imagines, deren Raupen mit gleicher Futterpflanze gezogen wurden, gleich gefärbt.

Was nun die Abhängigkeit der Imago-Färbung von derjenigen der Raupe anbelangt, so wird in gewissen Fällen beobachtet, dass auch verschieden gefärbte Raupen einer und derselben Species dennoch gleich gefärbte Imagines ergeben (MIycteroplus puniceago: gelb, grïn [Christoph, 145]; Chesias spartiata: gelb, grün [Goosens, 322]; Papilio machaon: aberrativ gefärbte Raupen [Schultz, 788]; Lilnythea celtis: gelb, griin, grau, violett, rosenroth [Mann, 544a]).

Werden rlic rlurch Futteränderung aberrativ geworilenen Raupen-Species, welche auch aberrative Imagines ergeben, durch mehrere Generationen hindurch mit diesem abgeänderten Futter weiter gezogen, so verstärken sich die erhaltenen Variationen (Pictot [637 a]).

Die durch solche anormale Fütterung während einer Generation erworbenen Eigenschaften verlieren sich nicht, wenn in zweiter und dritter Generation normales Futter gereicht wird (Pictet [637a]).

Erwachsene Raupen ändern ihre Färbung nicht mehr, wenn sie auf andere Pflanzen versetzt werden (Mac Lach]an [539]). 


\section{B. Einfluss der künstlichen Nahrung.}

a) Imago.

Vanessa urticae.

\begin{tabular}{|c|c|c|}
\hline Nahrung der Raupe & $\begin{array}{l}\text { Färbung und Zeichnung } \\
\text { des Imagos }\end{array}$ & Forscher \\
\hline $\begin{array}{l}\text { Brennessel }+ \text { blauge- } \\
\text { farbtes Sprudelwasser }\end{array}$ & Ockergelbe Grundfarbe. Zeich- & \\
\hline $\begin{array}{c}\text { Brennessel }+ \text { kaltes } \\
\text { Sprudelwasser } . . .\end{array}$ & $\begin{array}{l}\text { nung geändert . . . . } \\
\text { Dunkelockergelbe Grundfarbe }\end{array}$ & Hein (358). \\
\hline $\begin{array}{l}\text { Brennessel + Anilin- } \\
\text { farbelösung. . ... } \\
\text { Brennessel + Salzwasser }\end{array}$ & $\begin{array}{l}\text { Normal . . . . . . . . . } \\
\text { Dunkel, Oberflügel olıne Blau }\end{array}$ & Heissler (363). \\
\hline $\begin{array}{c}\text { Brennessel }+ \text { Salzwasser } \\
\text { Brennessel }+ \text { defibrir- } \\
\text { tes Blut ..... }\end{array}$ & $\begin{array}{l}\text { Dunkel, Oberflügel oline Blau . } \\
\text { Heller; Zeichnung verwaschen . }\end{array}$ & $\begin{array}{l}\text { Pabst }(620) \text {. } \\
\text { v. Linden (517). }\end{array}$ \\
\hline $\begin{array}{c}\text { Brennessel }+ \text { Eisenal- } \\
\text { buminat } . \ldots .\end{array}$ & & \\
\hline $\begin{array}{l}\text { Brennessel + Silber- } \\
\text { Kaseïnverbindung . - }\end{array}$ & Verdunklung der Grundfarbe. . & $n$ \\
\hline Brennessel + Zucker & Kräftigere, glänzendere Färbung & $n$ \\
\hline n + Lupulin. & 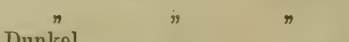 & 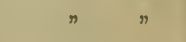 \\
\hline$n \quad$ + Capsicum & Dunkel & $n$ \\
\hline$n \quad+$ Morphium & $\begin{array}{l}\text { Verdunklung der Grundfarbe; } \\
\text { mehr Roth. . . . . }\end{array}$ & \\
\hline,$\quad+$ Hydrochinon & 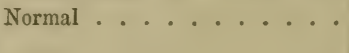 & $\Rightarrow \quad(527 a)$. \\
\hline
\end{tabular}

Andere Species.

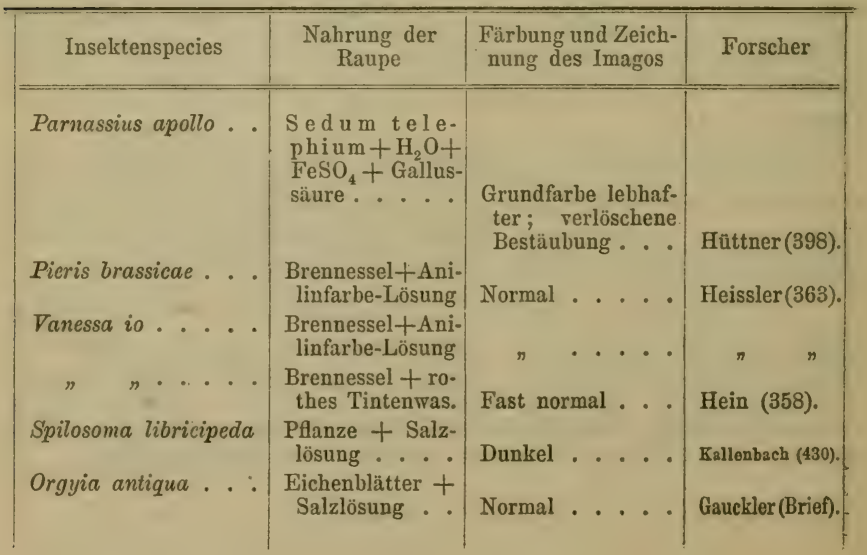


5. Einfluss der Nahrung und chemischer Stoffe.

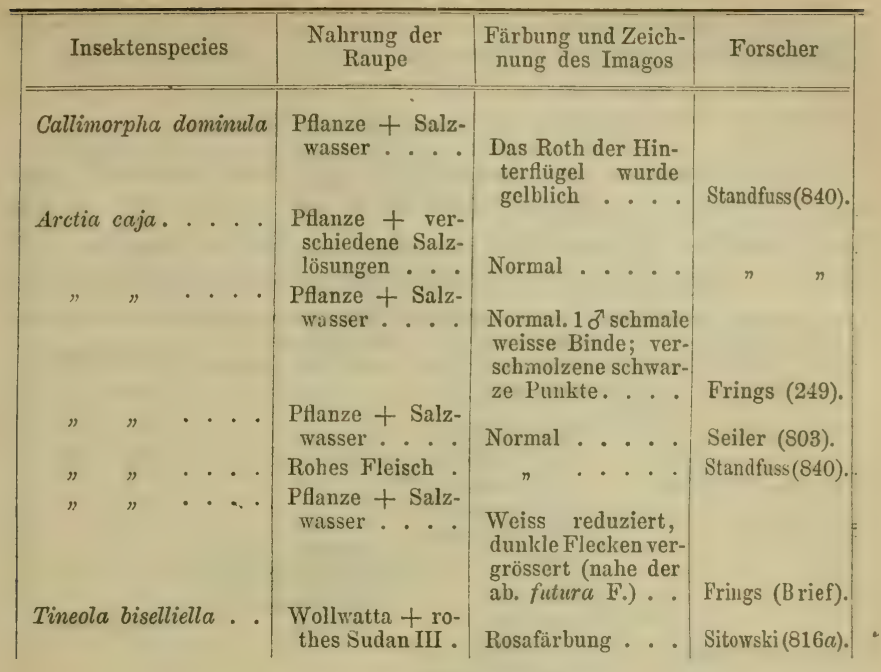

b) Raupen.

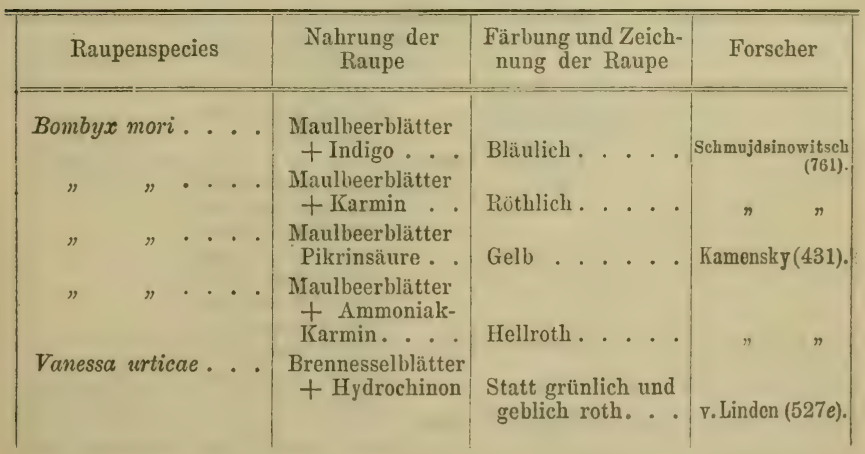

Aus diesen Zusammenstellungen folgt:

Es ist möglich, durch gewisse chemische Substanzen, welche dem Raupenfutter beigemischt werden, die Fürbung und sogar die Zeichnung einiger Imagospecies abzuändern (Standfuss [840], Kallenbach [430], Pabst [620], Hein [425], Hüttner [398], v. Linden [517], Frings [249], Sitowski [816a]). 
Eine Aenderung der Raupenfärbung wird darlurch auch erreicht (Schmujdsinowitsch [761], Kamensky [431], v. Linden [527e]).

\section{Einfluss der umgebenden Stoffe.}

Diese Versuche sind hauptsächlich an Puppen angestellt, und zwar hat man die letzteren entweder in ein anderes Gas als die Luft gebracht, oder man hat sie mit festen Stoffen umgeben. Die erhaltenen Resultate sind aus fulgender Zusammenstellung ersichtlich:

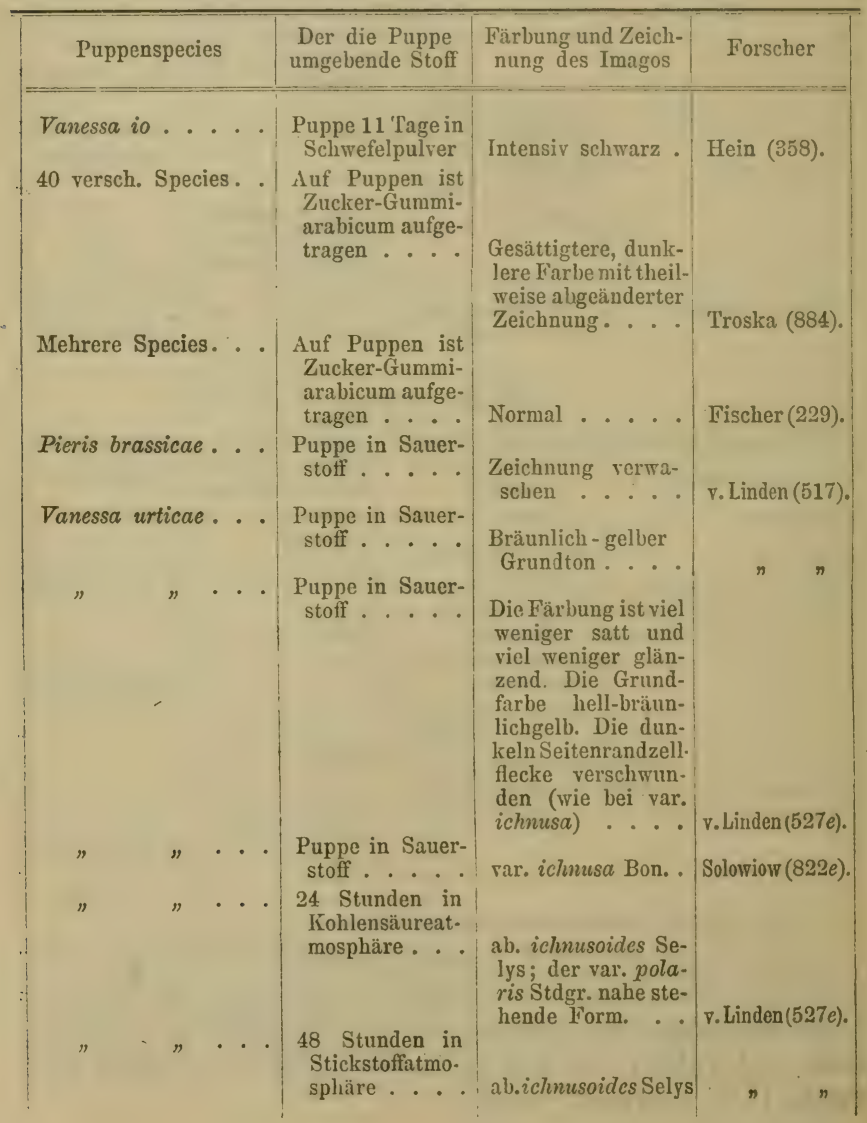




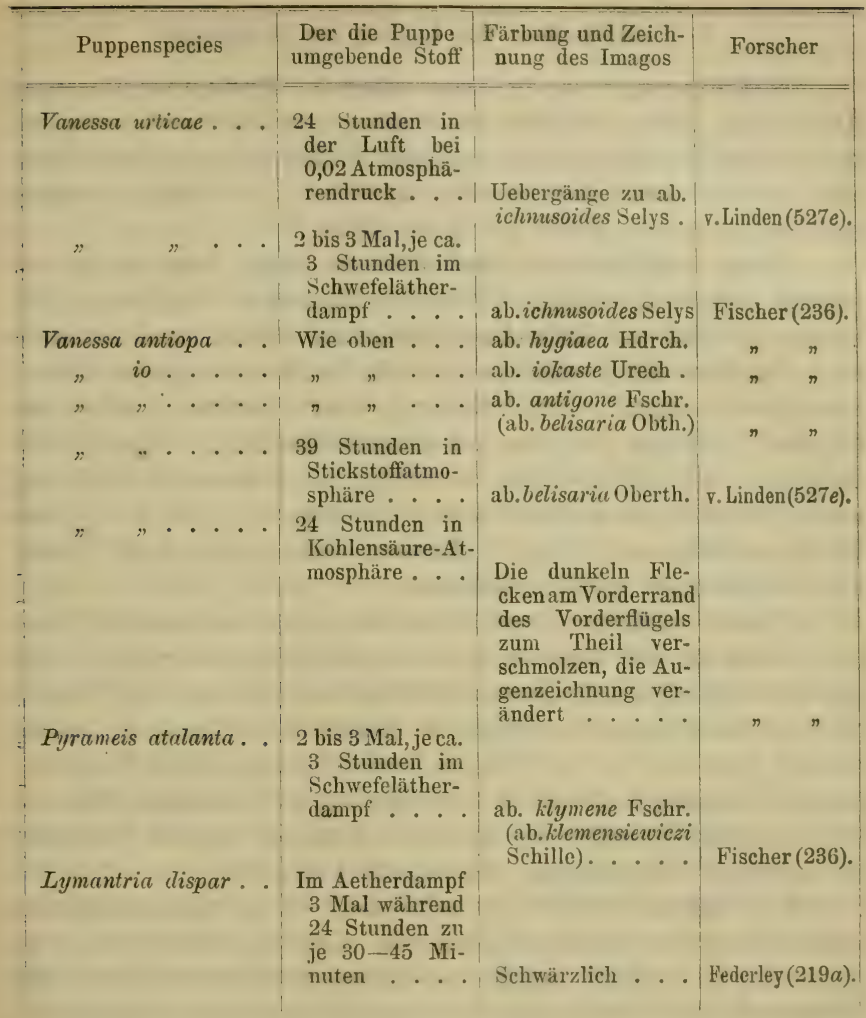

Diese Zussammenstellung ergiebt, dass die die Puppe umgebenden Stoffe nicht nur die Färbung, sondern auch die Zeichnung des werdenden Schmetterlings abzuändern vermögen, indem dabei meistens die sonst durch die Temperatur-Experimente erzielten aberrativen Formen entstehen.

\section{Theorien dieses Einflusses.}

Wir werden die Theorien über den Einfluss des Athemgases und die Theorien über den Einfluss der Nahrung getrennt von einander betrachten und nachher ihre Zulässigkeit prüfen. 


\section{Theorien uber den Einfluss der Athemgase.}

E. Fischer (1896. 229) untersuchte den Einfluss der Narcotica (Chloroform, Aether, Alkohol) auf Puppen verschiedener Species, um zu erfahren, ob dadurch das werdenile Falterkleid abgeändert wird. Die Resultate sind aber negativ ausgefallen: „alle Puppen ergaben tadellose, aber auch ganz normale Falter."

Später wiederholte er diese Versuche (236), indem er von folgenden Ansichten ausging: „Wenn die aberrative Veränderung der Farben wirklich auf Entwickelungshemmung beruhe, dann müsse es sehr wahrscheinlich möglich sein, durch Narkose typische Aberrationen zu erzeugen". Die bedeutend tiefere Narkose, als bei rlen früheren Versuchen, und zwar mit Schwefelätherdampf, ergab positive Resultate. Er erhielt dabei zu 100\%: ab. ichnusoides Selys, ab. nigrita Fickert, ab. antigone Fschr., ab. ioliaste Urech, ab. Tyggiaea Hilrch., ab. lilymene Fschr. - Formen, welche auch durch Temperatur-Experimente erhalten wurden.

Fischer erblickt in diesen Versuchen neinen schlagenden Beweis für die von mir seit 1894 vertretene Auffassung, dass die Aberration durch Entwickelungs-Hemmung entsteht, denn dass eine tiefe Narkose die Lebensfunktionen der Puppe in einen beinahe latenten Zustand versetzt, lässt sich an der völligen Reaktionslosigkeit der Puppe bei äusserer Reizung und aus der verzögerten Entwickelung erkennen. Die Hemmung ist mithin der primäre Zustand, d. h. die Ursache die aberrative Veränderung aber ist die Folge."

B. v. Linden $(1905.527 \mathrm{e})$ stellte die Versuche mit verschiedenen Gasen an, indem sie die Puppen von Vunessa urticae resp. io in Kohlensäure-, Stickstoff- und Sauerstoffatmosphäre brachte. Noch 1903 beobachtete sie (527b), dass die Puppen einen 12-36 stiindigen Aufenthalt in Kohlensäureatmosphäre ohne ernstliche Gefährdung des Lebens aushalten können. Die Puppen, welche in diese Gase gebracht wurden, ergaben:

In Kohlensäure: Vanessa urticae ab. ichmusoidcs, var. polıris; Vanessa io aberr.

In Stickstoff: Vanessı urticae ab. ichnusoides, Vanessa io ab. belisaria.

In Sauerstoff: Vanessa urticae var. ichnusa.

In luftverdüntem Raume: Upbergänge $\mathrm{zu}$ ab. ichnusoides.

Dabei hat sie folgendes beobachtet: ${ }_{n}$ Die Farbe des Blutes, des Fettgewebes und der in den Körper- und Darmepithelien abgelagerten 
Pigmente wurde durch längeres Verweilen in Kollensäure in charakteristischer Weise veränlert. Blutt unl Fettgewebe verloren ihre normalerweise grüngelbe Farbe und nahmen einen ausgesprochen hochgelben Ton an, gerale so wie bei den Puppen, die auf lem Termostaten in erhöhter Temperatur gestanden hatten." M. v. Linden ersieht die Aenderung des Farbenbildungsprozesses bei den Puppen in der Sauerstoffentziehung. „Da die Versuche in Kohlensäure die Frage offen liessen, ob die beschriebenen Veränderungen im Kleide der Vanessen der Giftwirkung des verwendeten Gases oder der Sauerstoffentziehung zuzuschreiben sind", hat sie die Versuche auch mit indifferentem Stickstofi angestellt. Auch in diesem Gase erhielt sie nach 14-tägiger Puppenruhe ab. ichnusoides und ab. belisaria. „Es war nicht mehr daran zu zweifeln, dass die Sauerstoffentziehung bzw. die Beschränkung der Oxydationsvorgänge in den ersten Tagen der Puppenruhe als die bewirkencle Ursache der eigenartigen Koloritveränderungen anzusehen' ist." Diese Anschaung glaubt sie bestätigt zu haben, indem die Pupjen in luftverdünntem Raume die Uebergänge zu ab. ichnusoicles lieferten. "Hieraus ersehen wir, dass die Puppen im evacuirten Raum unter einer so nielrigen Sauerstoffspannung stanten, dass eine Oxydation des in dem Insektenblut enthaltenen Chromogen nicht stattfinden konnte. “

Die Resultate in reinem Sauerstnff (var. ic/unusa) erklärt sie, wie folgt: „Was die Veränderung des Kolorites der Flïgel, besonders das Hellwerlen der Grundfarbe betrifft, so glaube ich diese Farbenverïnderung schon frïher mit Recht auf erhöhte Oxydationsprozesse zurickgeführt zu haben, auf denselben Vorgang, der anch das Ausbleichen der Schmetterlingsfarben im Licht bellingt."

Schliesslich seien die Versuche von Solowiow (822e) erwähnt, bei welchen er aus den in reinem Sauerstoft gehaltenen Puppen var. ichmusa erhalten hat. „Die Ergebnisse dieser Versuche beweisen, dass man bei der Pigmentbildung dem Atmen mit seinen oxydierenden Prozessen im Blute eine grössere Belleutung als der erhöhten Temperatur zuschreiben muss."

\section{Theorien über den Einfluss der Nahrung.}

Man hat früher behauptet (Felsko [855], Nauck [861], Heissler [363]), dass die Nahrung die Farbe der Insekten nicht ändern hann, da sich die aufgenommenen Stoffe im thierischen Körper zu ganz neuen Verbindungen vereinigen, und dass nur die unverdaulichen 
Farbstoffe dies bedingen könnten. Spätere Untersuchungen verschiedener Forscher widerlegten jedoch diese Ansicht.

Kowalewsky (468), Schmujdsinowitsch (761), Villon (925), Kamensky (431), Blanchard (85) wiesen nach, dass die im Wasser löslichen Farbstoffe, welche dem Futter beigemischt werden, ins Blut der Raupe gelangen können.

Es wurde auch nachgewiesen, dlass verschiedene in clen Körper eines Insektes künstlich eingespritzte Farbstoffe oller blosse Verbindungen von ganz bestimmten Organen absorbiert werden (Kowalewsky [469, 470], Metalnikow [578], Koschewnikow [466, 467]). Somit erscheint es möglich, dass die Aentlerung des Futters die künftige Färbung vom Imago beeinflussen kann, wie es die zahlreichen Untersuchungen verschieilener Forscher auch beweisen.

Was nun die Ursache des Einflusses der Nahrung auf die Farbenänilerung der Insekten anbetrifft, so sagt Standfuss (840), indem er die Ursachen des Albin smus betrachtet: "Auch mangelhafte Ernährung - so erfuhr ich dies wiederholt bei Bomb yciden kann zu diesem Ziele führen. .... Ich glaube bestimmt, dass die letzte Ursache für die Ausbildung eines totalen Albinismus in einer ganz speziellen Richtung und Beanlagung des betreffenten Individuums zu suchen ist, so zwar, das eine individuclle innere Hemmung vorliegt, welche eine allseitige normale Entfaltung hindert." Bei der Betrachtung des Farbenweschsels der Schmetterlinge sagt er: „Es scheint dabei eine gewisse Stufenleiter in der Farbenveränderung vorzuliegen, deren verschieilene Grade von der Einwirkung äusserer Faktoren abhängig zu denken sein dürften, und auf der sich die Arten je nach dem Wechsel dieser Faktoren bald in aufsteigenter, bald in absteigender Bewegung befinden. Als diese äusseren Faktoren sind am allerwahrscheinlichsten als Unterschiede der Temperatur, vielleicht teilweise auch als chemische Differenzen der Nahrung anzunehmen."

E. Fischer (229) sprach die folgende Meinung über die Ursache der Wirkung ier chemischen Stoffe auf die werdende Falterfärbung aus: „Ist z. B. ein Raupennest inficiert, so gehen einige Individuen schon als Raupe, andere erst als Puppe daran zugrunde, und ein geringer Prozentsatz gelangt oft noch inficiert zum Falterstadium, um dann die Krankeit auf die folgende Generation zu übertragen. Bekanntlich werden nun clurch die Infektionsträger Gifte (Toxine, Ptomaïne) produciert und es könnte daher die Frage gestellt werden, ob diese Ptomaïne nicht einen veränilernden Einfluss 
auf die Farben der bis zum Imagostadium gelangenden Individuen haben könnten. Wer für eine solche Ansicht eingenommen wäre, würle wohl viele meiner oben mitgetheilten Resultate [die durch die Temperatur-Experimente erhaltenen aberrativen Formen] darauf zurückführen, denn jene merkwürdigen Aberrationen testudo, ichnusoides, hygiaca etc. stammen aus inficierten Raupennestern."

M. v. Linden (517), welche bei ihren sehr ausgedehnten Fütterungsversuchen positive Resultate crhielt, sagt nur, dass die dabei erhaltenen Veräurlerungen der Zeichnung der Falter „vollkommen analog denen sind, welche durch Wärme- resp. Kältewirkung erzielt wurlen". Spätere Fütterungs-Versuche $(527 e)$ der Raupen von Vanessa urticae mit Brennesselblättern + Hydrochinon ergaben Raujen mit viel rothem Farbstoff, die Puppen waren gelblich rosa und die Filter kamen nicht zur Entwickelung. „Wenn es nach diesen Versuchen auch fraglich erscheint, ob das Hydrochinon im Organismus der Raupe oder Puppe derart verarbeitet wird, llass es die Flügelfärbung des Falters wesentlich beeinflusst, so hat es sich doch sowohl bei der Raupe, wie bei der Puppe übereinstimmend ergeben, dass die Bildung roter Pigmente im Insektenorganismus durch Einführung des genannten aromatischen Körpers wesentlich gefördert wird". Die Versuche mit der Injektion von Hydrochinon in den Puppenkörper ergaben, „dass das Blut der Puppen von Vanessu urticae am Anfang der Puppenruhe, wenn es an ler Luft steht, weniger melanotisches Pigment bildet wie später. ... Wird einige Zeit nach der Injektion der Schmetterlingspuppe Blut entnommen, so verfärbt sich der Tropfen sofort, wie es sonst nur bei älteren Puppen beobachtet wird".

A. Pictet $(637 a)$ fand bei seinen systematisch angestellten Versuchen, dass es weniger die chemische Beschaffenheit der verzehrten Blätter ist, als deren Struktur, welche auf die Variationsbildung Einfluss hat und dass das schwerverdauliche und schwerbekömmliche Baumlaub einen schlechten Einfluss auf die Entwickelung der Raupe und die Pigmentation des Falters ausïbt, während die Krautpflanzen mit ihrem grösseren Reichtum an Nährstoffen die Entwickelung der Raupen und damit die intensivere Entfaltung der Pigmente begünstigen. Weiter sagt er, dass nicht der Einfluss der Nahrung selbst, sondern vielmehr der Einfluss des Nahrungswechsels ist, welcher die Variationen hervorruft. Am Schlusse kommt er zu folgenden Resultaten: 1. Die Ernährung (ler Raupen spielt recht wohl eine gewisse Rolle bei der Färbung der Schmetterlinge. 
2. Eine schwerverdauliche Nahrung ruft im allgemeinen ungenügende Pigmentation hervor und erzeugt so albinotische Variationen. 3. Hingegen bringt ein nahrstoffreiches und reichliches Futter meist eine Vermehrung der Färbung des Pigmentes hervor und erzeugt melanotische Variationen. 4. Gewisse Arten (Vanessa urticae, polyy:luloros. io, Psitura monacha, Arctia caja) bililen eine Ausnahme von der Regel und bei ihnen ergiebt ungenïgende und Blïten-Ern:ïhrung Melanosen. 5. Die Männchen werden durch den Nahrungswechsel mehr in ihrem schliesslichen Kleide beeinflusst, als die Weibchen. 6. Die Raupenfürbung ändert nach dem gereichten fitter aib un! steht manchmal in Beziehung zur Falterfärbung. 7. Schwerbeliömmliche Pflanzen führen bei gewissen Raupen zur Ausbildung männ. licher seliunderer Merkmale, umgekiehrt, nährstoffreiche zur Ausbildung von weiblichen sekundären Merkmalen.

\section{Die Prüfung dieser Theorien.}

Wie aus den angeführten Theorien zu ersehen ist, wird ler Einfluss der Athemgase auf die Färbung des werdenden Filters entweder durch die Hemmung (Fischer) oder durch die beschränkten Oxydationsvorgänge (v. Linden) erklärt.

Was nun die Ursache der Nahrung anbelangt, so sieht Standfuss dieselbe in der individuellen inneren Hemmung, Fischer in Ptomaïnen, v. Linden (517) in denselben Unständen, welche sie auch für dic Temperatur angiebt (Stoffwechselstörung), oler $(527 e)$ in direkter Beeinflussung der Pigmente im Blute durch die in dasselbe gelangenden Substanzen, und Pictot im Nahrungswechsel resp. in der Struktur der Nahrungspflanze.

Wir wollén zuerst die Ursache der Athemgase auf dio Fürbung betrachten.

G. Lopriore (534a) untersuchte die Einwirkung der Kohlensäure auf die Plasmaströmung in den Staubfädenharen von Tralescantia virginica unı kam zu folgenden Resultaten. Bei längerem Aufenthalt dieser Pflanze in der Kohlensäureatınssphäre übt dieses Gas momentan eine hemmende Wirkung auf die Protoplas. maströmung aus, welche aber nicht dauernd schädlich ist. Diese Hemmung kann durch die Abrvesenheit des Sauerstoffs nicht erklärt werden, sie ist eine specifische. Man kann aber das Protoplasma nach und nach zur "schädlichen" Wirkung der Kohlensäure "gewöhnen", indem man zuerst das Gemisch von Kohlensäure und $10 \%$, 
dann 20\% etc. des Siuerstoffs nimmt. Diese Akkomorlation ist so stark, dass die Protoplasmaströmung auch dann nicht aufgehoben wird, wenn die Pflanze sich in reiner Kíohlensäure befindet. Die Wirkung des reinen Sauerstoffs auf die langsame Protoplasmaströmung ist zwar beschleunigend, aber nicht so stark, wie man bis jetzt glaubte. Die Beschleunigung der Protoplasmaströmung wird auch bei der Einwirkung vom Wasserstoff beobachtet, aber nur im Anfang, dann tritt die Verlangsamung derselben ein, welche aber nicht vollständig aufgelıoben wird.

Ausserlem beobachtete er bei Mucor-Sporen (Mlucor mucedo) eine Aenderung der Plasmastructur (vacoulenreiche Beschaffenheit), wenn dieselben in Kohlensäure sich befanten, wobei das Platzen einzelner Mycelfällen stattfand und die Bräunung des ausgetretenen Plasmas beobachtet wurde.

Diese Untersuchungen beziehen sich auf die Entwickelungsgeschwindigkeit. Folgende Versuche betreffen die Färbung der Thiere.

Lister (529a) und Biedermann (79b) fanden, dass die Kohlensäure eine direkt lähmende Wirkung auf die Pigmentzellen des Frosches ausiibt:

R. F. Fuchs $\left(268 \alpha^{\prime}\right)$ beobachtete bei Äthernarkosen ein starkes Dunkeln der Frösche, das zu einer Lähmung der Pigmentzellen führte, "weil alle Mittel, die sonst eine starke Aufhellung herbeiführen, wie z. B. $30-35^{0}$ warmes Wasser, Berlecken mit trockenem Filterpapier hier erfolglos blieben. Erst nach dem vollständigen Verschwinden der Aethernarkose kehrte die Reaktionsfähigkeit der Pigmentzellen zurïck."

Diese Beispiele genügen, um zu sagen, dass die Protoplasmaströmung in Zellen durch Kohlensäure eine "Kohlensäure-Starre" erleiden kann, welche ihrerseits die Lähıung der Pigmentzellen zur Folge hat Diese Starre tritt nicht teshalb ein, weil der Sutuerstoff abwesend ist, sondern in Folge der momentanen Aenderungen von normalen Bedingungen, da das Protoplasina die Fähigkeit besitzt, sich an die "schällichen" Gase zu akkomodieren. Jedes Gas hat seine specifische Wirkung, weshalb es "Stickstoffstarre", "Wasserstoffstarre" etc. geben muss, wenn auch dieser Unterschied an sich nicht sehr bedeutend ist.

Die Ansicht von M. v. Linden, dass die dabei erhaltenen aberrativen Formen in Folge der beschränkten Oxydationsvorgänge enstanden sind, wird unter anderem auch durch die neuesten Versuche von Federley (219a) widerlegt. Dieser Forscher sagt: „Um zu er- 
fahren, ob die Riespiration für die Entwickelıng der Puippen von grosser Belleutung ist, verklebte ich bei einer ziemlich grossen Anzahl Puppen von Lymantria dispar und Malacosoma neustria teils nur die Stigmen der einen Seite, teils sämtliche Stigmen. Alle Filter entwickelten sich jedoch binnen der gewöhnlicher Zeit und waren sowohl an Färbung als auch an Zeichnung vollstänlig normal und symmetrisch. Wenn die Verstopfung der Stigmen auch keine absolut dichte war, was wohl annehmbar ist, beweist dlas Experiment doch, dass das Sauerstoffquantum bei (ler Entwickelung eine ganz untergeordnete Rolle spielt, und die während les liaupenlebens gesammelten Reserverstoffe zunächst ins Gewicht fallen."

Ausserdem wirl auch in der Natur beobachtet, dass der Gasaustausch in der Puppe ein geringer ist, wie es Federley richtig bemerkt: „Viele Raupen kriechen nämlich vor der Verpuppung tief in die Erde hinein und spinnen dazu noch einen dichten Cocon, der eine sehr beschränkte Zufuhr von Luft gestattet."

Der wichtigste Prozess der Einwirkung z. B. der Kóhlensïure auf die Puppe besteht offenbar darin, dass, wie es die Versuche von G. Lopriore lehren, die Protoplasmaströmung in Zellen dadurch verlangsamt wird. Diese Verlangsamung, wie auch die durch die Wärme hervorgerufene, hat zur Fulge die aberrative Form. Der Umstani, dass v. Linden dabei ab. ichnusoides erhielt, deutet darauf hin, dass diese Verlangsamung von gleicher Kraft ist, wie die durch die Hitze resp. Frost hervorgerufene, $d$. h. es war die vorübergehende liohlensäure-Starre des Protoplasmas. Dasselbe gielt auch für die Einwirkung des Stickstoffs; es fand dabei die vorübergehende Stickstoffstarre statt, da die von v. Linden erhaltene aberrative Form ab. beìsaria (antigone Fschr.) war, welche gleichfalls auch bei Hitze resp. Frost entsteht

Noch ein wichtiger Umstand spricht dafür, dass die unter Einwirkung verschiedener Gase enstehenden Aberrationen nicht in Folge der beschränkten Oxydationsvorgänge erzeugt werden, sondern, wie erwähnt, in Folge des veränderten Bewegungszustandes des Protoplasmas. M. v. Linden erhielt aus der Puppe von Vunessa urticae, welche in reinem Sauerstoff gehalten wurde, var. ichnusa; dasselbe Resultat erhielt auch Solowiow. Diese aberrativen Schmetterlinge waren verblichen, "sie sahen aus, wie weun sie abgeschossen wären." M. v. Linden erklärt diese Verhellung der Färbung, wie folgt: "Was die Veränderungen im Kolorit der Flügel, besonders das Hellwerden der Grundfarbe betrifft, so glaube ich diese Farbenveränderungen 
schon früher mit Recht auf erhöhte Oxylationsprozesse zurückgreführt zu haben." Daraus ist ersichtlich, dlass v. Linden nur die Verhellung der Farben durch die "erhöhten Oxydationsprozesse" erklärt, was auch mit meinen Untersuchungen übereinstimmt. Ich fand nämlich, ılass der Stoffwechsel resp. Oxydationsprozesse im Schmetterlingskörper von Deilephila ulpenor noch bei der Lufttemperaturvon $49,2^{\circ}$ stark vor sich gehen, was die eigene Temperatur des Insekts (ca. $5^{0}$ höher als diejenige der Luft) beweist (vide p. 837), trotzlem dass die Flügelmuskeln eine Wärmestarre erlitten. Also es steht olıne Zweifel fest, dass die im Blute der Puppe entstehenden Pigmente durch starke Oxydation verbleicht werden.

Anderes verhält sich mit der $\mathrm{Zeichnung}$ des werdenden Schmetterlings. Wenn Vanessa urticae in Sauerstoff bei gewöhnlicher Temperatur die var. ichnusa ergab, so kann man nicht sagen, dass labei die „beschränkten Oxydationsvorgänge“ die Hauptrolle gespielt haben, denn die Oxydationsvorgänge sinı dlabei so stark, dass die Färbung verhellt. M. v. Linden sagt es auch nicht

Var. ichmusu gehört nach der Eintheilung Fischer's zu $C$-Formen (Wärmevariationen bei $35^{\circ}$ bis $\left.37^{\circ}\right)$. Wird die Luftemperatur bis $36-41^{\circ}$ erhöht, so entsteht var. pularis $\left(B_{2}\right.$-Form), die weitere Steigerung ler Temperatur bis $42-46^{\circ}$ erzeugt ab. ichmusoides $\left(D_{2}\right.$ Form). Man kann vermuthen, und es ist auch leicht anzustellen, dass bei einem noch grösseren Sauerstoffgehalt in dem Raume, in welchem sich die zu untersuchende Puppe z. B. von Vanessa urticae befindet, zuerst var. polaris und dann ab. ichnusoides entstehen werden, vorausgesetzt, (lass die Zimmertemperatur konstant bleibt (normal). Denn bestehen in Bezug auf ilen Sauerstoffgehalt normale Bedingungen, so befindet sich die Puppe bei optimaler Sauerstoffmenge und ergiebt die normale $A$-Form; wird aber dieses Optimum überschritten, so finden die Aenderungen im Berregungszustande des Protoplasuas statt, gerarle so wie es bei, der Temperatureinwirkung derFall ist, und es werden zuerst ichnusa, dann polaris und schliesslich ichmusoides entstehen. ${ }^{1}$ )

Wenn die hier vermutheten Resultate auch nicht erhalten werden, was sehr unwahrscheinlich ist, so kann man sich dennoch mit der von M. v. Linden ausgesprochenen Regel nicht einver-

1) Diesen Versuch kömnte man entweder mit Ozon, oder mit komprimiertem Sauerstoff anstellen; im letzteren Falle aber nur unter der Voraussetzung, dass der verunehrte Druck an und für sich schon keinen Einfluss auf dic Zeichnung ausüht- 
stantlen erklären, welche lautet: „Wir können also verallgemeinernt sagen, dass jeder Einfluss, der bei der jungen Puppe lie Verbrennungsprozesse herabsetzt, dass jeder Linfluss, ller die Atmungstiitigkeit hemmt, aberrative Bilkungen zur Folge hat." Im Sauerstoff unter normalem Druck finden keine herabgesetzte Verbrennungsprozesse statt, vielmehr werren sie intensiver, unil ilennoch entstehen darin aberrative Formen.

Indem wir somit zum Schlusse kamen, dass nicht die vermehrten oder verminderten Oxydationsvorgänge im Puppenorganismus die aberrative Formen erzeugen, sondern dass dabei die Aenderungen im Bewegungszustand des Protoplasmas die Hauptrolle spielen, liann man die von Fischer (236) mit verschielen intensiver AetherdampfNarkose erlaltenen $B$ - und $D$-Formen auch von diesem Standpunlit aus erklären.

Er erhielt bei sehr starker Narkose die $D$-Formen, weil dabei, sagen wir, die Protoplasmaströmung eine voriibergehenıle Starre erlitt. Als er eine leichtere Narkose anwendete, resultieren rlie Puppen $B$-Formen, dla dabei, wenn nicht gerade die Starre des Protuplasmas eintrat, so duch ein gewisse Verlangsamung seiner Bewegung stattfand.

Ruft der vermehrte Sauerstoffgehalt in der Luít die aberrativen Formen hervor, da das Sanerstoffoptimum nach rechts überschritten wird, so muss sein Ueberschreiten nach links auch aberrative Formen erzeugen. Dies wird in der That beobachtet.

M. v. Linden (527e) brachte die Puppen von Vunessa urticae in einen luftverdiinnten Raum unter einem Quecksilberdruck von $15-20 \mathrm{~mm}$., wo sie 24 Stunden lang verblieben. Es wurden damn Uebergänge zu ab. ichmusoides erhalten. Hättc v. Linden einen nicht so stark vermindlerten Druck benützt, dann würden sie gewiss var. polaris erzeugen.

Wenden wir uns jetzt zur Betrachtung der Ursache der Nahrung auf die Aenderung der Färbung und Zeichnung der Imagines.

Wir wollen zuerst die direkte Beeinflussung der Pigmente im Blute durch die in dasselbe gelangenden Substinzen betrachten.

Verschiedene Forscher wiesen nach, dass verschiedene Stoffe, welche der natürlichen Nahrung beigemischt werlen, in verschiedene Körpertheile der Insekten gelangen können.

A. Kowalewski (468) fütterte Fliegenlarven mit einer Mischung von verschiedenen Farbstoffen und Salzen und ist zum Schlusse ge- 
kommen, dass alle diese Farbstoffe ins Blut der untersuchten Inseliten gelangen.

R. Schneider (768) fand, dass Wasserküfer eine grosse Absorbtionsfähigkeit für Eisen in Muskeln zeigen.

A. Kowalowski (469) ermittelte, lass verschiedene Insekten im Stande sind, das Eisen und Karmin im Netze der PericardialZellen, in Muskeln und Speichel- und Web-Drüsen abzulagern.

I. Blanc (83) fand, dass Fuchsin alle Gewebe des Epytheliums beim Verdaungskanal, Speicheldriisen, Malpigni-Gefässe und auch den Fettkörper durchfürbt, wenn die Färbung sich dabei auch nur auf das Protoplasma, nicht aber auf den Kern, bezieht.

Villon (925) fiitterte die Raupen von Bombyx mori mit Maulbeerblättern, zu welchen Indigo, Marena und Cochenille beigimischt waren, und erhielt Seide, welche entsprechend gefärbt wurde.

W. Schmujdsinowitsch (761) ist der Meinung, dass Indigo und Karmin ins Blut der Raupen gelangen können.

S. Kamensky (433) wies nach, dass die Pikrinsäure in Webdrüsen von Bomliyx mori mit Futter gelangen kann.

S. Metalnikow (578a) fütterte Blatta orientalis mit Brod, welches mit Ferrum oxydatum sacharatum impregniert war, und konstatierte, dass das Eisen in Zellen des Darmkanals sich ablagert.

G. Koschownikow $(466,467)$ fütterte hungrige Bienen mit Honig, zu welchem ferrum sesquichloratum beigemischt wurde, und fand, dass die Fettzellen das Eisen aus dem Blute absorbieren.

D. Levrat und A. Conte $(509 a)$ wiesen nach, dass Neutralroth, zur Nahrung beigemischt, in die Webdrüen gelangt.

L. Sitowski (816a) fanıl, dass der rothe Farbstoff (Sudan III) den Fettkörper und die Zellen des Verdaungskanals färbt. Er wird auch iom Eierstock zurïckgehalten.

Diese Beispiele genügen, um zu sagen, dass gewisse Stoffe, welche dem Futter künstlich beigemengt werden, ins Blut der Insekten gelangen können. Befinden sich im Blute zu dieser Zeit Pigmente, welche die künftige Färbung des Imagos erzeugen sollen, so können dieselben verändert werden, falls sie mit den ins Blut gelangenden „Fremdstoffen" eine chemische Verbindung billen können. Dass etwas ähnliches wirklich vor sich gehen kann, beweisen folgende Beobachtungen:

M. v. Linden (525) setzte Hydrochinon zu der Lösung des rothen $\nabla$ anessen-Farbstoffs hinzu, wobei eine dunkelbraun gefärbte Flüssigkeit entstand. Wenn bei der Fütterung von Vanessa urticae 
mit Brennesselblättern + Hydrochinon die Färbung der Raupe und Puppe auch geänlert wurde, blieb das Imagi) jedoch unverändert. Dagergen ergaben Raupen von Tincolı lisellicllu, welche L. Sitowski (816a) mit Wollwatta + rother Farbstoff (Sulan III) fütterte, Schmetterlinge mit Rosafärbung.

Ausserdein beobachtete M. v. Linden (527e), dass das grüne Illut einer junger Puppe beim Zusetzen von nur einer Spur der Hydrochinonlösung sich roth färbt. Die Puppen von Tanessa witicae, welchen eine geringe Hydrochinonlösung in den Körper eingespritzt wurle, gingen zwar dabei ein, aber die darin enthaltencien schmettcrlinge besassen schwarzbraun gefürbte Flügel.

Schon aus dem Angeführten ist ersichtlich, dass obwohl das Blut mit eingeführten fremden Stoffen, wie es scheint, eine chemische Verbinlung in gewissen Fällen ergiebt, erleilet dabei das Blut zuweilen eine solche Veränlerung, welche der Entwickelung des Insekts schällich wird und schliesslich den Tod verursacht.

Wenn die direkte Einwirkung der fremden Stoffe, welche ins Blut der Insekten bei deren Fütterung gelangen können, auf die Pigmentänderung im Prinzipe zugelassen werden kann, so spielt dabei, wie es scheint. doch die inllirekte Wirkung dieser Stoffe die Hauptrolle.

So z. B fand Dogiel (189), dass gewisse Substanzen die Beschleunigung, die anderen dagegen die Verzögerung des Herzschlages bei Insekten hervorrufen. Höchstwahırscheinlich iiben sie auch auf die Protoplasmaströmung gewisser Zellen ihren Einfluss aus. So stellte R. Fuchs $\left(268 \alpha^{\prime}\right)$ in der neusten Zeit folgenden Yersuch an: Er injelitierte den Rana fusca $2 \mathrm{mg}$ Atropin und beobachtete, dass „nach einer balı vorübergehenden, nicht sehr berleutenden Aufhellung eine Verilunkelung des Versuchstieres erfolgte." Werden die Atropinthiere ganz trocken gehalten, dann kann die Verlunkelung vollkommen fehlen, was durch die lehmende Wirkung des Atropins auf Drüsensekretion zu erklären ist (Biedermann [79b]).

Anler Versuche von R. Fuchs (268 $\alpha^{\prime}$ ) an Rana fusca ergaben, dass bei Brucin-Injektion dies Thiere die Verdunkelung während der Lähmung und der späteren Stadien nach der vorhergegangenen Aufhellung im Kramfstadium aufweisen. Diese Verdunkelung kann in zweifacher Weise erklärt werden: „einmal als Lähmungrsbzw. Erschöpfungserscheinung der Pigmentzellen oder deren nervösen Apparate, oiler zweitens, was wahrscheinlicher ist, als gesteigerte Realition." Am Schlusse seiner Arbeit verspricht R. Fuchs eine 
Mittheilung $\mathrm{zu}$ veröffentlichen, welche sich mit der Innervation ler Pigmentzellen beschäftigen wird, da es durchaus nicht immer leicht zu beantworten ist, wie der Mechanismus der Farbenänderung bei der Beeinflussung der Farbe durch chemisohe Substanzen abläuft, .ob das Agens direkt auf die Pigmentzellen einwirkt, oder ob die Farbenveränderung erst auf dem Umwege des Nervensystems zustande gekommen ist."

In dieser Beziehung ist interessant die oben erwähnte Ansicht von E. Fischør (229), dass durch die Infektionsträger Gifte (Toxine, Ptomaine) produciert werden „und es könnte daher clie Frage gestellt werden, ob diese Ptomaïne nicht einen veränderten Einfluss auf die Farben der bis zum Imagostadium gelangenden Individuen haben könnten." Fischer sagt selbst, dass „jene merkwürdigen Aberrationen tesludo, ichnusoides, hygiaea etc. aus inficierten Raupennestern stammten."

Auch A. Voelschow (930) erhielt aus scheinbar lebensfähigen und erwachsenen Raupen von Dasychira pudibunda, welche' im Herbst, als an allen Baunstämmen die Raupenleichname hingen, gesammelt wurden, ab. concolor Stdgr. Es sei hier bemerkt, dass er aus einer Menge Raupen nur 7 Puppen erhielt, welche statt nach 8 monatlicher, nach 8 wöchentlicher Puppenruhe die Schmetterlinge ergaben. Dieser Umstand, verbunden mit demjenigen, unter welchem die Raupen gesammelt wurden, zeigt, dass die Puppen nicht gesund, sondern inficiert waren. Aehnliche Fälle der vorzeitigen Entwickelung in Folge der Krankeiten beobachteten auch andere Forscher.

So z. B. züchtete G. Taratynow (853) Raupen von Bombyx mori, welche vorzeitig untor sonst normalen Umstänilen ausgeschlüpft waren (im Juli). Dabei wurde folgeniles beobachtet: lie Raupenzeit dauerte 11 Tage länger als sonst (43 Tage statt 32); trotzlem waren die grössten Raupen unter normaler Grösse. Von 300 Räupchen konnten sich nur 42 verpuppen, die anderen starben, angefangen von ler 1. Häutung, an Pebrine. 22 Raupen fertigten Cocons, während die übrigen 20 nur ein flaches Netz gespinnt haben. Sowohl die Häutungen wie auch die Verpuppung fanden nicht zu derselben Zeit bei allen Raupen statt, sondern waren sehr ausgedehnt. Das Ausschlïpfen der Imagines dauerte 7 Tage, wobei die darauf stattfindende Eierablage auch sehr verschieden war: die maximale Eierzahl, welche von einem $\nmid$ abgelegt wurde, betrug 290 und die minimale 56. Die Schmetterlinge waren von sehr kleinen Dimensionen, energielos und lebten nur eine kurze Zeit. Taratynow kommt 
zum Schlusse, dass die Raupen bereits beim Schlüpten von Pebrine angesteckt waren:

K. Gorbatschow (324) studierte weiter diese Frage, indem er die in oben beschriebener Aufzucht von Taratynow am Schlusse erhaltenen Eier untersuchte. Er fand, dass di meisten Eier auf ibrer Oberflïche die Pebrina-Körperchen hatten; ausseriem lionstatierte er, dass sogar Eier, welche vor der mikroscopischen Untersuchung mit Salzsïure bearbeitet wurlen, in ihrem Inneren Vibrionen enthielten; (die Annahme ron Pasteur, dass Vibrionen und Microcokken auf die Nachkommenschaft nicht iibertragen werlen können; ist somit unrichtig).

Diese Beispiele zeigen deutlich, dass die inficierten Raupen einen gewissen Prozent Schmetterlinge ergeben liönnen, welche offenbar als pathalogische Erscheinungen zu betrachten sind. Es ist also zuzulassen, dass die dabei im Körjer entstehenden Ptomaïne die Pigmentzellen insofern beeintlussen können, dass ihre Funktionen geändert resp. gelehint werden.

Was nun den Einfluss der Nahrung ohne lïnstliche Beimischungen anbelangt, so könnte man denselben auf folgende Ursachen reduzieren:

Erstens kann die von der betreffenden Inselitenspecies bis dahin nicht gebrauchte Nahrung neue Bestanltheile ins Blut bringen, welche mit demselben neue Verbindungen bilden liönnten. Sind diese Verbindungen anderes gefürbt, als die bis jetzt gelieferten Pigmente, so wird es die Abänderung dtr Färbung vom Insekt zur Folge haben.

Zweitens kann die neus Nahrung nicht alle Bestandtheile ins Blut liefern, welche zur Ausarbeitung der normalen Pigmentstoffe nöthig sind.

Einen solchen Fall beobachtete Poulton (648). Er fütterte die Raupen von Agrotis pronubu mit Kohle und konstatierte, dass ihre griinen und gelben Hautfarben nur dann entstehen, wenn sie chlorophylloder etiolinhaltige Nahrung zu sich nelımen.

Drittens kann die neue Nahrung die Entwickelungsstörungen hervorrufen, indem die Verdaung nicht normal vor sich gehen und im extremen. Falle zum Hungern führen wird.

Als Pictot (637a) den Raupen einiger Species schwerverdauliche Nahrung reichte, erhielt er albinotische Variationen der Imagines. In Bezug auf die ungenigende Nahrung ist derselben Meinung auch K. Bartels (455a) und J. v. Lomnicki (534) (Erythropodismus). 
Aus anlerem Gebiete als die Entomologie seien hier die Versuche von v. Wittich (961 $a$ ) angeführt. Er fant, dass die grünen hungernden Frösche einen braunen, bronzefirbigen 'Ton ammehmen.

Viertens kann die neue Nahrung die sogenamnte Uebernihhung zu Stande bringen uni die Intensität der Pigmente, bzw. die Ueberhandnahme eines desselben über das andere belingen.

Pictet (637a) fütterte die Raupen einiger Species mit Blättern von Krïutern, welche besondern Reichtum an Nährstoffen enthalten, und erhielt melanotische Formen.

Fimftens kamn die neue Nahrung für den Insektenorganismus Stoffe liefern, welche auf die Pigmentzellen direkten reizenden und lehmenden Einfluss ausüben können. In diesem Falle hätten wir unbedingt eine aberrative Form erhalten.

Alle diese Fälle, sowohl einzeln wie auch combini'rt betrachtet, sind möglich und es muss erst untersucht werden, welchen Fall wir bei dieser oler jener Nahrung vor uns haben. Dic "NahrungswechselTheorie" von A. Pictet ist nur ein spezieller Fill von den hier erwälınten.

Was nun die Farbenänderungen der Raupen betrifft, welche mit verschiedenen Pflanzen gefuittert werden, so kann auch bei ihnen die Färbung durch versehiedene Zusammensetzung des Futters bedingt werilen; man nuss aber dabei nicht vergessen, dass ihre Haut das Anpassung-Vermögen an die Farbe der Umgebung (Körper-Photographie) besitzt, wobei (ler in diesem Abschnitte besprochene Einfluss verkompliziert wirl. (Siehe Abschnitt 3 dieses Kapitels).

Der Umstand, dass die Nahrungsïnderung nicht bei allen Inselitenspecies die Färbungs-Schwankungen verursacht, liegt wohl in versthiedenen phylogenetischen Alter der Species und auch in den individuellen Verschiedenheiten einzelner Exemplare (Standfuss [840]).

Somit wird der Einfluss der Nahrung und chemischer Stoffe auf die Färbung und Zeichnung der Insekten auf folgende Faktoren reduziert:

1. Direktes Gelangen der Pigmente ins Blut und ihre gegenseitige Wirkung auf das letztere.

2. Die hemmende resp. reizende Wirkung der in den Insektenkörper gelangenden Substanzen auf die Pigmentzelle.

3. Ernährungs-Störungen, wobei in Blute andere Farbstoffe entstehen können oder durch ihren Mangel die Interferenzfurben erzeugt werden. 
4. Das Anpassung-Vermögen der Raupen- und Puppenhaut an die Farbe der Umgebung (vide die Theorie von Wiener [959] auf p. 862).

\section{Einfluss des Klimas.}

Es ist schwer, über diesen Einfluss weite Verallgemeinerungen zu machen, da erstens an verschiedenen Orten die Anzahl der Generationen verschieden ist, welche dazu Saison-Dimorphismus zeigen, und zweitens sind nicht alle Kontinente in dieser Richtung genügend studiert worden. Wir werden deshalb nur Europa betrachten und zwar nehmen wir für den Ausgangspunkt Zentraleuropa. Sämtliche Färbungsvergleichnungen werlen wir nur auf diesem Theil des europäischen Kontinents machen.

Die horizontale Verbreitung der Arten bleibt niclit ohne Einfluss auf die Färbung und Zeichnung der Insekten und zwar:

A. In nördlichen Gegenden werden die Schmetterlinge:

a) dunkler Pupilio machaon (Slevogt, 822), Lymantria dispar, Aglia tau (Federley, 219u), Agrotis simulans, Agr. occulta, Larentia caesiata (Petersen, 633), im allgemeinen (Teich, 855), Satyrus maera, megcera (Meyer-Dür, 580).

b) heller: Drepana curvatula, Acronyctu rumicis, Endrosa irrorella, Acidalia immorata, Selenia bilunaria (Petersen, 633), Chelonia plantaginis (Koch, 457b), Lycaena-, Polyommatus-, ColyaArten (Teich, 855).

B. In südlichen Gegenden werden nach Meyer-Dür (580) bei Schmetterlingen:

a) alle rothgelben und rothen Farben erhöht und die scbwarzen Flecken verkümmert: Melithaea-Arten.

b) die weissblauen Lyca enen noch starker abgebleicht: coryidon.

c) das Gran der Unterseite der reinblauen Lycaenen in's Braungel be umgewandelt: adonis, alcxis.

d) das Metallgrün an der Flügelbasis uuf der Unterseite vermindert und vergelbt: Lycaena-Arten.

e) gelbliches und intensiveres Weiss: Pieris-Arten.

f) blasser ist Papilio podalirius.

g) mehr chrongelb: Papilio machaon. 
C. In östlichen Gegenden werden die Schmetterlinge:

a) dunliler: Lymuntria dispar ơ (Reichert, 684), Ancylelomia palpella, Calcophora nuopoucliella (Rebel, 676), Polyommutus yhlacas, Limenitis cumillu, Mclitaeu pleobe, Parurge megaera, Acontia licida (Holtz, 355), Heliothis peltiger, Hypochalcia dignella, Pteroph. metzneri (Iederer, 505), Purarge megaera (H:1tz, 385).

b) lieller: Limuntria dispar $\bigcirc$ (Reichert, 684), Catocala nupta (Holtz, 385).

c) In att: Thutpochares rosina (Mann, 545), Oxyptilus diductylus (Rebel, 676), Bombyx neustria, Vanessu cardui (Holtz, 385).

(l) greller: Melitaea athatia (Nann, 545), Argymis daphne, Arg. niobe, Pararge marra, Vanessa urticae, Boarmia gemmaria (Holtz, 385).

I). In nord-östlichen Gegenden werden die Schmetterlinge:

a) il unkler: Papilio machaon, Senta maritima (Krulikowski, 478), Agrotis polygona, Dianthoecia nonu, Caradrina taraxaci, Cucullia umbratica, Erastria uncula, Prothymia viridaria, Zanclognatha emartualis, Ciclaria vittata, Aporodes floralis, Oenectra pilleviana, Tularporia psenedobombycella, Depressuriu ocelluna, Depr. angellicella (Krulikowski, 479), Smerintlus populi (Krulikowski, 480 ), Bren. this seleric (Kusnezow, 489a).

b) blasser: Cidaria truncata (Krulikowski, 478b), Polyommatus phlaens var. eleus (Krulikowski, 475e), Gnopluria quadra (Krulikowski, 478), Agrotis aceri i, MLumestra genistae, Miselia oxyacanthae, Xylina ingrica, Plusia moneta, Pl. bractea, Pericallia syringaria, Botys repandulis, Bot. verbaseulis, Pentlinu antiquana (Krulikowski, 479).

c) intensiver: Agrotis dahlii, Leucania conigcia, Anphijingra pyramideu, Chariclea umbra, Pseidoterpme pruinuta (Krulikowski, 479).

(1) Reduktion der schwarzen Zeichnung: Picris rapae, var. -similis, Carterocephalus silvius, Setina irrorelia, S. mesomella, Calligenia rosea, Nemeophila plantaginis, Spilosma lubrocipesta, S. menthastri, Ocneria disyar, Acronycta leporina, Zonosoma pendularia, Z. punctaria, Zerene grossulariata, Z. sylvatu, Z. marginata, Angerona prunaria, Hypoplectis aclspersaria, Venclia macularia, Amphidasis betularia, Ciclaria corylata (Krulikowski, 478).

e) Zeichnungslos: Hypochaltia ahenella (Krulikowski, 478).

E. In süd-östlichen Gegenden werden die Schmetterlinge:

a) tunkler: Pieris napi ab. bryoniae (Aigner, 7c), Colcophora onopordiella (Rebel, 676), MLitituea cinxin, Mel. didyma, Aryynnis

Bachmetjew, Studien. II. 
amathusia, Satyrus semele, Heliothis armiger, Scotosia rhamnuta, Tephroclystia semigraphata, Boarmia perversaria, Ematurga atomaria, Seliclosema ericetaria, (Rebel, 677) Euctidia triquetra, Acidulia ornata (Ulbrich, $\$ 86 a$ ).

b) schwächer gezeichnet: Psorosa dahliella, Tephroclystia semigraphata, Scotosiu rhamnata (Rebel, 677), Erebia meclusa (Rebel, 676).

Schmetterlinge an der Meeresküste resp. in sümpfigen Gegenden werden:

a) Iunkler: Calymnia pyralina (Baillon, 44), Teras hastiana, Acronicta menyanthites, Acr. v. bractyporina, Teras hippopluëana (Hoffmann, 378), Turtryx podana (Sorhagen, S23), Orrhodia toridu (Rebol, 676), verschiedene Species (Enteman, $214 u$ ).

b) bleicher: Nemeophita russula, Talpochares purpminu (Baillon, 44), Papilio machaon (Tschugunow, 885).

c) feuriger: Coenonymplua pamphilus (Galvagni, 270a).

Die Höhe ïber dem Meeresniveau in einem und demselben Orte beeinflusst bei einigen Species die Fürbung des zu schliipfenden Imagos nach verschiedenen Richtungen hin und zwar werden die Inselsten mit zunehmender Höhe:

a) dunkler resp. schwärzer: Parnassius appollo, Pamassius mneumosyne (Rebel und Rogenhofer, 674), Pieris napi, Lycaena-, Argynnis-, Melitaea-Arten (De la Harpe, 354, 355; Trost, S84u; Rühl, 719), Hadena maillarcli, Had. lateritia (Bohatsch, 97), Setina (Hofmann, 381), Lygris populata ab. musunaria (Klemensiewicz, 551), Erebir mechusa, Chlountha radiosa (Rebel, 676), Lithosia aurita (De la Harpe, 354), Hesperia-Arten (Meyer-Dür, 580).

b) heller: Mclitaca artemis (v. merope), Argymis selene (MeyerDür, 580), Parasemiu pantlaginis (Riesen, 694b).

c) lebhafter gefärbt: Vancssa urticae (Meyer-Dïr, 580).

.l) metallglänzend statt schwarz: Culopterus selmanni (Наberfelner, 341).

e) unverändert: Ptcrostichus jurinei (Haberfelner, 341).

\section{Die Theorien dieses Einflusses.}

Die erște Theorie gab de la Harpe (1848. 354). Er sagt, dass dis warmblitigen Thiere im Norden deshalb weiss sind, weil sie innere Wärmequelle haben und sich von der Wärmestrahlung dụrch weisse Farbe der Federn, der Haare etc. schützen; während die Insekten 
die Wärme von aussen absorbieren und deshalb desto dumkler sind, je kälter das Klima in der betreffenlen Gegend ist ( ${ }_{n}$ Les seconds puisant le calorique dans l'atmosphère ou dauns les rayons du soleil, devaient avoir des couleurs foncées pour pouroir l'alsorber plus rapidement" [p. 398]):

v. Prittwitz (1866.653) vermuthet die Ursache des Entstehens der Farbe in cler Puppe in Licht und Wärme, inlem er sagt: „Ich denke, dass eine durchwärmte und durchleuchtete Pflanze andere Farben schafft, als etwa ein norilisches Lebermoos" (p. 263).

C. Teich (1870. 855) sagt in seinem Vortragge iiber „Klima und Schmetterlinge": „Die lebhaftere Farbe scheint zum Theil durch Wärme bedingt zu sein" (p. 2).

A. Fuchs (1873. 266) sagt, gestiitzt auf seine Beobachtungen im Freien über das Entstehen von Prrarge adrasta v. maja, dass "die mangelhafte Nahrung, die starke Hitze des Sommers, die gewöhnliche Trockenheit des Juli diese Varietït hervorbringen" (p. 106).

1874 veröffentlichte August Weismann (953) seine berïhmten „Studien zur Descendenz.Theorie. I. Ueber den Saison-Dimorphismus der Schmetterlinge." In denselben behantelt er unter Anderen auch die Frage über den Einfluss des Klimas auf Färbung und Zeichnung der Schmetterlinge, indem er sagt: „Wodurch bewirkt Klima-Wechsel eine Abänderung in Zeichnung und Färbung eines Schmetterlings? Es wäre vor allem zu entscheilen, ob das eigentlich Wirksame beim Klima-Wechsel in der Einwirkung löherer oder niederer Temperatur auf den Organismus liegt, oder vielleicht mehr in der durch höhere Temperatur beschleunigten, lurch nierlrige verlangsanten Entwickelung. Andere Faktoren der Gruppe von äusseren Lebensbedingungen, welche wir unter dem Namen "Klima" zusamenfassen, können als in diesen Fällen unwesentlich unberücksichtigt bleiben" (p. 38).

Da Polyommatus plulacas sowohl in Deutschland als in Italien in zwei Generationen auftritt, von denen die deutschen beide gleich sind, während in Italien die Sommergeneration schwarz wird, so sagt Weismann: „Ich bin desshalb der Ansicht, dass nicht die Entwicklungstlauer das umwandelnde Princip ist bei der Bildung klimatischer Varietäten der Schmetterlinge, sondern lediglich die Temperatur, welcher die Art während ihrer Verpuppung ausgesetzt ist" (p. 39).

Ueber den Einfluss des Klimas sagt er weiter: „Ich glaube, dass durch Klimawechsel niemals wieder die alten Formen entstehen, sondern immer wieller neue, dass somit allein eine periodisch sich wiederholende Veränderung des Klimas genügt, um im Laufe langer 
Zeiträume immer neue Arten aus einander hervorgehen zu lassen So wenigstens bei Schmetterlingen ${ }^{4}$ (p. 75).

Fr nimmt an, dass die Einwirkung des Kilimas allmälig stattfinclet, inlem er sagt: Die Wirkung des Klimas ist offenbar am best: $\mathrm{n}$ vergleichbar mit ler sogenannten cumulativen Wirkung, welche gewisse Arzneistoffe auf len menschlichen Körper ausüben; die erste kleine Dosis bringt kaum bemerkbare Veränderungen herror, wirl sie aber vielmal wierlerholt, so summirt sich die Wirkung, es tritt Vergiftung ain.

Für den Sarson-Dimorphismus und die klimatischen Varietäten, die in einander übergehen und mit einander verflochten sind, führt Aug. Woismann, um ihr verwickeltes Verhältniss zu illustrieren, folgendes Beispiel an:

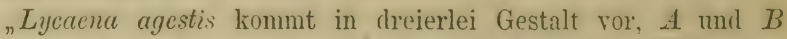
wechseln in Deutschlanil miteinander ab als Winter- und Sommerform, $B$ unil $C$ dlagegen folgen in Italien als Winter- und Sommerform aufeinaniler, di Form $B$ kommt als; beilen Kílimaten zu, aber in Deutschlimel tritt sie als Sommer- in Italien als Winterform auf. Die reutsche Winterform A fehlt Italien vollständig, wie ich aus zahlreichen selbstgefangenen Exemplaren weiss, die italienische Sommerform dagegen (var. allous) kommt in Deutschland nicht vor. Die Unterschiedle zwischen den drei Formen sind auffallend genug. Die Form $A$ ist auf der Oberseite schwarzbraun und zeigt höchstens eine Spur schmaler rother Raniflecke, während die Form $B$ mit grossen lebhaft ziegelrothen Randflecken geziert ist, und $C$ sich ron $B$ durch ein intensives Gelbbraun der Unterseite auszeichnet. Wer nur die deutsche Winter- und die italienische Sommerform vor sich hätte, wïrle sie ohne Zweifel als klimatische Varietäten auffassen, sie werlen aber verbunden durch die in den Entwickelungsgang beider eingeschaltete Form $B$, wodurch eben beide extreme Formen

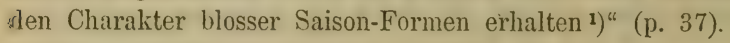

Alb. Bohatsch (1891. 94) fing in Wien 220 Exemplare von Carabus scheidleri Panz. F. der verschiedenen Färbung während ier Zeit von 1876 bis 1880 und zwar ausser ilen von Duftschmid (1811) und Sturm (1815) angegebenen Farbenvarietäten noch in einfärbigen Exemplaren: blaue, hellila, hellviolette, purpurfarbige und liupfer-

$\left.{ }^{1}\right)$ Es hat sich dort ein Fehler eingeschlichen: die Zahlen fur die Figuren, wolche bei $A, B$ und $C$ stehen, entsprechen der bei, Woismann angeführten Iafel nicht: 
rothe; von geränderten Exemplaren: blaugrüne, golılgrüne, messinggrüne, erzgrüne, bronzefärbige, blaue, lilafärbige, violette, purpurrothe, kupferrothe unil schwarze Exemplare mit purpurfärbigen, lila, violetten, blanen unı grünen Rändern. Da die dınklen Exemplare in dem geheizten Glashause unter den Blummzucht-Tischchen und in Gärten, welche gut gepflegt und durch viele Bämme beschattet waren, erbentet wurlen, so ist dieser Forscher hieilurch zur Annahme verlanlasst, " Hitze (welche sich in ilem zwischen Mauern abgeschlossenen baumunil schattenlosen (Gebiete entwickelte) die hellen Farben entstanclen sein mussten" (p. 2S). Die Thatsache, dass in einem Jahre manche Farben in besonderer Häufigkeit vorkommen, erlikït er durch Witterungsverhältnisse, vorüber er aber leiler lieine Aufzeichnungen besitzt. Purpurfärbige und ganz dunkelgrüne Exemplare erhielt er erst im Jahre 1880.

Auch L. Krulikowski (1893. 479), welcher im Gouvernement Kasan (Russland) Schmetterlinge sammelte, sagt: „Exemplare von Calymnia trapezina $\mathrm{L}$. variieren sehr in der Färbung, wobei man annehmen kann, dass diese Variabilität von irgen:l welchen meteorologischen Verhältnissen abhängt, da während eines Sommers nur die typischen Exemplare vorkommen, dann während des zweiten Sommers sind die Exemplare an der Mitte der Vorderfligel dunkel, während des dritten Sommers sind sie in der Mitte der Vorlerflügel röthlich etc." (p. 80).

E. Hoffer (1904: $376 a$ ) fand bei seinen Experimenten mit Hummeln, dass die Ursache des Farbenvariierens in der hohen Tageswärme, Feuchtigkeit und im Lichte liegt. Auch bei der Untersuchung der amerikanischen Wespengattung Polistes kam W. Enteman (1905. 214a) zum Schlusse, dass die Entwickelung des Pigmentes wesentlich von der Temperatur und Feuchtigkeit abhängt.

H. Federley (1905. 219a) untersuchte den Einfluss verschiedener Temperaturen auf das werdende Kleil von Leucodonta licoloria und seiner Aberrationen und als er negative Resultate dabei erhielt, sagt er: "Da nun die Temperatur nicht dic Formen hervorgebracht hat, so miissen wir die Ursache irgendwo anders suchen, und vermuthe ich, dass es die Feuchtigkeits- und Lichtverhältnisse sind, die hier die Hauptrolle spielen" (p. 8).

0. Meissner $(555 a)$ fing Ende Nai und Anfang Juni 1906 bei Potslam 314 Exemplare Phyllopertha horticola. Je nachdem, ob diese Kïäfer bei einfallendem (1) oder bei durchgehendem (2) Lichte 
betrachtet werden, zeigen sie verschierlene Färbungsvarietäten. Es wurden folgende fünf Gruppen festgestellt:

\begin{tabular}{|c|c|c|c|c|c|}
\hline Varietät & I & II & III & IV & V \\
\hline $\begin{array}{l}\text { Schild in }\left\{\begin{array}{l}1 \\
\text { Stellung }\end{array}\right. \\
\text { hellgrün } \\
\text { grün }\end{array}$ & $\begin{array}{c}\text { hellgrün } \\
\text { blau }\end{array}$ & $\begin{array}{c}\text { dunkelgrün } \\
\text { blau }\end{array}$ & $\begin{array}{c}\text { blaugrün } \\
\text { blau }\end{array}$ & $\begin{array}{c}\text { blau } \\
\text { blau }\end{array}$ \\
\hline Frequenz in $\%$ & 1,3 & $\mathbf{5 7 , 4}$ & 33,4 & 2,2 & 5,7 \\
\hline
\end{tabular}

Wanach sammelte diese Kïfer 1905 auch bei Potsclam und fand 30 bis $40 \%$ für die Gruppe IV + V, während Meissner 1906 nur $8 \%$ ermittelte. Ausserdem "war das Blau im Jahre 1905 viel heller als 1906, wo Blauschwarz zu nennen war. Zur Entscheidung, aus welchen Gründen das Verhältnis der grïnen zu den blaten Varietäten sich so geändert, ob vielleicht durch meteorologische Einflüsse, ist jedoch eine längere Beobachtungsreihe erforderlich."

Meissner sammelte 1906 auch eine grosse Anzahl von Chrysomela varians und fand bei diesen Käfern fünf Farbenvarictïten, welche verschieden häufig waren und zwar in $\%$ :

\begin{tabular}{|l|r|r|r|r|r|}
\hline \multicolumn{1}{|c|}{ Varietäten } & Roth & Grün & Blau & Violett & Schwarz \\
\hline I. Generation & 13,5 & $\mathbf{4 8 , 6}$ & 33,8 & 2,7 & 1,4 \\
II. $\quad n$ & 12,3 & $\mathbf{4 4 , 9}$ & 30,5 & 10,2 & 2,1 \\
III. $n$ & 20,4 & $\mathbf{4 6 , 0}$ & 23,0 & 8,0 & 2,6 \\
\hline
\end{tabular}

Wie aus dieser Tabelle hervorgeht, „ist die Häufigkeit der einzelnen Varietiten in beiden Generationen annähernd die gleiche, doch scheint in der Sommergeneration eine schwache Tendenz, die Farbe nach dem blauen Ende des Spektrums zu verschieben, angedeutet."

Aus diesen Citaten ist ersichtlich, dass die meisten Forscher die Ursache des Einflusses des Klimas auf die Farben- und Zeichnunsgänderung in Temperatur-, Feuchtigkeits-, Licht- und Nahrungsverhältnissen finden. Es sind hier deshalb alle diejenigen Betrachtumgen gültig, welche im 5. Abschnitte des II. Kapitels (des theoretischen Theils) auf p. $770-776$ auseinan(ler gelegt wurden. ${ }^{1}$ )

$\left.{ }^{1}\right)$ Auf p. $773-775$ hat sich ein Druckfohler eingeschlichen: statt Fig. 26, 27, 28 muss Fig. 29, 30, 32 stehen. 
Besonderes Interesse verdient die seit einigen Jahren zuerst in Deutschland beobachtete geographische Verbreitung der Verdunkelung gewisser Lepidopteren-Species:

Die in dieser Beziehung näher untersuchte Form ist Amiphidasis betularius ab. doubledayaria Mill. Nach Hoffmann (378a) ist diese schwarze Form früher nur in England und zwar hauptsïchlich in der Gegend von Manchester vorgekommen, wo sie noch in ten 60-er Jahren des vorigen Jahrhunlerts eine Seltenheit war, später aber sı häufig geworden ist, lass sie die Stammform vollstänılig verdrängte. P. Snollen (378a) fand sie vor 20 Jahren in Dordrecht und Grave, F. Knapp (37Sa) zu gleicher Zeit in Gotha, A. Hoffmann $(378 a)$ in Hannover und K. Kraepelin $(473 a)$ in Hamburg. Seit dann verbreitete sich diese melanistische Form weiter, und zwar fand sie H. Steinert (S44a) 1892 in Dreslen, Hartmann (S40) erbeutete sie in Schlesien, Standfuss (840) berichtet, dass sie ror 1896 in Barmen, Crefeld gefangen wurde, A. Riesen (694aa) fing sie 1900 auf der Insel Rïigen und Pauls (629) und H, Fischer 240 1900 in Harz. In der Sitzung (les Brrliner Entomologischen Vereins wies Rey (1900. 659) auf clie zunehmende Verbreitung von Amphidlasis ab. doubledayaria Mill. und Psilura monacha ab. eremita Ochs. in südlicher Richtung in Deutschland hin, und die Redlalition der "Inselkten-Börse" forlerte die Entomologen auf, über das Vorkommen schwärzlicher Aberrationen in letzter Zeit Nachricht zu geben. Baron Raoul de Vrière (934), Chr. Storch (847), Th. Voss (931), H. Gauckler (299) erstatten ausfiihrliche- Berichte darüber, aus welchen zı ersehen ist, dass in gewissen Fällen die Abarten die Stanmform bereits verdrängt haben, wenn auch vorläufig noch nicht ganz.

Als ich zu clieser Zeit in Düsselilorf war, theilten mir die dortigen Entomologen Th. Voss und J. Broit mit, dass sie die Ursache des Entstehens dieser Form im Eisengehalt der in der Nähe von Diisseldorf sich befindenden Sümpte erblicken.

Dieser Negritismus bei Schmetterlingen tritt in der letzten Zeit stärker und stärker auf uud zwar im Niederelbgebiet bei folgenden Arten: Dasychiru pudibunda var. concolor. Stclgr., Psilura monacha var. eremita Ochs., Haclena monoglypha var. obscura Stclgr., H. scolopacina var. Tummoniensis Sauber, $H$. ophiorgramma var. surtur Stdgr., Amplidasis betularia var. doubledayaria Mill., Tortrix podana var. sauberiana Sorh., Lithocolletis schreberella var. obumbrata Sorh. (Kraepelin, 473a), Boarmia roboraria, B. consortaria, Di'ynubia 
melagona (Broit, 113), Boarmia crrpuscularin ab. biunduluria Bkh. (Rey, 689; Breit, 113).

Auch an anderen Orten beobachtete man in ler letzten Zeit das Ueberhandnehmen der melanistischen Formen.

B. Slevogt $(822 \alpha)$ konstatierte, dass in Kurland gewisse Species in der letzten Zeit "lie beginnende Neigung zum Melanismus" zeigen, besonders wirl dies bei Argynnis-Arten (artippe, pap)hia), und Noctuen (Calocampa soliduginis var. obscril Lutzau, exoleta L., Catocalı mupta L.) beobachtet. „Bei mancheli Arten scheint die melanistische Form die Stammart ganz zu verilrängen."

0. Schultz $(790 a)$ beobachtete bei Acronyche remiris, lass die zunehmende bräunliche unil schwärzlich graue Nuance in der Grundfärbung der Vorderflügel schliesslich tiefschwarz geworilen ist (ab. lugubris Schultz). Er erhielt diese Form zuerst in Jahre 1599 uni 1900 aus Böhmen, wo sie auch 1901 von Gradl erleutet wirde.

Thurau (864) sagt, dass Argynnis paphia ab. valesina Esp. in einigen Gegentlen Deutschlands die Stammart an Zahl übertreffe oder ganz verdrängt hahe. In der gleichen Sitzumg wurle ron mehreren Anwesenden dasselbe bestätigt für Tirol, Schweiz, Stettin unıl Eberswalcle.

J. Breit (113) fing in Düsseldorf während einer Reihe von Jahren verdunkelte Form von Melitaea aurinia.

Auch bei Coleopteren wirl dieselbe Erscheinung in der letzten Zeit beobachtet. So fand R. Zang (965) in Darmstadt Carcibus auratus L. entwerler nur mit schwarzen Beinen oller nit vollstänlig schwarzen Extremitäten und ebensolchen Mundtheilen. In Posen fing E. Schumann (796) ganz schwarze Maikäfer und fast solche Anisoplic segetum 우. B. Feuerstacke (219d) berichtet aus Miagileburg, dass bei Clausthal im Harz ganz schwarze Carabus auratus L. gefangen wurlen, auch $C$. alpinus Dej., C. auronitens Fbr. und $C$. glacialis sind im Hochgebirge melanotisch.

Diese zunehmende Erscheinung kann man durch die Wanderzïge der Insekten nicht erklären. Wie wir bereits im 6. Abschnitte des I. Kapitels (iles theoretischen Theils) gesehen haben, werden solche Massenwanderungen nur für eine bestimmte Anzahl von Species beobachtet, wobei solche Species, wie Amplidasis betulariu, welche hier hauptsächlich in Frage kommt, nie Wanderzüge zu. 
beobachten Gelegrenheit gab.1) Ausserilem verbreitet sich die.e Form, wie verschiedene Forscher sthreiben, nur in einer gewissen Richtung und zwar von Nord- nach Sücl-Deutschland.

Pauls (629) versucht das Entstehen von var. doubledayuria in Deutschlanil durch fortgesetzte Inzueht der Stammform zu erklären.

Es ist bekannt, dass die fortgesetzte Inzucht eine Farbenänderung bei der Nachlommenschaft zur Folge hat. So z. B. ziichtete Standfuss (840) vun dem Jahr 1885 bis zum Jahr 1893 Aylia tar L. und rrhielt verdiisterte Form ab. luyens Stdfs. (ab. fere nigra Thierry-Mieg, ab. nigerrima Stdgr.).

Auch A. Kolisko (463a) ziichtete 1903 Dilina tiliae. 1904 setzte er die Inzucht fort und erhielt in diesem Jahre in der Zeit vom 24. April bis 20. Juni 52 Falter. Unter normalen Exemplaren wurlen $15 \mathrm{ab}$. brumncscens Stgr. erhalten. 11 Stiicke aber ergaben äusserst auffallende Abweichungen in der Zeichnung, welche zu folgen:len Abarten zugerechnet werden müssen: ab. maculata Wallgr., ab. centrimunctu Clark, ab. utmi Stgr., ab. cxtincta Stgr., ab. olsoleta Clark, ab. immaculata Bartel, ab. costipuncta Clark.

Gestiitzt auf diese Resultate sagt Kolisko: „Es scheint also erwiesen, dass man die in der Natur vorkommenden Aberrationen auch durch Degeneration, auf dem Wege fortgesetzter Inzucht, herverrufen kann. Die Annahme ist daher naheliegend, dass auch die in der Natur vorkommenden Aberrationen ebenfalls durch Degeneration entstanilen und die verschiedenen tiliae-Aberrationen nur degenerative Erscheinungen seien."

1) Als Ergänzung zu dem erwähnten Abschnitte sei hier noch folgender Fall ron Massenzïgen der Schmetterlinge angeführt:

N. Kusnezow (488a) beobachtete während der Zeit von 14.-19. VII. 1892 (alt. St.?) eine ungeheuere Menge von Pieris daplidice I. (meistens alogeflogene $\left.\delta^{\nearrow} \sigma^{\top}\right)$ bei ständigem starken Nord-Ost-Winde. Diese Wanderung stimmt zeitig vollkommen mit gleichem Zuge im Gouvernement St.-Petersburg. Vor und nach dieser Zcit wurde diese Species nicht beobachtet.

Von anderen Insekten beschreibt A. Montandon (588a) einen ausserordentlichen Massenflug von Harpalus calcertus Duft, welcher am 21. VII. 1S98 in Bukarest beobachtet wurde (auch in Braila, Galatz und Jassy). Nähere Angaben darüber fehlen beim Verfasser.

Auch in Bulgarien wurde die Stadt Silistra von einer Inselitenwolke (Eintagsfliegen) überrascht. Diese Inseliten fielen in ungeheuer Menge zu Boden mit dem Regen am 13. VIII. 1904 nach \& Uhr Abends. Am gleichen Tage herrsclite von 5 bis $7 \%$ Uhr Abends starker Nordost-Wind und um 8 Uhr begann der Regen. Am 11. VIII. wurde Wetterleuchten beolachtet. 
B. Slevogt $(822 \alpha)$ vermuthet die Ursache de's Ursprunges nancher melanistischer Varietäten in der progressiver Kremzung. "Denkt man sich nun eine Krreuzung in autsteigenler Linie, so kommen allmählig solche dunkle Exemplare zu Stande, wie man sie hier [in Kurland] alljälırig fängt."

Solche Fälle sind jedem Züichter bekannt und selr zahlreich in der entomologischen Litteratur zerstreut. Dass die entstanilene Aberration durch Kreuzung mit der Stammform nicht verschwinlen kann, beweisen die Untersuchungen mehrerer Forscher. Es genïgt hier nur die Resultate von Standfuss (840) für die Aglia tau L. und ab. lugens Stlfs. anzufuihren, welche er 1889-1891 durch die Kreuzung der Stammform und der Aberration in sehr exakter Weise érhielt.

$1 S 88$ hatte er die durch ziveimalige Inzucht erhaltenen $\sigma^{7} \sigma^{\top}$ von ab. lugens Stdfs. mit $\not \circ$ zurückgekreuzt, welche aus Eiern von im Freien gefangenen Weibchen erzogen worlen waren. Die aus dieser Krreuzung sich ergebenden ab. lugens. wurlen 1889 zur Weiterzucht benüżt.

I.

Aglia $\left\{\begin{array}{l}\text { ab. lugens } \sigma^{7} \\ \text { tau } \text { क (dieses } \\ \text { tau } \text { o stammte aus Aglia } \\ \text { Eiern cines im } \\ \text { Freien gesammel- } \\ \text { ten o und legte } \\ 95 \text { Eier ab.). }\end{array}\right.$

Ergebniss:

$14 \delta^{\top} \delta^{\top} ; 28$ 유 tau

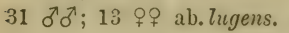

II.

III.

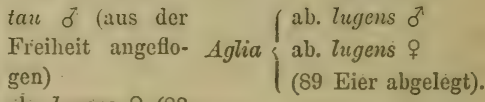
ab. lugens $q$ ( 82 Eier abgelegt).

Ergebniss:

13 ठำ; 25 우 tau

Ergebniss:

Davon wurden 1890,91 weitergezogen:

IV. (Nachzucht von III.). Aglia $\left\{\begin{array}{l}\text { ab. lugens } \delta^{\pi} \\ \text { ab. lugens } \% \text { (117 Eier). }\end{array}\right.$

Ergebniss :

$3 \delta^{\pi} \sigma^{\pi} ; 8$ 우 tan

49 ठ우 42 우 ab. lugens.
V. (Nachzucht ron IIIr). Aglia $\left\{\begin{array}{l}\text { ab. lugen's ơ } \\ \text { ab. lugens } \% \text { (103 Eier). }\end{array}\right.$

Ergebniss :

3 ठ주; 7 유 tau 46 ठ주; 31 ๆं ab. luggens.

Auch im Freien wird oft beobachtet, dass die Stammform mit ihren Aberrationen in gleicher Gegend und zur gleichen Zeit fliegen, ohne sich dabei zu mischen resp. eine mittlere Form als Endresultat zu ergeben. Von ungeheuerer Zahl faunistischer Arbeiten seien hier nur zıvei erwälnt: 
N. Kusnezow (48Sa) führt für das Gouvernement Pleskau an: Nycteola revayana Scop. und ab. dilatana Hïbn., Gastropacha quercifolia L. und ab. alnifolia Ochs., Acronycta leporina L. und var. bradyporina $\mathrm{Tr}$., Hadena adusta Esp. und var. baltica Hering.

L. Krulikowski $(470 \alpha)$ führt für das Gouvernement Jaroslaw an: Miana strigilis Cl. und ab. latruncula Hb., Hadena sccalis Bierk. und ab. nictitans Esp., Orhodia vaccinii L. und ab. spadicca $\mathrm{Hb}$. und ab. mixta Stgr., Aciclatia cmarginata L. und ab. mosquonsis Heyne, Ligris fluctuata L. und ab. incanata Reuter, Lygris comitata und ab. moldavinata Car.

Alle diese Aberrationen sind nicht vereinzelnt, sondern bilden bis zu $50 \%$ der Stammform.

Trotzdem dass die Inzucht als wahrscheinliche Ursache des Entstehens melanistischer Formen angesehen werlen kann, kann dieselbe jeloch nicht allein bei geographischer Verbreitung die Rolle spielen.

Es muss im Bezug der hier in Frage kommenten ab. double- dayaria bemerkt werden, dass zwischen ihr und der Stammform mehrere Uebergünge existieren, welche bei ihren Fortschreiten von Nordnach Siid-Deutschland auch gefangen wurden. Gegenwärtig haben diêse Uebergänge auch Zürich erreicht (Standfuss, 840). Nun hat er gefunden, dass bei gewissen Species und ihren Aberrationen keine Uebergänge bei ler Kreuzung entstehen. Wo aber Uebergänge zu beobachten sind, wie er z. B. bei Psilura monacha und ab. cremita fand, sagt er:

"Ich vermuthe, dass die Sache folgendermassen liegt: Psilura monacha gestaltet sich gegenwärtig, und zwar von ihren nördlichen Verbreitungsgebieten her beginnend, in südlicher Richtung hin fortschreitend, aus der normalen, überwigend weisslichen sehr allmählich zu einer mehr und mehr geschwärzten Form um. Dieser Umgestaltungsprozess, dessen letzte Gründe ich in der Einwirkung iuusserer Faktoren suchen möchte, wird durch die natürliche Zuchtwahl, da die geschwärzte Form eine wesentlich geschiitztere ist, sehr beschleunigt" (840. p. 309).

Dieser Ansicht ist auch A. Hoffmann (378), dessen thatsächlichen Angaben wir hior etwas ausfihrlicher betrachten werlen. Als er sich im Juli 1890 an der Norlsee aufhielt, hatte er Gelegenheit zu beobachten, „wie verschiedenartig die Nähe der See auf die Varietätenbildung der Lepidopteren wirkt, und dass ihr Einfluss in zwei giınz entgegengesetzten lichtungen, verdunkelnd 
unl verhellend sich geltend machen kann. Allerilings treten zwei verschielene Ursachen für diese divergiren len Pichtungen ein, das Filima und die Bollenverhältnisse, lie aher wielerum ihrerseits durch die See bellingt werlen. Zum ersten wirkt las kilte, triibe, nebelige: Klima mit seinen starken Nie lerschlïgen, welches besonter's unserer Nordseekïste eigen ist, verilunklnd auf die Firrbung verschielener Lepilopteren, gerale so wie auf ausgolehntem Flachlanil o ler Gebirgsmooren dlunkle Varietäten in grösserem Masse entstehen als in antern Gegenten." Als Beispiel hiefür gab ilım tlie Zucht von Teras hastirna L. Nach der Abrerhnung der hellerem Formen wurden erhalten für:

Dünen ler Norisee: $66 \%$ einfarbig schwarzbrame Stiicke. l)ie Zucht in Hannover: $12 \%$ einfurlig braune Stïcle.

Das Ergebniss auf die hellste Form war: $8 \%$ weissgrau gebänderte Stücke von der Nordsee, $41 \%$ $n$ $n$ "Hannover.

I) verdunkelnile Tendenz zeigt sich auch bei: Acronyctu menyanthidis View., Acr. v. bradyporina Tr., Teras hippopluëanr Heyilen.

In Bezug auf lie entgegengesetzte Variations-Richtung sagt er: „Ueberall, wo sich an ler Küiste erhebliche Dünnenbildungen zeigt, wirkt der weisse Dünnensand, welcher bei starkem Sonnenlicht nie ein Schneefell der Alpen das Auge blentet, verhellend auf die Farben. verschieilener Schmetterlinge. Natiurlich geschieht die Becinflussung, deren Resultat wir sehen, andersartig, als bei solchen Veränlerungen, die durch klimatische Einflüsse erzeugt werilen. Der weisse Sand bringt nicht etwa die hellen Farben bei Schmetterlingen hervor, er zwingt aber viele stänlige Bewohner solcher Gegenten, die helle Schutzfärbung ${ }^{1}$ ) nach und nach anzunehmen unıl zu vererben. ${ }^{u}$

Welche nähere Ursachen diese Verlunkelung resp. V'erhellung der Färbung hervorrufen, sagt Hoffmann nicht. „Ob der Salzgehalt der Luft und der Pflanzen, welche den Raupen als Nahrung dienen, die anlere oder anlere lichtung (resp. welche?) mit unterstützt, wage ich nicht zu entscheilen, anzunehmen ist es wohl."

Was nun den Einfluss der äusseren Faktoren auf das Entstehen der melanistischen Formen ambelangt, ron welchen Standfuss (840) spricht, so lauten Beobachtungen verschielener Forscher iiber das in der letzten Zeit bemerkte also wohl periodische Entstehen

1) Ich enthalte mich hier, die Schutzfïrbung näher zu betrachten, da es. im III. Bande meiner ${ }_{n}$ Studien" gethan wird. - Bachmetjew. 
der verlunkelten Formen und ihre allmählige geographische Verbreitung folgendes:

A. v. Caradja (130) sagt, dass den endlichen Sieg der dunklen Form über die helle Stammart sehr complicierte Verhältnisse bedingen, welche wohl haupstächlich in lem säcularen Wechsel ler klimate zu suchen sind.

Hensel (367) erklärt die periodischen Schwankungen des Auftretens von melanistischen Aberrationen durch das Fehlen gew isser Vorbedingungen, welche dis Vererben der vom Charaliter der Stammart abweichenden Eigenschaften auf die Nachkommenschaft erst ermöglichen.

J. Breit (113) erblickt die Ursache dieser Erscheinung in den eigenthümlichen Witterungsverhältnissen der letzten Jahre.

E. Schumann (796) ersieht die Ursache in dem Einflusse der feuchten und kalten Witterung.

R. Zang (965) sagt: „Es ist wohl nicht daran zu zweifeln, dass dies Nigrismen von auratus sind, zumal der Sommer des vorhergegangenen Jahres sehr heiss war."

B. Feuerstacke (219d) ersieht die Ursache des Nigrismus noch in anderen Ursachen als Zang (965), , tem derartige Formen kommen in ler Ungebung Magıleburgs alljährig vor, ob der vorjährige Sommer heiss orler kalt war. Es sind Lokalformen. Wir clürfen noch weit davon entfernt sein, die Entstehung der Nigrismen mit Sicherheit erklären zu wollen."

Experimentelle Untersuchungen uber den Einfluss der äusseren Faktoren auf die Färbung und Zeichnung der Insekten sind in entsprechenden Abschnitten nachzulesen. Hier kommt noch ein lort nicht erwähntes Experiment in lieser Richtung hinzu.

W. Geest (304b) sagt: „Hält man die Puppen von Daphnis nerii zu feucht, so verlieren die Falter auf der Seite, mit der die Puppe den Sand berïhrte, die grüne Fürbung; entweder fleckig oder vollständig, und werlen ockergelb oder braungelb."

Zieht man alles hier angeführte in Betracht, so ist die wahrscheinliche Erklärung des allmïhligen Dunkelwerdens iler Insekten, welches in der letzten Zeit beobachtet wurle, auf die Aenderung der klimatischen Verhältnisse zurückzuführen. Die Ursache dieser Èscheinung speziell für ab. daubledayaria kann nicht darin liegen, dass einige Exemplare dieser Aberration, welche ron Englanil z. B. nach Hamburg ofler Hannover vermuthlich eingeschleppt wurlen uni 
hier mit der Stammform sich gekreuzt haben sollen. Diese Vermuthung ist schon deshalb unwahrscheinlich, dass dadurch das allmählige Fortschreiten dieser Form von Nord- nach Südlleutschlancl, also nur in einer Richtung, nicht $\mathrm{zu}$ erkliiren ist. In Russland ist Amphiclasis betularia auch vorhanden (Kusnezow, $488 a$ ), jedoch wurde dort die genannte Aberration bis jetzt noch nicht heobachtet. Ausserilem wirl diese allmählige Verdunkelung nicht nur bei Amphidasis betularia, sontern bei einer Reihe anderer Species beobachtet.

Wie wir gesehen haben, kam ab. doublectayaria vor $40-45$ Jahren nur in England vor, wo folglich die Bedingungen für ihr Entstehen günstig waren. Zieht man den Umstand in Betracht, lass liese Form auf dem europäischen Fiontinent zuerst auf der Nordseekiiste entstan!, so müssen wir zugeben, dass die Entstrhungsbedingungen hier zu dieser Zeit dieselben geworlen sind, wie sie z. B. in der Umgebung von Mantschester herrschten. Diese für diese Aberration günstigen Bedingungen traten auch in anderen Gegenden ein, und zwar gegen Süden hin, und diese Form begann sich nach dieser Richtung hin zu verbreiten.

Dass das Entstehen von sulchen Aberrationen auch auschliesslich durch abgeänderte meteorologischen Verhältnisse, also ohne Einschleppen von anderer Gegend, bedingt wird, beweisen die Wirkungen der äusseren Faktoren, welche in entsprechenden Alsschnitten des thatsächlichen Theils angefuihrt wurlen. Hier sei noch die diesjührige Beobachtung von A. Drenowsky $(1956)$ in Sophia in dieser Richtung erwähnt. Er sammelte in der esten Hälfte Juni 1906 in Sophia ca. 500 Exemplare von Aporia craiacgi L.; dabei erwiesen sich mehrere Exemplare als var. augusta Trt. und ca. 200 Individuen waren Uebergänge zu clieser Varietät, welche in Sophia bis jetzt nicht beobachtet wurde, und ist sogar stärker ausgeprägt als auf der Zeichnung von Graf Turati $(886 \alpha$ ). Uie Ursache des Fntstehens dieser für Sophia neuen Varietät erklärt Drenowsky durch die lialte und nasse Witterung, welche im Mai und währenı der Puppenzeit von Aporia crataegi hier herrschte. Ob diese neue Varietät in Sophia auch für die Zukunft erhalten wird, hängt natürlich von Vorbelingungen ab, welche die Vererbung der erworbenen Eigenschaften ermöglichen (Standfuss, 841; Fischer, 237). Auch B. Slevogt $(822 c)$ mellet aus Kurland, dass er 1906 in Bathen bis dahin noch nicht beobachtete seltene ab. f-allum Esp. erbeutete. Dieselbe Aberration ist 1906 auch in Berlin zum ersten Mal gefangen worden. 
Dass das Klima in Europa in der letzten Zeit sich ändert, liest $m: n$ in vielen entomologischen Zeitschriften. Diese verbreitete Meinung ist aber dahin zu korrigieren, dass das Klima überhaupt nichts etwas konstantes darstellt. $\Lambda$ bgesehen von langjührigen Perioden, welche mit Tausenden von Jahren gemessen werilen, und zu welchen die Glazial- und Interglazialzeiten gehören, ändert sich das Klima beständig. Die Ursache dieser bestïndigen Kilimaänderung liegt in der allmähligen Abkühlung der Erile und der Sonne. Ausser diesen bestïnligen und fortschreitenden Ursachen sind noch Faktoren vorhanden, welche la. Klima periodisch ändern können: zu diesen werlen gezählt: die Aenderung in cler Schiefe der Elkliptik, die Oscillationen in der Grösse der Excentrizität der Erdbahn, die aus der Präcession der Nachtgleichen resultierende ungleiche Länge der Jahreszeiten ete. Diese Falituren haben aber so langen Perioden, dass sie nur bei solchen Erscheinungen, wie die wierlerkehrenden Eiszeiten und dergleichen, als Erklärungsmittel dienen können. Uns interessieren vielmehr Faktoren, welche kurzdauernde Perioden der Klimaänderung hervorzurufen im Standle sincl. Zu solchen sind in erster Linie die Sonnenflecken zu zuzählen.

Die Häufigkeit der Sonnenflecken ist periolisch. Diese Periole beträgt 10-11 Jahre. W. Köppon (461 $\measuredangle b)$ fand, dass die periodische Aenderung der mittleren Jahrestemperaturen mit der Sonnenfleckenperiode am besten in den Tropen ausgesprochen ist, dagegen weniger in den mittleren und höheren Breiten. Gleich gute resp. genügende Periodicität für diese Gebiete ist auch in Bezug auf die jührlichen Niederschlagsmengen konstatiert worden (Meldrum, Lockyer).

1890 erschien eine wichtige meteorologische Untersuchung von E. Brückner $(115 a)$, in welcher er eine 35-jährige Periote der Klimaschwankungen aufstellt. Die Beobachtungen über lie Schwankungen im Wasserspiegel des Kaspi-Sees ergaben eine Periode von 34-36 Jahren.

Aus den Untersuchungen von Rykatschew (727a) ist ersichtlich, dass das gesamte europäische Russland grosse periodischen Schwankungen des Klimas erlitten hat. Nasse Kälteperiorlen waren: $1745,1775,1810,1845,1880$ und trockene Wärmeperioden: 1715, $1760,1795,1825,1860$. Also die Differenz beträgt auch ca. 35 Jahre. E. Richter (690a) fand, dass "die Alpengletschervorstösse sich in. Perioden wiederholen, deren Länge zwischen 20 und 45 Jahren 
Schwankt und im Mittel der drei letzten Jahrhunilerte genall 35 Jahre betrug."

Wenn die periodische Häufigkeit der sommenflecken fiur die mittleren Breiten sich als nicht linreichend crwis, un die Irlinaschwanliungen deutlich wahrunehmen, sis ist amlererseits die von Brückner gefunılene 35-jährige Periodicitit der Killuaschwankungen auch für unsere Breiten von grosser Wirhtigkeit, wenn ihre Lisatche vorläufig auch noch nicht ermittelt wurde.

Die Jahre des Beginnes der Gletscherrorstüsse waren nach E. Richter: 1592, 1630, 1675, 1712, 1735, $1767,1914.1835$, 1575 uncl die kalten Periolen nach E. Brückner waren: 1591.1100(), $1611 / 1635,1646 / 1665,1691 / 1715,1730 / 1750,1766 / 1775,1806,1820$, 1836/1855. Wenn wir weiter diese Regehnässiglieit :us lehnen werlen, so erhalten wir für dic kalte Perinde 1875/1895 (die Juhreszahl 1 1575 ist bereits von Richter angegeben) und dann amnäherm 1905-1!10! 1920-1925, 1. h. wir befinden uns zur Zeit im Infiange der kalten Periode, welche bis 1920-1935 dauern soll.

Wie Hoffmann (378a) berichtet, kam als. to tpledayuriu auf -europäischen Kontinent in S0-er Jahren. Daraus unl aus llen Zahlen von Brückner folgt, dass diese Aberration an der Kïste von Yor.Isee währenıl der kalten Perinde entstand. Berlenkt man, dass gewölnlich die kalte und nasse Witterung solche Aberritionen erzeugt, so erscheint als Ursache des Entstehens dieser Alerration gerale um die 80 er Jahre herum die Kälte und die grosse Feuchtigkeit.

Der Umstand, dlass diese Form auch später (1900 in Harz), also nicht während ler kalten Periorle in Deuts hland gefunden worden ist, beweist nur, dsss die kalte unl nasse Witterung wälnenıl ca. 15 Jahre (1880-1895) liese Form so stabil gemacht resp). ihr Illioplasma betroffen hat, lass sie sich auch bei anleren meteorologischen Varhältnissen weiter fortpflanzen konnte. Wenn auch währenil dieser Zwischenperiode vielleicht atavistische Erscheinungen bei dieser Aberration zu beobachten waren, wird sie sich jetzt wieler verstärken, da die Periode 1905/1920 wieder zu den kalten gehört.

Das hier Gesagte kann seine Gültigkeit nur für solche Species haben, welche auf lie diabei stattfinlentien Klimaschwankung'n realgieren. Es sind aber viele Species vorhanden. für welche diese Abänderungen des Klimas in ler Optimum-Amplitude eingeschlossen sind, weshalb sich auch keine aberrativen Formen daclurch ergeben (vile Fig. 9). (Nüheres dariiber ist im III. Bande meiner - Studien ${ }^{4}$ nachzulesen). 
Es ist die Meinung verbreitet worden, dass die Insektenspecies, welche sich in nördlichen Gegenden orler auf hohen Bergen aufhalten. im allgemeinen düsterer, dunkler sincl. Wenn diese Regel im illgemeinen auch zutrifft, so sind auch viele Ausuahmen vorhanilen, welche im Anfang dieses Abschnittes nachizusphen sinu. Trotzilem yab diese verbreitete Meinung vielen Forschern den Instoss, entsprechende Theorien dieser Erscheinung aufzustellen.

Noch Walsingham unil de la Harpe (3ॅ4) sagten, dass während die warmbliitigen Thiere (besser zu sagen mit konstanter eigener T'emperatur) die innere Wärmequelle haben unı sich von der Wriirmestrahlung durch weisse Farbe der Federn, der Haare etc. schïtzen. alssnrbieren die Insekten die Wärme von aussen; deshalb sind die crsteren in kalten Gegenden weiss und die Insekten schwarz resp) dunkel gefürbt, da die weisse Farbe die Austrahlung der Körperwïrme verlangsamt, unıl die schwarze die für die Inseliten nöthige Wärme von aussen stärker absorbiert als die weisse.

Diese physikalisch richtige Thatsachen sind in ler letzten 7eit auch von Chr. Schröder (780) durch direkte Messungen an Insekten bestätigt worden. „Ich habe gerade jetıt eine eingehendere physilialische Untersuchnung der Wärmeabsorptionsfähigkeit, z. B. ron betularia F. und ihrer ab. Doudledayaria Nill., Lymantria monacha L. und ab. eremita O., pudibunda L. und ab. cuncolor Stgr., Boctrmia consortariu L. und ab. Humperti Hump., vorlïuflg ahgeschlossen, die 's ausser Frage stellt, dass die iiberwiegend mit Schwarz piomentierten Schuppen der abs. ein ganz erheblich höheres Absorptionsvermögen fïr Wärme besitzen als die Stammformen von ibjerwiegen! weisslicher, rein optischer Färbung" p. (441).

Da aus diesen Untersuchungen von Schrödor hervorgeht, dass \%. 13. ab. doubledayaria unter sonst gleichen Umständen mehr Wärme von aussen absorbieren kann als die Stammform betulariu, so sollte nach der Theorie von Walsingham und de la Harpe in nördlichen Gegenilen die Aberration und in den siidlichen die Stammform getroffen werden. Die faunistischen Arbeiten lehren jeloch das Cegentheil. Ebenso verhält es sich mit Chrysophumss phluects var. eleus L. u. s. w.

Der Fehler der erwähnten Theorie liegt oftenbar in den Umstande, dass die Fürbun nicht das einzige Mittel bei Insekten ist, die Temperaturverhältnisse ilıres Körpers für lie Lehensthïtigkeit zu regulieren, sondern dass es noch andere Wittel hiafiir gielit, welche einanler so kompensieren kömnen, dass auch dis Umgekehrte statt- 
finden kamn, nümlich: in Süden können gewisse Species dunkel sein, während dieselben in Norden heller gefärbt erscheinen.

Ich habe in einer meiner Abhandlungen (30) diese Frage ausführlicher besprochen; hier sei nur der Schluss derselben angeführt. "Ls eriibrigt mir noch, die biologische Becleutung einiger Schmetterlings-Eigenschaften zu erklären.

Betrachten wir zuerst die Art iles Fluges. Die Tagschmetterlinge flattern, die meisten Nachtschmetterlinge summen. Dieser Unterschied ist, wie wir gesehen haben, darlurch entstanden, dass die Nachtschmetterlinge eben durch das Summen ihren Körper so stark erwärmen, dlass sie Nachts fliegen können, ohne dass ihre Temperatur dabei unter die optimale heruntersinkt. Würlen sie nur flattern, dann liönnte ihre Körpertemperatur auf der Höhe des Optimums nicht erhalten bleiben und die immer weiter sinkende Nachttemperatur der Luft würde bei ilmen die Kältestarre schnell hervorrufen. Sie würden dlann zu Tagschmetterlingen werlen und des Nachts gar nicht fliegen können. Umgekehrt, würlen lie Tagschmetterlinge summen, dann würde ihre Temperatur nach einigen Sekunden so hoch steigen, dass sie sofort eine Lälmmung der Fliigelmuskeln erleiden und zum Fliegen unfähig gemacht würden.

Auch die Rolle der Beharung der Schmetterlinge besteht nicht nur darin, den Körper vor raschen Temperaturänderungen der Luft zu schützen und somit das allmählige Steigen und Fallen der Körpertemperatur zu bedingen (andernfalls erkranken die Falter), sondern die Behaarung verhindert die Wärmestrahlung des Körpers beim Fliegen des Nachtschmetterlings bei niederer Temperatur ler Nacht, welche Wärme im Körper durch die Muskelarbeit entsteht und für die optimale Temperatur des Schmetterlingskörpers nothwendig ist. Wäre die Balıarung z. B. bei Saturnia pyri geringer, dann müsste dieser Schmetterling pro Sekunde mehr, Flügelschläge als bis jetzt machen, um die grössere Wärmestrahlung durch die Arbeit $\mathrm{zu}$ kompensieren.

Daraus liann man auch den Schluss ziehen, lass die Schmetterlinge, welche zu immer späteren Nachtstunden fliegen, stärkere Behaarung haben müssen, als diejenigen, welche Abends fliegen, wenn nur diese Berlingung nicht durch andere Umstände ersetzt wird (grössere Muskelkraft, Summen statt Flattern, stärkere Respiration etc.) Die Behaarung erspart also die Arbeit des Nachtschmetterlings. Ganz anclere Bedeutung hat die Behaaruug bei Tagschmetterlingen. Die für sie nöthige optimale Temperatur des Körpers wird 
nicht durch dlas Fliegen angeschafft, sontern wird ihnen von iler warmen Luft resp. direkt von den Sonnenstrahlen mitgetheilt. Ein schnelles Erwärmen des Tagschmetterlings, um ihn zum Fliegen fähig zu machen, finclet aber llaun statt, wenn rler Absorbtionskoëfficient für die Wärme gross ist, 1 l. h. wenn der Körper wenig oder. gar nicht behaart ist. Diese mangelhafte Behaarung ist bei Tagschmetterlingen noch deshalb nothwendig, weil die im Körper durch Fliegen entstehende Wärme wieder rasch ausgestrahlt werden muss, damit der Schmetterling die Lähmungstemperatur der Flügelmuskeln nicht erreichen kann.

Die Becleutung der Färbung, von diesem Standpunkte aus betrachtet, sollte bei Schmetterlingen parallel mit der Bedeutung der Behaarung gehen, $d$. h. es sollten alle Tagschmetterlinge, um möglichst viel Wärme beim Fliegen auszustrahlen und möglichst rasch vor dem Beginn des Fliegens zu absorbieren, schwarz gefärbt sein; hingegen alle Nachtschmetterlinge weiss, damit sie beim Fliegen nicht so viel Wärme ausstralılen und folglich die optimale Temperatur beibehalten können.

Allein dies triftt nur selten zu (z. B. bei Erebia), offenbar deshalb, weil diese Bedingung durch andere gleichwertige Bedingungen ersetzt wird.

Somit wird das Fliegeu der Schmetterlinge am Tage uud Nachts durch folgende Hauptfaktoren bedingt:

1. Muskelarbeit, resp. Wärmeproduktion im liörper des Schmetterlings. Die Flügelmuskeln können die Arbeit nur (lann verrichten, wenn die Temperatur des Körpers nicht höher als $t_{2}{ }_{2}$ und nicht weniger als $t^{0}{ }_{1}$ beträgt. Die Untersuchungen zeigen, dass $t_{2} \mathrm{um}$ so grösser ist, je höher die Lufttemperatur steht, übersteigt jedoch $52,5^{\circ}$ nicht (bei der Luftemperatur von $48^{\circ}$ und starker Feuchtigkeit). Das Gesetz der Aenderung der Grösse $t_{2}$ ist noch nicht bestimint; $t_{2}$ beträgt ca. $14^{\circ}$, wenn der Schmetterling vor ilem Fliegen Kälte-Starre hatte.

2. Beharrung, les Schmetterlingskörpers. Sie änclert len Koëfficient der Wärmeabsorbtion resp. Wärmeausstrahlung.

3. Färbung. Sie verrichtet den gleichen Dienst, wie der zweite Faktor und schwankt zwischen schwarz und weiss.

Diese drei Faktoren stehen zu einander in gewissem Verhältnisse, welches für beide Gruppen von Schmetterlingen dasselbe ist, und zwar: je grösser die Muskelktaft, lesto schwächer ist die Behaarung, und die Färbung nähert sich mehr dem Schwarz, Das Umge- 
kehrte ist jedoch für beide Gruppen verschieden uul zwar: a) für Tagschmetterlinge: je geringer die Muskelkraft, desto schwïcher ist die Behaarung und ঐlie Färbung nähert sich dlem Schwarz; b) für Nachtschmetterlinge: je geringer die Muskelkraft, dests stärker ist die Behaarung unı die Färbung nähert sich dem Weiss.

Diese theoretische Regel lässt sich ableiten, wenn man die Gesetze der strahlenden Wärme in Betracht zieht. Anschaulicher ist dieselbe in folgender Tabelle enthalten:

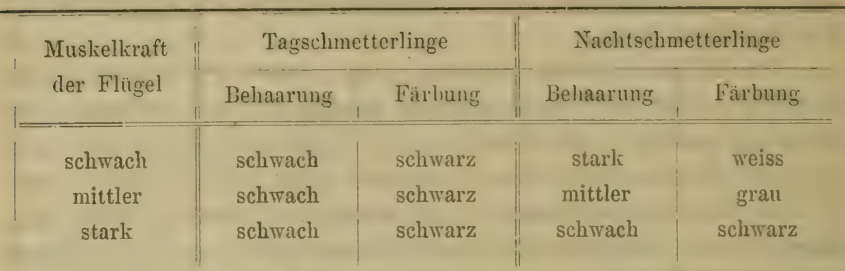

Daraus folgt, dass, wenn diese Regel auch in der Praxis anzuwenden wäre, alle Tegschmetterlinge schwach behaart und schwarz sein sollten; dem wilerspricht jedoch die Wirklichkeit. Dieser Umstand deutet darauf hin, dass ausser den erwähnten drei Faktoren noch andere im Spiel sind. Was nun die Nachtschmetterlinge anbelangt, so entspricht diese Regel der Wirklichkeit besser; so sind z. B. Geometriden nicht im Stande, in ihrem Körper viel Wärme durch das Fliegen zu entwickeln, da sie "flattern" unil nicht "summen" und haben in ler That meistens helle Färbung. Saturnia, Sphinx etc., welche eine grosse Muskelkraft besitzen, haben dunklere Färbung.

Es muss gesagt werien, dass dabei die Compensation eine grosse Rolle spielt.

Wenn z. B. ein Nachtschmetterling mit schwacher Muskelkraft nicht weiss (wie die Tabelle angibt), sondern grau ist, dann wird, um ihn vor der starken Abkiihlung zu schützen, seine Behaarung nicht die mittlere, sondern eine starke sein. Ein Nachtschmetterling, welcher eine mittlere Muskelkraft besitzt, ist z. B. weiss, statt gran (wie die Tabelle zeigt) gefärbt; (lann wird er, um die nothwenlige Wärmestrahlung beizubehalten, lieine mittlere, sondern eine schwache Behaarung haben.

ÉS ist allerdings interessant zu bemerken, dass die Nachtschmetterlinge, wie oben erwähnt, der Theorie der Flugfähigkeit besser angepasst sind, als dlie Tagschmetterlinge. Dieser Umstand lässt 
vermuthen, dass die Nebenfaktoren auf die Nachtschmetterlinge geringeren Einfluss ausüben, als auf die Tagschmetterlinge: es kann auch sein, dlass diejenigen Faktoren, welche an Tage zur Geltung kommen, auf die Nachtschmetterlinge gar keinen orler nur äusserst geringen Einfluss ausiiben."

In der letzten Zeit versuchte Chr. Schröder (779, 780) eine physiologische Erklärung der Verdunkelung der Färbung bei Insekten in Folge der unternormalen Temperatur zu geben. Inden er die Hemmungstheorie von $\mathbf{E}$. Fischer beztiglich der Aenderung des werdenden Falterkleides in Folge der Temperaturwirkungen kritisiert, sagt er (780, p. 441): „Ich stelle der Hemmungs- (u. a.) Theorie die folgende von mir bereits (779) ausgesprochene gegeniber, die eine ganz ungezwungene Erklärung liefern dürfte. Es liegen nur die Ergebnisse einer Anzahl von Beobachtungsreihen namentlich an Tephroclystia-species, der Dasychira pudibunda L, Abraxas grossulaviata L, Amphidasys betularia L. u. a., vor, die mit völliger Sicherheit dartun, dass diese Raupen durch eine vermehrte Pigmentbildung die Entwickelungsheminung zu paralysieren suchen, (ler sie bei unternormaler Temperatur ausgesetzt sind. Die zugehörigen Imagines scheinen gleichfalls einer erhöliten Pigmentbildung zuzuneigen; eine Nothwendigkeit liegt hierfiur aber bestimmt nicht vor."

Da z. B. Vanessa urticae-Puppen bei Wärne- und Hitze- resp. bei Kälte- und Frost-Experimenten die Formen $B$ und $D$ ergeben, welche unter anderem durch die Zunahme des dunkelen Pigments charakterisiert werden, so sagt Schröder (780, p. 442): „Das Ueberhandnehmen les schwarzen Pigments bildet demnach das Charakteristische der $B$ - und $D$-Formen (polaris, ichnusoides) im Gegensat\% zu (len $C$-Formen ${ }^{1}$ ) (ichnusa). Erstere stellen aber nur nach der von mir entwickelten, experimentell begriindeten Ansicht Realitionen des Organismus dar, um die durch unternormale Temperaturen hervorgerufene Entwickelungsverlangsamung zu paralysieren."

Dieser Theorie widersprechen jedoch viele Thatsachen. Sollte die Ansicht von Schröder: "Für Temperaturuntersehiede abex sincl auch die Insekten und ihre Entwickelungsstadien sehr empfindlich, und jene, denen die konstitutionelle Fähigkeit hierfür zukomnt, begregnen der durch Temperaturerniedrigung hervorgerufenen Verlangsamung (bezw. Hemmung) ihres Entwickelungsganges durch Mehr-

1) Vide p. S08. - Bchm. 
bildung des die Licht und Wärmestrahlen am stärksten absorbierenden schwarzen Pigmentes, zumal ihnen die Möglichkeit der Bildung von Körperwärme durch erhöhte Nahrungsaufnahme fehlt." (779, p. 182), richtig sein, dann, wie H. Fedorloy $(219 a)$ beim Kritisieren dieser Theorie bemerkt, „könnte man auch umgekehrt behaupten, dass die bei Hitzeversuchen zahlreich entwickelten, verblassten oder fast farblosen Falter, um die Wirkung der starken Wärme zu paralysieren, so wenig dunkles Pigment wie nur möglich entwickelten." (p. 57). In Wirklichkeit werden sowohl bei Kälte- resp. Frost- wie auch bei Wärme- resp. Hitze-Experimenten verdunkelte Schmetterlinge erhalten (vide dieses Kapitel, Abschnit 1). Nur Federley (219a) erhielt für Saturnia pavonia auschliesslich bei Einwirkung der Kälte eine Vermehrung des schwarzen Pigments, während Wärme und sogar starke Hitze entweder normale oder verblasste Falter dieser Species hervorrufen. Seine Experimente verursachten auch ein Verschwinden des schwarzen Pigments, „und es ist dies sowohl bei den niedrigen als auch bei den höchsten Temperaturen der Fall gewesen."

Dieser Theorie widersprechen ausserdem noch die Experimente mit narkotischen Mitteln, bei welchen bereits bei gewöhnlicher Temperatur die $B$ - und $D$-Formen entstehen (vide dieses Kapitel, Abschnitt 1), und welche nach Schröder nur "Reaktionen des Organismus darstellen, um die durch unternormale Temperaturen hervorgerufene Entwickelungsverlangsamung zu paralysieren."

\section{Einfluss der Schwerkraft und der mechani- schen Erschütterungen.}

Werden die Schmetterlings-Puppen der Wirkung der Centrifugalkraft so ausgesetzt, dass die Körperflüssigkeit sich hauptsächlich entweder im Kopfe orler am Schwanze ansammelt, so findet dabei eine gewisse Aenderung in der Färbung und Zeichnung der Schmetterlinge statt (Fischer, 229; v. Linden, 517).

Die dabei erhaltenen Formen erimnern an die, welche durch Temperatur unter $0^{\circ}$ (Fischer, 229) oder durch die Einwirkung der mässigen Wechselströme (v. Linden, 517) erhalten werden.

Puppen, welche der Erschïtterungswirkung ausgesetzt werden, können aberrativen Formen ergeben (Woismann, 953). 


\section{Die Theorie dieses Einflusses.}

H. Rebel (675) schreibt die durch die Centrifugalkraft erhaltene Aenderung der Färbung und Zeichnung nicht dem Einflusse dieser Kraft zu, sondern der veränderten Ruhelage der Stürzpuppen. Wäre diese Behauptung von Rebel richtig, dam sollten sich die aberrativen Formen nur bei solchen Versuchen von Fischer resultieren, in welchen die Ruhelage der Stürzpuppen wirklich geändert wurde; solche Aberrationen erhielt Fischer aber auch dann, wenn die Ruhelage der Puppen nicht geändert wurde.

Somit müssen wir annehmen, dass die Aenderung der Schwerkraft die Färbung und Zeichnung der Insekten zu ändern im Stande ist, umsomehr als ähnliche Versuche von v. Linden auch aberrative Formen ergaben.

Die theoretischen Betrachtungen von E. Fischer (229), welche diesen Einfluss betreffen, bestehen im folgenden:

„Zunächst ist so viel zweifellos sicher, dass die Schwerkraft auf die Theile einer Puppe, und zwar auf alle, auch die kleinsten Theile ihren Einfluss ausübt, d. h. alle diese Theile weisen die Eigenschaft der Ponderabilität auf. Es werden daher auch die wachsenden - Gewebe und das Blut in seiner Bewegung und Vertheilung davon berührt werden müssen." (p. 30).

Er verlegt die Ursache der Symmetrie bei Aberrationen in das Cirkulations- und Nervensystem und sagt: „Es würde also nach dieser Auffassung auf eine Circulationsveränderung event. Cir culationshemmung hinauskommen, wodurch eine Veränderung oder Hemmung der clurch das Blut dem Fliigel zugeführten pigmentbildenden Stoffe bewirkt würde. Mithin liessen sich auch aberrative Formen dadurch herstellen, dass man Blutcirculation und-Vertheilung auf irgend eine andere Weise als durch Kälteeinwirkung veränderte. " (p. 33).

Somit versucht Fischer den Einfluss der Schwerkraft auf dieselbe Ursache wie den Einfluss der Temperatur zu reluzieren; es wird deshalb genügen, auf seine Theorie im III. Kapitel, 1. Abschnitt. (des theoretischen Theils) hinzuweisein.

Wenn im Prinzip gegen die Möglichkeit der Circulationsänderung durch die Centrifugalkraft auch nichts zu sagen ist, so können hier doch die Ursachen der Farbenänderung durch andere Falitoren kompliziert werden: 
A. Weismann (953) machte die sonitierbare Beobachtung, lass mechanische andauernde Bewegung (sie stunden im EisenbahnWagon) aus Puppen von Pieris napi (der esten Sommerbrut) exquisite Winterform erzeugte. Auch Horvath fand beim Schütteln von Bacterien, dass für dlie Entwickelung der lebenden Wesen eine gewisse liuhe nïthig ist. Beobachtungen von Tumas, Hansen und Russell lehrten, dass ein Schïtteln von gewisser Stïrke und Daner auf manche kleine Lebewesen fördernd wirken kimn. In der nenesten Zeit fiand S. J. Meltzer (55y), dass das schiitteln rerschierlene Wirkungen auf verschierlene kleine Lebewesen ausïbt. Die rothen Blutkörperchen wurten trotz der starken und lange dauernden Bewegung nicht zerstört; beim Hinzusetzen ron feinkörniger, unlöslichen Substanzen trat beim Schuitteln immer ein Zeitpunkt ein, wo werler in der Blutflüssigkeit norh in den sich absetzenden Substanzen irgenıl etwas von ilen Blutkürperchen zu entdecken war. Die Versure mit verschienlenen Barillen ergaben, dass schwaches unıl kurz daurndes Srhütteln für ihre Vermehrung förilerlich, dagegen starkes und langilauernłes Schütteln zerstörend wirkt. Meltzer fanl aurh, dass die Ersihütterung als Lebensfaktor rin Minimum, ein Optimum unl rin Maximum hat; unter dem Minimum ist gar kein Warhsthum mehr möglich; bei dem Optimum gedeiht der. Organismus am bestren, bei dem Maximum geht er zu Grunde. Das Optimum ist für verschiedene Arten verschieden.

Einen Sthritt weiter in dem Verständniss der Wirkungsweise. des Srhïttehs auf dir Entwickelung der Lebewesen machte W. Ramsden (672). Er sthüttelte Eieralbumin, Eierglobulin, Vitellin, Serumalbumin, Srrumglobulin, Fibrinogen, Lactalbumin, Myosinogen, Kartoffeleiweiss, vegetabilisches Vitellin aus Kïirbissane'n, Alkalialbuminat unil Case'mogen! (in Kalkwasser) und fand, dass jeder dieser Stoffic sowohl in sauren Lösungen wie auch in vielen ne. utralen uni alkalische'n Lösungen in den festen Aggregatzustancl ïhergehem, d. h. sieh in der geronnenen Molification ausscheiden kann. Dass dieser Prozess von der Coagulierung durch Hitze verschicten ist, wirl dadurch bewiesen, dass Alkalialbuninat und Casë̈nogen in Kalkwasser, welehe durch Hitze üherhaupt nicht coagulieren, lureh Srhiitteln zum Gerimnen gebracht werclen.

Somit erscheint es für möglich, dass bei Versuchen von $\mathbf{E}$. Fischer unl bei späteren ven Gräfin M. v. Linden auch der Eintlus: de's "Srhüttelus" seine Rolle gespielt hat. Dann wäre die Ursarhe der Wirkung der Centrifugalkraft in erster Linie in der Aemorung 
der Constitution des Blutes zu suchen und erst in zweiter Lini die beobachtete Färbungsänderung auf die Cireulationsänderung zı reduzieren, welche durch Verstopfung gewisser Kapillaren verursacht sein mag.

\section{Einfluss der Schnürung und des mechanischen Druckes.}

Schmetterlings-Puppen, welche künstlich oder natürlich zu stark greschürt werden, ergeben Falter mit blasserer Färbung und zuweilen mit verschwommener Zeichnung. (Schröder, 774; Frings, 252; Urech, 895).

Unter dem Einfluss der Schnürung quer iber die Flügelchen der Puppe verändern sich nicht alle Farbstoffarten gleich stark (Schwarz bleibt unverändert, Gelb und Gelbroth wird isabellfarbig bis umbrabraun, Inter.erenzfarben verschwinden theilweise). Das neue Pigment verhält sich chemisch anters als das ursprüngliche (Urech, 895).

Dieselben Erscheinungen ergeben auch Puppen mit abnorm starke' Einsenkung der Fligelseheiden (Fischer, 230).

\section{Die Theorie dieses Einflusses.}

Alle Forscher, welche die Farbenändermg durch die Schniurung der Puppen beobachtet laben, sind damit einverstanden, dass dabei der im Blute vorhandene Farbstoff durch die Adern in die Flïgeln nicht gelangen komnte. („Als ob die weitere Stoffzufuhr jenen W i. derstand nicht hat überwinden kömen" " [Schröder, $7 i t]$. - ${ }_{n}$ Da bei mässigen Schnurdruck das Flïgelwachstum und die Beschuppung nicht getemmt wird, denn die Flügel entfalten sich vollständlig vex: Form ind Grösse nach, so muss das den Farlistoff liefernde Mittel durch den Schn̈̈rungsilruck, sei es direkt orter indirekt, in seines Verrichtung gestört worden sein" [Urech, 899]. „Die Siliniirung erweist sich als Hemmung der Ausfärlıng “ [Schröder, i 78 ]).

Gestuitzt daraut und auf die speziellen Untersuchungen von Urech, (895, 897, 899) kam man folgende theoretisehe Bet achtungen aussprechen :

Da schwach geselhuïrte Puppen normale Falter (rrgelene, so beginnt dic Farbenstörung erst bei einem Drucke, welcher einen gewissen Werth crreicht hat. Die Ursache dieser Verfärbung liegt 
in der Schürungslinie, von welcher an nach auswärts, d. h. gegen den Seitenrand des Flügels hin, der Schuppenfarbstoff mehr oder weniger verändert wird, hingegen nicht nach der Fliigelwurzel hin. An der Schnïrungslinie wird durch den Druck ein Widerstanıl erzeugt, welchen der Blutstrom zu überwinden lat. Ist dieser Druck resp. Widerstand schwach, so wird das Blut in ihrer Circulation nicht gestört und die Färbung fällt normal aus; wird derselbe hingegen so gross, dass die Kapillargefässe bei der Flügelwurzel, durch welche das Blut in die Flïgel gelangt, einen geringeren Querschnitt erhalten (wenn z. B. eine Irreisform sich in eine Ellipse umwandelt), so wirl jetzt auch eine geringere Menge des Blutes pro Zeiteinheit durch diese Kapillare passieren (das Gesetz von Poiseuille). Als Resultat erhalten wir anormale Entwickelung der Flügel, während der übrige Körper der Puppe in seiner Entwickelung normal fortschreiten wird.

Diese Hemmung in der Entwickelung der Flügel kann verschieden stark sein, je nach der Grösse des Druckes. In extremen Falle können die Kapillaren so stark gedrückt sein, dass die durch dieselben pasșierende Blutmenge nicht ein Mal genügt, um die Billung der Schuppen zu bewirken, und die Flügel werden schuppenlos bei sonst normal entwickeltem Imago. Ist dieser Druck etwas schwä. cher, so werden die Schuppen sich entwickeln, erhalten aber fast keinen Farbstoff; wird der Druck noch mehr vermindert, damn erhalten rie Schuppen blassere Färbung als bei sehr schwachem oder gar keinem Drucke.

Nun erhielt Urech bei seiner Untersuchung das Resultat, dass nicht alle Farbstoffarten durch die Schniirung gleich starken Veränderangen unterworfen werden; so z. B. das Schwarz wird dabei fast gar nicht geändert.

Für diese Thatsache kann man die Erklärung wohl darin finden, dlass wahrscheinlich nicht alle Pigmentstoffe dieselbe MolekularGrösse besitzen, vielmehr sind die Moleküle des schwarzen Pigments kleiner als die des gelben oder gelbrothen Pigments. Damn können die "schwarzen" Molekuile mit lem Blutstrom die Schnürungslinie passieren, während die ngelben" oder "gelbrothen" Moleküle zurïckbleiben werden und folglich im Flügel fehlen.

Was nun die von Urech beobachtete Thatsache betrifft, dass an Stelle des gelben und gelbrothen Pigments die Isabellfarbe und llas Umbrabraun erscheint, so würde dies nur zeigen, dass wir es hier mit anderen Pigmenten zu thun haben als mit ngelben" und 
"gelbrothen" Molekiulen, welche bereits hinter der Schnürungslinie zuriickgeblieben sind. Und in der That erwiesen sich die neuen Pigmente chemisch verschieden von den normalen (Urech, 895). Die Molekïle des neuen Pigments müssen ihrer Grösse nach denjenigen des schwarzen Pigments nahe gleich sein, damit sie mit demselben in die Flïgel gelangen können.

Urech sagt, dass dieses neue Pigment in seinen Eigenschaften mehr denen des Pigments der Unterseite der Vorderflïgel sich nähert. Daraus folgt, dass es als fertiger Stoff durch den Blutstrom in die Flügeln eingeschleppt worden ist und nicht erst in Schuppen sich gebildet hat.

Die ganze Erscheinung können wir uns folgendermassen vorstellen:

Im Blute sind verschiedene Pigmente vorhanden, welche während der Entwickelung der Puppe sucsesive entstehen. Die Molekulargrösse dieser Pigmente ist verschieden, ist aber bedeutend grösser als diejenige des Blutes. Werden die Kapillare der Flügel durch Druck verengert, so gelangen die Pigmente mit grossen Molekülen nicht mehr in die Flügel und werden darin fehlen.

Dass die Schuppenfarbstoffe nicht erst in den Schuppen entstehen, sondern schon im Blute der Puppe vorhanden sind, wies bereits A. G. Mayer nach $(552,553)$.

Zu der definitiven Annahme der Theorie der Verschiedenheit in der Grösse der Moleküle verschiedener Pigmente müssen zuerst die nöthigen Experimente angestellt werden, von welchen die wichtigsten sind :

Man soll das aus der Puppe während ihrer verschiedenen Entwickelungsperioden erhaltene Blut durch verschieden weite Kapillar-Röhren durchlassen, und sowohl die durchflossene wie auch zurückgebliebene Flüssigkeit chemisch und physikalisch (AbsorbtionsSpektrum) untersuchen.

Man soll die Kapillaren dex Flügel an verschiedenen Stellen und in verschiedenen Entwickelungsperioden der Puppe unter normalen Verhältnissen auf ihren Durchmesser untersuchen, zu welchem Zwecke vielleicht Röntgenstrahlen zu verwenden sind, indem man die Kapillaren zuerst mit einer für Röntgenstrahlen schlecht durchleitenden Flüssigkeit füllt.

Man soll die Methode aufsuchen, um die Aenderung des Durchmessers der Kapillaren der Flügel durch den Druck auf direktem. resp. indirektem Wege zu messen. 


\title{
Ueber die Ursachen des Entstehens von aberra- tiven Formen in der Natur.
}

\begin{abstract}
Xachuem wir das gesamte Material auf dem Gebiete der experimentellen Entnmologie in entsprechenden Kapiteln thronologisch angeführt und damn im "theoretischen Theil" systematisch geordnet uncl vom eimheitlichen Standpunkte aus (ler Bewrgungszustand des Protoplasmas in Zellen) zu erklären versucht haben, werden wir nun die neuesten Ansichten iiber die Ursache der Varietäten- und Rassenbildung in der Natur kurz betrachten. Von älteren Ansichten wird hier Abstand genommen.
\end{abstract}

\section{Der Begriff der aberrativen Formen.}

In seiner Arbeit "Leber den gegenwärtigen Stanıl der Lepi(lopteren-Systematik" sagt H. Røbel (675a) ïber den inneren Unterschied, der zwischen den bisherigen systematischen Arbeiten und jenen Arbeiten der Neuzeit besteht, welche auf stammesgeschichtlicher Grumllage beruhen, folgendes: „Friher traten die Systematiker planlos an die Formenmasse heran und suchten nur nach Merkmalen, die einen möglichst durchgreifenden Unterschied für ihre Eintheilungszwecke ergeben sollten. Sie liessen sich hierbei häufig von der Aufilringlichleit eines Merkmales z. B. der Fühlerbillung leiten, ohne sich zu fragen, ob das Auftreten oder Fehlen dieses Merkmals auch mit der imneren Blutsverwandschaft der Formen im Einklange stehe. Alle Formen, die ein zu Eintheilungszwecken bequemes Mrrkmal gemeinsam aufwiese'n, mussten unter cinamder näher, verwandt sein, als mit denjenigen, denen dieses Merkmal fehlt. ,Verwandschaft war also oft nicht viel mehr als Aehnlichleit in einzelnen, vom Systematiker gerarle beniitztey Merkmalen. Nur so ist es erklïrlich, llass systematisehe Ungehenerlichkeiten wie beispielweise die Super- 
familie der ,Sphinges' entstehen konnten, die so weit von cinander abstehenden Familien wie die echten Sphingidae, lie Sesidae, Thyrididae, Zygaenidae und Syntomidae in sich rereinigen sollten. Ganz anderes der auf phylogenetiseher Grundlage arbeitende Systematiker. Er kamn nicht planlos uni olne Vorarbeiten an sein Werk gehen, sondern muss sich vor Allem und zwar vorerst ohne Rüchsicht auf systematische resp. taxonomische Zwecke, durch vergleichende Untersuchungen eine Erkenntniss darüber verschaffen, welchen stammesgeschichtlich en Entwickelungsang jedes einzelne Merkmal genommen hat. Er wirl auf diese Weise zur Unterscheidung ursprünglicher (allgemeiner) und davon abgeleiteter (specialisirter) Charaktere gelangen. Erst jetzt können die Formen nach dem Verhalten ihrer wichtigsten Organsysteme und Entwickelungszustände und dem sich daraus ergebenden Abstancle von einem urspriinglichen, gemeinsamen Typus in natüliche Gruppen (Kategorien) gebracht werden und die stufenweise Umbildung der Charaktere bis zu hoch specialisirten Zuständen systematisch verwerthet werden."

Auf diese Weise kommt man auf „phylogenetischer Grundlage" zur Aufstellung von natiirlichen Gruppen (Familien uml Gattungen).

Im Privatgespräch theilte mir $D^{r}$ H. Rebel mit, dass im Lepidopteren-Kiataloge von 0. Staudinger und H. Rebel ( $843 a$ ) die als Arten angeführten Schmetterlinge nicht immer als solche zu betrachten sincl, sie kömen zuweilen auch als Subspecies sein, da in diesem Kataloge das als Species genannt wird (resp. mit li versehen ist), was zuerst von einem (ler Forscher als solche bezeichnet wurde; s p ä t er entdeckte ähnliche Formen werten nur als Varietäten verzeichnet (Vrgl. auch Standfuss [840, p. 217]).

In Bezug auf den Artenunterschied schreibt M. Standfuss $(841 ;)$ folgendes: „Dio Arten in der Insektenwelt werden unterschierlen:

1) nach Gestalt, Grösse, Färbung des vollkommenen Insektes, ৯er "Imago," häufig genug auch schon der Larve, der Raupe orler der Puppe - also, wie wir kurz sagen liömnen, auf Grunil körperlicher, morphologischer Eigentümlichkeiten;

2) es werden abex auch herangezogen gewisse Eigenarten dex Lebensweise, Lebensgewohnheiten, Nahrung, sowie Eigentiinlichkeiten bezüglich der Zeit und des Ortes des Vurkommens etc. ete. - also biologische Merkmale.

Allein selbst daun, wenn alle diese morphologischen und biologischen Eigentiimlichkeiten beriicksichtigt werien, so bleibt doch 
noch eine grosse Masse Insektenformen übrig, bei denen die Scheilung in sicher umschriebene Arten grosse Schwierigkeiten bietet. Es handelt sich dabei auf der einen Scite um Tierformen, die in hohem Grade varieren, und zwar, entweder an ein und demselben Orte ron Individuum zu Inlividuum stark alterieren, orler doch an den verschiedenen Orten ihres Vorkommens erhebliche Unterschiede von einander zeigen. Auf rler anderen Seite handelt es sich hier ebenso häufig um den umgekehrten Fall. Es finden sich in gewissen Insektenordnungen ganze Reihen von Tierformen, die nach ihrer äusseren Erscheinumg auch bei der grössten Sorgfalt kaum in sicher umgrenzte Arten auflösbar sind, wïhrend wir diese Formen doch auf Grund bestimmter Beobachtungen, vielleicht ebenfalls der Biologie, als verschiedenen Arten angehörige $\mathrm{zu}$ betrachten uns gezwungen sehen."

Nach der Betrachtung der Bastardformen kommt er noch zu einem dritten Unterscheidungs-Merkmal der Arten unter sich: „3) die physiologische Eigenschaft der Art, $11 \mathrm{ur}$ und $\mathrm{n}$ ur mit ihresgleichen eine erdgeschichtlich erhaltungsfähige Brut zu zeugen." Die Art stellt er sich vor als eine "physiologische Grösse."

Die Zoologie im allgemeinen zerlegt den Begriff "der Art," "der Species" folgendermassen (Standfuss (840):

Erstens in die "Grundart," "Grundrasse," "Grundform:"

die ursprïngliche, phylogenetisch älteste Form der Art, von der wir uns die übrigen Formen direkt oder indirekt abgezweigt zu denken haben.

Iass diese Form in den meisten Fällen bisher gar nicht festgestellt ist, oft genug auch in Zukmuft nicht wird festgestellt werden können, kann an dieser Definition nichts ändern.

Zweitens in die "Rassen," "Lokalrassen," „Lokalformen:" das heisst lokal konstant gewordene Formen der Art, welche (wenigstens im wesentlichen) sowohl die Grundart als auch sich gegenseitig ausschliessen.

Die Lepidopterologen gebrauchen dafür die Bezeichnung "Varietät."

Drittens in die "Varietäten:"

das heisst unter der Art und gleichzeitig mit dieser sich allerorts (wemn auch theilweise sehr selten) findende abweichende Individuen.

Die Lepilopterologen nemnen diese For'men "Aberrationen." 
IV. Kap. Ursachen des Entstehens von aberr. Formen in der Natur.

Selbstverständlich werden wir hier den Benemungen der Lepidopterologen folgen.

In der letzten Zeit, als verschiedene Formen auf experimentellem Wege erhalten wurden, entstand wieder die Frage: was wir unter Varietäten und Aberrationen verstehen sollen?

Standfuss (841) definiert sie, wie folgt: „Varietäten und Rassen sind solche Formen, die auf den Bahmen der erdgeschichtlichen Entwickelung der Art liegen. Die Aberrationen aber dürfen als Formen zu definieren sein, die sich nicht aut den Bahnen der erdgeschichtlichen Entwickelung der Art bewegen, sonclem Neubildungen individueller Natur, individuelle Färbungsanomalien darstellen."

Was nun die experimentelle Methode anbelangt, mittelst welcher man eine Art von einer anderen und von ihren Varietäten unterscheiden kann, so ist dieselbe nach Standfuss $(840,841$ ) die folgende:

Man kreuzt $A$ und $B$ unter einander. Die auf cliese Weise erhaltenen Bastarden $A$ und $B$ kreuzt man noch einmal unter sich. Wenn aus diesen von dieser Brut erhaltenen Eiern Räupchen ausschlüpfen und dann Falter ergeben, so sind $A$ u $B$ keine von einander getrennte Species gewesen. Ergeben aber die Räupchen dieser Brut keine Falter, so sind $A$ u $B$ zwei gesonderte Species.

Man kreuzt $A$ und $B$ unter einander. Dabei kann entweiler $A$ als $\sigma^{\top}$ und $B$ als $q$ sein oder umgekehrt. Ergiebt sich aus der Brut von $\delta^{\top} A$ mit $\bigcirc B$ ca. $100 \%$ Falter, welche auch weiter fortpflanzungsfähig sind, und aus der Brut von $\delta^{\top} B$ mit $q A$ ein sehr kleiner Prozentsatz Falter, so ist in diesem Falle $B$ eine Species und $A$ ihre Varietät. Diese Regel leitete Standfuss aus Bruten von Spilosoma mendica und $S p$. mendica var. rustica einerseits und von Callimorphla dominula und Call. dominula var. persona andererseits ab (840).

Es muss jedoch bemerkt werden, dass z. B. die Paarung zwischen der kleineren Form von Saturnia pavonia L. von nördlicher Herkunft und zwischen Individuen der grossen Mittelmeerform Sat. pavonia var. meridionalis Calb. Falter ergiebt, welche in gleich hohem Grade fortpflanzungsfähig sind wie die elterlichen Individuen. Diesen Fall könnte man vielleicht dadurch erklären, dass var. meridionalis von ihrer Stammform noch nicht stark divergent geworden ist, wie z. B. $S p$. var. rustica.

Hier sei die von Standfuss (841ß) mitgetheilte interessante Thatsache angeführt, „dass diese in den Paarungs-Resultaten ausgesprochene Divergenz bereits besteht, während die in Frage kom- 
menten Cienitalwerkzeuge der beiden in Divergenz begriffenen Formenpare irgentwie erhebliche mol nemenswerte Unterschiede noch nicht erkemnen lassen."

In Bezug auf dic durch Temperatur-Experimente ('rhaltenen Formen sagt er (841): „Mit den Typen, die sich bei den Kïlte- und Wärmeexperimenten als unzweif lhatt direkte Folge dieser mässig gesteigerten oder ernierhigten Temperatureinwirkung einstellen, steht die Sache andlers. Eine sehr berleutende Zahl derselben liegt thatsächlich gegenwärtig als Lokal orler Saison-Formen lelsenul vor, orler bewegt sich doch im wesentlichen auf ler Entwickelungsrichtung (ler letzteren erdgeschichtlich rückwärts orler vorwärts; $\left.{ }^{1}\right)$ - ganz anders die Aberrationen, sie laufen divergend von jenen Entwickelungsrichtungen und, dies erscheint somit als d ie $z$ w e it e Eigenart ihres Wesens, bewegen sich nicht auf len Bahnen der normalen erdgeschichtlichen Entwicklung der Art."

Indem Standfuss in allen seinen Abhanillungen und in dem "Handbuche" (840) zum Schlusse kommt, dlass "lie Aberrationen als Formen einer ausgesprochen atavistischen Richtung nicht wohl zu denken sind," ersieht E. Fischer darin Rückschlagstormen, welche in Folge der hemmenden Einwirkung der Wärme resp. Kälte auf die noch frischen Puppen entstanden sincl. Er unterscheidet Aberrationen und Varietäten. Die ersteren entstehen nach ihm bei ca. $0^{\circ}$ bis $-20^{\circ}$ und bei ca. $+42^{\circ}$ bis $+46^{\circ}$ und die letzteren bei ca. $0^{\circ}$ bis $+10^{\circ}$ und bei $+35^{\circ}$ bis $+42^{\circ}$. Ausserlem unterscheidet er noch echte Varietiiten, indem er sagt: „Sollte es somit höchst wahrscheinlich gemacht sein, dass wirkliche, echte $C$-Varietäten einzig unil allein nur durch eine wenig über die Norm gesteigerte Wärme (ca. $+32^{\circ}$ bis $+37^{\circ}$ ) entstehen und bei den unternormalen Graden keine Parallele dazu sich finclet, so müsste gesagt werden, lass nur durch ein Ansteigen ier Temperatnr über die normale ilurchschnittliche etwas Neues nnd dabei wirklich Specifisches (die Reihe $C$ ) geschaffen werden kann, dass aber diese Steigerung: nur bis ca. $37^{\circ}$ gehen darf, sonst provoziert sie bei genügend langer Exposition etc. wieder eine $B_{1}$-Varietät" (236. p. 270).

In derselben Abhandlung (236) stellt E. Fischer jedoch die These: „Einen irgendwie wesentlichen Unterschied $z w i-$ schen den $D$ - und $B$ - (oder $C$-) Formen, also zwischen Aberration und Variation, gibtes nicht" (p. 324). Zu dieser

1) Die darauf folgenden Zeilen sind als Zusatz zu dem Citierten einer anderen Abhandlung von Standfuss (841 $\beta$ ) entnommen. 
Behauptung bewegen ihn hauptsächlich die Resultate, welche er an Vanessen erhielt, und zwar gelang es ihm am gleichen Individuum die Variation mit der Aberration unter Einwirkung: hoher Wärme und Hitze zu kombinieren.

Derselben Meinung ist auch H. Federley (219a), welcher sagt: "Die in der Natur vorkommenden Mutationen der Schmetterlinge werden von den Systematikern in Varietäten und Aberrationen eingetheilt, von welchen die ersteren konstante Lokalrassen bililen. die letzteren dagegen nur zufällige Formen sind, die vereinzelt unter den Individuen der Hauptform auftreten. Aus praktischen Gründen kann eine derartige Einteilung verteidigt werden, vom theoretischen Standpunkte aus ist es aber unmöglich, dieselbe aufrecht zu erhalten; denn eine Varietät kann in manchen Gegenden als zufällige und vereinzelte Form auftreten, und die Aberrationen können ihrerseits so allgemein werden, dass man sie als Varietäten betrachten müsste. Ich verweise auf Aberrationen albida B. und inicolora (Mén.) Motsch. von Leucodonta bicoloria Schiff., welche bei vollständigem Fehlen der Hauptform im Jahre 1903 am See Ladoga als ,konstante Varietäten' auftraten, sich aber bei Weiterzucht nur in geringem Grade als erblich erwiesen. Da nun auch die Aberrationen nach den Untersuchungen von Standfuss (1898) und Fischer (1901) ihre Eigenschaften auf einen kleinen Teil ihrer Nachkommen uibertragen, so fällt auch dieser Unterschied weg, und wir haben tatsächlich kein einziges Kriterium für eine Trennung der Mutation in Varietäten und Aberrationen" (p. 105).

\section{?. Die Ansichten verschiedener Forscher über das Entstehen von aberrativen Formen in der freien Natur.}

M. Standfuss berührte diese Frage zum ersten Mal in seinem kleinen „Handbuche" (1891. 835), wo er auf p. 107-128 die Vernuthungen über die Entstehungsursachen des Albinismus, des Melanismus, der Local- und der Zeitvarietäten bei Lepidopteren. Jedoch fehlten damals die experimentellen Ergebnisse, um diese Vermuthungen besser $\mathrm{zu}$ begriinden. 3 Jahre später veröffentlichte er die Abhandlung „Ueber die Gründe der Variation und Aberration" (837), gestiitzt auf seine Unterschungen der iusseren Faktoren: Temperatur, Nahrung, Beleuchtung unı Feuchtigkeit auf die Färbung und Zeichnung der werdenden Falter. Von diesen Faktoren erhielt er nur durch die Temperatur und die Feuchtigkeit verïn- 
lertes Falterkleil, weshalb er speziell für die Temperatur zum Schlusse kommt: „Danach ist es im hohem (irade wahrscheinlich, dass eine ganze Anzahl der sich in ler freien Natur findenden Aberrationen, dieser in ihren letzten Ursachen bisher so ausserordentlich unverständlichen und dunklen Erscheinungen, durch abnorme Temperaturverhältnisse entstehen, welche auf das Puppenstadium einwirken. Allein als für alle Aberrationen giltig oder auch nur wahrscheinlich möchte ich diesen Satz gewiss nicht hinstellen" (p. 24).

In seinem grossen "Handbuche" (840) behanilelt er auf p. 305322 das Wesen der Aberrationen, verfolgt aber dabei „in erster Linie nicht theoretische, sondern praktische Zwecke." Gestiitzt auf seine weiteren Temperaturexperimente (841) kummt er zum Schlusse: „Die typischen Aberrationen der Nymphaliden, 1. h. etwa 80 bis $90 \%$ aller bekannten Aberrationen, werden in der ireien Yatur sehr wahrscheinlich ${ }^{1}$ ) (lurch zeitweilige Einwirkung hoher Hitzgrade $\left(40-45^{\circ}\right)$ erzeugt" (p. 13).

In einer seiner folgenden Abhamllungen $(841 \propto$ ) sagt Standfuss: .,Auch diese Aberrationen konnten experimentell ilurch gewisse Temperatureinwirkungen hergestellt werilen, und zwar von dem Verfasser zuerst auch durch solche Temperaturen, welche die betreffenden Arten sehr wohl gelegentlich in ganz gleicher Weise in der freien Natur treffen können, ja sicher treffen müssen" (p. 13). (Dasselbe wörtlich auch in der Abhandlung $841 a$, p. 18).

Eine sehr wichtige Entleckung machte Standfuss (841), indem er experimentell nachwies, dass die durch Temperaturexperimente erhaltenen Färbungs- und Zeichnungs-Modifikationen am werdenden Falterkleide auch auf die Nachkommenschaft übertragen werden, was später auch von E. Fischer $(237,238)$ bestätigt wurde. Dies in Betracht ziehend, schliesst Standfuss seinen Vortrag in der Züricher Naturforschenden Gesellschaft (841b) mit den Worten: „Die Wechselwirkung zwischen Faktoren der Aussenwelt und Organismen ruft individuell schwankende Neugestaltungen hervor, diese werden mehr oder weniger vererbt, durch Selektion gesichert und in bestimmten Bahnien erhalten" (p. 15).

Andeutungen beziiglich (ler Frage der Artbildung bei Lepi10 teren betinden sich im "Handbuche" von Standfuss (840).

E. Fischer hat eine etwas abweichende Anschaung über las Entstehen von Aberrationen in der freien Natur. In seinem Vortrage

$\left.{ }^{1}\right)$ In einer darauf folgenden Abhandlung ( $\left.811 \beta^{\prime}\right)$ erset 2 t Standfuss in diesem Schlusse die Worte ${ }_{n}$ sehr wahrscheinlich" durch "wohl sicher" (p. 12). 
in cler Naturwissenschaftlichen Gesellschaft zu St.-(Gallen (239) sagt er: „Da nun diese Aberrationen auch in der freien Natur, wenn auch als grösste Seltenheit, erscheinen (ohne das man bisher wusste, wie sie entstehen und was sie eigentlich berleuten sollen) und zudem die gleiche Veränderung (von oben nach unten und von vorn nach hinten) zeigen, wie die oben genannten, als Puppen den direkten Sonnenstrahlen ausgesetzten, so folgte daraus die Erkenntnis, dass diese Falter-Aberrationen in der Natur dadurch entstehen, dass dann und wann eine Puppe zufolge ihres besondern Ruheortes von den Sonnenstrahlen 4-6-10 Stunden getroffen wirc. Aber auch im Frühjahr und Herbst unzeitig auftretende Frostnächte (mit oder ohne Reifbildung) und selbst die Winterkälte können gelegentlich solche Aberrationen bewirken" (p. 8).

P. Born (104a) erblickt die Ursache des Artvariierens von Coleopteren in verschiedenen Gegenden in klimatischen Verhältnissen und äussert sich speziell über das Entstehen der Aberrationen wie folgt: „Lie Frage, warum in einer Lokalität öfters nur einzelne Exempiare variiren und sich.nur als Aberrationen oder Varietäten bilden, indem z. B. unter einer Anzahl auronites in einem Walde der Bretagne nur dieses oder jenes Exemplar blauschwarz wirl, die anderen aber griin bleiben, glaube ich dahin beantworten zu können, dass wahrscheinlich der Einfluss der Feuchtigkeit sich im Puppenzustande geltend macht, wenn dieselbe in der feuchten Erde ruht und dass es eben in derselben Lokalität Plätzchen von verschiedener Beschaffenheit geben kann, so dass eine Puppe mehr der Feuchtigkeit ausgesetzt ist, als eine andere" (p. 10).

\section{Consequenzen aus dem Gesammtmaterial der experimen- tellen Entomologie über diese Frage.}

Betrachten wir die Insektenwelt von Standpunkte der Arten aus, so finden wir, dass die "Art" kein Begriff für etwas unverändertes, konstantes sein kann, nicht nur dann, wenn wir die Arten ler vergangenen Epochen mit den jetzigen vergleichen, sondern auch lann, wenn die Exemplare einer und derselben Art in einer und ilerselben Gegend und im gleichen Jahre mit einander verglichen werden.

Standfuss sagt: „Die Arten sind ja nicht als für alle Zeiten feste, nicht verschiebungsfühige Grössen anzusehen, sondern sie entstehen und vergehen, wie alles zeitlich Existierende, in unbestimm- 
barer Zeit. Die Arten, welche wir gegenwärtig sehen, sind aus anderen Arten durch Umgestaltung hervorgegangen, und das Resultat der fortschreitenden Entrwickelung der Arten sind schliesslich neben der Veränderung dieser Arten selbst, auch von ihnen abgeschiedene, neue Arten" (841 $\beta)$.

Die Art ist etwas variabeles, was nicht nur in ler Entomologie und allgemein in der Zoologie, sondern auch bei Pflanzen und sogar in der "unorganisierten" Welt der Fall ist. Man soll sich nur an die neuesten Untersuchungen übre die Evolution der $\Lambda$ tome erinnern (vicle z. B. die Arbeit von Soddy $[824 a$, 824b] und die Re:le von Umow [887a]).

Wie wir oben gesehen haben, werten die Arten von einaniler unterschieden durch morphologische Eigenthümlichkeiten, durch biologische Merkmale und durch physiologische Eigenschaft. $\mathrm{Zu}$ den ersten gehören die Gestalt, die Grösse und die Färbung, zu den zweiten - die Lebensweis?, Lebensgewohnheiten, Lebensdauer, Nahrung etc. und zu der dritten - die Zeugungsfähigkeit. Wir wollen hier nur die morphologischen Merkmale betrachten.

Die Variabilität der Art kann in der Aenderung der Gestalt, der Grösse oder der Färbung bestehen, oder auf eimmal in mehreren morphologischen Merkmalen. Auf die Wichtigkeit der Untersuchungen über die Variabilität bei Insekten habe ich schon früher (32) hingewiesen und es sind später auch Beiträge in dieser Beziehung erschienen (z. B. von Schröder [778, 779], Gauckler [302], Auel [18], Koschewnikow [467a], Bachmetjew [22, 26, 34, 35, 36, 37, 38, 39, $39 a, 40,41,42,42 b]$, v. Aigner [7a,7b], Meissner [555a] etc.). Stellt man die Abhängigkeit eines gewissen Merkmals einer Art von der hinreichend grossen Anzahl der Exemplare derselben Art graphisch dar, indem man auf der Abscissenaxe die Werthe dieses Merkmals und auf iler Ordinatenaxe die Anzahl der Exemplare (die Frequenz), welche den betreffenden Werth dieses Merkmals besitzen, aufträgt, so erhält man annähernd die Curve, welche auf Fig. 4 dargestellt ist. Der Werth $l_{f}$ des betreffenden Merkmals entspricht dem Maximum der Curve, er ist der häufigste und folglich (der typische. ${ }^{1}$ ) Alles, was von der Linie $M_{f} l_{f}$ auf der Abscissenaxe nach links oder nach rechts abweicht, kann nicht mehr als Typus

1) Ueber die vermuthliche Annahme, dass $l_{f}$ die Projektion des Schwerpunktes der Fläche ist, welche durch diese Curve und die Linie $m \mathbb{M}$ begrenzt ist, und über die darauf gestützte Definition der Species wird im III. Bande meiner "Studien" auseinander gesetzt. 
IV. Kap. Ursachen des Entstehens von aberr. Formen in der Natur. 933

angesehen werden. Dies sind Mutationen, zu welchen unsere Varietäten und Aberrationen gezählt werden.

Unter Varietäten kann man somit solche Abweichungen vom Typus ansehen, welche nach links oder rechts von der Linie $M_{f} l_{f}$ nicht so weit sich entfernen, $d . h$. noch ziemlich häufig vorkommen können, während unter Aberrationen solche Exemplare zu verstehen sind, welche dem Punkte $m$ oder $M$ nahe stehen. Daraus ist ersichtlich, dass wir keinen strengen Unterschied zwischen Varietäten und Aberrationen machen können; dieser Unterschied ist vielmehr ein praktischer, wie Federley (219a) ganz richtig bemerkt.

Es leuchtet ein, dass wir für eine und dieselbe Species und für ein und dasselbe Merkmal mehrere solche Curven für verschiedene Lokalitäten erhalten, welche sich von einander mehr oder weniger unterscheiden werden. Der Typus, welcher für eine Gegend nach dieser analytisch-statistischen Methode festgestellt war, wird nicht mehr für die betreffende "Species" massgebend sein, sondern er wird nur für die Lokalrasse der betreffenden Gegend gültig sein und sugar hier nur für das betreffende Jahr, in welchem diese Exemplare gesammelt wurden, denn, wie es meine Untersuchungen ergaben $(37,39,40,41,42 b)$, ändert sich $l_{f}$ in verschiedenen Jahren in gleicher Gegend.

Es entstehet somit die Frage: welche Faktoren verschieben die Linie $M_{f} l_{f}$ in einer gegebenen Gegend, mit anderen Worten, welche Faktoren verursachen das Entstehen von aberrativen Formen ihrer Gestalt, ihrer Grösse oder ihrer Färbung und Zeichnung nach?

Das Studium der Variabilität bei Insekten führt zum Schlusse. (lass diese Verschiebung aus dem "Typus" sowohl durch den Einfluss der äusseren, wie auch der inneren Faktoren bewirkt wird (42b), Wir wollen hier nur die ersteren betrachten.

Das thatsächliche Material, welches in II. und III. Kapitel dieses Buches angeführt ist, weist darauf hin, dass das Entstehen von Aberrationen durch klimatische Verhältnisse verbunden mit der Nahrungsänderung verursacht wird. Weil das Klima seinerseits von verschiedenen Faktoren abhängt, hauptsächlich aber von der geographischen Breite und der Beschaffenheit des Bodens, bezw. der Vertheilung des Landes zum Meere und der Ebene zu den Gebirgen, so ist es klar, dass solche Gegenden, wo das Klima auf einer sehr ausgedehnten Fläche dasselbe ist, auch die Variabilität der "Species" sehr minimal sein soll. 
934 IV. Kap. Ursachen des Entstehens von aberr. Formen in der Natur.

So z. B. sagt P. Born (104a) bezüglich Nord-Amerikas: „Aus der Abwesenheit der Gebirge, dem Vorhandensein dieser grossen. kompakten Landmasse und dem daclurch bedingten gleichmässigen Klima erkiäre ich mir die Thatsache, dass in diessem grossen Gebiete die Caraben nicht variiren."

Ist aber das Klima in verschiedenen Orten einer sehr beschränkten Gegend verschieden, wie z. B. es für Kaukasus der Fall ist, so soll hier die Variabilität stärker sein als im ersten Falle. P. Born (104a) sagt: "In Asien und besonders an seiner Grenze zeigt uns der an prächtigen Lokalrassen so überreiche Kaukasus, wie die Gebirge auf einem verhältnissmässig kleinen Gebiete die Bildung solcher Lokalformen begünstigen. Allerdings kommt bei den Gebirgen noch ein wichtiger Faktor hinzu, nämlich die Isolirung der Arten auf einzelne Ketten, Berge und Thäler." Weiter sagt er: „Was mich besonders noch in der Ansicht bestärkt, dass klimatische Einflüsse dieses Variiren hervorrufen, dass ist der Umstand, dass sich öfters in ein und derselben Lokalität dieser Einfluss auf gleiche Weise bei mehreren daselbst vorkommenden Carabus-Arten bemerkbar macht."

Der Einfluss des Klimas ist aus verschiedenen Komponenten zusammengesetzt, die wichtigsten sind aber die Temperatur und die Feuchtigkeit.

H. Simroth $\left(816 x^{\prime}\right)$ sagt: „Die Verbreitung der Poekilothermen wird bestimmt durch ein Wärmeoptimum, das bestimmte Grenzen nach oben und unten nicht überschreiten kann. lhr Verbreitungsgebiet ist eine Funktion der astronomischen, bezw. planetaren Stellung der Erde. Jede Ueberschreitung der Temperaturgrenze löschte das Thier aus, oder zwang es zur Umbildung." Wie diese Umbildung vor sich geht, ist aus den Temperaturexperimenten verschiedener Forscher ersichtlich.

Ueber den Einfluss der Feuchtigkeit haben wir unter anderem die Beobachtungen von Standfuss (837). "Wenn grössere Massen von Saturnien-Puppen 7-10 Wochen zwischen Juni und Ende September sehr trocken gelegen hatten und dann mehrere Male intensiv a ufgefeuch tet wurden, so entwickeln sich etwa $1 \%$ Falter aus diesen Puppen 10-20 Tage nach dem Anfeuchten. Die entwickelten Falter zeigten meist einen von der Art abrveichenden Charakter, der sich dahin definiren läss'c, dass die Zeichnungs-Charaktere nicht scharf ausgeprägt, sondern mehr oder weniger verschwommen und verwaschen erscheinen." 
IV. Kap. Ursachen des Entstehens von aberr. Formen in der Natur. 93j

Würden wir uns eingehender mit dem gleichzeitigen Einfluss der Temperatur und der Feuchtigkeit auf die Umformung der Insekten beschäftigen, dann hätten wir einen sehr komplizierten Prozess vor uns. Ein Begriff von der Kiomplikation dieser beiden und zu gleicher Zeit auftretenden Faktoren giebt uns das Beispiel auf p. 774-776 und die Figuren 29, 30 und 31. Dort sind folgende Schlüsse angeführt, welche auch für die hier in Betracht. kommenden Mutationen gïltig sind:

Das Klima kann die Insekten in mannigfaltigster Richtung verändern, indem es verschieden stark auf verschiedene Organe einer und derselben Species einwirkt.

Wirken die klimatischen Komponenten alle in einer Richtung, wenn auch verschieden stark, so können verschiedene Klimas eine und dieselbe Veränderung des betreffenden Insekts nicht hervorrufen.

Wirken diese Komponenten, wenn auch nicht alle, nach verschiedenen Richtungen, so kann unter ihrem Einflusse in verschiedenen Klimas eine und dieselbe Abänderung gewisser Insekten entstehen.

Das Vorhandensein derselben Abänderungen bei Insekten in verschiedenen Gegenden ist somit noch kein Kriterium für die Gleichheit des Klimas in diesen Gegenden.

Wir haben im "theoretischen Theil" gesehen, dass verschiedene äusseren Faktoren deshalb aberrative Formen zu erzeugen im Stande sind, weil dabei eine vorïbergehende Starre des Protoplasmas in Zellen des Organismus auftritt. Der praktische Unterschied zwischen Aberrationen und Varietäten besteht darin, dass beim Entstehen von Aberrationen das Plasina (wenn auch nicht in allen Zellen) eine vorübergehende (temporäre) Starre erleidet, während beim Entstehen von Varietäten nur die Beschleunigung resp. Verzögerung der Plasmaströmmung stattfindet. Dieser Unterschied gilt nur für die extremen Fälle, da die Verzögernng der Protoplasmaströmung offenbar nicht auf ein Mal in clie Starre iibergeht, sondern diese Starre sucsessive stattfindet. ${ }^{1}$ )

Dabei spielt eine grosse Rolle das Optimum verschiedener äusseren Faktoren (vide Fig. 9). Dieses Optimum wird nicht durch

1) Dabei sind zwei Fälle möglich. Entweder tritt die starre in jeder Zelle sucssessiv ein, oder sie tritt bei einer bestimmten Temperatur auf ein Mal ein, aber nicht bei allen Zellen zu gleicher Zeit. In beiden Fällen häten wir alu从 dasselbe Resultat - das allmählige Auftreten der Starre im Organismus. 
936 IV. Kap. Ursachen des Entstehens von aberx. Formen in der Natur.

cine gewisse konstante Intensität des betreffenden Faktors bestimmt, sondern es giebt eine Optimum-Amplitude, welche für verschiedene Faktoren vermuthlich verschieden ist, und nicht nur für verschiedene Gegenden, sondern auch an einem und demselben Ort. Mit grosser Wahrscheinlichkeit kann behauptet werlen, lass die Optimum-Amplitude auch für verschiedene Exemplare einer und derselben Species und eines und desselben Geschlechts in der gegebenen Gegend variiert, zu welcher Vermuthung verschiedene im "thatsächlichen Theil" beschriebene Untersuchungen den Anlass geben.

Von der Existenz der Optimum-Amplitude überzeugen uns verschiedene Thatsachen. Wir wollen hier nur die Beobachtungen von L. Reh $(681 a)$ über die Schildläuse anführen. Er sagt: „Schildläuse sind hauptsächlich tropische und subtropische Thiere, ihre Verbreitung ist aber weniger von der Temperatur unmittelbar, als von der ihrer Nahrpflanzen abhängig. Namentlich Formen der gemässigteren Zonen sind eher geeignet, in den wärmeren Zonen sich auszusiedeln und zu gedeihen, als umgekehrt." Der Schluss dieses Citatates zeigt, dass dabei die Aklklimatisation auch nicht ohne Bedeutung bleibt.

Bewegt sich das betreffende Insekt in den Grenzen dieser Optimum-Amplitude für verschiedene Faktoren, so können dabei ausser der Stammform auch Varietäten entstehen; wird aber diese Amplitude überschritten, dann beginnt das Entstehen von Aberrationen. Kommt dieses Ueberschreiten der Optimum-Amplitnde häufig vor, so trifft man die betreffende Aberration in der gegebenen Gegend als ständige Form an, wie Federley (219a) es bei den Aberrationen allida B. und inicolora Motsch. von Leucodonta bicoloria Schiff. im Ladoga-See konstatiert hat.

Ziehen wir alle im "theoretishen Theil" besprochenen äusseren Faktoren in Betracht, so können wir folgende These aufstellen: Alles, auf was die Zellen reagieren, erzeugt bei der Aenlerung seiner optimalen intensität Varietäten. Beim Ueberschreiten der Optimum-Amplitude entstehen Aberrationen. Diese These kann nur dann aufrecht erhalten werden, wenn die äusseren Faktoren sich dabei nicht compensieren.

Es leuchtet ein, dass die progressiven resp. regressiven Formen (Varietäten) nur im Bereiche der Optimum-Amplitude entstehen können, da die ausserhalb dieser Amplitude entstehenden Formen 
(Aberrationen) als pathologische Produkte angesehen werden müssen (vrgl. p. 789 und ff.).

Im Zusammenhange mit dem Optimum steht die Aenderung der angewöhnten Lebensweise der Species. Diese Aenderung kann durch verschiedene Faktoren verursacht werden, welche aber in zwei Gruppen eingetheilt werden können: klimatische und Nahrungs-Verhältnisse. Sowohl die einen wie die anderen sind im Stancle, die normale Entwickelung der Insekten schwächer oder stärker zu beeinflussen, wobei ihre Richtung unter Umständen ganz oder theilweise umgeändert wird. Die Thatsachen sind im ersten Theil dieser "Studien" nachzulesen, hier werden wir aber nur je ein Beispiel (les Einflusses eines jeden der beiden Verhältnisse anführen:

Indem Standfuss (837) die Entwickelung bei 1\% von SaturniaPuppen dadurch beschleunigte, dass er dieselben mehrere Male stark anfeuchtete, erhielt er aberrative Formen, wobei er sagt: "Weiter aber gewinnt es bei Vergleichung dieser Beobachtungen an Wahrscheinlichkeit, dass ähnliche Verhältnisse in der freien Natur auch ähnliche Folge haben dürfen, dass also das ansnahmsweise Aftreten von Faltern im Hochsommer und Herbst von Arten, die normaler Weise in dieser Zeit als Imago nicht vorhandan sind, sondern regulärer Weise als Puppe überwintern, ähnliche Gründe, das heisst, reichliche Niederschläge nach längerer Zeit der Trockenheit und Dürre haben dürfte. Genügt nun die Zahl der sich so abnorm verhaltenden Individuen einer Art, deren Nachkommen sich allerdings dann an wesentlich veränderte Lebensbedingungen accomodiren müssen, zur dauernden Erhaltung derselben, dann werden diese Individuen den Ausgangspunkt für eine neue Entwickelungsreihe bilden, die sich im Laufe der Zeit, bei der Unmöglichkeit einer wieder eintretenden Vermischung mit den biologisch nicht veränderten Individuen der Art, zunächst zu einer constanten Variation und später zu scharf geschiedenen Arten gestalten." (Als Beispiel führt er Saturnia boisduvalii Ev., Bombyx catax L. und Bombyx rimicola $\mathrm{Hb}$. an, die sich von den verwandten Saturniden und Bombyciden in vergangenen Erdepochen wohl durch ähnliche Veranlassungen abgezweigt haben).

Pictet (637a) kam, gestützt auf seine sehr ausführliche Fütterungs-Experimente, zum Schlusse, dass es nicht der Einfluss der Nahrung selbst, sondern vielmehr der Einfluss der Nahrungswe echsels ist, welcher die Variationen hervorruft (vrgl. p. 556 u. ff.). 
938 IV. Kap. Ursachen des Entstehens von aberr. Formen in der Natur.

Somit können wir die zweite These aufstellen: Die Aenderung der normalen, von der Species eingeschlagenen Entwickelungsrichtung ruft abgeänderte Individuen hervor, welche unter Umständen zu Variationen resp. zu Aberrationen gezählt werden können.

$\mathrm{Ob}$ diese zweite These auf die erste reduziert werden kann, wird im III. Bande meiner "Studien" erörtet. 


\section{Nachträge zum theoretischen Theil.}

Zur Theorie von M. Standfuss (p. 801). - In der Generalversammlung der Schweizerischen entomologischen Gesellschaft bemerkte M. Standfuss $(841 c)$ zu dem Vortrage der Gräfin M. von Linden $(5277 h)$ folgendes:

"Es sei von hohem Interesse, dass bei der Behandlung der Puppen mit Kohlensäure oder mit Stickstoff stets nur Formen entstanden, wie sie die Frostexperimente (intermittierende Behandlung mit Temperaturen unter $0^{\circ}$ bis $-18^{\circ}$ C.) und die Hitzeexperimente (intermittierende Behandlung mit Temperaturen um $+40^{\circ}$ und über $+40^{\circ}$ C.) liefern; nämlich A berrationen). Er habe es bereits 1898 in seinen ,Experiment. zoolog. Studien' als wahrscheinlich vorausgesagt, dass Aberrationen nicht nur durch Frost und Hitze, sondern auch noch durch andere störende Einflüsse [841] provoziert werden können. Frost, Hitze, Kohlensäure, Stickstoff wirken eben nicht direkt, sondern indirekt als die ,Entwickelung störenden Einflüsse' [841] — , ungenügende Oxydation' nach Gräfin von Linden. Daher auch das ausserordentliche Schwanken der Aberrationen selbst bei dem gleichen Experiment nach Zahl und nach der von den verschiedenen Individuen eingeschlagenen Entwickelungsrichtung. Die Kälteexperimente (konstante Behandlung mit Temperaturen von $+4^{0}$ bis $+6^{\circ}$ C.) und Wärmeexperimente (konstante Behandlung mit Temperaturen von $+37^{\circ}$ bis $+39^{\circ}$ C.) lingegen wirken (irekt; ${ }^{1}$ ) jene

1) H. Rebel $(675 b)$ schreibt bei der Besprechung der experimentellen entomologischen Studien von M. Standfuss (841) folgendes: „Zu diesen theoretischen Ausführungen des Verfassers sei bemerkt, dass, wenn überhaupt eine scharfe Unterscheidung zwischen directem und indirectem Einfluss der Temperatur bei den Kälte- und Wärmeexperimenten einerseits und den Frost- und Hitzeexperimenten anderseits nothwendig erscheint, die umgekehrte Annahme näher liegen dürfte, dass es sich nämlich bei Kälte- und Värmeexperimenten um einen indirecten, bei Frost- und Hitzeexperimenten aber um einen directen Temperatureinfluss handeln müsse. Bei ersteren wirkt die Temperatur; 
, die Entwickelung verlangsamend, wie der berichtende [Standfuss] zahlenmässig [840. p. 250 und 251] nachweisen konnte; mit Gräfin von Linden zu sprechen: ,Stoffiwechsel herabsetzend ' - diese , die Entwickelung [840. p. 256] beschleunigend, , Stoffivechsel steigernd, wie sich Gräfin v. Linden ausdrückt. Darum enstehen bei den Kälteexperimenten Formen, die sich in entgegengesetzter Entwickelungsrichtung bewegen, wie die bei den Wärmeexperimenten auftretenden, und zugleich zeigt sich bei gleichem Experiment eine weitgehende Gleichartigkeit der erfolgten Umgestaltung unter den verschiedenen Individuen" (p. 84-85̃).

Zur Theorie der Gräfin I. von Linden (p. 816). - In der Generalversammlung der Schweizerischen entomologischen Gesellschaft hielt Gräfin M. von Linden $\left(527 h h_{h}\right)$ folgenden Vortrag: „Die Versuche, deren Ergebnisse ich hier kurz besprechen will, wurden im verflossenen Jahre [1903] und im Laufe dieses Sommers angestellt. Ich hatte mir die Frage vorgelegt, ob wohl die Beschaffenheit der Atemluft, namentlich eine zeitweilige Entziehung von Sauerstoff, die Entwicklung der Schmetterlingspuppen und die Färbung des Falters beeinflussen könne. Eine genaue Prüfung der Temperatur-Experimente und deren interessanten Ergebnisse hatte mir, wie an anderer Stelle ausführlich dargelegt wurde, die Vermutung nahegelegt, duss bei der Entstehung von Varietäten und Aberrationen die Temperatur nur insofern die bewirkende Ursache sei, als durch sie der Stuffwechsel der Puppe beschleunigt - Temperaturerhöhung bei Wärmeexperiment - verlangsamt - Temperaturerniedrigung beim Kälteexperiment oder aber in empfindlicher Weise gestört - Hitze- und Frostexperiment - werden kann. Da sich, so viel wir wissen, auch die Insekten, namentlich die Schmetterlingspuppen, der umgebenden

wie dies auch die Annahme Weismann's [954] ist, wahrscheinlich nur als auslösender Reiz für die Entscheidung, welche von mehreren latent vorhandenen Entwickelungsbahnen betreten werden soll, also indirect, wogegen bei den Frost- und Hitzeexperimenten, also bei Anwendung von Temperaturgraden, die im Naturleben niemals oder doch nur ganz ausnalımsweise die Art treffen können, jedenfalls nicht bloss überall ein Entwickelungsstillstand eintritt, sondern in manchen Fällen gewiss auch eine physiologische Störung im Ausfärbungsprocess zurückbleibt, so dass dann der Temperatureinfluss gewiss eher als ein directer bezeichnet werden kann. Dass die aus dem gestörten Entwickelungsprocess resultierenden Aberrationen so verschiedenen Typen angehören, erklärt sich wohl aus der Verschiedenbeit specifischer und individueller Reactionsfathigkeit

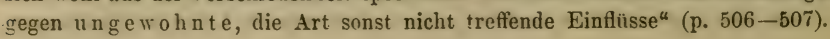


Temperatur gegenüber genau so wie alle übrigen wechselwarmen Tiere verhalten, so müsste die vorausgesetzte Beziehung zwischen Temperatur, Stoffwechsel und Färbungscharakter des Falters höchst verständlich erscheinen, so lang es sich um Experimente mit wenig hohen Wärme- und wenig tiefen Kältegraden, also um Temperaturen unter $40^{\circ}$ und über $0^{\circ}$ (bis $+6^{\circ}$ ) C. handelt. Der Stoffwechsel der Schmetterlingspuppe müsste durch den Wärmereiz in entgegengesetzter Weise beeinflusst werlen, als durch den Kältereiz; und die Versuche ergaben, wie nicht anders zu erwarten war, Schmetterlinge, die einander entgegengesetzte Entwicklungsrichtungen eingeschlagen hatten. Bei Vanessa urticae z. B. zeigten die Wärmeformen eine auf Kosten der dunkeln Schuppen weitausgebreitete Rotfärbung, bei der Kältevarietät hatten uıngekehrt die schwarz gefärbten Flügelstellen an Ausdehnung gewonnen. Ganz verschieden war die Wirkung der Frost- und Hitzeexperimente, bei denen die Puppen Temperaturen ausgesetzt wurden, die von den Insekten eben noch ertragen werden konnten. Die Ergebnisse derartiger Versuche waren, wie bekannt, höchst eigentümlich gefärbte und gezeichnete Aberrationen. Bei den meisten Vanessen unterscheiden sich diese Aberrationen von der Normalform durch eine besonders auffallende Zunahme schwarzer Beschuppung und durch eine Reduktion des roten Pigmentes der Grundfarbe. Während bei den Wärme- und Kälteversuchen von einer spezifischen Wirkung des Temperaturreizes gesprochen werden konnte, entstanden hier bei den Hitze- und Frostexperimenten durch Anwendung, wie man meinen sollte, verschieden wirkender Einflüsse gleichartige Veränderungen, die in der von Fischer versuchten Hemmungstheorie keine befriedigende Erklärung finden. Standfuss bezeichnet die Aberrationen viel richtiger als Abweichungen individueller Natur, als Färbungsanomalien, die, wie wir aus dem folgenden ersehen werden, von hoher physiologischer Bedeutung sind. Um nun der Lösung der Frage nach dem Zustandekommen dieser rätselhaften Bildungen näher zu treten, stellte ich mir die Frage, welchen Einfluss die Grenztemperaturen, die Hitzeoder Frostgrade, die von der Schmetterlingspuppe eben noch ertragen werden, auf ihren Stoffiwechsel haben können. Verhalten sich die Schmetterlingspuppen den andern gleichwarmen Tieren analog, so muss die notwendige Folge, die durch Hitze oder Frost bewirkte Lethargie, in einer Herabsetzung der Oxydationsvorgänge im Körper bestehen. Ist aber diese Schlussfolgerung richtig, so muss eine Aberration auch noch auf andere Weise, wie durch Temperaturänderung, 
entstehen können, sie muss dann durch jeden Eingriff zu stande liommen, der den Puppenorganismus in ähnlicher Weise schäligt, wie Hitze und Frost. Als solcher analoger Einfluss schien mir in erster Linie die Sauerstoffentziehung zu gelten. Von dieser Schluss* folgerung ausgehend, verbrachte ich die Puppen von Vanessa urticae in eine möglichst reine Kohlensäure-Atmosphäre, in der die Puppen 24 Stunden verblieben. Das Resultat entsprach der Voraussetzung: ich erhielt aus der ersten Vanessa urticac-Generation des vergangenen Sommers einen hohen Prozentsatz typischer Aberrationen von Vanessa urticae ab. ichnusoides.

Wenn dieses Ergebnis nun auch zeigte, dass tatsächlich der Eintluss iler $\mathrm{CO}_{2}$-Atmosphäre den Puppenorganismus zu gleicher Reaktion veranlasste, wie Hitze und Frost, so war damit rloch noch nicht endgültig bestimmt, ob tatsächlich die Sauerstoffentziehung als die bewirkende Ursache der Aberration zu betrachten sei. Ebenso gut konnte die aberrative Gestaltung von Färbung und Zeichnung eine Folge der durch die Kohlensäure auf jeden Organismus ausgeübten Giftwirkung sein. Es war daher notwendig, durch weitere Versuche mit einer aus indifferentem Gas bestehenden Atmosphäre den Zweifel $\mathrm{zu}$ heben. Ich stellte eine zweite Versuchsreihe mit den Puppen von Vanessa urticae und io an, bediente mich aber diesmal einer Stickstoffatmosphäre. Schon der erste Versuch ergab eine typische Aberration der Vanessa urticae ab. ichmusoides und zwei entsprechend aberrativ umgestaltete Schmetterlinge der Vanessa io. Damit war gezeigt, dass bei diesem Experimente tatsächlich die durch Entziehung von Sauerstoff' herabgesetzte Atmungstätigkeit der Puppe als bewirkende Ursache der Schmetterlingsaberrationen zu betrachten ist, und dass bei der Bildung dieser Formen die Grösse des Reizes und die individuelle Veranlagung für das Mass der Abweichung ausschlaggebend sind. Ich halte damit den Beweis für erbracht, dass alle Störungen der Puppenentwicklung, welche herabgresetzte Oxydation im Organismus nach sich ziehen, $\mathrm{zu}$ aberrativen Bildungen führen müssen, einerlei ob wir das lebendige Plasma lurch Hitze, Frost oder Narcotica reaktionsunfähig machen oder ihm direkt den Sauerstoff entziehen."

Zur Theorie von 0. Wiener (p. 862). - Nachdem R. Neuhauss $(606 a, 607)$ mittelst iles Ausbleichverfahrens, welches auf der Erscheinung beruht, dass gewisse Anilinfarbstoffe die Eigenschaft hảben, in dem Lichte, das zu ihrer eigenen Farbe komplementär ist, 
auszubleichen, die Consequenzen der Theorie der mechanischen Farbenanpassung in der Natur von 0. Wiener (959) bestätigt hat, stellte auch Worell $(962 b)$ ähnliche Versuche an, indem er das Papier mit einer Lösung von verschiedenen Farbstoffen tränkte. Er erhielt aut diese Art farbige Papierbilder, wobei es sich aber herausstellte, dass das Anfärben der Papierfaser mit den Farbstoffen das Papier sehr unempfindlich macht.

Man könnte wohl die Empfindlichkeit des Farbstoffes durch geeignete Substanzen steigern, aber, wie es J. Smith und W. Merckens $(822 d d)$ zeigten, erleiden dabei nicht alle Farbstoffe einer Farbenmischung einen und denselben Grad der Empfindlichlieit, ausserdem wirken die Farbstoffe in gewissen Fällen chemisch auf einander und bilden Yiederschläge, von welchen die meisten von grosser Unempfindlichkeit sind. Um diese Jachtheile zu beseitigen, untersuchten J. Smith und W. Merckens ca. 1200 Farbstoffe in dieser Hinsicht, fanden aber nicht einmal drei, welche diesen Anforderungen entsprechen wiirden, bis sie schliesslich eine neue Farbstoffklasse entdeckten, die brauchbarsten Farbstoffe heraussuchten und ein nahezu vollständig gleichmäsiges Farbstoffgemisch herstellten. Um den störenden Einfluss der Anfärbung der Papierfaser zu beseitigen, gelang es ihnen einen Ausweg zu finden. "Sie konnten nämlich eine Gesetzmässigkeit finden, darin bestehend, dass alle Farbstoffe, je nach ihrer Beschaffenheit, die Neigung haben, in gewissen Schichten in eine Ruhelage zu gelangen, aus der sie nicht mehr herauswandern. Auf Grund dieser Wanderungserscheinungen ist es len Verfassern nun schliesslich gelungen, die Farbstoffemulsion auf Papier zu bringen, und das Resultat ihrer Arbeiten ist das Uto-Papier" (p. 17).

Die von ihnen entdeckten Farbstoffe blau und gelb sincl an und für sich schon lichtempfindlich, wälrend das Roth noch durch eine $3 \%$ Wasserstoffsuperoxydlösung sensilibilisiert werden muss. Das Fixieren dieser farbigen Bilder nimmt höchstens eine halbe Stunde in Anspruch. Die Verfasser geben jedloch keine Zusammensetzung ihrer Farbstoffe an.

Von Forschern, welche Photographien in natuirlichen Farben auf Papier mittelst des Ausbleichungsverfahrens erhalten haben, seien noch erwähnt: A. Kitz (450a), H. Vogel $(926 \alpha)$ etc. Der letztere benützte bei seinen Versuchen auch Chlorophyll. Die neuesten Angaben über diese Frage enthält das Lehrbuch der Photochromie von W. Zenker (1900. 965b), und die älteren kann man in Werken von A. Davanne (164b) und von Ed. Becquerel (58a) finden. 
Ausserdem sind verschiedene Verfahren, die Farbenphotographie $\mathrm{zu}$ erhalten, in verschiedenen Patentzeitschriften zerstreut (z. B. von J. Szczepanik etc.).

Zur Theorie der Wanderzïge von Insekten (p. 741). B. Slovogt $(822 \beta)$ schreibt iber Pyrameis cardui L. folgendes: ${ }_{n}$ Alle sechs bis acht Jahre in grösseren Schwärmen auftretend [in Kurland, Livland und Estland], sonst selten; Juli, August. Einen solchen Massenflug, der aber nur 4-6 Tage währte, habe ich in Bathen Juli 1882, 1888 und 1895 beobachtet. Es schienen meist 우우 zu sein. Sie zogen alle nach Osten “ (p. 41). Im Juli 1903 beobachtete er in Bathen wiederum einen solchen Schwarm (822 $\left.\beta^{\prime}\right)$, welcher nur aus $\bigcirc \bigcirc$ bestand und eine Woche lauerte. Wegen der Ursache des massenhaften Auftretens dieses Sclimetterlings sagt er: „Wahrscheinlich muss der Begattungstrieb, bei Mangel an Tieren männlichen Geschlechtes, cardui veranlassen, fremde Gebiete aufzusuchen." Er vermuthet, dass alle in genannten Jahren beobachteten Schwärme von Westen her gekommen sind. 


\section{Litteratur-Verzeichniss.}

1. A., I. Crateronyx Dumi L. - Soc. ent., X. o 8, p. 58-59. 1895.

2. Absolon, $\mathbf{P h}$. C. Karl. Finige Bemerkungen über mährische Höhlenfauna. - Zool. Anz., XXIII. 주 605, p. 1-6; 스 607, p. 57-60; № 612, p. $189-195.1900$.

2 a. Adelung, N. Zur Kenntniss der Orthopteren-Fauna des Gouvernements Tobolsk. - Annuaire du Musée de Tobolsk., Ann. 12, livr. XV. (18 pp.) 1906. (Russisch: Аделунгъ, Н. Н. Къ познапію фауны прямокрылыхъ 'Тобольской губ. - Елегодницъ 'ободьскато Губернскаго Музея).

3. Aigner-Abafi, I. V. Lepkék szinváltozása. - Rovart. Lapok, VI. Je 1, p. 12-16.1899. (Ungarisch : Farbenabänderungen der Lepidopteren).

4. Aigner-Abat, L. v. Missbildungen bei Sclumetterlingen. - Ill. Zeitschr. für Entomol., V. ํ 7, p. 99-100. 1900.

5. Aigner-Abafi, I. v. Lycaena jolas 0. - Ill. Zeitschr. für Entomol., V. № 15, p. 225-227. 1900.

6. Aigner-Abafi, I. v. Zur Biologie der Lepidopteren. - Ill. Zeitschr. für Entomol., V. № 13, p. 201-202. 1900.

6a. Aigner-Abafi, L. v. Ueber Deilephila nerii L. - Allg. Zeitschr. für Entomolog., VI. № 14-15, p. 226-228. 1901.

6b. Aigner-Abafi, L. v. Lepidopteren-WVanderungen in Ungarn. - Allg. Zeitschr. für Entomol, VI. № 7, p. 102-103. 1901.

7. Aignor-Abafi, L. v. Zur Biologie der Agrotiden. - Allg. Zeitschr. für Entomol., VI. p. $72-74.1901$.

7๔. Aigner-Abafi, L. v. Wanterzüge des Distelfulters. - Allg. Zeitschr. für Entomol., IX. Ni 1-2, p. 6-9. 1904.

7a. Aigner-Abafi, L. V. Ueber Aporia crataegi L. - Zeitschr, für wiss. Insektenbiol., I. № 5, p. 204-209. 1905.

7b. Aigner, Lajos A. A galagonya pillangóról. - Rovar. Lapok, XII. 루 5-6, p. 89-95. 1905. (Ungarisch: Der Baumweissling).

7c. Aigner, A. Magyarország pillangói. VI. - Rovart. Lapok, XII. eㅡ $\delta$, p. 168-172. 1905. (Ungarisch: Die Tagfalter Ungarns. VI.).

8. Alibegow, MI. G. Einige Worte üher die rorzeitige Aushruitung der Eier (des Seidenspinners). - Arbeiten der kaukasischen SeidenzuchtStation, Jahrg. 1890, III, p. 198-199. Tiflis 1892. (Russisch: Алибөговъ, М. Г. Нъскодько словъ о лреждевременномъ оживленік грены. - Труды кавказск. Шелководств. Стандіи).

9. Alisch. Versuch einer Erklärung über das mehr oder minder häufige Auftreten von Coleopteren. - Krancher's Entomolog. Jahrb., X. p. 205-213. Leipzig 1901. 
10. Allen, Grant. The colour sence in Insects, its development and reaction. - Proc. Roy. Instit., IX. Part. II., p. 201 -202. London 1879.

10 a. Altum, B. Die Nadelholzprocessionsspinner, Cnethocompa pinivora und pityocampa. - Zeitschr. f. Forst- und Jagdwes., IX. p. 27-31. 1878.

11. Altum, B. Unzeitig frithe Entwickelung der Nonneneier. - Zeitschr. für Forst- und Jagdwesen, XXXI. 3. Heft, p. 162-164. Eberswalke 1899.

11 a. Altum, B. Forstzoologie. III. Insekten. Berlin 1882.

12. Altum, B. Bemerkenswerthes Auftreten ron Inseliten in der Cmgelung von Eherswalde im Sommer 1898. - Zeitschr. für forst- und Jagdwesen, XXXI. 5. Heft, p. 307-309. Eberswalde 1899.

13. Altum, B. Folgen einer unzeitig frühen Entwickelung der Nonneneier. Zeitschr. für Forst- und Jagdwesen, XXXI. 12. Heft, p. 736-737. Eberswalde 1899.

14. André, Ed. Species des Hyménoptères d'Europe et d'Algérie. 'T. IV-V. Les Braconides par T. Marshall. 1888-1895.

15. Antropow, D. P. Die Aufzucht ron mittel-asiatischer, chinesischer, japanischer und alt-kaukasischer Rassen. - Arbeiten der kaukasischen Seidenzucht-Station, Bd. VIl. Liefer. II, p. 2-11. Tiflis 1894. (Russisch: Антроповт, Д. П. Выгормка-среднеазіатскихъ кптайскпхъ, лионской и старой кавказской породъ. - Труды кавказск. Шелговодств. Станціп).

16. Arndt, R. Biologische Studien. I. Das biologische Grundgesetz. Greifswald 1892.

17. Auel, H. Beitrag zur Entwickelungsgeschite von Pieris brassicae L. (Kohlenweissling). Beobachtungen über das Erscheinen der Generationen. -- Allg. Zeitschr. für Entomol., VII. № 6, p. 113-117; № $7-8$, p. $139-142 ;$ № 9, p. 184-187. 1902.

18. Auel, H. Messungen an Lepidopteren. - Allg. Zeitschr. für Entomol., IX. № 23-24, p. 452-453. 1904.

19. Bachmetjew, P. Kleine Mittheilung. -- Soc. ent., XI. № 22, p. 182. 1897.

20. Bachmotjew, P. Ueber die Temperatur der Insekten. - Wissensch. Rundschau, V. p. 1602-1611. St.-Petersburg 1898. (Russisch : Бахметьевъ, II. Температура паськомых. - Научное Обозръвіе).

21. Bachmetjew, P. Die 'Temperatur der Insekten. - Krancher's Entomol. Jahrb., VIII. 1) 121-131. 1898.

22. Bachmetjew, P. Ueber Dimensionen der bulgarischen Schmetterlinge im Vergleich zu den West-Europäischen. - Periodische Zeitschrift, LVII. p. 34-48. Sophia 1898. (Bulgarisch: Бахметьевљ, II. Гольмшшата ва Българскит пे пенерди въ срависние съ Западио-Европейскпту. - Пернодическо Списание, LVII. p. 34-48. Соция 1598).

23. Bachmetjew, P. Der kritische Punkt der Inseliten und das Entstehen von Schmetterlings-Aberrationen. - Ill. Zeitschr. f. Ent., V. o 6, p. 86-S9; 스 7, p. 101-103; 승 8, p. 118-121. 1900.

24. Bachmotjow, P. Ueber die Temperatur der Inseliten nach den Beobachtungen in Bulgarien. - Zeitschr. für wissensch. Zoolog., LXVI p. 521-604. 1899 . 
25. Bachmetjew, P. Ueber Insektensïfte. - Krancher's Entomol. Jahrb., IX. (1900). p. 114-124. 1899.

26. Bachmetjew, P. Ueber die Deminsionen der bulgarischen Schmetterlinge im Vergleich zu den West-Europäischen. - Soc. ent., XIV. № 4, 1) $25-26$; № 5, p. 35-36; № 6, p. 43-45; № 7, p. 49-51. 1899 .

27. Bachmetjew, P. Ueber die Temperatur der Inseliten in Bulgarien. Sammelwerk des Unterrichts-Ministeriums in Sophia, XVI-XVII. p. 82-159. Sophia 1900. (Bulgarisch: Бахметьевъ, II. Върху температурата на пасыкомить́ въ България. - Со́орннъ за народни Умотворения, Наука и Книлшнна).

:27a. Bachmetjew, P. Anabiose. - Naturwiss. Rundschau, № 1, p. 17-29. St.-Petersburg 1900. (Russisch: Бахметьевъ, ПI. Анабіовъ.- Научи. Обозр.)

28. Bachmotjew, P. Lähmung bei Lepidopteren infolge erhölter Temperatur ihres Körpers. - Soc. ent. XV. № 12, p. 89-91; 소 13, p. $97-101 ;$ № 14, p. 105-110. 1900 .

28a. Bachmetjew, P. Unterkaltungs-Erscheinungen bei schwimmenden paraNitrotoluol-Kügelchen. - Mém. de l'Acad. imp. des scienc., VIII $\theta$ sér. Classe physiko-math., Vol. X. № 7, (63 pp.). St.-Pétersbourg 1900.

29. Bachmetjew, P. Experimentelle entomologische Studien. I. Temperaturverhältnisse bei Insekten. (160 pp.). Leipzig 1901.

29 a. Bachmotjew, P. Die Lage des anabiotischen Zustandes auf der Temperaturcurve der wechselwarmen Thiere. - Biolog. Centralbl., XXI. p. $672-675.1901$.

30. Bachmetjow, P. Warum fliegen die Tagsschmetterlinge nur am Tage und die meisten Nachtschmetterlinge in der Nacht? - Soc. ent., XV. № 22, p. 171-172; № 23, p. 179-181. 1901.

-31. Bachmotjew, P. Eigene Temperatur der Bienen und überhaupt der Insekten. - Die russische Bienenz.-Liste, XIV. № 3, p. 84-90; № 4, p. 114-119. 1899. (Russisch: Бахметвевг, ПI. Собствевная температура пчелъ и вообще насћкомыхъ. - Русск. Шчеловод. Листокъ).

31 a. Bachmotjew, P. Ueber Anabiose. - Allg. Naturforsch. Ztg., I. i. 1, p. $3-5$; № 3 , p. $29-30$, Berlin 1901 .

32. Bachmetjew, P. Lin neter im Entstehen begriftener Zweig der Entomologie. - Krancher's Entomol. Jahrb., X. p. 95-98. 1901.

32 a. Bachmotjew, P. Kalorimetrische Messungen an Schmetterlingspuppen. Zeitschr. für wissensch. Zool., LXXI. (4). p. 550-624. 1902.

32 b. Bachmetjew, P. Ein Verfahren, das XXI. Jahrhundert zu erleben. Zeitschr. für Naturwiss. und Geograph., IV. № 8, p. 1-13. Moskau 1901. (Russisch: Бахметьевъ, П. Рецеитъ дозить до XXI выка. зКурп. Естествсзн. п Геограб).).

33. Bachmetjew, P. Berorstehende Untersuchungen für Fntomologen. Krancher's Entomol. Jahrb., XII. p. 103-107. 1903.

34. Bachmotjew, P. Eine neue Methode zur Lösung der Frage über die Parthenogenese der Drohnen. - Russische Bienenz.-Liste, VIII. Moskau 1903. (Russisch: Вахметгевъ II. Вновь предлагаемый 
способъ рыпепін вопроса о партеногезись трутией. - Pусct. Пчеловод. .Іистокъ).

3.). Bachmotjow, P. Ihas fermetrische Mikroscop und seine Auwendunir ant dem Gebiete der Biologic. (Zur Frage ïber die Parthenogenese). Zeitschr. für Naturwiss. und Geograph., VIII. ki 1, p. 11-26. MIoskau 1903. (Russisch: Бахметєөвъ, II. І'еометрическій хшкроскопъ п его пршмьненіе ьъ области біологін. [Къ вопросу о партеногенезисъ]. - Жури. Естествозн. и Г'еографф.).

36. Bachmotjew, P. Ein Versuch, die Frage über Parthenogenese der Drohnen mittelst der analytisch-statistischen Methode zu lösen. IIl. Zeitschr. für Entomol., VIII: Le 2-3, p. 37-44. 1903.

37. Bachmotjow, P. Ueber die Anzahl der Augen auf der Unterseite der Hinterflügel von Epinephele jurtina L. - Allg. Zeitschr. für Entomologie, VIII. № 14-15, p. 253-256. 1903.

33. Bachmotjew, P. Die Flügellänge von Erebia euryale Lsp. 1903 in Sophia. - Insekt.-Börse, XX. ^ó 46, p. 364-365. 1903.

38 a. Bachmetjew, P. Biologische Analogien bei schwimmenden p-Nitrotoluol-Kügelchen. - Jenaische Zeitschr. für Naturw., XXXVII. p. 521-543. 1903.

39. Bachmotjew, P. Zur Variabilität der Flügellänge von Aporia crataegi L. in Sophia (Bulgarien). - Allg. Zeitschr. für Entomol., VIII. № 20-21, p. 389-395; 스 22-24, p. 470-494. 1903.

39 a. Bachmetjew, P. Der Luter-clied der sogenamuten falschen Drohnen vun den gewöhnlichen, betrachtet rom Standpunkt der analytisch-statistischen Methode aus. -- Inselst.-Börse, XXI. № 47, p. 371-372. 1904.

40. Bachmetjew, P. Zur Variabilitat der Flügellänge ron Aporia crataegi L. in Sophia (Bulgarien). 2. Aporia crataegi L. 1903. - Allg. Zeitschr. für Entomol, IX. 소 13-14, p. 269-271. 1904.

41. Bachmotjew, P. Ueber die Veränderlichkeit der Anzahl der Augen bei Epinephele jurtina L. - Allg. Zeitschr. für Entomol., IX. № 7-8, p. $143-1717.1904$.

42. Bachmotjew, P. Die Flügellänge von Epinephele jurtina L. 1903 in Sophia. - Insekt.-Börse, XXI. \゚ 2, p. 13. 1904.

42a. Bachmetjew, P. Ein Versuch, das periodische System der palaearktischen Lepidopteren aufzustellen. (Zur Prognose der neu zu entleckenden Arten in der Entomologie). - Arbeiten der NaturforsclerGesellsch. in Saratow, IV. ㅅ․ 2, p. 1-69. 1905. (Russisch: Baxметьев II. Шопытка установить періодическую систему шалеаритпческихъ бабочекъ. [Опытъ прогноза повыхъ впдовъ въ әнтомодогіи]. - Труды Саратовскаго Общ. Естествоиспытателей.).

$42 b$. Bachmotjow, P. Ueber die Variabilitït der Grösse beim Schmetterling Aporia crataegi. - Sammelwerk des Unterrichtsministeriums in Sophia, XXI. (N. F. III). (105 pp.). Sophia 1905. (Bulgarisch: Baxметьевь, II. ІІаушчивостьта па гопьивата у пеперудата Aporia cratregi. - Си́орниюъ за пародни Умотворения, Наука п Кінжннна).

43. Baer, IH. Ueber Bau und Farben der Flügelschuppen bei 'Tagfalter. Zeitschr. für wwissensch. Zoolog., LXV. p. 50-64. 1898. - Auch. in: Tübing. Zool. Arb., III. 수 4. Leipzig 1898. 
44. Baillon, E. Vorliutiges Verzoichnise der Silmetturlinge ans der Cmgegend ron Novorossiisk am Schwarzem Meere im Cancasus. - Bull. Societ. Natural. de Moscou, Année 1886. dỏ 2, p. 241-290.

4.). Balbianni, G. Mémoire sur la génération des Aphides. - Ann. d. scien. natur., V. Sér., Vol. XI. p. 1-89. 1869; Vol. XIV. p. 1-39. 1870; Vol. XV. p. $1-30.1872$.

46. Balbiani, G. Observation ou sujet d'rune note recente de Mr Donnadieu sur les pontes hivernales du. Pliylloxera. - Compt. rend. de l'Acarl. des scienc., (IV. p. 667-669. Paris 1887.

47. Ball, Fr. Notes sur l'effet de la température sur les clurysalides. - Ann. Soc. Ent. Belg., Vol. 45. XII. 1. 385-388. 1901.

48. Barber, M. E. Notes on the peculiar habitis and changes which take place in the larra and pupa of Papitio nireus. - Transact. Ent. Soc., p. 519-521. London 1874.

4y. Rarca, V. Sulla schiusura del seme bachi durante la stagione estiva. Rivista Settim. di Bachicolt., Ann. III, Ne i4, p. 53. Milano 1871.

5). Barfurth. Versuche über Verwandlnng der Froschlarven. - Arch. für miliroscop. Anatom., XXIX. p. 1-28. 1887.

51. Barfurth. Der Hunger als förnderndes Princip in der Natur. - Arch. für mikiosc. Anatom., XXIX. p. 28-34. 1887.

52. Barker, C. W. Seasonal dimorphism of Rhopalocera in Natal. Trans. Entomol. Soc., p. 413-428. London 1895.

52a. Bartels, K. Entomologische Skizzen aus der Umgegend von Káassel im Sommer 1881. - XXIX. und XXX. Ber. des Ver. für Naturk. zu Cassel über die Vereinsjahre rom 18. Apr. 1881 bis dahin 1883, p. 37-39. Kassel 1883.

53. Barthélemy. Fitudes et comsilirations générales sur la parthenogenèse. Ann. des Sc. Nat., IV. Sér., Vol. XII, p. 307-320. 1859.

51. Bastelberger, J. M. Ueher Eupitheciu ericeata Rln. und Euprtheciu millireat $九$ Stgr. (= pauxillaria Rbr. = expressaria Mill., non $=$ expressaria H.-S.). - Illustr. Zcitschr. für Entomol., V. o 9, p. $129-131$; 스 10, p. 146-148. 1900.

i) 4 . Bataillon, E. La métamorphose du ver à soie et le déterminisme évolutif. - Bull. scient. France Belgique, XXV. p. 18-55. 1893.

54b. Bataillon, B. Nouvelles recherches sur les mécanismes de l'évolution chez le Bombyx mori. - Annal. Univ. de Lyon, IV. 소 3, p. 1-16. 1893.

$5+c$. Bataillon, E. La pression usmotique et les grands problemes de la Biologie. - Arch. für Entwichelungsmech., XI. p. 149-184. 1901.

54d. Bataillon, E. Noureaux essais de Parthéuogenèse expérimentale chez les Vertébrés inférieurs (Rana fusca et Petromyzon planeri). - Arch. für Entwickelungsmech., XVIII. p. 1-56. 1904.

55. Bateson, W. Materials for the Study of Variation. London 1894.

5๊a. Baussingault. Agriculture, chimie agricole et physiologie.

56. Beauvais. Seidenwürmer. -- Isis von Oken, p. 781. 1837.

57. Béclard, J. Influence de la lumier sur les animaux. - Compt. rend. de l'Acad. des scien., XLVI. p. 441-453. Paris 1858.

5๖. Beckmanu, J. I. Nene und interessante Lífer fur St.-P'etersburger Gourernement, welche im Gute "PInskoje", Bezirk Luschk, gesammelt 
wurden. - Horae Socict. Entomol. Rossicae, XXXVI. № 3-4, p. CXXIII-CXXVII. 1903. (Russisch: Бегманъ, Ю. И. Новые п. питереспье для С.-ІІетербуріской губ. жуюп, собранные въ имьнів. „Шлоское Аужскаго уџзда. - Труды Русск. Эитомољ. Общ.).

59. Bedhard, Frank E. Animal colaration. London 1895.

60. Bellani, A. In „Cornalis: Monografia del bombici del gelso." Milano 1856. (p. 330.)

61. Bellati, M. e Quajat, E. Esperienze sullo schiudimento estemporaneo. delle uova del baco da seta. - Atti Ist. Veneto, Serie VII, t. III. p. $1715-1736.1892$.

62. Bellati, M. e Quajat, E. Sur l'eclosion anticipée des oeufs du ver-àsoie.-Arch. ital. Biolog., XXV. Fasc. II. 1896. (Extrait. 16 pp.).

63. Bellati, M. e Quajat, E. Sullo schindimento estemporanco delle uova del filugello. - Bollet. Mens. Bachicolt., Ser. II, p. 117-129. 1894; Ser. II, № 9-10, 1895; Ser. III, Ann. II: № 2, p. 13-28; № 3, p. $29-34$; № 4, p. 51-63. 1896. (Im Auszuge mitgetheilt im [62]).

64. Bellati, M. I raggi Röntgen e le scariche Tesla in relazione delle uova del filugello. - Boll. Mens. Bachic., Ser. III, Ann. III, ㅊo 5, p. $57-60,1897$.

65. Bellati, M. e Quajat, E. Nuove riccrche sullo schindimento estemporaneo delle uova del filugello. - Atti Ist. Ven., (7). IX. 1897. - Boll. Mens. Bachic., Ser. III, Ann. IV, № 2, p. 17-28. 1898.

66. Bellati, M. et Quajat, E. Influence de l'oxygène, et de l'air comprimé sur l'éclosion anticipée des oeufs du ver-à-soie. - Arch. Ital. de Biol., XXIX. facs. 1, p. 153-154. 1598; Auch in: Atti R. Ist. Ven. di Sc. Lett. Arti., IX. 1898.

66a. Bellevoye et Laurent. Les plantations de pins dans la Marne et les parasites qui les attaquent. Reims 1897.

67. Bellier de la Chavignerie. Mémoire sur les variétés accidentelles chez les Lépdoptères. - Ann. Soc. Ent. France, Troisiéme Série, VI. p. $299-310.1858$.

68. Bemmelen, I. F. van. Ueber die Entwicklung der Farben und Adern auf den Schmetterlingsflügeln. - Tijdschrift der Nederlandsche Dierkundige Vereeniging, Deel II, Apl. 4. Leiden 1889.

69. Benteli, A. Kleine Mittheilungen.- Soc. ent., VIII. № 11, p. 83. 1893.

69a. Berg, K. Termit a rio philie.-Com. Mus. Nac. Buenos-Airis, I. p. $212-215.1900$.

70. Berg, L. Ernäbrung der Seidenraupen, welche von ScorzoneraEiern abstammen, mit Maulbeeren-Blättern. - Nachr. des Comité für Seidenzucht, I. Lief. 6 und 7, p. 23-24. Moskan 1897. (Russisch: Бергъ, Л. Викормка шелковццей червей, пропсходящихъ пзъ скорпонерной трены. - Извьстія Комитета НІелковод. Импер. Общ. Сельск. Хозяйства).

71. Borg, Otto und Knauthe, Karl. Ueber den Einfluss der Elektricitit auf den Sauerstoffgehalt unserer Gewässer. -- Naturwissensch. Rundschau, XIII. p. 661-664; 675-677. 1898. 
72. Berger, Robert. Beiträge zum Melanismus der Sclmetterlinge. - Soc. ent., VI. № 23, p. 180; VII. № 3, p. 20-21; № 4, p. 27-28; № 5, p. $35-36$; № 6, p. $44-45$; № 7, p. $52-53$; 스 8, p. $59-60.1892$.

73. Berlepsch, A. v. Die Biene und die Bienenzucht in honigarmen Gegenden nach dem gegenwärtigen Standpunkt der Theorie und Praxis. Mühlhausen im Thüringen 1860.

74. Berlepsch, A. v. Bienenzucht nach ihrem jetzigen rationellen Standpunkte. II. Aufl, bearbeitet vion W. Vogel. Berlin 1891.

75. Borlese. Polymorphisme et Parthénogénèse de quelques Acariens Gamasides. - Arch. ital. de Biolog., II. p. 112. 1882.

76. Bernard. Vanessa io und iodes. - Entomol. Nachr., IX. ํ 2, p. 2627. 1883 .

77. Bernatzky, N. S. [Unvollständige Entwickelung der Schmetterlingsflügel bei andauernder trockenen. Witterung]. - Horae Societ. Entomol. Rossicae, XXXVI. № 1-2, p. LVII. 1903. (Russisch: Вернацвій, Н. С. Іротоколь 3 Дек. 1901 года),

7ia. Bernstein, J. Untersuchungen zur Thermodynamik der bioelektrischen Ströme. - Pflüger's Arch. für Physiol., XCII. p. 521-563. 1902.

78. Bertkau, Philipp. Bericht über die wissenschaftlichen Leistungen im Gebiete der Arthropoden während der Jahre 1877-78. - Arch. für Naturgeschichte, 44. Jahrg., II. Bd., p. 219-562. 1878.

79. Bezzi, M. Sulla presenza del genere chionea Dalm. in Italia e la riduzione delle ali nei Ditteri. - Rend. dal $\mathrm{R}$. Lombardo de c. e Lett., Ser. II, XXXIII. 1900. (Separ. 16 pp.).

79a. Biedormann, W. Die Schillerfarben bei Insekten und Vögeln. Denkschr. Med. Nat. Ges., XI. p. 217-300. Jena 1904.

80. Bieger. Kilcine lepidopterologische Mittheilungen.-Entom. Nachr., VIII. № 17 , p. $244-245.1882$.

81. Biró, Ludwig. Biologische Mittheilungen aus Neu-Guinea. - Berliner Entomol. Zeitschr., XLII. № 1--2, p. 129-138. 1897.

82. Blanc, I. Études sur la sécrétion de la soie et la structure du brin et de la bave dans le Bombyx mori. - Laboratoire d'Études de la soie. Lyon $1887-1888$.

83. Blanc, Louis. La coloration de la soie par les aliments. - Bullet. des soie et des soieries, № 701, p. 5. 1890.

84. Blanc, Iouis. Sur la coloration de la soie par les aliments. - Compt. rend. de.l'Acad., CXI. p. 230-282. Paris 1890.

85. Blanchard, Emile. De la production artificielle de lin soie. - Compt. 'rend. de l'Acad., CXI. p. 772-774. Paris 1890.

86. Blanchard, Emile. (Les remarques suivantes, sur les colorations de certains insectes de l'ordre des Lépidoptères). - Compt. rend. de l'Acad., CXXI. p. 961. Paris 1895.

87. Blasius, Wilhelm. Ueber die Gesetzmässigkeit in der Gewichtsabnahme der Lepidopteren von dem Zustande der ausgewachsenen Raupe an bis zu dem des entwickelten Schmetterlinges. - Zeitschr. für wissenschaftliche Zool., XVI. (1. Heft), p. 135-177. 1866.

88. Bloecker, H. Kleinere Mittheilungen. - Illustr. Wochenschr. für Entomologie, II. p. $63-64.1897$. 
59. Bogdanow, A. P. Note sur le pigment des plumes. - Bull. d. 1. soc. Imp. d. natur. d. Moscou, XXLX. 1. Part., p. 459-462. 1856.

90. Bogdanow, A. P. Note sur le pigment rouge de Galarus auriceps. Comp. rend. de l'Acad., XLV. p. 688-690. Paris, 1857.

91. Bogdanow, Anatoli. Medizinische Zoolngie. II. Moskan 1885. (Russisch: Богдановъ, Анатодій. Медпцйсіая зоотогія).

92. Bogdanow, E. A. Zur Biologic der Coprophaga. - Allg. Zeitschr. für Entomolog., VI. Ai 3, p. 35-41. 1901.

93. Bogdanow, E. A. Zehn Generationen der Fliegen (Musca domestica) in vexänderten Lebensbedingungen. -- Allg. Zeitschr. für Entomol, VIII. 소 14-15, p. 265-267. 1903.

94. Bohatsch, Albert. Ueber den Fang ron Carabus Scheidleri Panz. F. in Wien. - Jahresber. des Wien. entomol. Ver., p. 27-31. 1891.

95. Bohatseh, 0. Wupithecien Ousterreich-Ingars. - Wien. entomol. Zts., I. p. 105.1882.

96. Bohatsch, 0tto. Beiträge zur Lepidopteren-Fauna Slavoniens. - II. Jahresber. des Wien. entomol. Ver. (1891), p. 31-50. 1892.

47. Bohatsch, 0tto. Beitrag zur Lepidopteren-Fauna des SchneehergGebietes. - IV. Jahresber. des Wien. entomol. Ver. (1893), p. 2123. 1894.

9S. Böhm, C. Beitrag zur näheren Kenntniss des Pflanzengrüns. - Sitzber. Akad. der Wissensch. Wien, XI,VII. p. 349-354. 1863.

98 . Bohn, Georges. Comparaison entre les effets nerveux des rayons de Becquerel et ceux des rayons lumineux. - Compt. rend. de l'Acad. d. Scienc., CXXXVII. p. 883-885. Paris 1903.

99. Bolle, Giov. Intluenza di un repentino abbassi mento di temperatura sul seme in incubazione. - Ann. dell'i. r. Istituto bacol. sperim. di Gorizia, p. 54-56. 1873.

100. Bolle, Giov. Yersuchszuchten über den Linfluss ron plötzlichen Temperaturerniedrigungen auf zur Ausbrütung ausgelegten Samen. Jahrb. der Seidenbau-Versuchsstat. Görz, p. 60-63. 1873.

101. Bolle, $G$. La schiusura estemporanea del seme del baco da seta col mezzo di agenti chimici e del calorico. - Atti e Nem. dell'i. r. Soc. Agrar. di Gorizia, Anno XVII (Nuova Ser. Vol: III), p. 2-7. 1878.

102. Bonafous, M. Trattato e scritti vari intorno alla educacione dei bachi da seta ed alla coltivozione del gelsi. (216 pp.). Milano 1842.

103. Bonnet, Ch. Ueurres d'histoire et de philosophie. T. I. Traité d'insectologie. Neuchâtel 1779.

103 a. Bonnier, Gaston. Recherches experimentales sur ladaptation des plantes au climat alpin. - Ann. des Scienc. naturell., Sér. VII, Botan., T. $\mathrm{XX}$, p. $21 \mathrm{~T}-360.1895$.

104. Bordage, Edmond. Expériences sur la relation qui existe entre la couleur du Milieu et la couleur des Chrysalides de rertains Lépidoptères. Proced. Fourth International Congress Znology Cambdridge 22-27 August, 1S98. p. 235-244. - Discusion: Roland Trimen, p. 244245 ; H. Caracciolo, p. 245. London 1899.

10ta. Born, Puul. Ueber die Ursachen der Varietäten- und Rassenbildung bei den Caraben. - Insekt.-Börse, XIX. 1902. (Separ. 10 pp.). 
105. Bos, I. Ritzema. Futteränderung bei Inselkten. - Biolog. Centralbl., VII. 수 11, p. 322-331. 1887.

106. Bos, I. Ritzema. Futteränderung bei einem I anfkäfer. - Biolog. Centralbl., XIII. № 7-8, p. 255-256. 1893.

106a. Bonchard, Ch., Curie, P. et Balthazard, V. Action physiolngique de l'émanation du radium. - Compt. rend. de-l'Academie d. Scienc., CXXXVIII. p. 1384-1387. Paris 1904.

107. Boursier. Mémoire sux les eftets de l'influence solaire dans la fécondation des Lépidoptères. - C. R. Acad. Sc., XXV. p. 343. 1847.

108. Brandt und Ratzeburg. Nie Honigbiene. - Separat-Abdr. aus: „Darstellung und Beschreibung der in der Arzneimittellehre in Betracht kommenden Thiere." Berlin 1832.

109. Brauer, F. Beobachtungen in Bezuy auf den Farbenwechsel hei C:trysopa vulgaris. - Verhandl. k. k. Zool.-botan. Gesellsch., II. p. 12-14. Wien 1852.

110. Brauer. In „Bericht der Entomologie für 1869—1870." p. 85-86.

111. Brehm, Alfred Edmund. Illustrirtes Thierleben. 1. Auflage. VI. Wirbellose Thiere. Hildburghausen 1869.

112. Breit, Julius. Stauropus fagi. - Soc. ent., X. № 12, p. 90.1895.

113. Breit, Julius. Jeber die allmïhlige Verdunkelung einiger Lepidopterenarten aus der Umgegend von Düsseldorf. - Soc. ent., XV. io 10 , p. $73-74.1900$.

11. Breyer. Observations sur le dévelompement d'une chaleur propre et élevie chez le Sphinx convolvuli. - Ann. Soc. ent. Belg., IV. p.92-94. 1860.

115. Brücke, Ernst. Untersuchungen über den Farbenwechsel des afrikanischen Chamäleons.-Denkschr. Akad. IViss., Math.-naturw. Kls., IV. 1851/52.

116. Brunbauer, Paul. Der Einfluss der Temperatur auf das Leben der Tagfalter. - Inaug.-Dissert. München. Jena 1883. (115 pp.).

117. Bruner, Lawr. Grasshopper Notes for 1901. - U. S. Dept. Agric., Washington, Divis. Entom., Bull. ㅈo 38, N. S. p. 39-49. 1902.

118. Brunner von Wattenwyl, Carl. Betrachtungen üher die Farbenpracht der Insekten. Wien 1897.

119. Buckler, W. Description of the larra of Miana arcicosa. - Entom. Monthl. Mag., VII. p. 260. 1871.

120. Bütschli, 0. Fin Beitrag zur lienntnis des Stofiwechsels, ins besondere der Respiration bei den Insekten. - Arch. für Anat. u. Physiol. u. wiss. Medicin von Reichert u. du Bois-Reymond, p. 348-361. 1874.

121. Bunker, Robert. Effect of hot weather upon the transformation of the Sphinxes. - Canad. Entomol., IX. p. 120. 1877.

122. Burstert, Hormann. Eine eigentümliche einseitige Aluerration ron Sphinx pinastri. - Allg. Zeitschr. für Entomol., VI. № 11, p. 164-165. 1901.

123. Butler, A. G. Remarks upon certain Caterpillars, which are unpalatable to their ennemies. - Trans. Ent. Soc., p. 27-29. London 1869.

124. Butler, Arthur G. On the Lepidoptera of the Amazons, collected hy James W. H. Trail, during the jears 1873 to 1875. - Transact. Entomol. Soc., p. 19-76. London 1879.

124a. Battel-Reopen, H. v. Die Parthenogenesis bei der Honigbiene. - Natur und Schule, I. 스 4, p. 230-239. 1902. 
124乙. Buttel-Reepen, H. v. Ueber den gegenwärtigen Stand der Kenntnisse von geschlechtsbestimmenden Ursachen bei der Honigbiene (Apis mellifica L.). Ein Beitrag zur Lehre von der geschlechtlichen Präformation. Vortrag, gahalten auf dem Zoologen-Kíongress in Tübingen (1904). - 'Separ. aus den „Verhandl. der Deutsch. Zoolog. Ges." (77 pp.). Leipzig 1904.

124c. Buttel-Reopen, H. v. Die stammesgechichtliche Entstehung des Bienenstaates, sowie Beiträge zur Lebensweise der solitären und sozialen Bienen (Hummeln, Meliponinen etc.). - Vortrag, gehalten auf dem Zoologen-Congress in Giessen (1902). (138 pp.). Leipzig 1903.

125. Cameron. P. On the larvae of Tenthredinidae, with special reference to protective resemblance. - Trans. Ent. Soc., p. 193-199. London 1878.

126. Cameron, $\mathbf{P}$. Notes on the Coloration and Development of Insects. Trans. Ent. Soc., p. 69-79. London 1880.

127. Cantoni, G. L'éducation des vers à soie ì température élevée. -- Moniteur des soies, 11. Année, p. 3-4. 1872.

128. Capiomont, G. Monographie des Larinus. - Ann. Soc. Ent. France, T. IV, Sér. V, p. 64. 1874.

129. Caradja, Aristides de. Lepidopterologische Nittheilungen aus Rumänien. -- Soc. ent., VII. № 16, p. 125; № 18, p. 139. 1892.

130. Caradja, Aristides von. Bemerkungen über Spilosoma mendica Cl. var. rustica Hb. -- Soc. ent., IX. 주 5, p. 33-35. 1894.

131. Caradja, A. von. Zu der Notiz des Herrn M. Selmons über Lucunus cervu: - Soc. ent., X. № 10, p. 77. 1895.

132. Carpantier, L. Hivernage des Coléoptères. - Bull. Soc. Linnéenne NordFrance, XIV. p. 227-235. 1900.

132a. Carpenter, Fred. W. The reactions of the Pomace Fly (Drosophila ampelophila Loew) to light, gravity and mechanical stimulation. - Amer. Natural., XXXIX. p. 157-171. 1905.

133. Carrot. Raupenzuchten bei sehr hohen Temperaturen. - Oesterreich. Seidenbau-Ztg., III. Jahrg., 스 21, p. 167-168. 1871.

134. Carret. Education de rers is soie faite en 18 jours dans une magnanerie chauffée à haute temperature par un poêle-tout en tôle. - Moniteur des soies, X. № 460; p. 5-6. 1871.

135. Carret. Eine Aufzucht von Seidenraupen durchgeführt während 18 Tagen in der hohen Temperatur einer durch einen Blechofen erwärmten Rauperei. - Oesterreich. Seidenbau-Ztg., 4. Jahrg., p. 58-60. 1872.

136. Caretta, A. Intorno alla tolleranza che il seme bachi manifesta per immersioni prolungate nell'acqua comune. - Bollet. Mens. di Bachicolt., Serie III, Ann. IV, № 4, p. 41-52. 1898.

137. Caspari, W. Nochmals Raupenfütterung mit präparirtem Futter und Verwandtes. - Soc. ent., IX. № 24, p. 186-188. 1895.

138. Cauda, Lavini e Perroncito. Sull'azione del gas idrogeno, ossigeno, azoto e anidride carbonica e del vuoto nel seme bachi. - Ann. R. Accad. di Agricolt., XX. Torino 1880.

139. Chautard, I. Recherches sur le spectre de la chlorophylle. - Comp. rend, de l'Acad. Sc., LXXVII. p. 596--597. Paris 1873. 
139 a. Chrpman, T. A. Xotes on the geographical and seasonal variation of Heodes phlaeas in Western Europe. - The EntomoI. Rec. and Journ. of Variat., XVI. p. 167-172 1904.

140. Chapman, T. A. Cossus ligniperda: Change of habit of larva when ichneumoned. - The Entomol. month. Magaz., 2 Ser., IX. o 404, p. 5. 1898.

140 a. Cholodkowsky, N. Zur Kenntnis der Coniferen-Läuse. - Zool. Anz., XV. № 384, p. $66-70 ;$ 즈 385, p. $73-78.1892$.

141. Cholodkowsky, N. Aphidologische Mittheilungen.-ZooIng. Anzeig., XXII. p. $468-477.1899$.

142. Cholodkowsky, N. Ueber den Lebenscyklus der Chermes-Arten und die damit verbundenen allgemeinen Fragen. - Biolog. Centralbl., XX. № 8, p. 265-283. 1900 .

143. Cholodkowsky, N. Sur quelques variations artificielles du Papillon de l'Ortie (Vanessa urticae). - Ann. Soc. Entomol. France, LXX. (an. 1901), 2 e trimestre. p. 174-177. 1902.

144. Cholodkowsky, N. Neue Versuche über künstliche Variationen von Vunessa urticae. - Zcitschr. für wissensch. Insektenbiolog., I. 스 3 , p. $117-118$. 1905 .

145. Christoph. Biologische Notizen über einige Schmetterlinge. - Entomol. Zeitung, XXVIII. p. 240--246. Stettin 1867.

146. Ciccone, A. Trattato delle malattie del baco da seta. Napoli 1883.

147. Clare, Jas. Report ot the 62. Meeting of the British Association, p. 360. Edinbourgh 1892.

148. Claus, C. Lehrbuch der Zoologie. Marburg 1891.

149. Clorici. Studi ed observazioni relativi all industria bacologica. - Bollet. dell'Agricolt., XXX. Ni 15. Milano 1896.

150. Cobelli, R. Volume e peso specifico del Bombice del gelso nei vari suoi stadi. Rovereto 1878. (16 pp.)

151. Cobelli, R. Peso della razza verde del Bombyce del gelso. - Giornale Agrario di Rovereto 1877.

152. Cobelli, Rag. de. Contribuzione alla Biologia del Lophyrus pini L. Verhandl. k. k. Zool.-bot. Gesellsch. Wien 1900. (Separatum 4 pp.).

153. Cornalia, E. Monografia del Bombice del gelso. - Memorie dell'i. r. Istit. Lombardo di Scien., Lett. Art., VJ. p. 1-387. Milano 1856.

154. Corna, M. Études sur le Phylloxera vastatrix. Paris 1878.

155. Coutagne, G. Sélection des vers à soie pour l'améliomation du rendement en soic des cocons. - Labaratoire d'études de la soie, VII. p. 61-72. Lyon 1895.

156. Coutagne, G. Nouvelles recherches sur l'amélioration des races européennes de ver à soie. - Laboratoire d'études de la soie, VII. p. 1-44. Lyon 1895.

157. Coutagne, G. Sur le croisement des différentes races ou variétés des vers à soie. - Laboratoire d'études de la soie, VII. p. 45-60. Lyon 1895.

158. Crampton, Henry Edw. An Experimental Study upon Lepidoptera. With 3 pls. and 13 figs. in the text. - Arch. f. Entwickelungsmech, IX. 2. Hft, p. 293-312; Zusammenfassung, p. 312-313; Appendix p. 313-316; explan. p. 316-318. 1899. 
159. Crewe, H. Harpar. Description of additional varieties of the larva of Eupithecia fraxinata. - Zool., XXII. p. 9252, 53, 59. 1864.

160). Dahlbom. Hỵmenntera Furopaea. II. Chrysis in sensu Linneano. Mrrolini 1854.

161. Dahlström, I. Az idöjárás befolyísa a lepkék szinére. - Rovart. Lapok, VIII. Ji 9, p. 187-188. 1901. (Ungarisch: Einfluss der Witterung auf die Färbung der Lepidoptereu).

162. Dammer. Ueber die Aufzucht der Raupe des Seidenspinners mit den Blättern der Schwarzwurzel. Frankfurt a. 0. 1897.

163:3. Daniel, Gehrider. Anleitung zur Tültung ron Inseliten inslesondere von Coleopteren und Hymenopteren) mittelst Schwefeldioxyd (= schwefelige Säure). - Soc. ent., VII. jỏ 8, p. 61. 1892.

163a. Danilow, E. A. Schädliche Inseliten in Don-Forsterei 1886-1890. Nachr. des Forst.-Instit. zu St.-Petersburg, IV. p. 77-165. 1900. Mit einer farb. Tafel. (Russisch: Даниловъ, Е. А. Вредныл пасыкомыя въ Понскомъ льсппчействђ въ 1886-1890 годахъ. - Нзвђст.

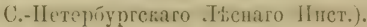

163h. Dannonborg. (Anszug aus seinem Vurtrage üher das Wesen und den Wert der infolge Einwirkung verschiedener Temperaturen auf die frische Puppe entstehenden Falterabweichungen aus der Gruppe der Vanessa, Apatura- und Limenitis-Arten). - Insekt.-Börse, XXIII. 소 16, p. 64. 1906. (Nachr. aus dem Berliner Ent. Ver.; Sitz. rom 26. X. 1905).

163c. Danysz, J. De laaction pathogène des rayons et des imanations emis par le radium sur différents tissus et différents organismes. - Compt. rend. de l'Acad. Sc., CXXXVI. p. 461--46t. Paris 1903.

164. Darwin, Charlos. Notes on the peculiar habits and changes which talie place in the larva and pupa of Papilio nireus. By Mrs. M. E. Barber. (Communicated by Charles Carwin). - Trans. Ent. Soc., p. 519-521. London 1874 .

16ta. Dauphin, I. Intluence des rayons du ralimu su le developpement et lit croissance des champignons inférieurs. - Compt. rend. de l'Acad. Sc., CXXXVIII. p. 154-156. Paris 1904.

165. Davenport, C. B. and Castle, W. B. Studies in Iorphogenesis, IJI. On the Acclimatization of Organismus to High Temperatures. - Arch. f. Entwickelungsmech. der Organismen, II. p. 227-249. 1895.

166. De-Geor. Abhandlungen zur Geschichte der Insekten. (Uebersetzt ron Göze). Nürnberg 1780.

166a. Delage, Yves. Ftudes expérimentales sur la maturation cytoplasmique et sur la parthenogénèse artificielle chez les échinodermes. - Arch. de Zool. Expérim., 3. Sèr., IX. p. 285-326. 1901.

1: $: 6$. Dolage, Yves. Les thénies de la fécondation, - Rev. gréner. des Sciences, p. 871. 1901.

166 c. Delage, Yves. Les théories de la fécondation. - Verl. des Y. internat. Zool.-Congr., p. 121-140. Berlin 1901.

167. Derewjanko, G. S. Vormessungen der Seidenraupen verschiedener Rassen, gezogen in der Station. - Arbeiten der kaukasischen SeidenzuchtStation, Jahrg. 1889, T. II, p. 83-97. Tiflis 1891. (Russisch: 


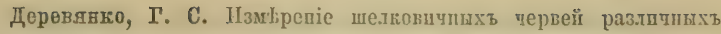
породъ, вынормдевшыхъ на стапін. - Труды кавказск. Шелкогодствешной Станиіи).

167 . Dovaux, M. Sux la résistance à l'asphyxie par submersion chez quelques insectes. - Bull. de la Soc. philomat., Sér. 8, T. III, p. 59-61. $1890 / 91$.

167 $\iota$. Dewitz, J. VI-e Congrès internat. d'agricult. II. Compt, rend. p. 304. Paris 1900.

16:. Dewitz, J. Der Anterismus bei Insekten, seine künstiche Erzenumg und seine physiologische Erklärung. - Arch. für Anat. und Physiol., Physiol. Abth., p. 61-67. 1902.

169. Dewitz, J. Untersuchungen über die Verwandlung der Insektenlarven. Arch. Physiolog. (Engelmann), p. 327-340. 1902.

170. Dowitz, J. Weitere Mittheilungen zu meinen Untersuchnugen über die Verwandlung der Insektenlarven..- Arch. Physiolog. (Engelmann), p. $425-442.1902$.

171. Dowitz, J. Ia suppression de la métamorphose chez des larves d'insectes. - C. R. Soc. Biol., LIV. p. 747-748. 1902.

17:2. Dowitz, J. Recherehes exprimentales sur la metamorphose des insectes.C. R. Soc. Biol., LIV. p. 44-45. 1902.

173. Dowitz, J. Sur laction des enzymes (oxylases) dans la metamorphose des insectes. - C. R. Soc. Biol., LIV. p. 45-47. 1902.

174. Dowitz, J. Ueber die Herkunft des Farbstoffes und des Materials der Lepidopterenkokons. - Zool. Anz., XXVII. Ni 5, p. 161-168. 1903.

175. Dewitz, J. Zur Verwandlung der Insektenlarven, - Zool, Anz., XXVIII. 수 5, p. $166-182.1904$.

176. Dewitz, J. Künstliche Verfärbung bei Insekten. - Zool. Anz., XXVIII. 승 10, p. $370-372.1904$.

177. Dowioz, J. Leber Fangrersuche angestellt mittelst Acetylenlampen an den Schnetterlingen von Tortrix pilleriana. - Zeitschr. für wissenschaftliche Inseltenbiolog., I. № 3, p. 106-116. 1905. .

177a. Dewitz, J. Beobachtungen, die Biologie der Traubenmotte Cochylis ambiguella Hübn. betreffend. - Zeitschr. für wissensch. Insektenbiol, I. № 5, p. 193--199; 소 6, p. 237-247; 추 7, p. 281-285. 1905.

1776. Dewitz. J. Die Farbe von Lepidopterenkokons. - Zoolog. Anz., XXVII. ํㅛㄹ 20-21, p. 617-621. 1904.

178. Dieck, Goorg. Beiträgen zur subterrauen Käferfauna. -- Berl. Ent. Ztg., XIII. p. 337-360. 1869 .

178a. Dickel, F. Ueher die Beweiskraft der v. Siebold'schen Untersuchungsergebnisse von Bieneneiern im Jahre 1S55. - Bienen Ztg., Nㅗ 21. 1897.

179. Dickel, Ferd. Die Ursachen der gesshlechtiichen Differenzirung im Bienenstaat. - Arch. für die ges. Physiol., XCV. p. 66-106. 1903.

179 a. Dickel, F. Ueber die Geschlechtsbildung bei der Honigbiene. - Die Biene, XLII. Ni 9, p. 132-135. 1904.

181. Diotze, K. Eu pithecien. - Ent. Ztg., XXXV. № 4-6, p. 214. Stettin 1874.

180. u. 182. Dietze, K. Beiträge zur Lienntnis ler Arten des Genus Eupithe cia Curt. - Stett. Ent. Ztg., Jahrg. 1872, Bd. XXXIII, 2. Hft., 
p. 184-204; 3. Hft., p. 329-331; Jahrg. 1874, Bd. XXXV, 2. Hft.,

p. 209-221; 3. Hft., p. 270-277; Jahrg. 1875, Bd. XXXVI, 1. Hft.,

p. $69-76$; 2. Hft., p. 236-256; Jahrg. 1877, Bd. XXXVIII, 1. Ifft., p. $98-100$.

183. Diotze, Karl. Beiträge zur Kenntnis der Eupithecien. - Entomol. Zeitschr. „Iris“; XUI. p). 306-327. 1900.

184. Dixey, F. A. On the phylogenetic significance of the wingnarkings in certain Genera of the N y m phalidac. - Trans. Ent. Soc., I-III. p. 89-129. London 1890 .

185. Dixey, Frederick A. Mr. Merrifield's Experiments in Temperature-Tariation as bearing on Theories of Heredity. - Trans. Ent. Soc., Part. III, (Sept.). p. 439-446. Loncion 1894.

185\%. Dixon, Henry H. and Wigham, J. T. Act:on of Radium on Bacteria. Nature, LXIX. p. 81. London 1903/04.

185ß. Dixon, Henry H. Radium and plants. - Nature, LXIX, p. 5. London 1903/04.

185 a. Döflein, Franz. Ostasienfahrt. Leipzig 1906.

186. Dönhoff. Beiträge zur Bienenkunde (X.XIV.) - Bienen-Ztg., XIII. .li 16 und 17, p. 199-201. $185 \%$.

187. Dönhoff. Beiträge zur Physiologie. I. Ueber das Verhalten Lialtblütiger Thiere gegen Frosttemperatur. - Arch. für Anat. und Physiol. und wissensch. Med. von Reichert und du Bois-Raymond, p. 724. 1872.

188. Dönitz. Leber die Echtheit der Farbentöne der brauen und grünen Form von Ornithopter (Icarus) zalmoxis. - Insekt.-Börse, XVI. ㅈï 4, p. 22. 1899. (Sitzung des Berliner Ent. Vereins vom 5. Januar 1899).

189. Dogiel, Joh. Anatomie und Physiologie des Herzens der Larve von Corethra plumicomis. - Mém. Acad. Sc., XXIV. 7. Sér., dè 10, (37 pp.). St.-Pétersbourg 1877.

190. Doherty. Mr. Tutt believed that Mr. Doherty had obtanied "wet-seasen form" of Oriental species be Keeping. - Proc. Ent. Soc., p. VI. London 1897.

191. Domenizki, H. Oxythyrea haemorrhoidales F. - Soc. cnt., VII. Jỉ 10, p. $74-75.1892$.

192. Donnadieu, A. L. Sur guelques points controversés de l'histoire du Philloxera. - C. R. Acad. Sc., CIV. p. 836-839. Paris 1887.

193. Dorfmeister, Georg. Ueber Arten und Varietäten der Schmetterlinge (Vorgetragen in der Versammlung am 27. Juni 1863). - Mittheil. des naturw. Vereins für Steiermark, II. Heft, p. 95-98. Graz 1864.

194. Dorfmeister, Georg. Ueber die Einwirkung verschiedener, während der Entwicklungsperioden angewendeter Wärmegrade auf die Färbung und Zeichnung der Schmetterlinge. - Mittheil. des naturw. Vereins für Steiermark, II. Heft, p. 99-108. Graz 1864.

195. Dorfmeister, $G$. Teber den Einfluss der Temperatur bei der Erzcugung der Schmetterlings-Varietäten. - Mittheil. des naturw: Vereins für Steiermark, Jahrg. 1879. Graz 1880. (Separat. 8 pp.).

195 a. Dorn, E., Baumann, E. und Valentiner, S. Üeber die Einwirkung der Radiumemanation auf pathogene Bakterien. - Physik. Zeitschr., VI. ㅊ: 16, p. $497-500$. 1905 . 
195b. Drenowsky, Al. K. Eine neue Le pido p teren-Varietät für Bulgarien. Die period. Zeitschr. des bulgar. Litterar. Vereins in Sophia, LXVII. (Jahrg. XVIII), № 5-6, p. 448-452. 1906. (Bulgarisch: Дpsновски, Ал. К. Единъ новъ пеперуденъ варпететь за България. Пернод. Списан. на Българск. Ккнвж. Друж. въ Соф̆щя).

196. Dreyfus, L. Neue Beobachtungen bei den Gattungen Chermes L. und Phylloxera Boyer de Fonsc. - Zoolog. Anzeig., 소 299, p. 65-73; № 300, p. 91-99. 1889.

197. Dschejranow, F. I. Die Vermessung der Seidenraupen von Rassen, welche in der kaukasischen Seidenzucht-Station 1891 gezüchtet wurden. - Arbeiten der kaukasischen Seidenzucht-Station. Jahrg. 1891, IV. Bd., p. 75-96. Tiflis 1892. (Russisch: Джейрановґ, $\theta$. И. Изщреніе породъ шелковичныхъ червей, выкармливавшихся при Кавказской пелководственной стапцін. - Трудк кавказск. Шелководственной Станціи).

197a. Ducke, A. Biologische Notizen über einige südamerikanische II y me n opt era. - Zeitschr. für wissenschaftl. Insektenbiologie, II. Nö 1 , p. 17-21. 1906.

198. Duclaux, E. Recherches sur la respiration et l'asphyxie de la graine des vers à soie. - Extrait des Ann. scientif. de l'Ecole Normale Supérieure, VI. 1869.

199. Duclaux, $\mathbb{E}$. De l'influence du froid de l'hiver sur le développement de l'embryon du ver à soie, ct 'sur l'éclosion de la graine. - C. R. Acad. Sc., LXIX. p. 1021-1022. Paris 1869.

200. Duclaux, E. Sur un moyen de produire à volonté l'éclosion de la graine de rers à soie. - C. R. Acad. Sc., LXXIII. p. 917. Paris 1871.

201. Duclaux, E. De l'action physiologique qu'exercent, sur les graines de rers à soie, des températures inferieures à zero. - C. R. Acad. Sc., LXXXIII. p. 1049-1051. Paris 1876.

202. Duclaux, E. Quesito II: Influenza del modo di conservazione del seme sull'esito degli allevamenti. - Memoria presentata al Comitato ordinatore del V. Congresso Bacol. Internaz, p. 245-249. Milano 1876.

202a. Dufour, Henri et Aug. Forel. La sensibilité des fourmis aux rayons ultra-riolets, - Revue Scient., (4). XVIII. Ni2 25, p. 793-794. 1902.

203. Düsing, Carl. Die Regulirung des Geschlechtsverhältnisses bei der Vermehrung der Menschen, Thiere und Pflanzen. Jena 1884.

204. Dunning. I. W. Note on the improbability of the same species of larva, feeding. both on oak and pine. - Trans. Ent. Soc., Proc. p. XX-XXI. London 1870.

205. Dutrochet. Recherches sur la chaleur propre des êtres vivants ì basse température. - Ann. des scienc. naturell. Part. botanique, ${ }^{2} \theta$ série, XIII. p. $5-49.1840$.

205a. Dzierzon. Theorie und Praxis des neuen Bienenfreundes oder neue Art der Bienenzucht mit dem günstigen Erfolge angewrendet und dargestellt. 1849.

205b. Dzierzon. Bienen-Ztg., IX. Na 10-11. 1853.

206. Dzierzon. Bei welcher Temperatur können die Bienen bestehen? - BienenZtg., XII. p. 265-266. 1856. 
207. Dzierzon. Rationelle Bienenzucht oder Theorie und Praxis des Schlesischen Bienenfreundes. Brieg 1878.

208. Edwards, W. H. An abstract of Dr Aug. Weismans paper on "The Season-Dimorphism" of butterflies to which is appended a statement of some experiments made upon Papilio ajax. - Canad. Entom., VII. № 7, p. 22S-240. 1875.

209. Edwards, W. H. On Account of somme fruther experiments show the effect of cold in changing the form of certain butterflics. (Briefliche Mitth. olne Titel). - Canad. Entom., IX. p. 18--19; p. 203-206. 1877.

210. Edwards, W. H. Eflects of cold applied to the chrysalidies of Butterties. Amer. Entomol., III. p. 110-111. 1880; Psyche, III. p. 1-4; p. $15-19$; p. $75-76.1880$.

211. Edwards, W. H. Notes on certain butterflies, their habits etc. - Canad. Entom., XIV. p. 21-28. 1882.

212. Eimer, Theodor. Die Entstehung der Arten auf Grund von Vererben erworbener Eigenschaften nach den Gesetzen organischen Wachsens. Ein Beitrag zur einheitlichen Auffassung der Lebewelt. Jena 1888.

213. Eimer, H. Th. Artbildung und Verwandschaft bei Schmetterlingen. Jena 1889.

214. Emory, C. et Forel, A. Catalogue de Fourmicides d'Europe. - Mittl. der schweiz. ent. Gesellsch., V. p. 441-4\$1. 1879.

211\%. Enock, Frederick. The Life-history of the Ilessian Fly, Cecintomyia destructor Say. - Trans. Entomol. Soc., p. 329-367. London 1891.

214a. Enteman, Wilhelmine Th. Carnegie Institution. Puhliation .1: 14. 1945. 214l. Errora, L. Philosophie botanique.

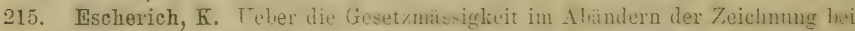
Insekten. - Deutsche entom. Zeitschr. I. Heft, p. 113-130. 1892.

216. Esper. Betrachtungen über die Entwickelungsgeschichte der Schmetterlinge von Keferstein. (p. 106). 1880.

21\%. Euler, Hans. Ueber den Einfluss' der Elektrizität auf den Sauerstofigehalt der Gewässer. -- Biolog. Centralbl., XXI. 소 !, p. 1-6. 1901.

21S. Fallon, J. Notes sur diverses variétés de Lépidoptères. - Ann. Snc. Ent. France., 6 Sér., III. p. 21-22. 1883.

21Sa. Favre, I. Versuch der Untersuchung der Malarie in Russland in Sanitäts-Bezichung. Charkow 1908. (Russisch: Фавръ, И. Опытъ изучепія маляріг въ Россіи въ савнтариощъ отношеніп. Харьковъ 1903).

219. Federley, Harry. Ueber zwei in Finnland gefangene Temperaturaberrationen von $\mathrm{R} h$ op a $10 \mathrm{ceren}$. - Meddelanden af Soc. pro Fauna et Flora Fennica, H. 30. p. 75-81. 1904.

219a. Fedorley, Harry. Lepidopterologische Temparatur-Experimente mit besonderer Berücksichtigung der Flügelschuppen. - Separatum aus „Festschrift für Palmén", 스 16. (117 pp.). Helsingfors 1905.

219b. Fornald, C. H. and Kirkland, A. H. The Brown-tail Moth. Euproctis chrysorrhoea (L). A report on the life history and habits of the imported Brown-tail Moth, together with a description of the remedies best suited for destroying it. - Massachusetts State Board of Agriculture. Boston 1903. 
219d. Fickert, C. Ueher die Zeichnungsverhältnisse der Gattung Ornithoptera. - Zool. Jahrb., Abth. f. Syst., IV. p. 692-770. 1889.

220. Fickert, C. Künstliche Kialteahartungen von Schmetterlingen. - Jahrhft. Ver. Naturk. in Württemberg, LIII. p. LXVIII-LXIX. 1897.

221. Fickert, C. Eimer: "Orthogenesis der Schmetterlinge“. Leipzig 1897. (p. 403).

222. Field, Adele, M. Observations on Ants in their relation to Temperature and to Submergence.-- Biol. Bull., VII. № 3, p. 170-174. 1904.

223. Field, Adele, M. Supplementary Notes on Ant. - Proc. Acad. Nat. Sci. Philadelphia, p. 491-495. 1903.

223a. Field, A. M. Temperature as a factor in the development of Ants. Biol. Bull. Woods Holl., IX. p. 361-367. 1905.

224. Field, W. L. W. A contribution to the study of individual variations in the wings of Le pidoptera. -- Proc. Amer. Ac. Art. Sc., XXXIII. № 21, p. 3ऽ9-395. 1898.

225. Fingerling, Max. Ueberwinternde Raupen. - Ent. Jahrb., II. p. 191198. $18 ! 13$.

226. Fingerling, Max. Die Ueberwinterung. - Insekt.-Börse, XV. 스 43, p. 253-254; 시 44, p. 258-259. 1898.

226a. Fink, Robert. Zur Lebensweise noriamerikanischer Schädlinge. - Soc. ent., XX. 시 12, p. 91-92; № 13, p. 98-99. 1905.

227. Fischer, E. Zwei neue Aberrationen von Vanessa antiopa. - Ent. Zeitschr., VIII. Jahrg., № 7, p. 56-57.. Guben 1894.

228. Fischør, E. Transmutation der Schmetterlinge infolge Temperaturänderungen. Experimentelle Untersuchungen über die Phylogenese der Vanessen. Berlin 1895.

229. Fischer, E. Neue experimentılle Untersuchungen und Betrachtungen über das Wesen und die Ursachen der Aberrationen in der Faltergruppe Vanessa. Berlin $1896^{\circ}$.

230. Fischer, E. Zwei sonderbare Aberrationen von Vanessa antiopa und eine neue Methode zur Erzeugung der Kälteaberrationen. - Sonderdruck aus der „Illustr. Wochenschr. firr Entomol.“. Neudamm 1897.

231. Fischer, E. Beiträge zur experimentellen Lepidopterologie. - Hllustrirte Wochensihr. für Ent., II: 수 33, p. 513-516; 스 37, p. 577-5॰3; № 38, p. 595-600; 스 44, p. 6s9-695. III : 스 4, p. 49-53; № 12 , p. $181-183 ;$ № 16, p. $241-243 ;$ № 17, p. 262-264; 숭 18, p. $278-280$; 으 23, p. $354-357$. 1898. Illustr. Zeitschr. f. Ent., IV: 승 3, p. $33-34$; № 5, p. $67-69$; 스 7 , p. $97-99$; № 9, p. 133 $135 ;$ № 11, p. 164-167; Nㅡ 14, p. 214-216; 싱 15, p. 228-230; № 16, p. $243-245.1899$.

232. Fischer, E. Experimentelle kritisehe Untersuchungen über das procentuale Auftreten der durch tiefe Kälte erzengten Vanessen-Aberrationen. - Soc. ent., XIII. № 22, p. 169-171; № 23, p. 177-179. 1899.

233. Fischer, E. Ein weiterer Fall von Farbenmuster-Kopie auf der Puppenschale. - Illustr. Zeitschr. für Ent., IV. № 11, p. 186-187. 1899.

234. Fischer, E. Dritte Mitheilung über Farbenmuster-Iinpie bei Falterpuppen. - Illustr. Zeitschr. für Ent., V. № 10, p. 154. 1900.

Bachmet $j \in w$, Studien. 11 . 
235. Fischer, E. Weitere Untersuchung über das procentuale Auftreten der V a nessen-Aberration. - Soc. ent., XVI. Ja 7, p. 49-51; 궁 8, p. 58-59. 1901.

236. Fischer, E. Lepidopternlogische Experimental-Forschungen - Illustr. Zeitschr. f. Entomol., V. № 1, p. 4-6; 스 2, p. 20-22. 1900; Allg. Zeitschr. f. Entomol., VI. ㅊe 20, p. 305-307; 스 21, p. 325-327. 1901. VIII. ㅊo $12-13$, p. 221-228; ํํ 14-15, p. 269-284; 그 $16-17$, p. $316-326$; 고 $18-19$, p. 356-368. 1903.

237. Fischer, E. Experimentelle Lntersuchungen über die Vererbung erworbener Eigenschaften. - Allg. Zeitschr. für Ent., VI. 스 t, p. 49-51; 스 23, p. 363-365; 스 24, p. 377-380. 1901.

238. Fischer, E. Weitere Untersuchungen über die Vererbung erworbener Eigenschaften. - Allg. Zeitschr. für Ent., VII. 샤 7-8, p. 129-134; 츠 9, p. 161-167; 스 10-11, p. 201-205; 스 12-13, p. 241-246; 스 $14-15$, p. $266-272$; 승 16, p. $301-306$; 스 21, p. 452-456; № 22 , p. $476-483$; № 23 , p. $506-514$; 즌 24, p. 521-525. 1902 .

239. Fischer, E. Natirliche und kiinstliche Umformung der Lebewesen. Referat über den am 25. Febr. 1902 in der Naturw. Gesellsch. St. Gallen gehaltenen Vortrag. (Separat. 12 pp.).

240. Fisoher, E. Ueber Zücht und Variationen von Charaxes jasius L. Entomol. Zeitschr., XVII. № 23. Guben 190t. (Separat. 10 pp.).

240a. Fischer, E. Ueber die Ursachen der Disposition und üher Frühsymptome der Raupenkrankheiten. - Biol. Centralbl., XXVI. 소 13, 14, 15, p. 448-463; 스 16, p. 534-544. 1906. (Separat.).

241. Flammarion, C. Intluence des couleurs sur lia production des sexes. Compt. rend. de l'Acad. des scienc., CXXXIII. 스 8, p. 397-400. Paris 1901.

241a. Flögel, J. H. L. IIonographie der Johaunisbeeren-Blattlaus. A phis ribis L. - Zeitschr. f. wissensch. Insektenbiol., I. o 5, p. 209-215. 1905.

241b. Forel, A. und Dufour, H. Ueber die Empfindlichkeit der Ameisen für Ultraviolett und Röntgensche Strahlen. - Zoolog. Jahrb., Abt. für Syst., Geogr. und Biol. der Tiere, XVII. № 2, p. 335-338. 1903.

242. Frey. Lin Beitrag zur Kenntniss der Microlepidopteren. - Ent. Ztg., XXXII. p. 101-130. Stettin 1871.

244. Freyer, C. F. Beiträge zur Naturgeschichte einiger Falterarten (mit Nachtrag). - Ent. Ztg., VI. p. 22-31. Stettin 1845.

243 u. 245 Freyer, C. F. Ueber die ungleiche Entwickelungs - und Erscheinungsperiode mehrer Falterarten. - Ent. Ztg., VI. p. 286-288. Stettin 1845.

246. Friederichs, K. Beiträge über paläarktische Coleopteren. - Allg. Zeitschr. für Ent., VIII. ํㅗ 14-15, p. 257-261. 1903.

247. Friedmann, Friz. Ueber die Pigmentbildung in den Schmetterlingsflügeln.Arch. für mikr. Anat., LIV. 1. Heft, p. 85-95. 1899.

248. Friese, H. Ueber Hummelleben im arktischen Gebiete. (Hym.). -- Allg. Zeitschr. für Ent., IX. ㅊ: 21-22, p. 409-414. 1904.

249. Frings, Carl. Ueber einige Aberrationen und Varietiten aus der Bonner Gegend. - Soc. ent., VIII. 스 1, p. 3-4. 1893.

250. Frings, Carl. Eine Aberration von Melitaea aurinia. - Soc. ent., VIII. № 11, p. 82.1893. 
251. Frings, Carl. Lokales Vorkommen ron Lucanus cervus. - Soc. ent., XI. 스 23, p. 191-192. 1897.

252. Frings, Carl. Ein Fall von Schein-Albinismus bei $P$. machaon. - Soc. ent., XII. № 11, p. 81. 1897.

253. Frings, Carl. Experimente mit erniedrigter 'Temperatur in Jahre 1897. Soc. ent., XIII: № 5, p. 35-36; 구 6, p. 41-42; № 7, p. 51-52; 승 8, p. 58-60; 스 9, p. 65-66; 느 10, p. 75-76. 1898.

254. Frings, Carl. Einige entomologische Beobachtungen. - Soc. ent., XII. 스 15, p. $114-115.1898$.

255. Frings, Carl. Besprechung einiger merkwiurdiger Aberrationen. - Soc. ent., XIII. 스 17, p. 129-130. 1898.

256. Frings, Carl. Vorliche der Lepidopteren fiur ihnen gleichartige Farbe. - Soc. ent.; XIV. 즈 2, p. 9. 1899.

257. Frings, Carl. Experimente mit erniedrigter Temperatur im Jahre 1898.Soc. ent., XIV: 수 6, p. 41-43; 스 7, p. 51-53; 스 8, p. 57-59; 고 9 , p. 65-67. 1899.

258. Frings, Carl. Experimente mit erniedrigter 'Temperatur im Jahre 1899. Soc. ent., XV. 즈 4, p. 25-27; 수 5, p. 33-36. 1900.

259. Frings, Carl. Temperatur-Versuche im Jahre 1900. - Soc. ent., XVI. 스 3, p. 17-19; 스 4, p. 26-27; 스 5, p. 35-37; 스 6, p. 42-44. 1901.

260. Frings, Carl. Bericht iiber Temperatur-Experimente im Jahre 1901.Soc. ent., XVII. № 2, p. 9-11; 소 3, p. 17-19; 즈 4, p. 25-26; 스 5, p. $33-35$; № 6 , p. $43-45$; № 7 , p. $52-54$; 스 8, p. $60-61$; № 9 , p. $66-68.1902$.

261. Frings, Carl. Temperatur-Versuche in Jahre 1902. - Soc. ent., XVIII. 스 1, p. 1-3; 서 2, p. 10-11; 즈 3, p. 19-21. 1903.

262. Frings, Carl. Bericht über meine Temperatur-Versuche in den Jahren 1903-1904. - Soc. ent., XIX. № 18, p. 137-138; № 19, p. 147-148; 스 20, p. 153-156; 슬 21, p. 163-164; № 22, p. 172-173; №ㅇ 23, d. $178--180.1905$.

263. Fruhstorfer, H. Neue Lepidopteren aus Lombok. - Soc. ent., XI. 스 13, p. 107-108. 1896.

264. Frahstorfer, H. Tonkin-Pieriden. - Soc. entom., XVIII. Ji 6, p. 4142. 1903.

264a. Frahstorfer, H. Bemerkungen über eine Schmetterlings-Ausbeute von der Insel Banka. - Soc. ent., XXI. № 1, p. 4. 1906.

265. Fuchs, A. Ueber die Unterschiede von Pararge adrasta Hb. und var. maja. - Jahrb. des nassauischen Ver. für Naturkunde, Jahrg. 1871/72, Hft. 25 und 26, p. 433-434. 1872.

266. Fuchs, A. Beobachtungen über einige Lepidopteren. - Ent. Zeitg,, XXXIV. p. 98-100. Stettin 1873.

267. Fuchs, A. Lepidopterologische Mittheilungen aus dem nassauischen Rheinthal. - Ent. Ztg., XXXVII. p. 94-106. Stettin 1876.

- 268. Fuchs, Fordinand. Neue Schmetterlingsformen. - Soc. ent., XIX. Ne 3, p. 17 -18. 1904.

$268 \alpha^{\prime}$. Fuchs, R. F. Zur Physiologie der Pigmentzellen. - Biolog. Centralbl., XXVI. № 23, p. 863-879. 1906. 
268 $\alpha$. Fürth, 0. . und Sehneider, H. Ueber tierische Tyrosinasen und ihre Beziehungen zur Pigmentbildung. Beiträge zur chemischen Physiologie und Pathologie. - Zeitschr. f. ges. Biochem., I. Hft. 5-6. 1901.

268 a. Funaro, Angiolo. Ueber die Zusammensetzung einiger [der] italienischer[n] Futterstoffe.-Landw.Versuchsstat., XXVIII. p. 119-1:22. Berlin 1883.

269. Gadeau de Korville, Henri. Note sur l'allinisme imparfait unilatéral chez les Lépidoptères. - Ann. Soc. Ent. France; V. 6 Sér., p. $431-434.1875$.

270. Gal, Jul. Influence des lumières colorées sur le développement des versà-soie. - Bull. Soc. Ét. Sc. Nat. Nimes., XXIV. p. 46-51. 1898.

$270 \propto$. Galli-Valerio, Bruno et Narbel, P. Études relatives à la malaria. Les larves d'Anopheles et de Culex en hiver. - Centralblatt für Bakteorol., Parasitenk. und Infekt., XXIX. № 23, p. 898-900. 1901.

270ß. Galli-Valerio, B. et Rochaz de Jongh. Sur la présence de Mochlonyx velutinus Ruthe dans le canton de Vaud. - Bull. de la Soc. vaudoise des sc. nat., Vol. XXXIX, 수 148, p. 453. 1903.

270ץ. Galli-Valerio, B. e J. Rochaz de Jongh. Studi e ricerche sui Culicili dei generi Culex e Anopheles. - Atti della soc. ital. per gli studi sulla malaria, Anno IV, p. 3-48; V. p. 1-48. Roma 1903-1905.

270a. Galvagni, Egon. Coenonympha pamphitus L. - Terh. der Zool.-botan. Ges., LV. 스 1--2, p. 25-27. Wien 1905. (Bericht der Sekt. für Lepidopt.).

271. Ganitzki, W. Mittel gegen Cleonus puncticentris. - Der Wirth, .12 13, 1897. (Russisch: Раницкій, В. Средство противъ свеклоппqнаго. долгоносика. - Хозяшнъ).

272. Garbowski, Tad. Descendenztheoretisches über Lepidopteren. - Biolog. Centralbl., XV. 수 18, p. $657-672.1895$.

273. Gartner, A. Ueber Colias myrmidone Esp. - Wiener Entomol. Monatsschrift, V. p. 306-309. 1861.

274. Gauckler, H. Entstehung von Lepidopteren-Tarietäten durch Nahrungswechsel. - Ent. Nachr., VIII. № 20, p. 275. 1882.

275. Gauckler, H. Untersuchungen üher heschlennigte Ueberwinterung ron Schmetterlingspuppen im Winter 1884-S5. - Ent. Nachr., XI. 스 22, p. $346-347.1885$.

276. Gauckler, H. Biologisches über Cymatophora or. - Ent. Nachr., X. № 20, p. 309. 1884.

277. Gauckler, H. Antheraea pernyi. - Ent. Nachr., XII. № 6, p. 86-88. 1886.

278. Gaucklor, H. Anthercea pernyi. - Entom. Nachr., XII. № 23, p. 363364. 1886.

279. Gauckler, H. Einfluss hoher Temnaraturen auf den Organismus von Insekten. - Ent. Nachr., XII. № 16, p. 2;6-2;7. 1886.

280. Gauckler, H. Lebenszähigkeit von Raupen gegen die Einwirkung des Wassers. -- Soc. ent., IV. 즈 4, p. 33-34. 18 s.

281. Gauckler, H. Experimente mit niedrigen Temperaturen an V anessaPuppen. - Iris, II. p. 394-397. 1896. (Separat.).

282. Gauckler, H. Experimente mit V a ness a-Puppen hei niedrigen Temperaturen. - Illustr. Wochenschr. f. Ent., I. p. 493-495. 1896. 
283. Gauckler, H. Beobachtungen aus dem Insektenleben. - Illustr. Wochenschr. f. Ent., II. p. 496. 1897.

284 u. 290. Gauckler, H. Eine Winterzucht von Arctia caja 1896 mit einigen Bemerkungen über die Entstehung von Aberrationen. - Illustr. Wochenschr. f. Ent., II. p. 500-502. 1897.

285. Gauckler, H. Riesenexemplare von Saturnin pyri und Lasioc. quercifolia. Illustr. Wochenschr. f. Lint., II. p. 143. 1897.

286. Gauckler, H. Biologisches über die Kiefer- oder Forleule, Panolis piniperda P. - Illustr. Wochenschr. f. Ent., II. p. 213-215. 1897.

287. Gauckler, H. Ueber Missbildungen und Formverinderungen der Schmetterlingsfluigel und deren mutmassliche Entstehungsursachen. - Illustr. Wochenschr. f. Ent., II. p. 84- -87; p. 374-376; p. 417-418. 1897.

288 u. 289. Gauckler, H. Anpassung und Schutzfïrbung. - Illustr. Wochenschr. f. Ent., II. p. 14-16. 1897.

291. Gauckler, H́. Der Einfluss des Wassers auf das Leben der Raupen. Illustr. Wochensehr. f. Ent., II. p. $295 \div 296$. 1897 .

292. Gauckler, H. Häufiges Vorkommen von Acherontia utropos in der Umgebung von Karlsruhe i. B. im Jahre 1896. - Illustr. Wochenschr. f. Enit., II. p. 303. 1897.

293. Gauckler, H. Ein Beitrag zu dem Kapitel „Inzucht." - Illustr. Wochenschr. f. Ent., II. p. 366-367. 1897.

294. Gauckler, H. Entomologische Mittheilungen. - Insek.-Bürse, XV. 스 8, p. 46.1898.

295. Gauckler, H. Experimente mit niedrigen Temperaturen an VanessaPuppen. II. - Entomol. Zeitschr. Iris., p. 14-19. 1898. (Separat.).

296. Gauckler, H. Ueher die Variationsfahigkeit von Cidaria hastuleta $\mathrm{Hb}$. subhastata Nolcken. - Ent. Nachr., XXV. o 2, p. 17-18. 1899.

297. Gauckler, H. Untersuchungen über beschleunigte Entwicklung überwinternder Schmetterlingspuppen (Treiben der Puppen). I. - Illustr. Zeitschr. für Ent., IV. 스 7, 12, 15. 1899. (Separàt. 8 pp.).

298. Gauckler, H. Die Raupe von Bombyx quercus var. sicula Stgr. - Insek.Börse, XVII. № 2, p. 11. 1900.

299. Gaucklor, H. Entomologische Mittheilungen. - Inselkt.-Börse, XVII. №̊ 42, p. 332. 1900 .

300. Gauckler, H. Untersuchungen über beschleunigte Entwickelung überwinternder Schmetterlingspuppen (Treiben der Puppen). Nachtrag I und II. - Illustr. Zeitschr. für Ent., Y. dò 13 ; p. 203; 스 14, p. 219. 1900.

301. Gauckler, H. Rasche Entwickelung von Deileph. nerii L. - Illustr. Zeitschr. f. Ent., V. 수 15; p. 234.1900.

302. Gauckler, H. Etwas üher Grössenbestimmung der Sclmmetterlinge. Insekt.-Börse, XX. Jỉ 37, p. 292-293. 1903.

303. Gebhard, W. Fangergebnisse. - Insekt.-Börse, XIII. N 2, p. 12.1896. 304. Gebhard, Wilhelm. Beiträge zur "Fauna Baltica". - Soc. ent., XII.

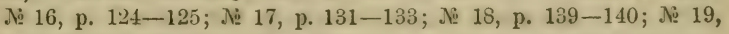
p. $146-147 ;$ № 20 , p. 154.1897.

305. Gentry, Thos. G. Remarkable variations in coloration, ornamentation etc. of larve. - Can. Ent., VI. p. 85-91. 1874. 
306. Gontry, T. Influence of Tactrition on. - Proc. Acad. Natur. Soc. Philadelphia, p. 281. 1873.

307. Ghiliani, V. Influenza del calore asciutto sulto sviluppo di alcune crisalidi. - Boll. Ent. Ital., V. p. 69-72. 1873.

308. Giard, A. La méthode expérimentale dans l'Entomologie. - Bull. Soc. Ent. France, № 4, p. 57-63. 1896. (Eine Rede, gehalten am 26. II. 1896).

$308 a$ u. b. Giard, A. Sur l'éthologie des lavres de Sciara medullaris Gd. C. R. Acad. Sc., CXXXIV. p. 1179-1185. Paris 1902.

309. Giardina, Andrea. Sulla biologia delle Mantidi. - Giorn. di Scienze Natur. e d'Econom., XXII. p. 286-326. Palermo 1899.

310. Giardina, Andrea. Ueber das Schlüpfen der Larven von Ameles spallangania Rossi. - Illustr. Zeitschr für Ent., V. № 18, p. 280-281. 1900.

310\%. Gillmer, M. Kurze Würdigung der beiden Aberrationen Mrimas titiae ab. tilioides, Holle (1865) und Amorpha populi ab. salicis seu palustris, Holle (1865). - Zeitschr. für wissensch. Insektenbiol., I. №̣ 8, p. 337 -338. 1905.

311. Ginestous, R. de. Influence de la lumière violette sur les vers ì soie.... Journ. d'agricult. pratique, 36. Année, T. II, p. 232-233. 1872.

312. Girard, Maurice. Note relative a des expériences sur l'action des courants electriques sur les chrysalides des Lépidoptères. - Ann. Soc. Ent. France, 4. Sér., VI. p. 207-212. 1866.

313. Girard, Maurice. Études sur la chaleur libre dégagée par les animaux invertébrés et specialement les insectes. - Ann. des scienc. natur. Zoologie, 5-e série, XI. p. 134-274. 1869.

313 a. Girard, M. Sur les pontes des Abeilles. - C. R. Acad. Sc., LXXXVII. p. 755-756. Paris 1878.

314. Girard, M. Sur la résistance du Phylloxera aux basses températures. C. R. Acad. Sc., XC. p. 173-174. Paris 1880.

314a. Glaser, I. Der neue Borkhausen oder hessisch-heinische Falterfauna. Darmstadt 1863.

315. Göldi, E. A. Aphorismen, neue Resultate und Conjecturen zur Frage nach den Fortpflanzungs-Verhältnissen der Phytophthiren enthaltend. Schaffhausen 1885.

315a. Gooldi, E. A. Stegomyia fasciata, der das Gelbfieber übertragende Mosquito und der gegenwärtige Stand der Kenntnisse über die Ursache dieser Krankheit. - Bericht des 6. Internat. Zool.-Kongr. in Bern, p. 193-203. 1905.

316. Goothe, Rud. Beobachtungen über Schildläuse und deren Feinde, angestellt an Obstbäumen und Reben im Rhungau. - Jahrb. nassau. Ver. Nat., XXXVII. p. 107-130. 1884.

317. Goote, R. Die Blutlaus, ihre Schädlichkeit, Erkennung und Vertilgung. 2. Auflage. Berlin 1885 .

318. Golfin. Note sur un cas de parthénogénèse. - Actes et mémoires du quatrième congrés séricole, p. 281. 1874.

318a. Goethe, R. Bericht der kgl. Lehranstalt für Obst-, Wein- und Gartenbau zu Geisenheim a. Rh. für das Etatsjahr 1898/99 erstattet von dem Direktor. Wiesbaden 1899. 
319. Golubajew, A. Vermessung der Seidenraupen von Rassen, welche in der kaukasischen Seidenzucht-Station 1890 aufgezüchtet wurden. Arbeiten der kaukas. Seidenz.-Stat., Jahrg. 1890, Bd. III, p. 163-191. Tiflis 1892. (Russisch: Голубаевъ, А. ІІзиюеніе шелковпннхъ червей породә, выкармливавшисл при Кавказской шелководственной станціп въ 1890 году. - Труды кавказ. Шелков. Станціп).

320. Golubajow, A. A. Beobachtungen über den Gewichtsverlust der Cocons mit nicht- und abgestorbenen Puppen. - Arbeiten der kaukas. Seidenz.Stat., Jahrg. 1890, III. Bd., p. 241-250. Tiflis 1892. (Russisch: Голубаөвъ, А. А. Наблюденія надъ потерей въса заморенвыхъ п незаморенныхъ коконовъ. - Труды кавказ. Шелков. Станціп).

321. Gonin, I. Recherches sur la métamorphose des I.épidoptères. Lausanne 1894.

322. Goossens, Th. Sur les varıations chez les chenilles - Bull. Soc. Ent. France, 4 Sér., X. p. 90-91. 1870.

323. Goossens, Th. Des variations des chenilles - Ann. Soc. Ent. France, 5 Sér., I. p. 111-118. 1871.

$323 a$. Goossens, Th. Expériences sur la reproduction consanguine de la Lasiocampa pini. - Ann. Soc. Ent. France, 5 Sér., VI. p. 429-433. 1876.

324. Gorbatschew, K. A. Einige Daten zur Frage über die vorzeitige Entwickelung der Eier des Seidenspinners. - Arbeiten der kaukasischen Seidenzucht-Station, Jahrg. 1887-188S, I. p. 41-49. Tillis 1889. (Russisch:- Горбачевъ, К. А. Нъготорыя данныя къ вопросу 0 случайнощъ оживленіи грены. - Труды кавказ. Шелков. Ставціи).

325. Gourean. Mémoire sur l'irisation des ailes des insectes. - Ann. Soc. Ent. France, 2 Sér., I. p. $201-215.1843$.

325a. Graber, V. Thermische Experimente an der Irüchenschabe (Periplaneta orientalis). - Arch. f. die ges. Physiol. der Menschen und der Thiere von Pflüger, XLI. p. 240-256. 1887.

326. Graber, Vitus. Die Insekten. Zweiter Band. (Doppelband.) Vergleichende Lebens- und Entwicklungsgeschichte der Insekten. I. Hälfte. München 1877. (Zugleich bildet den XXII. Band der „Naturkräfte ${ }^{\star}$ ).

327. Grassi, B. e Sandias, A. Constituzion e sviluppo della societa dei Termitidi. - Atti Accad. Scien. Natur. in Catania, Ser. 4, Vol. VI, 1993; Vol. VII, 1894.

$327 \alpha$. Grassi, B. and Sandias, A. The Constitution and Development of the Society of Termites: olservation of their habits, with appendices in the parasitic Protozoa of Termitidae, and on the Embiidae.The Quart. Journ. of Microsc. Science, XXXIX. № 155, p. 245-322. 1896 ; XL. № 157, p. 1-176. 1897.

327a. Grassi, B. Die Malaria. Jena 1901.

$327 b$. Green, Alan B. A Note on the Action of Radium on Microorganisms. Proc. Roy. Soc., LXXIII. p. 375-381. London 1904.

328. Gregson, C. S. Attempt to arrange the British Eupitheciae by their larval characteristics. - Entom., IX. p. 8-10. 1876.

329. Grevillius, A. Y. Zur Kenntnis der Biologie des Goldafters (Euproctis chrysorrhoea [L] $\mathrm{Hb}$.) und der durch denselben verursachten $\mathrm{Be}$ schädigungen. - Beiheft. zum Botan. Centralbl., XVII. Abt. II, Heft 2, p. 222-322. 1905. 
330. Griffiths, A. B. Recherches sur les couleurs de quelques Insectes. - C. R. Acad. Sc., CXV. p. 958-959. Paris 1892.

330 a. Griffiths, A. B. La pupine, nouvelle sulstance animale. - C. R. Acad. Sc., CXV. p. 320. Paris 1892.

331. Grosser, Paul. Geologische Reisebriefe. - Gäa, XxxII. p. 449-452; p. $527-529 ;$ p. $585-588 ;$ p. $657-661 ;$ p. $710-715.1896$.

332. Grum-Grschimajlo, G. E. Die Reise nach MIngolien. - Zeitschr. für Naturw. und Geograph., VIII. № 9, p. 88-90. 1903. (Russisch: Грущъ-Гржимайло, Г. Е. Путешествіе въ Монголію. - ॐұрп. Еестествозн. II I'еографі.).

333. Grunack, A. Rhagium bifasciatum F. - Insekt.-Börse, XV. 주 8, p. 44.1898.

334. Grund, F. Wanderung von Pieris brassicae L. - Illustr. Zeitschr. für Ent., V. 스 22, p. 352. 1900.

335. Guarinoni. Ueber den Einfluss des violetten Lichtes auf die Seidenraupen. Centralbl, für Agric.-Chemie, I, p. 207-208. 1872.

336. Guerin, Meneville. Sur une particularité remarquable dans les métamorphoses de Bombyx Jama-Maï. - Ann. Soc. Ent. France, 4 Sér., T. III, pa XLVI, 1863.

337. H. L. Ostpreussen. - Schwärmer. - Soc. ent., XI. № 4, p. 26-28; 스 5, p. $33-35$; 수 6, p. 42-43. 1896.

338. Haase, E. Duftapparate Indo-Australischer Schmetterlinge. - Corresp.Blatt Ent. Ver. Iris, I. ㅈi 3, p. 92-107. Dresden 1886.

339. Haase, Er. Untersuchungen über die Mimikry auf Grundlage eines natürlichen Systems der Papilioniden. - Bibl. Zool., III. 8. Heft, I. Theil, p. 1-120. 1891; II. Theil, p. 1-161. 1893.

340. Haberfelner, Jos. Ueber Inseliten-Wanderungen $10: 1$ und in die Alpen.Soc. ent., IV. 으 5, p. 10-41; 스 6, p. 50. 1889.

341. Haberfelner, Jos. Resultate aus meinem Zuclithäusern. - Soc. ent., VI. 주 4, p. $26-27.1891$.

342. Haberlandt, F. Ueber den Einfluss des Chlorgases auf die Eier des Seidenspinners. - Oesterreich. Seidenbau-Ztg., 3. Jahrg., p. 168. 1871.

343. Haberlandt, F. Der Seidenspinner des Maulbeerbaumes, seine Aufzucht und seine Krankheiten. (p. 155): 1871.

344. Haberlandt, F. Onde accertare l'influenza del cloro gasoso sulle uova del filugello. - Sericul. austr., Anno III, p. 167-168. 1871.

345. Haberlandt. F. Der Gewichtsverlust der Eier während ihrer Bebrütung. Oesterreich. Seidenbau-Ztg., 4. Jahrg., p. 55-56. 1872.

346. Haberlandt, F. Gewichtsabnalume der Spinndrüsen der Seidenraupen während den einzelnen Altersperioden. - Oesterreich. Seidenbau.Ztg., 4. Jahrg., p. 110. 1872.

347. Habich, Otto. Ueber den Einfluss des Futters auf die Färbung und Zeichnung der Raupen des Genus Eupithecia. - Ent. Ztg:, p. 36-37. Stettin 1891. (Separat.)

348. Habich, 0tto. Coenonympha pamphilus L. ab. Eburnea mihi. - Jahrber. des Ent. Ver., VII. p. 29. Wien 1896. (Separatum).

349. Hagen. Anfrage betreffend die Grössenverschiedenheit der Libellen je nach dem Klima. - Ent. Ztg., VII. p. 63-64. Stettin 1846. 
350. Hagen, H. Die Odonaten- und Neuropteren-Fauna Syriens und KíleinAsiens. - Ent. Monatschr., VII. № 6, p. 193-199. Wien 1863.

351. Hagen, H. A. On the Color and pattern of insects. - Proc. Amer. Acad. Arts a. Sc., p. 234-267. 1882.

352. Hamann, 0. Europäische Höhlenfauna. Berlin 1897.

353. Haneld. (Demostratives). - Insekt.-Börse, XXI. № 5, p. 36-37. 1904.

354. Harpe, A. de la. Verhandlungen der schweizerischen Naturforschenden Gesellschaft bei ihrer Versamlung zu So?othurn den 24., 25. und 26. Heumonat 1848. 33. Versamlung, p. 56-58.

355. Harpe de la. Influence du froid sur la coloration des lépidoptères. - Bull. Soc. Vaudoise scienc. natur., II. Années 1846-1848, p. 390-400. 1849.

$355 a$ u. $b$. Heath, Har. The habits of California Termites. - Biol. Bull. Woods Holl., IV. p. 46-63. 1903.

356. Heer, 0. Einfluss des Alpenklimas auf die Farbe der Insekten. Mittheil. aus dem Gebicte der theoret. Erdkunde, I. p. 161-170. 1836.

357. Hein, Ernest. Etwas über Kunstziichtung. - Ent. Zeitschr., VIII. p. 81. Guben 1894.

358. Hein, Ernest. Meine Zucht-Versuche. - Soc. ent., IX. № 9, p. 65-66. 1894.

359. Hein, Ernest. Achtung. - Soc. ent., IX. № 12, p. 92. 1894.

360. Hein, Ernest. Resultate meiner Zuchtversuche. - Soc. ent., IX. № 11, p. 83. 1894.

361. Heissler, I. Antherea pernyi. - Soc. ent., VIII. № 13, p. 97. 1893.

362. Heissler, Lud. Raupenfütterung mit präparirtem Futter. - Soc. ent., IX. 숭 14, p. $106-107.1894$.

363. Heissler, L. Neine Zucht-Tersuche. - Soc. ent., IX. ㄴ. 10, p. 73-74. 1894.

364. Heissler. Noch einmal ,präparirtes Futter“. - Soc. ent., X. № 10, p. 73. 1895.

365. Hemmerling, Hermann. Ueber die Hautfarbe der Insekten. - Inaug.Dissert. der Univers. zu Bonn. (26 pp.) 1878.

366. Hemmering. 'Ueber den Lixus par plecticus. - Illustr. Wochenschr. für Ent., I. p. 400-402. 1896.

367. Hensel, Sitzung des Berlin. Ent. Ver. vom 10. Mai 1900. - Insekt.Börse, XVII. № 23, p. 181. 1900.

367a. Herbst, C. Experimentelle Untersuchungen über den Einfluss der reränderten chemischen Zusammensetzung des umgebenden Mediums auf die Entwickelung der Thiere. I. Theil: Versuche an Seeigileiern. Zeitsclır. für wissensch. Zool, LV. p. 446-518. 1893.

368. Hermann, D. und Landois, Leonard. Ueber die numerische Entwickelung der histologischen Elemente des Insektenkörpers. - Zeitschr. für wissensch. Zool., XV. p. 307-327. 1865.

369. Herold, Joa. Maur. Entwickelungsgeschichte der Schmetterlinge. Marburg 1815.

370. Heroldi, Mauriti. Disquisitione de animalium vertebris carentium in ova formatione. Francfurt am Mein 1838.

370 á. Herpin, Jean Charles. Mémoires sur divers insectes nuisibles à l'agriculture, et plus particulierement au froment, au seigle, à l'orge et au trèfle. - Mćm. Soc. royale et centrale d'agriculture, p. 340368. 1842. 
370b. Hertwig, 0scar. Allgeneine Biologie. 2. Auflage des Lehrbuches: „Die Zelle und Gewebe." Jena 1906.

371. Hetschko, Alfred. Ueber die Entstehung der Zeichnung bei den Schmetterlingsraupen. - Jahrber. des acad. naturwiss. Ver., III. p. 47-50. Graz 1877.

372. Heyer, Emil. Zu Antherea pernyi. - Soc. ent., VIII. Ji 14, p. 105. 1893.

373. Heyden, L. von. Ueber des Vorkommen des Lucanus cervus (Kleine Form) am Rhein. - Soc. ent., XI. oㅡ 24, p. 199. 1897.

374. Himsl, Ferdinand. Prodromus einer II a crolepidopterenfauna des Innkreises in Oberösterreich. - Soc. ent., X. 소 고: 13, 14, 15, 16, 18, 1895; 그 스: 19, 20, 21, 22, 23, 24. XI. № 1, 1896.

375. Himsl, Ferdinand. Anthocharis cardamines, eine zweite Generation? -Soc. ent., XI. № 12, p. 102. 1896.

376. Hörmann, Geo. Die Kontinuität der Atomverkettung, ein Strukturprinzip der lebendigen Substanz. Jena 1899.

$376 a$. Hoffer, Eduard. Ueber das Farbenvariieren der Hummeln. - Bericht der ent. Sekt: des naturw. Ver. für Steiermark über ihre Tätigk. im Jahre 1903/4, p. LXV-LXVII. Graz 1905. (Sonderabdr. aus den Mitth. des Naturw. Ver. für Steiermark, Jahrg. 1904).

377. Hoffmann, 0. Zwei neue Tineen. - Ent. Ztg., XXIX. p. 28-31. Stettin 1868.

378. Hoffmann, August. Ueber norddeutsche Strand- und Dünen-Varietäten der Lepidopteren. - Soc. ent., VI. Nㅡ 16, p. 125; Nㅡ 17, p. 129-130. 1891 .

379. Hoffmann, C. Eine Winterzucht. -- Krancher's Entomol. Jahrbuch, X. p. $203-204.1901$.

380. Hofmann, E. Die Gross-Schmetterlinge Europas. 1-te Aufiage. Stuttgart 1886.

381. Hofmann, Ernst. Die Gross-Schmetterlinge Europaș. 2-te Auflage. Stuttgart 1894.

382. Hofmann, Karl. Ueber Raupenseuchen. - Soc. ent., VI. № 7, p. 52. 1891.

383. Hofmann, 0. Bemerkungen zu: Experimentelle zoologische Studien mit Lepidopteren von Prof. Dr phil. M. Standfuss. - Entomol. Zeitschr., Iris, 1. lepidop. Heft, p. 44-65. 1899. (Separat.).

$383 \propto$. Holland. W. J. The Butterfly Book. New-York 1899.

$383 a$. Hollrung, M. Zeitschr. für Oesterr.-Ungar. Zucker-Industrie und Landwirthschaft, XXIII. 수 4, p. 540-557. 1894.

384. Hollrung, M. Einige weitere Bemerkungen zu Otiorhynchus ligustici L. - Illustr. Wochenschr. f. Ent., II. p. 549-550. 1897.

384 a. Holmes, S. J. The reactions of ranatra to light. - Journ. Comp. Neur. Grauville, XV. p. 305-349. 1905.

385. Holtz, Martin. Die Macrolepidopteren-Fauna Ciliciens. - Illustr. Wochenschrift f. Ent., II. p. $42-47$; p. $60-63$; p. $77-79 ;$ p. $88-$ 93. 1897.

386. Holtz, Martin. Lygris peloponnesiaca Rbl., ihre Entwickelung und Gewohnheiten. - Insekt.-Börse, XXX. № 19, p. 148-149. 1904.

387. Hopkins, F. Gowland. Note on a yellow Pigment in Butterflies. - Proc. Chem. Soc., V. p. 117-118. London 1889. 
388. Hopkins, F. Gowland. Pigment in yellow Buttertlies. - Nature, XLV. p. 197-198. Jahrg. 1891. London and New-York 1892.

389. Hopkins, F. Gowland. The Pigments of the P i eridae. - Proc. Roy. Soc., LVII. ํㅜ 340, p. 5-6. London 1895.

390. Hormuzaki, C. von. Nachtfang am Fïder und an blïhenden Weiden im ersten Frühling 1893. - Soc. ent., VIII. ㅅ 4, p. 27-28. 1893.

390 a. Horner. Astronomica Itineraria. 1799. (Ein Manuscript in der ZürcherSternwarte. Eine entsprechende Notiz befindet sich in: Vierteljahrsschriften der Naturforsch., Gesellsch. XVI. № 4, p. 409-410. Zürich 1871).

391. Howard, L, 0. and Marlatt, C. I. The principal household insects of the Inited States. - U. S. Depart. Agric. Div. Ent. Bull., IV. № 8. 1896. (Separat.).

391a. Howard, L. 0. Temperature Experiments as affecting received Ideas on the Hibernation of injurious Insects. - 28. Ann. Rep. Ent. Soc. Ontario, p. 164-165. 1897; U. S. Depart. Agric. Div. Ent. Bull., IX. N. S. $18-20.1897$.

392. Huber, François. Nouvelles observations sur les abeilles. 2-e édition, considerableme et augmentée (par son fils Pierre Huber). 2 Tomes. Paris et Genève 1792-1814.

393. Huber, François. Neue Beobachtungen über die Bienen, in Briefen an Bonnet. Aus dem Französischen mit Anmerkungen und Zusätzen vermehrt von Riem. Dresden 1793.

394. Haber, François. Neue Beobachtungen über die Bienen. - Voigt's Magazin für den neuesten Zustand der Naturkunde, mit Rücksicht auf die dazu gehörigen Hilfswissenschaften, Bd. VIII, p. 433-434. 1804.

395. Huber, H. Der Köderfang, bei Tage. - Soc, ent., VI. № 3, p. 20-21; 스 4, p. 27-28. 1891.

396. Huber, Pierre. Recherches sur les moeurs des fourmis indigènes. Paris et G'enève 1810.

397. Huber, Pierre. The natural History of ants, translated from the French with notes by I. R. Johnson. London 1820.

398. Hüttner, Augrst. Kleine Mittheilungen. - Ent. Zeitschr., IX. p. 60. Guben 1895.

399. Ingenitzky, I. Schädliche Insekten des Siebenflüsse-Gebietes. - Landund Forstwirthsch., p. 177-197. 1897. (Russisch : Ингеницвій, И. Вредныя наськомыя Семшрьцья. - Сельск. хозяйство и дњсовод.).

400. Irmscher, Emil. Zum Entstehen der Aberrationen in der Natur. - Illustr. Zeitschr. für Ent., V. № 11, p. 166. 1900.

401. Iwanow, P. W. Verzeichniss von O $\mathrm{rth}$ opter a der Umgebung von der Stadt Kupjansk. - Arbeiten der Naturforscher-Gesellsch. bei der Univers. zu Charkow, XXI. (1887). p. 295-362. 1888. (Russisch: Ивановъ, II. В. Сппсогъ прямогрылыхъ [Orthoptera] окрестнстей г. Купянска. - Труды Общ. Испнтат. Прпроды шри Импер. Харьковскомъ Универс.).

402. Iwanow, P. W. Die Vergleichung der Qualität der Cocons und der Seide einiger Rassen des Seidenspinners des Maulbeerbaumes. - Arbeiten der kaukasischen Seidenzucht-Station, Jabrg. 1892, VI. Bd., 3. Lief., 
p. 75-89. Tiflis 1893. (Russisch: Ивановъ, В. ПI. Сравпеніс каqествъ коконовъ п шелка иькоторыхъ породъ тутовато шелкопида. - Труды кавказск. ШШелководств. Стацціп).

403. Iwanow, P. Das Verzeichniss der Ichneumonoiden (Familia I chneumonoidae Foerster) der Umgebung von der Stadt Kupjansk, mit Tabellen zur Unterscheidung der Gattungen und Arten dieser Insekten. - Nachr. der Gesellsch. der Liebhaber der Naturw., Anthropol. und Ethnogr., LXXXVI. Arbeiten der Zoolog. Abth. der Gesellsch., X. Das Tagblatt der Zoolog. Abth. der Gesellsch. und des Zoolog. Museums., II. № 6, p. 1-27. Moskau 1897. (Russisch: Ивановъ, II. Списокъ пхневмоновъ [Сем. I c h n e Forster] окрестностей города Кунлис: а, съ табл. для отлпія родовъ II видовъ этихъ наськомыхъ. - Шзв. Общ. Јюб. Естествозн., Антроп. и Этногр.; Труды Зоол. Отд. Общ.; Дневн. Зоол. Отд. Общ. и Зоод. Музел).

404. Iwanow, P. Braconidae cryptogastri und areolarii der Lmgebung ron Stadt Kúpjansk. - Arbeiten der Naturforscher-Gesellsch. bei der Univers. zu Charkow, XXXIII. (1898-1899). p. 273-382. 1899. (Russisch: Ивановъ, П. Брапониди скрытобрюхіе и зеркальевне [Braconidae cryptog stri et areolarii] окрестностей г. Купянска. Труды Общ. Исиытат. Прпродц ири Імпер. Харьюовскомь Универс.).

405. Iwanow, W. P. Zur Frage über das Aufziehen der Raupen mit Blättern der Schwarzwurzel. - Arbeiten der kaukasischen Seidenzucht-Station, X. Bd., J. Liefer., p. 19-21. Tiflis 1901. (Russisch: Ивановъ; B. II. Къ вопросу о выкормк' уервей лпстьями скорцонеры. Труды кавказск. Шелководств. Станціи).

406. Iwanow, W. P. Das Vergleichen rerschiedener Sorten ron MaulbeerenBäumen und einiger anderen Pflanzen in Bezug auf die Verwendung ihrer Blätter zum Füttern des Scidenspinners. - Arbeiten der kaukasischen Seidenzucht-Station, X. Bd., I. Liefer., p. 49-56. Tiflis 1901. (Russisch: Ивановъ, В. II. Сравненіе раздиныхъ сортовъ шелковицы и ныкоторыхъ другихъ растеній въ отношенів пригодностп ихъ листьевъ для выкормлевія тутоваго шелкорлда. - Труды кавказск. Нелководетв. Стацціи).

407. Jacobi, A. Fillonia piniaria L. im Forstrevier Stolbischtsche beim Dorfe Matüschino, Gouvernement Kasan. - Arbeiten der Naturforsch.Gescllsch. in Kasan, XXI. № 3, p. 1-16. 1859. (Russisch: §воби, A. Fidonia piniaria L. въ Столощенской лњсной дачњ, прп деревшъ Боровое Матюшино, Казаискаго уџзда. -- Труды Общества Естествонсп. ири Имиер. Казанскомъ Уииверс.).

408. Jacobi, A. Ueber die Entwickelung der Zeichnung an den Schmetterlingsflügeln. - Arbeiten der Naturforsch.-Gesellsch. in Kasan, XXI. p. 1-13. 1889-1890. (Russisch: Якоби, А. Матерьялы къ нсторіп развптія ршсунка крыла бабочекъ, - Труды Общ. Естествовсп. при Имп. Казанскомъ Увиверс.).

409. Jacobson, G. Ueber die Flügeldeckenmakeln der Coccinelliden. Hor. Soc. Ent. Rossicae, XXXIV. № 1-2, p. VI-XII. (1899). 1900. 
(Russisch: Яғобсонъ, Г. О пятнахъ па надкрыльяхъ божьих коровокъ. - Протоколь 1 февр. 1899).

410. Jaenichen, R. Eine neue Zeitvarietät von Iasiocampa populifolia Esp.Insekt.-Börse, XI. № 4, p. 38-39; 소 5. p.46-47; 수 6, p. 59-60. 1894.

411. Jänichen, R. Etwas über Aufzucht aus dem Ei. - Insekt.-Börse, XI. Je 11, p. 109-110. 1894 .

412. Jänichen, R. Resultat eines Experimentes mit Lasiocampa pini L. var. montana Stdgr. - Insekt.-Börse, XIII. Nㅗ 4, p. 27-28; 스 6, p. $46-47.1896$.

413. Jänichen. Entomologische Mittheilungen. - Insekt.-Börse, XIII. 소 37, p. 248. 1896.

414. Jänichen, R. Lasiocampa potatoria L. olne Ueherwinterung der Raupen. Insekt.-Börse, XIV. 승 31, p. 182-183; № 32, p. 189-190; 스 33, p. $195-196.1897$.

415. Jänichen, R. Die Kohlensäure als Schlafmittel für Raupen. - Insekt.Börse, XIV: 스 11, p. 62 ; 스 12, p. 69-70; № 13, p. $75-76$; № 14, p. $81-82 ;$ № 15, p. $87-88 ;$ № 16, p. $93-94 ;$ 싱 17 , p. 99. 1897.

416. Jänichen, R. Schlussbetrachtungen über Línhlensäure, Säurestarre (Wärmestarre) und Winterschlaf bei Raupen. - Insekt.-Börse, XVI. № 19, p. $110-111.1899$.

$416 a$. Jänichon, R. Die schleimige Anfeuhtung des Raupenkörpers vor dem Eingehen in den Puppenzustand. - Insekt.-Börse, XVII. 스 10, p. $75-76.1900$.

417. Jahn, Alfred. Zucht von Käfern in einem Drahtgazehüuschen. - Soc. ent., XI. 주 22, p. 179. 1897.

418. Jaroschewsky, W. A. Materialien zur Entomologie des Gouvernements Charkow. IV. - Arbeiten der Naturforscher Gesellsch. bei der Universität zu Charkow, XVI. (1882). p. 447-526. 1883. (Russisch: Яротевскій, В. А. Матеріалы для әнтомологіи Харьковской губерніи. IV. - Труды Общ. Нспытат. Природы при Імпер. Харьковскомъ Уншверс.).

419. Jaroschewsky, W. A. Sechster Zusatz zum Verzeiclıniss von Diptera in Chirkow und seiner Umgeluung mit der Angabe ihrer Verbreitung auf dem Gebiete des europäischen Russlands. - Arbeiten der Naturforscher-Gesellsch. bei der Univers, zu Charkow; XIX. (1885). p. 307-348. 1886. (Russisch: Ярошевскій, В. А. Шестое дополненіе къ списку двукрылыхъ наськомыхъ. [Diptera] Харькова и его окрестностей съ указаніемъ распространенія пхъ въ предьлахъ евјолейской Россіп. - Труды Общ. Нспыт. Природы при Нмпер. Харьковскомъ Универс.).

420. Jaroschewsky, W. A. Siebenter Zusatz zum Verzeichniss von Diptera in Charkow und seiner Umgebung mit der Angabe ihrer Verbreitung auf dem Geliete des europäischen Russlands. - Arbeiten der Naturforscher-Gesellsch. bei der Univers. zu Charkow, XX. (1886). p. 111-150. 1887. (Russisch: Ярошөвскій, В. А. Седьмое дополнепіе къ списку двукрылыхъ наськомыхъ [Diptera] Харькова и его окрестио тей съ уназаніемъ распространенія нхъ въ предьлахъ 


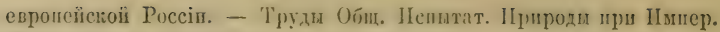
Харьковскомъ Јниверс.).

421. Jarosehowsky, W. A. Zur henntniss der Finnit von 'lenthredinidae des Gouvernements Charkow. - Arbeiten der Naturforselier-Gesellsch. bei der Univers. zu Charkow, XXI. (1887). p. 363-377. 1888. (Russisch: Ярошевскій, В. А. Іъъ свъдыніль о фауны Tentliredinidae Харьвовской губериін. - Трудн Общ. Јенитат. Прпроды при Илпер. Харьковсковъ Универс.).

422. Jaroschowsky, W. A. Verzeichniss von Chrysididae, welche in Gouvernement Charkow vorkommen. - Arbeiten der NaturforscherGesellsch. bei der Univers. zu Charkov, XXI. (1887). p. 279-293. 1888. (Russisch: Ярошөвскій, B. А. Перепепь Ch r ys idida e, водлдихся въ Харьковской губернін. - Труды Общ. Нспқат. Ірпроди при Импер. Харьковскомъ Упиверситеть).

423. Jarosehowsky, W. A. Notiz üher Trigonalys hahuii Spin. T'aschb. (Trigonalys nigra Westw.? Trigonalys aterrima Ev.). - Arbeiten der Naturforscher-Gesellsch. bei der Univers. zu Charkow, XXII. (1888). p. 133-142. 1889. (Russisch: Ярошөвегій, В. А. ЗамЖтпа о Trigonalys hahnii Spin. Taschb. [Trigonalys nigra Westw.? Trigonalys aterrima Ev.] - Трудц Общ. Шспыт. Ірпроды шрг Имп. Харьновсіомъ Іиив.).

$423 \alpha_{1}$. Jensen, Parl. Ueber individuelle physiologische Unterschiede zwischen Zellen der gleichen Art. - Pflüger's Arch. f. Physiol., LXII. p. 172. 1895.

$423 \alpha^{\prime}$. Jickeli, Carl Fr. Die Unvolliommenheit des Stoiliwechsels als Teranlassung fir Vermehrung, Wachstum, Differenzierung, Riickbildung und Tod der Lebewesen im Kampf ums Dasein. - Herausg. vom siebenbürgischen Vereines für Naturwiss. zur Feier seines 50-jährig. Bestandes. (353 pp.). Berlin 1903.

$423 \propto$. Johnson. Report Ent. Departem. New Jerrey Agrig. College Exper. Stat. for the Year 1902.

$423 \beta$. Joseph, G. L'influence de l'éclairage sur la disjonetion des organes visuels, leur réduction, leur atrophie complète et leur compensation chez les animaux cavernicoles. - Bull. Soc. Zool. Fr., p. 121125. 1892.

$423 a$. Judeich und Nitsehe. Lehrbuch der mitteleuropäischen Forstinsektenliunde. Bd. II. Berlin 1895.

124. Jung, Emile. Contributions à l'histoire de l'influence des milieux pliysiques sur les êtres vivants. - Arch. Zoolog. expérim., VII. p. 251-282. 1878.

425. Justi. Dunder, Seidenzucht. Wien 1854.

426. Kabis, G. Lasiocampa pini L. - Illustr. Zeitschr. für Ent., V. 츠 21, p. 331. 1900.

427. Kabsch, W. Anatomische und pliysiologiche Untersuchungen über einige Bewegungserscheinungen im Pflanzenreiche. -- Botan. Ztg., XIX: 스 47, p. $345-350$; 스 48, p. $353-358$; 스 49, p. $361-366$; № 50, p. $369-375.1861$.

428. Kalender, E. Untersuchungen über beschleunigte Entwicklung überwinternder Schnetterlings-Puppen mit Berïcksichtigung der Lebensund Verwandlungsart dieser Puppen.-Inaug.-Dissert. Rostock 1872. 
429. Kalender, E. Ist die Ueberwinterung gewisser Raupen-Arten zu der Entwicklung nothwendig? - Entomol. Zeitg., XXXIV. p. 366-367. Stettin 1873.

430. Kaltenbach, I. H. Hermophrodi et von Bupala piniaria. - Tijdschr. voor Ent. Versl., XXXII. p. XXII. 1878-1879.

$430 a$. Kaltenbach, I. H. Die deutschen Phytophagen aus der Classe der Insekten. - Verh. Naturhist. Ver. Bonn, XXI. p. 228-404. 1864; XXIV. p. 21--117. 1867; XXVI. p. 106-224. 1869.

431. Kamensky, S. N. Fütterungsversuch der (Seiden-) Raupen mit färbenden Stoffen. (Vorläufige Untersuchung). - Arbeiten der kaukasischen Seidenzucht-Station, Jahrg. 1891, IV. Bd., p. 96-101. Tiflis 1892. (Russisch.: Каменскін̈, С. Н. Опцтъ кормленія шеліовичныхъ червей красяцими веществази [предварителная дабота]. - Труди кавказк. Шелководсть. Ставціи).

432. Kamensky, S. N. Der Versuch der Aufzucht der Seidenraupen mit Blättern von Taraxacum officinale. - Arbeiten der kaukasischen Seidenzucht-Station;, Jahrg. 1891, IV. Bd., p. 101-103. Tiflis 1892. (Russisch: Кащенсвій, С. Н. Опнтъ выкорики пелковпчвыхъ червей лпстьями одувапчика. - Труды навказкой Ше.ловодственной Станціп).

433. Kamensky, S. N. Zur Frage über das Eineignen vom Organismus der Seidenraupe färbender Stoffe, welche mit Nahrung eingefülırt werden.Arbeiten der kaukasischen Seidenzucht-Station, Jahrg. 1892, Bd. VI, Lief. 3, p. 8-9. Tiflis 1893. (Russisch: Каменскій, С. H. Къ вопросу объ усвоеніи организмомъ пелковичнаго червя красящихъ веществъ, введенныхъ съ пищею. - Труды кавказск. Шелководств. Станціп).

434. Kamensky, S. N. Versuche über die Aufzucht des Seidenraupen mit Blättern von Taraxacum officinali und Schwarwurzel. Arbeiten der kaukasischen Seidenzucht-Station, Jahrg. 1892, VI. Band, 3. Lief., p. 9-11. Tiflis 1893. (Russisch: Каменевій, С. Н. Опыты кормленія пелковичныхъ червей листьями одуванчвка и скорзонерн. - Труды кавказск. Шелководств. Станцін).

435. Karsin, I. Kampf mit Erbsenläusen. - Der Wirth, 으 50. 1897. (Russisch: ґарзинь, И. Въ борьбъ съ гороховой тдей. - Хозяшнъ).

435 a. Kask, F. Ueber die Grösse des Bienenrassen und der Zellen der künstlichen Wachswaben. - Herold der russisch. Gesellsch. für Bienenzucht, IX. 수 6. 1902. (Russisch: Баскњ, Ф. 0 пелпчив' пиелишыхъ расъ в ячеекъ искуственной вощнын. - Вбесн. русск. Общ. Птеловодства).

436. Kathariner, L. Fürbungs-Anomalien bei Tagfaltern. - Illustr. Zeitschr. für Ent., 4. Bd., 소 5, p. 74. 1899.

437. Kathariner, I. Versuche über den Einfluss des Lichtes auf die Farbe der Puppe vom Tagpfauenauge (V. io L.). Biolog. Centralbl., XIX. 그 21, p. 712-718. 1899.

438. Kathariner, L. Ueber die Beziehungen zwischen der Zeichnung von Vorder- und Hinterflügel bei Lepidopteren. - Insekt.-Börse, XVII. 고 21, p. 164-165. 1900. 
439. Kathariner, L. Versuche über die Ursachen des „partiellen Albinismus" bei Schmetterlingen. - Illustr. Zeitschr. für Entomol., V. de 21, p. $321-323.1900$.

440. Kathariner, L. Versuche über den Einfluss der versehiedenen Strahlen des Spektrums auf Puppe und Falter von V.urticae L. und V. io L.Illustr. Zeitschr. für Ent., V. p. 361-364; p. 377-379. 1900; VI. p. 7-9. 1901.

441. Kawraisky, Th. Th. Ein Versuch des Aufziehens der Seidenraupen mit Blättern der Schwarzwurzel. - Arbeiten der kaukasischen Seidenzucht-Station, X. Bd., I. Liefer., p. 17-19. Tiflis 1901. (Russisch: Каврайскій, $\boldsymbol{\theta}, \boldsymbol{\theta}$. Опьтъ внгормпи шелковичнихъ червей листьями скорцонеры. - Труды кавказск. Шелководств. Станціп).

442. Keferstein, A. Lepidopterologische Bemerkungen. - Entomol. Zeitg., VI. p. 357-359. Stettin 1845 .

443 u. 444. Keferstein, A. Betrachtungen ueber Entwickelungsgeschichte der Sclimetterlinge und deren Variation. Erfurt 1880.

445. Keller. Die Wirkung des Nahrungsentzuges auf Phylloxera vastatrix.Zool. Anzeig., X. p. 583-588. 1887.

446. Keller, C. Reisestudien in den Somalilandern. - Globus, LXIX: i. 12, p. 181-187; 스 13, p. 203-208; 수 23, p. 361-367; LXX: 슨 10, p. 158-162; № 11, p. 170-173. 1896.

447. Kellog, V. L. and R. G. Bell. Variations induced in larval, pupal and imaginal stages of Bomby $x$ mori hy controlled varying food supply.Science, N. S., Vol. XVU. № 467, p. 741-748. 1903.

447a. Kendrick, Mac and Coleman, I. I. The mechanical production of cold and the effects of cold upon microphytes. - Chemical Nows, IIl. № 1341, p. $61-64.1885$.

448. Kе[0̈]ppen. Schädliche Insekten. III. Bd. (Russisch: Кеппенъ. Вредпшя паськомыя).

448 a. Kerschbaumer. Malaria, ihr Wesen, ihre Entstehung und ihre Verhütung. Wien und Leipzig 1901.

449. Kessler, H. Notizen zur Lebensgeschichte der Rosenblattlaus, Aphis rosae. Cassel 1886.

$449 a$. Kimakowicz, Frieda V. Pass Dusch und Umgehung im Zibiusgebirge. Jahrb. des Siebenbürgischen Karpatenvereins, XIII. p. 79. 1893.

450. Kisselew, G. Naphta als Vertilgungsmittel gegen Ocneria dispcr. - Der Wirth, № 43, p. 769. 1896. (Russisch: Кисөлөвъ, Г. Нефть, какъ средство противъ вепариаго шелкопряда. - Хозяпнъ).

451. Klapálek, Fr. Ein Beitrag zu Kenntnis der Neuropteroiden ron Ober-Steiermark. - Sitzber. der kgl. Böhm. Gesellsch. der Wiss., Math-Naturw. Classe, Jahrg. 1903, p. 1-5. 1904.

452. Klein, Josef. Die zum Ausschlüpfen des Seidenspinners und Ablegung der Eier erforderliche Temperatur. - 7. Jahrber. d. österreich.schles. Seidenbau-Ver., p. 55-58. 1865.

452a. Kleine, f. Ueber das Gesetz der Entwickelung der Geschlechter hei den Insekten. - Zeitschr. für wissensch. Zool.. XVII. p. 533-538. 1867.

453. Klemensiowiez. Verzeichniss einiger für Galizien neuer Schmetterlingsarten. - Soc. ent., VIII. № 18, p. 137,-139. 1893. 
454. Klooss, H. Hine zweite Generation von Ocneria clispar. - Illustr. Wochenschrift f. Ent., II. p. 175-176. 1897.

455. Knaggs, H. G. Notille. - Lepidopterist's Guide, new. ed. p. 47. 1884. 455a. Knatz, I. Ueber die Farben der Lepidopteren. - XXIX. und XXX. Ber. des Ver. für Naturk, zu Cassel über dic Vereinsjahre vom 18. Apr. 1881 bis dahin 1883, p. 63-65. 1883.

1556. Knatz, L. Versuch einer Aufstellung und Begründung einer Lokalfauna für Kassel und Umgegend. - XXIX. und XXX. Bericht des Ver. für Naturkunde zu Cassel über die Vereinsjahre vom 18. Apr. 1881 bis dahin 1883 , p. $71-89.1883$.

456. Knauer, Friedr. K. Ueber den Einfluss der äusseren Bedingungen auf Gestalt und Structur der Insektenlarven. - Naturhistoriker, III. 스 1, p. 1-2. 1880.

457. Knauthe, K. Zur Biologie der Amphibien. - Zool. Anzeig., XV. 소 381, p. $20-23.1892$.

457a. Knoehe, Ernst. Beiträge zur Generationsfrage der Borkenkäfer. - Forstwissenschaftliches Centralbl., XXVI. p. 1-73. 1904.

4576. Koch, G. Die Schmetterlinge des westlichen Deutschlands. Kassel 1856.

458. Koch, Gabriel. Die Indo-Australische Lepidopteren-Fauna in ihrem Zusammenhange mit der Europuiisehen nebst den drei Hauptfaunen der Erde. Leipzig 1865.

459. Kochs, W. Kann die Kontinuität der Lebensvorgänge zeitweilig völlig unterbrochen werden? - Biol. Centralbl., X. p. 673-686. 1890.

460. Kochs, W. Ueber die Vorgänge beim Einfrieren und Austrocknen von Thieren und Pflanzen. - Biol. Centralbl., XII. p. 330-339. 1892.

460 ж. Kodis, T. Die Unterkühlung der thierischen und pflanzlichen Gervebe. Centralbl. für Physiolog., XII. № 18, p. 593-595. 1898.

461. König, Clemens. Die Ursache der verschiedenen Bienenform und Bienentriebe. - Illustr. Wochenschr. f. Ent., I. p. 600-603. 1896.

$461 a$. König und Dietrich. Zusammensetzung und Verdaulichkeit der Futtermittel. - Zeitschr. d. landw. Centralv. für Rheinpreussen, 1858.

461b. König, J. Chemie der menschlichen Nahrungs- und Genussmittel. 2. Theil. Berlin 1904.

$4616 b$. Köppon. [Vide lauf. ㄱo 448].

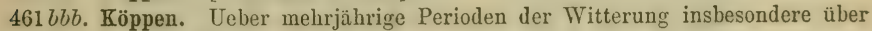
die 11-jährige Periode der Temperatur.

461c. Koornicke, Max. 1. Ueber die Wirkung von Röntgenstrahlen auf die Keimung und das Wachstum. 2. Die Wirkung der Radiumstrahlen. auf die Keimung und das Wachstum. - Ber. deutsch. botan. Gesellsch., XXII. p. 148-166. 1904.

462. Kolbe, H. J. Einfürnug in die Kenntnis der Insekten. Berlin 1889-1893. (Erschien ursprünglich in 14 Lieferungen).

463. Kolbe, W. Ueber das Eintreten eines Sommerschlafes bei Chrysomeliden. - Zeitschr. für Ent., N. F. XXIV. p. 26-37. 1900.

463a. Kolisko, Alfred. Ueber Inzucht von Ditina tiliae. - Verh. der Zool.bot. Ges., LV. № 3-4, p. 167-169. Wien 1905. (Bericht der Sekt. für Lepidopt.). 
$463 b$ u. $462 \pi$. Koschewnikow, G. Ujeber die Bedentung der die Bienen umgebenden Lufttemperatur für ilır Leben und über die Temperatur der Bienen selbst. - Russische Bienenzucht-Liste, Ne 10, p. 333-336; 주 11, p. 357-360; 스 12, p. 399-402. 1895; 스 2, p. 61-64; ‥ 3; p. 91-95. 1896. (Russisch: Кожевниковъ, Г. Значепіе температуры овружающаго пчелъ воздуха для ихъ жизни х температура сампхъ пчелъ. - Русск. ПІчеловод. Лпстогъ).

464. Koschewnikow, G. A. Anormale Erscheinungen im Leben des Bienenvolkes. - Nachr. der k. Gesellschaft der Liebhaber der Naturw., Anthropolog. und Ethnogr., LXXXVI. Arbeiten der Zool. Abth. der Gesellsch., X. Das Tagblatt der Zoolog. Abth. der Gesellsch. und des Zool. Museums, II. № 소 9 und 10, p. 53-57. Moskau 1899. (Russisch: Божевниговъ, Т. А. Ненормалшша явлепіл въ жизии пчелиной семьн. - ІІзвьст. Импер. Общ. Јюовт. Естествозн., Антроп. п Этногр.; Дневн. зоол. отқь.л.).

465. Koschownikow, G. A. Rassen der kaukasischen Bienen im Zusammenhange. mit der Frage über die Bienenrassen überhaupt. - Beilage zu der Zeitschr. der russisch. Ges. für Bienenzucht (24 pp.). St.Petersburg 1900. (Russisch: Боэкевниковъ, Г. А. Породв павказскпхъ пчелъ въ связп съ вопросомъ о породахъ пгчедъ вообще. Безплатное прпложеніе гъ Вьстнику Русск. Общ. Пичеловодства).

466. Koschewnikow, G. A. Ueber den Fettkörper und die Oenocyten der Honigbiene (Apis mellifera L.). (Vorläufige Mittheilung). - Zool. Anzeig., XXIII. ㄱį 618, p. 337-353. 1900.

467. Koschewnikow, Grigory. Materialien zur Naturgeschichte der Biene Apis mellifera L.). - Nachricht. der kaiserl. Gesellsch. der Liebhaber der Naturwiss., Anthropolog, und Ethnogr., XCIX. Arbeit. der Zool. Abth. Bd., XIV. 1. Lief. (144 pp.). Moskau 1900. (Russisch: Кожквниговь, Гриторій. Матеріа.ии по естественної исторів пчелы [Apis mellifera L.]. - Нзвћст. ІІмпер. Общ. Јюбвт. Естествозн., Антроп, II Этногр.; Труды зоолог. отдыл.).

467a. Koschownikow, Grigory. IIaterialien zur Naturgeschichte der Biene. (Apis mellifera L.). II. Lieferung. Ueber das Polymorphismus der Biene und anderer Insekten. - Nachr. der kaiserl. Gesellsch. der Liebhab. der Naturwiss., Anthropol. und Ethnograph., XCIX. 2. Liefer., Arbeiten der zoolog. Abth., XIV. (181 pp.). Moskau 1905. (Russisch: Ћожөвниговъ, Гршгорій. Матеріа.лы по естествевной исторіш пчелы. [Apis mellifera L.]. Випускъ второй. 0 полнморфизыљ у пчели и у другихъ наськомыхъ. - Извьст. Икиер. Общ. Лгобителей Естествозн, Антронод. п Этногр.; Труды зоодог. отдњд.).

468.- Kowalewsky, A. 0. Zum Terhalten des Rückengefásses und des guirlandenförmigen Zellenstranges der M u sciden während der Metamorphose. - Biol. Centralbl., VII. p. 74-79. 1887.

469. Kowalewsky, A. Ein Beitrag zur Kenntniss der Exkretionsorgane. - Biol. Centralbl., IX. p. $33-47$; p. $65-76.1 \varepsilon 89$.

470. Kowalewsky, A. 0. Sur les organes excréteurs chez les arthropodes terrestres. - Congrès internat. Zool. XII. Sess. à. Moscou, I. Partie. p. 187-235. Moscou 1892. 
47 i. Kramer, P. Zur Metholik der Zoologie. - Zeitschr. für wissensch. Zool., XXX. (Suppl.) p. 294-305. 1878.

472. Kramer, P. Reflexionen über die Theorie, durch welche der SaisonDimorphismus bei den Schmetterlingen erklärt wird. - Arch. für Naturgesch., 44. Jahrg., 1. Band, p. 411-419. 1878.

472a. Krasilschtschik, I. M. Zur Frage über die Wirkung der Gifte auf Insekten. - Arbeit. des Bureau für Ent. des gelehrt. Comité beim Minist. für Ackerbau, IV. 스 3. (25 pp.). St.-Petersburg 1903. (Russisch: Красильщикъ, И. М. Къ вопросу о дъйствіп ядовъ на насъкомыхъ. - 'Труды бюро по Энтомол. Учен. Компт. Мин. Земл. и Госуд. Имущ.).

472b. Krasilschtschik, I. M. Heliot7is dipsaceus L. und einige andere Schädlinge des Leins in Nord-Kaukasus. - Verlag des Depart. für Ackerbau beim Minist. für Ackerb. (64 pp.). St.-Petersburg 1900. (Russisch: Ћрасилщиљъ, П. М. .Іюцервовал или льняная совка [Heliothis dispaceus L.] и нььоторые другіе вредителп льна на сывернозъ Кавказћ. - Издан. Минист. Землед. п Госуд. Имуц., Департ. Земледыліе.)

472c. Krasilschtschik, I. Ein neuer Feind ron Pllyctacnodes (Eurycreon) sticticalis L. - Der Landwirth, № 1. 1902. (Russisch: Eраспльщикъ, И. Новый врагъ луговаго щотылька. - Хозяннъ.)

473. Krasnow, A. N. Der Versuch der Entwickelungsgeschichte der Flora von südlichem Theil der östlichen Tjan-Schar. - Ber. kaiserl. russisch. geograph. Gesellsch. Abth. allgem. Geograph., XIX. p. 10-11. 1888. (Russisch: Красновь, А. Н. Опытъ псторіп развитія ф)орн южной части восточнаго Тлнь-шаня. - Зап. Имп. Русск. І'еогр. Общ. по Общ. Теогр.).

473a. Kraepelin, K. Die Fauna der Umgegend Hamburgs. - Hamburg in naturwissenschaftlicher und medizinischer Beziehung, p. 32-56. Hamburg 1901.

474. Krauss, H. Einiges über Konservieren der Insekten. - Illustr. Wochenschr. f. Ent., II. p. 383-384. 1897.

475. Krodel, Ernst. Durch Einwirkung niederer Temperaturen aut das Puppenstadium erzielte Aberrationen der Ly caena-Arten: corydon Poda und damon Schiff. (Lep.). - Allg. Zeitschr. für Ent., IX. № 3-4, p. $49-55$; 스 5-6, p. 103-110; № 7-8, p. 134-137. 1904.

476. Krüger, Edgar. Ueber die Entwililung der Flügel der Insekten mit besonderer Berücksichtigung der Deckelflügel der Käfer. - Inaug.Dissert. Göttingen 1898. (60 pp.)

476a. Krüger. Wanderung von Pieris brassicae. - Illustr. Zeitschr. für Ent., V. № 19, p. 299.1900.

477. Krukonberg, C. Fr. W. Grundzinge einer vergleichenden Physiologie der Farbstoffe und der Farben. 1884.

478. Krulikowski, L. Ein Versuch des Lepidopteren-Catalogs des Gouvernements Kasan. II. S phinges et Bom by ces. - Bull. Soc. Natural. de Moscou, Année 1892, № 1, p. 17-48. (Russisch: Rрулшковсій, Л. Опытъ каталога чешуекрылыхъ Казанской губ. П. Sphinges et $\mathrm{B} 0 \mathrm{mbyces}$ ). 
478a. Krulikowski, L. Zur Kenntniss der Le pidojteren-Fiuna des Gouvernements Wjatka. I. Lepidopteren der Umgebung der Stadt Sarapul. II. Lepidopteren der Umgebung. der Stadt Urschum. - Berichte der Ural'schen Iiebhabergesell. der Naturwiss., XI. Nę 2, p. 203-246. 1858. (Separat.). (Russisch : Крулнговекій, Л. Гіъ свџдьніямъ о

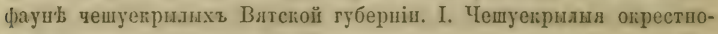
стей города Сарапуля. II. Четуекрылыя окрестностей города Уржума. - Записки Уральск. Общ. Любпт. Еетествозв.).

47ऽ6. Krulikowski, Leonid. Zur Kenntniss der Lepid opteren-Fauna des Gouvernements Wjatka. III. Lepidopteren, gesammelt 1887 in Bezirk Sarapul. - „Ekaterinburg'sche Woche", 스 35, 스 37, 소 39, p. 65-76. 1889. (Separat.). (Russisch: Круликовегій, Лөовидъ. Гъ свьдыніямъ о фаунь' чешуегрылыхъ Вятской губ. ІІІ. Чепуекрылыл, собранныя въ 1887 году въ Сарапульскомъ уъздњ. - „Епатеривбургекая Недьля").

478c. Krulikowski, $\boldsymbol{I}$. Zoologische Notizen. I. Verzeichniss der Orthopteren, welche in Bezirk Sarapul, Gouvernement Wjatka, vorkommen. Berichte der Ural'schen Liebhabergesellsch. der Naturwiss., XIII. No 1, p. 9-10. Ekaterinburg. 1891-92. (Russisch: Круликовскій, Л. Зоологпческія замдтки. І. Списогъ прямокрылыхъ насьвомкхъ, встр‡чающихся въ Сарапульсвомъ ућздъ Вятской губернін. - Запнски Уральск. Общ. Јюбпт. Естествозн.).

478d. Krulikowski, L. Zur Kenntniss der Ledidopteren-Fauna des Gouvernements Wjatka. IV. Notizen über Lepidopteren, gesammelt 1888 . und 1889 in Bezirk Sarapul. - „Ekaterinburg'sche Woche“, № 14, ․․ 16, p. 79-81. 1890. (Separt.). (Russisch: Крулнговекій, Л. Ііъ

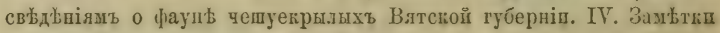
о тешуекрылыхъ, собранныхъ въ Сарапульскомъ ужздъ въ 1288 п 1879 г. г. - „Екатеринбургская Недвия

478e. Krulikowski, I. Zur Kenntniss der Lepidopteren-Fauna des Gouvernements Wjatka. V. Notiz über Lepidopteren der Umgebung derStadt Wjatka. VI. Einiges über Le pidopteren, gesammelt im Sommer 1890 in Bezirk Sarapul. VII. Zur Kenntnis der Lepidopteren. in Bexirk Malmisch. - Berichte der Ural'schen Liebhabergesellsch. der Naturwiss., XV. 스 1, p. 3-7. 1895. (Separat.). (Russisch: Круликовекій, Л. Кіъ свъдъніямъ о фаупь тепуекрылыхъ Вятской губерпік. V. Замъткка о чепуеврылыхъ окрестностеї r. Вяткп. VI. Нъсколько словъ о чепуегрылыхъ, собранинхъ въ Сарапульскомъ

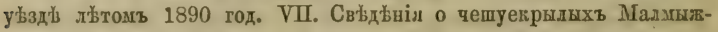
скаго у бъзда. - Запискп Уральск. Общ. Любит. Еетествозн.).

479. Krulikowski, I. Ein Versuch des Lepidopteren-Verzeichnisses des Gouvernements Kasan. - Bull. Soc. Natural. de Moscou, Ann. 1893, 슴 1, p. 43-105. (1893); Ann. 1896, 소 1, p. 25-52. (1896); Ann. 1898, 스 1, p. 42-67. (1898); Ann. 1898, 스 2-3, p. 302-319. (1898); Ann. 1899, 수 2-3, p. 157-229. (1900). (Russisch: Kpyликовскій, Л. Ошытъ списка чепуекрылыхъ Казанской губ. Изв. Общ. Естествонсіг, въ Москвъ). 
450. Kralikowski, I. K. Notiz über Lepidopteren der Umgebung der Stadt Saratow.- - Arbeiten der Naturforscher-Gesellschaft zu Saratow, Bd. I, (1895-1898), p. 35-43. Saratow 1901. (Russisch: Kруливовекіf, Л. Ћ. Замђтка о чешуекрнлихъ окрестностей г. Саратова. Труды Саратовскаго Общ. Естествошсп. и Любителей Естествозг.). $480 \propto$. Krulikowski, L. Zur Lepid opteren-Fauna des Gouvernements Jaroslaw. - Horae soc. ent. rossicae, XXXV, ㅅo 3-4, p. 534-560. 1902.

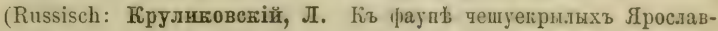
ской губернін. - Труды руск. Эптомол. Общ.).

-480 a. Kulagin, N. Zur Biologie von Ucneria dispar in Russland. - Illustr. Wochenschr, für Ent., II. p. 418-420. 1897.

-481. Kulagin, N. Beohachtungen ïber die Temperatur der Bienen im Bienenstock von Route. - Ztschr. der Land- und Forstwirthsch., Bd. CIXXXIX, 소 4, p. 163-169. Mnskau 1898. (Russisch: Будагинљ, Н. Наблоденіл шадъ темературой пчелъ въ уль' Рута. - Журн. Землед. и .Јсовод.).

482. Kulagin, N. Die Wirkung der Temperatur auf die Eier, Larven und Puppen der Bienen. - Illustr. Zeitschr. für Entomologie, IV. № 13, p. $193-195.1899$.

483. Kulagin, $\mathbf{N}$. Ueber das Entstehen des Geschlechtes bei Bienen. Russisch. Bienenz.-Liste, XVIII. № 1, p..118-124. 1902. (Russisch: Булагннъ, Н. Пропсхожденіе пола у пчелъ. - Русск. Пчеловодный Листокъ).

484. Kulikowski, E. Materialien zur Coleoptera-Fauna des Südrusslands. Berichte der Neuruss. Gesellsch. der Naturforsch., XXI. 샤 1, p. 1-274. Odessa 1897. (Russisch: Куликовекій, Е. Матеріалқ для фауны Coleoptera Южной Россіп. - Заппс. Новоросс. Общ. Еетествопеп.).

485. Kunckel d'Herculais. Le Criquet pèlerin (Schistocerca peregrina, Oliv.) et ses changements de coloration. - Rôle des pigments dans les phénomènes d'histolyse et d'histogenèse qui accompagnent la métamorphose. - C. R. Acad. Sc., CXIV. p. 240-242. Paris 1892.

486: Kurnali, N. T. Einige Zahlen-Angaben in Bezug auf die Aufzucht der Seidenraupen. - Arbeiten der kaukasischen Seidenzucht-Station, Bd. VII, Lief. II, p. 26-36. Tiflis 1894. (Russisch: Курнали, Н. Т. Нвкоторыя цифровыя данныя по выкормк' шелковпчныхъ червей. - Труды кавказск. Шелководств, Станціп).

487. Kurz, W. Ueber androgyne Missbildung bei Cladoceren. - Sitzber. Akad. Wissensch.; math.-naturw. Clas., LXIX. 1. Abth., p. 40-46. Wien 1874.

488. Kusdas, Wilh. Einige Fälle vorzeitiger Entwickelung von Lepidopteren. - Insekt.-Börse, XIV. 투 5, p. 26-27. 1897.

488a. Kusnezow, N. Zur Macrolepidoptera-Fauna des Gouvernements Pleskau. - Horae soc. ent. rossicae, XXXIII. 의 1-2, p. 85-131. 1900. (Russisch: Кузнецовъ, Н. Гъ фаупь Macrolepidopteru Псковской губернін. - Труды русск. Энтомол. Общ.).

489. Kusnezow, N. J. Temperaturversuche über Catocala fraxini Linn. (Lepidoptera, Noctuidae). - Revue Russe Ent., I. № 6, p. 225-230. 
1901. (Russisch: Куянедовъ, Н. Я્ Темиературиче оинти надъ. Catocala fraxini Linn. [Lepidoptera, Noctuidae]. - Pyccr. Әнтом. Обозр.).

489 a. Kusnezow, N. J. Zur Macrolepidoptera-Fauna des Gouvernements Pleskau. II. Neue Angaben. - Horae soc. ent. rossicae, XXXVII. № 1-2, p. 17-70. 1904. (Russisch: Кузнөцовъ, Н. Я. Къ фаушь Macrolepidoptera Псковской губерніп. II. Новня данныл. Труды русек. Эптомол. Общ.).

490. Kusnezow, N. J. Beobachtungen über Embia taurica Kusnezov (1903) auf dem Südufer des Krims. - Hor. Soc. Ent. Rossicae, XXXVII. № 1-2, p. 138-173. 1904. (Russisch : Еузнөцовъ, Н. Я. Наблюденія надъ Embia taurica Kusnezov (1803) на Іожномъ берегу Крыма. - Труды русск. Эвтомол. Общ.).

$490 a$. Kusnezow, N. J. Zur Frage über die Licht-Experimente mit Lepidopteren. - Zeitschr. für wiss. Insektenbiol., II. № 2, p. 43-44. 1906.

491. Kyber, J. E. Einige Erfahrungen und Bemerkungen über Blattläuse. Germar's Magazin der Entomologie, 2. Theil, p. 1-39. 1815.

491 $a$. Laborde, J. Étude sur la Cochylis et les moyens de la combattre par les traitements d'hiver. - Revue de viticulture, XIV, p. 225-228, p. $258-260$, p. 292-294, p. 339-342, p. 399-406. 1900.

492. Laddiman, $\boldsymbol{R}$. The weather and its effects on Lepidoptera. Entomolog., XII. p. 202. 1879.

493. Lafitole, Marquis de. Simples notes. - Pet. Nour. Entomol., № 154, p. $62-63.1876$.

493 a. Lagerheim, G. Zur Frage der Schutzmittel der Pflanzen gegen Raupenfrass. - Entomol. Tidskrift, XXI. p. 209-232. 1900.

494. Lambert, F. Essai d'une comparaison entre le mûrier dit „du Tonkin" et d'autres variétés du mûrier au point de vue de la valeur de leurs. feuilles pour l'alimentation des vers à soie. Mémoires et documents sur la sériciculture. Montpellier 1893.

495. Lambert, F. Influence d'une faible diminution de la chaleur pendant les derniers jours de l'élevage sur les cocons du rer à soie du mûrier. Journ. d'agricult. pratique, I. № 6. 1899. (Extrait des Ann. de l'École Nation. d'Agriculture de Montpellier, 1899).

496. Lambert, F. Recherches sur l'alimentation des vers à soie du mûrier. Bibliothèque de progrès agricole et viticole. 1891.

497. Lambrichs, E. et Douckier de Donceel, H. Descriptions des quelques abessations de Lepidoptères du genre Vanesse.-Ann. Soc. Ent. Belg., T. XXI. p. 9-11. 1878.

497 . Lampert, K. Verhalten niederer Tiere gegen Formalindämpfe. - Zeitschr. für wissensch. Insektenbiol., II. ㅅa 1, p. 12-13. 1906.

498. Landois, H. Beiträge zur Entwickelungsgeschichte der Schmetterlingsflügel in der Raupe und Puppe. - Zeitschr. für wissensch. Zool., XXI. Hft. 3, p. 305-316. 1871.

498a. Landois, H. Das Gesetz der Entwickelung der Geschlechter bei den. Insekten. - Schrift. d. k. phys.-ökon. Gesellsch., VU. p. 19. Königsberg 1867. 
49sし. Landois, H. Ueber das Gesetz der Entwickelung der Geschlechter bei den Insekten. - Zeitschr. f. wiss. Zool., XVI. 스 2, p. 375-379. 1867.

495c. Lange. Ueber den gegenwärtigen Frass der grossen Kiefernraupe (Phul. Bomb. pini) in der k. preussischen Oberförsterei Glücksburg. Förstl. Blätt., Hft. XI, p. 28-56. 1866.

499. Langsroth, L. L. Die Biene und der Bienenstock. Uebersetzt von G. P. Kondratjew. St.-Petersburg 1892. (Russisch: Лавгеротъ, Л. Л. IIqела и улеї).

500. Lanterborn, Robert. Vorläufige Mittheilungen über den Variationskreis von Anuraea cochlearis Gosse. -- Zoolog. Anzeiger, XXI. № 574, p. $567-604.1898$.

501. Latham, A. G. The causes of the Metallic Lustre of the Scales on the wings of certain MIoths. - Proc. Lit. Philosoph. Soc., III. p. 198-199. Manchester 1864.

502. Lea, Carey. On Red and Purple Chloride, Bromide and Jodide of Silver; on Heliochromy and on the Latent Photographic Image. - Amer. Journ., (Ser. III) XXXUI. p. 349.. 1887.

503. Lobedinski, J. Zur Höhlenfauna des Kryms. - Mémoires de la société des naturalistes de la Nouvelle-Russie, XXI. P. I, p. 47-59. Odessa 1900. (Russisch: Лебединскій, Я. Къ фаунъ Крымскихъ пещеръ. - Зашиски Новоросс. Общ. Естествопсп.).

504. Leech, J. H. On the Lepidoptera of Japan and Corea. - Proc. Zool. Soc., p. 398-431. London 1887.

505. Lederer, Jul. Verzeichniss der von Herrn Johann und Frau Ludmilla Haberhauer 1861 und 1862 bei Varna in Bulgarien und Sliwno in Rumelien gesammelten Lepidopteren. - Wien. Entomol. Monatschr., VII. № 1, p. 17-27; 수 2, p. 40-47. 1863.

506. Lehmann. Zur Biologie der Raupe von Eriopus purpureofasciata Pall. Zeitschr. f. Ent., n. F. IX. p. 26-27. Breslau 1884.

507. Lehmann, Georg. Einiges über die Bedeutung der Meteorologie für den Schmetterlingssammler. - Ent. Jahrb., XII. p. 68-77. 1904.

507a. Lenhossék, Michály v. Das Problem der geschlechtsbestimmenden Ursachen. Jena 1903.

508. Leuckart, Rud. Zur Kenntniss des Generationswechsels und der Parthenogenesis bei den Insekten. - Moleschott's Untersuchungen, IV. p. $327-437.1858$.

509. Lewis, G. A Supplementary Note on the specific modifications of Japanese $\mathrm{Carabi}$, and some observations on the mechanical action of solar rays in relation to colour during the evolution of species. Trans. Ent. Soc., p. 503-530. London 1882.

$509 \alpha$. Lewith, S. Ueber die Ursache der Widerstandsfähigkeit der Sporen gegen hohe Temperaturen. Ein Beitrag zur Theorie der Desinfektion. Arch. für experim. Pathol., XXVI. p. 341-354. 1900.

509a. Levrat, D. et Conte, A. Sur l'origine de la coloration naturelle des soies de Lépidoptères. - C. R. Acad. Sc., CXXXV. p. 700-702. Paris 1902.

510. Leydig, F. Bemerkungen üher Farben der Hautdecke und Nerven der Drüsen bei Insekten. - Archiv für microskop. Anatom., XU. p. $536-550.1876$. 
511. Liberich, Ferdinand. Biolngische Beiträge zur Käferkunde.-Soc. ent., IV. 스 8, p. 66.1889.

512. Lichtestein, J. Résistance des Pucerons aux froids rigoureux, - C. R. Acad. Sc., XC. p. 80. Paris 1880.

513. Lichtonstein, J. Monographie des $A p h i d$ iens. Les Pucerons. Partic I. Genera. Montpellier 1885. (188 pp.).

513a. Linde, A. L. Die Unfägigkeit einiger im MIoskau-Gourernement gefangenen Schmetterlinge zur Akklimatisation in dieser Gegend. - Nachr. der Gesellsch. der Liebhaber der Naturw., Anthrop. und Ethnogr., LXXXVI. Arbeiten der Zool. Abth. der Gesellsch., X. Das Tagbl. der Zool. Abth. des Gesellsch. und des Zool. Museums, II. Ai 5 , p. 40-41. Moskau 1897. (Russisch: Линде, А. Л. Неспособность иъкоторыхъ бабочевъ, пойманшыхъ въ Московской губ., къ аквлматизаціи въ этої мбстностн. - Изв. Общ. Любит. Естествози.; Антроп, и Этногр., трудш Зоод. Отд. Общ., Дневн. Зоол. Отд. Общ. и Зоол. Музея).

514. Lindemann. Untersuchungen über die Raupe, welche im Sommer 1867 im Gouvernement Tula erschien. - Landwirtsch. Ztg., № 44. 1867. (Russisch: Линдөманъ. Нзсльдовапіе гусеници, полвившейсл льтомъ 1867 г. въ Тульской губ. - Земдед. Газета).

515. Linden, Marie Gräfin v. Untersuchungen über die Entwickelung der Zeichnung des Schmetterlingsflügels in der Puppe. - Zeitschr. für wissensch. Zool., LXV. 1. Hft., p. 1-49. 1898. - Auch in Tübing. Zool. Arb., III. Bd., № 3. Leipzig 1898.

516. Linden, M. Gräfin v. Untersuchungen über die Entwickelung der Zeichnung des Schmetterlingsflügels in der Puppe. - Illustr. Zeitschr. für Ent., III. № 21, p. 321-323. 1898; IV. 스 2, p. 19-22. 1899.

517. Linden, M. Gräfin v. Versuche über den Einfluss äusserer Verhältnisse auf die Gestaltung der Schmetterlinge. - Illustr. Zeitschr. für Ent., IV. № 15, p. 225-227; 스 17, p. 261-263; 스 21, p. 321-323; № 22, p. 339-341; № 24, p. 369-372. 1899.

518. Linden, M. Gräfin v. Piepers, M. C.: Die Farbenevolution (Phylngenie der Farben) bei den Pieriden. - Illustr. Zeitschr. für Ent., IV. 즈 19, p. $300-302.1399$.

519. Linden, M. Gräfin v. [Vide lauf. № 517].

520. Linden, M. Gräfin v. [Vide lauf. № 518].

521. Linden, M. Gräfin v. Die Flügelzeichnung der Insekten. - Biol. Centralblatt, XXI. № 20, p. $625-633$; № 21; p. $657-672 ;$ № 23, p. $753-779.1901$.

522. Linden, M. Gräfin v. Hautsinnesorgane auf der Puppenhülle von Schmetterlingen. - Verh. der Deutschen Zool. Gesellsch., p. 126-133. '1902. (Separat.).

523. Linden, M. Gräfin v. Marphologische und physiologische Ursachen der Flügelzeichnung und Färbung der Insekten mit besonderer Berücksichtigung der Schmetterlinge. - Verh. des V. Internat. Zool. Congr. zu Berlin 1901. p. 831-837. Jena 1902.

524. Linden, M. v. Zusammenfassende Darstellung des experimentellen Ergebnisse über den Einflus der Temperatur wïhrend der Puppen Ent- 
wickelung auf die Gestaltung, Färbung und Zeichnung der Schmetterlinge. Die Vererbung erworbener Zeichnungscharaktere. - Zool. Centralbl., IX. ㅊo 19-20. 1902. (Separ. 19 pp.).

525. Linden, M. Gräfin v. Die gelben und roten Farbstoffe der V anessen.Biol. Centralbl., XXIII. № 23, p. 774-792; 그 24, p. 821-828. 1903.

526. Linden, M. v. Neue Untersuchungen über die Farben der Schmetterlinge. - Leopoldina, Hft. 39, p. 110-112; p. 116-120. 1903.

527. Linden, M. V. Das rote Pigment der Vanessen, seine Entstehung und seine Bedeutung für den Stoffiwechsel. - Verh. deutsch. Zool. Ges., 13. Vers., p. 53-65. 1903.

527a. Iinden, M. v. Die Ergebnisse der experimentellen Lepidopterologie. Biol. Centralbl., XXIV. 스 18-19, p. 615-634. 1904.

527b. Linden, M. Gräfin v. Der Einfluss des Stoffirechsels der Schmetterlingspuppe auf die Flügelfärbung und Zeichnung des Falters. - Arch. Rass. Geselsch. Biol., I. Jabrg., № 4, p. 477-518. Berlin 1904.

527c. Linden, M. Gräfin v. Ueber die Verïnderung der Fürbung und Zeichnung der Schmetterlinge durch anormale Lebensbedingungen während der Puppenperiode. - Sitzber. Niederrhein. Gesellsch., p. 25-33. Bonn 1904.

$.527 d$. Linden, M. v. Comparaison entre les phénomènes d'assimilation du carbone chez les Chrysalides et chez les Végétaux. - C. R. Soc. Biol., LIX. p. 694-696. Paris 1905.

527e. Linden, M. Gräfin v. Physiologische Untersuchungen an Schmetterlingen. - Zeitschr. für wiss. Zoolo, LXXXII. p. 411-444. 1905.

527f. Linden, M. v. L'assimilation de l'acide carbonique par les Chrysalides de Lépidoptères. -- C. R. Acad. Sc., CXLI. p. 1258-1260. Paris 1905. Auch in: C. R. Soc. Biol., LIX. p. 692-694. Paris 1905.

$527 g$. Linden, M. v. Recherches morphologiques, physiologiques et chimiques sur la matière colorante des Vanesses. - Ann. Sc. Nat., (8). XX. p. 295-363. 1905.

527h. Linden, M. Gräfin v. Ueber den Einfluss der Sauerstoffentziehung während des Puppenlebens auf die Gestaltung der Schmetterlinge.C. R. 6. Congrès Internat. Zool. Bern. p. 491-496. 1905.

527i. Linden, M. Gräfin v. Untersuchungen über die Veränderung der Schuppenfarben und der Schuppenformeu während der Puppenentwickelung von Pupilio podalirius. - Die Veründerung der Schuppenformen durch äussere Einflüsse. - Biol. Centralbl., XXVI. № 17-18, p. 580-600. 1906.

528. Linstow, 0. v. Ueber die Zu- und Abnahme des Gewichtes der Seidenraupe in ihrer verschiedenen Ständen. - Correspbl. Zool.-mineral. Ver., XXIII. p. 43-45. Regensburg 1869.

529. List, Theod. Ueber den Einfluss des Lichtes anf die Ablagerung von Pigment. - Arcli. für Entwicklungsmech., VIII. 4. Hft., p. 618632. 1899.

$529 a$. Lister, Jos. On the cutaneous pigmentary system of the frog. - Phil. Trans. Soc. London, CXLVIII. (For the year 1858), p. 627-642. 1859.

530. Lockyer, B. The weather and its effects on Lepidoptera. - Entomolog., XII. p. 228-229: 1879 . 
531. Loeb, J. Einfluss des Lichtes auf die Oxydationsvorgänge im thierischen Organismus. - Archiv für die gesammte Physiol., XLII. p. $393-407.1888$.

$531 a$. Loeb, J. Further experiments on artifical Parthenogenesis and the nature of the process of fertilisation. - Americ. Journ. Physiol., IV. p. $178-185$. 1900 .

531 l. Loeb, J. Experiments on artifical Parthenogenesis in Annelids and the nature ot the process of fertilisation. - Amer. Journ. Physiol., IV. p. $423-460.1901$.

$531 c$. Loeb, Jacques. Untersuchungen über die pbysiologischen Wirkungen des Sauerstoffmangels. - Pflüger's Arch. für Plyysiol., LXII. p. 249295. 1895.

532. Löw, H. Ueber bei Sliwno im Balkan gefangene Dipteren. - Wien. Ent. Monatschr., VII. 수 2, p. 33-35. 1863.

533. [Vide lauf. № 531].

534. Lomnicki, Jaroslav Ritter v. Erythropodismus der Laufkäferarten. -Zool. Anz., XXI. 소 560, p. 355-357. 1898.

534a. Lopriore, Giuseppe. Ueber die Einwirkung der Kohlensäure auf das Protoplasma der lebenden Pflanzenzelle. - Jahrbüch. fo wissensch. Botanik, XXVIII. p. 531-627. 1895.

535. Lorez, C. F. Aberrationen von Arctia flavia Fuessli. - Soc. ent., XIX. № 16, p. $123-124.1904$.

536. Luciani, L. e Lo Monaco, D. L'accrescimento progressivo in peso ed in azoto della larva del bombice del gelso in ordine all'alimentazione occorrente nelle successive età. - - Rend. Accad. dei Lincei. Seduta: del 7 Marzo 1897. Vol. VI, Ser. V, p. 155-162.

537. Ludwig, N. Futtersaft oder tierische Veranlagung als Beherrscher und Ordner der geheimnisvollen Vorgänge im Bienenvolke. Leipzig 1896.

538. Lübenetzki, J. Das vollständige praktiscke Handbuch für Bienenzüchter. 3 Bände. St.-Petersburg 1874. (Russisch: Любенецвій, I. Шодное практпческе руководство для пчеловодовъ).

539. Mac Lachlan, Robert. Notes générales sur les Variations des Lépidoptères. Traduit de l'anglais avec annotations par Maurice Girard et J. Fallon. - Ann. Soc. Ent. France, VII. 4 Sér. p. 323-350, ' 1867.

539 a. Macchiati, L. A proposito della teoria del Chiarissimo Sig. J. Lichtenstein del titolo: ${ }_{n}$ L'evoluzione biologica degli Afidi in generale e della Fillossera in Farticolare. ${ }^{“}$ - Bull. Soc. Ent. Ital., XVI. p. $259-268.1884$.

540. Maggiorani. Influenza del magnetismo sulla embriogenesi. Contributo allo. ricerche biologiche. Roma 1885 .

541. Maillot, E. De l'éclosion des graines de rers à soie par le frottement, l'électricité et l'hivernation artificielle. Revue des traveaux les plus récents. Montpellier 1876.

542. Maillot, E. Leçons sur le ver à soie du mûrier. Montpellier et Paris 1885.

543. Majoli, Cesare. Straordinario fenomeno di anticipata trasformazione in farfalla del verme da seta. - Giornale di fisica, chemica, storia. naturale etc. del regno italico, V. p. 399. Pavia 1813. 
544. Manger, K. Einiges über die Entwickelung von Tenebrio molitor L. Soc. ent., XVI. № 10, p. 73-74. 1901.

545. Mann, Josef. Aufzälung der im Jahre 1565 in der Dobrudscha gesammelten Schmetterlinge. - Verhandl. Zool.-bot. Gesellsch. in Wien, XVI. p. $321-360$. 1866.

546. Marchal, P. Les Cé ci dom yies des céréales et leurs parasites. - Ann. Soc. Ent. France, LXVI. p. 1-105. 1897.

546a. Marchal, Paul. La reproduction et l'évolution des guêpes sociales. Arch. Zool. exper. et gèner., III Sér., T. IV, p. 1-100. 1896.

547. Marlatt, C. L. Temperature Control of Scale Insects, - Proc. 11 Meet. Assoc. Econ. Entom. (U. S. Dept. Agric., Div. Entom., Bull. 20. N. S.), p. $73-76.1899$.

548. Martin, A. Eine Exkursion in den Harz. - Illustr. Wochenschr. f. Ent., II. p. $671-672.1897$.

548a. Martyno, W. A. Ein Bienenvolk ausschliesslich mit Drolnenwaben. Nachr. des Landwirth. Instituts zu Moskau, VII. № 1. 1901. (Separat. 4 pр.). (Russisch: Мартыновъ, В. А. Семья пчелъ съ. псключительно трутневой вощнной. - Нзвђст. Московск. СельскоХозяйств. Нвст.).

549. Masaraky, W. W. Ueber einige Insekten der Petersburger-Fauna. Horae Soc. Ent. Rossicae, XXXIV. 요 1-2, p. XXXII-XXXIV. (1899). 1900. (Russisch: Мазаравій, В. В. О нъсколькихъ наськомыхъ Петербургской фауны. - Протокодъ 20 Сент. 1899 года).

550. May, Hugo. Ueber die ersten Stande einiger Geometriden. - II. Jahresbericht Wiener Ent. Ver. (1891), p. 23--29. 1892.

551. May, Hugo. Ueber Colias chrysotheme Esp. - V. Jahresber. Wiener Ent. Ver. (1894), p. 41-46. 1895.

552. Mayer, Alfr. G. On the Color and Color-Patterns of Moths and Butterflies. - Proc. Boston Soc. Nat. Hist., XXVU. p. 243-330. Boston 1897.

553. Mayer, Alfred Goldsborough. The Development of the Wing Scales and their Pigment in Butterflies and Moths. - Bull. of the Museum of Compar. Zool. at Harvard College, XXIX. . 5, p. 209-236. Cambridge Mass. 1896.

553a. Mayer, A. G. On the Color and Color-Patterns of Moths and Butterflies Bullet. Museum of Comparat. Zool. at Harvard College, XXX. № 4, p. $169-256.1897$.

554. Meinhard, A. Verzeichniss der Sammlung der Lepidopteren aus dem Jakutsk-Gebiete, welche vom. Museum 1894 als. Geschenk von Hr. Antonowitsch erhalten wurden. - Verzeichnisse der Sammlungen von Wirbellosen des zoologischen Museums der kais. Universität zu Tomsk, herausgeg. von Prof. K. Th. Kaschtschenko. Verzeichnisse I-III. p. 3-12. Tomsk 1904. (Russisch: Мейнтардъ, А. Списокъ коллекціп чешуекрылыхъ изъ Якутской области, нолученныхъ музеемъ въ 1894 г. въ дајъ отъ Внлюйскаго окр. псправпика, т. Антоновича. - Списки поллекцій безпозвопочвыхъ Зоологиеспаго Музея Умиер. Томскато Универсптета, пздаваемыс подъ обцей редақціей прогі. Н. ө. Кащенко). 
555. Meinhard, A. Verzeichniss der Sammlung der Le pidopteren, welche dem zoologischen Museum der Universität in Tomsk von Ingenieur A. A. Meinhard geschenkt worden sind. - Verzeichnisse der Samml. von Wirbellosen des zool. Mus. der kais. Univers. zu 'lomsk, herausgeg. von Prof. K. Th. Kaschtschenko. Verzeichn. I-III, p. 13-37. 'Tomsk 1904. (Russisch: Мөйнгардъ, А. Списољъ көллекіи чешуекрылшх, принессипхъ въ дарь зоологичесіому музею Томснаго Универсптета внженерохъ А. А. Мейнгардъ, - Списки коллепдій безпозвоночныхъ Зоол. Мүзеи ІІмер. Томскаго Уншверс., пздаваемке подъ общей редагц. проф. Н. Ө. Нащенко).

555 a. Moissner, 0tto. Statistische Untersuchungen über Fürbungsvariationen bei Coleopteren (1906). - Zeitschr. fo wissensch. Insektenbiol, II. 스 11, p. 351-354. 1906.

556. Moldola, R. On a certain Class of Cases of Variable l'rotective Colouring in Insects. by R. Meldola (communicated by A. G. Butler) - Proc. Zool. Soc., p. 153-162. London 1873.

557. Meldola, R. The action of light upon the sensitive skin of a pupa had no analogy with its action on any known photographic chemical. No known substance retained permanently the colour reffected on it by adjacent objects, - Proc. Ent. Soc., p. XXIV. London 1874.

558. Meliehar, L. Beitrag zur Kenntnis der Schntzfärbung, Mimiliry, bei H o m o p te ren. - Ent. Jahrb., XIII. p. 213-217. 1904.

559. Meltzer, S. J. Ueher die fundamentale Bedeutung der Erschütterung für lebende Materie. - Zeitschr. für Biol., XXX. p. 464-509. 1894.

560. Mereschkowski, K. S. Materialien zur Kenntniss der thierischen Pigmente. - Ber. Akad. Wissensch., XLVII. № 2, p. 1-97. St.Petersburg 1884. (Russisch: Мөрөжковскій, Ћ. С. Матеріалы къ нознапію жнвотиыхъ пигментовъ. - Шзв. С.-Петербург. Акад. Наукъ).

560 a. Merriam, C. Hart. The influence of temperature upon the geographical distribution of terrestrial animals and plants. - Nature, LI. p. 441. London 1895.

561. Merrifield, Frederic. Report of Progress in Pedigree Moth-breeding, with observations on incidental points. -. Proc. Ent. Soc., London 1887. (Separatum).

562. Merrifield, F. Incidental Observations on Pedigree Moth-breeding. Proc. Ent. Soc., London 1888. (Separat. 2 pp.).

563. Merrifleld, F. Temperature experiments on Lepidoptera. - Proc. Ent. Soc. London 1889. (Separat. 4 pp.).

564. Merrifield, Frederic. Systematic temperature experiments on some Lepidoptera in all their stages. - Trans. Ent. Soc., Part. I, p. 131-159. I Iondon 1890.

565. Merrifield, F. Artificial Temperature Effects on the Colouring of several Species of Lepidoptera. - Repr. Ent. Soc. London 1891. (Separat. 4 pp.).

566. Merritiela, Frederic. Conspicnous Effects on the markings and colouring of Lepidoptera caused by exposure of the pupae to different temperature conditions. - I'rans. Entomol. Soc., Part. I, p. 155-168. London 1891. 
567. Merrifield, Frederic. The effects of artificial temperature on the colouring of several species of Lepidoptera, with an account of some experiments on the effect of light. - Trans. Ent. Soc., Part. I, p. 33-44. London 1892.

568. Merrifield, F. The effects of temperature in the pupal stage on the colouring of Pieris napi, Vanessa atalanta, Chrysophanus phlaeas. etc. - Trans. Ent. Soc., p. 55-68. London 1893.

569. Merrifield, Frederic. The colouring of Chrysophanus phlaeas affected by temperature. - Entomologist, XXVI. p. 333-338. 1893.

570. Merrifield, Frederic. Temperature Experiments in 1893 on several species of Vanessa and other Lepidoptera. - Trans. Ent. Soc., Part. III, p. 425-438. London 1894.

571. Merrifield, F. Experiments in Temperature-Variation on Lepidoptera, and their bearing on theories of Heredity. - Proc. Ent. Soc., Part. I. London 1894. (Separat. 4 pp.).

572. Merrifield, F. [Ohne 'Titel]. - Proc. Ent. Soc., II. p. XXV-XXVII. 1896.

573. Merrifield, F. Recent Examples of the Effect on Lepidoptera of Extreme Temperatures applied in the Pupal Stage. - Proc. South Ent. and Nat. Hyst. Soc., London 1897. (Separat. 4 pp.).

574. Merrifield, F. The Colouring of Pupal of $P$. machaon and $P$. napi causend by the exposure to coloured surroundings of the larvae preparing to pupate. - Trans. Ent, Soc., P. IV., Proc. p. XXXXXXII. Discussion: p. XXXII-XXXIII. London 1898.

575. Merrifield, Frederic. Gradual formation of pigment on the dark pupa of Papilio machaon. - Ent. Record Journ. Variation, XI. ํ 10. 1899. (Separat. 2 pp.)

576. Merrifield, 쪼. and Poulton, Bdward B. The Colour-relation betwen the pupal of Papilio machaon, Pieris napi and many other species, and the surroundings of the larvae preparing to pupate, etc. - Trans. Ent. Soc., Part. IV, p. 369-433. London 1899.

577. Merrifield, F. On the colour of pupae in relation to their surroundings. Trans. Union of South-Eastern Scient. Soc., p. 30-31. 1900.

578. Motalnikow, S. I. Ueber die ausscheidende Organe einiger Insekten. Ber. Akad. Wissensch., IV. ํo 1. St.-Petersburg 1896. (Russisch).

578a. Metalnikow, S. Ueber die Absorbtion der Eisensalze durch den Verdaungskanal von Blatta orientalis. - Bull. Acad. Sc., IV. № 5, p. 495-497. St.-Petersburg 1896. (Russisch: Мөтальниковъ, C.

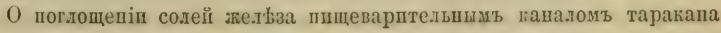
[Blatta orientalis]. - Нзвђст. Пмпер. Акад. Наукъ).

579. Metzger, Anton. Beitrag zur Lepidopteren-Fauna von Friesach in Kärnthen. - III. Jahresbericht Wiener Entomol. Ver., (1892). p. 27-35. 1893.

580. Meyer-Dür, H. Ueber climatische und geognostische Einflüsse auf Farben und Formen der Schmetterlinge. - Act. Soc. Helv. scienc. natur., réunie à Sion, les 17,18 et 18 Août 1852, 37. sess. p. $145-151.1852$.

581. Miot, H. Influence du gaz sulfhydrique sur les Insectes. - Ann. Soc. Ent. France, VI. 5 Sér., p. CLXIV. 1876. 
582. Möller, L. Die Abhängigkeit der Insekten run ihrer Umgebung. Leipzig 1867. (Inaug.-Dissert. 107 pp.).

583. Moller. The Colour of Insects dependent on their l'ood. - Science-Cossin., (1870). p. $247-248.1871$.

583a. Mokrzecki, S. A. Die Wanze Eurygaster maurus Fabr. in Kírim. Bericht des Tawrischen Gouvernements-Entonologes. Simpheropel 1894. (Russisch: Могржецкій, C. А. Хлџбпая черепашка въ Тiрнму. [Ккоиз Eurygaster maurus Fabr.] - Отчетъ Таврвческаго губернскаго эемскаго энтомолога. Симферополь 1894).

584. Mokrzecki, S. A. Wurzellüuse des Kiorns. - Tagbl. Zool. Abth. der Liebhaber Naturw., Anthropol, und Ethnogr., II. 고 4, p. 9. 1896. (Russisch: Мокржедвій, С. А. Корневня тли хлђбныхъ здавовъ. Дневвикъ Зоол: Отд. Об̆ц. Јюб. Еетествозн., Аптроп. п Этио́гр.).

585. Mokrzecki, S. A. Blutlaus in Kírim. - Fruchtisal, p. 253-264. 1s96. (Russisch: Могржещкіг, С. А. Кровяная тля въ Крыму, - Шлодоводство).

585a. Mokrzecki, s. A. Wurzelläuse des Korns. - Nachr. der Gesellsch, der Liebhaber der Naturw., Anthrop. und Ethnogr., LXXXVI. Arbeiten Zool. Abth., X. Tagbl. Zool. Abth. der Gesellsch. und des Zool. Museums, П. 고 4, p. 9-11. Moskau 1896. (Russisch : Мокравщхікі, С. А. Корневая тли здаковъ. - Нзв. Общ. Јшб. Естествознанія, Антроп. и Этпогр., Трудк Зоол. Отд., Дневи. Зоол. Отд. Общ. и Зоол. Муз.).

586. Mokrzecki, S. Zur Biologie der Obereu oculata Linné var. borysthenica nova. - Horae Soc. Ent. Rossicae, XXXIV. 시 1-2, p. 294-299. (1899). 1900. (Russisch : Мокржецкій, С. А. Ііъ біологіи Oberea oculata Linné var. borysthenica nova. - Труды Русск. Эатомох. Общ.).

586a. Mokrzecki, S. A. Schälliche Thiere und Pflanzen im Gouvernement Tawritschesk nach den Beobachtungen 1900. - Beilage zum Bericht des Tawrischen Gourernement-Entomologes. Simpheropel 1901. (Rus-

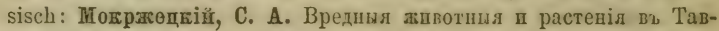
рпческой губервіи по пабдюдепіямъ 1900 года. - Прилолепіе къ отчету Таврическаго губ. энтомолога).

587. Mokrzecki, S. A. Das massenhafte Erscheinen der Raupen (Lythocolletis populifoliella $\mathrm{Fr}$.) und einiger anderen Schmetterlinge in der Umgebung der Stadt Charkow. - Trav. Soc. Nat. Univ. Kharkow, 1901. XXXVI. Lief. II, p. 83-87. 1902 (Russisch: Мокржецвій, C. А. 0 массовомъ появденіи гусеввцъ [Lythocolletis populifoliella $\mathrm{Fr}$.] и нылоторыхъ другпхъ бабочекъ въ окрестностяхъ г. Харькова. Труды Общ. Естеств. прпроды при Харьков. Увив.).

587 a. IIokizeoki, S. A. Schädliche Insekten. - Ber. über die Thätigkeit des Tawrischen Gouvernements-Entomologes für das Jahr 1904, Jahrig. XII. Simpheropel 1905. (Russisch: Могржецкій, С. А. Вредиия насьгомия. - Отчеть о дыятельности губернскаго әнтомодога Таврич. земства).

588. Moliseh, H. Das Erfrieren von Pflanzen bei Temperaturen über dem Eispunkt. - Sitzber. Wiener Akad. Wissensch., CV. (1). p. 8295. 1896. 
5ร8 a. Montandon, A. L. A propos des soi-disant pluies d'insectes. -- Bull. Soc. Scienc. Bucarest, VIII. 수 1-2. 1899.

.589. Mordwilko, A. Zur Biologie der Pflanzenläuse der Subfamil. Aphididae und Pemphigidae. - Zool. Laborat. Univers. Warschau, p. 1-123. 1896. (Russisch: Мордвилко, А. Къ біологіи тлей пзъ подсем. Aphididae n Pemphigidae. -- Нзъ Зоолоr. Лаборат. Варшавскаго Универс.).

590. Mordwilko, A. Zur Biologie und Morphologie der Pflanzenläuse (Fam. A phididae Pass.). - Horae Soc. Ent. Ross., XXXI. p. 253-313. 1897. (Russisch: Мордвиль0, А. Къ біологіп пи мор(ропогіп тлей [сем. A phididae Pass.]. - Труды русск. Энтом. Общ.).

591. Mordwilko, A. K. Ueber die Migration und einige andere Erscheinungen im Leben der Pflanzenläuse. - Arb. aus dem Laborat. des zool. Kabinets der Univers. zu Warschau, p. 1-20. 1898. (Russisch: Мордвилєо, А. К. О мпраціяхъ и нькоторыхъ другнх явленіяхъ въ жизип тлей. - Работы изъ лабор. зоол. кабпн. Варшав. Уншверс.).

592. Mordwilko, A. K. Heterogenie und Polymorphismus bei Pflanzenläusen in Zusammenhange mit den Bedingungen ihrer Existenz. - Arb. aus dem Laborat. des zool. Kabinets der Univers. zu Warschau, p. 191-217. 1898. (Russisch: Мордвилк0, А. Љ. Гетероговія и полпморизъ у тлей въ связи съ условіям ихъ существованія. Работы взъ лабор. зоолог. кабин. Варшавскато Универс.).

593. Mordwilko, A. Zur Biologie und Morphologie der Pfanzenläuse (Fam. A phididae Pass.). II. und III. 'Theil. - Horae Soc. Ent. Rossicae, XXXIII. № 1-2, p. 1-88, p. 162-302. 1900; XXXIII. 수 3-4, p. 303-1012. 1901. (Russisch: Мордвилго, Алөксандръ. liъ Сioлогіп и жорфологіп тлей [сен. A phididae Pass.]. Часть II и III. Труды русск. Энтомол. Ооц. въ С.-Петербургъ).

594. Morgan, C. F. Notes on experiments made with the winged form of Phylloxera vastatrix radicicola. - Trans. Ent. Soc., p. 27-32. London 1885.

595. Morris, A. W. Journ. Bombay Nat. Hist. Soc. 1890.

595 a. Morse, Albert Pitts. Researches on North American A cridi ida e. Carnegie-Instit. Publication № 18. 1905.

595b. Mottior, David M. The effects of Centrifugal Force uron cell. - Ann. of. Botan., XIII. p. 325-361. 1899.

596. Mouline, Eugène. Observations relatives à la maladie des vers-à-soie. Aubenas 1867.

:596a. Müllenberger, H. Ueber Schmetterlingszucht. - Ver. Luxemb. Naturfi. vorm. Fauna; Mitth. aus den Ver.-Sitz., 으 6, p. 95-98. 1905.

597. Müller, Fritz. Die Farbe der Puppen von Papilio polatirius. - Liosmos, Bd. XI, Jahrg. VI, p. 448. 1882-1883.

598. Müller, Hermann. Schützende Aehnlichkeit einheimischer Insekten. Kosmos, III. Jahrg., VI. № 7, p. 29-39; p. 114-124. 1879/80.

599. Müller, Max. Aus dem Leben der heimischen Insekten. - Illustr. Wochenschrift f. Ent., II. p. 106-109; p. 119-122; p. 141-143. 1897.

600. Müller-Erzbach, W. Die Widerstandsfähigkeit des Frosches gegen das Einfrieren. - Zool. Anz., XIV. p. 383-384. 1891. 
600a. Miüler-Targaz. Ueber Gefrieren und Erficien der I'tlanzen. - Landwirthschaftliche Jahrbüch., IX. p. 133-189. 1880; XV. p. 453610. 1886.

600 b. Mussehl. Ueber dis Winterleben der Stockbiene. - Oken's Isis, p. 572.1836.

601. Naacke. Ueber den Einflnss verschiedener Stoffe anf die Lebensliraft der Macrolepidopteren. - Jahrber. der Schles. Ges. für vaterl. Cult., p. $173-180.1874$.

602. Nagel. Biologische Bemerkungen über den Einfluss eines milden Winters auf die Flugzeit der ersten Geometriden. - Zeitschr. f. Ent. Ver. Schles. Insekt., n. F. 24. Hft., p. 38-39. 1899.

603. Nägeli, Karl Wilh. von. Beiträge zur wissenschlattlichen Botanik. Il. Leipzig 1860.

604. Nazari, Al. Richerche sulla struttura del tube digerente e sul processo digestivo del Bombyx mori allo stato larvale. - Rich. Labor. Anat. norm. Univer. Roma, VII. Fasc. I, p. 75-85. 1900.

605 a. Needham, James G. and Maude, H. Anthony. The sliewness of the thorax in the Odonata. - Journ. New York Ent. Soc., XI. p. 117 125. 1903.

606. Neuburger, Wilhelm. Zwei nete Abarten von Vanessa urticae L. - Soc. ent., XIX. № 22, p. 170. 1905.

607. Neuhauss, R. Direkte Farbenphotographie durch Körperfarben. - Photogr. Rundsch., p. 1-11. 1902.

607a. Neumayr und Jllmann. [Bestätigung der Ansichten von Liebig's über die Krankheiten der Seidenraupen]. - Wilda's landwirth. Centrabl., 13. Jahrg., II. p. 212-213. 1865. (Ein Referat des gleichnamigen Aufsatzes in Augsburger Allg. Ztg.).

608. Nowbigin, H. J. The Colours and Pigments of Butterflies. - Natural. Science, XIV. p. 138-142. 1899.

609. Newport, Goorge. On the Temperature of Insects, and its connexion with the Functions of Respiration and Circulation in this Class of Invertebrate Animals. - Philos. Trans. Royal Society, CXXVII. Part. II., p. 259-338. London 1837.

610. Newport, George. Insecta. - Cyclopaedia Anat. and Physiol., V. 2. p. $853-994.1839$.

611. Nicéville, Lionel de. List of the Butterflies of Calcutta and its neighbour hood. - Journ. Asiatic Soc. Bengal., LIV. Part. II, A 1, p. 39-54. 1885 .

611a. Nicolot, Hereule. Recherches pour servir à l'histoire des Podurelles. Mém. Soc. helvét., VI. Part. II, p. 1-88. 1842.

611b. Noleken, J. H. W. Baron. Lepidopterologische Fauna von Estland, Livland und Kurland. - Arb. d. Naturf.-Ver. zu Riga. Neue Folge, 2. Hft., p. 1-294. 1868.

612. Nüsslin. Die Tannen-Wurzellaus. Pemphigus (Holzneria) poschingeri Holzner. - Allgemeine Forst- und Jagd-Ztg., December-Heft 1899. (Separat. 7 pp.).

612a. Nüsslin, 0. Der Fichtenborkenkäfer Tomicus typographus L. im Jahre 1905 in Herrenwies und Pfullendorf. - Naturw. Zeitschr. für Landund Forstwirtsch., III. p. 450-468; p. 481-493. 1905. 
613. Gbuchow, A. Iiesultate der Bekïmpfung von Psilur monaclu und anderer schädlichen Insekten im Gebirgs-Bezirke Iiyschitymsk. - ForstZeitschr., p. 300-307. 1896. (Russisch: 0буховъ, А. Результаты борьбы съ мопаненко, совков п ннлндцикомъ въ дачахъ Кнштимскато горнато овруга. - ЈАсной Жуун.).

614. Ormerod, ‥ A. Considerations as to effects of temperature on insect developement. - Entomologist, XII. p. 137-142. 1879.

615. Ormerod, E. A. Oliservations of the effects of low temperature on larvae.Trans. Ent. Soc., p. 127-130. London 1879.

616. Oudemans, J. Th. Falter aus kastrierten Raupen, wie sie aussehen und wie sie sich benehmen. - Zoolog. Jahrbücher, Abth. für Syst., p. $71-88.1898$.

617. Oudemans, J. Th. Etude sur la position de repos chez les lépidoptères. Verh. Akad. Wetensch., 2. S., D. X., № 1. Amsterdam 1904. (Separat.).

$617 a$. Pabst. Die Heimat, das Verbreitungsgebiet und die Entwickelungsgeschichte von Acherontia atropos L., Totenkopf. - Ent. Jahrb., IV. p. $137-147.1895$.

618. Pabst. Die Papilionidae und Pieridae der Umgegend von Chemnitz und ilıre Entwicklungsgeschichte. - Ent. Jahrb., VIII. p. 144-157. 1898.

619. Pabst. Die Arctiidae, Hepialidae und Cossidae der Umgegend ron Chemnitz und ihre Entwickelungsgeschichte. - Ent. Jahrb., X. p. $136-152.1901$.

620. Pabst. Die Nymphaliden-Gattungen Vanessa, Melitaea und Argynnis, die Satyriden und Hesperiden der Umgebung von Chemnitz und ihre Entwickelungsgeschichte. - Ent. Jahrb., XI. p. $136-165.1902$.

621. Pabst. Die Sphingidae B., Zygaenidae B. und Sintomidae HS. der Ungegend von Chemnitz und ihre Entwickelungsgeschichte. Ent. Jahrb., XII. p. 144-159. 1903.

622. Palm, H. Der Farbencharakter der Lepidopteren. Vortrag, gehalten am 5. Juni 1896 in der Berliner Entomologischen Gesellschaft. Illustr. Wochensch. f. Ent., I. p. 207-210. 1896.

623. Pasqualis, G. L'amido e l'albumina nell'allevamento del baco. - Boll. Mens. Bachic., Ser. III, Ann. I, № 11, p. 153-158. 1895.

624. Passerini, N. Esperienze sopra l'alimentazione die bachi da seta confoglie asperse di poltiglia cupro-calcica. - Staz. Sperim. Agrar. Italiane, p. 563-567. Modena 1894; Atti d. R. Accad. dei Georgofili, XIX. p. 220. Firenze 1896.

625. Pauls. [Sachs, Paul]. Zur Züchtung von Sommergenerationen. - Soc. ent., XII. 조 20, p. 156-157; № 22, p. 170-171. 1898.

626. Pauls. [Sachs, Paul]. Experimentelle zoologische Studien ron Dr M. Standfuss. - Soc. ent., XIII. № 19, p. 145-148; № 24, p. 185188. 1899.

627. Pauls. [Sachs, Paul]. Wider die Totenstarre. - Ent. Zeitschr., XII. № 11, p. 82. 1899.

628. Pauls. [Sachs, Paul]. Zucht von Arctia hebe ex ovo in II. Generation. Ent. Zeitschr., XIII. № 16, p. 125-126. 1899.

Bachmetjew, Studien. II. 
629. Pauls. [Sachs, Paul]. Amphidasis v. doubledayaria im Harz. - Soc. ent., XV. № 15, p. 113-115. 1900.

630. Poch, R. Die Farbenänderungen der Inseliten. - Neisse, Philomathie, Bericht 25, ron 1888-90. p. 264-281.

630 a. Perroncito, E. Esperienze sullazione di liquidi antisettice sostanze diverse sul seme bachi. Torino 1893.

6306. Porroncito, E. Appunti sugli insetticidi, studi ed esperimenti. Turino 1894.

630 c. Perez, I. Sur la ponte de l'Abeille reine et la théorie de Dzierzon. C. R. Acad. Scienc., LXXXVII. p. 408-410. Paris 1878.

630 d. Perez, Charles. Contribution a l'études des métamorphoses. Lille 1902.

631. Poters, II. T. Naturalistische Aufzeichnungen aus der Provinz Rio de Janeiro in Brasilien. IX. -- Illustr. Woch. f. Ent., II. p. 65-69. 1897.

632. Petersen, Wilhelm. Zur Frage der Chromophotographie bei Schmetterlingspuppen. - Sitzber. der Dorpater Naturf. Geselsch., Jahrg. 1890, p. 232-272. (Separat.).

633. Petersen, W. Lepidopteren-Fauna ron Estland. - Beiträge zur Kunde Est-, Liv- und Kurlands. Reval 1902. (Separat. 217 pp.).

633a. Petersen, W. Der vorläufige Bericht über die Reise zum Studium der Lepidoptera und ihrer Verbreitung an Uralgebirgen im Jahre 1903. - Nachr. der russisch. Geograph. Gesellsch., XL. Lief. IV, p. 631-634. 1904. (Russisch: Петерсент, В. Предваритедьный отчетъ о путешествіп для пзучепія Lepidoptera и вхъ распространенія по Уральскому хребту въ 1903 г. - Изв. Шмпер. русск. Геогр. Общ.).

633aa. Potrunkowitseh, Al. Iünstliche Parthenogenese. - Zool. Tahrb. Suppl., VII. p. $77-138.1904$.

633b. Petrunkewitseh, Al. Die Richtungskörper und ihr Schicksal im befruchteten und unbefruchteten Bienenei. - Zool. Jahrb., Abth. f. Anat., XIV. ํㅗ 4, p. 573-608. 1901.

633c. Petrunkewitsch, Al. Das Schicksil der Richtungskörper im DrohneneiZool. Jahrb., Abth. f. Anat., XVII. 죠 3, p. 481-516. 1903.

634. Philipps, Josef. Ueber Farbenveränderungen bei Schmetterlingen auf chemischem Wege. - Ent. Zeitschr., VIII. № 17, p. 142. 1894 .

635. Pickel, W. Zur Biologie der Bettwanze. - Horae Soc. Ent. Rossi ae, XXXII. p. XVII-XXIII. 1898. (Russisch: Пккөль, В. Къ біологіп постельнаго клопа).

636. Pictot, Arn. Sur le développement aérien des ailes des Lépidoptères. Arch. sc. physiques et nat., (4). T. 7, № 3, p. 281-284. Genève 1899.

637. Pictet, Arnold. Influence des changements de nourriture des chenilles sur le développement de leurs papillons. - Arch. sc. physiques et nat., XIV. 소 11, p. 537-540. 1902.

637a. Pictot, Arnold. Des variations des Papillons provenant des changements d'alimentation de leur chenilles et de l'humidité. - 6-e Congr. Internat. Zool., C. R. séanc., p. 498-507. 1904.

6376. Piopors, M. C. Observations sur les Vols de Lépidoptères aux Indes orientales Naerlandaises et consideration sur la nature probable de ce phénomène. - Natuurk. Tijdschr. v. Neederlaudisch-Indië, L. p. $198-257.1891$. 
638. Piepers, M. C. Ueber die Farbe und den Polymorphismus der Sphingiden-Raupen. - Tijdschr. voor Ent., XL. p. 27-105. 1897.

639. Piepers, M. C. Die Farbenevolulion (Phylogenie der Farben) bei den Pieride n. - Tijdschr. Nederland. Dierkund. Vereenig., (2). Deel V, p. 70-289. 1898.

639a. Planta, A. v. Ueber den Futtersaft der Bienen. -- Zeitschr. physiol. Chem. von Hoppe-Seyler, XII. ㅊo 4, p. 327-354. 1888; XIII. 즈 6, p. $552-561.1889$.

639b. Plateau, F. Études sur la Parthénogenèse. 1868.

640. Pollack, W. Einfluss des Futterkrautes auf die Farbung der Imago ron Arctia caja. - XIV. Jahresber. Zool. Sekt. des westf. Prov.-Vereins, p. 26. Münster 1886 .

640b. Pomeranzew, D. Zur Kenntniss der schädlichen und nützlichen Insekten, welche sich auf Picea excelsa aufhalten. - Nachr. des Forst-Instit. zu St.-Petersburg, VIII. p. 3--24. 1902. (Russisch: Поверанцевт, Д. іъ познанію вредыхъ и полезныхъ насџкомыхъ, водящихся ва ели (§icea excelsa). - Извъст. С.-Петербургскаго Льсн. Ннст.).

640a. Portschinski, J. Anopheles cluviger F. in Zusammenhang mit dem Sumpffieber. - Arbeit. des Bureau für Ent. des gelehrt. Comité beim Minist. für Ackerbau., V. o 1, (108 pp.). St.-Petersburg 1904. (Russisch: Порчински, I. Маларійны комаръ (Anopheles claviger F.) въ связп съ болотной лнхорадкой. - Труды Бюро по Әнтомол. Ученаго liom. Минист. Землед. и Госуд. Имущ.).

641. Pospelow, W. Bericht üher die Ernährung dex Seidenraupen mit Scorzonera im Zoologischen Kabinet des Landwirthschaftlichen Instituts im Sommer 1898. - Nachr. des Comité für Seidenzucht, I. Lief. 9, p. 13-14. Moskau 1899. (Russisch: Поспьловъ, В. Отчетъ о выкормки пелковичныхъ червей скорлоперомъ въ Зоогогескощъ

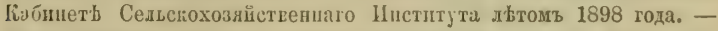

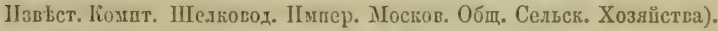

642. Pospelcw, W. P. Zur Biologie des Botis Sticticalis. - Mith. des landwirthsch. Instit. in Moskau, VII. № 3-4. 1901. (Separat. 12 pp.). (Russisch: Поспвловь. В. I. Лугової мотылекъ житомъ 1901-го года. - Извьст. Москов. Сельскохоз, Ннст.).

612a. Pouchet, F. A. Recherches expérimentales sur la congélation des animaux. - Robin's Journ. de l'anat. et de physiol., III. p. 1-36. 1866.

643. Poulton, E. B. The Essential Nature of the Colouring of Phytophagous Larvae (and their Pupae); with an Account of some Experiments upon the relation between the Colour of such Larvae and that of their Food-plants. - Proc. Roy. Soc., XXXVIII. p. 269-315. London 1885.

644. Poulton, E. B. A further inquiry into a special Colour-Relation between the larra of Smerinthus ocellatus and its food-plants. .. Proc. Roy. Soc., XL. p. 135-173. London 1886.

645. Poulton, E. B. Further experiments upon the protective value of colour and markings in Insects. - Rep. Brit. Ass., p. 763-765. 1887.

646. Poulton, Edw. An Inquiry into the Cause and Extent of a special Colour-Relation between certain exposed Lepidopterons Pupae and 
the Surfaces, which immediately surround them. - Proc. Roy. Soc., XLII. p. 94-108, London 1887; Philos. Transact., CLXXVIII. p. $311-441.1887$.

647. Poulton, Edward B. Further experiments upon the Colour-Relation hetween certain Lepidopterons larvae, pupae, cocoons, and imagines and their sorroundings. - Trans. Ent. Soc., p. 293-487. London 1892.

647a. Poulton, E. B. The experimental proof that the colours of certain Lepidopterons Larvae are largely due to modified plant pigments. Nature, XLVIII. p. 239. 1893.

648. Poulton, E. B. The experimental proof that the colours of certain Lepidopterous Larvae are largely due to modified plant pigments, derived from food. - Proc. Roy. Soc., LIV. p. 41-42, p. 417-430. London 1894.

649. Prest, W. On Melanism and Variation in Lepidoptera. - Entomologist, X. p. $129-131.1877$.

649a. Prohn. Ueber die Färbung der Lepidopteren. - Illustr. Wochenschr. f. Ent., I. p. 252-259. 1896.

650. Prehn. Die Schutzmittel der Raupe. - Illustr. Wochenschr. f. Ent., II. p. $24-27$; p. $39-42.1897$.

651. Prehu. Ueber Acclimatisieren von Insekten. - Illustr. Wochenschr. f. Ent., II. p. $122-127.1897$.

651a. Prohn. Die Verbreitung der Lepidopteren. - Illustr. Wochenschr. f. Ent., II. p. 305-309; p. 332-334. 1897.

652. Prittwitz, 0. F. W. v. Bemerkungen über die geographische Farbenvertheilung unter den Lepidopteren. - Ent. Ztg., XVI. p. 175-185. Stettin 1855.

653. Prittwitz, v. Literarisches. - Ent. Ztg., XXVII. A 7-9, p. 259-275. Stettin 1866.

654. Prittwitz, v. Lepidopterologisches. - Ent. Ztg., XXYH. p. 257-277. Stettin 1867.

(5j4a. Prowazek, S. Beitrag zur Pigmentenfrage. - Zool. Anz., XXIII. 스 623, p. 477-480. 1900.

(ij5. Quajat, Æ. Compendio di Bacologia. Seconda edizione. Padova 1877.

656. Quajat, E. Dell'influenza delle basse e medie temperature sulla nascita del seme bachi. - Boll. Mens. Bachic., X. p. 55-121. 1882.

657. Quajat, E. Sulla lavatura del seme proveniente da bigattiere infette da calcino. - Boll. Mens. Bachicolt., Ser. II, Ann. XII, 스 5-6. 1894.

658. Quajat, E. Della perdita in peso che subisce il seme nei mesi dell'inverno e durante l'incubazione.- Boll. Mens. Bachic., Ser. III, Ann. I, A6 2, p. $17-22$. 1895.

659. Quajat, E. Immersione delle uova in acido carbonico durante l'incubazione. - Boll. Mens. Bachic., Ser. III, Ann. I, № 2, p. 22-29. 1895.

66'). Quajat, E. Relazione tra il peso delle uova e quello dei gusci vuoti. Boll. Mens. Bachic., Ser. II, Ann. I, No 3, p. 33-37. 1895.

661. Quajat, E. Recherches sur les produits de respiration des œufs du verà-soie. - Arch. Ital. Biol., XXVI. p. 376-388. 1897. 
662. Quajat, E. Ricerche sui prodotti di respirazione delle uova elettrizzate del bómbice del gelso. - Boll. Mens. Bachic., Ser. III, Ann. III, № $9-10$, p. 113-133. 1897.

663. Quajat, E. Prodotti raspiratori delle uova del filugello dal momento della deposizione fino a completa svernatura. - Boll. Mens. Bachic., Ser. III, Ann. IV, № 9-10, p. 109-121. 1898: Auch in: Ann. R. Acc. di Agr. Torinò 1898.

664. Quajat, E. Prodotti respiratori della uova del filugello durante l'incubazione normale. - Ann. Accad. d'Agric. Torino, XLII. 1899. (Separat. $27 \mathrm{pp}$.).

665. Quajat, E. Prodotti respiratori delle uova (regolarmente svernate) durante l'incubazione normale. - Annuar. Staz. Bacolog., XXVII. p 57-81. Padova 1899.

666. Quajat, E. Sulla svernatura ed incubazione delle nova del filugello. Annuar. Staz. Bacolog., XXVII. p. 13-43. Padora 1899.

667. Quajat, E. Inpermeabilitì del guscio delle nova del filugello per l'alcool. Annuar. Staz. Bacolog., XXX. p. 33-36. Padova 1903.

668. Quajat, E. Effetti di una prolungata svernatura sulle uova del filugello, a seconda delle varie razze. - Annuar. Staz. Bacolog., XXX. p. 40-49. Padova 1903.

669. Quajat, E. Influenza dell'aria umida o della secca durante l'imboscamento e la moturità del bozzolo. - Annuar. Staz. Bacolog., XXX. p. 85-96. Padova 1903.

670. Quajat, Æ. Soernatura autunnale interrotta da temporanei ritorni a piu elevato calore. - Ann. Staz. Bacol., XXXII. p. 33-42. Padova 1904.

671. Quajat, E. und Rossinsky, D. Ueber das Auswaschen der Eier [von Bombyx mori], welche aus mit Muscardine angestecktem Raupenzuchthause stammen. - Nachr. des Comité für Seidenzucht, I. Liefer. 3 und 4, p. 29-34. Moskau 1894. (Russisch: Кваяту, 9. ㅍ Росеинскій, Д. 0 промив ' грень, пропсходящей пзъ зараякенной мускардиною червоводни. - Изв. Комит. Шелковод.).

$671 \propto$. Quajat, E. e Jordanoff, C. Studio comparativo fra la foglia di quattro varietà di gelsi, ed influcnza della medesima sull'alimentazione dei bachi. - Boll. Mens. Bachic., Ser. II, Ann. XI, № 9-10, p. 117135. 1893.

671 b. Rádl, E. Untersuchungen über den Phototropismus der Thiere. Leipzig 1903.

671 c. Rádl, Em. Ueber die Anziehung der Organismen durch Licht. - Flora, XCIII. p. $167-178.1904$.

672. Ramsden, W. Die Coagulirung von Eiweiss-Körpern auf mechanischem Wege. - Du Bois-Reymond's Arch. für Physiol., p. 517-534. 1894.

673. Réaumur. Mémoires pour servir à l'histoire naturelle des insectes. Pariser Ausgabe: I. 1734; II. 1736; III. 1737; IV. 1738; V. 1740; VI. 1742; Amsterdamer Ausgabe: I. u. II. 1737; III. 1738; IV. 1740; V. 1741 ; VI. 1748.

673a. Ratzeburg, J. T. C. Die Forstinselkten. 2. Aufl. 3 Bände. Berlin 1839-1844. 674. Rebel, H. und Rogenhofer, A. Zur Kenntniss des Genus Parnassius Latr. in Oesterreich-Ungarn. - III. Jahresber. Wiener Ent. Ver., (1892). p. 51-70. 1893. 
(775. Robel, H. Iitterarisches. - Insekt.-Birse, X1II. di 11, p. Ss-89. 1896. 675 a. Rebel, H. T'eher den gegenwärtigen Stand der Lepidopteren-Systematik. - Entomol. Zeitschr. Iris, p. 378-391. 1898.

Giti. Rebel, H. Studien über die Lepidopterentauna der Ballianländer. I. Teil: Bulgarien und Ostrumelien. - Ann. Naturhist. Hofmus., XVIII. p. 123-347. Wien 1903. (Separat.).

677. Rebel, H. Studien über die Lepidopterenfauna der Balkanländer. II. Teil: Bosnien und Herzegowina. - Ann. Naturhist. Hofmus., XIX. 스 2-3, p. $97--377$. Wien 1904 .

677a. Rebel, H. Lupernic zollikoferi Frr. - Verh. zool.-hot. Ges. in Wien, LV. 이 1-2, p. 21-23. 1905. (Ber. Selkt. für Lepidopt.).

6iтaa. Regen, Johann. Untersuchungen üher den Winterschlaf der Larven ron Gryllus campestris L. - Zool. Anz., XXX. № 5, p. 131-135. 1906.

$677 b$. Regener, E. Erfahrungen über den Nalurungsverbrauch der grossen Kiefernraupe. Magdeburg 1865.

678. Régnault et Reiset, G. Recherches chimiques sur la respiration des animaux des diverses classes. - Ann. chim. et Physique, III. Sér., XXVI: p. 299-519. 1849.

679). Reh, L. Versuche über die Widerstandsfihigkeit von Diaspinen gegen äussere Einflüsse. - Biol. Centralbl., XX. ํo 22, p. 741-751; № $23-24$, p. $799-815.1900$.

6S0. Reh, I. [Eigene Meinung beim Referieren der Arbeit von v. Schilling]. Allg. Zeitschr. f. Ent., VI. 지 12, p. 188. 1901.

681. Reh, I. Zur Naturgeschichte mittel- und nordeuropäischer Schildläuse. Allg. Zeitsclır. f. Ent., VIII: № 16-17, p. 301-308; № 18-19, p. $351-356$; 스 20-21, p. $407-419$; 스 22-24, p. 457-460. 1903. IX: № $1-2$, p. $13-36.1904$.

682. Reichenau, Wilhelm v. Die Züchtung des Nesselfalters (Vanessa urticae L.), ein Beweis fur den direkten Einfluss des Krlimas. -- Kosmos, V. Jahrg., 12. Bd., p. 46-49. 1882.

682a. Reichenbach, H. Ueber Parthenogenese bei Ameisen und andere Beobachtungen an Ameisenkolonien in künstlichen Nestern. - Biol. Centralbl., XXII. 수 14-15, p. 461-465. 1902.

682b. Reichenow. In der Abhandlung von L. Kohn: „Willkürliche Rildung des Geschlechtes", p. 16. - Wissensch. Rundsch., VI. 교 1, p. 1-36. St.-Petersburg 1899. (Russisch: Въ стать' л. Кона: „Произвольное образовапіе пола", стр. 16. - Научное Обозржніе).

683. Reichert, Alex. Ein interessanter Krïppel. - Ent. Jahrb., I. p. VII. 1892.

684. Reichert, Alex. Lymantria (Ocneria) dispar in Sibirien. - Ent. Jahrb., XII. p. 217. 1903.

68.5. Reinberger, Gust. Beitrag zum „Treiben“ der Schmetterlingspuppen. Illustr. Zeitschr. f. Ent., V. № 23, p. 370; 스 24, p. 382.1900.

685 a. Reisen, Th. Ueber das Leben und Treiben der Maulwurfsgrille. - Fauna, Ver. Luxemburg. Naturfr., II. p. 26--29. 1892.

686. Rengel, C. Zur Biologie des Hydroptritus piceus. - Biol. Centralbl., XXX. 스 6, p. 173-182; № 7, p. 209-220. 1901.

687. Rengger, J. R. Physiologische Untersuchungen über die thierische Haushaltung der Insekten. Tübingen 1817. 
688. Ronnie, J. Wunder der Insektenwelt oder Insekten-Verrandlung. I. (p. 247). Leipzig 1836.

689. Rey. Sitz. Berliner Ent. Ver. yom 10. Mai 1900, -- Insekt.-Börse, XVII. oㅡ 23, p. 181. 1900.

689a. Reh, L. Periodicität bei Schieldläusen. - Illustr. Zeitschr. f. Ent., V. ㅊo 11, p. 161-162. 1900.

690. Ribbe, C. [Vide lauf. № 219 d].

690 a. Richter, E. Gesehichte der Schwankungen der Alpengletscher. - Zeitschr. d. deutsch. und öster. Alpenvereins, XII. p. 51-74. Wien 1891.

691. Richter. Ent. Ztg., p. 83. Stettin 1869.

692. Richter. Ent. Ztg., p. 108. Stettin 1869.

693. Richter. Ent. Ztg., p. 215. Stettin 1874.

694. Riedel, M. P. Diptera pupipara. - Soc. ent., X. № 5, p. 35-36. 1895. 694a. Riem, Joh. Physikalisch-ökonomische Bienenbibliotliek, oder Sammlung auserlesener Abhandlungen, von Bienenwahrnehmungen und ausführlichem Urtheile über ältere und neuere Bienenbücher. 4 Bände. Leipzig $1776-1790$.

694aa. Riesen, A. Zur Verbreitung von Amphidasis v. doubledayaria Mill. Soc. ent., XVII. № 22, p. 171. 1903.

694b. Riesen. Parasemia plantaginis. - Nachr. Berliner Ent. Ver. in: Insekt.Börse, XXIII. № 12, p. 48. 1906.

695. Robinson, E. K. Causes of Melanism in Lepidoptera - Entomologist, X. p. $131-132.1877$.

696. Rodsjanko, W. N. Notizen über Orthoptera. III.-IV. - Arbeit. Naturf.-Gesellsch. Univers. Charkow., XXVI. (1891-1892). p. 39-44. 1892. (Russisch: Родвянко, В. Н. Замътки о прямокрылыхъ шаськомыхъ. IIT.-IV. - Труды Общ. Испшт. Прпроды прш Импер. Харьговскомъ Уииверс.).

697. Röber, J. Bemerkungen über eine zweite Generation von ArctiaArten. - Illustr. Zeitschr. f. Ent., V. № 3, p. 39-40. 1900.

698. Rödel, Hago. Ueber das vitale Temperaturminimum wirbelloser Thiere. Zeitschr f. Naturw., Vierte Folge, LIX. V. Bd., p. 183-214. 1886.

699. Roedel, Hugo. Schutzeinrichtungen bei Insekten gegen Kälte. Mit besonderer Rücksicht auf Prof. Bachmetjew's Untersuchungen über die Temperatur der Insekten. -- Helios, Organ Naturwiss. Ver. Regier. Bez. Frankfurt, XVII. p. 69-78. 1900.

699 a. Roesel, A. J. v. Rosenhof. Monatlich herausgegebene Insekten-Belustigung. - T. I, Tagvögel, II. Kilasse, num. III, § 7, p. 15-20. Nürnbery 1746.

700. Rössler, A. Lepidopterologisches. - Wiener Ent. MIonatschr,, VII. 소 4, p. $128-134.1863$.

701. Rösslor, A. Lepidopterologische Mittheilungen. - Wiener Ent. Monatschr., VIII. № 4, p. 131-132. 1864.

702. Rössler, Adolf. Die Schuppenflügler (L e pidopteren) des kgl. Regierungsbezirks Wiesbaden und ihre Entwicklungsureschichte. (392 pp.) Wiesbaden 1881. (Aus den Jahrb. des nassauschen Ver. für Naturk., Jahrg. XXXIII und XXXIV). 
703. Rösslor. Ueber die Zucht exotischer Schmetterlinge. - Ent. Jahrb., I. p. $122-132.1892$.

701. Rollat, Victor. Expériences sur les oeufs des vers ì soie du mûrier, race annuelle. - Comp. rend. Acad. Sc., CXIX. p. 612-614. Paris 1894.

704 . Ross, James Clark. (Anhang zux zweiten Teise). Will. Edw. Parry, Appendix to C. Parry's journal of a second voyage for the discovery of a North-IVest Passage from the Atlantic to the Pacific, performed in 1821-23 in H. M. Ss. Fury and Hecla. London 1824.

705. Rossi, Gustav de. Lange Ueberwinterung der Vanessa urticac L. Illustr. Zeitschr. f. Ent., V. № 22, p. 348. 1900.

705a. Rossikow, K. N. Wandernde oder asiatische Heuschrecken. - Ausgalie des Departements. für Ackerbau. (37 pp.). St.-Petersburg 1899. (Russisch: Россиковъ, Б. Н. Перелетнал пли азіатспал сарашча. ІІзд. Департ. Землед.).

7057. Rossikow, K. N. Pllyctaenodes (Eurycreon) stacticalis L. - Arbeit. des Bưreau für Entomol. des gelehrt. Comité beim Minist. für Ackerbau, Bd. III, 스 11. (95 pp.). St.-Petersburg 1903. (Russisch: Росснговъ, Ћ. Н. Луговой мотылекъ вли метелица Phlyctaenodes [Eurycreon] stacticalis L. - Труды бюро по Энтомодог. У ченаго Компт. Мпнпст. Землед. и Госуд. Имущ.).

705c. Rossilrow, K. Agrotis segetum Schiff. - Arbeit. des Bureau für Entomol. des gelehrt. Comité der Generalverw. für Land- und Ackerbau, Bd. VI. 스 5. (118 pp.). St.-Petersburg 1905. (Russisch: Россиковъ, К. Озпхан совпа [озпмый черпі]. [Agrotis segetum Sehiff.] - Tруды бюро по Эптомол. У чен. Јомпт. Главн. Управл. Землеустр. и Землед.).

706. Rossinsky, D. M. Ueber das Aufziehen der Grains, welche mit Karbolsäure ausgewaschen wurde. - Arbeit. der kaukas. Seidenz.-Station, X. Bd., 1. Liefer., p. 21-26. Tiflis 1901. (Russisch: Россинсвій, Д. М. Вықормка грены, промктой карболовой кпслотой. - Труды гавказск. Ше.товод. Стапціи).

707. Rostowzew, N. N. Botys sticticalis. - Herold der Landwitsch., .1: 26-27. 1901. (Russisch: Ростовцөвъ, Н. Н. Botys sticticalis. - Btcri. Земгдтиія).

708. Roulet, J. C. Le Phylloxera dans le canton de Neuchâtel. Rapports et documents officiels. Neuchâtel 1878.

708 . Rubner, Max. Die Gesetze des Energieverbrauches bei der Ernährung. (426 pp.). Leipzig und Wien 1902.

709. Rudow, F. Insektenleben im Winter. - Soc. ent., X. i 2, p. 11-12; № 3 , p. $18-20$. 1895 .

710. Radow. Linige Bemerkungen über Entwickelungszustände der Blattwespen. - Illustr. Wochenschr. f. Ent., II. p. 263-266. 1897.

711. Rudow. Triumph der Züchtung. - Insekt.-Bürse, XV. Ni 13, p. 74. 1898.

712. Rudow. Weiterer Beitrag zu den Grössenverhältnissen der Insekten. Insekt.-Börse, XVII. № 24, p. 188-189. 1900.

713. Rudow. Ueber die Grössen-Variation bei Insekten. - Insekt.-Börse, XVII. 스 2, p. $10-11.1900$.

714. Rübsaamen, Ew. H. Zur Blutlausfrage. - Allg. Zeitschr. f. Ent., VII. 스 12-13, p. $229-230.1902$. 
715. Rühl, Fritz. Ueber die Einwirkung verschiedenfarbigen Ijichtes auf die Raupen. - Soc. ent., I. № 5, p. 36--37. 1886.

716. Rühl, Tr. Ueber die Beschleunigung der Entwicklung ülerwinternden Puppen durch erhöhte Temperatur. - Soc. ent., II: № 18, p. 138139. 1887; № 19, p. 145-146. 1888.

717. Rühl, Fritz. Die Veränderlichkeit der Schmetterlinge. -- Isis (Russ). XIII. p. $282-283$; p. $298-299$; p. $324-325$ p. $330-331.1888$.

718, 720, 725 u. 726. Rühl, Fritz. Die MIacrolepidopteren-Fauna von Zürich und Umgeloung. - Soc. ent., IV. № 6, p. 50-51. 1889; V. ํ 20, p. 153-154. 1891; VIII. №̉ 11, p. 82-83; 시 13, p. 97-98. 1893.

719. Rühl, Fritz. Beitrag zur kritischen Sichtung der Melitaeen-Gruppe athatia Rott., parthenie Bork. und aurelia Nick. - Soc. ent., V. 스 5, p. 35-36. 1890.

720. [Vide lauf. № 718].

721. Rühl, Fritz. Die palaearktischen Grossschmetterlinge und ihre Naturgeschichte. Leipzig 1892.

722. Rühl, Fritz. Einige kurze lepidopterologische Mittheilungen. - Soc. ent., VII. 스 11, p. $85-86$; № 12 , p. 93.1892.

723. Rühl, Fritz. Melitaca parthenie Borkh. ab. und v. jordisi m. - Soc. ent., VII. № 21, p. 164-165. 1893.

724. Rühl, Fritz. Ueber Bombyx lanestris L. und Bombyx arbusculae Frr. Soc. ent. VII: 사 18, p. 140-142. 1892; 스 19, p. 151-152; 수 20, p. 158 ; № 22, p. 173; 스 23, p. 182-183; 스 24, p. 187-188. 1893. 725 u. 726. [Vide lauf. ㅀ. 718].

726 a. Ruhe, H. Schutzmittel einiger Grossschmetterlinsraupen. - Ent. Jahrb., XIII. p. $141-143.1904$.

727. Rahmer, G. W. Die Uehergänge ron draschniı levana L. zu var. prorsa L. und die bei der Zucht anzuwendende Kältemenge. - Entomol. Nachr., XXIV. p. 37-52. 1898.

727 a. Rykatschew. Über den Auf- und Zugang der Gewässer des Russisehen Reiches. - Wild's Rep. de Meteorolog., II. Suppl.-Bd. Petersburg 1887.

728. S. Notiz. - Soc. ent., X. 수 8, p. 60. 1895.

729. Sachs, Julius v. Gesammelte Abhandlungen über Pflanzen-Physiologie. I. Band. (674 pp.). Leipzig 1892.

729a. Sabanin, A. N. Ueher die chemische Zusammensetzung des Blattes von Scorzonera hispanica. - Nachr. des Comité für Seidenzucht, I. № 6-7, p. 1-14. 1897. (Russisch: Сабанинъ, А. Н. О химическомъ составь тиста скорцонера [Scorzonera hispanica]. Извьст. Комптета Шековод. Импер. Москов. Общ, Сельск. Хоз.).

730. Sajó, Karl. Sommerschlaf eines Käfers. - Illustr.. Wochenschr. f. Ent., I. p. 87-89. 1896 .

731. Sajó, Karl. Entomoscelis adonidis und E. sucru. - Illustr. Wochenschr. f. Ent., I. p. 117-120. 1896.

732. Sajó, Karl. Der Weinstock-Fallkäfer (Eumolpus vitis F.). - Illustrierto Wochens hr. f. Ent., I. p. 501-506; p. 517-524. 1896.

733. Sajó, Karl. Weitere Nittheilungen über den Weinstock-Fallkäfer. Illustr. Wochenschr. f. Ent., II. p. 129-134. 1897. 
733a. Sajó, Karl. Insektenreisen. -- Illustr. Wochenschr. f. Ent., II. p. 229-235; p. 241-242; p. 257-263. 1897.

734. Sajó, Karl. Noch einiges ïber Konservieren der Inseliten. - Illustrierte Wochenschr. f. Ent., II. p. 439-441. 1897.

734a. Salow, M. R. Die chemische Analyse von Scorzonera hispanica. Nachr. des Comité für Seidenzucht, I. № 6-7, p. 15. 1897. (Russisch: Заловъ, М. Р. Химическій анализъ скордонеры.- Извђст. Комитета Шелковод. Имшер. Москов. Общ. Сельск. Хоз.).

735. Sasaki, Chujiro. On the feeding of the Silkworms with the leaves of wild and cultivated Mulberry-trees. - Bull. Coll. Agricult. Tokyo Imp. Univ., VI. p. 37-41. Tokyo 1904.

735a. Sanson, A. Sur la parthènogénèse chez les abeilles. - Comp. rend. Acad. scienc., LXXXVII. p. 659-661. Paris 1878.

736. Sauvageon de. Sur l'emploi de l'électricité dans l'éducation des vers à soie. - Comp. rend. Acad. Sc., Paris, I. p. 1142-1143. 1860; LI. p. 1146.1561 .

737. Schäffer, C. Beiträge zur Histologie der Insekten. - Zool. Jahrb., Abt. f. Anat., III. 4. Heft, p. $611-652.1889$.

738. Schatz, E. Die Familien und Gattungen der Tagfalter systematisch und analytisch bearbeitet. (Zweiter Theil von: Exotische Schmetterlinge von Dr 0. Staudinger und Dr E. Schatz). 1. Lief., p. 29-31. 1885.

739. Schaufuss, C. Entomologische Mitlheilung (Lucanus cervus-Larve in Ulmenholz). - Insek.-Börse, Bd. XII, № 14, p. 111. 1895.

740. Schawrow, N. Die Krankheiten der Seidenraupe (Bombyx mori L.) und die Mittel zu deren Bekämpfung. (136 pp.). Tiflis 1885. (Russisch: шавровю, H. Бользви шелковичваго тервя [Bombyx mori L.] и средства борьбы съ ними).

741. Schawrow, N. N. Eine Bemerkung über die wilden exotischen Seidespinner und über die Cocons der Lepidopteren. - Nachr. der Gesellsch. der Liebhaber der Naturwiss., Anthrop. und Ethnogr., L. Lief. 2, Sitzungsprot. der Zool. Abth. der Geselsch., I. Lief. 2, p. 412-430. Moskau 1888. (Russisch: Шавровъ, Н. Н. Замьтка о дикихъ, әкзотпчесихъ шелкопрядахъ п о коков чешуекрылыхъ. Извъст. Общ. Любит. Естествозн., Автропод. п Әтногр., протокоды засџдан. Зоолог. Отд. Общ.).

742. Schawrow, N. N. Ueber die Bedeutung der Ernährung der Seidenraupen mit Blättern von Scorzonera. - Ackerbau-Ztg., № 9, 스 11. 1897. (Russisch: Шавровъ, Н. Н. Зваченіе выкормки пелковичныхз червей листьяп скорцонера. - Землед. Газета).

743. Schelver, F. J. Beobachtungen über den Einfluss des Geschlechtsunterschiedes auf die Farbe der Insekten. - Arch. f. Zool. und Zoot., II. 2. Stück, p. 223-224. Braunschweig 1802 .

744. Schemigonow, I. M. Ueber den Einfluss einiger physikalischen und chemischen Faktoren auf die Lebensthätigkeit der Eier von Ocneria monacha L. - Horae soc. ent. rossicae, XXXV. № 1-2, p. LXLXVI. 1901. (Russisch: Шемитоновъ, И. М. Вліяніе ныкоторыхъ (изическиъ п химическиъ факторовъ иа жизнеспособность яичекъ шелкопряда - моватенш [Ocneria monacha L.]). 
745. Schonkling-Prévôt. Parasiten, insbesontere die Parasiten des Menschen aus der Klasse der Insekten. - Illustr. Wochenschr. f. Ent., I. p. $376-380$; p. $407-414.1896$.

746. Schenkling-Prévôt. Höhleninsekten. - Illustr. Wochenschr. f. Ent., II. p. $97-100$; p. $116-118$; p. $137-141.1897$.

747. Schenkling-Prévôt. Nächtlicher Raupenfang. - Illustr. Wochenschr. f. Ent., II. p. 487-492; p. 502-505. 1897.

747a. Scheweiew, I. Die Honigrekolte 1902 und 1903 nach den Beobachtungen in Buraschewo, Gouvernement Twer. Der Einfluss der 'Temperatur und der Feuchtigkeit der Iuft auf die Honigrecolte. - Die russ. Bienenz.-Liste, XIX. 요 8, p. 288-299. 1904. (Russisch: Шөвелевъ, И. Медосборъ въ 1902 и 1903 г. но наблюденіямъ Бурашевской пасђи, Твер. губ. Вліяніе темературы п влажности воздуха на сборь педа. - Русс. Пчелов. Јист.).

748. Schowyrow, Iw. Die Beschreibung der schädlichen Insekten der SteppenFörstereien und der Bekämpfungsmittel. (143 pp.). St.-Petersburg 1893. (Russisch: Шөвырөвъ, Ив. Описаніе вредихъ наськомыхъ степныхъ льсицчествъ п способовъ борьбы съ ними).

749. Schille, Fr. Die Zucht von Cidaria lugubrata Stgr, luctuata Hb. Soc. ent., VII. № 2, p. 12-13; № 3, p. 18-19. 1892.

750. Schilling, H. Frhr. von. Eine strolchende Wollschildlaus, vielfache Blutlausgenossin. - Prakt. Ratg. Obst. und Gartenbau, XVI. № 3, 4, 5. 1901.

750a. Schima. Pieris rapae var. rossii Stef. - Verh. der zool.-bot. Ges. in Wien, LV. 소 1-2, p. 24-25. 1905. (Bericht der Sekt. f. Lepidopt.).

751. Schirach, Adam Gottlob. Die mit Natur- und Kunstverknüpfte neu erfundene Binnenvermehrung oder Binnenschwärme im Maimonat in Wohnstuben zu machen. Budissin 1761.

752. Schitkow, B. M. Versuch über die Ernährung der Seitenraupen mit Scorzonera hispanica im Gouvernement Simbirsk. - Nachr. des Comité f. Seidenzucht, I. Lief. 6-7, p. 16-18. Moskau 1897. (Pussisch: жІитеовъ, Б. М. Опытъ выкормки пелковниыхъ червей листонъ скорцонеры въ Спмбирской губершіш. - Извъст. Комитета ІІІлковод. Импер. Московск. Обџ. Сельск. Хозяйства).

754. Schmidberger. Beiträge zur Obstbaumzucht und zur Naturgeschichte der den Obstbäumen schädlichen Insekten. Linz 1839.

755. Schmidt, Franz. Zur Naturgeschichte einiger Lepidopteren. - Ent. Ztg., XIX. p. 344-381. Stettin 1858.

756. Schmujdsinowitsch, W. J. Der Lebensdauer der Seidenraupen, welche ohne Nahrung bei verschiedenen Bedingungen der 'Temperatur gelassen wurden. - Arbeit. der kaukas. Seidenz.-Station., Jahr. 1889, II. p. 104-107. Tiflis 1891. (Russisch: Жмуйдзиновичь, В. I. Iродолжительность жизи шелковпqныхъ червей, оставленныхъ безъ нищи ирп разлнчихъ условіяхъ температуры. - Труды кавказ. ПІельоводств. Стацціи).

757. Schmujdsinowitsch, W. J. Der Einfluss des Magnetismus auf die Entwickelung des Maulbecren-Seidenfalters. -- Arbeit. der kaukas. Sei- 
denzucht-Stat., Jahr. 1889, II. p. 105-:10. Tiflis 1891. (Russisch: Жмуйдзивовичъ, В. I. Вліяніе магнптиза иа развитіе тутоваго шелкошряда. - Труды кашгаз. Пелководств. Стапців).

758. Schmajdsinowitsch, W. J. Der Einfluss des Sonnenlichtes und verschiedener Sonnenstrahlen auf die Entwickelung des Maulbeeren-Seidenfalters. - Arbeit. der kaukas. Seidenz.-Station, Jahr. 1889, Bd. II, p. 111-114. Tiflis 1591. (Russisch: Жюуйдзиновндъ, В. I. Јліяніе солнечнауо свъта п разлпчныхъ солнечныхъ дучей на развитіе тутоваго шелкопряда. - Труды кавказ. Шелководств. Ставціп).

759. Schmujasinowitsch, W. J. Die Abhängigkeit der Entwickelungsperiode und Geschlechtes bei Maulbeeren-Seidenspinners von der Grösse, specifischem Gewichte und Färbung der Eier. - Arbeit. der kaukas. Seidenz.-Stat. Jahrg. 1889, II. p. 114-122. Tiflis 1891. (Russisch: жмуйдзиновичъ, В. І. Зависимость періода развптія и пола у тутоваго пелкопряда отъ величны, удьльаго выса п окраскп лицъ. - Труды кавказ. Шелководств. Ставціп).

760. Schmujdsinowitsch, W. J. Zur Frage über den zufilligen Biroltismus beim Saidenspinner. - Arbeit. der Seidenz.-Stat., Jahrg. 1889, Bd. II, p. 125-132. Tiflis 1891. (Russisch: Жмундвзновнчъ, В. I. Къ вопросу о случайномъ бввольтнинзы у тутоваго пелкопряа. Трудк кавказ. Шелководств. Станціп).

761. Schmujdsinowitsch, W. J. Ueber den Einfluss verschieden färbenden Substanzen, welche die Seidenraupen mit der Nahrung aufnehmen, auf die Farbe der Seide. - Arbeit. der kaukas. Seidenz.-Station, Jahrg. 1889, Bd. II, p. 132-135. Tiflis 1891. (Russisch: Жмуйдвиновнчъ, В. I. Вліяніе на цвътъ пелка различныхъ красящихъ вещестъ, прннимаеыхъ шелковичнымъ червемъ вмьсть съ пищей. - Труды кавтаз. Шелководств. Станціи).

762. Schmujdsinowitsch, W. J. Einfluss der schrofen Temperaturschwankungen auf die Entwickelung der Eier-[von Bombyx mori]. - Arbeit. der kaukas. Seidenz.-Station, Jahrg. 1890, III. Bd., p. 160-162. Tiflis 1892. (Russisch: Жиуйдзнновнчъ, В. І. Влілпіе рұзкихъ полебапій температуры на развитіс гренк. - Труды павказ. Педвоводств. Станціп).

763. Schmujdsinowitsch, W. J. Vertheilung der Rassen des Seidenspinners des Maulbeerbaumes nach der Eieranzahl in einem Gramm. - Arbeit. der kaukas. Seidenz.-Station, Jahrg. 1890, III. Bd., p. 162--163. Tiflis 1892. (Russisch: Жмуйдзкновнчъ, В. I. Раздълевіе породъ тутоваго шелюопяда по колпчесту яичевъ, прпходящихся на 1 граммъ. - Труды кавказ. Нелководств. Станціи).

764. Schmujdsinowitsch, W. J. Zur Frage üler die zufällige zweite Ausbrütung der Eier (Bivoltismus) des Seidenspinners des Maulbeerbaumes. - Arheit. der kaukas. Seidenz.-Station,' Jahrg. 1890, III. Band, p. 199-218. Tiflis 1892. (Russisch: Жщуйдзичовичъ, В. І. Къ вопросу о случайномъ вторпчпомъ ожшвленіи грены (бивольтизљ) у тутоваго шелкопря,да. - Труды кавказ. Шедководств. Станціи).

765. Sehmujdsinowitsch, W. J. Gewichtsänderung bei Puppen und Faltern des Seidenspinners des Maulbecrbaumes während verschiedener Mo- 
mente ihrer Entwickelung. - Arbeit. der kaukas. Seidenz.-Station, Jahrg. 1890, III. Bd., p. 218-222. Tiflis 1892. (Russisch: अмуйдзиновичь, В. I. Изжыеніе выса у куколокъ п бабочекъ тутоваго пелкопряда въ разлиные моменты пхъ развнтіл. - Труды кавказ. Нелиоводетв. Станціи).

766. Schmujdsinowitseh, W. J. Einige Beobachtungen über den Zusammenliang zwischen der Entwickelungsperiode bei Spinner des Maulbeerbaumes und der Eiergrösse und des Geschlechtes der zu entwickelnden Shmetterlinge. - Arbeit. der kaukas. Seidenz.-Station, Jahrg. 1891, IV. Bd., p. 49-75. Tiflis 1892. (Russisch: Жеууйдзиновичъ, В. I. Нькоторыя наблюденія надъ занисимостью періода развитія у тутоваго шелкопяда отъ величины лицъ и пола пмьющихъ разваться бабочекъ. - Труды кавказ. Шелководств. Стандіп).

767. Schmujdsinowitsch, W. J. Einige Beobachtungen aus dem Gebiete der Biologie, Terathologie und Pathologie des Maulbeeren-Spinners. Arbeit. der kaukas. Seidenz.-Stat., Jahrg. 1892, VI. Band, 3. Lief., р. 59-69. Tiflis 1893. (Russisch: ЖЖмуйдзновичъ, В. I. Нъъоторшя наблюденія пзъ области біологін, тератологіи и патологіи тутоваго шелкопряда. - Труды кавказ. Шелюоводств. Стапиіи).

768. Schnoider, R. Ueber Eisen-Resorption in thicrischen Organen und Geweben. - Abh. Akad. der Wissensch. zu Berlin, 수 2, (68 pp.). 1888.

769. Schönfeld. Der Wärmebedarf der Biene. - Bienen-Zeitung, XXII. II 2, p. $16-19.1866$.

$769 a$. Schönfeld. Die Wärmegrenzen, innerhalb deren die Bienen leben. Eichstädt. Bien.-Ztg., XXII. № 9, p. 89-92. 1866.

770. Schoh, Gust. Zuht von Euprepia caja in gefürbtem Licht. - Mitth. Schweiz. ent. Gesellsch., V. p. 540. 1880.

771. Schreiber, Friedrich. Ueber Fang und Zucht von Lophopteryx camelina L. aberr. giraffina Hb. - IV. Jahresber. des Wien. Entom. Ver., (1893), p. 21-23. 1894.

771a. Schreiner, J. Ueber einige Schmetterlinge, welche den Obstgärten schädigen. - Verlag von Depart. für Ackerbau. St.-Petersburg 1901. (Russisch: Шірейнеръ, Я. О нґкоторыхъ бабочкахъ, вредящихъ пдодовымъ садамъ. - Нздан. Департам. Землед.)

771b. Schreiner, J. Th. Carpocapsa pomonella L. -- Arbeit. des Bureau fur Ent. des gelehrt. Comité beim Minist. für Ackerbau, V. № 4. 1905. (40 pp.). (Russisch: Шрейнеръ, Я. $\theta$. Яблоннаи плодоліорка (Carpocapsa pomonella L.). - Труды бюро по Энтомољ. Учен. Комит. Минист. Земдед. п Госуд. Имущ.).

772. Schröder, Christoph. Entwickelung der Raupen-Zeichnung und Abhängigkeit der letzteren von der Farbe der Umgebung. - InauguralDissertation Univers. zu Kiel. (67 pp.). Berlin 1894.

773. Schröder, Chr. Experimental-Untersuchungen bei den Schmetterlingen und deren Entwickelungszuständen. - Illustr. Wochenschr. f. Ent.,. I. № 12 , p. 181-184. 1896.

774. Schröder, Chr. Skizzen aus der Entwickelungs des Schmetterlings. Illustr. Wochenschr. f. Ent., I. p. 341-344. 1596. 
775. Schröder. Die Schutzfärbung und ihr Wesen. - Illustr. Wochenschr. f. Ent., II. p. 94-95. 1897.

776. Schröder, Chr. Preisausschreiben. - Illustr. Zeitschr. f. Ent., IV. 12 19, 1899. (Auf zweiter Seite des Unschlages).

777. Schröder, Chr. Experimentelle Untersuchungen zur Vererlung von Charakteren im Larvenzustande. - Allg. Zeitsclır. f. Ent., VI. 스 16-17, p. 225-258. 1901.

778. Schröder, Chr. Die Variabilitiat der Adalia bipunctuta L. Greichzeitig ein Beitrag zur Descendenz-Theorie. - Allg. Zeitschr. f. Ent., VI: № 23, p. $355-360$; № 24, p. 371-377. 1901; VII: №: 1, p. 5-12; 스 2- 3, p. $37-43$; 수 4-5, p: 65-72. 1902.

779. Schröder, Chr. I) Zeichnungs-Variabilitiit von Alraxas grossuluriatu L. Gleichzeitig ein Beitrag zur Descendenz-Theorie. - Allg. Zeitschrift f. Ent., VIII. 스 6-7, p. 105-119; 스 8-9, p. 145-157; № $10-11$, p. 177-194; № 12-13, p. 228-234. 1903.

780. Schröder, Chr. Kritik der von dem Herrn Dr E. Fischer (Zürich) ans seinen "Lepidopterologischen Experimentalforschungen" gezogenen Schlüsse auf Grund einer neuen Erklärung des Wesens derselben. Allg. Zeitschr. f. Ent,, VIII. № 22-24, p. 437-447. 1903.

781. Schtschelkanowzew, J. P. Das Quantum der Blätter von Seorzonerat, welches zur Ernährung der Seidenraupen nöthig ist. - Nachr. des Comité für Seidenz., I. Lief. 9, p. 9-12. Moskaı 1899. (Russisch:

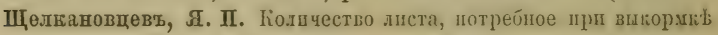
шелковпныхъ червей скорцонсромъ. - Цзв'ьст. Компт. Неаковод. Ґмпер. Общ. Сельск. Хозяйства).

782. Schtscherbakow, A. M. Die niedrigsten Insekten (Collembola) Spitzbergens. - Nachricht. der Univers. Kijew, XXXIX. 즈 1, p. 1-6. 1899. (Russisch: Щербаковъ, А. М. Низшія насъьмыя (Collembola) Шппцергена. - Универс. Нзвьст., Кіевъ).

783. Schugurow, N. Frühlingsnatur der Stadt Odessa. - Zeitschr. f. Naturw. und Geogr., VIII. № 7, p. 87-90. 1903. (Russisch: Шуруровъ, Н. Весенняя прпрода 1. Одессы. - Журн. Естествозп. п Геогр.).

784. Schugurow, Al. Eine kurze Beschreibung der Fianna und Flora des Sümpfehens bei der Quelle „der grosse Spritzbrunnen " in der Nähe von Odessa. - Zeitschr. für Naturw. und Geogr., VIII. 수 3, p. 87-90. 1903. (Russisch: IIугуровъ, Ал. Краткій очеркъ фаунк и ф)лоры болотца у истотншка „Большой фонташъ“ около Одесск. Журн. Естествозн. II Теогр.).

784a. Schultz, 0skar. Ueber das psychische Leben der Insckten. - Illustr. Wochenschr. f. Ent., I. p. 423-429. 1906.

785. Schultz, 0. Ueber einige Missbildungen der Form, und annrmale Ausbildung des Farbenpigments, des Geäders und der Fransen der Schmetterlingsflügel. - Illustr. Wochenschr. f. Ent., II. p. 143144. 1897.

786. Schultz, 0. Ueler das Auffinden und die Zucht der Raupe von Hudena adusta Esp. - Illustr. Wochenschr. f. Ent., II. p. 31-32. 1897.

787. Schultz, 0skar. Ueber den Allinismus bei Lepidopteren. - Illustr. Wochenschrift f. Ent., II. p. 705-707. 1897. 
788. Schultz, 0skar. Biologisihes über Papilio machaon L. - Illustr. Zeitschrift f. Entom., IV. № 21, p. 331, № 23, p. 360. 1899; V. 스 4, p. 56-57. 1900.

789. Schultz, 0. Lepidopterologisches (betreffend Papilio podalirius L. und Papilio machaon L. - Soc. ent., XV. 주 8, p. 57-58. 1900.

790. Sehultz, Oskar. Varietaten und Aberrationen von Papilio podalirius L. Uebersicht über die Variabilität dieser Species. - Berl. entomol. Zeitschr., p. 119. 1902.

790 a. Schultz, 0skar. Melanismus bei Acronycta rumicis L. - Soc. ent, XVI. № 22, p. 170.1902.

791. Schultz, 0skar. Ueber einige Aberrationen von Callimorpha dominula L. - Soc. ent., XIX. № 19, p. 148-149. 1905.

792. Schultze, Max. Das Protoplasma der Rhizopoden und der Pfianzenzellen. Leipzig 1863.

793. Schultze, 0. Ueber die Bedeutung der Schwerkraft für die thierische Gestaltung, sowie über die mit Hülfe der Schwerkraft mögliche künstliche Erzeugung von Doppelmissbildungen. - Sitzber. physik.med. Gesellsch. Würzburg, № 17, p. 385-391. 1894.

794. Schulzte, 0sk. Ueberliegen ron Puppen von Papitio machaon L. und Papilio podalirius L. - Illustr. Zeitschr. f. Ent., IV. № 15, p. $235-236.1899$.

794a. Schultze, 0. Zur Frage von den geschlechtsbildenden Ursachen. - Arch. für mikrosk. Anatomie und Entwickelungsgesch., LXIII. p. 197257. 1903.

795. Schulz, W. A. Materialien zu einer Hymenopterenfauna der westindischen Inseln. - Sitzber. der math.-physik. Klasse der Akad. der Wiss. zu München, Heft III, p. 453-488. 1903.

795 a. Schulz, G. B. Nachrichten aus dem Berliner Entomol. Ter. (Sitz. vom 14. IX. 1899). - Insekt.-Börse, XVI. № 41, p. 244. 1899.

796. Schumann, E. Schwarzfärbung bei Käfern. - Illustr. Zeitschr. f. Ent., IV. 스 19, p. 299.1899.

797. Schumbarg und Zuntz, N. Zur Kenntniss der Finwirkung des Hochgebirges auf den menschlichen Organismus. - Pflüger's Arch. f. Physiologie, LXIII. p. 461-494. 1896.

798. Swammerdamm, Johann. Bibel der Natur. Leipzig 1752.

799. Schwerin, N. W. Versuch über die Ernährung der Seidenraupen mit Scorzonera hispanica im Chudoschino, Gouvernement NischniNowgorod. - Nachr. des Comité für Seidenzucht., I. Lief. 6 u. 7, p. 19-20. Moskau 1897. (Russisch: Швөринъ, Н. В. Опытъ выкормии пелковпуихъ червей листомъ скордонера въ с. Худошивы Ардатовскато у'ъда Ннжегородскої губернін. - Извьстія Іімит. Шелковод. Изпер. Моспов. Общ. Седьск. Хозяйства).

800. Scott, W. N. Fatal Temperature for some Coccids in Georgia. - Proc. 11. Meet. Assoc. Econ. Entom. (U. S. Dept. Agric., Div. Entom., Bull. 20. N. S.), p. 82-85. 1899.

801. Scudder, S. H. The Butterflies of the Eestern United-States and Canada with special references to New-England. Cambridge (H. S.) 1889. 
802. Seeland, Br. v. Ueber die Nachwirkung der Nahrungsentzichung auf die Enährung. - Biol. Centralbl., VII. 소 5, p. 145-158; 승 6, p. $184-192 ;$ 스 7, p. $214-224 ;$ ㅅ․ 8, p. 246-256; 스 9, p. 271281. 1887.

803. Seiler, A. Arctia caja. - Entomol. Zeitschr., Jahrrg. IV, p. 10. Guben 1890.

803a. Seifert, 0tto. Contribution to the knowlegde of North American Arctiidac. IV. - The Canad. Entomol., XXXXVI. to 3. 1905.

804. Selmons, G. C. M. Beitrag zur Zucht von Purnassius apollo (L.). - Soc. ent., IX. ㄷ․ 7, p. 50-51. 1894.

805. Selmons, G. C. M. Lucanus cervus im Hochgebirge. - Soc. ent., X. ㄱì 7 , p. 52. 1895 .

806. Selmons, G. C. I. Beitrag zur Zucht von Parnussius delius L’sp. - Soc. ent., X. 구 5, p. 34-35. 1895.

807. Semenow, Andrey. Genus Pseudobruscus Scm. (Coleoptera, Carabidae), seine genetische Beziehungen und die Bedeutung in turanischen Fauna. - Horae Soc. entom. Rossicae, XXXIV. № 1-2, p. 41-51. (1899). 1900. (Russisch: Сөзевовъ, Авдрей. Родъ Pseudobroscus Sem. (Coleoptera, Carabidae), его генетпческія связи и эпаченіе въ турлшской фаунђ. - Труды русскаго Әнтомол. Общ.).

808. Semper, Carl. Die natürlichen Existenzbedingungeu der Thiere. I. 'Theil $(\mathrm{X}+299$ pp.); 2. Theil (VIII + 296 pp.). Leipzig 1880. (Bildet Bd. XXXIX und XL der internat. wissensch. Bibliothek).

808 a. Serebrjanikow, A. W. Gastropacha pini Ochsh. - Jachr. des Forst-Instit. zu St.-Petersburg, VII. p. 29-102. 1901. (Russisch: Сөрөбрянивовъ, А. Б. Большой сосповый пелвопрядъ [Gastropacha pini Ochsh.]. - Извъст. С.-Петербургскаго Лъвн. Ннстит.).

809. Sewerin, S. Bakterien in Bezug auf den Thierorganismus. - Herold der kais. russ. Gesellsch. für die Akklimat. der Thiere und Pflanzen, № 4. 1896. (Russisch: Сөверинъ, С. Бактеріп по отнотенію къ организму леивотныхъ. - В屯стншкъ Импер. Русск. Общ. Агклци. живот. іі растен.).

S10. Sidebotham, H. J. Ueber Schmetterlingsvarietäten. - Katter's Entom. Nachr., III. p. 1-2. 1877. (Aus den Bull. de la Soc. Linneenne. du Nord de la France, 1 Juni 1876).

811. Sidebotham, J. Influence of Food and Light on Lepidoptera. - Sc.Gossip. (1870), p. 273. 1869.

S11 a. Sieber, N. und Metalnikow, S. Ueber Ernährung und Verdauung der Bienenmotte (Galleria mellonella). - Archiv fo ges. Physiol., CII. p. 269-286. 1904.

812. Siebold. Wahre Parthenogenesis bei Schmetterlingen und Bienen. Leip zig 1856.

813. Sikora, F. Die Zucht exotischer Käfer. - Soc. ent., VII. ㄱo 15, p. 114115 ; № 18, p. 139-140. 1892.

$813 a$ u. 814. Sikora, Hilda. Entomologische Spaziergänge. -- Insekten-Börse, XXII. ㄱ. 28, p. 111-112. 1905. 


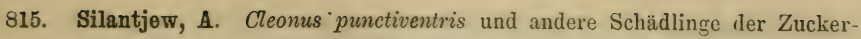
rübe. - Land- und Forstwirtsch., p. 1-16. 1896. (Separt.). (Russisch: Силантьевъ, А. Свекольный долгоносникъ и другіе враги сахарной свеқлы. - Седьское Хозяйство и Јьсоводство).

815a. Silantjew, A. A. Einfluss des Wetters im Sommer 1888 auf Pflanzen und Thiere. - Jahrb. des Forst-Instit. zu St.-Petersburg, III. p. 115118. 1888. (Russisch: Сплантьвљ, А. А. Отраженіе погоды льта 1888 года на растеніяхъ и животныхъ. - Ежегодникъ С.-Шетербургскаго Лћсн. Ивст.).

815b. Silfvenius, A. J. Beobachtungen über die Ökologie der Trichopterenpuppe. - Zeitschr. f. wiss. Insektenbiol., II. 3-4, p. 88-98. 1906.

815c. Silvestri, Filippo. Note preliminari sui Termitidi e Termitofili sudamericani - Bollet. d. Mus. d. Zool. e Anat. comp., Vol. XVII. Ne 419. 1902 .

$815 d$. Silvestri, Filippo. Ergebnisse biologischer Studien an südamerikanischen Termiten. - Allg. Zeitschr. für Entom., V. № 9, p. 173-178; 소 14-15, p. 257-260; № 16, p. 289-293; 시 17, p. 326-335. 1902.

816. Simroth, H. Ueber die einfachen Farben im Thierreich. - Biol. Centralbl., XVI. p. 33-51. 1896.

$816 \alpha$. [Vide lauf. 스 $822 d$ ].

$816 \alpha^{\prime}$. Simroth, Heinrich. Ueber Gebiete kontinuierlichen Lebens und über die Entstehung der Gastropoden. - Biolog. Centralbl., XXII. 즈 9, p. 262-278. 1902 .

816a. Sitowski, L. Biologische Beobachtungen über Motten. - Bull. Acad. Scienc. Cracovie, Class. d. scienc. mathém. et natur., p. 534-547. 1905. (Separat.).

316b. Sitowski, L. Spostrzezenia biologiczne nad molowcami. - Akadem. Umiejettnosci w Krakowie, Wydz. mat.-przyr, T. XLV, Ser. A, p. 239251. 1905. [Derselbe Inhalt wie der Abhandlung $816 \alpha$ ].

817. Skorikow, A. S. Neue Formen russischer Collembola. - Arbeiten der Natur-Forscher-Gesellsch. bei der Universit. zu Charkow, XXXIII. (1898-1899). p. 383-402. 1899. (Russisch: Свориговъ, А. С. Новыя формы русскшхъ Collembola. - Труды Общества Испит. Прир. при Импер. Харьков. Универс.).

818. Skorikow, A. S. Ueber arctische Beinschwänzer (Collembola). - Hor. societ. ent. Rossicae, XXXIV. (1899). № 1-2, p. XL-XLII. 1900. (Russisch: Сеоривовъ, A. C. Объ арктическихъ ногохвосткахъ [Collembola]. - Протоколь 13 Декаб. 1899).

819. Slater, J. W. On the Food of Gaily-coloured Caterpillars. - Trans. Ent. Soc., p. 205-209. London 1877.

820. Slater, J. W. Note on protected Coleoptera. - Entomologist, XI. p. 191.1878.

821. Slovogt, B. Reiche Novemberabende 1899. - Soc. entom., XIV. 소 23, p. $180-181.1900$.

822. Slevogt, B. Ueber neue kurländische RhopaIocera-Varietäten. - Horae soc. ent. Rossicae, XXXIV. № 3-4, p. 524-533. 1900.

$822 \alpha$. Slevogt, B. Ueber, namentlich bei Noctuen, zunehmenden Melanismus. - Soc. ent., XVII. ㅈo 6, p. 43. 1902. 
$822 a$. Slevogt, B. Veber melanotische Rhopalocera-Weilchen. - Soc. ent., XX. 스 11, p. 81-82. 1905.

822\%. Slevogt, B. Historisch denkwürdige Falter. - Soc. entom., XX. 수 12, p. 90-91. 1905.

822 c. Slevogt, B. Vorläufige Nittheilung. -... Inselkten-Börse, XXIII. N38 38, p. 152.1906.

$822 d$ ‥ $816 \alpha$. Slingerland, M. V. Some observations upon plantlice. - Sciènce, XXI. p. $48-49.1893$.

822e. Solowiow, Paul. Zur Pigmentbildung bei den Schmetterlingen. - Zeitschr. für wissensch. Insektenbiol., II. Hft. 10, p. 328-329. 1906.

823. Sorhagen, L. Grabowiana. Fin Nachtrsg zu den "Kileinschmetterlingen der Mark Brandenburg." - Allg. Zeitschr. f. Ent., VI. No 16-17, p. $241-245 ;$ 승 18 , p. $276-279$; 시 19 , p. $296-298$; 스 20 , p. $311-314$; 스 21 , p. $327-332$; 스 22 , p. $343-347$. 1901; VII. 스 1 , p. $19-25$; 승 $2-3$, p. $51-57$; 스 $4-5$, p. $77-81$; 스 6 , p. $97-100.1902$.

824. Sorhagen, I. Biologie von Nistophora hornigi Stgr. (St. ent. Z., 1883, 154). - Allg. Zeitschr. f. Ent., VII. № 20, p. 432-434. 1902.

825. Soule, Caroline G. Color-variation in larvae of Papilio polyxena and other Notes. - Psyche, VIII. ㅇ․ 284, p. 435-436. 1899.

825 a. Spallanzani, Lazaro. Trois mémoires sur la respiration, traduits en français, d'après le manuscrit inédit de l'auteur, par J. Sennebrer. Genève 1803.

826. Speiser, P. Ueber Reduktion der Flügel bei ectoparasitischen Inseliten. Insekt.-Börse, 16. Jahrg., № 20, p. 117; 스 21, p. 122. 1899.

827. Speiser, P. Stechmiicken. - Insekt.-Bürse, XViII. 수 1, p. 4-5; 살 2 , p. 11-12. 1901.

828. Speiser, P. Biologische Notizen über Dipteren. - Krancher's Entom. Jahrb., XII. p. 176-181. 1903.

829. Speyer, A. Empithecia actaeata. - Entom. Ztg., XXXIII. p. 173-175. Stettin 1872.

830. Speyer, A. Bemerkungen über den Einfluss des Nalrungswechsels auf morphologische Veränderungen, insbesondere bei den Arten der Gattung Eupithecia. -- Entom. Zeitung, XLIV. p. 333-356. Stettin 1883.

831. Speyer, A. Die Raupe ron Acronycta alni. Ein biologisches Rätsel. Ent. Ztg., XLIV. p. 419-425. Stettin 1883.

832. Spuler, A. Zur Plyylogenie der einheimisehen A patura-Arten. - Ent. Ztg., LI. p. 267. Stettin 1890.

833. Spuler, A. Weismann's neue Versuche zum Saison-Dimorphismus der Schmetterlinge. - Biol. Centralbl., XVII. 수 15, p. 559-573. 1897.

834. Standfuss, M. Lepidopterologisches. - Ent. Ztg., XLV. p. 193-210. Stettin 1884.

835. Standfuss, M. ITandbuch für Sammler der europäischen Gross-Schmetterlinge. 1891.

836. Standfuss, M. Vanessa io L. ab. fischeri m, - Ent. Zeitschr., VI. ㄱo 17 , p. 129. Guben 1892. 
\$37. Standfuss, M. Teher die Gründe der Variation und Aberration des Falterstadiums bei den Schmetterlingen. - Inseliten-Börse, XI. 스 21, p. $199-201$; № 22, p. 209-210; № 23, p. 217-218; 스 24, p. 225-226. 1894; XII. № 1, p. 4-5; № 2, p. 13; 스 3, p. 22-23; 스 4 , p. $29-30$; 스 5 , p. $36-37.1895$.

838. Standfuss, M. On the causes of variation and aberration in the imago stage of butterflies, with suggestions on the establishment of new species. - Entomologist, XXVIII. p. $69-76 ; 102-114 ; 142-150$. London 1895.

839. Standfuss, M. Weitere Mittheilungen über den Einfluss extremer Temperaturen auf Schmetterlingsgruppen. - Entom. Zeitschrift, 스 12, p. 89-91. Guben 1895 .

840. Standfuss, M. Handbuch der paläarktischen Grossschmetterlinge für Forscher und Sammler. 2-te Auflage. (392 pp.). Jena 1896.

841. Standfuss, M. Experimentelle zoologische Studien mit Lepidopteren. Denkschrift Schweiz. Naturf. Gesellsch., XXXVI. (1). Zürich 1898. (Separat. 81 pp.).

$841 \propto$. Standfuss, II. Der Einfluss der Umgebung auf die äussere Erscheinungen der Insekten. - Insekt.-Börse, XXI. № 39, p. 307-308; № 40, p. $315-316$; 스 41, p. 322-324. 1904.

841ß. Standfuss, M. Zur Frage der Unterscheidung der Arten bei den Insekten. - Entomol. Zeitschr. Guben 1903. (Separat. 15 pp.).

$841 \beta^{\prime}$. Standfuss, M. Gesammtbild der bis Ende 1595 an Lepidopteren vorgenommenenen Temperatur- und Hybridations-Experimente. Insekt.-Börse, XVI. 1899. (Separat. 29 pp.).

841 a. Standfuss, M. Die Resultate dreissigjähriger Experimente mit Bezug auf Artenbildungen und Umgestaltung in der Tierwelt. - Verhandl. der Schweiz. Naturf. Gesellsch. an der Jahresvers. in Luzern 1905. (Separat. 24 pp.).

841b. Standfuss, M. Zur Frage der Gestaltung und Vererbung auf Grund achtungzwanzigjähriger Experimente. - Vortrag in der Züricher Naturforsch. Gesell. am 13. Januar 1902. (15 pp.). Zürich 1905.

842. Stange, G. Lepidopterisches. - Ent. Ztg., p. 279-236. Stettin 1886.

843. Staudinger, 0. Reise nach Island zu entomologischen Zwecken unternommen. - Ent. Ztg., XVIII. № 7-9, p. 209-289. Stettin 1857.

843 a. Staudinger, 0. und Rebel, H. Catalog der Lepidopteren des palaearctischen Faunengebietes. Dritte Auflage. Berlin 1901.

844. Steinach, Eugen. Ueber Farbenwechsel bei niederen Wirbelthieren, bedingt durch direkte Wirkung des Lichtes auf die Pigmentzellen.Centralbl. f. Physiolog., V. p. 326-330. 1891.

844a. Stoinert, Hermann. Ueber das Auftreten von Ampliclasis L. ab. doubledayarius B. in Sachsen. - Iris, V. p. 424-427. Dresden 1892.

845. Stempkowska, I. A. Experimentelle Ernähruug der Seidenraupen mit Blättern von schwarzen Scorzonera in Gouvernement Woronesch. - Nachr. des Comité für Seidenz., Vol. I, Lif. 6 und 7, p. 21-22. (Pussisch: Стешповекая, Л. А. Опытнал вынориа шелковичныхъ червей дистомъ тернаго скорцонера въ Воронезіской губернін. Ізвьст. Комит. Шелковод. Импер. Москов. Общ. Сельск. Хоз.). 
846. Stepanow, P. G. Ueber Metamorphosen bei Dipteren der Familie Bombylidae. - Arbeit. der Naturforscher-Gesellsch, bei der Univers. zu Charkow, XV. (1881). p. 1-9. 1882. (Russisch: Степановъ, II. Г. 0 превращеніяхъ у двукрнлихъ семейства Bombylidae. Труды Общщ. Испыт. Прпр. прп Изпер. Харьвов. Универс.).

846a. Stichel, G. Nachrichten aus dem Berliner Entom. Ter. (Sitz. vom 14. IX. 1890). - Insekt.-Börse, XVI. ㅅo 41, p. 244. 1899.

847. Storch, Christian. Entomologische Mittheilungen. - Insekt.-Börse, XVII. 스 25, p. 197. 1900.

847a. Strobl, P. Gabriel. I chneumoniden Steiermarks (und der Nachbarländer). - Mitth. des Naturwiss. Ver. für Steiermark, XXXVI. Jahrg. 1900, p. $132-257.1901$.

848. Strohmayer. Deileph. euphorbiae. - Soc. ent., VII. Ai 18, p. 142. 1892.

$848 a$. Strabell, A. Untersuchungen über das Bau und die Entwickelung der Rübennematoden Heterodera schachtiii. - Bibliotheca Zoologica, № 2. Cassel 1888. (Separat. 49 pp.).

849. Sturm. Deutsche Insekten. III. Band. 1815.

850. Susaki, Chujiro. On the feeding of Silkworms with the leaves of Cudrenia tribola Hance. - Bull. Coll. Agricult. Tokyo Imp. Univ., Vol. VI, p. 15-19. Tokyo 1904.

851. Susani, G. Se nel fenomeno delle nascite dei bachi da seta, procurate collo strofinamento possa o no tenersi per accertata l'azione dell'elettricità? - Atti del R. Istituto Lombardo, Vol. VII, p. 876. 1874.

852. Susani, Guido. La schiusura del seme-bachi col mezzo di agenti chimici. - Rivista settim. di bachicolt., Anno X. p. 57-58. 1878.

$852 \alpha$. Tangl, F. Beiträge zur Energetik der Ontogenesis. - Pflïger's Arch. f. Physiol., XCIII. p. 327-376. 1903.

$852 a$. Taschenberg. Forstwithschaftliche Insekten-Kunde oder Naturgeschichte der deutschen schädlichen Insekten. Leipzig 1874.

853. Taratynow, G. P. Ein Versuch der Aufzucht von vorzeitig entwickelten Seidenraupen im Sommer 1887. - Arbeit. der kaukas. Seidenz.Station, I. Jahrg. (1887-1888). p. 35-40. Tiflis 1889. (Russisch: Таратыновъ, Г. ІІ. Опытъ внкормки прежтевременно ожившихъ червей львомъ 1887 года. - Труды кавказ. ПІелковод. Станцік).

854. Tarnani, I. K. Ueber die Parasiten der Larven von Maikäfer. (Vorläufige Mittheilung). - Horae Soc. Ent. Ross., XXXIV. (1899). 사 1-2. p. XLIV-L. 1900. (Russisch: Tарнани, И. K. 0 паразитахъ хрущей. - Протоколъ 20 Дек. 1899 года).

855. Teich, C. A. Klima und Schmetterlinge. - Correspond.-Bl. Naturf. Ver. Riga, 18. Jahrg., p. 1-3. 1870.

856. Terni, G. Atti e Memorie del Congresso Bacologico tenutosi in Rovereto. Anno 1872. p. 588.

857. Terre, M. L. Sur les troubles physiologiques qui accompagnent la métamorphose des Insectes Holométaboliens. - Compt. rend. Soc. Biologique, V. 스 32.1900.

858. Testenoire, J. et Levrat, $\mathbf{D}$. Applications des rayons $\mathrm{x}$ à la détermination du sexe des chrysalides à travers les cocons. - Labor. d'études de la soie, VIII. (1895-1896). p. 140a-140d. Lyon 1897. 
859. Testenoire, J. et Levrat, D. Les cocons à soie. - Nature, XXV. 주 1237, p. 173-174. 1897; auch in Bull. des soies et des soieries. Lyon 1897.

860. Thiele, R. Widerstandsfähigkeit der Locusta viridissima L. - Illustrierte Zeitschr. f. Ent., IV. № 23, p. 362. 1899.

861. Thiele, R. Die Blutlaus (Schizoneura lunigera Htg.). - Zeitschrift für Naturwiss., LXXIV. p. 361-430. Halle 1901.

862. Thiele. [Demonstratives]. - Insekt.-Börse, XXI. i 10, p. 77. 1904.

863. Thurau. [Demonstration]. - Insekt.-Börse, XXII. 소 3, p. 12. 1905.

864. Thurau. Sitzung des Berlin. Entomol. Ver. vom 10 Mai 1900. - Inselkt.Börse, XVII. № 23, p. 181. 1900.

865. Tichomirow, A. A. Sullo svilluppo delle uova del bombice del gelso sotto l'influenza di eccitazioni meccaniche e chimiche. - Boll. Mens. Bachicolt., III. p. 145. 1885.

866. Tichomirow, A. A. Neue Angaben zum Studium der Spinnereier. Forst- und Landwirthsch., № 2, p. 54. 1886. (Russisch: Tихомировъ, А. А. Новыя даниыя для пзученія яицъ шелвопряда. Льсовод. и Землед.).

867. Tichomirow, A. A. Einige Resultate der chemischen Analyse der Insekteneier. - Arbeit. des Comité für Seidenz., Jahrg. 1884-1886, p. 4-11. Moskau 1886. (Russisch: Тихомировъ, А. А. Нькоторые результаты химшческаго ашализа яицъ насьвомыхъ. - Труды Комит. Пелковод. Пмпер. Москов. Общ. Сельск. Хозяйства).

868. Tichomirow, A. Ueber den Einfluss des Reizes auf die Entwickelung der Seidenspinner-Eier. - Arbeit. des Comité für Seidenzucht, Jahrg. 1884-1886, p. 13-16. Moskau 1886. (Russisch: Tихомировъ, A. 0 вліяніп раздраженія на развитіе грены. -- Труды Комптета ПІелков. Импер. Москов. Общ. Сельск. Ховяйства).

869. Tichomirow, A. Die künstliahe Parthenogenese bei Insekten. - Arch. f. Anat. und Physiol., Suppl.-Bd. 1886.

870. Tichomirow, A. Grundsätze der praktischen Seidenzucht. 2-te Auflage. Moskau 1895. (Russisch: Тихомировъ, А. Основы правтическаго пелководства).

871. Tichomirow, A. A. Tagblatt der Bienenzucht-Austellung in Arbeiten der Gesellsch. zur Akklimatisation der Thiere und Pflanzen", 3. Lief., p. 22. Moskau 1900. (Russisch: Тихомировъ, А. А. Диевникъ Выставки Пqеловодства. - Труды Импер. Общ. Аквлимат.).

871a. Tichomirow, A. Künstliche Parthenogenese beim Seidenspinner. - Nachr. des Comité f. Seidenz. der Gesellsch. f. Landwirthsch., I. p. 3-10. Moskau 1903. (Russisch: Ткхомировъ, А. Искуственный шартепогенезисъ у шелковичнаго червя. - Извьстія Компт. Шелков. Пмпер. Москов. Обц. Седьск. Хозяйства).

871b. Tichomirow, A. Die Befruchtung und die Parthenogenesis. - Naturwiss. und Geogr., VII. № 5, p. 1-32. Moskau 1902. (Russisch: Trxoмировъ, А. Оплодотвореніе и партеногенезисъ. - Естествознаніе и Teorp.).

871c. Tichomirowa, 0lga. Zur Entwickelungsgeschichte von Pulex serraticeps Gerv. - Nachr. der Gesellsch, der Liebh. der Naturw., Anthrop. 
und Ethnogr. Das 'Tagbl. der zoolog. Abth. der Gesellsch. und des zoolog. Museums, Lief. 3. p. 33-36. Moskau 1895. (Russisch: Тихомирова, 0льга. Къ псторіи развитія Pulex serraticeps Gerv.Изв. Общ. Люб. Естестозн., Антроп. п Этногр., Дневн. Зоол. Общ. II Зоол. Музел).

872. Tichomirowa, 0. Ernährung der seidenratuen mit Scorzonera hispanica. - Nachr. des Comité für Seidenz., Vol. I, Lief. 5, p. 3-10. Moskau 1895. (Russisch: Тихомирова, 0. Выкормкп телковпчпыхъ червей скорцонерощъ. - Извьст. Комит. ПЕеловод. Импер. Общ. Сельск. Хозяйства).

873. Tichomirowa, 0. Ueber die Zucht der Seidenrauen uit Scorzonera. Ackerbau-Ztg., 우 6, p. 119. 1896. (Russisch: Тихомирова, 0. О выкорикђ шелковпныхь червей скорцонерощз. - Земл. Тазета).

874. Tichomirowa, 0. 0. und Tichomirow, A. A. Versuche iber Ernährung der Seidenraupen mit Scorzonera hispanica. - Nachr. des Comité für Seidenzucht, Vol. I, Lief. 3 und 4, p. 35-38. Moskau 1894. (Russisch: Тихомирова, 0. 0. п Тихомировь, А. А. Опыты выкормки червей скорцонерощъ. - Пзвьст. Кояит. Шедков. Импер. Оо̆щ. Сельск. Хозяйства).

875. Tidemann. Eine Notiz über einige schädliche Inseliten in Wäldern des Gouvernements Kasan. - Forstzeitschrift, № 2. 1877. (Russisch:

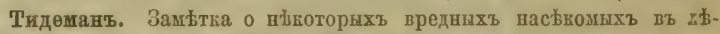
сахъ Казанской губернів. - Журн. Лнсовод.).

576. Timm, D. Die Biene und die Bienenwohnung. Güstrow 1582.

s76a. Tomala, Nándor. Sesia empiformis Esp. - Rov. Lap., VIII. p. 4750. 1901.

876b. Tomala, Nándor. Sesic anellata. - Rov. Lap., XI. p. 155-157. 1904. 877. Topsent, E. Note sur le Gribouri. - Bull. Soc. d'Étude Scien. natur. de Reims, 1896.

878. Tornier. Der Kampf mit der Nahrung. 1884.

879. Tornier, Gust. Das Entstehen ron Kïfermissbildungen, hesonders Hyperantennie und Hypermelic. - Arch. f. Entwickelungsmech., IX. Bd., 4, p. 501-562. 1900.

$\$ 79$ a. Tour, J. Ueber die Einwirkung der Radiumstrahlen aut die erste embrjo. nale Entwickelung des Hühnchens. - Arbeit. des zootom. Instit. der Univer. Warschau. 1904.

880. Tower, W. L. On the origin and distribution of Leptinotorsa decemlineatre Say, and the part that some of the climatic factors have played in its dissemination. - Proc. Amer. Assoc. for the Advance of Science, XLIX. p. 225-227. 1900.

880 a. Tower, W. L. The development of the colors and color patterns of Coleoptera, with observations upon the development of color in other orders of Insects. - Decenn. Publ. Univ. Chicago, X. p. 33--70. 1903.

881. Treat, Mary. Controlling sex in butterflies. - Americ. Natural, VII. p. 129-132. 1873 .

S82. Trimen, Roland. Edward B. Poulton: An inquiry into the cause and extent of a special colour-relation betweer certain exposed Lepidopterous Pupae and the surfaces which immediately surround them communi- 
cation by Ray Lankester. - Proc. Roy. Soc., XLII. № 252, p. 94108. London 1887.

883. Trimen, Roland. Seasonal Dimorphism in Lepidoptera (Adress). Nature, LIX. № 1537, p. 568-573. 1899.

884. Troska, A. Ueber künstliche Ernährung von schmetterlings-Puppen. Soc. ent., V. ํㅜ 1, p. 1-2; 스 2, p. 9-10; 스 3, p. 17-18; 수 4 p. 28-29; № 6, p. 43. 1890.

884a. Trost, Alois. Beitrag zur Lepidopteren-Fauna der iteicrmark. Mitth. des Naturw. Ver. für Steiermark, Jahrg. 1902, p. 328-340; Jahrg. 1903, p. 221-260; Jahrg.-1904, p. 108-118.

885. Tschugunow, S. und M. Entomologische Beobachtungen während der zoologischen Expedition zwischen den Flüssen $\mathrm{Ob}$ und Irtysch im Sommer 1899: - Naturwiss. und Geographie, VII. № 2, p. 32-40. Moskau 1902. (Russisch: Чугуновъ, C. п М. Энтомодогпческія наблюдевія во времл зоологическй экспедиціп мелду pp. Обьв и Иртышемъ льтом 1899 г. - Еетествози. I Геогр.).

886. Tümpel, R. Ueber die Lebensweise einiger Heuschrecken-Arten. - Allg. Zeitschr. für Ent., VI. 수 1, p. 3-7. 1901.

886 . Turati, Emilio Conte. Alcune nuove forme di lepidotteri. - Naturalista Siciliano, XVIII. № 2-3. 1905. (Separat. 26 pp.).

\$86a. Ulbrich, Ede. Adatok Magyarország leple-fauná-jához. II. - Rovart. Lapok, XII. o 8, p. 155-156. 1905. [Ungarisch]. (Beiträge zur Schmetterlingsfauna ron Ungarn. II.).

887. Ulbricht, Albert. Verzeichnis der in der Umgegend von Ditsseldorf beobachteten Chalastogastra Blatt-, Holz- und Halmwespen, nebst einigen Sammelbemerkungen. - Insekt.-Börse, XXII. jọ 6, p. 2324. 1905 .

888. Urech, F. Gewichtsabnahme der Winterpuppe. - Ent. Nachr., p. 220. 1880.

889. Urech, Friedr. Chemisch-analytische Untersuchungen an lebenden Raupen, Puppen und Schmetterlingen und an ihren Secreten. - Zoolog. Anz., 수 335 , p. 254-260; № 336, p. 272-280; 즈 337, p. 309-314; Jis 338 , p. $334-341.1890$.

390. Urech, Friedr. Beobachtungen über dic verschiedenen śchuppenfarben und die zeitliche Succession ihres Auftretens (Farbentelderung) aut den Puppenflügelchen von Vanessa urticae und io. - Zool. Anz., № 380 , p. $297-305.1891$.

891. Urech, Friedr. Beobachtungen über die zeitliche Succession des Auftretens der Farbenfelder auf den Puppenflügelchen ron Pieris brussicae. - Zool. Anz., XV. № 397, p. 284-290; № 398, p. 293-299. 1892.

392. Urech, Friedr. Ueber einen grünen Farbstoff in den Flügelchen (nicht in den Schuppen) der Crysalide von Pieris brassicae. - Zool. Anz., XV. ‥ 397, p. 281-283. 1892.

$392 \varkappa$. Uroch, F. Ueber Eigenschaften der Schuppenpignente einiger Le pi do 1teren-Species. - Zool. Anz., XV. Io 398, p. 299-306. 1892.

893. Urech, Friedr. Beiträge zur Kenntnis der Farbe von Inselitenschuppen. Zeitschr. für wissensch. Zool., LVII. (2). p. 306-384. 1893.

894. Urech, Friedr. Beohachtungen von Compensationsvorgängen in der Farbenzeichnung bezw. unter den Schuppenfarben an durch thermische 
Kinwirliung entstandenen Aberrationen und Subspecies einiger $\nabla a$ nessa-Arten. Erwägungen darüber und über die phyletische Recapitulation der Farbenfelderung in der Ontogenese. - Zool. Anz., № 500, p. 163-174; № 501, p. 176-185; 스 502, p. 201-206. 1896.

895. Urech, Friedr. Experimentelle Ergebnisse der Schnurung von noch weichen Puppen der Vanessa urticae quer über die Flügelchen. Zool. Anz., 수 547, p. 487-501. 1897.

896. Urøch, Friearr. Ergebnisse von Temperatur-Experimenten an Vanessa io L. - Illustr. Zeitschr. für Ent. (Separat. 7 pp.). 1898.

897. Urech, F. Mittheilungen über die diesjärigen aberrativen und clıromatotarachäischen Versuchsergebnisse an einigen Species der VanessaFalter. - Fasc. supplém. Revue Suisse Zool., V. Bull. Soc. Zool. Suisse. 1898.

898. Urech, Friedr. Einige Bemerkungen zum zeitlichen Auttreten der Schuppen-Pigmentstoffe von Pieris brassicae. - Illustr. Zeitschr. f. Entom. (Separat. 3 pp.). 1898.

899. Urech, Fried. Finige Bemerkungen über meine durch Schnürung noch weicher Vanessa urticae-Puppen erhaltenen Farbenveränderungen der Falterschuppen. - Soc. ent., XII. № 5, p. 33-34. 1898.

900. Urech, F. Kennzeichnung und kritische Bemerkungen über Terminologisches, Wärmeenergetisches und Farbenevolution meiner erzielten Aberrationen von Vunessa io und urticae. - Zool. Anz., XXII. 주 582 , p. 121-133. 1899.

901. Urech, F. Détermination du poids des chrysalides des Lépidoptères pendant leur transformation. - Comp. rend. des travaux presentés à la 48 session de la Soc. Helvétique des scienc. natur. à Zofingue, Ann. 1901, p. 51. - Arch. sc. phys. et natur., XII. № 11, p. 503504. 1901.

901 a. Vanha, J. und Stoklasa, J. Die Rüben-Nematoden (Heterodera, Dorylaimus und Tylenchus). Berlin 1896.

902. Vedovati, D. L'amido dei bachi. - Boll. Mens. Bachicolt., Ser. III, Ann. II, № 1, p. 3-6. 1896.

903. Venus, C. Ed. Ueber Varietätenzucht. - Corresp.-Bl. des ent. Ver. Iris zu Dresden, I. p. 209-210. Dresden 1888.

904. Verhoeff. Pphysiologische Notizen. - Ent. Nachr., XVII. p. 125-128. 1891.

905. Verhoeff. Weitere Versuche über den Ausfärbungsprocess. - Ent. Nachr. XVIII. p. 54-58. 1892.

906. Verhoeff. Zur Entwickelung vom Hemerobius subnebulosus und über Verfärbung der Neuropteren. - Ent. Nachr., XVIII. p. 297298. 1892.

907. Verhoeff. Ueber die Verfärbung der Coleopteren-Nimphen und Imagines. - Verh. Zcol.-bot. Ges., XLVIII. p. 679-688. Wien 1897.

908. Verhoeff, Carl. Einige Worte über europäische Höhlenfauna. - Zool. Anz., XXI. № 552, p. 136-140, 1898.

909. Verhoeff, Carl. Ueber europäische Höhlenfauna, insbesondere Diplopoden und Chilopoden. (2. Aufsatz). - Zool. Anz., XXII. p. 157164. 1899. 
910. Verloren, M. C. On the Effect of Temperature and Periodicity on the Development of certain Lepidoptera. - Report 30. Neet. British Assoc. Adv. Sc., (1860), p. 123. 1861.

911. Vorloren, M. C. On the Comparative Influence of Periodicity and Temperature upon the Development of Insects. - Trans. Ent. Soc., I. 3 Ser., p. 63-69. London 1862-1864.

912 u. $912 a$. Vermorel, V. et Gastine, G. Sur un nouveau procédé pour la destruction de la pyrale et d'autres insectes nuisibles. - C. R. Acad. Sc., CXXXV. p. 66-68. Paris 1902.

913. Vornon, H. MI. The Relation of the Respiratory Exchange of Cold bloodit Animals to Temperature. - Journal of Physiologie, XVI. p. $277-292.1894$.

914 u. 915. Verson, E. Ueber den Einfluss niedriger Temperaturen auf die Lebensfäbigkeit der Eier des gemeinen Seidenspinners. - Oesterreich. Seidenbau-Ztg., 3. Jahrg., № 8, p. 57-59; № 9, p. 65-66. 1871.

916. Verson, E. La formazione delle ali nella larva del Bomby $x$ mori. - Ric. Anat. Staz. Bac., IV. Padova 1890. (Separat. 15 pp.).

917. Verson, E. Importanza biologica delle basse temperature. - Boll. Mens. Bachic., Ser. III, Ann. I, ㅈo 12, p. 169-173. 1895.

918. Verson, E. Semi che schiudono in gennaio, spontaneamente o quasi. Boll. Mens. Bachic., Ser. III, Ann. III, № 3, p. 33-37. 1897.

919. Verson, E. L'amido nella coltivazione dei bachi. - Boll. Mens. Bachic., Ser. III, Ann. III, № 12, p. 145-154. 1897.

919a. Verson, E. Zur Färbung der Lepidopterencocons. - Zool. Anz., XXVII. № 12-13, p. 397-399. 1904 .

920. Verson, E. e Quajat, E. Sull'allevamento a temperatura elevata e crescente, di confronto a quello fatto col sistema ordinario. - Staz. Bac., Ann. I, (1872), p. 63-65. 1873.

921. Verson, E. e Quajat, E. Sullo strofinamento e sulla svernatura artificiale, allo scopo di anticipare lo schiudimento delle uova del baco da seta. - Boll. Mens. Bachic., Vol. I, p. 1-16. 1873.

922. Verson, E. e Quajat, E. Ancora sullo strofinamento dei semi di razza annuale. - Boll. Mens. Bachic., Vol. I, p. 113-118. 1873.

923. Verson, E. e Quajat, E. Intorno alla respirazione delle uova dei bruchi, delle crisalidi, e delle farfalle del filugello. - Boll. Mens. Bachic., Vol. VIII, tio 1, p. 1-22. 1876.

924. Verson, E. e Quajat, E. Il filugello e l'arte sericola. Trattato teoricopratico. (480 pp.) Padova 1896.

925. Vignon, Léo. La soie au point de vue scientifique et industriel. Bibliothèque des connaissances utiles, p. 359. Paris 1890.

925 a. Villard, Jules. Contribution à l'étude des chlorophylles animales. - Compt. rend. Soc. Bĩol., LV. p. 1580-1582. Paris 1903.

926. Vogel, Friedrich Wilhelm. Dle Honigbiene. Quedlinburg 1800.

926a. Vogel, J. W. Die ägyptische Biene (Apis fasciata), ihre Einführung durch den Acclimatisations-Verein in Berlin und ihre glückliche Eingewöhnung und Vermehrung in Deutschland. Berlin 1865.

927. Vogler. Die Schuppen der A n threnen. - Illustr. Wochenschr. Ent., II. p. $707-715$. 1897. 
928. Vogler. Insekten auf Poly porus. - Illustr. Zeitschr. Ent., IV. A2 22, p. 345. 1899.

929. Vogler, C. H. Entwickelung von Rhopalodontus glubratus Bris aus polyporus. - Allg. Zeitschr. Ent., VI. № 10, p. 156. 1901.

930. Voelschow, A. Dasychira pudibundı aber. concolor Stdgr. - Soc. ent., VIII. № 7, p. 50-51. 1893.

930 a. Vom-Rath, 0tto. Ueber abnorme Bildungen im Bienenstock. - Ber. Naturf. Gesellsch, zu Freiburg i. B. 1894.

931. Voss. Th. Entomologische Mittheilungen. - Insekt.-Börse, XVII. N 23, p. 181.1900.

932. Vosseler, J. Ueber Anpassung und chemische Vertheidigungsmittel bei nordafrikanischen Orthopteren. - Verh. dent. Zool. Gesellsch., XII. p. 108-120. 1902.

933. Vossolor, J. Beiträge zu Faunistik und Biologie der Orthopteren Algeriens und Tunesiens. - Zool. Jahrb., Abth. Syst., XVI. Hft. 2, p. 337-405. 1901; XVII. Hft. 1, p. 1-99. 1902.

934. Vrière, Raoul Baron de. Entomologische Mittheilumgen. - Inselit.-Börse, XVII. 수 25, p. 197. 1900.

935. Wagner, Moritz. Das Ausland, do 25, Stuttgart, den 24. Juni 1875. p. $491-492$.

936. Wagner, Nicol. Influence de l'électricité sur la formation des pigments et sur la forme des ailes des papillons. - Compt. rend. Acad. Sc., LXI. p. 170. Paris 1865; Ann. Soc. Ent. France, T. V, 4 Série, Bull. p. 47-48. 1865; Rev. et Mag. Zool., XVII, 2 Série, p. 245. 1865.

937. Wagner, W. A. Ceber Fürbung und Mimicry bei den Thieren. - Travaux de la Société Impériale des Naturalistes de St.-Pétersbourg, Vol. XXXI. Livr. 2, Section Zool. et Physiol., p. 1-66. Das deutsche Resumé p. 67-76: 1901. (Russisch: Вагнеръ, Владимірь. Сбъ окраску и жимирін у животныхъ. - Труды Пмпер. С.-Петербургскаго Общ. Естествоисп., Отд. Зоол. и Физіолог.).

938. Walker, James J. Notes on Lepidoptera from the region of the Straits of Gibraltar. - Trans. Entom. Soc., p. 361-391. London 1890.

939. Wallace, Alfred R. Dislike of birds for certain insectlarvae. - Trans. Ent. Soc., V. 3 Ser. London 1865-67; Proceed. Entomol. Soc. p. $80-81$, p. 85 . London 1867.

940. Wallace, Alfred Russel. Beiträge zur Theorie der natürlichen Zuchtwahl. Uebersetzt von Adolf B. Meyer. (434 p.). Erlangen 1870.

940 a. Wallace, Alfred Russel. Die geographische Verbreitung der Thiere. Uebersetzt von A. B. Meyer. I. und II. Bd. Dresden 1876.

941. Wallace, A. R. Die Tropenwelt. Übersetzt von Brauns, 1879.

942. Walter, B. Die Uberflächen- oder Schillerfarben. Braunschweig 1895.

942 a. Wanach, Bernhard. Statistisches über Melolontha hippocastani F. Ent. Zeitschr., L. № 2, p. 229-234. Berlin 1906.

943. Warnecke, G. Beiträge zur Entwickelungsgeschichte paläarktischer Le pidopteren. - Insekt.-Börse, XXI. 소 9, p. 68-69. 1904.

943 a. Wasiljew, I. W. Seidenspinner Dendrolimus pini L. und Dendrolimus segregatus Butl. - Arheit. des Bureau für Entomol. des gelehrt. Comité bei Minist. für Ackerbau, Bd. V, № 7. 1905. (101 pp.). 
(Russisch : Васильевъ, И. В. Шелвопряди сосновиї [Dendrolimus pini L.] в кедровнй [Dendrolimus segregatus Butl.], вхъ образъ ждзни, вредвая дьятелвость и способы борьби съ ншмп. - Труды Бюро по Энтомол. Учен. Комит. Минист. Земллед, и Госуд. Имущ.). 9436. Wasiljew, I. W. Aporia crataegi L. und seine Parasiten. - Arbeit. des Bureau für Entomol. des gelehrt. Comité bei Minist. für Ackerb. und Staatsgüt., III. № 8. (36 pp.). S.-Petersburg 1902. (Russisch: Васпльевъ, И. В. Боярышнца [Aporia crataegi L.] и ея паразитн. - Трудв Бюро по Эптомодогіщ Ученаго Комитета Мпнист. Землед. п Госуд. Имущ.).

944. Wasmann, E. Parthenogenesis bei Ameisen durch künstliche Temperaturverhältnisse: - Biolog. Centralbl., XI. № 1, p. 21-23. 1891.

945. Weale, J. E. Notes on the Habits of Papilio merope, with a description of its Larva and Pupa. - Trans. Ent. Soc., p. 131-136. London 1874.

946. Weale, J. E. On the variation of Rhopalocerous forms in South Africa. - Trans. Ent. Soc., p. 265-275. London 1877.

946a. Weber, L. Ueber das Verhalten der Insekten dem Röntgen'schen Lichte gegeniiber. - Abhandl. und Bericht XXxxil. des Ver. f. Naturkunde zu Cassel über das 61. Vereinsjahr 1896-97, p. XXXI-XXXII.

947. Webster, F. M. Fatal temperature for Diaspis amygdali. - Canad. Entomol., XXXI. p. 130. 1899.

948. Weir, J. Jenner. On Insects and Insectivorous Birds; and especially on the Relation between the Colour and the Exhibility of Lepidopter a and their Larvac. - Trans. Ent. Soc., p. 21-26. London 1869.

949. Weir, J. Jenner. Further observations on the Relation between the Colour and the Edibility of Lepidoptera and their Larvae. Trans. Ent. Soc., p. 337-339. London 1870.

950. Weir, J. Jenner. Are the Colours of Lepid opter a influenced by Electricity? - Entomologist, IX., p. 251-254. 1876.

951. Weir, J. Jenner. Neue Beobachtungen über schützende Ausrüstung bei Insekten. - Kosmos, I. p. 442-443. 1877.

952. Weir, J. Jenner. The weather and its effects on Lepidoptera. Entomologist, XII. p. 179-180. 1879.

953. Weismann, August. Studien zur Descendenz-Theorie. I. Teler den SaisonDimorphismus der Schmetterlinge. Leipzig 1875. (Separat-Abdruck aus den Annali del Museo Civico di Storia Naturale di Genova, Vol. VI, 94 pp. 1874).

953 a. Weismann, A. Aussere Einflïsse als Entwiekelungsreizc. Jena 1894.

953b. Woismann, August. Ueher die Parthenorenese der Bienen. - Anat. Anz., XVIII. ㅊ: 20-21, p. 492-499. 1900.

954. Weismann, August. Neue Versuche zum Saison-Dimorphismus der Schmetterlinge. - Zool. Jahrbuicher, Abth. f. Syst., Bd. VIII. 1895. (Separat. 74 pp.).

954 a. Welter, Adolf. Die tiefen Temperaturen. (86 pp.). Crefeld 1895.

955. Werneburg. [Nach Dr Prehn ${ }_{n}$ Die Schutzmittel der Raupe“]. - Illustr. Wochenschr. f. Entomol., II. p. 24-27: 1897.

956. Werner, Aug. Abarten von Papilio muchaon L. - Lntomolog. Zeitschr., VIII. 고 20, p. 168-169. Guben 1895. 
957. Weymer, Gust. Bemerkungen über einige Lepidopteren. - Entom. Zeitg., XXVI. p. 110-114. Stettin 1865.

958. White, William. Experiments upon the colour-relation between the pupae of Pieris rapae and their immediate surroundings by G. Griffiths, described and summarised by William White. - Transact. Ent. Soc., Part. II, p. 247-267. London 1888.

959. Wioner, 0. Farbenphotographie durch Körperfarben und mechanische Farbenanpassung in der Natur. - Ann. der Physik und Chemie von Wiedemann, Bd. LV, p. 225-281. 1895.

959 a. Wilkins, A. I. Echo der verflossenen Jahrhunderten. - Nach. der kais. Gesellsch. der Liebh. der Naturw., Anthrop. und Ethnogr., L. J6 1, p. 41-62. Moskau 1886. (Russisch: Внлькинсљ, А. И. Отrолоски протедшихъ вбковъ. - Изв. Имп. Общ. Любит. Естествозн., Антроп. и Этногр.).

960. Wilkins, A. I. Ueber die wilden Vorfahren der Seidenraupen. - Nachr. der kais. Gesellsch. der Libh. der Natur»., Anthrop. und Ethnograph., L. Lief. 1, p. 85-94. Moskau 1886. (Russisch: Вилькинсъ, А. И. Дпкіе прђдки пелюовиныхъ червей. - Изв. Іплер. Общ. Люб. Естествозн., Антроп. п Этногр.).

960 \%. Willcock, E. G. Radium and animalis. - Nature, LXIX. p. 55. London $1903 / 04$.

960 a. Winkler, Hs. Ueber die Furchung unbefruchteter Eier unter der Einwirkung von Extractionsstoffen aus dem Sperma. - Nachr. Ges. Wiss. Göttingen, 2. Hft., p. 187-193. 1900.

:961. Witmer, B. Zum Kampf mit Phylloxera in Russland. - Land- und Forstwirthsch., 수 6, p. 375; 스 7, p. 609. 1896. (Russisch: Burмөръ, Б. Къ борьбъ съ фнлловсерою въ Россін. - Сельск. Хозяйство ІІ Льсовод.).

961 a. Wittich, v. Die grüne Farbe der Haut unserer Frösche; ihre physiologischen und pathologischen Veränderungen. - Müller's Archiv, p. 41-60. 1854 .

962. Wood, T. W. Remarks on the Coloration of Chrysalids. - Proceed. Ent. Soc., p. 99-101. London 1867.

962a. Woojkow, A. I. Klimas der Erdkugel besonders Russlands. St.-Petersburg 1884. (Russisch: Воөйқовъ, А. П. Климаты земнаго тара въ особенвости Россіп).

963. Wünscher. Die Aufzucht einiger hervorragenden Schwärmer aus den Ei. - Krancher's Entomol. Jahrb., XII. p. 118-127. 1903.

964. Wurm, W. Tetronerythrin, ein neuer organischer Farbstoff. - Zeitschr. f. wissensch. Zoolog., XXI. p. 535-537. 1871.

964a. Wyman, J. Gavs on account of some observations which he had recently made on Hybernating Insects. - Proc. Boston Soc. Nat. History, V. p. 157. 1856.

965. Zang, Richard. Nigrismen von Carabus auratus L. - Illustr. Zeitschr. für Entomol, V. № 8, p. 121. 1900.

965 a. Zenkor, Wilhelm. Die Entstehung der Farben im Lippmannischen Spektrum. Berlin 1893. 
966. Zeselski, T. Bienenzucht, gegründet auf der Wissenschaft und der langjährigen Praxis oder die rentable Bienenwirthschaft. I. Theil. Die Natur der Biene. Kasan 1893. (Russisch: Щөсөльскій, T.

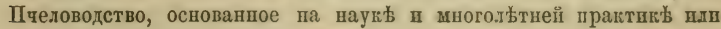
доходное пасьчное хозяйство. Часть первая. Природа пчелъ. Перевелъ съ польскаго оригвнала И. В. Любарскій. Казань 1893).

967. Zimmermann, Hugo. Ueber das Auftreten von Lithocolletis Platani Staudgr. - Insekt.-Börse, XXI. 스 4, p. 28-29. 1904.

968. ? Der Gewichtsverlust der Eier während ihrer Bebrütung. - Osterreich. Seidenbau-Ztg., IV. Jahrg. 스 7, p. 55. 1872.

969. ? Untersuchung der mittel-asiatischen Rassen der Seidenraupen. - Arbeiten der kaukasischen Seidenzucht-Station, Jarg. 1892, VI. Band, 3. Lief., p. 99-128. Tiflis 1893. (Russisch: Изсльдованіе среднеазіатскихъ породъ шелковнчнаго червл. - Труды кавказ. Пелковод. Станціи).

970. \& Die Chronique der kaukasischen Seidenzucht-Station. - Nachr. der kaukasischen Seidenz.-Stat., 1899. Serie für Seidenzucht, Lief. 1, p. 1.-20. Tiflis 1899. (Russisch: Хронпка Кавказской Пелководственной Станців. - Извьстія кавказ. Шелководств. Ставцін за 1899 годъ. Серія по телководству).

971. \& Eine Korrespondenz aus Tobolsk über Heuschrecken. - Anzeig. für die Landwirthsch., № 11, 1896. (Russisch: Корреспондевція изъ Тобольска о кобыльђ. - Сельскохозяйств. Въстникъ).

972. \& [Eine Zeitungsnotiz]. - St.-Petersburger Zeitung, №6 4, 1846. (Russisch: [Газетная замђтка]. - С.-Петербургская Газета). 


\section{Nachträge zum Litteratur-Verzeichniss.}

(Fehlende resp. corrigierte Litteratur-Angaben).

18 a. Axenfeld. L. Webor: Ueber das Verhalten der Insekten dem Röntgen'schen Lichte gegenüber. - Abhanảl. und Bericht XXXXII. des Ver. f. Naturk. zu Cassel über das 61. Vereinsjahr $1896 / 7$ p. XXXI-XXXII.

58a. Becquerel, Ed. La Lumière. Paris 1868.

79b. Biedermann, W. Ueber den Farbenwechsel der Früsche. -- Pflüger's Arch., LI. p. 455-509. 1892.

104a. Born, Paul. Ueber die Ursachen der Varietäten- und Rassenbildung bei den Caraben. - Insekt.-Börse, XIX. 긍 30, p. 234-235; 숭 31, p. $243-244$; № 32 , p. 251-252; 쇼 33, p. 259. 1902.

-55a. Boussingnault, J. B. Kconomie Rurale considérée dans ses rapports avec la chemie, la physique et la météorologie. Paris 1843.

115a. Brückner, Eduard. Ḱlimaschwankungen seit 1700 nelst Bemerkungen über die Klimaschwankungen der Dilivialzeit. Wien 1890.

164b: Davanne, A. La Photographie. II. Paris 1888.

$219 d$. Fenerstacke, B. Nigrismen von C a r a b e n. - Illustr. Zeitschr. f. Entom., V. 주 11, p. 167. 1900.

219 a. Ficke, H. Karl Sajó: Inselitenreisen. - Illustr. Wochenschr. für Entomol,, II. p. 257-263. 1897.

2406. Fischer, H. Kleine Mittheilung. - Soc. ent., XVII. ํํㄹ 21, p. 162-163. 1903.

240c. Flammarion, C. Action des diverses radiations lunineuses sur les êtres vivants. - Comp. rend. de l'Acad. des scienc., CXXIX. p. 398-401. Paris 1899.

$262 a$. Fritsch, A. Häufiges Auftreten des Kohlenweisslings und Ausbleiben anderer Insekten. - Ent. Nachr., II. p. 12-13. 1876.

269 a. Gootke, Heinrich. [Mittheilung von Honrath]. -- Protok.-Sitz. des Berliner Ent. Ver. vom 22. IX. 1890, in: Berliner Entom. Zeitschr., XXXVI. p. IX. 1891.

304a. Geest, W. Eine Aberration von Rhodocera rhamni und Entwickelung der Pieride n-Färbung. - Allg. Zeitschrift für Entom., VII. 스 24, p. 529-534. 1902.

304b. Geost, W. Neue Schmetterlings-Aberrationen, - Allg. Zeitshr. f. Entom., VIII. 시 $16-17$, p. 308-312. 1903.

378a. Hoffmann, Aug. Die Lepidopteren-Fauna der Moorengebiete des Oberharzes. - Entom. Ztg., XLIX. p. 133-199. Stettin 1888. 
450 a. Kitz, A. Chr. Beitrag zur Photographie in natürlichen Farben. - Jahrb. für Photogr. und Reprud. techn., VIII. p. 142. 1894.

502a. Lebedef, Pierre. Les forces de Maxwell-Bartoli dues à la pression de la lumière. - Rapp. congrès internationale de physique. Tome II, p. 133-140. Paris 1900.

502b. Lebedew, P. Maxwell-Bartoli'schen Druckkräfte der strahlende Energie. Journ. der russisch. phys.-chem. Gesellsch., XXXIV. p. 211-217. 1900. (Russisch: Лебөдевъ, П. Мансуель-Бартоли (или давлевія лучшстой энергін. - Зћур. рус. Фвз.Хщм. Общ.).

527hh. Linden, M. Gräfin von. Ueber den Einfluss der Sauerstoffentziehung wälırend des Puppenlebens auf die Gestaltung der Sclimetterlinge. - Mitth. der schweiz. entom. Gesellsch., XI. 스 2. p. 82-84. 1905.

544a. Mann, Jos. Verzeichniss der im Jahre 1853 in der Gegend ron Fiume gesammelten Schmetterlinge. - Wiener Entomol. Monatschrift, I. p. $139-189$.

$606 a$. Nouhauss, R. Die Farbenphotographie. - Encyklopädie der Photographie. № 33. Hälle 1898.

616a. Ormerod. Karı Sajó: Insektenreisen. - Illustr. Wochenschr. für Entomol, II. p. $257-263.1897$.

675b. Rebel, H. Dr M. Standfuss' experimentelle zoologische 'studien mit Lepidopteren. - Zool. Anzeig., XXI. № 568, p. 504-509. 1898.

$681 \propto$. Reh, I. Verbreitung und Nälnpflanzen einiger Diaspinen. - Allg. Zeitschr. f. Entomol., IX. № 9-10, p. 171-178. 1904.

681a. Reiber, F. Karl Fritsch: Notiz iiber den Zug des Distelfalters. - Entom. Nachr., V. p. 195-197. 1879.

691 u. 692. Richter, Ed. Verzeichniss der in der Umgegend ron Dessau aufyrefundenen Sschmetterlinge. - Entom. Ztg., X. p. 80-86, p. 107-113, p. $349-351$. Stettin 1849.

$822 \beta$. Slevogt, B. Die Grossschmetterlinge Kurlands mit Berücksichtigung Kownos, Livlands und Estlands. Mitau 1903.

822 $\beta^{\prime}$. Slovogt, B. Ein Pyrameis (Vanessa) cardui-Massenflug, beobachtet in Bathen Juli 1903. - Soc. ent., XVIII. № 13. p. 100-101. 1903.

$822 d d$. Smith, J. H. und Morckens, W. Ueber ein direkt in Farben kopierendes Papier. - Uto-Papier. - Mitth. der physikal. Gesellsch. Zürich, № 10, p. 15-19. 1906.

824a. Soddy, F. Radioaktivität. St.-Petersburg 1905. (Russisch: Радіоаптввость. Перев. Ф. Индриксона. С.-Петербургъ 1905).

824b. Soddy, Frederik. Radioactivity, an elementary Treatise from the Standpoint of the Desintegration Theory. London 1904.

830 a. Speyer. Prehn: Die Verbreitung der Lepidopteren. -- Illustr. Wochenschr. für Entomol., II. p. 332-334. 1897.

836a. Standfuss, M. Die Beziehung zwischen Färbung und Lebensgewohnheit bei den palaearctischen Schmetterlingen, - Vierteljahrschriften der naturforsch. Gesellsch. in Zürich, XXXIX. (Separat. 35 pp.). 1894.

841c. Standfuss, M. [Diskusion zu dem Vortrage der Gräfin M. v. Linden: Ueber den Einfluss der Sauerstoffentziehung während des Puppenlebens auf die Gestaltung der Schmetterlinge]. - Mitth. der schweizer. entomol. Gesellsch., XI. № 2, p. 84-85. 1905. 
887a. Umow, N. A. Die Evolution des Atoms. - Physik. Rundschau, V. Je 2. p. 67-92. Kjew 1906. (Russisch: Умовъ, Н. А. Эвопюція атова. Фпзич. Обозр.).

926 «. Vogel, H. W. Ueber die neue Methode der vervielfaltigenden Phothographie in Naturfarben. - Ann. der Physik und Chemie von G. Wiedemann, XLVI. p. 521-527. 1892.

946b. Weidinger, G. Karl Sajó: Insektenreisen. - Illustr. Wochenschrift für Entom., II. p. 257-263. 1897.

962b. Worell, K. Photographie in natürlichen Farben auf Papier. - Wiener Anzeig., p. 79-82. 1902.

965b. Zenker, W. Lerbuch der Photochromie. Braunschweig 1900. 


\section{Autoren-Register.}

(Die Zahlen beziehen sich auf die Seiten).

A. L.: 181. 199. 303. 304.' Balbiani, G.: 71. 174. 604.|Bellevoye: 577. 603. 313. 345. 691. 692.765 .

Aaron: 470 .

Absolon, Ph.C. K.: 183. 513. 550. 691. 692. 866 .

Adams, C. C.: 363.

Adelung, N.: 596. 770.

Aigner-Abafi, L. v:: 48 . 157. 183. 282. 285. 362 . 363. 511. 686. 716. 742 . 744. 745. 859. 932 .

Alibegow, M. G.: 32. 115. 232. 613. 668. 749: 750 . Alisch: 48. 159. 216. 688 . Altum, B.: 35. 36. 146. 576. 730. 721 .

Anderson, J.: 337.

Antropow, D. P.: 268. 285. 770.

Arndt, R.: 696 .

Aratiinow: 579.

Auel, H.: 37. 163. 278. 280. 288. 595. 604. 607. 611. 624. 730. 762. 932.

Axenfeld: 189.694.696.697.

Bachmetjew, P.: 24.52.139. Beckmann, J. I.: 166. 607. 210. 238. 574. 617. 653. Becquerel, Ed.: 943.

654. 659. 669. 681. 688. Bell, R.: 223. 310. 600. 700 . 701. 759. 769. 772.826 .। 831. 836. 914. 932.

Backer: 560 .

Bacon, F. 847.

Baer, M.: 331 .

Baillon, E.: 252. 347. 769. 898.

Baumann, E.: 698.
611. 732 .

Ball, Fr.: 113. 296. 452 . 607. 624. 650. 754. 777.

Balthazard, V: 699.

Barber, M. E.: 475. 481. 492. 859. 8611.

Barca, V. 63. 228. 612. 7to. 751.

Barfurth: 194. 195.

Barker, C. W.: 286. 367. 762. 855 .

Barret, C. G.: 37. 490. 858. Bartels, K.: 346. 533. 894.

Bastelberger, J. MI. : 512.858.

Bataillon, E.: 32. 572. 687. 719. 720.

Batelli, A.: 337.

Bates, H. W.: 473.520 .

Bateson, IV. 324. 520.

Bau, A.: 174.

Bauchard: 699 .

Baussingault: 747 .

Beauvais: 62.612.667.668.

Bécklard, J.: 177. 690. (191. 712. 739. 765 .

Bellati, M.: 115. 130. 131.

181. 186. 187. 188. 202 .

208. 234. 235. 613.614. Bocquigny-Adanson, G. de:

634. 665. 666. 691. 694 .

695. 696. 701. 702. 719. Bogdanow, A. P.: 230. 315. 748. 749. 751 .
Bellier de la Chavignerie: 522. 867.

Bemmelen, J. F. v.: 317.

Benteli, A.: 119. 732.

Berg, K.: 248. 511. 770. 860.

Berg,L.: 205. 305. 706. 765. Berg, O.: 696. 868.

Bergé, C.: 337. 350.

Berger, R.: 118. 366. 386. 611. 613. 635. 651. 854.

Berlepsch, A. v.: 275 . 300 . 765.

Bernard: 209.

Bernatzliy, N. S.: 49.

Bernstein, J.: 693.

Bertelli: 561.

Bertkau, Ph.: 794.

Bezzi, M.: 157. 678.

Biedermann, W.: 337. 887. 892.

Bieger: 532. 870. 877.

Biró, L.: 35. 500. 860.

Birschall, E.: 364.

Birula, A. A.: 333.

Blane, L.: 316. 534. 891.

Blanchard, E.: 498. 520. 536. 858. 884.

Blasius, W.: 4. 7. 8. 18. 52. 112. 609. 615. 836 .

Blutenmüller: 520. 32.

337. 
Bogdanow, E. A.: 49. 216. Capiomont, G.: 531. 875. 223. 309. 313. 688. 703. Caracciolo, H.: 507. 859. 765. 767.

Böhm, C.: 841 .

Bohatsch, A.: 900.

Bohatsch, O.: 263. 352. 353. 598.

Bohn, G.: 337. 698.

Boisduval: 341 .

Bold, Th.: 174.

Boll: 344 .

Bolle, G.: 78. 82, 175. 227. 237. 250.613.

Bonhote: 520. 653.

Bonnet, Ch.: 60. 61.633. 732.

Bonnier, G.: 735.

Bordage, E.: 299. 306. 503. 505. 506. 763. 76占. 765 . 860. 861.

Born, P.: 276. 931. 934.

Bos, J. R.: 194. 198. 704.

Brauner: 520.

Brelim, A. E.: 300.

Breit, J.: 41. 357. 687. 903. 904. 909.

Brown, E. W.: 38.

Brücke, E.: 337.

Brückner, E.: 911. 912.

Brunbauer, P.: 83. 93. 96.

653. 731. 732. 739. 747.

Bruner, L.: 49. 364. 686.

Buckel, F. J.: 337.

Büsgen: 246.

Bütschli, O.: 32.654 .

Bugnion, E。: 175. 341.

Bullot: 719 .

Burstert, H.: 49, 369. 854. 857.

Butler, A. G.: 365.470. 530. 876 .

Buttel-Reepen, H. v.: 592. 725. 726.

Butterfield, J. A.: 175.

Cailletet: 235.

Cameron, P.: 476. 726 .

Candolle, P. de: 658.

Cantoni, G.: 175. 635. 663.
Caradja, A. de: 118. 304. 353. 389. 731. 732. 909.

Caretta, A.: 45. 207. 227. 686.

Carlgren, 0.: 189.

Carpantier, L.: 157.

Carpenter, F. W.: 585.691.

Carret: 71. 175. 604. 663. Caspari, W. 290. 409. 544. Dewitz, J.: 163. 174. 216.

Castle, W. E.: 735. 830.

Cazalis, F.: 37.

Chapman, T. A.: 236. 337. 458. 470. 596. 749 .

Cholodkowsky, N.: 491.519 520. 549. 551. 576. 858. 860.865 .

Chramow, S. Ph.: 34. 730. Christoph: 528. 858, 877 .

Ciaccio, G. V.: 521 .

Clarc, Jas.: 829. 830.

Clerici: 41 .

Cobelli, R.: 12.32. 159.609. Cockerell, T. D. A. 337.561.

Collins, J.: 38.

Conte, A.: 554.561.601.891.

Corinaldi, A.: 600 .

Cornalia, E.: 3. 79.

Cornu, MI.: 37. 38. 82. 381. 653.

Coste, F. H. P.: 561.

Coverdale: 561.

Crampton, H. E.: 600.

Creolen: 555.

Croft, W. B.: 338.

Csiki: 745.

Curie, P: 669.

Dahlbom: 349.

Dahlström, J.: 358 .

Dammer: 138.

Daniel: 539.

Danilow, E. A.: 34.511. 578. 636. 653. 730. 860.

Dannenberg: 463. 469. 777.

Danysz, J.: 592. 694. 697. 699.
Darwin, Ch.: 475. 794. 859.

Dauphin, J.: 698.

Davanne, A.: 943.

Davenport, C. B.: 735. 830.

De-Geer : 210.

Deegener: 226.

Delage, Y.: 719. 720.

Derewjanko, G. S.: 256. 770.

Devaux, M.: 688.

222. 225. 282. 296. 311.

517. 518. 553. 574. 581. 600. 612. 635. 647. 648 . 687. 702. 703. 718. 722.

773. 839. 860 .

Dieck, G.: 38. 688.

Dickel, F.: 592. 725. 726. 728. 729.

Dietrich: 707. 708.

Dietze, K.: 475. 515. 531. 552. 859.

Distant, W. L.: 364.

Dixey, F. A.: 393. 400.

Dixon, H. H.: 698.

Döflein, F.: 590.

Dönhoff: 175. 227. 653. 681 . 830.

Dönitz: 356.

Dogiel, J.: 184. 192. 696. 703. 722. 834. 892 .

Doherty: 369.

Dolin: 712 .

Domenitzki, H.: 539.

Donnadieu, A. L.: 194. 700. 717.

Dorfmeister, G.: 63. 65. 82. 288. 372. 373. 377. 381. 606. 611. 615. 622. 628 . 636. 754. 777. 778. 779 . 796. 812 .

Dorn, E. : 698.

Draper: 488.

Drenowsky, A. K.: \$54. 910.

Dschejranow, F. J.: 257.

Ducke, A.: 372.

Dubois, R.: 175. 205.
Davis: 366.389.

Došek, J. F.: 312. 
Duclaux, E.: 9. 24. 32. 65. Fingerling, M.: 120. 606. 66. 81. 175, 191. 228. 612. 614. 667. 668. 695 . 701. 719. 748. 751 .

Düsing, C.: 192. 704.

Dufour, H.: 194. 691.

Duftschmid: 900 .

Duponchel: 347 .

Dzierzon, J.: 83. 175. 591. 650. 725. 726. 729.

Edwards, W. H.: 175. 338. 382, 400, 470, 779. 780 .

Egger: 345.

Eimer, H. Th.: 331. 338. 534. 564. 796. 816.

Elwes, H. J.: 364.

Emery, C.: 34. 733.

Engel, A.: 227.

Enock, F.: 572. 687.

Enteman, W. M.: 363. 898. 901.

Errera, L.: 661.

Esper: 531. 871. 877.

Euler, H.: 696.868.

Fallon, J.: 522. 867.

Faraday: 186.

Farre, J.: 713.

Federley, H.: 50. 363. 370. 371. 464. 556. 581. 590 . 595. 618. 620. 630. 631 . 632. 633. 687. 703. 755 . 769. 777. 779. 819. 821 . 824. 825. 838. 844. 845. 848. 855. 881. 887. 888. 896. 901. 918. 929. 933.

Felsko: 530. 883. [936.

Fenn, C.: 471.

Fernald, C. H.: 227. 716. Feuerstacke, B.: 904. 909. Ficke: 745 .

Fickert, C.: 135. 422. 609. 616. 777. 778.

Field, A. MI. 52. 589. 653. 654. 663. 681. 688. 701.

Field, W. L. W.: 171. 184. 224.
620. 621. 622 .

Fink, R.: 581. 609. 731.

Fischer, E.: 130. 136. 144. 145. 160. 171. 290. 296. 304. 370. 400. 401. 403. 410. 415. 432. 435. 437. 445. 450. 452. 460. 471 . 512. 516. 522. 524. 526 . 527. 545. 562. 608. 625 . 626. 627. 628. 638. 639 . 640. 641. 642. 643. 651 . 659. 660.672. 675. 680. 689. 719. 755. 765. 777 . 778. 779. 780. 781. 782 . 783. 781. 785. 786. 787. 788. 789. 796. 804. 807. 813. 815. 816. 822. 823. 825. 827. 828. 835. 836. 847. 848. 849. 850. 857 . 859. 867. 880. 881. 882. 884. 886. 889. 889. 890. 893. 903. 910. 918. 919. Galvagni, E.: 362. 463. 595. 920. 921. 928. 929. 930. 941.

Flammarion, C.: 183. 216. Ganitzki, W.: 44. 688. 299. 521. 600. 702.

Flögel, J. H. L.: 555. 573 . Forbush, E. H.: 227.

Forel, A.: 34. 184. 691. 733. Franceschini, E.: 175.

Freiwirth, O.: 189.

Iirey: 530.873.

Friedmann, F.: 338. 600 .

Friese, H.: 171.

Frings, I.: 119. 143. 257.

160. 161. 164. 167, 172. 209. 286. 287. 293. 295. 297. 298. 303. 366. 368. 424. 426. 428. 439. 446. 448. 449. 45:. 454. 455 . 461. 540. 554. 562.616. 620. 623. 630.631. 637. 638. 639. 640.641. 612. 643. 644. 615. 646. 648. 651. 678. 680, 702. 754 . 755. 757. 758. 762. 763. Geest: 871. 909.

765. 767. 777. 778. 779. Geissler: 502. S9S.

Gamble, 'T. W.: 338.

780. 781. 782. 784. 785 .

786. 787. 788. 789. 849 . 850. 854. 857. 879. 921 . 930.

Fritsch: 745 .

Frohawk: 471.

Fruhstorfer, H.: 287. 359. 363. 762 .

Fuchs, A.: 344. 370. 531. 875. 876. 899 .

Fuchs, F.: 854 .

Fuchs, R. F.: 853. 887. 892.

Fürth, O. v.: 844.

Funaro, A.: 708.

Gabba, L.: 227.

Gadeau de Kerville, H.: 32. 206. 315. 653. 703 .

Gaetke: 744.

Gal, J.: 32. 181. 227. 691. Galli-Valerio, B.: 573.580. 680, 727.

Garau, R.: 37.

Garbowski, T.: 403. 809 .

Garelli, A.: 227.

Gartner, A.: 471.859.

Gastine: 166. 579. 635.

Gatter, K.: 227.

Gauckler, H.: 39. 42. 47. 98. 135. 138. 139. 143. 147. 151. 157. 204. 278. 289. 305. 357. 38 2. 414. 422. 477. 501. 532. 546. 552. 609. 610. 615. 616 . 617. 618. 619. 620. 621 . 622. 623. 626. 627. 633 . 636. 639. 640. 642. 650 . 686. 637. 701. 741. 755 . 765. 777. 778. 779. 780 . 781. 786. 787. 788. 850 . 858. 859. 870. 871. 872 . 874. 878. 903. 932. 
Geoffroy St. Hilaire : 796. Gentry,Th. G.: 191.704.724.

Ghiliani, V.: 37.

Giard, A.: 42. 184. 573. 687. 688. 719.

Giardina, A.: 512.

Gillmer, M.: 555. 871.

Girard, M.: 37. 175. 189. 592. 600. 661 .

Glaser, L.: 528. 575. 609. 870.877.

Godard: 252.

Godnew, I. W.: 184.

Göldi, E. A.: 193. 590. 700. 704. 717. 727.

Goethe, R.: 98. 170. 680. 682. 784.796.

Goetschmann: 721.

Golubajew, A. A.: 19. 21. 263. 770.

Gonin, J.: 323.

Goossens, Th.: 343. 530. 751. 752.877.

Gorbatschew, K. A.: 229. 230. 232. 749. 894.

Gould, L. J.: 521.

Graber, V.: 476. 654. 681. 830. 858. 867.

Gradl: 904.

Gravenport, J. L. C.: 595.

Grassi, B.: 40. 578. 587.610. 701. 703.725.

Greatti, L.: 227.

Green, A. B.: 474.697.

Grevillius, A. Y.: 173. 225. 635. 636. 662. 680. 706 . 713. 714. 715. 716. 758. 767.

Griffiths, A. B.: 318. 319. 481. 482. 483. 484. 845. 860. 861.

Grosser P.: 502. 860.

Grote, A. R.: 32.

Grum-Grschimajlo, G. E.: 168. 653. 678.

Grunack, A.: 207. 703.

Guérin-Mèneville, F. E.: 37. Gumppenberg, F. von: 175.
H., L:: 767. 871.

Haas: 673 .

Haase, E.: 227. 316. 318.

Haberfelner, J.: 255. 302. 350. Б37. 765. 767. 873. 898.

Haberlandt, F.: 10. 32. 175. 176.

Habich, O.: 365.367 .536 . 853. 854. 875.

Haeckel, E.: 813.

Hagen: 315. 769. 770.

Hagen, H. A.: 62. 246. 247.

Hamann, 0.: 502. 546.

Hampson: 400.

Haneld: 297. 459. 755.

Hansen: 752. 920.

Harding, H. J.: 37.

Harpe, A. de la: 340.341. 898. 913.

Harrach: 227.

Hartmann: 903.

Harz: 138. 193. 700. 705. 706.

Heath, H.: 589. 704.

Hebhard, W.: 131. 731.

Hein, E.: 303. 393. 498. 541 . 542. 878. 879. 880.

Heissler, L.: 120. 303. 389. 542. 543. 732. 765. 766 . 777. 859. 878. 883.

Heller, A.: 312.493.

Hellins: 338.

Hemmerling, H.: 315. 325. Irmscher, E.: 439. 777. 781.

Heppe: 124. 399. 779. 780. Iwanow, P. W.: 195. 217.

Hensel: 356. 909.

Herbst, C.: 720.

Hering: 358.

Hermann, D.: 3. 842.

Herold, J. M.: 1.

Herpin, J. Ch.: 575. 654.

Herrich: 459.

Hertwig, O.: 692.

Heyer, E.: 389. 777. 778.779. Heyden, L. v.: 287.762. 763.

Himmelstoss, W.: 312.

Himsl, F.: 131. 731.

Hittorfi: 502 .
Hlasiwetz: 323.

Hoffer, E.: 361. 362. 901.

Hoffmann, A. : 257. 351. 490. 860. 898. 903. 907. 908. 912.

Hoffimann, E.: 350.354 .545$. 738.

Hofmann, K.: 197. 700. 703.

Holland, W. J.: 680.

Holle: 600.

Hollrung, MI.: 204. 577. 634. 701.

Holmes, S. J.: 585. 691.

Holtz, M.: 271. 355. 519. 769. 859. 897.

Holz: 184.

Hopkins, F. G.: 317.323. 338. 845.

Hormuzaki, C. v.: 38.121. 364.

Horner: 593.

Horvath: 752. 920.

Howard, L. O.: 176. 680.

Hoyer: 538. 539.

Huber, F.: 704.

Huber, H.: 190. 385.

Hübner: 459.

Hughes: 693.

Hunter: 719.

Hüttner, A.: 41. 303. 543. 686. 765. 878. 879 .

Ingenetzki, I.: 204. 220. 221. 227. 251. 266. 271. 309. 325. 700. 705. 706. 707. 712. 765. 767 .

Jacobi, A.: 110. 256. 317. 650. 769 .

Jacobson, G.: 171. 333. 439. 653.

Jaenichen, R.: 42. 205. 210. 290. 367. 390. 605. 608 . 690. 777. 778. 779. 780 . 853. 855 .

Jahn, A.: 138. 612. 
Janet, Ch.: 600.

Jaroscheirsky, W. A.: 38. 250. 252. 253. 254. 257. 345. 346. 347. 349. 477. 687. 769. 860 .

Jensen, P.: 849.

Jickeli, C. F.: 720.

Johansen, .H.: 32 .

Johnson: 58!. .704. 724.

Jordan, K.: 364.

Jordanott, C.: 707.

Jordis, K.: 389: 410, 606 .

Joseph; G.: 572. 688.

Joule: 870.

Jourdheuile: 176 :

Judeich: 577. 603.611.716.

Kabis, G.: 211.

Kablukow, J.: 32.

Kabsch, IV.: 558. 829.

Kalender, E.: 71. 77. 377. 474. 576. 614, 615. 616 . 617. 618. 619. 620. 621 . 622. 650. 777, 778, 858 .

Kallenbach: 535. 878, 879 .

Kaltenbach, J. H.: 715 .

Kamensky, S. N:: 120. 197. 290. 302. 537. 538. 539. 611. 614. 705. 754. 765. 767. 873. 87\%. 579. 880 . 884. 891:

Kane, W. F. de: 38.

Kanitz, J. G.: 60, 176. 227.

Karsin, .Т.: 35. 733.

Kiask, F.: 278.

Kathariner, L.: 182. 295. 299. 438., 439. 444. 509. 510. 513: 691. 692. 693 . 755. 763, 764. 779, 856 . 857: 858. 860. 864 .

Kawraisky, Th.: 216. 217 . 706.

Keferstein, A.: 32.343 .527$. 877.

Keller, C.: 194. 499. 700. 717: 860 .

Kellog, V: L.: 223. 310.600. 700. 712. 739. 765 .
Kendrik, M. = MacKendrik. Kratz, L.: 338.

Kennel, J.: 364.

Keppen $=$ Köppen.

Kerschbaumer: 57S. 587. 609. 653. 702 .

Kessler, H.: 99. 732.

Kimakowicz, F. v.: 745.

Kirkland, A. H.: 716.

Kisselow, G.: 201. 702.

Kitz, A: 943.

Klapálek, F.: 280.

Kleine, G.: 63. 300. 364. 650. 765 .

Klemensiewicz: 352. 898.

Klcoss, H.: 137. 613.

Knaggs: 601.

Knapp, F.: 903.

Knatz; L.: 345. 532. 533. Kulikowski, E.: 43. 275.688. 592.

Kinauthe, K.: 696.834 .868$.

Knoche, E.: 581: 653.

Koch; G.: 299. 342. 372. 471. 528. 572, 575. 601. 687, 765. 768: 859. 876 . 896.

Kodis, 'T.: 655.

Kïnig: 707. 708.

Köppen:-37, 256. 705.

Köppen, W.: 911.

Koernicke, M.: 697. 698.

Kíolbe, H. J.: 62. 255. 770 .

Kolle, W.: 47. 653. 688.

Kolisko, A.: 905.

Koschewnikow, G. A.: 153. 211. 212. 226. 273. 275. 282. 301. 309. 311. 334 . 551. 592. 653. 700. 701. 704. 724. 726. 727. 765. 769. 884. 891. 932 .

Kováes: 745 .

Krause, E.: 60.

Krrauss; H.: 546 ,

Kritz: 176 .

Krodel, E.: 458. 459. 464. 782.

Krügex, E.: 338. 745.

Krukenberg, C. Fr, TV.: 316. 320. 799 .

Krulikowski, L.: 263. 265. 348. ห50. 351. 352. 459. 491. 533. 545. 577. 593. 594. 598. 731. 764 . 770 . 858. 860. 897. 901. 907. Küchenmeister, F.: 176.372. Kulagin, N.: 216. $6>0$ ). 701. 729.

Kunckel, J. d' Herculais: 338. 493.858.

Kurnali, N. T.: 21. 267.

Kurz, WV: 191.

Kusdas, W.: 43. 368. 6ㄱ. 854. 855 .

Kuusnezow, N. I.: 51. 163. 446. 520. 612. 777. 775. 779. 780. 865.897 .905$. (9)7. 910.

Ky bex, J. E.: 62. 190. 704. 717.

Lahorde, J.: 578. 647. 648. Laboulbène: 601.

Laddiman, R.: 33.731.737.

Lafitole; Marquis de: $17 \%$. 131. 522. 531. 691. 692. 867. 870. 877 .

Lagerheim, G.: 713.714.

Lambert, F.: 195. 216. 294. 439. 707. 755 .

Lambrecht, A.: 32.

Lampert, K.: 590. 702.

Landois, H.: 190. 300. 704. 724.

Landois, L.: 3.842.

Lange: 575.

Laurent: 577. 603.

550. 587. 720. 875 .

Lauterborn, R.: 293. 756. 
Lawlinzew, S.: 592.

Lea, C.: 862.

Lebedinski, J.: 515.858.

Lederer, J.: 247. 342. 769.

Lee: 184.

[897.

Leech, J. H.: 253.770.

Lehmann: 171. 477. 859.

Lehmann, G.: 745.

Lenhossék M. v.: 730.

Leuckart, R.: 190. 227. 704 .

Levrat, D.: 186. 188. 554 .

561. 601. 694. 696. 891. Mac Kendrick: 682. 684.

Lewith, S.: 666. 668. 673. 736.

Leydig, F.: 315.

Lhotte, H.: 354.

Liberich, F.: 130. 611.

Lichtenstein, J.: 100. 633. 678. 681. 717.

Linde, A. L.: 139. 650.

Linden, MI. v.: 47. 136. 211. 298. 306. 330. 334. 335. 336. 338. 422. 432. 507. 509. 523. 526. 448. 574. 584. 585. 589. 596. 598. 599. 600. 609. 616. 688 . 691. 693. 694. 697. 702. 703. 718. 721. 722. 763 . 764. 765. 766. 777. 778. 814. 816. 817. 818. 819. 822. 824. 825. 838. 842 . 844. 845. 846. 847. 848. 849. 850. 853. 657. 858 860. 861. 867. 869. 878. 879. 880. 881. 882. 883. 884. 886. 887. 888. 889. 890. 891. 892. 918. 819. 920. 939. 940.

Linstow, 0 , von: 9.

List, Th.: 507. 521.

Lister, J.: 887.

Lo Monaco, Douchier: 32. 205.

Locke, H.: 305.

Lockyer, B.: 34. 731. 737. Lockyer: 911.

Loeb, J.: 178. 228. 237. 693. 719. 723. 861. 865 .
Löw, H.: 247. 343. 345.

Lomnicki, J., R. von: 503. 547. 859. 894.

Lopriore, G : 886. 888.

Lorez, C. F.: 458. 777. 779. 780.

Luciani, L.: 32. 205.

Ludwig, N.: 204. 705.

Lübenetzki, J.: 79. 650.

Lïstner: 748.

Mac Lachlan, R.: 529. 561. 875. 876. 877.

Macchiati, L.: 717.

Maillot, E.: 33. 669. 730. 749.

Majoli, C.: 62. 604. 610 . 665. 774.

Malies: 312 .

Manger, K.: 236. 749. 753.

Mann, J.: 247. 343. 769. 877. 897.

Marchal, P.: 204. 272. 305. 547. 571. 573. 687. 704. 727. 732 .

Marelli: 79 .

Marlatt, C. L.: 147. 682.

Martin, A.: 356.

Martin, J.: 32.

Martynow, W. A.: 275.

Masaraky, W. W.: 212. 701. 738.

Mathew: 364. 719.

Maude, H. A.: 245.

Maurel, E.: 176.

May, H.: 263. 324. 352. 769.

Mayer, A. G.: 324. 338. 564. 601. 838. 839. 845. 923.

Mc Aldowie, A.: 338.

Meigen: 346. 347.

Meinhard, A.: 280.

Meissuer, O.: 745. 901.902. 932.

Meldola, R.: 475. 515. 860. 861.

Meldrum: 911.

Melichar, L.: 518.867.
Meloni, N.: 176.

Meltzer, S. J.: 752. 920.

Merckens, W.: 943.

Méréjkowski, C.: 338.

Mereschkowski, K. S.: 315 .

Merriam, C. H.: 747.

Merrifield, F.: 101.103. 114. 120. 121. 133. 289. 290. 292. 338. 384. 385. 386 . 388. 390. 391. 392. 393. 399. 414. 416. 471. 489. 490. 507. 521. 601. 607. 608. 611. 612. 613. 615 . 617. 622. 626. 628. 629 . 630. 632. 635. 650. 651 . 674. 678. 754. 755. 757. 758. 763. 764. 777. 778 . 779. 780. 781. 782. 786 . 858. 859. 860. 861. 86i4. 865.

Metalnikow, S.: 545. 589. 703. 884. 891 .

Metzger, A.: 267.

Meyer-Dür, H.: 247. 340 . 341. 364. 769. 853. 854. 860. 896. 898.

Moberly, J, C.: 338.

Möller, L.: 473. 528. 571. 576. 594. 609. 730. 732 . 859. 860. 871. 872. 873 . 874. 875. 876 .

Mokrzecki, S. A.: 42. 135. 159. 166. 572. 577. 579 . 581. 585. 607. 609. 619 . 635. 653. 688. 701. 702.

Montandon, A. L.: 905.

Mordwilko, A. K.: 23. 61. 157. 208. 212. 304. 308. 441. 442. 443. 511. 653 . 678. 681. 700. 716. 727 . 765. 860 .

Morgan, C. F.: 192. 760. Morris: 489. 860. 863 . Morse, A. P.: 598. Mottier, D. M.: 753. Mouline, E.: 191. 702. Müllenberger, H.: 519. 585. 691. 692. 858, 865 . 
Müller, F.: 481. 506. 859. Pauls: 156. 292. 294. 438. 860.

Müller, M.: 501.

Müller-Erzbach, W.: 835.

Müller-Turgau: 655 .

Murray, A.: 474.

Mussehl: 830 .

Naacke: 474.530.

Nägeli, K. W. v.: 552.658. 794. 828.

Nauck: 859.883.

Nazari, A.: 212.

Needham, J. G.: 245.

Neilson: 719 .

Neuburger, W.: 463.

Neuhauss, R.: 864.865.942.

Neumayr: 708.

Newbigin, M. J.: 339.

Newport, G.: 2.

Nicéville, L. de: 365.855.

Nicolet, H.: 653.

Nitsche: 577. 603.611. 716.

Nolcken, J. H. W.: 571.741.

Nüsslin, O.: 147. 572. 732. 733.

Oberthür, Ch.: 441.

Obuchow, A.: 41. 636. 688 .

Ochsenheimer: 77.

Omboni, C.: 176.

Oppenheim, M.: 339.

Ormerod, E. A.: 741. 745.

Ostwald, W.: 760 .

Ottavi, O.: 32.

Oudemans, J. Th.: 236. 328. 519. 748. 751. 866 .

Pabst: 50. 224. 334. 336. 359. 455. 503. 554. 687. 703. 738. 740. 859. 878. 879.

Palmén, J. A.: 370.

Passerini, N.: 201. 702.

Pasqualis, G.: 200. 201. 228. 702.

Pasteur: 229.

Paulcke: 726.
549. 613. 614. 731. 754 .

755. 756. 761. 777. 903.

Peligot, A.: 228.

[905.

Perez, C.: 727.

Perez, J.: 176. 59I.

Perroncito, E.: 176. 199.228. 701.

Peters, H. T.: 501.859.

Petersen, W.: 15. 163. 164. 277. 299. 358. 361. 478 . 483. 484. 580. 613. 619 . 623. 763. 764. 769. 860 . 861. 896.

Petrunkewitsch, A.: 720 . 726. 729 .

Philipps, J.: 542.

Pickel, W.: 139. 181. 210. 271. 614. 682. 691. 700 . 701.

Pictet, A.: 189. 311. 371. 523. 556. 557. 559. 560 . 601. 680. 682. 694. 695 . 705. 728. 765. 768. 854 . 857. 867. 871. 872. 873 . 874. 876. 877. 884. 886 . 894. 895. 937.

Piepers, M. C.: 44. 325 . 327. 328. 339. 368. 498. 500. 546. 742. 743. 809 . 810. 813. 814. 823. 825 . 854. 859. 866.

Pierret: 601.

Pitra, J.: 176.

Planet: 287.

Planta, A. v.: 301.726. 727. Plateau, F.: 591.

Pogibko, A. J.: 38.

Poiseuille: 922.

Pollack, W.: 533. 870. 877.

Pomeranzew, D.: 517. 859.

Portschinski, J. A.: 32. 252. 339. 580.

Pospelow, W. P.: 37. 210. 276. 586. 704. 724. 730 .

Pouchet, F. A.: 680. 682. Régnault: 3 .

Poulton, E. B.: 33. 339. Reh, L.: 166. 170.213.216.

477. 478. 479. 480, 481. 222. 310. 333. 633. 654 .
482. 483. 484. 490. 491 . 492. 506. 521. 540. 542 . 561. 601. 859. 860.861 . 863. 874. 894 .

Prehn: 271. 413. 500. 738. 743. 744. 745. 770. 859 . 860 .

Prest, W.: 365. 531. 853. 871. 873.

Prittwitz, O. F. W. von: 472. 529. 858. 899.

Puhlmann: 339.

Quajat, E.: 11. 22. 24. 33. 78. 115. 130. 131. 143. 156. 168. 171. 176. 177. 181. 184. 186. 187. 188. 198. 199. 200. 202. 206. 208. 224. 228. 234. 235. 237. 250. 269. 287. 288. 604. 612. 613. 614. 633 . 634. 635. 663. 665. 666 . 668. 676. 680. 691. 694. 695. 701. 702. 707. 703. 719. 723. 749. 751. 755 .

Raband, E.: 471.

Rade, E.: 206. 703.

Rádl, E.: 693.

Ramsden, W.: 753. 920.

Ratzeburg, J. T. C.: 256. 575. 603. 610, 611. 730 .

Ratzky, O.: 228.

Raulin, J.: 228. 286.

Rawitz: 719.

Ray-Pailhade de: 176.

Réaumur: 1. 680 .

Rebel, H.: 267. 279. 281. 352. 359. 360. 362. 526. 623. 761. 769. 770. 897. 898. 919. 924. 925. 939. Regen, J.: 570. 574. 584. 591. 597. 599.

Regener, E.: 575. 607. 615. 663. 
672. 678. 652. 703. 721. Rossikow, K. N.: 571. 57̄.| Schäffer, C.: 318. 459. 748. 767. 936.

Reichenau, WV. v.: 282.382. 672. 777. 778, 779. 787. Reichenbach, H.: 592. 725 . Reichenow: 209. 704. 724 . Reichert, A.: 278. 312.359. 770. 807.

Reid, W.: 38.

Reinberger, G.: 158. 615 . 616. 617. 618. 619. 620. 622.

Reisen, T.: 571. 730. 898.

Reiset, G.: 3.

Rengel, C.: 159. 653.

Rengger, J. R.: 1.

Renner: 78.

Rennie, J.: 1.

Rey: 356. 903. 904.

Ribbe, C.: 365.853.

Richter: 529. 871.876.911. $9: 2$.

Riding, IV. S.: 339.

Riedel, M. P.: 131.

Riem, J.: 190.

Riesen, A.: 363. 903.

Robinson, E. K.: 38. 300. 365. 765. 853.857.

Rochaz de Jongh, J.: 573. 580. 680, 727 .

Rocquigny-Adanson, G. de: Rodsjanko,W. N.: 180.691. Roedel, H.: 680. 681.

Roelofs: 521.

Roesel, A. J. v. Rosenhof: 713.

Rössler, A.: 286. 302. 352. 471. 476. 528. 532. 5io. 762. 763. 765. 766. 77!! 859. 860. 870. 873. 875. 877.

Rogenhofer, A.: 267. 252. 769. 770.898.

Rollat, V.: 234. 749.

Rondani: 345 .

Rondeau, N. 707.

Ross, J. C.: 680. 685. Rossi, G. de: 212. 701. 580. 587. 635. 636. 70t. 724. 730.732 .

Rossinsky, D. M.: 198. 221. 701.

Roulet, J. C.: S2.

Rubner, M.: 757.

Rudow, F.: 124. 207. 286. 292, 294. 295. 306. 507. 308. 393. 502. 704. 724. 756. 765. 767. 860 .

Rudzsky, K. A.: 237.

Rübsamen, E. H.: 222.

Rühl, F.: 40. 100. 119. 197. 351. 365. 366. 383. 389. 491. 533. 537. 549. 616. 622. 645. 648. 650. 686 . 687. 731. 732. 777. 854 . 857. 859. 871 . 872.873 . 874. 875. 898.

Ruhe, H.: 518. 859.

Ruhner, G. IV.: 140. 141. 430. 431. 623. 620. 629. 636. 651. 674. 779. To(). 781.

Ruhmkorff: 186. 188. 502. Russel, A.: 339. 752.

Russel, S. G. C.: 521. 9:0.

Rye, E. C.: 521.

Rykatschew: 911.

Sabanin, A. N.: 709. 711. Sachs, J.: 655. 656. 657. 658. 659. 661. 676. 679. 692. 693. 743. 773. 826. 827. 828. 829. 830. 532 . S39. 840. 841. 846. 85‥ Sajó, Ki.: 131. 136. 202. 203. 545. 546. 633. 65:3. 702. 721. 742. 746 .

Salisbury: 1.

Salow, M. R.: 712.

Sandias, A.: 725 .

Sasaki, C.: 224. 310. 699. 700. 712 .

Sancon, M.: 592.

Saussure, H. de: 596.

Saurageon.de: 63.604, 663.
Schatz, E.: 316.

Schaufuss, C.: 304.

Schawrow, N. N.: 254. 316. 483. 845.860.

Schellenberg, G.: 60 i. Schelver, F. J.: 314.

Schemigonow, J. M.: 162. 217. 613. 635. 666. 650 . 702.

Schenkling-Prévôt: 138. 228. 499. 500. 617.

Schewelew, I.: 580. 650.

Schewyrew, I.: 34. 40. 121. 611. 657. 730. 783 .

Schille, Fr.: 119. 609. 621.

Schilling, H. v.: 222.

Schima: 596. 762.

Schiner: 345. 346. 348 .

Schirach, A. G.: 190. 704.

Schitkow, B. M.: 44. 137. 236. 607. 635. 664. 687. 700. 706.

Schmid, A.: 63. 650 .

Sclimidberger, Jos. : 62. 732.

Schmidt, F.: 874.

Schmujdsinowitsch, TV. J.: 16. 18.112. 115.178. 185. 186. 195. 231. 232. 233. 237. 260. 266. 537. 604 . 607. 611. 613. 614. 615 . 634. 635. 636. 662. 663 . 680. 690. 691. 692. 693. 694. 700. 749. 750. 758. 770. 879. 880. 884. 891. Schneider, H.: 534. 891. Schoch, G.: 178. 476. 691. 692. 693. 858.

Schönfeld: 176. 177. 653. Scholzinski: 711 .

Schreiber, F.: 199.541.871. Schreiner, J.: 579. 594. 609.

Schröder; Ch.: 170.336. 450. 451. 455. 493. 497. 498. 516. 561. 566. 781. 809. 814. 823. 858. 859. 913. 917. 921.932. 
Schtschelkanowzew, J. P.: 210.

Schtscherbakow, A. M.: 147. 682.

Schüftiner: 571 .

Schülke, A.: 441. 779.

Schugurow, A.: 166.

Schugurow, N.: 168; 621. 653.

Schultz, O.: 48. 139. 235. 237. 369. 464. 512. 614 . 620. 688. 689. 713. 780 . 843. 853. 860. 877. 904. Schultze, MI.: 669.827 .846$. Schultze, O.: 237. 526. 730.

Schulz, G. B.: 577.616. 619.

Schulz, W. A.: 279.

Schumann, E.: 369.438.854. 904. 909.

Schumburg: 839.

Schwerin, N. W.: 205.706. Scott, IV. N.: 146. 682.

Scudder, S. H.: 350. 738.

Seeland, Br. v.: 195.

Seifert, 0.: 464. 471. 782 .

Seiler, A.: 536. 870. 877. 879.

Seitz, A.: 38. 285. 364.

Selmons, G. C. MI.: 35. 121. 198. 303. 304. 611. 614. 700. 730. 731. 733.765.

Semenow, A.: 36. 733.

Semper, C.: 339.

Serebrjanikow, A. W.: 553. 573. 579. 585. 586. 594. 603. 614. 630. 634. 636. 686. 691. 716. 751. 872. 877.

Sewerin, S.: 201.

Shelodon, IV. G.: 471.

Sidebotham, H.J.: 476.858.

Sieber, N.: 589. 703.

Siebold: 3.726 .

Sikora, F.: 540.

Sikora, H.: 555 .

Silantjew, A. A.: 201.576. 703. 732 .

Silfvenius, A. J.: 584. 609.
Silvestri, F.: 725

Simaschko, J. J.: 177.

Simroth: 325. 934.

Singerland, M. V.: 700.717. 718. 720 .

Sitowski, L. : 555. 597. 765. 767. 879. 891. 892.

Skorikow, A. S.: 47. 333. 688.

Slater, J. IV.: 189. 531.

Slerogt, B.: 158. 295. 370.

444. 550. 552. 595. 599.

611. 627. 754. 770. 779 .

780. 855. 871. 877. 896.

904. 906. 910. 944.

Smith, G.: 601.

Smith, J.: 943.

Smith, W. W.: 471..528.

Snellen, P.: 903.

Sobolew: 267.

Soddy, F.: 932.

Solowiow, P.: 819: 880. 883. 888.

Sonier: 115.

Sorhagen, L.: 276. 357. 769 .

898.

Soule, C. G.: 339.

Spallanzani, L.: 680.

Speiser, P.: 216. 336. 701. 727.

Speyer, A.: 477. 530. 744. 858.

Spuler, A.: 246. 315. 325.

Standfuss, M.: 40.122. 123.

124. 133. 134, 141. 142.

181. 192. 202. 203. $29($ ). 291. 292. 297. 304. 31s. 324. 339. 366. 367. 37-2.|Susani, G.: 192. 228. 701. 393. 398. 399. 400. 409.

415. 416. 422. 441. 443. / Swammerdamm, J.: 314.

452. 451. 461. 489. 499. I Swinhoe: 365. 400.

510. 527. 544. 601. 603. Swinton, A. II.: 17

604. 605. 606. 607. 608. |Szczepanik, J.: 944.

609. 610. 611. 614. 616.

617. 619, 620. 62:2. 625. I Tammann: 634.

626. 627. 628. 629. 630.|'Tangl, k.: 723.

640. 641. 642. 645. 650. Taratynow, G. 1': 230. 7.4!.

651. 659. 664. 1:7... 675. 750. 893. 894.
676. 680. 687. 689. 690.

691. 692. 704, 723. 727 .

780. 79 s01. 802.808.

804. 813. 816. 822. ธ23.

824. 825. 827 . 846. s4s

849. 850: 853. 554. 055.

930. 991.

940. 941 .

Stange, G.: 208. 352. $47 \mathrm{~s}$.

533. 755. 777. 778.779.

859. 872 .

Staudinger, 0.: 623. 761 .

Stein, S.: $561 . \quad$ [9.25.

Stempkowska, L. A.: 44. 687. 706.

tepanow, P. G.: 39. 300. 680. 687.

Stichel, G.: 578. 619.

Stoklasa, J.: 572. 686. 687.

Strobl, P. G.: 595.

Strohmayer: 119. 732.

635. 653. 688 .

Studd, E. F. 38.

Studiati, C.: 177.

turm: 900.

719. 748.751. 
Tarnani, I. K.: 48. 687 . Ulbricht, A.: 370. 853.

Taschenberg: 576.603.611. Ullmann: 708.

Teich, C. A.: 247. 248. 300. Umow, N. A.: 932.

343. 377. 474. 530. 769. Urech, F.: 13. 14. 39. 52.

770. 870. 896. 899.

Terni, G.: 228. 748. 751.

Terre, M. L.: 24.

Tesla: 188.

Testenoire, J.: 186. 188.694. 696.

Thiele, R.: 37. 211. 222. 458. 561. 703. 732 .

Thurau: 172. 356. 630.904.

Tichomirow, A. A.: 12. 22. 32. 100. 130. 159. 193. 198. 201. 228. 229. 230. 303. 607. 608. 611. 613. 615. 663. 667. 668. 695. 701. 719. 720. 729. 748. 751. 752.834 .

Tichomirowa, O. O.: 193. Venus, C. E.: 289. 383. 481. 198. 201. 303. 700. 701. 706. 711. 712. 767 .

Tidemann: 82. 636. 650 .

Timm, D.: 83. 650 .

Töpler: 188.

Tomala, N.: 553. 573. 601. 687. 873.

Topsent, E.: 545. 873. Tornier, G.: : 195. 236.

Tour, J.: 699.

Tower, W. L. : 336. 339. 357. Treat, M.: 191. 704. 724. Trimen, R.: 364. 481. 506. 859.

Troska, A.: 301. 304. 535. 545. 765. 857. 880.

Trost, A.: 359. 361. 519. 580. 595. 609. 732. 898. Tschugunow, M.: 358. 898. Tschugunow, S.: 358. Tümpel, R.: 515. 860. Tumas: 752. 920 .

Turati, E. Conte: 910. Tutt, J. W.: 339.

Uffel, K. : 177.

Uibrich, E.: 362.
110. 112. 318. 319. 320. 321. 329. 339. 423. 563 . 565. 567. 569. 604. 608 . 609. 610. 611. 615. 680 . 688. 689. 731. 777. 778 . 782. 786. 787. 794. 796. 801. 806. 822. 834. 836 . 837. 842. 844. 845.850 . 856. 921. 922. 923.

Ušik, J.: 177.

Valentiner, S.: 698.

Valery-Mayet: 237.

Vágó: 745.

Vanha, J.: 572. 686.

Vedovati, D.: 201. 754. 756. 757. 758. 777. 778. 787. 858.

Verhoeff, C. 339. 340. 502 . 503. 546. 548. 549. 561. 866. 873.

Verloren, M. C.: 63. 732. Vermorel, V.: 166. 579. 635. Vernon, H. M.: 386.

Verson, E.: 11. 33. 66. 78. 79. 137. 177. 184. 206. 235. 237. 288. 318. 517. 604. 612. 614. 633. 634 . 635. 663. 668. 680. 682 . 694. 702. 708. 755. 774.

Viguier, C.: 228. 719.

Villard, J.: 336.

Villon: 536. 884. 891.

Vogel, F. W.: 62.650.

Vogel, H.: 943.

Vogel, J. W.: 312.

Vogler, C. H.: 156. 325.

Voelschow, A.: 313. 540. 893.

Vom-Rath, 0.: 211. 725.

Voss, Th.: 357. 903.

Vosseler, J.: 517. 518.

Voyle, J.: 177.
Vrière, R. de: 357. 903.

Vultée von: 533.

Wagner, M.: 250. 344. 770.

Wagner, N.: 522. 867.

Walker, F. A.: 340.

Walker, J. J.: 351.

Wallace, A. R.: 248. 344. 473. 736. 771. 860.

Walsingham: 384.777 .779$. 913.

Walter, B.: 324.

Wanach, B.: 596. 902.

Warnecke, G.: 519. 859.

Wasiljew, I.: 584. 590. 597. 603. 610, 617. 618, 700. 715 .

Wasmann, E.: 114.121. 129.

Waters: 471.

$[633$.

Weber, L.: 189. 694. 697.

Webster, F. M.: 146. 682.

Weindiger: 744.

Weir, J. J.: 33. 364. 368. 471. 419. 521. 531. 731. 737. 854.

Weismann, A.: 41. 79. 180. 181. 195. 229. 269. 290. 303. 329. 354. 366. 377. 380. 404. 430. 499. 561 . 592. 607. 608. 611. 616 . 624. 625. 626. 628. 629 . 630. 636. 664. 688. 689 . 691. 692. 726. 732. 739 . 749. 752. 765. 770. 771 . 777. 778. 779. 780. 787 . 789. 791. 793. 794. 796. 822. 825. 844. 846. 848 . 850. 854. 859. 899. 900. 918. 920.940.

Welkins: 737.

Werneburg: 501. 859.

Werner, A.: 408. 777. 778.

Weskamp: 399.

Westhoff, F.: 340.

Weymer, G.: 528.

White, W.: 481.482.

Wicke, B.: 4.

Wicke, W.: 4. 
Wiener, 0.: 510. 862. 863. Wood, T. W.: 472.475. 860. Zang, R.: 443. 904. 909. 864. 896. 942.943.

Worell, K.: 943.

Zarudski: 312 .

Willcock, E. G.: 177. 698. Wünscher: 170. 604. 608. Zeller: 324. 534. 871.

Wilkins, A. I.: 477.859. 610.

Willem, V.: 521.

Wurm: 315.

Winkler, H.: 228. 752.

Wurmb v.: 36.

Zenker, W.: 864. 943.

Witmer, B.: 203.

Wyman, J.: 682. 683 .

Zeselski, T.: 120. 130.650.

Zetterstedt: 523.

Wittich v.: 895 .

Zimmermann, H.: 51.

Wojejkow, A. I.: 747. Xambeu: 601.

Zuntz, N.: 839. 


\section{Verzeichniss der Gattungen.}

(Die Zahlen bezichen sich auf die Seiten).

Abraxas Leach (Lep.): 26. 144. 155. 161. 170, 365 . 429. 441. 455. 494. 531 . 540. 556. 557. 558. 622 . 646. 648. 649. 705. 780 . 782. 814. 815. 853. 873 . 917.

Abrostola 0. (Lep.): 621. Achcrontia 0. (Lep.): 43. 77. 138. 139. 571. 575 . 576. 580. 604. 608. 609 . 610. 617. 650. 687. 716 . 732. 738. 740. 741. 764 . Achorustes Templ. ('lhys.): 147. 682 .

Acidalia 'Tr. (Lep.): 163. 263. 277. 280. 342. 350. 352. 358. 362. 370, 494. 495. 545. 769. 770. 854 . 896. 898. 907.

Acocephalus Germ. (Hym.): 251.

Acontia Ld. (Lep.): 356. 897. Acronycta O. (Lep.): 43.50. 72. 99. 151. 155. 159. 271. 351. 358. 616. 620. 687. 769. 896. 897. 898. 904. 907. 908.

Actias Leach (Iep.): 354. Adalia Mulsant (Col.): 450. 516. 566. 814.

Agelastica Redt.(Col.): 576 . Aglia 0. (Lep.): 100. 135. 150. 155. 159. 202. 203. 304. 339. 363. 366. 468. 521. 527. 583. 595. 620.
631. 704. 713. 725. 727. Angerona Dup. (Lep.): 118. 755. 769. 854. 856. 896. 351. 356. 611. 613. 635. 905. 906 .

Agraylea Curt. (Neur.): 584. 609.

Agrotis 0. (Lep.): 77. 119. Anisopteryx Stph. (Lep.): 120. 133. 183. 192. 202. 40. 135. 578. 622. 687.

252. 265. 277. 288. 290. Anobium L.: 721.

291. 352. 353. 358. 382. Anopheles Meigen (Dip.): 383. 388. 409. 417. 540. 216. 311. 573. 578. 580. 571. 605. 606. 620. 724. 587. 589. 610. 680. 701. 730. 732. 754. 755. 769 . 778. 779. 874. 876. 894 . 896. 897.

Allantus Jur. (Hym.): 271. 770.

Aluctita Wisghm. (Lep.): 280. 770 .

Amaurorhinus Fairm. (Col.): 38. 688 .

Ameles Burm. (Orthop.): 512.

Ammophila Kirby (Hym.): 307. 308.

Amphidasis Tr. (Lep.): 72. 99. 135. 153. 351. 353. 356. 357. 358. 365. 492. 500. 501. 529. 531. 622 . 623. 815. 853. 873. ธ76. 897. 903. 904. 905. 907 . 909. 910. 912. 913.917. Amphipyra 0. (Lep.): 265. 353. 769. 897.

Ancylolomia Hb.(Lep.): 360 . 897.

Ancylosis Z. (Lep.): 353. 703. 704. 724. 728.

Antheraea Hb. (Lep.): 32. 99. 120. 389. 483. 484 . 554. 636. 732. 738, 755 . 778. 860 .

Antlıocharis B. (Lep.): 131. 135. 247. 275. 320. 324 . 332. 731. 769. 770.

Anthomyia Meigen (Dip.): 347.

Anthrax Scopoli (Dip.): 300.

Anuraea Ehrb. (Rotator.): 293. 756.

Apamea Tr. (Lep.): 732.

Apatura F. (Lep.): 88. 94. 95. 143. 144. 165. 167. 168. 297. 321. 332. 337. 338. 339. 417. 424. 427. 440. 453. 456. 457. 469. 470. 519. 576. 657. 638 . 647. 648. 649. 732. 808 . A phenogaster Mayr. (Hym.): 34.

Aphis L. (Hem.): 35. 42. 61. 62. 212. 274. 275 . 
442. 443. 555. 611. 633 . 678. 681. 717. 873 .

Aphodii Redt. (Col.): 49.

Aphrophora Germ. (Hem.): 251.

Apion Herbst (Col.): 575. 654.

Apis L. (Hym.): 28.592. 681. 701. 725. 738. 769. 830 . Apodacra Macq. (Dip.): 345. 477.

Aporia Hb. (Lep.): 25. 26. 27. 239. 240. 241. 242 . 244. 255. 271. 280. 282. 233. 285. 312. 338. 416. 417. 418. 559. 579. 596. 601. 609. 681. 715. 769 . 770. 776. 777. 779. 854. 871. 910 .

Aporodes Gn. (Lep.): 265. 353. 769. 897.

Appias Hb. (Lep.): 359.

Araepus Le Conte (Col.): 251.

Araschnia Hb. (Lep.): 173. 391. 430. 462. 608. 617. 622. 628. 629. 644. 648 . 649. 674. 675 .

Arctia Schrk. (Lep.): 50. 83. 123. 134. 138. 143. 144. 156. 160. 161. 168. 173. 177. 178. 191. 278. 291. 292. 297. 303. 320 . 334. 365. 388. 409. 417. 426. 428. 438. 440. 448 . 452. 458. 462. 463. 464. 468. 476. 501. 522. 527. 530. 531. 532. 533. 536 . 540. 544. 546. 552. 554. 560. 561. 580. 584. 604 . 606. 609. 610. 611. 614 . 633. 636. 646. 648. 687. 6!) 1. 731. 754. 755. 761 . 762. 767. 778. 779. 780 . 782. 808. 844. 853. 867. 870. 873. 876. 877. 879 . 886.

Arge Boisd. (Lep.): 88. 364 .
Argynnis F. (Lep.): 85. 86. 87. 88. 91.92. 93. 94. 95 . 122. 123. 168. 173. 247. 248. 255. 271. 277. 279. 315. 337. 340. 341. 355 . 357. 358. 360. 365, 370 . 388. 395. 397. 416. 417. 457. 463. 518. 594. 608. 611. 629. 644. 645. 648 . 649. 769. 770. 778. 779 . 782. 854. 855. 856. 858 . 897. 898. 904.

Argyra Macqu. (Dip.): 346. Aricia Rob. (Dip.): 345.

Arion Fir. (Moll.): 49.

Asilus L. (Dip.): 253. 347. Aspidiotus (Hem.): 748.

Aspilates Tr. (Lep.): 247. 343. 721. 769.

Atella Dbld. (Lep.): 299. 306. 504. 772 .

Atemelia HS. (Lep.): 281.

Athalia Leach (Hym.): 349. Athysamus Burm. (Hem.): 252. 518. 867.

Atlas Las. (Moll.): 302.

Atychia Hoftm. (Lep.): 322. Attacus L. (Lep.): 34. 83. 204. 483. 554. 701. 731. 860 .

Berosus Leach (Col.): 473. Bibio Geoffray (Dip.): 348. Bicornis (Hym.): 308.

Biston Leach (Lep.): 72. 135. 155. 361. 556. 622. 623 . 875.

Bithys (Lep.): 332.353.

Blaniulus Gerv. (Myr.): 503. 866.

Blatta L. (Orth.): 590. 654. 891.

Blennocampa Hg. (Hym.): 254. 349 .

Boarmia Tr. (Lep.): 121. 153. 155. 281. 356. 357. 361. 622. 815. 897. 898. 903. 904. 913.
Bombus Fabr. (Hym.): 171. 361. 682 .

Bombyx L. (Lep.): 3. 9. 11. 12. 16. 18. 19. 21. 22. 24. 32. 33. 40. 41. 44. 45. 62 . 63. 65. 66. 71. 74. 78. 79 . 81. 82. 83, 100. 114. 115. 119. 120. 130. 131. 134. 135. 137. 138. 143. 149. 154. 155. 156. 157. 158. 168. 176. 178. 181. 183. 184. 185. 186. 187. 188. 191. 192. 193. 194. 195. 197. 198. 199. 200. 201. 202. 204. 205. 206. 207. 208. 212. 216. 217. 220. 221. 223. 224. 2.27. 228. 229. 230. 231. 232. 233. 234. 235. 236. 237. 250. 254. 25 i. 260. 263. 266. 267. 268. 269. 2ง5. 286. 287. 288. 289. 290. 2!4. 302. 303. 305. 309. 310. 316. 318. 344. 355. 385. 387. 417. 424. 439. 448. 377. 517. 534. 536. 537. 538. 554. 5ร7. 572. 577. 604. 607. 608. 609. 610. 611. 612. 613. 614. 615. 616. 633. 635. 636. 663 . 664. 665. 666. 667. 668. 669. 677. 680. 681. 682. 686. 687. 6!0. 691. 694. 695. (699. 70). 701. 702. 705 706. 707. 711. 712. 713. 719. 723 . 730. 739 . 749. 750. 754. 755. 759 . 764. 765. 767. 770. 779. 860. 873. 874. 879.891. 897. 937.

Botys aut. (Lep.): 37. 265. 276. 730. 769. 897.

Brachycoma (Dip.): 253.

Brachydesmus Macq. (Dipl.): 503. 549. 866. 873 . Brachypalpus (Dip.): 345. Brephos O. (Lep.): 404. 
Bupalus Leach (Lep.): 154. 622. 636.650 .

Bythoscopus Germ. (Hem.): 251.

Cabera Tr. (Lep.): 153. 155. 494.

Callicore Hb. (Lep.): 332.

Callidium Fabr. (Col.): 302. 537. 767.

Callidryas Boisd.(Lep.): 250 .

Calligenia Dup. (Lep.): 351. 897.

Callimorpha Latr. (Lep.): 134. 173. 271. 281. 291. 409. 417. 424. 454. 463. 464. 544. 606. 609. 610. 647. 754. 757. 759. 764. 769. 779. 780. 879. 927.

Callnmyia Oken (Dip.): 346.

Callophrys Bilb. (Lep.): 617.

Calocampa Stph. (Lep.): 904 .

Calotermes (Hym.): 725.

Callosune Dbl. (Lep.): 316. 332. 333.

Calopterus Leach (Neur.): 255. 350. 898.

Calosoma Fabr. (Col.): 28. 324.

Calpe Tr. (Lep.): 73. 247. 769.

Calymnia Hb. (Lep.): 152. 347. 621. 898. 901.

Campogaster Macq. (Dip.): 346.

Camponotus Mayr. (Hym.): 224. 225. 701.

Campsicnemus Walk. (Dip.): 346.

Capnodis Lacord.(Col.): 572. 688.

Carabus L. (Col.): 28. 32. 443. 547. 594. 653. 900. 904. 934.

Caradrina O. (Lep.): 133. 152. 155. 265. 353. 606. 621. 769. 897.

Carpocapsa Tr. (Lep.): 594.
Carterocephalus Ld. (Lep.): 351.897.

Catagramma Boisd. (Lep.): 332.

Catocala Schrk. (Lep.): 78. 161. 163. 168. 173. 265. 271. 322. 353. 356. 446 . 449. 455. 458. 518. 609. 612. 613. 645. 646. 648 . 649. 769. 770. 778. 779. 780. 897. 904.

Catonephele Hb. (Lep.): 352. Catopsilia Hb. (Lep.): 742.

Caustoloma Ld. (Lep.): 362. Cecidomyia Meig. (Dip.): 212. 305. 547. 571. 572. 573. 687. 732 .

Celes Sauss. (Orth.): 596. 770.

Cemonus Jur. (Hym.): $30 \bar{\tau}$. Cerambyx L. (Col.); 28. 29. 681.

Cerura Schrk. (Lep.): 2. 519. 618. 860.

Cetonia Fabr. (Col.): 48. 337. 682. 687.

Chaerocampa Dup. (Lep.): 328. 500. 546. 618.

Chaitophorus Koch (Hem.): 309. 442.

Charaxes 0. (Lep.): 171. 460 . 780. 781.808.

Chariclea Curt. (Lep.): 265. 253. 532. 769. 897.

Chelonia Latr. (Lep.): 342. 385. 528. 529. 896.

Chematobia Stph. (Lep.): 474. 714.

Chermes Amiot (Hem.): 551 .

Chesias Tr. (Lep.): 528. 877.

Chionobas Boisd. (Lep.): 87.

Chionaspis Sign. (Hem.): 310. 748.767.

Chionea Dalman (Dip.): 157. 678.

Chironomus Meig. (Dip.): 336. 348.
Chloantha Gn. (Lep.): 279. 360. 898.

Chloroperla Newm. (Neur.): 280.

Chlorophanus Germ. (Col.): 315.

Chrypharis (Col.): 688.

Chrysis L. (Hym.): 254. 308. 349.

Chrysomela L. (Col.): 137. 356. 633. 902.

Chrysomyia Macq. (Dip.): 345.

Chrysopa Leach (Neur.): 393. 520.

Chrysophanus Hb. (Lep.): 120. 126. 129. 163. 269. 279. 290. 354. 360 . 366 . 390. 404. 499. 608. 611. 617. 629. 636. 770. 854 . 856. 913.

Cicada L. (Hem.): 251.

Cicadatra (Hem.): 251.

Cicadetta Am. (Hem.): 251.

Cicindela L. (Col.): 473.

Cidaria Tr. (Lep.): 119. 290. 319. 350. 351. 353. 383. 391. 399. 494. 609. 754 . 780. 897.

Cimbex Oliv.(Hym.): 35. 292.

Cimex L. (Hem.): 139. 181. 681. 682 .

Cirrhoedia Gn. (Lep.): 252.

Cladius Illig. (Hem.): 34. 578. 636.730.

Clairvillia (Dip.): 253. 348.

Cleonus Schoenh. (Col.): 44. 201. 688.

Cleptes Latr. (Hym.): 254. 349.

Clytus Fabr. (Col.): 28. 302. 537. 767.

Cnephalia Rond. (Dip.): 253. 348.

Cnethocampa Stph. (Lep.): 209. 622.

Coccinella L. Col.): 207. 212. 
Codonia Hb.(Lep.): 281.361.

Coenonympha Hb. (Lep.': 34. 86. 87. 92. 255. 272. 273. 277. 361. 362. 367. 681. 731. 769. 770. 854 . 856. 898.

Coenosia Meig. (Dip.): 253. 348.

Colaenis IIb. (Lep.): 332. 501.

Coleophora Hb. (Lep.): 35. 280. 360. 731. 770. 897.

Colias Leach (Lep.): 84. 86. 87. 92. 93. 94. 95. 118. 320. 324. 341. 343. 359. 417. 41S. 419. 471. 572. 687. 780. 896 .

Collembola (Aptirigota): 47. Conchylis Ld. (Lep.): 574 . 578. 581. 635. 617, 648. 687.

Conopidae Leach.(Dip.): 345 . Copris Geoff. (Col.). 282.

Coprophilus Latr.(Col.): 194 . 704. 727.

Coptolabrus Sol. (Col.): 32. Cordulia Leach (Neur.): 246. Cossus F. (Lep.): 26. 29. 236. 281. 487. 749 .

Crambus F. (Lep.): 281.

Crateronyx Dup.(Lep.): 181. 199. 303. 691.

Crematogaster Lund.(Hym): 224. 701.

Crypharis Fairm. (Lep.): 38 . Crocallis Tr. (Lep.): 501.

Cucullia Schrk. (Lep.): 33. 265. 353. 500. 529. 731. 737. 742. 769. 874. 875 . 876. 897.

Culex L. (Dip.): 573. 578. 580. 589. 590. 609. 680 . 681. 704. 724 .

Cyclogaster Macq. (Dip.): 247. 343. 769.

Cyloister Erich. (Col.): 473. Cyllo Boisd. (Lep.): 328. 365.855.
Cymatophora Tr. (Lep.): 99.

151. 477. 621.

Cynomyia Macq. (Dip.): 253.

Dactylopius Sign. (Hem.): 322.

Danais Latr. (Lep.): 324 332. 489. 505. 506. 507. Daphnis Hb. (Lep.): 604. 608. 610. 767. 871. 909. Dasychira Stph. (Lep.): 28. 34. 119. 123. 124. 134. 149. 155. 158. 166. 291. 313. 358. 397. 399. 409. 417. 430. 527. 534. 537. 540. 604. 608. 609, 610 . 611. 619. 623. 630. 732 . 754. 778. 779. 815. 871. 874. 877. 893. 903. 917. Davus (Lep.): 247.

Decticus Serv. (Orth.): 489. Deilephila 0. (Lep.): 14. 16. 26. 27. 28. 29. 30. 43. 76 . 100. 118. 119. 125. 126. 139. 148. 149. 154. $15 \pi$. 158. 167. 172. 271. 304 . 313. 320. 355. 367. 368. 382. 383. 417. 457. 545. 604. 608. 609. 610, 615 . 617. 618. 630. 645. 650 . 670. 671. 687. 699. 716 . 721. 731. 732. 756. 769 . 778. 831. 836. 837. 851 . 854. 855. 857. 889.

Deilinia Hmps. (Lep.): 622. Delias Hb. (Lep.): 332.

Delphacinus Fieb. (Hem.): 251.

Deltocephalus Burm.(Hem.): 252.

Demas Stph. (Lep.): 151. 468. 511. 584. 620. 755. 844.

Dendrolimus (Lep.): 173. 463. 576. 577. 5£4. 590. 597. 603. 605. 607. 608 610. 611. 615. 630. 634. Eccrita Ld. (Lep.): 491. 636. 645. 663. 686. 700. Estemnus Fieb.(Hem.): 308.
716. 732. 751, 757, 759 . 761. 762. 872.877 .

Depressaria $\mathrm{Hw}$. (Lep.): 265. 353. 770. 897.

Desoria Agass. (Thys.): 177. Dianthoecia B. (Lep.): 265. 353. 769. 897.

Diasemia Gn. (Lep.): 265. 769.

Diaspis Bouché (Hem.): 146. 147. 213. 214. 215. 333. 682. 721. 748.

Dichonia Hb. (Lep.): 252. 769.

Dicranura B. (Lep.): 34.388. 618. 731 .

Dilina Dalm. (Lep.): 617. 645. 648. 871. 905 .

Dinera Desv.(Dip.): 251.345 . Diorhina (Lep.): 337.

Diphthera 0. (Lep.): 135.

Dorcadion Dalm. (Col.): 28. 32. 574. 597. 681. 688 . 701. 831 .

Doritis B. (Lep.): 87. 92. 125. 135. 355. 417. 617

Doryphora (Col.): 738.

Dory tomus Germ.(Col.): 207. Drepana Schrk. (Lep.): 150. 277. 289. 358. 608. 620. 754. 769.896 .

Drosophila Fall. (Dip.): 555. 691.

Drymonia Hb. (Lep.): 571. 730.

Drynobia Dup. (Ler .): 457 . 903.

Dryobius Koch. (Hem.): 304. 442.

Dryomiza Fall. (Dip.): 216. 309. 767 .

Dytiscus I. (Col.): 32. 206. 473. 653. 682 .

Earias Hb. (Lep.): 149. 155. 622 
Ectima Dbl. (Lep.): 501.

Elaphrus Fabr. (Col.): 473.

Ellopia Tr. (Lep.): 345. 366. 389. 544. 854 .

Ematurga Ld. (Lep.): 155. 277. 361. 494. 622. 769. 898.

Embia Latr. (Neur.): 51.

Embiodea (Neur.): 40.

Empheria Winn. (Dip.): 347.

Emphytus Kỉ. (Hym.): 254. 349. 370. 853.

Emydia Boisd. (Lep.): 134.

Endrosa Hb. (Lep.): 281. 358. 896.

Endromis 0.(Lep.): 100. 135. 149. 159. 263. 383. 578. 619. 713. 769.

Ennomos Tr. (Lep.): 385. 463. 474. 595. 609. 612. 632.

Entomoscelis Chevr. (Col.): 136. 202. 581. 653. 688

Ephestia Gn. (Lep.): 581. 592. 694. 697. 731.

Ephyra Dup. (Lep.): 621. 872.

Epichnopteryx Hüb. (Lep.): 134. 263. 281. 769.

Epicnaptera Rbr. (Lep.): 518. 619. 762.

Epicometis Burm. (Col.): 28.

Epilachna Chevr. (Col.): 42. 573.

Epinephele Hb. (Lep.): 34. 86. 88. 92. 243. 244. 272. 273. 367. 438. 522. 731. 853. 867.

Erastria 0.(Lep.): 265. 353. 769. 897.

Erebia Dalm. (Lep.): 86. 87. 88. 92. 94. 95. 244. 272 . 279. 280. 281. 341. 360 . 367. 438. 680. 770. 854. 856. 898. 915.

Eriogaster Germ.(Lep.): 161 . 520. 619. 623, 872 .
Eriopus Tr. (Lep.): 472. 477. ' Fidonia Tr. (Lep.): 82. 110. 501.

Erynnia Desv. (Dip.): 253. 348.

Euacanthus Phil. (Crust.): 251.

Euchelia B. (Lep.): 74. 149. 158. 383.

Euchloë Hb. (Lep.): 617.

Euclidia 0. (Lep.): 362. 681. 898.

Eucosmia Stph. (Lep.): 265. 769.

Eudemis Wck. (Lep.): 578. Galleria F. (Lep.): 589. 703. Eugonia Hb.(Lep.): 101. 104. Gamasus Latr.(Arach.): 183. 105. 106. 10i. 108. 3\$4. 691. 674. 675. 778. 779. 780. Gastrolepta Rond. (Dip.): Eumenes Latr. (Hym.): 303.348.

Eumerus Meig. (Dip.): 252. Gastropacha 0. (Lep.): 15. Eumolpus Redt. (Col.): 131. 203. 545 . 873 .

Eupelix Germ. (Hem.): 251. Eupithecia Curt. (Lep.): 135. 155. 168. 365. 471. 475 . 476. 477. 478. 493. 494. 495. 496. 511. 516. 52s. 529. 531. 533. 534. 536. 537. 552. 623. 853.

Euplexia Stph. (Lep.): 152. 621.

Euploea Fabr. (Lep.): 337. 504. 506.

Euprepia 0. (Lep.): 74.77. 373. 533. 616.

Euproctis Hb. (Lep.): 173. 225. 635. 636. 662. 680 . 706. 714. 716. 758. 767 . 871.

Eurema Hb. (Lep.): 316.

Eurycreon Ld. (Lep.): 579. 580. 635.

Eurygaster Lap.(Hem.): 572. 577. 585, 586. 653. 688. 701.

Exochomus Redt. (Col.): 207.

Exorista Meig. (Dip.): 253. 315. 256. 317. 769, 876 .

Fonscolombia Licht: (Hem.): 166. 633. 678.

Forda Heyd. (Hem.): 42.

Formica L. (Hym.): 184. 225. 589. 681. 691. 701. 594.

Gaedia Meig. (Dip.): 346.

Galerucella Crot. (Col.): 134. $581,609,730$.

39. 518. 553. 573. 575. 579. 585. 586. 588. 594. 605. 608. 610. 611. 614 . 645. 761. 762. 907.

Geometra L.(Lep.): 317.417. 530. 531.

Geotrupes Latr. (Col.): 28.

Glaea Stph. (Lep.): 474.

Gnophos Tr. (Lep.): 271. 356. 490. 769 .

Gnophria Stph. (Lep.): 263. 352. 769. 897.

Gomphinae (Neur.): 245.

Gomphus Leach(Neur.): 246.

Gonioctena Chevr. (Col.): 130. 611.

Gonopteryx Leach (Lep.): 133. 414. 595. 607. 625 . 721. 770 .

Gortyna Hb. (Lep.): 598. Grapta Kirby (Lep.): 400. Gryllus L. (Orth.): 180. 570. 574. 584. 591. 597. 599. 691.

Gymnochaeta Desv. (Dip.): 348.

Gyrinus Geoffr. (Col.): 473. Habrostola Sod. (Lep.): 99. Fumea Stph. (Lep.): 350. 
Ifadena Schrk. (Lep.): 73. | Hydroporus Clair.(Col.): 473. 99. 133. 139. 279. 280. Hylesinus Fabr. (Col.): 581. 353. 358. 501. 532. 605. Hyloicus Hb. (Lep.): 358. 614. 620. 770. 898. 903 . 907.

Halias Treits. (Lep.): 35. 318. 731 .

Haliplus Latr. (Col.): 473.

Harpalus Latr. (Col.): 198. 747. 905 .

IIarpyia O. (Lep.): 74. 100. 150. 159. 339. 355.

Hebomoia Hb. (Lep.): 332. Hyponomenta Latr. (Lep.):

Hedychrum Latr. (Hym.): 349.

Heliodes. Gn. (Lep.): 342. 357. 361. 550. 769.

Heliothis O. (Lep.): 342. Hysteropterum Am. (Hem.): 357. 361. 550. 721. 875 . 251.

897. 898.

Helophilus Meig.(Dip.): 177. | Idioptera Macq. (Dip.): 347.

Hemaris Dalm. (Lep.): 618. Ino Leach (Lep.): 281. 319.

Hemerobius linn. (Neur.): 322. 455. 340.

Heodes Dalm. (Lep.): 458. 596.

Hepialus F. (Lep.): 281.

Hesperia Wats, (Lep.): 247. Lxias Hb. (Lep.): 359. 318. 342. 769.898 .

Heterodera: 572. 576. 577. Jodis Hb. (Lep.): 153. 634. 635. 653. 686. 688. Julus L. (Myr.): 503.

Heteromurus Waak.(Neur.): Junonia Hb. (Lep.): 332. 691.

Hibernia Latr. (Lep.): 39.'Kallima Westw. (Lep.): 333. 47. 135. 474. 622. 742. Kelisia Fieb. (Hem.): 251. 744 .

Himera Dup. (Lep.): 556. Hipocrita Hb. (Lep.): 622.

Hipparchią Fabr. (Lep.): 86. 88. 92. 94, 95. 288.

Homalomyia Bouché (Dip.): 252. 348 .

IIoplitis Hb. (Lep.): 618. 732.

Hybocampa Ld. (Lep.): 42. 47. 149. 623. 687.

Hydrophilus Geoffir. (Col.): 159. 682 .
Isotoma Bourl. (Thys.): 183. 521.

[sophia Brun. (Orth.): 572. 688.

Laccophilus Leach (Col.): 473.

Lachnus Burm. (Hem.): 193. 442. 443. 491. 511. 549. 550.

Laelia Stph. (Lep.): 247. 769.

Lamia (Lep.): 680 .

Lamellicornia (Col.): 687. | Limax: 682.

Laria Schr. (Lep.): 134. 291. 605. 609. 614. 754 .

Larinus (Col.): 681. 831.

Lasiocampa Schrk. (Lep.): 26. 29. 50. 123. 134. 135. 159. 173. 210, 211. 271. 290. 291. 298. 305. 367. 390. 409. 417. 418, 424. 463. 521. 556. 559. 604. 605. 608. 619. 687. 713. 754. 755. 761. 769. 773. 778. 779. 780. 853. 872 . 874.

Lasioderma: 721.

Lasius F. (Hym.): 184. 592. 691. 725 .

Lecanium Burm. (Hem.): 98. 170. 680 .

Leptidia Billb. (Lep.): 595. 770 .

Leptinotarsa Chevr. (Col.): 357.

Leptocircus Swains. (Lep.): 219.

Lestes Leach (Neur.): 246. Leucania Hb. (Lep.): 133. 265. 353. 518. 606. 769. 897.

Leucoma Steph. (Lep.): 263. 322. 769 .

Leucodonta Stgr.(Lep.): 371. 469. 581. 618. 630. 901. 929. 936 .

Leucophasia Stpl. (Lep.): 350.

Leucorhinia Britt. (Neur.): 255.

Libella Brauer (Neur.): 255.

Libellula L. (Neur.): 32. 246. 247. 255. 307. 314. 315. 681. 682. 744. 770 .

Libythea F. (Lep.): 877.

Limacodes Latr. (Lep.): 263. 769.

Larentia Tr. (Lep.): 277. Limenitis F. (Lep.): 86. 87. 278. 318. 358. 621. 769. 88.92.143.165.168.248. 896.
281. 297. 318. 332. 355. 
417. 424. 438. 453. 456. 457. 469. 576. 638. 647. 648. 713. 732. 780. 782 . 897.

Limnobia Meig. (Dip.): 347. Limnophora Macq. (Dip.): 347.

Lina Reclt. (Col.): 24.

Liparis Ochs. (Lep.): 441. 529. 738.

Lithinus Klug. (Col.): 500.

Lithocolletis Z. (Lep.): 51. 358. 903.

Lithosia F. (Lep.): 263. 340. 769. 898

Lithostege Hb. (Lep.): 247. 769.

Lixus Fabr.(Col.): 315. 325.

Locusta Fabr. (Orth.): 211. 336.

Lophopteryx Stph. (Lep.): 150. 199. 541. 618. 871.

Lophyrus Latr. (Hym.): 159. 577. 609 .

Loxocera Meig. (Dip.): 253. 347. 348 .

Lucanus L. (Col.): 282. 287. 303. 762 .

Lucilia Rob.(Dip.): 225. 311. 703. 723 .

Luperina B. (Lep.) 291. 362. 754.

Lycaena F. (Lep.): 26. 34. 84. 85. 86. 87. 88. 92. 94. 95. 125. 247. 271. 279. 281. 321. 337. 341 . 342 . 343. 350. 355. 459. 459 . 460. 511. 522. 577. 681 . 731. 769. 770. 782.867. 896. 900 .

Lyda Fab. (Iym.): 254. 350. Lygaeus Fieb. (Hem.): 42. 573. 687.688 .

Lygris Hb. (Lep.): 119. 352. 519. 898.907.

Lymantria Hb. (Lep.): 280. 363. 464. 468. 556. 582. 590. 630, 703, 755. 767.
815. 844. 871. 872. 874. 876. 877. 881. 888. 896 . 897. 913.

Macaria Curt. (Lep.): 154. Macroglossa Sc. (Lep.): 43. 75. 118, 149. 158. 474 . 575. 609. 618. 687. 731. 810.

M̀acropsis Lero (Hem.): 251. Macrotoma Bourl. (Thysanura): 183.

Magdalis Germ. (Col.): 121. Malacosoma Auriv. (Lep.): 466. 582. 755. 779. 872. 888.

Mamestra Hb.(Lep.): 73. 99. 133. 151. 152. 155. 159. 265. 353. 377. 501. 594. 605. 620. 769. 778. 872 . 897.

Mania 'Tr. (Lep.): 133. 605. Mantis L. (Orth.): 513.

Masicera Macq. (Dip.): 251. Meconema Serv.(Orth.): 515. Megachile Latr. (Hym.): 307.

Megamelus Fieb. (Hem.): Myzus Pass. (Hem.): 441. 251.

Melanargia Meig. (Lep.): 247. 272. 273. 522. 769 . 853. 854.856 .867$.

Melanitis (Lep.): 792.

Melasoma (Col.): 681.

Melitaea F. (Lep.): 85. 86. 87. 88. 91. 92. 94. 115. 119. 166.168 .247 .255 279. 286. 297. 340. 341 . 342. 343. 351. 355.357 . 359. 360. 366. 388. 389 417. 421. 454. 457. 490 . 608. 644. 648. 649. 731 . 769. 770. 854. 896.897 898. 904 .

Nelithreptus Löw. (Dip.): 253. 348.

Mellinus Latr. (Hym.): 308. Meloë L. (Col.): 28.
Melolontha Fab. (Col.): 48. 576. 596. 680. 681. 682 . 687.

Meromyza Meig. (Dip.): 347.

Metamorpha Staint. (Lep.): 501.

Metopsilus Dunc.(Lep.): 618.

Miana Stph.(Lep.): 605.907.

Mimas (Lep.): 555.

Miselia O. (Lep.): 265.353. 769. 897.

Monomorium: 738.

Morpho Fabr. (Lep.): 333. 337.

Musca L. (Dip.): 163. 177. 223. 303. 313. 612. 681 . 690. 703. 830.831 .

Mycalesis Hb. (Lep.): 363. 792.

Mycetaulus Loew. (Dip.): 252. 347.

Mycteroplus HS.(Lep.): 528. 877.

Myelophila Tr. (Lep.): 576 .

Miytilaspis (Hem.): 748 .

Mythymna O. (Lep.): 133. 606. 443. 717. 727

Naenia Stph. (Lep.): 120. 133. (06. 621.

Nematus Jur. (Hym.): 35. 254. 349. 517.

Nemcobius Stph. (Lep.): 88. 125. 339 .

Nemeophila Stpl..(Lep.): 43. 119. 120. 134. 292.347. 351. 368. 606. 687. 742 . 754. 755. 756. 761. 854 . 856. 897.898.

Nemoria Hb. (Lep.): 153. 621.

Neuronia HIb. (Lep.): 265. 769.

Niptus (Col.): 738.

Nisoniades (Lep.): 681.

Noctua (Lep.): 73, 528, 529, 
Noterus Clair. (Col.): 473. Otiorhynchus Germ. (Col.):

Notodonta O. (Lep.): 43.50. 74. 99. 150. 155. 474.500. Oxycera Nreig. (Dip.): 346. 618. 687.

Notus Fieb. (Hen.): 251. | Oxyptilus Z.(Lep.): 280.360. Nyctcola HS. (Lep.): 907. 770. 897.

Oberea Muls.(Col.): 159.6,7. Ocneria Hb. (Lep.): 26. 34. 137. 162. 201. 209. 217. 236. 267. 278. 311. 351 . 359. 371. 372. 556. 558. 559. 560. 572. 613. 635 . 666. 680. 688. 701. 728. 730. 751. 770. 854. 856 . 857. 897.

Odonestis Germ. (Lep.): 518. 6L5. 608. 610. 611. 761 .

Oedipoda Serv. (Orth.): 301. 336.

Oedipodinae (Orth.): 361.

Oenectra Gn. (Lep.): 265. 353. 769. 897.

Oeneis Hb. (Lep.): 680.

Oenophthira Dup. (Lep.): 687.

Oliarus Stal. (Hem.): 251.

Oniscus Latr. (Crust.): 680.

Onychocerus Serv.(Col.): 473. 474.

Opisthograptis I1b. (Lep.): 622.

Orchesella Templ. (Thys.): 47. 638 .

Orgyia 0.(Lep.): 33. 35. 73. 98. 112. 118. 149. 164 . 474. 531. 552. 604. 608. 610. 613. 619. 731. 874 . 878.

Ornithoptera Boisd. (Lep.): 248. 249. 356. 365. 853.

Orrhodia Hb. (Lep.): 279. 360. 552. 770. 898. 907.

Orthopelma Tach. (Hym.): 554.

Orthosia 0. (Lep.): 73.621. Oryctes (Col.): 697.

Osmia Latr.(Hym.): 307.308.
Oxythyrea Muls. (Col.): 210. 701.

Pachychaeta Loew. (Dip.): 251.

Pachytylus Fieb. (Orth.): 578. 635. 636. 737. 741.

Pamphila Wats. (Lep.): 518.

Panolis Hb. (Lep.): 139. 152. 265. 621. 769.

Panthea Hb. (Lep.): 47. 151. 620. 732.

Papilio Latr. (Lep.): 1. 25. 26. 44. 48. 75. 86. 88. 92. 93. 100. 112. 118. 119. 125. 126. 135. 136. 148. 155. 158. 161. 163. 164. 165. 167. 172. 248. 249. 253. 255. 271. 287. 295. 296. 297. 298. 304. 319. 320. 321. 322. 330. 331. 332. 333. 337. 339. 342. 350. 358. 368. 369. 382. 383. 388. 394. 395. 401. 408. 412. 417. 418. 419. 420. 422. 439. 448. 452. 453. 455. 461. 470. 472 . 475. 478. 480. 481. 503. 505. 506. 507. 520. 521. 523. 523. 534. 535. 561. 568. 559. 607. 609. 616. 6ะ3. 624. 637. 647. 703. 731. 754. 755. 762. 769. 770. 777. 778. 780. 782. 808. 853. 854. 860. 871 . \$77. 896. 897. 898.

Paracletus Heyd.(Hem.): 42. 443.

Paragus Latr. (Dip.): 253. 347.

P'ararge Hb. (Lep.): 86. 87. 128. 129. 271. 272.273.
324. 344. 355. 367. 390. 391. 399. 407. 608. 610. 611. 664. 665. 732. 754 . 769. 778. 780. 854. 856 . 597. 899.

Parasemia Hb. (Lep.): 173. 368. 462. 622. 646. 761 . 779. 876.898.

Parnassius Latr. (Lep.): 35 . 119. 121. 198. 204. 267. 277. 279. 303. 352. 355 . 359. 370. 417. 418. 543. 611. 614. 700. 730. 731 . 732. 733. 769. 770. 777. 779. 780. 855. 878. 89s. Parthenos Hb. (Lep.): 318.

Passaloecus Schuck. (Hym.): 307.

Pediculus L. (Apt.) 339. 499. Pediopsis Burm. (Hem.): 251. Pemphigus Hart. (Uem.): 147. 193. 208. 678. 681. 700.

Pemphredon Latr. (Hym.): 307.

Pentaphis Horv. (Hem.): 42. Penthina Tr. (Lep.): 265. 353. 769. 897.

Pentophora Germ. (Lep.): 48 . 686.

Pepsis Fabr. (Hym.): 279.

Pericallia Hb. (Lep.): 265. 353. 732. 769. 897.

Perineura Hart.(Hym.): 254. 349.

Periplaneta Burm. (Orth.): 195. 212. 681. 701. 738. 830.

Perotis Spin.(Col.): 572.688. Petalurinae (Neur.): 245.

Peteina Meig. (Dip.): 252. Phalaena Linn. (Lep.): 14. Phalera Hb. (Lep.): 26. 27. 29. 30. 99. 110. 151. 159. 611. 616. 619 .

I'haniosoma Meig. (Dip.): 253. 3.48.

Phasia Latr. (Dip.): $3 \pm 5$. 
Phasiane HS. (Lep.): 471. Pheosia Hb. (Lep.): 50. 618. 687.

Phigalia Dup. (Lep.): 47. 135. 623.

Philhydrus Solier(Col.): 473.

Phthirius Leach. (Apt.): 3 . Phlogophora Tr. (Lep.): 77.

Phlyctaenodes Hb. (Lep.): 580. 586. 704. 724. 732.

Phorocera Rob. (Dip.): 252. 345. 346.

Phortisia (Dip.): 346.

Phragmatolia Stph. (Lep.): 277. 358. 769.

Phthiria Meig. (Dip.): 252.

?hygadeuon Gr. (Hym.): 595.

Phyllaphis Koch(Hem.): 309 .

Phylloperta Kirby(Col.): 576 . 653. 901.

Plyllotoma Fallen. (Hym.): 349.

Phylloxera Fonsc. (Hem.): 37. 38. 82. 100. 192. 194. 203. 381. 681. 700. 717. 732. 738.

Physocephala Schin. (Dip.): 253. 348.

Phytodecta Kirb. (Col.): 47 . 346. 653. 688.

Phytoecia (Col.): 681 .

Phytonomus: 681.

Pieris Schrk. (Lep.): 19. 25. 34. 37. 39, 47. 75. 80 . 112. 121. 125. 126. 139. 143. 158. 163. 189. 204. 211. 229. 250. 255. 271. 278. 280. 238. 304. 316. 317. 319. 320. 329. 351. 362. 379. 380. 388. 349. 404. 405. 417. 418. 472. 475. 478. 479. 480. 481 . 482. 483. 484. 885. 486. 493. 521. 523. 542. 549 . 561. 565. 579. 593. 595. 596. 604. 607. 609. 611. 615. 617. 624. 625. 635. 650. 688. 689. 702. 730.
731. 738. 742. 745. 749. Procris Fabr. (Lep.): 364. 752. 762. 769. 770. $777 . \quad 854$.

778. 780. 789. 795. 844. Prothymnia Hb. (Lep.): 265. 859. 863. 878. 880. 896. 353. 769. 897.

897. 898. 905.920 .

Pimpla Gr. (Hym.): 307.

Protoparce Burm.(Lep.): 530. 604. 650. 876 .

Piophila Fall. (Dip.): 252. Psammophila Dahlh.(Hym.): 345. 308.

Platycheirus Serv. (Dip.): Pseudohroscus Sem. (Col.): 397. 36.

Platypteryx Leach (Lep.): Pseudoterpna IIb. (Lep.): 385. 265. 353. 770.897.

Platysamia Grote(Lep.): 484. Psilura Stph. (Lep.): 42. 201. Pleretes Ld. (Lep.): 614.

Plusia O. (Lep.): 26. 29. 120. 133. 152. 265.353. 606. 621. 721. 742.744 . 769. 897.

Poduridae Burm. (Thsip.): 653.

Poecilocampa Stph. (Lep.): 164. 623.

Polistes Latr. (Hym.): 164. 296. 363.

Polychrosis Rag. (Lep.): 647. 648.

Polydesmus Latr. (Diplopoda): 503.566.

Polygonia Hb. (Lep.): 173. 462. 463. 599. 608. 628 . 643. 648. 649. 785.

Polyommatus Scud. (Lep.): 86. 87. 88. 92. 94. 95 . 118. 125. 126. 139. 165. 167. 247. 332. 343. 350 . 352. 355. 417. 418. 453. Pyrameis IIl. (Lep.): 172. 456. 645. 648. 681. 731. 173. 461. 462. 469. 470. 771. 778, 779: 780, 790 . 791. 867. 896. 897. 899. Polyporus Grube (Vermes): 157. Pontia Fabr. (Lep.): 85. 86. Pyrrhocoris Fall. (IIem.): 87. 92.93 .94 .340 .342 . 166.

Porthesia Stph. (Lep.): 63. 216. 225. 311. 554. 557. 558. 723.

Potosia Muls. (Col.): 337. P'rocerus Dej. (Col.): 32. 607. 625. 638. 639. 647. 648. 649. 785. 848. 850 . 881. 944.

Pyrellia Rob. (Dip.): 253. 358. 439. 557. 559. 560. 686. 688. 742. 886. 903. 907.

Psorosa Z. (Lep.): 361.898. 204. 291. 754 .

Pterogon Boisd. (Lep.): 50 . 650.

Pteromalidae Walk. (IIym.): 308.

Pterophorus Geoffr. (Lep.): 342. 530. 873. 897.

Pterostoma Germ. (Lep.): 50. 151. 155. 618. 619. 687. Pterostichus Bon.(Col.): 350. 898.

Pulex L. (Dip.): 193. 700. 701.

Pygaera O. (Lep.): 50. 73. 77. 99. 151. 155. 166 . 609. 619. 687 .

Pyralis L. (Lep.): 166.

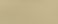

Rhaphiderus Serv. (Orth.): 555.

Retinia Gn. (Lep.): 35. 731. | Rhagium I. (Conl.): 207. 
Rhizotrogus Latr. (Col.): 48. Scolytus Geoffir. (Col.): 35. 687.

Rhodocera B. (Lep.): 124. Scotosia Stph. (Lep.): 361 . 320. 332. 351. 355. 398. 898 .

417. 441. 418. 754. 778. Scythris Hb.(Lep.): 280.770.

Rhopalodontus Mell. (Col.): Selenephera Rbr. (Lep.): 157.

Rhopalosiphum Koch(Hem.): Selenia Hb. (Lep.): 101. 102. 190. 309. $4+2.443$.

Rhynchoprion: 738 .

Rhyparia Hb. (Lep.): 173. 463. 646. 648. 649 .

Rumia Dup. (Lep.): 153. 265. 769 .

Rusi'al Stph. (Lep.): 133. 606. 769 .

Saperda Fabr. (Col.): 166. 302. 537. 607. 767. 873.

Sarcophaga Meig. (Dip.): 253. Sarcotachina Portsch.(Dip.): 251.

Saturinia Schrk. (Lep.): 26. 27. 40. 41. 93. 135. 150 . 155. 156. 159. 171. 204. 248. 304. 305. 366. 417. 429. 430, 440. 441. 454. 455. 466. 481. 517. 535. 557. 560. 582. 595. 619. 620. 623. 630. 631. 653 . 672. 686. 687. 690. 699 . 704. 713. 724. 738. 755 . 780. 844. 854. 855. 860 . 872. 874. 876. 877. 914. 916. 917. 927. 931.937.

Satyrus Westw. (Lep.): 247. 271. 272. 273. 281. 311. 342. 355. 361. 417. 769 . 770. 772. 778. 896. 898.

Schistocera Stal. (Ort.): 493. 858.

Schizoneura Hartig. (Hem.): 23. 37. 193. 208. 682. 700 .

Sciaria Mcig. (Dip.): 573. 687.

Scodiona B. (Lep.): 361.

Scoliopteryx Germ. (Lep.): 621.
103. 153. 289. 358. 383 . 385. 386. 387. 489. 490 . 521. 609. 612. 613. 622 . 632. 635. 678. 754, 755 . 778. 779. 860.896 .

Selidosema Hb. (Lep.): 361 898.

Semiadalia Crotsch. (Col.): 681.

Semiothisa H1). (Lep.): 622. Senta Stph. (Lep.): 350. 897. Sericomyia Meig.(Dip.): 252. 769.

Sesia F. (Lep.): 75. 247. 263. 553. 573. 687. 738. 769. 873 .

Setina aut. (Lep.): 348. 351. 354. 897. 898.

Silpha Fabr. (Col.): 194.704. 727.

Simulia Mcig. (Dip.): 166.

Simyra 0. (Lep.): 730.

Siphonophora Koch. (Hem.): 62. 71. 99, 157. 190, 304 . 441. 442.681 .

Smaragdesthes Ktz. (Col.): 337.

Smerinthus Latr، (Lep.): 3. 16. 34. 43. 75. 76. 98. 100, 119, 148, 158, 3ะ3. 334i 345. 359. 360, 383 . 474. 475. 477. 500. 528. 529. 533. 535. -544. 616 . 617. 622. 645.680، 687 . 731. 732. 858. 897 .

Solenius Dahlb. (Iym.): 398. Sphaeridium Fabr. (Col.): 49. Sphaeropyx Rossi (Hym.): 'Syntomis 0. (Lep.): 281. 271.

Sphex Latr. (IIym.): 307.
Sphinx 0. (Lep.): 2. 16.27. 34. 49. 52. 53. 55. 59. 60. 63. 76. 77. 98. 119. 119. 125. 126. 138. 148. 158. 369. 477. 500. 521. 527. 530. 531. 535. 566. 615 . 617. 731. 732. 826. 854 . 857. 871. 877. 916.

Spilogaster Macq. (Dip.): 253.

Spilosoma Stph. (Lep.): 99. 118. 134. 155. 158. 351. 354. 383. 417, 418, 536. 622. 732, 778, 87.8. 897 . 927.

Stauronothus (harp.(Orth.): 301. 741 .

Stauropus Germ. (Iep.): 41 . 47. 100. 125. 149. 618. 622. 623. 687. 732.

Stegomyia Theob. (Dip) ’: 590.

Stellaria Narlo (Ech.): 226. Stenamma Westw: (IIym.): 52. 225. 688. 701 .

Stenopteryx Leach (Dip.): 131.

Sternocera Eschselı, (Col.): 337.

Steropes B. (Lep.): 594.

Stigums .Jur. (Hym.): 307. Stilbum Spin. (Hym.): 308. Stomaphis Walk. (Hem.): 442.

Stomoxys Geoffr.(Dip.): $34 \overline{7}$.

Strongylocephalus Ficb.

(Hem.): 251.

Strumigenys Smith. (IIym.): 500.

Symmorphus Wasm.(Uym.): 308.

Sympycna Charp. (Neur.): 246. 255.

Symydobius Mord. ( $\mathrm{H \textrm {cm }}$ ): 443. 511 .

Syntomocera Schin. (Dijo): 345. 
Syrichtus B. (Lep.): 271. Tineola HS. (Lep.): รૅ5.597. 769. 767. 879. 592.

Syrphus E. (1)ip.): 253. 347. 'Titanio Hb. (Lep.): 361. 345 .

Systoechus Loew. (Dip.): 39. 300. 680. 687 .

Tabanus L. (Dip.): 343.

Taeniocampa Gn. (Lep.): 99. 121. 135. 152. 154. 155. 621.

Tachina Meig. (Dip.): 308.

Ta.aeporia Hb. (Lep.): 265. 353. 769. 897.

'T'enebrio L. (Col.): 236.749. 753.

Tentluredo Kl. (IIym.): 254. 349. 350 .

Tephroclystia IIb. (Lep.): 281. 361. 516. 621. 872 . 875. 876. 898 .

Teras Tr. (Lep.): 257. 351. 898. 903

Terias Sw. (Lep).: 250. 'T'ermes (Hym.): 725.

Tettigia Kol. (Hem.): 251.

Thais F. (Lep.): 25. 26. 52. 57. 60. 100. 125. 135. 148. 158. 165. 167. 330.388. 417. 453. 456. 535. 617. 637. 721. 778 .

Thalera Hb. (Lep.): 621 .

'Ihalpochares Ld. (Lep.): 343. 347. 897. 898.

Thamnotettix Zett. (Hem.): 252.

'Thecla F.(Lep.): S6. 92. 94. 95. 125. 135. 146. 148. 248. 271. 281. 324, 417. 769.

Thestor 11b. (Lep.): 355.

'Thryptocera Macq. (Dip.): 252. 346 .

'Thyatira Hb. (Lcp.): 29. 52. 58. 151. 155. 532. 621 . Tibicina Fieb. (Hem.): 251. 'Timandra Dup. (Lep.): 495. 'Tinea Z. (Lep.): 281: 680.
Tomicus Latr. (Col.): $5 T_{2}$. 576. 732 .

Tortrix Meyr. (Lep.): 164. 174. 225. 281. 282. 357. 358. 574. 579. 635. 723. 898. 903.

Toxotus Derv. (Col.): 259.

Trachea IIb. (Lep.): 151. 621.

Trichosea Grote (Lep.): 732. Trigonalys Westw. (Hym.): 257.

Trochilium Se. (Lep.): 622 .

Truxalis L. (Orth.): 517.

Tryphaena Hb. (Lep.): 77. 542.

Trypoxylon Latr. (Hym.): 307.

Urapteryx Ieach(Lep.): 410. 606. 609. 779 .

Uropus B. (Lep.): 121. 511. 611.

Vacuna IIeyd. (Hem.): 511. Yanessu F. (Lep.): 4. 5. 6. 7. 8. 25. 26. 27, 32. 34 . 63. 79. 80, 82. 84. 85. 86 . 87. 92. 93. 114. 122. 123. 124. 125. 126. 128. 129. 130. 135. 136. 140, 141. 143. 144. 145. 146. 148. 158. 160. 161. 165. 166. 167. 168. 172. 173. 180. 182. 183. 189. 209. 212. 248. 255. 280. 28i. 289. 290. 292. 293. 295. 296. 297. 298. 299. 303. 306. 311. 314. 317. 318. 319. 320. 321. 329. 330. 339. 344. 355. 367. 368. 370. 371. 372. 373. 374.377 . 381. 382. 383. 385. 387. Vespa L. (Hym.): 28. 204.

388. 390. 392. 393. 394. $\quad$ 212. 701. 704. 727. 395. 396: 397. 398. 399.
400. 401. 402. 403. 406. 408. 410. 411, 412, 414. 416. 417. 418, 41!) 420. 421. 422. 423. 424. 425 . 426. 427. 428. 429. 430. 432. 433. 434. 435. 436. 437. 438. 439. 440. 441. 444. 445. 446. 447. 448. 449. 450. 453. 454. 456 . 457. 458. 461. 462. 463. 468. 470. 472. 476.478 . 480. 481. 484. 491. 493. 498. 499. 507, 508. 509. 510. 512. 513. 514. 519. 520. 522. 523. 524. 525. 527. 541. 542. 548. 549 . 550. 554. 557. 559. 560. 562. 563. 564. 565. 567. 568. 569. 570. 574.58 . 585. 589. 592. 596. 598. 599. 600. 606. 607. 608. 615. 623. 626. 627. 636 . 639. 640. 641. 642. 647. 648. 649. 659. 664. 67:). 675. 680. 681. 688. 691 . 702. 703. 705. 721. 724. 731. 739. 740. 741. 742 . 744. 745. 754. 755 . 756 . 757. 758. 762. 763. 764 . 766. 768. 770. 772.777. 778. 779. 780. 781. 782. 784. 785. 786. 787. 788. 789. 790. 792. 793. 795 . 797. 798. 800. 801.806 . 807. 808. 809. 813. 818. 819. 844. 845. 848. 849 . 850. 853. 854. 855 . 856 . 857. 858. 859. 864. 865 . 873. 876. 878. 879. 880 . 881. 882. 883. 885. 886 . 888. 889. 890. 891. 892. 893. 897. 893. 917. 929. 941. 942 .

Venilia Dup. (Lep.): 351. 897. 
Xanthia 0. (Lep.): 373. 474. Xystophora Hein. (Lep.):|Zeuzera Latr. (Lep.): 35. 779. 276. 769 . 731.

Xylina Tr. (Lep.): 39. 40. Zodion Lab. (Dip.): 253.

73. 77. 265. 353. 769. Yphthima Westw. (Lep.):|Zonosoma Ld. (Lep.): 153. 897. 792. 155. 339. 351. 481.540 . 897.

Xylocopa Latr. (Hym.): 307.

Xylomiges Gn. (Lep.): 152. Zanclognatha Ld. (Lep.): Zygaena F.(Lep.): 224. 320. 500. 621 .

265. 353. 769. 897. 769.

Xyphidria Lep. (Hym.): 124. Zegris Rbr. (Lep.): 324. Zygina Fieb. (Hem.): 251. Xysta Meig. (Dip.): 345. Zerene Hb. (Lep.': 897. | 263. 277. 281. 361. 


\section{Berichtigungen.}

\begin{tabular}{|c|c|c|c|c|}
\hline \multirow[b]{2}{*}{ Pag. } & \multicolumn{2}{|c|}{ \%eile } & \multirow[b]{2}{*}{$\mathrm{Gedruckt}$} & \multirow[b]{2}{*}{ Soll stehen } \\
\hline & $\begin{array}{l}\text { ron } \\
\text { oben }\end{array}$ & $\begin{array}{c}\text { ron } \\
\text { unten }\end{array}$ & & \\
\hline 34 & 3 & - & O. fascelinu & D. fascelina \\
\hline 38 & 6 & - & Podipko & Pogibko \\
\hline 39 & 2 & - & Dioptera & Diptera \\
\hline 42 & 7 & - & Lygellus & Lygaeus \\
\hline 42 & 14 & 一 & C. Mokrzecki & S. Mokrzecki \\
\hline 48 & - & 7 & Melolantha & Melolontha \\
\hline 49 & - & 9 & J. Bruner & L. Bruner \\
\hline 50 & 10 & - & Pygoera & Pygaera \\
\hline 50 & 10 & - & Arconycta & Acronycta \\
\hline 74 & 15 & - & trotophus & tvitophus \\
\hline 77 & - & 15 & eine & seine \\
\hline 79 & 18 & - & Weisman & Woismann \\
\hline 83 & 11 & - & bernyi & pernyi \\
\hline 87 & 1) & - & Clinobas & Chionobas \\
\hline 87 & - & 1 & enmedon & cumedon \\
\hline 100 & - & 16 & Thaix & Thais \\
\hline 101 & 1 & - & antumnaria & autumnaria \\
\hline 115 & 17 & - & J. G. Alibegow & M. G. Alibegow \\
\hline 124 & - & 6 & Xiphideia & Xyphidria \\
\hline 125 & 9 & - & Thaix & 'Thais \\
\hline $1: 29$ & - & 11 & Chrysopham & Chrysophanus \\
\hline 131 & 14 & - & Hebhard & Gebhard \\
\hline 131 & - & 16 & Rellati & Bellati \\
\hline 132 & 15 & - & nicht ausgeschl. & nicht entwickelt \\
\hline 132 & - & 19 & - & $0,0 \%$ \\
\hline 135 & 12 & - & Mokrschezki & Mokrzecki \\
\hline 142 & - & 10 & $-42^{\circ}$ & $+42^{\circ}$ \\
\hline 149 & - & 3 & versicolara & versicolora \\
\hline 150 & 14 & 一 & , B" & ${ }_{n} \mathrm{~A}^{4}$ \\
\hline 150 & - & 6 & torna & torva \\
\hline 152 & - & 13 & Saeniocampa & Taeniocampa \\
\hline 155 & 19 & - & exauthemata & exanthemata \\
\hline
\end{tabular}




\begin{tabular}{|c|c|c|c|c|}
\hline \multirow[b]{2}{*}{ Pag. } & \multicolumn{2}{|c|}{$\mathrm{Z} e \mathrm{il} \mathrm{e}$} & \multirow[b]{2}{*}{ Gedruckt } & \multirow[b]{2}{*}{ Soll stehen } \\
\hline & $\begin{array}{l}\text { von } \\
\text { oben }\end{array}$ & $\begin{array}{c}\text { von } \\
\text { unten }\end{array}$ & & \\
\hline 155 & - & 16 & caraxaci & taraxaci \\
\hline 156 & 17 & - & 14 Tage & 74 'Tage \\
\hline 156 & 一 & 11 & 627 & 664 \\
\hline 159 & 2 & - & trimulifolia & tremulifolia \\
\hline 160 & 1 & - & 259 & 237 \\
\hline 164 & 5 & - & Portrix & Tortrix \\
\hline 166 & 3 & - & 60 Falter & $60 \%$ Falter \\
\hline 168 & - & 7 & indignate & indigata \\
\hline 178 & 8 & $-\cdots$ & Loow & Loeb \\
\hline 186 & - & 10 & 1895 & 1897 \\
\hline 188 & 17 & - & 64 & 661 \\
\hline 192 & - & 10 & 834 & 835 \\
\hline 200 & 1 & - & 593 & 657 \\
\hline 202 & 18 & - & 391 & 731 \\
\hline 204 & 17 & - & 641 & 461 \\
\hline 205 & 1 & - & 611 & 70 \\
\hline 211 & 6 & - & 322 & 517 \\
\hline 212 & 17 & - & Masarakia & Masaraki \\
\hline 246 & - & 10 & Synnpycna & Sympycn \\
\hline 247 & 16 . & - & Autoch. & Antoch. \\
\hline 251 & 4 & - & Pachycheta & Pachychacta \\
\hline 251 & 13 & - & Tebicina & Tibicina \\
\hline 251 & 18 & - & Kelesia & Kelisia \\
\hline 251 & - & 12 & Enacantlius & Euacantluus \\
\hline 255 & - & 16 & Leucorrhinia & Leucorhinirt \\
\hline 272 & 3 & - & Marshall & Marchal \\
\hline 282 & 14 & - & Fig. 4 & Fig. $4 a$ \\
\hline 298 & 11 & - & 322 & 519 \\
\hline 302 & - & 16 & 445 & 341 \\
\hline 306 & 19 & - & 322 & 519 \\
\hline 307 & 16 & - & Megachyle & Megactile \\
\hline 308 & 1 & - & Ectemius & Ectemnus \\
\hline 315 & 1 & 一 & Loidig & Leydig \\
\hline 324 & - & 2 & Tecla & Thecla \\
\hline 337 & 10 & - & Smaragdisthes & Smaragdesthes \\
\hline 340 & 一 & 13 & 343 & 354 \\
\hline 343 & - & 16 & Goosens & Goossens \\
\hline 361 & 5 & - & armigera & armiger \\
\hline 362 & - & 20 & H. Galvagni & E. Galvagni \\
\hline 367 & 一 & 9 & Coenympha & Coenonympha \\
\hline 385 & 8 & - & Eunomos & Ennomos \\
\hline
\end{tabular}

Bachmetjew, Studien. II. 


\begin{tabular}{|c|c|c|c|c|}
\hline \multirow[b]{2}{*}{ Pag. } & \multicolumn{2}{|c|}{$\mathrm{Z}$ e i l e } & \multirow[b]{2}{*}{ Gedruckt } & \multirow[b]{2}{*}{ Soll stehen } \\
\hline & $\begin{array}{l}\text { ron } \\
\text { oben }\end{array}$ & $\begin{array}{l}\text { von } \\
\text { unten }\end{array}$ & & \\
\hline 434 & - & 12 & Kbr. & Rbr. \\
\hline 434 & - & 15 & Kbr. & Rbr. \\
\hline 438 & 14 & - & klimene & klymene \\
\hline 442 & 16 & - & Stomachis & Stomaphis \\
\hline 462 & 5 & - & $+49^{\circ}$ & $+39^{\circ}$ \\
\hline 462 & - & 15 & Fchr. & Fschr. \\
\hline 466 & 12 & - & Melacosoma & Malacosoma \\
\hline 468 & 4 & - & Lymandria & Lymantria \\
\hline 473 & - & 3 & Onychoceros & Onychocerus \\
\hline 507 & - & 7 & 322 & 517 \\
\hline 512 & 15 & - & Vanesso & Vanessa \\
\hline 516 & - & 3 & 209 & 238 \\
\hline 517 & 14 & - & I. Devitz & J. Dewitz \\
\hline 517 & - & 8 & I. Devitz & J. Dewitz \\
\hline 518 & - & 14 & Gastpopacha & Gastropacha \\
\hline 530 & 5 & - & Goosens & Goossens \\
\hline 532 & - & 8 & Chareclea & Chariclea \\
\hline 541 & 13 & - & 425 & 358 \\
\hline 552 & 一 & 10 & Orghia & Orgyia \\
\hline 554 & - & 5 & I. Devitz & J. Dewitz \\
\hline 555 & - & 5 & Raphiderus & Rhupliderus \\
\hline 559 & - & 5 & Laucocerasuslaub & Laurocerasuslaub \\
\hline 561 & 13 & - & Leverat, G. aud & Levrat, G. and \\
\hline 561 & 24 & - & Thiele, I. & Thiele, R. \\
\hline 573 & 4 & - & Lygellus & Lygaeus \\
\hline 574 & 9 & - & 2. V. & 15. V. \\
\hline 574 & 10 & - & 3. V. & 16. V. \\
\hline 574 & 17 & - & 5. V. & 18. V. \\
\hline 587 & 9 & - & diese Anschaung & $\begin{array}{l}\text { die Anschaung von Pos- } \\
\text { pelow (642) }\end{array}$ \\
\hline 595 & 1 & - & Phygadenon & Phygadeuon \\
\hline 605 & 6 & - & Odonostis & Odonestis \\
\hline 606 & 15 & - & Mithymna & Mythimna \\
\hline 608 & - & 5 & Odonostis & Odonestis \\
\hline 609 & 7 & - & Urapterix & Urapteryx \\
\hline 611 & 4 & - & Odonostis & Odonestis \\
\hline 611 & 一 & 12 & Bow byx & Bombyx \\
\hline 616 & 7 & - & $716 b$ & $795 a$ \\
\hline 616 & 8 & - & Eupreria & Euprepia \\
\hline 621 & - & 18 & Scoliopterix & Scolioptery $x$ \\
\hline 635 & - & 9. & Cochylis & Conchilis \\
\hline
\end{tabular}




\begin{tabular}{|c|c|c|c|c|}
\hline \multirow[b]{2}{*}{ Pag. } & \multicolumn{2}{|c|}{ Zeile } & \multirow[b]{2}{*}{ Gedruckt } & \multirow[b]{2}{*}{ Soll stehen } \\
\hline & $\begin{array}{l}\text { von } \\
\text { oben }\end{array}$ & $\begin{array}{c}\text { von } \\
\text { unten }\end{array}$ & & \\
\hline 649 & 15 & - & Rhiparia & Rhyparia \\
\hline 650 & - & 12 & Schmidt & Schmid \\
\hline 653 & - & 18 & Entomosceli & Entomoscelis \\
\hline 653 & -. & 17 & Eurypaster & Eurygaster \\
\hline 653 & - & 2 & Dyticus & Dytiscus \\
\hline 681 & - & 10 & Musea & Musca \\
\hline 682 & $\check{5}$ & - & Ditictus & Dytiscus \\
\hline 687 & 15 & - & Lygellus & Lygaeus \\
\hline $6 s 8$ & 1 & - & Lygellus & Lygaeus \\
\hline 691 & - & 7 & Lasins & Lasius \\
\hline 692 & 5 & - & Hertwing & Hertwig \\
\hline 693 & - & 4 & (1 mgr. auf $\left.1 \mathrm{~m}^{2}\right)$ & $\left(1 \mathrm{mgr}\right.$ auf $\left.1 \mathrm{~m}^{2}[502 a]\right)$ \\
\hline 700 & - & 1 & Singerland & Slingerland \\
\hline 717 & - & 13 & Singerland & Slingerland \\
\hline $72 \vec{\gamma}$ & - & 9 & Singerland & Slingerland \\
\hline 727 & - & 6 & Bochaz & Rochaz \\
\hline 731 & 12 & - & Orgia & Orgyia \\
\hline 732 & 9 & - & Vurloren & Verloren \\
\hline 738 & - & 7 & Masarakia & Masaraki \\
\hline 744 & 3 & - & Helyoland & Helgoland \\
\hline 747 & - & 12 & Baussingault & Boussingault \\
\hline 748 & 12 & $\ldots$ & $689 a$ & $689 \alpha$ \\
\hline 751 & - & 21 & Sasani & Susani \\
\hline 755 & 9 & - & Sclania & Selenia \\
\hline 761 & - & 6 & Fig. 27 & Fig. 28 \\
\hline 765 & - & 17 & 611 & 70 \\
\hline 769 & 20 & - & Guophria & Gnophria \\
\hline 769 & - & 15 & Onectra & Oenéctra \\
\hline 769 & - & 3 & Anphipyra & Amphipyra \\
\hline 769 & - & 1 & Prothymia & Prothymnia \\
\hline 773 & $\ldots$ & 5. & Fig. 26 & Fig. 29 \\
\hline 774 & - & 6 & Fig. 26 & Fig. 29 \\
\hline 774 & - & 5 & Fig. 27 und Fig. 28 & Fig. 30 und Fig. 31 \\
\hline 775 & 1 & - & Fig. 27 und Fig. 28 & Fig. 30 und Fig. 31 \\
\hline 775 & 15 & - & Fig. 28 & Fig. 31 \\
\hline 775 & - & 7 & Fig. 26, 27 und 28 & Fig. 29,30 und 31 \\
\hline 777 & - & 17 & Jänicher & Jänichen \\
\hline 779 & 2 & - & Melacosoma & Malacosoma \\
\hline 779 & - & 10 & Parnassio & Parnassius \\
\hline 780 & 1 & - & Colyas & Colias \\
\hline 780 & 2 & - & Lymenitis & Limenitis \\
\hline
\end{tabular}




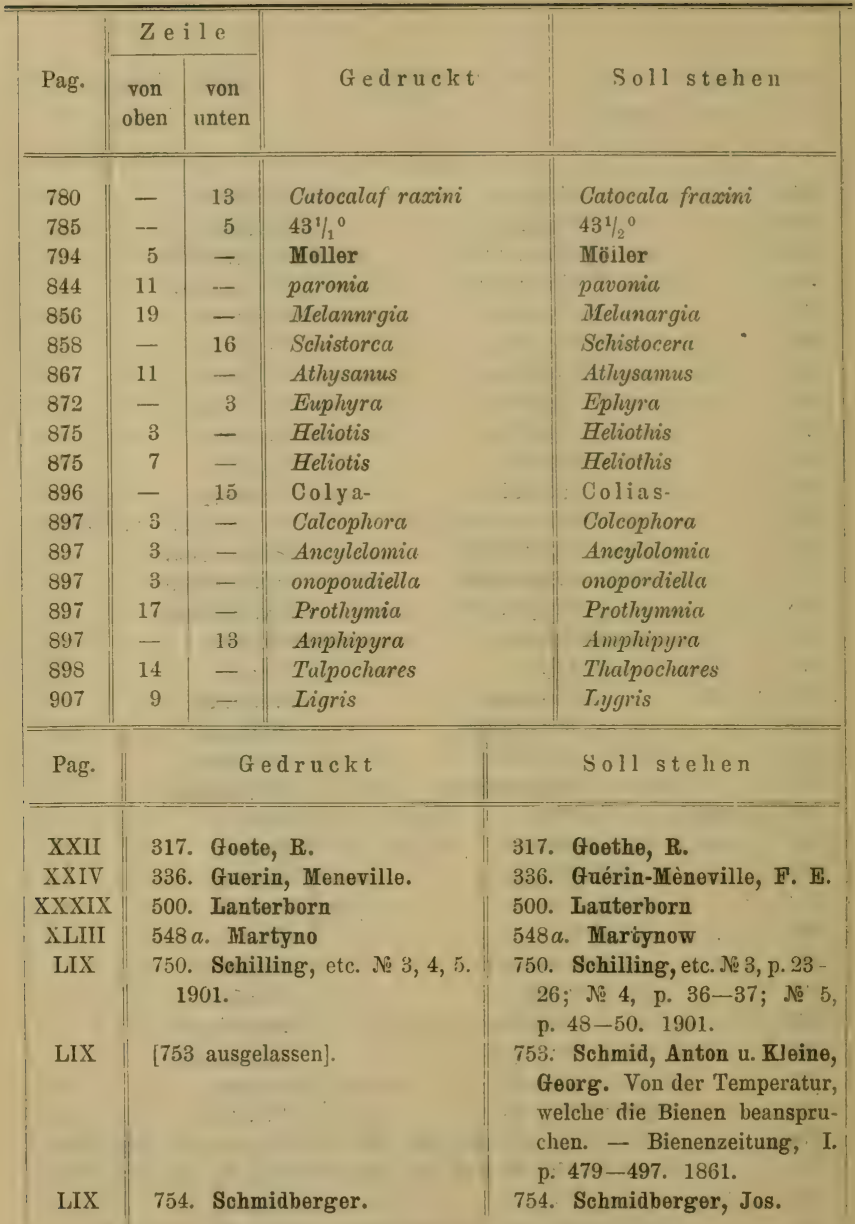


Fig. I. -4 .

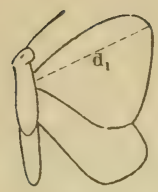

Fig. I.

Fig. 2 .

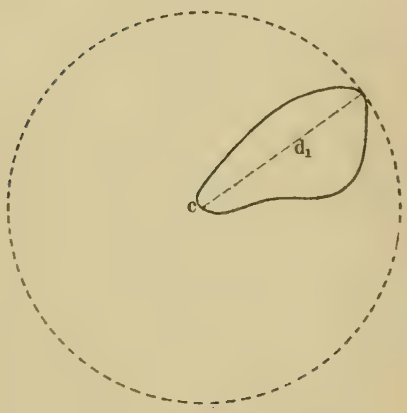

Fig. 3 .

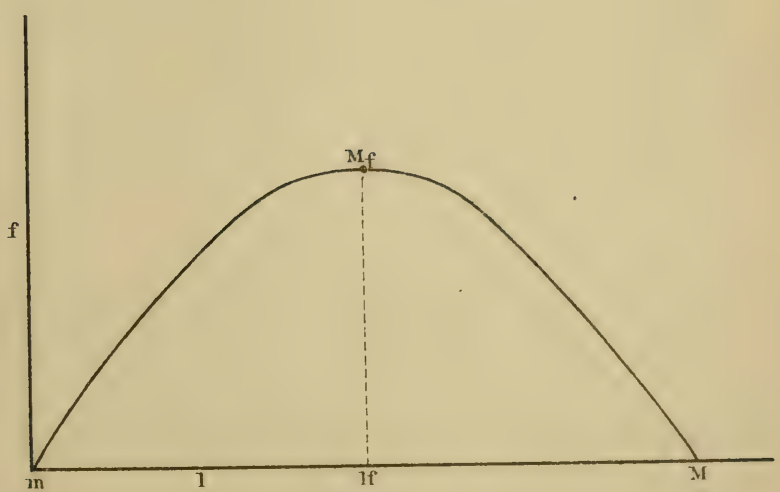

Fig. 4 . 

SCHEMATISCHE DARSTELLUNG VON COPRIS LIMARIS L. ठ (KoSCHEWNIKOW, 467-A) ZU P. 282.

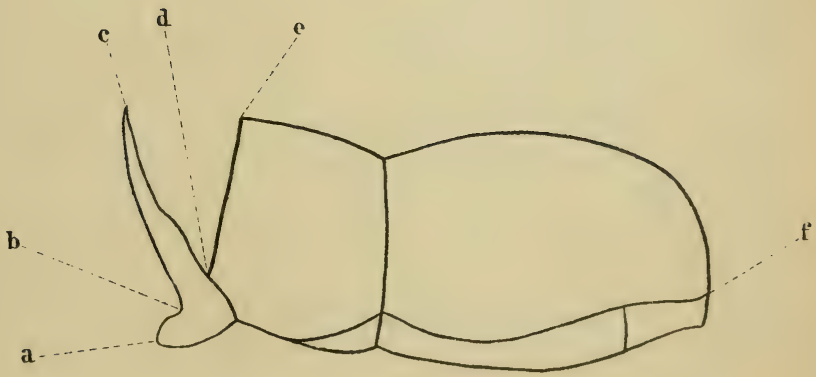



Fig. 5 .

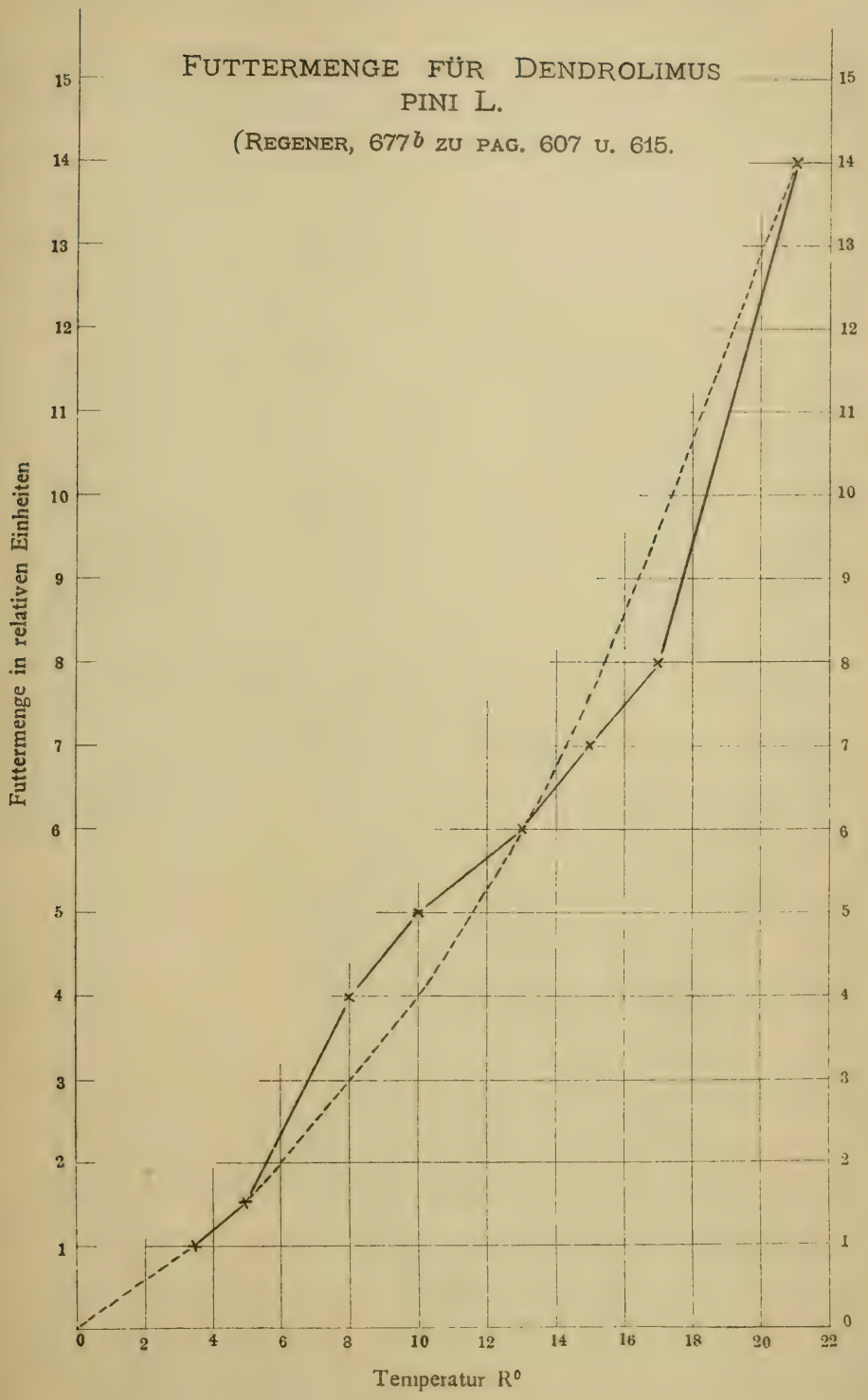



Fig. 6.

\section{HERZCONTRAKTIONEN PRO MINUTE BEI RAUPEN} VON BOMBYX MORI

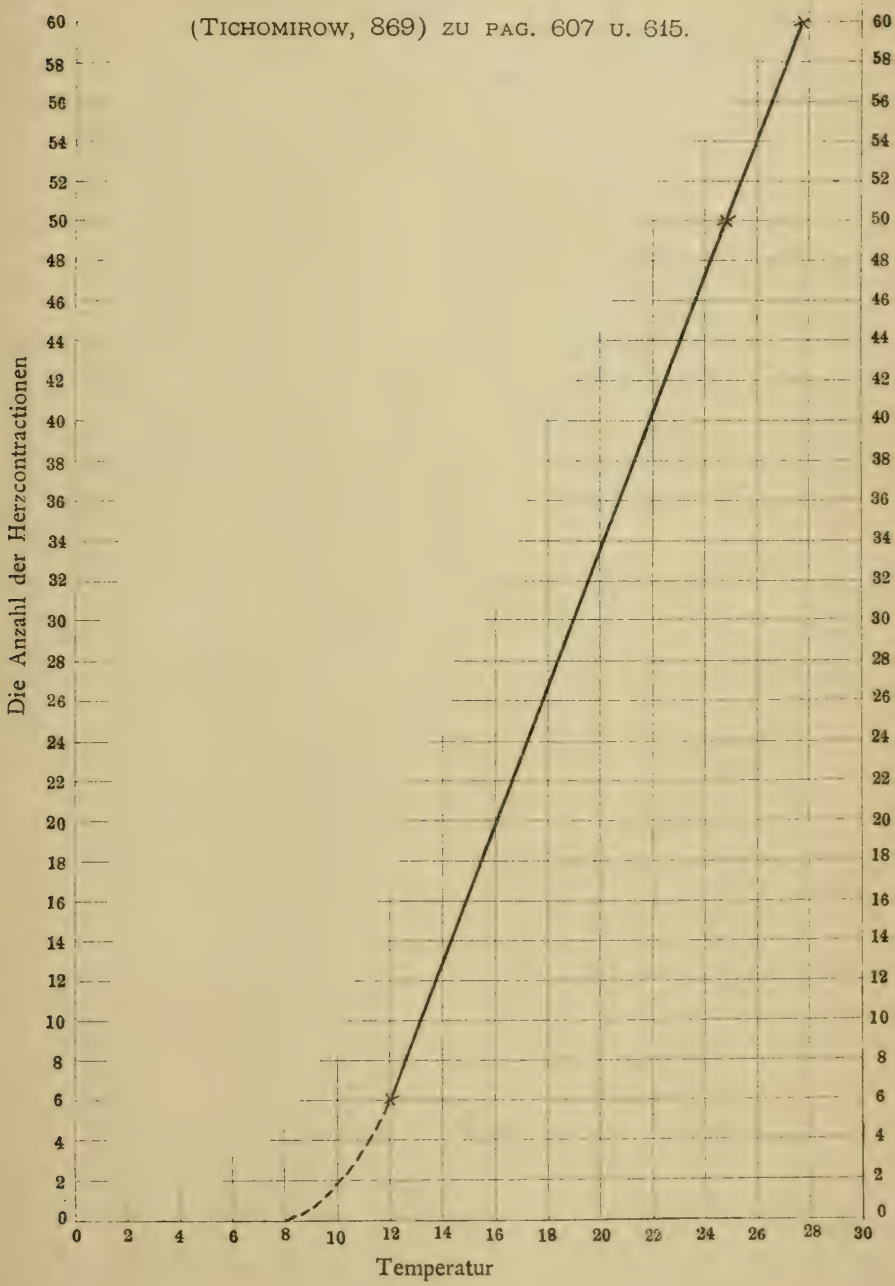





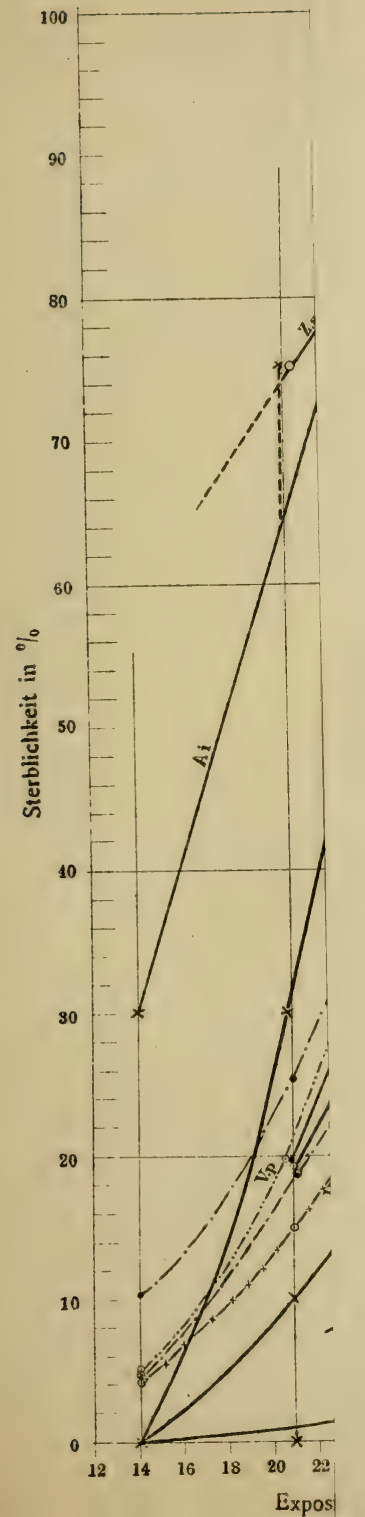




$$
-
$$




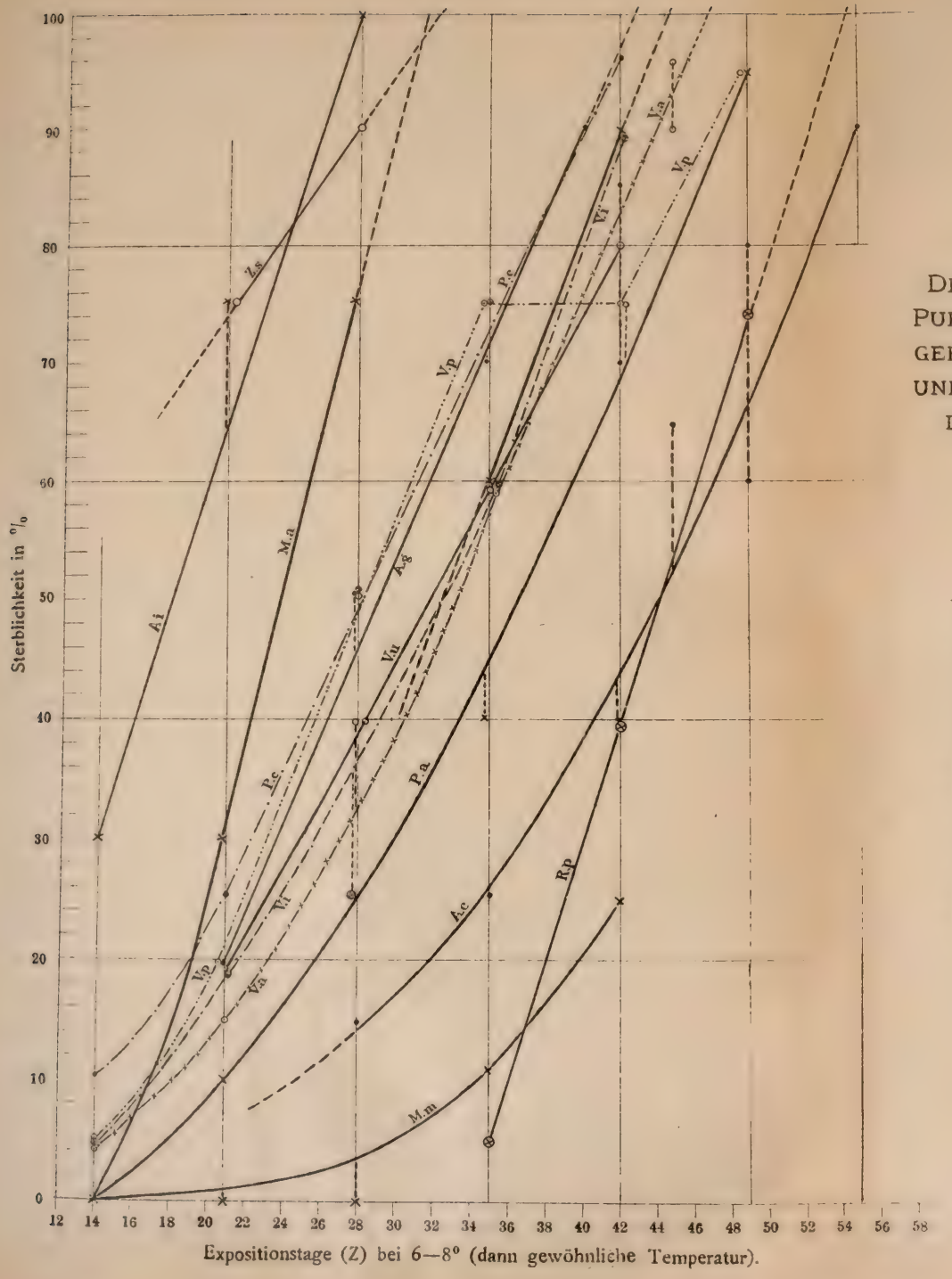

DIE STERBLICHKEIT DER PUPPEN IN \% NACH Z-TÄGIGER EXPOSITION BEI $6-8^{\circ}$ UND NACHHER BEI GEWÖHNLICHER TEMPERATUR.

Versuche von K. Frings.

P. $a=$ Pyrameis atalanta.

P. $c=川$ cardui.

V. $\mathrm{i}=$, Vanessa io.

V. $u="$ urticae.

V. $\mathrm{p}=$ " polychloros.

V. $a=$ ", antiopa.

M. $\mathrm{m}=$ Melitaea maturna.

M. $a=\quad$ aurinia.

A. $\mathrm{p}=$ Argynnis paphia.

L. $s=$ Limenitis sibylla.

A. $\mathrm{i}=$ Apatura iris.

A. $c=$ Arctia caja.

R. p - Rhyparia purpurata.

A. $g==$ Abraxas grossulariata. 

Fig. 8 .

ARASCHNIA LEV ANA-PUPPEN

(SOMMERGENERATION) Z TAGE BEI $2^{\circ}$.

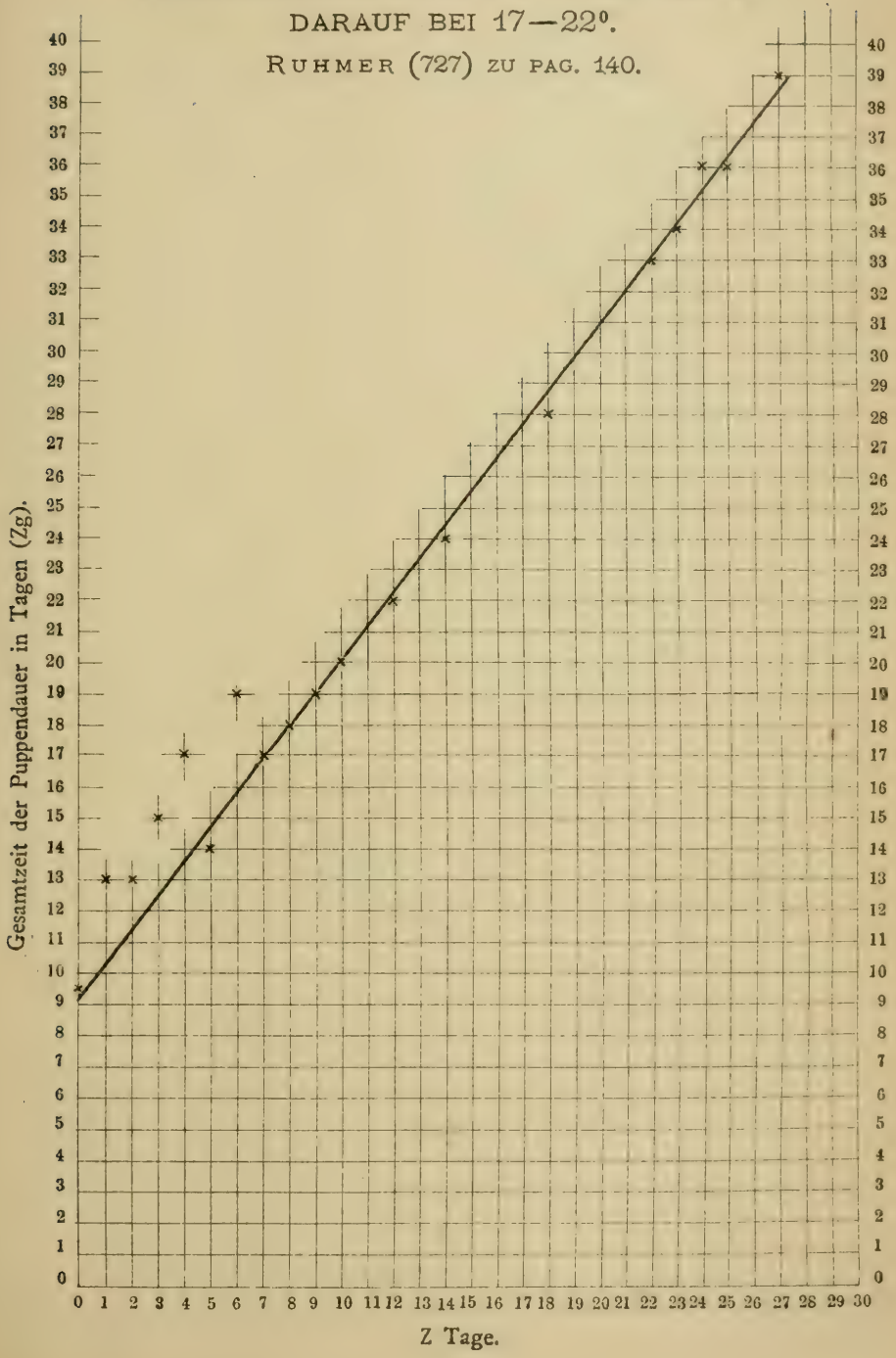



ZELLEN.

Säfte.

Feste

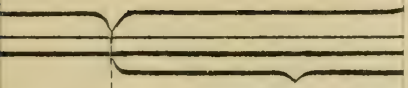

Aanabiotischer Zustas

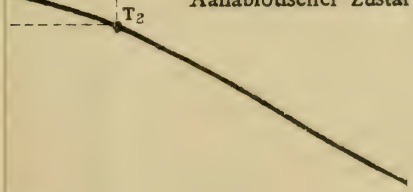

unkt. 


Fig. 10.-11

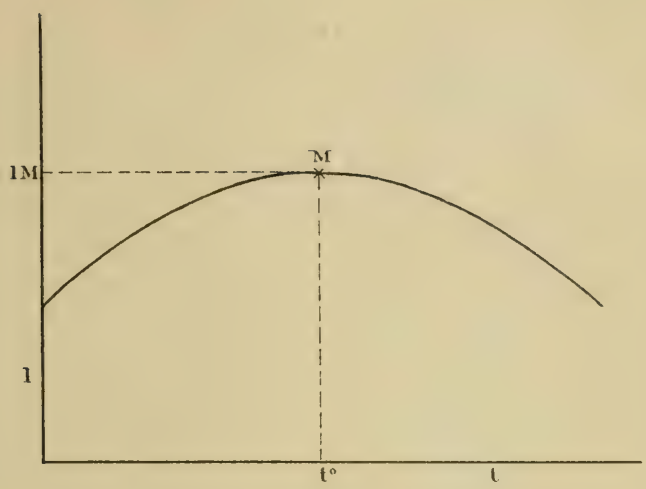

Fig. 10.

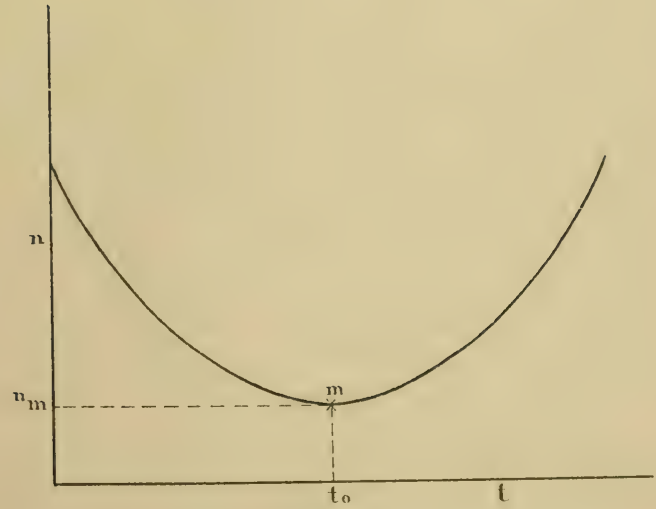

Fig. I $x$. 

Fig. 12 ,

PUPPENZEIT BEI KONSTANTER TEMPERATUR TO (DIE Puppe von ANFAng an IN $T^{0}$ ).

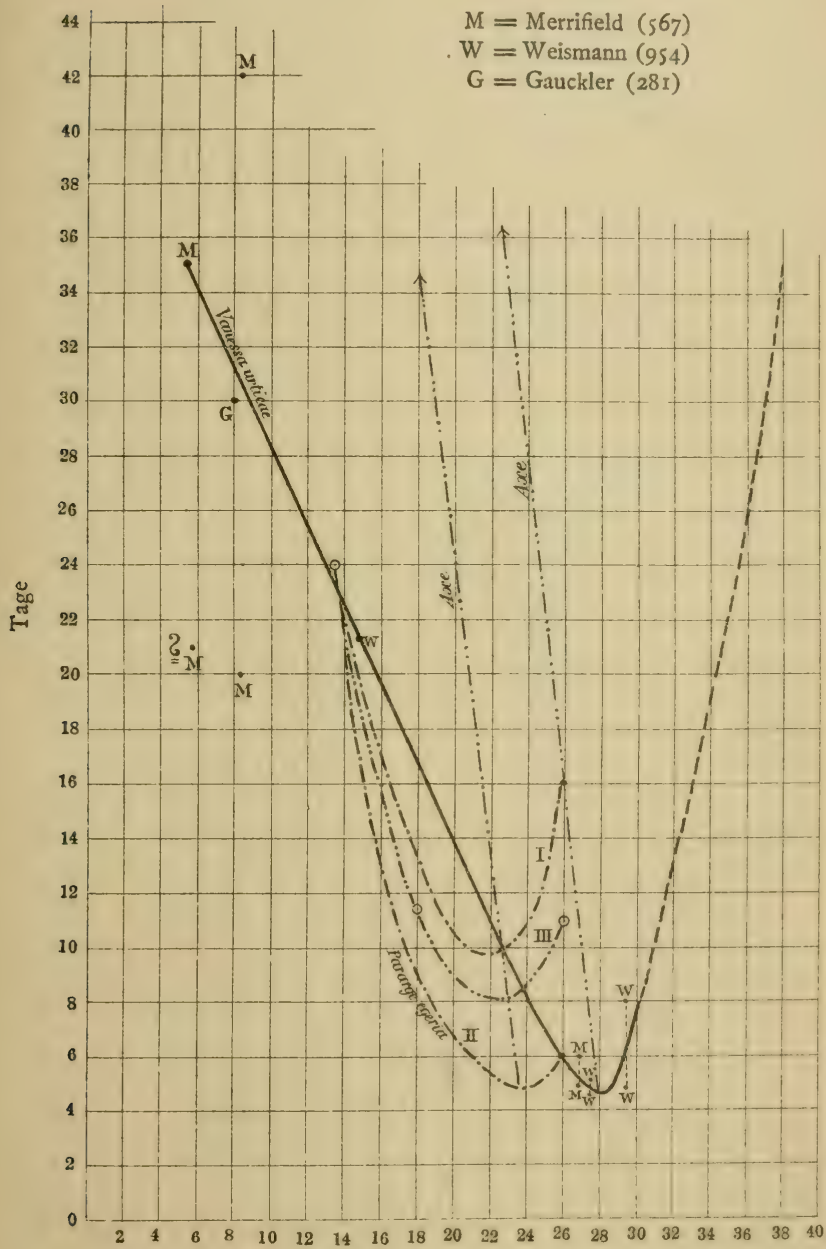



Fig. 13 .

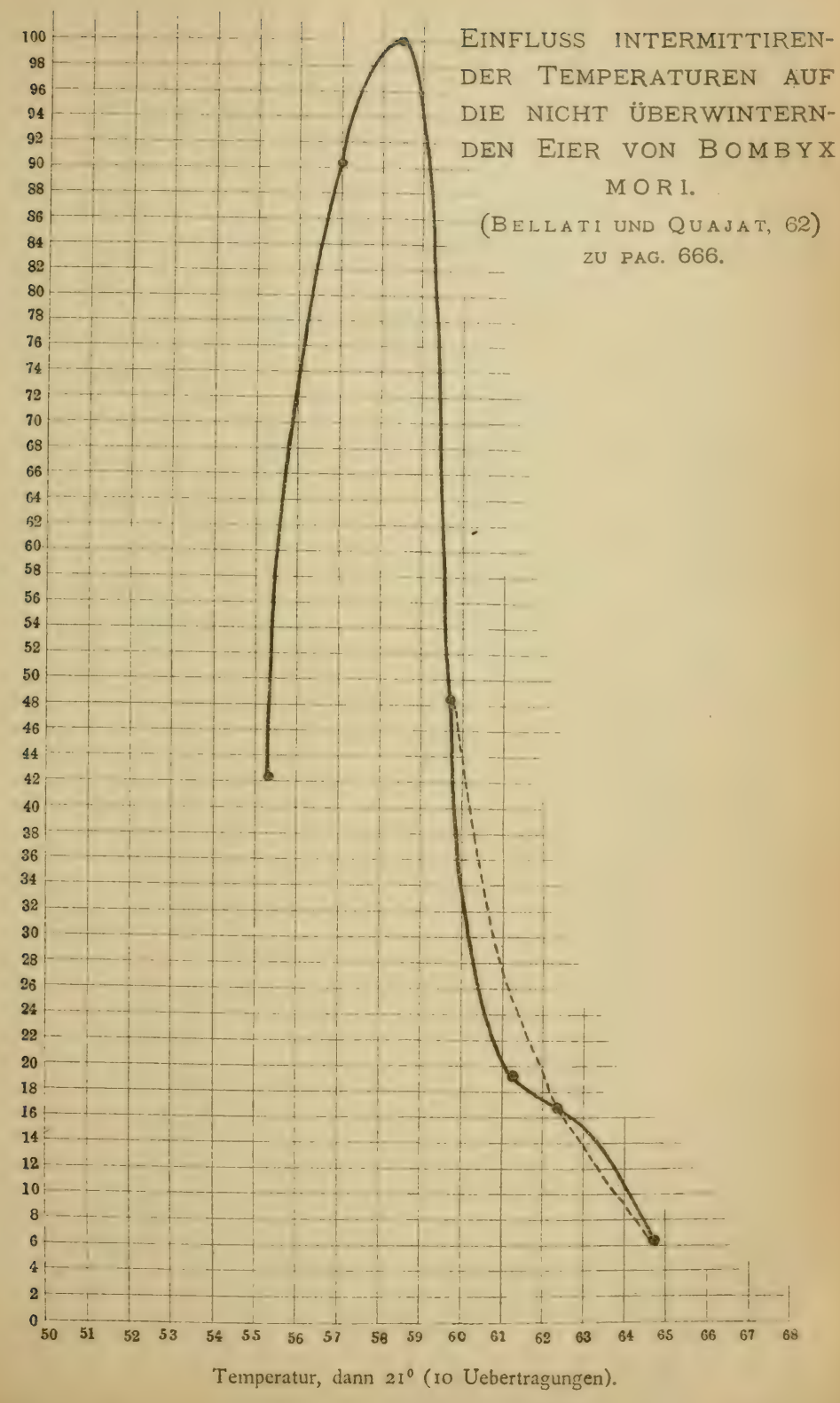







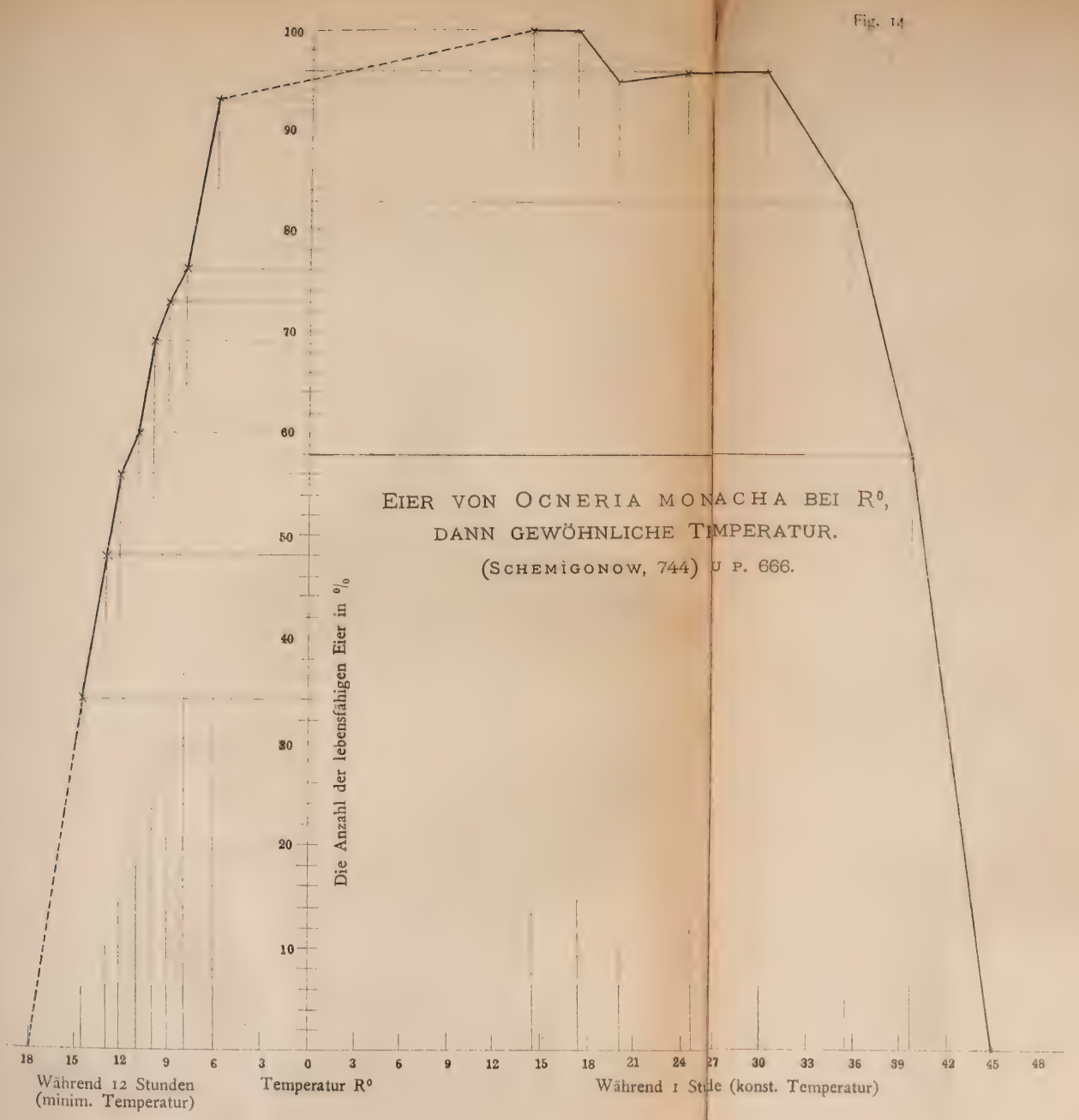





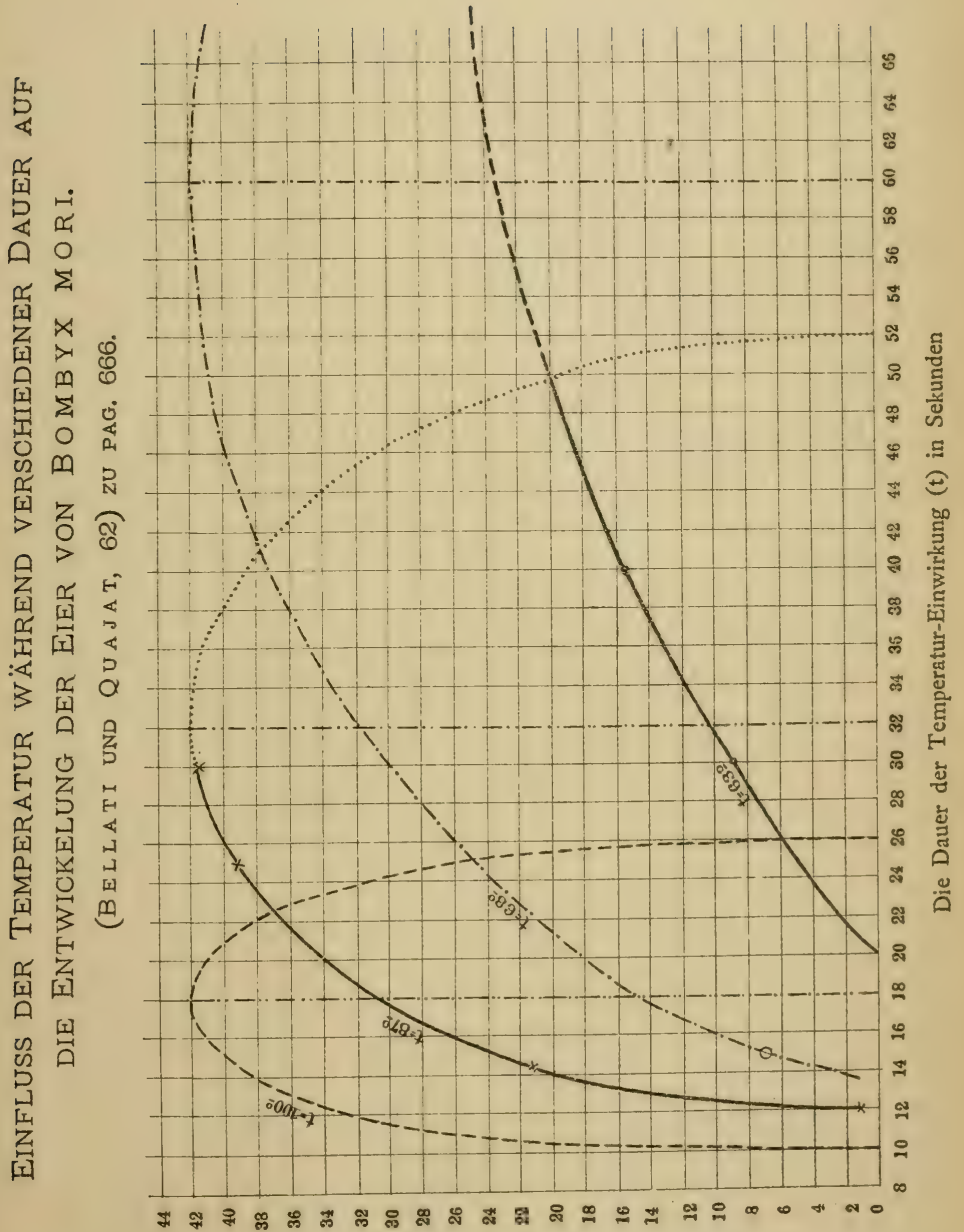

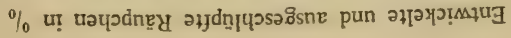





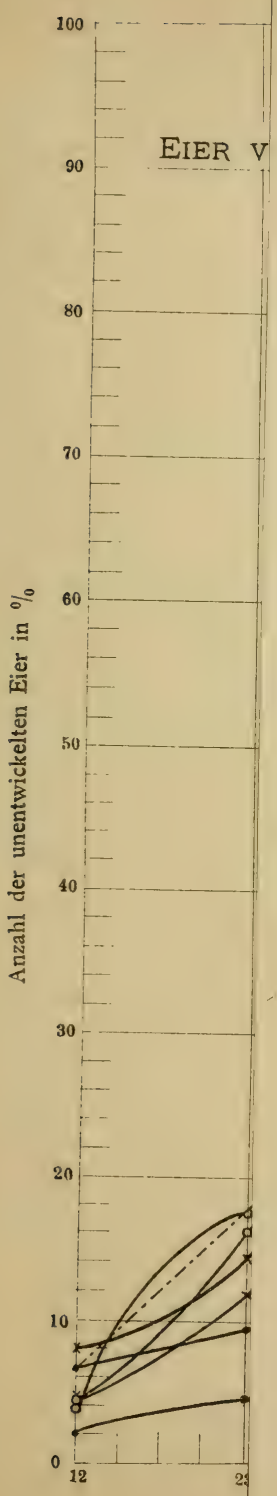





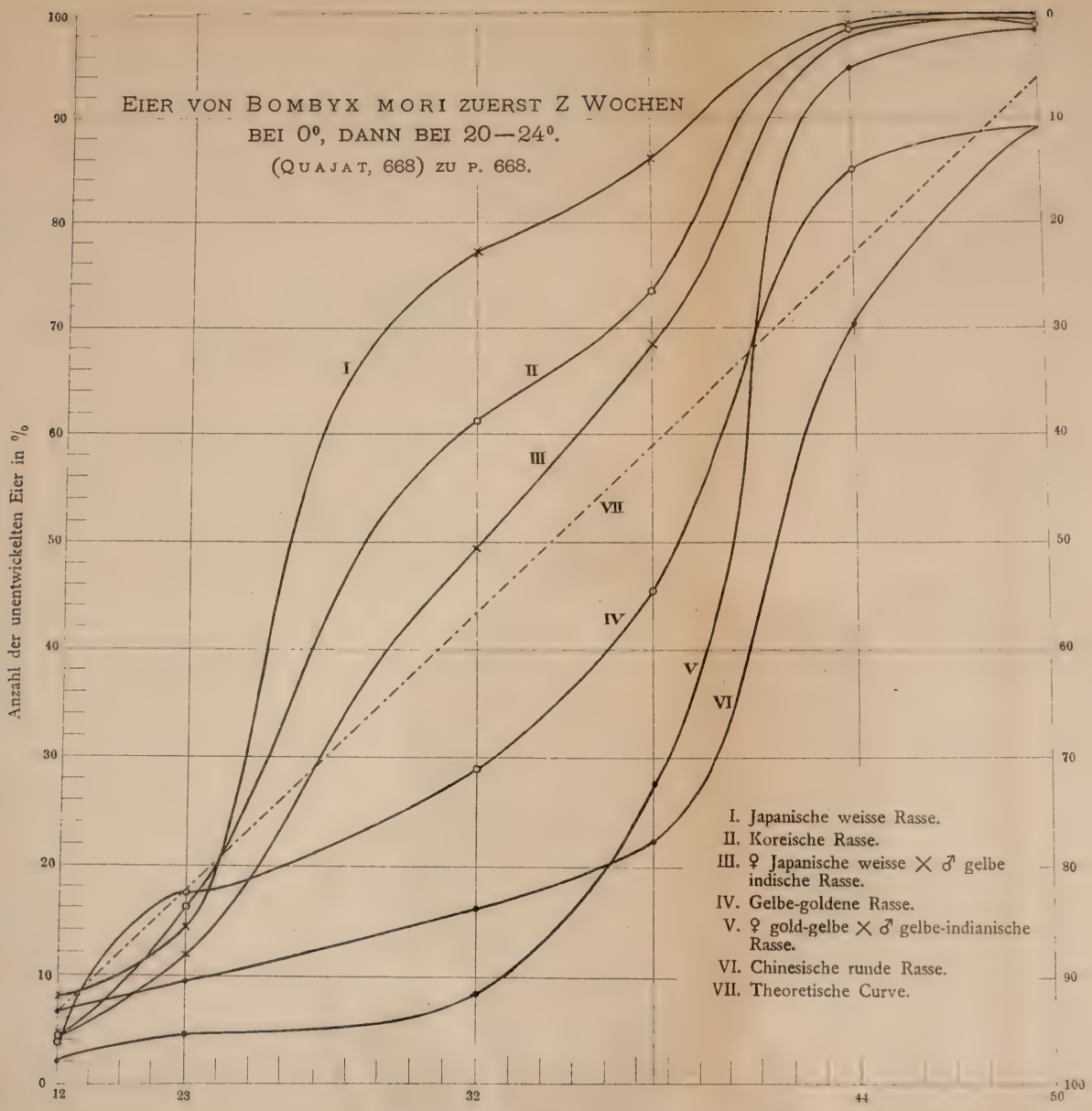

Ueberwinterungsdauer bei $0^{\circ}$ in Wochen $(z)$ 

Fig. 17 .

VERMUTHLICHE CURVEN FÜR DIE EINWIRKUNG DER MINUS-GRAdE AUF DIE ENTWICKELUNG DER EIER VON BOMBYX MORI (zU P. 669).

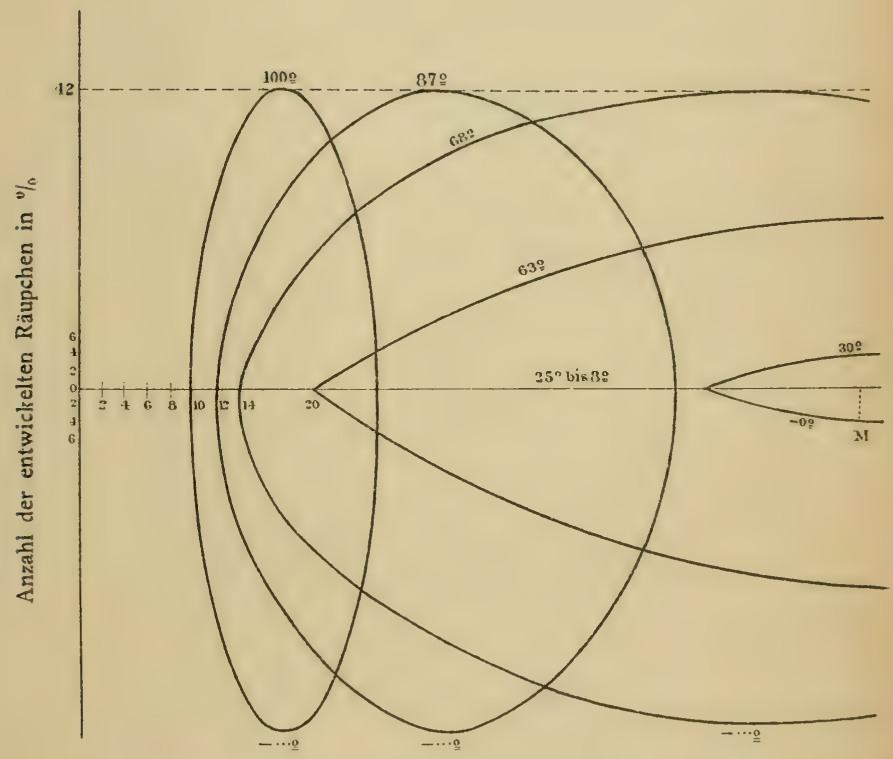



Fig. $r 8$.

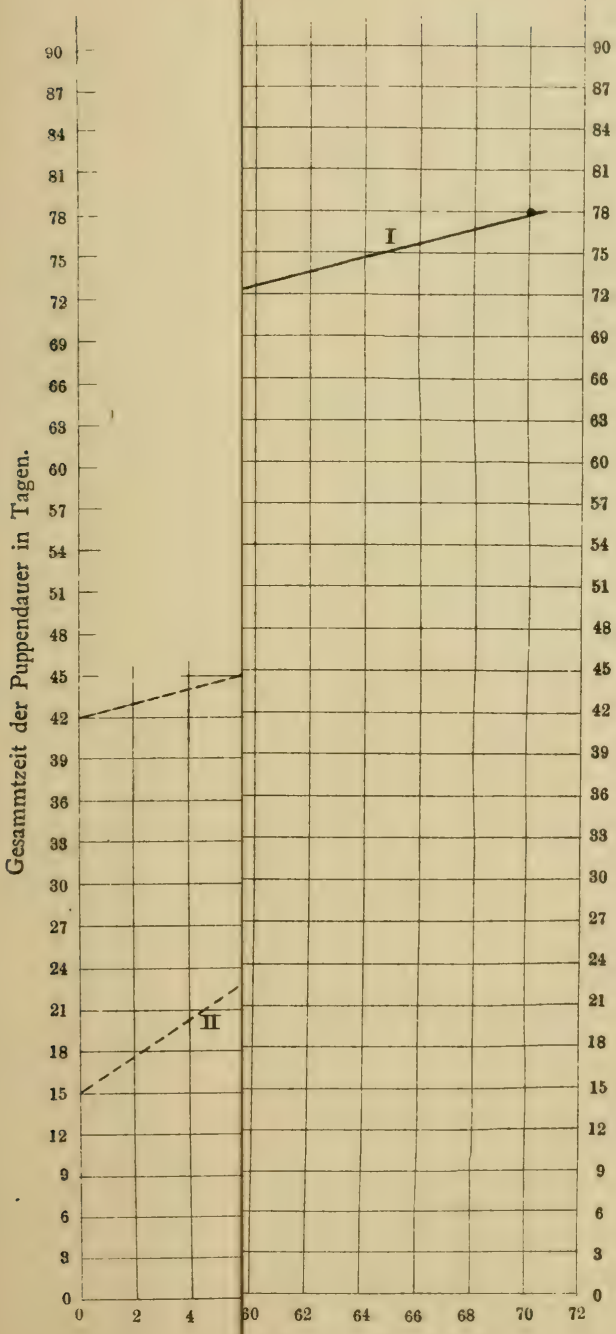




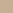

,

$$
\text { , }
$$


DiE PUPPEN VON EUGONIA AUTUMNARIA (I) UND EUGONIA ALNIARIA (II) IN DER K ̈̈̈LTE (T) Z TAGE (I BEI $T=2^{\circ}$ ?, II BEI $\mathrm{T}=0^{\circ}$ ),

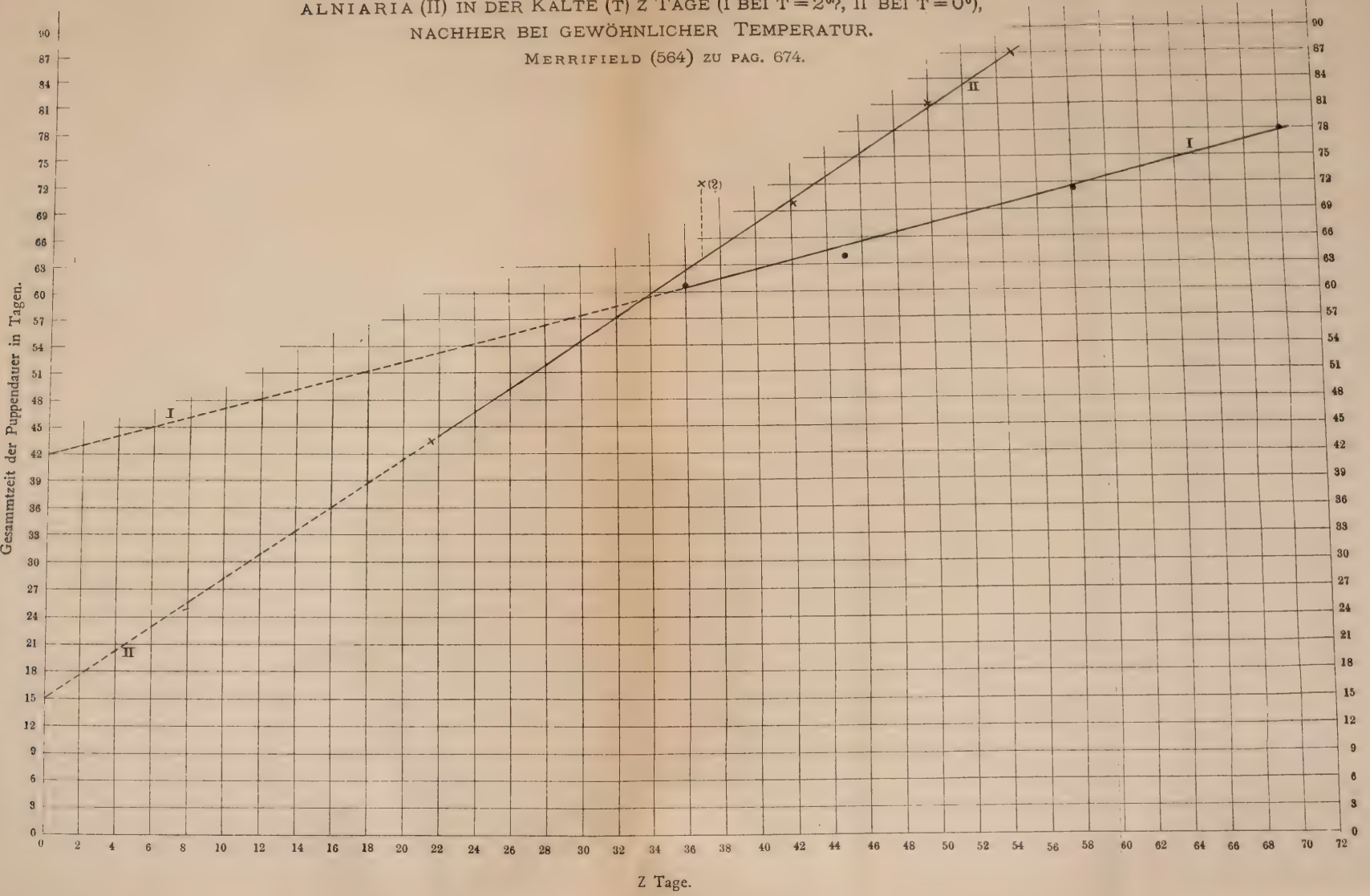



Fig. I9.

EN.

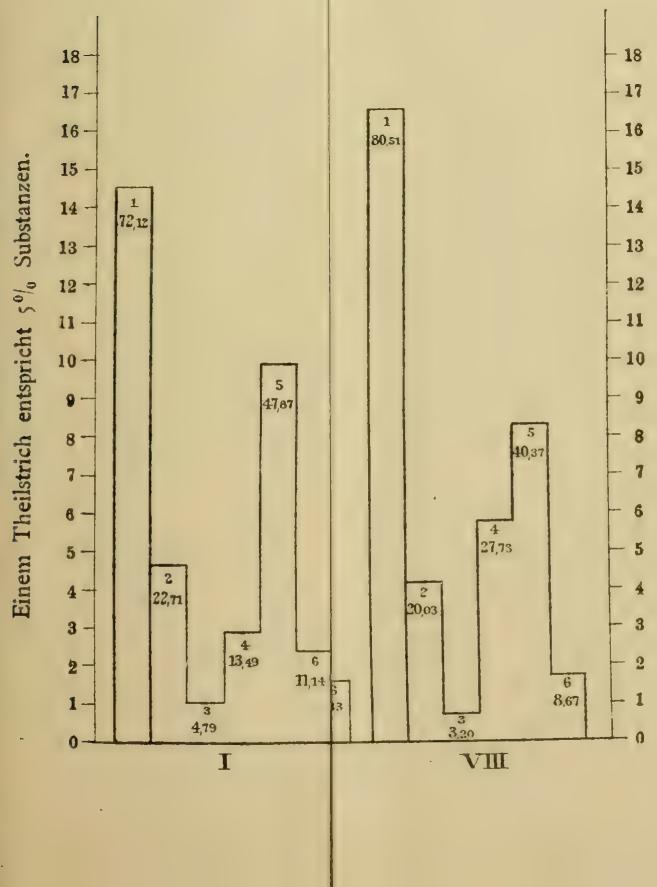




Fig. 20.

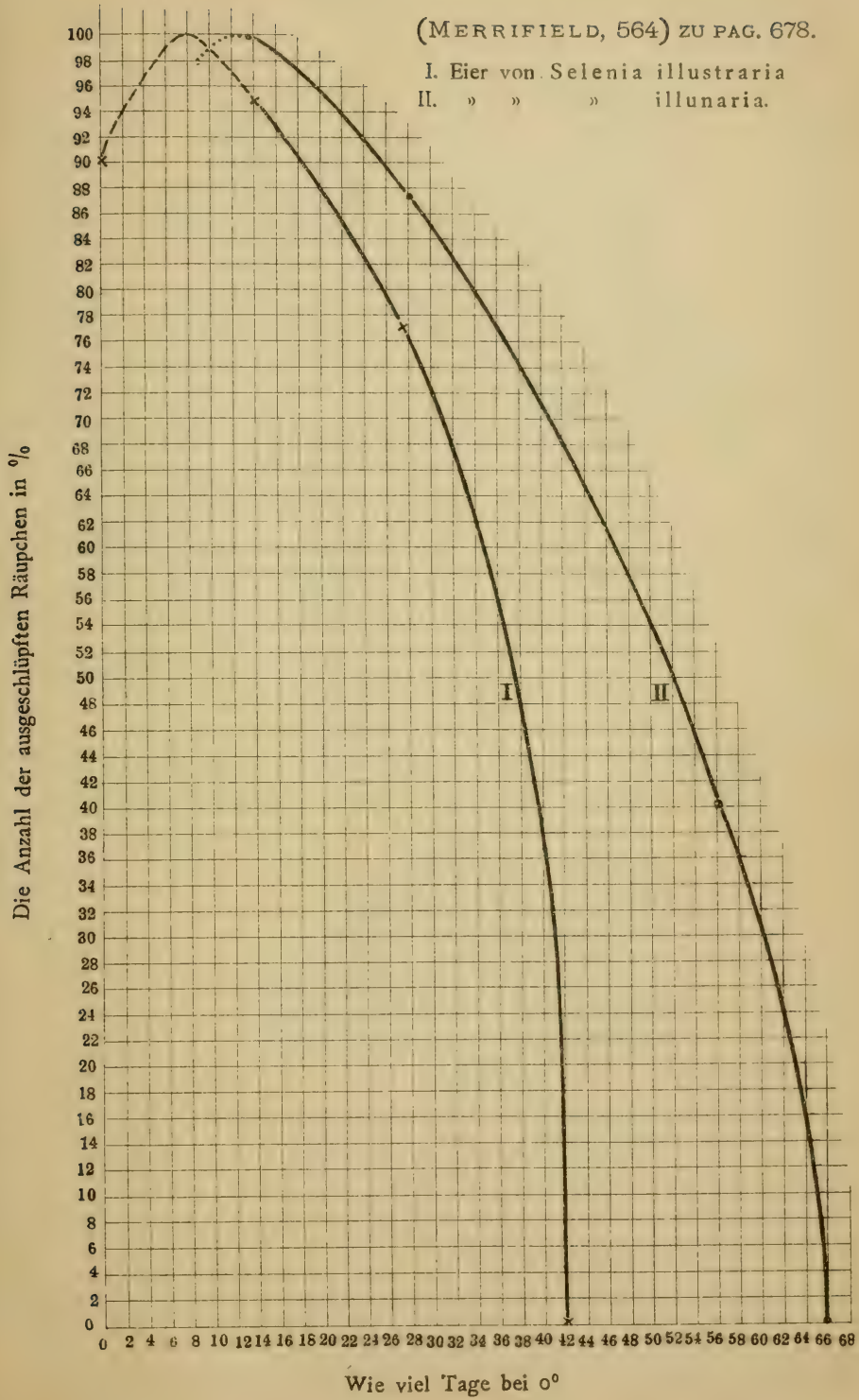



Fig. 21,-22.

Fig. $2 \pi$.

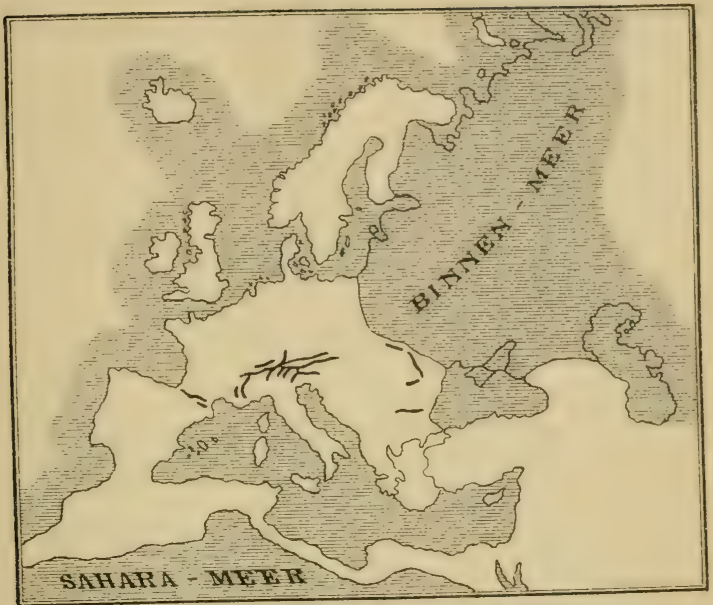

EUROPA ZUR TERTIÄRZEIT.

Fig. 22.

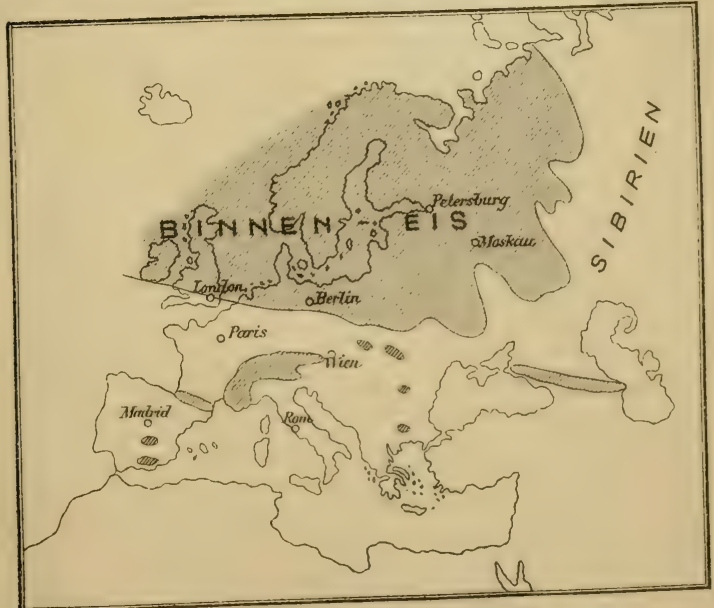

EUROPA ZUR EISZEIT 

Fig. $23-25$.

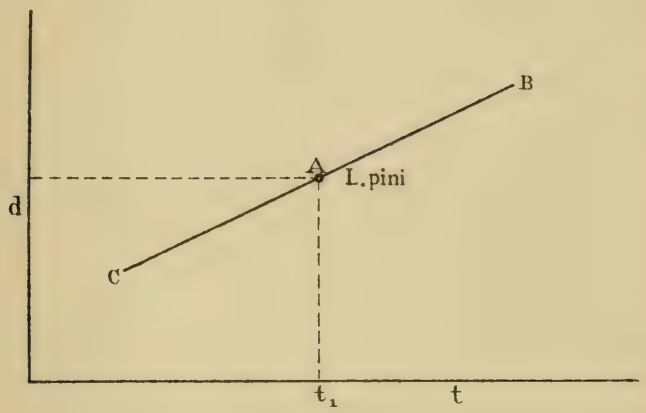

Fig. 23

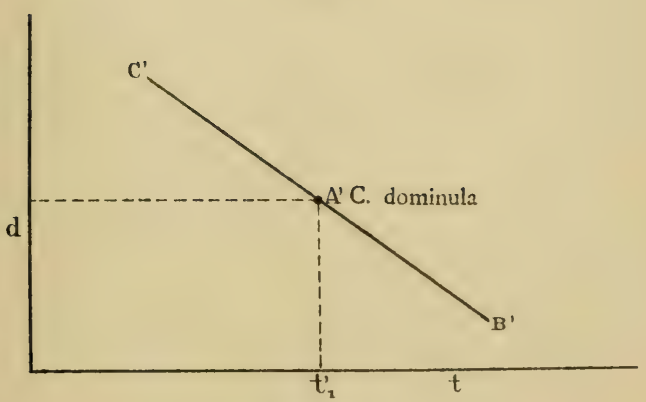

Fig. 24 .

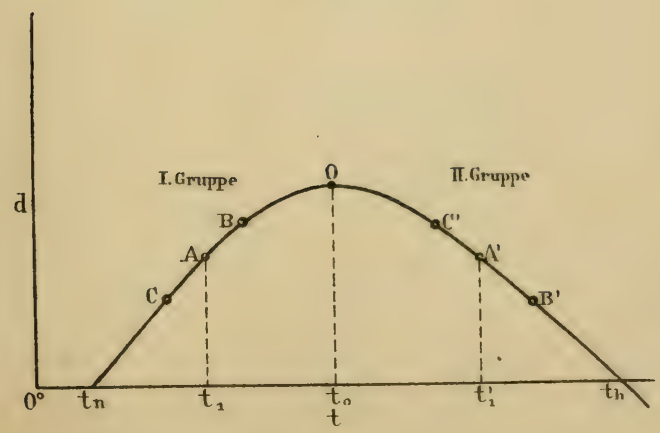

Fig. 25. 

Fig. $26-28$.

DiE VERSUCHE VON M. STANDFUSS

(840) ZU PAG. 761.

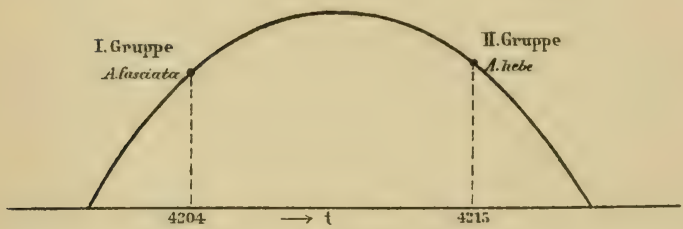

Fig. 26.

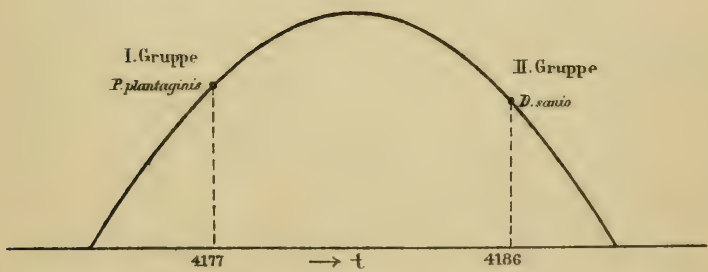

Fig. 27 .

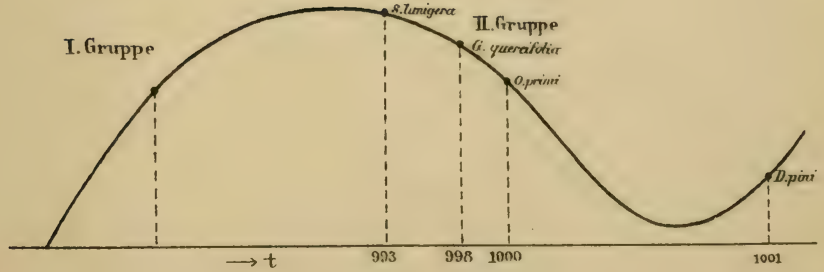

Fig. 28. 

Fig. 29.

EINWIKKUNG DER TEMPERATUR AUF DIE SPANNWEITE DES SCHMETTERLINGS-FLÜGELS VON RAUPENSTADIUM AN.

(ZU PAG. 773).

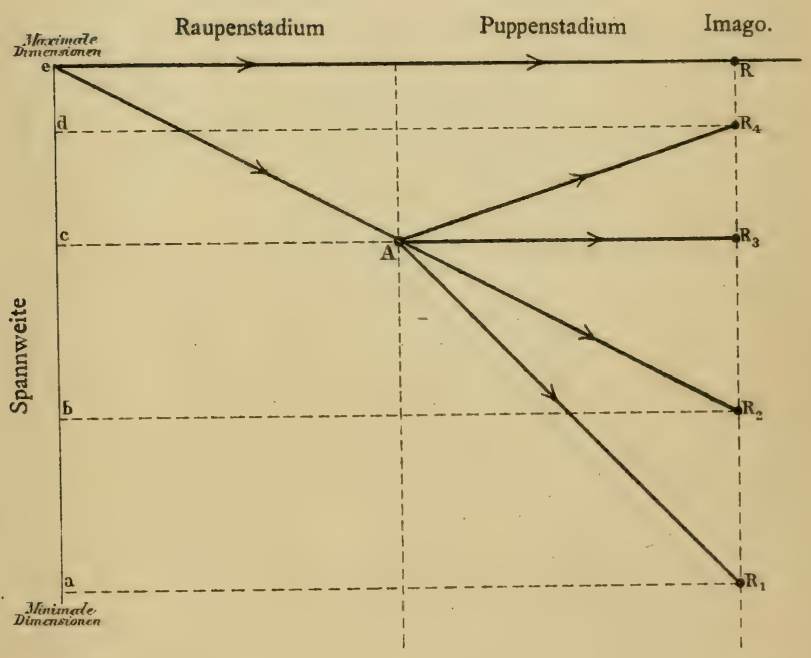



Fig. 30 .

EINWIRKUNG DER TEMPERATUR UND DER FEUCHTIG. KEIT AUF DIE SPANNWEITE DES SCHMETTERLINGS-

FLÜGELS.

(ZU PAG. 775).

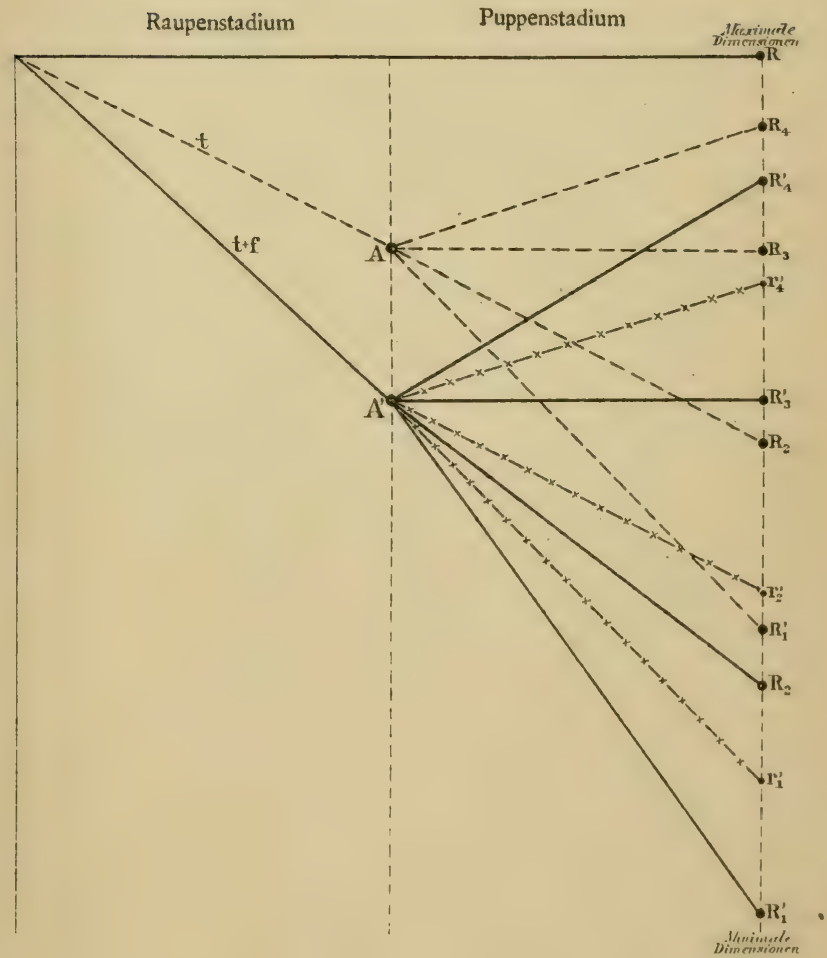



EINWIRKUNG DER TEMPERATUR UND DER FEUCHTIG. KEIT AUF DIE SPANNWEITE DES SCHMETTERLINGS-

FLÜGELS.

$$
\text { (ZU PAG. 774). }
$$

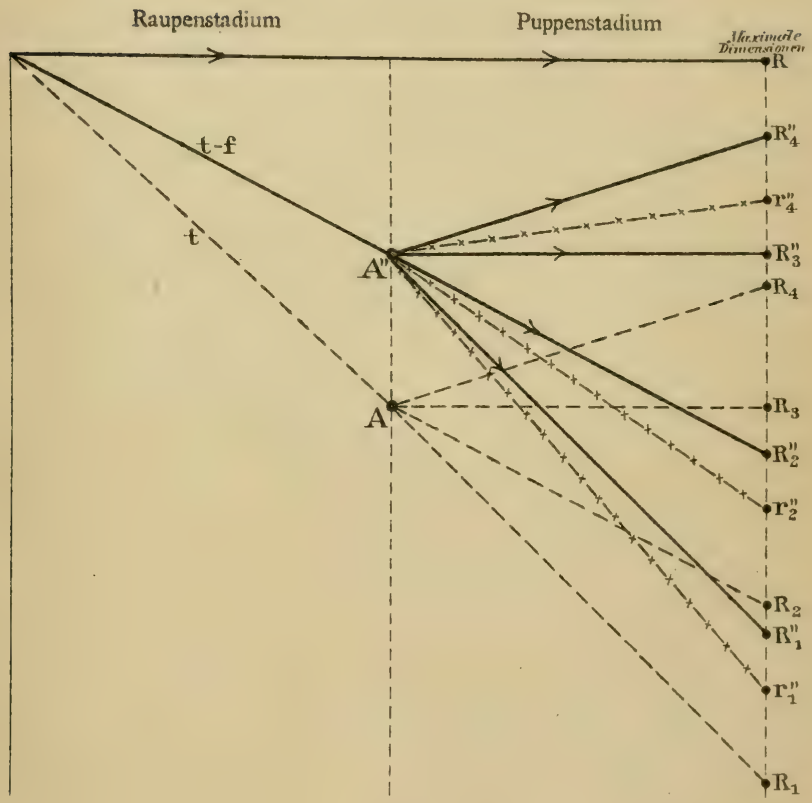


RU1. 2. 23.2 .11$. (3) 




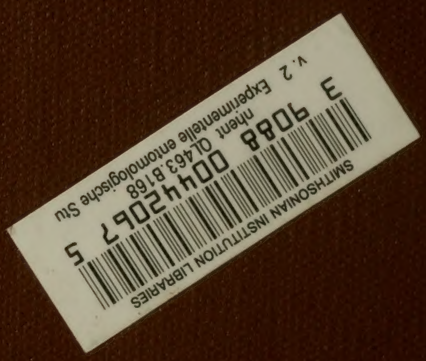

